\title{
2 \{\} New Challenges of Economic and Business Development - 2016
}

May 12-14, 2016, Riga, University of Latvia

\section{New Challenges of Economic}

and Business Development - 2016

Society, Innovations and Collaborative Economy

International Scientific Conference

http://www.evf.lu.Iv/conf2016

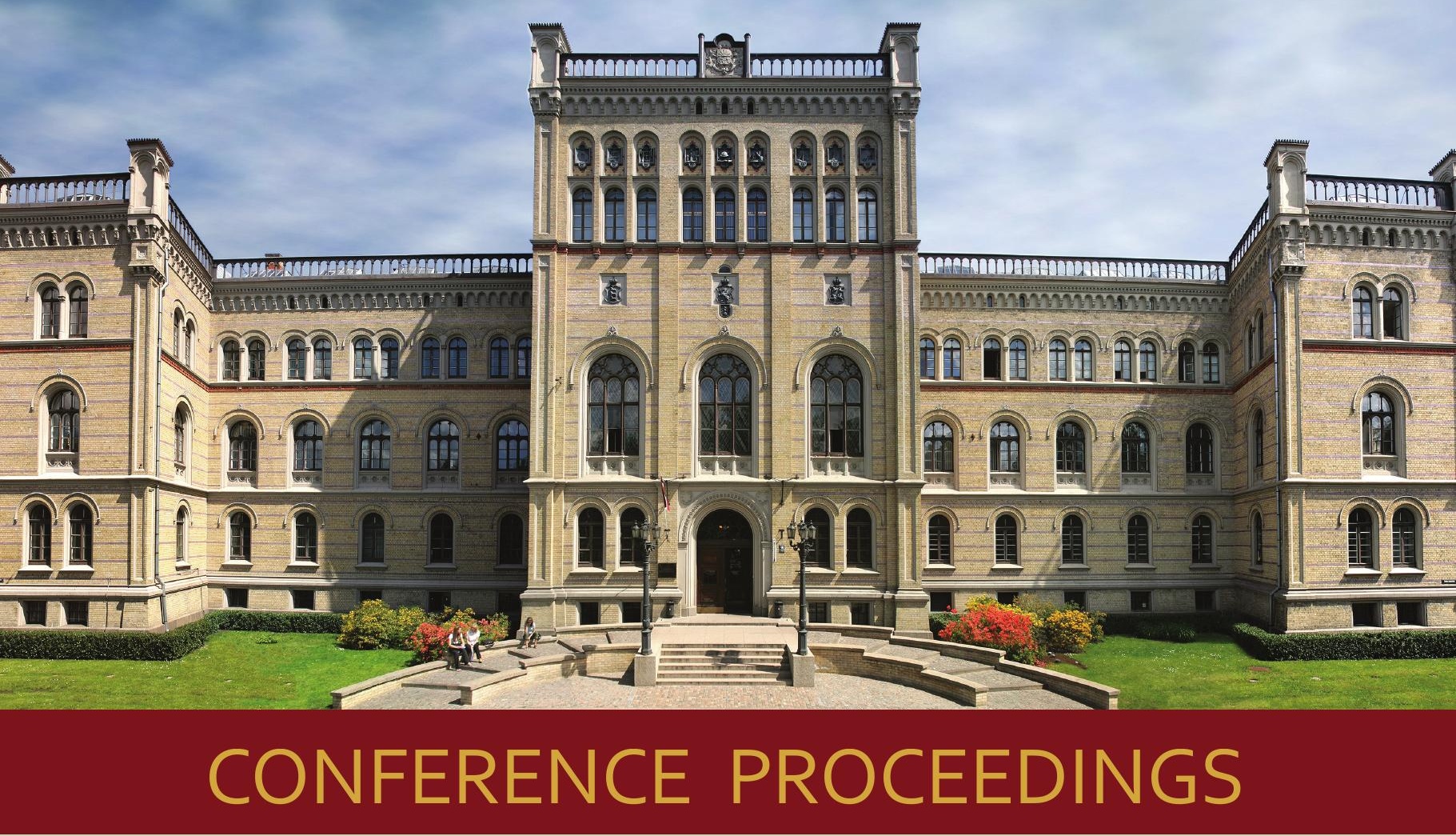

May 12-14, 2016, Riga, University of Latvia

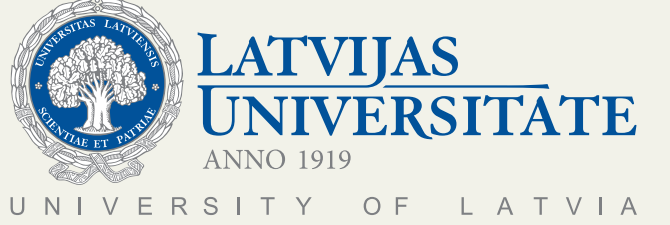

Faculty of Economics and Management 
New Challenges of Economic and Business Development - 2016

May 12-14, 2016, Riga, University of Latvia

\section{International Conference}

\section{New Challenges of Economic and Business Development - 2016}

Society, Innovations and Collaborative Economy

\section{PROCEEDINGS}

Organised by Faculty of Economics and Management, University of Latvia in cooperation with

Latvian European Community Studies Association

Institut CEDIMES - Lettonie

Econometrists Association of Latvia

Latvian Information and Communications Technology Association

Association of Statisticians of Latvia

Baltic Sea Region University Network (BSRUN)

Creativity Week radi!

Conference is supported by Latvijas Mobilais Telefons SIA

May 12-14, 2016

Riga, University of Latvia
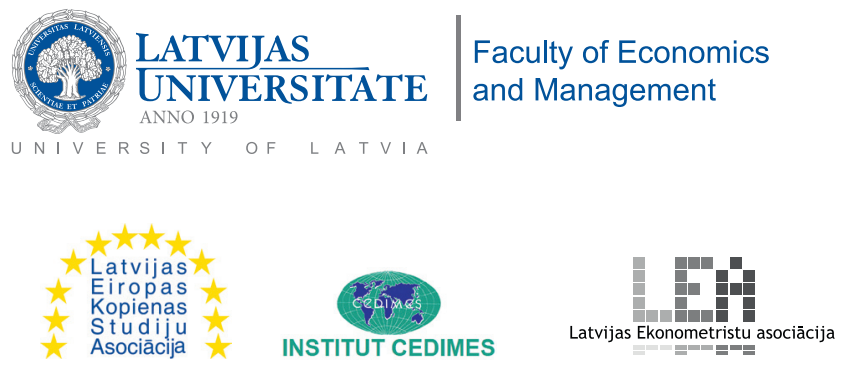

LIKTA

Latvijas Informācijas

un komunikācijas

tehnoloǵijas asociācija

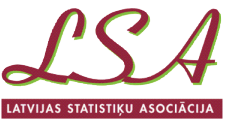




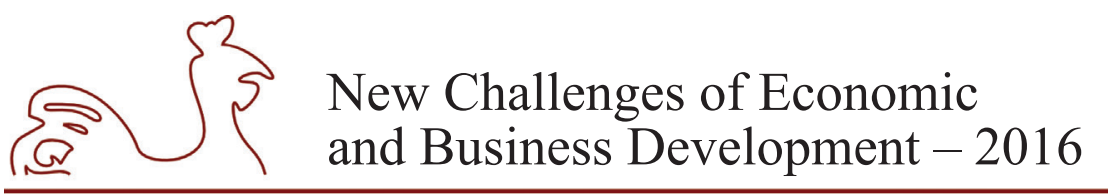

May 12-14, 2016, Riga, University of Latvia

International Conference "New Challenges of Economic and Business Development - 2016: Society, Innovations and Collaborative Economy": Riga, Latvia, May 12-14, 2016. Proceedings. Riga: University of Latvia, 2016, p. 948.

\section{Scientific Programme Committee}

Inta Bruna, Dr. oec., Professor, University of Latvia Jean D. Avenel, Dr., Professor, University Paris XII (France)

Ludmila Bandevica, Dr. habil. oec., Professor, University of Latvia

Anda Batraga, Dr. oec., Associate Professor, University of Latvia

Howard R. Balanoff, Dr., Professor, Texas State University (USA)

Andrejs Cekuls, Dr.oec., Associate Professor, University of Latvia

Galina Cernova, Dr. habil. oec., Professor, Saint Petersburg State University (Russia)

Rasa Daugeliene, Dr., Associate Professor, Kaunas University of Technology (Lithuania)

Andris Denins, Dr. oec., Professor, University of Latvia

Dzineta Dimante, Dr. oec., Associate Professor, University of Latvia

Elena Dubra, Dr. oec., Professor, University of Latvia

Simon Grima, Dr., Lecturer, University of Malta

Toomas Haldma, Dr., Professor, Tartu University (Estonia)

Arto Haveri, Dr., Professor, Tampere University (Finland)

Mihails Hazans, Dr., Professor, University of Latvia

Kari Hypponen, University of Turku, Finland Baltic Sea Region University Network (BSRUN)

Gundars Kaupins, Dr., Professor, Boise University (USA)

Juris Krumins, Dr. habil. oec., Professor, University of Latvia

Natalija Kuznecova, Dr. habil. oec., Professor, Saint Petersburg State University (Russia)

Karl-Heinz Leitner, Dr., AIT Austrian Institute of Technology GmbH (Germany)

Per Lind, Dr., Professor, Uppsala University (Sweden)

Tatjana Muravska, Dr. oec., Professor, University of Latvia

Shin'ya Nagasawa, Dr., Professor, Waseda University (Japan)

Josef Otto Neuert, Dr., Professor, University of Applied Sciences Kufstein (Austria)

Tiiu Paas, Dr. habil. oec., Professor, Tartu University (Estonia)

Gunnar Prause, Dr., Professor, Tallinn University of Technology (Estonia)

Janis Priede, Dr. oec., Associate Professor, University of Latvia

Maris Purgailis, Dr. oec., Professor, University of Latvia
Karlis Purmalis, Dr. oec., Assistant Professor, University of Latvia

Alari Purju, Dr., Professor, Tallinn University of Technology (Estonia)

Trond Randoy, Dr., Professor, University of Agder (Norway)

Inna Romanova, Dr. oec., Associate Professor, University of Latvia

Uldis Rozevskis, Dr. oec., Associated Professor, University of Latvia

Ramona Rupeika-Apoga, Dr. oec., Professor, University of Latvia

Eric Schoop, Dr., Professor, Dresden Technical University (Germany)

Bruno Sergi, Dr., Professor, Messina University (Italy)

Rasa Snapstiene, Dr., Associate Professor, Kaunas University of Technology (Lithuania)

Biruta Sloka, Dr. oec., Professor, University of Latvia

Aija van der Steina, Dr. oec., Senior Researcher, University of Latvia

Arild Sæther, Professor, Agder University (Norway)

Baiba Savrina, Dr. oec., Professor, University of Latvia

Ligita Simanskiene, Dr., Professor, Klaipeda University (Lithuania)

Roberts Skapars, Dr. oec., Professor, University of Latvia

Daina Skiltere, Dr. oec., Professor, University of Latvia

Erika Sumilo, Dr. oec., Professor, University of Latvia

Maaja Vadi, Dr., Professor, Tartu University (Estonia)

Inesa Voroncuka, Dr. oec., Professor, University of Latvia

\section{Organizing Committee}

Dzineta Dimante, University of Latvia (Coordination of Committees work)

Biruta Sloka, University of Latvia (Coordination of conference)

Aija van der Steina, University of Latvia (Coordination of conference)

Kaspars Cikste, University of Latvia (Finances, sponsoring)

Anda Batraga, University of Latvia (Social programme)

Kristine Berzina, University of Latvia (Social programme)

Ella Jakobsone, University of Latvia (Correspondence, registration)

Martins Danusevics, University of Latvia (IT support, design)

Rita Zuka, University of Latvia (Conference webpage design and update)

Layout: Andra Liepina

Logo: Martins Danusevics

(C) University of Latvia, 2016

ISBN 978-9934-18-140-5 


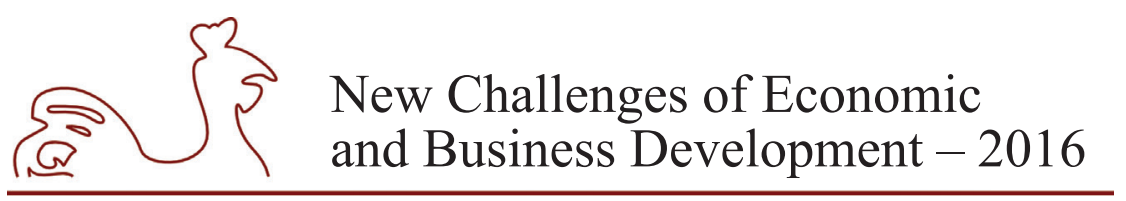

May 12-14, 2016, Riga, University of Latvia

\title{
REVIEWERS
}

\begin{abstract}
New Challenges of Economic and Business Development - 2016: Society, Innovations and Collaborative Economy have been doubleblind reviewed by the following reviewers:
\end{abstract}

Dr. Kristine Abolina, University of Latvia, Latvia Dr. Vitali Alexeev, University of Tasmania, Tasmania Dr. Jaan Alver, Tallinn University of Technology, Estonia

Dr. Dzintra Atstaja, BA School of Business and Finance, Latvia

Dr. Signe Balina, University of Latvia, Latvia

Dr. Peter J. Baldacchino, University of Malta, Malta

Dr. Anda Batraga, University of Latvia, Latvia

Dr. Nameda Belmane, SIA Ardenis, Latvia

Dr. Tom Berglund, Hanken School of Economics, Finland

Dr. Atis Berzins, University of Latvia, Latvia

Dr. Gundars Berzins, University of Latvia, Latvia

Dr. Andrejs Bessonovs, Bank of Latvia, Latvia

Dr. Leszek Bohdanowicz, University of Lodz, Poland

Dr. Ieva Brence, RISEBA, Latvia

Dr. Inta Bruna, University of Latvia, Latvia

M. Larisa Bule, University of Latvia, Latvia

Dr., Inga Bumane, University of Latvia, Latvia

Dr. Alessandro Danovi, University of Bergamo, Italy

Dr. Rasa Daugeliene, Kaunas University of Technology, Lithuania

Dr. Vida Davidaviciene, Vilnius Gediminas Technical University, Lithuania

Dr. Justs Dimants, University of Latvia, Latvia

Dr. Elena Dubra, University of Latvia, Latvia

Dr. Margarita Dunska, University of Latvia, Latvia

Dr. Ludmila Fadejeva, Bank of Latvia, Latvia

M. Ivita Faitusa, University of Latvia, Latvia

M. Rita Freimane, University of Latvia, Latvia

Dr. Simon Grima, University of Malta, Malta

Dr. Sergejs Gubins, Think-tank CERTUS, Baltic

International Centre for Economic Policy Studies, Latvia

Dr. Mara Gulbe, University of Latvia, Latvia

Dr. Ksenija Ijevleva, University College of Economics and Culture, Latvia

Dr. Sarmite Jegere, RPIVA, Latvia

Dr. Sandra Jekabsone, University of Latvia, Latvia

Dr. Elita Jermolajeva, Latvian Academy of Agricultural and Forestry Sciences

Dr. Jan Jezak, University of Lodz, Poland

Dr. Aina Joppe, University of Latvia, Latvia

Dr. Inara Kantane, University of Latvia, Latvia
Dr. Renata Korsakiene, Vilnius Gediminas Technical

University, Lithuania

Dr. Beata Kotowska, University of Gdansk, Poland

Dr. Olegs Krasnopjorovs, Bank of Latvia, Latvia

Dr. Zaiga Krisjane, University of Latvia, Latvia

Dr. Marina Kudinska, University of Latvia, Latvia

Dr. Agita Livina, Vidzeme University of Applied

Sciences, Latvia

Dr. Inta Millere, University of Latvia, Latvia

Dr. Irina Mozajeva, University of Latvia, Latvia

Dr. Elena Murashova, Pacific National University,

Russia

Dr. Tatjana Muravska, University of Latvia, Latvia

Dr. Viesturs Pauls Karnups, University of Latvia,

Latvia

Dr. Karlis Purmalis, University of Latvia, Latvia

Dr. Trond Randoy, University of Agder, Norway

Dr. Jurgita Raudeliuniene, Vilnius Gediminas Technical

University, Lithuania

Dr. Inna Romanova, University of Latvia, Latvia

Dr. Nils Rostoks, University of Latvia, Latvia

Dr. Ramona Rupeika-Apoga, University of Latvia,

Latvia

Dr. Baiba Savrina, University of Latvia, Latvia

Dr. Eric Schoop, TU Dresden, Germany

Dr. Rotem Shneor, University of Agder, Norway

Dr. Ligita Simanskiene, Klaipeda University, Lithuania

Dr. Roberts Skapars, University of Latvia, Latvia

Dr. Daina Skiltere, University of Latvia, Latvia

Dr. Ruta Sneidere, University of Latvia, Latvia

Dr. Irina Solovjova, University of Latvia, Latvia

Dr. Erika Sumilo, University of Latvia, Latvia

Dr. Svetlana Saksonova, University of Latvia, Latvia

Dr. Tatjana Tambovceva, Riga Technical University,

Latvia

Dr. Eleftherios Thalassinos, University of Piraeus,

Greece

Dr. Olegs Tkacevs, Bank of Latvia, Latvia

Dr. Aija van der Steina, University of Latvia, Latvia

Dr. Inesa Voroncuka, University of Latvia, Latvia

Dr. Renata Walczak, Warsaw University of Technology,

Poland

Dr. Ligita Zilite, Turiba University, Latvia

Dr. Kamil Zajaczkowski, Warsaw University, Poland

Dr. habil. Peteris Zvidrins, University of Latvia, Latvia 
May 12-14, 2016, Riga, University of Latvia

\section{CONTENTS}

Marta Abula, Inna Dovladbekova, Anzelika Berke-Berga

REVIEW OF THE LEGAL ISSUES OF EMPLOYEE SHARE OWNERSHIP IN EU

Inese Aleksejeva

HOW TRUST IN ORGANIZATIONS AND INFORMATION SOURCES IMPACTS

LATVIAN CONSUMERS' ATTITUDE TOWARDS GENETICALLY MODIFIED

ORGANISMS

Maria Aluchna, Anna Krejner-Nowecka, Emilia Tomczyk

WOMEN ON BOARDS AND SHAREHOLDER STRUCTURE

Jaan Alver, Lehti Alver, Lehte Alver

25 YEARS IN FINANCIAL REPORTING: THE CASE OF ESTONIA

Signe Balina, Dace Baumgarte, Edgars Salna

E-LEARNING AS A FACTOR FOR FACILITATING

THE DEVELOPMENT OF INFORMATION SOCIETY

Ilona Baumane-Vitolina, Madara Apsalone, Erika Sumilo

GENERATIONAL DIFFERENCES IN PERCEPTION OF VALUES

IN POST-SOVIET BUSINESS ENVIRONMENT

Demet Bayraktar, Susanna Ayvaz

REASSESSING EFFICIENCY IN HUMAN DEVELOPMENT AMONG OECD

COUNTRIES

Juris Binde, Vita Zvirbule, Zane Demjanova, Ilze Saulite

THE INTERNET OF THINGS (IOT) BUSINESS POTENTIAL IN LATVIA

Dina Bite, Zenija Kruzmetra

SOCIAL PRACTICES OF RURAL POPULATION

FOR RENEWAL OF SOCIETY IN LATVIA

Leszek Bohdanowicz, Jan Jezak

A TWO-TIER OR ONE-TIER BOARD MODEL?

THE NEED FOR CHANGE IN THE POLISH SYSTEM OF CORPORATE

GOVERNANCE

Ilze Buligina, Biruta Sloka

IMPROVED VET GOVERNANCE FOR LABOUR MARKET TRAINING AT

REGIONAL LEVEL

Aleksandrs Dahs

REGIONAL DEMOGRAPHIC DEVELOPMENT IN LATVIA - DOES POLICY

MATTER? 


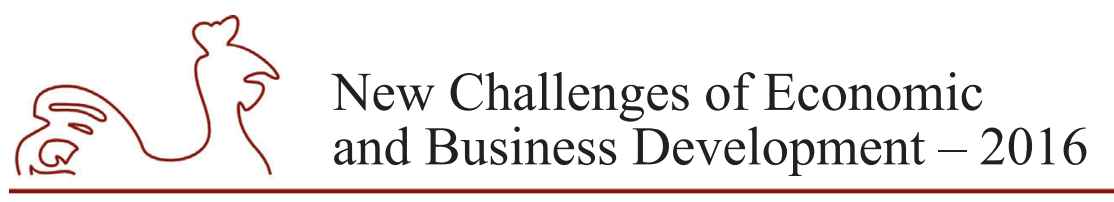

May 12-14, 2016, Riga, University of Latvia

Mindaugas Dapkus, Violeta Pukeliene, Jone Kalendiene

DUALISM OF TAXATION. CHANGES OF LONG RUN WELFARE TAX AND ITS

LINKAGE WITH WELLBEING

Dzineta Dimante, Juris Benders, Dzintra Atstaja, Tatjana Tambovceva

DEVELOPMENT OF BUSINESS EDUCATION FOR CIRCULAR ECONOMY

IN LATVIA

Tomasz Dorozynski, Anetta Kuna-Marszalek

ATTRACTING FDI TO THE VISEGRAD GROUP COUNTRIES

Natalja Dubkova

REGIONAL DIFFERENCES IN LIFE EXPECTANCY, REPORTED ACTIVITY

LIMITATIONS AND CHRONIC MORBIDITY IN LATVIA DURING 2006-2014

\section{Elena Dubra}

SOCIAL DISPARITY AND CONVERGENCE PROBLEMS IN THE EU STATES

Barbara Ehrnsperger

ANALYSIS OF DEVELOPMENT IN PATIENT SAFETY OVER

THE LAST 15 YEARS

Daiga Ergle, Inesa Voroncuka

METHODOLOGICAL APPROACH TO RESEARCH THE LINKAGE BETWEEN

EMPLOYEE ENGAGEMENT AND GAMIFICATION OF HUMAN RESOURCE

MANAGEMENT PROCESSES IN LATVIAN COMPANIES

Ivita Faitusa, Simon Grima, Peter J. Baldacchino

A COMPARATIVE ANALYSIS OF THE EU PUBLIC SECTOR INTERNAL AUDIT

METHODOLOGY AND REQUIREMENTS

Rita Freimane

PUBLIC AND BUSINESS RESEARCH AND DEVELOPMENT EXPENDITURES AND

ECONOMIC GROWTH IN EU: A PANEL DATA ANALYSIS

Elina Gaitniece, Anda Batraga, Kaspars Viksne

ELECTRONIC WORD OF MOUTH (EWOM) COMMUNICATION'S INFLUENCE ON

CONSUMER PURCHASE DECISIONS IN BALTIC STATES

Dzintra Gasune, Andris Denins

OPERATION OF STATE-OWNED COMPANIES IN LATVIA

Steffen Hossfeld

OPTIMIZATION ON DECISION MAKING DRIVEN BY DIGITALIZATION

279

Anne Jantos, Matthias Heinz, Eric Schoop, Ralph Sonntag

CREATING A SCALABLE FLIPPED CLASSROOM ARRANGEMENT TO ENABLE

PART TIME STUDIES TO FURTHER HUMAN DEVELOPMENT AND

MANAGEMENT EDUCATION 
May 12-14, 2016, Riga, University of Latvia

Sandra Jekabsone, Karlis Purmalis

LATVIAN LABOUR MARKET DEVELOPMENT CHALLENGES AND PROBLEMS .......

Svetlana Jesilevska

DATA QUALITY ASPECTS IN LATVIAN INNOVATION SYSTEM

\section{Inese Kalvane}

THE IMPACT OF PUBLIC EMPLOYMENT SERVICES ON JOB SEARCH

OUTCOMES - THEORY, METHODS AND EVALUATION

Olga Kanaeva, Alexander Kanaev

CORPORATE SOCIAL POLICY: A NEW MODEL FOR CONSCIOUS ECONOMY

Rasa Kanapickiene, Renatas Spicas

BANKRUPTCY PREDICTION MODELS: CASE OF THE CONSTRUCTION AND

TRANSPORT \& STORAGE SECTOR IN LITHUANIA

\section{Inara Kantane}

EMPLOYMENT AND FERTILITY IN LATVIA

\section{Lucija Kavale, Erika Zubule}

FISCAL POLICY IN LATVIA: RISKS AND CHALLENGES

Sergey Kirsanov, Eugene Safonov, Olga Starineca

THE SYSTEM OF PUBLIC SERVICES DELIVERY IN ST. PETERSBURG

Sabine Koklacova, Tatjana Volkova

DESIGN CONCEPTS FOR PROMOTING SOCIALLY RESPONSIBLE SOLUTIONS ......

Beata Kotowska, Olga Martyniuk

FINANCIAL AND TAX REPORTING IN THE SME SECTOR

IN SELECTED EASTERN-EUROPEAN COUNTRIES

\section{Marija Krumina}

ENTREPRENEURSHIP AND THE BUSINESS CYCLE IN LATVIA

Juris Krumins, Denize Ponomarjova

ETHNIC DIFFERENTIATION OF MORTALITY, LIFE EXPECTANCY AND HEALTH

IN LATVIA AT THE BEGINNING OF $21^{\text {ST }}$ CENTURY

Kuznetsova Natalia P., Pisarenko Zhanna V., Chernova Galina V.

FINANCIAL MARKET INSTITUTIONS COMPETITIVENESS AND FINANCIAL

CONVERGENCE

\section{Richard Mayr}

ANALYSES OF THE INFLUENCES OF ORGANIZATIONAL AND GROUP

PROCESSES IN RISK MANAGEMENT RELATED TO MEANINGFULNESS OF RISK ASSESSMENTS 


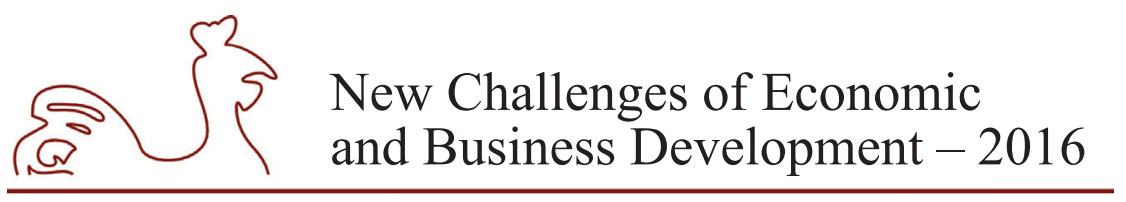

May 12-14, 2016, Riga, University of Latvia

Ilze Medne, Kristine Berzina

THE AWARENESS AND IMAGE OF LATVIA AS A TOURISM DESTINATION IN

GERMANY AS A HIGH PRIORITY TARGET MARKET

Vija Melbarde, Maira Ore

INFLUENCING FACTORS OF RURAL AREAS DEVELOPMENT VIDZEME REGION

CASE ANALYSIS

Vija Micune

DEVELOPMENT OF LENDING RATES IN THE BALTIC COUNTRIES:

COMMON AND DIVERGING ASPECTS

Ilze Mileiko

SOCIOECONOMIC IN FERTILITY DISCOURSE: A LATVIAN CASE

511

Dapkus Mindaugas, Stundziene Alina

THE LINKAGE BETWEEN INDUSTRIAL EXPECTATIONS AND PRODUCTION:

WHICH IS THE CAUSE?

\section{Dancho Petrov}

THE SYNDICATED LOAN MARKET - POST- OR PRE-CRISIS

Anna Pluta

INCENTIVES TO ENTER THE LABOUR MARKET IN LATVIA

Maris Purgailis, Annija Apsite

EU POLICY IMPACT ON HIGHER EDUCATION CAPACITY IN LATVIA

\section{Aivita Putnina}

IMPRINTS OF GLOBAL AND LOCAL ECONOMICS: FAMILIES AND HOUSEHOLD

ECONOMICS IN LATVIA

Romans Putans, Olga Starineca, Inesa Voroncuka

SOCIAL PARTICIPATION THROUGH VOLUNTEERING AS CO-PRODUCTION OF

PUBLIC SERVICES: CASE STUDY OF LATVIA

Elina Radionova, Valerijs Praude

RELATIONSHIP MARKETING: CONSUMER BEHAVIOUR COMPARISON IN THE TRADITIONAL AND ONLINE TRADE MARKETS

\section{Olga Rajevska}

THREATS TO SUSTAINABILITY OF NATIONAL PENSION SYSTEMS: THE RESULTS OF EUROPEAN AND BALTIC EXPERT POLL

Michel Rietze

MONITORING E-COLLABORATION: PREPARING AN ANALYSIS FRAMEWORK ...... 604

Uldis Rozevskis, Kristine Rozite, Juris Krasts, Rita Zuka

ESSENTIAL ELEMENTS OF BUSINESS PROCESS MODELLING

618 
May 12-14, 2016, Riga, University of Latvia

Tom Sander, Jurgita Pauzuoliene, Biruta Sloka

HUMAN RESOURCES MANAGEMENT USE OF SOCIAL NETWORK SITES TO

RECRUIT EMPLOYEES

Eric Schoop, Moritz, Hesse, Michael Breidung

COMPENSATING THE EFFECTS OF DEMOGRAPHIC SHIFT IN PUBLIC

ADMINISTRATION. A LESSON LEARNED FROM A LESSONS

LEARNED PROJECT

Stefan Schwerd

BLIND SPOT “INFORMATION RISK MANAGEMENT” - THE DIFFERENT

PERCEPTION OF EXPERIENCED MANAGERS AND IRM-PROFESSIONALS

Ligita Simanskiene, Erika Zuperkiene, Jurgita Pauzuoliene

SUSTAINABLE LEADERSHIP IN LITHUANIAN ORGANISATIONS

\section{Diana Sitenko}

INTERACTION OF ELEMENTS OF THE NATIONAL INNOVATION SYSTEM OF

KAZAKHSTAN AT THE REGIONAL LEVEL

668

Ronalds Skulme, Valerijs Praude

TWITTER AS A COMUNICATION CHANNEL IN LATVIA'S TOP COMPANIES

Ruta Sneidere, Inese Vigante, Inga Bumane

APPLICATION OF SOCIAL ACCOUNTING PRINCIPLES TO STATE-OWNED

ENTERPRISES

Kristaps Soms

SMART INDUSTRIAL SPECIALIZATON: CASE OF LATVIA

Renatas Spicas, Mindaugas Vijunas, Rasa Kanapickiene

SETTING AN OPTIMAL LOAN PERFORMANCE WINDOW AND A BAD LOAN

DEFINITION FOR THE CREDIT RISK ASSESSMENT MODEL FOR CREDIT UNIONS

IN LITHUANIA

Natalia Spiridonova

SOCIAL POLICIES OF THE STATE IN THE CONTEXT OF GLOBALIZATION

Ilze Sproge, Aina Joppe

MODERN TRENDS IN TAX PLANNING AND MINIMIZATION

Laila Stabulniece, Ilgvars Rukers

POSITIONING STRATEGY DESIGN (RADIO SWH)

Olga Starineca

PROFILE OF CURRENT AND POTENTIAL EMPLOYEES OF PUBLIC

ADMINISTRATION IN LATVIA AND LITHUANIA: EMPIRICAL STUDY 
May 12-14, 2016, Riga, University of Latvia

\section{Dzeina Steinberga, Inta Millere}

USE OF CASH FLOW STATEMENT IN EVALUATION OF COMPANY'S FINANCIAL SITUATION USING DATA FROM OPERATING AND LIQUIDATED COMPANIES IN

THE REPUBLIC OF LATVIA

\section{Yulia Stukalina}

MANAGEMENT OF THE LEARNIT INTERNATIONAL RESEARCH PROJECT

IMPLEMENTATION: MAIN CHALLENGES AND FOCUS AREAS

\section{Daiva Tamuleviciene}

THE INDICATOR SYSTEMS AND THE SUITABILITY OF THEIR APPLICATION IN CONTROLLING DEPARTMENT ACTIVITY

\section{Wissam Tawileh}

PREPARING BUSINESS STUDENTS FOR THE ENTERPRISE 2.0 - A CASE STUDY

FROM GERMANY

Maria Tissen, Ruta Shneidere

THE HISTORY OF FINANCIAL ANALYSIS,

ITS FOUNDERS AND THEIR SCHOOLS

Natalja Tocelovska

REVEALING THE STAGE OF DEVELOPMENT OF LATVIAN BOND MARKET

\section{Evgeniya Tonkova}

MULTI-CHANNEL DISTRIBUTION APPROACHES IN BUSINESS: SPECIFICS AND APPLICATIONS

\section{Evgeniya Tonkova}

MULTI-CHANNEL DISTRIBUTION DRIVERS AND ARGUMENTS FOR ADDING

NEW CHANNELS

Visvaldis Valtenbergs, Inguna Irbite, Inese Ebele

GLOBAL EDUCATION FOR FUTURE BUSINESS LEADERSHIP. WHAT DO

THE TEACHERS SAY?

Andzela Veselova

THE MOTIVATION AND BARRIERS FOR IMPLEMENTING THE EUROPEAN FOUNDATION FOR QUALITY MANAGEMENT BUSINESS EXCELLENCE MODEL

IN LATVIAN ENTERPRISES

\section{Renate Vidruska}

THE DIGITAL ECONOMY \& SOCIETY INDEX AND NETWORK READINESS INDEX: PERFORMANCE OF LATVIA ON EUROPEAN UNION ARENA

Karlis Vilerts, Olegs Krasnopjorovs

WHAT CAUSES THE GENDER WAGE GAP IN LATVIA? 


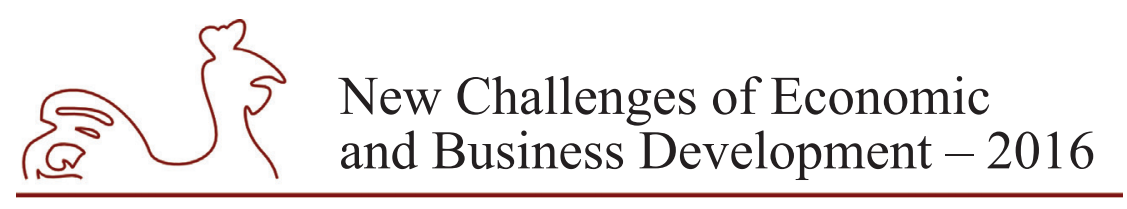

May 12-14, 2016, Riga, University of Latvia

\section{Mikhail Zaboev, Mikhail Meleshkin, Vladimir Khalin}

EVALUATION OF CURRENT LOCATION AND PROSPECTS OF THE EUROPEAN

AND RUSSIAN UNIVERSITIES AMONG THE WORLD'S LEADING UNIVERSITIES

WITH THE USE OF NEURAL NETWORK METHODS CLUSTERING OF DATA

\section{Andrejs Zlobins}

NINE MONTHS OF QUANTITATIVE EASING IN THE EUROZONE:

EMPIRICAL EVIDENCE FROM BAYESIAN VAR

Rita Zuka, Juris Krasts, Uldis Rozevskis

PREDICTIVE ANALYTICS AND CLOUD COMPUTING TECHNOLOGIES

FOR THE BUSINESS DATA ANALYSIS 


\title{
REVIEW OF THE LEGAL ISSUES OF EMPLOYEE SHARE OWNERSHIP IN EU
}

\author{
Marta Abula, Riga Stradins university, Latvia ${ }^{1}$ \\ Inna Dovladbekova, Riga Stradins university, Latvia \\ Anzelika Berke-Berga, Riga Stradins university, Latvia
}

\begin{abstract}
The paper examines legal issues concerning employee share ownership in the European Union and the latest achievements in the field by European Commission. The analyse of the legislative proposals set in EU Commission: Promotion of Employee Ownership and Participation and its' alleged impact on companies in EU member states is based on primary and secondary sources. European Commission is still not offering common legaldefinition of employee share ownership and employee financial participation across EU member states. The author argues that different national laws in EU member states regulating employee financial participation is an important obstacle for international companies to implement employee share ownership schemes in cross-board situations. The "Common European Regime" proposed by European Commission would offer employers and employees a choice between two alternative employee financial participation regimes one originating in national legislation, the other in European legislation. That could be considered to be a great step towards solution of cross-border situations when international companies are obliged to apply different national laws when implementing employee share ownership schemes, thus causing inequality between employees from different EU member states. This paper analyses problems with implementation process of employee share ownership schemes in cross-board situations and offeres most suitable way to implement common EU wide regime on employee share ownership.
\end{abstract}

Key words: employee ownership, employee financial participation, legal framework

JEL code: K22

\section{Introductions}

Employee share ownership and employee financial participation in general has been on European Union (Further: EU) agenda for over twenty-five years. Across the member states of EU, employee financial participation is the focus of increasing attention. Employee ownership and share ownership have a significant role to play in advancing economic growth and promoting a faire distribution of income and wealth. The first attempts to create systems enabling employees to receive regular shares in profit dates back to the early nineteenth century. (Blaszczyk 2014, p. 13) The subject of employee share ownership is interdisciplinary involving the issues of finance, economics, human recourse management and law perspective. It is important to note, that there is no common legal definition of employee share ownership and employee financial participation across EU member states. That makes the research of the subject more challenging and the need for collaboration of different study fields is essential.

1 Corresponding author - e-mail address: marta.abula@rsu.lv 


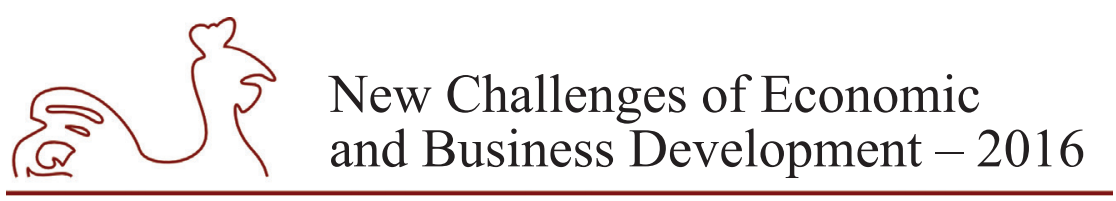

May 12-14, 2016, Riga, University of Latvia

This report describes legal aspects of employee share ownership and recent developments in financial participation of employees in their enterprises, especially employee share ownership, within the EU. The aim of the report is to present insights that will serve as a basis for discussion for further developments. Research tasks are to analyze literature about the issues mentioned above and latest EU Commission: Promotion of Employee Ownership and Participation. At the end of 2014 EU Commission initiated new Promotion of Employee Ownership and Participation where it offers legislative proposal creating uniform rules for employee financial participation schemes. In this article the new proposal, its critiques and impact on companies in EU member states is discussed. The research is based on legalistic approach where the main method used is legal analyse.

While financial participation has been supported in a number of EU Member States through tax incentives and other forms of legislation, approaches differ widely across the EU Member States. Some EU member states lack employee share ownership regulation at all. The fact that forms of employee financial participation continue to be purely national in scope means that it cannot be expanded in Europe to the extent desired to harmonize and remove impediments in the internal market for free movements of capital.

Fragmentation of regulations of employee share ownership in EU member states makes it demanding for international companies to use employee share ownership plans in crossborder situations without causing inequality between employees of different EU member states. International companies are faced with difficulties of applying different national law to implement employee share ownership schemes in cross border situations, thus making the application more complex and expensive. Principle of equality is one of the ground principle of EU and it means that the goal of EU wide employee share ownership regime would be to offer a regime applicable in all EU member states. That must be done taking into consideration that tax laws and labor laws are not in the competence of EU.

\section{Understanding employee share ownership from legal perspective}

In Europe, the participation issue of employees has always been a significant aspect of organization and management in companies. Some EU member states have developed legislative arrangements to promote the involvement of employees in various ways, employee share ownership being one of them.

Financial participation is the participation of employees in the profits of the company and / or assets of the company. Employee financial participation in companies covers a very wide range of solutions ranging from participation in profits, through individual shares in equity and employee stock options, to employee ownership systems specially designed to serve this purpose, which combine employees' participation in the profits and capital of the companies. (Bernard 2012, p. 695-696) Due to dissimilarities in the manner and degree to which employees are linked with the finances of their companies, it is possible to distinguish three basic forms of financial participation: individual employee share ownership; Employee Stock Ownership Plans and profit sharing. In the article the author will concentrate on share ownership legislative issues in EU.

Employee share ownership is a qualitatively different form of employee financial participation, since employees become co-owners and investors in the company by acquiring 


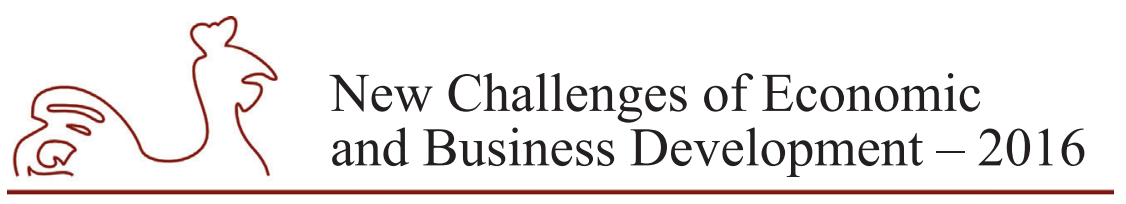

May 12-14, 2016, Riga, University of Latvia

shares. The practical meaning goes even farther, by defining the true meaning of employee share ownership. The employees' stake must underpin organisational structures that promote employee engagement in the company. Thus employee ownership can be seen as a business model in its own right. (Nuttall 2012)

Employee share ownership means that employees hold the legal right to a given part of the company's assets and to the profits produced by these assets. Employee share ownership exists either in the form of direct employee shareholding or indirect employee shareholding. An example for direct employee shareholding would be situation where employees individually acquire shares in joint stock companies. Indirect employee shareholding on the other hand includes special shareholder plans.

Employee ownership of a company's shares or bonds does not guarantee influence on business decisions. Most often, employees are represented at shareholder assemblies by substitution, and if they participate in person, their proportion among shareholders is usually too small to constitute the deciding vote. Some forms of employee ownership are purposefully designed so as not to give workers the full voting rights of their. (Blaszczyk 2014, p. 13) Nevertheless, some scholars have found positive links between employee ownership and productivity in workplaces where financial participation was combined with employee involvement in decision-making. (Bryson, Freeman 2010, p. 201-224)

There are several different ways in which employees obtain their shares in enterprises: in some systems, employees bear the acquisition costs at least partially, and in others, the acquisition of shares or stocks is fully covered by the employing company, through a bank loan or a combination of financing mechanisms, often supported by the state.

There are many justifications in different levels that support employee share ownership. For example, at the macroeconomic level it leads to higher productivity, greater competitiveness and growth. At company level it can solve labor turnover problems and improve business progression. At regional level it can encourage enterprises to stay rooted in their home communities. (InterUniversity center for European Commission's DG MARKT 2014, p. 1) During the last 20 years, a fast and resilient development of employee share ownership was detected across Europe. Some research shows that the number of employee shareholders in continental Europe decreased from 2011 to 2014. (EFES Position Paper 2015)

Research have long-established that companies partly or entirely owned by their employees are more profitable, create more jobs and pay more taxes than their competitors without employee ownership. (Inter-University center for European Commission's DG MARKT 2014, p. 1) The bulk of the empirical evidence on employee financial participation in a variety of countries and variety of settings have concluded that employee financial participation has a positive influence on the performance of companies. (Hashi, Hashani 2013, p. 188-190) There are more than 31 per cent of EU private firms who offer some form of employee financial participation - either employee share ownership or profit sharing. (Inter-University center for European Commission's DG MARKT 2014, p. 92)

Employee share ownership in European countries is strongly determined in detail by the relevant company, commercial and tax law. The legislative framework for employee financial participation varies widely across EU member states, reflecting their recent history and their different approaches and attitudes to the role of employees. The specific laws on financial participation are limited to only few countries. Mostly regulation on financial participation 


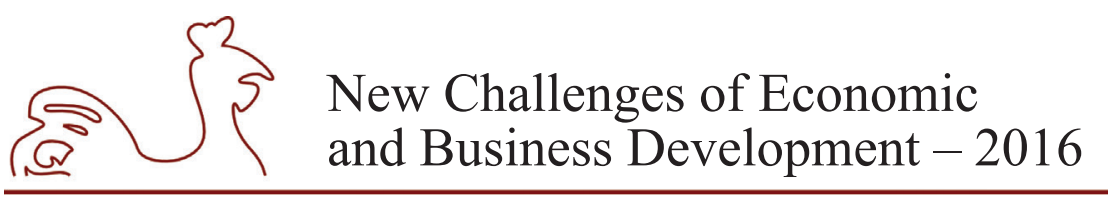

May 12-14, 2016, Riga, University of Latvia

is included in national commercial laws. It has to be stressed that there is no common legal definition of employee share ownership in EU member states, thus delaying cross-border employee financial participation plans.

The legislative framework for employee participation was largely developed in the course of privatization and complemented by the provisions of other laws, most importantly the company laws and the laws on cooperatives. These laws were intended to transform ownership of all or parts of companies from state to private. Those laws were not laws specifically aiming at financial participation. The specific laws on financial participation are limited to only few countries. Some EU member states as France, Belgium and United Kingdom provide detailed rules for the implementation of employee share ownership, but some, as Baltic states stipulate only a few rules for implementation on employee share ownership and on employee financial participation in general. Employee financial participation can be regulated in the form of company laws, tax laws, contract laws, commercial laws and labor laws in each EU member state, thus making the issue more complicated.

In Europe large companies operating in several countries can face practical implementation problems with share ownership schemes. Because of different tax laws and company statutes a participation offer of shares in a company represents different costs for the company and differing returns for individual employees, depending on the country in which the scheme is being run. For companies operating in several countries in cross-border situations important hindrances are identification of applicable law and adaption of their employee financial participation plans in other country.

Important distinguishing features of employee share ownership practice in Europe include: (Poutsman 2001, p. 14)

- access to participation schemes: for all employees or only a part;

- dependence of schemes on company performance;

- regulations on the introduction of a plan and approval: approval obligations of the authorities, collective bargaining parties or employees;

- voting rights and involvement of employees;

- range of participation: limited to one enterprise or even sectoral or regional schemes;

- state-recognized plans or voluntary company plans;

- prescribed holding periods and disposability for employees;

- allocation formula: according to company affiliation, level of earnings, and so on;

- financing of participation: profit-sharing or employees' contributions (deferred compensation).

Dissimilarities in national laws governing the forms of employee financial participation are major obstructions, which prevents employers and employees from reaping the advantages of the EU internal market. The use of all regulations is limited to their implementing Member state.

There is a need of transformation to facilitate employee plans going forward. For example, legislation and procedures relating to the offering of company shares to employees - principally under the EU Prospectus Directive. The Prospectus Directive has a number of implications for employers who wish to offer securities to employees in an EU country. An offer of shares to employees will in principle be classed as an offer of securities to the public under the Prospectus Directive, which requires the publication of a prospectus. All EU member states have implemented the EU Prospectus Directive (Prospectus Directive). However, the situation across 


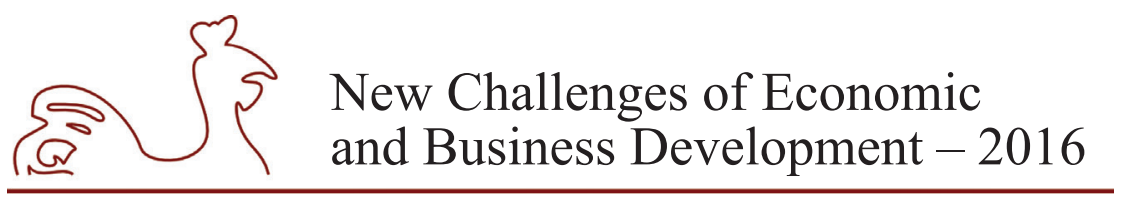

May 12-14, 2016, Riga, University of Latvia

Europe is still not a harmonized one, due to differences in the way in which the Prospectus Directive has been implemented and is being interpreted at a national level. Those stock-market laws have been reformed significantly, but the reform is only partially complete. In $2015 \mathrm{EU}$ Commission started a public consultation procedure regarding needed changes in Prospectus Directive, which closed on May, 2015. (European Commission 2015)

Recently, the European Commission and the European Parliament have undertaken initiatives to promote financial participation and to find common institutional solutions, so as to implement them on a broader scale.

\section{Recent development in EU regulation}

More than 25 years have elapsed since the Commission of the European Communities expressed an interest in promoting an EU instrument which would facilitate the implementation of financial participation of employees in companies. (European Commission 1989) At the European level, the deliberation on employee financial participation began in the early 1990s. First report of the European Commission was PEPPER I (full name: Promotion of employee participation in profits and enterprise results), was written in 1999. On the basis of this report, the Council of the European Union issued a recommendation concerning the promotion of employee participation and the European Parliament adopted a resolution on the same subject. Subsequent PEPPER reports, which were designed to diagnose progress in the field of financial participation in Europe, were written successively in 1997 (PEPPER II), where for the first time EU Commission admits that financial participation is an important way of promoting workers motivation and adaptability. (European Commission 1997) Further reports fallowed in 2006 (PEPPER III) and 2009 (PEPPER IV). The latest report also discussed the obstacles for implementation of the programs and legal, fiscal and other incentives for their application. (European Commission 2004) This report was followed by the opinion drafted by the European Economic and Social Committee in 2010. This report stressed the need to develop "a facultative, simple, uniform incentive model, with the same tax arrangements and incentives throughout the EU, [which] could considerably boost the number of cases where there is a willingness to introduce employee financial participation." (EESC opinion 2010) In the same year the Reports and Studies by the European Parliament was issued. Following that EU Commission issued the 2012 European Company Law and Corporate Governance Action Plan. Later on Commission considered options to promote employee share ownership throughout Europe.

In 2014 European Parliament issued Resolution on Employees Financial Participation emphasizing the growing importance of employee financial participation especially in small and medium sized enterprises.

So far a single common legal framework for the EU still has not been created. This is justified by the fact that the EU has no conclusive competences on internal regulations concerning enterprises or tax and fiscal systems within EU Member States. So far, the EU could only advise on good practices and provide recommendations on the mutual recognition of their rights in other EU member states.

In October, 2014 EU Commission issued The Promotion of Employee Ownership and Participation, which provides for an optional Common European Regime on employee financial participation. It introduces a "market approach" to harmonization, triggering competition 


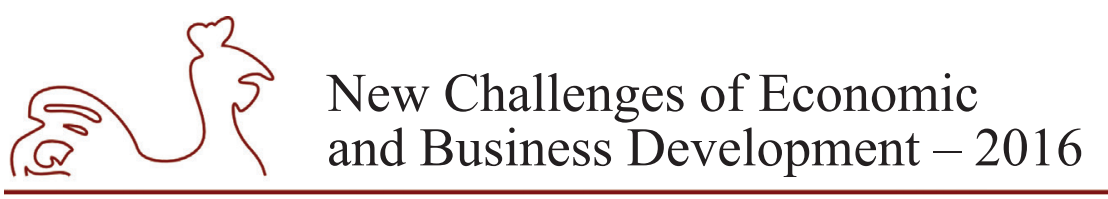

May 12-14, 2016, Riga, University of Latvia

between the existing national rules and the newly introduced second EU-wide regime. The proposed legislation is limited to the competences set for EU in the Treaty of Functioning of European Union. For example, EU competence does not extend to direct taxation and labor law.

EU Commission proposes the formation of the regime on Employee Share Ownership/ Employee Financial Participation, which would be an optional legal framework at the EU level that would exist on the top of 28 national legal regimes. Members States would be free to either keep their own national framework or opt for the proposed one. That means that there would be one single European regulatory framework. It is presumed that, since national best practice influencing the common European regime would be expected to prevail in this market-based approach, over time this development could eventually lead to mutual approximation of national regulation. The common European regime would be only an optional solution to supplement national law where there is a lack of regulation or if it is not sufficient. Advantage for state where there is no law regulating employee share ownership is the fact, that firms could utilize the common European Regime on employee share ownership in domestic setting. That would be imperative for small and medium size enterprises. In the longer term, employee share ownership schemes could also be part of the reflection on harmonization of national taxes, especially for the euro area Member States.

The most efficient instrument to be used is consider to be Regulation. The author agrees that, it would avoid a risk of discrepancies due to transposition, if the Directive were chosen as an appropriate instrument. Transposition does not require a verbatim or "copy-out," reproduction of a directive in national law, (Case C-59/89 Commission v Germany (1991) ECR I-2607, para. 18) and Member States have some leeway in deciding how to achieve the outcomes required by a Directive, using suitable legal concepts and terminology. (Case 363/85 Commission v Italy (1987) ECR 1733 Regulation on the other hand are measures that are directly applicable within all EU member states and should not be transposed in national regulations. (Case 34/73 Fratelli Variola S.p.A. v Amministrazione italiana delle Finanze. (1973) ECR 981)

The proposal of EU Commission is criticized as expensive and ineffective. (EFES Position Paper 2015, p. 8) It is argued that fiscal incentives are indispensable fundamentals for the development of employee share ownership, not the multiplicity of regulations in EU member states. The counter proposal is to implement in each EU member state a dedicated legislation, providing an optional simple, uniform incentive model, with the same tax arrangements and incentives. This option was included already in European Economic and Social Committee Opinion in 2010. (EESC opinion 2010, para. 4.2.1.) The goal of this option is the offer of the same tax arrangements and incentives throughout the EU. These tax arrangements and incentives could not be managed at EU level as they belong to the Member States' competence. Apart from EU Commission, the European Economic and Social Committee were calling for each Member State to introduce in its national legislation the same optional, simple incentive model, with the same tax arrangements and incentives. There is an obstacle for the authors to analyze this proposal as it doesn't offer any legal instruments for implementation in EU member states. It should be stressed that also European Economic and Social Committee states that before a European model with uniform tax incentives is established, mutual recognition of the schemes of the individual EU Member States should be the aim. (EESC opinion 2010, para. 4.2.3.) The new proposal of EU Commission is offering that and therefore doesn't contradict with the proposal of European Economic and Social Committee. Furthermore, it has been confirmed 


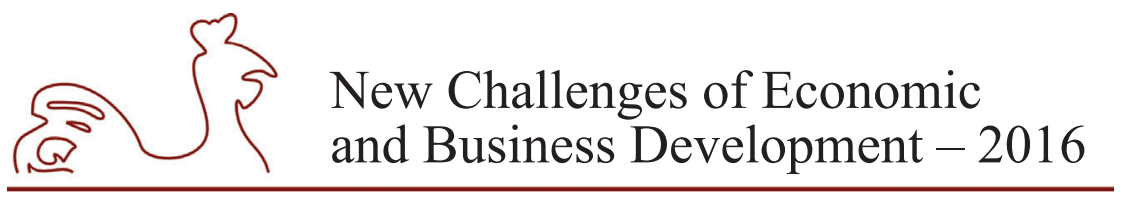

May 12-14, 2016, Riga, University of Latvia

(European Commission 2009, p. 56-58) that tax incentives are not a precondition for employee financial participation, but an effective instrument for promoting their dissemination in countries that offer them. That also shows that there is no inconsistency between the two proposals. The new proposal of EU Commission will provide for a single Employee Share Ownership regime helping to overcame obstacles raised by different regulations of employee share ownership in EU member states. It has to be added that in 2016, only non-binding recommendations will be made, which Member States may use as an orientation guide and in doing so employee share ownership will remain a voluntary instrument.

\section{Conclusions}

1. For the past years' employee financial participation, as profit-sharing and employee share ownership, has proved effective in the leading European economies

2. It has been proved that financial participation can deliver real benefits for employees, enterprises and national economies. However, despite this potential, it remains little used in most EU Member States, and is very unevenly distributed across the EU. Depending on the historical development and attitude towards employee share ownership, regulation in EU member states varies greatly in all areas including labor laws, tax lows, company laws and other laws concerning the issue.

3. The "Common European Regime" proposed by European Commission would offer employers and employees a choice between two alternative employee financial participation regimes one originating in national legislation, the other in European legislation. That could be considered to be a great step towards solution of cross-border situations when international companies are obliged to apply different national laws when implementing employee share ownership schemes, thus causing inequality between employees from different EU member states.

4. At a time when the issue of equality is increasingly relevant in EU internal market, it is time to launch a debate across the EU on employee share ownership schemes, which can help integrate the economies of the Union, while improving opportunities for businesses and their employees in the long term.

5. The research concentrated more on the instruments used in EU to regulate employee share ownership rather than on the substance of regulations, as it is impossible to intervene in national regulations by EU. It is argued that the best way to implement common EU wide regime on employee share ownership would be a regulation apart from recommendation or directive. Thus avoiding most common transposition problems and offering a simple and uniform regulation for companies to choose in EU internal market. It is important to conclude that single common legal framework for the EU is not possible because of the competences set in Treaty on Functioning of European Union.

\section{Acknowledgements}

Reaserch is supported by state reasearch programm ECOSOC. 


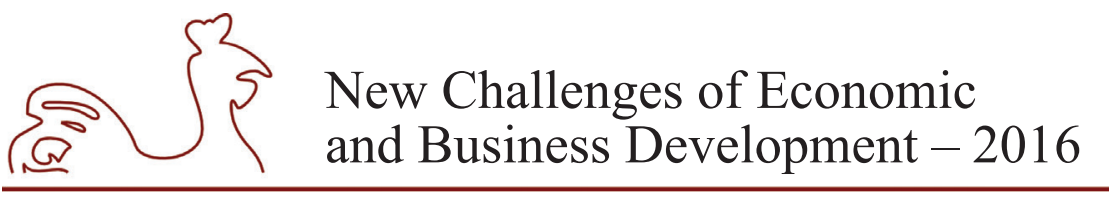

May 12-14, 2016, Riga, University of Latvia

\section{Bibliography}

1. Barnard, C. (2012), EU Employment Law, Oxford University Press, USA.

2. Blaszczyk, B. (2014), "Employee financial participation in business: Is it worth discussing?" CASE network, Studies \& Analyses, No. 472/2014.

3. Bryson, A., Freeman, R. (2010), "How does shared capitalism affect economic performance in the UK?", in Kruse, D., Freeman, R., Blasi, J. (Ed.), Shared Capitalism at Work: Employee Ownership, Profit and Gain Sharing, and Broad-based Stock Options, University of Chicago Press, Chicago, pp. 77-103.

4. Hashi, I., Hashani, A. (2013), "Determinants of financial participation in the EU: Employers' and employees' perspective", in Kruse, D. (Ed.), Sharing Ownership, Profits, and Decision-Making in the $21^{\text {st }}$ Century. Advances in the Economic Analysis of Participatory \& Labor-Managed Firms, Vol. 14 , Ch. 8.

5. Nuttall, G. (2012), "Sharing Success: The Nuttall Review of Employee Ownership", available at: https://www.gov.uk/government/uploads/system/uploads/attachment_data/file/31706/12-933sharing-success-nuttall-review-employee-ownership.pdf (accessed 27 January, 2016).

6. Poutsman, E. (2001), Recent Trends in Employee Financial Participation in the European Union. Luxembourg: Office for official Publications of the European Communities.

7. Directive 2003/71/EC of the European Parliament and of the Council of 4 November 2003 on the prospectus to be published when securities are offered to the public or admitted to trading and amending Directive 2001/34/EC, OJ 2003 L344/64.

8. EESC opinion: Employee financial participation in Europe, (2010), SOC/371 EESC-2010-1375.

9. European Commission. (1989), Communication from the Commission concerning its Action Programme relating to the implementation of the Community Charter of Basic Social Rights for Workers, COM (89) 569 final.

10. European Commission. (2015), Consultation Dokument. Review of the Prospectus Directive. Brussels, February 18, 2015.

11. European Commission. (1997), PEPPER II. Promotion of participation by employed persons in profits and enterprise results (including equity participation) in Member States 1996. Report from the Commission. COM (96) 697 final, January 8, 1997.

12. European Commission. (2009), The PEPPER IV Report: Benchmarking of Employee Participation in Profits and Enterprise Results in the Member and Candidate Countries of the European Union. Brussels, October, 2009.

13. Case 34/73 Fratelli Variola S.p.A. v Amministrazione italiana delle Finanze. (1973) ECR 981.

14. Case 363/85 Commission v Italy (1987) ECR 1733.

15. Case C-59/89 Commission v Germany (1991) ECR I-2607.

16. EFES Position Paper. (2015), European Federation of Employee Share Ownership. Employee Share Ownership For Building The Capital Market Union. The Need for a European Action Plan.

17. The PEPPER IV Report. (2009), Inter-University centre at the Institute of Eastern European Studies, Free University of Berlin, Berlin, October, 2009.

18. Inter-University center for European Commission's DG MARKT. The Promotion of Employee Ownership and Participation. Final report for European commission, October 2014. 


\title{
HOW TRUST IN ORGANIZATIONS AND INFORMATION SOURCES IMPACTS LATVIAN CONSUMERS' ATTITUDE TOWARDS GENETICALLY MODIFIED ORGANISMS
}

\author{
Inese Aleksejeva, University of Latvia, Latvia ${ }^{1}$
}

\begin{abstract}
This research examines public opinion towards genetically modified organisms (GMO) used for food, feed and other industries in Latvia and how trust in organizations and information sources impacts attitudes toward these organisms.

Consumer attitude towards GMO depends on a number of factors including the information obtained from a variety of information sources (scientific papers, TV, radio, relatives, friends etc.) and trust in regulatory actors involved in decision making process and stakeholders. Many consumers report that they receive information about genetically modified (GM) products from the media, Internet and other news sources. These sources may be less reliable than scientific experts whom consumers trust more to present the facts. Trust in regulatory actors and stakeholders involved in handling of GMO is important as they are primary source of information about new technologies. In all walks of life, individuals often look to others to help them make decisions, in particularly, when they admit a personal lack of knowledge in that area. However, if these actors are not trusted, their claims are likely to fall on deaf ears, or be consciously rejected. A lack of trust in public officials in this regard is likely to further erode public support for use of GMO.

The survey method was chosen as a tool to collect data and elicit Latvian consumers' attitude towards use of GMO in different industries. The survey was composed of 18 questions; seven of them have been structured on one to ten-point scale. The survey data of Latvia's inhabitants $(N=1184)$ were collected by the telemarketing company from September 2014 until June 2015. To select the units to be included in the sample systematic sampling was applied - every twentieth inhabitant was approached by phone call and invited to answer on survey questions.

In the frame of this research the part of the results obtained were discussed regarding the media's role in shaping public opinion, and how trust in regulatory actors and stakeholder impacts consumers' attitude towards GMO in Latvia.

The results of Latvian consumers' survey showed Latvians' attitude towards GMO were sceptical; less positive towards GM animals compared to GM plants. It was also indicated that scientific publications were the most trustful information source on GMO but friends and relatives - the lowest evaluated information source. Public trust in regulatory actors and stakeholders involved in handling of GMO played an important role on consumers' attitude shaping regarding GMO.
\end{abstract}

Key words: attitudes, consumers, genetically modified organism, information sources, regulatory actors, trust

JEL code: D81, I18, O31, Q18

1 Corresponding author - e-mail address aleksejeva.inese@gmail.com 


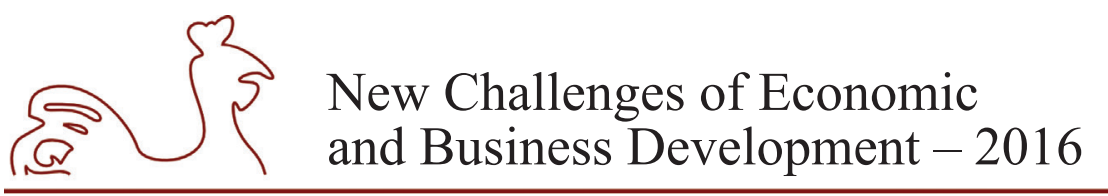

May 12-14, 2016, Riga, University of Latvia

\section{Introduction}

The question of use of genetic engineering in different industries is a hot debate in many countries all around the world. Many supporters of this technology point to potential to improve quality of life and environment. While genetic engineering refers to a number of economic benefits not just for food production but also for other industries, the community holds a lively discussion referring to health concerns, social and economic aspects, and political preferences.

The aim of this paper is to examine public opinion towards GMO used for food, feed and other industries in Latvia and how trust in regulatory actors, stakeholders and information sources on GMO issues impacts attitude towards these organisms. The main tasks were to evaluate scientific publications on consumers' trust in information sources and in regulatory actors and stakeholders involved in handling of GMO; to evaluate how trust impacts consumer's attitude towards GMO.

To date research on consumers' attitude to GM products have not been performed in Latvia and no factors identified that affect the consumers 'attitude to the products obtained with the help of genetic engineering. Our consumers' opinion is mainly reflected by the Eurobarometer without revealing the real reasons that form Latvian consumers' attitude.

Research methods applied: analysis of scientific publications, analysis of research results, analysis of statistical data and the consumers' survey on issues related to trust in regulatory actors, stakeholders and informative sources on GMO. Descriptive statistics (indicators of central tendency or location and indicators of variability), cross tabulations and correlation analysis were used.

Consumer attitude towards GMO depends on a number of factors including the information obtained from a variety of information sources (scientific papers, TV, radio, relatives, friends etc.) and trust in regulatory actors involved in decision making process and stakeholders. Many consumers report that mainly they receive information about GM products from the media, Internet, and other news sources. These sources may be less reliable than scientific experts whom consumers trust more to present the facts. But usually it is media what plays an important role informing the public about the new technologies, including genetic engineering. Media can reflect and shape public opinion on scientific achievements as well as to influence policy-making (Bubela et al., 2009; Mehendale, 2004).

Trust in regulatory actors and stakeholders involved in handling of GMO is important, it is a primary source of information about new technologies. In all walks of life, individuals often look to others to help them make decisions, in particularly, when they admit a personal lack of knowledge in that area. However, if these actors are not trusted, their claims are likely to fall on deaf ears, or be consciously rejected. A lack of trust in public officials in this regard is likely to further erode public support for use of GMO.

Most results show that consumer who trust the people who manage risk believe technology poses a lower risk but the consumer who express no trust in the managers of risk believes that technology poses a greater risk (Johnson, 1999; Metlay, 1999).

It is very important that public authorities provide reliable and objective information on GM food risks and benefits, because false information that can be distributed by specific interest groups and different private organizations affects consumer attitudes toward GM food. Role of the government in building of public confidence in the competent authorities would be a good strategic step in the field of GMO. Although, according to Costa-Font and Mossialos (2006), 


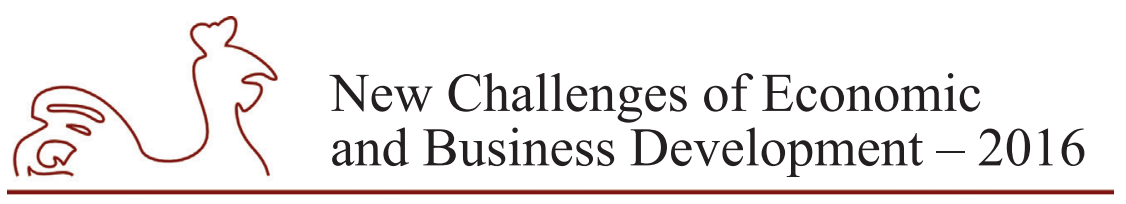

May 12-14, 2016, Riga, University of Latvia

there is a lack of effective communication in relation to the potential GMO risks and benefits, taking into account the fact that there is scientific uncertainty caused by a high number of information sources.

Considering the fact that the media (including - Internet and television) plays a vital role in shaping public opinion, the mutual cooperation of media, scientists and policy-makers should focus on offering the public a scientifically based and balanced information, not unfounded facts and data from a dubious source of information.

\section{Research results and discussion}

In order to understand public opinion regarding the new technologies, it is essential to be aware of public confidence in scientific institutions, institutions involved in the decisionmaking process and other interested parties (Bonny, 2003). For public risk assessment of the new products is one of the most sensitive and important steps in GMO decision-making process. Public and a number of non-governmental organizations have expressed their lack of confidence in the European Food Safety Authority (EFSA) - the main risk assessment body in the EU. GMO opponents pointed out and continue to point to the defective GMO environmental risk assessment - interbreeding with wild relative plants, possible impurities in conventional and organic crops, uncontrolled spread of herbicide-resistant crops into environment, erosion of biodiversity etc. (Priest, Bonfadelli, \& Rusanen, 2003).

One part of the public indicates that it is not sufficiently involved in the decision-making process regarding the release of GMO and express the desire to participate in the processes related to biotechnology (Miles, \& Frewer, 2001, 2002).

Others believe that sometimes the responsibility for decision-making should lie solely on the shoulders of experts, because they "know better" (Gaskell et al., 2010). This assumption cannot be generalized, because sometimes the issues are too sensitive to decide only at the expert level. Distrust in the competent authorities and companies involved in the commercialization of GMO, is growing rapidly, stimulated by the public faith that "they are hiding something from us" or that there is still too much unknown.

Often it is not clear for consumers or they are not aware of the existence of the legal framework on GMO risk assessment and handling. With regard to the regulatory system it is believed that "the regulatory system works well if there is a compliance" or "the rules always will be modified as needed" or "the rules have to be broken." The legislators are always reproached that they allow that citizens without specific knowledge depend on the imposed point of view or producers' influence (Marris, 2001).

The decisions of the scientific community and decision-makers should be well thought out, reliable and clear in relation to GM food safety or riskiness. But in recent years a number of food-related accidents (bovine spongiform encephalopathy, dioxin, foot and mouth disease, bird flu, etc.) is strongly undermined public confidence in food producers and their ability to produce safe food; the public has lost confidence in the researchers responsible for risk assessment and institutions involved in risk management (Gaskell et al., 2010). As a result, food security has become a key priority among the European legislative bodies.

Public and consumers have expressed distrust to the national authorities involved in GMO decision-making, to scientists responsible for GMO risk assessment and companies developing GMO for commercial purposes. The most obvious it is in relation to GM food, where 


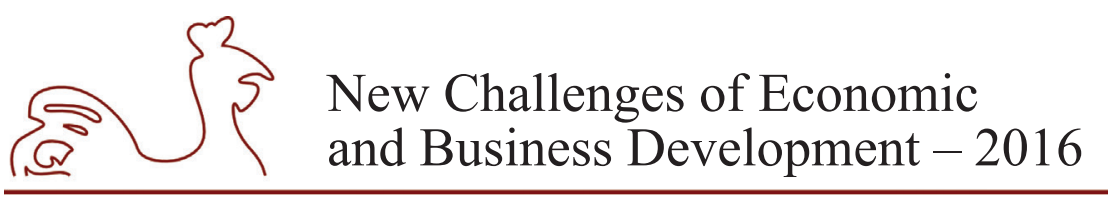

May 12-14, 2016, Riga, University of Latvia

environmental activists and organizations have launched a fight against the leading companies, such as Monsanto, thereby increasing public concerns about the safety of GM food (Weldon \& Laycock, 2009).

There is still a discrepancy in the scientific community regarding the risk assessment that makes the public dependent on interpretations and explanations of information provided by the scientists and the media (Bonny, 2003). Consumers have expressed frustration with the fact that the uncertainties related to the potential risks are not adequately taken into account in decisionmaking process and risk communication with the public.

According to Weldon and Laycock (2009) confidence to the competent authorities is essential for two reasons. First, the competent authorities are the primary source of information and data relating to new technologies. In all areas of life, individuals often look to others to help them make decisions, particularly when they perceive a personal lack of knowledge in that area. As "official" sources of scientific knowledge, scientists and state regulators can play a critical role in educating the public. However, if these institutional actors are not trusted, their claims are likely to fall on deaf ears, or be consciously rejected. Individuals will then look to other sources of information, such as relatives or friends, social or political organizations, or other perceived experts, as a conscious basis for their judgments (Bennett \& Calman, 1999). Secondly, and that is probably even more important in the development of relevant policies and the promotion of public welfare, the competent authorities are responsible for determining the balance between the potential risks and benefits of the new technologies. Lack of trust in competent authorities may adversely affect the support for new technologies (Weldon \& Laycock, 2009).

Despite the fact that in the society there are many different uncertainties related to the safety aspects, in many countries around the world scientists, government representatives and international companies continue to support GM food. They argue that the researchers conduct genetic changes in plants in order to increase their usefulness - quality and productivity, nutritional value, resistance to pests, diseases and drought, and in order to obtain proteins useful in human and animal treatment (Omobowale, Singer \& Daar, 2009).

According several studies, benefits indicated by the scientists, government representatives and international companies, often are denied by society that shows that the public is sceptical about the potential benefits of genetic engineering and concerned about the potential risks GMO may cause to the individual and society.

According to Durant and Legge (2005) support to GMO positively related to the trust of public to the competent authorities, if they provide the public with information about the potential benefits and risks of GMO, but Hossain et al. (2003) believes that confidence in the competent authorities constitutes indirect support for genetic engineering technology. Consequently, trust in the government and scientists is seen as an essential factor in GM food acceptance (Hossain and Onyango, 2004; Hossain et al., 2003; Onyango, 2004).

For example, Siegrist (2000) found that in Switzerland trust in the responsible authorities in the field of genetic engineering positively correlate with the potential benefits and negatively - with the potential risks. Similarly, Priest (2001) found that in the US the individuals' trust in representatives of agriculture, biotechnology and retail is much more important than individuals' knowledge of genetics or genetic engineering.

In the surveys conducted in Italy and the US it was found that the confidence in public institutions responsible for GMO control has a significant impact on Italian and American 


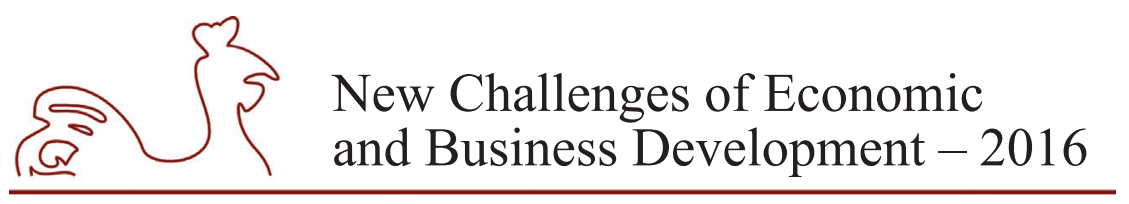

May 12-14, 2016, Riga, University of Latvia

consumers' wish to buy GM food. With increasing faith in ability of the competent authorities to control GMO and to carry out the monitoring, consumers' wish to buy GM food is also increasing (Harrison, Boccaletti \& House, 2004). According to another survey conducted by Lang (2012) in the US it was found that honesty was a key factor of confidence in the competent authorities involved in the handling of GM food.

Analysing public confidence in the existing legislation and legislative bodies in the UK it was found that the trust contributes to greater support for gene therapy, human cloning, gene databases, than, for example, individuals' interest in genetics or their education level in this field (Barnett et al., 2007). Investigations performed by Frewer et al. (1996) and Moon and Balasubramanian (2001) showed that according to American and British consumers' point of view the government and the scientific institutions are the main competent authorities for GM food control.

Study performed by Rodriguez-Entrena et al. (2013) showed that the Spanish trust in competent institutions, government and scientific representatives, raise awareness of the potential benefits of GM food. The same findings were proved in a study carried out by Costa-Font and Gil (2009) in Mediterranean countries (Italy and Spain). Thus, the confidence in the competent authorities responsible for risk assessment may increase confidence in the national competent authorities. Consumers will feel protected and informed about GM food development, therefore it is possible to predict potential future commercialization of GM food.

According to Durant and Legge (2005) the public preference to GM food is influenced by its understanding of the government's ability and wish to control GM food as well as to protect public health, safety and the environment. The greater the faith of individuals in the government and biotechnology policy development, the more likely that they will support GM foods.

In the study of Eurobarometer 2005 public confidence in the safety control and legislative bodies in the field of biotechnology was investigated, as well as how the trust correlates with support for this technology. Overall, the results showed that confidence in the relevant institutions in this area in the EU is quite low. Significantly large proportion of the EU citizens are not sure about the control bodies' ability to protect them from damage caused by GM (Gaskell et al., 2005).

Public distrust in decision-makers (especially in the EU) has negatively impacted the release and placing on the market of GMO, so it is essential to perform consumers' attitude analysis and to find out the sources of dissatisfaction in order to set up a regulatory system that meet consumers' needs and expectations and facilitate placing on the market of GM products (Miles, Ueland, \& Frewer, 2005).

It should be noted that five years later according to the Eurobarometer 2010 results, despite the controversy associated with GM food and GM crops and concerns regarding the new technologies, appeared robust and positive understanding of biotechnology. The Europeans left the distrust in the competent authorities in the past. It should be also noted that both national governments and the EU earned the same confidence in most of the EU Member States. It is possible that the idea of development of national GMO legislation in the frame of the EU legislation has gained public support (Gaskell et al., 2010).

Of course, it is important to understand that consumers are affected not only by the information available but also by the level of trust in the information source. For example, in a study conducted by Meijnders et al (2009) it was found that consumers have more trust in those information sources that provides information which is in line with their own views. 


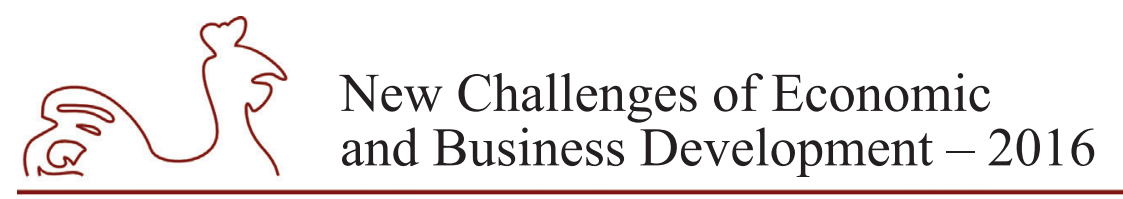

May 12-14, 2016, Riga, University of Latvia

When we open the newspaper, there is a chance that we will find an article on technological innovations in various fields. Testing of the new products allows the consumer himself to make conclusions about the usefulness of the product, but testing is not always possible, because the new product may not be available in the market or a new technology is not one consumer can directly test. When direct experience is not possible, the consumer is often looking for other sources of information. Although even product testing does not say anything about its long-term health effects; this information can be obtained by the consumer from other sources and here the press and the media play a key role, as it were, for example, in the case of bovine spongiform encephalopathy, when the increased press attention and negative information provided decreased beef consumption substantially.

In the 80 s of the last century, when there was a little article on GMO, the journalists positioned biotechnology as a promising innovation (Bonny, 2003). In 1995-1997 media attention to the issues on GMO increased in such countries as France, Austria, Great Britain, the Netherlands and Sweden. During this time several non-governmental organizations were involved in discussions on these issues and various advisory groups were established (Liakoupoulous, 2002). As a result, the articles on GMO and on pros and cons aspects increased rapidly and still continue to grow (Gaskell, Thompson \& Allum, 2002).

At the end of the $20^{\text {th }}$ century more and more critical articles on GMO appeared in the press. Several journalists focused only on potential risks of GMO and fought against placing on the market of GM products, sometimes by joining to various opposition movements. This is explained by the fact that initially the issues related to GMO were reflected by scientific journalists who had a relatively positive attitude. Later on when the issue became politically and economically sensitive the subject began to be challenged by those who worked with issues such as BSE, asbestos, etc. and who tried to draw a parallel between these issues (Durant \& Lindsey, 2002; Kassardjian, 2002).

Another explanation could be found in the specific of journalist profession and the growing competition among the media (Champagne, 2001). Research shows that the newspapers for majority of society are one of the main sources of information in relation to potential food risks (Frewer et al., 1996). Shocking titles reveal hidden dangers and dramatic presentation of the issue guarantees a wider audience and affects the readers more than reasonable titles and proficient information; it is a tendency to exaggerate and beat each other (Bonny, 2003).

In the study carried out by the US, the UK and Spain in 2008 it was found that, for example, in Spain and the UK press more focuses on the risks and potential dangers of GM foods to human health. As in other EU Member States (unlike the US) available articles highlight risks and show GM food in controversial light. The press articles in Spain and the UK rarely show GM food benefits (Vilella-Vila \& Costa-Font, 2008).

In the study conducted in 2012 in China an analysis of 77 articles of two major Chinese newspapers were made. It was found that the potential GMO benefits were more reflected compared to potential risks. $48.1 \%$ of the articles gave positive information about GMO but $51.9 \%$ - neutral. The potential risks were mentioned in the newspapers but none of the articles reflected a negative opinion which indicated that the Chinese media was more supportive of GMO. This situation could be explained by the fact that the Chinese government provides strong support for genetic engineering research and development of new products. Many articles reflected interviews with experts in the field as well as provided educational information about the nature of genetic engineering (Du \& Rachul, 2012). 


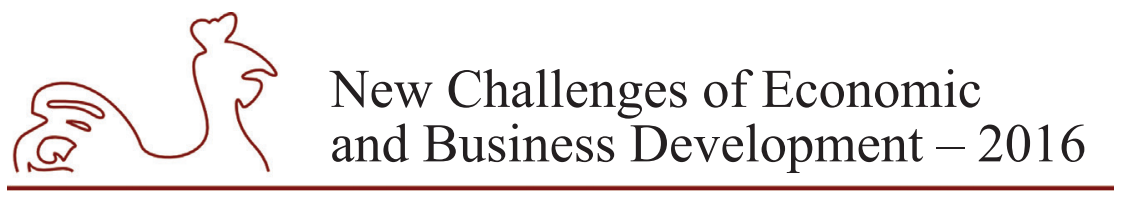

May 12-14, 2016, Riga, University of Latvia

In Latvian, for example, most of the articles related to genetic engineering reflect negative position as well as reflect more risks than potential benefits. This situation can be explained by the fact that in Latvian genetic engineering is not allocated as priority, in the country there is no almost research activities related to GMO, GM products available are imported and not produced locally and policy-makers are not directly involved in these issues. Thereby the media has greater opportunities to manipulate with information and data influencing public perception of GMO risks.

\section{Methodology of the Empirical Study}

This study has been carried out with survey method within the descriptive research method. The survey method was chosen as a tool to collect data and elicit Latvian consumers' attitude towards use of GMO in different industries. The survey was composed of 18 questions; seven of them have been structured on ten- point Likert scale. Likert scale is widely used since it allows the consumers to express their attitudes in a regular and meaningful way and it is easy to use for those who conduct market researches (Koç, 2008). The survey data of Latvia's inhabitants $(N=1184)$ were collected by the help of telemarketing company (contracted by author) from September 2014 until June 2015. To select the units to be included in the sample systematic sampling was applied - every twentieth inhabitant was approached by phone call and invited to answer on survey questions. Telemarketing company reported daily on results: number of respondents approached and responses received.

Among other questions about consumer attitudes towards GMO, the questionnaire contained question about information sources on GMO. The survey instructed respondents to choose among 8 sources (it was possible to choose several variants or to indicate other source): friends, relatives and acquaintances; books; informative events and seminars; Internet; newspapers and magazines; radio; TV; scientific publications. The survey instructed respondents also to rate their trust in these informative sources using Likert scale? (there 1 - no trust at all, but $10-$ complete trust).

In addition, the survey instructed respondents to rate their trust in eight organizational actors and stakeholders concerning GMO. Specifically, the instructions asked respondents "Is your attitude towards GMO impacted by trust in the following groups?" (there 1 - no trust at all, but 10 - complete trust). These groups - responsible decision makers, government agencies responsible for supervision and control, media, producers of GMO, scientists responsible for risk assessment, consumer protection organizations, food manufacturers, grocers and grocery stores, environmental organizations - were selected because of their importance in the organizational field, and because surveys such as the Eurobarometer have also included basic trust measures for some of these groups, permitting future cross-cultural comparisons.

General sociodemographic variables of the respondents consist of gender, age, income, education, marital status, occupation, religious affiliation and residence. The obtained data were analysed through SPSS programme. 
May 12-14, 2016, Riga, University of Latvia

\section{Analysing the Collected Data}

The results of the survey indicated that the most of the consumers use different information sources on GMO (Table 1).

Table 1

Which information sources do you use to obtain information and knowledge on genetic modification and GMO?

(Several options could be chosen)

\begin{tabular}{|l|c|c|}
\hline \multicolumn{1}{|c|}{ Information sources on GMO* } & Frequency & Percent \\
\hline Friends, relatives and acquaintance & 298 & 25.2 \\
\hline Books & 232 & 19.6 \\
\hline Informative activities and seminars & 236 & 19.9 \\
\hline Internet & 824 & 69.6 \\
\hline Newspapers and journals & 436 & 36.8 \\
\hline Radio & 270 & 22.8 \\
\hline TV & 524 & 44.3 \\
\hline Scientific publications & 326 & 27.5 \\
\hline $\begin{array}{l}\text { Do not have special interest on this issue and with special purpose } \\
\text { do not seek any information }\end{array}$ & 236 & 19.9 \\
\hline
\end{tabular}

Source: Author's calculations based on Inese Aleksejeva conducted Latvian consumers' survey in 2014 and 2015 $(n=1184)$.

*Original questionnaire was created in Latvian and alphabetic order was applied for information sources to exclude influence on respondents.

The results of the survey indicated that the respondents mostly used Internet $(69.6 \%)$ and watched TV (44.3\%) to obtain information and knowledge on GMO. The books, informative events and seminars was mentioned as the least usable information and knowledge sources (around 20\%); almost 20\% of respondents also stated that they have no particular interest in GMO issues and they did not purposely seek information.

According data obtained consumers' trust in different information sources on issues related to GMO in general were very different, but average evaluations for all analysed sources of information (friends, relatives and acquaintances; books; informative events and seminars; Internet; newspapers and magazines; radio; TV; scientific publications) were rather high and no one source of information related to GMO had average evaluations (neither arithmetic mean, neither mode, neither median) less than 5 in the 1-10 point scale as it is indicated in Table 2 . The results of the Latvian consumers' survey indicated that the most trustful source of information on GMO were scientific publications with average mean evaluation 8.2, mode 9 and median 9 although all evaluation scale was covered. The lowest evaluated source of information was expressed regarding friends, relatives and acquaintances with average mean evaluation 5.2, mode 5 and median 5 although all evaluation scale was covered. The biggest variability of evaluations was for source "friends, relatives and acquaintances" (see Table 2). 


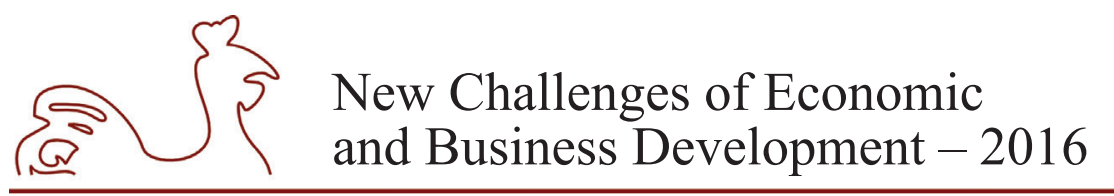

May 12-14, 2016, Riga, University of Latvia

Table 2

Main statistical indicators of consumer evaluations on trust for sources of information about GMO

\begin{tabular}{|c|c|c|c|c|c|c|c|c|c|}
\hline Information sources & $\sum_{\Sigma}^{\bar{E}}$ & 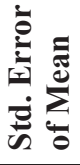 & & $\frac{0}{\Sigma}$ & 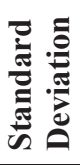 & 芯 & 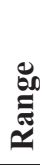 & 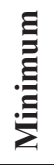 & 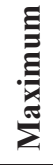 \\
\hline Friends and relatives & 5.2 & 0.08 & 5 & 5 & 2.37 & 5.62 & 9 & 1 & 10 \\
\hline Books & 6.9 & 0.07 & 7 & 7 and 8 & 2.07 & 4.27 & 9 & 1 & 10 \\
\hline $\begin{array}{l}\text { Informative events and } \\
\text { seminars }\end{array}$ & 6.8 & 0.07 & 7 & 8 & 2.07 & 4.29 & 9 & 1 & 10 \\
\hline Internet & 5.9 & 0.06 & 6 & 5 & 1.89 & 3.58 & 9 & 1 & 10 \\
\hline Newspapers and journals & 5.7 & 0.07 & 6 & 5 & 2.02 & 4.08 & 9 & 1 & 10 \\
\hline Radio & 5.8 & 0.07 & 6 & 5 & 2.04 & 4.17 & 9 & 1 & 10 \\
\hline TV & 5.8 & 0.07 & 6 & 5 & 2.23 & 4.96 & 9 & 1 & 10 \\
\hline Scientific publications & 8.2 & 0.06 & 9 & 9 & 1.79 & 3.19 & 9 & 1 & 10 \\
\hline
\end{tabular}

Source: Author's calculations based on Inese Aleksejeva conducted Latvian consumers' survey in 2014 and 2015 $(n=1184)$, evaluation scale $1-10$, where 1 - do not trust; 10 - fully trust.

Latvian consumers considered that scientific publications, books, informative events and seminars are the most trustful sources of information on GMO. About $75.6 \%$ of consumers trusted or fully trusted in information obtained from scientific publications, about $42.9 \%$ - in information from books, about $42.7 \%$ - in information from informative events and seminars (evaluations 8-10), consumers trusted less in information obtained from TV (about $24.8 \%$ trusted or fully trusted), Radio (about 21.4\%), Internet (about 20\%), newspapers and journals (about 19.9\%), friends, relatives and acquaintances (about 16.9\%) (see Table 3 ).

Table 3

Consumers' evaluations on trust in information sources on GMO

\begin{tabular}{|l|c|c|c|c|c|c|c|c|c|c|}
\hline \multirow{2}{*}{} & \multicolumn{10}{|c|}{ Evaluations (points) } \\
\cline { 2 - 12 } & $\mathbf{1}$ & $\mathbf{2}$ & $\mathbf{3}$ & $\mathbf{4}$ & $\mathbf{5}$ & $\mathbf{6}$ & $\mathbf{7}$ & $\mathbf{8}$ & $\mathbf{9}$ & $\mathbf{1 0}$ \\
\hline Friends and relatives & 6.9 & 8.7 & 10.3 & 9.8 & 24.5 & 10.5 & 12.4 & 7.3 & 4.6 & 5.0 \\
\hline Books & 2.5 & 0.9 & 3.2 & 3.4 & 15.9 & 10.9 & 20.4 & 20.4 & 12.7 & 9.8 \\
\hline Informative events and seminars & 1.8 & 1.6 & 5.5 & 2.5 & 15 & 13.4 & 17.5 & 22.8 & 11.8 & 8.1 \\
\hline Internet & 2.4 & 1.7 & 5.8 & 7.5 & 26.9 & 15.6 & 20.1 & 12.6 & 3.8 & 3.6 \\
\hline Newspapers and journals & 4.7 & 3.4 & 5.1 & 6.5 & 26.2 & 17.4 & 16.8 & 13.6 & 3.8 & 2.5 \\
\hline Radio & 4.3 & 3 & 6.4 & 6.4 & 26.1 & 16.5 & 15.8 & 14.4 & 4.3 & 2.7 \\
\hline TV & 4.7 & 5.6 & 5.3 & 4.9 & 26.7 & 12.2 & 15.8 & 14.2 & 6.4 & 4.2 \\
\hline Scientific publications & 0.6 & 1.1 & 0.9 & 0.9 & 6.9 & 3.5 & 10.6 & 22 & 27.9 & 25.7 \\
\hline
\end{tabular}

Source: Author's calculations based on Inese Aleksejeva conducted Latvian consumers' survey in 2014 and 2015 $(n=1184)$, evaluation scale $1-10$, where 1 - do not trust; 10 - fully trust. 


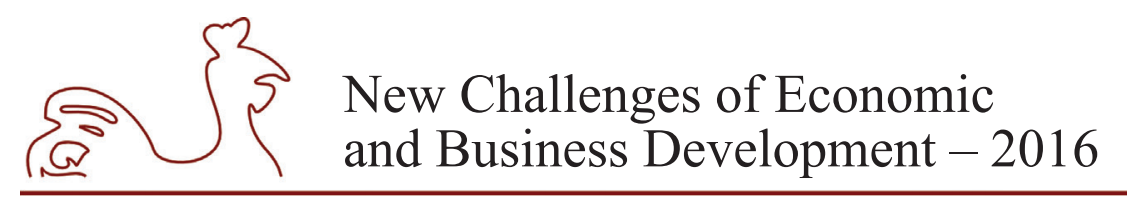

May 12-14, 2016, Riga, University of Latvia

The females evaluated the trust in information sources on GMO higher than males. The differences in the opinions of trust in scientific publications, informative events and seminars, newspapers and journals, books were statistically relevant with high probability, proved by Mann-Whitney test results (accordingly $z=-8.830, p=0.000 ; z=-5.448, p=0.000 ; z=-2.482$, $p=0.013 ; z=-3.130, p=0.002$ ). The females and males' evaluations of different information source on GMO are presented in figure.

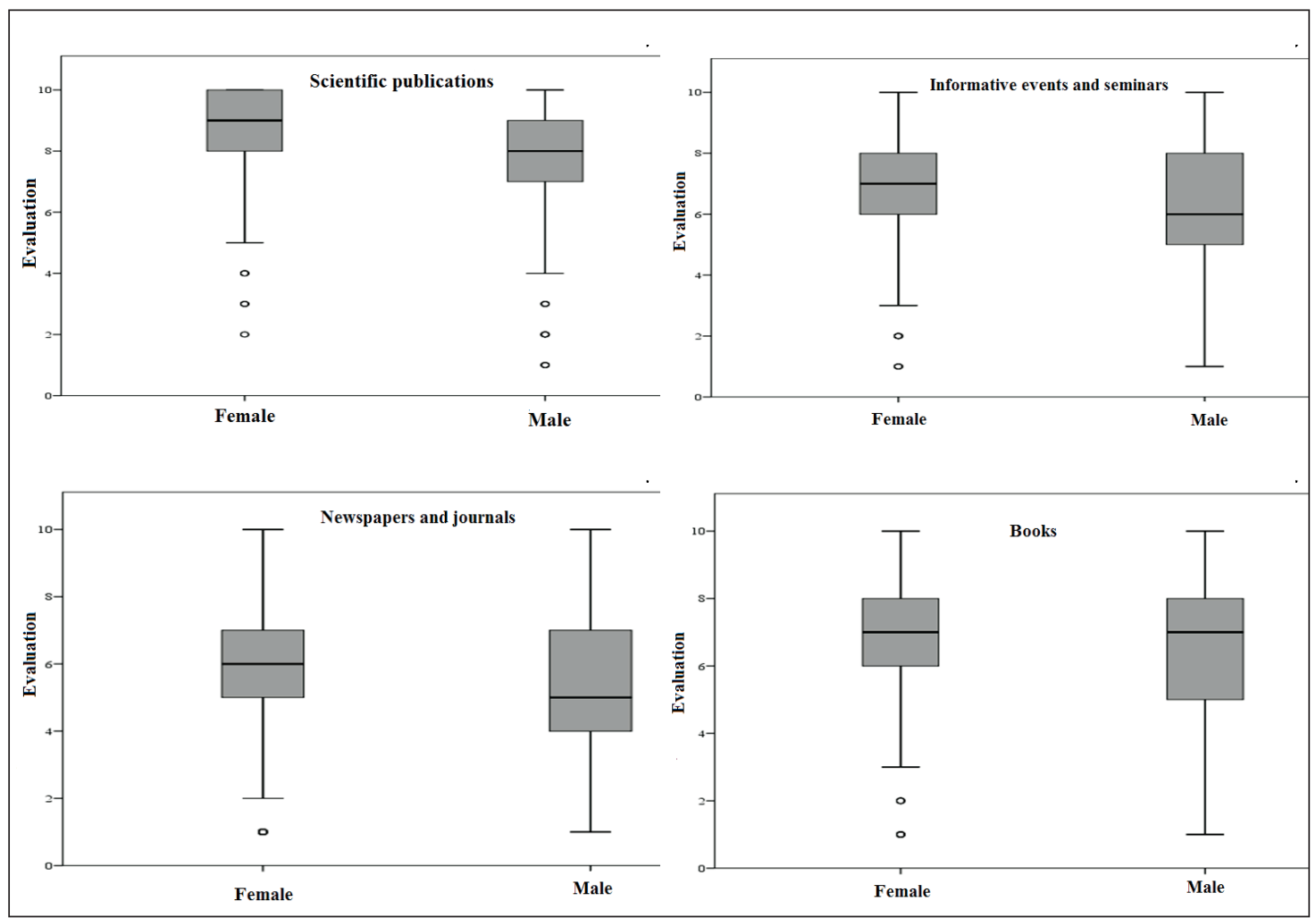

Source: Author's calculations based on Inese Aleksejeva conducted Latvian consumers' survey in 2014 and 2015 $(n=1184)$, evaluation scale $1-10$, where 1 - do not trust; 10 - fully trust.

Fig. The females and male's evaluations of different information sources on GMO

Latvian consumer trust in regulatory bodies and stakeholders involved in handling of GMO are reflected in Table 4. 


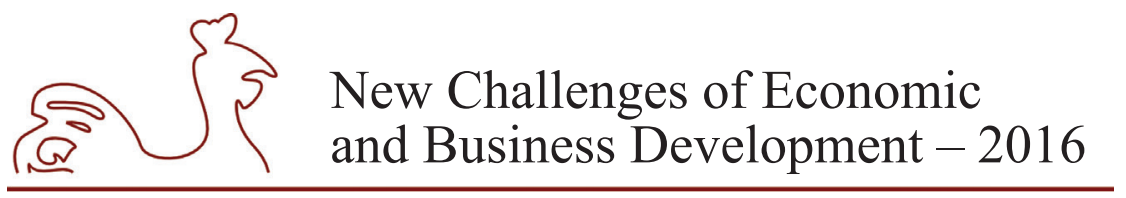

May 12-14, 2016, Riga, University of Latvia

Table 4

Main statistical indicators on respondent's evaluations for

"Do your attitude towards GMO influences trust level"

\begin{tabular}{|c|c|c|c|c|c|c|c|c|c|}
\hline Information sources & 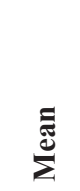 & 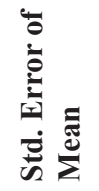 & 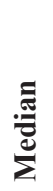 & $\frac{\mathscr{0}}{\tilde{g}}$ & 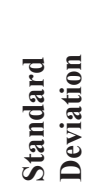 & 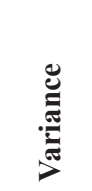 & 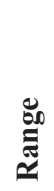 & 声 & 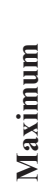 \\
\hline $\begin{array}{l}\text { Responsible politicians and decision } \\
\text { makers }\end{array}$ & 3.14 & 0.073 & 3 & 1 & 2.239 & 5.012 & 9 & 1 & 10 \\
\hline $\begin{array}{l}\text { Competent monitoring and control } \\
\text { institutions }\end{array}$ & 5.6 & 0.082 & 6 & 5 & 2.531 & 6.405 & 9 & 1 & 10 \\
\hline Mass media & 4.08 & 0.072 & 4 & 5 & 2.225 & 4.952 & 9 & 1 & 10 \\
\hline $\begin{array}{l}\text { Companies responsible for GMO } \\
\text { development }\end{array}$ & 3.99 & 0.088 & 4 & 1 & 2.724 & 7.42 & 9 & 1 & 10 \\
\hline $\begin{array}{l}\text { Scientists responsible for GMO risk } \\
\text { evaluation }\end{array}$ & 6.29 & 0.083 & 7 & 8 & 2.588 & 6.698 & 9 & 1 & 10 \\
\hline Consumer protection institutions & 5.58 & 0.081 & 6 & 5 & 2.503 & 6.263 & 9 & 1 & 10 \\
\hline Food producers and sellers & 3.15 & 0.07 & 3 & 1 & 2.164 & 4.683 & 9 & 1 & 10 \\
\hline $\begin{array}{l}\text { Environmental activists and } \\
\text { environmental organizations }\end{array}$ & 6.23 & 0.081 & 7 & 7 & 2.52 & 6.352 & 9 & 1 & 10 \\
\hline
\end{tabular}

Source: Author's calculations based on Inese Aleksejeva conducted inhabitants of Latvia survey in 2014 and 2015 $(n=1184)$, evaluation scale $1-10$, where $1-$ do not trust; 10 - fully trust.

The results of the survey indicated that consumers expressed the most confidence in scientists responsible for GMO risk evaluation (arithmetic mean was 6.29 , the most of respondents gave evaluation 8 (mode) and half of respondents gave evaluations 7 or less and half of respondents gave evaluations 7 or more (median). Environmental activists and environmental organisations were indicated as the second most trustful stakeholder (arithmetic mean was 6.23 the most of respondents gave evaluation 7 (mode) and half of respondents gave evaluation 7 or less and half of respondents gave evaluation 7 or more (median). The responsible politicians and decision makers were indicated as less trustful (arithmetic mean was 3.14 the most of respondents gave evaluation 1 (mode), half of respondents gave evaluation 3 or less and half of respondents gave evaluation 3 or more (median). Almost the same evaluation was expressed regarding food producers and sellers with arithmetic mean of evaluations 3.14 , mode -1 and median -3 . The biggest differences in respondents' evaluations were expressed regarding companies responsible for GMO development (the biggest standard deviation of the evaluations). 


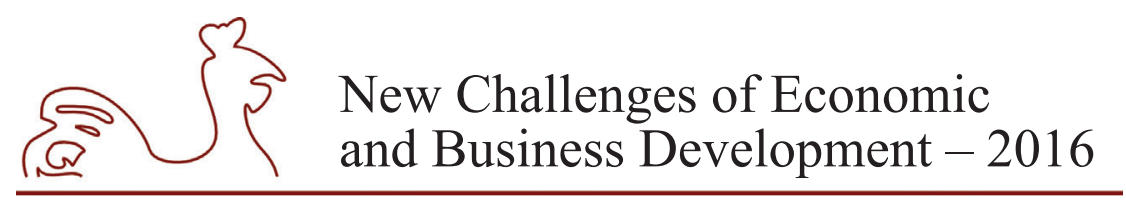

May 12-14, 2016, Riga, University of Latvia

\section{Conclusions}

\section{Conclusions resulting from the analysis of scientific publications:}

1. In a number of countries, public confidence in the competent authorities involved in GMO decision-making process and control affect consumers' attitude and willingness to buy GM products;

2. Trust in the competent authorities and related legislation is a precondition for acceptance of new technologies;

3. Trust in GMO risk assessment and authorization process is low in all EU Member States, although in recent years a positive tendency is observed.

4. Media plays an important role in public information reflecting and creating a public perception of genetic engineering thus affecting the relevant policy-making;

5. The consumers are affected not only by the information available but also by the level of trust in informative source; furthermore, the consumers more trust informative sources that provides information in line with their own views;

6. The predominance of negative information related to GMO in the media can be explained by a number of food crises to which journalists tried to draw a parallel reflecting the issues on GMO as well as in the specific of journalist profession and the growing competition among the media.

\section{Conclusions resulting from the analysis of survey's data:}

1. To obtain information and knowledge on genetic modification and GMO Latvian consumers mainly use Internet and TV as information sources.

2. The most trustful source of information on GMO were scientific publications, the lowest evaluated source of information was friends, relatives and acquaintances.

3. The females' trust in information sources on GMO was higher than males. The differences in the opinions of trust in scientific publications, informative events and seminars, newspapers and journals, books were statistically relevant with high probability.

4. From Latvian consumers' point of view he most trustful regulatory actors and stakeholders involved in GMO issues were scientists responsible for GMO risk evaluation and environmental activists and environmental organizations. The responsible politicians and decision makers and food producers and sellers were indicated as less trustful.

In the end, it is even questionable which degree of support of genetic modification can be reached and which degree is needed. As everywhere, people have different opinions about technologies and there is not a single one which is supported by all consumers. Genetic modification will likely never reach full support. Therefore, a successful management of the coexistence of GM and GM-free production appears to be a crucial step in fostering the social acceptance of the technology. 


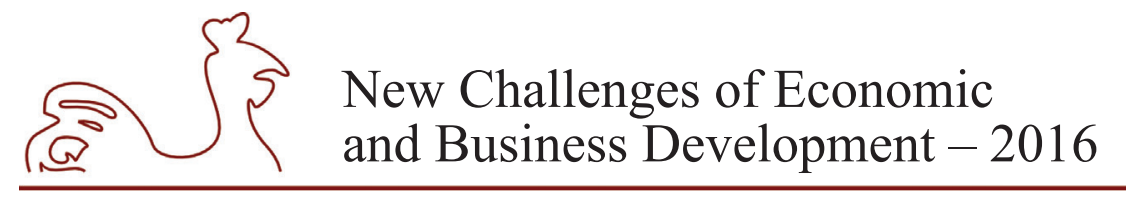

May 12-14, 2016, Riga, University of Latvia

\section{Bibliography}

Barnett, J., Cooper, H., \& Senior, V. (2007). Belief in Public Efficacy, Trust, and Attitudes Towards Modern Genetic Science. Risk Analysis 27(4), 921-933.

Bennett, P., \& Calman, K. (1999). Risk Communication and Public Health. Oxford: Oxford University Press, 3-19.

Bonny, S. (2003). Why are Most Europeans Opposed to GMOs? Factors Explaining Rejection in France and Europe. Electronic Journal of Biotechnology 6(1), 50-71.

Bubela, T., Nisbet, M.C., Borchelt, R., Brunger, F., Critchley, C., Einsiedel, E., Geller, G., Gupta, A., Hampel, J., Hyde-Lay, R., Jandciu, E. W., Jones, S. A., Kolopack, P., Lane, S., Lougheed, T., Nerlich, B., Ogbogu, U., O’Riordan, K., Ouellette, C., Spear, M., Strauss, S., Thavaratnam, T., Willemse, L. \& Caulfield, C. (2009). Science Communication Reconsidered. Nature Biotechnology 27, 514- 518.

Champagne, P. (2001). Effets médiatiques: réflexions sur l'éthique des médias. In: Proceedings of the Summer University of Innovation Rurale, Toulouse, Mission d'animation des Agrobiosciences, p. 27-32, [26.02.2015]: http://www.agrobiosciences.org/doc/7_univ_marciac.pdf.

Costa-Font M. \& Gil J. M. (2009). Structural Equation Modelling of Consumer Acceptance of Genetically Modified (GM) Food in the Mediterranean Europe: A Cross Country Study. Food Quality and Preference 20, 399-409.

Costa-Font, J. \& Mossialos, E. (2006). The Public as a Limit to Technology Transfer: The Influence of Knowledge and Beliefs in Attitudes towards Biotechnology in the UK. Journal of Technology Transfer 31(6), 629-645.

Du, L. \& Rachul C. (2012). Chinese Newspaper Coverage of Genetically Modified Organisms. BMC Public Health 12, 326.

Durant, J. \& Lindsey, N. (2002). The Great GM Food Debate - a Survey of Media Coverage in the First Half of 1999, London, Parliamentary Office of Science and Technology, Report 138, May 2000 [cited 20 December 2002], 52 p., [26.02.2015]: http://www.parliament.uk/post/report138.pdf. ISBN 1- 897941-96-X.

Frewer, L. J., Howard, C., Hedderley, D. \& Shepherd, R. (1996) What determines trust in information about food-related risks? Underlying Psychological Constructs. Risk Analysis 16, 473-486.

Frewer, L. J., Howard, C. \& Shepherd, R. (1996). The Influence of Realistic Product Exposure on Attitudes towards Genetically Engineering of Food. Food Quality and Preference 7, 61-67.

Gaskell, G., Allum N. \& Stares, S. (2003). Europeans and Biotechnology in 2002: A Report to the EC Directorate General for Research from the Project "Life Sciences in European Society", QLG7CT-1999-00286, Eurobarometer 58.0, $2^{\text {nd }}$ ed., 21 March.

Gaskell, G., Allansdottir, A., Allum, N., Corchero, C., Claude Fischler, C., Hampel, J., Jackson, J., Kronberger, N., Mejlgaard, N., Revuelta, G., Schreiner, C., Stares, S., Torgersen, H. \& Wagner, W.( 2005). Europeans and Biotechnology in 2005: Patterns and Trends. Eurobarometer 64.3. A Report to the European Commission's Directorate-General for Research.

Gaskell, G., Stares, S., Allansdottir, Allum, N., Castro, P., Esmer, Y., Fischler, C., Jackson, J., Kronberger, N., Hampel, J., Mejlgaard, N., Quintanilha, A., Rammer, A. Revuelta, G., Stoneman, P., Torgersen, H. \& Wagner., W. (2010). Europeans and Biotechnology. Winds of Change? A Report to the European Commission's Directorate-General for Research.

Harrison, R. W., Boccaletti, S. \& House, L. (2004). Risk Perceptions of Urban Italian and United States Consumers for Genetically Modified Foods. The Journal of Agrobiotechnology Management and Economics 7(4), 195-201.

Hossain, F., and Onyango, B. (2004). Product Attributes and Consumer Acceptance of Nutritionally Enhanced Genetically Modified Foods. International Journal of Consumer Studies 28(3), 255-267. 


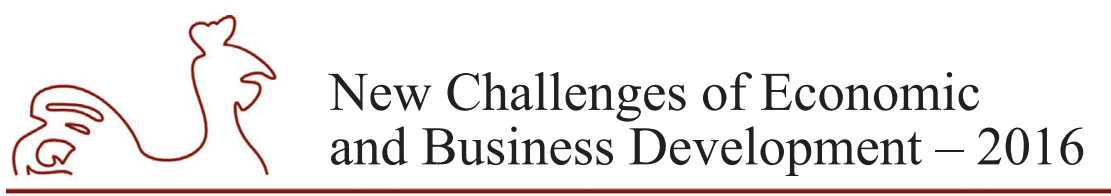

May 12-14, 2016, Riga, University of Latvia

Hossain, F., Onyango, B., Schilling, B., Hallman, W. \& Adelaja, A. (2003). Product Attributes Consumer Benefits and Public Approval of Genetically Modified Foods. International Journal of Consumer Studies 27 (5), 353-365.

Kassardjian, E. (2002). Appropriation de concepts en situation d'éducation non formelle, Cas d'une exposition scientifique sur les OGM. Lyon, Université Claude Bernard, Thesis.

Koç, E. (2008), Tüketici Davranısları Ve Pazarlama Stratejileri: Global Ve Yerel Yaklasım, Seçkin, Ankara.

Omobowale, E. B., Singer, P. A. \& Daar, A. S. (2009). The Three Main Monotheistic Religions and gm Food Technology: an Overview of Perspectives. BMC International Health and Human Rights 9, 18.

Onyango, B. (2004). Consumer Acceptance of Genetically Modified Foods: The Role of Product Benefits and Perceived Risks. Journal of Food Distribution Research 35, 154-161.

Johnson, B. B., 1999. Exploring Dimensionality in the Origins of Hazard Related Trust. Journal of Risk Research 2 (4), 325-354.

Marris, C., Wynne, B., Simmons, P. \& Weldon, S. (2001). Public Perceptions of Agricultural Biotechnologies in Europe, [11.10.14]: http://checkbiotech.org/pdf/.

Mehendale, H. M. (2004). Genetically Modified Foods: Why the Public Frenzy? Role of Mainstream News Media. Journal of Toxicology 23 (5), 279-280.

Meijnders, A., Midden, C., Olofsson, A., Ohman, S., Matthes, J., Bondarenko, O., Gutteling, J. \& Rusanen, M. (2009). The Role of Similarity Cues in the Development of Trust in Sources of Information About GM Food. Risk Analysis 29(8), 1116-1128.

Metlay, D., 1999. Institutional Trust and Confidence: a Journey into a Conceptual Quagmire. In: Cvetkovich, G. T., Lofstedt, R. E. (Eds.), Social Trust and the Management of Risk. Earthscan, London, pp. 110-116.

Miles, S., \& Frewer, L. J. (2001). Investigating Specific Concerns about Different Food Hazards. Food Quality and Preference 12(1), 47-61.

Miles, S., \& Frewer, L. J. (2002). QPCRGMOFOOD Work Package 6: Socio-economic Impact of GMO Regulation and GMO Detection. Final Report to the European Commission, available from the Institute of Food Research, Norwich.

Miles, S., Ueland, Ø., \& Frewer, L. J. (2005). Public Attitudes towards Genetically-Modified Food. British Food Journal 107(4), 246-262.

Moon, W. \& Balasubramanian, S. K. (2001). Public Perceptions and Willingness-To-Pay A Premium for Non- GM Foods in the US and UK. The Journal of Agrobiotechnology Management and Economics 3(4), 221-231.

Rodriguez-Entrena, M., Salazar-Ordóńez, M. \& Sayadi S. (2013). Applying Partial Least Squares to Model Genetically Modified Food Purchase Intentions in Southern Spain Consumers. Food Policy 40, 44-53.

Siegrist, M. (2000). The Influence of Trust and Perceptions of Risks and Benefits on the Acceptance of Gene Technology. Risk Analysis 20(2), 195-204.

Priest, S. H. (2001). A Grain of Truth: The Media, the Public, and Biotechnology. Lanham, Meriland: Rowman and Littlefield publishers.

Priest, S. H., Bonfadelli, H., \& Rusanen, M. (2003). The "Trust Gap" Hypothesis: Predicting Support for Biotechnology across National Cultures as a Function of Trust in Actors. Risk Analysis 23(4), 751766.

Vilella-Vila, M. \& Costa-Font, J. (2008). Press Media Reporting Effects on Risk Perceptions and Attitudes towards Genetically Modified (GM) Food. The Journal of Socio-Economics 37(5), 2095-2106.

Weldon, S., \& Laycock, D. (2009). Public Opinion and Biotechnological Innovation. Policy and Society 28, 315-325. 
May 12-14, 2016, Riga, University of Latvia

\title{
WOMEN ON BOARDS AND SHAREHOLDER STRUCTURE
}

\author{
Maria Aluchna, Warsaw School of Economics, Poland ${ }^{1}$ \\ Anna Krejner-Nowecka, Warsaw School of Economics, Poland \\ Emilia Tomczyk, Warsaw School of Economics, Poland
}

\begin{abstract}
Female involvement in governance and management is the outcome of the political, legal and social systems as well as culture and religion at the country level. At the company level, women's presence on board is determined by certain company characteristics (size, industry of operation, ownership structure, age) and is believed to be tied to firm performance. We add to this literature by examining the links between female presence on board and ownership structure in the post-transition Central European context. The goal of the paper is to identify how ownership concentration and shareholder identity are related to the presence of (at least) one woman on board. The paper is based on the empirical analysis of the composition of supervisory boards of 100 largest Polish companies for the period 2008-2014.
\end{abstract}

Key words: women on board, females on board, corporate governance, shareholder structure, gender equality

JEL code: G30, M14

\section{Introduction}

Female involvement in governance and management is the outcome of the political, legal and social systems as well as culture and religion at the country level. At the company level, women's presence on board is determined by certain company characteristics (size, industry of operation, ownership structure, age) and is believed to be related to firm performance. We add to this literature by examining the links between female presence on board and ownership structure in the post-transition Central European context as this research still remains very limited. The goal of the paper is to identify how ownership concentration and shareholder identity are tied to the presence of (at least) one woman on board. The paper is based on the empirical analysis of the composition of supervisory boards of 100 largest Polish companies for the period 2008-2014.

The article is organized as follows. The role of shareholders in corporate governance referring to the post-crisis challenges and recommendations towards the improvement of the oversight and control quality are discussed in the first section. The second section provides the outline of the relations between females presence on board and various ownership structure types with respect to the degree of ownership concentration and shareholder identity. The research method and the research results on the presence on women on corporate boards in regard to different shareholder structures are delivered in the third section. Final remarks are presented in conclusions.

Corresponding author - e-mail address maria.aluchna@sgh.waw.pl 


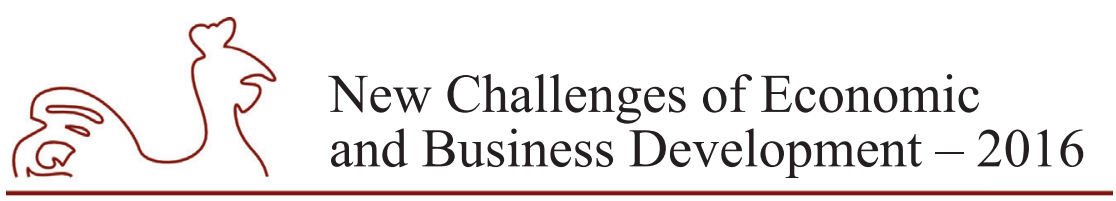

May 12-14, 2016, Riga, University of Latvia

\section{Ownership structure and corporate governance}

Ownership structure remains in the center of the principal-agent theory which based on the fundamental assumptions of conflicts of interests and information asymmetry (Fama and Jensen 1983). This theory identifies conflicts in the firm between shareholders, executives and creditors and offers a set of control mechanisms to improve the efficiency of the relations between agents and principals (Jensen and Meckling, 1976). The existing literature identifies various models of shareholder structure analyzing its impact upon performance as well as strategic decision, restructuring, and corporate governance practices (Holderness and Sheehan, 1988; Gedajlovic and Shapiro, 1998; Tihanyi et al., 2003). The shareholder structure is analyzed upon the application of two dimensions: ownership concentration and the shareholder identity. The first approach allows to distinguish dispersed ownership and concentrated ownership (Morck, 2000; Bennedsen and Nielsen, 2010). The dispersion of ownership refers to the situation of the absence of the majority shareholder with $10 \%$ or $20 \%$ seen as the threshold and is identified in AngloSaxon economies (US, UK). The ownership concentration revealed in continental Europe, Asia, Latin America (Morck, 2004) refers to the number of shares controlled by a single entity what can be simply realized by acquiring a large stake of shares. The second criterion for ownership structure analysis refers to the shareholders identity and usually identifies (Mallin, 2004; Tricker, 2012):

- individual investors who are represented by individuals directly buying the shares and include private investors and founders/ founders' family,

- institutional investors who encompass industry (strategic) investors, financial investors such as funds (pension, investment, venture, mutual and others), banks and insurance companies,

- insiders who include executives and employees,

- the State.

From the perspective of the principal-agent theory, the dispersed ownership allows for risk diversification and raising substantial funds as well as leads to a greater liquidity and the disciplinary role of the stock market (Becht el al., 2003). However, it lowers the engagement of the fragmented shareholders since, owning small stakes, they have neither the motivation nor the sufficient expertise and experience to provide active monitoring (Hawley et al., 2011; Tricker, 2012). The concentrated ownership as well as concentrated control are believed to address these issues as majority shareholders do not suffer from coordination problems, get involved in governance and provide efficient monitoring for the company (Morck, 2000). They, however, may show the tendency to realize private benefits abusing the minority shareholders. Although the growing role of institutional investors in today's companies is perceived as a positive change due to their expertise, the evidence on their activism remains deeply disappointing (Tricker, 2012; Hawley et al., 2011). The industry investors known for their long term orientation and involvement in management and governance are seen as efficient owners aiming at enhancement of corporate performance and firm value may also get involved in the related party transactions with business groups at the cost of minority shareholders (Morck, 2005). Finally, families and founders control are praised for their long term orientation and strategic dedication to the company development although may also depict the threat for expropriating minority shareholders (Bertrand and Schoar, 2006; Schulze et al., 2001). 


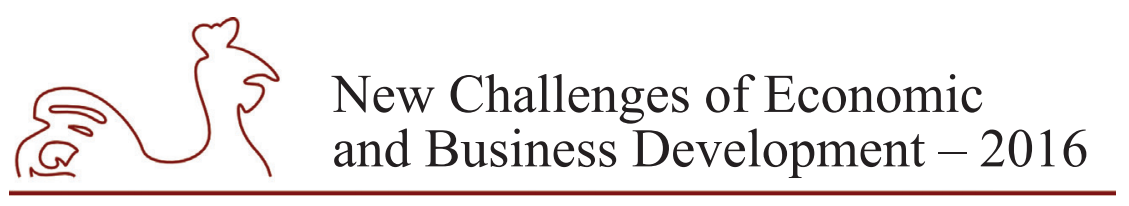

May 12-14, 2016, Riga, University of Latvia

\section{Shareholder structure and women on board}

Research shows that it truly matters who, in terms of the control and identity, owns shares and how engages in company's operation. The type of shareholder is tied to the strength of the focus on financial performance, time horizon, development scenarios, patterns for growth and profit distribution (Gedajlovic and Shapiro, 1998). It also impacts the characteristics of the company bodies such as supervisory board, management board and top management team in structural, demographic and procedural terms (Bozec et al., 2013; Tihanyi et al., 2003). Thus, based on the heterogeneity of shareholder interests we expect that ownership structure determines the presence of women on corporate boards. We formulate the following hypotheses:

H1: Ownership structure with respect to the various degree of concentration differentiates the presence of women on corporate boards.

H2: Ownership structure with respect to the largest shareholder type differentiates the presence of women on corporate boards.

\subsection{Ownership concentration}

Ownership concentration reflects the influence of the majority shareholders (Solomon, 2010). Large shareholders exert stronger influence on strategic decisions in the companies they own and are more involved in the process of appointing management board members. They can prevent the reproduction of the same 'male' elite. Thus, most researchers expect that higher ownership concentration consequently results in greater board diversity. As Hillman, Cannella and Paetzold (2000) point out it is important to have board members with varied skills, such as business experts, support specialists and community influentials who represent owners' interests. Oehmichen et al. (2012) find the evidence that the concentration of individual as well as institutional owners positively affects the probability of having female management board members. Their study is consistent with the studies by Carleton et al. (1998) and Farrell and Hersch (2005). Yet the results of Oehmichen et al. (2012) on the effect of ownership concentration on the number of women on German management boards do not confirm that the existence of a dominant owner affects the probability of having at least one female manager. Adopting the insight of principal-agent theory indicates that dominant shareholder may act at the cost of minority investor and pursue his or her own goals and interests (Thomsen et al., 2006). In emerging markets characterized by weak institutional environment, dominant shareholders may not particularly see a need for a dialogue with minority shareholders and may show stronger resistance to adoption of corporate governance guidelines. Thus their impact on the representation of females on boards may be negative. Therefore we formulate the following hypothesis:

H3: Companies characterized by the concentration of ownership are less likely to have women on corporate boards.

\subsection{Individual investors}

Regarding family-owned firms, a large number of studies (Campbell and Minguez-Vera, 2008; Moulin and Point, 2012; Ruigrok et al., 2007) show that women are more numerous in the boards of family controlled firms, which would mean that women directors are more frequently than man recruited within families (Bennedsen et al. 2006; Cucculelli and Micucci 


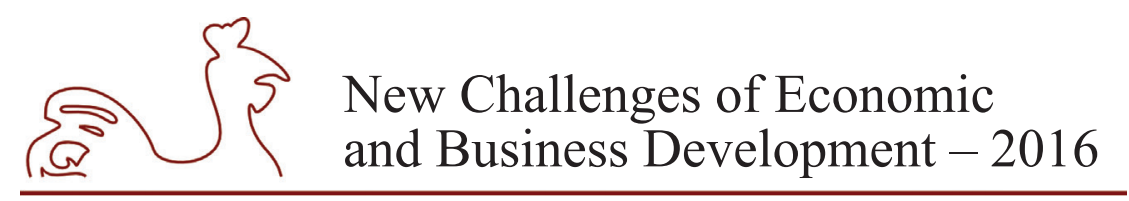

May 12-14, 2016, Riga, University of Latvia

2008). Dang et al. (2014) find, among other things, that $10 \%$ of women are on boards thanks to family link. Harrigan (1981) suggests that women may have more opportunities as directors in smaller organizations than in larger firms. For example Bianco et al. (2011) investigate the drivers of women presence overall and in the sub-groups of family and non-family female directors and report that female directorship is associated with some characteristics of firms and of women themselves, depending in particular on whether they are related (through family links) to the controlling agent. The evidence suggests that at a first glance, women are more frequently appointed in smaller companies, consumer sector and ITC. As for the ownership and control structure summary statistics show that women are common in single-controlled companies (rather than coalitions and widely-held firms) and in family-controlled companies (women sit in nearly half of family firms). Based on this findings we formulate the following hypothesis:

H4: Companies with the individual investor as the largest shareholder are more likely to have women on corporate boards.

\subsection{Institutional / financial ownership}

Institutional investors are viewed as an important governance mechanism. They have greater ability than the scattered investors to monitor management behavior. In addition they play an important role in aligning management interests with those of shareholders. Institutional investors are very rigorous about firm's reporting system and voluntary disclosure so might have a preference for diversity (Carson and Simnett, 1997). According to this reasoning, larger firms attract greater attention from the media, policymakers and regulators (Watts and Zimmerman, 1986) and are more exposed to societal and state pressures to hire women at the executive level (Dobbin and Sutton, 1998). Principal-agent theory suggests that board diversity is beneficial in terms of board independence and executive monitoring, and therefore may have a positive effect on firm performance. It provides rationale for increasing the presence of women in boards stipulating that outside directors will act as good monitors for shareholder's interest. Oehmichen et al. (2012) do not show any evidence for negative effect of banks and insurance companies or industry investors on the presence of women on management boards. However, this argumentation addresses institutional investors who are portfolio-oriented, enhance the standards of corporate governance and provide efficient monitoring proposing the adoption on best practice. The financial / institutional investors who are controlled by dominant shareholder directly or via a chain of firms in a pyramid do not follow this pattern as they represent the logic of large controlling shareholder. According to the principal-agent theory the large shareholders pursue their own interests and show stronger resistance to adoption of corporate governance guidelines. Additionally, when operating with the business group and institutional (financial and industry) shareholders are less responsive to external pressure. Thus we formulate the following hypotheses:

H5: Companies with financial investor as the largest shareholder are less likely to have women on corporate boards.

H6: Companies with (domestic and foreign) industry investor as the largest shareholder are less likely to have women on corporate boards. 


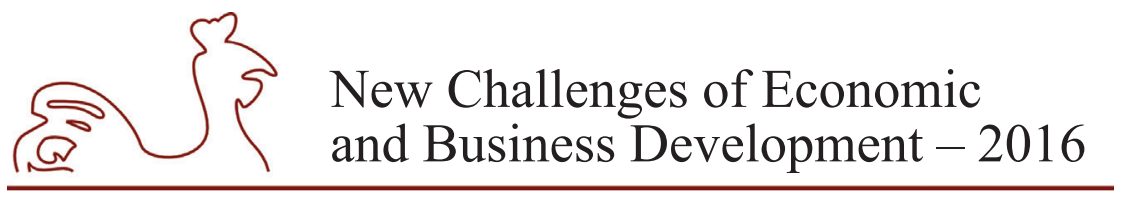

May 12-14, 2016, Riga, University of Latvia

\subsection{Governmental ownership}

State/governmental ownership represent a separate shareholder type which reveals long term orientation and provide stability and intervention if needed. The State as shareholder exerts political influence over corporate board composition and direction for strategic development of the company. Pursuing economic and social goals, the State is expected to increase the number of women on boards in line with the anti-discrimination policy and integrating social goals into corporate governance. Thus we formulate the following hypothesis:

H7: Companies with the State as the largest shareholder are more likely to have women on corporate boards.

\section{The empirical study}

The goal of the research is to identify the pattern for women's presence in corporate boards (in the case of Polish two-tier system, this means supervisory and management boards) in public companies listed on the Warsaw Stock Exchange with respect to selected criteria of the ownership structure. The finding would help estimate the degree of diversity management in companies characterized by concentrated ownership, controlled by the State, industrial, individual or financial investor. The research covers the period of 7 years (2008-2014) sampled every two years and reveals the characteristics of companies with larger presence of women on boards. The company characteristics refers to its size (assets, market capitalization), sector of operation, the stake controlled by and the type of the dominant shareholder, and the general board characteristics such as the size, and number of independent directors, number of board committees (audit, remuneration).

\subsection{Research sample and variables}

The research sample covers 100 largest companies by market capitalization as of the end of 2012. In order to trace the patterns between company ownership structure and female involvement in governance the information was hand collected for four years, i.e. 2008, 2010, 2012 and 2014. Altogether, this is the long period of seven years which gives an opportunity to trace the patterns for women presence on boards, measured every two years as the changes are not observed rapidly. For the purpose of the analysis, the data is taken from the annual reports as of December $31^{\text {st }}$ for each of the studied years. The variables on women's involvement in management and governance include the following measures:

- Supervisory board:

- Number of women on the supervisory board,

- Size of the supervisory board,

- Proportion of women on the supervisory board (\%),

- Is the board chairman a female (no / yes);

- Reporting on gender balance:

- Company reports on gender balance, the information is provided in the annual report / corporate governance compliance report (no / yes). 


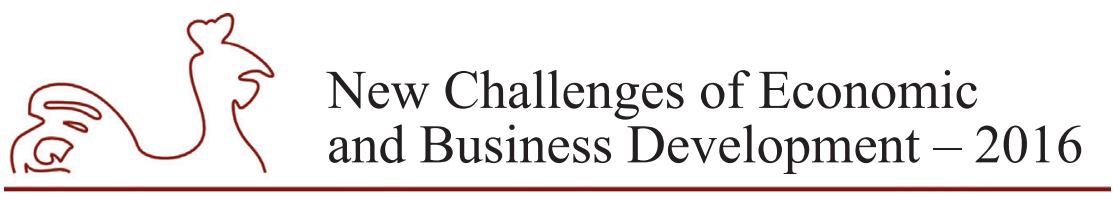

May 12-14, 2016, Riga, University of Latvia

Variables describing the company characteristics included the following measures:

- Market capitalization;

- Assets;

- Sector of operation categorized into:

- the 'typically masculine' sectors (coal and copper mining, energy generation) and other sectors (IT, trade, food and beverages, finance),

- the financial sector and other sectors;

- Stake of the largest shareholder: percentage of votes controlled by the largest shareholder during General Shareholder Meeting:

- The identity of the largest shareholder, categorized into the State, domestic industry investor, foreign industry investor, individual investor, financial institution, and other;

- Information on the compliance with the best practice of assuring for the balanced participation of men and women on corporate boards included in the annual report (no / yes);

- Number of independent directors: the number of supervisory board directors who declare compliance with independence criteria;

- Audit committee: the information whether the audit committee is formed within the board (no / yes);

- Remuneration committee - the information whether the audit committee is formed within the board (no / yes).

The analysis was carried out with the use of EViews 9 econometric software.

\subsection{Empirical results}

\section{Descriptive statistics}

The descriptive statistics of the selected research variables on supervisory boards of sample companies are presented in Tables 1 and 2 .

Table 1

Descriptive statistics on female presence on supervisory boards

\begin{tabular}{|l|l|c|c|c|c|}
\hline & & $\mathbf{2 0 0 8}$ & $\mathbf{2 0 1 0}$ & $\mathbf{2 0 1 2}$ & $\mathbf{2 0 1 4}$ \\
\hline $\begin{array}{l}\text { Presence of at least } \\
\text { one woman on } \\
\text { supervisory board }\end{array}$ & Mean & 0.48 & 0.51 & 0.49 & 0.52 \\
\cline { 2 - 5 } & $\begin{array}{l}\text { Standard } \\
\text { deviation }\end{array}$ & 0.50 & 0.50 & 0.50 & 0.50 \\
\hline $\begin{array}{l}\text { Percentage } \\
\text { of women on } \\
\text { supervisory board }\end{array}$ & Mean & 0.11 & 0.11 & 0.10 & 0.11 \\
\cline { 2 - 6 } & $\begin{array}{l}\text { Standard } \\
\text { deviation }\end{array}$ & 0.14 & 0.14 & 0.13 & 0.14 \\
\hline
\end{tabular}

Source: Authors' calculations.

As shown in Table 1, the presence of female directors on board remains relatively stable over the analyzed period. On average, every second listed company has a woman on its supervisory board. The high standard deviation indicates that analyzed companies are highly differentiated with respect to the average number and percentage of women on boards. 


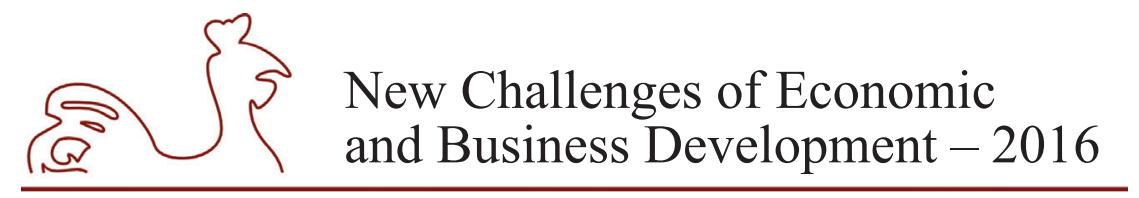

May 12-14, 2016, Riga, University of Latvia

Table 2

Descriptive statistics on supervisory boards of sample companies

\begin{tabular}{|l|c|c|c|c|}
\hline \multicolumn{1}{|c|}{ Variable } & $\mathbf{2 0 0 8}$ & $\mathbf{2 0 1 0}$ & $\mathbf{2 0 1 2}$ & $\mathbf{2 0 1 4}$ \\
\hline Number (\%) of boards with at least one woman & 43 & 31 & 49 & 49 \\
$(49 \%)$ & $(32 \%)$ & $(49 \%)$ & $(52 \%)$ \\
\hline Average no of women on supervisory board & 0.75 & 0.73 & 0.71 & 0.80 \\
\hline \% of women on supervisory board & $11 \%$ & $10 \%$ & $11 \%$ & $11 \%$ \\
\hline Average size of the supervisory board & 6.80 & 6.84 & 6.78 & 6.89 \\
\hline Number (\%) of boards with a female chairman & 10 & 13 & 8 & 8 \\
& $(11 \%)$ & $(14 \%)$ & $(8 \%)$ & $(8 \%)$ \\
\hline Number (\%) of companies reporting gender balance & 9 & 31 & 54 & 71 \\
& $(10 \%)$ & $(32 \%)$ & $(54 \%)$ & $(74 \%)$ \\
\hline No. of independent directors on supervisory board & 1.94 & 1.95 & 1.96 & 1.98 \\
\hline No. of boards with at least two independent directors & 44 & 57 & 58 & 60 \\
& $51 \%$ & $56 \%$ & $58 \%$ & $63 \%$ \\
\hline No. of boards with a separate audit committee & 37 & 59 & 59 & 70 \\
& $(43 \%)$ & $(61 \%)$ & $(59 \%)$ & $(74 \%)$ \\
\hline No. of boards with a separate remuneration committee & 28 & 38 & 51 & 48 \\
& $(32 \%)$ & $(40 \%)$ & $(51 \%)$ & $(51 \%)$ \\
\hline Number of analyzed companies & 87 & 96 & 100 & 95 \\
\hline
\end{tabular}

Source: Authors' calculations.

As shown in Table 2, the number of supervisory boards with at least one woman reveals slight changes over the analyzed period - the increase in 2010 was followed by the drop in 2012 and 2014 to reach the number of 49 boards. The female presence is estimated at $11 \%$ and the average number of women per board equals $0.7-0.8$ which means that usually $7-8$ women sit per 10 boards. The number of supervisory boards with a female chair remains very low and equals 8 boards in 2012 and 2014. Furthermore, Table 3 delivers brief characteristics of supervisory boards of sample companies. The average board is composed of approximately 7 members with slightly below 2 independent directors. The number of supervisory boards with an operating audit committee rises from 37 in 2008 to 59 in 2010 and 2012 and 70 two years later. The pattern is similar for remuneration committee: the increase starts from 28 boards in 2008 and climbs to 38 in 2010, 51 in 2012 and 48 in 2014. Additionally, 49 companies in 2010, 54 companies in 2012 and 71 companies in 2014 published information on the balancing presence of men and women according to corporate governance code of best practice.

\section{The econometric models}

In order the test whether companies of certain characteristics reveal higher or lower probability of the presence of women on supervisory board, the econometric analysis was carried out. We estimated two separate models to explain female presence on supervisory boards of the Warsaw stock exchange listed companies:

- a binary logit model for dependent variable equal to 1 if there is at least one woman on supervisory board and 0 otherwise,

- a tobit model for dependent variable equal to the number of women on supervisory board. 


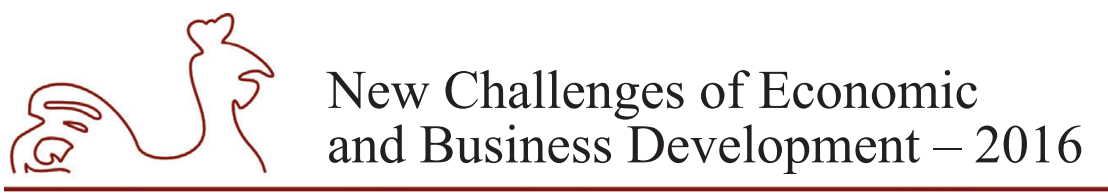

May 12-14, 2016, Riga, University of Latvia

All the factors listed in section 3.1 were considered as explanatory variables in the equations. Most of them were found not to influence the presence of women on supervisory boards in a statistically significant way, among them company size (measured in terms of market capitalization or logs of assets), sector of operation, percentage stake of the largest shareholder, ownership concentration, information on the compliance with the best practice code or establishment of audit or remuneration committees within the company. As the result, we reject hypotheses $\mathrm{H} 1$ and $\mathrm{H} 3$ which focus on relationships between presence of women on supervisory boards and concentration of ownership.

The only feature that was found to significantly impact presence of women on supervisory boards was the identity of the largest shareholder. For the purpose of the econometric analysis, the variables are coded as follows:

- binary variable equal to 1 for State Treasury and 0 otherwise (type_1),

- binary variable equal to 1 for domestic industry and 0 otherwise (type_2),

- binary variable equal to 1 for foreign industry and 0 otherwise (type_3),

- binary variable equal to 1 for individual investor and 0 otherwise (type_4),

- binary variable equal to 1 for financial investor and 0 otherwise (type_5).

Results of the logit estimation (the odds ratios and statistical significance tests), with variable type_l as the base category, are presented in Table 3.

Table 3

Female presence on board vs. shareholder type: results of the binary logit model

\begin{tabular}{|l|c|c|c|c|}
\hline & $\mathbf{2 0 0 8}$ & $\mathbf{2 0 1 0}$ & $\mathbf{2 0 1 2}$ & $\mathbf{2 0 1 4}$ \\
\hline No. of observations & 87 & 96 & 99 & 95 \\
\hline type_2 & $0.1231(*)$ & $0.1714\left(^{*}\right)$ & 0.4615 & $0.1875(*)$ \\
\hline type_3 & $0.2308(*)$ & 0.5429 & 0.4121 & 0.3516 \\
\hline type_4 & $0.0684(*)$ & $0.1587(*)$ & $0.2564(*)$ & $0.0993(*)$ \\
\hline type_5 & $0.0308(*)$ & $0.0857(*)$ & $0.1442(*)$ & $0.0469(*)$ \\
\hline count $\mathrm{R}^{2}$ & $70 \%$ & $69 \%$ & $61 \%$ & $70 \%$ \\
\hline
\end{tabular}

(*) variable statistically significant at 0.1 significance level.

Source: Authors' calculations.

As shown in Table 3, the odds ratio of having at least one woman on board in 2008 in the case when the domestic industry shareholder is the largest investor is lower by $87.7 \%(1-$ $0.1231=0.8769)$ than in the company controlled by the State. All the remaining coefficients are interpreted similarly; for all the types of largest shareholders considered, odds ratios are lower as compared to the category "State controlled". Therefore we find support for hypotheses H2 (that is, that ownership structure with respect to the largest shareholder type differentiates the likelihood of women's presence on corporate boards) and $\mathrm{H} 7$ (which states that companies with the State as the largest shareholder are more likely to have women on corporate boards). We find that companies with the individual investor as the largest shareholder (variable type_4) are more likely to have women on corporate boards than firms with financial investor as the major shareholder; this result lends partial support to hypothesis H4. 


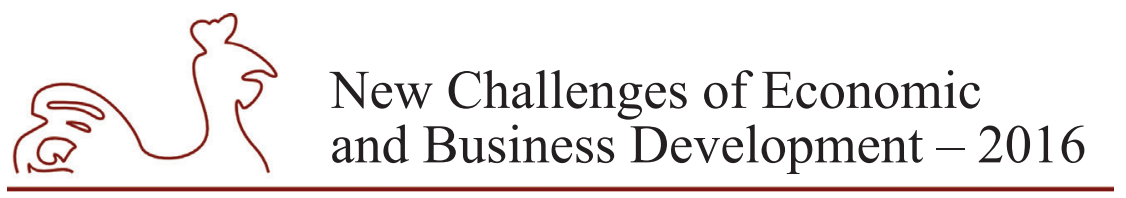

May 12-14, 2016, Riga, University of Latvia

Count $\mathrm{R}^{2}$ represents the number of observations classified correctly by the logit model as either 0 (company does not have a single woman on its supervisory board) or 1 (there is at least one woman on the supervisory board). The percentage of correctly classified observations reaching $70 \%$ may be interpreted as satisfactory.

In order to augment the quantitative analysis, we also estimate a tobit model for the percentage of women on supervisory boards. Selection of the tobit model instead of the classic linear model is dictated by the large percentage of companies with no women on their supervisory boards (about one half; see Table 1). Results of the tobit estimation (parameter estimates and statistical significance tests), with variable type_l as the base category, are presented in Table 4.

Table 4

Female presence on board vs. shareholder type: results of the tobit model

\begin{tabular}{|l|c|c|c|c|}
\hline & $\mathbf{2 0 0 8}$ & $\mathbf{2 0 1 0}$ & $\mathbf{2 0 1 2}$ & $\mathbf{2 0 1 4}$ \\
\hline No. of observations & 87 & 96 & 99 & 95 \\
\hline type_2 & -0.1405 & -0.1607 & -0.0656 & $-0.1771\left(^{*}\right)$ \\
\hline type_3 & -0.1276 & -0.06755 & -0.1123 & -0.1010 \\
\hline type_4 & $-0.2368\left(^{*}\right)$ & $-0.1716\left(^{*}\right)$ & $-0.1363\left(^{*}\right)$ & $-0.1861\left(^{*}\right)$ \\
\hline type_5 & $-0.3611\left(^{*}\right)$ & $-0.2342(*)$ & $-0.2509\left(^{*}\right)$ & $-0.3513(*)$ \\
\hline
\end{tabular}

$(*)$ variable statistically significant at 0.1 significance level.

Source: Authors' calculations.

As shown in Table 4, companies controlled by the State exhibit the highest willingness to employ larger percentage of women on their supervisory boards as compared with other shareholder types. Companies with individual or financial investors as the largest shareholders reveal the lowest willingness to have women on their boards. These findings partially remain in line with the results obtained on the basis of the logit model; they provide support for hypotheses $\mathrm{H} 2$ and $\mathrm{H} 7$. All the remaining factors considered in section 3.1 as possible explanatory variables remain statistically insignificant, and on this basis we reject hypotheses $\mathrm{H} 1$ and $\mathrm{H} 3$.

\subsection{Discussion}

Our empirical analysis shows that approximately 50\% of companies listed in the Warsaw Stock Exchange have at least one woman on supervisory board. The participation of females on board is estimated on average at $11 \%$. This data suggests that the female involvement in governance in Polish companies remains at the moderate level, placing Polish boards below the EU average. The changes in the corporate governance guidelines introduced at the Warsaw Stock Exchange were to assure for gender balance and reporting on the number of females on boards by companies. As the dynamic analysis carried out over the period of 2008-2014 indicates, they did not have any impact on the presence of females on corporate boards in Poland.

The research findings reveal links between ownership structure and presence and participation of females on board. More precisely, we do not identify links between ownership concentration and presence/ participation of women on boards (no support for hypotheses 1 and 3). However, the results show that the identity of the largest shareholder differentiates the presence and participation of women on board (support for hypothesis H2). 


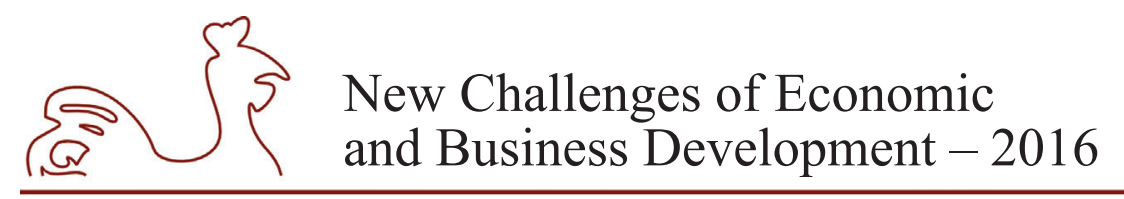

May 12-14, 2016, Riga, University of Latvia

The results show that the presence of the State as the largest shareholder promotes female presence and participation on boards (in support of hypothesis H7). Shareholder identity in terms of individual, industry and financial investors is shown to exert negative influence over the presence of women on boards. However, in terms of women's presence on board (measured by the variable of the presence of at least one woman) we find partial support for hypotheses H4 and H5 revealing that companies with the individual and financial investors as the largest shareholders are less likely to have at least one woman on board as referred to the state but are more likely as compared to industry investors. The second model examined the percentage of women on board and indicated that companies with the individual and financial investor as the largest shareholder are less likely to have women of supervisory boards (no support for hypothesis H4 and H5). In both models we find no support for hypothesis H6.

The research has failed to establish a convincing case for the presence of women on corporate board of directors and in this aspect it differs from previous researchers, mainly Oehmichen et al. (2012) it is not clear from the literature what the optimal ownership structure is in achieving good performance in general; in particular how two important aspects of ownership structure characteristics, that is, ownership type diversity and ownership concentration, influence the number of women on management boards. The authors of numerous studies argue that they find evidence for "business case" for female directors, but the results are very mixed. Because firms are not all the same and quotas are costly, Adams and Kirchmaier (2014) recommend other mechanisms to increase the representation of women on listed companies' boards. They argue that having a corporate governance code that emphasizes gender as a criterion for nominating committees is enough, because the problem is with the society, not just with companies (Adams, 2015). A gender quota (if implemented) would need to be supplemented by other policies in order to ease female inclusion into directors' social networks, associations, and other institutions, and so cultivate the emergence of a new, modern, post-traditional corporate elite. Changes in board composition follow a slow, evolutionary process. Corporate owners with a strong interest in supporting compliance with the new governance proposals and public expectations, such as institutional investors may be more likely to support gender diversity in the boardroom.

The demographic reflection of the social network of decision makers in banks and strategic investors expect to have a negative impact on the acceptance of women on management boards (McPherson et al. 2001). However, there are several plausible reasons to expect that women are more likely to ascend to board position when the environment is especially volatile, unstable, or turbulent. Instability could create opportunities for organizations to break from the status quo of organizational inertia and alter hiring and promotion practices (Khurana, 2002; Reskin and McBrier, 2000). Ryan and Haslam (2005) theorize that unstable environments provide an opportunity for women to attain leadership positions because the risk of failure is higher. Because executive positions in unstable firms are likely to be less prestigious, the competition from male candidates may be less intense. Indeed, Stainbeck and Tomaskovic-Devey (2009) find that women's growing presence in management has been circumscribed mostly to emergent sectors and to larger workplaces where they manage other women. Furst and Reeves (2008) contend that turbulence in four key industries financial services, consumer products, technology, and media - has facilitated the emergence of female executives in those fields. Similarly, Blair-Loy (1999) concludes that turbulence - within organizations, across industries, or the economy - significantly affects the career trajectories of female finance executives, creating risk, but also mobility and advancement opportunities. 


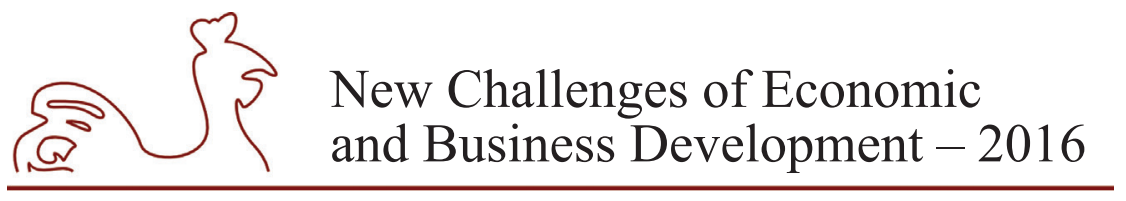

May 12-14, 2016, Riga, University of Latvia

\section{Conclusions}

The study examines the links between ownership structure on the presence and participation of women on supervisory boards of firms listed on Warsaw Stock Exchange. Adopting the framework of principal-agent theory, we relate the degree of ownership concentration and identity of shareholder to the presence and participation of women on boards. Empirical results may be summarized as follows. First, we distinguish between different types of investors and find that identity of the major shareholder remains the only statistically significant factor which influences presence of women on supervisory boards. Second, we confirm that the State ownership favors participation of women on supervisory boards as compared to all the other investor types. Third, we identify the complexity of women presence and participation on boards as we reveal different impact of individual and financial investors with respect to appoint at least one woman or have larger percentage of women on board. The research is not free of some shortcomings. The larger sample would allow to address the question whether the identified links remain stable over time. Additionally, the research should distinguish between different shareholder identities including families and portfolio-oriented financial investors. Relating the Polish finding to the larger CEE sample would offer a possibility to identify the examined relations with the vaster geographical region. We plan to address these issues in the next stages of our research project.

\section{Bibliography}

Adams, R. B. \& Kirchmaier, T. 2014. Barriers To Boardrooms, ECGI Finance Working Paper No. 347/2013; Asian Finance Association AsFA 2013 Conference.

Adams, R. B. 2015. Myths And Facts About Female Directors, IFC Corporate Governance Knowledge Publication, Issue 37.

Becht, M., Bolton, P. \& Roell, A. 2003. Corporate Governance And Control in Constamtinides G., Harris M., Stulz R. eds. Handbook Of The Economics Of Finance, 1, pp. 1-109.

Bennedsen, M. \& Nielsen, K. 2010. Incentive And Entrenchment Effects In European Ownership, Journal of Banking and Finance, 34 (9), pp. 2212-2229.

Bennedsen, M., Nielsen, K. M., Pérez-Gonzàlez, F. \& Wolfenzon, D. 2006. Inside The Family Firm: The Role Of Families In Succession Decisions And Performance, Quarterly Journal of Economics, 122, pp. 647-691.

Bertrand, M. \& Schoar, A. 2006. The Role Of Family In Family Firms, The Journal of Economic Perspectives, 20 (2), pp. 73-96.

Bianco, M., Ciavarella, A. \& Signoretti, R. 2011. Women On Boards In Italy, CONSOB Working Paper, No. 70. BIS.

Blair-Loy M. 1999. Career Patterns Of Executive Women In Finance: An Optimal Matching Analysis, American Journal of Sociology, 104, pp. 1346-97.

Bozec, R., Dia, M. \& Bozec, Y. 2013. Corporate Ownership And Governance Practices In Canada: A Longitudinal Study, International Journal of Corporate Governance, 4 (1), pp. 51-73.

Brady, D., Isaacs, K., Reeves, M., Burroway, R. \& Reynolds, M. 2011. Sector, Size, Stability, And Scandal, Gender in Management: An International Journal, 26 (1), pp. 84-105.

Campbell, K. \& Mínguez-Vera, A. 2008. Gender Diversity In The Boardroom And Firm Financial Performance, Journal of Business Ethics, 83 (3), pp. 435-451.

Carleton, W. T., Nelson, J. M. \& Weisbach, M. S. 1998. The Influence Of Institutions On Corporate Governance Through Private Negotiations: Evidence From TIAA-CREF, Journal of Finance, Vol. 53, pp. 1335-1363. 


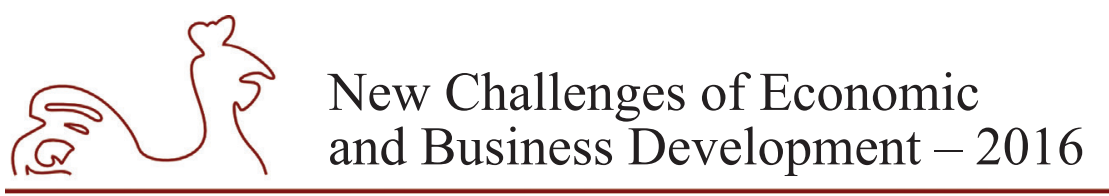

May 12-14, 2016, Riga, University of Latvia

Carson, E. \& Simnett, R. 1997. Voluntary Disclosure Of Corporate Governance Practices. Unpublished working paper, University of New South Wales, Sydney.

Cucculelli, M. \& Micucci, G. 2008. Family Succession And Firm Performance: Evidence From Italian Family Firms, Journal of Corporate Finance, 14, pp. 17-31.

Dang, R., Bender, A. \& Scotto, M. 2014. Women On French Corporate Board Of Directors: How Do They Differ From Their Male Counterparts?, Journal of Applied Business Research, 30 (2), pp. 490-508.

Dobbin, F. \& Sutton, J. R. 1998. The Strength Of A Weak State: The Rights Revolution And The Rise Of Human Resource Management Divisions, American Journal of Sociology, 104 (2), pp. 441-476.

Fama, E. \& Jensen, M. 1983. Separation Of Ownership And Control, Journal of Law and Economics, Vol. 26, pp. 301-325.

Farrell, K. A. \& Hersch, P. L., 2005. Additions To Corporate Boards: The Effect Of Gender, Journal of Corporate Finance, 11, pp. 85-106.

Furst, S. \& Reeves, M. 2008. Queens Of The Hill: Creative Destruction And The Emergence Of Executive Leadership Of Women, The Leadership Quarterly, 9, pp. 372-84.

Gedajlovic, E. \& Shapiro, D. 1998. Management And Ownership Effects: Evidence From Five Countries, Strategic Management Journal, 19, pp. 533-553.

Harrigan, K. R. 1981. Number And Positions Of Women Elected To Corporate Boards, Academy of Management Journal, 24 (3), pp. 619-625.

Hawley, J., Kamath, S. \& Williams, A. 2011. Corporate governance failures, University of Pennsylvania press, Philadelphia.

Hillman, A. J., Cannella, A. A. \& Paetzold, R. L. 2000. The Resource Dependence Role Of Corporate Directors: Strategic Adaptation Of Board Composition In Response To Environmental Change, Journal of Management Studies, 37 (2), pp. 235-256.

Holderness, C. \& Sheehan, D. 1988. The Role Of Majority Shareholders In Publicly Held Corporations, Journal of Financial Economics, 20, pp. 317-346.

Jensen, M. C., \& Meckling, W. H. 1976. Theory Of The Firm: Managerial Behavior, Agency Costs And Ownership Structure, Journal of Financial Economics, 3 (4), pp. 305-360.

Khurana, R. 2002. Searching For A Corporate Savior, Princeton University Press, Princeton, NJ.

Mallin, C. 2004. Corporate Governance, Oxford University Press, Oxford.

McPherson, M., Smith-Lovin, L. \& Cook, J. M. 2001. Birds Of A Feather: Homophily In Social Networks, Annual Review of Sociology, 27, pp. 415-444.

Morck, R. 2000. Concentrated Corporate Ownership, The University of Chicago Press.

Morck, R. 2004. How To Eliminate Pyramidal Business Groups - The Double Taxation Of Inter-Corporate Dividends And Other Incisive Uses Of Tax Policy, Tax Policy and the Economy, Vol. 19.

Morck, R. 2005. A History Of Corporate Governance Around The World: Family Business Groups To Professional Managers, University of Chicago Press, Chicago.

Oehmichen, J., Rapp, M. S. \& Wolff, M., 2012. Women On German Management Boards, Zeitschrift für Betriebswirtschaft, 82 (2), pp. 95-125.

Postuła, I. 2013. Nadzór Korporacyjny W Spótkach Skarbu Państwa, Wolters Kluwer, Warszawa.

Reskin, B. \& McBrier, D. B. 2000. Why Not Ascription? Organizations' Employment Of Male And Female Managers, American Sociological Review, 65, pp. 210-33.

Ruigrok, W., Peck, S. \& Tacheva, S. 2007. Nationality And Gender Diversity On Swiss Corporate Boards. Corporate Governance: An International Review, 15 (4), pp. 546-57.

Ryan, M. K., \& Haslam, S. A. 2005. The Glass Cliff: Evidence That Women Are Over-Represented In Precarious Leadership Positions, British Journal of Management, 16, pp. 81-90.

Schulze, W., Lubatkin, M., Dino, R. \& Buchholtz, A. 2001. Agency Relationships In Family Firms: Theory And Evidence, Organization Science, 12, pp. 99-116.

Shleifer, A. \& Vishny, R. 1997. A Survey Of Corporate Governance, Journal of Finance, 52, pp. 737-783. 


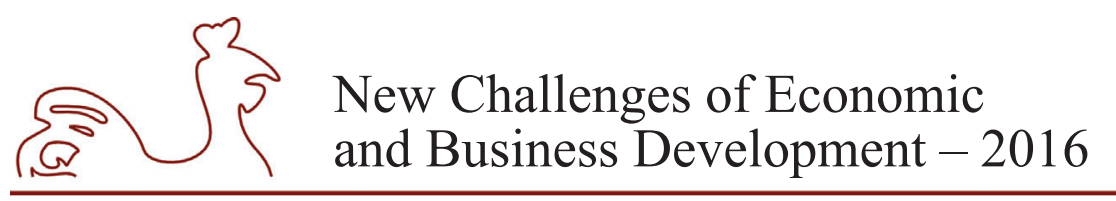

May 12-14, 2016, Riga, University of Latvia

Solomon, J. 2010. Corporate Governance And Accountability, John Wiley and Sons Publications.

Stainbeck, K. \& Tomaskovic-Devey, D. 2009. Intersections of power and privilege: long-term trends in managerial representation, American Sociological Review, Vol. 74, pp. 800-20.

Thomsen, S., Pedersen, T. \& Kvist, H. K. 2006. Blockholder Ownership: Effect On Firm Value In Market And Control Based Governance System, Journal of Corporate Finance, 12, pp. 246-269.

Tihanyi, L., Johnson, R., Hoskisson, R. \& Hitt, M. 2003. Institutional Ownership Differences And International Diversification: The Effect Of Boards Of Directors And Technological Opportunity, Academy of Management Journal, 46, pp. 105-211.

Tricker, B. 2012. Corporate Governance. Principles, Policies And Practices, Oxford University Press, Oxford.

Watts, R. L. \& Zimmerman, J. L. 1986. Positive Accounting Theory, Prentice Hall, Englewood Cliffs NJ.

Zattoni, A. 1999. The Structure of Corporate Groups: The Italian Case, Corporate Governance, 7 (1), pp. 38-48. 
May 12-14, 2016, Riga, University of Latvia

\title{
25 YEARS IN FINANCIAL REPORTING: THE CASE OF ESTONIA
}

\author{
Jaan Alver, Tallinn University of Technology, Estonia ${ }^{1}$ \\ Lehti Alver, Tallinn University of Technology, Estonia \\ Lehte Alver, Tallinn University of Technology, Estonia
}

\begin{abstract}
Financial statements are the principal means through which a company communicates its financial information to those outside it. Every country has its own requirements of financial reporting. Estonia has had market economy for 25 years. Through that time, financial statements have changed a lot. The aim of the current paper is to show how the balance sheet and income statement as the main financial statements have changed from 1991 to 2015.

The authors provide analysis of layouts of balance sheet and income statements (years 1991; 1995; 2003 and 2015). Quite different from others are 1991-year statements. This can be explained by the fact that there was a lack of experience how to prepare financial statements under conditions of market economy. The layouts of statements introduced in 1995 and 2003 are quite similar. The 2015-year statements are shorter, because many items have been moved to notes. There is a positive and negative effect on that. It is positive that financial statements have been simplified and include only essential information. At the same time, the main financial statements have lost a lot of information. To get this information, it is necessary to look at the notes.

Not all changes have been correct: some terms have been incorrectly used and some important words have been removed. In the paper, the two-factor variance model is used to estimate the changes in the number of words in financial statements. The indicators of rate variance and usage variance (volume variance, quantity variance) are calculated. From 1991 to 2015, the balance sheet and income statements have both lost approximately 100 words. During the last 10 years, the layouts of income statement have not changed as much as the balance sheet.
\end{abstract}

Key words: financial statements, content analysis, Estonia

JEL code: M40, M48

\section{Introduction}

Financial statements are important tools for understanding everyday business of companies. This information is used to reach decisions about how to manage the business, invest in it, or lend money to it. Official reporting requirements depend from regulations set up by countries.

Different studies have looked at disclosure practices in different countries. Robb, Single and Zarzeski (2001) undertake a topic-based analysis of non-financial disclosures. Jones and Shoemaker (1994) review studies concerning content of accounting narratives. Readability studies are designed to quantify the cognitive difficulty of text and generally use some readability formula (Beattie et al., 2004). Approach of linguistic analysis is used by Sudserff

Corresponding author - e-mail address: jaan.alver@ttu.ee 


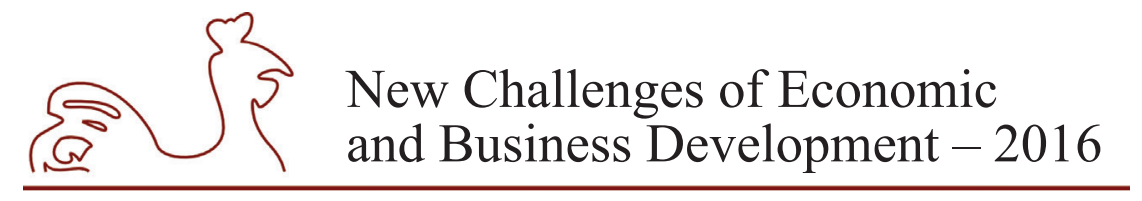

May 12-14, 2016, Riga, University of Latvia

and Weetman (1999), Roseberry (1995), De Beaugrande and Dressler (1981). Many authors (Baker, 2010; Baskerville \& Evans, 2011; Dahlgren \& Nilsson, 2009; Evans, 2004, 2009; Evans, Baskerville, \& Nara, 2010, 2011; Janicki, 2002; Kettunen, 2011; Mourier, 1996, 2000, 2004; Norberg \& Johansson, 2013; Zeff, 2007) have acknowledged the importance of language, translations and terminology.

During the Soviet period, the accounting terminology in the Estonian language was quite well developed but only in the frames of command economy and socialist accounting and under the pressure of the Russian language. Because of this (Soviet accounting) influence, there were and sometimes still are many international accounting and reporting terms and concepts unknown in the former Soviet republics, now independent countries, including Estonia. Hence, English/Estonian/English translation of accounting texts including the translation of IASs/IFRSs has been a big problem.

The aim of the current paper is to examine how the balance sheet and income statement as the main financial statements have changed from 1991 to 2015. The two-factor variance model is used to estimate the changes in the number of words in financial statements. The indicators of rate variance and usage variance (volume variance, quantity variance) are calculated.

\section{Research results and discussion}

On July 6, 1990, the Estonian Regulation of Accounting was adopted by the National Government and came into force on January 1, 1991. It is of special interest because it was the first measure adopted in any of the constituent republics of the USSR to mark a departure from the path of the Soviet accounting evolution. As pointed out by Bailey (Bailey et al., 1995), this event marked the beginning of the spread of accounting disharmony within the territories comprising the USSR. It was really an "accounting step" on the transition from command economy to market economy. The declared purpose of the Regulation was to bring about the organization of accounting in the conditions of a market economy. Real accounting continued to be perceived as properly subject to centralized prescription and its primary purpose the meeting of the needs of the central authorities of Estonia (Statistics Bureau, Tax Department) and not, as hitherto, those of the USSR (Alver and Alver, 2008). The Regulation was in force until 1995. This document introduced a number of new accounting concepts and principles, new terms and a new set of annual statements (included the balance sheet, the income statement and the statement of changes in the financial position and notes).

The second step started with the introduction of the first Estonian Accounting Act, which was passed by Parliament on June 8, 1994 and came into force on January 1, 1995. It was supported by introduction of the Estonian Commercial Code, which was passed by Parliament on February 15, 1995 and came into force on September 1, 1995. The Accounting Act did not contain a detailed set of rules and can best be characterized as constituting a legal framework. The legal framework was general and applied to all legal entities and physical persons registered as businesses in Estonia (referred to as accounting entities in the Act) with the exception of the Bank of Estonia (Alver et al., 2001). It was declared to be based on internationally recognized accounting principles, which were established with the Accounting Act and good accounting practice (Estonian accounting guidelines, Estonian GAAP). The true and fair view (TFV) override was declared. The main financial statements under Accounting Act included the balance sheet, the income statement and notes. 


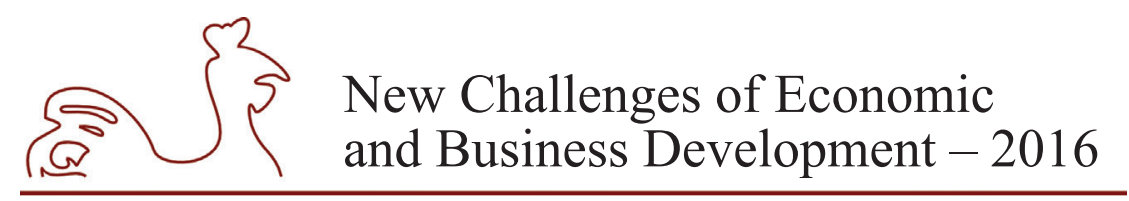

May 12-14, 2016, Riga, University of Latvia

The third step started with the introduction of the new Estonian Accounting Act, which was passed by Parliament on November 20, 2002 and came into force on January 1, 2003. The new Accounting Act regulates basic accounting functions in all business entities registered in Estonia. It does not regulate accounting for taxes, which are regulated by other laws and acts. The essence of the law is framed in compliance with IFRSs. For companies it is optional to select the Estonian GAAP or IFRSs for annual and consolidated accounts. An accounting entity which prepares its annual accounts in accordance with the Estonian GAAP shall use the balance sheet format set out in Annex 1 to this Act and one of the two income statement formats set out in Annex 2 to this Act. A more detailed subdivision of items in the formats of the balance sheet and income statement is permitted and new items may be added to the existing items if this makes for greater clarity. Instead of the former two basic statements (the balance sheet and the income statement) the annual accounts shall comprise the main statements (balance sheet, income statement, cash flow statement and statement of changes in owner's equity) and notes on the accounts.

The authors of current paper have analysed development of main financial statements during last 25 years. Special attention has been paid to readability and thematic content analysis.

\section{Analysis of developments in balance sheet}

The Estonian equivalents of the English term "balance sheet" are 'raamatupidamisbilanss' or simply 'bilanss'. The Estonian equivalent of the English term "income statement" ("profit and loss account") is 'kasumiaruanne'. It is necessary to note that the Estonian terms are not the literal translations of the English terms. For example, "balance" can be translated as 'bilanss', 'tasakaal' (equilibrium), 'tasakaalustama', 'kaal' (weight), 'saldo', 'jääk' (residual, remainder). "Sheet" is translated into Estonian as 'lina' (linen) or 'leht' (sheet of paper). The literal (but incorrect) translation of English term "balance sheet" into Estonian - 'bilansileht' - can be seen in almost all general English-Estonian dictionaries. English equivalent of the Estonian term 'kasumiaruanne' is "profit statement".

The 1991 balance sheet is most different from other (years 1995; 2003 and 2015) balance sheets. The 1991 balance sheet was not structured into current assets and non-current assets. The items were numbered and it made easier to follow the outlay. Despite of the fact that in 1991 Estonia only began to shift from centrally planned economy to a market economy the authors are in opinion that the 1991 balance sheet was well prepared. Within the equity side clear distinguish between two categories of shareholders' equity ("Tied up shareholders' equity" and "Free shareholders' equity") was made. The first item included "Paid-in capital" and "Reserves". The second item included "Retained earnings" and "Net profit of financial year". Unlike the following outlays, the 1991 balance sheet included line item "Untaxed reserves and governmental grants".

The 1995 balance sheet is more comprehensive than the 1991 balance sheet. The 1995 balance sheet includes a lot of new items, that were not in the 1991 outlay. There are also many items that were presented in separate lines in 1991 but were aggregated in 1995. Unfortunately, in the 1995 layout several incorrect wordings were found, for example "Advances to suppliers", which was translated into Estonian as "Advances to contractors" and "Treasury shares" ('tresooraktsiad') was translated into Estonian without knowing what the word 'tresoor' means. The 1995 balance sheet was subdivided into sections (current assets, non-current assets, current 


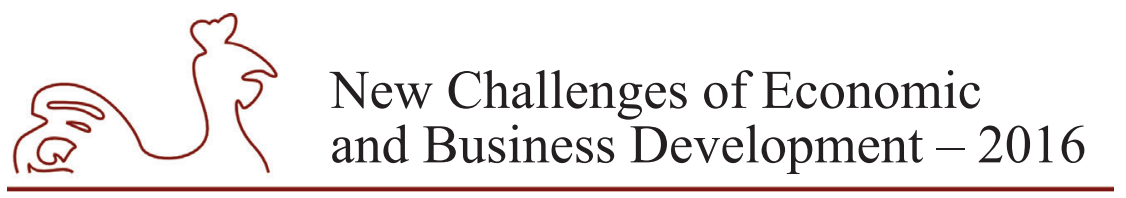

May 12-14, 2016, Riga, University of Latvia

liabilities, long-term liabilities and equity). The 2003 balance sheet is quite similar to the 1995 balance sheet. It must be emphasized that the wording has been improved, the sequence of words is set up more logically and line items are shorter.

The 2015 balance sheet is shorter than the previous ones, because many of the former line items are presented in aggregates. The separate line items of the balance sheet like "Accounts receivable" and "Advance payments" are now represented as one line item "Accounts receivable and prepayments". Since the items are aggregated, it is necessary to use the notes for receiving the full information about the company. In comparison the 2003 balance sheet layout with the 1995 balance sheet layout it must be noted that the corrections in the order of words and improvement of the wording took place, but in 2015 balance sheet layout there are not so many changes as were in the 2003 layout. If to compare the 2015 balance sheet layout with the 2003 layout the term "debt" was changed by the term "loan liability" (however, this change has not been done throughout all the 2015 layout). It should also be noted that thanks to the aggregation of the balance sheet items, the fixed tangible assets are presented in the carrying value.

The authors analysed the changes in the number of words and line items of the financial statements. The results of changes in the layouts of balance sheet (years 1991; 1995; 2003 and 2015) are shown in Table 1.

Table 1

Analysis of content of balance sheet 1991-2015

\begin{tabular}{|l|c|c|c|c|}
\hline \multicolumn{1}{|c|}{ Item } & January 1, 1991 & January 1, 1995 & January 1, 2003 & January 1, 2015 \\
\hline $\begin{array}{l}\text { Total number of words in } \\
\text { the balance sheet }\end{array}$ & 301 & 353 & 293 & 193 \\
\hline $\begin{array}{l}\text { Total number of line items in } \\
\text { the balance sheet }\end{array}$ & 94 & 118 & 109 & 77 \\
\hline $\begin{array}{l}\text { Average number of words per } \\
\text { one balance sheet line item }\end{array}$ & 3.202 & 2.992 & 2.688 & 2.506 \\
\hline
\end{tabular}

Source: authors' calculations.

In years 1991-2015, the balance sheet has lost more than 100 words. For the analysis purposes the authors used following formula:

Total number of words $=$ Number of line items $\times$ Average number of words per line item

The change of total number of words is caused by change in number of line items and change in average number of words per line item:

$$
\Delta \Sigma q p=q_{1} p_{1}-q_{0} p_{0}
$$

where,

$\Delta \Sigma q p$ - change of total number of words (total variance);

$q_{0} p_{0}$ - total number of words in the moment 0 ;

$q_{1} p_{1}$ - total number of words in the moment 1 ;

$q_{0}$ - total number of line items in the moment 0 ;

$q_{1}-$ total number of line items in the moment 1 ;

$p_{0}-$ average number of words per line item in the moment 0 ;

$p_{1}$-average number of words per line item in the moment 1 . 


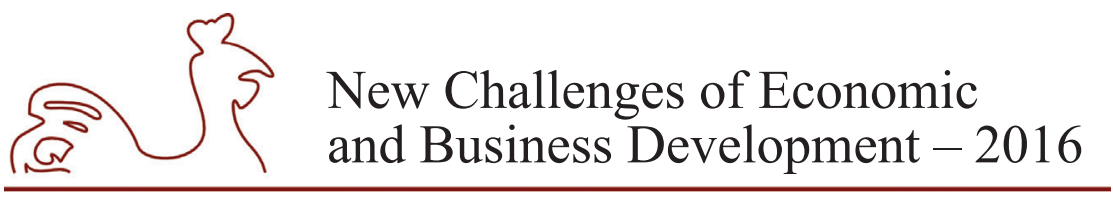

May 12-14, 2016, Riga, University of Latvia

The separate effects of changes of factors to the total number of words is calculated by following formulas:

$$
\begin{aligned}
& \Delta(q) \Sigma q p=q_{1} p_{0}-q_{0} p_{0} \\
& \Delta(p) \Sigma q p=q_{1} p_{1}-q_{1} p_{0}
\end{aligned}
$$

where,

$\Delta(q) \Sigma q p$ - effect of change in the number of line items (volume variance);

$\Delta(p) \Sigma q p$ - effect of change in the average number of words per line item (rate variance).

Following calculation shows the effect of factors to the change of total number of words in balance sheet from 1991 to 1995 . The effect of change in the number of line items to the total number of words was

$$
\Delta(q) \Sigma q p=q_{1} p_{0}-q_{0} p_{0}=118 \times 3.202-301 \approx 377.8-301 \approx 76.8 \text { (words) }
$$

The effect of change in average number of words per line item to the total number of words was

$$
\Delta(p) \Sigma q p=q_{1} p_{1}-q_{1} p_{0}=353-377.8=-24.8 \text { (words) }
$$

From 1991 to 1995 , the total number of words in balance sheet increased by 76.8 words because of increasing the number of balance sheet line items. Because of decreasing the average number of words per line item the total number of words decreased by 24.8 words. In total, the number of words in balance sheet increased by 52 words.

From 1995 to 2003 the effect of change in the number of line items to the total number of words in balance sheet was

$$
\Delta(q) \Sigma q p=q_{1} p_{0}-q_{0} p_{0}=109 \times 2,992-353 \approx 326.1-353 \approx-26.9 \text { (words) }
$$

The effect of change in the average number of words per item to the total number of words was

$$
\Delta(p) \Sigma q p=q_{1} p_{1}-q_{1} p_{0}=293-326.1=-33.1 \text { (words) }
$$

From 1995 to 2003, the total number of words in balance sheet decreased by 26.9 words because of decreasing the number of balance sheet line items. Because of decreasing the average number of words per item the total number of words decreased by 33.1. In total, the number of words in balance sheet decreased by 60 .

From 2003 to 2015, the effect of change in the number of line items to the total number of words in balance sheet was

$$
\Delta(q) \Sigma q p=q_{1} p_{0}-q_{0} p_{0}=77 \times 2,688-293 \approx 207-293 \approx-86 \text { (words) }
$$

The effect of change in the average number of words per item to the total number of words was

$$
\Delta(p) \Sigma q p=q_{1} p_{1}-q_{1} p_{0}=193-207=-14 \text { (words) }
$$

From 2003 to 2015 the total number of words in balance sheet decreased by 86 words because of decreasing the number of balance sheet line items. Because of decreasing of the average number of words per line item the total number of words decreased by 14 . In total the number of words in balance sheet decreased by 100 words. 


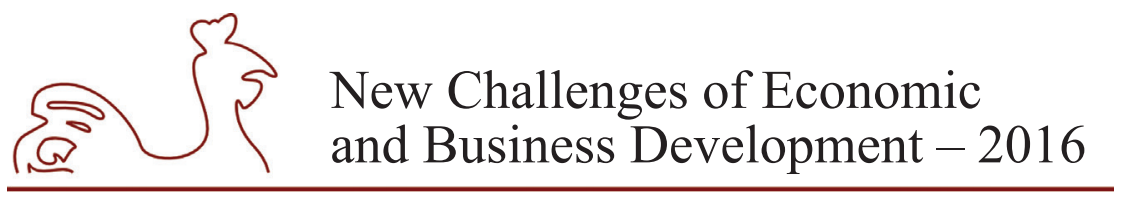

May 12-14, 2016, Riga, University of Latvia

For the 25-year period (from 1991 to 2015) the total number of words in the balance sheet decreased by 108 . The effect of change in the number of line items to the total number of words in balance sheet was

$$
\Delta(q) \Sigma q p=q_{1} p_{0}-q_{0} p_{0}=77 \times 3.202-301 \approx 247-301 \approx-54 \text { (words) }
$$

The effect of change in the average number of words per line item to the total number of words was

$$
\Delta(p) \Sigma q p=q_{1} p_{1}-q_{1} p_{0}=193-247=-54 \text { (words) }
$$

Both factors had equal effect to the decrease of the total number of words in the balance sheet.

\section{Analysis of developments in income statements}

The 1991 income statement differs quite a lot from the following ones. At first, there was only one income statement layout (similar to the layout 2). The layout of income statement was longer and had different structure from the following ones. The first item of the income statement was "Gross sales" (included value added tax). Today, the income statement starts by Net sales revenue. Also in the 1991 income statement used some terms that were not used in latter outlays.

When comparing the 1995, 2003 and 2015 income statements' layout 1 (income statement by nature of expenses), then it turns out, that the layouts have not changed a much. During this period layout 1 has lost about 60 words. The main difference between the 1995 and the 2003 income statements' layout 1 is that the order of lines have slightly changed. In the 2003 and the 2015 layouts financial income and expenses are merged into one-line item (in 1995 they were separate). It should also be noted that in 2003 and 2015 layout 1 there is a separate line item "Interest expense", but for interest income separate line item is missing (interest income was included in the line item "Other financial income and expenses").

The main difference between income statement layout 2 (income statement by function of expenses) and layout 1 (income statement by nature) is in the first part (till operating profit). Income statement layout 2 has not changed a lot since 1995 (schemes 2003 and 2015 are identical). During this period layout 2 has lost 42 words.

Comparative analysis of layouts of income statements (years 1995; 2003 and 2015) is provided. The analysis based on the changes in lines and words and the results are shown in Table 2. 


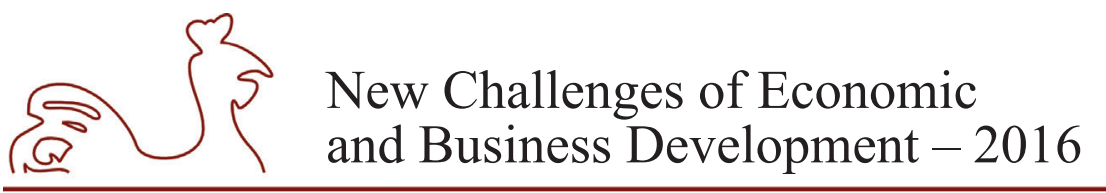

May 12-14, 2016, Riga, University of Latvia

Table 2

Content of income statement from 1995 to 2015

\begin{tabular}{|l|c|c|c|}
\hline \multicolumn{1}{|c|}{ Item } & January 1, 1995 & January 1, 2003 & January 1, 2015 \\
\hline $\begin{array}{l}\text { Total number of words in the income } \\
\text { statement (layout 1) }\end{array}$ & 140 & 96 & 80 \\
\hline $\begin{array}{l}\text { Total number of lines in the income } \\
\text { statement (layout 1) }\end{array}$ & 40 & 27 & 24 \\
\hline $\begin{array}{l}\text { Average number of words by one income } \\
\text { statement line (layout 1) }\end{array}$ & 3.500 & 3.555 & 3.333 \\
\hline $\begin{array}{l}\text { Total number of words in the income } \\
\text { statement (layout 2) }\end{array}$ & 102 & 73 & 60 \\
\hline $\begin{array}{l}\text { Total number of lines in the income } \\
\text { statement (layout 2) }\end{array}$ & 29 & 22 & 19 \\
\hline $\begin{array}{l}\text { Average number of words by one income } \\
\text { statement line (layout 2) }\end{array}$ & 3.517 & 3.318 & 3.158 \\
\hline
\end{tabular}

Source: authors' calculations.

To analyse changes taken place in layouts of income statement were used the same formulas (1-4) which were used in analysis of changes taken place in layouts of balance sheets.

Following calculation shows the effect of factors to the change of total number of words in income statement's layout 1 from 1995 to 2003. The effect of change in the number of line items to the total number of words was

$$
\Delta(q) \Sigma q p=q_{1} p_{0}-q_{0} p_{0}=27 \times 3.500-140 \approx-45.5 \text { (words) }
$$

The effect of change in average number of words per line item to the total number of words was

$$
\Delta(p) \Sigma q p=q_{1} p_{1}-q_{1} p_{0}=96-94.5=1.5 \text { (words) }
$$

From 1995 to 2003, the total number of words in income statement layout 1 decreased by 45.5 words because decreasing the number of line items. Because of increasing of the average number of words per item the total number of words increased by 1.5 words. In total, the number of words in income statement layout 1 decreased by 44 words.

From 2003 to 2015, the effect of change in the number of line items to the total number of words in income statement layout 1 was

$$
\Delta(q) \Sigma q p=q_{1} p_{0}-q_{0} p_{0}=24 \times 3.556-96 \approx 85.4-96 \approx-10.6 \text { (words) }
$$

The effect of the change of the average number of words per item to the total number of words was

$$
\Delta(p) \Sigma q p=q_{1} p_{1}-q_{1} p_{0}=80-85.4=-5.4 \text { (words) }
$$

From 2003 to 2015, the total number of words in income statement layout 1 decreased by 10.6 words because decreasing the number of line items. Because decreasing of the average number of words per item the total number of words decreased by 5.4 words. In total, the number of words in income statement layout 1 decreased by 16 words. 


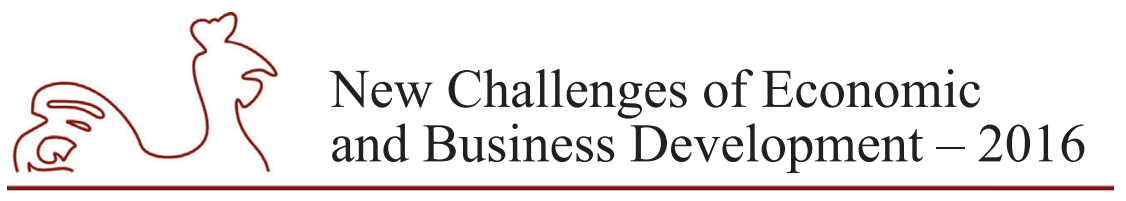

May 12-14, 2016, Riga, University of Latvia

For the 20-year period (from 1995 to 2015) the total number of words in income statement layout 1 decreased by 60 . The effect of change in the number of line items to the total number of words in income statement layout 1 was

$$
\Delta(q) \Sigma q p=q_{1} p_{0}-q_{0} p_{0}=24 \times 3.500-140 \approx 84-140 \approx-56 \text { (words) }
$$

The effect of change in the average number of words per line item to the total number of words was

$$
\Delta(p) \Sigma q p=q_{1} p_{1}-q_{1} p_{0}=80-84=-4 \text { (words) }
$$

The main effect to the decrease of the total number of words in income statement layout 1 had decrease of the number of line items.

In the following calculation, there is calculated the effect on the total number of words in income statement layout 2 in 01.01 .1995 and 01.01 .2003 by changing the factors.

Following calculations show the effect of factors to the change of total number of words in income statement's layout 2 from 1995 to 2003. The effect of change in the number of line items to the total number of words was

$$
\Delta(q) \Sigma q p=q_{1} p_{0}-q_{0} p_{0}=22 \times 3.517-102 \approx 77.3-102 \approx-24.7 \text { (words) }
$$

The effect of change in average number of words per line item to the total number of words was

$$
\Delta(p) \Sigma q p=q_{1} p_{1}-q_{1} p_{0}=73-77.3=-4.3 \text { (words) }
$$

From 1995 to 2003, the total number of words in income statement layout 2 decreased by 24.7 words because decreasing the number of line items. Because of decreasing the average number of words per line item the total number of words decreased by 4.3. In total, the number of words in income statement layout 2 decreased by 29.

From 2003 to 2015, the effect of change in the number of line items to the total number of words in income statement layout 2 was

$$
\Delta(q) \Sigma q p=q_{1} p_{0}-q_{0} p_{0}=19 \times 3.318-73 \approx 63-73 \approx-10 \text { (words) }
$$

The effect of the change of the average number of words per line item to the total number of words was

$$
\Delta(p) \Sigma q p=q_{1} p_{1}-q_{1} p_{0}=60-63=-3 \text { (words) }
$$

From 2003 to 2015, the total number of words in income statement layout 2 decreased by 10 words because decreasing the number of line items. Because decreasing of the average number of words per line item the total number of words decreased by 3 words. In total, the number of words in income statement layout 2 decreased by 13.

For the 20-year period (from 1995 to 2015) the total number of words in income statement layout 1 decreased by 60 . The effect of change in the number of line items to the total number of words in income statement layout 1 was

$$
\Delta(q) \Sigma q p=q_{1} p_{0}-q_{0} p_{0}=19 \times 3.517-102 \approx 66.8-102 \approx-35.2 \text { (words) }
$$




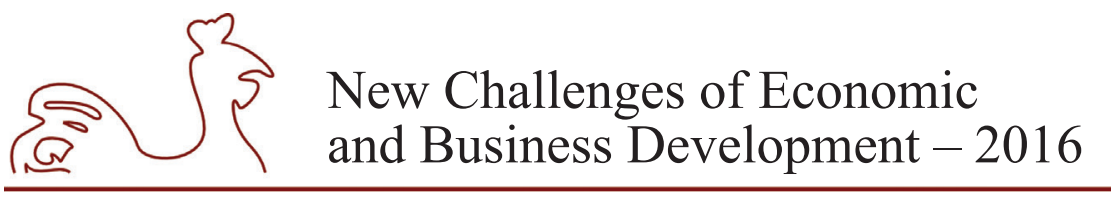

May 12-14, 2016, Riga, University of Latvia

The effect of change in the average number of words per line item to the total number of words was

$$
\Delta(p) \Sigma q p=q_{1} p_{1}-q_{1} p_{0}=60-66.8=-6.8 \text { (words) }
$$

The main effect to the decrease of the total number of words in income statement layout 2 had decrease of the number of line items.

\section{Conclusions}

1. The analysis of balance sheet shows that in two cases from three the change in total number of line items had an important effect to change of total number of words, but with opposite sign ( +76.8 and -86 , respectively). The change of the average number of words per line item had insignificant effect. From 1991 to 2015 the total number of words in balance sheet decreased by 108 , of which decrease by 54 words took place because of the decrease of the line items and decrease by 54 words took place because of the change in average number of words per item.

2. In both, income statement layout 1 and layout 2, the total number of words decreased mostly because of the decrease of the number of line items. The change of the average number of words per line item had insignificant effect.

3. Not all changes have been correct: some terms have been incorrectly used and some important words have been removed.

\section{Bibliography}

Alver, J., Alver, L., Mackevičius, J. \& Paupa, V. 2001. "Baltic states”, in Alexander, D. \& Archer, S. (eds). European Accounting Guide $4^{\text {th }}$ ed., New York: Aspen Law \& Business, pp. 1481-1504.

Alver, J., \& Alver, L. 2008. "Development of Accounting and Implementation of International Financial Reporting Standards in Estonia", in McGee, R. W. (ed). Accounting Reform in Transition and Developing Economies. New York: Springer, pp. 101-113.

Bailey, D., Alver, J., Mackevičius, J., Paupa, V. 1995. Accounting law reform in the Baltic States: the initial steps, The European Accounting Review, 4, pp. 685-711.

Barker, R., 2010. On the definitions of income, expenses and profit in IFRS. Accounting in Europe, 7(2), pp. 147-158.

Baskerville, R. \& Evans, L., 2011. Situating IFRS translation in the EU within speed wobbles of convergence. [Online] Available on-line at: http://www.victoria.ac.nz/sacl/centres-and-institutes/ cagtr/working-papers/WP81.pdf [Accessed 15 January 2016]

Beattie, V., McInnes, W. \& Fearnley, S. 2004. A Methodology for Analyzing and evaluating narratives in annual reports: a Comprehensive Descriptive Profile and Metrics for Disclosure Quality Attributes. Accounting Forum 28(3), pp. 205-236.

Dahlgren, J. \& Nilsson, S.-A., 2009. Destroying content while changing context. Translating IFRS into Swedish, paper presented at the EuFin conference in Catania, Italy, September 2009.

De Beaugrande, R. \& Dressler, W. 1981 Introduction to Text Linguistics, London and New York, NY: Longman

Evans, L., 2004. Language translation and the problem of international accounting communication. Accounting Auditing and Accountability Journal, 17(2), pp. 210-248. 


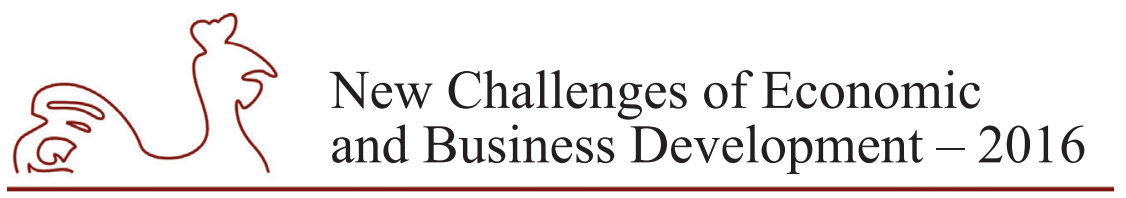

May 12-14, 2016, Riga, University of Latvia

Evans, L., 2009. Observations on the changing language of accounting. [Online] Available on-line at: http://storre.stir.ac.uk/bitstream/1893/8806/1/Observations\%20on $\% 20$ the $\% 20$ changing $\% 20$ language $\% 20$ of $\% 20$ accounting.pdf [Accessed 10 January 2016].

Evans, L., Baskerville, R. \& Nara K., 2010. The power of words and the power to interpret: an interprofessional perspective. [Online] Available on-line at: http://www.stir.ac.uk/media/schools/ management/documents/accountingfinance/eufin2010/EUFIN\%20-\%20Evans\%20-\%20 Baskerville\%20-\%20Nara.pdf [Accessed 5 January 2016].

Evans, L., Baskerville, R. \& Nara, K., 2011. Colliding worlds: language translation in accounting and other disciplines, [Online] Available on-line at: http://ssrn.com/abstract=1623310 1 [Accessed 15 December 2015].

Evans, L., Baskerville, R. \& Nara, K., 2010. Translation and its problems: an inter-professional perspective and lessons for accounting", [Online] Available on-line at: http://apira2010.econ.usyd.edu.au/ conference_proceedings/APIRA-2010-145-Baskerville-Inter-professional-perspective-lessons-foraccounting.pdf [Accessed 3 January 2016].

Janicki. K., 2002. A hindrance to communication: the use of difficult and incomprehensible language. International Journal of Applied Linguistics, 12(2), pp. 194-218.

Jones, M. J. \& Shoemaker, P. A. 1994. Accounting Narratives: A Review of Empirical Studies of Content and Readability. Journal of Accounting Literature, 13. pp 142-184.

Kettunen, J., 2011. Translation of IFRS Standards into Local Languages: Understanding Problematics of Translation, [Online] Available on-line at: www.lse.ac.uk/accounting/pdf/kettunen.pdf [Accessed 3 January 2016].

Mourier, L., 1996. "Translation challenges and quality problems in financial reporting", in Grinsted, A. (ed.) Language \& Business Life. (2). Kolding: Southern Denmark Business School.

Mourier, L., 2000. Integrating theory and practice in translator education for LSP. In Teanga 10. D. P. Ó Baoill \& M. Ruane (ed.), Integrating Theory and Practice in LSP and LAP, The Irish yearbook of applied linguistics. Dublin: IRAAL \& UCD.

Mourier, L., 2004. Communicating financial reporting across continents, [Online] Available on-line at: download1.hermes.asb.dk/archive/download/h32_07.pdf [Accessed 3 January 2016].

Norberg, C. \& Johansson, J. 2013. Accounting terminology and translation - a linguistic challenge [Online] Available on-line at http://lsp.cbs.dk [Accessed 3 December 2015].

Robb, S. W. G, Single, L. E. \& Zarzeski, M, T. 2001 Nonfinancial Disclosures Across Anglo-American Countries. Journal of international Accounting, 10(1), pp. 71-83.

Roseberry, R. L. 1995. A texture index: Measuring texture in discourse. International Journal of Applied Linguistics, 5 (2), pp. 205-223.

Sydserff, R. \& Weetman, P. 1999. A Texture Index for Evaluating Accounting Narratives: An Alternative to Readability Formulas. Accounting, Auditing and Accountability Journal, 12(4), pp. 459-488.

Zeff, S. 2007. Some Obstacles to Global Financial Reporting Comparability and Convergence at a High Level of Quality. The British Accounting Review, 39, pp. 290-302. 


\title{
New Challenges of Economic
} and Business Development - 2016

May 12-14, 2016, Riga, University of Latvia

\section{E-LEARNING AS A FACTOR FOR FACILITATING THE DEVELOPMENT OF INFORMATION SOCIETY}

\author{
Signe Balina, University of Latvia, Latvia ${ }^{1}$ \\ Dace Baumgarte, University of Latvia, Latvia \\ Edgars Salna, University of Latvia, Latvia
}

\begin{abstract}
Classroom training and e-learning are two main learning forms with their own benefits and methods for reaching learning aims. Blended learning is the combination of both main training forms that has been widely used in order to create useful training programs using a combination of teaching methods.

The challenge of life-long learning is to develop such learning process that is based on the opportunities provided by ICT, and that could increase the life-long learning involvement reaching the $21^{\text {st }}$ century needs and facilitating information society.

In modern society with its mobility and culture of using ICT, e-learning has become a useful media allowing self-regulated learning, learning in collaboration and providing opportunity to acquire digital skills through learning process.

To sustain learners' motivation for learning and to avoid cognitive overload it is crucial that the learning materials and information is presented in different forms - auditory and visual, avoiding redundancy and presenting information clearly and in a well organised way. Learning materials also need to be suitable for all learning styles giving an opportunity to learn in the most appropriate way for each learner.

The aim of the research is to apply e-learning principles to the design of online collaboration tools used to train teachers of secondary schools in Latvia Online4EDU. The research is based on literature review and the case study analysis including the evaluation of the usefulness of training process and course results.
\end{abstract}

Key words: blended learning, e-learning, information society, motivation

JEL code: I210, I250

\section{Introduction}

Nowadays, a learning process is organised in two main forms - classroom training using traditional pedagogical methods and e-learning using information and communication technologies (ICT). Each of these forms is beneficial and appropriate for reaching learning aims. The difference is in ways and methods how the knowledge is given and how the understanding and acquisition of skills is reached. The traditional learning process is mainly based on simultaneous joint activity, whereas the e-learning process is based on the individual and self-organised work.

In last decades more and more the combination of both main training forms are used in order to create an optimum training program for a specific audience - so called blended learning (Bersin, 2004). As pointed by Wedgwood (2013), the blended learning refers to a complementary

1 Corresponding author 


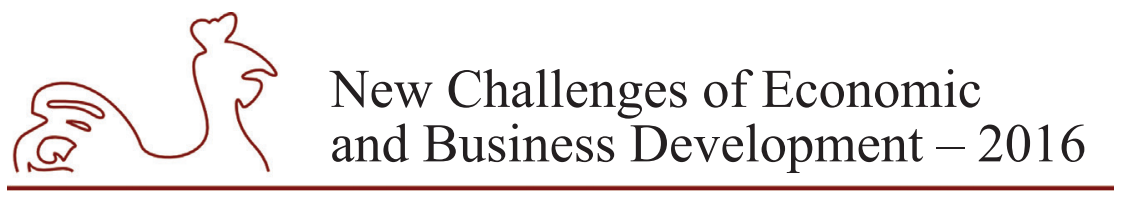

May 12-14, 2016, Riga, University of Latvia

mix of teaching methods delivered using an appropriate selection of related resources (often technology-based resources).

Due to the rapidly evolving information and communication technologies (ICT) and development of new products and technological solutions, people at their professional and everyday life have been more and more urged for immediate skills and transdisciplinary knowledge. More and more enterprises have started to rely on e-learning as a way to provide the acquisition of new knowledge, to assess the existing competencies, and to facilitate the improvement of qualification.

Taking into account that learning in a virtual environment depends greatly on learner's own self-discipline, motivation and time management, it is important to create concise, reliable and content appropriate learning materials in order to ensure the necessary knowledge and qualitative learning process.

The aim of the research is to apply e-learning principles to the design of online collaboration tools used to train teachers of secondary schools in Latvia Online4EDU. The research is based on literature review and the case study analysis including the evaluation of the usefulness of training process and course results.

\section{Research results and discussion}

\section{Motivational e-Learning within the Context of Information Society}

An individual is not only directed and influenced by his/her own will, abilities and needs for learning, but also by the ongoing processes and changes in the society, including the acquisition of necessary skills and knowledge. Nowadays these are innovations and opportunities caused by information and communication technologies that have already aroused changes in science and people daily and professional life by requiring new skills, mobility, and ability to orient oneself in the situation of informational overload. As pointed by Commission of the European Communities (2006), the education and training are critical factors for raising economic growth, competitiveness and social inclusion.

We all live in a society that is characterised by the term "information society", and, as it was agreed in year 2005 by the international community at the World Summit on the Information Society (WSIS), the overall vision is to build information society that is people-centred, inclusive and development-oriented (ITU, 2015). The concept "information society" is widely used, but as L. Z. Karvalics (2007) has explored, the central elements of different definitions of the term "information society" are information and knowledge. In order to acquire new knowledge and to get new information, the society participation in life-long learning is crucial.

Life-long learning participation rate is measured annually on the basis of EU Labour Force Survey data (that relate to all education or training whether or not relevant to the respondent's current or possible future job). The latest data shows that in 2015 the provisional percentage of adult population aged 25-64 participating in education and training in the European Union was $10.6 \%$. The leader in life-long learning activities is Denmark with participation rate $31.4 \%$, the lowest rate was in Romania (1.1\%). For Latvia this rate is also very low - in 2015 the provisional rate was $5.1 \%$. (Eurostat, 2016). These data show that there is a gap between different EU Member States with respect to life-long learning participation rates. 


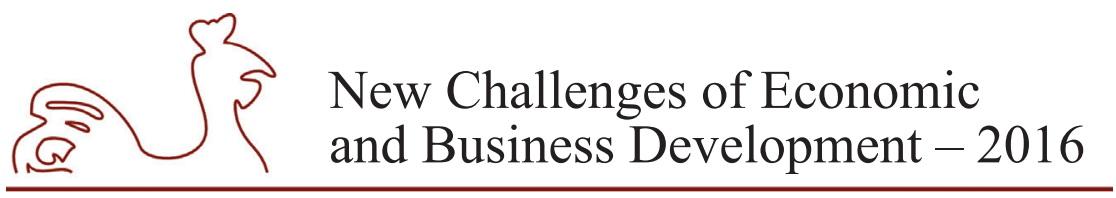

May 12-14, 2016, Riga, University of Latvia

The role of life-long learning for acquiring the necessary knowledge and skills for facilitating human resource competencies in modern society are not any more under question. The challenge emerges in the development of life-long learning process that is based on the opportunities provided by ICT, and that could increase the life-long learning involvement.

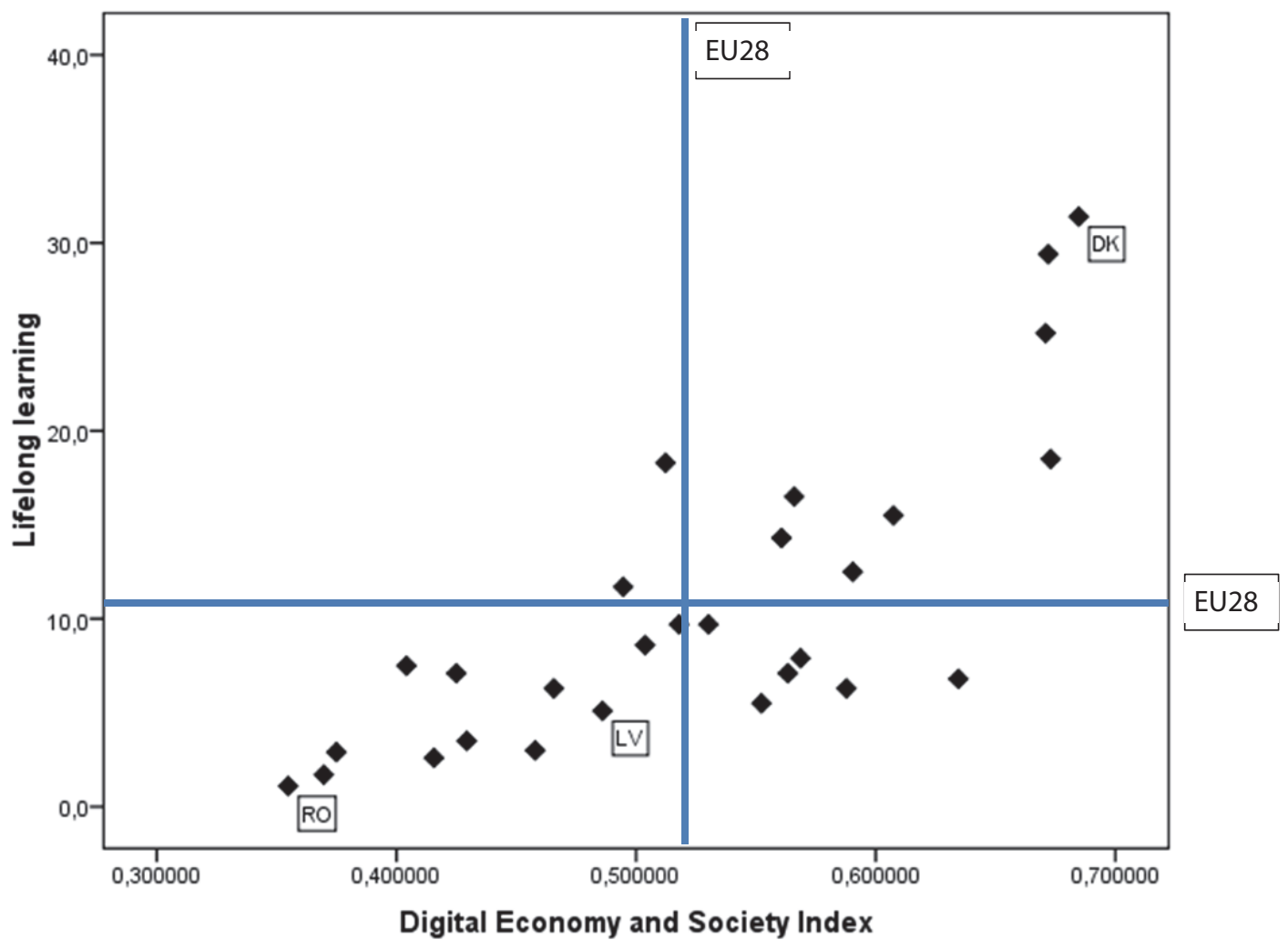

Source: author's construction based on Eurostat (2016), European Commission (2016).

Fig. 1. Correlation between life-long learning participations rate (2015, provisional) and Digital Economy and Society Index (2015)

There is a strong statistically significant positive correlation (0.779) between life-long learning participation rate and the Digital Economy and Society Index (DESI), see Figure 1. This index summarises indicators on Europe's digital performance and tracks the evolution of EU member states in digital competitiveness (European Commission, 2016). The member states with higher DESI index value have also higher participation rate in life-long learning. It means that states with better digital performance have more educated and trained adults (who foster the development of information society), and vice versa. Member states are at different levels of development and are progressing at different speeds in DESI, the same is also valid for life-long learning participation.

The use of technologies in e-learning shifts the focus from theoretical to practical activities and that are largely based on the opportunities provided by ICT. There is an ongoing trend of changing the learning form from the traditional full-time learning to e-learning or blended 


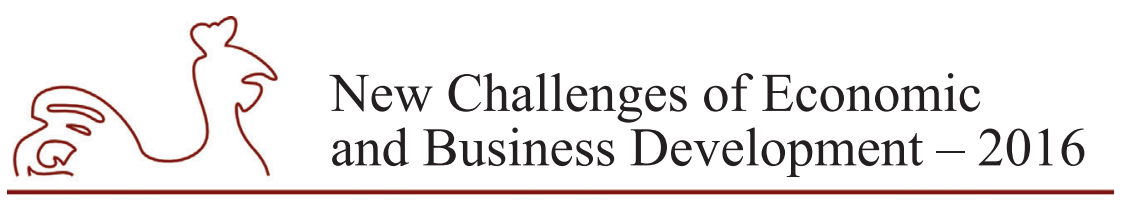

May 12-14, 2016, Riga, University of Latvia

learning (López-Pérez et al, 2011; Nazarenko A. L., 2015). Another one ongoing debate is about the learning quality when we compare learning at the online environment with the traditional classroom training (Güzer B., Caner H., 2014).

The usage of ICT in learning process brings in the necessity to overview the traditional learning methods and adapt to self-regulated learning. As Garrison and Kanuka (2004) stated that "blended learning is the thoughtful integration of classroom face-to-face learning experiences with online learning experiences". And it is argued that blended learning can improve and transform face-to-face learning (Donnelly, R., 2010; Okaz A. A, 2015).

Blended learning involves various media provided by ICT (Singh H., 2003) and mutual interaction between students and tutors (Donnely, 2010). In blended-learning, various eventbased activities (like practical works, laboratory works, creation of models, and usage of simulations) are mixed with face-to-face classrooms and self-paced e-learning (Singh H., 2003). The reasons why blended learning can be chosen, are improved pedagogy, increased access/ flexibility, and increased cost effectiveness (Graham, 2004). Blended learning also has reduced dropout rates and has raised final marks by means of the blended learning activities (LópezPérez et al, 2011).

In the design of a blended learning seven activities have to be incorporated - assimilative activities (reading, watching, listening), finding and handling information, communicative activities, productive activities, experimental activities, interactive activities, and assessment activities (Rienties R., Toetenel L, 2016).

The important factor for sustaining the learning motivation is receiving the feedback, evaluation, next tasks and control. By means of ICT tools, these motivational elements can be achieved providing correct answers or references, assigning following tasks and giving encouragement, for example, by means of badges. The feedback can be provided also by synchronous or asynchronous communication with tutor or groupmates if such communication is agreed upon. (Wedgwood, 2013).

It leads to the conclusion, that blended learning can provide personalized learning process where learner's individuality is not detached from the learning results that have to be achieved. The blended learning could be facilitated also by the materials that are developed on didactic principles with scientific, consistent, logical, and consecutive content. Logical and consecutive principles provide the content accordingly to the learner's previously obtained knowledge or accordingly to the learner's previous activity. ICT can be of a great help by providing individualized learning process, if contrasted to the traditional classroom training where lecturer works with a unified content within a definite timeframe with a group of learners. These traditional classroom training's traits do not comply anymore within the context of the dynamic, mobile and interbranch knowledge demanding society.

\section{Role of Learning Context and Cognitive Load}

Factor of a learning process is learning context: it is influenced by other factors and at the same time it influences other factors such as learning outcomes and results. The word "context" with its roots in Latin word "contextus" is defined in Merriam-Webster dictionary (2016) as the interrelated conditions in which something exists or occurs. As pointed by G. Chen and D. Kotz (2000) the various explanations of the meaning of context include: 


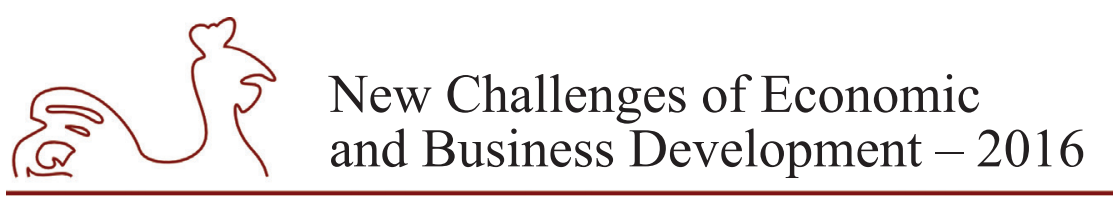

May 12-14, 2016, Riga, University of Latvia

- "Computing context, suchas network connectivity, communication costs, and communication bandwidth, and nearby resources such as printers, displays, and workstations.

- User context, such as the user's profile, location, people nearby, even the current social situation.

- Physical context, such as lighting, noise levels, traffic conditions, and temperature.

- Time context, such as time of a day, week, month, and season of the year."

The adjustment of learning content to the learner's needs with respect to the learning characteristics and context parameters requires to define the widest possible range of parameters that are included in the preferable learning process for the learner. As stated by Minu. M. Das, T. Chithralekha and S. Sivasathya (2010), these parameters are learner personal profile, level of expertise, learning style, learner preferences, learner intention, learner situation, quality of learning service, network and device.

Learner's personal profile contains information about learner's personal details such as name, ID, date of birth, knowledge of the learner. Level of expertise allows indicate whether the person is a beginner or if the learner has some previous knowledge about a topic or the learner is an expert in that topic. Learning style allows to define the type of delivery of learning materials: more theoretical or problem-oriented materials, and with learner preferences it is possible to determine the type of learning - theoretical, practical or simulations. The depths and specifics of necessary materials allows to understand the learner's intention. In order to perceive the best possible way for supplying learning materials the learner's situation is important (private or public place). Quality of learning service, network and device are parameters that allow to measure network response time or availability, network capacity and device type. (Das M. M., et al., 2010)

From the perspective of individuality, learners have different learning styles that influence their concentration to various types of information and define that information is perceived in various types, as it is stated by North Carolina State University's professor Richard M. Felder and Rebecca Brent. (Felder R. \& Brent R., 2005)

For the learning process it is advisable not only to obtain these context characterising parameters, but also to model and to organise the process in a way that it allows to structure information accordingly to the learner's needs.

By providing the individual approach of the learning process, it is also preferable to ensure that the learning process can be carried out in such amount and intensity as it is in accordance with learner's individual demands without overloading cognitive system (Eysenck M. W., Keane M. T., 2005; Sweller J., 1994; Johnson-Laird P. N., 1980). According to Jan L. Plass et al. (2010), one of the principles of how people perceive information is through dual channels - one channel is for perceiving information in words (auditory information), the other channel is for perceiving visual information. It also has to be taken into account in the development of learning materials that the perceived information is processed in 3 stages - sensory memory, working memory and long-term memory (Jones et al., 2011; Mayer R. E., Moreno R, 2003).

The factors that influence the cognitive ability to perceive and acquire the information in the given time of the learning process are as follows:

- learner's ability and talent,

- motivation,

- quality of the learner's previous knowledge, 


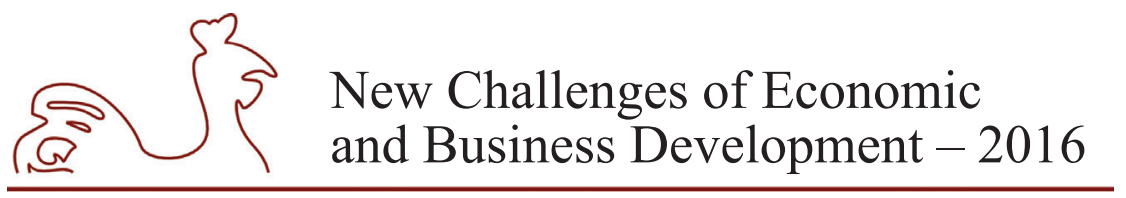

May 12-14, 2016, Riga, University of Latvia

- difficulty of the course,

- quality of teaching,

- quality of counselling. (Karjalainen A., et al., 2006: 16).

The problem could arise that the thinking and perceiving process for acquiring new knowledge during the learning task performance may exceed the capacity of a learner's cognitive system - a situation that is called cognitive overload (Mayer R. E. \& Moreno R., 2003).

Therefore, learning materials have to be designed to assist learners in transferring information from their working memory to their long-term memory. It means that in the training materials there is need to present the information without non-relevant items and, if possible, increase the usage of items that assist to acquire knowledge (Guyan M., 2013).

According to R. E. Mayer and R. Moreno (2003), there are 5 most common cognitive load problems in e-learning that can be solved by specific actions, see Table 1.

Table 1

\section{Solutions for Reducing Visual and Audio Channel Overload}

\begin{tabular}{|c|l|l|}
\hline No. & \multicolumn{1}{|c|}{ Overload Scenario } & \multicolumn{1}{c|}{ Solutions for Reducing Overload } \\
\hline 1. & Visual channel is overloaded. & $\begin{array}{l}\text { Off-loading: Items from visual channel has to be } \\
\text { transformed to auditory channel. }\end{array}$ \\
\hline 2. & $\begin{array}{l}\text { Both (visual and auditory) channels } \\
\text { are overloaded. }\end{array}$ & $\begin{array}{l}\text { Segmenting: Material has to be divided in smaller } \\
\text { segments (smaller piece of information). } \\
\text { Pretraining: Information about terms and main } \\
\text { concepts before the main training. }\end{array}$ \\
\hline 3. & $\begin{array}{l}\text { One or both channels overloaded by } \\
\text { additional information. }\end{array}$ & $\begin{array}{l}\text { Weeding: Eliminate interesting but not so important } \\
\text { information. } \\
\text { Signaling: Provide marks for additional and not for } \\
\text { main learning target necessary information. }\end{array}$ \\
\hline 4. & $\begin{array}{l}\text { One or both channels overloaded by } \\
\text { to many items in one segment. }\end{array}$ & $\begin{array}{l}\text { Aligning: Place legends near corresponding parts of } \\
\text { graphics. } \\
\text { Eliminating redundancy: Do not repeat the same } \\
\text { information in visual and audio format. }\end{array}$ \\
\hline 5. & $\begin{array}{l}\text { One or both channels overloaded by } \\
\text { memorizing. }\end{array}$ & $\begin{array}{l}\text { Synchronizing: Present pictures and corresponding } \\
\text { sound jointly. } \\
\text { Individualizing: Make sure learners have skills at } \\
\text { holding mental representations. }\end{array}$ \\
\hline
\end{tabular}

Source: Based on Mayer R.E. \& Moreno R., 2003.

The overview of the theories on cognitive overload and its problems points to the necessity that in order to sustain learners' motivation for learning and to avoid cognitive overload the learning materials and information has to be presented in different forms. The texts should be given in a clear and intelligible language, the schemes should be well organised with clearly given information, as well as audio and visual materials should be provided without redundancy. Learning materials need to cover all learning styles giving an opportunity to learn in the most appropriate way for each learner. 


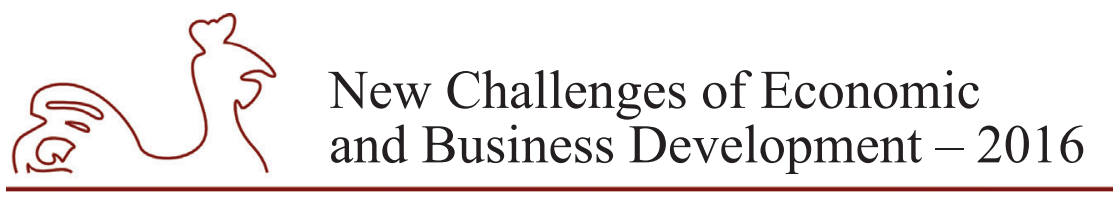

May 12-14, 2016, Riga, University of Latvia

\section{Case Study}

The presumption that self-regulated learning with receiving constant feedback combined with learning in collaboration using ICT can provide successful learning outcomes and motivate learners was tested in the project Online4EDU. This project was designed for school teachers with the aim to give them knowledge about how to use and apply various online collaboration tools in everyday school life - in teaching process. The teachers as target audience was chosen for two reasons - firstly, for their role in society as knowledge providers for digital natives, and, secondly, for their own lifelong learning necessity.

The project Online4EDU introduced online collaboration tools in education by providing a blended learning course for teachers. Five partner organizations from Estonia, Latvia, Lithuania, Germany and Ireland were involved in creating and establishing a training that complies with the ECDL-Test standards for online collaboration tools. The project was founded within the Erasmus+ program of the European Commission.

During the project the blended learning curricula and training materials about the usage of online collaboration tools were designed and tested for school teachers of primary, lower and upper secondary and vocational schools. The learning process for teachers was designed with a view to prepare teachers for the ECDL Online Collaboration certification test at the end of the training. The project "Online4EDU" lasts from September 2014 till the end of August 2016, the teachers' training was provided from January till April, 2016 (http://www.online4edu.eu/).

One of the project's targets was that at least 30 teachers from Latvia participate and successfully finish the training process. At the beginning of the training there were 34 teachers, and training was finished with 30 teachers. 4 teachers dropped out during the project in various its phases due to personal reasons.

The training was organised as a blended learning with the first and final face-to-face meetings and individual and group work in Moodle environment. The duration of the project was 11 weeks that consisted of covering 3 training modules. Training process started with pretraining survey, then followed face-to-face introduction meeting, after which the e-learning process started that consisted of 3 training modules, and it was finished with face-to-face final meeting (including final exam) during which the after-training survey was filled-in, see Figure 2. 


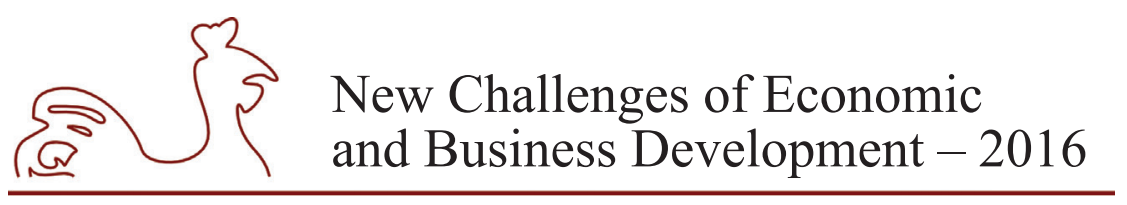

May 12-14, 2016, Riga, University of Latvia

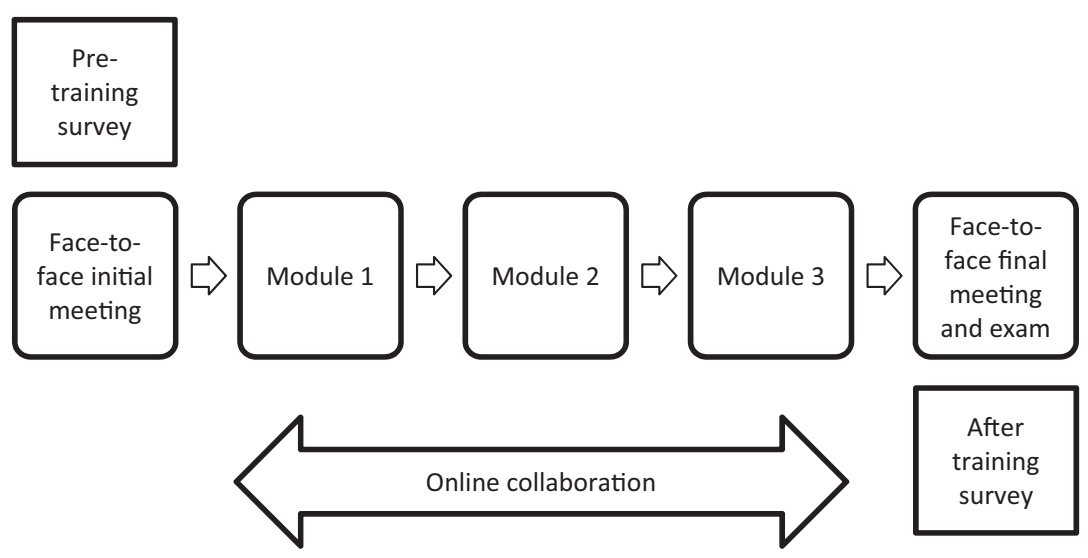

Source: authors' construction.

\section{Fig. 2. Blended learning process components in Online4EDU project}

The pre-training survey helped to understand the characteristics, experience and background of potential participants. The survey was carried out 1 month before the introduction meeting and allowed for course designers and tutors to adapt learning content. The pre-training survey showed that $50 \%$ of potential learners had previous experience with e-learning activities. Survey also indicated that almost half of learners have never used file sharing, social media, online calendars, and online collaboration tools. That was taken into account for making appropriate changes in learning curricula and adjusting the depth of materials.

The face-to-face introduction meeting gave an insight into the project and briefly acquainted learners with Moodle environment. At this meeting learners introduced themselves, and small working groups ( 4 to 5 people) were formed by game. During the game tutors mixed learners so that each group had participants with different knowledge levels, experience and location (but this was not known to learners). Then the individual learning process was started.

The Module 1 was designed for the theoretical acquisition of technical aspects of online collaboration tools (OCT). Its duration was 4 weeks. The Module 2 with its lengths of 3 weeks covered methodological aspects of online collaboration tools - how to use OCT in teacher's everyday life and how to implement OCT in a teaching process. During the learning process of the Module 1 and Module 2, teachers were asked to cover the theoretical training materials, to fill-in self-assessment tests, and hand-in individual and group works. These works were designed in a way that teachers were supposed to use OCT both for completing the task and for collaboration with each other during the task's fulfilment. The Module 3 was a creative process during which teachers were asked to create a concept of a lesson plan in groups of how to use OCT for freely chosen school subject, for example, how to incorporate OCT in teaching English, Arts, Geography, Literature etc. The length of Module 3 was 4 weeks. During the project teachers got acquainted and used such online collaboration tools as OneDrive, Doodle, OneNote, Trello, WebWhiteBoard, Padlet, Sway, Skype.

As the project involved teachers from all around Latvia, the groups were formed from teachers of various schools of various cities and they collaborated with each other and with tutors 


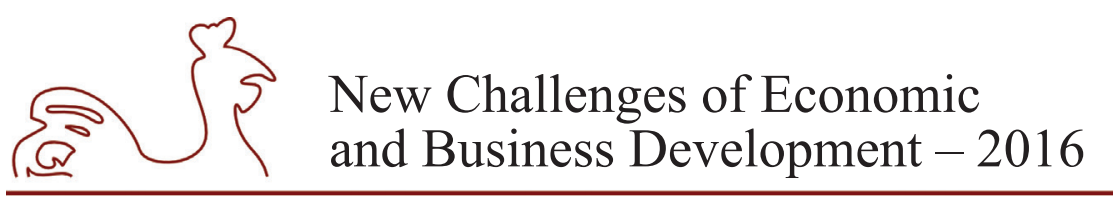

May 12-14, 2016, Riga, University of Latvia

by means of tools they were learning about. For the final face-to-face meeting learners were asked to prepare a presentation of their lesson plan involving OCT. At the final presentations it turned out that teachers successfully involved also their pupils and collaborated across schools.

All tasks, the teachers handed in, were evaluated by the tutors of the project. Participants were expected to participate actively in forum, participate in webinars at the end of Module 1 and Module 2 as well as to complete the necessary tasks. The learning process was supervised by the project's tutors who gave feedback, communicated with teachers and supported and motivated individually by e-mails or even phone calls.

All theoretical materials and tasks were designed so that 2-4 hours per week were necessary for covering the material and providing all required assignments. The total learning time was estimated to be 48 hours - 32 hours for individual and group work in Moodle environment and using OCT, and 16 hours for initial and final face-to-face meetings ( 8 hours for each). At the end of the training learners received the certificate about the participation in the training that will add up 48 hours for their annual professional qualification.

During the final face-to-face meeting the participants took ECDL tests that were mandatory. One of the tests was prepared specially for teachers on OCT usage in learning process. This was newly developed ECDL test that was piloted and tested in this project. The other was standard ECDL test on Online Collaboration.

30 out of 34 participants were highly interested in the learning process by handing-in their individual and groups' works, collaborating with their group mates as well as by participating in forum and contacting tutors. These participants attended the final face-to-face meeting, took ECDL examination, presented their concepts that were created during the Module 3 and received graduation certificate.

The low drop-out rate and the fact that $88.2 \%$ of participants successfully completed the training project signify that the initial concept of the project that involved constant feedback, support, mutual collaboration with group mates and communication with tutors was a sufficient motivator for participants. After the learning process tutors also received e-mails and thank-you words from learners about the received support and encouragement.

The after training survey gave information about learning process quality and usefulness. As we can see from Figure 3, the aim of the training was sufficiently defined $-82 \%$ of learners understood it clearly. For $61 \%$ of all learners the blended learning method was suitable for this course. The course content was in compliance with the course aims for $75 \%$ of learners. Only $43 \%$ considers that course duration was sufficient for acquiring the course content. $68 \%$ of learners have answered that self-assessment was a positive stimulus for successful course completion. 


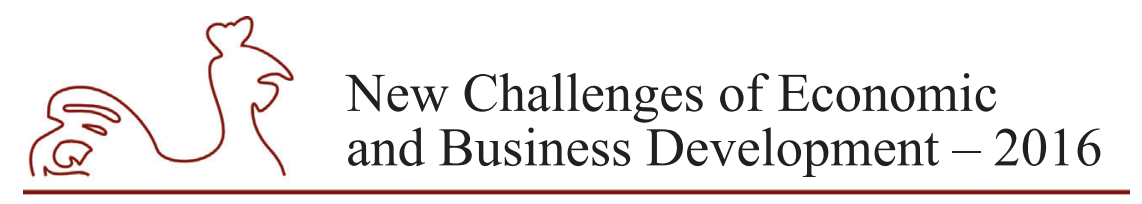

May 12-14, 2016, Riga, University of Latvia

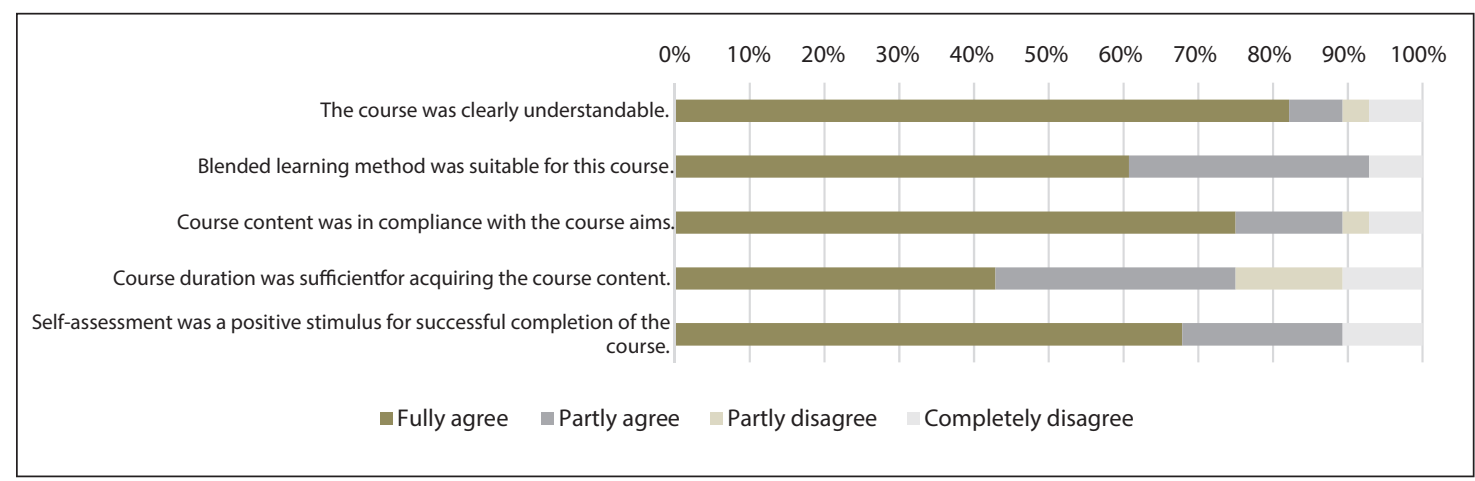

Source: authors' construction based on Online4EDU survey results.

Fig. 3. Online4EDU Training Process Evaluation by Trainers

Also the training course quality was evaluated by the learners. As it is shown in the Figure 4 the results are as follows: $79 \%$ of learners evaluated that support and assistance during the learning process was provided sufficiently. For $86 \%$ of learners the acquired knowledge and skills will be useful in their work. $79 \%$ of learners would advise and recommend this course for their colleagues - other teachers.

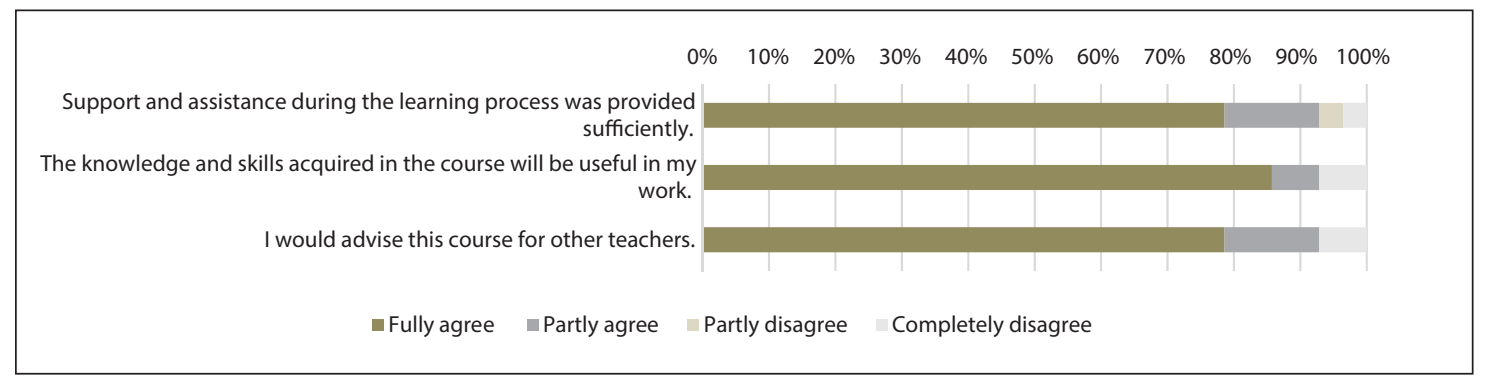

Source: authors' construction based on Online4EDU survey results.

Fig. 4. Online4EDU Course Quality Evaluation by Trainers

The lessons learned, taking into account the survey results, are as follows: there should be more face-to-face meetings or webinars during the learning process in the middle of each training module because there were misunderstanding of individual work. The time was allocated insufficiently - the learners spend more time than it was planned and the whole duration of the learning process was too short. The group work has a positive as well as negative impact. The positive is that mutual encouragement and support and driving force within the group. The negative is that not all people can be self-disciplined, the business trips, family life and individual interests or events sometimes interfere with other group members' time organization. There could be also made some changes to course materials by providing more practical instructions of how to perform certain tasks. 


\section{New Challenges of Economic and Business Development - 2016}

May 12-14, 2016, Riga, University of Latvia

\section{Conclusions, proposals, recommendations}

The research showed that ICT can be of a great help by providing context appropriate and useful learning process where the traditional classroom training methods can be used by means of online collaboration tools. The overview of the theories on cognitive overload and its problems pointed out the necessity that in order to sustain learners' motivation to reach learning aims and to avoid cognitive overload, the learning materials and information has to be adapted to learners' needs and experience, and collaboration should be provided for maintaining motivation and reducing dropout rates.

The main conclusions are as follows:

1) The central elements in different definitions of information society are information and knowledge. Consequently, the challenge of learning process emerges in the development of such life-long learning that in nowadays maintain learners' motivation, that have a concise and appropriate content and that are largely based on the opportunities provided by ICT.

2) In EU the member states with better digital performance have more educated and trained adults (who foster the development of information society).

3) E-learning materials need to cover all learning styles giving an opportunity to learn in the most appropriate way for each learner.

4) To create a complete context-aware learning, the context characterising parameters must be obtained and organized according to the needs of learner. A cognitive overload creates a negative effect that interferes with a learner's aim and motivation. This negative effect can overwhelm the positive effects. Therefore, cognitive overload as a negative effect must be managed.

5) Consequently, the usage of ICT in learning process brings in the necessity to overview the traditional learning methods and adapt its traditions to self-regulated learning, as well as learning in collaboration together with acquiring digital skills through learning process.

\section{Bibliography}

Bersin J., 2004. The Blended Learning Book. John Wiley \& Sons Inc., Pfeiffer

Chen, G. \& Kotz, D., 2000. A Survey of Context-Aware Mobile Computing Research. Dartmouth College Hanover, NH, USA, pp. 1-16. [Online] Available at: http://www.cs.dartmouth.edu/reports/TR2000381.pdf [Accessed 15 March 2016].

Commission of the European Communities, 2006. Adult learning: It is never too late to learn. Brussels, 23.10.2006 [Online] Available at: http://eur-lex.europa.eu/legal-content/EN/TXT/?uri=celex:52006 DC0614 [Accessed 10 April 2016].

Das, M. M., Chithralekha, T. \& Sivasathya, S., 2010. Static Context Model for Context Aware e-Learning. International Journal of Engineering Science and Technology, 2(6), pp. 2337-2346.

Donnelly, R., 2010. Harmonizing Technology with Interaction in Blended Problem-Based Learning. Computers and Education, Vol. 54, 2, pp. 350-359.

European Commission, 2016. The Digital Economy \& Society Index (DESI). [Online] Available at: https:// ec.europa.eu/digital-single-market/en/desi [Accessed 10 April 2016].

Eurostat, 2016. Employment and Social Inclusion Indicators. [Online] Available at: http://ec.europa.eu/ eurostat $/$ tgm $/$ table.do?tab=table \&init=1\&language=en\&pcode=tesem $250 \&$ plugin $=1 \_[\text {Accessed } 10$ April 2016]. 


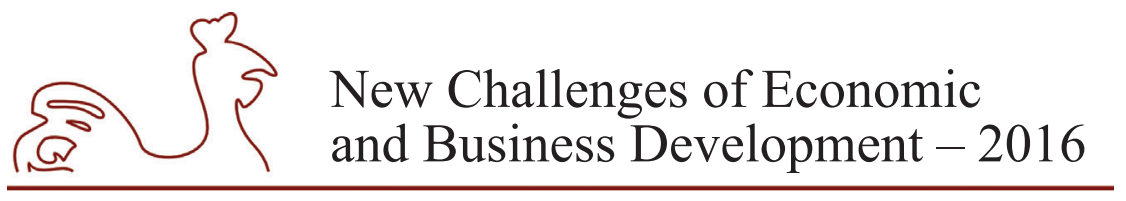

May 12-14, 2016, Riga, University of Latvia

Eysenck M. W., Keane M. T., 2005. Cognitive Psychology. A Student's Handbook. Psychology Press, Taylor \& Francis Group, Hove and New York. This edition published in the Taylor \& Francis e-Library, 2005. [Online] Available at: http://www.scribd.com/doc/67901312/Eysenck-W-MichaelKeane-T-Mark-Cognitive-psychology\#scribd [Accessed 10 April 2016].

Felder, R. \& Brent, R., 2005. Understanding Student Differences. Journal of Engineering Education, 94 (1), pp. 57-72.

Garrison D. R., Kanuka H., 2004. Blended learning: Uncovering its transformative potential in higher education. Internet and Higher Education 7, pp. 95-105.

Graham C. R., 2004 Blended Learning Systems: Definition, Current Trends, and Future directions. In: Bonk, C. J. \& Graham, C. R. (Eds.). (in press). Handbook of blended learning: Global Perspectives, local designs. San Francisco, CA: Pfeiffer Publishing.

Guyan, M., 2013. 5 Ways to Reduce Cognitive Load In eLearning. [Online] Available at: http:// elearningindustry.com/5-ways-to-reduce-cognitive-load-in-elearning [Accessed 10 April 2016].

Güzer B., Caner H., 2014. The past, present and future of blended learning: an in depth analysis of literature. Procedia - Social and Behavioral Sciences 116, pp. 4596-4603.

ITU, 2015. Measuring the Information Society Report, 2015. [Online] Available at: http://www.itu.int/en/ ITU-D/Statistics/Documents/publications/misr2015/MISR2015-w5.pdf [Accessed 10 April 2016].

Johnson-Laird P.N., 1980. Mental Models in Cognitive Science. Cognitive Science 4, pp. 71-115.

Jones N., Ross H., Lynam T., Perez P., Leitch A., 2011. Mental models: an interdisciplinary synthesis of theory and methods. Ecology and Society, 16 (1), pp. 46-46.

Karjalainen, A., Alha, K. \& Jutila, S., 2006. Give Me Time to Think. Determining Student Workload in Higher Education. Oulu University Press. [Online] Available at: http://www.oulu.fi/w5w/tyokalut/ GET2.pdf [Accessed 10 April 2016].

Karvalics, L. Z., 2007. Information Society - what is it exactly? (The meaning, history and conceptual framework of an expression). Network of Teaching Information Society (NETIS), funded by the European Commission under the Leonardo da Vinci Program. [Online] Available at: http://www.ittk. hu/netis/doc/ISCB_eng/02_ZKL_final.pdf [Accessed 10 April 2016].

López-Pérez M.V., Pérez-López M.C., Rodríguez-Ariza L., 2011. Blended learning in higher education: Students'perceptions and their relation to outcomes. Computers \& Education 56, pp. 818-826.

Mayer, R. E. \& Moreno, R., 2003. Nine Ways to Reduce Cognitive Load in Multimedia Learning. Educational Psychologist, 38(1), pp. 43-52.

Merriam-Webster, 2016. Merriam-Webster Dictionary. [Online] Available at: http://www.merriamwebster.com/dictionary/context [Accessed 10 April 2016].

Nazarenko A. L., 2015. Blended Learning vs Traditional Learning: What Works? (A Case Study Research). Procedia-Social and Behavioral Sciences 200, pp. 77-82.

Okaz A. A., 2015. Integrating Blended Learning in Higher Education. Procedia - Social and Behavioral Sciences 186, pp. 600-603.

Online4EDU, 2016. ERASMUS+ project Online4EDU published and unpublished materials. [Online] Available at: http://www.online4edu.eu/ [Accessed 10 April 2016].

Plass, J. L., Moreno, R., \& Brunken, R., 2010. Cognitive Load Theory. Cambridge: Cambridge University Press.

Rienties B., Toetenel L., 2016. The impact of learning design on student behaviour, satisfaction and performance: A cross-institutional comparison across 151 modules. Computers in Human Behavior 60 (2016), pp. 333-341.

Singh H., 2003. Building Effective Blended Learning Programs. Issue of Educational Technology, Vol. 43, No. 6, November-December 2003, pp. 51-54.

Sweller J., 1994. Cognitive Load Theory, Learning Difficulty, and Instructional Design. Learning and Instruction, Vol. 4, pp. 293-312.

Wedgwood J., 2013. Chapter 6. Blended Learning. IN: Hubbard R. (ed.) The Really Useful eLearning Instruction Manual. UK: Wiley \& Sons Ltd. pp. 91-106. 
May 12-14, 2016, Riga, University of Latvia

\title{
GENERATIONAL DIFFERENCES IN PERCEPTION OF VALUES IN POST-SOVIET BUSINESS ENVIRONMENT
}

\author{
Ilona Baumane-Vitolina, University of Latvia, Latvia ${ }^{1}$ \\ Madara Apsalone, University of Latvia, Latvia \\ Erika Sumilo, University of Latvia, Latvia
}

\begin{abstract}
Ethical behaviour and honesty had an ambivalent meaning in the Soviet Union compared to the Western approaches. The aim of our research is to analyse generational differences with regard to honest behaviour and honesty as a personal value in Post-Soviet Business Environment: in Estonia and Latvia.

In this study we explore differences in approaches towards values and especially honesty amongst four generations of retail sector employees - starting from those, who were still to great extent exposed to pre-Soviet values, continuing employees who started their careers during the Soviet times and ending with those, who were educated and entered the workforce after the collapse of the Soviet Union. 781 service employee from 6 retail organizations in Estonia and Latvia were surveyed to assess likelihood of dishonest behaviour and to rank their values according to the Rokeach instrumental value scale.

Arguing that for post-Soviet countries rather specific events and timelines could have left the main impact on worldviews, in order to assess the generational differences, we define four generations currently active in the workforce - Post-war generation, Early Gen X, Transition generation and Millennials.

We confirm that despite dual morality and ambiguous ethics in the Soviet Union, twenty-five years after the collapse of the system retail sector employees tend to report likelihood of rather honest behaviour. Moreover older generations report higher likelihood of honest behaviour than younger generations. And Post-war and Early generation X, born between 1945 and 1970, rate honesty and responsibility higher as their individual values. We also find that in a post-Soviet context there are significant differences between early and late generation $\mathrm{X}$, at least as far as honesty in the retail business environment is concerned.

Originality of this study is the following - the complexity of generational differences towards ethical behaviour, values and honesty amongst them has not been widely researched in Post-Soviet business environment.
\end{abstract}

Key words: Values, Honesty, Post-Soviet Business Environment, generational differences, retail JEL code: M14

\section{Introduction}

Ideas of equality and class struggles widespread among intellectuals at the end of 19th century in both Western Europe and Russia were based on altruistic and selfless moral reasoning. Indeed, situation of workers at that time was inhuman, leading to development of socialist and communist movements. However, when USSR became the first country trying to introduce communism, equality, unselfish and noble reasoning gradually became present only in the

1 Corresponding author - e-mail address: ilona.baumane@lu.lv 


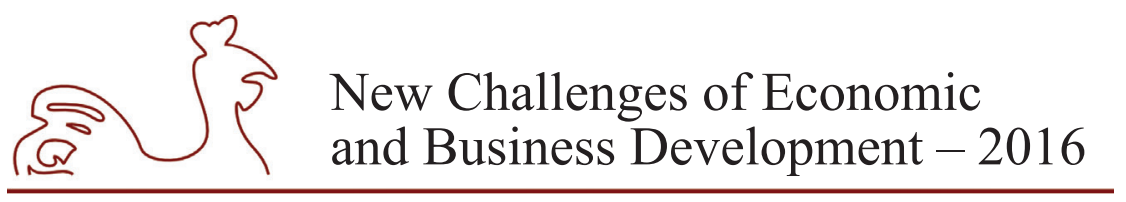

May 12-14, 2016, Riga, University of Latvia

formal ideology, while in reality double morale and special web of informal relationships (blat) was prevalent, when only certain layer of society was able to get particular commodities and services absent for others. Bribery and corruption, embedded in the communist leadership, were broadly accepted ways of action (Karklins, 2005).

Thus it could be assumed that under communism people from East Europe demonstrated less moral maturity than people from the Western societies (Riha, 1994). This assumption was practically tested by Smith, Sumilo and Karnups in 2009, concluding that Americans were associated with higher levels of moral judgement and moral development than Latvians (Smith, Šumilo and Karnups, 2009). Hisrich et al. (2003) studied specifically business people and found that Russians displayed the lowest level of business ethics, followed by Slovenians (belonging to former Socialist Yugoslavia), then Turks, and finally Americans.

Business ethics in transitional Post-Soviet countries has been mainly studied in Russia, while following the break-up countries had different paths of transition and development. For instance, countries that perceived the Soviet time mainly as oppression shared Soviet work values and double morality much lesser extent (Rees, Miazhevich, 2008).

While unethical and dishonest employee behaviour can harm enterprises in general, previous research finds retail sector particularly vulnerable with employee theft amongst the key reasons for loss (Moorthy et al., 2015). And retail sector was also amongst those business areas that experienced the most rapid changes transitioning from centrally planned economy under the communist regime to market economy after the Soviet Block collapsed. In Soviet times shortage of commodities ensured a more privileged status of retail employees, in market economy the power has shifted towards the customer.

In this study we explore differences in approaches towards business ethics and honesty among four generations of retail sector employees - starting from those, who were still to great extent exposed to pre-Soviet values, continuing employees who started their careers during the Soviet times and ending with those, who were educated and entered the workforce after the collapse of the Soviet Union.

\section{Ethics and Morality}

Business ethics can be understood and defined in different ways, as it is based on intangible qualities. In English literature, notions "morality" and "ethics" are frequently used as synonyms that have originated from different stems - the Latin word moralitas and the Greek word ethikos (Boatright, 1997).

Morality describes a sociological phenomenon - a presence of certain rules and standards in the society. Moral norms present in each society serve as a basis to ensure human intercommunication that is mutually beneficial. Without such fundamental rules as "Don't kill!" and "Don't steal!" a stable society would not be possible. However, it should be noted that not all rules are related to moral norms. For example, eating with a knife and a fork is part of a cultural etiquette while crossing the street on a green light is part of observing traffic regulations and not an adherence to social moral standards.

The word "ethics" is frequently applied when talking about moral standards of a particular social group or a profession. Ethics can be descriptive or regulatory. Descriptive ethics studies current norms and behavioural standards that exist in a certain social group or tries to understand processes of an ethical argumentation or decision making. On the other hand, regulatory ethics 


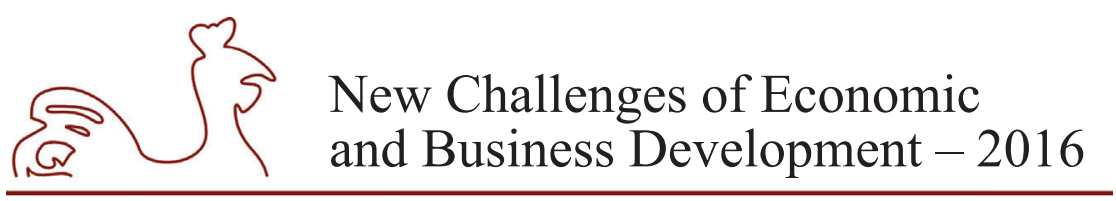

May 12-14, 2016, Riga, University of Latvia

carries out a theoretical scrutiny of moral principles based on the argumentation and fundamental moral principles.

Ethical theories are usually divided into the three big groups. Very widespread is the division into teleological, deontological and moral ethics theories (Boatright, 1997; Fisher, Lovell, 2003; Jonsson, 2011; Belak, Rozman, 2012). Teleological ethics theories are based on an assumption that a decision behind certain conduct has to be based on an assessment of a respective outcome. On the contrary, Deontological theories stress the presence of universal ethical principles that need to be followed irrespective of the outcome.

Another interesting group of ethical theories are the so-called Moral theories. These theories originated in Ancient Greece and have been associated with Aristotle. In this case, moral conduct is not determined by universal conduct code or an outcome of a specific action but by specific personal traits that guarantee the right choice in front of moral dilemmas. Thus, the object of moral ethics' analysis is not an ethical conduct but personal traits that ensure taking ethically correct decisions. In this case, a personal trait exhibited as a habit is considered to be a virtue. "A virtue can be thought of as a habit or character trait that is part of one's identity and that affects one's behaviour" (Jonsson, 2011: 31).

We can claim that a person is honest if we have observed him or her behaving honestly on several occasions. Furthermore, virtue is something admired in other people. Thus, we accept virtue's universal nature - it suits everyone and not merely representatives of certain professions or industries. In addition, virtue has got a rational foundation - it helps to reach set goals and to lead a complete life. For example, honesty increases trust that is helpful in mutual relationship and entrepreneurship. Courage helps in overcoming hardships. Whereas lack of virtues such as moderation will aggravate any situation as the person will be subject to different temptations and addictions.

It should be noted that personal traits deemed to be requirements for a moral life do not stay forever but change as the time goes by, for they depend on reigning social norms and values. For example, in Homer's time - 400 years before Aristotle, a period of continuous wars militancy was regarded as an ethical trait. During the later Athens city-state period which saw the development of Aristotle's Moral ethics concept, among the most important personal traits were intelligence, courage, self-control and justice. It was also believed that it was exclusively the prosperous aristocracy that were endowed with these virtues. Albeit Christianity introduced a number of significant changes in the list of the adopted ethical traits - in difference to Ancient Greek beliefs, slaves and the poor were regarded to be more ethical than the rich. In turn, industrial revolution defined other personal traits that became important in the $18^{\text {th }}$-century. For example, Benjamin Franklin advanced such virtues as cleanliness, punctuality and frugality, all having utilitarian nature (McMylor, 1994). However, contemporary authors that study aspects of moral ethics in modern international corporations distinguish such virtues as honesty, sense of responsibility and fairness, as well as the presence of vision and an ability to implement it in real life (Bertland, 2009; Moore, 2013; McCloskey, 1998; Jonsson, 2011).

It is important to note that ethical concept developed at the time when interpersonal relationship played a huge role - only those members of the society who were deeply integrated into their respective social classes and served their interests in good faith were deemed ethical. Besides, morality and ethics referred exclusively to the members of one's circle. Consequently, we can claim that moral ethics is closely linked with collective values. Besides, moral ethics is 


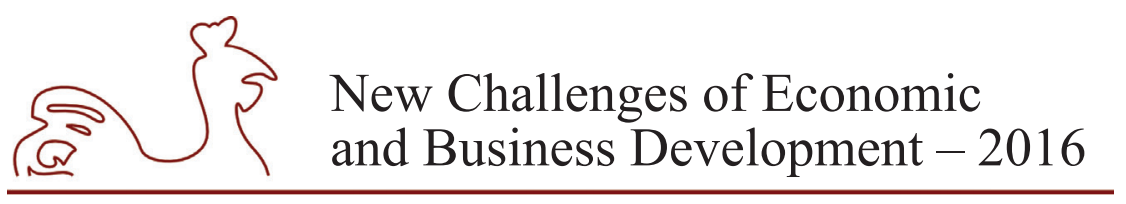

May 12-14, 2016, Riga, University of Latvia

closely related to values for they determine which personal traits will be deemed as virtues in certain societies - something that changes throughout the course of time.

Contemporary authors that study aspects of moral ethics in modern international corporations distinguish such virtues as honesty, sense of responsibility and fairness (Bertland, 2009; Moore, 2013; McCloskey, 1998; Jonsson, 2011). According to Schwartz, the three aforementioned values fall into benevolence cluster of Schwartz, being close also to helpful, forgiving and responsible - values emphasising concern over and preserving in-group welfare. These values, belonging to a broader group of self-transcendence, contradict values of self-enhancement values that emphasize personal interests and relative success and dominance over others (values of power, achievement) (Schwartz, 2012).

Lately, a research field called Behavioural ethics has evolved. In contrast to Classical or so-called normative ethics theories, Behavioural ethics is descriptive as it studies the individual decision making under ethically challenging real circumstances. Through the definition of Behavioural ethics one can claim that it studies "individual systematic and predictable ethical decision making that contradicts both intuition and welfare of a broader society" (Bazerman, Gino, 2012: 95) and as a discipline that "studies individual behaviour, assessed on the basis of universal moral standards" (Trevino, et al., 2006: 952).

Honesty is considered to be a moral value - society defines, whether certain actions are considered moral and honest, and therefore context is an important factor in this assessment (Vadi and Vissak, 2013). According to Rosenbaum (2014), two conceptual approaches explain, why some people are honest and others are not. First approach assumes that a wealthmaximizing, self-regarding person is honest as far as the material rewards of being honest exceed incentives of acting dishonesty. In this case the proportion of honest people in society depends on external incentives. The second approach suggests that societies internalize certain norms that are considered ethical and create intrinsic, psychological costs associated with lying. As the percentage of honest people in society increases, honesty becomes an integral value. Comparing results from different experiments, Rosenbaum concluded that $50 \%$ to $60 \%$ of all people could be characterized as in overall honest (Rosenbaum et al., 2014). Unfortunately no such comparable evidence is available for post-Soviet countries.

Honesty is described in value-terms, but its antipode, dishonesty, can only be described via behavioural manifestations. Lewicki and Stark (1996) have conceptualised dishonest behaviour as a three dimensional phenomenon, with discerning the following classical expressions of dishonest behaviour: stealing, lying and rule-breaking.

In the explanation and definition of dishonest behaviour, a number of authors have used lies as a prototype that forms the basis of further concepts and assumptions about an honest and dishonest behaviour. For example, the US scientists Elizabeth D. Scott and Karen A. Jenh in their article on the assessment of dishonest behaviour demonstrated by involved parties in organizations, have proposed a prototype of dishonesty model (Scott, Jehn, 2003):

a) Falsehood;

b) Deliberate action;

c) Intent to mislead.

With the three elements of the given set coming true, the claim can be unambiguously defined as lies. On the other hand, with no components of this prototype coming true, the claim cannot be allocated to the category of lies. In the event of juxtaposing the two claims - with 


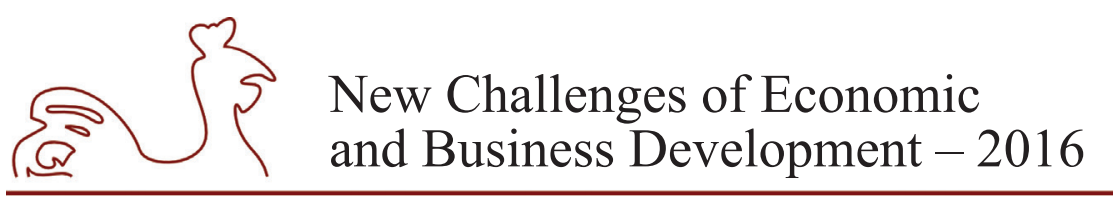

May 12-14, 2016, Riga, University of Latvia

two components of the set coming true in the first claim and a single component coming true in the second claim - the first claim will be more regarded as lies than the other one. Thus, it is possible to say that two poles - the lies and the truth - have been formed, both having numerous possibilities of categorizing claims as more or less corresponding to lies.

A similar principle has been applied to creating a prototype of dishonesty where besides lies, a set of other dishonest actions resembling lies have been included (Scott, Jehn, 2003). Thus, the prototype of dishonesty includes the following actions:

a) False claims, gestures, look, questions, facial expressions, signs, images, silence or any other kinds of communication;

b) Individual's belief that the action has been dishonest;

c) Individual's intent to mislead.

This is an interesting and a beneficial concept that aids in understanding the essence of dishonest behaviour; however, it is rather narrow and does not contain a full spectrum of expressions behind dishonesty. Although lies and deception are a significant component of dishonesty, there are many more expressions of dishonest behaviour that are very different to deception in their essence.

Values are socially constructed and develop early in the childhood, maturing within the moral reasoning of individual by the age of twelve (Hofstede, 2001). Previous research has found that people considering others broadly dishonest do not regard honesty highly themselves (Vadi and Jaakson, 2011) and have also demonstrated more dishonesty in experiments (Houser et al., 2012; Abeler et al., 2014). This can be explained by belief-action causality - a belief about and knowledge of others' norm violations lead to dishonest actions of the individual (Rauhut, 2013, Diekmann et al., 2011).

\section{Generational Differences and Post-Soviet Context}

As honesty by its nature is not a dichotomy but a full spectrum phenomenon with more cardinal and less pronounced expressions allowing assessing a specific behaviour as "slightly dishonest" or "almost honest", depending on the context, society and traditions, the same action might be considered honest in one setting, while perceived dishonest in another.

In the Soviet Union honesty had a twofold connotation. Dishonest actions such as stealing and not disclosing information towards the State were often considered necessary, broadly practiced and accepted. On the other hand, private ownership was respected and people were more honest, when interacting in social settings. This could be illustrated by an example, where stealing from the state and stealing from a private owner were seen as rather different actions, the first was generally practiced, the second - generally condemned (Grossman, 1977). However, this duality caused tensions and value ambiguity, when making daily decisions.

Informal practices and using relationships for one's benefit were widespread because formal governance system was not able to provide services and commodities needed (Morris, Polese, 2015). Ambiguity intensified with transition from a centrally planned to a free market economy such major system changes led to change of both - change of external incentives to be honest (private priority rights, legislation) and change of value patterns in society. System change was particularly visible at the retail sector. In Soviet system demand generally exceeded supply due to fixed state-subsidised prices. As retail employees were close to the limited goods they thus had relative power over customers. In the market economy power shifted from retail employees 


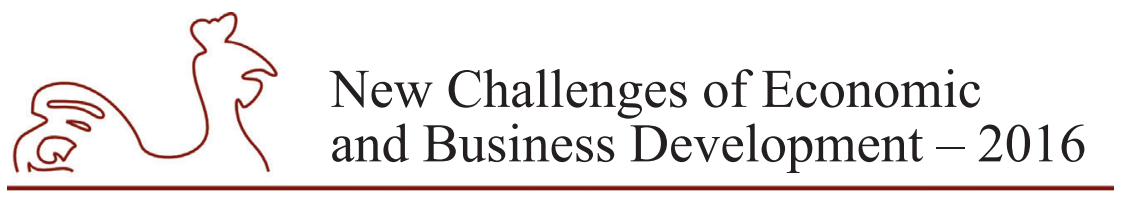

May 12-14, 2016, Riga, University of Latvia

to customers - the psychological legacy left behind by Communism created contrasting role expectations for employees and customers that are still evident in Estonia and Latvia (Vadi and Suuroja, 2006).

Twenty five years after the collapse of the Soviet Union, retail workforce in the Baltic States is very diverse and consists of employees with Soviet background as well as those who grew up and entered workforce in market economy after Estonia and Latvia restored independence. And while generational differences in workplaces are generally recognized due to different values, attitudes and commitments (Arsenault, 2004), the systemic change in Post-Soviet countries could result in significant differences towards honesty of actions and honesty as a value itself in Estonian and Latvian retail workforce.

Traditionally and biologically a generation could be defined as the time span between the parent cohort is born and their children cohort is born. Yet such definition has many limitations in modern societies, where generations are defined using sociological perspective and where focus on changes in events and processes would provide a more suitable basis for segmentation. Defining a generation sociologically, it refers to a cohort of people born within and shaped by a certain span of time - this way generation can be characterized by a certain pattern of attitudes, values and beliefs (Strauss and Howe, 1997). According to Wyatt (1993), generation is constituted of six determinations: (1) a traumatic or formative event, (2) a dramatic shift in demography, (3) a certain major economic cycle, (4) a creation of sacred space to sustain collective memory, (5) mentors and (6) work and cooperation of people, who know each other.

Many different approaches have been used to segment generations, most of them developed in the United States of America. In context of this research paper, one of the commonly used generation segmentations was developed by Zemke, dividing workforce into the Veterans (also called the Silent Generation, born 1922-1943), Baby Boomers (born 1944-1960), Generation X (Xers, born 1961-1980) and Generation Y (also named Nexters, Echo Boomers, Millennials, Internet Generation, born 1981-2000) (Zemke et al., 2000). With margin of changes and adoptions in starting and ending years of a generation, this framework has been extensively used for segmenting generations in the Western societies globally.

Yet we could argue that for the post-Soviet countries certain other events and timelines could have the main impact on worldviews. As no Baltic-specific model was found, we defined our model considering several events and processes, such as the end of the Second World War in 1944-45, end of the Stalin era in 1953, industrial development and labour immigration from other Soviet states in 1960s, influence of Western culture and values from the late Brezhnev era in 1970s, beginning of Gorbachev era in 1985, collapse of the Soviet Union and restoring independence in 1990-91, and joining the European Union in 2004.

Given the scope of this research paper, we focused on those generations currently active in the workforce (generally aged from 18 to 64), on the defining events and processes as well on the period a certain generation gained their education and work experience (Table 1). 
May 12-14, 2016, Riga, University of Latvia

Table 1

Defining generations

\begin{tabular}{|l|l|l|l|l|}
\hline \multicolumn{1}{|c|}{ Generation } & $\begin{array}{l}\text { Range of birth } \\
\text { years (roughly) }\end{array}$ & \multicolumn{1}{|c|}{ Defining events and processes } & Education & Employment \\
\hline $\begin{array}{l}\text { Post-war } \\
\text { generation } \\
\text { (Baby Boomers) }\end{array}$ & $1945-1960$ & $\begin{array}{l}\text { Post-war generation, end of Stalin } \\
\text { era. }\end{array}$ & $\begin{array}{l}\text { Soviet } \\
\text { Union }\end{array}$ & $\begin{array}{l}\text { Soviet Union } \\
\text { and Post- } \\
\text { soviet }\end{array}$ \\
\hline Early Gen X & $1961-1970$ & $\begin{array}{l}\text { Industrial development, increasing } \\
\text { welfare, labour immigration, } \\
\text { influence of Western culture from } \\
\text { 1970s. }\end{array}$ & $\begin{array}{l}\text { Soviet } \\
\text { Union }\end{array}$ & $\begin{array}{l}\text { Soviet Union } \\
\text { and Post- } \\
\text { soviet }\end{array}$ \\
\hline $\begin{array}{l}\text { Transition } \\
\text { generation } \\
\text { (late Gen X) }\end{array}$ & $1971-\sim 1984$ & $\begin{array}{l}\text { Gorbachev era and independence } \\
\text { movements, experience collapse of } \\
\text { the Soviet Union as young adults. }\end{array}$ & $\begin{array}{l}\text { Soviet } \\
\text { Union and } \\
\text { Post-soviet }\end{array}$ & Post-soviet \\
\hline $\begin{array}{l}\text { Millennials } \\
\text { (Gen Y) }\end{array}$ & $\sim 1985-\sim 2000$ & $\begin{array}{l}\text { Independence, globalization and } \\
\text { information technologies. Some } \\
\text { experience collapse of the Soviet } \\
\text { Union as children. }\end{array}$ & Post-soviet & Post-soviet \\
\hline
\end{tabular}

Source: compiled by the authors.

The earliest generation still active in the workforce is the Post-war generation, born in the period from the end of the Second World War till roughly 1960 (corresponding to the Baby Boomer generation in the Zemke framework). This generation is born in families of the Veteran generation, thus arguably influenced by values from pre-communist times, as well as by interpersonal attitudes developed throughout the war years.

Post-war generation is followed by Generation X, in Zemke framework born 19611980. Given the different context in Post-Soviet business environment, we have divided this generation in two - Early Gen X (born 1961-1970) and the Transition generation (born from 1971 till roughly 1985-1987). We assume that in comparison to the gradually developing US environment, the disruptive system change that affected the late Gen X as young adults could result in different values, attitudes and behaviours in comparison to the early Gen X.

Finally in our context Millennial generation start slightly later - from roughly 1985, this generation is educated and starts working in market economy and alike their counterparts in other Western cultures are influenced by globalization and the rapid development of information technologies.

In the following article we assess, whether those generations born during the Soviet time report higher levels of dishonest behaviour and lower ranking on honesty itself than the postSoviet educated Millennial generation. Research has found that ethics is positively related to age and experience (Hollinger, 1986; Trevino, 1992; Coscarella, 2005; Deshpande, 2010; Abeler et al., 2014), suggesting that older cohorts will exhibit more honest behaviour in comparison with the younger ones. On the other hand, in the our study context Millennial generation has grown up without the dual morality and centrally planned system and it may also be that younger employees have higher career aspirations and are therefore more concerned about their reputation and honesty (Mackevicius, Giriünas, 2013). 


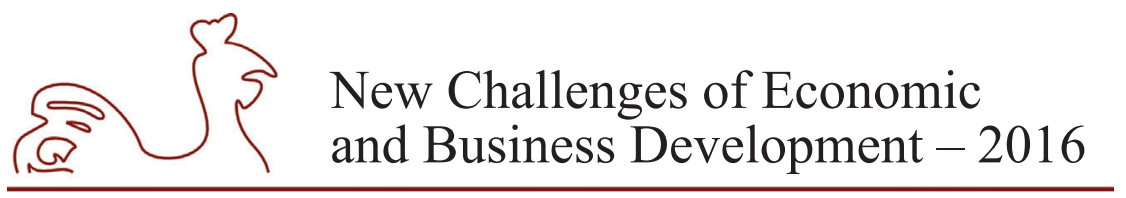

May 12-14, 2016, Riga, University of Latvia

\section{Method and Sample}

A questionnaire was designed to assess values and behaviours of retail service employees. They were asked to assume a role of a floor manager in a hypothetical retail enterprise in their country and evaluate the likelihood of dishonest behaviours of their hypothetical subordinates, as well as to rate their own values and provide socio-demographic data (gender, education, tenure and age). The hypothetical enterprise was described as a relatively well-known retailer in the given country. It was also said that the organization aims to become a market leader in its field.

Likelihood of nine dishonest behaviours was rated using a 7-point Likert scale, ranging from 1 (completely unlikely) to 7 (very likely). They included several forms of cheating employer (including shirking, misuse of facilities, hiding relevant information), stealing or damaging property, behaving disloyally, as well as several dishonest behaviours towards the customer lying to the customer, stealing from the customer and impolite behaviour towards customer.

Respondents' values were assessed using the Rokeach Value scale (Rokeach, 1973). Each respondent received 18 tags with Rokeach instrumental values, and they were asked to rate the values placing the most important value as first and a coloured test tag in the end. If the test tag was left in the middle, answers were not considered.

Questionnaires were provided in Latvian, Estonian and, if required, in Russian. They were placed in sealed envelopes and distributed via store managers, who did not take part in the research themselves.

Data from 6 retail organizations was collected during time period from 2012 till 2015. As a result 781 response was collected with the characteristics presented in the Table 2.

Table 2

Sample characteristics

\begin{tabular}{|c|c|c|c|c|}
\hline & Respondents & \% of female & Average age (years) & Average tenure (years) \\
\hline Estonia & 542 & $81.0 \%$ & 35.1 & 4.4 \\
\hline Latvia & 239 & $76.6 \%$ & 36.2 & 3.9 \\
\hline Total & 781 & $79.6 \%$ & 35.4 & 4.2 \\
\hline
\end{tabular}

Source: compiled by the authors.

Given that most of the retail sector employees are female, the sample was also female dominated. Service employees were on average 35.4 years old and had been working for their respective companies for over four years.

The youngest respondent was 18 by the time of completing the questionnaire, the oldest 64. Respondents represented four different generations using the framework defined in the previous section (Table 3).

Table 3

Sample characteristics of generations

\begin{tabular}{|l|c|c|}
\hline & Birth years of generation & Percent of sample \\
\hline Post-war & $1945-1960$ & 7.8 \\
\hline Early Gen X & $1961-1970$ & 16.4 \\
\hline Transition & $1971-1984$ & 34.3 \\
\hline Millennials & $1985-2000$ & 41.6 \\
\hline
\end{tabular}

Source: compiled by the authors. 


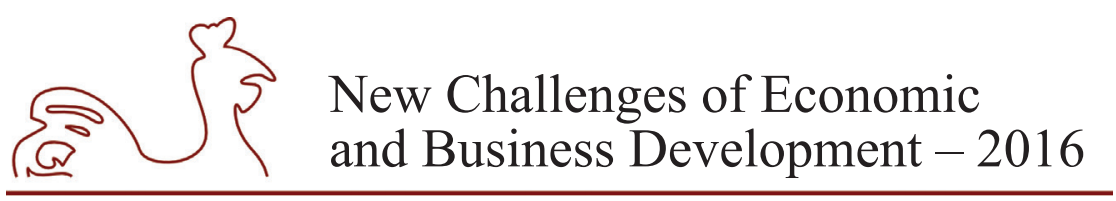

May 12-14, 2016, Riga, University of Latvia

\section{Research results and discussion}

\section{Dishonest Behaviour}

Looking at the overall results, we can conclude that honest behaviour is more prevalent than dishonest behaviour as respondents assess dishonest actions less likely than their corresponding honest actions.

Assessing nine forms of dishonest behaviour, we found that damaging employer property, cheating the customer financially and stealing from the employer were the least likely forms of dishonest behaviour, while shirking and misuse of facilities were more commonly reported (Fig. 1).

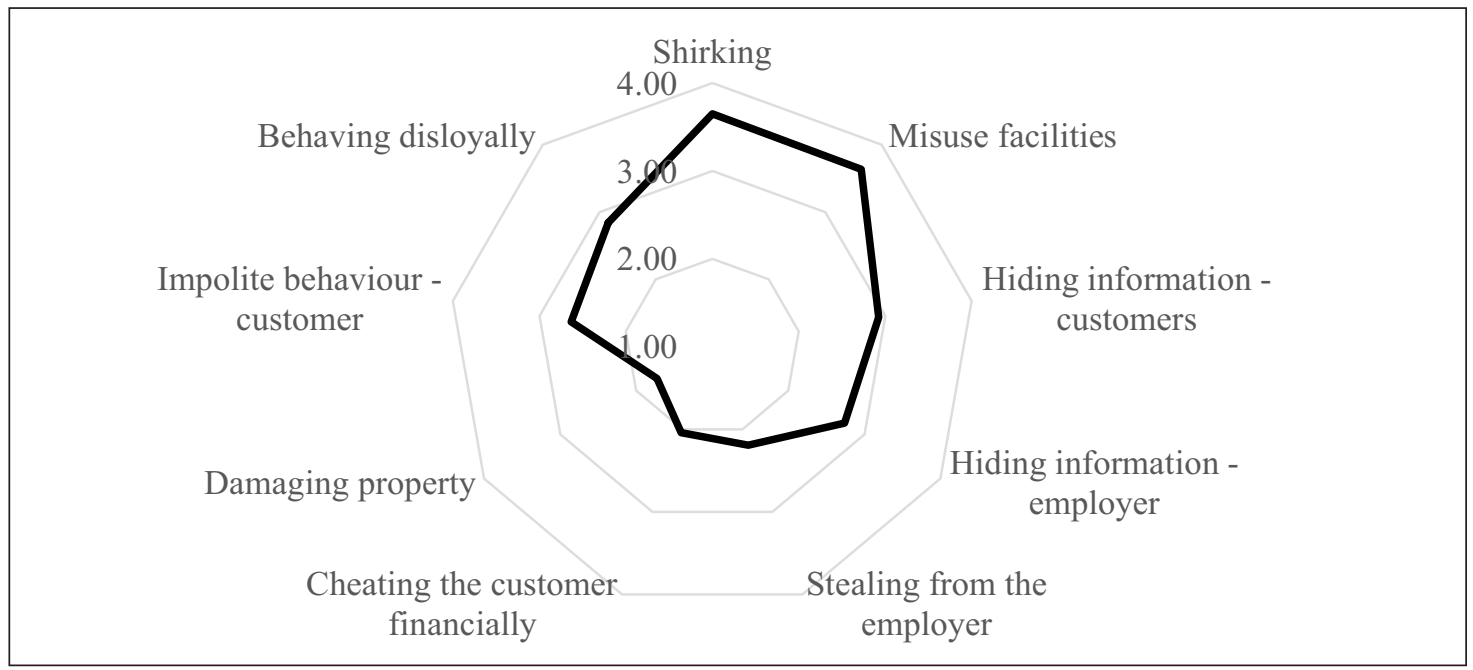

Source: authors' calculations.

\section{Fig. 1. Likelihood of various forms of dishonest behaviour}

Not surprisingly reporting likelihood of dishonest behaviour amongst various actions was slightly related - respondents considered dishonest behaviour more or less likely across various categories of action.

Our study also found female employees reporting more honest behaviour in all nine types of actions, and for misuse of facilities, hiding information from employer and customers, damaging property, as well as behaving disloyally this difference was statistically significant ${ }^{2}$. Yet, given the small male sample, these results cannot be generalized.

As suggested by earlier research, we were able to confirm that age is positively related to reporting of honest behaviours. Using Kendall's tau_b and Spearman's rho coefficients for nonparametric correlations, we found age negatively correlated with all nine researched forms of dishonest behaviour (Appendix I).

Tenure, on the other hand, was not statistically significantly linked to prescribed dishonest behaviours (Appendix I).

2 Tested with Mann-Whitney U test not assuming the same shape of distribution, Appendix II. 


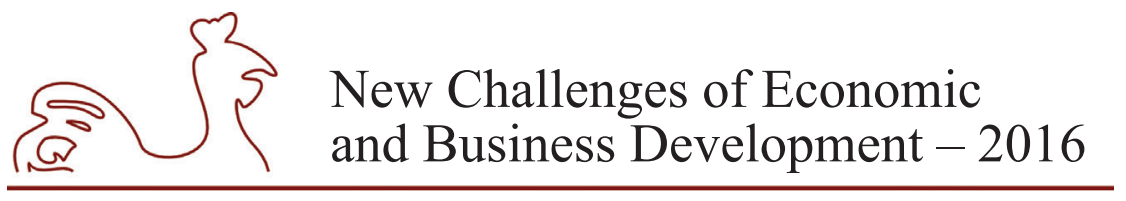

May 12-14, 2016, Riga, University of Latvia

\section{Generational Gaps and Dishonest Behaviour}

Despite the discussed dual morality and ethical dilemmas in the Soviet Union, our research found that the two generations that received education and started employment during the Soviet time, respectively the Post-war and Early X generations, reported more honest behaviour in all categories $^{3}$ (Fig. 2).

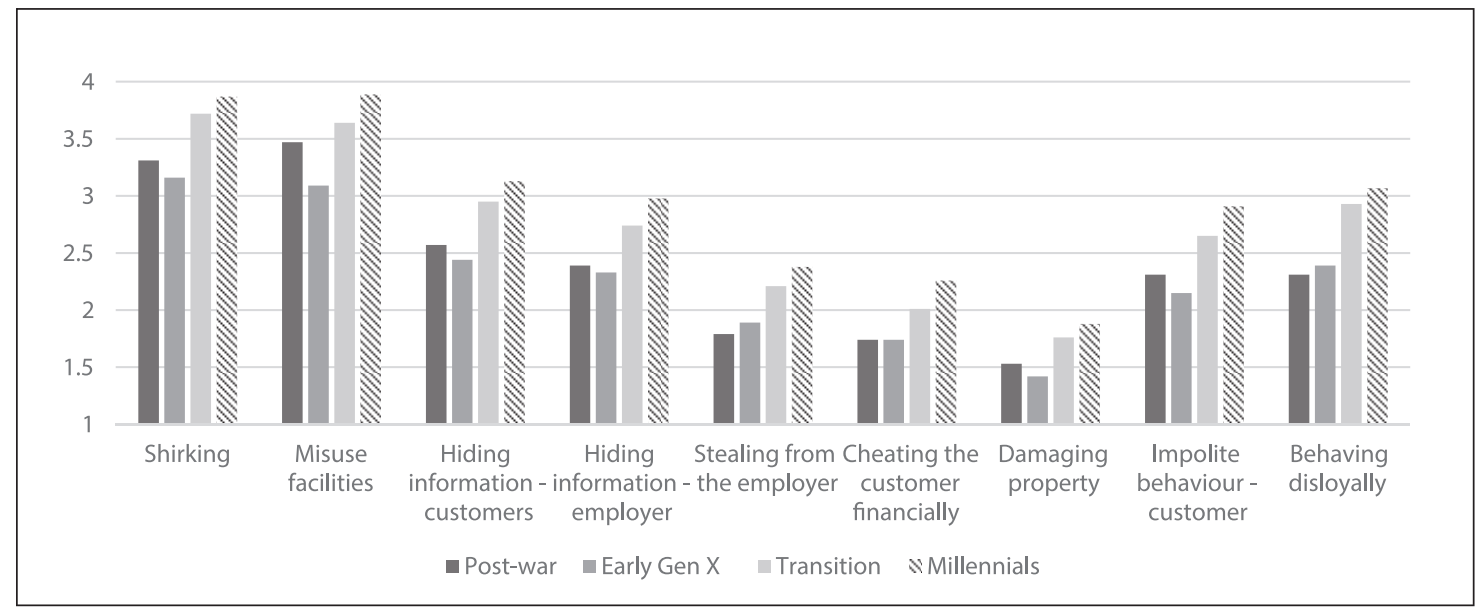

Source: authors' calculations.

\section{Fig. 2. Reporting of dishonest behaviours by generation}

As assumed when formulating the theoretical generation framework, significant differences can be observed between Early Gen X and the Late Gen X or the Transition generation. In fact, Early Gen X reported greater likelihood of honest behaviour in 4 out of 9 action categories than the previous Post War generation, and the difference for misusing facilities was particularly significant.

\section{Generations and Values}

Our research also confirms that certain instrumental values are related to dishonest behaviours. Honesty as a value is associated with lower likelihood of shirking, misuse of facilities, hiding information from employer and customers, stealing from the employer and behaving disloyally. Responsibility (being dependable and reliable) is related to less stealing from the employer, less cheating the customer financially, less damaging property, as well as more polite loyal and loyal behaviour. On the other hand individuals that rank higher independence are reporting more likelihood of hiding information from employer and customers, damaging property, being impolite towards the customer and behaving disloyally.

Similarly to likelihood of dishonest behaviour, generational differences can be observed, when ranking the Rokeach instrumental values. Post-war and Early X generations tend to rank honesty, responsibility and capability (competence, effectiveness) higher than their following generations, Millennials on the other hand rank helpfulness (working for the welfare of others), love (affection, tenderness) and cheerfulness (being light-hearted and joyful) higher (Fig. 3).

3 Using Kruskal Wallis Test we confirm that all these differences are statistically significant. 
May 12-14, 2016, Riga, University of Latvia

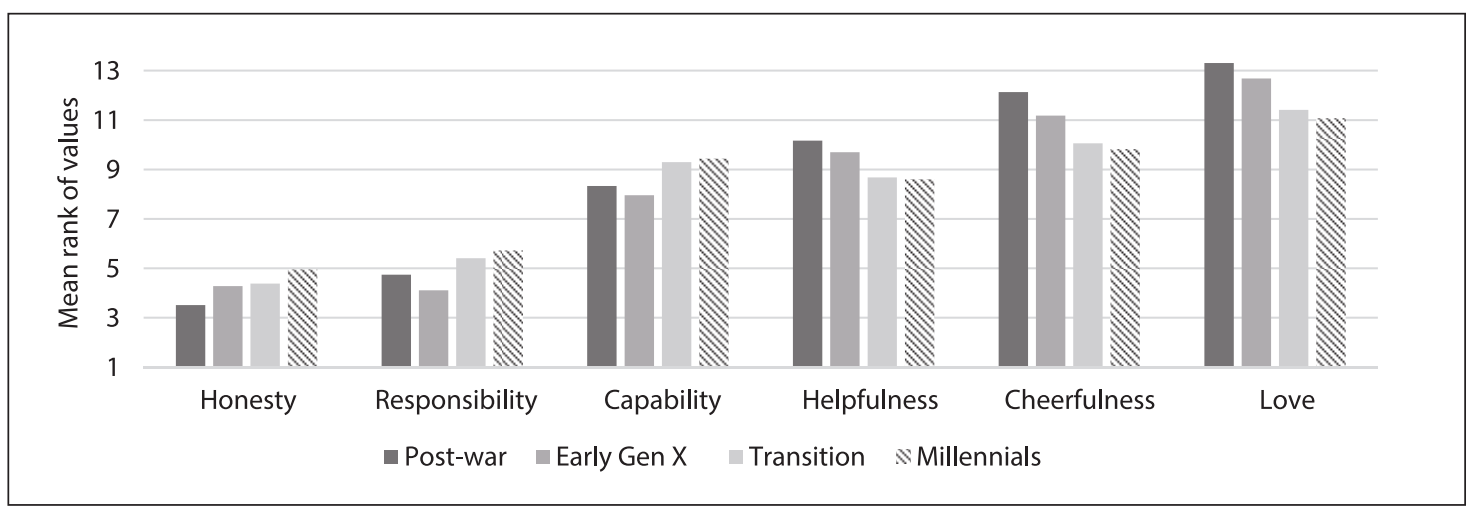

Source: authors' calculations.

\section{Fig. 3. Generations and instrumental values}

All four generations rank honesty and responsibility amongst the most important values. Interestingly, Post-war, Transition and Millennial generations rank honesty the highest amongst all values (while the Post-war generation exhibit a more clear preference towards this value than the later generations), at the same time Early X Generation ranks responsibility the highest, followed by honesty in the second place (full rankings are provided in Appendix III).

\section{Discussion}

In this research paper we confirm that despite dual morality and ambiguous ethics in the Soviet Union, twenty-five years after the collapse of the system retail sector employees tend to report likelihood of rather honest behaviour. Moreover older generations reported greater likelihood of honest behaviour than younger generations, even though earlier generations had been more exposed to the Soviet system. We also found that in post-Soviet context there are significant differences between early and late generation X.

These findings reopen the question, whether honest behaviour is more a function of generation or a function of age. Previous literature has suggested generations' attitudes as life-long effects (Arsenault, 2004), thus implying that generational effects should be the dominant, yet one could also consider that the external consequences and tendency to reduce risk at the workplace for older employees could play a role towards more honest behaviour for Post-war and Early Gen X.

These findings also question the extent of retained impact of the Soviet system over values, beliefs and attitudes in the Baltic States today. Given that the Soviet Union lasted slightly more than a generation and that this system was considered as oppressive in Estonia, it could be argued that early generations were still influenced by values of pre-Soviet generations and that Soviet work values and dual morality was not upheld after gaining independence (Rees, Miazhevich, 2009). Same could apply to Latvia. In addition, the impact of gradually incoming Western culture since 1970 s could also be considered in forming values and identities.

This leads to much broader consideration, whether certain values and worldviews could be shared by generations even across different systems - for instance, Generation X has been strongly characterized by honesty in the Western world - could we make an assumption that influence of the Western values from 1970s has been strong enough to form the tendency towards honesty also in Early Gen X in the Soviet system? 


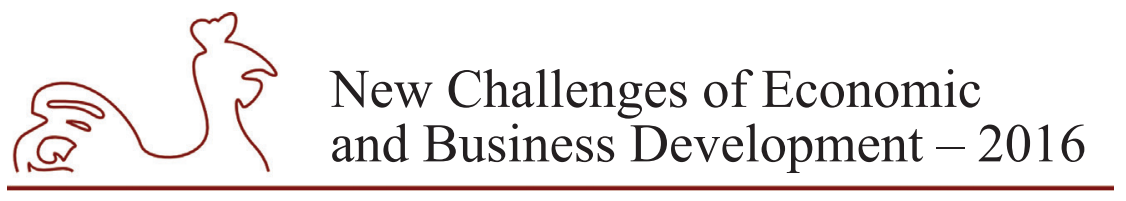

May 12-14, 2016, Riga, University of Latvia

\section{Conclusions, proposals, recommendations}

We can conclude that generational differences exist towards honesty as both behaviour and intrinsic value. And that despite exposure to the Soviet system, earlier generations tend to report higher likelihood of honest behaviour also in post-Soviet business environment.

We can also conclude that in the Baltic States as in the post-Soviet societies there are significant differences between early and late generation $\mathrm{X}$, at least as far as honesty in the retail business environment is concerned. This issue and differences of the so-called Transition generation could be explored further.

Our study has several limitations. As business ethics can be understood from many different perspectives, the potential research field is very broad and cannot be fully covered in a single study. This study is concerned with pre-defined forms of dishonest behaviour, yet many other aspects of business ethics could be assessed. Our study, moreover, analyses dishonest behaviour as reported by retail employees assuming a theoretical scenario - it does not measure the actual honesty or dishonesty. Different perceptions of what constitute dishonest behaviour also poses a significant challenge here - even though the survey clearly suggested whether a certain behaviour would be considered honest or dishonest, values and norms have changed and it cannot be excluded that some participants view a behaviour as dishonest while others - as fully acceptable. Thirdly given the scope of the study it cannot be excluded that certain behaviours are more affected by age than by belonging to a certain generation. This could be another important area of further research - to assess to what extent values, attitudes and behaviours of a given generation change over time with this generation ageing.

\section{References}

Abeler, J., Becker, A., \& Falk, A. (2014), "Representative evidence on lying costs", Journal of Public Economics, Vol. 113, pp. 96-104.

Arsenault, P. M. (2004), "Validating generational differences", Leadership \& Organization Development Journal Leadership \& Org Development J, Vol. 25, No. 2, pp. 124-141.

Bazerman, M., Gino, F. (2012), "Behavioral Ethics: Toward a Deeper Understanding of Moral Judgement and Dishonesty", Annual Review of Law and Social Science, Vol. 8, pp. 85-104.

Bertland, A. (2009), "Virtue Ethics in Business and Capabilities Approach", Journal of Business Ethics, Vol. 84, No. 1, pp. 25-32.

Boatright, J. R. (1997), "Ethics and the conduct of business", Upper Saddle River: Prentice-Hall.

Coscarella, R. (2005), "Small business ethics: An exploratory study examining the issues of Canadian women involved in international trade", Ottawa, Canada: Sprott School of Business, Carleton University.

Deshpande, S. P. (1997), "Managers Perception of Proper Ethical Conduct: The Effects of Sex, Age, and Level of Education", Journal of Business Ethics, Vol. 16, No. 1, pp. 79-85.

Diekmann, A., Przepiorka, W., \& Rauhut, H. (2011), "Lifting the veil of ignorance: An experiment on the contagiousness of norm violations", Discussion Papers, 4.

Grossman, G. (1977), “The 'second economy' of the USSR”, Problems of Communism, SeptemberOctober.

Hisrich, R.D., Bucar, B. \& Oztark, S. (2003), “A Cross-Cultural Comparison of Business Ethics Cases of Russia, Slovenia, Turkey, and United States", Cross Cultural Management, Vol. 10, No. 1, pp. 3-28.

Hofstede, G. (2001), "Culture's consequences: Comparing values, behaviors, institutions, and organizations across nations", Sage Publications, Thousand Oaks, California. 


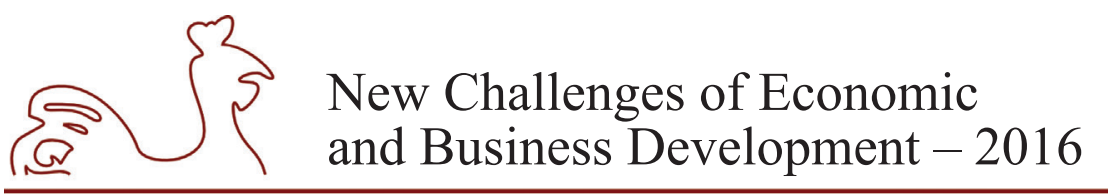

May 12-14, 2016, Riga, University of Latvia

Hollinger, R. C. (1986), "Acts against the workplace: Social bonding and employee deviance", Deviant Behavior, Vol. 7, No. 1, pp. 53-75.

Houser, D., Vetter, S., \& Winter, J. (2012), "Fairness and cheating”, European Economic Review, Vol. 56, No. 8, pp. 1645-1655.

Jonsson, P.O. (2011), "On utilitarianism vs virtue ethics as foundations of economic choice theory", Humanomics, Vol. 27, No. 1, pp. 24-40.

Karklins R. (2005), "The system Made me Do It: Corruption in Post-Communist Societies”, M. E. Sharpe, New York, NY.

Mackevicius, J., Girunas, L. (2013), "Transformational research of the fraud triangle", Economics, Vol. 92, No. 4, pp. 150-163.

McCloskey, D. N. (1998), "Bourgeois Virtue and the History of P and S", The Journal of Economic History, Vol. 58, No. 2, pp. 297-317.

Moore, G. (2013), "Re-imagining Morality of Management: A Modern Virtue Ethics Approach”, The Heart of the Good Institution Issues Business Ethics, Vol. 38, pp. 7-34.

Morris, J., Polese, A. (2015), "Informal economies in post-socialist spaces: practices, institutions and networks", Palgrave Macmillan, New-York.

Moorthy, M. K., Seetharaman, A., Jaffar, N., \& Foong, Y. P. (2015), “Employee Perceptions of Workplace Theft Behavior: A Study Among Supermarket Retail Employees in Malaysia", Ethics \& Behavior, Vol. 25, No. 1, pp. 61-85.

Rauhut, H. (2013), "Beliefs about lying and spreading of dishonesty: Undetected lies and their constructive and destructive social dynamics in dice experiments", PloS one, Vol. 8, No. 11, DOI: 0.1371/journal. pone. 0077878 .

Rees, C. J., \& Miazhevich, G. (2008), "Socio-Cultural Change and Business Ethics in Post-Soviet Countries: The Cases of Belarus and Estonia", Journal of Business Ethics, Vol. 86, No. 1, pp. 51-63.

Riha, T. J. F. (1994), "Missing morality in the transformation of former socialist countries," International Journal of Social Economics, Vol. 21, pp.10-31.

Rokeach, M. (1973), "The Nature of Human Values", The Free Press: New York, NY.

Rosenbaum, S. M., Billinger, S., \& Stieglitz, N. (2014), "Let's be honest: A review of experimental evidence of honesty and truth-telling", Journal of Economic Psychology, Vol. 45, pp. 181-196.

Schwartz, S. H. (2012), "An Overview of the Schwartz Theory of Basic Values", Online Readings in Psychology and Culture, Vol. 2, No. 1. http://dx.doi.org/10.9707/2307-0919.1116.

Scott, E. D., Jehn, K. A. (2003), "Multiple Stakeholder Judgements of Employee Behaviors: A Contingent Prototype Model of Dishonesty", Journal of Business Ethics, Vol. 46, No. 3, pp. 235-250.

Smith, C. G., Šumilo, E, \& Karnups, V. P. (2009), "Moral judgment: A comparison of Latvian and US business persons", Baltic Journal of Management, Vol. 4, No. 2, pp. 188-205.

Somanathan, E., \& Rubin, P. H. (2004), "The evolution of honesty”, Journal of Economic Behavior \& Organization, Vol. 54, No. 1, pp. 1-17.

Strauss, W. and Howe, N. (1997), "The Fourth Turning”, Broadway Books, New York, NY.

Treviño, L. K. (1992), "Moral reasoning and business ethics: Implications for research, education, and management", Journal of Business Ethics, Vol. 11, No. 4, pp. 445-459.

Trevino, L. K., Weaver, G. R., Reynolds, S. (2006), "Behavioral Ethics in Organizations: A Review", Journal of Management, Vol. 32 , No. 6, pp. 951-990.

Vadi, M. \& Jaakson, K. (2011), "The Dual Value of Honesty among Russians in Selected Former Soviet Countries", Cross Cultural Management: An International Journal, Vol. 18, No. 1, pp. 55-70.

Vadi, M. \& Suuroja, M. (2006), “Training retail sales personnel in transition economies: applying a model of customer-oriented communication", Journal of Retailing and Consumer Services, Vol. 13, No. 5, pp. 339-349. 


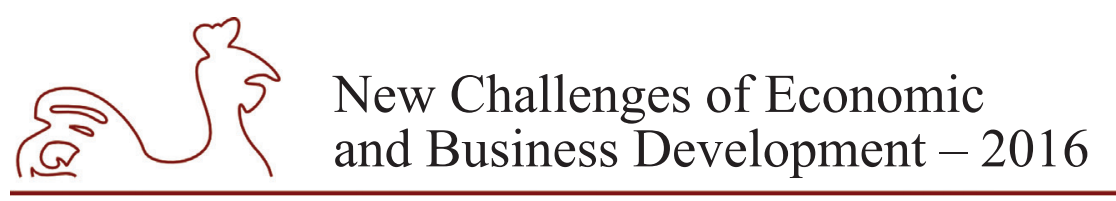

May 12-14, 2016, Riga, University of Latvia

Vadi, M. \& Vissak, T. (2013), "The Nature of (Dis) Honesty, Its Impact Factors and Consequences", In: Vissak, T. \& Vadi, M. (Eds). (Dis)Honesty in management: Manifestations and Consequences. UK: Emerald Group, pp. 5-19.

Wyatt, D. (1993), "Out of the Sixties: Storytelling and the Vietnam Generation", University Press, Cambridge, MA.

Zemke, R., Raines, C. and Filipczak, B. (2000), "Generations at Work: Managing the Clash of Veterans", Boomers, Xers, and Nexters in Your Workplace, AMACOM, New York, NY. 


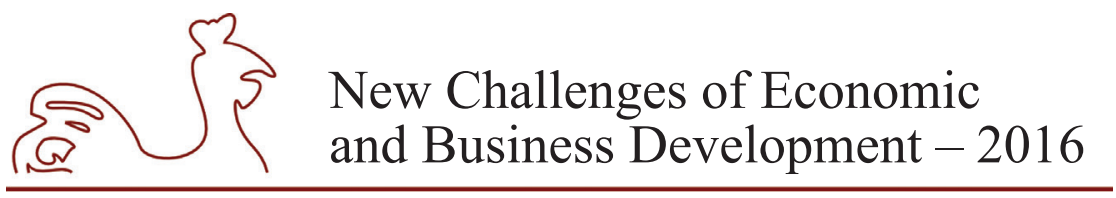

May 12-14, 2016, Riga, University of Latvia

\section{Appendix I}

Age, tenure and dishonest behaviour - non parametric correlations

\begin{tabular}{|c|c|c|c|c|c|}
\hline & \multicolumn{2}{|c|}{ Age } & \multicolumn{2}{|c|}{ Tenure } \\
\hline & & $\begin{array}{l}\text { Kendall's } \\
\text { tau_b }\end{array}$ & \begin{tabular}{|c|}
$\begin{array}{c}\text { Spearman's } \\
\text { rho }\end{array}$ \\
\end{tabular} & $\begin{array}{c}\text { Kendall's } \\
\text { tau_b }\end{array}$ & $\begin{array}{c}\text { Spearman's } \\
\text { rho }\end{array}$ \\
\hline \multirow[t]{3}{*}{ Shirking } & Correlation Coefficient & $-.122 * *$ & $-.168 * *$ & -0.037 & -0.052 \\
\hline & Sig. (2-tailed) & 0 & 0 & 0.178 & 0.164 \\
\hline & $\mathrm{N}$ & 746 & 746 & 729 & 729 \\
\hline \multirow[t]{3}{*}{ Misuse facilities } & Correlation Coefficient & $-.106 * *$ & $-.145 * *$ & -0.04 & -0.053 \\
\hline & Sig. (2-tailed) & 0 & 0 & 0.149 & 0.15 \\
\hline & $\mathrm{N}$ & 744 & 744 & 727 & 727 \\
\hline \multirow[t]{3}{*}{$\begin{array}{l}\text { Hiding information - } \\
\text { customers }\end{array}$} & Correlation Coefficient & $-.124 * *$ & $-.169 * *$ & -0.031 & -0.042 \\
\hline & Sig. (2-tailed) & 0 & 0 & 0.264 & 0.259 \\
\hline & $\mathrm{N}$ & 740 & 740 & 723 & 723 \\
\hline \multirow[t]{3}{*}{$\begin{array}{l}\text { Hiding information - } \\
\text { employer }\end{array}$} & Correlation Coefficient & $-.130 * *$ & $-.175 * *$ & -0.034 & -0.045 \\
\hline & Sig. (2-tailed) & 0 & 0 & 0.229 & 0.231 \\
\hline & $\mathrm{N}$ & 738 & 738 & 723 & 723 \\
\hline \multirow[t]{3}{*}{$\begin{array}{l}\text { Stealing from the } \\
\text { employer }\end{array}$} & Correlation Coefficient & $-.144 * *$ & $-.191 * *$ & -0.012 & -0.015 \\
\hline & Sig. (2-tailed) & 0 & 0 & 0.686 & 0.69 \\
\hline & $\mathrm{N}$ & 738 & 738 & 722 & 722 \\
\hline \multirow[t]{3}{*}{$\begin{array}{l}\text { Cheating the } \\
\text { customer financially }\end{array}$} & Correlation Coefficient & $-.161 * *$ & $-.210 * *$ & -0.016 & -0.02 \\
\hline & Sig. (2-tailed) & 0 & 0 & 0.576 & 0.583 \\
\hline & $\mathrm{N}$ & 740 & 740 & 723 & 723 \\
\hline \multirow[t]{3}{*}{ Damaging property } & Correlation Coefficient & $-.148 * *$ & $-.190 * *$ & -0.01 & -0.013 \\
\hline & Sig. (2-tailed) & 0 & 0 & 0.735 & 0.732 \\
\hline & $\mathrm{N}$ & 737 & 737 & 720 & 720 \\
\hline \multirow[t]{3}{*}{$\begin{array}{l}\text { Impolite behavior - } \\
\text { customer }\end{array}$} & Correlation Coefficient & $-.148 * *$ & $-.199 * *$ & -0.02 & -0.027 \\
\hline & Sig. (2-tailed) & 0 & 0 & 0.485 & 0.47 \\
\hline & $\mathrm{N}$ & 741 & 741 & 724 & 724 \\
\hline \multirow[t]{3}{*}{ Behaving disloyally } & Correlation Coefficient & $-.130 * *$ & $-.180 * *$ & -0.049 & -0.065 \\
\hline & Sig. (2-tailed) & 0 & 0 & 0.077 & 0.079 \\
\hline & $\mathrm{N}$ & 740 & 740 & 723 & 723 \\
\hline
\end{tabular}

** Correlation is significant at the 0.01 level (2-tailed).

* Correlation is significant at the 0.05 level (2-tailed). 


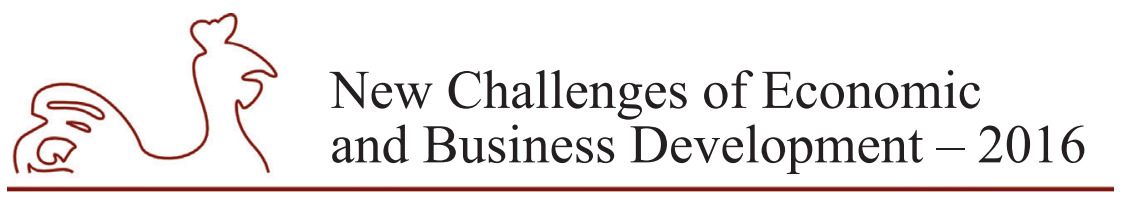

May 12-14, 2016, Riga, University of Latvia

\section{Appendix II}

Generations and dishonest behaviour - non parametric correlations

\begin{tabular}{|c|c|c|c|}
\hline & & Kendall's tau_b & Spearman's rho \\
\hline \multirow[t]{3}{*}{ Shirking } & Correlation Coefficient & $.115^{* *}$ & $.140 * *$ \\
\hline & Sig. (2-tailed) & 0 & 0 \\
\hline & $\mathrm{N}$ & 746 & 746 \\
\hline \multirow[t]{3}{*}{ Misuse facilities } & Correlation Coefficient & $.113 * *$ & $.137 * *$ \\
\hline & Sig. (2-tailed) & 0 & 0 \\
\hline & $\mathrm{N}$ & 744 & 744 \\
\hline \multirow[t]{3}{*}{ Hiding information - customers } & Correlation Coefficient & $.133 * *$ & $.160 * *$ \\
\hline & Sig. (2-tailed) & 0 & 0 \\
\hline & $\mathrm{N}$ & 740 & 740 \\
\hline \multirow[t]{3}{*}{ Hiding information - employer } & Correlation Coefficient & $.142 * *$ & $.170 * *$ \\
\hline & Sig. (2-tailed) & 0 & 0 \\
\hline & $\mathrm{N}$ & 738 & 738 \\
\hline \multirow[t]{3}{*}{ Stealing from the employer } & Correlation Coefficient & $.140 * *$ & $.164 * *$ \\
\hline & Sig. (2-tailed) & 0 & 0 \\
\hline & $\mathrm{N}$ & 738 & 738 \\
\hline \multirow[t]{3}{*}{ Cheating the customer financially } & Correlation Coefficient & $.154 * *$ & $.179 * *$ \\
\hline & Sig. (2-tailed) & 0 & 0 \\
\hline & $\mathrm{N}$ & 740 & 740 \\
\hline \multirow[t]{3}{*}{ Damaging property } & Correlation Coefficient & $.145^{* *}$ & $.164 * *$ \\
\hline & Sig. (2-tailed) & 0 & 0 \\
\hline & $\mathrm{N}$ & 737 & 737 \\
\hline \multirow[t]{3}{*}{ Impolite behavior - customer } & Correlation Coefficient & $.153 * *$ & $.182 * *$ \\
\hline & Sig. (2-tailed) & 0 & 0 \\
\hline & $\mathrm{N}$ & 741 & 741 \\
\hline \multirow[t]{3}{*}{ Behaving disloyally } & Correlation Coefficient & $.130 * *$ & $.158^{* *}$ \\
\hline & Sig. (2-tailed) & 0 & 0 \\
\hline & $\mathrm{N}$ & 740 & 740 \\
\hline
\end{tabular}

** Correlation is significant at the 0.01 level (2-tailed).

* Correlation is significant at the 0.05 level (2-tailed). 


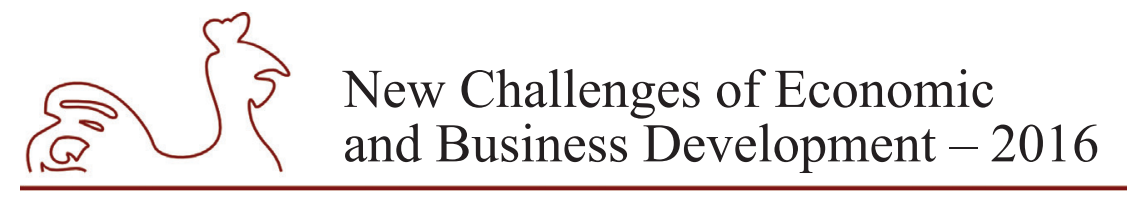

May 12-14, 2016, Riga, University of Latvia

Generations and dishonest behaviour - Kruskal Wallis Test

\begin{tabular}{|c|c|c|c|c|c|c|c|c|c|}
\hline \multicolumn{10}{|c|}{ Test Statistics ${ }^{\mathbf{a}, \mathbf{b}}$} \\
\hline & 些 & 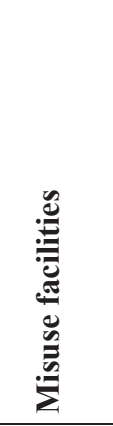 & 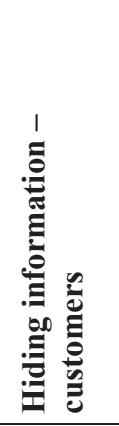 & 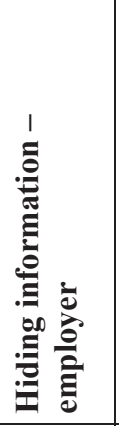 & 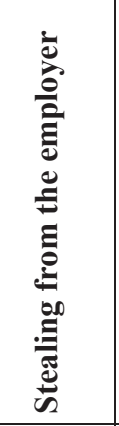 & 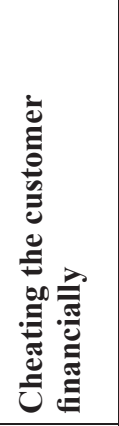 & 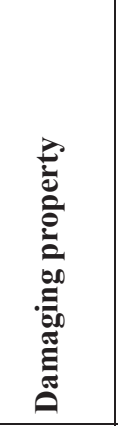 & 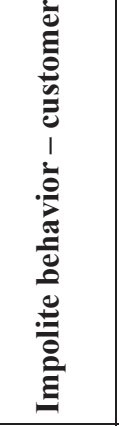 & 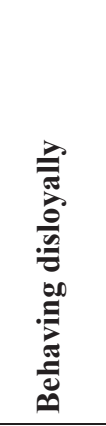 \\
\hline Chi-Square & 18.112 & 18.020 & 21.598 & 23.588 & 20.760 & 24.289 & 25.811 & 26.327 & 21.564 \\
\hline $\mathrm{df}$ & 3 & 3 & 3 & 3 & 3 & 3 & 3 & 3 & 3 \\
\hline Asymp. Sig. & .000 & .000 & .000 & .000 & .000 & .000 & .000 & .000 & .000 \\
\hline
\end{tabular}




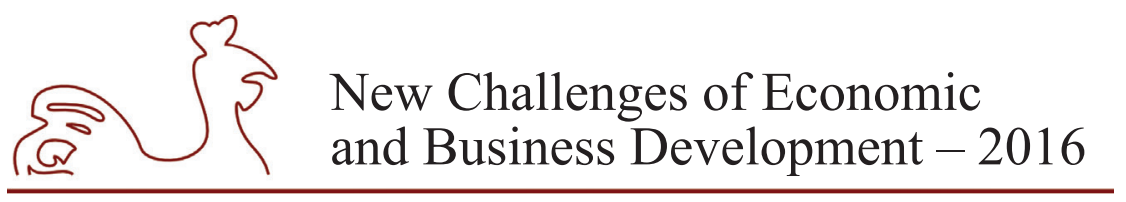

May 12-14, 2016, Riga, University of Latvia

\section{Appendix III}

Generations and mean rankings of instrumental values $(n=678)$

\begin{tabular}{|l|c|c|c|c|}
\hline & Post-war & Early Gen X & Transition & Millennials \\
\hline Honesty & 3.51 & 4.28 & 4.38 & 4.96 \\
\hline Responsibility & 4.74 & 4.11 & 5.41 & 5.73 \\
\hline Politeness & 7.39 & 7.36 & 7.35 & 7.1 \\
\hline Capability & 8.33 & 7.96 & 9.3 & 9.45 \\
\hline Obedience & 9.98 & 9.21 & 8.18 & 8.75 \\
\hline Helpfulness & 10.17 & 9.7 & 8.68 & 8.61 \\
\hline Self-Control & 8.57 & 9.42 & 9.8 & 9.83 \\
\hline Intellect & 8.67 & 9.68 & 9.87 & 10.06 \\
\hline Cleanliness & 9.31 & 9.47 & 9.79 & 10.12 \\
\hline Independence & 9.81 & 10.37 & 9.5 & 9.14 \\
\hline Ambition & 9.04 & 10.63 & 10.01 & 9.73 \\
\hline Logic & 9.78 & 9.75 & 10.67 & 10.23 \\
\hline Broad-mindedness & 10.46 & 10.26 & 10.51 & 10.92 \\
\hline Cheerfulness & 12.13 & 11.18 & 10.06 & 9.83 \\
\hline Courage & 11.78 & 11.41 & 11.37 & 10.76 \\
\hline Forgiveness & 11.94 & 11.95 & 12.3 & 12.1 \\
\hline Imagination & 11.87 & 11.59 & 12.35 & 12.55 \\
\hline Love & 13.31 & 12.68 & 11.41 & 11.08 \\
\hline
\end{tabular}


May 12-14, 2016, Riga, University of Latvia

\title{
REASSESSING EFFICIENCY IN HUMAN DEVELOPMENT AMONG OECD COUNTRIES
}

\author{
Demet Bayraktar, Suleyman Sah University, Turkey ${ }^{1}$ \\ Susanna Ayvaz, Suleyman Sah University, Turkey
}

\begin{abstract}
The measurement of human development has a potentially strong impact on investigation of development gap and building of new policies. In broad terms, the human development approach appeared as a means to reallocate human beings at the center of the actions related to politics, economy, and society. Therefore correct and fair measurement has got a great importance. The human development index (HDI) is a measure of human development based on the three major dimensions such as longevity, knowledge, and standard of living. In this paper, the assessment of the HDI for the OECD countries is reconsidered in the light of data envelopment analysis (DEA). The aim is therefore to provide complementary information for efficiency measure of HD in OECD countries. Instead of a ranking the countries, human development is benchmarked on the basis of empirical observations of the best practice countries by applying output-oriented DEA. As a result of the correlation analysis, there is a highly strong positive correlation between normalized HDI values and the values that we calculated from output oriented DEA model. Hence, the values that we calculated from DEA model fit HDI results. Both HDI and DEA results yield the same three topmost (Norway, Australia, and Switzerland) and the three lowermost countries (Hungary, Turkey, and Mexico).
\end{abstract}

Key words: Human Development, Efficiency, Data Envelopment Analysis

JEL code: C61, O15, O57

\section{Introduction}

The particularities of the development processes, both economic and human have been increasingly investigated even these processes, especially the latter are still not fully understood. Human development can be defined as the process of expanding people's capacity to perform freely chosen core value activities. It includes expanding well-being for all people and increasing the possibilities of individual choice (Marianoa et al., 2015).

The final aim of development should be to improve the welfare and to flourish each human being on this planet (Dahl, 2013). The term "well-being" is used in a general sense and encompasses work on the measurement of quality of life, social development, human development, sustainable development, and social and economic performance as well. In broad terms, the human development approach appeared as a means to reallocate human beings at the center of actions related to politics, economy, and society, in such a way that the central

Corresponding author-e-mail address: dbayraktar@ssu.edu.tr 


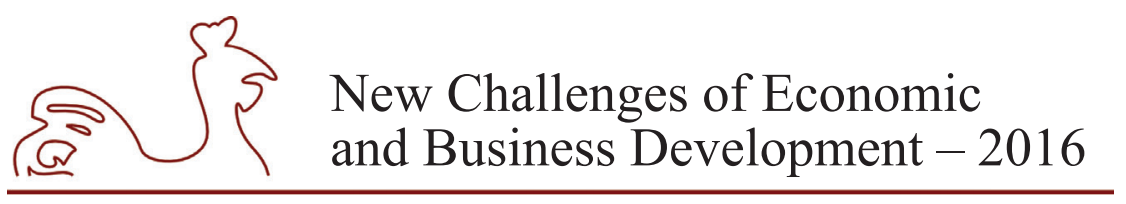

May 12-14, 2016, Riga, University of Latvia

concern is no longer how much is being produced, but rather how this affects people's quality of life (Marianoa et al., 2015).

It is possible to approach the human development and well-being from different points of view of diverse academic disciplines (such as psychology, sociology, education, anthropology, and philosophy), or as determined in many cultures and religious/spiritual customs of the world. At the same time there has been governmental and academic effort to determine and measure human development (Dahl, 2012).

During the last years, a huge interest in indexes of economic and social well-being at all levels (national, provincial, regional, and community) has been observed and this tendency is going on and even increasing. The social indicators movement that began in the 1960s elicited the emergence of today's interest in the development of indexes of economic and social wellbeing. The public's attention has been captured by these indexes in a very successful way (Sharpe, 2000). Country's economic development is frequently measured by per capita income. Nevertheless, per capita income cannot completely reflect country's development level, as it doesn't take into consideration the prosperity of society and individuals. (Wu et al., 2014).

Human Development Index (HDI) is the most famous composite index of social and economic well-being, developed by the United Nations Development Programme (UNDP). The index that was first published in 1990 has become a significant alternative to the traditional unidimensional measure of development (i.e. the gross domestic product) (Sagar and Najam, 1998). The HDI is founded on three indicators that are presented by longevity, that is estimated by life expectancy at birth; educational attainment, that is estimated by a combination of adult literacy (two-thirds weight) and the merged first, second- and third-level gross enrolment ratio (one-third weight); and standard of living, that is estimated by real GDP per capita in Purchasing Power Parity (PPP) terms (Sharpe, 2004). The geometric mean of these three indicators yields HDI value which falls between zero (0) and one (1), where one indicates the maximal value of human development and zero a deplorable lack thereof. In 2015, the HDI ranged from 0.944 (Norway) to 0.348 (Niger).

Since its establishment, the HDI has met considerable criticism from the various perspectives as the choice of indicators, weightings of the elements in the indicators, and measurement methods used. The first issue addresses lack of indicators in relation with economic, social, environmental well-being, although the developers of the HDI argue that the variables do capture all important dimensions of human development (Sharpe, 2000). The second emphasizes the necessity of endogenously calculation of the weights of the component indices. The third discourses the computational method for calculating the HDI (Mahlberg and Obersteiner, 2001). Data envelopment analysis (DEA) can greatly contribute to the second and third issues based on two basic arguments: (a) human development of a country should be assessed by means of benchmarking against best practice countries and (b) the weights of the component indices should be directly derived by the data themselves that were proposed by Mahlberg and Obersteiner (2001). Thus, employing an appropriate approach to overcome the above issues and to provide complementary information for the measured decision making units are vital (Wu et al., 2014).

In this paper, the assessment of HD for the OECD countries is reconsidered in the light of data envelopment analysis (DEA). Accordingly, the aim of this study is to provide complementary information for efficiency measurement of human development for the OECD countries in which the organization has the mission of promoting policies that will improve the economic and 


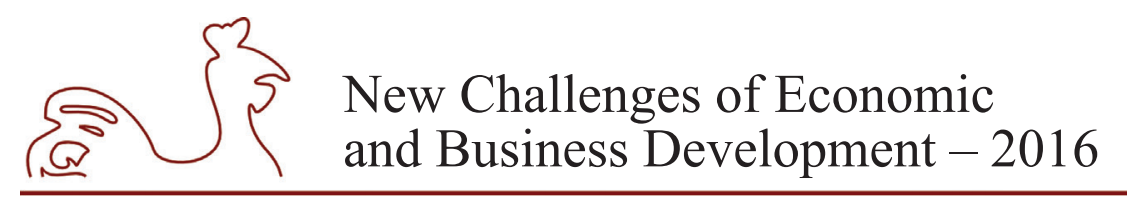

May 12-14, 2016, Riga, University of Latvia

social well-being of people around the world. The rest of this paper is structured as follows. In the second chapter, we briefly present DEA method. Then, we revisit the literature in the context of social dimensioned performance considerations and also human development evaluation by DEA. In chapter 3, we present output-oriented DEA model for the revisiting of HD values of OECD countries. We finally present results, conclusion, and future direction in chapter 4 .

\section{Data Envelopment Analysis}

Data Envelopment Analysis (DEA) is a "data oriented" approach for evaluating the performance of a set of homogenous entities called Decision Making Units (DMUs) (Coelli et al., 2005). It is a mathematical procedure based on linear programming, which can determine the set of weights that maximizes the efficiency of a DMU, allowing it to incorporate multiple inputs and outputs into a single value, without the need to convert them into a common unit of measure (Marianoa et al., 2015).

The typical DEA problem runs, through mathematical programming, a range of observed quantities of inputs consumed and outputs produced by a number of Decision Making Units (DMUs) to benchmark the implementation of decision-making units contrary to frontiers of best practices. These frontiers are formed by an inspection of the observed performance of all the units in the data set. Benchmarking contrary to these best practice frontiers forms the framework for computation of inefficiency measures for each DMU (Reig-Martinez, 2013). It measures the efficiency of each unit by its distance from the best practice frontier, which is represented by the best practice units (Mizobuchi, 2014). Basically, DEA provides a categorical classification of the units into efficient and inefficient ones by assuming either constant or variable returns to scale for the inputs and outputs (Despotis, 2005-a). Because it requires very few assumptions, DEA has also opened up possibilities for use in cases which have been resistant to other approaches because of the complex (often unknown) nature of the relations between the multiple inputs and multiple outputs involved in DMUs (Coelli et al., 2005).

DEA have been widely used to measure the performance of diverse substances from micro dimension as hospitals, universities, business firms to macro dimension as regions, countries, economies, etc. In the context of macro dimension, social facets of subject matters are widely included into the models. Debnath and Shankar (2014) measured the efficiency of happiness, Giambona and Vassallo (2014) calculated the composite indicator of social inclusion for European countries, Hsiao and Hsiao (2015) evaluated elderly social welfare performance, Wu et al., (2014) evaluated the performance efficiency of 21 OECD countries, Grubesic et al. (2012) investigated violence in urban areas, and Dominguez-Serrano and Blancas (2011) calculated a gender well-being composite indicator. As the part of social facets of macro dimension, evaluation of human development by DEA has been widely studied in the literature.

Mahlberg and Obersteiner (2001) proposed the idea of using two DEA approaches to reassess the HDI values for 174 countries on the basis of the data given in the Human Development Report of 1998. In their study, constant returns-to-scale output-oriented DEA model was applied since the scores of all indicators are preferred to be as high as possible (e.g. life expectancy, expected-mean school of year, and GNI per capita). They discussed the differences between HDI and DEA measurements and accentuated the advantage of their proposal.

Despotis (2005-a) reconsidered the measurement of HDI by data envelopment analysis (DEA). A new approach for HDI is proposed within two phases. He developed a DEA-like 


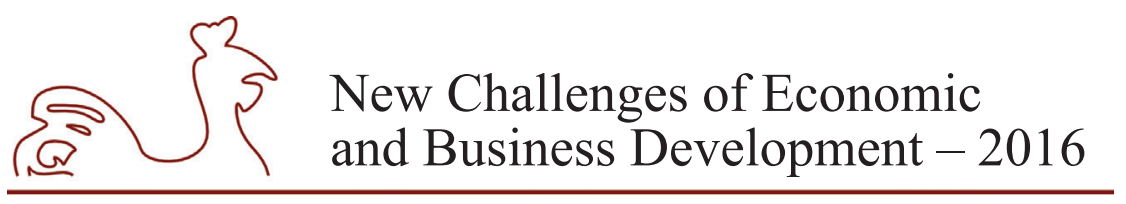

May 12-14, 2016, Riga, University of Latvia

linear programming model to assess the relative performance of the countries in terms of human development. Then he extended his calculations with a post-DEA goal-programming model to derive estimates of a new development index by using optimal weights for the socioeconomic indicators. He emphasized that the new measure of human development is comparable and highly correlated with the HDI. The transformation paradigm is also introduced in his paper to assess the relative efficiency of the countries in translating income to social prosperity. Hence, the real GDP per capita is used as input to reflect the expansion of peoples' ability to access the resources needed to acquire knowledge and to achieve a long and healthy life. This new approach is applied to the countries in the region of Asia and The Pacific to estimate an ideal value of the composite index for each one of the countries. Despotis (2005-b) extended his work by assessing 174 countries' HDI by DEA.

Bougnol et al. (2010) presented three "standard practices" each a well-established and widely used approach to make efficiency or performance evaluations such as evaluating the stores in the retail industry, evaluating bonds, and evaluating of 15 countries' human development. The last practice uses scorecard assessment ranking schemes which is a special case of DEA where all weights are constants and all attributes are outputs.

Despotis et al. (2010) proposed a general modeling approach with nonlinear virtual inputs and outputs in DEA. They revisited the work of Despotis (2005-b) on assessing the HDI by DEA that can assess the efficiency of the units in the presence of nonlinear virtual inputs and outputs. Their modeling approach eliminates the need for working with the logarithm of per capita income in the HDI.

Hatefi and Torabi (2010) proposed a common weight multi criteria decision analysis (MCDA)-data envelopment analysis (DEA) approach to construct composite indicators (CIs). In order to validate the proposed new MCDA-DEA model, it is applied to two case studies taken from the literature to construct two well-known CIs, as Human Development Index (HDI) and Sustainable Energy Index (SEI). They accentuated that the proposed method with an improved discriminating power and notable saving in the number of LP models to be solved, can be considered as a convenient decision tool and a sound alternative to the DEA-like models in CI construction.

Vierstraete (2012) assessed the performance of various countries in reaching a human development target as measured by the non-income HDI. Using classical and bootstrapped Data Envelopment Analysis (DEA) models, she investigated whether past or current expenditure levels in these various countries are yielding an optimal HDI-i.e. the "best" possible HDI in light of the resources invested.

Reig-Martínez (2013) calculated human Wellbeing Composite Index (WCI) for 42 countries, belonging to European space and the MENA countries. To attain this goal, different data envelopment analysis (DEA) models are used as an aggregation tool for seven selected socio-economic variables which are income per capita, environmental burden of disease, income inequality, gender gap, education, life expectancy at birth and government effectiveness. He expressed that this study highlights the usefulness of constructing a multi-dimensional index of wellbeing to cover more aspects than those traditionally considered by the HDI and discusses how to go about doing so.

Mizobuchi (2014) applied DEA to aggregating 11 individual well-being indicators into a composite indicator using the World Bank's estimates of each country's productive base. 


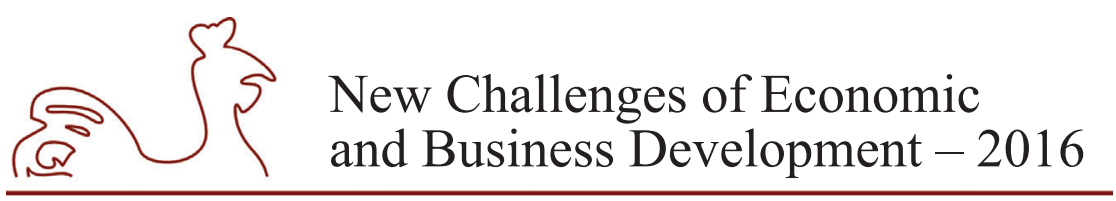

May 12-14, 2016, Riga, University of Latvia

The author adopted two approaches based on BOD and DEA to construct composite indicators. The composite indicator based on BOD is distributed similarly and is highly correlated with the existing HDI as well as GDP per capita while the composite indicator based on DEA is negatively correlated with HDI as well as GDP per capita.

$\mathrm{Wu}$ et al. (2014) proposed a super-efficiency model to empirically investigate whether the efficiency rankings of the selected 19 OECD countries provide a more reasonable conclusion than the HDI rankings. In the light of the estimated efficiency scores and input slack(s) in the super-efficiency model, they suggested the path of improving the usage efficiency of input resources. They emphasized that compared to the HDI rankings, the efficiency rankings measured by the super-efficiency model have the following two advantages: (1) they consider the inputs that are used to generate the indicators for constructing the HDI, and decide the weights of inputs and outputs endogenously; (2) the input slacks measured by the super-efficiency model can evaluate whether the inputs are over-used and provide the improvement path of each country's input variables.

All of the studies briefly discussed above contribute to the evaluation of human development process from various perspectives either the choice of indicators, the weightings of the elements in the indicator or the measurement methods used.

\section{DEA Model for Assessing the Human Development}

In this paper, we used Data Envelopment Analysis (DEA) to reassess the HDI in a multiple output setting. Since the most notable advantages of DEA models are that they endogenously construct a non-linearly arranged set of best practice countries and that the weights of each indicator entering the HDI is endogenously determined based on an optimization calculus. We utilized the output-oriented DEA proposed by Mahlberg and Obersteiner (2001) in order to evaluate the human development of 34 OECD countries drawing on the data published by the Human Development Report Office (UNDP, 2015) in this study. Thus, the purpose of this paper is to provide complementary information for efficiency measure of HD in OECD countries by employing a DEA. Notably, our purpose is not to propose a new HDI; rather, to assess the relative HD efficiency of the countries by means of DEA employing recently published data from UNDP (2015).

In order to assess countries' efficiency in achieving a certain value of the HD, we will perform inter-country comparisons and hold their results up to a target. The DEA method allows us to determine this target, which is defined by the best performers in the sample.

\subsection{Selection of Decision Making Units}

In this study, OECD countries were selected as the decision making units since the mission of the OECD is to promote policies that will improve the economic and social well-being of people around the world. In broad terms, the OECD promotes policies related with $\boldsymbol{i}$. achieving the highest sustainable economic growth and employment and a rising standard of living in member countries, while preserving financial stability, and in this way to promote the growth of the world economy ii. contributing to sound economic expansion in member as well as nonmember countries in the process of economic development and iii. contributing to the expansion of world trade on a multilateral, nondiscriminatory basis regarding to international responsibilities. 


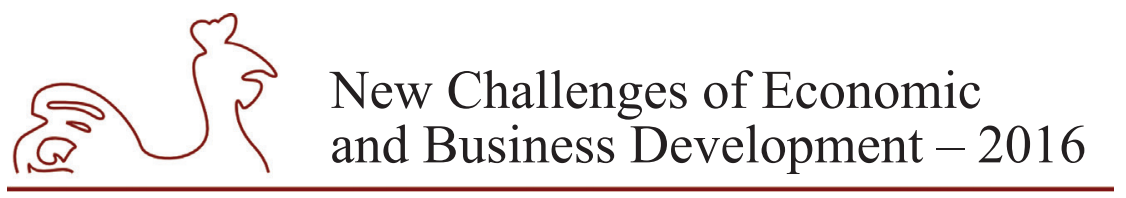

May 12-14, 2016, Riga, University of Latvia

\subsection{Selection of Input/Output}

In this study, life expectancy at birth, expected years of schooling, mean years of schooling, and $\boldsymbol{G N I}$ per capita are selected as outputs since the scores of all indicators are preferred to be as high as possible. All the individual indicators are considered as outputs and a dummy input (equal to one) is assumed for all the countries (Mahlberg and Obersteiner, 2001).

\subsection{Output-Oriented DEA Model}

In this study DEA, which is a non-parametric approach that uses a linear programming technique, is utilized. The DEA defines the best practice frontier which allows us to classify countries into best performing units if they are at the frontier and into worse performing units if they lie below. In this study, since the scores of all indicators (life expectancy at birth, expected years of schooling, mean years of schooling, and GNI per capita) are preferred to be as high as possible, output-oriented DEA model is applied (Mahlberg and Obersteiner, 2001).

The following optimization problem is solved for each individual country in the sample, for the computation of the performance score Zo of each country and weight of each indicator as well (Mahlberg and Obersteiner, 2001). See Appendix Table A.1 for the DEA results.

$$
\begin{gathered}
\mathrm{Zo}=\min \sum\left(\mathrm{v}_{\mathrm{i}} * \mathrm{X}_{\mathrm{ik}}\right) \\
\text { s.t. } \\
\sum\left(\mathrm{u}_{\mathrm{r}} * \mathrm{Y}_{\mathrm{rk}}\right)=1 \\
\sum \mathrm{u}_{\mathrm{r} *} \mathrm{Y}_{\mathrm{rj}}-\sum \mathrm{v}_{\mathrm{i}} * \mathrm{X}_{\mathrm{ij}} \leq 0 \\
\mathrm{u}_{\mathrm{r}}, \mathrm{v}_{\mathrm{i}} \geq 0
\end{gathered}
$$

where,

Zo - performance score,

$X_{i j}$ i-th resource of the $j$-th country

$Y_{r j}$ r-th indicator of the $j$-th country

$\mathrm{X}_{\mathrm{ik}} \mathrm{i}$-th resource of the country $\mathrm{k}$

$\mathrm{Y}_{\mathrm{rk}} \mathrm{r}$-th indicator of the country $\mathrm{k}$

$\varepsilon=10^{-6} \mathrm{~m}-$ number of resources, $\mathrm{m}=1$

$\mathrm{s}-$ number of indicators, $\mathrm{s}=4$,

$\mathrm{n}$ - number of countries, $\mathrm{n}=34$,

$\mathrm{k}-$ the country under instigation

$\mathrm{v}_{\mathrm{i}}$ - weight of the $\mathrm{i}$-th resource,

$\mathrm{u}_{\mathrm{r}}-$ weight of the $\mathrm{r}$-th indicator,

$\mathrm{i}=1, \ldots ., \mathrm{m}$

$\mathrm{j}=1, \ldots ., \mathrm{n}$

$\mathrm{r}=1, \ldots ., \mathrm{s}$

Because we combine the four indicators of the HDI as the output, the resource side consists of the unity vector. The model computes weights so that the country under consideration is determined as best as possible. The weights can differ from country to country in contrast to the standard definition of the HDI, where the weights are equal for all countries. 


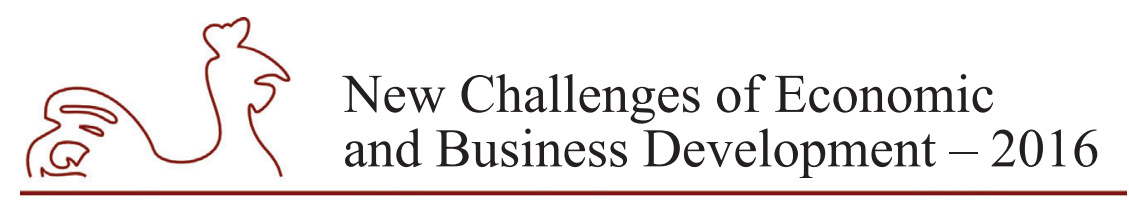

May 12-14, 2016, Riga, University of Latvia

\subsection{Data}

We used the same indicators as those in the 2015 Human Development Report that is published annually by the United Nations Development Program (UNDP), which are used to compute the Human Development Index (HDI). Correspondingly, our computations are based on data published by the Human Development Report Office (UNDP, 2015).

\subsection{Solution}

Basically, in order to measure the human development performance of OECD countries, we used indicators utilized in HDI calculation in the following three categories: longevity, knowledge, and standard of living. Applying the basic output oriented DEA model developed by Charnes et al. (1978) we revisited performance indices for each country in the sample.

The scores of output- oriented DEA-model are, by definition, 1 or larger and a value of 1 is assigned to the best performing country. By transforming the scores of the DEA to the domain between zero and one, we make the DEA scores comparable to the values of the HDI. The transformation is done by inverting the DEA scores. The values of the transformed indicators lie between 0 and 1 , as in the values of the HDI. The domain of the HDI, as published in the Human Development Report (See Appendix Table A.2), is between 0 and 1, but even the best performing country does not achieve the highest possible value. To ensure comparability with the DEA values we normalized the HDI. To the highest developed country a value of 1 is assigned and to all relatively less developed countries a value of less than 1. Accordingly, the normalized HDI values and the inverted DEA scores for each OECD country are given in Table 1.

The values of DEA indices show the distance that a country has already moved towards the maximum possible value of 1 and allows comparisons with other countries. The difference between the values achieved by a country and the maximum possible value of 1 shows the country's shortfall and indicates how far the country has to go.

\subsection{Discussion}

To analyze the relationship between two scores a correlation analysis was conducted $(r=$ $0.83, p=0.00)$. The result shows that there is a positive and strong correlation between the two scores. Thus, it can be said that the scores obtain from the normalized HDI and inverted DEA fit each other.

Both HDI and DEA results yield the same three topmost (Norway, Australia, and Switzerland) and the three lowermost countries (Hungary, Turkey, and Mexico). It can be observed that Norway (1), Australia (0.99046), and Switzerland (0.98516) record the highest first three values among the normalized HDI values while Norway, Australia, Switzerland, Germany, United States, and Japan record maximum value of "1" for inverted DEA scores. Germany (0.970338) and United States (0.969279) took place at the sixth and eight orders among the first ten normalized HDI values. The countries in the most favorable situation are usually among those that enjoy the highest level of human development as a result not only of their high level of GNI per capita, but also to their social policies applied. 


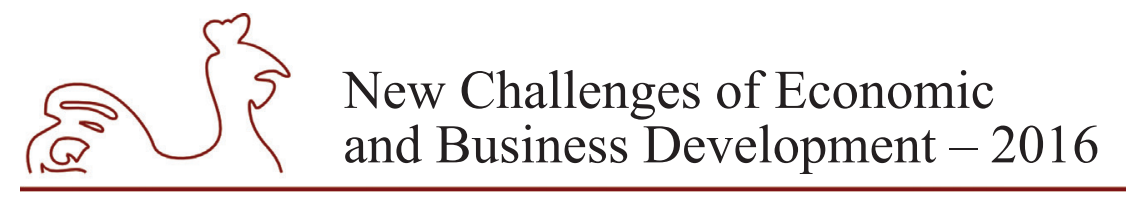

May 12-14, 2016, Riga, University of Latvia

Table 1

Normalized HDI values and inverted DEA scores OECD countries

\begin{tabular}{|c|c|c|c|}
\hline Countries & Normalized HDI values & Countries & Inverted DEA scores \\
\hline Norway & 1 & Norway & 1 \\
\hline Australia & 0.9904 & Australia & 1 \\
\hline Switzerland & 0.9851 & Switzerland & 1 \\
\hline Denmark & 0.9777 & Germany & 1 \\
\hline Netherlands & 0.9766 & United States & 1 \\
\hline Germany & 0.9703 & Japan & 1 \\
\hline Ireland & 0.9703 & United Kingdom & 0.9994 \\
\hline United States & 0.9692 & Iceland & 0.9984 \\
\hline Canada & 0.9671 & Canada & 0.9981 \\
\hline New Zealand & 0.9671 & Italy & 0.9965 \\
\hline Sweden & 0.9608 & Spain & 0.9938 \\
\hline United Kingdom & 0.9608 & Israel & 0.9903 \\
\hline Iceland & 0.9523 & New Zealand & 0.9896 \\
\hline Korea & 0.9512 & Luxembourg & 0.9896 \\
\hline Israel & 0.9470 & Sweden & 0.9883 \\
\hline Luxembourg & 0.9449 & France & 0.9869 \\
\hline Japan & 0.9438 & Netherlands & 0.9861 \\
\hline Belgium & 0.9427 & Korea & 0.9853 \\
\hline France & 0.9406 & Ireland & 0.9785 \\
\hline Austria & 0.9375 & Denmark & 0.9784 \\
\hline Finland & 0.9353 & Austria & 0.9784 \\
\hline Slovenia & 0.9322 & Chile & 0.9774 \\
\hline Spain & 0.9279 & Greece & 0.9744 \\
\hline Italy & 0.9247 & Finland & 0.9735 \\
\hline Czech Republic & 0.9216 & Belgium & 0.9723 \\
\hline Greece & 0.9163 & Portugal & 0.9712 \\
\hline Estonia & 0.9120 & Slovenia & 0.9675 \\
\hline Slovakia & 0.8940 & Estonia & 0.9540 \\
\hline Poland & 0.8930 & Czech Republic & 0.9495 \\
\hline Chile & 0.8813 & Slovakia & 0.9332 \\
\hline Portugal & 0.8792 & Poland & 0.9308 \\
\hline Hungary & 0.8771 & Mexico & 0.9178 \\
\hline Turkey & 0.8061 & Hungary & 0.9053 \\
\hline Mexico & 0.8008 & Turkey & 0.9019 \\
\hline
\end{tabular}

Source: author's calculations

In contrast, the countries whose current socioeconomic situation is far from their efficient frontiers including Hungary, Turkey, and Mexico share the worst three values for calculations. Normalized HDI values are 0.87711 for Hungary, 0.80614 for Turkey, and 0.80084 for Mexico while DEA values are 0.91783 for Mexico, 0.90535 for Hungary, and 0.90194 for Turkey. 


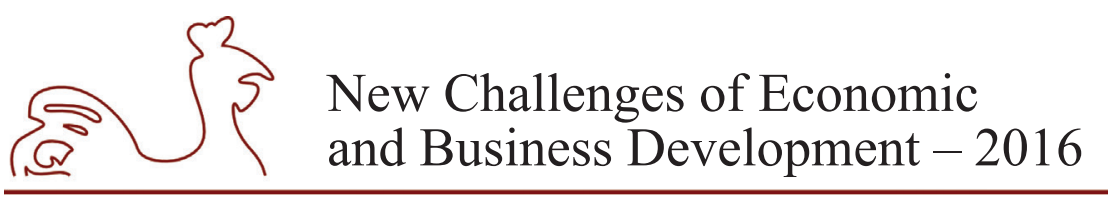

May 12-14, 2016, Riga, University of Latvia

The largest gap among the OECD countries are found in GNI per capita and mean years of schooling when comparing with the other factors which are life expectancy and expected years of schooling. Those countries especially Turkey and Mexico should increase their outputs level to their efficient frontier.

On the other hand, although both values for the rest of the OECD countries became different, the main argument has not changed. The countries in the rather favorable situation are usually among those that enjoy the highest level of human development as a result not only of their high level of GNI per capita, but also to their social policies applied. The countries which have the lower level of human development have highly lower level of GNI per capita when compared with the favorable ones.

\section{Conclusion and Future Work}

The purpose of this study is to provide complementary information for efficiency measure of HD in OECD countries. Instead of a ranking the countries, human development is benchmarked on the basis of empirical observations of the best practice countries by applying output-oriented DEA. The DEA problem handles a variety of observed quantities of inputs consumed and outputs produced by a number of DMUs to benchmark the performance of individual decision-making units against frontiers of best practices. It measures the efficiency of each unit by its distance from the best practice frontier, which is represented by the best practice units (Mizobuchi, 2014).

In the literature, DEA have been widely used to measure the performance of diverse decision making units from micro magnitude as banks, hospitals, universities, business firms to macro magnitude as regions, countries, economies, etc.. From the point of view of macro perspective, social aspect of subject matters are widely included into the models such as measurement of happiness efficiency, elderly social welfare performance, violence in urban areas, and a gender well-being composite indicator. As the part of social aspects of macro dimension, human development assessment has also been studied by DEA in the literature. The data envelopment analysis can be an excellent tool to help in the measurement and analysis of issues related to human development. It also makes an indirect appeal for assignors whose are economists, socialists, politicians, and researchers to pay more attention to the question regarding how to utilize human resources efficiently for further improving human development (Wu et al.; 2014).

In this paper, we used Data Envelopment Analysis (DEA) to reassess the HD in a multiple output setting. We utilized the output-oriented DEA proposed by Mahlberg and Obersteiner (2001) in order to evaluate the human development of 34 OECD countries drawing on the data published by the Human Development Report Office (UNDP, 2015). Thus, we aimed to provide complementary information for efficiency measure of HD in OECD countries by employing a DEA instead of proposing a new HDI. We rather employ a DEA model for reassessing the efficiency scores with recently published data by UNDP (2015). In this study, OECD countries were selected as the decision making units since the mission of the OECD is to promote policies that will improve the economic and social well-being of people around the world.

As a result of the correlation analysis, there is a highly strong positive correlation between normalized HDI values and the values that we calculated from output oriented DEA model. Hence, the values that we calculated from DEA model fit HDI results. Both HDI and DEA results yield the same three topmost (Norway, Australia, and Switzerland) and the three lowermost countries 


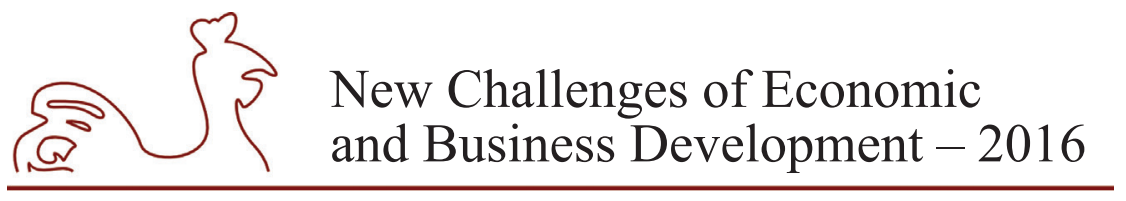

May 12-14, 2016, Riga, University of Latvia

(Hungary, Turkey, and Mexico). Additionally life expectancy, expected years of schooling, and mean years of schooling values of those countries are not compatible as well.

On the other hand, It should be noted that since the DEA gives the relative efficiency of the countries, if other countries were included in the study, the efficiency of some of those presented would change.

As a future direction, relative efficiencies of other countries belonging to other unions or committees should be analyzed in order to shed the light on human development issues. On the other hand, the efficiency of the countries can be analyzed by using other inputs and/ or outputs. Finally, the source of inefficiencies in our DEA model and the proposals for how to tackle with those issues should be studied as future work.

\section{Bibliography}

Bougnol ML, Dulá JH, Lins MPE and da Silva ACM (2010), "Enhancing Standard Performance Practices With DEA", Omega (38), pp. 33-45.

Charnes A, Cooper W. and Rhodes E. (1978), "Measuring The Efficiency Of Decision Making Units", European Journal of Operational Research (2), pp. 429-444.

Coelli TJ, Prasada Rao DS, O'Donnell CJ and Battese GE (2005), An Introduction to Efficiency and Productivity Analysis, Springer, ISBN-13978-0387-24265-1.

Dahl A. L. (2012), "Human Development: A Vision of Well-being", International Environment Forum, Geneva, Switzerland, http://iefworld.org/ddahl12m.

Dahl A. L. (2013), "Putting the Individual at the Centre of Development: Indicators of Well-Being for a New Social Contract", International Environment Forum, Geneva, Switzerland, [Online] Available at: http://iefworld.org/ddahl13a [Accessed 23 January 2016].

Debnath R. M. and Shankar R. (2014), "Does Good Governance Enhance Happiness: A Cross Nation Study?", Social Indicators Research 116 (1), pp. 235-253.

Despotis D. K. (2005-a), "Measuring human development via data envelopment analysis: the case of Asia and the Pacific", Omega (33), pp. 385-390.

Despotis D. K. (2005-b), "A reassessment of the human development index via Data Envelopment Analysis", Journal of the Operational Research Society (56), pp. 969-980.

Despotis D. K., Stamati L. V. and Smirlis Y. G. (2010), "Data Envelopment Analysis With Nonlinear Virtual Inputs And Outputs", European Journal of Operational Research (202), pp. 604-613.

Dominguez-Serrano M. and Blancas F. J. (2011), "A Gender Wellbeing Composite Indicator: The BestWorst Global

Evaluation Approach", Social Indicators Research, 102 (3), pp. 477-496.

Giambona F. and Vassallo E. (2014),"Composite Indicator of Social Inclusion for European Countries", Social Indicators Research (116), pp. 269-293.

Grubesic T. H., Mack E. A. and Kaylen M. T. (2012), "Comparative Modeling Approaches For Understanding Urban Violence”, Social Science Research, 41(1), pp. 92-109.

Hatefi S. M. and Torabi S. A. (2010), “A Common Weight MCDA-DEA Approach to Construct Composite Indicators”, Ecological Economics, (70), pp. 114-120.

Hsiao S. C. and Hsiao L. (2015), “Application of Data Envelopment Analysis to Evaluating Elderly Social Welfare Performance", Revista de Cercetare si Interventie Sociala (48), pp. 83-94.

Mahlberg B. and Obersteiner M. (2001), "Remeasuring the HDI by Data Envelopment Analysis", Technical report 01-69. International Institute for Applied Systems Analysis, Luxemburg, Austria. Interim Report.

Marianoa E. B., Sobreiro V. A. and Rebelatto D. A. N. (2015), "Human Development and Data Envelopment Analysis: A Structured Literature Review”, Omega (54), 33-49. 


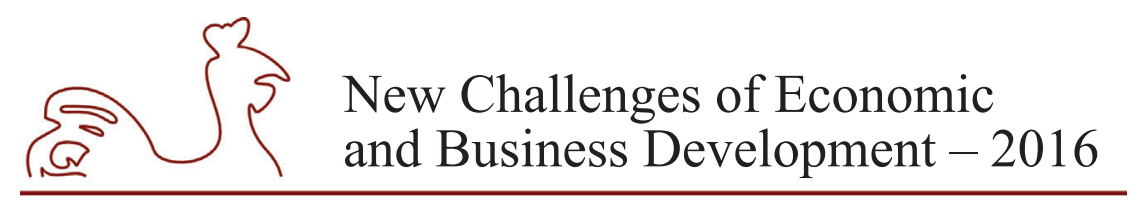

May 12-14, 2016, Riga, University of Latvia

Mizobuchi H. (2014), "Measuring World Better Life Frontier: A Composite Indicator for OECD Better Life Index", Soc Indic Res (118), pp. 987-1007.

Reig-Martínez E. (2013), "Social and Economic Wellbeing In Europe and the Mediterranean Basin: Building An Enlarged Human Development Indicator", Social Indicators Research (111), pp. 527547.

Sagar A. D. and Najam A. (1998), "The Human Development Index: A Critical Review", Ecological Economics (25), pp. 249-264.

Sharpe A. (2004), "Literature Review of Frameworks for Macro-indicators", CSLS research report, Centre for the Study of Living Standards, Ottawa.

Sharpe A. (2000), "A Survey of Indicators of Economic and Social Well-being”, paper prepared by the Centre for

the Study of Living Standards for Canadian Policy Research Networks, Research Report, Mar 7, 2000.

UNDP, Human Development Report 2015: work for human development, United Nations Development Programme, UNDP; 2015.

Vierstraete V. (2012), "Efficiency in Human Development: a Data Envelopment Analysis", The European Journal of Comparative Economics, Vol. 9, No. 3, 425-443.

Wu P. C., Fan C. W., and Pan S. C. (2014), "Does Human Development Index Provide Rational Development Rankings? Evidence From Efficiency Rankings In Super Efficiency Model”, Social Indicators Research, (116), pp. 647-658. 


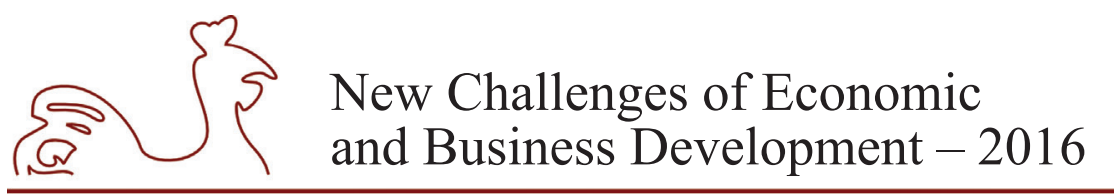

May 12-14, 2016, Riga, University of Latvia

APPENDIX A.

Table A.1

DEA Values and the weights of indicators

\begin{tabular}{|c|c|c|c|c|c|}
\hline Country & $\begin{array}{l}\text { DEA } \\
\text { Value }\end{array}$ & $\begin{array}{l}\text { Weight of life } \\
\text { expectancy }\end{array}$ & $\begin{array}{c}\text { Weight of } \\
\text { expected years } \\
\text { of schooling }\end{array}$ & $\begin{array}{c}\text { Weight of } \\
\text { mean years of } \\
\text { schooling }\end{array}$ & $\begin{array}{l}\text { Weight of GNI } \\
\text { per capita }\end{array}$ \\
\hline Norway & 1 & 0.0106 & 0.0042 & 0.0001 & 0.0008 \\
\hline Australia & 1 & 0.0114 & 0.0024 & 0.0001 & 0.0001 \\
\hline Switzerland & 1 & 0.0113 & 0.0017 & 0.0021 & 0.0001 \\
\hline Denmark & 1.022 & 0.0001 & 0.0025 & 0.0691 & 0.0015 \\
\hline Netherlands & 1.0139 & 0.0116 & 0.0023 & 0.0001 & 0.0002 \\
\hline Germany & 1 & 0.0037 & 0.0001 & 0.0508 & 0.0005 \\
\hline Ireland & 1.0219 & 0.0117 & 0.0024 & 0.0001 & 0.0001 \\
\hline United States & 1 & 0.0003 & 0.00001 & 0.0686 & 0.0015 \\
\hline Canada & 1.0018 & 0.0034 & 0.0001 & 0.0544 & 0.0001 \\
\hline New Zealand & 1.0104 & 0.0115 & 0.0024 & 0.0001 & 0.0001 \\
\hline Sweden & 1.0117 & 0.0114 & 0.0017 & 0.0022 & 0.0001 \\
\hline United Kingdom & 1.0005 & 0.0001 & 0.0001 & 0.0752 & 0.0001 \\
\hline Iceland & 1.0015 & 0.0114 & 0.0024 & 0.0001 & 0.0001 \\
\hline Korea & 1.0149 & 0.0114 & 0.0017 & 0.0022 & 0.0001 \\
\hline Israel & 1.0097 & 0.0114 & 0.0017 & 0.0022 & 0.0001 \\
\hline \begin{tabular}{|l|} 
Luxembourg \\
\end{tabular} & 1.0104 & 0.0109 & 0.0001 & 0.0001 & 0.0017 \\
\hline \begin{tabular}{|l|} 
Japan \\
\end{tabular} & 1 & 0.0114 & 0.0024 & 0.0001 & 0.0001 \\
\hline Belgium & 1.0284 & 0.0117 & 0.0023 & 0.0001 & 0.0002 \\
\hline France & 1.0132 & 0.0115 & 0.0023 & 0.0001 & 0.0002 \\
\hline Austria & 1.0220 & 0.0116 & 0.0023 & 0.0001 & 0.0002 \\
\hline \begin{tabular}{|l|} 
Finland \\
\end{tabular} & 1.0272 & 0.0117 & 0.0023 & 0.0001 & 0.0002 \\
\hline \begin{tabular}{|l} 
Slovenia \\
\end{tabular} & 1.0334 & 0.0116 & 0.0018 & 0.0022 & 0.0001 \\
\hline Spain & 1.0061 & 0.0115 & 0.0024 & 0.0001 & 0.0001 \\
\hline Italy & 1.0034 & 0.0115 & 0.0024 & 0.0001 & 0.0001 \\
\hline Czech Republic & 1.0531 & 0.0081 & 0.0001 & 0.0291 & 0.0001 \\
\hline Greece & 1.0262 & 0.0117 & 0.0025 & 0.0001 & 0.0001 \\
\hline Estonia & 1.0481 & 0.0001 & 0.0020 & 0.0764 & 0.0001 \\
\hline \begin{tabular}{|l|} 
Slovakia \\
\end{tabular} & 1.0715 & 0.0037 & 0.0001 & 0.0582 & 0.0001 \\
\hline Poland & 1.0743 & 0.0121 & 0.0018 & 0.0024 & 0.0001 \\
\hline Chile & 1.0231 & 0.0117 & 0.0024 & 0.0001 & 0.0001 \\
\hline \begin{tabular}{|l|} 
Portugal \\
\end{tabular} & 1.0296 & 0.0118 & 0.0025 & 0.0001 & 0.0001 \\
\hline Hungary & 1.1045 & 0.0124 & 0.0019 & 0.0025 & 0.0001 \\
\hline Turkey & 1.1087 & 0.0127 & 0.0027 & 0.0001 & 0.0001 \\
\hline Mexico & 1.0895 & 0.0129 & 0.0001 & 0.0001 & 0.0001 \\
\hline
\end{tabular}

Source: author's calculations 


\section{$2 \int^{2} 5$ New Challenges of Economic and Business Development - 2016}

May 12-14, 2016, Riga, University of Latvia

Table A.2

HDI of OECD Countries

\begin{tabular}{|l|c|}
\hline Norway & 0.944 \\
\hline Australia & 0.935 \\
\hline Switzerland & 0.930 \\
\hline Denmark & 0.923 \\
\hline Netherlands & 0.922 \\
\hline Germany & 0.916 \\
\hline Ireland & 0.916 \\
\hline United States & 0.915 \\
\hline Canada & 0.913 \\
\hline New Zealand & 0.913 \\
\hline Sweden & 0.907 \\
\hline United Kingdom & 0.907 \\
\hline Iceland & 0.899 \\
\hline Korea & 0.898 \\
\hline Israel & 0.894 \\
\hline Luxembourg & 0.892 \\
\hline Japan & 0.891 \\
\hline Belgium & 0.890 \\
\hline France & 0.888 \\
\hline Austria & 0.885 \\
\hline Finland & 0.883 \\
\hline Slovenia & 0.880 \\
\hline Spain & 0.876 \\
\hline Italy & 0.873 \\
\hline Czech Republic & 0.870 \\
\hline Greece & 0.865 \\
\hline Estonia & 0.861 \\
\hline Slovakia & 0.844 \\
\hline Poland & 0.843 \\
\hline Chile & 0.832 \\
\hline Portugal & 0.830 \\
\hline Hungary & 0.828 \\
\hline Turkey & 0.761 \\
\hline Mexico & 0.756 \\
\hline Sore: & 070 \\
\hline & \\
\hline
\end{tabular}

Source: UNDP, Human Development Report 2015: work for human development, United Nations Development Programme. 


\title{
THE INTERNET OF THINGS (IOT) BUSINESS POTENTIAL IN LATVIA
}

\author{
Juris Binde, Latvijas Mobilais Telefons, Ltd, Latvia ${ }^{1}$ \\ Vita Zvirbule, Latvijas Mobilais Telefons, Ltd, Latvia \\ Zane Demjanova, Latvijas Mobilais Telefons, Ltd, Latvia \\ Ilze Saulite, Latvijas Mobilais Telefons, Ltd., Latvia
}

\begin{abstract}
Over the recent years, there is a growing topicality in the business segment, as well as among individuals, of technologies that allow connecting a wide range of devices in a unified information environment, thereby providing automation and online monitoring of operations. Application of solutions ranges from transportation and logistics to health care, environment and rescue and safety.

Including the devices in a single network allows achieving increased operational optimization, improved accuracy and efficiency; therefore, ensuring a business potential in virtually any market or industry.

Although the topicality and prevalence of internet of things (IoT) are increasingly growing, as smart devices are seamlessly included in the day-to-day operations of the business environment, the benefits arising from the new digital technologies and online connectivity still remain largely underexplored in Latvia.

Hence, the aim of the paper is to identify the main development drivers and the business potential of internet of things in Latvia by exploring the current experience and future readiness to optimize the cost base, develop new technologies and business models, enter new markets or industries, as well as to strengthen cooperation with the current and potential business partners by capitalizing on $24 / 7$ connectivity of a range of devices.

To achieve the above-stated aim, in January 2016 a web-based questionnaire is sent out to business organizations' representatives in Latvia asking respondents to evaluate their current experience and future potential of application of internet of things solutions in their organization to achieve an increased efficiency or develop new technologies or business models.

Research results indicate that even though the general awareness of the benefits that internet of things has to offer can be considered as relatively high, the practical application of the respective solutions show that the technology adoption in this field is still fairly low; therefore, indicating unrealized potential of internet of things usage in day-to-day operations.

Practical implications of research results are mainly based on the opportunity to identify gaps that prevent business customers from wider application of internet of things solutions and, consequently, benefiting from opportunities in technological and efficiency advancement.
\end{abstract}

Key words: Internet of Things, IoT, efficiency, innovations

JEL code: M10, O30

${ }^{1}$ Corresponding author - e-mail address: Juris.Binde@lmt.lv 


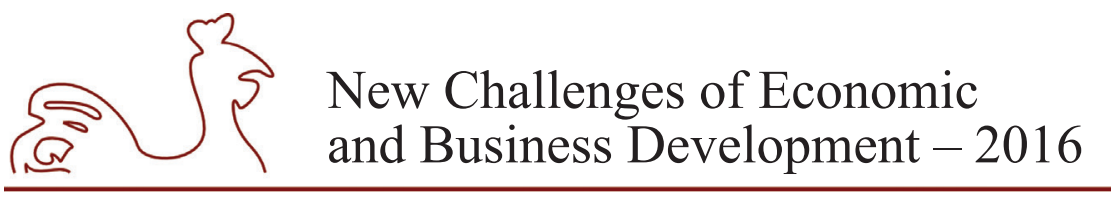

May 12-14, 2016, Riga, University of Latvia

\section{Theoretical background}

There is no doubt that over the last few years we have experience a spiralling development of new technology revolution. Various business sectors, as well as individuals have increasingly opted for technologies that allow connecting various devices in a single information environment, thus automating and continuously monitoring their operations - from vehicles in the area of logistics to health care equipment, surveillance in the environmental sector and operations of rescue services. According to a widely recognised descriptive definition of IoT in the sector "IoT allowing things and real world objects to connect, communicate, and interact with one another in the same way humans do via the web today" (Holler J. et al. 2014).

\section{IoT as a new efficiency potential}

By integrating devices in a single network, optimisation of operations is achieved, along with higher precision and increased efficiency, thus ensuring business potential in practically any area of business. According to technologies experts, in about 5-10 years we will already be able to evaluate the economic effect of the application of internet of things; moreover, it is expected that the effect will be rather far-reaching. According CISCO forecasts (Bradley J., et al. 2013), till 2022, the IoT Technologies and applications usage will generate $\$ 14.4$ trillion added value - from increased revenues and lower costs as well. The main added value contributors will be asset utilization generated from structurally lower operational costs through business process and capital utilization efficiencies - 2.5 trillion USD; employee productivity generated from labour efficiencies that result from higher productivity person-hours -2.5 trillion USD; supply chain and logistics based on improvement in business process efficiencies across the global supply chain -2.7 trillion USD; customer experience based on increasing a customer's lifetime value and technology adoption expansion through new customer additions -3.7 trillion USD; reduced time to market resulted from better R\&D investments returns and improved key business performance metrics such as time to market advantage, in addition to creating new revenue streams from new IOT business models and use cases - 3.0 trillion USD.

According to forecasts, internet of things is a new and promising concept. It is not merely a technological vision for development, but already a technological solution, which offers return already in the present. Internet, data analysis and cloud computing, in combination with sensors and remotely controlled devices, generally ensure the potential for a more effective use and optimisation of resources (see Figure 1 for graphical representation of the relationship).

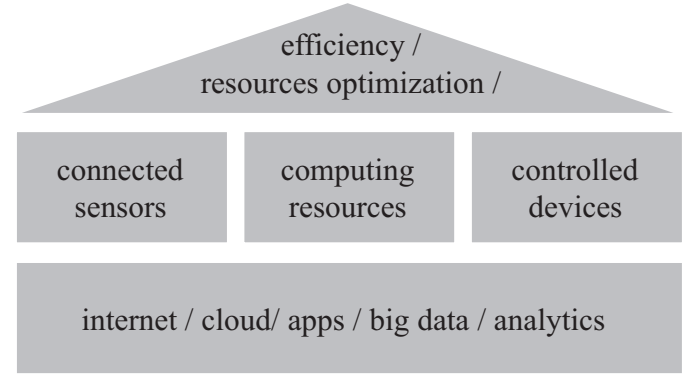

Source: Authors' construction based on IoT solution structure.

Fig. 1. IoT - conceptual model 


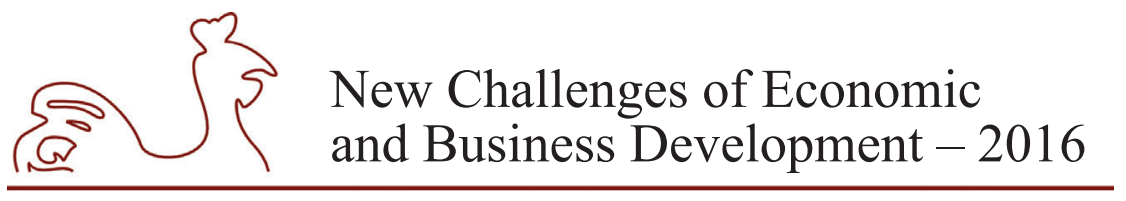

May 12-14, 2016, Riga, University of Latvia

IoT is not only a new paradigm in the modern society. First of all, it is a complex technological solution. From the functional viewpoint, IoT is the combination of sensors, computing resources, mobile networks as the hardware and specific mobile applications, big data, analytics as the software. In most cases, the ecosystem of IoT is only in the development stage (Sundmaeker H., et al. 2010), however, a range of sectors have already made significant steps to use this technological innovation in business development.

\section{IoT as new technological solution}

It is apparent that various technologies are involved in IoT development, therefore, in order to use the potential of IoT technologies as broadly and effectively as possible, it is necessary to identify the problems and risks, which will have to be faced at the time of introducing new technologies (Fleisch E., 2010). So far, IoT has not gained generally known or broad market recognition, and it is delayed by objective market hesitation, in evaluating the opportunities offered by new technologies and the associated possible risks. Since IoT solutions provide for a closer co-operation between various devices, by using internet as the co-operation environment, problems related to interoperability and data safety are brought to the forefront. There is no doubt that interoperability is a very significant aspect for promoting IoT applications in order to get the maximum return. McKinsey Global Institute estimated that "situations in which two or more IoT systems must work together can account for about 40 percent of the total value that can be unlocked by the Internet of Things." (Manyika J., et al. 2015) Even though International Telecommunication Union (ITU), the United Nations specialized agency in the field of telecommunications, information and communication technologies, already back in 2012 defined the basic requirements for IoT solutions, which would ensure a single standard and a stable interoperability of various devices in a network, no comprehensive agreement has yet been received about the creation of such standards. This delays not only further advancement of technological processes, but also makes the end users concerned about sustainability of use of specific IoT solutions and the ability of selected suppliers to adapt the existing solutions in the future to the necessary standards. The awaiting position of end users regarding investments into IoT solutions is understandable, before all technological conditions of their functioning are known.

Another aspect that objectively makes the end users cautious is cyber security and associated risks. As society becomes increasingly concerned about cyber security and threats caused by cyber-attacks increase, accordingly, concerns about the security of corporate activities are brought to the forefront. It is understandable that in addition to already ascertained risks, IoT can cause new threats as well. In situations when essential processes are managed autonomously, by fully trusting digital solutions and internet connections, billions of devices connected to a unified network, storing and transferring data of various types, large volumes of sensitive information about each of devices are processed and stored on a regular basis, the methods of protection that are widely used in the traditional IT environment are no longer sufficient. In order for IoT solutions to gain clients' trust, a new level data security and protection system must be developed to protect data from unauthorised access (Vermesan O., Friess P. 2014). Data anonymizing is one of the topical solutions, which allows reducing the value of the accumulated data to anyone, who would like to use it without authorisation. Certainly IoT security will be a hot topic for conversation in the next following years. 


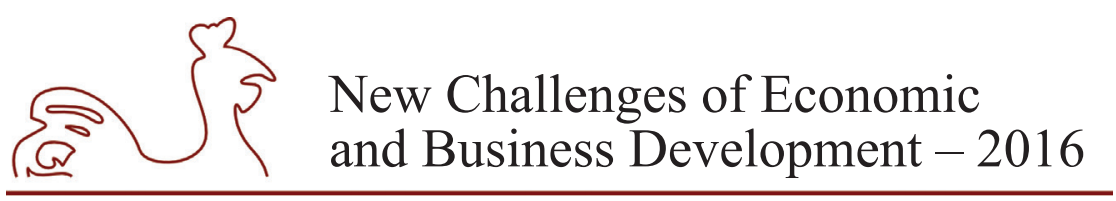

May 12-14, 2016, Riga, University of Latvia

Progress is also needed in creating software to collect, capture and analyse data received from various sensors, aggregate and convey complex findings in ways that make them useful for decision making and automated systems actions. As research shows, companies applying datadriven decisions in their regular business processes are, on average, by $6 \%$ more profitable and 5\% more productive than competitors. (McAfee A., Brynjolfsson E., 2012).

IoT solutions may have very different levels of complexity to support different activities and perform a particular automation task. IoT solutions can increase automation effectiveness and sophistication in two ways - in the way companies gather data and the way they use the collected information.

The level of application of IoT nowadays very often is limited to the visibility phase, expressed by connection and monitoring (depicted in Figure 2). In this phase some small steps in data gathering are done, data usage for process automation is limited, process monitoring is mainly done manually and a simple alert triggering system is implemented. If IoT systems usage is developed into the efficiency phase, expressed by more digitalized control and reaction mechanism, the company is involved in more systematic data gathering processes, higher processes automation, systems remote control usage and performance indicators analysis systems application.

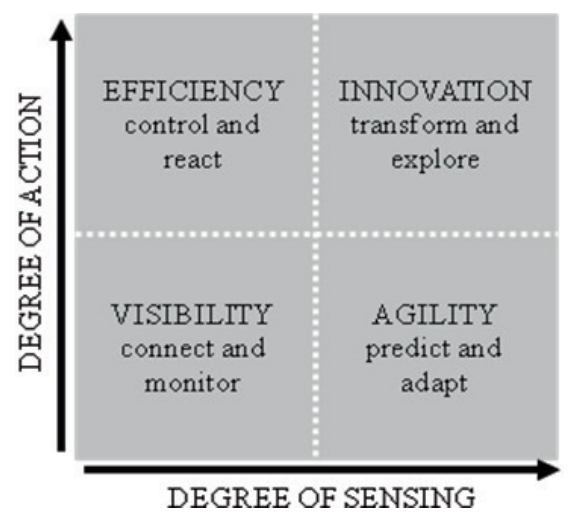

Source: Verizon, 2015.

\section{Fig. 2. IoT complexity and development model}

In the more sophisticated agility phase, data from IoT sensors are combined with widescale external data sets to perform an in-depth analysis. A lot of predictive analytic tools are used to describe and analyze various business processes to get integrated solutions for digital management of a particular process. Innovation, related to transformation and exploration, is the most developed and less visible phase in the everyday business environment. Data from IoT sensors and data analysis results are used in the entire company, every significant business process or targeted activity. Facts based insights are applied to run a new digital business model to get economy from full-scale data-based automated decisions.

The full potential of the IoT will be unlocked when small networks of connected things become one network of connected things extending across industries. New sensors and tags will generate a new data stream -the added data volume from sensors only will reach the data volume which is currently being produced and managed globally. Even more, since many business models emerging from the IoT will involve the exchange of data, the importance of free flow 


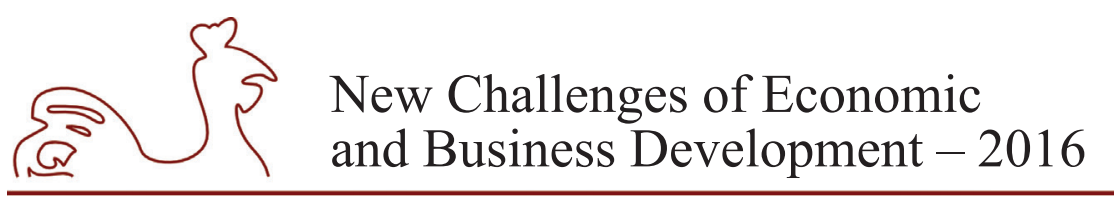

May 12-14, 2016, Riga, University of Latvia

of information across different networks will arise. (Atzori L., et al. 2014) Big data and data privacy issues are fundamental components of the IoT future. The lack of trust and concerns about data privacy would negatively influence consumer uptake of the IoT.

\section{Managerial implications of IoT implementation}

Even though technological solutions, their prevalence and performance ability are essential aspects in assessing the potential of IoT prevalence in the business environment, the digital environment can be only one of the aspects for a company to become truly data-driven. As the application of IoT increases, by automating processes and using digital assistants and robots more broadly, fundamental changes will be observed not only in the skill set required of employees, but also the contents of the work task itself. Aspects related to the introduction and management of digital processes and involvement in new business processes are equally important. Employees' abilities to work with complex IoT projects and a large data volume are of crucial importance, along with the ability to develop business systems and processes in a way that allows full use of IoT generated data and their application in decision-making and managerial processes. The need for highly qualified employees will grow very quickly. According to IDC forecasts, the amount of data processed "is doubling in size every two years, and by 2020 the digital universe - the data we create and copy annually - will reach 44 zettabytes, or 44 trillion gigabytes." (Turner V., et al. 2014) This process in a short term will lead the industry to the new problem - lack of welltrained and experienced data processing and analysis professionals. Some estimations show that "the number of gigabytes per IT professional will grow by a factor of eight between now and 2020, while the number of devices on the IoT grows by a factor of 2." (Turner V., et al. 2014) This trend of rapid development shows that companies must invest resources in due time to ensure that their IT experts have the necessary skills to work with Big Data.

The development of IoT solutions will require to develop and to enhance also other competences traditionally important for a product-oriented company. Competences and skills related to the development of new service concepts, business models and supply chains, which would result in a wholesome use of IoT resources and possibilities, are subject to increasing attention. It means that a broad spectrum of skills combined with the ability to focus on the performance of priority tasks, by ensuring constant adaptation to changes in the digital environment, are pre-requisites to take into account when building teams that will be responsible for implementing and using IoT solutions.

The introduction of IoT solutions will create new and yet unknown challenges because they will fundamentally change the business models known and applied up to now. In these circumstances, such questions are brought to the forefront, which are related to business management matters to maximise the effect achieved from introducing IoT. To reduce uncertainty and risks in this situation, it is important to start a company level initiative to determine where and how to focus the potential of IoT technologies. It must not only be determined what type of new products should be developed and what business processes to enhance or automate, but also a scheme must be developed for how to respond to technological changes and development in the most effective way possible not to lose momentum according to the overall trends of the industry. It means that regular and planned operations must be put in place for the development and application of IoT at a company, and that demands significant human resources and the ability to make relevant long-term decisions. 


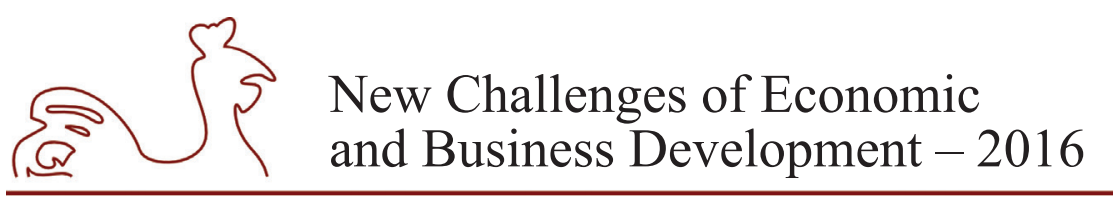

May 12-14, 2016, Riga, University of Latvia

\section{IoT acceptance from the global perspective}

It arises from the aforementioned that the introduction of IoT solutions is a complex task, the handling of which must be started in due time, before technological solutions are delivered for setting up at the company. To assess the prevalence, application and global development potential of IoT, in the summer of 2013, researchers from The Economist Intelligence Unit (The Economist Intelligence Unit, 2013) conducted a study by surveying representatives of 779 various business sectors around the world and asking to assess the current and future prevalence of IoT, effectiveness of its application in various sectors, gains offered by IoT, planned investments in IoT development, as well as barriers delaying effective introduction of IoT solutions.

Nearly a half (49\%) of the respondents in this study was senior level managers or board members. Regional division allows comprising the entire world in this study: 29\% of respondents in Europe, 29\% in North America, 30\% in Asia, and the remaining 12\% in South America, Middle East and Africa. Overall, 19 sectors are represented in the study, with the most widespread being financial services, manufacturing, health care, pharmacy, information technologies, energy, construction and real estate.

Upon examining the respondents' answers about the impact of IoT on business development in the upcoming three years, it is clear that company managers consider IoT an important innovation, which will comprehensively change business. $38 \%$ of respondents mentioned that the development of IoT will significantly affect most sectors and markets; $40 \%$ suggest that IoT will have certain, but limited impact - it will affect only some sectors or markets; $15 \%$ say that the IoT development will affect only global market players, while only $6 \%$ do not see a significant potential of impact of IoT solutions, by indicating that the importance of IoT is only a stir created by technologies industries without an actual added value. These data suggest that overall company managers globally see a significant potential of impact of IoT solutions development on the business environment in the global market.

Furthermore, when dividing smaller business areas which might experience the biggest gains from the development and introduction of IoT solutions in the upcoming 3 years, more than $30 \%$ of respondents see the added value in the client service/support area, as well as in ensuring products or services (both in the individual and business segment), from $20 \%$ to $29 \%$ of respondents believe that the development of IoT solutions will affect such areas as data processing, management and analysis, management of logistics systems and supply chains, development of employee productivity and management of technology infrastructures; moreover, 12\% of respondents recognise the positive effect of these solutions on the management of energy supply and consumption, as well as asset management; whereas only $2 \%$ cannot name any area of business, where IoT could provide added value in the upcoming 3 years. The results show that the sphere of areas, which could be directly affected by the development of IoT solutions, is vast, which points to the versatile application of IoT solutions in business practice.

When considering potential gains from IoT development, in order to assess the possible value added more accurately, respondents were asked to specify how IoT solutions will change the operations of the company they represent in the upcoming 3 years. $30 \%$ of respondents emphasised that it will open up new opportunities to gain new income from the implementation of existing products or services. $29 \%$ of respondents stressed that IoT solutions will foster the development of new business processes; $23 \%$ of respondents admitted that the development of 


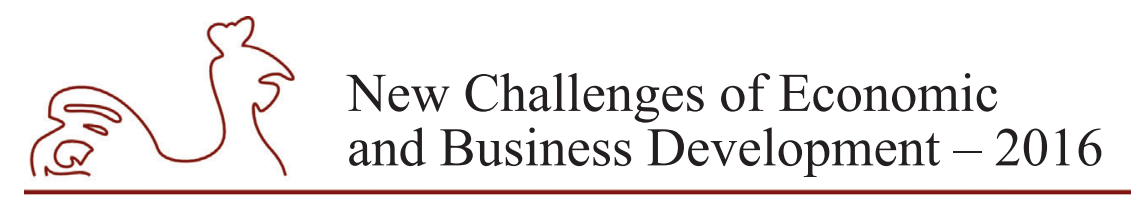

May 12-14, 2016, Riga, University of Latvia

IoT solutions will change the existing business model or strategy, as well as will foster a new wave of innovations. $17 \%$ admitted that these solutions will reduce the costs for company's basic activity. $16 \%$ of respondents pointed out that the introduction of IoT will allow entering new markets or expand the framework of the sector. Another $13 \%$ of respondents said that IoT solutions will promote investments in technological solutions, whereas less than $10 \%$ of respondents admitted that they see the most significant impact of development of IoT solutions in the increasing competitive pressure from new players in sectors, as well as in the possibility to have closer co-operation with the competition through various forms of partnership. Only $9 \%$ of respondents did not see how the development of IoT solutions could change the operations of the company they represent in the upcoming 3 years.

To assess the readiness of companies to use IoT solutions in the development of products and services, as well as in improving efficiency of business processes, respondents were asked to assess the extent to which their organisation is planning to apply or is already applying IoT solutions. Research results show that readiness to use these solutions in the development of products / services and in improving efficiency of internal processes is relatively similar $-26 \%$ of respondents said that they had not been planning to include IoT solutions in the produced products; whereas $24 \%$ in promoting effectiveness of business processes. Furthermore, accordingly $40 \%$ and $36 \%$ pointed out that they are looking into the possibilities of applying these solutions in the aforementioned areas. $17 \%$ and $20 \%$ stated that they are planning to introduce these solutions already in the nearest future, while $12 \%$ and $16 \%$ admitted that IoT solutions in the companies they represent are in the implementation phase; $5 \%$, however, said that IoT solutions are already applied in the development of products or services, and an equally large number of respondents said that these solutions are used in improving business process efficiency.

If we look at obstacles delaying IoT application, the most widespread reason for delays given by the representatives of companies are insufficient employee skills and knowledge (26\%), insufficient involvement of the company's management (23\%), apparent lack of coherence of the manufactured products or offered services with the gains offered by IoT (21\%), insufficient availability of standardised IoT solutions (19\%), significant investments that are needed in the development of IoT solutions (18\%), insufficient consumer awareness and demand for these products $(17 \%)$, infrastructural deficiencies at the company, delaying full-fledged application of IoT solutions (15\%), regulatory environment that is not stimulating innovations in the data protection area $(15 \%)$, insufficient public communications infrastructure $(12 \%)$, and overall economic instability which does not encourage investing $(10 \%)$. These results suggest that the spectrum of factors delaying the development of IoT solutions is broad - starting from weaknesses in the company's administration, to deficiencies in infrastructure and normative regulation, which prevents comprehensive use of potentially offered advantages of IoT.

\section{Assessment of IoT development potential in Latvia}

In order to compare the global experience with the readiness of companies to develop and apply IoT solutions in Latvia, a study was performed in the environment of business representatives in Latvia. Representatives of 2233 companies were approached in January 2016, by using a personalised online survey questionnaire. Of the approached respondents, 211 filled in the survey questionnaire (response rate $-9.5 \%$ ), by giving answers to questions that describe 


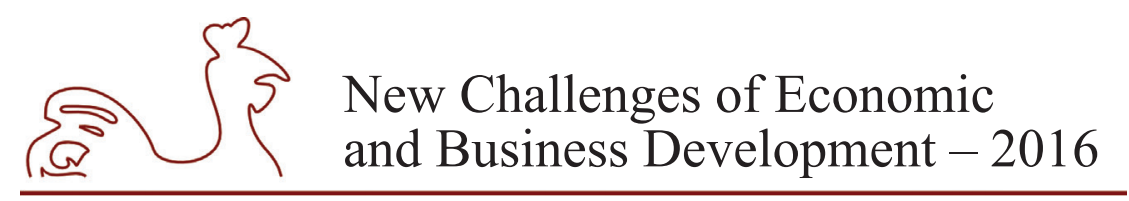

May 12-14, 2016, Riga, University of Latvia

the openness of the Latvian business environment to the application of IoT solutions, possible gains and obstacles.

Several limitations of the model applied needs to be taken into account - the respondent base is limited to those entities that are reachable via the internet, which is also the target group for IoT solutions, hence the results are representative only to the type of enterprises surveyed. Also, the model does not cover processes of IoT introduction and is limited to application, benefits and obstacles only.

The division of respondents according to the represented sector of activity and location is given in Table 1.

Table 1

Division of respondents according to the sector and region

\begin{tabular}{|c|c|c|c|c|c|c|c|c|c|c|c|c|c|c|c|}
\hline \multicolumn{16}{|c|}{ Represented sector } \\
\hline 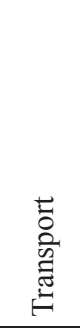 & 包 & 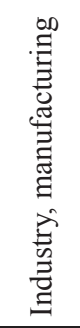 & $\begin{array}{l}\frac{0}{\widetilde{W}} \\
\frac{0}{0} \\
0 \\
\frac{1}{3}\end{array}$ & 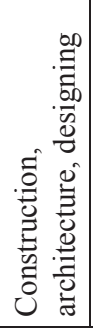 & 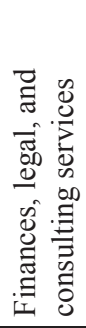 & $\begin{array}{l}\overline{\tilde{\pi}} \\
\simeq \\
\simeq\end{array}$ & 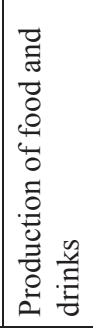 & 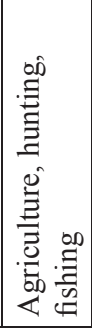 & 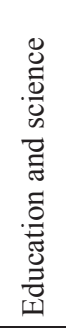 & 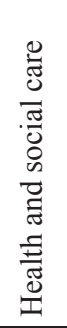 & 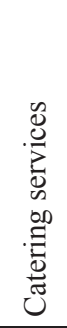 & 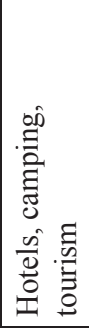 & 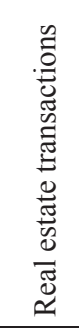 & 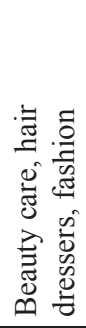 & $\begin{array}{l}\dot{\bar{\Xi}} \\
\overline{0}\end{array}$ \\
\hline $17 \%$ & $13 \%$ & $12 \%$ & $8 \%$ & $6 \%$ & $6 \%$ & $5 \%$ & $5 \%$ & $4 \%$ & $3 \%$ & $3 \%$ & $1 \%$ & $1 \%$ & $1 \%$ & $1 \%$ & $13 \%$ \\
\hline \multicolumn{16}{|c|}{ Region } \\
\hline \multicolumn{3}{|c|}{ Riga } & \multicolumn{3}{|c|}{ Other city } & \multicolumn{4}{|c|}{ Other town } & \multicolumn{3}{|c|}{ Village } & \multicolumn{3}{|c|}{$\begin{array}{l}\text { Outside settlements/ } \\
\text { rural areas }\end{array}$} \\
\hline \multicolumn{3}{|c|}{$45 \%$} & \multicolumn{3}{|c|}{$27 \%$} & \multicolumn{3}{|c|}{$16 \%$} & & \multicolumn{3}{|c|}{$7 \%$} & \multicolumn{3}{|c|}{$5 \%$} \\
\hline
\end{tabular}

Source: Survey of company representatives conducted by the authors.

As shown in Table 1, the respondents represent more than 15 sectors, and the representation of companies within Riga and outside is rather similar.

If considering the answers of representatives of surveyed companies when asked to assess how, in their opinion, the development of IoT will affect business in the upcoming 3 years, it is apparent that, even though the importance of IOT and the potential of its effect in Latvia is assessed lower than elsewhere in the world, the possible impact of IoT is recognised as relatively significant also in the local market. Respondents' evaluations are summarised and compared in Figure 3.

As seen from Figure 3, 72\% of respondents admit that the development of IoT solutions will have a significant impact on at least some sectors and markets $(19 \%$ of respondents admit significant impact on most sectors and markets; 53\% see potential impact in some sectors). It points to the fact that even though technological solutions are relatively recent and are in the development stage, over the 3-year report period, already now, representatives of the Latvian business environment see the potential of IoT impact in various business sectors. 


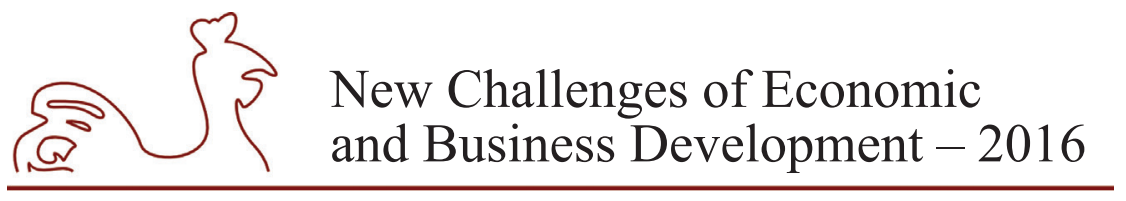

May 12-14, 2016, Riga, University of Latvia

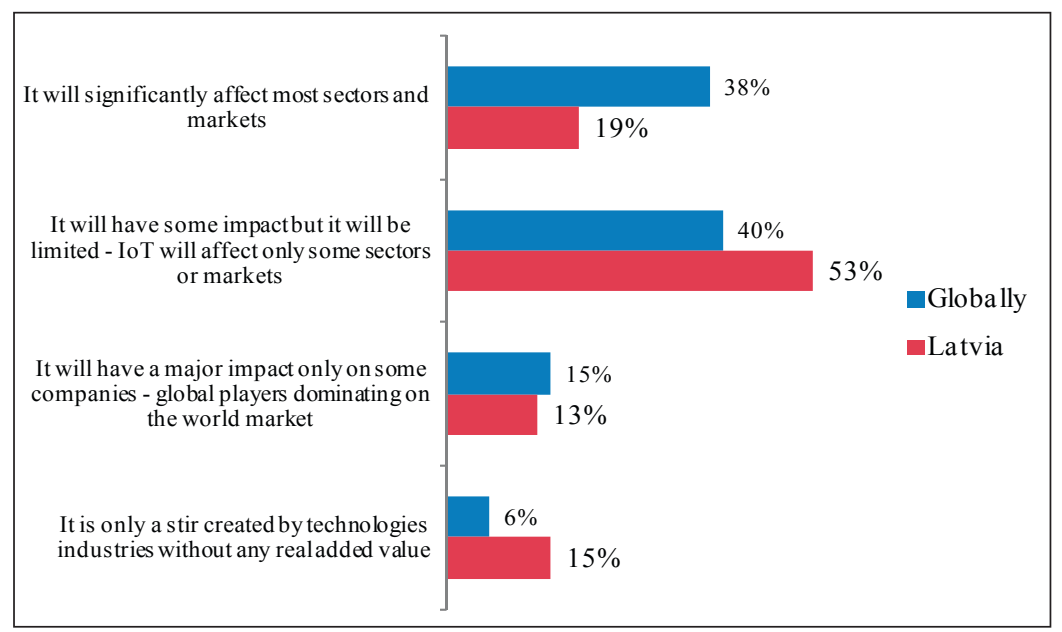

Source: Survey of company representatives conducted by the authors and the study by Economist Intelligence Unit.

\section{Fig. 3. Impact of IoT solutions on business in the upcoming 3 years}

When considering the areas of business, in which respondents see the biggest potential from application of IoT solutions (Figure 4), it is apparent that most frequently mentioned in Latvia are data processing, management and analysis (38\%), client service or support (29\%) and management of logistics systems or supply chains (25\%). Unlike the global experience, a significantly lower number of respondents point out that they see gains from the application of IoT solutions in ensuring products or services ( $21 \%$ in Latvia vs. $30 \%$ in the world), however, a significantly more important role is attributed by the surveyed representatives of the business environment in Latvia to data processing, management, and analysis, if compared to the global experience (29\% in the world).

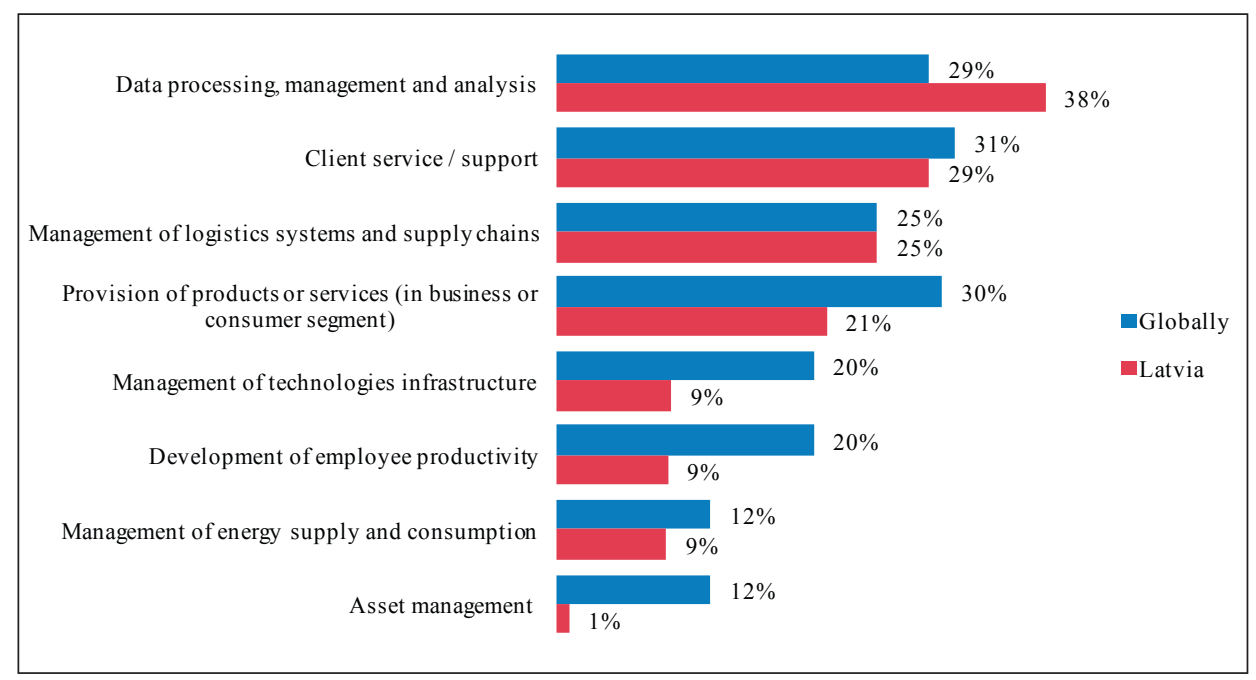

Source: Survey of company representatives conducted by the authors and the study by Economist Intelligence Unit.

Fig. 4. Division of impacts of IoT solutions in areas of entrepreneurship 


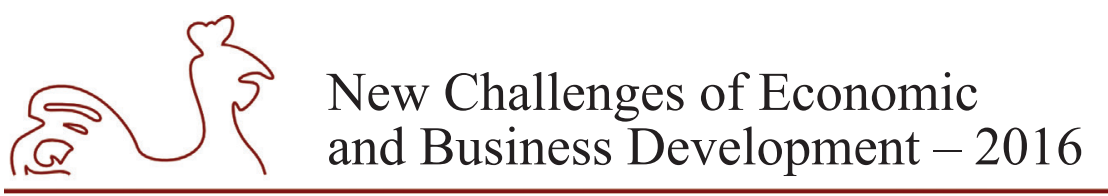

May 12-14, 2016, Riga, University of Latvia

Comparing with the global experience, respondents surveyed in Latvia attribute a significantly lower role to IoT solutions in management of technology infrastructure $(20 \%$ in the world vs. 9\% in Latvia), employees' productivity development (also 20\% in the world vs. $9 \%$ in Latvia), management of energy supply and consumption (12\% in the world vs. $9 \%$ in Latvia) and asset management (12\% in the world vs. only $1 \%$ in Latvia). Overall, it is apparent that business representatives of Latvia recognise lower impact from the development of IoT solutions in various business areas than respondents globally.

Evaluating the gains offered by IoT solutions, the most significant gains in Latvia are seen in the reduction of costs of basic activity (17\%), in development of new business processes $(13 \%)$ and in the possibility of gaining new income from sales of existing products or services $(12 \%)$, which, overall, points to the possibilities of IoT solutions to improve business efficiency and boost profitability. A more detailed division is presented in Figure 5.

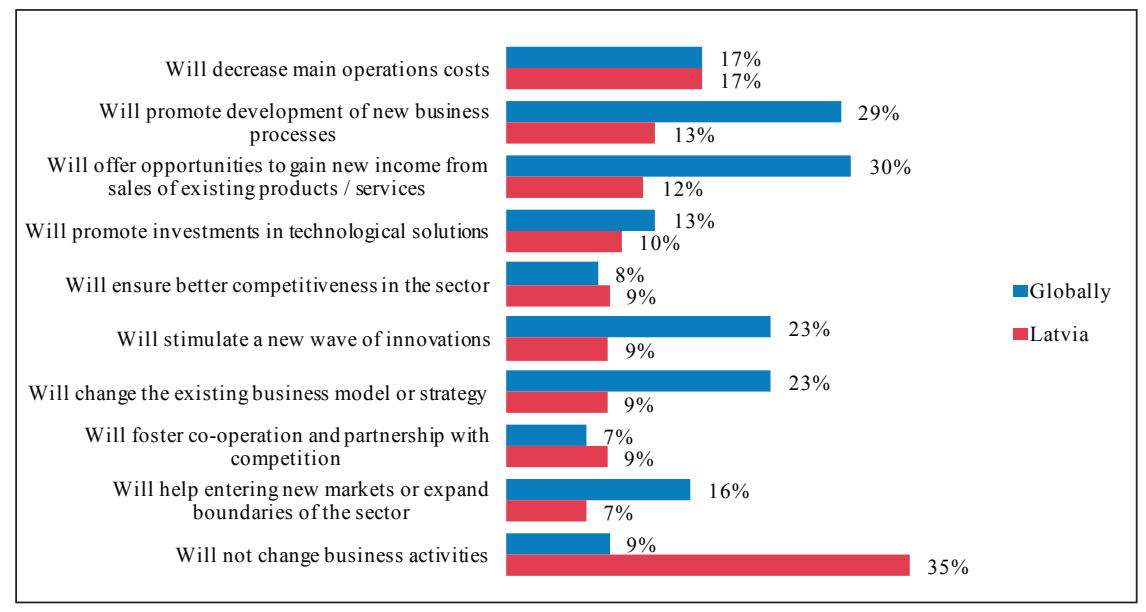

Source: Survey of company representatives conducted by the authors and the study by Economist Intelligence Unit.

\section{Fig. 5. Division of gains offered by IoT solutions}

It must be recognised that, in comparison with the global experience, a significant number of respondents (35\% in Latvia, $9 \%$ in the world) at this time do not see how the implementation of IoT solutions could improve the company's management in the upcoming 3 years, which suggests that, even though in the business environment overall respondents see the impact of IoT solutions (Figure 3), it is not directly linked to the sector represented by the respondent and to practical application of IoT, which implies that a broad, undiscovered potential opens up for the development and application of specialised IoT solutions adapted to the sector.

Comparing the readiness to use IoT solutions in the company's manufactured products or offered services and application in improving efficiency of business processes, polarisation of respondents can be observed. In Latvia, unlike the global experience, a significantly higher percentage of respondents claim that they are not planning to apply IoT solutions in products that they offer or in internal business processes (40\% in both aspects in Latvia, as opposed to accordingly $24 \%$ and $26 \%$ globally), a significantly lower percentage admit that the application of IoT solutions is in the research stage (22\% in both aspects in Latvia, if compared to $36 \%$ and $40 \%$ globally). Similarly, a substantially lower percentage of the respondents suggest that IoT 


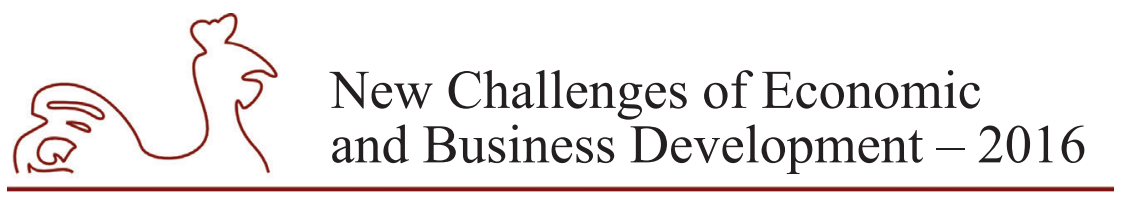

May 12-14, 2016, Riga, University of Latvia

solutions are in a test stage or that their implementation is planned in the nearest future ( $4 \%$ and $6 \%$ in Latvia, as opposed to $20 \%$ and $17 \%$ globally). A more detailed division of readiness to use IoT solutions, by applying them to the offered goods or services and the internal business processes, is provided in Figure 6.

At the same time, a substantially higher number of respondents in Latvia, if compared with the global experience, state that IoT solutions are already being used in the company's manufactured products or in business processes $(18 \%$ and $17 \%$ in Latvia vs. $5 \%$ around the globe in both aspects). The absolute leader in the application of IoT solutions at this time is already the ICT sector and the transport sector, the representatives of which have stated that IoT is already being used in company's products and business processes.
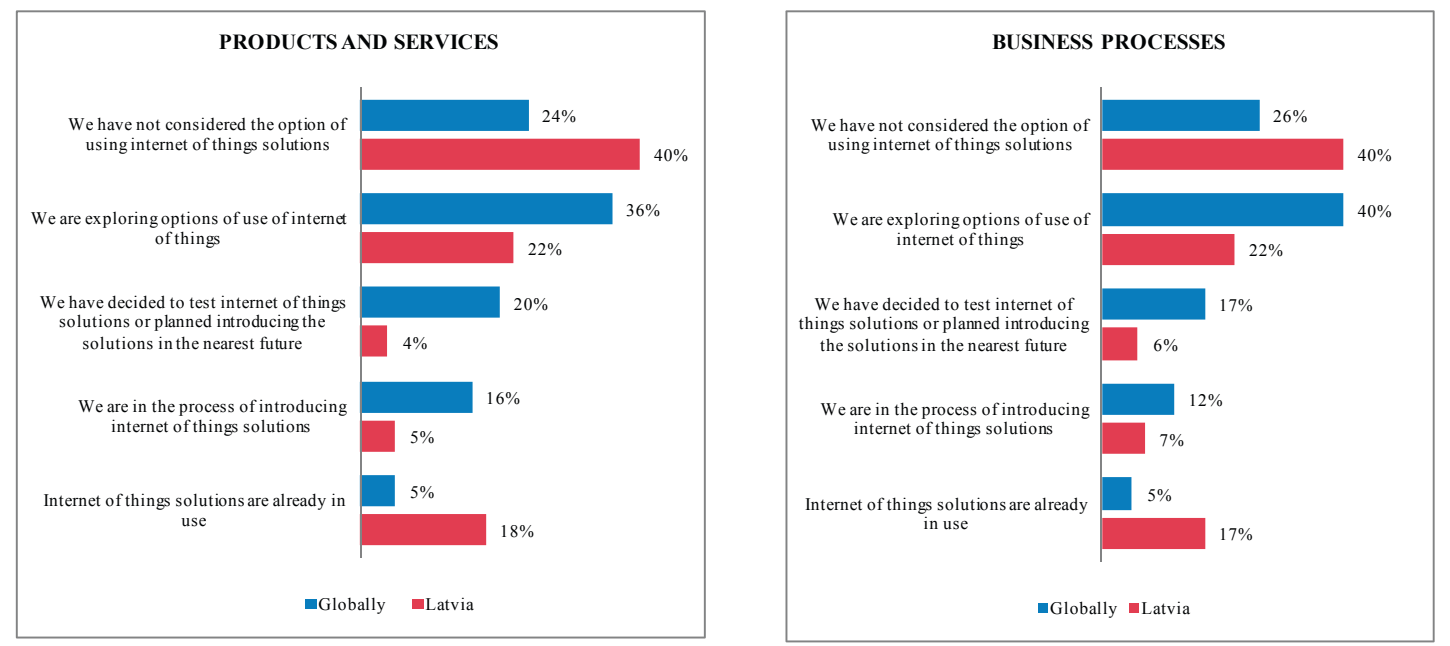

Source: Survey of company representatives conducted by the authors and the study by Economist Intelligence Unit.

Fig. 6. Readiness to use IoT solutions by applying them to the company's manufactured products (left) or in business processes (right)

If we consider obstacles delaying the implementation of IoT solutions in companies, the key aspect mentioned by representatives of the business environment of Latvia is the lack of coherence between the company's produced product or offered services with the offered possibilities (34\%), which suggests that the understanding of IoT possibilities and readiness of solutions as such are still in the development phase in Latvia. It is important to note that a lower proportion of respondents, if compared with the global experience, indicate that lack of knowledge or skills (23\%in Latvia, 26\% globally) or insufficient involvement of the company's management (18\% in Latvia, 23\% globally) is an obstacle, which suggests that the intellectual basis and theoretical openness to innovations is above the world average. The division of obstacles to introduction of IoT solutions, if compared to the global experience, is offered in Figure 7. 


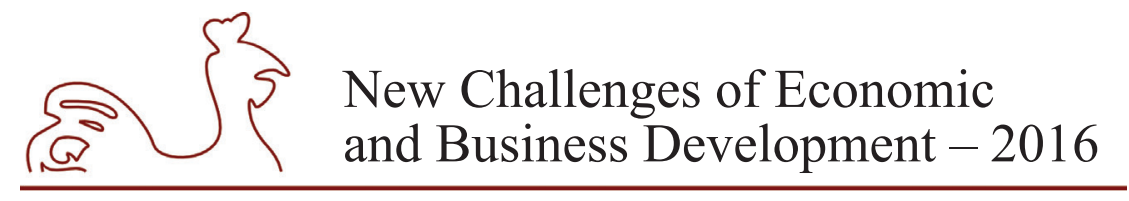

May 12-14, 2016, Riga, University of Latvia

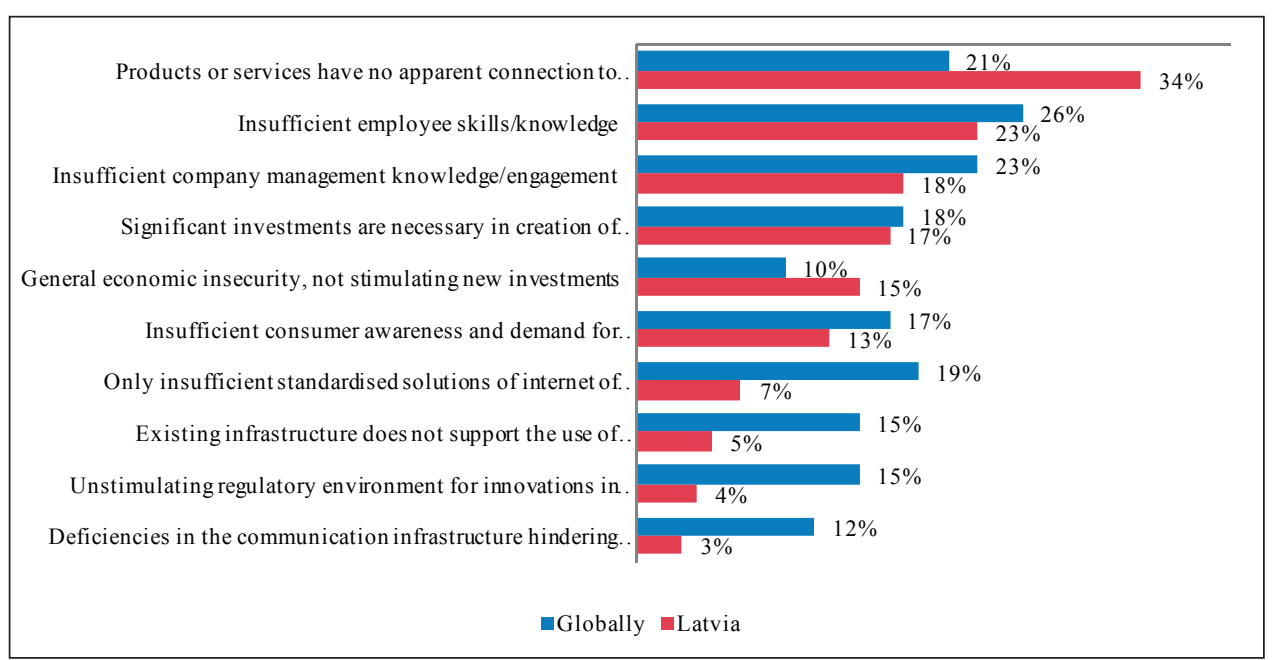

Source: Survey of company representatives conducted by the authors and the study by Economist Intelligence Unit.

Fig. 7. Obstacles delaying the introduction of IoT solutions in companies

Latvian respondents assess the role of economic insecurity in delaying the introduction of IoT solutions higher than the world average (15\% in Latvia, $10 \%$ globally), which suggests that macroeconomic growth in the country could promote a broader use of IoT solutions in practice. At the same time, only a small part of respondents recognises the existing normative regulation in the area of data protection as a deficiency (4\% in Latvia, 15\% globally), which means that the existing laws and regulations are not a significant factor delaying the application of IoT solutions.

\section{Conclusions and implications}

Having analysed the theoretical basis about possibilities offered by IoT solutions, the survey performed among business representatives regarding the practical experience in applying these solutions and comparing it to the global experience, the authors propose the following solutions: 1. The available literature about the opportunities and application of IoT solutions admits that in most cases the IoT ecosystem is only in the development stage, and therefore, in order to use the potential of IoT technologies as vastly and efficiently as possible, it is necessary to identify the problems and risks, which will have to be dealt with while introducing new technologies. Currently, the available academic literature about IoT solutions is relatively limited.

2. In the upcoming years, IoT solutions will fundamentally change the business model known and applied up to now will create new and yet unknown challenges, which, in the business environment, will demand enhanced involvement for the part of company management and new employee competences and technologies, in order for the development of IoT solutions to reach utmost gains.

3. If the level of IoT readiness in Latvia is looked at empirically, it can be assessed as relatively high - nearly three quarters of respondents admit that the development of IoT solutions is expected to have substantial impact on at least some sectors and markets. It suggests that, even though technological solutions are relatively recent and in the development phase, 


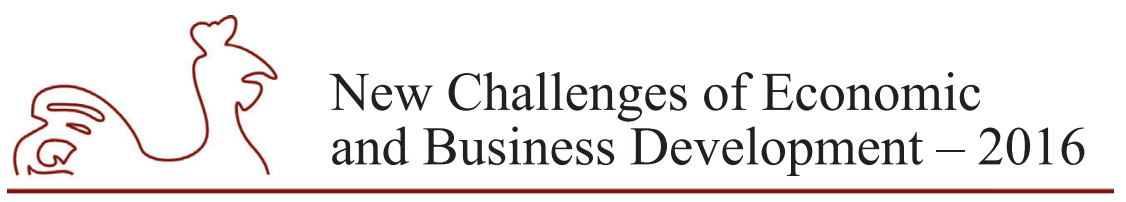

May 12-14, 2016, Riga, University of Latvia

over the three-year report period, Latvian business environment representatives already see the potential of IoT impact in various business sectors.

4. Considering the areas of business, in which respondents see the biggest potential to the application of IoT solutions, the following are mentioned most frequently: data processing, management, and analysis, client service or support and management of logistics systems or supply chains. ICT and transport sectors are already now using IoT solutions in their daily operations.

5. Even though the most significant gains from the introduction of IoT solutions are linked to reducing costs of basic activity, developing new business processes, and creating the opportunity to gain new income from sales of existing products or services, nevertheless, a significant part of business representatives do not recognise an apparent gain from the introduction of IoT in the company that they represent, which means that the potential of introducing IoT solutions in Latvia is not yet absorbed.

6. Among obstacles delaying the introduction of IoT solutions in companies, representatives of the Latvian business environments state the lack of coherence between products manufactured or services offered by the company with the possibilities offered by IoT, lack of employees' knowledge and skills and insufficient involvement of the company's management, which suggests that the understanding about the possibilities of IoT and the readiness of own solutions are only in the development stage in Latvia.

7. Consequently, factors that could foster a faster and more effective development of application of IoT solutions in Latvia include investments in technological solutions and increasing knowledge and qualification of employees, higher management involvement and better understanding of return on these investments, as well as macroeconomic environment and normative regulation promoting growth, which would ensure balanced development of the IoT sphere.

\section{Bibliography}

Atzori L., Iera A., Morabito G., (2014), "From "smart objects" to "social objects": The next evolutionary step of the internet of things," IEEE Communications Magazine, Vol. 52, No. 1, pp. 97-105.

Bradley J., Barbier J., Handler D., (2013), Embracing the Internet of Everything To Capture Your Share of \$14.4 Trillion, Cisco, http://www.cisco.com/c/dam/en_us/about/ac79/docs/innov/IoE_Economy. pdf, [Retrieved on December 15, 2015]

Fleisch E., (2010), What is the Internet of Things? An Economic Perspective. Economics, Management, and Financial Markets, Vol. 5, Issue 2, 125-157.

Holler J., Tsiatsis V., Mulligan C., Karnouskos S., Avesand S., Boyle D., From machine-to-machine to the Internet of Things : introduction to a new age of intelligence, 2014, Elsevier, p. 331.

Manyika J., Chui M., Bisson P., Woetzel J., Dobbs J., (2015), The Internet of Things: mapping the value beyond the hype, 2015, McKinsey Global Institute, p. 144.

McAfee A., Brynjolfsson E, (2012), Big Data: The Management Revolution, Harvard Business Review, at http://hbr.org/2012/10/big-data-the-management-revolution [Retrieved on January 14, 2016].

Sundmaeker H., Guillemin P., Friess P., Woelffle S. (eds.), Vision and Challenges for Realizing the Internet of Things, 2010, European Commission, p. 229.

The Internet of Things Business Index, A report from The Economist Intelligence Unit, (2013) at http:// www.economistinsights.com/analysis/internet-thingsbusiness- Index [Retrieved on January 21, 2016]. 


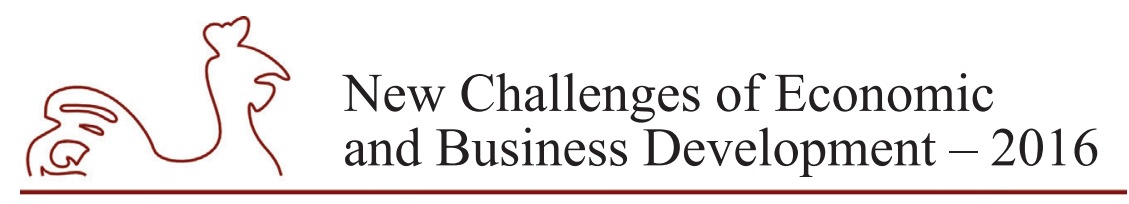

May 12-14, 2016, Riga, University of Latvia

Turner V., Gantz J., Reinsel D., Minton S., (2014), The digital universe of opportunities: rich data and the Increasing value of the Internet of Things. Open report., IDC Sponsored by EMC Corporation, April.

Verizon (2015), "State of the Market. Internet of Things 2015", http://www.verizonenterprise.com/ resources/reports/rp_state-of-market-the-market-the-internet-of-things-2015_en_xg.pdf, [Retrieved on January 21, 2016].

Vermesan O., Friess P., Internet of Things - From Research and Innovation to Market Deployment, 2014, River Publishers, p. 355. 


\title{
SOCIAL PRACTICES OF RURAL POPULATION FOR RENEWAL OF SOCIETY IN LATVIA
}

\author{
Dina Bite, Latvia University of Agriculture, Latvia ${ }^{1}$ \\ Zenija Kruzmetra, Latvia University of Agriculture, Latvia
}

\begin{abstract}
Renewal of society is a crucial point of Latvian reality because of depopulation, territorial polarization and shrinking processes during last decades. One of the tasks of local municipalities of rural territories has been to find ways of attracting people and promoting further development of rural territories. Renewal of society includes a set of interpretations concerning its quantitative and qualitative solutions, e.g., demographic solutions as well as social and economical traits and practices. The aim of the article is to identify social practices of rural population that fit with theoretical statements of renewal of society and give evidence of potential for rural communities to survive and develop.

The article is based on analysis of theoretical literature about renewal of society (Steiner R., Neumeier S., Hody E., Reckwitz A., Nicholls A. et al.) as well as empirical results collected using semi-structured interviews with representatives of local municipalities, entrepreneurs, farmers and representatives of the Latvian Rural forum and rural NGOs during the projects of the National Research Programme for the period 2014-2017.

Main results of the research reveal high level of cultural and social activities in rural territories that have developed recently and serve as a way of surviving of rural population and contain certain potential for economic development of rural territories. New institutionalized practices have appeared in order to meet common purposes of local agents. To conclude, current cultural, social and economical practices are quite new and still fragile, but they are relevant to meet challenges of depopulation of rural areas of Latvia.
\end{abstract}

Key words: renewal of society, social practices, social innovations, cultural and economic traits

JEL code: Z10, Z13

\section{Introduction}

Depopulation and changes in structure of labour market of rural areas, polarisation of settlements of Latvia that have emerged during the last two decades (Krisjane Z. et al., 2014, Cunska Z., 2010), have presented new challenges to the rural local municipalities and local communities forcing to seek for ways of survival and potential development (Dzenovska D., Aistara G. A., 2014, Cimdina A., 2012). Therefore, renewal of society is not only an academic issue but has turned out to be an important real-life aspect for rural development in Latvia. In addition to demographic or economic solutions of mentioned problems, the importance of social relations, social innovations as potential drivers for territorial development should be highlighted. Therefore, the aim of the article is to identify social practices of rural population that fit with theoretical statements of renewal of society and give evidence of potential for rural

1 Corresponding author - e-mail address: dina.bite@llu.lv 


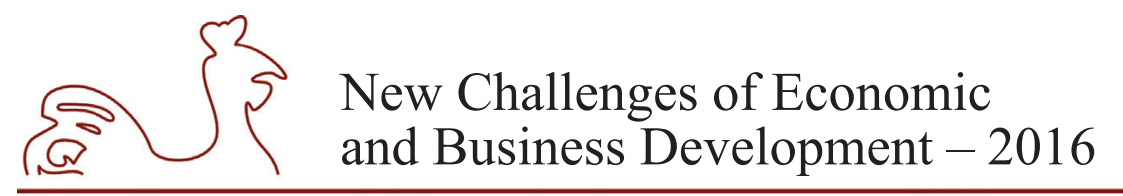

May 12-14, 2016, Riga, University of Latvia

communities for survival and development. Tasks of the article are related to the establishment of a set of theoretical statements and analysis of empirical information collected during field work in rural areas in Latvia. Authors use the qualitative approach of social studies, e.g. semistructured interviews with representatives of local municipalities, entrepreneurs, farmers and representatives of the Latvian Rural forum and rural NGOs. The research was done in 8 settlements in Latvia (case studies) interviewing different social agents $(N=60)$ and analysing documents (2015). In addition to this, interviews with representatives of 6 rural NGOs during the $2^{\text {nd }}$ session of the Parliament of Rural Communities (2015) and an interview with an expert of the Latvian Rural forum Anita Selicka (2016) were performed. The results of the research point out the main social and economical practices in rural areas as well as provide insight in the development of rural community.

Recent theoretical discussion concerning rural development highlights local initiatives and "bottom-up" development which is known under the name "endogenous development". It is an opposite way of discourse to what was experienced in post-Soviet countries, e.g. centralised economics, directed social and cultural life, low self-initiative and weak civil society. The postsoviet heritage is still apparent in rural areas where people have lost the sense of ideological and economic protection, are more conservative, less dynamic and less able to compete and are nostalgic for large industrial type enterprises. Still, the situation is gradually changing; people are getting more engaged in civil activities and take responsibility about their individual and collective benefits.

Renewal of society as a term has wide interpretations. Most of them are concerned with urban renewal that implies solving problems both in spatial-constructional and social system in urban areas (Zheng H. W. et al., 2014) as well as demographic solutions of shrinking societies (Strohmeier K. P., Bader S., 2004, Haffner J., 2010). Rural renewal has not been analysed very often (Vermeire B. et al., 2008; Husak J., 2012); however it is more important because of limited resources in rural areas.

Conceptual framework of renewal of society entails re-building (re-construction, recreation) of social and economical structures. Renewal is understood as an act of extending the period of time when something is effective or valid or the state of being made new, fresh, or strong again (Simple Definition of...). Other explanations of the term stress moving away from routine and repetitious behaviours, and sometimes behaviours are greatly affected (governed) by the rules and the traditions that are prerequisites for the stability that permanent organisations and the surrounding society can provide (Ekstedt E. et al., 1999). Thus, social norms and behaviours are closely linked to institutional structures of society. When the society faces serious difficulties (economical crisis, emigration, failure of political solutions of problems) previous economical and social patterns become less effective; and that calls for the renewal of existing order and behaviours. Sociologist Gary Runciman suggests that sometimes change should involve recovering or recreation of the past but more important is the coping with the challenges that exist in our rapidly changing world (Runciman G., 2012).

Theorists of endogenous and neo-endogenous development claim that the power and initiative for coping with different challenges come from local people and their ability to satisfy their needs (Lowe P. et al., 1995, Neumeier S., 2012). In relation to renewal of society, endogenous development was described by philosopher and social reformer Rudolf Steiner who noted that "the only way to renewal, to a really healthy economy and healthy system of 


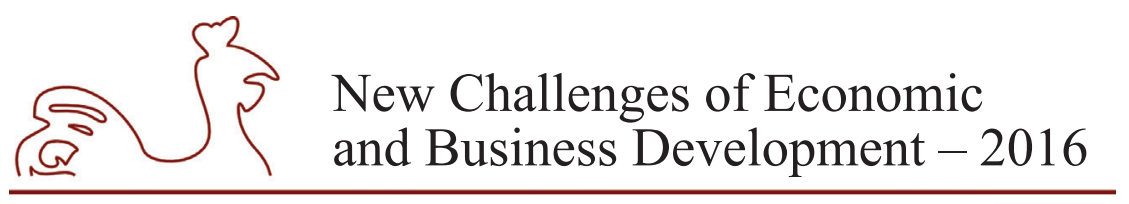

May 12-14, 2016, Riga, University of Latvia

justice, is to create free space for the good impulses and aspirations living in humans to come to the surface" (Steiner R., 2000). R. Steiner claimed that the main realms of society are economy, politics and culture because they cover basic people's needs. According to him, society needs freedom for all activities in the cultural sphere - education, science, art, religion - they must be independent of state and economic power (Steiner R., 2000). Recent discussions regarding renewal of society also highlight the importance of social and cultural activities (Marshall D., 2000), creativity, flexible thinking, communication and cooperation (Institute for Social..., 2013). Results of researches and several territorial planning documents confirm above mentioned ideas about significance of opportunity to build local society "bottom-up", to appreciate power of relationships (Kretzmann J. P., McKnight J. L., 1993) and often hidden resources in communities - the skills and talents of individual people, the resources offered by local associations and organisations, the resources offered by institutions such as major employers, schools, and the council, land, property, buildings, parks or the environment, local businesses or industries, the arts, culture and heritage of the community. Critical role in these processes is assigned to the community organisations that enable those who are vulnerable in some way to participate more fully in their community (Cavaye J., 2011). Similarly, the Great Britain strategy for social renewal stresses the necessity to find and develop local resources for further territorial development as programs of the state government or private sector cannot solve complicated social and economical problems. The document includes following strategies for developing of renewal of society: spreading of power and responsibilities (decentralisation), fostering contribution and reciprocity, strengthening shared institutions (activities of civil societies) (Lawton K., 2014). Another territorial planning source suggests that "village improvement is mainly a coordinating and moderating action in the local community. The main concern is to create a fruitful atmosphere in the community that improves their self-development potential and that strengthens their sense of responsibility for their surrounding living space. Mental, social and cultural renewal creates economical and creative renewal almost automatically" (Hody E., 2001). On the one hand, above mentioned issues are not widely popular and accepted in public space despite of social and economical benefits that can be achieved through active engagement and growing of cooperation and trust. Its main reasons are power relations and conservative opinion about economic determinism as a main driver of changes and development. On the other hand, the ideas about sustainable and based on cooperation establishment of communities, seeking of balance between extensive economics and intensive life of community and between crafts, creativity and consuming society (Chen M., 2015), and social economy as a new paradigm of production are being more acknowledged (Murray R. et al., 2010).

Activities of local communities in relation to renewal of society are discussed in a set of social theories - development of society (Nederveen Pieterse J. 2010; Social Progress Index, 2014), social sustainability (McKenzie S., 2004; Dillard J. et al., 2009; Colantonio A. et al., 2009) and social innovations that are especially important for rural development as they discover people's ability to develop sustainable structures for adapting and creating stability (Neumeier S., 2012).

Authors of the article use theories of social innovations in order to explain activities of rural inhabitants in Latvia. Social innovations are not defined uniformly and can refer to the effort, method, result or change initiated by collaborative actions. Social innovations have many different aspects but they serve as a tool for renewal of society. Social innovations are socially, 


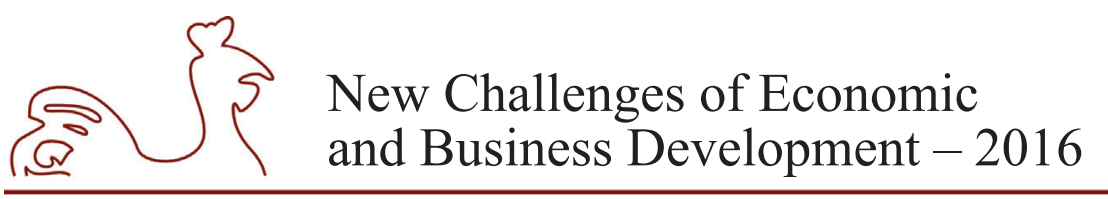

May 12-14, 2016, Riga, University of Latvia

culturally and territorially embedded. Here the focus is placed on the changes in social relations, people's behavior, and norms and values. Social innovation is combined with the concepts of social empowerment and inclusion, social capital and cohesion. Social innovations also have instrumental function - innovators should engage citizens in their practices so that new products and processes better meet their expectation and needs (Bock B. B., 2012). Social innovations are also strongly related to the innovation of established processes in politics and governance. Social innovation needs innovative governance that allows for the inclusion of non-traditional, marginalized actors, integrates various policy issues, and seeks to meet unmet public needs and to create public value where markets and common socio-economic policies have failed (Moularet F. et al., 2005, Phills J. A. et al., 2008). Newest researches suggest that social innovations appear to be entering a new phase - a phase in which it is increasingly seen as offering solutions not just to localized problems but to more systemic and structural issues (Nicholls A. et al., 2015).

Social innovations must be developed and supported on local and regional levels as they are significantly related to the renewal of society. They are vital in shrinking societies, communities experiencing deep crisis because they can help adapt to new circumstances, survive and even develop. The adapting to socio-demographic change is not just a passive reaction but rather active coping behavior that might also bring about innovation (Steinfuhrer A., 2014). Thus, collective learning, coordination and communication processes between different actors in teams, actor networks and other means of cooperation, that are new in relation to the horizon of experiences of the local people concerned are important factors for the success of neo-endogenous regional development (Neumeier S., 2012).

In relation to social innovation authors use the term of social practices. They are defined as "routinized type of behaviour which consists of several elements, interconnected with one other: forms of bodily activities, forms of mental activities, 'things' and their use, a background knowledge in the form of understanding, know-how, states of emotion and motivational knowledge. The practice as a 'nexus of doings and sayings' is a routinized way in which bodies are moved, objects are handled, subjects are treated, things are described and the world is understood. A practice is social, as it is a type of behaving and understanding that appears at different locales and at different points of time and is carried out by different body/minds" (Reckwitz A., 2002). Thus, social practices are interpreted as routinized, collective actions with certain aims and are considered as parts of social structure. In terms of the article, social practices are understood as current forms of organising social, cultural and economical life of rural population in Latvia. In relation to renewal of society, these social practices should create and maintain individual and collective ability to solve their problems and satisfy their needs.

\section{Research results and discussion}

During the interviews done in summer 2015 and in March 2016 significant number of examples emerged to reveal social reality of rural communities. It is possible to state that a certain part of rural population has overcome their nostalgia about past and expectations about "somebody that will come and give work":

"It was hard for me to accept that there will not be large production/factories in the area" (head of municipality, 2015) 


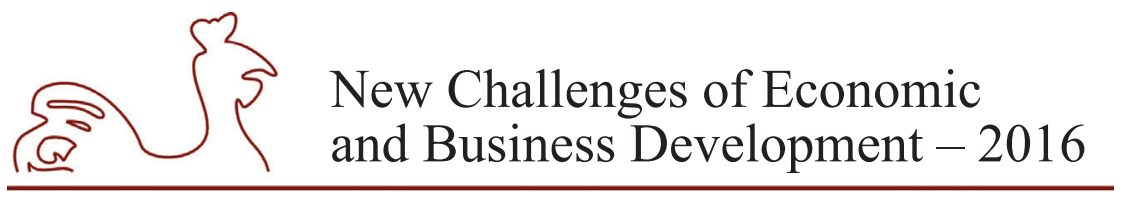

May 12-14, 2016, Riga, University of Latvia

The results of interviews disclosed diverse cultural and social activities in most of rural areas - cleaning of the area, preservation of natural and cultural heritage and promotion of new economic activities by creating new products using the natural resources, creation of new tourism services etc. Rural population develops different social and economical practices in their local places that bring out specific cultural and economic traits.

\section{Social and cultural practices in rural territories}

Rural population is not a homogenous system with clear set of characteristics; social relations vary in different regions, towns and villages. According to the results of interviews, it is possible to create relative division of rural population - incomers from urban territories, active rural people and passive rural people that plan to move away from rural territories. It is impossible to determine the correct size of those groups; they draw some trends in rural territories only. As proved by the results of interviews, there is a set of factors that influence these movements and attitudes. These factors are both objective like infrastructure, employment opportunities and subjective that include personal motivation, attitudes, relations in local community etc. Sometimes, the willingness to move to the country (or to stay there) is stronger than objective circumstances that limit their actions there, for example, rural people get involved in entrepreneurship but they have problems with sending formal accounts electronically due to periodic loss of power. People overcome these barriers and continue achieving their purposes developing ironical point of view on these things. It suggests that rural life and rural territory is not a place to be used rationally or for gaining certain benefits but rather must be viewed as a value in itself and that way serves as a more powerful motivator for action.

The interviews reveal a crucial point of rural attractiveness in Latvia - social relations that include acceptance of each other, common identity and support. It finds its expression in cultural activities, e.g. amateur groups, educational and sports activities, festivals and also in social relations of the daily life:

"The roots, the willingness, the understanding that you can go alongside, that things are happening... This understanding is important to everyone. It ensures capability, it is a safety tool for people; it gives you boldness to step out and do something. That is where the people's openness lies.." (representative of LRF, 2016)

Development of rural communities suggests that it is possible to transform passive people into active ones. It is a long-term process and it works through active leaders and welcoming of everyone:

"There are people covered with plaque as an old coin, nobody cares for them. But everyone has his or her even if small talent. It must be used" (representative of NGO, 2015)

It suggests that it is important to believe in people and let them express themselves. Above mentioned is more of a philosophical statement and does not sound rational, but it is an important characteristic of rural communities and should be taken into account during the planning process. As it was confirmed by the informants, it is not so much money, entrepreneurship and/ or economics that is able to transform passive people into active; the most important thing is the developing of solidarity within a local community: 


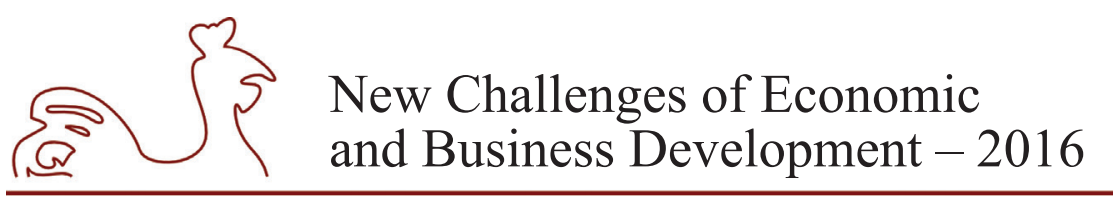

May 12-14, 2016, Riga, University of Latvia

"They are being seen by others as a community; they do things together, and that is where the sense is born that every single person is important and that every single person is a part of this place" (representative of LRF, 2016)

Obviously, this is an effective way to activate local people despite of limited resources and certain difficulties that must be overcome. Those patterns that are based on traditional views of economic growth as a driver for territorial development fail in rural areas.

Social activity spreads to neighbourhoods and to broader region. Specialists say that the main value of rural communities is active individuals or groups that encourage other people. They suggest that even competitive relations among entrepreneurs act like promoters for activating rural community.

It is difficult to estimate level of activity of rural communities but the current trend shows the multiplication of social and cultural activities. One of the mentioned positive moments is cooperation between sectors and crossing narrow borders between different sectors and levels of authority of similar activities. For example, a dance group develops small entrepreneurships based on the skills of its participants; Zebrus Lake managers' association organizes theatre performances with the involvement of local residents. Very successful practices have been found in Tirza village where a small local school offers a variety of educational opportunities; also they have their own credit union. The school cooperates with a farm and Tirza development association that includes representatives from local municipality and NGOs as partners. They carry out different projects and it is hard to see borders between the involved agents despite of their differences; they have merged their borders in order to achieve common purposes.

Collective activities of local community sometimes confirm or sometimes break existing statements and stereotypes about the certain location. It is related to the claims of local municipalities about specialisation and place marketing that help to survive and attach new residents. Most of them create their image based on traditional historical sites, cultural values and traditional producing, e.g. ice cream producing in Rüjiena is presented as "gastronomic tourism". In other cases, people change traditional perceptions about the place, and it must be stressed that it comes from local peoples' ideas is considered to be features of endogenous development. For example, there is the village of Druviena where the local community agreed on the future vision of the village as a centre of traditional Latvian wisdom. Druviena presents a good practice of how to involve inactive people: if they do not see themselves as the providing ideas for different events, they can take part in technical things or in marketing. It can be concluded that currently rural population is in a process of creating of the image of their villages or towns, as well as their identity and community. In addition to this, specialists say that rural people in Latvia are very good in creating their values and representing them. They do not need significant objects or specific traditions to build their "story":

"People have understood they identity; they have the products as representation of this identity in every place. It seems as they are holding hands; they know what is important to them and they are guarding them. At present we are trying to let go one of the hands and encourage people to look outside their circle" (representative of LRF, 2016)

"Rural tourism is like a show business currently, I like it” (entrepreneur, 2015) 


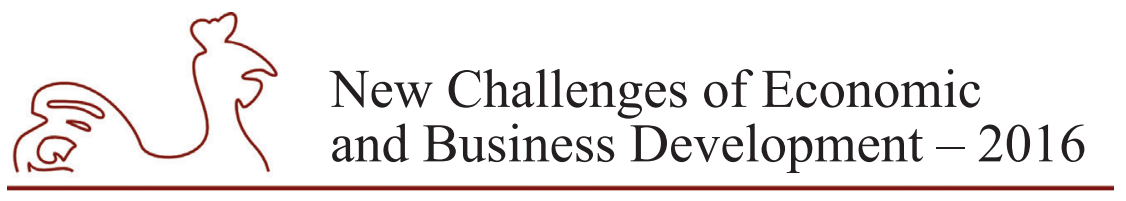

May 12-14, 2016, Riga, University of Latvia

Social and cultural activities can grow into economic ones, thus providing for further development. As mentioned before, the example of inter-sectoral cooperation in Tirza village has promoted the relocation of young people to Tirza in order to live and work there:

"Relocation to the countryside is reasonable if it concerns families with children. But if it is done by young singles... it means they are sure that they won't lose social ties, won't live in a degraded environment; they see some type of potential " (representative of LRF, 2016)

Good social and cultural practices spread gradually; nevertheless, the informants also point to a few weak points in rural areas and in the process of establishing of communities. Several representatives of NGOs have claimed that rural residents are active in carrying out different projects (e.g. LEADER program) and they have developed good skills of creating and performing different ideas through available financing. The LEADER program that is especially aimed to rural territories is a usual tool for local municipalities to arrange the infrastructure. The problem is their dependency on finances that mostly come from EU foundations, figuratively speaking "from above", and this dependency from EU funds limits their freedom to carry out the ideas that are birthed by the needs of community. It causes a situation when local agents apply to all possible contests of projects without a deeper analysis about their necessity. In order to survive, active people write project proposals and implement different ideas but these activities look more like short-term actions without long-term goals. In order to conquer this problem, the plan is to add list of criteria for carrying out projects that promote cooperation and coordination of local agents as well as sustainability of the project results. It would give a chance to guide the development of local territories leaving the definition of needs and development of aims to the local communities.

Another problem that specialists stress as important for community developing is a role of local municipality. There are cases when they try to keep control over local initiatives and make the involvement of NGOs highly formal and ineffective. According to the results of collected interviews, hypothetically it is possible to assume that the rural territories and communities with formally working local municipalities are weak and passive. And vice versa - in the communities that receive support from the council of local municipality, moreover, if it acts as a driver of social and economical activities, local population is more capable to develop new ideas:

"We must think of how to attract people. People must be creative; otherwise there is no production" (head of municipality, 2015)

As interviewed representatives claimed, all of these initiatives need support from all levels and in different ways. It includes both emotional recognition and gratitude from other people, local municipality, public authorities as well as transparent, stable and supportive legislation on the state level, growing of quality, capacity of NGOs, decentralisation, cross-sectoral and integrated look at the rural territories.

\section{Economical practices in rural territories}

According to the results of the research, it is possible to state that economic structure is changing in rural areas. Gradually, a number of small businesses increase in rural areas instead of large enterprises. Especially popular is home production that also receives certain state support. 


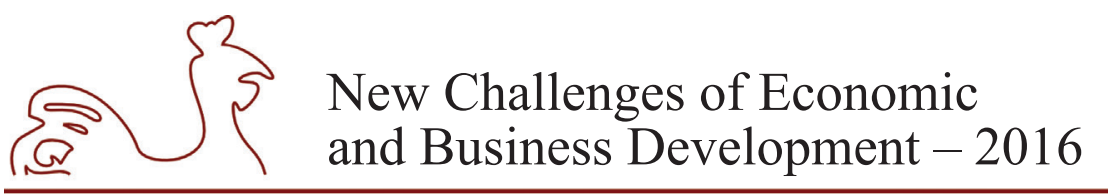

May 12-14, 2016, Riga, University of Latvia

Economical activities often start with small ideas and narrow social networks (family, friends), without confidence about further development. There are wide variety of small business ideas that are based on people's previous and current skills, examples in other countries and available personal and infrastructure resources in rural areas. For example, a woman in small village in Latgale has developed business of sewing blankets using ecologically friendly sheep wool from her own biological sheep farm:

"I thought I would never go back to sowing. But then I went back to making blankets.

It began giving them as gifts to my relatives and they loved them... You need to choose a positive direction that people can appreciate" (entrepreneur, 2015)

As other popular crafts examples are: carpentry, pottery, weavers, home winery, collecting of herb teas, beekeeping, and traditional baths that mostly are examples of traditional Latvian housekeeping and production. The informants recognize that the network of small businesses (obviously, not always formally registered) has widely developed in rural areas:

"You just need commitment and willingness [to start a business]... my mother-in-law sows, the neighbour up the hill smokes fish..." (entrepreneur, 2015)

It suggests that the network of mutual help and exchange of goods and services has developed in rural areas. It is difficult to point out which part of economic activities is registered legally and which is not; nevertheless it confirms the claim about people's self-organising and taking responsibility of themselves.

One of the positive moments is the development of cooperation between rural entrepreneurs and other social agents in local community. In the beginning of entrepreneurship, the family and relatives are involved in the business only (e.g. wife helps with accounting because she is an economist; daughter prepares webpage and the image of the enterprise etc.) but gradually the network of involved agents becomes broader. For example, local entrepreneur makes wooden dishes that local municipality uses for its representation activities.

Since small entrepreneurs base their business on their individual values and skills, they are not always interested in growing their production if it means to lose their originality. Therefore, some businesses stay on individual and local level escaping massive production and involvement in marketing chains. It confirms the above mentioned statement that people of rural areas appreciate their individual and cultural values and act in accordance with them. Therefore, the economic rationality is not always the main driver of activities. Probably, there are other factors too; some active people claim that post-soviet heritage is inability to manage things:

"Through the craft associations, we offer the opportunity to produce and sell products. There are still lots of barriers in peoples mind, but they slowly overcome them. One of them is lack of motivation to work more and more productively" (head of municipality, 2015)

There are examples in rural areas when organizers of events must cover the costs because they primarily think about social and cultural and not economical aspects of the event. Gradually, they learn to reconcile the emotional and practical sides.

Entrepreneurship in rural areas in Latvia is based on values and beliefs of entrepreneurs, on well-developed network of reciprocal exchange; but at the same time it is characterised by remoteness from the state and wide public space. Therefore, quite often these social and 


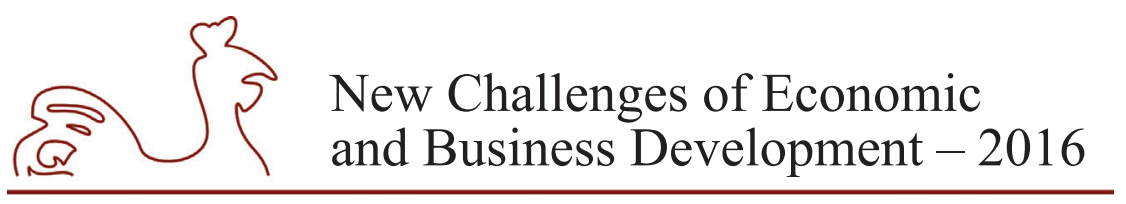

May 12-14, 2016, Riga, University of Latvia

economical practices are publicly invisible despite of their success. There are some attempts to collect and show examples of entrepreneurship in rural areas thus attracting consumers; but it is just a part of economical relations in rural areas.

Another effective tool for developing of rural territories in Latvia is a partnership between entrepreneurs, NGOs and local municipalities and the practice of using local raw materials for different projects. It helps to look at a village or a town as a system. According to interviews, this is the next step for rural communities - building of cooperation and searching for sustainability.

\section{Discussion}

The results of the research reveal only a part of social and economical practices in rural territories in Latvia. If they are compared with theoretical statements of endogenous development, renewal of society, and social innovations, they fit with them suggesting certain potential of rural population to re-create and re-build their society.

The highest point of identified examples is the situation when different agents involved in the development of rural territory act together creating well integrated network and merging borders of political power. It is the most appropriate mode of actions that confirms the ideas expressed by theorists of social innovations (Neumeier S., Bock B. B.) regarding people's ability to develop sustainable structures for adapting and creating stability as well as efforts, methods, results or changes initiated by collaborative actions. Cross-sectoral cooperation is considered to be the best driver in meeting the needs of community and leading it to the renewal of society by re-creating social and economic structures.

The existence of social innovations is also proved by examples of activation of community and its social and economical consequences when people's behaviour, norms and values have changed. These active members of the community are interested in improving their common life and they appreciate their collective work building social empowerment and inclusion, social capital and cohesion. As B. B. Bock claims, innovators engage citizens in their practices so that new products and processes better meet their expectation and needs. The situation in rural territories in Latvia fully proves this statement - socially and economically active individuals are the main resource for activating local community. An important social innovation and social practice is how innovators activate rural community. They act according to the ideas expressed by R. Steiner and E. Hody about significance of "creating free space for the good impulses and aspirations living in humans to come to the surface" through appreciation of talents of every individual in community and involving him or her in common activities. Quite often it starts with small projects or insignificant social activities. Gradually, if people are supported, they are able to further develop their ideas and build their common life.

Considering relocation of urban inhabitants to rural areas and perception of rural areas as a place to fulfil different ideas, as well as existing good social practices in rural communities, it is possible to state that rural territories have the potential for their re-creation, re-building, as it requests renewal of society.

At the same time economic activities (exchange of goods and services, development of small entrepreneurship) have developed as patterns of coping with existing economic and social challenges in rural areas. Probably, they are small and invisible; however they meet current needs of rural population. This also requests deeper investigation and analysis because data 


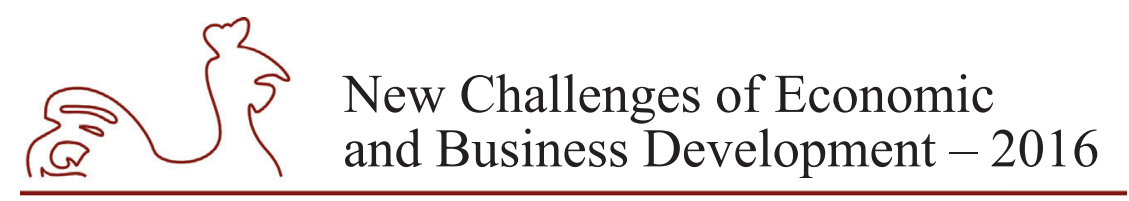

May 12-14, 2016, Riga, University of Latvia

found in Latvia rural areas are similar to what scientists call the invisible or the "hidden" creative rural economy or the "hidden" rural craft economy that means marginalised, statistically not differentiated and not supported economical activities (Raubisko I., 2012, Creative Rural Communities, 2010). Another one of the coping strategy is the creation of the image of the community and presentation of their main values and products in a way that attracts visitors and sells their production.

Social and economical practices are not yet stable in rural territories. They are quite new, dependent on a set of influencing factors and it is hard to predict their further development. They have replaced old social norms and practices and they have adapted to existing challenges to some extent. New social practices are based on active, energetic people (innovators), emerging of some signs of cooperation and trust, depending on project financing that is not considered to be a very sustainable base. Still, it is the beginning for further development and requires a set of supportive activities.

\section{Conclusions, proposals, recommendations}

1. Social, cultural and economical activities in rural territories of Latvia are diverse. Diversity is expressed as individual and collective activities, as well as realized practices in rural areas. As a whole, it is possible to identify social practices in Latvia that fit with theoretical guidelines of renewal of society, endogenous development and social innovations.

2. Integrated, common look to the development of village or town, cooperation between social agents of different sectors and levels of decision making, reducing political power and developing of horizontal ties serve as more successful drivers of renewal of society and rural development.

3. Socially important and relevant aspect for renewal of society is the type of relations in rural community that is characterized by emotional, social and economical support and significance of separate individual as well as common values of rural communities. Development of a complex and diverse system of different relations in rural territories and an opportunity to carry out creative ideas persuade people to stay in rural territories or to move there.

4. Population of rural towns and villages has created their identity and representative products by means of the local natural, cultural, social, economical resources. These products as well cultural activities, traditions and small entrepreneurship are seen as a way of surviving and a possible basis for further development both for community and settlement.

5. To conclude, there is a visible tie between social and cultural activities that grow into economic ones and vice versa. Although these structures are quite fragile, they can bring out new social practices, innovations and serve as a transition to new social and economic structures.

6. Existing social practices call for support from different levels of the system of decisionmaking (national, regional and local level) that includes public recognition, financial support, and establishment of appropriate legal framework and development strategies.

Authors express their appreciation to the National Research Programme for the period 2014-2017, project 5.2.4. "Renewal of society through reducing the risk of depopulation, through 


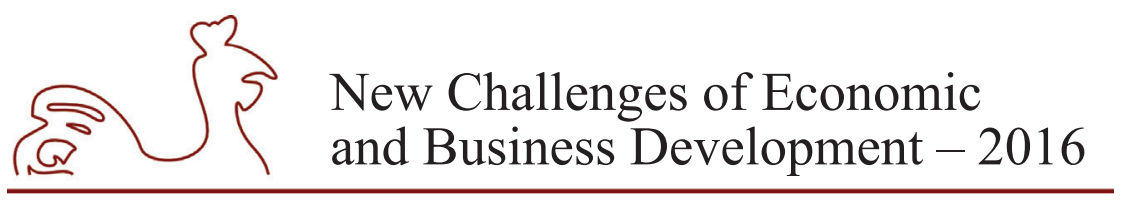

May 12-14, 2016, Riga, University of Latvia

demographic development and strengthening links with the diaspora for the transformation of the Latvian economy" and project "Cultural environment development, preservation of the nature diversity and urbanisation processes within the context of the balanced development of Latvia" for their support in the investigation of the topic.

\section{Bibliography}

Bock, B. B., 2012. Social Innovation and Sustainability: How to Disentangle the Buzzword and its Application in the Field of Agriculture and Rural Development. Studies in Agricultural Economics, 114, pp. 57-63.

Cavaye, J., 2011. Community Capacity Building Toolkit for Rural and Regional Communities. [Online] Available at: http://www.qld.gov.au/web/community-engagement/guides-factsheets/documents/ rural-capacity-building-toolkit.pdf [Accessed 5 March 2016].

Cimdina, A., 2012. The Embeddedness of Rural Life: The Case of Latvia. Humanities and Social Sciences Latvia, 20(2), pp. 4-17.

Chen, M., 2015. Grace Lee Boggs' Century for Social Renewal. [Online] Available at: http://america. aljazeera.com/opinions/2015/10/grace-lee-boggs-century-of-social-renewal.html [Accessed 7 March 2016].

Colantonio, A., Dixon, T., Ganser, R., Carpenter, J., Ngombe, A., 2009. Measuring Socially Sustainable Urban Regeneration in Europe. Oxford: Oxford Institute for Sustainable Development. [Online] Available at: http://www.innovateballymun.org/sites/default/files/socialinnovation/Social\%20 Sustainabilityand\%20Urban\%20Regenerationreport_0.pdf [Accessed 7 March 2016].

Creative Rural Communities, 2010. Proposal for a Rural Cultural Strategy [Online] Available at: http:// www.ruralculture.org.uk/wp-content/uploads/2010/07/RCS_web.pdf [Accessed 12 March 2016].

Cunska, Z., 2010. Where is Demography Leading Latvian Higher Education? Baltic Journal of Economics, 10(1), pp. 5-21.

Dillard, J., Dujon, V., King, M. C. (eds.), 2009. Understanding the Social Dimension of Sustainability. New York: Routledge.

Dzenovska, D., Aistara, G.A., 2014. Practices and Politics of Rural Living in Latvia: an Interdisciplinary View. Journal of Baltic Studies, 45(1), pp. 1-16.

Ekstedt, E., Lundin, R. A., Soderholm, A., Wirdenius, H., 2003. Neo-Industrial Organising: Renewal by Action and Knowledge Formation in a Project-intensive Economy. London: Routledge.

Institute for Social Renewal, 2013. [Online] Available at: http://socialrenewal.com/what-we-do/ [Accessed 4 March 2016].

Haffner, J., 2010. Immigration as a Source of Renewal in Japan. [Online] Available at: http://www. policyinnovations.org/ideas/commentary/data/000161 [Accessed 3 March 2016].

Hody, E., 2001. Village Renewal and the Preservation of Rural Culture. Challenges, Chances, Ideas. [Online] Available at: http://www.ainova.sk/files/file/BHCD\%20praca\%20Village\%20Renewal\%20 and\%20the\%20Preservation\%20of\%20Rural\%20Culture.pdf [Accessed 7 March 2016].

Husak, J., 2012. Synergy of Social and Human Capital in Rural Development - Czech and German Cases. European Countryside, 4(4), pp. 240-250.

Kretzmann, J. P., McKnight, J. L., 1993. Introduction to "Building Communities from the Inside Out: A Path Toward Finding and Mobilizing a Community's Assets”. [Online] Available at: http://www. abcdinstitute.org/docs/abcd/GreenBookIntro.pdf [Accessed 5 March 2016].

Krisjane, Z., Apsite-Berina, E., Grine, I., Feldmane, L., Berzins, M., 2014. The Anatomy of Rural Shrinking: Migration and Depopulation in Latvia's Countryside. IGU Regional Conference, Book of Abstracts, Krakow, Poland. [Online] Available at: www.geo.uj.edu.pl/conferencja/igu2014/ programme/pdf/C12_17_RCHM1/Krisjane_The_anatomy.pdf [Accessed 12 March 2016]. 


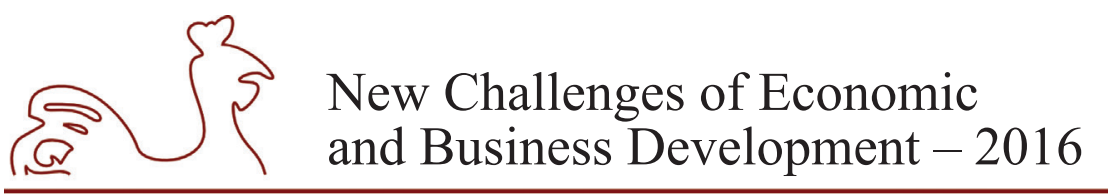

May 12-14, 2016, Riga, University of Latvia

Moularet, F., Martinelli, F., Swyngedouw, E., Gonzalez, S., 2005. Towards Alternative Model(s) of Local Innovation. Urban Studies, 42(11), pp. 1969-1990.

Lawton, K., Cooke, G., Pearce, N., 2014. The Conditions of Britain. Strategies for Social Renewal. Institute for Public Policy Research. [Online] Available at: http:/www.ippr.org/files/publications/ pdf/the-condition-of-britain_June2014.pdf?noredirect=1 [Accessed 7 March 2016].

Lowe, P., Murdoch, J., Ward, N., 1995. Networks in Rural Development: Beyond Exogenous and Endogenous Models. In: Ploeg J. D. van der, Dijk G. van (eds.), Beyond Modernization. The Impact of Endogenous Rural Development (Van Gorcum, Assen), pp. 87-105.

McKenzie S., 2004. Social Sustainability: Towards Some Definitions. Working paper series N.27. Hawke Research Institute, University of South Australia. [Online] Available at: http://w3.unisa.edu.au/ hawkeinstitute/publications/downloads/wp27.pdf [Accessed 7 March 2016].

Marshall, D., 2000. Renewing Cultural Studies. A Journal of Media and Culture, 3(6).

Murray, R., Caulier-Grice, J., Mulgan, G., 2010. The Open Book of Social Innovation. [Online] Available at: http://iisocial.cl/files/2015/12/H-The-Open-Book-of-Social-Innovation.pdf [Accessed 8 March 2016].

Nederveen Pieterse, J. 2010. Development Theory: Deconstructions/Reconstructions. $2^{\text {nd }}$ edition. London: SAGE Publications Ltd. [Online] Available at: http://www.tubar.com.tr/TUBAR\%20DOSYA/ development\%20theory\%20-\%20jan\%20nederveen\%20pieterse.pdf [Accessed 7 March 2016].

Neumeier, S., 2012. Why do Social Innovations in Rural Development Matter and Should They be Considered More Seriously in Rural Development Research? - Proposal for a Stronger Focus on Social Innovations in Rural Development Research. Sociologia Ruralis, 52(1), pp. 48-69.

Nicholls, A., Simon, J., Gabriel, M. (eds.), 2015. New Frontiers in Social Innovation Research. New York: Palgrave Macmillan.

Phills, J. A., Deiglmeier, K., Miller, D. T., 2008. Rediscovering Social Innovation. Stanford Social Innovation Review, 6(4), pp. 33-43.

Raubisko, I., 2012. Invisible Work in the Latvian Countryside. Humanities and Social Sciences Latvia, 20(2), pp. 18-51.

Reckwitz, A., 2002. Toward a Theory of Social Practices: A Development in Culturalist Theorizing. European Journal of Social Theory, 5, pp. 243-263.

Runciman, G., 2012. What Does Social Renewal Mean to You? [Online] Available at: https://www. youtube.com/watch?v=JHflY0O_Wf0 [Accessed 3 March 2016].

Simple Definition of Renewal. An Encyclopedia Britannica Company. [Online] Available at: http://www. merriam-webster.com/dictionary/renewal\# [Accessed 3 March 2016].

Social Progress Index, 2014. [Online] Available at: http://www.socialprogressimperative.org/data/spi\# [Accessed 7 March 2016].

Steiner, R., 2000. Toward Social Renewal: Rethinking the Basis of Society. London: Rudolf Steiner Press, $4^{\text {th }}$ edition.

Steinfuhrer, A., 2014. Innovations by Adaption? New Models of Providing Services of General Interest in Rural Areas Facing Population Decline. International Conference of Rural Geography "The Countryside: Spaces of Innovation in an Urban World", Nantes, France.

Strohmeier, K. P., Bader, S., 2004. Demographic Decline, Segregation, and Social Urban Renewal in Old Industrial Metropolitan Areas. [Online] Available at: http://www.difu.de/publikationen/demographicdecline-segregation-and-social-urban-renewal-in.html\#references [Accessed 3 March 2016].

Vermeire, B., Gellynck, X., de Steur, H., Viane, J., 2008. The Role of Social Capital Assets in Reconcilling Endogenous and Exogenous Drivers of Rural Renewal. [Online] Available at: http://ifsa.boku.ac.at/ cms/fileadmin/Proceeding2008/2008_WS6_06_Vermeire.pdf [Accessed 5 March 2016].

Zheng, H. W., Shen, G.Q., Wang H., 2014. A Review of Recent Studies on Sustainable Urban Renewal. Habitat International, 41, pp. 272-279. 


\title{
A TWO-TIER OR ONE-TIER BOARD MODEL? THE NEED FOR CHANGE IN THE POLISH SYSTEM OF CORPORATE GOVERNANCE
}

\author{
Leszek Bohdanowicz, University of Lodz, Poland ${ }^{1}$ \\ Jan Jezak, University of Lodz, Poland
}

\begin{abstract}
Previous studies mostly discussed how to improve the corporate board structure and processes. Therefore, they examined the relationship between the appointment of independent directors, board committees or female directors and firm performance. Although the results of this research were ambiguous, they contributed to the growth of our knowledge on corporate boards. In our study, we argue that these bodies still need enhancement, and institutional changes are also necessary. We present the point of view that these changes are especially important in systems of corporate governance with a two-tier board model, such as the Polish system of corporate governance. We present the results of our questionnaire research and argue that legislators in Poland should consider the implementation of the optional board model that is the introduction in law of the choice between a one-tier and two-tier board model. However, the main aim of this article is the description of the main features of the Polish board model and the directions of its possible changes.
\end{abstract}

Key words: corporate governance, board model, Poland

JEL code: G34, M19

\section{Introduction}

The role, structure and efficiency of corporate boards were widely discussed in the literature worldwide (Mallin, 2011; Nadler et al., 2006). The discussion became more intense and the critics more vociferous after the waves of managerial frauds, when these bodies turned out to be inefficient in the supervision of top managers and at the same time they were not able to protect shareholders from losses (Uzun et al., 2004; Zahra, et al., 2005). But in the literature it was also emphasized that despite their failings and contradictions, the critics of these fiduciary tools are like Churchill's critique of democracy, that is that corporate boards are the worst possible tools, except for all the alternatives (Ward, 2003). Hence, corporate boards still play a crucial role in public companies and are potentially the most important device of shareholder value creation (Carter and Lorsch, 2004).

At the same time, some authors tried to discuss how to improve board structure and board processes. Therefore, they examined the impact of the appointment of independent directors (Koerniadi and Tourani-Rad, 2012), board committees (Klein, 1998; Lam and Lee, 2012), female directors (Ahern and Dittmar, 2012; Campbell and Minguez-Vera, 2008) or generally

\footnotetext{
Corresponding author - e-mail address: lbohdan@uni.lodz.pl
} 


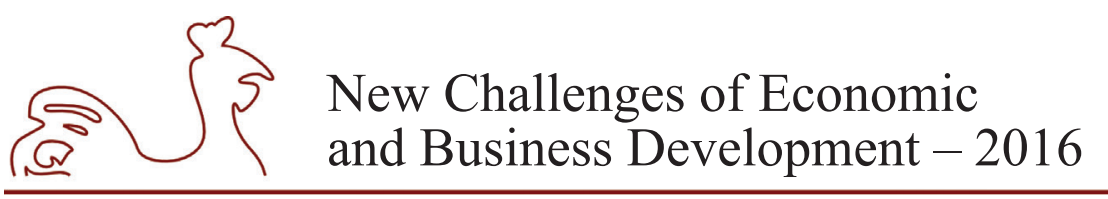

May 12-14, 2016, Riga, University of Latvia

board diversity in terms of age, gender and the nationality of the directors (Randøy et al., 2006) on firm performance. The results of this research were ambiguous, but they contributed to the growth of our knowledge on corporate boards. In our study, we argue that these bodies still need enhancement and institutional changes are also necessary. We present the point of view that these changes are especially important in systems of corporate governance where a two-tier board model exists, such as the Polish system of corporate governance. However, the main aim of this article is the description of the main features of the Polish board model and the directions of its possible changes.

The article consists of three sections. The first section deals with the functions and composition of the Polish two-tier board model. Amongst others, we present here the results of our research on board structure. In the second section there is a discussion on on the potential of a two-tier board model. The third section describes the results of questionnaire research in Polish listed companies.

\section{The Polish two-tier board model}

There are two corporate board models. The one-tier model is where companies are run by unitary boards. These boards are composed of outside and inside directors. Outside directors are members of a company's board of directors, but at the same time they are not employees of the company. Inside directors are typically top executives. In the two-tier board model there are two boards, i.e. the management board and a supervisory board. The management boards consist of only inside directors. Supervisory boards are composed of only outside directors.

In Poland the two-tier board model is obligatory and both boards have various functions. The management board is responsible for managing the company. It is the powerful and real decisionmaking body. Its main functions comprise the formulation of a strategy and the managing of the company's operations. Sołtysiński (2013) mentioned that the management board is the only permanent body in the companies, and jurisprudence has developed the principle of presumption of competence of the management board in all matters when the law does not empower the general meeting of shareholders or the supervisory board to perform a given function.

The supervisory board exercises day-to-day supervision in all areas of the company's activity. According to Polish company law, this board cannot issue commands to the management board. Its duties include:

1. Evaluating company financial reports for their compliance with accounting standards and the company's present situation;

2. Evaluating top management's proposals for profit sharing or loss coverage;

3. Appointing, dismissing and suspending top management members;

4. Establishing remuneration policies for top management.

Moreover, the responsibilities of the supervisory board can be extended by shareholders through provisions contained in the articles of association. It is commonly found that their duties also include approving long-term plans and annual budgets, selecting external auditors, representing companies in disputes with their management, approving issue prices, accepting unified texts of the articles of association, granting approval for the purchase or sale of real estate, giving investment guarantees, assuming financial obligations, raising equity capital, purchasing shares of significant value, purchasing or selling movables, establishing or liquidating 


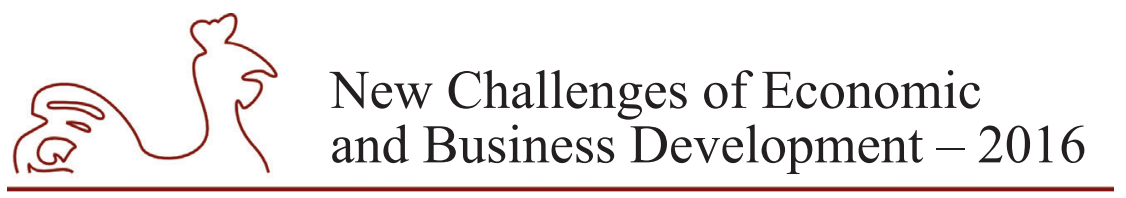

May 12-14, 2016, Riga, University of Latvia

company divisions, setting up new subsidiaries, granting procuration, and the sale of preferred shares or their exchange for ordinary shares (Bohdanowicz, 2014; Jeżak, 2010b; Rudolf, 2002). Furthermore, Sołtysiński (2013) underlined that, in practice, they often pass resolutions advising the management board to consider a concrete project or express opinions on a project presented by the management board.

Although the Polish system of corporate governance is regarded as a Germanic one (Aggestam, 2004; Weimer and Pape, 1998), the Polish two-tier board model differs slightly from the German two-tier board model. In Germany, companies are stakeholder-oriented and the co-determination rule requires one half of the supervisory board to represent the workforce with employee representatives as directors, the other half represents capital investors, elected by shareholders (Buck and Shahrim, 2005). Additionally, some shareholders' representatives are elected by large German banks, because company law entrusted these large banks with proxy voting rights. Thus, Germen banks have a great influence on companies both as providers of funds and proxy voters. In Poland there is no such legislation and the Polish supervisory boards are composed solely of shareholders' representatives, who are appoint by the annual shareholders' meeting and the banks only have an impact on companies as suppliers of capital, unless they have a share in ownership. In addition, there is no substantial workers' representation on Polish supervisory boards (Aluchna, 2007).

According to Polish company law, the minimum number of management board size is one, but the management boards of Polish listed companies usually have more members. Table 1 reports the mean, minimum, median, the first and third quantiles and the maximum for management board size of the non-financial Polish listed companies between 2008 and 2014. The mean for the whole period is 3.0102. In 2008 it was to 3.112 and then decreased to 2.9198 in 2014. The median has 3 members and the maximum has 11 members. The maximum for the period was 11 members. The first quantile, median and the third quantile show that most companies have management boards which consist of more than the minimum number of members. Previous research showed that the management board size of Polish listed companies is positively related to managerial ownership, foreign ownership, company size, company age and number of female directors (Bohdanowicz, 2010).

Table 1

Management board size of Polish listed companies between 2008 and 2014

\begin{tabular}{|c|c|c|c|c|c|c|c|}
\hline Year & Mean & Min & $\mathbf{1}^{\text {st }}$ quantile & Median & $\mathbf{3}^{\text {rd }}$ quantile & Max & $\mathbf{N}$ \\
\hline 2008 & 3.1122 & 1 & 2 & 3 & 4 & 11 & 312 \\
\hline 2009 & 3.0126 & 1 & 2 & 3 & 4 & 11 & 317 \\
\hline 2010 & 3.0793 & 1 & 2 & 3 & 4 & 10 & 328 \\
\hline 2011 & 3.0560 & 1 & 2 & 3 & 4 & 11 & 339 \\
\hline 2012 & 2.9625 & 1 & 2 & 3 & 4 & 10 & 347 \\
\hline 2013 & 2.9460 & 1 & 2 & 3 & 4 & 11 & 352 \\
\hline 2014 & 2.9198 & 1 & 2 & 3 & 3 & 11 & 349 \\
\hline All & 3.0102 & 1 & 2 & 3 & 4 & 11 & 2344 \\
\hline
\end{tabular}

Source: authors' own calculation. 


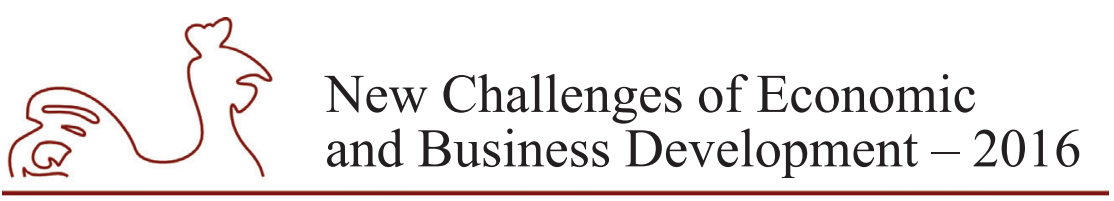

May 12-14, 2016, Riga, University of Latvia

Similarly, Table 2 describes the mean, minimum, median, the first and the third quantiles and the maximum for supervisory board size of the non-financial Polish listed companies between 2008 and 2014. Polish company law assumes that the minimum number of supervisory board's members counts 3 for private companies and 5 for public companies. The mean of supervisory board size for the whole period amounts 5.6933 and remained almost unchanged. In 2008 it was 5.6731 and in 2014 was 5.6791. The median counts 5 members, the third quantile 6 members, and the maximum 15 members. These results show that more than $50 \%$ of companies appointed supervisory boards which have only the minimum number of members. Moreover, research showed that the supervisory board size of Polish listed companies is positively related to foreign ownership, company size, company age and the number of female directors, but negatively related to managerial ownership (Bohdanowicz, 2010).

Table 2

Supervisory board size of Polish listed companies between 2008 and 2014

\begin{tabular}{|c|c|c|c|c|c|c|c|}
\hline Year & Mean & Min & $\mathbf{1}^{\text {st }}$ quantile & Median & $\mathbf{3}^{\text {rd }}$ quantile & Max & $\mathbf{N}$ \\
\hline 2008 & 5.6731 & 5 & 5 & 5 & 6 & 13 & 312 \\
\hline 2009 & 5.6593 & 5 & 5 & 5 & 6 & 13 & 317 \\
\hline 2010 & 5.7195 & 5 & 5 & 5 & 6 & 13 & 328 \\
\hline 2011 & 5.7109 & 5 & 5 & 5 & 6 & 13 & 339 \\
\hline 2012 & 5.7118 & 5 & 5 & 5 & 6 & 13 & 347 \\
\hline 2013 & 5.6960 & 5 & 5 & 5 & 6 & 15 & 352 \\
\hline 2014 & 5.6791 & 5 & 5 & 5 & 6 & 15 & 349 \\
\hline All & 5.6933 & 5 & 5 & 5 & 6 & 15 & 2344 \\
\hline
\end{tabular}

Source: authors' own calculation.

Furthermore, the Polish code of best practice in corporate governance (Dobre Praktyki Spółek Notowanych na GPW 2016) encourages companies to appoint independent directors on supervisory boards and to support gender diversity. Tamowicz (2006) mentioned that the introduction of independent board members in Poland seems to be a promising development and the most far-reaching innovation. However, it appears that neither solution significantly affects the quality of corporate governance as substantive compliance with codes of best practices in Poland is low (Campbell et al., 2009).

\section{Discussion on the potential of a two-tier board model}

A two-tier board model is often criticized in Poland (Jeżak, 2010b; Postuła, 2013; Rudolf et al., 2002; Siemiątkowski, 2004). This criticism applies in particular to supervisory boards and concerns: the lack of their members' professionalism, excessive dependence on the dominant shareholders and management boards, concentration on the monitoring and control functions and the lack of involvement in strategic decision-making processes.

Discussion on the potential of both board models has been carried out also worldwide and, so far, scholars and practitioners have not reached a consensus on the superiority of either of them. Previous studies underlined that problems with information asymmetries, dominant CEOs and group dynamics exist in both board models (Maassen and Van Den Bosch, 1999; Pettigrew and McNulty, 1995). Accordingly, they mentioned that regardless of the model, corporate boards 


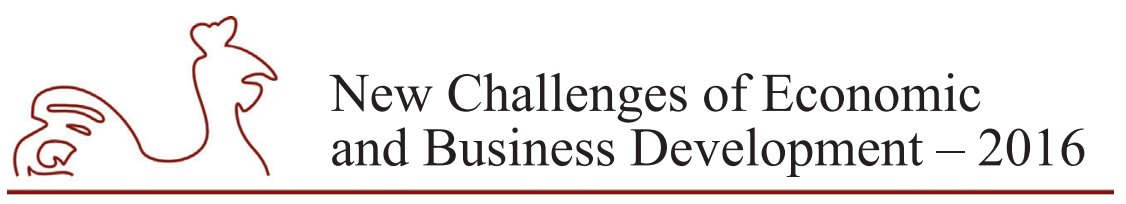

May 12-14, 2016, Riga, University of Latvia

need knowledge, information, power, motivation and time most of all (Bezemer et al., 2014, Conger, et al., 1998). Most prior research has been conducted in countries where a one-tier board model exists, hence, this model seems to be better known worldwide. However, some authors have also described the advantages and disadvantages of two-tier boards. For example, Bacon and Brown (1977) indicated that:

1. two-tier structures separate in a tangible way the direct management of a company and the function of supervising and overseeing the management function. In countries with a single board, these functions are perceived as separate and, to some extent, are carried out separately. But since certain individuals bear the responsibility for both, they can become muddled and the supervisory function may become weakened in the process;

2. the physical separation into two bodies not only results in delineating and defining the two functions of management and supervision, but it ensures that one person is not requested or expected to do both;

3. the two-tier structure changes - and to an important degree, diminishes - the role of the traditional director. The supervisory body is not granted direct managerial authority over company affairs;

4. a two-tier structure may insulate supervisory directors from the degree of liability that, in some countries at least, is attached to serving as a director on a single board.

Cadbury (2002) underlined that a unitary board remains in full control of every aspect of a company's activities. Unlike the unitary board, a supervisory board is primarily a monitoring body not an initiatory one. However, supervisory board members do not suffer from conflict of loyalties to top managers, which is possible in a one-tier board because they are the members of the same body. Hence, they are in a position to take an entirely independent view of the actions of management. In addition, the division of duties in a two-tier board model is clear and in line with the separate legal responsibilities of both boards. Tricker (2009) mentioned that criticisms of a two-tier board differ significantly from those of one-tier board models, and argued that twotier boards are inevitably dominated by top managers, and lack the information input, advice, and wise counselling that can be provided by external, non-executive directors in a unitary board. Jungmann (2006) stated that the key advantage of a two-tier model, i.e. the independence of the members of the supervisory board due to the separation of control and management, is, at the same time, the reason for a number of structural weaknesses. Consequently, the way in which the supervisory board exercises its control is always reactive and never active. Hence, it necessarily leads to a decrease in the quality of control. He added that the supervisory board is restricted to commenting on the chosen solution, and might criticize the choice made by the management board and even go so far as to remove management, but this does not enhance the current status of the company, but rather only reduces the possibility that the same mistake will be made again. Jungmann also remarked that due to a strong information asymmetry between supervisory and management boards, since providing information on the supervisory board meeting lies in the hands of the management board, there is a danger that the supervisory board cannot uncover any deficiencies.

With this backdrop, Millet-Reyes and Zhao (2010) carried out research on the French system of corporate governance, where companies can choose between a one-tier and a two-tier board model. They indicated that blockholders are in a position to manipulate two-tier boards. In particular, French institutional investors, mostly banks, are likely to misuse their dual role 


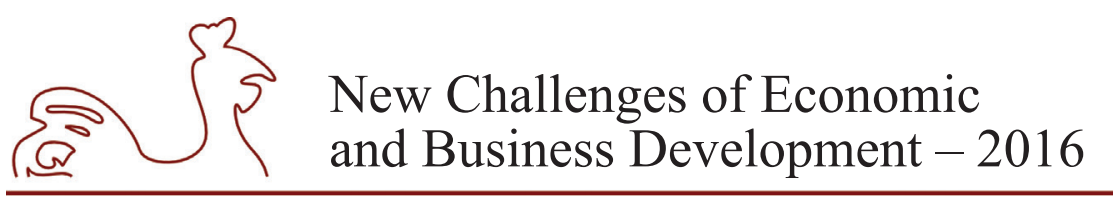

May 12-14, 2016, Riga, University of Latvia

as providers of both equity and debt capital whenever the board structure is more complex and less transparent. Additionally, Belot et al. (2014) scrutinized a sample of French companies and found that companies with severe asymmetric information are more likely to opt for a onetier board, while companies with the potential for private benefits extraction are more likely to utilize a two-tier board. Moreover, closely held companies controlled by their founders tend to have a one-tier board. Finally, they concluded that there are gains from allowing freedom of choice about board models.

Similar arguments on the two-tier board model were presented in Poland. Rudolf et al. (2002) mentioned that Polish supervisory boards fulfill, predominantly, a monitoring function. Jeżak (2010a) also underlined that Polish supervisory boards are heavily criticized in Poland because they are passive and mostly concentrate on monitoring and control functions. He also emphasized the need for their involvement in strategic decision-making processes, which is now difficult due to the current Polish legal framework. Postuła (2013) scrutinized Polish statedowned companies and emphasized that their supervisory boards are passive and politically influenced. Moreover, these supervisory boards are duplicated by the departments of corporate governance in the Ministry of Treasury and their members are mainly engaged in writing reports to the Ministry. Earlier, similar problems were emphasized by Sobolewski (2001) in the Polish subsidiary companies owned by international holding companies. In view of this, Wąchol (2002) suggested that a two-tier board model is simply too expensive in relation to the performed functions. Bohdanowicz (2014) also showed that the frequency of supervisory board meetings of Polish listed companies is lower than the frequency of board meeting in countries where a one-tier board model exists. These differences arise from the difference in functions of boards of directors and supervisory boards. Boards of directors perform four functions, i.e. accountability, strategy formulation, policy making and supervising executive activities, while supervisory boards mainly concentrate on supervising executive activities. Hence, taking in consideration the weaknesses of the Polish board model, some studies suggested that the legislators in Poland should consider the introduction of an optional board model and the possibility of the introduction into law of the choice between a one-tier and two-tier board structure (Jeżak, 2010b; Nartowski, 2002; Siemiątkowski, 2004; Wąchol, 2002).

\section{Research findings}

The problem of changes to the Polish board model was also raised by our research questionnaire, which was mostly devoted to the participation of the Polish supervisory boards in the strategic-decision making process. It involved a group of 86 supervisory board members from Polish companies listed on the Warsaw Stock Exchange in 2014. In this research, we asked the members of the Polish supervisory boards for their opinions on the need for change in the Polish system of corporate governance and implementation of the optional board model. The distribution of their answers is shown in Table 5. 41 respondents answered that a two-tier board model is suitable for Polish companies (47.67\%), whereas 32 respondents replied that the legislators should introduce into Polish law the possibility of a choice between a one-tier and two-tier board model (37.21\%). In addition, 6 respondents mentioned that a one-tier board model would be better for Polish companies. Hence, overall, 38 respondents recognized the need for change in the Polish board model (44.19\%). 


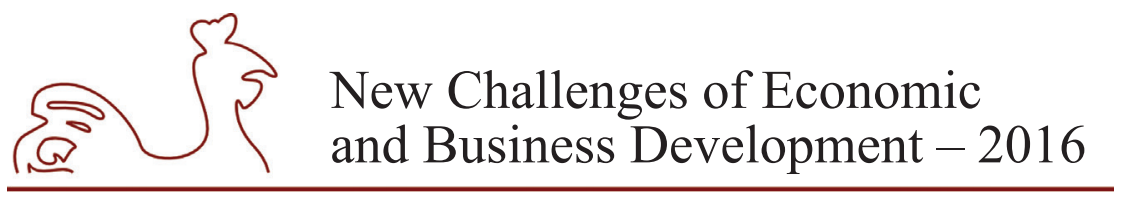

May 12-14, 2016, Riga, University of Latvia

Table 5

The need for change in the Polish board model. Views of the supervisory board's members

\begin{tabular}{|l|l|c|}
\hline \multicolumn{1}{|c|}{ Answer } & No & \% \\
\hline A two-tier board model is suitable for Polish companies & 41 & 47.67 \\
\hline $\begin{array}{l}\text { The legislators should introduce into the Polish law the possibility of } \\
\text { choice between a one-tier and two-tier board model (optional model) }\end{array}$ & 32 & 37.21 \\
\hline A one-tier board model would be better for Polish companies & 6 & 6.98 \\
\hline I have no opinion & 7 & 8.14 \\
\hline All & 86 & 100 \\
\hline
\end{tabular}

Source: J. Jeżak, L. Bohdanowicz, B. Kaźmierska-Jóźwiak, Z. Matyjas, 2016, Rola rad nadzorczych w procesach formułowania i realizowania strategii spółek, Lodz: Wyd. UŁ (forthcoming).

On the base of the previous Polish research, we assume that the confusion among certain respondents on the Polish board model may refer to the main responsibilities of the Polish supervisory boards. Jeżak (2010a) recognized that Polish supervisory boards are mostly monitoring bodies and their engagement in the strategic decision-making process is low, despite the members of Polish supervisory boards believing that these bodies should also be advisory and initiating bodies. We continue to explore this problem. In view of this, our research demonstrates that Polish supervisory boards devoted most of their professional time $(65 \%)$ to the implementation of control functions, that is, to supervising their company's activity to the extent stipulated by the Companies Code, and to appraising management performance. Two other functions, providing advice and using their own initiative, were deemed of secondary importance (Figure 1).

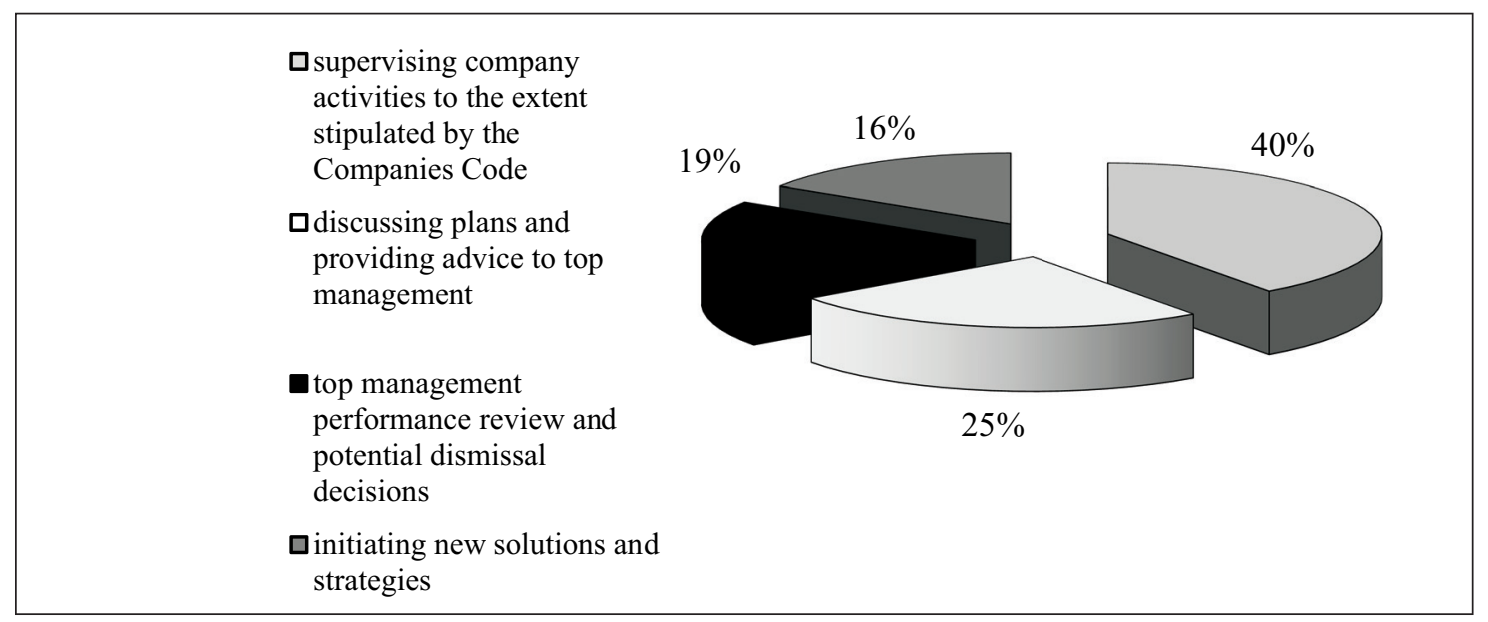

Source: J. Jeżak, L. Bohdanowicz, B. Kaźmierska-Jóźwiak, Z. Matyjas, 2016, Rola rad nadzorczych w procesach formułowania i realizowania strategii spółek, Lodz: Wyd. UŁ (forthcoming).

Fig. 1. The functions of supervisory boards of Polish listed companies. How supervisory board members believe boards balance their functions 


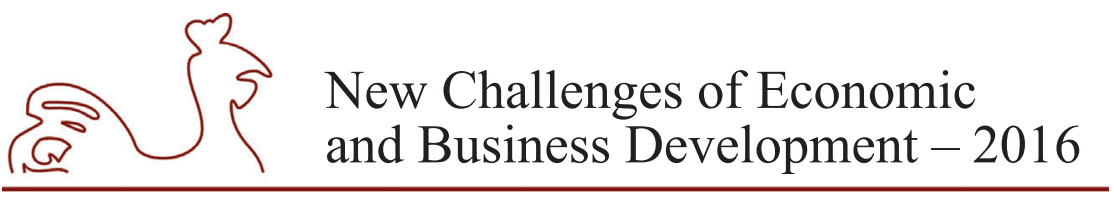

May 12-14, 2016, Riga, University of Latvia

The above mentioned research also evaluated the hierarchy of supervisory boards' duties. According to the respondents, i.e. supervisory board members, the most important were: evaluating the management board's performance, approving corporate strategies, establishing executive remuneration policies and selecting new management board members. Ranked relatively low on the respondents' agenda were important supervisory board activities such as: participation in investment planning, ensuring dividend payments, supervision of the executives' development plans, as well as mediating between stakeholders (Table 1). However, these results support a popular in Poland observation about the weakness of Polish supervisory bodies and their insufficient involving in strategic decision-making process (Jeżak, 2010; Rudolf et al., 2002).

Table 1

To what extent should the supervisory board perform the following activities? Views of the supervisory board members

\begin{tabular}{|c|l|c|c|}
\hline No. & \multicolumn{1}{|c|}{ Type of activity } & $\begin{array}{c}\text { Mean } \\
(\mathbf{1 - 5} \text { scale)* }\end{array}$ & $\begin{array}{c}\text { Standard } \\
\text { deviation }\end{array}$ \\
\hline 1. & Evaluating management board's performance & 4.66 & 0.77 \\
\hline 2. & Approving corporate strategy & 4.57 & 0.77 \\
\hline 3. & Establishing executive remuneration policies & 4.41 & 0.92 \\
\hline 4. & Selecting new management board members & 4.35 & 0.97 \\
\hline 5. & Monitoring the management board's key decisions & 4.30 & 0.78 \\
\hline 6. & Protecting the company's reputation & 4.30 & 0.97 \\
\hline 7. & Controlling the company's debt & 4.14 & 0.83 \\
\hline 8. & Participating in the formulation of corporate strategy & 3.85 & 1.07 \\
\hline 9. & Succession planning in the company & 3.72 & 1.16 \\
\hline 10. & Ensuring growth in shareholder wealth & 3.58 & 1.22 \\
\hline 11. & Participating in investment planning & 3.21 & 1.12 \\
\hline 12. & Ensuring dividend payments & 3.13 & 1.25 \\
\hline 13. & Supervising the executives' development plan & 2.98 & 0.96 \\
\hline 14. & $\begin{array}{l}\text { Mediating between top management and stakeholders } \\
\text { (shareholders, employees, banks and other creditors, local } \\
\text { government. etc.) }\end{array}$ & 2.72 & 1.22 \\
\hline
\end{tabular}

* Scale: from $1=$ least important to $5=$ most important.

Source: J. Jeżak, L. Bohdanowicz, B. Kaźmierska-Jóźwiak, Z. Matyjas, 2016, Rola rad nadzorczych w procesach formułowania i realizowania strategii spółek, Lodz: Wyd. UŁ (forthcoming).

The results of the aforementioned research as well as the analysis of the present legal regulations indicate that Polish supervisory boards primarily perform monitoring and control functions. At the same time, as mentioned in previous research, certain members of Polish supervisory boards consider that these bodies should be more active in the strategic decisionmaking process (Jeżak, 2010a). We argue that their greater involvement in this process is impossible under the current legal framework. Hence, we support previous opinions that Polish legislators should consider legal changes and introduce the optional board model (Nartowski, 


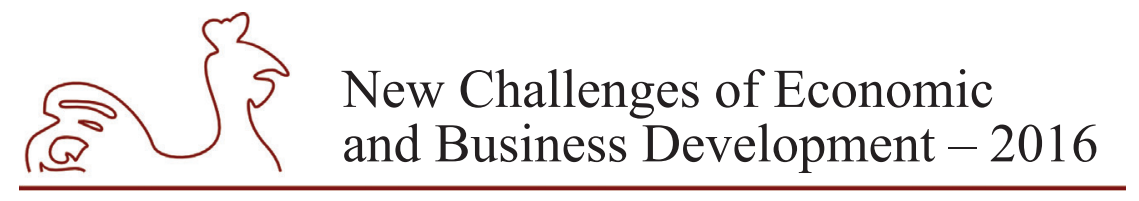

May 12-14, 2016, Riga, University of Latvia

2002; Siemiątkowski, 2004; Wąchol, 2002). This model would give companies the possibility to choose between a traditional two-tier board model and a new one-tier board model, removing certain disadvantages of the Polish board model and allowing Polish non-executive directors to engage in the formulation of strategy. Our research questionnaire showed that this opinion is shared by many Polish supervisory board members.

\section{Conclusions}

In our study we described in detail the Polish two-tier board model. We also underlined its imperfections and, amongst others, we pointed out that supervisory boards are perceived as passive and reactive. Moreover, they often have restricted access to information on companies and play a weak role in the process of strategy formulation. Hence, we argue that the Polish system of corporate governance needs certain institutional changes. Accordingly, we expect Polish legislators to consider the implementation of an optional model.

The implementation of an optional model would also increase the elasticity of corporate boards. Companies in countries where this model exists can employ a traditional board model or a new one. After these suggested institutional changes Polish companies could choose between a two-tier model and a one-tier model with its composition adjusted to ownership structure or company size, i.e. unitary boards with a majority of inside or outside directors. The need for change in the Polish board model was shown by our research questionnaire and is in line with trends in certain other European countries.

At the beginning of the $21^{\text {st }}$ century, several countries introduced the optional board model (e.g. Croatia, Hungary, Luxembourg, the Netherlands, Portugal, Romania and Slovenia). Belot et al. (2014) even suggested that there has been a slow but steady increase in national regulatory competition within European Union, and this competition brings to mind the competition for chartering among US states. They added that as a result of this competition several countries have adopted new national corporation law or codes that incorporate the key element of the French approach of allowing firms to choose between a unitary and two-tier board.

In view of this, our study is mostly of a practical value and has implications for both practitioners and public authorities. Most of all, it enhances the understanding of the deficiencies of the two-tier board model and thus contributes to the discussion on the institutional changes in the Polish model, including in other countries where a two-tier board model exists.

The results of this study are not without limitation as they are based on a research survey. It has to be underlined that a questionnaire is a tool which has its drawbacks. Amongst these is the inability to control the environment where the respondents provide answers to the questions in the survey, and the possible results limited to only those outlined in the original research proposal, due to the closed type questions and the structured format (Frankfort-Nachmias and Nachmias, 1996). Moreover, previous research has shown that the relationship between respondents' attitudes and their behavior is positive but not always strong (Chandon et al., 2005). Therefore, these drawbacks result in a need for caution when reaching conclusions. 


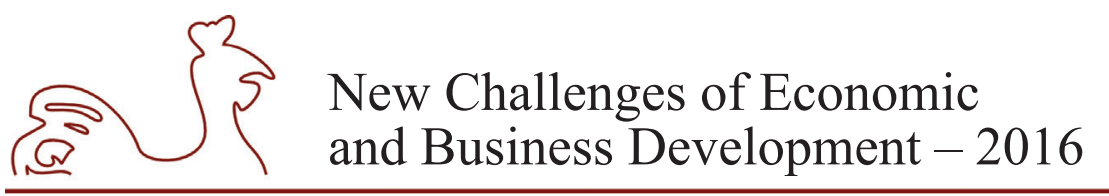

May 12-14, 2016, Riga, University of Latvia

\section{Bibliography}

Aggestam, M., 2004. Corporate Governance and Capital Groups in Poland. Journal for East European Management Studies, 9(4), pp. 367-390.

Ahern, K. R. \& Dittmar, A., 2012. The Changing of the Boards: The Impact on Firm Valuation of Mandated Female Board Representation. Quarterly Journal of Economics, 127(1), pp. 137-197.

Aluchna, M., 2007. Mechanizmy corporate governance w spółkach giełdowych. Warszawa: Oficyna Wydawnicza Szkoły Głównej Handlowej w Warszawie.

Bacon, J. \& Brown, J. K., 1977, The Board of Directors: Perspectives and Practices in Nine Countries. New York: The Conference Board

Bezemer, P.-J., Peij, S., de Kruijs, L. \& Maassen, G., 2014. How two-tier boards can be more effective. Corporate Governance, 14(1), pp. 15-31.

Bohdanowicz, L., 2010. Czynniki wpływające na liczebność organów statutowych polskich spółek publicznych. In: P. Urbanek (ed.), Nadzór korporacyjny w warunkach kryzysu gospodarczego, Łódź: Wyd. UŁ, pp. 397-415.

Bohdanowicz, L., 2014. Directions of change in the Polish two-tier board model. Journal of Positive Management, 5(1), pp. 21-30.

Bohdanowicz, L., 2014, Managerial ownership and supervisory board activity: Evidence from Polish listed companies, Management of Organizations: Systematic Research, 70, pp. 41-54.

Cadbury, A., 2002. Corporate Governance and Chairmanship: A Personal View. Oxford: Oxford University Press.

Campbell, K., Jerzemowska, M. \& Najman, K., 2009, Corporate governance challenges in Poland: Evidence from "comply or explain" disclosures. Corporate Governance, 9(5), pp. 623-634.

Campbell, K. \& Minguez-Vera, A. 2008. Gender Diversity in the Boardroom and Firm Financial Performance. Journal of Business Ethics, 83(3), pp. 435-451.

Carter, C. B. \& Lorsch, J. W., 2004. Back to the Drawing Board: Designing corporate boards for a complex world. Boston: Harvard Business School Press.

Chandon, P., Morwitz, V. G. \& Reinartz, W. J., 2005, Do intentions really predict behavior? Self-generated validity effects in survey research. Journal of Marketing, 69(2), pp.1-14.

Conger, J. A., Finegold, D. \& Lawler, E. E. III, 1998. Appraising boardroom performance. Harvard Business Review, 76(1), pp. 136-148.

Dobre Praktyki Spółek Notowanych na GPW 2016, [Online] Available at: http://static.gpw.pl/pub/files/ PDF/RG/DPSN2016__GPW.pdf [Accessed 14 March 2016].

Jeżak, J. 2010b. The board of directors as an active participant in the strategic decision-making process: Theory and practice (empirical evidence). Finance and Corporate Governance Conference 2010 Paper. [Online] Available at: http://papers.ssrn.com/sol3/papers.cfm?abstract_id=1533796\#\# [Accessed 9 January 2010].

Jeżak, J. 2010b. Ład Korporacyjny: Doświadczenia światowe oraz kierunki rozwoju. Warszawa: Wyd. C.H. Beck.

Jungmann. C., 2006. The Effectiveness of Corporate Governance in One-Tier and Two-Tier Board Systems. Company and Financial Law Review, 3(4), pp. 426-474.

Klein, A., 2008. Firm Performance and Board Committee Structure. The Journal of Law and Economics, 41(1), pp. 275-304.

Koerniadi, H. \& Tourani-Rad, A. 2012. Does Board Independence Matter? Evidence from New Zealand. Australasian Accounting, Business and Finance Journal, 6(2), pp. 3-18.

Lam, T.-Y. \& Lee, S.-K. 2012. Family ownership, board committees and firm performance: evidence from Hong Kong. Corporate Governance: The International Journal of Business in Society, 12(3), pp. 353-366. 


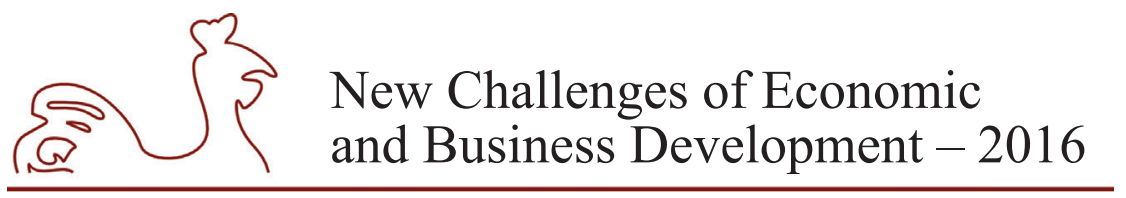

May 12-14, 2016, Riga, University of Latvia

Malin, Ch. (Ed.), 2011. Handbook on International Corporate Governance: Country Analyses. Cheltenham: Edward Elgar.

Maassen, G. F. \& Van Den Bosch, F. A. J., 1999. On the supposed independence of two-tier boards: Formal structure and reality in the Netherlands. Corporate Governance: An International Review, 7(1), pp. 31-37.

Millet-Reyes, B. \& Zhao, R., 2010. A comparison between one-tier and two-tier board structures in France. Journal of International Financial Management and Accounting, 21(3), pp. 279-310.

Nartowski, A., 2002. Zmierzch dwupłatowców. Gazeta Bankowa, 28 February.

Frankfort-Nachmias, Ch. \& Nachmias, D., 1996, Research Methods in the Social Science. New York: American/St. Martin's College Publishing Group.

Nadler, D. A., Behan, B. A. \& Nadler M. B., 2006. Building Better Boards: A blueprint for effective governance. San Francisco: Jossey-Bass.

Postuła, I., 2013. Cechy charakterystyczne i problemy funkcjonowania rad nadzorczych spółek Skarbu Państwa. Zarzadzanie i Finanse, 11(2), pp. 230-243.

Randøy, T., Thomsen, S. \& Oxelheim, L., 2006. A Nordic perspective on corporate board diversity. Nordic Innovation Centre, [Online] Available at: http://www.nordicinnovation.org/Global/ Publications/Reports/2006/The\%20performance\%20effects\%20of\%20board\%20diversity\%20 in\%20Nordic\%20Firms.pdf [Accessed 7 Fabruary 2016].

Rudolf, S., Janusz, T., Stos, D., Urbanek, P., 2002. Efektywny nadzór korporacyjny. Warszawa: PWE.

Pettigrew, A. M. \& McNulty, T., 1995. Power and influence in and around the boardroom. Human Relations, 48(8), pp. 845-873.

Rudolf, S., Janusz, T., Stos, D., Urbanek, P., 2002. Efektywny nadzór korporacyjny. Warszawa: PWE.

Siemiątkowski, T. 2004. System monistyczny ładu korporacyjnego - krok ku przyszłości. Nasz Rynek Kapitałowy, 11, pp. 53-55.

Sobolewski, A., 2001. Corporate governance w trakcie restrukturyzacji korporacji - przykład Grupy Exbud Skanska. Nasz Rynek Kapitałowy, 11, pp. 20-25.

Sołtysiński, S., 2013. Corporate Boards in Poland. In: P. Davis, K. J. Hopt, R. Nowak, \& G. Van Solinge (Eds.), Corporate Boards in law and Practice: A comparative analysis in Europe. Oxford: Oxford University Press, pp. 511-548.

Tamowicz, P., 2006. Corporate governance in Poland. In: Ch. Mallin, Handbook on International Corporate Governance, Cheltenham: Edward Elgar.

Tricker, B., 2009. Corporate governance: Principles, Policies, and Practices. Oxford: Oxford University Press.

Uzun, H., Szewczyk, S.H. \& Varma, R., 2004. Board Composition and Corporate Fraud. Financial Analysts Journal, 60(3), pp. 33-43.

Wąchol, J., 2002. Nadzór korporacyjny w Polsce i na świecie a cechy zespołów zarządzających. [In:] Stankiewicz, J. (ed.), Nowoczesne zarządzanie przedsiębiorstwem, konferencja naukowa. Zielona Góra: Wydawnictwo Matematyczno-Ekonomiczne, pp. 27-39.

Weimer, J. \& Pape, J. C., 1999, A taxonomy of Systems of Corporate Governance. Corporate Governance: An International Review, 7(2), pp. 152-166.

Zahra, S. A., Priem, R. L. \& Rasheed, A. A., 2005. The Antecedents and Consequences of Top Management Fraud. Journal of Management, 31(6), pp. 803-828. 
May 12-14, 2016, Riga, University of Latvia

\title{
IMPROVED VET GOVERNANCE FOR LABOUR MARKET TRAINING AT REGIONAL LEVEL
}

\author{
Ilze Buligina, University of Latvia, Latvia ${ }^{1}$ \\ Biruta Sloka, University of Latvia, Latvia
}

\begin{abstract}
The development of qualified and competitive labour force at all levels is the issue of paramount importance for the social and economic development. Therefore new approaches for vocational education and training (VET) governance are being introduced and tested by Latvian public administrators responsible for the implementation of the VET reform. The role of co-operation between the local governments, the local entrepreneurs and VET providers is the key aspect in the new governance approach aiming at improved labour market training with closer links between the worlds of education and work. The aim of the research is to study the opinions of local stakeholders regarding new approaches in the implementation of the VET reform and VET governance for improved labour market training. The research is based on an empirical study implemented in Latvia - a survey among public administrators and employers, as well as a focus group discussion with social partners at local level. Research methods applied: studies of scientific publications and policy documents; a survey and focus group discussions. The conclusions have been drawn based on the analysis and comparison of the opinions of local public administrators and entrepreneurs regarding the introduction of new approaches in VET provision and VET governance at local level. The key finding: the VET systems should be more integrated into the local/regional administrative, economic, employment and societal contexts. This implies a close coordination between the public administrations, the education, training and employment providers. This also implies the new role of local public administrations in potentially taking the lead in developing locally/regionally more integrated VET approaches - taking into consideration that VET in Latvia is primarily under the supervision of the centralised government. Consequently, the development of novel VET governance models in compliance with the improved legal framework and corresponding to the local characteristics is needed.
\end{abstract}

Key words: VET, governance, public administration, social partners

JEL code: J24, J44, M53, I28

\section{Introduction}

In Latvia the VET reform that started in 2009 in still ongoing, and new approaches for improved VET governance in the context of economic and labour market developments are being continuously sought. The identification and implementation of national VET priorities are set against the background of the most recent EU policy developments, thus securing better visibility of the Latvian approach in the overall European context. Currently a high level EU VET policy priority is the implementation of apprenticeship or work-based learning (WBL) schemes putting closer together the worlds of education and employment. These approaches

Corresponding author - e-mail address: ilze.buligina@gmail.com 


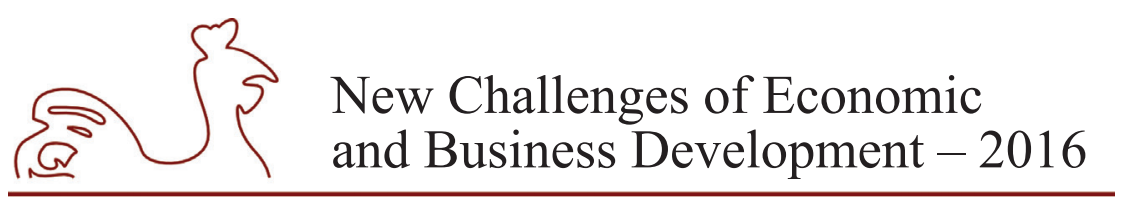

May 12-14, 2016, Riga, University of Latvia

require a much more co-operation between the various stakeholders not only at national level, but even more in regional and local settings. The reasons for this are diverse. However, they are greatly linked to the need for uniform strategic approaches at local level, since in Latvia in local communities there is a relatively limited diversity in economic activity, lack of large enterprises and traditionally shortage of skilled workforce. Thus, the public administrations in charge of VET provision should take measures to address these challenges specifically at local level, in order to improve the overall VET provision in the country and secure the training of competitive labour force in compliance with the national economic and employment demand.

The Latvian public authorities are taking immediate measures to address these issues through amendments to VET Law. These activities are prompted by the need to follow the most urgent training needs and labour market demands ${ }^{2}$. Regarding a longer perspective new goals are being set also in the Education Development Guidelines for the period 20142020. In the context of the amendments to the VET Law, the authors' interest lies in particular measures stipulated by these amendments - the promotion of new modes of governance and new modes of VET delivery - the WBL approaches in VET provision. These measures are aimed at providing closer links between education/training and actual work environment for improved competiveness of the trained labour force. This refers to both - VET provision and VET governance. The present research allows for deeper insights into the opinions of public administrators and employers at local level regarding new approaches to VET implementation and VET governance for improved labour force training.

The present research is especially relevant in relation to the establishment of the Conventions of VET institutions - as stipulated by the amendments to the VET Law - with this enhancing the role of the regional and local stakeholders in the VET provision is increasing. The authors performed the survey and the focus group discussions among the relevant stakeholders at local level in 2013 - when the amendments to the VET Law were in the process of preparation. Based on the textual analysis - academic and policy discourse, as well on the results of the empirical study - conclusions have been drawn on the opinions of local and regional stakeholders regarding the emerging approaches in VET provision and VET governance. This has allowed to analyse the results of the survey against the actual VET developments in this respect a few years later in 2015 - when the amendments to the VET Law have come into force. The focus has been laid on the development of closer links between the worlds of education and work, as well as on the changed VET governance approaches - with closer co-operation and shared responsibilities among social partners. This corresponds to the current top=level priorities in VET in Latvia, as well as in the broader European context.

\footnotetext{
2 The amendments determine work-based learning as a mode of vocational education and training (VET) program delivery; the role of Sector Expert Councils (SECs) in the implementation of WBL approaches is being established; changes in the VET governance by creating Conventions as the corporate coordination and management mechanism for VET institutions, with the involvement of local/ regional authorities, employers and other relevant stakeholders is prescribed. The amendments also address the issue of the linkage of the professional qualifications' levels to the national qualifications' framework, thus contributing to the integration of WBL approaches into the overall system of recognised qualifications. Thus, these amendments address the WBL issues in a complex way, by creating pre-conditions for the involvement of social partners in the WBL content and provision, by broadly determining the roles and responsibilities of the involved parties, by setting pre-conditions for improving the correspondence of the acquired skills to the labour market demands.
} 


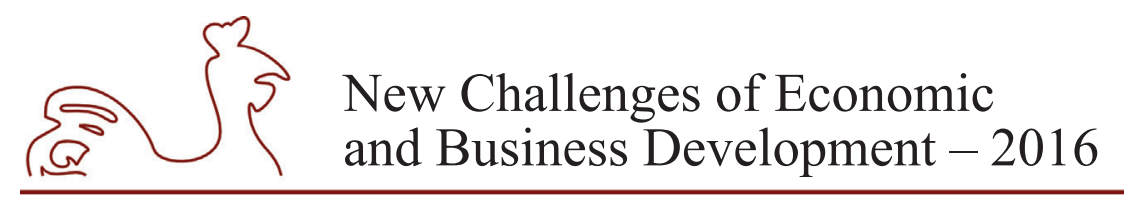

May 12-14, 2016, Riga, University of Latvia

\section{Theoretical justification - academic and policy discourse}

As increasingly pointed out by researchers - it is the regional level that can best address the local needs and initiatives in the context of global challenges, and close co-operation of the stakeholders can better address the future demands (Lansu et al., 2013). Arriving at novel and jointly supported solutions is possible only through exchange and integration of diversity of perspectives (Kraker et al., 2013). Moreover, as pointed out by Sotarauta - the key issue is how to bring these fragmented groups of involved actors to work together for the creation of a new perception of the needed changes; thus, also the issue of the motivation of the involved actors needs to be addressed - how and why they become enabled for supporting and participating in change processes (Sotarauta, 2009). This concerns also the issue of improved labour force training through the learning at a workplace, where not only the training institution as such is relevant but also the regional and networking aspect contributing to the overall process. Providing education model as a means for developing qualified workforce in relation to actual work environments is being seen as a potential means and solution for emerging challenges in industry, education and society in general - through involving of all relevant stakeholders and implementation of collaborative actions in linking education with employments (Ilyas, I. P., Semiawan, 2012). Education and respective skills are being seen as the determining factor for future social cohesion, prosperity and sustainability (Chenic et al., 2012), and appropriate skills can be obtained only through adequate labour market demands in view. The relationship between technical and vocational education and training and innovation are on the research agenda of many researchers (Ruth and Deithmer, 2010). The issues of perceived effects of competency-based training on the acquisition of professional skills are on research agenda also for researchers from the Netherlands (Boahin and Hofman, 2014) where new approaches are analysed and discussed. All this requires new governance models for efficient vocational education corresponding to the labour market needs.

The EU member states public administrations parallel to the identified national VET developments put much effort into keeping up with EU VET policy issues - not only for formal policy reasons but purely from the practical and pragmatic point of view - to align with and stay competitive in broader European contexts, as well as to benefit from the offered EU programs and other opportunities. In order to promote innovation, growth and competitiveness, the excellence in national VET systems has been put highly on European VET agenda among other issues implying 1) linkage between the world of education and the world of work with respective changes in the VET governance models; 2) aligning VET policies with regional or local economic and employment development strategies. The Bruges Communique - being the key VET policy document till 2020 - implies the changes in VET governance with a much closer involvement of regional stakeholders and social partners. In the context of more recent VET developments in Europe - The Riga Conclusions set work-based learning as a high-level European VET priority in medium term. The analysis of the current policy discourse shows that the Latvian VET public administrators are taking measures to address the VET development needs at national level, which generally comply also with EU VET priorities. This is clearly manifested in the draft amendments to the VET law, as well.

The Information note to the Cabinet of Ministers "On the implementation of WBL approaches in the VET developments in Latvia" alongside with the analysis of the current 


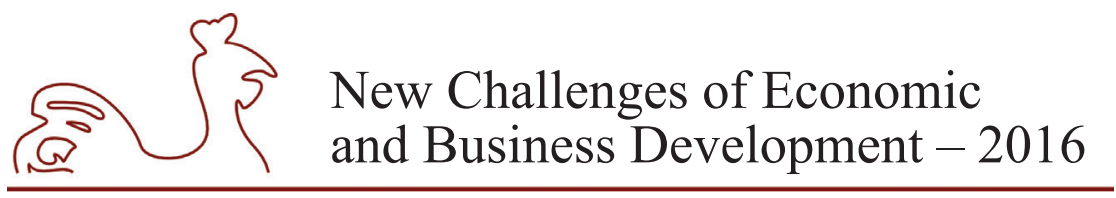

May 12-14, 2016, Riga, University of Latvia

situation in the implementation of the WBL (including the WBL pilot project started in 2013) also identifies the key challenges and proposes the possible solutions for the attention of the key involved stakeholders - branch ministries, sectoral expert councils (SECs), employers and employees organisations, chambers, local and regional governments and other authorities. Thus, it can be concluded that through the formal reference process on the amendments to the VET Law and to the Information note the public authorities and employers will be involved in discussion and joint decision making processes on the possible models of VET governance and WBL implementation, on the potential funding mechanisms of WBL (apprenticeship schemes), including the questions of ensuring adequate remuneration and social protection of learners (apprentices), and in the provision of appropriate incentives for all actors to participate. These priorities and planned activities by the Latvian VET public administrators are also in line with other EU high level VET priority - implementation of the Declaration of the Council of the European Union "European Alliance for Apprenticeships".

The Education Development Guidelines for 2014-2020 (EDG 2014-2020) also envisage the implementation of WBL approaches and improvement of practical training in Latvia - with a systemic impact by 2020. Changes in the VET governance are linked to the improved cooperation of stakeholders at all levels. According to the Information note - in order to reach the EDG 2014-2020 targets - a pilot project in WBL has been started in Latvia in 2013/2014 in 6 VET institutions in 17 programs with the involvement of around 140 learners in 29 enterprises. The continuation of the pilot project is being planned also for the 20014/2015 academic year altogether in 10 VET institutions with the involvement of around 300-500 learners. Provisional surveys among VET institutions indicate that even higher numbers of VET institutions might be involved - with the participation of more than 100 enterprises. There are ongoing discussions with social partners - ministries, employers organisations, chambers, professional associations and sectoral expert councils - on the issue of awareness raising, motivation and incentives for the involvement of employers (especially SMS) in the WBL processes.

Taking into consideration the policy discourse and development promoted by the Latvian VET public administrators, and in the light of the respective academic discourse, the authors have performed research on the opinions of local stakeholders regarding the implementation of innovative approaches in VET governance and provision and regarding the introduction of WBL approaches in the VET system. The analysis of the obtained results allows to draw conclusions regarding the linkage between the opinions of the local stakeholders and the latest development sin the VET legislation of Latvia.

\section{The Research Methodology}

To carry out the research on the above indicated issues, apart from the textual analysis consisting of analysis of relevant policy documents and academic discourse regarding our research problem, also an empirical study in the form of a survey has been carried out. For the implementation of the empirical study, a questionnaire was developed and experts were asked relevant questions to evaluate the current situation. Before the implementation of the survey the questionnaire was tested among proved professionals in the above mentioned fields and corresponding amendments made. The questionnaire was developed in such a way that the relevant opinions of stakeholders could be analysed in a detailed way and from several 


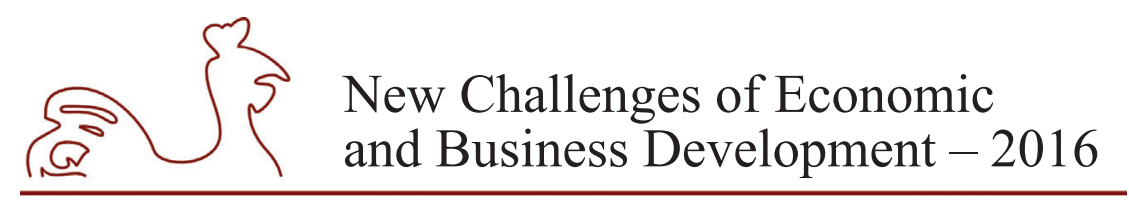

May 12-14, 2016, Riga, University of Latvia

perspectives. As our research interest primarily lies in the training of competitive labour force at all levels and the role of VET system for preparing such labour force, also the questions were formulated accordingly. Evaluations had to be made in scale 1-10, where 1: fully disagree; 10: fully agree. Based on the material obtained by the questionnaire, the primary analysis of the opinions of the various target groups has been conducted and the results compared. The results of the survey were complemented by the analysis of the focus group discussions.

\section{The Findings}

A survey among top level public education administrators at local/ community level was carried out. The intention of the authors in carrying out the survey was to learn about the opinion and attitude of public administrators at local level regarding innovation and reforms in the VET system, especially regarding work-based learning (WBL) approaches - a new and emerging trend in Latvian VET reform. Through an anonymous survey which was based on a questionnaire the Heads of the regional Education Departments (HED) of the municipalities of Latvia (public administrators at local/community level) in June 2013 were asked to answer questions on innovative approaches in VET and VET reform in Latvia, and to give comments to certain questions, also substantiating their answers. Evaluations had to be made in the scale 1-10, where 1: fully disagree; 10: fully agree. All in all 79 HEDs (or their nominated representatives) participated in the survey, constituting $93 \%$ of the total target group. The survey data testify to the fact that most HEDs support and are in favour in innovation and reforms in the VET system in Latvia. Parallel to this similar questions were put to employers at local level - if they saw it important and relevant to implement new approaches in the training of future workforce, e.g. through WBL approaches, requiring also new governance mechanisms. Further on these findings were analysed and compared in order to draw conclusions on the preparedness of the various local actors to get involved in new VET approaches for improved labour force training at local level, with certain implications for changed VET governance. A more detailed analysis of the survey follows. First - questioning the public education administrators at local level. Main statistical indicators of responses are included in Table 1. 


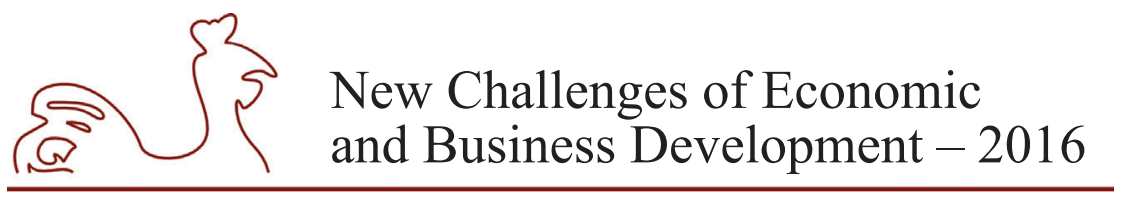

May 12-14, 2016, Riga, University of Latvia

Table 1

Main statistical indicators of responses of professional education administrators

\begin{tabular}{|c|c|c|c|c|c|c|c|}
\hline & 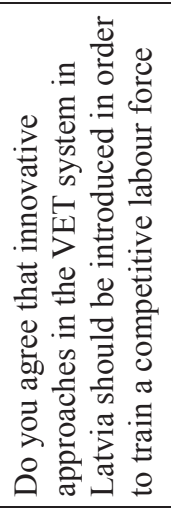 & 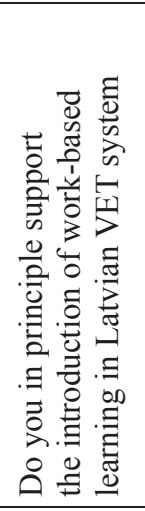 & 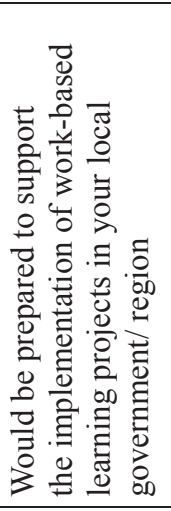 & 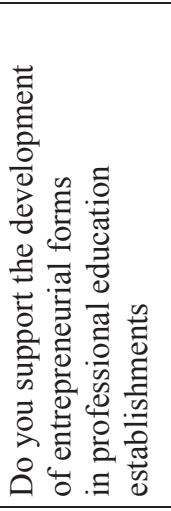 & 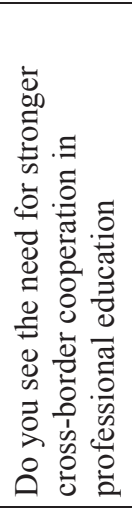 & 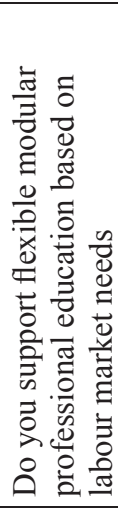 \\
\hline \multirow[t]{2}{*}{$\mathrm{N}$} & Valid & 79 & 78 & 76 & 73 & 78 & 75 \\
\hline & Missing & 0 & 1 & 3 & 6 & 1 & 4 \\
\hline \multicolumn{2}{|c|}{ Mean } & 9.30 & 8.97 & 7.62 & 8.42 & 8.15 & 9.31 \\
\hline \multicolumn{2}{|c|}{ Std. Error of Mean } & 0.114 & 0.188 & 0.289 & 0.180 & 0.214 & 0.109 \\
\hline \multicolumn{2}{|c|}{ Median } & 10.00 & 10.00 & 8.00 & 9.00 & 8.00 & 10.00 \\
\hline \multicolumn{2}{|c|}{ Mode } & 10 & 10 & 10 & 8 and 10 & 8 & 10 \\
\hline \multicolumn{2}{|c|}{ Std. Deviation } & 1.017 & 1.659 & 2.519 & 1.536 & 1.894 & 0.944 \\
\hline \multicolumn{2}{|c|}{ Variance } & 1.035 & 2.753 & 6.346 & 2.359 & 3.586 & 0.891 \\
\hline \multicolumn{2}{|c|}{ Range } & 4 & 9 & 9 & 6 & 9 & 3 \\
\hline \multicolumn{2}{|c|}{ Minimum } & 6 & 1 & 1 & 4 & 1 & 7 \\
\hline \multicolumn{2}{|c|}{ Maximum } & 10 & 10 & 10 & 10 & 10 & 10 \\
\hline
\end{tabular}

Source: Survey of regional professional education administrators in June $2013(n=79)$.

Evaluation scale 1-10, where 1 - do not support, 10 - support in full extent.

Data of Table 1 indicates that the average evaluations to the questions asked were high. The question "Do you support flexible modular professional education based on labour market needs"? received an especially high evaluation, with arithmetic mean of all responses 9,31; mode and median were of the highest evaluation ; moreover, surprisingly high was the lowest evaluation which was 7 . Very similar the situation was with the question "Do you agree that innovative approaches in the VET system in Latvia should be introduced in order to train a competitive labour force"? where the arithmetic mean was 9,30; mode and median were of the highest evaluation and the lowest evaluation was 6 . The distribution of responses is reflected in Figure 1. 


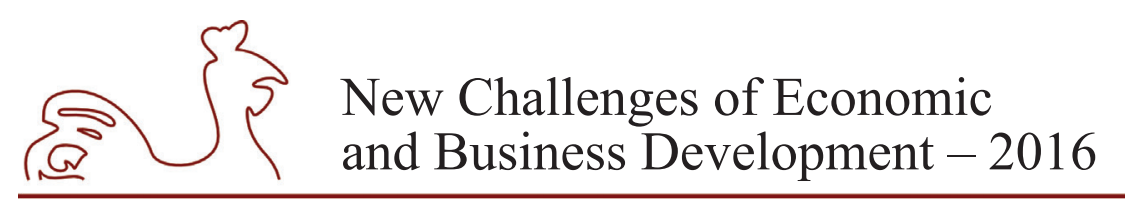

May 12-14, 2016, Riga, University of Latvia

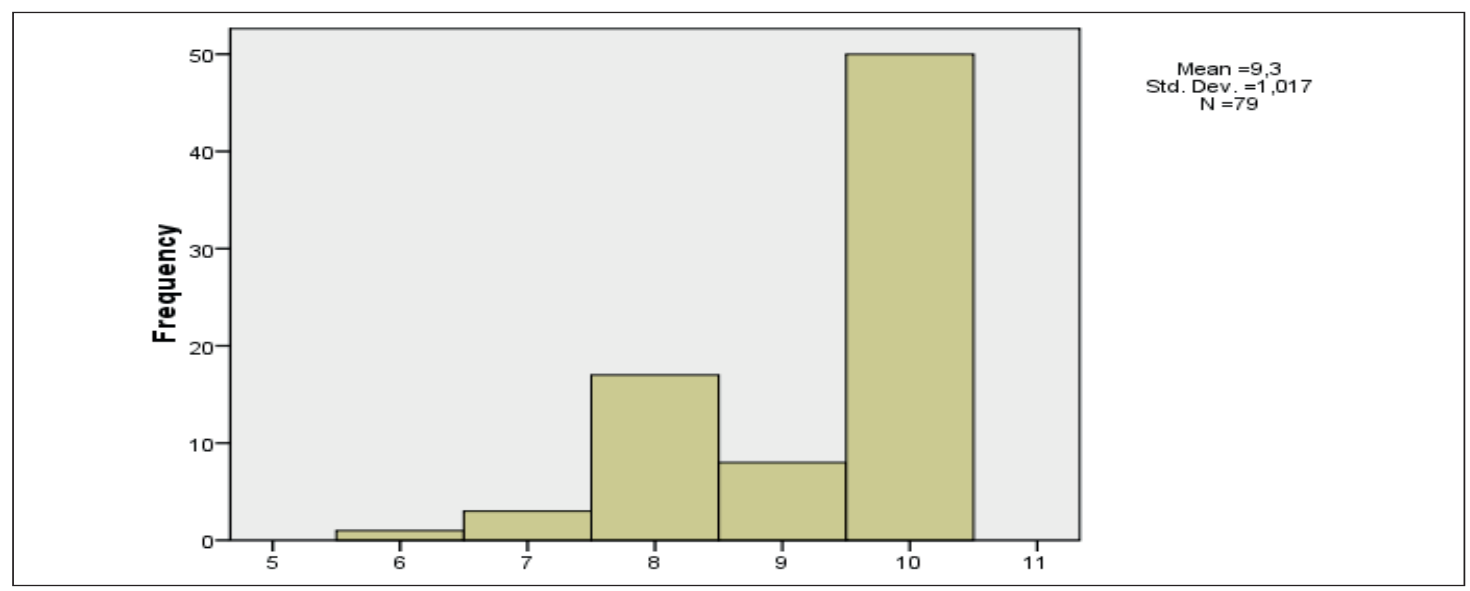

Source: Survey of regional professional education administrators in June $2013(n=79)$.

Evaluation scale 1-10, where 1 - do not support, 10 - support in full extent.

Fig. 1. Evaluations of regional professional education administrators on question "Do you agree that in Latvia new innovative approaches need to be implemented in VET for the training of competitive labour force"?

The same question "Do you agree that in Latvia new innovative approaches need to be implemented in VET for the training of competitive labour force? " was asked to local employers. Further on the results from the analysis of the survey results among public administrators at regional level were compared to the results obtained from the survey among local employers. The average evaluations on comparison of results obtained from entrepreneurs survey and from the survey among regional professional education educators are reflected in Figure 2. It is worth noting that the employers' evaluations on the average are lower.

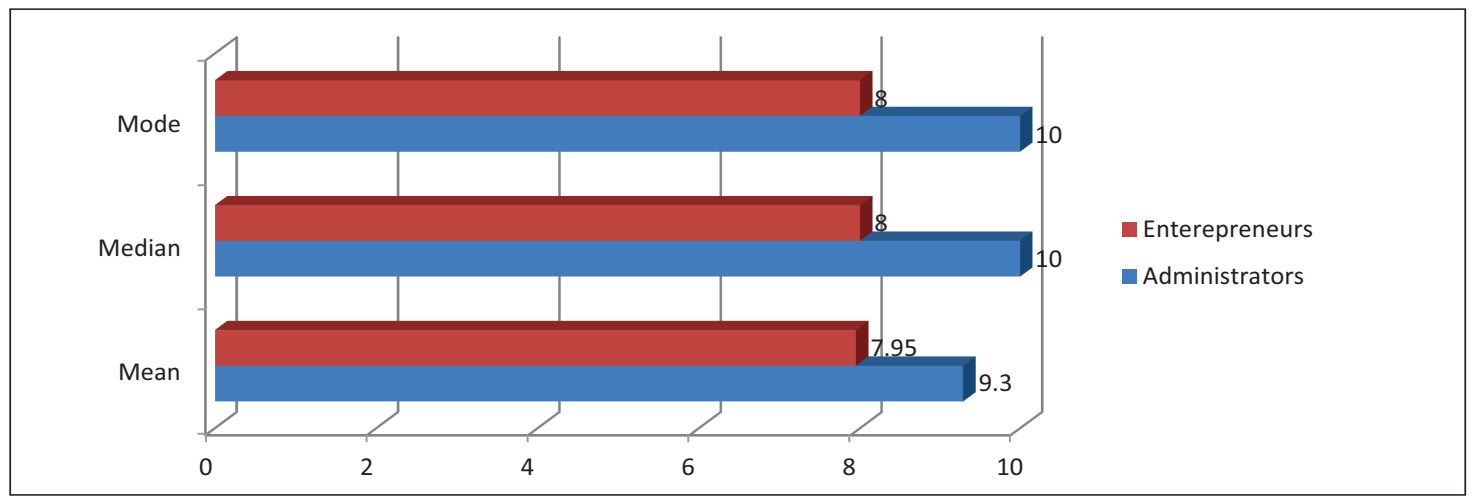

Source: Survey of regional professional education administrators in June 2013.

Survey of entrepreneurs in April-May, 2013.

Evaluation scale 1-10, where 1 - do not support, 10 - support in full extent.

Fig. 2. Average evaluations of regional professional education administrators and entrepreneurs on question "Do you agree that innovative approaches in the VET system in Latvia should be introduced in order to train a competitive labour force"? 


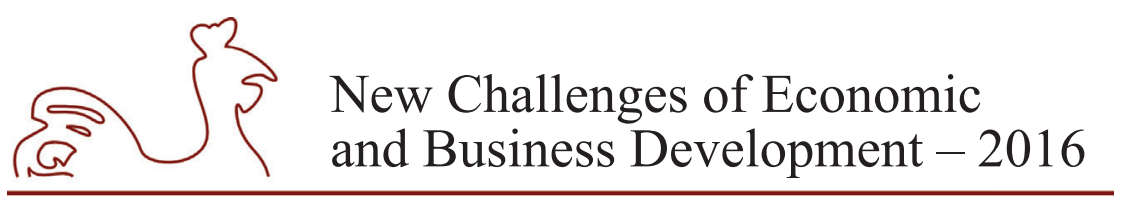

May 12-14, 2016, Riga, University of Latvia

The distribution of responses to the question "Do you in principle support the introduction of work based learning in Latvian VET system"? is reflected in Figure 3.

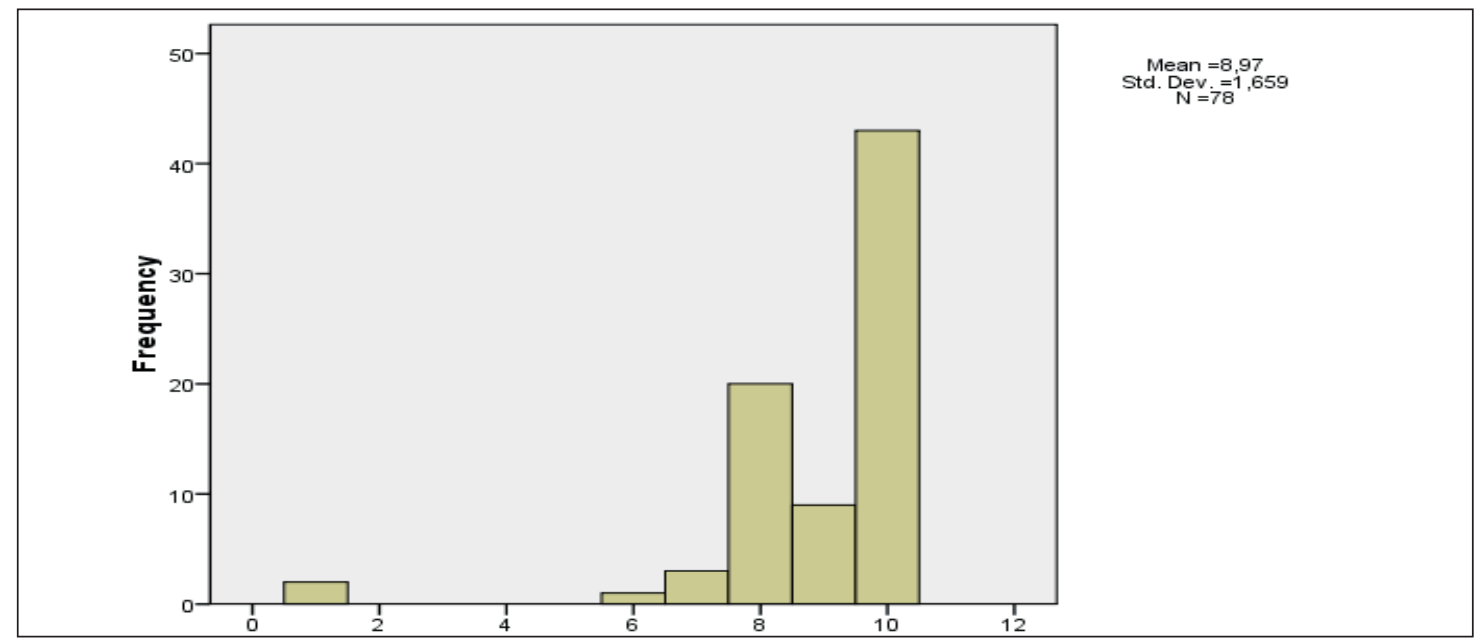

Source: Survey of regional professional education administrators in June $2013(n=79)$.

Evaluation scale 1-10, where 1 - do not support, 10 - support in full extent.

Fig. 3. Evaluations of regional professional education administrators on question "Do you in principle support the introduction of work based learning in Latvian VET system"?

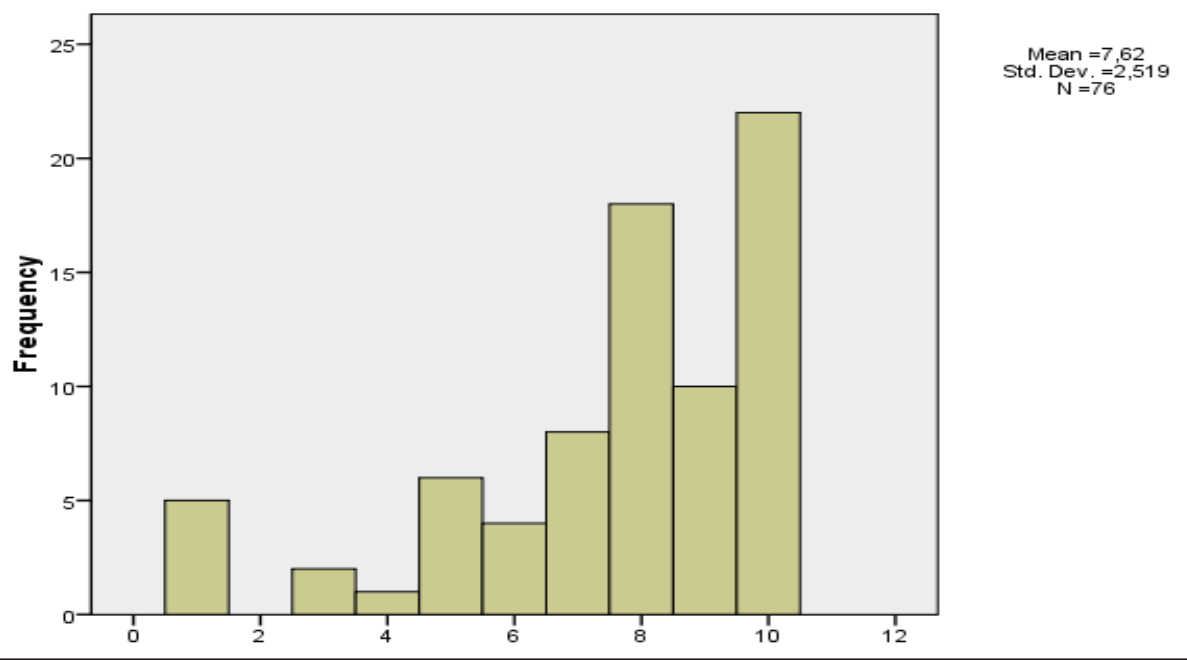

Source: Survey of regional professional education administrators in June $2013(n=79)$.

Evaluation scale 1-10, where 1-do not support, 10 - support in full extent.

Fig. 4. Evaluations of regional professional education administrators on question "Would you be prepared to support the implementation of work-based learning projects in your local government region"? 


\section{New Challenges of Economic and Business Development - 2016}

May 12-14, 2016, Riga, University of Latvia

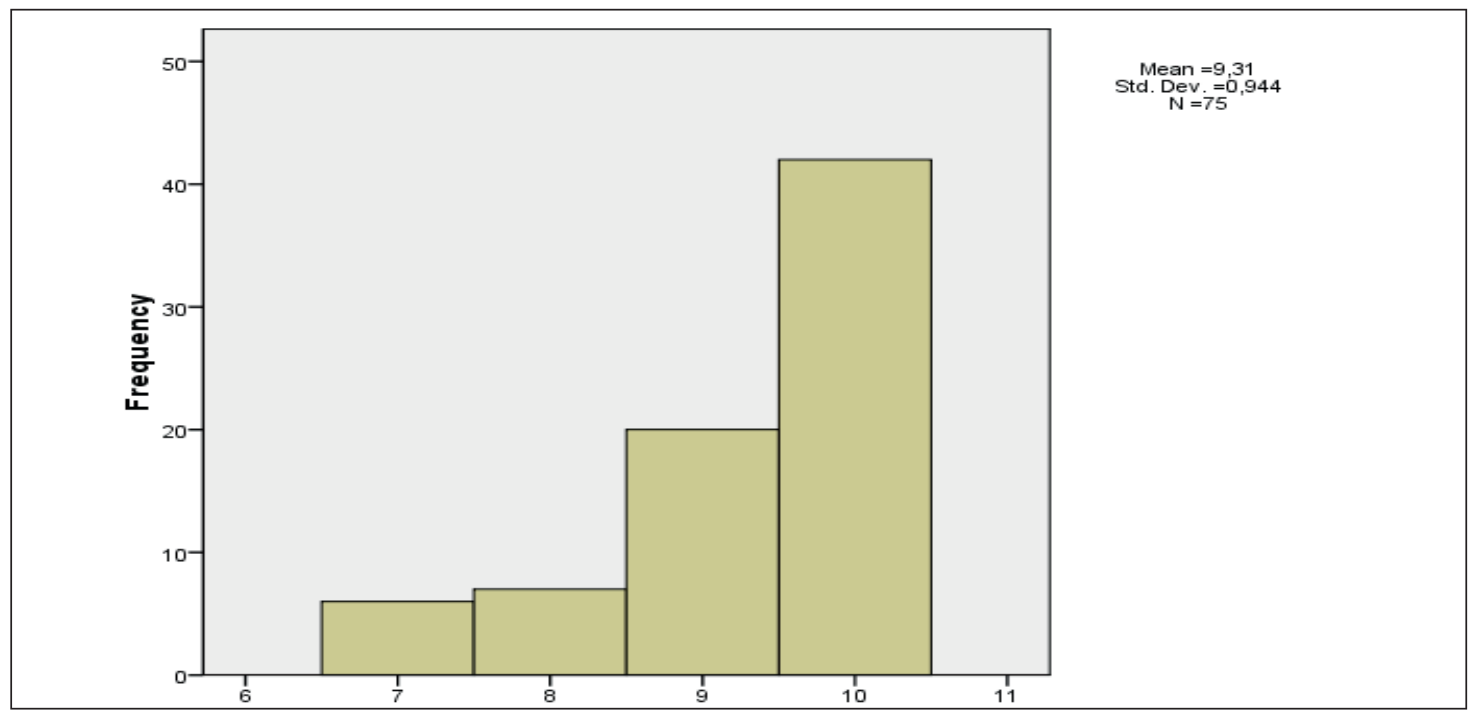

Source: Survey of regional professional education administrators in June $2013(n=79)$

Evaluation scale 1-10, where 1 - do not support, 10 - support in full extent

Fig. 5. Evaluations of regional professional education administrators on question "Do you support flexible modular professional education based on labour market needs"?

The answers by the respondents testify that most of them consider these innovative approaches as needed and necessary for the training of competitive labour force. Moreover, many of the respondents have given the highest score possible. The answers to the questions on the introduction of WBL approaches in the national VET system and on the implementation of WBL approaches and projects locally show a fairly consistent and positive evaluation. Also the attitude to the introduction of modular approach in the delivery of VET programs is equally highly evaluated by the local public administrators, showing their understanding of the importance of flexible modes of delivery of VET content for an improved labour market correspondence and faster adaption to the labour market needs. It should also be noted that the responses of evaluations of local education administrators on asked questions were not significantly different regarding their work experience. There was no significant correlation between the responses and the years of work experience which shows a fairly uniform understanding on the issues of the present research. Also through the focus group discussions on the improved VET governance models in local settings with a wider involvement of social partners in VET management and provision the opinions were generally uniform with no significant differences between the target groups questioned - the VET administrators, VET providers and employers.

The textual analysis and the empirical study has allowed to draw conclusions on the opinion and attitudes of local public administrators and local employers regarding the implementation of innovative approaches in VET governance and VET provision in local settings - with an implicit reference to broader national targets and respective EU VET policy priorities. 


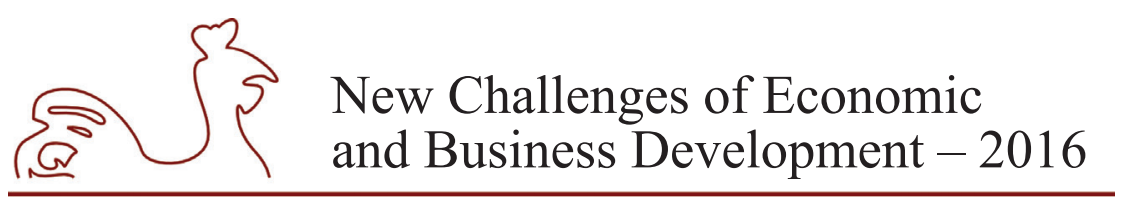

May 12-14, 2016, Riga, University of Latvia

\section{Conclusions, proposals, recommendations}

Based on the results of the textual and empirical analysis, the following conclusions, proposals and recommendations can be drawn:

1. The Latvian local public administrations in VET are supporting new approaches in VET governance - to promote an effectively functioning and labour market oriented VET system. This has been addressed by the amendments to the VET Law in 2015. Care should be taken to secure a balanced approached through effective communication between stakeholders at national and local levels.

2. Awareness should be raised that every education institution is a value in itself, and it promotes the social, intellectual and spiritual viability of the particular community. It is vital for Latvian communities, especially at local levels. The new role of VET institutions for promoting employability of the local workforce, especially in the context of continuing VET provision should be promoted, especially in the context of the newly established VET institutions' Conventions.

3. The VET systems should be integrated into the respective regional sectoral economic, employment and social contexts with effective and integrated co-ordination and decision taking mechanisms at local level. This implies a close coordination between the education, training and employment processes also at local level, with the local public administrations potentially taking the lead (acting as the driving force); this implies also the development of diverse local governance models in compliance with the local characteristics and needs, the local governments becoming more active, and the Conventions taking the lead.

4. The co-operation with the social partners and other relevant stakeholders, e.g. the Sectoral Expert Councils should be put on new grounds - with stronger promotion of the sectoral approach, especially in regional and local contexts, avoiding fragmentation of local strategic planning.

5. New approaches are needed for the involvement of small and micro enterprises in the VET provision and training of competitive labour force. A specifically Latvian model for this should be continually discussed and promoted by the key stakeholders, with the coordinating role of the public administrations at national and local levels. More far reaching strategic goals for VET and VET competence export should be developed by public administrations.

6. Since the local governments' representatives since 2013 in principle have been supportive to new VET developments, including innovative modes of delivery and improved modes of governance, the national level stakeholders should take care not to lose the momentum the willingness of the local stakeholders to take a more active role in VET developments and the new possibilities provided by the amendments to the VET Law.

7. The overall capacity, interest and motivation of the (VET) public administrations themselves to promote innovation in VET should be strengthened. This requires new forms of governance and management, that allow the public administrations reflect on the system, in this case, the VET system, as well as that encourages the public administration reflect on their own reflection in order to change the traditional mindsets. 


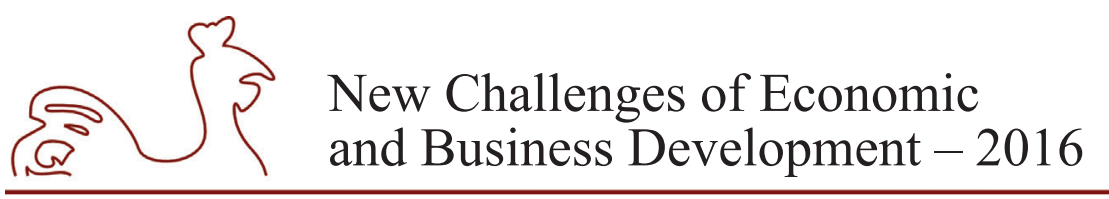

May 12-14, 2016, Riga, University of Latvia

\section{Bibliography}

Amendments to the Act on Vocational Education and Training (Likums "Grozijumi Profesionalas izglitibas likuma"), also available at http://likumi.lv/ta/id/273942-grozijumi-profesionalas-izglitibas-likuma (viewed 15.02.2016).

Boahin, P., Hofman, W. H. A. (2014). Perceived Effects of Competency-based Training on the Acquisition of Professional Skills, International Journal of Educational Development, Vol. 36, pp. 81-89.

Chenic, A. S., Angelescu, C., Gheorghita, A. R. (2012). Providing labor market flexicurity and quality of life through better education and professional training. Procedia - Social and Behavioral Sciences $46,4560-4566$.

Communication from the Commission to the European Parliament, the Council, the European Economic and Social Committee and the Committee of the Regions. Rethinking Education: Investing in skills for better socio-economic outcomes, Strasbourg, 20.11.2012, COM(2012) 669 final, also available at http://eur-lex.europa.eu/LexUriServ/LexUriServ.do?uri=OJ:C:2009:119:0002:0010:e $\mathrm{n}:$ PDF, accessed 7.02.2015).

Declaration of the Council of the European Union "European Alliance for Apprenticeships", available also at http://csdle.lex.unict.it/Archive/LW/Press\%20releases/Other\%20press\%20releases/20131021050847_139011pdf.pdf (viewed 10.03.2015).

Amendments to the Act on Vocational Education and Training (Likums "Grozijumi Profesionalas izglitibas likuma"), also available at http://likumi.lv/ta/id/273942-grozijumi-profesionalas-izglitibas-likuma (viewed 15.02.2016).

Information note to the Cabinet of Ministers "On the implementation of WBL approaches in the VET developments in Latvia", 12.08.2014, available also at http://www.mk.gov.lv/lv/mk/ tap/?pid=40319533 (viewed 10.02.2016).

Ilyas, I. P., Semiawan, T. Production-Based Education (PBE): The Future Perspective of Education on Manufacturing Excellent, Social and Behavioral Sciences 52 (2012), pp. 5-14.

Kraker, J. Cörvers, R. Valkering, P. Hermans, M. Rikers, J. (2013). Learning for sustainable regional development: towards learning networks 2.0? Journal of Cleaner Production, Vol. 49, pp. 114-122.

Lansu, A., Boon, J. Sloep, P.B. and Van der Dam-Mieras, R. (2013). Changing professional demands in sustainable regional development: a curriculum design process to meet transboundary competence, Journal of Cleaner Production, Vol. 49, pp. 123-133

Ruth, K., Deitmer, L. (2010). The Relationship between Technical and Vocational Education and Training and Innovation, International Encyclopedia of Education (Third edition), pp. 423-428.

Sotarauta, M. (2009). Power and Influence Tactics in the Promotion of Regional Development: An empirical Analysis of the Work of Finnish Eegional Development Officers, Geoforum, Vol. 40, 2009, pp. 895-905.

The Bruges Communique on Enhanced European Co-operation in Vocational Education and Training for the Period 2011-2020, 2011. European Union. Available at http://ec.europa.eu/education/ vocational-education/doc/bruges_en.pdf, (viewed 7.12.2015).

The Education Development Guidelines for 2014-2020 (Izglitibas attistibas pamatnostadnes 2014.2020. gadam), also available at http://www.mk.gov.lv/lv/mk/tap/?pid=40305684 (viewed 29.03.2014).

The Riga Conclusions. The New Mid-term Deliverables for Vocational Education and Training. 2015, http://ec.europa.eu/education/policy/vocational-policy/doc/2015-riga-conclusions_en.pdf (viewed 10.03.2016).

Tynjala, P. (2008). Perspectives into Learning at the Workplace, Educational Research Review 3, pp. 130-154. 


\title{
REGIONAL DEMOGRAPHIC DEVELOPMENT IN LATVIA - DOES POLICY MATTER?
}

\author{
Aleksandrs Dahs, University of Latvia, Latvia ${ }^{1}$
}

\begin{abstract}
In Latvia, the academic and political attention to the topic of regional demographic development has been growing since the restoration of independence in 1991. There is a limited amount of factors capable of influencing the aforementioned process on the national and/or regional level, and the direct policy actions carried out by the government are among the most important of these factors that can be adjusted on a relatively short notice. With the aim to gauge potential impact of policy actions on the regional demographic change, author reviews the available literature concerning regional demographic development policies, and proceeds with the content analysis of the available legal/policy documents, as well as the meeting proceedings of the national parliament - Saeima. Author evaluates the selected documents and political statements in the context of the ongoing nationwide and regional demographic processes. Study results indicate significant discrepancies between the regional demographic problems and the respective policy actions. Author concludes that over the last decade, Latvian policy makers have followed a reactive, rather than the pro-active approach to emerging demographic risks in the country and its regions.
\end{abstract}

Key words: regional demography, regional development, demographic policy, content analysis JEL code: J11, J18, I38

\section{Introduction}

While the local social and economic conditions have always been considered among core determinants of regional population change and are included in most contemporary demographic studies and surveys conducted in Latvia, the academic and political attention to this topic has been notably growing since the restoration of independence in 1991 and the beginning of a new chapter in the country's demographic development. Past few decades have been marked by a decline in population throughout the country with many regions showing particularly significant losses in terms of both population numbers and growing instability of their demographic structure (SRDA, 2013).

The pressing need to better understand the relations between local socio-economic and demographic dynamics and account for it in the national and EU-wide policy response was repeatedly underlined by many recent studies, including those carried out by the European Commission (e.g. see Fesus G. et al., 2008). It is well known, that there is a limited amount of factors capable of influencing the aforementioned socio-economic conditions on the national and/or regional level, and the direct policy actions carried out by the national or local government are among the most important of these factors, and the only ones which can be adjusted on a relatively short notice.

Corresponding author - e-mail address: aleksandrs.dahs@lu.lv 


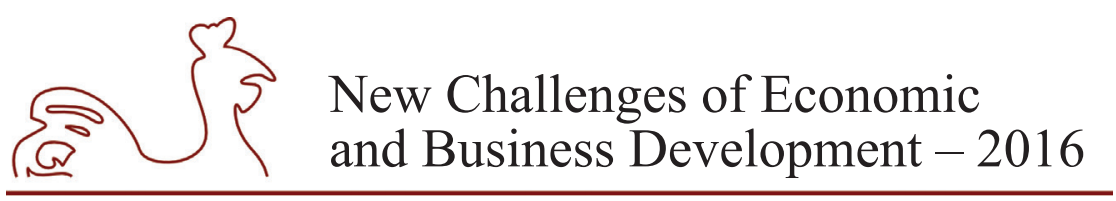

May 12-14, 2016, Riga, University of Latvia

With the aim to better understand and gauge the potential impact of policy actions on the regional demographic change, author begins by reviewing the available previous studies concerning regional demographic development and demographic policies; particularly focusing on the nature of the term "regional demography" and the processes it describes. Further, author follows with the selection and content analysis of the available legal/policy documents, as well as the meeting proceedings of the national parliament - Saeima, accumulated over the last decade. Finally, author studies the selected documents and political statements in the context of the ongoing nationwide and regional demographic processes and estimates the causal effects and the overall correlation existing between the political actions and the actual regional demographic processes.

Study results indicate significant discrepancies between the regional demographic problems and the respective policy actions. Author concludes that over the last decade, Latvian policy makers have followed a reactive rather than pro-active approach to the emerging demographic risks in the country and its regions. On the purely political level, some critical regional demographic issues have been included in the official Saeima debates several years after being observed by the academic and government institutions. The responsible government ministries were more active in tackling the regional demographic issues than the legislators. However, most of the proposed corrective policy actions have been largely linked to the nationwide development plans and programmes determined by the reliance on the EU Cohesion Policy funding. The lack of engagement with local stakeholders (outside of the framework of EU-funded projects) has been observed by the author and underlined in the political debates.

\section{Research results and discussion}

A sustainable demographic situation is recognised among the key preconditions for a successful regional and nationwide development, as the declining population dynamics and associated reduction of human capital unavoidably lead to serious socio-economic implications. On the other hand, evidence clearly shows that degrading socio-economic environment can significantly impair the population development potential of the region, hence, forming an infinite loop of degrading returns, which can be broken exclusively by a significant exogenous intervention. Keeping randomly occurring natural, geopolitical and economic occlusions aside, directed policy interventions and investments may be considered among the most significant exogenous interventions, which can be successfully planned, adjusted and controlled. This implies that links between policy actions and the resulting demographic responses on the regional level are not only relevant for the demographers, but also for policy-makers and the responsible public institutions.

Although, the demographic change, as well as the associated population development processes are often referred to as macro-phenomena influenced and driven by localised events and the individual decisions of local actors, all evidence suggests that these decisions and events are in turn a direct product of the social and economic context in which these actors are embedded (see Klusener S. et al., 2012). These ideas may be challenged by the assumption that majority of the demographic parameters (age, sex, birth rate, mortality etc.) and the associated population processes are natural and genetically inherited factors influenced by the environmental conditions at best. 


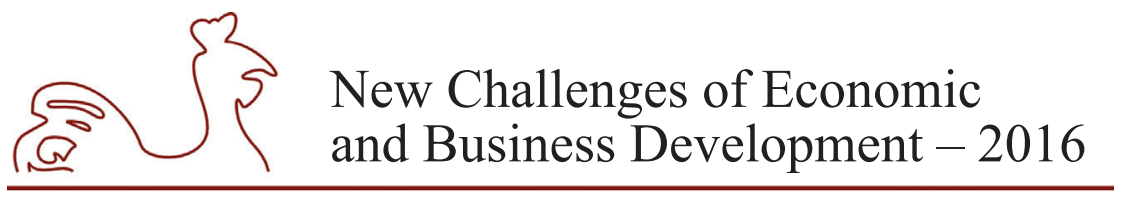

May 12-14, 2016, Riga, University of Latvia

However, the main question of regional demography in this context is - whether the socioeconomic factors and policy actions being exogenous to the natural demographic processes can actually influence individuals' decisions on migration, family planning, choice of lifestyle and healthcare on the regional level, or even go beyond that - altering the pseudo-exogenous environmental conditions like the Psychosocial stress, frequently cited as a contributing factor in higher mortality in former socialist countries (e.g. see Cockerham W. C., 1999 or Dinkel R. H., 1999). Contemporary literature sources dealing with this question are rather limited and divergent in terms of scope and methodologies, which is not surprising, as each country or region has its own characteristic demographic problems and the associated set of related influencing factors or corrective policy measures. However, some common principles and research dimensions can be deduced from the accumulated population studies both in Latvia and other countries around the world.

\section{Regional demographic development in the literature}

First, it is important to mention that multiple interpretations of the term "regional demography", which is quite often used by Latvian scholars, exist in the literature. One way of looking at the regional demography is to place it in between the spatial population statistics and population geography, connecting and enriching both disciplines by adding the theorybased interpretations and region-specific information to the spatial/geographical data (e.g. see Voss P. R., 2006). Another possible interpretation describes the regional demography as a process of adding the concept of place (and often - time) to the traditional population statistics, which is, basically, a new look at the century old techniques of building demographic trends and population data analysis within the framework of regional development processes. Such studies have been once referred to as "micro demography" (see Bogue D. J., 1957). Third and the most popular explanation of the term (which does not necessarily exclude the first two) sees Regional demography as any demographic/population research with the limited geographical scope (i.e. urban, rural, local, national or even international, but not global), depending on the existence of the wider framework under which the particular study is carried out (e.g. see Zvidrins P., 2009).

With this in mind, one might easily conclude that regional demography is just another name for the well-known discipline of spatial demography. For example, Paul Voss (2007) explains, that most of the traditional demographic research is, in fact, a direct product of spatial demography, with few exceptions involving the pioneering works of anthropologists, statisticians and mathematical demographers who have elaborated general theories and causalities of population development, free from the empirical factors like time and space (e.g. see Feller W., 1941; Lotka A. J., 1938; Dublin L. I. \& Lotka A. J., 1925). While finding this statement true, and after reviewing the available previous regional demographic studies conducted in Latvia (e.g. see Zvidrins P. et al., 2009, Gosa Z., 2008), author would like to argue that the concept of regional demography goes beyond the framework of spatial demography, by adding the regional development context and the regional impact factor analysis to the spatial population data. Such perception considerably broadens the research field, as the processes and implications of regional policy and regional development issues have to be analysed along with the population dynamics and the traditionally associated factors like the environment or socio-economic conditions. 


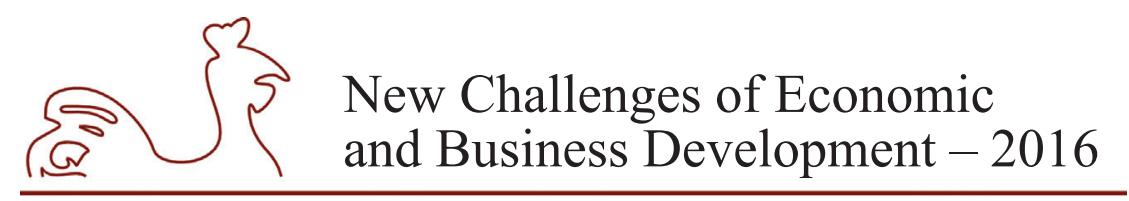

May 12-14, 2016, Riga, University of Latvia

Going into more detail, several key research dimensions can be identified within the accumulated literature connected with the topic of spatial and/or regional demography. While, in general, majority of the studies tend to analyse the differences of demographic development between various territorial units, only few follow the complex, multifactorial approach (see Krisjane Z., 2005; Krumins J., 2006; or Dahs A., 2014). More common are the studies on/ about variances in specific demographic factors among regions of the same country or populated by the same ethnic groups. For example, in Latvia, as well as other European countries, there is a significant amount of research available concerning regional variance of mortality (e.g. Kibele E., 2012; Gosa Z., 2008 or Krumins J. et al., 2009). Another group of studies evaluate the onset, progress and consequences of the demographic transitions at the specific territorial level (usually, countries or macro-regions) (e.g. Bjorvatn K. \& Farzanegan M. R., 2013). In some rare cases, the historical specifics of the territories in question is also placed under review (Brainerd E., 2010 or Golc G., 2004).

From the sources listed above, one can see, that many authors attempt to analyse the underlying social, economic or environmental factors preceding the regional demographic change, but only a handful of studies focus specifically on the demographic effects of the public policy (intentional or unintentional). Such studies are normally limited to the specific countries or regions, where there are known population development issues, which are/have to be addressed by the corrective policy measures (e.g. Smailes P. et al., 2014; Klusener S. et al., 2013; Pol L. G. \& Thomas R. H., 2013 or Eglite P. et al., 2004).

This fact makes it even more important to learn about the mechanics of interactions between the policy planning (e.g. at the executive levels of governance), political will (at the legislative level) and actual regional and nationwide demographic processes: What level of planning documents addresses the regional demographic issues in Latvia? What is the role of the EU Cohesion Policy instruments? How quick are the legislators to react to the emerging demographic challenges? Are regional demographic problems viewed separately or in line with the nationwide issues?

In the following two sections of this paper, author attempts to, at least partially, answer these questions and pave the way for further qualitative and quantitative research on this topic.

\section{Role of demographic development in Latvian policy planning}

In this section, author analyses the contents of several key Latvian national policy planning documents and relevant legal acts in the field of social, regional and cohesion policy, while searching for references or specific proposed actions concerning the nationwide and/or regional demographic issues.

Table 1 below, shows the number of references to the selected demography-related keywords associated within the main, currently relevant Latvian national policy planning documents. These results have been obtained using a software-based adaptive content analysis methodology, following the basic principles outlined in the literature (see Lowe W., 2002). Such methodology has been extensively reviewed and evaluated as a tool for the content analysis of the political texts and policy document by Grimmer and Stewart (2013). 


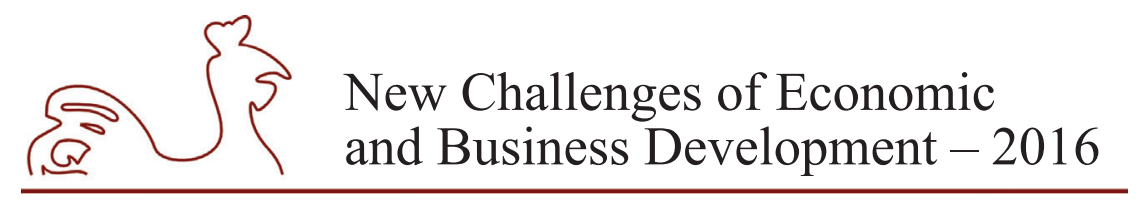

May 12-14, 2016, Riga, University of Latvia

Table 1

Content analysis results of several key Latvian national planning documents with the selected key-words

\begin{tabular}{|c|c|c|c|c|c|c|c|c|c|c|}
\hline \multirow[b]{2}{*}{ Document } & \multicolumn{10}{|c|}{$\begin{array}{c}\text { Key word } \\
\begin{array}{c}\text { (number of references related to the regional context is } \\
\text { given in the brackets) }{ }^{1}\end{array}\end{array}$} \\
\hline & 章 & 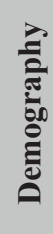 & ف를 & 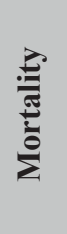 & 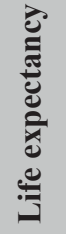 & 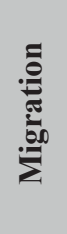 & & : & 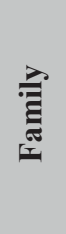 & 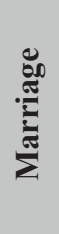 \\
\hline $\begin{array}{l}\text { 1. Sustainable Development Strategy of } \\
\text { Latvia until } 2030\end{array}$ & $\begin{array}{l}150 \\
(24)\end{array}$ & $\begin{array}{l}21 \\
(0)\end{array}$ & $\begin{array}{c}3 \\
(0)\end{array}$ & $\begin{array}{c}1 \\
(0)\end{array}$ & $\begin{array}{c}0 \\
(0)\end{array}$ & $\begin{array}{l}8 \\
(6)\end{array}$ & $\begin{array}{c}1 \\
(0)\end{array}$ & $\begin{array}{c}1 \\
(0)\end{array}$ & $\begin{array}{l}19 \\
(0)\end{array}$ & $\begin{array}{c}2 \\
(0)\end{array}$ \\
\hline 2. National Development Plan 2014-2020 & $\begin{array}{l}139 \\
(9)\end{array}$ & $\begin{array}{c}6 \\
(0)\end{array}$ & $\begin{array}{c}6 \\
(0)\end{array}$ & $\begin{array}{c}4 \\
(0)\end{array}$ & $\begin{array}{c}3 \\
(0)\end{array}$ & $\begin{array}{c}2 \\
(0)\end{array}$ & $\begin{array}{c}2 \\
(0)\end{array}$ & $\begin{array}{c}6 \\
(0)\end{array}$ & $\begin{array}{l}32 \\
(0)\end{array}$ & $\begin{array}{c}0 \\
(0)\end{array}$ \\
\hline $\begin{array}{l}\text { 3. Declaration on the Planned Activities by } \\
\text { the Maris Kucinskis' Cabinet of Ministers }\end{array}$ & $\begin{array}{c}9 \\
(0)\end{array}$ & $\begin{array}{c}5 \\
(0)\end{array}$ & $\begin{array}{c}2 \\
(0)\end{array}$ & $\begin{array}{c}0 \\
(0)\end{array}$ & $\begin{array}{c}1 \\
(0)\end{array}$ & $\begin{array}{c}3 \\
(0)\end{array}$ & $\begin{array}{c}1 \\
(0)\end{array}$ & $\begin{array}{c}1 \\
(1)\end{array}$ & $\begin{array}{l}18 \\
(0)\end{array}$ & $\begin{array}{c}0 \\
(0)\end{array}$ \\
\hline 4. National Regional Development Law & $\begin{array}{c}3 \\
(1)\end{array}$ & $\begin{array}{c}0 \\
(0)\end{array}$ & $\begin{array}{c}0 \\
(0)\end{array}$ & $\begin{array}{c}0 \\
(0)\end{array}$ & $\begin{array}{c}0 \\
(0)\end{array}$ & $\begin{array}{c}0 \\
(0)\end{array}$ & $\begin{array}{c}0 \\
(0)\end{array}$ & $\begin{array}{c}0 \\
(0)\end{array}$ & $\begin{array}{c}0 \\
(0)\end{array}$ & $\begin{array}{c}0 \\
(0)\end{array}$ \\
\hline $\begin{array}{l}\text { 5. EU Structural and Cohesion Funds } \\
\text { Operational Programme "Growth and } \\
\text { Employment" }\end{array}$ & $\begin{array}{l}250 \\
(18)\end{array}$ & $\begin{array}{l}15 \\
\text { (1) }\end{array}$ & $\begin{array}{c}1 \\
(0)\end{array}$ & $\begin{array}{l}10 \\
(0)\end{array}$ & $\begin{array}{c}3 \\
(0)\end{array}$ & $\begin{array}{c}4 \\
(2)\end{array}$ & $\begin{array}{c}0 \\
(0)\end{array}$ & $\begin{array}{c}2 \\
(1)\end{array}$ & $\begin{array}{l}57 \\
(7)\end{array}$ & $\begin{array}{c}0 \\
(0)\end{array}$ \\
\hline $\begin{array}{l}\text { 6. Addendum to the EU Structural and } \\
\text { Cohesion Funds Operational Programme } \\
\text { "Growth and Employment" }\end{array}$ & $\begin{array}{l}62 \\
(3)\end{array}$ & $\begin{array}{c}1 \\
(0)\end{array}$ & $\begin{array}{c}1 \\
(0)\end{array}$ & $\begin{array}{c}0 \\
(0)\end{array}$ & $\begin{array}{c}2 \\
(0)\end{array}$ & $\begin{array}{c}2 \\
(0)\end{array}$ & $\begin{array}{c}0 \\
(0)\end{array}$ & $\begin{array}{c}0 \\
(0)\end{array}$ & $\begin{array}{l}22 \\
(0)\end{array}$ & $\begin{array}{c}0 \\
(0)\end{array}$ \\
\hline 7. State family policy Guidelines 2011-2017 & $\begin{array}{l}88 \\
(2)\end{array}$ & $\begin{array}{l}44 \\
\text { (1) }\end{array}$ & $\begin{array}{l}45 \\
(0)\end{array}$ & $\begin{array}{l}13 \\
(0)\end{array}$ & $\begin{array}{c}2 \\
(0)\end{array}$ & $\begin{array}{c}9 \\
(1)\end{array}$ & $\begin{array}{c}1 \\
(0)\end{array}$ & $\begin{array}{c}2 \\
(0)\end{array}$ & $\begin{array}{l}811 \\
(2)\end{array}$ & $\begin{array}{c}109 \\
(0)\end{array}$ \\
\hline
\end{tabular}

Notes: ${ }^{1}$ ) matches located in the same sentences with the regional context key-words (e.g. rural, urban, regional, municipal etc.).

Source: author's elaboration based on Saeima, 2010; State Chancellery, 2012; Cabinet of Ministers, 2016; Regional Development Law, 2002; Ministry of Finance, 2014, 2015 and Ministry of Welfare, 2011.

It is important to note that the data mining software tool utilised in this particular part of the study (RapidMiner) allows for some degree of fuzzy-logical search, meaning that not only the exact key-word matches, but also the logically related word matches have been recorded and analysed (see Hofmann, M. \& Klinkenberg R., 2013). The quantitative content analysis of the selected national planning documents shows that key words associated with "population", "demography" and "family" are the most often used demographic terms in the policy planning documents. Term "Population" (and its various forms/combinations) has been frequently employed in the regional and or spatial context - together with terms "regional", "rural", "urban" etc. Most other terms, with some exceptions for terms "migration" and "family", had little to none connections to the regional and/or spatial perspective. 


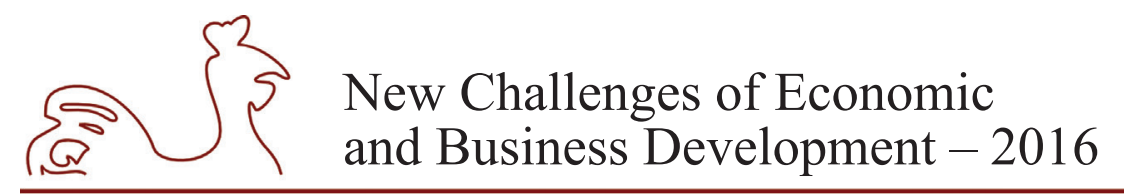

May 12-14, 2016, Riga, University of Latvia

"Sustainable Development Strategy of Latvia until 2030", and "National Development Plan 2014-2020" (Saeima, 2010; State Chancellery, 2012) have the largest share of the demographic references for the majority of key words analysed and the biggest total number of "regional population" mentions among all the documents under study. It is not surprising, since these strategic documents mainly address the long-term sustainability challenges for the country and its regions. On the contrary, "Declaration on the Planned Activities by the Maris Kucinskis' Cabinet of Ministers" (Cabinet of Ministers, 2016), being the key short-term operational planning document for the government priorities, has only few sentences specifically addressing the demographic challenges and regional disparities. National Regional Development Law (2002) also contains but a few references to the demographic issues, demonstrating, that on the legislative level, demographic issues are still viewed separately from the regional development concept.

EU Structural and Cohesion Funds Operational Programme "Growth and Employment" as well as its Addendum (Ministry of Finance, 2014, 2015) contain surprisingly numerous references to both, demographic and regional population development issues, which can be explained by government's attempt to (at least partially) use the available EU funding for tackling the pressing regional development needs. Despite the numerous key word matches found in the "State family policy Guidelines 2011-2017" (Ministry of Welfare, 2011), this document mostly ignores the regional context of demographic development, what places it in one group with the Government Declaration discussed above.

Figure 1 shows the graphical "word-cloud" representation of the text mining process. Particular example demonstrates the most popular logical association within the sentences containing key word "population" (iedzīvotāji) in all seven documents under review.

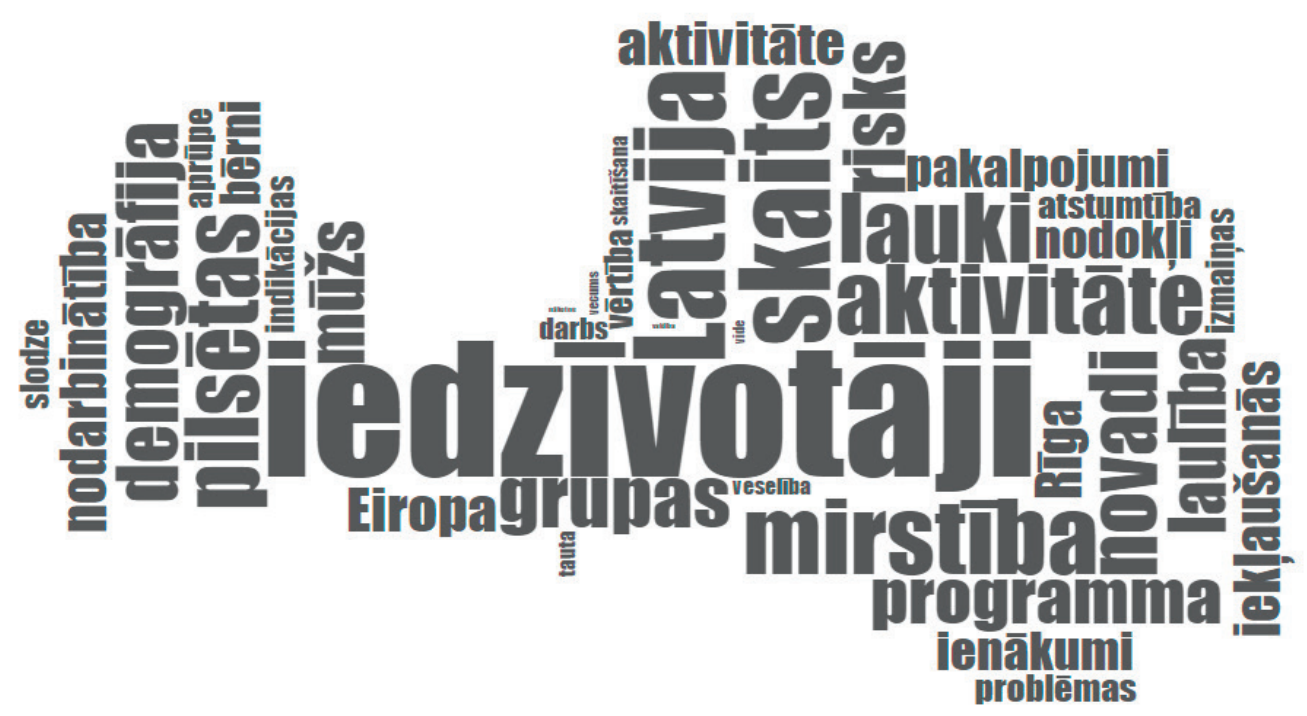

Source: author's construction.

Fig. 1. Word-could representation of the text mining results for key word "population" (iedzīvotāji) within the main Latvian national planning documents in 2016 


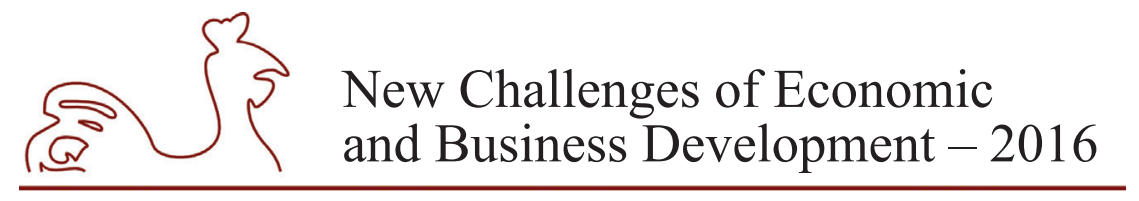

May 12-14, 2016, Riga, University of Latvia

The provided analysis example demonstrates how the term "population" is frequently used in connection with such regional context terms as "rural", "urban" and "municipalities", as well as several other logically associated keywords, including "demography", "mortality", "inclusion", "activity" etc.

\section{Demography as a political issue}

This section is devoted to the content analysis of the meeting proceedings of the Latvian national parliament - Saeima, accumulated over the last decade. A recently developed search tool and repository of the Saeima debate records "Saeima Debate Corpus" was used for this particular part of the study (see Dargis et al., 2016). Using the aforementioned tool, author was able to identify numerous occasions, when the demographic and regional demographic issues were referred to by the politicians and experts participating in the Saeima debate. By conducting the follow-up review of these debates, author attempts to associate them with some specific demography-related events (major reports and publications). Consolidate results of this analysis are provided in the Table 2 below.

First, the analysis results indicate a clear time lag between the specific events and the associated mentions in the Saeima debates, ranging from a few months up to several years. This is not surprising, as in most cases such references were made in order to support a position, motion or a legislative proposal when necessary, for example: I. Godmanis speech in support of the law "On Administrative Territories and Populated Areas", or V. Buzajevs proposal for amendments to the "Unemployed and Job Seeker's Support Law".

Second, it is interesting to note that over the first few years of the period under study regional demographic issues were often called upon by the left-wing and the so-called "pro-Russian" opposition parties in support of their anti-EU sentiment. As a result, for a time, such topics have become associated with the opposition's policy objectives and were received antagonistically and dismissively by majority of the members of parliament, irrespectively of the actual context. Some years later, with the onset of the 2008-2010 economic crisis, somewhat similar situation had developed, when representatives of both left and right-wing parties started using references to the regional demographic problems in order to question the economic consolidation policies implemented by the government.

Third, following the publication of the official 2011 census results, one can notice a growing understanding among the legislators of the severity and urgency of the regional demographic problems in Latvia. However, there is still a substantial lack of political will and decisiveness necessary to address these problems on the parliamentary level - either by allocating the necessary funding or by supporting the associated legislative proposals. 


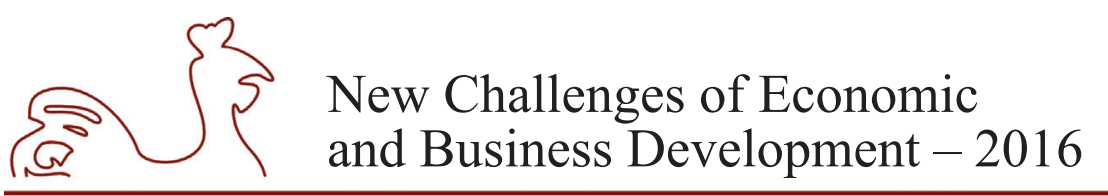

May 12-14, 2016, Riga, University of Latvia

Table 2

Content analysis results of the meeting proceedings of the Saeima, focusing on the specific population-related events in 2004-2014 period.

\begin{tabular}{|c|c|c|}
\hline Event & $\begin{array}{c}\text { Year } \\
\text { (approx.) }\end{array}$ & $\begin{array}{c}\text { Notable references in the Saeima debates } \\
\text { (Who? \& When? / Topic / Context / Conclusions) }\end{array}$ \\
\hline \multirow{2}{*}{$\begin{array}{l}\text { Reports on } \\
\text { increase in } \\
\text { economic } \\
\text { out-migration } \\
\text { after Latvia's } \\
\text { accession to } \\
\text { the EU }\end{array}$} & \multirow{2}{*}{2004} & $\begin{array}{l}\text { I. Ostrovska [New Era MP], August 2004/ } \\
\text { - Low birth-rate and poor socio-economic conditions in Latgale region/ } \\
\text { - Proposal for changes in the State budget } 2005 \text { for better regional } \\
\text { social support and education/ } \\
\text { - Proposal rejected by majority. }\end{array}$ \\
\hline & & \begin{tabular}{|l} 
ForHRUL MPs, December 2005/ \\
- Emigration and degrading demographic situation/ \\
- Motion for extraordinary hearing on emigration and demographic \\
risks/ \\
- Motion blocked by majority.
\end{tabular} \\
\hline \multirow{2}{*}{$\begin{array}{l}\text { SRDA reports } \\
\text { significant } \\
\text { depopulation } \\
\text { of rural } \\
\text { areas due to } \\
\text { the economic } \\
\text { crisis }\end{array}$} & \multirow[t]{2}{*}{2008} & $\begin{array}{l}\text { I. Godmanis [Prime Minister], December 2008/ } \\
\text { - Poor regional governance as a cause for ineffective regional support } \\
\text { policies and regional demographic risks/ } \\
\text { - Motion to support law "On Administrative Territories and Populated } \\
\text { Areas"/ } \\
\text { - Law approved. }\end{array}$ \\
\hline & & $\begin{array}{l}\text { V. Buzajevs [ForHRUL MP], April 2009/ } \\
\text { - Unemployment and poverty leading to regional depopulation/ } \\
\text { - Proposal for amendments to the "Unemployed and Job Seeker's } \\
\text { Support Law"/ } \\
\text { - Proposal denied by majority. }\end{array}$ \\
\hline $\begin{array}{l}\text { M. Hazans } \\
\text { publishes } \\
\text { estimations } \\
\text { of the true } \\
\text { emigration } \\
\text { numbers }\end{array}$ & 2009 & $\begin{array}{l}\text { I. Paradnieks [All to Latvia - FF/LNNK], December 2011/ } \\
\text { - Unregistered migration, low birth rate, rural depopulation/ } \\
\text { - Proposal for the amendment to the "Rules of Procedure of } \\
\text { the Saeima", foreseeing assessment of all future legislative proposals } \\
\text { by the Demography committee/ } \\
\text { - Proposal rejected by the majority. }\end{array}$ \\
\hline \multirow{2}{*}{$\begin{array}{l}\text { Full } 2011 \\
\text { census results } \\
\text { published, } \\
\text { confirming } \\
\text { worst-case } \\
\text { scenario } \\
\text { estimations }\end{array}$} & \multirow[t]{2}{*}{2012} & $\begin{array}{l}\text { V. Dombrovskis [Prime Minister], January 2013/ } \\
\text { - Depopulation and high dependency ratio demonstrated by the } 2011 \\
\text { census results as a risk for national stability and security/ } \\
\text { - Annual National Security Report/ } \\
\text { - Largely dismissive reception, highlighting ethnic and geopolitical } \\
\text { issues. }\end{array}$ \\
\hline & & \begin{tabular}{|l} 
I. Vanaga [Reform Party MP], March 2013/ \\
- Depopulation and re-emigration/ \\
- Report on thematic welfare programmes incl. "Re-emigration plan"/ \\
- Agreement on lack of financial resources for the Plan to be effective.
\end{tabular} \\
\hline
\end{tabular}

Source: author's elaboration based on Dargis et al., 2016; Hazans M., 2003; SRDA, 2009; Hazans \& Philips, 2011; CSB, 2012. 


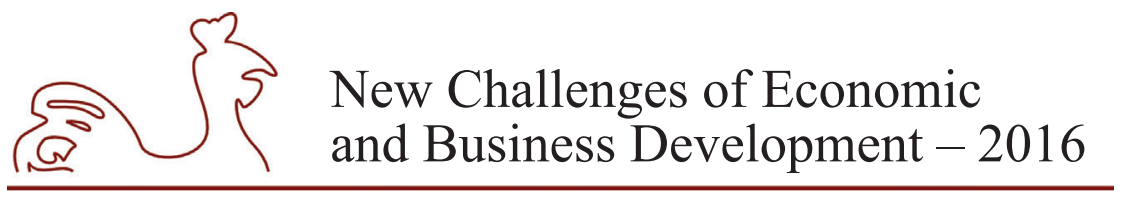

May 12-14, 2016, Riga, University of Latvia

\section{Conclusions}

1. Contemporary literature sources dealing with the concept of regional demography are rather divergent in terms of scope and methodologies, often placing it within the scope of such wider disciplines as population statistics, population geography or spatial demography.

2. By reviewing the relevant literature, one can observe that many authors attempt to analyse the underlying social, economic or environmental factors preceding the regional demographic change, but only a handful of studies focus specifically on the intentional or unintentional demographic effects of the public policy.

3. Content analysis results of the key national planning documents indicate that the strategic planning documents, addressing the long-term sustainability challenges for the country and its regions, have the largest share of demographic references in comparison to the short or medium term government planning frameworks.

4. From the perspective of national legislation and the specific national support programmes, regional population issues are viewed separately from the general regional development concept, which leads to the obvious lack of normative basis for a comprehensive policybased response to the contemporary demographic challenges.

5. Latvian Government's responsible institutions tend to rely on the use of available EU funding for tackling the pressing regional development needs (including demographic problems), hence the national Cohesion Policy planning documents include numerous references to the regional population development issues.

6. In the majority of Saeima debate transcripts reviewed in this study, demographic issues have been called upon only when required in order to gain support for a position, motion or a legislative proposal. As the result, there is a general time lag between specific demographic events and the associated reactions within the Saeima debates.

7. On several occasions, in the political discussions analysed by the author, the regional demographic issues have been referred to by the opposition parties (both far right and far left) with the obvious purpose of supporting their own political agendas. Consequently, for a time, it has made these topics undesirable for the ruling coalition and the government, irrespectively of the actual problems under question.

8. It is possible to observe a growing understanding among the legislators about the importance of the contemporary regional demographic situation in Latvia. However, there is still a substantial lack of political will and decisiveness required for tackling this issue on the legislative level.

\section{Acknowledgements}

The paper was supported by the Latvian National Research Programme 5.2. 'Economic Transformation, Smart Growth, Governance and Legal Framework for the State and Society for Sustainable Development - a New Approach to the Creation of a Sustainable Learning Community' (EKOSOC-LV). 


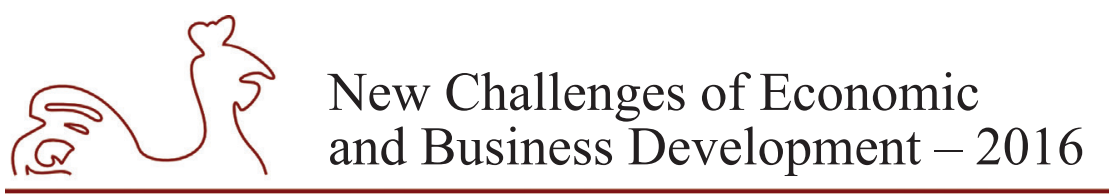

May 12-14, 2016, Riga, University of Latvia

\section{Bibliography}

Bjorvatn, K. and Farzanegan, M. R., 2013. Demographic transition in resource rich countries: A blessing or a curse? World Development, 45, pp. 337-351.

Bogue, D. J., 1957. Micro-demography. In D. J. Bogue ed., Applications of demography: The population situation in the U.S. in 1975. Oxford, OH: The Scripps Foundation, pp. 46-52.

Brainerd, E., 2010. The demographic transformation of post-socialist countries. Working paper No. 2010 / 15 of the World Institute for Development Economics Research.

Cabinet of Ministers, 2016. Declaration on the Planned Activities by the Maris Kucinskis' Cabinet of Ministers. Riga: Cabinet of Ministers of the Republic of Latvia.

Central Statistics Bureau, 2012. 2011 Census Final Results. [Online] Available at: http://www.csb.gov.lv/ dati/ [Accessed 12 March 2016].

Cockerham, W. C., 1999. Health and social change in Russia and Eastern Europe. London: Routledge.

Dahs, A., 2014. Historical Regional Demographic Divergence in Latvia: Lessons of the Common Past with Eastern Partnership Countries. Baltic Journal of European Studies, 4(2), pp. 119-133.

Dargis, R., Rabante-Busa, G., Auzina I. 2016. Saeimas debašu korpuss. Poster presentation at the University of Latvia $74^{\text {th }}$ annual conference, section "Computer linguistics".

Dinkel, R. H., 1999. East and West German mortality before and after reunification. Unpublished manuscript, University of Rostock.

Dublin, L. I., \& Lotka, A. J., 1925. On the true rate of natural increase. Journal of the American Statistical Association, 20, pp. 305-339.

Eglīte P., Markausa I., Pavlina, I., Brants, M., Gņedovska, I., Ivbulis, B., 2004. Latvijas sociālās politikas rezultativitāte iedzīvotāju ataudzes jomā. LZP Ekonomikas un juridiskās zinātnes galvenie pētījumu virzieni 2003. gadā, 9, pp. 58-61.

Feller, W., 1941. On the integral equation of renewal theory. The Annals of Mathematical Statistics, 12, pp. 243-267.

Fésüs, G., Rillaers, A., Poelman, H. \& Gáková , Z., 2008. Regions 2020: Demographic challenges for European regions: Background document to European Commission staff working document No. SEC(2008) 2868.

Golc, G. A., 2004. Долговременные исторические тренды как фактор экономического прогнозирования: транспорт, экономика, демография. Проблемы прогнозирования, 2, pp. 25-35.

Goša, Z., 2008. Vīriešu un sieviešu mirstības diferenciācija Latvijas reǵionos: tendences un faktori. Latvijas Universitātes Raksti, 737 (Ekonomika, VII). Riga: Latvijas Universitāte, pp. 121-139.

Grimmer, J. and Stewart, B.M., 2013. Text as data: The promise and pitfalls of automatic content analysis methods for political texts. Political Analysis, 21(3), pp. 267-297.

Hazans, M. and Kaia P., 2010. The Post-Enlargement Migration Experience in the Baltic Labor Markets, in M. Kahanec and K. F. Zimmermann eds, EU Labor Markets After Post-Enlargement Migration, Berlin: Springer, pp. 255-304.

Hazans, M., 2003. Potential emigration of Latvian labour force after joining EU and its impact on Latvian labour market, BICEPS research paper No 56.

Hofmann, M. and Klinkenberg, R. eds., 2013. RapidMiner: Data mining use cases and business analytics applications. CRC Press.

Kibele, E. U., 2012. Regional mortality differences in Germany. Springer Science \& Business Media.

Klüsener, S., Neels, K. and Kreyenfeld, M., 2013. Family policies and the Western European fertility divide: Insights from a natural experiment in Belgium. Population and Development Review, 39(4), pp. 587-610.

Klüsener, S., Szoltysek, M. and Goldstein, J. R., 2012. Towards an integrated understanding of demographic change and its spatio-temporal dimensions: concepts, data needs and case studies. DIE ERDE-Journal of the Geographical Society of Berlin, 143(1-2), pp.75-104. 


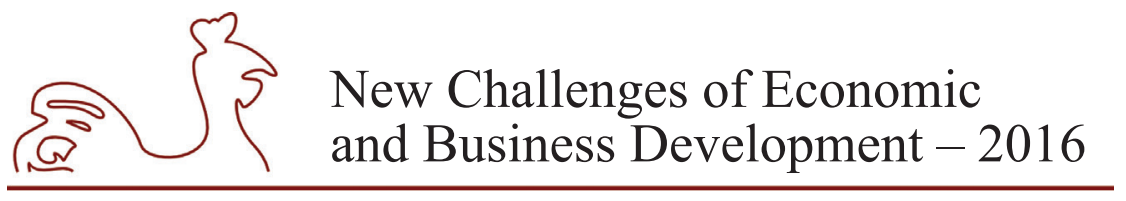

May 12-14, 2016, Riga, University of Latvia

Krisjane, Z., 2005. Latvia: a centre oriented country in transition. Muller B., Finka M., Lintz G. eds. Rise and decline of industry in Central and Eastern Europa. Berlin, Heidelberg, New York: Springer, pp. 131-153.

Krumins, J., 2006. Iedzìvotāju veselība, mirstība un mūža ilgums Latvijā: tendences, faktori, perspektīvas. Demogrāfiskā attīstība Latvijā 21. gadsimta sākumā. Riga: Zinātne, pp. 9-32.

Krumins, J., Jasilionis, D., Leinsalu, M. and Stankuniene, V., 2009. Changes of Geographical Mortality Differences in the three Baltic Countrie during the Period of Socio-Economic Transformation. Poster presentation at the XXVI International Population Conference. Marrakech, 27 September 2 October 2009. [Online] Available at: http://iussp2009.princeton.edu/papers/91432 [Accessed 03 March 2016].

Lotka, A. J., 1938. Some recent results in population analysis. Journal of the American Statistical Association, 33, pp. 164-178.

Lowe, W., 2002. Software for content analysis - A Review. Cambridge: Weatherhead Center for International Affairs and the Harvard Identity Project.

Ministry of Finance, 2014. Operational Programme "Growth and Employment". Riga: Ministry of Finance of the Republic of Latvia.

Ministry of Finance, 2015. Addendum to the Operational Programme "Growth and Employment". Riga: Ministry of Finance of the Republic of Latvia.

Ministry of Welfare, 2011. State family policy Guidelines 2011-2017. Riga: Ministry of Welfare of the Republic of Latvia.

Pol, L. G. and Thomas, R. K., 2013. Health Demography and Public Policy. Demography of Health and Healthcare. Netherlands: Springer, pp. 275-294.

Regional Development Law, 2002. Adopted on 23 April 2012.

Saeima, 2010. Sustainable Development Strategy of Latvia until 2030. Riga: Saeima of Latvia.

Smailes, P., Griffin, T. and Argent, N., 2014. Demographic Change, Differential Ageing, and Public Policy in Rural and Regional Australia: A Three-State Case Study. Geographical Research, 52(3), pp. 229-249.

State Chancellery, 2012. National Development Plan 2014-2020. Riga: State Chancellery of the Republic of Latvia.

State Regional Development Agency [SRDA], 2009. Survey "Development of Regions in Latvia 2008". [Online] Available at: http://www.vraa.gov.lv/uploads/BSR_INNOREG/Regionu_attistiba Latvija_2008_eng.pdf [Accessed 10 March 2016].

State Regional Development Agency [SRDA], 2013. Official report 'Attīstības centru ietekmes areālu noteikšana un analīze. Plānošanas reǵionu, republikas pilsētu un novadu pašvaldību attīstības raksturojums' (In Latvian). [Online] Available at: http://www.vraa.gov.lv/uploads/documents/ petnieciba/petijumi/regionu_attist_final_2012.pdf [Accessed 10 March 2016].

Voss, P. R., White, K. C. \& Hammer, R. B., 2006. Explorations in spatial demography. In: W. A. Kandel \& D. L. Brown eds. Population change and rural society. Netherlands: Springer, pp. 407-429.

Voss, P. R., 2007. Demography as a spatial social science. Population research and policy review, 26 (5-6), pp. 457-476.

Zvidriņšs, P., ed., 2009. Demogrāfiskā attīstība Latvijas regionos. Riga: LU Akadēmiskais apgāds.

Zvidriņš, P., Krūmiņš, J., Bērziņš, A., Goša, Z., Straume, I.,Vītoliņš, E., Jankovska, A., 2009. Demogrāfiskā attīstība Latvijas reǵionos. LZP Ekonomikas, juridiskās un vēstures zinātnes galvenie pētījumu virzieni 2008. gadā,14. Riga: LZP Ekonomikas un juridiskās zinātnes ekspertu komisija, pp. $165-170$. 


\title{
DUALISM OF TAXATION. CHANGES OF LONG RUN WELFARE TAX AND ITS LINKAGE WITH WELLBEING
}

\author{
Mindaugas Dapkus, Vytautas Magnus University, Lithuania ${ }^{1}$ \\ Violeta Pukeliene, Vytautas Magnus University, Lithuania \\ Jone Kalendiene, Vytautas Magnus University, Lithuania
}

\begin{abstract}
The article is orientated towards discussion of taxation aims and consequences. The authors argue that any tax is aimed for creation of welfare in the society because they play a transfer role. There is no definition of welfare taxes in economic literature. According to the authors welfare taxes are individual consumption, social security and wealth taxes related to the welfare of today and tomorrow. Long-run welfare tax (like excise, property tax, capital tax, etc.) is related with welfare in a long run. In Nordic countries where tax income level is higher wealth tax (property tax) are of bigger importance. In Baltic countries excise tax revenue has a bigger share. The authors perform panel regression that aims to test statistically the relation between welfare tax and wellbeing in the countries. The econometrical results prove a statistically significant but weak negative relationship between the variables. It suggests that higher welfare taxes led to lower wellbeing of the society.
\end{abstract}

Key words: welfare, taxes, structure, wealth transfers, inherited wealth

JEL code: E62, H23, I31

\section{Introduction}

Economic policy of every society is oriented to welfare creation and distribution. The taxes are the main instrument for the realisation this target and welfare creation. According to Hird S. (2003) and others there is no precise definition on what welfare is. However, most researchers agree on three things: first - government is the institution which should ensure the environmental conditions for welfare in society; second - welfare of an individual cannot be separated from welfare of society and do not oppose it; third: welfare has two dimensions (objective and subjective). Objective welfare can be described by satisfaction of objective material needs of human beings, while subjective - describes cognitive and emotional evaluation of life. We can say that welfare of society can be interpreted as sum of individual welfares, where welfare is environment determined satisfaction of objective human needs evaluated by subjective experience.

Virtually, terms "welfare" and "wellbeing" are usually used as synonyms in economic literature. However the first term is used to reflect government policy or objective conditions more frequently, while the second - state of individual or society (Braun B. and others, 2002; Blume L., 1996).

1 Corresponding author - e-mail address: m.dapkus@evf.vdu.lt 


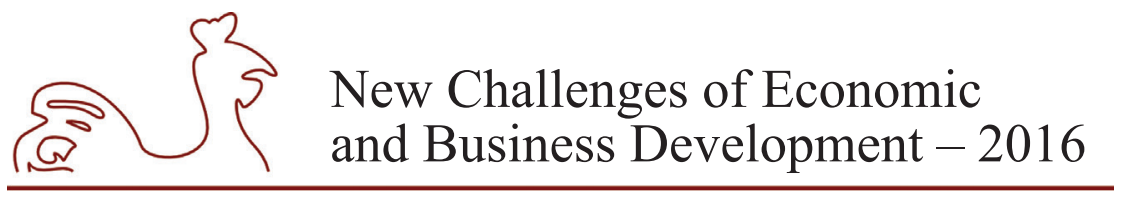

May 12-14, 2016, Riga, University of Latvia

As there are many indexes reflecting welfare and wellbeing, there is a scientific trend to value not the complex sum of multidimensional conditions, but rather societies reaction to environment in which it lives and acts (Easterlin R, 2004; Diener E., 2000; Huseyin N. and Ioannidis J., 2015). For this reason, many scholars tend to analyze how different economic phenomena influence subjective wellbeing - the reflection of how people react to various objective conditions (Cheung, 2015; Nevae J. and Oswald A., 2012). One of the most accepted and used valuations of subjective wellbeing is satisfaction of life (Veenhoven and others, 1996; Veenhoven R. 2011).

The target of the article is to define the welfare taxes in the tax system, to assess the possibilities of welfare tax structure optimization and the possible changes estimating the linkage between welfare tax and wellbeing.

The article was performed in fourth main sections: the first one was used for literature analysis, the second- for presentation of methodology, the following section was conceived to present dynamic analysis of excise and wealth taxes, their structural change over time and in the final section using regression analysis the contradictions between welfare taxes and wellbeing were revealed.

\section{Literature Review}

In general the existing literature reveals the dualism of taxation while talking about welfare. First, all tax decrease the welfare because they lead to lower disposable income and thus lower consumption. Second, looking at the tax as budgetary income it could be assumed that the entire public budget is actually constructed and used to increase the welfare of citizens. So, all taxes might be assumed to have an influence on wellbeing.

Macroeconomic environment changes show unfavourable social and wealth context. According to Keen M. (2013) and Bradbury D. (2015) there is rising income inequality (immobility) and wealth concentration (at the top) 1970-80+. It was the tendency of rising wealth-income and capital-output ratios to unprecedented levels since 1914. Rising wealth means ability to pay. But mainly (latent) there was a tendency of rising capital gains on housing. Rising longevity is other element of context: retire is later, inheritance is received in full property as late as 60 on average and social transfers are growing also. Wealth is more and more concentrated in the hands of elderly.

Evaluating the context and discussions in economic literature (Masson A., 2016) and others authors point current economic arguments and problems on household taxation:

- Incensement in labour income tax is not favourable, especially for the young, because of the massive unemployment, high labour costs, decreasing labour/output ratio;

- Annual wealth tax is increasing, but there are problems with the market value;

- Recurrent taxes on immovable property (housing-land) are growing but it must be the shift from transaction tax to increased recurrent property tax (there are arguments for the reducing transaction taxes on housing);

- There are different approaches to the taxation of wealth transfers.

Theory of optimal capital taxation is looking for optimisation of taxation level from individual perspective. Cremer and others (2010) says that for a number of social philosophers and classical economists, estate or inheritance taxation is the ideal tax. Cremer and others 


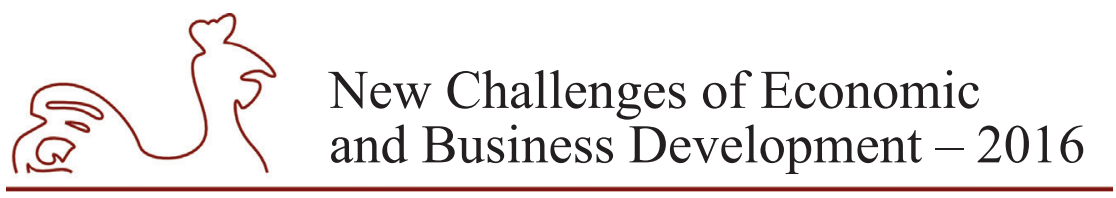

May 12-14, 2016, Riga, University of Latvia

(2012): "our basic goal of finance government services with a tax that is as efficient and painless as possible. On all counts it is difficult to imagine a better tax than the estate tax. Piketty, Saez, Zucman (2013) conclude that there are strong meritocratic reasons we should tax inherited wealth (an unearned income) more than earned income or self-made wealth. But people had resistance and wealth transfers tax becoming more and more unpopular today (Prabhakar R., 2008). They are decreasing as a percent of GDP since 1960, and not the same decline for the lifetime wealth or capital taxation, rations are higher in 2007 than in 1995. Wealth is more a sign of "success", no matter its original (Beckert J., 2008), because of the rising family values and morality: family is safe haven. Masson A. (2016) summing up the attitudes conclude that must be the tendency of the lowing wealth transfers tax and collective preference for life time taxation.

The analysis of theoretical discussions on wealth and wealth taxation, economic changes, and government policies, assumes that all taxes might have an influence on welfare but the authors conclude that the definition and classification of welfare tax is problematic. The authors of this paper suggest that welfare tax can be defined as taxes direct related with welfare. According to authors welfare taxes are individual consumption, social security and wealth taxes related to the welfare of today and tomorrow. Some of them are directly related with everyday consumption, income and social security, some of them - with the historical wealth (immovable property tax, wealth transfers tax and others) and future welfare (Excise tax). (Fig. 1).

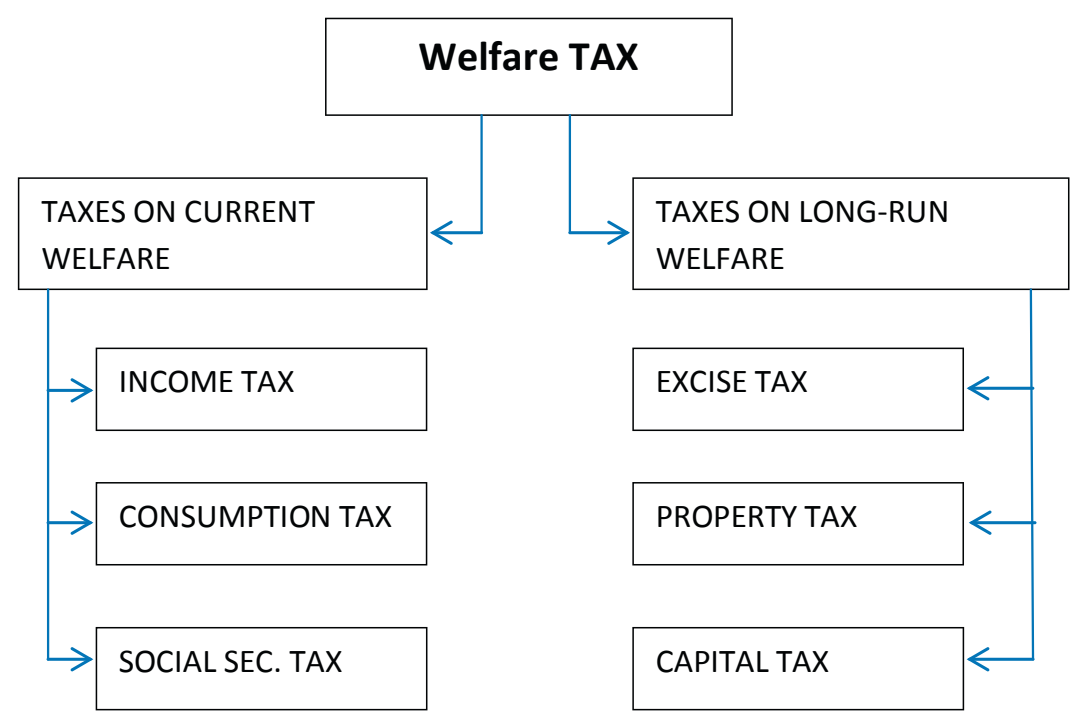

Fig. 1. The classification of tax according to welfare

Authors distinguish that the taxes directly related to welfare (or later just welfare tax) have important influence on social wellbeing in short and long run. Long run welfare taxes are most problematic. There are two groups of long run welfare tax:

- tax on created long run wealth (property and capital taxes) - represents the distribution role of taxes and social cohesion. That is mostly tax on physical (immovable) and financial assets. It means that if you are richer (you have more assets) you have to pay taxes because you probably need more services from the state (like security, better governance of county, etc.) and you can help those who lack the most in the society. 


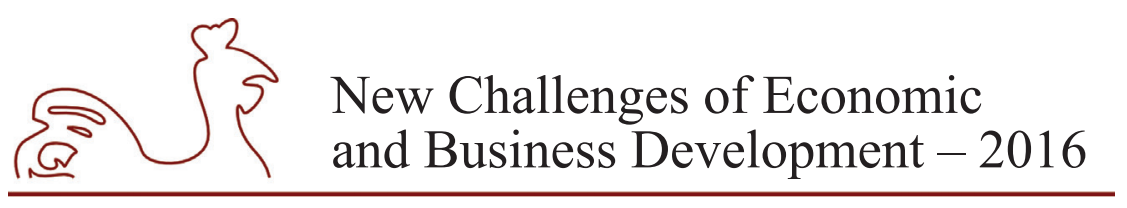

May 12-14, 2016, Riga, University of Latvia

- tax on future long run welfare - aims to create better societal welfare in the future. That is excise tax that aims to decrease socially and personally unfavourable consumption (alcohol, smoking, fuel and others) and is oriented towards better physical (material) and moral health of individuals' social wellbeing in the future.

Authors believe the excise tax in our classification suggested requires a little bit more explanation. First of all, excise tax is a penalty tax, which is applied on the sale or use of specific goods and services, such as alcohol, cigarettes or gasoline. Hines J. R. (2007) defines four reasons for application of excise tax. (1) Revenue generation and (2) application of the benefit principle of taxation is applicable to most of the taxes. But (3) control of externalities and (4) discourage consumption of potentially harmful substances are the motivations of excise tax that links it with welfare in a very specific way. The tax should increase the welfare of society by lower externalities (pollution, violence, illness, etc.) in a short and long run.

The paper discusses the taxes on long-run welfare and aims to analyse its effect on wellbeing. The literature review backgrounds the idea of tax having an effect on individual and societal wellbeing. As all the taxes can be considered as having an effect on wellbeing ("welfare tax"), the paper concentrates on the wellbeing in a long run and taxes that are related to it. So it can be conclude that excise and wealth tax are the ones that are named as welfare tax in this case.

\section{Methodology}

Logics of the analysis and methods. Authors start the analysis of welfare tax structure from looking at the taxation income in the selected countries and the relative size of welfare taxes (as define them in our paper) in government budget. This structural analysis is aimed to see if there are any noticeable differences from country to country and what explanations there might be. As we aim to link the structure of taxation income with the wellbeing of the countries, dynamics of welfare tax structure also might matter. So we analyse the trends of excise and wealth and capital taxes. For the first step we apply principles of comparative structural analysis

The second step of the analysis is based on econometrical tools which are used to test the hypothesis about the relation between welfare taxes and wellbeing of the countries. We test the relation between the relative size of welfare taxes (its share in total taxation revenue) and satisfaction with life, as a measure of subjective wellbeing. We construct a panel multivariate regression with time and place dummy variables. We include GDP per capita as controlled variable in order to represent "other" economic differences among countries.

Data. The empirical analysis includes Baltic and Nordic countries, namely Lithuania, Latvia, Estonia and Denmark Finland, Sweden, Norway. This data set of countries is constructed to have two very different groups of countries in terms of taxation practice and wellbeing of society. Nordic countries are famous for high taxation rates and big taxation income which leads to the creation of welfare state. Also in most of the rankings Nordic countries are among the leaders in wellbeing of society. On the other hand, Baltic and Nordic countries are from very similar region which might mean similarities in culture and history of the countries.

For taxation data we use official database of Eurostat. We treat Current taxes on capital as an indicator for taxation income from wealth and capital taxes. And we take a sum of excise duties and excise duties and consumption taxes as an indicator of excise taxation income. Our analysis takes a period of 16 years which is grouped into three groups: 2000-2004; 2005-2009; 2010-2014. 


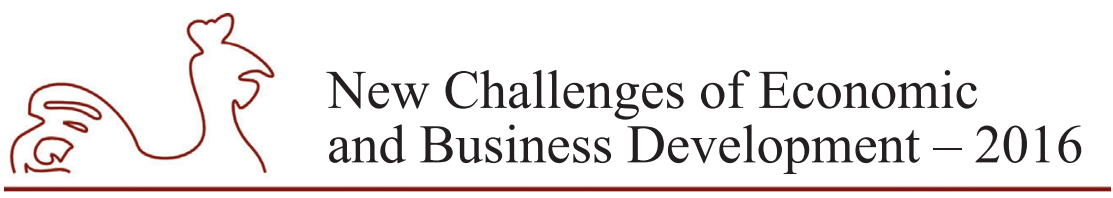

May 12-14, 2016, Riga, University of Latvia

\section{Structural analysis of welfare taxes}

In general, all the taxation income might be judged as having an influence on welfare if we see the initial aim of taxation is redistribution and provision of public services. So first of all we look at the total tax revenue in the selected countries (Fig. 2).

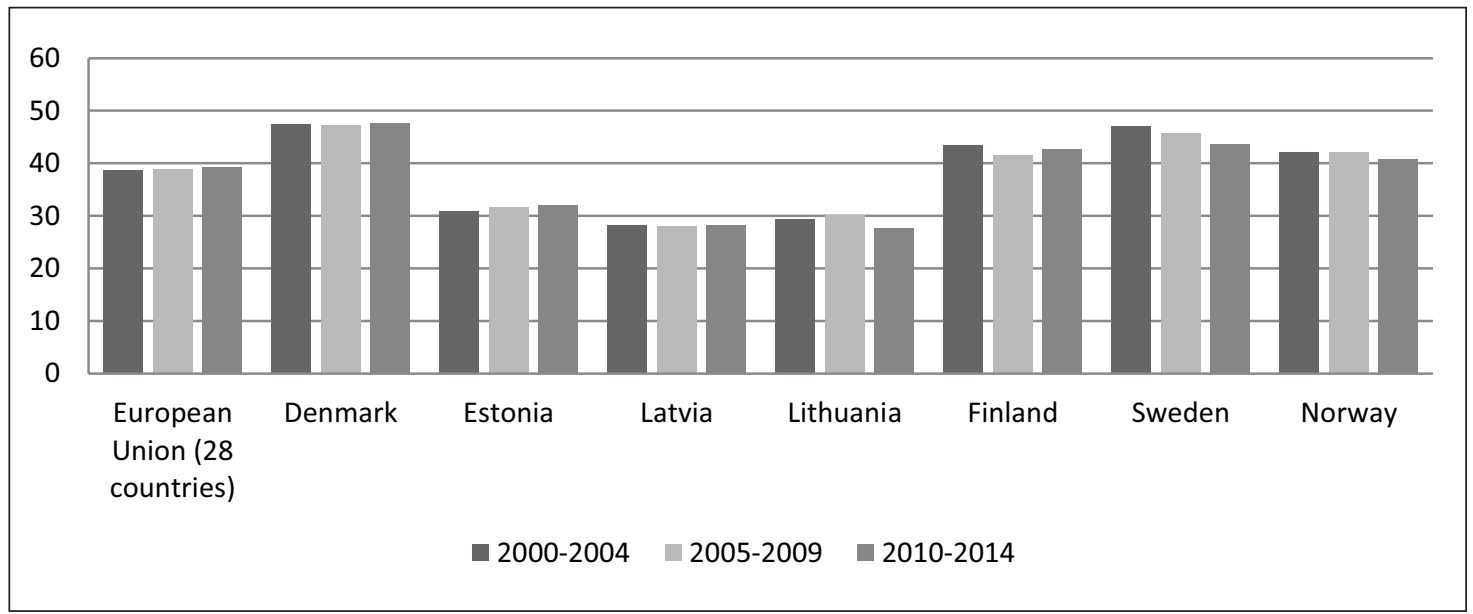

Source: EUROSTAT.

Fig. 2. Total taxes relative to GDP, $\%$

The relative size of tax revenue is much bigger in Nordic countries than in the Baltic countries. All four Nordic countries are above the EU level, where the tax revenue makes about $40 \%$ of GDP constantly. In Nordic economies taxation income is almost $50 \%$ of national GDP with the highest value in Denmark and the lowest in Finland. Meanwhile in the three Baltic countries taxes revenue is at about $30 \%$ of national GDP.

In Lithuania, Finland, Sweden and Norway there is a slightly decreasing trend in relative size of total tax revenue. And only in Estonia we can find an increasing trend. Coming back to our initial idea about the taxation aim to increase welfare and knowing that most of the indexes about quality of life and wellbeing of society rank Nordic countries far above the Baltic countries, we can suggest that increasing the relative size of taxes in Baltic economies may lead to higher welfare of society.

One of the taxes that are directly related with wellbeing is excise. We include both: excise duties on imports and excise into our analysis. The Fig. 3 represents the relative size of excise taxes in Nordic and Baltic countries. Here we can conclude few findings. First of all, obviously the share of excise tax in taxation income is bigger in the three Baltic countries than in the Nordic countries. The highest it is in Estonia (13\% on average in 2010-2014) and the smallest it is in Norway (a little above 4\% on average in 2010-2014). This finding may be explained by the fact that excise tax is partially fixed and united across the EU. Excise tax revenue is structurally bigger in countries with lower income and smaller in countries with higher income. Estonia leads in excise tax revenue probably because much of it is paid by Finnish tourists that come to buy cheaper alcohol. And we do not observe anything similar to that in other Baltic countries. 


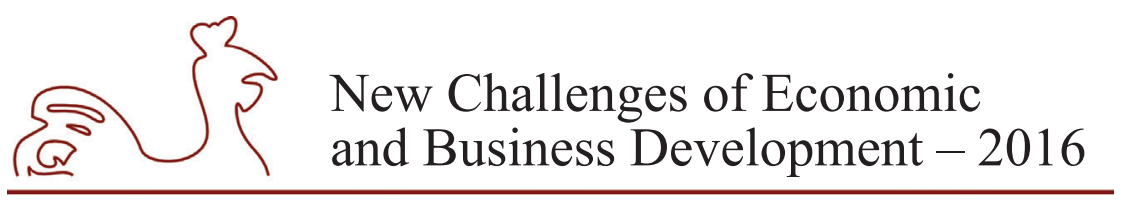

May 12-14, 2016, Riga, University of Latvia

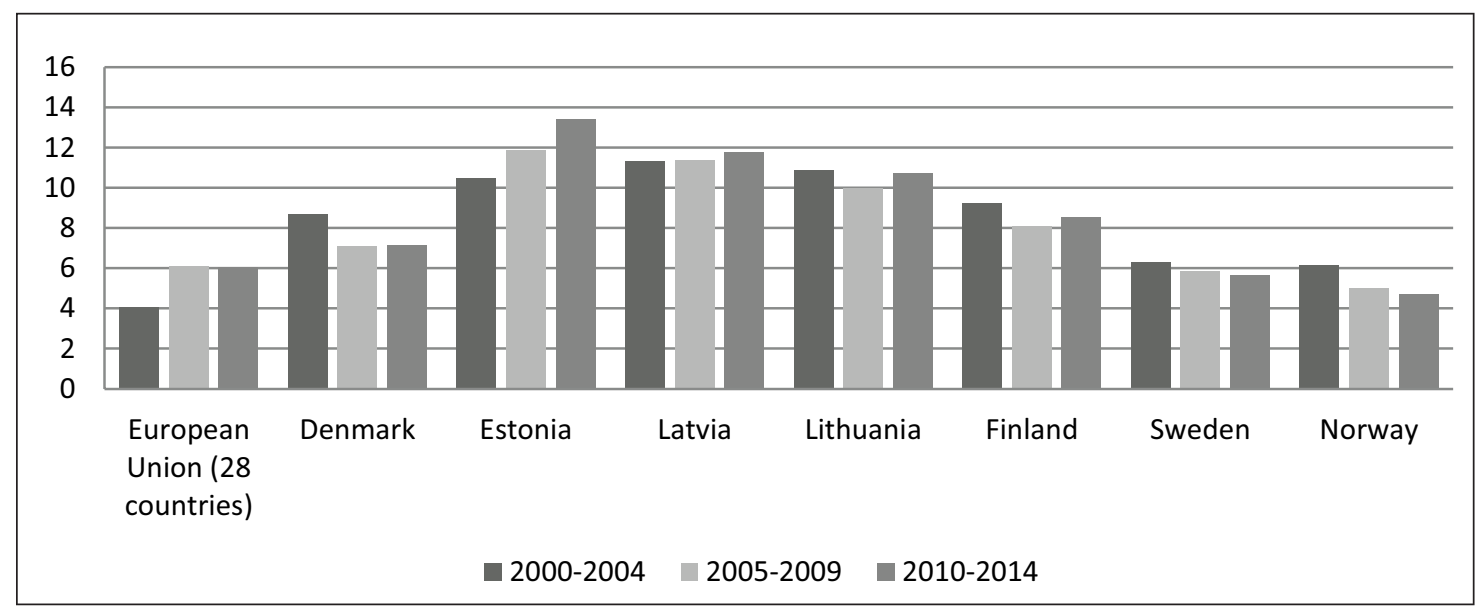

Source: EUROSTAT.

\section{Fig. 3. Excise duties relative to total taxes, $\%$}

The next finding says that the relative size of excise in Nordic and Baltic countries is bigger that the average of EU. This suggests that in the rest of EU countries excise plays much smaller role in taxation income. Probably as the economy is growing and causing taxation revenue to increase, the excise taxes lose their structural importance. So we may also expect the share of excise tax should decrease in taxation income in Lithuania, Latvia and Estonia.

Looking at the development of the structure of taxation revenue in selected countries we should say that we could not make a conclusion about the general trend in Nordic and Baltic countries. In EU the average share of excise tax is stable at $6 \%$ of total taxation income. We can also observe the decreasing trend in excise tax in Denmark, Norway and Sweden which brings countries close to EU average. But there is a clearly fast increasing trend estimated in Estonia. But maybe we can count it as an exception because of peculiarities of Estonian economy that was mentioned above.

The second type of welfare taxes - taxes on wealth - in the countries under investigation are presented in the Fig. 4. In this case Eurostat do not provide aggregate data for EU and they are not applicable in Estonia. In general the share of various wealth taxes is very small in taxation revenue in all the countries. On average it is the biggest in Denmark were wealth taxes make almost $1.5 \%$ of taxation income during 2000-2014. It is registered to be the smallest in Lithuania where wealth tax income stands at $0.1 \%$ of total tax revenue during entire period analyzed. In line with our expectations we find the share of taxes on wealth in total taxation income to very low in Latvia and Lithuania. That kind of taxes are just started to be introduced there. On the other hand, Latvians and Lithuanian have less property and its value is lower compared with Nordic countries. 


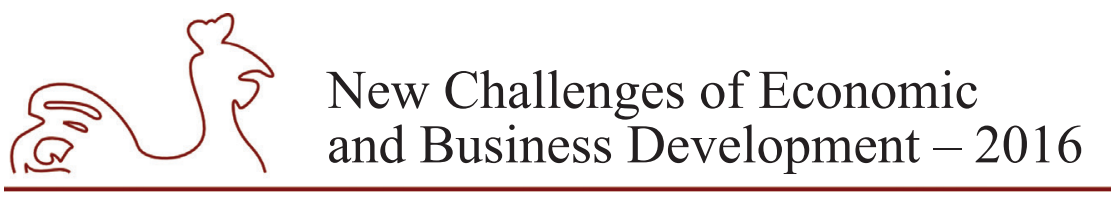

May 12-14, 2016, Riga, University of Latvia

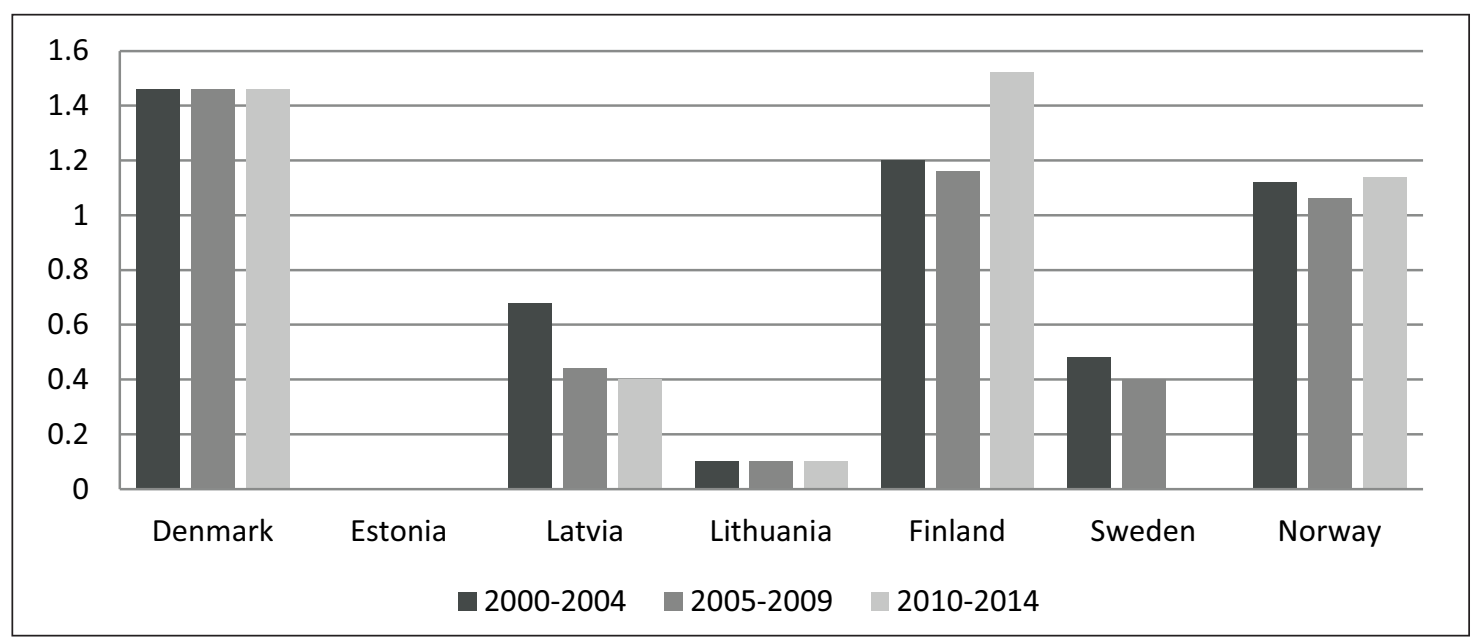

Source: EUROSTAT. Estonia provides no data.

Fig. 4. Taxes on wealth relative to total taxes, $\%$

Our data does not allow making any conclusions about the changes of structural importance of wealth tax in taxation income. As the average share is very low in all the countries its minor changes recorded in Finland, Latvia or Norway does not necessary mean the development trend. Aiming to make a better investigation, we need to have more detailed information about tax structure in Nordic and Baltic countries that would allow having a better judgement about other types of wealth taxes.

To generalize about the welfare tax structure in Nordic and Baltic countries we can already say that taxes related with indirect (social) welfare (excise) has a bigger share in taxation compared with the taxes on financial wealth. Aiming to analyze the welfare tax structure in more details we plot the figure presented in the Fig. 5.

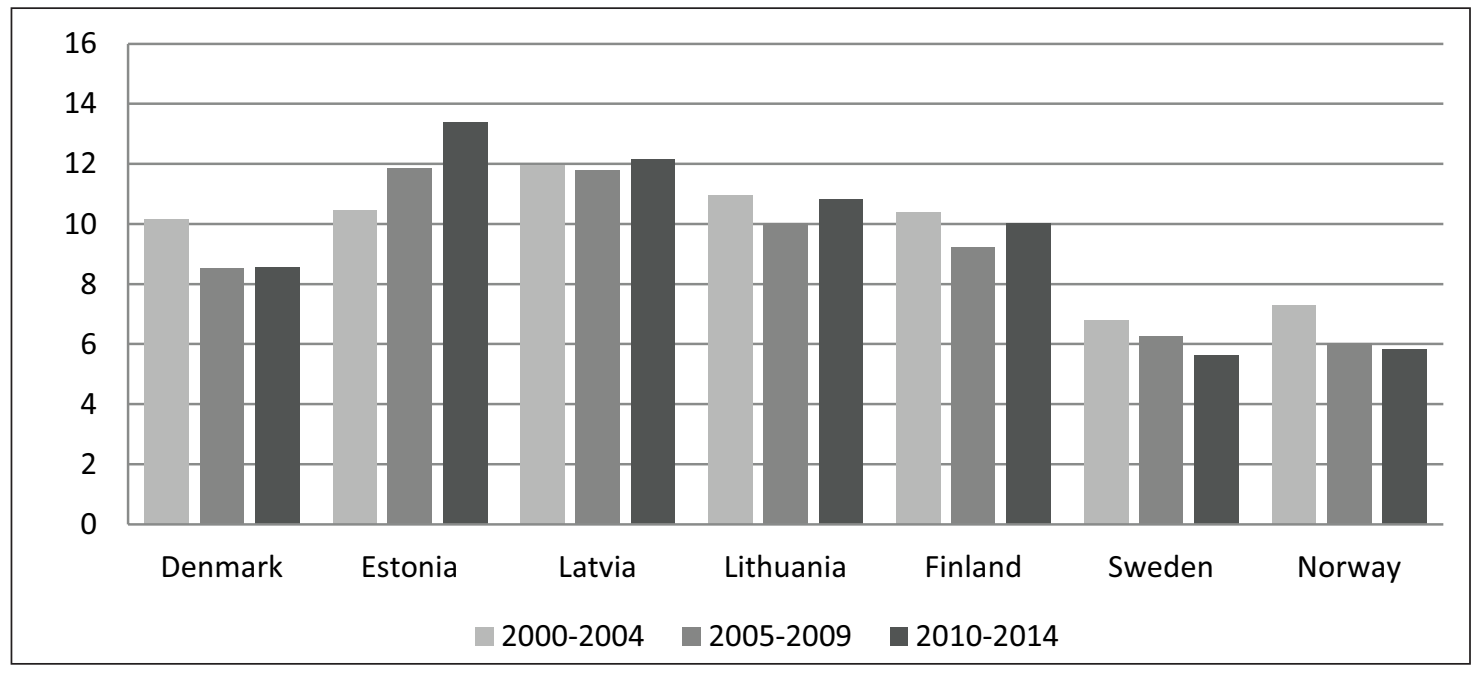

Source: EUROSTAT.

Fig. 5. Excises plus wealth taxes relative to total taxes, \% 


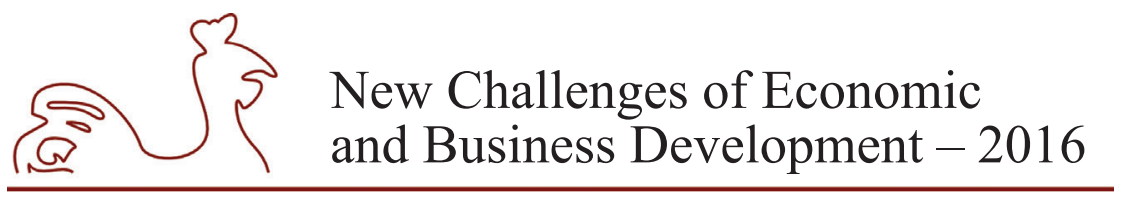

May 12-14, 2016, Riga, University of Latvia

Looking at the summarized values we cannot draw a clear line between Nordic and Baltic countries. Only Sweden and Norway goes out of the group with the lowest share of welfare taxes in taxation income. In both countries it stands at $6 \%$ on average during the period analysed. All three Baltic countries as well as Denmark and Finland records welfare taxes to make about 10\% of total taxation revenue. The leader here is Estonia where the share of welfare taxes increases to $13 \%$ in the last period analysed.

The data suggests some changes in tax structure since 2000. In most of the countries we find a trend of decreasing share of welfare taxes. Though, the changes are not very steep ( 1 or 2 percentage points). This allows us to make a conclusion about quite stable tax structure where wealth taxes have a constant share in total taxation revenue. Only in Estonia we can see a more dramatically increase of share of wealth taxes.

However, the biggest structural difference between welfare taxes in different countries is inside them. In Nordic countries the smaller share of excise is compensated by various wealth taxes and the Baltic countries rely much more on excise tax. This finding suggests that economic growth that leads to increasing income and wealth of society leads to structural changes in welfare taxes. The relative share of excise tends to decrease and taxation revenue is compensated by wealth taxes.

\section{The linkage between welfare tax and wellbeing}

In the second part of our research we aim to test statistically the relation between welfare tax and wellbeing (results in Table 1). The purpose is to see if the welfare taxes are linked with a better wellbeing of the society. From the theoretical point of view there should be a positive relation between the two as more taxes leads to better public services and bigger welfare tax leads to more even distribution of income in the society.

After solving the problems of heteroscedasticity and elimination of autocorrelation of errors the constructed panel regression proved to statistically significant negative relation between different types of welfare taxes and wellbeing. The coefficient of current taxes of capital is the highest. So we can assume that wealth taxes haves the biggest negative impact on current welfare. However, the coefficients are small indicating that the linkage is significant but weak. These findings suggest that welfare taxes as well as any other tax decreases the wellbeing of citizens as they perceive a direct loss of financial wellbeing. It is more complicated for people to link themselves with the public services and to see the indirect incensement of their wellbeing.

Table 1

Results of panel regressions

\begin{tabular}{|l|l|l|l|}
\hline \multicolumn{1}{|c|}{ Independent variable } & \multicolumn{1}{c|}{ Coefficient } & \multicolumn{1}{c|}{ p-value } & \multicolumn{1}{c|}{ Adjusted R-squared } \\
\hline Total taxes & $-1.54520 \mathrm{e}-05$ & $0.0259 * *$ & 0.999397 \\
\hline Pollution tax & -0.00335699 & $0.0028 * * *$ & 0.999372 \\
\hline Capital tax & -0.000491103 & $5.19 \mathrm{e}-05 * * *$ & 0.999426 \\
\hline Real estate tax & $9.92562 \mathrm{e}-05$ & $0.0758^{*}$ & 0.999251 \\
\hline Excise and consumption tax & -0.000157317 & $3.45 \mathrm{e}-10 * * *$ & 0.999445 \\
\hline
\end{tabular}

Source: authors' calculations based on EUROSTAT data. 


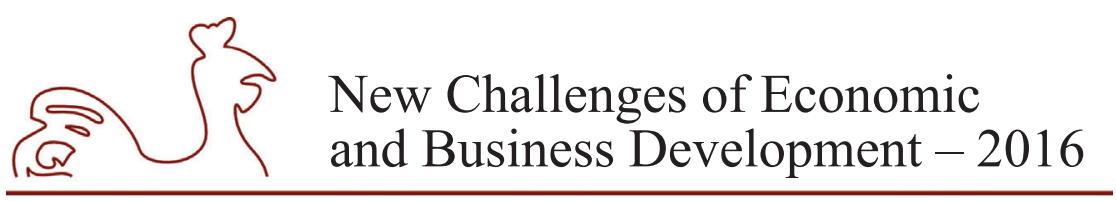

May 12-14, 2016, Riga, University of Latvia

On the other hand there might be some problems with data that was used in research. As changes in welfare tax structure and society wellbeing are very slow, 16 year period may be too short. The results of panel regression might be improved by including more countries into consideration. When doing this it is important to include countries that differ much more in welfare tax structure and wellbeing too. Most likely non-European countries should be included. The other way of improvement of the research is improvement in data. Taxes on wealth are very bad documented in EU statistics that we used. It would be advantageous to look for other data bases, such as OECD and other.

\section{Conclusions, proposals, recommendations}

1. The reviewed literature on taxation and wellbeing reveals the dualism of taxation from the welfare point. First, all taxes decrease the welfare. Second, looking at the taxes as budgetary income it could be assumed that the entire public budget is actually constructed and used to increase the welfare of citizens. General linkage between taxes and wellbeing is ambiguous.

2. Assuming that all taxes might have a negative influence on welfare the authors of this paper define some of the taxes as direct related with every day (SR) consumption (income and social security, VAT and others), and long run welfare taxes that are related with historical wealth (immovable property tax, wealth transfers tax and others) and future welfare (excise tax).

3. Long run welfare taxes are most problematic. They have a big influence on social wellbeing in long run: the taxes on created long run wealth (wealth and capital taxes) represent the distribution role of taxes and social cohesion. That is tax on physical (immovable) and financial assets mostly. The taxes on future long run welfare aim to create better society in the future. The excise taxes (here it is seen to be as future wealth) aim to decrease socially and personally unfavourable consumption (alcohol, smoking, fuel and others) and are oriented towards a better physical (material) and moral health of individuals (social wellbeing in the future).

4. Analysing the wealth and excise tax changes in Baltic states and Nordic countries the authors estimate same changes in taxation income structure in Baltic countries. First, total tax to GDP rate should growth. Second, as the excise tax rate is relatively big and increasing welfare pushes other types of taxation income, excise share should decrease in the future. Third, the tax on wealth is relatively small in Latvia, Lithuania, Estonia. So, authors suggest that it should increase as society becomes richer and income increases. In general the main suggestion in this paper concerning the structure of taxation income is the idea that there should be internal changes in welfare taxes in Baltic States: fall of excise tax and increase in wealth taxation.

5. After solving the problems of heteroscedasticity and elimination of autocorrelation of errors the constructed panel regression proved to statistically significant negative relation between different types of LR welfare taxes and wellbeing. The coefficient of current taxes of capital is the highest. So we can assume that wealth taxes have the biggest negative impact on current welfare. 


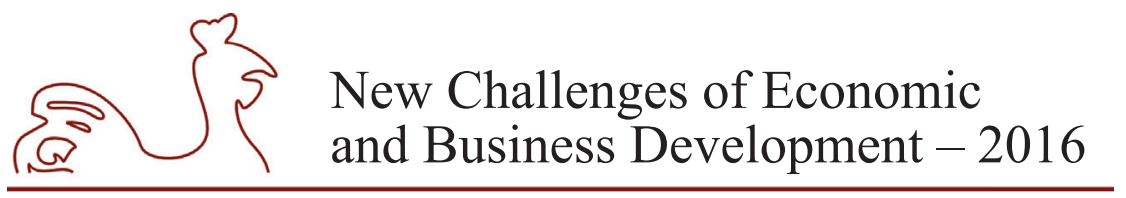

May 12-14, 2016, Riga, University of Latvia

\section{Bibliography}

Beckert, J., 2008. Why Is the Estate Tax so Controversial? Symposium: Domestic Reform or Social Revolution? Society. Vol. 45, Issue 6, pp. 521-528.

Blume, L. B., 1996. Introduction: From Welfare to Well Being. MFR, Vol. 2, Issue 2, pp.1-5.

Braun, B., Olson, P. D. \& Bauer, J. W., 2002. Welfare to Well-Being Transition. Social Indicators Research, Vol. 60, Issue 1, pp. 147-154.

Cremer, H., Firouz Gahvari, and Lozachmeur J. M., 2010. Tagging and Income Taxation: Theory and an Application. American Economic Journal: Economic Policy, 2(1): 31-50.

Cremer, Helmuth, Lozachmeur, Jean-Marie \& Pestieau, Pierre, 2012. Income taxation Of Couples And The Tax Unit Choice. Journal of Population Economics, Vol. 25, Issue 2, pp. 763-778.

Diener, E., 2000. Subjective well-being: The science of happiness and a proposal for a national index. American Psychologist, Vol. 55(1), pp. 34-43.

Easterlin, R., 2004. Happiness in Economics. History of Economic Ideas, Vol. 12, No. 1, pp. 173-178.

Hines, J. R., 2007. Excise Taxes. Office of Tax Policy Research. Working paper series WP 2007-2. Michigan Ross School of Business, p. 10.

Hird, S., 2003. What is Wellbeing? A Brief Review The Current Literature And Conceptions. NHS, Scotland.

Huseyin, N., Ioannidis, J., 2015. Evaluation of Wellness Determinants and Interventions by Citizen Scientists, JAMA 314 (2), pp. 121-122.

Keen, M., 2014. Targeting, Cascading And Indirect Tax Design. Indian Growth and Development Review, Emerald Group Publishing, Vol. 7(2), pp. 181-201.

Masson, A., 2016. Resistance to Reforming Property Taxes. In Political Economy of Tax Reforms. Workshop Proceedings. Discussion paper 025, p. 25.

Nevea, J., Oswald, A., 2012. Estimating the Influence of Life Satisfaction and Positive Affect on Later Income Using Sibling Fixed-Effects. Proceedings of the National Academy of Sciences (PNAS), Vol. 109, No. 49, pp. 19953-19958.

Piketty, T., Saez, E., Zucman, G., 2013. Rethinking Capital and Wealth Taxation. Working paper, p. 20 http://piketty.pse.ens.fr/files/PikettySaez2014RKT.pdf

Prabhakar, R., 2008. Wealth Taxes: Stories, Metaphors and Public Attitudes. The Political Quarterly, Vol. 79, Issue 2, pp. 172-178.

Veenhoven, R. (2012). Happiness: Also Known as 'Life-Satisfaction' and 'Subjective Well-being'. Springer. doi:10.1007/978-94-007-2421-1_3, p. 28.

Veenhoven, R., Scherpenzeel, A. C. \& Bunting, B., 1996. A Comparative Study of Satisfaction With Life in Europe, Eötvös University Press, p. 299.

Woo, Jae Young, 2012. An Analysis on Effect of Socio-Economic Factors on the Subjective Life Satisfaction of Women. Journal of Agricultural Extension \& Community Development, Vol. 20, Issue 2, pp. 555-585. 


\title{
DEVELOPMENT OF BUSINESS EDUCATION FOR CIRCULAR ECONOMY IN LATVIA
}

\author{
Dzineta Dimante, University of Latvia, Latvia ${ }^{1}$ \\ Juris Benders, University of Latvia, Latvia \\ Dzintra Atstaja, BA School of Business and Finance, Latvia \\ Tatjana Tambovceva, Riga Technical University, Latvia
}

\begin{abstract}
To develop a sustainable, low carbon, resource-efficient and competitive economy, transition to a circular economy is essential. The circular economy through eco-design, waste prevention and increased re-use and recycling of products, provides that the value of products, materials and resources is maintained in the economy for as long as possible, and tackles the current environmental problems. Circular economy is an industrial system that is restorative or regenerative by intention and design and calls for considerable change in the mindset of businesses and hence radical changes in business education. Circular economy and eco-design are a focus of EU policy, like the adopted Circular Economy Package that seems to be a crucial turning point for further implementation of the eco-design concept into various sectors of the economy and will contribute to "closing the loop" of product lifecycles.

The aim of the current paper is to study what competencies students should acquire in business and economics education and to formulate guidelines for human resource development through higher education according to requirements of a circular economy.

The authors use literature studies, semi-structured interviews and an analysis of the syllabuses of bachelor and master degree business and economics study programmes in three Latvian higher education establishments as the main methods for the study.

The authors concluded that study programmes in higher business and economics education should review the key competences regarding circular economy issues. Proposed measures in the development of a circular economy require systems thinking, development of an approach to product lifecycle, transdisciplinary knowledge, long-term thinking, more flexible approaches to interdisciplinary studies, as well as creativity, consciousness and a proactive attitude. According to the framework of a circular economy, human resource development should be considered as a principal precondition for a sustainable and competitive economy.
\end{abstract}

Key words: circular economy, eco-design, business education, economics education, competencies JEL code: A20, D83, I25, Q01

\section{Introduction}

Nowadays, to develop a sustainable, low carbon, resource-efficient and competitive economy, transition to a more circular economy is essential. Circular economy through ecodesign, waste prevention and increased re-use and recycling of products, provides that the

${ }^{1}$ Corresponding author - e-mail address dzineta.dimante@lu.lv 


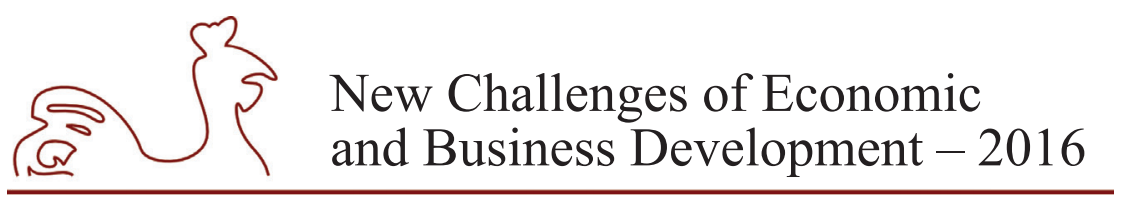

May 12-14, 2016, Riga, University of Latvia

value of products, materials and resources is maintained in the economy for as long as possible. Circular economy and eco-design are now a focus of EU policy. At the end of 2015, the European Commission adopted a Circular Economy Package that seems to be a crucial turning point for further implementation of the concept of eco-design into various sectors of the economy, and will contribute to "closing the loop" of product lifecycles through greater recycling and re-use. The circular economy development initiatives create new challenges for business and policymaking and draw up new perspectives. Implementation of circular economy principles in business and meeting EU Action Plan targets for the Circular Economy calls for considerable change in the mindset of businesses and hence radical changes in business education.

The aim of the current paper is to study what competencies students should acquire in business and economics education and to formulate guidelines for human resource development through higher education according to the requirements of a circular economy.

There have been numerous efforts to formulate essential competencies and personality traits for future leaders in scientific literature. However, there is a gap in research regarding the suitability of business education to meet the needs of future entrepreneurs and leaders in Latvia. This paper attempts to assess the current situation in Latvia's biggest higher business education establishments, namely, The University of Latvia, Riga Technical University and BA School of Business and Finance, regarding competencies necessary for the development of a circular economy.

The authors use literature studies, semi-structured interviews with stakeholders and analysis of the syllabuses of bachelor and master degree business and economics study programmes in three Latvian higher education establishments as the main methods for the study. The authors' research is organized as follows: 1) literature studies to reveal what the main characteristics of a circular economy are, and what competencies are necessary for future leaders and managers to implement the new business approaches; 2) An analysis of EU policy documents to understand the scope and speed in which circular economy implementation is intended in the member states; 3) Six in-depth, semi-structured interviews with experts from different stakeholder groups business, professional association, NGO and education, to gain a better understanding of the peculiarities in Latvia and their opinion regarding role of education in the process of circular economy implementation. Finally, following an analysis of the content of the three biggest study programmes, according to student numbers, in business and economics in each higher education establishment, the authors draw conclusions about the readiness of business education in Latvia for a circular economy and put forward proposals for the development of study programmes.

\section{Research results and discussion}

\section{Circular economy - roots and definitions}

Scientific literature urges us to adopt the principles of a circular economy and ways to tackle current environmental problems like the scarcity of resources, pollution and climate change. The idea that people must consider planetary boundaries in their social and economic activities is not new in the context of sustainable development. In 1966, Kenneth Boulding in his "The Economics of the Coming Spaceship Earth" pointed out that economists have failed to realize limitations of the closed system earth. The opinion that future generations will solve their 


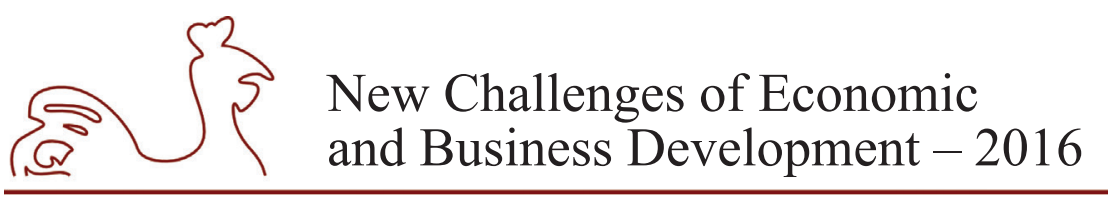

May 12-14, 2016, Riga, University of Latvia

problems according to their needs is dangerous, as problems created by not considering closed system earth are developing very quickly. He points out that in a closed system all outputs from consumption would constantly be recycled to become inputs for production (Boulding, 1966).

The main principles of circular economy correspond to the principles of "spaceman" economy introduced by Boulding

"in which the earth has become a single spaceship, without unlimited reservoirs of anything, either for extraction or for pollution, and in which, therefore, man must find his place in a cyclical ecological system which is capable of continuous reproduction of material form even though it cannot escape having inputs of energy."

There are various possibilities for defining a circular economy. In line with eco-industrial development, a circular economy is understood as "realization of closed loop material flow in the whole economic system" (Geng \& Doberstein, 2008). Another definition states that a circular economy is the circular (closed) flow of materials and the use of raw materials and energy through multiple phases" (Yuan, et al., 2006). Since 2012 a very active promoter of circular economy, the Ellen MacArthur Foundation, defines circular economy as "an industrial system that is restorative or regenerative by intention and design" (Ellen MacArthur Foundation, 2012, 2013). In this paper, the authors use the broad meaning of circular economy, which includes a restorative and regenerative industrial system, societal innovations necessary for implementing these systems, changes in consumer behaviour and ways to measure the success.

A review of the vast amount of literature available shows that the majority of scientific journal articles about circular economy comes from China as a result of the "Circular Economy Promotion Law of the People's Republic of China", which has been in force since 2009 (Lieder \& Rashid, 2016). Nevertheless, researchers from other regions are providing an increasing number of articles regarding the implementation of a circular economy and the role of higher education in this process.

We can find many other similar documented concepts which are part of the circular economy, like cradle-to-cradle (Braungart, et al., 2007) (Kumar \& Putnam, 2008), eco-design and whole process design (Hodgett, et al., 2014), industrial ecology (Ehrenfeld, 2000), the closed loop lifecycle management (Guide, et al., 2003), zero waste (Connett, 2006) (Zwier, et al., 2015), and others.

Eco-design and life cycle thinking is very closely related to the practical implementation of the circular economy. A product's full life cycle is the series of stages that each product inevitably goes through. The life cycle is usually assessed from the time raw materials are first removed from the ground, continues through various stages of manufacturing and transportation, through use and finally to re-capturing, recycling and perhaps the final discard and deposition. In many cases, the life cycle of a product will include re-use of components and recycling of materials.

Life cycle thinking means recognizing the various impacts that occur at all points along the life cycle of the product or material. It also means recognizing how certain choices - materials used, manufacturing process, energy sources, distribution channels, disposal possibilities influence those impacts. In practice, life cycle thinking means evaluating the potential influences as part of the decision making process (UNEP, 2007). Life cycle thinking is a broad concept that facilitates an integrated assessment of the benefits and the burdens in terms of environmental, social, and economic aspects, for specific products and regions, etc. The application of life cycle thinking requires specific methodologies. 


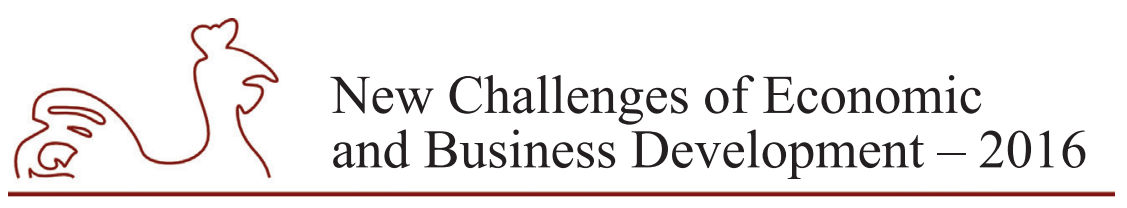

May 12-14, 2016, Riga, University of Latvia

A circular economy requires a different approach to defining economic success, development of fiscal systems to create the right incentives and building knowledge by embedding systems thinking in education and launching broad circular economy research programmes (Ellen MacArthur Foundation, 2015).

\section{EU policy analysis regarding circular economy}

The concept of the circular economy reflects the recognition that European systems of production and consumption need to be fundamentally transformed to achieve the EU's 2050 vision of "living well within the limits of our planet". Creating a circular economy in Europe can help to address many of these challenges, and further improving the efficiency of resource use has obvious economic benefits, such as reducing costs and risks while enhancing competitiveness. European leadership in the transition to a circular economy also offers opportunities to drive innovation in new materials and better products and services, creating new jobs and securing first-mover advantages in the global economy (EEA, 2016).

At end of 2015, the European Commission adopted a Circular Economy Package that seems to be a crucial turning point for further implementation of eco-design concept into various economy sectors and will contribute to "closing the loop" of product lifecycles through greater recycling and re-use. The Circular Economy Package is assumed to be a new and more ambitious step for EU Environmental policy. The Circular Economy Package consists of an EU Action Plan for the Circular Economy that establishes a concrete programme of action, with measures covering the whole cycle: from production and consumption to waste management and the market for secondary raw materials (Commission of the European Communities, 2015, Circular economy, 2016).

Moreover, the Circular Economy Package (CEP) highlights the scientific research and broad involvement. The CEP propose funding innovative projects under the umbrella of the EU's Horizon 2020 research programme, and have targeted action in areas such as plastics, food waste, construction, critical raw materials, industrial and mining waste, consumption and public procurement. The CEP action plan focuses on broad and long-term involvement at all levels and for various key target groups, including businesses and citizens (Commission of the European Communities, 2015, Circular economy, 2016).

The life cycle thinking and implementation of design for a sustainability concept are very important from an academic perspective and has been discussed over the last decade. A sustainable development concept in production leads to bridging environmental issues with product development reducing environmental, social and economic impacts along a product supply chain and throughout its life cycle. That should result in a "cradle to cradle" instead of a "cradle to grave" mentality (Clark, Kosoris, et al., 2009). Life cycle approach and eco-design issues focus on the integration of environmental considerations in product development, and that helps to combine business oriented design goals and environmental considerations.

Integrated Product Policy (IPP) had been considered as one of most principal EU policy level initiatives aimed at reducing the environmental impacts of products and services throughout their lifecycles by using policy instruments in order to obtain 'green' markets through 'greening' both the demand side (consumption) and the supply side (product development). IPP is not assumed to be a stand-alone policy, but to be integrated into already existing EU policies and objectives (Charter, Young et al 2001). Eco-design development had been defined 


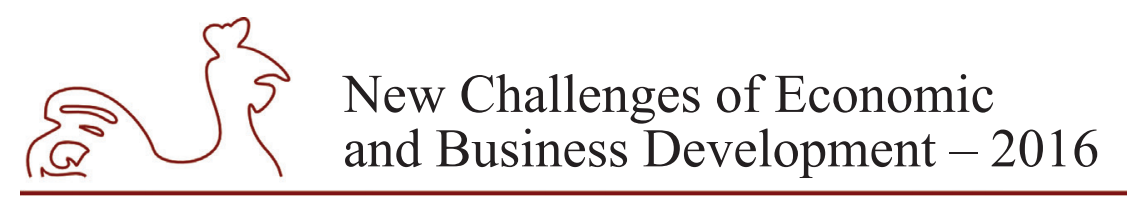

May 12-14, 2016, Riga, University of Latvia

by EC Integrated product policy, comprising together eco-design, green procurement and environmental technology issues. IPP includes a variety of tools, such as the use of economic instruments, eco-labelling and voluntary agreements. It is necessary to stress the IPP orientation not only to traditional instruments, but more to voluntary instruments; that means an increase in information, communication and awareness-raising within both supply and demand sides (Governance, 2006).

Another important circular economy promotion tool is Green Public Procurement (GPP). Although GPP is a voluntary instrument it has a key role in a resource-efficient economy and stimulates a demand for more sustainable goods and services - various eco-design issues which would otherwise be difficult to get onto the market (Commission of the European Communities, 2008).

Furthermore, the Europe 2020 strategy and its two Flagship Initiatives on Sustainable growth, i.e. Resource efficient Europe and Industrial Policy, emphasize the policy objectives of sustainable development and an increased attention to resource efficiency and EU competitiveness. The EU eco-design concept comprises a rather broad spectrum of product groups for the adoption of implementing measures and there is a trend which features a larger number of product groups in each of the forthcoming planning periods (European Commission, 2012).

\section{Business education for circular economy}

Both business management and business education related literature point out that the current global challenge requires future managers and leaders who are responsible and have knowledge in issues of central relevance to society and policy, including those related to environmental problems and exogenous events (Blass \& Hayward, 2015). In business education, it is important to acknowledge the main drivers and reasons which create global environmental problems, and business education should place a greater emphasis on the ethical and moral questions. High demands for future managers calls for a radical change in business and economics education. A report "Delivering the circular economy - a toolkit for policymakers", puts education and knowledge building in the foundation of development of the circular economy (Ellen MacArthur Foundation, 2015). In understanding the important role of education and particularly higher education, there is concern for the time lag in the education sector where the usual timeframe to update the curriculum for professional disciplines is too long to meet the changing market and regulatory requirements for emerging knowledge and skills (Desha \& Hargroves, 2014).

As circular economy is a very complex issue, involving resource extraction, transportation, production, consumption, distribution, waste management, social norms, biological and technological cycles, professionals from many disciplines have to work as a team. Business and economics students, as future leaders, need to understand the whole system and its interconnections; therefore they should receive problem-based interdisciplinary and transdisciplinary education. Along with the importance of professional competencies are the essential human capacities, like systems thinking, creativity, consciousness, responsibility, communication skills for cocreation, and knowledge of processes of human change. The future leaders have to be flexible in their approach, understanding their own strengths and the strengths of others. They would be embedded in networks rather than as isolated individuals, which would enable them to have different attributes and purposes in different networks and situations (Blass \& Hayward, 2015). 


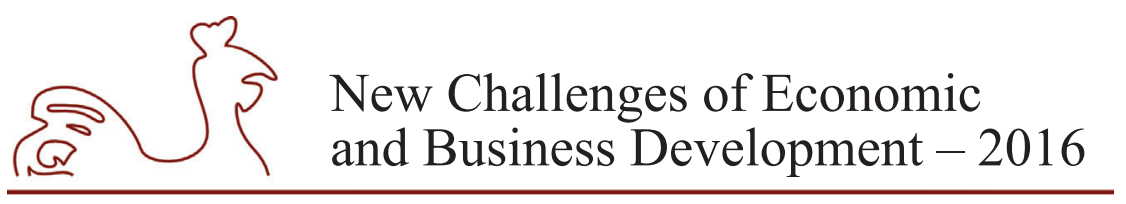

May 12-14, 2016, Riga, University of Latvia

Future leaders meeting the demands of a circular economy need many competencies, such as sustainable development - thinking and working both locally and globally, long-term thinking is essential, a broad understanding of how to measure success, learning and capacity building for the common good, focusing on community development and learning. These competencies require a shift in teaching methods and content, as well as conducting research across traditional subject silos to develop new technologies and business practices that work at a system level. For example, the use of metaphors both as markers of existing perceptions and possibly as didactic tools in teaching students about the value of nature could employ more positive models such as cradle-to-cradle and the circular economy, which could be applied both in business education and in general environmental education (Kopnina, 2014). Goal-oriented education for sustainability is crucial to permit transcendence from unsustainable practices. A circular economy also requires new approaches in accounting, reporting and financial regulations including accounting for natural capital and resources, and the fiduciary duty of investors and managers (Ellen MacArthur Foundation, 2015).

Life cycle thinking and circular economy related business education aspects have been analyzed in a number of publications. The integration of eco-design related strategies into strategic planning documents in sectors of the economy, improvement of eco-design competences in enterprises, better cooperation with science and technology are all issues recognized as principal measures for eco-design development. Environmental information and communication measures should comprise the main three target groups - state institutions, employers and consumers (Benders, 2015).

Development of study programmes regarding these three target groups had been considered as one of most important preconditions for eco-design development in the country promoting:

a) environmental awareness and life cycle thinking for all graduates as part of society and consumers;

b) eco-design competence for prospective enterprise staff;

c) eco-design professional competence for eco-design experts (Benders, 2007).

It is interesting to consider the role of legal and voluntary instruments in the ecodesign development process in Latvia. Research confirmed that legal measures are more or less in operation in the country (for instance Eco-design Directive requirements, Green public procurement). In return, voluntary measures (for instance, Design for sustainability, environmental performance of enterprise, eco-design focused trading, better cooperation with science and technology) which are based on environmental competence and, particularly on life cycle thinking, are not understood well enough and accepted in enterprises (Zucika, 2010; Danusevica, 2013, Koklacova, 2011).

Circular economy oriented education forms a great challenge to the Latvian education system. Previous investigations indicated insufficient eco-design understanding in entrepreneurship and society and insufficient proactive initiatives at state institutions level (Belmane, 2006). In addition, circular economy oriented education development should be reviewed within the whole higher education development process in the country because the quality aspects of contemporary education should enhance the circular economy oriented education process. The successful realization of a circular economy should be assumed as being the principal precondition for economic development of country (Benders, 2015). 


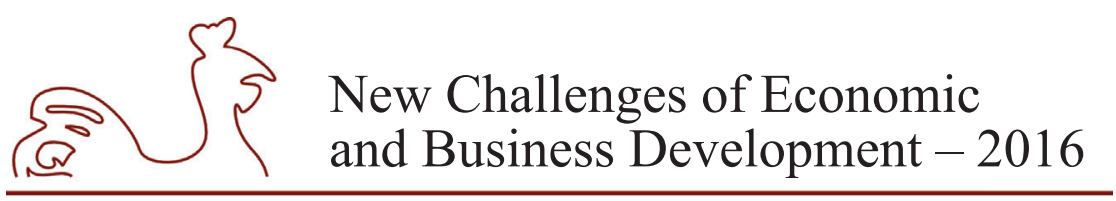

May 12-14, 2016, Riga, University of Latvia

The definition of key competencies and results to be achieved is a principal part of study programme development. Researchers and experts who have been interviewed support the large role of a systemic approach in eco-design development and motivation of eco-design measures within entrepreneurship and green economy development. It is important to achieve competences for analysis of causes and consequences of identified economic, environmental or social issues. Study programmes should focus on achieving competencies for assessing nature, economic and social aspects in new product development and entrepreneurship, as well as being proactive and having creative attitudes (Ellen MacArthur Foundation, 2013; Wolf, 2014).

\section{Necessary competencies and the current state of business education for the development of a circular economy}

In-depth, semi-structured interviews with experts from the spheres of eco-design and education were conducted to find out what perspectives of implementation of circular economy are in Latvia and what competencies are considered to be the most important for economics and business students. All experts were unanimous that the circular economy package includes very ambitious targets and its fulfillment could be complicated due to rather different economic development levels in EU countries. At the same time, appropriate education at all levels and forms could be one of the implementation tools for a successful circular economy in real life. The following competencies and knowledge of principles for future managers have been recognized:

- life cycle thinking and principal eco-design understanding,

- systemic thinking, ability to think in causal relationships,

- a multidisciplinary approach to problem solving,

- ability to work in interdisciplinary groups,

- creativity.

Interviews indicated that circular economy oriented education is current for wide study programmes: economists, finance sector, engineers for all levels (BSc, MSc and further education). As the most suitable ways in which these competencies could be obtained during bachelor and master studies, experts indicated the following:

- including study courses, which develop systems thinking and life cycle thinking, in the curriculum,

- including study courses or topics of circular supply chains, industrial ecology, green procurement,

- developing innovation platforms or business incubators at universities with particular attention to circular economy principles, which provide education by experience,

- ensuring good co-operation and coordination between academic staff and students of different study fields in universities to ensure multidisciplinarity,

- teaching by good examples from local and foreign companies,

- using IT provided opportunities to communicate product environmental and social impacts,

- stressing the benefits of a circular economy which are most important for ordinary people, like health issues and cost savings.

Experts suggested that there is a need for more comprehensive feasibility studies focused on eco-design understanding in Latvia for different target groups, as well as regarding the necessary measures for successful eco-design development in the country. In general, the level of eco- 


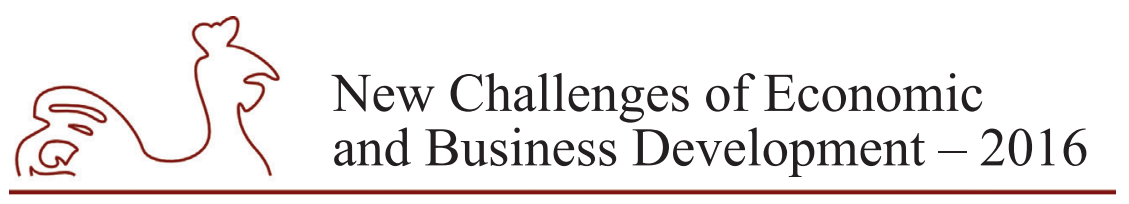

May 12-14, 2016, Riga, University of Latvia

design understanding varies considerably in the entrepreneurship sector. A comparatively higher level of awareness is in small innovative businesses, particularly craftworks. A considerable number of enterprises have eco-design understanding as a market driven issue and mainly from the point of view of cost reduction. A large part of the entrepreneurship sector is more focussed on production and technology processes and minimization of resource use, but not to the improvement of product. Biological farming was recognized as a sector with a great potential for implementing eco-design and circular economy principles, but it still lacks the understanding of the complexity of a full life cycle.

Public institutions play an important role in the implementation of a circular economy. Previous experience shows that, in general, public institutions have a positive attitude to the principles of a circular economy, but more target oriented activities and better cooperation with industries are very crucial. For example, The Ministry of Environmental Protection and Regional Development is one of the key institutions for implementing CAP targets, but they work very little with industry. Although the Ministry of Economics work with industry, CAP issues for them are of secondary importance. The State should stimulate and support research regarding environmental and health impacts of various substances when they enter the circular material supply loops. For example, if some substances are not harmful in one kind of product, they may become dangerous after recycling and be included in products which have contact with food. Promotion of research, use of expert knowledge, cooperation between state, universities and NGOs, understanding of the global perspective and promoting social responsibility of enterprises are key areas to affect a circular economy.

It is important to change society's attitude and behaviour to consumption. Some consumers believe eco-design to be an expensive extra, part of higher quality issues. As purchasing power generally is low, improved product qualities are often excluded from consideration when making a purchase. Up to now, attention has mostly been focussed on the reduction of resources and their re-use.

To increase public awareness and eco-design understanding, experts suggested:

- positive cases should have a principal role;

- formal and informal education at all levels is important, including general knowledge of chemical and biological processes;

- communication and information to society should be more effective;

- eco-labelling and information retrieving using IT possibilities could be made more attractive;

- more close cooperation with industries and increasing the role of Environmental awards;

- development of infrastructure for eco-design implementation.

The assessment of curriculum of business and economics education in three Latvian higher education establishments showed that there is a lot of room for improvement to develop competencies pointed out by experts during the interviews and discovered in the literature. The authors found out that from the nine programmes at bachelor degree level and nine programmes at master degree level there is not one study course devoted particularly to circular economy, life cycle thinking or eco-design. Amongst studied programmes, most attention to development of competencies necessary for circular economy is devoted in programmes of Riga Technical University. This could be explained by dominance of professional programmes and engineering approach. Nevertheless, there are several study courses which already have some topics and also 


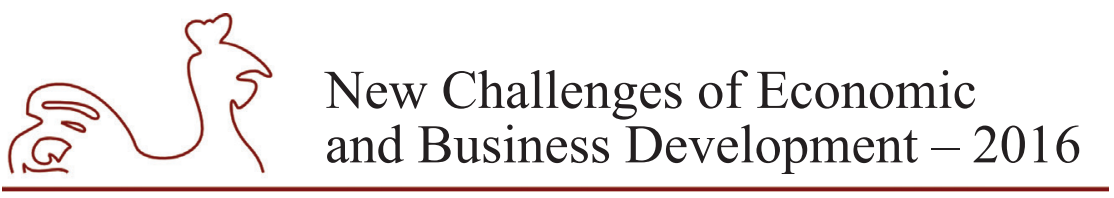

May 12-14, 2016, Riga, University of Latvia

good potential for development of necessary competencies and include circularity issues in the syllabus. Investigation revealed that quite often a publicly available description of the course does not completely disclose the real content of the course, therefore any quantitative assessment of the study programmes will not show a true picture. There is a trend to adapt study courses for implementation of circular economy, but this is rather vague. In understanding the limitations of the information available, we concluded that the focus should be put on suggestions for further development of curriculum and teaching methods in order to educate circular economy managers.

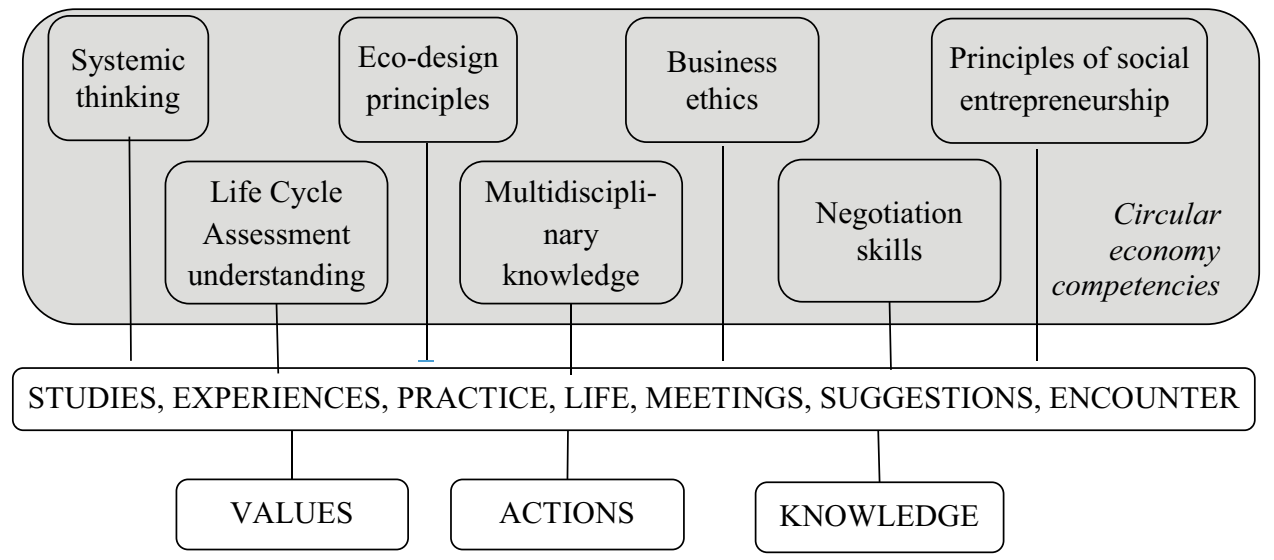

Source: author's construction based on literature studies and interviews.

\section{Fig. 1. Developing competencies for Circular Economy in business education}

In Figure 1, authors present main competencies necessary for development of circular economy and means by which these competencies could be acquired: studies of particular issues, gaining practical experience through study projects, participation in business incubators or innovation platforms, working in multidisciplinary teams and even encounter of different specialists during social activities. By putting values, actions and knowledge in the basis of competence development, authors stress important role of previous education, culture, family background and personality of students to become true implementers of circular economy.

\section{Conclusions, proposals, recommendations}

The current study provides support to research previously carried out in other countries regarding the essential competencies necessary for future entrepreneurs and managers. The authors concluded that circular economy implementation requires highly developed systems thinking and creativity skills combined with eco-design and life cycle thinking competencies, as well as the ability to work in multidisciplinary teams, long-term thinking and to pursue high ethical standards. Not only a general knowledge of science, but also an ability to cooperate with local communities and use of local knowledge is essential for solving current global problems.

In order to develop the required skills and competencies we recommend a revision of curricula in higher business and economics education study programmes, as these prepare future leaders, managers and state officials who can make a great contribution. Study programmes should include some separate study courses devoted to eco-design or life cycle approach 


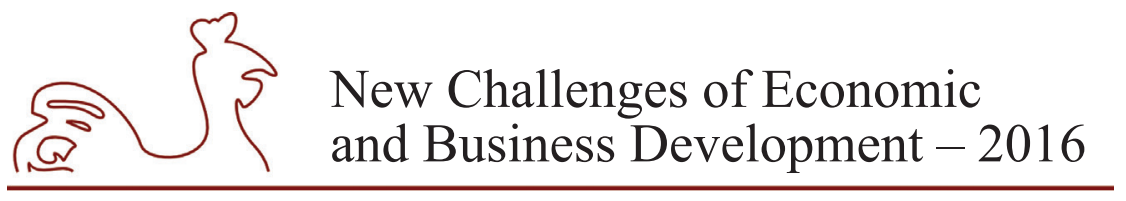

May 12-14, 2016, Riga, University of Latvia

principles and also various specific topics integrated in the existing study courses. The related topics include conscience economy; business models for a circular economy; support of IT for a circular economy; waste management principles; industrial symbiosis functioning; refurbishing, remanufacturing and redistributing products; ownership, insurance and taxation in sharing economy; carbon finance; environmental accounting; environmental voluntary instruments and others.

Teaching methods should foster students' creativity, systems thinking, proactive attitude, teamwork, long term thinking. For example, multidisciplinary study projects involving students from different faculties could enrich students' knowledge in different scientific disciplines, practice collaboration between unfamiliar team members, understanding different perspectives and defending one's opinion. Use of metaphors could help to explain the new paradigm and influence change. It is crucial that we find familiar systems with feedback loops for a better understanding and to explain how the economy, as a very complex system, works. Good examples of the use of biomimicry can help a lot to develop circularity thinking.

Furthermore, the authors propose the following support measures, which could promote the implementation of $\mathrm{CE}$ development in the country:

1) Further development of Green public procurement should have a principal catalytic impact due to promoting influence to eco-design successful implementation. Reversely, any obstacles for Green public procurement could endanger the CE development.

2) Comprehensive concordance between Ministries, especially the Ministry of Environment and Regional development and the Ministry of Economy, should be established. That is a principal precondition for life cycle thinking and circular economy based industry and business development. As circular economy concept includes both waste management and eco-design oriented industry development, they should be realized under the supervision of both Ministries.

3) Development of cooperation between state and industry, including various support measures from the state, as well as development of industry related NGO institutions.

4) Facilitation of feasibility studies and research activities and projects focused on ecodesign understanding in Latvia and necessary measures for successful eco-design development in country. Discovering and promoting successful examples of circular economy implementation in education and society in general.

\section{Bibliography}

Belmane I., 2006. Eco-design handbook (in Latvian). Riga, SIA Vides vadibas tehnologijas.

Benders J., 2007. Eco-design development in Environmental management studies (in Latvian). Acta University of Latvia. Management, Vol. 17. 1, pp. 332-341.

Benders, J., 2015. Eco-design development aspects in Latvia. 15th International Multidisciplinary Scientific GeoConference SGEM 2015. Ecology, Economics, Education and Legislation. Volume II. Bulgaria, Albena, pp. 149-156.

Blass, E. \& Hayward, P., 2015. Developing globally responsible leaders: What role for business schools in the future? Futures, Issue 66, p. 35-44.

Boulding, K., 1966. The Economics of the Coming Spaceship Earth. In: H. Jarrett, ed. Environmental Quality in a Growing Economy. Baltimore, MD: Resources for the Future/Johns Hopkins University Press, pp. pp. 3-14. 


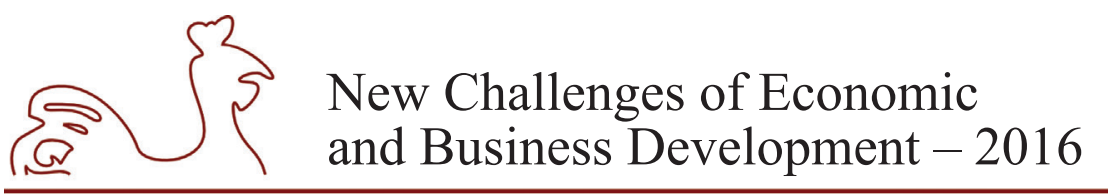

May 12-14, 2016, Riga, University of Latvia

Braungart, M., McDonough, W. \& Bollinger, A., 2007. Cradle-to-cradle design: creating healthy emissions a strategy for eco-effective product and system design. Journal of Cleaner Production, Issue 15, p. 1337-1348.

Charter, M., Young A., Kielkiewicz-Young A., Belmane I. Integrated product policy and eco-product development. In: Sustainable solutions: developing products and services for the future, Sheffield: Greenleaf, pp. 98-116, 2001.

Clark G., Kosoris J., Nguyen Hong L. and Crul M. Design for Sustainability: Current Trends in Sustainable Product Design and Development, Sustainability, Vol. 1, pp 409-424, 2009.

Commission of the European Communities, 2008. Communication from the Commission to the European Parliament, the Council, the European economic and social Committee and the Committee of the regions on the Sustainable Consumption and Production and Sustainable Industrial Policy Action Plan. Brussels: COM(2008) 397.

Commission of the European Communities, 2015. Communication from the Commission to the European Parliament, the Council, the European economic and social Committee and the Committee of the regions Closing the loop: An EU action plan for the circular economy. Brussels, COM(2015)614/F1.

Connett, P., 2006. Zero waste wins. Alternatives Journal $(A \mid J)$ - Canada's Environmental Voice, 32(1), pp. 14-15.

Danusevica, B., 2013. Eco-design Development model for Retail Industry in Latvia (in Latvian), Master Thesis. Riga: Faculty of Economics and Management, University of Latvia.

Desha, C. \& Hargroves, K., 2014. Higher Education in Urgent and Challenging Times. In: Higher Education and Sustainable Development: A Model for Curriculum. London and New York: Routledge.

Ehrenfeld, J. R., 2000. Industrial Ecology: Paradigm Shift or Normal Science? American Behavioural Scientist, Volume 44, pp. 229-244.

Ellen MacArthur Foundation, 2012. Towards the circular economy: Economic and business rationale for an accelerated transition, s.1.: Ellen MacArthur Foundation.

Ellen MacArthur Foundation, 2013Towards the Circular economy: Opportunities for the consumer goods sector, s.1.: Ellen MacArthur Foundation.

Ellen MacArthur Foundation, 2015. Delivering the circular economy - a toolkit for policymakers, s.1.: Ellen MacArthur Foundation.

European Commission, 2012. Establishment of the Working Plan 2012-2014 under the Ecodesign Directive, Brussels: European Commission.

European Environment Agency, 2016. Circular economy in Europe: Developing the knowledge base, Luxembourg: Publications Office of the European Union.

Geng, Y. \& Doberstein, B., 2008. Developing the circular economy in China: challenges and opportunities for achieving "leapfrog development". International Journal Sustainable Development and World Ecology, 15(3), pp. 37-41.

Guide, V. D. R. J., Harrison, T. P. \& Van Wassenhove, L. N., 2003. The Challenge of Closed-Loop Supply Chains. Interfaces, 33(6), pp. 3-6.

Hodgett, R., Martin, E. B., Montague, G. \& Talford, M., 2014. Handling uncertain decisions in whole process design. Production Planning \& Control: The Management of Operations, 25(12), pp. 1028-1038.

Kumar, S. \& Putnam, V., 2008. Cradle to cradle: Reverse logistics strategies and opportunities across three industry sectors. International Journal of Production Economics, 115(2), p. 305-315.

Koklacova, S., Atstaja, D., 2011. Paper and Cardboard Packaging Ecodesing and Innovative Life Cycle Solutions. Scientific Problems of Technogenic Environment Safety, Vol.1, pp 40-46.

Kopnina, H., 2014. Metaphors of Nature and Economic Development: Critical Education for Sustainable Business. Sustainability, Issue 6, pp. 7496-7513.

Lieder, M. \& Rashid, A., 2016. Towards circular economy implementation: a comprehensive review. Journal of Cleaner Production, Issue 115, pp. 36-51. 


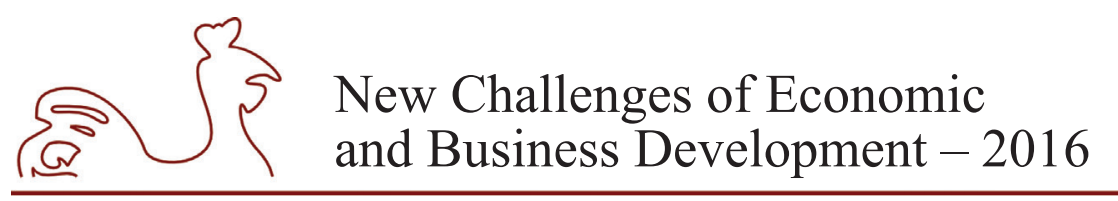

May 12-14, 2016, Riga, University of Latvia

Scheer D., Rubik F. (eds.), 2006. Governance of Integrated Product Policy. Sheffield: Greenleaf Publishing Ltd.

United Nations Environmental Programme, 2007. Life Cycle Management: A Business Guide to Sustainability, s.l. United Nations Environmental Programme.

Wolf M. de, 2014. Discussion paper: Entrepreneurial learning-topics and a didactical approach for a circular economy: creating competencies for a circular economy, Tilburg.

Yuan, Z., Bi, J. \& Moriguichi, Y., 2006. The circular economy: a new development strategy in China. Journal of Industrial Ecology, 10(1-2), pp. 4-8.

Zucika A. Eco-design Implementation Process and Development in Latvia (in Latvian), Master Thesis. UL Faculty of Economics and Management, University of Latvia, Riga, 204 pp., 2010.

Zwier, J., Blok, V., Lemmens, P. \& Geerts, R.-J., 2015. The Ideal of a Zero-Waste Humanity: Philosophical Reflections on the demand for a Bio-Based Economy. Journal of Agricultural and Environmental Ethics, 28(2), pp. 353-374. 
May 12-14, 2016, Riga, University of Latvia

\title{
ATTRACTING FDI TO THE VISEGRAD GROUP COUNTRIES
}

\author{
Tomasz Dorozynski, University of Lodz, Poland ${ }^{1}$ \\ Anetta Kuna-Marszalek, University of Lodz, Poland
}

\begin{abstract}
In the article, we have made attempt to identify factors determining the investment attractiveness of the New EU Member States using the Visegrad Group countries as examples. We engaged several groups of determinants of the investment climate connected, inter alia, with overall economic performance of the country, transport infrastructure, labour market situation, the size of the domestic market and business environment, household affluence, availability of State aid and investment incentives, IT advancement or corruption. Some of them have turned out to be statistically significant for the inflow of foreign direct investments into the Visegrad Group countries and, more broadly, to the so called new Member States of the European Union.

This study is structured as follows. First, it explores the existing literature on FDI definition and main effects of its inflow into the host country. Subsequently, we discuss the investment attractiveness and its determinants in theory and based on empirical studies. Then we discuss investment attractiveness of New Member States of the European Union in selected international rankings, paying special attention to the positions occupied by the four analysed countries. The final part studies the correlation between selected variables characteristic of investment attractiveness and the inflow of foreign investment. The study is based on statistical methods (Spearman's rank correlation and Pearson correlation). Lastly, we present the key conclusions. They demonstrated that factors important for the inflow of FDI are: infrastructure, market size, availability of suppliers, subcontractors, business partners and State aid schemes, including resources from the European Union budget.
\end{abstract}

Key words: investment attractiveness, FDI, Visegrad Group countries

JEL code: F20, F21

\section{Introduction}

The 'new' EU Member States have been attracting FDI for more than two decades. Integration with the European Union structures accelerated the dynamic development of the region and facilitated an increase in investment resources for economic and social projects, which additionally enhanced the attractiveness of FDI. We can observe this especially clearly in the countries of the Visegrad Group (V4 - the Czech Republic, Hungary, Poland, and Slovakia), which comprises an interesting collection of small open economies, all of which simultaneously embarked on systemic transformation. They offer investors a relatively good location and human resources at relatively low operational costs, and by investing in infrastructure have become attractive investment locations. Their overall security situation, related to the membership in international organizations and being a part of the European single market, is an additional asset.

Corresponding author - e-mail address: tdorozynski@uni.lodz.pl 


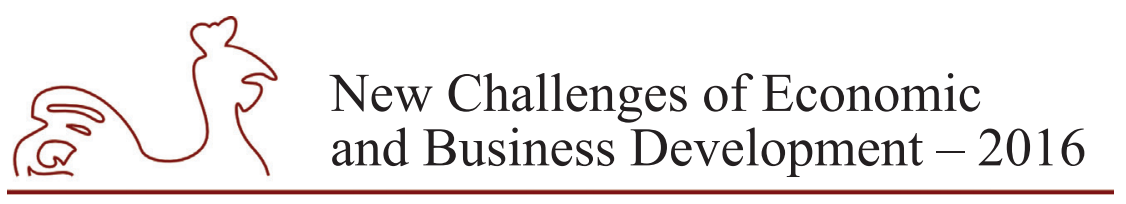

May 12-14, 2016, Riga, University of Latvia

Investors can meet their specific expectations in the V4 countries and may benefit from all sorts of allowances and preferences and boost business development.

According to the OECD definition, foreign direct investment "reflects the objective of establishing a lasting interest by a resident enterprise in one economy (direct investor) in an enterprise (direct investment enterprise) that is resident in an economy other than that of the direct investor." (OECD 2008, p. 48). FDI also covers subsequent capital flows between a parent company and the direct investment enterprise, such as reinvesting profits, net purchases of shares in the company and/or debt instruments by the direct investor, and internal borrowings from the direct investor. The usual threshold that allows a particular investment to be classified as FDI is ownership by the foreign investor of at least $10 \%$ of stock or shares of the direct investment enterprise.

Foreign direct investments are claimed to be key drivers of trade, financial stability, promotion of economic development, technological modernisation of the economy, increased well-being of societies, and international economic integration (OECD 2002). On top of that, they mobilise economic activity in less developed regions and improve economic efficiency (e.g., reduce unemployment as foreign investors create new jobs). These positive effects make countries compete for FDIs by offering favourable local conditions and investment incentives. This is especially visible in developing countries, emerging economies, and countries in transition. The exacerbated competition for capital poses the question about the factors decisive for the selection of a particular investment location, in other words, about the determinants of the investment attractiveness of a given country.

It is clear that areas attractive to investors are those which help reduce investment outlays and operating expenses, which facilitate profit maximisation and limit the potential risk of failure. This means that some regions offer advantages (connected e.g., with the size of the market, developed infrastructure, human capital, etc.) and better conditions for investment than others. The combination of location-related benefits and the specific characteristics of a particular area can be referred to as the investment attractiveness of a country or region. It is assessed by entrepreneurs using various criteria. Knowing the stimulants followed by investors enables a country or region to create a friendly investment climate conducive to attracting FDI.

Taking the above into account, we may assume that the 'investment climate' covers the entirety of actions of the FDI host country which encourage potential investors to make an investment, or discourage them from doing so. Numerous theories have sought since the 1960s to explain the determinants of FDI inflow. Some of them were based on microeconomic factors, such as organizational aspects, cost reduction, and economies of scale. Others related to macroeconomics, e.g., availability and allocation of resources, barriers to entry, political stability, market size, etc. Researchers dealing with the subject conclude that the most relevant determinants of FDI inflow into a host country usually refer to market size (e.g., Mottaleb 2007, Anyanwu 2012) and its growth rate (e.g., Mottaleb 2007, Busse, Hefeker 2007); cost of labour (e.g., Janicki, Wunnava 2004, Bellak, Leibrecht and Riedl 2008) and labour quality (e.g., Nunnenkamp 2002, Carstensen, Toubal 2004); taxes (e.g., Clausing, Dorobantu 2005, Bellak, Leibrecht 2007), special industrial parks (Guagliano, Riela 2005) and other investment incentives (Nene, Pasholli 2011, Owczarczuk 2013); infrastructure (e.g., Zhang 2001, Botric, Skuflic 2006, Mengistu, Adams 2007); openness to trade (e.g., Bhavan, Xu and Zhong 2011, Anyanwu 2012); political risk (e.g., Krifa-Schneider, Matei 2010, Asongu, Kodila-Tedika 2015); 


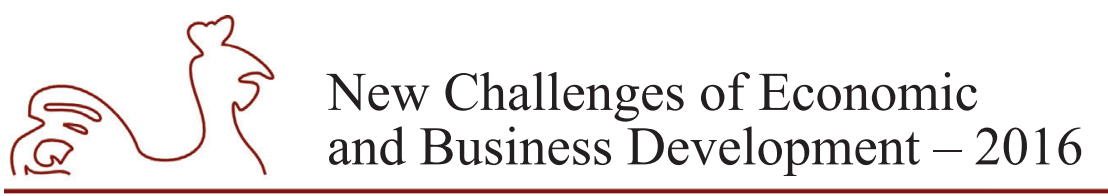

May 12-14, 2016, Riga, University of Latvia

quality of the institutional system (e.g., Du, Tao 2008, Ali, Fiess, MacDonald 2010, Bartels et al. 2014); low corruption (e.g., Mateev 2009, Castro, Nunes 2013).

As demonstrated by the above considerations, a large number of factors are decisive for investment attractiveness. Their multitude and diversity usually causes researchers narrow the research framework to several selected factors. In our study we analyse several groups of determinants of the investment climate connected, inter alia, with the overall economic performance of the country, transport infrastructure, labour market situation, the size of the domestic market and business environment, household affluence, availability of State aid and investment incentives, IT advancement, and corruption. Some of them have turned out to be statistically significant for the inflow of foreign direct investments into the Visegrad Group countries and, more broadly, to the so-called 'new' Member States of the European Union. Detailed results of our analyses are presented in the final part of the study.

\section{Rankings}

When analyzing the results of leading international rankings, we may conclude that over the last several years, including the times of crisis and economic downturn, the Visegrad Group countries have remained an attractive investment location. Studies by Ernst \& Young show that Central and Eastern Europe (CEE) is still the most attractive investment spot globally (E\&Y attractiveness survey, Europe 2015). Investors even ranked CEE ahead of Brazil, Russia and India. Countries of the Visegrad Group are popular among the countries of the CEE region, however, the attractiveness of Western Europe has increased very rapidly in recent years. Data shows that $50 \%$ of investors say Western Europe is the world's most attractive FDI destination (E\&Y attractiveness survey, Europe 2015, p. 7), while CEE is the first choice for ca. $28 \%$. The appeal of the CEE countries has diminished by 14 points since 2008 . That is most probably caused by the crisis in Ukraine and mutual sanctions imposed between Russia and the EU, which have damaged business, trade and confidence in CEE. Nevertheless, we need to stress that there has been a significant difference in the perception of the attractiveness of individual countries in the region. Even though Poland and the Czech Republic were voted the most attractive CEE countries, their overall attractiveness scores declined by six and four percentage points respectively, and they lost to, e.g., Romania (up two points) (EY's attractiveness survey, Europe 2014, p. 5).

Poland is also the leader, according to UNCTAD, when it comes to investment attractiveness. Its major competitive advantages are a large and rapidly developing internal market, an educated and flexible workforce, a stable banking system, access to international local markets, and the availability of suppliers and partners. The World Investment Report for 2014 also stresses that Poland adopted the "Programme to support investments of high importance to the Polish economy for 2011-2020", with the aim of increasing innovation and the competitiveness of the economy by promoting FDI in high-tech sectors (World Investment Report 2014, p. 113). Most probably the above-mentioned factors gave Poland, as the only member of the Visegrad Group, a place in the group of the top 15 attractive FDI locations in recent years (World Investment Report 2010, 2011, 2012, 2013, 2014).

Poland is also the only country among the Visegrad Group members included in the basket of 25 countries covered by the FDI Confidence Index. It occupied its highest ranking position - 


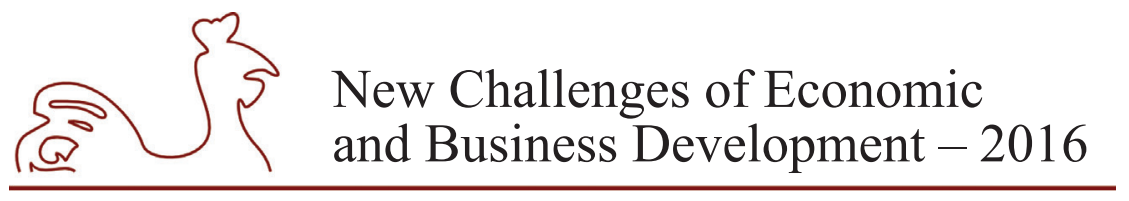

May 12-14, 2016, Riga, University of Latvia

sixth - in 2010, while in 2013 and 2015 it ranked $19^{\text {th }}$ and $23^{\text {rd }}$ respectively. In 2014 Poland dropped out of the ranking altogether. Authors of the Report highlight Poland's strategic location, large population, and economic stability as the major determinants of FDI inflow into the country. Apart from that, Poland is also likely to benefit from the substantial planned improvements of its infrastructure. In the years to come Poland will be the biggest beneficiary of EU structural funds, which will additionally stimulate regional development (A. T. Kearney, FDI Confidence Index 2015, pp. 16-17).

To sum up, we should cite the conclusions from the report of the Economist Intelligence Unit examining the business potential of the new EU Member States. It states, inter alia, that the rising labour costs in China is set to bring investors' attention back to the CEE region, especially Poland. On top of that, the gap in growth dynamics between the countries of Asia and CEE is narrowing, which additionally favours the countries of this region. The Visegrad Group countries are actively supporting their manufacturing sectors with investment incentives and special economic zones. Besides, one of the key trends is the growing importance of SMEs, which will shape the business environment in the region. Poland is considered a country with development potential in the manufacturing sector, $\mathrm{BPO} / \mathrm{SSC}$ services, and R\&D. This potential is enhanced by the highest rate of absorption of EU resources $(85 \%)$ among the new EU Member States (Economist Intelligence Unit 2015, p. 10).

\section{Examining relationships between selected determinants of investment attractiveness and FDI inflow into the new EU Member States}

As we have already mentioned in the first part of this article, investment attractiveness and the inflow of foreign direct investment to countries may result from various economic, social and territorial factors. In order to examine their relevance for the Visegrad Group countries, against the backdrop of the 13 new European Union Member States, we used Pearson correlation coefficients and Spearman's rank correlation coefficient.

In the analysis we used a series of variables which directly or indirectly determine the investment attractiveness of countries (and regions). They have been selected based on the review of the theoretical and empirical works more broadly discussed in the first part of this paper. These variables can be grouped in the following categories, which identify:

1) general economic performance of the country, e.g., GDP, GDP p.c.;

2) the labour market situation, e.g. unemployment rate, employment rate, labour productivity;

3) the development of transport infrastructure, e.g., total length of railway lines, total length of motorways;

4) the use of ICT, e.g., individuals using the internet for interacting with public authorities, computer use by individuals;

5) the size of the domestic market and business partners, expressed by the size of population, disposable income of households, and the number of enterprises;

6) the level of corruption (World Bank Aggregate Indicator: Control of Corruption);

7) the availability of EU resources under the budget for 2007-2013;

8) State aid, in particular tax allowances and support offered in special economic zones. 


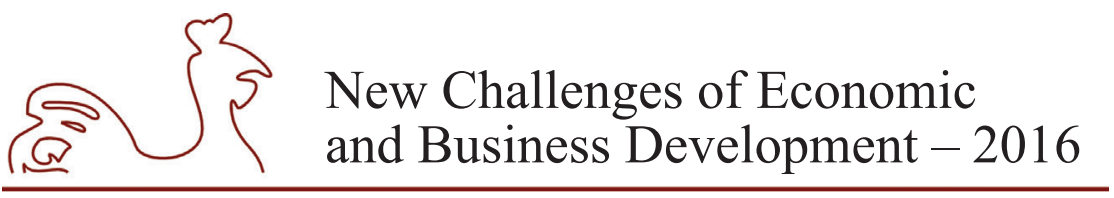

May 12-14, 2016, Riga, University of Latvia

We used data from the years 2007-2013 for the Visegrad Group countries, i.e. for Poland, the Czech Republic, Hungary and Slovakia, as well as for the nine remaining new EU Member States, i.e. for the Baltic States (Lithuania, Latvia, and Estonia) and for Romania, Bulgaria, Malta, Cyprus, Slovenia, and Croatia. Hence, the number of observations was usually thirteen, In some categories of variables it was slightly smaller due to the lack of data, especially for Malta and Cyprus. The variables were contrasted with cumulated value of foreign direct investment inflow to the above listed States at the end of 2013. The study uses data from Eurostat, UNCTAD, the World Bank, and additional data from the statistical offices of the countries included in the study.

The first step of our analysis consisted of identification of the strength of relationship between ratio variables. For that purpose we used one of the most popular correlation coefficients the Pearson correlation coefficient. Calculations were made using the SPSS software (version 14.0 PL). Results are presented in Table 1.

Table 1

Selected determinants of investment attractiveness and FDI inflow to new EU Member States Pearson correlation coefficient

\begin{tabular}{|l|c|c|c|}
\hline \multicolumn{1}{|c|}{ Independent variable } & No. of observations & $\begin{array}{c}\text { Pearson correlation } \\
\text { coefficient }\end{array}$ & $\begin{array}{c}\text { Significance } \\
\text { (p-value) }\end{array}$ \\
\hline Population & 13 & 0.927 & 0.000 \\
\hline $\begin{array}{l}\text { Number of all enterprises / } \\
\text { Number of SMEs }\end{array}$ & 13 & 0.977 & 0.000 \\
\hline EU funds 2007-2013 & 11 & 0.980 & 0.000 \\
\hline Total length of motorways & 11 & 0.618 & 0.043 \\
\hline Total length of railway lines & 9 & 0.970 & 0.000 \\
\hline Non-crisis state aid & 13 & 0.962 & 0.000 \\
\hline Tax exemptions & 13 & 0.834 & 0.000 \\
\hline
\end{tabular}

Source: authors' estimates using the SPSS software, based on UNCTAD, EUROSTAT and World Bank data.

The results in Table 1 indicate a statistically significant, strong relationship $(p=0.01)$ between selected factors which determine the investment attractiveness of the Visegrad Group countries and other new EU Member States, and the inflow of FDI. The relationship is particularly strong for variables identifying the size of internal market, State aid, investment incentives and transport infrastructure. A slightly weaker, but still statistically significant relationship, $\mathrm{p}=0.05$, was obtained for the variable representing total length of motorways. The remaining variables connected with overall economic performance, expressed in GDP and GDP per capita, variables describing the labour market, use of ICT or corruption turned out to be irrelevant for the inflow of FDI into the countries included in the study.

In the second stage of analysis we used Spearman's rank correlation coefficient, also referred to as the order correlation coefficient. It measures the strength and direction of associations between two characteristics by comparing the ranks (ranking orders) of two variables. This coefficient, unlike the Pearson correlation coefficient and linear regression, measures a wider class of relationships, showing monotonic, not necessarily linear, relationships between 


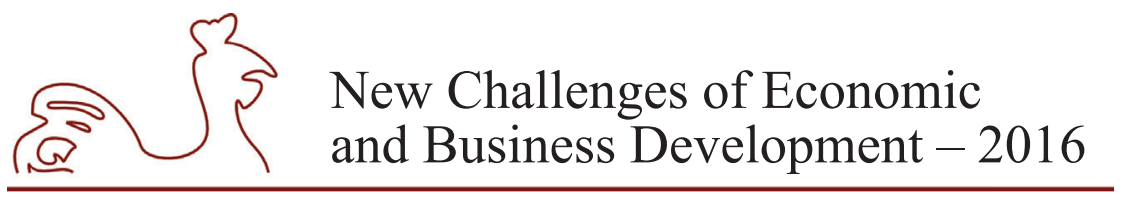

May 12-14, 2016, Riga, University of Latvia

the variables. It is also much more resilient to the presence of outliers in the sample (Sobczak 2000, pp. 249-251). Spearman's rank correlation coefficient has several versions. In our study we used the formula applied in the SPSS software (version 14.0 PL):

$$
r_{s}=\frac{\operatorname{cov}\left(R_{X}, R_{Y}\right)}{\delta_{R_{X}} \cdot \delta_{R_{Y}}}
$$

where:

$\operatorname{cov}\left(R_{X}, R_{Y}\right)$ - covariance of ranks for variables $\mathrm{X}, \mathrm{Y}$;

$\delta_{R_{X}} \cdot \delta_{R_{Y}}-$ standard deviation of ranks for variables $\mathrm{X}, \mathrm{Y}$.

The results are presented in Table 2.

Table 2

Selected determinants of investment attractiveness and FDI inflow into new EU Member States Spearman's rank correlation coefficient

\begin{tabular}{|l|c|c|c|}
\hline \multicolumn{1}{|c|}{ Independent variable } & No. of observations & $\begin{array}{c}\text { Spearman's rank } \\
\text { correlation coefficient }\left(\mathbf{r}_{\mathbf{s}}\right)\end{array}$ & Significance (p-value) \\
\hline Population & 13 & 0.890 & 0.000 \\
\hline $\begin{array}{l}\text { Number of all enterprises / } \\
\text { Number of SMEs }\end{array}$ & 13 & 0.907 & 0.000 \\
\hline EU funds 2007-2013 & 11 & 0.827 & 0.002 \\
\hline Total length of motorways & 11 & 0.618 & 0.043 \\
\hline Total length of railway lines & 9 & 0.900 & 0.001 \\
\hline Non-crisis state aid & 13 & 0.588 & 0.035 \\
\hline Tax exemptions & 13 & 0.665 & 0.013 \\
\hline
\end{tabular}

Source: authors' estimates using the SPSS software, based on UNCTAD, EUROSTAT and World Bank data.

Despite less restrictive assumptions, the results obtained in Spearman's test practically confirm those obtained when using the Pearson correlation coefficient. The relationship between FDI inflow into the Visegrad Group countries and to the remaining new EU Member States and the same determinants of investment attractiveness (size of the internal market, population of enterprises/business partners, availability of subsidies and incentives from EU resources, and the development of transport infrastructure) turned out to be significant at the level of significance 0.01 . Although absolute values were replaced with order data, we did not arrive at any significant level of ranks for any of the remaining variables. However, it is worth noting that for the Spearman's test the p-value for some variables was below the p-value for the Pearson correlation coefficient. This means a lower significance of the relationship, according to Spearman, for variables describing State aid.

In conclusion we may say that some variables used in the study significantly impact the inflow of FDI into the group of countries included in the study. A relationship was detected first and foremost in the case of certain factors that shape investment attractiveness, such as transport infrastructure, size of the domestic market, number of enterprises - potential suppliers, customers, business partners and the availability of subsidies and other forms of the EU assistance. 


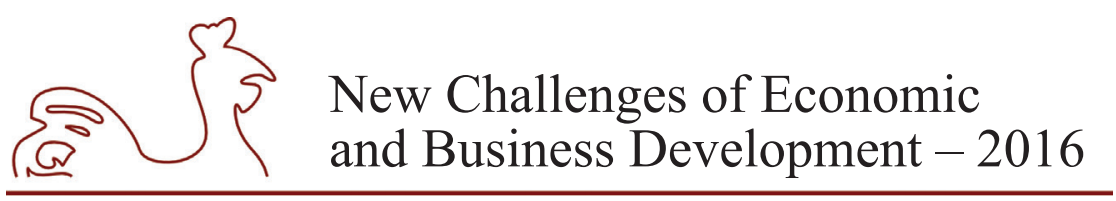

May 12-14, 2016, Riga, University of Latvia

Slightly weaker relationships with FDI inflows were identified for one of variables decisive for the development of road infrastructure, and State aid in Spearman test. Other relationships were not identified, e.g., with respect to the potential and development of countries expressed using GDP and GDP per capita.

All variables connected with the labour market proved insignificant. That should provide the basis for further and deepened quantitative analyses, especially when the earlier works of the authors who focused mainly on investment attractiveness of regions in Poland demonstrated slightly different foreign investors' preferences. Accordingly, the key factor considered by foreign investors was production costs, including labour costs and resources, but almost equally important were the conditions of running the business, such as economic and social infrastructure. State attempts to impact the choice of investment locations by differentiating the intensity of State aid and other incentives offered in, e.g., special economic zones, were usually secondary for investment decisions made by companies with foreign capital in Polish regions (Dorożyński, Świerkocki, Urbaniak 2014, 2015). The study is consistent with results of earlier works which validated the hypothesis on the existence of a statistical relationship between spending EU resources and the inflow of foreign direct investment into voivodeships in Poland (Dorożyński 2015).

\section{Conclusions}

The aim of this paper was to evaluate the investment attractiveness of the new EU Member States, using the Visegrad Group members as examples. We focused on the main determinants of the inflow of foreign direct investment to Poland, the Czech Republic, Hungary, and Slovakia. The choice of these four countries was dictated by geographic proximity, political, economic, and cultural similarities, as well as their shared experiences of economic transformation. These countries are also connected by their cooperation within the structures of the European Union, NATO, OECD, and WTO.

1. The general assessment of FDI inflow to Poland, the Czech Republic, Hungary, and Slovakia is positive. All these countries introduced significant changes, which made them attractive investment destinations.

2. This, however, should not be taken for granted. One must not forget the competition of other countries and regions in the world. Advantages based only on cheap labour and low operational costs are not enough. This means that public administration should continuously strive to improve the investment attractiveness of regions by, e.g., investing in hard and soft infrastructure.

3. The available rankings of investment attractiveness present the Visegrad Group countries as attractive prospective investment locations for FDI. Moreover, they highlight the strengths of the region, which include, inter alia, skilled labour and a quite well-developed infrastructure. Multiple assistance schemes should not be forgotten.

4. Our own studies in principle have confirmed these conclusions. They demonstrated that factors important for the inflow of foreign direct investment are: infrastructure, market size, availability of suppliers, subcontractors, business partners and State aid schemes, including resources from the European Union budget. 


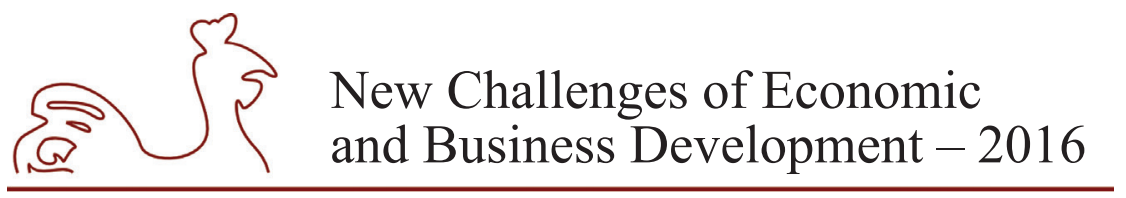

May 12-14, 2016, Riga, University of Latvia

\section{Bibliography}

A. T. Kearney, 2015. FDI Confidence Index.

Ali, F. A, Fiess N. \& Macdonald, R., 2010. Do Institutions Matter For Foreign Direct Investment. Open Economic Review. 21(2), pp. 201-219.

Anyanwu, J. C., 2012. Why Does Foreign Direct Investment Go Where It Goes? : New Evidence From African Countries. Annals Of Economics and Finance, 13(2), pp. 425-462.

Asongu, S. A. \& Kodila-Tedika, O., 2015. Conditional Determinants of FDI in Fast Emerging Economies: An Instrumental Quantile Regression Approach. African Governance and Development Institute Working Paper, 15/003, pp. 1-24.

Bartels, F. L., Napolitano, F. \& Tissi, N. E., 2014. FDI in Sub-Saharan Africa: a Longitudinal Perspective on Location-Specific Factors (2003-2010). International Business Review, 23(3), pp. 516-529.

Bellak, Ch. \& Leibrecht M., 2007. Some Further Evidence On The Role Of Effective Corporate Income Taxes As A Determinants Of Foreign Direct Investment In Central And East European Countries, Proceedings of the Annual Conference On Taxation.

Bellak, Ch., Leibrecht, M., Riedl, A., 2008. Labour Costs And FDI Inflows Into Central And Eastern European Countries: A Survey Of The Literature And Empirical Evidence. Structural Change and Economics Dynamics, 19(1), pp. 17-37.

Bhavan, T., Xu, Ch., Zhong, Ch., 2011. Determinants and Growth Effect of FDI in South Asian Economies: Evidence From a Panel Data Analysis. International Business Research, 4(1), pp. 43-50.

Botric, V., Skuflic, L., 2006. Main Determinants of Foreign Direct Investment in The Southeast European Countries. Transition Studies Review, 13(2), pp. 359-377.

Busse, M. \& Hefeker, C., 2007. Political Risk, Institutions And Foreign Direct Investment. European Journal of Political Economy, 23(2), pp. 397-415.

Carstensen, K. \& Toubal, F., 2004. Foreign Direct Investment in Central And Eastern European Countries: a Dynamic Panel Analysis. Journal of Comparative Economics, 32(1), pp. 3-22.

Castro, C. \& Nunes, P., 2013. Does Corruption Inhibit Foreign Direct Investment? Política/Revista De Ciencia Política, 51(1), pp. 89-113.

Clausing, K. A. \& Dorobantu, C. L., 2005. Re-Entering Europe: Does European Union Candidacy Boost Foreign Direct Investment? Economics of Transition, 13(1), pp. 77-103.

Dorożyński, T., 2015. Fundusze unijne a naptyw bezpośrednich inwestycji zagranicznych do Polski, [in:] Unia Europejska wobec wyzwań przyszłości. Aspekty społeczne, gospodarcze i środowiskowe, (eds.)

E. Małuszyńska, G. Mazur, P. Idczak. Poznań: Wydawnictwo Uniwersytetu Ekonomicznego w Poznaniu, pp. 163-177.

Dorożyński, T., Świerkocki, J. \& Urbaniak, W., 2014. Attracting FDI to the Region of Lodz by its Local Government. Comparative Economic Research, 17(2), pp. 101-118.

Dorożyński, T., Świerkocki, J. \& Urbaniak, W., 2015. Incentives for attracting FDI: The case of the Lodz Region. Gospodarka Narodowa, 1, pp. 147-168.

Du, J., Lu, Y. \& Tao, Z., 2008. Economic Institutions And FDI Location Choice: Evidence From US Multinationals In China. Journal of Comparative Economics, 36(3), pp. 412-429.

E\&Y Attractiveness Survey. Europe. 2015.

Economist Intelligence Unit. 2015.

Guagliano, C. \& Riela, S., 2005. Do Special Economic Areas Matter in Attracting FDI? Evidence From Poland, Hungary and Czech Republic. Working Paper ISLA, 21.

Janicki, H. P., Wunnava, P. V., 2004. Determinants Of Foreign Direct Investment: Empirical Evidence From EU Accession Candidates. Applied Economics, 36(5), pp. 505-509.

Krifa-Schneider, H. \& Matei, I., 2010. Business Climate, Political Risk And FDI In Developing Countries: Evidence From Panel Data. International Journal of Economics and Finance, 2(5), pp. 54-65. 


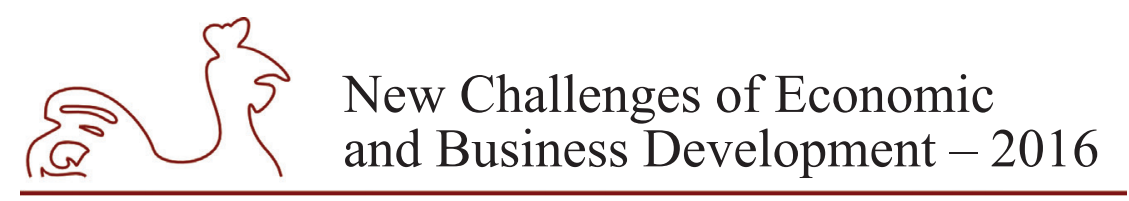

May 12-14, 2016, Riga, University of Latvia

Mateev, M., 2009. Determinants of Foreign Direct Investment in Central and Southeastern Europe: New Empirical Tests. Oxford Journal, 8(1), pp. 133-149.

Mengistu, B. \& Adams, S., 2007. Foreign Direct Investment, Governance And Economic Development In Developing Countries. Journal of Social, Political and Economic Studies, 32(2), pp. 223-249.

Mottaleb, K., 2007. Determinants Of Foreign Direct Investment And Its Impact On Economic Growth In Developing Countries. MPRA Paper, 9457, pp. 1-15.

Nene, M. \& Pasholli, A., 2011. Financial Incentives and Their Impact for Attracting FDI Survey With Foreign Investitures in Albania. Journal of Knowledge Management, Economics and Information Technology, 7, pp. 1-14.

Nunnenkamp, P., 2002. Determinants Of FDI In Developing Countries: Has Globalization Changed The Rules Of The Game? Kiel Institute For World Economics, Kiel Working Paper, 1122, pp. 1-44.

OECD. 2002. Foreign Direct Investment For Development. Maximising benefits, minimising costs.

OECD. 2011. Attractiveness for Innovation - location factors for international investment.

OECD Benchmark Definition of Foreign Direct Investment. 2008. OECD.

Owczarczuk, M., 2013. Government Incentives and FDI Inflow Into R\&D - the Case of Visegrad Countries. Entrepreneurial Business and Economics Review, 1(2), pp. 73-86.

Sobczak, M., 2000. Statystyka. Podstawy teoretyczne przyktady-zadania. Lublin: Wydawnictwo UMCS. World Investment Report 2010. 2010.

World Investment Report 2011. 2011.

World Investment Report 2012. 2012.

World Investment Report 2013. 2013.

World Investment Report 2014. 2014.

Zhang, K. H., 2001. What Attracts Foreign Multinational Corporations to China? Contemporary Economic Policy, 19(3), pp. 336-346. 


\title{
REGIONAL DIFFERENCES IN LIFE EXPECTANCY, REPORTED ACTIVITY LIMITATIONS AND CHRONIC MORBIDITY IN LATVIA DURING 2006-2014
}

\author{
Natalja Dubkova, University of Latvia, Latvia ${ }^{1}$
}

\begin{abstract}
During the last decade life expectancy from birth for males and females in Latvia has increased. The gap between genders during these years have not changed significantly and remained one of the biggest in Europe. In 2014 it amounted 10.2 years. Life expectancy at age 65 for males and females has improved by 1.3 and 1.7 years respectively compared to the year 2006. Despite the apparent improvement of the indicator, keeping in mind population aging issue special attention should be paid to the quality of life and in particular to the healthy life expectancy at pre-retirement and retirement ages. The decrease of the relative share of years spent without activity limitations to total life expectancy at age 65 for both genders emphasizes the necessity and importance of the study of mentioned indicators to evaluate the real society benefits from increasing life expectancy. Unlike other countries in Latvia life expectancy in recent years is calculated only for males and females, while information on the indicator by area and region is missing. Previous studies have shown that differences between Latvian regions in terms of life expectancy and healthy life expectancy exist. The current study aims to analyse regional differences and development trends of life expectancy and healthy life expectancy at age 65 for both genders based on activity limitations and chronic morbidity in Latvia during 2006-2014 as well as to identify Latvia's regions with the best and worst life expectancy and healthy life expectancy indicator values.
\end{abstract}

Key words: self-perceived health, activity limitations, chronic morbidity, healthy life expectancy JEL code: J10, J14, J19

\section{Introduction}

Healthy life expectancy extension is a main challenge in both Europe and the world. Population aging and related social and health care expenditure growth makes life expectancy and healthy life expectancy improvement for pre-retirement and retirement ages of a great importance.

Healthy life years in 2005 were accepted as one of the EU's structural indicators in the context of the Lisbon strategy. While the year 2012 was declared as European Year for Active Ageing and Solidarity between Generations. Numerous studies of the issue serve another evidence of the growing importance of the qualitative life especially in the elder population groups.

The general model of health transitions (WHO, 1984) shows the difference between years spent in different states: total survival, disability-free (without activity limitations) survival and survival without chronic disease (long-lasting illness). However there are as many health

Corresponding author-e-mail address: natalja.dubkova@inbox.lv 


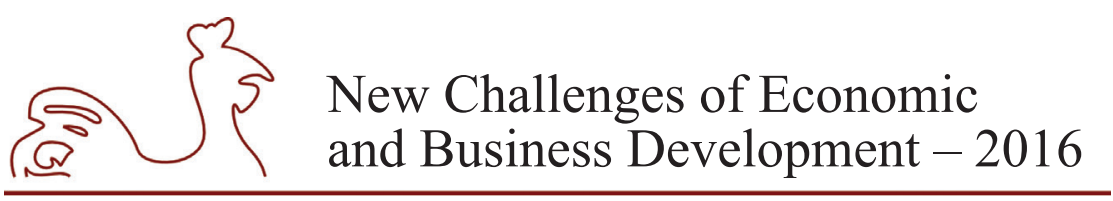

May 12-14, 2016, Riga, University of Latvia

expectancies as concepts of health. In the current study the most common approach is used health expectancies are calculated based on self-perceived health, activity limitations and long lasting illness.

In Latvia life expectancy in recent years is calculated only by gender, while information on the regional differences and moreover on the regional differences in quality of the remaining life years absents (Krumins J. et al. 1999, 2006, 2009). Such a data would help to define specific features of demographic and socio-economic development, as well as to allow for more detailed analysis of possible ways to raise quality of the life years lived.

All the regional indicators further presented and analysed are calculated by the author based on EU-SILC ${ }^{2}$ and mortality data as well as population numbers provided by Central Statistical Bureau of Latvia. Data should be compared and analysed keeping this in mind. Life expectancies were calculated from abridged life tables with Chiang (II) method which allows to handle zero deaths within an age interval for the variance calculation (Chiang, 1984, Stephens A. et al. 2013).

\section{Research results and discussion}

Previous study (Dubkova N., Krumins J., 2014, 2012) conducted for the year of Census (2011) showed that regional differences in life expectancy, healthy life years, long lasting illness free life expectancy as well as health perception in Latvia exist. Population of eastern regions of Latvia can expect to live shorter life with more years spent with long lasting illness and activity limitations. Life expectancy, healthy life years and long lasting illness free life expectancy of rural population in Latvia at all ages were found to be shorter than for those, living in urban areas (Krumins J., 2008; Dubkova N., 2014).

Taking into account the previous results but keeping in mind the impact of the sampling as well as subjective nature of the replies it was decided to evaluate presence of the regional differences at age 65 on the basis of the time series for the years 2006-2014. Sample size didn't allow splitting to both region and gender for three out of the four indicators covered by the study. Therefore for the consistency reasons all the indicators reflect both genders.

2 EU-SILC sample size in the years covered by the current research

\begin{tabular}{|l|c|c|c|c|c|c|c|c|c|}
\hline Year & $\mathbf{2 0 0 6}$ & $\mathbf{2 0 0 7}$ & $\mathbf{2 0 0 8}$ & $\mathbf{2 0 0 9}$ & $\mathbf{2 0 1 0}$ & $\mathbf{2 0 1 1}$ & $\mathbf{2 0 1 2}$ & $\mathbf{2 0 1 3}$ & $\mathbf{2 0 1 4}$ \\
\hline EU-SILC sample size & 6018 & 6717 & 7042 & 7610 & 8151 & 8463 & 8572 & 8510 & 8209 \\
\hline
\end{tabular}

Source: Central Statistical Bureau of Latvia. 


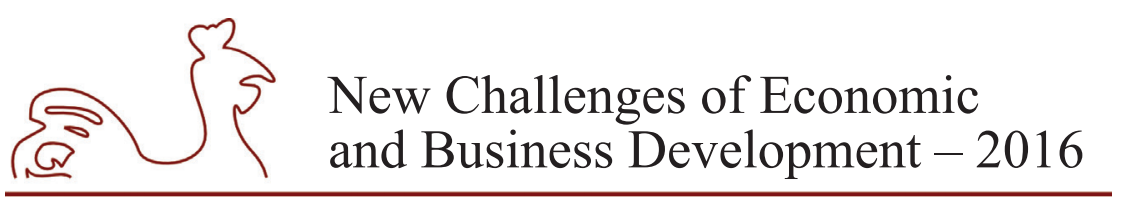

May 12-14, 2016, Riga, University of Latvia
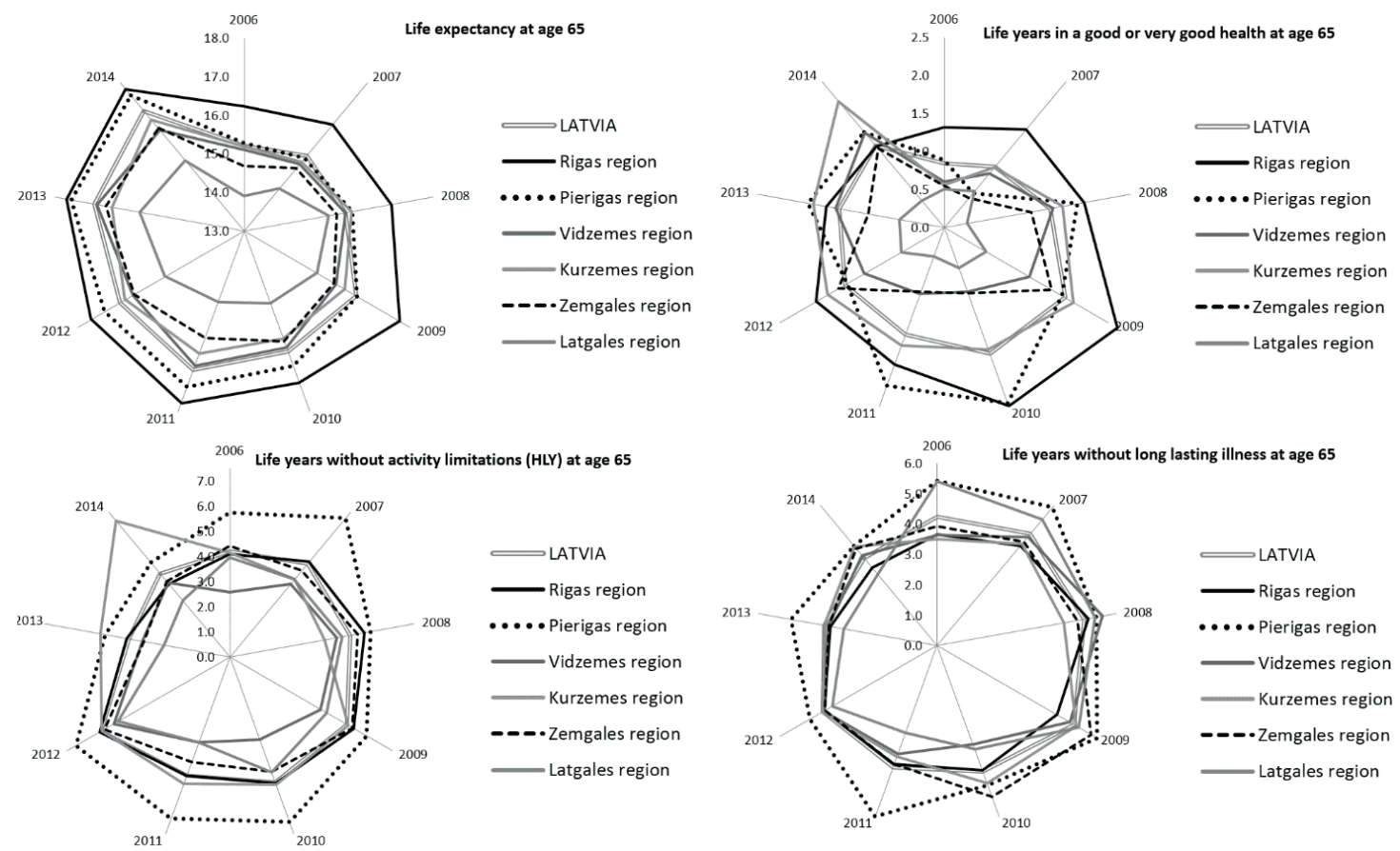

Source: author's calculations based on the data provided by the Central Statistical Bureau of Latvia.

Fig. 1. Life expectancy, Healthy life years, Long lasting illness free life expectancy, Self-perceived health for both genders at age 65 in 2006-2014 by Latvia's region

The first step performed in order to find an answer regarding the presence of regional differences was graphical presentation of the calculation results (Fig. 1). The format chosen allowed to evaluate both the development trend of each particular indicator as well as to identify regional differences. At this stage it was possible to conclude that the most stable indicator in terms of both development trend and regional differences was life expectancy. The conclusion is quite obvious taking into account absence of the subjective component in the indicator's structure. Though already at this stage significant difference from other regions demonstrated socio-economically least developed Latvia's region Latgale. For self-perceived health, healthy life years and long lasting illness free life expectancy, the differences were not so straightforward. Rigas, Pierigas and Latgales regions could be pointed out, but values and levels of the indicators as well as their development trends neither in Rigas nor Pieriegas or Latgales regions were found to show similarity or indisputable difference from other Latvia's regions. 


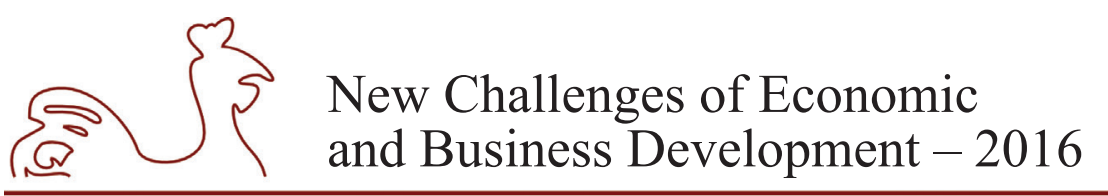

May 12-14, 2016, Riga, University of Latvia

Table 1

One-way between groups analysis of variance (ANOVA)

\begin{tabular}{|l|r|r|r|r|r|}
\hline Life expectancy & \multicolumn{1}{|c|}{$\begin{array}{c}\text { Sum of } \\
\text { Squares }\end{array}$} & df & \multicolumn{1}{c|}{$\begin{array}{c}\text { Mean } \\
\text { Square }\end{array}$} & \multicolumn{1}{c|}{ F } & \multicolumn{1}{c|}{ Sig. } \\
\hline Between Groups & 25.487 & 5 & 5.097 & 11.974 & .000 \\
Within Groups & 20.434 & 48 & .426 & & \\
Total & 45.920 & 53 & & & \\
\hline Healthy life years & & & & & .000 \\
\hline Between Groups & 32.699 & 5 & 6.540 & 9.099 & \\
Within Groups & 34.499 & 48 & .719 & & \\
Total & 67.198 & 53 & & & \\
\hline Long lasting illness free life expectancy & & & & & .015 \\
\hline Between Groups & 8.405 & 5 & 1.681 & 3.160 & \\
Within Groups & 25.532 & 48 & .532 & & \\
Total & 33.937 & 53 & & & \\
\hline Self-reported good and very good health & & & & & \\
\hline Between Groups & 10.596 & 5 & 2.119 & 11.711 & .000 \\
Within Groups & 8.686 & 48 & .181 & & \\
Total & 19.282 & 53 & & & \\
\hline
\end{tabular}

Source: author's calculations based on the data provided by the Central Statistical Bureau of Latvia.

Table 2

Tukey's HSD (honest significant difference) test

\begin{tabular}{|c|c|c|c|c|c|c|c|c|}
\hline \multicolumn{5}{|c|}{ Life expectancy } & \multicolumn{4}{|c|}{ Healthy life years } \\
\hline \multirow[b]{2}{*}{ V1 } & \multirow[b]{2}{*}{$\mathbf{N}$} & \multicolumn{3}{|c|}{ Subset for alpha $=0.05$} & \multirow[b]{2}{*}{ V1 } & \multicolumn{3}{|c|}{ Subset for alpha $=0.05$} \\
\hline & & 1 & 2 & 3 & & 1 & 2 & 3 \\
\hline \multirow{6}{*}{$\begin{array}{l}\text { Latgales region } \\
\text { Zemgales region } \\
\text { Vidzemes region } \\
\text { Kurzemes region } \\
\text { Pierigas region } \\
\text { Rigas region }\end{array}$} & 9.000 & \multirow{6}{*}{$\begin{array}{l}15.025 \\
15.817\end{array}$} & \multirow{6}{*}{$\begin{array}{l}15.817 \\
16.037 \\
16.062 \\
16.594\end{array}$} & \multirow{6}{*}{\begin{tabular}{|l|}
16.594 \\
17.263 \\
\end{tabular}} & Vidzemes region & 3.860 & & \multirow{6}{*}{$\begin{array}{l}5.174 \\
6.208\end{array}$} \\
\hline & 9.000 & & & & Latgales region & 4.028 & 4.028 & \\
\hline & 9.000 & & & & Zemgales region & 4.696 & 4.696 & \\
\hline & 9.000 & & & & Rigas region & 4.952 & 4.952 & \\
\hline & 9.000 & & & & Kurzemes region & & 5.174 & \\
\hline & 9.000 & & & & Pierigas region & & & \\
\hline Sig. & & 0.123 & 0.137 & 0.267 & & 0.087 & 0.064 & 0.120 \\
\hline \multicolumn{5}{|c|}{ Long lasting illness free life expectancy } & \multicolumn{4}{|c|}{ Self-reported good and very good health } \\
\hline \multirow[b]{2}{*}{ V1 } & \multirow[b]{2}{*}{$\mathbf{N}$} & \multicolumn{3}{|c|}{ Subset for alpha $=0.05$} & \multirow[b]{2}{*}{ V1 } & \multicolumn{3}{|c|}{ Subset for alpha $=0.05$} \\
\hline & & 1 & 2 & & & 1 & 2 & 3 \\
\hline Rigas region & 9.000 & 4.146 & & & Latgales region & 0.527 & & \\
\hline Vidzemes region & 9.000 & 4.222 & & & Zemgales region & 1.071 & 1.071 & \\
\hline Latgales region & 9.000 & 4.265 & & & Vidzemes region & & 1.156 & \\
\hline Kurzemes region & 9.000 & 4.285 & 4.2 & 85 & Kurzemes region & & 1.574 & 1.574 \\
\hline Zemgales region & 9.000 & 4.499 & 4.4 & 99 & Pierigas region & & 1.627 & 1.627 \\
\hline Latgales region & 9.000 & & 5.3 & 02 & Rigas region & & & 1.870 \\
\hline Sig. & & 0.907 & 0.0 & 51 & & 0.091 & 0.080 & 0.680 \\
\hline
\end{tabular}

Means for groups in homogeneous subsets are displayed.

a. Uses Harmonic Mean Sample Size $=9.000$.

Source: author's calculations based on the data provided by the Central Statistical Bureau of Latvia. 


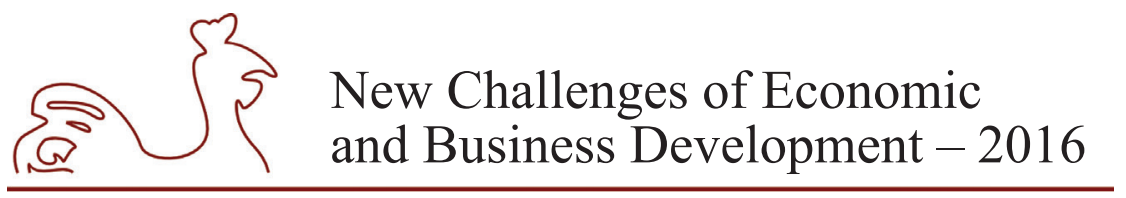

May 12-14, 2016, Riga, University of Latvia

Without prejudice to the previous study results, taking into account only the conclusions made on the basis of the visual test there was an evidence to think that regional differences do exist.

One-way between groups analysis of variance was conducted to explore the impact of the region on the life expectancy, healthy life years, long lasting illness free life expectancy and self-perceived health figures (Table 1).

The results of the analysis allowed to conclude that there are significant regional differences for all four indicators. However to define the regions with most significant deviations as well as to find out whether the "outliers" don't change by the indicator, additional tests were performed.

Post-hoc comparisons using the Tukey HSD test indicated that for life expectancy significant difference from other regions shows Rigas region and Latgales region ${ }^{3}$. While for healthy life years Pierigas region and Vidzemes region were found to be undisputable areas. For long lasting illness free life expectancy significant difference showed Pierigas region, though it should be mentioned that the indicator was the only one resulted with two not three homogeneous subsets (Table 2). After the study of the Tukey HSD test results it was possible to assume that no significant regional differences for the long lasting illness free life expectancy present. Above described regional differences could be obtained also from the discriminant analysis results which shows that on average $63.0 \%$ of original grouped cases are correctly classified. Predicted group membership for all indicators in Rigas, Vidzemes and Latgales regions had the highest rates $-77.8 \%$ (Table 3 ).

Table 3

Discriminant analysis

\begin{tabular}{|c|c|c|c|c|c|c|c|c|}
\hline \multirow[b]{2}{*}{ V1 } & & \multicolumn{6}{|c|}{ Predicted Group Membership } & \multirow[b]{2}{*}{ Total } \\
\hline & & 1 & 2 & 3 & 4 & 5 & 6 & \\
\hline & $\% 1$ Rigas region & 77.8 & 0.0 & 11.1 & 11.1 & 0.0 & 0.0 & 100.0 \\
\hline & 2 Pierigas region & 22.2 & 44.4 & 0.0 & 22.2 & 11.1 & 0.0 & 100.0 \\
\hline & 3 Vidzemes region & 0.0 & 0.0 & 77.8 & 0.0 & 11.1 & 11.1 & 100.0 \\
\hline & 4 Kurzemes region & 0.0 & 0.0 & 22.2 & 66.7 & 0.0 & 11.1 & 100.0 \\
\hline & 5 Zemgales region & 0.0 & 11.1 & 22.2 & 11.1 & 33.3 & 22.2 & 100.0 \\
\hline & 6 Latgales region & 0.0 & 0.0 & 11.1 & 0.0 & 11.1 & 77.8 & 100.0 \\
\hline
\end{tabular}

Source: author's calculations based on the data provided by the Central Statistical Bureau of Latvia.

3 The Post-hoc results are too expansive for the format of this paper therefore reference will be made to the homogeneous subsets (Table 2). 


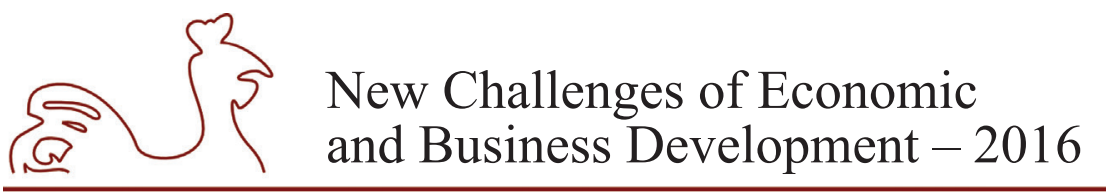

May 12-14, 2016, Riga, University of Latvia

Table 4

\section{Simple linear regression model summary}

Model Summary ${ }^{b}$

\begin{tabular}{|c|c|c|c|}
\hline Model & $\mathrm{R}$ & R Square & Std. Error of the Estimate \\
\hline 1 & $.714^{\mathrm{a}}$ & .510 & .657771659643357 \\
\hline \multicolumn{4}{|c|}{ Model Summary $^{\mathrm{c}}$} \\
\hline Model & $\mathrm{R}$ & R Square & Std. Error of the Estimate \\
\hline 1 & $.343^{\mathrm{a}}$ & .118 & 1.067797084797349 \\
\hline \multicolumn{4}{|c|}{ Model Summary $^{d}$} \\
\hline Model & $\mathrm{R}$ & R Square & Std. Error of the Estimate \\
\hline 1 & $.108^{\mathrm{a}}$ & .012 & .803141315830857 \\
\hline
\end{tabular}

Model Summary ${ }^{\mathrm{e}}$

\begin{tabular}{|c|c|c|c|}
\hline Model & $\mathrm{R}$ & R Square & Std. Error of the Estimate \\
\hline 1 & $.650^{\mathrm{a}}$ & .423 & .462538244460887 \\
\hline
\end{tabular}

a. Predictors: (Constant), Region.

b. Dependent Variable: Life expectancy.

c. Dependent Variable: Healthy life years.

d. Dependent Variable: Long lasting illness free life expectancy.

e. Dependent Variable: Self-reported good and very good health.

Source: author's calculations based on the data provided by the Central Statistical Bureau of Latvia.

The presence of the regional differences in the life expectancy, healthy life years, long lasting illness free life expectancy and self-perceived health figures was checked also within simple lineal regression models (Table 4). Model summaries showed that region is not a determining factor for the long lasting illness free life expectancy indicator values for both genders at age 65. Taking into account results of all the tests covered by the paper for the long lasting illness free life expectancy no distinct regional differences were found. Regional differences for the life expectancy indicator and self-perceived health for both genders at age 65 are the most pronounced ones and proved by all performed tests analysed throughout the paper.

\section{Conclusions}

1. Significant regional differences in life expectancy, healthy life years, as well as health perception at age 65 for both genders in Latvia exist;

2. Long lasting illness free life expectancy at age 65 for both genders doesn't depend on the Latvia's region;

3. Population of the eastern part of Latvia and in particular of Latgales region have the lowest values of the life expectancy indicator and can expect to live more years with activity limitations.

4. Significance of the regional differences as well as regions with the best and worst values for each particular indicator differs substantially. High value of the life expectancy indicator are not the necessary condition for healthier or higher valued life years and vice versa.

5. Research focused on the main determinants for the differences would give better understanding of the situation and serve as a good base for further improvements. 


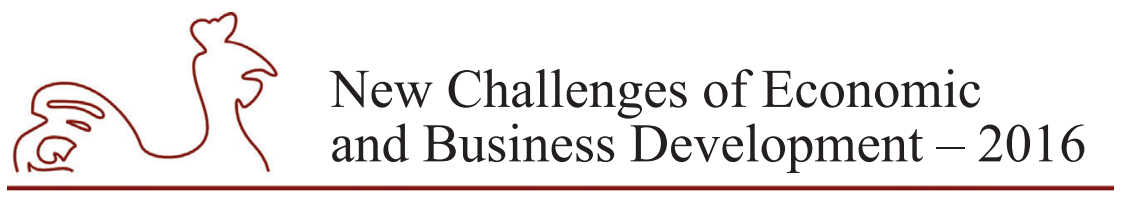

May 12-14, 2016, Riga, University of Latvia

\section{Bibliography}

Chiang C L (1984) The Life Table and its Applications, Malabar (FL), Robert E Krieger Publ Co.

Dubkova N., Regional differences in life expectancy, self-perceived health, reported activity limitations and chronic morbidity in Latvia during 2005-2012, European Association for Population studies, Budapest 2014.

Dubkova N., Krumins J. Life expectancy and health expectancy in Latvia: Changes and interpretation problems. Research papers of the Central Statistical Bureau of Latvia 2012. Riga, 2012. Pp. 21-33.

Dubkova N., Krumins J. Life expectancy and mortality changes in Latvia, Lithuania and Estonia since 1990: Comparative overview. Series of Economics and Business Administration of the Academic Papers of the University of Latvia. Riga 2011. Pp. 158-172.

Dubkova N. Changes in Mortality and Morbidity from Infectious Diseases during the Transition in the Three Baltic Countries: Comparative Study. International Conference for Doctoral Students "Current Issues in Economic and Management Sciences". Conference Proceedings. University of Latvia. Riga 2011. Pp. 165-173.

Health expectancy in Latvia. EHLEIS Country Reports - Issue 7. Full text: http://www.eurohex.eu/pdf/ CountryReports_Issue7/Latvia_Issue7.pdf

Khoman E., Weale M. Healthy life expectancy in the EU Member States: ENEPRI Research report n`33 AHEAD WP5. sl: ENEPRI; 2006.

Krumins J., Dubkova N. Life Expectancy and Mortality in the three Baltic countries during 1990-2010; Commonalities and differences; Programme and Abstracts, European Association for Population studies, Stockholm University Demography Unit, SUDA Department of Sociology, Sweden 2012. Full text: http://epc2012.princeton.edu/papers/121191

Krumins J. Health Policy and Recent Changes in Mortality and Life expectancy in Latvia. Humanities and Social Sciences: Latvia. 2008; 1 (54): 57-71.

Krumins, J., Jasilionis, D., Stankuniene, V., Meslé, F. and J. Vallin (1999) Geographical variations in mortality and causes of death in the Baltic countries. Revue Baltique, 14, 68-103.

Krumins, J., Leinsalu, M., Jasilionis, D., Stankuniene, V., Meslé, F. and J.Vallin (2006) Geographical differentials of mortality: experience of Estonia, Latvia and Lithuania over socio-political transformations. In: Mortality in countries of the former USSR. Fifteen years after break-up: change or continuity? International seminar, 12-14 October 2006. Vol. 2. Kiev, 90-119.

Krumins, J., Jasilionis, D., Leinsalu, M. and V.Stankuniene (2009) Changes of Geographical Mortality Differences in the three Baltic Countrie during the Period of Socio-Economic Transformation. XXVI International Population Conference. Marrakech, 27 September - 2 October 2009.

Jagger C., EHEMU team. Healthy life expectancy in the EU 15. In: Institut des Sciences de la Santé, editor. Living longer but healthier lives: how to achieve health gains in the elderly in the European Union Europe Blanche XXVI, Budapest, 25-26 November 2005. Paris: ISS; 2006. p. 49-62.

World Health Organization. The uses of epidemiology in the study of the elderly: Report of a WHO Scientific Group on the Epidemiology of Aging. Geneva: WHO, 1984 (Technical Report Series 706).

Alexandre S Stephens, Stuart Purdie, Baohui Yang, Helen Moore Life expectancy estimation in small administrative areas with non-uniform population sizes: application to Australian New South Wales local government areas BMJ Open 2013;3:e003710 doi:10.1136/bmjopen-2013-003710 


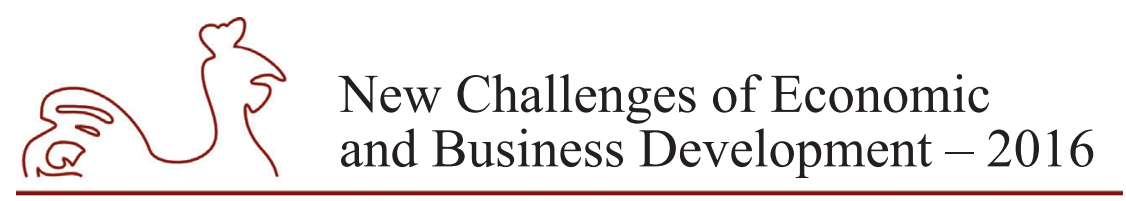

May 12-14, 2016, Riga, University of Latvia

\title{
SOCIAL DISPARITY AND CONVERGENCE PROBLEMS IN THE EU STATES
}

\author{
Elena Dubra, University of Latvia, Latvia ${ }^{1}$
}

\begin{abstract}
The purpose of this paper is to investigate social development condition and convergence evaluation in the EU-28 states in the context of the EU social policy goals. The arm of this research is to estimate social disparities and social convergence problems in the European states by applying real valuations of wellbeing situations and development challenges in the EU member states for avoid social disparities.

The research methodology is based on the European Commission legitimate documents application and socio-economic strategies, on the convergence theory and convergence scenario calculations and on the social forecasts analysis in the EU states. This research present information about different socioeconomic indicators, indexes and scheme of information's flows for convergence level estimation. This study contain objectives and general outlines of period 2014-2020 in the framework of Europe as a whole, as well its impact on the EU member states economics and living conditions. Changes of key socioeconomic concepts impact on EU convergence policy and rapidity of convergence depends on the initial discrepancy of the development level in the EU states. The efficiency of European convergence policy can also be improved by significant economic growth and by clever choice of the country-specific social activities. This research investigate major information for social situations estimations in EU states as well as GDP growth, unemployment, population's income level and different welfare indicators.

The main results reflect the overall social situation valuation in the EU countries and present European convergence policy's impact on social development in the European states. The conclusions contain socioeconomic situations appreciation in the context of European social strategy goals and social inequality problems clarification in the EU states.
\end{abstract}

Key words: Social disparity, EU strategy, convergence, cohesion

JEL codes: A130, E130, I380, F630

\section{Introduction}

European convergence policy is a place-based policy which gives a role to each European state in the sense that it is not an obstacle to the optimal allocation of economic activity but can become a source of growth on its own. Recent economic theory confirms this approach in numerous case studies which show that convergence policy can make a difference. In fact, the EU has achieved impressive economic and social convergence.

The passing decade has emphasised the fight against poverty and exclusion, particularly within the EU strategy and its economic, social and environmental pillars. It set the challenge of making Europe "the most competitive and dynamic knowledge-based economy in the world, capable of sustainable economic growth with more and better jobs and greater social cohesion" and included modernization of the European social model, investing in people, and combating

1 Corresponding author - e-mail address:elena.dubra@lu.lv 


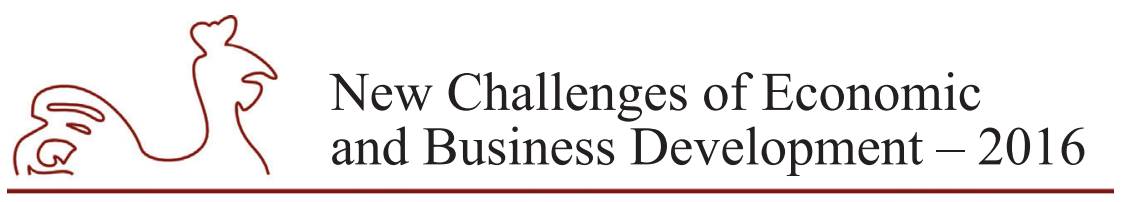

May 12-14, 2016, Riga, University of Latvia

social exclusion. "Europe 2020" strategy includes the Platform against Poverty and Social Exclusion and the Agenda for New Skills and Jobs. Through its Social Investment Package, the Commission provides guidance to member states to modernise their welfare systems towards social investment throughout life. The package complements: the Employment Package, which sets out the way forward for a job rich recovery; White Paper on Pensions, presenting a strategy for adequate, sustainable and safe pensions; and Youth Employment Package, which deals specifically with the situation of young people. This means in particular that labour markets and welfare systems need to function well and be sustainable in all euro area member states. Better labour market and social performance, as well as social cohesion should be at the core of the new process of social convergence (European Commission, 2010. "Europe 2020”).

The European strategy must ensure that policies are ranked with respect to their effects on short and long-term growth, employment and income distribution, social impact and fiscal sustainability. Evidence shows that fiscal consolidation instruments can have vastly different impact on equity and growth - such is the case of cuts in education, healthcare and family policy. For future's social development investigations and governmental decisions needs to be pragmatic approach into financing in order to create employment and reduce poverty level and social disparities in the national economy.

European national economies strategies have been related to the influence of several internal and external factors and EU convergence process can guarantee political stability and sufficiently consistent implementation of economic and social development. Taking into account the actual socio-economic problems in the EU countries European cohesion policy should provide more attention for countries with minimum income level and high income's disparity with target to reduce unequalities between EU countries and contribute social situation improvement in the EU states.

\section{Research results and discution}

\section{European social and convergence policies concepts}

The social policies are an integral part of the "Europe 2020" Strategy and European Commission also supports EU countries efforts to address their social challenges through the actions foreseen in the Platform against Poverty and Social Exclusion and Social Investment Package as well as the EU funds, in particular the European Social Fund. The Commission works together with EU countries through the Social Protection Committee using the Open Method of Co-ordination in the areas of social inclusion, health care and long-term care and pensions (social OMC). However this is a voluntary process for political cooperation based on agreeing common objectives and measuring progress towards these goals using common indicators. The process also involves close co-operation with stakeholders, including social partners and civil society (The Social protection committee, 2011).

European social policy priorities are already part of the European strategy, but they tend to be of a more generic nature in comparison to fiscal policy recommendations, which have specific numerical targets. The crisis pressured EU member states to pursue budget consolidation, which often led to indiscriminate cuts in social welfare systems as well as inordinate tax hikes on the working population. 


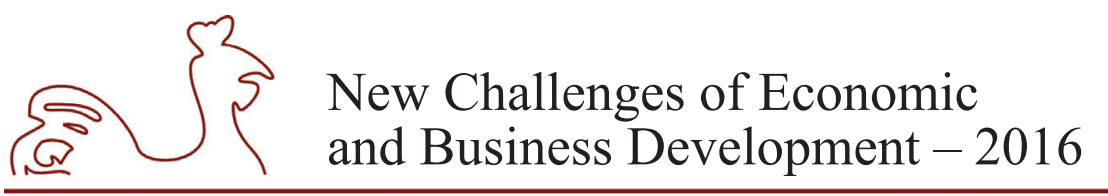

May 12-14, 2016, Riga, University of Latvia

In general, EU needs to augment the use of social indicators to better assess economic impact, both in the short- and long-term. The interplay between social and economic indicators can also serve as a tool to discourage countries from enacting indiscriminate cuts because it is the easiest way to bring budgets in line in the short-run, without understanding the scarring implications over time.

The forecasts and opinion of the socio-economic situation in EU states and its development analysis concerning issues of national policy improvement. The information's flows for national convergence level estimation is outlined in Figure 1. The basic directions of the socio- economic policy for the achievement of the established objectives and convergence are as follows:

- To reach macroeconomic stability;

- To create favourable preconditions for economic activities;

- To stimulate effective growth of national economy;

- To reduce social and economic disparities and ensure sustainable development.

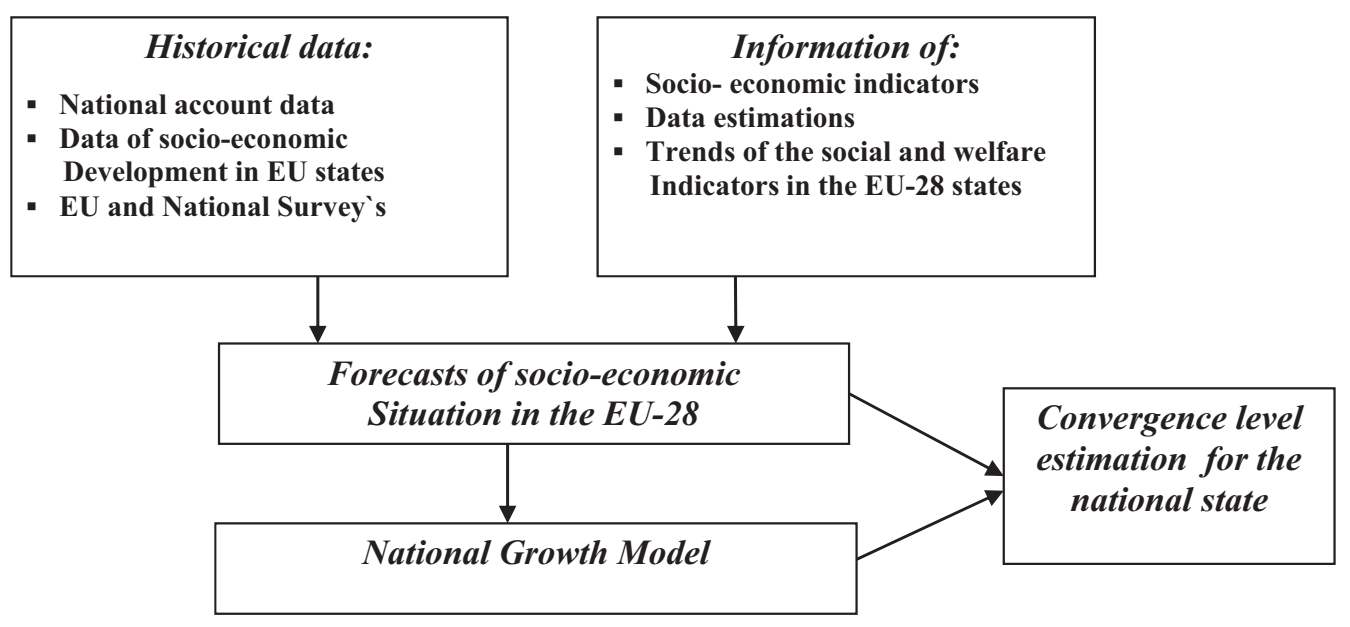

Source: author's construction based on forecasting theory.

Fig. 1. Scheme of information's flows for convergence level estimation

The social conditions and employees also become more and more aware of the possibilities offered by the global market. It requires not only a structure of national social models but also a discussion on the strategic choice of countries concerning the social policy. The social structure undergoes not only quantitative changes but also qualitative changes decreasing disproportions between the social indicators of national economy, which generates a range of problems in implementing national social development programmes. Development of social processes in the EU states to a large extent connected with guidelines of strategic documents of national economy development and social situation in the countries, reflecting goals and tasks defined by EU programmatic documents for the areas of social development in the EU states.

European convergence policy is an EU development policy. Convergence process in EU is trying providing recommendations for the future development with target to achieve socioeconomic well-being in the European states. 


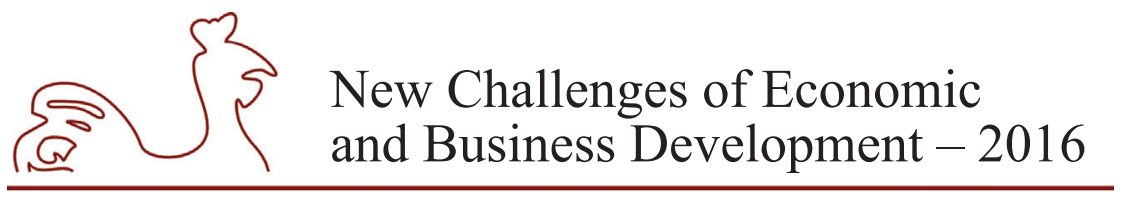

May 12-14, 2016, Riga, University of Latvia

The neo-classical theories of growth generate real social convergence. The standard growth model incorporate major factors of production and capital flows which influence on economy as long-term strategic scenario. National socio-economic growth model targets and forecasts are formulated by main priorities attainment for economy and social policy. Trends for the recent years are taken as socio-economic situation development strategy of the EU states which can be used for social estimation as income's and pension's policy improvement, labour market and education system optimization

Economic literature suggests that the term convergence in its economic essence describes gradual elimination of disparities in the income level. Economic growth theory provides two types of the convergence: $\sigma$-convergence (sigma) and $\beta$-convergence (beta) (Barro, Sala-iMartin, 2004).

The first kind serves as an indicator to measure weather the distribution of income across regions or countries has become less uneven over time. In contrast, $\beta$-convergence, attempts to describe the mobility of income within the same distribution and predominantly serves to find out whether the convergence occurred because poorer regions and/or countries have grown faster than the rest.

The results from convergence analysis are usually used to test the validity of the two economic growth models- neo-classical and endogenous. The former one predicts $\beta$-convergence scenario. Convergence reflects the measure of progress, while Catching-up convergence regardless full, partial or absence of the capital mobility (Marzinotto B., 2012).

The Catching-up rate is calculated by means of the historical actual growth rate. It gives a framework for ex-post analysis of the catch-up dynamism. In the case of negative catch-up rates the disparity between the country concerned and the EU average decreases, while the positive catch-up rate shows the increase of this difference. The negative rate indicates that there has been a reduction in the GDP gap between new member states and average GDP per capita of the EU-28. The positive catch up rate shows the actual growth of the rate.

The relationship between GDP growth and the level of income is considered as $\beta$ - measures the distance to be travelled. The pace of Catching-up usually relates to $\beta$-convergence and is expressed as a Catching -up rate $\left(\mathrm{R}_{\text {Catch-up }}\right)$. For convergence estimation used new measure how to calculate country's convergence of compared to average EU-28 level (Halmai P., Vasary V., 2010):

$$
R_{\text {Catch-up }}=100 \cdot \frac{\Delta\left(y_{i t}-y_{t}^{*}\right)}{\left(y_{i t-1}-y_{t-1}^{*}\right)}
$$

In the equation:

$\mathbf{y}_{\mathbf{i t}}$ - reflect the level of GDP per capita as PPS for country $i$ at a time $t$;

$\mathbf{y}_{\mathbf{t}}{ }^{*}$ - is the average for the $\mathrm{y}_{\mathrm{t}}$ of EU-28;

$\Delta$ - indicates the difference between $\mathrm{t}$ and $\mathrm{t}-1$;

$\mathbf{y}_{\mathbf{t}}{ }^{*}-$ is the weighted average of the EU-28.

Convergence policy must be connected with a judgement of the likely future evolution of the national economy and it depends on a member state's domestic policy orientations after it has joined the euro area. Convergence processes for the EU states must be based on the strong socio- economic development and GDP, investment flows, new technologies and productivity 


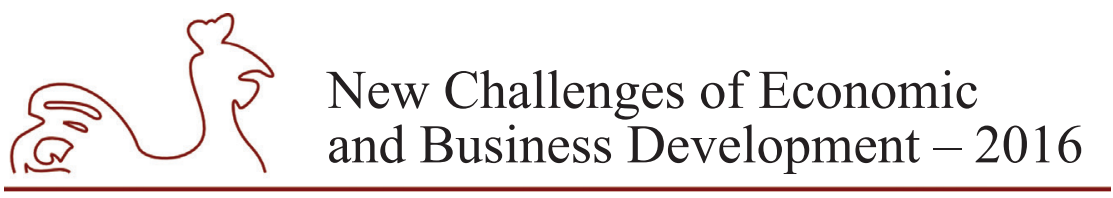

May 12-14, 2016, Riga, University of Latvia

growth. Trends of the recent years of development of EU-28 economy, which shows steady GDP growth require social legislation improvement, income's growth, education system and labour market development.

Using $\beta$-convergence scenario by formula (1) and European statistics forecasts in 20162017 the main calculations show that GDP growth and current economic situation improved in EU at whole and especial in Ireland, Latvia, Estonia, Lithuania, Slovakia, Poland and Romania. Nevertheless significant differences in levels between member countries continued to influence the current economic situation negatively. In several member states were significantly scaled back especially in Italy, France, Portugal and Finland. The GDP growth outlook for the next two years in the EU-28 increased slightly to an annual from 2.0 percent to 2.1 percent in 2020 .

Convergence processes for the EU states must be based on the strong economic growth of GDP per capita. Euro area real GDP is forecast to grow by $1.6 \%$ in 2015 , rising to $1.8 \%$ in 2016 and $1.9 \%$ in 2017 . For the EU as a whole, real GDP is expected to rise from $1.9 \%$ this year to $2.0 \%$ in 2016 and $2.1 \%$ in 2017 (European Commission data, 2015).

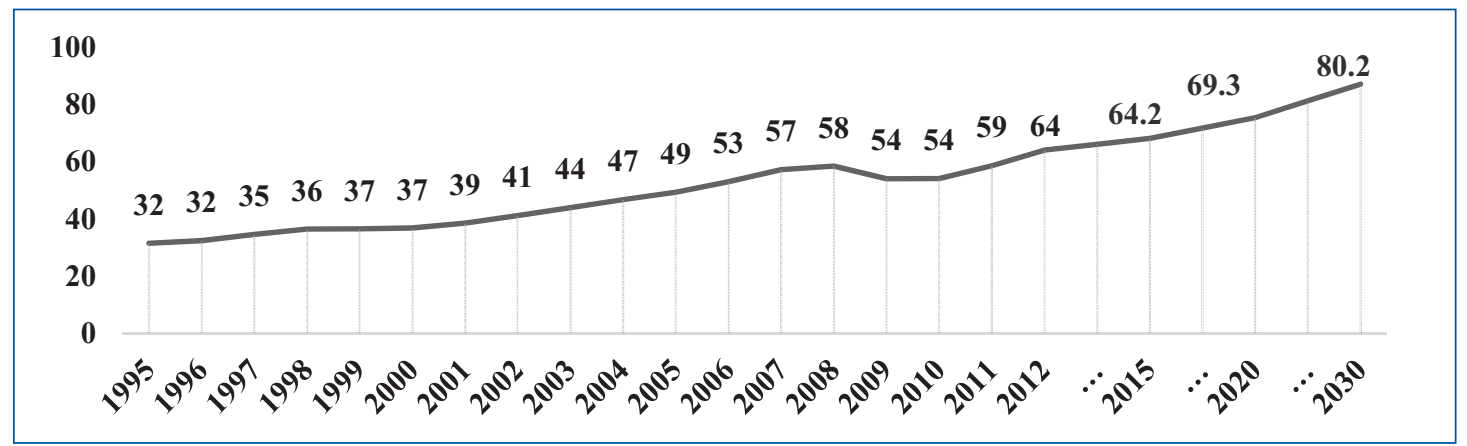

Source: author's construction based on convergence theory and Eurostat, 2014, Income and living conditions database. http://epp.eurostat.ec.europa.eu/portal/page/portal/income_social_inclusion_living_conditions/data/database.

Fig. 2. Differences between development of Latvia's GDP and EU-28 GDP

For example, the situation in the social policy in Latvia continues improving. Latvia's economy growth is projected to increase from $2.4 \%$ in 2015 to $3 \%$ in 2016 and $3.3 \%$ in 2017 as domestic demand improves.

According to author's calculation based on methodological framework of latest $\beta$-convergence scenario convergence theories, the level of Latvia's GDP per capita compared to EU-28 in 2015 was $64.2 \%$ and will increase up to $69.3 \%$ in 2020 and up to $80.2 \%$ in 2030 (see Figure 2).

Domestic demand is projected to be the main growth driver over the forecast horizon and private consumption is supported by steadily rising income growth. Risks to the GDP forecast are related to the government's ability to deliver on the revenue measures, unexpected spending pressures and overruns, as well as the uncertain growth outlook (European Commission - Press release, 2015).

The process of real economic convergence suggests Catching- up in standards of living in new member states with those of the old EU member states and describes gradual elimination of disparities in the income level. Catching-up and convergence process in the European Union 


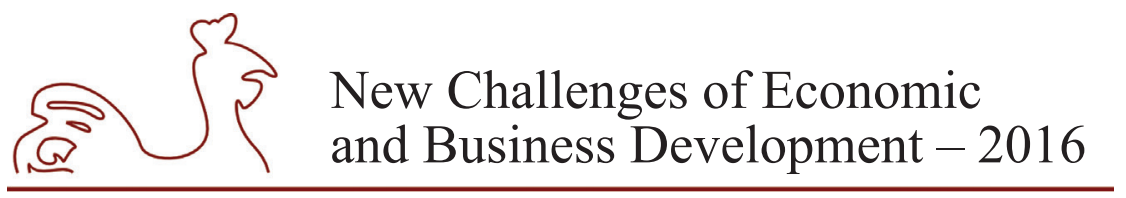

May 12-14, 2016, Riga, University of Latvia

is based on economic growth. This process, however, is usually accompanied by a rise in price levels, which is known as nominal convergence. The inverse relationship between growth and the level of income is considered $\beta$ - convergence scenario. If this factor is present, poorer countries get closer to the richer ones.

\section{Measurements of social disparity in the EU states}

Term social disparity is a multi-faceted phenomenon, which can have various origins and causes. According to Eurostat definitions and explanations term inequality refers to disparities in the distribution of monetary resources within or between populations. Socio-economic inequality has been rising in most EU countries over the past ten years. Europe, as part of the "Europe 2020" strategy, has committed itself to lifting 20 million Europeans out of poverty and inequality, which is interconnected with poverty and social exclusion.

The main principle for living standards growing and welfare increasing can defined as observance real proportions between indicators of productivity, wages and inflation's annual growth. Social conditions determined by the national economy development level, the number of population and level of urbanization, the geographical location, availability of infrastructure.

The social situation is influenced by the GDP level, economic structure of the national economy, which is determined by products offered by sectors and the total consumer's income and demand levels, labour force skills and education, but also a discussion on the strategic choice of countries socio-economic policy. Social standards can be compared by measuring the price of a range of goods and services in each country relative to income, using a common national currency called the purchasing power standard (PPS).

Table 1

GDP per capita in the EU countries (GDP in PPS EU-28 = 100, \%, 2015

\begin{tabular}{|c|l|l|c|}
\hline GDP per capita in PPS & \multicolumn{1}{|c|}{ Country } & \multicolumn{1}{c|}{ Country } & GDP per capita in PPS \\
\hline 45 & Cyprus (CY) & Bulgaria (BG) & 85 \\
\hline 54 & Spain (ES) & Romania (RO) & 93 \\
\hline 64 & Italy (IT) & Latvia (LV) & 97 \\
\hline 59 & United Kingdom (UK) & Croatia (HR) & 108 \\
\hline 68 & France (FR) & Poland (PL) & 110 \\
\hline 68 & Finland (FI) & Hungary (HU) & 119 \\
\hline 74 & Belgium (BE) & Lithuania (LT) & 124 \\
\hline 73 & Germany (GE) & Estonia (EE) & 124 \\
\hline 76 & Sweden (SE) & Slovakia (SK) & 124 \\
\hline 78 & Denmark (DK) & Portugal (PT) & 132 \\
\hline 72 & Ireland (IL) & Greece (EL) & 130 \\
\hline 84 & Netherlands (NL) & Czech Republic (CZ) & 128 \\
\hline 83 & Austria (AT) & Slovenia (SI) & 263 \\
\hline 85 & Luxembourg (LU) & Malta (MT) & 2015 \\
\hline
\end{tabular}

Source: calculation based on Eurostat and European Commission data 2015. European Forecast Autumn 2015. htpp://europa.eu/rapid/press-release, htpp://ec.europa.eu/eurostat/tgm/table, 2015. 


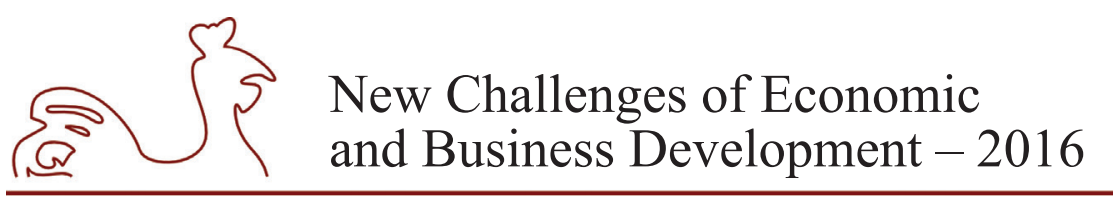

May 12-14, 2016, Riga, University of Latvia

Comparing GDP per capita in PPS provides an overview of living standards across the EU. The EU strives to improve living standards by protecting the environment, encouraging job creation, reducing regional disparities and connecting formerly isolated areas by developing cross-border infrastructure. This indicates the need for more structural reform to remove rigidities in the allocations of resources, which is essential in order to raise living standards. The real situation in EU states by main convergence indicator as the GDP per capita last years can illustrate in Table 1.

The convergence in the EU during the past decades showed a relatively steady pace. The social situation is influenced by the GDP level, economic structure of the national economy, the total consumer's income and demand levels, labour force skills and education. At the same time future projection shall be based on the GDP potential growth rate, but now forecasts of social development based of GDP per capita at purchasing power standard.

In EU much attention is currently being paid to the consequences of inequality, such as poverty and lack of social cohesion, and policy interventions generally tend to focus on how to redress these outcomes through tax instruments instead of addressing the underlying causes. However, relying solely on taxing more and spending more can only be a temporary measure, which is not a solution to redress inequality in the long- run. The EU strives to improve living standards by protecting the environment, job creation, reducing regional social disparities. Progress supports policy development work in fallowing five areas: 1) employment, 2) social inclusion and social protection, 3) working conditions, 4) anti-discrimination, 5) gender equality.

The disparity can be defined and measured as specific resource is distributed across the whole society, while economic inequality means primarily differences in earnings and incomes, social inequality relates to differences in access to social commodities including education and health care, but also social and institutional networks. The multidimensional term social exclusion relating many spheres:

In economic field - livelihoods, employment, housing, property, poverty and material deprivation;

In social field - education, health, personal contacts, respect;

In political field - civic engagement, citizenship, migration.

While the EU has a clear role, and competences, in reducing EU-wide inequality, still reducing inequality at national level within EU countries is a precondition for reducing European inequality. This might be a sign that tackling inequality has not featured prominently enough on the policy agenda and that social policies have not been efficient enough to redress the persistent tendency towards a worsening of inequality.

Income or earnings disparity is moderated by social transfers, taxes and benefits but these redistributive mechanisms have not prevented income inequality from rising over the past decades. One of the reasons for such an increase may also be that moving from household earnings to market income requires broadening the analysis to include self-employment and capital income, where the concentration among individuals is generally much higher than that of household earnings.

The national minimum wages on $\mathbf{2 0 1 5}$ of the EU-28 member states was ranged from $€ 194$ per month in Bulgaria to $€ 1923$ in Luxembourg. However, when adjusted for differences in purchasing power, the disparities between EU states are reduced from a ratio of $\mathbf{1}$ to $\mathbf{1 0}$ in euro to a ratio of $\mathbf{1}$ to $\mathbf{4}$ in purchasing power standards PPS (see Table 2). 


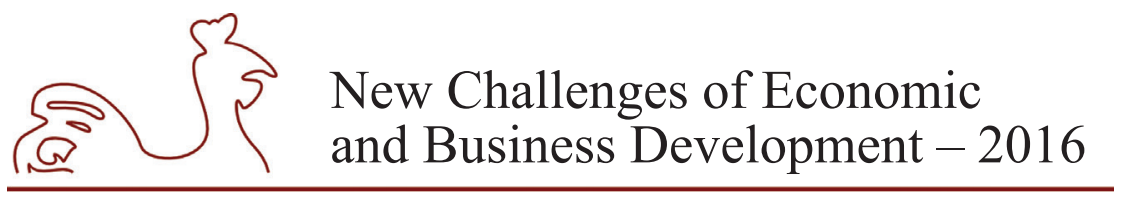

May 12-14, 2016, Riga, University of Latvia

Table 2

Monthly minimum wages in the EU countries 2015, euro

\begin{tabular}{|l|c|l|c|}
\hline \multicolumn{1}{|c|}{ Country } & $\begin{array}{c}\text { Monthly minimum wage, } \\
\text { euro }\end{array}$ & \multicolumn{1}{c|}{ Country } & $\begin{array}{c}\text { Monthly minimum wage, } \\
\text { euro }\end{array}$ \\
\hline Bulgaria (BG) & 194.2 & Greece (EL) & 683.7 \\
\hline Romania (RO) & 234.7 & Malta (MT) & 720.4 \\
\hline Lithuania (LT) & 325.0 & Spain (ES) & 756.7 \\
\hline Latvia (LV) & 360.0 & Slovenia (SI) & 790.9 \\
\hline Croatia (HR) & 398.9 & France (FR) & 1457.5 \\
\hline Hungary (HU) & 333.4 & Ireland (IL) & 1461.8 \\
\hline Czech Republic (CZ) & 337.5 & Germany (GE) & 1473.0 \\
\hline Slovakia (SK) & 380.0 & Belgium & 1501.8 \\
\hline Estonia (EE) & 390.0 & Netherlands (NL) & 1507.8 \\
\hline Poland (PL) & 417.5 & United Kingdom (UK) & 1509.7 \\
\hline Portugal (PT) & 589.1 & Luxembourg (LU) & 1922.9 \\
\hline
\end{tabular}

Source: calculation based on Eurostat and European Commission data 2015. European Forecast Autumn 2015.

htpp://europa.eu/rapid/press-release, htpp://ec.europa.eu/eurostat/tgm/table, 2015.

The Gini coefficient captures differences in inequality in household incomes over time or between different regions and countries. It ranges between 0 (absence of inequality) and 1 (total inequality); - quintile ratios measure disparities in earnings between high and low paid workers. Frequently used are the $80 / 20$ quintile ratio, which contrasts the top $20 \%$ of earners with the lowest $20 \%$. The gap between rich and poor, which is usually measured as the ratio of the top $20 \%$ of the population to the bottom $20 \%$ on the income scale, has been steadily growing: from a ratio of 4.8 in 2008 to 7.2 in 2015 across the EU as a whole (European Commission data, 2015).

Socio-economic inequality refers to disparities in a range of economic and social resources that have an impact on individuals' well-being, such as income, education and health. In nutshell, The EU uses an "at-risk of poverty" measure, defined as "those living below $60 \%$ national median equalised disposable income", as not all those with low incomes are necessarily poor. The unit of measurement is households adjusted for household size: equalised incomes are defined as the household's total disposable income divided by its "equivalent size". Europe, as part of the Europe 2020 Strategy, has committed itself to lifting 20 million Europeans out of poverty which is interconnected with poverty and social exclusion: the more unequal a society is, the more widespread poverty and social exclusion tend to be.

European statistics show that in $201524.5 \%$ or 121952000 people of all the EU population are at risk of poverty or social exclusion and this includes $27.6 \%$ of all children in Europe, $18.3 \%$ of those is over 65 age old and $25.3 \%$ of adults (see Table 3 ).

The at-risk-of-poverty rate or the share of the population below the poverty line increased during the period when the total income of the population was increasing substantially and the unemployment rate was comparatively low.

It means that the increase in income of the population was unequal and not all people were able to adapt to the changes and benefit from the growth opportunities. Poverty and social exclusion among those of working age (18-64 years) have increased significantly in two thirds of EU member states as a combined result of rising levels of unemployment and in-work poverty. 


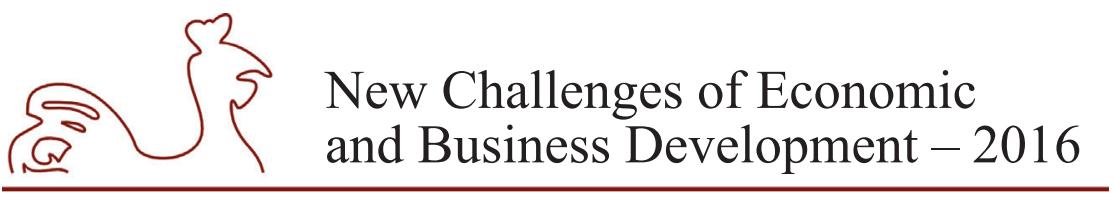

May 12-14, 2016, Riga, University of Latvia

The likelihood of entering into and exiting from poverty varies greatly across EU member states. In some countries a significant proportion of the population is trapped in persistent poverty, while in others they succeed in escaping poverty but often only temporarily.

Table 3

The at-risk-of-poverty rate or social exclusion in the EU states

(\% of total population, 2015)

\begin{tabular}{|l|l|l|c|}
\hline \multicolumn{1}{|c|}{ Country } & & \multicolumn{1}{c|}{ Country } & \\
\hline Bulgaria (BG) & 40.1 & Cyprus (CY) & 27.8 \\
\hline Romania (RO) & 40.4 & Spain (ES) & 27.3 \\
\hline Latvia (LV) & 35.1 & Italy (IT) & 28.4 \\
\hline Croatia (HR) & 29.9 & United Kingdom & 18.8 \\
\hline Poland (PL) & 25.8 & France (FR) & 16.0 \\
\hline Hungary (HU) & 33.5 & Finland (FI) & 20.8 \\
\hline Lithuania (LT) & 30.8 & Belgium (BE) & 20.3 \\
\hline Estonia (EE) & 23.5 & Germany (GE) & 16.4 \\
\hline Slovakia (SK) & 19.8 & Sweden (SE) & 18.9 \\
\hline Portugal (PT) & 27.4 & Denmark (DK) & 30.0 \\
\hline Greece (EL) & 35.7 & Ireland (IL) & 15.9 \\
\hline Czech Rebublic (CZ) & 14.6 & Netherlands (NL) & 18.8 \\
\hline Slovenia (SI) & 20.4 & Austria (AT) & 19.0 \\
\hline Malta (MT) & 24.0 & Luxembourg (LU) & \\
\hline
\end{tabular}

Source: calculation based on Eurostat and European Commission data 2015. European Forecast Autumn 2015, htpp://ec.europa.eu/eurostat/tgm/table. htpp://europa.eu/rapid/press-release, 2015.

Available data show that social mobility varies significantly across EU countries. For example, the UK is highly unequal but also mobile, while in Germany there is mobility but only within the original socio-economic group, making it hard to move from a lower to a higher category.

Not coincidentally, the recent financial crisis proved that countries with more dynamic and inclusive labour markets - as well as a better skilled labour force and interventionist social systems - are more resilient: they better withstand shocks and recover more quickly.

Increasing in the private consumption will depend on changes in personal income. The social and personal income taxes in EU is planned to be gradually decreased from 2016 and this changes can to increase personal incomes and fostering growth of private consumption. However, the still high unemployment rate does not allow to increase wages and the mediumterm changes in wages are unlikely to exceed the increase in productivity.

Domestic demand is strengthening in most euro area Member States resent years and economic activity should rise across the EU in 2016 and 2017. Private consumption is growing as a result of rising nominal incomes and low inflation. Investment is also expected to strengthen somewhat on the back of rising disposable incomes for households, improving profit margins of corporations and favourable financing conditions.

Unemployment rate in the $\mathbf{E U}$ in 2015 reached to $10.5 \%$. The social costs inflicted by the crisis continue to weigh heavily on the euro area's performance and internal cohesion. 


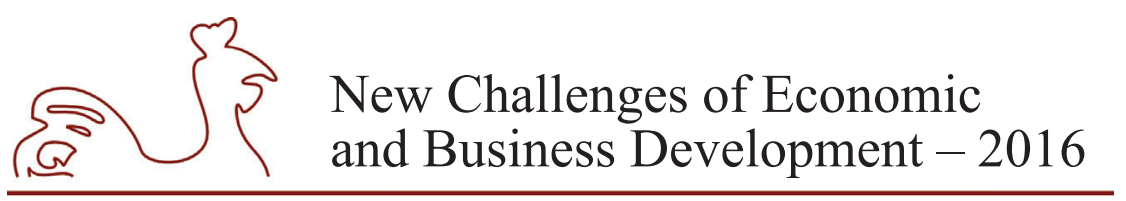

May 12-14, 2016, Riga, University of Latvia

They also reveal a dramatic divergence between EU member states - be it in unemployment rates, which vary from $4.7 \%$ in Germany to $25.7 \%$ in Greece, or the share of low skilled in the workforce, which ranges from $15.1 \%$ in Estonia to $56.3 \%$ in Portugal. Such divergence is not sustainable in the context of EU targets for social development (Eurostat and European Commission data, 2015). Income and living conditions database European Forecast Autumn 2015). One in five long-term unemployed EU citizens has never worked, three quarters of them being below 35 years of age. This creates a strong risk of marginalisation, exacerbated by the low demographic growth of the continent, which is pushing more and more European societies. Long-term unemployment (i.e. individuals unemployed for 12 months or more) has increased in most member states in recent years, doubling between 2008 and 2015 at EU level. The problem, however, is particularly acute in some countries, notably Spain, Cyprus and Greece. In recent months, very long-term unemployment (for 24 months or more) has continued to increase, while overall unemployment has only modestly declined. Men, youth and low skilled workers are more vulnerable to long-term unemployment, as well as those employed in declining occupations and sectors, whose skills often need upgrading (see Table 4).

Dynamic and inclusive labour markets are key for convergence high-performing, inclusive labour markets need to be at the heart of the social dimension of EU. Modern social policy must be both about enabling people to make the most out of their talent as well as ensuring equity in opportunity. Only effective social policy and labour markets development in European states can successfully master the challenge of overcoming mass unemployment and growing social exclusion. The European Union is committed to the principle of the free movement of people within its frontiers, which is central to the concept of EU citizenship. But this principle has given rise to concerns caused by the inclusion of more Eastern European countries with much lower wages. Many people in Germany, Britain, the Netherlands, Austria and other "old EU" members, particularly those with low skills in precarious low-wage jobs, who are threatened by unemployment and disadvantaged in housing markets, fear the consequences of the unlimited movement of workers from the East.

Table 4

Unemployment rate (\%) in the EU states 2007-2017

\begin{tabular}{|l|c|c|c|c|c|c|c|}
\hline \multicolumn{1}{|c|}{ Country } & $\mathbf{2 0 0 7 - 2 0 1 1}$ & $\mathbf{2 0 1 2}$ & $\mathbf{2 0 1 3}$ & $\mathbf{2 0 1 4}$ & $\mathbf{2 0 1 5}$ & $\mathbf{2 0 1 6} \mathbf{f}$ & $\mathbf{2 0 1 7} \mathbf{f}$ \\
\hline EU & 8.5 & 10.5 & 10.9 & 10.2 & 10.5 & 9.2 & 8.9 \\
\hline Germany & 7.3 & 5.4 & 5.2 & 5.0 & 4.7 & 4.9 & 5.2 \\
\hline Estonia & 10.5 & 10.0 & 8.6 & 7.4 & 6.5 & 6.5 & 7.6 \\
\hline Latvia & 13.4 & 15.0 & 11.9 & 10.8 & 9.8 & 9.5 & 8.8 \\
\hline Lithuania & 11.4 & 13.4 & 11.8 & 10.7 & 9.4 & 8.6 & 8.1 \\
\hline Spain & 15.7 & 24.8 & 26.1 & 24.5 & 22.3 & 20.5 & 19.0 \\
\hline France & 8.6 & 9.8 & 10.3 & 10.3 & 10.4 & 10.4 & 10.2 \\
\hline Italy & 7.5 & 10.7 & 12.1 & 12.7 & 12.2 & 11.8 & 11.6 \\
\hline Portugal & 10.7 & 15.8 & 16.4 & 14.1 & 12.6 & 11.7 & 10.8 \\
\hline Sweden & 7.4 & 8.0 & 8.0 & 7.9 & 7.7 & 7.7 & 7.4 \\
\hline United Kingdom & 6.9 & 7.9 & 7.6 & 6.1 & 5.4 & 5.4 & 5.5 \\
\hline
\end{tabular}

Source: htpp://europa.eu/rapid/press-release, 2015, calculation based on Eurostat and European Commission data 2015 European Forecast Autumn 2015, htpp://ec.europa.eu/eurostat/tgm/table. 


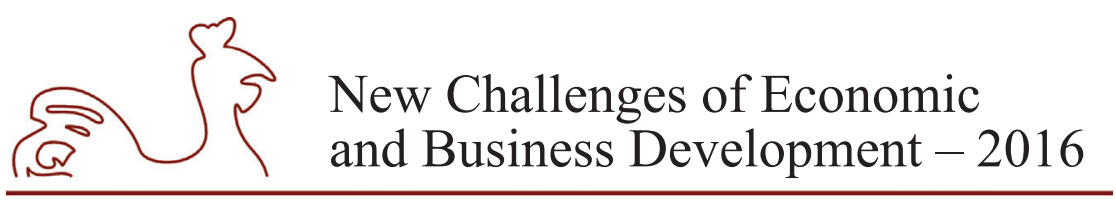

May 12-14, 2016, Riga, University of Latvia

They fear that their wage and job prospects may be undermined by the employment of immigrant workers at lower salaries; that incoming migrants may push up rents and property prices; that migrants may impose greater burdens on the welfare state, particularly if migrants have lower skills and wages than the indigenous population, are more prone to unemployment, and likely to pay lower taxes. The debate about migration and public policy has become highly charged for European community. The 2015 review of Employment and Social Developments demonstrates an urgent need to increase efforts to return to convergence, both economic and social. Jobs and Growth remain EU number one priority. Following recent initiatives on the integration of the long-term unemployed, the Youth Guarantee and the Youth Employment Initiative, EU states will take forward work on proposals for a European Pillar of Social Rights, on labour mobility and on skills. EU will continue working side by side with the social partners to achieve an inclusive recovery and to make a social progress for all Europe countries a reality (European Commission Press release, 2015).

The EU social and countries cohesion has been at risk because states and its regions are affected in different ways and to varied degrees of intensity. The mechanisms in social policy are not sufficient with regard to future progress in the European integration and with regard to the need to reduce social inequality. The European budget as the financial instrument promote economic, social and regional cohesion at the national and EU levels. Consequently, all policies and allcommunity budget spending will have to be more effective, in particular 2014-2020. One of the main step of social policy development in EU shoud be combine competitive economies that are able to innovate and succeed in an increasingly globalised world, with a high level of social cohesion between EU states.

\section{Conclusions, proposals, recommendations}

1. The EU states disparities in the GDP annual growth rates in terms of economic development are incentive structures for individuals, firms and countries need to be rethought in order to better link social and economic outcomes. Trends of the recent years (2014-2020) of EU states economies are taken as the important priorities developing of social legislation, situation in the income's growth, pension's policy improving, education system and labour market development.

2. EU national economies strategies have been related to the influence of several internal and external factors. EU convergence process can guarantee political stability and sufficiently consistent implementation of economic and social strategies and programmes. European social policy is shared competence between the EU and its member states and includes new objectives for social matters like full employment, social progress, the fight against social exclusion and social protection of EU citizens.

3. Socio-economic convergence of the EU new member states has been considered as one of the most important economic development targets in the EU. It supports job creation, competitiveness, economic growth, improved quality of life and modernising social protection.

4. Taking into account the actual problems of social situation in the EU countries, it is important for the national economies to open market and companies producing goods with a high value added, as well as to use modern information technologies in their work. 


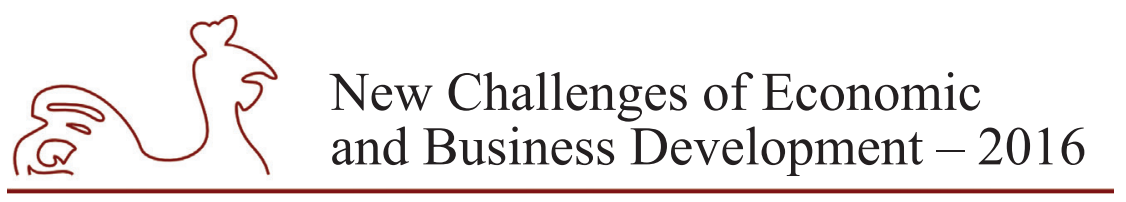

May 12-14, 2016, Riga, University of Latvia

The socio-economic policy improvement in general connected with investment flows, new technologies and productivity growth and more flexible and balanced labour market, taking into account the actual demographic situation of the society and national economies competitiveness EU and world market.

5. European Union main aims to reduce the economic, social and territorial disparities that still exist between Europe's states. Leaving these disparities in place would undermine some of the cornerstones of the EU, including its large single market and its currency - euro. Best Protection from poverty human capital is one of Europe's undisputed strengths, but emerging economies are quickly catching-up, threatening to erode our basis of competitive advantage and source of high living standards.

6. The necessity for the EU to move towards harmonization of social policy and a harmonisation of minimum social standards is becoming more obvious. Convergence policy must bet connected with a judgement of the likely future evolution of the national economy.

7. The effectiveness of European convergence policy can also be improved by significant economic growth and by clever choice of the country-specific social activities. Increasing EU economic integration at the regional or states level may have contributed to enclose of regional disparities by strengthening the more dynamic regions of the country, but at the same time, it can determine substantially growth prospects at the national level.

8. National economies will need to recognize that labour market and lower corporate taxes are the only competitive tools if they want to attract new capital - the key to lower unemployment, in the longer-term. In the short-term will mean that the restructuring of EU economy will continue with the innovative sector share increase into GDP.

\section{Bibliography}

Barro, R. J., Sala-i-Martin, X., 2004. Economic growth. $2^{\text {nd }}$ Ed. The MIT Press, England, London, pp. 44-51, 74-76.

Barro, R. J., Lee, J.-W., 2010. A new data set of educational attainment in the world, 1950-2010. Working Paper, No. 15902, 2010. http://www.nber.org/papers/w15902>

Bertola, Giuseppe, John Driffill, Harold James, Hans-Werner Sinn, Jan-Egbert Sturm and Ákos Valentinyi, 2015, "Summary", EEAG Report on the European Economy 2015, 2015, pp. 8-12.

Checherita C., Nickel C., Rother P., 2009. The Role of Fiscal Transfers for Regional Economic Convergence in Europe, ECB Working Paper, pp. 10-29.

CESifo Economic Studies, Vol. 2014-2015: http://www.cesifo-group.de/ifoHome.html

Convergence Report on Latvia, 2013. European Economy Nr. 3/2013, pp. 45-46. http://ec.europa.eu/ economy_finance

Dall'erba S. and Le Gallo J., 2008. Regional convergence and the impact of European structural funds 1989-1999: A Spatial Econometric Analysis, Papers in Regional Science, 87(2), pp. 219-244.

Dauderstadt, M., Keltek, C., 2012: Inequality is growing again in Europe: http://library.fes.de/pdf-files/ id/ipa/09331.pdf.

Dauderstaedt, M., 2010: Europe's hidden inequality, 05/10/2010, http://www.social-europe.eu/2010/10/ europes-hidden-inequality/

David M. Trubek and Louise G., 2015. Hard and Soft Law in the Construction of Social Europe: the Role of the Open Method of Co-ordination: http://eucenter.wisc.edu/Publications/trubekTrubekELJ.pdf;

Decent Life for All: Ending Poverty and Giving the World a Sustainable Future, COM (2013) 92 final (p. 6): http://ec.europa.eu/europe 2020/ 


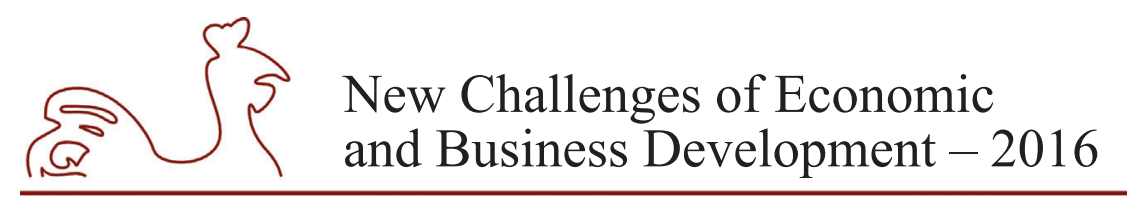

May 12-14, 2016, Riga, University of Latvia

Directorate-General for Economic and Financial Affairs, 2015. European Forecast Autumn 2015. European Economy. http://ec.europa.eu/economy finance

European Commission - Press release, 2015. Economic Forecast: Moderate recovery despite challenges, 2015. htpp://europa.eu/rapid/press-release

European Commission, 2013. Country - Specific Recommendations-Final Version, Approved by the Council: http://ec.europa.eu/europa2020/europa-2020-in-your-country/latvia

European Commission, 2010. "Europe 2020": A European strategy for smart, sustainable and inclusive growth, 2020: http://ec.europa.eu/eu2020/pdf/

European Commission data, 2015. Income and living conditions database European Forecast Autumn 2015, htpp://europa.eu/rapid/press-release

Eurostat, 2015. htpp://ec.europa.eu/eurostat/tgm/table, 2015.

Eurostat, 2014. Income and living conditions database. http://epp.eurostat.ec.europa.eu/portal/ page/ portal/income_social_inclusion_living_conditions/data/database

Ifo World Economic Survey (WES) of the $4^{\text {th }}$ quarter 2015. Ifo World Economic Climate Results. http:// www.cesifo-group.de/ifoHome.html

Halmai, P., Vasary, V., 2010. Real Convergence in the new Member States of the European Union. The European Journal of Comparative Economics, Vol. 7, Nr. 1, pp. 229-253.

Marzinoto B., 2012.The growth effects of EU cohesion policy: A Meta-analysis. Brugel Working Paper 2012/14, pp. 17.

Stiglitz J., 2009. Report of the commission on the measurement of economic performance end social progress $\mathrm{http}: / / \mathrm{www}$.stiglitz-sen-fitoussi.fr/en/index.htm

The Social protection committee, 2011. The social dimension of the Europe 2020 Strategy. The rise of income inequality amongst rich countries: http://inequalitywatch.eu/spip.php?article58

World Bank, 2015. "What's next in Ageing Europe: Ageing with Growth in Central Europe and the Baltics," http://www. worldbank.org/content/dam/World bank/Publications/ECA/ 


\title{
ANALYSIS OF DEVELOPMENT IN PATIENT SAFETY OVER THE LAST 15 YEARS
}

\author{
Barbara Ehrnsperger, University of Latvia, Latvia ${ }^{1}$
}

\begin{abstract}
Patient safety is a significant healthcare issue with substantial clinical and economic consequences. The extensive research in 1999 on patient safety stated that preventable medical errors in US were killing as many as 99,000 people per year (Kohn, 1999). This report increased awareness and concern about patient injuries worldwide.

The aim of this paper is the analysis of patient safety management development to identify main obstacles and success factors for its improvement, coming from global literature review combined with a case study where 15 hospitals were interviewed on an innovative labelling system.

Hospital management is increasingly confronted by governmental, regulatory, and consumer groups to demonstrate organizational safety culture that assures patients safely from medical error. This article helps to understand what really happened or improved regarding patient safety over the last 15 years and may support answer the question "what can we do to improve patient safety?"

A comprehensive review of patient safety literature globally. The review was a qualitative meta-analysis from which identified barriers and critical success factors for improvement. This research is underlined by a case study which also shows clear adoption barriers.

In the result of analysis of literature review and secondary statistical data main conclusions can be stated such as: 1) The scope of improving patient safety has not made significant progress and further efforts are rare and not centred, 2) several macroeconomic obstacles are still observable end especially in the field of commitment, funding, education, but main attention paid by author of this paper is the analysis of managerial aspects of patient safety on micro-level which is creating the third group of conclusions.
\end{abstract}

Key words: Patient safety, hospital management, medical error

JEL code: M10

\section{Introduction}

Patient safety is a significant healthcare issue with substantial clinical and economic consequences. What is patient safety? According to AHRQ, "patient safety refers to freedom from accidental or preventable injuries produced by medical care. Thus, practices or interventions that improve patient safety are those that reduce the occurrence of preventable adverse events." (AHRQ Patient Safety Network (AHRQ n.d.; Sherman et al. 2009).

The patient safety movement was brought to the medical mainstream by a report of the Institute of Medicine To Err is Human (Kohn, 1999), with the goal to eliminate preventable patient harm through improved systems and find solutions to previously "unpreventable" errors (Wachter 2012). Improvement in patient safety is also a major aim of hospital management these days. Five years after to err is human, two authors Leape and Berwick state "The groundwork for

1 Corresponding author - e-mail address: barbara.ehrnsperger@gmail.com 


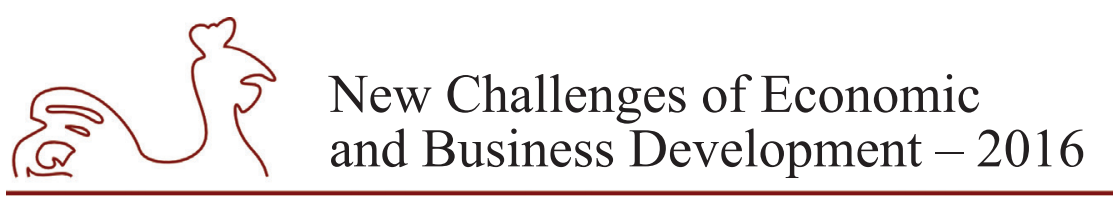

May 12-14, 2016, Riga, University of Latvia

improving safety has been laid in these past five years but progress is frustratingly low" (Leape and Berwick 2005). Nearly 10 years later, RAND Europe estimated that in the 27 European Union member states between $8 \%$ and $12 \%$ of patients admitted to hospital suffer from adverse effects while receiving healthcare (Conklin et al. 2008). A report from the National Patient Safety Foundation stated that 15 years after the IOM released To Err is Human the work to make care safer for patients has progressed at a rate much slower than anticipated. They further state that safety issues are far more complex and pervasive than initially appreciated (National Patient Safety Foundation 2015).

The two key underlying questions of this research are:

1. Why is the patient safety progress over the last 15 years slower than anticipated?

2. What are the key drivers to improve patient safety?

This research is fully based on literature research. The literature is used to analyse both kind of case studies, successful and not successful studies in improving patient safety. Based on the literature findings, the author analyses factors which are influencing the adoption of patient safety initiatives in hospitals to help management to overcome these barriers.

\section{Theoretical Background}

Even after 15 years of patient safety initiatives, recent research has found that roughly 1 in 2 surgeries had a medication error and/or an adverse drug event (Nanji et al. 2016) and more than 12 million patients each year experience a diagnostic error in outpatient care, half of which are estimated to have the potential to cause harm (Singh, Meyer, and Thomas 2014). On the other side, 1.3 Million estimated reduction in hospital-acquired conditions (2011-2013) as a result of the federal Partnership for Patients initiative (Agency for Healthcare Research and Quality 2015).

Although the current evidence regarding overall improvement in patient safety in the US and internationally is mixed (R. J. Baines et al. 2013; R. Baines et al. 2015; Landrigan et al. 2010; Shojania and Marang-van de Mheen 2015), the majority of the panel in "Free from Harm" and management felt that overall health care is safer than in the past (National Patient Safety Foundation 2015).

\section{Analysis}

Patient safety improvements demand a complex system-wide effort, involving a wide range of actions in performance improvement, environmental safety and risk management, including infection control, safe use of medicines, equipment safety, safe clinical practice, and safe environment of care (Hughes and Clancy 2005; Reid et al. 2005; Smits et al. 2008). Further, advancing patient safety requires an overarching shift from reactive, piecemeal interventions to a total systems approach to safety in which safety is systematic and is uniformly applied across the total process and also includes management commitment (Pronovost, Ravitz, et al. 2015). According to Ball, Kaminski and Webb, patient safety depends on the actions and beliefs of the person highest on the health care ladder (as health care has a long tradition of being hierarchical). The understanding of errors is linked to the ability to maintain a "fair and just culture" one in which errors are quickly reported and addressed rather than hidden. However, such a culture is often difficult to construct, modify and maintain (Ball, Kaminski, and Webb 2016). Patient 


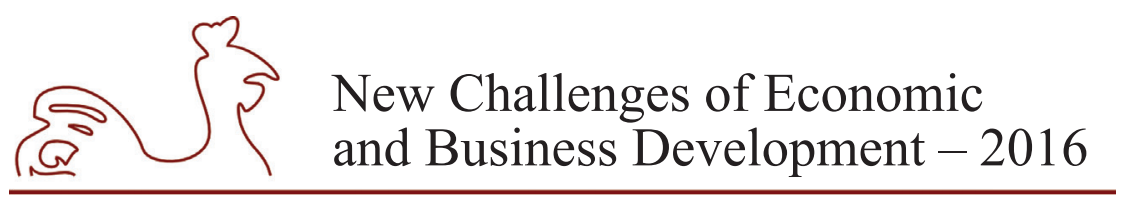

May 12-14, 2016, Riga, University of Latvia

safety culture, which is also called patient safety climate, is an overall behaviour of individuals and organizations, based on common believes and values which should be supported by hospital management (Nieva and Sorra 2003).

Already in 2005, two authors of to err is human, Leape and Berwick, stated that the main reason for no measurable improvement is due to culture of medicine. Creating a culture of safety requires changes that physicians may perceive as threats to their autonomy and authority. Fear of malpractice liability, moreover, may create an unwillingness to discuss or even admit to errors. Other issues include a lack of leadership from management at the hospital and health plan level; and a scarcity of measures with which to gauge progress (Leape and Berwick 2005). All this articles are showing that patient safety depends on the culture. Consequently, improvement fully depends on the culture. There is a growing change trend in the number of articles on patient safety culture research; however there has been no objective and quantitative evaluation of the quality of these researches so far (Xuanyue et al. 2013). A project-by-project approach did not lead to widespread, holistic change. To generate holistic change, we need to embrace a wider approach to safety rather than focusing on specific, circumscribed safety initiatives - meaning culture. This requires clear guidance and support from management in hospital with priority to patient safety and clear role modelling, that reporting mistakes is something which no one is blamed for.

After understanding that the major barrier for slower improvement in patient safety is culture, the author further analyses what drives patient safety culture. The following explains which factors are influencing culture while aiming to improve patient safety and what can help management with regard to improving the safety of patients.

An essential part of culture, and one key strategy to improve patient safety is enhancing transparency of performance on safety, clinical and service quality (Ball, Kaminski, and Webb 2016). This is of course not an easy goal since no one want to actively show mistakes. Already the IOM report in 1999 states, that if there is a safety culture where adverse events can be reported without people being blamed, they have the opportunity to learn from their mistakes and it is possible to make improvements in order to prevent future human and system errors, and thus promoting patient safety (Kohn, Corrigan, and Donaldson 1999). Actively showing mistakes also supported by management by being transparent is part of the successful patient safety culture.

By embracing safety as a core value, other industries have moved beyond competition to a stage of cooperation. Health care organizations should also make this shift. While some health care organizations have begun to work cooperatively with each other to advance patient safety, a commitment to share safety data and best practices is most evident among paediatric hospitals. For example, the Children's Hospitals' Solutions for Patient Safety (SPS) network has seen significant improvements in patient safety metrics as a result of collaboration (Lyren et al. 2013). Unfortunately, many other health care organizations respective their management seem to believe they must differentiate themselves based on their safety record. Organizations should not compete on safety; such competition slows progress in patient safety by blocking the free flow of information crucial to preventing harm.

The case study CLABSI (central line-associated bloodstream infections) from 2005 shows, that key success factor for improving patient safety is to create clinical communities in which peer hospitals are learning from each other (Aveling et al. 2012). These communities are powerful 


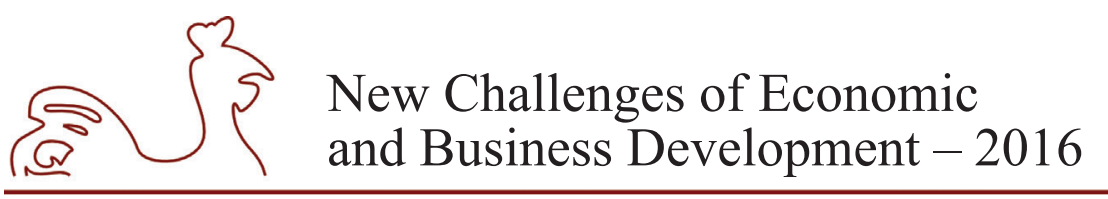

May 12-14, 2016, Riga, University of Latvia

vehicles in changing peer norms from infections are inevitable to infections are preventable and "I" can do something about it (Pronovost, Cleeman, et al. 2015). The power of peer communities comes from peer learning and tapping into intrinsic motivation among professionals (Dixon-Woods et al. 2013; Gould et al. 2015). This concept it has not reaped rewards in others (Reames et al. 2015; Urbach et al. 2014). To achieve success, some project-based initiatives, such as the CLABSI checklist, required major changes in teamwork and culture (Pronovost et al. 2006). It is telling that most initiatives succeed only when they implement tactics using a broader approach. In fact, a fundamental finding from the past 15 years is that patient safety initiatives can advance only by making teamwork, culture, management and patient engagement a key focus. By taking into account systems design, human failures, human factors engineering, safety culture, and error reporting and analysis, the systems approach epitomizes a more comprehensive view. Another example from Neily shows, that team training in surgery has been shown to reduce mortality by 50\% compared with control sites (Neily et al. 2011).

In the decades since the Institute of Medicine (IOM) issued its landmark report, "To Err Is Human: Building a Safer Health System," there have been a number of successful efforts undertaken to improve patient safety in the United States (Leape and Berwick 2005). Nevertheless, the nation remains far from realizing the vision of eliminating harm to patients from care that is meant to help them. The case study from Ball, Kaminski and Webb describes the progress that has been achieved by one organization committed to developing a culture of high reliability. ProMedica Health System is a non-profit integrated health care delivery system headquartered in Toledo, Ohio. In 2012, they set out to transform the cultural operating system with the goal of "zero events of harm." (Ball, Kaminski, and Webb 2016).

A study in 2015 states, that healthcare lacks robust mechanisms to routinely measure the problem and estimates of the magnitude vary widely. Further, this study states, that it is hard to gauge safety when healthcare uses multiple different measures for the same harm and provides limited investment in measurement, implementation and applied sciences. According to Pronovost, Cleeman, Wright and Srinivasan, a valid and reliable measurement system is essential to monitor progress, to do benchmarking, to hold clinicians accountable and to be able to compare and summarise measurements across different unit types (Pronovost, Cleeman, et al. 2015).

Culture is not only determined by the caregivers and the hospital management. The regulatory framework is also part of the overall safety culture and can help to improve patient safety. For example the current reimbursement system can also work against safety improvement and, in some cases, may actually reward less-safe care, Leape and Berwick say. For instance, some insurance companies will not pay for new practices to reduce errors, while physicians and hospitals can bill for additional services that are needed when patients are injured by mistakes (Leape and Berwick 2005). The complexity of the health care industry, with its vast array of specialties, subspecialties, and allied health professionals is also mentioned as a reason for slow improvement in patient safety (Leape and Berwick 2005).

The U.S. Health Information Technology for Economic and Clinical Health (HITECH) Act of 2009 earmarked more than $\$ 20$ billion to foster electronic health records (EHRs) at U.S. hospitals and other medical facilities, and facilities have spent billions of their own to digitize patient records and clinical workflows. What benefits have accrued? Have EHRs lowered the cost and improved the quality of healthcare? In particular, what has been the effect of EHRs on 


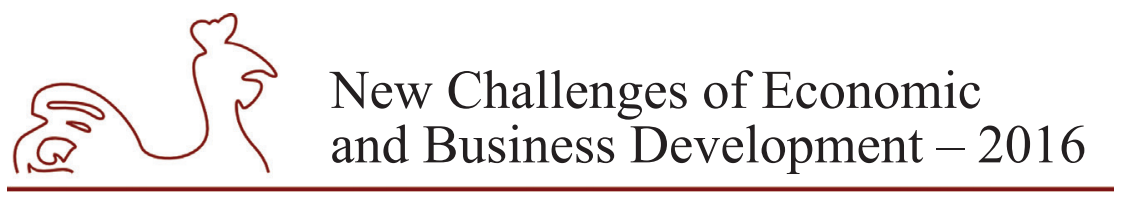

May 12-14, 2016, Riga, University of Latvia

patient safety? There is some evidence that EHRs reduce costs over the long term and under the right conditions (Payne 2015). But evidence is scant on the effect of EHRs on patient safety (Dranove, D., Forman, C., Goldfarb, A. and Greenstein 2014). An Institute of Medicine (IOM) 2012 study, Health IT and Patient Safety, concluded, "current literature is inconclusive about the overall impact of health IT on patient safety" (IOM 2011). This lack of evidence prompted an econometric study of patient safety at Pennsylvania (PA) hospitals. Patient safety improved for Pennsylvania hospitals that adopted EHRs: a $27 \%$ decline in overall patient safety events and a $30 \%$ decline in medication errors. Electronic health records were already recommended in the review of 5 years after to err is human as a next step (Leape and Berwick 2005) however so far not very widely spread. The example of EHR shows, that even if a safer system (like EHR) was implemented it must not be successful. Without having a safe culture and commitment from management the whole new system will not be successful. In general, electronic support in health care will lead to safer care, e.g. barcoding has been shown to reduce medication administration errors (Poon, Keohane, and Yoon 2010).

\section{Case Study}

Hospitals do have several drugs which are prepared in the hospital. These drugs are either prepared in the hospital pharmacy or directly before administering into the patient on the different wards. In both cases, the drug is not in the original packaging anymore, not primary nor is secondary packaging still the original. Therefore the information with regards to the drug, e.g. dosing, concentration is not with the drug anymore. In the case study we are looking at, the original drug comes in a vial and has to be wound into a syringe which is customized for a specific patient. There is the error potential: how does the nurse on the ward know which syringe is for which patient if there is not information on the syringe?

The case study on that question was conducted by the author in 2009. During that case study, the author interviewed fifteen relevant stakeholders of fifteen different hospitals in Germany. Aim was to analyse the process of preparing drugs in the hospital with regard to patient safety and to analyse the potential of a new labelling system which could increase patient safety and reduce medication errors.

If you compare the two processes, one as it is now and the other one as it would be with the labelling solution is it clear that the added label with reduce the risks of medication errors and therefore increase patient safety. 


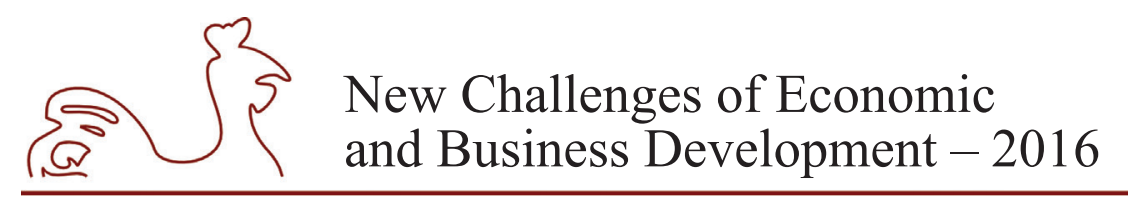

May 12-14, 2016, Riga, University of Latvia

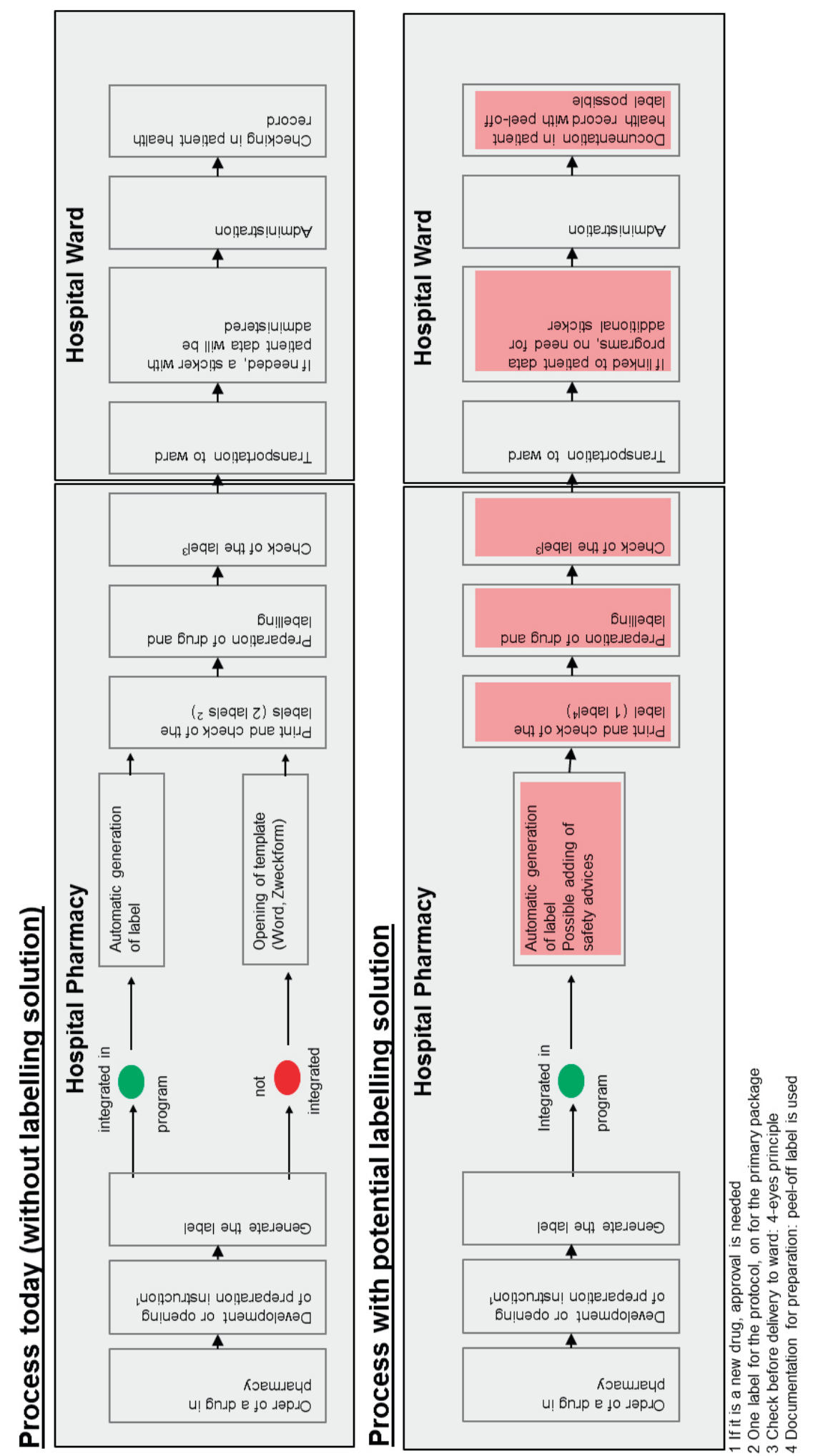

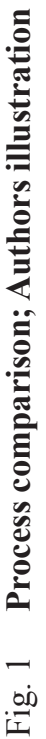




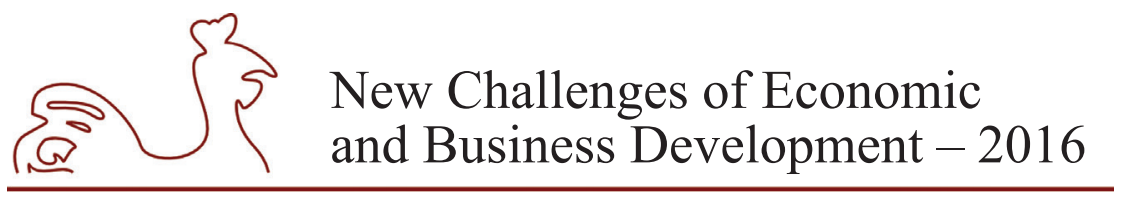

May 12-14, 2016, Riga, University of Latvia

As a result of comparing the processes with and without the label there are clear advantages of using a label: 1) Producing the label: More information at point of administration; saving of time and reduction of risk for the patient 2) Administration of drug: saving of time and reduction of risk for the patient 3) After administration: better cost effectiveness. To sum it up, the usage of labels would increase safety, reduce time and reduce costs.

In all 15 interviews, the interviewees confirmed the added value of the presented labelling solution. Further, they all confirmed that the labels would decrease the risk of medication errors and increase the level of patient safety. However they mentioned critical barriers of implementation. Most critical barrier is costs. All interviewed persons stated that costs are the major driver. Even if they see a clear reduction of patient risk, the hospitals are only willing to pay little money. The second major hurdle is the change in processes in the hospital. All hospitals involved are quite hesitating to change established processes in hospitals.

The result of the case study is clear: added value and increased patient safety is noticed however high adoption barriers due to cost sensitivity and internal switching barriers such as change of processes. 7 years later, the concept is still not implemented in hospitals.

\section{Conclusions}

These research findings are showing the picture that there is no clear evidence that patient safety has improved over the last 15 years. Further different authors explain why patient safety is not improved as expected. Figure 1 shows the flow of the research and also outlines key aspects and key literature of the research. After realizing that there is no clear improvement in patient safety until now, the question is to understand why. In order to help hospital management to improve their patient safety level, they have to understand where the barriers come from.

1999: To Err is Human
Patient safety movement
started with the goal to
eliminate preventable
patient harm
(Kohn, 1999; Wachter,
2012)

\begin{tabular}{|l|}
\hline Safety = Culture \\
Patient safety depends on \\
the actions and beliefs, it \\
is an overall behavior of \\
individuals and \\
organizations. \\
(Nieva \& Sorra, 2003; \\
Ball et all, 2016; \\
Pronovost et al, 2015) \\
\hline
\end{tabular}

\begin{tabular}{|l|}
\hline $\begin{array}{l}\text { Transparency } \\
\text { (Leape\&Berwick, 2005; Lyren et al 2013; Ball } \\
\text { et al 2016) }\end{array}$ \\
$\begin{array}{l}\text { Peer learning } \\
\text { (Neily et al, 2011; Aveling et al, 2012; Dixon- } \\
\text { Woods et al, 2015; Pronovost et al, 2006) }\end{array}$ \\
$\begin{array}{l}\text { Measurement } \\
\text { (Pronovost et al 2015) }\end{array}$ \\
$\begin{array}{l}\text { Regulatory Framework } \\
\text { (Leape\&Berwick, 2005; IOM, 2011) }\end{array}$ \\
\hline
\end{tabular}

Source: author's illustration.

\section{Fig. 2. Overview of Literature Research}

1. Progress in patient safety 15 years after to Err is Human is still slower than anticipated this was analyzed by various authors as described above. This means, that even after fifteen years and a lot of initiatives, there is still no clear improvement measurable. For hospital management this means they have to pay even more attention on patient safety and to analyze it more when they really want to effectuate something.

2. Safety depends on culture, not only on system improvements - this is the major reason for no incremental improvement of patient safety. Culture is not easy to change and it takes long time and full effort to change cultural behavior. For management, this means that if 


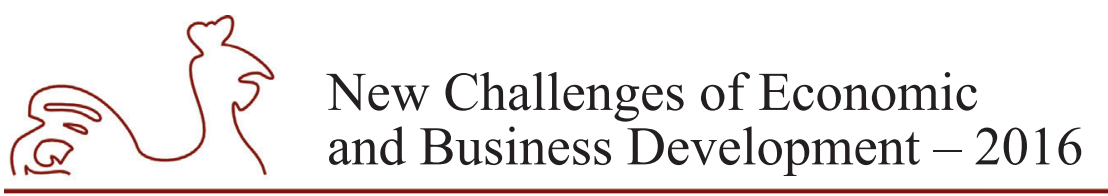

May 12-14, 2016, Riga, University of Latvia

they want to improve patient safety they have to be aware of culture and even of cultural change.

3. Success factors which are determining culture are transparency, peer learning, measurement and framework. Transparency, peer learning and measurement are factors which can be influenced and has to be driven by management. However frameworks or even more implementation of new frameworks are part of decision processes in hospitals.

4. The analysis of decision making process in the hospitals needs to be taken into account for the system improvements implementation. Hospital management has to understand how decisions are made in order to follow the aim of increasing patient safety by implementing initiatives.

In conclusion, patient safety has made slow improvement over the last fifteen years. This analysis showed that the main reason is lack of awareness with regard to culture and therefore lack of frameworks. Hospital management is required to pay attention to culture and to fully understand decision processes in hospitals to overcome the barriers and to overall improve patient safety.

\section{Bibliography}

Agency for Healthcare Research and Quality. 2015. "2013 Annual Hospital-Acquired Condition Rate and Estimates of Cost Savings and Deaths Averted From 2010 to 2013.” (AHRQ Publication No. 160006-EF). http://www.ahrq.gov/professionals/quality-patient-safety/pfp/index.html.

AHRQ Patient Safety Network (AHRQ, PSNet.). "Definition Patient Safety." Glossary. https://psnet. ahrq.gov/glossary/p (February 14, 2016).

Aveling, Emma-Louise et al. 2012. "Quality Improvement through Clinical Communities: Eight Lessons for Practice." Journal of Health Organization and Management 26(2): 158-74. http://www. emeraldinsight.com/doi/abs/10.1108/14777261211230754.

Baines, Rebecca et al. 2015. "How Effective Are Patient Safety Initiatives? A Retrospective Patient Record Review Study of Changes to Patient Safety over Time." BMJ Quality \& Safety: bmjqs 2014-003702. http://qualitysafety.bmj.com/content/early/2015/07/06/bmjqs-2014-003702.

Baines, Rebecca J et al. 2013. "Changes in Adverse Event Rates in Hospitals over Time: A Longitudinal Retrospective Patient Record Review Study.” BMJ quality \& safety 22(4): 290-98.

Ball, By Debra A, Brian Kaminski, and Kevin Webb. 2016. "FIRST; DO LESS HARM: A Health Care Cultural Operating System Case Study to Improve Safety.” People \& Strategy 39(1): 29-34.

Conklin, Analijn, Anna-Marie Vilamovska, Hans de Vries, and Evi Hatziandreu. 2008. "Improving Patient Safety in the EU: Assessing the Expected Effects of Three Policy Areas for Future Action." : 126. www.rand.org/randeurope.

Dixon-Woods, Mary, Myles Leslie, Carolyn Tarrant, and Julian Bion. 2013. "Explaining Matching Michigan: An Ethnographic Study of a Patient Safety Program." Implementation science : IS 8(1): 70. http://www.pubmedcentral.nih.gov/articlerender.fcgi?artid=3704826\&tool=pmcentrez\&rendert ype $=$ abstract.

Dranove, D., Forman, C., Goldfarb, A. and Greenstein, S. 2014. "The Trillion Dollar Conundrum: Complementarities and Health Information Technology." American Economic Journal 1.

Gould, Lois J. et al. 2015. "Clinical Communities at Johns Hopkins Medicine: An Emerging Approach to Quality Improvement." Joint Commission journal on quality and patient safety / Joint Commission Resources 41(9): 387-95.

Hughes, RG (Agency for Healthcare Research and Quality), and CM Clancy. 2005. "Working Conditions That Support Patient Safety.” Journal Of Nursing Care Quality 20 (4): 289-92. 


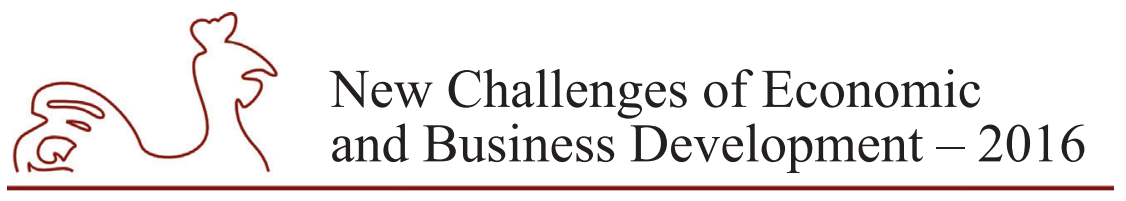

May 12-14, 2016, Riga, University of Latvia

IOM. 2011. "Health IT and Patient Safety: Building Better Systems for Better Care." (November): 220. http://www.nap.edu/catalog.php?record_id=13269.

Kohn, L.T., J.D. Corrigan, and M.S. Donaldson. 1999. 6 Behavioral and Brain Sciences To Err Is Human: Building a SaferHealth System. http://www.journals.cambridge.org/abstract_S0140525X00015685.

Landrigan, C P et al. 2010. "Temporal Trends in Rates of Patient Harm Resulting from Medical Care with Comments." N Engl J Med 363(22): 2124-34. http://www.ncbi.nlm.nih.gov/pubmed/21105794.

Leape, Lucian L., and Donald M. Berwick. 2005. "FIVE YEARS AFTER TO ERR IS HUMAN: WHAT HAVE WE LEARNED?” Journal of the American Medical Association 293 (19): 2384-90.

Lyren, Anne et al. 2013. "Ohio Children's Hospitals' Solutions for Patient Safety: A Framework for Pediatric Patient Safety Improvement.” DOI: 10.11.

Nanji, Karen C et al. 2016. "Evaluation of Perioperative Medication Errors and Adverse Drug Events." Anesthesiology 124(1): 25-34. http://www.ncbi.nlm.nih.gov/pubmed/26501385\nhttp://www. pubmedcentral.nih.gov/articlerender.fcgi?artid=PMC4681677.

National Patient Safety Foundation. 2015. "Free from Harm: Accelerating Patient Safety Improvement Fifteen Years after To Err Is Human."

Neily, Julia et al. 2011. "Association Between Implementation of a Medical Team Training Program and Surgical Morbidity." Archives of Surgery 146(12): 1368. http://www.ncbi.nlm. nih.gov/pubmed/22184295\nhttp://archsurg.jamanetwork.com/article.aspx?doi=10.1001/ archsurg.2011.762.

Nieva, VF, and J. Sorra. 2003. "Safety Culture Assessment: A Tool for Improving Patient Safety in Healthcare Organizations." Quality \& Safety In Health Care 12: ii17-23.

Payne, Thomas H. 2015. "Electronic Health Records and Patient Safety: Should We Be Discouraged?" BMJ Quality \& Safety 24(4): 239-40. http:/qualitysafety.bmj.com/lookup/doi/10.1136/ bmjqs-2015-004039.

Poon, EG, CA Keohane, and CS Yoon. 2010. "Effect of Bar-Code Technology on the Safety of Medication Administration." N Engl J Med 362(18): 1698-1707.

Pronovost, Peter J, James I Cleeman, Donald Wright, and Arjun Srinivasan. 2015. "Fifteen Years after To Err Is Human: A Success Story to Learn From.” BMJ quality \& safety (December): bmjqs - 2015004720. http://qualitysafety.bmj.com/content/early/2015/12/15/bmjqs-2015-004720?papetoc.

Pronovost, Peter J, Alan D Ravitz, Robert a Stoll, and Susan B Kennedy. 2015. Transforming Patient Safety: A Sector-Wide Systems Approach.

Pronovost, Peter J. et al. 2006. "An Intervention to Decrease Catheter-Related Bloodstream Infections in the ICU." The New England journal of medicine 355(26): 2725-32.

Reames, BN, RW Krell, DA Jr Campbell, and JB Dimick. 2015. "A Checklist-Based Intervention to Improve Surgical Outcomes in Michigan: Evaluation of the Keystone Surgery Program." JAMA Surg 150(3): 208-15.

Reid, Proctor P et al. 2005. "Building a Better Delivery System a New Engineering/health Care Partnership." http://site.ebrary.com/id/10160714.

Sherman, H et al. 2009. "Towards an International Classification for Patient Safety: The Conceptual Framework." International Journal for Quality in Health Care 21(1): 2-8. http://www.ncbi.nlm.nih. gov/entrez/query.fcgi?cmd=Retrieve\&db=PubMed\&dopt=Citation\&list_uids=19147595.

Shojania, Kaveh G, and Perla J Marang-van de Mheen. 2015. "Temporal Trends in Patient Safety in the Netherlands: Reductions in Preventable Adverse Events or the End of Adverse Events as a Useful Metric?" BMJ Quality \& Safety: bmjqs - 2015-004461. http://qualitysafety.bmj.com/lookup/ doi/10.1136/bmjqs-2015-004461.

Singh, Hardeep, Ashley N D Meyer, and Eric J Thomas. 2014. "The Frequency of Diagnostic Errors in Outpatient Care: Estimations from Three Large Observational Studies Involving US Adult Populations." BMJ quality \& safety (May): 1-5. http://www.ncbi.nlm.nih.gov/pubmed/24742777. 


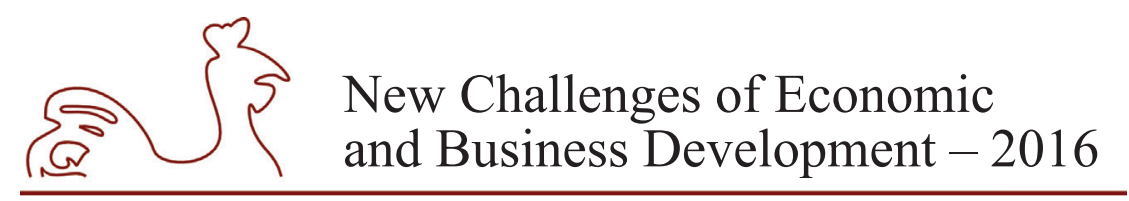

May 12-14, 2016, Riga, University of Latvia

Smits, Marleen et al. 2008. "The Psychometric Properties of the "Hospital Survey on Patient Safety Culture' in Dutch Hospitals." BMC Health Services Research 8(1): 230. http://www.biomedcentral. com/1472-6963/8/230.

Urbach, David R et al. 2014. "Introduction of Surgical Safety Checklists in Ontario, Canada." The New England journal of medicine 370(11): 1029-38. http://www.ncbi.nlm.nih.gov/pubmed/24620866.

Wachter, Robert M. 2012. Understanding Patient Safety.

Xuanyue, Mao et al. 2013. "Literature Review Regarding Patient Safety Culture." Journal of EvidenceBased Medicine 6(1): 43-49. 


\title{
METHODOLOGICAL APPROACH TO RESEARCH THE LINKAGE BETWEEN EMPLOYEE ENGAGEMENT AND GAMIFICATION OF HUMAN RESOURCE MANAGEMENT PROCESSES IN LATVIAN COMPANIES
}

\author{
Daiga Ergle, University of Latvia, Latvia ${ }^{1}$ \\ Inesa Voroncuka, University of Latvia, Latvia
}

\begin{abstract}
Due to increasing global competition, Employee Engagement has become a top issue on Human Resource Management agenda. Worldwide management consultancies year after year keep providing research based evidence that Employee Engagement levels strongly influence productivity of a firm. Companies with higher Employee Engagement scores also have better Employer brand and are more competitive at hiring top talent.

Employee Engagement is historically medium to low in Latvian companies, according to the market surveys provider TNS who have been researching Employee commitment and engagement with their Employers for many years in a row. Percentage of actively engaged ones fluctuates around $13 \%$ only. At the same time, share of actively disengaged or "detractors" represent high $40 \%$ and more.

Research shows that the most engaging setting is game environment. People are most engaged when feeling playful. In medicine, researchers even have been experimenting with game environment to reduce permanent pain in patients who became so much engaged with a game that reported relative reduction in pain levels. Appropriately designed games have ability to engage people for hours and psychologists have been researching game dynamics required to achieve such high levels of engagement.

Human resources is one of the business areas where gamification has been successfully used in different companies worldwide. Processes like Recruitment, Onboarding, Training and Development, Performance Management, Reward and Recognition, Internal Communication, are most commonly being gamified. Authors, therefore, have drawn the hypothesis that Employee Engagement in Latvia can be positively influenced through gamifying Human Resource Management processes. (Gamification for the purpose of this article is defined as application of game elements to the non-game context (S. Deterding, et al., 2011)). This article proposes methodology for researching the linkage between Employee Engagement and application of gamification in Human Resource Management processes at Latvian companies.

Result of the article is proposed methodology for quantitative and qualitative research to find out how many companies in Latvia are using game elements in their Human Resource Management processes. It intends to clarify, which processes are most commonly gamified in Latvian companies and whether or not those companies that do use gamification as a tool experience relatively more engaged workforce. Value of such research is in helping business organizations to design their Human Resource Management processes with the most positive impact on Employee Engagement. This is, however, a very early stage paper. It proposes methodology for the research to be carried out, while the actual research has not been started yet.
\end{abstract}

Key words: Employee Engagement, Gamification, Human Resource Management

JEL code: M54

1 Corresponding author - e-mail address: daiga.ergle@airbaltic.lv 


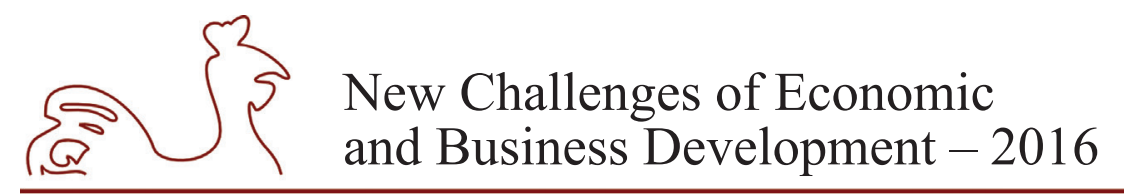

May 12-14, 2016, Riga, University of Latvia

\section{Introduction}

Since the focus in the paper is on impact of gamification on employee engagement, literature review presents definitions and discussion of both constructs, as well as offers arguments for why those are considered to be important. Within the discussion section relevant variables are briefly discussed, as well as methodology for potential data analysis described. Paper ends with conclusions.

The main reason why business community around the globe pays increasing attention to the construct of Employee Engagement, strives to understand, measure and increase it, is rather simple. Numerous research led by both, management consultants, business practitioners and academic researchers lead to proven belief that those organizations that manage raise their engagement levels, enjoy higher returns in terms of profitability, productivity, staff retention, etc. One of the persuasive and rich in data sources is Gallup's meta-analysis from 2012 "The Relationship between Engagement at Work and Organizational Outcomes" (J. J. Harter et al., 2013) where researchers have collected data from 192 organizations representing 49 industries and located in 34 countries around the globe. They have studied nine outcomes: customer loyalty/engagement, profitability, productivity, turnover, safety incidents, shrinkage, absenteeism, patient safety incidents and quality (defects). Researchers have chosen meta-analysis as a statistical technique that is useful in combining results of studies with seemingly disparate findings, correcting for sampling, measurement error and other study artefacts to understand true relationship between engagement and each performance measure, as well as to test for generalizability. According to study outcomes, relationship between engagement and performance of the business is substantial and highly generalizable across organizations. It also proves that the top organizations with the most engaged workforce outperform those at the bottom four times in terms of business results. This is impressive result and because of the size of the research and number of participating respondents $(1,390,941$ employees) can be viewed as rather trustworthy.

Employee Engagement is a construct that can be related to such concepts as employee commitment or job satisfaction. Nevertheless, it should not be confused with those and perceived being the same (S. Markos, M. S. Sridevi, 2010), as difference exists and satisfied employees are not necessarily also engaged. The same way, engaged employees are not necessarily satisfied (ADP Research Institute, 2012).

There are many definition to what Employee Engagement is. Nevertheless, they all contain similar characteristics and speak about emotional state of engaged employee who feels involved with the organizational purpose, inspired by the goals the organization pursues, experiences sense of importance of the own job in the organizational context. It is defined as the emotional commitment the employee has to the organization and its goals. (K. Kruse, 2013).

Gamification for the purposes of this article is defined as application of the game elements to the nongame context (S. Deterding et al., 2011). Gamification at work, just like Employee Engagement, is relatively new concept.

Gamification is the usage of game-thinking and game mechanics in non-game scenarios such as business environment and processes, specifically in recruitment, training and development, and motivation; in order to engage users and solve problems (M. Herger, 2014).

While one of the most common problems in the business world is getting people engaged, mounting evidence suggests that games are one of the most engaging mediums possible. To the 


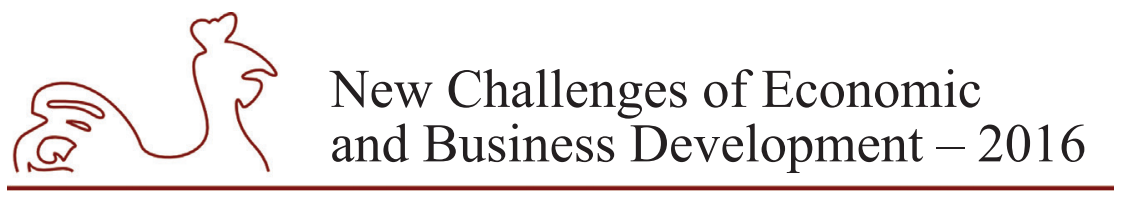

May 12-14, 2016, Riga, University of Latvia

extent that doctors are beginning to employ them as a form of pain relief for victims of severe burns and other extreme trauma. People are quite literally so engaged by gaming content that they are able to enjoy a measure of pain relief (Jameson, E., et al., 2011).

Common elements that are typically "borrowed" from traditional games and applied in nongame contexts include levels, badges, points, progress bars, leader boards, and virtual goods. Each serves to motivate users by providing feedback, recognition, status, and the potential for competition among users (Muntean, 2011).

The objective is to take techniques from game design and implement them in non-game contexts, so that the overall experience for the employee or "user" is more engaging (M. Herger, 2014).

Engagement strongly influences the state of happiness at work. (Cziksentmihalyi's "Flow Theory" suggests that people are most happy, or, being in a state of "flow", when their tasks are sufficiently challenging and enhancing their skill level. Games are excellent platforms for offering the state of "flow"). The results from a survey conducted by the research institute iOpener Institute for People and Performance show that happy employees:

- are twice as productive,

- stay five times longer in their jobs,

- are six times more energized,

- take ten times less sick leave.

Happier workers also help their colleagues 33\% more than their less happy colleagues. They raise issues that affect performance $46 \%$ more, and they achieve their goals $31 \%$ more often and are $36 \%$ more motivated. (iOpener Institute, 2015).

The author of Gamification of Learning \& Instruction, Karl Kapp (Kapp K., 2012), says the key to gamification is how addictive it can become across all generations of people. Kapp believes the advantages that are part of gamification encourage users to stay engaged and interact with each other, building stronger relationships. A number of organizations like Marriott, Cognizant, Deloitte, Aetna, and a few others are using gaming to improve workforce alignment, enhance employee skills, solve complicated issues and tap into new talent pools. Typical game design techniques consist of goal setting, competition, real-time feedback and rewards. There are also platforms such as eMee and MindTickle that facilitate Gamification in organizations.

The power of Gamification utilizes the competitive streak people have and while playing a game, we become more absorbed and engaged, we feel a greater sense of achievement and are more willing to go the extra mile in either making more effort to choose the right people, or completing more training programs, or even helping other employees to stay motivated. And as we progress, we continue to increase our engagement with the game and thus reach new levels.

Human Resources can use the traditional gamification principles to enhance the engagement of employees into different HR Processes. The most common techniques that games use to provoke users emotional response are competition, achievement, status, altruism, collaboration.

Competition is a core principle behind the performance management system, as everyone likes to be appraised as the top performer. However, the gamification can add another element to the system. For example, employees can compete who will be the first employee to finish the entire performance appraisal cycle. Most HR Teams send reminders to complete the assessment. When employees compete - they can see the progress of others. They can be motivated to speed up and finish the document as soon as possible. 


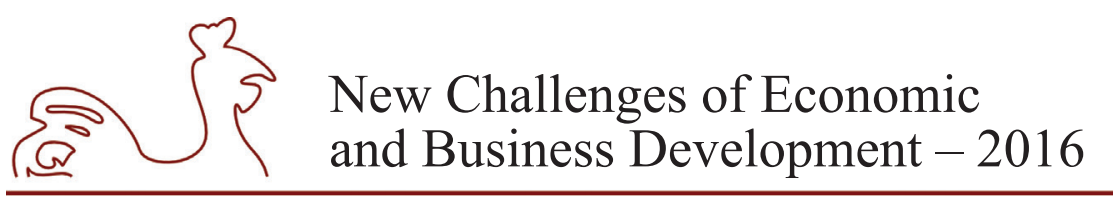

May 12-14, 2016, Riga, University of Latvia

The achievement and status are closely connected - everyone who reaches the threshold is awarded the achievement. However, few selected ones can be also awarded a higher status, which is an emotional prize that has a great value.

However, the best principles for Human Resources are altruism and collaboration, making people to work with others to win as a team is most often the best option. The team spirit should be the driving force behind most games and competitions run by the HR department, as the key intention of HR should be to form the group into an efficient team.

Gamified solutions in Human Resource management can be used to strategically and tactically drive, motivate and engage in main areas of people management, beginning with recruitment and onboarding of a new employee and proceeding to training, developing, rewarding, evaluating and appraising, through to informing and retaining.

Purpose of the Article is to propose the methodology for research how widely gamification is used currently in different Human Resource Management processes in Latvia and what is the impact of gamified HRM processes on employee engagement, if at all. Given the highly engaging character of the game environment, authors draw a hypothesis that Employee Engagement can be positively influenced by application of game elements to the organization's people management processes. If the hypothesis would be proven true, organizations could make a more widespread and better use of gamification to improve their environments and raise employee engagement, through that improving profitability and competitiveness of the business. Future research should be also able to determine those Human Resource Management processes, where investment into gamification would promise relatively highest return on such investment. Is it Recruitment, Onboarding, Performance Management, Reward \& Recognition, Learning and Development, Team Building or Internal Communication that responds best to the gamification effort and offers highest impact on employee engagement?

Article will propose methodology to gather information about how widely and in which HRM processes currently companies in Latvia mostly use game elements. It will also offer conceptual model for researching employee engagement effect of different dependent and mediating variables, suggest draft questionnaire and propose methodological approach to results' analysis. Qualitative dimension of the research methodology proposes interviews as a method for surveying opinions and observations of Human Resource Management professionals in those Latvian companies that already use gamification in their HRM routines.

\section{Research and discussion}

\subsection{Penetration rate of gamification in HRM processes in Latvia}

It is suggested by the authors that the first step to research the situation would be gathering information about how widespread currently is the trend between Latvian business enterprises to use game elements as part of the people management processes design. For that purposes a short questionnaire would be distributed through Latvian Personnel Management Association to its members asking to respond whether they do use gamification currently within any of their people management practices or not. For those who respond positively, it would be further asked to indicate specific, pre-defined HRM processes in which they use game elements. For the research purposes (because HRM terminology involves several terms for the same activities, 


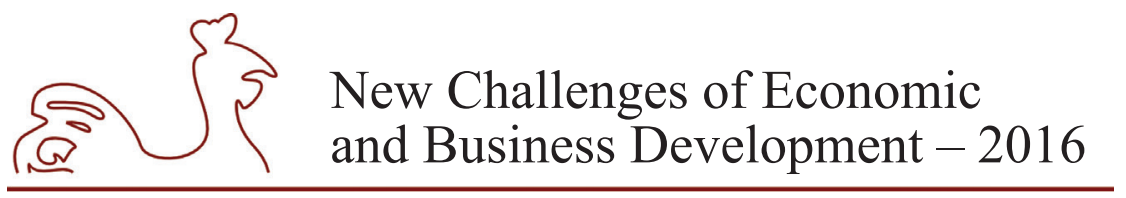

May 12-14, 2016, Riga, University of Latvia

as well as processes have a trend to overlap, it is advised to stick with specific, predefined terms throughout the research to ensure validity), 6 Human Resource Management processes are defined the following way:

Recruitment and Onboarding - $R O$

Performance Management (target setting and feedback) - PM

Reward and Recognition $-R R$

Learning and Development (training) - LD

Internal Communication (also ideas generation) - IC

Team Building - TB

The last question of this mini-questionnaire would be whether they do or do not measure employee engagement in their organization. Target of the authors would be to have around 100 responses to draw relevant conclusions.

Information acquired via this questionnaire would be used to assume the extent to which gamification is already widespread in HRM processes in Latvia, as well as to provide data for selecting HR Managers for the purpose of performing qualitative interviews.

\subsection{Employee Survey}

The second step of the research would be survey aimed at employees representing different business enterprises in Latvia. These would be a random respondents employed by business enterprises in Riga city and close area. The reason for choosing specific geographic location is the higher density of relatively more developed companies in this territory.

For the survey purposes dependent variable is Employee Engagement (ENG). There are six independent variables suggested that correspond to above outlined HRM processes, namely, Recruitment and Onboarding (RO), Performance Management (PM), Reward and Recognition (RR), Learning and Development (LD), Internal Communication (IC) and Team Building (TB). As a mediating variables are suggested Generation (GEN), Personality (PER), Job Content (JOB) and Colleagues (COL). Satisfaction (SAT) is there as a second order dependent variable to detect whether there is more influence on employee engagement or satisfaction when organizations invest in gamifying different people management processes and what is the impact that Satisfaction has on Engagement.

The reason for suggesting Personality (PER) as a mediating variable is observation that within the same environment and conditions certain individuals tend to be happier and act in a more engaged way that the others. It is believed by the authors that individuals whose personality is more positive, who assume their own accountability for their situation and conditions in life and are engaged with the life in general are also more engaged with their organizations irrespective of organizational policies and processes, including whether or not game elements are in use to better engage employees. It will be interesting to observe the extent to which this hypothesis is proved, as the outcome may have strong impact on the hiring process of the companies.

The other mediating variable, Generation (GEN), is suggested due to belief that younger individuals are more inclined to appreciate gaming and thus would feel happier and more engaged with the company that does use game elements in their people processes. Whether or not this turns out to be true may have an impact on personnel planning and future design of HRM processes when the organizations realize change of generations in their people resources. 


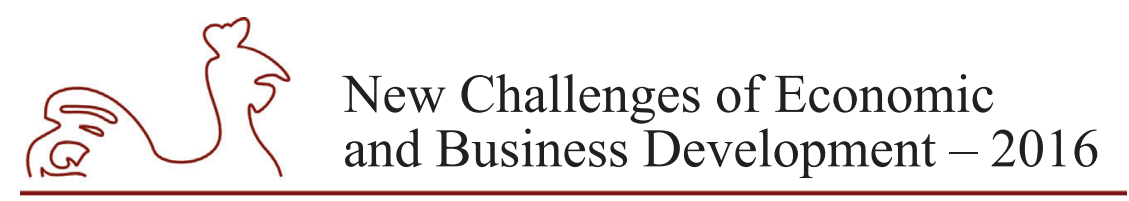

May 12-14, 2016, Riga, University of Latvia

Finally, mediating variable of Colleagues being positive and engaged (COL) is introduced under belief that those individuals whose direct team members (or most of them) are generally positive and having optimistic views on life in general, are also themselves more happy and engaged with their jobs and companies in general. The belief is influenced by the observation that many of methodologies that are applied to measuring concepts like employee commitment (TNS, www.tns.lv), employee engagement (Gallup, www.gallup.com), employee satisfaction and other close constructs, have questions related to team environment and assessment of direct colleagues. For example, one of the 12 criteria used by Gallup in measuring employee engagement, is whether or not an individual has his or her best friend at work. TNS, on their end, have questions regarding general positivity and engagement of the direct colleagues. With human beings having a high need for the close social connections and being strongly influenced by others' opinions, it is reasonable to assume that positive and engaged social environment will influence positively individual's own satisfaction and engagement.

Job content (JOB) is the element that according to Gallup (as well as many thought leaders in HRM domain) has high influence on employee engagement. Whether or not one perceives his or her job as being meaningful, adding up to a purpose bigger than themselves, strongly influences the extent to which such person will feel engaged with the organization he or she works for.

\subsection{Qualitative Survey - Interviews}

Interviews are planned with Human Resource Management professionals of those companies that will respond positively during the search for organizations who already use game elements within their people management processes. It is intended to have 10-15 structured interviews altogether. For the interviewing purposes not only such respondents will be chosen whose organizations apply gamification elements but also have measured employee engagement during the period of minimum past 3 years. Throughout interviewing authors will test observations made through the employee survey and discuss survey results to obtain more detailed background on specific work environment factors and how Human Resource Managers value the influence of different elements. Questions will be asked about general and historic employee engagement levels at their companies, what, according to them, are the factors most strongly influencing changes in engagement, as well as what are their observations about application and use of game elements in their people management processes. Throughout the interviews authors will collect information behind the reasons organizations have decided to use gamification, what are the benefits and faults of that, and whether or not HR professionals observe a link between gamification and employee engagement. Results of the qualitative interviews will be analyzed with the help of QCA - a platform designed by Mayring, Ph. (2014) for qualitative content analysis.

\subsection{Analysis of Survey Results}

Since the research aim is to link all the above-mentioned constructs together, they are included in the research model and the following research questions are outlined:

RQ1: Which constructs are the best predictors of employee engagement?

RQ2: what is the impact of individual's personality, generation, job content and engaged colleagues on his or her engagement with the organization? 


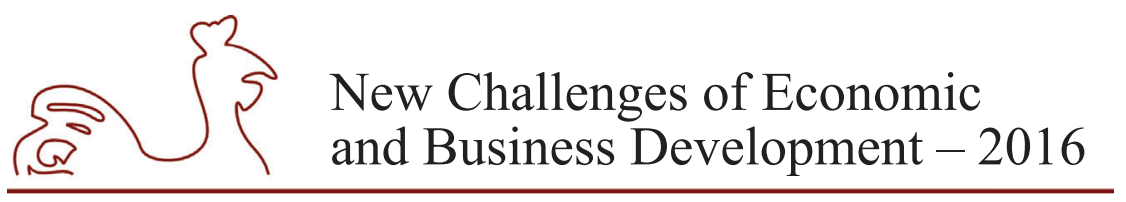

May 12-14, 2016, Riga, University of Latvia

RQ3: What is the relationship between application of game elements to Human Resource management processes and employee engagement, job satisfaction?

RQ4: Which Human Resource management processes have the highest impact on employee engagement when gamified?

RQ5: what is the penetration rate of gamification use within HRM processes in Latvian business organizations?

Sample size for this research is planned between 200 and 300 respondents to be appraised through the Survey instrument of a structured questionnaire with questions developed for measuring employee engagement and employee satisfaction. Satisfaction will include 4 subconstructs - work environment, management, team and job itself. The questionnaire will measure all items on a 5-point Likert-type scale, where $1=$ strongly disagree; $2=$ disagree; $3=$ neither agree nor disagree; $4=$ agree and $5=$ strongly agree. The survey will be prepared in Latvian language and include demographic variables like age and gender.

Engagement (ENG) will be measured with 7 statements that are developed based on Gallup, TNS and UWES (Utrecht Work Engagement Scale) instruments, as well as inspired by methodologies used by management consulting and management solutions provider organizations like Towers Watson, Hewitt, Officevibe, Globoforce, etc., and include engagement relevant statements.

Personality (PER) will be measured by 7 questions and will seek to understand respondent's individual optimism, positivity and enthuasiasm. These answers will allow to analyze to what extent individual personality type influences the fact whether an employee will be engaged with his or her employer.

Job Content (JOB) by many authors is believed to have a strong influence on engagement of workers. 5 questions related to job meaningfulness, developing nature and autonomy will seek to test this assumption.

Whether or not attitude of surrounding Colleagues (COL) has significant influence in individual's engagement with the organization will be checked through 5 statements related to this construct.

Satisfaction (SAT) in the model is second independent variable. It includes employee satisfaction with the job environment, workload, compensation in the company they work for, as well as organization in general. Satisfaction will be measured by 5 questions related to general work environment.

Authors will use SmartPLS software to analyze results, because it enables to look at the models from high level of abstraction instead of simply interrelating the dimensions (Kalvina, A., Ludviga, I., 2016). In order to differentiate job satisfaction from engagement authors will design higher order model that uses hierarchical components approach (May, D. R., et al., 2004).

All constructs will be measured with reflective type questions.

Survey participants will be also asked to answer the questions whether or not their Employer organization applies game elements (electronic games, virtual reality games, badges, competition, leaderboards, role plays, simulations, card games, etc.) to any of the outlined Human Resource Management processes. In case of positive answer they will have to respond about their own experience with those game elements. In case of negative answer they will have to respond whether they believe that such experience would be beneficial for them to better align with the company. 


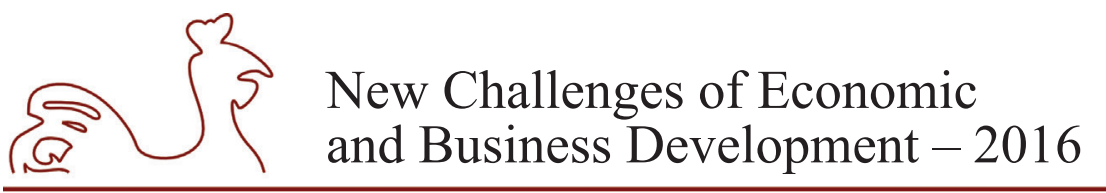

May 12-14, 2016, Riga, University of Latvia

\subsection{Draft Questionnaire}

\section{Draft Questionnaire for the Employee Survey}

\begin{tabular}{|c|c|}
\hline 1 & Engagement \\
\hline 1.1. & I strongly identify myself with the organization's vision and goals \\
\hline 1.2 . & My opinion at work is listened to and counts \\
\hline 1.3 . & I often do more at work than my direct responsibility is, without anybody asking for that \\
\hline 1.4. & I see and suggest new ideas at work or ways how to do our work better \\
\hline 1.5 & I receive timely and good quality feedback about my performance \\
\hline 1.6 & My supervisor, or someone at work, seems to care about me as a person and my development \\
\hline 1.7 & During the last year, I had opportunities at work to develop, learn and grow \\
\hline 2. & Satisfaction \\
\hline 2.1 & I have materials and equipment to do my work right \\
\hline 2.2 & My workload is reasonable and allows me to do a good quality work \\
\hline 2.3 & My work environment is convenient and complies with health and safety requirements \\
\hline 2.4 & The level of mental stress at work is reasonable and acceptable for me \\
\hline 2.5 & $\begin{array}{l}\text { My remuneration is fair for the work I do when compared to similar job holders internally and } \\
\text { externally }\end{array}$ \\
\hline 3 & Colleagues \\
\hline 3.1 & My colleagues are committed to doing good quality work. \\
\hline 3.2 & $\begin{array}{l}\text { My colleagues are generally positive individuals who approach their daily tasks and problems } \\
\text { with a "can do" attitude }\end{array}$ \\
\hline 3.3 & My colleagues strongly identify themselves with a vision and goals of the company \\
\hline 3.4 & $\begin{array}{l}\text { My colleagues often do more at work than their direct responsibility is, without anybody asking } \\
\text { for that }\end{array}$ \\
\hline 3.5 & My colleagues see and suggest new ideas at work or ways how to do our work better \\
\hline 4. & Job Content \\
\hline 4.1. & The work I do is important for the organization to achieve its goals \\
\hline 4.2 . & At work, I have the opportunity to do what I do best every day \\
\hline 4.3 & I know what is expected of me at work and how my performance is assessed \\
\hline 4.4 & My work offers me opportunity to master my skills and become consistently better at what I do \\
\hline 4.5 & I have freedom to decide in what ways to do my work \\
\hline 5. & Personality \\
\hline 5.1 & $\begin{array}{l}\text { I consider myself being generally positive and optimistic person, I expect things to turn out } \\
\text { well in a first place }\end{array}$ \\
\hline 5.2 & I am happy with my life in general \\
\hline 5.3 & I know my goals in life and sooner or later I am successfully achieving them \\
\hline 5.4 & I use my failures to learn from those and be more successful next time \\
\hline 5.5 & My success in life and at work is primarily dependent on my own thoughts, attitude and effort \\
\hline 5.6 & $\begin{array}{l}\text { If I see a situation where I know I can help, I will offer my advice or support even if I'm not } \\
\text { asked to do so }\end{array}$ \\
\hline 5.7 & $\begin{array}{l}\text { At work and in life I often do more than I'm expected or asked to do, because going an extra } \\
\text { step for the sake of better outcome is a natural thing for me }\end{array}$ \\
\hline
\end{tabular}




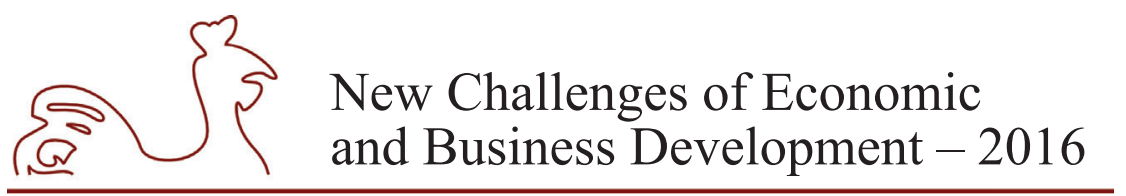

May 12-14, 2016, Riga, University of Latvia

\begin{tabular}{|c|c|}
\hline 6. & Age \\
\hline & Please, identify your age group \\
\hline 6.1 & Until (including) 1964 \\
\hline 6.2 & $1965-1980$ \\
\hline 6.3 & 1981-1996 \\
\hline 6.4 & 1997 and after \\
\hline \multirow[t]{2}{*}{7.} & Gender \\
\hline & Please, identify your gender \\
\hline 7.1 & $\mathrm{~F}$ \\
\hline 7.2 & $\mathrm{M}$ \\
\hline \multirow[t]{2}{*}{8.} & HR Processes - Recruitment and Onboarding \\
\hline & $\begin{array}{l}\text { My Employer uses game elements (electronic games, virtual reality games, badges, } \\
\text { competition, leaderboards, role plays, simulations, card games, etc.) during the process of } \\
\text { recruiting, selecting or onboarding new employees }\end{array}$ \\
\hline 8.1 & Yes \\
\hline 8.2. & $\begin{array}{l}\text { I have personally experienced game elements as part of recruitment/selection/onboarding at my } \\
\text { company }\end{array}$ \\
\hline 8.3. & $\begin{array}{l}\text { I personally like the game elements company is using in these processes, I find them fun and } \\
\text { helping to build better connection with the company }\end{array}$ \\
\hline 8.4. & No \\
\hline 8.5 . & $\begin{array}{l}\text { I would like if my company used game elements in these processes, it would be fun and } \\
\text { helping to build better connection with the company }\end{array}$ \\
\hline \multirow[t]{2}{*}{9.} & HR Processes - Performance Management \\
\hline & $\begin{array}{l}\text { My Employer uses game elements (electronic platforms, virtual reality games, badges, } \\
\text { competition, leaderboards, role plays, simulations, card games, etc.) during the process of } \\
\text { setting work related targets and measuring / showing achievement of those }\end{array}$ \\
\hline 9.1 & Yes \\
\hline 9.2 & $\begin{array}{l}\text { I have personally experienced game elements as part of target setting and performance } \\
\text { measurement at my company }\end{array}$ \\
\hline 9.3 & $\begin{array}{l}\text { I personally like the game elements company is using in these processes, I find them fun and } \\
\text { helping to build better connection with the company }\end{array}$ \\
\hline 9.4 & No \\
\hline 9.5 & $\begin{array}{l}\text { I would like if my company used game elements in these processes, it would be fun and } \\
\text { helping to build better connection with the company }\end{array}$ \\
\hline \multirow[t]{2}{*}{10.} & HR Processes - Reward and Recognition \\
\hline & $\begin{array}{l}\text { My Employer uses game elements (electronic platforms, virtual reality games, badges, } \\
\text { competition, leaderboards, role plays, simulations, card games, etc.) to praise employees for } \\
\text { good performance, extraordinary achievements or important personal or work related occasions } \\
\text { (like work or life anniversary, etc.) }\end{array}$ \\
\hline 10.1 & Yes \\
\hline 10.2 & I have personally experienced game elements as part of reward and recognition at my company \\
\hline 10.3 & $\begin{array}{l}\text { I personally like the game elements company is using in these processes, I find them fun and } \\
\text { helping to build better connection with the company }\end{array}$ \\
\hline 10.4 & No \\
\hline 10.5 & $\begin{array}{l}\text { I would like if my company used game elements in these processes, it would be fun and } \\
\text { helping to build better connection with the company }\end{array}$ \\
\hline
\end{tabular}




\section{New Challenges of Economic and Business Development - 2016}

May 12-14, 2016, Riga, University of Latvia

\begin{tabular}{|c|l|}
\hline 11. & HR Processes - Learning \& Development \\
\hline & $\begin{array}{l}\text { My Employer uses game elements (electronic platforms, virtual reality games, badges, } \\
\text { competition, leaderboards, role plays, simulations, card games, etc.) for employee training and } \\
\text { development purposes }\end{array}$ \\
\hline 11.1 & Yes \\
\hline 11.2 & $\begin{array}{l}\text { I have personally experienced game elements as part of training and development processes at } \\
\text { my company }\end{array}$ \\
\hline 11.3 & $\begin{array}{l}\text { I personally like the game elements company is using in these processes, I find them fun and } \\
\text { helping to build better connection with the company }\end{array}$ \\
\hline 11.4 & No \\
\hline 11.5 & $\begin{array}{l}\text { I would like if my company used game elements in these processes, it would be fun and } \\
\text { helping to build better connection with the company }\end{array}$ \\
\hline $\mathbf{1 2 .}$ & HR Processes - Internal Communication \\
\hline & $\begin{array}{l}\text { My Employer uses game elements (electronic platforms, virtual reality games, badges, } \\
\text { competition, leaderboards, role plays, simulations, card games, etc.) for internal } \\
\text { communication purposes and/ or collecting employee suggestions and ideas }\end{array}$ \\
\hline 12.1 & Yes \\
\hline 12.2 & $\begin{array}{l}\text { I have personally experienced game elements as part of internal communication and employee } \\
\text { ideas' generation at my company }\end{array}$ \\
\hline 12.3 & $\begin{array}{l}\text { I personally like the game elements company is using in these processes, I find them fun and } \\
\text { helping to build better connection with the company }\end{array}$ \\
\hline 12.4 & No \\
\hline 12.5 & $\begin{array}{l}\text { I would like if my company used game elements in these processes, it would be fun and } \\
\text { helping to build better connection with the company }\end{array}$ \\
\hline $\mathbf{1 3 .}$ & HR Processes - Team Building \\
\hline & $\begin{array}{l}\text { My Employer uses game elements (electronic platforms, virtual reality games, badges, } \\
\text { competition, leaderboards, role plays, simulations, card games, etc.) for building and improving } \\
\text { the teamwork for departments or employee groups (e.g. management) }\end{array}$ \\
\hline 13.1 & Yes \\
\hline 13.2 & I have personally experienced game elements as part of team building at my company \\
\hline 13.3 & $\begin{array}{l}\text { I personally like the game elements company is using in these processes, I find them fun and } \\
\text { helping to build better connection with the company }\end{array}$ \\
\hline 13.4 & No \\
\hline 13.5 & $\begin{array}{l}\text { I would like if my company used game elements in these processes, it would be fun and } \\
\text { helping to build better connection with the company }\end{array}$ \\
\hline & \\
\hline
\end{tabular}




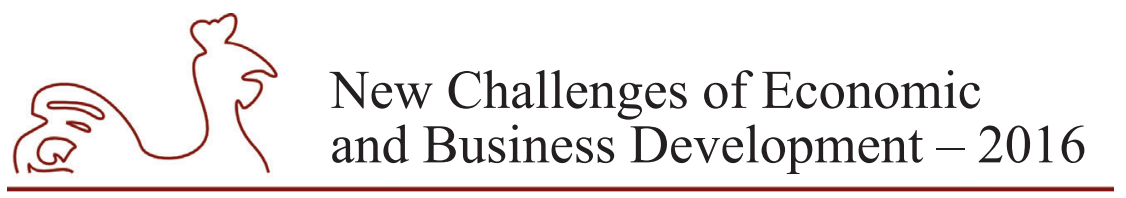

May 12-14, 2016, Riga, University of Latvia

\subsection{Conceptual Model of the Research}

Visually, relationship between the dependent, independent and mediating variables within the survey are explained by below conceptual model.

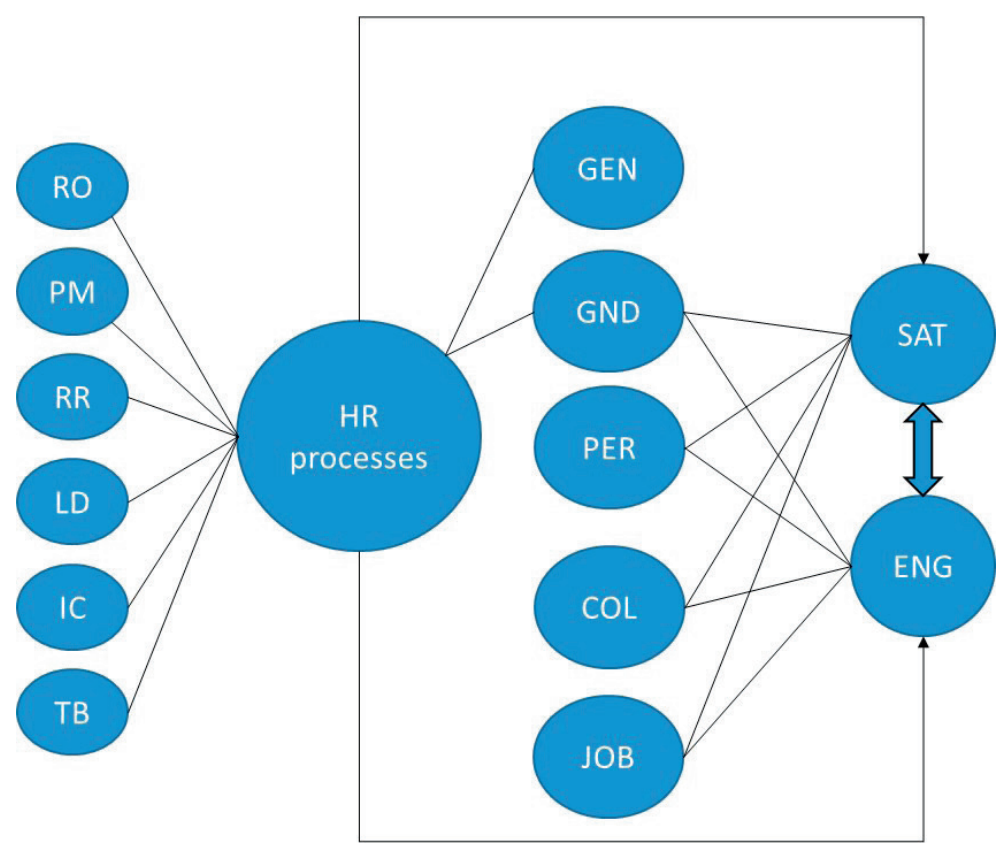

Fig. 1. Conceptual Model for analysis of factors influencing employee engagement

\section{Conclusions, proposals, recommendations}

Theory research suggests that employee engagement is influenced by a number of factors, including but not limited to the design of specific Human Resource Management processes in the organization. Article suggests approach and methodology to find out whether gamifying any particular of those processes can positively influence employee engagement and whether there is any specific process/processes where gamification has higher impact on employee engagement. Article also aims at proposing means for finding out to what extent currently gamification as a practice is widespread within Latvian enterprises and whether or not HR managers in those companies that use game elements in their people processes, observe higher engagement of their staff.

Proposal of the Authors is to validate the draft questionnaire by testing it with the sample group of 30-40 individuals representing different organizations, before applying to practice and commencing the field survey.

Based on conclusions acquired through testing, draft questionnaire will be adjusted and field survey launched in spring of 2016.

Results of the survey will help organizations to make better investment decisions when faced with the question how to improve employee engagement levels.

The research is currently at the very early stage, no survey has been conducted yet, article focuses on proposing approach and methodology for the future research to be carried out. 


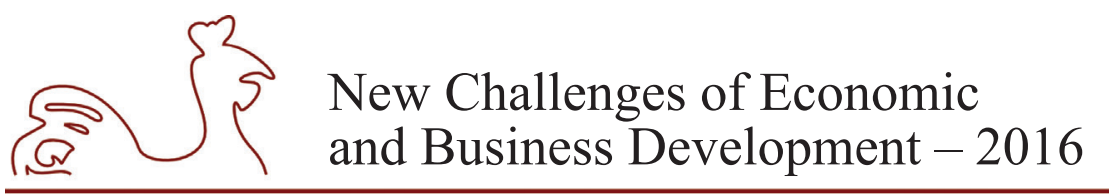

May 12-14, 2016, Riga, University of Latvia

\section{Bibliography}

ADP Research Institute, 2012, Employee Satisfaction vs Employee Engagement: Are They the same Things? ADP Inc.

Brandon, E., 2015, The Youngest Baby Boomers Turn 50. US News \& World Report. (Accessed 11 November 2015).

Burke, B., 2014, Gamify: How gamification motivates people to do extraordinary Things. Bibliomotion.

Czikszentmihalyi, M., 1990, The psychology of optimal experience. New York: Harpen \& Row.

Dale, S., 2014, Gamification: Making work fun, or making fun of work? Business Information Review, 2014, Vol. 31(2), pp. 82-90.

Deterding, S., Khaled, R., Nacke, L. E., Dixon, D., 2011, Gamification: Toward a definition, CHI 2011 Gamification Workshop Proceedings.

Dignon, A., 2011, Game frame: Unlocking the power of game dynamics in business and in life. Simon \& Schuster, NY.

Fry, R., 2015, This year, Millennials will overtake Baby Boomers, Pew research Center, (Accessed 11 November 2015).

Harter, J. K., Scmidt, F. L., Agrawal, S., Plowman, S. K., 2015, The Relationship Between Engagement at Work and Organizational Outcomes. www.gallup.com, (Accessed 23 May, 2015).

Herger, M., 2014, Gamification in HR. http://www.hr.com/en/topleaders/all_articles/gamification-in-hr_ i2caigde.html (Accessed 23 January, 2016).

iOpener Institute, 2015, The Science of Happiness at Work. https://www.iopenerinstitute.com/the-scienceof-happiness-at-work\%E2\%84\%A2.aspx, (Accessed January 29, 2016).

Hinchliffe, D, 2013, Does Technology Imporve Employee Engagement? http://www.zdnet.com/article/ does-technology-improve-employee-engagement/ (Accessed March 3, 2016).

Jameson, E., Trevena, J., Swain, N., 2011, Electronic gaming as pain distraction. Pain Research and Management, v. 16(1), pp. 27-32., http://www.ncbi.nlm.nih.gov/pmc/articles/PMC3052404/(Accessed March 5, 2016).

Kalvina, A, Ludviga, I., 2016, Exploring the Relationships between Job Satisfaction, Work Engagement and Loyalty of Academic Staff. World Academy of Science, Engineering and Technology, International Journal of Social, Behavioral, Educational, Economic, Business and Industrial Engineering Vol. 10, No. 1.

Kapp, K.M., 2012, The Gamification of Learning and Instruction: Game-based Methods and Strategies for Training and Education, ISBN: 978-1-118-09634-5, California, Pfeiffer

Kruse, K., 2013, Employee Engagement for Everyone. 4 Ways to Happiness and Fulfillment at Work. Philadelphia, The Center by Wholehearted Leadership.

Mann, A., Harter, J., 2016, Worldwide Employee Engagement Crisis. http:/www.gallup.com/business journal $/ 188033 /$ worldwide-employee-engagement-crisis.aspx?g_source $=$ The $\% 20$ relationship $\% 20$ between $\% 20$ engagement $\% 20$ at $\% 20$ work $\% 20$ and $\% 20$ or\&g_medium $=$ search\&g_campaign $=$ tiles (Accessed 28 February 2016).

Markos, S., Sridevi, M. S., 2010, Employee Engagement: The Key to Improving Performance. International Journal of Business and Management, 5(12), pp. 89-96.

May, D. R., Gilson, R. L., Harter, L. M., 2004, The psychological conditions of meaningfulness, safety, and availability and the engagement of the human spirit at work. Journal of Occupational and Organisational Psychology, Vol. 77, pp. 11-37.

Mayring, Ph., 2014, Qualitative content analysis. Theoretical foundation, basic procedures and software solution. http://nbn-resolving.de/urn:nbn:de:0168-ssoar-395173 (Accessed April 10, 2016).

Muntean, C.I., 2011, Raising engagement in e-learning through gamification. http://icvl.eu/2011/disc/icvl/ documente/pdf/met/ICVL_ModelsAndMethodologies_paper42.pdf, (Accessed 7 February, 2016).

Poggi J., 2013, Nickelodeon Targets 'Post-Millennials' in Upfront, Advertising Age. (Accessed 21 April 2013).

Strauss, W., Howe., N., 1991, Generations. Harper Perennial, NY.

TNS, 2015, airbaltic corporation TRI*M Employee Commitment Survey, Riga. 


\title{
A COMPARATIVE ANALYSIS OF THE EU PUBLIC SECTOR INTERNAL AUDIT METHODOLOGY AND REQUIREMENTS
}

\author{
Ivita Faitusa, University of Latvia, Latvia ${ }^{1}$ \\ Simon Grima, University of Malta, Malta \\ Peter J. Baldacchino, University of Malta, Malta
}

\begin{abstract}
There is currently no standard or requirement guiding the approaches taken by the European Union (EU) Public Sector internal audit. Therefore, the approaches taken by each country, although having some similarities are different.

The aim of this research is to compare the Latvian state administration internal audit approach with approaches of the following specific European countries: United Kingdom, Malta, Estonia, Lithuania, Latvia and Poland and evaluate each country's internal audit approach according to internal audit maturity determinants. The latter have been determined from literature, the Compendium report. Thereby, shedding light on the Latvian's internal audit approach maturity.

The methodology includes a comparative study of 5 European countries' public sector internal audit methodologies, by carrying out a documents analysis and evaluation of the existing normative acts, analysing cases and other scientific findings of internal audit methodology and legislation.

Authors recommend introducing a common internal audit procedures manual, standards and guidelines for the public sectors in the EU Member States. They believe that this will improve internal controls and internal audit data analysis around Europe.

The main results of the study will highlight the maturity of each of these countries' internal audit approaches and their pros and cons. It will also highlight where improvements might be required or where changes are necessary.
\end{abstract}

Key words: internal audit, public sector, internal control

JEL code: M42

\section{Introduction}

A professional, independent and objective internal audit service, whether using a centralised or decentralised approach, is one of the key elements of good governance in the public sector of county. Public sector internal auditors need to deal with both a broad stakeholder base and the increasing demands around the globe for better transparency and accountability among government agencies. This has boosted the demand for internal audits' services at a time when public sector internal auditors (..) are underfunded, compared to their counterparts outside the public sector. Despite these challenges, public sector internal auditors are concerned with their organisations' strategic risks and maintaining high-level standards (Piper A., 2015).

1 Corresponding author-e-mail address: ivita.faitusa@lu.lv 


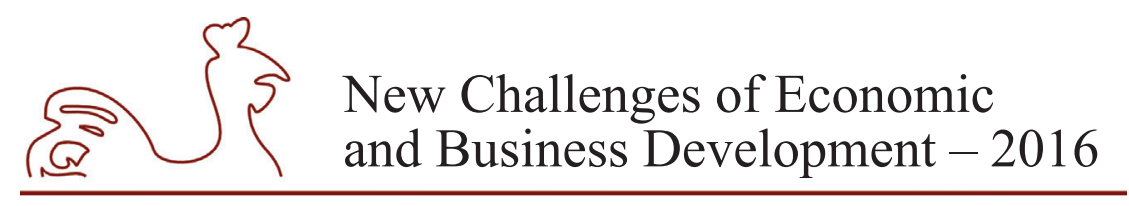

May 12-14, 2016, Riga, University of Latvia

An effective public sector audit activity will strengthen governance by materially increasing citizens' ability to hold their public sector entity accountable.

The aim of this research is to compare the Latvian state administration internal audit approach with approaches of the following specific European countries: United Kingdom, Malta, Estonia, Lithuania, Latvia and Poland and evaluate each country's internal audit approach according to internal audit maturity determinants. Thereby, shedding light on the Latvian's internal audit approach maturity.

The main results of the study will highlight the maturity of each of these countries' internal audit approaches and their pros and cons. It will also highlight where improvements might be required or where changes are required. Thereby creating a level playing field on approaches taken on the Internal Audit of Public Sector within different EU states.

\section{Research results and discussion Different main internal audit principles and requirements}

Phil Tarling (2013) highlights the vital role played by the audit committees in the effective internal audit process. Internal audit committees in each institution will ensure stronger monitoring.

Federation of European Risk Management Associations and European (FERMA, 2014) in the section roles and responsibilities of the Confederation of Institutes of Internal Auditors refers to effective risk management and controls and highlight that:

"The audit committee reports to the board of directors on the effectiveness of internal control and risk management systems based on information it acquires directly or with the assistance of the audit functions. Good audit committee practice includes review of all lines of defence in an organisation, including their interaction" (Guidance for boards and audit committees... 2010).

"Audit committee chairs and chief audit executives must have a clear understanding of expectations for internal audit. Have a detailed discussion of the personal expectations for the chief audit executives and those for internal audit overall - and address ball expectations in the audit charter" (The audit committee and the CAE, 2013).

When public organizations are directly under control of political authorities or elected bodies, the situation is far more complex. In that case, the seniority of political governance plays a more prominent role: political institutions were established a long time before the public internal control concept emerged. Implementing public internal control based on good practice, needs modification of the balances between the elected bodies, the central or local governments (political level), and the management (executive level). If the Audit committee is derived from the elected body, the question of separation of powers arises between the lawmaker and the government. In that event, the political level controls the executive level of administration, which would then lead to a situation where it could be very difficult to find enough experts to fill the committees, notwithstanding also the political considerations that have to be taken into consideration (Chapon, 2012).

"Although external audit and internal audit have some complementary relationships, coordination of their activities is essential. Internal audit's evaluation of the internal control systems provide significant information for the external auditor's assessment of control/ risk affecting the financial statements. The ideal situation is when the external and internal auditors meet periodically to discuss their scope of work, methodology and audit coverage." (Guidance for boards and audit committees, 2010). 


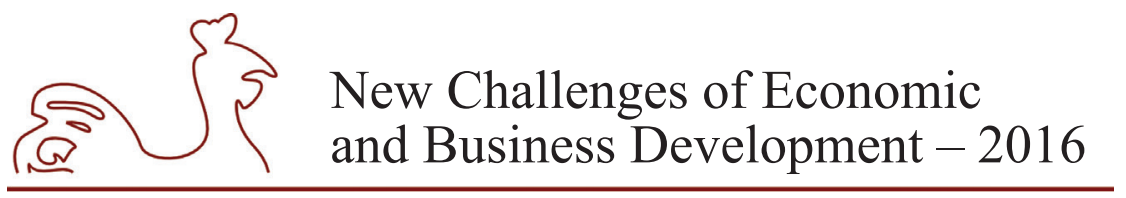

May 12-14, 2016, Riga, University of Latvia

Authors' hypothesis that a common internal audit manual for European Union Member States public administration (public sectors) will improve common internal audit data analysis around Europe.

Where public organisations constitute two-digit percentages of GDP and cover a wide span of activities, the complexity of their organisation and their interdependencies present a number of challenges for their internal audit (Chapon, 2012, 5).

The majority of European Union Member States have an internal audit function, but this does not cover all public administration systems. The majority of countries that have an internal audit established the function in their laws or regulations. Most of European Union countries indicate that their internal audit activities are based on standards. COSO model, INTOSAI, and Standards for Professional Practise of Internal Audit have a significant role in the system development. Moreover, most internal audit systems do not cover all parts of the public sector or every part in the same manner (Compendium... 2014).

Public internal control systems differ from country to country as they have to fit into the respective overall governance arrangements with each of the constitutional stakeholders government, parliament and the supreme audit institution - as well as the accountability arrangements that exist between these stakeholders. Within the government, internal accountability arrangements are also a determining factor, as is the content of accountability of those responsible for carrying out public tasks. A distinction can be drawn here between legal accountability for compliance with rules and regulations and managerial accountability for the use of public resources to achieve goals. Budgeting and accounting arrangements also have to be taken into account. (Analysis overview. Compendium, 2014).

Most of internal audit systems do not cover all parts of the public sector or every part in the same way. Even the coverage of the central government part varies from country to country.

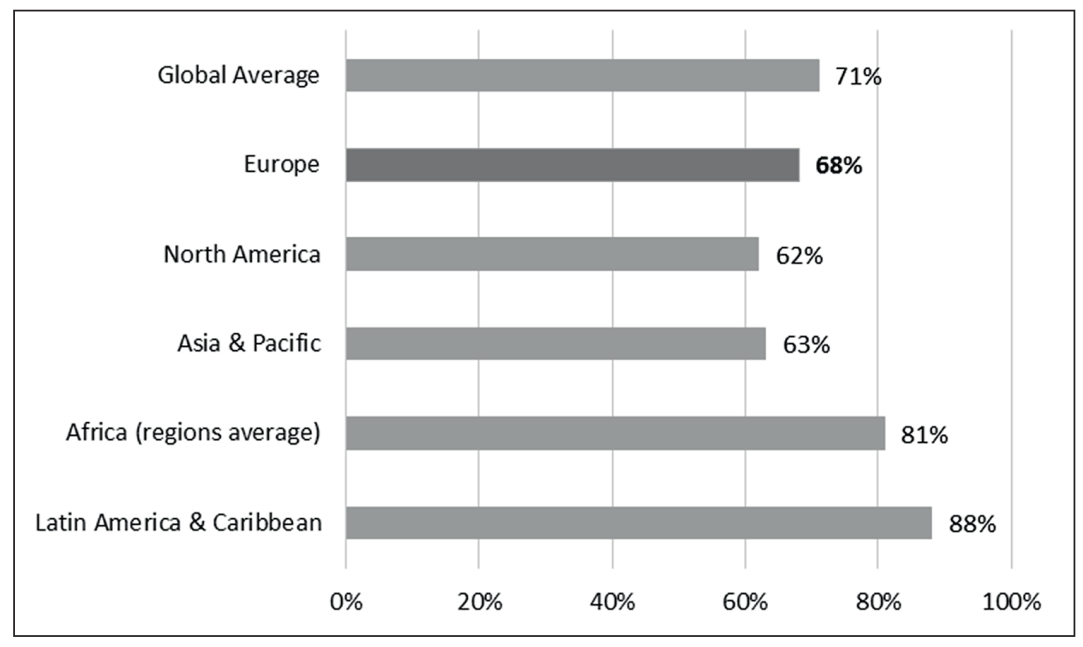

Source: Author's construction based on Piper A., CBOK 2015 practitioner survey.

Fig. 1. Internal Audit Mandated by Law in Public sector

A global average from the Global Internal Audit Common Body of Knowledge (CBOK) 2015 Practitioner survey (14158 respondents from 166 countries, 25\% from Europe, 19\% from 


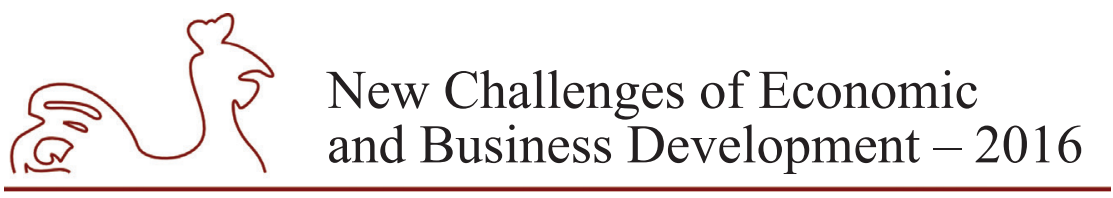

May 12-14, 2016, Riga, University of Latvia

North America, 14\% - Latin America, 14\% - Africa, 30\% - Asia) about 7 out of 10 from a total 2572 respondents noted that the existence of their internal audit function is mandatory by law (Fig. 1).

There are still quite many (average 29\%) countries around the world have no regulation for internal audit function, but they had a long history and traditions.

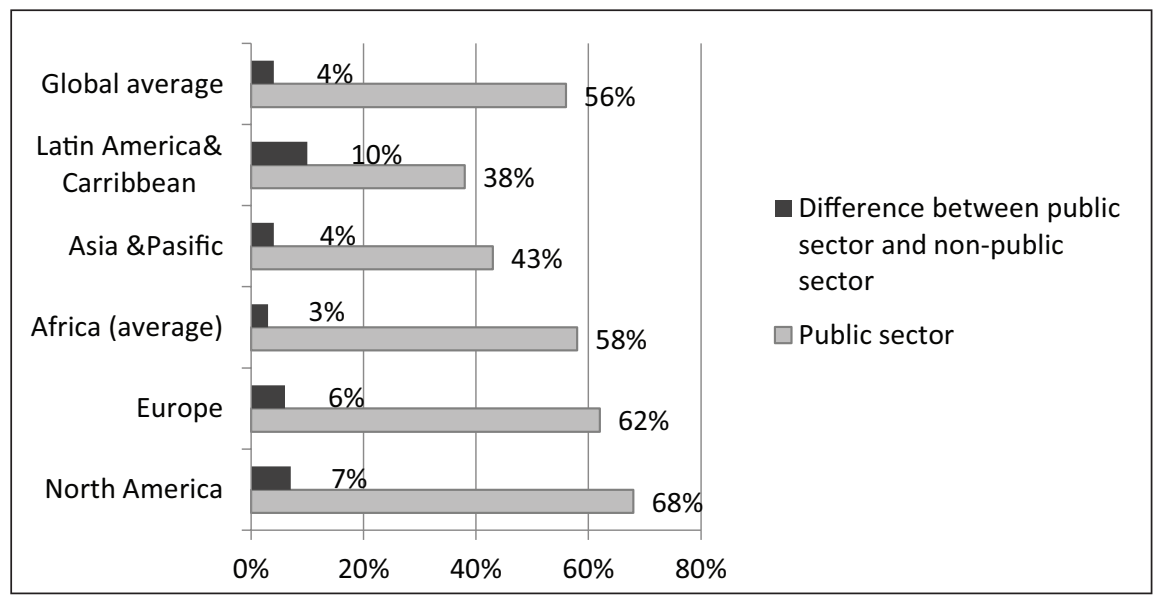

Source: Author's construction based on Piper A., CBOK 2015 practitioner survey.

\section{Fig. 2. Use of IIA's Standards (Public sector compare to Non-Public Sector)}

Across all regions, the public sector lags only slightly behind the non-public sector for use of Standards (Fig. 2). When the "use of all of the Standards" is analysed, more than half (56\%) of public sector auditors say they use all of the Standards, which is only slightly lower than the global average 60\% for the non-public sector respondents (Piper, 2015).

It can be noted from the Compendium report (2014) that, the majority of countries that have an internal audit established the function in national legislation or regulations. However, this is not the case in the United Kingdom, although it is nevertheless enshrined as a mandatory part of governance assurance arrangements within central policy rules, and de facto, every government department has an independent internal audit function. Similarly, Germany, did not establish this in their legislation or legal framework, but all Government departments follow the recommendations made by the Federal Ministry of Interior, in agreement with all other ministries. Some countries indicate that their internal activities are based on specified standards (Standards for the Professional Practice of Internal Audit, COSO model and INTOSAI.

Moreover, traditional compliance and financial audits are increasingly supplemented by various consultancy services and audits of performance that require professional and well trained internal audit staff. Very important in this case are competence and certification of internal auditors. Estonia and Lithuania are currently considering the introduction of national certification in order to meet the demands and needs of their public sector in a better way.

Also, it can be noted that the way member states have established audit boards or audit committees do not always follow the same criteria.

Relationships between internal audit and external audit have developed over time, and in some countries, they are formal and included in legislation, but they are equally often based 


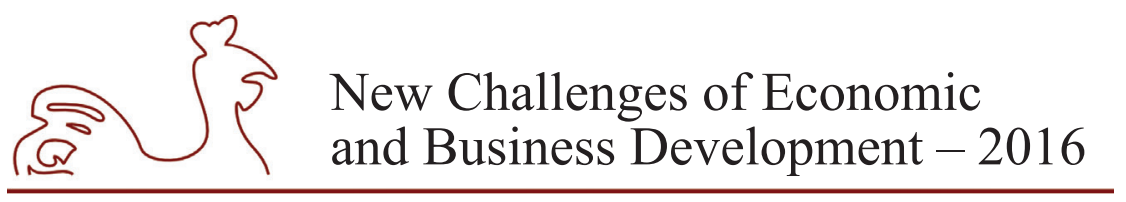

May 12-14, 2016, Riga, University of Latvia

on initiatives taken by the audit organisations themselves, for example to avoid duplication of work and facilitate the process for the auditee. A common basic relation is described in Maltese contribution, where Auditors share information and working papers for evaluating the effectiveness of internal control.

None of the reports drawn up by European Union countries compiled information relating to quantitative data such as the number of auditors, performed audits, certified auditors etc. Making this data a standard requirement to be reported in the Compendium report form for all countries will allow for better analysis.

After considering all the sources mentioned above the authors chose the following five indicators for comparison of the Internal Audit of Public entities in the six sampled EU countries:

1) year of establish Internal audit function - to compare year, structure, firs law, regulations;

2) laws and regulations changes - to compare how sustainable internal audit legislation is;

3) certification of internal auditors - to compare internal auditors competences;

4) audit committee existence - to compare growth of internal audit system;

5) Internal and external audit cooperation - to identify problems with duplication of work and facilitate the process for auditee.

This represents $24.1 \%$ from all 28 EU member States. The authors used a non-probability, convenience sampling, choosing three Baltic States: Latvia, Lithuania and Estonia as neighbour countries with similar historical and economic indicators, since one of the authors is from a Baltic State (Latvia). Malta and United Kingdom, Malta being a colony of the UK for a long period from the 1800 to 1974 and therefore having a large influence on the public entities structures and the economic and financial activity in the country, since 2 of the authors are from Malta and a random choice of a central European country Poland.

\section{Baltic States case study}

Baltic States countries, as noted by Diamond J. in 2002, like many central and eastern European countries, which were influenced by the old soviet system, have no tradition of internal audit. Rather, these countries inherited a control department in the Ministry of Finance, which operated as an investigative rather than preventative institution carrying out special investigations on alleged irregularities and fraud. Overlaid on this traditional audit function most republics have instituted an external audit institution unfortunately, there has often been confusion in the separation of roles of both institutions. While lines of reporting have been different - the Internal audit to the Ministry of Finance and external audit to the legislature some overlapping functions are evident. (Diamond, 2002).

\section{Estonia case}

Compendium (2014) highlights internal audit have been done since 2001. The most important legislative acts and interpretations are:

1) The Government of the Republic Act (2000) lays down: the concept of Internal audit system, responsibilities, competencies;

2) The Auditors Activities Act (2010) specifies, among other things, the legal basis for internal auditors activity in the public sector and public interest entities, the elements of 


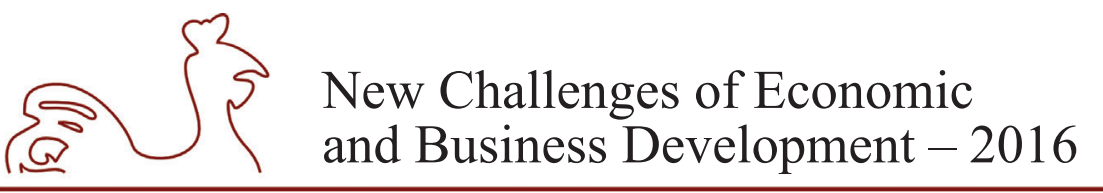

May 12-14, 2016, Riga, University of Latvia

the system for monitoring the quality - internal and external assessment, monitoring by the Ministry of Finance and consulting by the Professional Qualifications Committee;

3) Regulation by Minister of Finance "Adoption of Internal Auditor professional practices standards" (2003) - the important internal audit principles that auditors are required to follow;

4) Amendment to the Local Government Organization Act (2013) - conditions for implementation of internal audit system in rural municipality or city government and local government.

There have some more attempts to improve the professional quality of the internal audit profession in Estonia, but still the curricula of the internal audit profession has not been introduced on the levels of vocational or higher education in Estonia. Nevertheless, internal audit in Estonia has been Europeanized rather quickly despite its short history (Linnas, 2012).

\section{Latvia case}

The legal basis:

1) The Law on internal audits (2012) - internal audit system establish, coordination, the responsibilities of officials and internal auditors, tasks of the internal audit units, the principles underpinning the independence of the internal audit units, ethical principles;

2) Regulations of Cabinet of Ministers (2013) about internal audit process and internal audit evaluation and internal auditors certification;

3) An internal audit unit's rules of procedure are approved by the head of the relevant body - lay down the status, aims, functions, tasks, essence of consultations, scope of work, structure and rights and responsibilities of the internal audit unit. Internal audit guidelines,

Internal audit provide and external audit with the internal audit unit's strategic plan, annual plan and annual report. External auditors arranges meetings with internal audits once a year, at which the shortcomings detected audit priorities for the coming year and possible areas of cooperation are discussed. In 2013, internal and external auditors agreed on necessary action to be taken to further improve cooperation.

An Internal Audit Board operates in Latvia. A consultative body's aim is to improve the quality of internal audits, introduce, and develop internal audit policy and methodology in public administration.

The increase and decline of Internal audit growth in Latvia during last more than ten years can be explained with the different economic conditions before and after global financial crises and requirements of International Monetary Fund (IMF) as well. IMF required Latvia against loans to develop its control system regarding money usage in the public sector (Bruna, 2014).

\section{Lithuania case}

Compendium (2014) and Vaitkevicius (2014) highlights the legal basis:

1) The Law on Internal Control and Internal audit (2002) - goals and procedures for functioning internal audit in public legal entity, responsibilities;

2) The Standard Charter of the Internal Audit Unit (2003 Government resolution);

3) The Rules of the Professional Ethics for Internal Auditors (2003 - Ministry of Finance);

4) The Standard Internal Audit Methodology (2003 - Ministry of Finance); 


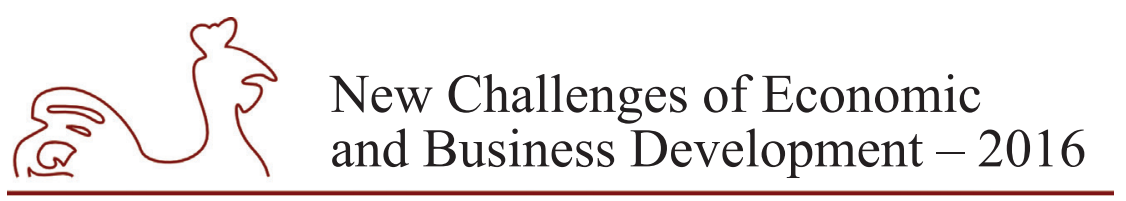

May 12-14, 2016, Riga, University of Latvia

5) The Internal audit Guidelines (2003 - Inter-Departmental commission for coordinating the development of the Internal audit system). Guidelines serve as an additional and comprehensive reference to provide the internal auditors of the public legal entities with principles, concepts and recommendations, which are to support them in conducting their activities and in preparing the specific manuals on internal audit; audit Needs Assessment determines the level of sufficient staffing resources.

System for internal audit is decentralized, but internal audit system of municipalities and some public legal entities are centralized - 169 internal audit units, 400 internal auditors and 1500 internal audits per year cover the entire public sector including municipalities (Vaitkevicius, 2014).

Table 1

Internal audit legislation in Baltic States

\begin{tabular}{|c|c|c|c|c|c|}
\hline U⿺辶 & $\begin{array}{l}\text { Establish Internal } \\
\text { audit (year, structure, } \\
\text { first law, regulations) }\end{array}$ & $\begin{array}{c}\text { Law and regulations } \\
\text { changes }\end{array}$ & $\begin{array}{c}\text { Certification of } \\
\text { Internal auditors }\end{array}$ & $\begin{array}{c}\text { Audit } \\
\text { committee }\end{array}$ & \begin{tabular}{|c|} 
Internal \\
and external \\
audit \\
cooperation
\end{tabular} \\
\hline 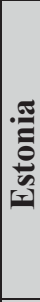 & $\begin{array}{l}\text { 2000 Ministry of } \\
\text { Finance, Finance } \\
\text { control department } \\
2000-\text { first } \\
\text { regulations } \\
\text { Audits carried out } \\
\text { since } 2001\end{array}$ & $\begin{array}{l}\mathbf{2 0 0 5} \text { - IA coordination } \\
\text { service } \\
\mathbf{2 0 0 6} \text { - "Blueprint for } \\
\text { the IA of authorities } \\
\text { with executive power" } \\
\mathbf{2 0 1 0} \text { - Auditors } \\
\text { Activities Act of } \\
\text { Estonia, } \mathbf{2 0 1 3}\end{array}$ & 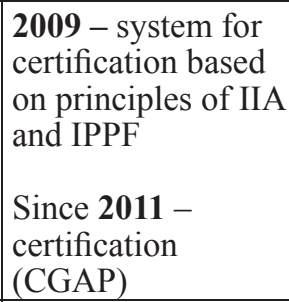 & $\begin{array}{l}\text { Ministries } \\
\text { do not have } \\
\text { responsibility } \\
\text { to establish } \\
\text { an audit } \\
\text { committee } \\
\text { according to } \\
\text { law } \\
\end{array}$ & \begin{tabular}{|l|} 
With \\
National \\
Audit Office \\
in 2 levels: \\
Ministries \\
IA units and \\
Ministry of \\
Finance \\
\end{tabular} \\
\hline & $\begin{array}{l}\text { 1999, Ministry of } \\
\text { Finance, Internal } \\
\text { audit department } \\
\text { 1999. Regulations of } \\
\text { Cabinet of Ministers }\end{array}$ & $\begin{array}{l}\mathbf{2 0 0 2 - 2 0 0 8} \text { Internal } \\
\text { audit law } \\
\mathbf{2 0 1 0} \text { - new Internal } \\
\text { audit law and } \\
\text { regulations - standards } \\
\text { requirements } \\
\mathbf{2 0 1 3} \text { - last Internal } \\
\text { audit law - improving } \\
\text { the regulatory } \\
\text { framework }\end{array}$ & $\begin{array}{l}\text { Since } 2011 \text { new } \\
\text { certification system } \\
\text { one level - exam } \\
\text { Obligatory for } \\
\text { heads of IA Units } \\
\text { or certificate from } \\
\text { IIA }\end{array}$ & $\begin{array}{l}\text { Audit board } \\
\text { since } 2000\end{array}$ & $\begin{array}{l}\text { The State } \\
\text { Audit Office } \\
\text { arranges } \\
\text { meetings } \\
\text { with IA once } \\
\text { a year }\end{array}$ \\
\hline 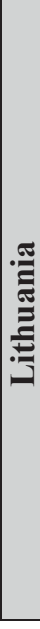 & $\begin{array}{l}2000 \\
\text { Ministry of finance } \\
\text { Financial Control } \\
\text { Methodology } \\
\text { department } \\
\text { Central Harmonising } \\
\text { Unit } \\
\\
\mathbf{2 0 0 0} \\
\text { Government } \\
\text { resolutions regarding } \\
\text { IA }\end{array}$ & $\begin{array}{l}\mathbf{2 0 0 3} \text { - Law on Internal } \\
\text { Control and Internal } \\
\text { Audit } \\
\mathbf{2 0 0 3} \text { - Standard } \\
\text { Charter of IA Unit; IA } \\
\text { methodology; } \\
\text { IA guidelines }\end{array}$ & $\begin{array}{l}\mathbf{2 0 1 0}-\text { new } \\
\text { certification } \\
\text { programme } \\
6 \text { level training } \\
\text { modules } \\
\text { (university } \\
\text { professors and } \\
\text { professionals) } \\
\text { Certification - } \\
\text { voluntary }\end{array}$ & $\begin{array}{l}\text { Till } 2009 \\
\text { was Inter- } \\
\text { departmental } \\
\text { Commission } \\
\text { for coordinat- } \\
\text { ing the devel- } \\
\text { opment of IA } \\
\text { system } \\
\text { Parliamentary } \\
\text { Audit Com- } \\
\text { mittee deals } \\
\text { broadly with } \\
\text { issues related } \\
\text { to the Na- } \\
\text { tional Audit } \\
\text { Office }\end{array}$ & $\begin{array}{l}\text { Based on } \\
\text { legislation. } \\
\text { Sharing audit } \\
\text { experiences }\end{array}$ \\
\hline
\end{tabular}

Source: Author's construction based on Compendium, 2014. 


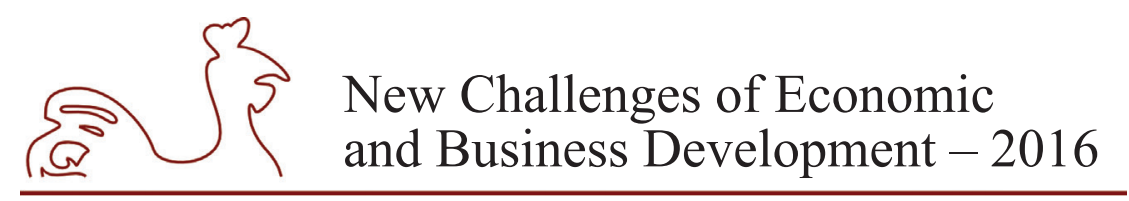

May 12-14, 2016, Riga, University of Latvia

In table one authors compare indicators in Baltic States internal audit development in public sector. Internal audit implementation started in 1999 in Latvia and in 2000 in Lithuania and Estonia with first regulations and formation of internal audit units, in all three countries responsible institution was Ministry of Finance. In Lithuania Central harmonization unit, in Latvia - Internal audit department and in Estonia - Finance control department. All Baltic States had 2-3 changes in internal audit legislation until 2014. Latvia and Lithuania have local training and certification system of internal auditors for public sector auditors, Estonia developed system for certification based on principles of IIA and IPPF. Different approaches are with audit committees establishment - In Latvia is one audit committee since 2000, in Lithuania was Interdepartmental Commission till 2009 and in Estonia no responsibility to establish audit committee. In different ways, all countries organize internal audit and external audit cooperation - meetings one a year in Latvia, in 2 levels in Estonia and with sharing audit experiences in Lithuania.

\section{Malta, United Kingdom and Poland case study}

Poland and Malta joined European Union in the same year 2004, but have different internal audit implementation systems. In Poland Financial Control and IA Coordination Department formed 2002, but in Malta in 2003 Internal and Investigations Department with Hybrid structuretwo Directorates, the Internal Audit \& Risk Management Directorate for entities with own Internal audit and the Internal Audit Central Harmonization Directorate for others. However, in large institutions and government, internal audit in some form has been around traditionally as long as it has been around in the United Kingdom. (Malta gained its independence from the United Kingdom in 1964; the country became a Republic in 1974. In Poland - since 2010 currently there are 17 audit committees in each ministry) the head of the Internal Audit Unit would ideally ensure avoiding duplication of the Supreme Audit Office and Internal Audit Unit activities, accesses coordination in terms of costs and effectiveness

\section{Poland case}

The Internal Audit Functions is governed by the following:

1) Public Finance act (2009) - basic issues concerning internal audit in the Public finance sector and proper regulations;

2) The Internal Audit Standards in the Public Finance Sector Entities (the International Audit Standards for the Professional Practice of Internal Auditing issued by Institute of Internal auditors are in force);

3) Guidelines - The Internal Audit Manual;

4) The Charter of Internal Audit in Public Finance Sector Entities;

5) The code of Ethics for Internal Auditors in Public Finance Sector Entities.

The head of the entity ensures conditions required for carrying out the internal audit procedure in an independent, objective and effective manner and, inter alia, organisational separateness of the internal audit function and continuity of the internal audit procedure in the said entity. The heads of public finance sector entities are responsible for the implementation and functioning of internal management and control mechanisms, procedures and internal regulations, such as an internal audit charter. A head of the internal audit unit reports directly to the head of the public finance sector entity and in the government administration offices, within the remit specified in 


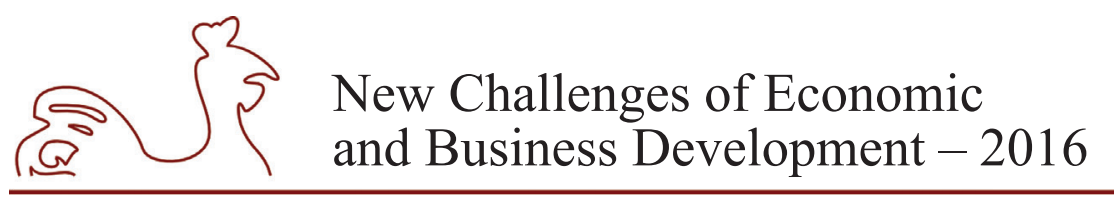

May 12-14, 2016, Riga, University of Latvia

Table 2

Internal audit legislation in Poland and Malta

\begin{tabular}{|c|c|c|c|c|c|}
\hline 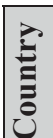 & $\begin{array}{c}\text { Establish Internal audit } \\
\text { (year, structure, first law, } \\
\text { regulations) }\end{array}$ & $\begin{array}{c}\text { Law and regulations } \\
\text { changes }\end{array}$ & $\begin{array}{c}\text { Certification } \\
\text { of Internal } \\
\text { auditors }\end{array}$ & $\begin{array}{c}\text { Audit } \\
\text { committee }\end{array}$ & $\begin{array}{c}\text { Internal and } \\
\text { external audit } \\
\text { cooperation }\end{array}$ \\
\hline 疍 & $\begin{array}{l}\mathbf{2 0 0 2} \text { - Ministry of } \\
\text { finance, Financial Control } \\
\text { and IA Coordination } \\
\text { Department }\end{array}$ & $\begin{array}{l}\text { Since 2002, Act } \\
\text { on Public Finance } \\
\text { concerning public } \\
\text { internal control was } \\
\text { updated in 2005, 2006, } \\
\text { and } 2009\end{array}$ & $\begin{array}{l}\text { Since } 2006 \\
\text { General auditor } \\
\text { post, the } \\
\text { examination } \\
\text { board and } \\
\text { the national } \\
\text { certification } \\
\text { process were } \\
\text { abolished }\end{array}$ & $\begin{array}{l}\text { In } 2010 \text { were } \\
\text { established } \\
17 \text { audit } \\
\text { committees } \\
\text { in the public } \\
\text { finance } \\
\text { sector } \\
\text { (in each } \\
\text { ministry) }\end{array}$ & $\begin{array}{l}\text { Since 2002, } \\
\text { Act on Public } \\
\text { Finance } \\
\text { concerning } \\
\text { public } \\
\text { internal } \\
\text { control was } \\
\text { updated in } \\
2005,2006 \text {, } \\
2009\end{array}$ \\
\hline$\frac{\pi}{\stackrel{\pi}{\pi}}$ & 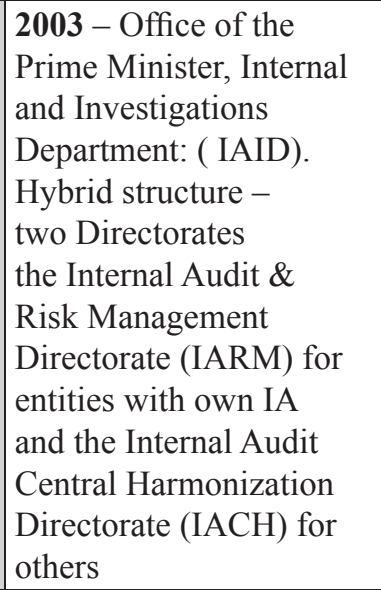 & $\begin{array}{l}\text { Internal Audit } \\
\text { and Financial } \\
\text { Investigations Act, Ch } \\
461 \text { updated in 2005, } \\
2007\end{array}$ & $\begin{array}{l}\text { International } \\
\text { certification - } \\
\text { voluntary }\end{array}$ & $\begin{array}{l}\text { Not } \\
\text { compulsory } \\
\text { by law, } \\
\text { However } \\
\text { operates for } \\
\text { those entities } \\
\text { falling } \\
\text { under the } \\
\text { decentralized } \\
\text { structure of } \\
\text { IARM }\end{array}$ & $\begin{array}{l}\text { Informal } \\
\text { cooperation }\end{array}$ \\
\hline 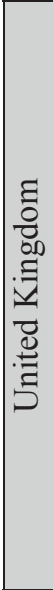 & $\begin{array}{l}\text { The main origins of } \\
\text { the current system of } \\
\text { accountability and audit } \\
\text { in the } 1860 \text { s }\end{array}$ & $\begin{array}{l}1960,1970-\text { changes } \\
1980-\text { Treasury } \\
\text { established a central } \\
\text { unit to oversee the } \\
\text { quality and caliber of } \\
\text { internal audit across } \\
\text { government. } \\
\text { The previous } \\
\text { Government Internal } \\
\text { Audit Standards have } \\
\text { been superseded from } \\
\text { April } 2013 \text { by the } \\
\text { Public Sector Internal } \\
\text { Audit Standards }\end{array}$ & $\begin{array}{l}\text { International } \\
\text { certification - } \\
\text { voluntary }\end{array}$ & $\begin{array}{l}\text { The Audit } \\
\text { and Risk } \\
\text { Assurance } \\
\text { Committee } \\
\text { is an } \\
\text { independent } \\
\text { committee } \\
\text { of the board } \\
\text { comprising } \\
\text { independent } \\
\text { non- } \\
\text { executive } \\
\text { directors. }\end{array}$ & $\begin{array}{l}\text { Cooperate } \\
\text { by sharing } \\
\text { strategies, } \\
\text { plans and } \\
\text { working } \\
\text { practices to } \\
\text { optimize audit } \\
\text { coverage } \\
\text { and reduce } \\
\text { the audit } \\
\text { burden on the } \\
\text { organization }\end{array}$ \\
\hline
\end{tabular}

Source: Author's construction based on Compendium, 2014. 


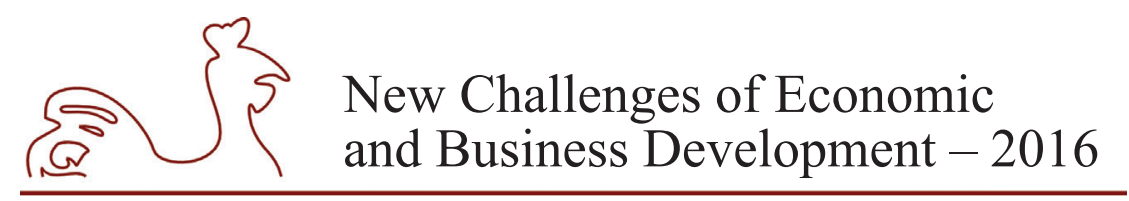

May 12-14, 2016, Riga, University of Latvia

a separate statute, to the director general. Any termination of the employment contract or any amendments to the payment and work conditions of the head of the internal audit unit require an approval of the competent audit committee. (Compendium, 2014).

\section{Malta case}

In the Public sector in Malta, the Internal Audit and Investigations Department provide its services through the four Directorates: the Internal Audit \& Risk Management Directorate; Central Harmonization Directorate; Financial Investigations Directorate; and EU Funds Audits Directorate. The IAID is fully committed to assist the Maltese Government to make the best use of public funds in order to achieve the results that the Maltese and EU citizens rightly expect to see. (About the IAID, 2016).

The IAID is governed by the following:

1) The Internal Audit and Financial Investigations Act (2003) provides for the regulation of the internal and financial investigative functions, including the power to carry out effective independent internal audits and financial investigations. Providing for the necessary safeguards to ensure the protection of the financial interests of Government including the funds it may have received or will be required to manage under Malta's international obligations (About the IAID, 2016);

2) The Code of Ethics for Accountants of the Malta Accountancy Board, which is applicable to all local accountants and auditors;

3) The Internal Audit and Investigation Manual.

Both internal and external auditors need to gain more standing in each other's eyes. For this to occur, a number of steps may be taken that will also enhance both audit efficiency and effectiveness. Within a holistic spectrum of government audit activities, the key is for the two functions to be and to be seen as complementing each other, rather than as treading on each other's toes (Zammit, Baldacchino, 2012). According to the article the barriers between internal and external audit functions could be explained by the restrictive ingrained culture of certain public officers, the open-door policy that existed between the two offices, the informal communication between them was too informal and the external audit function could not make use of internal auditors' work, limited resources. What needed to be done is to formalize the relationship with better communication and ensure more readiness to consult retention of work records;

Researchers in Malta have studied the role, function and effectiveness of the Internal Audit and Investigations Department (IAID) (Bartolo M.) and have introduced internal audit of the National Statistics Office. Issues included the building up of a diverse team, independence, reporting lines, senior support and the auditor/ auditee relationship, the audit charter and plan the application of operational auditing and the issue of co-sourcing were also found relevant (Baldacchino P. J., 2015)

\section{United Kingdom case}

Public sector internal audit in United Kingdom have a long history and tradition. In reports, this country did not comment on the internal auditor's certification and most countries did not give information about internal audit and external audit cooperation. 


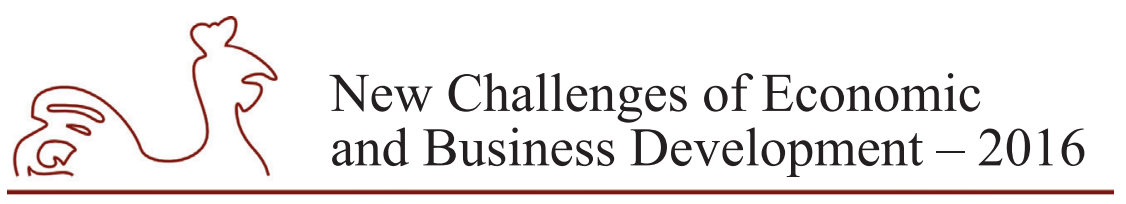

May 12-14, 2016, Riga, University of Latvia

Internal audit is not a regulatory requirement, but is enshrined as a mandatory part of governance and assurance arrangements within central policy rules. This means that every government department will have an internal audit function that is held at arm's length.

The Audit and Risk Assurance Committee plays a key role in ensuring that management's response and resolution of issues is satisfactory (Compendium, 2014).

United Kingdom internal audit regulations include Public Sector Internal Audit Standards, Audit and Risk Assurance Committee Handbook published by the Treasury.

Authors believe that there is the need for a common internal audit procedures manual, standards and guidelines for the public sectors in the EU Member States. They believe that this will improve internal controls and internal audit data analysis around Europe. From available data in Compendium of the Public Internal Control Systems in the EU Member States, each country give information without quantitative data.

The authors found that each country followed some kind of standard or a mixture of them and their focus/strengths depended on that country's specific requirements. However, each country had something to learn from the experience and work of the other. Estonia for example amended legislation with conditions for implementation of internal audit system in rural municipality or city government and local government. Lithuania started a certification program with training modules set by a diversity of university professors and practitioners. Poland has 17 audit committees in the public finance sector (in each ministry). Malta solutions for tackling the barriers between internal and external audit functions and the United Kingdom cooperation by sharing strategies, plans and working practices between internal audit and external audit to optimize audit coverage and reduce the audit burden on the organization can be something to focus on. Latvia and all these countries need to focus on the good things that they have done and learn from them, Latvia may be the forerunner in starting cooperation between the countries to have a set of EU Standards for the Public Sector.

\section{Conclusions and recommendations}

Internal auditors use formal and informal ways to achieve a relevant level of coordination and harmonisation. Traditional compliance and financial audits are increasingly supplemented by various consultancy services and audits of performance that require a professional and well trained internal audit staff. Not all European Union Member States have a common "basic" relationship between internal and external audit. The seniority of political governance plays a more prominent role. In fact, political institutions were established a long time before the public internal control concept emerged. Moreover, a basic component of today's work programme for most internal audit functions is the audit of financial information and financial management processes.

However, to ensure a level playing field within the EU on internal controls of public entities and to strengthen the services and processes, the authors believe that a common internal audit manual with common guidelines and standards for European Union Member states public administration with main components will improve internal control and internal audit data analysis. Furthermore, it is believed that the quantitative data available in the European countries annual reports form for all countries would ideally be increased to allow for more analysis that is effective. 


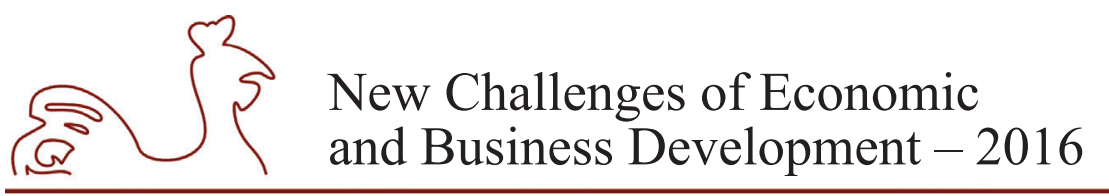

May 12-14, 2016, Riga, University of Latvia

The authors found that each country followed some kind of standard or a mixture of them and their focus/strengths depended on that country's specific requirements. However, each country had something to learn from the experience and work of the other. Latvia and all these countries need to focus on the good things that they have done and learn from them, Latvia may be the forerunner in starting cooperation between the countries to have a set of EU Standards for the Public Sector.

Authors recommend introducing a common internal audit procedures manual, standards and guidelines for the public sectors in the EU Member States. They believe that this will improve internal controls and internal audit data analysis around Europe.

\section{Bibliography}

About IAID [Online] Available at: https://opm.gov.mt/en/IAID/Pages/About-Us.aspx [Access 12 March 2016].

Analysis overview. Compendium of the Public Internal Control Systems in the EU Member States. Second edition. [Online] Available at: http://ec.europa.eu/budget/pic/lib/book/analysisoverview/HTML/ index.html\#/1/zoomed [Access 18 July 2015].

Baldacchino P. J. Recent research on Internal Auditing at The University of Malta. [Online] Available at: http://www.fiamalta.org/resources.htm [Access 12 March 2016].

Bruna I. (2014) Performance of the Public Sector's Internal Audit in the Baltic States. The $8^{\text {th }}$ International Days of Statistics and Economics, Prague, September 11-13, 2014, pp. 199-209.

Compendium of the Public Internal Control Systems in the EU Member States 2012, Luxembourg: Publications Office of the European Union, 2011. [Online] Available at: http://ec.europa.eu/budget/ library/biblio/publications/2011/compendium_27_countries_en.pdf [Access 9 July 2015].

Compendium of the Public Internal Control Systems in the EUMember States. Second edition, Luxembourg: Publications Office of the European Union, 2014, ISBN: 978-922-79-37868-3. [Online] Available at: http://ec.europa.eu/budget/pic/compendium/index_en.cfm [Access 9 July, 2015].

Chapon N. (2012) Questioning the Impact of IA in the Public Sector. Conference on "Public Internal Control systems in the EU Member states”, Brussels, 27/28 February, 2012, Discussion paper on Internal Audit, $8 \mathrm{p}$.

Diamond J. The Role of Internal Audit in Government Financial Management: An International Perspective. International Monetary Fund, 2002, Working Paper/02/94, p. 35.

Faitusa I. (2015) Public Internal Control in the European Union (2015), Proceedings of the 2015. International Conference "Economics Science for Rural Development" No. 37 - Jelgava, LLU ESAF, 23-24 April 2015, pp. 252-257.

Gleizda G. Jāsaprot, ko tas dara un kur aiziet nauda. Intervija ar IAI valdes priekšsēdètāju un Huawei Technologies IAD viceprezidentu Phil Tarling 14.03.2013, Dienas Bizness. Saldo, pp. 1-2.

Goodson S. G., Mory K. J., Lapointe J. R. The Role of Auditing in Public Sector Governance. [Online]. Available at: https://na.theiia.org/standards-guidance/Public\%20Documents/Public_Sector_Governance1_1_.pdf [Accessed 11 March 2016].

Guidance on the $8^{\text {th }}$ EU Company law directive 2006/43/EC article 41-46. ECIIA FERMA. Guidance for boards and audit committees, 21 September, 2010, pp. 7-17.

International Standards for the Professional Practice of Internal Auditing (Standards). [Online] Available at: https://na.theiia.org/standards-guidance/Public\%20Documents/IPPF\%202013\%20English.pdf [Accessed 11 March 2016].

Linnas R. Legal Regulation of Internal audit in Estonia. Conference on Internal Audit and Corporate Governance, April 18-19, 2012, [Online] available at: http://www.iacmaster.it/iacgconference2012/ wp-content/uploads/2012/04/Raivo-Linnas.pdf [Access 12 March 2016]. 


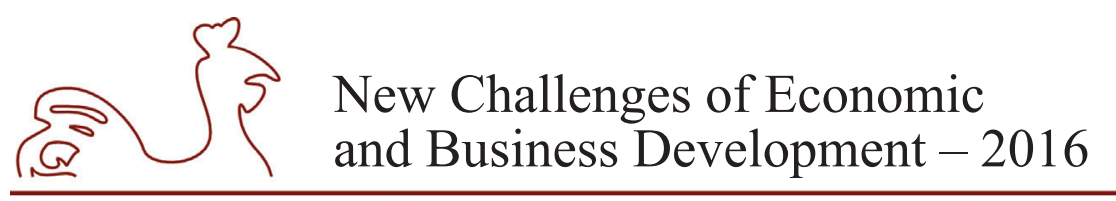

May 12-14, 2016, Riga, University of Latvia

Piper A. Auditing the Public sector. Managing Expectations, Delivering Results, 2015, CBOK study, Altamonte Springs, Florida, USA, IIARF, p. 24.

Quality assurance for internal audit. Public Internal Control Systems in the EU. An EU Approach. Discussion paper No. 3, 2014, p. 8.

Ramamoorti S. (2003) Chapter 1: Internal Auditing: History, Evolution, and Prospects. The IIA Research Foundation, Altamonte Springs, Florida, pp. 2-14.

The audit committee and the CAE: sustainable a strategic partnership. The IIARF White paper, The IIARF, 2013, Altamonte Spring, Florida, e/SBN-13: 978-0-89413-730-3, pp. 5-18.

Vaitkevicius J. Public sector internal audit in the Republic of Lithuania. Meeting of the INTOSAI Internal Control Standards Subcommittee.Vilnius, 27-28 May, 2014.

Zammit S., Baldacchino P. Overcoming Barriers between the Internal and External Audit Functions in Malta. International Journal of Government Auditing - April 2012, pp. 14-18. 


\title{
PUBLIC AND BUSINESS RESEARCH AND DEVELOPMENT EXPENDITURES AND ECONOMIC GROWTH IN EU: A PANEL DATA ANALYSIS
}

\author{
Rita Freimane, University of Latvia, Latvia ${ }^{1}$
}

\begin{abstract}
Theoretically, for achieving long term economic growth the amount of investments in research and development (R\&D) is highly important. Within the Europe 2020 strategy, research, development and innovation are key policy components of the EU strategy for economic growth. The European Commission invites the member states to allocate $3 \%$ of GDP to R\&D, with $2 / 3$ realized by the private spending. Therefore, it is interesting to focus not only on the amount of R\&D but also on its composition.

The purpose of the study is to assess the effect of private and public research and development expenditures on the economic growth in European Union countries. The dynamic panel for $28 \mathrm{EU}$ countries for time period 2004-2014 was estimated using Generalized Methods of Moments (GMM), based on a production function approach.

Main findings suggest statistically significant effect of private R\&D intensity on GDP per working population growth. The short run partial elasticity coefficient of private R\&D varies in the range $0.02-$ 0.04 (depends on model specification and subsample). The log run partial elasticity coefficient of private R\&D varies in the range 0.04-0.12 (depends on model specification). Statistical significance of public $R \& D$ is dependent on model specification. Insignificant effect of domestic R\&D in the business sector is not surprising result, the same conclusion dominates in empirical literature.

Conclusions from empirical work suggest that policy in EU countries should put more focus on the distinction between private and public $R \& D$, and governments should stimulate private $R \& D$.
\end{abstract}

Key words: business and public R\&D expenditures, economic growth, European Union, panel data model JEL code: O30, C23, F43

\section{Introduction}

Theoretically, for achieving long term economic growth the amount of investments in research and development $(R \& D)$ is highly important. $R \& D$ contributes to increased labor productivity, creation of new workplaces, achievement an industrial competitiveness. Thus, to increase international competitiveness and to build dynamic knowledge based economy, within the Europe 2020 strategy, research; development and innovation are set as the key policy components for economic growth. The European Commission recommended the member states to allocate $3 \%$ of GDP to R\&D (with $2 / 3$ realized by the private spending). (Europe 2020) Such a recommendation motivates in modelling process focus not only on the amount of R\&D but also on its composition; it raises an ongoing debate on how to allocate resources between public and private $\mathrm{R} \& \mathrm{D}$.

Corresponding author - e-mail address: rita.freimane@lu.lv 


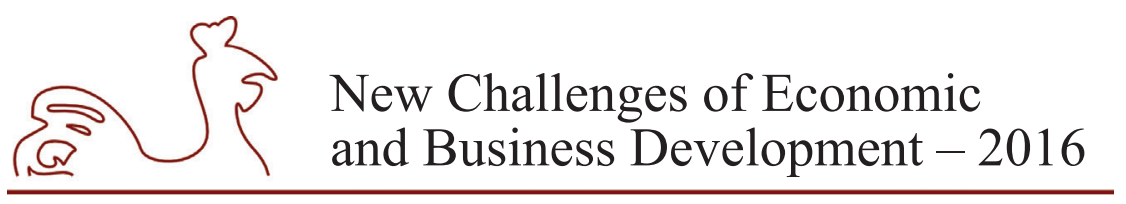

May 12-14, 2016, Riga, University of Latvia

The purpose of the study is to assess the effect of private and public research and development expenditures on the economic growth in European Union countries in period 20042014. Because of observed heterogeneity in data, analysis is made for all countries together and for more homogenous sub-groups (old and new EU countries) separately. Additionally, time dummy variables were introduced for comparison of sub-periods before, during and after recent economic crisis. After the analysis some policy implications could be addressed, like to improve the conditions for private R\&D sector in the union.

To accomplish the goal, following tasks were introduced. Firstly, theoretical and empirical literature background is given. Secondly, descriptive statistic is presented to show differences in R\&D intensity for the period 2004-2014 for EU countries. Then the distribution of R\&D expenditures by public and private funds is presented. Thirdly, to evaluate effect of R\&D on the economic growth, the panel study is applied. The dynamic panel was estimated using Generalized Methods of Moments (GMM), based on a production function approach. Following recommendations from the literature, first-differenced GMM estimator for an empirical growth model is used. (Caselli et al., 1996) The advantage of this type of models is estimation robustness in the presence of endogenous covariates, allowing for individual fixed effects, heteroscedasticity and autocorrelation within the cross - section units. (Arrellano, Bond, 1991). Obtained shortterm estimates reflect immediate changes in economic growth due to a temporary increase in explanatory variable with assumption that other factors do not change. The long-run coefficients then are deduced from the error correction form. For robustness check of the results, several specifications of the model are compared.

Theoretical and empirical literature background for the article is as follows. Romer (1990) proved that technological change must be included in the growth model, and R\&D was used as fundamental source of technological change. Aghion and Howitt (1992) employing US data, found that the share of R\&D expenditure in gross domestic product affects economic growth. In both publications results an augmented production function type was exploited. Additional factor was treated as knowledge spillover associated with R\&D and human capital. (Jones, 1995)

There are also publications that examine R\&D expenditures' effect on economic growth from the perspectives of the public and private sectors. Common findings are that although there is a positive effect of $R \& D$ expenditure on growth, private sector $R \& D$ expenditures are found to be more efficient and effective compared with public sector expenditures. (Lichtenberg, 1992; David et al., 2000; Silaghi et al., 2014) analyzed effectiveness of business and public sector $\mathrm{R} \& \mathrm{D}$ expenditures in CEEC. Their results imply significant business $R \& D$, but public $R \& D$ is found to be insignificant.

Some more recent publications pay attention to changes in R\&D and growth relationship during and after the crisis. Karczewska (2015) analyzed effect of the gross expenditures on R\&D to GDP per capita growth in the EU countries in three years separately: 2002, 2007 and 2012 and found differences in effectiveness. Gumus \& Celikay (2015) in their research, based on dynamic panel data model, revealed that the relationship between $R \& D$ expenditures in the long run is positive and significant for all countries, but significance of the short run effect depends on the degree of development of the economy. These findings in empirical literature motivate to make comparisons of estimates for different sub-groups and sub-periods in the short run and in the long run. Thus in a current research a dynamic panel with additional dummies is used like main analysis tool. 


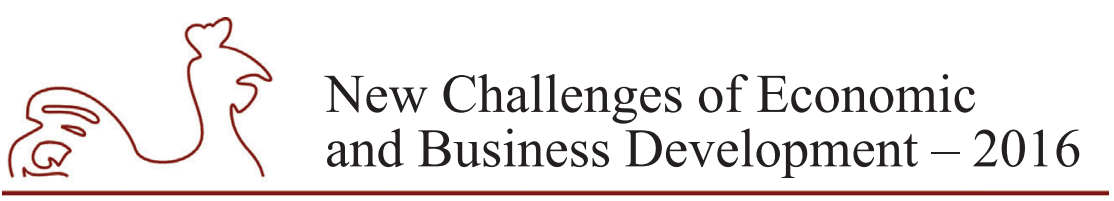

May 12-14, 2016, Riga, University of Latvia

The results are obtained for time period from 2004 till 2014, and that includes recent economic crisis with respective political reactions, influencing public R\&D allocation. Time period was chosen because of data availability for all countries, and because 10 of current $28 \mathrm{EU}$ countries entered EU in 2004. Estimation results are in line with previously mentioned empirical evidence. That confirms recommendation that governments should stimulate business R\&D investments.

The paper is organized as follows. Section 1 describes situation with R\&D expenditures in EU during the period of analysis. Section 2 describes panel regression model, data and estimation methods used in the analysis. Section 3 presents the empirical evidence from the model, and section 4 concludes.

\section{Research results and discussions}

\section{Situation}

Total R\&D expenditure is split between public and private funding. Public R\&D refers to both government and higher educational research activities. In several EU countries EU Structural Funds have become a significant source for public R\&D funding. These countries are Bulgaria, Czech Republic, Estonia, Hungary, Latvia, Lithuania, Poland, Romania, Slovenia and Slovakia.

Private or business R\&D includes activities run by firms, organizations and institutions that produce goods and services for sale to general public. In the more advances knowledge economies business R\&D funding is the main component of total R\&D expenditure, it is like an indicator of the research absorption capacity of an economy.

Figure 1 shows R\&D intensities in 2014 in 28 EU member states. Countries are arranged in decreasing order according to total R\&D expenditure as a percentage of GDP. Five leaders are Finland, Sweden, Denmark, Austria and Germany. In all these countries proportion of business R\&D in total R\&D already in 2014 exceeds 2/3, what is a suggested proportion in Europe 2020 strategy. Leading countries have set their national targets even bigger than suggested 3\% of GDP. Bottom five countries are Romania, Cyprus, Latvia, Croatia and Bulgaria. For these countries total R\&D do not reach even $1 \%$ of GDP, and proportion of business funding is less than $1 / 3$.

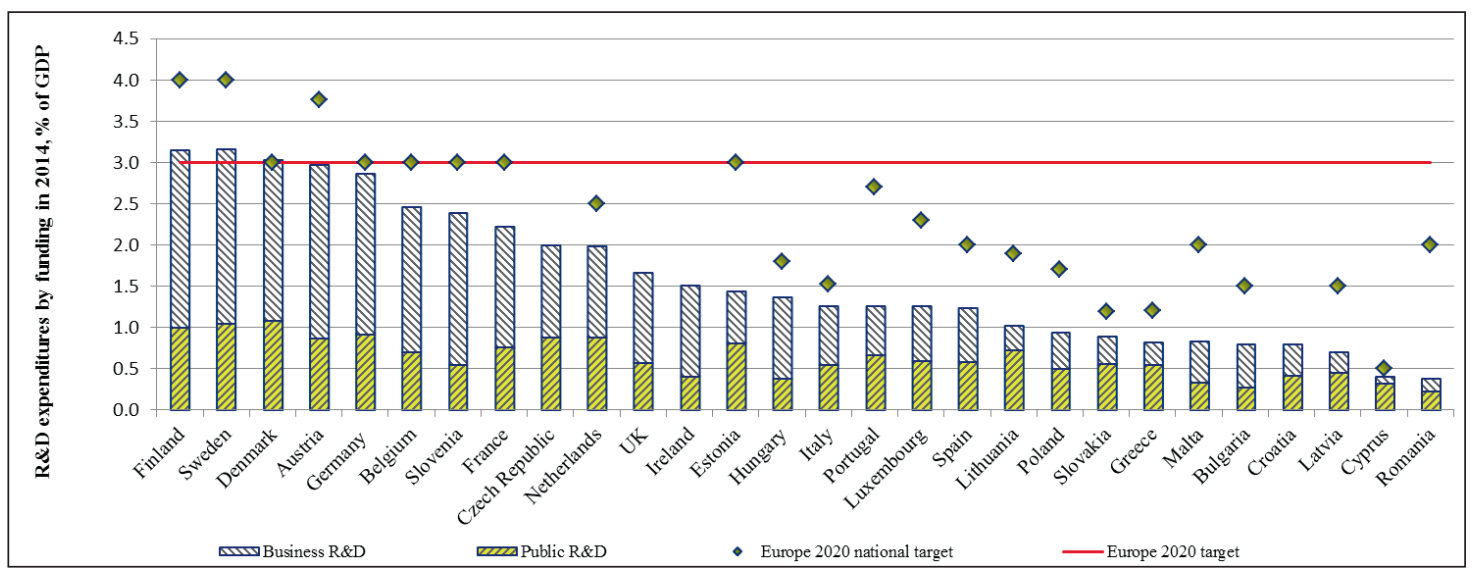

Source: author's construction based on Eurostat data.

Fig. 1. Research and development intensities as percentage of GDP in 2014 and Europe 2020 targets 


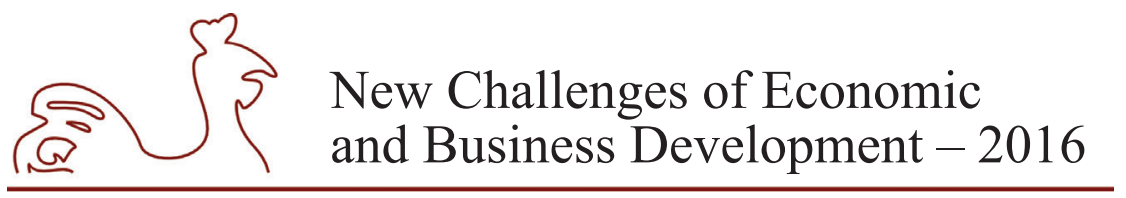

May 12-14, 2016, Riga, University of Latvia

Given the Europe 2020 objectives, in new EU countries (joined in 2004 and later) the R\&D intensities are low, still largely dependent on volatile and restricted public funding. Therefore econometric analysis has an additional task - to compare new and old blocks of EU.

\section{Econometric framework}

The initial model is like a standard growth equation model corresponding to the production function that adds two types of R\&D among other types of the capital (Eq. 1).

$$
\begin{aligned}
\ln Y_{i, t}= & \beta_{0} \ln Y_{i, t-1}+\beta_{1} \ln K_{i, t}+\beta_{2} \ln R D_{-} b u s_{i, t}+\beta_{2} \ln R D_{-} p u b_{i, t}+\beta_{4} \ln H C_{i, t}+ \\
& +\beta_{5} \ln F D I_{i, t}+\beta_{6} X_{i, t}+\eta_{i}+\varepsilon_{i, t}
\end{aligned}
$$

where $\mathrm{Y}$ is real GDP per employed person, FDI is FDI stock as percentage of GDP, $\mathrm{K}$ is domestic investment, RD_bus is the research and development expenditure in business (private) sector, $\mathrm{RD} \_$pub is the research and development expenditures in public sector, $\mathrm{HC}$ is proxy variable for assessment of human capital development. X represents a set of control variables: such as openness and government balance. $\eta_{i}$ represents the individual fixed effects specific to each country, and $\varepsilon_{\mathrm{i}, \mathrm{t}}$ is an error term, assumed to be homoscedastic and with no serial correlation. There is no labor variable separately included in Eq. 1. Like (Jones, 1995) and (Silaghi et al., 2014) and list of other authors, impact of labor force in the dependent variable is captured by the way how it is defined (in the current study: GDP per employed person). The detailed description of all variables is given in Table 1.

Table 1

\begin{tabular}{|c|c|c|}
\hline Variable & Description & Source \\
\hline $\ln Y_{i, t}$ & $\begin{array}{l}\text { Natural logarithm of GDP per employed person, million euro, } \\
\text { chain-linked volumes, reference year } 2010 \text {. Employment was } \\
\text { taken as annual averages of total employment by resident } \\
\text { population concept. }\end{array}$ & Eurostat \\
\hline $\ln \mathrm{K}_{\mathrm{i}, \mathrm{t}}$ & $\begin{array}{l}\text { Natural logarithm of domestic investments; computed as } \\
\text { a difference in Gross Fixed Capital Formation and FDI inflows, } \\
\text { percentage of GDP. }\end{array}$ & $\begin{array}{l}\text { Author's calculation, } \\
\text { based on Eurostat } \\
\text { and Unctad data }\end{array}$ \\
\hline $\operatorname{lnFDI} I_{i, t}$ & $\begin{array}{l}\text { Natural logarithm of Foreign Direct Investments, stocks, } \\
\text { percentage of GDP. }\end{array}$ & Unctad \\
\hline lnRD_bus ${ }_{\mathrm{i}, \mathrm{t}}$ & $\begin{array}{l}\text { Natural logarithm of R\&D expenditures in the business sector, as } \\
\text { a percentage of GDP }\end{array}$ & Eurostat \\
\hline lnRD_pub & $\begin{array}{l}\text { Natural logarithm of R\&D expenditures in the public sector, as } \\
\text { a percentage of GDP. Public R\&D was calculated summing up } \\
\text { government sector and high education sector activities, given as } \\
\text { a percentage of GDP }\end{array}$ & Eurostat \\
\hline $\mathrm{HC}_{\mathrm{i}, \mathrm{t}}$ & Human Capital Development index & World Bank \\
\hline G_balance $_{i, t}$ & $\begin{array}{l}\text { Net surplus(+)/net deficit (-) of general government, as } \\
\text { percentage of GDP }\end{array}$ & Eurostat \\
\hline $\operatorname{lnOPEN}_{\mathrm{i}, \mathrm{t}}$ & $\begin{array}{l}\text { Natural logarithm of the sum of exports plus imports, as } \\
\text { percentage of GDP }\end{array}$ & Eurostat \\
\hline
\end{tabular}

Dataset description and transformations 


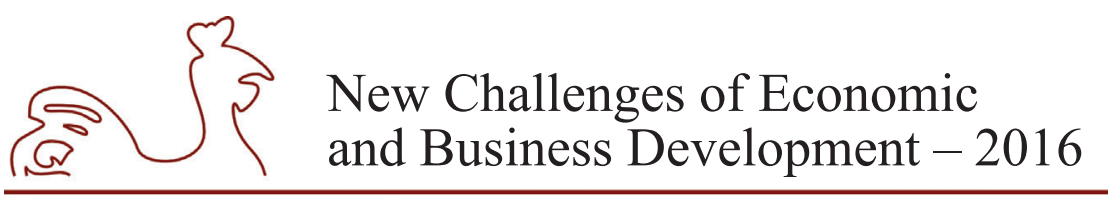

May 12-14, 2016, Riga, University of Latvia

Almost all variables are measured in logs, thus their respective partial regression coefficients will be interpreted as partial elasticities. Additionally different dummy variables were included in the model, with an aim to catch development level features of EU countries. Time period dummies cover recent economic crisis period, and let us to find its influence.

Talking about variable HC (human capital), there are several considerations to mention. Some recent theoretical articles give to R\&D and human capital accumulation essential roles in driving economic growth. Findings from empirical studies suggest that in the absence of human capital variable in the growth model, estimates of R\&D elasticities are very overestimated (Silaghi et al., 2014). So, it is important to include both variables in the model. In empirical literature we can see very different measures of human capital. One of most popular proxy is tertiary education: the share of population that has attained qualifications at the tertiary level. Romer (1986) was first who introduced knowledge spillover in an endogenous growth model. As tertiary education actually has just one aspect of human capital, there was idea to look for alternative measurements. OECD offers methodology how to capture two aspects of human capital as growth stimulator: "The human capital is a synonym of knowledge embedded in all levels such as an individual, an organizations and/or a nation" (Keeley, 2007). So, recently available Human Development Index was used as a proxy of typical human capital measure. "The Human Development Index (HDI) is a summary measure of average achievement in key dimensions of human development: a long and healthy life, being knowledgeable and have a decent standard of living." (http://hdr.undp.org/en/content/human-development-index-hdi)

To remove the individual effects, Eq. 1 is rewritten in first order differences with respect to time. Panel data regression is estimated with differenced Generalized Method of Moments $(\mathrm{GMM})$ procedure, that in following form (Eq. 2):

$$
\begin{aligned}
& \Delta \ln Y_{i, t}=\beta_{0} \Delta \ln Y_{i, t-1}+\beta_{1} \Delta \ln K_{i, t}+\beta_{2} \Delta \ln R D_{-} p u b_{i, t}+\beta_{3} \Delta \ln R D_{-} b u s_{i, t}+ \\
& +\beta_{4} \Delta \ln H C_{i, t}+\beta_{5} \Delta \ln F D I_{i, t}+\beta_{6} \Delta X_{i, t}+\Delta \varepsilon_{i, t}
\end{aligned}
$$

where denotations of variables are the same as in Eq. 1, $\Delta$ denotes first order difference of a variable. Endogeneity problem can occur in the estimation of the empirical model because of bidirectional causality of some variables, and the residual term may exhibit correlation with factors included in the model. Autocorrelation may appear in the model residuals because of the presence of the lagged dependent variable $Y_{i, t-1}$. To avoid possible endogeneity problems, Arellano - Bond type instruments were used. Correlation of the residuals and endogeneity problem is corrected by instrumenting $\Delta \ln Y_{i, t-1}$ with various dependent variable lags (up to 2 lags), and FDI, RD_bus, and RD_pub were instrumented with their values that lagged 1 or more periods behind. Estimated coefficients of Eq. 2 are short-term partial elasticity coefficient estimates, which can be interpreted as immediate percentage change in the dependent variable when a factor value temporary increase by $1 \%$, but all other factors do not change (ceteris paribus principle). Respective long term coefficients can be obtained from the error correction form (see Silaghi et al, 2014) via calculations by following formulas - error correction coefficient $\phi=\beta_{0}-1$ and for all other $\mathrm{i}=1, \ldots, 5: \theta_{i}=\frac{\beta_{i}}{1-\beta_{0}}$. Calculated coefficients $\theta_{\mathrm{i}}$ in this case will show the longrun change in the dependent variable, when a permanent increase in the factor occurs, with assumption that all other factors do not change. An error correction term $\phi$ reflects convergence towards the steady state; it is expected to be negative and less than unity by absolute value. 


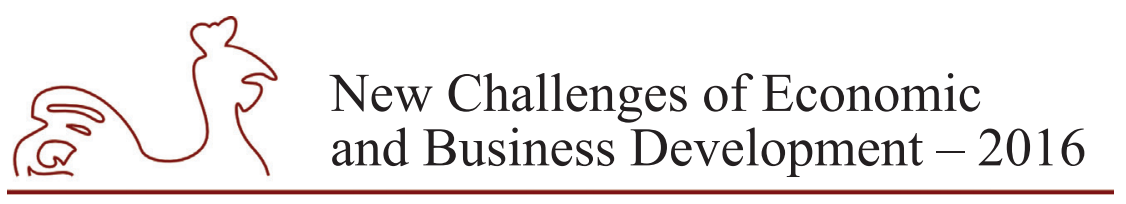

May 12-14, 2016, Riga, University of Latvia

Models are tested to obtain correct results. In section 3, empirical results and model test values are shown. For the GMM estimator to be consistent, firstly, it must pass the Hansen J-test of over-identifying restrictions with a joint validity of all instruments with its zero expectation of empirical moments. The null hypothesis is that the instruments are not correlated with the residuals. For all models respective test's p-values are included in the Table 2. The second order serial correlation problem is tested with Arellano and Bond Autocorrelation (AB test) test. This test examines the differenced residuals to identify the presence of residual autocorrelation in levels, which would be an indicator of weak exogenous instruments. Rejection of the null hypothesis of either or both tests disqualifies the estimated model (Arellano \& Bond, 1991). Respective p-value is reported for each model.

\section{Results and discussions}

In this section, the empirical results of the models are presented and interpreted. Comparisons with other empirical results are made too.

Table 2 presents dynamic panel data regression results with several regressors combination. In all case the dependent variable is growth rate of real GDP per employee (lnGDPi,t). Upper part of the Table 2 contains error-correction form estimation results, and is related to the short-run relationship evaluation. Values in brackets below each estimated partial regression coefficient are respective standard errors. $(*),(* *),(* * *)$ denote significance levels of $10 \%, 5 \%$ and $1 \%$, respectively. Lower part of the Table 2 presents calculated long-term coefficients.

For all reported models Arellano-Bond test with 2 lags could not reject the null hypothesis of no autocorrelation in the residuals. Hansen $\mathrm{J}$ test results indicate that for all reported models there is no evidence of correlation between instruments and residuals.

As it can be seen in the Table 2, R\&D in business in all specification is significant and varies around $0.02-0.03$ in the short run, and 0.04-0.06 in the long run for all EU countries sample. For CEEC, short-run elasticity is around 0.04, and long - run : 0.07-0.12.

Initial models (1) and (5) differ with sample of countries. Model (1) is estimated for all 28 EU countries, while model's (5) sample is CEE countries. Number of observations is counted after introducing lags. Comparison of the two models can show us differences for new EU members. Other purpose of the estimation was idea to compare (just in general terms) our results to Silaghi et al. (2014) estimates. Dissimilarities in the measurement of variables do not allow making direct comparisons, but main finding - highly significant business R\&D versus insignificant public $R \& D$ - is evident.

Basic models (2) and (6) have human capital variable like additional factor. Our human capital proxy, HDI, seems to be significant for growth. As it was expected from empirical literature, human capital diminishes R\&D coefficient values, but in all cases it is still significant at $5 \%$ level.

Model (4) involves additionally government policy measurement (Government balance) and international openness variable. Logic behind is that theoretically the government policies could stimulate education, increasing human capital and enhancing economic growth. Economic openness variable was included because of possible interactions between business $R \& D$ and international trade. 


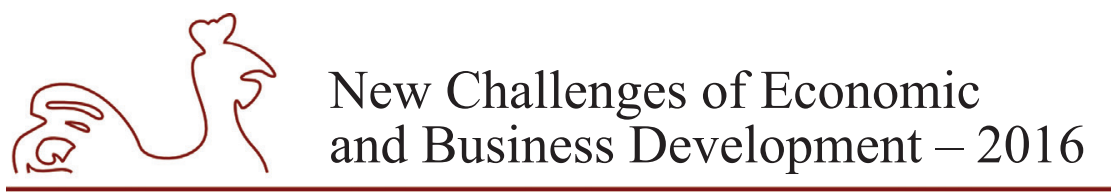

May 12-14, 2016, Riga, University of Latvia

Table 2

Panel regression results

\begin{tabular}{|c|c|c|c|c|c|c|}
\hline $\begin{array}{c}\text { Variable / } \\
\text { Model }\end{array}$ & $\begin{array}{c}\text { (1) } \\
\text { All sample }\end{array}$ & $\begin{array}{c}\text { (2) } \\
\text { All sample }\end{array}$ & $\begin{array}{c}\text { (3) } \\
\text { All sample }\end{array}$ & $\begin{array}{c}\text { (4) } \\
\text { All sample }\end{array}$ & $\begin{array}{c}(5) \\
\text { CEEC }\end{array}$ & $\begin{array}{c}(6) \\
\text { CEEC }\end{array}$ \\
\hline \multicolumn{7}{|c|}{ Short-run estimates } \\
\hline $\operatorname{lnGDP}_{\mathrm{i}, \mathrm{t}-1}$ & $\begin{array}{c}0.536^{* * * *} \\
(0.018)\end{array}$ & $\begin{array}{c}0.514 * * * \\
(0.027)\end{array}$ & $\begin{array}{c}0.512 * * * \\
(0.031)\end{array}$ & $\begin{array}{l}0.569 * * * \\
(0.028)\end{array}$ & $\begin{array}{c}0.455^{* * *} \\
(0.015)\end{array}$ & $\begin{array}{c}0.652 * * * \\
(0.012)\end{array}$ \\
\hline $\ln K_{i, t}$ & $\begin{array}{c}0.024 * * * \\
(0.011)\end{array}$ & $\begin{array}{c}0.056^{* * *} \\
(0.004)\end{array}$ & $\begin{array}{c}0.057 * * * \\
(0.01)\end{array}$ & $\begin{array}{c}0.037 * * \\
(0.017)\end{array}$ & $\begin{array}{c}0.054 * * * \\
(0.020)\end{array}$ & $\begin{array}{c}0.044 * * \\
(0.021)\end{array}$ \\
\hline $\operatorname{lnFDI} i_{i, t}$ & & & $\begin{array}{c}0.013 * * * \\
(0.002)\end{array}$ & $\begin{array}{c}0.066^{* * * *} \\
(0.008)\end{array}$ & & $\begin{array}{c}0.125^{* * *} \\
(0.008)\end{array}$ \\
\hline $\operatorname{lnRD\_ bus_{i,t}}$ & $\begin{array}{c}0.029 * * * \\
(0.004)\end{array}$ & $\begin{array}{c}0.021 * * * \\
(0.004)\end{array}$ & $\begin{array}{c}0.021 * * * \\
(0.004)\end{array}$ & $\begin{array}{c}0.022 * * \\
(0.105)\end{array}$ & $\begin{array}{c}0.038 * * * \\
(0.016)\end{array}$ & $\begin{array}{c}0.043 * * * \\
(0.017)\end{array}$ \\
\hline $\operatorname{lnRD\_ pub} b_{i, t}$ & $\begin{array}{l}-0.0025 \\
(0.0125)\end{array}$ & $\begin{array}{c}0.027 \\
(0.097)\end{array}$ & $\begin{array}{c}0.027 \\
(0.010)\end{array}$ & $\begin{array}{c}0.023 \\
(0.017)\end{array}$ & $\begin{array}{l}-0.084 \\
(0.13)\end{array}$ & $\begin{array}{l}-0.051 \\
(0.097)\end{array}$ \\
\hline $\operatorname{lnHC} C_{i, t}$ & & $\begin{array}{l}1.12 * * * \\
(0.124)\end{array}$ & $\begin{array}{c}0.977 * * * \\
(0.184)\end{array}$ & $\begin{array}{c}0.989 * * * \\
(0.187)\end{array}$ & & $\begin{array}{c}0.777 * * * \\
(0.187)\end{array}$ \\
\hline G_balance & & & & $\begin{array}{c}0.002 * * * \\
(0.0006)\end{array}$ & & $\begin{array}{r}0.018 \\
(0.007) \\
\end{array}$ \\
\hline $\operatorname{lnOPEN}$ & & & & $\begin{array}{l}0.124 * * \\
(0.084)\end{array}$ & & $\begin{array}{c}0.223 * * * \\
(0.078)\end{array}$ \\
\hline $\begin{array}{l}\text { Number } \\
\text { of time } \\
\text { dummies }\end{array}$ & 1 & 1 & 2 & 2 & 2 & 2 \\
\hline \multicolumn{7}{|c|}{ Long-run (deduced values) } \\
\hline $\begin{array}{c}\mathrm{ECM} \\
\text { coefficient } \beta_{0}\end{array}$ & 0.464 & 0.486 & 0.488 & 0.431 & 0.545 & 0.348 \\
\hline $\ln K_{i, t}$ & 0.052 & 0.115 & 0.117 & 0.086 & 0.099 & 0.126 \\
\hline $\operatorname{lnFDI}_{\mathrm{i}, \mathrm{t}}$ & & & 0.027 & 0.153 & & 0.359 \\
\hline lnRD_bus ${ }_{\mathrm{i}, \mathrm{t}}$ & 0.063 & 0.043 & 0.043 & 0.051 & 0.070 & 0.124 \\
\hline $\operatorname{lnRD\_ pub_{i,t}}$ & -0.005 & 0.056 & 0.055 & 0.053 & -0.154 & -0.147 \\
\hline $\operatorname{lnHC} \mathrm{C}_{\mathrm{i}, \mathrm{t}}$ & & & 2.002 & 2.295 & & 2.233 \\
\hline G_balance & & & & 0.005 & & 0.052 \\
\hline $\begin{array}{c}\text { Hansen test } \\
\text { (p-value) }\end{array}$ & 0.098 & 0.12 & 0.38 & 0.46 & 0.35 & 0.34 \\
\hline $\begin{array}{c}\mathrm{AR}(2) \\
\text { (p-value) }\end{array}$ & 0.077 & 0.21 & 0.14 & 0.16 & 0.09 & 0.11 \\
\hline $\begin{array}{c}\text { Number of } \\
\text { observations }\end{array}$ & 249 & 249 & 249 & 249 & 132 & 132 \\
\hline
\end{tabular}

Source: author's calculations (from EViews and Stata outputs). 


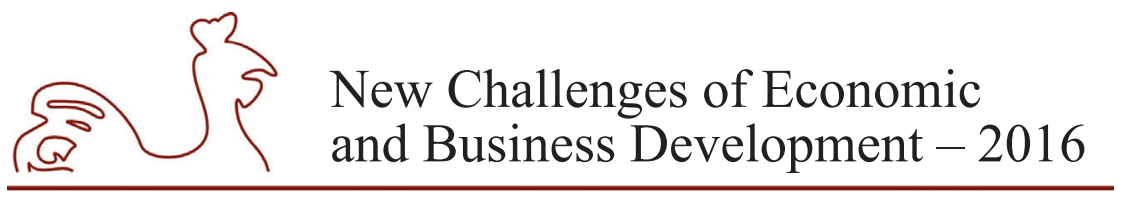

May 12-14, 2016, Riga, University of Latvia

Addition of more regressors in the model (Models (2)-(4) and Model (6)) does not cause principle changes in situation: public $R \& D$ is still insignificant, and business R\&D significance drops from $1 \%$ to $10 \%$ in case of CEEC.

One of the articles that can be used to compare results is Silaghi et al. (2014). They analyzed the role of public and private research and development stocks in explaining growth of GDP per working age population in Central and Eastern European Countries (CEE) during 1998-2008. Our sample is extended to all EU countries, and time period is 2004-2014. Silaghi et al. (2014) found that for business R\&D stocks partial elasticity is 0.050 in the short run and 0.213 in the long run. Public R\&D stocks were found to be statistically insignificant.

$\beta_{0}$ is the estimated Error Correction term. In the empirical literature for growth models with $\mathrm{R} \& \mathrm{D}$ component error term coefficient usually is statistically significant, and varies from $-0.6--0.01$. Models (1)-(6) show that error term coefficient is statistically significant for all specifications and is around $-0.5--0.4$. Negative coefficient can be interpreted as the speed of adjustment towards the steady state. Silaghi et al. (2014) for CEEC had quite similar values only in wider range: $-0.6--0.3$.

The long - run estimates are deduced from the short-run coefficients.

\section{Conclusions, proposals, recommendations}

Dynamic panel modelling approach was applied for all 28 European Union member states for annual data in 2004-2014 with the aim to assess the role of R\&D components in economic growth before, during and after recent economic crisis.

\section{Conclusions:}

1. Panel regressions with different specifications show a statistically significant impact of business R\&D on economic growth. Testing robustness the results, business R\&D coefficient remains highly significant to different sub-periods and time dummies. Estimated short-run partial elasticities imply that a $10 \%$ increase in business R\&D should generate an increase of $0.2-0.4 \%$ in the growth of the GDP per employed person, when all other factors remain constant.

2. Estimated long-run partial elasticities imply that a $10 \%$ permanent increase in business R\&D should generate an increase of about $0.4-1.2 \%$ in the growth of the GDP per employed person, when all other factors remain constant.

3. Public R\&D partial coefficient is not statistically significant in the most models. There is evidence in the literature that because of indirect effects, public R\&D partial elasticity becomes significant with certain lags. May be because of too short time series, current paper's results did not find such fact.

\section{Proposals:}

1. Our results suggest that policy in EU countries should put more focus on the distinction between private and public R\&D, and governments should stimulate private R\&D.

2. As modelling results showed that the public R\&D does not directly stimulate growth, it would be interesting to find out whether it has a neutral effect, or crowds out business, or acts as a stimulus for business R\&D. 


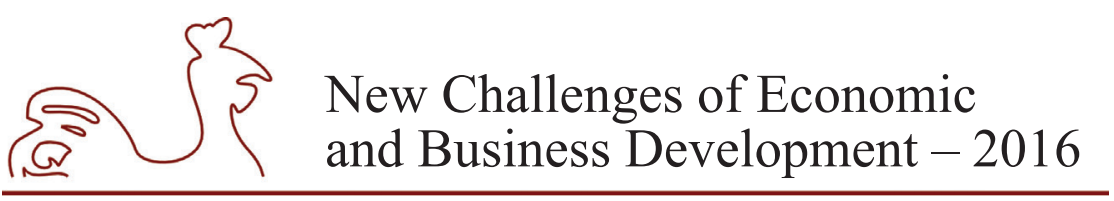

May 12-14, 2016, Riga, University of Latvia

\section{Bibliography}

Aghion, P., \& P. Howitt,1992. A model of growth through creative destruction. Econometrica (60), pp. 323-351.

Arellano, M. \& Bond, S. 1991. Some tests of specification for panel data, Monte Carlo evidence and an application to employment equations. The Review of Economic Studies, (58), pp. 277-297.

Becker, B., 2015. Public R\&D policies and private R\&D investment: a survey of the empirical evidence. Journal of Economic Survey, 29(5), pp. 917-942.

Casseli, F., Esquivel, G., Lefort, F., 1996. Reopening the convergence debate: a new look at cross country growth empirics. Journal of Economic Growth, (1), pp. 363-389.

David, P. \& B. Hall \& A. Toole, 2000, Is Public R\&D a Complement or Substitute for Private R\&D? A Review of the Econometric Evidence, Research Policy, (29), pp. 497-529.

Europe 2020. European strategy for smart, sustainable and inclusive growth, http://ec.europa.eu/eurostat/ statistics-explained/index.php/Europe_2020_indicators_-_research_and_development, retrieved on 15 January, 2016.

Gumus, E., Celikay, F. 2015. R\&D expenditure and economic growth: new empirical evidence. Journal of Applied Economic Research, 9(3), pp. 205-217.

Human Development Index description, (http://hdr.undp.org/en/content/human-development-index-hdi), retrieved on 31 March, 2016.

Inekwe, J. N., 2015. The contribution of R\&D expenditure to economic growth in developing economies. Social Indicators Research, 124 (3), pp.727-745.

Jones, C., 1995. R\&D-based models of economic growth. Journal of Political Economy, (103), pp. 759-784.

Karczewska, M., 2015. The gross expenditures on R\&D and the economic growth level in the EU countries. Research papers of Wroclaw university of economics, (394), pp. 27-35.

Keeley, B., 2007. Human Capital: How what you know shapes your life. OECD Insights. DOI 10.1787/9789264029095-en

Lichtenberg, R., 1992. R\&D Investment and International Productivity Differences, NBER Working Papers N.4161, National Bureau of Economic Research, Inc.

Pesaran, M. H., \& Smith, R., 1995. Estimating long-run relationships from dynamic heterogeneous panels. Journal of Econometrics, (681), pp. 79-113.

Romer, P. M., 1986. Increasing returns and long-run growth. Journal of Political Economy, (94), pp. 1002-1037.

Silaghi, M. \& Alexa, D. \& Jude, C. \& Litan, C., 2014. Do business and public sector research and development expenditures contribute to economic growth in Central and Eastern Europe Countries? A dynamic panel estimation. Economic Modelling, (36), pp. 108-119. 


\title{
ELECTRONIC WORD OF MOUTH (EWOM) COMMUNICATION'S INFLUENCE ON CONSUMER PURCHASE DECISIONS IN BALTIC STATES
}

\author{
Elina Gaitniece, University of Latvia, Latvia ${ }^{1}$ \\ Anda Batraga, University of Latvia, Latvia \\ Kaspars Viksne, University of Latvia, Latvia
}

\begin{abstract}
Word of mouth (WOM) communication is recognized as a critical marketing communication tool and internet widened seriously consumers' possibilities to share WOM about brands and products. This electronic WOM (eWOM) communication is one from many factors which influence consumer purchase decision. Research done in other countries does show that the power of eWOM factor is increasing. Still, companies in Baltics are not yet utilizing the full potential of available eWOM communication tools.

Therefore, the aim of the paper was - to assess how the influence of eWOM tools (particularly - social network communication and online recommendation systems) is evaluated by online retailers and digital marketing experts in Baltic countries.

Research methods used were: 1) analysis of literature which studied the latest research done on eWOM influence on consumer purchase decision; 2) expert survey within Baltics about perceived eWOM influence; 3) monitoring study discovering which types of recommendation systems are used by leading online retailers in the Baltic countries.

Research results revealed that experts in Baltics evaluate eWOM communication as a highly influential factor in consumers' decision where to buy and which brand to buy; they also acknowledged the eWOM ability to raise consumers' interest in some product. The research also discovered that significant barriers to advanced eWOM usage in Baltics are an availability of qualified specialists and investments needed. The study also revealed the contradiction between experts' opinion and current reality in eWOM usage as online retailers in Baltics are using a very limited range of online recommendation systems.
\end{abstract}

Key words: electronic word-of-mouth (eWOM), purchase decision, social networks, recommendation

JEL code: M31, M39

\section{Introduction}

Last decades has brought revolutionary changes in technology, globalization and sustainability. Those changes are also revising the complete paradigm of marketing communication. Partly it is because digitalisation allowed much easier and faster word of mouth communication between consumers. Word of mouth communication (further called WOM) in general is recognized by many authors (Kaufman \& Horton, 2015; Laudon \& Traver, 2015; Strauss \& Frost, 2014) as a very important marketing communication tool and assumed to be the

1 Corresponding author - e-mail address: elina.gaitniece@gmail.com 


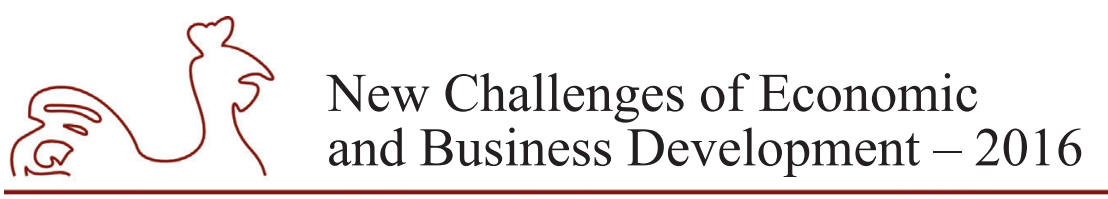

May 12-14, 2016, Riga, University of Latvia

primary factor behind $20-50 \%$ of all purchase decisions (Berger, 2013). Expansion of internet fostered appearance of a new electronic word of mouth (further called eWOM) communication tools which allow consumers to exchange information and their opinions about brands and products also online. This information which consumers are spreading with the help of social networks (further called SN), online recommendation systems (further called ORS) and other eWOM communication tools is one from many factors which influence consumer purchase decision in different phases - during trigger phase when a need for product is recognized, during information search, active evaluation and purchasing phases. As a result, companies and brands are not anymore owning and controlling communication about them, but have to take into account that consumers are freely disseminating online their opinion about products, brands, and companies. Communication from "company to consumers" or "one to many" has changed to "companies and consumers to consumers" or "many to many". And in many cases, this consumer to consumer word of mouth communication which is part of so-called earned media has been perceived by consumers as much more credible and trustworthy than information which brands or companies are spreading themselves through different owned or bought medias.

Research done in other countries does show that the influence of eWOM communication is increasing (Iyengar, et al., 2009; Oestreicher-Singer \& Sundararajan, 2012). Still, the experience shows that companies in Baltics are not yet utilizing the full potential of available eWOM communication tools and might not be fully aware of its possible influence. There exist prejudices and stereotypes that consumers in Baltics are often tended to express their negative opinions when leaving feedback and advising others on some brand or product, and those stereotypes restrict businesses from using advanced eWOM communication tools. But, the online market is not limited within the borders of one country and growing overall online retail share will attract more and more players from global market to Baltic market.

Online market in Baltic countries is still relatively small, according to Ecommerce Europe report ecommerce in Baltics takes only $0.8-1.1 \%$ of GDP (Ecommerce Europe, 2015). But impact of online is growing year by year along the global tendencies (Euromonitor, 2016). As said before online retailers are not anymore limited within borders of countries, and, therefore, local companies should be well prepared to safeguard their consumer loyalty and to withstand expected increasing competition which will not be limited only to local players.

Therefore, the aim of the paper was - to assess how the influence of eWOM tools is evaluated by online retailers and digital marketing experts in Baltic countries. To achieve the aim, following tasks for the paper were defined: 1) to study the theoretical aspects of eWOM influence on consumer purchase decision; 2) to carry out an expert survey based research within Baltics about perceived eWOM influence on consumer purchase decision; 3) to monitor which types of ORS according to Schafer's taxonomy are used by leading on-line retailers in Baltic countries; 4) to draw conclusions and to make recommendations.

There are many different ways how eWOM can be spread and reach the consumer. This paper was focusing only on two of them - eWOM spread through SN and eWOM provided using different ORS.

Research methods used were an analysis of literature, expert survey, and monitoring study. Analysis of literature contained a review of scientific research results in the field mentioned above. An experts' survey done during February 2016 was gathering opinions from major stakeholders - leading online retailers and digital marketing experts (specialized in social 


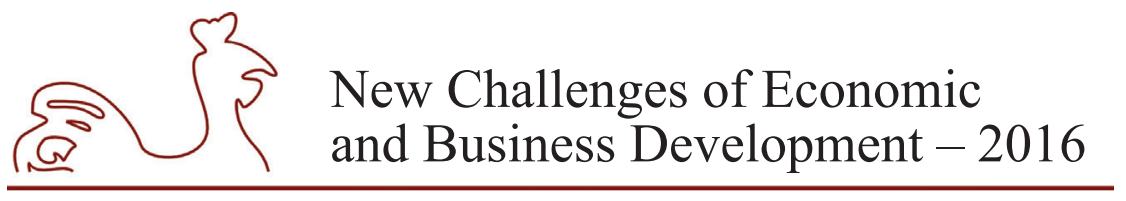

May 12-14, 2016, Riga, University of Latvia

communication) in Baltics about SN and ORS influence on consumer purchase decision, to reveal possible barriers for the further development of eWOM communication. Purposive, judgement based sampling method was used to select experts who are specialists in the field of research. Authors used database of contacts gathered during their professional work life to select the specific experts asked to fill the survey. As sampling method used was nonprobability sampling method there are limitations for the conclusions derived from the research. Electronic survey tool visidati.lv was used for survey distribution and data gathering. In total 42 experts were invited to participate in the survey and 23 of them provided the answers. For the group of online retailers the experts addressed were managers or marketing specialists of leading online retailers in Baltics (hansapost.ee; euronics.ee; xnet.lv; euronics.lv; kafijasdraugs.lv; senukai.lt; avitela.1t; elektromarkt.lt; ogmina.1t; kavosdraugas.lt; topocentras.lt and others). Twenty-one expert in this group was asked to participate in the survey (seven from each Baltic country) and thirteen experts provided their opinion. For the group of digital marketing specialists, the experts addressed were digital marketing professionals from agencies which do specialise into SN communication (WRONG digital; INSPIRED; BDF; Dentsu Aegis Network Baltics; Reach Smart Marketing; mCLOUD and others). Fifteen experts in this group were asked to participate in the survey, and ten experts provided their opinion. The biggest number of answers were received from Latvia (eleven responses), followed by eight responses from Lithuania and only four from Estonia. The small number of responses received from Estonia limited representativeness of expert opinion on country level and therefore conclusions were done almost only on Baltic level. Research results were summarised under four subchapters: (1) perception of the SN communication influence; (2) perception of the influence of ORS; (3) barriers to advanced eWOM communication tool usage in Baltic countries; (4) overview of ORS used in leading online retail shops in Baltics. Monitoring study done during February 2016 gathered information which types of ORS according to Schafer's taxonomy are currently used by 15 selected online retailers in Baltics.

\section{Literature review}

As defined by Burrow word of mouth (WOM) is passing of information among people through oral communication, and it often takes the form of storytelling. In the past, it was almost the only way how to transfer information, but after the invention of writing and other communication tools, WOM process has become more sophisticated, and it is not anymore so much linked with the "mouth" part of equitation (Burrow \& Fowler, 2012).

The power of WOM has been recognized in marketing world already long ago. In marketing, WOM means that consumer of a product or brand communicates information about that product or brand to another consumer. Positive WOM generates a very positive outcome for a brand or product as consumers tend to trust such consumer-generated WOM more than traditional marketing materials. Worth to mention that also opposite works and negative information spread by WOM is most likely trusted by consumers without checking whether it is true. According to research done by Berger, WOM is the primary factor in $20-50 \%$ of all purchase decisions (Berger, 2013) and is already many billion industry by itself. But nowadays individuals are not anymore limited in communication to their friends, families or colleagues. The internet allows 


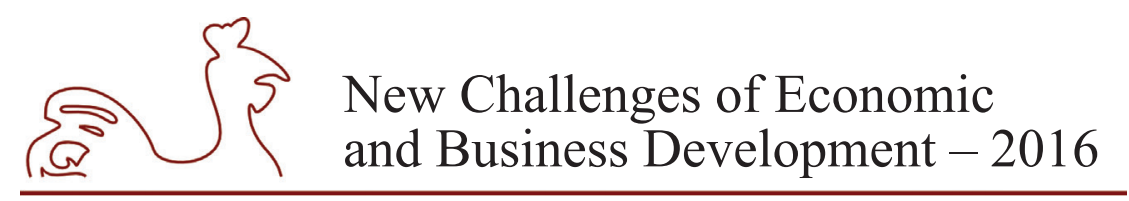

May 12-14, 2016, Riga, University of Latvia

a disappointed customer to tell a several thousand friends with one mouse click his word of mouth on a specific product (Strauss \& Frost, 2014). It is now called eWOM.

When a consumer wants to get info about some product - he can "Google it", post a question in $\mathrm{SN}$, read online customer reviews or do other online activities which will provide a vast amount of "customer experiences" in the form of eWOM (Kaufman \& Horton, 2015). Analysis of literature was focusing only on two types of eWOM - eWOM spread through SN and eWOM provided using different ORS.

\section{1. eWOM through social networks}

Social networks are the sites where consumers are joining to share their interests, personal and professional profiles. Like-minded individuals are connecting there for friendship or business purposes. Job recruiters search SN for job candidates, business deals are made between LinkedIn members and artists are increasing their popularity by gathering their Twitter followers. The name of the game today is about whom you know online and what they say about you (Strauss \& Frost, 2014).

Social networks have also changed the way how consumers seek and consume information. In fact, a social recommendation is a certain type of search - enabling environment where consumers can get advice from their friends and confederates on purchases of products or services. If Google helps a consumer to find certain things, social search is helping him to measure the quality of goods or services by listening to the advice of his acquaintances or their friends. An example is Amazon's social recommender system which can use specific person's Facebook profile to recommend a product (Laudon \& Traver, 2015). Several research projects have collected knowledge how so-called "neighbourhood effects" and social emulation within SN influences consumer purchase decisions - where to buy, which brand to choose and which product to buy.

According to Laudon and Traver (2015) consumer's decision to buy on the internet is closely related to the fact whether the consumer operates in "neighbourhood" where others purchase on the internet. These neighbourhoods might be consumer's relatives and friends, truly personal, or they might also be digital - communities in SN. There is a relationship between being a member of a social network and purchasing decisions. In the same time, this relationship is not straightforward and simple. Depending on the level of social "connectedness" (both online and offline) - different behaviours appear. Those who have highest scores on connectedness (top 10-15\%) try to do things differently than others, and usually, they do not share their "way" with others. Moreover, most probably those people will change their purchasing place to different if their friends will start to buy where they currently do. They are trying by all means differentiate themselves from others; they are so called "Iconoclasts". Another group of peoplethose why lay in connectedness scale in middle $40 \%$ - very often share their purchasing patterns of their friends and neighbours. The third group which scores lowest in connectedness with other members (approx. 48\%) - shows little or no social effect and, therefore, do not change their purchase patterns due to friends' purchase behaviour (Iyengar, et al., 2009). It is also important to mention that "neighbourhood" effect influences significantly consumers" choice of a brand, they become less price sensitive and also less susceptible to advertising when choosing brand for their purchase (Janakiraman \& Niraj, 2011). 


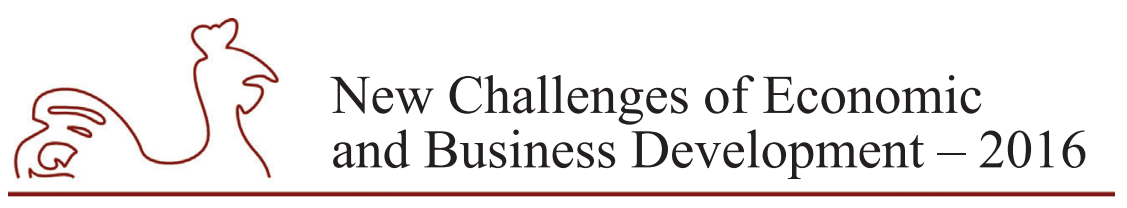

May 12-14, 2016, Riga, University of Latvia

Moreover, it is not only place and brand which is influenced by social emulation phenomena in SN. A Recent study which surveyed 6,000 SN participants showed that social media is driving substantial volume of purchasing (both in a physical store and online). The study also shows that this tendency is growing in importance compared to previous years. $40 \%$ of SN users made the actual purchase of the product which they previously "favorited" in Facebook, Twitter or Pinterest. Between those networks Facebook was showing highest score on link between "like" and purchase made, Pinterest and Twitter were following (Samuel \& D. Sevitt, 2013).

Surprisingly, purchases afterwards were made in quite equal proportion - online and offline - so SN drives both ROPO (information is gathered online, but purchase made in physical store) and "showrooming" (product is checked first in the physical store, afterwards purchased online) effects rather equally. Study also tells that $50 \%$ of SN related purchasing takes place within one week after sharing or favoriting an item (Samuel \& D. Sevitt, 2013) (Schleifer, 2013). Specifically, in the music industry, SN are very influential in driving up awareness and purchase of new independent music. Influence on already well-known products is lower than on innovations (Garg, et al., 2011).

Worth to mention that not always consumer communication in $\mathrm{SN}$ is "natural" as businesses are using viral marketing tools to create artificial eWOM and frequently those attempts result in success as the majority of readers does not recognize information provided by bloggers and opinion leaders as the marketing tool (Laudon \& Traver, 2015). In those cases, businesses should use knowledgeable consumers because the credibility of the source is a very important factor which has significant influence on consumer's purchase decision. In case marketing tactics involve communicators in SN, which are spreading information about the brand or products credibility of those communicators should be well considered. Arguments used should be qualitative to persuade potential purchaser to trust and buy (Zhu, et al., 2016).

\section{2. eWOM through online recommendation systems}

ORS are systems used in online retail shops to advise the consumer which product to choose, they learn from a customer and recommend products that she/he could find most appropriate for particular customer needs. There are different ways how ORS recommend products - based on the demographics of a specific customer, based on customer's historical purchasing behaviour, based on habitual behaviour gathered from customers who purchased or viewed similar products. There are also different methods how a site does personalization adapting itself to each specific customer (Schafer, et al., 1999). Those very specific personalization methods enhance greatly customer loyalty towards the specific site. Sites are learning their consumer habits and digesting this info through their systems. That allows them to present to consumer customized interfaces which are well matching needs of the specific customer. The more time consumer is spending for "teaching" ORS of some site - the more loyal she/he becomes to the specific site (Pine, et al., 1995).

Schafer and Kontan developed the taxonomy for ORS, which categorized those different types of ORS. According to it, there are distinguished four big groups of ORS - non-personalized; attribute based; item-to-item correlation based and people-to-people correlation based. Two main dimensions by which systems are measured are the degree of automation (viewed from consumer perspective - manual versus automatic) and the level of persistence in the recommendations (persistent versus ephemeral) as visible in Figure 1. 
May 12-14, 2016, Riga, University of Latvia
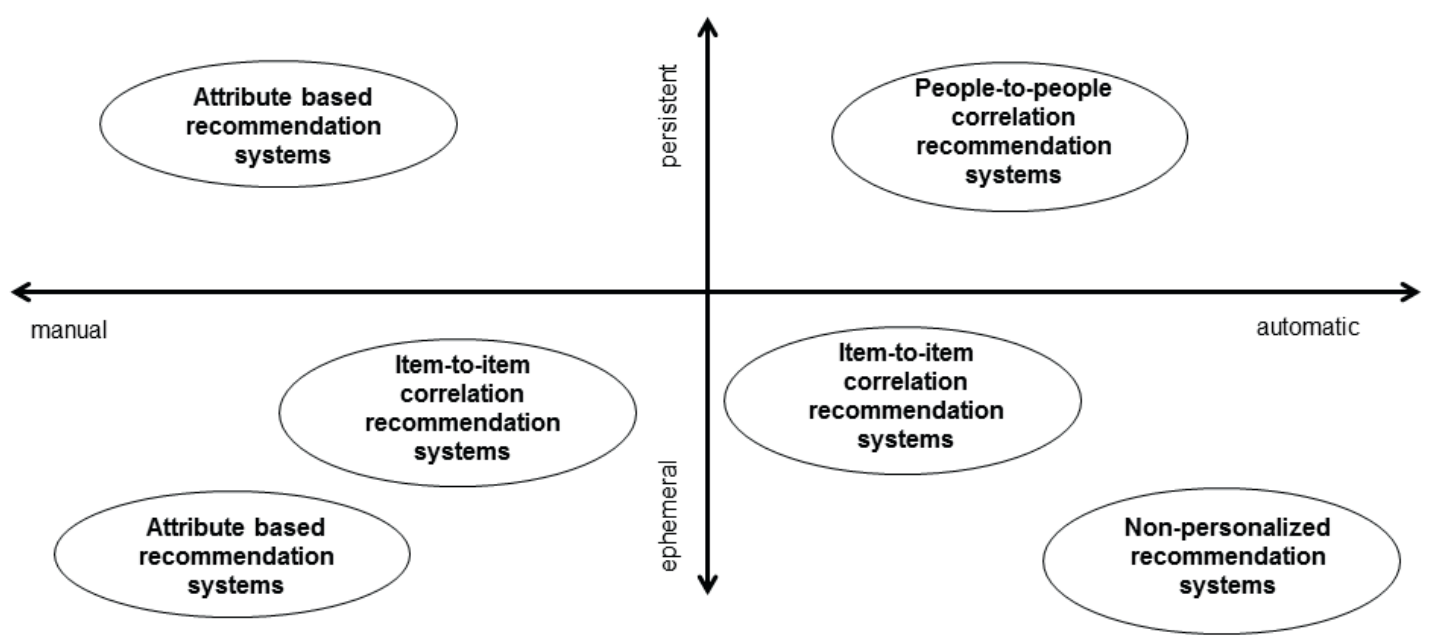

Source: authors' construction based on (Schafer, et al., 1999).

Fig. 1. Recommendation Taxonomy

Non-personalized ORS do recommend products to consumers based on feedback received from other customers on average. In this case, the recommendation is the same for all customers. Those systems are classified as automatic as they require very little customer effort to be generated, and they are also ephemeral as the system does not recognize the customer from one session to another. Any customer rating system using five stars measurement can be used as an example on non-personalized ORS as this recommendation is entirely independent of the particular client. Attribute based ORS recommend products to customers by analysing syntactic properties of the products. For example, if the client is searching for a particular book about modern architecture - ORS offers a list of alternative books about the same subject. This type of ORS can be either ephemeral or persistent depending on whether the site remembers attribute preferences of the specific customer. Those systems are mostly manual as customer has to enter all needed product properties. Item-to-item correlation ORS recommend products to customers based on a small set of products the customers have expressed interest in. An example of this system could be accessory or complementary product offer based on the content of customer shopping bag. Those systems can be either automatic or manual and usually are ephemeral as they do not need to know specific customer purchasing history. People-to-people correlation ORS recommend products to a customer based on the correlation between that customer and other customers who already made purchases on the specific site. Those systems are mostly automatic and persistent, but become ephemeral if a customer has long enough session. The best example of people-to-people correlation system is Amazon's "People who bought this item, bought also ..". This technology is also called "collaborative filtering" as it uses group opinions filtered to recommend specific items to the individual (Schafer, et al., 1999). This type of ORS proved to be very effective and triples purchases of complimentary products even people within network do not know each other personally (Oestreicher-Singer \& Sundararajan, 2012).

Non-personalized ORS usually are visible to all, but within people-to-people correlation category also exists innovative, very personalised recommendation type - so-called social 


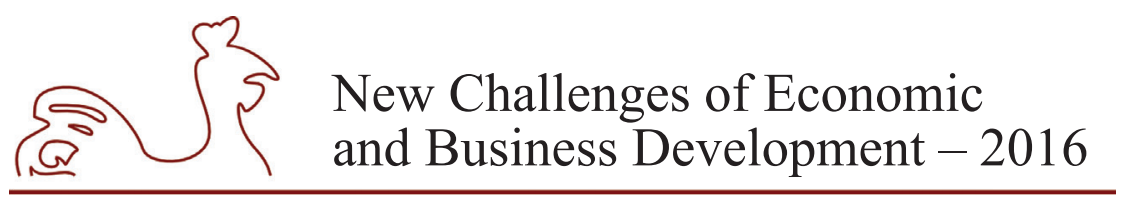

May 12-14, 2016, Riga, University of Latvia

recommendation which is based on profile similarities with other customers (e.g., Apple Genius Recommendations and Netflix Cinematch). It gives personal endorsement designed to realize value for the client. An analogy for those systems in traditional stores is when consumers ask a fellow shopper for advice (Strauss \& Frost, 2014). Before mentioned ORS is also a good example how SN influence purchasing decision through ORS as, for instance, Amazon's recommender system ("Consumers who bought this item also bought ...") creates a co-purchase network which provides to consumer recommendations based on her/his Facebook profile.

The experiment done by Senecal and Nantel showed that ORS have a strong influence not only on loyalty but also on consumers purchasing decision. Results showed that subjects who viewed product recommendations selected recommended products twice as often as subjects who did not consult recommendations. The experiment also showed that online recommendation source in the form of "recommender system" was more influential than traditional recommendation sources even perceived as possessing less expertise than human experts and as being less trustworthy than other consumers (Senecal \& Nantel, 2004).

It might be naturally assumed that only positive reviews play the role in influencing a consumer to make the purchase of a particular product. But, different researches are showing that best result is achieved when there are mixed (positive and negative) reviews provided. It is based on consumers' emotional trust - naturally people consider too positive reviews and comments to be artificially made and influenced by seller interested in them. When reviews are inconsistent, the influence of emotional trust on purchase decision is much stronger. This moderating effect of inconsistent reviews differs across genders. It is stronger for female consumers than for male consumers (Berger, et al., 2010) (Zhang, et al., 2014).

Online retailers use online ORS to recommend products and enhance promotion effect. ORS are an important element to increase consumer's loyalty towards the site. Many e-commerce sites disappeared because they were investing into consumer awareness, but were not increasing their customer loyalty. Well-functioning personalized ORS are keeping customers connected to the site which knows already a lot about his habits and preferences (Chaffey, 2011).

\section{Research results and discussion}

\section{3. eWOM specifics in Baltic states}

There are no statistics available about size or share of internet retail within Baltics, there is also no reliable research done which are the leading online retailers in the market. But according to Euromonitor report online retailing as a retail channel is growing in all three Baltic countries - in Lithuania many companies are starting multichannel approach for retail trying to join traditional channels with online retailing, many of those companies already generate a sizeable portion of their revenues from online sales. Online pure play retailers also performed well in Lithuania during 2015 as they continued to gain the trust of consumers gradually. In Latvia, factors such as - access to fast internet, increased security of payments by cards, doubled number of smartphone users and more attractive pricing - resulted in double-digit growth of online retailing in 2015. In Estonia as well consumers are increasingly searching for the most rational purchasing options and store-based retailers are forced to start multichannel strategies there (Euromonitor, 2016). Besides that, also Swedbank reports seriously increasing usage of 


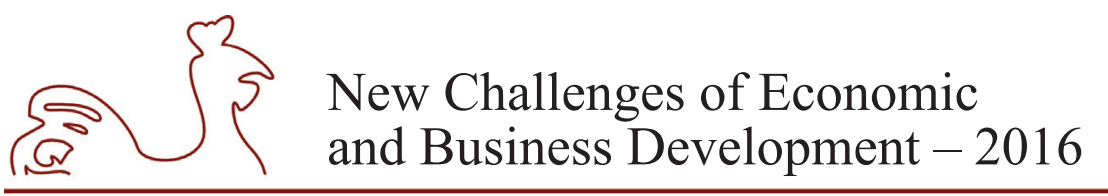

May 12-14, 2016, Riga, University of Latvia

online payments - payments by credit cards in online retail increased by $26 \%$, payments through internet bank in online retail increased by $23 \%$ (Swedbank, 2015). Euromonitor also reports that pre-purchase information search on the internet is increasing in Baltics. Both those facts increased internet retailing activity and growing pre-purchasing search for information on the internet in Baltic states - allow to conclude that factors which influence consumer decision process when buying online are becoming more and more important for entrepreneurs in Baltics. One of those factors is eWOM communication which will be analysed more deeply from an expert perspective further on.

\subsection{Perception of the social network communication influence}

The first part of the expert survey was focusing on the evaluation of SN influence on consumer's choice which store to choose for shopping, ability to raise the consumer interest about some product and influence on consumer's choice which brand to choose. Figure 2 presents experts' opinion about above mentioned factors.

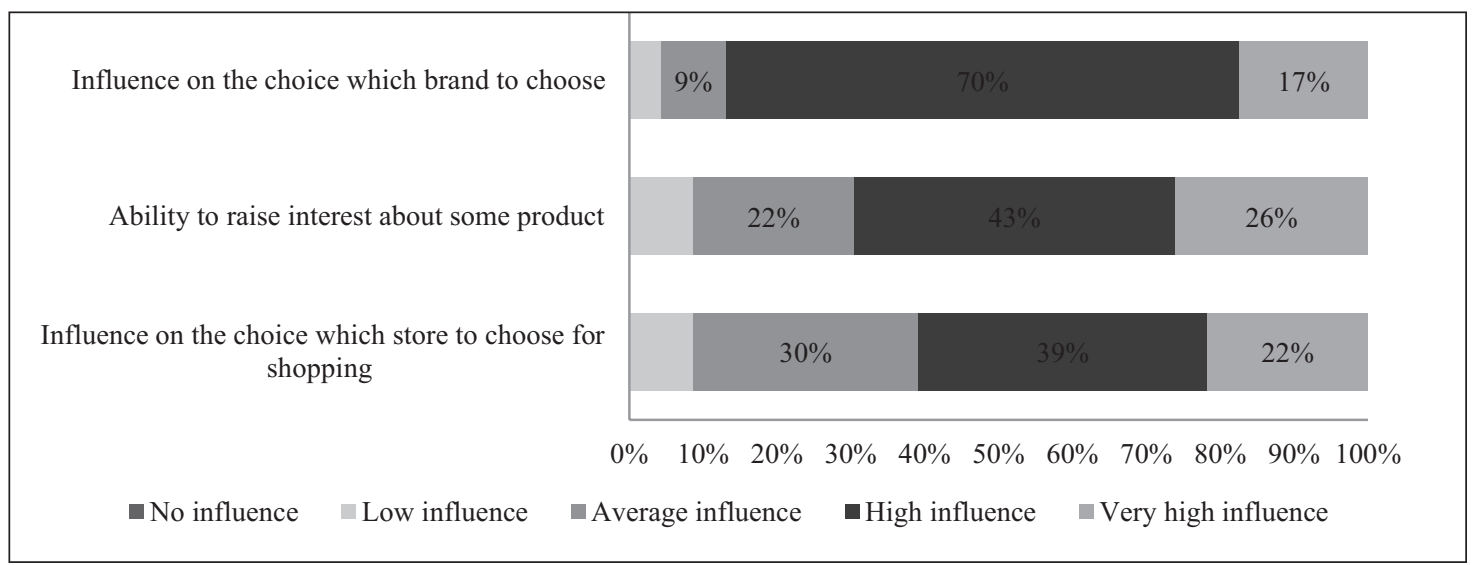

Source: authors' construction based on survey results.

Fig. 2. Experts' opinion about social network influence on specific elements of consumer decision process (\%)

According to Figure 2 communication within social networks have a high or very high influence on consumers' decision which brand to choose recognized by $87 \%$ of experts. In smaller extent, but still significant is the ability to raise interest about some product as $69 \%$ of experts evaluated it as high or very high. Also, influence on the choice which store to choose for shopping is assessed as high or very high by more than half of experts. It means that according to experts' opinion SN communication is a very important factor for awareness phase and also for information search and alternative evaluation phases of consumer decision.

Experts also evaluated SN communication as a very effective communication tool to inform consumers about promotional activities - average score given was 4.04 (78\% of experts evaluated it as having "high" or "very high" effect) and to inform about news in product range average score given 3.87 (74\% of experts evaluated it as having "high" or "very high" effect). Although many authors stress that communication in SN for companies should be the tool to 


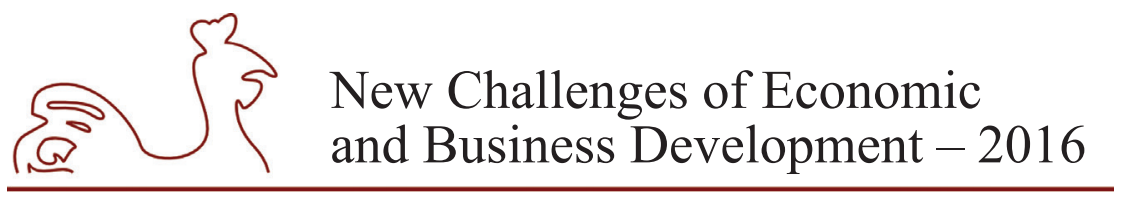

May 12-14, 2016, Riga, University of Latvia

listen to consumers, only $61 \%$ of experts surveyed saw SN communication as a highly effective tool to gather consumer opinions. It should also be mentioned that this particular aim (to gather consumer opinions) showed significant differences in evaluation between different groups of experts. Figure 3 visualizes differences in opinions between two groups of experts - digital marketing agency representatives and online retail representatives.

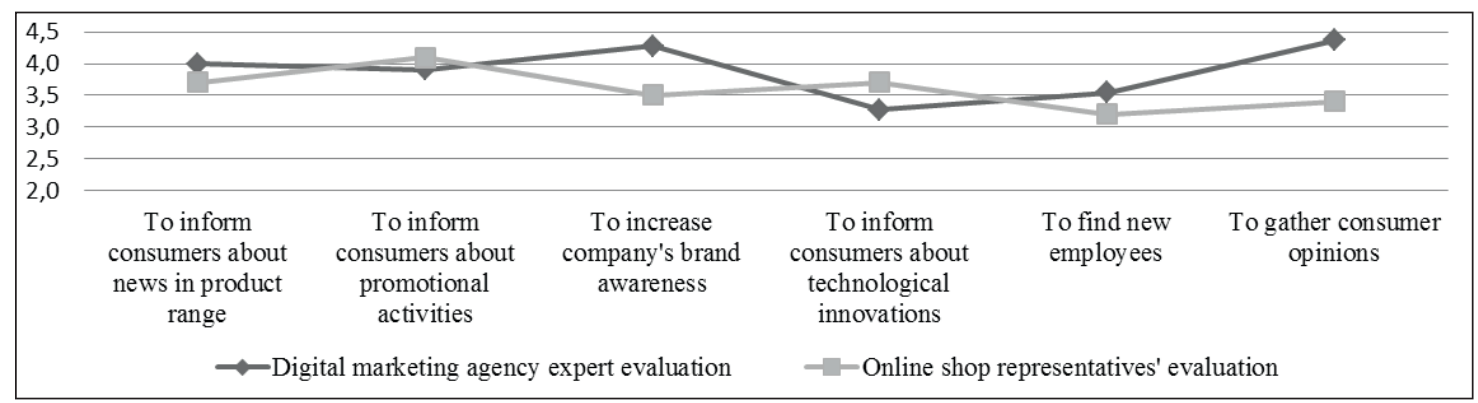

Source: authors' construction based on survey results.

Fig. 3. Differences between expert groups evaluating how effective is social networks' communication as the tool to reach the listed aims (Likert scale score from 0 to 5 )

As data were measured using five level Likert scale measurement with numerical values attached - it can we analysed as quantitative data and answers between two different groups were compared. T-test done showed with $95 \%$ probability statistically significant difference between opinions of marketing agency specialists and online retail representatives - the first group evaluated the effectiveness of $\mathrm{SN}$ as a tool to gather consumer opinions by average score 4.4, while the second group - only with score 3.3. Also evaluation of SN communication as an effective tool to increase company's brand awareness differed significantly (with $95 \%$ probability) between groups of marketing agency specialists and online retail representatives marketing agency specialists gave average score 4.3, while online retailers' group gave lower average rating 3.6.

There were no statistically significant differences recognized between expert opinions if split into country groups.

\subsection{Perception of the influence of online recommendation systems}

The second part of the expert survey was focusing on the evaluation of different ORS influence on consumer purchase decision. Three types of ORS from Schafer's taxonomy were chosen to be evaluated by experts. Figure 4 presents experts' opinion about the impact of those types of ORS. 
May 12-14, 2016, Riga, University of Latvia

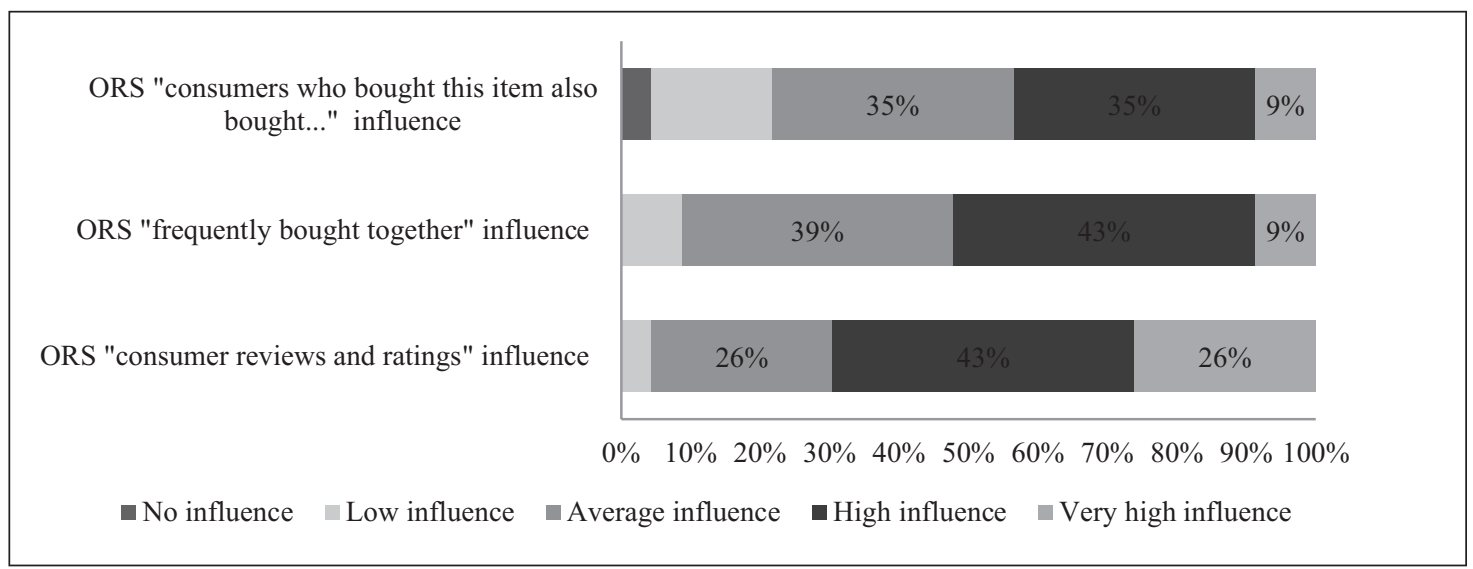

Source: authors' construction based on survey results.

Fig. 4. Experts' opinion about different ORS' influence on consumer decision process (\%)

According to Figure 4 ORS "consumer reviews and ratings" has the highest influence on consumer decision if compared with other more sophisticated ORS, evaluated as "high" or "very high" influencer by $69 \%$ of experts. According to Schafer's taxonomy "consumer ratings and reviews" belongs to non-personalized ORS and is the most simple form of ORS. ORS "frequently bought together" which belongs to more sophisticated ORS category - attribute based ORS - is also quite influential as $52 \%$ of experts said it has high or very high influence. Lower evaluation by experts is given to most sophisticated ORS "consumers who bought this item also bought ..." which belongs to the person to person correlation category of ORS and is not used at all by online retailers in Baltics. There were no statistically significant differences found between groups digital marketing agency representatives and online retail representatives. But, when data were analysed using split into country groups - statistically significant differences appeared even for relatively small country groups. Evaluation of people-to-people correlation ORS influence was significantly lower for Lithuanian expert group (average score 2.4) compared to Latvian and Estonian expert groups (average scores 3.5 and 4.2) when tested by using ANOVA test with 95\% probability.

\subsection{Barriers to advanced eWOM communication tool usage in Baltic countries}

Survey was also evaluating which factors experts recognize as obstacles for Baltic companies to implement innovative ORS. Figure 5 shows the importance of different factors. 


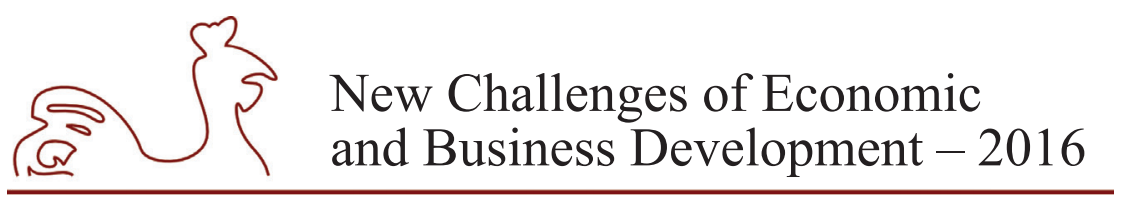

May 12-14, 2016, Riga, University of Latvia

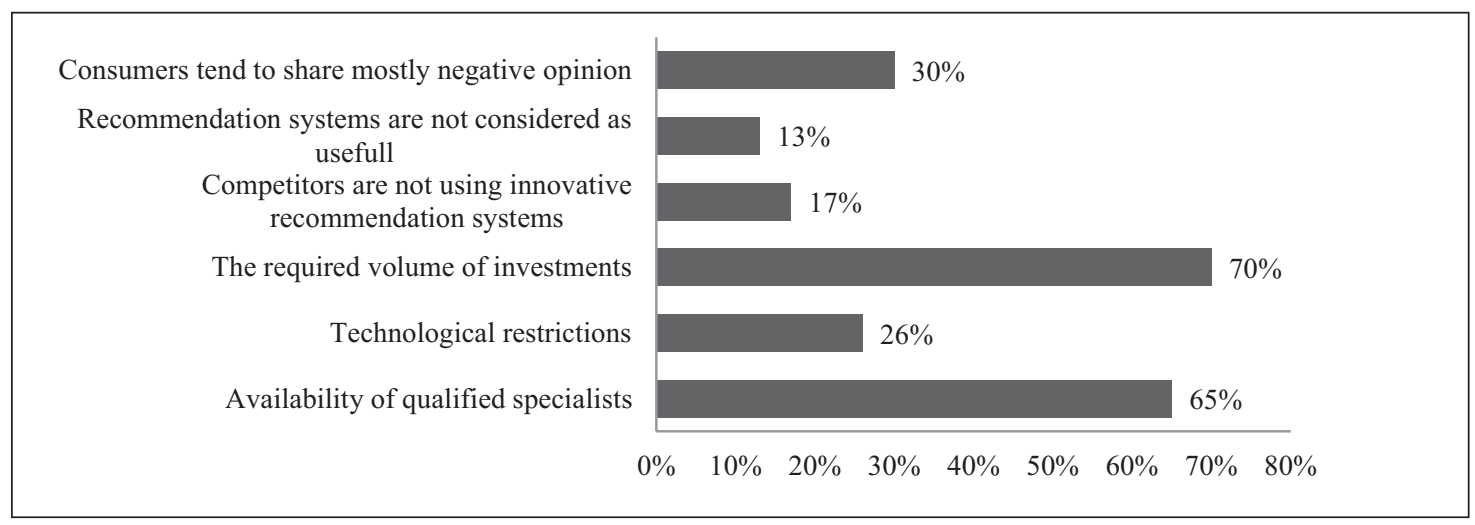

Source: authors' construction based on survey results.

Fig. 5. The shares of experts who recognize mentioned factor as an obstacle for advanced ORS (\%)

According to Figure 5 majority of experts surveyed see two important factors as leading barriers for advanced ORS system usage. First and leading barrier is the required volume of investments as advanced ORS need sophisticated and tailor-made software. Experts also mentioned that besides the investment also running costs for such systems can be rather high. The second barrier recognized by the majority of experts is the availability of qualified specialists. But, the tendency that consumers tend to share only negative opinion was identified as a barrier only by $30 \%$ of experts and majority of experts acknowledged that competitors (mostly international online retailers) are already using quite advanced ORS. Another factor mentioned by some experts was companies' management attitude that this question is not a priority for today.

\subsection{Overview of online recommendation systems used in leading online retail shops in Baltics}

To evaluate the current level of ORS usage with Baltic online retail, monitoring study evaluating usage of different types of ORS within selected online retail was done. As there were no official statistics available which are leading online retailers in Baltics, authors' used their own gathered knowledge and experience to select shops representing the online market. Both types of channels were selected - pure play online retailers and multichannel retailers. Table 1 contains the overview of used ORS according to Schafer's taxonomy. 


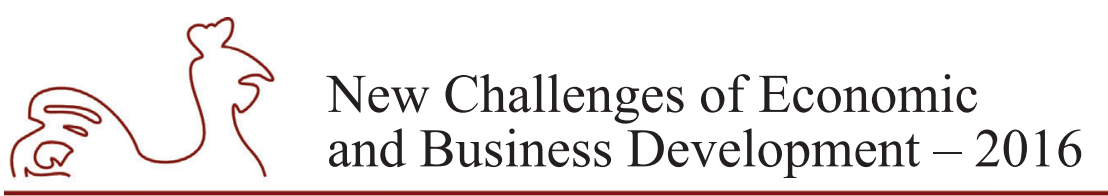

May 12-14, 2016, Riga, University of Latvia

Table 1

Overview of ORS used within selected online retail shops in Baltic states

\begin{tabular}{|c|c|c|c|c|c|c|}
\hline No. & Country & Online retailer & $\begin{array}{c}\text { Non-person- } \\
\text { alized recom- } \\
\text { mendation } \\
\text { systems }\end{array}$ & $\begin{array}{c}\text { Attribute based } \\
\text { recommendation } \\
\text { systems }\end{array}$ & $\begin{array}{l}\text { Item-to-item } \\
\text { correlation } \\
\text { recommenda- } \\
\text { tion systems } \\
\end{array}$ & \begin{tabular}{|} 
People-to-people \\
correlation \\
recommendation \\
systems \\
\end{tabular} \\
\hline 1. & EE & euronics.lv & \begin{tabular}{|l} 
"ratings and \\
reviews"
\end{tabular} & $\begin{array}{l}\text { "additional } \\
\text { accessories" }\end{array}$ & NA & NA \\
\hline 2. & EE & onoff.ee & NA & "similar products" & NA & NA \\
\hline 3. & $\mathrm{EE}$ & hansapost.ee & NA & $\begin{array}{l}\text { "alternative } \\
\text { products"" }\end{array}$ & NA & NA \\
\hline 4. & $\mathrm{EE}$ & 1a.ee & NA & NA & NA & $\begin{array}{l}\text { "consumers who } \\
\text { purchased this, } \\
\text { purchased also .." }\end{array}$ \\
\hline 5. & LT & pigu.lt & NA & NA & NA & $\begin{array}{l}\text { "consumers who } \\
\text { purchased this, } \\
\text { purchased also .." }\end{array}$ \\
\hline 6. & LT & elektromarkt.lt & NA & NA & NA & NA \\
\hline 7. & LT & senukai.lt & NA & NA & NA & $\begin{array}{l}\text { "consumers who } \\
\text { purchased this, } \\
\text { purchased also .." }\end{array}$ \\
\hline 8. & LT & topcentras.lt & NA & NA & NA & NA \\
\hline 9. & LT & varle.1t & $\begin{array}{l}\text { "ratings and } \\
\text { reviews" }\end{array}$ & "similar products" & NA & NA \\
\hline 10. & LT & 1a.lt & NA & NA & NA & NA \\
\hline 11. & LV & xnet.lv & NA & $\begin{array}{l}\text { "alternative } \\
\text { products" }\end{array}$ & NA & NA \\
\hline 12. & LV & $220.1 v$ & NA & NA & NA & $\begin{array}{l}\text { "consumers who } \\
\text { purchased this, } \\
\text { purchased also .." }\end{array}$ \\
\hline 13. & LV & elkor.lv & $\begin{array}{l}\text { "ratings and } \\
\text { reviews" }\end{array}$ & "related products" & NA & NA \\
\hline 14. & LV & euronics.lv & $\begin{array}{l}\text { "ratings and } \\
\text { reviews" }\end{array}$ & $\begin{array}{l}\text { "additional } \\
\text { accessories" }\end{array}$ & NA & NA \\
\hline 15. & LV & 1a.ee & NA & NA & NA & $\begin{array}{l}\text { "consumers who } \\
\text { purchased this, } \\
\text { purchased also .." }\end{array}$ \\
\hline
\end{tabular}

Source: authors' construction based on monitoring study results (monitoring date 27/02/2016).

The table shows that part of online retailers does not use any ORS, and none from online retailers use more than two different ORS according to Schafer's taxonomy. This study also discovered that in some online retail stores people-to-people correlation system "consumers who purchased this, purchased also..." might be offering products based on a different algorithm, and 


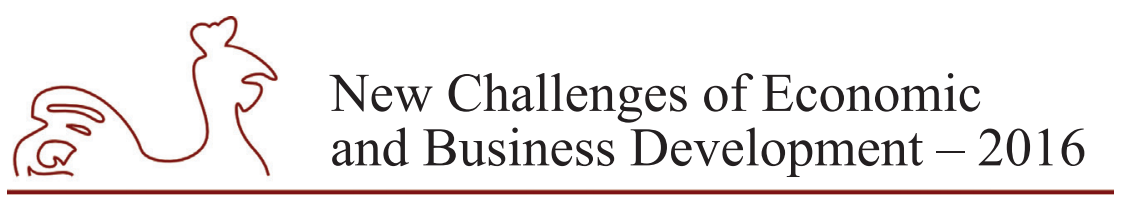

May 12-14, 2016, Riga, University of Latvia

not on real people-to-people correlation algorithm. The study was limited by the fact that results might be different if some specific product group would be searched and results might also be different if monitored on various dates. Even factor "consumers tend to share mostly negative opinion" was not evaluated as a significant barrier to advanced ORS usage still monitoring study revealed that only four from fifteen observed online retailers were allowing consumers to express their opinion about a product through "ratings and reviews" option.

\section{Conclusions, proposals, recommendations}

Based on the results of the theoretical analysis and the research done the following conclusions are derived:

1. Previous research done in other countries show that SN communication and ORS are important factors influencing consumers' decision which product to purchase, which brand to choose, which retail channel to use.

2. Specialists in Baltics (particularly - internet retailers and digital marketing specialists) recognize the eWOM communication through social networks as the factor which has a high influence on consumer's decision during the trigger, initial consideration and active evaluation phases of consumer decision process.

3. Specialists in Baltics also recognize the eWOM communication in different forms of online recommendation systems as the factor which has a high influence on consumer's decision during the active evaluation and moment of purchase phases of consumer decision process.

4. The results of the expert survey do not prove the assumption that the stereotype that consumers in Baltics are often tended to express their negative opinions when leaving feedback or advising others restrains businesses from using advanced online recommendation systems.

5. The significant barriers recognized by experts for businesses in Baltic markets to use advanced online recommendation systems are required the volume of investments and availability of qualified specialists.

6. Although experts recognize the importance of online recommendation systems, online retailers in Baltic countries are using a quite limited number of online recommendation systems or are not using them at all.

Retail on the internet is growing its share within markets of three Baltic countries and factors influencing consumers' decision process are becoming more and more important for local retailers to stay competitive in the online market which also allows global players to take part in fighting for consumer attention. In conclusion, we propose online retail businesses in Baltics to include advanced eWOM communication tools as part of their integrated marketing communication strategies to be better prepared to withstand pressure in online market from global players which are using very sophisticated eWOM systems in the form of ORS and also through social network communication. More open two-way communication with consumers in social networks would also correspond with the global trend that companies should adapt their "mindset" becoming radically transparent with their customers and extremely responsive to them while being honest, to be able to sustain their business within new "open communication" era.

Research can be further continued by carrying out consumer survey which would discover eWOM communication specifics in Baltic countries from a consumer perspective. 


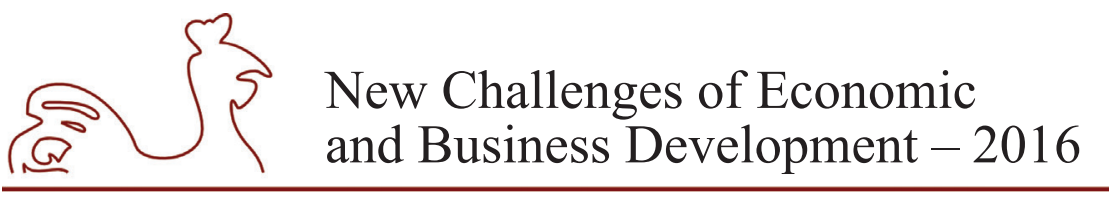

May 12-14, 2016, Riga, University of Latvia

\section{Bibliography}

Berger, J., 2013. Contagious: Why Things Catch On. $1^{\text {st }}$ ed. New York: Simon \& Schuster.

Berger, J., Sorensen, A. T. \& Rasmussen, S. J., 2010. Positive Effects of Negative Publicity: When

Negative Reviews Increase Sales. Marketing Science, September-October, 29(5), pp. 815-827.

Burrow, J. L. \& Fowler, A. R., 2012. Marketing. $4^{\text {th }}$ ed. Boston: Cengage Learning.

Chaffey, D., 2011. E-Business \& E-Commerce Management Strategy, Implementation and Practice. $5^{\text {th }}$ ed.

Harlow: Pearson.

Ecommerce Europe, 2015. Northern B2C E-commerce Report 2015, Brussels: Ecommerce Foundation.

Euromonitor, 2016. Euromonitor Estonia. [Online] Available at: http://www.euromonitor.com/retailingin-estonia/report; Euromonitor Lithuania. [Online] Available at: http://www.euromonitor.com/ retailing-in-lithuania/report; Euromonitor Latvia. [Online] Available at: http://www.euromonitor. com/retailing-in-latvia/report [Accessed 26.02.2016].

Garg, R., Smith, M. \& Telang, R., 2011. Measuring Information Diffusion in an Online Community. Journal of Management Information Systems, 28(2), pp. 11-38.

Iyengar, R., Han, S. \& Gupta, S., 2009. Do Friends Influence Purchases in a Social Network. Harvard Business School Marketing Unit Working Paper, 123(9).

Janakiraman, R. \& Niraj, R., 2011. The Impact of Geographic Proximity on What to Buy, How to Buy, and Where to Buy: Evidence from High-Tech Durable Goods Market. Decision Sciences, 42(4), p. 88-919.

Kaufman, I. \& Horton, C., 2015. Digital Marketing: Integrating Strategy and Tactics with Values. $1^{\text {st }}$ ed. New York: Routledge.

Laudon, K. C. \& Traver, C. G., 2015. E-commerce. 11 $1^{\text {th }}$ ed. Harlow: Pearson.

Oestreicher-Singer, G. \& Sundararajan, A., 2012. The Visible Hand? Demand Effects of Recommendation Networks in Electronic Markets. Management Science, 58(11), pp. 1963-1981.

Pine, B. J., Peppers, D. \& Rogers, M., 1995. Do You Want to Keep Your Customers Forever? 1 ed. Boston: Harvard Business Review Press.

Samuel, A. \& D. Sevitt, L. L. L., 2013. From Social to Sales: 8 Questions to Ask Your Customers, New York: Vision Critical Corporation.

Schafer, J. B., Konstan, J. \& Riedl, J., 1999. Recommender Systems in E-Commerce. New York, Proceedings of the $1^{\text {st }}$ ACM conference on Electronic commerce, pp. 158-166.

Schleifer, D., 2013. Which Social Netwrok Makes Your Customers Buy? Harvard: Harvard Business Review.

Senecal, S. \& Nantel, J., 2004. The influence of online product recommendatios on consumers online choices. Journal of Retailing, 80(2), p. 159-169.

Sevitt, D. \& Samuel, A., 2013. Vision Statement: How Pinterest Puts People in Stores. Harvard Business Review, Issue July-August.

Strauss, J. \& Frost, R., 2014. E-Marketing. $7^{\text {th }}$ ed. Harlow: Pearson Education Limited.

Swedbank, 2015. swedbank.lv. [Online] Available at: https://www.swedbank.lv/zinas/09.02.2015/1 [Accessed 26.02.2016].

Zhang, K. Z. K., Cheung, C. M. K. \& Lee, M. K. O., 2014. Examining the Moderating Effect of Inconsisyent Reviews and Its Geder Differences on Consumers' Online Shopping Decision. International Journal of Information Management, Vol. 34, pp. 89-98.

Zhu, D. H., Chang, Y. P. \& Jian, J. L., 2016. Understanding the Influence of C2C Communication on Purchase Decision in Online Communities from a Perspective of Information Adoption Model. Telematics and Informatics, Vol. 33, p. 8-16. 
May 12-14, 2016, Riga, University of Latvia

\title{
OPERATION OF STATE-OWNED COMPANIES IN LATVIA
}

\author{
Dzintra Gasune, University of Latvia, Latvia ${ }^{1}$ \\ Andris Denins, University of Latvia, Latvia
}

\begin{abstract}
Foundation of state-owned companies has a relatively long history. Over time, the state can both intensively found companies and, later on, make decisions on company privatization based upon situation assessment. These processes are defined state-specific goals, needs, and the state, as the company owner, defines specific functions and tasks of the company.

Bailey's (Bailey, 2010) statement: "As the regulatory movement of the 1930s reflected the view that market failure was pervasive, so the deregulation movement of the late 1970s and early 1980s reflected the view that economic regulation of prices and entry was a government failure, generating misallocations and inefficiencies." The Latvian government has also admitted that involvement of public persons in commercial operation creates the risk of market disturbance. The main economically justified purpose of a public person participation in a capital company is the elimination of market deficiencies and, thereby, enhancement of public welfare.

Up until now, this sector in Latvia has been relatively poorly researched - operation of state-owned companies, therefore the aim of the research is to analyse the state-owned companies, their establishment purposes and scope of operation, for example, the number of employees, state capital investments and profit during two periods of time (1920s-1940s and the period after Latvia regained its independence). In addition, the research gather the main reasons and economic aspects, which are the reason for establishing the state companies in Latvia during the respective period of time, as well as the risks and problems identified in respect to their management and control. For comparison, also the data on state-owned companies located outside the state were summarized.

In the research qualitative analysis methods were used - analysis of scientific literature, normative acts and historical sources, as well as quantitative analysis methods - analysis of statistical data.

Both in the $20^{\text {th }}$ and $21^{\text {st }}$ century, profit-making is not the main argument for the state during the process of company establishment, as the owner. Survey results show that, the state invested more in companies than received from them. The reasons of establishment can be found in the economic and historical situation, for example, takeover of companies owned by other states, and in the social aspect, for example, companies operating in the hospital sector or cultural sector where a private owner is not able to make profits sufficient enough for the company operation and development. Certain of examined sectors the operating volumes of state-owned companies are relatively significant.
\end{abstract}

Key words: state-owned enterprise, state enterprise formation, state enterprise management JEL code: L32

1 Corresponding author - e-mail address:dzintra.gasune@inbox.lv 


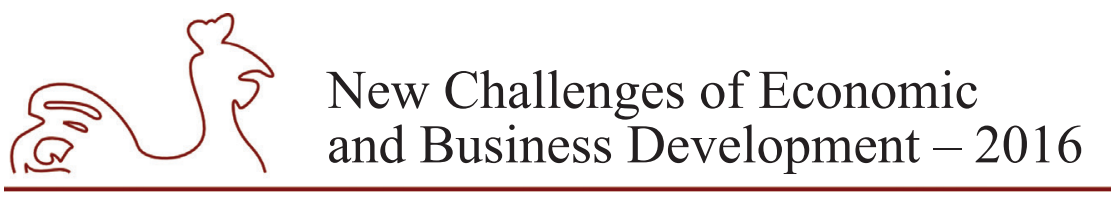

May 12-14, 2016, Riga, University of Latvia

\section{Introduction}

Discussions on the involvement of the state in business are known already since the establishment of the first state-owned enterprises. The critics of establishing such businesses have counter-arguments on the operating efficiency of state-owned enterprises, the amount of state-invested financial resources, the operational transparency of sate-owned companies and the fulfilment of objectives.

This study was carried out to assess the involvement of the Latvian state in business regarding two historical periods $-20 \mathrm{~s}-40 \mathrm{~s}$ of the $20^{\text {th }}$ century, and from 1991 to 2015 . These two periods are marked by a different situation in economy, since the first period began with difficulties arising from the new government to be formed and the consequences of the war, while the second - by receiving the Soviet heritage - can be referred to as the time for state ownership becoming private. Since during these periods a variety of changes was also present, the study has stressed out the following points:

- What are the reasons for the start-up and establishment of state-owned companies;

- What is their role in the national economy;

- Why were such companies dismantled.

\section{Research results and discussion}

\section{The involvement of the Latvian government in business during $20 \mathrm{~s}-40 \mathrm{~s}$ of the $20^{\text {th }}$ century}

Since the establishment of the Latvian government, it has been actively involved in business. Already during the first Latvian independence (1918-1940), because of different goals and reasons the State was carrying out business. Discussions on the State as a company owner were updated also during this time. E. Jakobsons, head of the State Economic department declared, that "the State need to fulfil the obligations of an entrepreneur, if it required by particular economic considerations. A certain economic sector can, in general, be removed from the private sector, thereby creating a national monopoly, but it can also introduce private initiatives and activities in the desired direction by using state-owned companies" (Jākobsons Ē., 1938).

The grounds for establishing Latvian state-owned companies during the $20 \mathrm{~s}-40 \mathrm{~s}$ of the $20^{\text {th }}$ century:

- companies taken over from the former Russian government or the German occupation authorities (national railways, post, telegraph and telephone, electricity company "Jugla", Liepaja port workshops, Spirits monopoly, Kemeri sulphur spring institution and the printing press);

- companies, that were founded by economic considerations and the goal of which was to find ways to place products on the external market more profitably, as well as to serve the society and the state objectives (Latvian Bank, the State Land Bank of Latvia and the Latvian Mortgage bank, the State forests, Cereals institution, Sugar monopoly, Kegums power plant, Country freezer, National artificial slate factory, Radio and the Herbal company);

- companies that were established for fiscal purposes - for supporting agricultural and flax cultures, the Government paid higher prices to flax farmers than they would receive by exporting their products (flax and hemp monopoly); 


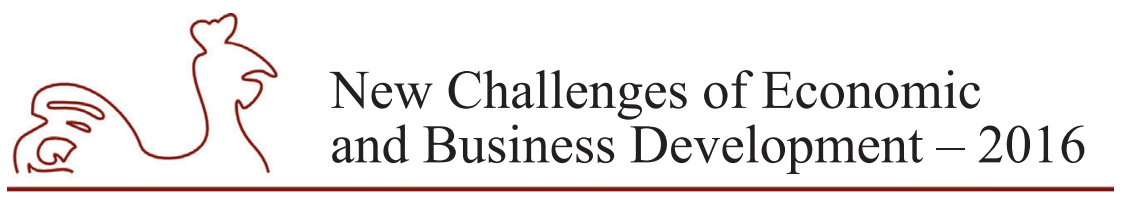

May 12-14, 2016, Riga, University of Latvia

- companies established due to the lack of private initiative (National Management Bureau of peat factories with several companies: in Sloka, Aizpute, Ploci, Livani, Salaspils etc., the State forest development department and the Baldone sulphur spring institution);

- companies established for fulfilling more narrow/specific tasks (the National Insurance Company, the state land holdings, the Ship Management bureau, the State Electrotechnical Factory, Army economic shop and companies of the Ministry of War, Prison Department workshops, teaching aid company, Latvian University serum station, "Leta", Country paper mill, pharmacies of the University of Latvia and the Ministry of People's Welfare, Liepaja Freeport, "Economist" and other monthlies, as well as the workshops of the Latvian Institute for the blind).

Already in 1919 the country founded various state-owned enterprises, monopolies and workshops to gain additional revenue, currency, to restore the industry that was damaged during the war and to supply itself with the necessary goods. Major companies were evacuated to Russia; the owners were abandoned, looted or destroyed. At first, private companies were not trusted, because of making price speculations (Aizsilnieks, 1968). One of the first companies to be founded was the Flax monopoly according to the Government's Provisional order of March 27, 1919 on the import monopoly. Still, the operation of a monopoly began only after the Government returned to Riga from Liepaja (Loze, 1934). This monopoly provided substantial revenue and expanded the national treasury of foreign exchange that was very necessary for the new state. However, not all monopolies worked so positive, so e.g., two years after its launch, the leather and linseed monopoly was liquidated (the Cabinet of Ministers, 1921). In order to promote the production of goods and private initiatives, the Government set up a variety of workshops, factories, plants, that were under the umbrella of the State Supreme Board factory founded in December 1919 (Jubilee Commission, 1928). Furthermore, in 1920 a spirits monopoly was established, and, later on, a sugar and grain monopoly (Aizsilnieks, 1968).

As mentioned above, the objective of establishing state-owned enterprises was not always attributable to gaining profit, and a relatively large amount of state budget funds was invested in these companies. During the first years of the Latvian independence, even half of the period's budget was invested in state-owned enterprises, see Table 1.

Table 1

Investments of the Latvian country in state-owned companies, 1918-1922

\begin{tabular}{|l|c|c|c|}
\hline Years & $\begin{array}{c}\text { Total national } \\
\text { expenditure, mln. lats }\end{array}$ & $\begin{array}{c}\text { Included capital } \\
\text { investments, mln. lats }\end{array}$ & $\begin{array}{c}\text { National capital } \\
\text { investments, \% of } \\
\text { the total expenditure }\end{array}$ \\
\hline $1918 / 20$ & 60.6 & 26.1 & 43.1 \\
\hline $1920 / 21$ & 97.4 & 48.5 & 49.8 \\
\hline $1921 / 22$ & 66.5 & 19.1 & 28.7 \\
\hline
\end{tabular}

Source: Aizsilnieks, 1968, p. 212.

Even in the later years, investment in these enterprises was relatively large, so until 1938 the country had invested 1211.1 million lats (see Table 2) in state-owned companies (Jakobsons E., 1938). 


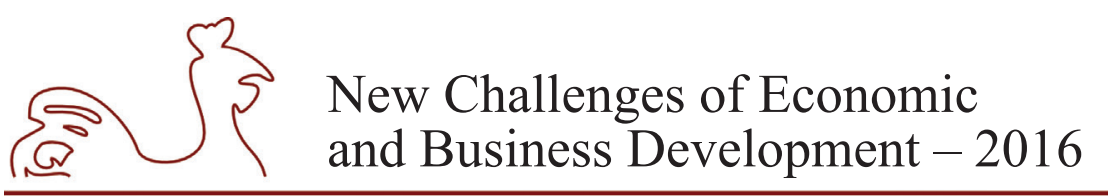

May 12-14, 2016, Riga, University of Latvia

Table 2

Investment of the Latvian country in state-owned companies, 1919-1938

\begin{tabular}{|l|c|}
\hline \multicolumn{1}{|c|}{ Type of company } & Investment, mln. lats \\
\hline $\begin{array}{l}\text { companies taken over from the former Russian government or } \\
\text { the German occupation authorities }\end{array}$ & 341.2 \\
\hline companies, that were founded by economic considerations & 807.8 \\
\hline companies established for fiscal purposes & 18.4 \\
\hline companies established due to the lack of private initiative & 10.4 \\
\hline companies established for fulfilling more narrow /specific tasks & 33.3 \\
\hline \multicolumn{1}{|c|}{ In total } & $\mathbf{1 2 1 1 . 1}$ \\
\hline
\end{tabular}

Source: author's construction based on Jakobsons, 1938.

The country was running business in various forms, such as a monopoly, as an institution (e.g., Forest Exploitation Administration), joint stock companies, banks and public autonomous companies. On January 12, 1922, the Cabinet of Ministers adopted "Regulations on the autonomous national enterprises" (the Cabinet of Ministers, 1922). Paragraph 1 of this provision states that " 1 . The state-owned enterprises can be turned into an autonomous economic entity with the structure and status of a private company, which is then determined by the Cabinet of Ministers, according to the proposal of the head of the policy department." However, the autonomous national companies acquired rights of a legal person only with the law adopted in 1935 (Prime Minister, 1935).

The newly established companies added some value to the Treasury of the new country, and according to the Credit Department the revenue during the period from November 18, 1919 until 1920 was $8,585,480$ lats which was $13.26 \%$ of the total revenue and took the second place just behind the national Treasury notes. Flax monopoly revenues amounted to 554,974 lats or $0.86 \%$ (Credit Department, 1923). Also in the coming years these companies generally provided quite a lot of revenue to the state budget, see Figure 1.

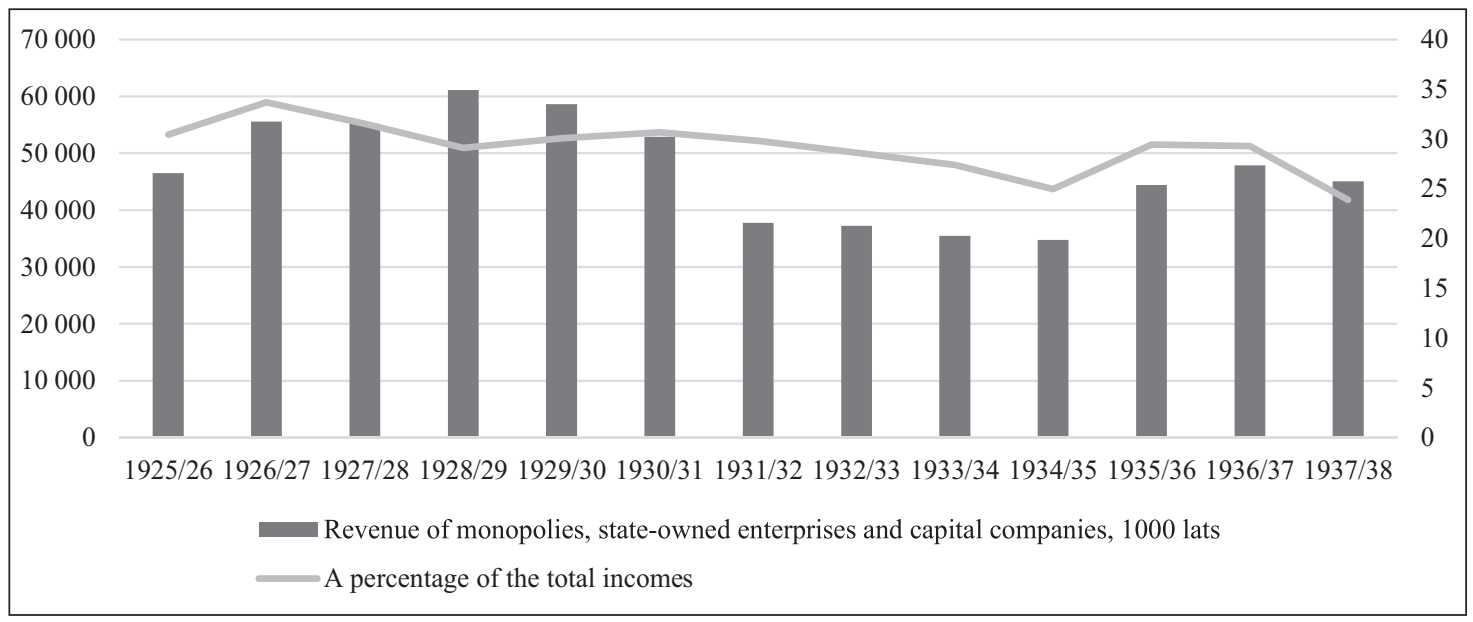

Source: author's construction based on data of the Statistical Bureau.

Fig. 1. Revenue of monopolies, state-owned enterprises and capital companies from 1925/26 to 1937/38 


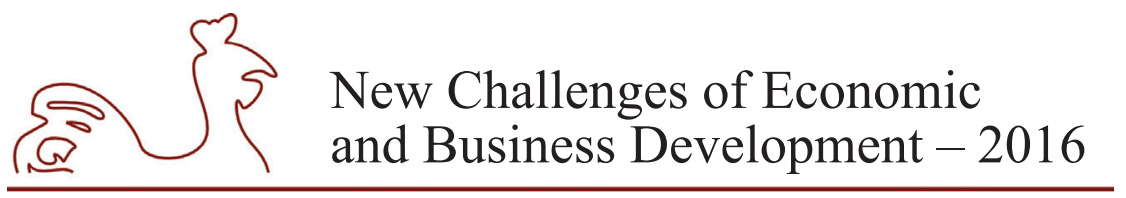

May 12-14, 2016, Riga, University of Latvia

The next phase of new national business start-ups began in 1935 when the law on Latvian credit cooperatives was adopted (the Cabinet of Ministers, 1935), where it was expected that the bank may participate in the establishment of a new joint stock company. Bank "on behalf of the government, freed the farms from commercial and industrial businesses that could not successfully operate due to large losses or whose performance did not meet the interests of the State" (Latvian Credit Bank, 1939). However, this action was not evaluated unambiguously, since the country began to operate as an entrepreneur in different sectors of economy and had a significant impact on cross-cutting activities. In the period up to March 1939, the bank had founded 38 companies (e. g., "Aldaris", "Bekona eksports", "Laima”, "Maiznieks", "Vairogs"). In order to attract private capital to public undertakings, shares of advantage were released (Latvian Credit Bank, 1939). Although state-owned enterprises grew relatively quickly, the number of employees accounted for about $10 \%$ of the total number of employees in industrial enterprises.

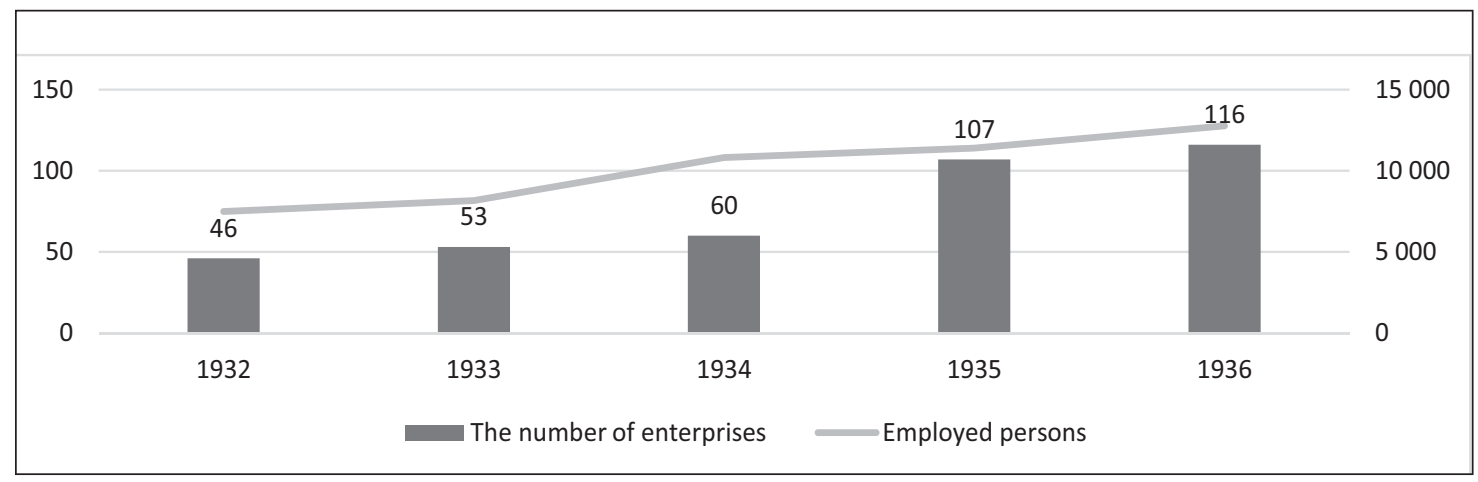

Source: author's construction based on data of the Statistical Bureau.

Fig. 2. The state-owned industrial enterprises and the number of persons employed therein, 1932-1936

Biggest contribution in income to the state provided monopoly, for instance, in financial year 1926/27 profit of monopoly provided 33.7\% income for the state (State Statistical Bureau, 1937). Biggest profit was to monopoly of alcohol and vodka, sugar monopoly, post, telegraph. Separating the only state-owned companies, it can be seen, that they accounted for a relatively small revenue budget, see Figure 3. The largest part of profit comprised from railways, forestry companies and state institutions. These profits comprised only from 2.2 till $9 \%$ from total budget income. Only profits of financial year 1936/38 exceeded investments. From 1925 till 1936 these investments were $5.6-10 \%$ from all budget expenditures. 
May 12-14, 2016, Riga, University of Latvia

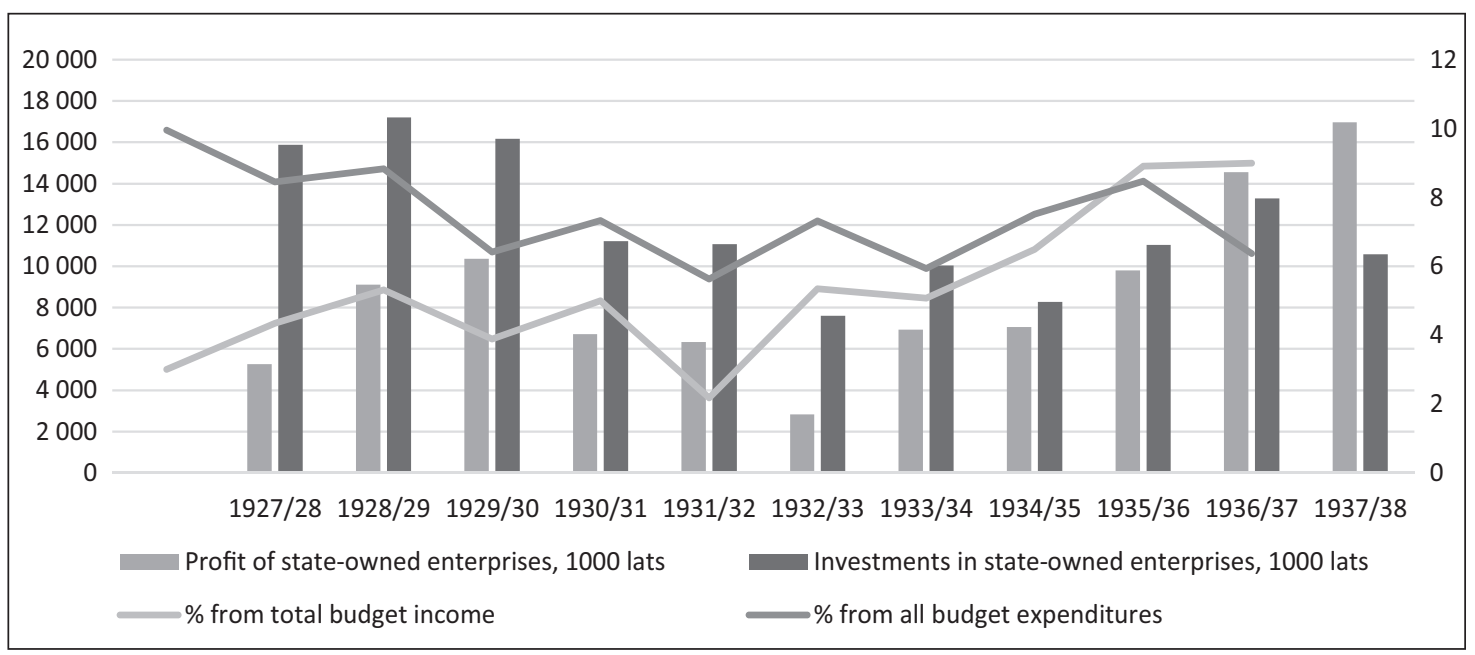

Source: author's construction based on data of the Statistical Bureau.

Fig. 3. State corporate earnings and capital investment in State-owned enterprises, from financial year 1925/26 till 1937/38

Assessing large investment in state-owned enterprises, relatively early started a discussion on the usefulness of state-owned enterprises. Thus after achieving the set objectives or failing to achieve set objectives, the state ceased to participate in enterprises, for private investors, in the area in question, to operate. Already in 1921 Ministry of Finance stated that private initiative has to be widened, and Ministry of Finance reduced participation in state-owned enterprises and dealt only with supervision measures (Ministry of Finance, 1921). As previously mentioned, in 1921 several monopolies were liquated, as well as Forest Operations Manager and Ministry of Maintenance. Director of Credit department of Ministry of Finance A. Karklins stated (Karklins, 1927) "State-owned enterprises, events and installations failed to meet expectations. They requested more and more funds, came up with new projects and gave promises after promises to the state, only not the money, pretexting one or another accident."

Activity of state-owned enterprises had plenty of positive aspects, for instance, reduction of unemployment, support for farmers and other sectors, but also number of aspects were indicated to burden national corporate governance (Jakobsons E., 1938):

- Complicated form of enterprise's administration and organization, which makes it relatively inelastic;

- Implementation of key questions required consent of highest instances;

- Need for thorough control, that would raise the cost of enterprise's administration;

- Interest of enterprise's management in the results.

The situation changed significantly in 1940. After inclusion of Latvia in Soviet Union, on July 22, 1940 Saeima implemented a declaration about the proclamation of the state property of large industrial, commercial and transport companies, and on the basis of this declaration, on July 25, 1940 law "Nationalization of banks and large industry companies in territory of Latvian Soviet Socialist Republic" was adopted and it was accompanied by list of 804 companies to be nationalized (Cabinet of Ministers, 1940). The process of nationalization of companies continued and other documents determining nationalization of other companies were issued, for instance, 


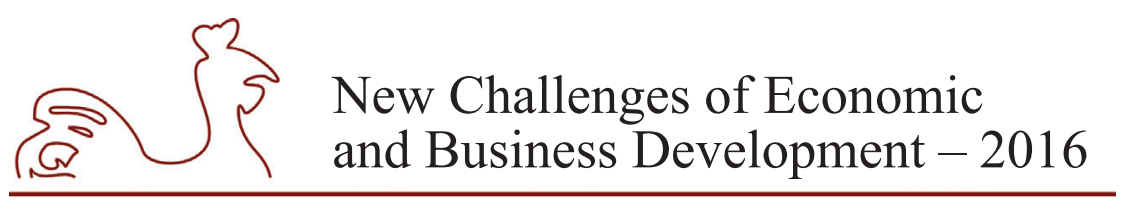

May 12-14, 2016, Riga, University of Latvia

Decree for nationalization of trading companies, 28.09.1940. (Latvian SSR Supreme Council, 1940), Decree for nationalization of private cinemas, large hotels, clinics, pharmacy warehouses and chemical pharmaceutical industrial enterprises, 28.10.1940. (Latvian SSR Supreme Council, 1940). Thus in a relatively short time, most private companies became state-owned.

\section{State-owned enterprise in Latvia at the end of the $20^{\text {th }}$ century and early $21^{\text {st }}$ century}

Following regaining Latvian independence it was need to launch privatization of stateowned enterprises. Thus on August 3, 1990 The Supreme Council adopted a decision On development programs on national economy of Republic of Latvia, that stated "to assign Cabinet of Ministers of the Republic of Latvia till September 15, 1990 to develop and present to the Supreme Council for approval program for conversion of state property and privatization, in which provide - options for return of illegally confiscated property to citizens and legal persons, State property transfer procedures to individuals and legal entities Republic of Latvia" (The Supreme Council of the Republic of Latvia, 1990). On March 20, 1991 also a decision On basic principles of state property and its conversion, which identified the essential conditions of public property denationalisation and privatization was adopted (The Supreme Council of the Republic of Latvia, 1991). On June 16, 1992 law On State and local government property (company) privatization procedure, set methods of privatization, also process of privatization, provided by ministry or committee, in charge of state property, or district, city, parish governing board, in charge of state property. To ensure privatization process in 1994 (Cabinet of Ministers of the Republic of Latvia, 1994) Privatisation Agency was established, that provided privatisation process for state property. In time frame from April of 1994 till October 31, 2015, 2552 state property (except land) privatization regulations were approved and 94 companies were converted into a public joint stock companies (The Ministry of Economics of Republic of Latvia, 2015a). In turn, in State and municipal property privatization and privatization certificates Law on completion (Saeima of the Republic of Latvia, 2005) state-owned enterprises are set, which cannot be privatized and disposed and they are: public limited company "Latvenergo", public limited company "Latvijas pasts", public limited company "Starptautiska lidosta "Riga"”, public limited company "Latvijas dzelzcels", public limited company "Latvijas gaisa satiksme" and public limited company "Latvijas valsts mezi".

On December 12, 1990 LR Supreme Council approved law On state-owned enterprises, which determined the company's founding, operations, management, and disposal procedures (The Supreme Council of the Republic of Latvia, 1990). With January 1, 2003 State Administration Structure Law provided (Saeima of the Republic of Latvia, 2002) that public person can do commercial activities: 1) if the market is not able to provide the company's interests in the relevant field; 2) in a sector in which there is a natural monopoly, thus ensuring the public availability; 3) strategic sector; 4) new sector; 5) in a sector in which the development of infrastructure require large capital investments; 6) in a sector in which according to the public interest need to provide a higher quality standard.

Amendments of law (Saeima of the Republic of Latvia, 2015) which entered into force on January 1, 2016 significantly narrowed the cases in which the State may establish limited liability companies:

1) It is a market failure - a situation where the market is not able to ensure the implementation of the public interest in the area; 


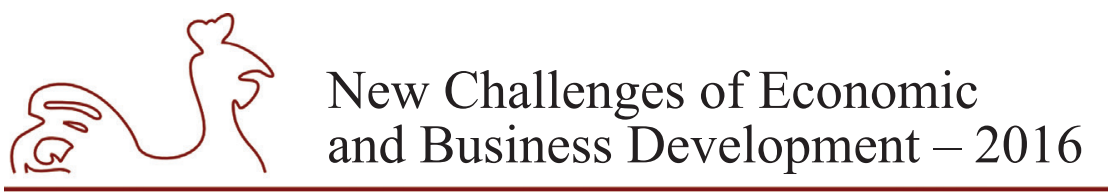

May 12-14, 2016, Riga, University of Latvia

2) public persons, corporate or public person controlled capital activities leading to the creation of goods or services, which are strategically important to development of the state or local government administrative territory or national security;

3) such properties are managed, which are strategically important for development of the state or local government administrative territory or national security.

With these law amendments public persons has to evaluate and justify the capital startups or acquisitions. Also Cabinet of Ministers of the Republic of Latvia should determine "development of the country or the security of strategically important assets or market failure, or goods and services, that in result of capital activity are created and are strategically important for the state's development or safety (Saeima of the Republic of Latvia, 2015)". This indicates that the state wants to give sufficient and clear reasons for participation in the capital.

Latvian State wholly or partly owns a relatively large number of limited liability companies that have major impact on national economy, that is, after financial data in the end of $201218,2 \%$ from Latvian gross domestic product (Ministry of Economics of Latvia, 2015). On July 1, 2015 $100 \%$ in state's cooperation were 67 limited liability companies, in state's decisive impact 5 (Cross-Sectoral Coordination Centre, 2015). Situation in economics is variable, and after a certain time, that is, not less frequently than once every five years, it is necessary to reassess the state's cooperation holding in limited liability companies and its compliance with the public person business principles (Saeima of the Republic of Latvia, 2014).

As it is seen in table 3, state-owned enterprises are represented in most of the sectors, with a tendency to decrease. As an exception is year 2014 when a number of the Ministry of Health subordinated state medical institutions and rehabilitation centres were transformed into public companies with share capital. The largest number of people employed is in the transport sector represented by public limited company "Latvijas dzelzcels", and the health sector, in which are hospitals and rehabilitation centres.

Table 3

Number of companies and employees divided in sectors that is $100 \%$ state - owned companies or the company's equity interest is $100 \%$, between 2000 and 2014

\begin{tabular}{|c|c|c|c|c|c|c|c|c|c|c|c|c|c|c|c|c|c|}
\hline \multirow{2}{*}{ NACE 1.1} & \multicolumn{2}{|c|}{2000} & \multicolumn{2}{|c|}{2002} & \multicolumn{2}{|c|}{2004} & \multirow{2}{*}{ NACE 2.red. } & \multicolumn{2}{|c|}{2006} & \multicolumn{2}{|c|}{2008} & \multicolumn{2}{|c|}{2010} & \multicolumn{2}{|c|}{2012} & \multicolumn{2}{|r|}{2014} \\
\hline & No. & Empl. & No. & Empl. & No. & Empl. & & No. & Empl. & No. & Empl. & No. & Empl. & No. & Empl. & No. & Empl. \\
\hline A Agriculture, hunting and forestry & 2 & 611 & 2 & 668 & 3 & 967 & AAgriculture, forestry and fishing & 3 & 1076 & 3 & 1352 & 3 & 1271 & 2 & 1335 & 2 & 1432 \\
\hline D Manufacturing & 12 & 3480 & 5 & 183 & 5 & 169 & C Manufacturing & 1 & 6 & 1 & 1413 & 1 & 1409 & 1 & 1445 & 1 & 1454 \\
\hline E Electricity, gas and water supply & 1 & 6985 & 1 & 6544 & 1 & 6389 & D Electricity, gas, steam and air cond. & 2 & 5615 & 1 & 1367 & 2 & 1337 & 2 & 1335 & 3 & 1483 \\
\hline F Construction & & & 1 & 69 & 0 & 0 & F Construction & 1 & 8 & 1 & 502 & 1 & 467 & 1 & 478 & 2 & 624 \\
\hline G Wholesale and retail trade & 2 & 345 & 2 & 238 & 2 & 228 & G Wholesale and retail trade & 1 & 188 & 1 & 19 & 0 & 0 & 0 & 0 & 0 & 0 \\
\hline $\mathrm{H}$ Hotels and restaurants & & & 1 & 30 & 2 & 65 & H Transporting and storage & 7 & 23013 & 7 & 19953 & 6 & 17572 & 6 & 16755 & 5 & 13663 \\
\hline I Transport, storage and communication & 10 & 24379 & 10 & 22667 & 10 & 23355 & I Accommodation and food service act. & 4 & 116 & 4 & 91 & 4 & 69 & 3 & 167 & 2 & 61 \\
\hline J Financial intermediation & 3 & 38 & 3 & 30 & 5 & 683 & $\mathrm{~J}$ Information and communication & 6 & 1350 & 5 & 1328 & 5 & 1056 & 4 & 1049 & 4 & 1043 \\
\hline K Real estate, renting and business act. & 31 & 1938 & 29 & 1669 & 27 & 1859 & K Financial and insurance activities & 6 & 664 & 5 & 706 & 4 & 600 & 4 & 569 & 5 & 306 \\
\hline L Public admin. and defence; compulsory & 19 & 2078 & 18 & 1980 & 13 & 1541 & L Real estate activities & 12 & 783 & 11 & 863 & 10 & 846 & 7 & 819 & 6 & 922 \\
\hline M Education & 8 & 640 & 7 & 620 & 7 & 649 & M Professional, scient. and techn. act. & 14 & 971 & 12 & 891 & 12 & 970 & 12 & 734 & 9 & 725 \\
\hline $\mathrm{N}$ Health and social work & 25 & 9527 & 26 & 9742 & 41 & 11940 & N Administr. and support service act. & 6 & 2072 & 4 & 2379 & 4 & 2124 & 5 & 2176 & 7 & 1989 \\
\hline O Other community, personal serv. act. & 20 & 2936 & 21 & 2929 & 21 & 2954 & O Public adm. and defence; social sec. & 4 & 1086 & 4 & 1227 & 4 & 1064 & 5 & 1095 & 5 & 1120 \\
\hline In total & 133 & 52957 & 126 & 47369 & 137 & 50799 & P Education & 2 & 255 & 2 & 257 & 2 & 236 & 2 & 358 & 2 & 394 \\
\hline & & & & & & & Q Human health and social work act. & 25 & 10990 & 19 & 13210 & 17 & 12496 & 16 & 13770 & 16 & 14123 \\
\hline & & & & & & & R Arts, entertainment and recreation & 17 & 1580 & 18 & 1699 & 18 & 2093 & 17 & 2157 & 18 & 2296 \\
\hline & & & & & & & S Other services activities & 0 & & 0 & & 0 & & 1 & 7 & 0 & \\
\hline & & & & & & & In total & 111 & 49773 & 98 & 47257 & 93 & 43610 & 88 & 44249 & 87 & 41635 \\
\hline
\end{tabular}

Source: author's construction based on data taken from Statistical Bureau. 


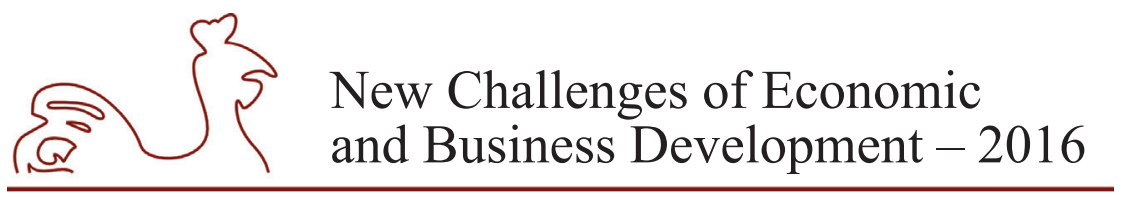

May 12-14, 2016, Riga, University of Latvia

Comparing the 34 countries that provided information for year 2012 to The Organization for Economic Co-operation and Development, a great variety of public corporations can be seen in this country. For example, in some such companies do not exceed 10 (Austria, Belgium, Switzerland), while in others even exceeds 100 (the Czech Republic, Hungary, Lithuania and Poland). As can be seen, the situation is very different and it is after the country's privatization program in the 1990s, when aim was put forward to increase national efficiency and reduce the budget burden. See Table 4 .

Table 4

The size and sectoral composition of national state-owned enterprise, 2012

\begin{tabular}{|l|c|c|c|c|c|c|c|c|}
\hline \multirow{3}{*}{ Country } & \multicolumn{2}{|c|}{$\begin{array}{c}\text { Majority-owned } \\
\text { listed entities }\end{array}$} & \multicolumn{2}{c|}{$\begin{array}{c}\text { Minority-owned } \\
\text { listed entities }\end{array}$} & \multicolumn{2}{c|}{$\begin{array}{c}\text { Majority owned } \\
\text { non-listed } \\
\text { enterprises }\end{array}$} & \multicolumn{2}{c|}{$\begin{array}{c}\text { Statutory } \\
\text { corporations and } \\
\text { quasi-corpor. }\end{array}$} \\
\cline { 2 - 10 } & $\begin{array}{c}\mathbf{N}^{\circ} \text { of en- } \\
\text { terprises }\end{array}$ & $\begin{array}{c}\mathbf{N}^{\circ} \text { of em- } \\
\text { ployees }\end{array}$ & $\begin{array}{c}\mathbf{N}^{\circ} \text { of en- } \\
\text { terprises }\end{array}$ & $\begin{array}{c}\mathbf{N}^{\circ} \text { of em- } \\
\text { ployees }\end{array}$ & $\begin{array}{c}\mathbf{N}^{\circ} \text { of en- } \\
\text { terprises }\end{array}$ & $\begin{array}{c}\mathbf{N}^{\circ} \text { of em- } \\
\text { ployees }\end{array}$ & $\begin{array}{c}\mathbf{N}^{\circ} \text { of en- } \\
\text { terprises }\end{array}$ & $\begin{array}{c}\mathbf{N}^{\circ} \text { of em- } \\
\text { ployees }\end{array}$ \\
\hline Austria & 2 & 26281 & 2 & 45104 & 6 & 47872 & 1 & 8 \\
\hline Belgium & 1 & 15859 & 4 & 53554 & 7 & 72617 & - & - \\
\hline $\begin{array}{l}\text { Czech } \\
\text { Republic }\end{array}$ & 1 & 31300 & - & - & 89 & 33900 & 35 & 75100 \\
\hline Estonia & - & - & - & - & 29 & 16046 & 24 & 9170 \\
\hline Finland & 3 & 21761 & 11 & 139911 & 37 & 60916 & 2 & 2083 \\
\hline Germany & - & - & 3 & 713890 & 71 & 349197 & 1 & 6 \\
\hline Hungary & 1 & 1920 & 2 & 40401 & 370 & 123004 & - & - \\
\hline Latvia & - & - & 1 & 32 & 74 & 52240 & - & - \\
\hline Lithuania & 2 & 701 & 1 & 1700 & 46 & 26724 & 89 & 13821 \\
\hline Norway & 3 & 63187 & 5 & 64211 & 25 & 49261 & 17 & 108597 \\
\hline Poland & 6 & 36074 & 10 & 64525 & 295 & 117738 & 25 & 5918 \\
\hline Sweden & - & - & 3 & 73156 & 46 & 132727 & 3 & 2881 \\
\hline Switzerland & 1 & 19514 & - & - & 1 & 7739 & 2 & 73845 \\
\hline
\end{tabular}

Source: author's construction based on OECD data.

As shown in Table 4, the highest level constitutes significant state-owned companies, but the following are statutory corporations and quasi-corporations.

\section{Conclusions, proposals, recommendations}

State-owned enterprise objectives and tasks, in both historical periods reviewed in the study are similar in certain areas, but in some - different:

1. Both in the $20^{\text {th }}$ century and in the $21^{\text {st }}$ century in setting up businesses with the state as the owner for making profit is not the only argument. The reasons are found in the economic situation, such as alcohol, flax monopoly, and the social aspect, for example, companies operating in the hospital sector, where the private owner does not have the opportunity to earn a fair income for company's operation and development. 


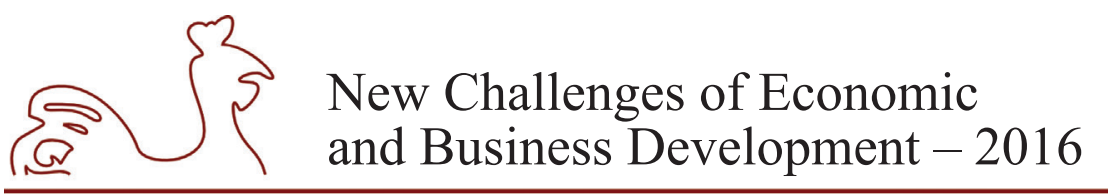

May 12-14, 2016, Riga, University of Latvia

2. Latvian State in both reviewed periods by means of establishing companies, the objectives were different, because the first period was affected by the war legacy, and the second period began with the privatization. However, there are identifiable and similar stateowned enterprise establishing objectives, such as if the market is not able to ensure the implementation of the public interest in the certain field.

3. State as the owner, taking into account the economic situation, had to take decisions on the extension of ownership, reduction or preservation of companies. These decisions must be justified and weighted so that the state may conduct business in a particular area. Unjustified, unexplained decision-making can lead to a negative public reaction.

4. Latvian state-owned companies and the number of employees is not unusual and does not stand out in comparison with other countries; in some countries the number is significantly lower while in others - higher.

5. In order to compare the Latvian companies in various sectors, not only those who are well represented, but also in those companies that have a monopoly, the next research will be carried out, assessing the Latvian state companies, compared with other countries' stateowned companies.

\section{Bibliography}

Aizsilnieks, A., 1968. Latvian Economy History 1914-1945. Sundbyberg: Daugava. Available at: http:// gramatas.Indb.lv/periodika2-viewer/view/index-dev.html\#panel:pp|issue:/g_001_0302015606|artic le:DIVL2556|page:217|issueType:B [Accessed 2 March 2016].

Bailey, E., 2010. Air-Transportation Deregulation, Better Living through Economics. Siegfried ed., Cambridge: Harvard University Press, pp. 188-202.

Cabinet of Ministers, 1921. Government Action. Government Gazette, 165, p.2. [Online] Available at: http://www.periodika.lv/periodika2-viewer/view/index-dev.html\#panel:pp|issue:/p_001_wawe192 1n165|article:DIVL11|page:2|query:?du|issueType:P. [Accessed 10 February 2016].

Cabinet of Ministers, 1922. Terms of the Autonomous Public Companies. Government Gazette, 11, p. 1. [Online] Available at: http://periodika.lv/periodika2-viewer/view/index-dev.html\#panel:pp|issue:/ p_001_wawe1922n11|article:DIVL25|query:Noteikumi par valsts uz??mumiem Valsts uz??mumu autonom? uz??mumiem|issueType:P [Accessed 10 February 2016].

Cabinet of Ministers, 1935. The Law on the Latvian Commercial Bank. Government Gazette, 85, p. 1. [Online] Available at: http://www.periodika.lv/periodika2-viewer/view/index-dev.html\#panel: pp|issue:/p_001_wawe1935n85|article:DIVL22|issueType:P [Accessed 10 February 2016].

Cabinet of Ministers, 1940. The Law of the Nationalization Banks and Large Industrial Enterprises in the Latvian Soviet Socialist Republic Territory. Government Gazette, 168, pp. 1-2. [Online] Available at: http://www.periodika.lv/periodika2-viewer/view/index-dev.html\#panel:pp|issue:/ p_001_wawe1940n168|page:1|issueType:P [Accessed 10 February 2016].

Cabinet of Ministers, 1994. The Non-profit Organization State Joint-stock Company "Privatisation Agency". [Online] Likumi.lv. Available at: http://likumi.lv//ta/id/198369?\&search=on [Accessed 5 Mar. 2016].

Cabinet of Ministers, 2004. The Concept of Education, Culture, Health and Social Care Sector, Public Institutions (except universities) legal status. [Online] Likumi.lv. Available at: http://likumi.lv/ta/ id/85266-par-koncepciju-par-izglitibas-kulturas-veselibas-aprupes-un-socialas-aprupes-nozaresvalsts-instituciju-iznemot-augstskolas [Accessed 5 Mar. 2016].

Credit department, 1923. State Revenues and Expenditures. Economist, 13-14,pp. 519. [Online] Available at: http://www.periodika.lv/periodika2-viewer/view/index-dev.html\#panel:pa|issue:/p_001_ ekon1923n13-14|article:DIVL162|page:15|issueType:P [Accessed 2 March 2016]. 


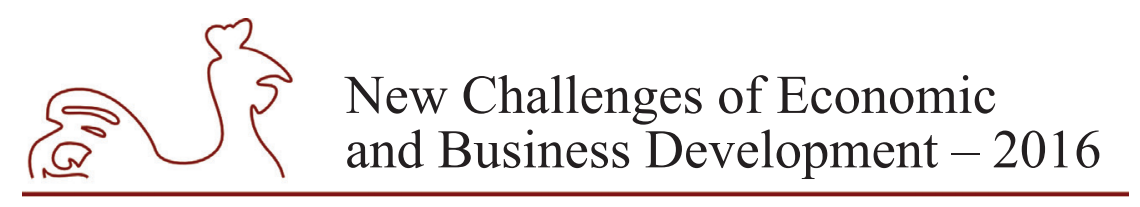

May 12-14, 2016, Riga, University of Latvia

Cross-Sectoral Coordination Centre, 2015. State capital, the State Capital Companies and their Subsidiaries Shareholdings. [Online] Available at: http://www.pkc.gov.lv/images/ Kapitalsabiedribas/VKS_01072015_lidzdaliba.pdf [Accessed 3 March 2016].

Jakobsons E., 1938. Public Investment in Manufacturing and Trading Companies. In: United efforts of the country and the people. Riga: Latvian Chamber of Commerce, pp. 63-74. [Online] Available at: http://gramatas.lndb.lv/periodika2-viewer/view/index-dev.html\#panel:pp|issue:/g_001_030909396 2|article:DIVL766|page:1|issueType:B [Accessed 2 March 2016].

Jubilee commission, 1928, Latvia in Ten Years. Riga: The State printing house. [Online] Available at: http://www.csb.gov.lv/sites/default/files/latvija_10_gados_1928.pdf [Accessed 4 March 2016].

Karklins, A., 1927. Our Monetary Reform. Riga: magazine ,Economist‘ Publishing. [Online] Available at: http://gramatas.lndb.lv/periodika2-viewer/view/index-dev.html\#panel:pp|issue:/g_001_0307093 166|page: 1 |issueType:B [Accessed 2 March 2016].

Lavian Credit Bank, 1939. Lavian Credit Bank Activity in 1938. Government Gazette, 199, pp. 2-3. [Online] Available at: http://www.periodika.lv/periodika2-viewer/view/index-dev. html\#panel:pp|issue:/p_001_wawe1939n199|article:DIVL141|page:3|query:Latvijas kreditbankas darb?ba 19381938 Latvijas kreditbanka|issueType:P [Accessed 2 March 2016].

Latvian SSR Supreme Council, 1940. Decree on Private Cinemas, Large Hotels, Clinics, Pharmacy Warehouses and Chemical Pharmaceutical Industrial Enterprises Nationalization. Latvian SSR Supreme Soviet Presidium Reporter, 51, p. 1. [Online] Available at: http://www.periodika.lv/ periodika2-viewer/view/index-dev.html\#panel:pp|issue:/p_003_vpvs1940n051|article:DIVL29|que ry:Dekr?ts par nacionaliz?ciju Dekr?ts par|issueType:P [Accessed 1 March 2016].

Latvian SSR Supreme Council, 1940. Decree on Nationalization of Commercial Enterprises. Latvian SSR Supreme Soviet Presidium Reporter, 26, p.1. [Online] Available at: http://www.periodika.lv/ periodika2-viewer/view/index-dev.html\#panel:pp|issue:/p_003_vpvs1940n026|article:DIVL21|que ry:DEKRETS par nacion?liz?ciju|issueType:P [Accessed 1 March 2016].

Latvian Supreme Council of the Republic, 1990. Law on State-owned Enterprises. [Online] Likumi.lv. Available at: http://likumi.lv//ta/id/64792?\&search=on\#pn2 [Accessed 1 March 2016].

Latvian Supreme Council, 1990. Economic Development Programm of Latvian Republic. [Online] Likumi.lv. Available at: http://likumi.lv/doc.php?id=76078 [Accessed 1 March 2016].

Latvian Supreme Council, 1991. National Property and its Conversion Principles. [Online] Likumi.lv. Available at: http://likumi.lv/doc.php?id=65829 [Accessed 1 Mar. 2016].

Loze, R., 1934. Country Flax Monopoly 15 years. Economist, 16, pp. 553-557. [Online] Available at: http:// www.periodika.lv/periodika2-viewer/view/index-dev.html\#issue:/p_001_ekon1934n16|article: DIVL5|issueType:P [Accessed 1 March 2016].

Ministry of Finance, 1921, Department of Economic activity. Economist, 23, pp. 826. [Online] Available at: http://www.periodika.lv/periodika2-viewer/view/index-dev.html\#panel:pa|issue:/p_001_ekon 1921n23|article:DIVL5|page:2|query:par likums par valsts uz??mumiem|issueType:P [Accessed 1 March 2016].

Ministry of Economy, 2015. Report on the Latvian economy, December 2015. Riga: Ministry of Economicsof the Republic of Latvia. [Online] Available at: https://em.gov.lv/files/tautsaimniecibas attistiba/zin/2015_dec_lv.pdf [Accessed 10 March 2016].

Ministry of Economy, 2015. Report on the Latvian economy, June 2015. Riga: Ministry of Economicsof the Republic of Latvia. [Online] Available at: https://em.gov.lv/files/tautsaimniecibas_attistiba/ zin/2015_jun_lv.pdf [Accessed 10 March 2016].

State Statistical Bureau, 1937. Latvian statistical year book 1937. Riga: Valters un Rapa.

The Prime Minister, 1935. The Law on the Autonomous Public Companies. Government Gazette, 275, p. 1. [Online] Available at: http://www.periodika.lv/periodika2-viewer/view/index-dev.html\#panel: pp|issue:/p_001_wawe1935n275|article:DIVL50|page:1|issueType:P [Accessed 10 March 2016]. 


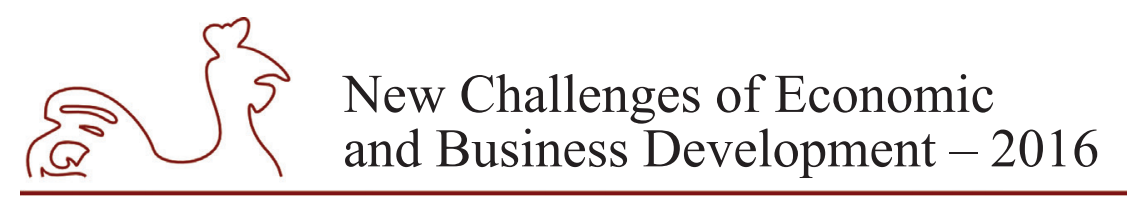

May 12-14, 2016, Riga, University of Latvia

The Saeima, 2002. The State Administration Structure Law. [Online] Likumi.lv. Available at: http:// likumi.lv/doc.php?id=63545 [Accessed 5 Mar. 2016].

The Saeima, 2005. State and Local Government Property Privatisation and Use of Privatisation Certificates of Completion Act. Available at: http://likumi.lv//ta/id/111962?\&search=on [Accessed 3 Mar. 2016].

The Saeima, 2014. Public Personal Shares and Limited Liability Companies Management Act. [Online] Likumi.lv. Available at: http://likumi.lv/doc.php?id=269907 [Accessed 3 Mar. 2016].

The Saeima, 2015. Amendments of the State Administration Law. [Online] Likumi.lv. Available at: http:// likumi.lv//ta/id/63545? \&search=on [Accessed 5 Mar. 2016]. 


\title{
OPTIMIZATION ON DECISION MAKING DRIVEN BY DIGITALIZATION
}

\author{
Steffen Hossfeld, University of Latvia, Latvia ${ }^{1}$
}

\begin{abstract}
The content of this paper refers to the global trend of digitalization and its implications on decision making. Digitalization is currently the key driver for change in business and organizations. Affected is everything, from market structures to customer behaviour over supply chain and production itself. Internal processes have opportunities for a new design, production and logistics. Therefore digitalization will influence every work place and create new challenges for the entire organization. This massive game changing opportunity has to be steered by management and hence management decisions are a must while this transition phase; furthermore decisions will influence this transition but decisions itself are also affected. In the first part of the paper, typical decision models will be discussed; a rational model with first ideas of the neoclassical economists (e.g. Adam Smith or Max Weber) and scientific approaches of Pascal and de Fermat or Bernoulli, mainly focused on agents which maximize their utility. Further developed by von Neumann/Morgenstern economic decisions seem to be a strong rational and mathematical process to find utility maximization. This rational model is illustrated on the one hand to explain the traditional way and have a view on the model of homo oeconomicus. On the other hand, a new view on decision making was completely described by an emotional model from Kahneman/Tversky, which shows an emotional aspect of decisions, because humans don't follow strict rational rules. Especially in organizations a mixed view of both ideal models are still vital, as explained from March/Simon, continued in Simon's bounded reality. In the second part of the paper, digitalization as one part of globalization will be explained. Digitalization will change completely the business environment and the setup of organizations. New market structures, customer behaviour and processes will change the entire operations of business and organizations. Then the main discussion of the paper, the impacts of digitalization on decision making will show the trend toward the well known model of homo oeconomicus, which is a common model in economics; but known with a lot of limitations. Automatization of processes will affect the decision process in organization and consequently an adoption of business models seems obvious. This new decision making processes will be mainly automated in the future, hence an algorithm logic is required and enables the model of homo oeconomicus a revivial, driven by machines.
\end{abstract}

Key words: decision making, globalization, digitalization

JEL code: F60

\section{Introduction}

These days, two main trends are on the agenda of organizations; globalization and digitalization. The ongoing trend of globalization increased tremendously the complexity of business. This trend shows two flipsides of a coin, opportunities and challenges. Huge opportunities are a wider scope of a customer base and further possibilities of global sourcing.

1 Corresponding author - e-mail address: shossfeld@web.de 


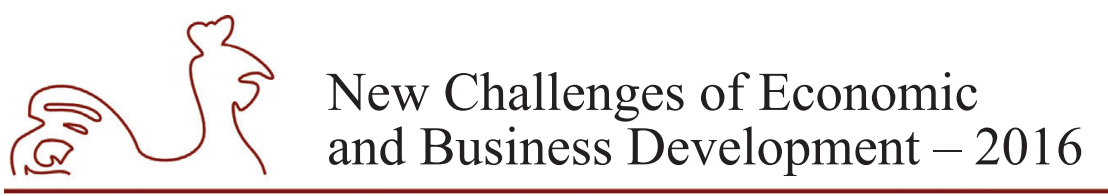

May 12-14, 2016, Riga, University of Latvia

These variety of alternatives increased the complexity of an organization; decisions are today more extensive than in the past, because the need for decisions in organisations was since ever an endogenous procedure, but the quality of a decision was never so complicated but important than today. The new megatrend of digitalization supports the opportunities of globalization and will change decision models dramatically, because concentration of business is one part of this trend, a "winner takes it all" mentality is a digital phenomenon, e.g. the global success of Amazon, but who's number two? The possibilities for organizations by increasing efficiency or designing a new business model are manifold. Machines already took over routine jobs, but in the new age machines will communicate between each other and will independent optimize their production flow (Spath D., 2013). For instance, in 2010 Google made the first driverless car test in California (Brynjolfsson E. and McAfee A., 2014). Hence the attitude and process of decisions will change by these trends. Contemporary literature and research regarding decision making, have to re-evaluate the current status. Today's view on behavioural driven decision (human view) is very popular, discussed from Daniel Kahneman and Amos Tversky, e.g. the "prospect theory" or the "endowment effect" - well collected in their book "Thinking, Fast and Slow" (Kahneman D., 2011).

Today's view on digitalization is eye opening, because it is not temporary fashion, it will change the entire economy. Kondratieff's waves shows the evidence, that in the last years the next step of Kondratieff's waves already started; about the year 2009/2010 (Wilenius M., 2014), in the beginning of the financial crisis. Hence a new era of business will start with the trend of the second machine age (Brynjolfsson E. and McAfee A., 2014). For a new era a new type of decision making is necessary and this paper will analyse the current status of decision making in organizations and will discuss the new way of making decisions in the new era of intelligent machines.

\section{Research results and discussion}

\section{Theoretical Foundation of Decision Making}

Decision theory is a wide area in science, with a long tradition. The first idea of decision theory reaches back over hundreds of years and is still relevant in the presence. Rational models were discussed from the neoclassical economists (e.g. Adam Smith or Max Weber) with a view on rational behaviour of agents which maximize their utility - the homo oeconomicus. A more scientific approach of Pascal and de Fermat shows a calculation of probabilities and Bernoulli laid the foundation of risk science by examining random events. Further developed by von Neumann/ Morgenstern economic behaviour in a strong rational and mathematical approach, decision making follows utility maximization. Today's view of decision theory as an interdisciplinary science (economics, psychology, sociology, philosophy, mathematics, computer science and statistics) with different approaches is generally accepted (Buchanan L. and O'Connell A., 2006). One of the most popular is still the theory of games and economic behaviour (von Neumann J. and Morgenstern O., 1944). The theory of von Neumann/Morgenstern explains a rational behaviour of market participants (either consumers or entrepreneurs). Consumers strive for a maximum utility or satisfaction and entrepreneurs strive for maximum profits. Meanwhile a wide area of mathematical approaches and models of rational theories were further developed 


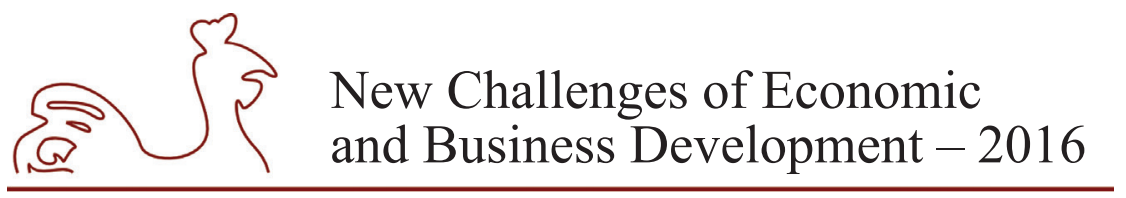

May 12-14, 2016, Riga, University of Latvia

on the foundation of von Neumann/Morgenstern theories. The opposite of the rational view, is a behavioural view on decisions. In the late 1940ies Simon discussed the theory of bounded reality, which means a certain influence of human attitudes with not pure rational decisions (Simon H.A., 1997). A deeper view in the psychology science shows that theories on behavioural economy are currently quite popular, because human behaviour is on part of organizational actions. In the 70ies Kahneman/Tversky developed the prospect theory. The idea of the prospect theory is a human approach in decision making. The theory of Kahneman/Tversky demonstrates that market participants don't act as rational as assumed, i.e. by von Neumann/Morgenstern. Depending on the used system of a human (system 1 or system 2) a choice is more emotional or more rational. The drivers of the emotional system have a different set up, hence loss aversion and optimistic bias or overconfidence are important to understand in a decision making process and will be explained in detail.

\section{a. Rational View}

In the classical field of the economical view on decision theory, a rational, mathematical founded approach is discussed. The process of pure calculating to find a maximum of utility or profit is a typical rational procedure. First of all an overview of the basic elements will enable a better view on the concept of a decision model. In figure 1 "Basic Elements of a Decision Model" the common structure of decision models is shown.

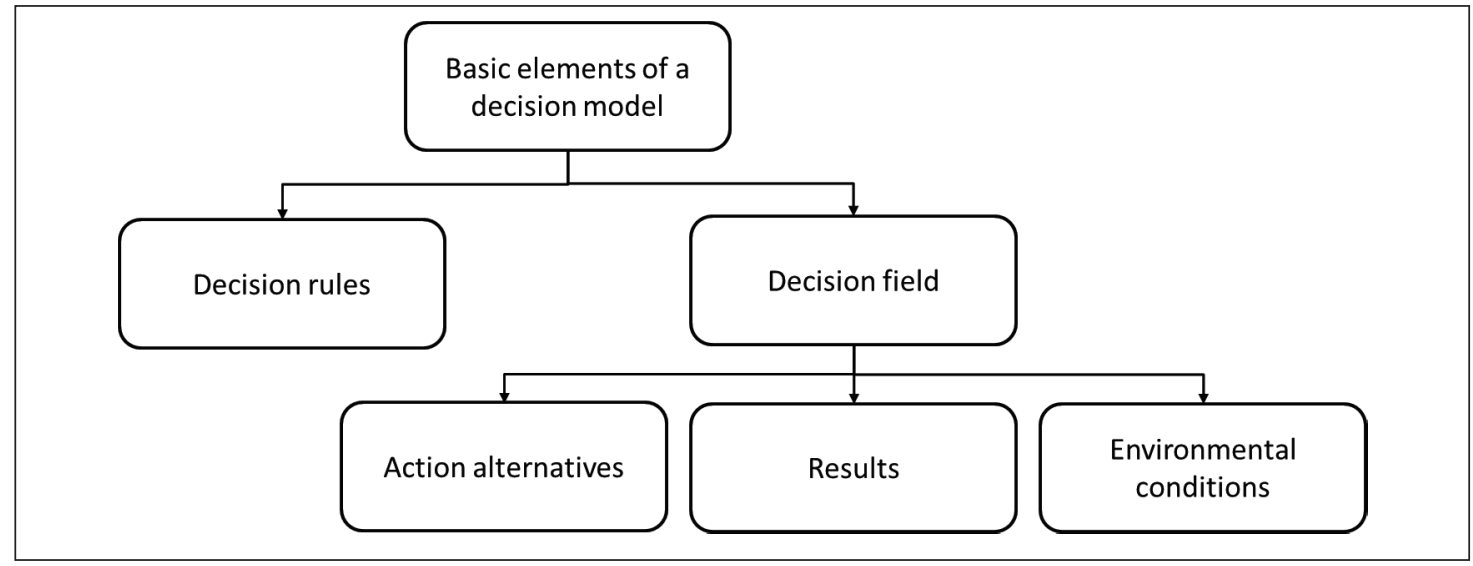

Source: Author's construction based on Bamberg G., 2012.

\section{Fig. 1. Basic Elements of a Decision Model}

In the dimensions of decision fields the alternatives are very important to analyse. There is only a decision problem, if there are minimum two alternatives. Hence a determination of these alternatives must be reflected in the decision model. In the next step an evaluation of these alternatives must be done. These consequences will lead to a result of the alternatives into the decision model. Important figures of the decision maker are defined as targets, these values are the result. (Laux H., 2014).

Key for a structured process the environmental conditions are very important. Measures are not manipulable by the decision maker, these measures are called decision relevant data. 


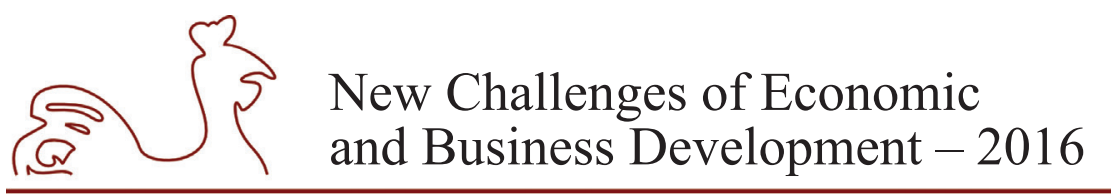

May 12-14, 2016, Riga, University of Latvia

These data are no variables of the decision maker. These characteristics are decision relevant environmental conditions. The illustration of figure 2 "Structures of Environmental Conditions" (Laux H., 2014) shows different environmental situations and a possibility of designing decision conditions.

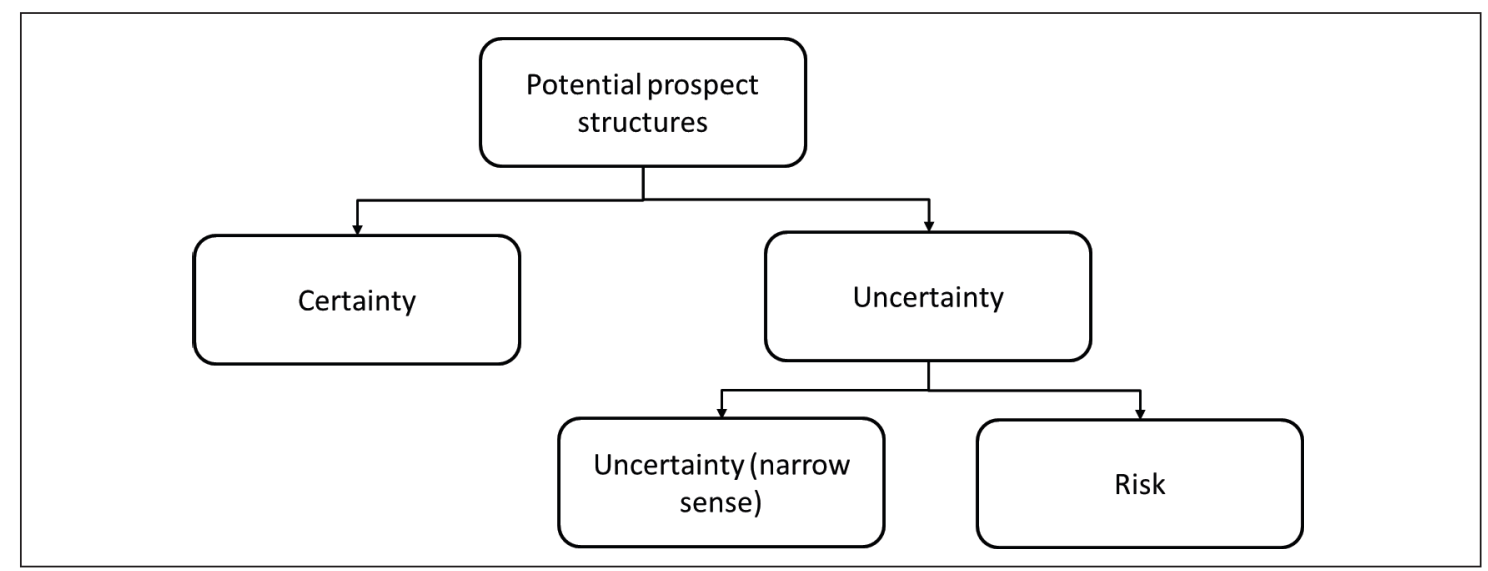

Source: Author's construction based on Bamberg G., 2012.

\section{Fig. 2. Structures of Environmental Conditions}

A decision structure under certainty means, that the decision maker has the real condition of the alternatives, hence all relevant information for the decision are given. Therefore the result is known and alternatives are certain. In reality quite often decision models are formed as models of decision under certainty, because the set up and the usage of this model type is easier to handle (Bamberg G., 2012).

A decision structure under uncertainty means, that the decision maker has minimum two possible alternatives, but not all relevant information for a decision are given. Therefore the result is not known and alternatives are uncertain. In the case of uncertainty there are two more possibilities. Either for the decision maker it's not possible to calculate a likelihood of conditions (uncertainty - narrow sense) or for the decision maker the probability of occurrence of a condition is computable (risk); (Laux H., 2014).

This differentiation of the environmental conditions is important to define; especially decision making in the context of globalization and digitalization. While globalisation creates a more complex world with an increase of uncertain decision structures, a more sophisticated model with an adopted process of decisions is a need for an organization. In terms of digitalization a need for an algorithmic structure is necessary, computers need a mathematical logic in their system to calculate a result for a decision process.

\section{b. Human View}

Important developments in decision theory took place over the recent decades, though a trend to a behavioural approach was supported by psychological science. An outstanding contribution to the development of behavioural economies was made by Kahneman and Tversky. A collection of their scientific contribution and analysis is made in the book "Thinking, Fast 


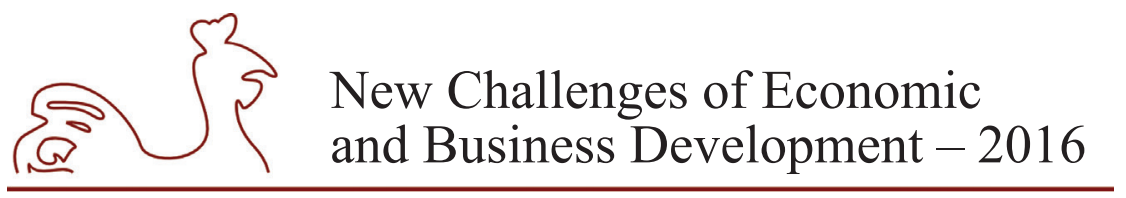

May 12-14, 2016, Riga, University of Latvia

and Slow" (Kahneman D., 2011). Describing decision theory with a strong psychological view makes decision more emotional than rational. Depending on the activated system in the mind; Kahneman named it system 1 and system 2.

- "System 1 operates automatically and quickly, with little or no effort and no sense of voluntary control" (Kahneman D., 2011)

Examples: answer of $2+2=$ ?; Drive on an empty road, orient the source of a sudden sound

- "System 2 allocates attention to the effortful mental activities that demand it, including complex computations. The operations of system 2 are often associated with the subjective experience of agency, choice, and concentration.” (Kahneman D., 2011)

Examples: tell someone your mobile number, fill out a form, look for a woman with white hair.

- The human structure is based on usage of system 1, only if really necessary, system 2 is activated.

This concept of system 1 and system 2 set the basis for a human behaviour of decision making, which absolutely defers from a rational decision view. Continuing this idea, the question what prevents a rational decision should be answered with Kahneman/Tversky's prospect theory. The fact that lot of decisions have both elements, a risk of loss and an opportunity of gain, effects a decision to gamble or to deny. Focussing on loss aversion (Kahnemann D. and Tversky A., 1974) means, people avoid losses while there is a huge opportunity to gain this particular option. As a result people deny this option and this is controversial to a rational choice, with a pure calculation of probability. On the other hand the "optimistic bias" means that chances for success are overestimated. Risks are undervalued or not in scope of the decision maker (Kahneman D., 2011).

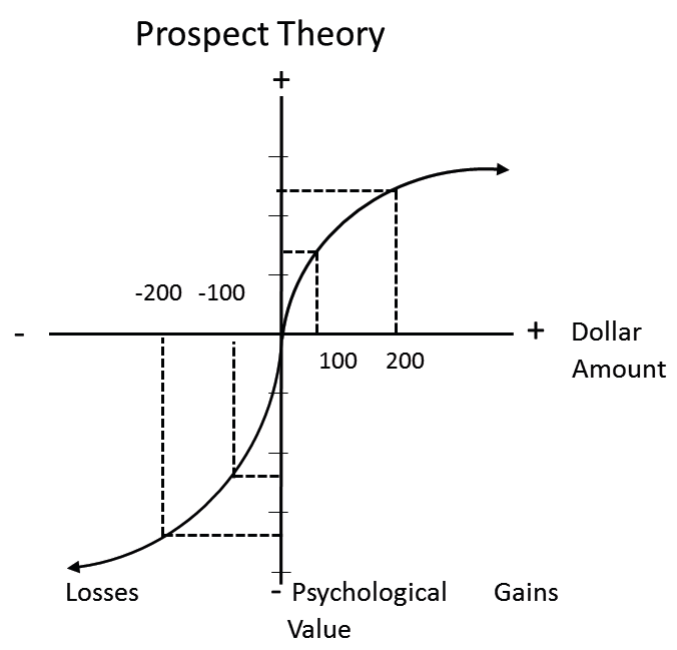

Source: Author's construction based on Kahneman D. and Tversky A., 1974.

Fig. 3. Prospect Theory 


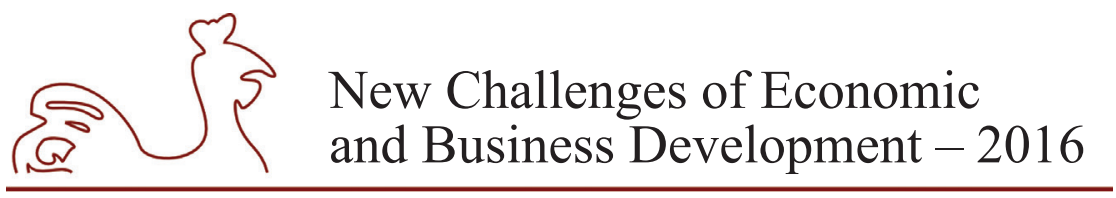

May 12-14, 2016, Riga, University of Latvia

Figure 3 explains the loss aversion theory and as opposite to a rational decision it's not a straight line. The chance of losses is moving the decision and also the chance of gains is moving the line, with a peak to losses.

The graph is showing the following effects:

- The psychological value of gains and losses as carriers of values (as opposite Bernoulli stated wealth as carrier of value);

- Reduced sensitivity for gains and losses;

- The slope of the function changes at the reference point;

- The response to losses is stronger than the response to corresponding gains (loss aversion);

- The two curves of the $\mathrm{S}$ are not symmetrical.

Prospect theory is only one topic raised in the context of behavioural decision making. Further effects were discussed from Kahneman/Tversky, e.g. adjustments, anchoring or frames, but will not discussed in this paper. Many ideas were based on these fundamental theories and contributed a lot to this scientific field.

\section{c. Rational Choice}

In the standard view, rational choice is defined to mean the process of determining what options are available and then choosing the most preferred one according to some consistent criterion. In a certain sense, this rational choice model is already an optimization-based approach. We will find that by adding one empirically unrestrictive assumption, the problem of rational choice can be represented as one of maximizing a real-valued utility function. Rational choice is based on individual decision making (Levin J. and Milgrom P., 2004). Rational choice is an idea, based on social and psychological perceptions, to reach maximum utility, based on human decisions. But as we have seen from Kahneman/Tversky, a rational decision made by a human is more a wish than reality.

\section{d. Decision Process in Organizations}

The decision making process in organizations is made by humans and hence reflect human behaviour in organizations. March/Simon grouped this in 3 classes (March J. \& Simon H. A., 1993):

1. Organization members are primarily passive instruments; performing their work and accepting direction, but not initiating actions.

2. Organization members bring their own attitudes, values and goals into the organization.

3. Organization members are decision makers and problem solvers.

This classification refers to a different type of decisions in organizations, hence a robust process must enable decision making and decision execution, over the varied layers in an organization.

Therefore it is important to understand the decision process in organizations. The theoretical process is rational designed (Laux H., 2014):

1. Problem definition: a decision maker realises, that a situation is not satisfactory.

2. Specification of the target system: Targets will be formulated for the defined goal. 


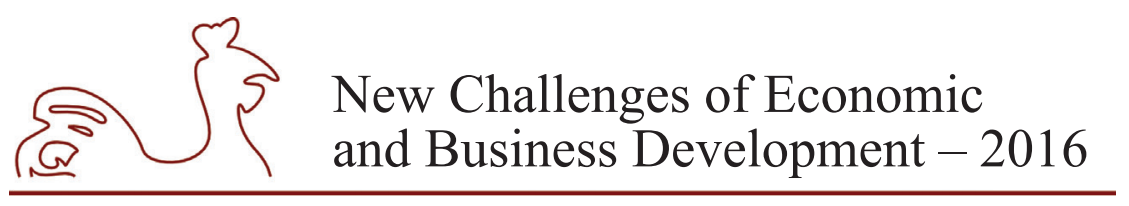

May 12-14, 2016, Riga, University of Latvia

3. Investigation of possible action alternatives: Search, analysis and prognosis for alternatives are designed, collected, calculated and analysed.

4. Choice of an alternative: Based on the target system, the best alternative should be chosen

5. Decision in the realization phase: still while realizing the alternative, decisions have to be made and followed up.

Following this process, the maximum utility for the decision will be made. But the main question is, if in an organization this strict process will be executed. As H. A. Simon explains, "all decision is a matter of compromise". In an organization with different interests of members, the question of a maximum utility for the decision problem is to be questioned. In an organization there is never a perfect achievement of targets reachable. The environment of the organization limits the alternatives and the maximum of utility (Simon H. A., 1997).

Further questions will be raised in today's business world with an increase of a democratic leadership style, that for decisions committees are installed. The set up of a committee is quite important and all restrictions have to be taken into consideration, e.g. information asymmetries in different areas (Bamberg G., 2012).

This opposite view to a rational decision process raises the question how the decision process in organizations is really made. Are organizations as rational as expected or are there emotional driven which have effects on decisions. The behavioural influence in organizations has to be respected and the result is based on this set up (March J. \& Simon H. A., 1993).

\section{Globalization and Digitalization}

\section{a. Globalization}

Globalization is the international integration arising from the interchange of world views, products, ideas and other aspects of culture (Albrow M. and King E., 1990). "Globalization is a process of interaction and integration among the people, companies, and governments of different nations, a process driven by international trade and investment and aided by information technology. This process has effects on the environment, on culture, on political systems, on economic development and prosperity, and on human physical well-being in societies around the world." (http://www.globalization101.org) The global phenomenon of business technology diffusion is worth to analyze in detail. For the paper this particular part of globalization is in scope - digitalization.

\section{b. Digitalization}

"Digitalization refers to the practice of taking processes, content or objects that used to be primarily (or entirely) physical or analogue and transforming them to be primarily (or entirely) digital. The effect of digitizing processes, aside from potential efficiency gains, is to make processes more tailorable and malleable" (Fichman R., 2014). Not only based on data, moreover targeted on markets, organizations and processes digitalization will deploy its full value to businesses and industries. The new era of digitalization has started already and shows today a first step of a new business world with a change in division of work. In the early $20^{\text {th }}$ century a "computer" was an employee calculating tables the whole day. In a first step, an automated computer (as we understand today) took over this task and increased quality and efficiency of 


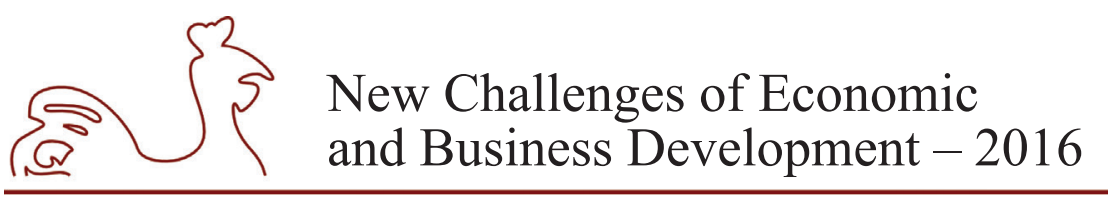

May 12-14, 2016, Riga, University of Latvia

this process. Since then, the automation of our world was ongoing and influenced by computers and machines. Important for the development was the definition of rules for computers, because computers are perfect in following algorithmic rules. (Brynjolfsson E. and McAfee A., 2014). Further actions took place to develop more feasibilities of machines, i.e. Apple iPhone is now with the software Siri able to understand and direct the user. This is a real quantum leap, because to automatize language and transfer this into instructions was a giant step change for the industry. Currently the speed of development is increasing, either the trend of "Industry 4.0" with full automation of the production flow (Zelinski P. 2016) or "artificial intelligence" that robots tend to make autonomous decisions and developed self-awareness and self-maintenance (Lee J. 2014). Robots and machines are striving into our working environment and will stronger replace human work. The balance of division on work changed already but will change dramatically in the future, though traditional professions will disappear, but new professions will appear. To close the loop of digitalization and globalization means, that a global business process only can be managed successful, if a proper digital support is in place, e.g. automated warehousing or supply chain management.

Referring to the effects of digitalization on decision making, this trend will completely change the way of making decisions. Flexibility and transformability are key attitudes of successful organizations in the future and drive them on the road of digitalization (Bauer W., 2015). Digitalization will have an effect on customer structure, increase the efficiency of operations and at the end change the entire business model. (Westerman G., 2014)

4 levers of transformation have to be in scope of the decision maker (BDI, 2015)

1. Digital data (big data): recording, processing and analysis of mass data will enable more predictable forecasts and decisions.

2. Automation: the combination of traditional work and artificial intelligence will enable autonomous work in self-organization systems with high quality and high efficiency.

3. Integration: connection of the entire value chain will enable synchronized supply chains with shorter production cycles and faster innovation (mobile or fiber opic net).

4. Digital customer access: new competitors, new services and new transparency will increase competition.

\section{Digitalization Implications on Decision Making}

Described above, the digitalization of businesses and organizations will change dramatically decisions with all related circumstances. The decision making process will be stepwise automated, hence machines will make choices. In the past, this scenario was unthinkable, because independent machine decisions are under big criticism. But today's world shows that machines make decisions for humans, e.g. in current cars, lots of electronic systems help to drive the car, like anti-lock braking systems or intelligent speed assistance systems. In the next step we will face an autonomous driving car, as mentioned in the introduction. Today we face earmarked and specialized machines, in the future we will face all-purpose robots (Brynjolfsson E. and McAfee A., 2012).

The author's view in this paper is a revitalized view on decision making. In Table 1 "Development over Time of Decision Making" the development of decisions is illustrated. In the past the decision process was typically an administrative task of managers and consequently human based, with all emotional influences. The development over time shows a trend towards 


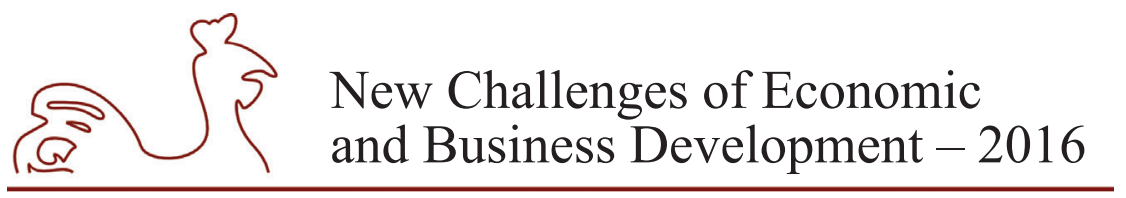

May 12-14, 2016, Riga, University of Latvia

a decision making automation, based on the capabilities of machines. In the future, more sophisticated machines and artificial intelligence will be the decision maker for businesses.

Table 1

Development over Time of Decision Making

\begin{tabular}{|c|c|c|c|}
\hline Decision conditions & Past & Today & Future \\
\hline Decision under certainty & human & automated & automated \\
\hline Decision under risk & human & automation started & automated \\
\hline Decision under uncertainty & human & human & partly automated \\
\hline
\end{tabular}

Source: author's construction.

Supported by digital data and creating the opportunity to get massive volumes of data (big data) recorded and processed in an robust process, the analysis and usage of these data will organizations enable to create a rational decision process to reach maximum utility (v. Neumann J. / Morgenstern O., 1944).

Automation of workforce by robots and artificial intelligence with autonomous processes in a self-organizing system will improve decisions on a rational level. In a real-time manner intelligent machines are able to make fast decisions with a precise result.

In the next level of integration on an inter-organizational view, data flow will ensure the real-time communication of systems with an efficiency gain for all participants (win-win situation). Decisions are made based on algorithmic logic and strive toward maximum utility.

New customer access, with a lot of relevant customer data, will enable organizations to create a customized offer per each customer, i.e. a tailor-made solution with services and new products.

\section{Conclusion}

After analyzing the theoretical background of decision making, the two opposite theories of rational view, as von Neumann/Morgenstern describe the game theory to reach maximum utility and to analyze the psychological view of decision making, explained by Kahneman/Tversky with a huge participation of system 1, with spontaneous respond to decisions, currently a new paradigm occurs. Moreover the rational choice theory will also not deliver the expected outcome, because human beings are still involved in the decision making process in an organization. The theoretical homo oeconomicus, which was over decades in the economic science an exemplary agent for utility maximization seems now becoming reality, but in form of automated decisions in the era of digitalization. Automation of processes with self-organizing systems have a clear algorithmic structure, this logical structure will be followed by the system. That means, homo oeconomicus will be first time reality, by recording, processing and analyzing all relevant data and draw autonomous decisions to reach maximum utility. This step changing process will increase efficiency and profitability of organizations. As a result, utility maximization seems first time reachable with a win-win situation, for customers and organizations. Based on these rules, no human error probability is will occur in organizations; at the end it is a "digital oeconomicus". 


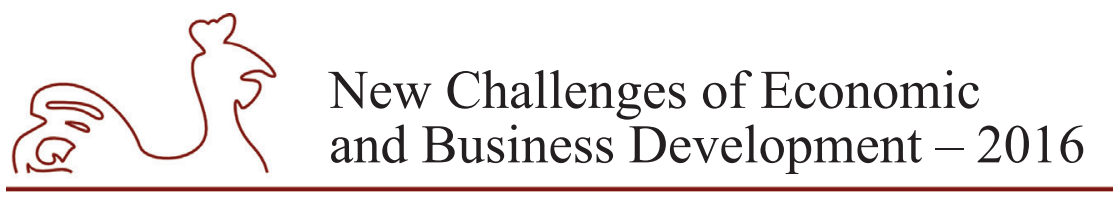

May 12-14, 2016, Riga, University of Latvia

\section{Bibliography}

Albrow M. \& King E., 1990. Globalization, Knowledge and Society. London: SAGE.

Bamberg G. \& Coenenberg A. \& Krapp M., 2012. Betriebswirtschaftliche Entscheidungslehre. München: Verlag Franz Vahlen.

Bauer W. \& Hämmerle M. \& Schlund S. \& Vocke C., 2015. Transforming to a hyper-connected society and economy - towards an "Industry 4.0". Science direct, Procedia Manufacturing 3 (2015), 417424, Elsevier.

BDI Research. 2015. Die digitale Transformation der Industrie; BDI - Bundesverband der deutschen Industrie.

Brynjolfsson E. \& McAfee A., 2014. The Second Machine Age. New York: W.W. Norton \& Company.

Buchanan L. \& O’Connell A., 01/2006. A Brief History of Decision Making. Harvard Business Review.

Fichman R. \& Dos Santos B. \& Zheng Z., 06/2014. Digital Innovation as a Fundamental and Powerful Concept in the Information Systems Curriculum. MIS Quarterly. Vol. 38, No. 2, pp. 329-353.

IMD and Cisco Initiative. 09/2015. Digital Business Transformation, Trends E-Magazine, pp 1-7.

Kahneman D., 2011. Thinking, Fast and Slow. UK: Penguin Random House.

Kahneman D. \& Tversky A., 1974. Judgment Under Uncertainty: Heuristics and Biases. Science, New Series, Vol. 184.

Laux H. \& Gillenkirch R. \& Schenk-Mathes H., 2014. Entscheidungstheorie. Berlin; Heidelberg: Springer Verlag.

Lee J. \& Kao H. \& Yang S., 2014. Service innovation and smart analytics for Industry 4.0 and big data Environment. Science direct, Procedia CIRP 16 (2014) 3-8: Elsevier.

Levin J. \& Milgrom P., 2004. Introduction to Choice Theory. [Online] Available at: http://web.stanford. edu/ jdlevin/Econ\%20202/Choice\%20Theory.pdf [Accessed 15.03.2016].

March J. \& Simon H. A., 1997. Organizations. Cambrigde and Oxford: Blackwell.

Neumann von, J. \& Morgenstern O., 1944. Theory of Games and Economic Behaviour. Princeton: University Press.

Simon H. A., 1997. Administrative Behaviour. New York: The Free Press.

Smith J. \& Winterfeldt D., 05/2004. Decision Analysis in Management Sciences. Management Science, Vol. 50, pp. 561-574.

Spath D., 2013. Produktionsarbeit der Zukunft - Industrie 4.0. Fraunhofer IAO; Stuttgart, Fraunhofer IRB-Verlag, The Levin Institute [Online] http://www.globalization101.org [Accessed 20.03.2016].

Westerman G. \& Bonnet D. \& McAfee A., 2014. Leading Digital. Boston: Harvard Business School Publishing.

Wilenius M., 2014. Leadership in the sixth wave-excursions into the new paradigm of the Kondratieff cycle 2010-2050. Eur J Futures Res. Springerlink.com.

Zelinski P., 02/2016. Where 4.0 Might Go. [Online] http://www.mmsonline.com/ [Accessed 10.04.2016]. 


\title{
CREATING A SCALABLE FLIPPED CLASSROOM ARRANGEMENT TO ENABLE PART TIME STUDIES TO FURTHER HUMAN DEVELOPMENT AND MANAGEMENT EDUCATION
}

\author{
Anne Jantos, Technische Universitat Dresden, Germany ${ }^{1}$ \\ Matthias Heinz, University of Applied Sciences Dresden, Germany \\ Eric Schoop, Technische Universitat Dresden, Germany \\ Ralph Sonntag, University of Applied Sciences Dresden, Germany
}

\begin{abstract}
Addressing the time-sensible schedule of part time students creates the need to provide flexible online preparation to ensure continuous learning progress. Introducing the Flipped Classroom method focusses the teacher's attention on knowledge acquisition in face-to-face sessions by providing online preparation beforehand. This approach promotes meaningful learning and media competencies by applying a sensible mix of multi-media tools that is able to offer any kind of content online, thereby leaving time for group work and discussions when learners and teachers actually meet.

Focusing on part-time students needs, a scheme of interchanging phases has been compiled in an explorative design by the means of literature review and design science. This approach is the centre of the description of how of how to flip a classroom successfully under ideal conditions; moreover, the approach will be put to use in real-life circumstances, which will provide further knowledge on details such as choice of tools, schedule construction and general organisation.

This project achieves two outcomes. Firstly, it allows for an independent, scalable framework, which can be adapted to different learners' and teachers' needs as well as different contents and numbers of students; not only in part-time situations but in distant learning and regular courses as well. Secondly, this project includes an evaluation which in the future will be interpreted and summarized in a guideline.
\end{abstract}

Key words: Flipped Classroom, Inverted Classroom, Blended Learning, E-Learning, Part Time Students JEL code: I21, I23, I25

\section{Introduction}

The key aspect of introducing the flipped classroom method to any course or content is to further meaningful learning as well as provide flexibility to both learner and teacher. But how should a course be structured to satisfy all participants' needs for transparency, coaching, organizational flexibility and success in learning - and especially for part-time students? This paper provides the reader with explicit techniques and methods to plan and implement a flipped classroom arrangement successfully. These methods are based on a literature review and an extensive knowledge base we derived over the past decade from numerous practical blended

1 Corresponding author-e-mail address: anne.jantos@tu-dresden.de 


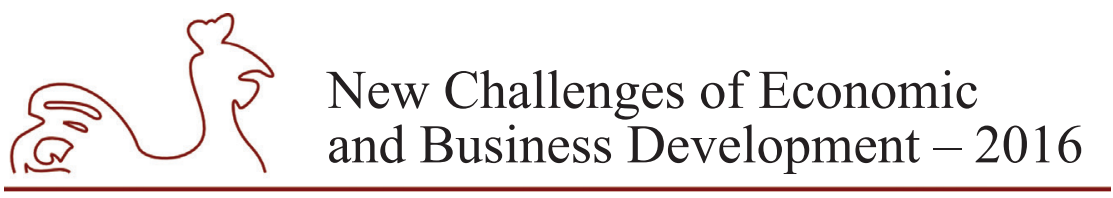

May 12-14, 2016, Riga, University of Latvia

Learning arrangements at our institutions; they also represent a theoretical approach which has been implemented and will be evaluated during this semester.

Applying our well-known arrangement to further the part time studies brings a yet unprecedented combination with new and unexpected potential and obstacles. This paper offers an overview of the general opportunities and limits given by the flipped classroom method, as well as show the application to a B2B-Marketing course.

\section{Designing the scalable Flipped Classroom Framework}

Most university courses aim to provide a high number of students with large quantities of information. Most teachers revert to handing out extensive materials in big lecture halls and give recitation (Butt, A., 2014, Cassidy, S., 2011). That leaves the student to deal with the main part of learning and understanding alone and out of reach of the teacher. The flipped classroom method enables the teacher to shift the data-driven part of the lecture outside of class to make room for meaningful learning in class and evolve from a one dimensional mediator to an actual partner in learning (Bull, G., 2012, Handke, J., 2012, Koh, C., 2016). In addition, the flipped classroom offers numerous opportunities to allow part time and distance learning because it leaves the student free to decide how, when, where and for how long they work on the material (Schäfer, A. M., 2012).

This paper shows the development of a scalable framework to introduce the flipped classroom to a university course using design science, literature review, and the reprocessing of the vast experience we gathered over the past decade on an actual practical example, addressing especially the potentials for part time students. Fig. 1 shows the three cycles of design science combined with our proceedings through the cycles (Hevner. A., 2007). It shows the current state of this project:

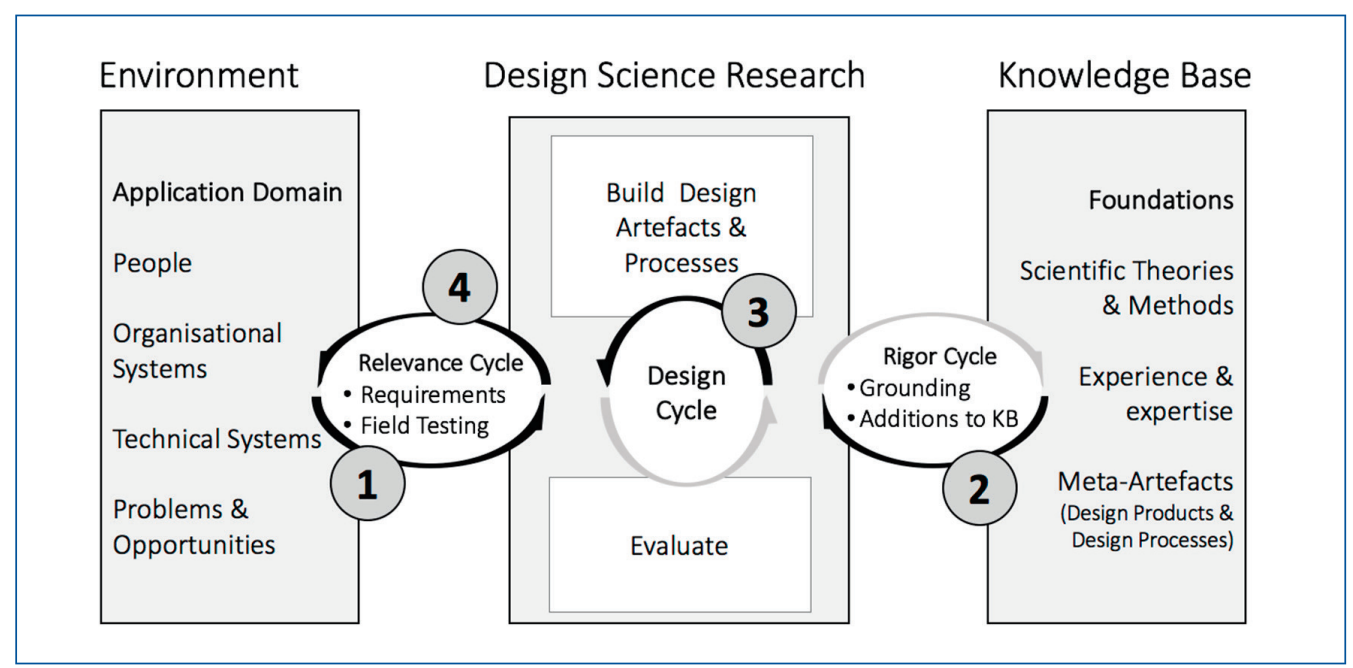

Construct by Hevner A., 2007.

Fig. 1. Proceedings through the design science cycles to create scalable Flipped Classroom Framework 


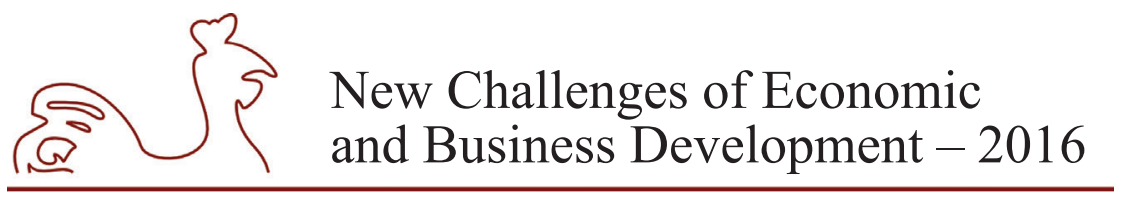

May 12-14, 2016, Riga, University of Latvia

\section{Research}

Firstly, we focused on the environment. We perceived a general change in teaching and learning over the past years and found that a regular course at university does not sustain the demand to improve and promote meaningful learning. Teacher-centred teaching has been reduced gradually in some courses, but still presents the most common teaching method at universities (Pfäffli, B. K., 2005). Secondly, we gathered information by reviewing previous experiences in E-Learning (Knowledge Base) over the past decade (Virtual Collaborative Learning (VCL), eTutor Qualification, Case studies in the Virtual Classroom etc.) and created an overview of how to approach part-time students, and identified various concepts to create a more flexible and meaningful learning environment (Lerche, J., 2015, Balázs, I. E., 2005). Furthermore, we analysed lessons learned and student feedback by interviewing students and teachers alike and identified profiles for students to be able to assess their needs, experiences and potential.

To improve teaching and meet the students' needs, we have decided on a flipped classroom arrangement which offers time-sensible teaching and promotes meaningful learning (Rigor Cycle). Based on the extensive knowledge base, we have been able to create a scalable flipped classroom framework that can be freely adjusted (Design Cycle). The flipped classroom method is a combination of various blended learning tools and traditional teaching. This approach in "flipping" a course separates the transmission of information and the acquisition of knowledge in several successive phases (Handke, J., 2013, Lage, M. J., 2000, Giannakos, M. N., 2016). Information transmission will mainly take place in a virtual manner. Content will be delivered before students and teachers meet to discuss the content of that particular part of the course (Schäfer, A. M., 2012). Students are required to acquire basic knowledge by consumption of said content before the according face-to-face session starts. Tools and methods like the following are suitable for online content delivery and have been used widely for a long: videos, texts of any kind, e-lectures, podcasts, forums and wikis. Knowledge consolidation takes place in face-toface sessions. Students come to the university sporadically to discuss and thereby intensify what they have learned. Teaching methods suitable to achieve meaningful learning are i.g.: group work, discussion, students' presentations, responsive classroom discussion (Lyman, F., 1981), video creation (Lave, J., 1991), storytelling (Frenzel, K., 2006), self assessment (Andrade, H., 2009), portfolios, journals, and concept maps.

\section{The Prototype}

Consequently, we describe the prototype design which, under ideal circumstances, creates a learner-centred environment providing steady input via an online platform, regular face-toface meeting opportunities to broaden and intensify the learning, and both online and personal feedback as well as peer review and self assessment. 


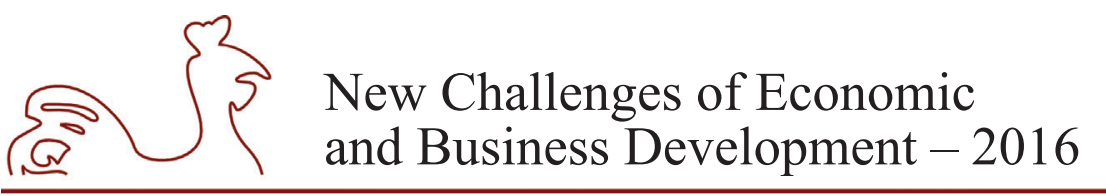

May 12-14, 2016, Riga, University of Latvia

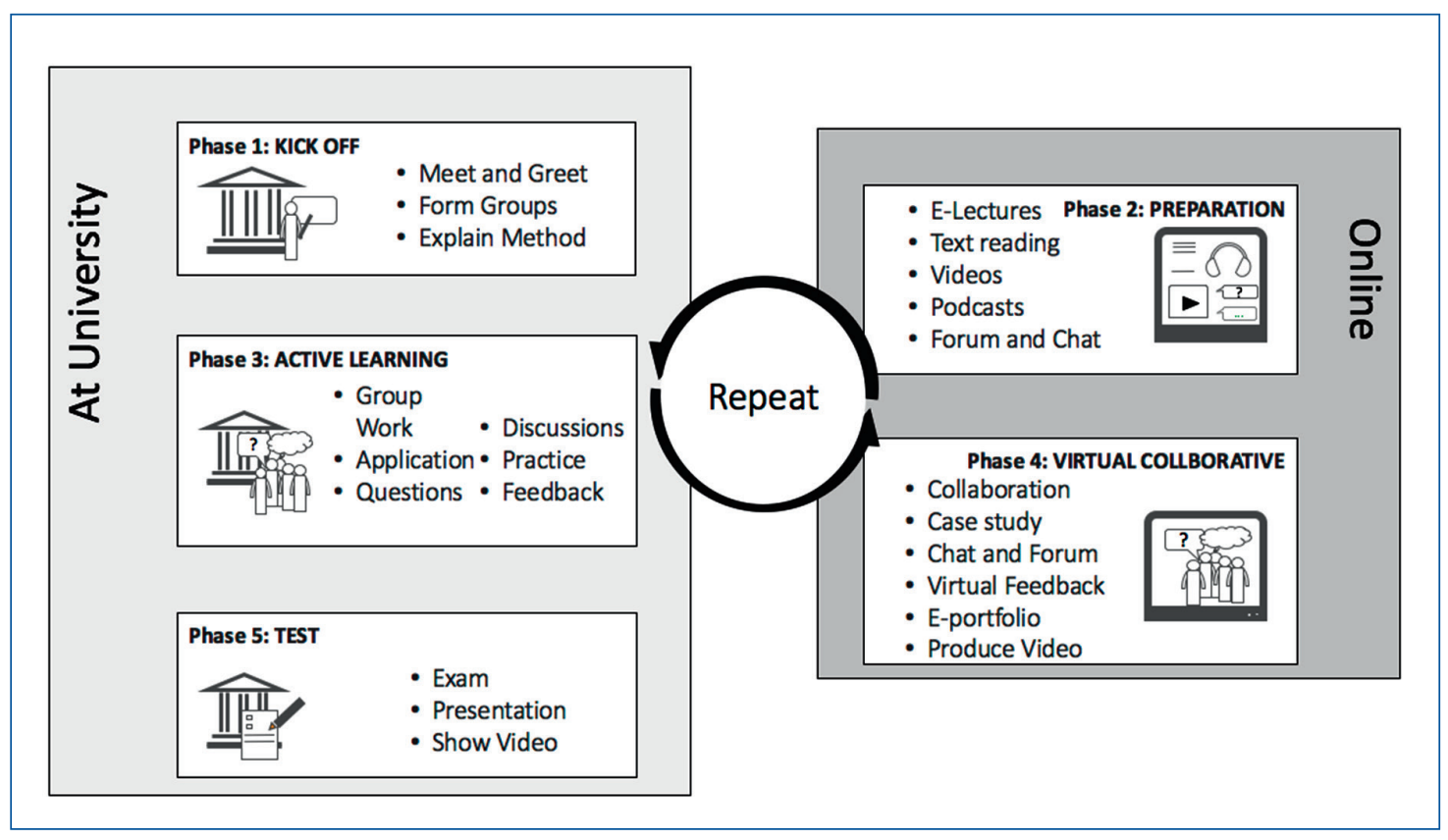

Design by the author.

Fig. 2. Design of the scalable Flipped Classroom Framework

To ensure stable learning success, the didactical design for the scalable framework for parttime students follows a more flexible and time-saving way with successive phases that ensure constant steady learning with comparatively long preparation phases and face-to-face session which are spread evenly over the learning period (Handke, J., 2012).

The kick off phase gives teachers and learners the opportunity to get acquainted with each other and with the flipped classroom method. Teachers give an overview of the upcoming phases and their challenges. They form groups and introduce the media that are going to be used. Preparation phase enables the learner to get acquainted with the topic by consuming contents specially prepared for the coming phases. Multimedia tools deliver content which can be discussed in groups or recessed in additional research. Previous sessions are evaluated separately or in groups by means of peer assessment and journals or e-portfolios (Andrade, H., 2009). The active learning phase offers educational space for varied learning activities. Learners are actively involved in knowledge consolidation by using concept practice, engage in discussions and debates as well as brainstorming. This way, they find and solve problems while constructing knowledge. Teachers function as tutors, coaches, guides or moderators to oversee and encourage the transmission of meaning. Face-to-face sessions last two to three hours. In VCL, learners check their understanding with reflexion tools and extend their learning. Teachers act as tutor managing online discussions and oversee and encourage collaborative group work and reflexion. Learners immerse themselves in case studies to prepare for the upcoming exam (Arbaugh, J. B., 2000). Phases 2, 3, and 4 are supposed to be repeated regularly until the course aims are met. The organisation of the cycle will depend on the scope of the course in general as well as on the number of students and the available time frame to finish the course. The course ends with either 


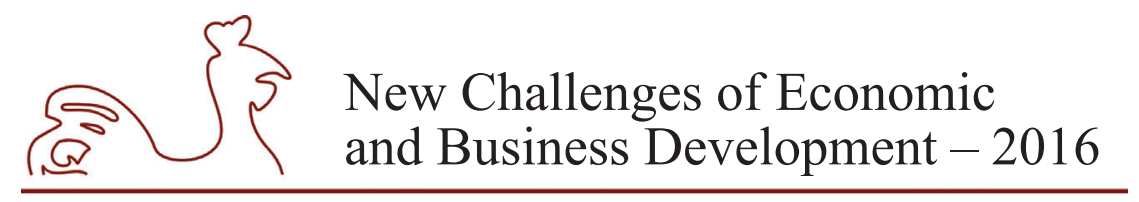

May 12-14, 2016, Riga, University of Latvia

the obligatory exam or with any other kind of learning artefact, such as a video presentation or a personal presentation, which is assessed by the teacher with consideration of online and face-to-face interaction and e-portfolio work. Students do not necessarily need to be present for this phase. Most universities, however, will need to hold an actual exam for regular credit acquisition.

\section{Application}

The University of Applied Sciences Dresden offers a part-time course in B2B-Marketing with 5 ECTS points awarded to every student who is enrolled in a business Master program. The course is addressed to master students in their first semester. It started on March $17^{\text {th }} 2016$. All participants were expected to have fundamental knowledge of multimedia usage and basic knowledge of Business and Management. They were also expected to be between 20 and 30 years of age and to have previous experiences with various teaching and learning methods. This course was chosen for the trial run of the research as it had not jet been planned and offered a suitable subject and a promising audience.

In an attempt to apply the framework to an actual course in the best possible way, research has been carried out with more specific focus on the target group. Jödicke, C., Schoop, E., Freudenreich, R., Lorenz, T., Claus, T., Schuster, E., and Kawalek, J. (2014) identified various factors that influence students learning in virtual classroom situations and outlined a rather non-independent picture of students in such a learning environment. She pointed out, that most students see coordination and communication in teams as the main challenge in online learning. They prefer detailed guidance as they work on their online assignments and frequently ask for help regarding content and organisation. Sporadically, they even demand active tutor involvement in tasks and regular meetings.

An interview with the professor who will be teaching the B2B-Marketing course in question showed that the potential target audience is even less self-efficacious. The professor pointed out the fact that students usually participate passively in lectures delivered in big lecture halls. It is not common to interact with the lecturer and group work is usually not a part of regular courses. The professor feared that the slightest obstacle would scare students off and reported that it is necessary to introduce the new approach of teaching slowly and gradually to ease the audience into the new learning and teaching style. He also viewed as wise to clearly point out what there is to be gained by this change. Students should be repeatedly motivated to make sure that they are fully aware of the opportunity and willing to take a risk or try something new.

Based on the information we had gathered from literature review, interviews, and our own previous experiences, a shortlist today's students' needs was possible to be compiled:

- Students demand higher flexibility in learning (Lübben, S., 2015);

- They are less willing to travel to lectures or study groups;

- They ask for learner-centred learning and teaching;

- They need transparent organisation of time and place (Minks, K.-H., 2011);

- They want to use multimedia and online learning as a crucial part (Bargel, T., 2014);

- They require frequent help and motivation (Jödicke, C. et al, 2014).

A great number of issues affects learning and learning organisation, but time proves to be the main issue (Maschwitz, A. and Brinkmann, K., 2015). These needs mostly amplify when 


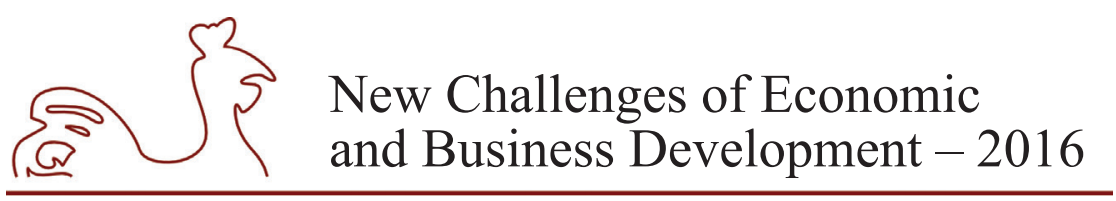

May 12-14, 2016, Riga, University of Latvia

working with part time students. Students frequently face the following issues when they study part-time (Fischer, M., 2012):

- They have a fulltime job but still want to study for personal or professional reasons;

- They rely on income from the daytime job or have other financial reasons not to quit;

- They take care of family members such as elderly or children;

- They cope with illnesses or disabilities which might make traveling and attending class harder;

- They have to commute to attend classes.

After the start of the B2B-Marketing course, within the kick-off session, we handed out a questionnaire which identified several factors about the actual audience. We asked about the students' online behaviour and preferences in online tools as well as their employment and degrees. The class counted 30 students. They all show very high affinity to social media (Facebook) and online video (Youtube) consumption (90\%). The following online tools turned out to be merely used (neither passively nor actively) by our focus group (20-30\%): blogs, file-sharing, photosharing and Wikipedia. About $50 \%$ of the audience are employed and consequently study parttime. All of the participants have a bachelor's degree in business. According to this evaluation, we can assume that our audience's needs coincide with the needs and profiles we described above.

After having designed the scalable framework which can be used to fit any content, purpose, time frame or attendance numbers the flipped classroom method was applied to an actual course. We worked out a detailed flipped classroom arrangement to fit all course contents into either online phases or face-2-face sessions by dividing the didactical outline into transmission of information and acquisition of knowledge always considering the taxonomy levels of learning (Bloom, B. S., 1956). By this means, we were able to reposition various parts of the course to the preparation phase. Students will now be able to read texts and watch videos by themselves in there own pace and at their own convenience as long as they're finished by the time the face-to-face-session starts. That fits the need of the part time students perfectly and offered the opportunity to improve multimedia competencies as well.

The following table shows the detailed plan for this semester's course in B2B-Marketing. It consists of eight face-to-face sessions which include the kick off session in the beginning and the final session in the very end. The course load was designed to fit 150 working hours. Visible also are the seven sequenced online preparation phases which are placed right between the faceto-face sessions. 


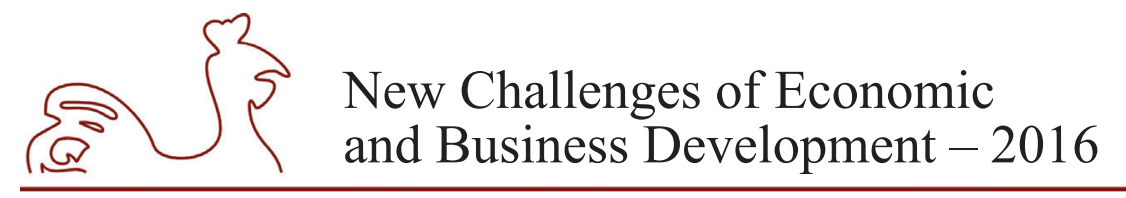

May 12-14, 2016, Riga, University of Latvia

Table 1

Organisation of the course B2B-Marketing

\begin{tabular}{|c|c|c|c|}
\hline Phase & Content & Methods & Duration \\
\hline Kick Off & $\begin{array}{l}\text { Introduction to } \\
\text { B2B-Marketing }\end{array}$ & $\begin{array}{l}\text { meet and greet, short lecture by the } \\
\text { professor to introduce the flipped classroom } \\
\text { method }\end{array}$ & 90 Minutes \\
\hline 1.Online Preparation & \multirow{2}{*}{$\begin{array}{l}\text { Organization } \\
\text { and Processes in } \\
\text { B2B-Marketing }\end{array}$} & $\begin{array}{l}\text { videos, email, literature, submit at least } 2 \\
\text { questions via email }\end{array}$ & 7 Days \\
\hline 1. Face-2-Face Session & & $\begin{array}{l}\text { form groups, group work, feedback, } \\
\text { discussion, professor moderates discussions }\end{array}$ & 120 Minutes \\
\hline 2. Online Preparation & \multirow{2}{*}{$\begin{array}{l}\text { Buying } \\
\text { behaviour, } \\
\text { customer benefit }\end{array}$} & $\begin{array}{l}\text { videos, literature, interactive social media } \\
\text { learning platform, submit at least } 2 \text { questions } \\
\text { via email }\end{array}$ & 14 Days \\
\hline 2. Face-2-Face Session & & $\begin{array}{l}\text { short student presentation, discussion, } \\
\text { lecture, feedback }\end{array}$ & 120 Minutes \\
\hline 3. Online Preparation & \multirow[t]{2}{*}{$\begin{array}{l}\text { Different kind of } \\
\text { Businesses }\end{array}$} & $\begin{array}{l}\text { videos, interactive social media learning } \\
\text { platform, literature, small online group } \\
\text { work, concept map, ePortfolio, submit at } \\
\text { least } 2 \text { questions via email } \\
\end{array}$ & 14 Days \\
\hline 3. Face-2-Face Session & & $\begin{array}{l}\text { short student presentation, discussion, } \\
\text { lecture, feedback }\end{array}$ & 120 Minutes \\
\hline 4. Online Preparation & \multirow[t]{2}{*}{ Marketing Mix } & $\begin{array}{l}\text { videos, interactive social media learning } \\
\text { platform, literature, online group work. } \\
\text { concept map, ePortfolio }\end{array}$ & 14 Days \\
\hline 4. Face-2-Face Session & & $\begin{array}{l}\text { short student presentation, discussion, } \\
\text { lecture, feedback }\end{array}$ & 120 Minutes \\
\hline 5. Online Preparation & \multirow{2}{*}{ Trade Marketing } & $\begin{array}{l}\text { videos, interactive social media learning } \\
\text { platform, VCL, ePortfolio, peer review }\end{array}$ & 14 Days \\
\hline 5. Face-2-Face Session & & $\begin{array}{l}\text { short student presentation, discussion, } \\
\text { lecture, feedback }\end{array}$ & 120 Minutes \\
\hline 6. Online Preparation & \multirow{2}{*}{$\begin{array}{l}\text { Quality } \\
\text { Management }\end{array}$} & $\begin{array}{l}\text { create videos, interactive learning platform, } \\
\text { literature, VCL, ePortfolio, peer review }\end{array}$ & 14 Days \\
\hline 6. Face-2-Face Session & & $\begin{array}{l}\text { short student presentation, discussion, } \\
\text { lecture, feedback }\end{array}$ & 120 Minutes \\
\hline 7. Online Preparation & \multirow{2}{*}{$\begin{array}{l}\text { Customer } \\
\text { Relationship } \\
\text { Management }\end{array}$} & $\begin{array}{l}\text { videos, interactive social media learning } \\
\text { platform, literature, VCL, ePortfolio, peer } \\
\text { review }\end{array}$ & 14 Days \\
\hline Final Session & & feedback, summary, peer review & 180 Minutes \\
\hline
\end{tabular}

Designing a schedule which is repetitive and follows simple rules provides a structure and transparency to the course which is demanded (see above) and appreciated by most students. The following simple graphic shows how each step brings the students closer to the end of the course which is thereby highly motivating. The simplicity counteracts with the high complexity of the content itself and helps the student to navigate through the course. 


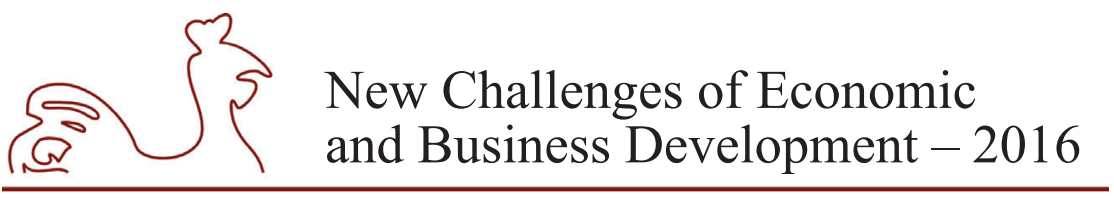

May 12-14, 2016, Riga, University of Latvia

Content delivery in preparation phases takes place by the means of reading literature and watching video. We have excluded any other media to ensure that students are not overwhelmed. In the very first online phase we provided content using a simple e-mail. Starting April $8^{\text {th }}$ we introduced a social media platform (elgg) to the course which offers all necessary tools to cooperate. Students will be asked to submit at least one question for each artefact they have consumed to be handed in before the face-2-face session starts. This creates a bridge between preparation and application and offers the teacher to address these questions and watch the students' progress. Students must be prepared to really participate in the active learning so we will not provide any content delivery while meeting face-2-face.

For the knowledge consolidation phases in the face-2-face session we have prepared several techniques for group work and active learning in big crowds, such as: case studies, pro and contra debates, poster creation and jeopardy question rounds. Face-2-face sessions will be video-taped and provided online for those who could not attend the session. Thus, we hope to create content and have the opportunity to watch ourselves and improve our techniques.

These face-2-face techniques are going to be intensified with the progression of the course. Soft and less intimidating forms will suffice for the first two sessions but more complex and demanding tasks will be part of the active learning as the course progresses to increase meaningful and self-efficacious learning. This progression will be mirrored in the online preparation work as there will be more reflexion of the learning progress as well as peer review and self assessment

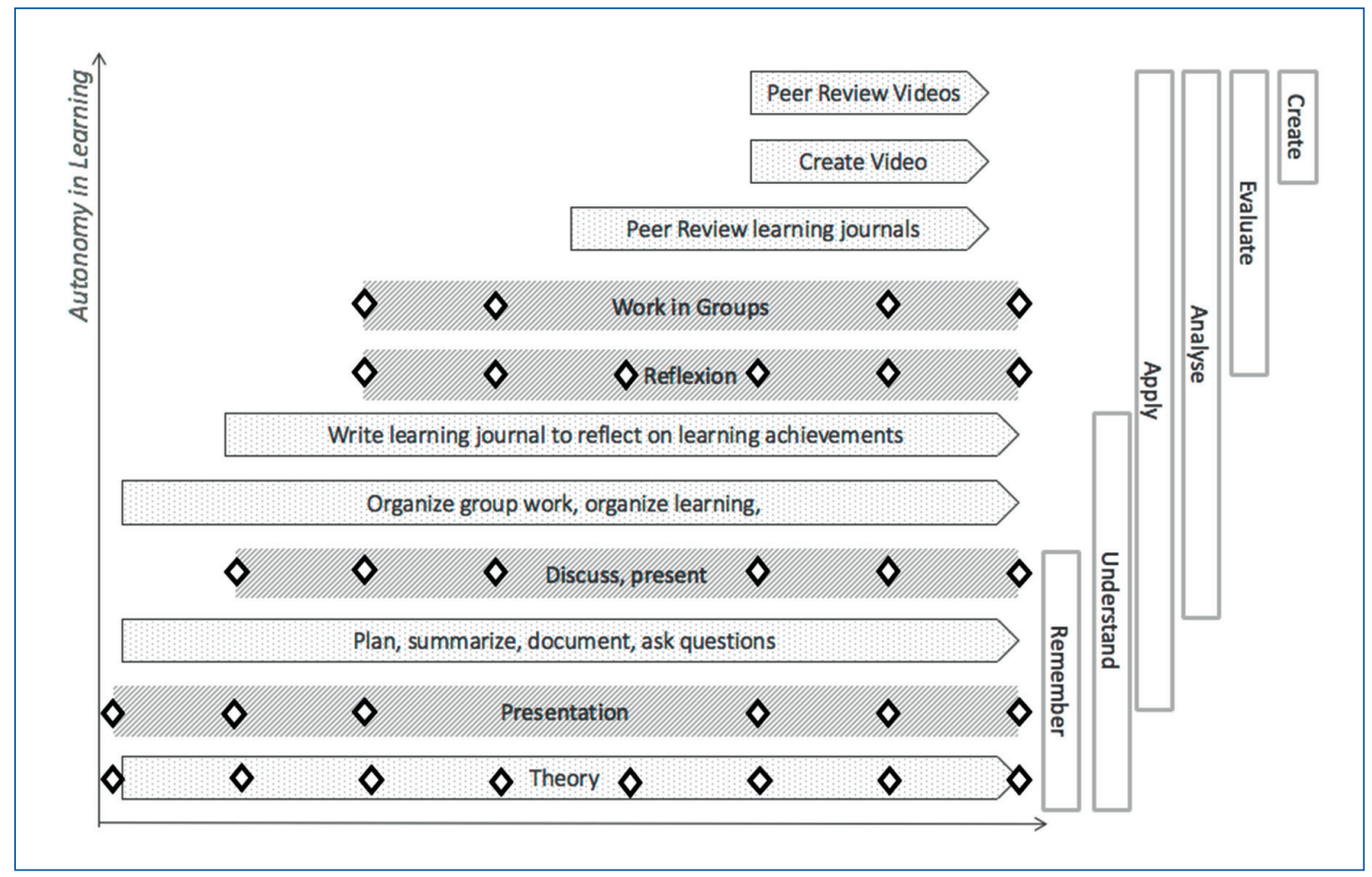

Construct by the author.

Fig. 3. Learners' Autonomy in different Stages of the Course 


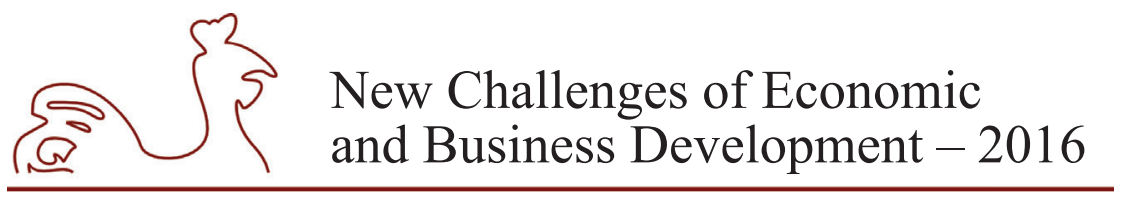

May 12-14, 2016, Riga, University of Latvia

of all artefacts. To intensify group work even further, we offer virtual collaborative learning (VCL, Balázs, I. E., 2005) which will focus on the creation of a case study by student teams and will be monitored and supervised by an eTutor who is fully trained in pedagogics and marketing. He or she will chaperone the students throughout the course and offer help and feedback.

The final task in this course will be the creation of a video in group work. This video will serve other teams as content delivery and will be subject for grading the teams - together with any other artefact they have submitted and a detailed evaluation by the teacher. Each group submits the video they produced and other teams are required to review and feedback those videos. The following figure shows the students autonomy in learning while the course progresses. The increase of autonomy dependent on the teaching method a well as the taxonomy levels are shown in relation to time.

We aim to increase the autonomy in learning and thereby improve meaningful learning with this explicit approach. We have gradually raised the autonomy in learning by changing the tasks accordingly with the progress of this course. The figure shows that with passing time we have arranged learning opportunity with increasing complexity and virtuality to address all taxonomy levels (Bloom, 1956).

\section{Evaluation}

We shall evaluate the results of this particular course and hope to reiterate the design cycle. By this we hope to achieve better results for future application of the flipped classroom framework to other courses. As pictured in Fig. 4, we shall use the results for redesign and adjustments of the methods and tools we suggested above.

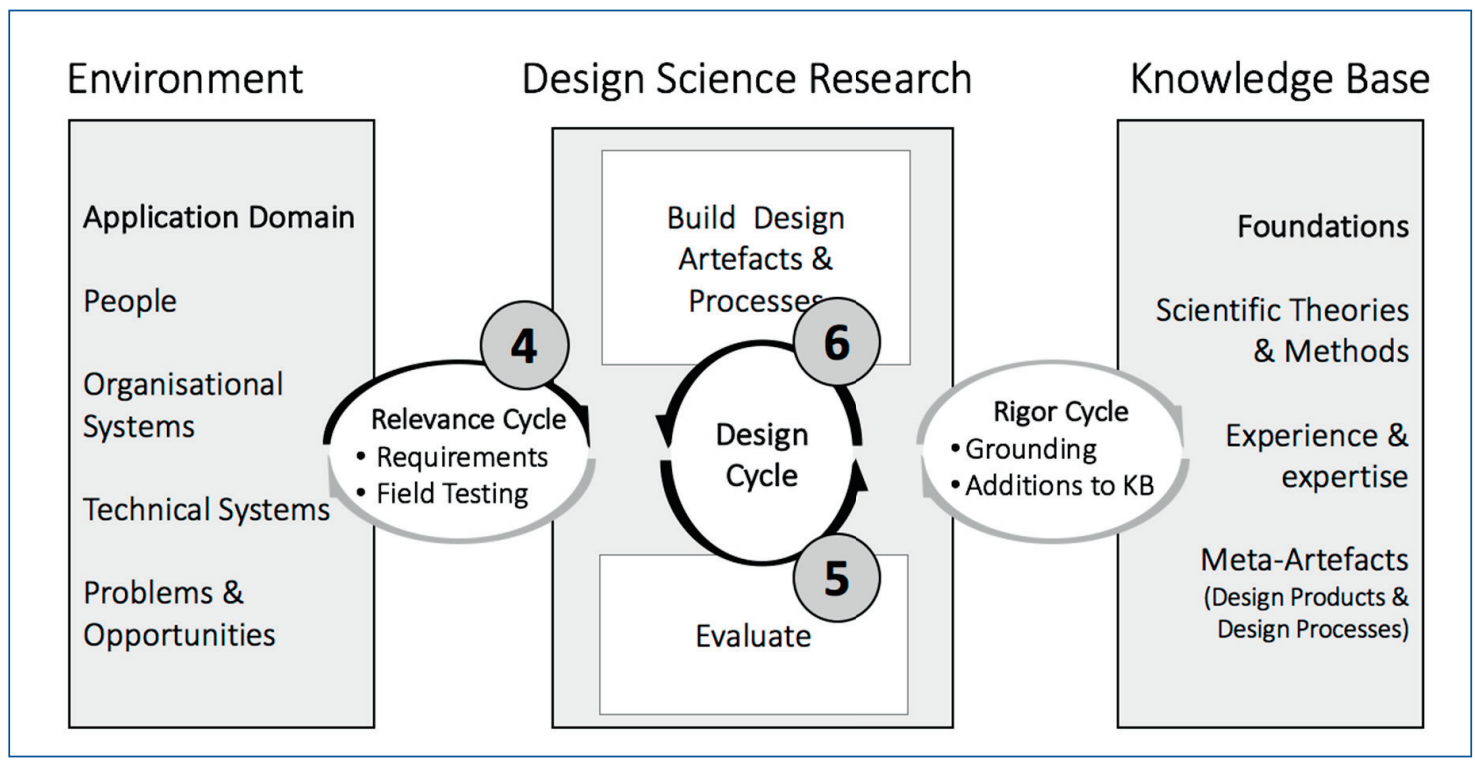

Construct by Hevner, A., 2007.

Fig. 4. Future Proceedings through the science cycles to create a scalable Flipped Classroom Framework 


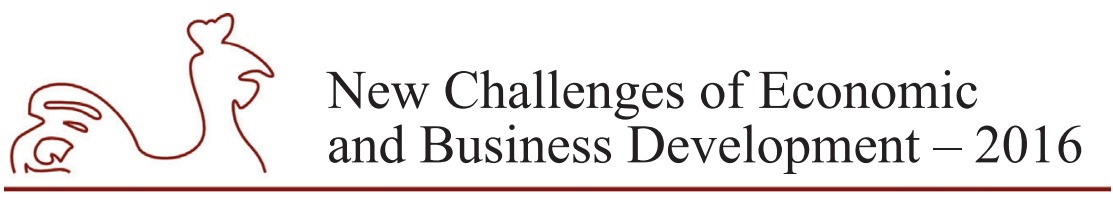

May 12-14, 2016, Riga, University of Latvia

\section{Problems}

While applying the framework to the B2B-Marketing course we faced a great number of problems which arose both on teacher's and students' side, both regarding to the content of the course as well as its organisation and technology. Firstly, there were legal issues to be dealt with. Some universities obligate their students to attend all sessions to get the credit and thereby don't allow working from home. We did not face that particular problem in this case, but still were forced to ensure that this approach was in fact legally acceptable.

Secondly, professors might not wish to merely be moderator or coach in learning - they are used to their position in front of the class and are not necessarily comfortable with this approach. They might also fear loss of image because the visibility of the course decreases. Furthermore, they have to cope with the additional workload to apply the flipped classroom and face new challenges in didactics and organisation.

Thirdly, we assume quite a lot of commitment from the students, which can not be depended on universally. Students might not want to change their learning habits or fear the additional work triggered by this new approach. They might prefer the regular teaching methods and be reluctant to put dedication into this new approach.

Fourthly, even though most people use new media, we can not take it for granted, yet, that every student has proper access to all sorts of media. There are no requirements for students to own technological devices or have the know-how on online collaborative work.

\section{Conclusions and further proceedings}

We have found that applying a new framework to an actual course creates a number of difficulties; and are therefore interested in the outcomes of this trial run and are positive that a flipped classroom actually provides many advantages to new learning methods and the ever changing needs of today's students. But of course, this demands not only learning processes on students' but also on teachers' and course designers' side.

After our current prototype is evaluated, we intend to apply our scalable framework gradually to other courses and to spread the method of flipping a course further. In future, we also see a high relevance for the business world. A transfer of the suggested framework to learning-on-the-job situations seems promising. On the conference, we plan to present first results of our practical project in forms of lessons learned and discuss the potential of our approach for transfer into further educational and business qualification scenarios.

\section{Bibliography}

Andrade, H., Valtcheva, A., 2009. Promoting Learning and Achievement Through Self-Assessment. Theory Into Practice (48), pp. 12-19.

Arbaugh, J. B., 2000. Virtual Classroom versus Physical Classroom: An Exploratory Study of class Discussion Patterns and Student Learning in an Asynchronous Internet-Based MBA Course. Journal of Management Education, pp. 213-233.

Balázs, I. E., 2005. Konzeption von Virtual Collaborative Learning Projekten: Ein Vorgehen zur systematischen Entscheidungsfindung. PhD Thesis, Technische Universitaet Dresden.

Bloom, B. S. (Ed.). Engelhart, M. D., Furst, E. J., Hill, W. H., Krathwohl, D. R., 1956. Taxonomy of Educational Objectives, Handbook I: The Cognitive Domain. New York: David McKay Co Inc. 


\section{New Challenges of Economic and Business Development - 2016}

May 12-14, 2016, Riga, University of Latvia

Bull, G. Ferster, B., \& Kjellstrom, W., 2012. Inventing the Flipped Classroom. Learning and Leading with Technology, 40 (1), pp. 10-11.

Butt, A., 2014. Students views on the use of a Flipped Classroom Approach. Evidence from Australia. Business Education\&Accreditation, 6 (1), pp. 33-43.

Cassidy, S., 2011, Self-regulated learning in higher education: identifying key component processes. Studies in Higher Education, 36(6), 989-1000.

Fischer, M., Spannagel, C., 2012. Lernen mit Vorlesungsvideos in der umgedrehten Mathematikvorlesung. In: Desel, J./Haake, J. M./Spannagel, C. (Hrsg.): DeLFI 2012 - Die 10. E-Learning Fachtagung Informatik der Gesellschaft für Informatik e.V. Bonn: Köllen, pp. 225-236.

Frenzel, K., Müller, M., Sottong, H., 2006. Storytelling. Das Praxisbuch. München. Hanser.

Giannakos, M. N., Krogstie, J., Aalberg, T. 2016. Torward a Learning Ecosystem to Support Flipped Classroom: A Conceptual Framework and Early Results. In: Li, Y./Chang, M./Kravcik, M./Popescu, E./Huang, R./Chen, K. N.-S. (Eds.): State-of-the-Art and Future Directions of Smart Learning. Singapore: Springer. pp. 105-114.

Handke, J., 2013. Beyond a simple ICM. In: Handke, J., Kiesler, N., \& Wiemeyer, L., (Hgg.). The Inverted Classroom Model. The $2^{\text {nd }}$ German ICM-Conference - Proceedings. München: Oldenbourg, pp. $15-21$.

Handke, J., Sperl, A., 2012. Das Inverted Classroom Modell. Begleitband zur ersten deutschen ICMKonferenz. De Gruyter Oldenbourg.

Hevner, A., 2007. “A Three Cycle View of Design Science Research," Scandinavian Journal of Information Systems (19:2), pp. 87-92.

Jödicke, C., Schoop, E., Freudenreich, R., Lorenz, T., Claus, T., Schuster, E., Kawalek, J.: E-Tutoren als Erfolgskriterium für komplexe e-learning-Szenarien. In: 12. Workshop on e-Learning-Tagungsband. 25. September 2014, Hochschule Zittau/Görlitz (2014), S. 105-113

Koh, C., 2016. Translating Motivational Theory into Application of Information Technology in the Classroom (pp. 245-258). In: Chia, L. W./Keng, J. W. C./Ryan, R. M. (Eds.): Building Autonomous Learners. Perspectives from Research and Practice using Self-Determination Theory. Singapore: Springer.

Lage, M. J., Platt, G. J., Treglia, M., 2000. Inverting the classroom: A Gateway to Creating an inclusive learning Environment. The Journal of Economic Education, 31(1), pp. 30-43.

Lerche, J., 2015. Flipped Classroom in der Hochschulehre der TU Dresden - ein Work in ProgressBericht. In: Köhler, T., Kahnwald, N., Schoop, E. (Hrsg.): Wissensgemeinschaften in Wirtschaft und Wissenschaft. Dresden, pp. 39-44.

Lave, J., Wenger, E., 1991. Situatetd Learning: Legitimate Peripheral Participation. Cambridge: Cambridge University Press.

Lübben, S., Müskens, W., Zawacki-Richter, O., 2015. Nicht-traditionelle Studierende an deutschen Hochschulen. Implikationen unterschiedlicher Definitions- und Einteilungsansätze. In: Hanft, A./ Zawacki-Richter, O./Gierke, W. B. (Hrsg.): Herausforderung Heterogenität beim Übergang in die Hochschule. Münster/New York: Waxmann, pp. 29-51.

Lyman, F., 1981. The Responsive Classroom Discussion: The Inclusion of Students. In Anderson A.S. (Hrsg.). Mainstream Digest. University of Maryland, College Park, MD., pp. 109-113.

Maschwitz, A., Brinkmann, K. (2015): Das Teilzeitstudium - ein zeitgemäßes Studienmodell? In: Beiträge zur Hochschulforschung, 1/2015, pp. 52-69.

Minks, K.-H., Netz, N., Völk, D., 2011: Berufsbegleitende und duale Studienangebote in Deutschland: Status quo und Perspektiven. In: HIS: Forum Hochschule, 11. Hannover: HIS.

Pfäffli, B. K. (2005). Lehren an Hochschulen - Eine Hochschuldidaktik für den Aufbau von Wissen und Kompetenzen. Bern: Haupt Verlag.

Schäfer, A. M., 2012, Das Inverted Classroom Model. In J. Handke \& A. Sperl (Hrsg.), Das Inverted Classroom Model. Begleitband zur ersten deutschen ICM-Konferenz. Oldenbourg Wissenschaftsverlag GmbH. 
May 12-14, 2016, Riga, University of Latvia

\title{
LATVIAN LABOUR MARKET DEVELOPMENT CHALLENGES AND PROBLEMS
}

\author{
Sandra Jekabsone, University of Latvia ${ }^{1}$ \\ Karlis Purmalis, University of Latvia
}

\begin{abstract}
The article's scientific problem is to assess the main problems and development challenges of Latvian labour market. Significant problems in Latvian labour market are structural unemployment as well regional disparities in unemployment figures, which can be solved complex, attracting both national and EU structural funds and business funds for the development of depressive regions. Still actual is labour emigration and increase of labour cost because of economic growth and open labour market. The aim of research is to investigate Latvian labour market development tendencies during post crisis period (20102014) and to identify most significant problems that limit more rapid employment increase, as well to evaluate expected structural changes in Latvian labour market and national economy till 2020. By the assessment of data there have been used methods of analysis and synthesis, reference and dynamical line. The main research sources include the information available in the databases of the CSB and Eurostat, as well as the studies and publications by the Ministries of Economics and National Employment Agency of the Republic of Latvia. Results of the analysis highlighted the potential economic policies to improve the situation in Latvian labour market. In order to promote increase of competitiveness of Latvian economy and labour market development, there is a need for further structural reforms that will facilitate the transition from low to medium and high-tech industries, as well productivity growth, improving innovation capacity, export promotion, access to finance, development of industrial zones and efficient use of resources.
\end{abstract}

Key words: economic activity, the labour market, the unemployment rate

JEL code: E24, J21, J24

\section{Introduction}

Since 2011 the growth of GDP in Latvia was positive and one of the fastest in EU, average GDP growth from 2011 to 2014 was 4.4\% per year (Ministry of Economics, 2015). However the economy of Latvia is still in the recovery phase after the economic crisis, as the pre-crisis level of GDP has not been reached yet. Faster growth was limited by weak increase in the EU and weakening of economic situation in Russia that hinder investments and the increase of the export. Under such conditions, the most important role in promoting the economic growth of Latvia is attributed to the ability to improve competitiveness, implementing structural reforms that will facilitate the transition from low to medium and high-tech industries, as well productivity growth. After the recent economic crisis situation in labour market continues to improve. In the 1 st half of 2015 the number of employed was by $0.6 \%$ larger than a year ago, but unemployment level reduced to $9.8 \%$ (Ministry of Economics, 2015). However, the improvements are slowing

1 Corresponding author - e-mail address sandra.jekabsone@lu.lv 


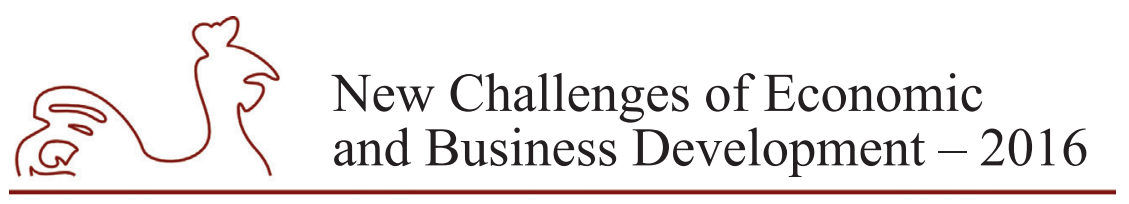

May 12-14, 2016, Riga, University of Latvia

down due to a gradual decrease in the base effect in the labour market, as well as the drop in the pace of growth related to external tendencies. Still significant problems in Latvian labour market are structural unemployment, regional disparities in unemployment figures, as well labour emigration and increase of labour cost because of economic growth and open labour market. The aim of research is to investigate Latvian labour market development tendencies during post crisis period (2010-2014) and to identify most significant problems that limit more rapid employment increase, as well to evaluate expected structural changes in Latvian labour market and national economy till 2020. Tasks of the research are to overview Latvian labour market and the developments in the post-crisis period, discovering risk factors that should be addressed in order to promote a balanced development of the labour market in the future. Major labour market challenges and problematic questions in future are related to the imbalances between higher education supply and labour market demand, the economically active population decline, large proportion of young people entering the labour market without any particular specialty and skills, shortage in labour with secondary professional education. The topicality of the research is related to the fact that the industries, which have more rapid job growth is not the same as those where jobs were lost during the crisis, which pose new challenges in the labour market, to improve the skills of job seekers and to prevent the existence of long-term unemployment.

By the assessment of data there have been used methods of analysis and synthesis, reference and dynamical line. The main research sources include the information available in the databases of the CSB and Eurostat, as well as the studies and publications by the Ministries of Economics and National Employment Agency of the Republic of Latvia. Results of the analysis highlighted the potential economic policies to improve the situation in Latvian labour market. To promote economic growth and employment creation through stimulating demand is no longer possible. One of the main conditions for a balanced development of the labour market is the ability to reduce the productivity gap, achieving the most rapid productivity convergence with the EU average, while maintaining high wage increase rates. This can be done either by attracting additional investments, which is currently problematic taking into account investors' uncertainty, or to increase total factor productivity through structural reforms, improving innovation capacity, efficient use of resources and developing the high-tech industry.

\section{Research results and discussion}

Although the overall unemployment rate in Latvian, compared with other EU countries is not high and more than a year already strengthened single digit range (according to CSB data, 2015 Q4. It was $9.8 \%$ of the economically active population), it has a slow reduction influenced by the base effect of the gradual decline in the labour market, as well as the relatively low growth rates. In addition, the post-crisis period has seen a downward trend of the economically active population that is mainly determined by two factors- the low birth rate in the last century 90-ies and emigrations which can be seen in Table 1, are considered. Since the economically active population has decreased more slowly than the total number of population aged 15-74 years, Latvian level of economic activity in 2015 compared with 2010 has increased by 2.9 percentage points, however, the continuing emigration of economic active population in the future may reduce economic activity negatively impacting on growth potential. 
New Challenges of Economic and Business Development - 2016

May 12-14, 2016, Riga, University of Latvia

Table1

Population by economic activity (15-74 years) Latvian

\begin{tabular}{|c|c|c|c|c|c|c|c|c|}
\hline & \multicolumn{6}{|c|}{ Years } & Changes & $2015 / 2010$ \\
\hline & 2010 & 2011 & 2012 & 2013 & 2014 & 2015 & tūkst. & $\%$ \\
\hline Total population & 1635.3 & 1595.3 & 1560.0 & 1536.1 & 1495.8 & 1472.6 & -162.7 & -10 \\
\hline $\begin{array}{l}\text { Economic active } \\
\text { population }\end{array}$ & 1056.5 & 1028.2 & 1030.7 & 1014.2 & 992.3 & 994.2 & -62.3 & $-5,9$ \\
\hline $\begin{array}{l}\text { Level of economic } \\
\text { activity (\%) }\end{array}$ & 64.6 & 64.5 & 66.0 & 66.0 & 66.3 & 67.5 & - & $+2,9$ \\
\hline
\end{tabular}

Source: author's calculations based on CSB databases.

Evaluating the economic activity by age and sex, it can be concluded that the lowest economic activity is (in 2015 12.8\%) among women of 65-74 years, but the highest (93.1\%) of men 25 to 34 years, although in general during 2015 most active population is in age group 35 to 44 years (CSB Database, 2016). The relatively low economic activity is among young people (from 15 to 24 years), but during the post-crisis period, it has increased, reaching $41.3 \%$ in 2015. We must point out that during the recession (from 2008 until 2010) there was a trend of decreasing of the demand for the employees in the age group of 15-24 that can be explained by the demand of the employers for more experienced employees.

Another feature characterizing Latvian labour market is economic activity and employment rates among regional perspective. Riga and near Riga region has the highest economic activity and employment rates, while they are lowest in Latgale. Latgale region has also seen the biggest difference between the economic activity and employment (in 2015 this region had economic activity $63.4 \%$, while employing only $51.6 \%$ of the population aged 15 to 74 years), which could be explained by the fact that in Latgale it is the most difficult to find suitable job. Looking at the breakdown of employees by sectors of the economy it should be noted that the sectors in which the last two years has demonstrated faster job growth is not the same as those jobs were lost during the crisis (Table 2).

As shown in Table 2, during the crisis there was lost a significant number of jobs in the manufacturing sector and in construction, which in times of crisis, recovering very slowly. Manufacturing job growth limited by the adverse situation in the manufacture of basic metals, which was affected by the JSC "Liepajas Metalurgs" suspension of activities in 2013, as well as Russia's sanctions imposed on food products export. By contrast, robust job growth has occurred in health and social care, as well as the financial, insurance, scientific and administrative services, as well as operations with real estate sectors. Relatively little suffered transport, storage and IT services sector during the crisis, as well as education. However, in recent years the number of people employed in the education sector will decrease and that is related to the demographic situation (number of pupils and students decreases) and carried out educational reforms (decrease in the number of schools). Overall employment changes closely related to Dynamics of development of certain sectors, as the demand for labour is directly dependent on the economic structure and that accordingly has an impact on employment change, as well as the structure of individual branches and professions ("Project and Quality Management" Ltd., 2013). Also an important factor is labour productivity, which in Latvian is one of the lowest in 


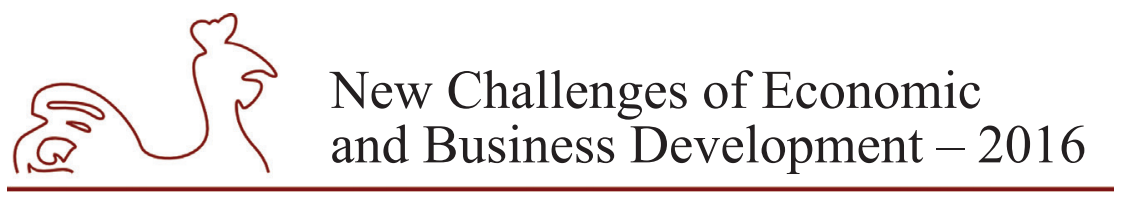

May 12-14, 2016, Riga, University of Latvia

Table 2

Employment by economic activity (thous.)

\begin{tabular}{|l|c|c|c|c|c|c|}
\hline \multicolumn{1}{|c|}{ Years } & $\mathbf{2 0 0 8}$ & $\mathbf{2 0 1 0}$ & $\mathbf{2 0 1 4}$ & $\mathbf{2 0 1 5}$ & $\begin{array}{c}\text { Changes } \\
\mathbf{2 0 1 5} / \mathbf{2 0 0 8}\end{array}$ & $\begin{array}{c}\text { Changes } \\
\mathbf{2 0 1 5 / 2 0 1 0}\end{array}$ \\
\hline Employed population & 1054.9 & 850.7 & 884.6 & 896.1 & -158.8 & +45.4 \\
\hline Agriculture, forestry and fishing & 83.9 & 73.3 & 66.3 & 71.1 & -12.8 & -2.2 \\
\hline Processing and mining etc. industry & 185.9 & 138.7 & 137.6 & 139.9 & -46.0 & +1.2 \\
\hline Construction & 124.1 & 57.6 & 73.2 & 71.9 & -52.2 & +14.3 \\
\hline Trade, accommodation and food services & 197.3 & 162.0 & 161.6 & 159.2 & -38.1 & -2.8 \\
\hline $\begin{array}{l}\text { Transport, storage, information and } \\
\text { communication services }\end{array}$ & 112.4 & 98.1 & 111.1 & 111.3 & -1.1 & +13.2 \\
\hline $\begin{array}{l}\text { Financial, insurance, scientific, } \\
\text { administrative services; Real estate }\end{array}$ & 82.8 & 87.8 & 99.0 & 102.2 & +19.4 & +14.4 \\
\hline $\begin{array}{l}\text { Public administration and defence; } \\
\text { compulsory social security }\end{array}$ & 83.9 & 59.7 & 58.6 & 59.1 & -24.8 & -24.2 \\
\hline Education & 86.8 & 84.5 & 85.1 & 83.4 & -3.4 & -1.1 \\
\hline Health and social work & 48.2 & 49.5 & 52.0 & 55.8 & +7.6 & +6.3 \\
\hline Other services & 49.2 & 39.4 & 39.6 & 41.7 & -7.5 & +2.3 \\
\hline
\end{tabular}

Source: author's calculations based on CSB databases.

the EU, particularly in the manufacturing industry (Jekabsone S., Skribāne I., 2014). In 2014 productivity levels in Latvia is $44 \%$ of EU-28 average, but in the manufacturing just 35\% (see picture 1).

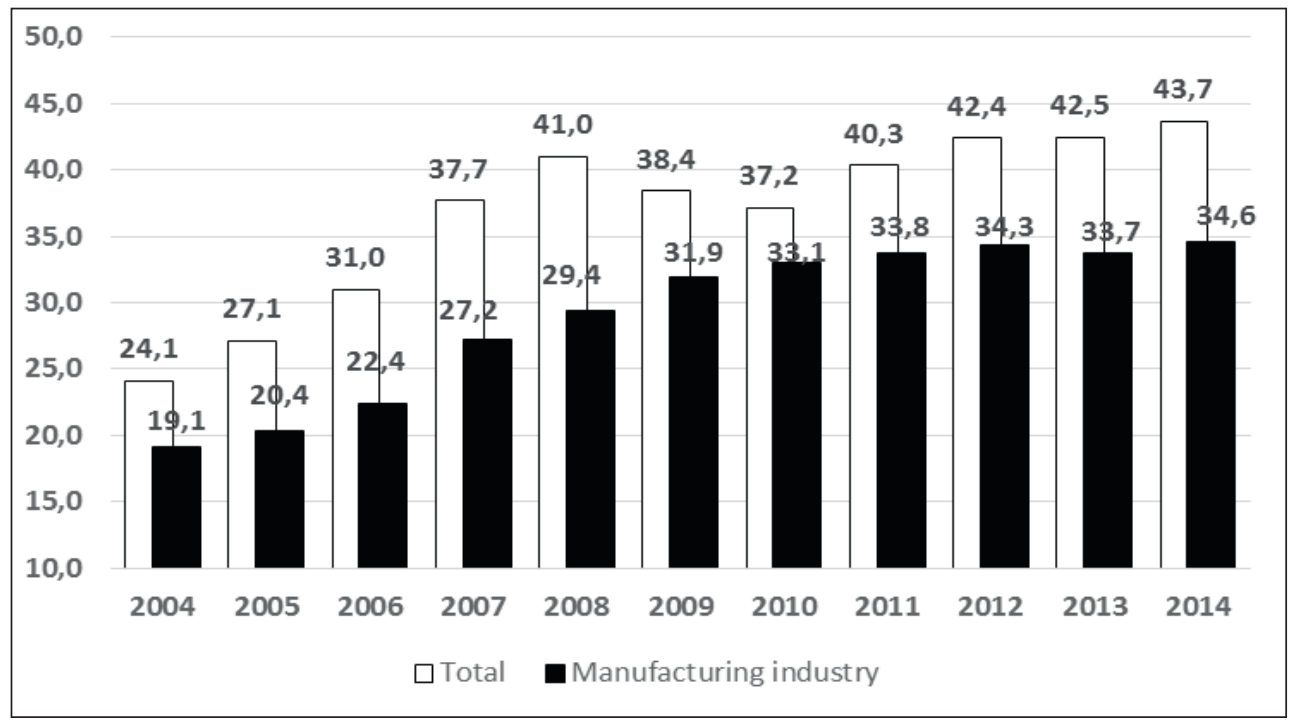

Source: author's construction based on. Eurostat databases.

Fig. 1. Labour productivity in Latvia 2004-2014 (\% of EU average level) 


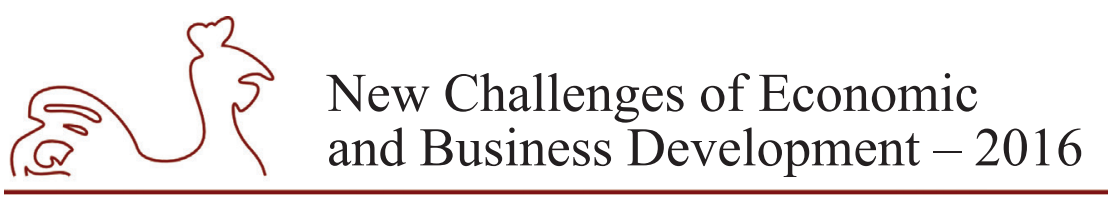

May 12-14, 2016, Riga, University of Latvia

Low productivity level in manufacturing of Latvia is largely due to the qualitative substructure. As according to the Eurostat data the low-tech industries dominate in the processing industrial structure, which account for $60 \%$ of manufacturing value added (the EU average share of these sectors is almost one and a half times lower than Latvian). The increase in productivity is determined by several factors, such as: structures, that are related to scientific and technical progress in the role of intensification of production; socio-economic, which is mainly related to investment in human capital (education of human capital, training, knowledge, motivating people to be productive) and organizational, which are related to the production process organization and management, production specialization and concentration of production territorially, as well as horizontal and vertical cross-link establishments. The main problem of all these abovementioned factors is how to allocate investments to increase productivity between employers, workers and the state. In the same way in the near future by increases in labour costs and economic growth, and by the open labour market in Latvia, there is a risk of losing competitiveness in low cost segments faster than getting the advantages by producing goods with higher added value, therefore, to avoid the "middle income trap", it is needed for structural reforms to facilitate the transition from low-tech to medium-tech to high-tech industries (World Bank, 2013).

One of the major problems in Latvian labour market is long-term unemployment, because looking at the unemployment breakdown by nature of the search duration, shows that more than $1 / 3$ of looking for work from 6 months to 2 years and a further $10 \%$ over 2 years (CSB Database, 2016). This indicates a large economically active population unable to enter the labour market and a high level of structural unemployment. Most of the unemployed in 2015 were in elementary occupations, as well as skilled workers and craftsmen occupations group, while the greatest demand (vacancies) was after the various types of professionals, but simple professions group job vacancies amounted to a mere $12 \%$ of all registered vacancies in 2015 Q3 (CSB Database, 2016). It shows the mismatch between labour demand and supply within profession groups. Also job vacancy rates in Latvia are extremely low by international standards (Hazans, M., 2013). Vacancies ratio of the number of jobs in all of 2015 Q3 Latvian was only $0.4 \%$ (CSB Database, 2016). Although the State Employment Service offers a variety of retraining courses, even though the activities of involving the unemployed into the labour market is not enough. In general, different initiatives of labour market are more directed to the improvement of skills but they are less directed to support the enterprises which can create the workplaces. There is a typical unconformity between what one learns and what the real situation is which offers the opportunities. As a result, there is a demand for specialists but there is no supply. On the one hand, the people do not have a job but on the other hand other people are needed. The people have studied social sciences for a long time but now the emphasis is on engineering, the sciences, and information technologies but still there is no movement towards a potential demand. Besides, in Latvia the Labour law is rather strict, accordingly, there is a big bureaucracy and the law could be in favour of the employee who gets different protections but at the same time it causes a counter-reaction from the employers and thus, they promote illegal employment

The level of education remains one of the most important determinants of unemployment. In 2015 the highest number of unemployed, broken down by level of education were people with vocational education or vocational secondary education, as almost $30 \%$ of the unemployed had general secondary education (CSB Database, 2016). To prevent existing disproportions in the 


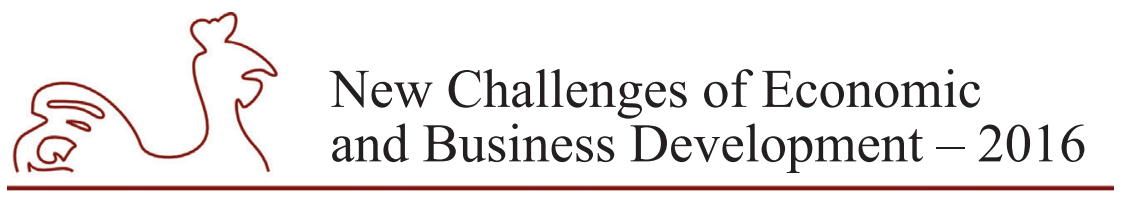

May 12-14, 2016, Riga, University of Latvia

labour market and contribute to reduce the unemployment rate below the SEA should expand the active labour market policy measures range, reinforcing its focus on certain target groups, as well as improving the quality of the implementation measures. The studies carried out confirm that both development and depression cycle most affected workers (Krasnopjorovs, O., 2015). During the crisis, workers 'unemployment rose particularly rapidly, 3rd quarter of 2009 to almost $25 \%$, that is, twice higher than the level of executives and specialists in the unemployment rate, so special attention should be paid to improving the efficiency of workers' eligibility.

Besides, in Latvia the Labour law is rather strict, accordingly, there is a big bureaucracy and the law could be in favour of the employee who gets different protections but at the same time it causes a counter-reaction from the employers and thus, they promote illegal employment. As evidenced by both Latvian and abroad studies, labour market developments are limited by the high labour taxes (Project and Quality Management Ltd., 2013). The influence of taxes on labour market implies the difference between labour costs of the employers and the wages of the employees. From the point of view of the demand higher costs of labour directly and indirectly reduce the demand for labour. The IMF also notes that the high labour taxes is one of the high structural unemployment causes in the Baltic States (IMF, 2014)

\section{Conclusions, proposals, recommendations}

1. Economic structural changes, as well as various external shocks lead to changes in labour demand volume, as well as its structure and a discrepancy between supply and demand and for individual groups of professions and sectors and the economy as a whole.

2. Economic growth and jobs by stimulating aggregate demand is not possible in Latvia, because it cannot bring down the unemployment rate without causing inflationary pressures and reducing competitiveness.

3. Latvia has one of the lowest labour productivity levels in the EU, largely on account of the very low productivity directly in the manufacturing industry, where labour productivity reaches only $35 \%$ of the EU average level.

4. Consequently, by increases in labour costs and economic growth, and by the open labour market in Latvia, in the near future there is a risk of losing competitiveness in low cost segments faster than getting the advantages by producing goods with higher added value, which would create "low income trap".

5. In order to achieve faster growth of labour productivity, it is important not only to foster modernization of the production technology in all sectors of manufacturing, but also to develop the structure of production, which would increase the share of manufacturing sectors, which are marked by higher productivity.

6. In order to remedy the existing disproportion between labour supply and demand and to promote a reduction in unemployment Latvian SEA should expand the active labour market policy measures range, reinforcing its focus on certain target groups, as well as improving the quality of the implementation of measures to make it a better unemployment and vacancies compliance effectiveness. 


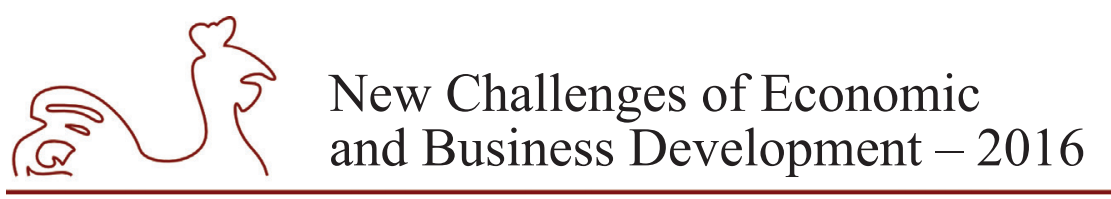

May 12-14, 2016, Riga, University of Latvia

\section{Bibliography}

Central Statistical Bureau (CSB) of Latvia, 2016. Statistic Database. [Online] Available at: http://www. csb.gov.lv/dati/statistikas-datubazes-28270.html [Accessed 14 March 2016].

European Commission, 2015. EU structural change 2015, EU 2015.

Eurostat, 2016. Statistic Database. [Online] Available at: http://ec.europa.eu/eurostat/data/database [Accessed 10 March 2016].

Hazans, M., 2013. Structural or Cyclical? Unemployment in Latvia since 2008-09 Financial Crisis. Joint Presentation by BICEPS, SSE Riga and Faculty of Economics and Management of the University of Latvia (1 March 2013, Riga). [Online] Available at: http://www.sseriga.edu/en/news-and-events/ upcoming-events/event-archive/2013/presentation.html. [Accessed 12 March 2016].

IMF, 2014. Baltic Cluster Report. IMF Country Report No. 14/117. [Online] Available at: http://www.imf. org/external/pubs/ft/scr/2014/cr14117.pdf. [Accessed 12 March 2016].

Jekabsone S., Skribāne I., 2014. Structural weaknesses and challenges of economics growth of Latvia, Social Research Nr. 1, Siauliai University, p. 74-85.

Krasnopjorovs, O., 2015. Dabiskā un cikliskā bezdarba Latvijā novērtējums ar Beveridža līknes modeli, Latvijas Banka, Rīga.

Ministry of Economics, 2015. The National Economic of Latvia Macroeconomics Review \#64/2015-3, Riga: Ministry of Economicsof the Republic of Latvia.

"Project and Quality Management" Ltd., 2013. Strategically Most Demanded Skills in Future Latvia. [Online] Available at: https://www.em.gov.lv/files/tautsaimniecibas_attistiba/1st_research_skills_ eng.pdf [Accessed 3 March 2016].

World Bank, 2013. "Middle Income Traps: a Conceptual and Empirical Survey", Policy Research Working Paper 6594, September 2013. 


\title{
DATA QUALITY ASPECTS IN LATVIAN INNOVATION SYSTEM
}

\author{
Svetlana Jesilevska, University of Latvia, Latvia ${ }^{1}$
}

\begin{abstract}
The research and analysis of the quality of statistics is extremely important. The ESS Vision 2020, a common strategic response of the European Statistical System, adopted by the ESS Committee in May 2014, identifies five key areas in which common action is needed for European statistics to be "fit for the future". The quality is one of these key areas (European Statistical System. ESS Vision 2020.). Until little analysis on the quality of the Latvian innovation surveys was made. On the basis of scientific studies on data quality and methodological peculiarities of statistics on innovation, author developed an expert survey questionnaire and conducted an expert survey about the quality of the Latvian survey on innovation 2015. Based on the expert survey results, the author concluded that the most problematic data quality dimensions for survey on innovation are objectivity, data completeness, representativeness, methodological quality. The theoretical and methodological evidence is based on the analysis of the economic literature, scientific works published by foreign scientists (Wang R. Y., Strong D. M, Ballou D. P., Pazer H. L., English L. etc.); the statistics database of the Central Statistical Bureau of Latvia; Eurostat methodological materials on innovation statistics. Bibliography review, as well as methods of statistical analysis such as grouping, processing and comparative analysis has mainly been used in the paper.
\end{abstract}

Key words: innovation, survey, data quality, data quality dimensions

JEL code: $\mathrm{C} 0, \mathrm{C} 13, \mathrm{O} 31$

\section{Introduction}

Innovation level of the companies in Latvia is one of the most important factors affecting the sustainable development of Latvian economy and long-term competitiveness. In order to evaluate the level of innovativeness, innovation surveys are conducted. These surveys are certainly among the most commonly used statistical surveys by economists to identify the determinants of innovation, the effects of innovation, the interrelations between various innovation indicators etc. (Mairesse J. \& Mohnen P., 2010). According to the recent results of innovation surveys in Latvia, Latvian innovative activity is low, for example, during the reference period 2008-2010 only $29.9 \%$ of enterprises were innovation active in Latvia, during the next reference period 2010-2012, the proportion of innovative enterprises increased slightly and remained at the level 30.4\% (CSP Informatīvais apskats "Inovācijas Latvijā̄").

The quality of statistical data is the main characteristic for the "official statistics". The ESS Vision 2020 identifies five key areas in which common action is needed for European statistics to be "fit for the future". One of the areas is strive for quality with the following objectives: abide with the European Statistics Code of Practice; apply fit-for-purpose tools to enhance quality assurance; assess the usability and quality of source data areas (European Statistical System.

${ }^{1}$ Corresponding author - e-mail address: mozir@inbox.lv 


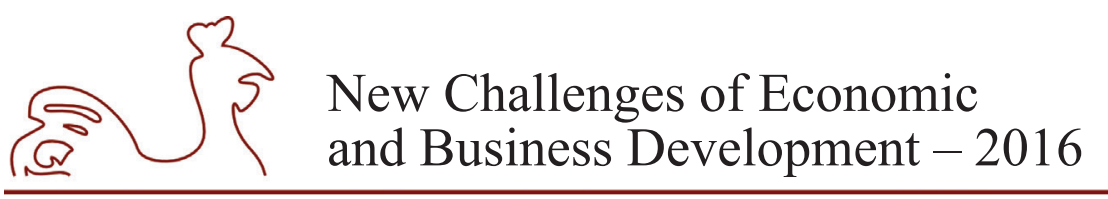

May 12-14, 2016, Riga, University of Latvia

ESS Vision 2020.). In the context of the ESS Vision 2020 the following problems concerning quality of statistics are stated:

- Modern societies and policy makers show little awareness of the necessity to invest in the production of high quality statistics.

- Respondents are not enthusiastic when they are asked to fill in a questionnaire.

- Tightened budgets in the public sector have led to shrinking resources also for statistical administrations (European Statistical System. ESS Vision 2020 (1)).

The research and analysis of the quality of statistics on innovation in Latvia is extremely important to successful and efficient innovation support policy making. Until little analysis on the quality of the Latvian innovation surveys was made. Summarizing the scientific studies on theoretical aspects of statistical data quality, the author found that a greater contribution in this field gave the following foreign researchers: Wang R. Y., Strong D. M, Ballou D. P., Pazer H. L., English L., Lee Y., Strong D., Parker M. B., Redman T. C., Olson J. On the basis of scientific studies on data quality and methodological peculiarities of statistics on innovation, author developed an expert survey questionnaire and conducted an expert survey about the quality of the Community Innovation Survey carried out in Latvia in 2015. Based on the expert survey results, the author concluded that the most problematic data quality dimensions for survey on innovation are objectivity, data completeness, representativeness, methodological quality.

This paper provides information on the state of innovation in Latvia, identifies some methodological peculiarities of statistics on innovation as well as discusses the results of the expert survey on the quality of Innovation Survey in Latvia. Author identifies areas that should be improved in the innovation data collection process in Latvia.

\section{What is the Community Innovation Survey and where statistics on innovation is used?}

The Community Innovation Survey in Latvia highlights innovation activities in Latvian enterprises with 10 employees or more. The survey is conducted every second year and is based on a harmonised survey questionnaire provided by Eurostat. The surveys cover a 3-year timespan and follow the general guidelines of the Oslo Manual. The Community Innovation Survey collects information about different types of innovations that the enterprises have introduced during a three-year period. In addition, the survey collects information about the enterprises' expenditures for innovation activities with respect to product and process innovations as well as sources of information and cooperation deemed to be important for innovation, etc.

The target population of the innovation survey is economically active statistical units merchants (individual merchants and commercial companies) carrying out economic activities in the following areas: NACE Rev. 2 Sections B, C, D, E, H, J, K and NACE Rev.2 Divisions 46, $71,72,73$. The final sampling frame for 2014 consisted of 5006 enterprises and sample for 2014 consisted of 1501 enterprises. The sample was built as stratified simple random sampling. The enterprises in the sampling frame were stratified by two main variables: by economic activity at the two-digit division level of NACE Rev. 2; and by the number of employed persons, enterprises being distributed into four size-classes, namely over 250, 50-249, 10-49, 1-9 and 0 employees (Methodological documents of the Central Statistical Bureau of Latvia).

For international comparisons, combined size-classes are used: large $(250+$ employed persons), medium (50-249 employed persons) and small (10-49 employed persons) enterprises. 


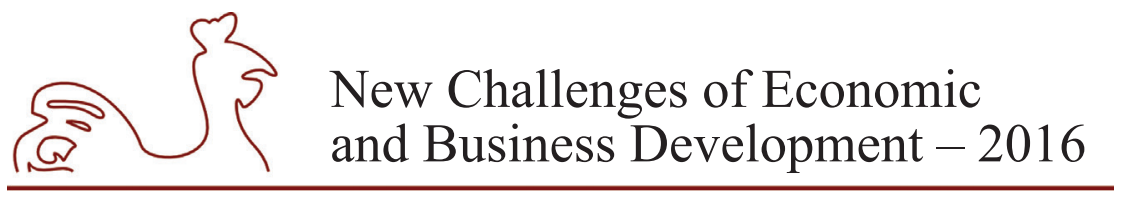

May 12-14, 2016, Riga, University of Latvia

According to the Community Innovation Survey 2014 Methodological recommendations, microenterprises (less than 10 employees) could be surveyed on a voluntary basis. In Latvia, filling out a survey questionnaire is an excessive burden for micro-enterprises, so microenterprises were excluded from the sample (Community Innovation Survey 2014 Methodological recommendations). Regional sampling as the third dimension could not be taken into consideration in Latvia as most strata had too small number of enterprises in them.

The CIS 2014 was mainly an online survey; the main data transmitting media was available on the website of the Central Statistical Bureau of Latvia. Enterprises still had the possibility of printing out the survey questionnaire as a pdf-file and returning it after filling by post or by e-mail. Only $4.2 \%$ of respondents used the old-fashioned way, $95.8 \%$ of respondents preferred the online version. The response rate was high. In absolute figures, out of 1501 sampled enterprises 1437 or $95.7 \%$ responded. The main non-response reasons: 29 sampled enterprises or $45.3 \%$ of non-respondents refused to provide a survey questionnaire; 23 sample enterprises or $35.9 \%$ of non-respondents stopped their work for a fixed period of time; 12 of sampled enterprises or $18.8 \%$ of non-respondents were impossible to contact (Methodological documents of the Central Statistical Bureau of Latvia).

The Community Innovation Surveys are certainly among the most exploited statistical surveys by economists in the many countries. The main purpose of innovation surveys is certainly to inform the research and innovation policies, it is not primarily to provide data for econometric analyses of innovation.

In Latvia statistics on innovation was primarily used for developing new programs for EU funding period 2014-2020, in the regular Report on the Economic Development of Latvia, Guidelines for Science, Technology Development, and Innovation 2014-2020 (Framework for Smart Specialisation Strategy), the corporate income tax incentive for R\&D costs (Working documents of the Central Statistical Bureau of Latvia).

In the European Union individual innovation indicators are often aggregated to construct composite innovation indexes such as the ones of the European Innovation Scoreboard or the Global Summary Innovation Index (Arundel A. \& Hollanders H., 2008). Innovation scoreboards have been used for instance by the directorates of the European Commission to check whether there is an innovation gap between the European Union and some other parts of the world, a convergence in innovation between old and new EU member states, and an improvement in the overall European innovation performance as promoted by the Lisbon strategy (Mairesse J. \& Mohnen P., 2010).

\section{How innovative is Latvia?}

The latest survey of innovation activities in Latvian enterprises shows that 30.4 percent of the enterprises conducted innovation activities during 2010-2012 (CSP Informativais apskats "Inovācijas Latvijā̄"). This is a higher share than before. Over the last few years, Latvia's innovative performance has not improved significantly.

In 2010-2012 innovative were 64.6\% of large enterprises (more than 250 employees), $43.2 \%$ of medium enterprises (50-249 employees) and 26.5\% of small enterprises (10-49 employees) (CSP Informatîvais apskats "Inovācijas Latvijā"). Micro enterprises (less than 10 employees) were not surveyed. 
May 12-14, 2016, Riga, University of Latvia

In comparison with Baltic countries, Latvia had the lowest innovative activity (see Fig. 4).

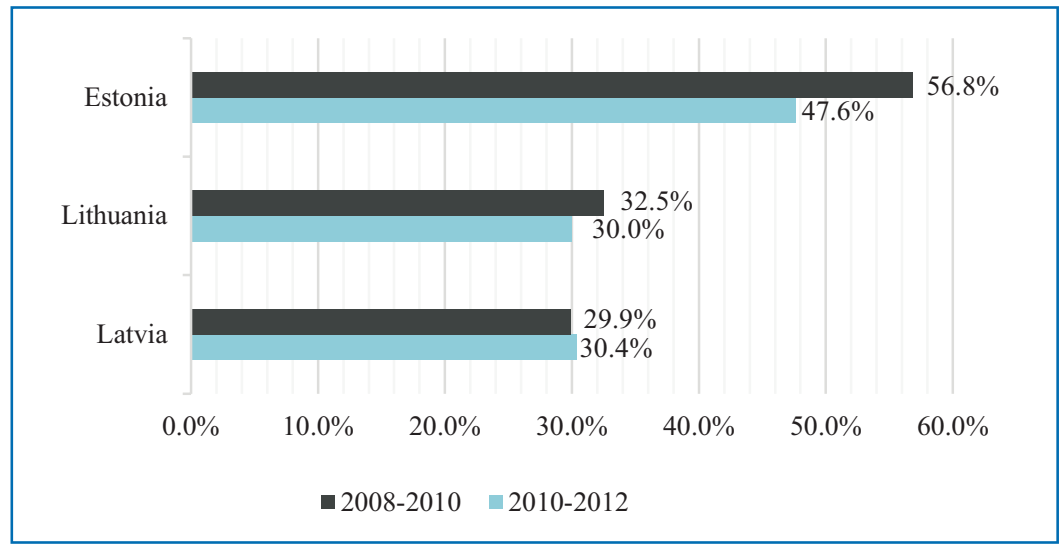

Fig. 1. Innovative activity of Latvia, Lithuania and Estonia (author's chart based on CSP Informatīvais apskats "Inovācijas Latvijā")

In 2015, Latvia has been ranked 33rd among 141 countries in the latest Global Innovation Index released by the World Intellectual Property Organization. Latvia also ranked as the $22^{\text {nd }}$ most innovative country in the European region. In 2015, Latvia was ranked 30th by innovation output, 34th by innovation input and $26^{\text {th }}$ by innovation efficiency ratio (Lsm.lv).

According to the Innovation Union Scoreboard 2015, Latvia together with Bulgaria and Romania are rated as "modest innovators" (countries with innovation performance well below that of the EU average). At the same time, Latvia is one of the fastest growing innovators (ASA Portal Austria).

The survey data on innovation show that only every fourth enterprise $(25.5 \%)$ during the reference period 2010-2012 co-operated with other enterprises or institutions for product and process innovation activities. Most of the surveyed enterprises co-operated with other enterprises within their enterprise group (57\%), the next popular co-operation partners are suppliers of equipment, materials, components, or software (44\%). Most rarely enterprises co-operate with universities or other higher research institutes and with government, public or private research institutes (CSP Informatīvais apskats "Inovācijas Latvijā"). Lack of co-operation with universities or research institutes confirm the problem that Latvian enterprises do not participate in development of innovation.

Co-operation between enterprises and scientists and researchers is especially essential as they complement each other in different ways. Scientists produce an invention and the function of the enterprise is to develop the product to the mass-production stage and market it. In collaborative implementation, the university does the research, while the entrepreneur focuses on development, marketing, and production (Branstetter L. \& Hyeog Ug. K., 2004).

The Europe 2020 Strategy set a 3\% objective for R\&D intensity for the EU as a whole and most Member States have adopted a national R\&D intensity target for 2020. Latvia has set a national R\&D intensity target of 1.5\%. During the period 2007-2012, Latvian R\&D intensity grew at an average annual rate of $2.0 \%$, which is somewhat below the EU average. Latvia needs to increase this rate significantly; an average annual growth rate of $10.8 \%$ is required over the 
May 12-14, 2016, Riga, University of Latvia

period 2012-2020 to reach the 1.5\% target (Research and Innovation performance in Latvia. Country Profile 2014).

Innovative activity in Latvia is influenced by various factors, like political and legal factors (policy agendas and legislation), economic factors (e.g., availability of external funds for social innovation), social and cultural factors (e.g., lack of information, risk of changes and instability), technological factors, individual factors (e.g., knowledge, motivation, skills) etc. According to statistical data discussed above, most valuable are policies for Latvia are that improve cooperation between the enterprises and research institutions in the innovation system and increase the innovative capacity of enterprises.

\section{Data quality dimensions}

Studies in data quality are not new; they have been conducted since at least the 1970s (Sadiq S. et al., 2011). Summarizing the foreign scientific studies on theoretical aspects of statistical data quality, the author found that a greater contribution in this field gave the following foreign researchers: Wang R. Y., Strong D. M, Ballou D. P., Pazer H. L., English L., Lee Y., Strong D., Parker M. B., Redman T. C., Olson J. In Latvia there is a lack of both popular and scientific literature on statistical data quality.

The most popular approach of defining data quality is the "fitness for use" introduced by Juran (Juran J. M., 1962). There is a consensus that the quality of data or information is contextual and must be evaluated relative to the context of its use (Strong D., Lee Y. \& Wang R., 1997; Stvilia B., Gasser L., Twidale M. \& Smith L., 2007).

In author's view, statisticians and data consumers define data quality differently. For data consumers the main criteria is how well data is able to serve the purposes of its intended use or uses. From statistician's point of view, statistical quality is embedded both in the statistical products themselves and in the processes used to produce them. Statisticians are responsible not only for data collection and dissemination, but also for promoting the use of statistical data.

This also supports that data quality is a multi-dimensional concept and should include various data quality dimensions and different types of indicators (e.g., objective \& subjective, qualitative \& quantitative).

A data quality dimension, as defined by Wang R. and Strong D. (Wang R. \& Strong D., 1996), is "a set of data quality attributes that represent a single aspect or construct of data quality." I author's opinion, data quality dimensions deal with measurements or, in other words, are quantifications of characteristics of an object or phenomenon.

Many scientists have identified various frameworks for assessing and improving data quality through different techniques on the data quality dimensions (Batini C. et al., 2009). Some scientists identified important data quality dimensions (Batini C. et al., 2009; Wand Y. \& Wang R., 1996; Pipino L. L. et al., 2002). For example, Ballou D. P. and Pazer H. L. (Ballou D. P. \& Pazer H. L., 1985) proposed accuracy, completeness, consistency, timeliness as significant data quality dimensions; Wand Y. and Wang R. (Wand Y. \& Wang R., 1996) proposed the following data quality dimensions: correctness, completeness, unambiguity, meaningfulness. Bertossi and Bravo split data quality dimensions into three groups: dimensions that characterize metadata quality, dimensions that characterize quality of data values and dimensions that characterize presentation quality (see Table 1). 


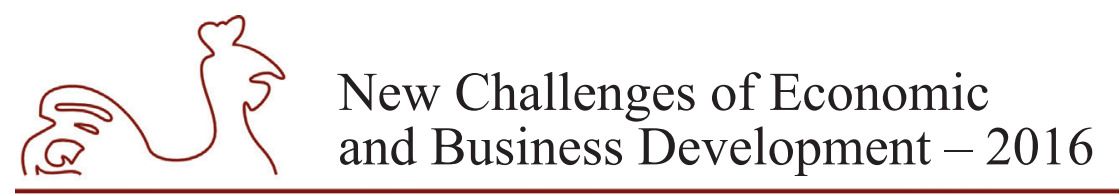

May 12-14, 2016, Riga, University of Latvia

Table 1

Data quality dimensions

\begin{tabular}{|l|l|}
\hline Conceptual view/associated metadata & Data values \\
Appropriate use & Accuracy \\
Areas covered & Completeness \\
Attribute granularity & Consistency \\
Clear definition & Timeliness \\
Comprehensiveness & \\
Essentialness & Presentation quality \\
Flexibility & Appropriateness \\
Homogeneity & Ease of interpretation \\
Identifiability & Formats \\
Naturalness & Format precision \\
Obtainability & Flexibility \\
Precision of domains & Handling of null values \\
Relevancy & Language \\
Robustness & Portability \\
Semantic consistency & Representation consistency \\
Sources & Use of storage \\
Structural consistency & \\
\hline
\end{tabular}

Source: Bertossi L. \& Bravo L., 2005; Bravo L. \& Bertossi L., 2006.

In author's view, basic dimensions that need to be addressed in order to present information that can be identified as reliable include: data completeness, data actuality, data accessibility, data interpretbility, data informativeness, data utility, statistical disclosure control, costs effectiveness, validity concept.

In author's opinion, validity in the context of statistical data quality is a complex concept- it shows whether the methodology of research is oriented on the certain purpose (methodological quality), it characterizes the accuracy of the research results (objectivity, consistency, accuracy of calculations) and it characterizes justified conclusions (representativeness) derived from the research results. That is why validity is evaluated in the context of a particular research and one universal approach to the determination of validity does not exist. Depending on the aspect of validity is necessary to evaluate certain specific dimensions are analyzed, that is why validity itself is multi-dimensional concept.

\section{Quality of the Community Innovation Survey in Latvia}

Based on scientific studies on data quality and methodological peculiarities of statistics on innovation, author developed an expert survey questionnaire and conducted an expert survey about the quality of the last Latvian survey on innovation. The expert survey questionnaire was paper-based. The survey covered representatives of the Central statistical bureau of Latvia, who were responsible of the Community Innovation Survey, conducted in Latvia in 2015.

The proposed data quality assessment framework contained 13 dimensions:

1. Data objectivity - the ability of statistical data to reflect the actual situation and its independence from the data users' interpretations or evaluations. 


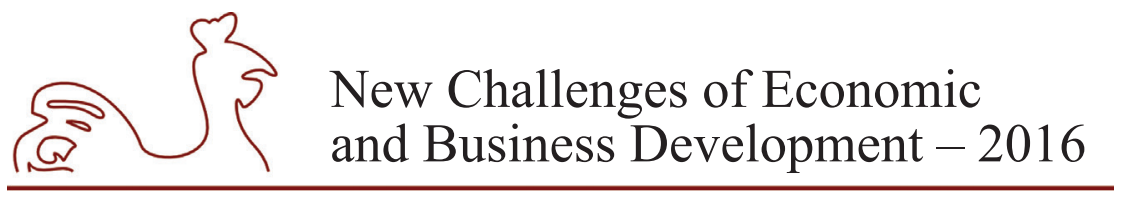

May 12-14, 2016, Riga, University of Latvia

2. Data completeness - data meets user needs.

3. Data representativity - Sample data generalization capabilities.

4. Data accuracy - The degree of reflection of the actual situation.

5. Quality of methodology-Methodological scientific justification(including methodology approbation), correct use of methodology and unification level of methodology.

6. Coherence - Logical links between different statistical surveys findings, the data from different sources are comparable.

7. Actuality - Data collection and processing speed and frequency of renewal.

8. Data accessibility - Simplicity of data availability to the users.

9. Interpretability - statistical data collection and processing methodologies is available to the data users in order to make the correct interpretation of data.

10. Informativeness - Data presentation form that will enable data users to capture data quickly and easily navigate the data range.

11. Utility - Data users demand to the data.

12. Statistical disclosure control - Confidentiality of the information provided by respondents.

13. Cost efectiveness - Efficient use of existing resources for data collection and processing.

For evaluation of each data quality dimension, author developed indicators. Experts were asked to evaluate how certain data quality indicators affect the quality of the Community Innovation survey results.

Based on the expert survey results, the author concluded that the most problematic data quality dimensions in the context of the Community Innovation survey are objectivity, data completeness, representativeness and methodological quality.

\section{Objectivity}

Objectivity - a dimension that reflects the extent to which information is without distortion by personal feelings, prejudices, or other information (Malá J. \& Černá L., 2012).

Author define objectivity as the ability of statistical data to reflect the actual situation and its independence from the data users' interpretations or evaluations.

Indicators for objectivity, proposed by the author:

1. Data acquisition form (statistical survey)

2. Data stability over time

3. Data changes freedom from external random events (e.g., political)

4. Different survey question understanding (statistician - respondent), the question is asked ambiguously

5. Influence level of mentality (e.g., religion, culture, history, traditions, climate) on the respondents' answers

6. Impact level of public opinion on the respondent's answers

7. Statistical data relevance to reality

In experts' view, Data stability over time is not necessary for the quality of the innovation survey results, because the process of innovation development is a wavelike: innovation is developed and introduced to the market only after some research is carried out. 


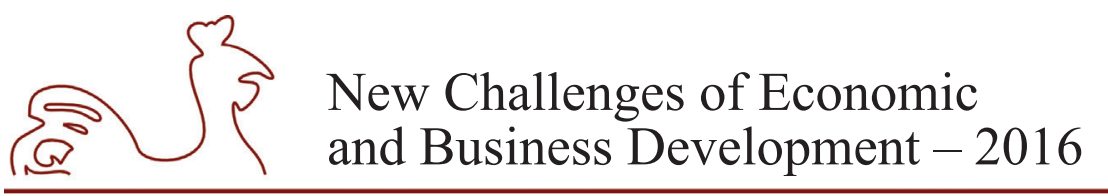

May 12-14, 2016, Riga, University of Latvia

According to results of the experts' survey, most notably objectivity of the results of the innovation survey is aggravated by Different understanding of the survey question by statistician and by respondent. Data acquisition form (statistical survey in the case of the Community Innovation survey) also has a strongly negative impact on the objectivity of the innovation survey results.

In practice, there are two mains actors in the communication process of official statistics statisticians and respondents (respondents at the same time could be the users of statistical information). Both sides - statisticians as well as respondents are responsible for the quality of statistical information. Good practice is when statisticians consult respondents during the survey, they provide guidelines to fill the questionnaires as well as assist respondents to get desired statistical information. This approach promote the correct understanding of the question by respondents and is extremely important in the context of innovation survey. Firstly, because the innovation survey is conducted every second year (not every year). Secondly, every next innovation survey questionnaire contains new additional questions, which were not included in the previous one, as a result respondents are asked to provide completely different information. Thirdly, the concept of innovation is difficult to understand for the majority of respondents.

\section{Representativeness}

If the samples are not representative, any conclusions or decisions based on data will not be correct. A complete understanding of the data quality objective process, sample plan design, sample plan implementation, and quality control is required to assess sample representativeness (Ramsey C. A. \& Hewitt A. D., 2005).

Author define representativeness as sample data generalization capabilities.

Indicators for representativeness proposed by the author:

1. Selected sample technique is in compliance with the task of statistical survey

2. Sample size is in compliance with the statistical survey task

3. The specific sample survey results attributing to the entire population

4. The survey response rate

5. Number of incorrect answers obtained during the survey

In experts' opinion, the indicator Selected sample technique is compliance with the task of statistical survey is difficult to justify. According to the Community Innovation Survey Methodological recommendations, data on innovation should be collected through a census, sample survey or a combination of both. The stratification variables to be used for the Community Innovation Surveys, i.e. the characteristics used to break down the sample into similarly structured groups, should be the economic activities (NACE classification), enterprise size according to the number of employees, regional sampling (NUTS 2 classification). No statistical variables are provided in the methodological quidelines the choice of sampling techniques is based on.

The same problem is with the indicator Sample size is in compliance with the statistical survey task. According to the Community Innovation Survey Methodological recommendations, there is no minimum sample size defined needed. The expected response rate should be borne in mind i.e. the sample size should take into account the non-response rates experienced in the previous Community Innovation Survey and compensate accordingly. 


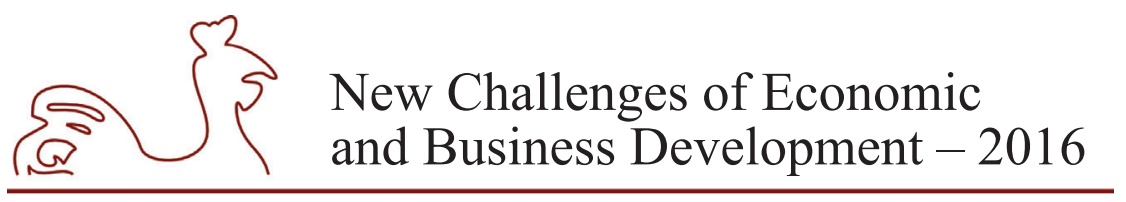

May 12-14, 2016, Riga, University of Latvia

What concerns The survey response rate, focus on just this indicator of survey quality can be misleading as a low response rate does not necessarily imply that the accuracy of survey estimates is poor. The literature on survey methodology contains examples showing that response rates by themselves are poor indicators of non-response bias, see e.g. Curtin R., Presser S. \& Singer E., 2000; Groves R. M. \& Peytcheva E., 2006; Heerwegh D. et al., 2007. As a result, additional survey quality indicators are necessary to provide more insight in the possible risk of biased estimators.

\section{Quality of methodology}

Author developed the following definition: quality of methodology is scientific justification of methodology (including approbation of methodology), correct use of methodology and unification level of methodology.

Indicators for quality of methodology proposed by the author:

1. Complexity of statistical data collection and processing, calculation methodology of statistical indicators for statistician

2. Data collection and treatment process can be adapted to the needs of data users and a rapidly changing environment

3. Speed of implementation of new data collection and processing methodology and / or new indicators calculation methodology

4. Complexity of statistical data collection and processing for data users

5. The proportion of complex indicators (e.g., GDP)

6. Applied data correction and imputation methods, which are regularly reviewed, corrected and updated

7. Unification level of statistical data collection and processing methodology

8. Capability of resources (time, labor, finance, etc.) for data collection and processing

9. Quality programs and quality assurance procedures are approved and running in the statistical office

10. Questionnaires testing before launching the statistical survey

11. Data collection and processing methodology is in compliance with EU and international benchmarks

12. Data audits in accordance with the operational experience and clearly understandable procedures

13. Errors and shortcomings repair is carried out in accordance with certain standards

14. Statistical indicators calculation methodology is scientifically justified, regularly monitored and improved

15. Data collection and processing methodology is scientifically justified, regularly monitored and improved

In experts' opinion, the indicator Questionnaires testing before launching the statistical survey is one of the most important for identifying possible shortcoming and should be placed among the most important indicators. Unfortunately in Latvia innovation survey questionnaires are not tested. This is a serious omission, because every new innovation survey questionnaire differs from the previous one. 


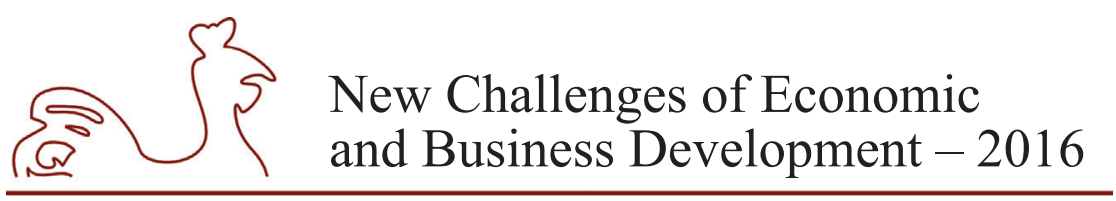

May 12-14, 2016, Riga, University of Latvia

In experts' view, the indicator Complexity of statistical data collection and processing, calculation methodology of statistical indicators for statistician is the most important in evaluation quality of methodology as lack of understanding in this context leads to decrease in quality and confidence in statistical research findings.

Statistical measures of innovation are based on operational definitions of the measured phenomenon - innovation. Definitions of innovation specify it, include some aspects of it and exclude some others. This, in turn, affects not only the idea of the innovation but also the quality of the information of the statistical indicators (Nieminen M. \& Lehtoranta O., 2015). At the core of innovation statistics is the concept of innovation. In author's opinion, the current concept of innovation provided in the Oslo Manual has some shortcomings, e.g.:

- The current Oslo Manual states that innovation can occur in any sector of the economy, including government services such as health or education, at the same time the current measurement framework applies only to business innovation.

- According to the Oslo Manual, "An innovation is the implementation of a new or significantly improved product (good or service), or process, a new marketing method, or a new organisational method in business practices, workplace organisation or external relations" (Oslo Manual).) Currently, it is difficult to distinguish between significantly improved and non-significantly improved products, it is too subjective.

- According to the Oslo Manual, "A common feature of an innovation is that it must have been implemented" (Oslo Manual). The concept of implementation provides a means for objectively assessing whether an innovation has taken place. Nevertheless it is necessary to define implementation more specifically to avoid confusion.

- The Oslo Manual does not classify innovations according to how radical they are.

- The Oslo Manual does not distinguish between "(a) commercialising something for the first time and (b) copying it and introducing it in a different context" (Fagerberg J., Mowery D. C. \& Nelson R., 2004). However, scientists point out that the innovation process is not only a process of inventing, designing, testing, redesigning and marketing (Kline S. J. \& Rosenberg N., 1986) but also of adopting, modifying, testing, re-modifying and marketing or implementing (Fagerberg J. \& Godinho M. M., 2004).

- The Oslo Manual does not give answer to the questions, like: how abandoned and ongoing innovation activities should be reported or how a potential innovator can be identified in practice.

In author's view, the concept of innovation during the 2000s has broadened from technological product and process innovations towards broader content, including service and social innovations, organisational and behavioural innovative changes. As a result, innovation nowadays should be defined in wider socio-economic context. Author shares the opinion of E. von Hippel, that "innovation processes have become more open and require multifaceted collaboration as reflected for instance in the concepts of open and inclusive innovation, democratising innovation and consumer innovation" (von Hippel E., 2005). 


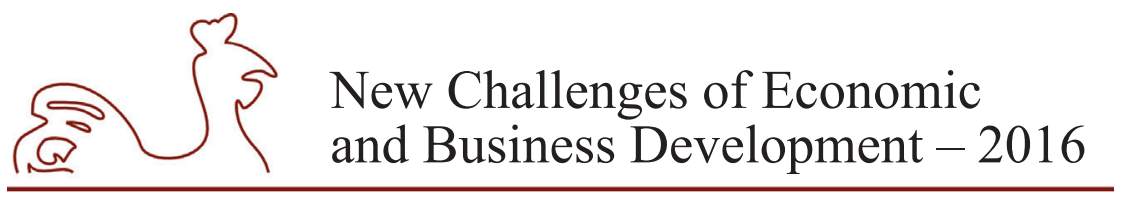

May 12-14, 2016, Riga, University of Latvia

\section{Data completeness}

Author developed the following definition for data completeness: Data meets user needs. Indicators for quality of methodology proposed by the author:

1. All the data that are needed to carry out the assessment of the dynamics of the phenomena are collected

2. All the data that are needed to carry out the assessment of the phenomena by the objects (by industry, by enterprise size classes, by types of innovations, etc.) are collected

3. All the data that are needed to carry out the assessment of the phenomena by the objects (by regions, etc.) are collected

4. Data interpolation required

In Latvia all the data according to the methodological guidelines provided by Eurostat (Eurostat. Community Innovation Survey 2014 Methodological recommendations) is collected and in the experts' opinion indicators proposed by the author to evaluate data completeness positively effect the quality of innovation statistics.

In author's opinion, statistical data on innovation mostly satisfy needs of European Commission, not Latvian policy makers. Indicators on innovation are essential for better understanding of the Latvian Innovation system. Innovation statistics is a collection of indicators. Quantitative data on innovation needs to be complemented with qualitative data for sound interpretations. Deeper analysis of statistical data on innovation in Latvia needs to be performed to understand functional-structural analysis of the Latvian Innovation system. Deeper analysis of indicators gives a comprehensive picture of the functioning of the Innovation system in Latvia and shows connections between the elements the Innovation system.

Nieminen M. \& Lehtoranta O. (Nieminen M. \& Lehtoranta O., 2015) provide some examples of components for the functioning of the innovation system and a number of indicators for analysis (see Table 2):

Table 2

System functions and indicator examples

\begin{tabular}{|l|l|}
\hline \multicolumn{1}{|c|}{ Function } & \multicolumn{1}{c|}{ Examples of indicators } \\
\hline Entrepreneurial activities & $\begin{array}{l}\text { New enterprises, closed enterprises, growth enterprises, R\&D intensive } \\
\text { enterprises, innovative enterprises etc. }\end{array}$ \\
\hline Knowledge development & $\begin{array}{l}\text { Number of articles, patents and innovations, public and private R\&D } \\
\text { personnel in various disciplines and branches of industry etc. }\end{array}$ \\
\hline Knowledge dissemination & $\begin{array}{l}\text { Collaboration in research and innovation, co-publications, co-patenting, } \\
\text { general knowledge infrastructure (e.g. number of libraries, open access } \\
\text { scientific journals and articles, broadband connections) etc. }\end{array}$ \\
\hline Resources mobilisation & $\begin{array}{l}\text { Public and private R\&D finance, public support for new enterprises and } \\
\text { innovation etc. }\end{array}$ \\
\hline
\end{tabular}

Source: Nieminen M. \& Lehtoranta O., 2015.

Nieminen M. \& Lehtoranta O. point out that this is the way to organise and interpret indicators. In addition, indicators should measure issues, which are relevant targets for policymaking. 


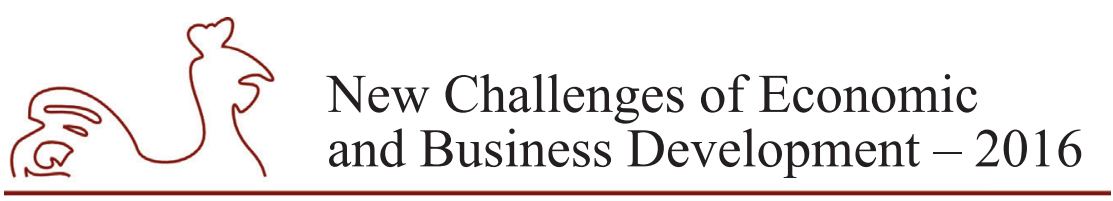

May 12-14, 2016, Riga, University of Latvia

In author's view, in future some steps should be performed to make statistics on innovation more relevant for the needs of Latvian policy makers:

- The Community Innovation Survey data appears with a time lag, e.g., in 2015 the data was collected for the reference period 2012-2014. During the time period when the Community Innovation Survey is not conducted, it would be necessary to carry out smaller sample surveys (for example, only for large enterprises with 250 and more employees) so as to collect the basic indicators of innovative activity which are essential for national policymaking. This approach gives the possibility to obtain operational data.

- The Community Innovation Survey is a sample survey which does not cover all enterprises and sectors of the business economy. In author's opinion, it would be useful to collect time series on innovation activities in the manufacturing sectors. The output from this study shall be used by policy makers in analysing and understanding the diffusion, usage and practice of innovation in the manufacturing sectors in Latvia.

- According to NUTS classification Latvia is one region, that is why the Community Innovation Survey collects data for Latvian region. Nevertheless, in author's view, it would be useful to develop additional innovation survey to collect data on innovation activities on the regional level (Kurzemes, Latgales, Vidzemes, Zemgales, Rìgas regions etc.) for Latvian policymaking.

Summarizing experts' survey results, author concluded that in the official statistics data quality is determined mainly by the following factors:

- The quality of information provided by respondent (respondent has enough knowledge and skill in the area of statistical surveys, to give true information, respondent give thoughtful answers, respondents are prone to cooperation, conscientiously take part in statistical surveys);

- The professionalism of the statistician (knowledge of mathematical statistics, practical experience and knowledge about the development and characteristics of the survey object);

- Cooperation between institutions involved in the preparation of the information, as well as users of information;

- Validity and relevance of the statistical methodology used (including the legal basis of the statistical survey, the purposes for which the data is necessary, the data protection measures).

\section{Conclusions, proposals, recommendations}

Until little analysis on the quality of the Latvian innovation surveys was made. That is why author's study is a significant contribution in the analysis of the quality of statistical data on innovation in Latvia.

Based on scientific studies on data quality and methodological peculiarities of statistics on innovation, author developed an expert survey questionnaire and conducted an expert survey about the quality of the last Latvian survey on innovation. Author provides indicators for evaluation of the most problematic data quality dimensions according to experts' survey results: objectivity, data completeness, representativeness, methodological quality. 


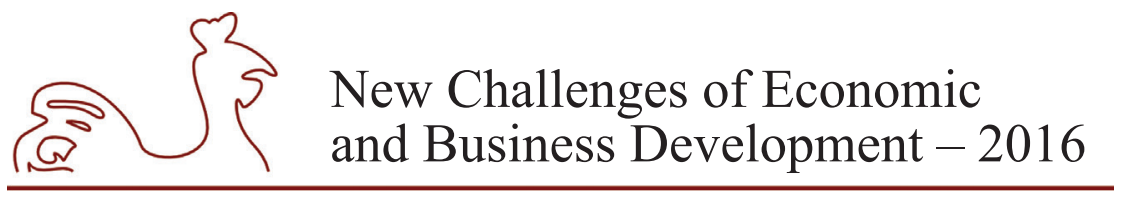

May 12-14, 2016, Riga, University of Latvia

Author discusses some shortcoming of the current methodology of statistics on innovation, like no recommendations on how abandoned and ongoing innovation activities should be reported or how a potential innovator can be identified in practice, lack of clarification on the concept of implementation of innovation etc. Author provides some future steps that should be performed to make statistics on innovation more relevant for the needs of Latvian policy makers.

\section{Bibliography}

Aerts, K. \& Czarnitzki, D., 2004. Using Innovation Survey Data to Evaluate R\&D Policy: The Case of Belgium. Centre for European Economic Research. Discussion Paper, No. 4-55.

Arundel, A. \& Hollanders, H., 2008. Innovation scoreboards: indicators and policy use, Innovation Policy in Europe: Measurement and Strategy. Edward Elgar Publishing Ltd, Nauwelaers C and Wintjes R (ed.), Cheltenham, UK, pp. 29-52. [Research Book Chapter].

ASA Portal Austria. European Commission publishes Innovation Union Scoreboard 2015. Retrieved March 2, 2016, from: https://era.gv.at/object/news/1788

Ballou, D. P. \& Pazer, H. L., 1985. Modeling data and process quality in multi-input, multi-output information systems. Management science, 31(2), pp. 150-162.

Batini, C. et al., 2009. Methodologies for data quality assessment and improvement. ACM Computing Surveys, 41(3), p. 16-52.

Bertossi, L., Bravo, L., 2005. Consistent query answers in virtual data integration systems. In: Bertossi L., Hunter A., Schaub T. (eds.) Inconsistency tolerance, LNCS, Vol. 3300. Springer, Berlin, pp. 42-83.

Branstetter, L. and Hyeog, Ug. K., 2004. The Restructuring of Japanese Research and Development: The increasing impact of science on Japanese R\&D. RIETI Discussion Paper Series 04-E-021. Retrieved March 2, 2016, from: http://www.rieti.go.jp/jp/publications/dp/04e021.pdf.

Bravo L., Bertossi L., 2006. Semantically correct query answers in the presence of null values. In: Proceeding of the EDBT WS on inconsistency and incompleteness in databases (EDBT'06). Springer, Berlin, pp. 336-357.

Curtin, R., Presser, S. \& Singer, E., 2000. The effects of response rate changes on the index of consumer sentiment. Public Opinion Quarterly, 64, 413-428.

CSP (2014) Informatīvais apskats "Inovācijas Latvijā". Retrieved February 20, 2016, from http://www. csb.gov.lv/sites/default/files/nr_37_inovacijas_latvija_14_00_lv.pdf

European Statistical System. ESS Vision 2020. Retrieved March 10, 2016, from: http://ec.europa.eu/ eurostat/web/ess/latest-news

European Statistical System. ESS Vision 2020 (1). Retrieved February 21, 2016, from: http://ec.europa. eu/eurostat/documents/10186/756730/ESS-Vision-2020.pdf/8d97506b-b802-439e-9ea4$303 \mathrm{e} 905 \mathrm{f} 4255$

European Commission. Research and Innovation performance in Latvia. Country Profile 2014. Luxembourg: Publications Office of the European Union.

Eurostat. Community Innovation Survey 2014 Methodological recommendations. Retrieved March 1, 2016, from: https://circabc.europa.eu/faces/jsp/extension/wai/navigation/container.jsp

Fagerberg, J., Mowery, D. C., Nelson, R. (eds.), 2004. The Oxford Handbook of Innovation. Oxford: Oxford University Press.

Fagerberg, J., Godinho, M. M., 2004. Innovation and Catching-up, in Fagerberg, J., Mowery, D. C., Nelson, R. (eds.), The Oxford Handbook of Innovation, Oxford: Oxford University Press, pp. 514544.

Groves, R. M. \& Peytcheva, E., 2006. The impact of nonresponse rates on nonresponse bias: a metaanalysis. 17th International Workshop on Household Survey Nonresponse, Omaha, NE, USA. 


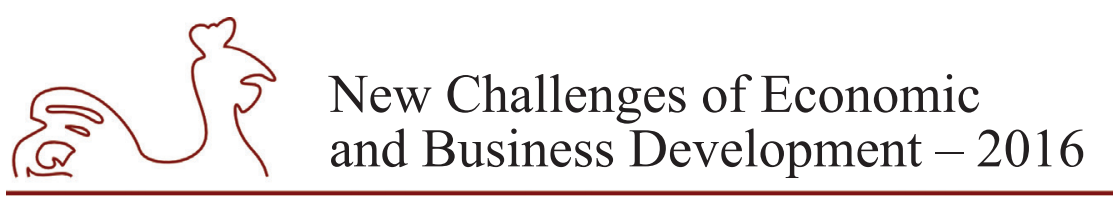

May 12-14, 2016, Riga, University of Latvia

Heerwegh, D., Abts, K. \& Loosveldt, G., 2007. Minimizing survey refusal and noncontact rates: do our efforts pay off? Survey Research Methods, 1, 3-10.

Juran, J. M., 1962. Quality control handbook, New York, McGraw-Hill Publishing.

Kline, S. J., Rosenberg, N., 1986. An Overview of Innovation, in: R. Landau and N. Rosenberg (eds.) The Positive Sum Strategy: Harnessing Technology for Economic Growth, Washington D.C.: National Academy Press, pp. 275-304.

Lsm.lv. Latvia ranks $33^{\text {rd }}$ in Global Innovation Index. Retrieved February 11, 2016, from: http://www.lsm. lv/en/article/economics/economy/latvia-ranks-33rd-in-global-innovation-index.a147136/

Mairesse, J. \& Mohnen, P., 2010. Using Innovation Surveys for Econometric Analysis, In Bronwyn H. Halland and Nathan Rosenberg: Handbook of the Economics of Inovation, Vol-II. Burlington: Academic Press, pp. 1129-1156.

Malá, J. \& Černá, L., 2012. Information quality, its dimension and the basic criteria for assessing information quality. Research Papers. Faculty of Materials Science and Technology in Trnava, Slovak university of Technology in Bratislava.

Nieminen, M. \& Lehtoranta, O., 2015. Measuring broad-based innovation. Juvenes Print, Tampere.

OECD, Eurostat, 2005. Oslo Manual: Guidelines for Collecting and Interpreting Innovation Data, $3^{\text {rd }}$ Edition. Retrieved August 27, 2014, from: http://www.oecd.org/document/33/0,3746, en_2649_34451_35595607_1_1_1_1,00.html.

Pipino, L. L., Lee, Y. W. \& Wang, R. Y., 2002. Data Quality Assessment. Communications of the ACM, Vol. 45, p. 211-218.

Ramsey, C. A. \& Hewitt, A. D., 2005. A Methodology for Assessing Sample Representativeness. Environmental Forensics, Vol. 6, Issue 1, pp. 71-75.

Sadiq, S., Yeganeh, N.Y. \& Indulska, M., 2011. An Analysis of Cross-Disciplinary Collaborations in Data Quality Research. European Conference on Information Systems, Helsinki Finland.

Strong, D., Lee, Y., \& Wang, R., 1997. Data quality in context. Communication of the ACM, 40(5), 103110 .

Stvilia, B., Gasser, L., Twidale, M., \& Smith, L., 2007. A framework for information quality assessment. Journal of American Society of Information Science and Technology, 58(12), 1720-1733.

Von Hippel, E., 2005. Democratizing Innovation. Cambridge, Massachusetts: The MIT Press.

Wang, R., \& Strong, D., 1996. Beyond accuracy: What data quality means to data consumers. Journal of Management Information Systems, 12(4), 5-35.

Wand, Y. \& Wang, R., 1996. Anchoring data quality dimensions in ontological foundations. Communications of the $A C M$, Vol. 39, Issue 11, pp. 86-95.

Working documents of the Central Statistical Bureau of Latvia.

Methodological documents of the Central Statistical Bureau of Latvia. 


\title{
THE IMPACT OF PUBLIC EMPLOYMENT SERVICES ON JOB SEARCH OUTCOMES - THEORY, METHODS AND EVALUATION
}

\author{
Inese Kalvane, University of Latvia, Latvia ${ }^{1}$
}

\begin{abstract}
Public employment services (hereinafter - PES) operate as governments' tool for implementation of the employment policy, reduction of unemployment and facilitation of competitiveness of the labour market. The key task of the PES is matching of labour supply and demand in order to stabilize the labour market and provide sustainable employment. To achieve these goals, the PES implement employment programmes.

According to the job search theory, the outcome of job search depends on

(i) jobseeker's human capital (education level, experience, professional and other ("soft") skills, health, etc.) personality traits (ambition, motivation etc.) and social capital (networks);

(ii) job search strategy (including the reservation wage) and intensity/effort of job seeking, but

(iii) the number of available vacancies and their distribution with respect to offered salary, required qualification and skills, terms and conditions of work.

The PES provide assistance in all above-mentioned respects

The purpose of this study is to assess efficiency indicators of support methods provided by PES to jobseekers and to collect and analyse local labour market experts' opinions of on the efficiency of the support provided by PES and possible ways to improve it.

Using the job search theory as a conceptual framework, this study performs a comparative analysis and assessment of business models of the Latvian, Estonian and Danish PES, support measures implemented by these PES, as well as efficiency indicators used by them. Furthermore, for Latvia we present two citylevel case studies using semi-structured interviews with eight labour market experts in Valmiera (a lowunemployment city) and Liepaja (a high-unemployment city).

The study results in conclusions regarding the relation of assessment indicators of the support provided by PES in job seeking with the elements of the theory of job search and recommendations for further research of the efficiency of the work of PES. The vision of the local employment experts of efficient PES operation can be ensured through cooperation of the PES and other institutions (municipalities, representatives of employers, trade unions, and educational institutions). The operational efficiency of the PES must be evaluated together with the operation of the mentioned institutions.
\end{abstract}

Key words: theory of job search, public employment services, efficiency indicators

JEL code: J64, H75

Corresponding author - e-mail address inese.kalvane@lu.lv 


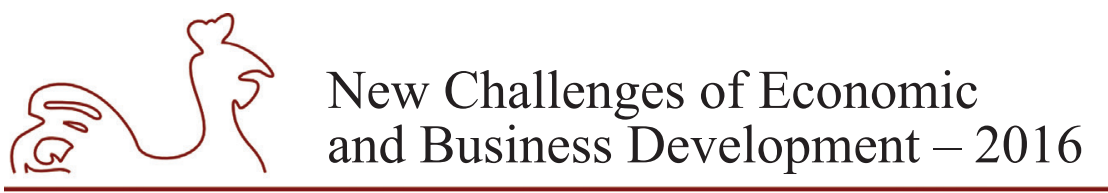

May 12-14, 2016, Riga, University of Latvia

\section{Introduction}

PES services provide population with support in creating, implementing, evaluating, and reviewing job seeking strategy.

PES can impact and create an individual's understanding of an appropriate job seeking strategy if the respective individual is using the services of PES. In labour market theoretical literature one can find theory and researches on job seeking theory and the role of PES in the process of seeking a job or employees. However, the number of studies related to PES operational efficiency evaluation and preconditions necessary for such operation to be efficient is limited. In this study, the author proposes a new approach to the PES operational efficiency evaluation, which is based on the elements of job seeking theory and the evaluation of efficient PES operation and organization performed by local employment experts.

Using the job search theory as a conceptual framework, this study performs a comparative analysis and assessment of business models of the Latvian, Estonian and Danish PES, support measures implemented by these PES, as well as efficiency indicators used by them. Furthermore, for Latvia we present two city-level case studies using semi-structured interviews with all together eight labour market experts in Valmiera (a low-unemployment city) and Liepaja (a highunemployment city).

The study results in conclusions regarding the relation of assessment indicators of the support provided by PES in job seeking with the elements of the theory of job search and recommendations for further research of the efficiency of the work of PES. PES business mandate and role is related to human resource management of the aiming at improving social welfare through the following three channels: (i) increasing labour market effectiveness; (ii) promoting equal access to labour market; (iii) mitigating the negative consequences of cyclical and structural changes in labour demand.

People tend to have several workplaces during their working age. Transfer from one workplace to another can also interchange with periods of unemployment.

Osberg (Osberg, 1993) compares job seeking with fishing; making a decision on accepting an appropriate job offer he compares with making a decision on a caught fish - analysis of which fish is "big enough" to keep (if you can only keep one).

According to Osberg, contemplation on whether the fish is big enough for keeping it is similar to an individual's contemplation on reservation wage and the factors of job seeking process impacting such contemplation.

According to Osberg (Osberg, 1993), it can be written down in a general form:

$$
P_{i t}=f_{t}\left(e_{k i t}, C_{i}, X_{i p}, Y_{i t}\right),
$$

which express the probability of an individual $i$ getting a job in period $t\left(P_{i t}\right)$, as a function of the effort used by the individual $\left(e_{k i t}\right)$ in all the $(k)$ methods used, personal contacts in the labour market $\left(C_{i}\right)$, the personal characteristics $\left(X_{i t}\right)$ that influence the reservation wage, and the characteristics of the labour market in which they search $\left(Y_{i t}\right)$.

By setting the reservation wage relatively high, the worker is less likely to receive an acceptable wage offer and will, on average, spend more time waiting for an acceptable offer than if she set reservation wage lower. Fitzgerald \& Fitzgerald (Fitzgerald \& Fitzgerald, 1998) has noted that the lower reservation wage implies a higher job-acceptance rate, lower 


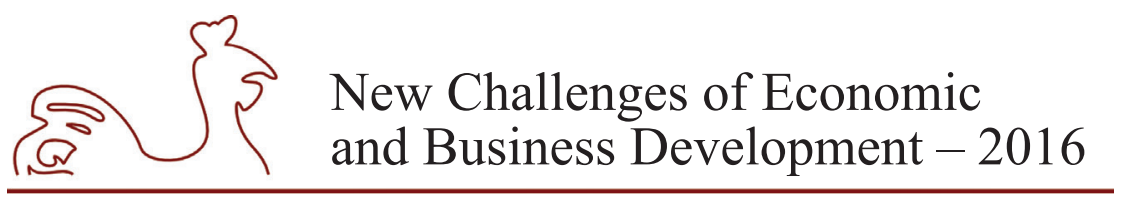

May 12-14, 2016, Riga, University of Latvia

unemployment duration, and lower steady state unemployment. An increase in the firing rate reduces the expected length of time at a given job, and thus reduces the benefit of waiting for a relatively high wage offer.

McCall in his model (McCall, 1970) assumes that a job seeker knows the distribution of wage for his particular skills, and the costs of search is a known constant. The individual continues to search and remains unemployed as long as the offers are less than some minimally accepted value. A critical value is associated with each individual's optimal search policy. The expected length of unemployment is calculated when the individual follow the optimal policy. Information on the labour market is very significant in job seeking and in economics in general.

Job search strategy is promoted by the following social skills of an individual: efficient use of information and services in job seeking, including use of information and communications technologies, ability to use informal social contacts efficiently, ability to prepare a CV curriculum vitae, ability to take part in job interviews and present oneself, availability of recommendations, understanding of one's own strong and weak sides, and understanding of the opportunities provided by the labour market.

Employers announce their vacancies both at the PES and seek employees on their own by placing advertisements in mass media, social networks and the services of private recruitment companies. All things equal, direct application to potential employers is associated with a higher probability of employment at the subsequent date of interview, while replying to advertisements results in higher paying employment. Job search intensity, measured by the number of search methods used, has a positive impact on both the probability of employment and on the wage at the subsequent date of interview. The fact that individual characteristics determine the use of various job search strategies, and different strategies have different effects on labour market outcomes (employment and wages) suggests that job search strategy plays an important role in matching workers with jobs (Rene \& Mark, 2001).

The key task of the PES is matching of labour supply and demand in order to stabilize the labour market and provide sustainable employment. To achieve these goals, the PES assists job seeker in the job search strategy and implement employment programmes.

\section{PES business models and indicators}

National governance structure in which PES operate depends on PES degree of autonomy from parent ministry or department, the involvement of private sector, the organisation of benefit system, the participation of social partners in decision making process and degree of administrative decentralisation. When social partners are involved in decision making of PES, this can contribute to better and more informed decision. The implementation phase may be less troublesome because these partners are able to create support among their respective stake holders, namely employers and employee organisations (Leroy \& Ludo, 2014).

For implementation of Europe 2020 strategy (European Commision, 2010) PES of European countries have developed their own strategy "PES 2020 Strategy" (European Commision, 2012). According to this strategy PES services are divided into five groups: services for employers, services for alignment between labour market supply and labour market demand, services for improving workforce skills and competences, the unemployed sustainable activation services, 


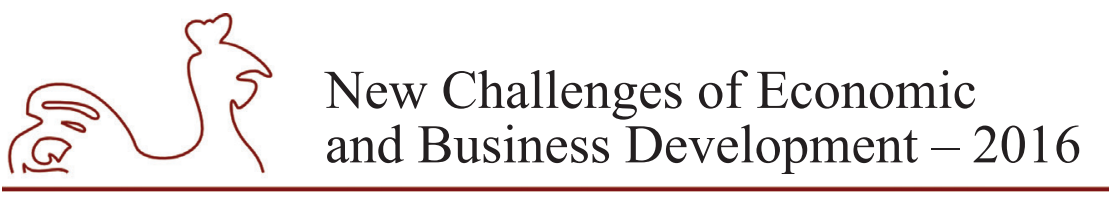

May 12-14, 2016, Riga, University of Latvia

services for improvement of career of the unemployed. ALMP measures cover two of these groups of PES services - services for improving workforce skills and competences (various vocational education programs) and the unemployed sustainable activation services (various subsidized employment, public works programs).

PES use different groups of indicators for business monitoring. Table 1 summarises these indicators.

Table 1

Comparison of Latvia's, Estonia's, and Denmark's PES business monitoring indicators

\begin{tabular}{|l|c|c|c|c|}
\hline \multirow{2}{*}{$\begin{array}{c}\text { ALMP and other PES } \\
\text { measure types }\end{array}$} & $\begin{array}{c}\text { PES business monitoring indicators } \\
\text { Number of } \\
\text { thobseekers } \\
\text { involved }\end{array}$ & $\begin{array}{c}\text { Number of } \\
\text { the created } \\
\text { workplaces }\end{array}$ & $\begin{array}{c}\text { \% of entrances } \\
\text { to employment } \\
\text { after jobseekers } \\
\text { participation in } \\
\text { ALMP (in 4, 6 or } \\
\mathbf{1 2} \text { month period) }\end{array}$ & $\begin{array}{c}\text { Number of } \\
\text { jobseekers } \\
\text { involved in } \\
\text { another ALMP } \\
\text { in 6r 12 month } \\
\text { period) }\end{array}$ \\
\hline Training measures & L, E & & L, E & L, E \\
\hline Employment measures & L, E & L & L \\
\hline Other measures & L, E & & & L \\
\hline $\begin{array}{l}\text { Decreasing of the unemploy- } \\
\text { ment duration }\end{array}$ & L, D & & & \\
\hline $\begin{array}{l}\text { Decreasing of } \\
\text { the unemployment duration } \\
\text { for young people }\end{array}$ & D & & & \\
\hline $\begin{array}{l}\text { Decreasing of the unemploy- } \\
\text { ment duration for immigrants } \\
\text { from third world countries }\end{array}$ & D & & & \\
\hline
\end{tabular}

Source: table developed by the author; designation: L - Latvia, E - Estonia, D - Denmark.

The process of accumulation of information about job vacancies isn't being monitored in Latvian PES, as well as the speed of finding a job. The Latvian PES' performance is not evaluated by the amount of days in which PES provides unemployment benefits, because Latvian PES does not grant them. On the other hand, the Latvian PES does not monitor its speed of granting services, which could be an important PES business efficiency indicator. Due to data limitations, the Latvian PES does not evaluate if there are positive changes in the wage levels of the unemployed placed to jobs via PES although in principle this is possible by matching PES data with data of the State Social Insurance Agency (this has been done in the World Bank project "Latvia - Who is Unemployed, Inactive or Needy?", (The World Bank \& Hazans Mihails, 2013)). Latvian PES doesn't evaluate the expenses for PES of recruiting one unemployed person, and also PES doesn't even out the business evaluation results according to regions, taking into account the different unemployment rates in country's regions. Latvian PES doesn't separately evaluate the effectiveness of services provided to the immigrants.

For the countries examined in this research - Latvia, Estonia and Denmark - PES organization and management are different. 


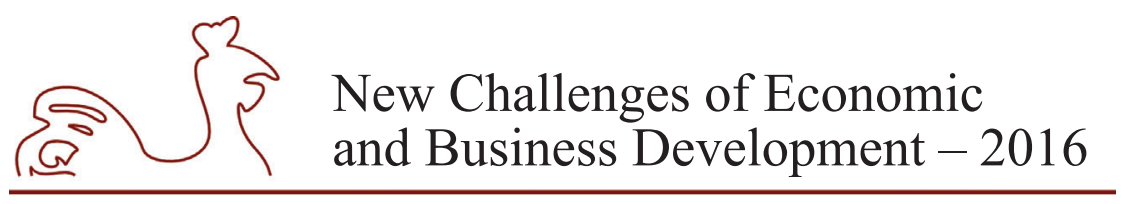

May 12-14, 2016, Riga, University of Latvia

In Latvia the social partners, non-governmental organizations and municipalities are not involved in the organization and management the PES. The Latvian PES cooperates and consults with social partners, non-governmental organizations and local authorities in the process of performing its duties. The cooperation with municipalities take place in accordance with the provisions of the Law of the Support to the Unemployed and Job Seekers, on the basis of the cooperation agreements concluded between PES branch manager and the local government. The PES organization of Latvia has only two levels - central office and 28 regional branches, whose managers are subject and accountable to the central management of the PES.

The Latvian PES uses the following indicators to assess performance efficiency and the impact on the labour market: (i) the number of jobseekers involved in ALMP measures; (ii) rate of jobseekers entrances to employment by ALMP measures within 6 months after the person's participation in ALMP measures; (iii) rate of long-term unemployed involved in ALMP measures; (iv) the share of unemployed youth (\%) who within six months after getting the status of the unemployed have become active - recruited or involved in any of the ALMP measures; (v) the filled vacancy rate (\%) in cooperation with employers; (vi) the unemployment duration for registered unemployed placed to jobs. For each of 28 Latvian PES branches the annual goals to be achieved are defined according to "Management by Objectives" methodology.

The Latvian PES operations are financed centrally and from the state budget, special budget, financial resources of the EU Structural Funds and other investment projects attracted.

The Estonian PES operates as an independent public institution managed by three bodies representing the government, the trade unions and the employers' organizations. The three bodies have equal rights and responsibilities. The organization of Estonian PES has a three-level structure - central office, 15 regional branches and 26 customer service points.

The Estonian PES is financed by the Estonian Unemployment Insurance Fund, governmental and other financial resources of the EU Structural Funds. The decisions on the aims of use of financial resources and their proportion are adopted by the Estonian Unemployment Insurance Fund (EUIF hereafter) tripartite council.

The goals and indicators of the EUIF are divided into four sets: impact indicators (labour market integration); output indicators (access of employment services); quality indicators; activity indicators. The Estonian PES applies the following performance indicators: (i) rate of entrances to employment within 12 (6 or 4) months for newly registered unemployed (excl. recipients of unemployment insurance benefit), \%; (ii) rate of entrances to employment within 12 (6 or 4) months for new recipients of unemployment insurance benefit, \%; (iii) participation rate on ALMP of long-term unemployed (period of registered unemployment at least 12 month) within past 12 month; (iv) participation rate on ALMP (monthly average), \%; (v) satisfaction index of job seekers and employers (Estonian Unemployment Insurance Fund, 2013).

The governance model of the Danish PES more than the other models discussed in this study focuses on the co-ordination of implementation of employment policy at three-tier levels (national, regional and local) and on the involvement of stakeholders of all levels in this process.

The municipalities have political competence to prioritise and design employment measures. Together with political accountability follows financial accountability. The refunds system provides a strong incentive for prioritising the employment area locally by carrying out active employment-direct measures. Financial management is basically deemed to provide each municipality with flexibility in relation to deciding budget levels and resource allocation for 


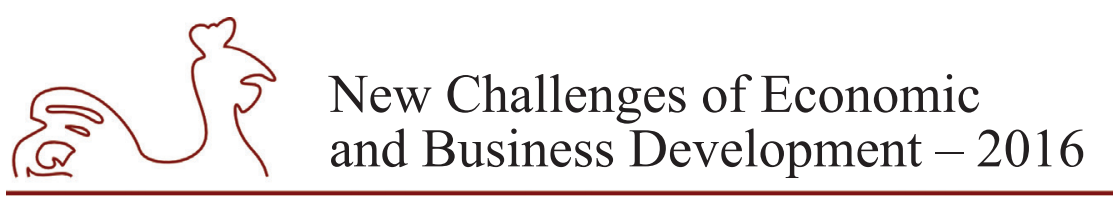

May 12-14, 2016, Riga, University of Latvia

employment measures. Each municipality can determine allocation of operating resources and staffing levels at job centres, as well as the resources used on ALMP (Mploy, 2011).

The system of the assessment of the Danish PES performance and the impact on the labour is complex because the employment policies of the implementation of the system are complex. At the national level strategic objectives and indicators are set for assessing the implementation of employment policy. At the regional level, these national objectives are coordinated with the needs of employers. Compared with the indicators used for the assessment of the Latvian PES performance, these indicators are more directly focused on the faster involvement of the unemployed into the labour market, as well as the involvement of the young people without education into the education system in order to obtain professional qualifications. Positive is the fact that in the process of implementation of employment policy objectives in Denmark, they are adjusted regionally in order to account for considerable differences in labour markets between the four Danish regions.

\section{Data and conceptual framework}

In order to compare how the local employment experts assess the operation of PES at a local scale and how such approach to assessment is consistent with the indicators of efficient operation of PES used by the PES and factors specified in job seeking theory that the PES can impact in the process of an individual seeking a job, the author interviewed employment experts in Valmiera and Liepaja.

In this study the author applies the approach of grounded theory and partially structured interviews, which involved asking a total number of 18 questions related to the role of the PES, their operational efficiency and institutional form to eight local level employment experts.

The study sample is created with the aim to acquire in-depth understanding of the studies issue at a local level. Employment and labour market issues of a local level are addressed not only by the job seeker, but also by the municipality, trade unions and a PES branch. Therefore, representatives of these institutions are the most competent experts and provide the most information on the issue under study.

Interviews involved four local employment experts from Valmiera and Liepaja, with each group of experts represented by one expert. Such size of aimed sample is justified, proportional and sufficient since it is possible to interview only one municipal manager and PES branch manager. Therefore, in order to maintain balance of experts among different groups, only one representative from each group in each city participated in the interview. For expressing the opinion of employees, employers with the biggest number of employees (large company) and with experience of at least ten years in addressing issues of local employment promotion from the most characteristic sectors of each city participated.

Valmiera was selected for interviewing local employment experts by the researcher because this city has a stable and below state average unemployment level in various stages of state economy development. Liepaja, in its turn, was selected for interviewing employment experts by the researcher because this city has a stable and above state average unemployment level in various stages of state economy development, and also - during the last three years more than 1000 employees lost their job because a large company ceased its operation. 


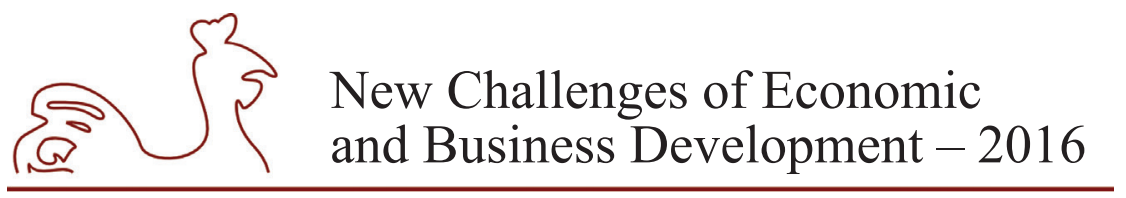

May 12-14, 2016, Riga, University of Latvia

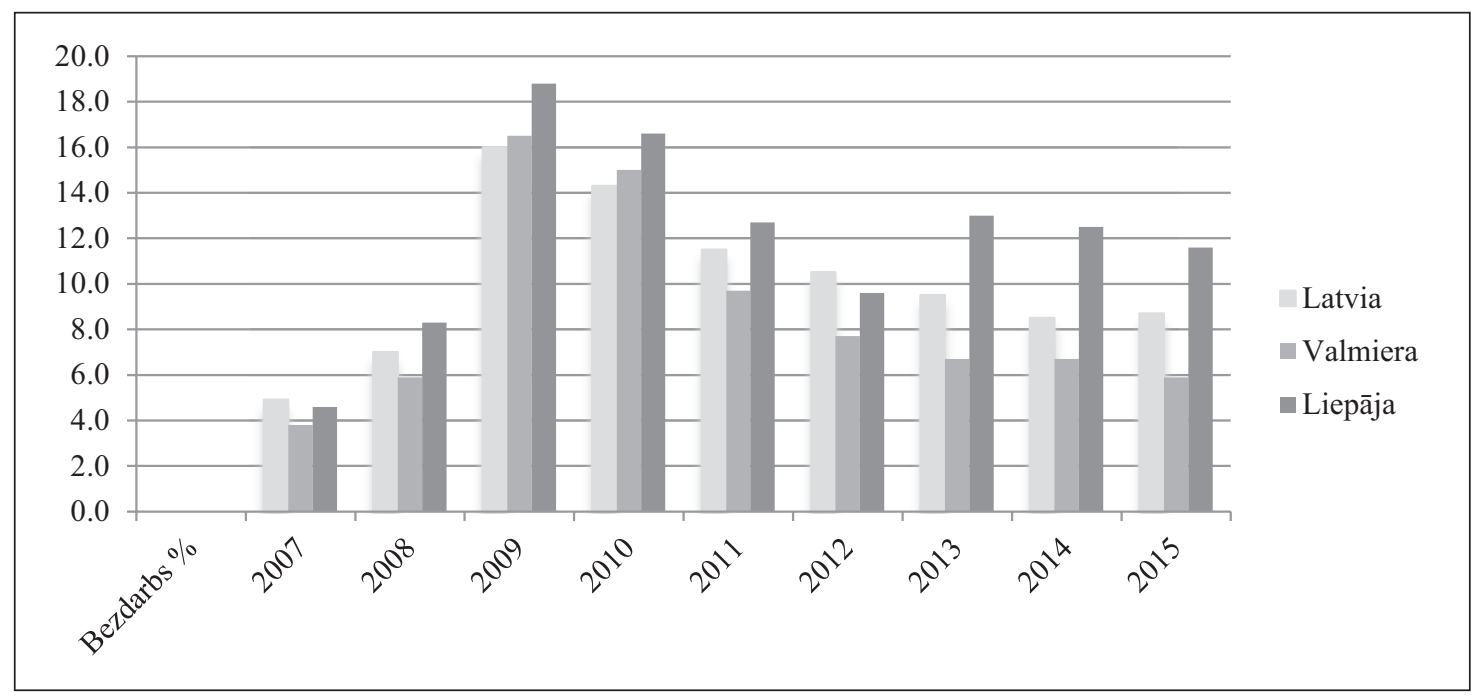

Source: State Employment Agency.

Fig.1. Registered unemployment level in Latvia, Valmiera, Liepaja, \%

The researcher carried out all interviews on-site in Valmiera and Liepaja during time period from 20.01.2016-27.01.2016, and recorded them in a recording device, created interview transcripts, and coded them using the approach of open coding. The researched numbered the codes according to the interview question number. The codes retain the designation of the person interviewed.

Afterwards, the researcher transformed these codes into categories, each of them retaining also the code number and, as a result, creating six PES evaluation category groups: (i) PES operation; (ii) scope of PES functions; (iii) PES communication; (iv) subjective evaluation of the PES; (v) PES cooperation partners; (vi) external economic environment. These categories are interrelated and impact one another (Table 2).

Table 2

\section{PES operation evaluation categories of local experts}

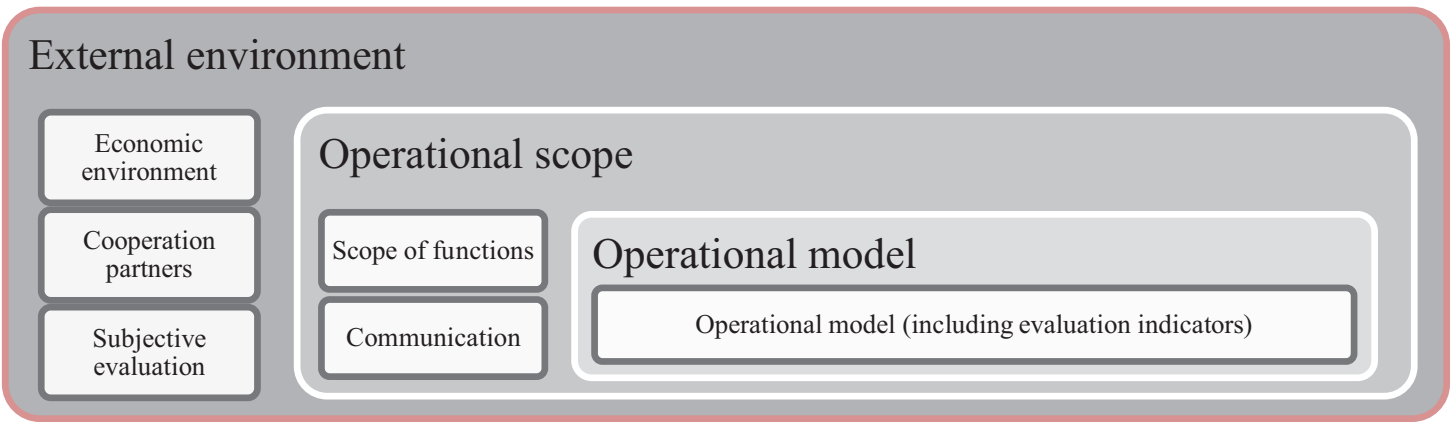

Source: table created by the author. 


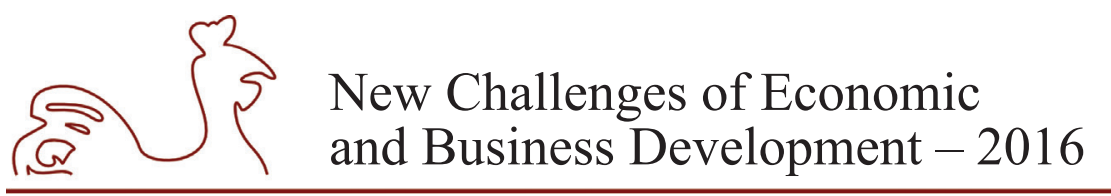

May 12-14, 2016, Riga, University of Latvia

During validation phase the researched validated the acquired theory by comparing it with the job seeking theory and the general practice of PES and the practice of the Latvian PES for the evaluation of PES operational efficiency.

\section{Research results and discussion}

In this study on PES operational efficiency, the experts most commonly expressed their opinion on the scope of functions of the PES (especially, regarding retraining, employment and labour market issues), external environment (especially, on cooperation partners) and on the scope of functions of the PES (especially, on services provided to the employees, retraining and labour market issues).

Table 3

Data analysis review broken down by PES performance evaluation (done by local experts) code categories

\begin{tabular}{|c|c|c|c|c|c|c|}
\hline $\begin{array}{c}\text { Code } \\
\text { categories }\end{array}$ & PES operational model & & Scope of PES fu & & PES cooperation part & \\
\hline & centralization & 6 & employment & 6 & municipality & 6 \\
\hline & branch network & 3 & retraining & 6 & cooperation & 5 \\
\hline 冚 & coordination & 3 & labour market & 5 & trade union & 3 \\
\hline 䟫 & $\begin{array}{l}\text { unsuccessful PES } \\
\text { operation }\end{array}$ & 2 & unemployed & 4 & educational institutions & 3 \\
\hline 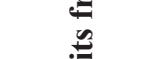 & administrative decision & 1 & motivation & 2 & business incubator & 2 \\
\hline 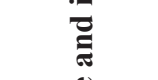 & partially centralized & 1 & assistance & 2 & $\begin{array}{l}\text { cross-institutional } \\
\text { coordination }\end{array}$ & 2 \\
\hline$\stackrel{\mathscr{E}}{=}$ & limitations & 1 & for youth & 2 & LTRK & 1 \\
\hline ? & NVA & 1 & centralization & 2 & LDDK & 1 \\
\hline & planning & 1 & career & 2 & social partners & 1 \\
\hline & municipality programmes & 1 & target audience & 1 & employers & 1 \\
\hline & reputation & 1 & lifelong education & 1 & $\begin{array}{l}\text { social function } \\
\text { bank }\end{array}$ & $\begin{array}{l}1 \\
1\end{array}$ \\
\hline $\begin{array}{c}\text { Code } \\
\text { categories }\end{array}$ & PES communication & & PES public $r$ & & $\begin{array}{c}\text { External economic } \\
\text { environment }\end{array}$ & \\
\hline & informing & 5 & satisfaction & 3 & economics & 4 \\
\hline & communicate & 2 & quality & 3 & data & 4 \\
\hline & Internet & 2 & traditions & 2 & public transportation & 1 \\
\hline$\underbrace{\bar{\sigma}}_{0}$ & information analysis & 1 & stereotypes & 2 & business environment & 1 \\
\hline $\bar{\partial}$ & good practice & 1 & PES branch & 1 & population & 1 \\
\hline $\bar{E}$ & homepage & 1 & & & large companies & 1 \\
\hline & social networks & 1 & & & $\begin{array}{l}\text { geographical location } \\
\text { shops }\end{array}$ & $\begin{array}{l}1 \\
1\end{array}$ \\
\hline
\end{tabular}

Source: table created by the author; designations: NVA - State Employment Agency, which is the PES in Latvia, LTRK - Latvian Chamber of Trade and Industry, LDDK - Employers' Confederation of Latvia, mentioned times - n. 


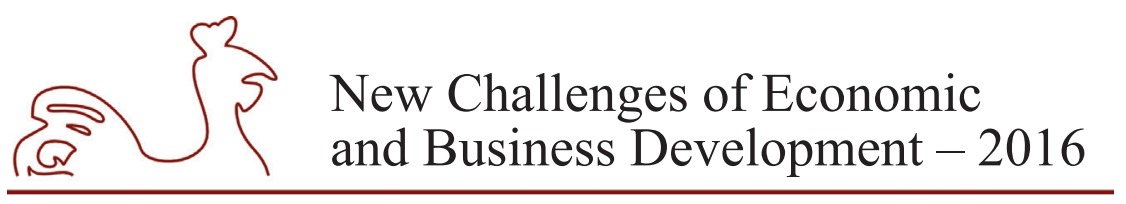

May 12-14, 2016, Riga, University of Latvia

This leads to conclusion that that efficient PES operation is primarily associated with actions promoting employment, forecasting the labour market and promoting cross-institution cooperation. The priority of PES operation must be the local level so that the services of the PES would correspond to the specifics and needs of the local level.

In order to achieve the expected operation results from the PES at a local level, the interviewed experts pointed out that additionally to the currently implemented registering of unemployed persons, training and cooperating with municipalities, the PES must also be an ombudsman of the labour market, inform on the activities within the labour market, make inquiries about the plans, problems and needs of the employers, and organize a dialogue between the employers and educational institutions on the preparation of skills and competencies required by the workforce. The PES must also explain to the job seekers how job seeking strategy is formed; they must work only with motivated job seekers. Their external communication must contain advertisements of their own services and examples of good practices.

Thereby, according to the opinions of the local employment experts, the PES could change the existing stereotypes among population on their operation (PES works only with unmotivated, poorly qualified and unhappy people; the PES offer only vacancies of low quality; the PES provide services of bad quality because they are free-of-charge) and strive to find job seekers and employers/employees of higher priority of order within the list. It is indicated in the studies that the PES is not the primary job seeking method. The relatively good jobs paying are usually found through "informal information network" (Osberg, 1993). Also, the local employment experts pointed out in the interviews that in the search for qualified employees placing advertisements in mass media is the choice of priority instead of the PES since people who are really looking for a job respond to such advertisements.

The local employment experts evaluated in the interviews that the reservation wage of a non-competitive job seeker would be justified in the range 370-500 EUR, for an average competitive job seeker - 550-1100 EUR, and for a fully competitive one - 600-1500 EUR.

External PES environment promoting employment was characterized in the interviews as a good business environment, well organized public transportation, beneficial geographical location, and successfully retained sectors of historical production industry with adaptation to the nowadays globalized world.

The local employment experts admitted in the interviews that the PES, municipality, employers and their associations, and educational institutions are not the only ones interested in the efficient operation of the PES. At a local level, the operation of the PES should be of interest also to such institutions as trade unions and Employers' Confederation of Latvia. Also, experts pointed out the need for institutions, at a local level, to analyse their operational results in a comparative manner and plan their improvement.

For its operation to be efficient, the PES operational model must take into account the specifics of the local situation. The precondition for successful operation of a local branch must be the implementation of national-level tasks of the PES.

By defining a good job seeking result, the employment experts defined it as a combination of variables, which is made up by a factor of an individual's employment and satisfaction. 


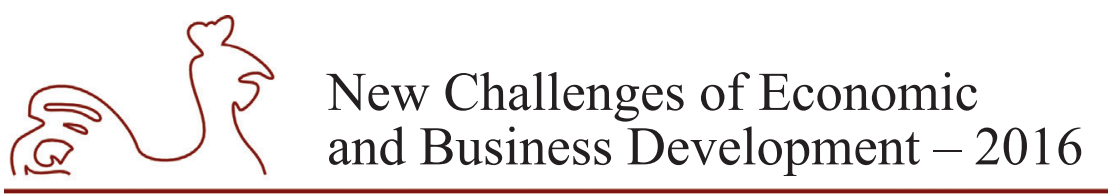

May 12-14, 2016, Riga, University of Latvia

The following indicators should be applied in evaluating the PES operation:

Table 4

Comparison of job seeking theory elements and PES operational efficiency indicators suggested by the local employment experts

\begin{tabular}{|l|l|}
\hline \multicolumn{1}{|c|}{ Job seeking theory elements } & $\begin{array}{l}\text { PES operational efficiency evaluation indicators } \\
\text { suggested by the local employment experts }\end{array}$ \\
\hline $\begin{array}{l}\text { Job seeking strategy } \\
\text { Abservation wage }\end{array}$ & $\begin{array}{l}\text { Number of unemployed } \\
\text { Duration of unemployment period (in days) } \\
\text { Number of people who found jobs } \\
\text { Contingency between the number of job seekers } \\
\text { and number of vacancies }\end{array}$ \\
\hline $\begin{array}{l}\text { Skills } \\
\text { Competency }\end{array}$ & $\begin{array}{l}\text { Recruitment of unmotivated unemployed (in } \\
\text { numbers) } \\
\text { Recruitment according to the acquired } \\
\text { qualification (in numbers) }\end{array}$ \\
Acquiring a qualification according to \\
the company needs (qualitative assessment) \\
Labour market monitoring
\end{tabular}

Source: table created by the author.

The view of the local employment experts regarding the PES operational efficiency indicators corresponds to their opinion on the role of the PES in the local labour market and its ability to impact this labour market. The PES operational indicators must be defined so that they would promote the PES operational efficiency at a local level, especially: (i) through occupying the free vacancies of the employers, (ii) through dedicated promotion of the competitiveness of job seekers and (iii) through ensuring information on the labour market.

\section{Conclusions and recommendations}

The centralized approach of the Latvian PES operational models, together with the state policy and limited allocated financing for the employment promotion activities ensures a unified approach to the promotion of workforce competitiveness, however, it does not take into account the specifics and solutions of the local labour market, as it is offered by other PES in cooperation with municipalities.

Workforce competitiveness promotion requires fast and precise support from the PES, therefore, the PES operation model must ensure both equal approach to the services throughout 


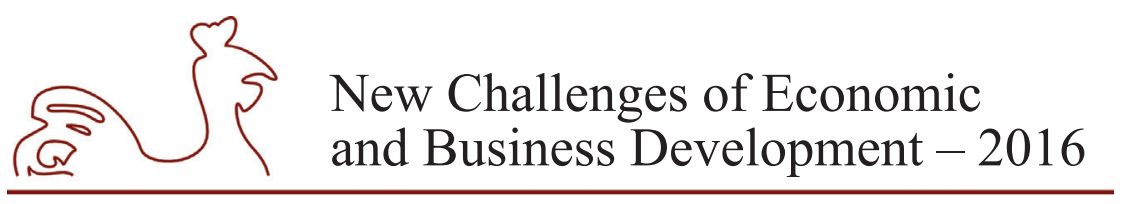

May 12-14, 2016, Riga, University of Latvia

the whole country, as well as it must take into account the specifics of the local labour market. The PES operational monitoring indicators must be comprehensive, so that it would be possible to evaluate the changes in the standard of living and improvement of competitiveness within the labour market of an individual.

For its operational efficiency evaluation the Latvian PES does not use such important elements mentioned in the job seeking theory as (i) duration of employment after a period of unemployment, (ii) amount of wage and the dynamics of its changes, (iii) work conditions, as well as (iv) does not complexly evaluate the impact of the PES on the implementation of the job seeking strategy of an unemployed.

The signs mentioned by the local employment experts based on which the operation of the PES is considered efficient, correspond to the elements of job seeking theory. The vision of the local employment experts of efficient PES operation can be ensured through cooperation of the PES and other institutions (municipalities, representatives of employers, trade unions, and educational institutions). Hence it is clear that the operational efficiency of the PES must be evaluated together with the operation of the mentioned institutions.

Efficient PES operation is primarily associated by local experts with actions promoting employment, forecasting the labour market and promoting cross-institution cooperation. The priority of PES operation must be the local level so that the services of the PES would correspond to the specifics and needs of the local level. PES must also be an ombudsman of the labour market. PES must also explain to the job seekers how job seeking strategy is formed. PES could change the existing stereotypes among population on their operation. PES operational model must take into account the specifics of the local situation. The precondition for successful operation of a local branch must be the implementation of national-level tasks of the PES.

Therefore, in the future studies it is advisable to evaluate whether the range of PES operational evaluation indicators must be complemented, as well as - it must be evaluated, whether the use of all indicators is efficient and possible in cross-sections of data availability, including at the local level. The ability of the PES to impact the labour market must undergo more studies: (i) PES customer survey on the efficient PES operation, through including unemployed, job seekers, employees with experience of unemployment in Liepaja and Valmiera in the sample, as well as - (ii) to interview unemployment experts of a national scale regarding efficient operation and organization of the PES.

\section{Bibliography}

Estonian Unemployment Insurance Fund. (2013). PEER PES PAPER. Peer Review "Peer Review on Performance Management in Public Employment Services (PES).” European Commision.

European Commision. (2010). Europe 2020. A European strategy for mart, sustainable and inclusive growth. Retrieved August 25, 2014, from http://ec.europa.eu/eu2020/pdf/COMPLET EN BARROSO 007 - Europe 2020 - EN version.pdf

European Commision. (2012). Public Employment Services 'Contribution to EU 2020.

Fitzgerald, T. J., \& Fitzgerald, T. J. (1998). An introduction to the search theory of unemployment An Introduction to the Search Theory. Researchgate, (September), 1-15. Retrieved from http://www. researchgate.net/publication/5028931

Leroy, F., \& Ludo, S. (2014). Buildins Bridges. Shaping the Futureof Public Employment Services Towards 2020. Brugge: die Keure Professional Publishing. 


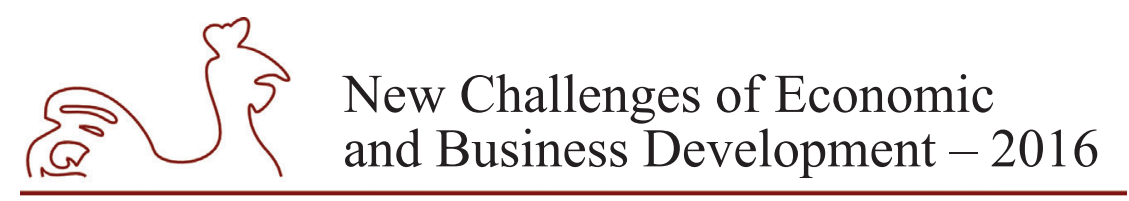

May 12-14, 2016, Riga, University of Latvia

McCall, J. J. (1970). ECONOMICS OF INFORMATION AND JOB SEARCH. Quarterly Journal of Economics, 84(1), 113-126. Retrieved from https://datubazes.lanet.lv/login?url=http://search. ebscohost.com/login.aspx?direct $=$ true $\& \mathrm{db}=\mathrm{bth} \& \mathrm{AN}=4965993 \&$ site $=$ eds-live

Mploy. (2011). Accountability Into Local Employment Services : Country Report for Denmark Building Flexibility and Accountability into. Retrieved from http://dx.doi.org/10.1787/5kg3mktsn $4 \mathrm{tf}-\mathrm{en}$

Osberg, L. (1993). Fishing in Different Pools: Job - Search Strategies and Job - Finding Success in Canada in the Early 1980s. Journal of Labor Economics, 11(2), 348-386. Retrieved from http:// myweb.dal.ca/osberg/classification/articles/academic journals/fishing in different pools/fishing in different pools.pdf

Rene, B., \& Mark, T. (2001). Job search methods. Retrieved September 28, 2015, from https://www.iser. essex.ac.uk/research/publications/working-papers/iser/2001-07.pdf

The World Bank, \& Hazans Mihails. (2013). Scientific research: Latvia: "Who is Unemployed, Inactive or Needy? Assessing Post-Crisis Policy Options." Ministry of Welfare, Latvia. 


\title{
CORPORATE SOCIAL POLICY: A NEW MODEL FOR CONSCIOUS ECONOMY
}

\author{
Olga Kanaeva, Saint Petersburg State University, Russia ${ }^{1}$ \\ Alexander Kanaev, Saint Petersburg State University, Russia
}

\begin{abstract}
Problem statement and research aim. The modern model of social policy implemented in many countries, both at the macro (state) and the micro (companies) levels shows low efficiency. The lack of serious systemic shifts in social sector, growth of social risks testify the crisis of the idea and practice of a social state, give grounds to skeptical assessment of corporate social performance effects. The latter necessitates rethinking the prevailing notions and theories, the formation of new research approaches, bringing the objectives and content of corporate social policy (CSP) into line with the modern challenges and risks, the implementation of a new model of CSP in practice.

The article shows the features of corporate social performance of major international and Russian companies, the reasons for its poor results, substantiates the necessity of transformation of the goals and content of CSP, reveals the basic principles and directions of CSP version 2:0. adequate to the conscious economy principles.

Research methods used. The propositions and conclusions of the paper are based on the modern corporate social responsibility (CSR) and sustainable development conceptions, the comparative analysis of scientific research approaches used and the results of studies of corporate social practices of Russian and international companies conducted by Russian and foreign research centers in the years 2004-2015, as well as on the results of research carried out at Economics Faculty of St. Petersburg State University in the years 2008-2015, aimed at identifying the characteristics features of Russian companies social policy. Main results and findings. The authors conclude on the necessity of CSP reconceptualization (one of its directions should be the integration of CSR, CSP and sustainable development issues); bringing the objectives and content of CSP in compliance with the modern challenges and risks; the implementation of a new CSP model in the Russian companies practice. For its formation should be solved a set of interrelated problems of theoretical and applied research, such as the instrumentalization and operationalization of CSP, its professionalization and institutionalization. Their solution requires the joint efforts of academic, professional and business communities.

Practical implication. The results could be the basis for CSP reconceptualization and the formation of the modern CSP model.
\end{abstract}

Key words: conscious economy (capitalism), corporate social responsibility, corporate social performance, corporate social policy, corporate social policy reconcepualization

JEL code: M 14

1 Corresponding author - e-mail address: olga.kanaeva.58@mail.ru 


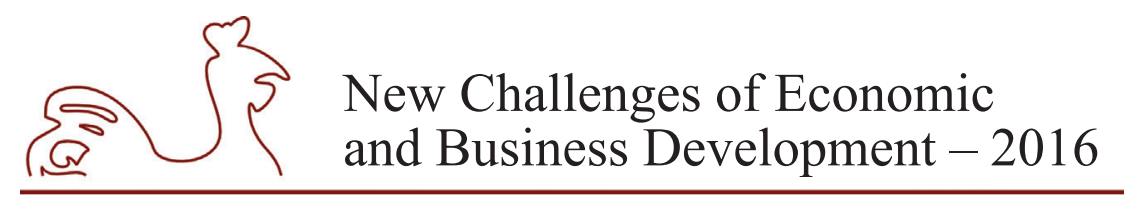

May 12-14, 2016, Riga, University of Latvia

\section{Introduction}

In recent years some researchers in their work are increasingly using an original scientific technique - they introduced the concept of "versions" of 1.0 and 2.0. to indicate that studies carried out analysis of the current trends in the study area and the necessity of relevant changes, the transformation of attitudes and research approaches, the search for alternative development models (Hamel G., 2010; Hamel G. et al., 2011; Visser W., 2010, 2011, 2012). The situation we are witnessing today in the sphere of social policy, including CSP, gives every reason to use this technique. And it isn't a tribute to the fashion trends, for it usage there are valid reasons.

No serious systemic changes in the social sphere, growth of social risks testify about the crisis of the idea and practice of the social state, about low efficiency of social policy model being implemented in many countries, both at macro (state) level and at micro (corporate) level, and low efficiency of corporate social performance, in general, (Visser W., 2011). This situation forced to rethink current approaches to social policy, its objectives and content (Aganbegian A., 2013; Barton D., 2011; Bljahman L., 2012).

The corporate social policy, in the most general terms, we can define as a form of implementation of corporate social responsibility (CSR); the company's activities aimed at identifying social needs and expectations of interested parties, implementation of its relevant social obligations; mechanism of development and implementation of decisions in the social sector at the level of individual companies (corporate level).

A number of studies (international, national, regional), aimed at investigating the characteristic features of business ideas and perception of CSR, analysis of the social practices of Russian companies and assessing the structure and dynamics of social investments were carried out in Russia in 2004-2015 (The report on social investments in Russia, 2004, 2008, 2014; Analytical review, 2015). Related subjects research aimed at studying the characteristics of corporate social performance and CSP of Russian and international companies operating in Russia were conducted in the Faculty of Economics of St. Petersburg State University in 2008-2014: "CSR: St. Petersburg Companies Experience" (2008); "Social practices of 200 companies included in the list of the largest companies of Russia according to the "Expert" journal" (2010). These researches was conducted by the method of content-analysis of the materials placed on the official corporate websites, as well as by analysis of social reports of these companies. The results made it possible to identify a number of criteria to actualize companies social policy typology by the following criteria: CSP formalization (formalized and non-formalized policy); CSP integration into the company's strategy (integrated and nonintegrated policy); the scope of the CSP implementation (foreign and domestic policy); CSP objectives (short-term, local, long-term, sustainable development); CSR pattern (proactive, reactive, democratic, authoritarian); CSP complexity (complex, fragmented SP). The research results were presented in the monograph "Corporate Social Policy: Theory and Practice of Management Decisions" (Kanaeva O., 2013).

The generalization of the results of above mentioned studies, as well as of the studies of companies' financial statements, the materials placed in the "Library of corporate practices" (Russian Union of Industrialists and Entrepreneurs (RSPP) publishes them since 2008) and corporate web sites reveal the features of corporate social performance and Russian companies' social policy, the reasons for its low efficiency. Despite of the obvious lack of empirical data obtained and their limited representativeness and comparability, the research 


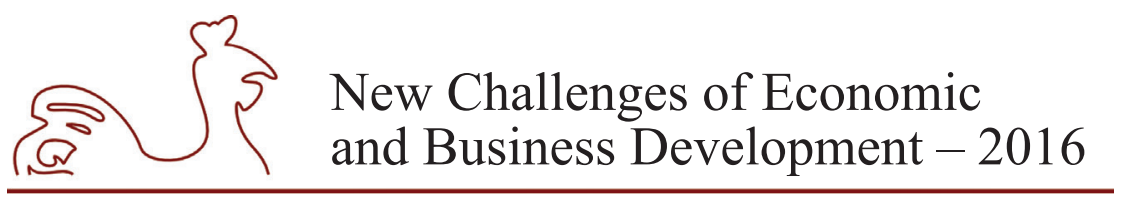

May 12-14, 2016, Riga, University of Latvia

results adumbrates the extent of Russian companies' involvement in the corporate social performance, the most common approaches to the understanding of directions of the CSP, its trends and constraints.

\section{Research results and discussion}

\section{Social policy of Russian companies $\mathbf{1 . 0}$}

Comparative analysis of Russian and foreign scientists' research approaches to CSR and CSP indicates that there are some differences between them. Abroad, the social aspects of company activities traditionally considered within the broader perspective of CSR. In Russia, we are observing a certain alienation, autonomy of CSP research from a more general perspective of CSR and sustainable development (Kanaeva O., 2013. P. 190-207).

So, abroad corporate social policy CSP has become a subject of debate since the mid $\mathrm{XX}$ century, firstly within in the emerging corporate social responsibility concept and issues associated with it - the corporate social responsiveness and corporate social performance concepts and the concept of shred value proposed by M. Porter and M. Kramer (2011).

One of the first author who described the relationship between CSR and company policies was H. Bowen. In famous work "Social responsibility of the businessman" he defined social responsibility as "the obligations of businessmen to pursue those policies, to make those decisions, or to follow those lines of action which are desirable in terms of the objectives and values of our society" (Bowen H., 1953, 6). Thereby H. Bowen linked CSR implementation with an adoption of appropriate management decisions. Later in 1960 the need to consider CSR within a management context was firmly highlighted by K. Davis, who define business social responsibilities as "businessmen's decisions and actions taken for reasons at least partially beyond the firm 's direct economic or technical interest" (Devis K., 1960, 70).

However the most significant contribution to the formation of CSP theoretical bases has been made by the creators of the corporate social performance conception, which has become the starting point of wide theoretical and applies researches of CSR management aspects, forms and mechanisms for its implementation - A. Carroll, S. Wartick, P. Cochran, D. J., E. M. Epstein, D. J. Wood and D. Swanson. The key provision of this conception which allows us to incorporate the concept of "social policy" in the CSR conceptual system and to disclose their relationships is S. Wartick and P. Cochran notion: "the CSP model reflects an underlying interaction among the principles of social responsibility, the process of social responsiveness, and the policies developed to address social issues. The CSP model relies on this expanded version of social responsibility and this principle/process/policy approach in order to provide a distinctive view of a corporation's overall efforts toward satisfying its obligations to society" (Wartick S. et al., 1985, 758).

Familiarity with CSR modern publications as a whole shows that the "social policy of the company" concept is widely used in corporate social responsibility issues researches, although this phenomenon per se has not become a subject of special studies. Despite some differences in its interpretation, the most of authors consider CSP as a particular form of CSR realization or a special managerial mechanism of response to social demands of corporate stakeholders as decisions taken by companies to solve to identified social problems. The analysis of above mentioned concepts indicates that at the present time an approach was formed to build 


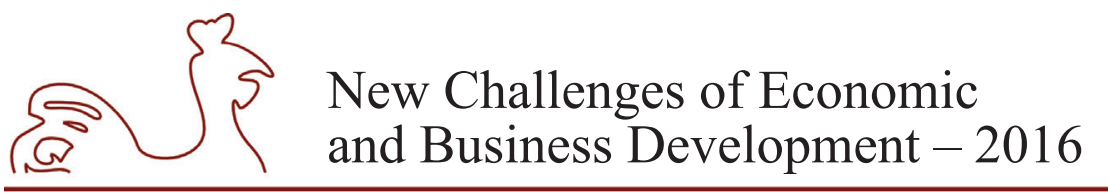

May 12-14, 2016, Riga, University of Latvia

a sufficiently harmonious system of concepts reflecting companies position in respect of its social responsibility (CSR), the nature and means of possible responses to social problems and stakeholder requests (corporate social performance) as well as the forms and mechanisms of social responsibility realization and implementation - corporate social strategy and policy (tab). For purposes of our study the CSP concept could be defined as a form of CSR implementation; the system of settings, goals and principles of the company activities in the social area (sphere); defined sequence of actions a system of measures aimed at achieving these goals; a mechanism for appropriate decisions making and their implementation.

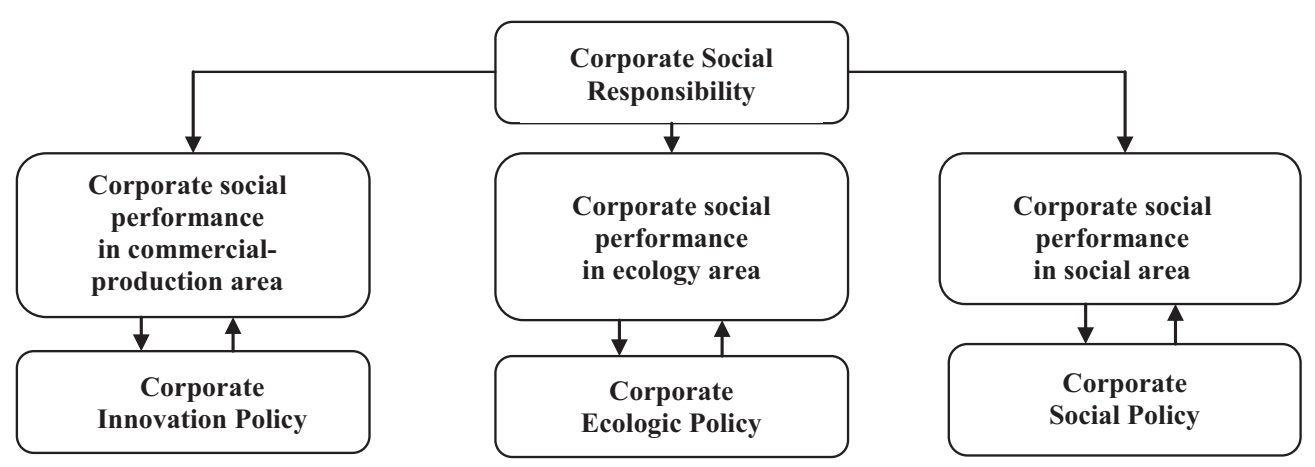

Source: author's construction.

Fig. 1. Corporate social policy as a CSR realization and implementation

The situation in Russia publications can be characterized as highly ambiguous. On the one hand, studies show that the number of companies that declare their commitment to CSR, following the international CSR standards and implementing non-financial reporting is increasing (see National register of corporate non-financial reports). Development of social activity of Russian companies in general corresponds to global trends (The report on social investments in Russia-2008, 2008). Currently, it is possible to select a group of leading companies (about 60 major Russian and international companies operating in Russia), implementing effective social policies. In professional and scientific communities outlined common approaches to the interpretation of content and form of CSP implementation, its objectives and directions. However, on the other hand, the research findings also confirm the availability of certain contradictions in manifestation of this trend and indicate the existence of serious problems and limitations.

1. There is no common approach to the interpretation of the content and the possible forms of implementation of CSR, the objectives and content of the relevant corporate policies; there is a high variability of CSP types. The range of approaches to understanding of the contents and implementation of CSR is very wide - from liberal ideologist of which was Milton Friedman (Friedman, 1970), to a strategic approach (Porter M. et al., 2006). In our opinion, at present, we can distinguish at least five approaches to CSR companies realized in practice: liberal, traditional (traditional charity), social-oriented, integrated and strategic (Kanaeva O., 2013. P. 129-169). The overwhelming majority of Russian companies adhere to the traditional and socially-oriented approaches.

2. The studies conducted confirm the availability of link between the approach to CSP implemented in practice and its objectives and priorities. As CSP objectives are generally 


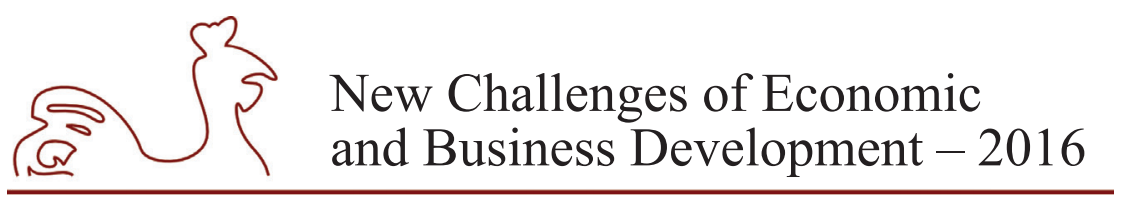

May 12-14, 2016, Riga, University of Latvia

considered to achieve short- and medium-term social effects (local in nature) related to internal social problems solutions: fulfillment of current requests of staff and local community; strengthening the company's reputation; increase staff loyalty. The CSR priority areas includes HR development, health and safe working conditions.

3. These studies indicate as a distinct feature of modern Russian business practice the presence of high variability of social projects and programs, of evident underestimation of comprehensive and systematic approach to CSP. Companies focus on detached elements of the CSP, which is not seen as a multidimensional process.

4. There are no clear conception about the criteria and mechanisms for determining of CSP priorities. In most companies the priorities of CSP choice is carried out based on the subjective assessment of severity of existed social problems, company resource potential, managerial internal attitudes and power of external pressure. Criteria such as effectiveness of CSP measures, assessment of the priorities degree of certain social programs executed by company's stakeholders and severity of non-financial risks, with rare exceptions, are not considered.

5. The number of Russian companies with an interest in the identification of stakeholders, their needs and expectations, the analysis of the possible ways to respond to them is small. The activity in this issue displayed those companies that intends to enter to international markets or companies who are forced to bear greater social responsibility (for example, town-forming). The mechanism to identify stakeholders, the interaction with them and define their needs is under development - only $8 \%$ of companies made an attempt to detect their stakeholders, only $17 \%$ of companies were planning such research in the future according to the studies conducted (The report on social investments in Russia-2008, 2008; Kanaeva O., 2013)

6. A small part of Russian companies assess the effectiveness of social investment - only $17.9 \%$ of companies taking part in research "CSR: St. Petersburg Companies Experience" (2008)" recognized the need to evaluate the CSP effectiveness (Kanaeva O., 2013). In practice, the assessment of the socio-economic impact of corporate social performance and CSP implementation were replaced by assessing the individual social programs costeffectiveness, which, in turn, was reduced to measuring quantitative results (amount of investment, number of persons involved in particular program, number of employees who took part in implementation of these programs, number of measures undertaken).

7. The most Russian companies underestimated the efficiency of the management approach to CSP (according to which the latter is treated as an independent object of management), as well as the possibility of using methods of operational and strategic management in CSP realization. The integration of CSR in the company corporate governance system and the development of organizational support of corporate social performance are very slow and generally chaotic.

8. There is no clear understanding of the mechanism of CSP formation, methods and tools for its implementation. The most widely used by Russian companies internal and external social policy tools reflect the dominant practice approaches to CSR, the degree of company involvement in solution of particular social problems. According to the "set" of these tools can be judged on the type of social policy specific for a particular company. 


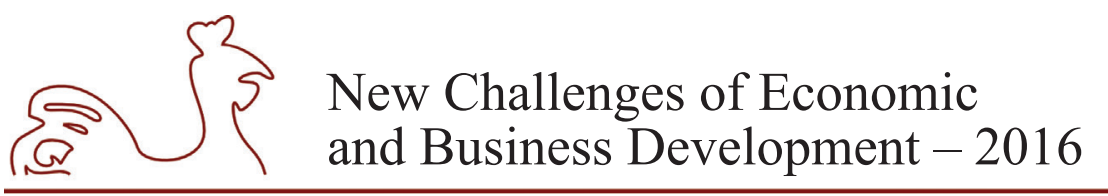

May 12-14, 2016, Riga, University of Latvia

9. The rather characteristic feature of the Russian companies' CSP is, on the one hand, a clear underestimation of the importance of CSP formalization, and on the other hand - the lack of generally accepted ideas about which documents should reflect CSP principles, objectives and direction. This situation is confirmed by a wide variety of documents reflected their accepted social obligations.

10. Despite of the tendency growth of Russian companies engaged in the non-financial reporting published on a regular basis were being revealed the information on the triple bottom line mode (economic, environmental and social performance), the expansion of reporting companies industrial structure and the improvement of reporting quality, the total number of companies involved is relatively small . During the period from 2000 to 2015 only 159 companies published 634 non-financial reports (Analytical Surveys of RSPP on non-financial reporting).

11. Only in a few cases CSP is seen as a factor in improving the competitiveness and corporate sustainability and the sustainable development of society as a whole. However, the global international and some major Russian companies implementing a strategic approach to CSR are increasingly considering CSP as a strategic management tool applied to social factors for improving the company competitiveness and sustainability, as a company's contribution to socio-economic development of regions, to solution of national social policy problems. Among them are: the raw material companies (Lukoil, Gazprom, SUEK, Polyus Gold), the ferrous and non-ferrous metallurgy companies (UC Rusal, "VSMPO-Avisma", Evraz Group, MMK), the chemical and petrochemical industry companies (Fosagro, EuroChem, Sibur), the engineering companies (Power machines, Kamaz, OMZ), the transportation companies ("RZ", Aeroflot) etc.

Thus, above mentioned researches confirm the commitment of the majority of Russian companies to CSR "reactive" model, in which the CSP is treated as a set of social projects and programs aimed primarily at company personnel and are able to provide a local effect of short-term and medium-term. The CSP objects are company's staff and local community; and its subject is (identified in some way) social problems and requests (primarily related to provision of social packages, creation of favorable working conditions, personnel training) and corresponding to them a set of social obligations.

\section{CSP 2.0: formation principles and directions}

The characteristic features of Russian companies' social activities formulated in the above mentioned studies lead to conclusion that for the most of companies social policy are characterized as non-formalized, fragmented, local on objectives and reactive in nature. Revealed approaches to CSP formation and implementation indicate varying degrees of involvement of Russian companies in corporate social performance, as well as the certain logic of this involvement - motion from the traditional and socially-oriented approaches to strategic one. At the same time, the model of strategic CSR is still exotic, even for companies have perceived CSR ideas. These features also indicate the necessity to rethink approaches to the interpretation of objectives, content and mechanisms of realization of CSP, to bring them in line with modern challenges and risks, the implementation in practice of Russian companies a new model of social policy - CSP 2.0. 


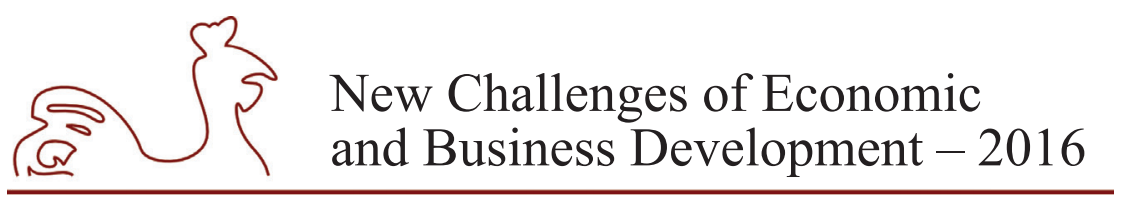

May 12-14, 2016, Riga, University of Latvia

In order to form a new CSP model it is practical to solve a set of interrelated theoretical and applied tasks, such as reconceptualization, instrumentalization and operationalization of CSP, its professionalization and institutionalization. Their implementation requires joint efforts of the academic, professional and business communities.

CSP reconceptualization involves the development of a holistic, consistent and generally accepted system of views on the objectives, functions, content and mechanism of CSP implementation adequate to the principles of responsible and conscious economy, as well as system-relevant concepts. Formation of the conceptual foundations of CSP should, in our view, be based on a multidisciplinary, multisubjective and systemic approaches and suggests integration of CSP theories and conceptions associated with CSR and sustainable development problematic (conceptions of: CSR, corporate social performance, creating shared values, corporate citizenship, sustainable development, corporate sustainability).

The multidisciplinary approach involves study of CSP phenomenon in the framework of the sociological, economic and management research areas. Its advisability is associated with the necessity to integrate such scientific areas approaches for interpretation of the research methods and tools of CSP phenomenon. In the sociological framework researchers attention focuses on interaction in social sector between companies, the state and society, on the problems of their interests balance. In the economic framework - on the effectiveness of CSP assessment, CSP influence on company core activities and its long-term competitive advantages formation. With management science positions CSP is considered as an independent management object, and in this regard, of particular interest are the managerial aspects of the CSP.

In accordance with multisubjective approach received, at the moment, quite broad support, a business organization is regarded as one of social policy subjects, along with the state, regional and municipal administrations, civil society institutions. According to this approach one of the CSP fundamental principles should be considered the principle of solidarity responsibility of all parties interested in solving social problems and social development: government, business and citizens.

In accordance with the systematic approach, CSP should be considered, on the one hand, as an element in a system of national social policy, on the other - as a phenomenon with complex internal structure, its specific (local) goals, object and subject, as well as an integral part of corporate strategy. The integrity of this system should be ensured by common (shared by all) social values, the unity of the strategic goals of social policy.

The severity and nature of the social problems, the specifics of socio-economic situation in Russia and innovative type of economic development requirements allow us to consider as a social policy strategic objective a human potential development and creation of favorable conditions for its implementation. It is clear that achievement of this goal requires solution of a set of tasks, which priority is determined by many factors and conditions. As a priority should be considered problems, which implementation will be able as soon as possible to provide the greatest contribution to the established goals achievement. These, in our view, should include a set of tasks for population health management, formation of the system of education adequate to today's challenges and creation of equal opportunities, improving personal social stability of citizens.

The identified problems solution and as a result, the strategic goal implementation will require not only a change in the principles and the institutions functioning in these spheres, but also assessment of feasibility of each social policy subjects in their implementation, development 


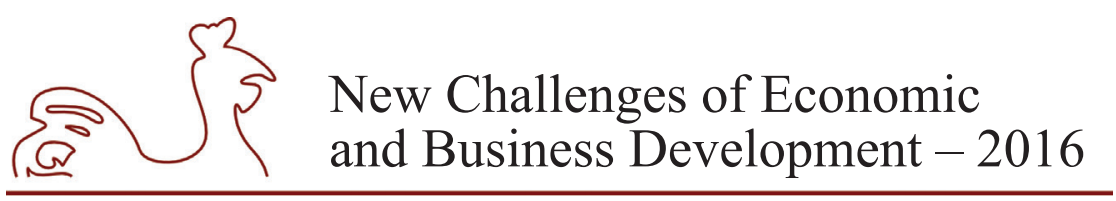

May 12-14, 2016, Riga, University of Latvia

of appropriate mechanisms for CSP. Thus, on the one hand, the focus should be on delimitation of the responsibility scope of the state, regional authorities and companies, on the general and local, specific social functions definition, and on the other hand - on finding the intersection of their interests in the field of social policy. The latter is particularly important from the point of view of increasing business interest in solving various social problems and can be treated as a condition of effective CSR formation, serve as a guide to determine the priorities of internal and external social policy of the company and contribute to the goals of social policy.

Obviously, that as these areas of business and the society interests intersection, and consequently, as a priority CSP directions could be considered kinds of activity, which results of the implementation will be so-called shared social values, the overall socio-economic impact consists for companies - in the formation of unique intangible assets (in the form of intellectual, human, social and reputation capital) and, consequently, to ensure the long-term competitive advantages, improving corporate sustainability; for the individual - in the development of his personal capacities and personal social sustainability; for society as a whole - in human development and sustainable development.

Thus, as the CSP objectives should be considered the accumulation and improvement of quality of human, social and intellectual company capital, since a solution of complex problems is relevant to the social policy long-term objectives and the interests of both companies and society.

CSP operationalization and instrumentalization - the formation of a clear understanding of the basic managerial processes and functions, as well as the methods and tools of CSP formation and implementation - are possible within the framework of management approach to company social policy according to which it is regarded as a particular object of management.

The managerial approach to CSP implies the interpretation of company social policy as company's involvement in corporate social performance, including a specific sequence of interrelated steps: CSP formation (planning, formalization, organization); social policy implementation; evaluation of its effectiveness and stakeholders informing. It also means the incorporation of stakeholders and strategic management conceptions in CSP theory and practice. It should be emphasized that building relationships with stakeholders on a systematic basis (stakeholder management), CSP formation based on identified stakeholders requests are an important feature of the managerial approach.

The CSP management mechanism (mechanism of its formation and implementation) development has not only theoretical, but also of a great practical importance, since it would identify the main stages of CSP formation and implementation, indicate the corresponding management processes and functions, i.e. makes CSP manageable. Talking about the practical significance of CSP management mechanism formation, it should be emphasized the necessity to develop a standard (reference) CSP management model which, on the one hand, would be a reflection of the best corporate social practices, on the other hand - would give companies an idea of appropriate actions algorithm and management functions.

The implementation of the managerial approach to CSP makes the necessary of CSP and corporate social performance professionalization, which presumes the implementation in companies practice scientific and professional approaches to CSP creation and implementation, integration CSP management in corporate governance system, the involvement of experts with appropriate knowledge and competences who are able to develop and implement in Russian companies' practice strategies and mechanisms of socially responsible business. 


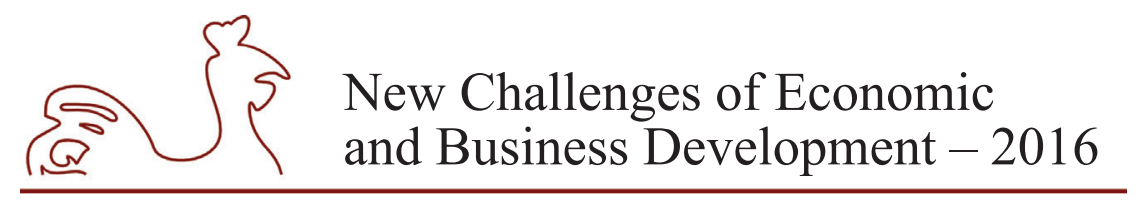

May 12-14, 2016, Riga, University of Latvia

\section{Conclusion}

In conclusion it should be underlined that characteristic features of Russian companies CSP indicate the necessity of CSP institutionalization, i.e. the formation of generally accepted understanding of CSP possible objectives and directions, its rules, regulations and requirements, the reflection of such understanding in the relevant documents and business community and other stakeholders wide informing. From our point of view successful solution of these problems could be facilitated by the development of national standards of CSP, which, in contrast to the Russian National Standard GOST R ISO 26000-2012 "Guidance on Social Responsibility" (2012) and the Russian National Standard RF GOST R ISO 26000-2011 "Enterprise management. Guidance for managing sustainable development" (2012) should contain the uniform requirements to the company activities in social sphere and the recommendations for their implementation, as well as criteria and indicators for effective CSP.

Thus, within the framework of this understanding of CSP nature, the company social policy should be regarded simultaneously as a complex (system) object; form of business organizations social responsibility realization; set of corporate principles, values and objectives; the activities aimed at achieving of social objectives and execution of liabilities; the tool of strategic management of corporate sustainability social factors.

The fundamental principles of the CSP version 2.0 should be the following ones:

- solidarity responsibility (business is responsible for social policy objectives implementation, along with other social policy subjects);

- objectives convergence (CSP objectives must comply with the main social policy objectives and company strategic objectives);

- aims orientation (CSP should be focused on the establishment of shared (common) social values and sustainable development promotion);

- systemacy and harmonization of interests (CSP implies consistency of stakeholders interests, short-term company interests and the long-term interests of society);

- manageability (CSP is a management object);

- efficiency (CSP efficiency should be considered as a criterion for social policy priorities determination);

- transparency and accountability (information on the results and effectiveness of the CSP should be reported to the stakeholders).

The rejection of an ideology of forced replacement of a state in social sphere, the reorientation of CSP objectives from local social problems solving and negative effects of company activities on the establishment of common social values minimizing, as well as the positive effects increasing; the transition from management of individual social programs to CSP and social risks management will indicate the formation of a new model of CSR as social policy 2.0 .

\section{Bibliography}

Aganbegian, A., 2010. On the Priorities of Social Policy. SPERO. Spring-Summer, No. 12. pp. 13-30.

Association Managers of Russia (AMR). 2004. The report on social investments in Russia-2004. M, AMR. 80 p.

Association Managers of Russia (AMR). 2008. The report on social investments in Russia-2008: Integration of CSR into corporate strategy. M.: AMR. 88 p. 


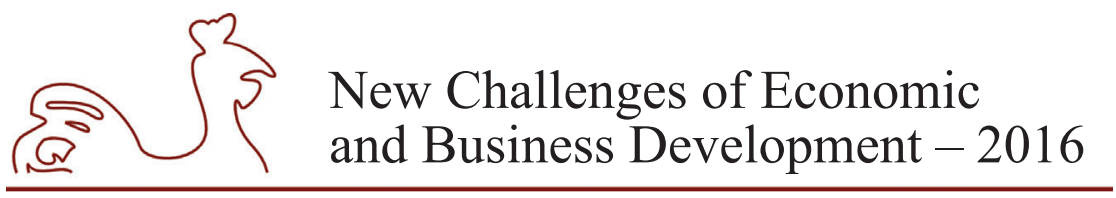

May 12-14, 2016, Riga, University of Latvia

Association Managers of Russia (AMR). 2014. The report on social investments in Russia-2014: To create value for business and society. SPb., ATM Book, 2014, $144 \mathrm{p}$.

Bowen, H., 1953. Social responsibility of the businessman. New York.

Barton, D., 2011. Capitalism for the Long Term. Harvard Business Rev. March. pp. 85-91.

Bljahman, L., 2012. Social Policy As a Subject of a New Political Economy. Problems of Modern Economics. No. 3. pp. 37-46.

Carroll, A. \& Hall, J. 1987. Strategic Management Processes for Corporate Social Policy / Strategic Planning and Management Handbook / ed. by W. R. King, D. I. Cleland. N-Y. New York: Van Nostrand Reinhold Co.

Carroll, A. B. \& Shabana K. M., 2010. The Business Case for Corporate Social Responsibility: A Review of Concepts, Research and Practice . Journal of Management Review. 12, pp. 85-105.

Davis, K., 1960. Can business afford to ignore social responsibilities? California Management Review, 11(3). pp. 70-76.

Epstein, E. M., 1987. The Corporate Social Policy Process: Beyond Business Ethics, Corporate Responsibility and Corporate Social Responsiveness. California Management Review, 29(3), pp. 99-114.

Friedman, M., 1970. The Social Responsibility of Business Is to Increase Its Profits. The New York Times Magazine, September 13.

Hamel, G., 2010. Management 2.0. Empowered Individuals and Empowering Institutions. The Wall Street Journal. April 20.

Hamel, G. \& Labarre, P., 2011. Inventing Management 2.0. The Wall Street Journal. February 17, 2011. [Online] Available at: http://blogs.wsj.com/management/2011/02/17/inventing-management-20/. [Accessed 23 March 2016].

Kanaeva, O., 2013. Corporate Social Policy: Theory and Practice of Management Decisions. St. Petersburg State University Press. 364 p.

KPMG, 2015. Analytical review of the study results "Valuable bases of social activity of Russian business". M.: $2015.85 \mathrm{p}$.

National register of corporate non-financial reports. [Online] Available at: http://www.corporateregister. com. [Accessed 23 February 2016].

Porter, M. \& Kramer, M., 2006. Strategy and Society: The Link Between Competitive Advantage and Corporate Social Responsibility. Harvard Business Rev. 84(12). pp. 91.

Porter, M. \& Kramer, M,. 2011. Creating Shared Value: How to Reinvent Capitalism - and Unleash a Wave of Innovation and Growth. Harvard Business Rev. 89(1/2). pp. 62-77.

Rosstandard., 2012. National Standard RF GOST R ISO 26000-2012 “Guidance on social responsibility”. M.: Standartinform.

Rosstandard., 2012. National Standard RF GOST R 54598.1-2011 "Enterprise management. Guidance for managing sustainable development”. M.: Standartinform.

Russian Union of Industrialists and Entrepreneurs (RSPP)., 2014. Analytical Surveys of RSPP on nonfinancial reporting. [Online] Available at: URL: http://www. rspp.ru. [Accessed 23 February 2016].

Swanson, D. L., 1995. Addressing a theoretical problem by reorienting the corporate social performance model. Academy of Management Review, 20, pp. 43-64.

Visser, W., 2010. CSR 2.0: From the Age of Greed to the Age of Responsibility / Reframing Corporate Social Responsibility: Lessons from the Global Financial Crisis / ed. by W. Sun et al. Bingley: Emerald, 2010.

Visser, W., 2011. CSR 2.0: The New Era of Corporate Sustainability and Responsibility. CSR Inspiration Series. No. 1. [Online] Available at: URL: http://www. csrinternational.org. [Accessed 23 February 2016].

Visser, W., 2011. The Age of Responsibility: CSR 2.0 and the New DNA of Business. London: Wiley. 408 p. 


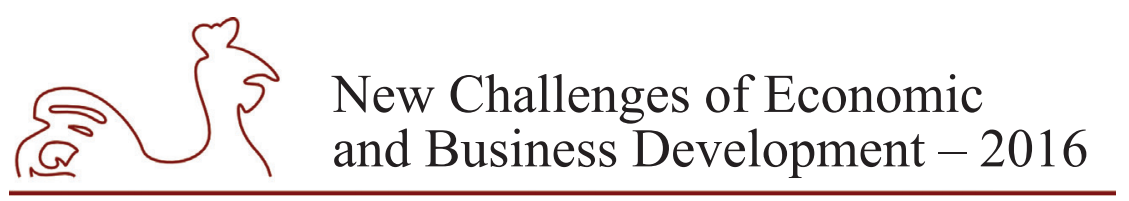

May 12-14, 2016, Riga, University of Latvia

Visser, W., 2012. The Future of CSR: Towards Transformative CSR, or CSR 2.0. Kaleidoscope Futures Paper Series. No 1. pp. 1-17.

Wartick, S. \& Cochran P., 1985. The Evolution of the Corporate Social Performance Model. Academy of Management Review. 10(4), pp. 758-769.

Wood, D., 1991. Corporate social performance revisited. Academy of Management Review. 16(4), pp. 691718.

Wood, D., 2010. Measuring Corporate Social Performance: A Review. International Journal of Management Review, 12(1), pp. 50-84. 
May 12-14, 2016, Riga, University of Latvia

\title{
BANKRUPTCY PREDICTION MODELS: CASE OF THE CONSTRUCTION AND TRANSPORT \& STORAGE SECTOR IN LITHUANIA
}

\author{
Rasa Kanapickiene, Vilnius University, Lithuania ${ }^{1}$ \\ Renatas Spicas, Vilnius University, Lithuania
}

\begin{abstract}
.
The article presents the results of the research in the development of bankruptcy prediction models in the sectors of construction and transport \& storage in Lithuania.

The possibility to apply the models of logistic regression for bankruptcy prediction is investigated. A logistic regression model was developed on the basis of financial ratios. Logistic regression model employs the financial ratios which statistically significantly differ in the financial statements of bankruptcy and non-bankruptcy companies (in Lithuanian companies in construction and transport \& storage sectors) 3 year before bankruptcy were distinguished in prior research works of authors.

The present study distinguishes itself by its broad scope that was targeted for the first time. In order to evaluate the accuracy of bankruptcy prediction models and ensure the quality of the acquired data, empirical calculation was carried out including 485 companies whose bankruptcy processes were initiated in 2009-2013 and 459 companies that did not go bankrupt during this period.
\end{abstract}

Key words: bankruptcy, bankruptcy prediction models, logistic regression

JEL code: G33

\section{Introduction}

Financial failures of businesses have a negative impact on the interested parties including shareholders, creditors, clients, suppliers and employees. Therefore, in order to ensure business continuity and guarantee the interests of interested parties, it is crucial to constantly evaluate financial situation of companies, solve financial problems before companies become insolvent. The object of the research is bankruptcy prediction of companies.

Beaver (1967) and Altman (1968) studies on the bankruptcy prediction of companies prompted scientists' and practitioners' interest in this field. The abundance of the scientific research in this field is determined by the performed summarising studies of research of the bankruptcy models. For instance, Altman and Narayanan (1997) have analysed and summarised 43 studies carried out in 22 countries. Currently, the topicality of this theme remains unaltered. Beaver Correia and McNichols (2012) divide the analysed models into three groups that are accountingbased, market-based, and combined. These models that are created on different grounds are analysed and compared (Wu, Gaunt, Gray, 2010). Some authors analyse the application of existing models in various countries (Xu, Zhang, 2009; Siddiqui, 2012; Kwak, Shi, Kou, 2012;

Corresponding author - e-mail address: rasa.kanapickiene@ef.vu.lt 


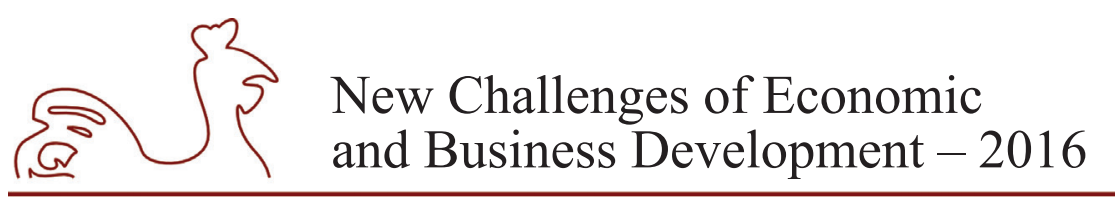

May 12-14, 2016, Riga, University of Latvia

Kasilingam, Ramasundaram, 2012, Li, Rahgozar, 2012; Muminovic, 2013; Lu, Yang, Huang, 2014). While others are more interested in analysing the possibilities of creating new models (Kim, 2011). The application of bankruptcy prediction models in specific business sectors is also a field of investigation (Kim, 2011; Lu, Yang, Huang, 2014). Although this subject is analysed by quite a large number of authors, there is no single opinion on which bankruptcy forecasting methods could produce the most accurate results.

Lithuanian scholars have contradictory opinions about the possibilities to apply bankruptcy prediction models. Empirical researches provide conflicting results as well. Having performed the analysis of the empirical research which has been carried so far, it was determined that by this research companies of different branches were tested. Also, conclusions about the applicability of bankruptcy prediction models in Lithuanian companies were drawn only after testing a small sample of companies. It is important to emphasise the fact that the analysis of separate sectors is not given an adequate attention.

The aim of the research is to create the bankruptcy prediction models in Lithuanian companies in construction and transport \& storage sectors. The formulation of the aim is drawn on the fact that mainly transport and construction companies have gone bankrupt since the world crisis. The article uses the following methods - modelling, statistical analysis and evaluation of corporate data.

\section{The research of the bankruptcy prediction models in Lithuania}

The research of the applicability of the bankruptcy prediction models in Lithuanian companies began in 1999. Mackevičius and Poškaitè (1999) employed the possibilities to apply Altman bankruptcy prediction models in Lithuanian companies. The researchers arrived at the conclusion that it is expedient to use the Altman Z-Score model dedicated for companies whose shares are quoted in a stock-exchange market. Lithuanian scholars have mostly applied the model of Altman to examine and apply bankruptcy prediction models. However, they have not reached a common agreement as to the application of this model in Lithuanian companies. After the analysis of the research studies, Mackevičius (2010) pointed out that the opinions of Lithuanian scholars regarding the Altman model differ because the tested companies come from different branches of industry and their number varies.

Further investigations embrace not only the Altman model but other traditional multicriteria models of bankruptcy prediction: in most cases, the linear discriminant analytical models (Springate, Taffler\&Tisshaw) and the logistic regression models (Chesser, Zavgren). Moreover, later research provides conflicting results as well. It is possible to state that scholars have no common agreement on the application of bankruptcy prediction models in Lithuania. Some scholars have expressed doubts about bankruptcy prediction models created in different countries being appropriate for predicting bankruptcy of Lithuanian companies. Some authors claim that bankruptcy prediction models might be applied in practice on condition that they are adapted. Others state that it is pointless to apply these models because the economic environment and periods of time differ, whereas the abundance of the factors that must be considered make it inexpedient to construct analogical indicators or rely on experimental methods. For instance, Purvinis et al. (2005) emphasize that due to the different conditions of operation between the companies which served as the basis for the created models and Lithuanian companies, the appropriateness of the models for bankruptcy prediction in Lithuania remains doubtful. 


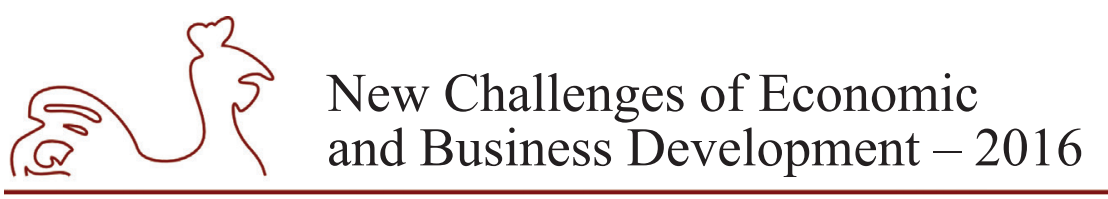

May 12-14, 2016, Riga, University of Latvia

The majority of empirical research studies that were carried out by applying bankruptcy prediction models in Lithuanian companies showed that the Altman's models are suitable for the bankruptcy prediction in Lithuanian companies. A very wide range of the application of these models is proposed by Mackevičius and Rakštelienè (2005): the scholars suggest applying all three Altman's models to predict bankruptcy in Lithuanian companies. Empirical research authors also approve of the application of the Springate, Taffler \& Tisshaw models. Garškaite (2008) found the Taffler \& Tisshaw model to be the most accurate one of linear discriminant analytical models; while Mackevičius and Silvanavičiūtè (2006) compare linear discriminant analytical models with logistic regression models and note that 1) the most accurate bankruptcy probability was obtained by linear discriminant analytical models: Altman, Springate, Taffler \& Tisshaw; 2) the results of logistic regression models - Zavgren and Chesser - were contradictory, they often did not reflect real financial state of the companies.

There are only a few studies which analysed the applicability of bankruptcy prediction models in Lithuanian companies of separate sectors. It should be emphasised that only the construction and transport \& storage sectors were analysed individually. The enterprises of transport \& storage sector were examined by Jurevičienè, Bercevič (2013). Moreover, the enterprises of construction and transport \& storage sectors were examined by the author group of this continuing research (Marcinkevičius, Kanapickienė, 2014; Kanapickienė, Marcinkevičius, 2014; Kanapickienė, 2014; Špicas, Kanapickienè, Ivaškevičiūtè, 2015).

Jurevičienè and Bercevič (2013), Kanapickienè (2014) applied the Altman, Springate, Taffler \& Tisshaw, Zavgren, Chesser models in Lithuanian transport \& storage companies. Jurevičienė and Bercevič (2013) applied the Liss models too. Jurevičienè and Bercevič (2013) found out that the application of these models in Lithuanian companies shows that, by using Altman model, it is possible to predict possible failure even three years before bankruptcy, yet with medium accuracy. Springate and Taffler \& Tisshaw models are also appropriate for the companies in this sector, however these models could help to predict possible failure only two years (Springate) or one year (Taffler \& Tisshaw) before bankruptcy, while Liss, Zavgren and Chesser models are unreliable for transport \& storage enterprises due to ratios used for bankruptcy prediction. Despite the narrow sample of the research, which embraced 10 companies only, the research is important since it considers the data of three years before the bankruptcy of the companies. On the other hand, Kanapickiene (2014) claims that the most accurate bankruptcy prediction models showing the highest bankruptcy probability are the Altman model dedicated for service and individual companies and the Springate model (the probability of the bankruptcy prediction one year before the bankruptcy is 92-93\%). These models show low probability of the Type I error, whereas the indices of correct classification are the highest. Taffler \& Tisshaw and Chesser models show medium accuracy. The probability of the bankruptcy prediction one year before the bankruptcy was designated with the following accuracy: $75.0 \%$ according to the Taffler \& Tisshaw model, $78.90 \%$ according to the Chesser model. The survey proved that the least accurate bankruptcy prediction model is the Zavgren model.

Having applied bankruptcy prediction models in Lithuanian companies in the construction sector, it was found out that the Springate bankruptcy prediction model is the most accurate one (the probability of the bankruptcy prediction one year before the bankruptcy is $88.7 \%$ ). However, the drawback of this model in companies in the construction sector is that the more time there is left to bankruptcy, the less accurate the model becomes. The majority of models 


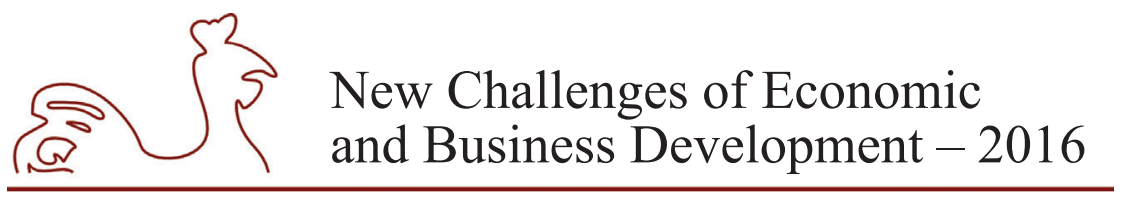

May 12-14, 2016, Riga, University of Latvia

(Altman model dedicated for service and individual companies, Altman model dedicated for for companies whose shares are not quoted in stock-exchange markets, Taffler \& Tisshaw, Chesser, Zavgren) show medium accuracy: the probability of the bankruptcy prediction one year before the bankruptcy is $74-78 \%$.

\section{Methodology of research}

Data collection. The companies forms the construction and transport \& storage sectors in Lithuania were selected for the present research. The choice was determined by the following factors:

1. According to the data of the Statistics Lithuania, the majority of the economic operators in Lithuania was constituted by business units working in the fields of manufacturing, construction, wholesale \& retail trade, and transport \& storage (on 1 January 2009, respective to the type of the economic activity $8.7 \% ; 8.4 \% ; 26.3 \% ; 7.2 \%$; on 1 January $2013,7.8 \% ; 6.9 \% ; 25 \% ; 7.5 \%$ ). What concerns these four major sectors, in 2009-2013, most of bankruptcy processes were initiated in the construction, wholesale \& retail trade, transport \& storage sectors (in 2009, respective to the type of the economic activity $23.6 \% ; 23.2 \% ; 14.9 \%)$.

2. The analysis of the sectors which show the highest bankruptcy rate reveals the fact that the construction and transport \& storage sectors have the highest per cent of the initiated bankruptcy processes in the respective year regarding the whole number of economic operators in the sector registered in the beginning of the year (in 2009, respective to the type of the economic activity $6.1 \% ; 4.5 \%$ ).

While organizing the research, the population, sampling, minimal screening scope and the method of source data acquisition were determined.

The population size. The present research is concerned with the construction and transport \& storage companies filed for bankruptcy in 2009-2013. During this period the process of bankruptcy was initiated for 1571 companies in the construction sector and 873 companies in transport \& storage sectors.

Sampling and screening scope. In statistic investigation, the relevant data is obtained by means of sampling. The elements of the population for the research were selected by means of probability sampling.

In order to ensure the quality of the acquired data, empirical calculation of 485 companies whose bankruptcy processes were initiated in 2009-2013 was carried out. These include 350 construction companies and 135 transport \& storage companies.

459 companies that did not go bankrupt during the period and were still operating on 31 December, 2013 were also included in the research. Among these companies there are 329 from the construction sector and 130 - from transport \& storage sectors.

Source data acquisition. Annual financial statements of 2007-2012 of the investigated companies were analysed. Since bankruptcy processes for the investigated companies were initiated in 2009-2013, the financial data of the companies was taken from the period of three years before the bankruptcy initiation. The following requirements were held for operating companies: 1) the company was operating in 2007 and has continued its activity up to now (i.e., 2014); 2) the company is not being liquidated, reformed, reorganized, restructured, it does 


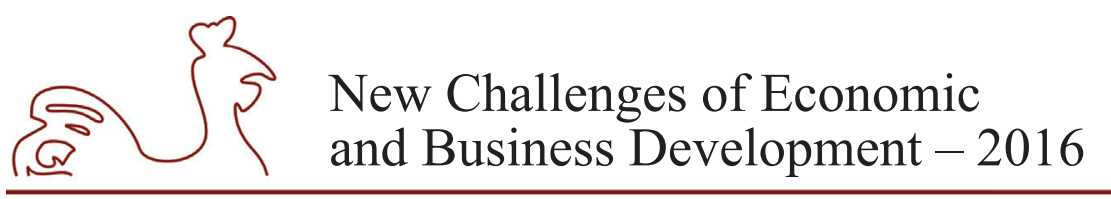

May 12-14, 2016, Riga, University of Latvia

not participate in separation, reorganization, etc.; 3) liabilities of the company did not exceed the assets of the company on 31 December, 2013. Here the idea is based on the assumption of Grigaravičius (2003) that the company is considered to be insolvent if its value (market and balance) is negative or equal to zero, i.e. the company's liabilities shall exceed the current asset of the company.

Research composition. This research is a continuation of the abovementioned authors' studies (Marcinkevičius, Kanapickienè, 2014; Kanapickienè, Marcinkevičius, 2014; Kanapickienė, 2014; Špicas, Kanapickienė, Ivaškevičiūtė, 2015). Throughout time research works of authors were 1) to investigate and evaluate the possibilities to apply bankruptcy prediction models (Altman, Springate, Taffler \& Tisshaw, Chesser, Zavgren models) in Lithuanian companies of construction and transport \& storage sectors (Marcinkevičius, Kanapickienė, 2014; Kanapickienè, Marcinkevičius, 2014; Kanapickienè, 2014); 2) in order to test all the relative financial ratios, the analysis of which was carried out in the theoretical research and which are used in the credit risk determination and bankruptcy prediction (Špicas, Kanapickienè, Ivaškevičiūtė, 2015). In the analysed literature authors identified 168 different relative financial ratios.

However, not all of these ratios may be calculated on the basis of financial statements of the Lithuanian companies since in Lithuania the majority of businesses are small and medium businesses. Since small companies are very important for socio-economic development, it is admitted that in order to reduce the administrative burden, the financial statement in such companies shall be simplified. However, financial statements that are not detailed enough do not allow calculating of all the desired company's financial ratios. Therefore, the users of financial statements are not able to get necessary information about financial statements.

Due to a condensed set of financial statements, 115 of the said 168 ratios cannot be calculated. In this manner, in total 53 financial ratios were analysed in the prior research (Špicas, Kanapickienè, Ivaškevičiūtè, 2015). Each financial ratio was examined in the financial statements of the companies which went bankrupt as well as of those which did not go bankrupt. The financial ratios which statistically significantly differ in the financial statements of nonbankruptcy and bankruptcy companies (in Lithuanian companies in construction and transport \& storage sectors) 3 year before bankruptcy were distinguished.

Financial ratios were analysed in several aspects. First of all, they were analysed in the sector level - the ratios were investigated in transport \& storage sector, in construction sector and in both sectors. Secondly, in the level of time - the aim was to find out if a) the ratios significantly changed a year, two or three years ago (Year-1, Year-2 and Year-3) until the bankruptcy, b) if these ratios differ from the successfully operating companies at that time.

What is more, in order to substantiate the expediency of the ratios included into the model, financial statements which show statistically significant differences were grouped as follows: Profitability ratios; Liquidity ratios; Solvency ratios; Activity ratios; Structure ratios. The analysis was carried out to indicate which ratios from each group are expedient to be included in the model. Correlation matrix for the variables was developed. It is appropriate to consider the possibility to remove from the model some of the ratios that strongly correlate with each other.

Logistic regression was used in creation of bankruptcy prediction model. During the first stage of research, the following was included in the model: a) all investigated financial ratios, b) financial ratios that show statistically significant differences in the group of bankruptcy and 


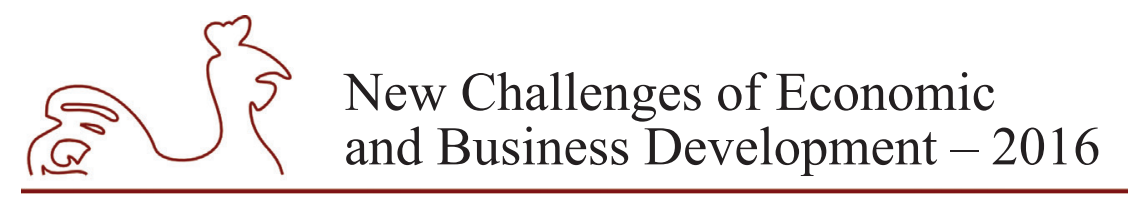

May 12-14, 2016, Riga, University of Latvia

non-bankruptcy companies. The backward method was also used, i.e. the number of financial ratios was gradually reduced in the model. The following was applied: a) statistical method, i.e. statistically insignificant financial ratios with the highest $p$-values were removed; $b$ ) expert method, i.e. each group of ratios were analysed, insignificant ratios were removed only after the analysis of ratio relations. During the second, the forward method was applied, as initially the constants are determined and later independent variables are gradually included into the models, i.e., financial statements with a strong correlation relationship to the dependent variable. During the research the most appropriate model for predict bankruptcy of companies (in construction and transport \& storage sectors) was selected.

Under this logistic regression model, the probability of the bankruptcy prediction is calculated as:

$$
P=1 /\left(1+e^{-\mathrm{z}}\right) ; z=b_{0}+b_{1} x_{1}+b_{2} x_{2}+\cdots+b_{n} x_{n}
$$

Where, $b_{i}(i=1, \ldots, n)$ is the regression coefficient, $x_{i}(i=1, \ldots, n)$ is the corresponding explanatory variable (financial ratio). $P$ is the probability of bankruptcy (from 0 to 1 ). In this study, companies with $P>50 \%$ were classified into the bankruptcy group; companies with $P<$ $50 \%$ were classified into the non-bankruptcy group.

The model is considered to be appropriate when Chi square criterion p-value $<0.05$; Cox \& Snell R Square, Nagelkerke R Square $\geq 0.2$. Statistically significant variables should be included in the model, i.e., $p$ values of Wald's p-value $<0.05$.

In addition, the researchers have investigated the possibility to apply the models of logistic regression for bankruptcy prediction. The models of logistic regression for bankruptcy prediction in Lithuania have been created by Grigaravičius (2003), Butkus, Žakarè, Cibulskienè, (2014). The model created by Grigaravičius (2003) was based on the financial analysis of 88 Lithuanian stock companies. Butkus, Žakarè, Cibulskienè, (2014) have suggested a model that was based on the analysis of financial statements of 158 Lithuanian companies (63 companies went bankrupt and 95 companies did not go bankrupt). It is recommended to apply in practice prepared bankrupt likelihood prediction model and its variations for companies operating in construction, industry, trade, service and other branch specific business and also models for size specific micro-small and medium-sized companies. The models of logistic regression for bankruptcy prediction have been applied by Ohlson (1980), Ho, McCarthy, Yang, Ye, (2013), Lu, Yang, Huang (2014).

\section{Empirical Results and discussion}

Having analysed the financial ratios, it was established that 1) 24 ratios (NP/S; EBT/S; EBIT/CL; CA/CL; (CA-I)/CL; Cash/CL; (Cash-I)/CL; (CL- Cash)/TA; WC/TA; CA/TL; AR/ TL; Cash/TL; Eq/TL; TL/TA; Eq/TA; EqA; Eq/FA; WC/S; S/Cash; Eq/S; CL/S; WC/OE; Cash/ TA; RE/TA) statistically significantly differ in the financial statements of the bankruptcy and non-bankruptcy companies (Table 1). The difference existed when investigating the companies in both sector and time levels. 2) Ratios which significantly differ in one sector. This sector is observed in all years (All Year, Year-1, Year-2, Year-3). However these ratios are not suitable to be used in another sector. Ratios, that are suitable to analyse companies in transport \& storage sector: EBT/TA, NP/TA, EBIT/TA, CA/(TL-Cash), AR/(TL-Cash), CA/S, CA/TA. Ratios, which are suitable to analyse companies in construction sector: ROE, EBT/Eq, Cash/Eq, S/I, I/TA, 


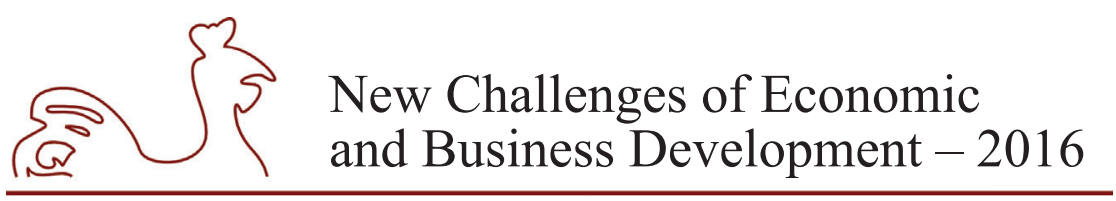

May 12-14, 2016, Riga, University of Latvia

AR/I. In addition, all financial ratios are tested with Mann-Whitney U test (The null hypothesis $H_{0}$ is drawn: the distributions of financial ratio of companies which went bankrupt and those which did not are not equal if $\mathrm{p}<\alpha$, there $\alpha$ - level of significance $(\alpha=0.05)$ ).

The following financial rations indicate the possibility of bankruptcy in financial statements (Table 1):

1) Profitability ratios. Profitability ratios were divided into two groups: Return of sales and Return of investment. There were distinguished two Return of sales ratios that showed statistically significant differences in financial statements of bankruptcy and non-bankruptcy companies in both sectors (NP/S; EBT/S). However, each sector is characterized by different Return of investment ratios.

2) Liquidity ratios. This is the largest group of ratios, i.e. there were distinguished even 9 ratios that showed statistically significant differences in financial statements of bankruptcy and non-bankruptcy companies in both sectors.

3) Solvency ratios. There were distinguished 5 ratios that showed statistically significant differences in financial statements of bankruptcy and non-bankruptcy companies in both sectors. It should be noted that there were no financial ratios that were specific only to one sector.

4) Activity ratios. These ratios were divided into three groups: Asset turnover, Equity turnover (two ratios were distinguished in this group), Level of expenses (only one ratio was distinguished in this group). There were no Equity turnover and Level of expenses ratios distinguished as being specific only to one sector.

5) Structure ratios. These ratios were divided into two groups: Total assets structure ratios, Property structure ratios (in this group, only one ratio specific to both sectors was distinguished).

Logistic regression model of bankruptcy prediction. During the first stage of research, the following was included in the model: a) all investigated financial ratios, b) financial ratios that show statistically significant differences in the group of bankruptcy and non-bankruptcy companies. It was determined that multicollinearity problem exists in such models. Therefore, these models cannot be used and they have to be improved.

During the second stage, the forward method was applied. However, the models developed for transport \& storage and construction sectors did not fit data as outliers were present in the models (Analog of Cook's influence statistics $>1$ ). Such models cannot be used as they are not reliable. 


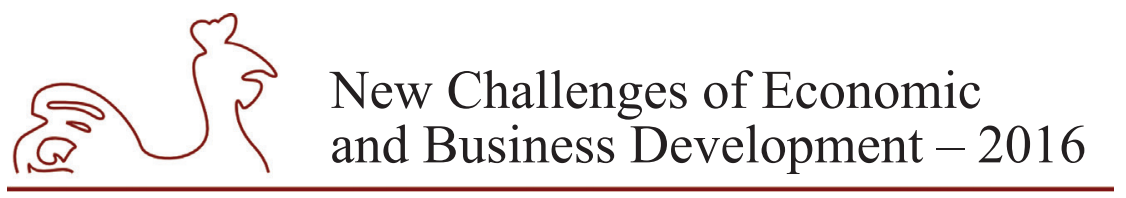

May 12-14, 2016, Riga, University of Latvia

Table 1

The financial ratios indicated the possibility of bankruptcy in financial statements

\begin{tabular}{|l|l|l|l|}
\hline \multirow{2}{*}{ The financial ratios a } & \multicolumn{3}{|c|}{ Variables* } \\
\cline { 2 - 4 } & \multicolumn{1}{|c|}{ Both sectors } & \multicolumn{1}{|c|}{$\begin{array}{c}\text { Transport \& } \\
\text { storage sector }\end{array}$} & $\begin{array}{l}\text { Construction } \\
\text { sector }\end{array}$ \\
\hline 1a. Profitability ratios (Return of sales) & NP/S; EBT/S & & \\
\hline 1b. Profitability ratios (Return of investment) & EBIT/CL & $\begin{array}{l}\text { EBT/TA; NP/TA; } \\
\text { EBIT/TA }\end{array}$ & $\begin{array}{l}\text { ROE; } \\
\text { EBT/Eq }\end{array}$ \\
\hline 2. Liquidity ratios & $\begin{array}{l}\text { CA/CL; (CA-I)/CL; Cash/CL; (Cash-I)/CL; } \\
\text { (CL-Cash)/TA; WC/TA; CA/TL; AR/TL; Cash/TL }\end{array}$ & $\begin{array}{l}\text { CA/(TL-Cash); } \\
\text { AR/(TL-Cash) }\end{array}$ & Cash/Eq \\
\hline 3. Solvency ratios Eq/TL; TL/TA; Eq/TA; EqA; Eq/FA & & \\
\hline 4a. Activity ratios (Asset turnover) & WC/S; S/Cash & CA/S & S/I \\
\hline 4b. Activity ratios (Equity turnover) & Eq/S; CL/S & & \\
\hline 4c. Activity ratios (Level of expenses) & WC/OE & & I/TA; AR/I \\
\hline 5a. Structure ratios (Total assets structure ratios) & Cash/TA & CA/TA & \\
\hline 5b. Structure ratios (Property structure ratios) & RE/TA & & 6 \\
\hline Total & 24 & 7 & \\
\hline
\end{tabular}

* The variables are tested with Mann-Whitney U test. Significant at the 5\% level.

a NP/S = Net Profit/Sales; EBT/S = EBT/Sales; EBIT/CL = EBIT/Current Liabilities; EBT/TA = EBT/Total Assets; NP/TA = Net Profit/Total Assets; EBIT/TA = EBIT/Total Assets; ROE = Net Profit/Equity; EBT/Eq = EBT/Equity; $\mathrm{CA} / \mathrm{CL}=$ Current Assets/Current Liabilities; (CA-I)/CL $=$ (Current Assets - Inventories)/Current Liabilities; Cash/ $\mathrm{CL}=\mathrm{Cash} /$ Current Liabilities; $($ Cash-I $) / \mathrm{CL}=($ Cash - Inventories $) /$ Current Liabilities; $(\mathrm{CL}-\mathrm{Cash}) / \mathrm{TA}=($ Current Liabilities - Cash)/Total Assets; WC/TA = Working Capital/Total Assets; CA/TL = Current Assets/Total Liabilities; $\mathrm{AR} / \mathrm{TL}=$ Accounts Receivable/Total Liabilities; Cash/TL $=\mathrm{Cash} /$ Total Liabilities; CA/(TL-Cash) $=$ Current Assets $/$ (Total Liabilities - Cash); AR/(TL - Cash) = Accounts Receivable/(Total Liabilities - Cash); Cash/Eq = Cash/Equity; Eq/TL = Equity/Total Liabilities; TL/TA = Total Liabilities/Total Assets; Eq/TA = Equity/Total Assets; EqA = (Equity - Intangible Assets)/(Total Assets - Intangible Assets - Cash - Lands and Buildings); Eq/FA = Equity/Fixed Assets; $\mathrm{WC} / \mathrm{S}=$ Working Capital/Sales; $\mathrm{S} /$ Cash $=$ Sales/Cash; CA/S = Current Assets/Sales; $\mathrm{S} / \mathrm{I}=$ Sales/Inventory; $\mathrm{Eq} / \mathrm{S}=$ Equity/Sales; $\mathrm{CL} / \mathrm{S}=$ Current Liabilities/Sales; WC/OE = Working Capital/Operating Expenses; Cash/TA = Cash/Total Assets; CA/TA = Current Assets/Total Assets; I/TA = Inventory/Total Assets; AR/I = Accounts Receivable/ Inventories; RE/TA = Retained Earnings/Total Assets.

Source: author's calculations based on Špicas, Kanapickienė, Ivaškevičiūtè, (2015).

The issue of outliers was also encountered upon application of the backward method. Thus, there was a failure in developing an expert model for the companies in the construction sector. The developed suitable models are presented in Table 2. These models are appropriate as 1) Chi square criterion p-value $<0.05 ; 2$ ) Cox \& Snell R Square, Nagelkerke R Square $\geq 0.2$; 3) statistically significant variables should be included in the model, i.e., p values of Wald's p-value $<0.05$; 4) the total percentage of the model's correctly classified cases is a) $82 \%$ in transport \& storage sector, b) $78 \%$ in construction sector (Table 2).

The authors would like to give a few argumentative comments on the application of Model 1 (Table 2). As mentioned above, the model fits data, i.e. meets all the requirements. However, attention should be drawn to the fact that 1) the model included even 5 Liquidity ratios and 3 Solvency ratios; 2) Activity is not reflected in the model. Therefore, this model is not suitable for the bankruptcy prediction. Meanwhile, the model for the transport \& storage sector developed by means of the expert method (Model 2) better reflects different aspects 


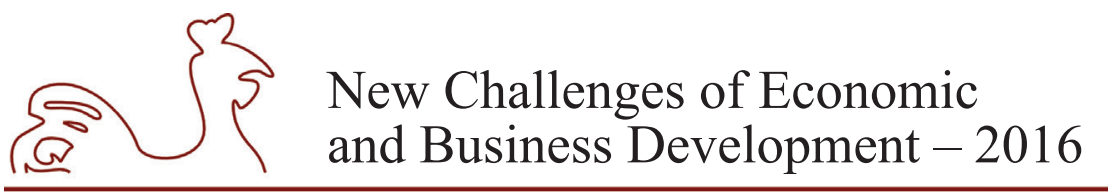

May 12-14, 2016, Riga, University of Latvia

of the company activities: financial ratios from 5 different groups are included in the model. The conclusion might be drawn that Model 2 is more suitable for bankruptcy prediction than Model 1. Even 4 liquidity ratios were included in Model 3, however, the reduction of the number of liquidity ratios is not possible as further reduction of the number of ratios would result in the model not fitting the data.

Table 2

Logistic regression models of bankruptcy prediction

\begin{tabular}{|c|c|c|c|c|c|c|c|}
\hline & \multicolumn{3}{|c|}{ Transport \& storage sector } & \multirow{2}{*}{\multicolumn{2}{|c|}{$\begin{array}{c}\begin{array}{c}\text { Construction } \\
\text { sector }\end{array} \\
\text { Model } 3 \\
\end{array}$}} \\
\hline & & & Model 1 & \multicolumn{2}{|c|}{ Model 2} & & \\
\hline & & & \multicolumn{5}{|c|}{ Model development method } \\
\hline & & & Statistical method & \multicolumn{2}{|c|}{ Statistical method } & \multicolumn{2}{|c|}{ Statistical method } \\
\hline \multicolumn{3}{|l|}{ Selected Cases } & 1092 & \multicolumn{2}{|c|}{1092} & \multicolumn{2}{|c|}{2857} \\
\hline \multicolumn{3}{|c|}{$\begin{array}{l}\text { The percentage of the model's correctly } \\
\text { classified non-bankrupt cases }\end{array}$} & 91.1 & \multicolumn{2}{|c|}{91.5} & \multicolumn{2}{|c|}{87.8} \\
\hline \multicolumn{3}{|c|}{$\begin{array}{l}\text { The percentage of the model's correctly } \\
\text { classified bankrupt cases }\end{array}$} & 63.9 & \multicolumn{2}{|c|}{62.1} & \multicolumn{2}{|c|}{60.2} \\
\hline \multicolumn{3}{|c|}{$\begin{array}{l}\text { The total percentage of the model's } \\
\text { correctly classified cases }\end{array}$} & 82.2 & \multicolumn{2}{|c|}{81.9} & \multicolumn{2}{|c|}{78.4} \\
\hline \multicolumn{3}{|c|}{ Chi-square p-value } & 0.000 & \multicolumn{2}{|c|}{0.000} & \multicolumn{2}{|c|}{0.000} \\
\hline \multicolumn{3}{|c|}{ Cox \& Snell R Square } & 0.376 & \multicolumn{2}{|c|}{0.382} & \multicolumn{2}{|c|}{0.329} \\
\hline \multicolumn{3}{|c|}{ Nagelkerke R Square } & 0.524 & \multicolumn{2}{|c|}{0.533} & \multicolumn{2}{|c|}{0.455} \\
\hline \multicolumn{3}{|c|}{ Analog of Cook's influence statistics } & 1.12 & \multicolumn{2}{|c|}{1.22} & 1. & \\
\hline $\operatorname{DfBeta}(\mathrm{s})$ & & & $<1$ & $<$ & & $<$ & \\
\hline The financial & & & Coefficients, Wald ( & p-value)* & & & \\
\hline ratios $^{\text {a }}$ & Model 1 & & Model 2 & & & Model 3 & \\
\hline Constant & $-1.634, \quad 3.868$ & $(0.049)$ & $-3.349, \quad 38.337$ & $(0.000)$ & -2.524 & 97.686 & $(0.000)$ \\
\hline 1. Profitability $r$ & tios & & & & & & \\
\hline EBIT/TA & $-1.242, \quad 7.272$ & $(0.007)$ & $-1.226, \quad 6.350$ & $(0.012)$ & & & \\
\hline 2. Liquidity ratic & & & & & & & \\
\hline $\mathrm{CA} / \mathrm{CL}$ & & & & & 0.104 & 15.644 & $(0.000)$ \\
\hline $\mathrm{Cash} / \mathrm{CL}$ & & & & & -1.006, & 16.615 & $(0.000)$ \\
\hline (CL- Cash)/TA & $-3.759, \quad 18.090$ & $(0.000)$ & $-1.845, \quad 12.868$ & $(0.000)$ & & & \\
\hline $\mathrm{WC} / \mathrm{TA}$ & $-3.549, \quad 14.396$ & $(0.000)$ & $-1.843, \quad 10.878$ & $(0.001)$ & & & \\
\hline $\mathrm{CA} / \mathrm{TL}$ & $1.893, \quad 7.410$ & $(0.006)$ & & & -0.325 & 17.503 & $(0.000)$ \\
\hline $\mathrm{Cash} / \mathrm{TL}$ & & & & & 1.032, & 11.896 & $(0.001)$ \\
\hline CA/(TL-Cash) & $-0.142, \quad 4.494$ & $(0.034)$ & & & & & \\
\hline AR/(TL-Cash) & $0.334, \quad 9.541$ & $(0.002)$ & & & & & \\
\hline 3. Solvency ratic & & & & & & & \\
\hline $\mathrm{Eq} / \mathrm{TL}$ & $-1.782, \quad 7.273$ & $(0.007)$ & & & & & \\
\hline TL/TA & $2.559, \quad 9.013$ & $(0.003)$ & $4.141, \quad 46.588$ & $(0.000)$ & 3.351, & 154.287 & $(0.000)$ \\
\hline $\mathrm{Eq} / \mathrm{FA}$ & $-0.192, \quad 4.120$ & $(0.042)$ & $-0.090, \quad 1.498$ & $(0.221)$ & & & \\
\hline
\end{tabular}


New Challenges of Economic and Business Development - 2016

May 12-14, 2016, Riga, University of Latvia

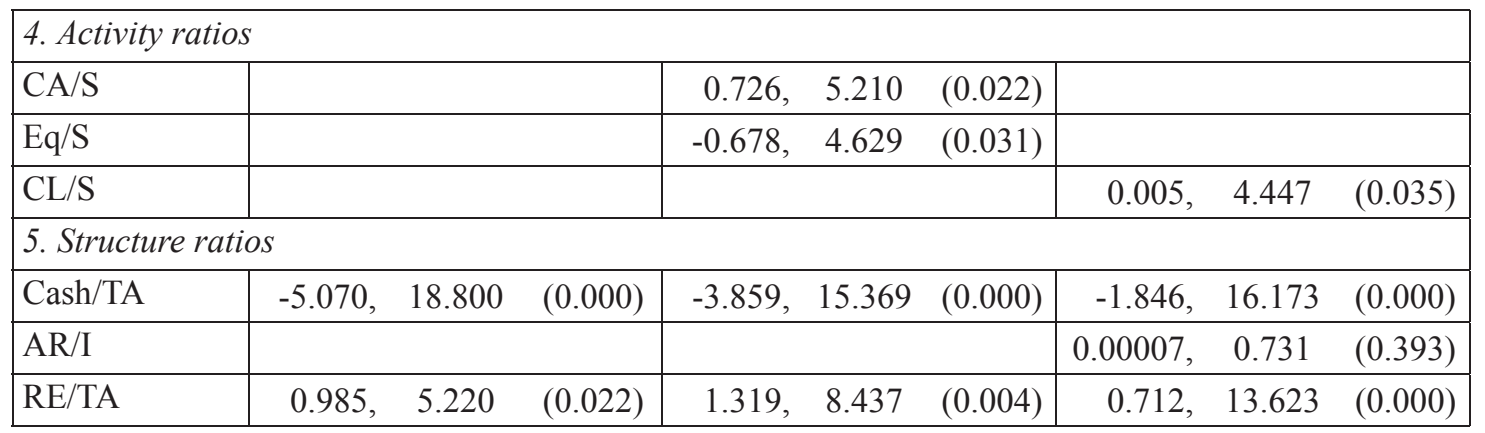

**significant at the $5 \%$ level

${ }^{\mathrm{a}} \mathrm{EBIT} / \mathrm{TA}=\mathrm{EBIT} /$ Total Assets; $\mathrm{CA} / \mathrm{CL}=$ Current Assets/Current Liabilities; Cash $/ \mathrm{CL}=\mathrm{Cash} /$ Current Liabilities; $(\mathrm{CL}-\mathrm{Cash}) / \mathrm{TA}=($ Current Liabilities - Cash $) /$ Total Assets; WC/TA $=$ Working Capital/Total Assets; CA/TL $=$ Current Assets/Total Liabilities; Cash/TL $=$ Cash/Total Liabilities; CA/(TL-Cash) $=$ Current Assets/(Total Liabilities - Cash); $\mathrm{AR} /(\mathrm{TL}-\mathrm{Cash})=$ Accounts Receivable/(Total Liabilities - Cash $) ; \mathrm{Eq} / \mathrm{TL}=$ Equity/Total Liabilities; TL/TA = Total Liabilities/Total Assets; Eq/TA = Equity/Total Assets; CA/S = Current Assets/Sales; Eq/S = Equity/Sales; CL/S = Current Liabilities/Sales; Cash/TA = Cash/Total Assets; AR/I = Accounts Receivable/Inventories; RE/TA = Retained Earnings/Total Assets.

Source: author's calculations.

The probability of the bankruptcy prediction in the sectors of transport \& storage is calculated as (Table 2, Model 2) $P=1 /\left(1+e^{-\mathrm{z}}\right)$, where:

$$
z=-3.349-1.226 X_{1}-1.845 X_{2}-1.843 X_{3}+4.141 X_{4}-0.090 X_{5}+0.726 X_{6}-0.678 X_{7}-3.859 X_{8}+1.319 X_{9}
$$

The following financial ratios were used: $X_{1}=\mathrm{EBIT} / \mathrm{TA} ; X_{2}=(\mathrm{CL}-\mathrm{Cash}) / \mathrm{TA} ; X_{3}=\mathrm{WC} / \mathrm{TA}$; $X_{4}=\mathrm{TL} / \mathrm{TA} ; X_{5}=\mathrm{Eq} / \mathrm{FA} ; X_{6}=\mathrm{CA} / \mathrm{S} ; X_{7}=\mathrm{Eq} / \mathrm{S} ; X_{8}=\mathrm{Cash} / \mathrm{TA} ; X_{9}=\mathrm{RE} / \mathrm{TA}$.

The probability of the bankruptcy prediction in the sectors of construction is calculated as (Table 2, Model 3) $P=1 /\left(1+e^{-\mathrm{z}}\right)$, where:

$$
z=-2.524+0.104 X_{1}-1.006 X_{2}-0.325 X_{3}+1.032 X_{4}+3.351 X_{5}+0.005 X_{6}-1.846 X_{7}+0.00007 X_{8}+0.712 X_{9}
$$

The following financial ratios were used: $X_{1}=\mathrm{CA} / \mathrm{CL} ; X_{2}=\mathrm{Cash} / \mathrm{CL} ; X_{3}=\mathrm{CA} / \mathrm{TL} ; X_{4}=$ $\mathrm{Cash} / \mathrm{TL} ; X_{5}=\mathrm{TL} / \mathrm{TA} ; X_{6}=\mathrm{CL} / \mathrm{S} ; X_{7}=\mathrm{Cash} / \mathrm{TA} ; X_{8}=\mathrm{AR} / \mathrm{I} ; X_{9}=\mathrm{RE} / \mathrm{TA}$.

Where, $\mathrm{P}$ is the probability of bankruptcy (from 0 to 1 ). In this study, companies with $P>$ $50 \%$ were classified into the bankruptcy group; companies with $P<50 \%$ were classified into the non-bankruptcy group.

When comparing the bankruptcy models for the construction and transport \& storage sectors it can be noted that

1) Profitability ratios. The company profitability is significant only in predicting bankruptcy in the transport \& storage sector.

2) Liquidity ratios. Different financial ratios are significant for the bankruptcy prediction in each sector.

3) Solvency ratios. TL/TA ratio is significant with regard to both sectors. Even though Eq/ FA ratio (used in the transport \& storage sector) is not significant, its removal, however, reduces suitability of the model. 


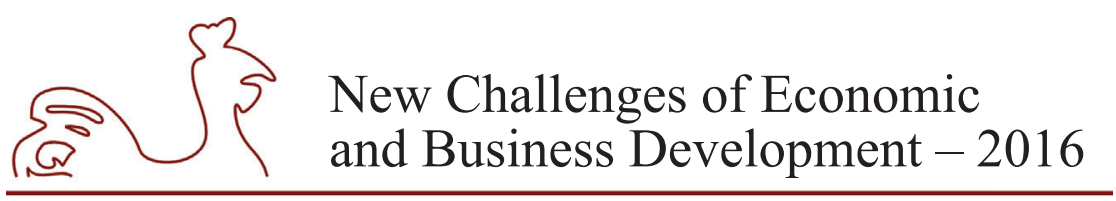

May 12-14, 2016, Riga, University of Latvia

4) Activity ratios. Different activity ratios are significant to different sectors: $\mathrm{CA} / \mathrm{S}, \mathrm{Eq} / \mathrm{S}$ ratios are significant to the transport \& storage sector, whereas $\mathrm{CL} / \mathrm{S}$ ratios are significant to the construction sector.

5) Structure ratios. Cash/TA and RE/TA ratios are significant to both sectors. Even though $\mathrm{AR} / \mathrm{I}$ ratio (used in the construction sector) is not significant, its removal, however, reduces suitability of the model.

\section{Conclusions}

The paper is intended to develop bankruptcy prediction models for the Lithuanian companies in the construction and transport \& storage sectors. Previous research of the authors distinguished the financial statements which showed statistically significant differences with regard to the Lithuanian bankruptcy and non-bankruptcy companies in the construction and transports sectors.

In order to substantiate the expediency of the ratios included into the models, financial statements which show statistically significant differences were grouped as follows: Profitability ratios; Liquidity ratios; Solvency ratios; Activity ratios; Structure ratios.

A logistic regression models were developed to predict the bankruptcy in the sectors of construction and transport \& storage in Lithuania on the basis of financial ratios. When predicting the bankruptcy of transport \& storage sector companies financial indicators from five groups of indicators are statistically important (Profitability ratios (EBIT/TA); Liquidity ratios ((CL-Cash)/ TA; WC/TA); Solvency ratios (TL/TA); Activity ratios (CA/S; Eq/S); Structure ratios (Cash/ $T A)$ ). The company profitability is not significant in predicting bankruptcy in the construction sector. Thus when predicting the bankruptcy in the companies of construction sector financial indicators from four groups of indicators are statistically important (Liquidity ratios $(C A / C L$; Cash/CL; CA/TL; Cash/TL); Solvency ratios (TL/TA); Activity ratios (CL/S); Structure ratios $(C a s h / T A ; A R / I))$. The total percentage of the model's correctly classified cases is a) $82 \%$ in transport \& storage sector, b) 78\% in construction sector (the percentage of the model's correctly classified non-bankrupt cases is a) $92 \%$ in transport \& storage sector, b) $88 \%$ in construction sector; the percentage of the model's correctly classified bankrupt cases is a) $62 \%$ in transport \& storage sector, b) $60 \%$ in construction sector).

The designed models can be used by external users of financial statement information when making decisions for investment and company evaluation. The data of Lithuanian companies was used when creating the models. Without performing additional research it cannot be stated that logistic regression models can be applied to the bankruptcy prediction of other countries' transport sector companies. It can be a future field of research.

\section{Bibliography}

Altman, E. I.; Narayanan, P., 1997. An International Survey of Business Failure Classification Models. Financial Markets, Institutions \& Instruments, 6, pp. 1-57.

Beaver,W. H.; Correia, M.; McNichols, M. F., 2012. Do Differences in Financial Reporting Attributes Impair the Predictive Ability of Financial Ratios for Bankruptcy? Review of Accounting Studies, 17(4), pp. 969-1010. 


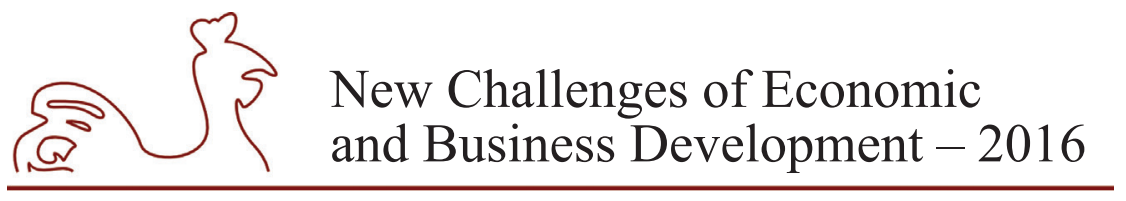

May 12-14, 2016, Riga, University of Latvia

Butkus, M.; Žakare, S.; Cibulskienė, D., 2014. Bankruptcy diagnostic model and its application to predict company's bankrupt likelihood in Lithuania. Applied economics: systematic research, 8(1), pp. 111-132.

Garškaitè, K., 2008. Application of Models for Forecasting of Enterprise Bankruptcy. Business: Theory and Practice, 9(4), pp. 281-294.

Grigaravičius, S., 2003. Corporate Failure Diagnosis. Reliability and Practice. Management of Organizations: Systematic Research, 28, pp. 29-42.

Ho, Ch.; McCarthy ${ }_{2}$ P.; Yang, Y.; Ye, X., 2013. Bankruptcy in the Pulp and Paper Industry: Market's Reaction and Prediction. Empirical Economics, 45(3), pp. 1205-1232.

Jurevičienè, D.; Bercevič, E., 2013. The Evaluation of Bankruptcy Prediction Models for Lithuanian Companies. Trends Economics and Management, 7 (13), pp. 43-55.

Kanapickienè, R., 2014. Investigation of the Application of Bankruptcy Prediction Models in the Transport and Storage Sector in Lithuania. Economy and management: Issues and Perspective, 3, pp. 35-43.

Kanapickienė, R.; Marcinkevičius, R., 2014. Possibilities to apply classical bankruptcy prediction models in the construction sector in Lithuania. Economics and Management, 19(4), pp. 317-332.

Kasilingam, R; Ramasundaram, G., 2012. Predicting Solvency of Non-Banking Financial Institutions in India Using Fulmer and Springate Model. Journal of Services Research, 12(1), pp. 65-88.

Kim, S. Y., 2011. Prediction of Hotel Bankruptcy Using Support Vector Machine, Artificial Neural Network, Logistic Regression, and Multivariate Discriminant Analysis. The Service Industries Journal, 31(3), pp. 441-468.

Kwak, W.; Shi, Y.; Kou, G., 2012.Bankruptcy Prediction for Korean Firms after the 1997 Financial Crisis: Using a Multiple Criteria Linear Programming Data Mining Approach. Review of Quantitative Finance and Accounting, 38(4), pp. 441-453.

Li, J.; Rahgozar, R., 2012. Application of the Z -Score Model with Consideration of Total Assets Volatility in Predicting Corporate Financial Failures from 2000-2010. Journal of Accounting and Finance, 12(2), pp. 11-19.

Lu, Ch.; Yang, A. Sh.; Huang, J., 2014. Bankruptcy Predictions for U.S. Air Carrier Operations: a Study of Financial Data. Journal of Economics and Finance, 39(3), pp. 574-589.

Mackevičius, J., 2010. Integrated Business Bankruptcy Forecasting Methodology. Current Issues of Business and Law, 5, pp. 123-138.

Mackevičius, J.; Poškaitè, D., 1999. İmonių bankroto prognozavimo analizès metodikų tyrimas, remiantis finansinių ataskaitų duomenimis. Economics, 49, pp. 541-63.

Mackevičius, J.; Rakštelienė, A. (2005). Employing Altman's Models to Predict Bankruptcy of Lithuanian Companies. Monetary Studies, 1, pp. 24-42.

Mackevičius, J.; Silvanavičiūte, S. (2006). Evaluation of Suitability of Bankruptcy Prediction Models. Business: Theory and Practice, 7(4), pp. 193-202.

Marcinkevičius, R.; Kanapickienė, R., 2014. Bankruptcy prediction in the sector of construction in Lithuania. Procedia - Social and Behavioral Sciences, 156, pp. 553-557.

Muminovic, S., 2013. Revaluation and Altman's Z-score - the Case of the Serbian Capital Market. International Journal of Finance and Accounting, 2(1), pp. 13-18.

Ohlson, J., 1980. Financial Ratios and the Probabilistic Prediction of Bankruptcy. Journal of Accounting Research, 18, pp. 109-131.

Purvinis, O., Šukys, P., Virbickaitė, R., 2005. Research of the Possibility of Bankruptcy Diagnostics Applying Neural Network. Engineering Economics, 41(1), pp. 16-22.

Siddiqui, S. A., 2012. Business Bankruptcy Prediction Models: A Significant Study of the Altman's Z-Score Model. Asian Journal of Management Research, 3(1), pp. 212-219. 


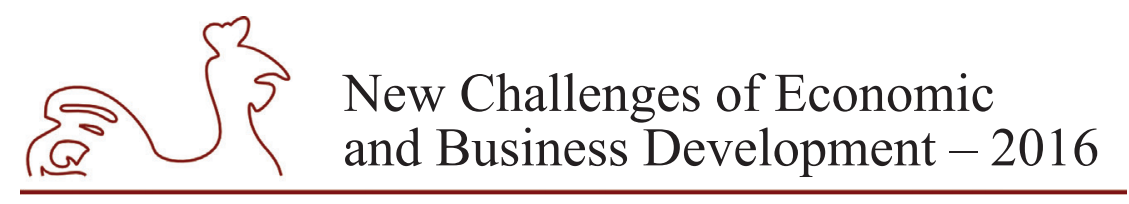

May 12-14, 2016, Riga, University of Latvia

Špicas, R.; Kanapickienė, R.; Ivaškevičiūtè, M., 2015. Filter Methods of Variable Selection for Enterprise Credit Risk Prediction. Perspectives of Business and Entrepreneurship Development: Economic, Management, Finance and System Engineering from the Academic and Practitioners Views, May 28-29, 2015, Brno, Czech Republic : proceedings of selected papers, pp. 147-160.

Wu, Y.; Gaunt, C.; Gray, S., 2010. A Comparison of Alternative Bankruptcy Prediction Models. Journal of Contemporary Accounting \& Economics, 6, pp. 34-45.

$\mathrm{Xu}$, M.; Zhang, Ch., 2009. Bankruptcy Prediction: the Case of Japanese Listed Companies. Review of Accounting Studies, 14(4), pp. 534-558. 


\title{
EMPLOYMENT AND FERTILITY IN LATVIA
}

\author{
Inara Kantane, University of Latvia, Latvia ${ }^{1}$
}

\begin{abstract}
The employment instability, insufficient income, lack of means of subsistence are factors that impact the well-being of inhabitants and wherewith fertility decisions. The scientific researches show that employment is one of the key factors which are evaluated when planning children, employment stability is a determinant of children's well-being.

The aim of the study is to examine the employment, incomes and means of subsistence sources of inhabitants in Latvia and its impact on fertility. The tasks of this paper are the analyses of scientific publications and the analyses of employment, subsistence sources of the inhabitants and fertility rate in Latvia. The research is based on analysis of scientific publications, analysis of secondary statistical data (provided by Central Statistical Bureau of Latvia and Eurostat). For determine the strength of the association between the employment rates and fertility rates the correlation analysis was used.

Main results: only about 70\% of household's incomes in Latvia are incomes from paid employment and self-employment, large parts of the household's incomes are another person's maintenance, pensions, benefits and other forms of financial aids as well as other sources of subsistence. The smallest incomes from employment are in Latgale region and in households with children up to the age of 15 years. In Latvia the relationship between the employment rates and fertility rates is statistically significant moderate, positive.
\end{abstract}

Key words: employment, incomes, fertility, subsistence sources

JEL code: J31, J13

\section{Introduction}

The issues related to the improvement of the demographic situation are very topical in Latvia. In 2015 the number of population in Latvia was still decreasing, since 2010 the number of population decreased by 134408 inhabitants (Central Statistical Bureau of Latvia, 2016). The total fertility rate in Latvia is not enough, in 2014 - 1.65, comparison with 2013 fertility rate slight grew (in 2013 - 1.52). The total fertility rate in European Union also is low in $2014-1.58$. The highest fertility rate in 2014 was in France - 2.01 and Ireland - 1.96 (Eurostat, 2016).

The total fertility rate necessary for the generational change in Latvia is 2.1-2.2 (Demography, Central Statistical Bureau of Latvia, 2014).

In Latvia the important factors that impact the demographic situation are employment, insufficient incomes, lack of means of subsistence. The aim of the study is to examine the employment, incomes and means of subsistence sources of inhabitants in Latvia and its impact on fertility.

The first task of this paper is to analyse the theoretical findings in scientific publications, second task is to analyse employment, subsistence sources of the inhabitants and fertility rate in Latvia. Methods applied in the current paper: analysis of scientific publications, analysis of secondary statistical data. For the analysis of the statistical data - cross tabulations and correlation analysis were applied.

Corresponding author - e-mail address: inara.kantane@lu.lv 


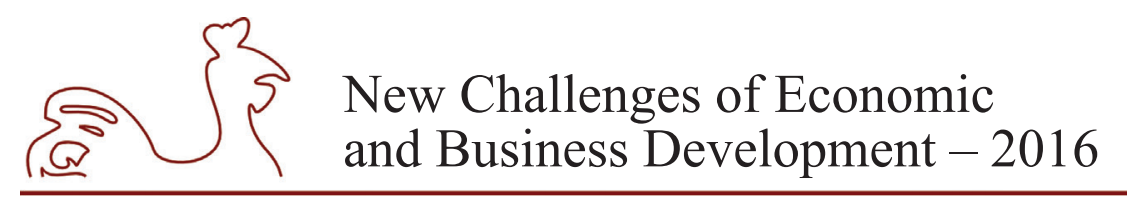

May 12-14, 2016, Riga, University of Latvia

\section{Research results and discussion}

The scientific researches world - wide have devoted a lot of attention to issues on employment, subsistence sources of inhabitants and its impact on well-being of inhabitants, fertility decisions, children's well-being, new mothers and women with small children discrimination. The employment instability has a strong and persistent negative effect on the final number of children for both men and women (Ciganda D., 2015). Employment status is a significant predictor of fertility, child care services are an effective means for increased fertility (Hilgeman \& Butts, 2009). The researcher Lutz (2014) analysed the impact of occupational activity on the timing of first births in Germany. Lutz found that differences in the timing of fertility according to occupation for women were small, greater - for men, participating in the labour market was crucial for men before becoming a parent, and less important for women. Lutz proved that occupational characteristics correlate highly with educational levels and occupational changes were rare. Erosa et al. (2002) found that in US fertility decisions generate important gender differences in labour turnover rates, with long lasting effects in employment and wages. Number of children, education, age of woman, marital status and having a preschool child are the significant predictors of female employment while marriage status is not significant (Gelo J., 2011). Hwang and Lee (2014) carried out cross-country research and established the association between women's education and the timing and level of fertility in 1980, 1995, and 2005, researchers proved that a higher women's education tends to delay of child birth or family formation. The researcher from Poland Mishtal (2009) made detailed research on women's reproductive intentions and decision making. Mishtal found that the widespread fear of discrimination by employers against pregnant women, new mothers, and women with small children drives women's decisions to postpone or refuse childbearing; researcher established that income was the most often cited barrier to childbearing, closely followed by problems with housing, gendered discrimination in employment, and lack of childcare. The increasing child care subsidies, conditional on employment increase the labour supply of all women as well as the fertility rates of the childless (Haan \& Wrohlich, 2011). The fertility was affected by changes in female employment, real wage and real per capita output in the long-run (Papapetrou E., 2004). Nieuwenhuis et al. (2012) proved that both mothers and women without children were more likely to be employed in societies with a large service sector and low unemployment. Parents' labour market status is a strong determinant of children's economic well-being (Härkönen J., 2011).

For getting back into the labour market the important are start-up subsidies for unemployed females. Promoting of own business, self-employment among unemployed women might increase their labour market participation and give women more independence and flexibility to reconcile work and family (Caliendo \& Künn, 2015). The employment has also affected migration. Bonasia and De Siano (2016) proved that worsening of the employment rates have increased migration and characterized by early retirement in Italia. Overall, these studies indicate that employment is a significant predictor of fertility. 


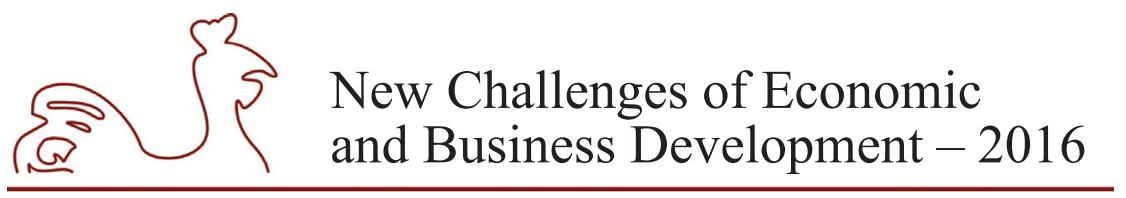

May 12-14, 2016, Riga, University of Latvia

In Latvia the number of live births slightly increased in 2014 year - 1150 children more than in 2013. The highest fertility rates in 2014 were recorded for parents aged 25-34 - about $42.2 \%$ of children were born to parents at this age. Fertility rate per 1000 population constituted 10.9 (Central Statistical Bureau of Latvia, 2016). In 2014 total fertility rate in Latvia was 1.65 (Eurostat, 2016).

In Latvia in ages groups in which are the highest fertility rates the unemployment rate is high. According to the data of Central Statistical Bureau in 2015 in Latvia in age group 20-24 years unemployment rate was about $15.1 \%$, in age group 25-29 unemployment rate - 10.6\%; in age group 30-34-7.8\%. The total employment rate was about $60.8 \%$, unemployment rate about $9.9 \%$ in Latvia in 2015. In 2015 in comparison with 2014 the total employment rate increased by $1.7 \%$ but unemployment rate decreased by $0.9 \%$. The unemployment rates in Latvia from 2004 to 2015, by age groups are reflected in Table 1.

Table 1

The unemployment rates in Latvia, 20104-2015, by age groups, percentages

\begin{tabular}{|c|c|c|c|c|c|c|c|c|c|c|c|c|}
\hline Age groups & $\mathbf{2 0 0 4}$ & $\mathbf{2 0 0 5}$ & $\mathbf{2 0 0 6}$ & $\mathbf{2 0 0 7}$ & $\mathbf{2 0 0 8}$ & $\mathbf{2 0 0 9}$ & $\mathbf{2 0 1 0}$ & $\mathbf{2 0 1 1}$ & $\mathbf{2 0 1 2}$ & $\mathbf{2 0 1 3}$ & $\mathbf{2 0 1 4}$ & $\mathbf{2 0 1 5}$ \\
\hline Total & 11.7 & 10 & 7 & 6.1 & 7.7 & 17.5 & 19.5 & 16.2 & 15 & 11.9 & 10.8 & 9.9 \\
\hline $15-19$ & 32.6 & 28.8 & 26.9 & 19.4 & 30.3 & 58 & 63 & 58.5 & 59.3 & 35.7 & 33.3 & 27.9 \\
\hline $20-24$ & 16.8 & 11.9 & 10.5 & 8.4 & 10.8 & 29.5 & 32.8 & 28.2 & 24.9 & 21.9 & 18.4 & 15.1 \\
\hline $25-29$ & 12.9 & 9.8 & 7.2 & 6.5 & 8.5 & 19.5 & 21.2 & 16.6 & 14.6 & 11.3 & 10.7 & 10.6 \\
\hline $30-34$ & 10 & 9.7 & 5.7 & 5.4 & 7.1 & 15.2 & 15.9 & 15.4 & 11.8 & 10.9 & 10.5 & 7.8 \\
\hline $35-39$ & 9.2 & 8.1 & 5.1 & 5.3 & 7.5 & 14.5 & 18.5 & 13.3 & 11.4 & 10.8 & 12.3 & 9.8 \\
\hline $40-44$ & 10.4 & 8 & 5.5 & 5.7 & 6.9 & 16.2 & 16.5 & 14.5 & 14.9 & 9.6 & 8.5 & 9.5 \\
\hline $45-49$ & 9.9 & 8.8 & 7.1 & 5.7 & 7.3 & 16.3 & 17.4 & 14.5 & 15.3 & 11.2 & 10.6 & 9.2 \\
\hline $50-54$ & 14.1 & 13.4 & 6.4 & 5.8 & 6.9 & 15.4 & 18.5 & 14.8 & 13.8 & 12.4 & 9.7 & 10.4 \\
\hline $55-59$ & 12 & 10.7 & 7.9 & 5.5 & 7.5 & 15.5 & 17.4 & 17.8 & 17.7 & 11.7 & 11.3 & 10.5 \\
\hline $60-64$ & 5.5 & 5.8 & 4.5 & 2.2 & & 9.8 & 12.2 & 8.1 & 8.3 & 7.9 & 6.8 & 7.1 \\
\hline
\end{tabular}

Source: author's prepared based on Central Statistical Bureau of Latvia, 2016.

Wages and salaries were the main source of household's disposable income in Latvia. Since 2010 year the share of wages and salaries in the total income increased from $63.7 \%$ in 2010 to $70.2 \%$ in 2014 but social transfers decreased from $32.4 \%$ in 2010 to $24.8 \%$ in 2014 . In 2014 grew household's income from self-employment and income from rental of a property or land - the shares in the total income $4.1 \%$. The structure of household's disposable incomes per household member per month is reflected in Table 2. 


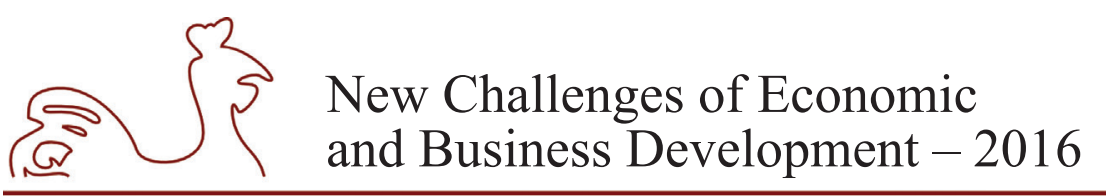

May 12-14, 2016, Riga, University of Latvia

Table 2

Composition and structure of household's disposable income average per household member per month in Latvia, 2004-2014, percentages

\begin{tabular}{|l|c|c|c|c|c|c|c|c|c|c|c|}
\hline \multicolumn{1}{|c|}{ Income } & $\mathbf{2 0 0 4}$ & $\mathbf{2 0 0 5}$ & $\mathbf{2 0 0 6}$ & $\mathbf{2 0 0 7}$ & $\mathbf{2 0 0 8}$ & $\mathbf{2 0 0 9}$ & $\mathbf{2 0 1 0}$ & $\mathbf{2 0 1 1}$ & $\mathbf{2 0 1 2}$ & $\mathbf{2 0 1 3}$ & $\mathbf{2 0 1 4}$ \\
\hline Total disposable income & 100 & 100 & 100 & 100 & 100 & 100 & 100 & 100 & 100 & 100 & 100 \\
\hline Wages and salary & 68.2 & 72.1 & 73.4 & 77.3 & 75.5 & 67.7 & 63.7 & 65.8 & 67.5 & 68.8 & 70.2 \\
\hline $\begin{array}{l}\text { Income from self- } \\
\text { employment }\end{array}$ & 6.8 & 5.3 & 4.6 & 3.9 & 3.3 & 2.6 & 3.3 & 4.5 & 4.1 & 3.9 & 4.1 \\
\hline $\begin{array}{l}\text { Income from rental of } \\
\text { a property or land }\end{array}$ & 0.9 & 1.3 & 0.6 & 1.0 & 1.1 & 0.7 & 0.3 & 0.7 & 0.8 & 0.9 & 4.1 \\
\hline Social transfers & 23.9 & 21.1 & 21.4 & 17.7 & 20.0 & 28.6 & 32.4 & 28.9 & 27.4 & 26.2 & 24.8 \\
\hline Private transfers & 2.0 & 1.9 & 0.8 & 1.3 & 1.4 & 1.5 & 1.8 & 1.5 & 1.5 & 1.2 & 1.0 \\
\hline $\begin{array}{l}\text { Expenses decreasing } \\
\text { total disposable income }\end{array}$ & -1.8 & -1.6 & -0.9 & -1.2 & -1.4 & -1.2 & -1.6 & -1.4 & -1.4 & -1.0 & -1.1 \\
\hline
\end{tabular}

Source: author's prepared based on Central Statistical Bureau of Latvia, 2016.

Over the period 2010-2014, household's disposable income per household member grew (from 285 euro in 2010 to 387 euro in 2014). Less household's disposable income grew for household with dependent children. The higher incomes were for households without dependent children but lower for households -2 adults, 3 and more dependent children. Household's mean disposable incomes per household member are reflected in Table 3.

Table 3

Mean disposable incomes per household member by household's type in Latvia, 2004-2014, euro, per month

\begin{tabular}{|l|c|c|c|c|c|c|c|}
\hline Year & $\begin{array}{c}\text { All } \\
\text { households }\end{array}$ & $\begin{array}{c}\text { All } \\
\text { households } \\
\text { without } \\
\text { dependent } \\
\text { children }\end{array}$ & $\begin{array}{c}\text { All } \\
\text { households } \\
\text { with } \\
\text { dependent } \\
\text { children }\end{array}$ & $\begin{array}{c}\text { 2 adults, } \\
\text { dependent } \\
\text { child }\end{array}$ & $\begin{array}{c}\text { 2 adults, } \\
\text { 2 dependent } \\
\text { children }\end{array}$ & $\begin{array}{c}\text { 2 adults, } \\
\text { 3 and more } \\
\text { dependent } \\
\text { children }\end{array}$ & $\begin{array}{c}\text { 3 or more } \\
\text { adults with } \\
\text { dependent } \\
\text { children }\end{array}$ \\
\hline 2004 & 141.33 & 162.75 & 125.01 & 151.82 & 132.67 & 72.91 & 121.93 \\
\hline 2005 & 175.59 & 203.73 & 154.08 & 198.45 & 153.36 & 88.08 & 144.51 \\
\hline 2006 & 223.07 & 250.50 & 201.07 & 246.63 & 194.08 & 122.84 & 197.84 \\
\hline 2007 & 316.48 & 356.81 & 283.81 & 347.64 & 295.42 & 189.51 & 270.69 \\
\hline 2008 & 355.45 & 398.93 & 319.88 & 398.48 & 321.88 & 184.52 & 315.08 \\
\hline 2009 & 302.88 & 346.46 & 266.70 & 326.39 & 283.88 & 175.57 & 250.71 \\
\hline 2010 & 285.70 & 325.00 & 250.77 & 296.53 & 270.84 & 174.80 & 238.10 \\
\hline 2011 & 304.51 & 345.25 & 267.67 & 315.85 & 288.17 & 211.05 & 248.13 \\
\hline 2012 & 319.90 & 367.20 & 275.91 & 337.26 & 287.98 & 218.82 & 254.69 \\
\hline 2013 & 353.99 & 401.47 & 306.39 & 373.48 & 310.78 & 255.79 & 287.88 \\
\hline 2014 & 386.91 & 433.98 & 342.52 & 417.34 & 349.98 & 287.24 & 318.80 \\
\hline
\end{tabular}

Source: author's prepared based on Central Statistical Bureau of Latvia data, 2016. 


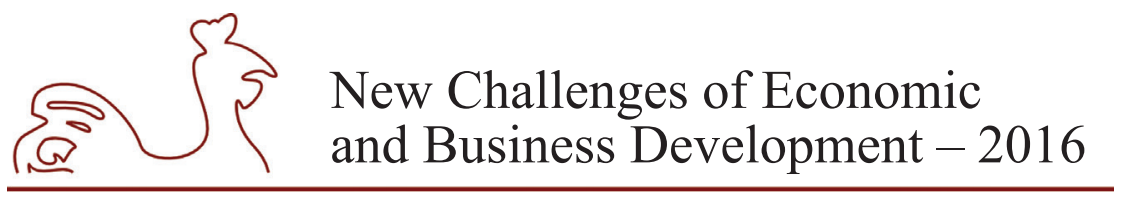

May 12-14, 2016, Riga, University of Latvia

The smallest households incomes are in Latgale region there is the highest unemployment rate (in 2013 and 2014 the unemployment rate was 12.1\%, in $2015-13.6 \%$ ). The highest households incomes are in Riga and Pieriga regions there are the smallest unemployment rates (the unemployment rate in Riga region and Pieriga region respectively in $2013-8.4 \%$ and $6.4 \%$, in $2014-6.5 \%$ and $6.0 \%$, in $2015-6.0 \%$ and $4.5 \%$ ). In 2013 household's average disposable income per household member in Latgale region was about 264 euro per month, in Riga region about 432 euros. In Pieriga region household's average disposable income per household member per month was about 376 euro, in Kurzeme region - 330 euro, in Vidzeme region - 299 euro, in Zemgale region - 292 euro. Since 2010 year household's average disposable income slightly increased. (see Table 4).

Table 4

Household's disposable income average per household member per month, in statistical regions of Latvia, 2004-2013, euro

\begin{tabular}{|c|c|c|c|c|c|c|}
\hline Year & Riga region & $\begin{array}{c}\text { Pieriga } \\
\text { region }\end{array}$ & $\begin{array}{c}\text { Vidzeme } \\
\text { region }\end{array}$ & $\begin{array}{c}\text { Kurzeme } \\
\text { region }\end{array}$ & $\begin{array}{c}\text { Zemgale } \\
\text { region }\end{array}$ & $\begin{array}{c}\text { Latgale } \\
\text { region }\end{array}$ \\
\hline 2004 & 189.01 & 145.33 & 109.07 & 117.12 & 117.08 & 102.76 \\
\hline 2005 & 248.62 & 167.01 & 132.67 & 154.45 & 138.97 & 112.11 \\
\hline 2006 & 281.52 & 239.54 & 189.04 & 212.15 & 191.96 & 141.50 \\
\hline 2007 & 402.06 & 370.22 & 248.85 & 254.62 & 272.84 & 212.45 \\
\hline 2008 & 437.00 & 411.13 & 272.13 & 322.68 & 304.58 & 245.92 \\
\hline 2009 & 368.06 & 326.71 & 260.02 & 269.25 & 262.17 & 228.15 \\
\hline 2010 & 348.78 & 292.84 & 252.44 & 261.45 & 240.23 & 223.20 \\
\hline 2011 & 357.67 & 331.97 & 249.66 & 297.12 & 268.35 & 230.15 \\
\hline 2012 & 387.56 & 336.95 & 260.37 & 308.64 & 276.86 & 238.32 \\
\hline 2013 & 431.90 & 376.06 & 298.52 & 330.05 & 291.99 & 263.94 \\
\hline
\end{tabular}

Source: author's prepared based on Central Statistical Bureau of Latvia, 2016.

The scientific researches have shown that income of households is one of the factor that affect fertility decisions. In 2014 in Latvia the highest fertility rate in common with household's disposable income was in Riga region 11.7, the smallest in Latgale region 8.6. The number of births slightly increases in all regions of Latvia that can be partially explained by increases of household's income. The changes of fertility rates in regions of Latvia are reflected in Table 5. 


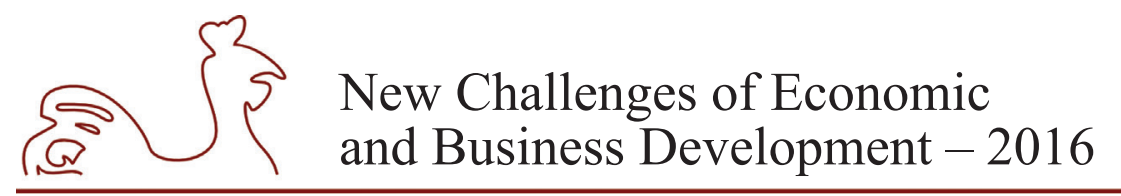

May 12-14, 2016, Riga, University of Latvia

Table 5

Fertility rates in regions of Latvia, 2002-2014, per 1000 population

\begin{tabular}{|c|c|c|c|c|c|c|c|}
\hline Year & Total & Riga & $\begin{array}{c}\text { Pieriga } \\
\text { region }\end{array}$ & $\begin{array}{c}\text { Vidzeme } \\
\text { region }\end{array}$ & $\begin{array}{c}\text { Kurzeme } \\
\text { region }\end{array}$ & $\begin{array}{c}\text { Zemgale } \\
\text { region }\end{array}$ & $\begin{array}{c}\text { Latgale } \\
\text { region }\end{array}$ \\
\hline 2000 & 8.6 & 7.2 & 9.3 & 9.1 & 9.9 & 9.6 & 8.5 \\
\hline 2001 & 8.4 & 7.5 & 8.8 & 9 & 9.4 & 9.2 & 8.4 \\
\hline 2002 & 8.7 & 8.1 & 8.9 & 8.9 & 9.9 & 9.4 & 8 \\
\hline 2003 & 9.2 & 9.2 & 9.2 & 9.1 & 10.1 & 10 & 8.4 \\
\hline 2004 & 9.1 & 9.5 & 9.1 & 8.7 & 9.4 & 9.5 & 7.9 \\
\hline 2005 & 9.8 & 10.1 & 10.2 & 9.2 & 10.5 & 9.9 & 8.3 \\
\hline 2006 & 10.3 & 10.9 & 11.2 & 9.2 & 10.6 & 10.3 & 8.8 \\
\hline 2007 & 10.9 & 11.7 & 11.9 & 9.5 & 10.9 & 10.9 & 9.1 \\
\hline 2008 & 11.2 & 11.9 & 11.3 & 10.3 & 11.4 & 11 & 10.1 \\
\hline 2009 & 10.3 & 10.7 & 11.7 & 9.1 & 10.2 & 10.3 & 8.7 \\
\hline 2010 & 9.4 & 10.2 & 10.6 & 8.5 & 9.2 & 9 & 7.6 \\
\hline 2011 & 9.1 & 9.6 & 10.2 & 8.5 & 9 & 8.9 & 7.6 \\
\hline 2012 & 9.8 & 10.4 & 10.8 & 9.2 & 9.3 & 9.5 & 8.1 \\
\hline 2013 & 10.2 & 10.9 & 11.2 & 9.2 & 9.9 & 10.3 & 8.4 \\
\hline 2014 & 10.9 & 11.7 & 12.0 & 10.4 & 10.5 & 10.7 & 8.6 \\
\hline
\end{tabular}

Source: author's prepared based on Central Statistical Bureau of Latvia, 2016.

The averages employment rate of women at the fertility age (15-49) was $63.5 \%$ in 2015 , compared with 2014 year employment rate has increased by $2.7 \%$ but it was still below precrisis period. The fertility rates of women at the fertility age slightly have increased. In 2014 the fertility rate of women at the fertility age was 48.35 per 1000 women of corresponding age. The women's at the fertility age employment rates and fertility rates in Latvia are reflected in Table 6. 


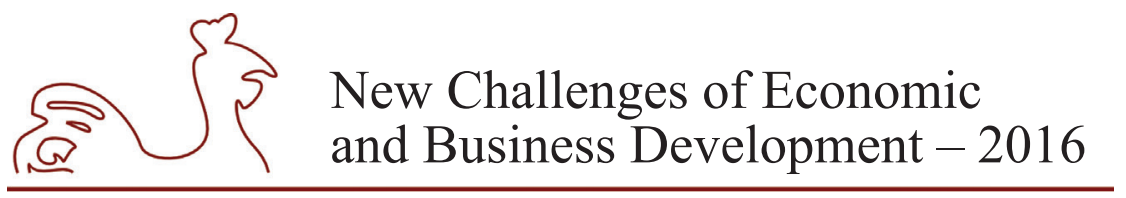

May 12-14, 2016, Riga, University of Latvia

Table 6

The women's at the age of 15-49 years employment rates and fertility rates in Latvia, 1996-2015

\begin{tabular}{|c|c|c|}
\hline Year & $\begin{array}{c}\text { Average employment rates (women at } \\
\text { the age of 15-49 years) (\%) }\end{array}$ & $\begin{array}{c}\text { Age-specific fertility rates (women at } \\
\text { the age of 15-49 years)* per 1000 women of } \\
\text { corresponding age }\end{array}$ \\
\hline 1996 & 58.4 & 33.09 \\
\hline 1997 & 60.4 & 31.60 \\
\hline 1998 & 60.3 & 30.97 \\
\hline 1999 & 59.5 & 32.67 \\
\hline 2000 & 59.0 & 34.33 \\
\hline 2001 & 59.7 & 33.59 \\
\hline 2002 & 59.7 & 34.43 \\
\hline 2003 & 60.4 & 36.30 \\
\hline 2004 & 60.1 & 35.56 \\
\hline 2005 & 60.4 & 38.27 \\
\hline 2006 & 63.6 & 40.48 \\
\hline 2007 & 64.9 & 42.97 \\
\hline 2008 & 65.8 & 44.63 \\
\hline 2009 & 60.3 & 41.62 \\
\hline 2010 & 59.3 & 38.84 \\
\hline 2011 & 59.3 & 38.37 \\
\hline 2012 & 60.0 & 41.82 \\
\hline 2013 & 61.4 & 44.56 \\
\hline 2014 & 60.8 & 48.35 \\
\hline 2015 & 63.5 & - \\
\hline
\end{tabular}

* Including births to women under 15 and at the age of 50 and over.

Source: author's prepared based on Central Statistical Bureau of Latvia, 2016.

In 2014 in Latvia the fertility rate of women at the fertility age was above pre-crisis period and the highest in period from 1996 to 2014. The growth of fertility rates can explain by the increase of employment and incomes of households. For determine the strength of the association between the employment rates of women at the age of 15-49 years and fertility rates (women at the age of 15-49 years per 1000 women of corresponding age) the correlation analysis was used. The results of the correlation analysis show that there is a statistically significant, moderate positive correlation between the employment rates of women at the age of 15-49 years and fertility rates (women at the age of 15-49 years per 1000 women of corresponding age), Pearson correlation coefficient 0.566 , level of significance $p=0.012$.

The study results is in line with prior research findings (Ciganda D., 2015; Hilgeman \& Butts, 2009; Lutz K., 2014; Mishtal J. Z., 2009; Papapetrou E., 2004) showing that employment are a significant predictor of fertility. 


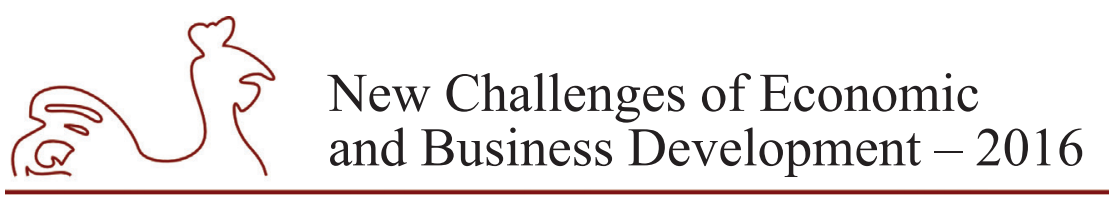

May 12-14, 2016, Riga, University of Latvia

\section{Conclusions}

1. The scientific researches have shown that employment status, employment instability, incomes, child care subsidies have a significant impact on fertility decisions.

2. In Latvia about $74 \%$ of household's incomes are incomes from paid employment and selfemployment, about $25 \%$ of the household's incomes are social transfers.

3. The higher incomes are for households without dependent children, lower for households 2 adults, 3 and more dependent children.

4. The smallest fertility rate and the smallest household's income are in Latgale region, the highest fertility rate and household's income are in Riga region and Pieriga region. Since 2012 the fertility rates have slightly increased in all regions of Latvia.

5. The highest unemployment rates are in Latgale region, the smallest in Riga and Pieriga regions. The unemployment rate is high in age groups 20-24 and 25-29 years in which are the highest fertility rates.

6. The correlation between the employment rates of women at the age of 15-49 years and agespecific fertility rates (women at the age of 15-49 years per 1000 women of corresponding age) are moderate, positive, statistically significant.

7. Promoting of own business, self-employment among unemployed women might increase their labour market participation, give for women more independence and flexibility to reconcile work and family.

\section{Bibliography}

Bonasia, M., De Siano, R., 2016. Population Dynamics and Regional Social Security Sustainability in Italy, Regional Studies, Vol. 50, Issue 1, pp. 124-136.

Caliendo, M., Künn, S. Getting Back into The Labor Market: The Effects of Start-up Subsidies for Unemployed Females, Journal of Population Economics, Vol. 28, Issue 4, pp. 1005-1043.

Central Statistical Bureau of Latvia, 2016. Population and Social Processes. Personal Income. [Online] Available at: http://www.csb.gov.lv/en/dati/statistics-database-30501.html [Accessed 15 February 2016].

Central Statistical Bureau of Latvia, 2014. Demography, Collection of statistical data, Riga: Central Statistical Bureau of Latvia.

Ciganda, D., 2015. Unstable Work Histories and Fertility in France: An Adaptation of Sequence Complexity Measures to Employment Trajectories, Demographic Research, Vol. 32, pp. 843-876.

Erosa, A., Fuster, L., Restuccia, D., 2002. Fertility Decisions and Gender Differences in Labor Turnover, Employment, and Wages, Review of Economic Dynamics, Vol. 5, Issue 4, pp. 856-891.

Euorstat, The Statistical Office of the European Union, 2016. Population and Social Conditions. [Online] Available at: http://ec.europa.eu/eurostat/data/database [Accessed 5 March 2016].

Haan, P., Wrohlich, K., 2011. Can Child Care Policy Encourage Employment and Fertility? Evidence from a Structural Model, Labour Economics, Vol. 18, Issue 4, pp. 498-512.

Härkönen, J., 2011. Children and Dual Worklessness in Europe: A Comparison of Nine Countries, European Journal of Population, Vol. 27, Issue 2, pp. 217-241.

Hilgeman, C., Butts, C., T., 2009. Women's Employment and Fertility: A Welfare Regime Paradox, Social Science Research, Vol. 38, Issue 1, pp. 103-117.

Hwang, J., Lee, J., H., 2014. Women's Education and the Timing and Level of Fertility, International Journal of Social Economics, Vol. 41, No. 9, pp. 862-874. 


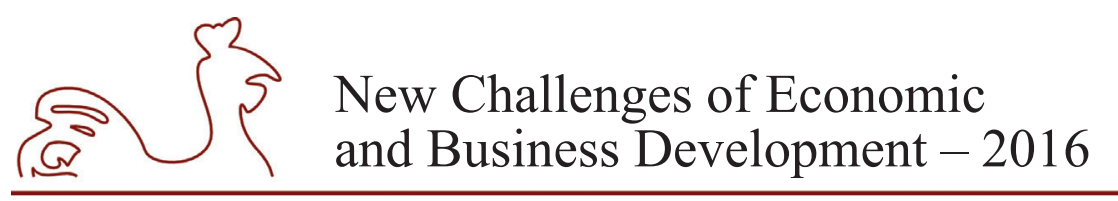

May 12-14, 2016, Riga, University of Latvia

Gelo, J., Smolić, S., Strmota, M., 2011. Socio-Demographic Determinants of Female Employment in Croatia, Društvena istraživanja, Vol. 20, No. 1, pp. 69-81.

Lutz, K., 2014. Compensating Dissatisfaction in the Job by Turning to the Family? The Impact of Current Occupation on Timing of First Births in Germany, Advances in Life Course Research, Vol. 21, pp. 43-58.

Nieuwenhuis, R., Need, A., van der Kolk, H., 2012. Institutional and Demographic Explanations of Women's Employment in 18 OECD Countries, 1975-1999, Journal of Marriage and Family, Vol. 74, Issue 3, pp. 614-630.

Mishtal, J. Z., 2009. Understanding Low Fertility in Poland: Demographic Consequences of Gendered Discrimination in Employment and Postsocialist Neoliberal Restructuring, Demographic Research, Vol. 21, pp. 599-626.

Papapetrou, E., 2004. Does Female Employment Affect Fertility? Evidence from the United Kingdom, The Social Science Journal, Vol. 41, Issue 2, pp. 235-249. 
May 12-14, 2016, Riga, University of Latvia

\title{
FISCAL POLICY IN LATVIA: RISKS AND CHALLENGES
}

\author{
Lucija Kavale, University of Latvia, Latvia ${ }^{1}$ \\ Erika Zubule, Rezekne Higher Education Institution, Latvia
}

\begin{abstract}
Until now the development of Latvia has not proved to have an effective and balanced implementation of a socio-economic policy in the country. There is a need for an unambiguous rapid economic breakthrough for a further development of the country where the implemented state fiscal policy is an important instrument. At present the economic development in the world and Europe, geopolitical situation, the migration of the population as well as the domestic problems of the development of Latvia pose new challenges to the government's fiscal policy, they create new fiscal risks and problems that require strong fiscal discipline and an efficient fiscal policy. Unfortunatelly, during the past years the fiscal policy in the country is not sustainable, each year it is adjusted and the government steps away from the previous decisions which cause the discontent of the society and as a whole it slows down the economic development.

The aim of the research is: to evaluate the fiscal policy in Latvia in accordance with the theoretical and practical conclusions of the scientific investigations in the world, to determine the main fiscal risks and to find the fiscal policy gaps in the formation of the revenues of the state budget as well as in the use of funds and to define the recommendations for making a sustainable fiscal policy in the country.

During the investigation the most essential factors which influenced the fiscal policy were determined: administrative, political, ideological, economic, international and the fiscal risks were summarized: quantified and not quantified as well as the recommendations have been worked out in order to minimaze the risks and to reduce their negative influence. In the paper the development trends of the state expenditure structure have been critically analyzed and the drawbacks of the fiscal policy have been investigated. At the end of the research the authors have defined the necessary measurements for making a sustainable fiscal policy of a rapid economic development of the country and the decrease of social inequality.

During the investigation the qualitative and quantitative statistical research methods were used.
\end{abstract}

Key words: fiscal policy, fiscal risks, expenditures

JEL code: E62, H20, H50

\section{Introduction}

25 years have passed since the beginning of the economic changes in Latvia and at present we can estimate the results of the process of the economic changes and restructurization as well as the aims achieved in the development of the society and in the social area, we can also identify the drawbacks and analyze problems. The previous decades were characterized by significant fluctuations in the social and economic development in the world and, especially, in Europe which have certainly influenced the development processes in Latvia. The recent crisis and the fact that Latvia did not create the resources of the fiscal reserves to overcome the crisis easier is a severe and painful lesson from the mistakes in the fiscal policy. At present we are in a new

1 Corresponding author - e-mail address: lucija.kavale@lu.lv 


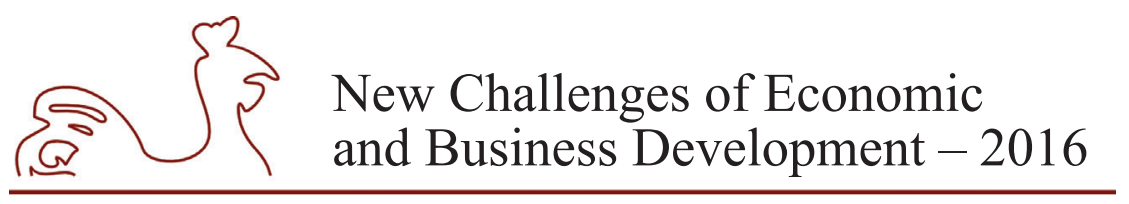

May 12-14, 2016, Riga, University of Latvia

situation which should be taken into account by the politicians. The complicated geopolitical situation, the migration of population, the slowdown of the economic development in Europe and other countries show that the policy persued by the government is no more efficient. A lot of big problems have accumulated in Latvia: social stratification, emigration, the unsettled educational and health care systems, shadow economy, the unwieldy state government. All that is the proof of the fact that the fiscal policy so far has not given the expected results. In order to make an efficient fiscal policy it is necessary to find out the most influential factors, whether they are of an objective or subjective character and which fiscal risks can endanger the implementation of some fiscal indicators and how big the fiscal reserves should be. The choice of the research in this field was stated by the fact that the problems of fiscal policy have rarely been investigated and the government of Latvia has only recently begun the investigation of risks.

The aim of the research is to analyze the factors which affect the fiscal policy in Latvia in accordance with the theoretical conclusions of financial science, to determine the main fiscal risks and drawbacks of the fiscal policy as well as to define the recommendations for making a sustainable state fiscal policy.

The main tasks of the research are:

- The review of the opinions and the viewpoints on the use of the state fiscal instruments and the factors which influence them;

- The identification of the factors influencing the fiscal policy and the investigation of their effect;

- Finding the risks of the fiscal policy and the analysis of the situation in Latvia;

- The elaboration of recommendations and suggestions for the improvement of the fiscal policy in Latvia.

During the research the main challenges to the formation of the fiscal policy have been characterized and the main factors influencing the fiscal policy have been identified, i.e., administrative, political, ideological, economic and international; the fiscal risks have been identified: to be quantified and not to be quantified as well as the recommendations have been worked out to reduce the risks and their negative influence.

The article is based on the research and theoretical conclusions of foreign and Latvian authors, the legislation of Latvia and other regulatory documents about particular issues.

\section{The factors influencing fiscal policy}

The government of Latvia has set an ambitious goal - to join the countries of OECD. In order to achieve this goal the amendments to the legislation and other regulatory documents have been made, the changes in the state administration have been implemented and the economic and fiscal policy have been specified and changed. Unfortunately, the above mentioned activities have not given the expected results. Therefore, there is a reason to examine the state fiscal policy which is a precondition for an efficient state administration.

The experts of the OECD countries have estimated the public sector of Latvia and the results were not complimentary for Latvia. As follows from the research of OECD (OECD, 2015), Latvia is one of the most uneque societies compared with OECD countries, a big part of the population is at risk of poverty. The social safety net is underdeveloped and not well targeted at those most in need. The tax structure is skewed towards distortive taxes on labour, 


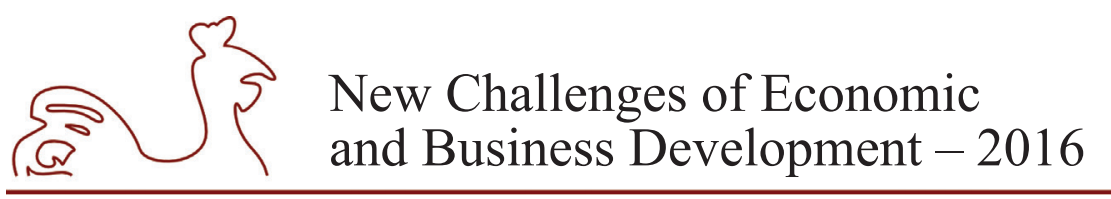

May 12-14, 2016, Riga, University of Latvia

with relatively low property and environmental taxes. The efficiency of tax administration and collection stands well below international standards, not least due to a prevalent grey economy. In the long term, there is a risk that spending allocated to key public services (education, health, pensiones) will prove inadequate in view of desired outcome improvements. Despite significant improvements since its independence, Latvia still lags behind the average OECD or EU and its regional peers in a number of social and economic dimensions measuring the quality of life. In the research there are a lot of recommendations for a more rapid development of the economy and public sector in Latvia paying a special attention to the increase of the efficiency of the public sector, fiscal and social policy.

The problem of the estimation of the quality of work in the state administration is longlasting and in some periods it has becomes especially topical. As it is justly stated in the economic literature the aim of the administrative investigation is mainly to detect what the government can correctly and successfully do and, secondly, how they can perform these right things with a greater efficiency and possibly lower costs (Fry, Brian R., 2008). The importance of the costeffectiveness in the fiscal policy is emphasized by other authors, too. The principle of outcome orientation is a central point of the new public management paradigm. It requires a shift of control of resources towards a product- and outcome-based management (Reichard, Ch., 2003).

The theory of finance and the world experience suggest different methods for using and application of public finance but there is not a universally recognized mechanism which could be used in all the cases. According to Alberto F.Alesina and Silvia Ardagna fiscal stimuli based upon tax cut are much more likely to be growth enhancing than those on the spending side (Alesina F. A., Ardagna S., 2009). Other authors speak about necessity to analyze public sector efficiency and size of the government (Afonso, Schuknecht, and Tanzi. 2006., Alesina, 1998). Some authors investigate the influence of the political factors to the public policy. Political distortions lead to excessive accumulation of government debt and procyclical fiscal policy. Procyclicality of fiscal policy is more often driven by a distorted policy reaction to booms, rather than to recessions. (Alesina, Campante, and Tabellini, 2008; Rogoff, K., 2003). Issues of budget consolidation were investigated by another economist C. Mulas-Granados (Mulas-Granados, C., 2006).

However, we must point out that an ideal fiscal policy is not possible because there are always some influencing factors which lead to the choice of other ways to solve particular problems. Particular influencing factors of the fiscal policy are very similar in a lot of countries but the degree of influence can be very different and there can also be typical influencing factors only in one country. The authors have tried to summarize and analyze the most typical of them.

One of the main factors which influences the fiscal decisions in a particular country is, of course, the socio economic level of development in the country (resources available) resulting in the goals and priorities of the government as well as the needs of the population. In underdeveloped countries the fiscal decisions are focused on the satisfaction of the basic needs of inhabitants in everyday life and social sphere, besides, there is always scarcity of funds because the underdeveloped entrepreneurship and low income can not ensure tax payments to the state budget in an appropriate amount. No matter how ambitious the goals of the governments in these situations are, they are forced to go step by step, to adopt unpopular decisions in the sphere of taxes or expenses causing the dissatisfaction of a part of the society. In underdeveloped countries the governments usually think about saving money. However, in this situation the fiscal policy must not be blindly saving. During the crisis in underdeveloped countries the government must 


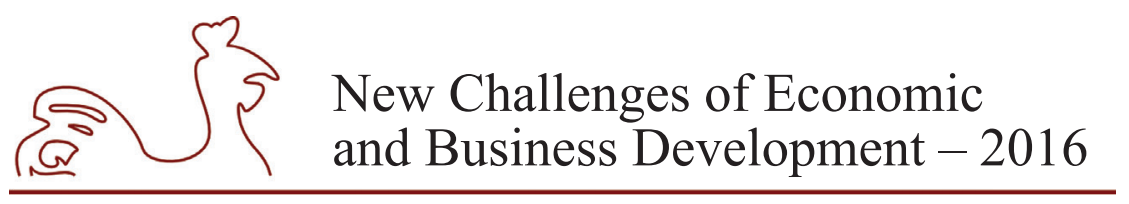

May 12-14, 2016, Riga, University of Latvia

find the possibility to stimulate the development with the help of taxes and the state support mechanisms. The higher the level of the socio economic development, the easier and simpler for governments to make the fiscal policy, it has already proved its effectiveness and sustainability, therefore, only small adjustments are needed along with the changes in economy. In any case, a responsible fiscal policy must be implemented which means to spend money correctly during the crisis and save money in the boom years. The biggest problem is, usually, to create reserves and to follow the austerity policy in the boom years. Unfortunately, Latvia has demonstrated it in the boom years when the government expenditures increased rapidly, but the fiscal support reserves were not created.

As the second factor, which influences the fiscal policy, are the international factors. The international factors manifest themselves in different ways. In the case of Latvia they are very important. Being the members of different organizations (WTO, IMF, EU, UN, NATO), it is understandable that the member states have legal obligations (also financial) to comply with contractual liabilities. First of all, it is the member fee, which must always be predicted in the budget expenditures. Besides, there are a lot of other liabilities which directly influence the fiscal policy in the country. For example, the participation in the World Trade Organization (WTO) envisages that beside all other duties the member states have decided not to subsidize export which means the restrictions of the implementation of the state support instruments for their entrepreneurs. These liabilities were incorporated in a special law of Anti-dumping (Anti-dumping law, 2000) which along with joining the EU was terminated and now these issues are regulated by the EU. The application of the state financial support instruments which is an important part of a fiscal policy, is regulated also by the Treaty on the Functioning of the European Union (TFEU), where there is such an connotation as "compliant with TFEU and not compliant with the state support" (it deals with the EU internal market) which shows the cases when the state support (subsidies) is not disputable. Basically, the acceptable support measures are focused on the prevention of the emergency situations in connection with natural disasters, in the regions of an underdeveloped economy and the support of such measures which promote the implementation of important projects in the interests of the EU. In accordance with TFEU there is no support to the domestic market which poses threat to the distortion of competition giving preferance to particular enterprises or the production of certain goods. The government must observe these restrictions when making their support policy which are not always in the interests of the domestic producers. As we know, the member states must also take into account certain international criteria about the amount of the permissible budget deficit and the state debt. Besides, entering the EU it was necessary to restructure particular taxes (excise tax, VAT, customs duty). With the entering the Euro area the Fiscal Stability Treaty (TSCG- Treaty on Stability, Coordination and Governance in the Economic and Monetary Union) is legally binding for Latvia which impose an obligation to coordinate the planning of the state budget with the European Commission, to report, to discuss, to coordinate and to obey instructions. A vivid example is the implemented budget consolidation in Latvia in 2009-2011 during the crisis when during the implementation the government refused to satisfy the viatal needs of the society but the fiscal policy was focused on the fullfilments of the requirements of the international creditors. In the theory of public finance there is a term "budget agreement" which means that the governments are responsible for all international financial liabilities so that all the financial liabilities are included in the annual state budget. Basically, the budget of each country is like a budget agreement because each country has international payments, the 


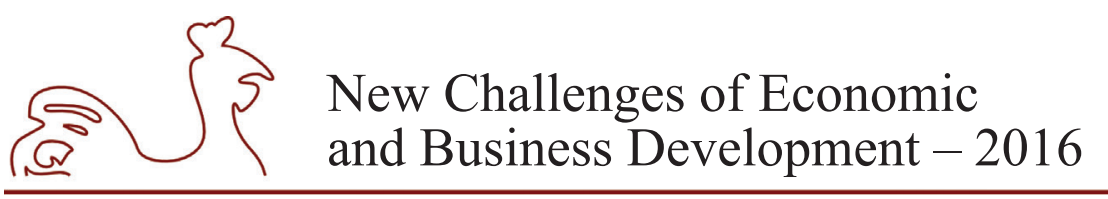

May 12-14, 2016, Riga, University of Latvia

necessity to include the co-financing of the EU structural funds, the expenses for credit servicing and so the revenue part must include the financial aid of foreign countries, borrowings, the EU structural funds, etc. Different requirements from the international organizations may be with a positive influence (especially in the cases when the domestic politicians are not able to adopt some important decisions or obey the fiscal discipline) but the influence can also be negative if it is not in compliance with the domestic interests.

The international factors also mean that the country must respond to the economic changes in the world, to the financial markets, to the economic development trends in the countries of cooperation, to geopolitical events and to the problems caused by migration of the population. These factors can emerge rapidly and unexpectedly and they can endanger the economic development of the country. Therefore, the governments will have to correct the previous fiscal policy which can also cause the dissatisfaction in the society.

The authors make a conclusion that as a whole the international factors denote that to a certain extent the governments have less independence for fiscal decisions which is a negative factor because in such a way the fulfilment of international obligations comes first. The authors consider that the government of Latvia must put forward the arguments more actively to defend the domestic interests and they must try to achieve more favourable decisions for the society of Latvia. In Latvia the influence of the international factors on the state budget, the tax policy and expenditures is not enough investigated and analyzed. There are no calculations about the gains and losses and they are not explained to the society.

The next influencing factor on the fiscal decisions is the political factor. The political factor is usually connected with the desire of politicians to gain the votes, to increase the rating of the party, to get a higher recognition which is not always achieved with an economically substantiated increase of financing for a certain field or project, the State guarantee is unjustifiably given for a credit of a private business, there are premature and doubtful amendments in the policy of taxes, social sphere, pensions and benefits. The state activities usually increase under the influence of politicians and also its role in economy which means the increase of the costs and larger state administration. It is called the political distortions of fiscal policy. We can mention several examples in Latvia when in the political interests there were or were not adopted particular decisions in different spheres of fiscal policy. Most often we can see it when the Parliament elections are approaching, then the political parties enthusiastically try to get financing for the projects which so far were not topical or they suggest tax changes which refer to a big part of the electorate, etc.

The fiscal policy is also influenced by the ideology of the political force which is in power, whether it is a left or liberal oriented government. Basically, it is the question of the state role in economy and its functions and also an appropriate fiscal policy. A certain ideological platform of the ruling parties determines the predictability of the policy to be implemented and the reforms to be done. Unfortunatelly, during 25 years the political forces with a strong ideological platform have not been formed, i.e. for specifically defined economic and social objectives and an appropriate fiscal policy. There are too many parties, their programmes are mostly similar which makes it difficult for the society during the elections to choose one political party. In the countries with a high political culture the people do not vote for personalities (last names) which is the case in Latvia but the people vote for an ideological platform of the party which is included in the objectives.

The authors want to emphasise one more factor which influences the effectiveness and implementation of the fiscal policy, namely, administrative factor. It is known that each perfectly 


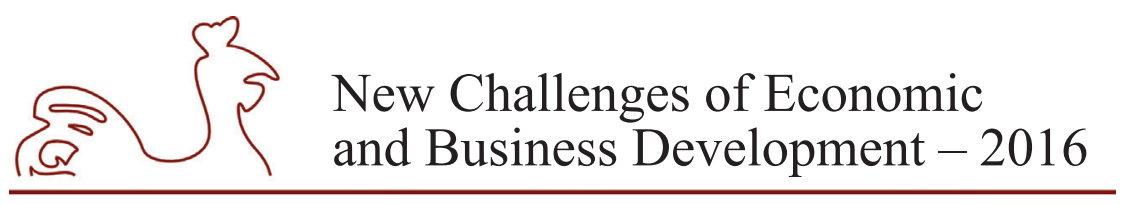

May 12-14, 2016, Riga, University of Latvia

elaborated fiscal policy can be distorted if it is incompetently administered. It is stated that if the administrators' capacity is weak then the policy must be changed. The administrative factor must be dealt with in a broader aspect as an institutional provision of the fiscal policy. This involves a wide range of issues and it usually has a lack of attention. The institutional provision involves clear and understandable elaboration of the regulatory base, an appropriate establishment of the governance institution, an adequate personnel selection, good management, allocation of responsibilities, etc. In all the countries the main financial manager is the Ministry of Finance, although there are some differences. As we know, in Latvia the State Treasury and the State Revenue Service are under the Ministry of Finance but there are countries where these institutions are independent, they have an independent status with the motivation that in such a case the political influence on the decision-making is excluded by the administration of the ministry and the decisions are made more effectively. In the science of public finance the question about the role of civil servants in the fiscal policy has always been topical. The responsibility and resources of the civil servants to influence the fiscal policy and the budget process can not clearly be defined. There is a viewpoint that beginning with the years 70-ties and 80-ties the influence of the civil servants in the fiscal policy has substantially become less because the politization of this process has rapidly increased and the civil servants perform only technical functions (Kliman, A., 1997). But other authors (W. A. Niskanen, 1994; J. L. Migue, G. Belengers, 1994) point out that the civil servants have a decisive meaning in the maximization of expenditures without respective results. The above mentioned authors emphasize that the unproductive costs of the budget are the result of the irresponsibility of civil servants. The authors of the research agree that the expansion of civil service substantially slow down the effectiveness of the decisionmaking. However, speaking about the civil servants as only technical performers we must point out that in the situation of Latvia when the governments (ministers) change rather often, the role and responsibility of civil servants in certain areas increase.

Summarizing this short review about the factors influencing the fiscal policy we must point out that the authors have mentioned only the most important ones. The fiscal decisions can be influenced also by several other factors: culture, religion, environment, demography, geopolitical situation and others. It means that, basically, unchanged and stable fiscal policy is not possible. In certain situations it is important for the governments to pursue a flexible fiscal policy and at the right time to be able to respond to the changes of any of the factors and if it is necessary to change the previously adopted decision. The authors consider that timely decisions are one of the preconditions for success because there is nothing worse than the fiscal policy which does not conform to the situation.

In order to reduce the dissatisfaction of the society and to avoid unreasonable speculations, the changes of the decisions must be explained to the society understandably and with arguments. The communication of the Latvian governments with the society as to the fiscal and other decisions is a weak point which needs radical improvements.

As we can see, the factors, influencing the fiscal policy, can be subjective and objective and they may have a different influence on the state budget. We can also conclude that there is no absolutely "clear" fiscal policy because it will always contain compromise decisions which infer from the factors which influence. 


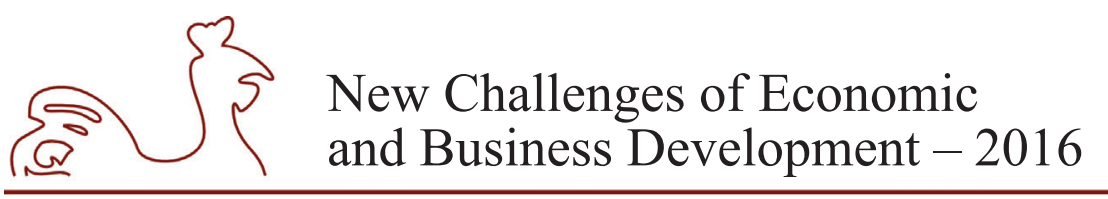

May 12-14, 2016, Riga, University of Latvia

\section{The risks of fiscal policy}

From the problems previously discussed infers that the fiscal policy is influenced as a result of subjective activities and also as a result of objective processes. In public finance, it no longer suffices for analysts and institutions to focus solely on budget revenues and expenditures. Recent history demonstrates that fiscal performance and, in turn, economic development can be seriously disrupted by the sudden, unexpected costs of hidden contingent liabilities and other unanticipated fiscal risks. This in turn requires the government to identify, classify, and assess its fiscal risks so that it can provide reliable estimates of future payments that may ensure from past and pending liabilities. Only by identifying and measuring its exposure can a government bring its risks under effective control.

The international experience and also the experience in Latvia proves that dilatory identification of the fiscal risks and the lack of the plan to prevent them can cause additional financial liabilities for the govrnment (for example, the budget consolidation 2009-2011), the necessity to increase financing, a substantial increase of the state debt, the risk to re-finance the state debt and even the financial crisis. Nowadays the identification of fiscal risks is especially topical because at present the economic and social environment has substantially changed under the influence of different factors and especially in the European Union. We can see the slowdown of growth in the developed countries, the influence of oil prices on the inflation, geopolitical tension and the migration of population. The governments search for the ways to face the challenges in order to protect the countries form a negative influence. The authors consider that in the policy of the EU and the euro area one can see the discrepancy and contradictions between theory and practice. Theoretically, in EU the principles of the fiscal policy and discipline are defined: a responsible fiscal policy, the levelling of economic development, the improvement of the investment environment, the stabilization of the financial sector, etc. It is stated that the national budgets must be coordinated, there are different fiscal regulations and criteria, there is a coordination of activities, etc, but at present the economic reality is Europe with a lot of speeds, which makes a choice for Latvia which group of countries to join. In the fiscal decision-making there is a big flexibility and compromise in Europe and some countries get preferences and extensions for the solution of fiscal problems, ignoring the non-observance of particular fiscal criteria. More often we can see the differences of national interests and objectives. In order to prevent these differences the question about the formation of the Ministry of Finance of the Euro area has been raised, the competence of which could include the harmonization of policy, the increase of the efficiency of supervision and a greater integration of the countries in the Euro area. There are countries which oppose a bigger integration and centralization, for example the UK. In this situation it is important for Latvia to strengthen its economy ant to adopt reasonable decisions in fiscal policy. When making decisions one must take into account the possible fiscal risks, in the occurance of which the planned goals can not be achieved. Until now in Latvia the investigations of the financial risks have been mainly based on the private sector: banks and other private institutions. The problems of the fiscal risks in the government policy are considered to be new and they are relatively little investigated but recently they are especially topical and therefore, the main investigations and conclusions will be in the future.

A fiscal risk is a financial stress which the government can face in the future. More specifically, a fiscal risk is the possibility of short-to medium-term deviations in fiscal variables compared with 


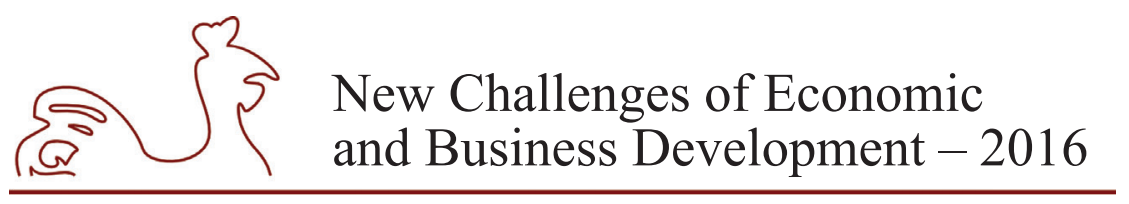

May 12-14, 2016, Riga, University of Latvia

what was anticipated in the government budget or other fiscal forecast. On this basis, fiscal risk is the exposure of the central government to events or circumstances that could cause short- to medium-term variability in the overall level of revenues, spending, the fiscal balance, and the value of assets and liabilities. Defining fiscal risks as the exposure of the central government reflects the fact that central government is responsible for macroeconomic management, including initiating fiscal policy responses as required. This does not mean that fiscal risk management should ignore potential risks arising outside central government. The risks must be identified and the possible consequences of their occurance must be estimated. It means that the government needs financing in order to ensure the liabilities not only in stable but also in changing macroeconomic conditions.

Fiscal risks can be classified according to different parameters. Foreign authors have contributed to the investigation of fiscal risks (Brixi, Hana Polackova, Schick, A., 2002; Cebotari, A., 2008; Allen, R., Hemming, R., 2013). The above mentioned authors have investigated fiscal risks and their influence on the budget as well as the risk management methods. On the basis of the investigations of foreign researchers the authors of this paper will try to identify and systemize the most important fiscal risks as well as to ivestigate the situation in Latvia.

According to the origin of risks the authors divide them into external and internal risks.

External risks are those whose origin is outside the country and directly or indirectly they affect the social economic activities of a particular country. In the first part of the paper the authors have already pointed at the external factors which influence the fiscal policy in Latvia. Not all the external factors are with a negative risk. External negative risks are a serious threat to the economy and financial system in Latvia because practically it is not possible to influence them. The task is to be ready to reduce their negative impact. The authors consider that at present the negative risks prevail which are connected with a geopolitical situation in the region, the recession of the economy in Russia and the mutual economic sanctions between the EU and Russia, a slow growth in the Euro area, the present imigration problem, unclear financial situation in Greece and the slowdown of economy in the second world economy in China. The potential negative fiscal impact is the decrease of local and foreign investments in the region and in Latvia, the decline of economic relations with cooperation partners, in such a way reducing the potential of growth in short-term and also reducing the potential of growth in the medium term and long-term.

The origin of internal fiscal risks is in the country. The internal fiscal risks have also a negative impact on the state budget but acting in a timely manner it is possible to affect or reduce them or in general to prevent them. The internal risks can arise from the government decisions which are made without a full assessment of the enterprise which gets the state bail and the credit guarantees. The risk is connected with a probability that insolvency can set in and the obligations will not be met. It is the same with the loans provided by the state because they may be connected with the risk not to be repaid. As a result there can arise the necessity for unplanned short-term credits which is not a good practice. The state insurance budget is a special issue in connection with internal fiscal risks and it can be a big burden to this budget with a lot of expenditures which could not be covered by the state obligatory insurance payments. The increase of expenditures can arise either due to the political decisions of the government (increased benefits; new benefits introduced; the pensions increased, etc.) or due to the increase of the group of people to receive benefits. Such a situation causes an additional fiscal stress and makes it necessary to do some activities to balance the social budget. The above mentioned fiscal risks are the main subject of investigation in foreign literature. But in the situation of Latvia we must also mention other risks which are serious 


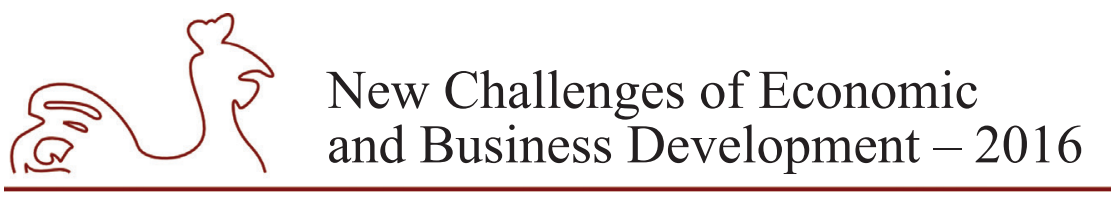

May 12-14, 2016, Riga, University of Latvia

threats to the financial stability. One must mention the shadow economy, non-observance of the tax discipline, the tax evasion, illegal salaries (money in the envelope), different schemes of VAT fraud, etc. which means that a big part of money is not paid to the budget. The internal risk with serious fiscal consequences in Latvia is a big corruption which to a certain extent is connected with activities in shadow economy, the corruption can also be the reason for the decisions which are economically not substantiated in the cases which were mentioned above, i.e., the problems with state guarantees, bails and state loans, etc. We can also mention poor work of the controlling authorities and slow and inefficient litigation system. We must mention such risks as demographic situation, emigration, unemployment, a.o. Latvia is characterized by a political risk, too, which means the instability of governments and the frequent changes of them that can cause the review of fiscal decisions of the previous government which is a negative signal for investors, entrepreneurs, consumers and which can also cause the lack of confidence in the programs of the governments.

According to the possibilities to assess the risks we can divide them into quantified and not quantified.

There are risks which can be quantified, to estimate the probability of occurance and calculate their real fiscal effect on the budget revenues or expenditures and so to prepare the plan B for the future activities. But it is is more complicated with the risks which can be difficult or even impossible to be quantified. In such a case it is advisable to work out several scenarios of activities (optimistic and pessimistic) in order to reduce the adverse impact of the risk occurance. In this connectoin we would like to appreciate the fact that drawing up the budget for 2016 and the next two years the Ministry of Finance has done a sensitivity analysis of the occurance of fiscal risks as a result of which different scenarios of development have been predicted.

According to their characteristics the risks can also be divided into explicit and implicit ones. Their characteristics are shown in Table 1.

Table 1

\section{Classification of the risk sources}

\begin{tabular}{|c|c|c|}
\hline Sources of obligations & $\begin{array}{c}\text { Direct liabilities (obligation in any } \\
\text { event) }\end{array}$ & $\begin{array}{c}\text { Contingent liabilities (obligation if a } \\
\text { particular event occurs) }\end{array}$ \\
\hline $\begin{array}{l}\text { Explicit } \\
\text { Government liability } \\
\text { as recognized by a law } \\
\text { or contract }\end{array}$ & $\begin{array}{l}\text { - Sovereign debt (loans contracted } \\
\text { and securities issued by central } \\
\text { government) } \\
\text { - Expenditure composition } \\
\text { (nondiscretionary spending) } \\
\text { - Expenditures legally binding } \\
\text { in the long term ( civil service } \\
\text { salaries and pensions) }\end{array}$ & $\begin{array}{l}\text { - Government bails, guarantees and } \\
\text { loans, including private investment } \\
\text { bails } \\
\text { - Private-public partner investment } \\
\text { projects } \\
\text { - State insurance schemes (deposit } \\
\text { insurance, income from private } \\
\text { pension funds insurance) }\end{array}$ \\
\hline $\begin{array}{l}\text { Implicit } \\
\text { A moral obligation } \\
\text { of government } \\
\text { that reflects public } \\
\text { and interest group } \\
\text { pressures }\end{array}$ & $\begin{array}{l}\text { - Future public pensions } \\
\text { - Social security schemes } \\
\text { - Future health care financing } \\
\text { - Future recurrent costs of public } \\
\text { investment projects }\end{array}$ & $\begin{array}{l}\text { - Default of a subnational government } \\
\text { or public/private entity on } \\
\text { nonguaranteed debt/obligations } \\
\text { - Banking failure } \\
\text { - Failure of a nonguaranteed pension } \\
\text { fund } \\
\text { - Insolvency of the employment funds, } \\
\text { social security fund and other funds }\end{array}$ \\
\hline
\end{tabular}

Source: made up by authors using Brixi, Hana Polackova; Schick Allen. 2002. 


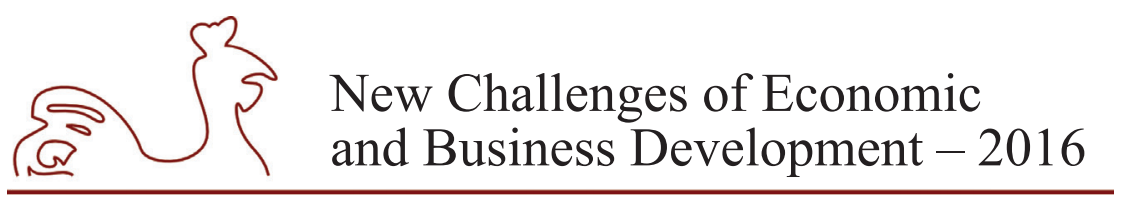

May 12-14, 2016, Riga, University of Latvia

The enumeration of the risks mentioned in the table in each group is not complete because each country may have its specifics.

Government direct explicit liabilities are legal or contractual obligations of the government that will arise in any event. They are: the repayment of sovereign debt, expenditures based on budget law in the current fiscal year, and expenditures in the long term for legally mandated items such as civil service salaries and pensions.

Government direct implicit liabilities will also arise in any event, but the government will not be legally obliged to act on them. Such obligations often arise as a presumed consequence of public expenditure plicies in the longer term.

Contingent explicit liabilities are government legal obligations to make a payment only if a particular event occurs. It is very difficult to assess these liabilities because the financial impact is not known until it occurs, besides, it can substantially exceed the government fiscal resources.

Contingent implicit liabilities depend on the occurrence of a particular future event and on government willingness to act on them. Such obligations are tipically not officially recognized until after a failure occurs. The triggering event, the cost at risk, and the required size of government outlay are uncertain.

Contingent liabilities are recognized as one of the important causes of fiscal instability. The government should assess risk even when it has already decided to provide guarantees, and even when it does so because the beneficiary is a bad risk. It should do so in order to have an accurate picture of its financial condition and of potential downstreem losses and payments. Ideally, it should use this information to estimate the money needed to cover losses in the current budget or future ones. Unfortunately, governments often take on contingent liabilities in an ad hoc manner, without regard for the impact on their financial condition. The authors emphasize that each guarantee programm, and sometimes each guarantee must be treated as a special case, with its own rules and procedures. The government should establish a risk management strategy to guide public organizations when they take actions that expose them to financial liability.

As we can see, there are various risks both from the source of their origin and from the possibility to assess them and the probability of the occurance. Therefore, it is important to deal with risk management. In the process of risk management it is important to cover all issues which together make up the management cycle of the risk management.

The fiscal risk management cycle according to different authors consist of following steps (Allen, R., Hemming, R., Potter, B. H., 2013):

1. Establish the context. This means the internal and external political and economic context. The fiscal risk management cycle starts by establishing the external and internal context in which the government is operating. The external context should include the broader economic context as well as political context. The inner environment must also be estimated as comprehensively as possible. Next we must understand the ability of the government to respond to fiscal risks from the capacity of organization and from the viewpoint of financial flexibility. The understanding of context is the basis for further goals and objectives of the risk management.

2. Identify risks. Next we must estimate the possible changes in the external and internal environment and identify what can happen and how it can happen.

3. Analyze risks. Assess similar consequences of risks, given existing control measures. Categorize risks according to their significance (probability of occurance times potential loss). 


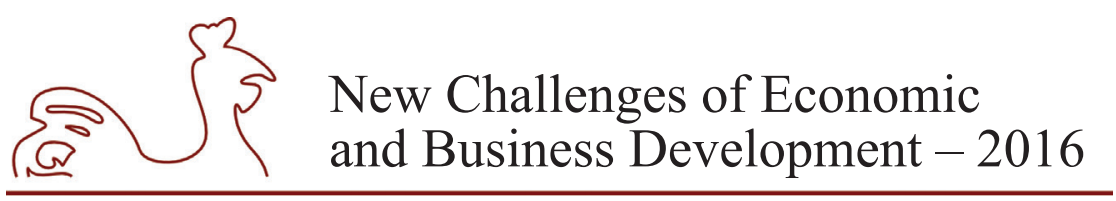

May 12-14, 2016, Riga, University of Latvia

4. Mitigate risks. Implement cost-effective options for increasing potential benefits and reducing potential costs. The reduction of the occurance of the potential risks and the mitigation of potential consequences has an important impact on the decrease of the budget.

5. Incorporate retrained risks in fiscal analysis and budget.

6. Monitor and review.

The results of the previous stages must be kept under regular review as events occur or circumstances change. The overall risk management function should also be reviewed periodicially for efectiveness and efficiency. At all stages: communicate information on risks within government and disclose publicly.

Next the authors will deal with the identification of fiscal risks and the management evaluation in Latvia. Adopting the budget of Latvia for 2016 the government has defined that as a whole in the future the course of fiscal policy will be focused on providing the growth of sustainable economy and the implementation of a responsible fiscal policy, taking into account the conditions of the fiscal discipline. According to the provisions of the Law on fiscal discipline, the basis of the strategy of fiscal policy in Latvia is the precondition of a balanced budget in the economic cycle and the deficit of the structural budget must not exeed $0.5 \%$ from the GDP.

The first decade of euro is over with a clear conclusion that further existence of the European monetary Union requires urgent changes in the expenditures of the countries because a common currency can not be imaginable when some member states live beyond their means for a long time. Since the crisis and especially when joining the Euro area the Latvian government has also assessed the state fiscal risks more seriously and the management mechanism has been created. Since March 2013 the Law on fiscal discipline has been in effect (Fiskālās disciplīnas likums, 2013) which states such principles and conditions of fiscal policy which ensure balanced budget in the economic cycle in order to ensure the macroeconomic stability in the medium term and long-term and to reduce the adverse effect of external factors on the economy and state fiscal position. The law imposes an obligation to be economical during the boom years and to form the reserves for the fiscal risks, the aim of which is the creation of security mechanism in the cases of macroeconomic, fiscal or demographic shock. The law states that every year the government must form not only the budget for the next year but also the framework of a medium term budget where on the basis of the acceptable level of budget deficit the upper level of the budget will be defined for the next year and the year after the next. This condition is accepted as correct in order to avoid the practice in the boom years when the economy developed above its potential and the government implemented procyclical and growth stimulating policy and spent all unplanned additional revenues. The law on fiscal discipline is considered to be the management framework of the fiscal risks where the fiscal risks can be identified on the level of the govenment to make the assessment of the potential impact on the state budget and to choose and adjust an appropriate management instrument.

According to the law of 29 April, 2014 the Regulations No. 299 of the Cabinet of Ministers "Regulations on a general management of fiscal risks and on the methodology to determine the amount of the reserves for the fiscal support" were approved. (MK noteikumi Nr. 299, 2014). In general, giving a positive assessment for the elaboration of the regulations, the authors would like to point out that the regulations contain some shortcomings,i.e., the norms and terms can be differently interpreted and they need some clarification. According to the regulations the 


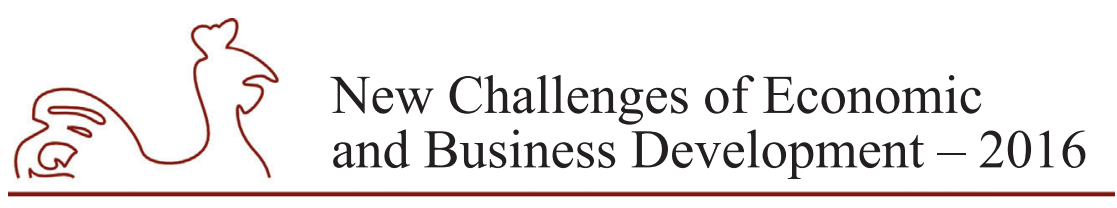

May 12-14, 2016, Riga, University of Latvia

fiscal risks are divided into specific and typical risks but their definition is very similar that a specific risk can also be taken as a separate case. The regulations define specific activities of the government to follow the rules of financial discipline. The general management of fiscal risks is involved in the identification of fiscal risks, the probability of their occurance and the assessment of the fiscal impact and a specific elaboration of measures for the reduction and prevention of fiscal risks. A register of fiscal risks and the methodology to determine the amount of reserves for the fiscal provision have been worked out, too. The general management of fiscal risks has been determined on three levels:

1. The general management of fiscal risks, responsible for which is the Ministry of Finance;

2. The management of specific fiscal risks, responsible for which are the central state institutions;

3. The management of certain fiscal risks, responsible for which are the project and activity promoters financed by the state budget and the European political instruments and other funds of foreign financial aid, the project promoters of the public and private partners and the commercial associations in the government sector.

The regulations also envisage the rules of the cooperation procedure and the information exchange among the above mentioned institutions which are involved in the risk management. The central state institutions, which are responsible for any of the issues of the management of fiscal risks, must prepare a report on particular risks and submit it to the Ministry of Finance each year until 15 February. In addition to the Law on fiscal discipline and the Regulations No. 299, the Ministry of Finance has elaborated the Declaration of fiscal risks where we can find the classification of fiscal risks, besides, quantified and not quantified fiscal risks are precisely defined as well as the methods of the occurance and impact of risks and the calculation of the fiscal security reserve have been prescribed (Finanšu ministrija, 2014). According to the Law on fiscal discipline the Council of the fiscal discipline has been established which analyzes the conformity of the amount of fiscal security reserves approved in the Fiscal declaration supplementing with the existing fiscal risks in the country.The Council of fiscal discipline as an independent collegiate institution supervises the compliance with the Law on the fiscal discipline.

So we can see that, although belatedly, Latvia has seriously begun the work on the identification of fiscal risks and the introduction of the mechanism of management which is positively. However, as we have already mentioned, there are also drawbacks. The authors of this research shares the opinion of the economist of the Bank of Latvia Baiba Traidase (Traidase, B., 2016), that such a risk management is too complicated. Besides, Latvia has chosen a wide range of quantified (the government bails and loans, the risks in the welfare system, etc.) and not quantified (insolvency of corporations, the verdicts of international courts, direct and indirect obligations of public and private partnerships) risks. Besides, each risk has an assessment of the occuerce probability according to the five-point scale and alsso the stage of the impact of the fiscal risks (relevant, medium or low). At the initial period of the assessment of fiscal risks when there is a lack of experience, according to the authors, it is too much. The proof of it is the numeruous entries in the register of fiscal risks - at present it is not possible to assess the fiscal risk, or - the impact can be substantial but there is no possibility to calculate it. Therefore, the reduction of the number of risks for the year 2017 can be justified. As a whole, we have an impression that Latvia has focused on the creation of the fiscal risk reserves, by means of which to reduce the impact of macroeconomic and demographic fluctuations in the budget balance. It is 


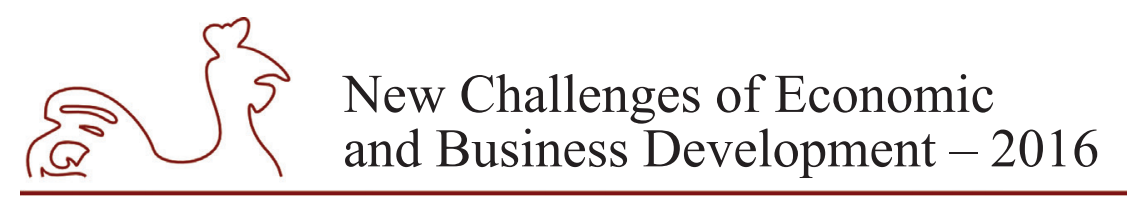

May 12-14, 2016, Riga, University of Latvia

advisable to learn the experience of other countries which focus their activities on the division of fiscal risks between the state budget and the private or state stock companies in the case of giving bails or guaranties.

In the budget of the year 2016 the reserves of fiscal risks have been envisaged for the first time with the aim to create the security mechanism which can be ussed in different cases of economic or fiscal shock. The transitional provisions of the Law on fiscal discipline envisage that in 2016 the fiscal security reseve will be in the amount of $0.1 \%$ from GDP but in 2017 it is stated as $0.13 \%$ from GDP. The authors point out that stating the reserve of fiscal security one must expect that basically it means the reduction of the budget expenditures of the same year in the same amount which can negatively affect the financing of the current expenses predicted in the budget. Therefore, there is a question about the amount of created reserves - is it enough? The answer can be both - yes and no because on the one hand $0.13 \%$ or $37.3 \mathrm{mlj}$ euros may turn out to be too little to compensate the rapid increase of social expenses if the number of benefit receivers increase or the medium pay-outs increase. On the other hand, the fiscal reserve is "frozen" money.

Therefore, the authors consider that the "airbag", of course, is good and it must exist, but a too big reserve can cause the necessity to consolidate the budget which takes away a lot of resources from economy. It is believed that the government must more concentrate on the measures which preventively decrease the need for big security reserves of fiscal risks. The authors consider that the main areas of risks are the government bails and guarantees (JSC Liepajas Metalurgs) and the state loans, especially to the private sector. As the information of the Ministry of Finance shows, in 2015 the amount of state loans for liquidated companies (entrepreneurships) or cooperations was almost $6 \mathrm{mlj}$ euros, in 2016 it is already $4 \mathrm{mlj}$ euros. (Finanšu ministrija, 2016). It means that granting the loans the company's financial situation and the development prospects are not appropriately assessed. According to the authors there is one more problem, there are increasing risks in the area of pensions and social security benefits when the expenditures exceed revenues. The proof of it is the promise of the new government to improve the formula of the pension indexation which is not predicted in the budget of 2016. The authors have already mentioned the change of governments as a special political risk when the decisions of the previous government have been reviewed.

\section{Conclusions}

1. At present the economic development in the world and Europe, geopolitical situation, the migration of the population as well as the domestic problems of the development of Latvia pose new challenges to the government's fiscal policy. Nevertheless, Latvia has set an ambitious goal - to become the member of the group of OECD countries.

2. The fiscal policy-making is influenced by different factors, under the influence of which it is not always possible to achieve the goals promptly. The main factors influencing the fiscal policy in the macroeconomic situation are international, administrative, political and demographic. The authors consider that making the fiscal policy in Latvia the emphasis is on the macroeconomic indicators, but other factors are not fully investigated and their impact on the effectiveness of the fiscal policy is not investigated. The government should 


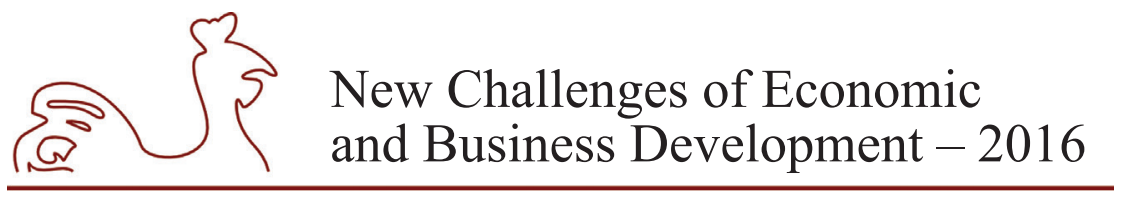

May 12-14, 2016, Riga, University of Latvia

more seriously analyze the impact of other above mentioned factors on fiscal policy in order to adopt decisions for Latvia in the most efficien way.

3. Recent history demonstrates that fiscal performance and, in turn, economic development can be seriously disrupted by the sudden, unexpected costs of hidden contingent liabilities and other unanticipated fiscal risks. This in turn requires the government to identify, classify, and assess its fiscal risks so that it can provide reliable estimates of future payments that may ensure from past and pending liabilities. Only by identifying and measuring its exposure can a government bring its risks under effective control.

4. The fiscal risk is the possibility of short-to medium-term deviations in fiscal variables compared with what was anticipated in the government budget or other fiscal forecast. On this basis, fiscal risk is the exposure of the central government to events or circumstances that could cause short- to medium-term variability in the overall level of revenues, spending, the fiscal balance, and the value of assets and liabilities.

5. The risks can be divided into: the source of origin - internal and external; the assessment possibilities - quantified and not quantified; the probability of their emergancy - explicit and implicit. The most serious problem is the obligations of the government: guarantees, bails and the state loans.

6. The risk management cycle consists of the identification of the environment, risk identification, risk analysis, risk reduction and risk mitigation, the impact of the risk on budget, monitoring and review.

7. In Latvia the process of the fiscal management risk has been started since 2014. Several regulating documents are elaborated, a risk register and the assessment system of risks have been worked out and a three level management and responsibility have been determined. The authors consider that the risk governance system created in Latvia is clumsy and complicated. A wide range of risks has been covered, as a result in the risk register there are multiple entries such as "it is not possible to assess the impact of the risk now" or "the impact can be substantial but it is not possible to calculate". We think that the administrative factor, which is mentioned in the article, could play a negative role, namely, the capacity of administrators (mainly lack of experience) does not conform with the requirements of the regulatory documents, in which there are a lot and detailed requirements for the risk management. It is advisible to act step by step but efficiently.

8. The main attention in the risk management in Latvia is paid to the state bails and guarantees and the chief goal is to identify the necessary reserve of fiscal risks which, of course, is very important but little has been done about the measures to reduce and mitigate the risks and also about other risks. As the creation of the security reserves of fiscal risks reduce the budget expenditures for other needs, the preventive work with risks is very important.

9. Before the government accepts a new contingent liability, a government should assess the risk to its fiscal condition, including the probability of future payouts. The assessment should be conducted by an independent entity. 


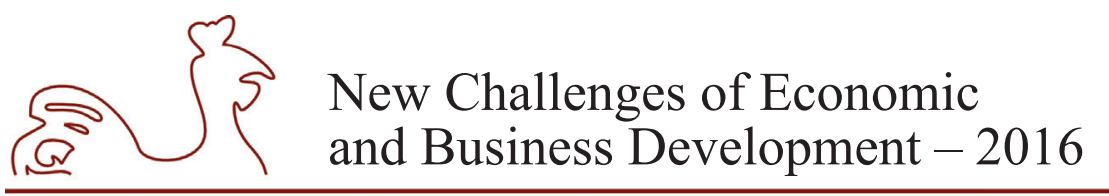

May 12-14, 2016, Riga, University of Latvia

\section{Bibliography}

Afonso, A., Schuknecht, L., Tanzi, V. 2006. Public Sector Efficiency: Evidence for New EU Member States and Emerging Markets. Applied Economics, Vol. 42, No. 17, pp. 2147-2164.

Allen, R., Hemming, R., Potter, B. H. The International Handbook of Public Financial Management. Springer, 2013, Palgrave handbooks. p. 881.

Alesina, F. A., 1998. Too Large and Too Small Governments. Economic Policy \& Equity. Edited by V. Tanzi, K. Chu and S. Gupta. Washington D.C.: International Monetary Fund, pp. 216-234.

Alesina, F. A., Ardagna S. 2009. Large Changes in Fiscal Policy: Taxes Versus Spending. NBER Working Paper Series. Working Paper 15438. National Bureau of Economic Research, p. 20.

Alesina, A., Campante, F. R., Tabellini,G. 2008. Why is Fiscal Policy Often Procyclical? Journal of the European Economic Association. Vol. 6, No. 5, pp. 106-136.

Antidempinga likums 2000. Available at: http://m.likumi.lv/doc.php?id=40.

Brixi, Hana Polackova; Schik, Allen. 2002. Government at risk: contingent liabilities and fiscal risk. Washington, D.C. The World Bank. A Copublication of the World Bank and Oxford University Press. Available at: http://documents.worldbank.org/curated/en/2002/04/2017569/risk-contingentliabilities-fiscal-risk.

Cebotari, A., 2008. Contingent Liabilities: Issues and Practice. IMF Working Paper, Fiscal Affairs Department. October, $2008 \mathrm{WP} / 08 / 245$ p. 60.

Fiskālās disciplīnas likums. Available at: http://www.likumi.lv/doc.php?id=254896.

Finanšu ministrija, Valsts budžeta paskaidrojumi. Likuma "Par valsts budžetu 2015. gadam" paskaidrojumi. Available at: http://www.FMPask_020315_bud2015.xlsx.

Finanšu ministrija ir izstrādājusi Fiskālo risku deklarāciju. Available at: http://titania.saeima.lv/LIVS12/ saeimalivs12.nsf/0/86BO19E63E787422C2257DA90.

Fry, Brian R., Mastering Public Administration: from Max Weber to Dwight Waldo/Brain R. Fry, Jos C.N. Raadschel, 2008. p. 365.

Kliman, A., Public Budgeting and Finance. 1997.

Līgums par Eiropas Savienības darbību (LESD). Available at: https://www.ecb.europa.eu/ecb/legal/ pdf/c_32620121 026en.pdf.

Līgums par stabilitāti, koordināciju un pārvaldību ekonomiskajā un monetārajā savienībā. Available at: http://likumi.lv/doc.php?id=249048.

MK noteikumi 2014, Nr. 299 "Noteikumi par fiskālo risku vispārējo vadību un par fiskālās nodrošinājuma rezerves apjoma noteikšanas metodoloğiju”. Available at: http://www.likumi.lv/doc.php?id=266132.

Migue, J. L., Belenger, G. 1994. Toward a General Theory of Managerial Discretion. Public Choise, Vol. 17, p. 37-46.

Mulas-Granados, C., 2006. Economics, Politics and Budgets: the Political Economy of Fiscal Consolidation in Europe. Basingstoke, New York: Palgrave Macmillan.

Niskanen, W. A. 1994. Bureaucracy and Public Economics. Cheltenham: Edward Elgar, p. 287.

OECD (2015), OECD Economic Surveys: Latvia 2015, OECD Publishing, Paris, pp. 114. Available at: http://dx.doi.org/10.1787/9789264228467-en.

Reichard, Ch., 2003. Local Public Management Reforms in Germany. Public Administration, Vol. 81, No. 2, pp. 345-363, p. 352.

Rogoff, K., 2003. Debt Intolerance. Brookings Papers on Economic Activity. Vol. 1, pp. 1-74.

Traidase, B., Budžeta drošības spilvens - fiskālo risku rezerve, 28.07.2015. Available at: https://www. makroekonomika.lv/print/budzeta-drosibas-spilvens-fiskalo-risku-rezerve [Accessed 17.01.2016.]. 
May 12-14, 2016, Riga, University of Latvia

\title{
THE SYSTEM OF PUBLIC SERVICES DELIVERY IN ST. PETERSBURG
}

\author{
Sergey Kirsanov, Russian State Hydrometeorological University, Russia \\ Eugene Safonov, Russian State Humanitarian University, Russia \\ Olga Starineca, University of Latvia, Latvia ${ }^{1}$
}

\begin{abstract}
To develop a service governance, it is required to be open for the information technologies, ensure a high degree of St. Petersburg authorities' information execution transparency and citizens' accessibility to information on the procedure public services delivery. Transition to public and municipal services e-delivery could significantly increase the services accessibility, reduce corruption risks, and reduce time and financial cost of the state and citizens. E-government efficiency can be reached and improved towards the Lean thinking that could bring the added value to both public service receivers and deliverers.

The aim of the research is to identify features of the public services delivery system analysing the case of St. Petersburg. The objective of the research is identification of the features integration that could be identified as a lean thinking result. The main focuses of the research are a system of public services delivery and the portal of state and municipal services of St. Petersburg.

The main objectives of the portal are improvement of the public and municipal services quality, decries paper document circulation providing the services, increase level of the citizens' comfort and satisfaction by the services delivered in St. Petersburg as well as increase their awareness of the services delivery in the megalopolis. As the conclusion it was identified that the government of St. Petersburg is actively participated in improvement of public services attainability for the local population.

The research is descriptive by design. The document and statistical data analysis, comparison and synthesis are the main research methods applied. The results and findings of the research draw an example of the public service delivery system that could be a ground for further studies on the system's improvement, development and adaption in different cases. Besides the theoretical value of the article, the provided research results and conclusions could be helpful for practitioners.
\end{abstract}

Key words: public service, attainability of public services

JEL code: H83

\section{Introduction}

Modern web-industry is developing rapidly in many countries including Russia. This process is influenced by both the increase of the internet users' number and increased demand for online services. Based on the evidence on "popularity of interactive information and communication technology" (Iskender G. \& Özkan S., 2013) many developing countries (IUGG, 2015) e.g. Malaysia (Rosnah Wan Abdullah, N. et al., 2013), Turkey (Iskender G. \& Özkan S., 2015), Zambia (Bwalya K.J. \& Mutula S., 2015) etc. started a transition process from traditional public

1 Corresponding author-e-mail adress olga.starineca@lu.lv 


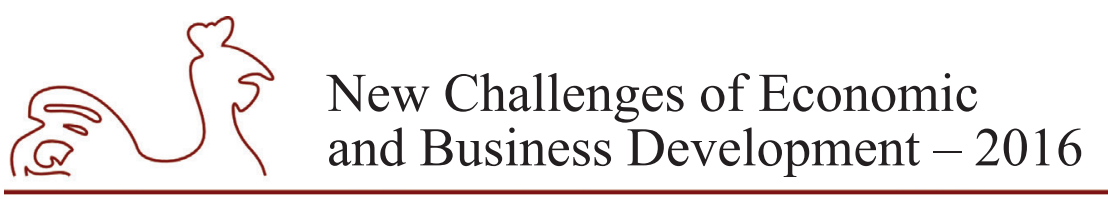

May 12-14, 2016, Riga, University of Latvia

service delivery to e-government. In 2010, the Russian Federation had $59^{\text {th }}$ position in the world e-government ranking (United Nations, 2010) i.e. took a position in the middle cluster (Dumpe D. \& Arhipova I., 2010) and $68^{\text {th }}$ position in the online service index receiving the biggest amount of points for emerging information services (United Nations, 2010). To develop a service governance, it is required to be open for the information technologies, ensure a high degree of the authorities' information execution transparency and citizens' accessibility to information on the procedure public services delivery (Reece B., 2006). Transition to public and municipal services e-delivery could significantly increase the services accessibility, reduce corruption risks, and reduce time and financial cost of the state and citizens (Moon M. J., 2002). The current paper reflects the St. Petersburg experience in public services delivery towards online systems.

The portal of "The public services in St. Petersburg" (the portal) were developed as a result of the Administrative reform implementation in Russia. The administrative reform was focused on ensuring both the high level of informative transparency on St. Petersburg's executive authorities' activity and citizens' access to information on the procedure for public services delivery (SanktPeterburgskiy informatsionno..., 2007-2016). Transition from the information and reference to interactive approach i.e. a possibility to submit applications for the services delivery via the portal besides usual possibility to view information on the public services was implemented towards the development of the integrated automated system called "One window". The system was designed for the public services delivery according to the one window principle (Holding RBK, 1995-2016; Hudash A., 2008). In 2009, eight public services connected to providing child allowances implemented towards the portal were presented to the employees of public authorities. So, the applications e-acceptance was possible for implementation (Andronova O., 2009). A feature that is acceptable in the portal is a possibility to ensure access using special e-card (Andronova O., 2009). There was developed the analogical system that works by the one window principle - the net of multifunctional centres (MFC) for the public services delivery. Therefore, in 2010 the portal was merged with the information system (IS) that ensure activity of the MFC (Isayev B., 2010). The united Interdepartmental IS was developed based on these two systems merging that could be literally translated as "Operational support for the MFC for the public services delivery in St. Petersburg and public services delivery via public services portal in St. Petersburg"' (Pravitel'stvo Sankt-Peterburga, 2015).

In 2012, the Register of municipal services were published on the portal. These services are delivered by the local governments of intercity municipal unions of St. Petersburg. Therefore, the portal was given another name and started to be called The portal of public and municipal services of St. Petersburg (Pravitel'stvo Sankt-Peterburga, 2012). For example, it is possible to submit application and book time for marriage registration as well as pay the state duty via the portal towards implementation of the public service delivery in full cycle mode. Currently, the MFC issue login name and password for multiple authorisation and authentication of the users (Administratsiya Sankt-Peterburga, 2012; Spbnews, 2013).

The aim of the research is to identify features of the public services delivery system in case of St. Petersburg. The main focuses of the research are a system of public services delivery and the portal of state and municipal services of St. Petersburg. The research tasks performed are describe lean thinking principles possible application in public service delivery sphere, summarize St. Petersburg's e-government development steps, emphasise the main elements of 


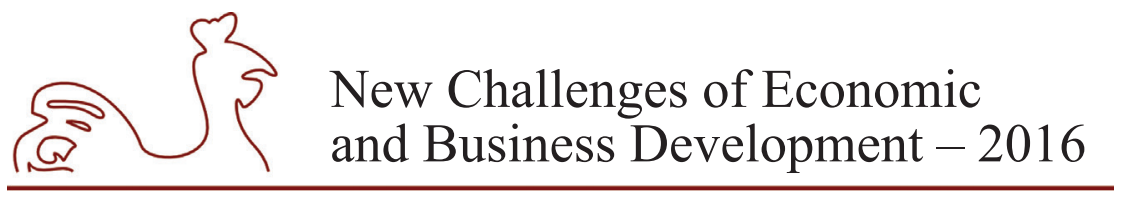

May 12-14, 2016, Riga, University of Latvia

the public services delivery in St. Petersburg, and analyse the main aspects of the public services delivery system's development in St. Petersburg.

The research is descriptive by design. The document and statistical data analysis, comparison and synthesis are the main research methods applied. As the main sources of information are official relevant documents, official information published online and some scientific articles. The results and findings of the research draw an example of the public service delivery system that could be a ground for further studies on the system's improvement, development and adaption in different cases. Besides the theoretical value of the article, the provided research results and conclusions could be helpful for practitioners i.e. another cities administration representatives that implement or develop a new public services delivery system as well as for the public administration of St. Petersburg considering improvements of the described system.

\section{Research results and discussion}

\section{E-government development in St. Petersburg}

The Federal Target Program "Electronic Russia (2002-2010)" included information on the public services transition to e-environment for the first time. In 2006, the more concrete terminology and plans to transfer the services to e-environment appeared in the project as well as a link to the electronic interdepartmental document circulation was added (Ministerstvo ekonomicheskogo razvitiya..., 2016). For the last years the Informatization and Communications Committee of St. Petersburg has carried out the considerable work on creation and development of e-government of the complex (Komitet po informatizatsii..., 2016).

The main tasks performed by the Informatization and Communications Committee of St. Petersburg are (Komitet po informatizatsii..., 2016):

- Automatization and consequently increase of the public services delivery's quality,

- Increase of the services interaction efficiency.

To fulfil the tasks, various cross-industry databases and united IS are developed and successfully integrated. One of the most successful this kind of unification results is the Interdepartmental Automated Information System of St. Petersburg for the state and municipal services delivery in electronic format (IAIS EPS). It ensures automatization procedure of the state and municipal services delivery on the territory of the metropolis using information and communication technologies (ICT). The IAIS EPS system maintains and ensures services delivery in e-format towards "E-reception" service on the information portal Public and municipal services of St. Petersburg (www.gu.spb.ru). Thus, the citizens can receive a list of public services via internet (Komitet po informatizatsii..., 2016).

Currently, there is published information on more than 470 public services that are delivered by the executive authorities of St. Petersburg. The users of the portal can also leave their feedback on the reception of the public service they experienced as there is a special feedback form. Since the portal existence, more than 80 million people have become its users. Towards the MFC the citizens can receive more than 260 public services at the same place. According to data for year 2014 there are 37 stationary and four mobile MFC successfully functioning in the city (Komitet po informatizatsii..., 2016). 


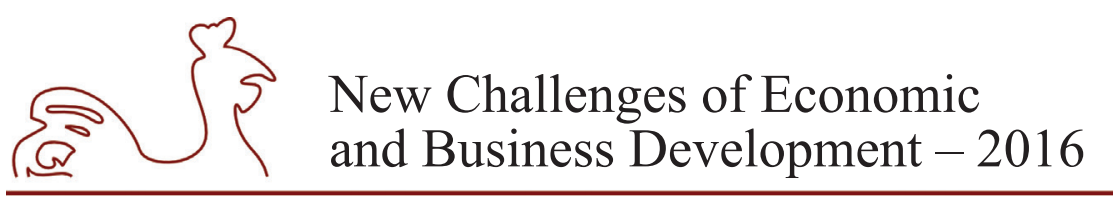

May 12-14, 2016, Riga, University of Latvia

"E-reception" is quite popular among citizens, it also offers a wide range of various public services, so it could be assumed as one of the leading innovative centres in Russia by two criteria, namely level of effectiveness and attainability of the public services for the population. Considering four stages of online service development (United Nations, 2010) St. Petersburg could be positioned between stage three and four, where (United Nations, 2010):

- Government WEB site engages in two-way communication with its citizens;

- Some form of electronic authentication of the citizen's identity is required to successfully complete the exchange;

- Government WEB site process non-financial transactions, and handle financial transactions;

- Government is proactive in requesting information and opinions from the citizens using interactive tools;

- Government has moved from a government-centric to a citizen-centric approach, where e-services are targeted to citizens through life cycle events and segmented groups to provide tailor-made services.

It is possible to conclude that e-government in St. Petersburg has development precipitously and has already reached good results. The next subsection is focused on the main elements of the public services delivery in St. Petersburg.

\section{Public services delivery in St. Petersburg}

Within this subsection the authors of the present paper emphasize the main elements and peculiarities of the public services delivery in St. Petersburg. Currently, it is possible to receive public services electronically using the portal of state and municipal services of St. Petersburg. The users need to register on the portal to be able to receive all offered services as transition to public services e-delivery requires to ensure all applicants secure online identification. The portal of state and municipal services of St. Petersburg is an internet resource devoted to the state and municipal services that are delivered by the executive authorities to the citizens, legal entities and individual entrepreneurs (applicants) in St. Petersburg (Administratsiya SanktPeterburga, 2016).

It is possible to receive public services in St. Petersburg if a person (Administratsiya SanktPeterburga, 2016):

1. Contact the responsible public authority (or other organization authorized by the state) in-person with an application and a package of documents collected from various bodies;

2. Apply to the MFC for the state and municipal services delivery in St. Petersburg that are working according to the one window principle i.e. the applicants' participation into the various necessary for the public services reception certificates and documents collection is minimized or totally excluded;

3. Submit an e-application and receive the public service via the portal for the state and municipal services delivery in St. Petersburg.

Coming back to the users' registration process on the portal it is necessary to emphasize that the registration happens based on the united identification and authentication system (UIAS). The UIAS ensures protection of accommodated therein information in accordance with the legislation of the Russian Federation towards implementation of the test of the relevant 


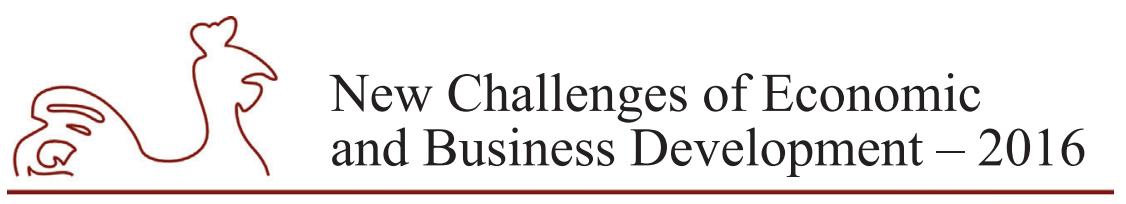

May 12-14, 2016, Riga, University of Latvia

criteria for the person's identification while registering in the UIAS. For example, the person (applicant), who is registering in the UIAS, needs to deliver accurate and up to date personal information that will be kept on the portal and used further on for filling in the e-forms for the public services reception vis the portal. It is possible to register in the UIAS applying to the MFC for the state and municipal services delivery or fulfil the registration independently via the united portal for the public services, however it is needed to verify the identity after the accounts creation on the UIAS. (Administratsiya Sankt-Peterburga, 2016).

There are various convenient possibilities to receive public services in St. Petersburg. However, wishing to use e-service possibilities the users need to realize some peculiarities of registration that are implemented to ensure security of the citizens/public services clients. After the retrospective and present situation overview of the public services delivery approaches in St. Petersburg, the authors would like to devote the next subsection to the summary of information on the further development of the public services delivery system in St. Petersburg. The authors focuses on some e-government transformation indicators (United Nations, 2010) to identify the possible ways of further development.

\section{Development of the public services delivery system in St. Petersburg}

Development of the public services delivery in St. Petersburg has a various range of possibilities (Kirsanov S. A., 2010) that are going to be discussed within this subsection. There are various services and functions that are implemented in all fields of activity of the Administration of St. Petersburg. The authors of the present paper summarized some of them identifying the major groups (Pravitel'stvo Sankt-Peterburga..., 2012):

- Acceptance of the documents according to established order. The documents are given by the citizens for the various issues solution connected to:

- The decision making by the departments of the regional administration,

- The certain functions implementation focused on provision of social support,

- Consideration of citizens' applications and documents,

- Addressing issues of social policy (e.g. creating a list of orphans and children left without parental care etc. that are subject of the living quarters provision from the specialized housing fund of Saint-Petersburg);

- Implementation of activities on the consumers' rights protection;

- Implementation of activities within the education system focused on the acquisition of the state educational institutions that execute the basis comprehensive program of the pre-school education and subordinate to the administrative districts of St. Petersburg;

- Provision of information contained in the information resources of the administrative districts of St. Petersburg (issuing archival information, statements, copies of documents related to the composition of the Archival Fund of St. Petersburg and other archival documents);

- Registration and consideration (in the certain order) of notices about cultural and sports events organisation on the territory of the city outside designated places etc.

The Portal of state and municipal services of St. Petersburg is a useful tool for both service deliverers and customers. Its development presumed various additional functions integration. Currently, the Portal has 190 e-services and the list is expanding continuously. One of the functions is a developed interactive section of the portal that ensures possibility of e-communication with 


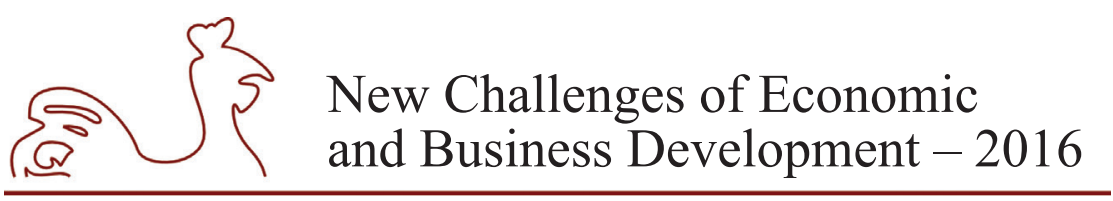

May 12-14, 2016, Riga, University of Latvia

the authorities responsible for the services delivery (Komitet po informatizatsii, 2016a). The options that are offered are (Komitet po informatizatsii, 2016a):

- A comfortable approach to submit an e-application for the services towards filling in a convenient and easy in usage e-forms (questionnaires);

- A possibility to give feedback from the authorities responsible for the services delivery i.e. a possibility to follow the application status;

- Fast help of information technology (IT) support service in cases of applicants inquires on the e-forms completion.

- One more function is fulfilled via the information and reference section of the Portal. It includes (Komitet po informatizatsii, 2016a):

- Address-reference information on organizations involved in the services delivery;

- Contact information and schedule of the MFC for the state and municipal services delivery in St. Petersburg;

- Data on the alternative possibilities of the services reception (e.g. the traditional services delivery, MFC for the state and municipal services delivery, e-services);

- Information on the content, structure, terms and conditions of the certain state and municipal services reception that are delivered in the region as well as documents, templates and completion samples of applications for services reception;

- Information on the legal basis for the services delivery;

- News feed.

So called "personal office" helps the applicants to follow the status and history of the applications for the services reception online as well as have the access to the e-documents and their usage applying for the services reception. One more opportunity is pre-trial appeal of actions and inaction of officials and authorities (organizations) in the state and municipal services provision/delivery. All these opportunities are focused on increasing of convenience to receive state and municipal services electronically (via the portal). As it was already mentioned before, the portal is integrated with the UIAS that ensures the portal users access to their "personal office" (Komitet po informatizatsii, 2016a).

The convenience of the portal is ensured by the opportunity to apply for the services reception from any e-device connected to the internet without time limits i.e. 24/7.

In 2012, the administration of St. Petersburg announced a contest on the monitoring of the public services delivery (towards MFC and online services) quality that is expected to explore improvements of the public services (Rosbalt, 2012). According to the documents that were published on the official WEB site of the state procurement, the services delivery seeks (Rosbalt, 2012):

- Guarantee of interdepartmental interaction of executive authorities of St. Petersburg and subordinate government institutions;

- Identification of gaps in the legislative basis of the public services delivery;

- Transfer of the most demanded services to the MFC. 


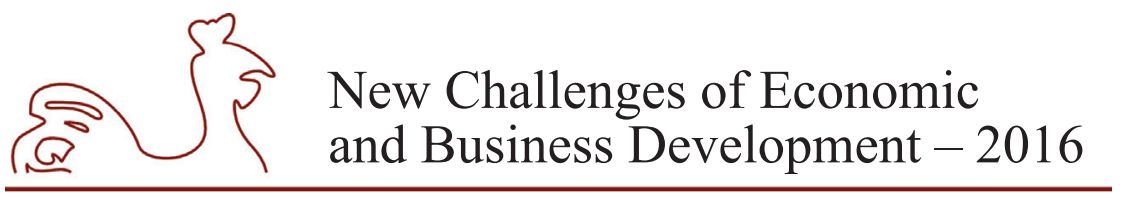

May 12-14, 2016, Riga, University of Latvia

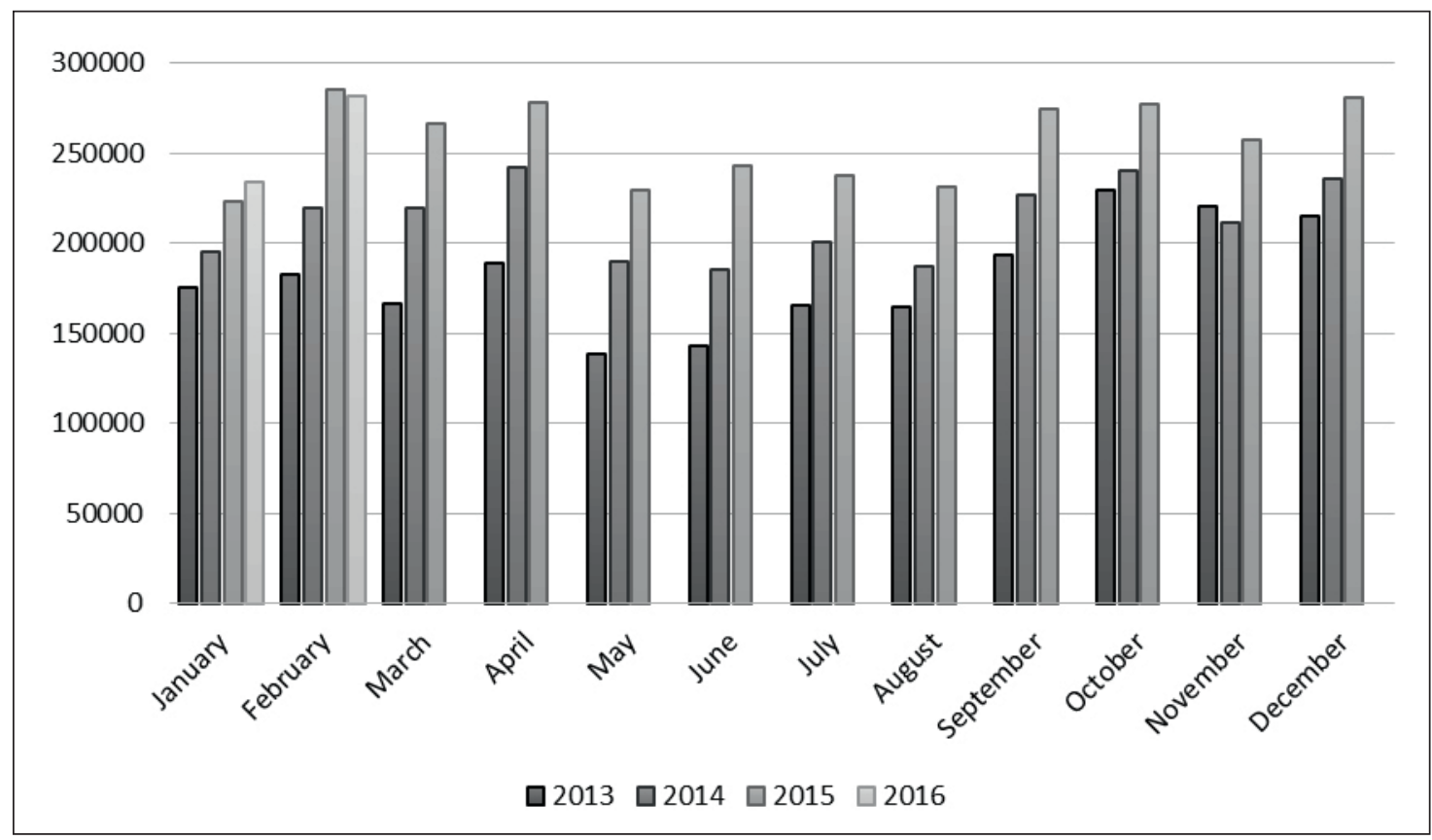

Source: author's construction based on Portal gosudarstvennykh i munitsipal'nykh..., 2016; Kirsanov S. et al., 2016.

Fig. 1. Dynamics of a number of appeals received by MFC in St. Petersburg for years 2013-2016

Bearing in mind efficiency of the public services delivery, it is worth to mention that compliance with a single methodological approach in establishing a typology of public services is a key factor in the implementation of the financial valuation of these services. Incidentally, the procedure presumes formation of sectoral lists of the public services (Pravitel'stvo SanktPeterburga..., 2011). Some of the services were already mentioned before.

Considering a number of regional and municipal services ordered, it is possible to conclude that there is quite a constant increase of the services demanded by the number of appeals received by MFC since 2014 (Fig. 1). Comparing the data by month it is clear that the number of the appeals received is growing each year at the same month. This is a positive tendency that might reflect the users' satisfaction by the provided opportunities and probably the quality of the services.

The issues on the law effectiveness of the IT application by the government of St. Petersburg could be solved towards usage of the latest e-services and motivation/stimulation by the superior city leaders. Besides, the authors of the present paper would propose to implement the regular services delivery monitoring by the independent organisation that are not subordinated by the authorities. One of the criteria could be efficiency of the authorities' functions implementation. The results could be a base for the further improvements plan. 


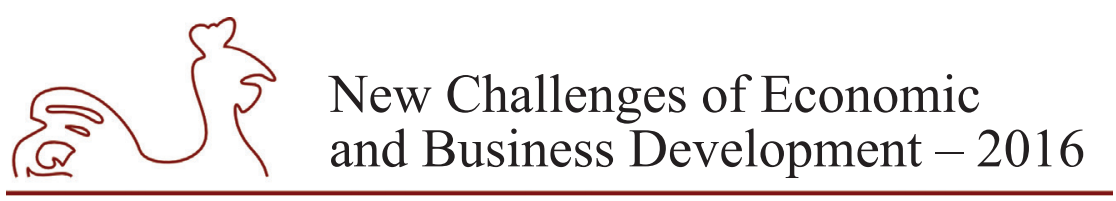

May 12-14, 2016, Riga, University of Latvia

\section{Lean thinking application and public service delivery}

Analysing the case of St. Petersburg in delivering of public services towards e-government tools, the authors concluded that this is an example of the Lean thinking/philosophy (Alagaraja M., 2014) principles application. The Lean thinking traditionally is based on waste reduction (Stewart P. et al., 2016) principle as well as value maximization (Bortolotti T. et al., 2016), however, it could also be focused on "ability to engage human resources, for enhancing learning and performance at multiple levels in the organization" (Alagaraja M., 2014). Lean is more applicable for industrial area organisations (Kupiainen E. et al., 2015) rather than for organisations that deliver service, however, it is adopted for non-manufacturing organisations more often nowadays (Alagaraja M., 2014; Bortolotti T. et al., 2016).

Lean presumes the customer-centric approach (Alagaraja M., 2014) that in case of public service delivery is a focus on the citizens' needs. In case of St. Petersburg, the MFC and mobile MFC is an example of the processes optimisation based on the customers' needs i.e. the MFC and mobile MFC increased the public services attainability and their convenient reception. E-government as a concept presumes a constant decision-making process (Reddick C. G., 2006). As the "extension of lean programmes should include practices that involve suppliers in finding and reducing problems that affect internal and external processes" (Bortolotti T. et al., 2016) it is likely to be applicable implementing e-government activities. The present paper reflects the case of St. Petersburg public service delivery that already is focused on the services delivery systems enhancement in terms of effectiveness and efficiency. Five Lean principles focuses on enhancement of the overall performance of the organization that "essentially simplify managerial decision-making by focusing on" (Alagaraja M., 2014):

1. Identification of the organizations' value to the customer (services in the observed case that are easy to receive avoiding queues and going to the service delivery centres in person as well as application of "one window" principle);

2. Mapping processes that create value or the value stream (St. Petersburg public service deliverers need to be examined from the internal environment to identify, if the organisations focus on the mapping);

3. Improvement of the value stream to create flow (Petersburg public service deliverers need to be examined from the internal environment to identify, if the organisations focus on the improvement);

4. Emphasise a pull of customers demanded for service triggers the delivery process (one of the example observed reflects the application of this i.e. for example couples that are looking for the marriage registration (Administratsiya Sankt-Peterburga, 2012; Spbnews, 2013);

5. Perfection achievement by consistently practicing the Lean principles.

Lean is applicable for various organizations (Fliedner G. \& Mathieson K., 2009) and even project management (Ballard G. \& Howell G., 2003), however the certain set of techniques (Green S. D. \& May S. C., 2005) as well as metrics (Kupiainen E. et al., 2015) that presumed to be applied need to be adapted to each organization depending on the type of activity, output, culture etc. Lean might also lead to sustainability of the organization (Hartini S. \& Ciptomulyono U., 2015; Piercy N. \& Rich N., 2015). If the public service delivering bodies in St. Petersburg do not consciously apply the Lean, they might to apply it as its application in public administration and the sector in general is possible and can be beneficial. 


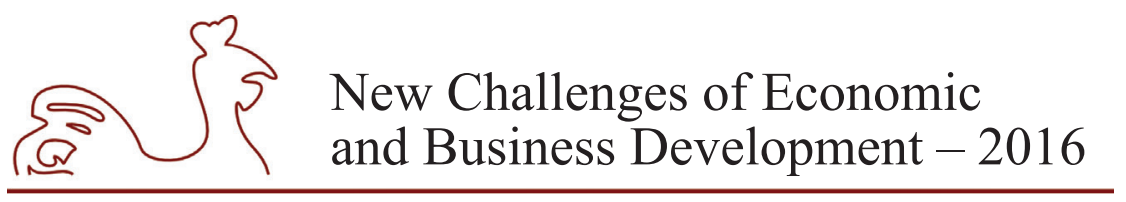

May 12-14, 2016, Riga, University of Latvia

\section{Conclusions, proposals, recommendations}

All research tasks have been performed and some conclusions were drawn.

1. Even the Russian Federation was only in top 70 by the online service in the world in 2010, the public online services of St. Petersburg could be evaluated high and it is moving to the fourth stage of online services development as both the service deliverers and their customers benefiting from the online services provided.

2. The increase of the public services deliverers' work efficiency could be connected to both orientations on customers or "citizen-centric approach" and online and e-tools advantages. Therefore, it is possible to conclude that St. Petersburg's public service deliverers most probably unconsciously implement the Lean thinking principles.

3. In St. Petersburg, the constant activity forced to formation of information technology (IT) infrastructure is conducted that ensures necessary condition for the decision-making on enhancement process of the public services delivery. In addition, the problems are solved that are connected to both automatization and consequently the state agencies work quality rising and these agencies collaboration effectiveness rising. To perform the mentioned tasks accordingly, various cross-sectoral databases and common information systems have been developed and successfully implemented.

4. The portal for public services delivery in St. Petersburg ensures mainly two tasks fulfilment namely, increase a level of St. Petersburg executive authorities' activity informative transparency and ensure information on the public services delivery procedure attainability for the citizens.

5. More IT service is transparent and easy to use, more internet users are striving to use it, therefore attainability of online services in St. Petersburg influences increase of the e-services demand.

6. The public services transition to e-environment made them more attainable for the citizens of St. Petersburg as well as it stimulated corruption risks decrease and decrease of time and financial costs on both the services delivery and reception, hence it simply made the population life easier that can be concluded based on information about St. Petersburg government's active work to increase a level of the public services attainability for population.

The authors of the paper would like to propose implementation of the regular services delivery monitoring by the independent organisation that are not subordinated by the authorities. One of the criteria could be efficiency of the authorities' functions implementation. The results could be used for the further improvements plan development that could be based on reducing the public e-services delivery problems that might affect internal and external processes of the public organisations.

The authors recommend to compare the case with other public services delivery systems implementation cases in the national and international context for the further studies and good case practices as well as common challenges identification. 


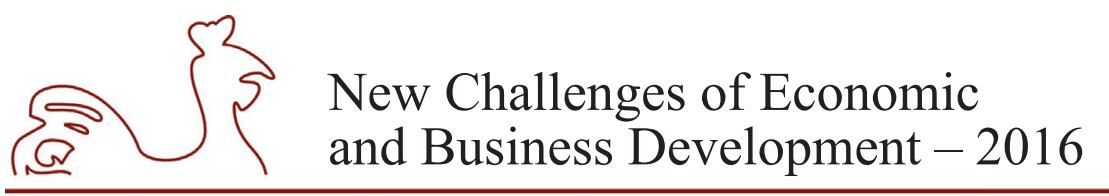

May 12-14, 2016, Riga, University of Latvia

\section{Bibliography}

Administratsiya Sankt-Peterburga, 2012. Poryadok podachi zayavleniya cherez Internet na registratsiyu zaklyucheniya braka v Sankt-Peterburge. [Online] Available at: http://gov.spb.ru/gov/otrasl/zags/ news/27727/ [Accessed 7 March 2016].

Administratsiya Sankt-Peterburga, 2016. Gosudarstvennyye uslugi. [Online] Available at: http://gov.spb. ru/gosuslugi/ [Accessed 7 March 2016].

Alagaraja, M., 2014. A Conceptual Model of Organizations as Learning- Performance Systems: Integrative Review of Lean Implementation Literature. Human Resource Development Review, 13(2) pp. 207233.

Andronova, O., 2009. Chto vidno v peterburgskoye "odno okno"? [Online] Available at: http://old.ci.ru/ inform10-11_09/p_08.htm [Accessed 7 March 2016].

Bortolotti, T., Romano, P., Martínez-Jurado, P.J. \& Moyano-Fuentes, J., 2016. Towards a theory for lean implementation in supply networks. Int. J. Production Economics, 175(2016), pp. 182-196.

Ballard, G. \& Howell, G., 2003. Lean project management. Building Research \& Information, 31(2), pp. 119-133.

Bwalya, K. J. \& Mutula, S., 2015. A conceptual framework for e-government development in resourceconstrained countries: The case of Zambia. Information Development, pp. 1-16.

Dumpe, D. \& Arhipova, I., 2010. Analysis of Latvian E-government Effectiveness. Scientific Journal of Riga Technical University. Computer Science. Information Technology and Management Science, 44, pp. 55-59.

Fliedner, G. \& Mathieson, K., 2009. Learning Lean: A Survey of Industry Lean Needs. Journal of Education for Business, 84(4), pp. 194-199.

Green, S. D. \& May, S. C., 2005. Lean construction: arenas of enactment, models of diffusion and the meaning of 'leanness'. Building Research \& Information, 33(6), pp. 498-511.

Hartini, S. \& Ciptomulyono, U., 2015. The Relationship between Lean and Sustainable Manufacturing on Performance: Literature Review. Procedia Manufacturing, 4, pp. 38-45.

Holding RBK, 1995-2016. V Peterburge sozdadut IAS «Odno okno». [Online] Available at: http://corp. cnews.ru/news/line/v_peterburge_sozdadut_ias_odno_okno [Accessed 7 March 2016].

Hudash, A., 2008. Posobiya stanovyatsya blizhe. [Online] Available at: http://www.spbit.su/news/n49229/ [Accessed 7 March 2016].

Isayev, B., 2010. Evolyutsiya Termina, ili Elektronnyye uslugi v Sankt-Peterburge. IT-Manager, 4, pp. 1214.

Iskender, G. \& Özkan, S., 2015. Analysis of success factors in e-government transformation in Turkey: are these factors really the causes of success? Information Development, 31(4), pp. 323-332.

IUGG, 2015. List of developing countries. [Online] Available at: http://www.iugg2015prague.com/list-ofdeveloping-countries.htm [Accessed 8 April 2016].

Kirsanov, S., Safonov, E. \& Starineca, O., 2016. Enhancement of administrative reform in Russia: Case of St. Petersburg. (Z. Cekerevac, Ed.). MEST Journal, 4(1), pp. 19-28.

Kirsanov, S. A., 2010. Problemy i perspektivy deyatel'nosti MFTS v regionakh. Praktika munitsipal'nogo upravleniya, 12 , pp. 34-40.

Komitet po informatizatsii i svyazi Sankt-Peterburga, 2016. Elektronnoye pravitel'stvo. [Online] Available at: http://kis.gov.spb.ru/elektronnoe-pravitelstvo/ [Accessed 7 March 2016].

Komitet po informatizatsii i svyazi Sankt-Peterburga, 2016a. Portal gosudarstvennykh i munitsipal'nykh uslug Sankt-Peterburga. [Online] Available at: http://kis.gov.spb.ru/projects/project-portal-popredostavleniyu-gosudarstvennyh-uslug-na/ [Accessed 10 March 2016].

Kupiainen, E., Mäntylä, M. V. \& Itkonen, J., 2015. Using metrics in Agile and Lean Software DevelopmentA systematic literature review of industrial studies. Information and Software Technology, 62, pp. 143-163. 


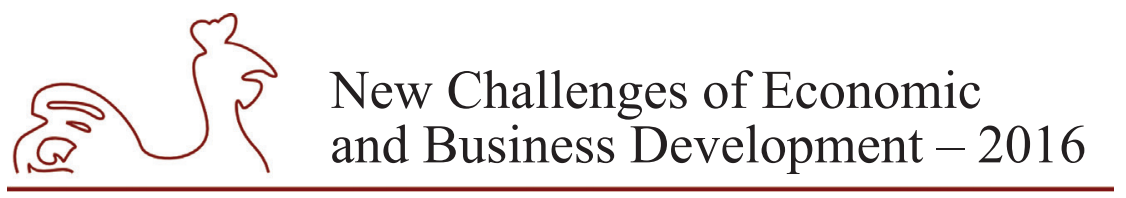

May 12-14, 2016, Riga, University of Latvia

Ministerstvo ekonomicheskogo razvitiya Rossiyskoy Federatsii, 2016. Uslugi v elektronnom vide. [Online] Available at: http://ar.gov.ru/ru/gos_uslugi_03_uslugi_v_electronnom_vide/index.html [Accessed 7 March 2016].

Moon, M. J., 2002. The Evolution of E-Government among Municipalities: Rhetoric or Reality? Public Administration Review, 62(4), pp. 424-433.

Piercy, N. \& Rich, N., 2015. The relationship between lean operations and sustainable operations. International Journal of Operations \& Production Management, 35(2), pp. 282-315.

Portal gosudarstvennykh i munitsipal'nykh uslug Sankt-Peterburga, 2016. Dinamika kolichestva obrashcheniy v MFTS. [Online] Available at: https://gu.spb.ru/mfc/stat/ [Accessed 7 March 2016].

Pravitel'stvo Sankt-Peterburga Arkhivnyy komitet Sankt-Peterburga, 2012. Rasporyazheniye ot 17 maya 2012 goda $N 37$ O vnesenii izmeneniya v rasporyazheniye Arkhivnogo komiteta Sankt-Peterburga. [Online] Available at: https://gov.spb.ru/law?d\&nd=537918968\&nh=1 [Accessed 8 March 2016].

Pravitel'stvo Sankt-Peterburga Komitet ekonomicheskogo razvitiya, promyshlennoy politiki i torgovli, 2011. Pis'mo ot 29 aprelya 2011 g. N 11/6539. [Online] Available at: https://gov.spb.ru/static/ writable/ckeditor/uploads/2014/03/27/Pismo-11-6539.docx [Accessed 10 March 2016].

Pravitel'stvo Sankt-Peterburga, 2012. Postanovleniye ot 17.10.2012 №1113. [Online] Available at: http://46.182.26.58/SpbGovSearch/Content/Cache/1362_images.pdf [Accessed 7 March 2016].

Pravitel'stvo Sankt-Peterburga, 2015. Postanovleniye ot 7 iyunya 2010 goda N 736 O sozdanii Mezhvedomstvennoy avtomatizirovannoy informatsionnoy sistemy predostavleniya $v$ SanktPeterburge gosudarstvennykh i munitsipal'nykh uslug $v$ elektronnom vide (s izmeneniyami na 27 marta 2015 goda). [Online] Available at: http://gov.spb.ru/law?d\&nd=891831614\&nh=0 [Accessed 7 March 2016].

Reddick, C.G., 2006. Information Resource Managers and E-government Effectiveness: A Survey of Texas State Agencies. Government Information Quarterly, 23(2), pp. 249-266.

Reece, B., 2006. E-Government Literature Review. Journal of E-Government, 3(1), pp. 69-110.

Rosbalt, 2012. Smol'nyy zaplatit za monitoring kachestva gosuslug 500 tysyach rubley. [Online] Available at: http://www.rosbalt.ru/piter/2012/07/23/1014094.html [Accessed 10 March 2016].

Rosnah Wan Abdullah, N., Binti Mansor, N. \& Hamzah, A., 2013. Keeping ahead of the game: Innovations and challenges in e-government in Malaysia. The Economic and Labour Relations Review, 24(4), pp. 549-567.

Sankt-Peterburgskiy informatsionno-analiticheskiy tsentr, 2007-2016. Portal gosudarstvennykh i munitsipal'nykh uslug Sankt-Peterburga. [Online] Available at: https://gu.spb.ru/ [Accessed 7 March 2016].

Spbnews, 2013. Zayavleniya na registratsiyu braka $v$ Peterburge teper' mozhno podavat' cherez Internet. [Online] Available at: http://saint-petersburg.ru/m/spb/old/314824/ [Accessed 7 March 2016].

Stewart, P., Mrozowicki, A., Danford, A. \& Murphy, K., 2016. Lean as ideology and practice: A comparative study of the impact of lean production on working life in automotive manufacturing in the United Kingdom and Poland. Competition \& Change, 0(0) pp. 1-19.

United Nations, 2010. United Nations E-Government Survey 2010. Leveraging e-government at a time of financial and economic crisis. New York: UN Publishing Section. 
May 12-14, 2016, Riga, University of Latvia

\title{
DESIGN CONCEPTS FOR PROMOTING SOCIALLY RESPONSIBLE SOLUTIONS
}

\author{
Sabine Koklacova, Banku augstskola, Latvia ${ }^{1}$ \\ Tatjana Volkova, Banku augstskola, Latvia
}

\begin{abstract}
Problem statement. In recent years there has been growing interest about design concepts that seek for solutions that are more eco-effective and develop systems that have more positive output rather than less negative impact. Moreover, design concepts for socially responsible solutions in design and architecture industries are becoming even more complicated, asking for new knowledge and management methods.

Research aim is to take a critical look at the design concepts, in order to promote socially responsible solutions and concepts that have different meanings, purposes and approaches depending on their context and origin and to develop structured framework of these concepts.

Research method used is content analysis of scientific literature on design concepts that supports socially responsible solutions, abstract modeling and synthesis.

Main results and findings of the study are: (1) there are great gaps between different design concept approaches and origins, education and practice in different areas that are involved in design and architecture processes, (2) design concepts and approaches solve only certain level or some parts of social issues, (3) there is a gap between theoretical concepts and actual practices in creative industries, (4) here is a lack of design management methods and assessment tools available for socially responsible design concepts.
\end{abstract}

Key words: socially responsible design, social responsibility, design, architecture, design concepts JEL code: M19

\section{Introduction}

Topicality. The need for socially responsible products and environment has sensibly increased in recent years even though well-established tools have been developed to help designers and architects in facing with environmental (i.e., eco-design) or social problems (i.e., universal design). In recent years there has been growing interest about design concepts that seek for solutions that are more eco-effective such as Cradle to Cradle design and Biomimicry and develop systems that have more positive output rather than less negative impact. Moreover, design concepts for socially responsible solutions in design and architecture industries are becoming even more complicated, asking for new knowledge and management methods. There is no doubt that social responsibility of the architect is an important tool to enhance accessibility awareness in the society. Nevertheless, sensitivity and awareness of responsibilities cannot be expected to exist in human nature from birth. (Ergenoglu, 2015)

1 Corresponding author - e-mail address: sabine.koklacova@gmail.com 


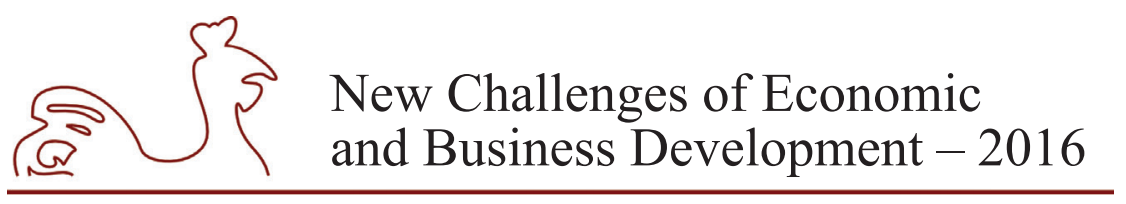

May 12-14, 2016, Riga, University of Latvia

Sustainability and socially responsible solutions are widely researched recent years and also in the context of the design and architecture. The key idea of the research is to reveal social responsibility of design in the context of architecture, to identify design concepts that promotes social responsibility, to describe the meaning, essence and context for each of them, make analysis, compare them and create brief conceptual framework for further researches. It is important because design and architecture plays the key role in shaping the world we live in and they are creating not only forms and functions, but also contexts and our quality of life. There is ongoing discussion about sustainability issues, social responsibility of designers and architects as mediators between different disciplines and creators of our future living environment. Design concepts are the ones to start with in order provide design management methodology for promoting socially responsible solutions because they hold the essence of the idea. A design concept is the one that gives a central character to the whole project and without it the project would be a chaos.

Research questions are: (1) What is context of design concepts for promoting socially responsible solutions in architecture? (2) What design concepts exist for promoting socially responsible solutions in architecture industry? (3) What is the meaning or essence, aim, approach, origin of each design concept and what is discussions and criticism? (4) What are the differences, gaps or similarities between them?

Contribution to the discipline. This study provides deeper understanding about social responsibility in the context of architecture and the latest design concepts. It determines gaps between design concepts applied for promoting socially responsible solutions and provides directions for further theoretical and practical research implications towards promoting socially responsible solutions in creative industries and these are the main contributions to the discipline.

Description of study. First part of the study determines what are socially responsible solutions in the context of architecture. It describes the context of further research based on the latest approaches and researches about social responsibility, design and sustainability. Authors have created models in order to set their own approach for this study. The second part of the research is analysis of design concepts for promoting socially responsible solutions. This part is based on previous researches in this field, adapted and improved for this particular research. There is deduction method used with three filters in order to find design concepts that might be used for further research.

The problem of the research is that there is no overview and comparison of design concepts for promotion socially responsible solutions and in order to understand their weaknesses and opportunities for further development there is need for deeper analysis.

Research aim is to take a critical look at the design concepts, in order to promote socially responsible solutions and concepts that have different meanings, purposes and approaches depending on their context and origin and to develop structured framework of these concepts.

Tasks of the research are: (1) To ascertain the context of design concepts for promoting socially responsible solutions in architecture. (2) To select design concepts for promoting socially responsible solutions that will be analyzed in this research. (3) To reveal the meaning, discussion and criticism of each design concept for promoting socially responsible solutions and analyze them. (4) To create conceptual framework for design concepts for promoting socially responsible solutions. (5) To develop conclusions, proposals, and recommendations for further research in this field - design concepts for promoting socially responsible solutions. 


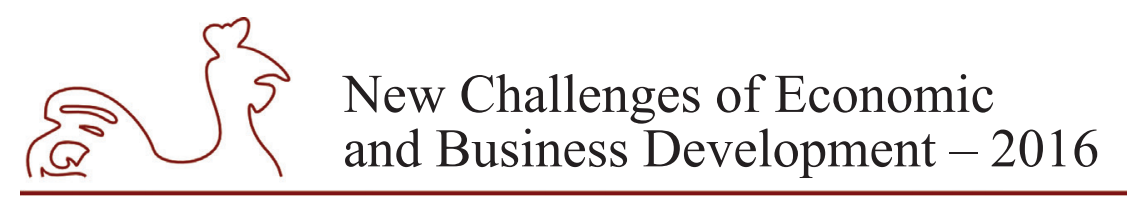

May 12-14, 2016, Riga, University of Latvia

Research method of this paper is content analysis of scientific literature on design concepts that supports socially responsible solutions, abstract modeling and synthesis.

Novelty of this research is that it is the first attempt to compare and analyze such design concepts that are used in the practice in the context of social responsibility in architecture. As there are several streams of design concepts and approaches that are trying to solve certain dimensions of social issues, there is no one united design concept that supports all areas of social responsibility - social, economical, environmental and cultural and the aim of this work is to analyze current design concepts, to create conceptual framework and to create approach for design concept that supports all dimensions. There are new models and tables created by authors.

Problematic questions of the conducted research are connected with limitations set by authors that there are only design concepts analyzed that might be relevant to design and architecture industries.

Sources of information for this research are scientific journals and academic books. Authors used for this research findings from scientific papers from available databases - EBSCO, JStore and Science Direct and looked for the context and content depending on the relevancy for this research. Keywords used in databases for this research are: sustainable design, sustainable architecture, eco-design, biomimicry, cradle to cradle, universal design, social design, social responsibility, socially responsible design, socially responsible architecture, green design, design for sustainability.

There are following limitations set for this research subject: (1) This research analyzes only the latest design concept approaches and only the scientific literature that are available for authors in databases. (2) Design models are widely dispersed in the literature, and some interesting publications were indirectly found. Therefore, not all possibilities were covered, and this research can be considered as an in-depth exploratory study. (3) Explored design concepts are limited by relevancy and cope with socially responsible solutions. (4) There are only design concepts analyzed that might be relevant to design and architecture industries. (5) Another potential limitation was the subjectivity in the analysis of the concepts. The presented conceptual framework does not intend to cover all of the depth and richness of approaches used in the publications, and a more detailed content analysis is underway.

There has been ongoing theoretical discussion about social responsibility and sustainability issues and the need for sustainable products and environments has sensibly increased in recent years. In the field of sustainable product development and architecture, a new type of design strategies or concepts is being implemented. However, research into their application and how they influence the outcome of the design process is scarce. (de Pauw et al., 2014a) Consequently, there is a lack of knowledge as to how these design concepts differ from and does they concentrate to all aspects of social responsibility. Studies show that even though wellestablished tools have been developed to help designers in facing with environmental problems (i.e., eco-design), a more user-centered approach which follows design for sustainability issues or socially responsible solutions has not been proposed yet. (Fargnoli et al., 2014) Different studies show significant differences (de Pauw et al., 2014a) in the design focus and there are theoretical discussion and criticism for each design concept what this work is about to reveal in further sections. 


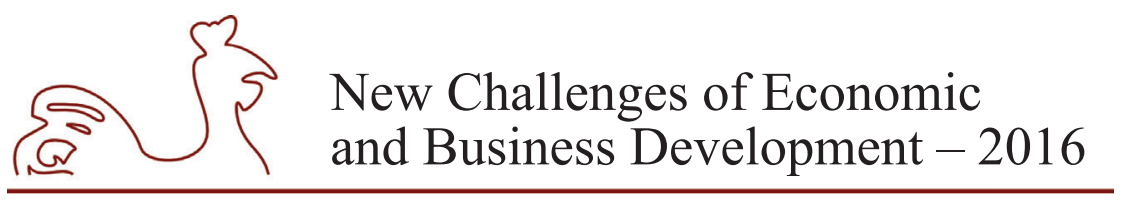

May 12-14, 2016, Riga, University of Latvia

\section{Research results and discussion}

This research is divided in two parts - the first part reveals the context of design concepts for promoting socially responsible solutions in architecture and the second part determine design concepts for further research, reveal the meaning or essence, aim, approach, origin of each design concept and discussions and criticism about them. Further research analysis and compare these concepts, create conceptual framework and approach for design concepts for promoting socially responsible solutions.

\section{The context of design concepts for promoting socially responsible solutions in architecture}

Being socially responsible means that people and organizations must behave ethically and with sensitivity toward social, cultural, economic and environmental issues not only in short term, but also in longer time frame perspective. Like social responsibility, sustainability can be categorized to three main dimensions: environmental, economic and social, including culture. World Commission on Environment and Development (1987) describes sustainable design as the guiding concept to create the built environment that "meets the needs of the present without compromising the ability of future generations to meet their own needs" (Kadir and Jamaludin, 2013). As there are so many interpretations and meanings of sustainability, in this research authors will use social responsibility that address also cultural dimension which is important in the context of architecture and design. In this context socially responsible solutions are solutions that are dealing with environmental, economic, social dimensions and, or cultural problems. Design concepts that promote social responsibility deals with problems that are related to some or all areas of the concept of social responsibility.

In the context of architecture, development of design concept for promotion socially responsible solutions has significant role and opportunity to make a positive influence to society and environment. Authors propose that this influence might be measured by environment or level where socially responsible design concept is used (Figure 1). The wider is environment or field of activity design concept for promoting socially responsible solutions is dealing with, the complicated it is and the stronger is influence to society and social issues.

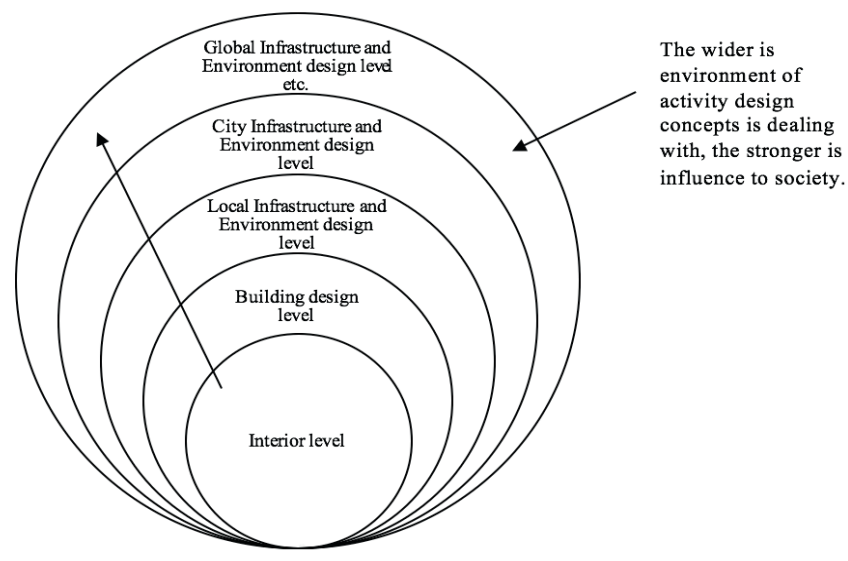

Source: created by authors.

Fig. 1. Relationship between dimensions in architecture and influence of design concepts 


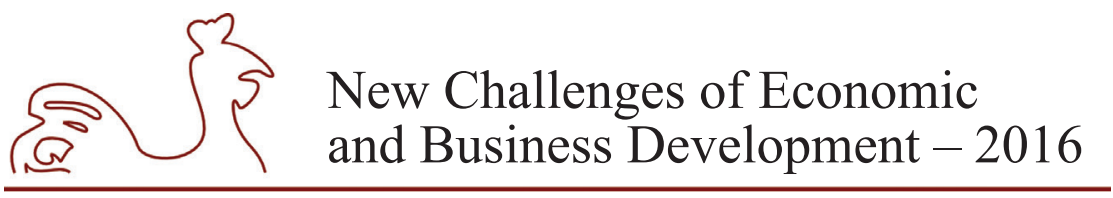

May 12-14, 2016, Riga, University of Latvia

In order to compare development of design concepts for promotion socially responsible solutions, impact to society and time that might be spent in order to create more complicated design concepts and systems, authors propose "Design concept development model" (Figure 2). This model is developed and adopted based on two well known models: Eco-design Innovation model created by Brezet (1997) and Innovative eco-design four step model created by Shervin, C. (2000). This model indicates three levels of design concepts for promoting social responsibility and their relation between time and impact to society. The first - Improvement level, can make small changes in relatively short period of time. The second - Re-design level that is more pro-active but still uses incremental approaches for development and can make more important changes in longer period of time. The third - re-thinking level is using innovative and future oriented approaches and striving for delivering radical socially responsible, eco-efficient solutions. It takes time, competence and different approaches and tools to create and implement such concepts and systems but these concepts can make the significant changes for society and its wellbeing.

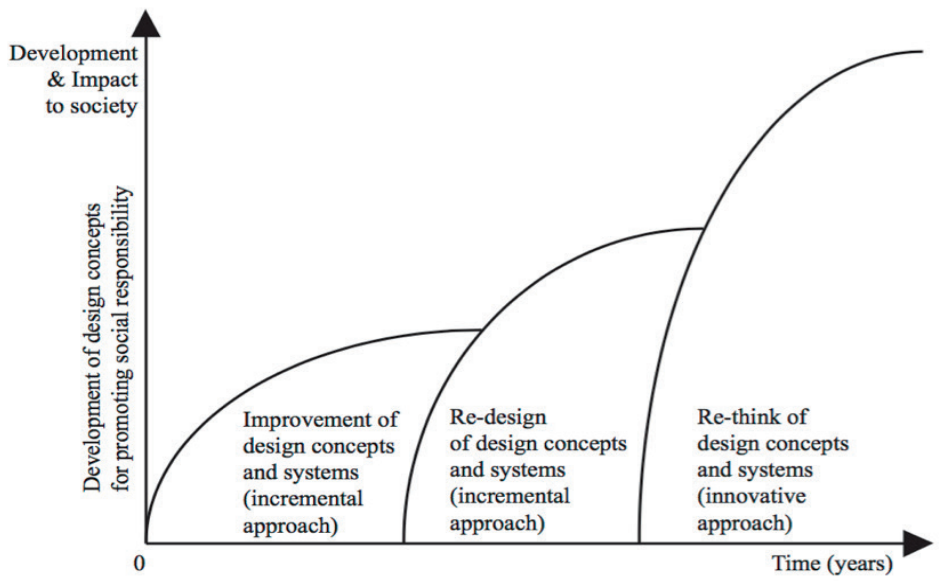

Source: created by authors based on Ecodesign Innovation model created by Brezet (1997) and Innovative ecodesign four step model created by Shervin, C. (2000).

Fig. 2. Design concept development model

Latest trends in literature. As mentioned before, following the latest researches there is growing interest about solutions and design concepts that are trying to optimize positive impact on society instead of minimize negative. It is because negative impact minimization does not solve problems but only extend and postpone problems for the distant future. According to Braungart and McDonough (2002) eco-efficient engineering does not deliver in a sufficient long-term goal. It may reduce pollution and resource consumption in the short term, but it does not address the source of the problem: the design defect of current industry. Optimization of positive solutions instead deals with problems from different perspective - trying to find solutions that creates more positive output. And most of these are Nature-Inspired systems and design concepts. In reference to literature, this study shows that design concepts for promoting socially responsible or sustainable solutions might be divided in three types by their purpose (Figure 3): (1) Concepts that tries to reduce negative impact (optimize resources, eco-efficiency) - older literature, 


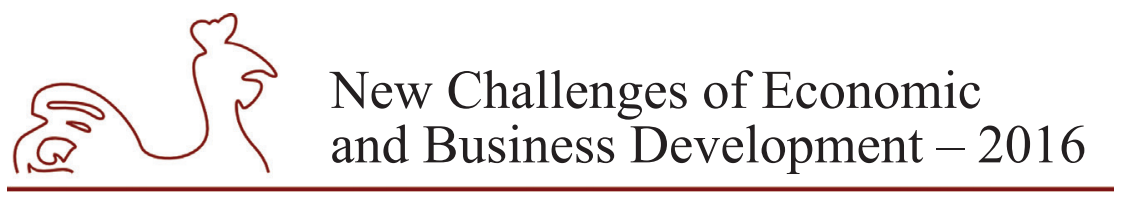

May 12-14, 2016, Riga, University of Latvia

(2) Concepts that tries to reach zero - emission point - younger concepts, (3) Concepts that tries to increase positive effect (eco-effectivity) - the latest concepts. Visual model for these tendencies and concepts is visually illustrated below.

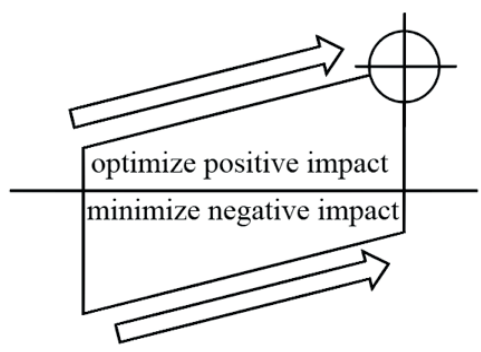

Source: author's construction based on (Toxopeus et al., 2015).

Fig. 3. Eco-effective vs. eco-efficient design concepts

Life Cycle Thinking. What is common to all newest design approaches and concepts is that most of them are based on Life Cycle Thinking instead of Linear thinking or also known as Cradle-to-Grave thinking. This approach evaluates how both consuming products and engagement in activities that are related to this product impacts environment and takes a holistic picture of an entire product or activity system. And from this point of view again, Life Cycle Thinking approaches are used not only to minimize negative impact and the latest approaches, but also move towards positive output doing "more good" instead of doing "less bad".

\section{Design concepts for promoting socially responsible solutions - conceptual framework}

First step. Selection of design concepts. To determine which design concepts to incorporate in the research project, an analysis was made of a comprehensive list of sustainability approaches which has been compiled in by AIGA (2009) and further developed by Ingrid C. de Pauw (2014a). The list consists of 'the major sustainability visions, manifestos, principles frameworks and tools that have been developed over the past 50 years and that are relevant to design' (De Pauw et al., 2010), authors have improved this list with more design concepts starting from Number (31).

Sustainable design approaches. If we look at the design from the lens of sustainability, Ingrid C. de Pauw (2010) based on Brick (2009) classified several sustainable design approaches: (1) First Thing First 1964, (2) first Thing First (2000), (3) World Economic Forum, (4) The Ceres Principles, (5) The EIDD Stockholm Declaration, (6) The Hannover Principles, (7) The Wingspread Statement on the Precautionary Principle, (8) IDSA Eco Design Principles and Practices, (9) American Institute od Architects Sustainable Architectural Practice Position Statement, (10) The Designers Accord, (11) Kyoto Design Declaration, (12) Graphic Design Canada Sustainability Principles, (13) The Natural Step TM, (14) Total Beauty, (15) Biomimicry, (16) Natural Capitalism, (17) Cradle to Cradle, (18) The Sustainability Helix, (19) The Presidio Model, (20) Life Cycle Assessment, (21) LEED (green building certification system), (22) Social Return on Investment (SROI), (23) The Sustainability Scorecard, (24) The Sustainable Packaging Coalition (SPC), (25) The PHAROS Project, (26) Okala (Eco-design curriculum), (27) Design Can Change, (28) 11 Design Questions, (29) The Designer's Field Guide to Sustainability, 


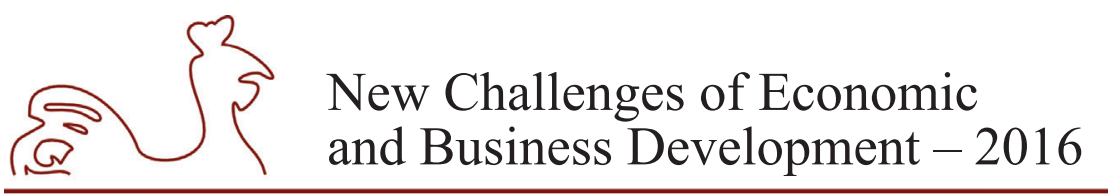

May 12-14, 2016, Riga, University of Latvia

(30) Re-nourish. And these approaches can be supplemented with: (31) Frugal Innovation (Navi Radjou and Jaideep Prabhu, 2014) (32) Ten Principles for Good Design (Dieter Rams, 1970), (33) The Upcycle (W. McDonough, 2013) (34) Universal Design (Ergenoglu, 2015; Kadir and Jamaludin, 2013), (35) Upcycling (unknown).

Second step. Selection of design concepts for promotion socially responsible solutions.

Our main task was to select approaches which can be labeled as "design concepts for promotion socially responsible solutions" and can be applied for architecture. The following criteria have been applied as filters for selection if design concepts: Filter 1: Approaches that are based on design concepts and do not provide only principles or abstract vision. Filter 2: Approaches that are based on "Life Cycle Thinking" approaches. Filter 3: Approaches that refers to nature and/or to universality of the use of design (equal opportunities for all members of society).

In order to cover all dimensions of social responsibility, the following design concepts promoting socially responsible solutions have been selected for the current research project: Universal design, Eco-design, Cradle to Cradle design (also known as the Upcycle in latest literature), Biomimicry. The aim of following chapters is to give an overview of selected design concepts - their essence and meaning.

Universal Design (UD) is a worldwide movement that approaches the design of the environment, products, and communications with the widest range of users in mind. The term was proposed by the American architect Ronald L. Mace in 1985 during the development era of "barrier-free design" (Kawauchi, 2001). UD has evolved from a focus on disabling barriers in the environments in USA and implies to plan and manufacture goods, buildings, outdoor spaces and facilities to be useable by all people to the fullest possible extent (Lid, 2013) according to democratic principles of enabling equal citizenship (Gibson, 2014). The democratic potential for UD lies in recognizing all people as equal, it looks beyond minimums (Ergenoglu, 2015) and its implementation in the built environment is crucial due to human changing abilities over a lifetime in order to sustain everybody's quality of life (Kadir and Jamaludin, 2013).

Discussion and different perspectives: Nevertheless, there are a plethora of books and technical packets devoted to the subject of UD (Joines, 2009), there are different perspectives such as seeing the concept of human through the lens of disability (Lid, 2013), architect has an approach that will facilitate the design to consider every user as 'normal' (Kadir and Jamaludin, 2013) or UD have an opportunity to improve the quality of life for clinical patients (Joines, 2009). On the other hand, UD risks limiting possibilities by bodies are included within the scope of the "universal" (Gibson, 2014). Different approaches developed characteristics of UD by adding three supplemental dimensions: durability and economics, quality and aesthetics, and health and environment (Satoshi Nakagawa). Comparatively, the 3B principles proposed by Ronald L. Mace (1970) (better design, more beautiful, and good business) focused on the economic and aesthetics dimensions, but were overly abstract when used in actual applications (Lin and $\mathrm{Wu}, 2015$ ). The results indicated that the principles and context of UD evolved over 20 years, the principles have been amended to include more details, tools, they provide significant impact and principles have been applied in different countries. (Siu, 2011) Today, UD extends beyond removing barriers and can be seen as guidelines how to increase usability to as many as possible, UD eliminates discrimination and thus supports social participation for all members of society. UD sets goals and redefines disability as a universal condition (Christophersen and 


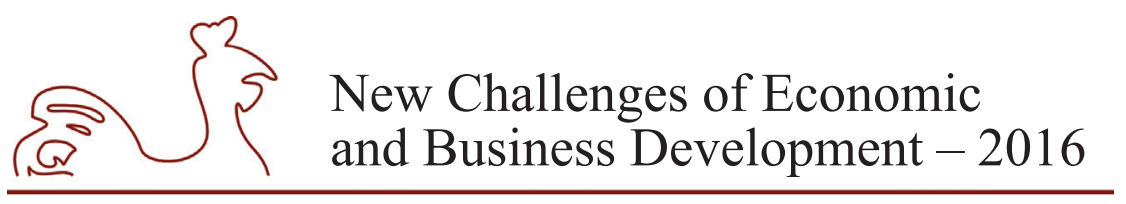

May 12-14, 2016, Riga, University of Latvia

Norske stats husbank, 2002). UD expands the focus to broader population, it has an innovative approach, strives for full social participation. It is about solutions that provide flexibility in use and handling (Christophersen and Norske stats husbank, 2002). UD has seven principles: equitable use, flexibility in use, simple and intuitive use, perceptible information, tolerance for error, low physical effort, size and space for approach and use (NCSU (1997), (Siu, 2011).

UD Criticism coming from ideas that UD principles, however, have not been successfully adopted by professionals and companies in general and the theoretical content of the concept is, however, poorly developed (Imrie 2012; Lid 2012), (Lid, 2013). There is opinion that it is impossible to determine what is universal and what is not because there are so many different needs of society. Although UD is highly human centered and social, it does not mean that it should be also environment-friendly and that part of social responsibility might be excluded.

Eco-design has been described in literature for more than 35 years, with more widespread research emerging as of 1990-1995. And nowadays it is one of the most widely recognized and utilized strategies for including environmental sustainability in the product design process. (de Pauw et al., 2014b) Eco-design as defined in ISO 14062 (ISO/TR 14062, 2002) is a design approach aiming to reduce the environmental impacts of products and services throughout the whole life cycle, while assuring similar or improved services to the end customer. Aims of eco-design are to reduce the consumption of resources, to use environment-friendly materials, to optimize the production, distribution and use of the product as well as to ensure proper management at the end of its life cycle, i.e. renewal, recycling or disposal (M. Klavins, 2010). Looking back to history, eco-design has constantly borrowed ideas and terminology from ecology and environmentalism. The transition from "green" to "eco-" to "sustainable" in the design field represents a steady broadening of scope in theory and practice. (Madge, 1997) V. A. Lofthouse (1999) stated that eco-design is a key element in the journey towards sustainable development, having the potential to reduce the environmental impact of products and open up real opportunities for industry to make progressive steps beyond compliance. Several authors made an effort to clarify this generic definition. Ultimately eco-design can be seen as an industrial activity, which involves integrating environmental considerations into the design process, while maintaining price, performance and quality standards (Lofthouse et al., 1999). And literature shows many more definitions of eco-design.

Discussion and different perspectives: In eco-design the complexity of designing is increased by the necessity to explore unusual domains such as biology or climatology to validate the environmental impacts of a product. "Eco-Design can be interpreted as Design with more intelligent interrelationship to Nature". In addition, it is characterized by the "life-cyclethinking" which relies on a transversal integration of the environmental concern in each stage of the development of the product: from cradle to grave, or cradle to cradle (Braungart et al., 2007). Therefore, adding the environmental parameter to the usual ones forces the design process to be collaborative. (Rio et al., 2013) Wide range of contexts, numerous and diverse eco-design methods and tools have been developed by research centers, companies or public organizations (including ISO). These methods focus essentially on two main aspects of eco-design: (1) the analysis of life cycle assessment (LCA) (ISO 14040 2006). (Lye, Lee, and Khoo 2001) ad (2) design for recycling (DFR) (Hundal 2000), (Goepp et al., 2013). Some authors propose to classify those supports in categories (checklists, guides, guidelines, databases, product lifecycle assessment tools, etc.) and to study their applications. The number of eco-design methods and 


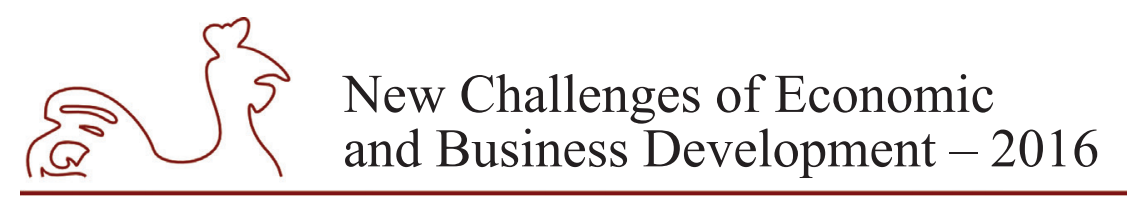

May 12-14, 2016, Riga, University of Latvia

tools are still growing. (Vallet et al., 2013) (de Pauw et al., 2014a) Ant the seven traditional eco-design strategies proposed by Brezet and Van Hemel (1997) cover the product life cycle as follows: Low impact material, Reduction of material use, Optimization of production techniques, Optimization of distribution system, Reduction of impact during use, Optimization of product lifetime, Optimization of End of Life systems. (Vallet et al., 2013)

Criticism: Despite the potential benefits of eco-design and the existence of several tools and techniques for product design, the actual application of eco-design has not reached companies worldwide, mainly due to difficulties in eco-design implementation and management. (Pigosso et al., 2013) Pigosso and McAloone work showed that there are relevant gaps that may explain why eco-design integration still remains a challenge, particularly in the innovation management processes and generally in operations management. (Pigosso and McAloone, 2015) Research shows that Eco-design needs to be practiced in multidisciplinary teams in industry. (Vallet et al., 2013) It also showed that as mentioned before - Eco-design is focused on reduction of environmental impact but it does not solve the problem, it also does not pay enough attention to social and cultural dimension.

Nature inspired design concepts. Biomimicry and Cradle to Cradle are two examples of a relatively new type of strategic tool and design concepts currently adopted in design practice and education, that take inspiration from the natural world. (de Pauw et al., 2014a) From the point of authors, Biomimicry and Cradle to Cradle could be defined not as a strategy but rather as a strategic tool applied by companies to deliver long term sustainable solutions. Following chapters will briefly represent the main idea for each of them.

Biomimicry. The field of biomimicry, where flora, fauna or entire ecosystems are emulated as a basis for design, has attracted worldwide interest in the fields of architecture and engineering. This is due to both the fact that it is an inspirational source of possible new innovation and because of the potential it offers to create a more sustainable built environment (El-Zeiny, 2012). It is new science that observe the materials in nature and then aim to produce solutions for humans by imitating these designs or by taking inspiration from them. Biomimicry can be defined as imitating or taking inspiration from nature's forms and processes to solve problems for humans (Benyus, 1997). The core concept of Biomimicry is that nature has developed highly effective, sustainable ways of performing functions, which could benefit designers when tackling comparable challenges. It might be defined accordingly as learning from nature for developing sustainable solutions. (de Pauw et al., 2014b) (Lurie-Luke, 2014). It can be expressed as the imitation of the life system in nature ir defined as 'the innovation that gets inspired by nature' (Tavsan et al., 2015). The word 'biomimicry' stems from the roots bios life and mimesis to imitate. Biomimicry 3.8, an institute co-founded by Benyus, has developed different methods and tools for sustainable product design. Benyus argues that a full emulation of nature engages at least three levels of mimicry: form, process, and ecosystem (Benyus, 2008). Biomimicry is a concept that was first put forward 1997 by writer and science observer Janine M. Benyus from Montana - a biologist and leader of the emerging discipline of biomimicry (Tavsan et al., 2015). Since then various definitions are used interchangeably in literature for Biomimicry - Biomimetics, Bio-inspired design, and Bionics. However, when the emphasis is on finding solutions that are (environmentally) sustainable, Biomimicry is typically the term used (de Pauw et al., 2014b). 


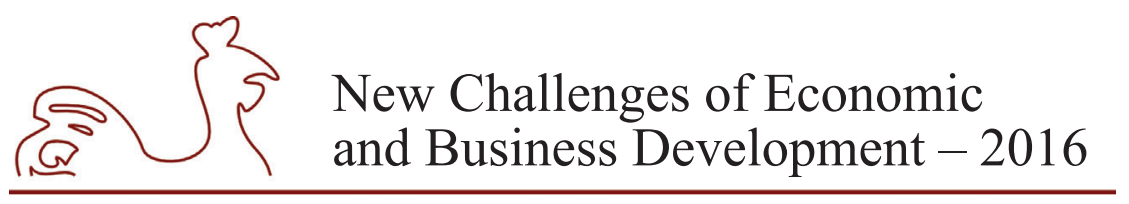

May 12-14, 2016, Riga, University of Latvia

Discussion and different perspectives: Benyus emphasizes that in order to achieve environmentally sustainable solutions, designers need to integrate biological knowledge at the level of forms, processes, and systems. To integrate ecosystem insights into design, so called 'life's principles' of biology are provided. The aspirational goal of their application is to create "conditions conducive to life" (Benyus, 1997). According to its proponents, the Life's Principles can be used to measure the success of a design. Biomimicry started to be considered as a new science by materializing the 'possible solutions and solution potential in nature'. According to Benyus 'a biomimitric revolution' is going to take place in the forthcoming years (Tavsan et al., 2015). In modern science, the search for biomimetic applications has developed into a scientific discipline and biomimicry based innovations are now the subject of systematic study (Lurie-Luke, 2014). Undoubtedly, Biomimicry will be increasingly influential on the understanding of design in the future. (Tavsan and Sonmez, 2015). On the other hand, the development of biomimicry applications can be a long and failure-prone path. Approaches to biomimicry as a design process typically falls into two categories: Problem-based (Top-Down) and Solution-based (BottomTop) (El-Zeiny, 2012). For design professionals, it opens up a whole new world of innovative ideas and will help connect the work with the natural environment. (El-Zeiny, 2012)

Criticism: Biomimicry has revealed new opportunities for material development across a range of fields, to utilize our environment in a new, safe and environmentally-sustainable manner. (Lurie-Luke, 2014) But studies on the application of Biomimicry in sustainable product design are scarce. Earlier studies show that it does not necessarily render more sustainable outcomes. The widespread and practical application of biomimicry as a design method remains unrealized; interior architecture commonly uses biology as a library of shapes, but this alone is not biomimetics; it has to have some biology in it. (El-Zeiny, 2012) For interior environment, it is still in its infancy. In spite of a growing number of bio-inspired materials and products, projects that incorporate biomimicry at the macro scale are few and far between. (El-Zeiny, 2012) Montana-Hoyos (2008) acknowledges the need to include the systems' level of Biomimicry. Volstad and Boks, explicitly limit their study to the reductive form and its use "as a source of inspiration and as a toolkit for solving practical design problems". (de Pauw et al., 2014b) It might be seen as inspiration for design, innovation, architecture and it have an opportunity to create new sustainable standard for interior spaces, buildings, communities and cities worldwide (El-Zeiny, 2012) but this nature inspired approach pays too little attention to social responsibility in sense of human needs or UD principles. To be more socially responsible this approach asks for further development.

Cradle to Cradle (C2C) design. The systems theory of $\mathrm{C} 2 \mathrm{C}$ aims at a positive impact or eco-effectiveness; this could suggest that the state-of-the-art becomes inadequate when adopting C2C as a strategy for improvement (van Dijk et al., 2014). C2C design concept defines a framework for designing products and industrial processes that turn materials into nutrients by enabling their perpetual flow within one of two distinct metabolisms: the biological metabolism and the technical metabolism. (Braungart et al., 2007) It also defines a broad framework for creating eco-effective industrial systems, but for businesses to put this framework into practice they need both the right technologies and the right strategies. (Braungart et al., 2007) The core concept of $\mathrm{C} 2 \mathrm{C}$ is to "take nature as a model for making things" and design products that, after their useful lives, become resources for new products (McDonough and Braungart, 2002). Architect William McDonough drew the first outlines of Cradle to Cradle with the Hannover 


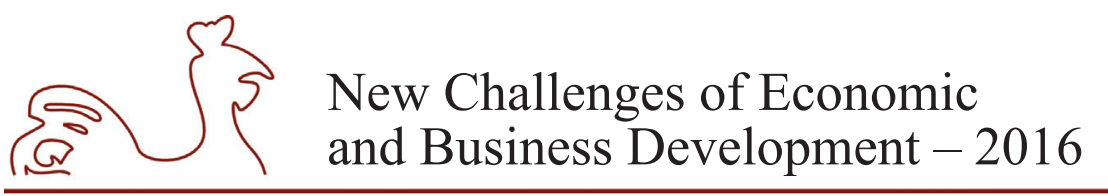

May 12-14, 2016, Riga, University of Latvia

Principles (1992). Half a decade earlier, Michael Braungart - founder and former leader of Greenpeace's chemical division - established the Environmental Protection Encouragement Agency (EPEA). Together, they conceived the C2C concept and composed the book in 2002 "Cradle to Cradle - remaking the way we make things" (2002) (Toxopeus et al., 2015). C2C proposes to replace eco-efficiency by eco-effectiveness or "state of zero: zero waste emissions, zero resource use and zero toxicity" (Llorach-Massana et al., 2015).

Discussion and different perspectives: $\mathrm{C} 2 \mathrm{C}$ design strategy challenges designers to move towards 'eco-effectiveness'(de Pauw et al., 2014b), aims to avoid downcycling materials and promote upcycling ones to achieve closed cycles. C2C provides designers with three design principles, based on learning from natural systems: 'waste equals food', 'use current solar income', and 'celebrate diversity'. (Llorach-Massana et al., 2015) It also provides strategy for businesses on the level of product design (Braungart et al., 2007). Apart from the principles, various design tools are available, offered via courses by EPEA, an agency founded by Braungart, as well as a number of Universities. Next to the design tools, a certification program has been developed to allow companies to market their progress at $\mathrm{C} 2 \mathrm{C}$ Products Innovation Institute (de Pauw et al., 2014b). The C2C certification has gained popularity. (Llorach-Massana et al., 2015) Several studies describe advantages and disadvantages of $C 2 C$, but studies analyzing the application of the concept in product design are scarce (de Pauw et al., 2014b). The concept of eco-effectiveness also addresses the major shortcomings of eco-efficiency approaches, ecoeffectiveness encompasses a set of strategies for generating healthy, cradle-to-cradle material flow metabolisms. (Braungart et al., 2007)

Criticism: Among supporters there are also criticism and skepticism found in the literature and researches. Authors argue that $\mathrm{C} 2 \mathrm{C}$ is not always an appropriate scheme to distinguish environmentally preferable products. (Llorach-Massana et al., 2015) The $\mathrm{C} 2 \mathrm{C}$ concept promotes an infinite economic and production growth, however, there are some limitations regarding the bio capacity of the planet and $\mathrm{C} 2 \mathrm{C}$ biological nutrient metabolism does not seem to be a solution as simple as $\mathrm{C} 2 \mathrm{C}$ principles suggest. Implementing the $\mathrm{C} 2 \mathrm{C}$ concept in a worldwide scenario requires social, infrastructure, important logistic changes etc. In addition, sceptics think that it cannot be considered that renewable energies have zero environmental impact (Llorach-Massana et al., 2015). Or advise to add a minimum control from the government on certifications to ensure transparent and truthful certificates. Some authors suggest to include other eco-efficiency strategies to $\mathrm{C} 2 \mathrm{C}$ (Llorach-Massana et al., 2015). According to research, C2C certification could not be always distinguishing environmental preferable products. (Llorach-Massana et al., 2015) C2CPII only accepts material and process evaluations submitted by an C2C assessment institutes and certification is valid for two years and must be biennially renewed(Toxopeus et al., 2015). C2C got criticized by several professionals and scholars from the field of sustainability in Netherlands. The main comment was that this new theory was not something new (van Dijk et al., 2014). C2C will probably lead to a shift in its popularity due to the lack of an innovation driver and open development and due to limitations from different sources, $\mathrm{C} 2 \mathrm{C}$ in practice often turns out to be merely efficient (Toxopeus et al., 2015). And looking through the lens of social responsibility, there are dimensions of focus missing again - social and cultural dimensions that leads to universal design approach or design concept.

In summary, there are different design concepts for promoting socially responsible solutions and even within the concepts there are discussions, criticism and different approaches. This 


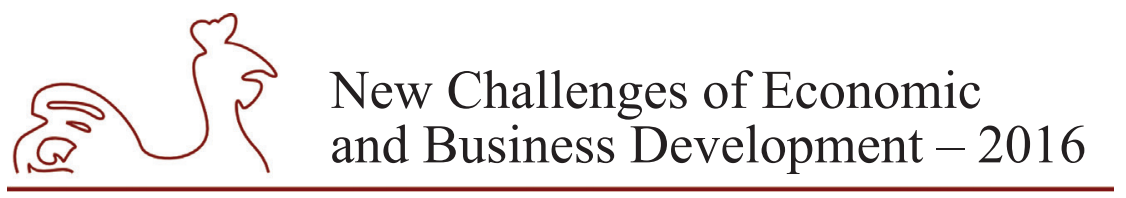

May 12-14, 2016, Riga, University of Latvia

research shows that no-one of the design concepts are trying to solve or focus to all dimensions of social responsibility and from our perspective it is important to analyze them more deeply, understand differences and potential to sublime them in order to create more socially responsible solutions. Authors have summarized research findings that characterizes each design concept by different criteria and gives an essence for each of them (Table 1). Table shows that there are great gaps between different origins and approaches such as architecture, product design,

Table 1

Comparison of different design concepts for promoting socially responsible solutions

\begin{tabular}{|c|c|c|c|c|}
\hline & $\begin{array}{c}\text { Universal } \\
\text { Design }\end{array}$ & Eco-Design & Biomimicry & Cradle to cradle \\
\hline $\begin{array}{l}\text { Main idea of } \\
\text { design approach }\end{array}$ & $\begin{array}{l}\text { Aim: to be } \\
\text { useable by all } \\
\text { people to the } \\
\text { fullest possible } \\
\text { extent }\end{array}$ & $\begin{array}{l}\text { Aim: to reduce } \\
\text { the environmental } \\
\text { impacts of products } \\
\text { and services } \\
\text { throughout the whole } \\
\text { life cycle }\end{array}$ & $\begin{array}{l}\text { Imitate or take } \\
\text { inspiration from } \\
\text { nature's forms } \\
\text { and processes to } \\
\text { solve problems }\end{array}$ & $\begin{array}{l}\text { Turn materials into nutrients } \\
\text { by enabling their perpetual } \\
\text { flow within one of two distinct } \\
\text { metabolisms: the biological } \\
\text { and the technical }\end{array}$ \\
\hline Origin & Architecture & Product design & Biology & Architecture and chemistry \\
\hline Year of origin & 1986 & $1990-1995$ & 1997 & 2002 \\
\hline Author & Ronald L. Mace & - & $\begin{array}{l}\text { Janine } \\
\text { M. Benyus }\end{array}$ & $\begin{array}{l}\text { W. McDonough and } \\
\text { M. Braungart }\end{array}$ \\
\hline Inspiration & $\begin{array}{l}\text { humans } \\
\text { (disabilities) }\end{array}$ & $\begin{array}{l}\text { environmental } \\
\text { problems }\end{array}$ & nature & nature \\
\hline Social focus & $\mathrm{x}$ & $\mathrm{x}$ & - & - \\
\hline $\begin{array}{l}\text { environmental } \\
\text { focus }\end{array}$ & - & $\mathrm{x}$ & $\mathrm{x}$ & $\mathrm{x}$ \\
\hline $\begin{array}{l}\text { Economical } \\
\text { focus }\end{array}$ & - & $\mathrm{x}$ & - & - \\
\hline Use of concepts & $\begin{array}{l}\text { design and } \\
\text { architecture }\end{array}$ & wide range & wide range & wide range \\
\hline Solutions & - & Eco-efficient & Eco-effective & Eco-effective \\
\hline $\begin{array}{l}\text { Life Cycle } \\
\text { Thinking }\end{array}$ & no & yes & yes & yes \\
\hline Biology involved & no & no & yes & yes \\
\hline $\begin{array}{l}\text { Methods and } \\
\text { tools }\end{array}$ & in progress & maturity & in progress & in progress \\
\hline $\begin{array}{l}\text { Design Man. } \\
\text { methods }\end{array}$ & no & no & no & no \\
\hline $\begin{array}{l}\text { Assessment } \\
\text { methods }\end{array}$ & no & maturity & in progress & in progress \\
\hline $\begin{array}{l}\text { Certificate or } \\
\text { Standard }\end{array}$ & - & ISO 14062 & - & C2CPII certificate \\
\hline Institute & $\begin{array}{l}\text { The RL Mice } \\
\text { Universal Design } \\
\text { Institute }\end{array}$ & about 23 Institutes & Biomimicry 3.8 & $\begin{array}{l}\text { C2C Product Innovation } \\
\text { Institute, } \mathrm{C} 2 \mathrm{C} \text { assessment } \\
\text { institute (MBDC and EPEA) }\end{array}$ \\
\hline
\end{tabular}

Source: created by authors. 


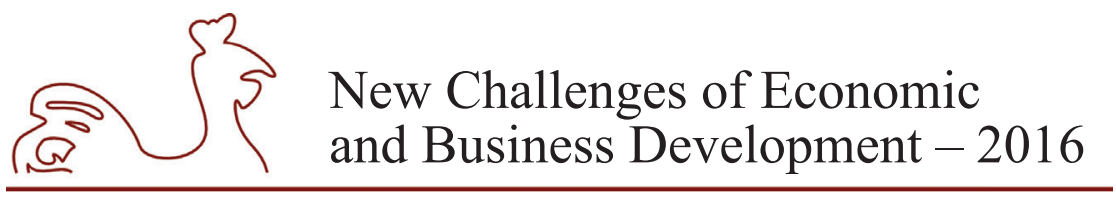

May 12-14, 2016, Riga, University of Latvia

biology or even chemistry. That means that gaps are also in education and practice in different areas that are involved in design and/or architecture process. It can be concluded also from different sources of inspiration for design. These design concepts are relatively new and shows that design concepts and approaches solve only certain level or some parts of social issues, excluding cultural problems that is inalienable part of the society. There is also a gap between theoretical concepts and actual practices due to the lack of well established methodologies and limited access to methods and tools. Most of the books available for public reveal only vision or main ideas. There is a lack of design management methods and assessment tools available for socially responsible design concepts like it is for traditional design management.

Authors have created model that reveal their approach for further researches. As mentioned before, there are four dimensions that need to be covered in order to create more socially responsible design concepts. In order to create "universal" design concept for promoting socially responsible solutions it is crucial to take in consideration all these dimensions. Moreover, it is essential to increase the radius for each dimension. Besides, it is also important to create designs and systems that not only reduce negative impact but increase positive effect instead (Figure 4).

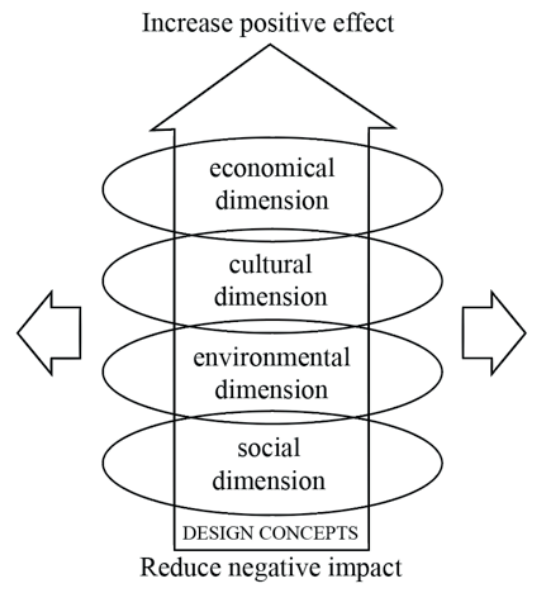

Source: author's construction.

Fig. 4. Model: Dimensions for socially responsible design concept

\section{Conclusions, proposals, recommendations}

Conclusions. (1) There different design concepts such as universal design, eco-design, biomimicry, cradle to cradle for promoting socially responsible solutions and even within the concepts there are discussions, criticism and different approaches. (2) This research shows that no-one of the design concepts tries to solve or focus to all dimensions of social responsibility, (3) there are great gaps between different origins such as architecture, product design, biology or even chemistry and approaches, that means that (4) there are gaps also in education and practice in different areas that are involved in design and/or architecture process. (5) Design concepts are relatively new and solve only certain level or some parts of social issues. (6) There is a gap between theoretical concepts and actual practices in creative industries and it has several reasons 


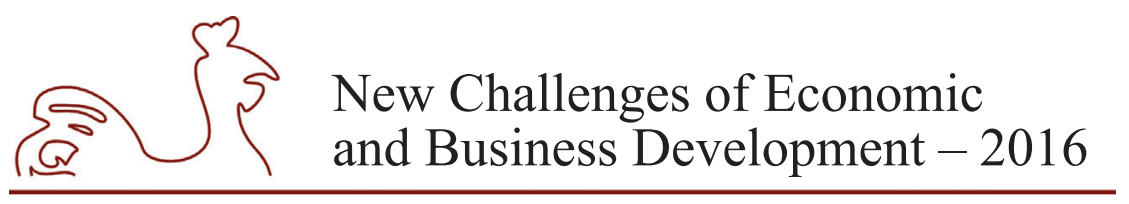

May 12-14, 2016, Riga, University of Latvia

(as mentioned before). (7) This research showed that here is a lack of design management methods and assessment tools available for socially responsible design concepts. (8) There is a gap in understanding of design meaning and purpose and (9) there is a need for new design concept that supports life cycle thinking in all areas of social responsibility and multidisciplinary design management theory, methods and tools that helps to create, manage and evaluate socially responsible solutions and creates more eco-effective and socially responsible output, instead of mainly focusing on the reduction of negative impact on environment.

Proposals. (1) Authors proposes that is a need for new design concept that supports life cycle thinking in all areas of social responsibility and design management that has multidimensional characteristics. Based on previous work and conclusions, (2) authors have created model that reveal their approach for further researches - "Dimensions for socially responsible design concepts" that might be used as a frame for further theoretical development in order to create socially responsible solutions, (3) it is crucial to take in consideration all areas and create multidimensional theoretical models, frameworks and further - methods and tools that supports all of them. (4) There is need to seek for solutions with more positive output rather than focusing on reduction of negative effects to the environment or society.

Recommendations. Recommendations for further research are (1) to make more detailed analyses of different design concepts and to develop new design concepts in order to create more structured framework for design concepts for socially responsible solutions that covers all dimensions. (2) Because of the lack of concepts in cultural dimension - there is a need to deliver research in this field in order to create guidelines for cultural development in this sense. (3) Another possible research area recommended by authors are design approaches, methods, tools and principles that are used for each of the design concepts. It would be useful to compare them in order to understand the gaps and similarities between them and adapt them to architecture. (4) Based on empirical research there might be new approaches developed. (5) It is necessary to look at the practical implication of design concepts. (6) Because of the differences between private and public spaces, there might be need for different approaches for each of them. (7) The last but not the least research recommendation would be design management tools and methods for socially responsible solution implication and development.

\section{Bibliography}

Braungart, M., McDonough, W., Bollinger, A., 2007. Cradle-to-cradle design: creating healthy emissions a strategy for eco-effective product and system design. J. Clean. Prod. 15, 1337-1348.

Christophersen, J., Norske stats husbank (Eds.), 2002. Universal design: 17 ways of thinking and teaching, 1. utg. ed. Husbanken, Oslo.

de Pauw, I. C., Karana, E., Kandachar, P., Poppelaars, F., 2014a. Comparing Biomimicry and Cradle to Cradle with Ecodesign: a case study of student design projects. J. Clean. Prod. 78, 174-183.

De Pauw, I., Kandachar, P., Karana, E., Peck, D., Wever, R., 2010. Nature inspired design: Strategies towards sustainability, in: Knowledge Collaboration \& Learning for Sustainable Innovation: $14^{\text {th }}$ European Roundtable on Sustainable Consumption and Production (ERSCP) Conference and the $6^{\text {th }}$ Environmental Management for Sustainable Universities (EMSU) Conference, Delft, The Netherlands, October 25-29, 2010. Delft University of Technology; The Hague University of Applied Sciences; TNO.

El-Zeiny, R. M. A., 2012. Biomimicry as a Problem Solving Methodology in Interior Architecture. Procedia - Soc. Behav. Sci. 50, 502-512. 


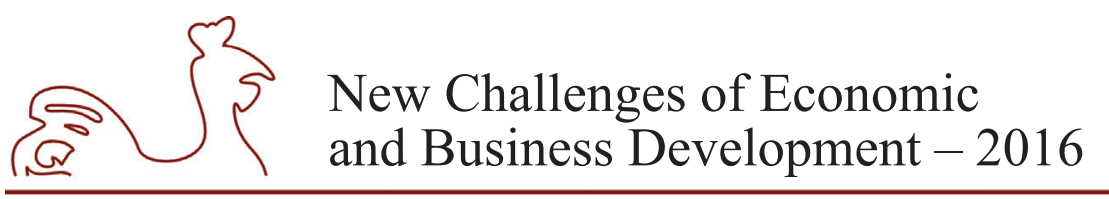

May 12-14, 2016, Riga, University of Latvia

Ergenoglu, A. S., 2015. Universal Design Teaching in Architectural Education. Procedia - Soc. Behav. Sci. 174, 1397-1403.

Fargnoli, M., De Minicis, M., Tronci, M., 2014. Design Management for Sustainability: An integrated approach for the development of sustainable products. J. Eng. Technol. Manag. 34, 29-45.

Gibson, B. E., 2014. Parallels and problems of normalization in rehabilitation and universal design: enabling connectivities. Disabil. Rehabil. 36, 1328-1333.

Joines, S., 2009. Enhancing quality of life through Universal Design. NeuroRehabilitation 25, 155-167.

Jones, P., 2014. Situating universal design architecture: designing with whom? Disabil. Rehabil. 36, 13691374.

Kadir, S. A., Jamaludin, M., 2013. Universal Design as a Significant Component for Sustainable Life and Social Development. Procedia - Soc. Behav. Sci. 85, 179-190.

Klavins, M., Filho, W. L., Zaloksnis, J., 2010. Environment and Sustainable Development. Riga: Academic Press of University of Latvia, pp. 192-193.

Lid, I. M., 2013. Developing the theoretical content in Universal Design. Scand. J. Disabil. Res. 15, 203215.

Lin, K.-C., Wu, C.-F., 2015. Practicing universal design to actual hand tool design process. Appl. Ergon. $50,8-18$.

Llorach-Massana, P., Farreny, R., Oliver-Solà, J., 2015. Are Cradle to Cradle certified products environmentally preferable? Analysis from an LCA approach. J. Clean. Prod. 93, 243-250.

Lofthouse, V. A., Bhamra, T. A., Evans, S., 1999. Effective ecodesign: finding a way forward for industry.

Lurie-Luke, E., 2014. Product and technology innovation: What can biomimicry inspire? Biotechnol. Adv. 32, 1494-1505.

Madge, P., 1997. Ecological Design: A New Critique. Des. Issues 13, 44. doi:10.2307/1511730

Pigosso, D. C. A., McAloone, T. C., 2015. Supporting the Development of Environmentally Sustainable PSS by Means of the Ecodesign Maturity Model. Procedia CIRP 30, 173-178.

Pigosso, D. C. A., Rozenfeld, H., McAloone, T. C., 2013. Ecodesign maturity model: a management framework to support ecodesign implementation into manufacturing companies. J. Clean. Prod. 59, 160-173.

Rio, M., Reyes, T., Roucoules, L., 2013. Toward proactive (eco)design process: modeling information transformations among designers activities. J. Clean. Prod. 39, 105-116.

Siu, K. W. M., 2011. Public Toilets for Visually Impaired Persons: Application of the Principles of Universal Design. Int. J. Interdiscip. Soc. Sci. 6.

Tavsan, C., Tavsan, F., Sonmez, E., 2015. Biomimicry in Architectural Design Education. Procedia - Soc. Behav. Sci. 182, 489-496.

Tavsan, F., Sonmez, E., 2015. Biomimicry in Furniture Design. Procedia - Soc. Behav. Sci. 197, 22852292.

Toxopeus, M. E., de Koeijer, B. L. A., Meij, A. G. G. H., 2015. Cradle to Cradle: Effective Vision vs. Efficient Practice? Procedia CIRP 29, 384-389.

Vallet, F., Eynard, B., Millet, D., Mahut, S. G., Tyl, B., Bertoluci, G., 2013. Using eco-design tools: An overview of experts' practices. Des. Stud. 34, 345-377.

van Dijk, S., Tenpierik, M., van den Dobbelsteen, A., 2014. Continuing the building's cycles: A literature review and analysis of current systems theories in comparison with the theory of Cradle to Cradle. Resour. Conserv. Recycl. 82, 21-34.

Watchorn, V., Larkin, H., Ang, S., Hitch, D., 2013. Strategies and effectiveness of teaching universal design in a cross-faculty setting. Teach. High. Educ. 18, 477-490. 


\title{
FINANCIAL AND TAX REPORTING IN THE SME SECTOR IN SELECTED EASTERN-EUROPEAN COUNTRIES
}

\author{
Beata Kotowska, University of Gdansk, Poland ${ }^{1}$ \\ Olga Martyniuk, University of Gdansk, Poland
}

\begin{abstract}
The purpose of this paper is to carry out a comparative analysis of the reporting obligations of SMEs in selected Eastern-European countries (Latvia, Lithuania, Poland, Russia, Ukraine). These are countries with different levels of economic development, but with a common political-economic ground, where the principles of market economy were introduced at a similar time.

Micro, small and medium enterprises are an important element of European economies, both those within the EU as well as those outside it. The results of the analysis of macroeconomic data, which are presented in the article, will indicate significance of this sector in Latvia, Lithuania, Poland, Russia and Ukraine.

Literature studies and analysis of the national legal regulations allowed to indicate different ranges of the mandatory elements of the financial statements and of the additional information which the entities from the SME sector must prepare in individual countries. The differences also exist in case of tax evidence and tax reporting. As a result, the scope of the financial information for decision-making and for evaluation of the enterprises is not homogenous in the researched Eastern-European countries. This impedes comparability, however, it can also be a prerequisite to seek the best solutions and practices, not only for the reporting purposes, but also for constructing effective information systems meeting the needs of the managers.
\end{abstract}

Key words: Accounting, Financial reporting, Small business, Eastern Europe, Financial statement JEL code: L25, M13, M41

\section{Introduction}

Over the past several years, highly developed countries as well as emerging economies, having a different political, social and cultural structure, have been devoting much attention to micro, small and medium enterprises (SME). This sector plays a crucial role in the national economies; it is a driving force of business, of growth, innovation and competitiveness. Furthermore, it can be observed that most enterprises in Europe are SMEs (i.e. 99.8\%) and that the most part of these enterprises $(64.4 \%)$ is not covered by an EU-level accounting legislation (Accounting Guide for SME, 2015). The study made by the European Commission in 2011 shows that the accounting requirements for those SMEs which are not regulated at an EUlevel are very different, ranging from almost non-existent to quite rigorous requirements (Study on Accounting ..., 2011). SMEs prepare their financial statements according to local reporting framework. Financial reporting in various countries may vary in:

- the system of accounting regulation,

1 Corresponding author-e-mail address: beata.kotowska@ug.edu.pl 


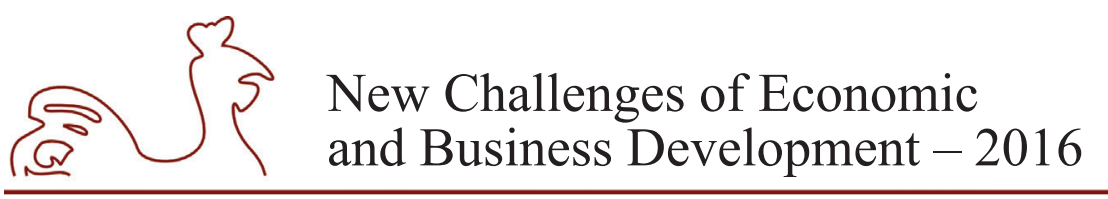

May 12-14, 2016, Riga, University of Latvia

- interaction between accounting and taxation,

- application of accounting methods and accounting principles.

In order to ensure that the requirements for small enterprises are to a large extent harmonised throughout the European Union, European Directive 2013/34/EU was introduced but differences still exist.

The purpose of the paper is to provide information about the current legal accounting requirements in Poland, Latvia, Lithuania, Russia, Ukraine for the SMEs which are not covered by harmonised EU accounting rules; and to carry out a comparative analysis of the components of financial statements and tax reporting. The analysis concerns reporting obligations of both, the entities which keep account books, as well as those which are not required to do so.

The objectives of the study were achieved through a desk research aimed at identifying and analysing the accounting and tax requirements in the reporting area. The survey of empirical European research studies on the SME financial reporting, made by Eirle(Eirle B., Schonefeldt A., 2010), shows that there is a research gap in the literature on financial reporting in this sector, especially relating to micro enterprises. This gap is surely partly fulfilled by the reports and studies made by the European Commission published in 2015 (Accounting Guide for SME, 2015) and in 2011 (Study on Accounting ..., 2011). However, these reports only concern the members of the European Union. The survey in this paper was concentrate not only on European Union members, but also on the countries outside the EU, which makes our study unique. For analysis were chosen countries with different levels of economic development, but a common political-economic ground, where the principles of market economy have been introduced at a similar time. Poland, Latvia and Lithuania are members of the European Union, as opposed to Russia and Ukraine. The literature review was conducted using an internet search engine Google and an electronic database EBSCO. Three groups of key-words were used:

- small business, SME,

- financial reporting, financial statements, financial reports, tax reporting,

- CEE, Eastern Europe, Poland, Latvia, Lithuania, Russia, Ukraine.

For each search a key-word from each group was used simultaneously. The limitation of study was the fact that the publication had to be written in English.

Results show that most publications were available on the subject of IFRS for SME, concerning one particular country eg.: Romania (Neag R., 2010; Girbina M., Albu N. \& Albu C., 2011), Croatia (Baldarelli M. G., et al., 2012), Estonia (Alver L., Alver J. \& Talpas L., 2014), Poland (Grabinski K., Kedziora M. \& Krasodomska J., 2014), The Czech Republic (Mullerova L., Pasekova M. \& Hyblova E., 2010; Strouhal J., 2012), Russia (Morozova T. V., 2014) or group of countries (Borker D. R., 2012; Strouhal J., Pasekova M. \& Mullerova L., 2010; Albu C. N. et al., 2013; Albu N., Albu C. N., 2014; Strouhal J. et al., 2011; Strouhal J. et al., 2011a). Less publications describe national financial reporting requirements for the SME in Romania (Sava R., Marza B. \& Esanu N., 2013), Russia (Solovyeva O., 2007), The Czech Republic (Nerudova D., 2007), Central and Eastern Europe countries (Bogdan V. \& Cristea S. M., 2010). Unfortunately, it was not found any publications about tax reporting requirements for the SME in Eastern Europe. In order to gather information about accounting and tax requirements for the SMEs, in the context of reporting in selected countries, we provided a questionnaire, which was sent to the academics who deal with the subject of accounting or financial reporting in Latvia, 


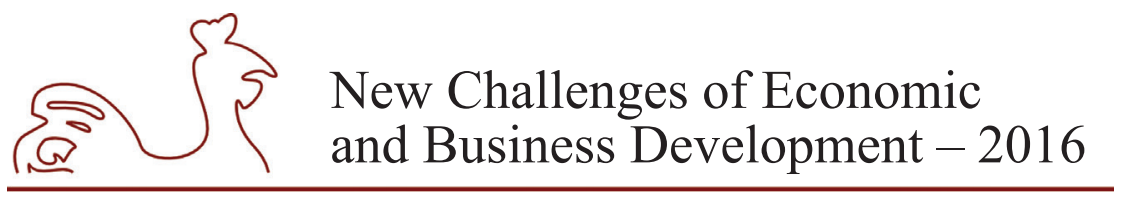

May 12-14, 2016, Riga, University of Latvia

Lithuania, Russia and Ukraine ${ }^{2}$. The data in the questionnaire was based on the information from national accounting law, tax law and the statistical data from each country. The limitation of this part of study is that did not obtain full data for all countries. The reason for this is that the amount of the information in the reports of the state statistics in countries is not equal. Moreover, different definitions of SME in selected countries cause that comparative analysis of statistic data were difficult.

This paper is written within project UMO-2013/09/B/HS4/01175 financed by The National Science Centre in Poland.

\section{The SME sector in the researched countries}

The basic criterion for division of companies is their size. However, the criteria for classification of an entity as a micro, small, medium or large-sized enterprise are not explicit. In selected countries, definitions of individual groups of enterprises are contained in the Accounting Acts (Latvia, Lithuania, Poland, Russia) or in other legal regulations (Poland, Russia, Ukraine). In Poland and in Russia, two definitions of micro and small enterprise function - one for the purpose of financial reporting and the second referring to the remaining areas of enterprise activity.

Table 1

Definition of enterprises according to size arising the Act of Accounting

\begin{tabular}{|c|c|c|c|c|}
\hline Enterprise & Employment & Revenues from sales & Total assets & Other \\
\hline \multicolumn{5}{|c|}{ Latvia } \\
\hline Micro & $0-9$ & $\leq$ EUR $2 \mathrm{mln}$ & $\leq$ EUR $2 \mathrm{mln}$ & - \\
\hline Small & $10-49$ & $\leq$ EUR $10 \mathrm{mln}$ & $\leq$ EUR $10 \mathrm{mln}$ & - \\
\hline Medium & $50-249$ & $\leq$ EUR $50 \mathrm{mln}$ & $\leq$ EUR $43 \mathrm{mln}$ & - \\
\hline \multicolumn{5}{|c|}{ Lithuania } \\
\hline Micro & $0-9$ & EUR $2 \mathrm{mln}$ & EUR $1,5 \mathrm{mln}$ & - \\
\hline Small & $10-49$ & EUR $7 \mathrm{mln}$ & EUR $5 \mathrm{mln}$ & - \\
\hline Medium & $50-249$ & EUR $40 \mathrm{mln}$ & EUR $27 \mathrm{mln}$ & - \\
\hline \multicolumn{5}{|c|}{ Poland } \\
\hline \multirow[t]{2}{*}{ Micro } & $<10$ & $<$ PLN $3 \mathrm{mln}$ & $<$ PLN $1.5 \mathrm{mln}$ & Commercial companies \\
\hline & & EUR $1.2 \mathrm{mln}-2 \mathrm{mln}$ & & $\begin{array}{c}\text { Other companies, } \\
\text { natural persons }\end{array}$ \\
\hline Small & $<50$ & $<$ PLN $34 \mathrm{mln}$ & $<$ PLN 17 mln & $\begin{array}{c}\text { Entities do not exceed two } \\
\text { of the three values }\end{array}$ \\
\hline \multirow{2}{*}{\multicolumn{5}{|c|}{$\begin{array}{l}\text { No special definition } \\
\text { Russia }\end{array}$}} \\
\hline & & & & \\
\hline Micro & $<15$ & - & - & - \\
\hline Small & $<100$ & - & - & - \\
\hline Medium & $100-250$ & - & - & - \\
\hline
\end{tabular}

Source: author's description based on: Accounting Law of the Republic of Lithuania 2001; Komisijas Regula (EK) 2004; Act of 29 September 1994 about accounting; Федеральный закон от 24.07.2007.

\footnotetext{
2 N. Ostapiuk - Kyiv National Economic University named after Vadym Hetman, R. Rupeika-Apoga, University of Latvia; L. Klovienė, Kaunas University of Technology, School of Economics and Business; A. Malyshkin Iwanowicz - The Kyiv State Maritime Academy named after hetman Petro Konashevich-Sahaydachniy (KSMA).
} 


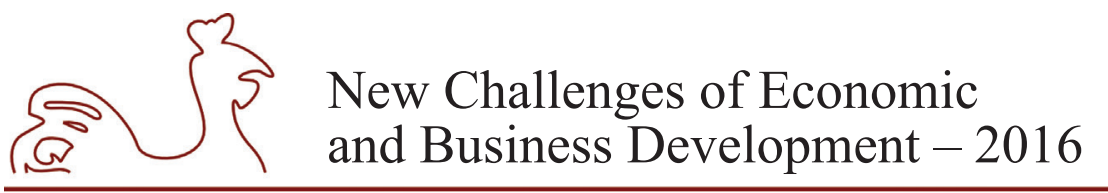

May 12-14, 2016, Riga, University of Latvia

European Union countries (Latvia, Lithuania, Poland) apply three measures for division of enterprises: employment, revenues from sales and the total assets. Just in Poland the limits of these measures are similar to ones presented in the Directive 2013/34/EU. In Russia, the number of the employed is one of the criteria - significantly higher than in other countries (Table 1) so that presented later statistic data are not comparable.

In Table 2 is presented other legal regulations that are in force in Poland, Russia and Ukraine, which refer to those classifications.

In Poland, the law on freedom of economic activity is in force, which is consistent with the European Commission's Recommendation of the $6^{\text {th }}$ of May 2003 (Commission Recommendation, 2003). In Russia, the Russian Federation government's resolution number 702, dated the $13^{\text {th }}$ of July 2015 (Постановление Правительства), classifies enterprises, in terms of the size, according to the sales income only. In Ukraine, according to the Commercial Code (Commercial Code Ukraine), division of enterprise sizes is carried out using the employment criterion and the sales income. The sizes of these criteria are consistent with the European Commission's Recommendation of the $6^{\text {th }}$ of May 2003 excluding the size of the assets.

Table 2

Definition of enterprises according to size arising from the other regulations

\begin{tabular}{|c|c|c|c|c|}
\hline Enterprise & Employment & Revenues from sales & Total assets & Other \\
\hline \multicolumn{5}{|c|}{ Poland } \\
\hline Micro & $0-9$ & $<$ EUR 2 mln & < EUR 2 mln & - \\
\hline Small & $10-49$ & $<$ EUR 10 mln & $<$ EUR 10 mln & - \\
\hline Medium & $50-249$ & $<$ EUR 50 mln & $<$ EUR 43 mln & - \\
\hline \multicolumn{7}{|c|}{ Russia } \\
\hline Micro & - & $<$ RUB 120 mln & - & - \\
\hline Small & - & $<$ RUB 800 mln & - & - \\
\hline Medium & - & $<$ RUB 2 bln & - & $\begin{array}{l}\text { Commercial companies, other } \\
\text { companies, natural persons }\end{array}$ \\
\hline \multicolumn{7}{|c|}{ Ukraine } \\
\hline Micro & $0-10$ & $\leq$ EUR 2 mln & $\begin{array}{l}\text { Commercial companies, other } \\
\text { companies, natural persons }\end{array}$ \\
\hline Small & $10-50$ & $\leq$ EUR 10 mln & Commercial companies \\
\hline Medium & $51-250$ & $\leq$ EUR 50 mln
\end{tabular}

Source: author's description based on: Act of 2 July 2004 on freedom of economic activity; Постановление Правительства Российской Федерации от 13.07.2015 № 702; Commercial Code Ukraine.

In four researched countries (Latvia, Lithuania, Poland, Ukraine), SMEs are a dominating group of business entities. They constitute nearly $100 \%$ of the total number of enterprises (Table 3). Russia, where micro, small and medium enterprises constitute $42.9 \%$ of the total number of enterprises, is an exception among the analyzed countries. It is worth to keep in mind that the Russian definition of the SME differs significantly from the EU definition, thus comparability of the statistical data is subject to interference. 


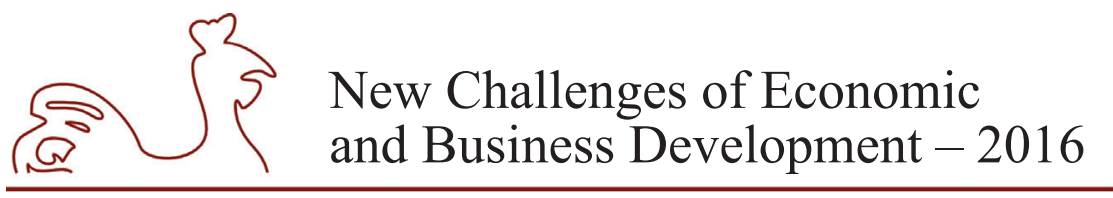

May 12-14, 2016, Riga, University of Latvia

Table 3

Number of entities according to the size, as of $31 / 12 / 2013$

\begin{tabular}{|c|c|c|c|c|c|c|c|c|c|c|}
\hline \multirow{2}{*}{ Enterprise } & \multicolumn{2}{|c|}{ Latvia } & \multicolumn{2}{|c|}{ Lithuania } & \multicolumn{2}{|c|}{ Poland } & \multicolumn{2}{|c|}{ Russia } & \multicolumn{2}{|c|}{ Ukraine } \\
\hline & Number & $\%$ & Number & $\%$ & Number & $\%$ & Number & $\%$ & Number & $\%$ \\
\hline Micro & 143946 & 92.8 & 121502 & 90.4 & 1693785 & 95.6 & 1828589 & 37.8 & 1637180 & 95.1 \\
\hline Small & 9327 & 6.0 & 10442 & 7.8 & 59128 & 3.3 & 234537 & 4.8 & 65021 & 3.8 \\
\hline Medium & 1624 & 1.0 & 2165 & 1.6 & 15329 & 0.9 & 13700 & 0.3 & 19210 & 1.1 \\
\hline SME & 154897 & 99.8 & 134109 & 99.8 & 1768242 & 99.8 & 2076826 & 42.9 & 1721411 & 100.0 \\
\hline Large & 233 & 0.2 & 288 & 0.2 & 3218 & 0.2 & 2766574 & 57.1 & 659 & 0.0 \\
\hline Total & 155130 & 100 & 134397 & 100 & 1771460 & 100 & 4843400 & 100 & 1722070 & 100 \\
\hline
\end{tabular}

Source: author's calculations based on : CSB; SME Performance Review 2013/2014; Raport, 2014, Swaid; Maлое, 2014, Федеральная служба ..., Федеральный портал ..., Ukrstat.

Comparison of share of the employed in this sector clearly indicates significance of the work positions offered by these entities for economies of the discussed countries. Average employment in SMEs in the analyzed countries constitutes $73.12 \%$ of the total number of the employed - from $69.5 \%$ in Poland to $78.5 \%$ in Latvia (Table 4). In the EU countries, average employment in micro enterprises amounts to $29.1 \%$, in small $20.6 \%$, and in medium $17.2 \%$, which in total constitutes $66.9 \%$ of the employed in these entities (SBA - Poland, 2014). In all the analyzed countries, it is higher than the EU average: in Lithuania by $11.6 \mathrm{pp}^{3}$ in Latvia by $9.7 \mathrm{pp}$, in Poland by $2.6 \mathrm{pp}$, in Russia by 2.9 pp, and in Ukraine by 4.3 pp. Distribution of the employed in micro, small and medium enterprises in Latvia and Lithuania is even, as opposed to Poland, Ukraine and Russia. In case of Latvia, Lithuania, Ukraine and Russia, employment in micro entities is lower than the EU average, as opposed to Poland, where employment in micro-enterprises is higher by $8.8 \mathrm{pp}$. This probably results from the fact that self-employment has become very popular on the Polish job market over the past few years. The highest number of the employed in small entities is in Russia (36.1\%), while the lowest in Poland (13.7\%). In turn, medium enterprises that employ the most persons are in Ukraine (36.9\%), in comparison to the $8.9 \%$ of the employed in Russia.

Table 4

Number of employees (in thousands) according to the size, as of 31/12/2013

\begin{tabular}{|l|r|r|r|r|r|r|r|r|r|r|}
\hline \multirow{2}{*}{ Enterprise } & \multicolumn{2}{|c|}{ Latvia } & \multicolumn{2}{c|}{ Lithuania } & \multicolumn{2}{c|}{ Poland } & \multicolumn{2}{c|}{ Russia } & \multicolumn{2}{c|}{ Ukraine } \\
\cline { 2 - 12 } & Number & \multicolumn{1}{c|}{$\%$} & Number & \multicolumn{1}{c|}{$\%$} & Number & \multicolumn{1}{c}{$\%$} & Number & $\%$ & Number & $\%$ \\
\hline Micro & 160,5 & 27.5 & 220,8 & 25.8 & 3371,5 & 37.9 & 4769,5 & 24.8 & 1535,5 & 18.5 \\
\hline Small & 153,2 & 26.3 & 215,4 & 25.2 & 1218,1 & 13.7 & 6926,2 & 36.1 & 1308,4 & 15.8 \\
\hline Medium & 144,2 & 24.7 & 218,2 & 25.5 & 1592,4 & 17.9 & 1705,5 & 8.9 & 3051,8 & 36.9 \\
\hline SME & $\mathbf{4 5 7 , 9}$ & $\mathbf{7 8 . 5}$ & $\mathbf{6 5 4 , 4}$ & $\mathbf{7 6 . 6}$ & $\mathbf{6 1 8 2 , 0}$ & $\mathbf{6 9 . 5}$ & $\mathbf{1 3 4 0 1 , 2}$ & $\mathbf{6 9 . 8}$ & $\mathbf{5 8 9 5 , 7}$ & $\mathbf{7 1 . 2}$ \\
\hline Large & 125,7 & 21.5 & 200,4 & 23.4 & 2716,9 & 30.5 & 5800,0 & 30.2 & 2383,7 & 28.8 \\
\hline Total & $\mathbf{5 8 3 , 6}$ & $\mathbf{1 0 0}$ & $\mathbf{8 5 4 , 8}$ & $\mathbf{1 0 0}$ & $\mathbf{8 ~ 8 9 8 , 9}$ & $\mathbf{1 0 0}$ & $\mathbf{1 9 2 0 1 , 2}$ & $\mathbf{1 0 0}$ & $\mathbf{8 2 7 9 , 4}$ & $\mathbf{1 0 0}$ \\
\hline
\end{tabular}

Source: author's calculations based on: SBA - Latvia 2014; SME Performance Review 2013/2014; Raport, 2014; Swaid; Малое, 2014, Федеральная служба ..., Федеральный портал ..., Ukrstat.

3 pp-percentage point. 


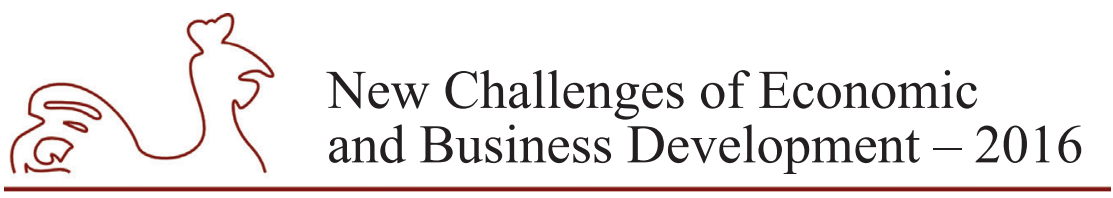

May 12-14, 2016, Riga, University of Latvia

The share of the GDP of the SME sector has been presented only for three countries, since it was not possible to obtain appropriate information on Latvia and Lithuania. In Russia, the share of the SME sector in formation of the GDP is $44.2 \%$, in Poland $48.5 \%$, and in Ukraine it constitutes as much as $60.3 \%$ (Table 5). However, a more detailed analysis of the micro and small enterprises only indicates that these economic entities in Poland and in Russia compose $38.5 \%$ and $34.1 \%$ of the GDP accordingly, while in Ukraine it only constitutes $21.5 \%$.

Table 5

Share in the GDP (in \%), according to the size, as of 31/12/2013

\begin{tabular}{|l|c|c|c|c|c|}
\hline Enterprise & Latvia & Lithuania & Poland & Russia & Ukraine \\
\hline Micro & - & - & 29.7 & 13.6 & 10.6 \\
\hline Small & - & - & 7.8 & 23.5 & 10.9 \\
\hline Medium & - & - & 11.0 & 7.1 & 38.8 \\
\hline SME & - & - & $\mathbf{4 8 . 5}$ & $\mathbf{4 4 . 2}$ & $\mathbf{6 0 . 3}$ \\
\hline Large & - & - & 51.5 & 55.8 & 39.7 \\
\hline Total & - & - & $\mathbf{1 0 0}$ & $\mathbf{1 0 0}$ & $\mathbf{1 0 0}$ \\
\hline
\end{tabular}

Source: author's calculations based on: Raport, 2014; Swaid; Малое, 2014, Федеральная служба ..., Федеральный портал ..., Ukrstat.

The above-presented macroeconomic data characterizing the SME sectors in individual countries confirm the importance and significance of this sector for those countries' economies. It is a premise for a statement that the most effective tools supporting the managers of these entities in information acquisition and in creation of information systems ought to be sought.

\section{The components of financial reporting and tax reporting - research results and discussion}

The institutional relation between the financial reporting and corporate income taxation has been the subject of number of discussions. Accounting principles are objective in nature, basically unchanging, universal. The rules of accounting law, however, often are variable in nature, temporary, economically biased, dependent on the current tax policy, which is reflected in the constant changes of the tax regulations and their interpretation. Defenders of the disconnection between financial reporting and tax reporting fear the connection of the systems, because it could deform the information provided by those systems. They claim that financial and tax accounting cannot be the same, because they have different aims, are subjected to the different rules and serve different purposes. Financial reporting is intended to provide information for the purpose of control and management; while the tax reporting is aimed at collecting the tax. Supporters of the disconnection between the financial and the tax reporting predicate that, if the same practice is used by both systems, there is no need to keep the books twice. The connection of the systems would mean a significant decrease in the compliance costs of taxation, especially for the SMEs, in the area of tax consultancy and tax return completion at the most. On the side of the tax administration, the connection of the systems would result in saving the costs connected with tax collection and with creation of legislation. Another advantage which the connection of the systems could bring is represented by a restriction of the tendency of the enterprises to overvalue 


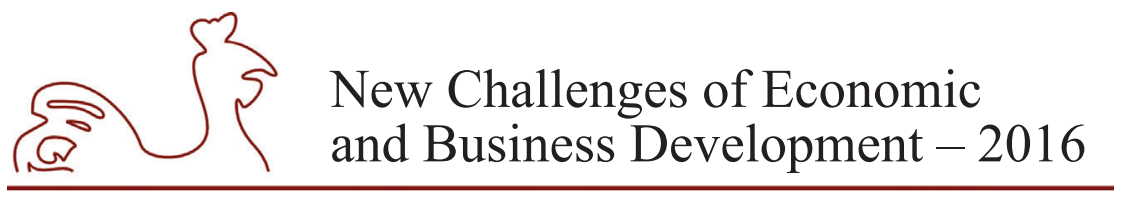

May 12-14, 2016, Riga, University of Latvia

the profit. When there is a positive correlation between the reported profit and the management rewards, in a situation when there is connection between the systems, a higher reported profit means a higher management reward, but also higher tax liability (Nerudova D., 2007).

According to the legal regulations currently in force in the analyzed countries, enterprises are obliged to keep economic records and to compile reporting separately, as to serve the balance sheet law and the tax law. Smaller entities, which are exempt from keeping accounting books, are an exception. They only keep tax records and prepare reports for the purposes of income tax (tax declarations). In Poland, this group of enterprises constitutes $86 \%$ of all registered entities (Swaid), similar to Russia where the entities preparing only tax reports constitute $88 \%$ (Филобокова, Л. Ю. \& Григорьева, О. В., 2014). National statistics in this regard unfortunately were not available for Latvia, Lithuania and Ukraine.

In the researched countries, the criteria for exempting smaller units from keeping accounting books are: the legal form and the sales income. While analyzing the legal form criterion, it can be noticed that natural persons are exempt from keeping accounting books (Latvia, Poland, Russia, Ukraine $^{4}$ ), partnerships (Poland, Russia ${ }^{5}$ ). Private limited companies in all analyzed countries are not subject to this exemption. In case of the sales income, the limits exempting enterprises differ significantly. In Poland this limit is EUR 1200 000, in Latvia EUR $300000^{6}$, in Russia RUB 45 million, which is around EUR $540000^{7}$. Unfortunately, the authors did not obtain information on Lithuania and Ukraine, which does not mean that such sales income limits in these two countries do not exist.

The forms of recording economic events for the purposes of the income tax are similar in Poland and in Russia. The units subjected only to tax law regulations can compile one of three forms of tax records. Characteristics of these records for Poland are presented in Table 6 and for Russia in Table 7.

\footnotetext{
4 No information about Lithuania.

5 No information about Lithuania.

6 Latvia - microenterprise tax. Rights to choose to pay micro-enterprise tax exist, if the following criteria are complied with (Micro tax company):

- income from economic activities - turnover - per calendar year does not exceed EUR 100 000;

- members of a limited liability company are only natural persons;

- board members of a limited liability company are only micro-enterprise employees;

- number of micro-enterprise employees at any time does not exceed five (number of employees does not include employees who are absent or dismissed);

- income of a micro-enterprise employee does not exceed EUR 720 per month.

Rights for becoming a micro-enterprise exist to:

- individual merchant;

- individual enterprise, farms and fish farms;

- natural person, which is registered in the State Revenue Service (SRS) as a performer of economic activities;

- person is not a member of partnership;

- limited liability company.

71 RUB = 0,0524 PLN; 1 EUR = 4,3589 PLN. Currency exchange rate RUB and EUR, as at date 29/02/2016. www.nbp.pl
} 


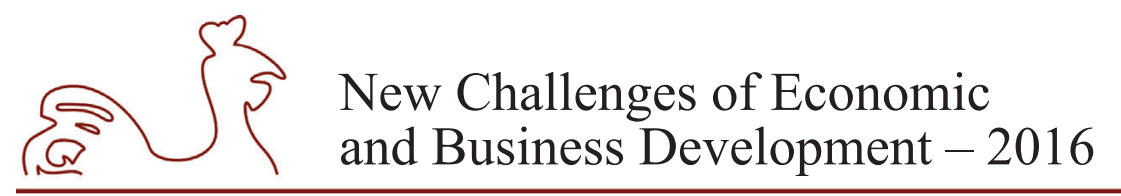

May 12-14, 2016, Riga, University of Latvia

Table 6

Types of income tax records in Poland

\begin{tabular}{|c|c|c|}
\hline Name & Criteria & The scope of the financial data \\
\hline $\begin{array}{l}\text { Revenue and } \\
\text { Disbursement } \\
\text { (RaD) }\end{array}$ & $\begin{array}{l}\text { Natural persons, partnerships of } \\
\text { individuals, partnerships of individuals } \\
\text { and partnerships, } \\
\text { if their turnover does not exceed EUR } \\
1200000\end{array}$ & $\begin{array}{l}\text { 1. As part of RaD: } \\
\text { - divided revenues breakdown by value } \\
\text { of the goods and services and other } \\
\text { income; } \\
\text { • costs divided: purchase of the } \\
\text { commercial goods and materials at } \\
\text { a purchase price, ancillary costs of } \\
\text { purchase, the costs of representation } \\
\text { and advertising funding limit, the pay } \\
\text { in cash and in kind, other expenses } \\
\text { 2. Records of the fixed and intangible assets } \\
\text { 3. Equipment registry } \\
\text { 4. Salary cards of employees } \\
\text { 2. Inventories at the end of year }\end{array}$ \\
\hline $\begin{array}{l}\text { Flat-rate tax of } \\
\text { income }\end{array}$ & $\begin{array}{l}\text { Partnerships of natural persons, } \\
\text { partnerships of individuals, } \\
\text { individuals - if income does not exceed } \\
\text { EUR } 0.15 \text { million excluding certain } \\
\text { activities }\end{array}$ & $\begin{array}{l}\text { 1. List of the fixed and intangible assets } \\
\text { 2. Equipment registry } \\
\text { 3. Records of revenue } \\
\text { 4. Salary cards of employees } \\
\text { 1. Inventories at the end of year }\end{array}$ \\
\hline Tax card & $\begin{array}{l}\text { The list of the services included in the } \\
\text { Act, Employment up to } 5 \text { people }\end{array}$ & 1. Employment records \\
\hline
\end{tabular}

Source: author's descritpions based on: Regulation of the Minister of Finance August 26, 2003; Act of November 20, 1998.

A tax statement prepared on the basis of the RaD contains information on the company's total revenues, its deductible expenses and income. Moreover, enterprises keeping RaD must prepare a list of stocks on the last day of the year. In case of a flat-rate income tax, the annual tax declaration contains only information on the revenues. In turn, in case of the tax card, no annual tax return is prepared.

Table 7

Types of income tax records in Russia

\begin{tabular}{|c|c|c|}
\hline Name & Criteria & The scope of financial data \\
\hline $\begin{array}{l}\text { Revenue and Disbursement } \\
\text { (RaD) } \\
\text { or }\end{array}$ & $\begin{array}{l}\text { Partnerships of individuals } \\
\text { Partnerships if their income does not } \\
\text { exceed RUB } 45 \text { mln during } 9 \text { months of } \\
\text { the year of transition }\end{array}$ & $\begin{array}{l}\text { Tax return } \\
\text { A Book of Revenue and } \\
\text { Disbursement }\end{array}$ \\
\hline Revenue & $\begin{array}{l}\text { Tax rate }-15 \% \text { (Revenue and } \\
\text { Disbursement) or tax rate }-6 \% \text { (Revenue) }\end{array}$ & \\
\hline Flat-rate tax of income & & Tax return \\
\hline Tax card & & Book of Revenue \\
\hline
\end{tabular}

Source: author's descritpions based on: Налоговый кодекс Российской Федерации (часть вторая) от 05.082000 № 117-Ф3. 


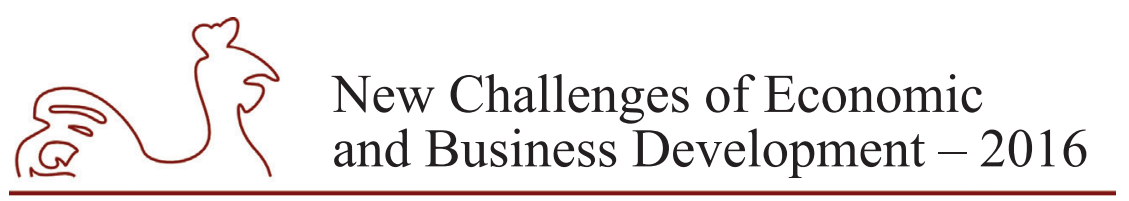

May 12-14, 2016, Riga, University of Latvia

Revenue and Disbursement is also obligatory in Ukraine and Lithuania for the entities which only prepare reports for tax purposes. Additionally, in Ukraine, keeping any other books depends on the kind of activity. For example, for retailers who use a register of payment transactions, an appropriate book is obligatory. In Latvia, if an enterprise does not keep any accounting books (double booking system), it is required to keep records for income tax. Single-entry accounting is a simplified register of the economic operations that could be carried out by an entrepreneur, without professional knowledge in the field of accounting. The data registered in a singleentry system mainly is intended for tax calculation and for preparation of a tax declaration. In the single-entry accounting system, the cash-basis accounting principle is used, provided that revenues are registered at the moment when a payment for a transaction is received, while expenses - when they are paid (Arbidāne I., Poḷaka G. \& Ruža O., 2015).

A financial statement of an SME, according to IFRS for SMEs, should consist of: a balance sheet, a profit and loss account, a statement of stockholders' equity, a cash flow statement, and notes to the financial statement. In certain cases, an entity can prepare a statement of the revenues from a retained income instead of a profit and loss account and a statement of stockholders' equity. The standard does not lay down any specific patterns of reports (Jaworski J., 2012). According to the Article 4.1 of The Directive 2013/34/EU the annual financial statements shall constitute a composite whole and shall for all companies comprise, as a minimum, the balance sheet, the profit and loss account and the notes to the financial statements. In none of the surveyed countries an IFRS for SMEs is obligatory, therefore, provisions of the national balance accounting law should be applied while preparing financial statements. A summary of reporting obligations for micro, small and medium enterprises in Latvia, Lithuania, Poland, Ukraine and Russia is presented in Table 8. 


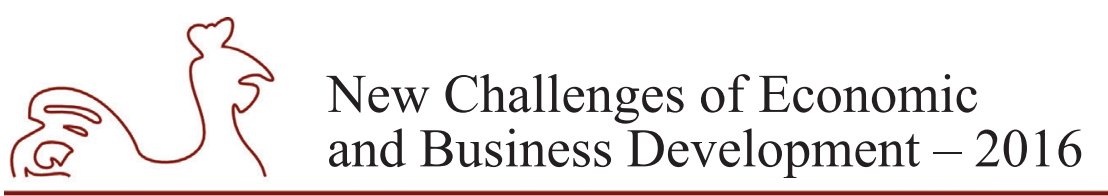

May 12-14, 2016, Riga, University of Latvia

Table 8

Mandatory elements of a financial statement

\begin{tabular}{|c|c|c|c|c|c|c|c|}
\hline \multirow[b]{2}{*}{$\begin{array}{c}\text { Element of } \\
\text { financial } \\
\text { statement }\end{array}$} & \multirow{2}{*}{ 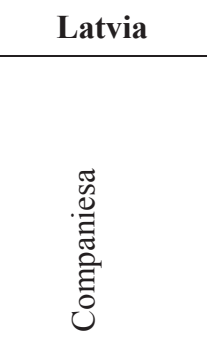 } & \multicolumn{2}{|c|}{ Lithuania } & \multirow{2}{*}{ 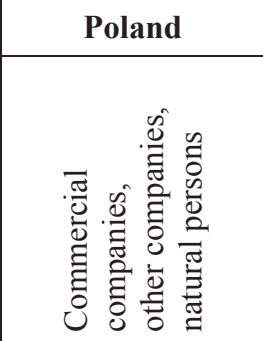 } & \multicolumn{2}{|c|}{ Russia } & \multirow{2}{*}{ 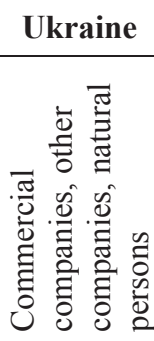 } \\
\hline & & 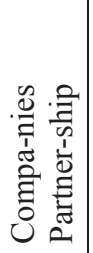 & 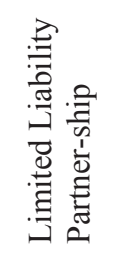 & & 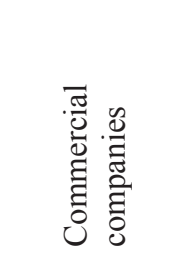 & 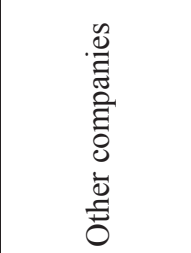 & \\
\hline $\begin{array}{l}\text { Balance } \\
\text { Sheet }\end{array}$ & + & + & + & + & + & + & + \\
\hline $\begin{array}{l}\text { Profit and } \\
\text { Loss Account }\end{array}$ & + & + & + & + & + & $\begin{array}{l}\text { If they have } \\
\text { received } \\
\text { entrepreneu- } \\
\text { rial income } \\
\end{array}$ & + \\
\hline $\begin{array}{l}\text { Notes to the } \\
\text { Financial } \\
\text { Statement }\end{array}$ & + & + & + & $\begin{array}{c}\text { Medium entities, } \\
\text { Optional - small } \\
\text { entities } \\
\text { (not obligated } \\
\text {-micro entities) }\end{array}$ & $\begin{array}{l}\frac{\text { Annex to the }}{\text { Financial }} \\
\underline{\text { Statements }} \\
\begin{array}{c}\text { Optional } \\
\text { form. }\end{array}\end{array}$ & $\begin{array}{c}\frac{\text { Annex to the }}{\text { Financial }} \\
\text { Statements } \\
\begin{array}{c}\text { Optional } \\
\text { form. }\end{array}\end{array}$ & $\begin{array}{c}\quad+ \\
\quad \text { (not } \\
\text { applicable } \\
\text { to small } \\
\text { and micro } \\
\text { entities) }\end{array}$ \\
\hline $\begin{array}{l}\text { Cash Flow } \\
\text { Statement }\end{array}$ & $\begin{array}{l}\text { If they exceed } \\
2 \text { of the } \\
3 \text { conditions: } \\
\text { - } 25 \text { employees } \\
\text { - average } \\
\text { employment }\end{array}$ & + & + & $\begin{array}{l}\text { All stock } \\
\text { companies }+ \text { other } \\
\text { companies if they } \\
\text { exceed } 2 \text { of the } \\
3 \text { conditions: } \\
-50 \text { employees }\end{array}$ & $\begin{array}{l}\text { If you need } \\
\text { additional } \\
\text { information, } \\
\text { without } \\
\text { which no } \\
\text { assessment of }\end{array}$ & $\begin{array}{l}\text { If you need } \\
\text { additional } \\
\text { important } \\
\text { information } \\
\text { that is not } \\
\text { presented in }\end{array}$ & $\begin{array}{c}\quad+ \\
\quad \text { (not } \\
\text { applicable } \\
\text { to small } \\
\text { and micro } \\
\text { entities) }\end{array}$ \\
\hline $\begin{array}{l}\text { Statement of } \\
\text { Stockholders' } \\
\text { Equity }\end{array}$ & $\begin{array}{l}\text { in full time } \\
\text { equivalent } \\
\text { - EUR } \\
400000 \text { - total } \\
\text { assets of the } \\
\text { balance sheet } \\
\text { - EUR } \\
800000 \text { - net } \\
\text { revenues from } \\
\text { sales of goods } \\
\text { and products }\end{array}$ & + & $\begin{array}{l}+ \text { macro } \\
\text { - micro } \\
\text { and } \\
\text { small }\end{array}$ & $\begin{array}{l}\text { - average } \\
\text { employment in full } \\
\text { time equivalent } \\
\text { - EUR } 2500000 \\
\text { - total assets of the } \\
\text { balance sheet in } \\
\text { PLN } \\
\text { - EUR } 5000000 \text { - } \\
\text { net revenues from } \\
\text { sales of goods and } \\
\text { products in PLN }\end{array}$ & $\begin{array}{l}\text { the financial } \\
\text { position or } \\
\text { profits and } \\
\text { losses }\end{array}$ & $\begin{array}{l}\text { the Balance } \\
\text { Sheet and } \\
\text { Statement on } \\
\text { the Intended } \\
\text { Use of Funds }\end{array}$ & $\begin{array}{c}+ \\
\quad \text { (not } \\
\text { applicable } \\
\text { to small } \\
\text { and micro } \\
\text { entities) }\end{array}$ \\
\hline Other & & - & - & - & - & $\begin{array}{l}\text { Statement on } \\
\text { the Intended } \\
\text { Use of Funds }\end{array}$ & - \\
\hline
\end{tabular}

$a$-commercial companies, cooperative societies, a Latvian European economic interest groups, European cooperative societies and European commercial companies as well as individual businesses, farms and fisheries in which the turnover (revenue) from economic transactions during the previous accounting year exceeds EUR 300000.

Source: author's description based on: Act of 1 January 1993 Accounting; Law on Financial Statements of Entities 6 November 2001; Act of 29 September 1994 about accounting,; Федеральный закон от 06.12.2011 № 402-Ф; Приказ Минфина России от 02.07.2010 N 66н; Информация Минфина России N П3-3/2012 и N П3-3/2015; Письмо Минфина России от 03.04.2012 N 03-02-07/1-80; The Act of Accounting and Financial Reporting of Ukraine. 


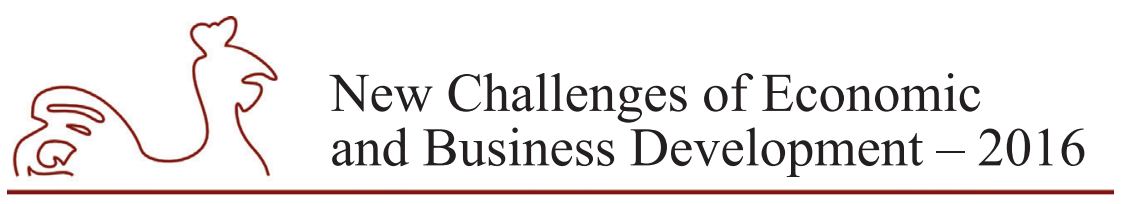

May 12-14, 2016, Riga, University of Latvia

In all analyzed countries, it is compulsory for the SMEs to prepare a balance sheet and a profit and loss account (except the enterprises not achieving income from business activity entrepreneurial income in Russia). Notes to the financial statements are obligatorily prepared by micro, small and medium enterprises in Latvia and Lithuania, as well as by medium enterprises in Poland and Ukraine. In Poland, if small entities do not prepare the notes to the financial statements, they must provide an annex to the balance sheet containing the information included in the Act of Accounting (Act of 29 September 1994). A cash flow statement is mandatory only for the units from the SME sector in Lithuania, the SME stock companies in Poland, as well as for medium enterprises in Ukraine. In Latvia and in Poland, the statement of cash flows is obligatorily prepared only by the SMEs which excede certain criteria presented in Table 8. A statement of stockholders equity is mandatory for all medium enterprises in Lithuania and Ukraine, while in the case of Poland and Latvia, in relation to this element of financial reporting, the same criteria are obligatory as for the cash flow statement. Only partnership companies from Lithuania are obligated to prepare a statement of stockholders' equity. In the case of Russian SMEs, apart from the balance sheet and the profit and loss account, they prepare one annex to the financial statement and additionally some of them a statement on the intended use of funds (see Table 8). This comparison shows the differences in the financial reporting obligations of the SMEs in the analyzed countries, particularly the differences concern micro and small units. The differences in the scope of the reporting duties concern all the countries, regardless whether a given country is a European Union member or not. This results in a diverse range of the information provided by the SMEs.

\section{Conclusions and proposals}

In today's world, information has becomes the most significant resource for a developed economy, while its value has been increasing constantly as technology has been improving. Accounting is said to be a universal language of business and it should provide decision makers relevant information at appropriate an time. Normally, decisions are made based on the financial statement, which are a communication tool between enterprises and the environment. The ongoing discussion is based on the premise that organization, the scope and the shape of SME financial reporting directly determines the possibilities of this sector's development. Consequently, it also determines growth and development of the economies in which these entities operate. In cases when the financial statements are not kept properly, the decisions are made without a real and sound knowledge of the financial position of a given business, which might have serious consequences for its future. In economies of the surveyed countries, SMEs are the most significant group of enterprises employing nearly $3 / 4$ of the all employed. It ought to be, however, underlined that the differences in the definition of micro, small and medium enterprises in selected countries cause the comparison of the statistical data bear a certain error. It would thus be advisable to unify the criteria for enterprise classification as micro, small and medium entities, including:

- the use, in selected criteria, a unified currency ex. EUR. Currently, in Poland and in Russia, some criteria apply PLN and RUB accordingly,

- supplementing the criteria, in the case of Ukraine, with a criterion - the total assets value,

- the use of a single uniform definition of SME, for the purposes of financial reporting and other areas of business activity. Currently, in Poland and in Russia, different definitions of SME function. 


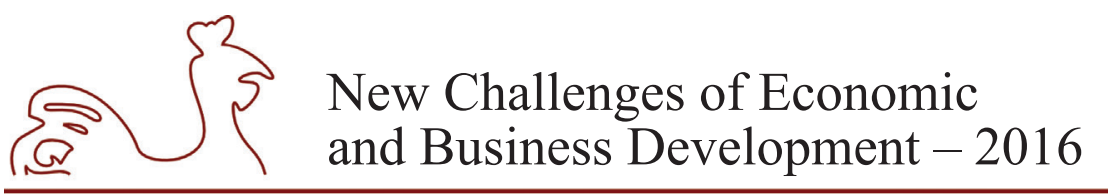

May 12-14, 2016, Riga, University of Latvia

Due to the need for international comparability in financial reporting of the SMEs, the International Accounting Standards Board (IASB) issued the International Financial Reporting Standard for Small and Medium-sized Entities (IFRS for SMEs) in July 2009. However, in all selected countries, the IFRS for SMEs is not required to be applied. Consequently, SMEs prepare financial reports in accordance with national accounting acts. Legal requirements relating to financial reporting differ considerably between the analysed countries, especially in case of micro and small entities. Preparation of financial statements containing at least a profit and loss account and a balance sheet is usually a legal requirement, other elements of financial statements significantly differ. It would be worth implementing in case of annual financial statements elements, as Latvia and Lithuania, recommendation presented in The European Directive 2013/34/EU. This paper involved only analysis of the reporting duties in terms of financial reporting, thus it would be advisable to analyze the scope of the information contained in the SME balance sheet and in the profit and loss account in further studies.

During our analysis some difficulties were experienced when gathering the information about tax reporting requirements. In addition, there are no publications in English referring to SME tax reporting, which does not mean that the question of accessibility to financial information on these entities is not important in economic practice. For instance, in Poland and in Russia, entities preparing only such reports constitute $89 \%$ and $85 \%$ of the SMEs accordingly. Statistical data for the remaining researched countries is not available.

Solutions for tax reporting duties are significantly different in most of the researched countries. The most information on the activity of the SMEs not keeping accounting books can be obtained in Poland, what can be strength of Polish SME tax reporting system. It should be, however, underlined that the highest value allowing exemption from keeping account books concerns this country precisely and perhaps this is where the most complicated reporting obligations derive from. The suggestion for other selected countries is to higher the limits exempting from keeping accounting books to Polish level and to extend the obligations of tax reporting. Harmonization in terms of tax reporting, however, seems to be very difficult.

\section{Bibliography}

Accounting Guide for SME. SME Accounting in Europe: insights provided by a desk research and survey, CIP Programme 153/PP/ENT/CIP/12/F/S01C04, Ernst\&Young 2015. [Online] Available at: http:// ec.europa.eu/growth/smes/business-friendly-environment/accounting/index_en.htm [Accessed 1 March 2016].

Accounting Law of the Republic of Lithuania 6 November 2001, Nr. IX-574.

Act of Accounting and Financial Reporting of Ukraine (16/07/1999 \# 996) and Cabinet of Ministers of Ukraine \# 419.

Act of January 1, 1993 Accounting / Likums par Grāmatvedības likums/. [Online] Available at: http:// likumi.lv/doc.php?id=66460 [Accessed 21 January 2016].

Act of July 2, 2004, about freedom of the economic activity, Dz. U.173/2004, pos. 1807 as amended.

Act of September 29, 1994, about accounting, Dz. U. 121/1994, pos. 591 as amended.

Act of November 20, 1998, about the flat-rate tax on some parts of income of natural persons, Dz. U. $144 / 1998$, pos. 930 , as amended.

Albu, N. \& Albu, C. N., 2014. IFRS application in Central and South-Eastern European countries. Accounting \& Management Information Systems/Contabilitate si Informatica de Gestiune, 13.2, pp. 182-197. 


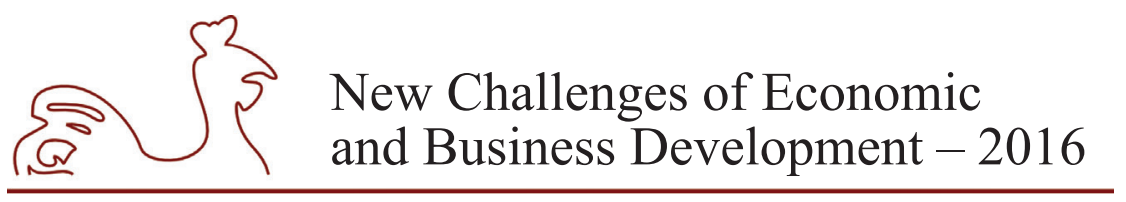

May 12-14, 2016, Riga, University of Latvia

Albu, C. N. \& Albu, N. \& Pali-Pista, S. F. \& Gîrbină, M. M. \& Selimoglu, S. K. \& Kovács, D. M. \& Lukács, J. \& Mohl, G. \& Müllerová, L. \& Paseková, M. \& Arsoy, A. P. \& Sipahi, B. \& Strouhal, J., 2013. Implementation of IFRS for SMEs in Emerging Economies: Stakeholder Perceptions in the Czech Republic, Hungary, Romania and Turkey. Journal of International Financial Management \& Accounting, 24, pp. 140-175.

Alver, L. \& Alver J. \& Talpas, L., 2014. Implementation of IFRSs and IFRS for SMEs: the case of Estonia. Accounting and Management Information Systems, 13.2, pp. 236-258.

Arbidāne, I. \& Poḷaka, G. \& Ruža, O., 2015. Calculation of Financial Indicators in a Single-Entry Accounting System. Journal of Social Sciences, 1(7). [Online] Available at: http://www.ru.lv/uploads/ source/content_EN/Science\%20publications/Journa 1\%20of\%20Social\%20sciences/Journal_7_2015. pdf [Accessed 1 March 2016].

Baldarelli, M. G. \& Demartini, P. \& Mošnja-Škare, L. \& Paoloni, P., 2012. Accounting Harmonization for SME-S in Europe: Some Remarks on IFRS for SME-S and Empirical Evidences. Ekonomska istraživanja, 1, pp. 1-26.

Bogdan, V. \& Cristea, Ş.M., 2010. Consistencies and Inconsistencies in Financial Reporting. The Case Study of Central and Eastern Europe. Timisoara Journal of Economics, 3.1 (9), pp. 15-26.

Borker, D. R., 2012. Accounting, culture and emerging economies: IFRS in Central and Eastern Europe. The International Business \& Economics Research Journal, 11.9, pp. 1003-1018.

Commercial Code Ukraine. [Online] Available at: http://www.ukraine.fnst.org/ files/1185/2014_11_03_ SME_in_Ukraine final.pdf [Accessed 1 March 2016].

Commission Recommendation of May 6, 2003 concerning the definition of micro, small and medium-sized enterprises, 2003/361/EC. [Online] Available at: http://eur-lex.europa.eu/LexUriServ/ LexUriServ. do?uri=OJ:L:2003:124:0036: 0041:en:PDF [Accessed 1 March 2016].

CSB, Statistikas datubāzes. [Online] Available at: http://www.csb.gov.lv/dati/statistikas-datubazes-28270. html [Accessed 20 December 2015].

Directive 2013/34/EU of the European Parliament and of the Council of 26 June 2013 on the annual financial statements, consolidated financial statements and related reports of certain types of undertakings, amending Directive 2006/43/EC of the European Parliament and of the Council and repealing Council Directives 78/660/EEC and 83/349/EEC [Online] Available at: http://eur-lex. europa.eu/LexUriServ/LexUriServ.do?uri=OJ:L:2013: 182:0019:0076:en:PDF [Accessed 1 April 2016].

Eirle, B. \& Schonefeldt, A., 2010. The Research Landscape: research in SME financial reporting, presentation 33 ${ }^{\text {rd }}$ EAA Congress 2010. [Online] Available at: http://eaa2010.eaa-online.org/userfiles/ file/EAA\%202010\%20-\%20Symposium\%205\%20-\%20B_\%20Eierle.pdf[Accessed 1 March 2016].

Girbina, M. \& Albu, N. \& Albu, C., 2011. Implications Of The Application Of Ifrs For Smes In Romania On Taxable And Distributable Profit. Annals of Faculty of Economics, 1.2, pp. 517-522.

Grabinski, K. \& Kedziora, M., \& Krasodomska J., 2014. The Polish accounting system and IFRS implementation process in the view of empirical research. Accounting and Management Information Systems, 13.2, pp. 281-310.

IFRS for SMEs, International Financial Reporting Standard for Small and Medium Sized Entreprises. [Online] Available at: http://www.ifrs.org/IFRS-for-SMEs/Pages/IFRS-for-SMEs-and-relatedmaterial.aspx [Accessed 1 March 2016].

Jaworski, J., 2012. Informacja finansowa w zarządzaniu matym przedsiębiorstwem. Potrzeby - źródtawykorzystanie, CeDeWu, Warszawa.

Komisijas Regula (EK) Nr. 364/2004 2004. gada 25. februāris.

Law on Financial Statements of Entities 6 November 2001 No IX-575.

Micro tax company. [Online] Available at: https://www.vid.gov.lv/default.aspx?tabid=8\&id=5831\&hl=2 [Accessed 1 March 2016]. 


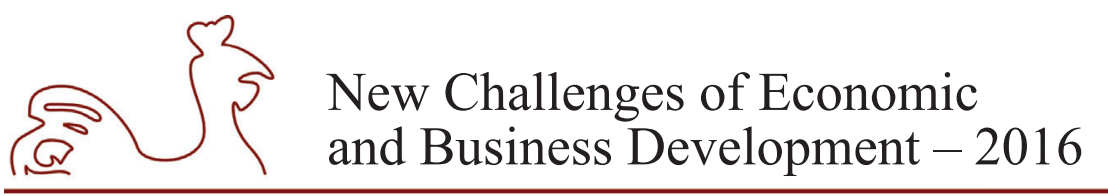

May 12-14, 2016, Riga, University of Latvia

Morozova, T. V., 2014. Prospects of Application of International Financial Reporting Standards for Small and Medium-sized Entities. Economics \& Law, 36.2, pp. 17-20.

Müllerova, L. \& Paseková, M., \& Hýblová, E., 2010, Harmonization of financial reporting of small and medium-sized enterprises in the Czech Republic. Journal of Modern Accounting and Auditing, 6.1, pp. 55-64.

Neag, R., 2010. IFRS for SMEs are an Accounting Solution for SMEs and Micro-entities. Applied Economics, Business And Development, pp. 181-185.

Nerudova, D., 2007. The Relationship between Corporate Income Tax and Financial Reporting in the Czech Republic. Economics \& Management, 12, pp. 87-92.

Raport o stanie sektora małych i średnich przedsiębiorstw w Polsce w latach 2012-2013, 2014. PARP, Warszawa [Online] Available at: https://www.parp.gov.pl/files/74/81/713/21789.pdf as at a date [Accessed 13 November 2015].

Regulation of the Minister of Finance August 26, 2003, about the conduct of tax revenue and expense ledger, Dz. U. 152/2003, pos. 1475.

Sava, R. \& Mârza, B. \& Eşanu, N., 2013. Financial Reporting for SMEs-Past and Perspectives. Procedia Economics and Finance, 6, pp. 713-718.

SBA - Latvia, The Small Business Act for Europe, SBA Fact Sheet 2014 - Latvia [Online] Available at: http://ec.europa.eu/growth/smes/business-friendly-environment/performance-review/files/countriessheets/2014/latvia_en.pdf [Accessed 2 March 2016].

SBA - Poland, The Small Business Act for Europe, SBA Fact Sheet 2014 - Poland [Online] Available at: http://ec.europa.eu/growth/smes/business-friendly-environment/performance-review/files/countries-sheets/2014/poland_en.pdf [Accessed 2 March 2016].

SME Performance Review 2013/2014, [Online] Avaible at: http://ec.europa.eu/growth/smes/businessfriendly-environment/performance-review/files/supporting-documents/2014/annual-reportsmes-2014_en.pdf [Accessed 1 March 2016].

Solovyeva, O., 2007. Accounting Standards and SMEs In Russia, presentation, Milano.

Strouhal, J., 2012. Applicability of IFRS for SMEs in the Czech Republic. Economics and Management, 17.2, pp. 452-458.

Strouhal, J. \& Bonaci, C. \& Mustata, R. \& Alver, L. \& Alver, J. \& Praulinš, A., 2011. Accounting Harmonization Measurement: Case of Emerging CEE Countries. International Journal Of Mathematical Models And Methods In Applied Sciences, 5.5, pp. 899-909.

Strouhal, J. (ed.), 2011a. Harmonization of SME's Financial Reporting in Emerging CEE Countries. WSEAS Press.

Strouhal, J. \& Pasekova, M. \& Mullerova L., 2010. Is Harmonization of SMEs Reporting Really Necessary? A Case of Central and Eastern European Countries. Journal of Business \& Economics, 2.1, pp. 48-63.

Study on Accounting requirements for SMEs, 2011. [Online] Available at: http://ec.europa.eu/growth/ tools-databases/newsroom/cf/itemdetail.cfm?item_id=8381 [Accessed 24 February 2016].

Swaid, Konowledge Databases. [Online] Available at: http://swaid.stat.gov.pl/SitePages/StronaGlowna DBW.aspx [Accessed 13 November 2015].

Федеральная служба государственной статистики. [Online] Available at: http:/www.gks.ru/wps/wcm/ connect/rosstat_main/rosstat/ru/statistics/enterprise/reform/ [Accessed 1 March 2016].

Федеральный портал малого и среднего предпринимательства. [Online] Available at: http://smb.gov. ru/statistics/officialdata/ [Accessed 1 March 2016].

Федеральный закон от 24.07.2007 № 209-Ф3 «О развитии малого и среднего предпринимательства в Российской Федерации» (в редакции от 29.06.2015 № 156-Ф3).

Федеральный закон от 06.12.2011 № 402-Ф3 «О бухгалтерском учете». 


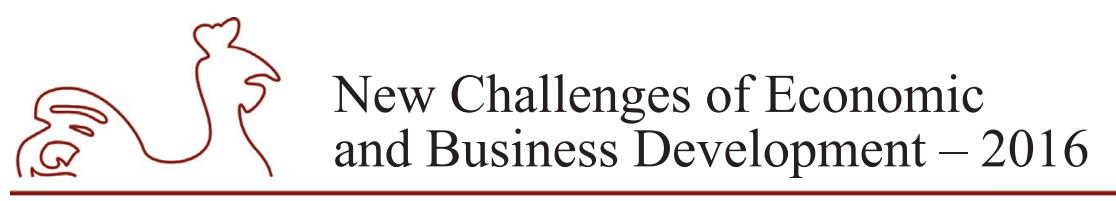

May 12-14, 2016, Riga, University of Latvia

Филобокова, Л. Ю. \& Григорьева, О. В., 2014. Налоговая политика и налогообложение субъектов малого предпринимательства. Аудитор, 12.

Информация Минфина России N ПЗ-3/2012 и N ПЗ-3/2015.

Малое и среднее предпринимательство в России. 2014: Стат.сб./ Росстат. - М., 2014, 86 с.

Налоговый кодекс Российской Федерации (часть вторая) от 05.082000 № 117-Ф3 (в редакции 05.10.2015). Глава 26.3. (введена Федеральным законом от 24.07.2002 N 104-Ф3). Глава 26.5. (введена Федеральным законом от 25.06.2012 N 94-Ф3).

Письмо Минфина России от 03.04.2012 N 03-02-07/1-80.

Постановление Правительства Российской Федерации от 13.07.2015 № 702 «О предельных значениях выручки от реализации товаров (работ, услуг) для каждой категории субъектов малого и среднего предпринимательства.

Приказ Минфина России от 02.07.2010 N 66н «О формах бухгалтерской отчетности» (в ред. от 06.04.2015 № 57н).

Ukrstat, Публикація документів Державної Служби Статистики України. [Online] Available at: https:/ukrstat.org/uk/operativ/operativ2012/fin/osp/osp_u/osp_u.htm [Accessed 2 March 2016]. 
May 12-14, 2016, Riga, University of Latvia

\title{
ENTREPRENEURSHIP AND THE BUSINESS CYCLE IN LATVIA
}

\author{
Marija Krumina, University of Latvia, Latvia ${ }^{1}$
}

\begin{abstract}
Entrepreneurship is considered to be an important driver for economic growth through employment, productivity improvements and overall welfare effects (Schumpeter, 1934, Acs and Audretsch, 1988, Wennekers un Thurik, 1999, Baumol, 2002, Acs and Storey, 2004). The paper contributes to an understanding of how the concepts of necessity driven and opportunity driven entrepreneurship vary over the business cycle in Latvia (the country with highly volatile macroeconomic environment and with modest unemployment benefits). In particular, the paper discusses the way how the labour market conditions affect the entrepreneurial activity level as such as well as the balance between necessity and opportunity driven entrepreneurship. Logit regression models were used for the analysis of repeated crosssection data of the Global Entrepreneurship Monitor (GEM) Adult Population Survey's (APS) for the time period from 2005 till 2012. Data seem to support what in the literature is labelled the "refugee" or "push" effect, i.e. bad years see a larger share of necessity driven entrepreneurs motivated by adverse labour market conditions.
\end{abstract}

Key words: necessity driven entrepreneurship, opportunity driven entrepreneurship, business cycle JEL code: E39, L26, M13

\section{Introduction}

Entrepreneurship is considered to be an important driver for economic growth through employment, productivity improvements and overall welfare effects (Schumpeter, 1934, Acs and Audretsch, 1988, Wennekers un Thurik, 1999, Baumol, 2002, Acs and Storey, 2004). A developed small and medium-sized enterprise sector is a crucial condition for a country's competitive growth (Mulhern, 1995).

Changes in macroeconomic conditions brought substantial variation in the prevalence rate of early-stage entrepreneurs in Latvia. The prevalence rate was about 6.6\% in 2005-2006, dropped to $4.4 \%$ in 2007 , and then sharply increased to more than $10 \%$ in 2009 . Theory suggests that economic recession can have two opposite effects on early-stage entrepreneurial activity. It is crucial to understand to what extent macroeconomic conditions influence entry rates of entrepreneurial activity, as well as whether entry rates vary pro- or counter-cyclically; along with what factors stimulate or hinder the willingness to become an entrepreneur and whether these factors change over time. Various studies analyse the determinants of involvement in entrepreneurial activity. Grilo and Thurik (2008) in their study conclude that being a female substantially reduces the probability to be involved in early-stage entrepreneurial activity. Dombrovsky and Ubele (2005) determine that a typical average Latvian entrepreneur is 39 years old ethnic Latvian male. Parker (2011) proves that human capital plays a major role when

1 Corresponding author - e-mail address: marija.krumina@gmail.com 


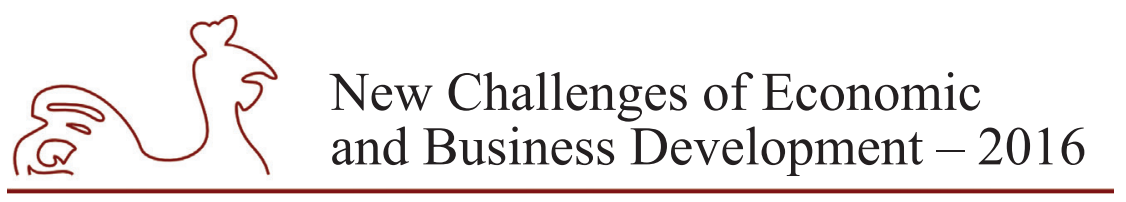

May 12-14, 2016, Riga, University of Latvia

promoting nascent entrepreneurship. Sanditov and Verspagen's (2011) find that being employed increases the probability to establish the own business. Acs et al. (1994) analysing regional aspect, find that people in the cities are more entrepreneurial than those living in the countryside. Arenius un Minniti (2005) identify, that besides the impact of demographic and economic characteristics, perceptional variables such as alertness to opportunities, fear of failure, and confidence about one's own skills are also very important determinants of one's decision to engage in entrepreneurial activity.

The aim of this paper is to evaluate the impact of various individual, socioeconomic and perceptional variables on the probability of becoming an early-stage entrepreneur in Latvia. The paper contributes to an understanding of how the concepts of necessity driven and opportunity driven entrepreneurship vary over the business cycle in Latvia (the country with highly volatile macroeconomic environment and with modest unemployment benefits). In particular, the paper discusses the way how the labour market conditions affect the entrepreneurial activity level as such as well as the balance between necessity and opportunity driven entrepreneurship.

The research question to be answered in the paper is the following: what are the main determinants of early-stage entrepreneurship in Latvia, and are they different for those individuals who are driven by necessity and those who are driven by opportunity motives?

Logistic regression analysis and the Global Entrepreneurship Monitor Adult population data is used for the analysis.

The paper is structured as follows: firstly, methodological approach and data are described. Secondly, entrepreneurial activity and the Latvian business cycle are analysed and regression results are presented. Further, the results are analysed, conclusions and propositions made.

\section{Research results and discussion}

\section{Data and methodology}

The empirical part of the paper is based on repeated cross-section data of the Global Entrepreneurship Monitor (GEM) ${ }^{2}$ Adult Population Survey's (APS) for the time period from 2005 till 2012.

According to GEM definition, an early-stage entrepreneur is an adult individual (1864 years old) who is either a nascent entrepreneur (i.e. actively involved in setting up the business that (s)he will fully or partially own, but that has not paid wages or other payments to owners for more than three months) or a new business owner-manager (i.e. an adult individual who owns and runs a business that has paid wages to its owners for more than three months but less than 42 months (3.5 years).

Entrepreneurship does not affect an economy simply through higher number of entrepreneurs. The motivation for entrepreneurship matters a lot. GEM methodology distinguishes between individuals pulled into entrepreneurship because of opportunity recognition (perceived entrepreneurial opportunity, desire to be independent or earn higher income) and pushed into entrepreneurship for reasons of necessity (limited employment possibilities, threat of

\footnotetext{
2 GEM is a not-for-profit academic research consortium that produces evaluation of the entrepreneurial activity across the world. GEM's hallmark is its focus on the role played by individuals in entrepreneurship.
} 


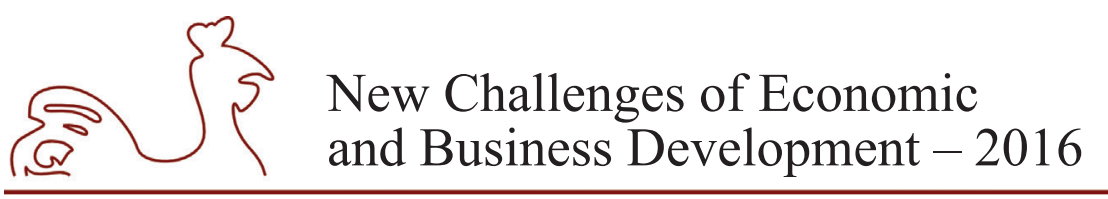

May 12-14, 2016, Riga, University of Latvia

unemployment). Individuals that are pushed into entrepreneurship because of no alternative options are called -necessity driven entrepreneurs and those who are pulled into entrepreneurship to pursue a business opportunity are called improvement driven opportunity entrepreneurs.

To test which factors influence the probability to become an early-stage entrepreneur, we use pooled data and run logistic regression models. The dependent variable thereby takes the value 1 if an individual is an early-stage entrepreneur and 0 - otherwise. We run separate regressions for necessity driven and opportunity driven early-stage entrepreneurs. We include indicators for social networks, perceived skills, opportunity recognition and fear of failure. In addition, we include controls for gender, income, age and the level of formal education. To account for time differences, we use year dummies.

\section{Entrepreneurial activity and the Latvian business cycle}

Changes in macroeconomic conditions brought substantial variation in the prevalence rate of early-stage entrepreneurs in Latvia Figure $1 \mathrm{~A}-\mathrm{F}$ illustrates various aspects of the dynamics of Latvian entrepreneurial activity over 2005-2012. One immediate observation is that Latvian entrepreneurial activity has exhibited considerable variability. In the boom years of 2005-2007 entrepreneurial activity fell as the economy grew faster. With the recession of 2008-2010 entrepreneurial activity, measured as the TEA (total early-stage entrepreneurial activity) rate, increased almost threefold from approximately 4\% in 2007 to around $12 \%$ in 2011 , thus identifying counter-cyclical nature of the Latvian early-stage entrepreneurial activity. At first sight this might appear counter-intuitive since one would expect entrepreneurship to increase in good times, following increased demand for products and services, and fall in a recession. However, the other force at work is the opportunity cost of entrepreneurship; in the boom years of 2005-2007 the Latvian economy in general and its labour market in particular became seriously overheated. For many potential entrepreneurs very large increases in wages and salaries meant high and rising opportunity cost of leaving highly paid employment.

Furthermore, the fact that the labour market was overheated and virtually anyone employable was employed naturally reduced the number of individuals forced into necessitydriven entrepreneurship. By contrast, when the economic crisis hit, jobs were cut or wages reduced, or both, so that many were forced into entrepreneurship in order to survive. Figure 1-F confirms this scenario: during the good years 2005-2007 necessity-driven entrepreneurship was fairly stable around $15 \%$ of early-stage entrepreneurial activity. When the crisis struck, the share of necessity-driven entrepreneurship almost doubled and although it has fallen slightly it still amounted to $26 \%$ of Latvian early-stage entrepreneurial activity in 2012 .

We also observe (from Figure 1-A and Figure1-B) that during most of the period studied a fairly strong co-variation exists between the two components of TEA: 'new business owners' correlates positively with nascent entrepreneurs (that is, people who only do first steps towards starting an own business). This is reasonable since nascent entrepreneurship 'feeds into' new business owners even though not all nascent entrepreneurs end up as new business owners. In the 2010 this co-variation seems to be broken: although the prevalence rate of nascent entrepreneurs has increased since 2009, the prevalence of new business owners has fallen from its peak in 2009. This can be seen as an indication that many start-ups during the crisis were not viable and most likely necessity-driven. 


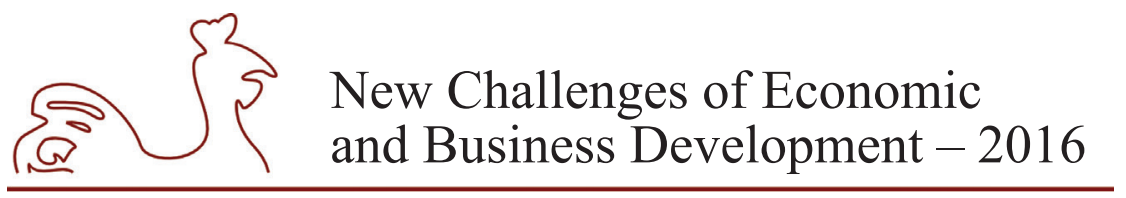

May 12-14, 2016, Riga, University of Latvia

The business discontinuation rate (percentage of the 18-64 age group who in the past 12 months have discontinued a business) is presented in C. It should be no surprise that the discontinuation rate has moved with the Latvian business cycle. When the economy reached its peak in 2007 the percentage of adult population that had discontinued a business was less than $1 \%$ and this peaked at 4\% in 2010 (reflecting businesses closed down from May 2009 to May 2010). Part of this increase stems from the fact that during the crisis (as discussed above) the early-stage entrepreneurial activity level more than doubled and hence, everything else being equal, the fraction of the adult population who with a time-lag had discontinued a business should roughly double as well. However, this could roughly explain just half of the increase in the business discontinuation rate. The remaining failures can probably be attributed to the large number of necessity-driven and in many cases non-viable businesses started during the recession.

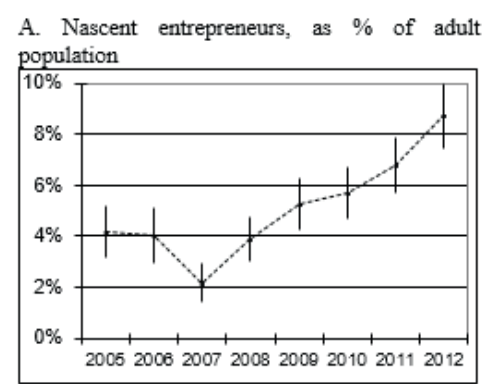

D. Total Early Stage entrepreneurial activity, as \%

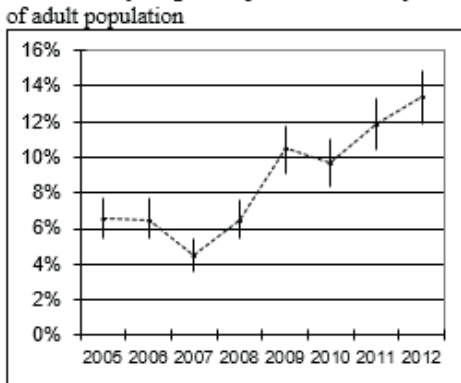

B. New business owners, as $\%$ of adult population
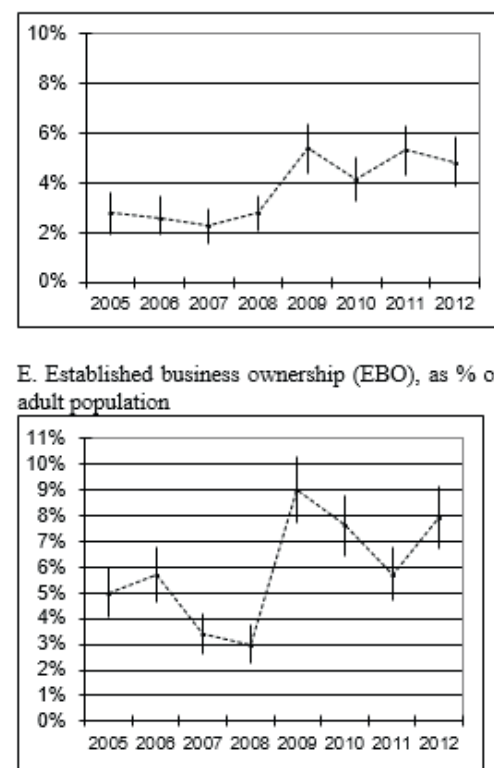

C. People who discontinued business, as $\%$ of adult population

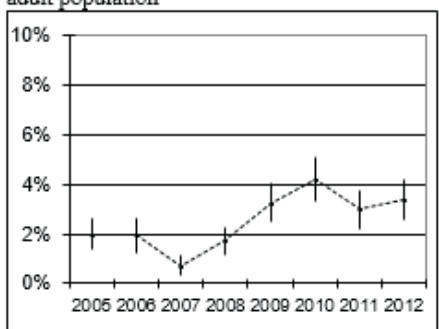

F. Necessity-driven entrepreneurship, as $\%$ of

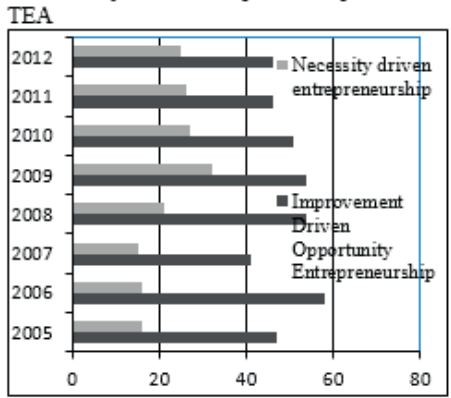

Source: GEM Adult Population Surveys 2005-2012.

Fig. 1. A-F: Indicators of entrepreneurial activity in Latvia, 2005-2012

A logistic regressions were studied to determine the relationship between the individual, socioeconomic and perceptional variables; and involvement in early stage entrepreneurial activity (See Table 1). Model 2 shows the results for involvement in early stage entrepreneurial activity driven by necessity and Model 3 shows the results for involvement in opportunity driven entrepreneurship. The models include dummy variables for each year of the survey. Models a-c present the results excluding the effect of perceptional variables (social networks, business opportunity recognition, entrepreneurial skills and the fear of failure). 


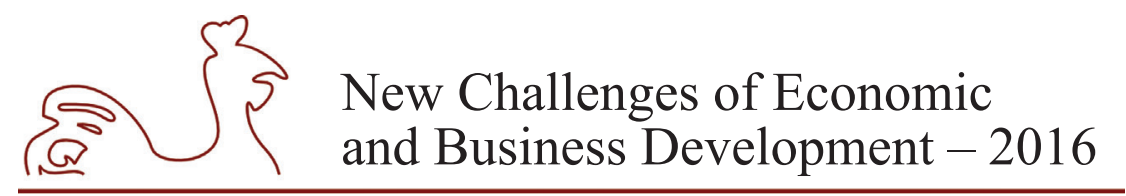

May 12-14, 2016, Riga, University of Latvia

Table 1

Determinants of early-stage entrepreneurial activity. Latvia, 2005-2012

Average marginal effects of logistic regressions

\begin{tabular}{|c|c|c|c|c|c|c|}
\hline & Model a & Model b & Model c & Model 1 & Model 2 & Model 3 \\
\hline & $\begin{array}{l}\text { Involvement } \\
\text { in TEA }\end{array}$ & \begin{tabular}{|c|} 
Involvement \\
in TEA \\
necessity- \\
driven \\
\end{tabular} & \begin{tabular}{|c|} 
Involvement \\
in TEA \\
opportunity- \\
driven \\
\end{tabular} & $\begin{array}{c}\text { Involvement } \\
\text { in TEA }\end{array}$ & \begin{tabular}{|c|} 
Involvement \\
TEA \\
necessity- \\
driven \\
\end{tabular} & \begin{tabular}{|c} 
Involvement \\
in TEA \\
opportunity- \\
driven \\
\end{tabular} \\
\hline & $\mathrm{dy} / \mathrm{dx}$ & $\mathrm{dy} / \mathrm{dx}$ & $\mathrm{dy} / \mathrm{dx}$ & $\mathrm{dy} / \mathrm{dx}$ & $\mathrm{dy} / \mathrm{dx}$ & $\mathrm{dy} / \mathrm{dx}$ \\
\hline Female & $-0.052 * * *$ & $-0.011 * * *$ & $-0.041 * * *$ & $-0.056 * * *$ & $-0.011 * * *$ & $-0.044 * * *$ \\
\hline \multicolumn{7}{|l|}{ Age: } \\
\hline \multicolumn{7}{|l|}{$18-24$} \\
\hline $25-34$ & 0.012 & 0.008 & 0.002 & 0.012 & 0.008 & 0.001 \\
\hline $35-44$ & $-0.029 * * *$ & 0.001 & $-0.031 * * *$ & $-0.033 * * *$ & 0.001 & $-0.035 * * *$ \\
\hline $45-54$ & $-0.049 * * *$ & -0.002 & $-0.047 * * *$ & $-0.055^{* * *}$ & -0.002 & $-0.052 * * *$ \\
\hline $55-64$ & $-0.077 * * *$ & $-0.012 * * *$ & $-0.065 * * *$ & $-0.086 * * *$ & $-0.013 * * *$ & $-0.073 * * *$ \\
\hline \multicolumn{7}{|l|}{ Education: } \\
\hline \multicolumn{7}{|l|}{ Basic or less } \\
\hline Secondary & $0.03^{* * *}$ & 0.003 & $0.026 * * *$ & $0.031 * * *$ & 0.002 & $0.028 * * *$ \\
\hline Higher & $0.058 * * *$ & 0.006 & $0.051 * * *$ & $0.064 * * *$ & 0.005 & $0.056 * * *$ \\
\hline \multicolumn{7}{|l|}{ Income: } \\
\hline \multicolumn{7}{|l|}{ Lower 33\% } \\
\hline Middle 33\% & $0.018 * * *$ & -0.0001 & $0.018 * * *$ & $0.022 * * *$ & -0.000 & $0.023 * * *$ \\
\hline Upper 33\% & $0.053 * * *$ & 0.004 & $0.033 * * *$ & $0.058 * * *$ & 0.004 & $0.053 * * *$ \\
\hline Social networks & & & & $0.054^{*}$ & 0.0001 & $0.005 * * *$ \\
\hline \begin{tabular}{|l} 
Business \\
opportunity
\end{tabular} & & & & 0.001 & 0.0005 & -0.000 \\
\hline \begin{tabular}{|l}
$\begin{array}{l}\text { Entrepreneurial } \\
\text { skills }\end{array}$ \\
\end{tabular} & & & & $0.010 * *$ & $0.003 * *$ & $0.006 * * *$ \\
\hline Fear of failure & & & & $-0.010 * *$ & $-0.002 *$ & $-0.012 * * *$ \\
\hline \multicolumn{7}{|l|}{ Year dummies: } \\
\hline \multicolumn{7}{|l|}{2005} \\
\hline 2006 & 0.011 & 0.001 & 0.003 & -0.011 & -0.0024 & -0.016 \\
\hline 2007 & $-0.017^{*}$ & -0.003 & \begin{tabular}{|l|}
-0.017 \\
\end{tabular} & $-0.039 * * *$ & -0.0071 & $-0.037 * * *$ \\
\hline 2008 & 0.007 & 0.004 & -0.002 & 0.018 & 0.0078 & 0.003 \\
\hline 2009 & $0.045 * * *$ & $0.022 * * *$ & 0.019 & $0.059 * * *$ & $0.032 * * *$ & $0.022 *$ \\
\hline 2010 & $0.041 * * *$ & $0.0168 * * *$ & 0.018 & 0.019 & $0.015 * *$ & -0.0002 \\
\hline 2011 & $0.064 * * *$ & $0.021 * * *$ & $0.038 * * *$ & $0.045 * * *$ & $0.019 * * *$ & 0.019 \\
\hline 2012 & $0.051 * * *$ & $0.025 * * *$ & $0.031^{*}$ & $0.0352 * *$ & $0.0213 * * *$ & $0.0332 *$ \\
\hline
\end{tabular}

Notes: Number of observations 15249.

* significant at $10 \%$ level, ** at $5 \%$ level, *** at $1 \%$ level. 


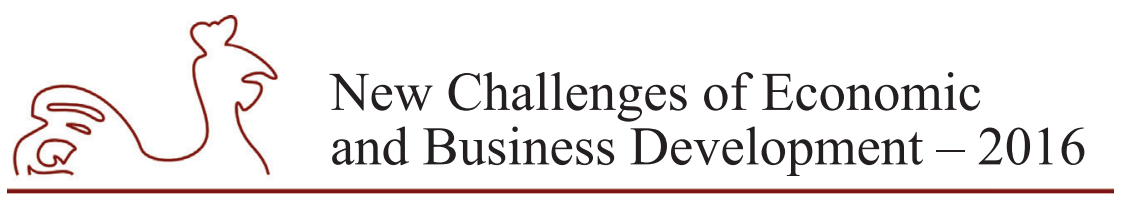

May 12-14, 2016, Riga, University of Latvia

It is worth noting several potential shortcomings. For example, due to the variables indicating individual perceptions the regressions might have some level of simultaneous causality. Namely, it might not necessarily be the case that knowing other entrepreneurs (social networks) has increased one's chances to get involved into entrepreneurship, it rather might be that launching an enterprise helped to get to know other entrepreneurs. Secondly, the selected set of variables does not allow controlling for such factors as economic situation in other countries that may affect the decision of involvement in entrepreneurial activity. Thirdly, some variables might also capture the effect of other variables. Therefore, potential threats should be kept in mind and results interpreted with caution.

As can be seen from the models, females have lower chances to get involved in entrepreneurial activity. This holds true both for involvement in necessity entrepreneurship and for the opportunity driven entrepreneurship. However, the effect is stronger for entrepreneurship by opportunity. Probability to start a new venture decreases with age. This is particularly true for opportunity driven entrepreneurship. Analysing entrepreneurs driven by necessity, the effect of age is not so clear and the results, with an exemption of the age group 55-64, are not statistically significant. More educated people in general have higher probability to become entrepreneurs. The effect of education is not statistically significant, analysing involvement in entrepreneurship driven by necessity. Higher income increases chances to get involved in opportunity driven entrepreneurship. Social networks and self-evaluation of entrepreneurial skills in general are positively correlated with involvement in entrepreneurial activity; and fear of failure-negatively. Business opportunity recognition do not have statistically significant impact.

\section{Conclusions, proposals, recommendations}

Data seem to support what in the literature is labelled the "refugee" or "push" effect, i.e. bad years see a larger share of necessity entrepreneurs in Latvia motivated by adverse labour market conditions. The paper aimed to emphasize the impact of various individual, socioeconomic and perceptional variables on the probability of becoming an early-stage entrepreneur in Latvia, analysing separately those who are driven by necessity and those who are driven by opportunity motives. The probability to get involved in opportunity entrepreneurship decreases with age. Individuals with higher income as well as people that are more educated have higher chances to get involved in opportunity driven entrepreneurship compared to less wealthy and less educated. On the other hand, education, age and income have no statistically significant impact on involvement in necessity driven entrepreneurship.

The study of the effects of tax environment, bankruptcy law, social security and other institutional variables as well as expanding research to include more countries are among suggestions for further research.

\section{Bibliography}

Acs, Z., and Audretsch, David B., 1988. Innovation in Large and Small Firms: An Empirical Analysis. American Economic Review, American Economic Association, 78(4), pp. 678-690.

Acs, Z., and Storey D., 2004. Introduction: Entrepreneurship and Economic Development. Regional Studies, Taylor \& Francis Journals, 38(8), pp. 871-877. 


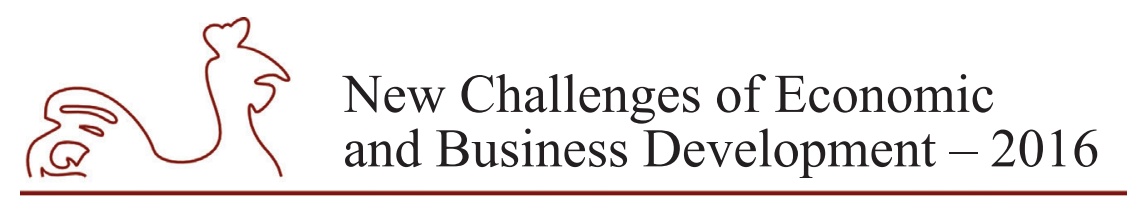

May 12-14, 2016, Riga, University of Latvia

Acs, Z. J., Audretsch, D. B. and Evans, D. S., 1994. The Determinants of Variations in Self-employment Rates across Countries and over Time, Discussion Paper 871, London: CEPR

Arenius, P., and Minniti, M. 2005., Perceptual Variables and Nascent Entrepreneurship. Small Business Economics, 24(3), pp. 233-247.

Baumol, W. J., 2002., Entrepreneurship, Innovation and Growth: The David- Symbiosis., Journal of Entrepreneurial Finance and Business Ventures, 7 (2), pp. 1-10.

Dombrovsky, V., \& Ubele, I., 2005, Entrepreneurship in Latvia. Riga: TeliaSonera Institute Discussion Paper (2).

Grilo I. and Thurik R., 2008. Determinants of entrepreneurial engagement levels in Europe and the US, Industrial and Corporate Change, Oxford University Press, 17(6), pp. 1113-1145.

Mulhern, A., 1995. The SME sector in Europe: A broad perspective. Journal of Small Business Management, 33(3) pp. 83-87.

Parker, S C., 2011, Intrapreneurship or entrepreneurship?, Journal of Business Venturing, Elsevier, Vol. 26(1), pp 19-34.

Sanditov, B., \& Verspagen, B., 2011, Multilevel Analysis of the Determinants of Innovative Entrepreneurship across Europe. Maastricht: UNU-MERIT, School of Business and Economics. Paper presented at final DIME Conference 2011

Schumpeter, J., 1934. The Theory of Economic Development. Cambridge, Mass: Harvard University Press.

Stock, J. H., \& Watson, M. W., 2003. Introduction to Econometrics. Addison Wesley.

Wennekers, A. R. M., and Thurik, A. R., 1999. Linking entrepreneurship and economic growth. Small Business Economics 13, pp. 27-55. 


\title{
ETHNIC DIFFERENTIATION OF MORTALITY, LIFE EXPECTANCY AND HEALTH IN LATVIA AT THE BEGINNING OF $21^{\text {sT }}$ CENTURY
}

\author{
Juris Krumins, University of Latvia, Latvia \\ Denize Ponomarjova, University of Latvia, Latvia ${ }^{1}$
}

\begin{abstract}
Ethnic origin of individuals is among the variables used in socio-demographic analysis in Latvia. Nevertheless, not so many studies have explored mortality, life expectancy and health in relation to ethnicity. Emerging literature in many countries on ethnicity and health contains a number of highly debated topics, with researchers disagreeing on terminology, focus, and approach. This paper is in line with this.

During the Soviet period, only in the time of Gorbachev's reforms, there appeared evidence of existing ethnic inequalities in mortality in the former USSR. Studies on ethnic inequalities in mortality and life expectancy advanced in Latvia, after the country regained independence. The scope for analysis was enlarged after population censuses were organised in 2000 and 2011. Data of censuses were used for specifying data on population numbers and studies in socio-demographic differentials among subgroups of the population. The aim of this study is to analyse differences in mortality, life expectancy and health between the two largest ethnic groups in Latvia - Latvians and Russians - at the beginning of $21^{\text {st }}$ century. Age-specific and age-cause-specific death rates, life tables and standardized death rates for Latvians and Russians by sex and urban-rural residence were calculated in the time period of four years around population censuses. Ethnic differentiation in self-assessed health is analysed based on FINBALT survey data and other health studies.

Ethnic differentiation in health, mortality and life expectancy is determined by health behaviour and gaps between sub-groups of the population concerning beginning and entering different phases of epidemiologic transition. More detailed analysis by use of linkage of vital events with individual population census data could clarify obtained results from cross-sectional analysis.
\end{abstract}

Key words: ethnicity, inequalities, health, mortality, life expectancy

JEL code: I14

\section{Introduction}

There is no universally accepted concept of ethnicity. Questions on ethnicity are regarded as non-core topics in population statistics, for which international comparability and comparability in time is difficult to obtain. Each nation implements definitions that address its own statistical and administrative needs.

Regardless of the existence or absence of independent nationhood, Latvia has always been a multiculturally and multi-ethnically structured society, predominantly in towns and large

Corresponding author - e-mail address denize.ponomarjova@gmail.com 


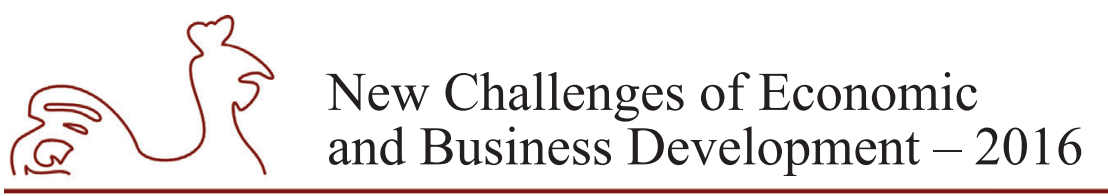

May 12-14, 2016, Riga, University of Latvia

cities, where ethnicity as a variable has always played an important role in population statistics, sociological and demographical studies. After the restoration of independence in the Baltic States, when political, economic and sociological reforms took place, studies on ethnicity in the socio-demographic processes advanced in these countries (Pabriks, 2003; Zvidrins, 1998).

Ethnicity, together with citizenship, place of birth and language use are among the variables used in socio-demographic statistics in Latvia. Ethnic background of individuals in Latvia has been declared in all ten population censuses since 1920 and has been registered in vital statistics over almost a hundred years. That tradition continues in the $21^{\text {st }}$ century by keeping ethnicity as a variable in the population register, different databases and surveys.

Until the end of the $20^{\text {th }}$ and the beginning of the $21^{\text {st }}$ century, not so many sociodemographic studies explored mortality and life expectancy in relation to ethnicity (see: Bos, Kunst et al., 2004; De Grande, Deboosere, 2012). Emerging literature in many countries on ethnicity and health contains a number of highly debated topics, with researchers disagreeing on terminology, focus, and approach (Haug, Courbage, Compton, 1998 and 2000; Laridon, 1999; Detels et al., 2005).

During the Soviet period, only in the time of Gorbachev's reforms, there appeared evidence of existing ethnic inequalities in mortality in the former USSR (Dobrovolskaya, 1990). Studies on ethnic inequalities in mortality and life expectancy advanced in the three Baltic countries Estonia, Latvia and Lithuania - after they regained independence and is continuing until today (Krumins, 1992; Krumins \& Usackis, 2000; Leinsalu, Vågerö, Kunst, 2004; Jasilionis, Shkolnikov et al., 2007; Baburin, Lai, Leinsalu, 2011; Karelson \& Sakkeus, 2012). In some cases, results of studies are used not only for academic purposes to put them in the frame of demographic or epidemiologic transition theories, but also for ideological speculations (Libeka, M., 2014).

The aim of this study is to analyse differences in mortality and life expectancy between the two largest ethnic groups in Latvia - Latvians and Russians - at the beginning of $21^{\text {st }}$ century. Due to the small number of population and demographic events, other ethnic groups are not included in this analysis. Ethnic differences in population composition, reproduction and mobility are among the tasks of the Latvian National Research Programme in social sciences EKOSOC-LV, which was launched in 2014 and is supporting current research. Some results of this study have been presented by authors and discussed at the Workshop of the EAPS Health, Morbidity and Mortality Working Group in Prague in September 2015.

\section{Data and methods}

A clear understanding of primary data used for the calculation of rates and other indicators to study ethnic differentiation of demographic processes is crucial. Ethnicity as a variable was obtained in all population censuses in Latvia, predominantly as a self-identification or an identification given by members of a household. Ethnic background of children, if their parents have different ethnic backgrounds, usually was agreed among them or, in case of disagreement, preference was given to the mother's ethnicity. The only exception was with Population Census 2000, where data on ethnicity was processed from the Population Register.

The tradition of declaring ethnic identity for different administrative purposes during a time of independence and the Soviet time led to high figures of ethnic self-identification during the population censuses, surveys and current registration of socio-demographic events. In Population Census 2000, the response "Ethnicity not specified" was identified for 


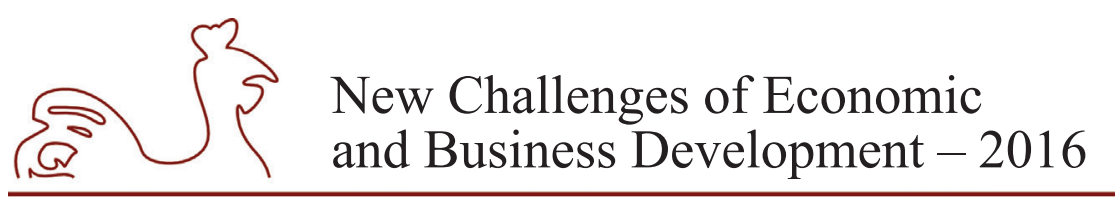

May 12-14, 2016, Riga, University of Latvia

5012 individuals or only $0.2 \%$ of the total population. Similar results appeared in Population Census 2011 - "ethnicity not specified" and "ethnicity unknown" correspondingly was declared by $0.3 \%$ and $0.1 \%$ of the total population. For $9 \%$ of the total population, ethnicity as a variable was obtained during the data processing from the Population Register, where ethnic background is among mandatory registered indications.

A newborn child is only registered in Latvia if at least one parent is a permanent resident of the Republic of Latvia. Until 2004 births were categorized according to ethnicity of the newborn's mother. From 2005 onwards a number of newborns are included in the Central Statistical Bureau's database based on the registered ethnicity of newborns, which means that the ethnic background of at least one parent or grandparent should be chosen. The ethnicity of children born in multi-ethnic households therefore is determined pretty subjectively and depending on the person providing information. After reaching age 16, a person from an ethnically mixed family may choose which official ethnicity background to keep in the register - the one identified by parents or to change the record for the other ethnicity of one of their parents or grandparents. For children born during a period of five years before the last Census (2006-2010) and registered as Latvians during Population Census 2011, were in 3-8\% cases declared another ethnic identity. The corresponding figure for children registered as Russians was 15-19\%. Such discrepancy is diminishing comparability of data on ethnicity for children, if different information sources on ethnic background are used. Data on "Ethnicity not selected" and "not indicated" in 2009-2012 constituted only 435 cases or $0.5 \%$ of the total number of births. In this regard socio-demographic analysis for the adult population in relation to ethnicity are more reliable.

Registration of deaths by ethnicity of the deceased is performed according to the ethnicity entered in documents (passports for adults or birth certificates for children) or in the Population Register. Due to the small numbers of population or deceased with particular ethnic background, data on mortality in this study were analysed for the two numerically largest ethnic groups Latvians and Russians. Data on deaths of males and females (if possible, by place of previous residence in urban-rural areas) are aggregated in age groups $(0,1-4,5-9, \ldots, 75-80,85+$ or even larger age intervals) and summarized covering four year periods with the Population Census in middle. Data on "Ethnicity not selected and not indicated" during 2009-2012 constitute 416 individuals or only $0.4 \%$ of the total number of deaths.

Absence of individual data about the deceased until the mid-1990s did not allow to perform linked-data studies to analyse long-term changes in differentiation of mortality. Researchers have to rely on aggregated data, cross-tabulations and survey results, predominantly focusing on numerically larger ethnic groups of the population. In the case of Latvia - Latvians (61\%) and Russians (26\%) altogether currently constitute 87 percent of the total population (CSB, 2014).

Age-specific and age-cause-specific death rates, based on available vital statistics and Population Census data - the Population and Housing Census 2000; 2011 and death records from Population Register - were calculated. To eliminate differences in age compositions a direct method of standardization was applied. During the whole post-war period and since 1990, the life expectancy pattern in Latvia was characterized by 2-3 years excess of urban over rural population life expectancy. Differences exist in the settlement of ethnic groups across a territory of the country (Table 1). Therefore, in all cases when possible, calculations of death rates and life expectancies were performed separately for urban and rural population and the method of double standardization was used to eliminate age and residency differences. 


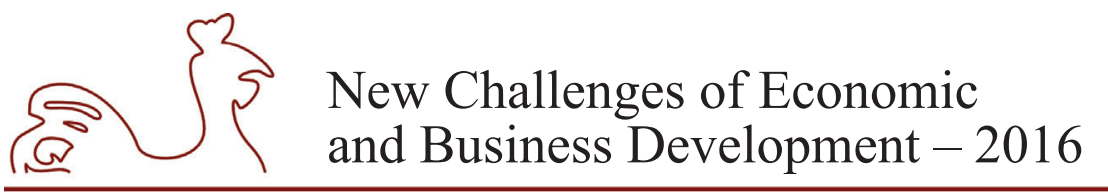

May 12-14, 2016, Riga, University of Latvia

Analyses of causes of death were performed for the most important categories based on the WHO ICD-10 Infectious diseases (3 sub-groups/causes); malignant neoplasms (9); cardioand cerebrovascular diseases and other acute and chronic diseases (6); other chronic and acute diseases (7) and external causes of death (5). In this particular study 5-8 groups of causes of death used: infectious diseases (A00-B99); neoplasms (C00-D48); circulatory system diseases (I00-I99); traffic injuries (V01-V99); suicide (X60-X84); homicide (X85-Y09); other external causes and all other causes of death.

Table 1

Share of Latvians and Russians among the resident population in Latvia, cities under state jurisdiction and counties, 1 March 2011 (\%)

\begin{tabular}{|l|c|c|c|c|}
\hline \multirow{2}{*}{ All population } & \multicolumn{3}{|c|}{ of which } \\
\cline { 3 - 5 } & & Latvians & Russians & $\begin{array}{c}\text { other and unknown } \\
\text { ethnicity }\end{array}$ \\
\hline Country total of which & 100 & 62.1 & 26.9 & 11.0 \\
\hline \multicolumn{1}{|c|}{} & 100 & 46.3 & 40.2 & 13.5 \\
\hline Capital city Riga & 100 & 19.8 & 53.6 & 26.6 \\
\hline Daugavpils & 100 & 57.7 & 30.4 & 11.9 \\
\hline Other republican cities & 100 & 74.4 & 14.7 & 10.9 \\
\hline Counties & & & & \\
\hline
\end{tabular}

Source: authors' calculations based on data of Central Statistical Bureau of Latvia.

Mortality and life expectancy by ethnicity have to be interpreted carefully due to the numerator-denominator bias in the death rates. Ethnicity of the deceased is obtained mostly from documents (passports for adults or birth certificates for children), but ethnicity as a variable in Population Censuses is given by the respondents without certification. The census data on the ethnic structure of population are partially influenced by subjectivity, especially if the share of ethnically mixed marriages is high. More reliable results in analyses of inequalities in mortality are demonstrated by census-linked studies (Jasilionis, Stankuniene et al., 2011). For the reason that in Population Census 2000 data on ethnicity in Latvia were obtained in two ways - from self-assessed ethnicity and controlled from documented ethnicity in the Population Register, agespecific death rates and life tables in this study were calculated by using Population Register data about deceased individuals, which allows eliminate problem of numerator-denominator bias.

\section{Research results and discussion}

\section{Mortality by causes of death and age groups}

Previous studies of differentiation in mortality among ethnic groups in Latvia did not include causes of death analysis (Krumins, J., 1993). Such opportunity emerged with the Population Census 2000, which allowed to do cross-sectional analysis without the problem of numerator/ denominator bias. Ethnicity as a variable (for deaths and for population) was based on registered ethnicity in the Death Register (years 1998-2001) and Population Register (Population Census, 2000). To avoid the influence of differences in age composition of Latvians and Russians in 


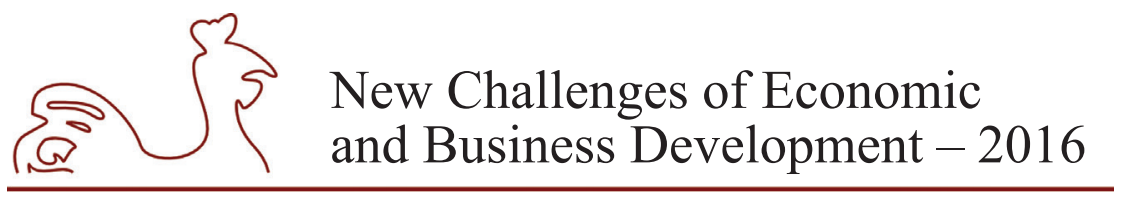

May 12-14, 2016, Riga, University of Latvia

mortality rates, a standardization method was applied. Standardized mortality rates were calculated based on the European Standard Population (Table 2).

Table 2

Age-standardized death rates by causes of death for Latvian and Russian ethnic groups in Latvia, 1998-2001 (deaths per 100000 pop., standard: European standard population)

\begin{tabular}{|l|c|c|c|c|}
\hline \multirow{2}{*}{ Causes of death } & \multicolumn{2}{c|}{ Males } & \multicolumn{2}{c|}{ Females } \\
\cline { 2 - 5 } & Latvians & Russians & Latvians & Russians \\
\hline All causes of death & 1619.7 & 1750.9 & 788.7 & 891.4 \\
\hline \multicolumn{1}{|c|}{ of which } & & & & \\
\hline Infectious and parasitic diseases (A00-B99) & 26.1 & 32.4 & 7.2 & 9.2 \\
\hline Neoplasms (C00-D48) & 294.7 & 319.2 & 137.7 & 155.2 \\
\hline Diseases of the circulatory system (I00-I99) & 826.7 & 863.2 & 466.1 & 524.4 \\
\hline Transport accidents (V01-V99) & 53.4 & 38.1 & 11.3 & 13.2 \\
\hline Intentional self-harm (suicide) (X60-X84) & 57.4 & 53.0 & 10.8 & 10.4 \\
\hline Assault (X85-Y09) & 13.0 & 25.9 & 4.2 & 9.9 \\
\hline Other external causes & 119.1 & 164.1 & 31.4 & 39.8 \\
\hline All other causes & 228.4 & 255.1 & 120.0 & 129.3 \\
\hline
\end{tabular}

Source: authors' calculated based on the data of Population and Housing Census 2000 and Death Register.

Mortality rates by death causes for each sex group shows that ethnic differences remain in all main categories of death causes. The highest difference in mortality was observed within the diseases related to neoplasms and the circulatory system, where death rates of the Russian ethnic group prevails Latvian rates for both sexes. The highest mortality rate was detected in the group of circulatory system diseases for Russian males.

\subsection{Life expectancy}

Differentiation of mortality among the ethnic groups of the population was observed in all republics of the former USSR. Life expectancy at age 5 for all of the titular nationalities of former Soviet republics (excluding RSFSR, Belorussia and Moldova) in 1978-1979 were higher than for Russians. In the Baltic republics, that difference was 0.9-1.8 years for males and 0.4-1.2 years for females (Dobrovolskaya, V. M., 1990). Already in the time period 1988-1989 this tendency has changed - the difference in life expectancy years increased and became greater for Latvians of both sexes. Standardized indicators by urban and rural area for Latvians were 71.4 and 69.7 for Russians (Zvidrins, 1998).

The results of the calculation of life tables for Latvians and Russians by sex and place of residence show that in the period 1998-2001, ethnic differences in life expectancy at birth are evident for all four groups. Life expectancy at birth for the population with Latvian ethnicity prevails over Russian, especially in the rural areas. Significant ethnic differences were observed among the rural population -4.57 years for males and 3.24 for females. The lowest life expectancy was detected among Russian males who live in the rural areas (59.39 years), but the highest for Latvian females in the cities - 76.61 (Fig. 1). 


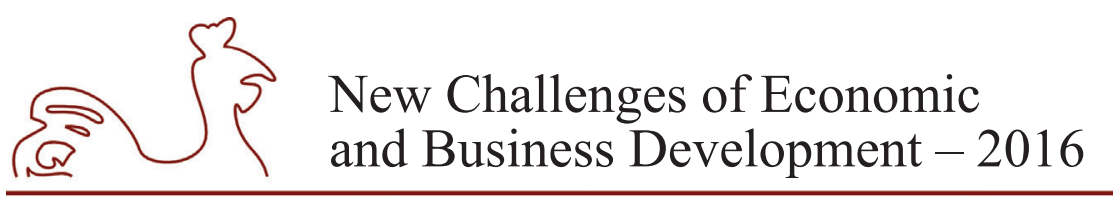

May 12-14, 2016, Riga, University of Latvia

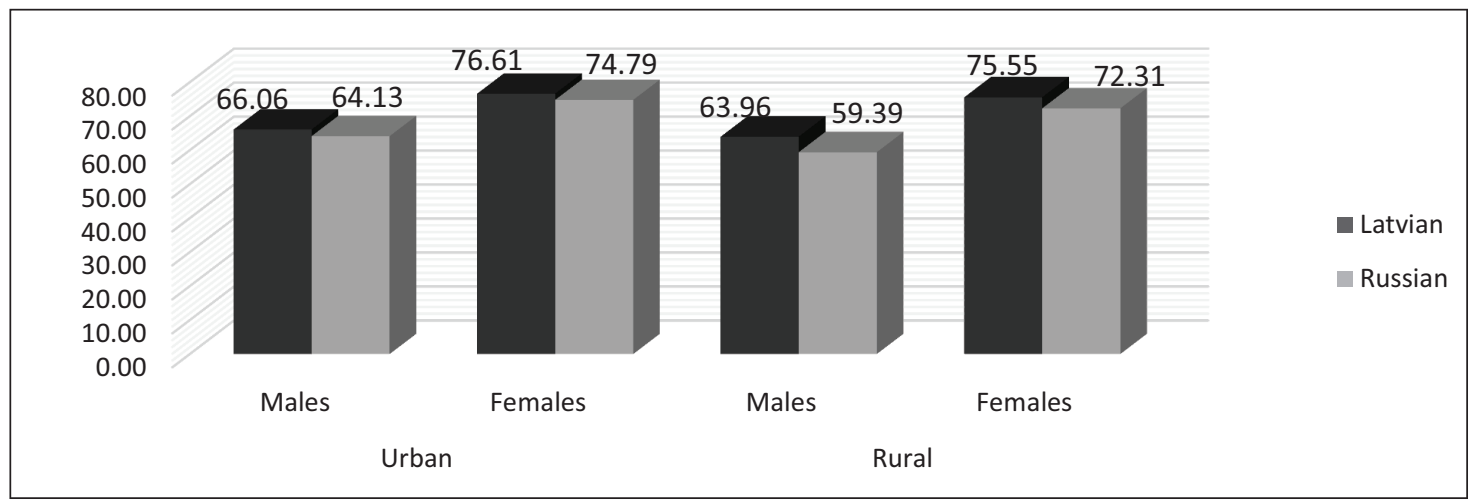

Source: authors' calculated based on the data of Population and Housing Census 2000 and Population Register.

Fig. 1. Life expectancy at birth by ethnicity, sex and urban-rural area (1998-2001)

Factual differences in life expectancies between the two ethnic groups did not exceeded 1.75 years during the time period 1998-2001. Since the years 1988-1989 the difference in factual life expectancy has increased more than double (Table 3), whereas differences among standardized life expectancies, eliminating urban-rural differences in the place of residence of both ethnic groups, dropped since the 1980s and were lower than factual (1.29 years).

Table 3

Factual and standardized* life expectancy at birth for both sexes in Latvia, Latvians and Russians (years)

\begin{tabular}{|c|c|c|c|c|c|c|}
\hline \multirow{2}{*}{ Years } & \multicolumn{3}{|c|}{ Factual life expectancy } & \multicolumn{3}{c|}{ Standardized* life expectancy } \\
\cline { 2 - 7 } & Latvians (1) & Russians (2) & $\begin{array}{c}\text { Difference } \\
\mathbf{( 3 ) = ( 1 ) - ( 2 )}\end{array}$ & Latvians (1) & Russians (2) & $\begin{array}{c}\text { Difference } \\
\mathbf{( 3 )}=\mathbf{( 1 )}-\mathbf{( 2 )}\end{array}$ \\
\hline $1988-1989$ & 71.03 & 70.19 & +0.84 & 71.34 & 69.63 & +1.71 \\
\hline $1998-2001$ & 70.70 & 68.95 & +1.75 & 71.03 & 69.74 & +1.29 \\
\hline
\end{tabular}

Standard: urban-rural distribution of the total census population in respective years.

Source: authors' calculations based on data of Central Statistical Bureau of Latvia.

After identifying an evident inequality in mortality and life expectancy among the two numerically largest ethnic groups, decomposition of the difference between the life expectancy at birth by age and the causes of death for Latvians and Russians for males and females separately was performed (Fig. 2, Fig. 3). Decomposition of differences is a useful way to understand the underlying mechanisms of the observed inequalities in life expectancy (Khang, Y.-H., Yang, S., et al., 2010). 


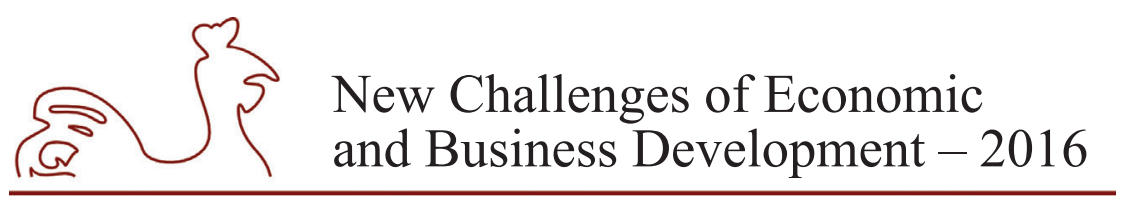

May 12-14, 2016, Riga, University of Latvia

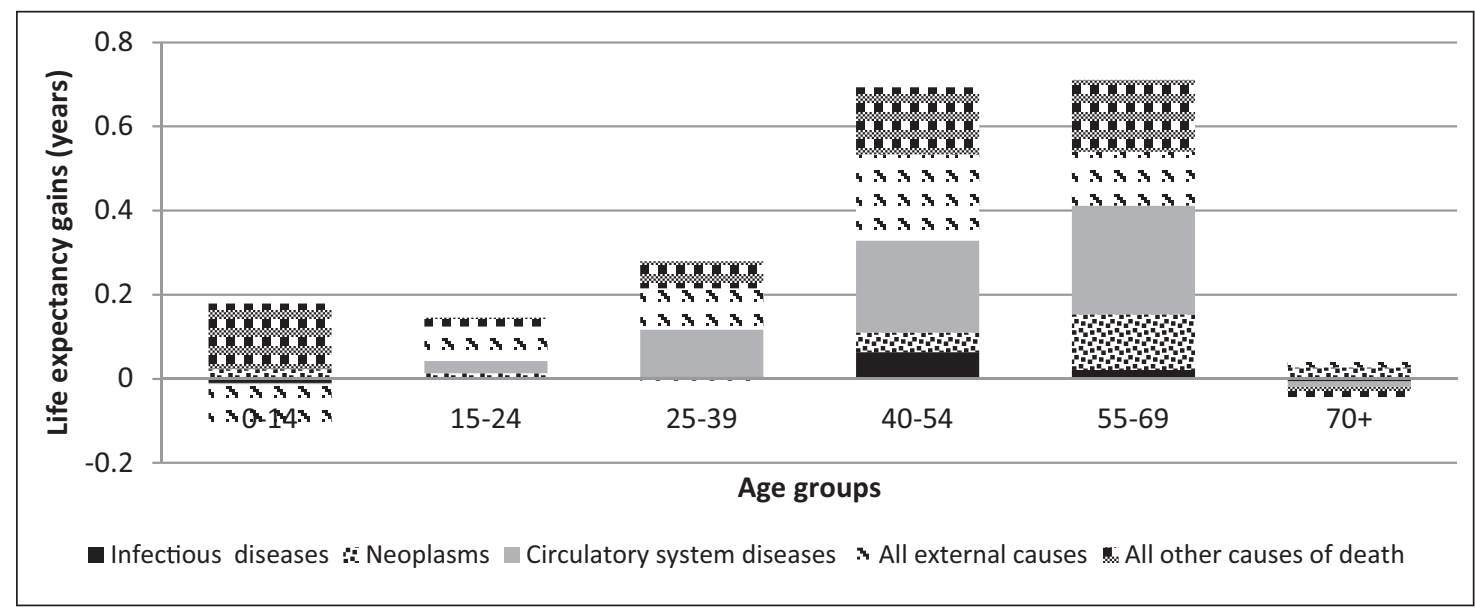

Source: Decomposition performed by authors using method of Andreev \& Shkolnikov (2012).

Fig. 2. Decomposition of differences in life expectancies between Latvian and Russian males by age and causes of death in Latvia, 1998-2001

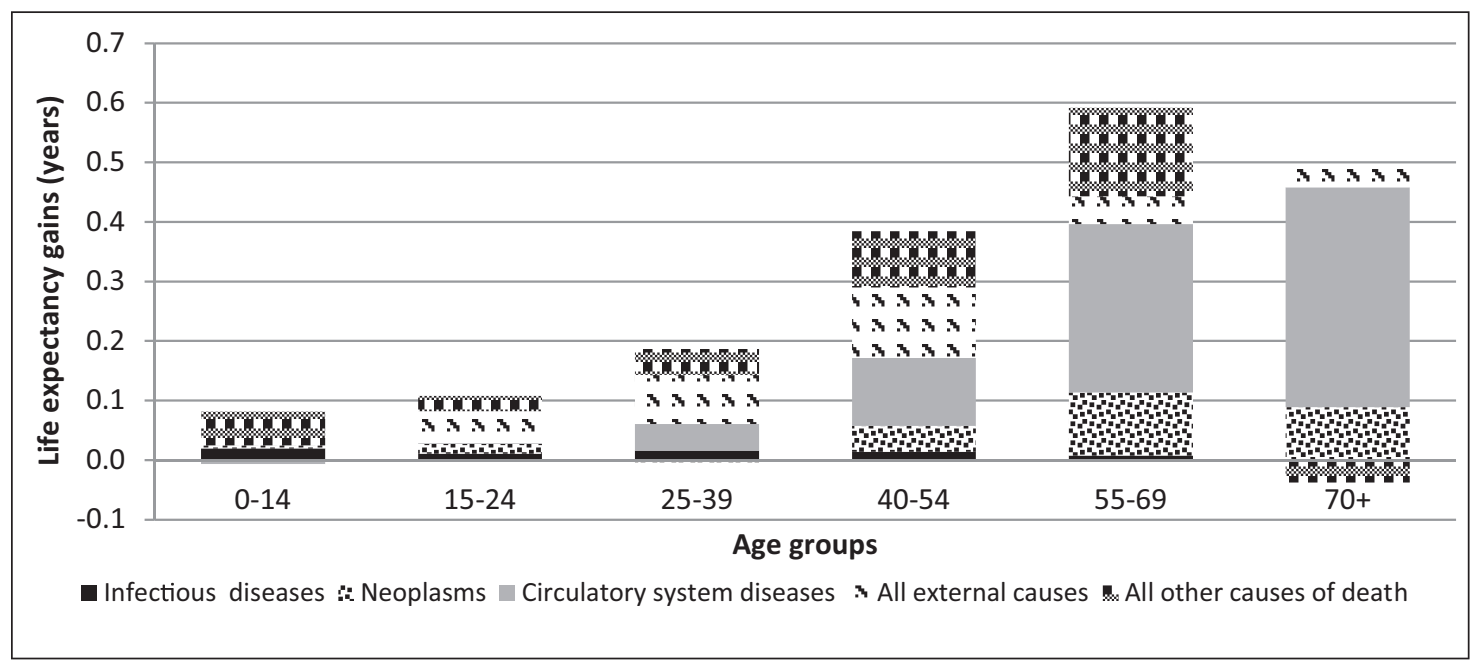

Source: Decomposition performed by authors using method of Andreev \& Shkolnikov (2012).

Fig. 3. Decomposition of differences in life expectancies between Latvian and Russian females by age and causes of death in Latvia, 1998-2001

Due to the small population with a particular ethnic background, decomposition results were aggregated in age groups $0-14,15-24,25-39,40-54,55-69,70+$. In the results, for men inequalities were determined by excess mortality in the ages of 40-69, particularly from circulatory system diseases and external causes of death (difference for all causes: 1.87 years or $3.0 \%$ ); for women, in the ages of 40-69 and 70+ mortality was mostly from the same categories of causes of death (difference for all causes: 1.79 years or $2.4 \%$ ). 


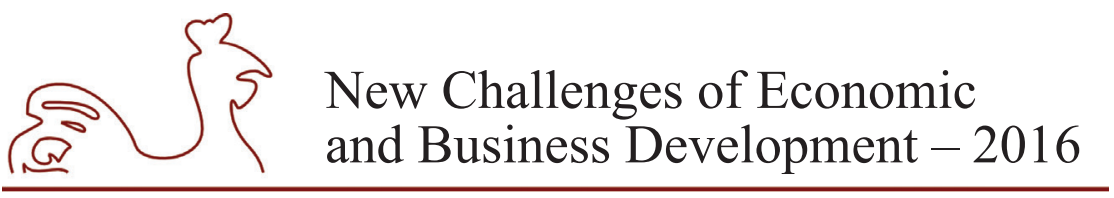

May 12-14, 2016, Riga, University of Latvia

\subsection{Changes in age-specific mortality}

The authors have calculated age-specific death rates based on the data of Central Statistical Bureau. To analyse a changes of age-specific mortality, death rates in the years 2009-2012 were divided by the rates in 1998-2001 (Fig. 4.).
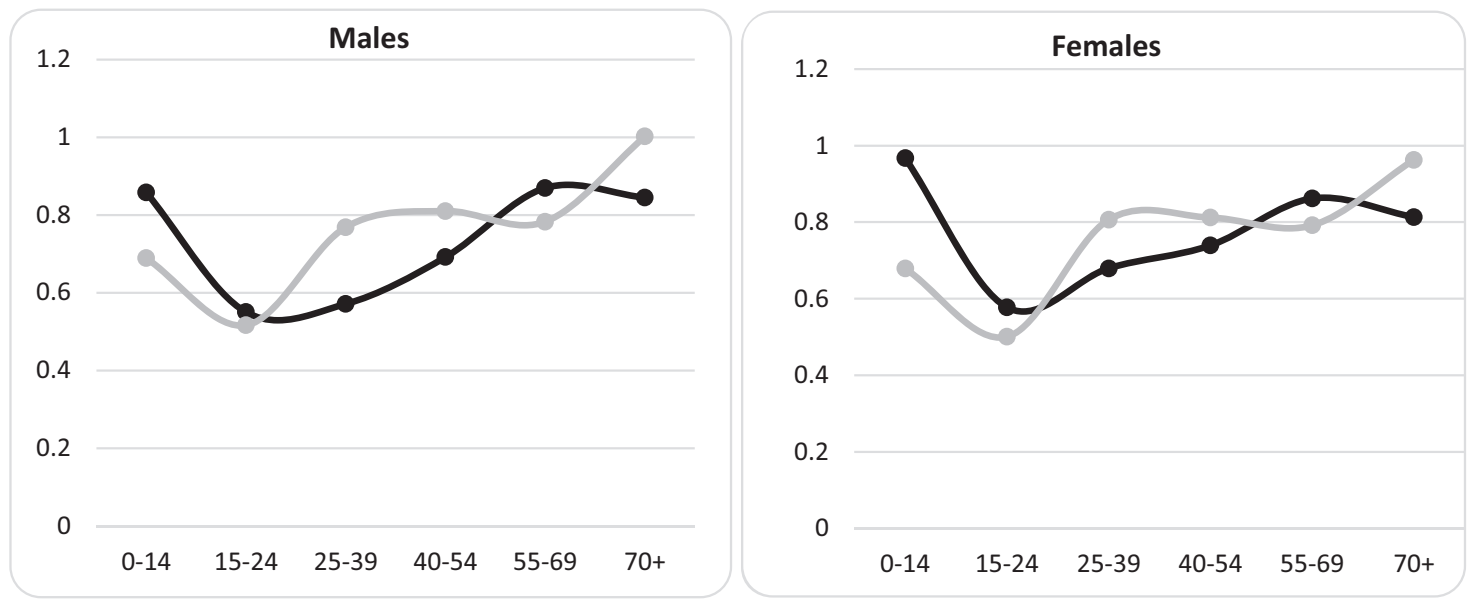

Source: authors' calculations based on Latvian CSB of Latvia data.

Fig. 4. Ratio of age-specific death rates: rates in years 2009-2012 divided by rates in years 1998-2001 (black line - for Latvians, grey line - for Russians)

Death rates for the Russian ethnic population in the age group of 0-24 and 55-69 have declined more compared to Latvians for both sexes. Slower mortality decline was observed in working ages 25-54 and age group 70 years and older. Further detailed analysis is needed to evaluate changes in life expectancy among Latvian and Russian ethnic groups during the first decade of the $21^{\text {st }}$ century.

\subsection{Health and health behaviour}

Self-rated health is an important health indicator and is associated with mortality and other demographical processes (Harschel, S. K, Tomsone, S., et al., 2015). At the beginning of the $21^{\text {st }}$ century few surveys on health and its behaviour with a question about the ethnicity of respondents were performed. One of the most significant surveys is Health Behaviour among Latvian Adult Population (FINBALT) which is carried out every second year with the aim to monitor health behaviour among the population aged 15-64. In Latvia, FINBALT has been performed since 1998, however the aspect of the ethnicity in the report has only been included since 2002. It is also important to note that in 2010 the research methodology of the FINBALT survey was changed due to the following reasons: The Personal Data Protection Law of Citizenship and Migration Affairs and the National Population Register banned the possibility to obtain a personalized sample selection. As a result, it was no longer possible to send out the questionnaire to respondents. Besides, the response rate for the questionnaire sent by mail had declined significantly (Pudule, Villeruša, Grīnberga et al., 2011). After 2010 the study sample of the FINBALT survey was selected using the combined sampling method - stratified random 


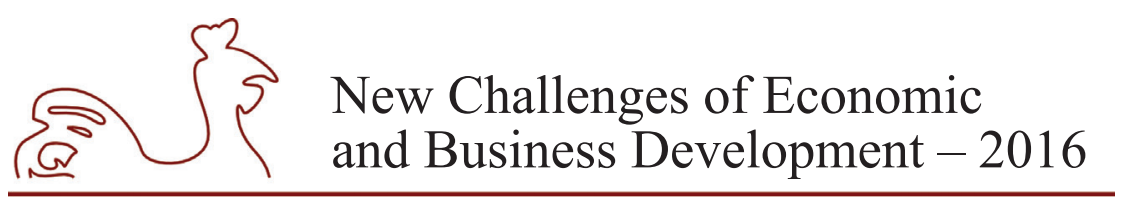

May 12-14, 2016, Riga, University of Latvia

sampling and quota method - and the data were collected by face to face standardized interviews in the Latvian or Russian language (Grīnberga, Pudule, et al., 2015). Due to the aforementioned reasons, the results of FINBALT surveys should be interpreted and compared carefully. Another survey that focused on the health assessment in relation to ethnicity is a Living Condition survey Norbalt-II carried out on the eve of the $21^{\text {st }}$ century $(1994,1999)$.

The results of the study about ethnic inequalities based on the Norbalt-II 1999 show that ethnicity is not significantly associated with health among men, but for women significant differences are found, especially for longstanding health problems. After analysing ethnic groups by age, sex, education and level of income, the results indicate that non-Latvian women report poor health and longstanding health problems more often than Latvian women (Monden, 2004). According the Norbalt survey, it could also be concluded that non-citizens and ethnic Russians are among the vulnerable segment in Latvian society (Zvidrins, 1998).

After analysing the results of the FINBALT survey for Latvian and Russian ethnic groups by sex for the time period 2002-2014, similar tendencies as in the Norbalt-II for a good or reasonably good self-assessed health were observed. The lowest proportion of respondents who assessed their own state of health to be good or reasonably good was found among Russian females. An evident ethnical difference (18\%) was detected in 2010 when more than half of respondents with a Latvian ethnic background indicated their health as good or reasonably good $-60 \%$, whereas only $42 \%$ of respondents with Russian ethnicity replied positively. In the rest of the period of time, response rates indicating a good/relatively good health condition was about $10-12 \%$ higher for Latvian females.

Since 2002 up to 2014 it was observed that there was a growing tendency in the total number of respondents who assess their health as good between both largest ethnical groups. In 2002 only $48 \%$ of Latvian and $44 \%$ of Russian males indicated their health as good, whereas in 2014 the share of both ethnic groups increased up to $68 \%$. The proportion of Latvian and Russian females increased from $43 \%$ to $60 \%$ and from $31 \%$ to $55 \%$, correspondingly, in this period of time.

Smoking is one of the most important factors in the development of cardiovascular, chronic respiratory, oncological (lung cancer) and other diseases (Peto, 1994). In analysing the differences in daily smoking habits between the natives and persons with other ethnicities (mainly Russians) in 1998-2002, the only difference has been indicated for females where daily smoking was common among non-natives females in Latvia. The statistical significance of the main effect of ethnic origin in females in Latvian was $\mathrm{p}<0.01$ (Helasoja, Lahelma, et al., 2006).

In 2014 the highest number of daily smokers has been detected among Russian males with a primary education living in rural areas, and among females - non-Latvian females with primary education who live in Riga. Irrespective of sex, most daily smokers are Russians or non-Latvians, and those with the low education (The Centre for Disease Prevention and Control of Latvia, 2015).

According to the results of the FINBALT survey, the prevalence of daily smokers during the time period from 2002 to 2014 was evidently observed among the population with Russian ethnicity, both for males and females. The evident ethnic difference by sex has been observed among females, similar to the very beginning of the $21^{\text {st }}$ century.

Alcohol consumption causes such diseases as cirrhosis, heart disease, injuries, and others. No studies on alcohol consumption in relation to ethnicity in Latvia have been performed at 


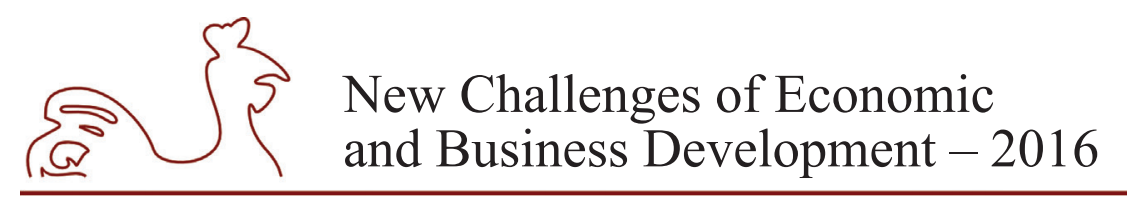

May 12-14, 2016, Riga, University of Latvia

the beginning of the $21^{\text {st }}$ century. Despite the fact that respondents of FINBALT survey were asked about their habits in alcohol drinking, data have not been aggregated by ethnicity yet. However, a few analyses performed within the eve of the $21^{\text {st }}$ century state that in Latvia, there is very little difference between Latvians and Russians who drink weekly (Brunovskis, Ugland, 2002). Furthermore, in other studies on alcohol consumption (1994-2002) it has been found that in Latvian males, the age gradient was steeper among non-natives than among natives, and the interaction between ethnicity and age was statistically significant $(\mathrm{P}<0.05)$ (Helasoja, Lahelma, Pudule, et al., 2007).

\section{Conclusions}

1. Self-identification of ethnic background due to a growth in ethnically mixed marriages and cohabitation, its determination in various registration procedures brings to different interpretations of ethnic inequalities in socio-demographic processes, particularly in childhood. Data on the ethnic backgrounds of the adult population are more reliable.

2. From the years 1988-1989 till 1998-2001 the difference in factual life expectancy between Latvian and Russian ethnic groups has increased more than double, whereas differences among standardized life expectancies, eliminating urban-rural differences in the place of residence of both ethnic groups, dropped since the 1980s and were lower than factual (1.29 years).

3. On the eve of the $21^{\text {st }}$ century, ethnic inequalities in mortality between Latvian and Russian ethnic groups remained in all main categories of causes of death. For men, inequalities were determined by excess mortality within the ages 40-69, particularly from circulatory system diseases and external causes of death, and for women - within the ages 40-69 and $70+$, mortality was mostly from the same categories of causes of death.

4. During the first decade of the $21^{\text {st }}$ century age specific mortality declined both for Latvians and Russians. Further detailed analysis is needed to evaluate changes in life expectancy among Latvian and Russian ethnic groups during the first decade of the $21^{\text {st }}$ century.

5. A slight difference in the self-assessment of a good health status remains among all ethnic groups of the adult population aged 15-64. However, in the last few years, the reporting of good health between males of both ethnic groups has increased to the same level which is a positive signal for a further reduction of differences. Females with Russian ethnicity are those who report poor health condition more often than the rest of the population. The results of self-assessed health might explain the gap in cause-specific mortality between both ethnic groups. However, a small number of studies on health behaviour in the context of ethnicity at the beginning of the $21^{\text {st }}$ century do not allow for performing precise analyses of underlying mechanisms that lead to ethnic inequalities in mortality and life expectancy. Depending on the availability of data, further studies should be focused on social (e.g. poverty) and economic (e.g. income) factors that may influence ethnic differences, specifically for males of Russian ethnicity living in the rural areas.

6. Ethnicity as a variable to analyse differentiation in mortality is losing its traditional usage to make space for other socio-economic variables. 


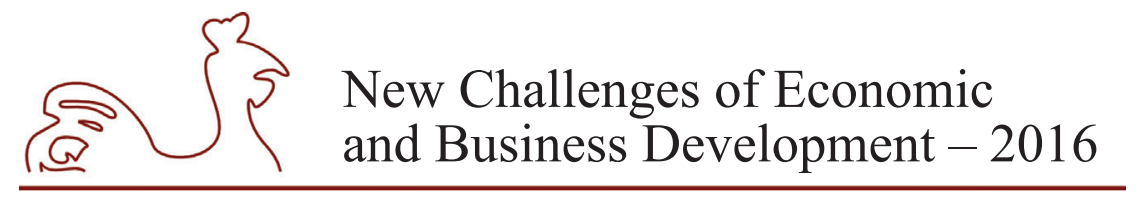

May 12-14, 2016, Riga, University of Latvia

\section{Bibliography}

Aasland, A., 2000. Ethnicity and Poverty in Latvia. Riga: Ministry of Welfare of the Republic of Latvia, 52 p. Baburin, A., Lai, T., Leinsalu, M., 2011. Avoidable Mortality in Estonia: Exploring the Differences in Life Expectancy between Estonians and non-Estonians in 2005-2007. Public Health, 125, pp. 754-762.

Bos, V., Kunst, A., Keij-Deerenberg, I. M., Garssen, J., \& Mackenbach, J., 2004. Ethnic Inequalities in Age- and Cause-specific mortality in the Netherlands. International Journal of Epidemiology, 33, pp. 1112-1119.

Central Statistical Bureau of Latvia (CSB), 2014. Demography 2014. Collection of Statistical Data. Riga: CSB.

CSB of Latvia, 1991. 1989. gada tautas skaitǐšanas rezultāti Latvijā (Results of the Population Census 1989). II daļa. Rīga: VSK, p. 30.

CSB of Latvia, 2002. Results of the 2000 Population and Housing Census in Latvia. Riga: CSB, p. 140.

CSB of Latvia. Database. Tables ID0110, TSG11-06. Available at: http://data.csb.gov.lv

Daniel, A., Powers, D.A., Parker Frisbie, W., Hummer, R., Pullum, S.G., Solis, P., 2006. Race/Ethnic Differences and Age-variation in the Effects of Birth Outcomes on Infant Mortality. U.S. Demographic Research, 14(10), pp. 179-216.

De Grande, H. \& Deboosere, P., 2012. Social and Ethnic Inequalities in Adolescent and Young Adult Mortality in the Brussels-Capital Region. Paper presented at the European Population Conference. Stockholm, Sweden, 13-16 June 2012.

Detels, R. et al. (eds.), 2005. Oxford Textbook of Public Health. $4^{\text {th }}$ edition. Oxford: Oxford University Press.

Dobrovolskaya, V. M., 1990. Ethnic Differentiation of Mortality. In: Demographic Processes in the USSR. Moscow: Nauka, pp. 150-166 (In Russian).

Erin, H., Berger Cardoso, J., Hummer, R., Padilla, Y. C., 2011. Assimilation and Emerging Health Disparities among New Generations of U.S. Children. Demographic Research, 25(25), pp. 783-818.

Grīnberga, D., Pudule, I., Velika, B., Gavare, I., Villeruša, A. 2015. Latvijas iedzīvotāju veselību ietekmējošo paradumu pètījums, 2014 (Health Behaviour among Latvian Adult Population, 2014). Riga: SPKC.

Harschel, A. K., Schaap, L. A., Iwarsson, S., Horstmann, V. \& Tomsone, S., 2015. Self-Rated Health Among Very Old People in European Countries: An Explorative Study in Latvia and Sweden. Gerontology \& Geriatric Medicine, January-December 2015, pp. 1-10. DOI: 10.1177/2333721415598432.

Haug, W., Courbage, Y., Compton, P. (eds.), 1998. The Demographic Characteristics of National Minorities in Certain European States. Population Studies, No. 30; Vol. 1.

Haug, W., Courbage, Y., Compton, P. (eds.), 2000. The Demographic Characteristics of National Minorities in Certain European States. Population Studies, No. 31, Vol. 2.

Helasoja, V., Lahelma, E., Prattala, R., Pudule, I., et al., 2006. Determinants of Daily Smoking in Estonia, Latvia, Lithuania, and Finland in 1994-2002. Scandinavian Journal of Public Health; 34: 353-362.

Jasilionis, D., Shkolnikov, V., Andreev, E., Jdanov, D., Ambrozaitiene, D., Stankuniene, V. et al., 2007. Sociocultural Mortality Differentials in Lithuania: Results Obtained by Matching Vital Records with the 2001 Census Data. Population: English Edition, Vol. 62 (4): 597-646.

Jasilionis, D., Stankuniene, V., Ambrozaitiene, D., Jdanov, D., Shkolnikov, V., 2011. Ethnic Mortality Differentials in Lithuania: Contradictory Evidence from Census-linked and Unlinked Mortality Estimates. Journal of Epidemiology and Community Health. doi: 10.1136/jech.2011.133967.

Karelson, K. \& Sakkeus, L., 2012. Diagnosis Based Life Expectancy and its Determinants among Estonian Native and Immigrant Population. Paper presented at the European Population Conference. Stockholm, Sweden, 13-16 June 2012.

Khang, Y.-H., Yang, S., Cho, H.-J., Jung-Choi, K. \& Yun, S.-C., 2010. Decomposition of Socio-economic Differences in Life Expectancy at Birth by Age and Cause of Death among 4 Million South Korean Public Servants and their Dependents. Int. Journal of Epidemiology, 39(6), pp. 1656-1666. doi: 10.1093/ije/dyq117. 


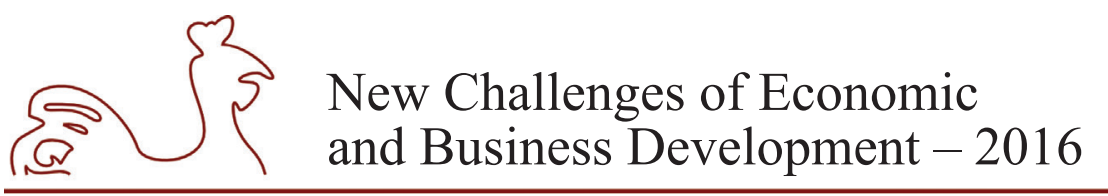

May 12-14, 2016, Riga, University of Latvia

Krūmiņš J., 1993. Iedzīvotāju mūža ilgums - tendences un palielināšanās problēmas (Life expectancy of population - the problem of increasing and tendencies). Rīga: Latvijas Universitāte, 130.-135. lpp.

Krumins, J. \& Usackis, U., 2000. The Mortality Consequences of the Transition to Market Economy in Latvia, 1991-1995. In: G. A. Cornia \& R. Paniccia (eds.), The Mortality Crisis in Transitional Economies. Oxford: Oxford University press, pp. 280-302.

Krumins, J., 1992. Territorial and Ethnical Differences of Mortality and Life Expectancy of Population in Latvia. In: Latvijas sociali demografiskas attistibas problemas. LU Zinatniskie raksti, 571. sej. Riga: University of Latvia., pp. 52-72 (In Russian, English summary).

Laridon, H., 1999. The "Ethnic" Variable as a Statistical Category. Population: An English Selection, Vol. 11, pp. 189-192.

Leinsalu, M., 2004. Troubled Transitions. Social Variation and Long-term Trends in Health and Mortality in Estonia. Stockholm: Almqvist \& Wiksell International.

Leinsalu, M., Vågerö, D., Kunst, A.E., 2004. Increasing Ethnic Differences in Mortality in Estonia After the Collapse of the Soviet Union. Journal of Epidemiology \& Community Health, 58: 583-589.

Libeka, M., 2014. ANO ekspertus noskaņo pret valsti; Latviju pārstāv Nepilsoņu congress (UN experts being turned against the country; Latvia is represented by Non-Citizens' Congress. Latvijas avize, 12 March.

Mackenbach, J. P., Stirbu, I., Roskam, J. A., Schaap, M., Menvielle, G., Leinsalu, M., Kunst, A. E., 2008. Socioeconomic Inequalities in Health in 22 European Countries. New England Journal of Medicine; 358, pp. 2468-81.

McKibben, J. N., 2004. Chapter 8. Racial and Ethnic Composition. In: J. S. Siegel \& D. Swanson (eds.), The Methods and Materials of Demography. 2nd Edition. California, London: Elsevier Academic Press, pp. 175-189.

Monden, Ch. W. S. 2004. Socioeconomic Health Inequalities in Latvia: A Cross-sectional Study. Scand J Public Health, 32: 217-233.

Pabriks, A., 2003. Ethnic Structure, Inequality and Governance of the Public Sector in Latvia. Project of United Nations Research Institute for Social Development. Geneva: UNRISD.

Peto, R., Lopez, A.D., Boreham, J., et al.,1994. Mortality from Smoking in Developed Countries 1950 2000. Oxford: Oxford University Press.

Pudule, I., Villeruša, A., Grīnberga, D., Velika, B., Taube, M., Behmane, D. et al., 2011. Latvijas iedzīvotāju veselību ietekmējošo paradumu pētījums, 2010 (Health Behaviour among Latvian Adult Population, 2010), Rīga: Veselības ekonomikas centrs.

Reitan, T., 2003. Democracy in a Bottle: Attitudes towards Alcohol Regulation in the Post-communist Baltic Sea Region. Journal of Baltic Studies; 34, pp. 131-158.

Saenz, R. \& Embrick, D. (eds.), 2015.The international Handbook of the Demography of Race and Ethnicity. International Handbooks of Population. Vol. 4. Springer.

Slimību profilakses un kontroles centrs (The Centre for Disease Prevention and Control of Latvia), 2015. Smêķēšanas izplatība un sekas Latvijā 2014. gadam (Distribution and consequences of smoking habits in Latvia in 2014). Riga: SPKC.

Solé-Auró, A. \& Crimmins, E.M., 2008. Health of Immigrants in European Countries. International Migration Review, 42(4), pp. 861-876. doi:10.1111/j.1747-7379.2008.00150.x.

Soroko, E., 2012. New Factors of Population Ethnic Structure Formation. Presented at the European Population Conference. Stockholm, Sweden, 13-16 June 2012.

Trapenciere, I., 2005. Poverty in Latvia, Project "Poverty, Social Assistance and Social Inclusion Developments in Estonia and Latvia in a Comparative Perspective", Fafo-report 503.

Uretsky, M. \& Mathiesen, S., 2007. The Effects of Years Lived in the United States on the General Health Status of California's Foreign-born Populations. Journal of Immigrant \& Minority Health, 9(2), pp. 125-136. doi:10.1007/s10903-006-9017-7. 


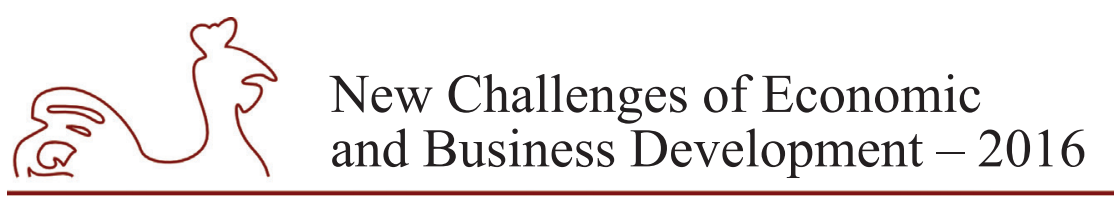

May 12-14, 2016, Riga, University of Latvia

Vågerö, D. \& Leinsalu, M., 2005. Health Inequalities and Social Dynamics in Europe. British Medical Journal, 331, pp. 186-187.

Vågerö, D., 2006. Do Health Inequalities Persist in the New Global Order?. In: G. Therborn (eds.), Inequalities of the World. London: Verso Publications.

Vågerö, D., Ferlander, S., Leinsalu, M., Mäkinen, I.H., Stickley, A. 2006. Unhealthy Societies? Health Stagnation, Growing Health Inequalities are not Consistent with Sustainable Development. In: L. Ryden (eds.), Realizing a Common Vision for a Baltic Sea Eco-region - Report from a Research Symposium on Sustainable Development Patterns. Uppsala: The Baltic University Programme, pp. 39-46.

Zvidrins, P. \& Krumins, J., 1993. Morbidity and Mortality in Estonia, Latvia and Lithuania in the 1980's. Scandinavian Journal of Social Medicine, 21(3), pp. 150-158.

Zvidrins, P., 1998. Latvijas iedzīvotāju etniskā sastāva izmainas 90. gados (Changes in the Ethnic Composition of Population in Latvia during the 90s). Riga: University of Latvia. 


\title{
FINANCIAL MARKET INSTITUTIONS COMPETITIVENESS AND FINANCIAL CONVERGENCE
}

\author{
Kuznetsova Natalia P., Saint-Petersburg State University, Russia ${ }^{1}$ \\ Pisarenko Zhanna V., Saint-Petersburg State University, Russia \\ Chernova Galina V., Saint-Petersburg State University, Russia
}

\begin{abstract}
Problem statement. Whether insurance companies, pension funds, banks as parts of financial conglomerates (FC) are more competitive inside the group than outside it being individual entities. Authors consider Russian financial market as a field of empirical study. Goal is to reveal the nature of the financial convergence as a mechanism of competitiveness for the parts of FC. Methods of the article are based on the "Performance-Conduct-Structure" (PCS) idea known as Boone "effective competition" indicator applied for insurance financial conglomerate member competitiveness evaluation. Objectives. 1) To reveal the process of competition on financial markets using mechanism of financial convergence. 2) To give definition of financial conglomerates as a basic institutional and organizational form of financial convergence. 3) To implement Boone "effective competition" indicator for empirical study of the financial convergence as the mechanism of the competitiveness increase for the Russian biggest financial-insurance groups. Results and findings. The results and novelty of the study are (1) refined definitions of "financial convergence" and "financial conglomerate". (2) Boone indicator is used to estimate financial convergence, which is a tool to improve competitiveness through competition between insurance organizations. (3) Assessment for competitiveness of Russian insurance companies as part of financial groups and as independent companies. (4) proposed hypothesis is confirmed only partly. Financial Convergence as a mechanism to enhance the competitiveness of its members presupposes the solution of a number of issues related to its institutional and organizational for empirical study of leading Russian insurance financial conglomerates competitiveness based on the proposed method of Boone "effective competition" indicator evaluation and on the alternative method of coefficient variation of the insurance undertaking financial result's activity calculation. Analyzing some basic indicators of the annual financial statements of these entities for the period 2009-2015 the study argues that insurance companies being the members of financial conglomerate have higher competitiveness than individual non-member-firms.
\end{abstract}

Key words: financial convergence; financial conglomerate; types of different sectors of the financial market similarity; financial conglomerate's members and non-members competitiveness

JEL code: G10, G20, G23, G20

\section{Introduction}

Relevance of the study. Processes of financial capital globalization, liberalization of state regulation, emergence of information economy, harmonization of the financial markets policy supervision in the second half of the XX century have generated new outlines of a global

1 Corresponding author - e-mail address: janna12000@yandex.ru 


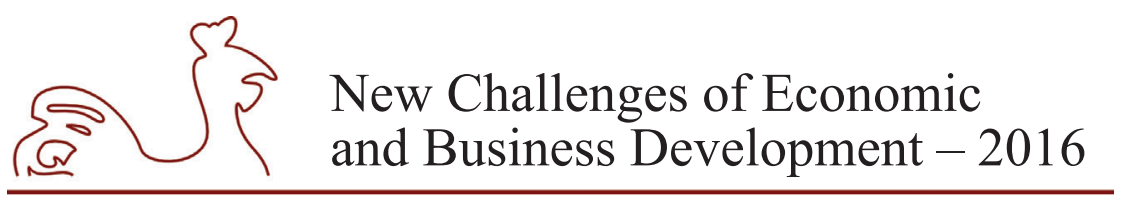

May 12-14, 2016, Riga, University of Latvia

financial architecture (Dowrick St., Bradford J. D. 2003). Financial convergence (Berghe L. Van den \& Verweire K. 2000; Fein M. L. 2007.) as diffusion process between different capital market sectors (Chernova G. V. Kuznetsova N. P., 2001) becomes central element and moving force for the world financial system development. Financial markets institutions face challenges that require new mechanisms of competitiveness increase. The paper deals with the disclosure of the contents of financial convergence as a paramount mechanism of competitive strength for financial market institutions operating in its different sectors. (Shakhpazov K. A., 2012, Pisarenko Zh. V., Belozyorov S. A., 2013). The financial convergence process was caused by a competition between different sectors of financial market, meaning a fierce struggle to maintain and/or increase dominance (due to reduction of other financial market sectors participation). The relevance of this study is determined by the odd interconnection between economic practice and theoretical comprehension that is reflected in the following contradiction: despite the rapid development of financial convergence and financial conglomeration their commonly accepted definitions and unique understanding as well as competitiveness evaluation of the financial conglomerates' members still do not exist.

The hypothesis of the article. The institutions inside the financial conglomerates achieve higher competitiveness. Methods. The empirical study of financial convergence as a mechanism of competitiveness is based upon annual financial reports data from top 20 Russian insurance organizations. The study is based on the "Performance-Conduct-Structure" (PCS) approach proposed by Bikker (Bikker J., 2012) for insurance companies' competitiveness assessment and earlier econometrically implemented in Boone's "effective competition" indicator (Boone, 2007) for insurance companies. The novelty is to use proposed methodology for assessment of conglomerate members. The authors involved the methods of systematic and logical analysis, concretizing the concept of financial convergence and financial conglomerate; identifying types of similarity of different sectors of the financial markets, which determine financial convergence prerequisites; clarifying the main factors, which contribute to the financial convergence of the insurance and pension sectors.

The main goal of the paper is to reveal the characteristics of the financial convergence as a mechanism for improving the competitiveness of the financial market institutions operating in its different sectors, as well as to figure out the specifics of the financial conglomerate as a major institutional and organizational form of financial convergence. The goal of the paper clarifies its objectives, logic and structure which has the following issues: literature review, data and methods, empirical study, conclusions and recommendations. The paper objectives are: 1) concept of financial convergence understanding figured out as interpenetration of competing financial entities activities; 2) financial conglomerates definition as a basic institutional and organizational forms of financial convergence; 4) implementation of Boone "effective competition" indicator method for empirical study of the financial convergence as the mechanism of the competitiveness increase for the Russian emerging insurance market biggest financial-insurance groups. The research results cause a lists of problematic questions and discussions concerning: 1) opportunities of further new statistical-econometric methods implementation for a) different-leveled and different-scaled countries: namely space-context; b) different phases of the long-wave cycle during down- and up-swings: namely multicyclicity time-context; 2) perspectives of financial conglomerate's new members and non-members competitiveness assessment meaning pension funds in the framework of different economies pension systems reforming. 


\section{New Challenges of Economic and Business Development - 2016}

May 12-14, 2016, Riga, University of Latvia

\section{Literature review}

Financial market represents a set of interrelated but separate sectors (due to the specifics of their activities) - banking, insurance, pension schemes, investment, etc. The relationship of the financial market sectors manifests itself primarily in the fact that the functioning of each sector is connected with the activities of other sectors. For example, the insurance entity cannot exist without interaction with banking, investment sectors, etc.

The struggle for the survival, for a consumer leads to fierce competition between financial sectors which offer similar financial products. However, increased competition in certain financial sector leads to the competition of institutions in the different sectors of national and international financial markets.

General issues of the financial markets competition are presented in the (Claessens, 2008), which gives an idea about the nature of competition between financial institutions. At the same time one has to keep in mind that competition in the financial markets is difficult to measure due to a lack of public information regarding the costs of different financial market participants as well as the cost of certain financial products themselves (Bikker, 2012).

Competition measurement focuses mainly on financial market individual sectors. The banking sector's competition measurement is represented in a set of publications (Bergeretal, 2009; Tabakcetal, 2012; Beck et al., 2013; Mamonov 2012; Cummins and Weiss, 2012, etc.), which show a non-linear effect of competition on the stability of the banking sector financial institutions, where excessive competition could become a source of financial instability. A set of academics (Berger et al., 2009; Beck et al., 2013; Mamonov, 2012) analyzed the level of competition based on the Lerner index, which reflects the market share premiums in interest rates.

Some authors showed that fierce competition makes insurers to increase business management efficiency, forcing managers to reduce marginal costs in order to remain profitable (Raith, 2003; Hay and Liu, 1997; Kuznetsova N. P. Chernova G. V., 2001; Kuznetsova N. P., Pisarenko Zh. V., 2012).

Analysis of insurance companies in life and non-life sectors competitiveness was performed by (Bikker J., 2012; Popesku A. \& Bikker J., 2014), where the method for measuring the competitiveness of insurance companies on the basis of Mason and Bain paradigm developed in 1939 was applied. This method is based on the Performance-Conduct-Structure (PCS) idea known as Boone "effective competition" indicator.

This alternative model explains the structure of the market through the so-called hypothesis of efficiency (Smirlock, 1985; Goldberg and Rai, 1996) according to which via competitive fight more efficient players gain bigger market share and bigger profit than less efficient players which lose a part of profits and, therefore, market share. This concept is based on two premises: first - a low entry cost on the market (contestable markets); second - a high degree of interchangeability of products (substitute products).

Accordingly, the space for the product market competition expansion through the efficiency channel starts to decline alongside with 1) market entry costs increase and/or 2) reduction of interchangeability of products offered on the market. In the first case - due to the weakening of players incentives to increase efficiency, in the second - due to the segmentation of competition between groups of players, providing more or less homogeneous products. 


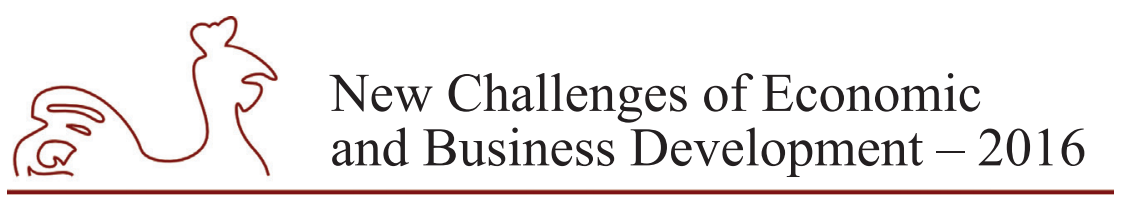

May 12-14, 2016, Riga, University of Latvia

Specific feature of Boone's indicator is that it can "catch" the growth of competition in the market in case of increase of the interchangeability of products offered on the market (Tabak et al. 2012), while the structural competition will produce conflicting conclusions. For example, if more efficient banks have already occupied a leading position in the market before the increase the products interchangeability, an increase in competition will allow them to redistribute bigger share of the market lost by less efficient players.

Under these conditions, the structural indicator - the Herfindahl-Hirschman Index (HHI) will increase despite the strengthening of competition. Nonstructural Lerner index indicator can indicate both the increase and decrease of competition as the share of the market allowance in price declines or grows. Another advantage of the "Performance-Conduct-Structure" model is that it can be used for a small set of statistical surveys (Bikker and Van Leuvensteijn, 2015)2. This is particularly important in the analysis of emerging market economies financial architecture and space having short history.

Emerging financial markets shows the same trend in competition among different sectors. Different financial institutions search for such mechanisms of competition, which would take into account not only the specificity, but also the similarity and proximity of the financial market sectors. Named similarity could manifest itself, for example in the following facts: 1) all financial market sectors may have the same customer; 2) the customer may be offered similar products and services, etc. Therefore, the inspiration of financial market participants to increase their competitiveness leads to the desire of one sector of the financial market subjects to implement this similarity, for using, for example, customer base, markets, and products that already proved their competitiveness (Fein Melanie L., 2007), the technology and methods of other sectors' management of the financial market subjects.

Competition measurement in the scientific literature focuses mainly on individual players of financial market. Both financial groups and individual companies compete for similar financial market shares. This mechanism of competitive struggle needs further investigation.

\section{Methods for the study and data}

Financial convergence is away to compete for financial dominance on the market. Financial institutions from different sectors of financial market penetrate into similar sectors to widen their influence. The penetration can occur in the following forms:

- Aggressive (enforced) form of penetration. It is implemented by an institution via involvement into activities of certain spheres and/or functions initially inherent to other financial market sector. For example, it can be realized through a creation of new complex financial products with elements of products belonging to other financial market sectors. This situation corresponds to the aggressive behavior of a certain sector of the financial market representative. In this case, increase of the latter financial market sectors actor share of their own in the overall financial market happens due to the specific sphere of activities and/or other participants' functions "capture" by specific aggressive member of a specific financial market sector. The additional income caused by such seizure,

\footnotetext{
2 A New Measure of Competition in the Financial Industry: The Performance-Conduct-Structure Indicator (Routledge International Studies in Money and Banking) $1^{\text {st }}$ Edition by Jacob A. Bikker (Editor), Michiel van Leuvensteijn (Editor). NY: Routledge; 228 pages. 2015.
} 


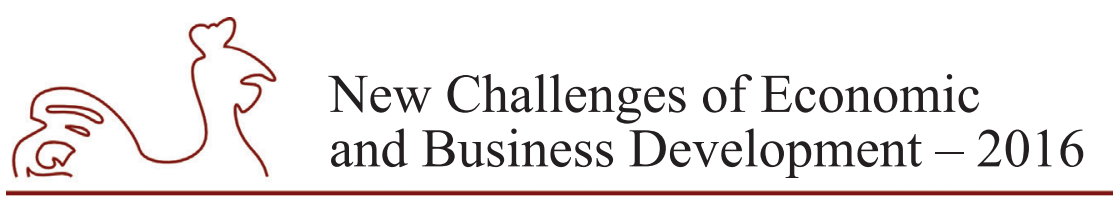

May 12-14, 2016, Riga, University of Latvia

mainly goes to the capture initiator. For example, a banking product "mortgages" can include a mandatory condition of insurance contract. In this case, if the insurance provision is provided by the insurance company independent from the bank's activities, the latter penetration into the activities of the insurance sector is supposed to be absent. If the bank under the credit contract stipulates the specific insurance company, which can provide insurance indemnity and at the same time this bank conclude a contract with an approved share of profits of its own with the appropriate insurance company, one can observe an aggressive form of convergence. We should note that due to the different sectors activities' of financial market mandatory licensing the aggressive form of financial convergence is limited. Actually each sector performs inherent functions of its own. Aggression is manifested in the fact that the initiator of spheres and/or other sectors' functions capture dictates the conditions of its own to the representatives of seized sectors, which involve compulsory income of capture initiators.

- A voluntary form of penetration. It is implemented through the joint efforts of different sectors of the financial market representatives, and aimed to increase each participant's share. This form of convergence involves pooling areas and functions of different sectors of the financial market representatives on a voluntary basis.

Although the options for synergies associated with the penetration of the representatives of some financial market segments into the spheres and/or functions of other market sectors may be different (for example, on the basis of informal agreements either on the basis of a contracts), this form of financial convergence presupposes benefits gained by all the parties of a convergence process. An example of the financial convergence, implemented on a voluntary basis, is the creation of financial conglomerates. In the framework of the representatives of financial market different sectors combined activity income resulted from such mergers (interpenetration) is redistributed among all financial conglomerate participants. Under such circumstances a share of different sectors of the financial market representatives that are members of the conglomerate increases (not decreases). Examples of voluntary forms of interpenetration, i. e. financial convergence implemented on a voluntary basis, could be referred also to a joint activity of insurance and investment companies.

Penetration of the investment company into the activities of the insurance company via the replacement of assets covering insurance reserves and own funds could happen on the basis of the investment outsourcing contract is also an example of voluntary form of financial convergence when an investment company voluntarily on a contract basis implements investment activities of an insurance company. At the same time, both parties receive additional benefits.

The financial convergence distinguished feature is that its members are subjects of the financial market various sectors, which were competing with each other severely forming financial conglomerates. For example, in developed markets, insurance companies and pension funds because of the high competition are forced to seek ways to improve the investment attractiveness for customers by investing in high-risk assets.

Financial conglomerate is the institutional and organizational form of its member-companies integration. These companies belong to financial market different sectors and integratory process is aimed to improve their competitiveness by combining capital and interpenetrating into each other's activities, which are characterized by certain similarity and interrelationship. 


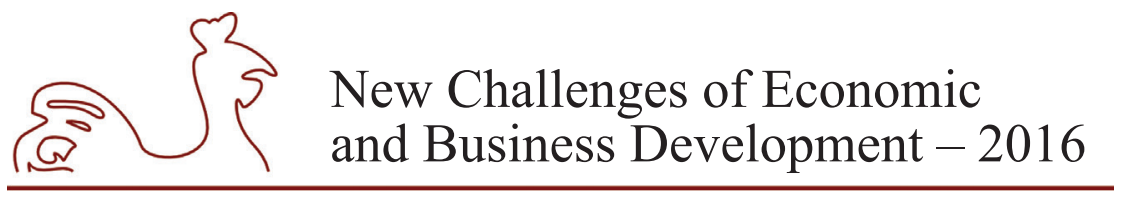

May 12-14, 2016, Riga, University of Latvia

In general, participants of the financial conglomerate can provide both financial and nonfinancial services, but the financial component should prevail in their activities.

Financial conglomerates as institutional and organizational form of the financial convergence has the following specifics:

1. Firms forming a financial conglomerate belong to different sectors of the financial market, but they tend to be linked functionally - the activity of each of conglomerate firms in some way is associated with the activities of other conglomerate member-companies. As a rule all conglomerate members, is functionally linked with the activities of the bank, included into the conglomerate.

2. Member-firms in a financial conglomerate activities interpenetration is based on various financial market sectors possible similarities. The parameters of similarity are: a) the client similarity, b) product likeliness, c) technology correspondence, d) marketing resemblance.

3. Incorporation of member-firms capital within the financial conglomerate may go on within different options. The first option - the union is based on the conglomerate assets control via the property right ownership or the cross-ownership. Firms incorporated into a conglomerate are either in possession of the parent company - holder of shares or other similar financial instruments, (Almeida H. V. \& Wolfenzon D., 2006; Chirinko R. S. \& Elston J. A., 2006; Bebchuk, L. A. et al. 2000).

In this case the actual exchange of resources does not occur (Repullo R., 2004) meanwhile a mechanism for companies participation in decision-making procedure that are of interest to each other is provided (Belozerov S. A., Pisarenko Zh. V., 2014). The second option of different financial institutions association into a conglomerate can be a system of contracts. Financial association in this case does not create new economic entity.

The third variant of joining means a mixed unification implementing together first and second options of association, i.e. an option figuring out a relationship of property right management and contractembodiment. In contrast to the industrial conglomerates, that in practice, occurred to be ineffective or inefficient, financial conglomerates have the following advantages: 1) they are less distanced from each other (all of them working at the financial market), 2) they have a high mutual similarity of activities, 3) they are using almost one resource - financial with high transaction speed and low transaction cost within the conglomerate.(Kuznetsova N. P. \& Pisarenko Zh. V., 2012).

4. Financial conglomerate is an independent form of its member-firms integration. As noted above, these undertakings are created in order to enhance the competitiveness of memberfirms belonging to different sectors of the financial market. However, their specific features are: a) reliance on the functional interaction of firms affiliated with the conglomerate and belonging to different financial market sectors, b) the similarity of the various sectors of financial market according to certain parameters, c) the possible capital copulation of those companies, which enter into financial conglomerate causing the independence of the institutional and organizational form financial convergence - forms of integration of firms belonging to the conglomerate.

5. Financial conglomerate - is an informal association of companies belonging to different sectors of the financial market. The informality of this association of companies is caused by the following phenomena. Firstly, products or services produced by the conglomerate can be simple copies from the member-companies belonging to the conglomerate that does 


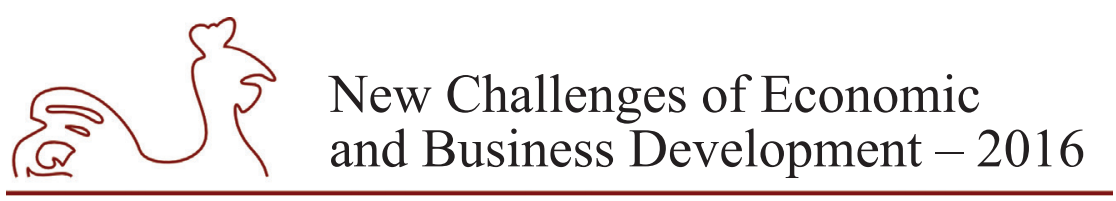

May 12-14, 2016, Riga, University of Latvia

not require rigid fixing ties of these companies within the conglomerate. Secondly, so far as consumers interests are the first priority and consumers make a choice of financial services in the first turn there are the following requirements necessary for consumer demand coverage: a) brand recognition, b) access to services both geographically and within certain price limits, c) wide range of well-assembled services offered. These requirements could be provided by financial conglomerate in case of the following factors influence: informal association of member-companies entering a conglomerate, the lack of entrenched ties firms within the conglomerate, flexibility of these firms and conglomerate's reaction to the market situation change. These processes, thereby, allow to maintain or improve competitiveness of member-firms and conglomerate as a whole.

Since the entry of companies into a conglomerate occurs either through the control of these companies, carried out on the basis of property rights, or/and through a common system of binding contracts without creating a new economic entity, the form of the conglomerate becomes quite blurred, and its structure - supposed to be unstable. That is why there are problems with the regulation of financial conglomerates at both the national, sub-national and international levels.

We use Boone indicator or in other words, the idea of "Performance-Conduct-Structure' (PCS) to investigate the process of financial convergence as the mechanism for competitive struggle and the competitiveness growth of individual companies and the companies belonging to the conglomerate. The choice of method is caused by the following consideration: its calculation does not require information on the cost of insurance (either pension) product. In addition, this indicator is able to catch the "competition on quality" and "competition on quantity".

The proposed approach allows its implication to evaluation of the financial conglomerate member and non-member-companies competitiveness. Moreover, the study analyzes not only the conglomerate's insurance component but also conglomerate's new component in the face of autonomous pension funds.

This approach allows to obtain the values of the Boone indicator for each insurer in the sample for a period of observation and to analyze these values within the product niche in which the degree of interchangeability of products is higher than that in the insurance products market in general. In addition, each insurance company (either pension fund) is characterized by the unique response of its business-model performance to its cost efficiency change. From this point of view, the proposed methodology becomes resistant to disruption of the two conditions of effective market structure hypothesis mentioned above.

The approach "Performance-Conduct-Structure' PCS as the indicator of competitiveness for the insurance market was proposed by Bikker (Bikker, J. 2012). It is calculated as a ratio of profit (or market share) to marginal costs.

However, the insurance companies marginal cost are implicit, and that's why they need to be evaluated only roughly. This method (to implement econometric techniques) of evaluation has become a function of the insurance companies costs in the translogarithmic form (translog cost function), where the costs will be included into the formula of "Performance-ConductStructure' PCS model as an indicator of company's performance. Classical cost function is as follows

$$
C=f(Y, P, t)
$$

Where: $\mathrm{Y}$ - is a vector of output (insurance policies, annuities, pension insurance programs), $\mathrm{C}$ - total costs, $\mathrm{P}$ - vector of input prices, $\mathrm{t}$ - year. 


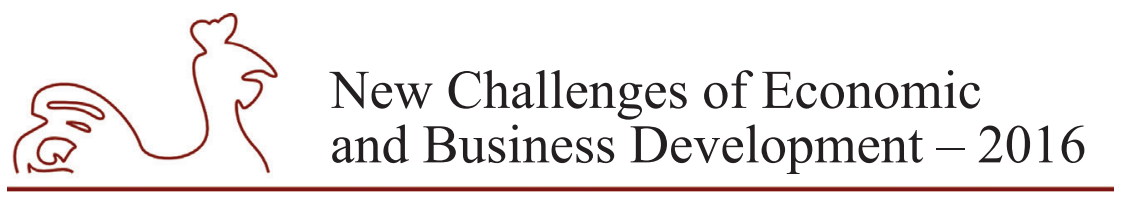

May 12-14, 2016, Riga, University of Latvia

In our case, under the empirical calculations, we do not have the parameter $\mathrm{P}$ value, so the model is simplified:

Equation (1)

$$
\ln O C_{s t}=\beta_{0}+\sum_{i=1}^{N} \beta_{Y i}\left(\ln Y_{i s t}-\ln Y_{i \bullet \bullet}\right)+\frac{1}{2} \sum_{i=1}^{N} \sum_{k=1}^{N} \beta_{Y i k}\left(\ln Y_{i s t}-\ln Y_{i \bullet \bullet}\right)\left(\ln Y_{k s t}-\ln Y_{k \bullet \bullet}\right)+\sum_{j=1}^{L} \gamma_{s} X_{j s t}+\varepsilon_{s t}
$$

OCst - total transaction costs of the company (minus the value of investments) $\mathrm{s}$ in year $\mathrm{t}$; Yist - the output of different types of products $i(i=1, \ldots, N)$;

$\mathrm{Xjst}$ - control variables or market variables that vary only in time-specific insurance market $(\mathrm{j}=1, \ldots, \mathrm{L})$;

$\varepsilon s t$ - regression error;

Yk - the geometric mean of output;

$\beta, \gamma-$ factors to be assessed.

To overcome multicollinearity effect transaction costs and output are presented in logarithmic form, which allows to carry out a comparison of the rates of growth indicators over time more accurately. Output (in logs) is presented as a deviation from their average values over the year.

$\ln Y i \bullet-$ average indicator for the output of type i product. Dots indicate the sub-indexes of the time series via the whole insurance companies' panel. It should be noted that the use of expressions of variables as deviations from their average values helps to distribute the linear and quadratic effects of the output on the costs and to simplify the interpretation of factors.

Marginal costs (equation 2) are calculated as follows (based on the equation (1):

$$
M C_{s i t}=\left(\frac{\partial \ln O C_{s t}}{\partial \ln Y_{i s t}}\right)\left(O C_{s t} / Y_{i s t}\right)=\left(\beta_{Y i}+\sum_{k=1}^{N} \beta_{Y i k}\left(\ln Y_{k s t}-\ln Y_{k . .}\right)\right)\left(O C_{s t} / Y_{i s t}\right)
$$

Where: $\mathrm{i}$ - the output of the company s in year $\mathrm{t}$.

The average marginal cost can be calculated (2) on the entire panel data, as well as on product classes or companies grouped according to specific features such as the amount of output a) average for all types of products (k) of the company $\mathrm{S}$, or a group of companies $\mathrm{S}$, b) price elasticity of the product, c) deviations of separate company output from the entire panel, d) the respective share of input-output.

To investigate the effect of the financial convergence one should pay attention to its specific features. A peculiar feature of the financial convergence (which was thought initially to be an instrument of the competitive struggle) is its characteristics as the mechanism of improving the competitiveness of entities (companies) from different financial market sectors using the similarity of the different financial market sectors. Following the above logic, we can formulate a hypothesis: the more competitive at the financial market should be the subjects of financial conglomerates, with access to common areas of relevant financial market sectors such as:

- client - consumer of products and services of different financial market sectors,

- products or services similar to the products and services offered by different sectors of the financial market, 


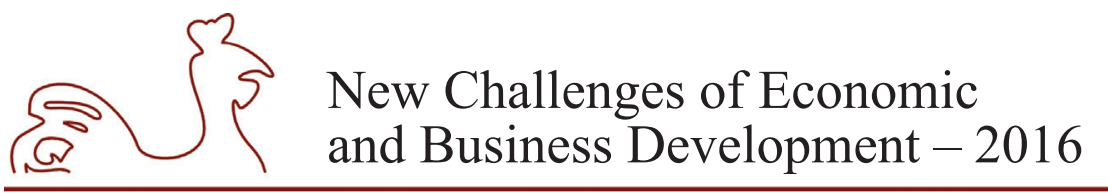

May 12-14, 2016, Riga, University of Latvia

- application of advanced technologies of creation, promotion and sale of certain products and services. These technologies are supposed to be already used effectively in other financial market sectors' activities,

- channels and markets for their products and services used by other financial market sectors.

\section{Case-study of financial convergence and conglomeration in the Russian emerging financial market}

To investigate the financial convergence as the mechanism of the competitiveness increase of the Russian insurance market, we analyzed some basic indicators of the annual accounting financial statements of twenty Russian insurance companies for the period 2009-2015 (Table 1). The choice of insurance companies was carried out from the Central Bank RF official list of insurance companies by the end of 2015 (31.12.2015). The selection of insurance companies for the analysis was completely random, based on the following criteria:

1) insurance company should be included into the rating of "Expert RA";

2) insurance company should belong to one of four group types (bancassurance groups, insurance groups, industrial groups and organizations that do not belong to any of the groups);

$3)$ insurance company is in the top five by annual turnover (2013 \& 2014) in each of the above mentioned entities. Insurance companies were selected regardless of the priority of its activity.

Table 1

Selected Russian insurance companies

\begin{tabular}{|c|c|c|c|}
\hline $\begin{array}{c}\text { Participants of } \\
\text { bancassurance groups }\end{array}$ & $\begin{array}{l}\text { Members of insurance } \\
\text { groups }\end{array}$ & $\begin{array}{l}\text { Members of industrial } \\
\text { groups }\end{array}$ & $\begin{array}{l}\text { Do not belong to the } \\
\text { group }\end{array}$ \\
\hline $\begin{array}{l}\text { "Rosgosstrakh" Joint } \\
\text { Stock Insurance } \\
\text { CompanyLTd }\end{array}$ & $\begin{array}{l}\text { "Ingosstrakh" Open } \\
\text { Joint Stock Insurance } \\
\text { Company }\end{array}$ & $\begin{array}{l}\text { "Transneft" Joint Stock } \\
\text { Insurance Company }\end{array}$ & $\begin{array}{l}\text { Moscow Joint Stock } \\
\text { Insurance Company }\end{array}$ \\
\hline $\begin{array}{l}\text { "RESO-Garantia" } \\
\text { Insurance Company" } \\
\text { Joint Stock Insurance } \\
\text { Company LTd }\end{array}$ & $\begin{array}{l}\text { "VSK "Insurance } \\
\text { Company" Joint Stock } \\
\text { Company }\end{array}$ & $\begin{array}{l}\text { "Surgutneftegas" } \\
\text { Joint Stock Insurance } \\
\text { Company LTd }\end{array}$ & $\begin{array}{l}\text { "YUZHURAL-ASKO" } \\
\text { Joint Stock Insurance } \\
\text { Company LTd }\end{array}$ \\
\hline $\begin{array}{l}\text { "Alpha Insurance" } \\
\text { Joint Stock Insurance } \\
\text { Company }\end{array}$ & $\begin{array}{l}\text { "Alliance" Joint Stock } \\
\text { Insurance Company }\end{array}$ & $\begin{array}{l}\text { "Chulpan" Joint Stock } \\
\text { Insurance Company }\end{array}$ & $\begin{array}{l}\text { "GUIDE" Joint Stock } \\
\text { Insurance Company }\end{array}$ \\
\hline $\begin{array}{l}\text { "VTB Insurance" } \\
\text { Joint Stock Insurance } \\
\text { Company LTd }\end{array}$ & $\begin{array}{l}\text { “ZHASO”Joint Stock } \\
\text { Insurance Society }\end{array}$ & $\begin{array}{l}\text { "Hephaestus "Joint } \\
\text { Stock Insurance } \\
\text { Company }\end{array}$ & $\begin{array}{l}\text { "PARIS" Joint Stock } \\
\text { Insurance Company }\end{array}$ \\
\hline $\begin{array}{l}\text { "UralSib" Joint Stock } \\
\text { Insurance Company }\end{array}$ & $\begin{array}{l}\text { "Energogarant" Joint } \\
\text { Stock Insurance Society }\end{array}$ & $\begin{array}{l}\text { "Joint Insurance } \\
\text { Company" Joint Stock } \\
\text { Insurance Company }\end{array}$ & $\begin{array}{l}\text { "Helios Reserve" Joint } \\
\text { Stock Insurance Society } \\
\text { LTd }\end{array}$ \\
\hline
\end{tabular}

Thus, even with a small sample of data an adequate representativeness to the study goal and objectives is achieved. It is worth noting that for some companies we failed to obtain 


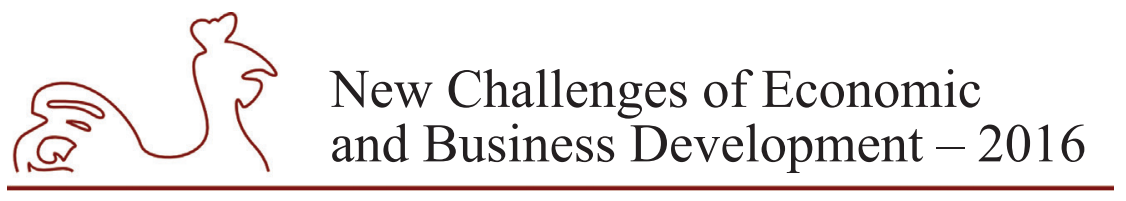

May 12-14, 2016, Riga, University of Latvia

necessary open access information. Taking into account the peculiarities of the Russian insurance market development there are no insurance companies with single medical insurance license in our sample. At the last stage of the selection procedure, those companies that did not provide public access to the necessary information in the form of public report were excluded. The participants of bancassurance groups include organizations belonging to groups that involve both banks and insurers. Members of insurance groups - a group of companies that include only insurance companies. Participants of industrial groups will assume those insurers that are part of the group, where industrial enterprises are included.

\section{The results of empirical analysis}

We evaluated the results of the Boone indicator equation, using panel data of the Russian Federation insurance companies for the period 2009-2015. Mind that that Boone indicator measures competitiveness. The more premium written (profit) depends on marginal costs, the higher the level of (insurance undertaking competitiveness) at the market. The available studies argue that the dependent variable in equation (1) is supposed to be the company's profit (market share adequate to premium written). We suppose in our study, that market shares of insurance companies under consideration are approximately equal. Hence the higher value of the Boone's indicator points to the more competitive and efficient company. For evaluation of results we also examined the alternative variant for company's competitiveness assessment, based on the reduction of financial results spread for those insurers which are (either are not) included into the financial insurance group.

Implementation of this instrument makes it possible to judge more accurately the results of financial convergence.

Companies' competitiveness assessment process consists of the following phases:

First phase. Marginal costs evaluation. To ensure the stability of the results regarding the Boone indicator the equation of costs was assessed in two different ways.

A first method (a boundary estimate) presupposes using the idea of maximum likelihood (ML) in the analysis of stochastic efficiency frontier (SFA calculated in a standard way both within the boundary estimate of the cost function for each insurance entity in each quarter. By construction, the index takes values ranging from 0 (least efficient insurance entity in a sample), up to 100 (the most efficient insurance entity.

The second method (the first non-boundary estimate) presupposes using the method of least squares (OLS) with robust standard errors.

Second phase. Preliminary assessment of the Boone indicator (for the panel as a whole). At this stage, the average assessment for all insurance companies and for all time-periods of observation is considered examining the impact on the cost effectiveness of one indicator insurance premiums written (MS, Market Share). The equation for marginal costs assessment MS is as follows (2).

To calculate the Boone indicator, we used the simplified empirical regression mode (equation 3) (Bikker, 2012):

$$
m s s t=\alpha+\beta t m c s t+\Sigma t=1, \ldots,(T-1) \gamma t d t+u s t
$$




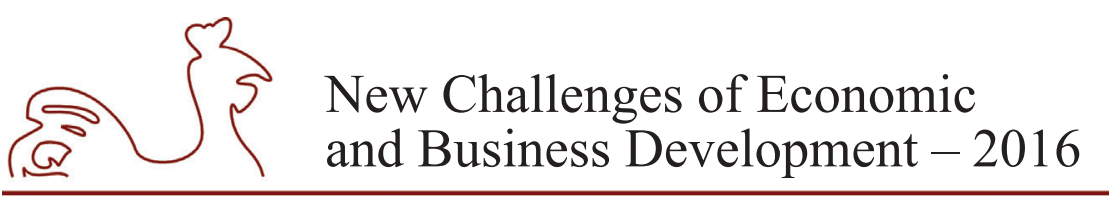

May 12-14, 2016, Riga, University of Latvia

where

msst - premium written share (market share) of insurance company S at time period t;

$\beta \mathrm{t}$ - parameter of competitiveness indicator (insurance company's effectiveness), supposed to be negative, so far as we propose that effective insurance company tend to increase its premium written share (market share);

mcst - insurance company's S marginal costs at time period t;

dt - a time dummy

ust - an error term.

Note that the parameter $\beta_{\mathrm{t}}$ supposed to be negative, under the assumption that an efficient company increases its market share (increase insurance premium written). $\beta$ t also depends on marginal cost, that is an indicator of competitiveness (either its absence). Additional condition for this model relevance is the homogeneity of the service/product (in this case the insurer's insurance portfolio), which is valid for the Russian insurance market.

Boone indicator will be calculated by the following formula (4)

$$
B O O N E_{1, R, j}=\frac{\partial \ln R_{i t}}{\partial \ln M C_{j, i t}^{L N S}}=\beta_{j, R}
$$

Where: $\mathrm{R}$ is replaced by MS

Table 2 represents Boone indicator values $(\beta)$ counted on the marginal and average costs basis.

(dependant variable - insurance premium written $\%$ in the sample)

Table 2

Values $(\beta)$ counted on the marginal and average costs basis

\begin{tabular}{|c|c|c|c|c|c|c|c|c|}
\hline \multicolumn{5}{|c|}{ Panel 1. Bancassurance groups } & \multicolumn{4}{|c|}{ Panel 2. Insurance groups } \\
\hline Indicators & \begin{tabular}{|l} 
Assessment \\
method
\end{tabular} & SFA & OLS & GMM & $\begin{array}{l}\text { Способ } \\
\text { оценки }\end{array}$ & SFA & OLS & GMM \\
\hline \multirow[t]{2}{*}{$\begin{array}{l}\text { Marginal costs } \\
(\mathrm{MC})\end{array}$} & A & $\begin{array}{l}-0.128^{* * *} \\
(0.015)\end{array}$ & $\begin{array}{l}-0.170 * * * \\
(0.015)\end{array}$ & $\begin{array}{l}-0.185^{* * *} \\
(0.015)\end{array}$ & $\mathrm{a}$ & $\begin{array}{l}-0.056^{* * * *} \\
(0.017)\end{array}$ & \begin{tabular}{|l|}
-0.071 \\
$(0.016)$
\end{tabular} & \begin{tabular}{|l}
$-0.097 * * *$ \\
$(0.015)$
\end{tabular} \\
\hline & 6 & \begin{tabular}{|l}
$-0.147 * * *$ \\
$(0.043)$ \\
\end{tabular} & $\begin{array}{l}-0.180^{* * * *} \\
(0.040) \\
\end{array}$ & $\begin{array}{l}-0.185^{* * * *} \\
(0.038) \\
\end{array}$ & 6 & \begin{tabular}{|l}
$-0.014 * * *$ \\
$(0.037)$ \\
\end{tabular} & \begin{tabular}{|l}
$-0.049 * * *$ \\
$(0.035)$ \\
\end{tabular} & \begin{tabular}{|l}
$-0.054 * * *$ \\
$(0.035)$ \\
\end{tabular} \\
\hline \multirow[t]{2}{*}{$\begin{array}{l}\text { Average costs } \\
\text { (AC) }\end{array}$} & $\mathrm{a}$ & & $\begin{array}{l}-0.404^{* * *} \\
(0.013) \\
\end{array}$ & & $\mathrm{a}$ & & \begin{tabular}{|l}
$-0.014 * * * *$ \\
$(0.015)$ \\
\end{tabular} & \\
\hline & 6 & & $\begin{array}{l}-0.381 * * * \\
(0.036)\end{array}$ & & 6 & & \begin{tabular}{|l}
$-0.067 * *$ \\
$(0.035)$ \\
\end{tabular} & \\
\hline \multirow{2}{*}{$\begin{array}{l}\text { SFA(Cost } \\
\text { effectiveness } \\
\text { index) }\end{array}$} & $\mathrm{a}$ & \begin{tabular}{|l}
$-0.110^{* * * *}$ \\
$(0.025)$ \\
\end{tabular} & & & $\mathrm{a}$ & \begin{tabular}{|l}
$-0.111^{* * *}$ \\
$(0.025)$
\end{tabular} & & \\
\hline & 6 & $\begin{array}{l}-0.057 * * * \\
(0.046)\end{array}$ & & & б & $\begin{array}{l}-0.049 * * * \\
(0.060)\end{array}$ & & \\
\hline
\end{tabular}


New Challenges of Economic and Business Development - 2016

May 12-14, 2016, Riga, University of Latvia

\begin{tabular}{|c|c|c|c|c|c|c|c|c|}
\hline \multicolumn{5}{|c|}{ Panel 3. Industrial groups } & \multicolumn{4}{|c|}{ Panel 4. Non-members } \\
\hline Indicators & $\begin{array}{l}\text { Assessment } \\
\text { method }\end{array}$ & SFA & OLS & GMM & $\begin{array}{l}\text { Способ } \\
\text { оценки }\end{array}$ & SFA & OLS & GMM \\
\hline \multirow[t]{2}{*}{$\begin{array}{l}\text { Marginal } \\
\text { costs }(\mathrm{MC})\end{array}$} & $\mathrm{a}$ & $\begin{array}{l}-0.214 * * * \\
(0.016) \\
\end{array}$ & $\begin{array}{l}-0.190 * * * \\
(0.016)\end{array}$ & $\begin{array}{l}-0.111 * * * \\
(0.017)\end{array}$ & $\mathrm{a}$ & $\begin{array}{l}-0.152 * * * \\
(0.013)\end{array}$ & $\begin{array}{l}-0.161 \\
(0.013)\end{array}$ & $\begin{array}{l}-0.260 * * * \\
(0.013)\end{array}$ \\
\hline & 6 & \begin{tabular}{|l}
$-0.225 * * *$ \\
$(0.025)$ \\
\end{tabular} & $\begin{array}{l}-0.216^{* * *} \\
(0.035) \\
\end{array}$ & $\begin{array}{l}-0.156^{* * *} \\
(0.038) \\
\end{array}$ & 6 & $\begin{array}{l}-0.014 * * * \\
(0.037) \\
\end{array}$ & \begin{tabular}{|l}
$-0.049 * * *$ \\
$(0.035)$ \\
\end{tabular} & $\begin{array}{l}-0.054 * * * \\
(0.035)\end{array}$ \\
\hline \multirow[t]{2}{*}{$\begin{array}{l}\text { Average } \\
\text { costs (AC) }\end{array}$} & $\mathrm{a}$ & & $\begin{array}{l}-0.390 * * * \\
(0.013)\end{array}$ & & $\mathrm{a}$ & & \begin{tabular}{|l|}
$-0.452 * * *$ \\
$(0.015)$ \\
\end{tabular} & \\
\hline & 6 & & $\begin{array}{l}-0.346^{* * *} \\
(0.029)\end{array}$ & & 6 & & $\begin{array}{l}-0.401 * * * \\
(0.035)\end{array}$ & \\
\hline $\begin{array}{l}\text { SFA(Cost } \\
\text { effectiveness } \\
\text { index) }\end{array}$ & $\begin{array}{l}a \\
\sigma\end{array}$ & $\begin{array}{l}-0.133 * * * \\
(0.052) \\
\\
-0.112 * * * \\
(0.025)\end{array}$ & & & 6 & $\begin{array}{l}-0.100 * * * \\
(0.025) \\
\\
-0.098 * * * \\
(0.025)\end{array}$ & & \\
\hline
\end{tabular}

Notes:

1) Assessment values on 1\%, 5\% and $10 \%$ levels adequately ***, ** and *.

2) Robust standard errors of coefficients.

The results of two-ways models of assessment with fixed effects (two-way fixed effects), are represented. The evaluation of one (from three) alternative methods of cost effectiveness (AC, MC either SFA-index) is related to aggregate insurance premium written.

Marginal costs MC were calculated on the basis of empirical cost function estimate. Empirical cost function was estimated in the framework of stochastic boundary effectiveness (SFA), and with the help of OLS (least squares method) and GMM.

3) Average costs are not dependant from the marginal costs methods of calculation

4) Two alternative estimates: 1 - estimate of current value of costs impact on the dependant variable with the help of two-steps GMM with fixed effects (the tool is the previous costs lag); 2 - estimate of summing-up effect of the previous four costs lags on the dependant variable with the help of ordinary (usual) OLS with fixed effects

Competitiveness Boone indicator assessment lies within $-0.24--0.13$ (are significant on $1 \%$ level) figures out on the strong economic effect. Average costs AC influence MS as twice as much impact compared to MC effect.

Boone indicator analysis for the insurance companies belonging to different financial groups either being individual insurance entities. At this phase the important objective of this study is figured out. According to this objective we argue that financial convergence is one of the competitiveness increase factor.

It is assumed that the Boone indicator will be negative, and the existing competitiveness is effective, as soon as the competitiveness of insurance companies - members of the group is higher than the individual insurance company's competitiveness.

The third phase. Competitiveness analysis uses the coefficient of variation of insurance premium written for the same panel data. The coefficient of variation characterizes a relative measure of the deviation of the measured values from the arithmetic mean. The higher the value of the coefficient of variation, the relatively greater dispersion and less uniformity of values under consideration. Therefore, the larger the coefficient of variation, the greater the uncertainty 


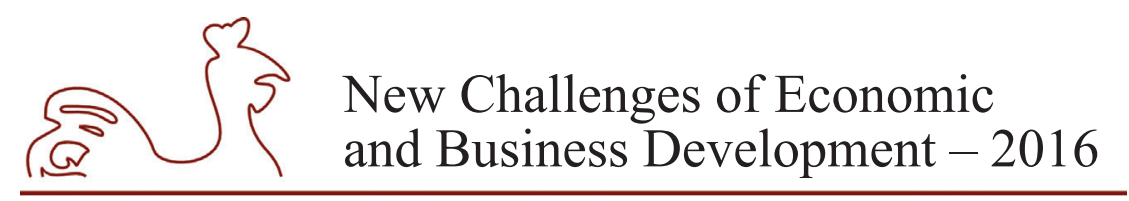

May 12-14, 2016, Riga, University of Latvia

and higher risk exposure. Hence coefficient of variation shall be calculated by the following formula (5):

$$
C V=\frac{\sigma}{\hat{k}}
$$

Where

$\boldsymbol{\sigma}$ - standard deviation value;

$\hat{k}$ - The expected (mean) value.

The coefficient of variation of the insurance undertaking financial result's activity (net profit) is calculated by Formula 5. The standard deviation for the period $(\sigma)$ is calculated by the formula 6 .

$$
\sigma=\sqrt{\frac{\sum_{i=1}^{n}\left(k_{i}-\bar{k}\right)^{2}}{n-1}}
$$

Where ki - financial result of period i

$\mathrm{k}$ - Average financial result for $\mathrm{n}$ periods,

$\mathrm{n}$ - number of periods

The amount of the insurance premium written and its fluctuations exhibit insurer's sales strategy as well as risks associated with this strategy. Before calculating the coefficient of variation, consider the dynamics of the indicator "written premium" for four groups of companies through the 2010-2015 period. These data are shown in Table 3.

Table 3

Average premium written for the group " in the selected sample, (thousand rubles)

\begin{tabular}{|l|r|r|r|r|}
\hline & $\begin{array}{c}\text { Participants of } \\
\text { bancassurance groups }\end{array}$ & $\begin{array}{c}\text { Members of insurance } \\
\text { groups }\end{array}$ & $\begin{array}{c}\text { Members of industrial } \\
\text { groups }\end{array}$ & $\begin{array}{c}\text { Do not belong to the } \\
\text { group }\end{array}$ \\
\hline 2015 & 26589956 & 30265112 & 3988734 & 5139753 \\
\hline 2014 & 23563949 & 30683835 & 4178877 & 5236958 \\
\hline 2013 & 49934557 & 31938774 & 4408898 & 4491415 \\
\hline 2012 & 44523568 & 25729890 & 3858572 & 4204454 \\
\hline 2011 & 34043782 & 21056049 & 3463945 & 3443391 \\
\hline 2010 & 32187023 & 19591736 & 3122583 & 3194518 \\
\hline
\end{tabular}




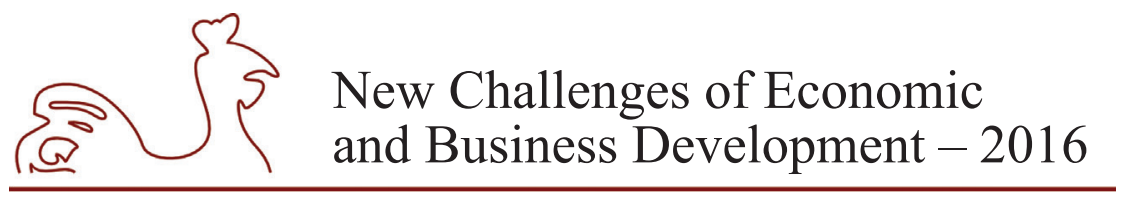

May 12-14, 2016, Riga, University of Latvia

Data of Table 3 are converted into Figure 1.

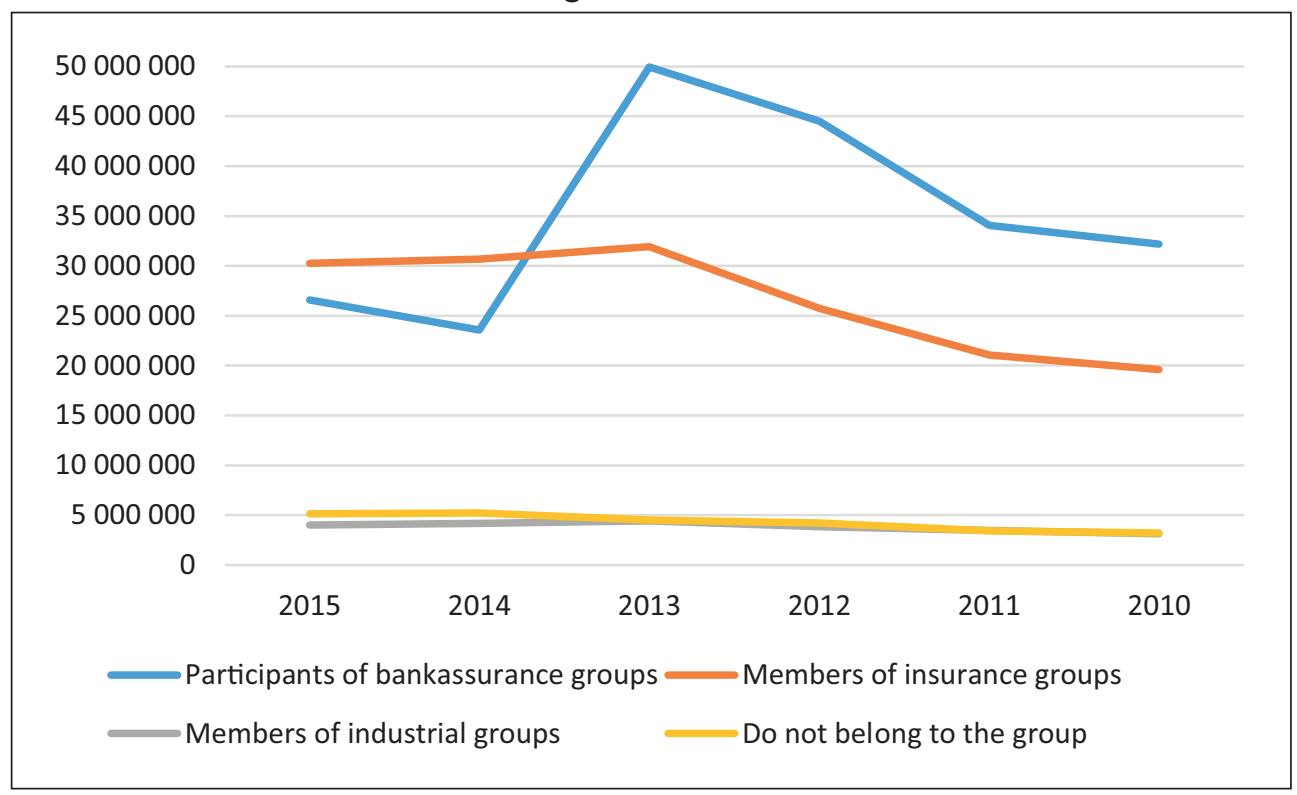

Fig. 1. Average premium written for the group" in the selected sample, (thousand rubles)

Figure 1 data show that premium written for bancassurance group and insurance group participants is significantly greater than that of members of industrial groups and independent insurers. This suggests that bancassurance group and insurance group participants are significantly larger insurers and their market share in the Russian market is significant. In order to assess the competitiveness via the estimate of premium written fluctuations we calculated the coefficients of variation of premiums written for each group of insurers. The results are shown in table 4.

Coefficient of variation of premium written for the selected sample

Table 4

\begin{tabular}{|c|r|r|r|r|}
\hline $\begin{array}{c}\text { Premium written } \\
\text { coefficient of variation }\end{array}$ & $\begin{array}{c}\text { Participants of } \\
\text { bancassurance } \\
\text { groups }\end{array}$ & $\begin{array}{c}\text { Members of } \\
\text { insurance groups }\end{array}$ & $\begin{array}{c}\text { Members of } \\
\text { industrial groups }\end{array}$ & $\begin{array}{c}\text { Do not belong to } \\
\text { the group }\end{array}$ \\
\hline $2009-2015$ & $26.60 \%$ & $15.77 \%$ & $8.93 \%$ & $14.78 \%$ \\
\hline 2015 & $26.01 \%$ & $19.40 \%$ & $9.01 \%$ & $17.29 \%$ \\
\hline 2014 & $27.90 \%$ & $18.90 \%$ & $11.90 \%$ & $18.90 \%$ \\
\hline 2013 & $28.76 \%$ & $16.50 \%$ & $8.77 \%$ & $16.50 \%$ \\
\hline 2012 & $24.11 \%$ & $15.09 \%$ & $9.11 \%$ & $15.09 \%$ \\
\hline 2011 & $24.91 \%$ & $15.97 \%$ & $9.75 \%$ & $14.22 \%$ \\
\hline 2010 & $24.22 \%$ & $12.77 \%$ & $8.00 \%$ & $11.22 \%$ \\
\hline 2009 & $23.24 \%$ & $11.65 \%$ & $9.14 \%$ & $10.73 \%$ \\
\hline
\end{tabular}

One could observe from the Table 4 data that the highest premium written coefficient of variation is acquired by the insurers undertaking belonging to bancassurance groups. This could 


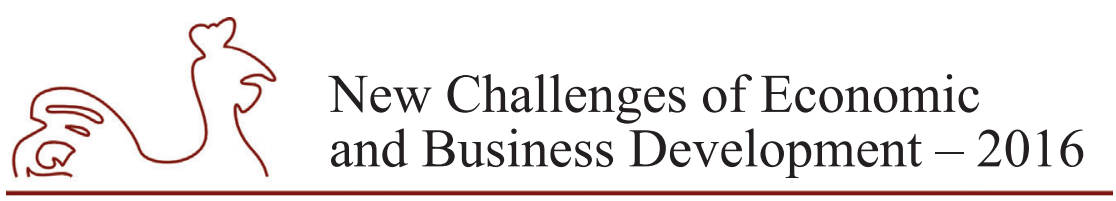

May 12-14, 2016, Riga, University of Latvia

be explained by the growth of premiums written during the 2011-2013 period. The latter is certainly supposed to be a positive trend, so far as from an economic point of view, does not pose any risk. The decline in premiums written in 2014 can be explained by the fact that a significant portion of the insurance premium in this group of insurers is resulted from the bancassurance implementation. In 2014-2015 one could observe a decline in bank loans, which reduced the volume of insurance products sold through the bank sales channel. The organizations belonging to industrial groups had least risk of fluctuations in the volume of premiums written through the period under consideration.

\section{Conclusions}

The main results consider the following ideas:

1) financial convergence is the interpenetration of competing financial entities activities occurring in aggressive and voluntary forms. These financial market various sectors actors activities is based on their interrelationship and a certain similarity;

2) financial conglomerate is the institutional and organizational form of its membercompanies integration. These companies belong to financial market different sectors and integratory process is aimed to improve their competitiveness by combining capital and interpenetrating the parameters of similarity are: clients' and products' technology, marketing, capital incorporation of member-firms;

4) the proposed method of Boone "effective competition" indicator is implemented for empirical study of the financial convergence as the mechanism of the competitiveness increase of the Russian emerging insurance market twenty biggest financial-insurance groups. Analyzing some basic indicators of the annual accounting financial statements of these entities for the period 2009-2015 we argue that insurance companies being the members of financial conglomerate have higher competitiveness than individual firms and simultaneously they cause the increase of the financial conglomerate's competitiveness as a whole;

5) implication of Boone indicator showing the competitiveness of insurance groups and insurance companies in the Russian insurance market allows to identify four insurancefinancial groups: insurance companies, with core bancassurance business, with core insurance business, industrial-insurance groups and some individual insurers not included into the group;

6) bancassurance groups are characterized by the highest Boone indicator values. This classification shows the consistency of the selected methodology for assessing the market power of the examined banks' dominance in the Russian financial system, which causes a large share of embodied insurance. The biggest competition is observed between insurance companies - non-members of the group; less intense competition is characteristic for insurance and industrial groups;

7) the proposed hypothesis is confirmed only partly so far as individual insurance companies being less competitive than financial conglomerate member firms during economic 


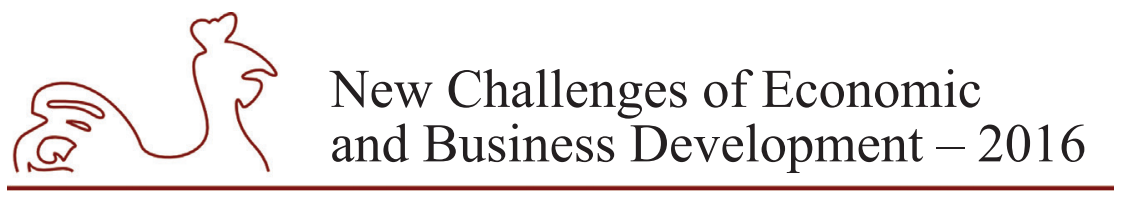

May 12-14, 2016, Riga, University of Latvia

development up-swing appeared to be more competitive during economic development down-swing having less risks exposure.

\section{Bibliography}

Adam K., Jappelli T., Menichini A. et al., 2002. Analyze, Compare and Apply Alternative Indicators and Monitoring Methodologies to Measure the Evolution of Capital Market Integration in the European Union, Working Paper. Center for Studies in Economics and Finance. Italy: University of Salerno, 2002, 66 p. [online]. Available at: URL: http://www.ec.europa.eu/internal_market/economic [Accessed March 2016].

Almeida H. V., Wolfenzon D., 2006. A theory of pyramidal ownership and family business groups. Journal of Finance, 2006, № 61, pp. 2637-2680.

Baele L., Ferrando A., Hoerdahl P. et al. Measuring Financial Integration in the Euro Area. European Central Bank. Occasional Paper Series, 2004, No. 14, 98 p. [online], [cited 29 June 2015]. Available at: URL: http://www.ecb.europa.eu/pub/pdf/scpops/ecbocp14.pdf [Accessed December 2015].

Bain J. S., 1951. Relation of profit ratio to industry concentration: American manufacturing 1936-

Bebchuk L. A., Kraakman R., Trianis G., 2000. Stock pyramids, cross-ownership and dual class equity. R. K. Morck (ed). Concentrated Corporate Ownership. Chicago: University of Chicago Press, 2000.

Belozerov S. S., Pisarenko Zh. V., 2014. Testirovanie rossiiskogo strahovogo rinka na nalichie konvergentsii [Empirical analyses for financial convergence of Russian insurance market]. Ekonomika Regiona (Economy of region), 2014, No. 3, pp. 198-208.

Bikker J., 2012. Performance of the life insurance industry under pressure: efficiency, competition and consolidation, DNB Working Paper No. 357. AMSTERDAM. The Netherlands.

BohnertA., Born P., Gatzert N., 2014. Dynamic hybrid products in life insurance: assessing the policyholders' viewpoint, Working paper. Department of Insurance Economics and Risk Management. Nürnberg: Friedrich-Alexander-University (FAU) of Erlangen, 2014. [online]. Available at: URL: http://www. vwrm.rw.fau.de/DHP_Policyholder_2014-09-01_WP.pdf [Accessed December 2015].

Boone J., 2008. A new way to measure competition. Economic Journal, 188, 1245-1261.

Brunnermeier M. K., Crockett A., Goodhart Ch. et al., 2009. The Fundamental Principles of Financial Regulation. New York: International Center for Monetary and Banking Studies, 2009, $182 \mathrm{p}$.

Chirinko R. S., Elston J. A., 2006. Finance, control and profitability: the influence of German banks. Journal of Economic Behavior \& Organization, 2006, № 59, p. 69-88.

Claessens, S., 2009. Competition in the Financial Sector: Overview of Competition Policies. IMF Working Paper WP/09/45, International Monetary Fund.

Dowrick St., Bradford J. D., 2003. Globalization and Convergence. Globalization in Historical Perspective. USA: University of Chicago Press, 2003. [online]. Available at: URL: http://www.nber.org/books/ bord03 [Accessed December 2015].

Fabozzi F. J., Choundhry M., 2004. The Handbook of European Structured Financial Products. USA: Wiley, 2004, $800 \mathrm{p}$.

Fein Melanie L., 2007. The Convergence of Financial Products and the Implications for Regulatory Convergence. Can We Improve Policy Making in Financial Services Regulation. USA: Washington, D.C. 2007.

Hatanaka H., 2013. Product Strategies for the Corporate Market. Group Pension Insurance. FALIA Seminar in Japan. Product Development Strategy. Tokio, 2013. [online]. Available at: URL: http:// www.falia.or.jp/english/materials/pdf/2013/201309 [Accessed February 2016].

Hay D. A., and Liu G. S., 1997. The efficiency of firms: what difference does competition make? The Economic Journal, 107, pp. 597-617. 


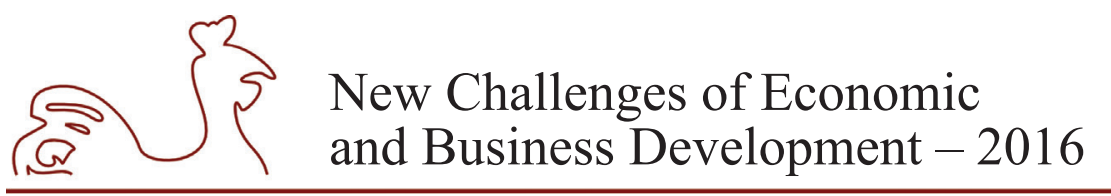

May 12-14, 2016, Riga, University of Latvia

Kallgren C. A., Raymond R. R, Cialdini R. B. A focus theory of normative conduct: when norms do and do not affect behavior. Personality and Social Psychology Bulletin, 2000, № 26, pp. 1002-1012.

Kuznetsova N. P., Chernova G. V., 2001. Konvergentia v sfere finansovih uslug [Convergence in financial services industry]. Vestnik Sankt-Peterburgskogo Universiteta (Vestnik of St. Petersburg University), 2001, Ser. 5. Economika, Vipusk. 4, No 29.

Kuznetsova N. P., PisarenkoZh. V., 2012. Insurance Activities Governance: World Experience Implementation - Proceedings of International Scientific Conference «New Challenges Of Economic And Business Development». Riga: University of Latvia, 2012, pp. 147-154.

Mamonov M.E., 2014. Microeconomic modification of an industry-wide Boone indicator: Market power of Russian banks revisited. - SPb, VSHE, RFFI grant №14-0600472 2013.

Masaharu K. US and European Financial Conglomerates Organizations and Their Implications for Japan and other Large Diversified Financial Firms in Asia. - Ritsumeikan: Asia Pacific University. [online]. Available at: URL: http://www.apu.ac.jp/rcaps/uploads/fckeditor/publications/journal/ RJAPS_V21_Kuhara.pdf [Accessed February 2015].

Mason E. S., 1939. Price and Production Policies of Large-Scale Enterprise, American Economic Review 29 (1, Supplement), 61-74. [online]. Available at: http://www.jstor.org/stable/1806955[Accessed February 2015].

Massimo M. Rehman Z. Information flows within financial conglomerates: Evidence from the banksmutual funds relationship. Journal of Financial Economics, 2008, 89 (2), p. 288-306.

Pisarenko Zh. V., 2013. Osobennosti bankosreahovaniya v Rossii: zachita interesov potrebitelei sloznih finansovih uslug [Special Features of Bancassurance in Russia: Consumer Protection in Complex Financial Services]. Aktualnie problem ekonomiki I prava (Actual problems of Economy and Legislation), 2013, No. 2, pp. 140-146.

Popescu A., Bikker, J., 2014. Efficiency and competition in the Dutch non-life insurance industry: Effects of the 2006 health care reform. DNB Working Paper No. 438. 2014. AMSTERDAM. The Netherlands. Available at: http://www.dnb.nl/en/binaries/Working Paper 0438_tcm47-312516.pdf [Accessed February 2015].

Raith M., 2003. Competition, risk, and managerial incentives. The American Economic Review 93, 14251436.

Rajan R. G., Zingales L., 2000. The Governance of the New Enterprise, in X. Vives (ed.) Corporate Governance: theoretical and empirical perspectives, Cambridge University Press: Cambridge, 2000.

Repullo R., 2004. Capital requirements, market power, and risk-taking in banking. Journal of Financial Intermediation, 2004, Vol. 13, № 4, p. 156-182.

Schmid M. M., Walter I., 2008. Do financial conglomerates create or destroy economic value? Journal of Financial Intermediation, 2008, No. 2, pp. 77-84.

Shakhpazov K.A., 2012.Finansovie conglomerati v zerkalestatistiki [Financial Conglomerates from statistical point of view].Vestnik INGEKONA = Vestnik of INGEKON, 2012, Ser.: Economics, No. 3, pp. 431-433.

Slijkerman J. F, Schoenmaker D, de Vries, C. G., 2005. Risk Diversification by European Financial Conglomerates (No. TI 05-110/2). Tinbergen Institute Discussion Paper Series, 2005. [online]. Available at: http://hdl.handle.net/1765/7426 [Accessed February 2015].

Tabak B., Fazio D., Cajueiro D., 2012. The relationship between banking market competition and risk taking: Do size and capitalization matter? Journal of Banking and Finance, 36 (12), 3366-3381. 


\title{
ANALYSES OF THE INFLUENCES OF ORGANIZATIONAL AND GROUP PROCESSES IN RISK MANAGEMENT RELATED TO MEANINGFULNESS OF RISK ASSESSMENTS
}

\author{
Richard Mayr, University of Latvia, Latvia ${ }^{1}$
}

\begin{abstract}
This dissertation demonstrates that working company-wide risk management systems are never the responsibility of a single risk manager. In fact, the implementation of effective risk management processes always involves numerous individual responsibilities and employees, all of whom must make their own contribution within the organization. The respective organization structures play a key role in supporting the risk management processes. Socio-psychological aspects must also be taken into account during the evaluation and assessment of risk portfolios. Indeed, every single hierarchy level, extending from non-managerial employees, through department managers and top management, to supervisory boards, must play a part in order to ensure that risk management within the company succeeds. The risk manager plays a special role in this, whether this is his sole or partial responsibility. Categorized by responsibilities and roles, the letter highlights the extent to which their activities are to be reflected in risk management, the interaction with other roles within the risk management process and how risk management is implemented in the company's organizational structures and strategies. Individual and group-based decision-making processes are accorded just as much attention for the decision making as the influences from the social roles of the members of the process. Particular attention is paid to the leadership qualities of each person in charge. The incentive for all employees to develop their risk awareness, display sensitivity with respect to risks, and relay information relevant to risks can be essentially found in the leadership roles and in the leadership qualities of all managerial positions - from supervisors to top management. To measure the aspects described above, a research design on the empirical study on influences of organizational and group processes on risk management was established.

The research design is based upon the comparison of expert and daily practitioner opinions. Ten wellknown experts completed the survey "Expert Interviews with Structured Survey on the Latent Exogenous Variables" and 131 professionals completed "Case Study with Structured Survey on the Cause Effect of the Endogenous Variables". The results of these two surveys were analysed.

Initial analysis shows, none of the dependent or independent variables may be clearly removed from the model, although there seems to be a substantial discrepancy between the expert opinions and the daily routine of the professionals. Additional statistical analysis will provide further insights into this divergence.
\end{abstract}

Key words: Risk Management, Risk Assessment, Fat Tails, Organizational Theory, Group Processing JEL code: $\mathrm{C} 01$

' Corresponding author - e-mail address: mail@richardmayr.de 


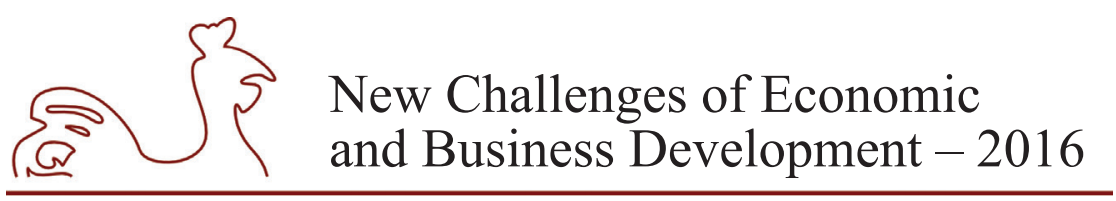

May 12-14, 2016, Riga, University of Latvia

\section{Introduction}

The implementation of effective risk management processes always involves numerous individual responsibilities and employees. All of them must make their own contribution within the organization. The respective organization structures play a key role in supporting the risk management processes. Individual and group-based decision-making processes are accorded just as much attention for the decision making as the influences from the social roles of the members of the process. In particular, by handling quality-based risk measurements or stochastic models and simulations will not work (e.g. fat tails) the risk assessment have to be done by human judgment.

The main hypothesis of this research paper is that the group size in relation to the organizational hierarchy of the decision maker is important for the meaningfulness of risk assessments. At the bottom-level of organizational hierarchy the groups can be sized at least to one decider. On top-level trust and information groundwork should be that strong to size to only one decider. Larger groups have to be built for risk assessments in mid management. There are ways for calculating bigger sizing than one. When groups are too small the distribution of the risk assessments is higher than by midsized groups. On the other hand, building large groups will only increase the processing time, not the quality of results.

\section{Research results and discussion}

Working company-wide risk management systems are never the responsibility of a single risk manager. In fact, the implementation of effective risk management processes always involves numerous individual responsibilities and employees, all of whom must make their own contribution within the organization. Indeed, every single hierarchy level, extending from non-managerial employees, through department managers and top management, to supervisory boards, must play a part in order to ensure that risk management within the company succeeds. However, it is important to note that the factors involved in this success are not limited to internal forces only, as they also include external employees and consultants (certified public accountants, auditors, and external institutions) who have a decisive influence on all aspects related to a company's risks.

It is precisely these external parties that frequently take over risk management processes and analyses, and they enjoy such a high level of exposure while doing so that one is left with the impression that risk management is the exclusive domain of consultants and supervisory bodies. In reality, however, it is necessary for the risk management process to be influenced by the company's entire business process, which in turn means that a corporate organization will always have involved and non-involved - or internal and external - positions and offices that are relevant to risk management (Brünger Ch., 2009). In fact, every position within an organization is affected by risk management, and can have a significant impact on the way active risk management approaches evolve. This widespread interrelation makes it necessary to define a clear strategy and structure in order to be able to establish clear risk management roles and responsibilities within a company.

Key characteristics of the organization theory are based on exactly these strategies and structures, which can be filled by the responsibilities and roles. 


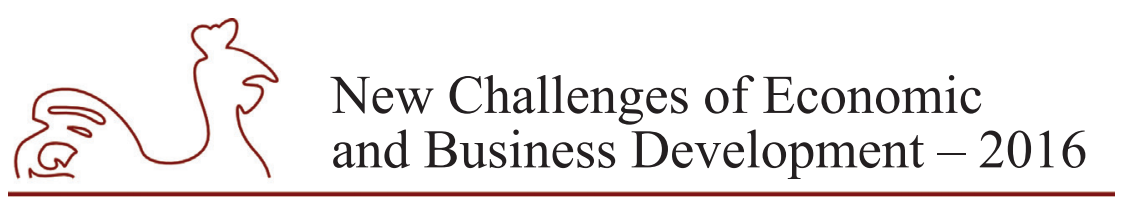

May 12-14, 2016, Riga, University of Latvia

The individual stands at the center: the better he or she is integrated and the better the specific training, the better the output will be. The more intensive the analysis and processing of groupdynamic processes, the better the groundwork for effective interpretation. Different personnel combinations and group sizes for the decision-making process can produce different results. The proper configuration ensures efficiency of the group. Top decision making is achieved if a group is formed where the members do not behave cohesively and where the members take various roles (expert competencies mixed with decision makers and participants from the technical departments) (cf. Janis I.L., 1977). Large groups (bigger than 3-4 members) do not necessarily bring more facets into decision making, but rather typically lead members to align themselves with the group opinion if it does not match their own (Asch S., 1955).

The information technology also plays an important role. The amount of data of the individual control points in risk management can simply not be handled without a sophisticated IT organization. See also "The way information flows through the organization affects work processes and outcomes, so knowing organization theory can help IT specialists identify, understand and serve the organization's informational needs as they design and promote the use of their information systems." (Hatch M.J., 2006).

But let us get back to the strategies in regard to which the only characteristic that must be defined is that they must be in a continuous state of evolution: "the improvement of the original leading thought in accordance with continually changing situations" (Hinterhuber H.H., 2004). This makes it all the more important for there to be a clear structure when a strategy itself may undergo all manners of evolutionary adjustments. Employees can only identify with their responsibilities if they know what these are exactly, and this is of central importance.

\section{Leadership as part of a working risk management}

Leadership, beside the organizational structure, plays an essential role in the success and sustainability of a working risk management system. Within this context, the risk awareness (i.e. risk identification and assessment) and risk sensitivity of each level of responsibility creates the crucial added value in a company's organizational structure. Each role inside and outside a company is strongly affected by the leadership displayed by the next higher role. In fact, the impact of this leadership is even greater than that involved in processes that rely on strictly factual information and are directly measurable. However, it is also important to note that negative leadership behaviour related to risk management does not have an immediate effect on the success or profits of a company. Management figures should be aware that the simple statement of their position frequently has a disproportional impact during group-oriented decision making processes. Group members who are not of a strong opinion on the matter simply adopt their position. The decision making process is thus not based on facts, opinions, expert testimony or discussion, but rather on an assumed consolidation of a previously held opinion (Hovland C.I., 1951). Indeed, the damage caused by flippant or ignorant behaviour in this regard often becomes evident only several months thereafter (if it does at all, as missing or poor risk assessments do not necessarily mean that something will happen).

At this point, it is important to mention that leadership should not be simply classified as "good" and management as "bad" (Kotter J.P., 1990), as both play a crucial role in terms of risk management and have an impact on results. Nevertheless, management variables are 


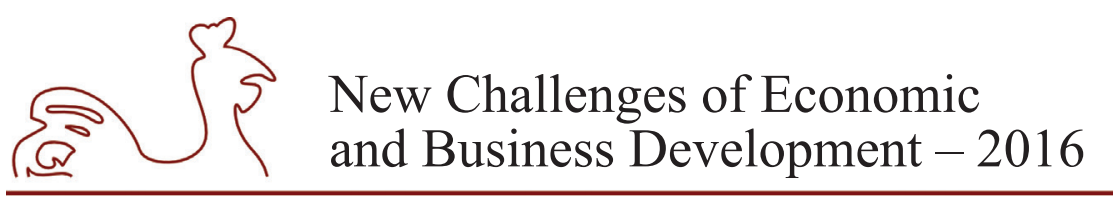

May 12-14, 2016, Riga, University of Latvia

usually clear and traceable in terms of their impact on overall results (as are those related to many other processes), whereas leadership can rarely be directly measured. On the other hand, it is indisputable that motivational, delegation-based leadership in particular has a direct and positive impact on a company's risk management system when looked upon as an example to be followed. Because of this, responsibilities and roles, within the context of risk management, must be closely analysed so as to be able to rely on the right positions and interfaces.

The following responsibilities and roles can be identified within a risk management process:

- Employees

- Business unit managers

- Risk manager

- Internal auditing

- General manager/board of management

- Supervisory boards

- Certified public accountants/auditors

- Lawmakers and regulatory agencies

- Suppliers and customers

- Analysts

As previously mentioned, company-wide risk management is the collective responsibility of all parties. However, a company's employees bear the greatest portion of this responsibility (in both quantitative and qualitative terms). After all, hazards and risks originate and are found in day-to-day interactions with business processes and the tasks they entail.

Employees who have already been designated as risk owners are bound to have a higher affinity for identifying and assessing risks. But awareness must also be developed in employees who have not yet been integrated into a company's risk management processes. Within this context, it is important to mention that proactive communication is a part of risk management (Pechlaner H., 2005). And that relaying information that is relevant in terms of risks and ensuring that this information is both complete and correct is the cornerstone behind it. The natural continuation of this process - being able to see how a risk situation has changed must have a solid foundation at the very bottom of the company hierarchy; otherwise, the very foundation of the risk assessment pyramid will be flawed from the beginning. Communication is an important element of organization structures. This must be observed also in establishing a working risk management organization: "Corporate communication specialists must understand the interpretive processes of organizational stakeholders and need to address the many ways in which different parts of the organization interact with each other and the environment, in order to design communication systems that are effective or to diagnose ways existing systems are misaligned with the organization's needs." (Hatch M.J., 2006).

Another role within the risk management structure is that of business unit managers especially chief financial officers and comptrollers, who, by virtue of their activities i.e., forecasts, budget planning, and setting business objectives, seem to have always been predestined for it. Since the duties of finance departments and comptroller's offices are often of a cross-departmental nature, i.e., are rooted squarely in the company's central management, these entities have an enormous influence on the risk management process. In fact, the internal reporting systems set up in these departments often form the basis for a very high level of risk awareness. 


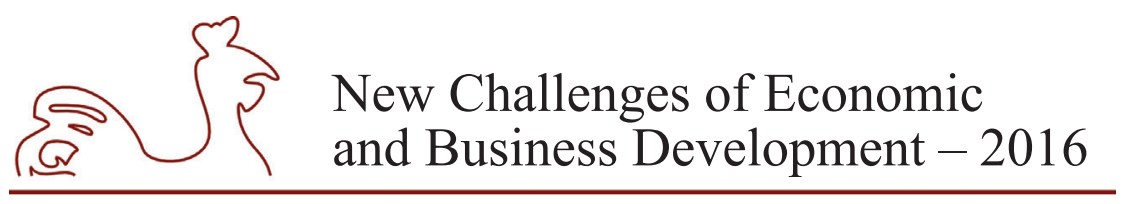

May 12-14, 2016, Riga, University of Latvia

As a result of all of the above, the heads of these departments often become role models in terms of risk management. They are also usually the ones that set up and develop that part of the organizational structure, for which they are responsible. Although this usually happens within the framework of the global organizational structure, they do usually have a certain degree of freedom. The same fundamental principles already discussed for senior management in terms of influence on group-oriented decision-making processes also apply for the business unit leaders. Basic principles of socio-psychological elements, especially in handling of groups and groupdynamic processes are the prerequisite for successful working in the area of risk identification and risk valuation.

To avoid the risk of ending up with several companies within the company, and thereby losing the ability to compare risks and opportunities, clear structural guidelines must be drawn up. So as not to undermine the business unit managers' motivating "enterpreneurial" freedom and thereby stifle their creativity, those degrees of freedom must be defined. The resulting corridor of freedom to act encourages creative activity while at the same time ensuring comparability in risk management.

Appointing a central risk manager serves not only to establish risk management strategies within a corporate organization, but also to ensure that they take root. Accordingly, the sustainable implementation of risk assessment measures, periodic reassessments, central analyses, and coherent decisions are part of their responsibilities. In addition, they must constantly exchange information with the management level (or be a part of it). However, risk managers should not only be assigned responsibilities, but staff and financial resources as well. Otherwise, trying to maintain an effective risk management system will prove to be an impossibility. The risk manager is part of every larger organization structure. This gives rise to the question, what exactly is a larger organization structure? In general, we can assume that companies with 50 employees or more already have reasonably workable structures, with risk management being an issue. This happens on one hand through individuals' own initiative and on the other due to legal requirements. The 50 employee threshold is not written in stone: There are also smaller companies who must or want to practice risk management.

Risk managers are also responsible for implementing responsibilities and roles, as well as for deciding on the risk management methods best suited to achieve their goals. They must develop standardized terminologies and concepts, establish a framework for assessments, and define interfaces to other business process systems. The risk environment determined on the basis of these activities must consist of areas that can be subdivided into groups and point out where management is paying attention to the risks in these areas (Brühwiler B., 2003). Finally, risk managers are responsible for periodic reporting and for supervising processes, and must always be able (or should at least always be able) to provide an overview of the company's overall risk situation and identify the greatest existing risks and opportunities (Brünger Ch., 2009).

In short: risk managers must run a prudent - but always visible - risk policy. While this must be done without stoking any unnecessary fears, it must also be done without closing one's eyes to the truth, even when uncomfortable. Accordingly, a risk manager's leadership qualities must be stronger than most people would think at first. True, risk managers usually have very little responsibility in terms of personnel: they might be in charge of a couple of employees; but in comparison to business unit managers, their responsibility in this area is almost negligible. 


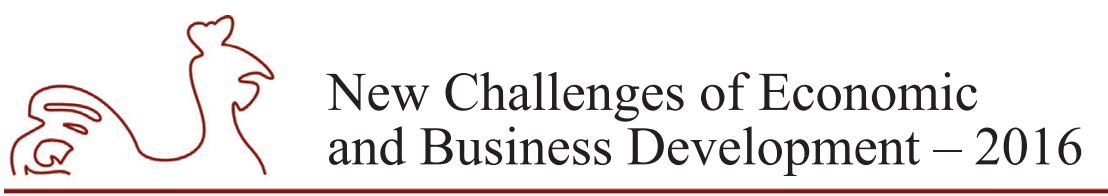

May 12-14, 2016, Riga, University of Latvia

Compared to adjacent units, they are usually responsible for only a small organizational unit or have responsibility for another area in a combination of functions.

In general parlance, internal auditing is often thought of as being associated with risk management, but this is only accurate to a certain extent. While it does involve the review of risk management systems (and also internal control systems), this is only one of its many functions. Naturally, the results of an internal audit must be used in order to evaluate the effectiveness of a risk management strategy, and while this is of great importance to a working system, it is important to keep in mind that its effect on processes is not operational, but rather regulatory. Even then, however, internal audits must never be disregarded within the big picture of a risk management strategy.

If the auditor is also responsible for risk management within the company, they are likely to have a good insight into the location of the right control points within processes and underlying organizational structures. They must also, however, be careful not to let themselves be drawn into a conflict of interests between auditing and risk management, or to lose sight of issues that lie beyond their auditing role.

General managers (or a board of management, as the case may be) are responsible for managing their company, and are therefore responsible for an integral company-wide risk management strategy as well. More specifically, management determines how risk management is practiced and creates the necessary environment for it. It defines whether risks should be accepted, avoided, diminished, or shifted (Dörner D., 2000), which requires the establishment of a risk management philosophy, a risk management office (central risk manager), an integral (IT-supported) system, and a risk culture.

Risk management should not simply be used as a fig leaf. Instead, it should be an integral part of a company's culture. Insights gathered from identification, analysis, supervision, and reviews should be discussed with individual groups of responsibility during regular meetings, which should also serve to accumulate and follow up on such insights. On one hand, this should provide management with an up-to-date overview of things (cf. Gleissner W., 2008) that goes beyond merely relaying reports and that can also be enriched with nuances. On the other, it should also make it possible to initiate and monitor any necessary measures. It is also important to mention that the focus of these activities should not be limited to risks, but should extend to opportunities as well. After all, those who do not believe in the concept of opportunity management will be hard-pressed to find an argument denying the fact that failure to take advantage of opportunities is a risk in and of itself.

Management should not forget that each organizational area is responsible for its own risks, i.e., that each area should run its own risk management sub processes within the overall process (something that the IT system must also support). More specifically, management should delegate and not dictate, as this is the only way to spread risk awareness throughout a company. The more employees are involved in the risk management process, the more they will be able to contribute with their skills in applying methods and with suggestions.

A supervisory board's general duties include not only supervising management, but also defining guidelines and framework rules for the board of management. These guidelines and rules will in turn represent the key factors to take into account for monitoring and supervision purposes later on. 


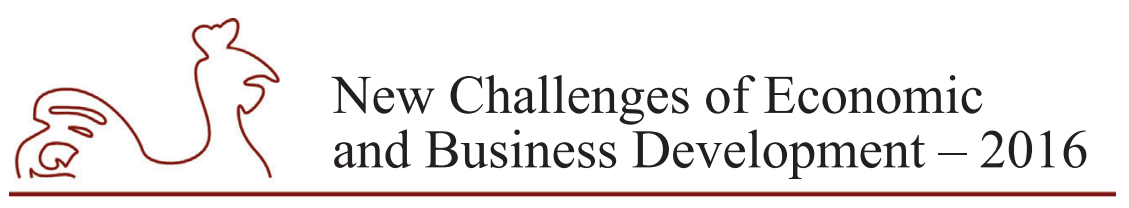

May 12-14, 2016, Riga, University of Latvia

Risk management also plays an important role within this context. By their very nature, legal regulations compel supervisory boards to monitor the effectiveness of risk management strategies (or arrange for it to be monitored). Within this context, general management must ensure that A) a risk management system has been implemented, B) a willingness to make adjustments based on coordination with the supervisory board exists, and C) a transparent overview is given so that the supervisory board is able to oversee important company risks and evaluate general management's strategies for them (BilMoG, 2009). Naturally, this requires for supervisory boards to be staffed with highly-qualified members who are able to perform their duties within the specific internal corporate environment in their company. Expert risk assessments, experience, up-to-date know-how that is relevant to the company, and a certain level of availability all form the basis for working together with management.

It is important to mention that the interaction between risk management responsibilities is certainly not limited to a company's internal offices. Indeed, by providing an objective point of view that is fully independent from the company in question, certified public accountants and external auditors provide an important source of information.

Annual financial statements and reports are one of the most important components of financial reporting. During the preceding financial statement analysis, certified public accountants also review the risk management system being applied and, if they detect any shortcomings, give appropriate recommendations for correction, informing management, or the supervisory board if necessary, of the shortcomings depending on the importance of the annotations made. In addition to normal annual financial statement activities (during which risk management is merely a side issue), it is also possible to arrange for a comprehensive review of risk management systems, e.g., in order to check and comply with rules and regulations.

Legislation is an additional external element with a direct influence on how risk management strategies should be set up. In fact, laws and regulations with an impact on risk management have long been in effect, especially in the area of financial reporting. In turn, complementary regulatory agencies often check compliance with these regulations, preparing audit reports in the process. As a result, lawmakers can have a significant influence on a company's risk management practices through rules, requirements, laws, and audits. However, this has more to do with defining frameworks for rules and standards than with having an influence on specific responsibilities and roles.

Aside from external regulatory bodies, there are also external business activity interfaces that deserve and require just as much attention. In other words, the companies suppliers and customers. These entities, as well as the environment surrounding them, provide a plethora of information that directly affects company-wide risk management practices. Relevant data, such as delivery situations, market demand, quality levels, customer solvency, interest rate trends, etc. should be collected and incorporated into the risk management process. However, it is important to note that these interfaces must be identified, listed, and maintained by the relevant risk owners exclusively - only the employee with the necessary skills for applying the relevant methods will be able to identify whether a technical interface or a simple conversation can help achieve these goals.

Finally, analysts and the role they play must not be forgotten. Analysts take into consideration a multitude of factors, such as business strategies and business goals, combined with financial statement data and forecasts, in order to provide an assessment regarding a company's development 


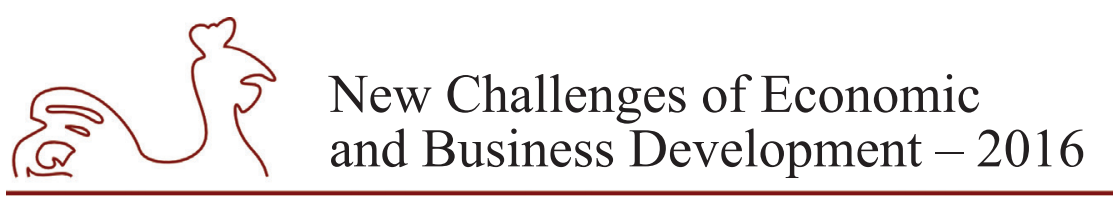

May 12-14, 2016, Riga, University of Latvia

(which very often includes risk assessments as well). These indicators and assessments from an external, and therefore impartial, analyst can and should be used by general management as additional input for improving company-wide risk management practices. On the other hand, however, general management should not be driven by possibly inflated expectations and tone down, or even do away with, its risk management philosophy. Analyst contributions should be cause for reflection - not for acting blindly.

\section{New Technology Influence on Risk Management Communication Workflows}

Written communication creates a barrier, where those who write and read control the evaluations and votes. A written record removes part of the element of trust established between reviewer and evaluator. Reviews are often placed and evaluated after the risk assessment. This often takes place weeks later. Reviewers are no longer involved in the process. They are left only to hope the evaluation is placed correctly. Reviewers become a spectator instead of an active participant in the risk management process.

Command line programs cause customer to be illiterate in the language of managing risks. Programs are used with key combinations that take years to learn. These esoteric commands force the risk manager to completely remove the reviewer from the management process.

With the next step in digitization, even more is conducted behind the scenes than before. ERP, CRM \& ERM programs provide further esoteric languages and complex interactions. While CRM usage has demonstrated a positive impact on performance and process effectiveness (Rodriguez M., 2011), not only is the reviewer but also the risk manager removed from some aspects the process.

Digitization breaks down the teamwork during the risk assessment. The risk manager has additional information but this information is not always passed on to the reviewer. Often, the reviewers' ability to check the process is hindered by the complex programs governing the risk management process.

Laptops build the ultimate physical and psychological wall. Instead of quickly jotting down notes on a risk, the risk manager types away at the keyboard. Eye contact is lost. Connection is lost. Focus is lost.

Social interaction is greatly reduced. When entering data or searching for an item, the risk manager is not fully engaged in the conversation. The risk manager interacts primarily with the computer during those moments. Taking breaks to allow for data entry disrupts the flow of the meeting.

One solution is to share the laptop but sharing the laptop breaches the comfort-zone of the two parties. Instead of sitting next across from each other, the two parties sit awkwardly next to each other. Even reviewing the assessment can become an uncomfortable affair.

Handing over the laptop removes the risk manager's ability control that magic moment, when the reviewer's interest is piqued, to take back the assessment.

Hide unnecessary details but have them available when questions arise. There is no need to show a long list of assessment details to each and every reviewer, for each and every control. That is a pronounced weakness of printed risk assessment. Keeping that information only a button push away, the tablet allows the reviewer to see all the information necessary to make a decision but not the information which would only cloud their judgment and deviate from the risk managers pitch. 


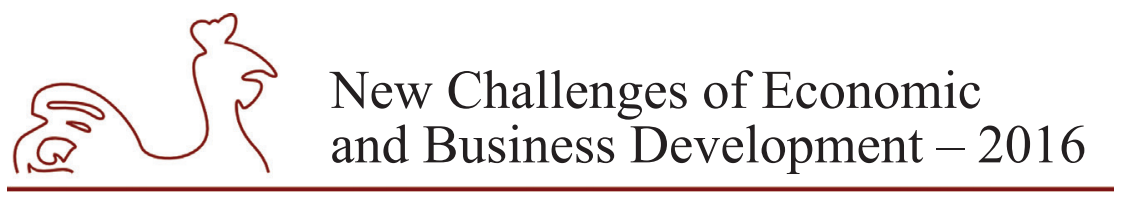

May 12-14, 2016, Riga, University of Latvia

Have real-time information about controls and additional information at the tip of your fingers. Shift that information to the reviewer. Build that relationship through teamwork and learn something together. Remove the physical and psychological barriers between the risk manager and reviewer. Do not speak esoteric languages, write secret codes, or use technologies that can only benefit and be interpreted by one party. Communicate visually with pictures instead of text. Let the reviewer zoom in to view greater details of the control.

The addition of related controls to the tablet's screen can better catch the reviewer's attention and increase accuracy. Allow the reviewer's eye to be caught by a picture or a trend graph of a control they may not have considered before. Group controls logically based on the reviewer. Facilitate discovery together instead of only suggesting what the reviewer's may need.

\section{The Research Design on the Empirical Study on Influences of Organizational and Group Processes on Risk Management Efficiency}

The empirical experimental structure is based upon the comparison of expert opinions with applied approaches, i.e. those gained through daily practice. To facilitate this comparison, ten well-known experts completed the survey "Expert Interviews with Structured Survey on the Latent Exogenous Variables" and their relation to the "Case Study with Structured Survey on the Cause Effect of the Endogenous Variables" (131 participants) was measured.

Based upon the literature research described above, a range of independent variables was extracted, which could affect group-based risk analysis processes. To measure these variables' plausibility and importance, an "Expert Interview with Structured Survey" was completed. Its goal is to provide a ranking of the independent latent exogenous variables and eliminate those which are deemed superfluous.

The first part of the survey aims evaluate/verify the independent variables of the causal model. An expert interview combined with a structured survey was performed with the goal of removing insignificant variables.

The survey included parameters:

- Group size

- Personality type

- Professional background

- Age

- Gender

- Culture

whose influence on risk management has been evaluated. The available responses are derived from the Likert-type scale (strongly agree $=1$, agree $=2$, neither $=3$, disagree $=4$, strongly disagree $=5$ ).

\section{Results and Findings}

The results regarding the causal model are based on the survey. The latent exogenous variables are proven by the experts and the results shown that the independent variable "gender" is insignificant (Median 3,3). The variable "culture" (Median 2,37) could be relevant but in the study difficult to verify, due to potential multicollinearity. 


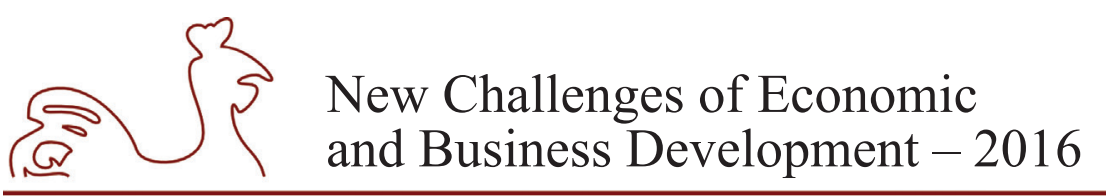

May 12-14, 2016, Riga, University of Latvia

Table 1

Results of the expert interviews with structured survey

\begin{tabular}{|l|c|c|c|c|c|c|}
\cline { 2 - 6 } \multicolumn{1}{c|}{} & \multicolumn{6}{c|}{ Result counting } \\
\hline $\begin{array}{c}\text { Independent } \\
\text { variable }\end{array}$ & $\begin{array}{c}\text { Strongly } \\
\text { Agree }\end{array}$ & Agree & Neither & Disagree & $\begin{array}{c}\text { Strongly } \\
\text { Disagree }\end{array}$ & Median \\
\hline Group Size & 9 & 18 & 6 & 4 & 3 & 2.35 \\
\hline Personality Type & 7 & 18 & 4 & 1 & 0 & 1.9667 \\
\hline $\begin{array}{l}\text { Professional } \\
\text { Background }\end{array}$ & 13 & 24 & 7 & 5 & 1 & 2.14 \\
\hline Gender & 0 & 2 & 12 & 4 & 2 & 3.30 \\
\hline Age & 3 & 9 & 11 & 5 & 2 & 2.80 \\
\hline Culture & 7 & 12 & 5 & 5 & 1 & 2.37 \\
\hline
\end{tabular}

Source: author's calculations based on the expert interviews with structured survey on the latent exogenous variables.

Cultural aspects are part of a wide area of similar physiological aspects influenced by many personal behaviours. Most of these personal behaviours are better covered by professional background and age. (e.g. Gleißner W., 2012, Psychologische Aspekte im Risikomanagement). Because of this the two variables "gender" and "culture" will dropped out of the causal model.

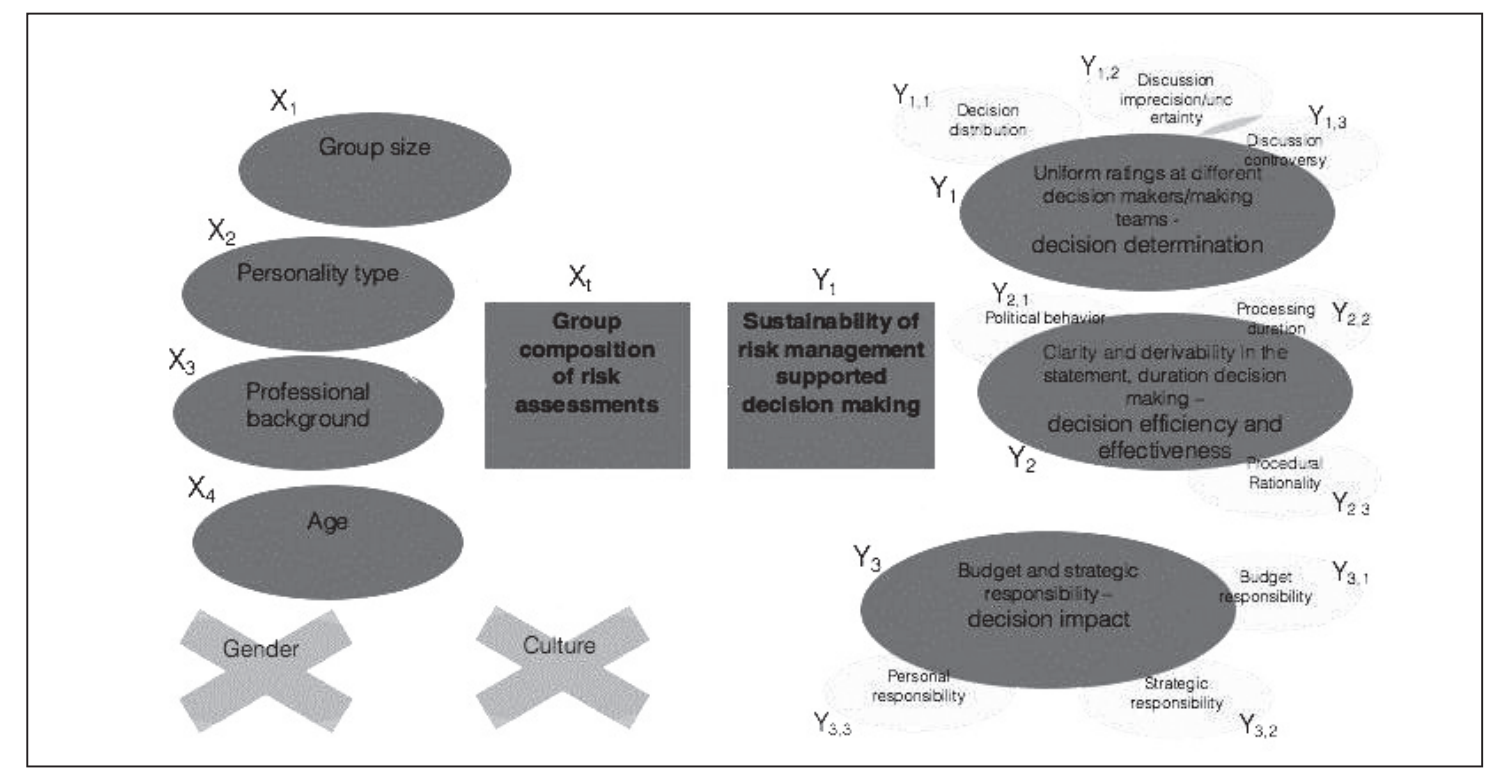

Source: author's construction based on literature for independent und dependent variables and export interviews.

\section{Fig. 1. Causal Model}

A survey using the remaining factors was directed towards a larger sample size of professionals. The case study involving the structured survey (Pipers Case study type) is designed based on different cases (case study with survey) to evaluate the dependencies. 


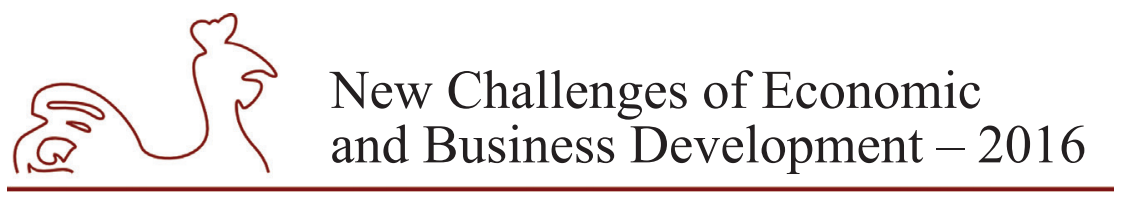

May 12-14, 2016, Riga, University of Latvia

As the "case study including a structured survey" was conducted with 131 professionals, its results provide a proxy for the view of the practitioner. 57 different questions, whose answers are based on the Likert-type scale, brought the independent variables listed above in relation with the following dependent endogenous variables:

- Decision determination (Uniform ratings at different decision makers/making teams)

- Decision distribution

- Discussion imprecision/uncertainty

- Discussion controversy

- Decision efficiency and effectiveness (Clarity and derivability in the statement, duration decision making)

- Political behaviour

- Processing duration

- Procedural Rationality

- Decision impact (Budget and strategic responsibility)

- Budget responsibility

- Personal responsibility

- Strategic responsibility

The survey results provide a basis for further statistical tests. Thereby the dependent variables will be analysed along with the corresponding sub-variables. The first statistical test is the one sample t-test.

A one sample t-test is used to compare the mean difference of a population mean's given value and that of a sample (Wackerly D., 2008). In this case, the responses from "Expert Interviews with Structured Survey on the Latent Exogenous Variables" are the given value and the responses of the 131 participants in the "case study including a structured survey" are the sample. The one sample t-test is calculated as follows:

$$
t=\frac{\bar{X}-\mu}{\sqrt{\frac{\sum(X-\bar{X})^{2}}{n-1}}} \sqrt{n}
$$

where,

$t=$ one sample t-test value

$\mu=$ population mean

$\bar{X}=$ Sample mean

$n=\#$ of observations

\section{Conclusions, proposals, recommendations}

Initial one sample t-tests demonstrated partial consensus between the responses of expert and professional groups, but also the yielded variance.

The respective independent variable's median needed to first be normalized. The Likerttype scale values of $1-5$ were converted to yield an independent variable result between $0-1$ using the following formula:

$$
t v=1-\frac{x_{n}-1}{4}
$$




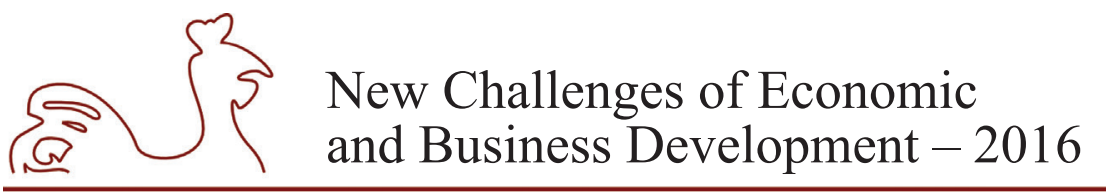

May 12-14, 2016, Riga, University of Latvia

Table 2

Normalisation of the know population mean for one sample t-test

\begin{tabular}{|l|c|c|}
\hline \multicolumn{1}{|c|}{ Independent variable } & Median & $\begin{array}{c}\text { One sample t-test } \\
\text { Test value }\end{array}$ \\
\hline Group Size & 2.35 & 0.6625 \\
\hline Personality Type & 1.9667 & 0.758325 \\
\hline Professional Background & 2.14 & 0.715 \\
\hline Age & 2.80 & 0.55 \\
\hline
\end{tabular}

Source: author's calculations based on the expert interviews with structured survey on the latent exogenous variables.

Using these values, a one sample t-test was carried out to compare the significance of each independent variable ( $\mathrm{p}$ values). The null hypothesis is as follows:

$\mathrm{H} 0$ : Practitioners survey responses do not vary from the expert reference values

If the $\mathrm{p}$ value of the one sample t-test is larger than 0.05 , the null hypothesis may not be rejected and the variance between expert reference values and practitioner responses is deemed to be insignificant.

The following table presents the results of main dependent variables (an average of each subcategory's result Yn.1 - Yn.m) and their p value:

Table 3

p value overview from the one sample t-test

\begin{tabular}{|l|c|c|c|}
\hline & $\begin{array}{c}\text { Decision } \\
\text { determination }\end{array}$ & $\begin{array}{c}\text { Decision efficiency } \\
\text { and effectiveness }\end{array}$ & Decision impact \\
\hline Group Size & 0.2260 & 0.0464 & 0.1951 \\
\hline Personality Type & 0.1117 & 0.1061 & 0.0860 \\
\hline Professional Background & 0.1693 & 0.1447 & 0.2800 \\
\hline Age & 0.038 & 0.0741 & 0.000 \\
\hline
\end{tabular}

Source: author's calculations based on a t-test between the expert results and a professional group survey.

Initial analysis and first results shows, none of the dependent or independent variables may be clearly removed from the model, although there seems to be a substantial discrepancy between the expert opinions and the daily routine of the professionals. Additional statistical analysis will provide further insights into this divergence by examining the significance of the dependent variables' subcategories.

\section{Bibliography}

Arrow, K. J. (1976): Essays in the Theory of Risk-Bearing, North-Holland, Amsterdam Asch, S. (1955): Opinions and Social Pressure, Scientific American

BilMoG (2009): Bilanzrechtsmodernisierungsgesetz (BilMoG), Deutsche Bundestags-Drucksache $16 / 12407$

Bitz, M. (1981): Entscheidungstheorie" Franz Vahlen, München

Brühwiler, B. (2007): Risikomanagement als Führungsaufgabe, Haupt, Bern, 2nd edition

Brünger, Ch. (2009): Erfolgreiches Risikomanagement mit COSO ERM, Schmidt, Berlin 


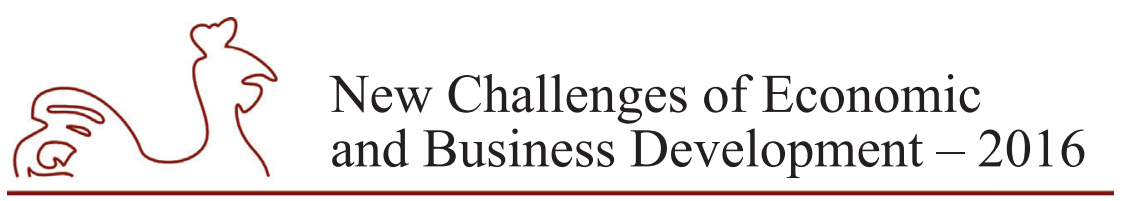

May 12-14, 2016, Riga, University of Latvia

Dörner, D. \& Doleczik, G. (2000): Prüfung des Risikomanagement, Schäffer-Poeschel, Stuttgart

Gleissner, W. \& Mott, B.P. (2008): Risikomanagement auf dem Prüfstand - Nutzen, Qualitäten und Herausforderungen in der Zukunft, ZRFG Zeitschrift für Risk, Fraud \& Governance, Vol. 2

Gleissner, W. \& Romeike, F. (2012): Psychologische Aspekte im Risikomanagement, Risk, Compliance \& Audit, Vol. 6/2012, pp 43-46

Hatch, M.J. \& Cunliffe A.L. (2006): Organization Theory, Oxford University Press, New York, 2nd edition

Hinterhuber, H.H. (2004): Strategische Unternehmensführung, Walter de Gruyter, Berlin, 7th edition

Hovland, C.I. \& Weiss, W. (1951): The Influence of Source Credibility on Communication Effectiveness, Public Opinion Quarterly, Vol. 15

Janis, I. L., \& Mann, L. (1977): A psychological analysis of conflict, choice, and commitment, Free Press, New York

Kimball, M. S. (1993): Standard Risk Aversion, Econometrica, Econometric Society, Vol. 61

Kotter, J.P. (1990): A Force for Change: How Leadership Differs from Management, Simon\&Schuster, New York

Pechlaner, H. \& Glaesser D. (2005): Risiko und Gefahr im Tourismus, Schmidt, Berlin

Rodriguez, M. \& Yim, F. (2011): Utilisation of CRM and its impact on sales performance: a study of sales professionals working in a virtual environment, International Journal of Electronic Customer Relationship Management Vol. 5, pp 203-219.

Ruble, D.N. \& Frey, K.S., (1991): Changing patterns of comparative behavior as skills are acquired: A functional model of self-evaluation, Hillsdale, New York

Schneeweiß, H. (1967): Entscheidungskriterien bei Risiko, Springer, Berlin

Wackerly, D. \& Mendenhall, W. \& Scheaffer, R.L. (2008): Mathematical Statistics with Applications, Thomson Brooks/Cole; 7 th edition

Weitz, B. A. \& Bradford, K.D. (1999): Personal selling and sales management: A relationship marketing perspective, Journal of the Academy of Marketing Science Vol. 27, pp 241-254. 


\title{
THE AWARENESS AND IMAGE OF LATVIA AS A TOURISM DESTINATION IN GERMANY AS A HIGH PRIORITY TARGET MARKET
}

\author{
Ilze Medne, University of Latvia, Latvia ${ }^{1}$ \\ Kristine Berzina, University of Latvia, Latvia
}

\begin{abstract}
Purpose: The aim of the research is to examine the image of Latvia as a tourism destination among potential travelers in Germany as a high priority target market of Latvian tourism. Three research questions that have been raised are: RQ1. What is the level of recognition and awareness of Latvia as a tourism destination in Germany? RQ2. What are the associations with Latvia as a tourism destination in terms of key words and colours and how they comply with the Latvian tourism brand concept? RQ3. What is the image of Latvia in terms of several attributes of a tourism destination?

Methodology: To achieve the aim of the study a survey of German residents was carried out. The survey was conducted in June 2015 among local population of Germany in federal states of Bayern and BadenWürttemberg. The questionnaire was made to determine the recognition and the image of Latvia as a tourism destination as well as to determine the associations in connection with Latvia expressed via key words and colours. SPSS software tools were used for analysing the data: descriptive statistics, cross tabulation, data correlation.

Results: The results of the research show that the knowledge of German residents about Latvia as a travel destination is poor; the Latvian tourism brand concept both in colour and keyword terms correspond with the German citizens' perceptions about Latvia; German residents' associations with holiday travel in terms of colours meet Latvian tourism brand concept; German residents' associations with holiday travel in key words partly correspond with the Latvian tourism brand concept. Suggestions are addressed towards Tourism Department of Latvian Investment and Development Agency to improve marketing communication with Germany as a high priority tourism market of Latvia.
\end{abstract}

Key words: tourism, destination, destination image, destination awareness

JEL code: M31, L83

\section{Introduction}

Competition between tourism destinations in recent decades has become global. The process of globalization in the tourism sector is even more significant than in other sectors, tourists are choosing their destinations out of hundreds of options and are influenced by many factors. Destination image and identity play a significant role in differentiating between objectively similar travel alternatives.

There have been several images for Latvia as tourism destination since second independence including the slogan "Latvia - the Land that sings". Since 2010, the basic idea of the new Latvian tourism image "Best enjoyed slowly" invites tourists to slow down their pace of life, to stop and

1 Corresponding author - e-mail address: ilze.medne@lu.lv 


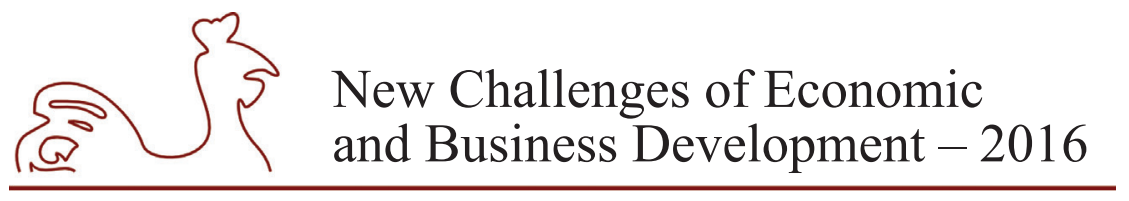

May 12-14, 2016, Riga, University of Latvia

enjoy a slow and detail-oriented recreation and think about the important issues of life. The core values of Latvian tourism image are described by truthfulness, profoundness, lightness and selfrespect lying in the nature, culture and people of Latvia. "Best enjoyed slowly" encourages staying longer and enjoying things whose realization requires time and peace, i.e., tea can be enjoyed only slowly and bird songs can be heard only in silence. (Latvian Tourism Development Agency)

Latvian tourism image logo consists of teardrop-like elements, the word "Latvia", "Lettland" or "Латвия" and the slogan at the bottom of the logo in English, German or Russian. (Visual Brand Guidelines for Latvia's Tourism Image, 2015) The logo of Latvian tourism image has been designed in colouration green-blue-white.

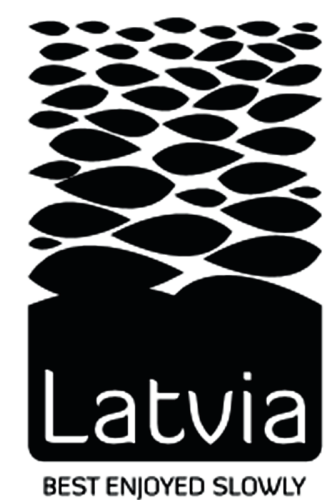

Fig. 1. The logo of Latvian tourism image (single colour logo)

Latvian tourism image has been most actively popularized in high priority tourism target markets, i.e., Lithuania, Estonia, Germany, Russia, Sweden and Finland, which are determined in the Latvian tourism marketing strategy.

Germany has become one of the most important tourism markets since the independence of Latvia. Indications for the German market significance from the tourist amount point of view can be stated by its fourth place in the flow of the overnight travellers (after our neighbouring countries Russia, Lithuania, Estonia) as well as the tendency of this phenomenon to increase during the last four years. The peak of German overnight travellers in Latvia was in 2008 reaching 176.2 thousand (See Table 1).

Table 1

Characteristics of German overnight travellers in Latvia 2008-2014

\begin{tabular}{|c|c|c|c|c|c|c|}
\hline \multirow[t]{2}{*}{ Year } & \multicolumn{2}{|r|}{ Travellers } & \multicolumn{2}{|c|}{$\begin{array}{l}\text { Total expenditure during } \\
\text { the trips }\end{array}$} & \multirow{2}{*}{$\begin{array}{c}\text { Average daily } \\
\text { expenditure } \\
\text { per traveller, } \\
\text { EUR }\end{array}$} & \multirow{2}{*}{$\begin{array}{c}\text { Average } \\
\text { length of } \\
\text { trips, } \\
\text { nights }\end{array}$} \\
\hline & $\begin{array}{l}\text { Number, } \\
\text { thsds }\end{array}$ & $\begin{array}{l}\text { In \% of all overnight } \\
\text { travellers in Latvia }\end{array}$ & $\begin{array}{l}\text { MIn. } \\
\text { EUR }\end{array}$ & $\begin{array}{c}\text { In \% of all } \\
\text { overnight travellers }\end{array}$ & & \\
\hline 2008 & 176.2 & 10.5 & 56.2 & 12.2 & 75.1 & 4.2 \\
\hline 2009 & 117.4 & 8.9 & 33.0 & 8.6 & 68.2 & 4.1 \\
\hline 2010 & 108.6 & 7.9 & 25.6 & 6.8 & 63.5 & 3.7 \\
\hline 2011 & 116.4 & 7.8 & 39.0 & 8.6 & 77.4 & 4.3 \\
\hline 2012 & 122.6 & 8.5 & 43.1 & 9.8 & 87.4 & 4.0 \\
\hline 2013 & 123.4 & 8.0 & 43.8 & 9.1 & 88.6 & 4.0 \\
\hline 2014 & 168.3 & 9.1 & 49.4 & 9.6 & 77.0 & 3.8 \\
\hline
\end{tabular}

Source: author's calculations based on Database of Central Statistical Bureau of Latvia. 


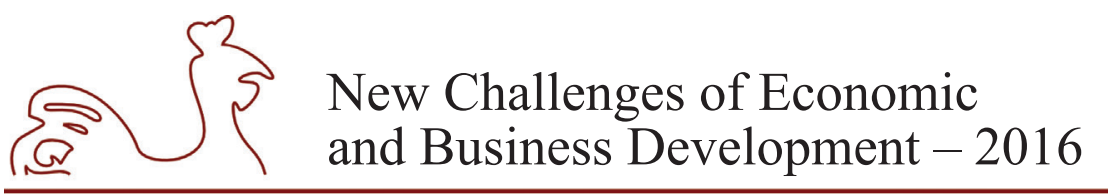

May 12-14, 2016, Riga, University of Latvia

As a result of global economic crises in years 2009-2010, tourist flow from Germany decreased significantly. Only since 2011, we have a gradual positive tendency in number of Germany overnight travellers. Similar tendencies are characteristic to other indicators of German overnight traveller flow to Latvia.

Nevertheless, the potential of Germany as a high priority market could be used more effectively. The forecasts of Euromonitor International indicate that, apart from fairly "traditional" destinations such as Spain and Turkey, good performances are expected for the Eastern European countries. Despite the fact that the "Iron Curtain" has been down for more than two decades, many Germans have still never been to Eastern Europe (Euromonitor International, 2014). Additionally, Germany is the largest outgoing tourism market in the European Union with 730.1 million nights spent abroad by residents of the country or $26.5 \%$ from all EU countries in 2014. (Eurostat, 2015)

\section{Theoretical background}

It is necessary for people to develop a positive attitude towards a country as a tourism destination before they make a choice to visit it. According to Ph. Kotler, D. H. Haider, I. Rein (2002), destination image is the sum of beliefs, ideas and impressions that people have of a place or a country. A country image is defined by I. M. Martin and S. Eroglu (1993) as "the total of all descriptive, inferential and informational beliefs one has about a particular country". N. Papadopoulos and L. A Heslop (2002) suggested that country images might be influenced by factors like culture, media, sport, economy and the political and social environment. According B. Jenes (2005), country image is formed on the basis of experience and opinions about the nation or country and on, primarily, information received through various channels. Possible channels are politics (internal affairs and foreign policy), telecommunication, entertainment (movies) and rumour. Country image comprises many elements: national symbols, colours, clothing, typical buildings, objects, tunes, pieces of literature, specialties of the political system, customs, historical heritage, and many more.

The destination image includes tangible and verifiable destination attributes as well as perceptions of more psychological nature and emotions regarding that destination (Stepchenkova, $\mathrm{Li}, 2014)$.

Leisen (2001) suggested that tourists' choice between the various destinations depends on a favourable image of the townships in question. The image acts as a transmitter of tourists' expectations to the destination, thus the images in the individuals' minds might lead to marketing success. A. Milman and A.Pizam (1995) argues that, when a destination wants to be successful, it must first achieve tourist awareness and second, a positive image.

A number of authors (Laroche, Papadopoulos, Heslop, Mourali, 2005; Papadopoulos, Heslop, Beracs, 1990; Parameswaran, Pisharodi, 1994; Roth, Diamantopoulos, 2009, Shakoori, Nazemi, Rahimnia, 2013) suggest that a country image should comprise

- a cognitive component which includes consumers' beliefs about a certain country,

- an affective component that describes the country's emotional value to the consumer, and

- a connotative component capturing consumers' behavioural intentions with regard to the sourcing country. 


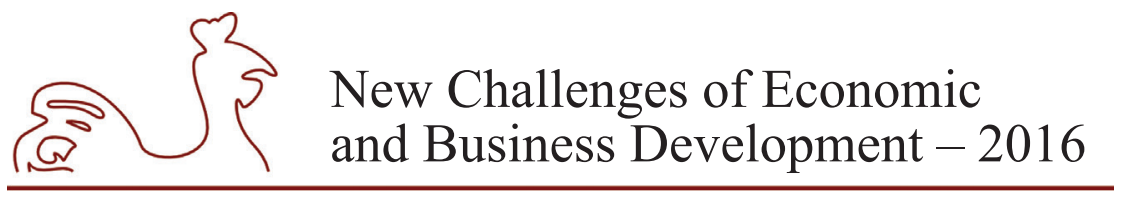

May 12-14, 2016, Riga, University of Latvia

Researchers (Mahler, Carter, 2011) indicate that the cognitive component captures the beliefs held of another country while the affective component captures the emotional reactions of consumers toward another country. Country image refers to the attitude toward a country and its citizens and is distinct from product country images that refer to the image that consumers have of products from a specific country and thus country image refers to the attitude toward a country and its citizens.

Studies have shown that some logos have been successful in eliciting positive emotions conveying meaning, enhancing behavioural intentions, and raising recognition about a brand (Lee, Rodriguez, Sar, 2012) as people transfer sensations generated by visual elements such of logos (logo, name, symbol, colour, typography, and slogan) to the destination itself. Thus logos of poor quality can damage a country's reputation. People generally choose to travel to countries they like and about which they have good impressions. A strong country brand has been found to equate to substantial tourist arrivals; and therefore, prospective visitors and investors rely significantly on the destination's image in making their decisions (Fetscherin, 2010, Harish, 2010, Lee, Rodriguez, Sar, 2012).

From a branding perspective, many researchers view image as a critical part of a brand reflected by a set of brand associations, too (Stepchenkova, Li, 2014).

The aim of the research was to examine the image of Latvia as a tourism destination among potential travellers in Germany as a high priority target market of Latvian tourism. Three research questions that have been raised are: What is the level of recognition and awareness of Latvia as a tourism destination in Germany? What is the image of Latvia in terms of several attributes of a tourism destination? What are the associations with Latvia as a tourism destination in terms of key words and colours and how they comply with the Latvian tourism brand concept?

\section{Methodology}

Destination image quantitative analysis is measured mainly using either a structured or an unstructured approach. The structured approach uses semantic differential and Likert scales to measure the destination image on a list of cognitive or affective attributes due to their flexibility, and ease of analysis. The unstructured approach primarily uses open-ended questions and tests. The unstructured approach allows decrease the deficiencies of inherent bias and irrelevance. Respondents were asked multiple choice questions, Likert scale type of questions as criteria respondents' perceptions about various destination attributes, as well as open-ended questions to understand tourists' associations thus allowing respondents to describe their perceptions in their own words without directions or restrictions. One of the approaches in association research includes top-of-mind method. Tourism marketing researchers (Stepchenkova, Li, 2014) quite often identify the tourists' first responses as their top-of-mind destination brand associations as the most straight measure.

To achieve the aim of the study, a German residents' survey was carried out. The face-toface survey was conducted in June 2015 among local population of Germany in federal states of Bayern and Baden-Württemberg using random sampling for data collection resulting in gathering of 358 valid questionnaires. 


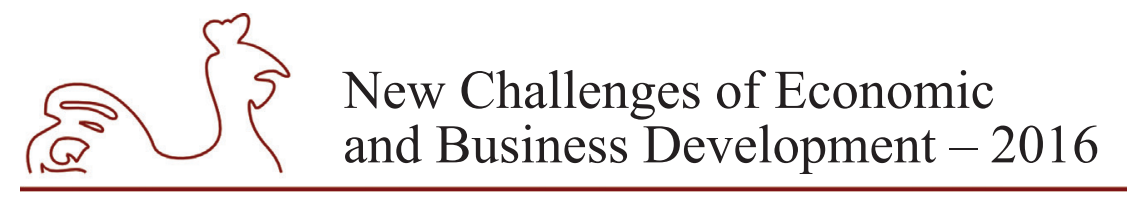

May 12-14, 2016, Riga, University of Latvia

The demographic profile of the realized sample indicates that the sample is representative of the active consumer population of Germany; in other words, the respondents tend to be younger in age, better educated, and with higher incomes than the respective overall population norms. (See Table 2) The sample comprises respondents who are likely to reflect the views of consumers knowledgeable about and with interest in travel.

Table 2

Sample characteristics $(n=358)$

\begin{tabular}{|r|r|r|r|r|r|}
\hline Gender: & Male & $47 \%$ & Age & $18-24$ & $42 \%$ \\
& Female & $53 \%$ & & $25-44$ & $38 \%$ \\
& & & $45-64$ & $16 \%$ \\
& & & & $65+$ & $4 \%$ \\
\hline Education & Professional & $13 \%$ & Income level & Below average & $18 \%$ \\
level & High school & $26 \%$ & $\begin{array}{r}\text { compared to an } \\
\text { average income in }\end{array}$ & Average & $52 \%$ \\
& University degree & $53 \%$ & Germany & Above average & $26 \%$ \\
& Other & $8 \%$ & & High & $4 \%$ \\
\hline
\end{tabular}

Source: author's calculations based on survey data.

\section{Analysis and findings}

To determine the recognition, awareness and attitude toward Latvia as a tourism destination, two questions were asked to the respondents: "How well do you know Latvia?" (in a seven-point scale from 1 - "not at all" to 7 - "very good") and "What is your opinion about Latvia as a travel destination as a whole?" (in a seven-point scale from 1 - "very negative" to 7 - "very positive").

To analyse the results of the survey, the respondents' samples were divided into two groups: respondents who have been in Latvia (visitors) and respondents who have not been in Latvia (non-visitors). The group of non-visitors were divided into three age groups: from 18 to 24 years, from 25 to 44 years and 45 years and over $(45+)$.

The results of the survey show that the German residents' knowledge about Latvia is poor: among all the respondents, the average recognition assessment is 2.12 points (in a seven-point scale from 1 - "not at all" to 7 - "very good"), among the non-visitors - 2.02. In the age group $45+$, the recognition assessment is only 1.66 points. For the respondents who have been in Latvia (visitors), the Latvian knowledge is higher - 3.81 point, which is logical because they have got to know Latvia during the visit. (See Table 3)

Despite this, the German residents' opinion about Latvia as a travel destination is rather positive: among all the respondents, the average assessment of attitude towards Latvia is 4.83 (in a seven-point scale from 1 - "very negative" to 7 - "very positive"), among nonvisitors -4.76 . The opinion about Latvia as a travel destination is more positive in the age group $45+-5.11$ points, the least positive opinion about Latvia is in the age group from 18-24 years 4.63 points. Respondents who have been in Latvia (visitors) presented the highest positive opinion -5.90 points. 


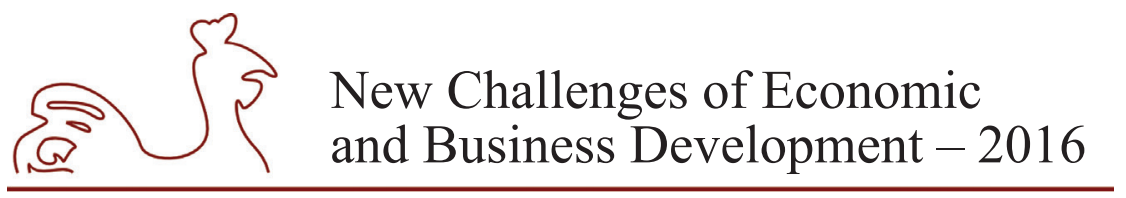

May 12-14, 2016, Riga, University of Latvia

Table 3

Respondents' knowledge and opinion about Latvia and their intentions to travel to Latvia

\begin{tabular}{|l|c|c|c|c|c|c|}
\hline & \multirow{2}{*}{$\begin{array}{c}\text { All } \\
\text { respondents } \\
(\boldsymbol{n}=\mathbf{3 5 8})\end{array}$} & $\begin{array}{c}\text { have been } \\
\text { in Latvia } \\
(\boldsymbol{n}=\mathbf{2 1})\end{array}$ & $\begin{array}{c}\text { have not } \\
\text { been in } \\
\text { Latvia } \\
(\boldsymbol{n}=\mathbf{3 3 7})\end{array}$ & $\begin{array}{c}\text { from them in the age group } \\
(\boldsymbol{n}=\mathbf{1 4 5})\end{array}$ & $\begin{array}{c}\mathbf{1 5 - 4 4} \\
(\boldsymbol{n}=\mathbf{1 2 6})\end{array}$ & $\begin{array}{c}\mathbf{4 5 +} \\
(\boldsymbol{n}=\mathbf{6 6})\end{array}$ \\
\hline $\begin{array}{l}\text { How well do you know Latvia? (in a } \\
\text { seven-point scale from 1- "not at all" } \\
\text { to 7 - "very good") }\end{array}$ & 2.12 & 3.81 & 2.02 & 2.11 & 2.10 & 1.66 \\
\hline $\begin{array}{l}\text { What is your opinion about Latvia as } \\
\text { a travel destination as a whole? (in } \\
\text { a seven-point scale from 1 - "very } \\
\text { negative" to 7 - "very positive") }\end{array}$ & 4.83 & 5.90 & 4.76 & 4.63 & 4.76 & 5.11 \\
\hline $\begin{array}{l}\text { How likely are you to travel to Latvia } \\
\text { within the next three years? (in a } \\
\text { seven-point scale from 1 - "definitely } \\
\text { no" to 7 - "definitely yes") }\end{array}$ & 3.60 & 4.81 & 2.52 & 3.25 & 3.45 & 4.36 \\
\hline
\end{tabular}

Source: author's calculations based on survey data.

For each travel destination not only the opinion of potential visitors is important, but also their intentions to visit the particular destination. The results of the survey show that, among all the respondents, the average assessment of willingness to visit Latvia is 3.60 points (in a seven-point scale from 1 - "definitely no" to 7 - "definitely yes"), which shows a tendency to a rather negative answer. Among the non-visitors, this indicator is even lower and leans to a more negative assessment -2.52 points. From the non-visitors, the higher willingness rate (4.36 points) to visit Latvia for the first time in the next three years present respondents from the age group 45+. Respondents who have been in Latvia (visitors) show the highest rate of desire to visit Latvia again -4.81 points.

To find out the relevance between recognition, awareness and opinion about Latvia from one side and the intentions to travel to Latvia from another side, a correlation of those indicators using Pearson bivariate correlation was carried out.

The results of the correlation analysis show a moderate positive relationship between the opinions about Latvia as the tourism destination and the intentions to visit Latvia among all respondents $(r=0.514)$ in the age groups from 25 to 44 years $(r=0.522)$ and $45+(r=0.540)$, somewhat weaker in the age group from 18 to 24 years $(r=0.457)$. (See Table 4$)$

Correlation between respondents' knowledge and opinion about Latvia and their intentions to travel to Latvia

\begin{tabular}{|l|c|c|c|}
\hline \multirow{2}{*}{} & \multirow{2}{*}{ Age groups } & $\begin{array}{c}\text { How well do you } \\
\text { know Latvia? }\end{array}$ & $\begin{array}{c}\text { What is your opinion about Latvia as } \\
\text { a travel destination as a whole? }\end{array}$ \\
\cline { 2 - 4 } & & \multicolumn{2}{|c|}{ Pearson Correlation } \\
\hline \multirow{2}{*}{$\begin{array}{l}\text { How likely are you to travel } \\
\text { to Latvia within the next three } \\
\text { years? }\end{array}$} & $18-24$ & $0.434^{* *}$ & $0.457^{* *}$ \\
\cline { 2 - 4 } & $25-44$ & $0.370^{* *}$ & $0.522^{* *}$ \\
\cline { 2 - 4 } & $45+$ & 0.172 & $0.540^{* *}$ \\
\cline { 2 - 4 } & All age groups & $0.324^{* *}$ & $0.514^{* *}$ \\
\hline
\end{tabular}

** Correlation is significant at the 0.01 level (2-tailed).

Source: author's calculations based on survey data. 


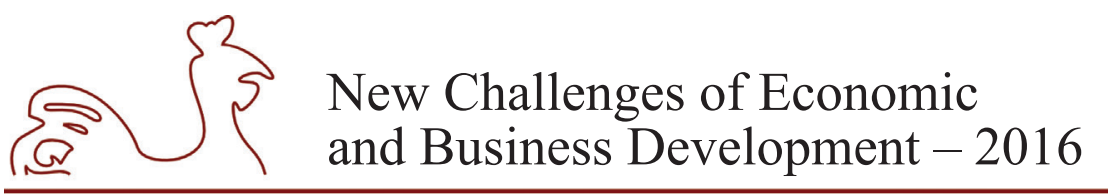

May 12-14, 2016, Riga, University of Latvia

A weak positive relationship is seen also between the knowledge about Latvia and the willingness to visit it within the next three years: among all respondents $(r=0.324)$, in the age group from 18 to 24 years $(r=0.434)$ and from 25 to 44 years $(r=0.370)$. In the age group $45+$, there is no significant relationship $(r=0.172)$.

To measure the awareness of image of Latvia in terms of several attributes of tourism destination, a seven-point Likert scale ranging from 1 - "strongly disagree" to 7 - "strongly agree" was used. All attributes of tourism destination to be analysed have to be divided into two dimensions: cognitive image: natural and cultural resources, quality, prices, and affective image: atmosphere, friendliness, safety.

The cognitive country image of Latvia from the point of view of all the respondents is positively tended ( $>=5$ points in a 7-point scale) in relation to three attributes: "Green country with untouched nature" (5.62), "Country with rich cultural heritage" (5.00) and "Good value for money" (5.15). (See Table 5)

Table 5

Image of Latvia as a tourism destination from respondents' point of view

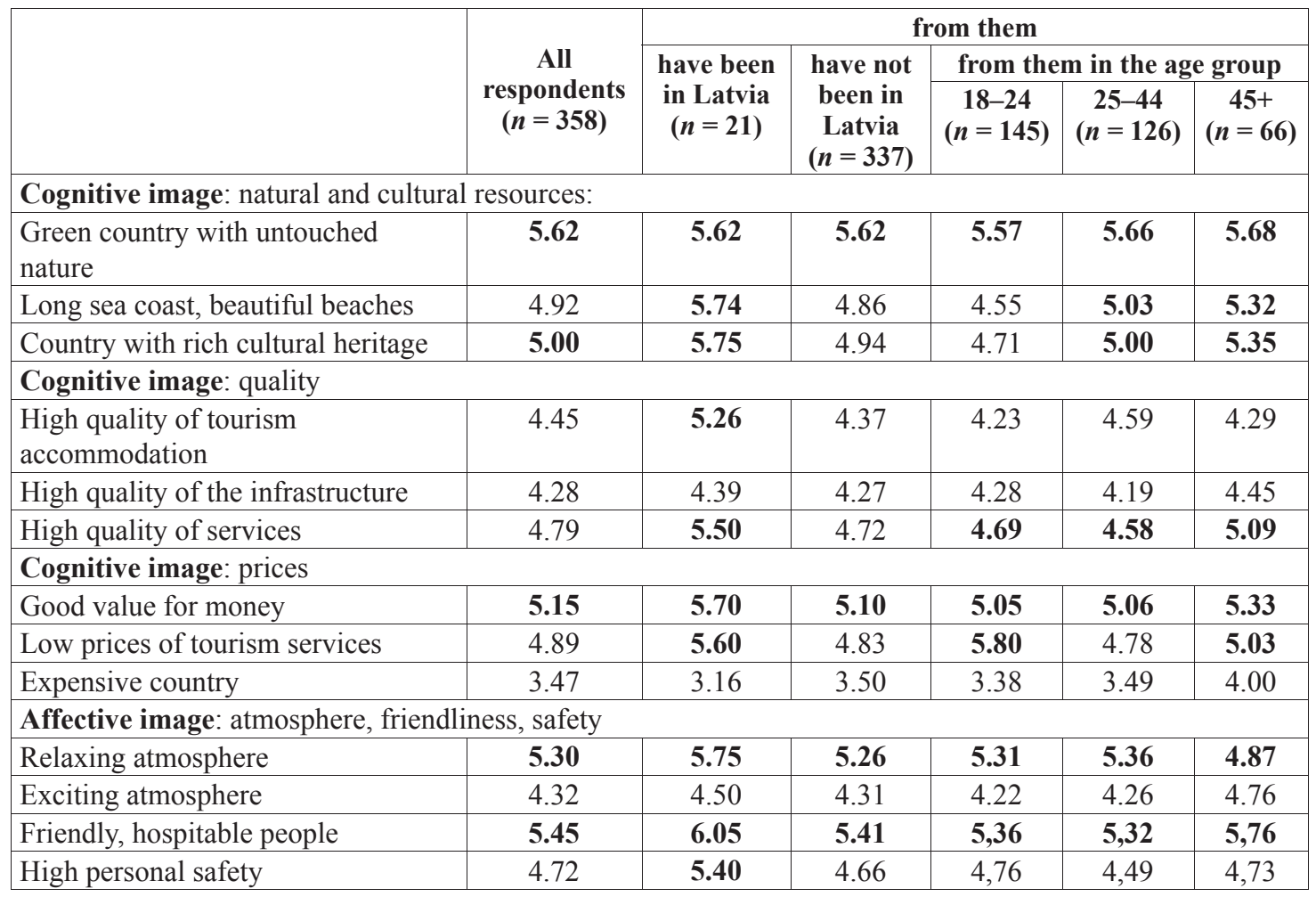

Source: author's calculations based on survey data.

The affective country image of Latvia from the point of view of all the respondents is positively tended ( $>=5$ points in a 7-point scale) in relation to two attributes: "Relaxing atmosphere" (5.30) and "Friendly, hospitable people" (5.45). The cognitive country image of Latvia among respondents who have not been in Latvia (non-visitors) is positively tended in relation to two attributes: "Green country with untouched nature" (5.62) and "Good value for money" (5.10). Respondents from different age groups have different opinions about attributes 


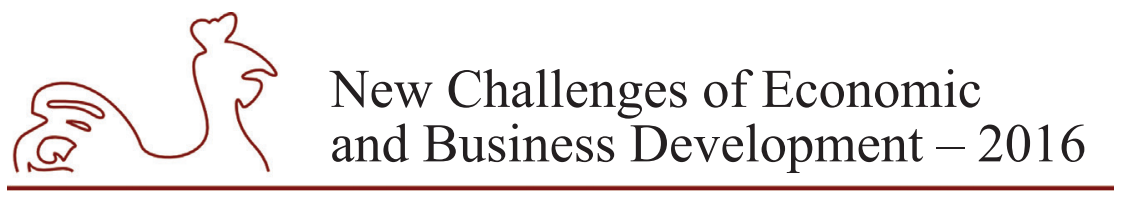

May 12-14, 2016, Riga, University of Latvia

of Latvia as a tourism destination. The affective country image of Latvia from the point of view of the non-visitors is positively tended in relation to two attributes: "Relaxing atmosphere" (5.26) and "Friendly, hospitable people" (5.41), also in each age group separately.

The cognitive country image of Latvia from the point of view of the respondents who have been in Latvia (visitors) is positively tended in relation to seven attributes: "Green country with untouched nature" (5.62), "Long sea coast, beautiful beaches" (5.74), "Country with rich cultural heritage" (5.75), "High quality of tourism accommodation" (5.26), "High quality of services" (5.50), "Good value for money" (5.70) and "Low prices of tourism services" (5.60). The affective country image of Latvia from the point of view of the visitors is positively tended in relation to three attributes: "Relaxing atmosphere" (5.75), "Friendly, hospitable people" (6.05), "High personal safety" (5.40).

Based on the results of the analysis, it can be concluded that the perceptions of the German residents about Latvia as a tourism destination are largely consistent with the image concept of Latvian tourism. The coastal and cultural resources of Latvia are slightly undervalued by younger German residents who have not been in Latvia.

To determine what German residents associate Latvia as the tourism destination with, the open-ended question "When you think about Latvia as a travel destination, what three words come to your mind?" was asked. The Top 3 answers for all the respondent groups, only in a different order, are "Riga", "Baltic/ Baltic Sea/ Baltic states", "Nature/ landscape". Only in the age group from 18 to 24 years, the most frequently named key words are "Cold", "Nature/ landscape" and "Baltic/ Baltic Sea/ Baltic states". (See Table 6)

Table 6

The associations in connection with Latvia expressed with key words - Top 10 answers

\begin{tabular}{|c|c|c|c|c|c|}
\hline \multirow{3}{*}{$\begin{array}{c}\text { All respondents } \\
\text { (all answers } \\
n=630)\end{array}$} & \multicolumn{5}{|c|}{ from them } \\
\hline & \multirow{2}{*}{$\begin{array}{c}\text { have been in } \\
\text { Latvia (all } \\
\text { answers } n=51 \text { ) }\end{array}$} & \multirow{2}{*}{$\begin{array}{l}\text { have not been } \\
\text { in Latvia } \\
\text { (all answers } \\
n=579)\end{array}$} & \multicolumn{3}{|c|}{ from them in the age group } \\
\hline & & & $\begin{array}{c}18-24 \\
\text { (all answers } \\
\mathrm{n}=257)\end{array}$ & $\begin{array}{c}25-44 \\
\text { (all answers } \\
n=221 \text { ) }\end{array}$ & $\begin{array}{c}45+ \\
\text { (all answers } \\
n=101)\end{array}$ \\
\hline Riga (57) & Riga (9) & $\begin{array}{l}\text { Baltic/Baltic } \\
\text { Sea/ Baltic } \\
\text { states (53) }\end{array}$ & Cold (24) & $\begin{array}{l}\text { Baltic/Baltic Sea/ } \\
\text { Baltic states (26) }\end{array}$ & Riga (17) \\
\hline $\begin{array}{l}\text { Baltic/Baltic } \\
\text { Sea/ Baltic } \\
\text { states (56) }\end{array}$ & $\begin{array}{c}\text { Nature/ } \\
\text { landscape (7) }\end{array}$ & Riga (48) & $\begin{array}{c}\text { Nature/ } \\
\text { landscape (21) }\end{array}$ & $\begin{array}{c}\text { Nature/ } \\
\text { landscape (23) }\end{array}$ & $\begin{array}{c}\text { Baltic/Baltic } \\
\text { Sea/ Baltic } \\
\text { states (13) }\end{array}$ \\
\hline $\begin{array}{c}\text { Nature/ } \\
\text { landscape (56) }\end{array}$ & $\begin{array}{l}\text { Baltic/Baltic } \\
\text { Sea/ Baltic } \\
\text { states (3) }\end{array}$ & $\begin{array}{c}\text { Nature/ } \\
\text { landscape (49) }\end{array}$ & $\begin{array}{l}\text { Baltic/Baltic } \\
\text { Sea/ Baltic } \\
\text { states (14) }\end{array}$ & Riga (19) & $\begin{array}{c}\text { Nature/ } \\
\text { landscape (5) }\end{array}$ \\
\hline Cold (39) & \multirow{3}{*}{$\begin{array}{l}\text { beautiful, forest, } \\
\text { Hansa, history, } \\
\text { nice people (2) }\end{array}$} & Cold (38) & Riga (12) & Sea (13) & \multirow{3}{*}{$\begin{array}{c}\text { North; } \\
\text { Sea; } \\
\text { Russia, near } \\
\text { Russia (4) }\end{array}$} \\
\hline Sea (28) & & Sea (27) & $\begin{array}{l}\text { Small/small } \\
\text { country (12) }\end{array}$ & Forest (11) & \\
\hline Forest (23) & & Forest (21) & Lithuania (12) & Cold (11) & \\
\hline Lithuania (14) & \multirow{4}{*}{$\begin{array}{l}\text { Beach, beer, } \\
\text { cold, clouds } \\
\text { culture, EU, fun, } \\
\text { ice hockey, mod- } \\
\text { ern, sea, sun (1) }\end{array}$} & Lithuania (14) & Sea $(10)$ & North (5) & \multirow{4}{*}{$\begin{array}{l}\text { Cold; } \\
\text { Estonia; } \\
\text { Euro (3) }\end{array}$} \\
\hline Estonia (13) & & Estonia (13) & Forest (8) & Russia (5) & \\
\hline $\begin{array}{l}\text { Small/small } \\
\text { country (13) }\end{array}$ & & $\begin{array}{l}\text { Small/small } \\
\text { country (13) }\end{array}$ & Estonia (7) & $\begin{array}{c}\text { Beach; } \\
\text { Lakes; Eurovision }\end{array}$ & \\
\hline Green (9) & & Green (9) & Culture (6) & song contest & \\
\hline
\end{tabular}

Source: author's calculations based on survey data. 


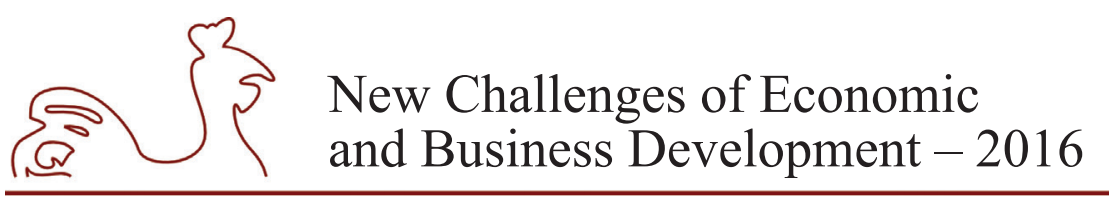

May 12-14, 2016, Riga, University of Latvia

To find out whether the German residents colour associations with Latvia meet the Latvian tourism logo colouration, the open-ended question "When you think about Latvia as a travel destination, what three colours comes to your mind?" was asked. The Top 3 answers for all the respondent groups are "Blue/ light blue/ dark blue", "Green/ light green" and "White"; the only exception is the age group 45+, to which the third most frequently named colour is red. (See Table 7) The Top 3 answers fully meet the Latvian tourism logo colouration.

Table 7

The associations in connection with Latvia expressed with colours

\begin{tabular}{|c|c|c|c|c|c|}
\hline \multirow{3}{*}{$\begin{array}{c}\text { All respondents } \\
\text { (all answers } \\
n=672)\end{array}$} & \multicolumn{5}{|l|}{ from them } \\
\hline & \multirow{2}{*}{$\begin{array}{l}\text { have been in } \\
\text { Latvia } \\
\text { (all answers } \\
n=49 \text { ) }\end{array}$} & \multirow{2}{*}{$\begin{array}{l}\text { have not been } \\
\text { in Latvia } \\
\text { (all answers } \\
n=623 \text { ) }\end{array}$} & \multicolumn{3}{|c|}{ from them in the age group } \\
\hline & & & $\begin{array}{c}18-24 \\
\text { (all answers } \\
n=299 \text { ) }\end{array}$ & $\begin{array}{c}25-44 \\
\text { (all answers } \\
n=239 \text { ) }\end{array}$ & $\begin{array}{c}45+ \\
\text { (all answers } \\
n=82 \text { ) }\end{array}$ \\
\hline $\begin{array}{c}\text { Blue, } \\
\text { light blue, dark } \\
\text { blue (162) }\end{array}$ & Green (15) & $\begin{array}{c}\text { Blue, } \\
\begin{array}{c}\text { light blue, dark } \\
\text { blue (147) }\end{array}\end{array}$ & $\begin{array}{c}\text { Blue, } \\
\text { light blue, dark } \\
\text { blue (73) }\end{array}$ & $\begin{array}{c}\text { Blue, } \\
\text { light blue (56) }\end{array}$ & Green (19) \\
\hline $\begin{array}{l}\text { Green, } \\
\text { light green } \\
(142)\end{array}$ & $\begin{array}{l}\text { Blue, light } \\
\text { blue (12) }\end{array}$ & $\begin{array}{l}\text { Green, light } \\
\text { green (130) }\end{array}$ & White (65) & $\begin{array}{l}\text { Green, light } \\
\text { green }(52)\end{array}$ & Blue (18) \\
\hline White (137) & White (9) & White (128) & Green (59) & White (46) & Red (18) \\
\hline Red (115) & Red (7) & Red (108) & Red (52) & Red (37) & White (16) \\
\hline Yellow (52) & Yellow (3) & Yellow (49) & Yellow (22) & Yellow (23) & $\begin{array}{c}\text { Red-white-red, } \\
\text { dark red (7) }\end{array}$ \\
\hline Brown (22) & $\begin{array}{c}\text { Red-white-red } \\
\text { (1) }\end{array}$ & Brown (22) & Brown (10) & Brown (12) & Yellow (4) \\
\hline $\begin{array}{l}\text { Red-white-red, } \\
\text { dark red (15) }\end{array}$ & Beige (1) & $\begin{array}{l}\text { Red-white-red, } \\
\text { dark red (14) }\end{array}$ & Grey (7) & Grey (5) & \\
\hline Grey (12) & Orange (1) & Grey (12) & Black (4) & $\begin{array}{l}\text { Red-white- } \\
\text { red (4) }\end{array}$ & \\
\hline Black (7) & & Black (7) & $\begin{array}{c}\text { Other } \\
\text { colours (7) }\end{array}$ & Black (3) & \\
\hline $\begin{array}{c}\text { Other } \\
\text { colours }(8)\end{array}$ & & $\begin{array}{c}\text { Other } \\
\text { colours (7) }\end{array}$ & & & \\
\hline
\end{tabular}

Source: author's calculations based on survey data

To find out what colour the German residents associate with vacation/ holidays, the respondents were asked: "When you think about your next vacation, what three colours come to your mind?" The Top 3 answers for all the respondent groups were "Blue/ light blue", "Green" and "Yellow", the next two most frequently named colours were "Red" and "White". (See Table 8) 


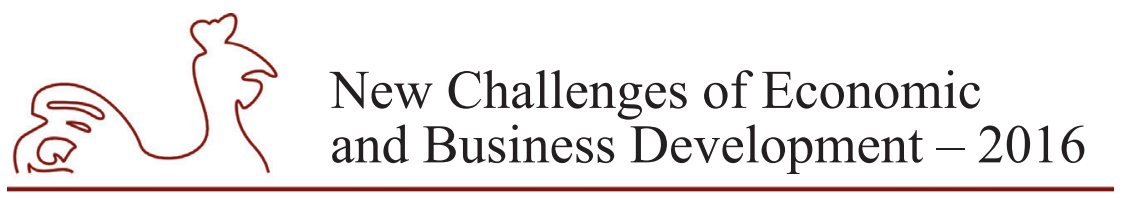

May 12-14, 2016, Riga, University of Latvia

Table 8

The associations in connection with holiday travel expressed with colours

\begin{tabular}{|c|c|c|c|}
\hline \multirow{2}{*}{$\begin{array}{c}\text { All respondents (all } \\
\text { answers } n=738)\end{array}$} & \multicolumn{3}{|c|}{ from them in the age group } \\
\cline { 2 - 4 } & $\begin{array}{c}18-24 \\
\text { (all answers } n=352)\end{array}$ & $\begin{array}{c}25-44 \\
\text { (all answers } n=289)\end{array}$ & $\begin{array}{c}45+ \\
\text { (all answers } n=94)\end{array}$ \\
\hline Blue/light blue (210) & Blue/light blue (94) & Blue/light blue (91) & Green (26) \\
\hline Green (161) & Yellow (75) & Green (70) & Blue (25) \\
\hline Yellow (136) & Green (64) & Yellow (45) & Yellow (15) \\
\hline Red (101) & Red (53) & Red (37) & White (12) \\
\hline White (72) & White (31) & White (29) & Red (10) \\
\hline Orange (14) & Orange (8) & Orange (5) & Black (3) \\
\hline Black (12) & Black (7) & Brown (4) & Brown (1) \\
\hline Brown (10) & Brown (5) & Black (2) & Orange (1) \\
\hline Other colours (22) & Other colours (15) & Other colours (6) & Red-white (1) \\
\hline
\end{tabular}

Source: author's calculations based on survey data.

Based on the results obtained from the survey, it can be concluded that the German residents' associations with Latvia and associations with holiday travel expressed in colours correspond with each other and with Latvian tourism logo.

To find out what German residents associate their holiday travel with, the open-ended question "When you think about your next vacation, what three words come to your mind?" was asked. (See Table 9)

Table 9

The associations in connection with holiday travel expressed with key words

\begin{tabular}{|c|c|c|c|}
\hline \multirow{2}{*}{$\begin{array}{c}\text { All respondents (all } \\
\text { answers } n=778)\end{array}$} & \multicolumn{3}{|c|}{ from them in the age group } \\
\cline { 2 - 4 } & $\begin{array}{c}\text { 18-24 } \\
\text { (all answers } n=342)\end{array}$ & $\begin{array}{c}25-44 \\
\text { (all answers } n=324)\end{array}$ & $\begin{array}{c}45+ \\
\text { (all answers } n=112)\end{array}$ \\
\hline Sun (128) & Sun (60) & Beach (53) & Sun (17) \\
\hline Beach (119) & Beach (54) & Sun (51) & Sea (11) \\
\hline Sea (96) & Sea (37) & Sea (48) & Recreation (10) \\
\hline Relaxation (31) & Relaxation (15) & Recreation (12) & Culture (8) \\
\hline Recreation (30) & Party (13) & Relaxation (11) & Nature (4) \\
\hline Culture (27) & Warmth (11) & Nature (10) & Landscape (3) \\
\hline Nature (19) & Culture (10) & Culture (9) & \multicolumn{2}{|c|}{ Hike (7) } & Mountains (5) & Food (5) &
\end{tabular}

Source: author's calculations based on survey data.

The Top 3 answers for all the respondent groups were "Sun", "Beach" and "Sea". 


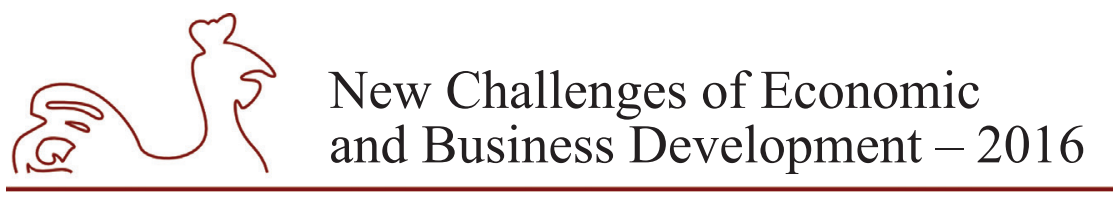

May 12-14, 2016, Riga, University of Latvia

\section{Conclusions and suggestions}

The results of the research show that the German residents' knowledge of Latvia as a travel destination is poor; the Latvian tourism brand concept both in colour and keyword terms correspond with the German citizens' perceptions about Latvia; German residents' associations with holiday travel in terms of colours meets Latvian tourism brand concept; German residents' associations with holiday travel in key words partly correspond with the Latvian tourism brand concept.

To promote Latvia as a tourism destination in the German market, we need to consider red and yellow colours additionally to current traditional green-blue-white colour combination. It would be particularly considerable for young generation highlighting possibilities that are offered by Latvian sea side.

Continue to acquaint German inhabitants with Latvia as tourism destination emphasizing aspects that German inhabitants associate with holiday, for example, for the middle and senior age audience - recreation and relaxation possibilities in nature of Latvia and "calm sea side", and for the young generation - active holiday possibilities in seaside of Latvia.

\section{Bibliography}

Elliot S., Papadopoulos N. 2016. Of products and tourism destinations: An integrative, cross-national study of place image, Journal of Business Research Volume 69, Issue 3, March 2016, pp. 1157-1165.

Fetscherin, M. 2010. The determinants and measurement of a country brand: the country brand strength index, International Marketing Review, Vol. 27, Issue 4, pp. 466-479.

Harish, R. 2010. Brand architecture in tourism branding: the way forward for India, Journal of Indian Business Research, Vol. 2 (3), pp. 153-165.

Jenes, B. 2005. Possibilities of shaping country image. Marketing and Management, 2005/2, pp. 18-29.

Kotler, Ph., Haider, D. H., Rein, I. 2002. Marketing Places. New York: The Free Press, 400 p.

Laroche, M., Papadopoulos, N., Heslop, L.A., Mourali, M. 2005. The Influence of Country Image Structure on Consumer Evaluations of Foreign Products. International Marketing Review, 2005. Vol. 22, No. 1. pp. 96-115.

Lee S., Rodriguez L., Sar S. 2012. The influence of logo design on country image and willingness to visit: A study of country logos for tourism, Public Relations Review 38, pp. 584-591.

Leisen, B. 2001. Image Segmentation: The Case of a Tourism Destination. Journal of Services Marketing. 2001. Vol. 15, No. 1, pp. 49-66.

Mahler A., Carter L. 2011. The affective and cognitive components of country image, International Marketing Review, Vol. 28, Iss, 6, pp. 559-580.

Martin, I. M., Eroglu, S. 1993. Measuring a Multi-Dimensional Construct: Country Image. Journal of Business Research, Vol. 28, pp. 191-210.

Milman, A., Pizam, A., 1995. The Role of Awareness and Familiarity with a Destination: The Central Florida Case. Journal of Travel Research 33(3): pp. 21-27.

Papadopoulos, N., Heslop, L. A., Berács, J. 1990. National Stereotypes and Product Evaluations in a Socialist Country. International Marketing Review, Vol. 7/1. pp. 32-46.

Papadopoulos, N., Heslop, L. A. 2002. Country Equity and Country Branding - Problems and Prospects. Journal of Brand Management, Vol. 9. / 4-5. pp. 294-314.

Parameswaran, R., Pisharodi, R. M. 1994. Facets of Country of Origin Image: An Empirical Assessment. Journal of Advertisement, 1994. Vol. 23, No. 1, pp. 43- 61.

Roth, K. P., Diamantopoulos, A. 2009. Advancing the Country Image Construct. Journal of Business Research, 2009. Vol. 62, pp. 726-740. 


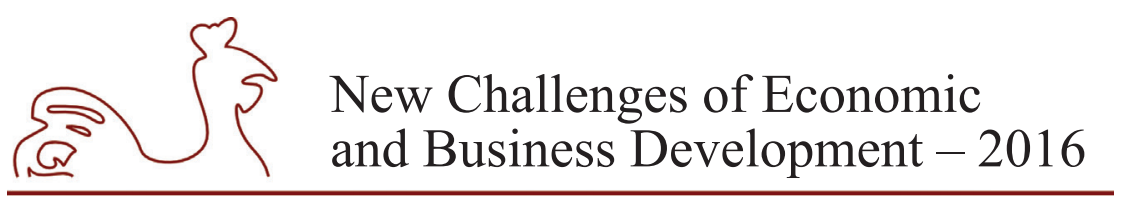

May 12-14, 2016, Riga, University of Latvia

Shakoori N., Nazemi S., Rahimnia F. 2013 Investigating Relationship between Internal Structure of Country Image and Product Attitude, International Journal of Management Sciences and Business Research, Vol. 2, Issue 12, pp. 1-14.

Stepchenkova, S., Li, X. (Robert) 2014. Destination image: Do top-of-mind associations say it all? Annals of Tourism Research, 45(2), pp. 46-62.

Latvian Tourism Image [Online] Available at: http://tava.gov.lv/en/latvian-tourism-image [Accessed 29 February 2016].

Tourism Flows Outbound in Germany. - Euromonitor International, September 2014 [Online] Available at: http://www.slovenia.info/pictures\%5CTB_board\%5Catachments_1\%5C2014\%5CTT14_DE_ Tourism_Flows_Outbound_19142.pdf [Accessed 1 March 2016]

Tourism Statistics. - Eurostat, 2015 [Online] Available at: http://ec.europa.eu/eurostat/statistics-explained/ index.php/Tourism_statistics\#Nights_spent_by_tourists_travelling_abroad [Accessed 1 March 2016]

Visual Brand Guidelines for the Latvian Tourism Image, 2015 [Online] Available at: http://tava.gov.lv/en/ latvian-tourism-image [Accessed 29 February 2016]

Overnight Non-resident Travellers by the Country of Residence. - Database of Central Statistical Bureau of Latvia [Online] Available at: http://data.csb.gov.lv/pxweb/en/transp/transp_ikgad_turisms/ TU0110.px/?rxid = a79839fe-11ba-4ecd-8cc3-4035692c5fc8 [Accessed 29 February 2016] . 
May 12-14, 2016, Riga, University of Latvia

\title{
INFLUENCING FACTORS OF RURAL AREAS DEVELOPMENT VIDZEME REGION CASE ANALYSIS
}

\author{
Vija Melbarde, Vidzeme University of Applied Sciences, Latvia ${ }^{1}$ \\ Maira Ore, Vidzeme University of Applied Sciences, Latvia
}

\begin{abstract}
An important precondition for the growth of welfare of any nation is provision of sustainable economic development and increase of the competitiveness of the country. Nowadays it is possible to reach this goal by implementing a polycentric model of the country's development based on a balanced progress of the whole territory of the country, accessibility of services and growth of economics. The statistical data show a significantly different pace and level of economic development in rural areas in Latvia, including Vidzeme Planning Region. Therefore, it is necessary to evaluate the factors determining the differences mentioned above. Koceni and Mazsalaca Counties were selected for an expanded research in Vidzeme Region.

The goal of this research is to identify the factors influencing the differences of economic development among counties, thus serving as the basis for creating a model of balanced and sustainable rural and regional development in the context of smart development. In order to identify the factors that determine the level and pace of the development in the research area and affect their performance, the authors have used the monographic method, carried out a statistical data analysis and interviewed focus groups of municipal staff, entrepreneurs and representatives of non-governmental organizations.

The article examines theoretical concepts of sustainable and smart spatial development, depicts comparative analysis of economic development indicators in Koceni and Mazsalaca Counties in the context of sustainable development of rural areas. In the course of analysis, the main groups of factors influencing economic growth in rural areas were identified. The most important factors influencing performance of the area are: geographical location; entrepreneurial capabilities of residents; municipality's attitude and support to entrepreneurship; intensity of cooperation among the municipality, entrepreneurs and nongovernmental organizations.

The theoretical and practical results of the research will be used in the process of selecting indicators for creating a sustainable development model of rural areas and regions, as well as for defining proposals for the municipalities' policy performance in the context of development of smart territories.
\end{abstract}

Key words: sustainable development, rural areas, influencing factors

JEL code: O18, R11, R23

\section{Introduction}

The main precondition for sustainable development of national economy is implementation of a balanced and polycentric country development providing balanced development of the area, accessibility of services and growth of national economy. The precondition for implementing

1 Corresponding author - e-mail address: vija.melbarde@va.lv 


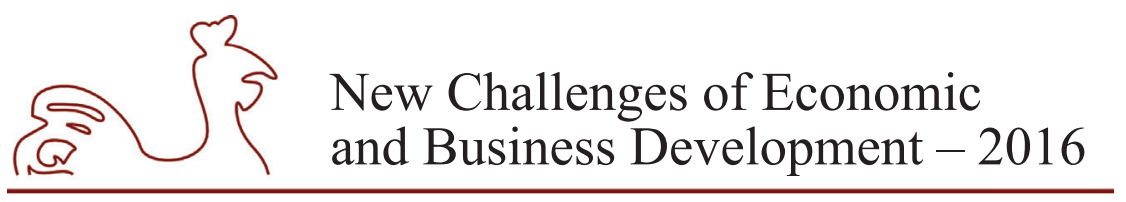

May 12-14, 2016, Riga, University of Latvia

this development model is provision of sustainable development of regions. Balanced economic development of a country is possible only with economically strong regions.

The statistical data in Latvia show that development pace and levels differ greatly in different rural areas, which prove unbalanced development of the regions, including counties in Vidzeme Planning Region, therefore it is necessary to explore and evaluate the factors determining the differences of the development of these areas.

The goal of the research is to identify the factors influencing the economic growth of the counties; it would serve as a basis for elaboration of balanced and sustainable development model in the context of smart development.

The following objectives were set for achieving of the goal: to explore the theoretical aspects of the main sustainable and smart rural area development in the context of planning documents; to carry out comparative analysis of economic development indicators in Koceni and Mazsalaca Counties, to identify the factors significantly affecting economic differences on the basis of a Case Study.

The research includes Koceni and Mazsalaca Counties located in Vidzeme Planning Region of Latvia. Vidzeme Planning Region provides regional planning and coordination, cooperation between municipalities and other state authorities; it comprises 25 counties and one city of republic importance.

The choice of counties under research was based on the ESPON CUBE methodology applied in the National Research programme ECOSOC-LV regarding rural area grouping and research (ESPON, 2015). The ESPON CUBE model was created for selection of in-depth research areas; it is based on three indicators: geographic location (if it is the centre of agglomeration, outskirts of agglomeration, the nearest or the farthest rural area); spatial characteristics (shows the proportion of rural population in each of the counties - predominantly rural (more than 50\% rural population), intermediate (15-50\% rural population), predominantly urban (up to $15 \%$ rural population); pace of development (high, above average, below average, low). In further research four county clusters were identified for creating the matrix of development level-pace of development. To create the matrix for Vidzeme Region counties, the authors used the territory development index (TDI) and the increase of economically active statistical units in the period of 2009-2013 (economically active population per 1000 inhabitants, the number of individual entrepreneurs and commercial companies per 1000 inhabitants).

\begin{tabular}{l|l}
$\begin{array}{l}\text { II Low level of development } \\
\text { High pace of development }\end{array}$ & $\begin{array}{l}\text { I High level of development } \\
\text { High pace of development }\end{array}$ \\
\hline $\begin{array}{l}\text { III Low level of development } \\
\text { Low pace of development }\end{array}$ & $\begin{array}{l}\text { IV High level of development } \\
\text { Low pace of development }\end{array}$
\end{tabular}

Source: author's construction based on ESPON, 2015.

Fig. 1. Development level - the rate matrix

Two areas with distinctly different development pace and level and geographical location were selected: Mazsalaca County (high pace of development, low level of development), located near the border of Estonia, distance to Valmiera $45 \mathrm{~km}$, to Rujiena $21 \mathrm{~km}$, no motorways in the 


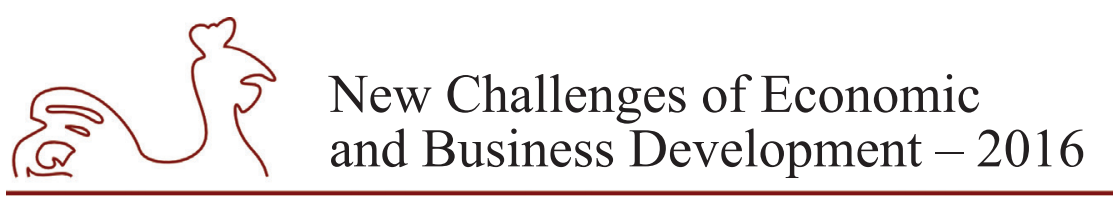

May 12-14, 2016, Riga, University of Latvia

vicinity), and Koceni County (pace of development below average, high level of development), bordering on Valmiera City, near a motorway).

To identify the factors affecting the differences in pace and levels of economic development in areas under research, a comparative analysis of statistical data was carried out (TDI indexes, direct foreign investments, financing from European Structural Fund projects) and focus group interviews. In total 31 focus group participant was interviewed, including 9 municipal staff members ( 5 in Mazsalaca County, 4 in Koceni County) 10 representatives of non-governmental (NGO) organizations ( 7 in Koceni County, 3 in Mazsalaca County); 12 entrepreneurs (7 in Koceni County, 5 in Mazsalaca County).

In order to represent the broadest possible spectrum of business, the entrepreneurs' focus groups were formed by the following selection criteria: sector of activity, turnover growth trend within three years, and the number of employees. Local governments were represented by management and development planning specialists, all NGO-s registered in the counties were invited to the focus groups.

The novelty of the research is application of a new research methodology for the analysis of rural development. Previously rural areas in Latvia were researched using quantitative indicators' analysis, however qualitative research, covering municipal employees, entrepreneurs and NGOs representing local communities, was limited. The aggregate of factors affecting the area development, identified by the research, will be used for elaborating a model of smart development for the rural territory.

During the research, certain problems were created by low response rate from entrepreneurs and residents in the process of creating focus groups. The research is only an initial stage of a further in-depth study, marking the future research directions. In further research attention should be paid to the differences in the statistical data of the Regional Development Indicators Module of Spatial Development Planning Information System (RDIM) and State Employment Agency databases. The chief information sources are planning documents, theoretical literature, county statistical data, and focus group interview data.

The survey covers municipal employees, entrepreneurs and NGOs, identifying their views on critical aspects of the spatial development, while the role of the state and impact of related factors are viewed only indirectly. The research encourages a discussion on factors that significantly affect a long-term development of rural areas and should be applied for elaboration of rural ad regional development model.

\section{Research results and discussion}

\section{Factors influencing sustainable regional development and provision of development in documents of economic policy}

Regional development has a multi-dimensional character affected by a manifold set of factors. Most of the regional development theories are based on the capital theory.

One of the most in-depth regional development models offered by Maheran, Haslina, Filzah, Norezam (2011), emphasizes social capital, employment and human capital (knowledge, skills, innovation) which are the chief factors, affected by social inequality, changes in production, external migration that, together with social climate and public administration, determine the regional development. Other authors consider human capital as the main influencing factor, 


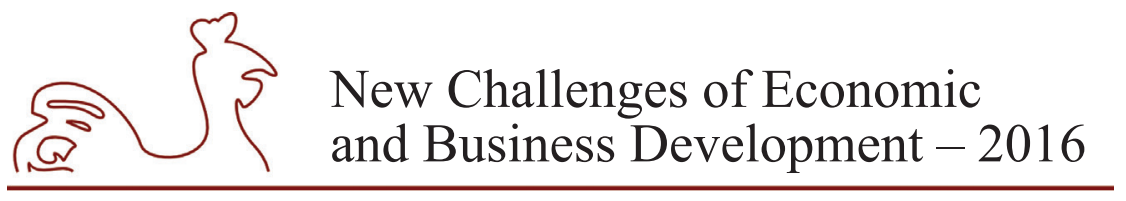

May 12-14, 2016, Riga, University of Latvia

pointing out the importance of education system in the region that determines the attraction of educated people to the area (Maheran N. M., Haslina C. Y., Filzah M. I., Siti Norezam O., 2011).

Hammond and Thompson's (2008) research of human capital investments in urban and rural areas confirm the previous viewpoint: investment in human capital considerably affects the total spatial development; however, it demonstrates a bigger influence on the increase of people's income in large cities than in areas outside them.

Acemoglu D., Gallego F. A., Robinson J. A. (2014), using a multi-factor analysis, proved that regional development is affected by many factors, the most significant being cultural, religious and historical factors. Acemoglu and Robinson (2012) represent a direction that considers activity of economic institutions and management as an essential factor for economic development. The leading Latvian scientists stick to belief that the capital is the determining factor for the regional development: physical, financial, human and social capital (Boruks A., Kruzmetra M., Rivza B., Rivza P., Stokmane I., 2000).

Theoretical concepts offer a broad range of multidimensional factors for the research of the region; these factors may critically affect the rural area development, and the most significant of them refer to human capital, investments, employment and social capital.

Currently, the researchers widely use impact factor grouping in four factor groups for the study of rural areas: Economy, People, Environment, and Governance (George C., 2007).

EU and Latvian economic planning documents provide guidelines for provision of sustainable regional development.

"The principle of sustainable development provides for quality environment and balanced economic development for the present and future generations as well as rational use of natural, human and material resources, preservation and development of natural and cultural heritage" (Vidzeme Planning Region, 2015)

Sustainable development is linked with smart economy and specialization. Smart specialisation is a strategic approach to economic development, by developing research and innovations for the needs of local entrepreneurship with an aim to promote innovation and growth of production in the spheres where the region has competitive advantages and innovation potential (Vidzeme Planning Region, 2015).

Vidzeme Planning Region has defined smart specialisation spheres to be developed to provide a balanced and sustainable development: wood products with high added value; healthy food and beverages, recreation and sustainable tourism, rehabilitation and health care services; the use of biomass for chemical processing and energy; smart materials; information technology; creative industries; remote professional services (Vidzeme Planning Region, 2015).

\section{Analysis of statistical data}

The research area is located in Vidzeme Region, Latvia. Koceni County surface area is $498.52 \mathrm{~km}^{2}$, and Mazsalaca County, including Mazsalaca Town, surface area is $417.08 \mathrm{~km}^{2}$, the population density (pers. $/ \mathrm{km}^{2}$ ) in 2014 was 13.56 and 8.73 respectively (Central Statistical Bureau, 2015). According to OECD regional grouping both counties were classified as predominantly rural regions (over 50 percent of the population living in rural communities) (OECD, 2009).

State Regional Development Agency calculates territory development indexes (TDI) according to the order set by Regulations of Cabinet of Ministers "Regional Development 


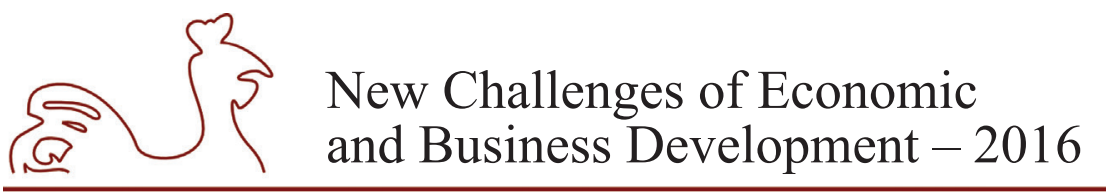

May 12-14, 2016, Riga, University of Latvia

and Supervision Arrangements". The calculated indexes of the counties and their changes in comparison to year 2013 are shown in Table 1 (State Regional Development Agency, 2015).

Table 1

Territory development indexes in counties (data of 2014)

\begin{tabular}{|l|c|c|c|c|}
\hline \multirow{2}{*}{} & \multicolumn{2}{|c|}{ Koceni County } & \multicolumn{2}{c|}{ Mazsalaca County } \\
\cline { 2 - 5 } & Value & Rank & Value & Rank \\
\hline Territory development index (units) & 0.001 & 35 & -0.411 & 71 \\
\hline Territory development change index (units) & 0.198 & 36 & -0.271 & 72 \\
\hline
\end{tabular}

Source: author's construction based on State Regional Development Agency, 2014.

To explore the influencing factors of the different development rates of Koceni and Mazsalaca Counties, we compared the TDI indicators of 2014.

Table 2

Parameters and their weight of importance in the counties for calculation of territory development index

\begin{tabular}{|l|l|c|c|c|}
\hline Nr. & \multicolumn{1}{|c|}{ Parameter } & Weight & $\begin{array}{c}\text { Koceni } \\
\text { County }\end{array}$ & $\begin{array}{c}\text { Mazsalaca } \\
\text { County }\end{array}$ \\
\hline 1. & $\begin{array}{l}\text { Number of economically active individual entrepreneurs and } \\
\text { commercial companies per 1000 inhabitants }\end{array}$ & 0.25 & 27.8 & 24.4 \\
\hline 2. & Unemployment level, \% & 0.15 & 5.3 & 5.7 \\
\hline 3. & Percentage of poor people vs. total population, \% & 0.1 & 9.09 & 8.1 \\
\hline 4. & Total number of criminal offenses per 1000 population & 0.05 & 16.3 & 7.6 \\
\hline 5. & Natural movement of the balance per 1000 population & 0.1 & -3 & -7 \\
\hline 6. & Long-term net migration rate per 1000 population & 0.1 & -10 & -16 \\
\hline 7. & Population over working age per 1000 working age population & 0.05 & 304 & 402 \\
\hline 8. & Personal income tax per capita, in euro & 0.2 & 391.43 & 312.21 \\
\hline & Weight amount & 1.0 & & \\
\hline
\end{tabular}

Source: author's construction and calculations based on Central Statistical Bureau, 2015, Cabinet of Ministers, 2014, State Regional Development Agency, 2015.

Data in Table 2 prove that more important weight parameters in TDI calculations are comparatively lower in Mazsalaca County than in Koceni: the number of economically active entrepreneurs per 1000 population (deviation minus $12.23 \%$ ), personal income tax per capita $(-20.23 \%)$, unemployment level $(+8 \%)$, which proves that entrepreneurial activity is lower than in Koceni County, and this affects demographic indicators.

Attraction of finance is an important precondition for territory development. Within the period of 2012-2014, there is a significant disparity in the amount of direct foreign investments in the researched counties. In Koceni County the total amount of investment in 2012 was 619129 EUR per 1000 population, while in Mazsalaca County it was more than eight times less (74 538 EUR). Moreover, during the next two years the total amount of direct investments sharply decreased below 550 EUR per 1000 population (in 2013 - 532 EUR, in 2014 - 549 EUR), while the decrease of investments in Koceni County compared to 2012 was within $4.2-5.3 \%$ (State Regional Development Agency, 2014). 


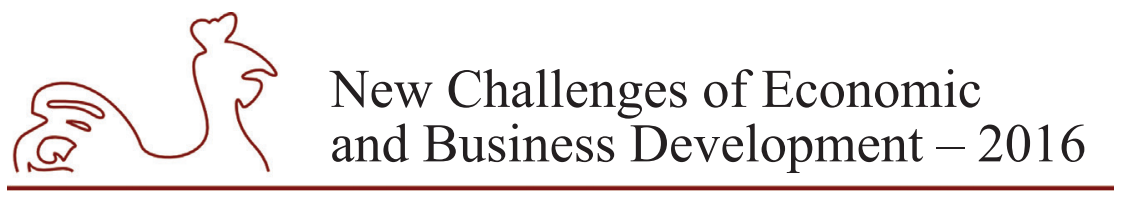

May 12-14, 2016, Riga, University of Latvia

As regards the EU funds project acquisition (ERDF, ESF, the Cohesion Fund) within the period of 2001-2015, we can see the decrease of attracted financing in both counties. In 2013 Koceni County attracted resources from the European Regional Development Funds for 548 800 EUR, but in 2015 only for 56000 EUR. Mazsalaca County attracted respectively 190000 EUR in 2013 and 24800 EUR in 2014. Mazsalaca County, contrary to Koceni County, received Cohesion Fund financing for 193500 EUR (in 2013) and 9800 EUR (in 2014). Koceni County received support from the European Social Fund in the amount of 72000 EUR, while Mazsalaca County attracted 20 times less support (36000 EUR) (State Regional Development Agency, 2016).

\section{Case Study}

What creates the development differences between the two geographically close areas? To explore the factors affecting the disparity in economic development of the counties, the authors carried out focus group interviews with municipal staff, entrepreneurs, and representatives of NGOs in Koceni County in July 2015 and in Mazsalaca County in September 2015. The main issues in the interviews for municipal staff members included characteristics of county residents; specifics of entrepreneurial potential of the region; living space; factors affecting entrepreneurship and prospects of development; municipal influence instruments for promotion of economic activity in their area; opportunities of agricultural development; cooperation between entrepreneurs, residents and regional governments.

Characterising the rural territory as a living space, Mazsalaca County municipal employees accentuate the fact that it is relatively easier to switch to something else in the rural area to provide one's living in variable conditions of political or economical environment. The economic justification in rural life is measured and comparable in alternate expenses. For the elder generation beautiful environment is an important factor in the choice of the living space, while young people stay in the country mainly to earn money. Koceni County municipal employees characterise the area as an attractive place to live near Valmiera City, with beautiful surroundings, convenient public transport to Riga. There exists a distinctive internal migration within the county territory and outside it to the economic and cultural life centre. There is a shortage of living space in the county centre, but no demand in the remote areas where mainly the historical family properties are inhabited. The choice of residence is connected with large expenses, as living in the country means comparatively large expenses to reach the objects of infrastructure and services relevant to modern life expectations. The people are attracted to counties due to personal contacts and attitude.

Sketching the portrait of a county entrepreneur in Mazsalaca, it is emphasised that an important aspect is family involvement in entrepreneurship, generational continuity (especially in agricultural enterprises). The entrepreneurs are responsive to support, including social support without undue self-promotion, yet they are restrained in cooperation with other business partners of the county. The entrepreneurs are ready to take responsibility; they are adequately educated, motivated and courageous. The average Mazsalaca entrepreneurs are about 40 years old, 55\% of them are male, $45 \%$ female, they are flexible in their actions, not afraid to switch in critical situations. It is more difficult to change the field of activity in case of bank loans, especially when the people have invested large money in their business, e.g., dairy farming. Young people are cautious to start their businesses, they would rather be employees than employers; the most 


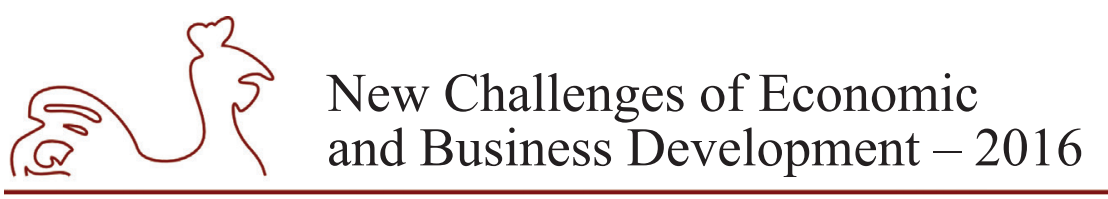

May 12-14, 2016, Riga, University of Latvia

capable of them leave the area. Koceni County residents are characterised as self-sufficient and enterprising, they manage their business problems on their own. The entrepreneurs do not have an association as most of them are actively involved in nearby Valmiera business activities. They are proud of their status, flexible to change, ready to diversify their activities, to offer new products and services. They are willing to cooperate with other sectors of industry; however, the attitude to cooperation within one sector is reserved. They are demanding to themselves as to high quality of products and require loyalty from the customers as well. It is a maledominated business, majority of them are experienced in business. They have flexible attitude to business, a desire to increase their product export capacity. The most active are tourism business representatives. Home producers and individual entrepreneurs need more assistance from the local government. The municipal experts render sufficient support to the entrepreneurs, thus promoting their cooperation.

Mazsalaca municipal staff indicate the following unused opportunities: remote working possibilities in knowledge intensive industries are not actively used; entrepreneurs fail to use the nearby Estonian market opportunities, including tourism sector; the development of home producers is hindered by the location of the county far away from urban centres and lack of the interest from the residents themselves. Koceni Council staff members admit that entrepreneurs are slow to exploit the scientific potential, which is the basic precondition for optimising business processes and achieving better results.

Evaluating the future development prospects, employees of Mazsalaca municipality express a forecast that tourism industry will not have an essential impact on the national development either in the county or on a national level. The focus should be on adding more value in extracting and processing industries. In the future, the main skills necessary for entrepreneurs will be foreign language skills; application and modelling of IT solutions; selling skills. The municipal employees consider that sustainable development and smart specialisation mean to create a comfortable and creative environment for support of modern and innovative (the municipality has already invested in IT modernisation and training). The biggest challenge for Koceni municipal employees is to create the most attractive place for living and entrepreneurship, to find a balance between entrepreneurial, living, social and cultural environment. Entrepreneurs actively react to changes; there is large export potential for manufacturing enterprises (woodworking, dairy farming, ceramics, charcoal, pellets, and peat production). Tourism is a priority in the services sector. Entrepreneurial activities keep changing - transformation and diversification of entrepreneurship is in process, production is combined with services (for instance, dairy farming and tourism services). In the future, legal, accounting and planning services, and project consultation will be concentrated in satellite companies affiliated to production. Small enterprises have all preconditions to turn to biological farming. A new perspective service is emerging - maintenance of small territories. Workforce mobility in the county is high: workforce both arrives from Valmiera and other counties and leaves for them. Proximity to Valmiera is a threat to the population of outlying areas.

As regards available municipal impact tools, Mazsalaca Council members point out creation of entrepreneurial environment within the function and financial possibilities of the local government. If the planned property tax increase in the national fiscal policy is implemented, it will be a significant tool for promotion of economic development of the county. Municipal support to entrepreneurs is often restricted by the regulatory framework and poor road infrastructure. 


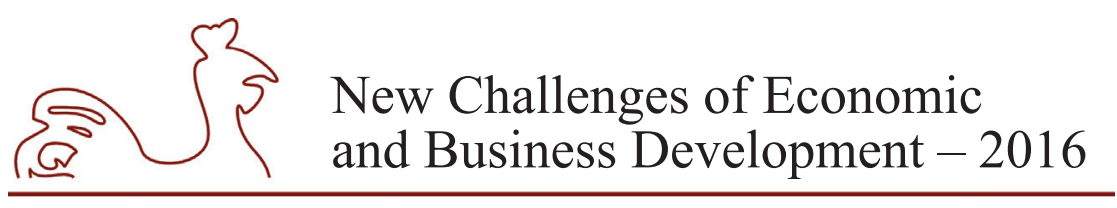

May 12-14, 2016, Riga, University of Latvia

Entrepreneurs incur losses from the uncompleted project 'Northern String' as the $20 \mathrm{~km}$ section Mazsalaca-Staicele is still not paved. As the result, entrepreneurs have additional expenses due to transport maintenance and overdue deliveries. Koceni municipality believes that personal income tax, a great part of which comes from residents working in Valmiera City, is fundamental for the county development. Support instruments are the benefits systems as a whole, especially newborn benefits, free meals for schoolchildren, tax reliefs and provision of favourable business environment. There should be a new tool on a national level, by redistributing corporate income tax to create a local government fund for the maintenance of infrastructure, and part of corporate tax operating in the local government should be transferred to this fund. An important national instrument is acquisition of the European Structural Fund resources where enterprises from regions with lower Territory Development index should be given prioritary support intensity.

Characterising agricultural sector and its development prospects, Mazsalaca focus group respondents admit that agriculture (beef cattle and sheep farming, grain growing) and woodworking are profitable businesses, capable of attracting EU financing. Cattle farming and processing of agricultural products have better development prospects in the future, considering relatively low soil fertility. Intensive agriculture is damaging environment; the focus should be on biological farming. Professional forest management is a perspective direction. Koceni municipality employees' view is that agricultural sector will survive and develop. Both municipalities do not have a possibility to expand on the expense of agricultural land, as there is no free land on offer, so traditional agricultural sectors should increasingly offer additional services, or production of new products (for instance, meet breeders in Koceni County have started processing their own product, or core production is combined with tourist services). Existence of small farms is under threat; therefore, one possibility is organic farming.

Both Koceni and Mazsalaca municipalities positively evaluate cooperation with Vidzeme regional government, both on everyday advisory level and within new joint project development.

As regards cooperation between entrepreneurs and population, Mazsalaca municipal employees' opinion is that in general entrepreneurs are generally responsive, though reserved in mutual communication, in some cases even reluctant. Public life depends on leaders' activities. There is a sense of competition among residents, sometimes the younger generation is unwilling to cooperate and learn craft skills or knowledge from the older generation. Intergenerational cooperation is observed more in the sphere of culture. In Koceni County, business cooperation is best manifested in collaboration with non-governmental organizations supporting grassroots activities in the county. The numerous associations' activities are bustling. The municipal employees consider that the economic development of the county $30 \%$ depends on activities of NGOs and $70 \%$ on business as it stimulates entrepreneurship, offers services and invests in infrastructure. The associations operate on a local level; however, they promote public activity in their surroundings and the county. The associations basically use financing from the LEADER projects. The entrepreneurs are more open, they willingly cooperate with other partners in Valmiera and surrounding areas from earlier administrative territorial breakdown.

Interview questions to NGO representatives were elaborated with an aim to find out the motivation of residents to get involved and participate in the respective organization; contributing and hindering factors of the operation of these organizations; cooperation aspects, ways of gathering and exchange of information; to identify sources of financing and activities that NGOs would be ready to develop in their area. 


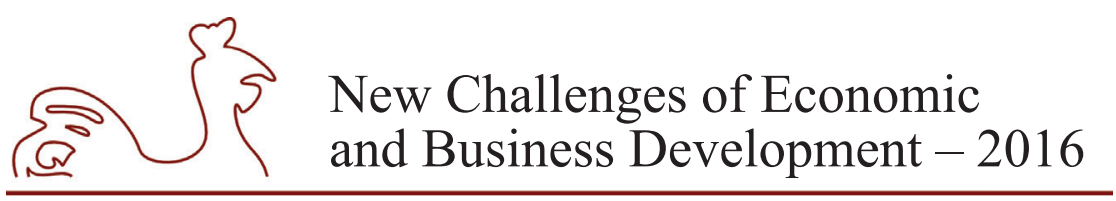

May 12-14, 2016, Riga, University of Latvia

Regarding issues of their motivation to participate in NGO activities, Mazsalaca organization members mention maintaining and popularising the cultural-historical landscape in the area; for some people the organization is a friends and peers' group; an opportunity to raise money for various training courses; participation in fairs and development of traditional crafts; participation promotes individual development. Koceni residents maintain the viewpoint that the main motivator is the sense of mission and raising the common good for the county and the region. The wish to participate is promoted by personal interest, a possibility to share one's personal experience and a desire to help the rural people to get away from their everyday problems; an opportunity to earn extra income. Many people are motivated by their family members, friends, support from the municipality and co-financing.

The respondents list the operation of interest clubs and availability of the LEADER programme as the contributing factors in organizations in Mazsalaca, while the main hindering factors are lack of support to small farmsteads for conservation of landscape; the feeling of self-sufficiency in the society, youth inertia, different interests of members. Respondents are disappointed that such a geologically rich area (Mazsalaca, Rujiena, and Naukseni) has not been granted a national status, which prevents its development into a European level recognized geopark that would attract a certain category of travellers. Koceni NGO participants are dissatisfied with bureaucracy in project documentation and the fact that there is no national vision for development of NGO; in daily work, the problem is lack of financial resources. The people in Koceni are active and enterprising; they have their local government support, interesting cultural-historical environment encouraging NGO activity.

Attracted financial sources. In Mazsalaca associations and foundations have used only the Environmental Protection Fund resources, while Koceni County associations are active in a variety of fundraising activities: LEADER projects, local governmental co-financing, Rural Support Services resources, Rural Women's Association's and other private funds, including financing from Boriss and Inara Teterevi Fund, the Netherland's Community Foundation, support from Guterslo District in Germany.

In Mazsalaca and Koceni Counties, internet resources and social networks are actively used by NGOs as sources for searching and exchanging information, equally popular are association home pages, Rural Support Services websites, tourist information centres, contacts with business people and municipalities, cooperation with other NGOs in Latvia and abroad, county newsletters, school and local government meetings with NGOs.

Mazsalaca NGO members are ready to offer the following services in near future: to organize a nature camp for schoolchildren in Finland, to organize a summer school for women. In Koceni, there is an idea to expand water sports offer (wakeboard, wakeskate and freestyle) and increase children's activity in them, to develop activities for children with special needs in tourist objects, provision of horse drawn transport or rickshaws for viewing of cultural-historical objects.

The scope of questions for entrepreneurs includes clarification of motivational factors affecting the desire to engage in business activity: how the skills and knowledge, necessary for economic activity, are acquired and developed; who the cooperation partners are, how fundraising is organized; what the positive factors and the main obstacles for economic activity in the region are; what the future prospects for the next five year are. 


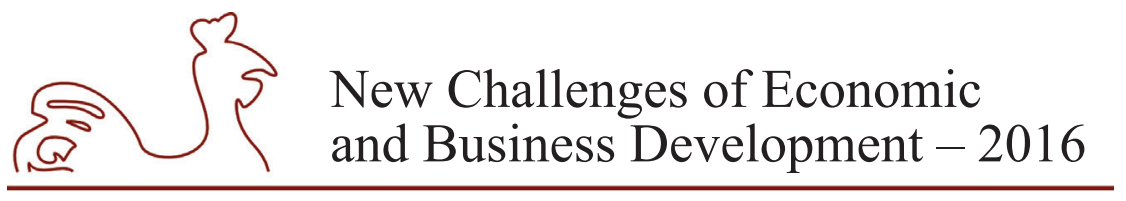

May 12-14, 2016, Riga, University of Latvia

Characteristics of the interviewed entrepreneurs: Mazsalaca entrepreneurs are active people, three of them run business on their own, and two of them have family businesses. Majority of Koceni entrepreneurs have more than 10 years experience in business, five businesses are family owned. The chief industries are woodworking, charcoal production, grain growing, potato growing, cattle breeding, catering services, metalwork.

Motivation and inspiration for economic activity: Mazsalaca entrepreneurs admit that it is unemployment and a desire to live and work in their ancestors' place, liquidation of the collective farm; discovering of trading skills in oneself; biological farming as a way of life; inheritance of a merchant's gene; patriotic feelings. They find inspiration in sports activities, grandchildren, attending cultural events. Koceni entrepreneurs mention family influence and experience, desire to manage the family property, an opportunity to earn and freely plan their work and life, be independent, provide for their family more substantially, enterprising character and previous experience.

Mazsalaca entrepreneurs indicate that abilities and skills that help in management are determined by long-term experience in business and earlier top management positions; relevant education; practical experience under father's guidance, experience in the household lot and on collective farms; inherited grandfather's craftsman's skills and training of many- sided skills of one's own. Koceni entrepreneurs point out upbringing in early childhood in the family, the role of work and self-education.

Fund raising. Mazsalaca entrepreneurs mainly rely on their own finances. Two projects have failed in the Rural Support Service, one entrepreneur has used a loan from the Mortgage Bank. This fact is also confirmed by previous statistical data, and it proves that total direct foreign investment per 1000 population in Mazsalaca County is almost a 1000 times less than in Koceni County. In Koceni, all the entrepreneurs rely both on their own financing and on other financing sources: bank loans, ESF resources; and farms receive the state support program Altum.

Development prospects. Three enterprise owners in Mazsalaca County are positive about the future, they are planning to expand their activity, however, two companies do not see any perspective and are looking for alternatives. In Koceni County, all the interviewed companies are planning to retain the existing amount of production; one agricultural farm is planning to expand by involving family members. For Koceni entrepreneurs the most essential thing is improvement of production efficiency indicators rather than the amount of the product, although the charcoal, woodworking and metalwork companies are planning to expand their export to EU countries.

In both counties, the entrepreneurs use the internet resources and social networks as information channels. Koceni entrepreneurs use a more versatile channel range: partners' networks, involvement in industry professional association, participation in international exhibitions, and cooperation with State Employment Agency.

\section{Conclusions, Proposals, Recommendations}

1. Statistical indicators characterising county business activity show that business activity in Mazsalaca County is lower than in Koceni County, and this is the reason for active workforce outflow from Mazsalaca County. 


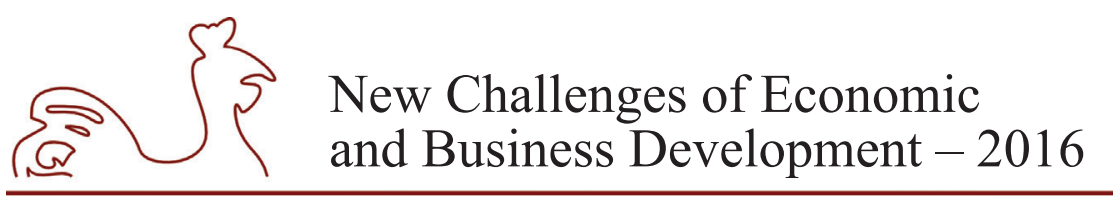

May 12-14, 2016, Riga, University of Latvia

2. The basis for the differences in development rate and level in the counties under research are created by environmental factors: location and developed infrastructure. Koceni has certain advantages in exploiting these advantages, as the county is located near a national importance motorway, bordering on Valmiera City providing developed infrastructure. On the contrary, Mazsalaca has limited infrastructure, located far away from national importance development centres and motorways.

3. Another important group is the human factor: availability of workforce, community activity, initiative of residents. Closeness to Valmiera City provides Koceni County with workforce, and on the other hand, the county residents can find jobs in Valmiera, which is of mutual benefit and affects the county income tax revenue. Activity of NGOs, which is an indicator for business start-ups, and unlocking of initiative is considerably higher in Koceni than in Mazsalaca. Mazsalaca County people are more reserved in mutual communication and do not fully realize the versatile resource potential of the area.

4. The most significant economic factor is the ability to attract financing and workforce migration processes. Koceni entrepreneurs are more active in attraction of external financing (foreign investments and EU Structural funds financing per 1000 population is larger than in Mazsalaca County), thus finding an opportunity to expand production and creating additional jobs in the county and preventing population outflow.

5. Koceni County municipality demonstrates bigger involvement and support to business activities and the local community; it takes initiative in shaping communication between the interest groups of population, which are the most important management factors.

6. On the basis of this research, elaborating a model of balanced and sustainable rural and regioanl development model, the authors recommend to focus on the following main indicators: indicators of environmental factors - geographical location, landscape and biological diversity, proportion of cultivated agricultural land (\%), total density of road network $\left(\mathrm{km} / \mathrm{km}^{2}\right)$; indicators of human factors - positive long-term net migration per 1000 population, residents with higher education per 1000 population, the number of NGOs per 1000 population, lifelong learning for the employed and training of the unemployed per 1000 population; indicators of economic factors - proportion of innovative companies (\% of the total number), the number of self-employed people per 1000 population, direct foreign investments per 1000 population, and residents' personal income tax per 1000 population; management indicators - total local government expenditure (per capita), EU Fund Project financing per 1000 population and the number of municipal website visits per 1000 population, internet coverage ( $\%$ of the territory), proportion of residents who participated in local elections (\%).

Acknowledgement. The paper was supported by the National Research Program EKOSOCLV 5.2.3., a subproject for Latvian rural and regional development processes and opportunities in the context of the knowledge economy regarding development of rural areas and affecting indicators. 


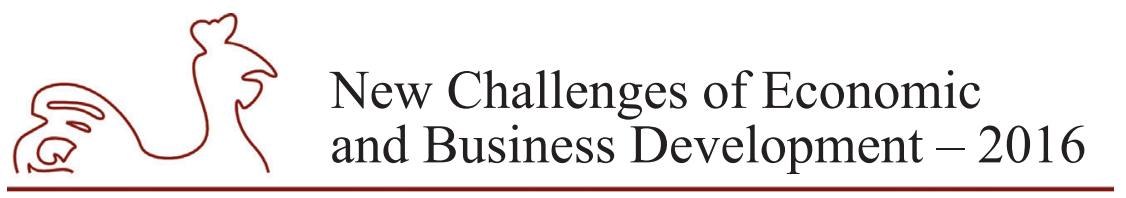

May 12-14, 2016, Riga, University of Latvia

\section{Bibliography}

Acemoglu, D., Gallego, F. A., Robinson, J. A., 2014. Institutions, Human Capital and Development. Annual Review of Economics, Vol. 6(1), pp. 875-912. [Online] Available at: http://www.nber.org/ papers/w19933.pdf [Accessed 15 December 2015].

Boruks A., Kruzmetra M., Rivza B., Rivza P., Stokmane I., 2000. Natural and Socio-economic Conditions and the Interaction Effecton Latvian Rural Development. Jelgava: LLU, pp. 169. Economics and Rural Development, Vol. 7, No. 2, 2011.

Cabinet of Ministers, 2014. Regional Development and Supervision Arrangements. [Online] Available at: http://likumi.lv/doc.php?id=267737 [Accessed 17 February 2016].

Central Statistical Bureau, Republic of Latvia, 2015. [Online] Available at: http://www.csb.gov.lv/dati/ statistikas-datubazes-28270.html [Accessed 15 January 2016].

ESPON, 2015. OLAP Cubemethodologie. [Online] Available at: http://database.espon.eu/db2/ resource?idCat $=31$ [Accessed 10 December 2015].

George C., 2007. Sustainable Development and Global Governance. The Journal of Environment and Development, Vol. 16, No. 1, March 2007, pp. 102-125.

Hammond, G. W., Thompson, E. C., 2008. AJAE Appendix for "Determinants of Income Growthin Metropolitan and Non-metropolitan Labor Markets". American Journal of Agricultural Economics APPENDICES, Vol. 90, No. 3, August 2008. [Online] Available at: http://purl.umn.edu/164020 [Accessed 1 November 2015].

Nik Maheran N. M., Haslina Che. Y., Filzah M. I., Siti Norezam O., 2011. Regional Economic Development: Rethinking the Region. Journal of Information Technology and Economic Development 2(1), pp. 74-82, April 2011. [Online] Available at: http://datubazes.lanet.lv:3532/eds/ pdfviewer/pdfviewer?sid=429c0680-75e3-4a17-958d-36f6773a4bc8\%40sessionmgr112\&vid=0\&h $\mathrm{id}=104$ [Accessed 13 November 2015].

OECD, 2009. Regional Typology: Updated Statistics. [Online] Available at: www.oecd.org/gov/regional/ statisticsindicators [Accessed 13 November 2015].

State Regional Development Agency, 2015. Regional Development Indicators Module of Spatial Development Planning Information System. [Online] Available at: http://raim.gov.lv/cms/tiki-index. php?page=Home [Accessed 30 January 2016].

State Regional Development Agency, 2014. Territory development indexes in counties. [Online] Available at: http://www.vraa.gov.lv/lv/publikacijas/attistibas_indekss/ [Accessed 30 January 2016].

Vidzeme Planning Region, 2014. Smart specialization possibilities of Vidzeme Planning Region. [Online] Availableat:http://www.vidzeme.lv/lv/regionalie_petijumi/50/128234/[Accessed 7 January 2016].

Vidzeme Planning Region, 2015. Sustainable Development Strategy for Vidzeme Planning Region 2030. [Online] Available at: http://jauna.vidzeme.lv/upload/VPR_IAS.pdf [Accessed 12 January 2016]. 


\title{
DEVELOPMENT OF LENDING RATES IN THE BALTIC COUNTRIES: COMMON AND DIVERGING ASPECTS
}

\author{
Vija Micune, Bank of Latvia, Latvia ${ }^{1}$
}

\begin{abstract}
In the Baltic countries, lending rates have been among the highest in the euro area mainly reflecting national differences in the market structure as well as relatively strict credit standards applied by banks in response to the changes in their perception of risk. In this context, the deeper econometric analysis could provide additional information about the common and diverging aspects of the dynamics of lending rates in the Baltic countries. Therefore, the aim of the paper to explore the pass-through of funding costs of banks to lending rates in different lending segments in the Baltic countries during the period of 2005-2015 taking in account risk considerations. To reach the set aim, appropriate comparisons are made between different specifications of the error correction model, first of all, relating specifications with three- month EURIBOR rate and weighted average costs of short-term euro liabilities and, secondly, specifications with and without the measures of borrower credit risk and banking risk. As a result, the conclusion was reached about superiority of three-month EURIBOR rate as a measure of funding costs of banks. The measures characterizing creditworthiness of borrowers and banking risk are significant factors determining lending rates in the Baltic countries. Across the Baltic states, the pass-through from funding costs of banks to lending rates are high. Long-term pass-through from funding costs of banks to lending rates tends to be higher in Lithuania, but creditworthiness of borrowers appeared to have the highest influence on lending rates in Latvia.
\end{abstract}

Key words: lending rate, interest rate pass-through, error correction model, credit risk of borrowers, banking risk

JEL code: C22, E43, G21

\section{Introduction}

The level and changes of lending rates is in the scope of interest of the European Central Bank, which bases its monetary policy on the interest rate channel. The ECB determines the official interest rates as well as influence the level of liquidity in the money market to ensure the appropriate level of short term money market rates, which, in turn, influence the path of development of longer-term market rates. Those market rates usually have a direct effect on lending rates; and, if the changes in market rates are fully reflected in lending rates, this phase of the monetary policy could be considered as effective. Low interest rates on loans newly granted to non-financial corporations implicitly stimulate country's investment and international competitiveness in the same way as low interest rates on loans newly granted to households encourage consumption. In addition, declining money market interest rates may transform into a smaller interest rate burden on the borrowers.

Corresponding author - e-mail address: vija_micune@yahoo.com 


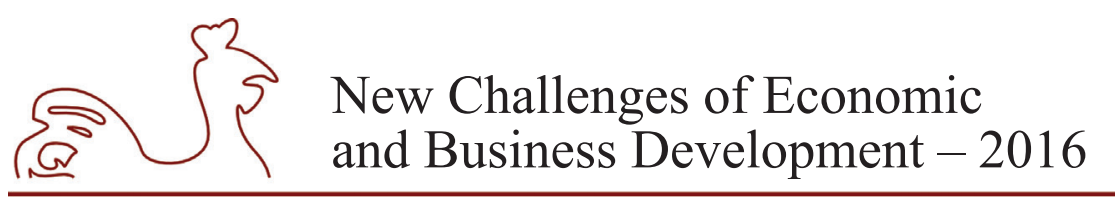

May 12-14, 2016, Riga, University of Latvia

Finally, higher investment and consumption stimulates the overall growth of the economy and medium-term inflation, which is in the primary focus of the ECB. In the Baltic countries, lending rates presently have been among the highest in the euro area mainly reflecting national differences in the market structure as well as relatively strict credit standards applied by banks in response to the changes in their perception of risk. In this context, the question arises about what common and diverging aspects explain the dynamics of lending rates in the Baltic countries in general and how they could be affected by the monetary policy of the ECB in particular.

The dynamics of lending rates is studied in depth in the empirical literature. An important strand of this literature concerns a pass-through from money market rates to lending rates. Many scientific papers (for example, Cottarelli, C. \& Kourelis, A., 1994; Winker, P., 1999; DeBondt, G., 2002; Sander, H. \& Kleimeier, S., 2004; Egert, B. et al.,2007; DeGreave, F. et al.,2007; Banerjee A. et al.,2013) show that lending rates adjust to the changes in funding cost of banks described by money market rates with a time lag; the level of pass-through from money market rates to lending rates and the speed of their adjustment differ among countries, financial institutions, and various types of loans. Frequently, a faster and more complete adjustment is considered to characterize a more efficient monetary policy (Mojon, B., 2000.; Sander, H. \& Kleimeier, S., 2004; Illes, A. et al.,2015). The newest research papers (Hansen, F. N.-J. H.\& Welz, P., 2011; Arnold, I. \& van Eivijk, S., 2014; Paries, M.D. et al.,2014; Illes, A. et al.,2015; von Borstel, J. et al.,2015) show that, after 2008 global financial crisis and successive European debt crisis, the dynamics of lending rates is affected not only by policy or money market rate, but also by credit risk of borrowers, sovereign risk and banking risk.

Hence the aim of the research is to explore the pass-through of funding costs of banks to lending rates in different lending segments in the Baltic countries during the period of 20052015 taking in account risk considerations. To reach the set aim, the paper addresses several research questions. First of all, it assesses whether the pass-through from funding costs of banks to lending rates and the speed of lending rate adjustment differ significantly for two alternative measures of funding cost of banks, namely three-month EURIBOR rate and weighted average cost of euro liabilities. Secondly, it addresses the question whether and how credit risk of borrowers and banking risk have affected the previously observed relationships between lending rates and funding costs of banks. Finally, the work compares the pass-through from funding costs of banks to lending rates for different types of loans and across the Baltic states. The work is based on foreign and Latvian scientific publications, as well as on statistical data published on the websites of the national central banks of each of the Baltic countries, the European Central bank and the European Commission. The dynamics of lending rates in the Baltic states is analysed with the error correction model and state space model.

In Europe, the most of the research papers about the pass-through of policy rate or banks' funding costs to lending rates are devoted to the largest euro area countries (Weth, A. M., 2002; Banerjee, A. et al.,2013; Paries, M.D. et al.,2014; Avouyi-Dovi, S. et al.,2015; Illes, A. et al.,2015; von Borstel, J. et al.,2015). Nevertheless, the dynamics of lending rates are analysed also in the Baltic countries either for each country separately or as a part of the larger group of the Central and Eastern countries (see, for example, the paper by Männasoo, K. (2013) in Estonia, Lapinskas, V. (2011) in Lithuania, and Mičūne, V. (2010) in Latvia). The development of lending rates has not been analysed for the separate group of three Baltic countries yet. As concerns the analysis of pass-through from money market rates to lending rates in the Baltic 


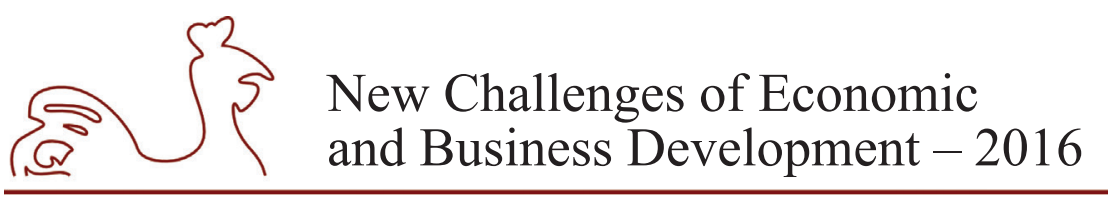

May 12-14, 2016, Riga, University of Latvia

countries, the standard form of the error correction model has been used in different lending segments, currencies and time periods only in Latvia. In those econometric estimations, lending rates have been related to the dynamics of the appropriate money market rates (Mičūne, 2009). In this paper, the analysis of the dynamics of lending rates in the Baltic states involves not only estimation of the standard error correction model between lending rates and money market reference rate, but also estimation of other specifications of error correction model that include several risk factors and weighted average cost of short-term euro liabilities as an alternative measure of funding costs of banks. Furthermore, the time variability of the related long-run pass-through coefficients has been checked within the state space model for the first time for the Baltic countries. The findings of the research would contribute to the understanding on how lending interest rates are set in commercial banks; and they would provide insight about the effectiveness of the monetary policy of the European Central Bank in the Baltic countries.

\section{Research results and discussion}

\section{Statistical Data and Methodological Considerations}

In this paper, the analysis is based on monthly data of monetary financial institutions' lending rates for the time period from January 2005 to January 2016, which are published on the Statistical Data Warehouse on the website of the European Central Bank. The lending interest rates used herein cover the greatest part of the lending products offered by banks in the Baltic countries: loans granted to resident households for house purchase, consumer loans, and for other purposes, as well as loans granted to resident non-financial corporations (further in the text - enterprises) of small and medium size (up to 1 million euro) and of large size (over 1 million euro). Due to data availability issues, the article considers only floating interest rates or interest rates with an initial rate fixation period of up to one year on newly granted euro loans.

In order to get better understanding about the factors affecting lending rates in the Baltic countries, their dynamics is analysed within five specifications of the selected econometric model. In three from five specifications of the model, lending rates are analysed in connection with 3-month EURIBOR, which is the most popular interest rate for pricing euro loans in the Baltic countries. In two specifications, the article uses an alternative benchmark for bank funding costs proposed by Illes, A. et al (2015), namely weighted average cost of short-term euro liabilities of the banks in each of the Baltic countries. The measure is compiled using four types of liabilities: interbank deposit liabilities, private non-financial sector deposit liabilities, debt securities and funding from central bank operations. Each type of liabilities is linked to the corresponding interest rate. The weights are based on outstanding stock of liabilities from banks' balance sheets (for details see the paper by Illes, A. et al (2015).

In addition, several risk measures are tested in the specifications of the proposed model. Taking in consideration the article by Arnold, I. \& van Eivijk, S. (2014), the Economic Sentiment Indicator, measuring the current business climate and its future outlook, is used as a variable describing the credit risk of borrowers. The time series for this indicator is taken from the webpage of the European Commission. Based on the work by Paries, M.D. et al (2014), banking risk also is included in the last specification of the model. It is represented by the median of credit default swap rates on 1-year senior debt of European Union banks from the Statistical Data Warehouse of the European Central Bank. Both risk measures are transformed in logs. 


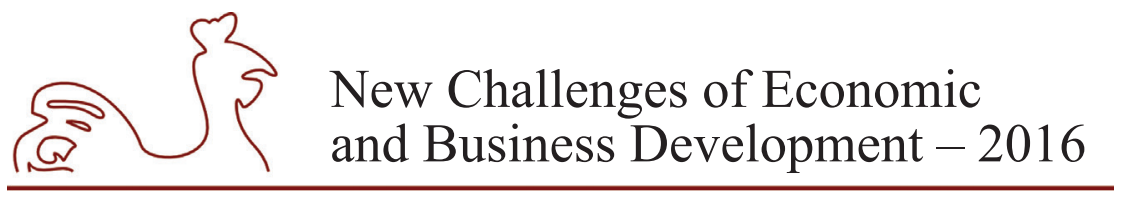

May 12-14, 2016, Riga, University of Latvia

After the analysis of time series properties of the data, all of the proposed data of lending rates and their explanatory factors in the Baltic states appear to be integrated with order one. Therefore, the framework of the well-known error correction model could be the most appropriate for the deeper analysis of the dynamics of lending rates in the Baltic states. In this framework, analysis procedure starts with estimating the long-run relationship between lending rates and their explanatory factors (see, for example, DeBondt, G. (2002), Heffernan, S. A. (1997), Paries, M.D. et al (2014)). For different specifications of the model used in this article, this relationship is expressed by the following equations:

Specification I

Specification II

$$
L R_{j, i, t}=\alpha_{j, i}^{S 1}+\beta_{j, i}^{S 1} M R_{i . t}+u_{j, i, t}^{S 1}
$$

$$
L R_{j, i, t}=\alpha_{j, i}^{S 2}+\beta_{j, i}^{S 2} W A C L_{i, t}+u_{j, i, t}^{S 2}
$$

Specification III

$$
L R_{j, i, t}=\alpha_{j, i}^{S 3}+\beta_{j, i}^{S 3} M R_{i . t}+\gamma_{j, i}^{S 3} C R_{i, t}+u_{j, i, t}^{S 3}
$$

Specification IV

$$
L R_{j, i, t}=\alpha_{j, i}^{S 4}+\beta_{j, i}^{S 4} W A C L_{i . t}+\gamma_{j, i}^{S 4} C R_{i, t}+u_{j, i, t}^{S 4}
$$

Specification V

$$
L R_{j, i, t}=\alpha_{j, i}^{S 5}+\beta_{j, i}^{S 5} M R_{i . t}+\gamma_{j, i}^{S 5} C R_{i, t}+\tau_{j, i}^{S 5} B R_{t}+u_{j, i, t}^{S 5}
$$

where $L R_{j, i, t}$ is lending rate in the $j$-th segment in the $i$-th Baltic country; denotations $M R_{i . t}$ and $W A C L_{i . t}$ stand for two alternative measures of banks' funding costs, respectively three-month EURIBOR rate and weighted average cost of banks' short-term euro liabilities; $C R_{i, t}$ is the proxy for creditworthiness of borrowers in the $i$-th Baltic country; and $B R_{t}$ represents banking risk. Variables $u_{j, i, t}^{S 1}, u_{j, i, t}^{S 2}, u_{j, i, t}^{S 3}, u_{j, i, t}^{S 4}$ and $u_{j, i, t}^{S 5}$ are the deviations of lending rates from their long-term equilibrium level for different specification of the model in the $j$-th lending segment in $i$-th Baltic country. Parameters $\alpha_{j, i}^{S 1}, \alpha_{j, i}^{S 2}, \alpha_{j, i}^{S 3}, \alpha_{j, i}^{S 4}$ and $\alpha_{j, i}^{S 5}$ measure a mark-up over of banks' funding cost for different specification of the model in each lending segment and country. They show by how many percentage points the lending rate is set above the related measure of banks' funding costs. Parameters $\beta_{j, i}^{S 1}, \beta_{j, i}^{S 2}, \beta_{j, i}^{S 3}, \beta_{j, i}^{S 4}$ and $\beta_{j, i}^{S 5}$ reveal by how many percentage points lending rates in different segments in the Baltic sates would change in the long-run if the related measures of banks' funding costs changes by one percentage point. The expected value of those parameters is positive and, under perfect competition and complete information, close to one. Parameters $\gamma_{j, i}^{S 3}$ and $\gamma_{j, i}^{S 4}$ characterize the influence of creditworthiness of borrowers and parameter $\tau_{j, i}^{S 5}-$ of banking risk in each lending segment of the Baltic countries.

The next step of the analysis involves estimation of the short-run relationship between the lending rates and explanatory variables. The short-run equations for five specifications of the model is generalized into one equation as:

$$
\begin{gathered}
\Delta L R_{j, i, t}=\alpha_{j, i}^{n, S R}+\beta_{j, i, 0}^{n, S R} \Delta R R_{i . t}+\lambda_{j, i}^{n} \hat{u}_{j, i, t-1}^{n} \\
+\sum_{k=1}^{K_{1}} \beta_{j, i, k}^{n, S R} \Delta R R_{i . t-k}+I_{C R} \sum_{k=0}^{K_{2}} \gamma_{j, i, k}^{n, S R} \Delta C R_{i, t-k}+I_{B R} \sum_{k=0}^{K_{3}} \tau_{j, i, k}^{n, S R} \Delta B R_{i . t-k}+\varepsilon_{j, i, t}^{n}
\end{gathered}
$$




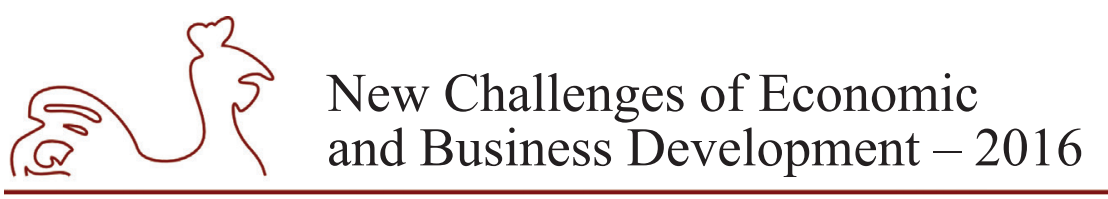

May 12-14, 2016, Riga, University of Latvia

where $R R_{i . t}$ is the funding cost measure of $i$-th Baltic country either based on three-month EURIBOR rate (the first, third and fifth specifications) or weighted average cost of shortterm euro liabilities (the second and fourth specification); $\hat{u}_{j, i, t-1}^{n}$ is an estimated longterm equilibrium error incurred in the previous period for $n$-th specification in $j$-th lending segment of $i$-th country; and all other variables correspond to the definitions given above. Denotation $\Delta$ stands for a first order operator. Denotations $\alpha_{j, i}^{n, S R}$ stands for a constant, $\beta_{j, i, 0}^{n, S R}-$ an immediate or short-term pass-through coefficient from funding costs of banks to lending rates and $\lambda_{j, i}^{n}-$ an error correction quotient or the adjustment speed of lending rates towards their long-term equilibrium value, but $\beta_{j, i, k}^{n, S R}, \gamma_{j, i, k}^{n, S R}$ and $\tau_{j, i, k}^{n, S R}$ - coefficients corresponding to $k$-th lag of funding costs, creditworthiness of borrowers and banking risk accordingly for the $n$-th specification in $j$-th lending segment of $i$-th country. A number of lags determined arbitrary by a criteria of the coefficient of determination. Instrumental variable $I_{C R}$ takes the value of one if the specifications with the creditworthiness of borrowers are considered and the value of zero otherwise. Variable $I_{B R}$ takes the value of one if the fifth specification with banking risk is estimated and the value of zero otherwise. A short-term for $n$-th specification and $j$-th lending segment in $i$-th country is denoted by $\varepsilon_{j, i, t}^{n}$. If the long-term equilibrium error is statistically significant, the parameter $\lambda_{\mathrm{j}, \mathrm{i}}^{\mathrm{n}}$ shows what fraction of the long-term equilibrium error could be eliminated during the next period. The expected value of parameter $\lambda_{\mathrm{j}, \mathrm{i}}^{\mathrm{n}}$ is negative. The following equation could be used to calculate the time necessary for complete adjustment of lending rates to their long-run equilibrium value $\left(1-\beta_{\mathrm{j}, \mathrm{i}, 0}^{\mathrm{n}, \mathrm{SR}}\right) / \lambda_{\mathrm{j}, \mathrm{i}}^{\mathrm{n}}$ for the corresponding specification of the model, lending segment and country.

Estimated coefficients before the respective explanatory variable and their $t$-values are presented in four tables. Tables 1 and 2 report the results from estimating the long-term relationship of the error correction model for loans to households and enterprises respectively. Table 3 presents the results from estimating the short-run equation of the model for loans to households and Table 4 - for enterprises. All tables show the results across five model specifications for the three Baltic countries. Table 3 and 4 include the additional information about adjusted coefficients of determination and adjustment time of lending rates.

\section{Evaluation of Different Specifications of the Error Correction Model}

In the Baltic countries, there is no clear evidence that the measure of funding costs based on the weighted average cost of liabilities serves better than simple three-month EURIBOR interest rate (Tables 1-4). However, the measure based on weighted average cost of liabilities similarly as the measure based on 3-month EURIBOR interest rate tend to be statistically significant and have a positive sign in the long-run equations across different lending segments and across three Baltic countries. According to the obtained coefficients of determination pertaining to the short-run relationships between lending rates and considered explanatory variables, the short-run dynamics of lending rates could be explained better if the comparable specification includes three-month EURIBOR. Comparing the results of model specifications that includes the measure of weighted average cost of liabilities with the corresponding specifications that include 3-month EURIBOR rate (the first specification with the second and the third with the fourth one), the long-run impact of the measure based on weighted average cost of liabilities on lending rates tends to be higher than the the long-run impact of three-month EURIBOR rates in different lending segments in all of the Baltic countries. In the short-run, however, changes of 


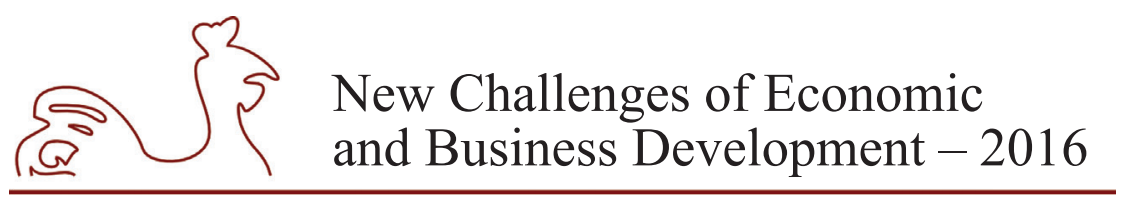

May 12-14, 2016, Riga, University of Latvia

weighted average cost of liabilities tend to influence the short-term fluctuation of lending rates by a smaller extent. The adjustment to the long-run equilibrium tend to take longer period of time in the most of lending segments of the Baltic states if the measure of weighted average cost of liabilities is considered.

In almost all lending segments in each of the three Baltic states, models of lending rates strongly benefit from inclusion of the measure characterizing creditworthiness of borrowers (Tables 1-4). In the third specification, where lending rates is explained by three-month EURIBOR and the proxy for creditworthiness of borrowers, the latter measure is statistically significant and has a negative sign in the long-run equation (except loans to households for other purpose in Estonia). In this specification as compared with the simple relationship between lending rates and three-month EURIBOR (the first specification), the long-run pass-through coefficient of reference money market rate to lending rate tend to be slightly higher and have a greater statistical significance across different lending segments and all three Baltic states. In addition, the short-run dynamics of lending rates also are explained better if the creditworthiness of borrowers are considered together with three-month EURIBOR rate. The third specification of the model tend to have the highest coefficient of determination among the first four specifications of the model for loans to enterprises regardless their size and for loans to households for house purchase in all of the Baltic states. Estimation of the related long-term relationships with weighted average costs of liabilities also provides supportive evidence for inclusion of the proxy of creditworthiness of borrowers. Although the corresponding results are less encouraging if the short-run equations are considered.

Another measure reflecting banking risk also is helpful in explaining the dynamics of lending rates in the Baltic countries (Tables 1-4). In the last specification, linking lending rates to three-month EURIBOR rate, the proxy for creditworthiness of borrowers and the proxy for banking risk, the latter risk factor is statistically significant and has a positive sign in the longterm equation in such lending segments as large loans to enterprises, small and medium term loans to enterprises, loans to households for house purchase and loans to households to other purposes at least in two of the Baltic countries. The credit risk measure of banking system is insignificant in the long-term equation for loans to households for house purchase in Latvia as well as for consumption loans in Latvia and Lithuania. The sign of the proxy for creditworthiness of borrowers becomes positive (theoretically wrong) after inclusion the proxy for banking risk in the third specification in the case of consumption loans and loans to households to house purchase in Estonia. In the short-run, the proxy for banking risk often appears insignificant. Although, in more than half of cases across different lending segments and three Baltic countries, the shortrun equation of the error correction model has the highest coefficient of determination if the fifth specification of the model with the proxy of banking risk is considered.

Taking in account the sign and statistical significance of the explanatory variables in the long-run equation, the best specification could be selected, from one side, between the first, third and fifth specifications that include three-month EURIBOR rate and, from another side, between the second and fourth specifications that include the measure based on weighted costs of liabilities (see the grey area in Table 1 and Table 2). From those, the specification with the highest coefficient of determination in the short-run equation could be considered to be superior (see the grey area in Table 3 and Table 4). Following the described rule of thumb, in seven from fourteen cases the fifth specification of the model, including the proxy of creditworthiness of 


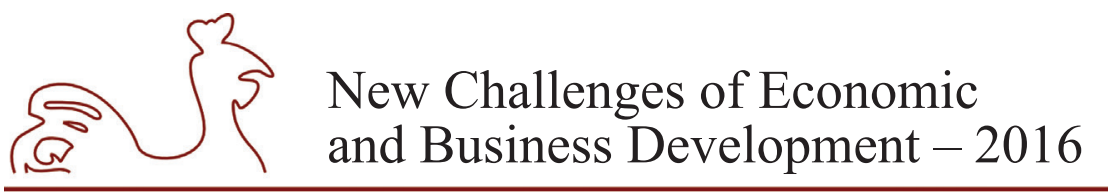

May 12-14, 2016, Riga, University of Latvia

borrowers and the proxy for banking risk, appears the most appropriate, but in four from fourteen cases the fourth specification, including the measure of weighted average cost of liabilities and the proxy of creditworthiness of borrowers, could be selected as the leading one.

\section{Interpretation of the Estimated Long-run Relationship of the Error Correction Model}

Across lending segments, the long-pass through coefficients in all the three Baltic countries are highest in the lending segments where interest rates usually are linked to a variable money market reference rate (Tables 1-2). In Latvia and Lithuania, the money market rate or weighted average cost of liabilities affect the long-term level of lending rates by most in the segment of large loans to enterprises, but in Estonia - in the segment of loans to households for house purchase. In the fifth specification of the long-run relationship for large loans to enterprises, the long-run pass-through coefficient is 0.80 and 0.82 respectively in Latvia and Lithuania. Relatedly, the long-run pass-through coefficient is 0.76 in the corresponding specification for loans to households for house purchase in Estonia. The long-run pass-through coefficient of money market rate is the lowest for consumer loans in Estonia and Lithuania. In the same lending segment in Latvia, the money market rate has a theoretically wrong sign in the first four specifications and is insignificant in the fifth specification of the long-term relationship. The influence of money market rates or weighted average cost of liabilities could be assessed as average for loans to households for other purposes as compared with loans in other lending segments in all Baltic countries.

Across lending segments, the proxy of creditworthiness of borrower influence the longterm level of lending rates by a smaller extend for large loans to enterprises and loans to households for house purchase (Tables 1-2). The large enterprises tend to be less affected by economic fluctuations than the smaller ones; and banks in the Baltic states prefer lending to large enterprises to lending to smaller and riskier enterprises after 2008 financial crisis. Similarly, loans to households for house purchase usually is guaranteed by collateral; and therefore their margins are lower and less affected by the changes in the external circumstances.

Across the Baltic countries, long-term pass-through from funding costs to lending rates tends to be higher in Lithuania in the majority of considered lending segments, especially after taking in account the direct influence of risk factors (Tables 1-2). However, with some exceptions, the differences between the long-run pass-through coefficients are not principal. In the segment of small and medium sized loans for enterprises, long-run pass-through coefficient depending on the model specification ranges from 0.60 to 0.76 in Latvia, from 0.62 to 0.74 in Estonia and from 0.67 to 0.84 in Lithuania. In the segment of large loans to enterprises, longrun pass-through coefficients in Latvia, Estonia and Lithuania are in the range from 0.74 to 0.86 , from 0.72 to 0.92 , and from 0.73 to 0.91 accordingly. Similarly, $70 \%$ to $82 \%$ of change in funding cost measure is transmitted to interest rates on loans to households for house purchase in Latvia, $72 \%$ to $85 \%$ of change in funding cost measure - to corresponding rates in Estonia and $75 \%$ to $95 \%$ - in Lithuania. In the segment of loans to households for other purposes, the pass-through coefficient is significantly smaller in Latvia (in the range from 0.45 to 0.58 ), but relatively close in Lithuania (in the range from 0.55 to 0.73 ) and Estonia (in the range from 0.63 to 0.74 ). The pass-through coefficient from funding cost measure to lending rate is relatively higher in most specifications in Estonia than in Lithuania. 


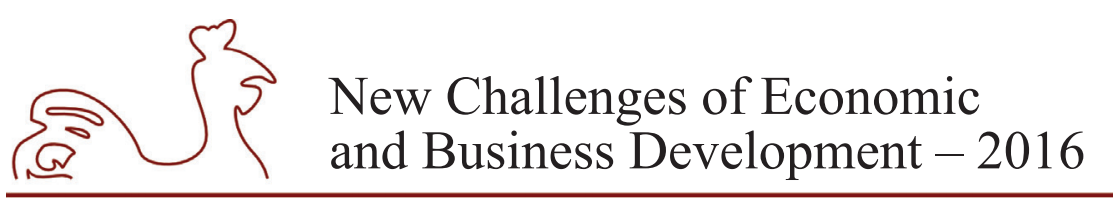

May 12-14, 2016, Riga, University of Latvia

Table 1

Assessment of Long-Run Relationship for Loans to Households

\begin{tabular}{|c|c|c|c|c|c|c|c|c|c|c|c|c|}
\hline \multicolumn{13}{|c|}{ Loans to Households for House Purchase } \\
\hline \multirow{2}{*}{$\begin{array}{l}\text { Speci- } \\
\text { fication }\end{array}$} & \multicolumn{4}{|c|}{ Latvia } & \multicolumn{4}{|c|}{ Lithuania } & \multicolumn{4}{|c|}{ Estonia } \\
\hline & $M R_{i, t}$ & $W A C L_{i, t}$ & $C R_{i, t}$ & $B R_{t}$ & $M R_{i, t}$ & $W A C L_{i, t}$ & $C R_{i, t}$ & $B R_{t}$ & $M R_{i, t}$ & $W A C L_{i, t}$ & $C R_{i, t}$ & $B R_{t}$ \\
\hline I & $\begin{array}{r}0.70 \\
31.6\end{array}$ & $\mathrm{X}$ & $\mathrm{x}$ & $\mathrm{x}$ & $\begin{array}{c}0.75 \\
30.9\end{array}$ & $\mathrm{x}$ & $\mathrm{x}$ & $\mathrm{x}$ & $\begin{array}{r}0.72 \\
40.1\end{array}$ & $\mathrm{x}$ & $\mathrm{x}$ & $\mathrm{x}$ \\
\hline II & $X$ & \begin{tabular}{|r|}
0.82 \\
34.9 \\
\end{tabular} & $\mathrm{x}$ & $\mathrm{x}$ & $\mathrm{X}$ & \begin{tabular}{|r}
0.90 \\
31.0
\end{tabular} & $\mathrm{x}$ & $\mathrm{x}$ & $\mathrm{x}$ & \begin{tabular}{|r|}
0.82 \\
32.2 \\
\end{tabular} & $\mathrm{x}$ & $\mathrm{x}$ \\
\hline III & \begin{tabular}{|c|}
0.73 \\
51.9
\end{tabular} & $\mathrm{X}$ & \begin{tabular}{|l|}
-2.84 \\
-14.2
\end{tabular} & $\mathrm{X}$ & $\begin{array}{r}0.81 \\
54.1\end{array}$ & $\mathrm{X}$ & $\begin{array}{r}-3.12 \\
-15.5 \\
\end{array}$ & $\mathrm{x}$ & \begin{tabular}{|r|}
0.73 \\
53.8
\end{tabular} & $\mathrm{x}$ & $\begin{array}{r}-1.88 \\
-10.0\end{array}$ & $\mathrm{x}$ \\
\hline IV & $\mathrm{X}$ & \begin{tabular}{|c|}
0.82 \\
37.8 \\
\end{tabular} & $\begin{array}{r}-1.30 \\
-4.9\end{array}$ & $\mathrm{X}$ & $\mathrm{X}$ & \begin{tabular}{|c|}
0.95 \\
40.4
\end{tabular} & $\begin{array}{r}-2.38 \\
-9.2 \\
\end{array}$ & $\mathrm{x}$ & $\mathrm{x}$ & \begin{tabular}{|c|}
0.85 \\
44.0 \\
\end{tabular} & $\begin{array}{r}-2.34 \\
-10.2\end{array}$ & $\mathrm{x}$ \\
\hline $\mathbf{V}$ & \begin{tabular}{|r}
0.74 \\
45.6 \\
\end{tabular} & $\mathrm{x}$ & \begin{tabular}{|r|}
-2.73 \\
-12.0 \\
\end{tabular} & $\begin{array}{r}0.03 \\
1.0\end{array}$ & \begin{tabular}{|r|}
0.85 \\
56.5
\end{tabular} & $\mathrm{x}$ & \begin{tabular}{|l|}
-2.59 \\
-12.6
\end{tabular} & \begin{tabular}{|r}
0.14 \\
5.6 \\
\end{tabular} & \begin{tabular}{|l|}
0.76 \\
49.4 \\
\end{tabular} & $\mathrm{x}$ & $\begin{array}{r}-1.46 \\
-6.9\end{array}$ & $\begin{array}{r}0.09 \\
3.7\end{array}$ \\
\hline
\end{tabular}

\begin{tabular}{|c|c|c|c|c|c|c|c|c|c|c|c|c|}
\hline \multicolumn{13}{|c|}{ Consumption Loans (accounting for euro introduction effect) } \\
\hline \multirow{2}{*}{$\begin{array}{c}\text { Speci- } \\
\text { fication }\end{array}$} & \multicolumn{4}{|c|}{ Latvia } & \multicolumn{4}{|c|}{ Lithuania } & \multicolumn{4}{|c|}{ Estonia } \\
\hline & $M R_{i, t}$ & $W A C L_{i, t}$ & $C R_{i, t}$ & $B R_{t}$ & $M R_{i, t}$ & $W A C L_{i, t}$ & $C R_{i, t}$ & $B R_{t}$ & $M R_{i, t}$ & $W A C L_{i, t}$ & $C R_{i, t}$ & $B R_{t}$ \\
\hline I & $\begin{array}{r}-0.70 \\
-3.3 \\
\end{array}$ & $\mathrm{X}$ & $\mathrm{X}$ & $\mathrm{x}$ & $\begin{array}{r}0.47 \\
8.0 \\
\end{array}$ & $\mathrm{X}$ & $\mathrm{X}$ & $\mathrm{x}$ & $\begin{array}{r}0.39 \\
1.7 \\
\end{array}$ & $\mathrm{X}$ & $\mathrm{X}$ & $\mathrm{X}$ \\
\hline II & $\mathrm{X}$ & $\begin{array}{r}-0.69 \\
-2.7 \\
\end{array}$ & $\mathrm{X}$ & $\mathrm{x}$ & $\mathrm{X}$ & $\begin{array}{r}0.56 \\
7.9 \\
\end{array}$ & $\mathrm{X}$ & $\mathrm{x}$ & $\mathrm{X}$ & \begin{tabular}{|r|}
0.29 \\
1.1 \\
\end{tabular} & $\mathrm{X}$ & $\mathrm{X}$ \\
\hline III & $\begin{array}{r}-0.40 \\
-2.0 \\
\end{array}$ & $\mathrm{X}$ & $\begin{array}{r}-12.5 \\
-5.3 \\
\end{array}$ & $\mathrm{X}$ & \begin{tabular}{|r|}
0.55 \\
9.2 \\
\end{tabular} & $\mathrm{X}$ & $\begin{array}{r}-2.67 \\
-3.8 \\
\end{array}$ & $\mathrm{X}$ & $\begin{array}{r}0.50 \\
2.1 \\
\end{array}$ & $\mathrm{X}$ & $\begin{array}{r}-4.55 \\
-2.0 \\
\end{array}$ & $\mathrm{X}$ \\
\hline IV & X & \begin{tabular}{|r|}
-0.54 \\
-2.3 \\
\end{tabular} & $\begin{array}{r}-13.2 \\
-5.8 \\
\end{array}$ & $\mathrm{X}$ & $\mathrm{X}$ & \begin{tabular}{|r|}
0.62 \\
8.6 \\
\end{tabular} & $\begin{array}{r}-2.11 \\
-3.0 \\
\end{array}$ & $\mathrm{X}$ & $\mathrm{X}$ & $\begin{array}{r}0.45 \\
1.6\end{array}$ & $\begin{array}{r}-4.53 \\
-1.9 \\
\end{array}$ & $\mathrm{X}$ \\
\hline $\mathbf{V}$ & $\begin{array}{r}-0.29 \\
-1.2\end{array}$ & $\mathrm{X}$ & $\begin{array}{r}-9.44 \\
-3.5\end{array}$ & $\begin{array}{r}0.45 \\
1.3\end{array}$ & $\begin{array}{r}0.59 \\
8.3\end{array}$ & $\mathrm{X}$ & $\begin{array}{r}-2.08 \\
-2.6\end{array}$ & $\begin{array}{r}0.13 \\
1.2\end{array}$ & $\begin{array}{r}0.51 \\
2.3\end{array}$ & $\mathrm{X}$ & $\begin{array}{r}6.83 \\
2.3\end{array}$ & $\begin{array}{r}2.12 \\
5.6\end{array}$ \\
\hline
\end{tabular}

\begin{tabular}{|c|c|c|c|c|c|c|c|c|c|c|c|c|}
\hline \multicolumn{13}{|c|}{ Loans for Other Purposes } \\
\hline \multirow{2}{*}{$\begin{array}{c}\text { Speci- } \\
\text { fication }\end{array}$} & \multicolumn{4}{|c|}{ Latvia } & \multicolumn{4}{|c|}{ Lithuania } & \multicolumn{4}{|c|}{ Estonia } \\
\hline & $M R_{i, t}$ & $W A C L_{i, t}$ & $C R_{i, t}$ & $B R_{t}$ & $M R_{i, t}$ & $W A C L_{i, t}$ & $C R_{i, t}$ & $B R_{t}$ & $M R_{i, t}$ & $W A C L_{i, t}$ & $C R_{i, t}$ & $B R_{t}$ \\
\hline $\mathbf{I}$ & $\begin{array}{r}0.45 \\
7.9\end{array}$ & $\mathrm{x}$ & $\mathrm{x}$ & $\mathrm{x}$ & $\begin{array}{r}0.55 \\
15.9\end{array}$ & $\mathrm{x}$ & $\mathrm{x}$ & $\mathrm{X}$ & $\begin{array}{r}0.63 \\
7.6\end{array}$ & $\mathrm{x}$ & $\mathrm{X}$ & $\mathrm{x}$ \\
\hline II & $\mathrm{X}$ & $\begin{array}{r}0.56 \\
8.9\end{array}$ & $\mathrm{X}$ & $\mathrm{x}$ & $\mathrm{x}$ & $\begin{array}{r}0.66 \\
15.9\end{array}$ & $\mathrm{X}$ & $\mathrm{X}$ & $\mathrm{x}$ & $\begin{array}{r}0.70 \\
7.0\end{array}$ & $\mathrm{x}$ & $\mathrm{x}$ \\
\hline III & $\begin{array}{r}0.52 \\
12.6 \\
\end{array}$ & $\mathrm{x}$ & $\begin{array}{r}-6.41 \\
-11.0\end{array}$ & $\mathrm{X}$ & $\begin{array}{r}0.63 \\
24.2 \\
\end{array}$ & $\mathrm{X}$ & $\begin{array}{r}-3.83 \\
-10.9 \\
\end{array}$ & $\mathrm{X}$ & $\begin{array}{r}0.63 \\
7.6\end{array}$ & $\mathrm{x}$ & $\begin{array}{r}-0.46 \\
-0.4\end{array}$ & $\mathrm{X}$ \\
\hline IV & $\mathrm{x}$ & $\begin{array}{r}0.56 \\
11.2\end{array}$ & $\begin{array}{r}-5.32 \\
-8.7\end{array}$ & $\mathrm{x}$ & $\mathrm{x}$ & \begin{tabular}{|c|}
0.73 \\
21.1
\end{tabular} & $\begin{array}{r}-3.22 \\
-8.4\end{array}$ & $\mathrm{x}$ & $\mathrm{x}$ & $\begin{array}{r}0.70 \\
7.0 \\
\end{array}$ & $\begin{array}{r}-0.81 \\
0.7\end{array}$ & $\mathrm{x}$ \\
\hline $\mathbf{V}$ & \begin{tabular}{|r|}
0.58 \\
12.3
\end{tabular} & $\mathrm{x}$ & $\begin{array}{r}-5.64 \\
-8.6\end{array}$ & $\begin{array}{r}0.19 \\
2.5\end{array}$ & \begin{tabular}{|r}
0.70 \\
26.9
\end{tabular} & $\mathrm{x}$ & $\begin{array}{r}-2.88 \\
-8.1\end{array}$ & $\begin{array}{r}0.24 \\
5.8\end{array}$ & $\begin{array}{r}0.74 \\
7.6\end{array}$ & $\mathrm{X}$ & $\begin{array}{r}1.01 \\
0.7\end{array}$ & $\begin{array}{r}0.33 \\
2.0\end{array}$ \\
\hline
\end{tabular}

Source: author's calculations based on the data from ECB Statistical Data warehouse and from the national banks of Latvia, Lithuania and Estonia. 


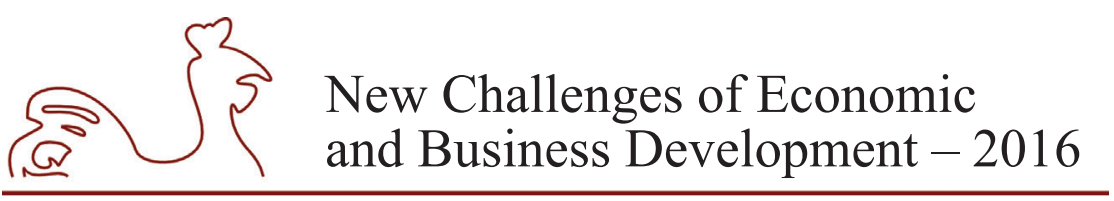

May 12-14, 2016, Riga, University of Latvia

The credit risk of clients plays the most important role in determining lending rates in Latvia as compared to the rest of the Baltic countries (Tables 1-2). This applies mostly to small and medium sized loans to enterprises as well as to consumption and other loans to households. For loans to households for house purchase, the effect of borrowers' credit risk is the smallest in Estonia, while relatively similar in Latvia and Lithuania. At the same time, the creditworthiness of borrowers is almost equally important in all of three Baltic states in the segment of large loans to enterprises. The measure of the credit risk of the banking system is significant in the last specification of long-term relationship in all segments of loans at least at one from all the three Baltic countries.

Table 2

Assessment of Long-Run Relationship for Loans to Non-Financial Corporations

\begin{tabular}{|c|c|c|c|c|c|c|c|c|c|c|c|c|}
\hline \multicolumn{13}{|c|}{ Small and Medium Loans } \\
\hline \multirow{2}{*}{$\begin{array}{l}\text { Speci- } \\
\text { fication }\end{array}$} & \multicolumn{4}{|c|}{ Latvia } & \multicolumn{4}{|c|}{ Lithuania } & \multicolumn{4}{|c|}{ Estonia } \\
\hline & $M R_{i, t}$ & $W A C L_{i, t}$ & $C R_{i, t}$ & $B R_{t}$ & $M R_{i, t}$ & $W A C L_{i, t}$ & $C R_{i, t}$ & $B R_{t}$ & $M R_{i, t}$ & $W A C L_{i, t}$ & $C R_{i, t}$ & $B R_{t}$ \\
\hline I & $\begin{array}{r}0.60 \\
12.0\end{array}$ & $\mathrm{x}$ & $\mathrm{x}$ & $\mathrm{x}$ & $\begin{array}{r}0.67 \\
25.9\end{array}$ & $\mathrm{x}$ & $\mathrm{x}$ & $\mathrm{x}$ & \begin{tabular}{|r|}
0.62 \\
15.7
\end{tabular} & $\mathrm{x}$ & $\mathrm{x}$ & $\mathrm{x}$ \\
\hline II & $\mathrm{x}$ & \begin{tabular}{|r}
0.76 \\
14.6
\end{tabular} & $\mathrm{x}$ & $\mathrm{x}$ & $\mathrm{x}$ & \begin{tabular}{|r|}
0.80 \\
25.0
\end{tabular} & $\mathrm{x}$ & $\mathrm{x}$ & $\mathrm{x}$ & $\begin{array}{r}0.69 \\
13.8\end{array}$ & $\mathrm{x}$ & $\mathrm{x}$ \\
\hline III & $\begin{array}{r}0.67 \\
19.0\end{array}$ & $\mathrm{x}$ & \begin{tabular}{|r}
-5.92 \\
-11.9 \\
\end{tabular} & $\mathrm{x}$ & \begin{tabular}{|r|}
0.73 \\
36.2
\end{tabular} & $\mathrm{x}$ & \begin{tabular}{|r}
-2.77 \\
-10.3 \\
\end{tabular} & $\mathrm{x}$ & $\begin{array}{r}0.65 \\
21.2\end{array}$ & $\mathrm{x}$ & $\begin{array}{r}-4.07 \\
-9.5\end{array}$ & $\mathrm{x}$ \\
\hline IV & $\mathrm{x}$ & \begin{tabular}{|c|}
0.76 \\
18.8
\end{tabular} & $\begin{array}{r}-4.52 \\
-9.1\end{array}$ & $\mathrm{x}$ & $\mathrm{x}$ & \begin{tabular}{|r|}
0.84 \\
29.4
\end{tabular} & $\begin{array}{r}-2.08 \\
-6.5\end{array}$ & $\mathrm{x}$ & $\mathrm{x}$ & \begin{tabular}{|r}
0.74 \\
19.2
\end{tabular} & $\begin{array}{r}-4.45 \\
-9.6\end{array}$ & $\mathrm{x}$ \\
\hline $\mathbf{V}$ & $\begin{array}{c}0.73 \\
18.5\end{array}$ & $\mathrm{x}$ & \begin{tabular}{|r|}
-5.12 \\
-9.3
\end{tabular} & \begin{tabular}{|r|}
0.19 \\
3.0
\end{tabular} & \begin{tabular}{|l}
0.78 \\
40.0
\end{tabular} & $\mathrm{x}$ & $\begin{array}{r}-1.98 \\
-7.4\end{array}$ & $\begin{array}{r}0.20 \\
6.4\end{array}$ & $\begin{array}{c}0.72 \\
20.7\end{array}$ & $\mathrm{x}$ & $\begin{array}{r}-3.12 \\
-6.5\end{array}$ & \begin{tabular}{|r|}
0.21 \\
3.7
\end{tabular} \\
\hline
\end{tabular}

\section{Large Loans}

\begin{tabular}{|c|c|c|c|c|c|c|c|c|c|c|c|c|}
\hline \multirow{2}{*}{$\begin{array}{c}\text { Speci- } \\
\text { fication }\end{array}$} & \multicolumn{4}{|c|}{ Latvia } & \multicolumn{4}{|c|}{ Lithuania } & \multicolumn{4}{|c|}{ Estonia (since 2008) } \\
\hline & $M R_{i, t}$ & $W A C L_{i, t}$ & $C R_{i, t}$ & $B R_{t}$ & $M R_{i, t}$ & $W A C L_{i, t}$ & $C R_{i, t}$ & $B R_{t}$ & $M R_{i, t}$ & $W A C L_{i, t}$ & $C R_{i, t}$ & $B R_{t}$ \\
\hline I & \begin{tabular}{|r|}
0.74 \\
22.0 \\
\end{tabular} & $\mathrm{x}$ & $\mathrm{x}$ & $\mathrm{x}$ & \begin{tabular}{|r|}
0.73 \\
29.5 \\
\end{tabular} & $\mathrm{x}$ & $\mathrm{x}$ & $\mathrm{x}$ & \begin{tabular}{|r|}
0.78 \\
18.8 \\
\end{tabular} & $\mathrm{x}$ & $\mathrm{x}$ & $\mathrm{x}$ \\
\hline II & $\mathrm{x}$ & \begin{tabular}{|r|}
0.86 \\
23.4
\end{tabular} & $\mathrm{X}$ & $\mathrm{x}$ & $x$ & \begin{tabular}{|r|}
0.87 \\
28.5
\end{tabular} & $\mathrm{x}$ & $\mathrm{x}$ & $\mathrm{x}$ & \begin{tabular}{|r|}
0.92 \\
16.7
\end{tabular} & $x$ & $\mathrm{x}$ \\
\hline III & \begin{tabular}{|r|}
0.77 \\
29.0 \\
\end{tabular} & $x$ & \begin{tabular}{r|}
-3.38 \\
-8.9 \\
\end{tabular} & $\mathrm{x}$ & \begin{tabular}{|c|}
0.78 \\
39.1 \\
\end{tabular} & $\mathrm{x}$ & $\begin{array}{r}-2.50 \\
-9.3 \\
\end{array}$ & $\mathrm{x}$ & \begin{tabular}{|r|}
0.72 \\
17.7 \\
\end{tabular} & $\mathrm{x}$ & $\begin{array}{r}-2.05 \\
-3.8 \\
\end{array}$ & $\mathrm{x}$ \\
\hline IV & $\mathrm{x}$ & \begin{tabular}{|c|}
0.86 \\
24.9 \\
\end{tabular} & \begin{tabular}{|r|}
-1.75 \\
-4.1 \\
\end{tabular} & $\mathrm{X}$ & $x$ & \begin{tabular}{|r|}
0.91 \\
32.2 \\
\end{tabular} & \begin{tabular}{|r|}
-1.77 \\
-5.6 \\
\end{tabular} & $\mathrm{X}$ & $\mathrm{x}$ & \begin{tabular}{|c|}
0.85 \\
15.7 \\
\end{tabular} & $\begin{array}{r}-2.28 \\
-3.9\end{array}$ & $\mathrm{x}$ \\
\hline $\mathbf{V}$ & \begin{tabular}{|r}
0.80 \\
26.4 \\
\end{tabular} & $\mathrm{X}$ & \begin{tabular}{|r|}
-2.96 \\
-7.0 \\
\end{tabular} & \begin{tabular}{|r|}
0.10 \\
2.0 \\
\end{tabular} & \begin{tabular}{|r|}
0.82 \\
38.3 \\
\end{tabular} & $\mathrm{x}$ & \begin{tabular}{|r|}
-2.02 \\
-7.0 \\
\end{tabular} & \begin{tabular}{|r|}
0.12 \\
3.6 \\
\end{tabular} & \begin{tabular}{|r|}
0.73 \\
19.3 \\
\end{tabular} & $\mathrm{x}$ & $\begin{array}{r}-2.38 \\
-4.8 \\
\end{array}$ & $\begin{array}{r}0.52 \\
4.3 \\
\end{array}$ \\
\hline
\end{tabular}

Source: author's calculations based on the data from ECB Statistical Data warehouse and from the national banks of Latvia, Lithuania and Estonia. 


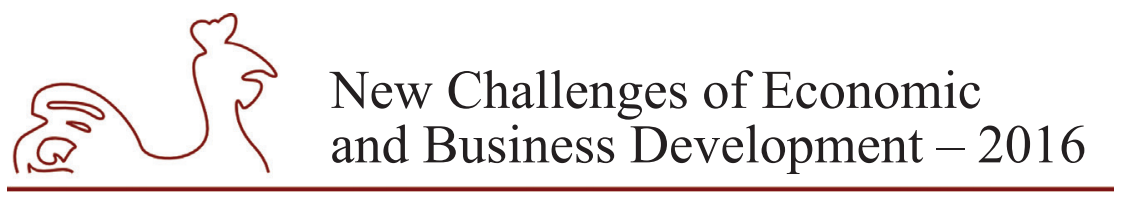

May 12-14, 2016, Riga, University of Latvia

\section{Interpretation of the Estimated Short-run Equation of the Error Correction Model}

Assessment of the short-run equation of the error correction model shows that, in the Baltic countries, a relatively large part of the change in funding costs of banks is covered by the adjustment of lending rates at the same point of time (Tables 3-4). The difference of the corresponding measure of funding costs is statistically significant in the most of lending segments in the Baltic countries reflecting strong short-run relationship between the mentioned variables. In addition, the estimated coefficients for the short-term pass-through $\beta_{j, i, 0}^{S R}$ are comparatively high for loans to enterprises and households for house purchase. In many of the analysed cases across the Baltic countries, especially for loans to enterprises, the shortterm pass-through is higher than 50\%. If all the other factors affecting lending interest are held constant, then an increase of one percentage point on the measure of funding costs of banks in the most of lending segments across the Baltic states would transform into an increase that is on average larger than 0.5 percentage points.

The average time necessary for lending rates on newly granted loans to enterprises to adjust to changes in the funding cost of banks is less than three months in all three Baltic countries if those specifications of the model are considered that describe the patterns observed in the data in the most precise way (Tables 3-4). The average time necessary for lending rates on newly granted loans to households to adjust to changes in the funding cost of banks, as a rule, is longer in all of the Baltic countries. Nevertheless, the adjustment of interest rates on loans to households could be evaluated as relatively fast. Adjustment time of interest rates on loans to households to house purchase lasts on average two to six months in the Baltic countries if the most appropriate specification of the model is taken in account. Similarly, adjustment time of interest rates on loans to consumption loans is on average two-three months and adjustment time of interest rates on loans to households for other purchases - one-three months.

Table 3

Assessment of Short-Run Relationship for Loans to Households

\begin{tabular}{|c|c|c|c|c|c|c|c|c|c|c|c|c|}
\hline \multicolumn{13}{|c|}{ Loans for House Purchase } \\
\hline \multirow{2}{*}{$\begin{array}{l}\text { Speci- } \\
\text { fication }\end{array}$} & \multicolumn{4}{|c|}{ Latvia } & \multicolumn{4}{|c|}{ Lithuania } & \multicolumn{4}{|c|}{ Estonia } \\
\hline & $\Delta R R_{i t}$ & $\hat{u}_{j, i, t-1}$ & $R_{a d j}^{2}$ & Period & $\Delta R R_{i t}$ & $\hat{u}_{j, i, t-1}$ & $R_{a d j}^{2}$ & Period & $\Delta R R_{i t}$ & $\hat{u}_{j, i, t-1}$ & $R_{a d j}^{2}$ & Period \\
\hline I & \begin{tabular}{|r|}
0.24 \\
2.2
\end{tabular} & $\begin{array}{r}-0.26 \\
-5.4\end{array}$ & $35.6 \%$ & $3 \mathrm{M}$ & $\begin{array}{r}0.65 \\
9.5\end{array}$ & $\begin{array}{r}-0.05 \\
-2.3\end{array}$ & $50.0 \%$ & $7 \mathrm{M}$ & $\begin{array}{r}0.44 \\
6.0\end{array}$ & $\begin{array}{r}-0.08 \\
-2.6\end{array}$ & $51.5 \%$ & $7 \mathrm{M}$ \\
\hline II & $\begin{array}{r}0.26 \\
2.4 \\
\end{array}$ & $\begin{array}{r}-0.32 \\
-6.4\end{array}$ & $29.1 \%$ & $3 \mathrm{M}$ & $\begin{array}{r}0.32 \\
3.3\end{array}$ & $\begin{array}{r}-0.08 \\
-2.8\end{array}$ & $23.6 \%$ & $9 \mathrm{M}$ & $\begin{array}{r}0.36 \\
4.0\end{array}$ & $\begin{array}{r}-0.06 \\
-2.2\end{array}$ & $46.4 \%$ & $11 \mathrm{M}$ \\
\hline III & $\begin{array}{r}0.50 \\
5.1\end{array}$ & $\begin{array}{r}-0.44 \\
6.3\end{array}$ & $40.3 \%$ & $2 \mathrm{M}$ & $\begin{array}{r}0.66 \\
7.8\end{array}$ & $\begin{array}{r}-0.10 \\
-2.6\end{array}$ & $53.1 \%$ & $4 \mathrm{M}$ & $\begin{array}{r}0.47 \\
6.2\end{array}$ & $\begin{array}{r}-0.10 \\
-2.8\end{array}$ & $51.5 \%$ & $6 \mathrm{M}$ \\
\hline IV & $\begin{array}{r}0.39 \\
3.5\end{array}$ & $\begin{array}{r}-0.35 \\
-6.3\end{array}$ & $28.1 \%$ & $3 \mathrm{M}$ & $\begin{array}{r}0.46 \\
4.9\end{array}$ & $\begin{array}{r}-0.08 \\
-2.1\end{array}$ & $17.6 \%$ & $7 \mathrm{M}$ & $\begin{array}{r}0.39 \\
4.2\end{array}$ & $\begin{array}{r}-0.08 \\
-2.6\end{array}$ & $46.8 \%$ & $8 \mathrm{M}$ \\
\hline V & $\begin{array}{r}0.42 \\
3.4 \\
\end{array}$ & $\begin{array}{r}-0.40 \\
-5.4 \\
\end{array}$ & $42.6 \%$ & $2 \mathrm{M}$ & $\begin{array}{r}0.66 \\
7.8 \\
\end{array}$ & $\begin{array}{r}-0.13 \\
-3.0\end{array}$ & $53.5 \%$ & $3 \mathrm{M}$ & $\begin{array}{r}0.47 \\
6.1 \\
\end{array}$ & $\begin{array}{r}-0.10 \\
-2.6\end{array}$ & $50.8 \%$ & $6 \mathrm{M}$ \\
\hline
\end{tabular}


May 12-14, 2016, Riga, University of Latvia

\begin{tabular}{|c|c|c|c|c|c|c|c|c|c|c|}
\hline \multirow{3}{*}{$\begin{array}{c}\text { Consum } \\
\text { Speci- } \\
\text { fication } \\
\end{array}$} & ption Loans (ac & counting for e & uro intr & oductio & $n$ effect & & & & & \\
\hline & \multicolumn{2}{|c|}{ Latvia } & \multicolumn{4}{|c|}{ Lithuania } & \multicolumn{4}{|c|}{ Estonia } \\
\hline & \begin{tabular}{|l|l|}
$\Delta R R_{i t}$ & $\hat{u}_{j, i, t-1}$ \\
\end{tabular} & \begin{tabular}{l|l}
$R_{a d j}^{2}$ & Period \\
\end{tabular} & $\Delta R R_{i t}$ & $\hat{u}_{j, i, t-1}$ & $R_{a d j}^{2}$ & Period & $\Delta R R_{i t}$ & $\hat{u}_{j, i, t-1}$ & $R_{a d j}^{2}$ & Period \\
\hline \multirow{2}{*}{ I } & \multirow{2}{*}{\multicolumn{2}{|c|}{$\begin{array}{l}\text { In the long-term equation, } \\
\text { at least one variable has } \\
\text { the wrong sign }\end{array}$}} & 0.60 & 0.01 & \multirow[b]{2}{*}{$49.3 \%$} & \multirow[b]{2}{*}{$>1 Y$} & -0.08 & -0.31 & \multirow[b]{2}{*}{$8.3 \%$} & \multirow[b]{2}{*}{$4 \mathrm{M}$} \\
\hline & & & 7.1 & 0.8 & & & -0.1 & -3.7 & & \\
\hline \multirow[b]{2}{*}{ II } & \multirow{2}{*}{\multicolumn{2}{|c|}{$\begin{array}{l}\text { In the long-term equation, } \\
\text { at least one variable has } \\
\text { the wrong sign }\end{array}$}} & -0.08 & -0.39 & \multirow[b]{2}{*}{$36.7 \%$} & \multirow[b]{2}{*}{$3 \mathrm{M}$} & -0.39 & -0.31 & \multirow[b]{2}{*}{$8.5 \%$} & \multirow[b]{2}{*}{$5 \mathrm{M}$} \\
\hline & & & -0.2 & -4.4 & & & -0.2 & -3.7 & & \\
\hline III & \multicolumn{2}{|c|}{$\begin{array}{l}\text { In the long-term equation, } \\
\text { at least one variable has } \\
\text { the wrong sign }\end{array}$} & \begin{tabular}{r|}
0.42 \\
1.0
\end{tabular} & $\begin{array}{r}-0.42 \\
-4.5\end{array}$ & $37.3 \%$ & $2 \mathrm{M}$ & $\begin{array}{r}0.21 \\
0.1\end{array}$ & \begin{tabular}{|r|}
-0.32 \\
-3.7
\end{tabular} & $8.3 \%$ & $3 \mathrm{M}$ \\
\hline \multirow[b]{2}{*}{ IV } & \multirow{2}{*}{\multicolumn{2}{|c|}{$\begin{array}{l}\text { In the long-term equation, } \\
\text { at least one variable has } \\
\text { the wrong sign }\end{array}$}} & 0.35 & -0.40 & \multirow[b]{2}{*}{$36.3 \%$} & \multirow[b]{2}{*}{$2 \mathrm{M}$} & 0.11 & -0.31 & \multirow[b]{2}{*}{$8.4 \%$} & \multirow[b]{2}{*}{$3 \mathrm{M}$} \\
\hline & & & 0.7 & -4.4 & & & 0.6 & -3.7 & & \\
\hline $\mathbf{V}$ & \multicolumn{2}{|c|}{$\begin{array}{l}\text { In the long-term equation, } \\
\text { at least one variable has } \\
\text { the wrong sign }\end{array}$} & $\begin{array}{r}0.44 \\
1.0\end{array}$ & $\begin{array}{r}-0.49 \\
-5.0\end{array}$ & $38.6 \%$ & $2 \mathrm{M}$ & \multicolumn{4}{|c|}{$\begin{array}{l}\text { In the long-term equation, } \\
\text { at least one variable has } \\
\text { the wrong sign }\end{array}$} \\
\hline
\end{tabular}

\begin{tabular}{|c|c|c|c|c|c|c|c|c|c|c|c|c|}
\hline \multicolumn{13}{|c|}{ Loans for Other Purposes } \\
\hline \multirow{2}{*}{$\begin{array}{c}\text { Speci- } \\
\text { fication }\end{array}$} & \multicolumn{4}{|c|}{ Latvia } & \multicolumn{4}{|c|}{ Lithuania } & \multicolumn{4}{|c|}{ Estonia } \\
\hline & $\Delta R R_{i t}$ & $\hat{u}_{j, i, t-1}$ & $R_{a d j}^{2}$ & Period & $\Delta R R_{i t}$ & $\hat{u}_{j, i, t-1}$ & $R_{a d j}^{2}$ & Period & $\Delta R R_{i t}$ & $\hat{u}_{j, i, t-1}$ & $R_{a d j}^{2}$ & Period \\
\hline $\mathbf{I}$ & \begin{tabular}{|r|}
-0.21 \\
-0.5
\end{tabular} & \begin{tabular}{|r|}
-0.28 \\
-3.5
\end{tabular} & $37.8 \%$ & $5 \mathrm{M}$ & $\begin{array}{r}0.66 \\
2.8\end{array}$ & $\begin{array}{r}-0.18 \\
-2.7\end{array}$ & $33.7 \%$ & $2 \mathrm{M}$ & $\begin{array}{r}0.56 \\
0.8\end{array}$ & $\begin{array}{r}-0.51 \\
-6.6\end{array}$ & $24.4 \%$ & $1 \mathrm{M}$ \\
\hline II & $\begin{array}{r}-0.90 \\
-2.1\end{array}$ & $\begin{array}{r}-0.36 \\
-4.6 \\
\end{array}$ & $40.2 \%$ & $6 \mathrm{M}$ & \begin{tabular}{|r|}
0.58 \\
2.0
\end{tabular} & $\begin{array}{r}-0.21 \\
-3.1\end{array}$ & $31.0 \%$ & $2 \mathrm{M}$ & $\begin{array}{r}-0.07 \\
-0.1\end{array}$ & $\begin{array}{r}-0.49 \\
-6.5\end{array}$ & $23.3 \%$ & $3 \mathrm{M}$ \\
\hline III & $\begin{array}{r}0.57 \\
1.5\end{array}$ & $\begin{array}{r}-0.55 \\
-5.0\end{array}$ & $40.1 \%$ & $1 \mathrm{M}$ & $\begin{array}{r}0.79 \\
3.5\end{array}$ & $\begin{array}{r}-0.42 \\
-4.6\end{array}$ & $32.7 \%$ & $1 \mathrm{M}$ & $\begin{array}{r}0.69 \\
1.0\end{array}$ & $\begin{array}{r}-0.51 \\
-6.6\end{array}$ & $23.9 \%$ & $1 \mathrm{M}$ \\
\hline IV & \begin{tabular}{|r|}
-0.30 \\
-0.7
\end{tabular} & \begin{tabular}{|r|}
-0.56 \\
-5.3
\end{tabular} & $39.3 \%$ & $3 \mathrm{M}$ & $\begin{array}{r}0.80 \\
3.0\end{array}$ & $\begin{array}{r}-0.32 \\
-3.8\end{array}$ & $28.2 \%$ & $1 \mathrm{M}$ & $\begin{array}{r}0.18 \\
0.2\end{array}$ & \begin{tabular}{|r|}
-0.49 \\
-6.4
\end{tabular} & $22.7 \%$ & $2 \mathrm{M}$ \\
\hline $\mathbf{V}$ & $\begin{array}{r}0.49 \\
1.2\end{array}$ & \begin{tabular}{|r|}
-0.52 \\
-4.8
\end{tabular} & $39.2 \%$ & $1 \mathrm{M}$ & $\begin{array}{r}0.72 \\
3.4\end{array}$ & $\begin{array}{r}-0.70 \\
-8.4\end{array}$ & $38.1 \%$ & $1 \mathrm{M}$ & $\begin{array}{l}\text { In th } \\
\text { at le }\end{array}$ & $\begin{array}{l}\text { e long- } \\
\text { east on } \\
\text { the w }\end{array}$ & $\begin{array}{l}\text { erm equ } \\
\text { variable } \\
\text { ng sign }\end{array}$ & $\begin{array}{l}\text { ation, } \\
\text { has }\end{array}$ \\
\hline
\end{tabular}

Source: author's calculations based on the data from ECB Statistical Data warehouse and from the national banks of Latvia, Lithuania and Estonia.

Across the Baltic countries, short-term pass-through from funding costs to lending rates tends to be higher for loans to households in Lithuania, for large loans to enterprises - in Estonia and for small and medium loans to enterprises - in Latvia (Tables 3-4). The average time necessary for lending rates on newly granted loans to households for house purchase to adjust to changes in the funding cost of banks is shortest in Latvia, but the average time necessary for the full adjustment of lending rates on newly granted consumption loans and loans to households for other purposes - in Lithuania. Interest rates on large loans to enterprises adjust faster in Estonia (immediately or during a month) and on small and medium loans to enterprises in Latvia (immediately or during three months). 


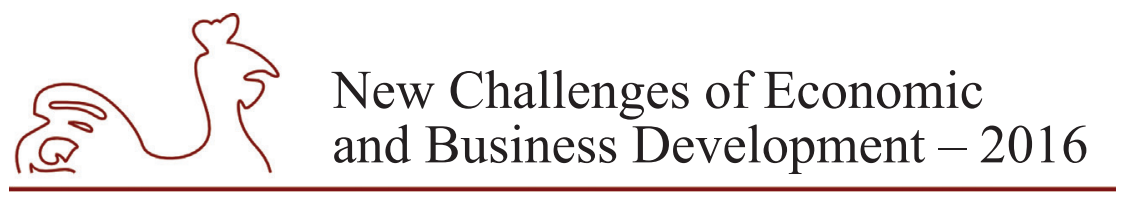

May 12-14, 2016, Riga, University of Latvia

Table 4

Assessment of Short-Run Relationship for Loans to Enterprises

\begin{tabular}{|c|c|c|c|c|c|c|c|c|c|c|c|c|}
\hline \multicolumn{13}{|c|}{ Small and Medium Loans } \\
\hline \multirow{2}{*}{$\begin{array}{r}\text { Speci- } \\
\text { fication }\end{array}$} & \multicolumn{4}{|c|}{ Latvia } & \multicolumn{4}{|c|}{ Lithuania } & \multicolumn{4}{|c|}{ Estonia } \\
\hline & $\Delta R R_{i t}$ & $\hat{u}_{j, i, t-1}$ & $R_{a d j}^{2}$ & Period & $\Delta R R_{i t}$ & $\hat{u}_{j, i, t-1}$ & $R_{a d j}^{2}$ & Period & $\Delta R R_{i t}$ & $\hat{u}_{j, i, t-1}$ & $R_{a d j}^{2}$ & Period \\
\hline \multirow[t]{2}{*}{ I } & 0.55 & -0.15 & \multirow{2}{*}{$33.9 \%$} & \multirow{2}{*}{$3 \mathrm{M}$} & 0.50 & -0.08 & \multirow{2}{*}{$36.9 \%$} & \multirow{2}{*}{$7 \mathrm{M}$} & 0.38 & -0.13 & \multirow{2}{*}{$34.7 \%$} & \multirow{2}{*}{$5 \mathrm{M}$} \\
\hline & 1.9 & -2.6 & & & 3.3 & -1.9 & & & 2.1 & -2.9 & & \\
\hline \multirow{2}{*}{ II } & 1.31 & -0.14 & \multirow{2}{*}{$41.1 \%$} & \multirow{2}{*}{$0 \mathrm{M}$} & 0.61 & -0.12 & \multirow{2}{*}{$24.9 \%$} & \multirow{2}{*}{$4 \mathrm{M}$} & 0.44 & -0.11 & \multirow{2}{*}{$33.1 \%$} & \multirow{2}{*}{$6 \mathrm{M}$} \\
\hline & 4.2 & -2.2 & & & 4.1 & -2.9 & & & 2.0 & -2.6 & & \\
\hline \multirow{2}{*}{ III } & 0.88 & -0.28 & \multirow{2}{*}{$35.0 \%$} & \multirow{2}{*}{$1 \mathrm{M}$} & 0.60 & -0.15 & \multirow{2}{*}{$39.2 \%$} & \multirow{2}{*}{$3 \mathrm{M}$} & 0.58 & -0.19 & \multirow{2}{*}{$36.0 \%$} & \multirow{2}{*}{$3 \mathrm{M}$} \\
\hline & 3.0 & -3.1 & & & 3.9 & -2.8 & & & 3.4 & -3.5 & & \\
\hline \multirow{2}{*}{ IV } & 1.43 & -0.28 & \multirow{2}{*}{$36.2 \%$} & \multirow{2}{*}{$0 \mathrm{M}$} & 0.71 & -0.12 & \multirow{2}{*}{$23.1 \%$} & \multirow{2}{*}{$3 \mathrm{M}$} & 0.69 & -0.16 & \multirow{2}{*}{$36.1 \%$} & \multirow{2}{*}{$2 \mathrm{M}$} \\
\hline & 4.7 & -3.5 & & & 4.8 & -2.4 & & & 3.2 & -3.1 & & \\
\hline \multirow[b]{2}{*}{ V } & 0.89 & -0.32 & \multirow{2}{*}{$35.0 \%$} & \multirow{2}{*}{$1 \mathrm{M}$} & 0.59 & -0.21 & $407 \%$ & $2 \pi$ & 0.58 & -0.23 & & \\
\hline & 3.0 & -3.2 & & & 3.8 & -3.3 & & 2101 & 3.4 & -3.8 & $36.6 \%$ & $2 \mathrm{M}$ \\
\hline
\end{tabular}

\begin{tabular}{|c|c|c|c|c|c|c|c|c|c|c|c|c|}
\hline \multicolumn{13}{|c|}{ Large Loans } \\
\hline \multirow{2}{*}{$\begin{array}{l}\text { Speci- } \\
\text { fication }\end{array}$} & \multicolumn{4}{|c|}{ Latvia } & \multicolumn{4}{|c|}{ Lithuania } & \multicolumn{4}{|c|}{ Estonia (since 2008) } \\
\hline & $\Delta R R_{i t}$ & $\hat{u}_{j, i, t-1}$ & $R_{a d j}^{2}$ & Period & $\Delta R R_{i t}$ & $\hat{u}_{j, i, t-1}$ & $R_{a d j}^{2}$ & Period & $\Delta R R_{i t}$ & $\hat{u}_{j, i, t-1}$ & $R_{a d j}^{2}$ & Period \\
\hline \multirow[t]{2}{*}{ I } & 0.73 & -0.49 & \multirow{2}{*}{$50.7 \%$} & \multirow{2}{*}{$1 \mathrm{M}$} & 0.59 & -0.27 & \multirow{2}{*}{$32.2 \%$} & \multirow{2}{*}{$2 \mathrm{M}$} & 0.73 & -0.27 & \multirow{2}{*}{$44.5 \%$} & \multirow{2}{*}{$1 \mathrm{M}$} \\
\hline & 2.4 & -4.8 & & & 3.2 & -3.9 & & & 2.9 & -3.1 & & \\
\hline \multirow{2}{*}{ II } & -0.31 & -0.84 & \multirow{2}{*}{$44.2 \%$} & \multirow{2}{*}{$2 \mathrm{M}$} & 0.39 & -0.30 & \multirow{2}{*}{$25.9 \%$} & \multirow{2}{*}{$3 \mathrm{M}$} & 0.83 & -0.22 & \multirow{2}{*}{$42.1 \%$} & \multirow{2}{*}{$1 \mathrm{M}$} \\
\hline & -1.0 & -10.3 & & & 1.7 & -4.3 & & & 2.7 & -2.7 & & \\
\hline \multirow{2}{*}{ III } & 0.90 & -1.00 & \multirow{2}{*}{$53.1 \%$} & \multirow{2}{*}{$1 \mathrm{M}$} & 0.61 & -0.57 & \multirow{2}{*}{$34.5 \%$} & \multirow{2}{*}{$1 \mathrm{M}$} & 1.01 & -0.22 & \multirow{2}{*}{$43.6 \%$} & \multirow{2}{*}{$0 \mathrm{M}$} \\
\hline & 3.4 & -11.8 & & & 3.5 & -7.1 & & & 3.8 & -2.1 & & \\
\hline \multirow{2}{*}{ IV } & 0.07 & -0.88 & \multirow{2}{*}{$43.4 \%$} & \multirow{2}{*}{$2 \mathrm{M}$} & 0.47 & -0.35 & \multirow{2}{*}{$25.6 \%$} & \multirow{2}{*}{$2 \mathrm{M}$} & 1.32 & -0.13 & \multirow{2}{*}{$42.4 \%$} & \multirow{2}{*}{$0 \mathrm{M}$} \\
\hline & 0.2 & -10.1 & & & 2.2 & -4.3 & & & 3.9 & -1.4 & & \\
\hline \multirow[b]{2}{*}{ v } & 0.95 & -1.08 & \multirow{2}{*}{$55.2 \%$} & \multirow{2}{*}{$1 \mathrm{M}$} & 0.62 & -0.64 & $382 \%$ & 11 & 0.95 & -0.34 & 0 & 111 \\
\hline & 3.6 & -12.4 & & & 3.7 & -7.9 & $30.2 \%$ & IIVI & 3.7 & -2.9 & $42.0 \%$ & $11 \mathrm{VI}$ \\
\hline
\end{tabular}

Source: author's calculations based on the data from ECB Statistical Data warehouse and from the national banks of Latvia, Lithuania and Estonia.

Figure 1 shows the level of lending rates to enterprises from 2007 till 2015 in the three Baltic states together with the contribution of market reference rates, borrower and bank risk. In all of the three countries, lending rates are affected by reference money rates, but, in the last years, changes in the money rates have a relatively small contribution. In 2008, lending rates on small and medium loans to enterprises were affected upwards by the slight increase in bank risk. In 2009, the fall in reference money market rates have put downward pressure on lending rates, but pass-through was obstructed by the substantial increase in borrower risk. The contribution of risk factors has decreased somehow since the peak of the global financial crisis and the European debt crisis and since the correction of housing prices in the local real estate markets. Still, risk factors explain a relatively large part of lending rates in the Baltic countries. 


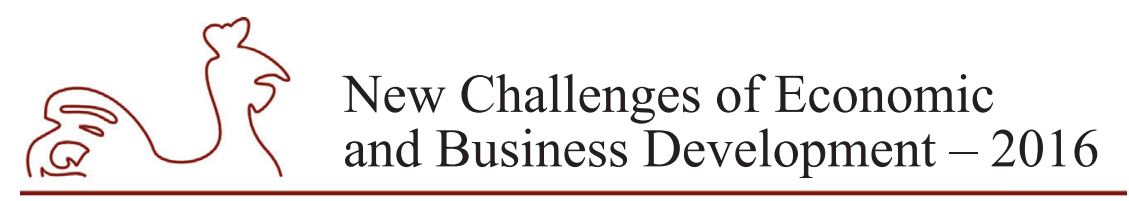

May 12-14, 2016, Riga, University of Latvia

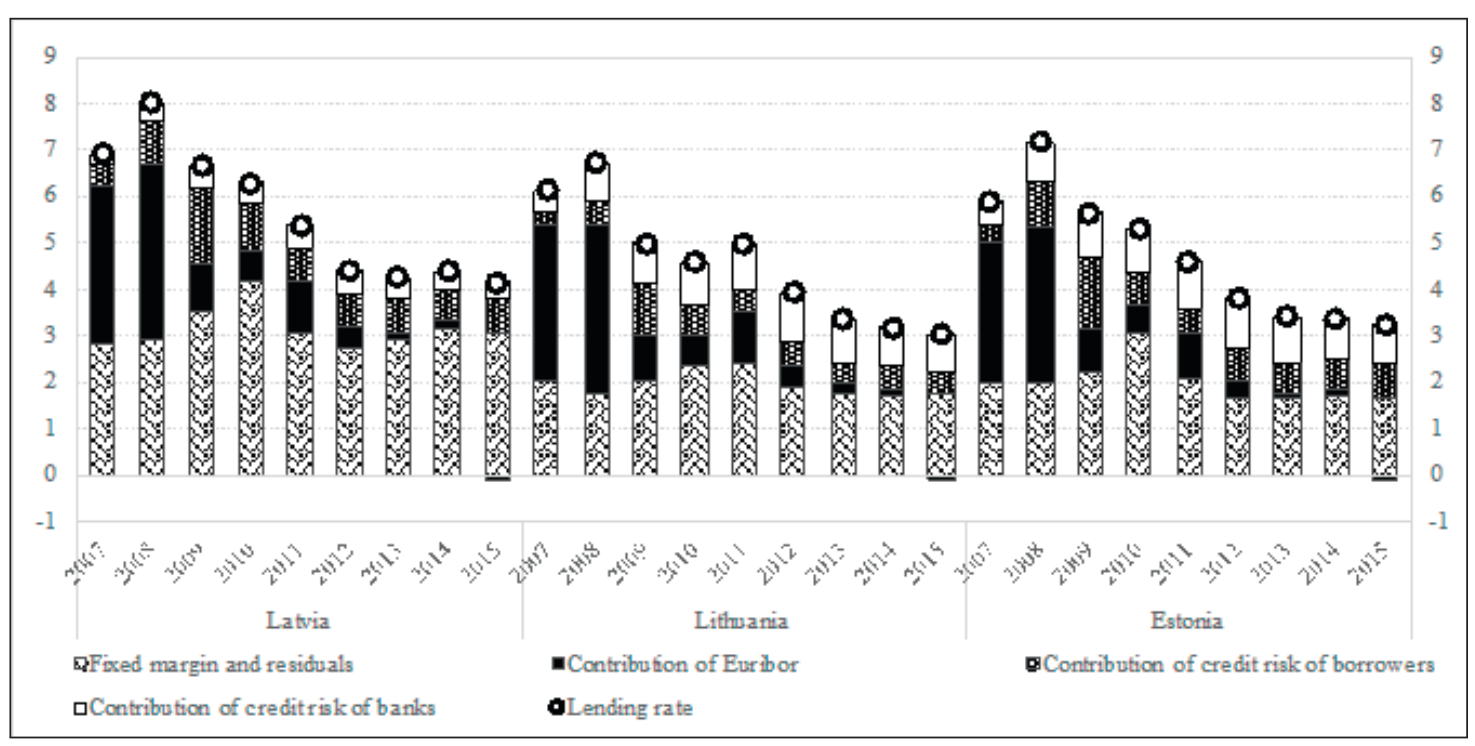

Source: author's calculations based on the data from ECB Statistical Data warehouse and from the national banks of Latvia, Lithuania and Estonia.

Fig. 1. Lending rates on small and medium loans to enterprises in the Baltic countries

\section{Conclusions, proposals, recommendations}

1. Although rising popularity of the measure of funding costs based on weighted average cost of liabilities in the estimations of the pass-through of funding costs to lending rates, three - month EURIBOR rate better describes the dynamics of lending rates in the Baltic states. When analysing the dynamics of lending rates in the Baltic states, the measure characterizing creditworthiness of borrowers must be taken in account as it is significant factor determining the dynamics of lending rates in the Baltic countries. In addition, the analysis of the dynamics of lending rates in the Baltic states could benefit from inclusion of the measure reflecting banking risk in the region. However, this measure should be used with caution as its importance notably varies over time.

2. In the Baltic countries, the long-run relationship between lending rates and the measure of banks' funding costs is strong and tend to be the highest for loans to enterprises and loans to households for house purchase. In the same lending segments, creditworthiness of borrower has a relatively smaller effect on lending rates. Lending rates of loans to enterprises adjust to the changes in funding cost more quickly - in less than three months. Adjustment of interest rates on loans to households takes a longer time span, but for the best specifications of the model, which take in account risk considerations, does not exceed six months.

3. In the Baltic countries, the long-run level of lending rates is affected by the same factors. However, the strength of their influence slightly differ. In general, long-term pass through from funding costs to lending rates tends to be higher in Lithuania, but creditworthiness of borrowers appeared to have the highest influence on lending rates in Latvia. The time necessary for different lending rates to adjust to the changes in funding costs of banks varies 


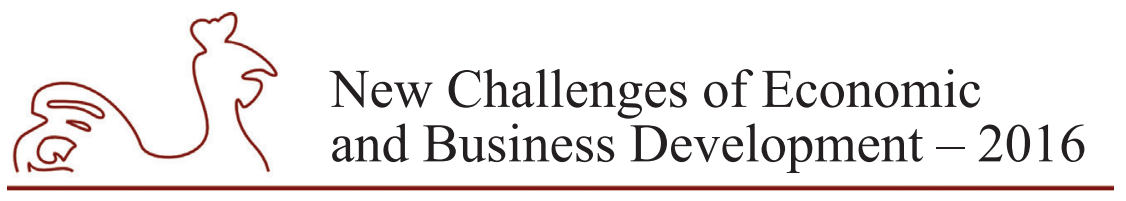

May 12-14, 2016, Riga, University of Latvia

across the Baltic states. Lending rates tend to adjust faster to the changes in funding costs of banks for consumption loans and loans to households for other purposes in Lithuania, for loans to households for house purchase and mall and medium loans to enterprises in Latvia, as well as for large loans to enterprises in Estonia.

4. The influence of borrower risk and bank risk on the changes of lending rates in the Baltic countries was the most prominent in 2009. However, the effect of those factors decreased later; their influence remains higher than before the global financial crisis and the correction of housing prices in the local real-estate markets. In the future, the expansionary monetary policy of the ECB will reduce the level of lending rates in the Baltic states. However, banks could be reluctant to decrease them appropriately taking due to risk and profitability consideration.

5. The analysis of the dynamics of lending rates in the Baltic countries shows that their experience is similar to the experience of other euro area countries in the respect that credit risk of borrowers and banking risk have a significant role in determination of the dynamics of lending rates in the region. On the other hand, the use of weighted average cost of liabilities as an alternative measure of banks' funding costs added little value to the analysis of the dynamics of lending rates in the Baltic states. In other euro area countries, this measure substantially improved the analysis of the pass-through of banks' funding costs to lending rates. The pass-through from banks' funding rates to lending rates is relatively high in the Baltic countries as compared to the other countries, especially when the risk considerations are taken in account.

6. The analysis of lending rates in the Baltic countries could be developed further by considering alternative measures of borrowers' credit risk and banking risk as well as alternative econometric models for the analysis. Interesting area of investigation would be the stability of the pass-through coefficients over time. Additional insight could be reached from the analysis devoted to the investigation how the partial pass-through of interest rates impact the overall development of the economy.

\section{Bibliography}

Arnold, I. \& van Eivijk, S., 2014. The Impact of Soverign and Credit Risk on Interest Rate Convergence in the Euro Area. De Nederlandsche Bank Working Paper, No. 425, June 2014.

Avouyi-Dovi, S., Horny, G. \& Sevestre, P., 2015. The Stability of Short-Term Interest Rates Pass-Through in the Euro Area during the Financial Market and Sovereign Debt Crises. Banque of France Working Paper, No. 547.

Banerjee, A., Bystrov, V. \& Mizen, P., 2013. How Do Anticipated Changes to Short-Term Market Rates Influence Banks' Retail Interest Rates? Evidence from the Four Major Euro Area Economies. Journal of Money, Credit and Banking, Vol. 45(7), pp. 1375-1414.

Cottarelli, C. \& Kourelis, A. Financial Structure, Bank Lending Rates and Transmission Mechanism of Monetary Policy. IMF Staff Papers, 1994, No. 4, Vol. 41, pp. 587-623.

DeBondt, G., (2002), Retail Bank Interest Rate Pass-Through: New Evidence at the Euro Area Level. European Central Bank Working Paper, No. 136.

DeGreave, F., De Jonghe, O. \& Vennet, R. V., 2007. Competition, Transmission and Bank Pricing Policies: Evidence from Belgian Loan and Deposit Markets. Journal of Banking \& Finance, 31(1), pp. 259-278.

Egert, B., Crespo-Cuaresma, J. \& Reininger, T., 2007. Interest Rate Pass-Through in Central and Eastern Europe: Reborn from Ashes Merely to Pass Away? Journal of Policy Modeling, 29(2), pp. 209-225. 


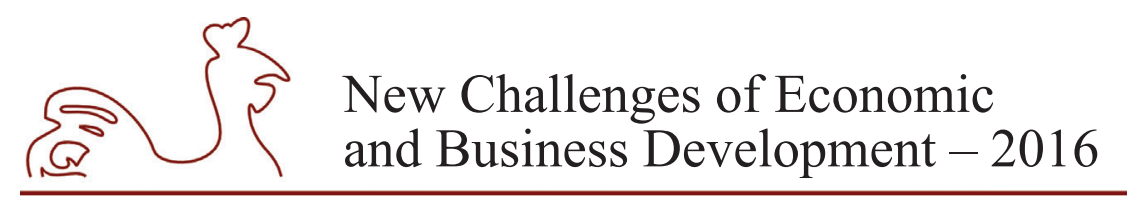

May 12-14, 2016, Riga, University of Latvia

Hansen, F. N.-J. H.\& Welz, P., 2011. Interest Rates Pass-through During the Global Financial Crisis. The Case of Sweden. OECD Economics Department Working Papers, No. 855.

Heffernan, S. A., 1997. Modelling British Interest Rate Adjustment: An Error Correction Approach. Economica, 64(254), pp. 211-31.

Illes, A., Lombardi, M. \& Mizen, P., 2015. Why Did Bank Lending Rates Diverge from Policy Rates After the Financial Crisis? Working Paper Series by Centre for Finance, Credit and Macroeconomics, WP $15 / 05$.

Lapinskas, V., 2011. Interest Rate Pass-Through in Lithuania. EKONOMIKA, 90(2), pp. 28-46.

Männasoo, K., 2013. Determinants of Bank Interest Spreads in Estonia. Eastern European Economics, 51(1).

Mičūne, V. , 2010. Interest Rate Pass-Through in Latvia: How It Is Affected by the Crisis. Proceedings of the 5th International Conference "An Enterprise Odyssey: From Crisis to Prosperity - Challenges for Government and Business". Zagreb: Faculty of Economics and Business, University of Zagreb.

Mičūne, V., 2009. Mājsaimniecībām un uzn̦ēmumiem noteikto procentu likmju dinamikas analīze. $L U$ Raksti, 744, pp. 354-372.

Mojon, B., 2000. Financial Structure and the Interest Rate Channel of ECB Monetary Policy. ECB Working Paper, N 40.

Paries, M.D., Moccero, D. N., Krylova, E. \& Marchini, C., 2014. The Retail Bank Interest Rate PassThrough The Case of the Euro Area During the Financial and Sovereign Debt Crisis. ECB Occasional Paper Series, No. 155.

Sander, H. \& Kleimeier, S., 2004. Convergence in Euro-Zone Retail Banking? What Interest Rate PassThrough Tells us about Monetary Policy Transmission, Competition and Integration, Journal of International Money and Finance, 23(3), pp. 461-492.

Von Borstel, J., Eickmeier, S. \& Krippner, L., 2015. The Interest Rate Pass-Through in the Euro Area during the Sovereign Debt Crisis. Deutsche Bundesbank Discussion Paper, No. 10.

Weth, A. M., 2002. The Pass-Through from Market Interest Rates to Bank Lending Rates in Germany. Economic Research Centre of the Deutsche Bundesbank Discussion Paper, N 11/02.

Winker, P., 1999. Sluggish Adjustment of Interest Rates and Credit Rationing: An Application of Unit Root Testing and Error Correction Modelling. Applied Economics, 31, pp. 267277. 


\title{
SOCIOECONOMIC IN FERTILITY DISCOURSE: A LATVIAN CASE
}

\author{
Ilze Mileiko, University of Latvia, Latvia ${ }^{1}$
}

\begin{abstract}
Fertility and policy relating to it is widely discussed in Latvian public media. For example, Cabinet of Ministers Order No. 84 (Cabinet of Ministers, 2012) sets the improvement of the demographic situation as a priority in cross-sector policy decisions. Family support forms to stimulate second, third, and further children born to a family have been initiated, including fiscal incentives and implementing the principle of the progressivity in state support and creating a support program for the treatment of infertility. In public the concept of fertility is closely linked to population statistics and a desired increase in the national birth rate. Depopulation is often defined as a threat to the development of Latvian society. In this paper fertility is explored in micro perspective. Likewise, the use of the concept itself has social and economic aspects that are essential for understanding fertility dynamics. The aim of this paper is to explore how ideas concerning socioeconomic are included in the fertility discourse in Latvia. This paper is based on doctoral research in progress. 30 semi-structured interviews (11 interviews with users of assisted reproduction techniques, 4 interviews with egg donors, and 15 expert interviews) are analyzed. All data was processed using Atlas.ti. The Foucauldrian 'archaeology of knowledge' methodology allows for the systematic study of knowledge, where knowledge is localized in discourse. Fertility as an object of knowledge is a fragmented and multi-sited phenomenon that outlines various aspects that define fertility and its management.
\end{abstract}

Key words: Socioeconomic, fertility, discourse

JEL code: Z1 Cultural Economics; Economic Sociology; Economic Anthropology

\section{Introduction}

Fertility is widely discussed in public media and state policy which relate it to different social and economic aspects and become part of social organization. For example, the Cabinet of Ministers Order No. 84 (Cabinet of Ministers, 2012) sets the improvement of the demographic situation as the state priority in the cross-sector policy decisions. Family support forms are introduced to stimulate second, third, and further children born to a family and to provide fiscal incentives: the principle of the progressivity in state support according to the number of children in the family and the support program for the treatment of infertility. According to policy documents and media discourse, fertility is closely linked to population statistics. Decrease in the national birth rate is often perceived as one of the main causes for depopulation in Latvia and thus defined as the threat to a societal development. Sustainable Development Strategy for Latvia until 2030 (CCSC, 2010) and the National Development plan of Latvia for 2014-2020 (CCSC, 2012) - the most important policy planning documents for the upcoming periods in Latvia - show that policy makers see fertility as a macro level phenomenon and relate it to social and economical aspects important in social organization, which are perceived as resource to the future development of the state.

\footnotetext{
1 Corresponding author - e-mail address: ilze.mileiko@lu.lv
} 


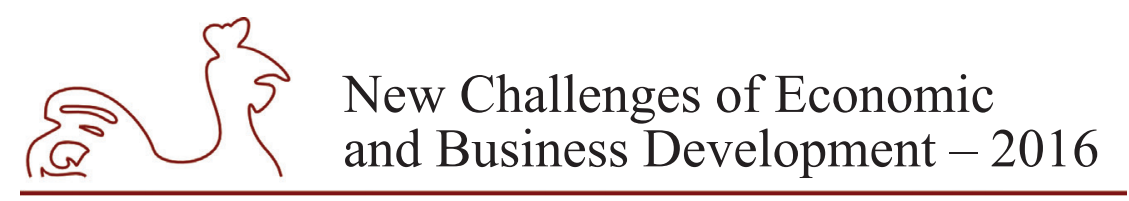

May 12-14, 2016, Riga, University of Latvia

In this paper fertility is explored in a micro perspective that allows discovering how fertility experience is formed at the personal level. I apply anthropological perspective on fertility that allows exploring the social and cultural organization of human biological ability to conceive and to carry children.

Empirical data shows that exploration of an individual's fertility experience allow to critically evaluating state reproductive politic. Informant's fertility explains including ideas on social and economic that impacts the meaning of fertility as well as meaning of social and economic that changed in different context. These socioeconomic explanations are used as a context that impact the perception, structure the experience and set a social value of fertility. The understanding of fertility perception at the micro level allows for re-evaluating state policy including new ideas that are more associated with the experience of personal fertility. Therefore the aim of this paper is to explore how ideas concerning to the socioeconomic are included in the fertility discourse in Latvia and how it impact fertility perception.

The theoretical perspective of the paper is based on Michel Foucault combined with approach developed by F. Lyotard. Although Foucault's ideas on discourse were developed in 1972, he is still one of the most cited authors in social sciences. He defines discourse as a place where the object of discourse is constructed. Foucault argues that the object cannot exist by itself; it comes into being only as the result of discourse formation, where knowledge of the object is shared and created. Using this perspective, fertility can be seen as an object of knowledge formed in a particular discourse. Lyotard (2008, pp. 43) defines knowledge not only as denotation of certain objects, but also includes skills and competences to communicate the object. This approach allows us explaining fertility as a situated and fragmented object of knowledge. Foucault offers a methodological frame to explore the discourse. Therefore I use his 'archaeology of knowledge' methodology (1972, pp. 27) to explore fertility as an object of knowledge localized in discourse. This paper examines how the informants explain their understanding of fertility which they relate their understanding to socioeconomic aspects of the social organization in the discourse. By extending the concept of knowledge, the objects of knowledge become ideas that go beyond the criteria of truth; they may be associated with speech and practice, or related to a specific situation, culture, or tradition. This approach explains fertility as a situated and fragmented phenomenon based on contextual and varied knowledge. This makes it possible to expand the idea of fertility to include the analysis of socioeconomic and cultural aspects of human reproduction

The novelty of this paper is linked with its research methodology. The current dominant perspective on fertility in Latvia is based in demographic approach and the use of the macro perspective. This research analyses fertility from the micro perspective applying an anthropological approach. Fertility has been an object of anthropological research for many decades. Anthropology has generated substantial body of knowledge about the construction of kinship, families, impact of biotechnologies, and other social and economic aspects of fertility. There has been only one anthropological study on fertility conducted from a micro perspective In Latvia (Mezinska et al., 2013, 2012). When compared to the demographic contribution to fertility research, anthropological knowledge in Latvia is marginal. The anthropological approach explains fertility in a localized context, allowing us to investigate how fertility is perceived and defined by Latvians themselves, and how they include ideas on economic and social to explain their fertility experience. 


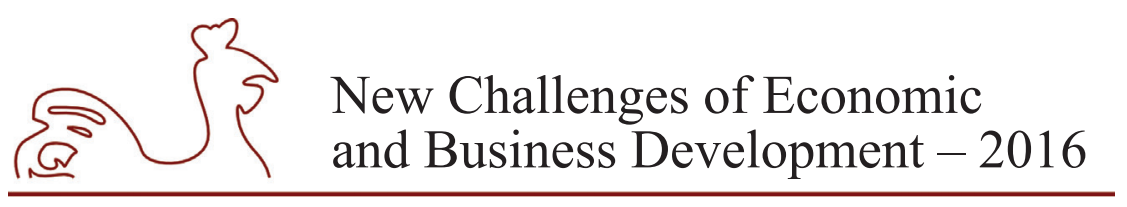

May 12-14, 2016, Riga, University of Latvia

\section{Fertility research in anthropology}

Fertility in anthropology is explored through various theoretical approaches - feminism, political economy, practice theories etc. Susan Greenhalgh (1994, pp. xv) argues that the "anthropology of reproduction entails critical reflection". The contribution of anthropology is a cultural understanding of fertility that allows rethinking ideas of personhood, gender, family, and kinship. Greenhalgh (1994, pp. 4) focuses her attention on diverse intellectual perspectives: one approach represented by Jane Schneider and Peter Schneider stresses the link between [macro] social processes and [micro] reproductive behaviour. Another feminist approach focuses on reproductive process through the cultural construction of the body and sexuality, as well as procreation (Martin, E., 1991, Ginsburg, F., Rapp, R 1991). Thirdly, there is a discussion on kinship that is related to the analysis of assisted reproduction, which develops new ideas on relatedness on the bases of fertility (Strathern, M., 1995; 2005, Bonocorso, M., 2009).

In contrast to demographers that trust in quantifying approaches, anthropologists contextualize reproductive behaviour in political, social, and economic processes. Greenhalgh (1994, pp. 13) argues that from 1970 to 1980 the focus of anthropological research fertility in the local, regional, and global situation. In these studies explain how fertility was shaped at different localities. The aim of this approach was understand "how a particular set of reproductive institutions and behaviours evolve and how its constitutive elements relate to each other" (Greenhalgh S., 1995, pp. 13).

Another research direction in the anthropology of reproduction explains fertility as a gendered process. The work of Emily Martin represents this approach. Martin (1991) explores how male/female stereotypes are used to explain fertility in terms of bodily processes. Also Rayna Rapp (2001) researches the social stratification based on fertility, and demonstrates how perceptions of fertility contribute to the construction of a personal experience, including experience of stigmatization within different social groups. Through these approaches, the anthropologists focus on the ways in which the ideas of biology and the sociality of fertility are used in gender relations and what kind of inequalities and power relations evolve from these ideas. There are studies on how fertility impacts gender relations, offers a certain status, and is used in construction social life (Rapp R., 2001, pp. 466-477).

The social constructionist perspectives for fertility research in anthropology used ideas developed by Berger and Lucman (1991), Bourdieu (1977), and Foucault (1972) providing another productive approach. This perspective makes it possible to explain how fertility is constructed socially and exposes the content of this construction.

\section{Data}

The paper is based on doctoral research in progress. The data sources used are thirty semistructured interviews (eleven interviews with users of assisted reproduction techniques, four interviews with egg donors (females aged 26-42), and fifteen expert interviews (including three clinic heads, one andrologist, two embryologists, one psychologist employed by a fertility clinic, and eight representatives of governmental institutions and NGOs)). The interviews were carried out by Signe Mežinska during the period from 2011 to 2012 within the framework of the ESF project Capacity building for interdisciplinary biosafety research. I use them for secondary data analysis that was conducted with the permission of the sub-project leader Aivita Putnina. 


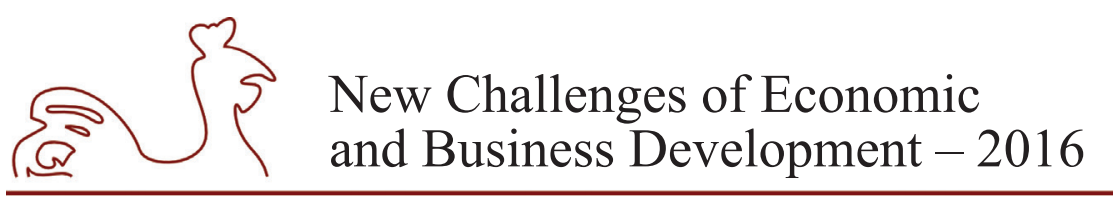

May 12-14, 2016, Riga, University of Latvia

Interviews were part of a study focusing on reproductive technologies that was a part of the larger above mentioned project. The aim of this study was to explore the practice of reproductive technologies in Latvia and to develop recommendations for improving their biosafety. The interview questions covered the participants' perception of fertility, experience of infertility and the process of treatment or donation, and their opinions on policies related to and governance of ART. The average length of the interviews is 60-90 minutes. Informed consent was obtained orally from all participants. All data was processed using Atlas.ti.

The methodology of the data analysis is based on the ideas of M. Foucault. The Foucauldian 'archaeology of knowledge' methodology justifies conducting a systematic study of knowledge, where knowledge is localized in discourse. Foucault (1972, pp. 29-30) call for identifying discursive units that determine the internal configuration of an object of knowledge. Foucault (1972, pp. 41-44) claims that the sufficient attention should be pays to the different aspects: how the object is named, described and made visible. The different ways of description allow identifying discursive units and limits of their variation. The variations of the concept of fertility are identified through the coding and described through discourse analysis process. The analysis results in a description of fertility and its links to other phenomena, including gender, age, family status, economic status. The paper describes only those discursive units that explain fertility including some ideas on how socioeconomic impact fertility.

\section{Fertility discourse and socioeconomic}

Various fields - general practitioner, infertility clinic, a closed Internet forum, and the family, the circle of friends, public institutions, and media are mentioned as places where fertility is discussed. These fields become the contexts in which a particular fertility discourse is created. These contexts also determine the evaluation of knowledge and divide it into what knowledge of fertility is true and what is not. In some of the field's fertility are described using ideas on socioeconomic that impact fertility definition and social evaluation. The main discursive unit which includes links to socioeconomic are described in the following subchapters: infertility as a result of social impact, the Latvian demographic situation and social development, costs of the treatment and the economics of infertility, 'artificial fertility', and fertility as family resource.

\subsection{Infertility as a result of social impact}

Female informants described their conversations with medical personnel as one of the contexts where questions about fertility and infertility are discussed. Fertility in this context is defined as an aspect of the human body - the ability to procreate and to give birth to a healthy child - and is explained as a part of human biology. Emily Martin (2001, pp. xi) indicates that the medical version of the human body becomes its dominant meaning in the Western culture. She points out that the medical view dominates in the perception of fertility and infertility in the social sciences as well as humanities; she calls this process the medicalization of fertility. Lauren Jade Martin (2010, pp. 528) defines medicalization as a process by which medical technologies create and define the meaning of fertility and infertility. As a result of the medicalization of fertility, infertility becomes a diagnosis that is justified by medical claims, evidence and the doctor's competence. Not only medical specialists, but also most lay informants used medical language to describe their experiences of fertility and infertility showing that the medicalization of fertility 


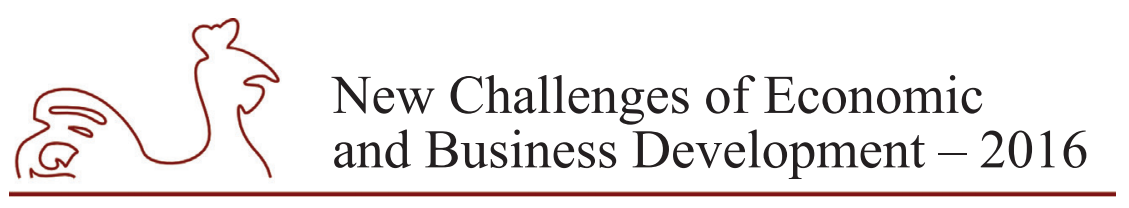

May 12-14, 2016, Riga, University of Latvia

is also dominant fertility definition in Latvia. Informants describe fertility as the normal human condition, but infertility is becomes the situation when some outer cause influences this 'natural body' and decreases an individual's ability to procreate.

The specialists named a number of medical, environmental, and social reasons for infertility. Social reasons are applied differently in relation to female or male fertility. When medical experts speak about male infertility, alcohol and drug abuse, environmental pollution, as well as sexually transmitted diseases are more often mentioned social causes of infertility and as such they were associated with poorly organized sexual life. Although these causes are perceived as negative, they are not widely discussed and attributed to particular contexts, but rather recognized as neutral facts. When medical experts speak about the social causes for female infertility, most often late pregnancy is mentioned and it is associated with female careerism, abortion, and sexually transmitted diseases. These social aspects are more likely to be discussed in public.

"Therefore, one of the reasons infertility is becoming more and more of a problem is because females are planning their pregnancies too late..." (Andrologist)

It is important to note that informants described some of the reasons for infertility neutrally and viewed these as inevitable; for example, causes related to a modern lifestyle, environmental pollution. Other social causes for infertility were perceived as an individual's personal responsibility and were therefore used to stigmatize the infertile person, e.g. abortion or pregnancy in later life. Social causes of female infertility were often mentioned and described in interviews in a stigmatizing way. However, this could be related to the fact that male infertility was much less discussed in general. This use of different social reasons for explanation of infertility in the interviews were created in gender unequal way, often stigmatizing infertile females but silencing the male experience of infertility at all. Social in this context characterized as negative force that impact human body and fertility as well.

\subsection{The Latvian demographic situation and social development}

The 'demographic situation' and 'demographic development" are discursive constructions that used to explain fertility at the macro level. The ideas on socioeconomic expressed in relation to fertility used by both experts and lay people in the analyzed interviews. This issue often comes up in discussions about the need to finance infertility treatment in Latvia. In this context, human fertility is described as the national state resource that delivers future citizens for Latvia. Therefore, infertility treatment is seen as fertility measure that the state should provide. Seeing fertility is a national resource, re-contextualizes female and male experience. However, when describing fertility at the macro level, the personal and gender aspect in fertility is usually ignored even by lay persons themselves.

Both of these discursive constructions - current demographic situation and its future projections - social development - are used in relation to the Latvian population. In this context infertility is perceived as one of the causes for the current and future decrease in population and seen as a threat to the long-term national development. Experts use population statistics in constructing their arguments and emphasize the risk associated with infertility. In this context, state funding for infertility treatment becomes a tool for population management in Latvia.

"If we take into account the demographic situation and raise of infertility, then all progressive states have their funding for infertility treatment" (Andrologist) 


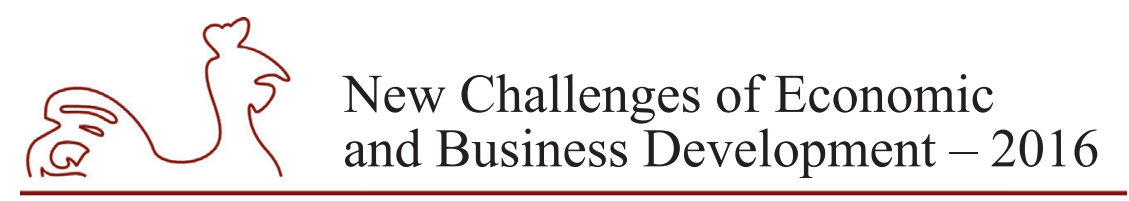

May 12-14, 2016, Riga, University of Latvia

Demographic development is also described as the basis for the national and cultural continuation of future Latvia. The mechanisms by which national and cultural continuation intersects with fertility are variously imagined. Some informants argue that the capacity for fertility is essential for creating the next generation of Latvians to ensure the continuity of the national culture, but most informants did not explain the process in any detail. However, some informants believe that Latvians have special 'Latvian gene', common to all Latvian citizens, which ensures the continuation of Latvian culture, not through socialization, but through blood and gametes. Therefore, in this line of argumentation, nationality and culture become grounded in the bodily substance that is passed from one generation to another. In this context, giving birth becomes a civic responsibility. However, other ethnic groups (not Latvians) livings in Latvia are not discussed in this context.

The constructions of 'demographic situation' and 'demographic development' explain fertility as part of population processes at macro level and describe them in relation to the state. Such constructions ignore fertility as a personal experience and objectify both men and women as instruments in the state development strategies. Economic in this context mentioned to justify need for infertility treatment financing by the state, but the low birth rates in Latvia that is explained in a link to infertility is perceived as a risk to future economy and society. Therefore in this case fertility and economic is explained interconnected.

\subsection{Costs of the treatment and the economics of infertility}

Medical specialists describe medical technologies as instruments used to transform a body from infertile to fertile. In most of the interviews, assisted reproduction is described as an extremely expensive medical procedure and, therefore, not available to all those who might want it due to the average small income in Latvia.

An important aspect of this discussion is the question of who should cover infertility treatment and why. The economic situation' as the discursive construction is often used regardless the source of funding. In cases when infertility treatments were covered by informants themselves, they still used the construction 'the economic situation' to explain why access to infertility treatment was limited. Some informants identified specific strategies for obtaining resources for infertility treatment, e.g. a bank loan, borrowing from relatives or selling their property.

When informants used the construction 'the economic situation' to argue why state should or should not cover assisted reproduction, solutions varied. For example, if an informant believed that the most important aspect of the continuation of the Latvian state was the highest possible number of citizens living in Latvia, then the amount of money invested by the state (even if the investment is high) was evaluated as small when compared to actual price to achieve this important aim:

'If we can get 500 or 1000 wanted children with a few million [Euros], then it is the cheapest way to increase the number of people in Latvia.'(NGO expert)

'If those children will be important for the state and for all of society, then it is important for all of society to participate and to help to fund [assisted reproduction].' (NGO expert) 


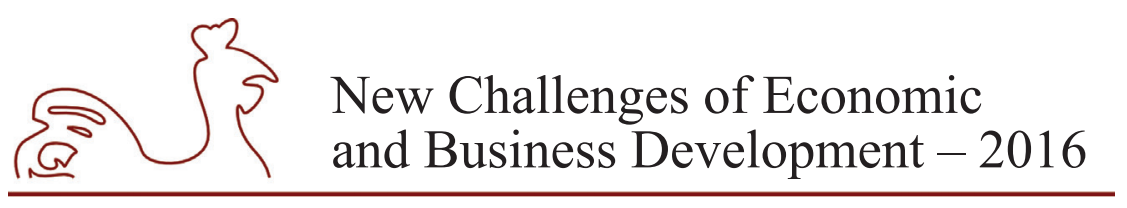

May 12-14, 2016, Riga, University of Latvia

Some of the informants compared the cost of infertility treatment to other kinds of state spending which they saw as less useful. However, the reverse argument was used in other interviews; if 'the economic situation' was explained as the amount of money currently available for Latvian society, then state funding for assisted reproduction was luxury in comparison with other pressing needs, e.g. the support for pensioners, the benefits for families with children and the treatment of other life-threatening diseases such as cancer.

Economic arguments and discursive constructions, such as 'the economic situation', can be used as tools to demonstrate a rational perception of fertility management. The examples from this context show that economic categories, such as 'expensive' and 'cheap', become relative in the discussion on fertility, depending on the contextual definition of fertility used and the informant's attitude toward infertility treatment. In this context the state economic support for infertility treatment is perceived as a social evaluation of fertility.

\section{4. 'Artificial' fertility}

The interviews often identified the general public and the Internet as locations and contexts that are hostile to families with fertility issues. Most informants with experience of assisted reproduction described the public attitude as unfriendly, hostile and judgmental. Interviews, online articles, and the comments to media articles on infertility are perceived as an abstract general public opinion that stigmatizes people with fertility problems as well as their children. Several interviews spoke about infertile people and their children being described as 'cyborg' or 'robot' and other similar terms. Data analysis showed that distinction between 'natural fertility' and 'artificial fertility' ('māksliga auglība' in Latvian) is made in media. This shows that different fertilities exist in the perceptions of the public. 'Natural fertility' is described as a "normal" process of procreation without of the use of biotechnologies, but 'artificial fertility' is procreation using assisted reproduction techniques.

The term 'artificial' or ' $m \bar{a} k s l \bar{g} g s$ ' in Latvian also includes the connotations of being 'false' and 'synthetic'. These meanings may also be transferred to children born with the help of assisted reproductive technology. Therefore, some of the informants admitted that they have had hidden their infertility in society in general, but sometimes even from their relatives and friends. In such cases infertility becomes a silent issue, even in close personal relationships. Informants recognize that the cause of this silence is a social bias and lack of knowledge about infertility. This stigmatization is similar to the situation in the United States described by Rapp (2001, pp. 469). It is also possible to identify elements that indicate the stratification of society according to the ability to reproduce in Latvia.

Some informants used the alternative space to discuss their fertility issues and avoid stigmatization. In closed internet forums, informants shared experience building community and using the term 'we', contrasted to the general public, who are seen as 'they'.

$[\ldots]$ the others should not hide from society, and then the public will understand how many couples have this problem here. If, in a population of 10,000, only two couples talk openly about it $[\ldots]$ they think there are only two of us. But if we show how many of us there are, they would understand.(Patient)

Such conversations are characterized as a social support from those with similar experience. In five cases, both emotional and psychological support was mentioned as particularly important 


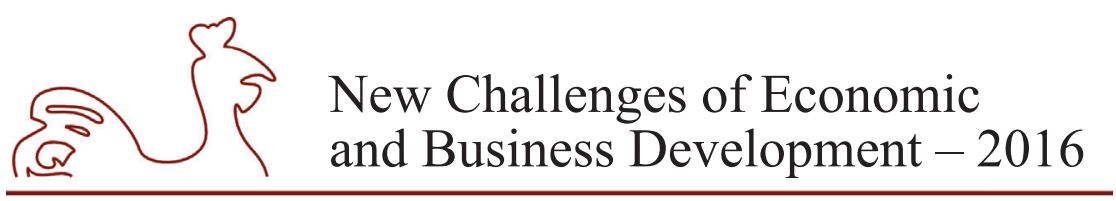

May 12-14, 2016, Riga, University of Latvia

benefit of the closed Internet communication forum. The informants explained that infertility becomes a personal and painful experience that the greater society cannot understand. The anonymity and social distance that characterize closed Internet forums are aspects that allow forum members to speak more intimately and not to worry that their infertility might be used against them.

\subsection{Fertility as family resource}

In the context of family and friends, fertility is understood as the ability to create a family and is the source that allows the family to continue into the future. In this case fertility is described as a family resource and gametes are described as material that can be shared with relatives by means of donation. In this example a woman explains that fertility can be exchanged between close relatives:

"If my sister will want children but cannot deliver, then I will deliver for her if I can." (Ova Donor)

The informants explained that by sharing biological material with their relatives it would be possible to conceive children with characteristics belonging to their family, e.g. body shape, temperament, etc. Informants felt saddened; when they were informed that gamete donation to a family member was prohibited. They believed that if a family member was infertile, then sharing gametes within the family would make it possible to conceive children that would be more similar to other members of the family. Fertility is described as an ability that can be managed in the context of the family, not only by sharing gametes, but also by participating in fertility management - willing to assist in conception or in funding infertility treatment. The importance of continuation of the family is related to the fact that informants imagine the family as a support system where generations create a system of reciprocity during the whole of a life time.

\section{Conclusions, proposals, recommendations}

1. In my analysis of the discourse, I have identified a number of different types of descriptions of fertility that include ideas on socioeconomic. Fertility may be explained (1) as a physical ability, (2) as a national resource that impacts the country's demographic situation and future development, (3) as the aim of an expensive service, and (4) as a family resource that can be shared between family members. These some examples show that fertility as a knowledge object is a fragmented and multi-sited phenomenon and the true definition of fertility and the set of meanings for 'social' and 'economic' depends on the context in which it is discussed.

2. The explanations of the social and economic included in the content of the fertility and are essential to understanding it. An analysis of the economic and social aspects of fertility allows identifying the various power relations and systems of classification that are based on fertility and create social stratification. To protect those with infertility problems, it is important to avoid social stigmatization. One of the results of stigmatization is silence about infertility-related issues.

3. Currently, fertility is widely discussed in Latvia, both in public media and in the political sphere, as a demographic issue linked to population statistics. Such a macro perspective 


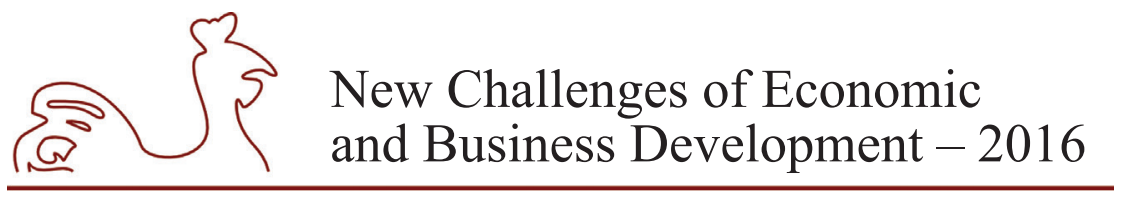

May 12-14, 2016, Riga, University of Latvia

depersonalizes and objectifies an individual's fertility, transforming it into an instrument for achieving the state's long-term aims. I recommend changing the discussion and end ignorance of fertility in the micro perspective. This will be useful for revaluating the Latvian state policy on reproduction and for including greater respect for the individuals involved. The change of perspectives also allows avoiding construction of persons living in Latvia as state resources.

\section{Acknowledgements}

This paper was supported by the University of Latvia and the EKOSOC-LV Programme, Project No 5.2.4: The renewal of society through reducing the risk of depopulation through demographic development and strengthening links with the diaspora for the transformation of the Latvian economy.

\section{Bibliography}

Berger L., Luckmann, T., 1991. The social construction of reality: a treatise in the sociology of knowledge. London: Penguin Books.

Bonocorso, M., 2009. Conceiving kinship. Assisted Conception, Procreation and family in Southern Europe. New York: Berghahn Books.

Bourdieu, P., 1977. Masculine Domination. Cambridge: Polity.

Cabinet of Ministers, 2012. Cabinet of Ministers Order No. 84, Riga: Cabinet of Ministers.

Cross-Sectoral Coordination Centre, 2010. Sustainable Development Strategy for Latvia until 2030.

Riga: Cross-Sectoral Coordination Centre. Available at: http://www.pkc.gov.lv/images/LV2030/

LIAS_2030_parluks_en.pdf

Cross-Sectoral Coordination Centre, 2012. National Development Plan of Latvia for 2014-2020. Riga:

Cross-Sectoral Coordination Centre. Available at: http://www.pkc.gov.lv/images/NAP2020\%20 dokumenti/NDP2020_English_Final__.pdf

Foucault, M., 1972. The Archaeology of Knowledge. London: Tavistock.

Ginsburg, F., Rayna, R., 1991. The politics of reproduction. Annual Review of Anthropology, Vol. 20 (1991), pp. 311-343.

Greenhalgh, S., 1995. Anthropology theorizes reproduction: Integrating practice, political economic and feminist perspectives. Situating Fertility, Cambridge: University Press, pp.1-28.

Liotārs, Ž. F., 2008. Postmodernais stāvoklis. Pārskats par zināšanām. Rīga: Laikmetīgās mākslas centrs. Martin, E., 1991. The Egg and the Sperm: How Science Has Constructed a Romance Based on Stereotypical Male-Female Roles. Journal of Women in Culture and Society, Vol. 16, No. 3, pp. 485-501.

Martin, E., 2001. The woman in the body. A Cultural Analysis of Reproduction. Boston: Beacon Press.

Martin, L. J., 2010. Anticipating Infertility: Egg Freezing, Genetic Preservation, and Risk. Gender \& Society, Vol. 24, pp. 526-547.

Mezinska, S., Mileiko, I., 2013. Risk Communication in Assisted Reproduction in Latvia: From Private Experience to Ethical Issues. Medical Philosophy and Medical Ethics in the Nordic and the Baltic Countries, Vol. 6.2, pp. 79-96.

Mezinska, S., Mileiko, I., Putnina, A., 2012. Sharing Responsibility in Gamete Donation: Balancing Relations and New Knowledge in Latvia.Medicine Studies, Vol. 3(3), pp. 185-196.

Rayna, R., 2001. Gender, Body, Biomedicine: How Some Feminist Concerns Dragged Reproduction in the Centre of Social Theory. Medical Anthropology Quarterly 15(4).

Strathern, M., 1995. No nature, no Culture: The Hagen case. Nature, Culture and gender, ed. MacCormak, Cambridge: University Press, pp. 174 -222.

Strathern, M., 2005. Kinship, Law and the Unexpected. New York: Cambridge University Press. 


\title{
New Challenges of Economic
} and Business Development - 2016

May 12-14, 2016, Riga, University of Latvia

\section{THE LINKAGE BETWEEN INDUSTRIAL EXPECTATIONS AND PRODUCTION: WHICH IS THE CAUSE?}

\author{
Dapkus Mindaugas, Kaunas University of Technology, Lithuania ${ }^{1}$ \\ Stundziene Alina, Kaunas University of Technology, Lithuania
}

\begin{abstract}
Industrial confidence indicator is very important for economists as it is considered to be the predictor of production level and macroeconomic tendencies. Actually it is calculated by the statistic departments on the basis of industry survey. Nevertheless some researchers doubt about the reliability of such indicator for prediction. Others state that this indicator just demonstrate the changes that already manifest in the real economy. So the question is still open and under consideration.

That's why the purpose of this research is to test what type of relationship between the industrial confidence indicator and the production indices exist, i.e. "Can the production indices be forecasted by the industrial confidence indicator?" and "Is the industrial confidence indicator based on the current level of production?"

Three techniques are applied for the analysis of the linkage between the industrial confidence indicator and the production indices: correlation analysis, Granger-causality test and autoregressive distributed lag model. The research is based on the analysis of eight production indices (intermediate goods, capital goods, consumer goods, durable consumer goods, non-durable consumer goods, mining and quarrying, manufacturing, electricity, gas, steam and air conditioning supply) and the industrial confidence indicator of Germany during the period of January 1995 - October 2015.

The results of the research showed that the changes in industrial confidence indicator have significant and positive impact on the changes in all production indices, except electricity, gas, steam and air conditioning supply. Meanwhile the changes in industrial confidence indicator can be explained only by the changes of two production indices, i.e. intermediate goods and mining and quarrying. Generally, it can be stated that industrial confidence is related with the real levels of production.

This research was made on the basis of Germany statistical data and a similar study for other countries should be done in order to find out whether these findings are specific for Germany or universal. The same methodology presented in this paper can be applied for this purpose.
\end{abstract}

Key words: industrial confidence indicator, production index, linkage, Germany

JEL code: C82, D22, E03

\section{Introduction}

There are several indicators that have deservedly long been known as predictors of the economic cycles. Production output is one of such indicators. Production determines the use of resources and labours and hence influences the growth, income generation, and prosperity. The production index is regarded as one of the most important measures of the economic activity. Developments in the industrial production index describe the economic cycles of industry, and

1 Corresponding author - e-mail address: mindaugas.dapkus@ktu.lt 


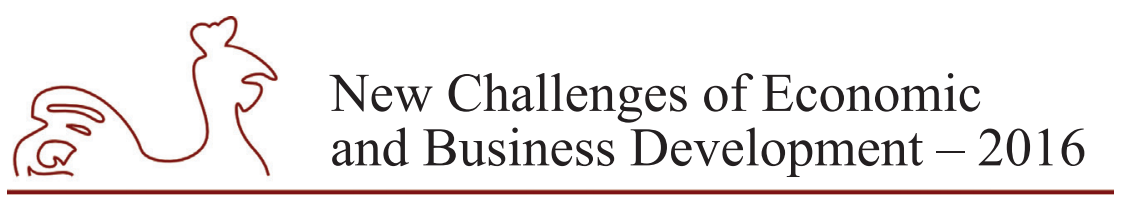

May 12-14, 2016, Riga, University of Latvia

this can be used to assess the development of GDP as a whole. This index is the reference indicator for economic development and it is used in particular to identify the turning points in economic development at an early stage (European Commission, 2006).

The major advantage of the production index compared with other indicators is its combination of fast availability (relative to GDP for example) and at the same times its detailed activity breakdown (European Commission, 2006). The governments and central banks need to have an accurate and timely assessment of indicators for the current month, as this is essential for providing a reliable and early analysis of the current economic situation. The index of industrial production is probably the most important and widely analysed monthly indicator, given the relevance of the manufacturing activity as a driver of the whole business cycle (Brunhes-Lesage $\&$ Darne, 2012). The studies showed that industrial production is important for prediction of not only business cycles (Iyetomi et al., 2011), but also oil prices (Gokmenoglu et al., 2015; Ewing \& Thompson, 2007), stock prices (Tsagkanos \& Siriopoulos, 2015) and other indicators.

Survey data are also leading indicators of an economic activity and even preceding the data of production output. Lots of researchers agree that consumer and business surveys are very important for the prediction of the future changes of economy. The business tendency surveys are also known as the economic opinion surveys or business climate surveys. Generally they focus on the conclusions about the economic activity, based on the results of business leaders' forecasts concerning their current positions on the market, plans and expectations in the nearest future. The business tendency surveys are carried out to obtain the qualitative information for use in monitoring the current business situation and forecasting the short-term developments (Stundžienè et al., 2015).

The basic purpose of business tendency surveys in the past was to collect the information on business conditions for the benefit of respondents and as a result many such surveys are carried out by trade associations. Today, the business tendency surveys have become a valuable tool for economic analysis for all types of users because the survey information focuses on the assessments and expectations of the economic situation by actors in the market (Nilsson, 2001; OECD, 2003). Results from business tendency surveys are often used to construct the leading indicators (Abberger, 2007b; Hansson et al., 2005), predict the employment (Siliverstovs, 2013; Abberger, 2007a), private investments (Roman et al., 2013; Abberger, 2005) and for other purposes (Stundžienė et al., 2015). Research of Cesaroni (2011) concludes that business tendency surveys are able to predict the Italian business cycle, and are therefore useful for prediction of Italian real economy in the short run.

The business and consumer surveys have become an essential tool for gathering information about the different economic variables. While the fast availability of the results and the wide range of variables covered have made them very useful for monitoring the current state of the economy, there is no consensus on their usefulness for forecasting the macroeconomic developments. Group of researches leaves doubts that survey data are suitable for prediction of various economic indicators. Claveria and others (2007) have included the information from business and consumer surveys in their research to explain the behaviour of macroeconomic variables, and stated that they are not conclusive about its role. Lui and others (2011) indicate that survey has little role to play in enhancing our knowledge of what has recently happened to manufacturing output.

Dapkus and Pridotkiene (2014) stated that companies can lie about its economic situation. The results of the research of Dapkus and Maksvytiene (2012) on the basis of Germany's data demonstrate that there is a strong probability to be a lying symptom in the producer's behaviour 


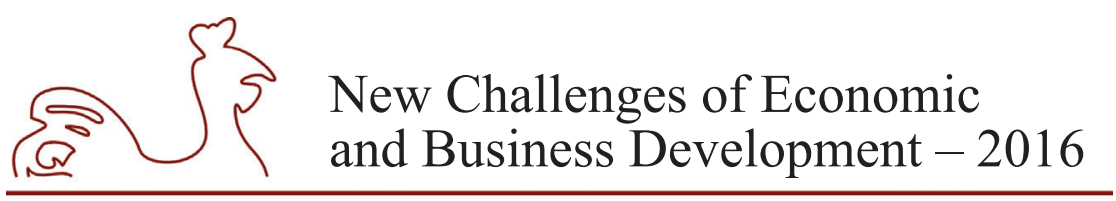

May 12-14, 2016, Riga, University of Latvia

especially in the moments of possible recession of an activity. The issue leaves the space for scientific discussion about the use of surveys data for economic forecasting. The question how the forecasting methods can be improved taking into account the possibility of intentional lying in the surveys remains open.

Berttrand and Mullainathan (2001) declare that a set of experiments has shown that simple manipulations can affect how people process and interpret the questions, for example the ordering of questions, question wording and so on. An even more fundamental problem is that the respondents may make little mental effort in answering the question, such as by not attempting to recall all the relevant information or by not reading through the whole list of alternative responses.

Beyond purely cognitive issues, the social nature of the survey procedure also appears to play a large role in shaping answers to subjective questioning. Respondents want to avoid looking bad in front of the interviewer. Part of the problem comes from the respondents' reluctance to admit the lack of an attitude. More profound problem is that people may often be wrong about their "attitudes". People may not really be good at forecasting their behaviour or understanding why they did, what they did. A final and related problem is cognitive dissonance. Subjects may report (and even feel) attitudes that are consistent with their behaviour and past attitudes.

As a conclusion Berttrand and Mullainathan (2001) declare that put in an econometric framework, these findings cast serious doubts on attempts to use the subjective data as dependent variables, because the measurement error appears to correlate with a large set of characteristics and behaviours. These data may be useful as explanatory variables, but one must take care in interpreting the results since the findings may not be causal.

Based on the overview of the earlier researches, it is obvious that the question "Are the business survey data suitable for the prediction of economic indicators?" is still under discussion. That's why the purpose of this research is to test the linkage between the business survey data, namely industrial confidence indicator, and one of the economic indicators, i.e. production index, that is closely related with the companies (business) and these companies in turn are the sources of the survey data. The research aims to answer the questions: 1) Can the production indices be forecasted by the industrial confidence indicator? 2) Does the industrial confidence indicator just reflect the current situation of the production (i.e. whether the industrial confidence indicator depends on the current and/or past levels of production)?

This research is based on Germany data as this country is one of the leading economies in Europe and has the longest series of statistical information. Eight seasonally adjusted and adjusted by working days production indices are analysed, i.e.:

- intermediate goods (ING),

- capital goods (CAG),

- consumer goods (COG),

- durable consumer goods (DCG),

- non-durable consumer goods (NCG),

- mining and quarrying (MAQ),

- manufacturing (MAN),

- electricity, gas, steam and air conditioning supply (EGS).

The analysed time period covers January 1995 - October 2015. The calculations are made with the econometric software EViews. 


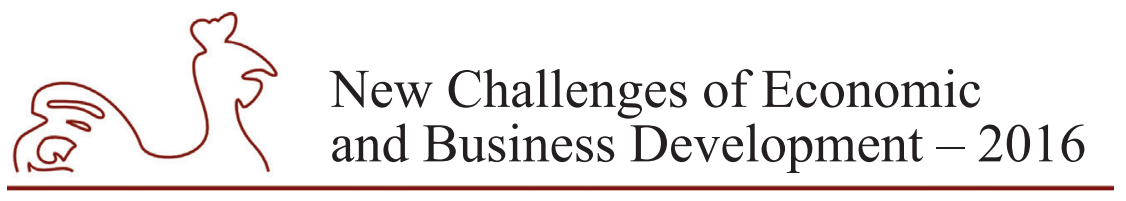

May 12-14, 2016, Riga, University of Latvia

\section{Research results and discussion}

\section{Research methodology}

Three techniques will be applied for the analysis of the linkage between the industrial confidence indicator (ICI) and the production indices:

- correlation analysis,

- Granger-causality test,

- autoregressive distributed lag (ADL) model.

Correlation analysis will be done in order to check the contemporaneous linkage between the industrial confidence indicator and the production indices. Pearson's correlation coefficient $(\rho)$ will be calculated. In order to test the significance of linear relationship between variables, the following hypothesis will be tested:

$$
\begin{aligned}
& H_{0}: \rho_{x y}=0, \\
& \mathrm{H}_{1}: \rho_{\mathrm{xy}} \neq 0 .
\end{aligned}
$$

The hypothesis will be tested by calculating Student $(t)$ statistics and the probability for Student's $t$-distribution. The calculated probability is compared with the significance level that is chosen 0.05 . It indicates a $5 \%$ risk that null hypothesis will be rejected when it is correct. The significance of Pearson's correlation coefficient will be made according to the rule: if probability is less than 0.05 , then significant linear relationship between variables exist and if probability is more than 0.05 , then significant linear relationship between variables does not exist.

The linkage between the industrial confidence indicator and the production indices may be not only contemporaneous. So Granger-causality test will be done in order to test the potential delayed effects. The Granger-causality test is a statistical hypothesis test for determining whether one time series is useful in forecasting another. In other words the Granger approach to the question of whether $x$ causes $y$ is to see how much of the current $y$ can be explained by past values of $y$ and then to see whether adding lagged values of $x$ can improve the explanation. $y$ is said to be Granger-caused by $x$ if $x$ helps in the prediction of $y$, or equivalently if the coefficients on the lagged $x$ 's are statistically significant.

The effect of twelve previous months (twelve lags of the variables) will be examined. The bivariate regressions take the form:

$$
\begin{aligned}
& y_{t}=\alpha_{0}+\alpha_{1} y_{t-1}+\alpha_{2} y_{t-2}+\ldots+\alpha_{12} y_{t-12}+\beta_{1} x_{t-1}+\beta_{2} x_{t-2}+\ldots+\beta_{12} x_{t-12}+\varepsilon_{t}, \\
& x_{t}=\alpha_{0}+\alpha_{1} x_{t-1}+\alpha_{2} x_{t-2}+\ldots+\alpha_{12} x_{t-12}+\beta_{1} y_{t-1}+\beta_{2} y_{t-2}+\ldots+\beta_{12} y_{t-12}+\varepsilon_{t} .
\end{aligned}
$$

Here $t$ denotes the time period dimension, $y_{t-l}$ and $x_{t-l}$ are variables with lags $(l=0,1, \ldots, 12), \alpha_{l}$ and $\beta_{l}$ are parameters of the model, $\varepsilon_{t}$ is an error of the model. The following hypothesis is tested for each equation:

$$
\beta_{1}=\beta_{2}=\ldots=\beta_{12}=0 .
$$

The null hypothesis is that $x$ does not Granger-cause $y$ in the (1) regression and that $y$ does not Granger-cause $x$ in the (2) regression.

Lastly the relationship between indicators will be described by autoregressive distributed lag model. It will be created according to the results of correlation analysis and Granger-causality 


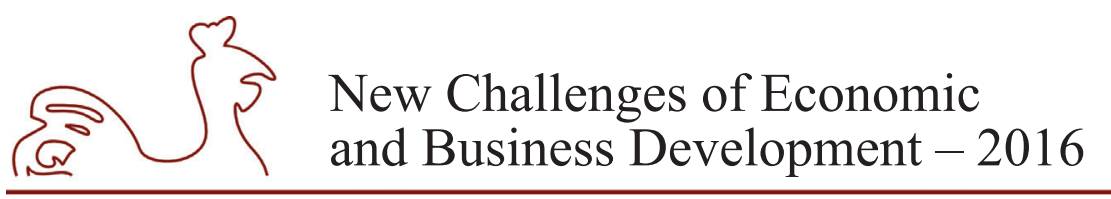

May 12-14, 2016, Riga, University of Latvia

test. In addition, the best lag value of dependent variable will be chosen according to the Akaike (AIC) criterion (it's minimums value). The general form of ADL model when the lag period can be not greater than 12 can be written as following:

$$
y_{t}=\alpha_{0}+\alpha_{1} y_{t-1}+\alpha_{2} y_{t-2}+\ldots+\alpha_{12} y_{t-12}+\beta_{0} x_{t}+\beta_{1} x_{t-1}+\beta_{2} x_{t-2}+\ldots+\beta_{12} x_{t-12}+\varepsilon_{t} \text {. }
$$

The analysis will be based on the first differences of the indicators, i.e. the purpose will be to test whether the changes in industrial confidence indicator has influence (for what time and what extent) on the changes in various production indices.

\section{Research results}

Correlation analysis. The correlation analysis shows that the changes in industrial confidence indicator are weakly correlated with the changes in various production indices, but correlation coefficients between the changes in industrial confidence indicator and the changes in the certain production indices, i.e. intermediate goods, capital goods and manufacturing are significant. The significant correlation coefficients are marked with an asterisk in the Table 1 $(5 \%$ critical value (two-tailed) $=0.1244$ for $n=249)$. The analysis of scatter plots also confirms that not only linear, but also any non-linear model can be appropriate for the description of the relationship between these indicators.

Table 1

The results of correlation analysis

\begin{tabular}{|c|c|c|c|c|c|c|c|c|c|}
\hline & $\Delta \mathrm{ICI}$ & $\Delta \mathrm{ING}$ & $\Delta \mathrm{CAG}$ & $\Delta \mathrm{COG}$ & $\Delta \mathrm{DCG}$ & $\Delta \mathrm{NCG}$ & $\Delta \mathrm{MAQ}$ & $\Delta \mathrm{MAN}$ & $\Delta \mathrm{EGS}$ \\
\hline$\Delta \mathrm{ICI}$ & 1 & $0.3385^{*}$ & $0.1711^{*}$ & 0.0148 & 0.0351 & -0.0017 & 0.0052 & $0.257^{*}$ & 0.1183 \\
\hline
\end{tabular}

Source: authors' calculations.

Granger-causality test. The results indicate that there is no strong simultaneous relationship between the changes in industrial confidence indicator and the changes in production indices, but delayed effect can exist. That's why Granger-causality test is made in order to test that. The results are presented in Table 2. 


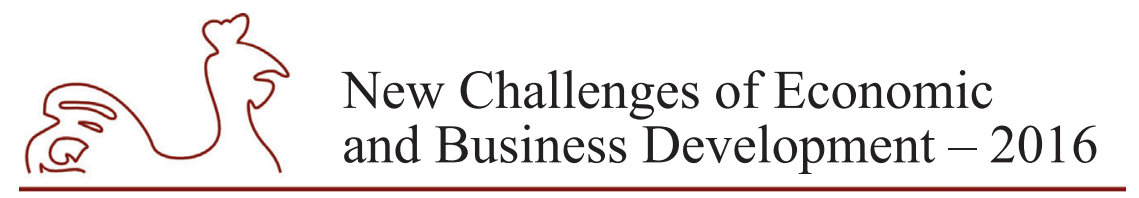

May 12-14, 2016, Riga, University of Latvia

Table 2

The results of Granger causality test

\begin{tabular}{|c|c|c|c|c|c|c|c|c|}
\hline $\begin{array}{r}\text { Indicators } \\
(\mathbf{y} \leftrightarrow \mathbf{x})\end{array}$ & $\begin{array}{c}\Delta \mathbf{I C I} \leftrightarrow \\
\Delta \mathbf{I N G}\end{array}$ & $\begin{array}{c}\Delta \mathbf{I C I} \leftrightarrow \\
\Delta \mathbf{C A G}\end{array}$ & $\begin{array}{c}\Delta \mathbf{I C I} \leftrightarrow \\
\Delta \mathbf{C O G}\end{array}$ & $\begin{array}{c}\Delta \mathbf{I C I} \leftrightarrow \\
\Delta \mathbf{D C G}\end{array}$ & $\begin{array}{c}\Delta \mathbf{I C I} \leftrightarrow \\
\Delta \mathbf{N C G}\end{array}$ & $\begin{array}{c}\Delta \mathbf{I C I} \leftrightarrow \\
\Delta \mathbf{M A Q}\end{array}$ & $\begin{array}{c}\Delta \mathbf{I C I} \leftrightarrow \\
\Delta \mathbf{M A N}\end{array}$ & $\begin{array}{c}\Delta \mathbf{I C I} \leftrightarrow \\
\Delta \mathbf{E G S}\end{array}$ \\
\hline$l=1$ & $\leftrightarrow$ & $\rightarrow$ & $\rightarrow$ & $\rightarrow$ & $\rightarrow$ & & $\rightarrow$ & \\
\hline$l=2$ & $\rightarrow$ & $\rightarrow$ & $\rightarrow$ & $\rightarrow$ & $\rightarrow$ & & $\rightarrow$ & \\
\hline$l=3$ & $\rightarrow$ & $\rightarrow$ & $\rightarrow$ & $\rightarrow$ & & & $\rightarrow$ & \\
\hline$l=4$ & $\leftrightarrow$ & $\rightarrow$ & $\rightarrow$ & $\rightarrow$ & $\rightarrow$ & & $\rightarrow$ & \\
\hline$l=5$ & $\rightarrow$ & $\rightarrow$ & $\rightarrow$ & $\rightarrow$ & $\rightarrow$ & $\leftrightarrow$ & $\rightarrow$ & \\
\hline$l=6$ & $\leftrightarrow$ & $\rightarrow$ & $\rightarrow$ & $\rightarrow$ & $\rightarrow$ & $\leftrightarrow$ & $\rightarrow$ & \\
\hline$l=7$ & $\rightarrow$ & $\rightarrow$ & $\rightarrow$ & $\rightarrow$ & $\rightarrow$ & $\rightarrow$ & $\rightarrow$ & $\rightarrow$ \\
\hline$l=8$ & $\leftrightarrow$ & $\rightarrow$ & $\rightarrow$ & $\rightarrow$ & $\rightarrow$ & $\rightarrow$ & $\rightarrow$ & $\rightarrow$ \\
\hline$l=9$ & $\leftrightarrow$ & $\rightarrow$ & $\rightarrow$ & $\rightarrow$ & $\rightarrow$ & $\rightarrow$ & $\rightarrow$ & $\rightarrow$ \\
\hline$l=10$ & $\leftrightarrow$ & $\rightarrow$ & $\rightarrow$ & $\rightarrow$ & $\rightarrow$ & $\rightarrow$ & $\rightarrow$ & $\rightarrow$ \\
\hline$l=11$ & $\leftrightarrow$ & $\leftrightarrow$ & $\rightarrow$ & $\rightarrow$ & $\rightarrow$ & $\rightarrow$ & $\rightarrow$ & \\
\hline$l=12$ & $\rightarrow$ & $\rightarrow$ & $\rightarrow$ & $\rightarrow$ & & $\rightarrow$ & $\rightarrow$ & \\
\hline
\end{tabular}

Source: authors' calculations.

Granger-causality test indicates that the changes in industrial confidence indicator Granger-cause the changes in all production indices, but different effect of time exists. The changes in industrial confidence indicator Granger-cause the changes in production indices of manufacturing, intermediate goods, capital goods, consumer goods and durable consumer goods when the lag varies from 1 to 12 . The changes in industrial confidence indicator can also be a good predictor for production index of non-durable consumer goods as ICI doesn't Grangercause the production index of NCG only when the lag is 3 and 12. The changes in industrial confidence indicator have longer delay for two production indices, i.e. mining and quarrying and electricity, gas, steam and air conditioning supply. The changes in ICI have an impact on the changes in production index of mining and quarrying after 4 months while the impact on the changes in production index of electricity, gas, steam and air conditioning supply appears only after half a year. Besides, the last effect is quite short. It disappears again after four months.

Meanwhile only the changes in production index of intermediate goods Granger-cause the changes in industrial confidence indicator. Granger-causality of the changes in production index of MAQ on the changes in ICI can also be observed, but only when the lag is 5 and 6.

Autoregressive distributed lag (ADL) model. Lastly ADL models are created in order to find the function that describes the relationship between the changes in production indices and the changes in ICI the best. The lag values (not exceeding 12) of changes in ICI are also taken into account. Created eight models are presented below according to the dependent variable (production index). 


\section{New Challenges of Economic and Business Development - 2016}

May 12-14, 2016, Riga, University of Latvia

Intermediate goods. The best lag period that minimizes Akaike criterion for the changes in production index of intermediate goods is 5 . The best significant model is got adding the changes in ICI of the last two months, i.e.:

$$
\begin{aligned}
& \Delta I N G_{t}=\underset{(0.0770)}{0.1358^{*}}-\underset{(0.0607)}{0.2180^{* * *}} \cdot \Delta I N G_{t-1}+\underset{(0.0566)}{0.2034^{* * *}} \cdot \Delta I N G_{t-3}-\underset{(0.0553)}{0.1811^{* * *}} \cdot \Delta I N G_{t-5}+ \\
& +\underset{(0.0393)}{0.2288^{* * *} \cdot \Delta I C I_{t-1}}+\underset{(0.0439)}{0.1871^{* * *} \cdot \Delta I C I_{t-2}}
\end{aligned}
$$

Note: one asterisk (*) means that the parameter is significant at the significance level of 0.1 , two asterisks $(* *)$ show that parameter is significant at the significance level of 0.05 , while three asterisks $(* * *)$ represent the significance level of 0.01 in this equation and all the equations below. Standard error is presented below the parameter.

The autoregression shows stopping effect, i.e. the increase in production index of intermediate goods one and five months ago (with the particular corrections of $\Delta I N G_{t-3}$ ) decreases the rise of the index in the current period. But the changes in ICI have positive and in general higher impact on the changes in ING, i.e. two-month rise of ICI increases the production index of intermediate goods after two months. However the precision of the model is not high. Adjusted R2 (coefficient of determination) of the model is 0.3188 , standard error of regression is 1.1902 and residuals of the model are not correlated according to Breusch-Godfrey test (p-value is 0.734).

Capital goods. The best lag period that minimizes Akaike criterion for the changes in production index of capital goods is 4 , but the best significant model is got removing the third and fourth lags and adding the changes in ICI of the last three months, i.e.:

$$
\begin{aligned}
& \Delta C A G_{t}=\underset{(0.1327)}{0.3613^{* * *}}-\underset{(0.0625)}{0.5197^{* * *}} \cdot \Delta C A G_{t-1}-\underset{(0.0621)}{0.1929^{* * *} \cdot \Delta C A G_{t-2}}+\underset{(0.0717)}{0.1446^{* *} \cdot \Delta I C I_{t-1}}+ \\
& +\underset{(0.0716)}{0.2421^{* * *}} \cdot \Delta I C I_{t-2}+\underset{(0.0756)}{0.2571^{* * *} \cdot \Delta I C I_{t-3} .}
\end{aligned}
$$

It is obvious that three-month increase in ICI raises the production index of CAG after three months. But autoregression of $\triangle \mathrm{CAG}$ has stopping effect as the increase in production index of $\mathrm{CAG}$ during the last two months reduces the growth of production index of CAG in the current month. Adjusted R2 of the model is 0.2803 , standard error of regression is 2.0529 and residuals are not correlated ( $\mathrm{p}$-value is 0.834 ).

Consumer goods. The best lag period that minimizes Akaike criterion for the changes in production index of consumer goods is 2 and the best significant model is got adding the changes in ICI one and five months ago, i.e.:

$$
\Delta C O G_{t}=\underset{(0.0778)}{0.0287}-\underset{(0.0598)}{0.4982^{* * *}} \cdot \Delta C O G_{t-1}-\underset{(0.0610)}{0.3183^{* * *}} \cdot \Delta C O G_{t-2}+\underset{(0.0360)}{0.1050^{* * *}} \cdot \Delta I C I_{t-1}+\underset{(0.0367)}{0.1214^{* * *}} \cdot \Delta I C I_{t-5}
$$

Rising ICI has positive impact on the production index of COG. The changes in production index of COG also depend on its previous values and their impact has stopping and greater effect than the changes in ICI. Adjusted R2 of the model is 0.2612 , standard error of regression is 1.2146 and the residuals of the model are not correlated ( $\mathrm{p}$-value is 0.524 ). 


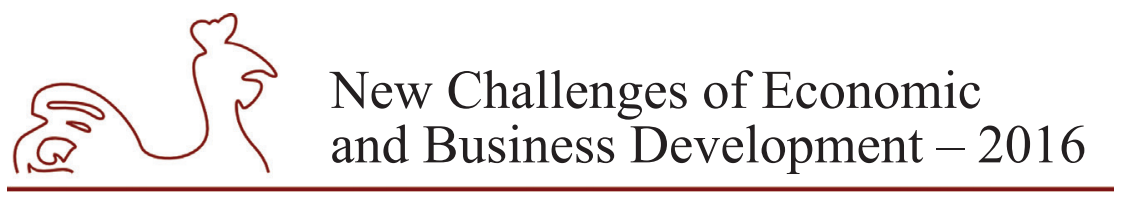

May 12-14, 2016, Riga, University of Latvia

Durable consumer goods. The best lag period that minimizes Akaike criterion for the changes in production index of durable consumer goods is 4 , but the best significant model is got removing the third and fourth lags and adding the changes in ICI of one, three and five months ago, i.e.:

$$
\begin{gathered}
\Delta D C G_{t}=-0.1410-0.6967^{* * *} \cdot \Delta D C G_{t-1}-0.4272^{* * *} \cdot \Delta D C G_{t-2}+\underset{(0.0586)}{0.1795)} \begin{array}{c}
(0.0568) \\
(0.0937)
\end{array} \\
+0.2708^{* *} \cdot \Delta I C I_{t-3}+\underset{\left(0.1860^{* *} \cdot \Delta I C I_{t-5} .\right.}{(0.1073)}
\end{gathered}
$$

The results are similar to the previous case. Raising ICI has positive impact on the production index of DCG, but the changes in production index of DCG also depend on its previous values and their impact has stopping and greater effect than the changes in ICI. Adjusted R2 of the model is 0.4148 , standard error of regression is 2.8019 and the residuals of the model are not correlated (p-value is 0.7$)$.

Non-durable consumer goods. The best lag period that minimizes Akaike criterion for the changes in production index of non-durable consumer goods is 3 , but the best significant model is got removing the third lag and adding the changes in ICI five months ago, i.e.:

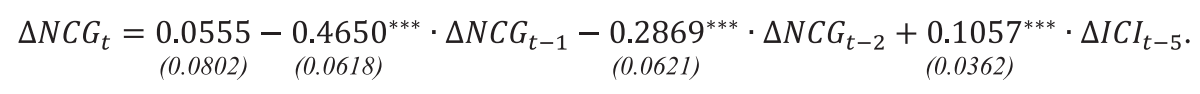

Rising ICI has also positive impact on the production index of NCG, but the changes in production index of NCG also depend on its previous values and their impact has stopping and greater effect than the changes in ICI. Adjusted R2 of the model is 0.1995, standard error of regression is 1.2513 and the residuals of the model are not correlated ( $\mathrm{p}$-value is 0.423 ).

Mining and quarrying. The best lag period that minimizes Akaike criterion for the changes in production index of mining and quarrying is 5, but the best significant model is got removing the second and third lags and adding the changes in ICI five months ago, i.e.:

$$
\begin{gathered}
\Delta M A Q_{t}=\underset{(0.3148)}{-0.6011^{*}-0.1850^{* * *} \cdot \Delta M A Q_{t-1}-0.1297^{* *} \cdot \Delta M A Q_{t-4}}-0.1804^{* * *} \cdot \Delta M A Q_{t-5}+ \\
+0.00624) \\
+0.3949^{* * *} \cdot \Delta I C I_{t-5} .
\end{gathered}
$$

Rising ICI has positive impact on the production index of MAQ, but the changes in production index of MAQ also depend on its previous values and their impact has stopping and greater effect than the changes of ICI. Adjusted R2 of the model is 0.0830 , standard error of regression is 4.8694 and the residuals of the model are not correlated (p-value is 0.487 ).

Manufacturing. The best lag period that minimizes Akaike criterion is 5 and the best significant model is got adding the changes in ICI of the last three months, i.e.:

$$
\begin{aligned}
& \Delta M A N_{t}=\underset{(0.0807)}{0.1714^{* *}}-\underset{(0.0598)}{0.3239^{* * *}} \cdot \Delta M A N_{t-1}+\underset{(0.0569)}{0.1860^{* * *}} \cdot \Delta M A N_{t-3}-\underset{(0.0556)}{0.1267^{* *}} \cdot \Delta M A N_{t-5}+ \\
& \begin{array}{c}
0.1751^{* * *} \cdot \Delta I C I_{t-1} \\
(0.0437) \\
(0.0444)
\end{array}
\end{aligned}
$$

The autoregression of $\triangle \mathrm{MAN}$ shows stopping effect, i.e. the increase in production index of manufacturing one and five months ago (with the particular corrections of $\triangle \mathrm{MAN}_{\mathrm{t}-3}$ ) decreases 


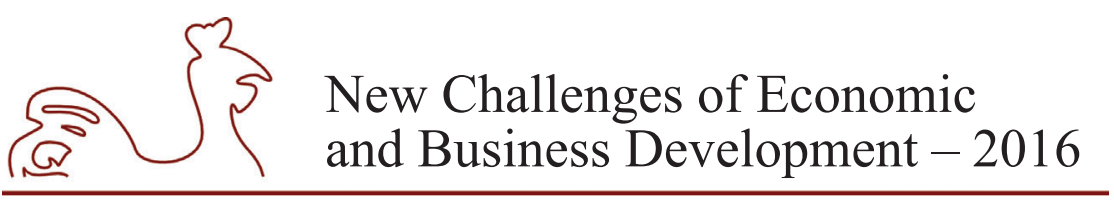

May 12-14, 2016, Riga, University of Latvia

the rise of the index in the current period. But the changes in ICI have positive and in general higher impact on the changes in MAN, i.e. three-month rise of ICI increases the production index of manufacturing after the quarter of a year. However the precision of the model is not high. Adjusted R2 of the model is 0.2852 , standard error of regression is 1.2429 and residuals of the model are not correlated according to Breusch-Godfrey test (p-value is 0.998).

Electricity, gas, steam and air conditioning supply. The analysis of production index of electricity, gas, steam and air conditioning supply showed that the best lag period that minimizes Akaike criterion is 4 . The best significant model is got adding the changes in ICI with the lag periods of 4 and 8 , i.e.:

$$
\begin{aligned}
\Delta E G S_{t}= & 0.0366-0.2784^{* * *} \cdot \Delta E G S_{t-1}-0.3292^{* * *} \cdot \Delta E G S_{t-2}-0.1648^{* *} \cdot \Delta E G S_{t-3}- \\
(0.1715)(0.0639) & (0.0651) \\
& -0.1310^{* *} \cdot \Delta E G S_{t-4}+0.2301^{* * *} \cdot \Delta I C I_{t-4}-0.2782^{* * *} \cdot \Delta I C I_{t-8} . \\
& (0.0643) \\
(0.0802) & (0.0803)
\end{aligned}
$$

The equation describes stopping effect. For example, the increase in production index of electricity, gas, steam and air conditioning supply for 4 months $\left(\Delta E G S_{t-1}, \ldots, \Delta E G S_{t-4}\right.$ are positive) decreases the rise of it in the current period. The changes in ICI 8 months ago reinforce this effect. Meanwhile the changes in ICI 4 months ago make some positive corrections but its impact is not high. However the precision of the model is low. Adjusted R2 of the model is 0.1413 , standard error of regression is 2.6605 and residuals of the model are not correlated according to Breusch-Godfrey test (p-value is 0.582).

ADL models of the changes in ICI as the dependent variable. New ADL models where the ICI is the dependent variable are created in order to answer into the second question "Does the industrial confidence indicator depend on the current and/or past levels of production?". The lag values (not exceeding 12) of production indices of intermediate good and mining and quarrying changes are taken into account.

The best lag period that minimizes Akaike criterion for the changes in ICI is 2. One significant model is got adding the changes in production index of ING four and eleven months ago, i.e.:

$$
\begin{gathered}
\Delta I C I_{t}=\underset{0.0796}{0.1180)}+0.2974^{* * *} \cdot \Delta I C I_{t-1}+0.3932^{* * *} \cdot \Delta I C I_{t-2}-\underset{(0.0599)}{0.2165^{* * *} \cdot \Delta I N G_{t-4}-} \\
-0.2259^{* * *} \cdot \Delta I N G_{t-11} .
\end{gathered}
$$

Differently from the results above the changes in ICI are going to give up the tendency, i.e. two months of growth of ICI increases its growth next month. Meanwhile the changes in production index of ING in the previous months have negative impact on the changes in ICI. Adjusted R2 of the model is 0.3636 , standard error of regression is 1.8071 and residuals of the model are not correlated (p-value is 0.752 ).

As $\Delta I N G_{t-11}$ presents quite old data and logically, it cannot have a significant impact on the changes in ICI at the time moment $t$, this component can be eliminated from the equation without major losses in precision of the model. A new model can be written as

$$
\Delta I C I_{t}=\underset{(0.1165)}{0.0343}+\underset{(0.0597)}{0.3149^{* * *}} \cdot \Delta I C I_{t-1}+\underset{(0.0590)}{0.3980^{* * *} \cdot \Delta I C I_{t-2}}-\underset{(0.0830)}{0.2125^{* *}} \cdot \Delta I N G_{t-4}
$$




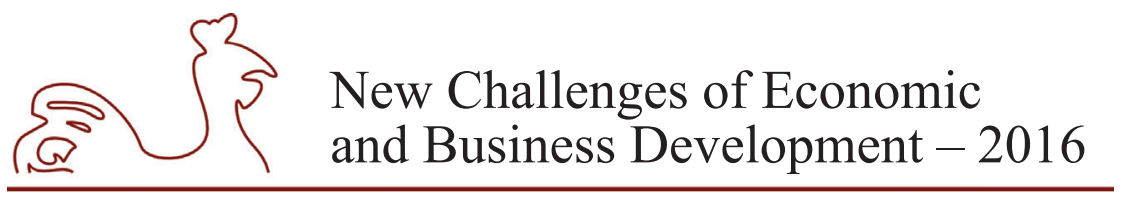

May 12-14, 2016, Riga, University of Latvia

Adjusted R2 of the model is 0.3488 , standard error of regression is 1.8160 and residuals of the model are not correlated (p-value is 0.89 ).

The best significant model adding the changes in production index of MAQ into equation is:

$$
\Delta I C I_{t}=\underset{(0.1166)}{0.0287}+\underset{(0.0594)}{0.3105^{* * *}} \cdot \Delta I C I_{t-1}+\underset{(0.0595)}{0.3682^{* * *}} \cdot \Delta I C I_{t-2}+\underset{(0.0230)}{0.0610^{* * *}} \cdot \Delta M A Q_{t-5}
$$

The changes in production index of MAQ have positive impact on the changes in ICI. Adjusted R2 of the model is 0.3496 , standard error of regression is 1.8178 and residuals of the model are not correlated ( $p$-value is 0.756 ).

Summarizing the results, it is obvious that inclusion of the changes in ICI improves the autoregressive models of various production indices, but its benefit is not large. As well as the prediction of the changes in industrial confidence indicator can be slightly improved taking into account the changes in production indices of ING and MAQ. It means that only two sectors, i.e. intermediate goods and mining and quarrying, demonstrate statistically significant impact on the formation of industrial expectations. Meanwhile industrial expectations can help to foresee the future production levels of all sectors. In most cases production indices can be explained (partly) by the industrial confidence indicators of a maximum of six months (only production index of EGS is an exception as it has higher lag), but the real levels of production can be better explained taking into account more factors.

\section{Conclusions, proposals, recommendations}

1. The research showed that the production indices can be forecasted by the industrial confidence indicator, but the industrial confidence indicator weakly depends on the current and/or past levels of production.

2. In general the changes in industrial confidence indicator have positive impact on the changes in all production indices, except production index of electricity, gas, steam and air conditioning supply. The created autoregressive functions of the changes in all production indices showed that they tend to return to the equilibrium, i.e. positive (or negative) change in production index reduces the probability of its growth (or decline) next period (it has a tendency to move to 0 ). Meanwhile the changes in industrial confidence indicator give up the tendency.

3. However most of the created ADL models have low precision. The model of the changes in production index of durable consumer goods (as the dependent variable) has the highest R2, i.e. 0.4148 and R2 of the model of the changes in production index of intermediate goods (as the dependent variable) is 0.3188 , while the precisions of all other models are lower. The changes in ICI can be forecasted with the precision of about $35 \%$ based on the changes in production indices of intermediate goods or mining and quarrying.

4. The results suggest continue the research by looking for other indicators that let to improve the prediction of the changes in production indices. Moreover the results raise the question, what indicators have the impact on the changes in industrial confidence indicator as all of production indices, except intermediate goods and mining and quarrying, do not Grangercause the changes in industrial confidence indicator. 


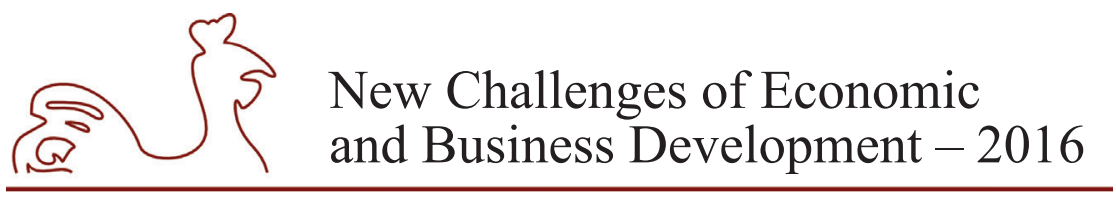

May 12-14, 2016, Riga, University of Latvia

5. The research should be also continued as these results represent the linkage between the industrial confidence indicator and the production indices for Germany case. Similar study based on the data of other countries should be done in order to find out whether these results are specific for this country or universal. The same methodology presented in this paper can be applied for this purpose.

\section{Bibliography}

Abberger, K., 2005. The Use of Qualitative Business Tendency Surveys for Forecasting Business Investment in Germany. Ifo Working Paper No. 13.

Abberger, K., 2007. Qualitative business surveys and the assessment of employment - a case study for Germany. International Journal of Forecasting 23 (2), pp. 249-258.

Abberger, K., 2007. Forecasting Quarter-on-Quarter Changes of German GDP with Monthly Business Tendency Survey Results. Ifo Institute for Economic Research at the University of Munich, Ifo Working Paper No. 40.

Berttrand, M., \& Mullainathan, S., 2001. Do People Mean What They Say? Implications for Subjective Survey Data. American Economic Review, 91(2).

Brunhes-Lesage, V., \& Darne, O., 2012. Nowcasting the French index of industrial production: A comparison from bridge and factor models. Economic Modelling, 29(6), pp. 2174-2182.

Cesaroni, T., 2011. The Cyclical Behavior of the Italian Business Survey Data. Empirical Economics, 41(3), pp. 747-68.

Claveria, O., Pons, E., \& Ramos, R., 2007. Business and consumer expectations and macroeconomic forecasts. International Journal of Forecasting, 23(1), pp. 47-69.

Dapkus, M., \& Maksvytienè, I., 2012. Makroekonominio melo identifikavimas. Economics and management, 17(2).

Dapkus, M., \& Pridotkiene, J., 2014. Testing of Macroeconomic Lying Hypothesis: French Industry Case. Procedia - Social and Behavioral Sciences, 156, pp. 286-291.

European Commission, 2006. Methodology of short-term business statistics. Interpretation and guidelines. Luxembourg: Office for Official Publications of the European Communities.

Ewing, B. T., \& Thompson, M. A., 2007. Dynamic cyclical comovements of oil prices with industrial production, consumer prices, unemployment, and stock prices. Energy Policy, 35(11), pp. 55355540.

Gokmenoglu, K., Azin, V., \& Taspinar, N., 2015. The Relationship between Industrial Production, GDP, Inflation and

Oil Price: The Case of Turkey. $16^{\text {th }}$ Annual Conference on Finance and Accounting, ACFA Prague 2015, Procedia Economics and Finance 25, pp. 497-503.

Hansson, J., Jansson, P., \& Löf, M., 2005. Business survey data: Do they help in forecasting GDP growth? International Journal of Forecasting, 21, pp. 377-389.

Iyetomi, H., Nakayama, Y., Yoshikawa, H., Aoyama, H., Fujiwara, Y., Ikeda, Y., \& Souma, W., 2011. What causes business cycles? Analysis of the Japanese industrial production data. Journal of the Japanese and International Economies, 25(3), pp. 246-272.

Lui, S., Mitchell J., \& Weale, M., 2011. Qualitative business surveys: signal or noise? Journal of the Royal Statistical Society: Series A, 174, 327-348.

Nilsson, R., 2001. Business tendency surveys: methodology, analytical use and presentation of results. OECD statistics. [Online] Available at: http://stats.oecd.org/mei/default.asp?e [Accessed 23 January 2016].

Organisation for Economic Co-operation and Development, 2003. Business Tendency Surveys: A Handbook. 


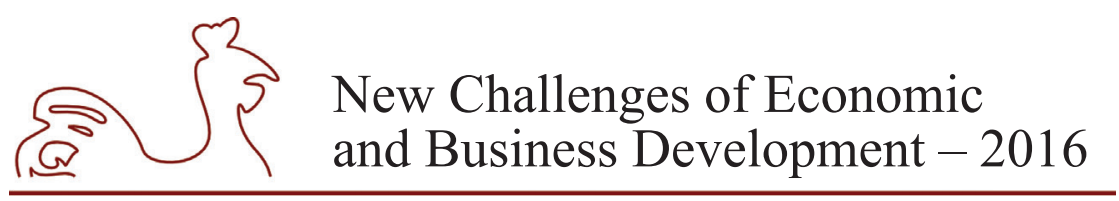

May 12-14, 2016, Riga, University of Latvia

Roman, P. A., \& Vasquez, D. M., 2013. Are business tendency surveys useful to forecast private investment in Peru? A non-linear approach. Banco Central de Reserva del Peru.

Siliverstovs, B., 2013. Do business tendency surveys help in forecasting employment? A real-time evidence for Switzerland. Journal of Business Cycle Measurement and Analysis, 10(2), pp. 129-151.

Stundžienė, A., Startienė, G., Remeikienė, R. \& Dapkus, M., 2015. Does the survey data on new orders lie? Procedia social and behavioral sciences: 20th international scientific conference economics and management 2015, 213, pp. 5-11.

Tsagkanos, A., \& Siriopoulos, C., 2015. Stock markets and industrial production in north and south of Euro-zone: Asymmetric effects via threshold cointegration approach. The Journal of Economic Asymmetries, 12(2), pp. 162-172. 
May 12-14, 2016, Riga, University of Latvia

\title{
THE SYNDICATED LOAN MARKET - POST- OR PRE-CRISIS
}

\author{
Dancho Petrov, University of Economics, Varna, Bulgaria ${ }^{1}$
}

\begin{abstract}
Unlike the traditional bank credit, the syndicated loan is provided by a group of lenders and is managed by one or several banks. Each bank in the syndicate takes part with its own share of financing, the aim being to distribute the credit risk among the participating banks. In the last decade syndicated loans turned into one of the most dynamically developing segments of the global debt market. The annual volume of syndicated loans in 2015 reached the sum of 4.7 trillion USD compared to 1.8 trillion USD in the year of crisis 2009. Syndicated loans contribute considerably to economic development because they provide an important part of financing of large capital investments in industrial production, services and the public sector. The trends in the volumes of provided loans, their distribution according to sectors and purposes, setting prices of contracts and setting up the syndicate composition are the basic factors for providing a clear indication for the investment activity, market situation and the expectations of key investors.

The main purpose of the research lies in discovering the post-crisis challenges for the syndicated loan market development in Europe. The analysis of the regional and sector profiles of the provided syndicated loans in Europe in the 2009-2015 period sends contradictory messages that suggest pessimism rather than optimism. Based on that, the focus of the research widens to include issues about the evolution in the philosophy of syndicated financing, the development of the elements of the syndicated composition, the necessity to update the tools of risk management, the use of buffers and non-price compensatory mechanisms and the opportunities for making corrections in the price setting of the syndicated loan agreement.
\end{abstract}

Key words: banks, syndicated loans, financial crisis, global syndicated loan market

JEL code: G21, G01, G15

\section{Introduction}

Unlike traditional bank loans, a syndicated loan envisages distribution of the loan and sharing the investment risk among a group of lenders united in a syndicate. Compared to the original format of syndicated loans, these days there are a number of substantial differences in the composition of borrowers. As early as the 1990s in the developed countries banks and companies in the utility sector, transport and extractive industries displaced the government sector as a major beneficiary (Robinson M., 1996). Syndicated lending is considered by borrowers as a convenient tool for external funding, allowing a relatively flexible and quick access to resources in exchange for, or in addition to, the traditional sources of capital - issuing shares and bonds (Coffey M., 2000; Dennis S. \& Mullineaux D., 2000).

What are the benefits of syndicated lending for banks? The results of a number of studies show that syndicated loans can be used by leading banks to alleviate the regulatory capital

1 Corresponding author - e-mail address: danchopetrov@abv.bg 


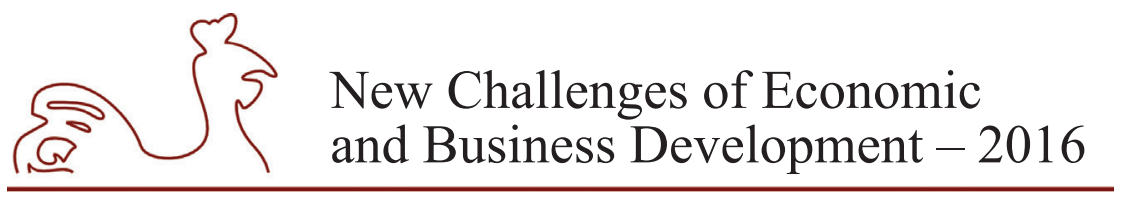

May 12-14, 2016, Riga, University of Latvia

constraints (Hubbard, G., Kuttner, N. \& Palia D., 2002). For smaller banks involvement in syndicated loans helps for new business developments or credit portfolio diversification by granting a loan to large corporate borrowers, with which, under other conditions, the said banks stood little chance of having credit relationships (Sufi, A., 2007; Esty, B. \& Megginson, W., 2003; Altunbaş, Y., Gadanecz, B., Kara, A., 2005). The advantage of syndicated loans over bilateral loans is their higher liquidity, owing to the possibilities for secondary trading. Secondary markets provide banks an option to sell their syndicated loans and over the first decade of the $21 \mathrm{C}$ the volume of secondary traded syndicated loans has grown considerably (Howcroft, J., Kara, A., Marques-Ibanez, D., 2014).

On a global scale syndicated loans have turned into one of the most important sources for corporate financing over the last decade. Even in 2009 - the year of record slump, international syndicated loans reached 1.8 trillion USD, overtaking by 0.3 trillion USD the overall size of newly issued bonds by non-financial companies at the international market. Only two years later, in 2011, the share of syndicated loans as a share of total corporate financing already reached $62 \%$ (Dealogic Global Loans Review, 2013).

Using secondary data from the information bases of Thomson Reuters, Bloomberg and Dealogic this paper aims to find an answer to the questions of what is happening on the global syndicated loan market, what are the trends in Europe and what are the major challenges in the development of this market in the post-crisis period? In parallel, the paper analyzes certain aspects that are of substantial relevance to the discussed problems, like for instance the organizational peculiarities of the bank syndicates, the tendencies in loan pricing, sector and regional profiles of syndicated lending.

\section{The global syndicated loan market - organizational peculiarities of a bank syndicate and transaction pricing}

The composition of the bank syndicate and the specific features of its organizational hierarchy depend on the scale of the deal, the amount of financing, the type of mandate contract, the number of participating institutions and the activity of the mandated arranger. In most syndicated loan agreements at least two levels of syndicate hierarchy can be clearly distinguished (Gadanecz B., 2004). On the first level the main part is played by the banks that are mandated arrangers. These are leading institutions which sign a memorandum with the borrower, negotiate the basic parameters of the deal and take on certain responsibilities to provide the necessary resource. They either manage the loan directly, or delegate part of activities to agent banks. Some of the most important functions of the arrangers, and at the same time the touchstone for their efficiency as mandated arrangers, is the successful formation of a syndicate and finalizing the deal with funding provided. To this end, they carefully study the market and investor interest in the deal and place offers to other banks to join the financing. The lending institutions approached belong to the second group of banks, whose role in the syndicated lending is that of lower level managers or junior syndicate members. These banks are usually located in various geographical regions and consist of smaller banks with relatively limited experience in international lending (Gadanecz, B., Kara, A., Molyneux, P., 2012). Throughout the duration of the loan they have the so called "arm's-length" relationship with the borrower and their activity is represented by the arrangers or the agent bank (Sufi, A., 2007). 


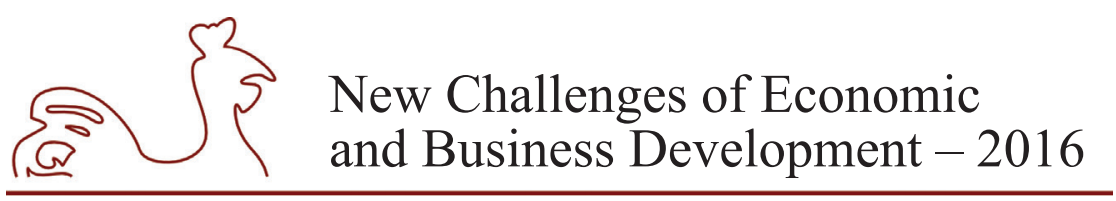

May 12-14, 2016, Riga, University of Latvia

Depending on the commitment of the arranging banks in negotiating and receiving a mandate, three basic types of syndicated loan agreements can be identified (Miller S., 2006; Rhodes T., 2006):

- Underwritten deal;

- "Best-efforts"syndication;

- Club deal.

Under the arrangement of "Underwritten deal" the underwriter (arranger bank) of a syndicated loan is firmly committed to the borrower and guarantees to provide the necessary resource within the pre-defined parameters and conditions. This poses certain risks for the arrangers, if their plans for syndicate formations and selling parts of the loan are not fully realized. Having in mind the possible complications from unpredictable market conditions, we can, with good reason, ask the following question: Why should arrangers ever take the risk of acting as underwriter of syndicated loans, provided that they also have other alternative? There are at least two good reasons for this particular decision of theirs. Firstly, the offer for an entirely underwritten deal turns into a competitive tool for getting a mandate. Secondly, underwriters usually earn higher fees in exchange for the firm promise to ensure the necessary financing.

Syndicated loans containing the "best efforts" clause are those, where the arranger banks do not make commitment to provide the entire resource. Typically such clauses in syndicated loans are used in more complicated deals or in leverage loans for beneficiaries whose rating is lower than investment grade ratings.

By "Club deals" we mean the smaller size loans (usually between 25 and 100 m USD), which are provided by a committed group of banks. In these deals the arranger is "first among equals", as this type of syndication lacks the strict hierarchy that characterizes the composition of the remaining forms of bank syndicate. Thus for example, it is typical for the club 'members' to share all earnings, including those from fees, according to their share of participation in financing.

The changes in the syndicate composition can indicate restrictions in lending. For example, syndicated loans of the "club deals" type grow from $12 \%$ in 2008 to $17 \%$ in 2009. Similar forms of syndicate suggest lower costs for debt monitoring and restructuring and are therefore preferred by lead arrangers, when there is a high likelihood of default. So the growing number of club deals can be an indicator for the risk-avoiding behavior of the banks and a growing credit risk in times of economic and financial uncertainty (Chui M. et al., 2010). Such a thesis is also supported by Esty and Megginson, who find a positive connection between the size of the syndicate, on the one hand, and the reliable protection of the rights of lenders on the other (Esty, B. \& Megginson W., 2003).

The pricing of syndicated loans is usually done along a floating interest rate spread, which is tied to a certain benchmark index (most often Libor) and various types of fees. Leading banks are entitled to the lion share of fee income, whereas the remaining banks in the syndicate mostly make do with income from interest (Armstrong J., 2003). In an aggregate format the main pricing components of the syndicated loans - interest spread and fees, as well as the proportion between them, vary widely, depending on a number of key factors. One of these is the base index used as benchmark for the interest spread. For instance, for Euribor or Libor- based loans, a higher relative share of fees is observed than that of loans tied up with other market indices (Gadanecz B., 2004).

The market and sector affiliation of the borrower are other factors to impact the price of syndicated loans. For borrowers from developed economies the share of fees in the aggregate 


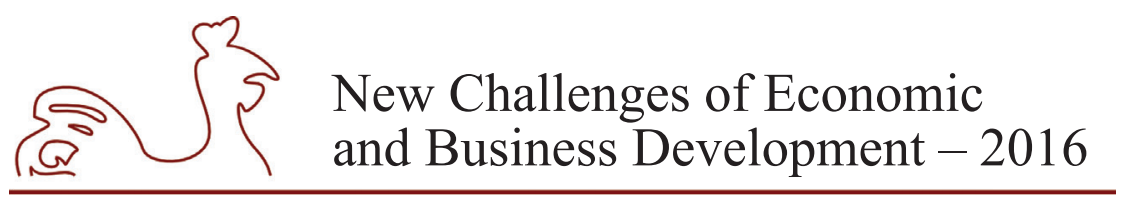

May 12-14, 2016, Riga, University of Latvia

price of syndicated loans is higher than for borrowers from emerging markets (Eichengreen B. \& Mody A., 1999). This fact is related to the circumstance that in the industrially developed countries exposures to the non-governmental sector prevail. Borrowers from this particular market segment, driven mostly by fiscal and market concerns, prefer the larger part of the aggregate loan price to be formed by fees and not by the interest spread. Nevertheless, in general the price of exposures to borrowers from developed countries is lower than the price paid by borrowers from emerging markets. This finding is not surprising in view of the specifics of risk pricing depending on the type of borrower.

Along with fees and interest spread, bank syndicates use a number of non-price compensatory mechanisms aimed at minimizing credit risk. These are the familiar from classical corporate loans covenants, collaterals and guarantees. The use of collaterals and guarantees for syndicated loans occurs more often with exposures to borrowers from emerging markets, while covenants in syndicated loans are more frequent in contracts with borrowers from industrially developed countries.

Covenants set clearly defined limits, prohibitions and various types of restrictions borrowers must follow until the entire loan is paid back. Some of the restrictive clauses forbid borrowers to take particular actions unless they are discussed and approved by the banking syndicate in advance. They may refer to the sphere of the company's dividend policy (for example, forbidding to pay out dividends) and the possibilities for transformations of capital, mergers, acquisitions, takeovers, etc. Other covenants fix certain values for financial indicators (most often connected with leverage and financial autonomy), which should not be violated. A study of the US market of syndicated loans over the period 1996-2010 identifies over 80 different covenants in loan contracts (Freudenberg F. et al. 2012). Violation of a clause gives creditors sufficient ground to change the status of the exposure to a "state of technical default" with all the ensuing consequences included in the loan contract.

\section{Post-crisis projections in European syndicated loan market}

Collapses of international markets in times of financial crisis are not unusual. For example, during the Japanese crisis of the 1990s Japanese banks and companies temporarily withdrew from the international financial and commodity markets (Amiti M. \& Weinstein D., 2009). The global financial crisis that began in the USA was not much different. Following the bankruptcy of Lehman Brothers in September 2008, the capital raising markets ended up temporarily "frozen". This along with the growing credit losses put bank balances under enormous strain and stress towards the end of 2008. As a result, banks limited lending and global syndicated loans registered a record slump of $41 \%$ in 2008. At the same time global economic activity took a rapid downturn. Over the last quarter of 2008 export of goods and services fell $18 \%$ compared to the same period of the year before. Export-oriented companies suffered cancelled orders and delayed payments for delivered goods (Malouche M., 2009). This reduced the demand for loans. Collapse in global trade led to a drop in the gross capital flows, reversal of capital flows between developed and emerging markets and a decline in international bank lending (Cetorelli, N. \& Goldberg, L., 2011). In many countries banks abruptly cut lending (Aisen, A. \& Franken, M., 2010). This forces companies with limited borrowing perspective to reduce investments (Duchin, R., Ozbas, O. \& Sensoy, B., 2010), which further facilitated the spread of the crisis from the financial into the real sector of the economy. 


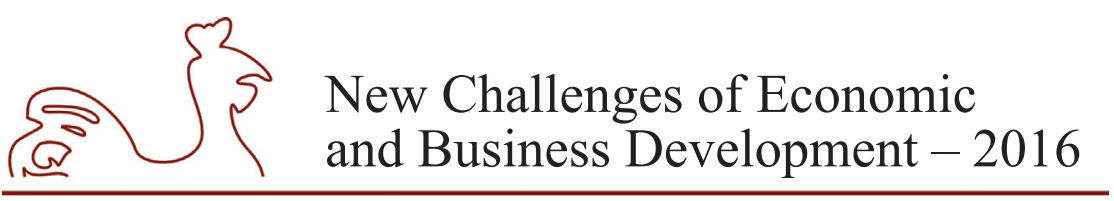

May 12-14, 2016, Riga, University of Latvia

The evolution of syndicated loans has its ups and downs, but is, in general, a mirror image of the economic activity and market conditions (Chui M. et al., 2010). The post-crisis period begins with the lowest volume of syndicated loans over the last decade - a little over 1,8 trillion USD in 2009 (in comparison, the pre-crisis 2007 saw loans for the then record high 4,8 trillion USD). The trend for gradual recovery was broken by a more clearly expressed drop in 2012 and a considerably slighter decline in 2015. (Fig. 1).

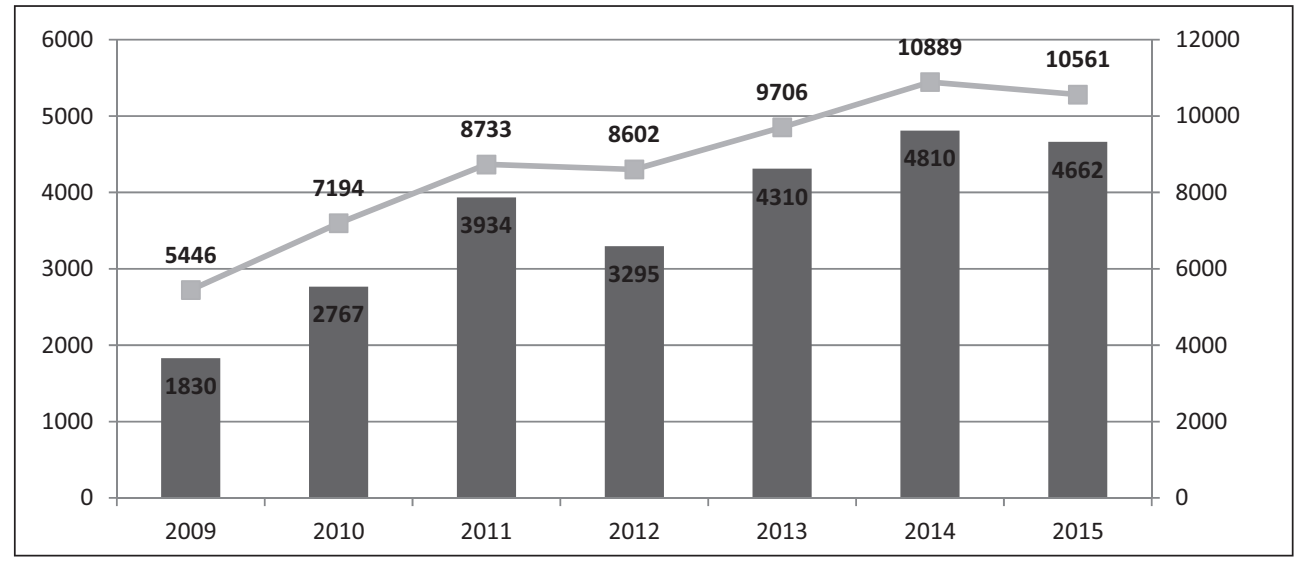

Source: Thomson Reuters, Global Syndicated Loans Reviews 2009-2015; Bloomberg, Global Syndicated Loans 2009-2015; Dealogic, Global Loans Reviews 2009-2015.

Fig. 1. Global Syndicated Loans - Proceeds US\$ billion (primary axis) and Number of Deals (secondary axis)

Analyzing the volume of the syndicated loans in a regional aspect, it is obvious that postcrisis recovery does not follow the same scenario in different markets. Although in 2009 Europe and the American markets set off from nearly the same positions, only two years later syndicated loans across the Atlantic are in relative share twice the amount of syndicated loans on the Old continent (Fig. 2).

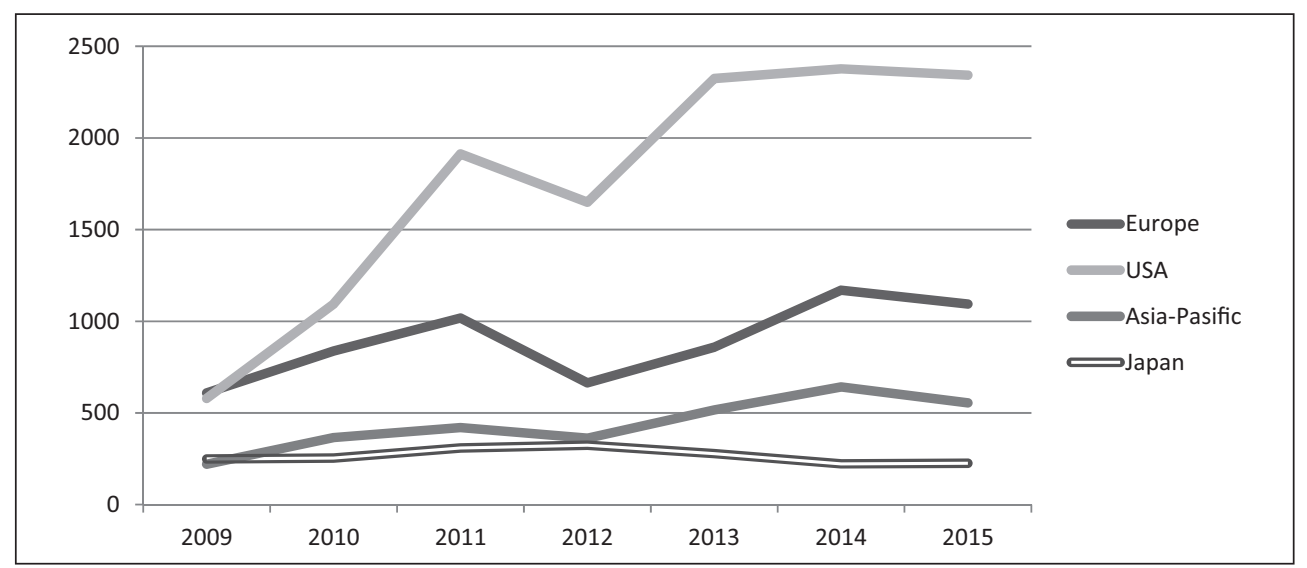

Source: Thomson Reuters, Global Syndicated Loans Reviews 2009-2015

Fig. 2. Global Syndicated Loans by Regions (Proceeds US \$ billion) 


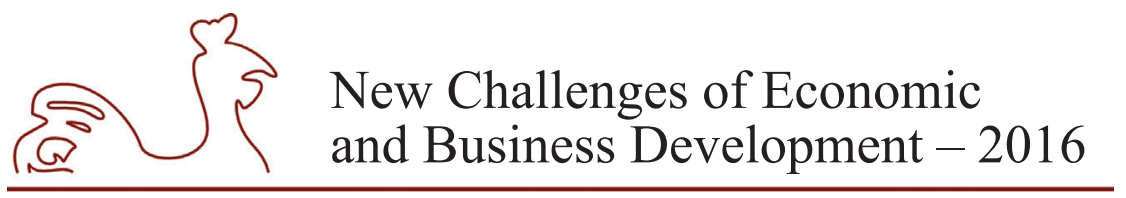

May 12-14, 2016, Riga, University of Latvia

What are the reasons for the domination of the American syndicated loan market over the last five years, while the European one suffers prolonged stagnation? It could be assumed that this is a logical result of the deepening debt crisis in Europe in the middle of this period, and investor concerns associated with it that the "contagion" will spread, as well as the prevailing uncertainty on the European financial market following these adverse events. These facts, however, do not explain the continuous fluctuations in the volume of syndicated lending in Europe and the decline in 2015, when the problems with the debt crisis are considered to be subsiding. Reducing the share of syndicated lending after the financial crisis may be a consequence of the multi-layer structure of the lending syndicate, where participating banks do not have total control over the status of the borrower, but instead rely on the arranger banks. In times of crisis, however, particularly in Europe, there can be observed a growing information asymmetry between the participants on the financial markets. Another argument to add can be the falling demand for loans on the part of corporations and increased uncertainty in cross border lending, taking into consideration the markedly international profile of the main borrowers on the syndicated loan market. In a volatile environment European banks are increasingly less interested in syndicated lending and even major banks, especially those with solid capital base, remain too reserved and passive (Howcroft, J., Kara, A., Marques-Ibanez, D., 2014).

It is an indicative fact that most highly developed economies in Europe register an abrupt fall in syndicated lending over the problematic 2012. (Fig. 3). Of the three countries with largest share on the syndicated lending market only the United Kingdom has succeeded in preserving stable volumes over the last two years, while in Germany and France there is an obvious fall in 2015 compared to the previous year.

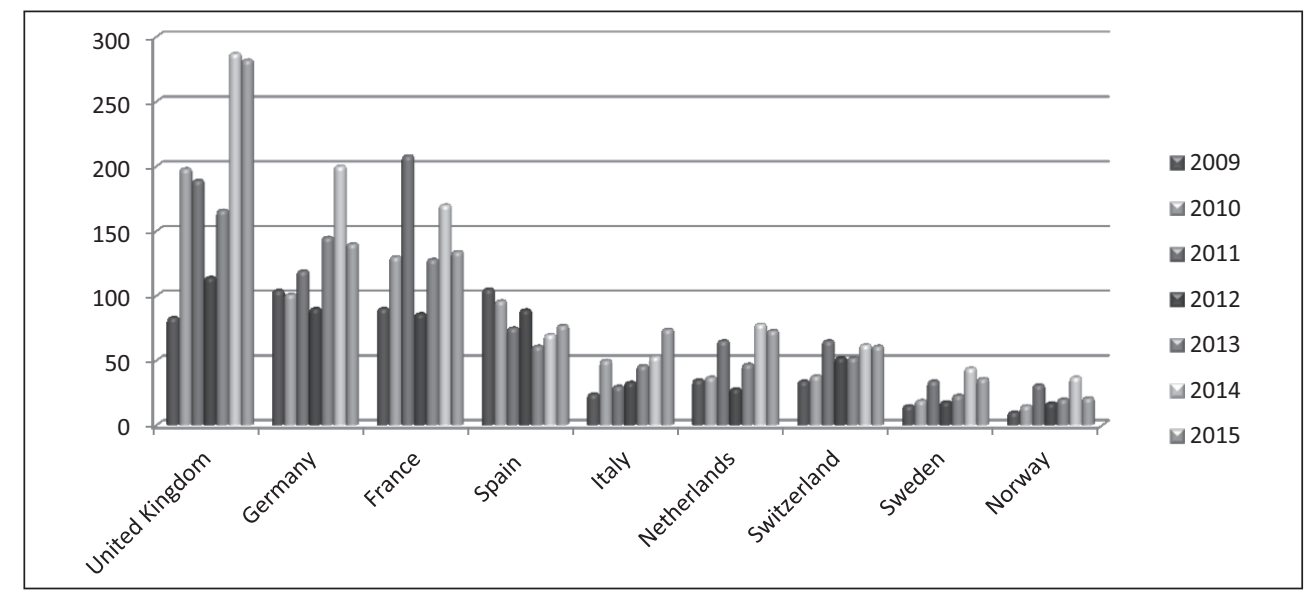

Source: Thomson Reuters, Global Syndicated Loans Reviews 2009-2015.

Fig. 3. Syndicated Loan Volume in Western European Countries (US\$ billion)

In the research period syndicated lending in Central and East European countries is characterized by very modest volumes and shares - 71 trillion USD in 2015 (approximately the market share of Netherlands only). In Eastern Europe the most dramatic slump in syndicated lending to be observed over the last two years is the one in Russia (Fig. 4). Over the analyzed period Turkey is turning into a principal leader on the East European market for syndicated loans.

Data on earmarking of syndicated loans and their sector profile can provide valuable information during the analysis of post-crisis projections of the European syndicated loan 


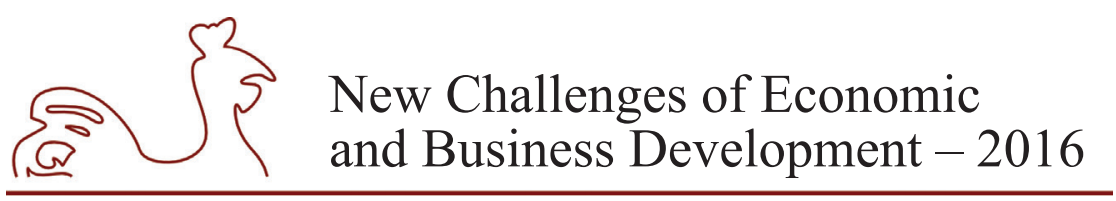

May 12-14, 2016, Riga, University of Latvia

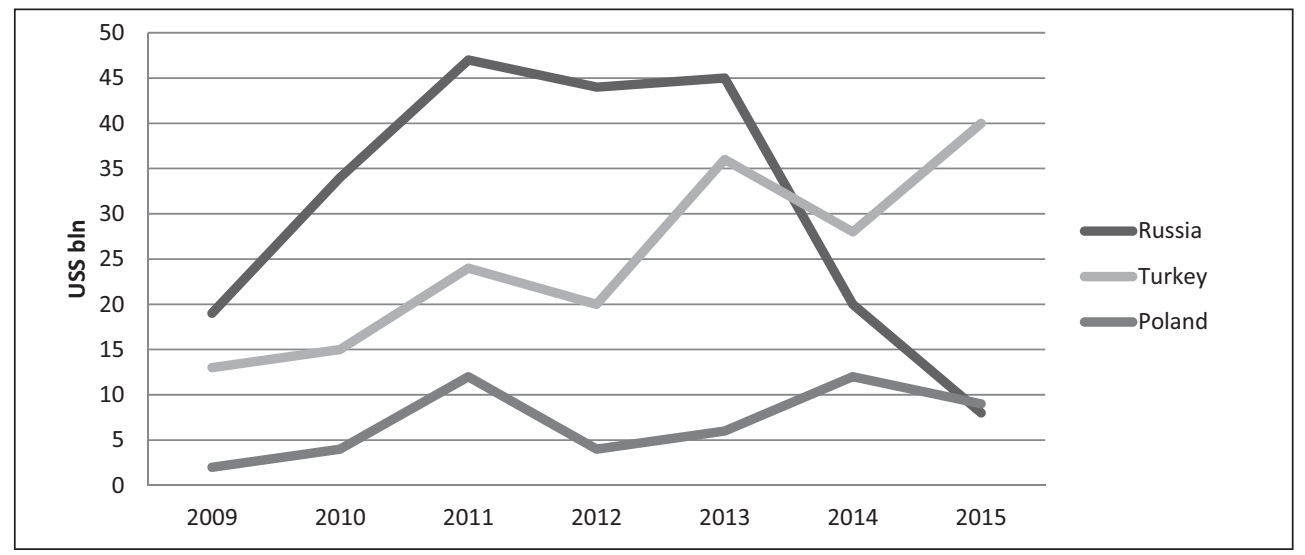

Source: Thomson Reuters, Global Syndicated Loans Reviews 2009-2015.

Fig. 4. Syndicated Loan Volume in Central and Eastern European Countries (US\$ billion)

market. As stated by Giannetti \& Laeven syndicated loans are granted not only for real asset investment, but also for highly cyclical restructuring activities such as leverage buyouts, mergers and acquisitions and stock repurchases. Demand for such type of loans can be sluggish in times of financial disturbances, even if the borrower's country is not affected by the banking crisis. Less cyclical loans are considered to be the loans earmarked for real asset investments - for example, for general corporate purposes or working capital (Giannetti, M. \& Laeven, L., 2011).

Table 1

Syndicated Loans by Use of Proceeds and by Industries in EMEA Region ${ }^{2}$

\begin{tabular}{|l|r|r|r|r|r|r|}
\hline \multirow{2}{*}{} & \multicolumn{2}{|c|}{$\mathbf{2 0 1 3}$} & \multicolumn{2}{c|}{$\mathbf{2 0 1 4}$} & \multicolumn{2}{c|}{2015} \\
\cline { 2 - 7 } & US\$bn & \multicolumn{1}{c|}{$\%$} & US\$bn & $\%$ & US\$bn & \multicolumn{1}{c|}{$\%$} \\
\hline Ry Use of Proceeds & & & & & & \\
Refinance Bank Debt & 276.2 & 30 & 257.5 & 22 & 55.9 & 4 \\
General Corporate Purposes & 338.1 & 36 & 411.6 & 35 & 586.1 & 47 \\
Refinancing & 63.3 & 7 & 123.7 & 10 & 72.2 & 6 \\
Project Finance & 45.3 & 5 & 50.2 & 4 & 70.2 & 6 \\
Acquisition Financing & 51.6 & 6 & 156.8 & 13 & 267.9 & 21 \\
\hline By Industries & & & & & & \\
Energy and Power & 122.5 & 19 & 202.8 & 17 & 242.1 & 19 \\
Industrials & 188.2 & 18 & 225.3 & 19 & 206.5 & 17 \\
Financials & 85.7 & 13 & 126.7 & 11 & 138.0 & 11 \\
Materials & 98.1 & 15 & 137.1 & 11 & 131.4 & 10 \\
Consumer Staples & 38.2 & 6 & 108.4 & 9 & 138.5 & 11 \\
Healthcare & & & 66.1 & 5 & 76.6 & 6 \\
Real Estate & & & 63.3 & 5 & 69.9 & 6 \\
Consumer Products and Services & & & 56.3 & 5 & 49.4 & 4 \\
Media and Entertainment & & & 68.2 & 6 & 58.5 & 5 \\
Telecommunications & 41.6 & 6 & 57.5 & 5 & 59.1 & 5 \\
High Technology & & & 44.9 & 4 & 34.4 & 3 \\
\hline
\end{tabular}

Source: author's calculations based on Thomson Reuters, Global Syndicated Loans Reviews 2013-2015.

2 According to Thomson Reuters Investment Bank Loans data EMEA Region includes Europe, Middle East and Africa with usual very little relative share of Middle East and Africa in total volumes. 


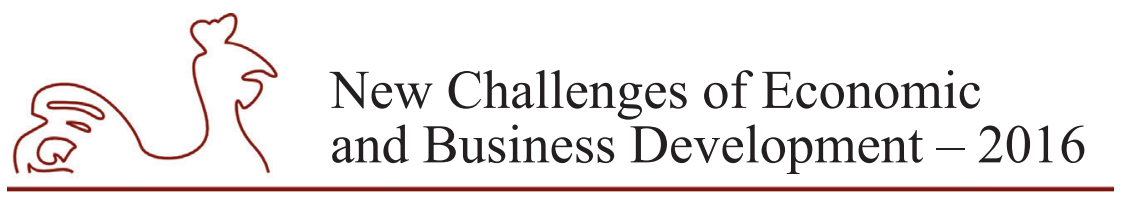

May 12-14, 2016, Riga, University of Latvia

From the data presented in Table 1 there can be reported a growth in the relative shares of loans aimed at "General Corporate Purposes" and "Acquisition Financing". In 2015 there is an abrupt fall in both volume and relative share of loans for refinancing bank loans. The leading industries that are an object of syndicated loans are "Energy \& Power" and "Industrials". A comparison of the sectoral profile of syndicated loans in Europe and the much more dynamically developing American market shows certain differences. On the American market in 2015 loans in the sphere of "healthcare" and "high technologies" have higher relative shares of $9 \%$ and $7 \%$ respectively. Loans for "materials" and "consumer staples", which in Europe jointly amount to $21 \%$, are only $13 \%$ in North America. Such differences in the relative share of financed industries may be indicative for the more substantial progress in placing resources to priority and technological sectors beyond the Atlantic.

\section{Conclusions}

Over the last two decades global syndicated loans have become a powerful instrument for financing the growing needs for massive resources on the part of various sectors and industries. This turns syndicated loans into a driving engine for stimulating economic activity and global economic development. Syndicated lending is distinguished by the specific relationships between borrower and lender and bank syndicates are characterized by a complex organizational hierarchy and internal relations. The pricing of a syndicated loan is an important component of the deal, whereby banks employ various instruments and mechanisms. Analysis of the trends in the globally granted syndicated loans has shown that in a regional perspective post-crisis recovery takes place according to different scenarios in Europe and America. The considerably slighter growth of syndicated lending in Europe, with occasional periods of decline and stagnation, can be explained with the impacts of the debt crisis and the uncertainty on the European financial markets. The growing information asymmetry of participants and the weaker demand for syndicated loans on the part of large corporations also exercise an influence in this. Stagnation can be observed in the more developed economies as well as in those of the East European market. Sector analysis of syndicated loans shows that there are a number of differences in the relative shares of loans for various industries compared to those on the American continent, where there is a great deal more placement of resources to priority and technological sectors, than in pro-cyclic spheres. Post-crisis projections on the market for syndicated loans outline symptoms which do not rule out the likelihood of the global financial system falling into a new spiral of recession. In Europe the outcome remains entwined in the complicated puzzle of the not-fully solved problems with financial stability, a drop in the price of staple raw materials and petrol, the refugee crisis and the difficult political and financial decisions that are to be made by United Europe.

\section{Bibliography}

Aisen, A. \& Franken, M., 2010. Bank credit during the 2008 financial crisis: A cross-country comparison, IMF Working Paper 10/47, International Monetary Fund, Washington, D.C.

Altunbaş, Y., Gadanecz, B., Kara, A., 2005. Key factors affecting internationally active banks' decisions to participate in loan syndications. Applied Economic Letters 12, pp. 249-253.

Amiti, M. \& Weinstein, D., 2009. Exports and financial shocks. NBER Working Paper 15556. 


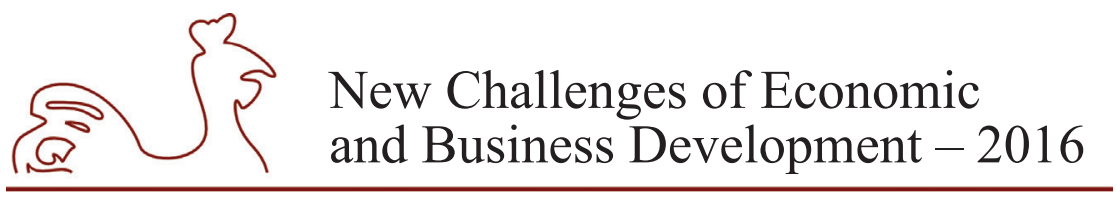

May 12-14, 2016, Riga, University of Latvia

Armstrong J., 2003. The syndicated loan market: developments in the North American context", Bank of Canada Working Paper 2003-15.

Bloomberg, 2014-2015. Global Syndicated Loans.

Cetorelli, N. \& Goldberg, L., 2011. Global Banks and International Shock Transmission: Evidence from the Crisis, IMF Economic Review 59, No. 1, pp. 41-76.

Coffey, M., 2000. The US leveraged loan market: from relationship to return in T. Rhodes (ed), Syndicated Lending, Practice and Documentation, Euromoney Books.

Chui, M. et al., 2010. The Collapse of International Bank Finance During the Crisis: Evidence from Syndicated Loan Markets, BIS Quarterly Review, Sept. Available at: http://www.bis.org/publ/ qtrpdf/r_qt1009f.pdf.

Dealogic, 2013-2015. Global Loans Reviews.

Dennis, S. \& Mullineaux D., 2000. Syndicated Loans, Journal of Financial Intermediation, Vol. 9, October, pp. 404-426.

Duchin, R., Ozbas, O., Sensoy, B., 2010. Costly external finance, corporate investment, and the subprime mortgage credit crisis, Journal of Financial Economics, 97, pp. 418-435.

Eichengreen, B. \& Mody, A., 1999. Lending Booms, Reserves, and the Sustainability of Short-Term Debt, Inferences from the Pricing of Syndicated Bank Loans, The World Bank Development Prospects Group, Washington, DC.

Esty, B. \& Megginson, W., 2003. Creditor rights, enforcement and debt ownership structure: evidence from the global syndicated loan market, Journal of Financial and Quantitative Analysis, Vol. 38, No. 1, pp. 37-59.

Freudenberg, F. et al., 2012. Covenant Violations, Loan Contracting, and Default Risk of Bank Borrowers, Working Paper, Goethe University Frankfurt. Available at: www.wiwi.uni-muenster.de/fcm/ downloads/forschen/ ifk_bankenworkshop_2012/Steffen.pdf

Gadanecz, B., 2004. The Syndicated Loan Market: Structure, Development and Implications, BIS Quarterly Review, December.

Gadanecz, B., Kara, A., Molyneux, P., 2012. Asymmetric information among lenders and the value of repeat lending. Journal of International Financial Markets, Institutions and Money 22, pp. 913-935.

Giannetti, M. \& Laeven, L., 2011. The Flight Home Effect: Evidence from the Syndicated Loan Market During Financial Crises, ECGI-Finance Working Paper No. 304. Electronic copy available at: http:// ssrn.com/abstract $=1726050$

Howcroft, J., Kara, A., Marques-Ibanez, D., 2014. Determinants of syndicated lending in European banks and the impact of the financial crisis, Journal of International Financial Markets, Institutions and Money, Vol. 32, pp. 473-490.

Hubbard, G., Kuttner, N. \& Palia D., 2002. Are there bank effects in borrowers' costs of funds? Evidence from a matched sample of borrowers and banks. Journal of Business 75, pp. 559-81.

Malouche, M., 2009. Trade and trade finance developments in 14 developing countries post September 2008, World Bank Policy Research Working Paper, No. 5138, November.

Miller, S., 2006. Syndicated Loan Primer, A Guide to the Loan Market, Standard and Poor's.

Robinson, M., 1996. Syndicated Lending: A Stabilizing Element in the Latin Markets, Corporate Finance Guide to Latin American Treasury \& Finance.

Rhodes, T., 2006. Syndicated Lending, Fourth edition, Euromoney Institutional Investor plc.

Sufi, A., 2007. Information asymmetry and financing arrangements: Evidence from syndicated loans. Journal of Finance 17, pp. 629-668.

Thomson Reuters, 2009-2015. Global Syndicated Loans Reviews. 
May 12-14, 2016, Riga, University of Latvia

\title{
INCENTIVES TO ENTER THE LABOUR MARKET IN LATVIA
}

\author{
Anna Pluta, University of Latvia, Latvia ${ }^{1}$
}

\begin{abstract}
The aim of this paper is to analyse a number of reforms of the labour tax system - introduction of the regressive non-taxable minimum, increase in the amount of the allowance for dependents, solidarity tax charged on high salaries - that came into force since January 2016 with respect to their effect on the changes in incentives to enter the labour market. The participation tax rate (PTR) is used as the indicator of the incentive to work. Using the European Union tax-benefit microsimulation model (EUROMOD) and the European Union Statistics on Income and Living Conditions (EU-SILC) survey microdata, PTRs are computed in two different ways. At first, PTRs are computed only for those in work, while another way of the calculation takes into consideration both employed and unemployed. Heckman two stage estimation method is used to predict the hypothetical wage rates for those actually not working on the basis of the observed workers' wage rates. The results suggest that implemented reforms slightly reduces PTRs for low-income earners, nonetheless high PTRs in the lowest deciles suggests a particularly strong disincentive for low-income persons to participate in the labour market. Solidarity tax charged on high salaries could slightly increase the PTRs of high-income earners.
\end{abstract}

Key words: work incentives, participation tax rate, tax-benefit system, EUROMOD microsimulation model JEL code: $\mathrm{C} 15, \mathrm{H} 24, \mathrm{H} 31$

\section{Introduction}

Incentives to enter the labour market are greatly affected by the labour tax and social benefit system valid in the country. Level of employment affects the level of output and ensures the sustainability of social security system. Relatively high tax wedge holds off the employment: it decreases the disposable income of earners and increases the labour costs faced by employers. This paper analyses a number of reforms of the labour tax and benefit system that came into force since January 2016 (introduction of the regressive non-taxable minimum, increase in the amount of the allowance for children/dependents, solidarity tax charged on high salaries) (Ministry of Finance, 2016) with respect to their effect on the changes in incentives to enter the labour market. The participation tax rate (PTR) is used as the indicator of the incentive to work and is defined as the proportion of total gross earnings lost in the form of tax and withdrawn benefits when a person enters employment (Mirlees et al. (2011). The European Union tax-benefit microsimulation model $\left(\mathrm{EUROMOD}^{2}\right)$ is used as a tool for the assessment of the effects of the planned labour tax

\footnotetext{
Corresponding author - e-mail address: anna.pluta@inbox.lv

2 EUROMOD has been developed by the Institute for Social \& Economic Research (ISER, University of Essex) in co-operation with national teams and is supported by PROGRESS funding from EC DG-EMPL. EUROMOD aims to simulate as much as possible of the tax and benefit components of household disposable income. The following instruments are simulated: income tax, social contributions (paid by the employees, self-employed and employers), unemployment benefit, family benefits, housing benefit, guaranteed minimum income benefit (EUROMOD, 2016).
} 


\section{New Challenges of Economic and Business Development - 2016}

May 12-14, 2016, Riga, University of Latvia

policy reforms (Sutherland and Figari, 2013), that is valuable for the policy makers in the process of the design of the labour tax and benefit system.

\section{Research results and discussion}

\section{Measures of work incentives}

Work incentives created by the tax-benefit system are usually divided in two groups incentives to work versus not working and incentives to work more and earn more for those already in work (Adam et al., 2006). In this paper the author attempts to assess whether the recently implemented tax reforms affects the incentives to enter the labour market. It can be measured using the replacement rate, which is defined as the income an individual would receive if they were not working as a percentage of the income they would receive if they were working. Another indicator of the incentive to work at the extensive margin is the participation tax rate (PTR). The PTR is defined as the proportion of total gross earnings lost in the form of tax and withdrawn benefits when a person enters employment. The PTR can be expressed as follows (Mirlees et al., 2011):

$$
P T R=1-\frac{\text { Net income in work }- \text { Net income out of work }}{\text { Gross earnings }}
$$

The measures of work incentives depend on the gross employment income of the individual when he/she is working, and the labour tax and social benefit structure, while the economic status and incomes of all other household members are fixed. Higher numbers for the indicators imply weaker work incentives.

In this report, we use PTR as a measure of reporting incentives to work at all. For the calculation of the PTRs, personal income tax, social benefits and social insurance contributions are computed for all household members for two scenarios: when the person works and he/she does not work.

Using EUROMOD and the European Union Statistics on Income and Living Conditions (EU-SILC) survey microdata, PTRs are computed in two different ways. At first, PTRs are computed only for those in work (similar to Immervol et al. (2004), BICEPS (2014)), by comparing an individual's equivalised disposable income at actual earnings and equivalised disposable income at zero earnings.

Another way of the calculation of PTRs takes into consideration both employed and unemployed or inactive, that requires making some assumptions about potential wage for the unemployed or inactive in case of entering the labour market (Kaliskova, 2015). The author uses a classical wage equation - Heckman two stage estimation method (Heckman, 1976; Stata, 2016) - to impute the hypothetical wage rates for those actually not working on the basis of the observed workers' wage rates.

Table1. in appendices shows the regression coefficients of monthly employment income (in $\mathrm{ln}$ ) and employment status (being employed or not) using a two-step Heckman selection model. The selection equation is identified using explanatory variables of gender, region the person leaves, marital status, number of children below age of 2, age, income of other household 


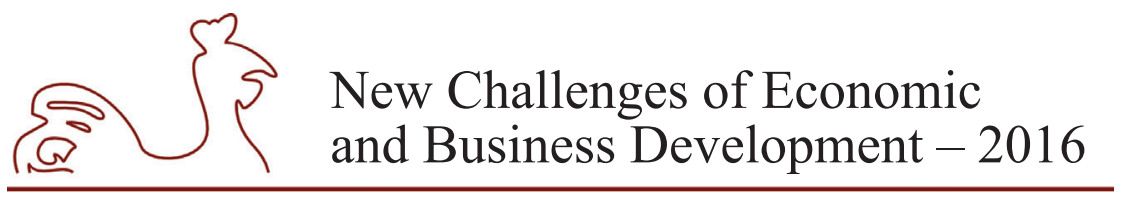

May 12-14, 2016, Riga, University of Latvia

members and dummy for the level of education. Explanatory variables in the monthly wage regression include dummy for the level of education, gender and age. The selection of the explanatory variables is conditional on the data availability in the EU-SILC database. All coefficients have the expected signs, both in the wage equation and in the selection equation.

\section{Tax Policy reforms}

So far, introduced labour tax policy reforms equally affected entirely all employees without considerably diminishing the income inequality and the regressive tax structure. Proposals for the tax reforms of 2016 are purposefully aimed at the increasing of the degree of progressivity and decreasing of the level of income inequality.

\section{The differentiated non-taxable minimum income}

The differentiated non-taxable minimum income - is introduced gradually starting from January 1, 2016 - depends on the taxpayer's total annual taxable income. As of 2016, maximum non-taxable minimum is set at EUR 100 and is granted to employed people with monthly income of EUR 380. The non-taxable minimum is gradually reduced based on the taxpayer's monthly income until it reaches EUR 75 at the monthly income level of EUR 1000. The non-taxable minimum for the employed people with monthly income between EUR 380 and EUR 1,000 will be calculated using the formula (Ministry of Finance, 2016; Latvijas Vēstnesis, 2016a). Lowincome earners qualifying for the maximum non-taxable minimum are supposed to submit their tax returns to the State Revenue Service to get the compensation for the overpaid amount.

\section{Increase in the amount of the allowance for dependents}

For tax allowance purposes, a taxpayer can claim a child or other relative as a dependent if they meet the requirements: do not work, do not receive unemployment benefit (or unemployment stipend), old age or disability pension, do not receive taxable income above the allowance amount, and are not dependents of any other person. A child is considered dependent if he/she is younger than 18 years old or younger than 24 years old and continues secondary, professional, special or higher education (Pluta A., Zasova A., Rastrigina O., Vanags A., 2015). As of 2016, the tax allowance for a dependant is increased from EUR 165 to EUR 175 (Ministry of Finance, 2016; Latvijas Vēstnesis, 2016a)

\section{Solidarity tax charged on high salaries}

The social contribution rate in Latvia is flat and is split between an employee and an employer. A maximum level of income from which social contributions can be made is introduced in 2014 and as of 2015 is set at 48,600 EUR. The next tax year the State Social Insurance Agency makes the repayment to high-income earners whose income exceeded the imposed ceiling (Latvijas Vēstnesis, 2016b).

The tax reform provides that these repayments will not be further made because the solidarity tax is charged at the rate equivalent to the rate of social security contribution faced by employees. After the introduction of solidarity tax, the employers are liable to paying equal social security contributions for all their employees. Solidarity tax charged on high salaries is the instrument for making the labour tax more progressive and improving the fairness of the tax system. 


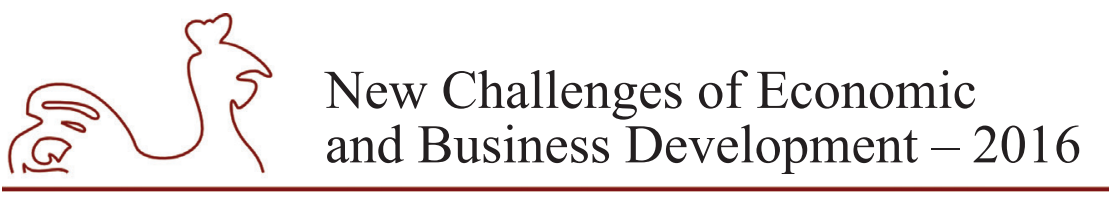

May 12-14, 2016, Riga, University of Latvia

\section{Participation tax rate calculation: the effect of the labour tax reform in $\mathbf{2 0 1 6}$}

Below the author reports the results on the comparison of the incentives to work at all as the measure for work incentives using the PTR, which shows the proportion of gross earnings that are "taxed away" in the form of lost benefits or additional taxes when a person starts working. PTRs are calculated for different income groups by looking at the distribution of PTRs by deciles of disposable income. Higher numbers for the participation tax rate imply weaker incentives to start working paid job.

The curves in Fig. 1. and Fig. 2. show the pre and post reform distribution of PTRs in Latvia, in 2015 and 2016 respectively, by deciles of equivalised disposable income. Furthermore, Fig. 1 displays the PTRs computed only for employed persons, while Fig. 2 reflects the PTRs calculated for employed, unemployed or inactive, by imputing the hypothetical employment income for those not in work using Heckman two stage estimation method.

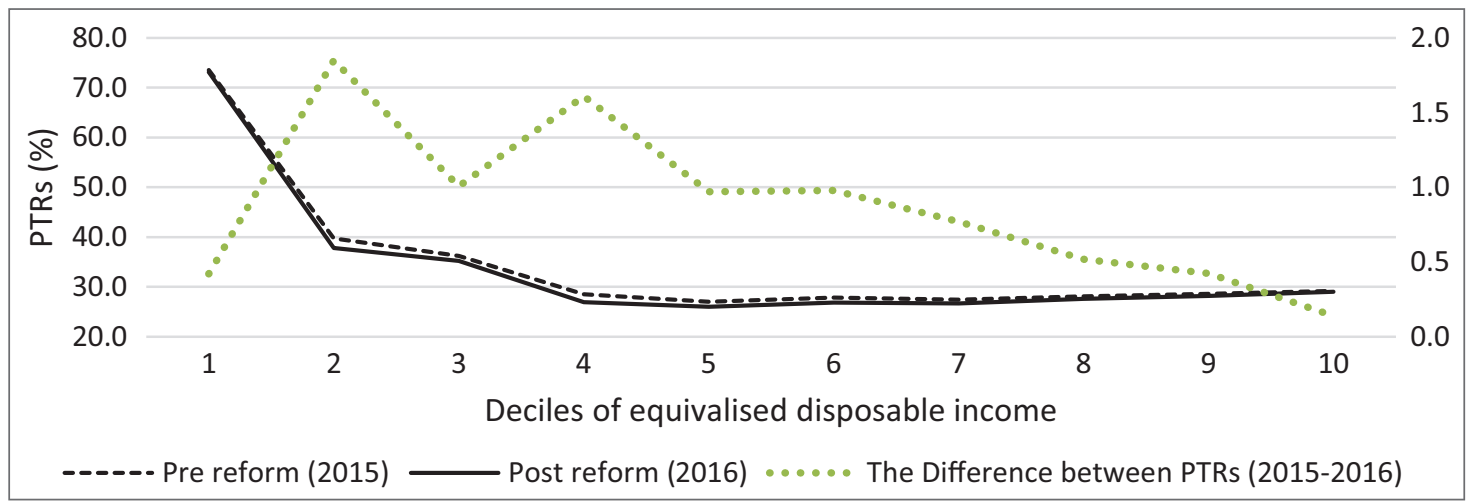

Source: author's calculations based on EU-SILC 2012 using EUROMOD-LV.

Fig. 1. Pre and Post reform distribution of participation tax rates in Latvia by deciles of equivalised disposable income in 2015 and 2016, computed only for those in work

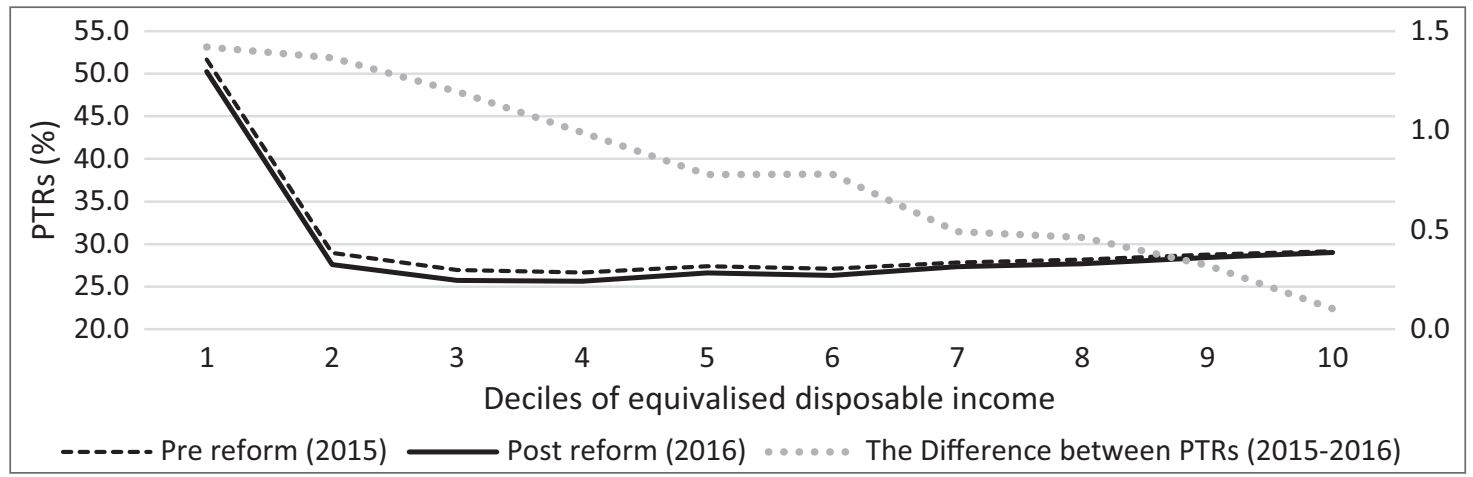

Source: author's calculations based on EU-SILC 2012 using EUROMOD-LV.

Note: The hypothetical wage rates for those actually not working are predicted using Heckman two stage estimation method.

Fig. 2. Participation tax rates in Latvia by deciles of equivalised disposable income in 2015 and 2016 computed taking into consideration both employed and unemployed 


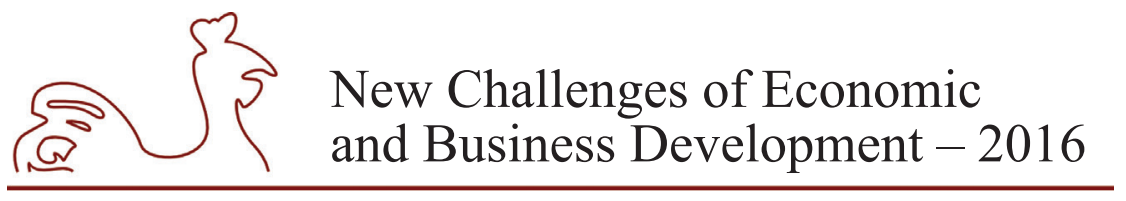

May 12-14, 2016, Riga, University of Latvia

The PTRs reduced along all the deciles of equivalised disposable income (see Fig. 1). In average, the labour tax reform reduced the PTR by 0.85 percentage points increasing incentive to work at all of the Latvian population (see Table 2. in appendices). However, the change in PTRs due to reform for the low-income earners is the second least among the all deciles (the difference is equal to 0.4 percentage points) while they face the highest PTRs that suggests the strong disincentive to participate in the labour market. This small change can be explained by the design of the means-tested benefit system (See Fig. 3a. and 3b.): means tested benefits (Guaranteed Minimum Income (GMI) benefit and housing benefit) are withdrawn at the same rate as income rises, i.e., for every additional EUR of income a recipient of GMI or housing benefit faces an equivalent reduction in the amount of benefits. (BICEPS, 2014). The tax reform of 2016 almost did not affect the work incentives of the high-income earners (the difference between pre and post reform PTR is 0.1 percentage points ) as the financial gain from the taxbenefit reform makes up the small proportion of gross earnings when a high-income earner starts working.

The PTRs calculated for employed, unemployed and inactive, by imputing the hypothetical employment income for those not in work using Heckman two stage estimation method - are noticeably lower along $1^{\text {st }}-3^{\text {rd }}$ decile than those calculated only for employed (see Fig. 2). This can be explained by the fact that imputed hypothetical employment income abolished or reduced the eligibility for means-tested benefits for the part of population. The difference between the PTRs in 2015 and 2016 reduces along with deciles, providing the highest improvement in work incentives to the poorest population groups.

Fig. 3a and Fig. 3b display the pre and post reform contribution of taxes, benefits and social insurance contributions to PTRs in Latvia by deciles of equivalised income, 2015 and 2016, computed only for those in work (Fig. 3a) and taking into consideration both employed and unemployed (Fig. 3b). The results suggest that people in the $1^{\text {st }}$ decile of disposable income distribution face weakest incentives to enter employment. The poor groups of population from the lowest deciles gain from the implemented reforms aimed at the increase of the allowance for dependents for all taxpayers and the non-taxable minimum - the negative effect of the contribution of PIT on the PTR. Nevertheless, as already mentioned, the gain from PIT is cancelled out due to the design of means-tested benefit system that makes the benefits the major contributor to high PTRs in the lowest deciles of income distribution. The reported results are in line with the results of the study of [1] the World Bank (2013), that identify the design of means tested benefits as a source of potential problems, and the author's results suggest that the mentioned problem is still extremely topical despite the implemented tax policy reforms and [2] the study of BICEPS (2014) that analyses the Latvian tax-benefit system from the point of view of fairness, redistribution, progressivity and work incentives in order to provide the recommendations for a number of reforms aimed at addressing the low work incentives observed in the Latvian taxbenefit system. 


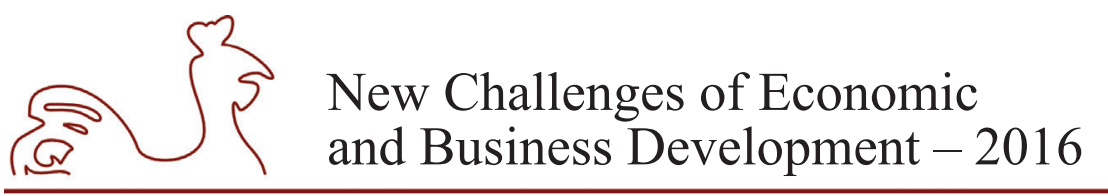

May 12-14, 2016, Riga, University of Latvia
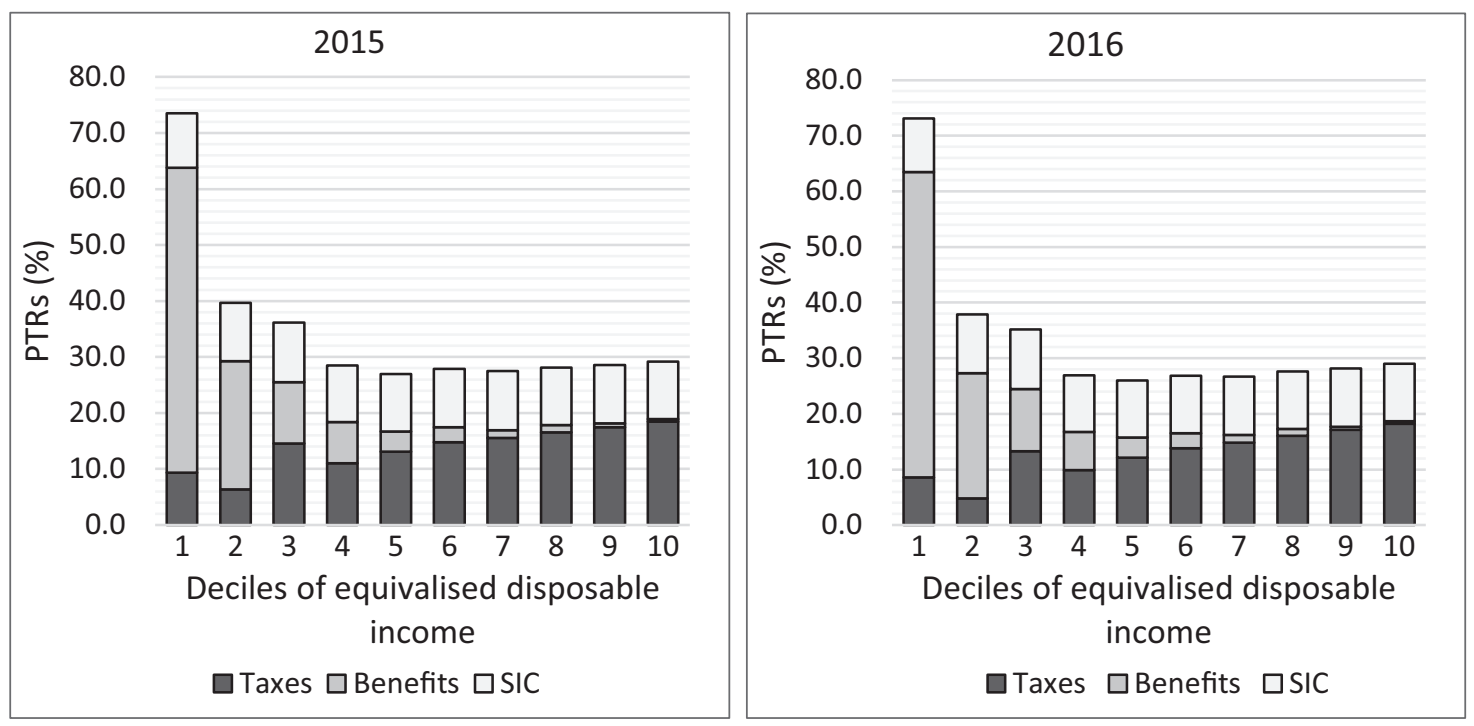

Source: author's calculations using EUROMOD-LV and EU-SILC 2012 data (2011 income).

Fig. 3a. Pre and Post reform contribution of taxes, benefits and social insurance contributions to PTRs in Latvia by deciles of equivalised income, 2015 and 2016, computed only for those in work
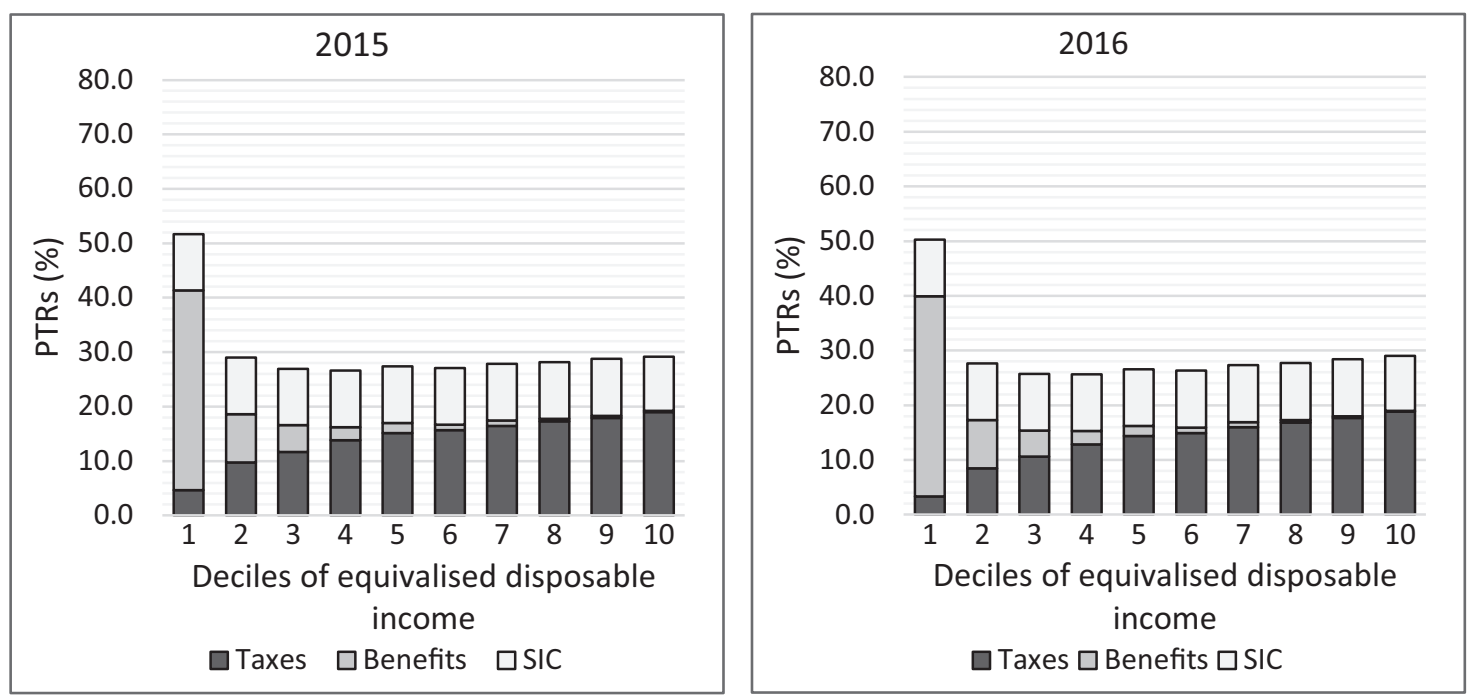

Source: author's calculations using EUROMOD-LV and EU-SILC 2012 data (2011 income).

Fig. 3b. Pre and Post reform contribution of taxes, benefits and social insurance contributions to PTRs in Latvia by deciles of equivalised income, 2015 and 2016, computed taking into consideration both employed and unemployed 


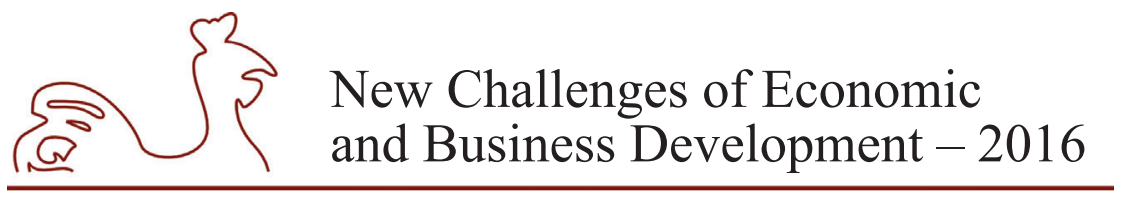

May 12-14, 2016, Riga, University of Latvia

However, it is generally known that survey data, as well as EU-SILC survey, do not fully capture the very highest income earners. Consequently, the PTRs do not reflect the real size of the effect of the introduction of solidarity tax. Analysed data contain only 5 observations of high-income earners who have the monthly employment income above EUR 4050 (EUR 48600 per year), while the Ministry of Finance (2016) states that among $0.8 \mathrm{mln}$ of employed persons there are approximately 4700 persons liable to pay the solidarity tax. Nevertheless, solidarity tax charged on high salaries could slightly increase the PTRs of high-income earners and negatively affect their work incentive.

\section{Concluding remarks}

\section{Conclusions:}

1. In average, the labour tax reform reduced the PTR by 0.85 percentage points increasing incentive to work at all of the Latvian population: in the result of tax reform, in average, when a person enters employment he/she loses by 0.85 percentage points less in the form of tax, social contribution and withdrawn benefits.

2. The change in PTRs due to reform for the low-income earners is the second least while they face the highest PTRs that and the strong disincentive to participate in the labour market. This small change can be explained by the design of the means-tested benefit system: means tested benefits are withdrawn at the same rate as income rises.

3. The tax reform of 2016 almost did not affect the work incentives of the high-income earners as the financial gain from the tax-benefit reform makes up the small proportion of gross earnings when a high-income earner starts working.

4. The PTRs calculated for employed, unemployed and inactive, are noticeably lower than calculated only for employed along $1^{\text {st }}-3^{\text {rd }}$ decile, that is explained by the fact that hypothetical income from employment (imputed using Heckman two stage estimation method) reduced the eligibility for means-tested benefits for the part of the population.

5. The poor groups of population from the lowest deciles gain from the implemented reforms aimed at the increase of the allowance for dependents for all taxpayers and the non-taxable minimum - the negative effect of the contribution of PIT on the PTR. Nevertheless, the gain from PIT is cancelled out due to the design of means-tested benefit system that makes the benefits the major contributor to high PTRs in the lowest deciles of income distribution.

6. The calculated PTRs do not reflect the real size of the effect of the introduction of solidarity tax.

\section{Proposals:}

1. So far as the benefits are the major contributor to high PTRs in the lowest deciles of income distribution, the reform of the benefit policy design is the best and major tool to improve incentives to enter the employment particularly for low-income earners. Author proposes to implement the reforms of the benefit policy design.

2. So far as the tax reform of 2016 almost did not affect the work incentives of the highincome earners and their PTRs are the lowest in the Latvian population, further tax reforms should be aimed at the improvement of the degree of redistribution and progressivity of the tax system, at the same time limiting the size of the shadow economy. Collected taxes can be directed to the financing of the benefit reform. 


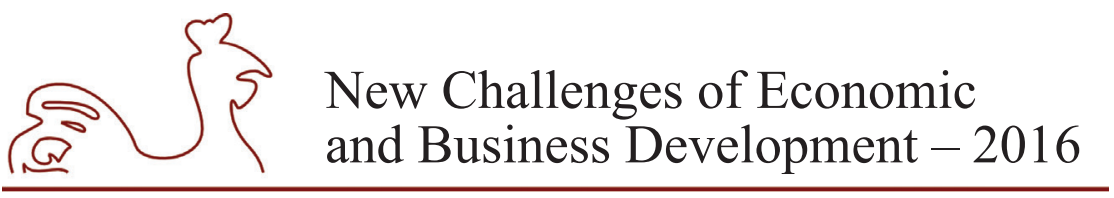

May 12-14, 2016, Riga, University of Latvia

\section{Bibliography}

Adam, S. \& Brewer, M. \& Shephard, A., 2006). The poverty trade-off. Work incentives and income redistribution in Britain, Institute for Fiscal Studies.

BICEPS, 2014. Tax System Reform in Latvia. Procurement No. EM 2013/58. [Online] Available at: https:// www.em.gov.lv/files/tautsaimniecibas_attistiba/Final_report_ENG.pdf

EUROMOD, 2016. How EUROMOD works? accessed at https://www.euromod.ac.uk/about/what-iseuromod/how-euromod-works

Heckman, J., 1976. The common structure of statistical models of truncation, sample selection and limited dependent variables and a simple estimator for such models. Annals of Economic and Social Measurement 5: 475-492. Accessed at http://www.nber.org/chapters/c10491.pdf

Immervoll, H. \& H. J. Kleven \& C. T. Kreiner \& E. Saez, 2004. Welfare Reform in European Countries: A Microsimulation Analysis, EUROMOD Working Paper No. EM1/04.

Kaliskova, K., 2015. Tax and transfer policies and female labor supply in the EU, EUROMOD Working Paper No. EM1/15.

Latvijas Vēstnesis, 2016a. Noteikumi par neapliekamā minimuma un nodokḷ atvieglojuma apmēru iedzīvotāju ienākuma nodokļa aprēķināšanai. Latvijas Republikas tiesību akti. Accessed at http:// likumi.lv/ta/id/279022-noteikumi-par-neapliekama-minimuma-un-nodokla-atvieglojuma-apmeruiedzivotaju-ienakuma-nodokla-aprekinasanai

Latvijas Vēstnesis, 2016b. Par valsts sociālo apdrošināšanu. Latvijas Republikas tiesību akti. Accessed at http://likumi.lv/ta/id/45466-par-valsts-socialo-apdrosinasanu

Ministry of Finance, 2016. Neapliekamais minimums un nodoklsa atvieglojumi. Accessed at http://www. $\mathrm{fm} . g o v . l v / \mathrm{lv} /$ sadalas/nodoklu_politika/iedzivotaju_ienakuma_nodoklis/neapliekamais_minimums_ un nodokla_atvieglojumi/

Mirrlees, J. \& Adam, S. \& Besley, T. \& Blundell, R. \& Bond, S. \& Chote, R. \& Gammie, M. \& Johnson, P. \& Myles, G. \& Poterba, J., 2011. Tax by Design. Oxford University Press.

Pḷuta A. \& Zasova A. \& Rastrigina O. \& Vanags A., 2015. Latvia (2011-2015). EUROMOD Country Report, Institute for Social \& Economic Research.

Stata (2016). Manual: Heckman Selection Model. Accessed at http://www.stata.com/manuals13/ rheckman.pdf

Sutherland, H. \& Figari, F., 2013. EUROMOD: the European Union tax-benefit microsimulation model. International Journal of Microsimulation, International Microsimulation Association, vol. 1(6), pp. 4-26. 


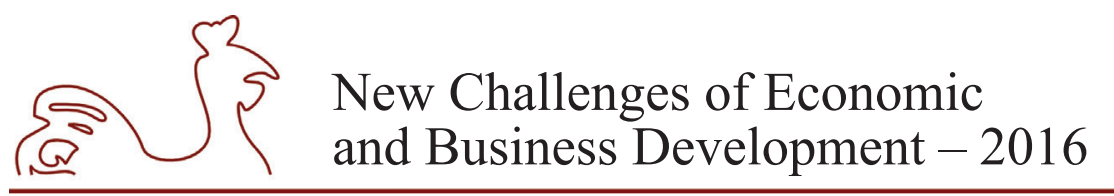

May 12-14, 2016, Riga, University of Latvia

\section{APPENDICES}

Table 1

Potential Wage for the Unemployed computed via Heckman Two Step Wage Regression

\begin{tabular}{|c|c|c|c|c|c|}
\hline & & & \multicolumn{2}{|c|}{ Coeff. } & p-value \\
\hline \multicolumn{6}{|l|}{ Employment income $(\ln )$} \\
\hline \multicolumn{3}{|c|}{$\begin{array}{l}\text { Secondary Education (ref. Primary Education) } \\
\text { (rion }\end{array}$} & \multicolumn{2}{|c|}{-0.9471} & 0.000 \\
\hline \multicolumn{3}{|c|}{ Tertiary Education (ref. Primary Education) } & \multicolumn{2}{|c|}{-0.6154} & 0.000 \\
\hline \multicolumn{3}{|c|}{ Male (ref. Female) } & \multicolumn{2}{|c|}{0.1264} & 0.000 \\
\hline \multicolumn{3}{|l|}{ Age } & \multicolumn{2}{|c|}{0.0889} & 0.000 \\
\hline \multicolumn{3}{|l|}{$\mathrm{Age}^{2}$} & \multicolumn{2}{|c|}{-0.0025} & 0.000 \\
\hline \multicolumn{3}{|l|}{$\mathrm{Age}^{3}$} & \multicolumn{2}{|c|}{0.0000} & 0.000 \\
\hline \multicolumn{3}{|l|}{ Constant } & \multicolumn{2}{|c|}{5.6708} & 0.000 \\
\hline \multicolumn{6}{|l|}{ Employment status } \\
\hline \multicolumn{3}{|l|}{ Male (ref. Female) } & \multicolumn{2}{|c|}{0.1500} & 0.000 \\
\hline \multicolumn{3}{|c|}{ Region: Degree of urbanisation - cities (ref. Thinly populated area) } & \multicolumn{2}{|c|}{0.1723} & 0.000 \\
\hline \multicolumn{3}{|c|}{ Married (ref. Single, Divorced, Widowed) } & \multicolumn{2}{|c|}{0.0749} & 0.000 \\
\hline \multicolumn{3}{|l|}{ Number of children below age of 2} & \multicolumn{2}{|c|}{-0.0689} & 0.084 \\
\hline \multicolumn{3}{|l|}{ Age } & \multicolumn{2}{|c|}{0.2714} & 0.000 \\
\hline \multicolumn{3}{|l|}{$\mathrm{Age}^{2}$} & \multicolumn{2}{|c|}{-0.0046} & 0.000 \\
\hline \multicolumn{3}{|l|}{$\mathrm{Age}^{3}$} & \multicolumn{2}{|c|}{0.0000} & 0.000 \\
\hline Secondary Education (ref. Primary $\mathrm{E}$ & cation) & & 0.97 & & 0.000 \\
\hline Tertiary Education (ref. Primary Edu & ion) & & 1.38 & & 0.000 \\
\hline Other income in a household & & & 0.00 & & 0.000 \\
\hline Constant & & & -5.15 & 53 & 0.000 \\
\hline Lambda & & & & -1.380 & \\
\hline Number of obs. & & & & 1516 & \\
\hline Censored obs. & & & & 8486 & \\
\hline Uncensored obs. & & & & 6679 & \\
\hline Wald chi2 (6) & & & & 673.4 & \\
\hline Prob>chi 2 & & & & 0.000 & \\
\hline & No. of observations & Mean & Std. Dev. & Min & Max \\
\hline Observed employment income $(\ln )$ & 6679 & 5.423 & 1.228 & 3.337 & 9.199 \\
\hline Predicted employment income (ln) & 6679 & 5.361 & 0.398 & 3.518 & 6.303 \\
\hline
\end{tabular}

Source: Author's computations using EU-SILC 2012 data (2011 income).

Table 2

PTRs in Latvia in baseline 2015 system and change due to reform in 2016 mean, median, $\mathrm{p} 25$ and $\mathrm{p} 75, \%$

\begin{tabular}{|l|c|c|c|c|}
\hline $\begin{array}{c}\text { An approach of } \\
\text { calculation of PTRs }\end{array}$ & \multicolumn{2}{|c|}{$\begin{array}{c}\text { PTRs are computed only for those } \\
\text { in work }\end{array}$} & $\begin{array}{c}\text { Employed and unemployed or inactive } \\
\text { are taken into consideration }\end{array}$ \\
\hline & 2015 & 2016 & 2015 & 2016 \\
\hline Mean & 31.98 & 31.14 & 29.19 & 28.46 \\
\hline Median & 28.69 & 28.23 & 28.53 & 28.07 \\
\hline p25 & 25.16 & 23.76 & 25.69 & 24.45 \\
\hline p75 & 31.08 & 31.08 & 29.87 & 29.81 \\
\hline
\end{tabular}

Source: Author's computations using EU-SILC 2012 data (2011 income). 
May 12-14, 2016, Riga, University of Latvia

\title{
EU POLICY IMPACT ON HIGHER EDUCATION CAPACITY IN LATVIA ${ }^{1}$
}

\author{
Maris Purgailis, University of Latvia, Latvia \\ Annija Apsite, University of Latvia, Latvia ${ }^{2}$
}

\begin{abstract}
Policy-making for the development of "Europe of Knowledge" has relied on a number of different policy instruments. Comparing their relative impact and also comparing their impact across national and institutional borders may provide new insights as to what instruments work in higher education (HE) reforms. Since both Bologna Process and Erasmus + , as well as EU research funding schemes include a number of various initiatives, it would be then possible to identify where effort should be put to make a difference in HE reforms and how to make the process more efficient. It is crucial especially for EU countries like Latvia, where the GDP per capita and the average income for inhabitants is comparatively low, thus a problem emerges on how to manage the HE system efficiently. The purpose of this research is to find main factors hindering the changes in higher education capacity and to emphasize the kinds of instruments to carry out policy changes. Capacity is systems potencial to realize systems function, thus authors have identified and offer five HE capacity elements. The next step the analysis was the evaluation of quality for these elements done by experts. To do this, expert interviews were carried out and they judged about the significancy of elements and the interrelated impact of these elements. As a result, the most important capacity elements were identified to develop HE in Latvia.
\end{abstract}

Key words: higher education, capacity, expert evaluation, knowledge triangle

JEL code: E61, F62

\section{Introduction}

Since the restoration of independence of Latvia, the education system has experienced several challenges. However, in this paper the authors are limiting the research and concentrating particularly on the topic of higher education, not the other levels of education system. The main aim for the higher education in Latvia set by the Council of Higher Education, is to integrate, develop and raise competitiveness of the higher education system of Latvia among the European countries. The main challenges are raising the level of enrolment, improving the quality of higher education, giving more opportunities for the students with international exchanges, strengthening the link among education, science and entrepreneurship and ensuring the efficiency of the distribution of finances (The Council of Higher Education, 2012).

Since Latvia has a comparatively low experience in planning, organizing and implementing a powerful long-term strategy in its education system and the external factors like demographic

\footnotetext{
1 The research has been done under the project Nr. NFI/R/2014/006 "EU policies impact on the transformations of the higher education and research system in Norway and Latvia".

2 Corresponding author - e-mail address: annija.apsite@lu.lv
} 


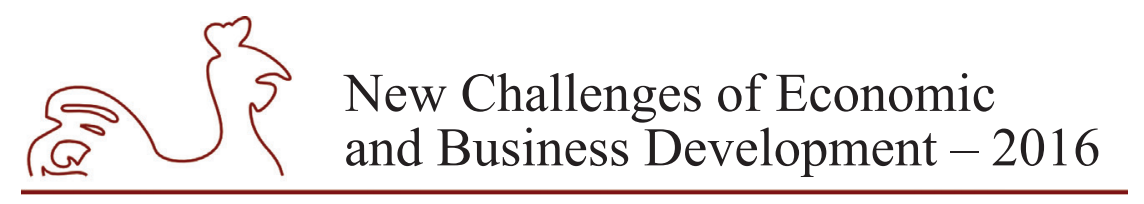

May 12-14, 2016, Riga, University of Latvia

and economic situation in the country are not favorable for the Higher Education system to develop successfully, there are several serious challenges to be faced and thus the main internal and external influencing factors have to be detected to foster the development of Higher Education system. It is crucial especially for EU countries like Latvia, where the GDP per capita and the average income for inhabitants is comparatively low. Out of all the overview of the current situation it is possible to conclude that there emerges a problem on how to manage the HE system efficiently. Thus, the purpose of this research is to find main factors hindering the changes in higher education capacity and to emphasize the kinds of instruments to carry out policy changes.

This far there the education system has experienced several important occurrences and some of them are - adaption of Education Law, (1991), Law of Higher Education (1995) Bologna declaration (1999), the introduction of ECTS system (2007), joining the EU (2004), financial crisis (2009) and other occurrences, but it is absolutely indubitable that further changes will happen and are necessary for the system to develop successfully.

To conduct the research, the authors have identified a theoretical background, which is strongly connected with the Knowledge Triangle (education, innovation and research) and there are also 5 main capacity factors identified, which are interacting with each other and providing the current situation as it is. Those capacity factors are policy making capacity, legal capacity, the organization of teaching and research capacity, funding capacity and information capacity. The novelty lies in the method which will be used to conduct the research. Usually, when higher education is being analyzed and researched, authors use qualitative (Gornitzka 2014, Gornitzka 2013, Witte 2009) not quantitative methods. Quantitative methods are mainly used to analyze different rankings among Universities (Rauhvargers, 2014, Espeland, 2007). However, quantitative analysis is also very important to make a research in the macro level - to manage the whole HE system. Also, sometimes questions about finances are also covered (Howlett, 2005, Trebilock, 2005) but in authors' opinion although finances are important, it is not the only element which determines the capacity of HE development. Thus in this paper the authors are going to use matrix methods to find bottle neck factors. For it to be possible expert interviews were carried out and they judged about the significant and interrelated impact of elements (capacity factors). After conducting the research it is possible to answer the research question and to determine the factors which are hindering a successful development of Higher Education system in Latvia. Thus, further these conclusions can be used in further implementation and management of the education system in Latvia, which not only contributes the discipline, but may give a practical positive gain to the overall education system development.

To conduct the research the authors studied large amount of theoretical and analytical literature and other information resources, while the data to analyze the current situation in Latvia has been obtained from a number of statistical resources, from which the main statistical data from The Ministry of Education and Science, Central Statistical Bureau and the Global Competitiveness Index, which is designed by the World Economic forum.

\section{The Overview of current situation in Latvia 2006-2016}

The education system in Latvia is administered at three levels - national, municipal and institutional. The Parliament, the Cabinet of Ministers and the Ministry of Education and Science are the main decision-making bodies in Latvia at national level. The Ministry of 


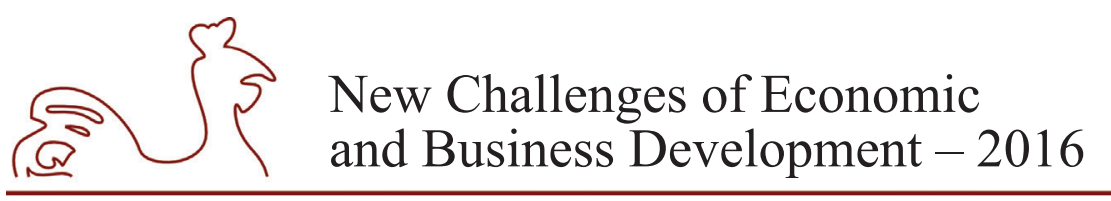

May 12-14, 2016, Riga, University of Latvia

Education and Science is the education policy development and implementation institution that oversees the national network of education institutions, sets standards of education and determines teacher training content and procedures. (Ministry of Education and Science, 2015). Thus, the main institutions responsible for the guidelines for science, technology and innovation development are Ministry of Education and Science (MES) and Ministry of Economics (ME).

\section{Institutions responsible for Higher Education and Science Development}

Table. 1.1.

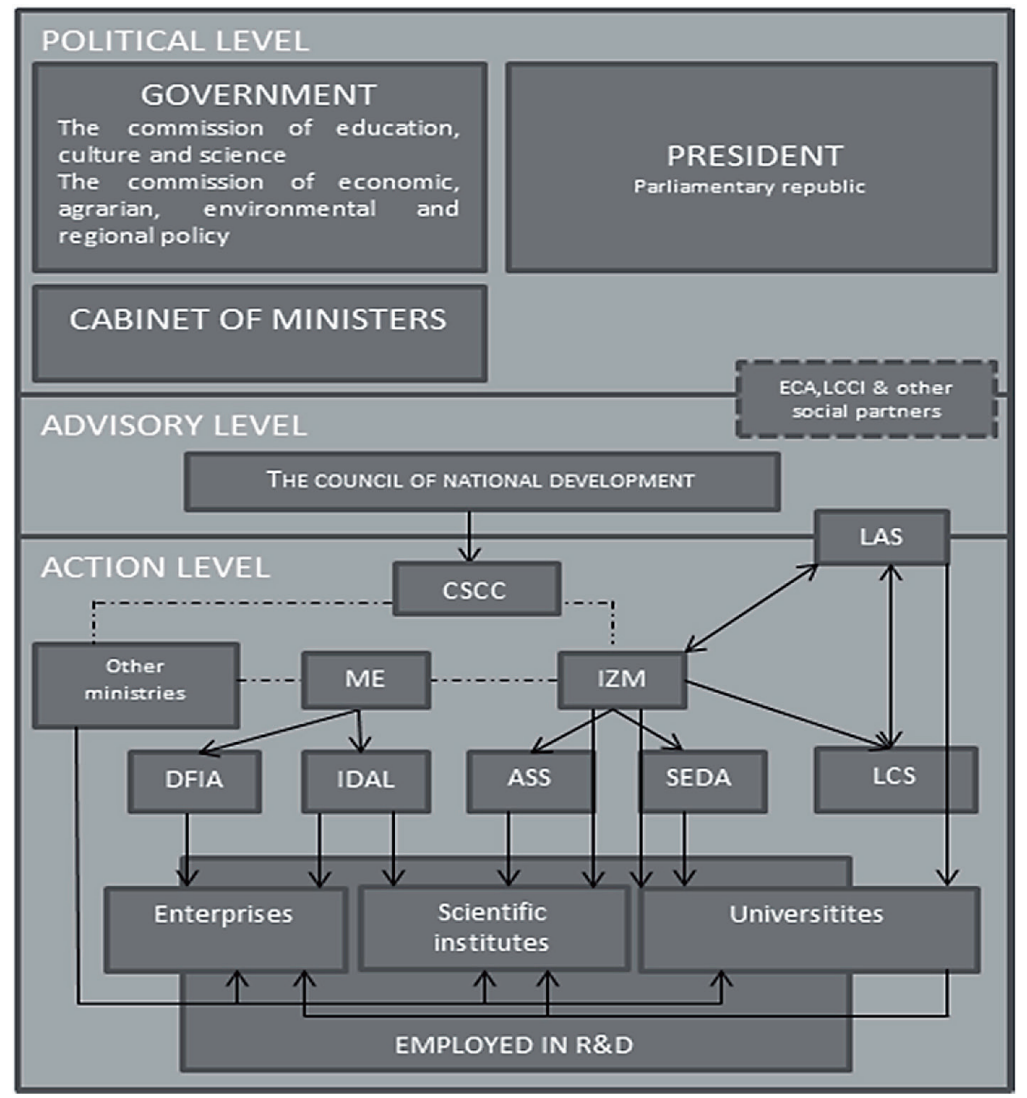

Source: Authors' compilation.

CSCC - Cross-Sectoral Coordination Centre $=$ PKC - Pārresoru koordinācijas centrs

ME - Ministry of Economics of the Republic of Latvia $=\mathrm{EM}-$ Ekonomikas ministrija

MES - Ministry of Education and Science = IZM - Izglitīibas un zinātnes ministrija

LAS - Latvian Academy of Sciences = LZA - Latvijas Zinātnu akadēmija

LCS - Latvian Council of Science $=$ LZP - Latvijas Zinātnes padome

DFIA - JSC Development Finance Institution Altum (Former Latvian Guarantee Agency+ALTUM+RDF) = AS

Attīstības finanšu institūcija Altum (agrāk LGA + ALTUM + LAF)

IDAL - Investment and Development Agency of Latvia = LIAA - Latvijas Investīciju un attīistības aǵentūra

ASS - Administration of Studies and Science $=$ SZA - Studiju un zinātnes administrācija

SEDA - The State Education Development Agency = VIAA - Valsts izglîtības un attīstības aǵentūra

ECA - Employers' Confederation of Latvia - LDDK - Latvijas Darba devēju konfederācija

LCCI - Latvian Chamber of Commerce and Industry $=$ LTRK - Latvijas Tirdzniecības un rūpniecības kamera 


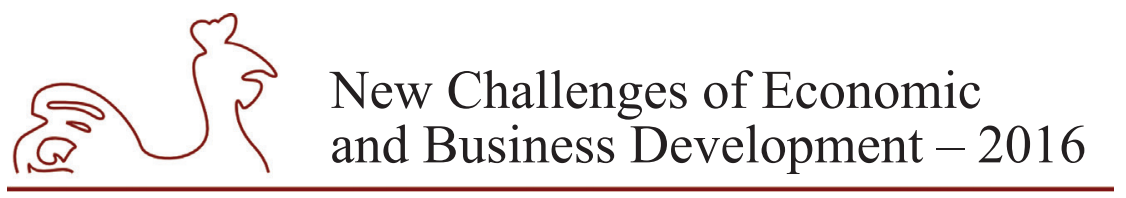

May 12-14, 2016, Riga, University of Latvia

MES develops the policy, coordinates its implementation and ensures the representation of Latvia in the institutions of European Union research management. In this process MES cooperates with ME and other ministries, it also cooperates with its social partners (ECA, LCCI and others) and sectoral associations. ASS, SEDA and LCS are responsible for administering the financing instruments. Ministry of Economics is mostly responsible for coordination and development of the policy of innovations. DFIA and IDAL are responsible for administering financial instruments connected with the transfer of knowledge and raising the capacity of innovations in enterprises and scientific institutions. However, in the system there are several imperfections, for example, duplication of functions, unclear division of policy implementation functions, inadequacy of functions with the institutional level etc. Further, there will be examined indicators which characterize the current situation in Latvia.

\subsection{The tendencies and peculiarities of higher education in Latvia}

The institution which provides the most accurate and detailed statistical data is Central Statistical Bureau of Latvia. As it is possible to conclude from the Figure 1.1 the number of students has been decreasing for the past 10 years. Since the demographic situation is dramatic, the education system to survive and sustain quality needs to be adapted to the current circumstances. To sustain the workload of higher education system in the current level, there has to be a serious step made to attract international students to study in Latvia. For it to possible there have to be serious steps made and all of the capacity factors must be activated. In authors' opinion, the most important factor in the current situation could not only be the financial capacity, but especially the policy making capacity.

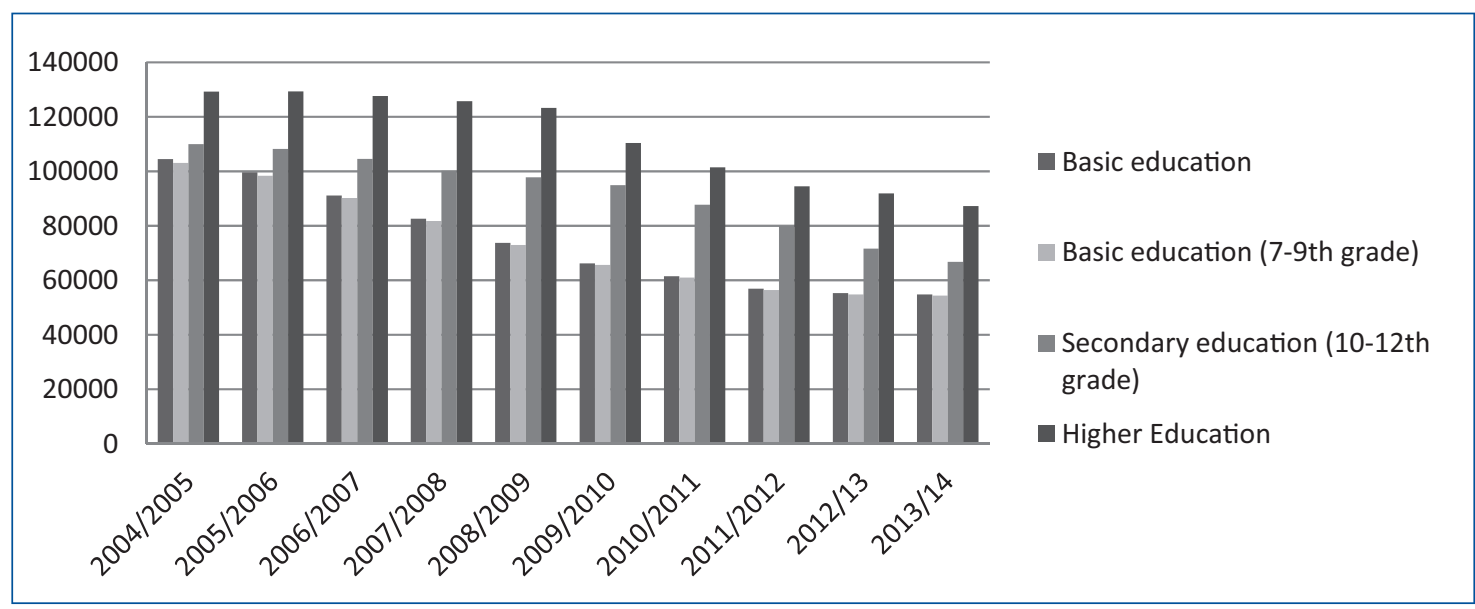

Source: author's compilation of data from Central Statistical Bureau of Latvia.

Fig. 1.1. The number of students according to the level of education

The demographic issues clearly reflect also in the number of higher education institutions (Figure 1.2) in Latvia. Although the number of private high schools has even increased in the past years, the total amount of the students in private education institutions is not high. As it is possible to see, the number of state higher education institutions has been decreasing due 


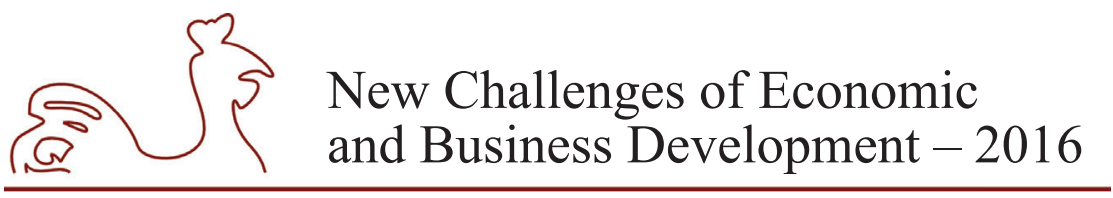

May 12-14, 2016, Riga, University of Latvia

to the previously mentioned reasons - mostly because of the dramatic demographic situation and the issues in the economic situation which foster youngsters to go abroad to obtain higher education.

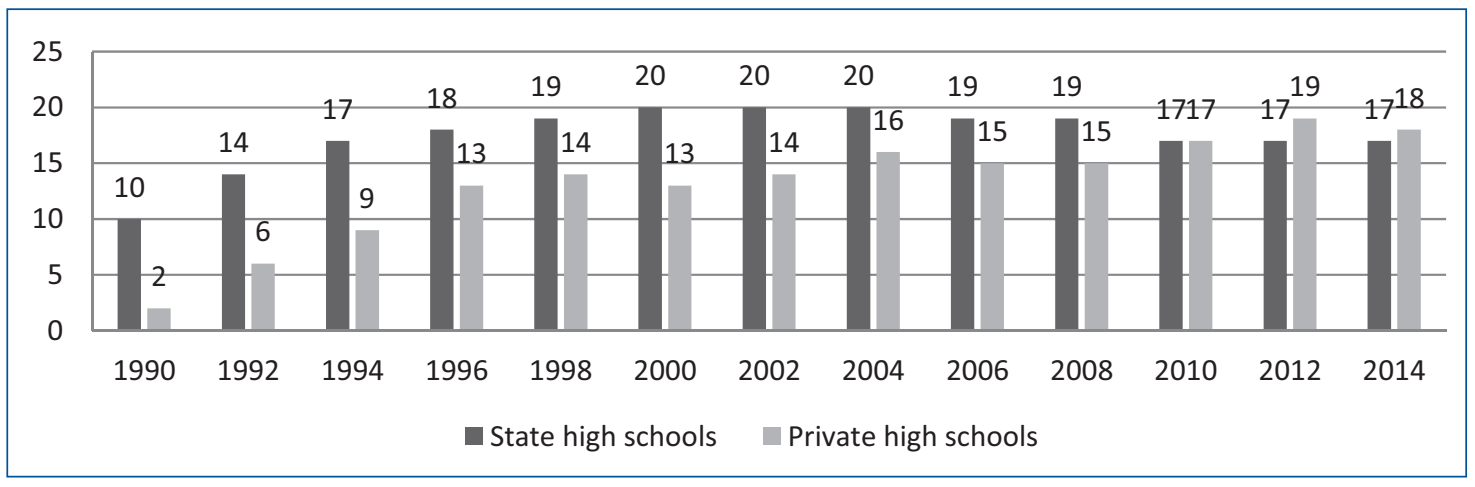

Source: author's compilation of data from Central Statistical Bureau of Latvia.

\section{Fig. 1.2.Dynamics of number of high schools (1990-2014)}

Since state has a great power of fostering particular fields of expertise by adjusting the money flow for budget financed study positions and by fostering the quality of studies in particular fields, it is very important to have a long-term economic plan to ensure workplaces for the future specialists. Currently, there is still an overproduction of specialists in social sciences, economics and law and a lack of specialists in engineering, manufacturing, IT and math. However, the overall tendency is slowly becoming more positive - the structure of students in the particular fields is slowly changing. Another issue connected with the young specialists in the strategically important fields is that the state and the private sector cannot guarantee a well paid job after graduating, because foreign markets offer a lot more competitive salary that inside the country.

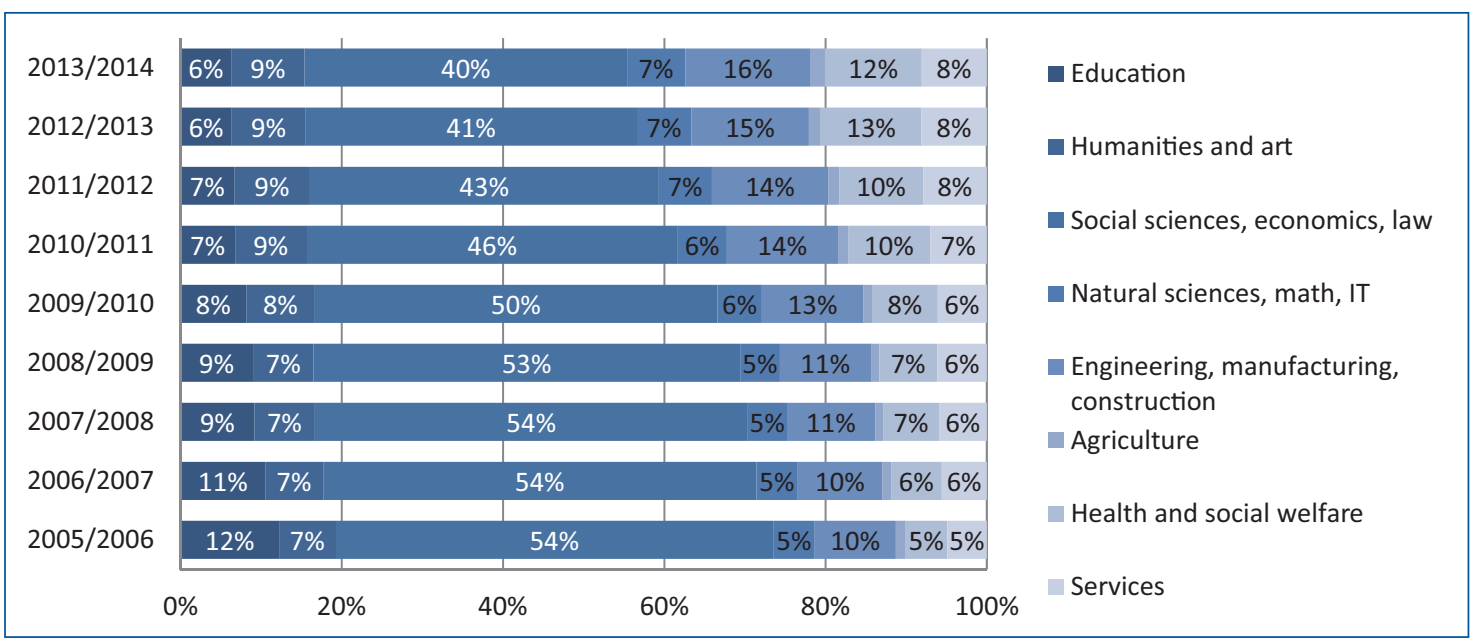

Source: author's compilation of data from Central Statistical Bureau of Latvia.

Fig. 1.3. The number of students according to thematic groups (in colleges and high schools) 


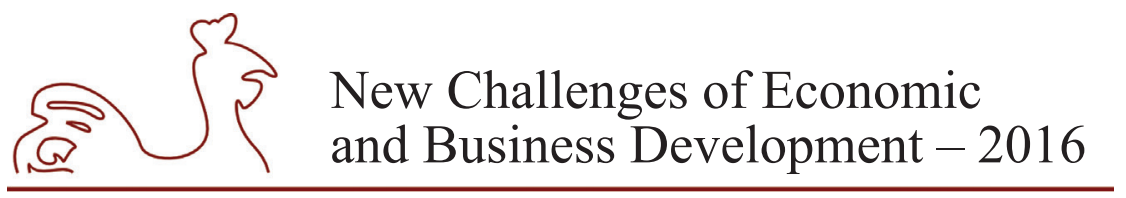

May 12-14, 2016, Riga, University of Latvia

\subsection{Global Competitiveness Index in the context of Higher Education in Latvia}

One of the options, as already mentioned, is to analyze the success of the used policies in education is to use World Competitiveness Index analysis. The main purpose of GCI is to assess the ability of countries to provide high levels of prosperity to their citizens, where one of the main prosperity indicating branches is the development of education system. In the particular research the authors have used the comparison of Norway and the Baltic States as small countries with similar economic and political development.

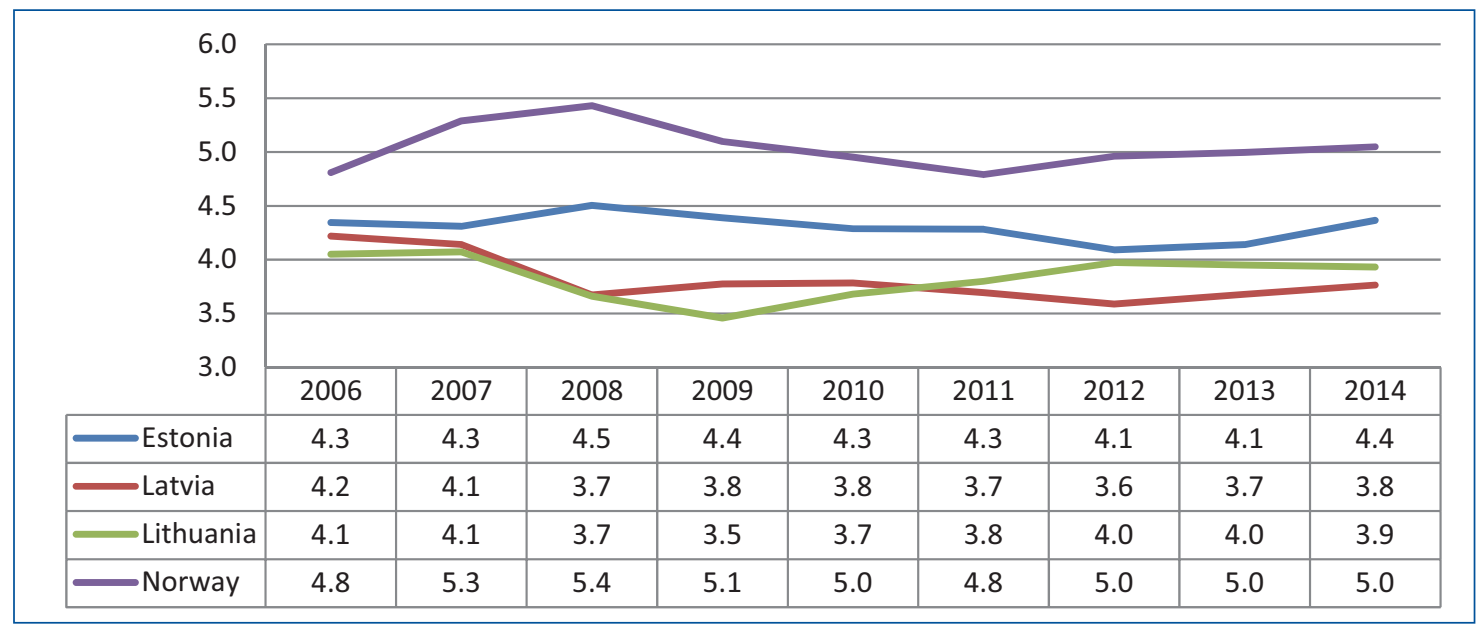

Source: author's compilation of data from Global Competitiveness Report 2006-2014.

Fig. 1.4. Quality of the education system, (1-7)

The quality of education system is being measured by several indicators weighted together, where the Knowledge Triangle has been taken into account. The trend which can be seen in the quality of the education system can be seen in most of the other (further) indicators of the education system as well - there is an obvious gap between Norway and the Baltic states. Although Norway had recently (in 2009) experienced a slight downfall, it has a convincingly stronger indicator than the Baltic States. Interestingly, Latvia and Lithuania had a stronger evaluation in 2006 than it is now, while Estonia has had an absolutely stable evaluation for the past years. Although the level of Estonia is closer to the other Baltic States, it is ahead Latvia and Lithuania in most of the indicators. Surely, the data seems optimistic for all of these countries if compared with the lowest level (Egypt 2.1; Paraguay 2; South Africa 2.2). However, it absolutely asks for improvement if compared with the leader Switzerland (6) or, for instance, Singapore, UAE, Germany or New Zealand. To understand the differences between Latvia and Norway in a wider perspective, according to the latest GCI (2014-2015), Latvia holds the $65^{\text {th }}$ position, while Norway holds the $14^{\text {th }}$ position in the rank.

Quality higher education and training is crucial for economies that want to move up the value chain beyond simple production processes and products. In particular, today's globalizing economy requires countries to nurture pools of well-educated workers who are able to perform complex tasks and adapt rapidly to their changing environment and the evolving needs of the production system. 


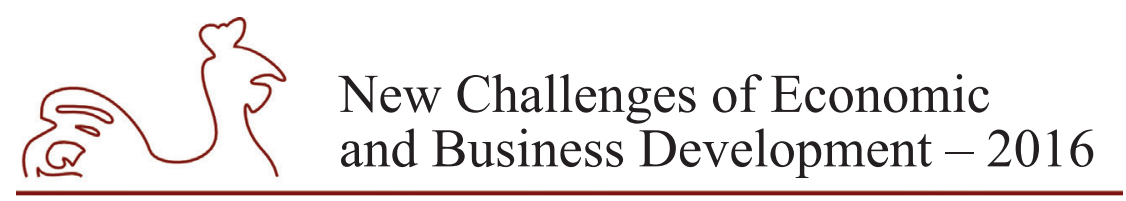

May 12-14, 2016, Riga, University of Latvia

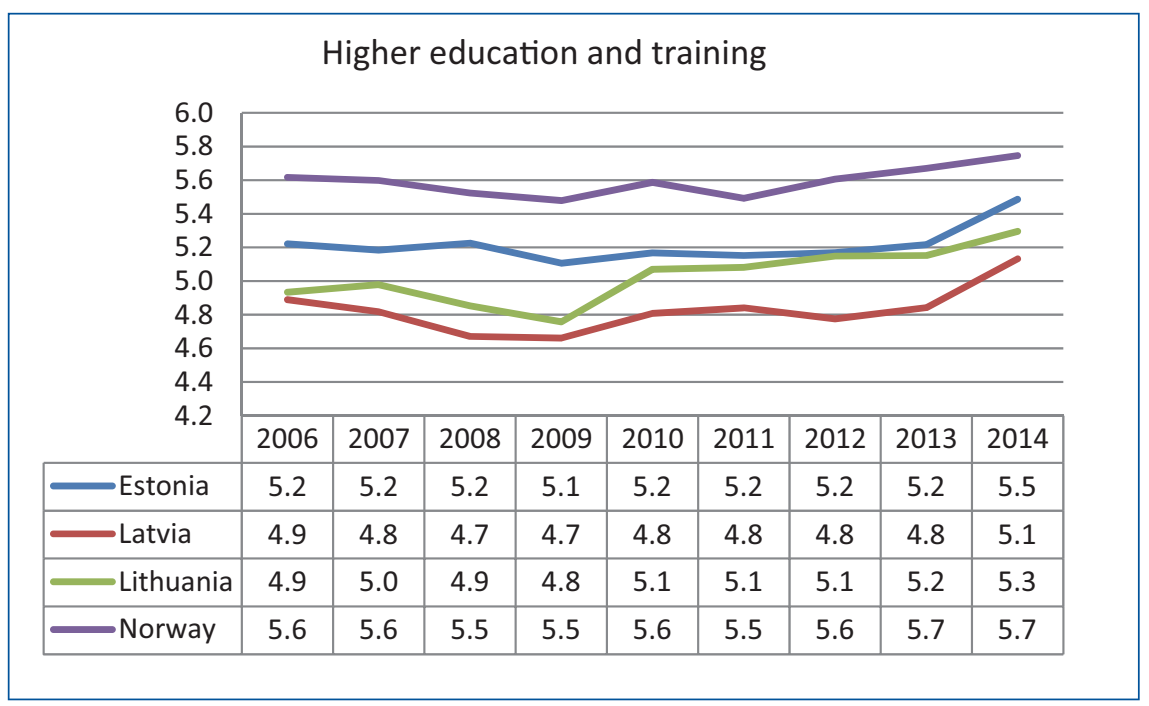

Source: author's compilation of data from Global Competitiveness Report 2006-2014.

Fig. 1.5. Higher education and training

Higher education and training is the $5^{\text {th }}$ pillar of the Global Competitiveness Index and shows the overall trends in the area of the country. As it is possible to conclude, although the results are not homogenous, the situation can be evaluated as good, since all countries are experiencing an increase and have stepped over the sum of 5 in 2014.

\subsection{The income and expenditure on Higher Education Institutions in Latvia, 2006-2014}

Higher Education is not an exceptional area, thus it does need funding to exist and develop. The institution which provides data about the income and expenditure on higher education is the Ministry of Education and Science.

Below it is possible to see an overview of the income structure of higher education institutions in Latvia in 2014, which is currently the latest available statistics. First of all, it is possible to conclude that state governed higher education institutions have a much larger impact on the overall education system. Thus, in higher education system, the state has to have a clear plan and instruments to implement changes and the new strategies. Since most of the turnover is among state institutions, there is not only the power in state's hands, but also - responsibility. As it is possible to see, the funding for studies consists of 5 parts - state budget transfers, EU structural funds, income from tuition fees, international funding and other income. As it is possible to see from the latest data, the funding from European Union structural funds provides approximately $1 \%$ of all funding for studies. If comparing with the previous years, then it has to be mentioned that the amount of EU structural fund funding for studies has even decreased in the past years. The greatest part of funding for studies is being provided by state, income from tuition fees and international funding. Although financial capacity should be enhanced by attracting the funding available from European Union structural funds, authors believe that another important type of capacity should be enhanced and it is the policy making capacity. Since most of the higher education institutions are state governed, the state has the power to set 


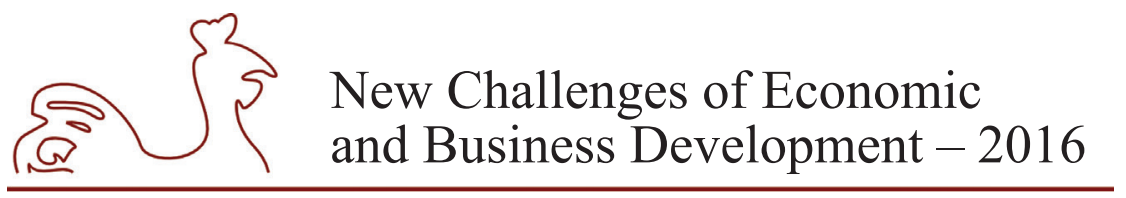

May 12-14, 2016, Riga, University of Latvia

the aims, to design and implement national policy strategies according to the needs of the state itself. Thus, the state has the opportunity to adjust the priorities in higher education according to the long-term plans in the development of state economy, which, according to the examined indicators currently is not being done or is not being done efficiently enough.

Table 1.2

The funding in Higher Education System in Latvia, 2014

\begin{tabular}{|c|c|c|c|c|c|c|c|c|c|c|c|c|}
\hline & : & 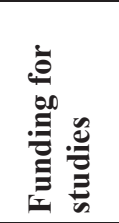 & $\theta^{\theta}$ & 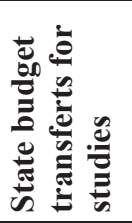 & 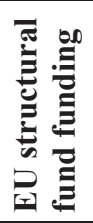 & 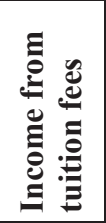 & 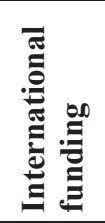 & 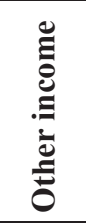 & 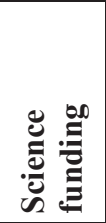 & $\theta^{\circ}$ & 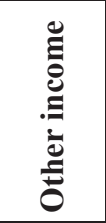 & $\partial^{e}$ \\
\hline $\begin{array}{l}\text { All high } \\
\text { schools }\end{array}$ & 238750 & 153986 & 64 & 85068 & 942 & 42634 & 23242 & 3041 & 47108 & 20 & 37656 & 16 \\
\hline All colleges & 21398 & 19787 & 92 & 18082 & 7 & 1210 & 303 & 190 & 0 & 0 & 1608 & 8 \\
\hline $\begin{array}{l}\text { State high } \\
\text { schools and } \\
\text { colleges }\end{array}$ & 260148 & 173773 & 67 & 103150 & 949 & 43844 & 23545 & 3231 & 47108 & 18 & 39264 & 15 \\
\hline $\begin{array}{l}\text { Private high } \\
\text { schools and } \\
\text { colleges }\end{array}$ & 33149 & 27118 & 82 & 180 & 72 & 25539 & 720 & 678 & 1678 & 5 & 4352 & 13 \\
\hline $\begin{array}{l}\text { Highschools } \\
\text { and Colleges } \\
\text { together }\end{array}$ & 293297 & 200891 & 68 & 103330 & 1021 & 69383 & 24265 & 3909 & 48786 & 17 & 43616 & 15 \\
\hline
\end{tabular}

Source: Data retrieved from Ministry of Education and Science.

Table 1.3

Income of all state high schools and colleges in Latvia, 2006-2014

\begin{tabular}{|c|c|c|c|c|c|c|c|c|c|}
\hline & $\mathbf{2 0 0 6}$ & $\mathbf{2 0 0 7}$ & $\mathbf{2 0 0 8}$ & $\mathbf{2 0 0 9}$ & $\mathbf{2 0 1 0}$ & $\mathbf{2 0 1 1}$ & $\mathbf{2 0 1 2}$ & $\mathbf{2 0 1 3}$ & $\mathbf{2 0 1 4}$ \\
\hline Income & 191691,2 & 259668,6 & 291244,0 & 225540,8 & 263837,8 & 264755,7 & 270731,3 & 252012,0 & 260148,0 \\
\hline
\end{tabular}

Source: Data retrieved from Ministry of Education and Science.

In the Table 1.2 it is possible to see the expenditures of all higher education institutions in Latvia in 2014. As it is possible to notice, $\sim 40 \%$ of all expenditure is devoted to wages of academic, administrative and general personnel, while, for example, only $0.05 \%$ of expenses is devoted to support students with scholarships and transport compensation. If the take a look at the expenditure of state high schools in dynamics from 2006-2014, it is possible to see that it has a high dependence on the overall economic situation - until 2009, when the global economic crisis took place, the expenses were growing in an enormous speed. In 2009 the higher education system experienced cuts on expenditure and after these cuts the growth of expenditure is now at a moderate pace. Although the pace of expenditure has not been increasing for the past 2 years already, it is still an issue since, first of all, the number of students in the past years has been 


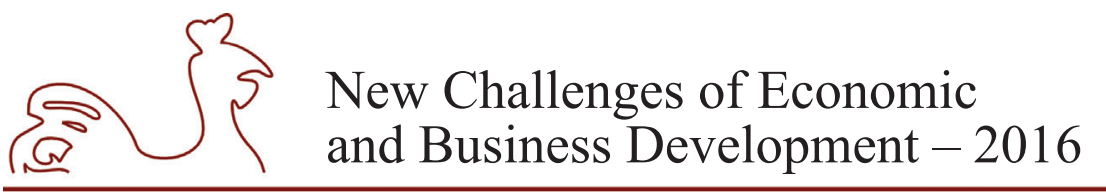

May 12-14, 2016, Riga, University of Latvia

decreasing and it is in the nearest years the trend will not change and, second of all, the necessary cuts in budget make a serious damage on the quality of education. First of all, because the wages are being cut, secondly, the number of academic staff is being reduced and, thirdly, there is a greater pressure and workload on the academic staff currently still working in higher education institutions.

Table 1.4

Expenditure of all Higher Education Institutions in Latvia, 2014

\begin{tabular}{|c|c|c|c|c|}
\hline & & State high schools & State colleges & $\begin{array}{l}\text { State high schools } \\
\text { and colleges }\end{array}$ \\
\hline \multirow{16}{*}{ 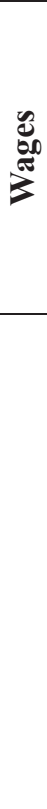 } & Expenditure (all) & 235203 & 20727 & 255930 \\
\hline & All & 88918 & 12405 & 101323 \\
\hline & $\%$ & 0,378047899 & 0,598495 & 0,395901 \\
\hline & Academic personnel & 48336 & 4871 & 53207 \\
\hline & Administrative personnel & 16843 & 3009 & 19852 \\
\hline & General personnel & 23739 & 4527 & 28266 \\
\hline & Social insurance tax & 20606 & 3081 & 23687 \\
\hline & $\%$ & $8,7 \%$ & $14,9 \%$ & $9,3 \%$ \\
\hline & Goods and services & 49842 & 2957 & 52799 \\
\hline & $\%$ & $21,2 \%$ & $14,3 \%$ & $20,6 \%$ \\
\hline & Subsidies, dotations & 432 & 2 & 434 \\
\hline & Scholarship, transport compensation & 12811 & 784 & 13595 \\
\hline & $\%$ & $5,4 \%$ & $3,8 \%$ & $5,3 \%$ \\
\hline & Payments for fixed capital & 45689 & 1268 & 46957 \\
\hline & Other expenditure & 16899 & 229 & 17128 \\
\hline & $\%$ & $7,1 \%$ & $1,1 \%$ & $6,7 \%$ \\
\hline
\end{tabular}

Source: Data retrieved from Ministry of Education and Science.

Table 1.5

Expenditure of all state high schools in Latvia, 2006-2014

\begin{tabular}{|c|c|c|c|c|c|c|c|c|c|}
\hline & $\mathbf{2 0 0 6}$ & $\mathbf{2 0 0 7}$ & $\mathbf{2 0 0 8}$ & $\mathbf{2 0 0 9}$ & $\mathbf{2 0 1 0}$ & $\mathbf{2 0 1 1}$ & $\mathbf{2 0 1 2}$ & $\mathbf{2 0 1 3}$ & $\mathbf{2 0 1 4}$ \\
\hline Expenditure & - & 253436,22 & 291878,5 & 198368,7 & 206753,9 & 244228 & 275208 & 261096 & 255930 \\
\hline
\end{tabular}

Source: Data retrieved from Ministry of Education and Science.

Although the situation seems very unstable, the dynamics of income and expenditure is not dramatic in terms of the difference between expenditure and income. However, in the past years expenses have been higher than income and it is possible that the trend will not change in the next few years, thus it is exclusively important to foster the policy making capacity and teaching and research capacity to attract international students and to raise the current quality and competitiveness of higher education system in Latvia. To be fair, right now the number of foreign students is still increasing (Figure 1.7). However, it is still not enough to cover the deficiency which has been caused by the dramatic demographic situation (Figure 1.6). 


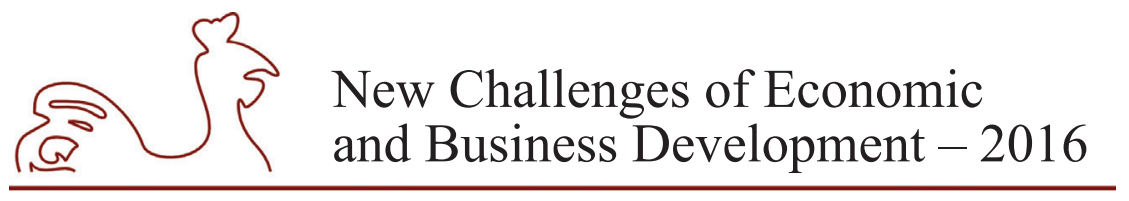

May 12-14, 2016, Riga, University of Latvia

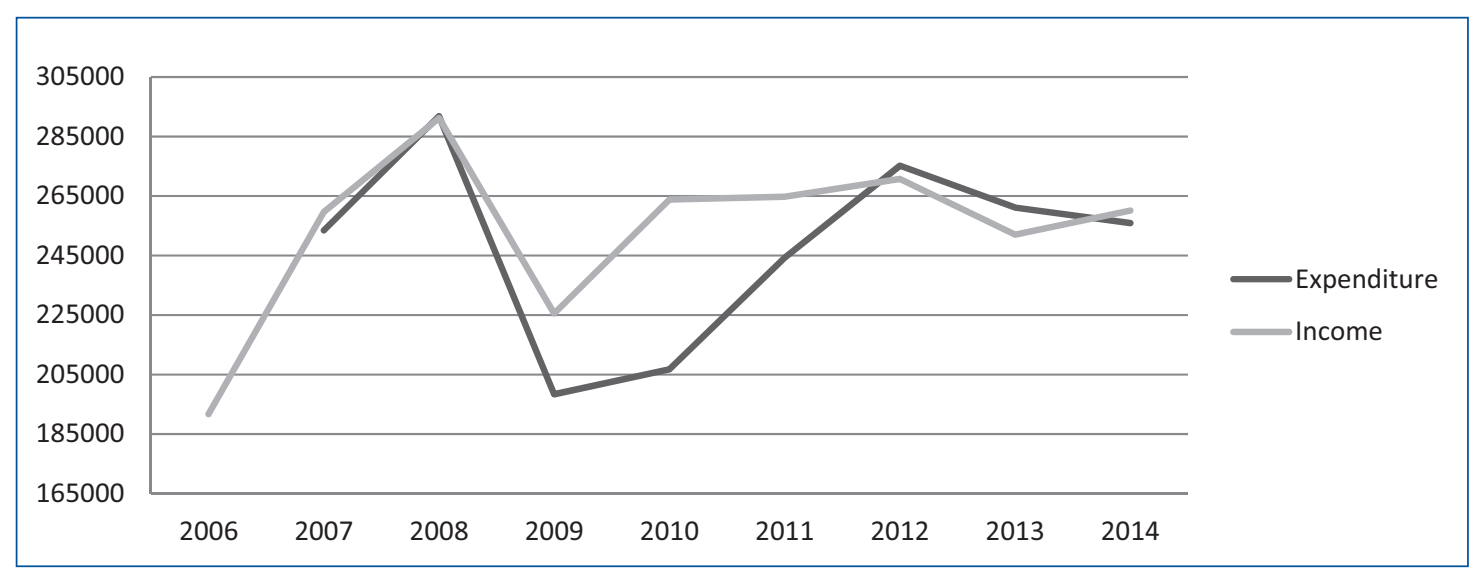

Source: Data retrieved from Ministry of Education and Science.

Fig. 1.6.Income and expenditure of state high schools and colleges

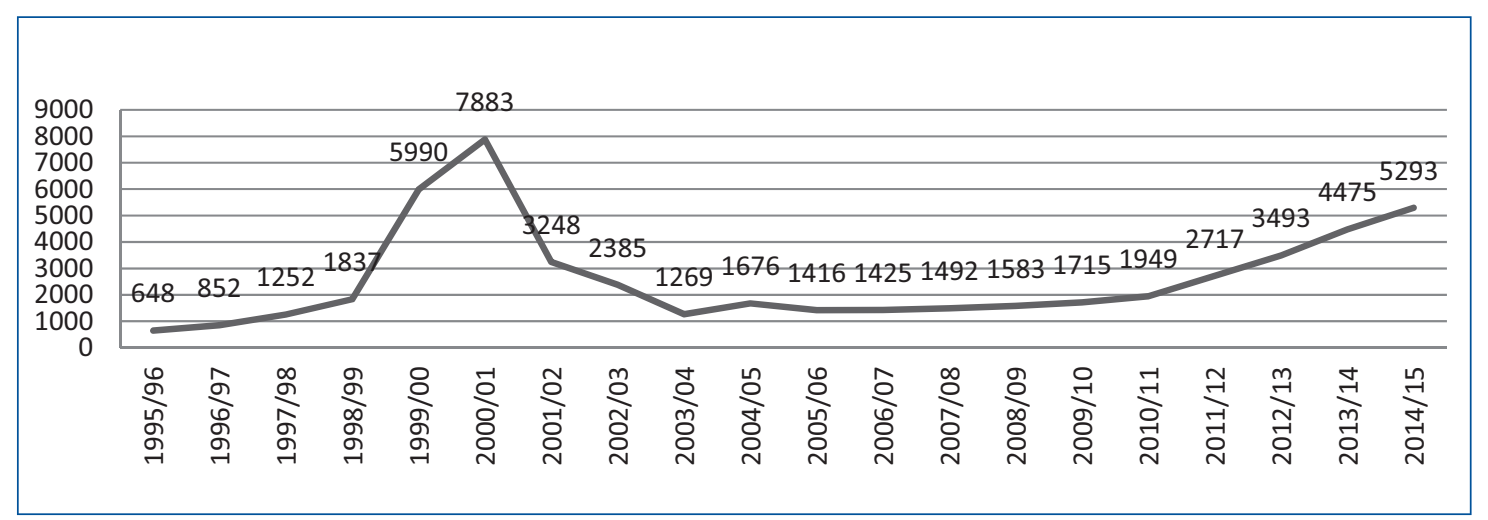

Source: Data retrieved from Ministry of Education and Science.

Fig. 1.7. The number of foreign students in high schools and colleges in Latvia 1995/1996-2014/2015

\section{Capacity analysis of Higher Education in Latvia}

In authors' opinion the greatest issue preventing business to grow and innovations to be made is the unsettled situation with the internal economic and demographic situation which clearly reflects in the tendencies of higher education. Right now the situation is unstable the number of students is decreasing, secondary and higher education institutions are being shut down and there are serious cuts made in the budgets. These changes, of course, influence the overall quality of education and the wish of young people to stay and become a part of the education system - more and more youngsters choose to continue their studies abroad, thus the number of students is being endangered even more. Undoubtedly, a great amount of financial support and thus the improvement of financial capacity would enhance the situation and would make the structural changes easier (which are necessary to stabilize the situation and 


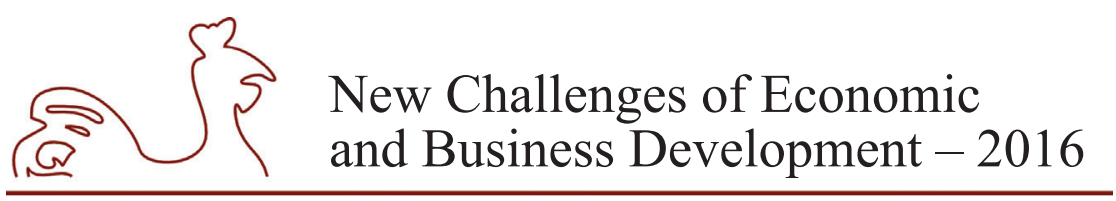

May 12-14, 2016, Riga, University of Latvia

raise the competitiveness of the education system in Latvia). However, authors see that other capacity factors must be seriously taken into account as well and thus they were deeper analyzed in the following expert interviews.

The purpose of this research is to find main factors hindering the changes in higher education and to emphasize the kinds of instruments to carry out policy changes we propose to make analysis based on capacity of the system.

Capacity in short is systems potencial to realize systems function, thus authors have identified and offer five main HE capacity elements:

- policy making capacity (what are the aims, desired outcome, are policies linked to other policies, policy implementation process etc.) - PC,

- legal capacity (normative base, accreditation system, potencial of state organizations etc.) - LC,

- the organisation of teaching and research capacity (including the relationship among the central level, constituent faculties and chairs or the internal organisation departments, curricular governance organization and structure, internal quality assurance mechanisms, external cooperation, etc.) - TRC,

- funding capacity (including national resources and European funding as Horizon 2020. Erasmus + , etc.) $-\mathrm{FC}$,

- information capacity (benchmarking exercises, exchange of good practices etc. ) - IC.

These capacity elements are nonformalized categories, but the authors need to evaluate the role of these elements to change systems capacity. To do this, expert interviews and elements judging was done.

The group of experts consisted of 5 very expierenced specialists in the field of Higher Education (representatives from Latvian Council of Science, State Education Development Agency, top managers of universities, including former minister of Higher Education and Science).

There were three questions formulated for the experts. The first question was about EU policy impact to the capacity elements of higher education in Latvia during the last 20 years. .Experts was asked to judge these elements (capacity elements) in interval scale from 1-10 (10 very high impact, 1 - very low impact.). The results can be seen in the Table 2.1.

The second question was about the significance of HE capacity elements to make a necessary changes in HE in Latvia. Experts were asked in the same scale to judged elements of capacity. The results can be seen in the 2.2.

Table 2.1

Experts' opinions about the impact of capacity elements on Higher Education

\begin{tabular}{|l|c|c|c|c|c|}
\hline & PC & LC & TRC & FC & IC \\
\hline Std. Deviation & 1,095 & 1,14 & 0,837 & 2,345 & 0,837 \\
\hline Variance & 1,2 & 1,3 & 0,7 & 5,5 & 0,7 \\
\hline Median & 7 & 5 & 7 & 8 & 8 \\
\hline
\end{tabular}

Source: authors' compilation from expert interviews. 


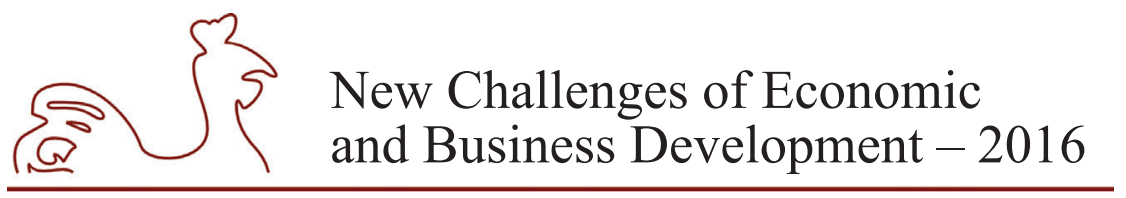

May 12-14, 2016, Riga, University of Latvia

Table 2.2

Experts' opinions about the significance of capacity elements on Higher Education

\begin{tabular}{|l|c|c|c|c|c|}
\hline & PC & LC & TRC & FC & IC \\
\hline Std. Deviation & 1,14 & 1,732 & 0,837 & 0,548 & 1,095 \\
\hline Variance & 1,3 & 3 & 0,7 & 0,3 & 1,2 \\
\hline Median & 9 & 9 & 8 & 10 & 8 \\
\hline
\end{tabular}

Source: authors' compilation from expert interviews.

When comparing the results of the question number 1 and number 2, it can be concluded that the most significant difference between impact and significance marks of elements is for one particular capacity element, which in this case is - legal capacity. It can be concluded that legal capacity is the main factor, which hinders the development of higher education in Latvia.

Table 2.3

The level of importance on influencing the development of HE

\begin{tabular}{|c|c|c|c|c|}
\hline Policy capacity & Legal capacity & $\begin{array}{c}\text { Teaching and research } \\
\text { capacity }\end{array}$ & Funding capacity & Information capacity \\
\hline 2 & 4 & 1 & 2 & 0 \\
\hline
\end{tabular}

Source: authors' compilation from expert interviews

After, experts were asked to judge interrelated impact of HE capacity elements in the following scale:

+2 - high positive impact,

+1 - positive impact,

0 - no impact,

-1 - negative impact,

-2 - very negative impact.

The interrelated impact of elements was used to find second level impact of each element, for this reason the third question answers were standartized in a scale: $1 ; 0.5 ; 0 ;-0.5 ;-1$.

The results (Table 2.4) first figure-impact, the figure in brackets-variance.

Table 2.4

Interrelated impact of $\mathrm{HE}$ capacity elements

\begin{tabular}{|l|c|c|c|c|c|}
\hline & PC & LC & TRC & FC & IC \\
\hline PC & XXXXXX & $1,0(0,2)$ & $0(0,315)$ & $1,0(0,25)$ & $0,5(0,05)$ \\
\hline LC & $0(0,175)$ & XXXXXX & $0(0,2)$ & $-0,5(0,075)$ & $0(0)$ \\
\hline TRC & $0(0,2)$ & $0(0,067)$ & XXXXXX & $0,5(0,125)$ & $0,5(0,05)$ \\
\hline FC & $0(0,125)$ & $0(0,05)$ & $1,0(0,45)$ & XXXXXX & $0,5(0,175)$ \\
\hline IC & $0,5(0,125)$ & $0,5(0,075)$ & $0,5(0,0)$ & $0,5(0,05)$ & XXXXXX \\
\hline
\end{tabular}

Source: authors' compilation from expert interviews.

The only negative impact was evaluated for legal capacity. Results shows that teaching and research capacity, which is the final outcome element of education and research very signifantly depends on funding capacity, while legal capacity has a negative impact on funding capacity. It means that if the government changes and promotes legal capacity, it is possible to substantially change the teaching and research capacity.

It is possible to make a conclusion about the necessary steps of the research - to find capacity elements second level impact to other element, which will allow us to find necessary actions to change capacity of all HE system. 


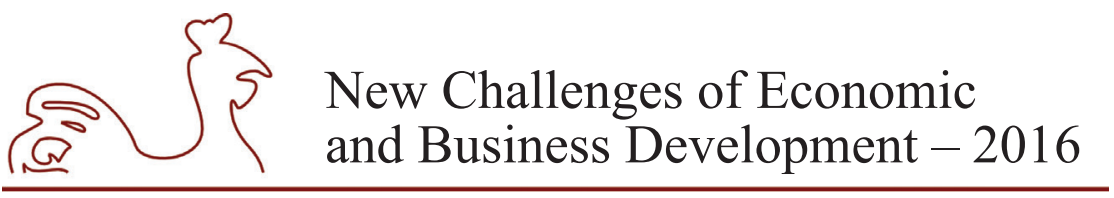

May 12-14, 2016, Riga, University of Latvia

The authors mark the significance of elements (Table 2.2) are organize as vector - column $\mathbf{B}$, while elements of (Table 2.4) .as matrix $\mathbf{C}$. Then multiplication of the elements will show the second level impact to other elements

$C^{*} \mathbf{B}$

Table 2.5

Second level interrelated impact on HE capacity elements

\begin{tabular}{|c|c|c|c|c|}
\hline PC & LC & TRC & FC & IC \\
\hline 23 & -5 & 9 & 12 & 18 \\
\hline
\end{tabular}

Source: authors' compilation from expert interviews.

Again it is possible to see the same result, which the authors obtained previously - the most negative impact has been detected in legal capacity as the main negatively influencing factor. While, for instance, teaching and research capacity as final outcome element has not significant impact to other elements. If the information capacity has to be analyzed, experts also make an emphasis that information exchange and contacts with partners in other countries help to make positive changes in teaching process and organize international teams to win project tenders.

The results of expert interviews allow authors to determine and provide next steps of research to clearly identify the further strategy which has to be implemented to develop a successful higher education development. It is necessary to make audit procedures in particular higher education organizations to measure and identify lack of capacities in these organizations. Thus, after identifying weaknesses in particular organizations (especially paying attention to the questions connected with legal capacity) it would be then possible to plan the next steps to enhance the situation of further development. Since legal capacity element impact was negative, audit in particular organizations can give more precise information about decisions, which need to be made to increase the capacity of HE system.

\section{Conclusions}

1. The education is very important factor in small countries like Latvia to achieve economic and social growth and welfare.

2. The education system is strongly interrelated with different internal and external factors, which means that the long term strategy to be successful, it has to be well planned and has to have a well-designed environment to operate in.

3. However, for the EU policy to be successfully implemented in the particular situation of Latvia, some adjusted have to be made.

4. After, EU policy will have significant impact to the HE development, if the necessary changes will have been introduced.

5. It can be concluded that expert interviews and expert judging approach of HE capacity elements allowed finding weaknesses of the system and this method can be used in further researches in the field.

6. The element which can be perceived as the main hindering element in experts' opinion is lack of legal capacity. 


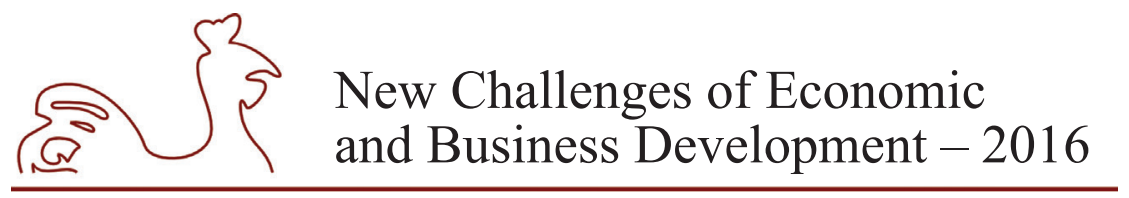

May 12-14, 2016, Riga, University of Latvia

\section{Bibliography}

Central Statistical Bureau, Data on the number of students currently studying in higher education institutions, 2015.

Espeland W. N. \& Saunder, M. Rankings and reactivity: how public measures recreate social worlds, American Journal of Sociology, 113, pp. 1-40, 2007.

Gornitzka, Å. Channel, Filter or Buffer? National Policy Responses to Global Rankings. In T. Erkkilä (Ed.), Global university rankings: Challenges for European higher education (pp. 75-91): Palgrave Macmillan, 2013.

Gornitzka, A., \& Maassen, P. Dynamics of convergence and divergence: Exploring accounts of higher education policy change. In P. Mattei (Ed.), University Adaptation in Difficult Economic times (pp. 13-30): Oxford University, 2014.

Howlett, M. What is a policy instrument? Tools, mixes and implementation styles. In F. P. Eliadis, M. M. Hill, \& M. Howlett (Eds.), Designing Government: From Instruments to Governance (pp. 31-50). Quebec: McGill-Queen's University Press - MQUP, 2015.

Ministry of Education and Science, personally retrieved data, 2015.

Rauhvargers A. Where Are the Global Rankings Leading Us? An Analysis of Recent Methodological Changes and New Developments? European Journal of Education, Vol. 49 , No. 1, 2014.

The Global Competitiveness Report 2006-2007, 2008-2009, 2009-2010, 2010-2011, 2011-2012, 2012-2013, 2013-2014, 2014-2015, Klaus Schwab, prof. Michael Porter, World Economic Forum.

The Council of Higher Edcuation "The conception of development of higher education and universities, 2013-2020”, AIP, Latvijas Augstakās izglītības un augstskolu attīstības nacionālā koncepcija 2013.-2020. gadam Retrieved on January $11^{\text {th }}$, http://www.aip.lv/informativie_zinojumi_5.htm.

Trebilcock, M. J. The Choice of Governig Instrument: A Retrospective. In F. P. Eliadis, M. M. Hill, \& M. Howlett (Eds.), Designing Government: From Instruments to Governance (pp. 51-73). Quebeck McGill-Queen's University Press - MQUP, 2005

Witte, J. Parallel Universes and Common Themes: Reforms of Curricular Governance in The Bologna Context. In A. Amaral, G. Neave, C. Press.Musselin, \& P. Maassen (Eds.), European Integration and the Governance of Higher Education and Research (Vol. 26, pp. 227-255): Springer Netherlands, 2009. 


\title{
IMPRINTS OF GLOBAL AND LOCAL ECONOMICS: FAMILIES AND HOUSEHOLD ECONOMICS IN LATVIA
}

\author{
Aivita Putnina, University of Latvia, Latvia ${ }^{1}$
}

\begin{abstract}
The aim of paper is to address the family and household economics as a crucial area for understanding the context for social innovations and the conscience economy. It is based upon a piece of 3 year-research on financial literacy among Latvian adolescents and their families. It combines both quantitative and qualitative methods: a regionally-representative household survey (561 households, including 203 double interviews), 29 qualitative interviews with 38 persons and participant observation in 8 families conducted by anthropology students at the University of Latvia. Starting as a project on financial education at schools it soon moved to the families as centre for forming financial literacy knowledge and skills. The logic and development of household economics permits the answering of questions on the high resilience of the Latvian population during years of austerity, comparatively low trust towards formal financial instruments in investing, saving or borrowing money. Social solidarity, investment in durable goods and in morally highly valued products and possessions such as education or a house in countryside, comprises a system of economics with its own rules. So, it is not the lack of knowledge but rather a different kind of knowledge which expresses itself when families face formal economics. The paper shows that a person's financial literacy is deeply rooted in his or her household economics and any change and innovation in the larger economic system is possible only at the cost of transforming socially-embedded economic behaviour in family.
\end{abstract}

Key words: conscience economics, financial literacy, household economics

JEL code: $\mathrm{I} 3, \mathrm{Y} 8, \mathrm{Z} 1$

\section{Introduction}

Latvian national development is encored in the concepts of "economic breakthrough" (National Development Plan of Latvia 2014-2020), innovative, "eco-efficient economy" and change of paradigm in education (Sustainable Development Strategy of Latvia until 2030). At the same time surveys show that only $34 \%$ of the inhabitants of Latvia evaluate their financial literacy as good or rather good. In the generation in which hope for the "breakthrough" is placed - 15-24 year olds - the percentage whose evaluation of their financial literacy is good is 38\% (SKDS, 2011: 17). Around 36\% of school teachers evaluate themselves as financially literate (ibid: 41). It is often assumed that poor financial literacy is responsible for the economic behaviour of the Latvian population: relatively low participation in the formal sector banking with a poor understanding of economic processes preventing the larger part of population from active economic activity. I argue that the problem of low economic activity, the slow rate of innovations and entrepreneurship development should be understood taking a wider social

Corresponding author - e-mail address: aivita.putnina@lu.lv 


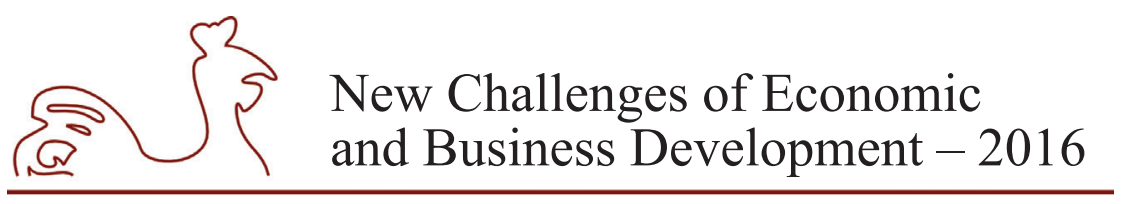

May 12-14, 2016, Riga, University of Latvia

context into account. Knowledge and skills for economic activity that most Latvians have cannot be counted as financial literacy in terms of formal economic theory but those still have allowed them to endure economic hardships and years of austerity measures without showing any significant social protests. Thus, in order to look into innovations and the boosting of economic activity, one should look into the social embeddedness of all economic activity even it lies outside the scope of conventional economics.

Cosgel (2009: 86, 92), reviewing the relationship between economics and anthropology, points out "the different division of labour" in both disciplines, resulting in different approaches and understandings of economics. Economists apply a more universalistic model and theories, macro approaches and use quantitative data (ibid: 86-7) while anthropologists give preference to qualitative approaches and diversity of economic activity and its logic. The anthropological perspective highlights the embeddedness of economics in culture and society allowed for the questioning viability of the universal principles underlying economic processes everywhere around the globe (Hart, Hann, 2009: 14). The call to look at economics as a discipline equally embedded in its theories as in other social contexts (Callon, 1998) inaugurates a cultural relativist approach to economics in science and technology studies (also MacKenzie, 2001, Green, 2000). However, economists themselves have been concerned with the social - Nobel prize winners Gary Becker (1993) and Amartya Sen (1998) being prominent examples, but also Robison, Ritchie (2010), e.g., embed social relations and conscience in economic analysis through the concepts of social capital and socio-emotional good.

Economic anthropology has developed two main approaches relevant to understanding relationship between the economic and social spheres. The approach was developed in societies and cultures often lacking market and that allowed criticising a universalistic position and trace the continuity of the social in organizing economic life in particular communities. The relativist approach starts with Polanyi noting that the shifting place of economy in a society allows distinguishing four basic models of economic behaviour based on different kind of social relationships and institutions and conceptually separating non-market and money-making principles of economic behaviour (2001[1944]). Stephen Gudeman (2001: 6-7) proposes, instead of the neoclassical model of economy where the value relativism is based upon the link between individual preference influencing demand and which in combination with supply determines the good's value, considering human existence within "inconsistent or incommensurate domains of value that are locally specific". Another approach uses the concept of informal economics as a variety of alternative economic system, following Keith Hart (1973). It focusses on those societal sectors and activities which fall out of the scope of the formal production process.

Gudeman (2001) calls us to pay attention to two distinct realms where 'economics' takes place: the community and the market taking into account the differences in social relationships and exchange in both realms. The distinction is a conceptual one and allows uncovering complex relationships between the realms in a cross-cultural perspective. This distinction is useful in my interpretation as it allows capturing not only the impact of transition to the economic system but also the changing relationship between the market and the community. According to Gudeman, the 'base' is the grounds for any community (community ranging from domestic group to a state). He (ibid: 27) deliberatively uses the notion of commons distinctly from economics or political science and claims that "the commons is the material thing or knowledge a people have in common, what they share, so that what happens to a commons is not a physical incident 


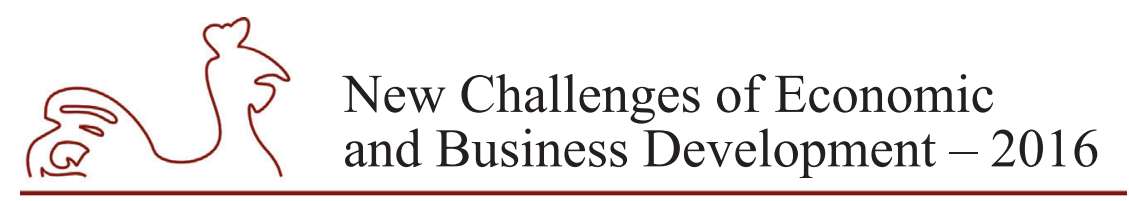

May 12-14, 2016, Riga, University of Latvia

but a social event." This base is sustained by moral sanctions and is "a symbol of identity, an expression of values, or a source of material sustenance such as a dam or reservoir - and it may be used for market purposes" (ibid: 29). Gudeman (2005: 97) sees the market "a powerful solvent of community" seeing this economic realm being built on contractural relations and dissolving bonds between people and communities but simultaneously creating new relations via goods and services. However, the market realm should not be demonized as there is evidence of the presence of morality - notions of respect, equality and goodness - in all economic activity (Sayer 2000, Fischer, 2012).

\section{Research methodology}

The paper is based on three related research projects conducted by social anthropology students under supervision of experienced researchers, these being myself, Ilze Birzniece, Mara Pinka and Maris Brants. The first research project in 2012 dealt with secondary school teachers and students aged 16-19 and involved 19 schools across Latvia. In total, 67 interviews with students and 15 teachers of economics were conducted, as well as 21 focus group discussions involving 210 students in total. In this choice of schools, diversity was taken into account, selecting schools in different regions and with different curricula: 11 of the schools had a special course in economics or commerce while eight schools did not; 4 of the schools were vocational schools.

The second stage of research was conducted in March 2013 and included eight Latvian households using interviews and on average three-day participant observation as tools. The criteria for the selection of households was the presence of at least one 16-19-year-old person in the household. To diversify the data, families were selected according to the location of their residence (rural areas and cities, regions) and family structure (number of children and number of generations living together). In total 29 interviews were conducted, part of them double or triple interviews with 38 participants in total.

The quantitative survey was conducted in April-May 2013 in all regions of Latvia. The survey approached domestic units and consisted of a set of quantitative self-completed questionnaires including an adolescent and at least one of the parents or guardian. In total 561 valid questionnaires were collected; 203 were sets with two parent or guardian questionnaires. Two data files were created for analysis: a unified data file for households and a consolidated data file for parents and guardians. The consolidated data file combined a adolescent's questionnaire and one of his or her parents' questionnaires. As the number of men participating as parents was in a considerable minority (264 of 764), in those cases when two parent questionnaires were available, that of the male parent was selected. In those cases, when the both parental questionnaires were completed by women (e.g. mother and grandmother), the choice was random. All parental questionnaires were included in the consolidated file for parents and guardians, weighting was applied to balance the input of two-parent and one-parent questionnaire sets. 
May 12-14, 2016, Riga, University of Latvia

\section{Findings and discussion}

\section{Financial literacy: market and community realms}

The first cycle of researched showed that the school curricula has contributed to the definition of financial literacy. Students understood it as knowledge in economics, finance and budget planning. However, it simultaneously had generated low self-evaluation of one's own financial literacy and had created a perceived lack of practical experience in utilizing that knowledge. Teaching economics at school had, rather, produced scepticism and passivity and allowed students to position themselves as immature and still irrational persons in relation to economic activity, thus effectively placing themselves outside it. The data showed that moral criteria prevail in evaluating one's economic behaviour - economizing, saving, planning, the ability to take decisions rationally - were recognized as superior to their everyday economic behaviour which was often related to their actual experience of overspending, spontaneous consumption and short-term thinking.

Using the analytical division between community and market realms (Gudeman, 2001), one can see that students and their teachers attribute their financial literacy to the market realm and speak of it the context of formal economics. It is not that students do not participate in economic activity but rather those (often even monetary) exchanges are placed outside the market sector. For example, students often borrow from or lend money to each other but those transactions are operated on a principle distinct from the market. Friendship, one's position in a group and other factors influence when, whether and how money would circulate and students deduce that this exchange is somehow different from that discussed in class. The link between the community and market proves to be weak in most cases. Students do not see themselves as a part of the economic process. Sometimes this concern is expressed through the wording that economics at school is too theoretical to be applied in real life. Students see themselves as consumers and consumption forms their strongest link to the formal economy. The financial skills they practice are tightly clustered around consumption though the logic of consumption often is generated in the community realm. For example, students see saving as an act of consumption, consciously choosing discount offers and limiting spontaneous purchases:

I try to think do I really need that or another thing? Should I buy that now or later? Such simple planning. (Female student in private school, interview)

Students of vocational schools make an exception, establishing better links between community and market realms as they start their independent life earlier and have a regular income outside the household. In general, all students who had regular work experience in the formal economic sector could build better links between community and market realms and could apply formal economics to their daily economic activity. Another link between the market and community realms was made out of personal links in the community groups. Financial expertise of a household most often came from the experts working in the financial fields but this expertise was validated through their relatedness to household members. So, a Riga secondary school teacher, when asked about the financial literacy of her family, said:

It is good. [In the family] I have a Master in Economics in the Ministry of Welfare, I have a Master in Computer Programming in the Ministry of Finance and now from a private structure 


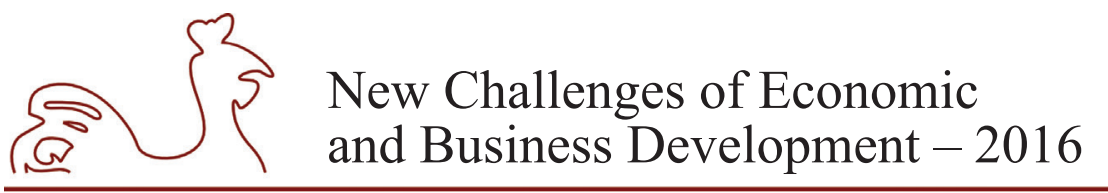

May 12-14, 2016, Riga, University of Latvia

[...] I have one, two, three shop keepers. Our family would be a success in a financial literacy contest.

In general, households tend to draw expertise not from just any bank expert as those would work in the interest of their employer bank but from a bank expert loyal to their family. Students avoided direct contacts with banks as they did not see themselves as worthwhile clients.

\section{Household economics}

A closer look at households allows for the explaining and positioning of the economic behaviour of students. When asked of the source of their financial skills, $60 \%$ of students mentioned their family, the next popular option being "it is hard to say" at $21 \%$. School and friends appear as 5\% each, scoring just above internet or media at $-4 \%$. Qualitative and quantitative research of domestic units showed their high ability to adapt to economic crises but a low ability to improve one's economic position rapidly. Regularity of income in households plays a greater role than its size and this factor allowed for the accepting of lowering salaries as a lesser risk than losing a job (Fig. 1.).

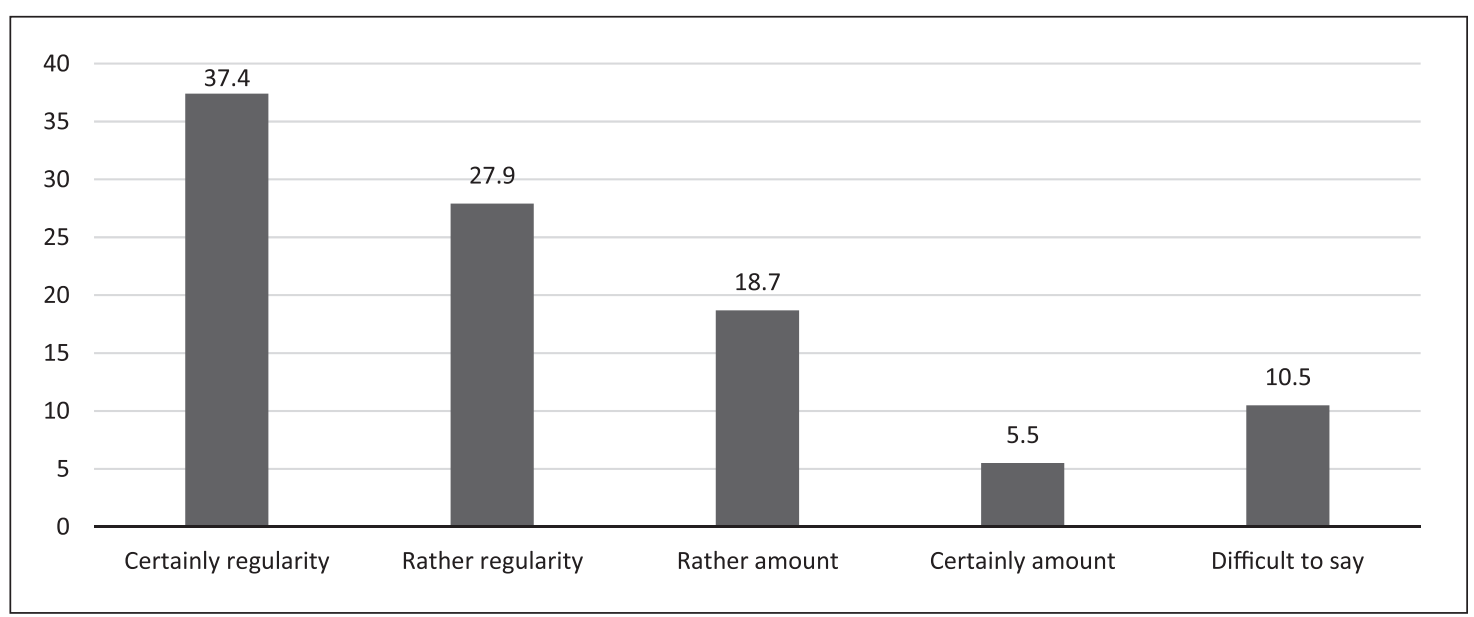

Fig. 1. Which of the mentioned below is more important to you - regularity or amount of income? Answers of parents, \%

According to household logic, job loss is the most significant threat to the household, followed by health problems. Threats rising from national economic crises are less significant. When asked about the ability of their household to survive with a complete cut of income, $43.7 \%$ of parents and $37 \%$ of students estimated a potential period less than one month. 19.5\% of parents and $31.2 \%$ of students could not answer the question.

The quantitative survey confirms the qualitative data that households tend to see themselves as autonomous units trying to protect themselves from the influence of the state and financial system. Vulnerability of the household is seen as its internal strength; this is why the loss of a job or health is most significant threat to households. Households see tax increases or communal building service charges as a threat to the household which is inevitable and out of the scope of its control but those threats could be compensated in the closest communal realm by accepting 


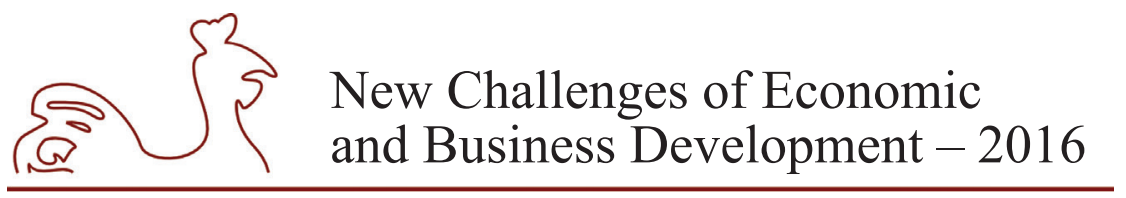

May 12-14, 2016, Riga, University of Latvia

help from family, friends and immediate community, e.g., acquiring products from family or a friend's farm or preparing food reserves that could be shared.

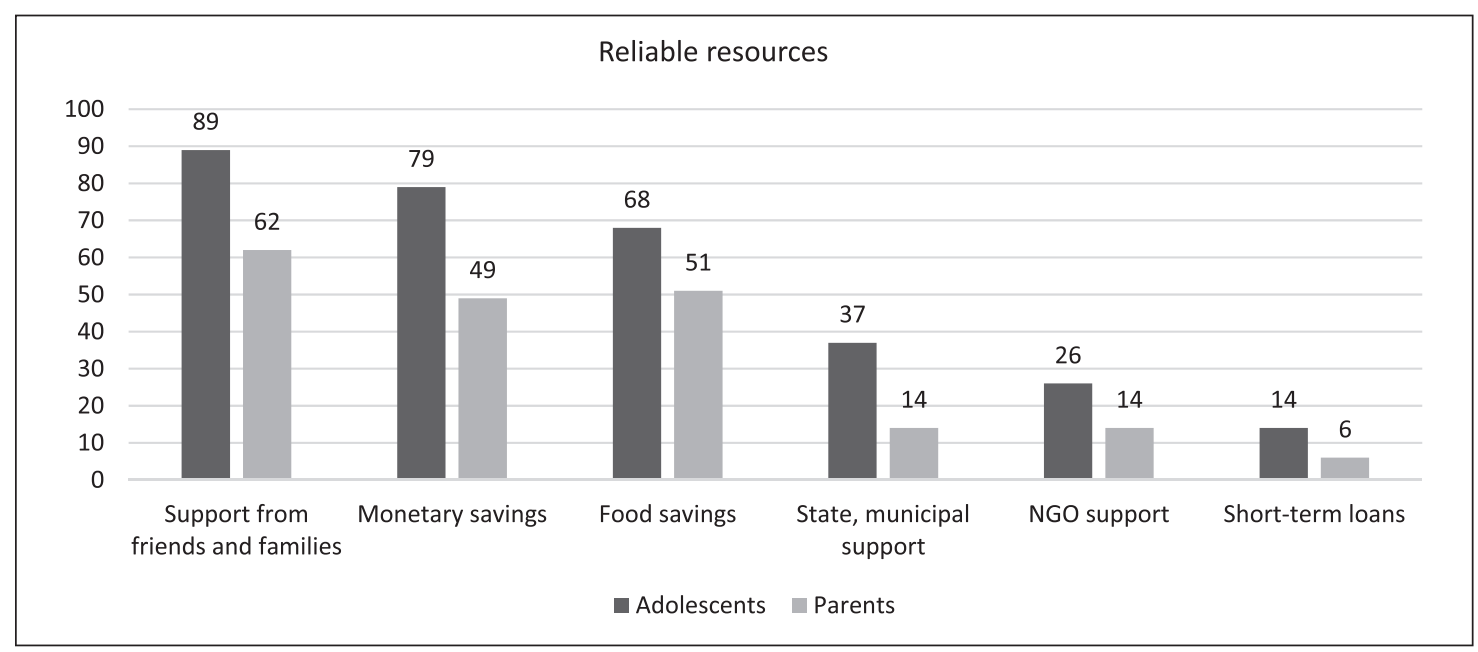

Fig. 2. To what extent would you rely upon those resources should your family loose regular income? Answers: "would rely" and "would rather rely", \%

Figure 2 shows the priorities of households in crisis situations. For the parents' group, support of family and friends plays the most important part in adjusting to crisis $(62 \%)$, the next being food supplies (51.1\%), monetary savings taking only third place (49\%). Reliance upon formal structures such as local governments or NGO support is much lower. Adolescents are more optimistic about support but the grading of the reliability of support is similar to their parents', except that adolescents put more emphasis on monetary savings than on food savings.

Qualitative household research allows for a deeper understanding of the household logic. According to this research, most households operate on a zero budget. A short zero cycle lasted one month from one payday to another. A decrease or increase in income was adjusted to this cycle, making household spend less or more.

This is not that we would not spend and would not go to a concert but would put it [money] somewhere for emergency situations. No, that is not so, absolutely not... At the end of month, of course, everything rounds to zero, zero and that's it. (Father, Riga)

The zero cycle also operates in the long-term as an inter-generational relationship. Parents are expected to support their children through their process of education and children are expected to help their parents when elderly. The zero budgeting provides an illusion of independence and autonomy from the market. The monthly budget allows for the controlling of means in the shortterm but the life-time budget balances income and out-payments during one's life-cycle. The aim of the zero budget is reproduction of the household but not the production of surplus value. 


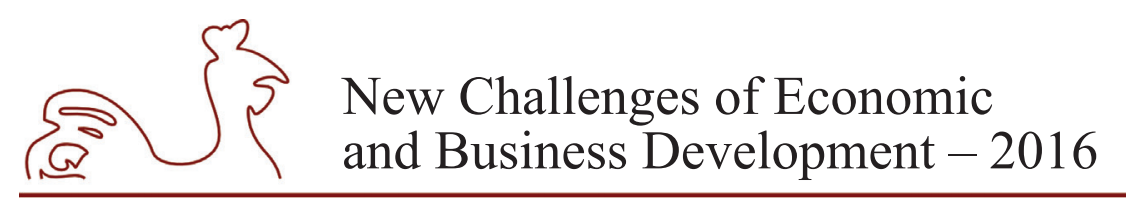

May 12-14, 2016, Riga, University of Latvia

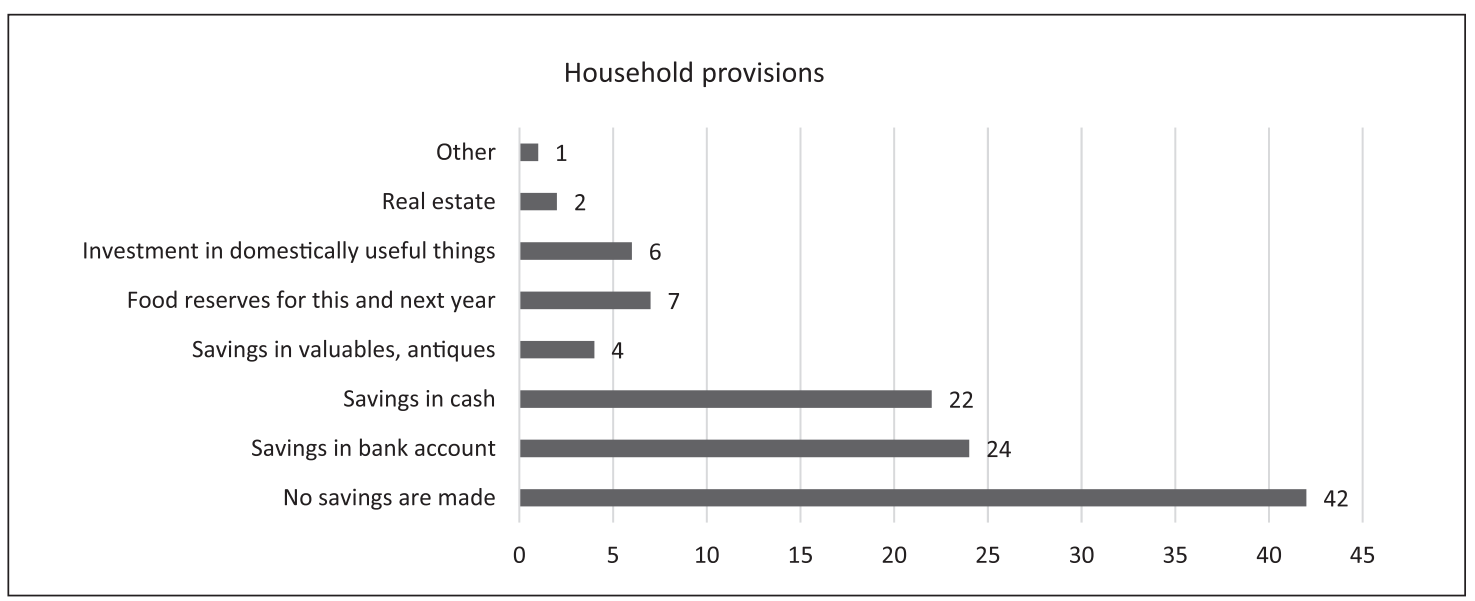

Fig. 3. Which provisions does your family make for crisis situations? Parents' answers, \%

Looking at the provisions of Latvian residents, economics looks at bank accounts and financial investments. As Rivera and Gudeman (1990) point out, saving is a larger scope of activities directed at various savings. Participants of household survey do not consider all savings equally beneficial. Most often households save on clothing, natural resources and sometimes food. Monetary savings most often are used to acquire particular goods. Large monetary savings without a goal are considered impracticable. The quantitative survey (Fig. 4.) shows that almost a quarter of respondents used banks but most often did not save at all. Savings in cash lagged just 2 points below.

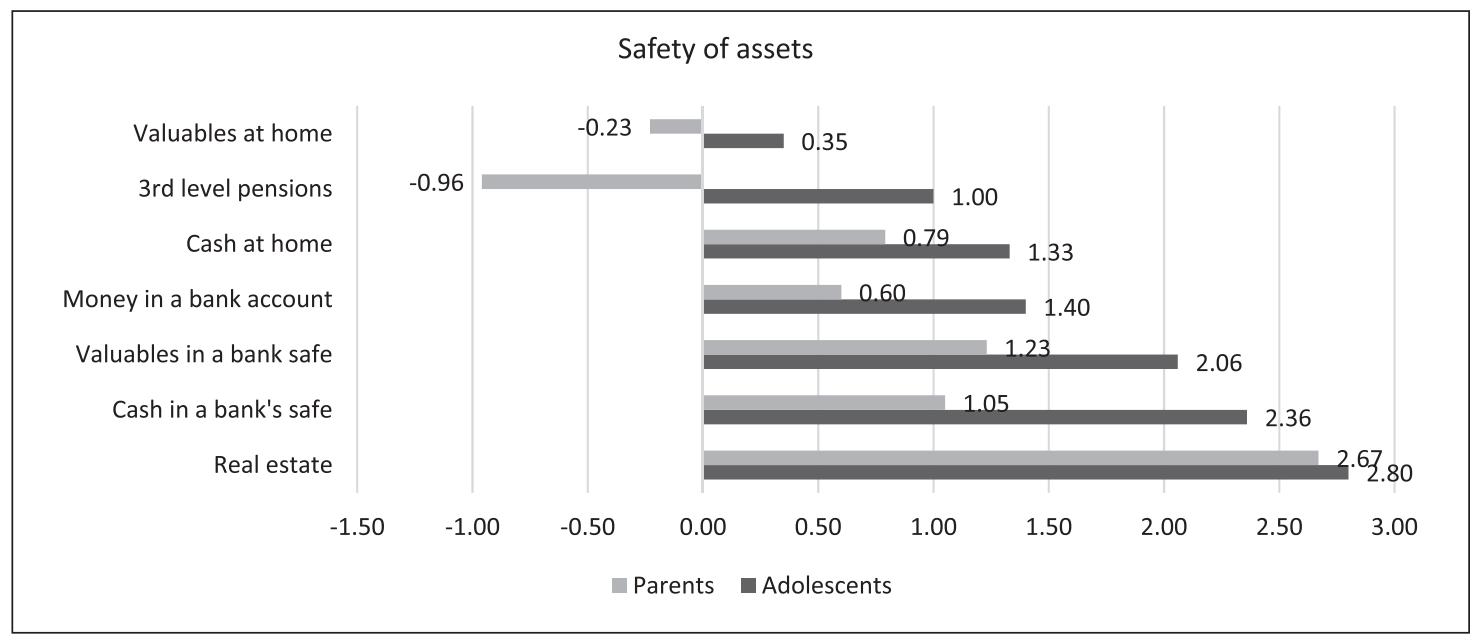

Fig. 4. How would you evaluate the safety of following assets in a scale -5 to +5 ? Mean scores of answers

Provisions and investments depend upon their perceived safety. Real estate (and especially when it is inherited and free from mortgages) is considered the safest asset. In the scale from -5 to +5 parents ranked real estate with an average of 2.67 points and adolescents ranked it 


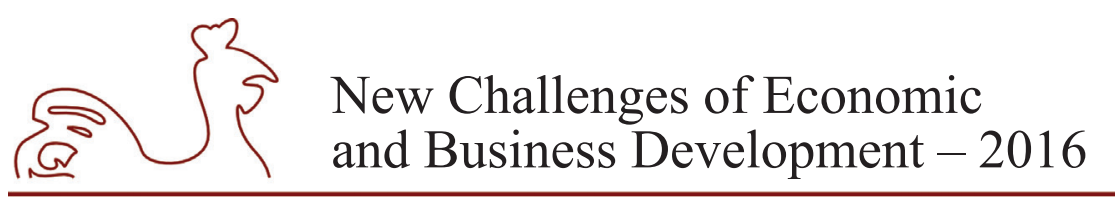

May 12-14, 2016, Riga, University of Latvia

with an average of 2.8. It was followed by cash savings and valuables in bank safety deposit facilities which is a popular option of imagining money not only among adolescents but also their parents. Bank accounts and the third-level pension system are considered less safe. Parents did not see this pension level as security. Adolescents repeated their parents' pattern and, though being more optimistic, do not demonstrate any fundamental change in thinking about assets those forms of assets that are controllable by an individual and households still seem to be the safest. Qualitative household research shows that individual members of households do have savings in banks but they did not want to speak about this openly and the amount of the savings sometimes was not disclosed to other members of the household. Individual savings run against the community interest and are a disruption from common base resources.

\section{Commons in Latvia: education and "one's corner of land"}

According to Gudeman, the base is understood as material and social entities created and used by a particular community. Research shows that Latvians share two important base assets: education and real estate. Education functions as a base asset which is important for nation building and it is expected to reproduce not only labour but common national values. Adolescents see education as the main driver for their future careers. This allows adolescents and their family to rely upon education as a base resource without questioning its economic rational validation. Thus students see education as the most available form of investment which might yield results in the future, though they do not feel its immediate gain in the present. Adolescents mostly think of their future in terms of social position they could acquire via education rather than in terms of their position in the labour market. Adolescents evaluate classes in economics highly but they do expect it utility in unforeseen future:

We learnt a lot during classes in economics but it is not so well with my own budget in weekly or monthly terms. (Female student, interview, Riga secondary school)

The base value of education is upheld by the general assumption that education is a good investment. Survey data shows that $93.5 \%$ of parents support the investment in their child's education. Education thus becomes an important element in the household budget and parents believe it is their duty to support their children through the educational process. Almost half of parents $(46.5 \%)$ do not expect their children to begin wage earning and sustaining themselves in the near future. The survey data clearly shows that education is highly respected as a value in itself $-93.5 \%$ of parents support a free unconditional choice of their child's profession, respect the autonomy of choice $(80.2 \%)$ but at the same time expect that the education would provide a well-paid job (83.9\%). Parents invest in their children's education from the age of kindergarten attendance, believing in the natural goodness of such investment.

Another example of base economics is real estate, which can be located both in communal and market realms. Countryside real estate is a typical example of such a communal base. The family house is considered as especially valuable property as it is linked to family values, history and unity of the family, disregarding its costs and price. So, a mother from the Zemgale region talks of her family trips to their family house in countryside:

I did calculate this summer [expenses related to sustaining countryside estate], we have spent 370 lats on petrol and guess what? Did we get potatoes and courgettes for those 370 lats? No. This is not such kind of gain. (Mother, Zemgale) 


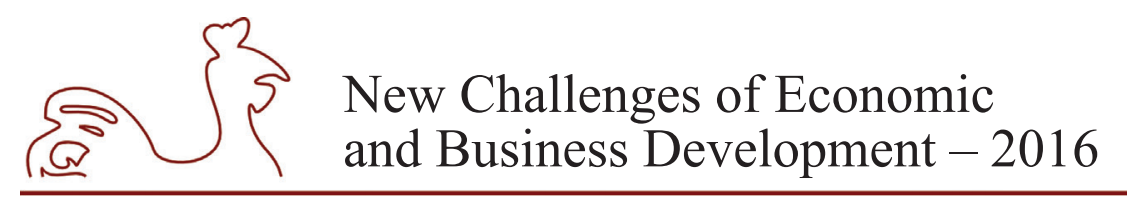

May 12-14, 2016, Riga, University of Latvia

A newly acquired city apartment, often burdened by debt, is seen differently - not as part of domestic community but a market product which can be exchanged and sold. Interviews show that adolescents support the reproducing of the family realty and education as economics of base.

\section{Conclusions}

1. Base economy and community realm are useful tools in analysing economic processes in 'transit societies' such as Latvia. The change of economic system involved not only the transit from a socialist to market economy but involved a more complex social change. The base economy is embedded in social relations ranging from one's family and closest community networks to the nation and thus operates on a different system of values and logic. Education and real estate are more prominent examples of base resources important for household and national level communities in Latvia.

2. The whole education system in Latvia and especially that of higher education relies upon zero cycles of households as parents are expected to cover the educational costs of their children. Parents do not rely on the pension system as they expect a return from their children. It is also difficult to reform the system of education as it depends not only on measurable criteria of efficiency but is used as a base, a symbol for nation building, social structure and ethics. Therefore, as the research shows, the education system is not expected to deliver rationally-defined skills and respond to the needs of the economic system but to reproduce base-related values.

3. Household economics are well tuned to survival in the midst of austerity measures but badly fitted for economic breakthrough. Inner social security networks, investment in goods and education prevent persons investing in other sectors. The lack of social security strengthens the isolation of households and facilitates their passivity in formal economics. An unconditional belief in the power of education system as a general community-based value prevents adolescents becoming active participants in market realm.

5. Economic breakthrough requires the making of new connections which markets could offer - improvement of living conditions in households, fostering the ability to look at economic processes differently and creatively - and those are inevitably related to breaking the zero domestic cycle and the critical revision of education system, household habits and current societal values. This change would call for a greater individualization of society.

6. The inclusion of notions of base economics in research, teaching and national development plans would allow for a better understanding and addressing of the local economy, would encourage critical thinking and reflexivity about one's economic habits. The market economy and its financial literary is entering a space already pregnant with meanings, values and social relationships.

7. Reforms in the sectors of education and economics should take into account the wider social context which could be translated into culture-specific economic indicators which built upon native understanding and practice of economics. Bridging the gap between anthropology and economics would thus contribute to a more encompassing approach to national development and innovations. 


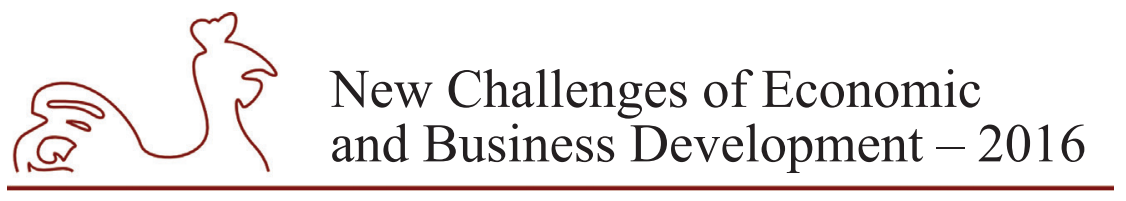

May 12-14, 2016, Riga, University of Latvia

\section{Acknowledgements}

This paper was supported by University of Latvia and EKOSOC - LV programme project No 5.2.4. "Renewal of society thought reducing the risk of depopulation, through demographic development and strengthening links with the Diaspora for the transformation of the economy in the Latvia".

\section{Bibliography}

Becker, G. S., 1993. Nobel Lecture: The Economic Way of Looking at Behavior. Journal of Political Economy 101(3), pp. 385-409.

Callon, M., 1998. Introduction: The Embeddedness of Economic Markets in Economics. The laws of the markets (ed.) M. Callon. Oxford: Blackwell.

Cosgel, M., 2009. Conversations Between Anthropologists and Economists. Economic Persuasions. (ed.) S. Gudeman. New York: Bergham Books, pp. 81-96.

Fischer, E., 2012. The Good Life: Values, Markets, and Wellbeing [e-book]. Available at http://openanthcoop. net/press/2012/09/20/the-good-life-values-markets-and-wellbeing/ [Accessed: 15 March 2016].

Green, S., 2000. Negotiating with the Future: The Culture of Modern Risk in Global Financial Markets. Environment and Planning D: Society and Space. 18 (1), pp. 77-89.

Gudeman, S., 2001. The Anthropology of Economy Community, Market, and Culture. Blackwell Publishers.

Gudeman, S., 2005. Community and Economy: Economy's Base. A Handbook of Economic Anthropology. (ed.) J. G. Carrier. Edward Elgar Publishing Limited, pp. 94-106.

Hart, K., Hann, C., 2009. Introduction: Learning from Polanyi 1. Market and Society: The Great Transformation Today. Cambridge University Press, pp. 1-16.

MacKenzie, D. 2001. Physics and Finance: S-terms and Modern Finance as a Topic for Science Studies. Science, Technology and Human Values. Vol. 26 (2), pp.115-44.

Pārresoru koordinācijas centrs, 2012. Latvijas Nacionālais attīstības plāns 2014.-2020. gadam. Available at http://www.pkc.gov.lv/images/NAP2020\%20dokumenti/20121220_NAP2020_apstiprinats_Saeima. pdf [Accessed: 15 March 2016].

Polanyi, K., 2001 [1944]. The Great Transformation: The Political and Economic Origins of Our Time. Boston, Mass.: Beacon.

Rivera, A., Gudeman, S., 1990. Conversations in Colombia. The Domestic Economy in Life and Text. Cambridge: CUP.

Robison, L. J., Ritchie, B. K., 2010. Relationship Economics: The Social Capital Paradigm and Its Application to Business, Politics, and Other Transaction. Surrey: Gower Publishing.

Saeima of the Republic of Latvia, 2010. Sustainable Development Strategy of Latvia until 2030. Available at http://www.pkc.gov.lv/images/LV2030/LIAS_2030_en.pdf [Accessed: 15 March 2016].

Sayer, A., 2000. Moral Economy and Political Economy. Studies in Political Economy. 61, pp. 79-104.

Sen, A., 1998. The Possibility of Social Choice. Nobel Lecture, December 8, 1998. Available at http:// www.nobelprize.org/nobel_prizes/economic-sciences/laureates/1998/sen-lecture.pdf [Accessed: 15 March 2016]

SKDS, 2011. Mērķa grupu finanšu pratības izpēte. Pētījuma rezultātu ziṇojums. [unpublished] 
May 12-14, 2016, Riga, University of Latvia

\title{
SOCIAL PARTICIPATION THROUGH VOLUNTEERING AS CO-PRODUCTION OF PUBLIC SERVICES: CASE STUDY OF LATVIA
}

\author{
Romans Putans, University of Latvia, Latvia \\ Olga Starineca, University of Latvia, Latvia ${ }^{1}$ \\ Inesa Voroncuka, University of Latvia, Latvia
}

\begin{abstract}
Active civic and social participation is considered to be significantly important for a country's development in democratic societies. One of the popular forms of active citizenship is volunteering - the third economy sector that produces civic goods and/or services in which the public and private sectors are weak or inactive. In this aspect, volunteering is also a means for organized civil society to participate in the production of public services i.e. co-production.

The aim of this research is the exploration of social participation in Latvia through volunteering, including its legal regulation and organizational setup, and identification of the aspects and prospects of volunteering in Latvia within the concept of co-production of public services. The research is exploratory by design. The main methods of the study applied are analysis and synthesis.

Volunteering in Latvia is yet on its way to being considered a valuable part of general active citizenship and social participation, and admittedly even further from being a serious part of co-production. Compared to other European countries, volunteering in Latvia is a new way of social participation that mostly attracts youth and seniors. Volunteering is only a relatively recent recognized activity in Latvia, however this sector of economy is developing and has its achievements.

The current research has both theoretical and practical application. The study is organised within the framework of the EU program's "Europe for Citizens" international project "Volunteering - Code of Active Citizenship" implemented in cooperation with six partners from different EU member states under the leadership of Kaunas University of Technology.
\end{abstract}

Key words: Volunteering, Social participation, Active Citizenship, Co-production, Public good JEL code: D71, O15

\section{Introduction}

Active civic and social participation is considered to be significantly important for a country's development in democratic societies. One popular form of active citizenship is volunteering - the third economy sector that produces civic goods and/or services in which the public and private sectors are weak or inactive. In this aspect, volunteering is also a means for organized civil society to participate in the production of public services i.e. co-production.

Volunteering in Latvia is yet on its way to being considered a valuable part of general active citizenship and social participation, and admittedly even further from being a serious part of co-

1 Corresponding author - e-mail address: olga.starineca@lu.lv 


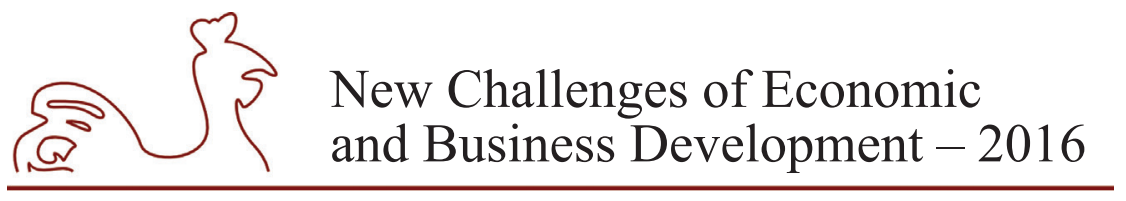

May 12-14, 2016, Riga, University of Latvia

production (Alford J., 2013; Hansen G.V., 2015; Tuurnas S., 2015). Given that co-production is comparatively new term and also a newly recognized trend in public administration, it is still rather a topic in scientific research than a practice. However, there is growing number of good case examples both ongoing and recognized by the concept of co-production, as well as newly emerging from the concept. Comparing to other European countries, volunteering in Latvia is a new way of social participation that mostly attracts youth and seniors. Volunteering is only a relatively recent recognized activity in Latvia, however this sector of the economy is developing and has its achievements.

The aim of this research is to explore social participation in Latvia through volunteering, including its legal regulation and organizational setup, and in this regard to identify aspects and prospects of volunteering in Latvia within the concept of co-production of public services. The authors compare some aspects of volunteering as a part of social participation and co-production in Latvia to Croatia to identify common and different aspects and to make conclusions for perspectives and good case practices. In addition, the authors of the present paper summarize the definitions of volunteering, social participation and co-production concepts towards the scientific literature review and define the hypothesis for further studies to explore volunteering as a means of social participation and co-production in Latvia. The research is exploratory by design. The main methods of the study applied are analysis and synthesis. The research is a subject to some limitations. The main sources of information for the research are documents available in English and online as well as published on the WEB sources.

The current research has both a theoretical and practical application as it emphasizes the co-production application opportunities in the public sector, as well as provides the overview of volunteering in Latvia and Croatia as good cases to practice.

The study is organised within the framework of the EU program's "Europe for Citizens" international project "Volunteering - Code of Active Citizenship" implemented in cooperation with six partners from different EU member states under the leadership of Kaunas University of Technology.

\section{Research results and discussion}

The authors of the present paper begin with the overview of theoretical basis of volunteering, focusing on its administrative aspects, then continue with the case analysis and reflect on the research results analysing experience of the volunteering organisations in Latvia.

\section{The concepts of Social Participation and Volunteering as Co-production of public services}

First of all, the authors of the present paper explored the definitions of the main concepts used starting with social participation. The last century's social participation definition and description emphasizes the individuals', citizens' initiative that is "generated by social participation" (Critto A., 1999). Here the social participation is discussed as "an integral part of decision making" as authorities need to involve citizens to make the right decision that will impact the whole community. The $21^{\text {st }}$-century authors, however, focus on the social aspect of the term rather than the citizenship. J. Huang (2010) defines that "social participation refers to people's social involvement and interaction with others". He also highlights that social participation 


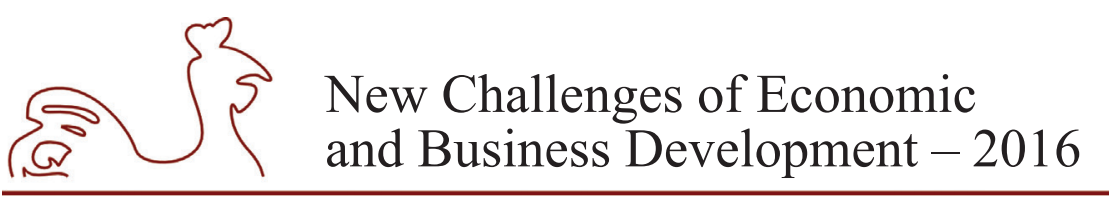

May 12-14, 2016, Riga, University of Latvia

presumes collective voluntary participation of the community people into the community living and welfare maintenance activities. A volunteering element is stressed as "social participation is a form of effective or value rational behaviour; it constitutes its own reward and is regarded as a type expressive action" (Huang J., 2010). Rational and mature behaviour of the community members in the form of social participation is also called "the essential community function" (Hardcastle D. A., 2011). This is something that defines a community's level of social health and competence (Hardcastle D. A., 2011), thus not every community is ready for social participation. However, if the community is mature enough to ensure social participation of its members, it develops social capital (Hardcastle D. A., 2011). Summing up, the authors of the present paper can define social participation as a form of active voluntary action of the community members that are involved in activities related to community life by their initiative.

The next concept that should be defined is volunteering. Social participation should be voluntarily driven, meaning the volunteering itself is free time given for other valuable activities' conduction for no pay, however, some side expenses could be covered to ensure active voluntarily social participation by people with limited financial resources (Dekker P. \& Halman L., 2003). Four major characteristics of volunteering might be one's free will, organized activity, un-rewarded (remunerated) participation and its benefit to strangers as the output (Musick M. A. \& Wilson J., 2008). As volunteering according to definitions should be "done outside one's family" (Smith et al., 2006), it should be an activity that contributes to the community, society, environmental maintenance or development (Fig. 1). Volunteering does not have any work obligations, however, it is structured and organized action, "unpaid productive work" (Stebbins R. A., 2015) of the volunteers i.e. it is goal oriented.

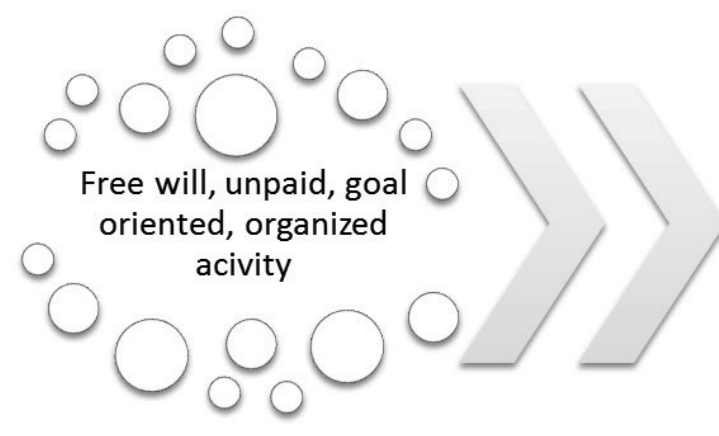

Volunteers

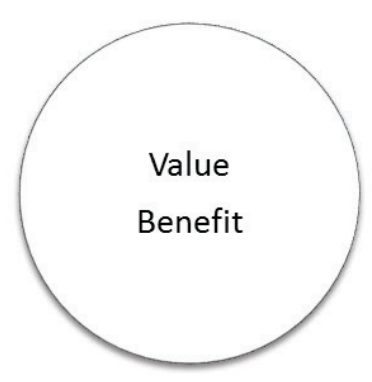

Community

Source: authors' construction based on Dekker P. \& Halman L., 2003; Smith et al., 2006; Musick M. A. \& Wilson J., 2008; Stebbins R. A., 2015.

\section{Fig. 1 Volunteering concept}

Volunteering as an approach is described using the concept of co-production concept. One of the growing trends widely explored in scientific literature related to the relationships between public administration and social participation is the increasing impact of the different roles of citizens within public administration. The main observation is that organized civil society and its individuals are coming closer and closer to the processes of planning, designing, decision- 


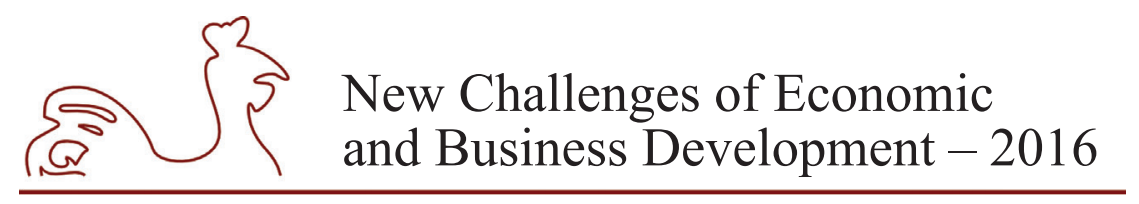

May 12-14, 2016, Riga, University of Latvia

making and implementing different public policies. One of the newest roles "assigned" to citizens are partners or co-producers of public services. John Alford, Australian public administration academics, in 2009 (Alford J., 2012; Pllit C., 2010) has widely explored this concept and invented the terms "co-production" or "co-creation" to define the process of this communitystate partnership (Alford J., 2009; Fledderus J., et al., 2015; Pearson O., 2015), which in further scientific exploration is considered to be the next development phase in the evolution of the relationships between public governance and civic social participation (Koppe S. et al., 2015; Weaver B., 2011). The concept of co-production emphasizes the cooperation between producers (state and public institutions) and receivers or beneficiaries of public services where the latter is taking an increasing role participating in the creation of public good (Guarini S. M. et al., 2015; Alford J., 2014). Stephen P. Osborne from University of Edinburgh, UK, and Kirsty Strokosch from Cardiff Business School, UK, define this cooperation as social co-production (Osborne S. \& Strokosch K., 2013), meaning the involvement of public service beneficiaries in the decisionmaking and provision of the very public services that take place mainly through organized civil society. Co-production is the mix of activities where both public service agents and citizens contribute to the provision of public services. The former are involved as professionals, or 'regular producers', while 'citizen production' is based on voluntary efforts by individuals and groups to enhance the quality and/or quantity of the services they use (Brandsen T. \& Honingh M., 2015).

The concept of co-production is still under development in both theory and practice (Buick F., 2016) and one of the most demonstrative practical examples of co-production is the involvement of the so called third economic sector - social participation through voluntary work (Pestoff V., 2012) Volunteering is the third economy sector that produces civic goods and/or services in which the public and private sector are weak or inactive in (Pestoff V., 2012; Brandsen T. et al., 2012). As defined by the Latvian Voluntary Work Law (Saeima, 2015) and the Associations and Foundations Law (Saeima, 2003), voluntary work is a form of social participation, which is done by a physical person's free will without payment. Volunteering is often underestimated based on myths in its scope of people's involvement and societal impact. Voluntary work is oriented towards an activity of public benefit and promotes the development of knowledge, skills and abilities, as well as the useful utilisation of leisure time. Some of the clearest examples are for instance the involvement of Red Cross volunteers driving ambulance cars or many local fire brigades and rescue teams basically consisting of volunteers in Austrian regional municipalities (Romano M., 2013). Another even more considerable example chosen by the authors that shows the involvement of citizens in public governance comes from the UK in the anticipation of public expenditure cuts announced by the UK Government over the next three years (2016-2018), the Welsh Government and local councils sought the views of residents regarding proposed changes to Library services, Youth Engagement and Participation Services and Supported Bus Routes through an eight week targeted public consultation undertaken with anyone potentially affected by the change proposals (Welsh Government, 2015). In addition, health and social care public services are amongst the most innovative and populated with volunteers and voluntary sector organisations, undertaking roles ranging from fundraising to direct service provision (Buddery P., 2015).

The increasing role of co-production through volunteering is considered to be one of driving forces for the development of public services (Buddery P., 2015), particularly in local communities where the volunteering also contributes to the field of regional development (Bartenberger M. \& 


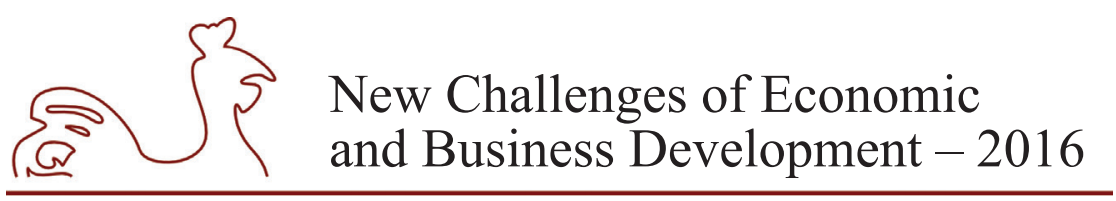

May 12-14, 2016, Riga, University of Latvia

Szescilo D., 2015; Schlappa H., 2015; Munoz S.A., 2014), that is a recognized trend by the scientific community (Calabro A., 2011; Riccucci N. M., 2016; Brandsen T. \& Honingh M., 2015) as well as by international organizations such as Organisation for Economic Co-operation and Development (OECD, 2011) and World Bank (Ngouo L. B., 2016). The involvement of organized civil society in the provisions of community good is a win-win situation for the public administration and for the communities since it ensures that these co-produced services are to a higher extent adjusted to the needs of state clients (Thomas J. C., 2012), thus increasing the satisfaction (Matthews J., 2015) of state clients according to public needs agendas (Eijck van K. H. J. \& Lindermann B., 2016). It also allows the public administration to provide and the clients or beneficiaries to receive the expected public services of the higher quality that also consecutively ensures lower and/or more efficient "production" and provision costs of the respective services (Andrews R. \& Entwistle T., 2014). Besides, it is considered that co-production through volunteering facilitates and improves the communities' civic social participation (Jakobsen M., 2013; Brandsen T. et al., 2015), which leads to better trust and understanding-based, relationships between the public and communities, and in its turn strengthens the legitimacy of state actions as a result of co-production (Johnston M. K. \& McTavish D., 2013; Bartenberger M. \& Szescilo D., 2015).

Social participation is voluntary by nature and needs to be initiated by community members aiming to maintain its life and development. Volunteering is a form of social participation and is a free will organised unpaid activity that focuses on bringing value and benefit to some strangers or contributing to a community, society life maintenance or development. Volunteering could also be a tool for the delivery of public services since volunteer activity should be organized and goal oriented. Thus co-production takes place. Some countries already use benefits of volunteering, however, there are a lot of countries that still cannot implement the principles of volunteering through co-production of public services or other public/social areas as they are still not socially mature enough to be ready for it.

\section{Administrative aspects of volunteering in Latvia and Croatia}

As volunteering in Latvia and Croatia becoming popular since about 1998 (Jaunatnes lietas, 2012; Volonterski centar Zagreb, 2008), the authors decided to compare the volunteering experiences in Latvia with a European country such as Croatia. Volunteering in Latvia has been regulated by the Volunteering Law since January 1, 2016 (Saeima, 2015). For instance, in the case of Croatia, the Croatian Parliament had already adopted the Law on volunteering in 2007 (Horvat M., 2007, Volonterski centar Zagreb, 2008). For Latvia such a law is a great leap in developing volunteering culture in terms of its legislative regulation. The Law is concise and focused. According to the Law, volunteering is an individual from age of 13, who does not replace any employee, organized and based on free will physical or intellectual unpaid work that is beneficial to society (Saeima, 2015). The Law on Volunteering of Croatia provides detailed definition of volunteering i.e. "an investment of personal time, effort, knowledge and skills out of free will with which services and activities are executed for the well-being of another person or wider public, and are executed by persons in a way anticipated by this Law, without existence of any conditions of providing a financial reward or seeking any other material benefit for volunteering accomplished" (Zakon o volonterstvu, 2007, Volonterski centar Zagreb, 2008), however the definitions are quite the same by the idea. 


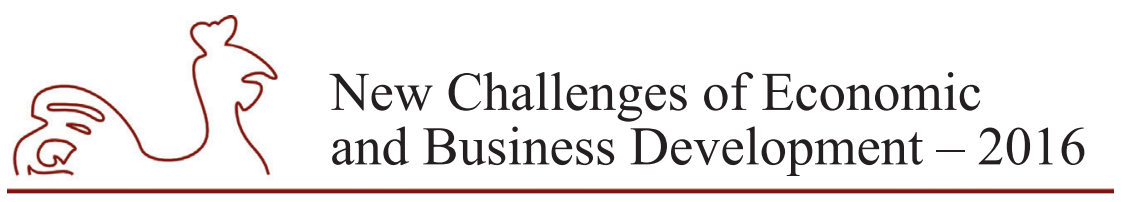

May 12-14, 2016, Riga, University of Latvia

Volunteering in Latvia does not aim to make profit. By definition volunteering activity should only be organized by three types of organisations namely associations and foundations, including the trade unions and their associations, the state and local authorities, and political parties and their unions. Therefore, there is no chance for a private sector organisation to be involved in the organising volunteering. All volunteers need to sign a contract with the volunteering organizer. (Saeima, 2015) Additional Laws that might be concerned dealing with volunteering in Latvia are the Youth Law (Saeima, 2008) and the Associations and Foundations Law (Saeima, 2003).

Besides the Law on volunteering (Hrvatski sabor, 2007), there are also some other documents that should be considered for organizing or performing volunteering in Croatia. These documents are the National strategy for the creation of enabling environment for civil society development including the operational plan (part of the strategy is devoted to volunteering development) and the Volunteer Ethics Code (Volonterski centar Zagreb, 2008). The Law on Volunteering of Croatia (Hrvatski sabor, 2007) regulates, in addition to other comments in the case of Latvia's aspects, code of ethics and volunteer certificates, and foresees the National Volunteer of the Year award (Volonterski centar Zagreb, 2008). This is an example of volunteering active administration that could lead to its co-production of public services and could be considered for implementation in Latvia.

Administrative regulation of volunteering differs in Latvia and Croatia. The certain Law on volunteering has already been applied for almost nine years in Croatia, while the Law on volunteering in Latvia has only entered into force in 2016. The law on volunteering in Latvia is concise and focused as there are also other laws that need to be considered when dealing with volunteering activities. The law on volunteering of Croatia is detailed and includes additional features containing administrative regulations such as a volunteer code of ethics and foresees the National Volunteer of the Year award that could be an additional driver/motivation for potential volunteers' active participation in volunteering activities.

\section{Volunteering organisations in Latvia}

Exploring volunteering organisations in Latvia, the authors of the present paper focused on certain criteria of the analysis, which are:

- Approximate age of member

- Area of activity

- Past achievements

- Purpose/ mission of the organisation

- Year of establishment.

A total of 40 volunteering organisations were analysed, and these organisations were active in Latvia by the beginning of 2016. The data were collected applying the organisations' WEB sites exploration. The authors used a convenience sample.

As some of the organisations are local chapters of the international organisations such as Latvian Red Cross and Latvian Red Cross Youth, their year of establishment was till 1990. There is an organisation in the sample that was established in 1975 in the territory of the Latvian Soviet Socialist Republic and is still active. Other organisations from the sample were established in the period from 1990 to 2011 . 


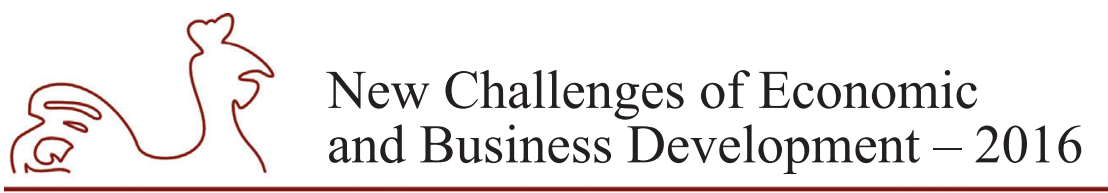

May 12-14, 2016, Riga, University of Latvia

The members' approximate age range varies from 10 up to 70 years (Table 1). According to the Volunteering Law of the Republic of Latvia (as stated in the previous sub-section), the minimal age of the volunteers is 13 , therefore some organisations will need to redefine the age of the volunteers involved or clarify the status of the organisation's member. There is an organisation that defines the age of its members as 5+ years, however, most probably these youngest members are involved in the organisation's activities more as service receivers rather than deliverers. There are three organisations that do not have their members' age limitations (Table 1). Two major target age groups of the organisations from the sample are people from 16 up to 25 -year-old and people, who are 18 or older, i.e. young adults.

Table 1

Number of volunteering organisation in Latvia from the sample by the members' approximate age

\begin{tabular}{|c|c|}
\hline Approximate age of members & Number of the organisations \\
\hline No age limitations & 3 \\
\hline $5+$ & 1 \\
\hline $10+$ & 3 \\
\hline $10-25$ & 1 \\
\hline $12+$ & 2 \\
\hline $12-25$ & 1 \\
\hline $13+$ & 1 \\
\hline $13-70$ & 1 \\
\hline $14+$ & 1 \\
\hline $14-25$ & 1 \\
\hline $14-70$ & 5 \\
\hline $15+$ & 1 \\
\hline $15-25$ & 6 \\
\hline $15-30$ & 3 \\
\hline $15-70$ & 1 \\
\hline $16+$ & 1 \\
\hline $16-30$ & 1 \\
\hline $18+$ & 1 \\
\hline $18-30$ & 2 \\
\hline $18-65$ & 1 \\
\hline $21-30$ & 1 \\
\hline $25-45$ & 1 \\
\hline
\end{tabular}

Source: authors' calculations based on the research data.

Fourteen organisations from the sample are focusing on educational issues and activities, three more organisations are focusing on health education, and five more focus on religious education, i.e. the main area of activity for 22 - the majority of the organisation from the sample is education. Another large group of the organisations from the sample are working on various social service deliveries. Three more organisations' activity area is animal welfare, two more for LGBT, and one more for vehicle.

Using the online tool Wordcounter (2016), the authors identified the most popular words amongst the organisations' purpose/mission definitions. These words' rating is: 


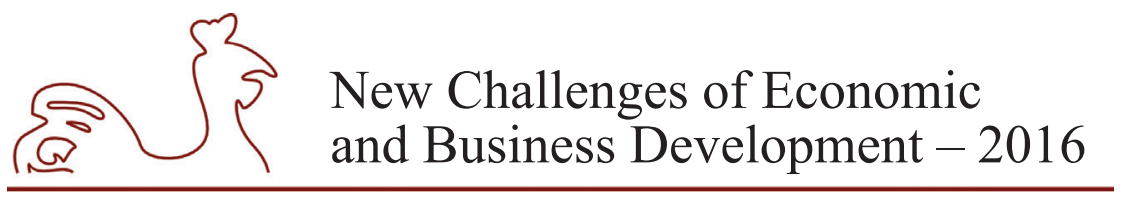

May 12-14, 2016, Riga, University of Latvia

1. People

2. Society

3. Promote

4. Social

5. Disabilities

6. Young people

7. Latvian

8. Participation

9. Culture

10. Development.

It is possible to conclude that the volunteering organisations in Latvia, both purely local and chapters of the international ones, are focusing on the development of social aspects of local people, especially people with disabilities and youth in Latvia, as well as involving participation into the society's activities e.g. cultural ones.

Among the organisations' past achievements mentioned are local and international awards, societal awareness on the certain subject towards specially developed informative sources (e.g. short films, newsletters etc.) or events (e.g. educational activities, conferences, forums, symposiums etc.), successful and recognized project implementation or particular help for the target audience/groups (people with vision disabilities, animals etc.).

All organisations from the sample are different, however the majority is focused on some areas' implementation of education activities or delivery of social services. People from all age groups can be involved into the observed voluntary organisations activities. The organisations put forward information on certain rising the certain social issues through their activities, rising awareness about them and volunteering opportunities in Latvia. The observed organisations are different in terms of their experiences in Latvia, some of them have already been active for 25 or more years, while some of them have just started their existence a few years ago. The organisations observed reflect a positive start of volunteering initiative in Latvia, however, it is impossible to conclude that volunteering through co-production of public services will even get started here. The majority of the observed organisations are independent NGOs; they provide their services and fulfil activities by their own initiative. To develop volunteering in Latvia to the next level, volunteering should become a usual social activity for people in Latvia as well as become a subject of various stakeholders' discussions for volunteering projects to bring together a social potential and all stakeholders' needs and interests.

\section{Conclusions, proposals, recommendations}

The authors of the present paper fulfilled all set tasks of the research and reached its aim, thus they were able to summarize the following conclusions and develop proposals for further subject studies.

1. Volunteering is a form of social participation based on one's free will that is, to some extent formed by the set of values of the respective community. An integral part of volunteering is the delivery of public good which in recent years in many cases has been advanced to so called co-production - a close cooperation between public administration and organized civil society in the provision of public services. 


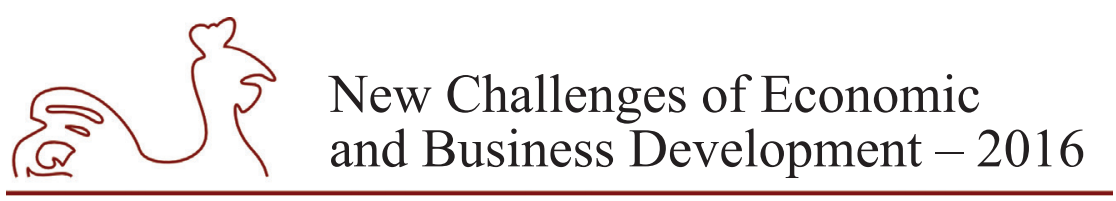

May 12-14, 2016, Riga, University of Latvia

2. While the concept of co-production is still under development in both theory and practice, and for that matter also in modern volunteering labels, the volunteering itself as a form of social participation in many countries demonstrates a vivid example of the involvement of the third economic sector that produces a civic good and in many cases actual public services in which public administration and the private sector are weak or inactive.

3. By having direct administrative regulation of volunteering nine years ahead, Croatia (Law on Volunteering in 2007, including, volunteer code of ethics) in comparison to Latvia (Law on Voluntary work) shows wider enthusiasm for volunteering recognizing it also as an action of prestige (the title National Volunteer of the Year is being awarded annually).

4. The majority of the researched voluntary organizations, including those with of 25+ years of experience and those newly established, are focusing on areas of educational activities implementation or social services delivery attracting volunteers from all age groups. The majority of the observed organisations are independent NGOs providing their services and fulfilling activities on their own initiative. The main interaction with the public administration forms through compliance to NGOs' regulations and rare funding, but not in terms of both parties serving public good.

5. The next phase of volunteer development in Latvia is expected to involve more and more "ordinary" people as well as involving more various stakeholders that the phase will emphasize the social potential of volunteering and its ability to meet the needs and interests of all stakeholders being public or private.

The authors suggest several proposals aimed at social stakeholders, including NGOs, academic institutions, state institutions, municipalities, and employers:

1. Given the nature of providing public good, volunteering might also be more widely recognized by employers with extra possible benefits e.g. in working hours on a given day or in number of days of vacation (a close example of this is blood donation).

2. Voluntary work should also be more widely recognized and accepted as working experience. One of the main obstacles for higher youth employment is lack of experience. Voluntary work is often underestimated as not real work experience by both the young people themselves and employers, although in many cases voluntary actions show a lot of youth responsibilities and stimulates skills development.

3. Also within an education system, in particular where there is a close university-business partnership model, the voluntary work should be recognized, and where possible also evaluated and in specific cases also awarded with the ECTS points.

Based on the conducted research and analysis about volunteering as social participation and its contribution to the provision of public services - the co-production concept - in Latvia, the authors define the following hypothesis for further exploration of volunteering as a means of social participation and co-production in Latvia: with the sufficient coordinated social impact on the concept of volunteering, volunteering itself can produce significant social impact with positive spill-over effects such as increased social participation in public policy management and increased trust in public institutions and their service provision. 


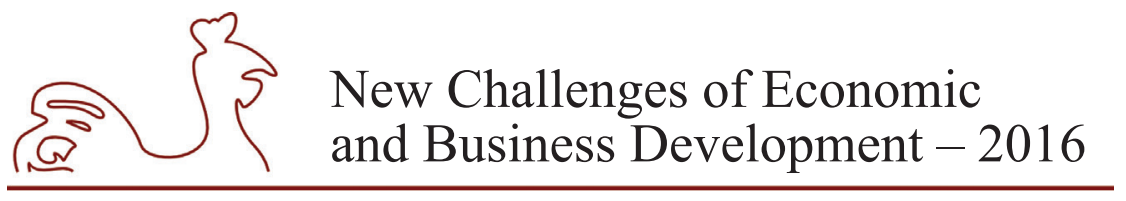

May 12-14, 2016, Riga, University of Latvia

\section{Acknowledgement}

The authors would like to thank all volunteers who contributed to this study while recruited within the EU program's "Europe for Citizens" international project "Volunteering - Code of Active Citizenship”, namely - Agnese Zariņa, Alise Jātniece, Anastasija Rešetova, Elīna Enne, Elīza Miglāne, Līva Černoglazova, Māra Ikere, Sigrija Skricka.

\section{Bibliography}

Alford, J., 2009. Public Value From Co-Production By Clients. Working paper. Australia and New Zealand School of Government. [Online] Available at: http://igps.victoria.ac.nz/events/downloads/2009/ Building the Public - Spring Series/ALFORD - Client coproducers.pdf [Accessed 1 March 2016].

Alford, J., 2012. Engaging Public Sector Clients: From Service-Delivery To Co-Production. Basingstoke: Palgrave.

Alford, J., 2013. Engaging Citizens In Co-Producing Service Outcomes. In Lindquist, E. A., Vincent, S., Wanna, H. (eds.) Putting Citizens First. Engagement in Policy and Service Delivery for the 21st Century (pp. 75-82). Canberra: The Australian National University.

Alford, J., 2014. The Multiple Facets Of Co-Production: Building On The Work of Elinor Ostrom. Public Management Review, 16 (3), pp. 299-316.

Andrews, R. \& Entwistle, T., 2014. Public Service Efficiency: Reframing The Debate. New York: Routledge.

Bartenberger, M. \& Szescilo, D., 2015. The Benefits And Risks Of Experimental Co-Production: The Case Of Urban Redesign In Vienna. Public Administration, 93 (4), pp. 7-23.

Brandsen, T. \& Honingh, M., 2015. Distinguishing Different Types Of Coproduction: A Conceptual Analysis Based On The Classical Definitions. Public Administration Review, 76 (1), pp. 1-9.

Brandsen, T., Pestoff, V. \& Verschuere, B., 2012. Co-Production As A Maturing Concept. In Pestoff, V., Brandsen, T. \& Verschuere, B. (eds.) New Public Governance, the Third Sector and Co-Production (pp. 1-12). New York: Routledge.

Brandsen, T., Trommel, W. \& Verschuere, B., 2015. The State And The Reconstruction Of Civil Society. International Review of Administrative Sciences.

Buddery, P., 2015. Volunteering And Public Services: Where Co-Production Meets Localism. Action and Research Centre, Wiltshire Council, UK, p. 11, 21.

Buick, F., Blackman, D., O’Flynn, J., O’Donnell, M. \& West, D., 2016. Effective Practitioner-Scholar Relationships: Lessons From A Co-Production Partnership. Public Administration Review, 76 (1), pp. 35-47.

Calabro, A., 2011. Governance Structures And Mechanisms In Public Service Organizations: Theories, Evidence and Future Directions. Berlin: Springer.

Critto, A., 1999. Choosing Models Of SocietyAand Social Norms: Improving Choices And Quality Of Life. Lanham: University Press of America.

Dekker, P. \& Halman, L., 2003. The Values Of Volunteering: Cross-Cultural Perspectives. New York: Kluwer Academic/Plenum Publishers.

Eijck, van K. H. J. \& Lindermann, B., 2016. Crafting Spaces: Strategies For Managing Public Needs Agendas. International Journal of Public Administration, 39 (1), pp. 49-62.

Fledderus, J., Brandsen, T. \& Honingh, M. E., 2015. User Co-Production Of Public Service Delivery: An Uncertainty Approach. Public Policy and Administration, 30 (2), pp. 145-164.

Hansen, G. V., 2015. Can Collaboration Provide Integrated Services For Prisoners In Norway? International Journal for Crime, Justice and Social Democracy, 4 (4), pp. 136-149. 


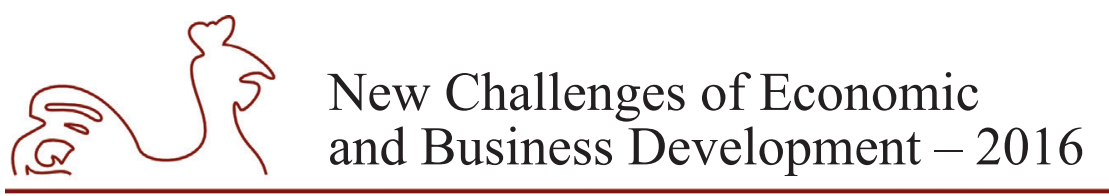

May 12-14, 2016, Riga, University of Latvia

Hardcastle, D. A., Powers, P.R. and Wenocur S., 2011. Community Practice: Theories and Skills for Social Workers. $3^{\text {rd }}$ ed. New York: Oxford University Press.

Horvat, M., 2007. Volunteering Legislation in Croatia, Ministry of Family Affairs, War Veterans and Intergenerational Solidarity and European Centre for Not-for-Profit Law. [Online] Available at: http://www.vcz.hr/userfiles/SMART_Fact\%20sheet\%20on\%20volunteering.pdf[Accessed 4 March 2016].

Hrvatski sabor, 2007. Zakon o volonterstvu. [Online] Available at: http://www.zakon.hr/z/258/Zakon-ovolonterstvu [Accessed 4 March 2016].

Huang, J., 2010. Education And Social Capital. Empirical Evidence From Microeconomic Analysis. PhD thesis. [Online] Available at: http://dare.uva.nl/document/2/76232 [Accessed 4 March 2016].

Jakobsen, M. (2013). Can Government Initiatives Increase Citizen Co-Production? Results Of A Randomized Field Experiment. Journal of Public Administration Research and Theory, 23 (1), pp. 27-54.

Jaunatnes lietas, 2012. Volunteering. [Online] Available at: http://www.jaunatneslietas.lv/en/volunteering [Accessed 4 March 2016].

Johnston, M. K. \& McTavish, D., 2013. Making and Managing Public Policy. New York: Routledge.

Koppe, S., Ewert, B. \& Blank, F., 2015. Welfare User Roles in a Conservative Welfare State. Are Germans Citizens, Consumers or Co-Producers? Journal of International and Comparative Social Policy, 32 (1), pp. 1-16.

Matthews, J., 2015. Assessing Outcomes and Value: It's All a Matter of Perspective. Performance Measurement and Metrics, 16 (3), pp. 211-233.

Munoz, S. A., Farmer, J., Warburton, J. \& Hall, J., 2014. Involving Rural Older People In Service CoProduction: Is There An Untapped Pool Of Potential Participants? Journal of Rural Studies, 34 (1), pp. 212-222.

Musick, M. A. \& Wilson, J., 2008. Volunteers: A Social Profile. Bloomington: Indiana University Press.

Ngouo, L. B., 2016. The World Bank's Approach To Public Sector Management For 2011-2020: Proposals To Push Forward The Debate. International Review of Administrative Sciences, 79 (3), pp. 391-397.

OECD, 2011. Together For Better Public Services: Partnering With Citizens And Civil Society. Paris: OECD Publishing.

Osborne, S. \& Strokosch, K., 2013. It Takes Two to Tango? Understanding the Co-Production of Public Services by Integrating the Services Management and Public Administration Perspectives. British Journal of Management, 24 (1), pp. 31-47.

Pearson, O., 2015. Co-Producing The School? A Case Study Of Youth Participation In Time Banking. Doctoral (Ph.D.) Dissertation, Cardiff University.

Pestoff, V., 2012. Co-Production And Third Sector Social Services In Europe: Some Concepts and Evidence. Voluntas: International Journal of Voluntary and Non-Profit Organizations, 23 (4), pp. 1102-1118.

Riccucci, N. M., Van Ryzin, G. G. \& Li, H., 2016. Representative Bureaucracy And The Willingness To Coproduce: An Experimental Study. Public Administration Review, 76 (1), pp. 121-130.

Romano, M., 2013. Common Agency Theory, Corporate Governance, And Not-For-Profit Organizations. In Gnan, L., Hinna, A., Monteduro, F. (eds.) Conceptualizing and Researching Governance in Public and Non-Profit Organizations (Studies in Public and Non-Profit Governance). UK: Emerald Group Publishing Limited.

Saeima, 2003. Biedrību un nodibinājumu likums. Latvijas Vēstnesis, 161 (2926). [Online] Available at: http://likumi.lv/doc.php?id=81050 [Accessed 4 March 2016].

Saeima, 2008. Jaunatnes likums. Latvijas Vēstnesis, 82 (3866). [Online] Available at: http://likumi.lv/doc. php?id=175920 [Accessed 4 March 2016]. 


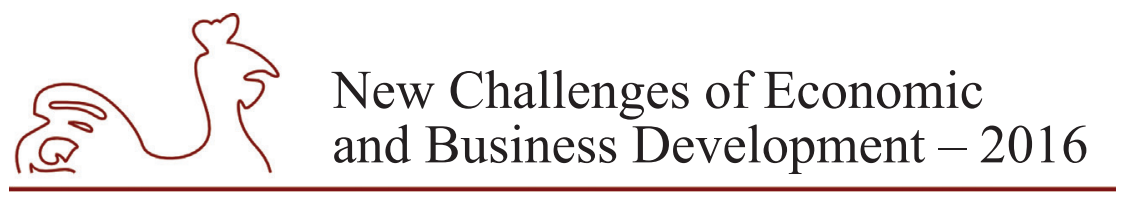

May 12-14, 2016, Riga, University of Latvia

Saeima, 2015. Brīvprātīgā darba likums. Latvijas Vēstnesis, 127 (5445). [Online] Available at: http:// likumi.lv/ta/id/275061-brivpratiga-darba-likums [Accessed 4 March 2016].

Schlappa, H., 2015. Co-Producing the Cities of Tomorrow: Fostering Collaborative Action to Tackle Decline in Europe's Shrinking Cities. European Urban and Regional Studies, pp. 1-13.

Sicilia, M., Guarini, E., Sancino, A., Andreani, M. \& Ruffini, R., 2015. Public Services Management and Co-Production in Multi-Level Governance Settings. International Review of Administrative Sciences, pp. 1-21.

Smith, D. H., Stebbins, R. A. \& Dover, M., 2006. A Dictionary of Nonprofit Terms and Concepts. Bloomington: Indiana University Press.

Stebbins, R. A., 2015. The Motive to Volunteer: Theory and Research on Serious, Casual, and ProjectBased Leisure. New York: Palgrave Macmillan.

Thomas, J. C., 2012. Citizen, Customer, Partner: Engaging the Public in Public Management. New York: M. E. Sharpe.

Tuurnas, S., 2015. Learning to Co-Produce? The Perspective of Public Service Professionals. International Journal of Public Sector Management, 28 (7), pp. 583-598.

Volonterski centar Zagreb, 2008. Volunteering in Croatia. [Online] Available at: http://www.vcz.hr/ userfiles/SMART_Fact\%20sheet\%20on\%20volunteering.pdf [Accessed 4 March 2016].

Weaver, B., 2011. Co-Producing Community Justice: The Transformative Potential of Personalisation for Penal Sanctions. British Journal of Social Work, 41 (6), pp. 1038-1057.

Welsh Government, Rhondda Cynon TafCouncil, UK, 2015. Consultation on Service Changes. Available at: http://www2.rctcbc.gov.uk/en/news/archive/2015/november/consultationonservicechangesbegins. aspx [Accessed 2 March, 2016].

Wordcounter, 2016. Word Counter. [Online] Available at: https://wordcounter.net/ [Accessed 2 March, 2016]. 


\title{
RELATIONSHIP MARKETING: CONSUMER BEHAVIOUR COMPARISON IN THE TRADITIONAL AND ONLINE TRADE MARKETS
}

\author{
Elina Radionova, University of Latvia, Latvia ${ }^{1}$ \\ Valerijs Praude, University of Latvia, Latvia
}

\begin{abstract}
Nowadays a consumer has become much more developed, more knowledgeable and more effective in taking his decisions concerning the market. Now it is more difficult to reach the consumer and to offer him some products. Therefore for a company to be able to communicate effectively with the customer the choice of the only one-way channel of communication would be wrong. Satisfaction, which appears there in consumers during and after the purchasing process, has become important. It produces a long-term relationship between the consumer and the company, forms loyalty and trust to the company's products / brands.

The aim of the paper to develop and modify a customer loyalty model to the internet store as a part of relationship marketing to show a comparison of the consumer behaviour in traditional and online trade markets.

The following methods were used - literature study and analysis, respondents survey and statistical analysis conducting.

The paper include a comparison of relationship marketing and consumer behaviour in online trading. In the perspective it could be a mistake to apply the same approach to communication with consumers in the traditional market and in the online trading market, because the consumer behaviour in those markets is different. During this study, the author analyses and evaluates not only differences in consumer behaviour in two different markets - the traditional and the Internet, but also finds the best possibility of relationship marketing of consumer behaviour on the Internet.

The study shows the main characteristics of the consumer in the online trading environment. The analyses of the conducted survey will help encourage relationship marketing efficiency in online trading.

The research results can be used practically in choosing effective communication with consumers, in creating a long-term relationship with them, and in using relationship marketing and adapting it to the Internet trading market.
\end{abstract}

Key words: relationship marketing, customer behaviour, online trading

JEL code: M31

\section{Introduction}

The authors of the paper compares relationship marketing key ideas in the online trading and in the traditional market. How it influence consumers' behaviour and make long - term relationship with them. In the age of technology, it is important to not only find customer but also have a long - term relationship with him in order to make an e-loyalty base. In the online

1 Corresponding author - e-mail address: elinaradionova@gmail.com 


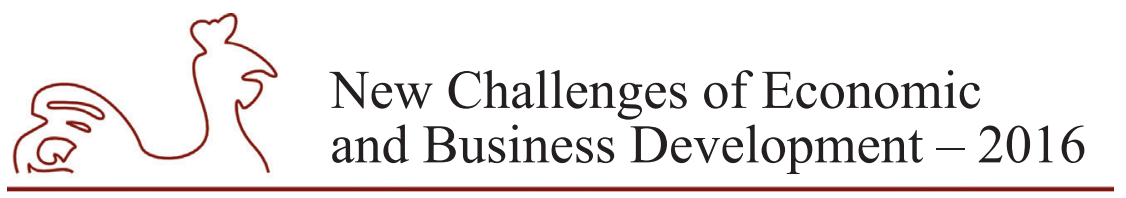

May 12-14, 2016, Riga, University of Latvia

trading, it is more necessary because of the numerous vendors and product offers. The key idea is not only to sell the product but also to continue working with the consumer after purchase, to make him return and advice the online shop to friends and relatives.

The aim of the paper to develop and modify a customer loyalty model to the internet store as a part of relationship marketing to show a comparison of the consumer behaviour in traditional and online trade markets.

The following methods were used - literature study and analysis, respondents survey and statistical analysis conducting.

The authors put forward the following hypotheses:

H1: Consumers do mostly hedonic shopping in the online trade market.

$\mathrm{H} 2$ : Consumers evaluate product quality lower than delivery quality on the online trade market.

H3: Consumers use mostly foreign online stores not the local one for different product purchasing process.

\section{Research results and discussion}

The number of consumers who use online stores every year becomes bigger, and in 2014 $71 \%$ of Latvian internet users are involved in online shopping, which is by 4 percentage points more than in 2013. As it is shown in Gemius data, people aged between 25 and 34 are more active in online trading; women do that more often and act as professionals or office workers (KursorsLv, 2014). Analysis of Citadele Bank data shows that the number of transactions into foreign online shops increased by $42 \%$, and into Latvian shops - by 9 percentage more in 2013 than in 2014 (Haka, 2015 [6]). In spite of the fact that in Latvia the popularity of online stores is growing, consumers shop more in foreign online stores. Comparing the Baltic States countries between each other, Latvia takes the second place in terms of the percentage of people who are aged between 16 and 74 and who get the goods or services on the Internet (Latvian Internet Association, 2014).

Table 1

People purchasing goods or services online (aged 16-74) \%

\begin{tabular}{|c|c|}
\hline Country & Residents, $\%$ \\
\hline Latvia & 33.5 \\
\hline Estonia & 48.6 \\
\hline Lithuania & 26.0 \\
\hline
\end{tabular}

Source: Latvian Internet Association E- Commerce Statistics, 2014.

By gathering and analyzing the available information, authors can conclude that in Latvia it is necessary to promote local online stores and to increase consumer e-loyalty and e-trust for online vendors. However, before that it is important to study how relationship marketing can effect consumers' behavior in both markets traditional and online. 
May 12-14, 2016, Riga, University of Latvia

\section{Theoretical analysis of consumer behavior in the traditional and online trade market}

Marketing channel in the Internet differs from the traditional one. Customers should choose and evaluate product only from the provided information on the website (Bilgihana, Bujisic, 2015). It is impossible to touch the product or to try it before buying. That is why for the vendor it is necessary to provide full and trustful information about the all products, prices, delivery and payment terms.

In the online trading consumer has two ways of purpose to use Internet - hedonic and utilitarian shopping (Bilgihana, Bujisic, 2015). Hedonic shopping consumer uses when he wants to entertain himself like surfing the Internet, watching different pictures or reading funny quotes and after that just do shopping with no specific reason. Utilitarian shopping has a particular goal to buy something such as buying products with the lower price. Customers' behavior and attitude about the product offered by the company is differs how website fulfills the utilitarian or hedonic requirements of the customer.

For finding those requirements there is a necessity to come with a special approach and communication that could be integrated into online environment (Kotler, 2014). Three approaches are mentioned in different sources to increase consumer satisfaction and loyalty in the Internet world (Yi, 2103):

- professional approach - in terms of traditional marketing it means professional services associated with direct service and staff skills. The quality of provided information and service is important to consumer (Chang, Chen, 2008). It is honesty, while selling products on the Internet only best pictures should be displayed and a good description should be provided; the prices should be up to date. If there are any problems and getting the product the consumer sees that the product and the picture are two different things in real life, then there is no doubt that consumer returns it immediately. The same is connected to prices - some online shops do not count the full price with delivery and other options and when consumer start to pay the price increase. In this case, the consumer often refuses from the purchase and is looking for other alternatives. All provided information should be trustable and easy to use (Labrecque, Esche, Mathwick, Novak, Hofacker, 2013);

- interaction with consumers - it is possible to leave feedbacks in the virtual environment both positive and negative. Without a doubt, even the best online shop cannot get only positive feedbacks. It should not be forgotten that that reviews are written by people and psychological factors also should be taken into account. It is necessary to deal with any review very quickly. It is interaction with the consumer and requires a two-way communication in order to build a sustainable relationship with the consumer, which increase trust and satisfaction as well (McCole, Ramsey, Williams, 2010). Therefore, it is necessary to interact with the consumer kindly and with understanding and respect (Ivanov, 2012); in case of any problems that may be arisen there need to be find a solution to satisfy consumer. There should be a possibility to return the product, refund etc. In any situation it is essential to demonstrate that the consumer is important and that you care about him. Besides there is the necessity to ensure a convenient buying process (Andrews, Bianchi, 2013), delivery and billing processes. In short, the process 


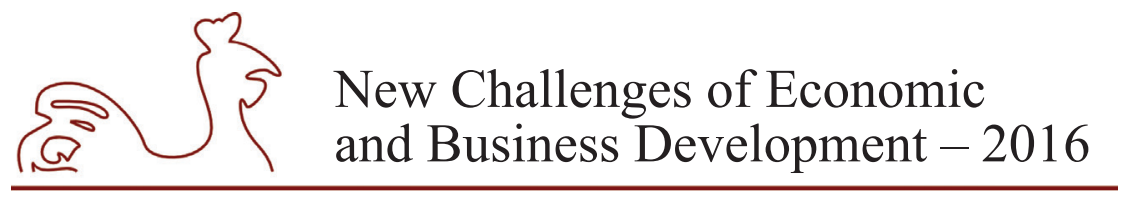

May 12-14, 2016, Riga, University of Latvia

of purchasing the product should provide the consumer with satisfaction and comfort (Martínez-López, Pla-García, Gázquez-Abad, Rodríguez-Ardura, 2014);

- stimulation - it is impossible to forget that any internet store wants to make a profit, which means that the consumer is more likely to be motivated to visit the website and make as many purchases as he can. A variety of promotions and discounts motivate consumers to buy products very well (Sewell, Brown, 2002). Sometimes such actions are coordinated with traditional stores if the company has both stores in traditional and internet environments. Loyalty programs become topical and stimulate to buy in a particular online store in order to accrue bonus points, to get free delivery, discounts or various gifts etc. (Ткачев, 2015). A personal approach to each customer is important too, such as a thank-you letter, holiday greetings, faster delivery etc. After such service the consumer wants to share his positive experience with either his friends or acquaintances, or in social networks and blogs, or elsewhere, thus, creating a positive impression about the company.

Using all three approaches company establishes a long - term relationship with the customer. In that case, it will mean an e-loyalty to the online vendor. It is important to understand that relationship marketing and e-loyalty are close and relate with each other. Loyalty is the unity of interaction and behavioral and attitudinal components, as shown in Figure 1, the model designed by the author from research made in early 2015 which was conducted within the master's thesis (Radionova, 2015). In turn, loyalty influences directly customer satisfaction (Audrain-Pontevia, N'Goala, Poncin, 2013), which may be affected by different values such as functional, social and emotional values and the value of money. The developed model points out that there are also factors that can influence consumer loyalty from outside, such as socio-demographic, usage duration, a variety of marketing activities. The analysis of loyalty models showed that satisfaction is the general impact factor to loyalty (Christodoulides, Michaelidou, 2011). The model can be used in general but each sector has its own characteristics and, of course, the Internet trade market has its own specific features that allow modifying the specific model and applying it to online stores. 


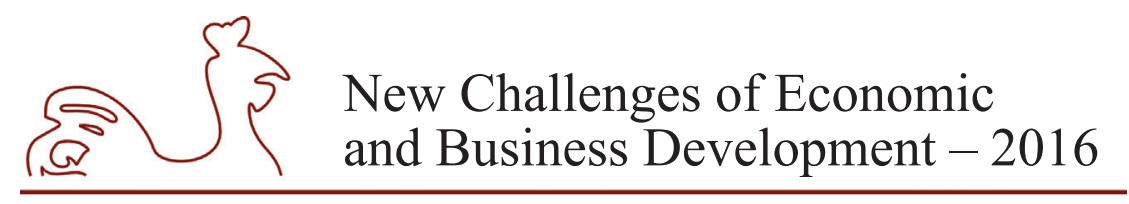

May 12-14, 2016, Riga, University of Latvia

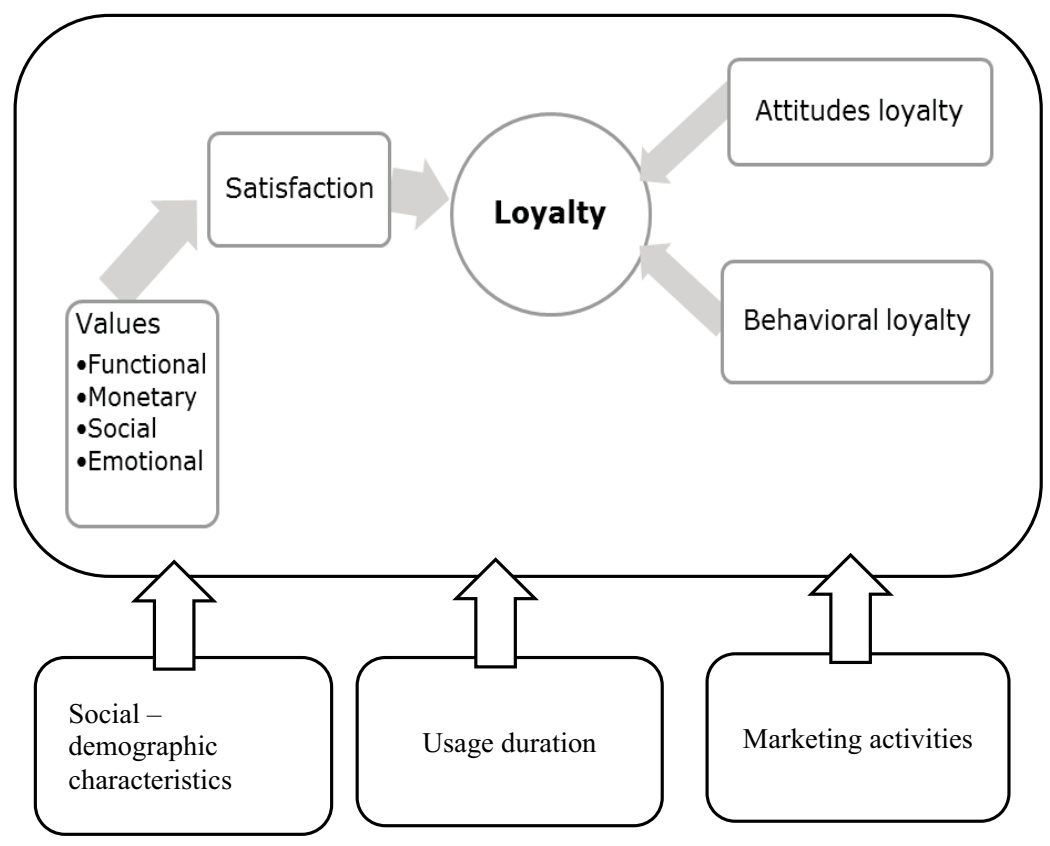

Source: Authors created model based on Radionova, 2015.

Fig. 1. Consumer loyalty model

After having analysed the theoretical part, authors have modified and adapted consumer loyalty model to the internet environment (Figure 2) and to the internet trade market (online store) (Figure 3).

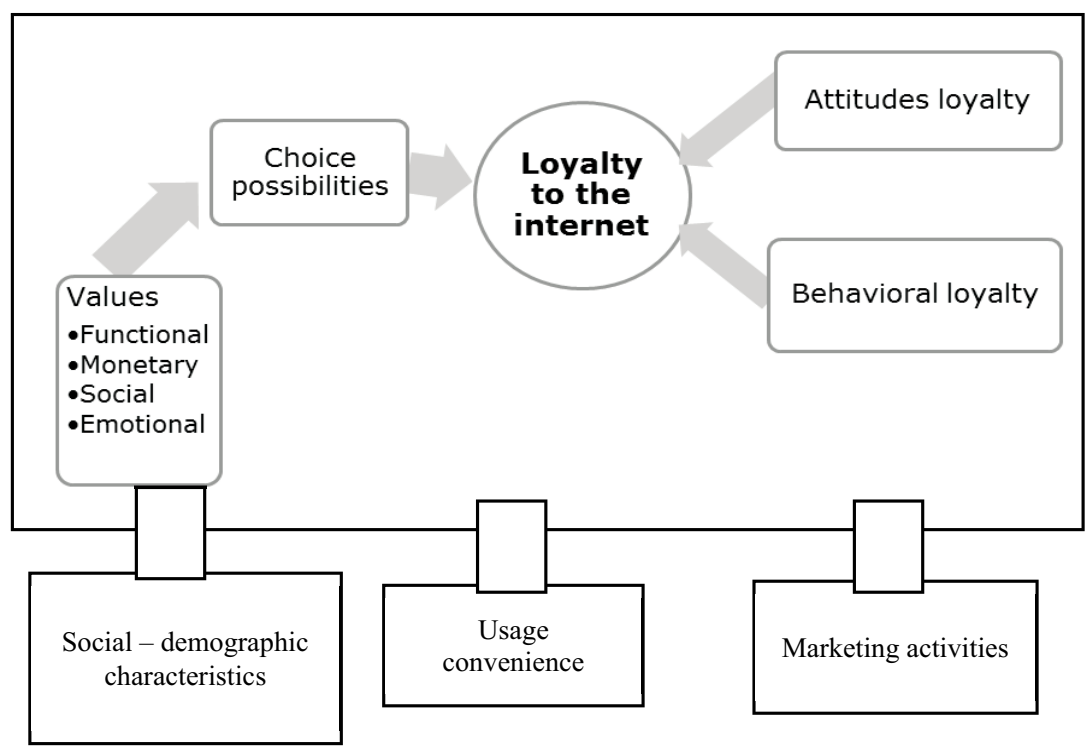

Source: Authors created model based on Radionova, 2015.

Fig. 2. Consumer loyalty model to the internet 


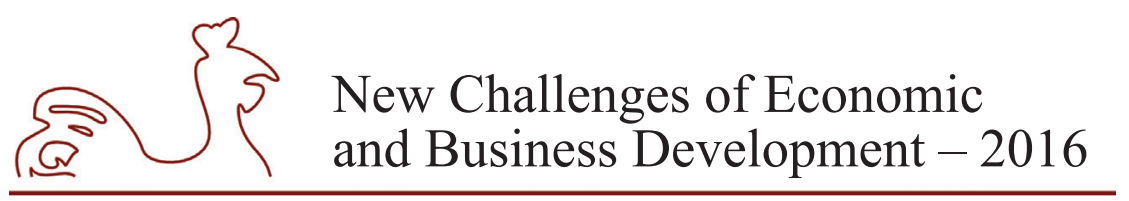

May 12-14, 2016, Riga, University of Latvia

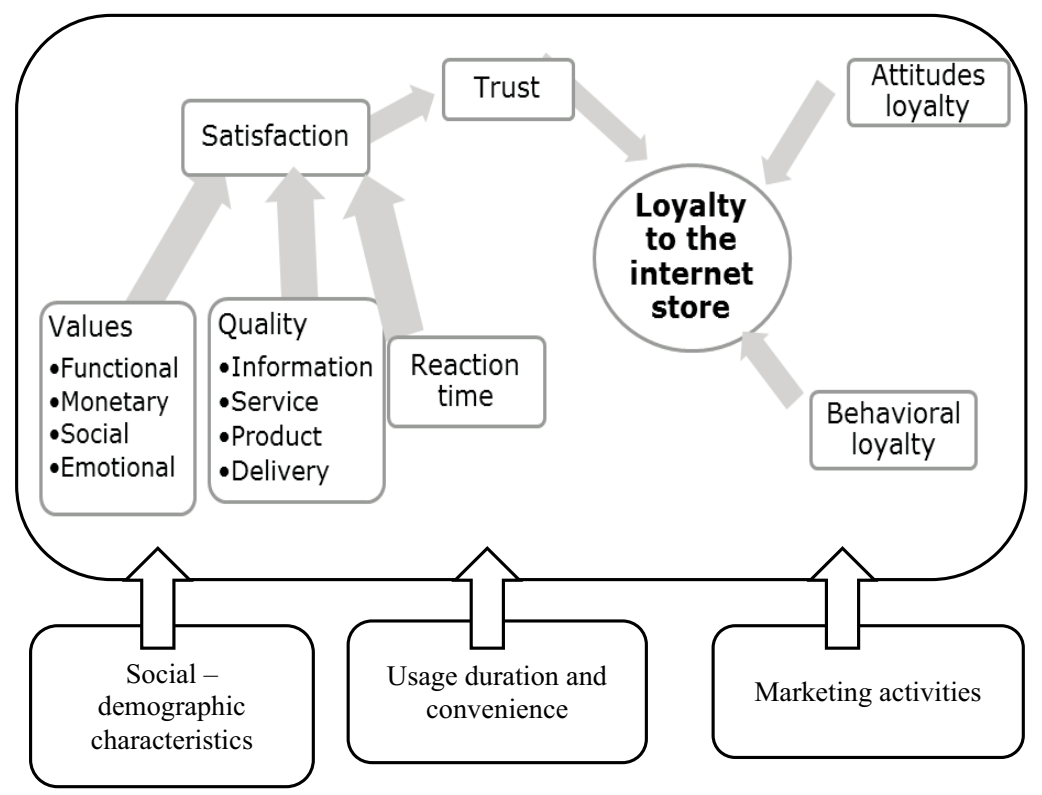

Source: Authors created model based on Radionova, 2015.

\section{Fig. 3. Consumer loyalty model to the internet store}

The models developed by authors point out that the e-loyalty building process on the internet and in particular online stores is more complicated process than it is considered to be, because it is affected by several factors. In this case, it is necessary to mention repeated purchases (re-purchases), which will appear in case of the high level of trust, which affects satisfaction. Authors would like to single out that the chosen opportunities are what make the difference in loyalty to the traditional market and to the online market. While on the internet it is much faster to find required products, also to find a product that is not available in a traditional store, so foreign stores are more popular than local ones in Latvia. Because of these factors, online sellers need to react fast on different changes and interact with the consumer in order to prevent wrong and negative cases that could be in the online trading. In the traditional market, it is possible to talk face-to-face to the customer to explain some things or to show the product and provide all necessary information. Talking about online trading it should be pointed out that the online communication should be in a high level in order to build a long-term relationship with consumers.

\section{Consumers' behaviour evaluation in the online trade market}

Data were collected during January and February 2016 using random selection. Authors come up with the results based upon the questionnaire presented to 319 respondents who answered the questions from self-designed survey. In order to have a more reliable results, the respondents were personally contacted by one author of the paper. The research is still continuing to obtain the data from over several years and to compare the changes that take place over time, so today there are only interim results. 


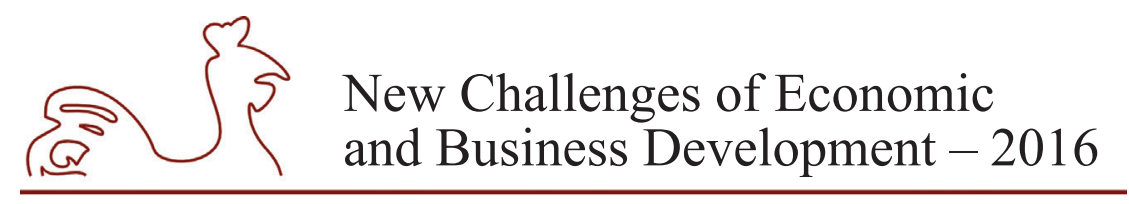

May 12-14, 2016, Riga, University of Latvia

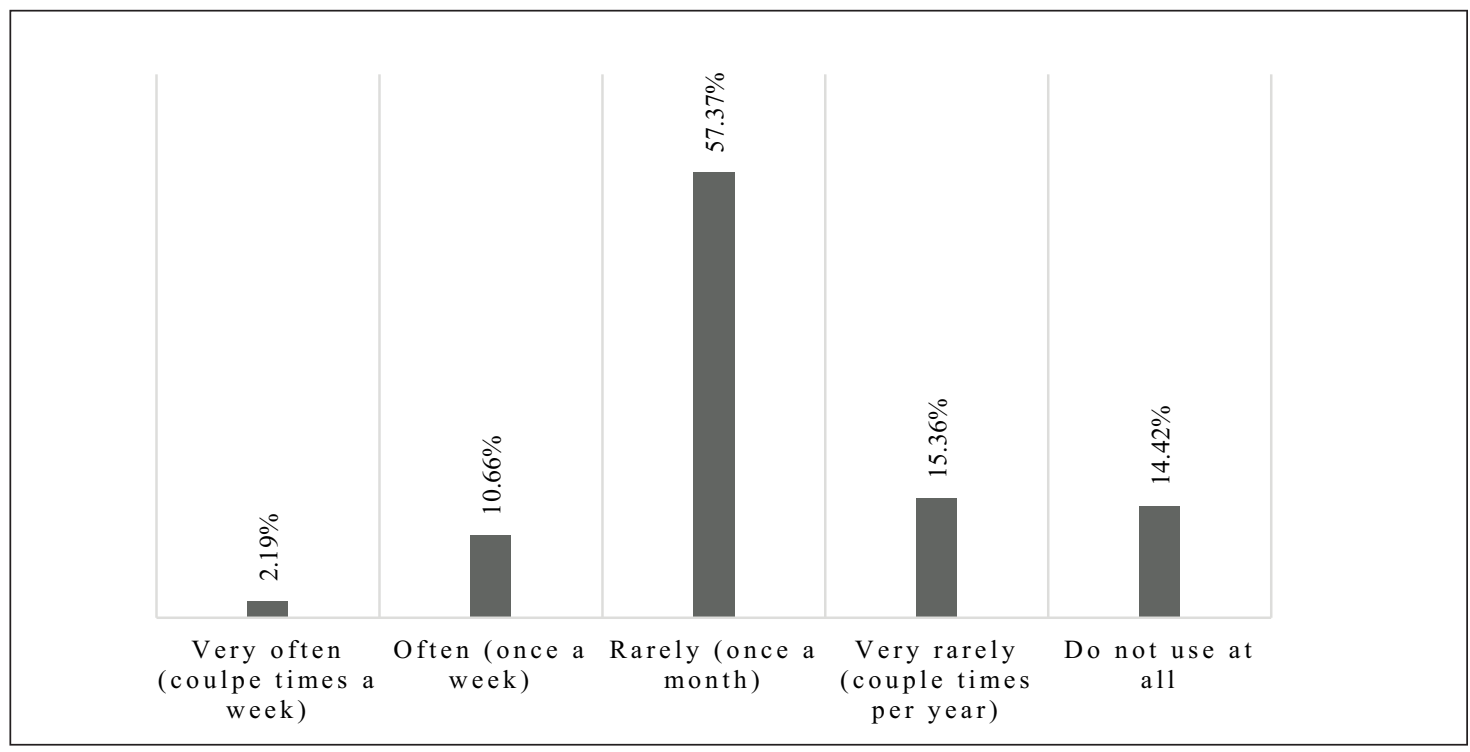

Source: Authors created graphic based on survey results.

\section{Fig. 4. The usage of internet stores}

After having analysed the results, it can be concluded in the Fig. 4. that the consumers use internet-trading services at least once a month $-57.37 \%$ of respondents. $10.66 \%$ and $2.19 \%$ of the respondents use the internet shops once a week and a couple times a week. $15.36 \%$ of respondents use internet trading only a few times a year, while $14.42 \%$ do not use it at all. Most of respondents (43.57\%) give preference to foreign stores as it is shown on the Fig. 5. 24.76\% respondents use both foreign and Latvian internet market services and only $10.66 \%$ use only Latvian internet shops. In contrast, $4 \%$ of respondents are not interested in what country and in which internet shop to make purchases and $6.58 \%$ of respondents do not buy online at all. That situation can be explained by the fact that foreign consumers can buy any product by a low price, with a good and free delivery and from a wider assortment. In online stores such as ebay.com, alibaba.com, aliexpress.com etc. consumers choose products from different sellers, gathering thousands of offers in one place. 


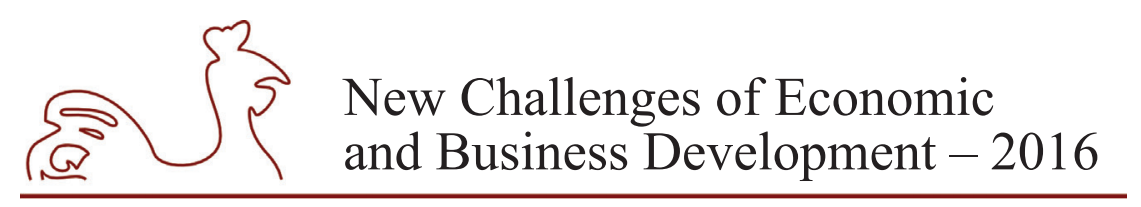

May 12-14, 2016, Riga, University of Latvia

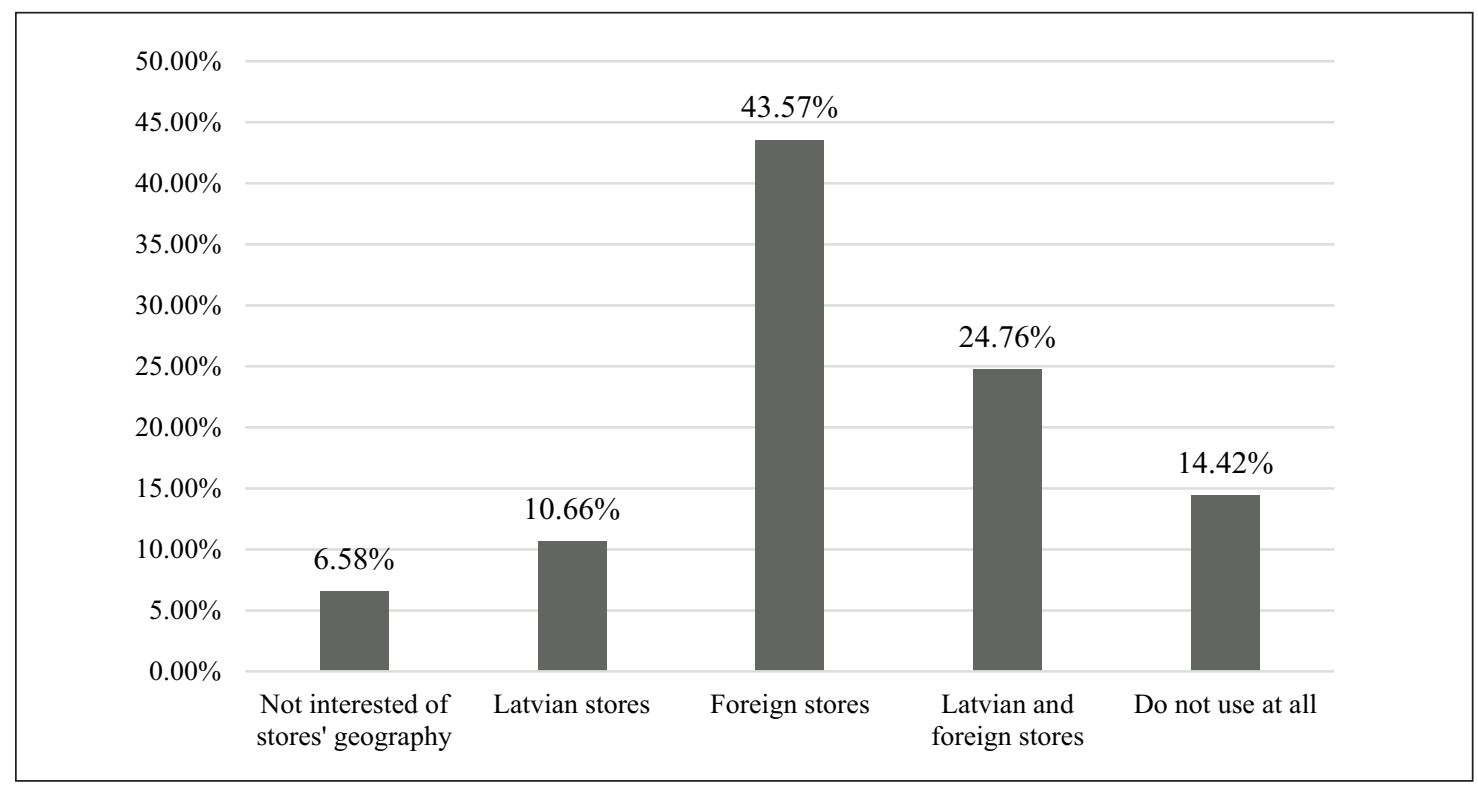

Source: Authors created graphic based on survey results.

Fig. 5. The usage of internet stores by its' geography

Respondents (23.08\%) answered that the most important factors for re-purchase are delivery opportunities and quality; $18.68 \%$ stated that it is product variety, $17.22 \%$ presented offer price, $16.48 \%$ - delivery price, $10.62 \%$ - quality of products, $8.06 \%$ - offered brand and $5.86 \%$ - service quality. The authors would like to point out that sometimes foreign online stores do not deliver products to Latvia or delivery cost is high and the delivery duration is too long, so this is becoming an important factor for consumers. The internet trade market service quality as the factor for repeated purchases has been used least of all, this can be explained by the fact that communication with the seller is rare and it is not also popular for customers. Internet sellers should expand their territorial delivery options and the range of products; that could not only attract new customers but also promote existing consumer satisfaction and loyalty. Most of respondents (30.41\%) do online shopping after communication with the seller (e-mail, social media, etc.) or getting a special offer from him. Almost the same number of consumers do shopping in two different cases like buying e-products with someone (relatives, friends, colleagues, etc.) $23.82 \%$ and spontaneous shopping do $21.32 \%$ of respondents. Only $10.03 \%$ do purpose shopping when they analyse the situation in the online sector and after evaluation do shopping. As it was mentioned before $14.42 \%$ of respondents do not shopping online. After analysis it could be pointed out that in Latvia mostly do hedonic online shopping, it means that online sellers should provide not only trustful and informative information about the all shopping aspects but also interact with the consumer in order to increase the interest to the shopping process in current online shop. 


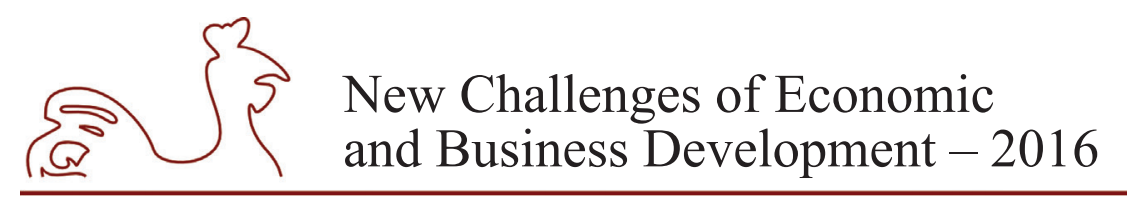

May 12-14, 2016, Riga, University of Latvia

\section{Conclusions, proposals, recommendations}

1. Consumers do online shopping in two ways - hedonic and utilitarian, when they do not have and have special purpose. It is recommended for online vendors to understand what their customers want and their behaviour using relationship marketing to fulfil consumer needs and find the right way of communication.

2. Online purchase process consists of three stages - pre-purchase stage, the online purchase stage, after-sales stage. On the first stage the consumer is directed to a specific website to a specific seller/shop. The second stage is when the customer is provided with full information and secure purchase via the Internet. The third stage is quick delivery to the buyer and the product should fully coincide with the information provided by the seller, and feedback should be provided to express gratitude or complaints, to evaluate the service, to return a purchase or ask questions. While interacting with consumers, sellers need to specify full and appropriate information that will not confuse consumers, increasing not only satisfaction but also trust to the seller. After that process, it is necessary for sellers to react as quickly as it is possible to increase trust that influences satisfaction and loyalty and will ensure a long - term relationship.

3. Professional skills, interaction with consumers and consumer stimulation can be used to increase consumer e-loyalty in the Internet environment. The formation of loyalty to the Internet and Internet stores are influenced by such factors as opportunities, quality (in all dimensions), reaction time, usage duration and convenience. Internet traders have to expand their territorial delivery options and the range of products; it could not only attract new customers but also promote existing consumer satisfaction and loyalty. Because of the big number of other sellers and opportunities of Internet sellers need to find the most efficient way of communication with consumer to make long - term relation with consumer.

4. H1, H2, H3 - proved. All hypothesis were proved. H1 - consumers do mostly hedonic shopping in the online trade market, as the respondents answered only $10.03 \%$ do utilitarian shopping with special purpose. $\mathrm{H} 2$ - by the survey results consumers evaluate the quality of products lower $(10.62 \%)$ than the quality of supply $(23.08 \%)$ of the Internet trade market. H3 - 43.57\% of respondents use only foreign online stores. The results showed that consumers in Latvia are not loyal to the local online stores. To improve the situation the sellers need to analyse what consumers like in foreign stores and improve the communication by make changes in all quality dimensions that will increase the satisfaction and the level of trust.

5. It is recommended to react on different situations as soon as possible and rise the all quality dimensions in case to satisfy consumers and increase the level of efficient communication with customers. That helps to increase the level of e-loyalty both to product and vendor and ensure a long - term relationship. 


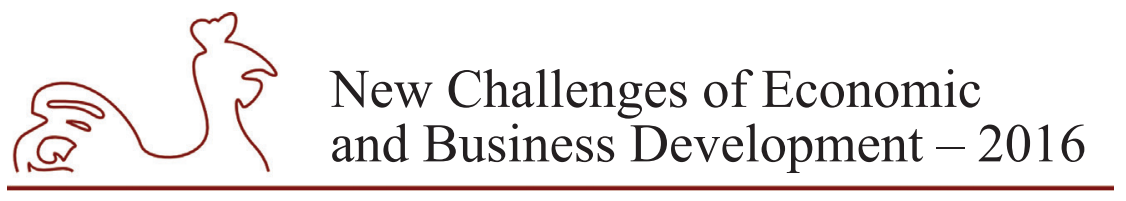

May 12-14, 2016, Riga, University of Latvia

\section{Bibliography}

Andrews L., Bianchi C. 2013. Consumer Internet Purchasing Behavior in Chile. In Journal of Business Research 66, 1791-1799.

Audrain-Pontevia A. F., N'Goala G., Poncin I. 2013. A Good Deal Online: The Impacts Of Acquisition And Transaction Value On E-Satisfaction And E-Loyalty. In Journal of Retailing and Consumer Services 20, 445-452.

Bilgihana A., Bujisic M. 2015. The effect of website features in online relationship marketing: A case of online hotel booking. In Electronic Commerce Research and Applications Volume 14, Issue 4, July-August 2015, Pages 222-232.

Chang H. H., Chen S. W. 2008. The Impact Of Customer Interface Quality, Satisfaction And Switching Costs On E-Loyalty: Internet Experience As A Moderator. Computers in Human Behavior 24, 2927 2944.

Christodoulides G., Michaelidou N. 2011. Shopping Motives As Antecedents Of E-Satisfaction And E-Loyalty. In Journal of Marketing Management Vol. 27, No. 1-2, 181-197.

Haka Z. 2015. Strauji aug interneta tirdznieciba; vairak ieperkas arvalstu interneta veikalos (Haka Z., The Increase Of Internet Trading; Buying More In Foreign Online Stores) Retrieved: http://www.db.lv/ tirdznieciba/strauji-aug-interneta-tirdznieciba-vairak-ieperkas-arvalstu-veikalos-426351 Access: 15.12.2015.

Haka Z. 2015. Vienam Latvijas iedzivotajam ir videji divi norekinu konti (Haka Z., The Latvian Resident Has Average Two Accounts) Retrieved: http://www.db.lv/finanses/vienam-latvijas-iedzivotajamvideji-ir-divi-norekinu-konti-431950 Access: 17.12.2015.

Haka Z. 2015. Visvairak sudzas par tradicionala pasta pakalpojumiem (2015) (Haka Z., The Most Complaint About the Traditional Post Services). Retrieved: http://www.db.lv/tirdznieciba/visvairaksudzas-par-tradicionala-pasta-pakalpojumiem-430054 Access: 16.12.2015.

Ivanov A. E. 2012. The Internet's Impact on Integrated Marketing Communication. Procedia Economics and Finance 3, 536-542.

Kotler P. 2014. Kotler On Marketing: How To Create, Win, And Dominate Markets, Free Press.

KursorsLV. 2014. Interneta ieperkas jau 71\% Latvijas interneta lietotaju Technology blog Kursors.lv, (KursorsLV, 71\% Of The Latvian Internet Users Already Buy Online) Retrieved: http://kursors. lv/2014/08/03/interneta-ieperkas-jau-71-latvijas-interneta-lietotaju/ Access: 16.12.2015.

Labrecque L. I., Esche J., Mathwick C., Novak T. P., Hofacker C. F. 2013. Consumer Power: Evolution in the Digital Age. Journal of Interactive Marketing 27, 257-269.

Latvian Internet Association. 2014. Statistika e-komercija (Latvian Internet Association, E-Commerce Statistics). Retrieved: http://www.lia.lv/ekomercija/_Access: 15.12.2015.

Martínez-López F. J., Pla-García C., Gázquez-Abad J. C., Rodríguez-Ardura I. 2014. Utilitarian Motivations in Online Consumption: Dimensional Structure and Scales. Electronic Commerce Research and Applications 13, 188-204.

McCole P., Ramsey E., Williams J. 2010. Trust Considerations On Attitudes Towards Online Purchasing: The Moderating Effect Of Privacy And Security Concerns. Journal of Business Research 63, 10181024.

Radionova E. 2015. Klientu lojalitates izvertesana un analize, GlobeEdit (Radionova E., Customer Loyalty Evaluation And Analysis, GlobeEdit, 2015).

Sewell C., Brown P.B. 2002. Customers For Life: How to Turn That One-Time Buyer into a Lifetime Customer, Crown Business; Revised edition.

Yi J. 2013. 3 Simple Strategies to Increase Customer Retention, Ecommerce Rules Retrieved: http:// ecommercerules.com/3-simple-strategies-increase-customer-retention/ Access: 18.12.2015.

Ткачев С.С. 2015. Дисконтные системы: внедряем и развиваем. Ростов н/Д: Феникс (Tkachev S. S. Discount Systems: Introduce and Develop. Rostov n/D: Feniks, 2015). 
May 12-14, 2016, Riga, University of Latvia

\title{
THREATS TO SUSTAINABILITY OF NATIONAL PENSION SYSTEMS: THE RESULTS OF EUROPEAN AND BALTIC EXPERT POLL
}

\author{
Olga Rajevska, University of Latvia, Latvia ${ }^{1}$
}

\begin{abstract}
The paper presents the results of the expert poll, where leading experts from 11 European countries were asked to fill the questionnaire elaborated by the author. The proposed answers' entries have been developed on the basis of the analysis of respective academic literature and the author's previous research.

The answers were collected in person and electronically by e-mail in September-October 2015. The total amount of the responded questionnaires -15 ( 7 experts from the Baltic States and 8 from other European countries).

The first and foremost threat to future adequacy and overall sustainability of pension systems is population ageing. On the second place the experts from the Baltic States put the problem of labour market globalisation, leading to emigration of working-age population and further worsening of dependency ratio. The third place in this rating is taken in the Baltics by shadow economy with a significant amount of persons' earnings not covered by social insurance. With the growing importance of the funded pillars, the sustainability of future pensions can be undermined also by poor performance of private pension funds, not able to generate sufficient levels of profitability.

All the experts have also agreed that the sustainability may be threatened by disadvantageous labour market patterns: unemployment, part-time employment, spread of freelance and self-employment not properly secured by social insurance schemes.

The overall level of concern demonstrated by the Baltic experts is higher than that of their colleagues from other European countries.
\end{abstract}

Key words: pension systems, Baltic States, public pensions

JEL code: $\mathrm{H} 55$, H75

\section{Introduction}

The presented paper is a part of the author's research of pension systems of Latvia, Estonia and Lithuania, their design and performance, pitfalls and bottlenecks. The objective of this study was to identify the factors threatening sustainability of the systems as seen by branch experts. The questionnaire was elaborated by the author using the conceptual framework for pension system analysis developed by the World Bank experts (Holzmann R. and Hinz R. P., 2005; Holzmann R., Hinz R. P. and Dorfmann M., 2008; Holzmann R., 2012) and included three major questions: assessment of measurement instruments of pension adequacy, assessment of measurement instruments of pension equity, assessment of pension sustainability threats.

1 Corresponding author - e-mail address: olga.rajevska@lu.lv 


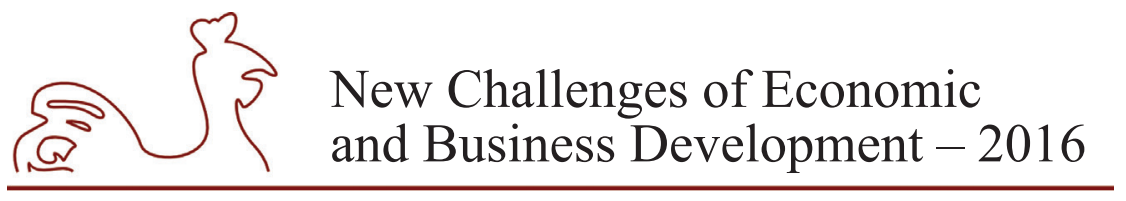

May 12-14, 2016, Riga, University of Latvia

The first two questions are beyond the scope of this paper, while the wording of the third question and suggested answers are shown below.

The proposed answers' entries have been developed on the basis of the analysis of respective academic literature. The notion of sustainability has many dimensions and many aspects. The review of conceptual and methodological approaches to evaluating sustainability when this term is used in respect of pension systems can be found in the author's earlier publications (Rajevska O., 2015). Since 2001, the provision of adequate, safe and sustainable pensions is a confirmed common objective at EU level. Generally, the main challenge pension systems sustainability is seen in the ageing of modern European societies and increasing burdens on public finances undermining fiscal sustainability (EC, 2010). The other widely recognised important factors that can positively or negatively influence pension sustainability include labour market participation rates and respective labour policies (Janicko M. and Tsharakyan A., 2013) and immigration/emigration of working age population (Angrisani M. et al., 2012).

However, social practices in the area of social security, or social sustainability (Rasnaca L. and Niklass M., 2014, p. 13) are less commonly considered as a risk factor to a pension system. The issue of political aspect of pensions sustainability as a political feasibility of pension reforms is also covered in the academic literature (Ebbinghaus B., 2015), but was intentionally left aside for the purpose of the given study.

The suggested set of potential threats has been worked out based on previous research of the author (see Rajevska F., Rajevska O. and Stavausis D., 2013; Rajevska O., 2014) and other Latvian scholars (Pukis M. and Dundure I., 2012; Stavausis D., 2013; Dundure I. and Pukis M., 2015).

The paper was supported by the National Research Program 5.2. "Economic Transformation, Smart Growth, Governance and Legal Framework for the State and Society for Sustainable Development - a New Approach to the Creation of a Sustainable Learning Community (EKOSOC-LV)".

\section{Research results and discussion}

The wording of the question put forward to the experts and suggested answers are presented in the Table 1 . The questionnaire was intentionally not providing any definition for the term "sustainability" in order to provoke the pollees to disclose their own understanding of the term tacitly, via scores and eventual comments, at the same time keeping the questionnaire straightforward and easy-to-fill. One of the experts has inserted the word "financial [sustainability]" into the very wording of the question, another one requested to clarify whether the question was "a question about financial sustainability? Long run or short-run?"

The answers were collected in person (by prof. Feliciana Rajevska during ESPN meeting in Brussels on 28-29/09/2015) and electronically by e-mail. The total amount of the responded questionnaires equals 15.

Mainly the pollees are European Social Policy Network (ESPN) national coordinators. ESPN was established in 2014 to provide the European Commission with independent information, analysis and expertise on social policies. In particular, the ESPN supports the Commission in monitoring progress towards the EU social protection and social inclusion objectives set out in the Europe 2020 strategy. At the heart of the ESPN are country teams of independent experts 


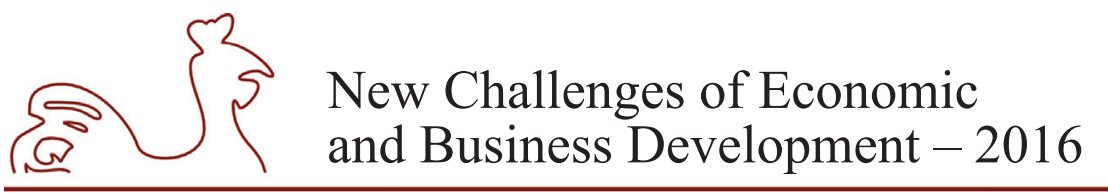

May 12-14, 2016, Riga, University of Latvia

on social policies from 35 countries (including 28 Member States). They are supported and coordinated by a central team of international experts.

For the Baltic States, more than one expert was included from each country (two from Estonia and Latvia and three from Lithuania): in addition to ESPN Network country experts, the questionnaires were sent also to ASISP (Analytical Support on the Socio-Economic Impact of Social Protection Reforms) network country pension experts Ruta Zilvere (Latvia) and Teodoras Medaiskis (Lithuania) (in Estonia the ESPN country pension expert and ASISP country pension expert is one and the same person - Andres Vork), as well as to Jolanta Aidukaite in Lithuania, known for her numerous publications on a social policy development in the three Baltic States, and to Avo Trumm in Estonia, expert in social policy analysis.

Table 1

\section{Wording of the question to the experts and suggested answers' entries}

Do you agree the below factors threaten pension system sustainability in your country?

(Evaluation scale 1-10, where 1 -fully disagree, 10 - fully agree)

\begin{tabular}{|c|c|c|c|c|c|c|c|c|c|c|c|c|c|}
\hline & & 1 & 2 & 3 & 4 & 5 & 6 & 7 & 8 & 9 & 10 & $\begin{array}{l}\text { Don't } \\
\text { know }\end{array}$ & $\begin{array}{l}\text { Not } \\
\text { appli- } \\
\text { cable }\end{array}$ \\
\hline \multirow[t]{5}{*}{1} & $\begin{array}{l}\text { Changing labour patterns } \\
-\quad \text { late start (youth unemployment) }\end{array}$ & $\square$ & $\square$ & $\square$ & $\square$ & $\square$ & $\square$ & $\square$ & $\square$ & $\square$ & $\square$ & $\square$ & $\square$ \\
\hline & - more fragmentised careers & $\square$ & $\square$ & $\square$ & $\square$ & $\square$ & $\square$ & $\square$ & $\square$ & $\square$ & $\square$ & $\square$ & $\square$ \\
\hline & - part-time employment & $\square$ & $\square$ & $\square$ & $\square$ & $\square$ & $\square$ & $\square$ & $\square$ & $\square$ & $\square$ & $\square$ & $\square$ \\
\hline & $\begin{array}{ll}- & \text { spread of freelancing and self- } \\
\text { employment }\end{array}$ & $\square$ & $\square$ & $\square$ & $\square$ & $\square$ & $\square$ & $\square$ & $\square$ & $\square$ & $\square$ & $\square$ & $\square$ \\
\hline & - other (please indicate and evaluate) & $\square$ & $\square$ & $\square$ & $\square$ & $\square$ & $\square$ & $\square$ & $\square$ & $\square$ & $\square$ & $\square$ & $\square$ \\
\hline 2 & $\begin{array}{l}\text { Globalisation of labour markets causing } \\
\text { migration of working age population }\end{array}$ & $\square$ & $\square$ & $\square$ & $\square$ & $\square$ & $\square$ & $\square$ & $\square$ & $\square$ & $\square$ & $\square$ & $\square$ \\
\hline 3 & $\begin{array}{l}\text { Poor performance of funded pension } \\
\text { schemes }\end{array}$ & $\square$ & $\square$ & $\square$ & $\square$ & $\square$ & $\square$ & $\square$ & $\square$ & $\square$ & $\square$ & $\square$ & $\square$ \\
\hline 4 & Population ageing & $\square$ & $\square$ & $\square$ & $\square$ & $\square$ & $\square$ & $\square$ & $\square$ & $\square$ & $\square$ & $\square$ & $\square$ \\
\hline 5 & $\begin{array}{l}\text { Shadow economy (earnings uncovered } \\
\text { with social insurance) }\end{array}$ & $\square$ & $\square$ & $\square$ & $\square$ & $\square$ & $\square$ & $\square$ & $\square$ & $\square$ & $\square$ & $\square$ & $\square$ \\
\hline 6 & $\begin{array}{l}\text { Significant difference in social security } \\
\text { standards between Eastern and Western } \\
\text { Europe }\end{array}$ & $\square$ & $\square$ & $\square$ & $\square$ & $\square$ & $\square$ & $\square$ & $\square$ & $\square$ & $\square$ & $\square$ & $\square$ \\
\hline 7 & Unemployment & $\square$ & $\square$ & $\square$ & $\square$ & $\square$ & $\square$ & $\square$ & $\square$ & $\square$ & $\square$ & $\square$ & $\square$ \\
\hline \multirow[t]{4}{*}{8} & $\begin{array}{l}\text { Views and expectations of the population } \\
- \text { excessive reliance on the state } \\
\end{array}$ & $\square$ & $\square$ & $\square$ & $\square$ & $\square$ & $\square$ & $\square$ & $\square$ & $\square$ & $\square$ & $\square$ & $\square$ \\
\hline & - overoptimistic individual expectations & $\square$ & $\square$ & $\square$ & $\square$ & $\square$ & $\square$ & $\square$ & $\square$ & $\square$ & $\square$ & $\square$ & $\square$ \\
\hline & - poor financial literacy & $\square$ & $\square$ & $\square$ & $\square$ & $\square$ & $\square$ & $\square$ & $\square$ & $\square$ & $\square$ & $\square$ & $\square$ \\
\hline & - other (please indicate and evaluate) & $\square$ & $\square$ & $\square$ & $\square$ & $\square$ & $\square$ & $\square$ & $\square$ & $\square$ & $\square$ & $\square$ & $\square$ \\
\hline 9 & Other (please indicate and evaluate): & $\square$ & $\square$ & $\square$ & $\square$ & $\square$ & $\square$ & $\square$ & $\square$ & $\square$ & $\square$ & $\square$ & $\square$ \\
\hline
\end{tabular}

Source: questionnaire elaborated by the author. 


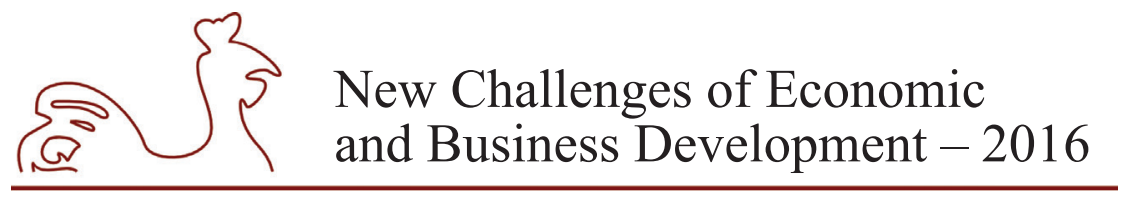

May 12-14, 2016, Riga, University of Latvia

The list of experts in the alphabetical order:

1) Aidukaite Jolanta (Lithuania), Lithuanian Social Research Centre;

2) Cabrero Gregorio Rodriguez (Spain), University of Alcalá, ESPN national coordinator for Spain, Country Expert in Social inclusion, Long-term care and Pensions;

3) Gerovska Mitev Maja (FYR of Macedonia), Institute of Social Work and Social Policy, Faculty of Philosophy, Ss. Cyril and Methodius University, ESPN national coordinator for FYR of Macedonia, Country Expert in Social inclusion and Pensions;

4) Kangas Olli (Finland), Social Insurance Institution of Finland - Kela, ESPN national coordinator for Finland, Country Expert in Social inclusion, Healthcare and Pensions;

5) Kvist Jon (Denmark), Roskilde University, ESPN national coordinator for Denmark, Country Expert in Social inclusion, Long-term care and Pensions;

6) Lazutka Romas (Lithuania), Vilnius University, ESPN Country Expert in Pensions and Social inclusion;

7) Marxer Wilfried (Liechtenstein), Liechtenstein-Institut, ESPN national coordinator for Liechtenstein, Country Expert in Social inclusion, Healthcare, Long-term care and Pensions;

8) Medaiskis Teodoras (Lithuania), Vilnius University, ASISP Country Expert for Lithuania on Pensions;

9) Olafsson Stefan (Iceland), University of Iceland, ESPN national coordinator for Iceland, member of ESPN Network Core Team, Country Expert in Social inclusion, Healthcare, Long-term care and Pensions;

10) Pedersen Axel West (Norway), Institute for Social Research, ESPN national coordinator for Norway, Country Expert in Social inclusion and Pensions;

11) Rajevska Feliciana (Latvia), Vidzeme University of Applied Sciences, ESPN national coordinator for Latvia, Country Expert in Long-term care and Pensions;

12) Topinska Irena (Poland), Centre for Social and Economic Research, CASE Foundation, ESPN national coordinator for Poland, Country Expert in Social inclusion and Pensions;

13) Trumm Avo (Estonia), University of Tartu;

14) Võrk Andres (Estonia), Praxis Centre for Policy Studies, ESPN national coordinator for Estonia, Country Expert in Healthcare, Long-term care and Pensions;

15) Zilvere Ruta (Latvia), ASISP Country Expert for Latvia on Pensions and Long-Term Care.

The experts' responses have been analysed with the assistance of SPSS. The major results are summarised in the below Table 2. 


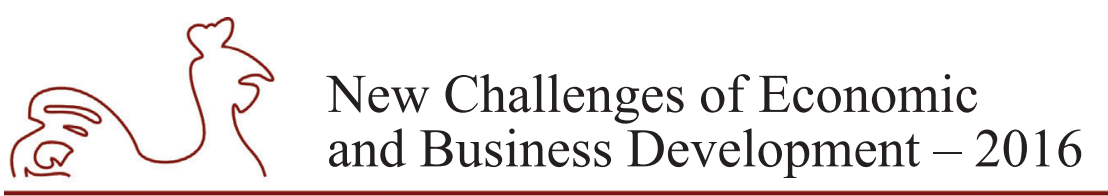

May 12-14, 2016, Riga, University of Latvia

Table 2

Descriptive statistics on expert poll results (September-October 2015)

\begin{tabular}{|l|c|c|c|c|c|c|c|}
\hline & $\mathbf{N}$ & Min & Max & Mean & $\begin{array}{c}\text { Std. } \\
\text { deviation }\end{array}$ & Mode & Median \\
\hline late start (youth unemployment) & 13 & 2 & 10 & 5.92 & 2.900 & 8 & 7 \\
\hline fragmentised careers & 14 & 1 & 10 & 6.14 & 2.685 & 8 & 6.5 \\
\hline part-time employment & 14 & 2 & 10 & 6.21 & 2.517 & $3 ; 6 ; 7 ; 8 ; 9$ & 6.5 \\
\hline $\begin{array}{l}\text { spread of freelancing and self- } \\
\text { employment }\end{array}$ & 14 & 3 & 8 & 6.50 & 1.506 & $6 ; 7 ; 8$ & 7 \\
\hline $\begin{array}{l}\text { labour market globalisation causing } \\
\text { migration of working age population }\end{array}$ & 14 & 1 & 10 & 6.64 & 2.790 & $7 ; 10$ & 7 \\
\hline $\begin{array}{l}\text { poor performance of funded pension } \\
\text { schemes }\end{array}$ & 14 & 1 & 10 & 5.36 & 2.649 & 7 & 5.5 \\
\hline $\begin{array}{l}\text { population ageing } \\
\text { shadow economy (uninsured } \\
\text { earnings) }\end{array}$ & 15 & 3 & 10 & 8.07 & 2.017 & 8 & 8 \\
\hline $\begin{array}{l}\text { significant difference in social } \\
\text { security standards between Eastern } \\
\text { and Western Europe }\end{array}$ & 11 & 1 & 7 & 4.00 & 1.949 & $2 ; 3 ; 5 ; 6$ & 4 \\
\hline unemployment & 15 & 2 & 10 & 6.53 & 2.532 & $4 ; 5 ; 8$ & 7 \\
\hline $\begin{array}{l}\text { excessive reliance of population on } \\
\text { state }\end{array}$ & 13 & 1 & 8 & 4.38 & 2.434 & 2 & 4 \\
\hline $\begin{array}{l}\text { overoptimistic expectations of } \\
\text { population }\end{array}$ & 14 & 2 & 8 & 5.21 & 1.718 & $4 ; 5 ; 7$ & 5 \\
\hline \begin{tabular}{l} 
poor financial literacy of population \\
\hline
\end{tabular} & 14 & 2 & 8 & 4.86 & 1.875 & 3 & 5 \\
\hline
\end{tabular}

Source: author's calculations using SPSS, the answers were given using ordinal scale 1-10.

It clearly demonstrates that all proposed answers' entries are eligible. At least one expert gave a high score (from eight to ten) to all entries but one ("significant difference in social security standards between Eastern and Western Europe"), where the observed maximum value is seven.

At the same time, at least one expert gave a very low score (from one to three) to all entries, demonstrating significant variations in experts' opinions in different countries. The answers of the experts vary significantly, proving the complexity and multi-dimensionality of the studied phenomenon. Some of the listed negative factors (e.g., shadow economy or unemployment) are of different importance in different countries, and the experts were requested to evaluate them for their home country. Even within one country, the views of experts are quite dissimilar: for instance, when evaluating the importance of potential underperformance of II pillar pension funds, three Lithuanian experts returned " 2 ", "7" and " 10 ".

The two main almost unquestioned risks include population ageing and interruptions in service record due fragmentation of labour careers and unemployment. 


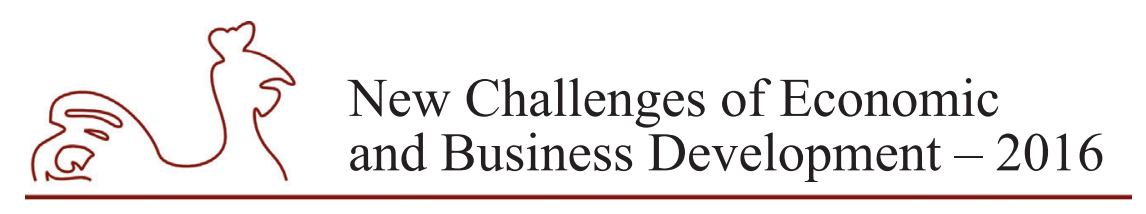

May 12-14, 2016, Riga, University of Latvia

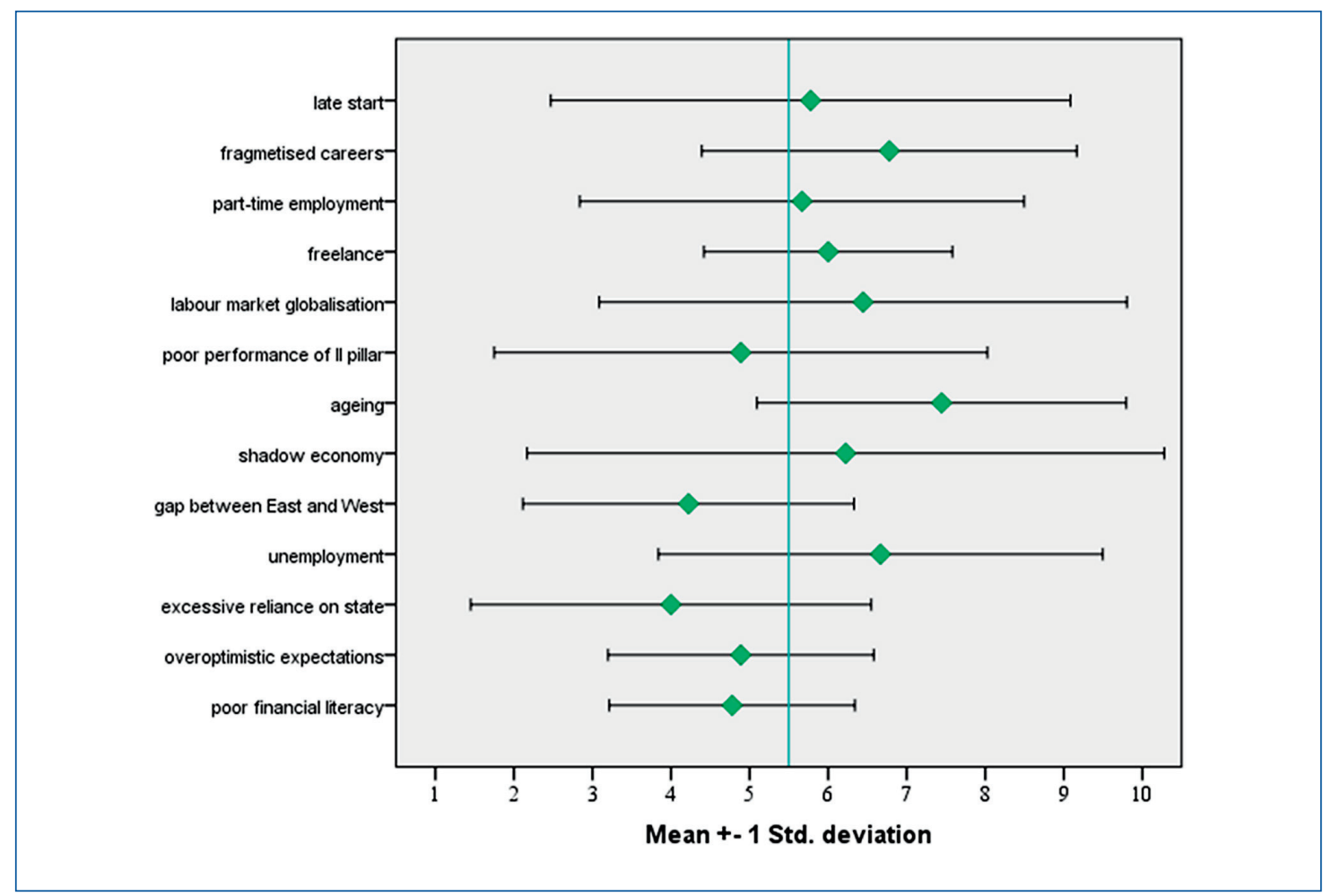

Source: author's plotting using SPSS.

\section{Fig. 1. Evaluation of threats to pension systems sustainability}

The first and foremost threat to future adequacy and overall sustainability of pension systems in the Baltic States is population ageing: all Baltic experts demonstrated great concern on that factor: Estonian, Latvian and Lithuanian experts gave scores from "8" to "10" (mean = 9.0). The majority of other experts also assign high score to this threat: "10" from Finland, "9" from Poland and Spain, "8" from Norway and Liechtenstein. However, two experts evaluated this risk as non-significant: "5" from Denmark and "3" from Iceland (indeed, the expert from Iceland scored practically all suggested answers as non-significant threats to pension system sustainability, granting scores from " 1 " to " 4 ", with the only exception for "more fragmentised labour career" that received "8").

On the second place the Baltic experts put the globalisation of labour markets, leading, in our circumstances, to emigration of working-age population and further worsening of dependency ratio. Mean score among Baltic experts is 8.67, Estonians are a bit less concerned ("6" and "7"), while Latvians and Lithuanians, whose countries face much more wide-spread 'exodus', assign "9" and "10". The majority of experts from Western Europe do not consider this factor as a threat to their pension systems (mean score among them $=4.5$ ). However, Liechtenstein expert commented on this entry that the "provision of social security must be internationally well coordinated".

The third place (mean $=8.0$ ) in this rating is taken by shadow economy with a significant amount of persons' earnings not covered by social insurance. And again, Western experts do 


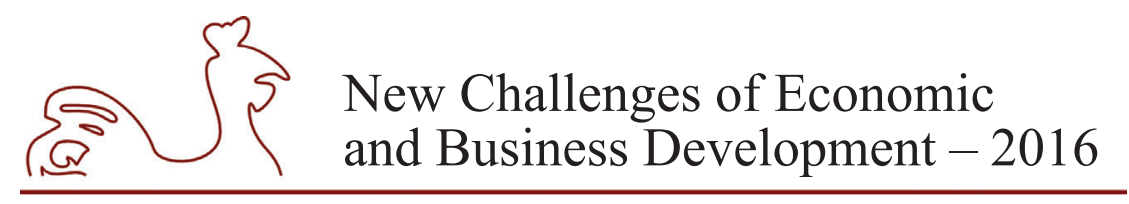

May 12-14, 2016, Riga, University of Latvia

not express serious concern about shadow economies in their home countries (except for Spain, where the score is " 10 ").

With the growing importance of the funded pillars, the sustainability of future pensions can be undermined by poor performance of private pension funds, not able to generate sufficient levels of profitability (the Baltic experts scored this factor with " 7 " as average). In this question, the level of concern demonstrated by the Baltic experts is higher than that of their colleagues from other European countries - only Finnish expert marked this potential threat with "7" and Polish expert gave " 6 ", all the rest disagree with the suggested entry.

And, finally, practically all experts (with the only exception for Finland) agreed that the sustainability may be threatened by disadvantageous labour market patterns: unemployment, part-time employment, spread of freelance and self-employment not properly secured by social insurance schemes. They have also added to this list three more entries, namely - early retirement, special pension schemes and gender gap through maternity.

The least popular answer, both among Baltic experts and their Western counterparts was the threat caused by significant difference in social security standards between Eastern and Western Europe. The underlying reason for including this entry into the list was the ongoing political debate in a number of Western countries to put more strict limitations on the so called "social tourism" from new Member States. However, the surveyed experts do not express concern on the matter.

Two experts suggested additional threatening factors to be included into the list: "austerity measures of the state due to financial cut-downs" (Liechtenstein) and a more broad wording of a similar problem - "political interventions" (Poland).

\section{Conclusions}

1. All suggested answers' entries in the questionnaire are eligible. The listed factors are threatening pension systems in the experts' home countries, although to a different extent. Meanwhile, the answers of the experts vary significantly, proving the complexity and multi-dimensionality of the studied phenomenon.

2. The two main almost unquestioned risks include population ageing and interruptions in service record due fragmentation of labour careers and unemployment.

3. The first and foremost threat to overall sustainability of pension systems in the region is population ageing: all Baltic experts demonstrated great concern on that factor: Estonian, Latvian and Lithuanian experts gave scores from " 8 " to "10" $($ mean $=9.0)$. This factor is vital in other experts' home countries as well.

4. On the second place the Baltic experts put the globalisation of labour markets, leading, in our circumstances, to emigration of working-age population and further worsening of dependency ratio.

5. The third place (mean $=8.0$ ) in this rating is taken in the region by shadow economy with a significant amount of persons' earnings not covered by social insurance.

6. With the growing importance of the funded pillars, the sustainability of future pensions can be undermined by poor performance of private pension funds, not able to generate sufficient levels of profitability (the Baltic experts scored this factor with "7" as average). 


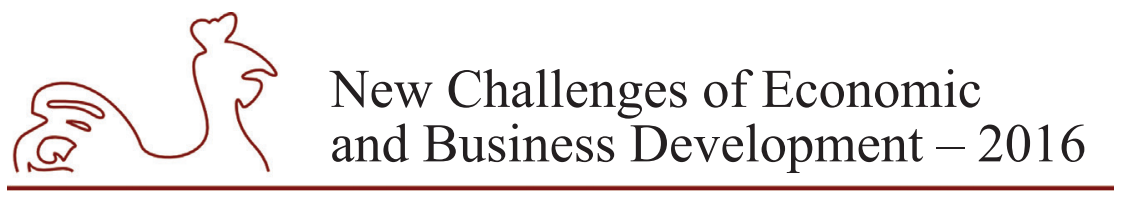

May 12-14, 2016, Riga, University of Latvia

At the same time, the majority of experts from Western Europe do not consider this factor as a threat to their pension systems.

7. In all the above answers, the level of concern demonstrated by the Baltic experts is higher than that of their colleagues from other European countries. The overall preoccupation with the (un-)sustainability of their pension systems is more strongly pronounced among the experts from the Baltic States, than among the experts from Western Europe.

8. Western experts are more concerned with the threats caused by disadvantageous labour market patterns: unemployment, part-time employment, spread of freelance and selfemployment not properly secured by social insurance schemes.

\section{Bibliography}

Angrisani, M., Attias, A., Bianchi, B. \& Varga, Z., 2012. Sustainability of a pay-as-you-go pension system by dynamic immigration control. Applied Mathematics and Computation, 212(5), pp. 2442-2452.

Dundure, I. \& Pukis, M., 2015. Criteria for Sustainability of Old-Age Pension System Based on the NDC Principles. European Integration Studies, 9, pp. 86-99.

Ebbinghaus, B., 2015. Demographic Ageing and Pension Reforms in Europe: Problems of Economic, Social and Political Sustainability. Kölner Zeitschrift für Soziologie und Sozialpsychologie, 67 (1), pp. 325-348.

European Commission, 2010. Progress and key challenges in the delivery of adequate and sustain-able pensions in Europe. European Economy, 71, Brussels: DG Economic and Financial Affairs.

Holzmann, R. \& Hinz, R.P., 2005. Old Income Support in the 21st Century: An International Perspective on Pension Systems and Reform. Washington, D.C.: The World Bank.

Holzmann, R., Hinz, R.P. \& Dorfman, M., 2008. Pension Systems and Reform Conceptual Framework. Social Protection Discussion Paper 0824, The World Bank. Available at: http://siteresources. worldbank.org/ SOCIALPROTECTION/Resources/SP-Discussion-papers/Pensions-DP/0824.pdf [Accessed 15 February 2016].

Holzmann, R., 2012. Global Pension Systems and Their Reform: Worldwide Drivers, Trends and Challenges. Social Protection \& Labor Discussion Paper 1213. The World Bank.

Janicko, M. \& Tsharakyan, A., 2013. Note on the Sustainability of the Pay-As-You-Go Pension Scheme in the Context of Population Ageing in the Czech Republic. Politicka Ekonomie, 61(3), pp. 321-337.

Pūķis, M. \& Dundure, I., 2012. Sustainability of the Pension System in Latvia. Journal of Economics and Management Research, 1, pp. 139-154.

Rajevska, F., Rajevska, O. \& Stāvausis, D., 2014. Challenges for the Sustainability of Latvian Pension System. In B. Bela (Ed.), Latvia. Human Development Report 2012/2013. Sustainable Nation, Riga: University of Latvia, pp. 13-33.

Rajevska, O., 2014. Latvian Pension System: Calibration by Crisis. In: International scientific conference "New Challenges of economic and business development": conference proceedings, 8-10 May, 2014, Riga: University of Latvia, pp. 307-315.

Rajevska, O., 2015. Sustainability of Pension Systems in the Baltic States. Entrepreneurial Business and Economic Review, 3(4), pp. 139-153.

Rasnača, L. \& Niklass, M., 2014. Social Sustainability: Are Unequal Societies Sustainable?. In B. Bela (Ed.), Latvia. Human Development Report 2012/2013. Sustainable Nation, Riga: Advanced Social and Political Research Institute of the University of Latvia, pp. 34-44.

Stavausis, D., 2013. Izglīî̄ibas veicināšana finanšu jautājumos kā spējināšanas instruments Latvijā: valsts fondēto pensiju gadījums. In F. Rajevska (Ed.), Sociālā cilvēkdrošǐba: spēju attīstība, sadarbība, iekļaušana. Rīga: LU Akadēmiskais apgāds, pp. 141-160. 
May 12-14, 2016, Riga, University of Latvia

\title{
MONITORING E-COLLABORATION: PREPARING AN ANALYSIS FRAMEWORK
}

\author{
Michel Rietze, TU Dresden, Germany ${ }^{1}$
}

\begin{abstract}
This paper is part of an extensive action research project on learning analytics and focuses on the aspects for analysing a Virtual Collaborative Learning (VCL) setting that has been applied for over 15 years now. Therein 40 students (mostly of Business and Economic Faculty) work together in small groups of 3 to 6 members. They collaborate in international teams and solve ill-structured problems using social software. During the in average 6 week working period they are supported by lecturers and eTutors as virtual learning facilitators. Therefor we analyse how learning facilitators can increase their efficiency by (semi-) automated learning analytics. For the purpose of the main project's research objective to ensure successful learning facilitating in formal eLearning settings through learning analytics, this paper fulfils the subgoal of preparing an analysis framework for assessing eCollaboration. We used a systematic literature review for analysing 32 publications of 11 databases of EBSCOhost regarding their assessment aspects. As the overall results we can present the differentiating dimensions for eCollaboration as well as an overview of the appropriate assessment facets for the concrete course setting. These will serve as a framework for applying an assessment catalogue.
\end{abstract}

Key words: eCollaboration, Collaborative Learning, eLearning, Assessment, Learning Analytics JEL code: D83, O15, I21

\section{Collaborative Work}

Worldwide economic as well as social affordances impressively show that the complexity of a solution cannot be handled by individuals. It rather requires a collaboration of experts to create economic innovations and solve social problems sensibly and sustainably. Necessarily companies have to form teams in or between speciality departments and between companies joining the special competences to produce competitive products. A solution for social problems is similar. Governments have to collaborate (inter)national and with regional Non-GovernmentalOrganizations (NGOs) to gain the relevant knowledge, the experiences and competences of all group members for a solution.

Diverse studies show the advantages of group vs. individual activities by means of solving problems that could not be solved alone (Bos, 1937; Stahl, 2006; Thagard, 1997). Addressing differences of place and time Computer Supported Collaborative Work (CSCW) offers possibilities for digital collaboration for 30 years now. Later on the Web 2.0 extended various functionalities in so called social software (Alexander, 2006). The digital collaboration, known as eCollaboration, is already spread in practice. So new employees should be aware of comprehensive knowledge to work collaboratively in digital environments (Trentin, 2009).

Corresponding author - e-mail address: michel.rietze@tu-dresden.de 


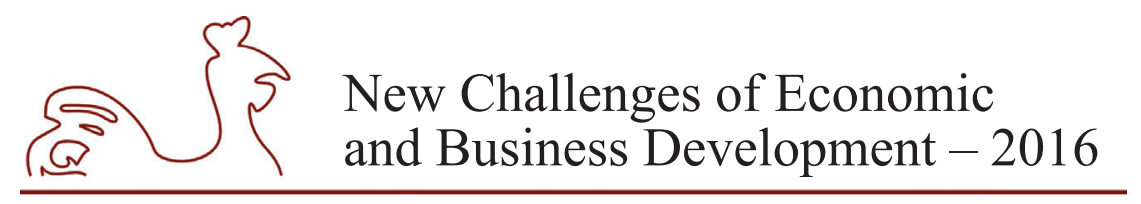

May 12-14, 2016, Riga, University of Latvia

To be prepared the employees have to be confronted with eCollaboration during their studies to understand the relevant characteristics of virtual collaboration and develop competences accordingly.

But unfortunately the sole hosting of an online collaboration platform does not guarantee the collaboration between the participants (Murphy, 2004). Consequently a successful learning respectively working process cannot be established due to missing coordination of activities (Erkens, Prangsma, \& Jaspers, 2006) and no participation in discussions (Weinberger \& Fischer, 2006). So accompanying and supporting the unexperienced participants is especially necessary within the context of education. To motivate students predefined measures are required to initiate concrete behavior (Murphy, 2004). To conclude: successful eCollaboration needs supporting learning facilitation and comprehensive criteria for evaluation as an incentive for participation.

Based on applying eCollaboration, the demand for measuring the results increases. In traditional courses individuals or groups produce and deliver a result. Based on this final result the same grade is given to all group members. Virtual collaborative work makes it possible to grade the collaborative working process of result construction additionally (Eddy \& Lawrence, 2013). Especially this circumstance irritates many students and they ask for a concrete definition which activities they have to perform. So an explicit explanation and transparent communication of the grading criteria to the participants are necessary (Kalb, Kummer, \& Schoop, 2011).

As a second aspect the learning facilitators supports the students in an unfamiliar setting. They facilitate cognitive und social processes to reach the learning goals. Therefor they identify problems immediately, hint the groups to the problems and suggest ways to solve these before the conflicts emerge (Pozzi, Manca, Persico, \& Sarti, 2007; Reneland-Forsman, 2012). Murphy (2004) concludes that the learning facilitator takes a supportive function for the eCollaboration of the participants. To fulfil their tasks they have to monitor the group activities continuously. Because the data are mostly wide spread across platforms and are very massive keeping up to date is difficult within the resource restrictions (Zedadra \& Lafifi, 2015). So they impose requirements on integrated learning analytics (Bravo, Redondo, Verdejo, \& Ortega, 2008; Rodríguez-Triana, Martínez-Monés, Asensio-Pérez, \& Dimitriadis, 2015):

1. Data should be aggregated and integrated from various platforms (Observation),

2. The status quo should be compare with the desired state (Abstraction),

3. Problems should be identified to encourage the learning facilitator to intervene focussed and effective (Intervention).

This article focuses on the transition between "Observation" and "Abstraction". Therefor it is necessary to be aware of the factors that influence the productivity, so knowing the interdependences of collaborative processes, activities and tools is required (Hyunkyung Lee \& Bonk, 2014). But Soller (2004) points out that especially this is very complicated and thus states that the evaluation of eCollaboration settings has not been sufficiently explored yet. Currently missing is a holistic approach for evaluation that considers facets and the belonging criteria. Existing approaches remain either too abstract to measure collaborative team work or are too specialized to take the number of facets into account.

In this paper we elaborate a framework to close this gap. Based on the Learning Analytics Reference Model of Chatti, Dyckhoff, Schroeder, \& Thüs (2012) the facets of eCollaboration will be identified and specified with hereto belonging aspects. As an example we use a course setting which has been applied for over 15 years now. 


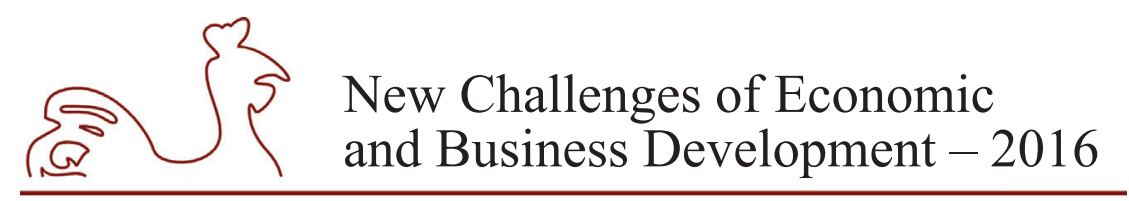

May 12-14, 2016, Riga, University of Latvia

\section{Virtual Collaborative Learning}

Because evaluation criteria differ regarding the context we introduce the underlying learning arrangement at first. The described course setting addresses the virtual collaborative learning (VCL) where small groups up to six members work together over a period of a couple of weeks up to a few months. Meanwhile they work on ill-structured cases that are constructed realistically and have a certain complexity (Balázs, 2005). The students analyse these complex assignments, deduce tasks to be solved by the group and spread them to the members. Afterwards they search for appropriate information that are relevant for the solution before they are integrated meaningfully to construct solutions, evaluate them und decide between existing alternatives afterwards. At the end they propose and defend their prioritised solutions. So collaboration is a central part of the group work. It is a learning objective and simultaneously serves as a mechanism to reach all other learning objectives (Rietze \& Hetmank, 2016). Hereto belong the creation of professional, method, communication and intercultural competences (Balázs, 2005).

The main problem is the low external prestructuring of collaborative group work (Perrez, Huber, \& Geißler, 2006), so the students have to plan, steer and control the solution of the assignments on their own (Geyken, Mandl, \& Reiter, 1998). Because they continuously have to work individually to prepare and work together to discuss, integrate and edit subtasks they iteratively produce new solutions by sharing ideas, opinions and arguments (Carell, 2006; Dillenbourg, 1999). To perform the interactions and participations successfully students usually need training, experiences and support (Pauleen \& Yoong, 2001). Preventing low learning activities and thus superficial examination of the content or even rising drop-outs (Carell, 2006) specially trained learning facilitators are required to force and direct the self-guided and collective learning (Kerres, Ojstersek, \& Stratmann, 2011). In the described learning arrangement of this paper eTutors undertake this role after they have been qualified in preparation to the upcoming tasks. Since 2001 the setting has been applied in over 52 courses with Bachelor, Master and MBA students from national partners (e.g. Freie Universität Berlin, Ruhr-Universität Bochum) and international partners (e.g. Latvijas Universitate Riga, Princess Sumaya University for Technology Amman). To enable the spatially separate group work we used modern Web 2.0 plattforms (e.g. ELGG, NING), as well as other communication tools (e.g. Skype, Whatsapp) and collaboration tools (e.g. GoogleApps, Doodle) (Rietze \& Hetmank, 2016). Hence we will concentrate on analysis of social software.

\section{Research Design}

As part of a superior Action Research approach on eCollaboration learning analytics should enable an efficient learning facilitation. The above described learning arrangement serves as a practical example and predefines the structure of this paper. Upon this a literature review identifies assessment aspects of other learning arrangements, compare them and create an enhanced assessment approach as a generalized framework. The research objective of this paper is thus the creation of a course spanning framework to determine the quality of collaborative group work in the virtual environment. Therefor Chatti et al. (2012) already published a generalized model for learning analytics that we now concretize for eCollaboration courses. The findings serve as alternatives that should be aligned with concrete assessment criteria to implement a 


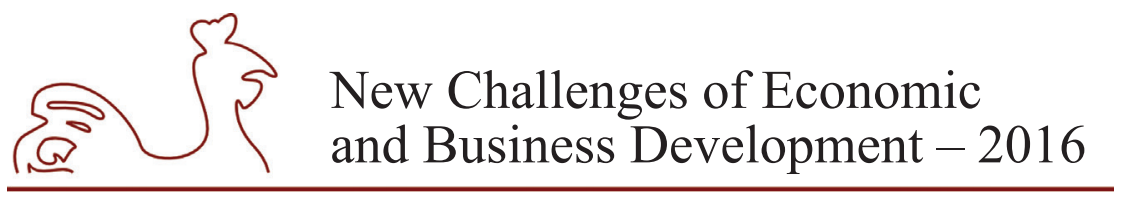

May 12-14, 2016, Riga, University of Latvia

process for learning analytics. To reach the research goal we focus on what facets of assessment are distinguished and which aspects of assessment are connected to these facets?

A systematic literature review according to Fettke (2006) is used as the method for data generation. It has been conducted based on a request on the EBSCOhost available databases Academic Search Complete; Business Source Complete; Communication \& Mass Media Complete; eBook Collection; EconLit with Full Text; E-Journals; Library, Information Science \& Technology Abstracts; PsycARTICLES; PsycINFO; Regional Business News und TOC Premier. On the 2016-02-07 we searched the term "(collaborat* OR cooperat*) AND (KPI OR measur* OR assess* OR quali* OR perform* OR indicat* OR analy*) AND ((social AND software) OR (social AND media) OR wiki OR CSCW OR CSCL) NOT (medic* OR health* OR (social AND work*)) AND (enterprise OR (group work) OR (team work) OR learn* OR educat* OR school OR pedagog*)" on entries that were available as "Full Text", "Scholarly Peer Reviewed" and in the English Language. We included results without restrictions to the year. After reducing the duplicates we received 634 results that were manually evaluated according to their relevance and finally filtered based on the information in the title, abstract and keywords. A content analysis had been conducted on the remaining 32 results based on the full text. The focus for selecting the final results has been placed on paper that describe the assessment of collaborative processes and student produced course content. We excluded descriptions of used toolsets as well as success factors, barriers or benefits of collaboration. If paper addresses included as well as excluded topics they were also considered. So e.g. Walthall et al. (2011) who measured the group performance and deduced the suitability of tools were also scanned as well as Pombo et al. (2010) who evaluated the setting and thereby focused on evaluating the content.

The procedure of this paper is subdivided into five chapters. At the beginning we introduced the underlying problems of this paper (Chap. Collaborative Work). Subsequently we illustrated the exemplary learning arrangement (Chap. Virtual Collaborative Learning) before this chapter details the objective and the procedure (Chap. Research Design). Now there follows the elaboration of both research questions by means of the above explicated systematic literature review (Chap. Facets for Analysis of eCollaboration). The paper ends with a discussion of the results, a conclusion and an outlook on further necessary research work (Chap. Conclusion).

\section{Facets for Analysis of eCollaboration}

Based on 32 preselected articles we identified the ones that thematises and applied procedures to assess the collaborative work. In comparison to conventional assessments of results and the undifferentiated grading for all group members the digital collaboration creates various data traces that enable a differentiated analysis. The interdisciplinarity of the research area some main topics emerged which propagate their focus on the assessment of eCollaboration. To offer a better overview of the results we will list them in the forthcoming tables grouped by their facets. The Learning Analytics Reference Model (Chatti et al., 2012) hereby prestructures the analysis into four dimensions: 


\section{New Challenges of Economic and Business Development - 2016}

May 12-14, 2016, Riga, University of Latvia

\begin{tabular}{|l|c|c|c|}
\hline Why? & Who? & What? & How? \\
\hline Time & Learning Analytics for eCollaboration \\
\hline Actor & $\begin{array}{c}\text { Data, Content, } \\
\text { Activity }\end{array}$ & Method \\
\hline
\end{tabular}

Source: author's construction based on Chatti et al. (2012).

Fig. 1. Facets for Analysis of eCollaboration Settings

The dimension "Why?" describes the actual goals of the applicable analysis. Chatti et al. (2012) distinguish between "monitoring, analysis, prediction, intervention, tutoring/mentoring, assessment, feedback, adaptation, personalization, recommendation, and reflection" (Chatti et al., 2012). Within this paper we pursue the goal of monitoring and assessment, even if the results will influence e.g. the tutoring and interventions in a next step. Thus there remains a distinguishable characteristic in the time of the assessment. While the traditional group work allows only assessing of the deliverables at the end (summative), the digital group work now enables us to gain an insight into the collaboration itself and consequently prepare a formative assessment on the processes of the group work. Of course the summative assessment of the delivered results remains unchanged (Armellini \& Aiyegbayo, 2010; Eddy \& Lawrence, 2013; Ferreira, Antunes, \& Pino, 2009; Pozzi et al., 2007; Rice, Davidson, Dannenhoffer, \& Gay, 2007).

The next dimension "Who?" initially addresses the stakeholder of the analysis which should be informed. Hereto appertain i.a. "Learners, Teachers, Tutors, Mentors, Institutions, Researchers, System designers" (Chatti et al., 2012). The monitoring and the assessment of the herein presented course setting serve mainly for eTutors or docents. So we will not concentrate on stakeholders that should be informed but rather on students as stakeholders that are monitored and assessed. Contrary to the guideline to determine the individual performance the grading mostly is done uniformly on the group level because the contributions of individuals to the group results remain invisible (Collazos, Guerrero, Pino, \& Ochoa, 2004; Swan, Shen, \& Hiltz, 2006). Similarly to the time facet the comprehensive processual insight now offers the opportunity to differentiate between the group and the contribution of individuals (Balázs \& Schoop, 2004; Dennen \& Wieland, 2007; Pombo et al., 2010; Stahl, 2006). Hence the determination of the degree of reaching the learning goal as well as the success of the participants is easier. Beyond the community communications could indicate correlations between group results (Fessakis, Dimitracopoulou, \& Palaiodimos, 2013; Kirschner \& Erkens, 2013).

Similar advantages from the course setting occur on the dimension "What?" that is split into the facets "Activity", "Data" and "Content". The following tables will thematise them one by one, starting with "Activity". We therein can ascertain how active or passive a group member had engaged with the existing material. So differentiating between types of activity is possible. The objective is a graduated consideration with a weighted assessment based on the intensity of engagement with the existing material. Hence we can ensure that not every little activity is equal to substantial contributions and at the same time we can consider actions that have been neglected due to their missing visibility or insignificance. Therefore (Ferreira et al., 2009; Fessakis et al., 2013; Hyunkyung Lee \& Bonk, 2014) grouped these activities into authorship and usership. 


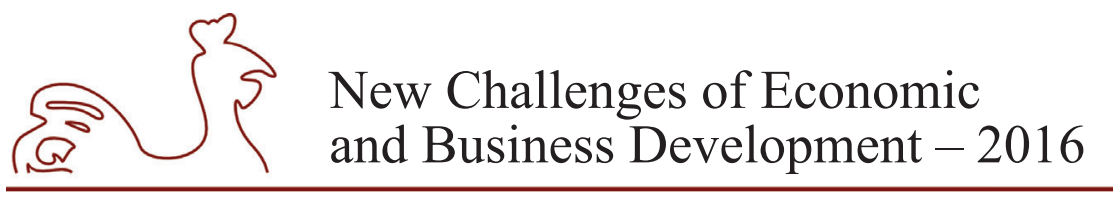

May 12-14, 2016, Riga, University of Latvia

Facet "Activity"

\begin{tabular}{|c|c|c|}
\hline \multicolumn{2}{|r|}{ Aspects } & References \\
\hline \multirow{5}{*}{ 冚 } & $\begin{array}{l}\text { Adding (creating, posting, } \\
\text { uploading) }\end{array}$ & $\begin{array}{l}\text { Arazy et al., 2010; Fessakis et al., 2013; Hyunkyung Lee } \\
\text { \& Bonk, 2014; Pozzi et al., 2007; Rodríguez-Triana et al., } \\
\text { 2015; Silveira et al., 2013; Trentin, 2009; Walthall et al., } 2011\end{array}$ \\
\hline & $\begin{array}{l}\text { Editing (rewriting, formatting, } \\
\text { restructuring, extending, linking, } \\
\text { updating) }\end{array}$ & $\begin{array}{l}\text { Arazy et al., 2010; Ferreira et al., 2009; Ferreira et al., 2009; } \\
\text { Hyunkyung Lee \& Bonk, 2014; Rodríguez-Triana et al., } \\
\text { 2015; Silveira et al., 2013; Trentin, } 2009\end{array}$ \\
\hline & $\begin{array}{l}\text { Annotating (reviewing/ revising, } \\
\text { rating, commenting) }\end{array}$ & $\begin{array}{l}\text { Arazy et al., 2010; Fessakis et al., 2013; Hyunkyung Lee } \\
\text { \& Bonk, 2014; Trentin, } 2009\end{array}$ \\
\hline & Reusing & Silveira et al., 2013 \\
\hline & Deleting & Arazy et al., 2010 \\
\hline $\begin{array}{l}\dot{s} \\
:\end{array}$ & Accessing (reading, using) & $\begin{array}{l}\text { Ferreira et al., 2009; Fessakis et al., 2013; Hyunkyung Lee } \\
\text { \& Bonk, 2014; Pozzi et al., 2007; Rodríguez-Triana et al., } \\
\text { 2015; Walthall et al., } 2011\end{array}$ \\
\hline
\end{tabular}

Continuing with the facet "Data" we can see a range of data sources. So we can especially analyse content of working and learning platforms as well as their logfiles. These logfiles consist of the system-logfile containing the metadata of the platform and the server-logfile with the communication data of the webserver (e.g. IP-address, time, read/write). Depending on concrete characteristics of the collaboration setting further data generation techniques are necessary alongside the existing platform. Thus a blended-learning setting could require an observation as soon as collaboration happens face 2 face. As required also certain learning goals can enforce pre- and posttests. Basically we can distinguish the data sources from the platform itself and additional data from data generation methods. Therein we should differentiate between synchronous and asynchronous tools on the platform (Huang \& Nakazawa, 2010; Rice et al., 2007; Zedadra \& Lafifi, 2015), qualitative and quantitative data (Rodríguez-Triana et al., 2015; Trentin, 2009) and their origin. This means that additional and qualitative data sources can be crucially biased regarding their subjectivity and objectivity (Pozzi et al., 2007), especially if they come from students rather than teachers (Pombo et al., 2010; Trentin, 2009). 


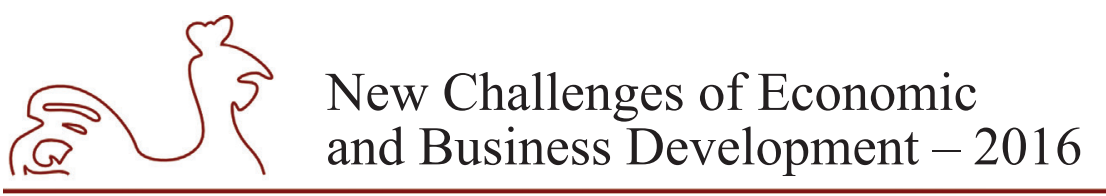

May 12-14, 2016, Riga, University of Latvia

Table 2

Facet "Data"

\begin{tabular}{|c|c|c|}
\hline \multicolumn{2}{|r|}{ Aspects } & References \\
\hline \multirow{12}{*}{ 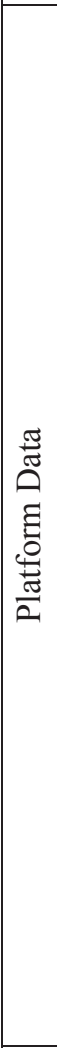 } & Discussion/Forum & $\begin{array}{l}\text { Beers, Boshuizen, Kirschner, \& Gijselaers, 2007; Chang Zhu, 2012; } \\
\text { Dennen \& Wieland, 2007; Iandoli, Quinto, Liddo, \& Buckingham } \\
\text { Shum, 2014; Kirschner \& Erkens, 2013; Murphy, 2004; Pozzi et al., } \\
\text { 2007; Reneland-Forsman, 2012; Rice et al., 2007; Tan \& Tan, 2006; } \\
\text { Trentin, 2009; Zedadra \& Lafifi, } 2015\end{array}$ \\
\hline & LogFiles & $\begin{array}{l}\text { Eddy \& Lawrence, 2013; Ferreira et al., 2009; Fessakis et al., 2013; } \\
\text { Hyunkyung Lee \& Bonk, 2014; Lanqin Zheng, Ronghuai Huang, \& } \\
\text { Junhui Yu, 2014; Pozzi et al., 2007; Soller, 2004; Stahl, 2006; Trentin, } \\
\text { 2009; Zedadra \& Lafifi, 2015; Zemel, Xhafa, \& Cakir, 2007 }\end{array}$ \\
\hline & Chat & $\begin{array}{l}\text { Capponi, Nussbaum, Marshall, \& Lagos, 2010; Kirschner \& Erkens, } \\
\text { 2013; Rice et al., 2007; Soller, 2004; Stahl, 2006; Zemel et al., } 2007\end{array}$ \\
\hline & Graphical/Whiteboard & Soller, 2004 \\
\hline & $\begin{array}{l}\text { Product/Document } \\
\text { Sharing }\end{array}$ & Kirschner \& Erkens, 2013; Pozzi et al., 2007 \\
\hline & Meeting Schedulers & Kirschner \& Erkens, 2013 \\
\hline & $\begin{array}{l}\text { Learning System } \\
\text { (unspecified) }\end{array}$ & Zedadra \& Lafifi, 2015 \\
\hline & E-Tivities & Armellini \& Aiyegbayo, 2010 \\
\hline & Twitter & Liwen Chen \& Tung-Liang Chen, 2012 \\
\hline & Wiki & $\begin{array}{l}\text { Altanopoulou, Tselios, Katsanos, Georgoutsou, \& Panagiotaki, 2015; } \\
\text { Eddy \& Lawrence, 2013; Trentin, } 2009\end{array}$ \\
\hline & Messages/Email & Liwen Chen \& Tung-Liang Chen, 2012; Zedadra \& Lafifi, 2015 \\
\hline & Blogs & $\begin{array}{l}\text { Dos \& Demir, 2013; Fessakis et al., 2013; Rice et al., 2007; Zedadra } \\
\text { \& Lafifi, } 2015\end{array}$ \\
\hline \multirow{13}{*}{ 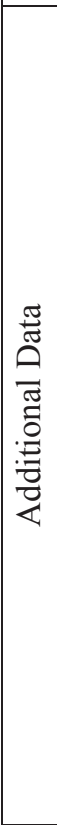 } & Observation & $\begin{array}{l}\text { Armellini \& Aiyegbayo, 2010; Capponi et al., 2010; Rodríguez-Triana } \\
\text { et al., 2015; Tan \& Tan, } 2006\end{array}$ \\
\hline & Self-Assessment & Eddy \& Lawrence, 2013; Pombo et al., 2010; Rice et al., 2007 \\
\hline & Peer-Assessment & $\begin{array}{l}\text { Altanopoulou et al., 2015; Armellini \& Aiyegbayo, 2010; Ferreira et } \\
\text { al., 2009; Pombo et al., 2010; Rice et al., 2007; Trentin, } 2009\end{array}$ \\
\hline & Interviews (Pre) & Armellini \& Aiyegbayo, 2010 \\
\hline & Interviews (Post) & $\begin{array}{l}\text { Armellini \& Aiyegbayo, 2010; Dennen \& Wieland, 2007; Liwen Chen } \\
\text { \& Tung-Liang Chen, } 2012\end{array}$ \\
\hline & Interviews (unspecified) & Pozzi et al., 2007; Rice et al., 2007; Rodríguez-Triana et al., 2015 \\
\hline & Focus Groups & Rodríguez-Triana et al., 2015 \\
\hline & Survey & $\begin{array}{l}\text { Armellini \& Aiyegbayo, 2010; Huang \& Nakazawa, 2010; Hyunkyung } \\
\text { Lee \& Bonk, 2014; Rice et al., } 2007\end{array}$ \\
\hline & Questionaires (Pre) & Altanopoulou et al., 2015 \\
\hline & Questionaires (Post) & $\begin{array}{l}\text { Altanopoulou et al., 2015; Chang Zhu, 2012; Iandoli et al., 2014; } \\
\text { Pombo et al., } 2010\end{array}$ \\
\hline & $\begin{array}{l}\text { Questionaires } \\
\text { (unspecified) }\end{array}$ & Rodríguez-Triana et al., 2015 \\
\hline & Test (Pre) & Baeza-Yates \& Pino, 2006; Soller, 2004 \\
\hline & Test (Post) & Baeza-Yates \& Pino, 2006; Soller, 2004 \\
\hline
\end{tabular}




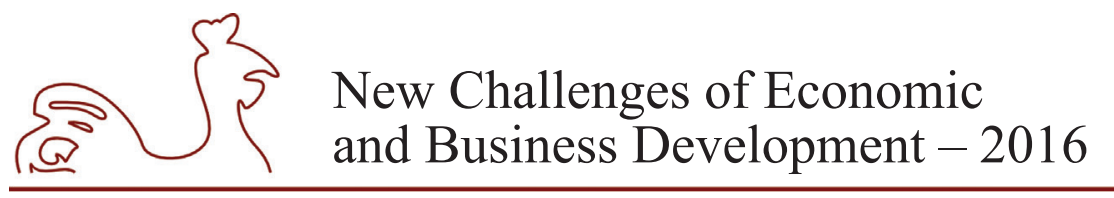

May 12-14, 2016, Riga, University of Latvia

The Facet "Content" further distinguished aspects of the process and the product (Lanqin Zheng et al., 2014; Pombo et al., 2010; Pozzi et al., 2007; Yu-Fen Yang, 2013) in order to deduce interdependences between them (Bravo et al., 2008). The aspects of the process can further be split into educational, technical and administrative subprocesses (Rice et al., 2007). Beside the two main aspects some authors also analyse the participants of the collaboration as well as the existence of roles and how well they are fulfilled.

Table 3

\section{Facet "Content"}

\begin{tabular}{|c|c|c|}
\hline \multicolumn{2}{|r|}{ Aspects } & References \\
\hline \multirow{14}{*}{$\begin{array}{l}\infty \\
\delta^{2} \\
0 \\
\infty\end{array}$} & $\begin{array}{l}\text { Organizing \& } \\
\text { Interaction }\end{array}$ & $\begin{array}{l}\text { Huang \& Nakazawa, 2010; Iandoli et al., 2014; Kirschner \& Erkens, } \\
\text { 2013; Murphy, 2004; Silveira et al., 2013; Trentin, 2009; Zemel et al., } \\
2007\end{array}$ \\
\hline & Content Contribution & $\begin{array}{l}\text { Altanopoulou et al., 2015; Beers et al., 2007; Capponi et al., 2010; } \\
\text { Chang Zhu, 2012; Dennen \& Wieland, 2007; Eddy \& Lawrence, 2013; } \\
\text { Huang \& Nakazawa, 2010; Iandoli et al., 2014; Murphy, 2004; Pozzi et } \\
\text { al., 2007; Silveira et al., 2013; Zemel et al., 2007 }\end{array}$ \\
\hline & Content Verification & $\begin{array}{l}\text { Altanopoulou et al., 2015; Beers et al., 2007; Capponi et al., 2010; } \\
\text { Chang Zhu, 2012; Iandoli et al., 2014; Kirschner \& Erkens, 2013; } \\
\text { Murphy, 2004; Pozzi et al., 2007; Soller, } 2004\end{array}$ \\
\hline & $\begin{array}{l}\text { Clarification and } \\
\text { Argumentation }\end{array}$ & $\begin{array}{l}\text { Altanopoulou et al., 2015; Beers et al., 2007; Chang Zhu, 2012; Dennen } \\
\text { \& Wieland, 2007; Dennen \& Wieland, 2007; Eddy \& Lawrence, 2013; } \\
\text { Kirschner \& Erkens, 2013; Liwen Chen \& Tung-Liang Chen, 2012; } \\
\text { Murphy, 2004; Pozzi et al., 2007; Soller, 2004; Stahl, 2006; Trentin, } \\
2009\end{array}$ \\
\hline & $\begin{array}{l}\text { Negotiation and } \\
\text { Acceptance }\end{array}$ & $\begin{array}{l}\text { Beers et al., 2007; Capponi et al., 2010; Dennen \& Wieland, 2007; Eddy } \\
\text { \& Lawrence, 2013; Kirschner \& Erkens, 2013; Pozzi et al., 2007; Stahl, } \\
\text { 2006; Zemel et al., } 2007\end{array}$ \\
\hline & Critics and Rejection & $\begin{array}{l}\text { Beers et al., 2007; Iandoli et al., 2014; Liwen Chen \& Tung-Liang Chen, } \\
\text { 2012; Pozzi et al., 2007; Silveira et al., } 2013\end{array}$ \\
\hline & Agreement & $\begin{array}{l}\text { Beers et al., 2007; Capponi et al., 2010; Chang Zhu, 2012; Pozzi et al., } \\
\text { 2007; Silveira et al., 2013; Soller, } 2004\end{array}$ \\
\hline & Disagreement & Beers et al., 2007; Capponi et al., 2010 \\
\hline & $\begin{array}{l}\text { Elaboration and } \\
\text { Solving }\end{array}$ & $\begin{array}{l}\text { Beers et al., 2007; Capponi et al., 2010; Chang Zhu, 2012; Dennen } \\
\text { \& Wieland, 2007; Iandoli et al., 2014; Murphy, 2004; Pozzi et al., 2007; } \\
\text { Silveira et al., 2013; Zemel et al., } 2007\end{array}$ \\
\hline & $\begin{array}{l}\text { Monitoring and } \\
\text { Review }\end{array}$ & $\begin{array}{l}\text { Beers et al., 2007; Capponi et al., 2010; Huang \& Nakazawa, 2010; } \\
\text { Silveira et al., } 2013\end{array}$ \\
\hline & Regulation & Beers et al., 2007; Kirschner \& Erkens, 2013; Soller, 2004 \\
\hline & $\begin{array}{l}\text { Production and } \\
\text { Writing }\end{array}$ & $\begin{array}{l}\text { Altanopoulou et al., 2015; Chang Zhu, 2012; Eddy \& Lawrence, 2013; } \\
\text { Huang \& Nakazawa, 2010; Kirschner \& Erkens, 2013; Murphy, 2004; } \\
\text { Pozzi et al., 2007; Silveira et al., } 2013\end{array}$ \\
\hline & $\begin{array}{l}\text { Releasing and } \\
\text { Publishing }\end{array}$ & Eddy \& Lawrence, 2013; Silveira et al., 2013 \\
\hline & Helping & Huang \& Nakazawa, 2010 \\
\hline
\end{tabular}




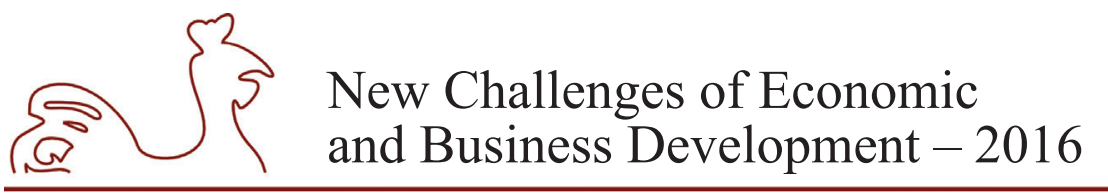

May 12-14, 2016, Riga, University of Latvia

\begin{tabular}{|c|c|c|}
\hline \multirow{9}{*}{$\begin{array}{l}0 \\
\stackrel{0}{0} \\
0 \\
0\end{array}$} & Appropriateness & Altanopoulou et al., 2015; Trentin, 2009 \\
\hline & $\begin{array}{l}\text { Compliance to } \\
\text { structure }\end{array}$ & Altanopoulou et al., 2015; Trentin, 2009 \\
\hline & Accuracy & Altanopoulou et al., 2015; Trentin, 2009 \\
\hline & Completeness & Altanopoulou et al., 2015; Trentin, 2009 \\
\hline & Stylistic homogeneity & Altanopoulou et al., 2015; Trentin, 2009 \\
\hline & Source of References & Altanopoulou et al., 2015; Trentin, 2009 \\
\hline & Originality & Altanopoulou et al., 2015; Trentin, 2009 \\
\hline & Consistency & Altanopoulou et al., 2015; Trentin, 2009 \\
\hline & Other & Altanopoulou et al., 2015 \\
\hline \multirow{6}{*}{ 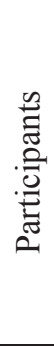 } & Student-Instructor & Huang \& Nakazawa, 2010; Liwen Chen \& Tung-Liang Chen, 2012 \\
\hline & Student-Student & Huang \& Nakazawa, 2010; Liwen Chen \& Tung-Liang Chen, 2012 \\
\hline & $\begin{array}{l}\text { Student-Student- } \\
\text { Instructor }\end{array}$ & Huang \& Nakazawa, 2010 \\
\hline & Collaborative Group & Huang \& Nakazawa, 2010 \\
\hline & $\begin{array}{l}\text { Non-Human- } \\
\text { Interaction }\end{array}$ & Huang \& Nakazawa, 2010; Liwen Chen \& Tung-Liang Chen, 2012 \\
\hline & Self-Interaction & Huang \& Nakazawa, 2010 \\
\hline \multirow{5}{*}{$\frac{\tilde{0}}{2}$} & $\begin{array}{l}\text { Content Producer/ } \\
\text { Editor }\end{array}$ & Altanopoulou et al., 2015; Silveira et al., 2013 \\
\hline & $\begin{array}{l}\text { Idea Generator/ } \\
\text { Collector }\end{array}$ & Altanopoulou et al., 2015; Silveira et al., 2013 \\
\hline & Reviewer/Controller & Altanopoulou et al., 2015; Silveira et al., 2013 \\
\hline & Organizer & Altanopoulou et al., 2015; Silveira et al., 2013 \\
\hline & Other & Silveira et al., 2013 \\
\hline
\end{tabular}

To analyse the amount of data we need appropriate methods to achieve significant information. These methods are listed in the dimension "How?". As simple counting of contributions mostly do not offer enough evidence on the performance of individuals, groups or the quality of the results, a variety of specific quantitative and qualitative methods (Chang Zhu, 2012; Ferreira et al., 2009; Huang \& Nakazawa, 2010; Lanqin Zheng et al., 2014; Pozzi et al., 2007) or mixed-method approaches (Pozzi et al., 2007) are available to analyse the existing data traces. 


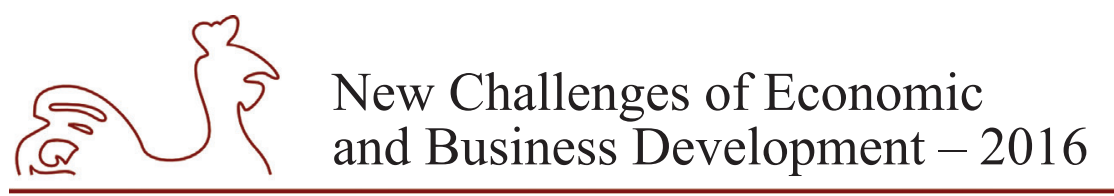

May 12-14, 2016, Riga, University of Latvia

Table 4

Facet "Method"

\begin{tabular}{|c|c|c|}
\hline \multicolumn{2}{|r|}{ Aspects } & References \\
\hline \multirow{12}{*}{ 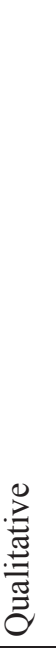 } & Case Analysis & Lanqin Zheng et al., 2014 \\
\hline & Content Analysis & $\begin{array}{l}\text { Beers et al., 2007; Chang Zhu, 2012; Dos \& Demir, 2013; } \\
\text { Lanqin Zheng et al., 2014; Murphy, 2004; Pozzi et al., 2007; } \\
\text { Soller, } 2004\end{array}$ \\
\hline & Conversation Analysis & Stahl, 2006; Tan \& Tan, 2006; Zemel et al., 2007 \\
\hline & Critical Event recall & Lanqin Zheng et al., 2014 \\
\hline & Descriptive Analysis & Lanqin Zheng et al., 2014 \\
\hline & Discourse Analysis & $\begin{array}{l}\text { Dennen \& Wieland, 2007; Lanqin Zheng et al., 2014; Reneland- } \\
\text { Forsman, } 2012\end{array}$ \\
\hline & Ethnographic Analysis & Lanqin Zheng et al., 2014 \\
\hline & Grounded Theory & Lanqin Zheng et al., 2014 \\
\hline & Interaction Analysis & Lanqin Zheng et al., 2014 \\
\hline & Narrative Analysis & Lanqin Zheng et al., 2014 \\
\hline & Thematic Analysis & Liwen Chen \& Tung-Liang Chen, 2012 \\
\hline & Protocol Analysis & Lanqin Zheng et al., 2014 \\
\hline \multirow{15}{*}{. } & Artificial Immune System & Zedadra \& Lafifi, 2015 \\
\hline & Cluster Analysis & Iandoli et al., 2014; Lanqin Zheng et al., 2014; Soller, 2004 \\
\hline & Event sequence Analysis & Lanqin Zheng et al., 2014 \\
\hline & Eye-tracking analysis & Lanqin Zheng et al., 2014 \\
\hline & Gaming path analysis & Lanqin Zheng et al., 2014 \\
\hline & Hidden Markov Model & Lanqin Zheng et al., 2014; Soller, 2004 \\
\hline & Hierarchical Linear Model & Lanqin Zheng et al., 2014 \\
\hline & Keystroke-Level Model & Ferreira et al., 2009 \\
\hline & Lag-sequential Analysis & Lanqin Zheng et al., 2014 \\
\hline & (Social) Network Analysis & $\begin{array}{l}\text { Fessakis et al., 2013; Iandoli et al., 2014; Lanqin Zheng et al., } \\
\text { 2014; Trentin, 2009 }\end{array}$ \\
\hline & Participation Graphs Analysis & Lanqin Zheng et al., 2014 \\
\hline & Pattern Analysis & Dos \& Demir, 2013 \\
\hline & Structural Equation Model & Lanqin Zheng et al., 2014 \\
\hline & Statistical Analysis & $\begin{array}{l}\text { Altanopoulou et al., 2015; Capponi et al., 2010; Chang Zhu, } \\
\text { 2012; Dennen \& Wieland, 2007; Eddy \& Lawrence, 2013; } \\
\text { Fessakis et al., 2013; Hyunkyung Lee \& Bonk, 2014; Iandoli et } \\
\text { al., 2014; Lanqin Zheng et al., 2014; Pombo et al., 2010; Pozzi } \\
\text { et al., 2007; Rice et al., 2007; Trentin, 2009; Zedadra \& Lafifi, } \\
\text { 2015; Zemel et al., } 2007\end{array}$ \\
\hline & Statistical Inference Analysis & Capponi et al., 2010 \\
\hline
\end{tabular}

These methods serve as connectors between the facets further up. For assessing the eCollaboration the identified facets either have to be filtered as relational databases depending on the set of assessment objectives or they can be combined in a multidimensional matrix $(\mathrm{m} \times \mathrm{n})$ as an Online Analytical Processing (OLAP)-cube to enable an ad-hoc navigation through the data of learners. 


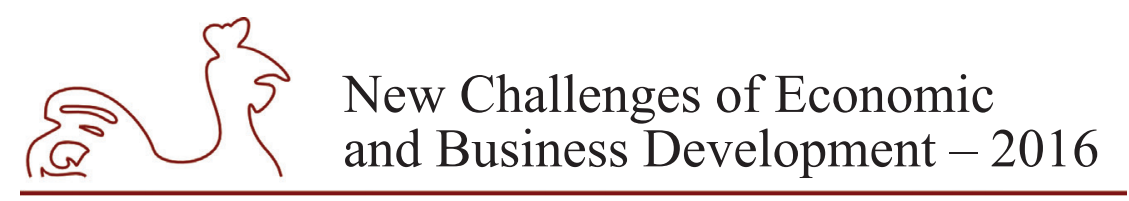

May 12-14, 2016, Riga, University of Latvia

\section{Conclusion}

Now we like to conclude the findings of this paper. The tables above show aspects for analyzing an eCollaboration setting und thus concretize the Learning Analytics Reference Model (Chatti et al., 2012) for a specific field. As an example we used a concrete VCL-Arrangement and listed the dimensions, their facets and detailed aspects that have to be distinguished in an analysis. Based on the existing literature we identified dimensions as well as facets that are relevant for the described course setting. In a next step we used a systematic literature review to specify these facets listing aspects for them at the end. As a finding we worked out four leading dimensions "Why?", "Who?", "What?" and "How?" that are subdivided into six central facets that have been further detailed. Thus we identified a differentiation in the time of assessment between formative and summative as well as levels of assessment subjects in individual, group or community. Further we created four tables of facets with a comprehensive list of distinguishable aspects.

Regarding a critical view on the results we have to state that the complexity of an assessment of eCollaboration does only allow an overview of isolated dimensions that have to be further researched. Currently the facets serve as alternatives in an analysis process but the connections between these alternatives are still missing. At the same time the limitations of a literature review according the sample and the selection have to be considered. A completeness of facets and aspects cannot be guaranteed even if the sample and the selection criteria tried to reach it best possible (Fettke, 2006).

Further research thus should focus on connecting the actual isolated dimensions at first. These connections should be aligned to concrete assessment criteria. In a next step it is necessary to define the characteristics of each criterion that signalises the status of the quality of collaboration. This includes the identification of concrete characteristics of aspects (e.g. which type of logdata are required) and the combination with other aspects (e.g. which types of content has been produced at which time). The last step is an implementation of learning analytics to evaluate the use and achieve the benefits for the learning facilitator.

\section{Bibliography}

Alexander, B. (2006). Web 2.0: A New Wave of Innovation for Teaching and Learning? EDUCAUSE Review. (41), 33-44.

Altanopoulou, P., Tselios, N., Katsanos, C., Georgoutsou, M., \& Panagiotaki, M.-A. (2015). Wiki-Mediated Activities in Higher Education: Evidence-Based Analysis of Learning Effectiveness Across Three Studies. Journal of Educational Technology \& Society, 18(4), 511-522.

Arazy, O., Stroulia, E., Ruecker, S., Arias, C., Fiorentino, C., Ganev, V., \& Yau, T. (2010). Recognizing contributions in wikis: Authorship categories, algorithms, and visualizations. Journal of the American Society for Information Science \& Technology, 61(6), 1166-1179.

Armellini, A., \& Aiyegbayo, O. (2010). Learning design and assessment with e-tivities. British Journal of Educational Technology, 41(6), 922-935.

Baeza-Yates, R., \& Pino, J. A. (2006). Towards formal evaluation of collaborative work. Information Research, 11(4), 13.

Balázs, I. (2005). Konzeption von Virtual Collaborative Learning Projekten: Ein Vorgehen zur systematischen Entscheidungsfindung. Dissertation, Technische Universität Dresden, Dresden. 


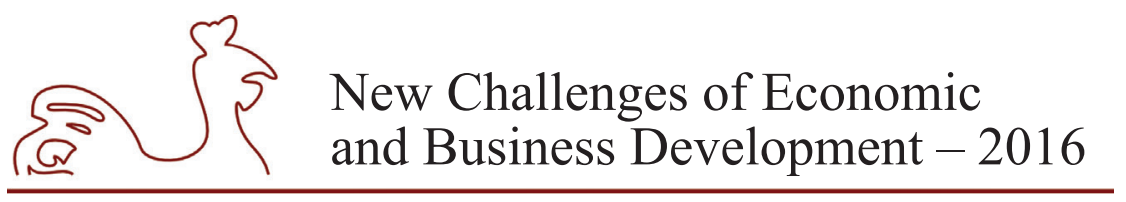

May 12-14, 2016, Riga, University of Latvia

Balázs, I., \& Schoop, E. (2004). Erfahrungen mit Virtual Collaborative Learning am Lehrstuhl Wirtschaftsinformatik insb. Informationsmanagement an der Technischen Universität Dresden: Band 1: Virtual Collaborative Learning: Ziele, Design, Erfahrungen. Technische Universität Dresden.

Beers, P. J., Boshuizen, H. P. A., Kirschner, P. A., \& Gijselaers, W. H. (2007). The analysis of negotiation of common ground in CSCL. Learning and Instruction, 17(4), 427-435.

Bos, M. C. (1937). Experimental study of productive collaboration. Acta psychologica, 315-426.

Bravo, C., Redondo, M. A., Verdejo, M. F., \& Ortega, M. (2008). A framework for process-solution analysis in collaborative learning environments. International Journal of Human-Computer Studies, 66(11), 812-832.

Capponi, M. F., Nussbaum, M., Marshall, G., \& Lagos, M. E. (2010). Pattern Discovery for the Design of Face-to-Face Computer-Supported Collaborative Learning Activities. Journal of Educational Technology \& Society, 13(2), 40-52.

Carell, A. (2006). Selbststeuerung und Partizipation beim computergestützten kollaborativen Lernen: Eine Analyse im Kontext hochschulischer Lernprozesse. Medien in der Wissenschaft: Vol. 37. Münster: Waxmann.

Chang Zhu (2012). Student Satisfaction, Performance, and Knowledge Construction in Online Collaborative Learning. Journal of Educational Technology \& Society, 15(1), 127-136.

Chatti, M. A., Dyckhoff, A. L., Schroeder, U., \& Thüs, H. (2012). A Reference Model for Learning Analytics. International Journal of Technology Enhanced Learning.

Collazos, C. A., Guerrero, L. A., Pino, J. A., \& Ochoa, S. F. (2004). A method for evaluating computersupported collaborative learning processes. International Journal of Computer Applications in Technology, 19(3/4), 151.

Dennen, V. P., \& Wieland, K. (2007). From Interaction to Intersubjectivity: Facilitating online group discourse processes. Distance Education, 28(3), 281-297.

Dillenbourg, P. (1999). What do you mean by 'collaborative learning'? In P. Dillenbourg (Ed.), Collaborative Learning. Cognitive and Computational Approaches (pp. 1-15). Emerald.

Dos, B., \& Demir, S. (2013). The analysis of the blogs created in a blended course through the reflective thinking perspective. Kuram ve Uygulamada Eğitim Bilimleri, 13(2), 1335-1344.

Eddy, P., \& Lawrence, A. (2013). Wikis as Platforms for Authentic Assessment. Innovative Higher Education, 38(4), 253-265.

Erkens, G., Prangsma, M., \& Jaspers, J. G. M. (2006). Planning and coordinating activities in collaborative learning. In A. M. O'Donnell, C. E. Hmelo-Silver, \& G. Erkens (Eds.), The Rutgers invitational symposium on education series. Collaborative learning, reasoning, and technology (pp. 234-264). Mahwah, N.J.: L. Erlbaum Associates.

Ferreira, A., Antunes, P., \& Pino, J. A. (2009). Evaluating shared workspace performance using human information processing models. Information Research, 14(1), 3.

Fessakis, G., Dimitracopoulou, A., \& Palaiodimos, A. (2013). Graphical Interaction Analysis Impact on Groups Collaborating through Blogs. Journal of Educational Technology \& Society, 16(1), 243-253.

Fettke, P. (2006). State-of-the-Art des State-of-the-Art: Eine Untersuchung der Forschungsmethode "Review" innerhalb der Wirtschaftsinformatik. Wirtschaftsinformatik, 48(4), 257-266.

Geyken, A., Mandl, H., \& Reiter, W. (1998). Selbstgesteuertes Lernen mit Tele-Tutoring. In R. Schwarzer (Ed.), Schriftenreihe / ADIA-Stiftung zur Erforschung neuer Wege für Arbeit und Soziales Leben: Vol. 10. Multimedia und Telelearning. Lernen mit Cyberspace (pp. 181-196). Frankfurt/Main: Campus.

Huang, W.-H. D., \& Nakazawa, K. (2010). An empirical analysis on how learners interact in wiki in a graduate level online course. Interactive Learning Environments, 18(3), 233-244.

Hyunkyung Lee, \& Bonk, C. J. (2014). Collaborative Learning in the Workplace: Practical Issues and Concerns. International Journal of Advanced Corporate Learning, 7(2), 10-17. 


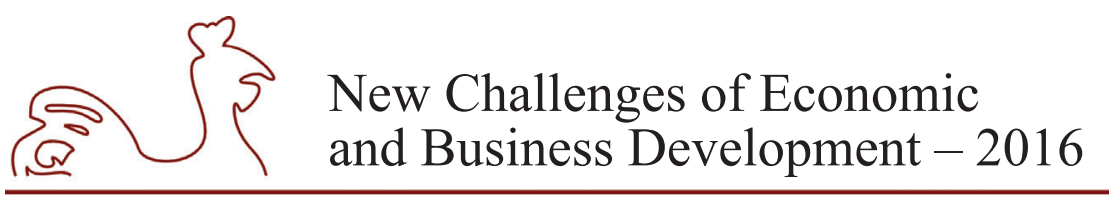

May 12-14, 2016, Riga, University of Latvia

Iandoli, L., Quinto, I., Liddo, A. de, \& Buckingham Shum, S. (2014). Socially augmented argumentation tools: Rationale, design and evaluation of a debate dashboard. International Journal of HumanComputer Studies, 72(3), 298-319.

Kalb, H., Kummer, C., \& Schoop, E. (2011). Implementing the "Wiki Way" in a course in higher education. In S. Friedrich, A. Kienle, \& H. Rohland (Eds.), Lecture Notes in Informatics (LNI) - Proceedings: P-188. DeLFI 2011 Die 9. e-Learning Fachtagung Informatik der Gesellschaft für Informatik e.V. 5.8. September 2011, Technische Universität Dresden. Bonn: Gesellschaft für Informatik e.V. (GI).

Kerres, M., Ojstersek, N., \& Stratmann, J. (2011). Didaktische Konzeption von Angeboten des OnlineLernens. In P. Klimsa \& L. Issing (Eds.), Online-Lernen. Planung, Realisation, Anwendung und Evaluation von Lehr- und Lernprozessen online (2nd ed., pp. 263-272). München: De Gruyter.

Kirschner, P. A., \& Erkens, G. (2013). Toward a framework for CSCL research. Educational Psychologist, $48(1), 1-8$.

Lanqin Zheng, Ronghuai Huang, \& Junhui Yu (2014). Identifying Computer-Supported Collaborative Learning (CSCL) Research in Selected Journals Published from 2003 to 2012: A Content Analysis of Research Topics and Issues. Journal of Educational Technology \& Society, 17(4), 335-351.

Liwen Chen, \& Tung-Liang Chen (2012). Use of Twitter for formative evaluation: Reflections on trainer and trainees' experiences. British Journal of Educational Technology, 43(2), E49-E52.

Murphy, E. (2004). Recognising and promoting collaboration in an online asynchronous discussion. British Journal of Educational Technology, 35(4), 421-431.

Pauleen, D. J., \& Yoong, P. (2001). Relationship building and the use of ICT in boundary-crossing virtual teams: A facilitator's perspective. Journal of Information Technology, 16(4), 205-220.

Perrez, M., Huber, G., \& Geißler, K. (2006). Psychologie der pädagogischen Interaktion. In A. Krapp, B. Weidemann, A. Krapp, \& B. Weidenmann (Eds.), Anwendung Psychologie. Pädagogische Psychologie. Ein Lehrbuch (5th ed., pp. 357-422). Weinheim: Beltz.

Pombo, L., Loureiro, M. J., \& Moreira, A. (2010). Assessing collaborative work in a higher education blended learning context: strategies and students' perceptions. Educational Media International, 47(3), 217-229.

Pozzi, F., Manca, S., Persico, D., \& Sarti, L. (2007). A general framework for tracking and analysing learning processes in computer supported collaborative learning environments. Innovations in Education and Teaching International, 44(2), 169-179.

Reneland-Forsman, L. (2012). Toward a broader understanding of social talk in Web-based courses. Text \& Talk, 32(3), 349-369.

Rice, D. J., Davidson, B. D., Dannenhoffer, J. F., \& Gay, G. K. (2007). Improving the effectiveness of virtual teams by adapting team processes. Computer Supported Cooperative Work (CSCW), 16(6), 567-594.

Rietze, M., \& Hetmank, C. (2016). Learning Analytics für eine verbesserte Lernbegleitung in kollaborativen formellen E-Learning-Angeboten. In V. Nissen, D. Stelzer, S. Straßburger, \& D. Fischer (Eds.), Multikonferenz Wirtschaftsinformatik (MKWI) 2016 (Vol. 1, pp. 567-578).

Rodríguez-Triana, M. J., Martínez-Monés, A., Asensio-Pérez, J. I., \& Dimitriadis, Y. (2015). Scripting and monitoring meet each other: Aligning learning analytics and learning design to support teachers in orchestrating CSCL situations. British Journal of Educational Technology, 46(2), 330-343.

Silveira, I. F., Ochôa, X., Cuadros-Vargas, A., Pérez Casas, A., Casali, A., Ortega, A., et al. (2013). A Digital Ecosystem for the Collaborative Production of Open Textbooks: The LATIn Methodology. Journal of Information Technology Education, 12, 225-249.

Soller, A. (2004). Understanding knowledge-sharing breakdowns: a meeting of the quantitative and qualitative minds. Journal of Computer Assisted Learning, 20(3), 212-223.

Stahl, G. (2006). ANALYZING AND DESIGNING THE GROUP COGNITION EXPERIENCE. International Journal of Cooperative Information Systems, 15(2), 157-178. 


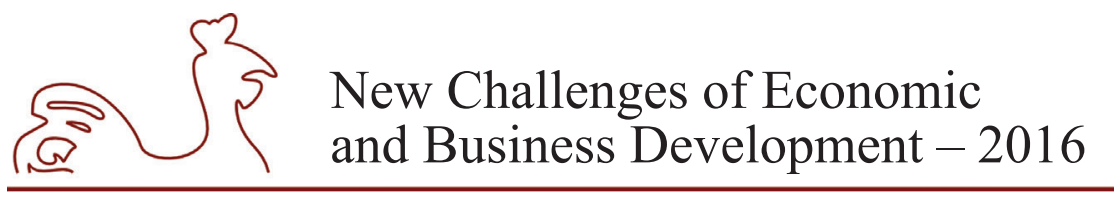

May 12-14, 2016, Riga, University of Latvia

Swan, K., Shen, J., \& Hiltz, S. R. (2006). Assessment and Collaboration in Online Learning. Journal of Asynchronous Learning Network, 45-62.

Tan, S., \& Tan, A. (2006). Conversational analysis as an analytical tool for face to face and online conversations. Educational Media International, 43(4), 347-361.

Thagard, P. (1997). Collaborative Knowledge. Nous, 31(2), 242-261.

Trentin, G. (2009). Using a wiki to evaluate individual contribution to a collaborative learning project. Journal of Computer Assisted Learning, 25(1), 43-55.

Walthall, C. J., Devanathan, S., Kisselburgh, L. G., Ramani, K., Hirleman, E. D., \& Yang, M. C. (2011). Evaluating Wikis as a Communicative Medium for Collaboration Within Colocated and Distributed Engineering Design Teams. Journal of Mechanical Design, 133(7), 071001-071001-11.

Weinberger, A., \& Fischer, F. (2006). A framework to analyze argumentative knowledge construction in computer-supported collaborative learning. Computers \& Education, 46(1), 71-95.

Yu-Fen Yang (2013). Exploring Students' Language Awareness through Intercultural Communication in Computer-supported Collaborative Learning. Journal of Educational Technology \& Society, 16(2), 325-342.

Zedadra, A., \& Lafifi, Y. (2015). Learning Faults Detection by AIS Techniques in CSCL Environments. Journal of Educational Technology \& Society, 18(1), 276-291.

Zemel, A., Xhafa, F., \& Cakir, M. (2007). What's in the mix? Combining coding and conversation analysis to investigate chat-based problem solving. Learning \& Instruction, 17(4), 405-415. 
May 12-14, 2016, Riga, University of Latvia

\title{
ESSENTIAL ELEMENTS OF BUSINESS PROCESS MODELLING
}

\author{
Uldis Rozevskis, University of Latvia, Latvia ${ }^{1}$ \\ Kristine Rozite, University of Latvia, Latvia \\ Juris Krasts, University of Latvia, Latvia \\ Rita Zuka, University of Latvia, Latvia
}

\begin{abstract}
In the scientific research of Business Administration and Management important role play different type of business process models. Two sides of model usage are: misty business process models in the scientific research papers and strongly formalized notations and tools in real process modelling. It is necessary to reconcile both sides for scientific findings testing and converting them to the innovations. Paper explains new approach how to identify essential elements and aspects of business process modelling and to develop it's logic. Studies are based on business process modelling in scientific research, acquainted practice in the course delivering and real life model developing, notations analysis.

Research results show, that it is possible to define essential elements, aspects and stages for business process modelling. Modelling we can imagine as abstracting, only main important details are maintained in the fully developed model. As highest criteria for process details selecting is model goal, but the set of essential things should be represented in the every case. Inspection of essential elements allow to develop logically complete and interconnected views and aspects of models system which represent the business process.

Modelling logic approach described in the paper is implemented in different level (bachelor, master, doctoral) study courses. Students were able to identify, to develop, to evaluate, to simulate business process models without assistance. Introduction of modelling logic in personnel training will allow more widely to use IT tools in the business administration and management scientific research, in the business improving and reengineering.
\end{abstract}

Key words: process, modelling, business, logic, elements

JEL code: M12, M15, M53

\section{Introduction}

New theories, methods, principles, approaches in the business administration and management are explained by models: structure, process, changes and others. Business process development, reconstruction, reengineering usually is based on modelling. Business process modelling nowadays is actual and are used in EU countries companies and organizations to improve processes. For example recent publication (Fleaca E, Fleaca B, Negoita, O, \& Danalache, F, 2015) shows process modelling importance in environment management. As mentioned (Trad, A, 2015), sustainable business must adapt frequent business transformation processes and it is not possible without modelling.

Object of research is stable manufacturing or servicing process which recur instantly without structural changes. This paper goal is to describe possible process modelling logic for better

1 Corresponding author - e-mail address: uldis.rozevskis@lu.lv 


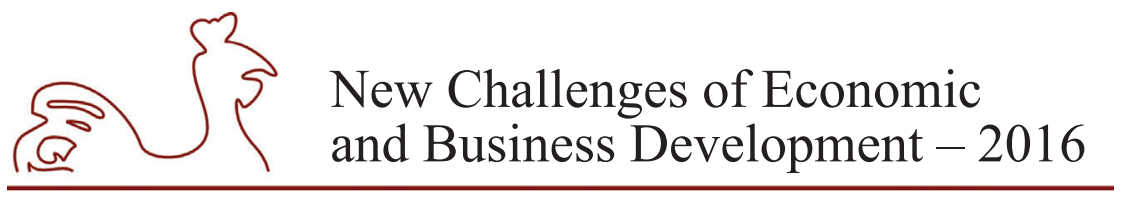

May 12-14, 2016, Riga, University of Latvia

process understanding, managers and researchers thinking changing, so there is no description of process modelling development, which, of course, influence process understanding progress, no analysis or discussion about visual models interpretation and no precise data of students skills evaluation. All these things may take a lot of places and for that may be subject for other articles.

Studies are based on real life model developing, notations analysis, observation of business process modelling in scientific research. Findings are tested in practice in the course delivering to different level (bachelor, master, doctoral) students. Students ability to identify, to develop, to evaluate, to simulate business process models from descriptions and without assistance is evaluated to prove developed modelling logic.

\section{Research results and discussion}

In the business process modelling very important is communication, how the participants and the team members understand each other. For unambiguous model building in practice, in companies different process modelling notations are developed and used (e.g. flowcharts, EPC, UML, BPMN). In scientific research creative point of view is most popular: each researcher try to develop his own method to demonstrate, how processes should be organized.

A lot of different visual modelling languages exists, but main part of them are ITC system development oriented. In this research we are discussing about essential elements of business process modelling and this means, that model should include business logic and sense, so we can say, that studies are delimited to semantic process modelling. According to (Thomas $\mathrm{O}$ \& Fellmann M, 2015) semantic modelling languages are EPC (Event-driven Process Chain), BPMN (Business Process Modelling Notation) and OWL (Web Ontology Language). More suitable for business process purposes are EPC and BPMN. Both of them are used to describe process steps. Another reason, why research is oriented on such type visual modelling languages, is possibility to develop modelling tools which can perform formal model validation as stated (Thomas O \& Fellmann M, 2015) and what is already introduced in some software: Bizagi, Visio. At the moment validation is restricted only to process models, but semantic approach to business modelling create potential chance to validate other type of models (collaboration, status) and reconcile them.

Business managers need to understand business modelling logic to employ modern modelling tools, but modelling logic is not so simple. Different methods are offered to facilitate business model usage.

Van Nuffel, D \& De Backer, M, 2012 offer multi-level modelling framework to structure modelling and to improve usability. Such solution is worthwhile for companies, where model system is already installed and may help to others to introduce complex system, but will not be support for those who start modelling.

Koschmider, A, Hornung, T, \& Oberweis, A, 2011 for novice business process modellers offer recommendation-based modelling support system, which covers different aspects of business process modelling. Support system can help to develop model, no doubt. But no recommendations will help to business manager, if he will not understand the basic principles modelling, how to build model, how model works.

Figl K, Recker J \& Mendling J, 2013 discuss different symbol designs which affect an individual's ability to comprehend process models and mention, that semantic transparency and 


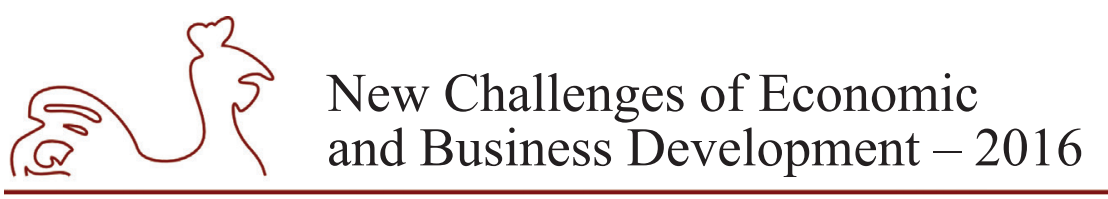

May 12-14, 2016, Riga, University of Latvia

aesthetic design of symbols lower the perceived difficulty of comprehension. We can agree, that usability make easy tools usage. What is important in this research: recognition, that semantic symbols can help to go into modelling. Symbol represents the concept, essential element in the business process modelling. But, unfortunately, there is just a couple of symbols, which are common in different modelling languages (tasks or activities, process flow).

Modelling is abstracting, we should lay aside many details to concentrate on main and important parts. What will remain, what goes away? The question is: what should be represented in the business process model to make it more understandable for stakeholders. The key idea of this research is: some essential modelling elements exists, which are important in the every case of business process modelling regardless of used display method or symbols form and understanding essential concepts will help better comprehend how process is performed. Even more: validating presence of essential elements in the model allows avoid gaps and mistakes. Reconciling understanding of the both sides of business process improvement stakeholders: developers and introducers will facilitate faster converting scientific findings to innovations.

Research results show, that emerging managers skills in business process conception can be improved by clear modelling logic. Main steps in skills mastering for ability of model extraction from real life observations, experience and descriptions are:

- playing with ready-made model and getting understanding of process important aspects,

- familiarization with some modelling notations, model reading,

- understanding process classification by type and hierarchy,

- single process model building,

- complex model development.

Business manager novice lack of experience with modelling should be compensated as the first step. Playing with prepared, ready-made model for exploration gives first inkling about process reflecting, about essential things. Simulation include main part of essential modelling elements because model should work. Simulation model is used as case study. Students task is to search and to find best parameters for business results, management knowledge is necessary to take the decision. Students also get some idea about simulation capabilities for business purposes.

Flowcharts is most simple and more suitable notation for first visual business process modelling language. Regardless to simplicity in the flowchart models is possible to recognise some essential elements: tasks or activities, called "process" in flowcharts, decisions and, what is important, events. "Start/end" visual symbols in flowcharts can be interpreted as events. Each process starts with definite event. Event put in motion all process. Event is important for business control and administration, management should react of events, so this is essential element in modern modelling.

BPMN standard include also collaboration models (choreography and orchestration), but they are too detailed and serve information system development. Also in BPMN standard token idea is used to explain process flow. Token correspond to entity in the simulation models and this element or concept is important for business modelling: there is some things which flow through activities and are changed during process.

BPMN standard models enable rich different type event disclose what may be essential for business model understanding. It is important concept, which is necessary to accept and understand. We can consider, that not only decisions, but also events conduct process follow. 


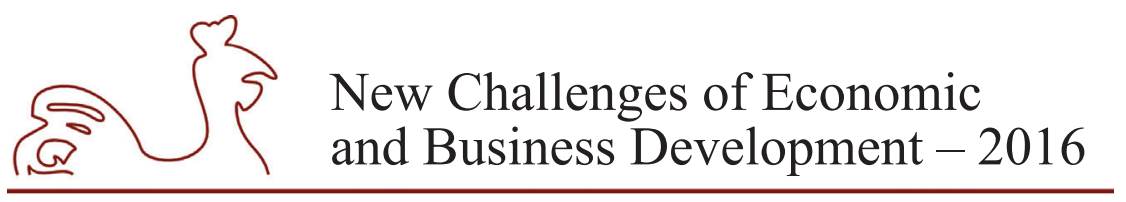

May 12-14, 2016, Riga, University of Latvia

On events are based process management systems and their data can be analysed by process management tools to recognize bottlenecks and improve processes. As stated (Appel, S, Kleber, P, Frischbier, S, Freudenreich, T, \& Buchmann, A, 2014) real data in modern business environment can be interpreted as event stream.

So for single process flow model essential elements are: tasks or activities, events, decisions or gateways, entities. That is enough to start simple process building. At this step next challenge is met: how to find, identify, separate process for modelling. Processes in the real life are continuous, each activity has ancestor and successor. Processes are different by their performance and different types of processes have distinct modelling tools. Unique processes are controlled by project management tools. Dynamic modelling is used for process development prediction. Visual business process modelling is used for stable manufacturing or servicing process which recur instantly. Processes in the company have hierarchy. Highest level: functions are realised by process set. Process also may be recognised as procedure. Procedure consists of tasks or activities or operations. Activities may be described by algorithms - elementary activities. Conception of process hierarchy is necessary for orientation and subject selection. To identify process beginning and end helps entity "life cycle" concept: process starts, when something happens and it is entity arrival. Entity "life" ends after some task is fulfilled, it is end event. Here we see, that for individual process separation important role play entities or our understanding, what is entity in real business process.

Valuable business process model should include some other aspects which reflect engaged participants, their hierarchy and collaboration, entity changes during life cycle.

For process management important element is performer of tasks or activities. Performers have some hierarchy: company, department, group, person, which is simple to show in structure diagram. To accomplish process performers collaborate by exchanging messages, this concept is used also in BPMN. Collaboration model can identify messages, their content and sequence. Entity status attainment model reflect its changes during life cycle, its stable forms and possible ways for status changes. All type models pack should be reconciled. Conflict elimination helps improve model.

\section{Conclusions}

1. Business process modelling notations based on business sense and concepts are more easy accepted by novice managers.

2. Business process modelling acquiring should start with practice accumulation. Simulation models are suitable for practice gathering.

3. Main concepts of modelling should be adopted by novice modellers step by step starting with simple visual modelling notations. For better concept understanding more then one modelling notation should be mastered.

4. Important and essential elements of business process modelling are: task or activity, performer, decision, process flow, event, entity, entity status, message.

5. Complete business modelling should include process follow model, entity status change model and performers collaboration model, which should be reconciled with each other. 


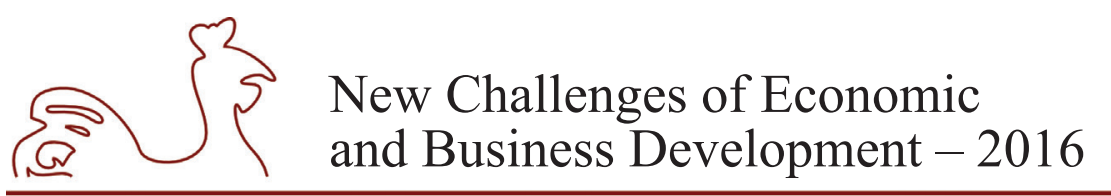

May 12-14, 2016, Riga, University of Latvia

\section{Bibliography}

Appel, S, Kleber, P, Frischbier, S, Freudenreich, T, \& Buchmann, A 2014, 'Modeling and execution of event stream processing in business processes', Information Systems, 46, 1, pp. 140-156, E-Journals, EBSCOhost, viewed 10 March 2016.

Figl K, Recker J \& Mendling J 2013, 'A study on the effects of routing symbol design on process model comprehension' Decision Support Systems, Volume 54, Issue 2, pp. 1104-1118.

Fleaca, E, Fleaca, B, Negoita, O, \& Danalache, F 2015, 'Raising the Enterprises' Environmental Performance by Taking Advantage of Business Process Modeling', Procedia Technology, 19, 1, pp. 333-340, E-Journals, EBSCOhost, viewed 10 March 2016.

Koschmider, A, Hornung, T, \& Oberweis, A 2011, 'Recommendation-based editor for business process modeling', Data \& Knowledge Engineering, 70, 6, pp. 483-503, E-Journals, EBSCOhost, viewed 10 March 2016.

Thomas, O, \& Fellmann M. A., M 2015, 'Semantic Process Modeling - Design and Implementation of an Ontology-based Representation of Business Processes', Business \& Information Systems Engineering, Preprints, pp. 1-12, E-Journals, EBSCOhost, viewed 10 March 2016.

Trad, A 2015, 'A Transformation Framework Proposal for Managers in Business Innovation and Business Transformation Projects-intelligent Atomic Building Block Architecture', Procedia Computer Science, 64, 1, pp. 214-223, E-Journals, EBSCOhost, viewed 10 March 2016.

Van Nuffel, D, \& De Backer, M 2012, 'Multi-abstraction layered business process modeling', Computers In Industry, 63, 2, pp. 131-147, E-Journals, EBSCOhost, viewed 10 March 2016. 


\title{
HUMAN RESOURCES MANAGEMENT USE OF SOCIAL NETWORK SITES TO RECRUIT EMPLOYEES
}

\author{
Tom Sander, University of Latvia, Latvia ${ }^{1}$ \\ Jurgita Pauzuoliene, Klaipeda University, Lithuania \\ Biruta Sloka, University of Latvia, Latvia
}

\begin{abstract}
Trust and data protection is an important part of social network sites (SNS). The mechanism of SNSs is influenced by data security. Individuals are not providing information about them or provide access to resources if data protection is not given. Trust is needed to exchange information or resources. This paper investigates the use of SNSs relationships for the employment seeking process. The paper research the level of willingness of SNSs member to pass their access to other profiles for the employment seeking process to their employer. The aim of the paper is to evaluate attitude of SNS users on their willingness to share information about employment possibilities. Research methods applied: scientific publications analysis, survey by questionnaire with 210 participants. In survey evaluation scale 1-6 was applied (as it is corresponding to the evaluation system in German schools). For data analysis there were used descriptive statistics with indicators of central; tendency or location and indicator of variability as well as correlation analysis. The result support to understand mechanism of SNSs, to test the social capital theory and provides human resource management (HRM) information how to use SNSs contacts from their employees for the recruiting process. HRM can use the full potential of SNSs because than the company has a competitive advantage. HRM is able to identify the best suitable candidates for the companies with the support of SNSs. The results give an answer about the acceptance of SNSs member to use their contacts at SNS for the employment seeking process to support their HRM.
\end{abstract}

Key words: networks, employment seeking, human resources management

JEL code: L14, E24, O15

\section{Introduction}

Organisations need new channels to identify needed candidates and talents. The employees with their human capital are important for the competitive advantage for organizations. SNSs can support the search of suitable candidates e.g. using the contacts of employees (Sander, Teh, Majlath, \& Sloka, 2015). The important question for the organization is how they can use the contacts of SNSs of their employees without any negative consequences or undesired results for them or their employees. That means the use of SNSs contacts may not have a disadvantage for the involved parties. The acceptance of the use of SNSs contacts by the employees and potential candidates is important. Referrals are a good opportunity to identify candidates. A misuse of SNSs contacts and profiles damage the reputation of the organization and undesired results are expected e.g. damaging the employer brand.

1 Corresponding author - e-mail address: tomsander@hotmail.de 


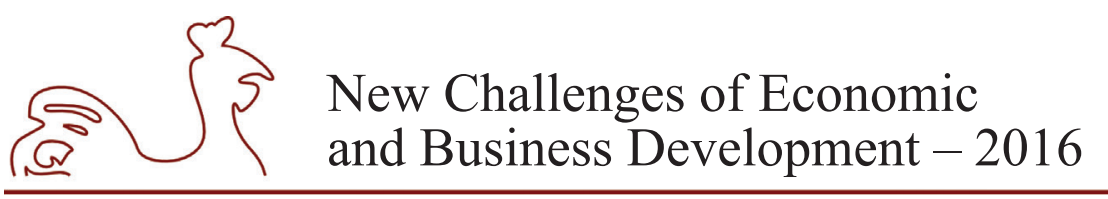

May 12-14, 2016, Riga, University of Latvia

The labour market is changing and the number of available candidates is decreasing. The shortage of specialists is an important issue for the economy and new channels are needed to reach potential candidates. Many companies have difficulties to identify well educated candidates. The demographic changes reduce the number of candidates. This challenging environment needs new HRM strategies and new tools to solve the difficulties. The assumption is that similar educated and skilled individuals are member of specialised networks (Roebken, 2010). These networks with the specialised members can be used for the recruiting process by HRM if they need related skills. The forwarded information motivates potential candidates to apply for a position and the trustfulness of the information can be increased if the information is provided via a SNSs contact.

SNSs are increasing the number of members and enables individuals to maintain their relationships without any barrier. SNSs are an important part of the society and complement real social networks. The SNSs influence the society and is an important part of many individuals in their daily life(Hampton \& Wellman, 2003). SNSs can be used to present skills and knowledge to a large audience and to organize contacts. The contacts are friends, colleagues or acquaintance. The relationship at SNSs provides additional information about the contact and gives access to interesting resources and information. SNSs contacts can be mobilized for the interest of an individual or used to support the interest of an individual. The power of the SNSs is the number of members (Ellison, Steinfield, \& Lampe, 2007). The technical development supports to organize large networks and to maintain friendship globally. Real social networks do not have these opportunities.

The aim of this paper is to evaluate attitude of SNS users on their willingness to share information about employment possibilities. This provides HRM knowledge about the use of social networks to recruit new employees and explain the usefulness of social networks and SNSs to identify employment. The task of this paper is to support HRM to be more successful with their recruiting of employees and the use of social networks for their recruiting process. This support the time to hire candidates and reduce the transaction costs to identify potential candidates. Problematic questions are related to willingness to share information about employment issues on SNSs as often employment seeking process could be sensitive one and persons could have no willingness to share this sensitive information. The research methods: analysis of scientific literature, interpretation, quantitative research of survey data using indicators of central tendency or location (arithmetic mean, mode, median), indicators of variability, cross tabulations, correlation analysis. Data analysis was carried out using Statistical Package for the Social Sciences (SPSS) program.

This paper investigates the openness and readiness of SNSs members to transfer the control of SNSs contacts to the employer. There are passive and active opportunities for SNSs members to provide their SNSs contacts and details about their SNSs contacts to their employer. In this survey was applied the quantitative research method, questionnaire. The online survey has been done in October 2015. In total 210 participants $(n=210)$ filled out the questionnaire. The results represented in the paper are obtained by use of SPSS program. For statistical analysis of data has been used frequency, indicators of central tendency or location: arithmetic mean (the average of the evaluations), median (the middle value - indicating that half of the evaluations are less than median and half of evaluations are bigger than median), mode (most often indicated value on evaluation scale) and most used indicator of variability - standard deviation. Standard deviation 


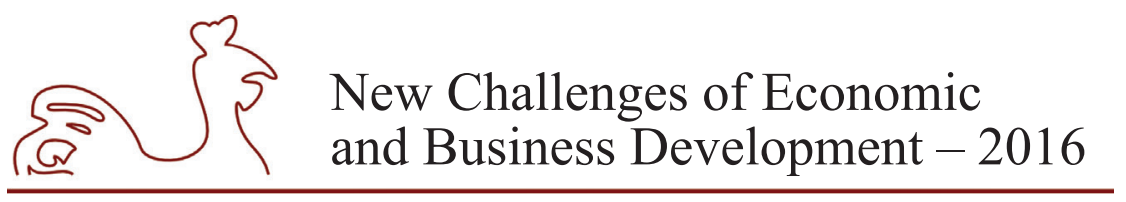

May 12-14, 2016, Riga, University of Latvia

shows how much variation or dispersion exists from the average (mean) and respective value. A low standard deviation indicates that the data points tend to be very close to the mean; high standard deviation indicates that the data points are spread out over a large range of values. For data analysis it was used also correlation analysis. The data collected in accordance with research ethics. SNSs users are online and they are well trained to use online tools. The questionnaire asked the participants to evaluate following statements on a scale from one - very useful to six very unuseful (the evaluation scale is designed taking into account German evaluation system at schools) to investigate the evaluations on statements:

- I would advertise job advertisements at my online profile that potential candidates could send an application to my employer;

- I would get in touch personally with candidates and after we have discussed the position I will forward the application to my employer;

- I would investigate my contacts and forward contact details to my employer. The employer would get in touch with the candidates;

- I would give access to my contacts at SNSs to my employer. The employer forwards the job description to interesting contacts.

The evaluations of those statements explain the use of SNSs contacts, level of information about other SNSs members which is acceptable to transfer to other individuals and the level of trust in SNSs.

The limitation of the research is that the research does not divide the SNSs in private and business SNSs contacts.

\section{Theoretical framework}

Social networks are a construct of ties between the social network members. This ties existing at SNSs too and can be described as a contact. A contact is a friend in the SNSs. The contact provides additional information about the SNS member and channel to exchange information or resources fast and easily without any restriction. SNSs contacts are an important part of SNSs and the number of contacts at SNSs is increasing compared with real social networks. The relationships are important asset of SNSs and the individuals value is the access to other individuals (Obukhova \& Lan, 2012). The access is important to collect knowledge and information about other SNSs member. This information is important to know who could give access to resources or information. The contacts are the value and number of contacts could be a sign for prestige or ownership of a needed or desired resources or information. Trust is an important issue of SNSs and influences the exchange in SNSs. The readiness to provide access to the network to other people needs a lot of trust (Moolenaar \& Sleegers, 2010). The research investigates the readiness and openness of individuals to provide their employer information about their contacts and to provide access to the contacts on different levels. Contraire is the perspective of the employment seeking individual. The employment seeking individuals use their contacts to get in touch with employees and decision makers to get valuable information. The objective is to get a superior employment and to increase the chance to be selected for the open position. They are trying to have an advantage with their network and use the network to collect information about the position or to influence the decision maker for example (Mouw, 2003). The first step to use the SNSs for the employment seeking process is to advertise job opportunities and to provide 


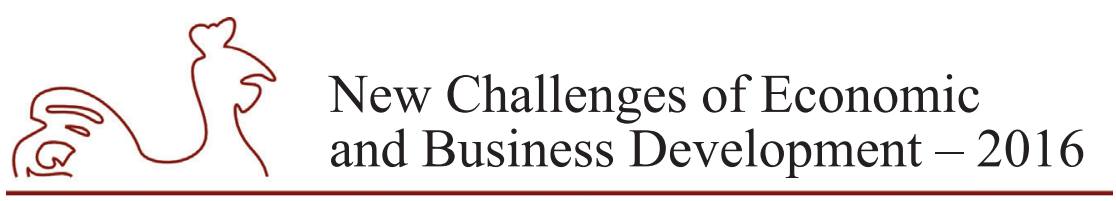

May 12-14, 2016, Riga, University of Latvia

the information to their network. The next step would be to investigate the contacts by the contact owner and to discuss the employment opportunity with the contact. If the contact is interested than the application will be forwarded to the employer. With the following two statements is described the situation that the employer get the power about the contacts and decide which contact get the information about employment opportunities. Another opportunity would be that the contact owner screen the contacts and provides details to the employer if the contact has the required skills and knowledge. That means the contacts are not informed that their details are forwarded to the potential employer. The last opportunity is to provide the access to contacts to the company. That means the control about the contacts has been transferred to the company.

\begin{tabular}{|c|c|c|c|}
\hline $\begin{array}{l}\text { Advertising job } \\
\text { opportunities on } \\
\text { their SNSs profile } \\
\text { to exchange } \\
\text { information about } \\
\text { open positions }\end{array}$ & $\begin{array}{l}\text { Exchange employment } \\
\text { information with full } \\
\text { control of the SNSs } \\
\text { member e.g. bespoke } \\
\text { the position with the } \\
\text { contact and forward } \\
\text { the application to } \\
\text { the employer }\end{array}$ & $\begin{array}{l}\text { Investigate profiles of } \\
\text { the contacts and forward } \\
\text { interesting contacts for } \\
\text { employment opportunities } \\
\text { to the employer. That } \\
\text { means the employer decide } \\
\text { and control who will be } \\
\text { contacted }\end{array}$ & $\begin{array}{l}\text { Provide access to } \\
\text { SNS contacts to } \\
\text { the employer that } \\
\text { the employer can } \\
\text { use the contacts for } \\
\text { the employment } \\
\text { seeking process }\end{array}$ \\
\hline
\end{tabular}

Decreasing control and power about access to SNSs contacts

Source: constructed by Tom Sander.

\section{Fig. 1. Level of control about SNS contacts}

SNSs members know their contacts. They have experience with their contacts. That knowledge and experience can be used by the employer. The SNSs members choose the contacts which provide the information about the employment opportunities. That is a pre selection for the company and can reduce the costs e.g. the transactions costs. Further can the individual provide additional information to their contacts. That provide an advantage for the potential candidate and the candidate is recommended by an employee. That means the prestige of the employee is transferred to the potential candidate because the employee would not forward the application to the company if the employee would be not sure that the candidate is an excellent candidate (Chiang \& Suen, 2015). A recommendation of a low performer has influence on the recommender. Referrals are influencing the selection decision to hire an employee or to reject an employee (Beaman \& Magruder, 2012). The employer can use the referral of employees but the employer has to be aware that the referral can be misused or groups do not have access to an employee who provides a referral.

The decision power about the use of SNSs contact is important for SNSs member. They have the power to decide what happens with their contacts and who can use their contacts for economic reasons for example. That is an advantage for SNSs member to have the power about their contacts and the contacts are the value for the SNSs member. They can present with their contacts a strong network. The network is interesting for other user to get access to interesting resources and information the relationships are an important asset for SNSs and a reason to 


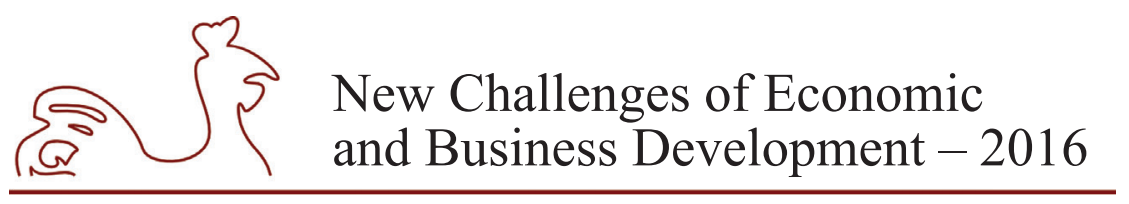

May 12-14, 2016, Riga, University of Latvia

be member in SNSs. But the membership in social networks can have a negative impact on the result for the individual (Smith, 2005). The membership in some social networks can lead to discrimination and negative outcome for the social network member. That means not anytime any contact is positive for the individuals. SNSs member have to be aware that relationships to undesired individuals can guide to negative results and that other SNSs member cutting their relationship.

Privacy and data protection is an important issue of SNSs. Member of SNSs emphasize that their details are protected and that other SNSs members have only access to presented and for them tailored information. They protect their data and only desired information is visible for other members. The individuals control their data and use the setting of the SNSs to protect their data and to make the data only accessible to authorized individuals. The openness of the profile and to share details about contacts need trust. The misuse of information about contacts or misuse of the SNSs tools would be penalized.

The social capital theory explains the mechanism of SNSs. The exchange of information and resources depends on the trust of individuals in the network and the advantage of the individual with the exchange. The individual invest their resources and information in SNSs and expect a positive advantage for the investment. The most important point is to identify the contact with the best information and resource. That is only possible if a tie exist to this SNSs member to get access to the desired information. The employees fill the structural hole between the company and potential employers (Burt, 2001). The assumption is that the employees have contacts with similar human capital. Companies use this access to forward information and to identify interesting candidates. The companies use their employees social network and social capital to have access to needed resources e.g. suitable candidates and to have a competitive advantage with the best suitable candidates. The employee is the agent who has access to the network and ability to transfer information between the company network and the network of potential candidates which are part of their network. The contact owner has the decision and control about the exchange between the two networks and both networks have the advantage that they increase their knowledge and share their information which could be an advantage for all involved individuals. The negative perspective is that individuals misuse their position in the network and to create a disadvantage to other social network members to have an advantage against other people. That can bias the result and support cronyism. The discrimination or overseeing of potential candidates because there does not exist a tie between the company and potential candidate can lead to an undesired result (Portes, 2000). That means if companies use only the social networks of their employees they have the danger that they create a monoculture with similar knowledge and interest which barriers innovations and the access to new resources and information (Moolenaar \& Sleegers, 2010). This can be a competitive disadvantage for the company. The positive result of an organization with similar characters and ideas is the reduction of transaction costs for example. The use of social networks for the employment seeking process is explained with the social capital theory (Granovetter, 1995) and chance to get a job is increased with the support of social capital (Behtoui, 2015). Social capital is an important factor that the labour market is operating successfully and social capital can support individuals to identify new employment. 


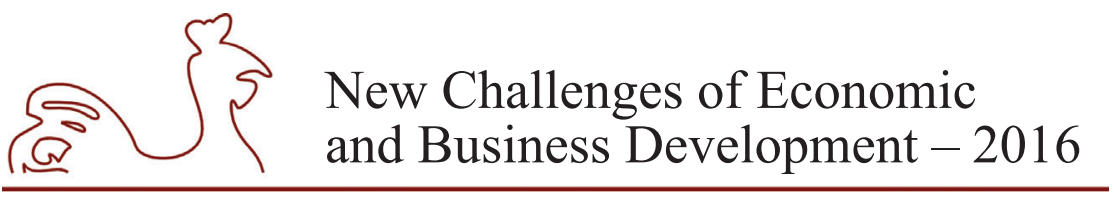

May 12-14, 2016, Riga, University of Latvia

\section{Method to investigate social network sites}

The research of SNSs is possible with different methods. The used method for this paper has been a survey by help of specially designed questionnaire and selection of young participants from Germany in the employment seeking process with 210 participants and the data has been collected in October 2015. The questionnaire was designed to make evaluations on main aspects interesting for this paper. It was applied evaluation scale 1-6, where 1 - very useful and 6 - very unuseful (the evaluation scale is designed in accordance to German evaluation system in schools). The questionnaire has been located online to collect the data from respondents. SNSs users are online and they are well trained to use online tools. The online survey is a good tool to collect data to investigate SNS. The gender distribution is $34.4 \%$ men and $65.6 \%$ woman by $n=195$. The educational level indicates that over $97.9 \%$ of the participants have minimum a school degree. The individuals with school degree have to search in the near future an employment and the individuals with an apprenticeship or university degree have an employment or looking for employment.
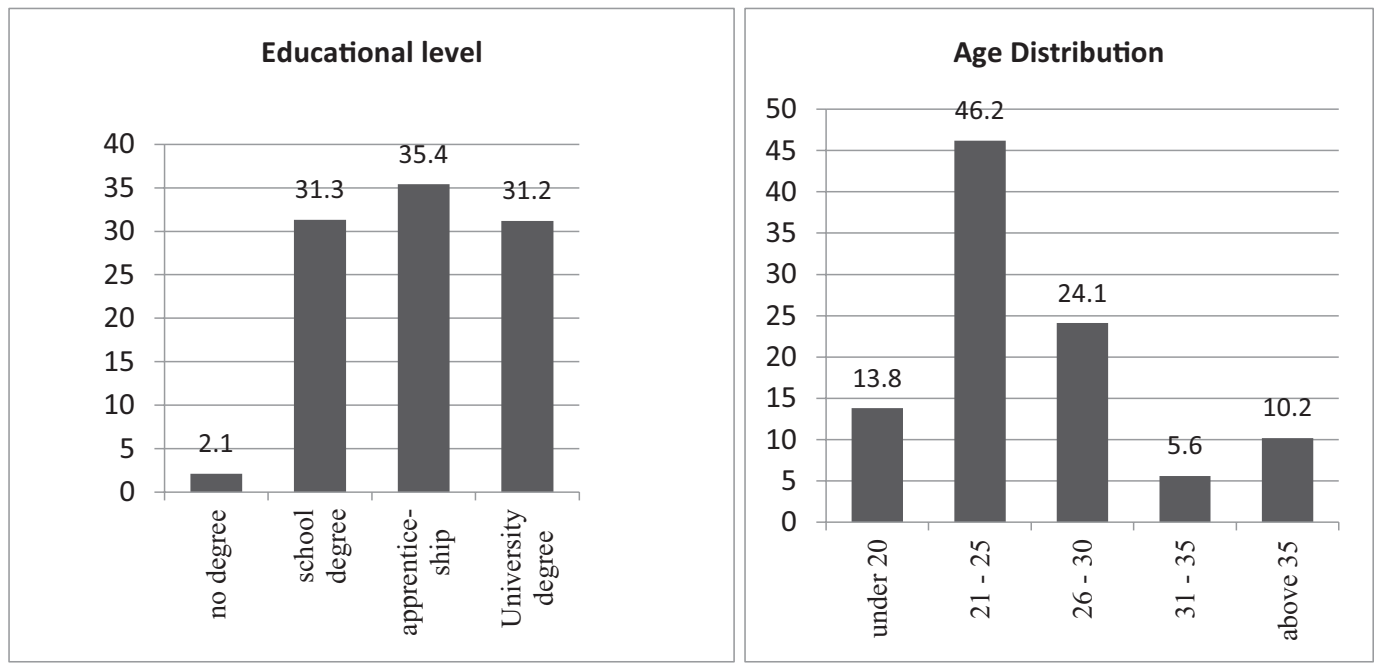

Source: conducted by Tom Sander in October 2015.

Fig. 2. Distribution of respondent's educational level and age (share in \%), $n=195$

Only $15.8 \%$ of the participants are over 31 years. The individuals under 20 years are $13.8 \%$. The group between 20 and 30 years are $70.2 \%$ of the participants. People between 20 and 30 years are mainly looking for new employment opportunities because they have finished their education and they are keen to identify an entrance to the labour market to identify employment. Young people are involved in the employment seeking process or they have done in near history of their employment search. 


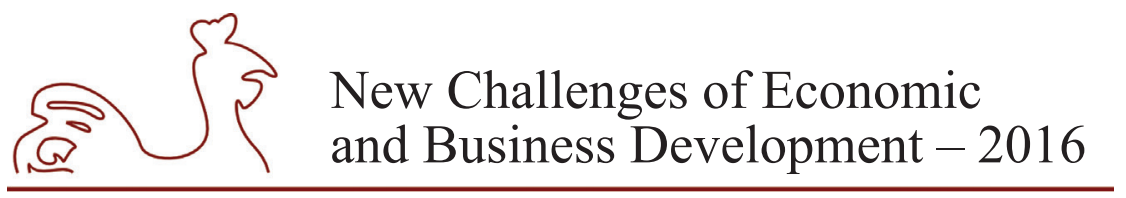

May 12-14, 2016, Riga, University of Latvia

\section{Results for the use of social network sites profiles to forward information about employment opportunities}

The use of SNSs contacts is an important opportunity to get in touch with each other. The paper investigates the openness and readiness of individuals to provide their SNSs contacts to their employer for the employment seeking process. The SNSs provide different opportunities how contacts of SNSs can be used. That needs different levels of trust to the employer because the privacy is important for the SNSs member (Krasnova, Günther, Spiekermann, \& Koroleva, 2009). The researches investigate the trust of individuals and there is a clear result that the openness and readiness to make personnel data available to the employer is not accepted by the participants. They are trying to control and monitor their access to contacts. The results of statistical calculations are presented in Table 1.

Table 1

Main statistical indicators of evaluations on question "How would you recommend open positions / candidates?" (Scale from one "very useful" to six "very unuseful")

\begin{tabular}{|l|c|c|c|c|c|}
\hline \multicolumn{1}{|c|}{ Items } & $n$ & $\begin{array}{c}\text { Arithmetic } \\
\text { Mean }\end{array}$ & Median & $\begin{array}{c}\text { Standard } \\
\text { Deviation }\end{array}$ & Mode \\
\hline $\begin{array}{l}\text { I would get in touch personally with candidates } \\
\text { and after we have discussed the position I will } \\
\text { forward the application to my employer }\end{array}$ & 193 & 1.86 & 2 & 1.083 & 1 \\
\hline $\begin{array}{l}\text { I would investigate my contacts and forward } \\
\text { contact details to my employer. The employer } \\
\text { would get in touch with the candidates }\end{array}$ & 190 & 4.22 & 4 & 1.567 & 6 \\
\hline $\begin{array}{l}\text { I would advertise job advertisements at my } \\
\text { online profile that potential candidates could } \\
\text { send an application to my employer }\end{array}$ & 193 & 3.19 & 3 & 1.676 & 3 \\
\hline $\begin{array}{l}\text { I would give access to my contacts at SNSs to } \\
\text { my employer. The employer forwards the job } \\
\text { description to interesting contacts }\end{array}$ & 193 & 5.1 & 6 & 1.313 & 6 \\
\hline
\end{tabular}

Source: conducted by Tom Sander in October 2015, $n=210$.

There is a clear tendency that SNSs member are keen to protect their data and to retain the control about their contacts. That means individuals would use their contacts at SNSs to exchange information about employment opportunities. The individuals are able to use their SNSs membership passive or active. That means the individual get actively in touch with their SNSs friends and presents them open positions. Only to present the open position to their friends via SNSs without direct contact has the mode value three and median three. Completely none accepted is the opportunity to provide access to contacts at SNS to employer. The median and mode is six. That is not surprising as data protection and security is an important issue for SNSs. The misuse of SNSs is a reason to penalize SNSs members and in very negative cases the SNSs members who misuse the SNSs are banned from the network. That means the banned member of the SNS lose the advantage of the network. The most useful anticipated opportunity to exchange information about employment opportunities is to transfer and discuss the open position with suitable contacts of the SNSs and than to forward the application to the employer. 


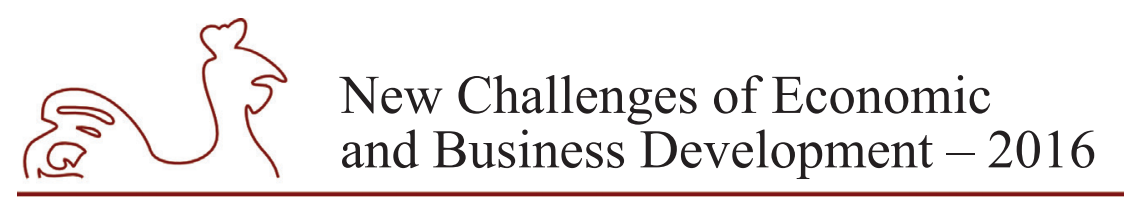

May 12-14, 2016, Riga, University of Latvia

That means the owner of the contact has the full control about the exchange of information and responsible for the transfer. The applicant is informed about the transfer of personal information to the company and agrees. The owner of the access to the suitable interesting candidate and company who is searching for candidates is filling the structural hole. That is the advantage for the company and potential candidate and gives the power to the SNSs member who connects the potential candidate and company like a broker. The structural hole is filled by the SNSs member who has access to the potential candidate network and employer network. The statistical results are a median with two and mode with one. The opportunity to investigate the contacts of SNSs to identify suitable candidates and to forward contact details of the selected candidates to the company is not accepted. The median is four and the mode is six. That means to forward private information of contacts from SNSs to potential employer that the employer can contact the potential candidate is not accepted. That the company has the power to use the relationship of their employee is not desired and explainable with the desire of SNSs members to protect their contacts against negative consequences or to be penalized to forward information about individuals without their permission.

The results in detail are presented in the figure below and confirm the results. The participants answer with $93.2 \%$ on scale one to three that they would get in touch personally with candidates and after they have discussed the position than they will forward the application to the company. That is a good opportunity for the potential candidate if employees forward the candidate to the right person who is responsible for the position and decide about the position. That is a large advantage for the potential candidate. The contraire result is for the statement "I would give access to my contacts at SNSs to my employer. The employer forward the job description to interesting contacts." with $86 \%$ on the scale four to six. The readiness to provide access to contacts at SNSs to employer is not accepted in Germany and individuals do not agree that they should give a third party access to their contacts. The opportunity to advertise job opportunity at the own SNSs profiles is on scale one to three with $63.2 \%$ accepted. That means the majority would accept that their profile and is used as advertisement platform for employment opportunities to transfer the information to their contacts. That is a passive opportunity to reach individuals and the SNSs contacts have the choice to apply for the position or to ignore the position. The efforts of the employee are limited to advertise the position. The SNSs member borrows their reputation to their company. The company can have a benefit with the advertisement of job offers on SNSs of employers because the use of their employer as an ambassador for the job advertisement gets a positive attitude from the SNSs member. But this positive outcome depends on the situation and reputation of the SNSs member. The SNSs contact cannot use the recommendation of the employee to have an advantage. The only advantage is to get the information from the SNSs. The last opportunity with $65.3 \%$ on scale four to six is the opportunity to investigate the profile and to forward contact details of suitable contacts to the employer. The use of data of other individuals is not appreciated by the majority of the participants. Companies and individuals have to be careful if they transfer information because data protection is important and the misuse can be a disadvantage for the potential candidate if negative or undesired information is transferred. The responsible person who forwards the information can be penalized because the transfer of private information is not accepted. 


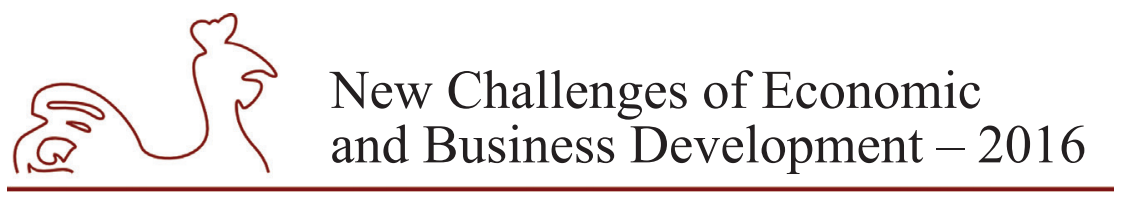

May 12-14, 2016, Riga, University of Latvia

All answers have clear tendency which are visible in the diagram below (see Figure 3). The comparison between the different opportunities to use contacts of SNSs provides the result that the control about contacts is important and that individuals take care about the data of other people and that individuals protect their access to data from other individuals.

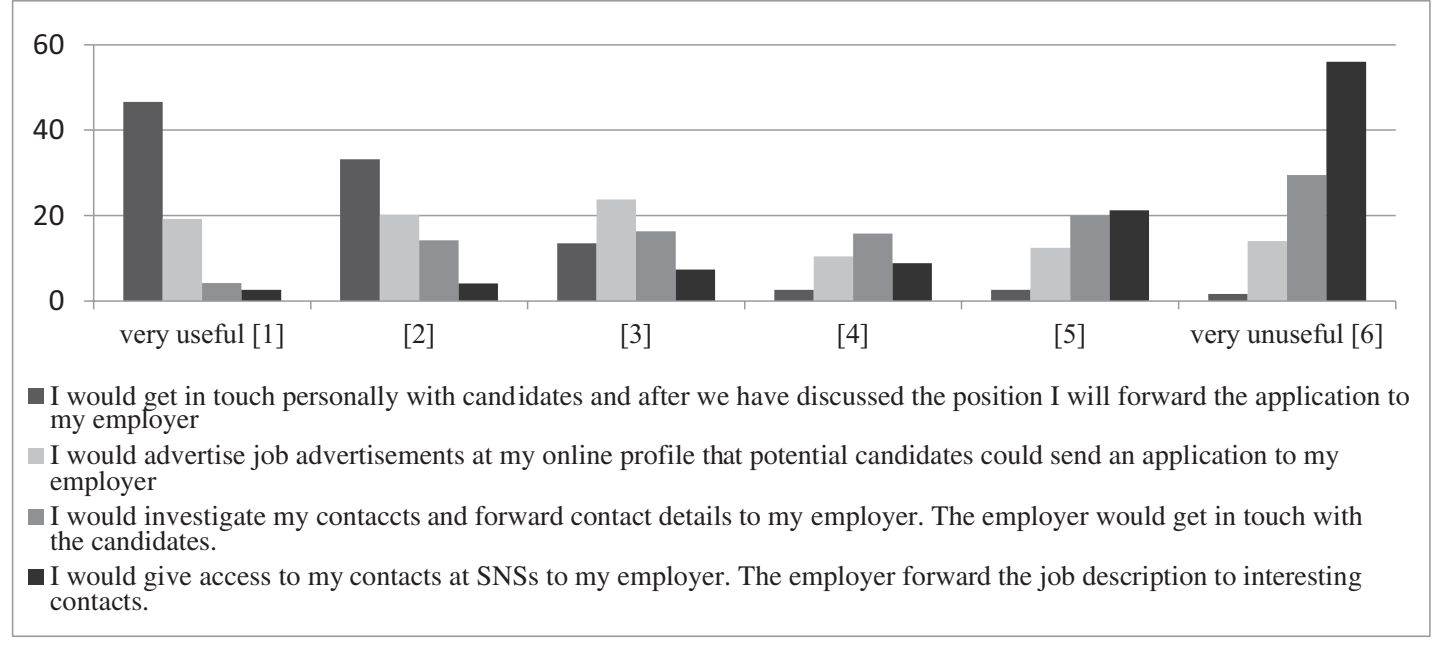

Source: conducted by Tom Sander in October 2015, $\mathrm{n}=210$.

Fig. 3. Distribution of frequencies of the evaluation of the statements about access to SNSs contacts, $n=210$

The investigation of the correlation between the use of SNSs explained with the use in minutes per day, duration of membership and number of contacts at SNSs with the statements does not give any statistical relevant result. The only significant correlation is between the use of SNSs in minutes per day and the statements. But the correlation coefficient is too weak to explain an influence of the use of contacts of SNSs with the use of SNSs. The interesting point is that the correlation results are all negative. The results are presented in the table below. That means if people use more often SNSs in minutes per day than they are using less often contacts or give less often access to their contacts. The investment of time in SNSs has a negative influence on the readiness and openness to use contacts of SNSs of individuals for the transfer of employment opportunities. That means heavy user with a lot of experience of SNSs has less interest to use their contacts for the employment seeking contact. Correlation coefficients and significance levels are included in Table 2. 


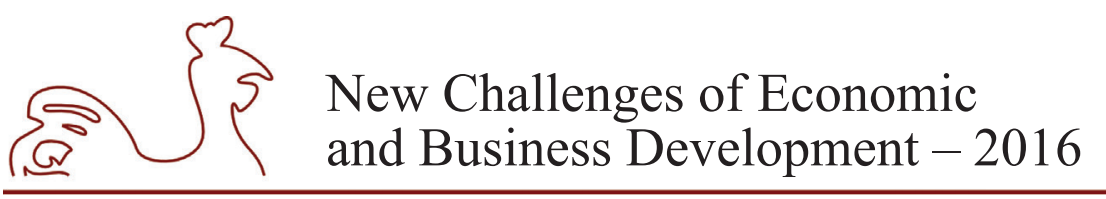

May 12-14, 2016, Riga, University of Latvia

Table 2

Correlation between the statements and use of business SNS and private SNSs in minutes per day

\begin{tabular}{|l|c|c|c|c|c|c|}
\hline \multirow{2}{*}{ Items } & \multicolumn{3}{c|}{$\begin{array}{c}\text { Use of business SNS in } \\
\text { minutes per day }\end{array}$} & \multicolumn{2}{c|}{$\begin{array}{c}\text { Use of private SNS in minutes } \\
\text { per day }\end{array}$} \\
\cline { 2 - 7 } & $\begin{array}{l}\text { Correlation } \\
\text { Coefficient }\end{array}$ & $\begin{array}{c}\text { Sig. } \\
\text { (2-tailed) }\end{array}$ & $n$ & $\begin{array}{c}\text { Correlation } \\
\text { Coefficient }\end{array}$ & $\begin{array}{c}\text { Sig. } \\
\text { (2-tailed) }\end{array}$ & $n$ \\
\hline $\begin{array}{l}\text { I would get in touch personally } \\
\text { with candidates and after we have } \\
\text { discussed the position I will forward } \\
\text { the application to my employer }\end{array}$ & $-.176^{*}$ & 0.015 & 192 & $-.208^{* *}$ & 0.004 & 190 \\
\hline $\begin{array}{l}\text { I would investigate my contacts } \\
\text { and forward contact details to my } \\
\text { employer. The employer would get in } \\
\text { touch with the candidates }\end{array}$ & $-.274^{* *}$ & 0 & 191 & $-.180^{*}$ & 0.013 & 189 \\
\hline $\begin{array}{l}\text { I would give access to my contacts at } \\
\text { SNSs to my employer. The employer } \\
\text { forwards the job description to } \\
\text { interesting contacts }\end{array}$ & -0.085 & 0.247 & 189 & $-.164^{*}$ & 0.025 & 187 \\
\hline $\begin{array}{l}\text { I would advertise job advertisements } \\
\text { at my online profile that potential } \\
\text { candidates could send an application } \\
\text { to my employer }\end{array}$ & $-.176^{*}$ & 0.014 & 192 & $-.219^{* *}$ & 0.002 & 190 \\
\hline
\end{tabular}

** Correlation is significant at the 0.01 level (2-tailed).

Source: conducted by Tom Sander in October 2015, $n=210$.

The results give the clear tendency that contacts of SNSs are important for SNSs members. They protect their contacts and are not willing to provide a third party access to their contacts but they are open to use their contacts for the employment seeking process for example to get in touch with their contacts and to share with them information about employment opportunities. They invest their knowledge about employment opportunities in the relationship to provide an advantage to their contacts and expect later a return of the investment. That is the social capital of the network. The important result is that the SNS members are only willing to use their contacts if they have the control and power about their contacts.

\section{Conclusions}

1. The use of SNSs contacts is an opportunity to identify suitable candidates. The potential of SNSs is amazing but the practical use is actual limited.

2. Individuals share and exchange information on SNSs but the openness and readiness to give the control and power about contacts to employer is mainly not accepted. The privacy and data protection is an important issue for SNSs member. The member of a social network trusts each other that their data is safe. That is the reason to create a tie. The tie provides extended access to personnel information and resources. The tie is an exchange channel and value for SNSs member but the SNSs members do not give access a third party to 


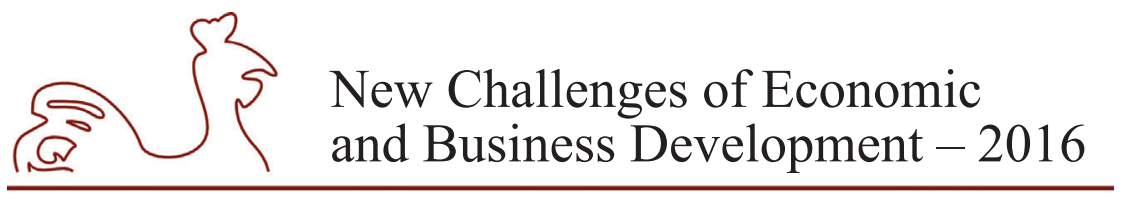

May 12-14, 2016, Riga, University of Latvia

their contacts if they do not have the control about the tie or power to decide what kind of resources or information is shared with their contacts. The power of social networks is to have power about ties to other contacts.

3. The use of SNSs variables does not have an influence on the behaviour of SNSs members. Only the "Use of private SNSs in minutes per day" or "Use of business SNS in minutes per day" have a correlation on a significant level. But the correlation coefficient is too weak to have a statistical relevance. The only abnormality is that all significant correlations are negative. That means heavy user agree less with the statements than "normal" user.

4. The social capital theory explains the mechanism in SNSs. A reason not to give access to their contacts can be explained with trust. Individuals give access to their profile because they trust each other and expect that their privacy is respected. If a social network member misuse the access to their contacts than the member is penalized by the network and the trust level is reduced. That means SNSs member with less reliability and low trust level in the network have difficulties to get access to valuable resources and information. The access to private information depends on the trust between the SNSs member.

5. Further research has to take under consideration that the purpose and objective of SNSs depends on the kind of the SNSs e.g. private or business SNSs. Further is the relationship and trust to the employer an important variable to provide access to private information like SNSs contact. The research has to be transferred to other situations and has not to be limited to the employment seeking process to generalize the results more.

\section{Bibliography}

Beaman, L., \& Magruder, J., 2012. Who gets job referral? Evidence from a social network experiment. American Economic Review, 102(7), pp. 3574-3593.

Behtoui, A., 2015. Beyond social ties: The impact of social capital on labour market outcomes for young Swedish people. Journal of Sociology, 50(1), pp. 1-14.

Burt, R. S., 2001. Structural Holes versus Network Closure as Social Capital. In N. Lin, K. Cook, \& R. S. Burt (Eds.), Social Capital, Theory and Research (pp. 31-57). London: Aldine Transaction.

Chiang, J. K.-H., \& Suen, H.-Y., 2015. Self-presentation and hiring recommendations in online communities: Lessons from LinkedIn. Computers in Human Behavior, 48, pp. 516-524.

Ellison, N. B., Steinfield, C., \& Lampe, C., 2007. The benefits of facebook "friends:" Social capital and college students'use of online social network sites. Journal of Computer Mediated Communication, 12 , pp. 1143-1168.

Granovetter, M. S., 1995. Getting a job. (Gran, Ed.) (2 $2^{\text {nd }}$ ed.). Chicago: The University of Chicago press.

Hampton, K., \& Wellman, B., 2003. Neighboring in Netville: How the Internet supports community and social capital in a wired suburb. City \& Community, 2(4), pp. 277-311

Krasnova, H., Günther, O., Spiekermann, S., \& Koroleva, K., 2009. Privacy concerns and identity in online social networks. Identity in the Information Society, 2(1), pp. 39-63.

Moolenaar, N. M., \& Sleegers, P. J. C., 2010. Social Networks, Trust, and Innovation. In A. J. Daly (Ed.), Social Network Theory and educational change (pp. 97-114). Cambridge MA: Harvard Business Review Press.

Mouw, T., 2003. Social capital and finding a job: Do contacts matter? American Sociological Review, 68, pp. 868-898.

Obukhova, E., \& Lan, G., 2012. Do Job-Seekers Benefit from Contacts? A Within-Individual Test with Contemporaneous Searches. Management Science, 59(10), pp. 2204-2216.

Portes, A., 2000. The two meanings of social capital. Sociological Forum, 15(1), pp. 1-12. 


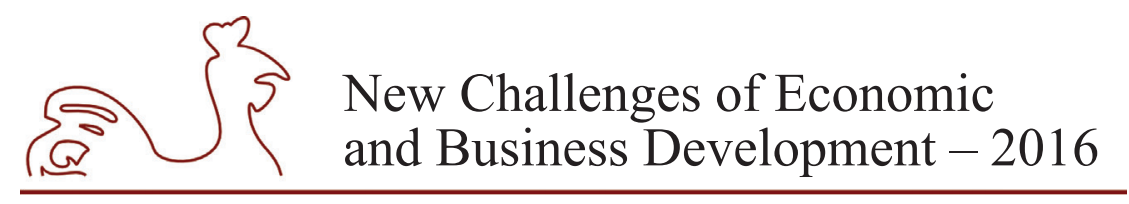

May 12-14, 2016, Riga, University of Latvia

Roebken, H., 2010. Similarity Attracts: An Analysis of Recruitment Decisions in Academia. Educational Management Administration \& Leadership, 38(4), pp. 472-486.

Sander, T., Sloka, B., \& Pauzuoliene, J., 2015. The Difference of Social Network Sites Explained with the Employment Seeking Process. Regional Formation and Development Studies, 03(17), pp. 145-153.

Sander, T., Teh, P. L., Majlath, M., \& Sloka, B., 2015. Use Preference and Channels Use in the Employment Seeking Process. In P. Michelberger (Ed.), Management, Enterprise and Benchmarking in the $21^{\text {st }}$ Century II. (pp. 240-249). Budapest: Obuda University.

Smith, S. S., 2005. "Don't put my name on it”: Social capital activation and job-finding assistance amont the black urban poor. $A J S, 111(1)$, pp. 1-57. 


\title{
COMPENSATING THE EFFECTS OF DEMOGRAPHIC SHIFT IN PUBLIC ADMINISTRATION. A LESSON LEARNED FROM A LESSONS LEARNED PROJECT
}

\author{
Eric Schoop, Technische Universitaet Dresden, Germany ${ }^{1}$ \\ Moritz Hesse, Technische Universitaet Dresden, Germany \\ Michael Breidung, Eigenbetrieb IT-Dienstleistungen der Landeshauptstadt Dresden, \\ Germany
}

\begin{abstract}
This paper is motivated by the demographic menace for the public administration of the Free State of Saxony, Federal Republic of Germany. It focuses on the intensified situation for the public IT sector. Due to forthcoming retirements and increasing changes of jobs from public IT sector to private organisations, in combination with severe public budget reductions, a fast approaching loss of professional work expertise (e.g. software application and process knowledge) in the electronic government sector has to be expected. To compensate this loss, answers have to be found to these questions: "What knowledge will get lost in the electronic government sector in Saxony? When and where? How should this loss be compensated?" The authors represent a network of knowledge management experts from Higher Education, IT and electronic government experts on municipal and regional level and representatives from the Saxon State Government responsible for the electronic government strategy. In summer 2015, a preliminary study introducing into a large-scale research was initiated. Several teams of Master students performed qualitative analyses based on in-depth interviews to find first answers to the questions above and thus establish a basis for future compensation measures, and to test if knowledge management methods accepted in the private sector are also applicable in the public sector. As a lesson learned from the preliminary study, the findings demonstrate a broad unpreparedness in Public Administration to the need for systematic knowledge management. While the question, how the knowledge loss can be compensated, remained unanswered for now, the studies triggered a re-design of knowledge management Master modules in 2016 to better prepare the next students' teams for more focused knowledge preservation actions, aiming to gain answers to that question.
\end{abstract}

Key words: Knowledge Management, Electronic Government, Demographic Shift, Public Administration JEL code: M15, J26, H54

\section{Initial Situation and Need for Action}

Societies in Central Europe dramatically suffer from a demographic shift; innovations in the medical sector lead to an increased expectation of life whereas a low average rate of birth is not able to sustainably compensate this development. While this is a general demographic problem, the effects consequently also have a radical impact on the private and public sector.

1 Corresponding author - e-mail address: eric.schoop@tu-dresden.de 


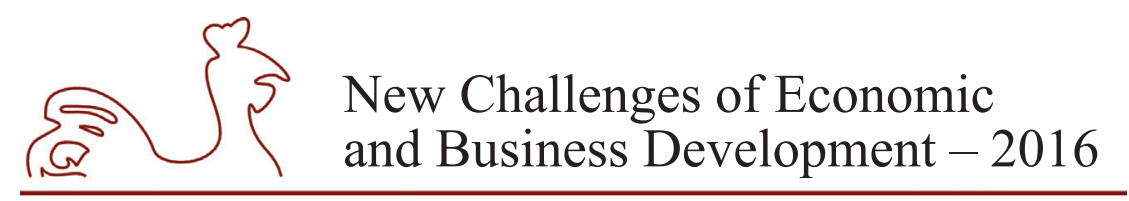

May 12-14, 2016, Riga, University of Latvia

This problem especially takes effect on the IT administration of the public sector, which can be observed in three manners.

Firstly, the average age of employees in the public IT administration in general is at a worrying high level. The Federal Statistical Office records approximately 2.29 million employed persons in 2005 in Saxony (Statistisches Bundesamt 2009). This number will drastically decrease within the next 15 years; forecasts prognosticate approximately 1.6-1.8 million employees for this area in 2030. That is a decrease of nearly 30 percent. Furthermore, the Saxon society had an average age of 46.4 years in 2011. This is the second highest average age in comparison to other German federal states (Sächsische Staatskanzlei 2014). In addition, the retirement in the public sector due to age is at a rate of nearly 10 percent within the next five years and will increase up to 27 percent within the next ten years (Statistisches Landesamt des Freistaates Sachsen 2013).

Secondly, the demand for cost cutting, streamlining and reorganisation efforts in the public sector leads to the fact, that a growing number of job positions, that cease to exist due to the retirement of elderly employees, are not reemployed by young labour. This is negatively supported by the general decline in population - especially in rural areas. The result of this development is a decreasing financial base for the public sector which even increases the necessity for cost cutting in the public administration.

Thirdly, the IT sector of public administrations directly has to compete with according organisations of the private sector, which typically create higher attraction to skilled labour, leading to significant changes of jobs to the private sector.

This triple demographic pitfall involves the danger of a severely limited capacity to act. The retirement of employees with years of working expertise in public administration, especially electronic government, directly causes the loss of essential administrational process knowledge, even if reemployed by younger labour. Additionally, and typical for the public sector, the reemployment of job positions after retirement suffers from a delayed hiring and allocation process due to bureaucratic reasons. The caused lack of overlapping coexistence of leaving expert and reemployed follower leads to a missing transfer especially of tacit knowledge in forms of individual socialisation processes (c.f. the SECI model, Nonaka \& Takeuchi 1995). These effects are intensified by skills shortage: besides missing working process experience, often basic qualifications in public administration and especially in electronic government are not present at the time of employment and have to be acquired on the job. This situation is further intensified by a growing complexity of new administrative processes and the demand for their automation in forms of new electronic government applications.

The imminent need for action is transparent and led in 2014 to the foundation of an informal interdisciplinary network, partly represented by the authors of this paper:

1) Knowledge management researchers from the Technische Universitaet Dresden (Chair of Wirtschaftsinformatik - Information Management)

2) IT and electronic government experts on municipal level (Eigenbetrieb IT / municipal IT service center of the city of Dresden, capital of the Free State of Saxony)

3) IT experts on regional level (Staatsbetrieb Saechsische Informatik Dienste / IT service center of the Free State of Saxony) and

4) representatives from the Saxon State government (Saechsisches Staatsministerium des Inneren, Abteilung IT und E-Government in der Staatsverwaltung / Ministry of the Interior of the Free State of Saxony, department IT and electronic government) 


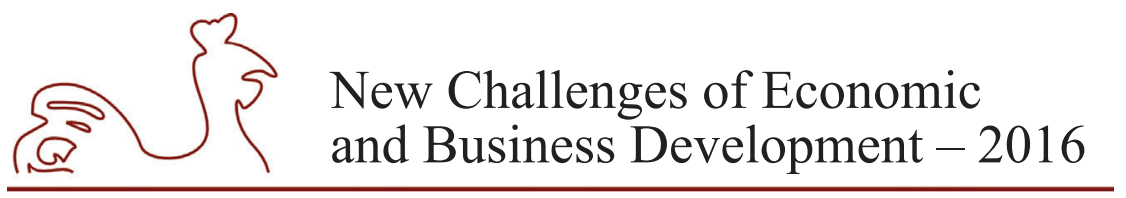

May 12-14, 2016, Riga, University of Latvia

being responsible for the modernisation of public administration and for the electronic government strategy of the Free State of Saxony.

The network's intention is to start a large-scale common research initiative to compensate the effects of demographic shift in Public Administration. This initiative has both scientific and practical potentials for the institutions taking part.

Scientifically, new impulses are set for

- application-oriented design science research (c.f. Hevner et al. 2004) with future focus on qualitative and quantitative empirical studies as objectives of Doctoral Theses (e.g. frameworks for knowledge-based workflow automation, TAM (technology acceptance model) - c.f. Bagozzi, Davis \& Warshaw, 1992, IS success model - c.f. DeLone, McLean, 2004) and

- research-based and application-oriented teaching on the level of Master study programs in Business Management, Business Pedagogics and Business Information Systems (e.g. Master course on knowledge management, team collaboration in practical research projects, seminar on research methodologies, Master Theses).

Practically, the need for action has to be answered by the following steps, taking also into regard many contextual issues and specialities of Public Administration in Germany (but this context is not to be discussed in this paper):

1) gain detailed insight into the demographic situation in the participating public institutions and in further institutions of the public sector,

2) document the findings,

3) perform systematic literature analyses and compare the findings

4) derive recommendations for action,

5) design concrete prototype solutions (informational artefacts like workflow applications or training courses),

6) evaluate the effects (e.g. acceptance or success),

7) re-design the approach based on these findings.

A successful compensation of the demographic shift in Public Administration, especially in electronic government, is a project of high complexity. It has to cover the following objectives:

- Acquisition of the process knowledge of the leaving experts,

- Intensified process automation to meet the future demands for productivity enhancement,

- Successful replacement of the retired staff by fewer, unexperienced employees,

- Appropriate training of the new staff on the job in process management competencies and in electronic government tools, complemented by the qualification of knowledge managers moderating knowledge-based process automation and human resource development.

So the resulting research questions for the large-scale research can be bundled into two dimensions:

1) Process Dimension: Which processes will keep or increase their contemporary relevance in future? Which processes are becoming less important or obsolete? Which new processes have to be expected and implemented due to compensation or to legislative changes?

2) Knowledge Dimension: Who are the key knowledge holders? When will they probably leave? What type of knowledge do they have? By what methods can their knowledge be identified and preserved? 


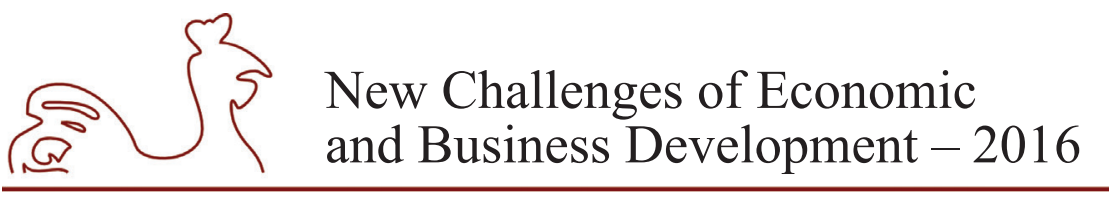

May 12-14, 2016, Riga, University of Latvia

\section{Research Process, Results and Discussion}

Besides making first arrangements for the design of the large-scale research (sensitisation of political decision makers to the problem, acquisition of public support and funding, integration of knowledge management into the mid-term electronic government and human resource development strategies on regional and on municipal level), the network decided not to lose time and started in 2015 a preliminary study. This was carried out by students of network partner 1 in pilot institutions of the network partners 2 to 4 with step (1) and step (2) of the above listed practical project steps. Research objectives were to sensitise the management in the institutions to systematic knowledge management, especially knowledge (gap) identification and knowledge preservation, to gain experience with the practical application of methods for knowledge preservation and to allow perhaps a re-adjustment of the (knowledge management) methodology applied before starting in large.

The preliminary study is included in the practical large-scale research initiative. This is a typical design science research (see Fig. 1). Steps (1) and (2) (preliminary study) can be allocated on the left side (environment), step (3) on the right side (knowledge base), steps (4) to (7) in the middle of the model (IS research).

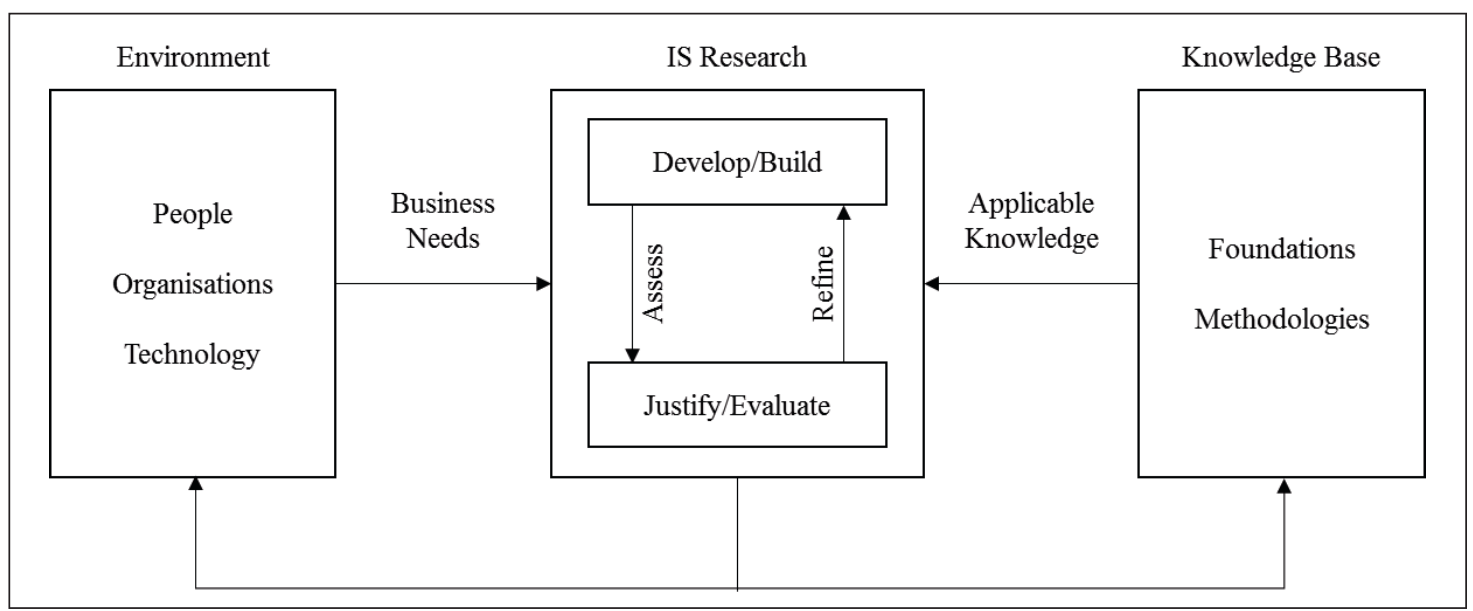

Source: Design science in information systems research (Hevner, March, Park \& Ram, 2004).

Fig. 1. Design Science in IS Research

The research process of the preliminary study presented in this paper consisted of 3 phases:

1) Qualification and team building (Master module in knowledge management, 2015/04-07);

2) Execution of the study (practical Master project in knowledge management, 2015/08-09);

3) Results and Discussion of the findings (2015/10).

\section{Qualification and Team Building}

To gain and to document knowledge about the environment where the planned IS research is to take place is a typical knowledge management research objective. Therefore, Master students in Business Management, Business Pedagogics and Business Information Systems participated in a standard knowledge management module having been established already for 


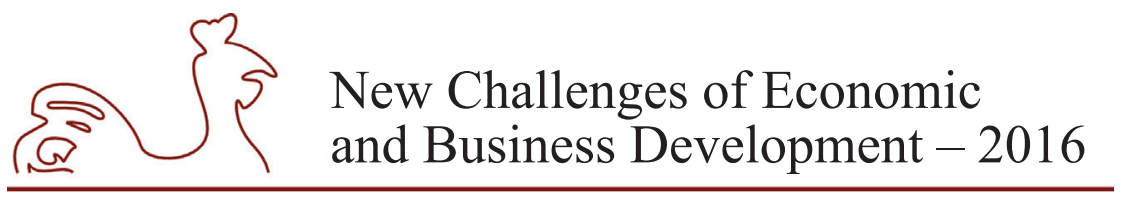

May 12-14, 2016, Riga, University of Latvia

years. The module consists of digitally captured conceptual lectures and readings on knowledge management theory and models (virtual classroom), of practical method-related exercises (real classroom) and of six seminar units (also in the real classroom).

In the seminar, 12 student teams (each with up to 6-7 participants) had to present, interpret and discuss arbitrary knowledge management cases and methods applied which they found in literature (mostly of private sector organisations). Each seminar unit covered one of six internal knowledge management components (fields of action) of the well-known knowledge management component model (Probst et al., 2006; see Fig. 2). In each unit two student teams had to cover the component from two different viewpoints:

1) Knowledge management strategy mix with codification priority (i.e. documentation of explicit knowledge) and

2) Knowledge management strategy mix with personification priority (i.e. preservation and sharing of implicit/tacit knowledge - c.f. Hansen, Nohria \& Tierney, 1999).

The knowledge management methods trained in the practical exercises were also structured in orientation to the component model (c.f. Wildner \& Scholz, 2006). After having passed this module, 11 out of the 69 Master students who were also interested in the subsequent practical teaching project were re-combined into three teams considering a competency mix from the different component-related case study perspectives.

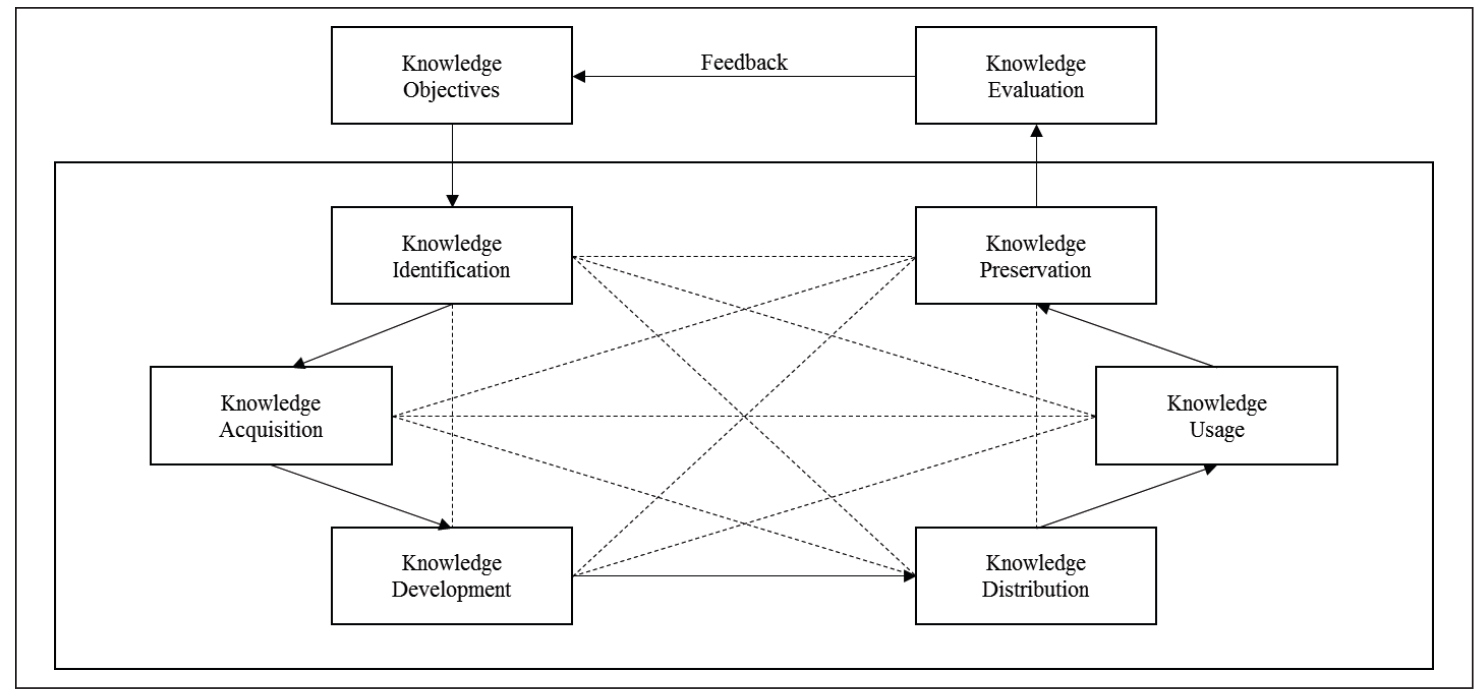

Source (translated): Bausteine des Wissensmanagements (Probst, Raub, Romhardt, 2006).

Fig. 2. Knowledge Management Components Model

\section{Execution of the Study}

The practical knowledge management teaching project started with preparation for the electronic government context (having been new for the participating students). For this purpose, the participants studied several actual Bachelor and Master Theses having addressed different aspects of electronic government and knowledge management in the public sector 


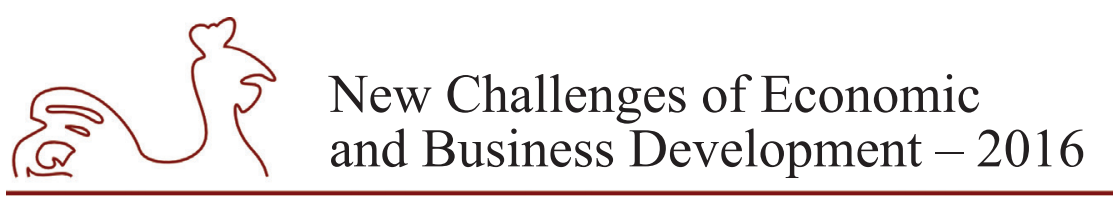

May 12-14, 2016, Riga, University of Latvia

of Saxony (e.g. the values of e-government-supported biddings for public administration services and reorganisation potentials based on Web 2.0 technologies in external and internal communication - Henning, 2013, Khamaza, 2015, Schneider, 2015). Empirical results of these analyses identified (amongst others), that knowledge management is yet unregistered or insufficiently implemented in the public sector of Saxony (Khamaza 2015).

The subsequent study consisted of qualitative empirical analyses based on in-depth interviews. As it was just a fast preliminary study run in 2 months of time and generating $150 \mathrm{~h}$ workload (5 ECTS credits) per student, the interviews were processed and evaluated manually, not - lege artis in larger and well-planned studies - systematically with the help of qualitative content analysis methods according to Mayring (2008). To keep irritation and rejection on interviewees side as low as possible, the student teams - under supervision of research assistants were sent out in one whole group to 10 different experts (4 heads of departments, 6 staff) in institutions of the three network partners on municipal and regional level and in the ministry, running only one interview with each expert. While the results of the Design Science Research methodology are usually supported also by quantitative analyses, the data collection of this preliminary study did not contain any relevant quantitative data that could be processed and analysed.

Afterwards, each team had to analyse the commonly gained information with focus on a specific knowledge management method already assigned before (to allow specific questions in the interviews, to make external notes for contextualisation and for focussing purposes in the content analyses). Additionally, they had to try to compare the results of the different interview sessions (representing the three application levels of electronic government - municipality, regionality, ministry), thus to gain insight into the applicability and effectiveness of the method and to find out about existing or imminent knowledge gaps. Based on scientific research works of Müller-Stewens \& Pautzke (1991) and Argyris \& Schön (2008),

- one student group has analysed change processes that had taken place about five years ago and their resulting consequences; to obtain and document the results, the lessons learned method has been applied (with focus on the codification of explicit knowledge linked to tacit knowledge/reflections behind);

- a second group of students had to focus on the newly employed IT staff concerning the same process and time frame by applying and developing the results using the story telling method (with focus on explication and sharing information about tacit knowledge);

- a third student group had to concentrate on job positions where future retirement would have the most impact and should try to derive the corresponding knowledge competences for the next upcoming years; obtained results are documented in the form of competence and knowledge maps (with focus on the codification of explicit knowledge linked to persons, applications and structures).

\section{Documentation and Discussion of the Findings}

The student teams summarised their approaches, reflections and findings in a MS SharePoint application using the visualisation suitable for their respective knowledge management method applied (lessons learned in forms of structured wiki nodes, told stories as linear/narrative text documents, competence \& knowledge maps as graphical concept/mind maps). The reflections on approach, applicability of knowledge management method and identified risks of potential 


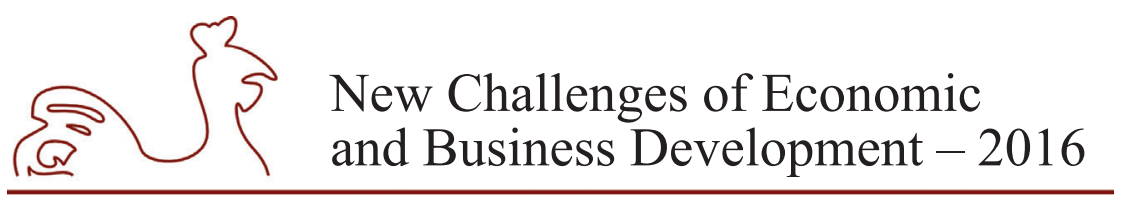

May 12-14, 2016, Riga, University of Latvia

knowledge loss due to missing knowledge preservation measures were written as group assignments being subject of the final project assessment. Focal point was not so much the methodological rigour (content analysis) or the scientific relevance of the findings, but the usage of and reflection about knowledge management methods and their applicability in Public Administration (practical relevance).

The results of the study can be summarised in three aspects:

- Imminent knowledge gaps and references to knowledge preservation action: The impossibility of overlapping replacement (due to financial and bureaucratic reasons) demands for the provision of codified knowledge (individual work expertise linked to mostly existing, but sometimes unclear - standard process description). Yellow pages (who is who and who knows what and should be called in by newcomers) or other formal navigational instruments do not exist. Systematic initial trainings (documentations or familiarisation materials) are also missing. Instead of systematic push information or an established mentoring system, the newcomers are left to pull the information presumably needed on their own (to find out where to ask or look). Due to missing knowledge about informal social networks, often it is unclear what knowledge will get lost besides the mere professional work competence (which can be derived relatively easily from standard job/competence description). Human resource management is not yet zeroed in on mediating cultural context, sensitivity to the demographic shift and to the demand for knowledge development, sharing and preservation is not explicitly incorporated. Several interviewees mentioned (and agreed) that HR department would not intervene in knowledge management tasks but leave this responsibility completely to the functional superiors (no centralised/standardised knowledge preservation plan of action). Architectural support (e.g. space management, coffee corners) is often missing due to financial bottlenecks in Public Administration and to the inappropriateness of many public buildings (e.g. historical buildings). Last but not least, the IT infrastructure - even in the analysed departments responsible for electronic government - is not appropriate to modern knowledge management support (the accessibility of documents is poor due to redundancy of structures and systems, no social intranet or systematic training exists to make use of wikis, blogs, or social tagging). Access to (Public Administration related) formal trainings by the special Saxon University for Public Management, needed at the very beginning point for lateral entrants, is complicated and takes months. Flexible work structures are not implemented (e.g. home office in combination with open-plan office with flexibly changing desktops). This could physically enable knowledge sharing and socialisation processes and could foster work satisfaction (enabling individually different combinations of professional and private life $=$ work-life-balance).

- Methods' application: Knowledge maps seemed easy to apply and to communicate their functionality and benefit to the interviewees. More complex was the analysis and visualisation of role-specific or process-specific competencies, as these were often related to real persons and could only with difficulty be abstracted to a more generic view. Lessons learned also seemed firstly to have a clear functionality and ease to use. But as no systematic reflections on the experiences of the past retirement processes existed in the analysed institutions, and no clear replacement strategy could be detected, the students had difficulties to enhance the easy "descriptive" part of the lessons learned 


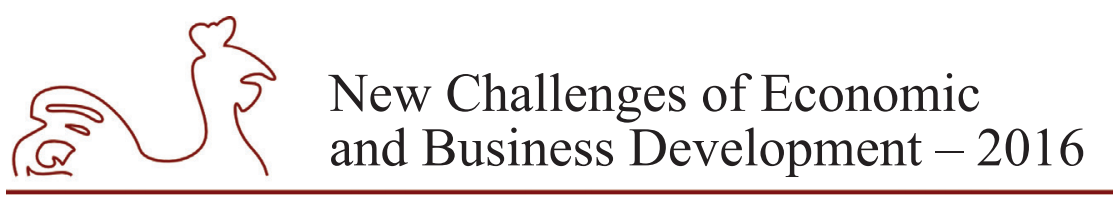

May 12-14, 2016, Riga, University of Latvia

by the - more important - reflective cycles and to communicate clear and concise. Significant problems both interviewers and interviewees had with the story-telling method. The desired character of the stories to be developed demands unstructured, hardly by the interviewer controlled, creative narrations. For this the interviewees were not prepared, the stories told seemed boring, repetitive, ill-focused and diffuse, making it difficult for the students later to generate "interesting" stories with metaphors and focal points potentially catching the attention of future listeners (follow-up employees).

- Project approach and success: Regardless of the previously in the Master module applied qualification measures, deepened by specific readings on electronic government themes, the students felt not always appropriately prepared to understand the complex field of Public IT services and electronic government, to link the information gained to knowledge (loss, identification, sharing, preservation) and to apply their knowledge management methods. The interview situation had not been practically trained before, the interviewees had tight time schedules and often no deep understanding of the study's purpose and format. The results did not seem very convincing to the students, they had expected more significant and obvious findings.

\section{Conclusions - Lessons learned from a Lessons Learned Project}

As a whole, both students and the network partners who initiated the preliminary study were satisfied with process and results, regardless to the deficiencies mentioned above. The problem is understood, the need for action is obvious, knowledge preservation has an increasing importance on the strategic agenda. But what did we learn from the preliminary study? How can this study foster the large-scale research to be pursued in 2016 ?

Obviously, the detailed questions for the large-scale research, which are explicated at the end of chapter 2, could not be answered satisfactory in the preliminary study. But this had not been the primary intention. In orientation on the research questions, the preliminary study discussed in this paper should rather find out

- if the awareness of the imminent risk of knowledge loss due to demographical effects is present at the institutions analysed and if there are already solutions planned or even implemented,

- if the knowledge identification and knowledge preservation methods used to prepare the findings of the qualitative analysis are applicable and the results interpretable and

- if it is possible to run the planned large-scale research with significant help of student resources.

All three objectives have been achieved, principally:

- The awareness is there, conclusions from the results of the preliminary study have been drawn and first organisational measures have been taken (e.g. on municipal level knowledge management is actually discussed to become a strategic pillar in the midterm human resource development strategy). The institutional partners shall identify the number and sequence of the next departments and institutions to be analysed with regard to the difficulties experienced in the preliminary study, with more focus and with enough preparation time for the $2^{\text {nd }}$ half of 2016.

- The knowledge management methods applied are suitable but have to be trained further (on students' side), have to be explained and supporting materials have to be demanded 


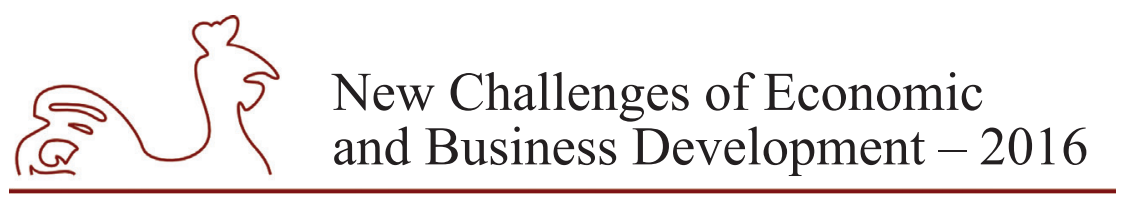

May 12-14, 2016, Riga, University of Latvia

precisely in advance (on the institutions' side). It is recommended to start with rather simple but intuitively understandable and usable methods. So firstly knowledge maps should be designed to describe the knowledge base, its structure, refer to the main knowledge holders and to the most critical knowledge-intensive applications and give hints to further knowledge development. Then, the lessons learned method should be trained and implemented stepwise in the relevant institutions under supervision of researchers from the academic partner. Thirdly, experienced interviewers could follow up later with the story-telling method to try to grasp specific tacit knowledge from identified and critical experts on the verge to retire.

- Qualified Master students can be integrated into the further research activities. But they have to be better prepared (in preliminary on-case teaching and readings) and within the research have to be supervised by research assistants being integrated and doing their research in this topic.

As reaction to these conclusions, the academic partner of the project network redesigned the Master modules to be held in 2016 for the preparation and qualification of the next generation of Master students who shall be integrated into the project. This time,

- the digital materials on knowledge management in the virtual classroom will be enhanced by specific basic information about electronic government in general and specifically in Saxony;

- the practical exercises will concentrate upon the methods to be applied in a follow-up practical teaching project module; they will not only be analysed but trained in role-playsituations and will be positioned in the first half of the semester;

- the seminar part will cover the 6 internal fields of action from the knowledge management components model (Probst et al., 2006) in orientation on a running case study about an authentic knowledge preservation situation in an IT service department in the Public Administration; the seminar groups will have the task to develop specific recommendations for their respective perspective (knowledge (gap) identification, knowledge acquisition etc. - c.f. Fig. 2) and for the detailed application of the methods and the interpretation of the information to be gained;

- the practical teaching project is planned for the following winter term, allowing more time between the two modules to select and train the participants beforehand in the practical application of the methods and inform them more detailed about the context of the interviewees they shall address; additionally, the interviews shall be transcribed and the data processed as a state of the art content analysis (c.f. Mayring, 2008), to enhance rigour and scientific relevance of the research;

- the teaching project teams shall be supervised and coached by research assistants whose dissertation projects cover the research area addressed here (both knowledge codification and knowledge personification perspectives), thus assuring a high personal involvement of the supervisors in the project.

On the side of the Public Administration network partners, it is planned stepwise to develop and apply standardised competence maps and knowledge maps, qualify project leaders and heads of departments in the lessons learned method and identify key knowledge holders for potential later application of the complex story-telling method. Besides these actions, gradually the institutions should produce standardised starter packages for the new employees, develop 


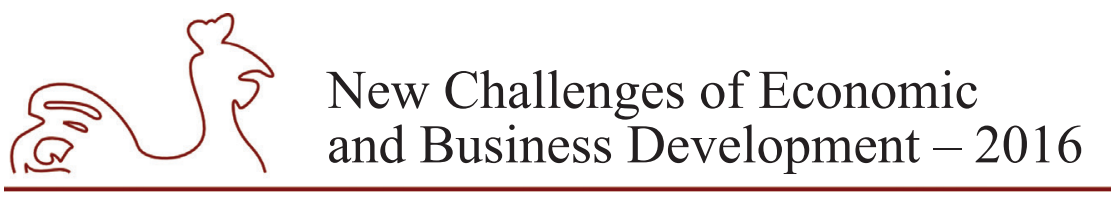

May 12-14, 2016, Riga, University of Latvia

a "culture of knowledge transparency and sharing" and support this by establishing suitable IT infrastructure (e.g. internal social media applications).

Summing up, the preliminary study discussed in this paper delivered valuable results and triggered a set of actions which should improve the quality and effectiveness of the large-scale research initiative.

\section{Bibliography}

Argyris, C., Schön, D. A., 2008. Die lernende Organisation: Grundlagen, Methode, Praxis. 3. Auflage. Klett-Cotta, Stuttgart.

Bagozzi, R. P.; Davis, F. D.; Warshaw, P. R., 1992. Development and test of a theory of technological learning and usage. Human Relations 45 (7), pp. 660-686.

DeLone, W. H., McLean, E. R. 2004. Measuring E-Commerce Success: Applying the DeLone \& McLean Information Systems Success Model. International Journal of Electronic Commerce (9:1), Fall, pp. 31-47.

Hansen, M. T., Nohria, N., Tierney T., 1999. What's Your Strategy for Managing Knowledge? Harvard Business Review 77 (2), pp. 106-116.

Henning J, 2013. Reorganisationsmöglichkeiten des kommunalen Vorschlagswesens aus technischer Sicht - Eine Analyse am Beispiel der Stadtverwaltung Dresden. Bachelor Thesis, Faculty of Business and Economics, Technische Universitaet Dresden.

Hevner A. R., March S. T., Park J., Ram S., 2004. Design science in information systems research. MIS quarterly 28 (1), pp. 75-105.

Khamaza, O., 2015. Preparing knowledge retention: How to identify IT knowledge in the public sector of Saxony. Master Thesis, Faculty of Business and Economics, Technische Universitaet Dresden.

Mayring, P., 2008. Qualitative Inhaltsanalyse. Grundlagen und Techniken. $10^{\text {th }}$ Edition. Beltz, Weinheim und Basel.

Müller-Stewens, G., Pautzke, G., 1991. Führungskräfteentwicklung und organisatorisches Lernen. In: Sattelberger, T. (Hrsg.). Die lernende Organisation: Konzepte für eine neue Qualität der Unternehmensentwicklung. Gabler, Wiesbaden, pp. 183-205.

Nonaka, I., Takeuchi, H., 1995. The knowledge-creating company: How Japanese companies create the dynamics of innovation. Oxford University Press, New York.

Probst G. J. B., Raub, S., Romhardt, K., 2006. Wissen managen: Wie Unternehmen ihre wertvollste Ressource optimal nutzen, $5^{\text {th }}$ revised edition. Gabler, Wiesbaden.

Sächsische Staatskanzlei, 2014. Durchschnittsalter der Bevölkerung in Sachsen (Referat 35).

Schneider, A., 2015. Evaluation des Mehrwertes von kommunalen Verwaltungsleistungen als E-Government-Angebot. Bachelor Thesis, Faculty of Business and Economics, Technische Universitaet Dresden.

Statistisches Bundesamt, 2009. Demografischer Wandel in Deutschland: Auswirkungen auf die Zahl der Erwerbspersonen (Heft 4).

Statistisches Landesamt des Freistaates Sachsen, 2013. Personal im öffentlichen Dienst des Freistaates Sachsen, pp. 22-23.

Wildner, S., Scholz, M. (2006). Managing Knowledge Methodically, In: Lehner, F., Nösekabel, H., Kleinschmidt, P. (Hrsg.). Proceedings der Multikonferenz Wirtschaftsinformatik, Passau, Germany, Vol. 2, pp. 403-415. 


\title{
BLIND SPOT "INFORMATION RISK MANAGEMENT" - THE DIFFERENT PERCEPTION OF EXPERIENCED MANAGERS AND IRM-PROFESSIONALS
}

\author{
Stefan Schwerd, University of Latvia, Latvia ${ }^{1}$
}

\begin{abstract}
Nowadays computer mediated communication (CMC) (Chang C., 2015): and the high volume of computed and stored information is getting a business on its own. Information is collected, aggregated, analysed and used to create real business advantage and value but also risks within companies and also outside on the markets in a high volume (Spears Janine L., 2010). On the other hand, single individuals still need to deal and interpret this sheer mass of increasing information continuously.

The areas of decision making processes, methods and methodologies are well researched (Ayyub B., 2014) at all also on the base of Current Management Theories (Greenwood W. T., 1974) (Barney J. B., 2009). The field of Information Risk Management as a sub-discipline of Enterprise-Risk-Management (Choi J., 2013) theories is in a constant change. This change is triggered by the dramatic ongoing changes in the computerized information management Power, (Daniel J., (2008) capabilities. Well accepted, in $21^{\text {st }}$ century Information itself is a valuable asset (Wagner H., 2014). The correct information at the point in time needed decides on success (Pfeiffer T., 2010) - within milliseconds. Current Organizational Management theories don't take this constantly and rapidly changing environment into account (Huang K., 2015). An undertaken series of 10 interviews of Information Risk Management Professionals compared with field-study of 131 Business Managers examines the differences in perception of related risks, actions and counter activities.

In Management Theory as well as in Organizational Theories the Information-Risk-Management discipline needs to be considered through the whole value chain (Holtgrewe U., 2014) as a separate value adding process and function. Esp. managers in middle management are exposed to this area risks, but might get into a conflict of interest (Biocca M., 2005) between performing the required IRM-actions against showing a high cost-benefit rationale.

This article examines the different perception, the resulting needs and recommendations for changes in organizational theory to resolve this conflict of interest for stronger overall performance.
\end{abstract}

Key words: Information Risk Management, Management Theory, Decision Making, Enterprise Risk Management

JEL code: C01, D81, O33

\section{Introduction: Findings and Hypothesis}

The central point of this research work was based on various observations in midsized and big enterprises in various businesses around the globe. It was observed, that "Information Risk Management" is not seen as a serious factor for business success esp. in the day to day decision making processes at the average "mid-managers" level. But on the other hand, IRM is seen as

1 Corresponding author - e-mail address: stefan@schwerd.eu 


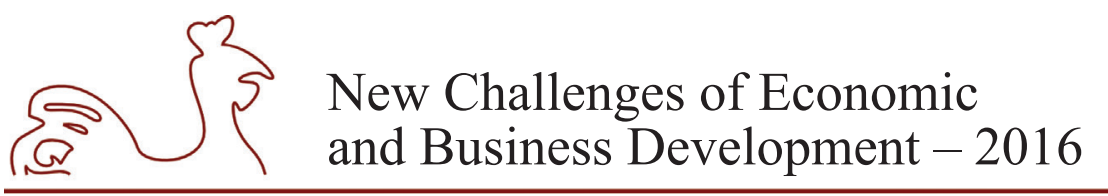

May 12-14, 2016, Riga, University of Latvia

getting fast increasing relevance in the more and more developing information technology ages. So, the Hypothesis were formed as:

$\mathrm{H}_{0}$ : Active Information Risk Management (IRM) significantly correlates positively to Improvement of Strategic Decision Making

$\mathrm{H}_{1}$ : There is no difference in perception between IRM Professionals and Midlevel-Managers of the correlation between IRM and Improvement of Strategic Decision Making

\section{Research Results and Discussion - Building the Model}

The initial question on how to measure the quality and characteristics of "Information Risk Management" mechanism, a choice of several operationalized measurable variables and indicators were preselected based on a broad literature research. In essence there are two focus areas to look into

1. Human Factor - Social and Psychological Research

2. Methodical/Technical Factors - General Risk Management Research

In the area of Social- and Psychological Research, which describes the perception and the behaviour, the "buy-in" theory of participation in IRM contexts associates' user acceptance with users' psychological involvement (Markus M. L., 2004) that develops during their participation. In other words, as users participate in IRM activities, they begin to view the focal system as personally important and relevant, and are therefore likely to be more accepting of the system than they would otherwise be had they not participated. On the other Hand John D'Arcy (D'Arcy J., 2015) describes situations where security requirements increase workload for employees and, as a result, create added time pressure for them to complete job duties. For example, employees who do not have administrative access to their work computers may have to spend valuable time completing paperwork and waiting for an IT professional to install needed software or download needed materials. As a result, employees have to work harder and faster to compensate for the overload caused by this security requirement. These conditions are known causes of frustration and stress (Gilboa S., 2008) (Pearsall M.J., 2009) Employees have also lamented that many security requirements force them to adapt their work procedures (e.g., not sharing passwords with co-workers) (Beautement A., 2008) (Stanton J.M., 2006), which can be stress inducing.

As a first interim result the real of IRM-“AWARENESS" of the employees could be seen as one of the key indicators of IRM as such - This includes not only the theoretical knowledge of IRM at all levels of the organization but also the willingness to follow combined with a proactive "all day" attention.

Methodologically/Technically, holistic Risk Management consists itself out 3 steps:

1. Risk Identification - Information Classification

2. Protection of Risk-Areas

3. Active Controls of Risk-Areas

In mid-sized and big enterprises the effective implementation of Standards and Controls is key for any kind of compliance reporting done by internal and external auditors. When responding to a specific business risk, an auditor has to search for relevant and reliable audit evidence and list the accounts and assertions to test in response to that risk. Cognitive research 


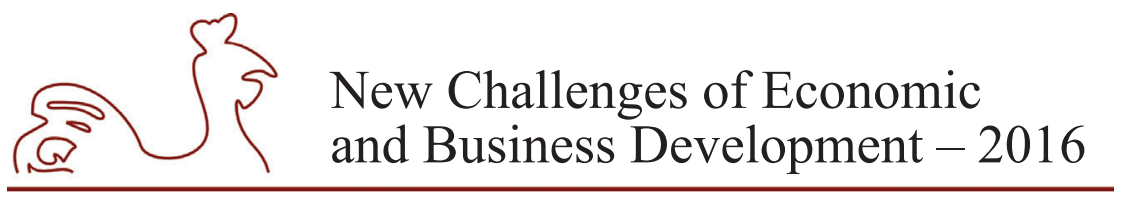

May 12-14, 2016, Riga, University of Latvia

has found that experts / specialists have more complete knowledge and memory organization than novices (Bédar J., 1989) have a more complete problem representation, which they bring to an unstructured industry task (Hammersley J. S., 2006). IRM was over a long time a not structured task. In the beginning a holistic view on all Information Assets needs to be in place to further classify and segregate the "important to look at" assets from the irrelevant. Further on an appropriate protection of this information assets need to be established as well as an "over time" controlling" of these security measurements.

In a first round 10 independent IRM Experts were personally interviewed in a structured method along a Likert-5 scaled (it was explained that the underlying distance of each sector is assumed $20 \%$ of the range which equals "linear") questionnaire to validate the validity of the measurement variables and also give the EMERICAL NORM for the second evaluation later on. All 4 criteria were highly accepted and seen as THE measurement criteria for the quality of IRM.

It could be shown, that the average mean and the normalized mean are

Table 1

Expert's Interview Resulting IRM Measurement Variables' Mean

\begin{tabular}{|l|c|c|}
\hline \multicolumn{1}{|c|}{ Variable } & $\begin{array}{c}\text { Mean } \\
\text { Empiric Norm }\end{array}$ & Normalized mean \\
\hline IRM Awareness & $\mathbf{0 . 8 5 3 6}$ & 1 \\
\hline Information Protection & $\mathbf{0 . 8 5 3 3}$ & 0.9996 \\
\hline Information Classification & $\mathbf{0 . 8 3 8 3}$ & 0.9820 \\
\hline Information Controls & $\mathbf{0 . 8 2 7 6}$ & 0.9696 \\
\hline
\end{tabular}

Source: author's calculations based on structured IRM-Expert Interviews in Phase 1.

On the other hand the Endogen Variables on how to measuring "Improvement of strategic decision making" is a variety selected out of a broad literature research. In total the 3 following main criteria with their measurement criteria were identified:

1) Improve (Mutual) Trust (McKnight D., 2002) into the company
a. Level of Competence, Expertness, Dynamism
b. Level of Goodwill, Benevolence, Responsiveness
c. Level of being credible, moral, integer, reliable
d. Level of being attractive, predictable, careful, open

2) Improve Decision Making Effectiveness/Efficiency (Schulz C., 2013) (Haws K., 2016) (Biehl M., 2006)
a. Level of willingness to see "Information" as an intellectual property (= Profitability)
b. Level of temporal efficiency (accuracy and integrity of information)
c. Level of readiness of communication and for growth and for using multiple information sources
d. Level of socio economic efficiency e.g. "Need to Know" principal
e. Level of willingness to treat information also as valuable good or good sold
f. Level of individual personal efficiency in information handling 


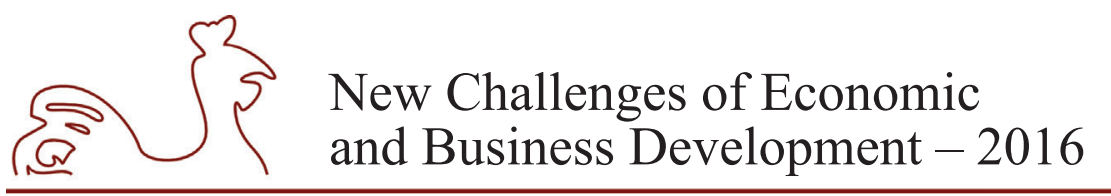

May 12-14, 2016, Riga, University of Latvia

3) Anticipated Damage Control Prevention (Cornish D.B., 2003) (Worthley R., 2002)

a. Level of readiness in information access control

b. Level of actively decreasing risks

c. Level of readiness to reduce rewards for theft / disclosure

d. Level of readiness to reduce provocations (e.g. stress / frustration/ etc.)

e. Level of readiness to remove excuses (e.g. clear rules, alerting conscience etc.)

The resulting proposal of the causal model to be tested could be shown as following:

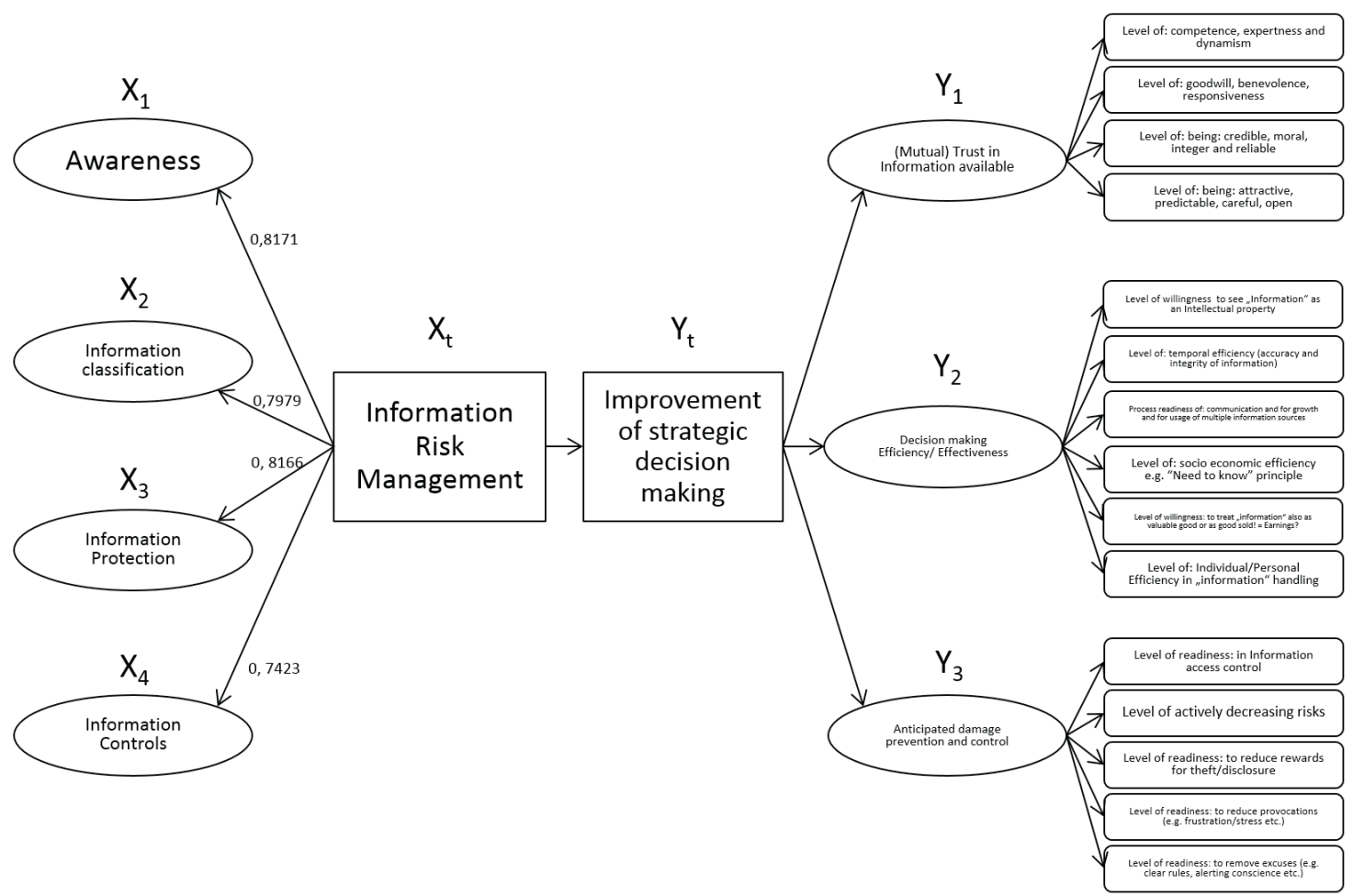

Source: author's construction based on Literature research and structured IRM Expert Interviews.

Fig. 1. Causal Model

\section{Scientific Design / Methodology}

In a sample of 131 business professionals (mid-level-managers) the referenced model (Figure 1) was tested.

As Information Risk Management methods are not obvious and therefore not very well known in the community of average mid-managers, a "Case Study" was invented to give the full spectrum of possibilities from "doing nothing" up to "doing everything possible" in IRM with sounding examples. The case-study was handed out to all 131 participants prior to the questionnaire. It is based on a fictive merger situation of a private owned company having no formalized IRM in place and on the other hand having a fictive multi million global enterprise having all IRM methods implemented. The participants were fictively asked to help 


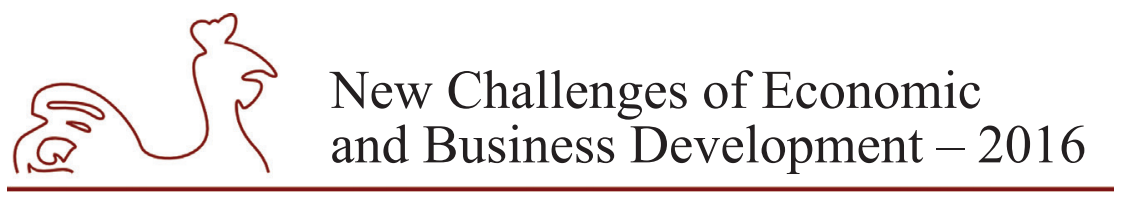

May 12-14, 2016, Riga, University of Latvia

the M\&A team consisting of people of both companies to discuss the meaning and the sense of IRM for the future Joint venture company and esp. the relation to the positive contribution in the Improvement of Strategic Decision Making factors.

To ensure exact mapping of the exogenous- and the endogenous variables and also to ensure same "expressions" and the underlying precise definitions of the IRM Variables, already concatenations (all exogenous to all endogenous) variables were formed. The participants were asked to give their appraisal to what extend an explicit relation would be valid (between exogenous and endogenous variables) via a Likert-"5"-Scale (Strongly Agree, Agree, Neither, Disagree, Strongly Disagree).

\section{Statistical Method}

The statistical evaluation, whether a significant ( $>95 \%$ confidence) similarity or significant difference between the opinion of the experts and the mid-Managers was performed via a 2-tailed T-test where the results out of evaluation 1 (Structured Expert-Interviews) were taken as Empirical Norm to test against results out of evaluation 2 (Case Study with Questionnaire 131 midlevel managers).

Table 2

Cross-table of 2-tailed T-Test results

\begin{tabular}{|c|c|c|c|c|}
\hline & 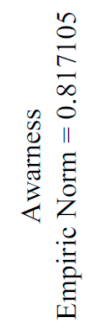 & 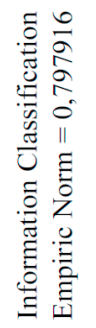 & 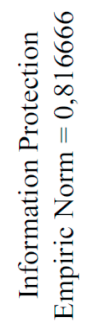 & 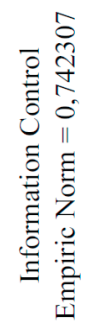 \\
\hline Trust in Information Availabiltiy 1 & 0,3790 & 0,2700 & 0,9720 & 0,9450 \\
\hline Trust in Information Availabiltiy 2 & 0,6600 & 0,9950 & 1,0000 & 0,8750 \\
\hline Trust in Information Availabiltiy 3 & 0,1870 & 0,9400 & 1,0000 & 0,8650 \\
\hline Trust in Information Availabiltiy 4 & 0,9730 & 0,9930 & 1,0000 & 0,6890 \\
\hline Trust in Information Availabiltiy AVG & 0,7360 & 0,9920 & 1,0000 & 0,8000 \\
\hline Decision Making Effic./Effect. 1 & 1,0000 & 1,0000 & 1,0000 & 1,0000 \\
\hline Decision Making Effic./Effect. 2 & 0,9780 & 1,0000 & 0,9990 & 1,0000 \\
\hline Decision Making Effic./Effect. 3 & 0,8690 & 0,9150 & 1,0000 & 1,0000 \\
\hline Decision Making Effic./Effect. 4 & 1,0000 & 0,9980 & 1,0000 & 1,0000 \\
\hline Decision Making Effic./Effect. 5 & 1,0000 & 1,0000 & 1,0000 & 0,9980 \\
\hline Decision Making Effic./Effect. 6 & 1,0000 & 1,0000 & 1,0000 & 0,9240 \\
\hline Decision Making Effic./Effect. AVG & 1,0000 & 1,0000 & 1,0000 & 1,0000 \\
\hline Anticipated Dam. Prev./Contr. 1 & 0,7340 & 0,9980 & 0,9770 & 1,0000 \\
\hline Anticipated Dam. Prev./Contr. 2 & 0,2400 & 0,5210 & 0,4710 & 0,9990 \\
\hline Anticipated Dam. Prev./Contr. 3 & 1,0000 & 1,0000 & 0,8420 & 0,1600 \\
\hline Anticipated Dam. Prev./Contr. 4 & 1,0000 & 1,0000 & 1,0000 & 1,0000 \\
\hline Anticipated Dam. Prev./Contr. 5 & 0,7120 & 0,1670 & 0,8990 & 0,9880 \\
\hline Anticipated Dam. Prev./Contr. AVG & 1,0000 & 1,0000 & 1,0000 & 0,5720 \\
\hline
\end{tabular}

Source: author's calculations based on 131 Business Experts (Midlevel-Managers) Questionnaires and IRM-Experts Interviews. 


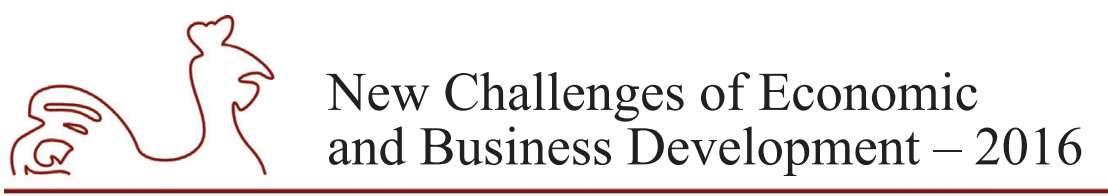

May 12-14, 2016, Riga, University of Latvia

The 2-tailed T-Test is testing differences against the given Empiric-Norm (from Expert Interviews). The Table 2 shows the T-Test resulting cross-table including the average results (“< ..>AVG") for all criteria aggregated. Values shown are inverted (Result=1-Value):

Result $\geq 0,99 \stackrel{\text { def }}{=}$ "Highly Significant Difference" between the view of the 10 IRM-Experts and the view of the 131 Midlevel Managers tested

Result $\geq 0,95 \stackrel{\text { def }}{=}$ "Significant Difference" between the view of the10 IRM-Experts and the view of the 131 Midlevel Managers tested

Result $<0,95 \stackrel{\text { def }}{=}$ "No Significant Difference" $\triangleq$ "significant conformity" between the view of the 10 IRM-Experts and the view of the 131 Midlevel Managers tested

\section{Results}

As shown in Table 1 the result of the structured IRM-Expert-Intervies proves significantly the validity of the choosen endogenous variables (IRM Awareness, Information Classification, Information Protection and Information Controls) and the positive correlation to be seen as essential contributing factors for future successful Improvement of Strategic Decission Making.

With this, $\mathrm{H}_{0}$ : "Active Information Risk Management (IRM) significantly correlates positively to Improvement of Strategic Decision Making” could be seen as accepted

On the other hand, according to Table 2 obviously only a selection of endogenous variables does not significantly differ / significantly confirm the correlation. Quite interesting, that the number of Averages conformity is quite low - whereas the number of single measured indicators significantly confirming the correlation e.g. for "Trust" 9 out of 16 indicators confirm, for "Anticipated Damage Prevention" 9 out of 20 indicators correlate significantly. Decision Making Effectiveness / Efficiency only is proven on 3 out of 24 indicators. Looking into the details the following correlation in the Averages could be proven:

- IRM Awareness \& Information Control is seen as significant to improve "Trust"-factors

- Information Controls is seen as significatn to improve "Anticipated Damage Prevention and Control'-factors

Looking at the significant different opinions between the IRM-Experts and the Mid-LevelManagers it schows a high number of "Highly Significant Differences" (Result T-Test $\geq 0.99$ ). In Particular this Averages are:

- ALL 4 IRM Variables are seen as highly significant different to improve "Decision making Effectiveness / Efficiency"

- IRM Awareness, Information Classification \& Information Protection are seen as highly significant different to improve "Anticipated Damage Prevention and Control"-factors

- Information Classification \& Information Protection seen as highly significant different to improve "Trust"- factors

Resulting out of this, $\mathrm{H}_{1}$ : "There is no difference in perception between IRM Professionals and Midlevel-Managers of the correlation between IRM and Improvement of Strategic Decision Making” could not be seen as fully acceptable.

There are some (highly) significant differences in perception between IRM Professionals and Midlevel-Managers according the correlation between IRM-Experts and the Improvement of Strategic Decision Making. 


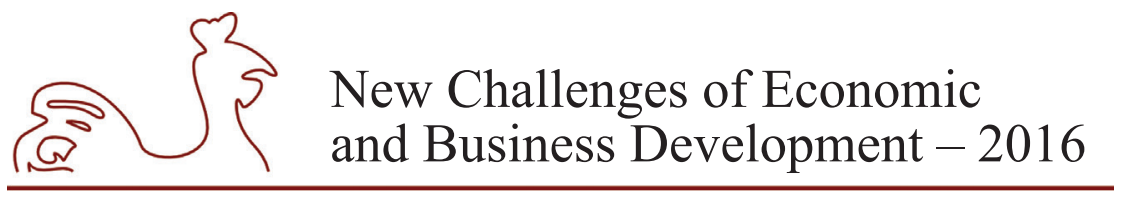

May 12-14, 2016, Riga, University of Latvia

\section{Practical Implications}

Experts significatly prove the impact of IRM on the Improvement of Strategic Decision Making whereas Midlevel-Mangers do only partly confirm. Very interesting are some logical implications that are not seen by the Midlevel-Managers-Community:

1. To be able to implement and follow-up on "Information Controls" it is essential to start with a Information-Asset-Classification, on what Information-Assets are critical and have to be protected and how (Information Protection) in the light of Anticipated Damage Prevention and Control (accroding Table 2). It seems to be important to educate the average MidlevelManager on this needs - otherwise, not doing this preselection of critical Information Assets, this could also be seen as a tendency to control Information-Assets without clear guidance on what exactly - resulting in a high risk of either:

a. controlling too much and too many, with enormous economic disadvantage

b. Controlling too less and too few means exposing critical information assets to risks and therefore economic loss esp. in the light of Damate controle/prevention

c. Controling the wrong Information-Assets with exposing missleadingly critical ones to risks, producing sunk costs for checking the wrong ones.

$\Rightarrow$ High need to consitently Inform/educate/mandate Midlevel-Managers to also focus on the need of Information Classification and Information Proteciton in the light of Anticipated Damage Prevention/Control.

2. The IRM-Awareness is seen as the most important methode/criteria for solid IRM(According Table 1) by IRM-Experts. The Midlevel-Managers would only see a significant correlation to the "Trust"-factors but no significant correlation to "Decision Making Effectivenss/ Efficiency" and to "Anticipated Damage Prevention and Control".

$\Rightarrow$ According IRM Experts Awareness of risks, threats, technical implications, but esp. on protection in non IT-Environment is key success to reach the goal of "high quality Information" and therefore the Improvement of Startegig Decision Making. It seems to prove to be inline with the lack of overall knowhow, acceptance and resistance descibed by D'Arcy (D'Arcy J., 2014) and extends this to the fact, that obvious most MidlevelManagers “didn't know what they didn't know themselves. This could be seen as the underlying risk at all.

\section{Conclusion, Proposal, Recommondation, Limitation}

In current and future times, where Information is a more and more important successfactor for any business person, also individually, to make good and sustainable business decision, it is important to ensure solid IRM enterprise-wide. Therefore, as a result ot of this study, it is recommanded to mandatorily anchor IRM Methodology as a formal funktion in top-Management like a "Quality-Assurance" - being independet and mandated to drive, follow up and change where necessary, to support ALL business functions proactively and with state of the art methodology and toolsets to unburden Midlevel-Management from this principal activities and individual approaches but clearly not taking the accountability for the departmental owend/required information assets. All this paired with a solid and everlasting IRM-Awareness to ALL assosiates.

Future Scientists might procede on how to exactly setup and drive this methods in an economic meaningful way, setup procedures and models and define the kind of organizational relations (e.g. reporting-lines) necessary which was not part of this scientific work. 


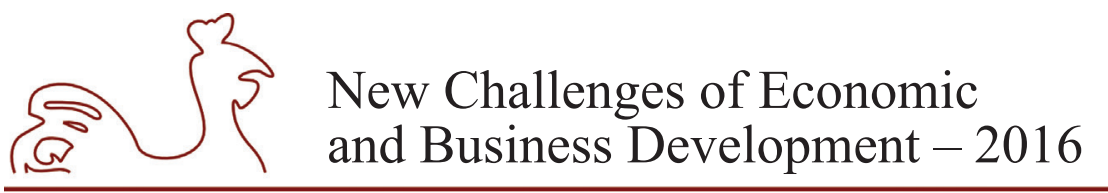

May 12-14, 2016, Riga, University of Latvia

\section{Bibliography}

Ayyub, Bilal M. (2014): Systems Resilience for Multihazard Environments. Definition, Metrics, and Valuation for Decision Making, Risk Analysis 34 (2), pp. 340-355. DOI: 10.1111/risa.12093.

Barney, Jay B. \& Zhang, Shujun (2009): The Future of Chinese Management Research. A Theory of Chinese Management versus $A$ Chinese Theory of Management, Management and Organization Review 5 (1), pp. 15-28. DOI: 10.1111/j.1740-8784.2008.00102.x.

Biehl, Markus \& Cook, Wade \& Johnston, David A. (2006): The efficiency of joint decision making in buyer-supplier relationships, Ann Oper Res 145 (1), pp. 15-34. DOI: 10.1007/s10479-006-0023-x.

Biocca, Marco (2005): Risk Communication and the Precautionary Principle, Human and Ecological Risk Assessment: An International Journal 11 (1), pp. 261-266. DOI: 10.1080/10807030590920097.

Chang, C. (2015): Responses to conflicting information in computer-mediated communication. Gender difference as an example, New Media \& Society 18 (1), pp. 5-24. DOI: 10.1177/1461444814535344.

Choi, Jongmoo Jay \& Mao, Connie X. \& Upadhyay, Arun D. (2013): Corporate Risk Management under Information Asymmetry, Journal of Business Finance \& Accounting 40 (1-2), pp. 239-271. DOI: $10.1111 / \mathrm{jbfa} .12008$.

D’Arcy, John \& Herath, Tejaswini \& Shoss, Mindy K. (2014): Understanding Employee Responses to Stressful Information Security Requirements. A Coping Perspective, Journal of Management Information Systems 31 (2), pp. 285-318. DOI: 10.2753/MIS0742-1222310210.

Derek B. Cornish \& Richard V. Clarke (2003): Opportunities, Precepitations and Criminal Decisions: A Reply to Worthley's Critique of Situaional Crime Prevention, Crime Prevention Studies Vol. 16, pp. 41-96.

Greenwood, W. T. (1974): Future Management Theory. A “Comparative” Evolution to a General Theory, Academy of Management Journal 17 (3), pp. 503-513. DOI: 10.2307/254653.

Haws, Kelly \& Davis, Scott \& Dholakia, Utpal (2016): Salad = success and fries = failure? Conceptualizing and assessing self-control outcome measures in food decision-making research, J. Consumer Behav. 15 (2), pp. 99-116. DOI: $10.1002 / \mathrm{cb} .1560$.

Holtgrewe, Ursula (2014): New technologies. The future and the present of work in information and communication technology, New Technology, Work and Employment 29 (1), pp. 9-24. DOI: 10.1111/ntwe.12025.

Huang, Kuo-Feng \& Dyerson, Romano \& Wu, Lei-Yu \& Harindranath, G. (2015): From Temporary Competitive Advantage to Sustainable Competitive Advantage, Brit J Manage 26 (4), pp. 617-636. DOI: 10.1111/1467-8551.12104.

McKnight, D. Harrison \& Choudhury, Vivek \& Kacmar, Charles (2002): Developing and Validating Trust Measures for e-Commerce: An Integrative Typology, Information Systems Research Vol. 13 (Issue 3), p. p334-359. 26p.

Pfeiffer, Thomas \& Schneider, Georg (2010): Capital budgeting, information timing, and the value of abandonment options, Management Accounting Research 21 (4), pp. 238-250. DOI: 10.1016/j. mar.2010.07.001.

Power, Daniel J. (2008): Understanding Data-Driven Decision Support Systems, Information Systems Management 25 (2), pp. 149-154. DOI: 10.1080/10580530801941124.

Schultz, Carsten \& Salomo, Søren \& Brentani, Ulrike de \& Kleinschmidt, Elko J. (2013): How Formal Control Influences Decision-Making Clarity and Innovation Performance, J Prod Innov Manag 30 (3), pp. 430-447. DOI: 10.1111/jpim.12009.

Spears, Janine L. (2010): User Participation in Information System Security Risk Management, MIS Quarterly Vol. 34 (Issue 3), p. p503-A5. 25p.

Wagner, Heinz-Theo \& Beimborn, Daniel \& Weitzel, Tim (2014): How Social Capital Among Information Technology and Business Units Drives Operational Alignment and IT Business Value, Journal of Management Information Systems 31 (1), pp. 241-272. DOI: 10.2753/MIS0742-1222310110. 


\title{
SUSTAINABLE LEADERSHIP IN LITHUANIAN ORGANISATIONS
}

\author{
Ligita Simanskiene, Klaipeda university, Lithuania ${ }^{1}$ \\ Erika Zuperkiene, Klaipeda university, Lithuania \\ Jurgita Pauzuoliene, Klaipeda university, Lithuania
}

\begin{abstract}
The theory of sustainable leadership is relevant not only to some specific organisation and its community, but to the world community at large: it means responsible leadership and rational use of resources without making attempts to obtain maximum benefit for minimum cost. Therefore it is necessary to analyse the phenomenon of sustainable leadership, although frequently one can only regret that in Lithuania it is vastly underestimated. The research problem is obvious: insufficient understanding of the conception of sustainable leadership and its application in organisations. The research aim - to define the conception of sustainable leadership and to carry out research in sustainable leadership - has been implemented. The employed research methods included analysis of scientific literature, comparison, synthesis, methods of summarisation and logical abstraction, and a questionnaire. For the research, non-stochastic random selection of respondents was chosen. 5,142 organisations were invited to participate; however, only 311 questionnaires were filled in and returned. We sought to involve organisations from different fields of activity in our research. The majority of the respondents came from the field of services, as well as of the fields of trade, education, and industry. As established, there were great differences between state-owned and private business organisations with respect to sustainable leadership. Thus, e.g., the respondents of state-owned organisations mainly tended to disagree that the leaders of their enterprises focused on the development and reinforcement of organisational values and that the organisational values coincided with the employees' personal values, while the respondents from the organisations of private. To sum up, we can conclude that business organisations were more guided by the principles of sustainable leadership than the state-owned organisations.
\end{abstract}

Key words: sustainable leadership, organisation, Lithuania

JEL code: M10, Q01

\section{Introduction}

Currently, both politicians and businessmen pay substantial attention to regional and national sustainable development, although in some cases the conception of sustainable development is used not to improve the quality of people's lives, but to pursue the political aims of an organisation or of an individual party. Therefore, some people are still skeptical about sustainable development, as they see the discrepancies between what is being declared and what is actually happening in their countries, regions, or organisations. Therefore it is an important global issue. It can be dealt with only by conscious leaders, both politicians and managers of business organisations, who are

1 Corresponding author - e-mail address: ligita.simanskiene@gmail.com 


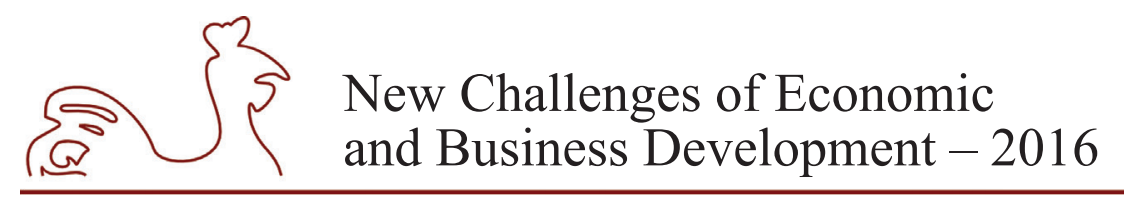

May 12-14, 2016, Riga, University of Latvia

aware of the benefits of sustainable development. Sustainable development can be defined as a systemic thinking-based philosophy of development whose essence is for humans not to violate the fundamental laws of nature provided they want to ensure the sustainability of the system and the continuity of human life on the planet, and simultaneously also to enjoy social justice and economic welfare. As stated by Leunberger D. (2006), biological diversity, functional resistance, labour productivity, state-owned spirit, and social justice are practical constituents of sustainable development. Thus it is clear that sustainable economic decisions have to be ecological, and they are only possible provided fundamental changes in human value-based altitudes take place, new ethics is developed, and a new view on nature comes into being which provides for the responsibility of all of us and ensures a healthy relationship with nature (Čiegis, R., Gavenauskas, A., 2005; Štreimikienè, D., Vasiljevienè, N., 2004). Sustainable development becomes increasingly important in production planning, where such issues as global warming, child labour and observation of social and environmental standards have to be taken into account. Most frequently, sustainable development is defined as a comprehensive analysis of three dimensions (economic, ecological, and social) and their long-term prospects. Appropriate indicators and the application of quality methods and procedures are necessary for the evaluation of organisational processes with respect to sustainable development (Jochem R., 2011, p. 130). The factors that ensure sustainable development are not merely economic: they are also related to natural resources, social welfare, and stability (Bruno K., Karliner J., 2002; Clifton D., Amran A., 2010). Environment and business are closely related, and long-term business success depends of the ability of an organisation to harmoniously integrate into the environment and to feel the social moods of the community. Contemporary business that historically paid attention just to profit accumulation presently has to take environmental sustainability and broader social interests into account, as they form a basis for business success, indispensable for the continuous development of that business (Jochem R., 2011, p. 130). Currently succesful business organisations "educate" and "enlighten" consumers. They do that by participating in environmental and other civil campaigns, by not polluting nature and explaining to their customers why it is beneficial to people. "The EU policy aims to promote the use of renewable resources by companies year after year in a higher degree, implement the recycling of all the materials and eco-design products in a way that diminishes the waste" (Bodosca S., Štreimikienè D., 2015, p. 555). That promotes ethical and environmental consumption which, on the one hand, may seem disadvantageous for organisations, and on the other hand, it is great advertising which helps them to stand out among other organisations engaged in similar activities (Juščius V., Šneiderienė A., 2013, p. 72). Sustainable organisation is not a spontaneous phenomenon. For that, it is necessary to create appropriate conditions: to establish the factors of sustainable initiatives in an organisation, a management system to stimulate and to support them, and to regularly develop and improve them (Atkočiūnienè Z., Radiunaite R., 2011, p. 56). A sustainable organisation is an excellent milieu for progress promotion, when the staff, continuously stimulated by the management, can improve the existing technologies and to develop new ones. Therefore, to promote progress we first have to build a sustainable organisation. Raišienè A. G. (2015, p. 84-85) created "a model that influence of organisation management success factors on organization's competitiveness and sustainability. There key success factors of management in organisation (leadership, collaboration, communication, organizational culture) and key success factors of management of organization (effective organization strategy, human resources, innovations, gain of competitive advantages; identification of client's needs, quality of 


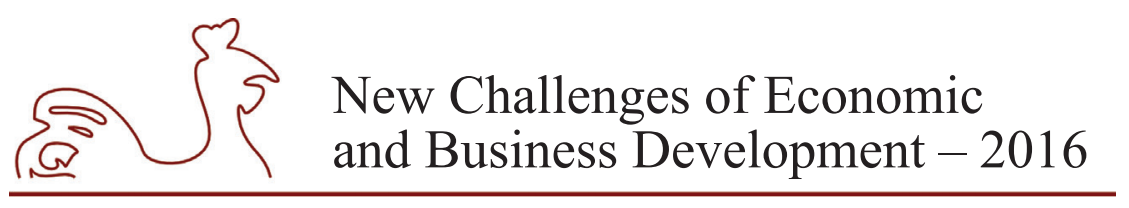

May 12-14, 2016, Riga, University of Latvia

products and services, use of informational technologies and electronic business, entrepreneurship, creation and maintenance of value by ensuring effective organization management."

Research problem. Even though sustainability issues are currently intensely analysed in scientific works of different fields, active discussion on the issue of sustainable leadership is actually missing. Sustainable leadership tends to precondition social welfare by influencing people, promoting changes, and fostering the values in compliance with the highest social principles. The theory of sustainable leadership is relevant not merely to a specific organisation and its community, but to the global community at large: it means responsible management and rational use of resources without making attempts to obtain maximum benefit for minimum cost. Therefore it is necessary to analyse the phenomenon of sustainable leadership, even though frequently one has to regret that in Lithuania it is vastly underestimated. Thus, the research problem is obvious: insufficient understanding of the conception of sustainable leadership and its application in organisations. A sustainable organisation can only be created by a sustainabilityminded leader. Sustainable leadership is not the same as sustainable development, although those concepts.

Relevance and the level of investigation. Lately, the issue of sustainability has been widely reflected in research works (see Jiliberto H.R., 2003, Křupka J., Provazníková R., 2013, Juknys R., 2008), however, sustainability is analysed at the national, regional, or organisational levels (Balkytė A., Tvaronavičienė M., 2010, Čiegis R., 2008, Čiegis R. et al. 2010), while in order to achieve sustainable regional development, we have to start with the sustainable leadership of their managers. In the absence of managers' sustainable thinking, regions will never come to sustainable development. Sustainable leadership was analysed in the works of Hargreaves A. and Fink D. $(2003,2006)$ in which the authors justified the benefits of sustainable leadership. The number of papers that analyse sustainable leadership is not large, and that is a particularly important and new issue, and not merely in the research of Lithuania. In the present article, we deal with sustainable leadership merely at the level of organisations on the basis of their staff opinion survey, but not with the indicators of the regional or national sustainability on the basis of statistical data. Research aim. Upon defining the conception of sustainable leadership, to carry out research in sustainable leadership in Lithuanian organisations and to reveal the implementation of sustainable leadership in practice. Research objectives: 1) to reveal the conception of sustainable leadership; and 2) to carry out research in sustainable leadership in Lithuanian organisations. Research object: sustainable leadership.

Research methods. For the obtaining of innovative ideas as an outcome of the process of consideration and the implementation of the established objectives, the methods of analysis of scientific literature, synthesis, comparison, summarisation, and logical abstraction were used. To get to know and to present the structure of the sustainable leadership conception and its constituents, the method of analysis was employed, and the summarisations obtained from the interaction with the method of synthesis were related to the analysed concepts. In the combination of analysis and synthesis, first of all, the idea of sustainable leadership was raised; after the analysis of the whole problem, summarisations were made, and the synthesis of the analysis data was done. By combining analysis, synthesis, and comparisons by mean of abstraction, the conception of sustainable leadership was formulated, and the guidelines of sustainable leadership were presented. For the research, a questionnaire survey was used. Non-stochastic random respondent selection was chosen through easily identified and well-known individuals, as well 


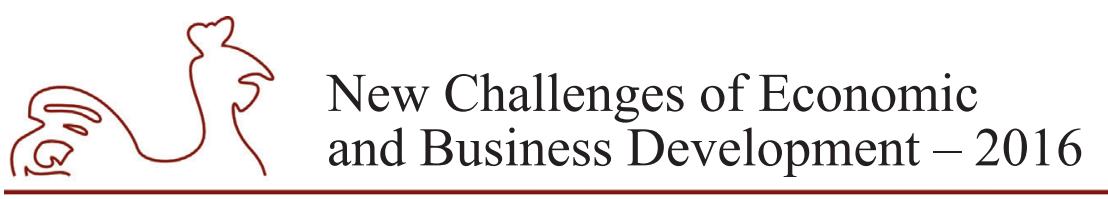

May 12-14, 2016, Riga, University of Latvia

as personal contacts, and also through using the addresses of business associations available on the Internet. The survey was conducted by means of a standardized questionnaire, distributed to the respondents by e-mail. The majority of the questionnaire items were closed-ended, and the Likert assessment scale was applied. For the data processing, the SPSS 15.0 software package was applied. The principal advantage of the SPSS software package is a large choice of contemporary statistical analysis methods, a diversity of visualisation tools for the outcomes of data analysis (data tables, charts, distribution curves), and easily manageable interactive interface (Pukenas K., 2009, p. 4). To present properly formatted research outcomes, the obtained data were processed both by SPSS 15.0 and Ms. Excel, which enabled a comprehensive analysis of the data and their presentation in various charts and tables: all that helped us to better reflect the research outcomes, their trends, and to understand them.

Research limitations. We had aimed to survey organisations in compliance with the classifier provided by the Department of Statistics (Statistics Lithuania) in order to involve organisations from all areas and to assess which areas boasted the greatest progress from the viewpoint of sustainable leadership, and which ones faced the largest numbers of problems. However, representatives of the organisations were reluctant to participate in the survey. In fact, out of 5, 142 distributed questionnaires, only 311 were returned fully completed. The questionnaires were distributed merely by e-mail, on the assumption that virtually all the contemporary organisations were using e-mail. The method was also chosen due to our reluctance to use paper questionnaires as a way of promotion of responsibility and harmonious relationship with nature through saving it from pollution.

\section{The conception of sustainable leadership}

To quote M. Van Marrewijk and M. Werre (2003), sustainability is related to organisational activities which indicate that the social and environmental issues are included in the activity and in the interaction with interest groups. Sustainable leadership and changes mean not only the future, but also the past, as both the future, the present, and the past are respected, and a better future is built on the foundations of the past (Hargreaves A., Fink D., 2003). Sustainable leadership primarily encourages one to see what is happening and how initiatives change the events and to anticipate the consequences of the changes. Personal responsibility for social and environmental commitments predetermine the decision of the organisation leadership to integrate the pursuit of sustainability into the organisational strategy. The managers of organisations include economic, social, and environmental responsibility in the conception of sustainable activity. Sustainability is not simply a continuation of something. Sustainability defines how a specific initiative can be developed without harming the surrounding environment either at the moment or in the future (Hargreaves A., Fink D., 2008). Sustainability means the capacity of the system to pursue continuous improvement for the sake of humanity goals through a complex set of values.

Leadership is named as one of the measures that contribute to the achievement of the sustainability of activities (Epstein M., 2009). The concept of sustainable leadership was introduced in the process of dealing with the youth education (Hargreaves A., Fink D., 2006; Davies B., 2007) and health care (Kantabutra S., 2011) issues. The significance of the pursuit of sustainability emphasised at different levels predetermined the dissemination of the concept. The concept of sustainable leadership was used by T. Casserley and B. Chritchley (2010) at all 


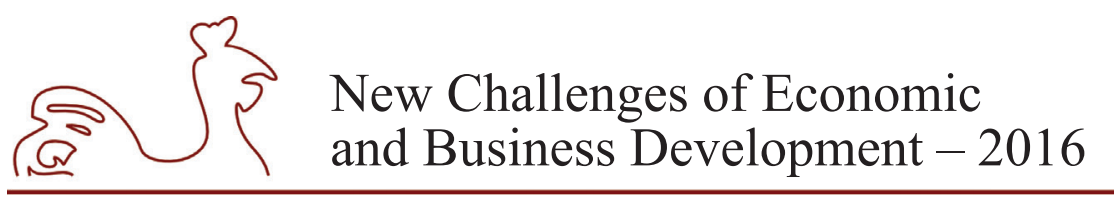

May 12-14, 2016, Riga, University of Latvia

levels: at the level of individual psychological and physiological health; at the organisational level through the maintenance and fostering of the organisational environment and culture, so that employees can flourish and realise their potential in the pursuit of organisational goals that coincide with their personal goals; at the sociological level by occupying a responsible position in the community; and at the ecological level, by protecting the surrounding environment. The principles of sustainability are related to the changes in thinking, activity, and knowledge that can justify the said principles (Rogers K. S., 2011): the development of the sustainability-focused self-awareness; the creation of the sustainability-oriented knowledge; and learning to apply the latest ecological systems in the organisation. As stated by Avolio B. J., Walumbwa F. O., and Weber T. J. (2009), it is only conscious leaders, honest managers observing ethical values who can build long-term organisations and motivate the staff to provide quality services and to develop sustainability values for the organisation. Through their research, L. Quinn and M. Dalton (2009) established that sustainable activity-minded leaders are similar to other effective leaders, they just possess additional qualities: they think broader than imposed by the organisation and mind the interests of their stakeholders. The leaders interested in sustainability have to pay attention to how the ideas are presented to the organisation and to introduce and develop different systems (training, remuneration, communication, etc.). It is important to support the ideas of sustainability through organisational culture and through the involvement of the interest groups in the process. The organisation's commitment to sustainable activity makes increasingly complex demands on the leadership (Morsing M., Oswald D., 2009): in the implementation of the corporate organisational strategy, the managers are responsible for the harmonisation of the goals, values, and procedures in all the organisational management systems and for the promotion of the management and staff loyalty.

G. Avery and H. Bergsteiner (2011) present a sustainable leadership pyramid which consists of three levels: the foundation is made up of 14 basic practical activities, 6 higher-level practical activities are implemented on the basis of the foundation, and the third level covers innovations, quality, and staff involvement. Practical activities affect five activity outcomes: the brand and reputation, customer satisfacion, activity funding, long-term share value, and long-term value for most of the interest groups. G. Avery and S. Kantabutra (2011) grouped 19 elements of sustainable leadership and investigated whether sustainable leadership practices in those categories could result in long-term prosperity of the organization. Sustainable leadership stands out for the following qualities (Šimanskienė L., Župerkienė E., 2013): a clear sustainabilityoriented business vision; the goals oriented towards long-term, and not short-term, progress; leaders assume responsibility not only for their own or the working group activity, but also for each individual, group, organisation, and society; organisational culture is strong and oriented towards sustainable organisational development; for the achievement of the activity outcomes not only individual, but also joint efforts through helping one another, are pooled; leaders are characterised by a high degree of trust in people and good-willingness; work outcomes are characterised by the synergy of the joint efforts of the team members; changes in the organisation are initiated not by destroying the old and creating the new, but by re-using, re-distributing, and merging organisational resources already possessed by the organisation; the focus is not on the group, but on the team work; quality is achieved not through control, but through organisational culture focused on sustainability; the management of the organisation and its employees are aware of what sustainability is and are guided by the sustainability principles; the employees are 


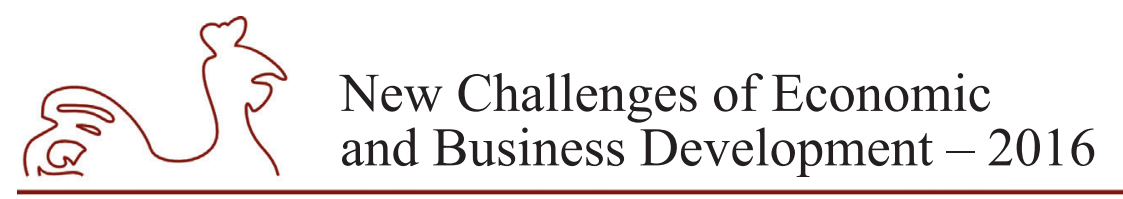

May 12-14, 2016, Riga, University of Latvia

loyal to the organisation, as their needs are met and their security ensured; all the members of the organisation are trained and regularly develop professionally, they are taken care of; innovations are introduced regularly and systematically, creativity is encouraged, and funds are allocated for that; and working relations are not formal but focused on cooperation. Sustainability-minded leaders are able to agree and to unite their approaches. They grant employees more power and make a huge impact on them. Moreover, they are empathic, take care of their employees, and maintain great emotional relationships with them. Should such leaders need help, the staff would be always ready to help them (George B., Sims P., 2008). The A. Hargreaves and D. Fink (2006) developed definition of sustainable leadership suits all the areas of organisational activity. The essence of sustainable leadership can be defined in the following way: sustainable development covers all what develops and continues without harming anything and by ensuring a positive impact on everything that surrounds us at present and will surround in the future. To have sustainable activity, a personal contribution is needed: it is necessary to change the way of thinking of any individual involved in the said activity. Thus, changes start with an individual's self-awareness, and then move to the levels of a group, organisation, and society.

Therefore, we propose the following definition of sustainable leadership: sustainable leadership means responsibility to individuals, groups, organisations, and the community, given the ecological, social, and economic sustainability principles in the context of a group, organisation, and community, through the promotion of the introduction of the ideas of sustainability, the dissemination of sustainability principles - based teaching, learning, and human self expression, and through nature protection. Sustainable leadership complements the conception of leadership through the inclusion of new variables: it is no longer elementary activity when in the pursuit of the intended goals the behaviour of other people both individually and in groups is affected; in our case, leader who seeks to affect other people's behaviour has to evaluate economic, ecological, and ethical (social) aspects. The outcome of sustainable leadership is associated with comprehensive benefits not only to specific members of the organisation, to the organisation at large, but also to the society, given its needs in the long-term perspective: to preserve harmony with the environment in both the economic, social, and ecological aspects. For sustainable leadership, different areas of activity should be included. Sustainable leadership can be analysed at three levels: individual, group (team), and organisation. When seeking sustainable leadership, it is very important to properly evaluate leader's personality and creativity, to build a harmonious team through the evaluation of the employees' harmonious relationships and competences, through the encouragement of the employees' loyalty and organisational culture, and through the evaluation and development of the organisation's image and corporate social responsibility. Although it is obvious that each area makes an impact on another area and everything is interrelated, relatively it can be attributed to the levels of an individual, a group (team), or an organisation.

The aim of sustainable leadership is to guide the organisation and its members towards sustainable development, to carry out socialy responsible activity, and to act under the methods of a socially responsible enterprise. Sustainable leadership is not easy to implement: it depends not only on the leader's abilities and commitment; it is important to maintain constant attention and efforts in the pursuit of progress, however, most leaders and their supporters often burn out, and new people who replace them are not always able to continue the work and to preserve the achieved results. The biggest benefit is understood as the outcome of the organisation's activity, 


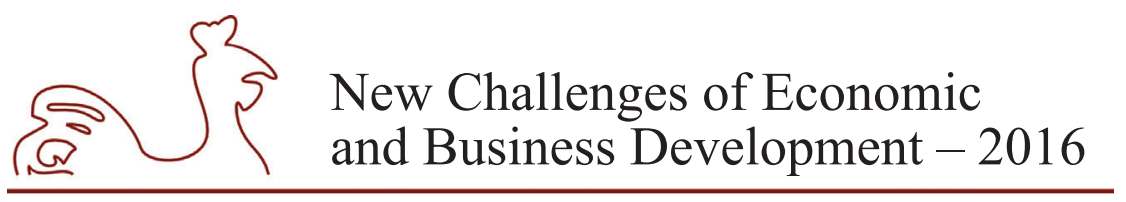

May 12-14, 2016, Riga, University of Latvia

beneficial not only to the organisation itself in the form of the final product, but also to the community and environment with which and in which the organisation operates. Sustainable leadership seeks to avoid any negative consequences of the economic and social development. Sustainable leadership fosters common social values that serve as a basis for the organisation's activity and the management of the expected risks.

\section{Sustainable Leadership Research: Methodology and Process}

The research aimed to find out which aspects of sustainable leadership had been paid greatest attention to in various organisations. It was conducted in Lithuania by surveying the employees of organisations operating in Lithuania. Non-stochastic random respondent selection was chosen through easily identified and well-known individuals, as well as personal contacts. The survey was conducted by means of a standardized questionnaire, distributed to the respondents by e-mail.

The majority of the questionnaire items were closed-ended, and the Likert assessment scale was applied (1 - I totally disagree, 2 - I disagree, 3 - it is difficult to say, 4 - I agree, and 5 I totally agree): the higher the mean, the more respondent agreed with a respective item. The standard deviation showed the variations of the mean; the smaller it was, the more unanimous the respondents were. The survey was carried out on an individual basis, and the respondents could take as much time as they wanted to answer the questions; they were not affected either by the environment or by the interviewer. However, in that kind of survey, the questionnaire return rates were reduced, and the level of the answers to the questions was lower (Luobikienè I., 2010, Kardelis K., 2005).

The general totality of the research and the sample. On the data of the Department of Statistics, in the early 2015, 90, 790 enterprises operated in Lithuania. 5,142 respondents were invited to participate in the survey, and 311 respondents agreed to participate and answered the questions in the questionnaire (the return rate was $\sim 6 \%$, and the survey error, $5.6 \%$ ).

Demographic data. The organisations whose representatives participated in the survey were very different. The majority (63) were organisations in the field of services, as well as in the fields of trade (53), education (49), and industry (29). The larger part of the surveyed organisations (156) were of private Lithuanian capital (50.2\%), another large part (81) were stateowned organisations (26\%), 25 private foreign capital organisations (8\%), 21 joint (foreign and Lithuanian) capital organisations $(6.8 \%)$, and 9 state and private capital organisations $(2.9 \%)$; 19 organisations $(6.1 \%)$ chose the option "other" as an answer to that question. In accordance with the number of employees, the largest number of the respondents came from small organisations with up to 19 people (35.7\%); the second largest group of organisations $(30.5 \%)$ employed 100 to 199 people, the third group (26.6\%) employed from 20 to 99 people, and several large organisations (7.1\%) had over 1,000 employees. The respondents included $42.1 \%$ of men and $57.9 \%$ of women. The organisation representatives were holders of various positions: senior executives (103, or 33.1\%), 72 mid-level managers (23.2\%), 19 lower level managers (master foremen, $6.1 \%), 108$ individuals who had no subordinate staff (34.7\%), and 9 indicated other options: those were mainly people who held executive positions in organisations, however, had no direct subordinates (owners, specialists, etc.). 


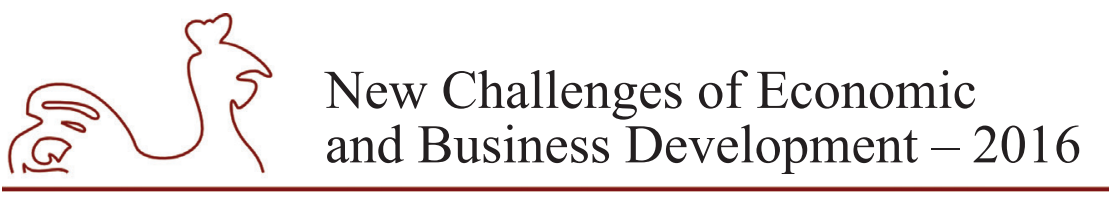

May 12-14, 2016, Riga, University of Latvia

\section{Research outcomes}

To evaluate the internal consistency of the questionnaire scale, Cronbach's alpha coefficient is most frequently used, which is based on the correlation of individual items of the questionnaire and which evaluates whether all the scale items sufficiently reflect the investigated dimension and allows to specify the number of required items on the scale (Pukenas K., 2009). Table 1 indicates the Cronbach's alpha coefficient value which for an appropriately and efficiently developed questionnaire should be over 0.7 (as stated by some authors, 0.6). In our case, the analysis of the questionnaire scales revealed that Cronbach's alpha coefficient was over 0.7, therefore, the scale was developed properly.

Table 1

Evaluation of the internal consistency of the questionnaire scale

\begin{tabular}{|l|c|c|c|}
\hline \multicolumn{1}{|c|}{ Name of the scale } & $\begin{array}{c}\text { Cronbach's } \\
\text { alpha coefficient }\end{array}$ & $\begin{array}{c}\text { Cronbach's alpha } \\
\text { coefficient for } \\
\text { standardised data }\end{array}$ & $\begin{array}{c}\text { Number of the } \\
\text { scale items }\end{array}$ \\
\hline $\begin{array}{l}\text { Evaluation of the organisation's } \\
\text { harmony with the environment }\end{array}$ & 0.8108 & 0.8158 & 6 \\
\hline $\begin{array}{l}\text { Fulfillment of the organisation's legal } \\
\text { obligations }\end{array}$ & 0.8681 & 0.8705 & 5 \\
\hline $\begin{array}{l}\text { Fostering of the organisational culture } \\
\text { and mutual relations in the organisation }\end{array}$ & 0.9337 & 0.9341 & 13 \\
\hline $\begin{array}{l}\text { Performance control and observation } \\
\text { of the quality principles in the } \\
\text { organisation }\end{array}$ & 0.8905 & 0.8953 & 13 \\
\hline
\end{tabular}

Source: author's calculations based on research data.

Spearman-Brown's enhanced reliability coefficient was named as the standardised data Cronbach's alpha coefficient. As seen in Table 2, its value was close to the value of the Cronbach's alpha coefficient, which meant that the variance of the answers to individual questions was similar.

For the mean comparison, an analysis of variance was chosen and the ANOVA test was applied. The ANOVA test showed the interrelation of the variables, i.e. whether the variables were statistically related and affected one another: when the significance level was $p \leq 0.05$, the variables affected one another, and when $p>0.05$, they did not. In the analysis of the statistical difference of the mean significance for the items for which the statistical link existed, the Turkey criterion of the ANOVA test was analysed. Significant data were presented in the tables in bold. 


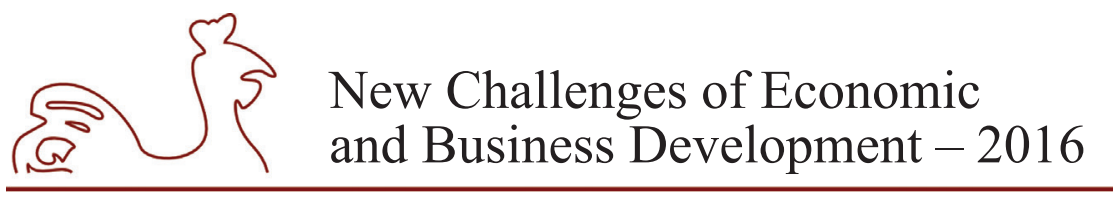

May 12-14, 2016, Riga, University of Latvia

Table 2

Evaluation of the organisation's harmony with the environment in relation to the organisation's type and size

\begin{tabular}{|l|r|r|}
\hline \multicolumn{1}{|c|}{ Items } & \multicolumn{1}{|c|}{$\begin{array}{c}\text { Organisation } \\
\text { type p value }\end{array}$} & $\begin{array}{c}\text { Organisation } \\
\text { size p value }\end{array}$ \\
\hline $\begin{array}{l}\text { The organisation focuses on the reduction and elimination of the } \\
\text { harmful impact on the environment }\end{array}$ & .000 & .250 \\
\hline The organisation sorts waste/garbage & .002 & .439 \\
\hline $\begin{array}{l}\text { The organisation saves paper (e.g., uses it for drafts, prints on both } \\
\text { sides, etc.), as well as energy and water }\end{array}$ & .002 & .002 \\
\hline $\begin{array}{l}\text { The organisation participates in the organisation and the city } \\
\text { environment management activities (on a voluntary basis) }\end{array}$ & .000 \\
\hline $\begin{array}{l}\text { The organisation ensures safe and healthy (ergonomic) working } \\
\text { conditions }\end{array}$ & .000 & .000 \\
\hline $\begin{array}{l}\text { The organisation uses only environmentally friendly means and } \\
\text { equipment in its activities }\end{array}$ & .000 & .003 \\
\hline
\end{tabular}

Source: author's calculations based on research data.

In the analysis of the statistical mean significance differences, the Turkey criterion of the ANOVA test was carried out. As a result, the respondents employed in state-owned enterprises mostly tended to disagree that their organisations paid attention to the reduction and elimination of the harmful impact on the environment $p \leq 0.05=0.000$, while those from private (foreign) and private (foreign and Lithuanian) capital organisations agreed with the item. The respondents from state-owned enterprises mainly denied that they sorted waste and garbage $p \leq 0.05=0.002$ or saved paper and energy $p \leq 0.05=0.002$, while the respondents from private (foreign and Lithuanian) capital organisations agreed with the items. The participation of their organisations in voluntary environment management $(p \leq 0.05=0.000)$ was mostly confirmed by the respondents from state-owned enterprises and the state and private capital organisations, while the respondents from the private (Lithuanian) capital organisations tended to disagree. The respondents from state-owned enterprises also disagreed that their organisations ensured safe and healthy (ergonomic) working conditions $p \leq 0.05=0.000$ and used only environmentally friendly means and equipment in its activities $p \leq 0.05=0.000$, while the respondents from the private foreign and Lithuanian capital organisations tended to agree with the item.

In the analysis of the data by the organisation size, we found out that larger organisations (100-999 employees) were reluctant to save paper, water, and energy $p \leq 0.05=0.002$, while smaller organisations were inclined to save paper, water, and energy. The organisations that employed 1 to 19 people did not participate in the voluntary environment management activities $p \leq 0.05=0.000$, while slightly larger organisations (20-99 and 100-999 employees) participated in the environment management. The organisations with over 1,000 employees, as stated by the respondents, did not ensure ergonomic working conditions $p \leq 0.05=0.000$, while the respondents of smaller organisations tended to argue that ergonomic working conditions in their organisations were ensured. The respondents of smaller organisations (1-19 and 20-99 employees) stated that in the activity of their organisations only environmentally friendly means 


\section{New Challenges of Economic and Business Development - 2016}

May 12-14, 2016, Riga, University of Latvia

and equipment were used $p \leq 0.05=0.003$, while larger organisations tended to disagree with the item.

We shall present the outcomes of the ANOVA test in the evaluation of the organisation's fulfillment of legal commitments in relation to the organisation's type and size.

Table 3

The organisation's fulfillment of legal commitments in relation to the organisation's type and size

\begin{tabular}{|l|r|r|}
\hline \multicolumn{1}{|c|}{ Items } & $\begin{array}{c}\text { Organisation } \\
\text { type p value }\end{array}$ & $\begin{array}{c}\text { Organisation } \\
\text { size p value }\end{array}$ \\
\hline $\begin{array}{l}\text { The employees understand the system of organisation rules and } \\
\text { procedures }\end{array}$ & .002 & .000 \\
\hline $\begin{array}{l}\text { The organisation does not tolerate bribery or any other kind of } \\
\text { corruption }\end{array}$ & .000 & .000 \\
\hline $\begin{array}{l}\text { The organisation ensures equal rights for its employees (by age, } \\
\text { gender, origin, etc.) }\end{array}$ & .000 & .000 \\
\hline $\begin{array}{l}\text { The organisation observes the Labour Code (work, recreation, } \\
\text { payroll, etc.) }\end{array}$ & .001 & .000 \\
\hline The organisation respects the opinion of employees and trade unions & .000 & .000 \\
\hline
\end{tabular}

Source: author's calculations based on research data.

The employees of private Lithuanian capital and private (Lithuanian and foreign) capital organisations agreed that their staff understood the system of organisation rules and procedures $p \leq 0.05=0.002$, while the respondents from state-owned enterprises were inclined to disagree with the item. Again, the employees of private Lithuanian and foreign capital organisations mostly agreed with the items that their organisation did not tolerate bribery or any other kind of corruption $p \leq 0.05=0.000$, ensured equal rights for its employees $p \leq 0.05=0.000$, observed the Labour Code $p \leq 0.05=0.001$, and respected the opinion of trade unions $p \leq 0.05=0.000$, while the employees from state-owned enterprisess tended to disagree with the items.

In the analysis of the data by the organisation size, we found out that the respondents from smaller organisations ( 1 to 19 and 20 to 99 employees) agreed that the employees in their organisation understood the system of organisation rules and procedures $p \leq 0.05=0.002$, while those from larger organisations only partly agreed with the item. The respondents of the organisations employing 1 to 19 employees tended to agree with the items that their enterprises did not tolerate bribery or any other kind of corruption manifestation $p \leq 0.05=0.000$, ensured equal rights for their employees $p \leq 0.05=0.000$, and observed the Labour Code $p \leq 0.05=$ 0.001 , and those from larger organisations only partly agreed with the item. The respondents of smaller organisations (1 to 19 and 20 to 99 employees) tended to agree that their organisation valued the opinion of their employees and trade unions $p \leq 0.05=0.000$, while those from larger organisations only partly agreed with the item.

In Table 4 we shall present the outcomes of the ANOVA test in the evaluation of the fostering of the organisational culture and mutual relations with respect to the organisation's type and size. 


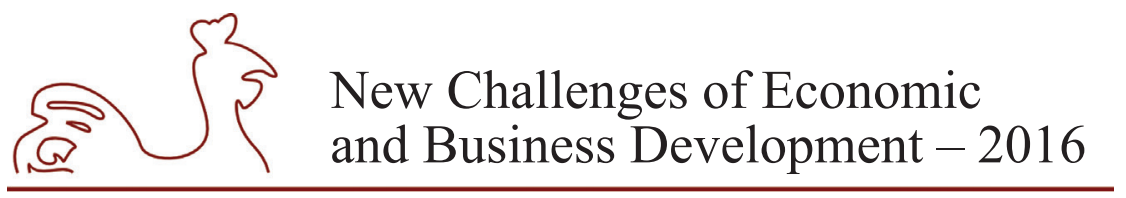

May 12-14, 2016, Riga, University of Latvia

Table 4

\section{Fostering of the organisational culture and mutual relations with respect to the organisation's type and size.}

\begin{tabular}{|l|r|r|}
\hline \multicolumn{1}{|c|}{ Items } & $\begin{array}{c}\text { Organisation } \\
\text { type p value }\end{array}$ & $\begin{array}{c}\text { Organisation } \\
\text { size p value }\end{array}$ \\
\hline $\begin{array}{l}\text { Organisation managers pay great attention to the development and } \\
\text { reinforcement of organisational values }\end{array}$ & .000 & .000 \\
\hline Organisational values coincide with the employee's personal values & .003 & .232 \\
\hline The organisation has a clearly formed vision and mission & .339 & .000 \\
\hline Organisation aims are clearly formulated and mastered & .064 & .124 \\
\hline Organisation aims are oriented towards long-term results in the future & .113 & .185 \\
\hline The employees know the history of the organisation development & .000 & .002 \\
\hline The use of the organisation symbols is widespread in the organisation & .001 & .212 \\
\hline The organisation observes traditions & .000 & .000 \\
\hline The organisation values the employees' experience & .000 & .000 \\
\hline The organisation promotes employee loyalty & .000 & .000 \\
\hline $\begin{array}{l}\text { The employees are satisfied with the communication atmosphere in the } \\
\text { organisation }\end{array}$ & .000 & .000 \\
\hline When necessary, common results are pursued by means of team work & .123 & .000 \\
\hline $\begin{array}{l}\text { The organisation employs personalities able to bring together the staff } \\
\text { for common aims }\end{array}$ & .333 & .110 \\
\hline $\begin{array}{l}\text { The organisation pays attention to the building of a positive } \\
\text { organisation's image }\end{array}$ & & \\
\hline
\end{tabular}

Source: author's calculations based on research data.

As revealed by the ANOVA test, the employees of state-owned enterprises were most inclined to disagree with the item that organisation managers paid great attention to the development and reinforcement of organisational values $p \leq 0.05=0.000$ and that organisational values coincided with the employee's personal values $p \leq 0.05=0.003$, while the respondents of the private enterprises of Lithuanian capital or joint private foreign and Lithuanian capital tended to mostly agree with the said items.

The fact that the use of symbols was widespread in the organisation $p \leq 0.05=0.000$ was mostly denied by the respondents from the Lithuanian capital organisations, while those from the private (foreign and Lithuanian) capital and state-owned enterprises agreed with it. The private (foreign and Lithuanian) capital organisations observed traditions $p \leq 0.05=0.001$, while the employees of the private (Lithuanian) capital organisations and state-owned enterprises tended to disagree with the item. The employees of the state-owned institutions, as compared with the private (foreign and Lithuanian) capital organisations were less inclined to agree with the items to the effect that the organisation valued the employees' experience $p \leq 0.05=0.000$, promoted loyalty, $p \leq 0.05=0.000$, that the staff were satisfied with the communication atmosphere in the organisation $p \leq 0.05=0.000$, or that, when necessary, common results were pursued by means of team work $p \leq 0.05=0.000$. 


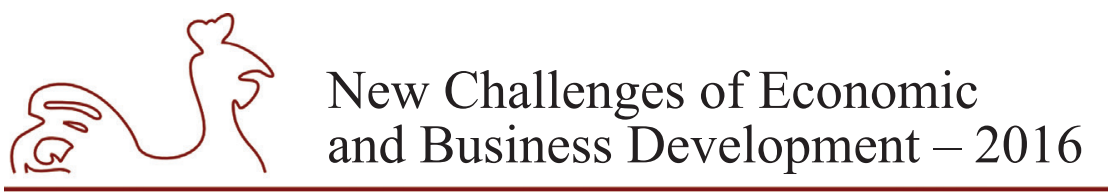

May 12-14, 2016, Riga, University of Latvia

In the analysis of the data by the organisation size, we found out that the employees of smaller organisations ( 1 to 19 and 20 to 99 employees) were more inclined to confirm the items that the organisation managers paid great attention to the development of organisational values and their reinforcement $p \leq 0.05=0.000$ or that the organisational values coincided with the employee's personal values $p \leq 0.05=0.000$ than the employees of larger organisations. The use of the organisational symbols $p \leq 0.05=0.002$ was more widespread in larger organisations (100-999 employees) than in smaller ones (1 to 19 and 20 to 99 employees). Loyalty and experience $p \leq$ $0.05=0.000$, to quote the respondents, was more valued in smaller organisations than in those that employed over 1,000 people. Moreover, the employees of smaller organisations were more satisfied with the atmosphere of communication $p \leq 0.05=0.000$, in them, whenever necessary, common results were pursued by means of team work $p \leq 0.05=0.000$, and those organisations employed personalities able to bring together the staff for common aims $p \leq 0.05=0.000$.

In Table 5 we shall present the outcomes of the ANOVA test in the evaluation of the performance control and observation of the quality principles in the organisation in relation to the organisation's type and size.

Table 5

Performance control and observation of the quality principles in the organisation in relation to the organisation's type and size

\begin{tabular}{|l|r|r|}
\hline \multicolumn{1}{|c|}{ Items } & \multicolumn{1}{|c|}{$\begin{array}{c}\text { Organisation } \\
\text { type p value }\end{array}$} & $\begin{array}{c}\text { Organisation } \\
\text { size p value }\end{array}$ \\
\hline $\begin{array}{l}\text { The organisation boasts a high degree of trust in people without } \\
\text { strict control }\end{array}$ & .001 & .000 \\
\hline The organisation focuses on performance quality & .002 & .000 \\
\hline The organisation promotes the pursuit of aims and results & .000 & .000 \\
\hline $\begin{array}{l}\text { The organisation takes care of continuous professional } \\
\text { development }\end{array}$ & .074 \\
\hline All the staff is involved in staff training & .536 & .449 \\
\hline $\begin{array}{l}\text { The organisation focuses on meeting the needs of its consumers } \\
\text { (clients, patients, etc.) }\end{array}$ & .000 & .000 \\
\hline $\begin{array}{l}\text { The organisation focuses on the improvement of its profitability } \\
\text { indicators }\end{array}$ & .000 & .054 \\
\hline $\begin{array}{l}\text { The organisation allocates funds for charity, sponsorship, and } \\
\text { support }\end{array}$ & .000 & .580 \\
\hline The organisation promotes employee productivity & .000 & .019 \\
\hline The organisation encourages new ideas & .000 & .000 \\
\hline $\begin{array}{l}\text { To implement changes in the organisation, its resources shall be } \\
\text { re-used }\end{array}$ & .116 & .047 \\
\hline $\begin{array}{l}\text { Changes in the organisation are implemented by destroying the old } \\
\text { and creating the new (experience, technologies, etc.) }\end{array}$ & .540 & .299 \\
\hline The organisation implements quality standards & .000 & .000 \\
\hline
\end{tabular}

Source: author's calculations based on research data. 


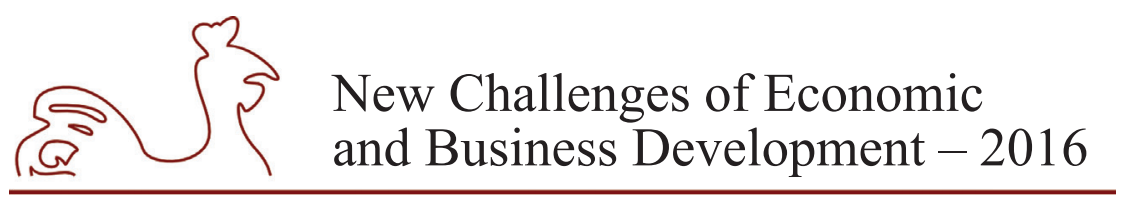

May 12-14, 2016, Riga, University of Latvia

As revealed by the ANOVA test, the employees of state-owned enterprises, as compared to the respondents of private (Lithuanian), (foreign and Lithuanian), and (foreign) capital organisations, were less inclined to agree that their organisation boasted a high degree of trust in people without strict control $p \leq 0.05=0.001$, that it focused on performance quality $p \leq 0.05=$ 0.002 , promoted the pursuit of aims and results $p \leq 0.05=0.000$, focused on meeting the needs of its consumers (clients, patients, etc.) $p \leq 0.05=0.000$, focused on the improvement of its profitability indicators $p \leq 0.05=0.000$, allocated funds for charity, sponsorship, and support $p \leq 0.05=0.000$, promoted employee productivity $p \leq 0.05=0.000$, and encouraged new ideas $p \leq 0.05=0.000$. Moreover, as found out, the employees of the private (Lithuanian) capital enterprises and of state-owned institutions tended to only partially agree with the item that their organisation implemented quality standards $p \leq 0.05=0.000$, while the employees of the private (foreign and Lithuania) capital organisations agreed the most with the item.

In the analysis of the data by the organisation size, we found out that the employees of smaller organisations were more inclined to agree that their organisation boasted a high degree of trust in people without strict control $p \leq 0.05=0.000$ than those from the organisations employing over 1,000 people. Moreover, the employees of smaller organisations ( 1 to 19 and 20 to 99 employees) more supported the items to the effect that their organisation focused on performance quality $p \leq 0.05=0.000$, promoted the pursuit of aims and results $p \leq 0.05=0.000$, and focused on meeting the needs of its consumers (clients, patients, etc.) $p \leq 0.05=0.000$ than those from larger organisations. The employees of smaller organisations tended to agree with the items that their organisation promoted employee productivity $p \leq 0.05=0,019$ and encouraged new ideas $p \leq 0.05=0.000$. However, it was the employees of medium-size organisations (100 to 999) who agreed that their organisation was implementing quality standards, while the respondents of small organisations (1 to 19 employees) tended to disagree with the item.

\section{Conclusions}

By summarising the theoretical insights we conclude that merely long-term decisions taken in organisations can affect sustainability. Environment and business are closely interrelated, while the long-term business success will depend on the organisation's ability to harmoniously integrate itself into the environment and to feel social moods of the general public. Most frequently the concept of sustainable development is used in the analysis and assessment of regional and national development. However, it is obvious that sustainable regional or organisational development is impossible without sustainable leadership. Therefore, we believe that sustainable leadership requires changes in the mindset of each individual involved in the activity, starting with the individual's self-awareness and moving on to other levels: of a group and an organisation. In order to sustainably manage the organisation, its leader has to start with himself, i.e. to analyse his personal qualities and skills, to identify his weakneses, and to make efforts to develop in those directions. The factors of sustainable leadership are analysed in the following sequence: starting with an individual level (the leader's personality, including his creativity) and via the team (group activity (the group level) coming to the organisational level (the discussion of the significance of the organisational culture, social responsibility, and the image of the organisation). In turn, sustainable leadership requires changes in the way of thinking of every individual involved in the process, which starts with an individual's self-awareness and moves on to other levels: those of a group and an organisation. Sustainable leadership definition was presented. 


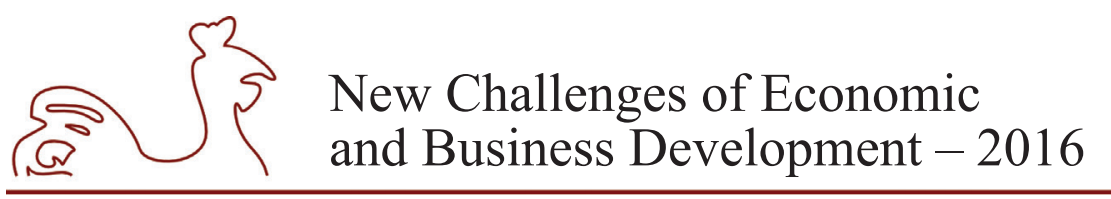

May 12-14, 2016, Riga, University of Latvia

The research findings revealed the differences in the approaches of state-owned and private organisations. The employees of private (and especially smaller) organisations more than the employees of the state-owned (and especially larger) organisations tend to agree that the resources are saved, and the used means and equipment are environmentally-friendly. State-owned and foreign capital enterprises are more involved in the environment management, while the organisations of private (Lithuanian) capital are not so active in the field. Smaller organisations pay greater attention to the development of organisational values, organisational values coincide with the employees' personal values, and loyalty and experience are valued more than in larger organisations. In smaller organisations, the employees are more satisfied with the communication atmosphere as, whenever necessary, the goals in such organisations are more frequently pursued through team work; moreover, such organisations have personalities that bring together the staff for the achievement of common goals. In accordance with the presented data, the respondents mainly indicated the items that emphasised merely economic results, such as the pursuit of quality performance and customer satisfaction; regretfully, they failed to understand that "soft" management was also able to solve economic problems. We missed the understanding that, e.g., a developed system of values and attention to the staff needs and opinions were effective management tools both in the pursuit of sustainable leadership and of better results in general.

The heads of organisations and of institutions responsible for national sustainable development are recommended: to deepen their understanding of sustainable leadership by means of professional development in various training courses, seminars, and conferences, or by self-studies; to involve as many as possible employees in discussions on the benefits of sustainable development to the organisations, the region, and simultaneously to the state, by contributing to public assistance (e.g., by managing the environment, finding out the needs of the local communities, and collaborating with the neighbouring organisations or the population); to develop and foster sustainability-based values in the organisation, so that the staff would not only know the expectations of the organisation management in terms of sustainability, but would be guided by them; and to train and to motivate in practice the employees and divisions that followed the principles of sustainability in the organisation.

\section{Bibliography}

Atkočiūnienè, Z. O., Radiunaitè, R., 2011. Žinių vadybos įtaka darnaus vystymosi reikšmėms įgyvendinti organizacijoje. Informacijos mokslai, 58, pp. 56-73.

Avery, G. C., Bergsteiner, H., 2011. Sustainable Leadership Practices for Enhancing Business Resilience and Performance. Strategy \& Leadership, 39(3), pp. 5-15.

Avery, G. C., Kantabutra, S., 2011. Sustainable Leadership at Siam Cement Group. Journal of Businesss Strategy, 32(4), pp: 32-41.

Avolio, B. J., Walumbwa, F. O., Weber, T. J., 2009. Leadership: Current Theories, Research, and Future Directions. Annual Review of Psychology, Vol. 60, pp. 421-449.

Balkyte A., Tvaronavičienè M., 2010. Perception of Competitiveness in the Context of Sustainable Development: Facets of "Sustainable Competitiveness". Journal of Business Economics and Management. 11(2), pp. 341-365.

Bodosca, S., Štreimikienè, D., 2015. Cradle to Cradle: a Step Further for Sustainable Development in Tourism. Transformation in Business and Economics, Vol. 14, 2B (35B), pp. 548-556.

Bruno, K., Karliner, J., 2002. Earth summit.biz: The Corporate Takeover of Sustainable Development. Food First Books. Oakland: CA. 


\section{New Challenges of Economic and Business Development - 2016}

May 12-14, 2016, Riga, University of Latvia

Casserley, T, Chritchley, B., 2010. A New Paradigm of Leadership Development. Industrial and Ccommercial Training, 42(6), pp. 287-295.

Clifton, D., Amran, A., 2010. The Stakeholder Approach: A Sustainability Perspective. Journal of Business Ethics- Springer, 98(1) pp. 121-136.

Čiegis, R., Gavenauskas, A., 2005. Darnaus vystymosi valdymas: etiniai aspektai. Tiltai, 4, pp. 31-38.

Davies, B. (ed.) 2007. Developing Sustainable Leadership. London: Paul Chapman Sage.

Epstein, M. J., 2009. Making Sustainability Work: Best Practices in Managing and Measuring Corporate Social, Environmental, and Economic. Published by Berrett-Koehler Publishers.

George, B., Sims, P., 2008. Tikroji kryptis. Kaunas: Smaltija.

Hargreaves, A., Fink, D., 2006. Sustainable Leadership. San Francisco, CA, Jossey Bass.

Hargreaves, A., Fink, D., 2003. The Seven Principles of Sustainable Leadership. [Online] Available at: http://www.marylandpublicschools.org/NR/rdonlyres/F7D49A8D-E9D0-4C49-9DE6-3A878B C9F1F4/18748/seven_principles.pdf [Accessed 10 April, 2014].

Jiliberto, H., R., 2003. Models for Regional Sustainability Assessment: the Case of the Region of Murcia, Spain. Towards Regional Sustainable Development: Evaluation Methods and Tools. Manchester, June 11-13, 2003.

Jochem, R., 2011. Sustainability Modelling as an Enterprise Quality Requirement. Current Issues of Business and Law, 6(1), pp. 129-140.

Juknys, R., 2008. Darnus vystymasis. Kaunas: Vytauto Didžiojo universiteto leidykla.

Juščius, V., Šneiderienè, A., 2013. Imonių socialinės atsakomybès įtaka regioninei plètrai. Regional Formation and Development Studies. 1 (9), pp. 66-78.

Kantabutra, S., 2011. Sustainable Leadership in a Thai Health Care Services Provider. International Journal of Health Care Quality Assurance, 24(1), pp. 67-80.

Kardelis, K., 2005. Moksliniu tyrimu metodologija ir metodai: (edukologija ir kiti socialiniai mokslai). Lietuvos kūno kultūros akademija. Šiauliai: Liucilijus.

Křupka, J., Provazníková, R., 2013. Modeling of Standards of Living in Euro zone Countries on the Basis of Multiple Criteria Decision Analysis. Recent Researches in Applied Economics and Management. Business Administration and Financial Management, Vol. 1, pp. 425-432.

Leuenberger, D. 2006. Sustainable Development in Public Administration: A Match With Practice? Public Work Management \& Policy. Sage Publications, 10 (3), pp. 195-202. [Online] Available at: http:// pwm.sagepub.com/content/10/3/195.full.pdf+html [Accessed 10 March 2011].

Luobikienè, I., 2010. Sociologiniu tyrimu metodika : mokomoji knyga. Kaunas: Kauno technologijos universitetas.

van Marrewijk, M., Werre, M., 2003. Multiple Levels of Corporate Sustainability. Journal of Business Ethics, 44(2-3), pp. 107-119.

Morsing, M., Oswald, D., 2009. Sustainable Leadership: Management Control Systems and Organizational Culture in Novo Nordisk A/S. Corporate governance, 9(1), pp. 83-99.

Pukènas, K., 2011. Kokybiniu duomeny analizé SPSS programa: studiju knyga. Kaunas: Lietuvos kūno kultūros akademija.

Quinn, L., Dalton, M., 2009. Leading for Sustainability: Implementing the Tasks of Leadership. Corporate Governance, 9(1), pp. 21-38.

Raišienè, A.G., 2015. Business and Management Success: what Course is Supported by Sustainable Organization Managers. Transformation in business and economics, Vol.14, 3 (36), pp.66-91.

Rogers, K., S., 2011. Leading Sustainability. In: Mobley W. H., Li M., Wang Y. (eds.). Advances in Global Leadership, Vol. 6, pp. 137-153.

Šimanskienè, L., Župerkienè, E., 2013. Darnus vadovavimas. Klaipėda: Klaipėdos universiteto leidykla.

Šreimikienė, D., Vasiljevienė, N., 2004. Etiniai darnaus vystymosi aspektai ir jų ryšys su socialinėmis ir aplinkosauginėmis darnaus vystymosi dimensijomis. Organizacijų vadyba: sisteminiai tyrimai, 32, pp. 189-206. 


\title{
INTERACTION OF ELEMENTS OF THE NATIONAL INNOVATION SYSTEM OF KAZAKHSTAN AT THE REGIONAL LEVEL
}

\author{
Diana Sitenko, Buketov Karaganda State University, Kazakhstan ${ }^{1}$
}

\begin{abstract}
The development of the national innovation system directly depends on the effectiveness of innovation process at the regional level. Kazakhstan during the past 10 years actively creates conditions for the development of innovation, but the share of innovative products in the GDP remains low. The universityindustry government linkages are not active. The aim of the article is to identify the main problems in the interaction of the innovation system actors at the regional level and provide the proposals for enhancing cooperation between science, entrepreneurs and government in R\&D activity.

The study reveals a gap in the innovation process which takes place on the stages of prototyping and testing of innovations at the regional level. This gap is the case only for domestic R\&D, involved into full innovation cycle. Methodology of the article includes scientific methods: system approach, analysis, synthesis, comparative approach, statistical method, cause-and-effect analysis, deduction.

The paper provides the mechanism of interaction between NIS institutions with the central role of technology parks and regional venture capital funds at the stage of prototyping and testing of innovation. Within the mechanism the services of technology park are not limited to business incubation, but include technical and technological expertise and receiving a prototype in laboratory conditions. Another feature of the mechanism is the financing of the innovation project not at the expense of state development institutions, but through the regional venture fund.

Overcoming this gap is of great importance for the development of an innovative system of Kazakhstan, as the domestic $\mathrm{R} \& \mathrm{D}$ is involved in the full innovation process and its implementation can give positive impact on all subsystems of the national innovation system.
\end{abstract}

Key words: innovative economy, industry-government relation, innovation process, Kazakhstan JEL code: $\mathrm{N} 15, \mathrm{O} 32$

\section{Introduction}

System approach to innovation activity involves a comprehensive study of the innovation system taking into account all parts of its internal structure (elements) as well as a system of relationships between the elements within it.

Analysis of the innovative indicators gives quantitative characteristic of the development of the innovation process in the country. However, it should be taken into account the "cooperative effect" - the appearance of new qualities and properties of elements from the system interaction with each other. The elements of the innovation system do not exist independently and have certain links with each other.

1 Corresponding author-e-mail address: diana.sitenko@gmail.com 


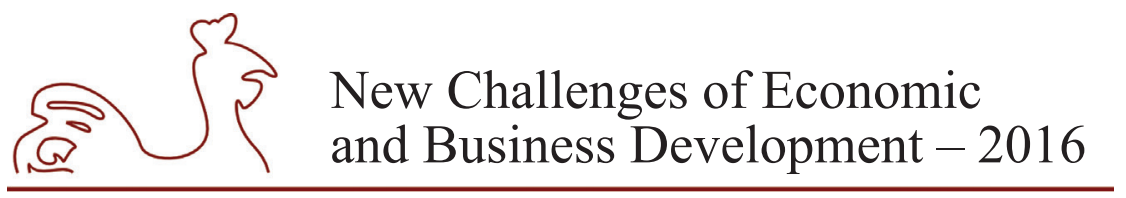

May 12-14, 2016, Riga, University of Latvia

Statistical analysis of the elements of the innovation system does not provide fully identification of missing or weak links between the major actors of the innovation system. Therefore, additionally for evaluation the relationships between the elements of the NIS there was used the system of expert assessments, implemented in the framework of an independent methodology of Global Competitiveness Index of World Economic Forum (WEF).

This rating made cross-country comparisons by 12 factors that are independent of each other and can be used alone to characterize a particular socio-economic sphere. The advantage of this methodology is, firstly, a large coverage of countries with different levels of the economy (rating of 2014-2015 covered 144 countries, including Kazakhstan). Secondly, two-thirds of the set of indicators of the methodology consist of the results of a survey of business executives (in order to cover a broad range of factors affecting the business sector in the studied countries), and onethird from public sources (statistics and studies carried out on a regular basis by international organizations). Thus, the instrument embodies both quantitative and qualitative assessment of the socio-economic phenomena, including innovation.

The need to use the rating is also justified by the fact that in Kazakhstan there is no available statistics on the activity of the regional institutions of development - technological parks, socioentrepreneurial corporations (SEC), business incubators. Their activity is not transparent; some of them operate nominally.

The article examines the hypothesis that the activity of key players of NIS at the regional level poorly coordinated and has no significant effect on the innovation cycle of innovation, whereby innovation indicators in the country demonstrate no positive dynamics.

\section{Research results and discussion}

\section{Innovation policy and main indicators of innovation activity in Kazakhstan}

In 2010 Kazakhstan adopted the State program of forced industrial-innovative development of Kazakhstan for 2010-2014 (SPFIID). The program was to contribute to the achievement of the following results by 2014: increase of GDP by 50\% compared to 2008, growth of the share of non-oil exports up to $40 \%$, increase up to $10 \%$ the share of innovation active enterprises. This program was to promote the convergence of the government initiatives in the field of innovation development with priorities of the business sector. Separately Kazakhstan launched The program for the development of innovations and promote technological modernization for 2010-2014 years (PDIPTM), which included the following goals: increase of government spending on science and innovation up to $1 \%$ to GDP by 2015; growth of the share of innovative products in the total volume of GDP up to $1 \%$ by 2015; increase in the number of projects implemented through the commercialization centers up to 90 , through technology parks - 250; number of internationally recognized patents up to 30 patents by 2015 .

The analysis of the dynamics of the main indicators of innovation activity in the country from 2006 to 2014 showed that the programs implemented in the sphere of innovative development do not bring the expected results.

Thus, Intramural expenses on R\&D were only $0.17 \%$ of GDP in 2014 , even drop down with respect to 2006 (Table 1). The number of internationally recognized patents has not reached the target value, amounting to no more than 25 patents per year. As for the number of the internal 


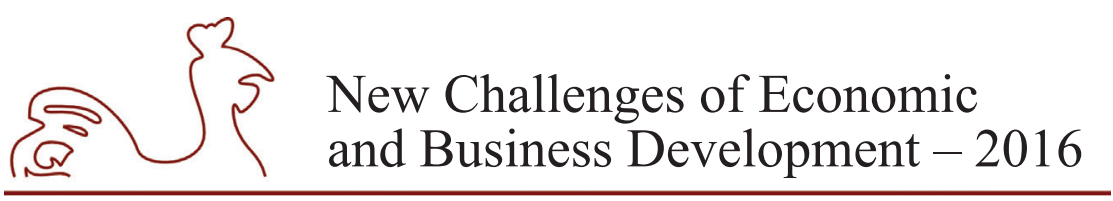

May 12-14, 2016, Riga, University of Latvia

patenting, it also shows a decline in 19.5\% in 2014 compared to 2010 (Figure 1). Another goal was increase the share of refined goods in total export of the country. But mineral resources still play important role in the structure of Kazakhstani export taking about $80 \%$.

Table 1

R\&D indicators in Kazakhstan in 2006-2014

\begin{tabular}{|l|c|c|c|c|c|}
\hline \multicolumn{1}{|c|}{ Indicators } & $\mathbf{2 0 0 6}$ & $\mathbf{2 0 0 8}$ & $\mathbf{2 0 1 0}$ & $\mathbf{2 0 1 2}$ & $\mathbf{2 0 1 4}$ \\
\hline GDP, billion tenge & 10213.7 & 15907.0 & 21815.5 & 30347.0 & 38033.1 \\
\hline $\begin{array}{l}\text { Intramural Expenses on R\&D in } \\
\text { Current Prices, million tenge }\end{array}$ & 24799.9 & 34761.6 & 33466.8 & 51253.1 & 66347.6 \\
\hline as percent to GDP & 0.24 & 0.22 & 0.15 & 0.17 & 0.17 \\
\hline Export, million US dollars & 38250.3 & 71183.5 & 60270.8 & 86448.8 & 79459.8 \\
\hline Mineral resources, \% & n/a & n/a & 74.7 & 77.9 & 80.4 \\
\hline $\begin{array}{l}\text { Patent applications filled under } \\
\text { the PCT, number }\end{array}$ & 23.2 & 13.2 & 19.8 & 16.8 & $\mathrm{n} / \mathrm{a}$ \\
\hline
\end{tabular}

Source: author's construction based on Kazakhstan Statistical Committee. Dynamics of the major socio-economic indicators [Online]. Available at: http://stat.gov.kz/ [Accessed 13 February 2016]; OECD Patent Statistics [Online]. Available at: http://stats.oecd.org/Index.aspx?DatasetCode=PATS_IPC [Accessed 13 February 2016].

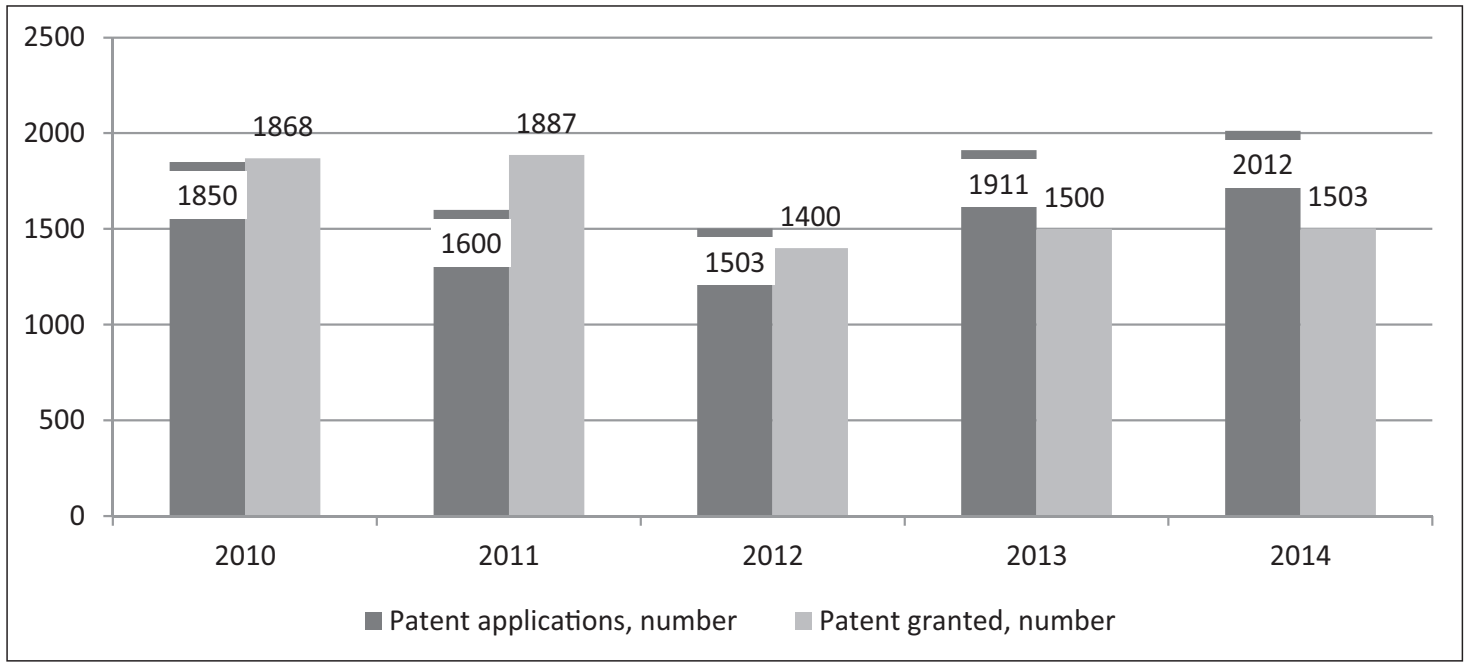

Source: author's construction based on Kazakhstan Statistical Committee. Science and innovations [Online]. Available at: http://stat.gov.kz/ [Accessed 13 February 2016].

Fig. 1. Patents applications and granted patent in Kazakhstan patent office, number

Since 2010, the share of innovative products in the GDP has demonstrated nearly 3 times growth from 0.66 to $1.5 \%$. However, despite the increase, the value of indicator remains low and does not exceed the level of 2006 along with fewer innovative enterprises (see Figure 2). 
May 12-14, 2016, Riga, University of Latvia

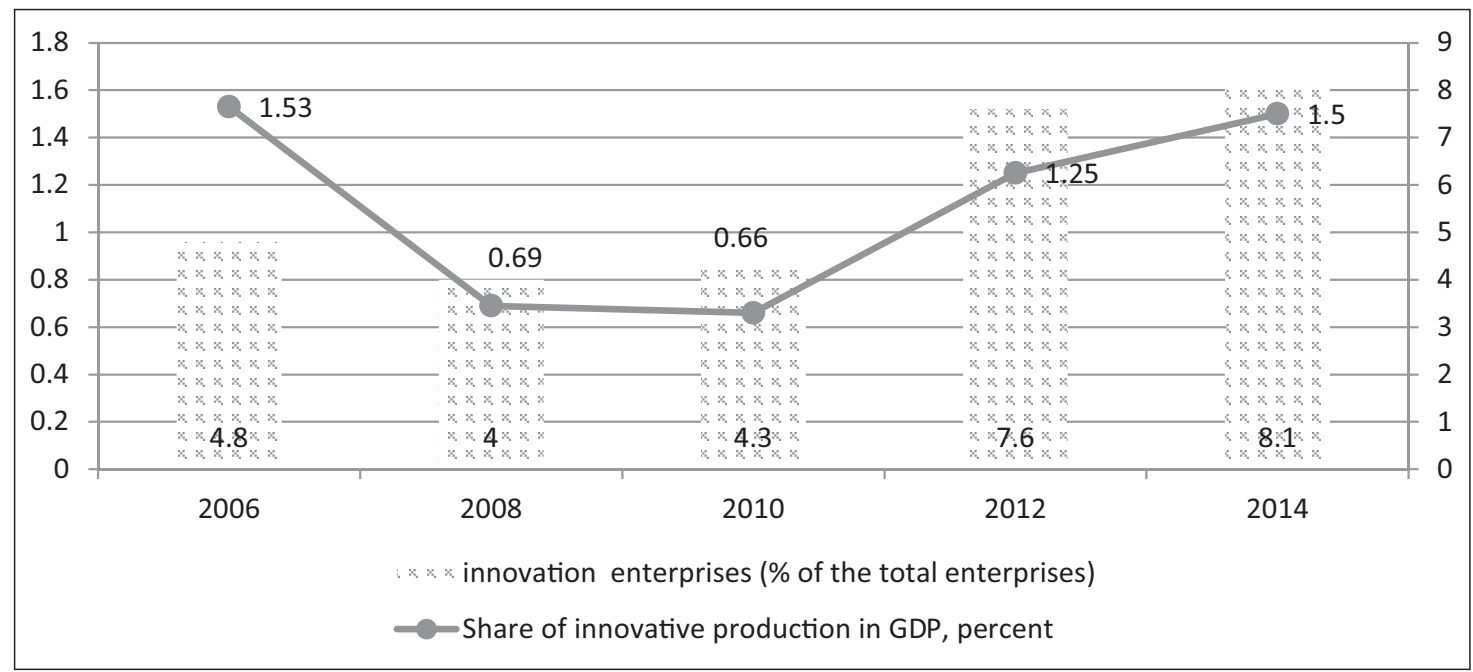

Source: author's construction based on Kazakhstan Statistical Committee. Science and innovations [Online]. Available at: http://stat.gov.kz/ [Accessed 14 February 2016].

Fig. 2. Innovation activity and share of innovative production

The growth of the number of innovative enterprises might to break the negative tendencies of innovation indicators of the country but its increase may be explained mostly by change in methodology of accounting of innovative enterprises in 2012. Now the survey of innovation activity of enterprises is conducted in accordance with international recommendations with division on product, process, organizational and marketing innovations, whereas in previous periods only the product innovations were taken into account. This explains the significant growth of innovative enterprises in the country (Fig. 2).

Thus, the implementation of two programs of innovative development for the last 5 years has not brought the desired results. Indicators either declined or just reach the level of 2006-2010. This indicates the ineffectiveness of the activity of the innovation infrastructure and mechanisms of interaction between the elements of the innovation system.

\section{Innovation infrastructure on regional level and its place in innovation system}

In 2014 regional innovation infrastructure of the republic included 8 technology parks and 4 design bureaus.

Evaluation the effectiveness of the work of technology park is quite difficult, because technopark initially deals with risky projects that can bring significant profits in the future, but the payback period is often not known. Therefore, the expenses incurred and the revenue analysis in a particular period is not enough informative. An interesting analysis of the work of Kazakhstan technoparks carried out by researchers Radosevic S. and Myrzakhmet M. (2009). Based on data of survey of employees of five technology parks and some off-firms they identified following weaknesses of this institute in Kazakhstan.

Compared to other countries, where technology parks locate mainly high-tech companies, in Kazakhstan technopark companies engage mainly in traditional industries (production of furniture, souvenirs) and promote mainly traditional products and services to the market. From 


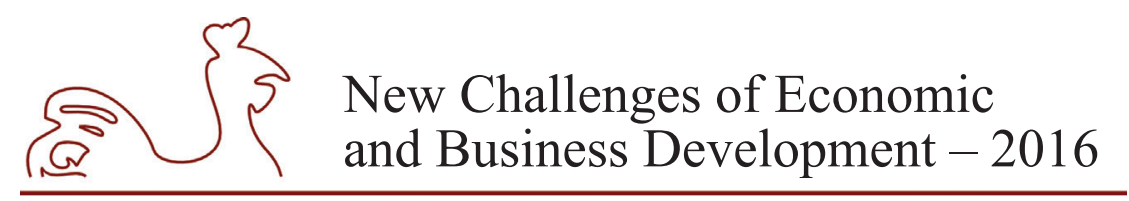

May 12-14, 2016, Riga, University of Latvia

the 110 respondents, only 4 firms provide services in information technology, 11 companies are engaged in the development of pharmaceuticals. The study also showed that firms located in technology parks mainly targeted at local markets (up to $90 \%$ of the goods and or services sell in local markets).

At the moment, one of the main problems of the development of technology parks is a lack of clear understanding of their objectives and place in the innovation system. The lack of mechanisms for the implementation of technology parks into the Kazakhstan NIS can turn these promising institutions in only nominally innovative organizations that do not have a significant impact on the development of innovative processes in the republic.

Most technology parks set up laboratory facilities focused on providing services for industrial companies in the region. However, demand from industrial enterprises on laboratory services remains low. Moreover, some technology parks did not finished installation and facility commissioning and did not pass of accreditation of laboratories. In result, the studies conducted in these laboratories may not be recognized by foreign organizations and enterprises.

Funding of regional technology parks, as well as the formation of their initial authorized capitals carried out from the republican budget. Local government authorities do not have any significant impact on the technology parks policy because their share in the authorized capital of the park is small or zero. In this regard, despite the fact that the activity of the regional technology parks should be focused on the implementation of local innovative projects the technology parks at the regional level are formal players.

From 2009 Kazakhstan creates design bureaus which are created to promote the implementation of new engineering

products, including through the transfer of technology, acquisition, adaptation, development of design and technology documents and its subsequent transfer to industrial enterprises. In 2014 all bureaus have tested totally 10 prototypes of products and certified 9 prototypes. These results could not have a significant impact on the innovation process in the country. Another limitation of impact of design bureaus is their orientation on the traditional sectors of industry: transport engineering, mining and metallurgical equipment, oil and gas equipment, agricultural engineering.

In rating WEF Kazakhstan has negative tendency by the innovation and sophistication factors in 2014-2015 to compare with report 2009-2010. Only 3 indicators from two pillars are grown. Other 13 has negative dynamics. Table 2 presents the selected indicators of innovation and sophistication factors which are important for estimation of the regional innovation process development. As table shows Kazakhstan ranks $116^{\text {th }}$ on the indicator of state of cluster development, dropped 40 places. It confirms the weakness of links between innovation system actors that can not create effective clusters in industries. 


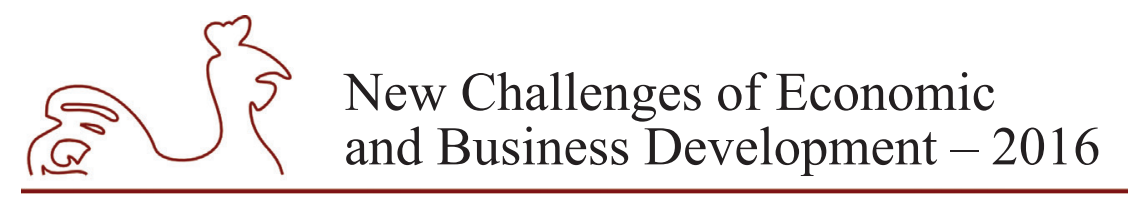

May 12-14, 2016, Riga, University of Latvia

Table 2

Selected indicators of innovation and sophistication factors of WEF

\begin{tabular}{|c|c|c|c|c|c|c|}
\hline \multirow[t]{2}{*}{ Indicator } & \multicolumn{2}{|c|}{$\begin{array}{c}2009-2010 \\
(133 \text { countries) }\end{array}$} & \multicolumn{2}{|c|}{$\begin{array}{c}2014-2015 \\
\text { (144 countries) } \\
\end{array}$} & \multicolumn{2}{|c|}{$\begin{array}{l}\text { Deviation } \\
2014 / 2009\end{array}$} \\
\hline & rank & value & rank & value & rank & value \\
\hline State of cluster development & 76 & 3.3 & 116 & 3.2 & -40 & -0.1 \\
\hline Value chain breadth & 96 & 3.1 & 109 & 3.3 & -13 & 0.2 \\
\hline Control of international distribution & 58 & 4.1 & 91 & 3.8 & -33 & -0.3 \\
\hline Production process sophistication & 62 & 3.7 & 72 & 3.8 & -10 & 0.1 \\
\hline Capacity for innovation & 50 & 4.3 & 69 & 3.7 & -19 & -0.6 \\
\hline Quality of scientific research institutions & 80 & 4.0 & 99 & 3.2 & -19 & -0.8 \\
\hline University-industry collaboration in R\&D & 77 & 3.2 & 88 & 3.3 & -11 & 0.1 \\
\hline
\end{tabular}

Source: author's construction based on WEF Global Competitiveness Report 2009-2010, Geneva and WEF Global Competitiveness Report 2014-2015, Geneva.

The drop of Quality of scientific research institutions indicator reflect the slow process of development of university and public laboratories. The most problematic factors for doing business according to WEF report are corruption and difficult access to financing.

Based on the analysis of main elements of innovation system and indicators of innovation process, author represented the innovation system of Kazakhstan as a set of key actors and interactions between them which operate at a certain stage innovation life cycle (Figure 3 ).

The life cycle of innovation is divided into 3 blocks, which are formed by a set of interrelated phenomena, processes, activities, forming a complete circle of development in any certain period of time.

The first block of processes includes a stage of fundamental research, the development of new ideas, as well as applied research. At this stage of creation of innovation the active role belongs to research institutes, academic universities. Scientific organizations conduct fundamental and applied research, arise innovative ideas, which subsequently can be implemented in practice in the form of new or improved technologies, products and services.

At this stage the universities and research institutes can fill the state order for fundamental or applied research, as well as to receive funding to perform research through development institutions and venture capital funds. The active role of universities is confirmed by publications of domestic scientists in impact factor journals and number of patents in local and foreign patent offices.

The second block is connected with the process of the creation of the prototype and testing of new technology or the resulting product. At these stages active role belongs to technology parks and social and entrepreneurial corporations. Material and technical basis of many research institutes and most universities do not allow to produce prototypes of new products. At this stage it is necessary to use the laboratory equipment, which technology parks have. However, laboratory equipment of technology parks is not used in full capacity due to lack of demand from the private and scientific sectors. Some technology parks have not completed the installation of equipment purchased in prior periods and have legal problems with the rights for the use of this equipment. 
$\frac{\left\{\begin{array}{l}\text { New Challenges of Economic } \\ \text { and Business Development }-2016\end{array}\right.}{\text { May 12-14, 2016, Riga, University of Latvia }}$

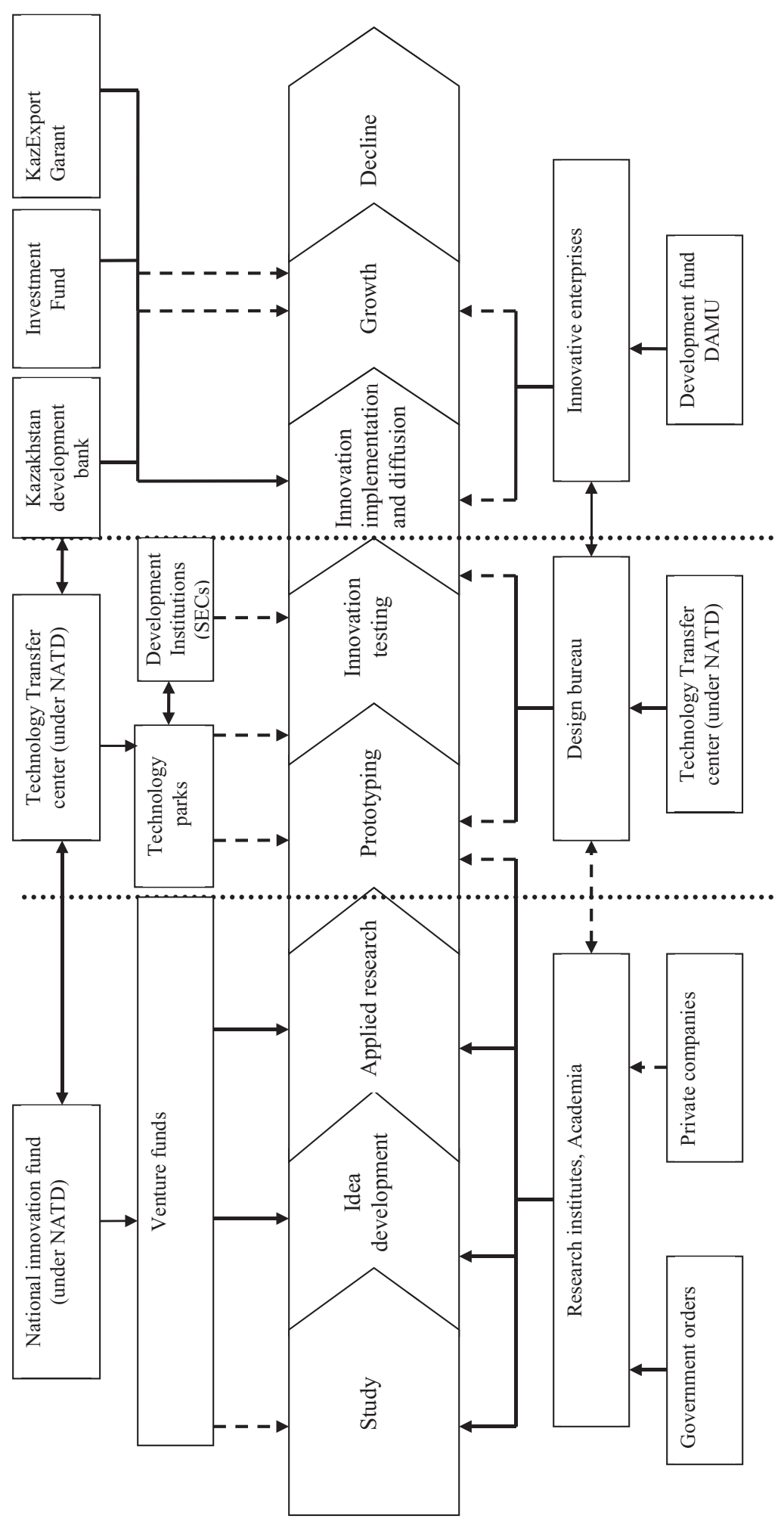

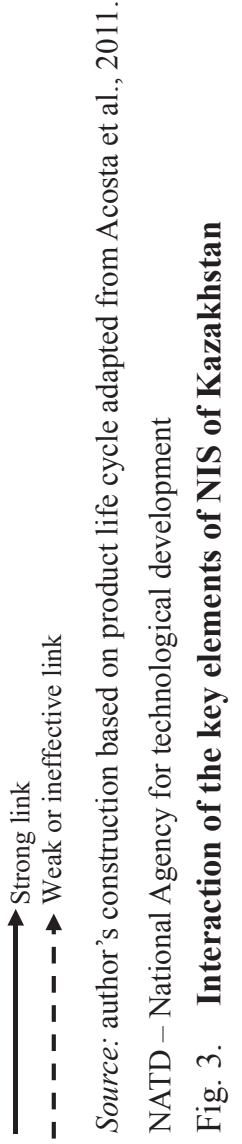




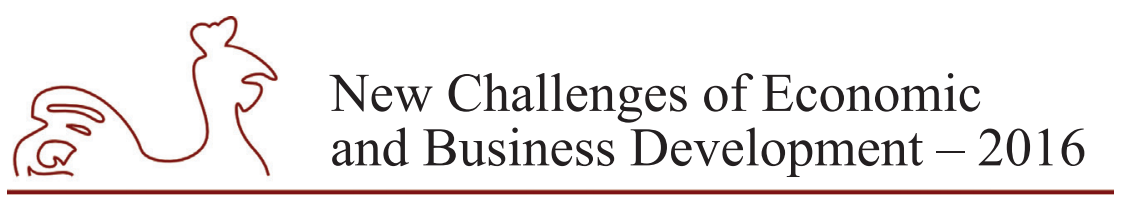

May 12-14, 2016, Riga, University of Latvia

Taking into account that the relationship between the elements at the stage of the prototype are characterized as weak, similar links raise and at the stage of innovation testing, as only a few of inventions come to this stage.

The last block includes the implementation, diffusion of innovation, as well as growth caused by them and, then, a slowdown and decline in production.

At this stage the leading role belong to the development institutions which carried out the processes of transfer of foreign technologies. However, the implementation of domestic technologies due to the weakness of the previous stage is characterized as insignificant.

Thus, at present the innovative system does not create conditions for full implementation developed by local scientists of innovative R\&D. For a number of characteristics the national innovation system of Kazakhstan is behind the innovation systems of developed countries.

\section{Mechanism of interaction between NIS institutions at the stages of prototyping and testing of innovations}

Figure 3 shows a gap in the innovation process which takes place on the stages of prototyping and testing of innovations. This gap is the case for domestic scientific developments, which go through the all stages of the innovation cycle from the creation of ideas within the university or research institutes and ending with the introduction of new products or technologies in the enterprise. In cases of pure technology transfer new R\&D immediately included in the innovation system on the implementation and the diffusion of innovation phase, bypassing this gap.

Overcoming this gap is of great importance for the development of innovation system of Kazakhstan, as the domestic R\&Ds go through the full innovation cycle. Their implementation will activate all subsystems of the innovation system, especially the innovative potential and innovative entrepreneurship.

In this paper author suggests the following mechanism for the interaction of NIS institutions with the central role of technology parks and regional venture capital funds at the stage of prototyping and testing of innovations (Figure 4).

Within the proposed mechanism the services of technology park are not limited to business incubation, but include technical and technological expertise and receiving prototype in the laboratory. The feature of this mechanism is the funding of the project through a regional venture fund but not at the expense of state development institutions.

According to the PDIPTM program the republic forms regional venture funds (RVF) based on the principles of public-private partnership. The objects of investment support are the private entrepreneurs operating in priority for each region sectors, with preference given to business projects that are just starting the implementation stage. It is planned that the regional venture capital fund will provide innovative projects with financial resources in the regions on a regular basis through the annual involvement of private investors, capitalization of own funds, as well as in the result of withdrawals of the founders of the projects.

The purpose formed regional venture funds is to invest the financial resources in the form of a contribution to the authorized capital of SMEs, fast-growing companies focused on the production of high-tech products. Also, regional funds have the ability to finance the development teams which have a prototype of a commercial product or objects of intellectual property. 


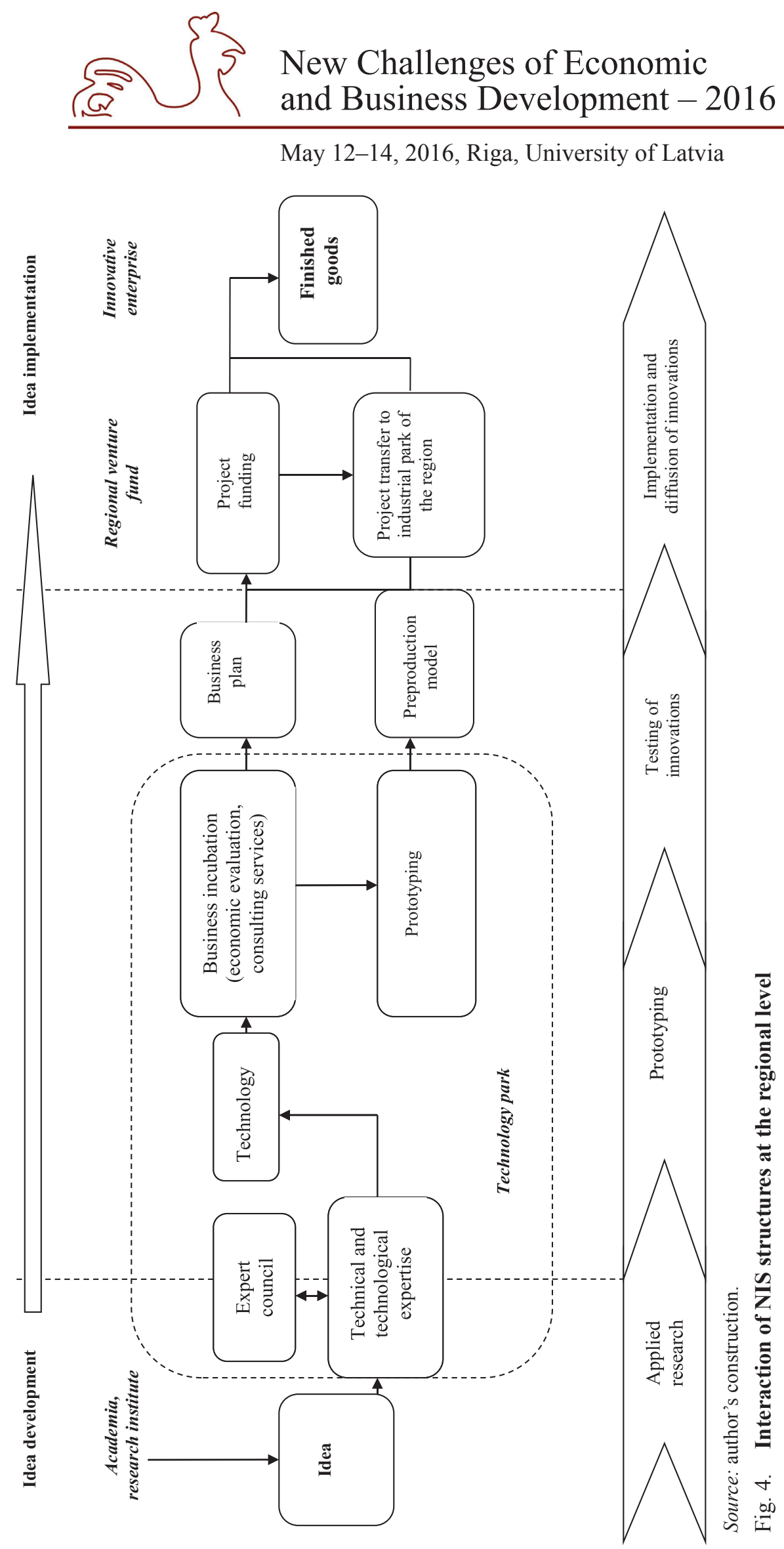




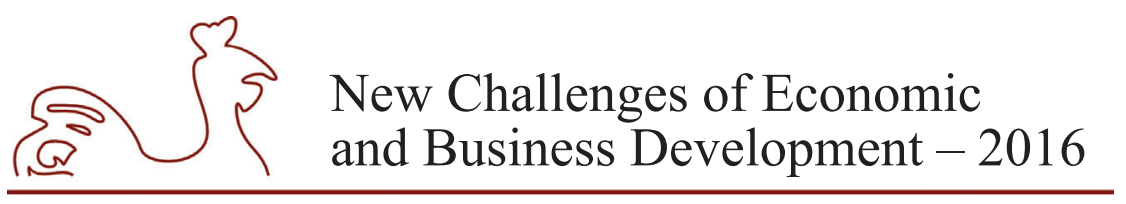

May 12-14, 2016, Riga, University of Latvia

Implementation of innovations in production is associated with large financial investment, so for small and medium-sized enterprises borrowing is the most urgent task. The mechanism of bank credit is often limited for SMEs by the lack of sufficient collateral and the lack of ability to use existing object of intellectual property as collateral. Thus, the financing of innovative small and medium-sized enterprises can be achieved by the formation of the mechanism of unsecured funding, which may be implemented through the regional venture capital funds.

Venture Fund provides financing in the form of investments, which are sent to the stock of the company, either in the form of investment credit provided for the long term, without collateral and at lower interest rates than a bank loan.

Regional venture Fund can be created in the form of a joint stock company, limited liability partnership or a non-profit organization.

In our view, the most appropriate organizational and legal form of a regional venture capital fund is a joint stock company. This form is the most attractive for private investors (founders) of the fund and allows to implement the market-based mechanisms of venture investment of strategic innovative projects in the region. The proposed mechanism of functioning of a regional venture capital fund is shown in Figure 5.

Public development institutions and local government authorities along with the private investors may be the founders of the fund. The fund is managed by a Board of Directors, which defines the main activities of the Fund, the procedure of distribution of profit among its members. In our opinion, the contribution to the authorized capital of a regional venture capital fund should not be limited to the financing from the national budget but the regional budget as well. Thus, local authority could directly participate in the management of RVF, to carry out the selection of projects that are in priority for businesses in the region. At the same time, the only receivers of the income from invested funds will be private investors. The share of profit of development institutions and local authorities is refinanced.

Incoming projects are going through the comprehensive assessment, which can be both internal and external with the assistance of outside experts. Comprehensive assessment includes scientific, technical, financial and legal aspects, and is applied to applications for funding which meet the requirements of the rules of the Fund. As a result, comprehensive examination determines the selection of innovative projects. Preference should be given to innovative projects, which are in demand in certain region.

The advantage of venture capital fund for SMEs in comparison with other mechanisms to support innovative projects (for example, private equity funds), is the ability to obtain financing for the project at an early stage, which contributes to its intensive development in a short time. For the investor financing through venture capital fund also has a number of advantages. Firstly, there is no need for an independent search of promising innovative projects. Secondly, a private investor in the initial stages of investment may invest strictly certain amount and, in the case of successful development of the project, to increase funding, thereby reducing his business risk.

For local government the benefit is in the financing of investment R\&D projects for implementation on small businesses in the region.

The possibility of participation of representatives of local government (akimat) in the formation of a regional venture capital fund is now implemented in the adopted Law "On state support of industrial and innovative activity" on January 9, 2012. 


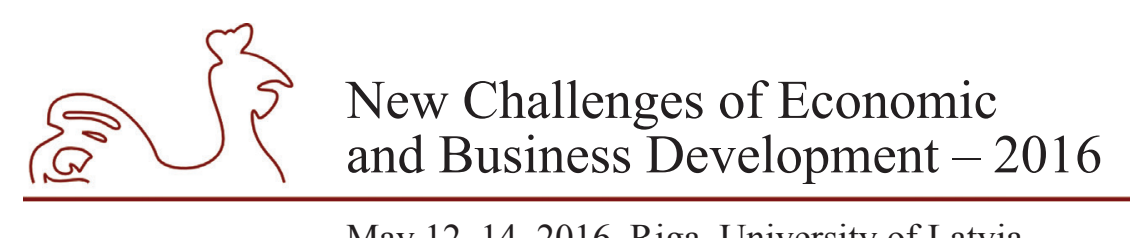

May 12-14, 2016, Riga, University of Latvia

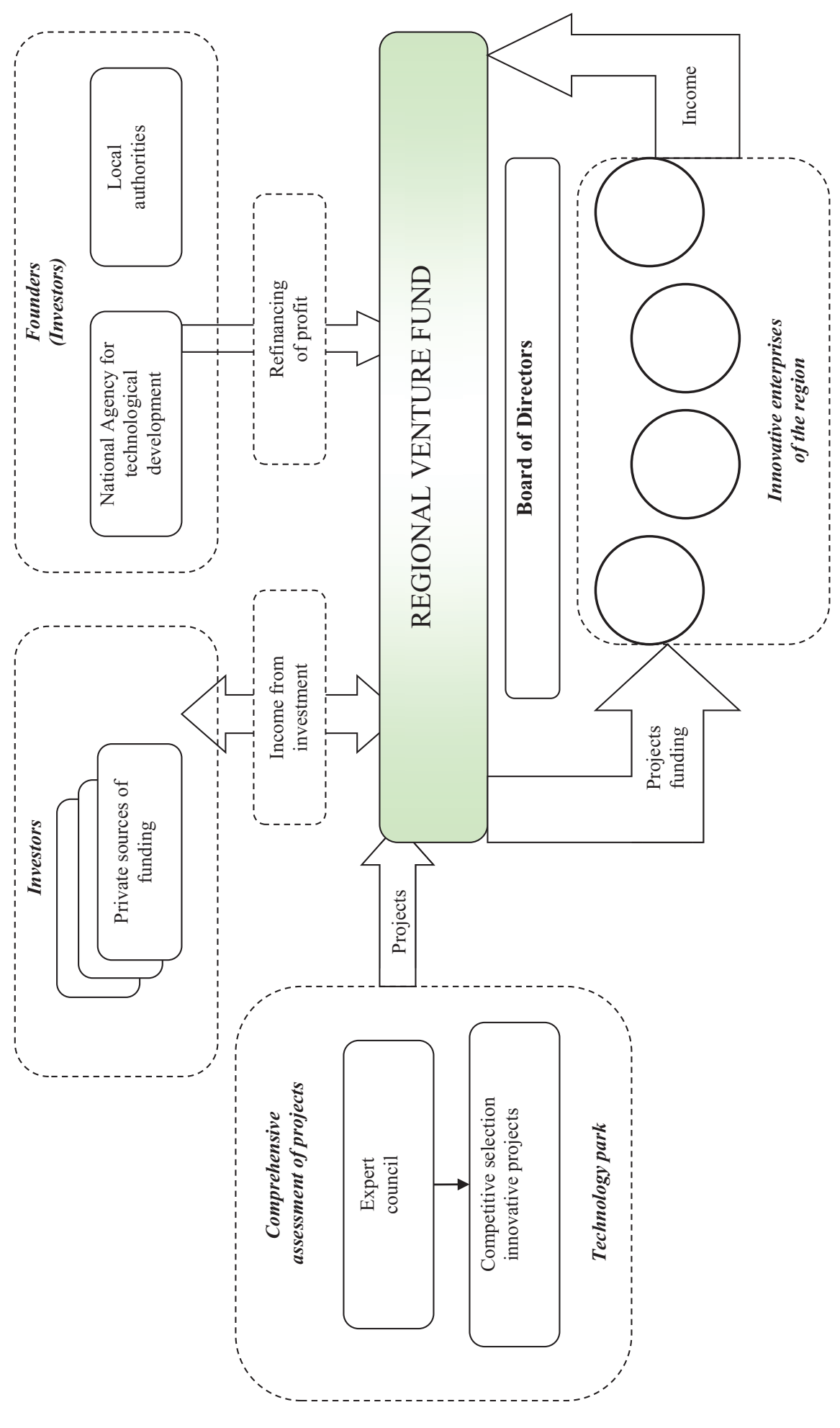

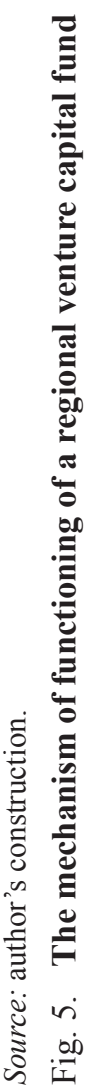




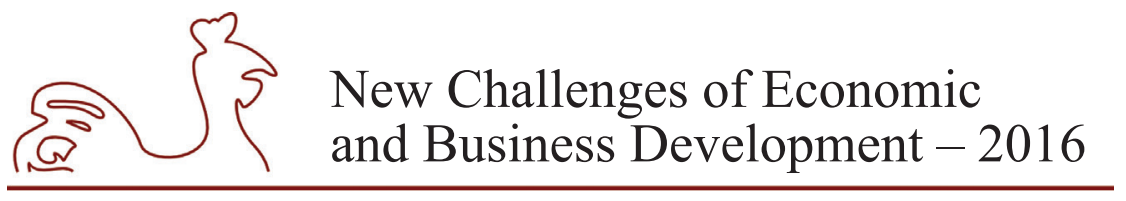

May 12-14, 2016, Riga, University of Latvia

However, further development of effective forms of venture capital financing of innovative projects demands making changes in the legislation of the republic concerning the development of investment and innovative activity. So, in our opinion, the Law "On state support of industrial and innovative activity" should be supplemented with new provisions on the establishment and functioning of the regional venture capital funds. The capacity of local authorities in relation to participation in venture funds as a founder and/or investor should be expanded. Their representatives should be included in the board of directors of the Fund and, therefore, participate in its management.

Amendments to the law should apply to the regulation of financial flows of the Fund, the order of distribution of the profit received by the Fund, taking into account the interests of all participants. Now there is no specialized legislation on venture funds in Kazakhstan. Individual questions of investment activity of venture funds are governed by the law of the Republic of Kazakhstan "On state support of industrial and innovative activity", "On Investment Funds", the provisions of the Government of Kazakhstan, in particular, the memorandum on the investment policy of NATD.

Expansion of the membership the investors of venture capital fund, especially regional, would help to make this mechanism of commercialization of domestic R\&D more flexible and adapted to the Kazakhstani economy.

Currently, most of the small and medium enterprises in Kazakhstan are characterized by unstable financial situation, the lack of a liquid collateral and possibility to provide collateral for loans. However, some of them in the case of attracting the necessary capital, including through the regional venture capital funds could have a significant growth of potential and attract investors. The proposed mechanism of the interaction of the elements of the innovation system at the regional level can be used for the formation of an effective state policy in the field of venture capital investment, and the promotion of innovative activity of the enterprises and industries at the regional level.

\section{Conclusions}

1. During the past decade Kazakhstan has formed the innovation infrastructure, but some actors are still poorly integrated into the innovation process. Technology parks do not impact on the innovative development of regions due to organizational and financial difficulties as well as weak demand for their services from private enterprises. Development institutions and venture capital funds realized very few really innovative projects.

2. The republic has a significant gap between the stages of the innovation process that does not allow realizing the innovative potential of the country, available in science. The gap is crucial for the development of an innovative system of Kazakhstan because it prevent the implementation of domestic R\&Ds, involved into full innovation cycle. The use of the proposed mechanism of interaction between NIS institutions with the participation of technology parks and regional venture capital funds at the stages of prototyping and testing of innovations will contribute to the commercialization of an increasing number of domestic R\&D. 


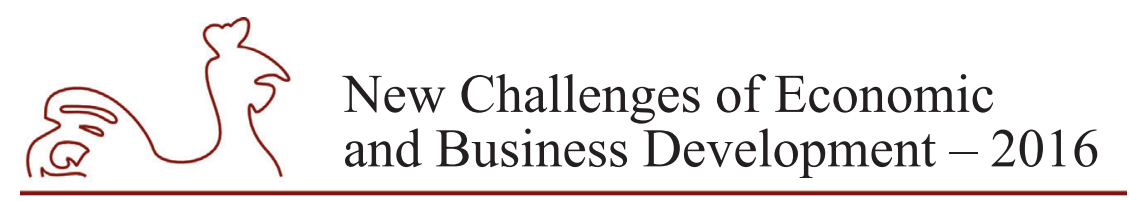

May 12-14, 2016, Riga, University of Latvia

3. Study of the problems of implementation of innovations into industry revealed the need to support innovation activity at regional level, to strengthen the links between the government, academia and the business sector. The paper present a proposal for the mechanism of functioning of a regional venture capital fund, which work will contribute to the accumulation of financial resources for enterprises focused on the production of high-tech goods in the region on priority directions of economic development.

\section{Bibliography}

Acosta, G., Morales, K., Lagos, D., \& Ortiz, M., 2011. Addressing Human Factors and Ergonomics in Design Process, Product Life Cycle, and Innovation: Trends in Consumer Product Design. Human Factors and Ergonomics in Consumer Product Design: Methods and Techniques, pp. 133-154.

National Agency for Technological Development, 2015. Annual Report 2014, Astana.

Radosevic, S. \& Myrzakhmet, M., 2009. Between vision and reality: Promoting innovation through technoparks in an emerging economy. Technovation, 29(10), pp. 645-656.

Sitenko, D., 2011. Kazakhstan National Innovation System: an Analysis of Innovative Performance. Actual problems of economics. 5 (119), pp. 361-369.

World Economic Forum, 2009. Global Competitiveness Report 2009-2010, Geneva.

World Economic Forum, 2014. Global Competitiveness Report 2014-2015, Geneva. 


\title{
TWITTER AS A COMUNICATION CHANNEL IN LATVIA'S TOP COMPANIES
}

\author{
Ronalds Skulme, University of Latvia, Latvia ${ }^{1}$ \\ Valerijs Praude, University of Latvia, Latvia
}

\begin{abstract}
Growing number of company social media accounts and social media users are indicators of social media importance in company communication strategies. These changes can also be observed in Latvia.

One of the most often used social media channels in Latvia is Twitter. Twitter has been developing through the years and offers users more communication, advertising and analytic possibilities than ever before. These changes have influenced how customers and companies communicate with each other. That is why systematically researches must be conducted in this field.

The aim of this paper was to conduct Twitter account analysis of 100 largest companies in Latvia to determine which Twitter metrics could influence the amount of company websites visitors.

To achieve the aim of the paper several research methods were used: 1 . Theoretical analysis to determine with Twitter metrics should be analysed; 2 . Secondary data research method was used to: a. Collect data from Firmas.lv database to determine which are the biggest companies by turnover in Latvia; b. Collect data from company Twitter accounts, such as: likes per tweet, retweets and other metrics; c. Collect data from company websites, such as: total visitors, visitors from twitter and other metrics; 3. Statistical package for the social sciences (SPSS) was used to analyse collected data.

The main results of the paper were: 1 . Authors discovered factors that can influence the number of visitors from Twitter to company website; 2 . Authors developed suggestions that can increase amount of company website visitors from Twitter.

This paper is both theoretical and practical. In practice this paper can be used as an informational material when developing social media marketing strategies.

The theoretical contribution of this paper is that it can be used as a basis for other social media researches in Latvia.
\end{abstract}

Key words: Twitter, Latvia, communication tools, analysis

JEL code: M31

\section{Introduction}

The number of social media users is systematically growing all over the world. According to Statista research there were 970 million social media users in 2010 . Five years later the amount of social media users more than doubled and reached 1,966 billion users. The number of Twitter users has also grown significantly. The number of Twitter users in 2010 was 30 million; in 2015 the number of Twitter users reached 305 million.

We can also see that the number of company Twitter accounts is growing. More companies than ever are using social media networks to achieve their marketing goals. According to Eurostat

1 Corresponding author - e-mail address: valerijs.praude@lu.lv 


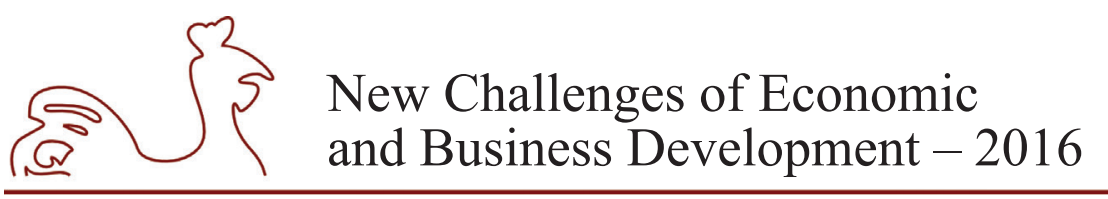

May 12-14, 2016, Riga, University of Latvia

data in 2013 approximately 28\% from 1,5 million European companies were using social media networks for their business purposes. In Latvia only $13 \%$ of the companies that participated in the survey were using social media networks. Now the numbers are much higher.

The opportunities that social media networks have provided us with have left some significant marks on the way the people make purchase decisions. There have been numerous studies about how different aspects of social media influences purchase decision processes, for example, there is a study how reviews of an online shop influence purchase decision process (E. Ioanas et al., 2014).

In these past years also Twitter has evolved. Users of Twitter have more communication options than ever before. For example, from 2013 Twitter users can share with the text messages also their photos or videos, and add their location (Twitter, Inc., 2013). Then in 2014 Twitter added a new feature, that users can add up to 4 images to their tweets. After that, in 2015 Twitter changed favourite button to like button. We can see that Twitter has been evolving by adding new features every year. These and other changes according to author's opinion have influenced the way Twitter users are communicating with each other. It has also influenced the way how companies communicate with their followers.

According to our study Twitter is one of the most popular social media channels used by Latvia's top 100 companies. It is also very popular by Latvians. Companies mainly use Twitter to communicate with their audience and to advertise their products and services. So it is very important for Latvian top 100 companies to understand how to correctly use Twitter, what are the main differences of Twitter compered to other communication channels, what are the main metrics that could indicate of effective use of Twitter, and how Twitter is used by other companies. Lack of the necessary knowledge could lead to incorrect use of Twitter as a communication channel and could damage company reputation and decrease sales.

Based on the previously mentioned facts, authors believe that research must be conducted in this field systematically. We must keep track of the changes that have been made in social media networks. We must analyse how these changes influence the communication with the audience. Understanding these changes can help business grow and could help them create more effective marketing strategies.

Authors raised the following research question, which are the Twitter indicators that we must keep track of, if we want to increase the number of visitors to our website? To answer the research question, authors followed the following steps: 1. Authors conducted theoretical analysis to determine which Twitter metrics should be analysed; 2. Authors researched data collection option from Twitter and company websites; 3. Authors used Firmas.lv database to collect data about Latvia's top 100 companies; 4. Authors determined which of the top 100 companies have Twitter account; 5. The data from Twitter accounts was extracted; 6 . The data from analysed companies websites was extracted; 7. The collected data from Twitter and websites was analysed.

Due to this analysis we will have the information about those Twitter metrics that are the indicators of Twitter account effectiveness in Latvia. We will see how Latvia's top 100 companies are using Twitter and what results they have. This information will be useful to marketing specialists that want to compare their social media results with the Latvia's top company marketing results. Afterwards they will be able to improve their marketing strategies. This research can also serve as a basis for other social media related research in Latvia. 


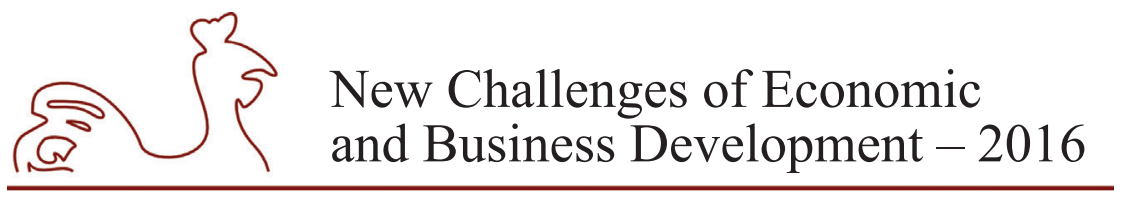

May 12-14, 2016, Riga, University of Latvia

To answer the research question the following research aims were defined: 1 . Conduct an analysis of Latvia's top 100 companies Twitter accounts; 2. Determine the correlation between gathered Twitter metrics and company websites statistics.

To achieve this aim of the research the following research methods were used: 1 . Theoretical literature analysis; to determine which Twitter metrics should be analysed; 2 . Secondary statistical data analysis, to: a) determine which are the biggest companies by turnover in Latvia in 2015; b) collect data from Twitter; c) collect data from company websites; 3. SPSS for grouping and statistical analysis (IBM, 2016).

While conducting the theoretical analysis authors came across multiple research papers that examined Twitter metrics. In 2014 the number 1 leading CRM (customer relationship management) system provider in the world Salesforce conducted a study about social engagement. In this study, more than 3 million Twitter Messages were analysed. For the analysis of Twitter engagement rates following metrics were used: replies, retweets and number of tweets. Authors also agree that these Twitter metrics are very effective while measuring the engagement of Twitter users and decided to use them in this research.

In other researches, following metrics were used to analyse Twitter user engagement, such as: the number of followers and the number of following users (Haustein et al., 2015). In this research Twitter engagement metrics from different studies were combined and used.

Theoretical literature analysis was used to determine the main website metrics that should be analysed. These metrics were used to determine how engaged users from Twitter were in company websites. While conducting theoretical analysis author came across multiple researches that used different website metrics. To analyse the engagement of users in websites following metrics were used: pages views, number of sessions, time on page, bounce rate, pages views per session etc. (Huntington et al., 2008., Pakkala et al., 2012., Bhatnagar, 2009).

After the analysing multiple theoretical sources authors decided to use the following Twitter metrics in our study: followers, following, likes, retweets, tweet likes, tweets, and type of a message.

Based on the literature research analysis the following website metrics were chosen for the analysis: total visits, time on site, page views, bounce rate, visitors from twitter.

The names and data of the top 100 Latvia's companies by turnover were extracted from Firmas.lv data base.

The company turnovers varied between 61.43 million EUR and 1.135 billion EUR per year. The companies were representing different industries, e.g., food sales, fuel and oil production, forestry, metalworking, wood working, banks, retail, architecture, and other industries.

After extracting the information about the Latvia's largest companies, authors determined which of these companies have Twitter accounts. Out of the 100 companies analysed in the first stage, 33 had Twitter accounts.

To extract data from companies' Twitter accounts authors used Python 3.5 programming language (Python, 2016). This language was used to create a code that was used to extract the necessary information from the Twitter accounts. Python has been used by other researchers for data extraction from Twitter (Lipizzi et al., 2015, Yu et al., 2015). From these 33 Twitter accounts author extracted 15467 tweets. These tweets were written from 1 August 2015 till 31 January 2016. 


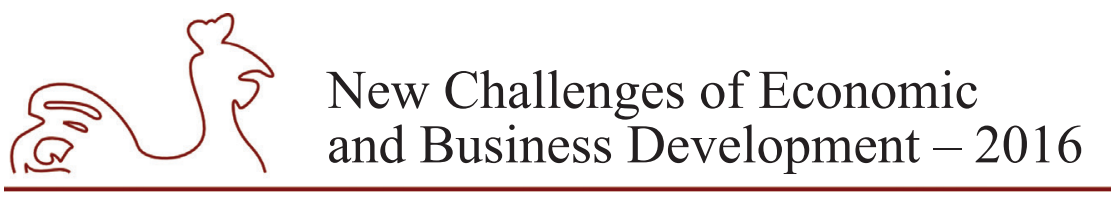

May 12-14, 2016, Riga, University of Latvia

To collect the necessary data from company websites, Similarweb software was used. Similarweb uses multiple sources to gather data from company websites. The data is gathered from 4 main sources: 1 . A panel of over 200 million monitored devices, which is the largest panel currently in the industry; 2 . Local industry service providers; 3 . From web crawlers that are scanning every public website; 4 . Hundreds of thousands of direct measurement sourcing from websites.

These all data sources are combined together to provide an accurate information about website visitor statistics.

\section{Research results and discussion}

The study yielded the following results. Firstly, authors analysed the company twitter profiles. The results from this analysis are displayed in Table 1. We can see that the number of total tweets from a profile varies between 73 and 52339. In total, all these companies have written 222102 tweets.

In the time period from August 2015 till January 2016 the Twitter accounts have published on average 468.7 tweets. In total they have published 15467 tweets. The amount of company tweets varies between 11 and 2610 tweets.

The amount of Twitter accounts these companies are following varies from 4 till 6337 accounts, on average one Twitter account follows 1079 other accounts.

On average, one Twitter account has 6229.94 followers. The company with the most Twitter followers has 39179 followers.

In total companies have 19334 likes. The account with the largest amount of Twitter likes has 7790 likes.

From this information we can conclude, that: 1. most of Latvia's top 100 companies do not use Twitter, only 33\% have a Twitter account; 2 . some of the companies that are using Twitter are not very active.

Table 1

Twitter account statistics

\begin{tabular}{|l|r|r|r|r|r|}
\hline & \multicolumn{1}{|c|}{ Range } & \multicolumn{1}{c|}{ Minimum } & Maximum & \multicolumn{1}{c|}{ Sum } & \multicolumn{1}{c|}{ Mean } \\
\hline Total tweets & 52266 & 73 & 52339 & 222102 & 6730.36 \\
\hline Tweets Aug-Jan & 2599 & 11 & 2610 & 15467 & 468.70 \\
\hline Total following & 6333 & 4 & 6337 & 35609 & 1079.06 \\
\hline Total followers & 39101 & 78 & 39179 & 205588 & 6229.94 \\
\hline Total likes & 7787 & 3 & 7790 & 19334 & 585.88 \\
\hline
\end{tabular}

** Correlation is significant at the 0.01 level (2-tailed).

* Correlation is significant at the 0.05 level (2-tailed).

Source: author's calculations based on gathered Twitter data.

After conducting correlation analysis authors concluded that these metrics are interrelated. See Table 2. The more companies write the more likely they will get more likes. Companies that have more tweets are following more accounts. Also the more you tweet the more likely you will get more followers. 


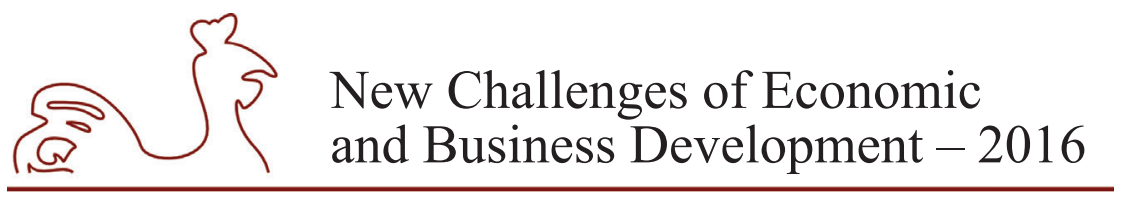

May 12-14, 2016, Riga, University of Latvia

The fact that according to our study the more company has tweets the more likely they will have more likes can be explained as follows, people have different interests and the more company provides different useful information the more likely is that more information will be useful to the followers. So the more likely they will like the information.

According to the data in Table 2, we can see also that by simply following more Twitter users we can get more followers. It may explained as follows, every time a Twitter user follows somebody the follower receives a message. The Twitter user get more exposure. Also some of the Twitter users would like to follow the account back so the company accounts keeps to follow them. Follow for follow.

Table 2

Correlation analysis between Twitter profile metrics

\begin{tabular}{|ll|r|r|r|r|}
\hline & & Total tweets & Following & Followers & \multicolumn{1}{|c|}{ Likes } \\
\hline \multirow{5}{*}{ Total tweets } & Pearson Correlation & 1 & $.726^{* *}$ & $.552^{* *}$ & $.854^{* *}$ \\
& Sig. (2-tailed) & & .000 & .002 & .000 \\
& $\mathrm{~N}$ & 28 & 28 & 28 & 28 \\
& Pearson Correlation & $.726^{* *}$ & 1 & $.686^{* *}$ & $.606^{* *}$ \\
Following & Sig. (2-tailed) & .000 & & .000 & .001 \\
& $\mathrm{~N}$ & 28 & 28 & 28 & 28 \\
& Pearson Correlation & $.552^{* *}$ & $.686^{* *}$ & 1 & $.434^{*}$ \\
Followers & Sig. (2-tailed) & .002 & .000 & & .021 \\
& $\mathrm{~N}$ & 28 & 28 & 28 & 28 \\
& Pearson Correlation & $.854^{* *}$ & $.606^{* *}$ & $.434^{*}$ & 1 \\
Likes & Sig. (2-tailed) & .000 & .001 & .021 & 28 \\
& $\mathrm{~N}$ & 28 & 28 & 28 \\
\hline
\end{tabular}

** Correlation is significant at the 0.01 level (2-tailed).

* Correlation is significant at the 0.05 level (2-tailed).

Source: author's calculations based on gathered Twitter data.

In the next stage, authors analysed top 100 company Twitter tweets in period from 1 August 2015 till 31. January 2016. See Table 3 . We can see that on average a company tweets 2.59 times per day. The most active company tweets 14.18 times per day, the less active only 0.06 tweet tweets per day.

Table 3

Twitter tweets per day and month

\begin{tabular}{|l|r|r|r|r|r|}
\hline & \multicolumn{1}{|c|}{ Range } & \multicolumn{1}{c|}{ Minimum } & \multicolumn{1}{c|}{ Maximum } & \multicolumn{1}{c|}{ Sum } & \multicolumn{1}{c|}{ Mean } \\
\hline Tweets per day & 14.12 & .06 & 14.18 & 85.43 & 2.59 \\
\hline Tweets per month & 423.76 & 1.78 & 425.54 & 2562.86 & 77.66 \\
\hline
\end{tabular}

Source: author's calculations based on gathered Twitter data.

We can see that the time a company spends on communicating with their followers varies very much. From our study we can see that there are two main factors that influence the amount of tweets per day or month: 1 . The industry the company represents; 2 . The purpose of the Twitter account. Is the Twitter account used to communicate with people or mainly to spread information. 


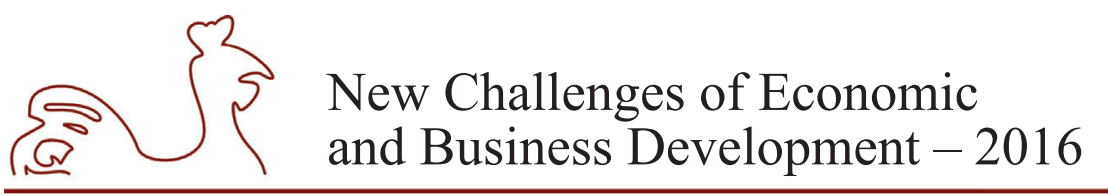

May 12-14, 2016, Riga, University of Latvia

In the next stage authors analysed Twitter tweet metrics. See Table 4 . We can see that one Twitter tweet on average had 1.16 retweets and 0.63 likes. The most popular tweet had 1857 retweets. This tweet was about helping a NBA player to get him in the all-stars game. Whereas the most popular tweet in Facebook was a contest. The maximum likes that got a tweet was 113.

Authors also conducted correlation analysis between tweets retweets and likes, the results showed that there exists was very weak correlation between these two metrics, 0.114 .

From the collected data, we can see that Twitter users more likely like to retweet interesting and useful content then like it. In comparison Facebook users are more likely to like content. Authors opinion is that the like button in Twitter has lesser importance then retweeting.

Table 4

Twitter tweet retweets and like count

\begin{tabular}{|l|r|r|}
\hline & Retweet count & \multicolumn{2}{|c|}{ Like count } \\
\hline Mean & 1.6157 & .6352 \\
\hline Range & 1857.00 & 113.00 \\
\hline Minimum & .00 & .00 \\
\hline Maximum & 1857.00 & 113.00 \\
\hline Sum & 24409.00 & 9596.00 \\
\hline
\end{tabular}

Source: author's calculations based on gathered Twitter data.

In the next stage authors analysed how many of the tweets are answers to some kind of a question. See Table 5. It appeared that 60.2 tweets were replies to some of kind of a question. We can assume that some companies are using twitter as a two way communication channel with their audience.

Table 5

Twitter replies

\begin{tabular}{|l|r|r|}
\hline & Frequency & \multicolumn{1}{|c|}{ Percent } \\
\hline Simple tweets & 6158 & 39.8 \\
\hline Tweets that are answers to a question & 9309 & 60.2 \\
\hline Total & 15467 & 100.0 \\
\hline
\end{tabular}

Source: author's calculations based on gathered Twitter data.

In the next stage, website analysis of the 33 companies was conducted. The website data was collected from 1 August 2015 till 31 January 2016. Authors were able to collect data from 28 websites. Some of the websites had insufficient traffic to gather precise data. The results are displayed in Table 6 and 7.

The main metrics of a website were analysed, such as total visitors, time on site, page views and bounce rate. The results are displayed in Table 6 . The websites with the most number of visitors per month were banks. It is because the websites visitors check multiple times per month to check their balance, to pay bills and do other important tasks. 


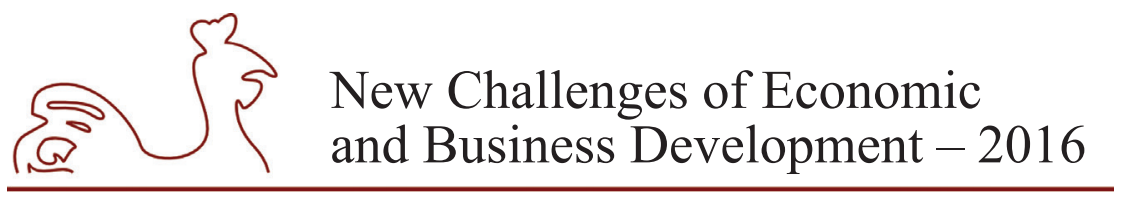

May 12-14, 2016, Riga, University of Latvia

Table 6

Websites main metrics

\begin{tabular}{|l|r|r|r|r|r|}
\hline & \multicolumn{1}{|c|}{ Range } & \multicolumn{1}{c|}{ Minimum } & \multicolumn{1}{c|}{ Maximum } & \multicolumn{1}{c|}{ Sum } & \multicolumn{1}{c|}{ Mean } \\
\hline Total number visits & 4070666.67 & 4333.33 & 4075000 & 11297666.67 & 403488.1 \\
\hline Time on site & $0: 10: 26$ & $0: 00: 52$ & $0: 11: 18$ & $1: 39: 40$ & $0: 03: 33$ \\
\hline Page views & 15.87 & 2.22 & 18.09 & 142.84 & 5.1014 \\
\hline Bounce rate & 54.38 & 13.36 & 67.74 & 1039.87 & 37.1382 \\
\hline
\end{tabular}

Source: author's gathered data from websites.

We can see that the amount of home page visitors varies between 4333 and 407500 users per month. On average a user spends 3 minutes and 33 second in a website and looks at 5.1 pages. From the collected data we can see also that the engagement in the website very differs from the industry. In some websites people spend more than 11 minutes and visit more than 18 pages. The average bounce rate of a website is $37.13 \%$.

While conducting a deeper analysis of the websites, we came to the conclusion that most visitors are coming to these websites from direct traffic, on average $42.76 \%$ of all visitors. A large amount of traffic comes from search portals, on average 39.6\% from all traffic. But from social networks according to our data comes $1.7 \%$ of traffic. See Table 7 .

Table 7

Websites traffic from different sources

\begin{tabular}{|l|r|r|r|r|}
\hline & \multicolumn{2}{|c|}{ Range } & \multicolumn{1}{c|}{ Minimum } & \multicolumn{1}{c|}{ Maximum } \\
\hline Direct & 61.62 & 12.79 & 74.41 & 42.7621 \\
\hline Referrals & 25.32 & 2.58 & 27.90 & 12.9079 \\
\hline Search & 69.09 & 11.83 & 80.92 & 39.6036 \\
\hline Social & 10.75 & .00 & 10.75 & 1.7057 \\
\hline Mail & 22.46 & .00 & 22.46 & 2.9375 \\
\hline Other & .51 & .00 & .51 & .0818 \\
\hline
\end{tabular}

Source: author's gathered data from Similarweb.

In the next stage authors analysed how visitors from social media influence home page metrics. Authors looked at the following metrics: time on site; page views; bounce rate. Author conducted correlation analysis of these previously mentioned metrics. See Table 8.

We can see that there is a correlation between previously mentioned parameters. We can see that there exists almost moderate correlation between the amount of time spent on site and users from social media sites. We may say that the users from social media sites will spend more often more time in companies' websites than users from other sources. Also more users from social media sites can influence positively amount of viewed pages and decrease websites bounce rates. It means that the visitors from social media sites we more often look at least one more page before they leave the website. See Table 8 . 


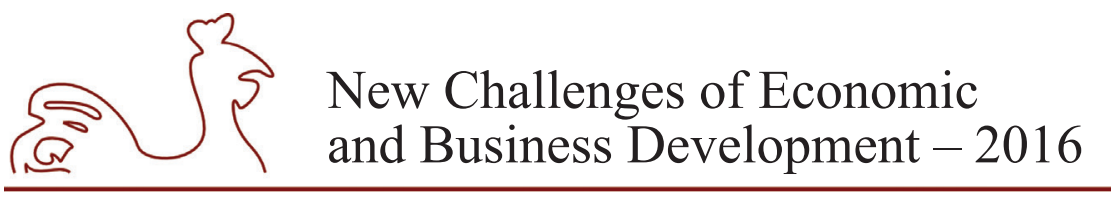

May 12-14, 2016, Riga, University of Latvia

Table 8

Correlation between users from social media sites and website metrics

\begin{tabular}{|ll|r|r|r|}
\hline & & Time on site & Page views & Bounce rate \\
\hline \multirow{3}{*}{ Users from Social media } & Pearson Correlation & $.453^{*}$ & $.385^{*}$ & $-.384^{*}$ \\
& Sig. (2-tailed) & .015 & .043 & .044 \\
& $\mathrm{~N}$ & 28 & 28 & 28 \\
\hline
\end{tabular}

* Correlation is significant at the 0.05 level (2-tailed).

Source: author's calculations based on collected data from websites.

In the next stage authors conducted correlation analysis between home page visitors from Twitter and Twitter metrics, such as amount of tweets from August till January, number of followers, number of likes, number of following, and other metrics. In this part authors analysed 16 companies.

The correlation analysis results are displayed in Table 9. As we can see from the results, there is a strong or moderate correlation almost between all of the metrics. We can see that, the more followers or the more they tweet the more visitors from twitter they will have. Also it is more likely that if Twitter profile tweets have more likes, the more visitors from Twitter the company will get.

Table 9

Correlation between home page visitors from Twitter and Twitter metrics

\begin{tabular}{|c|c|c|c|c|c|c|c|c|c|}
\hline & & $\begin{array}{c}\text { Tweets } \\
\text { Aug-Jan }\end{array}$ & Following & Followers & Likes & $\begin{array}{c}\text { Avg. } \\
\text { Tweets } \\
\text { per day }\end{array}$ & $\begin{array}{c}\text { Avg. } \\
\text { Tweets } \\
\text { per } \\
\text { month }\end{array}$ & $\begin{array}{c}\text { Avg. } \\
\text { Retweets } \\
\text { per tweet }\end{array}$ & $\begin{array}{l}\text { Avg. } \\
\text { Likes } \\
\text { Per } \\
\text { tweet }\end{array}$ \\
\hline \multirow{3}{*}{$\begin{array}{l}\text { Users } \\
\text { from } \\
\text { Twitter } \\
\text { account }\end{array}$} & $\begin{array}{l}\text { Pearson } \\
\text { Correlation }\end{array}$ & $.544^{*}$ & $.690^{* *}$ & .421 & .230 & $.550^{*}$ & $.550^{*}$ & .182 & $.516^{*}$ \\
\hline & $\begin{array}{l}\text { Sig. } \\
\text { (2-tailed) }\end{array}$ & .029 & .003 & .104 & .391 & .027 & .027 & .499 & .041 \\
\hline & $\mathrm{N}$ & 16 & 16 & 16 & 16 & 16 & 16 & 16 & 16 \\
\hline
\end{tabular}

$* *$ Correlation is significant at the 0.01 level (2-tailed).

* Correlation is significant at the 0.05 level (2-tailed).

Source: author's calculations based on websites and Twitter data.

The fact that accounts that are following more Twitter users have more website visitors can be explained as follows, if company start to follow a Twitter user, the Twitter user will receive a notification that the certain Twitter user has started to follow them. The notification appear in the Twitter website and sometimes are sent through email. The companies Twitter account also be visible in the followers list of the user. So if company follows a certain user the company receives much more exposure.

From our collected data we can see that the amount of Twitter user tweets that there exists a moderate correlation between the amount of tweets published between August and January and the number of visitors to the company's website. This could be explained as follows, the more company writes something on their timeline the more likely is that the followers will receive the message and visit their website. Also the more message are out there, the more likely the follower will remember the brand when it is looking for some kind of product of service. 


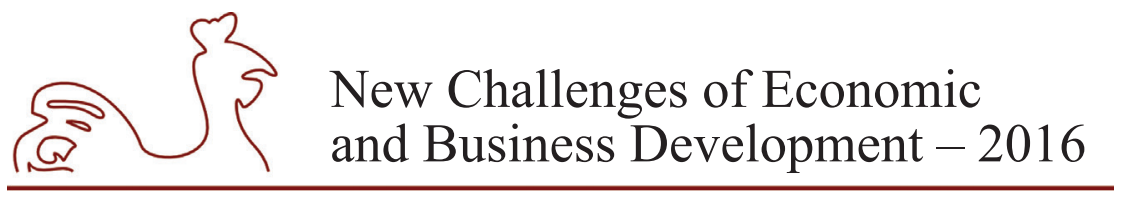

May 12-14, 2016, Riga, University of Latvia

\section{Conclusions, proposals, recommendations}

Authors came to the following main conclusions: 1 . As we can see the from data collected data to increase the amount of Twitter account likes is to tweet more often; 2. 60.2\% of tweets of analyzed Twitter accounts are answers to a question, it means that some of the companies are using twitter more as a two way communication tool to help them solve their issues; 3 . From collected data we can see that there exists moderate correlation between users from social media sites and time spent on site. So to increase the amount of time spent on site we can attract more users from social media sites; 4. The main two traffic sources of top 100 companies are direct traffic and search engine traffic; 5 . We can see from the results that there exists a moderate correlation between users to website from Twitter and following Twitter metrics: amount of followers, average tweets per day, average likes per tweet. It means that influencing these metrics can lead to more traffic from Twitter to your website.

In practice this paper can be used as an informational material for internet marketers to compare their marketing results. This paper can also be used as guide and informational material while developing marketing communication strategy.

\section{Bibliography}

Bhatnagar, A. (2009). Web analytics for business intelligence beyond hits and sessions. 33(6), pp. 32-35.

Carlo Lipizzi, Luca Iandoli, José Emmanuel Ramirez Marquez, Extracting and evaluating conversational patterns in social media: A socio-semantic analysis of customers' reactions to the launch of new products using Twitter streams, International Journal of Information Management, Vol. 35, Issue 4, August 2015, pp. 490-503. [Online] Available at: http://www.sciencedirect.com/science/article/pii/ S0268401215000377 [Accessed 8 April 2016].

Eurostat, 2016, Archive:Social media - statistics on the use by enterprises - data 2013. [Online] Available at: http://ec.europa.eu/eurostat/statistics-explained/index.php/Archive:Social_media_-_statistics on_the_use_by_enterprises_-_data_2013 [Accessed 15 March 2016].

Firmas.lv, 2015, Latvijas Biznesa Gada Pārskats. [Online] Available at: https://www.firmas.lv/lbgpp/2015/ raksti\#// [Accessed 15 March 2016].

H. Pakkala, K. Presser, T. Christensen, Using Google Analytics to measure visitor statistics: The case of food composition websites, International Journal of Information Management, Vol. 32, Issue 6, December 2012, pp. 504-512. [Online] Available at: http://www.sciencedirect.com/science/article/ pii/S026840121200062X [Accessed 8 April 2016].

Haustein, S., Bowman, T. D., Holmberg, K., Tsou, A., Sugimoto, C. R. and Larivière, V., 2016, Tweets as impact indicators: Examining the implications of automated "bot" accounts on Twitter. Journal of the Association for Information Science and Technology, 67: 232-238. [Online] Available at: http:// onlinelibrary.wiley.com/doi/10.1002/asi.23456/full [Accessed 8 April 2016].

IBM, 2016. IBM SPSS Software. [Online] Available at: http://www.ibm.com/analytics/us/en/technology/ spss/ [Accessed 8 April 2016].

Mashable, 2014, Twitter Lets You Add 4 Photos to Tweets, Tag Anyone in Them. [Online] Available at: http://mashable.com/2014/03/26/twitter-photos-social/\#6SSyjVn3nZqn [Accessed 15 March 2016]

Paul Huntington, David Nicholas, Hamid R. Jamali, Website usage metrics: A re-assessment of session data, Information Processing \& Management, Vol. 44, Issue 1, January 2008, pp. 358-372. [Online] Available at: http://www.sciencedirect.com/science/article/pii/S0306457307000817 [Accessed 8 April 2016].

Python, 2016. Python is powerful... and fast; plays well with others; runs everywhere; is friendly \& easy to learn; is Open. [Online] Available at: https://www.python.org/about/ [Accessed 8 April 2016]. 


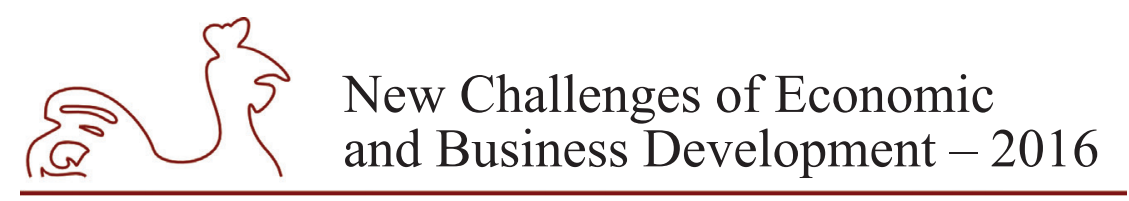

May 12-14, 2016, Riga, University of Latvia

Saleforce, 2016. Social Engagement Benchmark Report for Twitter. [Online] Available at: https:// www.exacttarget.com/resource-center/digital-marketing/benchmark-2014/social-engagement-tw $? 1 \mathrm{~s}=\mathrm{B} \log \& 1 \mathrm{ssm}=$ Corporate $\& 1 \mathrm{ss}=\mathrm{B} \log .2014$ BenchmarkReport.Twitter \&camp=701 A0000000xh UEIAY \& content $=701$ A0000000xhUEIAY [Accessed 8 April 2016].

Similar Web, 2016, Our Data. [Online] Available at: https://www.similarweb.com/ourdata [Accessed 15 March 2016]

Statista, 2016, Number of social network users worldwide from 2010 till 2018 (in billions). [Online] Available at: http://www.statista.com/statistics/278414/number-of-worldwide-social-network-users/ [Accessed 15 March 2016]

The Verge, 2015, Twitter officially kills off favorites and replaces them with likes. [Online] Available at: http://www.theverge.com/2015/11/3/9661180/twitter-vine-favorite-fav-likes-hearts [Accessed 15 March 2016]

Twitter, 2016. Posting photos or GIFs on Twitter. [Online] Available at: https://support.twitter.com/ articles/20156423 [Accessed 8 April 2016].

Yang Yu, Xiao Wang, World Cup 2014 in the Twitter World: A big data analysis of sentiments in U.S. sports fans' tweets, Computers in Human Behavior, Vol. 48, July 2015, pp. 392-400. [Online] Available at: http://www.sciencedirect.com/science/article/pii/S074756321500103X [Accessed 8 April 2016]. 


\title{
APPLICATION OF SOCIAL ACCOUNTING PRINCIPLES TO STATE-OWNED ENTERPRISES
}

\author{
Ruta Sneidere, University of Latvia, Latvia ${ }^{1}$ \\ Inese Vigante, University of Agriculture, Latvia \\ Inga Bumane, University of Latvia, Latvia
}

\begin{abstract}
Information availability and disclosure are a precondition for effective governance of state-owned enterprises. The principles of social accounting are the tool that ensures information disclosure to the public about the operational environment of a state-owned enterprise and the justification for its achieved outcomes. Defined and publicly available goals are a characteristic feature of a good and effective practice of the management of state-owned shares. The research purpose is to study the development of social accounting principles and their application practice in the European state enterprises and, based on the research findings, to develop recommendations for ensuring the performance disclosure and transparency of state enterprises in Latvia. In the first part of the research, the authors pay the main attention to evaluating the business purpose of state enterprises in philosophical aspect. In the second part requirements for information disclosure and publication of state-owned enterprises in particular European countries are studied. At the end, the authors summarized the main research findings and develop recommendations for ensuring disclosure and publication of sustainability reports of state enterprises in Latvia. At least the large state enterprises should be assigned the responsibility to publish sustainability reports following the social accounting principles of Global Reporting Initiative. The monographic, analysis and synthesis methods have been used in the current research.
\end{abstract}

Key words: accounting, state-owned enterprise, transparency, sustainability report JEL code: M14, M48

\section{Introduction}

As provided by the Latvian regulatory framework, a state-owned enterprise (hereinafter referred to as a state enterprise or SOEs ) can do business only in particular cases - if the market is not capable of ensuring public interests in the respective field or industry where natural monopoly exists, thus the state enterprise ensures the availability of the respective service to the public. A state enterprise can also do business in a nationally strategically important industry or in the industry whose development of the infrastructure requires large capital investment and in the industry that requires higher quality standards due to public interests (Administrative Structure Law, 2012). State enterprise must frequently implement somewhat controversial goals, namely, must attain socio-political goals useful for society, at the same time also do business. Therefore, it is necessary to ensure good corporate governance, i.e. a mix of measures for state

${ }^{1}$ Corresponding author - e-mail address: ruta.sneidere@lu.lv 


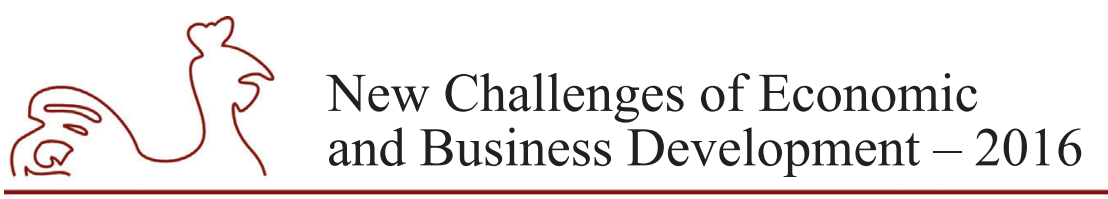

May 12-14, 2016, Riga, University of Latvia

enterprise to attain their operational goals and control their operations, as well as to evaluate the risks associated with the operation of state enterprise.

State enterprise are supervised (in a broader sense) by civil servants, politicians and all society, therefore the requirement for information availability and disclosure in state enterprise is larger, because all tax payers are considered to be their owners. The condition that tax payers are indirect owners of state enterprise is also the basis for their operating results to be disclosed and the available information to be clear and precise. As our research approves, most European countries admit that information about the operations of state enterprise and their operating results should not be less disclosed than of the public limited companies. Analyzing the available information about the business of Latvian state companies, the authors arrived at a conclusion that there exists lack of information both on state companies' websites and in a summarized form on the state's part about the economic and specific industry policy goals, their implementation results and corporate governance. Therefore, it is of utmost importance to research experience of other countries about the corporate governance of state companies. One of the tools that ensures the transparency of corporate governance and is developing very fast in the $21^{\text {st }}$ century is social accounting. Social accounting emphasizes the notion of corporate accountability. D. Crowther defines social accounting in this sense as "an approach to reporting a firm's activities which stresses the need for the identification of socially relevant behavior, the determination of those to whom the company is accountable for its social performance and the development of appropriate measures and reporting techniques" (Crowther D., 2000). It is an important step in helping companies independently develop corporate social responsibility (CSR) programs which are shown to be much more effective than government mandated CSR (Armstrong et al., 2012). In the international practice, issues of corporate governance are solved at various level international organizations. The Principles of Corporate Governance developed by the Organization for Economic Cooperation and Development (OECD), as well as the OECD Guidelines on Corporate Governance of State-owned Enterprises and Global Reporting Initiative (GRI) guidelines are internationally recognized standards of best practice. Principles of good corporate governance are on its basis, including such principles as information disclosure, flexible and enterprise value increasing dividend policy, motivating remuneration policy, a non-political, transparent procedure for appointing members of state enterprise management institutions, definition of the business goals of state enterprises and evaluation of outcomes, effective supervision of state enterprises. The transparency of corporate governance allows preventing an evil use of the status of a state enterprise in the market environment and, what is most important, attaining public trust.

The research purpose is to study the development of social accounting principles and their application practice in the European state enterprises and, based on the research findings, to develop recommendations for ensuring the performance disclosure and transparency of state enterprises in Latvia. In the first part of the research, the authors pay the main attention to evaluating the business purpose of state enterprises in philosophical aspect. In the second part requirements for information disclosure and publication in particular European countries are studied. At the end, the authors summarize the main research findings and develop recommendations for ensuring disclosure and publication of sustainability reports of state enterprises in Latvia. The monographic, analysis and synthesis methods have been used in the current research. 


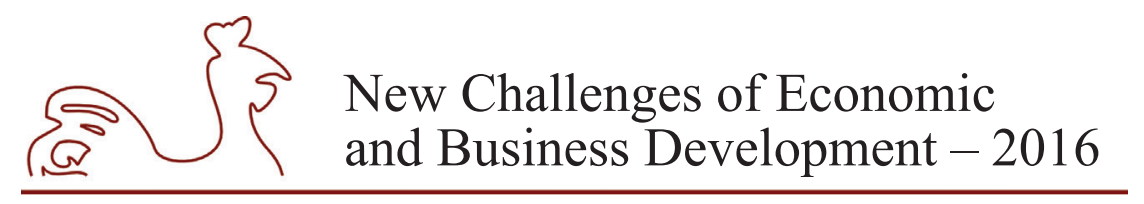

May 12-14, 2016, Riga, University of Latvia

\section{Business purpose of state enterprises and their philosophical aspect}

To provide the development of sustainable and competitive economics in a country, it should ensure balanced growth of various economic sectors, which at the same time provide a sufficient number of workplaces according to the skills possessed by the population, as well as offer new ones - with higher value added and remuneration. A topical issue is whether the state as the owner should establish enterprises to ensure the overall economic development or it is a prerogative of private business entities. Literature studies show that a power exercised by government or a federal state is ruling elite, and was typically rooted in political dogma, even though sometimes euphemistically referred to as governance by the people. Experience of the mid- $20^{\text {th }}$-century structures in China and Russia provide salutary warnings of the effect of centralized state planning and control. The privatization of many state-run enterprises, which were seen in the later years of the 20th century, such as the denationalization of British railways, power utilities, and water enterprises, reflected a shift towards the investor-power model, although, in most cases, the state retained influence, sometimes through a shareholding, or formally through regulators and informally through political processes. The company strives to respond to market forces and to meet the goals of its owners and directors (Tricker B., 2012).

Our research indicates, state enterprises exist in every national state and they perform a functional role in sustainable growth. Ownership goals of state enterprises are related to strategically important interests, gaining revenue, ensuring employment and preserving environment. In European countries state-owned enterprises exist if it is strategically significant regarding the economic, political or social aspects. Corporate level strategies are aimed at starting new business directions to increase the company value on long-term (Volkova T., 2010). The main business field of state enterprises is in industries service - power and gas, air and sea, as well as railway transportation and passenger transportation, public media, forest and health insurance industries and in providing the required infrastructure. State enterprises constitute a significant proportion in national economy and they employ a large number of people. They should attain the social goals based on the cost efficiency principle. Through their performance, state enterprises should also return the invested tax payers' money.

State enterprises usually have both financial and social goals. One the one hand, they should help to achieve social and political success, on the other hand - should act according to the economic laws in order to be able to operate and obtain profit within the market economy. The hardships of attaining such goals are partly attributed to the fact that the real costs of the social policy of state enterprises and the investment required to implement it are not fully realized. The close link with the state can politically affect state enterprises - sometimes political targets become primary and the commercial goals are assigned the secondary role. In many cases, it makes state enterprises inefficient, which in turn hampers attaining the social goals (Baltic Institute, 2010). J. Brooks, when visiting Vilnius Governance Coordination Centre and shared some of his insights on the good governance of state-owned enterprises, points out: "The SOEs needs to prepare a budget, where clearly and transparently stated non-commercial goals are taken into account. It does not have a direct profit and loss responsibility because by being assigned non-commercial goals, the enterprise is given targets which usually won't allow it to operate in profit. However, such an enterprise should still put in effort so as to carry out the assigned non-commercial functions at lowest possible costs - a task that requires a transparent and efficient financing system of non-commercial functions" (State-Owned Enterprises, 2013). 


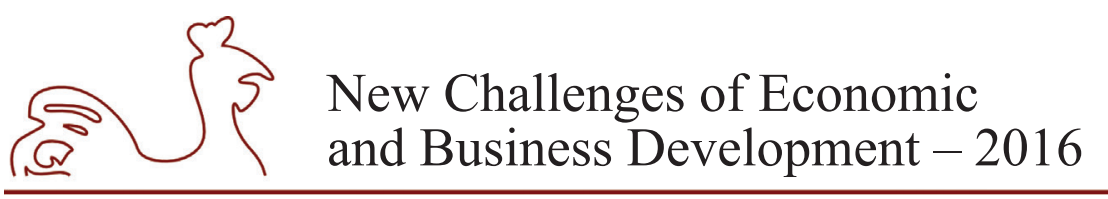

May 12-14, 2016, Riga, University of Latvia

Studying the operation of state enterprises in Finland, researchers mention the following categories of state enterprises: "enterprises entrusted with a special assignment and enterprises that operate on free market competition terms" (Kalniňš V., et al., 2011).

To enhance the public trust in the state's commercial activities, the topicality of the mission and goals of state enterprises and their justification should be regularly evaluated. Otherwise there is a risk that state enterprises will deviate from their goals or the targets of each particular task might not correspond to the national economy development needs. Therefore, it is necessary to evaluate the following positions:

1) the rationality of the state operations in particular market sectors to determine what the goals, both collective and individual, of state enterprises should be;

2) the role and the importance of state enterprises in support for a wider economic growth with a cost-based competitive infrastructure, e.g. the role of state enterprises should be evaluated when ensuring the use of the best telecommunication tools (Kalniņš V., et al., 2011).

In several studies, the issue of covering the losses of state enterprises from the tax payers' money is highlighted. Governments frequently oblige companies to do business and sell their goods below cost price with resulting business losses. These losses are then financed out of tax revenue to prevent the bankruptcy of public companies. The public company has a different "business philosophy" from the private company, which in the event of business loss has to cease operation and go into bankruptcy. Generally speaking, public companies will not face bankruptcy when the market rejects their business inefficiency or poor management (Grahovac B., 2004). Nowadays there are disagreements among economists, politicians, government representatives about whether the state should cover the expenses for social goods and services. One part considers that the state should always increase these expenditures while the other thinks that these expenditures and also tax payments should be decreased (Bikse V., 2007). While some state subsidies, loans and loan guarantees have been provided to Estonian SOEs, these appear to have been exceptional cases that have been provided at commercial market rates and handled transparently and with clear designation of the public policy objectives they are intended to serve. Subsidies have been offered and transparently disclosed to serve specific policy and public service objectives when an SOE has not been able to obtain sufficient revenue from its clients to cover the costs required to offer such products or services (Corporate governance in Estonia, 2011).

Within the present research, the authors analyze the mission and goals of state enterprises in certain European countries.

In Finland, the SOEs goals are defined based on the enterprises mission and the state enterprises are classified in two groups:

1) enterprises, who operate on market terms and whose goal is to gain the largest possible economic benefit;

2) enterprises, who are entrusted with special state assignments and whose primary objective is to attain social goals, as well as perform profitability.

Enterprises that execute a special task should attain social goals although they also have a general goal to operate with profit. The goals are developed so that the best social and economic outcomes are achieved. The state as an owner may also have strategic interests regarding some of these enterprises, e.g. to maintain the infrastructure or provide certain services, but 


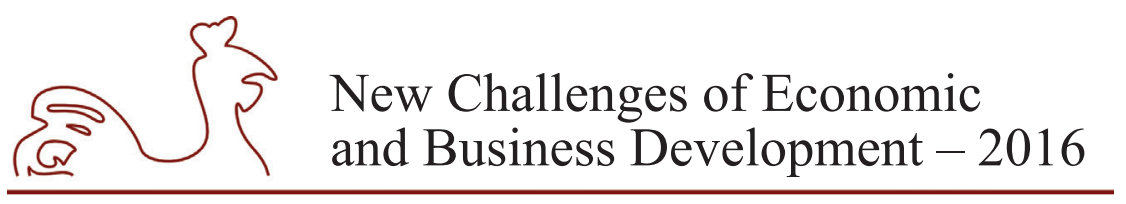

May 12-14, 2016, Riga, University of Latvia

it should also happen according to clear business principles. In such enterprises, the goal of state ownership execution is to gain maximum economic benefits that are regularly evaluated. Profitability and value increase on long-term, taking into account the state's strategic interests and their protection, are on the basis of the evaluation. If the state fully owns an enterprise, it can freely define the social goals and objectives. If the state is only a partial owner, such tasks can be assigned when all owners agree (Kalniņš V., et al., 2011).

Also in Great Britain, the ownership goals are constantly defined, thus aligning the commercial and the social goals of state enterprises and ensuring disclosure regarding the use of finances in order to satisfy social needs. Attention is paid to attaining the social goals of enterprises according to the cost efficiency principle. Taking into account the parameters set by the UK government, operating results of state enterprises should be sustainable, with positive yield and they should pay back within a certain period of time or exceed the capital costs (Kalniņš V., et al., 2011).

The Estonian State participates in companies generally where a market distortion occurs or where there is a strategic public interest involved. With respect to foundations, the Estonian State operates through a foundation when the state's objective is more specific, less commerciallyoriented (generally for social, cultural or educational purposes or to promote entrepreneurship), and the form of company or government unit is not suitable. Regarding the state ownership functions, ministries are obliged to set operational and financial objectives for each SOE, and report to the Ministry of Finance on these year on year. This forms the basis of the Ministry of Finance's annual consolidated report, in which among other issues the State's ownership policy is stated (although this is not done with the same level of detail every year). This consolidated annual report is then presented to the Government (Corporate governance in Estonia, 2011).

Seeking to make Lithuanian SOEs operating as efficiently as possible, the states must clearly identify objectives set for SOEs, while these objectives have to be harmonized with the long-term strategies of the enterprises. The goal of the guidelines is to provide a certain level of disclosure, responsibility to Lithuanian society, attractiveness to investors and business partners, as well as to introduce internationally recognized good governance principles of enterprises - to prepare and publish comparative and topical information about the activities and results of state enterprises. To the greatest extent possible, the objectives must quantifiable, and the enterprises should be subject to regular evaluation with respect to how they achieve the set objectives. SOEs can operate efficiently only when they clearly know what the state expects from them. At Lithuania all SOEs are divided into three groups by the state objectives:

1) A group which includes enterprises from which the state expects growth in their business value and a yield from dividends or profit contributions.

2) A group which comprises companies from which the state expects, in addition to growth in their business value and a yield from dividends or profit contributions, safeguarding of national strategic interests: national economic security, implementation of strategic projects, quality infrastructure and other objectives.

3) Governing the enterprises included in this group, the state gives priority to the implementation of social and political objectives, and profitable activities have a secondary role. The enterprises of this group must engage in non-commercial operations which other profit-making companies would refuse to perform or would do that for a higher price. 


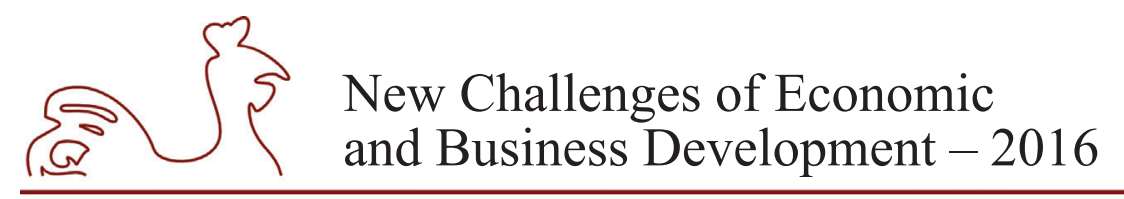

May 12-14, 2016, Riga, University of Latvia

Having divided all SOEs into these three groups, the state started to expect to achieve the pre-set return on its capital invested in Group 1A and Group 1B enterprises. With respect to enterprises assigned to Group 2, the state has begun demanding the most possible transparent and efficient use of funds in their operations (State-Owned Enterprises in Lithuania, 2013).

In Sweden, the goals of state enterprises are divided into three groups: financial, socioeconomic and special goals. Financial goals are defined by both the state as the owner and the company management, and both parties communicate and monitor at both levels. The importance of the financial goals from the owners' point of view is: to ensure the increase of the company value, to achieve efficient use of the capital clarifying the capital costs, to maintain company risks at a standard level, to ensure the owner's possibility to receive dividends sustainably and predictably taking into consideration the future capital needs of financial positions of the enterprise, to ensure and facilitate achieving operating results, to monitor and evaluate the company's profitability, effectiveness and level of risks. Goals and their definitions are different in each enterprise, taking into account the industry they operate in, the structure of business activities, the financial situation of the enterprise etc. Socio-economic goals are defined for state enterprises that have special social tasks. In these enterprises, financial goals are juxtaposed to the goals aimed at attaining especially significant public interests. For example, there might exists a demand for a state enterprise to provide services or offer goods across the entire territory of the country although it is not economically feasible. One of the most significant enterprise indicators is cost efficiency. Special objectives are defined regarding the environmental, social, human rights and gender equality issues, variability, ethics and financial risks (goals and their attainment results are reflected in the sustainability report). Special objectives differ from the socio-economic goals because they do not define the economic outcomes of the enterprise operation, but they determine the quality of operations regarding the environment, human rights etc. (Kalniņš V., et al., 2011).

In Latvia the situation is different. The foundation of state enterprises is regulated by the State Administrative Structure Law, which stipulates that a public entity establishes a state enterprise if the market is not capable of implementing public interests in the respective area (Administrative Structure Law, 2003). Secondly, Latvia started significant reforms in the governance of state enterprises in 2012, the aim of which is to increase the profitability and value of the state-owned enterprises, to improve their governance transparency, as well as to release the ministries from the functions not characteristic to them. In total there are 137 state enterprises in Latvia. They have state-owned shares and 109 state-owned enterprises of them have a dominant impact (Cross-cut Coordination Centre, 2014). Therefore, it is important to investigate what are the goals of these state enterprises, if the enterprises are aimed at gaining profit, thus distorting the market environment, or if they have social or political goals.

After profound research on the current state enterprises governance reform the authors discovered that the foundation goals of state enterprises are defined in laws and regulations and are divided by their importance:

- to ensure the implementation of public interests in the respective area or industry where natural monopoly exists, thus providing the respective service to the society;

- to develop a strategically important industry or an industry whose infrastructure development requires large capital investment and an industry that requires a higher quality standard to be implemented in the interests of society (Administrative Structure Law, 2014). 


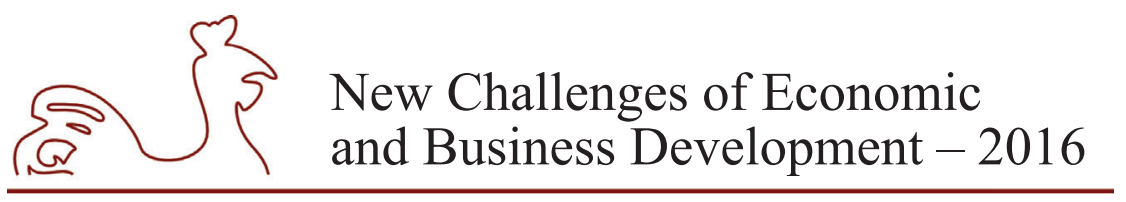

May 12-14, 2016, Riga, University of Latvia

As our analysis indicates, the law does not stipulate that the goal of a state enterprise is gaining profit. It is determined by the Conception of the Commercial Activity of Public Entities that not to damage the competition, the state should operate as an equal partner for private business only in the cases when it is necessary for ensuring the security function and the state policy in one of the areas of public life, for example, ensuring the availability of the public service to the country's population (Cabinet of Ministers, 2012). Therefore, the issue of the contents of the information available to public, based only on the financial positions, is arguable. Non-financial information serves for following up and assessing the companies' corporate governance, sustainability work and performance of societal tasks.

\section{Provision of the information transparency and publication requirement}

Most of the European countries have followed Global Reporting Initiative guidelines when developing and altering the governance of their state enterprises. The GRI is an international independent standards organization that helps businesses, governments and other organizations understand and communicate their impacts on issues such as climate change, human rights and corruption. The GRI Guidelines offer Reporting Principles and Standard Disclosures and an Implementation Manual for the preparation of sustainability reports by any type of organization, regardless of size, sector or location (GRI, 2015). As of 2015, 7,500 organizations used GRI Guidelines for the sustainability reports. GRI Guidelines apply to multinational organizations, public agencies, smaller and medium enterprises (CNBC Africa, 2015). The guidelines provide links with the United Nations Global Compact's Ten Principles, the OECD's Guidelines for Multinational Enterprises and the UN's Guiding Principles on Business and Human Rights (EY, 2013).The first objective of the Global Reporting Initiative (GRI) guidelines is to provide a global framework that supports a standardized approach to transparent and consistent sustainability reporting. A second, equally important objective is to drive organizations to prepare more relevant and credible sustainability reports by focusing on the topics that are material to their business and their key stakeholders, thus enabling such sustainability reporting to become standard practice. The guidelines are designed to align and harmonize as much as possible with other internationally recognized standards.

There are four key elements in the guidelines framework:

- Sustainability reporting guidelines are the cornerstone of the framework. These consist of Principles for defining report content and ensuring the quality of reported information. They also include Standard Disclosures made up of performance indicators and other disclosure items, as well as guidance on specific technical topics in reporting.

- Indicator protocols provide definitions, compilation guidance, and other information to assist report preparers and to ensure consistency in the interpretation of the performance indicators.

- Sector supplements complement the Guidelines with interpretations and guidance on how to apply them in a given sector, and include sector-specific performance indicators.

- Technical protocols are created to provide guidance on issues in reporting, such as setting the report boundary. They are designed to be used in conjunction with the Guidelines and sector supplements and cover issues that face of the most organizations during the reporting process (Proving and improving, 2015). 


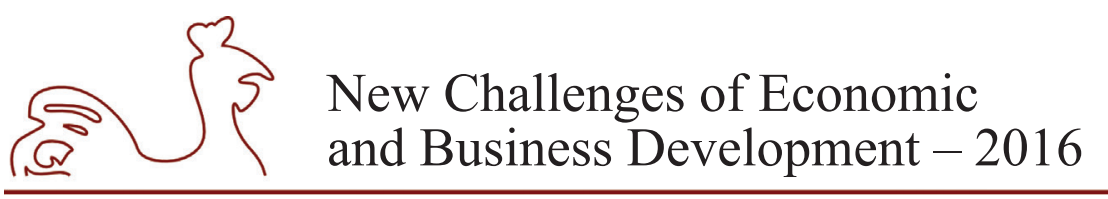

May 12-14, 2016, Riga, University of Latvia

In addition, specific standard disclosures have been added for anti-corruption practices, greenhouse gas emissions and energy. These disclosures are required when the aspects to which they relate have been identified as material. The emphasis on materiality will allow to reported information that is critical to business and stakeholders (EY, 2013).

At the European Union (EU) level the strategy "Europe 2020" has been developed. Its goal is to enhance wise, sustainable and inclusive economics, helping the EU and its Member States to achieve a high employment, productivity and social cohesion level. Its success also depends on the institutional factors, for example, good governance, rule of law and corruption control. Disclosure is significant in the governance of state enterprises in order to ensure the rule of law. The research performed by the European Commission (EC) reveals that in some European countries insufficiencies regarding the governance of state-owned enterprises can be observed and there exists a large corruption risk (EC Report, 2014).

Irrespective of the country's development level, the economic and social development objectives in all countries should be defined so that they comprise sustainability. To ensure sustainable development it is necessary to integrate environmental, economic and social aspects in a single system. GRI guidelines provide the opportunity to characterise the enterprises with a system of complex indicators - systemic indicators and universal cross-cutting indicators which cover several operational areas (Kočanova R., 2013).

In the majority of European countries, their governments have approved disclosure guidelines for developing the external reports of state enterprises and the procedure for the report publication. Reports should be available on the internet sites of state enterprises. If the enterprises do not have them, the reports should be available via the websites of supervising institutions.

Already in the past research of different international organizations approved that in Scandinavian countries the information availability is ensured at the highest level. Fifty years ago, the information availability and disclosure principle was included in the Swedish law on press freedom; the official information availability principle is also included in Swedish Constitution. The essence of the main disclosure principle is that everyone has the right to look inside the state governance documents. If the civil servants realize that they are performing in front of the nation all the time, this awareness affects them. It makes them act fairly. Such a situation impacts positively on the overall corruption prevention. Regarding the corruption index, the Swedes traditionally occupy the highest ranks (Indrāns I., 2001).

Sweden, where reporting has been mandatory from January 2008 onwards, has significantly increased the reporting of its 55 state-owned companies. Since January 2008, Swedish stateowned companies have been required to publish a sustainability report in accordance with the GRI guidelines. The sustainability reports need to be quality-assured by independent checks. The financial report is required to explain how the GRI guidelines have been applied and to comment on any deviations (CSR, 2011). The reports should describe the commercial activities of enterprises, and the reports serve as a benchmark for evaluating attainment of goals and objectives.

In Sweden state enterprises should submit the different types of public reports: the annual report, interim reports, the year-end report, the corporate government report, the statement on internal control and the sustainability report. Statistical data approve of positive trends of introducing social accounting principles in Sweden - if in 2006 only 14\% of enterprises 


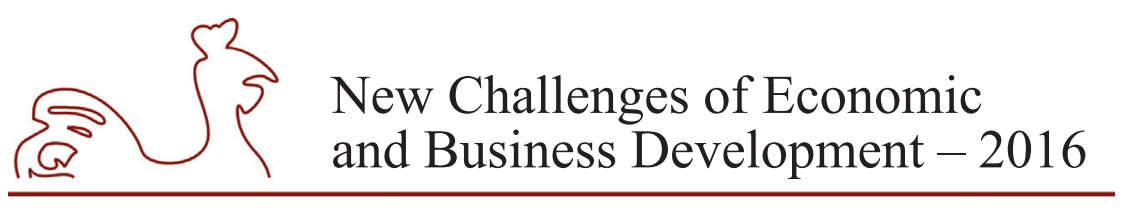

May 12-14, 2016, Riga, University of Latvia

submitted the sustainability report, then in 2009 it was around $94 \%$ of enterprises that published the report (Kalniņš V., et al., 2011).

Sustainability reports are developed also by state enterprises of such European countries as Denmark - from 2008, Norway - from 2009, the Netherlands - from 2009. Also in Great Britain, Austria and Belgium state enterprises should report on the environmental and social issues. In Finland in state enterprises in which the state has the majority interests, the enterprises should exhibit the same disclosure and information availability as those enterprises that trade their shares on the stock exchange and as it is stipulated by the Code of Corporate Governance. Similar to Sweden, Lithuania has also developed Disclosure Guidelines for state enterprises, which describe how to ensure disclosure in the operation of state enterprises (Kalniņš V., et al., 2011).

In Latvia, the state influence on entrepreneurship is still large. The state possesses strategic industries, as well as such that perform social functions. As our research indicates, using the public information available on the internet, up to now the publicity of state enterprises in Latvia does not follow the GRI Guidelines. At the national level, the information is not summarized about the public reports of all state enterprises and the laws and regulations do not stipulate that either. Currently only some state enterprises publish their annual reports on the internet. State corporations Latvenergo and Latvia's State Forests can be mentioned as a good example. For several years already, they haves been developing sustainability reports following the social accounting principles of GRI guidelines for ensuring quality - balance, clarity, preciseness, timeliness, comparability and trust to provide a balanced and adequate view about the economic, ecological and social indicators to the stakeholders and about the contribution of the enterprise to sustainable development. After the performed reform, the main regulating document that contains provisions for the introduction of social accounting principles is the Public personal shares and capital management law, which set in force on January 1, 2015. Provisions for the information publication of state enterprises are comprised in Article 58 that stipulates an enterprise of public entity and a public private enterprise publish information on their internet webpage, but if the enterprise does not have the webpage - on the webpage of the owner of the shares. The information about the overall strategic goals of state enterprises, news about their types of operational and commercial activities shall be provided on the internet, as well as not less than once a year the information about:

- the financial goals of state enterprises (according to the approved annual report) and results of the implementation of non-financial goals (including the total balance, net turnover, profit and loss account, cash flow, various performance indicators characterising the operations of state enterprises),

- the payments to the state or the municipality budget (including dividends, deductions, tax payments),

- the received state or municipality budget financing and its use (if applicable),

- principles of the remuneration policy,

- sponsorships (donation) strategy of state enterprises and the procedure of sponsoring.

The state enterprises also have the duty to publish unaudited quarterly, half-the year reports, as well as the audited annual report. Likewise, the law stipulates that the information about the structure of the ownership (including the participation in other enterprises) and the organizational structure, as well as other significant information if it is not related to releasing a commercial secret, should be constantly and accordingly updated (The Public personal ..., 2014). 


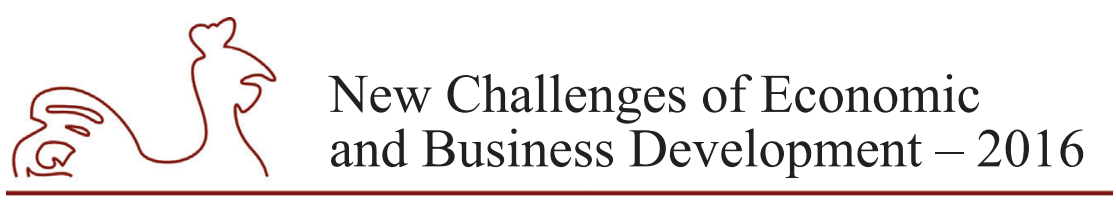

May 12-14, 2016, Riga, University of Latvia

To facilitate society's trust in the commercial activity of public entities, it would be reasonable for Latvia to acquire the practice of Swedish state enterprises where sustainability reports must be written as required by the guidelines of Global Reporting Initiative.

\section{Conclusions}

Summarizing the research results on the application of social accounting principles in the state-owned enterprises in certain European countries, as well as analyzing their business goals, the authors have come to the following main conclusions and proposals:

1. In international practice, corporate governance issues are solved at different level international organizations. Among the most influential is the Organization for Economic Cooperation and Development and its developed corporate governance principles; as well guidelines for the governance of state enterprises are taken into consideration when implementing social accounting principles. The importance of implementing these can be well explained by the condition that state enterprises relatively belong to all tax payers. Therefore that is the basis for their operational results to be disclosed and the available information to be clear and precise.

2. In most countries it is admitted that the information about the business and the outcomes of state enterprises should not be less open than the one about the enterprises listed on the stock exchange. In Europe the state possesses enterprises if it is strategically important from the economic, political and also from the social aspect.

3. Analyzing the goals of the state enterprises in the European countries, it can be stated that they are different. In Finland, the goals of state enterprises are defined based on the company mission and it is to govern state enterprises to attain the possibly best social and economic benefits. Whereas in Norway, the main goal of state enterprises is long-term growth and industry development. In Great Britain, the basis of business activity is to align commercial and social goals and to ensure disclosure regarding the use of finances related to satisfying the social needs. The attention is paid to the fact that enterprises attain the social goals as provided by the cost efficiency principle.

In Sweden, the definition of goals and their attainment supervision is a fundamental part of corporate governance. It is the government's duty to see that the value of state enterprises increases to its maximum according to the current circumstances. Within the framework of supervision, the attaining of financial, socio-economic and other goals is assessed.

4. In Latvia more emphasis is placed on the financial outcome of state enterprises. Within the reform, a report on the changes in the positions of assets and profit has been prepared and Bureau of the State-owned Shares Management will regularly follow the value of the assets and the dynamics of profit and loss of state enterprises informing the society about it. This information will provide society the opportunity to see how the value of the assets and the profitability of these enterprises have changed over time. The authors would like to indicate that it would be reasonable to inform society about the goals of state enterprises, especially emphasizing the social and economic significance of the operation of state enterprises.

5. After researching the information disclosure and publication requirements in certain European countries, it can be stated that in most countries their governments have approved guidelines for external reporting of state enterprises and for the procedure of report publication. Reports should be available on the internet sites of state enterprises. If the 


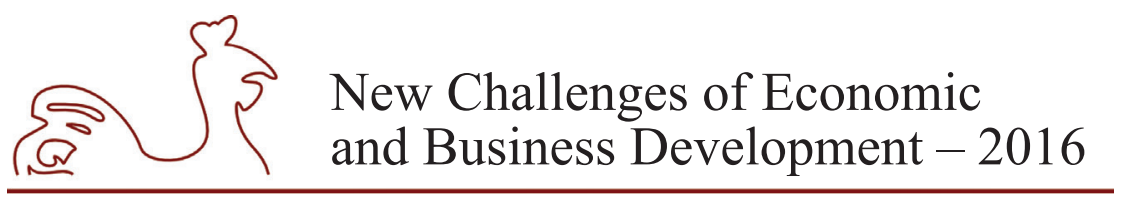

May 12-14, 2016, Riga, University of Latvia

enterprises do not possess such internet sites, then the websites of their supervising state institutions should be used.

6. To ensure sustainable development, it is necessary to integrate environmental, economic and social aspects into a single system. Social accounting principles offer the possibility for enterprises to develop a complex reporting system that provides open information about the operation and the performance outcomes of state enterprises regarding particular goals.

7. Swedish practice reveals that in their business state enterprises should serve as examples for other enterprises. In Sweden, the principle of official information availability is widely observed.

8. As a result of the reform performed in Latvia, the Public personal shares and capital management law, set in force on 01.01.2015. One would like to see that the attitude of state enterprises to the requirements of the new law is not formal but involves a high level of responsibility and that the information included in the reports approves of the responsibility to the society, doing business for ensuring the state interests.

9. In Latvia, at least the large state enterprises should be assigned the responsibility to publish sustainability reports following the social accounting principles of GRI guidelines, and it would be reasonable to develop the reporting culture taking into account Swedish experience. Sustainability reports must be published together with the annual report on the enterprise website. Likewise, it would be reasonable at the national level to summarize the public reports of state enterprises and to post them on a single internet site available to society.

\section{Bibliography}

Armstrong J., Green S., Kesten C., 2012. Effects of Corporate Social Responsibility and Irresponsibility Policies. Journal of Business Research. [Online] Available at: http://mpra.ub.uni-muenchen. de/43007 [Accessed 28 October 2015].

Baltic Institute of Corporate Governance, 2010. National Corporate Governance Guidelines in the Baltic States. [Online] Available at: http://www.ecgi.org/codes/documents/bicg_guidance_lv.pdf [Accessed 7 November 2015].

Bikse V., 2007. Ekonomikas teorijas pamatprincipi. Izglītības soḷi, Rīga.

CNBCAfrica, 2015. The Value of Sustainability Reporting - GRI. [Online] Available at: http://www. cnbcafrica.com/ [Accessed 14 May 2015].

Corporate Governance in Estonia, 2011. OECD Publishing. [Online] Available at: http://www. keepeek.com/Digital-Asset-Management/oecd/governance/corporate-governance-in-estonia2011_9789264119079-en [Accessed 10 December 2015].

Cross-cut Coordination Centre, 2014. The Listing of Shares on 1 July 2014 of Country, State Corporate and Decisive Influence of the State-owned Limited Liability Companies With Share Capital.[Online] Available at: http://www.pkc.gov.lv/darba-grupas [Accessed 20 November 2014].

Crowther D., 2000. Social and Environmental Accounting. London: Financial Times Prentice Hall.

European Commission, 2011. Corporate Social Responsibility, National Public Policies in the EU. [Online] Available at: http://ec.europa.eu/growth/industry/corporate-social-responsibility/index en.htm [Accessed 10 December 2015].

European Commission, 2014. EU Anti-Corruption Report. [Online] Available at: http://ec.europa.eu/dgs/ home-affairs/e-library/_lv.pdf - 2014 [Accessed 10 December 2015]. 


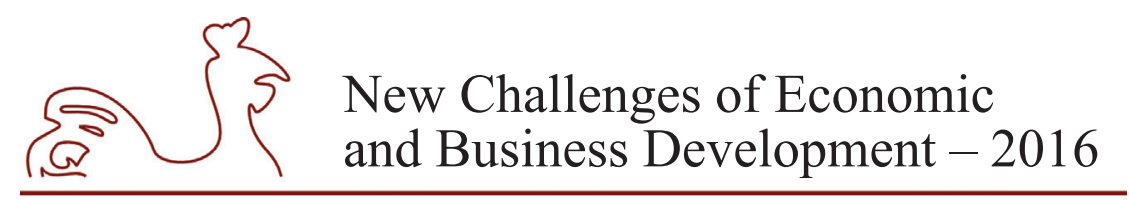

May 12-14, 2016, Riga, University of Latvia

Ernst and Young (EY), 2013. G4 Sustainability Reporting Guidelines. [Online] Available at: http://www. ey.com/Publication/vwLUAssets/G4-Sustainability-Reporting-Guidelines/.pdf [Accessed 7 November 2015].

Grahovac B., 2004. East and West European Public - Private Partnerships Public Companies in Restructing and Privatization. Nova Science Publishers, Inc. New York.

Global Reporting Initiative, 2015. Sustainability Reporting Guidelines. [Online] Available at: https:// www.globalreporting.org/resourcelibrary/G4-FAQ.pdf [Accessed 8 November 2015].

Indrāns I., 2001. Informācijas atklätība. Rīga, RTU izdevniecība.

Kalniņš V. Litvins G., 2011. Augošas vērtības meklējumos valsts un pašvaldību kapitālsabiedrības: rīcībpolitikas un praksesizvērtējums. [Online] Available at: http://www.lnb.lv/ [Accessed 10 December 2015].

Kočanova R., Geipele I., Niedrīte V., 2013. Stratēgiskās vadīšanas sistēma organizāciju ilgtspējīgai attīstībai. Rīga: RTU izdevniecība.

Proving and improving, 2015. Global Reporting Initiative Guidelines. [Online] Available at: http://www. proveandimprove.org/tools/griguidelines.php [Accessed 11 January 2016].

State-Owned Enterprises in Lithuania, 2013. Annual Report. [Online] Available at: http://vkc.vtf.lt/static/ uploads/ataskaitos/2013_metine_VVI_ataskaita_EN.PDF [Accessed 7 November 2015].

The Cabinet of Ministers Republic of Latvia, order No 245, 2012. Public Persons Business Concept. [online] Available at: www.likumi.lv [Accessed 20 November 2014].

The law of Republic of Latvia, 2012. The State Administrative Structure Law. [Online] Available at: www. likumi.lv [Accessed 20 November 2014].

The law of Republic of Latvia, 2014. Public personal shares and capital management law. [Online] Available at: www.likumi.lv [Accessed 20 November 2014].

Tricker B., 2012. Corporate Governance Principles Policies, and Practicies. Second Edition, Oxford University Press.

Volkova T., 2010. Bizness pāri robežām: praktisks cel̦vedis jaunu tirgu apgūšanā. Rīga: LU Akadēmiskais apgāds. 


\title{
SMART INDUSTRIAL SPECIALIZATON: CASE OF LATVIA
}

\author{
Kristaps Soms, University of Latvia, Latvia ${ }^{1}$
}

\begin{abstract}
The economic model of Latvia, which fostered an increase in domestic demand was not a sustainable and consequently led to an economic crisis. During after-crisis period transition to sustainable economic model has happened, where exports and manufacturing were the key drivers of growth. It shall be mentioned that debate on the necessity of industrial policy was initiated comparatively late after the independence, i.e., in 2008/2009, when the first analytical studies concerning necessity of the concept of industrial policy in Latvia were conducted, thus defining the role and activities of the State in fostering economic development.

Similarly, to development of Latvia's economy it is possible to look on development of industrial policy thinking, because it has gone through several changes in its fundamentals during last century including rapid changes in the set of necessary actions for successful industrial policy.

Most recent trend within economic policy of the EU, is usage of so called smart specialization concept. The idea of smart specialisation has two sides. Firstly, it is important to focus on certain domains in order to realise the potential for scale, scope and spillovers in knowledge production and secondly, it is important to focus on certain domains in order to develop distinctive and original areas of specialisation for the future.

This paper discusses the development of industrial policy and economy of Latvia, discusses the smart specialization concept, and analyses the possibility of applying this concept within industrial policy of Latvia.
\end{abstract}

Key words: Industrial policy, specialization, Smart specialization strategy

JEL code: L52

\section{Introduction}

Latvia's economy has gone through important macroeconomic adjustments. The economic model, which has fostered an increase in domestic demand, especially housing boom, was not a sustainable and consequently led to an economic crisis. During after-crisis period transition to sustainable economic model is taking place in the economy of Latvia, in which exports and manufacturing are the key drivers of growth. At this stage of economic development concept of Industrial policy has been seen as a potential tool to foster and support development in Latvia's economy.

Debate on the necessity of industrial policy was initiated comparatively late after the independence, i.e., in 2008/2009, when the first analytical studies concerning necessity of the concept of industrial policy in Latvia were conducted, thus defining the role and activities of the State in fostering economic development. These debates were followed by recommendations from the Ministry of Economics regarding the role of the State in the economy. It should be

1 Corresponding author - e-mail address kristaps.soms@gmail.com 


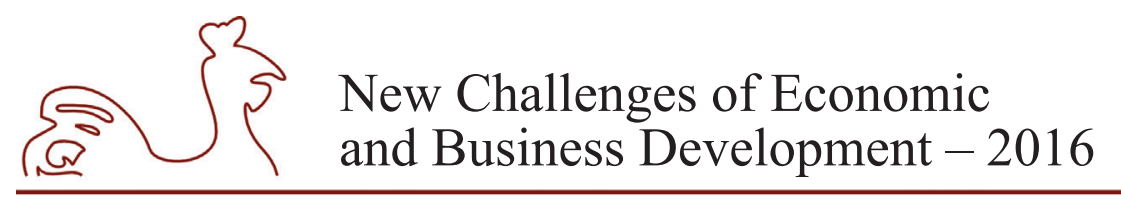

May 12-14, 2016, Riga, University of Latvia

noted that the recommendations of the Ministry of Economics and empirical studies highlighted the fact that theoretical and empirical studies of the economic science prove the benefits of an active state intervention in the economy. Which ensures that future development and welfare of the state can be free of restrictions and conditions imposed by the economic structure, and it forms an essential challenge for the present growth in Latvia

Aim of the paper is to analyse development of industrial policy in Latvia, as well to analyse implementation of smart specialization concept in Latvia.

\section{Research results and discussion}

\section{Development of the concept of industrial policy}

Looking back at development of industrial policy concept in economic literature, it shall be noted that it has changed during times and adapted according to development of thinking what industrial policy is and what is role of state within industrial policy. Reich (Reich, 1982) who was a great supporter of industrialisation in the United States, defined industrial policy as a set of measures performed by the state with the aim to support such industries that present great potential for export and creation of new jobs, as well as promote the development of infrastructure.

However, Pinder (Pinder, 1982) has proposed a more comprehensive definition, which includes all the policies that have been formed in support of industries, including fiscal and monetary initiatives that would promote investments, public procurement initiatives, as well as initiatives to facilitate research and development, state programmes for the development of national champions in strategic sectors, and various activities in support of small and mediumsized enterprises. As can be concluded from the definition, Pinder's approach is all-inclusive and any state initiative is regarded as a part of national industrial policy.

Landesmann (Landesmann, 1992) differs from the above mentioned authors as he has made a unique contribution to the definition by underlining the selective component. He argues that industrial policy includes such activities of a state that discriminate and select among industries, sectors and agents, and as are designed specifically for a chosen industry and agent within a given territory. Namely, Landesmann in his definition has included two aspects, firstly, a very high level of selectivity and, secondly, influence of the regional aspect on the selection.

Pack (Pack H., 2000) defines industrial policy as actions designed to target specific sectors to increase their productivity and their relative importance within the manufacturing sector.

Discussions on the industrial policy have re-emerged especially in the $20^{\text {th }}$ century after the Second World War during the reconstruction of Europe and Japan, as well as after many colonies in Africa and South America gained their independence. During this period such aspects of economics as coordination failure, size of economies and absence of the demand side were at the heart of the discussions on development economics. This period is represented by such authors as Rozenstein-Rodan (Rozenstein-Rodan, 1943), Hirschman (Hirschman, 1958) and others. During those days selective intervention instruments were widely used by governments, for example, market protection measures in the form of tariffs and quotas.

The next stage of the development of industrial policy represents the period after 1970 . During this time the principles of Washington Consensus strongly prevailed in economic 


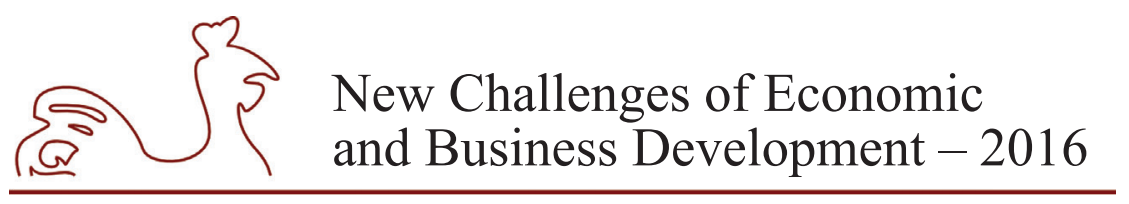

May 12-14, 2016, Riga, University of Latvia

theory and were also used by several international organisations, for example, the International Monetary Fund and the World Bank, as a basis for their activities. Under the influence of the Washington Consensus the concept of industrial policy was possible but emphasis of its contents was substantially altered and restricted. It was presumed that industrial policy employed by a state as a set of instruments that have an influence on the economic structure should be restricted to the elimination of a limited number of market failures (for example, improvements of education system or infrastructure), and a substantial widely practised and maintained element included termination of restrictions on import as well as decreasing of state participation in enterprises. Implementation of the concept of industrialisation of this period, especially trade liberalisation question in Sub-Saharan Africa, has been extensively analysed and criticised in economic theory. Carmody and Tregenna (Carmody, 2009; Tregenna, 2009) in their arguments emphasize that the application of the industrial policy of this period, especially market liberalisation, has had an adverse impact that has resulted in industrial downturn.

A significant turning-point in the development of the concept of industrial policy occurred due to the East Asian financial crisis at the end of the 90s. Discussions on the concept became more active as the authors focused on the analysis of causes of the economic crisis. For example, Pack (Pack, 2000) assumes that the crisis was caused by the previous industrial policy implementation decisions that encouraged a situation in which banks provided loans to unproductive sectors of national economy. In the post-crisis period when an intensive analysis of aspects that had caused the crisis was performed, there emerged several sceptics of the concept of industrialization, as for example Lall (Lall, 2004) admits that selective industrial policy is economically undesirable and destructive.

Rodrik and Hausmann (Hausmann, Rodrik, 2003; Rodrik, 2004) in their conclusions as to industrial policy introduce essential modifications in the previously existing definitions, which can be explained by the changes in the prevailing opinion of what the industrial policy is. Hausmann and Rodrik use the term new industrial policy defining it as an ongoing dialogue between the government and the private sector to acquire the necessary information for the identification and elimination of factors that hinder development. Alongside the changes in the definition also the meaning of industrial policy becomes broader and in this case includes not only manufacturing industry but the economy as a whole comprising the service sector as well as other sectors of national economy.

Notwithstanding the fact that in economic literature Rodrik and Hausman's definition has been recognised as well-grounded and is regarded as one of the most developed in defining the role of a state, there exist also opinions of other authors. For example, Pack and Saggi (Pack, Saggi, 2006) define industrial policy as any selective state intervention which attempts to change the structure of economy towards the sectors that are expected to provide better prospects for economic growth and welfare, which would be impossible to achieve without governmental intervention.

Nabli (Nabli M., Keller J. et al., 2006) argue that any policies or interventions that influence how industries expand are referred to as "industrial policies", but there is distinction between "horizontal" and "vertical" industrial policies. Vertical policies usually target the economic output of specific industries and even firms. Horizontal policies essentially focus on improving the quality of inputs in the production process, which presumably benefits all firms. 


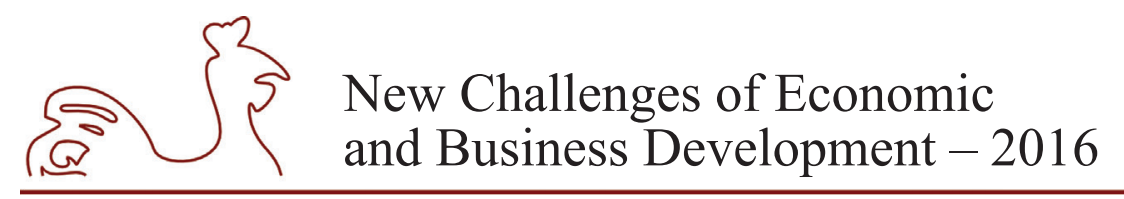

May 12-14, 2016, Riga, University of Latvia

\section{Development of a National Industrial policy in Latvia}

In the course of the last 20 years in Latvia industrial policy has not been described or defined before 2009, when the first attempt was made at describing industrialization and defining its goal.

Beņkovskis et al (Beņkovskis, Rutkaste, Vìtola, 2009) performed an empirical study to identify priority sectors in Latvia's economy. Defining of priorities was based on considerations which emphasised that it is necessary to concentrate the resources available by the State (financial and human) to foster the growth of national economy thus improving purposeful investment and efficiency of resources and that the defining of priority sectors is a requisite instrument of structural policy. The authors acknowledged that the market fails to guarantee a high income and prosperity level that would be comparable to indicators of the developed countries, and therefore an active and targeted economic policy is required. However, when production factors are considered, the authors admit that sectors and products have their own specific set of production factors, which in the course of time have developed among the existing industries taking into account production circumstances of the specific products, and therefore, due to the established production factors in the country, it is highly possible that companies will focus on the production of the existing or closely related products. The export structure that derives from Latvia's economic openness and dimensions served as the basis for sector identification, and it was assumed that promotion of export would help to enable faster economic development and increase prosperity. When comparing historical development of the concept of industrial policy and Latvia's approach to the defining of industrial policy, it is essential that alongside the identification of priorities the authors provide also several crucial restrictions. They argue that open protectionism and subsidies are not the instruments to be employed by the State to support priority sectors. Industrial policy should focus on provision of production factors and, primarily, on the preparation of human resource base.

The next stage of industrial policy development is related to the actions of the government in respect to its definition. In 2009 the Ministry of Economics prepared and the Cabinet of Ministers approved report on recommendations for economic recovery in the medium term. The project provided two courses of action. Firstly, strengthening of the competitiveness or horizontal support policy aimed at the improvement of general business environment and, secondly, the defining of priority sectors. Similarly as in the previous research, assertions of the Ministry of Economics were based on the presumption that the resources needed to be concentrated to achieve greater yield and efficiency. State intervention, in particular selective intervention, was specified as the leading instrument, i.e., the defining of priorities is necessary in order to get out of the economic structure that emerged during the crisis and as a result of it. In contrast to the research performed by Benkovskis et al., the Ministry of Economics extends the selection instruments to include not only identification of priority sectors and products, but also specific companies that show high growth potential even though they do not represent priority sectors. The priority sectors that were defined from practical perspective were comparatively widely supported in the activities performed by ministries representing various sectors and aimed at the improvement of production factors, including also direct subsidies and grants.

Recent approach to the concept of industrial policy in Latvia are based on the latest contemporary theories, primarily on the works of Rodrik, Hausmann et al. In 2012 the Ministry of Economics presented a new structural policy approach to national economy, naming it the 


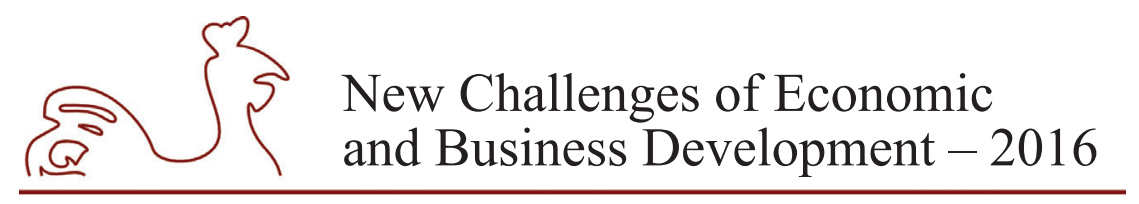

May 12-14, 2016, Riga, University of Latvia

National Industrial Policy. Experts from the Ministry of Economics have performed an up-todate analysis of the economic structure and development, as a result of which several corrections have been introduced in respect of the previously offered instruments for the implementation of the concept of industrialization in Latvia.

The latest industrial policy in Latvia is based on the opinions of Rodrik, Hausmann et al., as a result of which an emphasis in the development of the concept of industrialization falls on a single principle that industrialization policy is not aimed at "picking the winners" but rather the process that includes a dialogue between the public and private sector to identify the binding constraints that prevent new economic activities and to offer solutions how to prevent or overcome such constraints. In the document prepared by the Ministry of Economics this process is emphasised as a key element of industrial policy and lies at the basis of the analytical part of the document.

\section{Development of Smart specialization concept and its application to the case of Latvia}

Forey et al (Forey, David, Hall, 2011) notes that Smart specialisation is a policy concept developed by a group of academia in 2008. The concept made a significant impact on the policy audience, particularly in Europe as the European Commission decided to use this concept as a key element of the EU 2020 innovation plan and as a conditionality for structural fund attribution.

Within a renaissance of industrial policy, idea of smart specialization has become part of the discussion agenda. As Forey notes regions cannot do everything in science, technology and innovation and they need to promote what should make their knowledge base unique. So the idea of smart specialization concept have had in fact two general lines. Firstly, it is important to focus on certain domains in order to realise the potential for scale, scope and spillovers in knowledge production and use, as these important drivers of productivity in the domain of R\&D and other innovation-related activities and secondly it is important to focus on certain domains in order to develop distinctive and original areas of specialisation for the future.

Smart specialisation must not be associated with a strategy of the simple industrial specialisation of a particular region e.g. picking winners. Instead, smart specialisation is about R\&D and innovation. Forey et al (Forey, David, Hall, 2011) notes that smart specialisation is a process addressing the missing or weak relations between $R \& D$ and innovation resources and activities on the one hand and the sectoral structure of the economy on the other.

One of the key parts of Smart specialisation is an entrepreneurial discovery process that reveals what a country or region does best in terms of $R \& D$ and innovation. This principle is so important that any model that did not include this provision would have an entirely different character. Also it is important in order to make a clear distinction between the smart specialisation approach and some older policy approaches involving centralised planning procedures as the main way to identify industrial development priorities.

Entrepreneurial knowledge involves much more than knowledge about science and techniques. Forey et al. (Forey, David, Hall, 2011) notes that entrepreneurial knowledge combines knowledge about science, technology and engineering with knowledge of market growth potential, potential competitors as well as the whole set of inputs and services required for launching a new activity. According to the Haussmann and Rodrick (Haussmann, Rodrick, 2003) for many regions and countries it may be the case that the most important innovations 


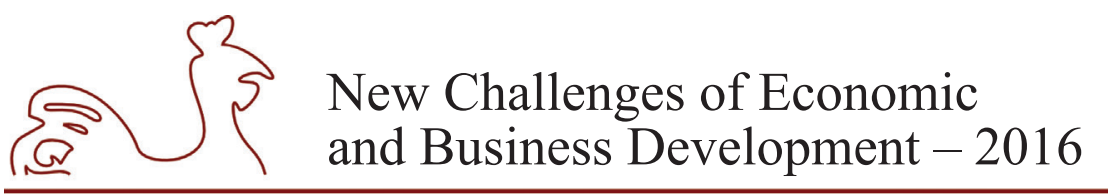

May 12-14, 2016, Riga, University of Latvia

are not technical but instead consist in the revelation of the particular business orientation that currently should be pursued in directed inventive and innovative activities.

In case of Latvia, smart specialization strategy prescribes the development of a vision, finding competitive advantages, choosing strategic priorities and a policy that would unleash the maximum potential of national knowledge-based development, and thus ensures economic growth.

The goal of the Latvian smart specialization strategy is to increase the capacity for innovation, as well as to create an innovation system that facilitates and stimulates technological progress in the economy.

Secondary goal of the smart specialization strategy is to ensure the selection and regular review of development priorities, targeting of public investment, including the selection of policy instruments corresponding to the strategic goals, and creation of a monitoring system that allows assessing the influence of public investments and ensures maximum progress towards the achievement of established goals.

An essential precondition for the transition to innovative economy is the strengthening of the Latvian innovation system, eliminating its shortcomings and facilitating the interaction between all subjects of the innovation system - entrepreneurship, science and education, as well as the finance and legislative systems.

The choice of a strategy for transformation of economy is closely related to the current level of economic development and competitive advantages (the existing and potential ones).

The established growth priorities were determined from the problems created by globalization, including the fact that Latvia is losing competitive advantages of a developing country - the use of low labour cost.

To foster sustainable growth of Latvian processing industry the diversification of the processing industry and the achievement of a more rapid development of medium-hightechnology and high-technology sectors, as well as the facilitation of the production of products with a high added value in the traditional economic sectors is required.

Furthermore, important requirement to foster rapid development is a continuous search and fostering of production of new niche products. Here important role has close cooperation with the science sector. Both of this activities can create competitive advantages that can substitute cheap labour.

The five smart specialization areas identified in the smart specialization strategy firstly identify and ensure the development of knowledge in the science sub-sectors with the greatest potential for improving the economic competitiveness, and secondly provide a platform for discussions between the sectoral and research organizations and universities for establishing the priorities of public investment, development of tools and monitoring of the progress.

The Latvian industry is characterized by a high relative specialization, therefore the specialization of the industry in general is not a problem of the Latvian economy. Exportoriented Latvian companies are highly specialized and constantly looking for specialization opportunities in niches or specific product sectors. Identifying and funding of "winner sectors" must be avoided when implementing the smart specialization strategy - instead, an economic environment must be created and human resource development ensured that facilitates economic activity. 


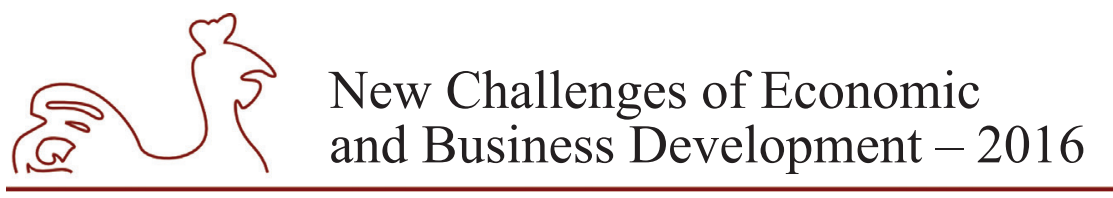

May 12-14, 2016, Riga, University of Latvia

Table 1

The directions of the transformation of economy, priorities and specialization areas defined by the Smart specialization strategy

\begin{tabular}{|c|c|c|}
\hline $\begin{array}{l}\text { Directions of the } \\
\text { transformation of } \\
\text { economy }\end{array}$ & Growth priorities & $\begin{array}{c}\text { Smart } \\
\text { specialization } \\
\text { areas }\end{array}$ \\
\hline $\begin{array}{l}\text { The change of } \\
\text { production and } \\
\text { export structure } \\
\text { in the traditional } \\
\text { sectors of the } \\
\text { economy }\end{array}$ & $\begin{array}{l}\text { More efficient use of primary products for the production of } \\
\text { products of higher added value, development of new materials } \\
\text { and technologies and diversification of their application. More } \\
\text { extensive use of non-technological innovations, the potential of } \\
\text { the Latvian creative industry for the production of products and } \\
\text { services with a higher added value in the economic sectors. }\end{array}$ & \multirow{7}{*}{$\begin{array}{l}\text { Knowledge- } \\
\text { intensive bio- } \\
\text { economics } \\
\text { Biomedicine, } \\
\text { medical } \\
\text { technologies, } \\
\text { biopharmacy } \\
\text { and } \\
\text { biotechnologies } \\
\text { Smart } \\
\text { materials, } \\
\text { technologies } \\
\text { and engineering } \\
\text { systems } \\
\text { Smart } \\
\text { energetics } \\
\text { Information and } \\
\text { communication } \\
\text { technologies }\end{array}$} \\
\hline $\begin{array}{l}\text { The sectors of } \\
\text { future growth, } \\
\text { where products and } \\
\text { services with a high } \\
\text { added value exist or } \\
\text { could appear }\end{array}$ & $\begin{array}{l}\text { Constant search for new products/services that requires } \\
\text { creation of an efficient identification system that could find and } \\
\text { provide support for the development of new products within } \\
\text { the framework of the existing sectors and cross-sector areas, as } \\
\text { well as creation of new sectors with a high growth potential. }\end{array}$ & \\
\hline \multirow{5}{*}{$\begin{array}{l}\text { Sectors with } \\
\text { a significant } \\
\text { horizontal impact } \\
\text { and contribution to } \\
\text { the transformation } \\
\text { of economy. }\end{array}$} & $\begin{array}{l}\text { Increase in energy efficiency, including the development } \\
\text { of new materials, optimization of production processes, } \\
\text { introduction of technological innovations, use of alternative } \\
\text { energy resources, and other solutions. }\end{array}$ & \\
\hline & $\begin{array}{l}\text { State-of-the-art ICT system in the private and public sector that } \\
\text { meets today's requirements. }\end{array}$ & \\
\hline & $\begin{array}{l}\text { A modern education system that meets the requirements of } \\
\text { the future labour market and facilitates the transformation of } \\
\text { economy and the development of competencies, undertaking } \\
\text { and creativity necessary for the implementation of the Smart } \\
\text { specialization strategy priorities at all levels of education. }\end{array}$ & \\
\hline & $\begin{array}{l}\text { Developed knowledge base and human capital in the areas } \\
\text { of knowledge, where Latvia has comparative advantages } \\
\text { and that are significant for the process of transformation of } \\
\text { economy: areas of knowledge related to the development } \\
\text { needs of knowledge-intensive bio-economics, biomedicine, } \\
\text { medical technologies, biopharmacy and biotechnologies, } \\
\text { smart materials, technologies and engineering systems, } \\
\text { smart energetics and ICT areas, and the key technology } \\
\text { areas identified by the EC (nanotechnologies, micro- and } \\
\text { nanoelectronics, photonics, advanced materials and production } \\
\text { systems, biotechnologies). }\end{array}$ & \\
\hline & $\begin{array}{l}\text { Identification and specialization of the existing resources of } \\
\text { the territories, proposing the possibilities and directions of } \\
\text { potential economic development, including the leading and } \\
\text { prospective business directions in municipal territories. }\end{array}$ & \\
\hline
\end{tabular}

Source: Authors construction based on Ministry of Education and Science. 


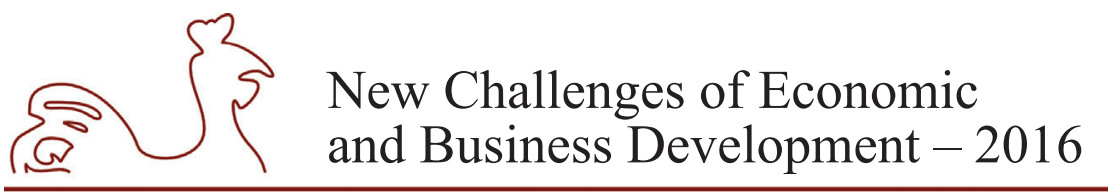

May 12-14, 2016, Riga, University of Latvia

One of the tasks of the entrepreneurial discovery process was to identify possible niches of competitiveness within each specialization area. The potential specialization niches of Latvian industry within each specialization area identified by the participants of the entrepreneurial discovery process are presented in Table 2 . It must been noted that the identified specialization niches are the ones where Latvia already currently possesses certain competitive advantages and in which, according to the available information, further growth is possible.

Table 2

The potential specialization niches for the Latvian industry in the context of the specialization areas

\begin{tabular}{|c|c|}
\hline Specialization areas & $\begin{array}{c}\text { Potential specialization niches of the industry, } \\
\text { Entrepreneurial discovery } 2014 \text { edition }\end{array}$ \\
\hline $\begin{array}{l}\text { Knowledge-intensive } \\
\text { bio-economy }\end{array}$ & $\begin{array}{l}\text { Sustainable and productive forest cultivation in changing climate conditions; } \\
\text { Full use of wood biomass for chemical processing and energy; Innovative, } \\
\text { risk-reducing plant cultivation and animal breeding technologies; Production } \\
\text { of innovative niche products with high added value from wood, traditional } \\
\text { and untraditional agricultural plant and animal raw materials; Technological } \\
\text { solutions for using plant cultivation and animal breeding and processing by- } \\
\text { products; Food safety. }\end{array}$ \\
\hline $\begin{array}{l}\text { Biomedicine, medicine } \\
\text { technologies, bio- } \\
\text { pharmacy and } \\
\text { biotechnologies }\end{array}$ & $\begin{array}{l}\text { Chemical and biotechnological methods and products for obtaining } \\
\text { pharmaceutical and bioactive substances. Development and research of new } \\
\text { and existing human and veterinary drugs. Molecular and individualized } \\
\text { medical treatment and diagnostics methods and cell technologies. Functional } \\
\text { food, medical cosmetics and bioactive natural products. }\end{array}$ \\
\hline $\begin{array}{l}\text { Smart materials, } \\
\text { technologies and } \\
\text { engineering systems }\end{array}$ & $\begin{array}{l}\text { Implant materials, composite materials, thin layers and coatings, devices, } \\
\text { mechanisms and machine tools, glass fibre products and glass fibre-based } \\
\text { smart materials. }\end{array}$ \\
\hline Smart energetics & $\begin{array}{l}\text { Resource prices; Intensity of energy resource consumption; } 2030 \mathrm{EU} \\
\text { Framework for climate and energy. }\end{array}$ \\
\hline $\begin{array}{l}\text { Information and } \\
\text { communication } \\
\text { technologies }\end{array}$ & $\begin{array}{l}\text { Innovative knowledge management, system modelling and software } \\
\text { development methods and tools; innovative uses for industry ICT hardware } \\
\text { and software; cyber-physical systems, language technologies and semantic } \\
\text { web; large-scale data and knowledge infrastructure; information security and } \\
\text { quantum computers; computer system testing methods. }\end{array}$ \\
\hline
\end{tabular}

Source: Authors construction based on Ministry of Education and Science.

\section{Conclusions, proposals, recommendations}

1. Development of Latvia's economy, especially in after-crisis period, has led to restart of debate about necessity of industrial policy in Latvia, which defines role, field and way of state intervention in development of further growth.

2. Latvia's approach in development of industrial policy firstly has been based on very selective and narrowed scope of proposals, the set of priority industries has been determined, but upon one year of implementation the approach has changed to those based on findings and works of Rodrik, Housmann et al., which implies that "picking winners (priorities)" 


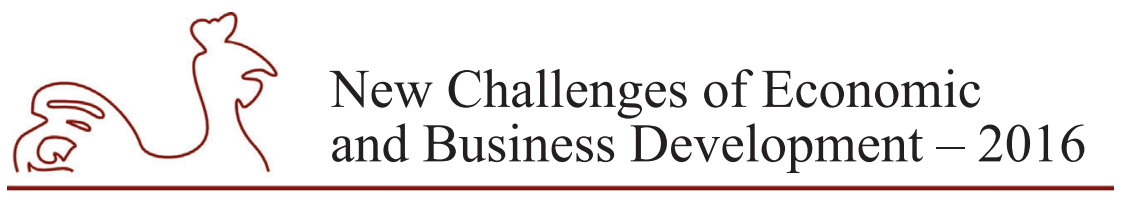

May 12-14, 2016, Riga, University of Latvia

approach has to be eliminated and strong dialogue between government and stakeholders is essential to assess economy with the aim to find out market and government failures.

3. Smart specialization strategy in Latvia foresees the development of a vision, finding competitive advantages, choosing strategic priorities and a policy that would unleash the maximum potential of national knowledge-based development, and thus ensures economic growth.

4. The five smart specialization areas identified in the smart specialization strategy allows the identification and ensures the development of knowledge in the science sub-sectors with the greatest potential for improving the economic competitiveness, as well as these areas provide a platform for discussions between the sectoral and research organizations and universities for establishing the priorities of public investment, development of tools and monitoring of the progress.

5. Smart specialisation strategy of Latvia, cannot consist of simple solution by defining priority industries, e.g. "picking winners" approach is the worst medicine for Latvia's economy.

6. It was clearly noted that the specialization of the industry in general is not a problem of the Latvian economy, as the Latvian industry is characterized by a high relative specialization, as a result of structure of economy and structure of entrepreneurs in Latvia.

\section{Bibliography}

Amsden A., 1989, “Asia’s Next Giant: South Korea’s Late Industrialization”, Oxford University Press, Oxford.

Andreea-Maria C., Alexandru I., 2009, “Common Industrial Policy And Competitiveness", Young Economists Journal / Revista Tinerilor Economisti, 7, pp. 148-156, Business Source Complete, EBSCOhost.

Beņkovskis K., Rutkaste U., Vītola K., 2009, "Pētījuma par prioritāro nozaru noteikšanu gala ziņojums" [online] Available at: http://www.president.lv/images/modules/items/PDF/item_1690_Prioritaras_ nozares.pdf, [Accessed 23 September 2015].

Carmody, P., 2009. “An Asian-Driven Economic Recovery In Africa? The zambian Case". World Development, 37 (7): 1197-207.

Chang H-J., 1994, “The Political Economy of Industrial Policy”, St. Martin's Press.

Chang H-J., 2002, “Kicking Away The Ladder: Development Strategy In Historical Perspective”, Anthem Press, London.

Chang H-J., 2003, "Kicking Away The Ladder: Infant Industry Promotion In Historical Perspective", Oxford Development Studies, 31, 1, p. 21, Academic Search Complete, EBSCOhost.

Chang H-J., 2009, "Industrial Policy: Can We Go Beyond An Unproductive Confrontation?", [online] Available at: http://siteresources.worldbank.org/INTABCDESK2009/Resources/Ha-Joon-Chang.pdf, [Accessed 17 October 2015].

Ciuriak D., 2011, "The Return Of Industrial Policy", [online] Available at: http://ssrn.com/ abstract $=1929564$, [Accessed 10 September 2015].

Foray D., David P., Hall B. 2011, "Smart specialization - from academic idea to political instrument, the surprising career of a concept and the difficulties involved in its implementation", MTEI Working Paper.

Haque I., 2007, "Rethinking Industrial Policy", UNCTAD Discussion Paper N. 183, United Nations Conference on Trade and Development, Geneva.

Hausmann, R., Rodrik D., 2003, “Economic Development as Self-Discovery', Journal of Development Economics, 72 (2). 


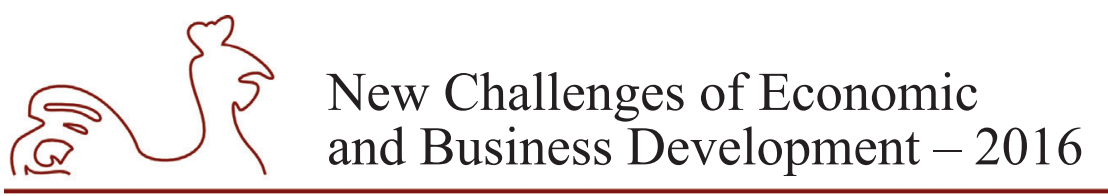

May 12-14, 2016, Riga, University of Latvia

Hausmann R., Rodrik D., Sabel Ch., 2008, "Reconfiguring Industrial Policy: A Framework With An Application To South Africa", CID working paper No. 168, Center for International Development at Harvard University, Cambridge.

Hirschman A. O., 1958, "The Strategy Of Economic Development", Yale University Press.

Johnson C., 1984, “The Industrial Policy Debate Re-Examined”, California Management Review, 27, 1, pp. 71-89, Business Source Complete, EBSCOhost.

Johnson S., 2009, "The Economic Crisis and the Crisis in Economics", Revised version of a speech prepared for the presidential address to the Association for Comparative Economics, 4 January, San Francisco.

Lall S., 2004, "Reinventing Industrial Strategy: The Role of Government Policy in Building Industrial Competitiveness", G-24 Discussion papers 28, UNCTAD, Geneva.

Landesmann M., 1992, "Industrial Policies and Social Corporatism”, Social Corporatism, Oxford Clarendon Press.

Ministry of Economics, 2013, "Nacionālās industriālās politikas pamatnostādnes 2014.-2020. gadam" [online] Available at: http://polsis.mk.gov.lv/documents/4391 [Accessed 25 October, 2015].

Ministry of Education and Science, 2013, "Zinātnes un tehnologiijas attīstības un inovācijas pamatnostādnes 2014.-2020. gadam”, [online] Available at: http://polsis.mk.gov.lv/documents/4608 [Accessed 25 October, 2015].

Nabli M., Keller J., Nassif C., Silva-Jauregui C., 2005, "The Political Economy Of Industrial Policy In The Middle East And North Africa", [Online] Available at: http://siteresources.worldbank. org/INTMENA/422183-1131656931098/20895775/ThePoliticalEconomyofIndustrialPolicy March302006.pdf, [Accessed 13 October 2015].

Naude W., 2010, "Industrial Policy". UNI-WIDER Working paper No. 2010/106, United Nations University World Institute for Development Economics Research, Helsinki.

Pack H., 2000, "Industrial Policy: Growth Elixir or Poison". World Bank Research Observer, Washington DC.

Pack H., Saggi K., 2006, “The Case for Industrial Policy: A Critical Survey”. World Bank Policy Research Working Paper 3839, Washington DC.

Peres W., Primi A., 2009, “Theory and Practice of Industrial Policy”, [online] Available at: http://www.cepal. cl/ddpe/noticias/paginas/9/23739/Theory-PracticeofIndustrialPolicyver.pdf, [Accessed 13 September 2015].

Pinder J., 1982, "Causes and Kinds of Industrial Policy", National Industrial Strategies and the World Economy, Croom Helm, London.

Reich R., 1982, "Making Industrial Policy”, Foreign Affairs, 60, 4, pp. 852-881, MasterFILE Premier, EBSCOhost.

Robinson J., 2009, "Industrial Policy and Development: A Political Economy Perspective" [Online] Available at: http://scholar.harvard.edu/files/jr_wb_industry_policy20-20Robinson_0.pdf, [Accessed 13 December 2015].

Rosenstein-Rodan P., 1943, "Problems of Industrialization of Eastern and South-Eastern Europe", The Economic Journal, Vol. 53, No. 210/211(Jun.-Sep., 1943), pp. 202-211.

Rodrik D., 2004, "Industrial Policy for the Twenty-First Century", CEPR Discussion Paper 4767, Centre for Economic Policy Research, London.

Rodrik D., 2008, "Normalizing Industrial Policy", Working paper Nr. 3, Commission on Growth and Development, Washington DC: The World Bank.

Tregenna, F. (2009), "Characterizing Deindustrialization: An Analysis of Changes in Manufacturing Employment and Output Internationally", Cambridge Journal of Economics, 33 (4).

Verdoorn P. J., 1980, "Verdoorn's Law in Retrospect: A Comment", The Economic Journal, Vol. 90, No. 358, pp. 382-385. 


\title{
SETTING AN OPTIMAL LOAN PERFORMANCE WINDOW AND A BAD LOAN DEFINITION FOR THE CREDIT RISK ASSESSMENT MODEL FOR CREDIT UNIONS IN LITHUANIA
}

\author{
Renatas Spicas, Vilnius University, Lithuania ${ }^{1}$ \\ Mindaugas Vijunas, Vilnius University, Lithuania \\ Rasa Kanapickiene, Vilnius University, Lithuania
}

\begin{abstract}
The aim of the research is to provide suitable methods for the setting of an appropriate definition of a bad loan and an optimal loan performance window for the statistical credit risk prediction models in credit unions. The article uses the following methods: survey, modelling, statistical analysis and evaluation of corporate loan data.

In the scientific literature, expert methods are usually applied in the analysis of the issues of credit risk model construction. However, the expert approach does not reflect the external environment, therefore, such methods cannot ensure high accuracy and can lead to significant losses for credit providers. For this reason, the authors have taken a different approach. Firstly, seeking to investigate business needs, expectations and risk tolerance of credit unions, a survey of these market players was conducted. The authors of this article surveyed 56 of existing 74 credit unions in Lithuania. Secondly, the Markov chain method for bad loan definition and ever delinquency curves, based on a cohort analysis for definition of optimal loan performance window were applied to a corporate loan data set from the credit union sector. The survey has shown that credit unions are inhomogeneous in terms of tolerance of credit risk; most credit unions specified 90 days past due as a major bad loan indicator. However, a quantitative analysis shows that loans that reached 30 or 60 days past due in the first year, are characterised by a high probability of migrating to a worse state. In order to meet business needs of credit unions, we set 60 days past due as a major bad loan definition criterion and 25 months as an optimal loan performance window. The research results will contribute to the development of a state-of-the-art credit risk assessment and pricing model, suitable for use by credit unions having regard to the challenging modern financial market.
\end{abstract}

Key words: credit risk, credit unions, loan performance window, bad loan definition JEL code: G32

\section{Introduction}

Since the formation of the first credit unions, the development of these unions until 1950 1990 was based on the philosophy of social purpose and the reduction of poverty and financial seclusion. Scientific research has shown that such model of credit unions' activities has failed to attain set objectives; moreover, it has had a negative impact on the credit union movement itself: the majority of the credit unions the operation of which was based on this model remained small, operated inefficiently and were unprofitable (Chambers, Ryder, 2008; Jones, 2008; Richardson,

1 Corresponding author - e-mail address: renatas.spicas@gmail.com 


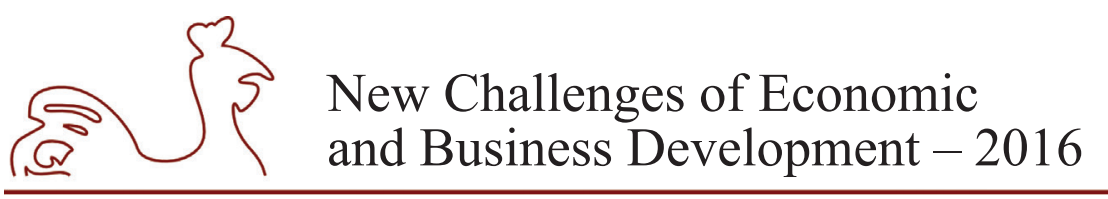

May 12-14, 2016, Riga, University of Latvia

Lennon, 2001). In response to this situation, the largest credit unions' associations developed a new operating model, which is known as the 'commercial' operating model, which provides for market-oriented activities of credit unions. Upon switching to the new commercial model, credit unions started operating in a new, unusual environment where they compete directly with conventional financial organisations. The literature on co-operative banking often emphasises that credit risk assessment is one of the most problematic aspects of credit unions ' operations upon transition from the socially-oriented model to the commercial one (Power et al., 2014, MacPherson, 2007, Guinnane 1994). The problematic nature of this aspect arises from three main factors. Firstly, upon transition to the commercial operating model, while attempting to deliver services beyond the boundaries of the community, credit unions lose the 'social control' element. Secondly, in the process of direct communication with a potential borrower, credit unions can use a more exhaustive database of analytical information, and this advantage is also lost when operating beyond community boundaries. Thirdly, while operating in the same market with conventional financial institutions, credit unions are still applying expert credit risk assessment methods, which does not ensure accuracy of assessments and does not provide analytical information required for an objective decision making and efficient management of a financial organisation.

The process of development of a statistical credit risk model consists of the following main stages (Finlay, 2012; Dzidzevičiūtè, 2010, Anderson, 2007; Siddiqi, 2006): definition of a 'bad loan' and setting of a period over which loan performance will be examined (the 'loan performance window'); formation of a sample; selection of variables; and model formation and testing. The bad loan definition and the setting of a loan performance window are mandatory stages that determine the discriminatory power of the model as well meeting of the creditor's needs. While the formation of credit risk assessment models has received considerable attention in the literature, the quantitative definition of a bad loan and the setting of a loan performance window have not been studied sufficiently: usually the authors perform these tasks by expert methods according to legal acts or recommendations made by the Basel Committee for Bank Supervision. As credit unions represent an exceptional market participant with a relatively short experience of commercial activities in the financial sector, the discriminatory power of the credit risk assessment model and its compliance with business needs are factors of strategic importance.

The following tasks have been identified in order to develop a statistical credit risk assessment model for Lithuania's credit unions, considering the importance of the correct definition of the dependant variable: 1) Analyse the methods for the bad loan definition and the setting of the loan performance window; 2) Conduct a survey of credit unions in order to determine what loans are considered to be bad loans by credit unions operating in Lithuania; 3) Using quantitative methods and data on loans made by credit unions to legal entities in 20102015 (provided by the Lithuanian Central Credit Union), set an optimal bad loan definition and an optimal loan performance window.

\section{Literature review}

The dependant variable in a statistical credit risk assessment model is usually a category variable, with two possible characteristics of a debtor: good or bad. A credit institution does not grant a loan application filed by a person to whom an attribute of a 'bad loan' was 


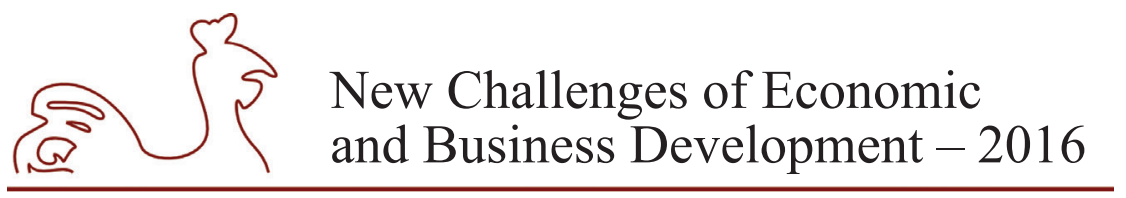

May 12-14, 2016, Riga, University of Latvia

assigned by the model. Therefore, a bad loan definition is one of the most important factors determining whether the model will meet a credit institution's expectations and business needs. The formulation of the definition is mainly influenced by the purpose of development of the model, the area of application, and the information available to the creditor (Choy, Laik, 2010; Dzidzevičiūtè, 2010; Valvonis, 2006). Anderson (2007) has pointed out that the bad loan definition is a less obvious setting of a credit risk tolerance level. Both the credit risk assessment model and the bad loan definition are applicable to a group of homogenous loans, for example, consumer loans, mortgage loans or business loans. In the formulation of the definition, it is very important to accurately characterise an attribute or a set of attributes based on which a loan is categorised as a bad loan. If a too strict bad loan definition is adopted, the probability of treating a solvent borrower as an insolvent one is increased; such situation is called 'technical default'. On the contrary, if the definition is too liberal, insolvent borrowers may be classified as solvent ones (Valvonis, 2006).

The bad loan definition is formed on the basis of attributes characterising the creditor's assets with the highest risk and with the highest probability of turning into a loss; therefore, the development of models is often based on the definitions of 'non-performing loans' set in legislation or by the Basel Committee for Bank Supervision (BCBS). In the BCBS documents (BCBS 2005, 2006), non-performing loans include loans with payments past due by 90 days or more and/or loans which, in the bank's view, will not be fully repaid to the bank unless the bank takes special measures (e. g. realisation of the security given for the loan). Based on these documents (BCBS 2005, 2006), a Regulation of the European Parliament and of the Council No $648 / 2012$ on prudent requirements for credit institutions and investment undertakings has been drafted. It provides for exceptions in case of which arrears of 180 days are permitted: the loan forms part of the retail loans group, has been secured by a mortgage of residential or commercial property, or has been made to the public sector.

The literature that analyses matters related to credit risk assessment, the attribute of 90 days past due or more is usually applied in the definition of bad loans (Sorokin, 2014; Nguen, HaThu, 2014; Rajan et al., 2010; Bloem, Freeman, 2005; Thomas, 2009, 2000; Jiménez et al., 2014; Beck et al., 2013; Leow, Crook, 2016, 2014; Bendendo, Bruno, 2012; Khemraj, Pasha, 2009). Different bad loan definitions and loan performance windows are applied in the development of credit risk assessment models. Table 1 presents examples of bad loan definitions used in recent scientific publications. 
May 12-14, 2016, Riga, University of Latvia

Table 1

Bad loan definitions in credit risk assessment models

\begin{tabular}{|c|c|c|c|}
\hline Source & $\begin{array}{l}\text { Homogenous } \\
\text { loan group }\end{array}$ & Bad loan definition & $\begin{array}{l}\text { Justification of bad } \\
\text { loan definition }\end{array}$ \\
\hline Cardoso et al., 2016 & Credit cards & Payments past due 60 days in succession & Expert \\
\hline Dzidzevičiūtè, 2010 & Business loans & Bankruptcy & Expert \\
\hline Fernandes, Artes, 2016 & $\begin{array}{l}\text { Small and medium } \\
\text { business loans }\end{array}$ & Payments past due 90 days or more & $\begin{array}{l}\text { Requirement set by } \\
\text { Central Bank of Brazil }\end{array}$ \\
\hline Glennon et al., 2008 & Credit cards & $\begin{array}{l}\text { Payments past due } 90 \text { days or more over } \\
24,18 \text { and } 12 \text { month loan performance } \\
\text { windows }\end{array}$ & Expert \\
\hline Kelly, O’Malley, 2016 & Mortgage loans & Payments past due 90 days or more & BCBS \\
\hline Khadani et al., 2010 & Credit cards & $\begin{array}{l}\text { Payments past due } 90 \text { days or more over } \\
3,6 \text { and } 12 \text { months loan performance } \\
\text { windows }\end{array}$ & Expert \\
\hline Koutanaei, 2015 & Business loans & Payments past due 60 days in succession & Expert \\
\hline Manab et al., 2015 & Business loans & Bankruptcy & Expert \\
\hline Petropuolos et al., 2016 & Business loans & $\begin{array}{l}\text { Payments past due } 90 \text { days or more, or } \\
\text { the loan is recognised as a loss according } \\
\text { other internal criteria of the creditor }\end{array}$ & BCBS \\
\hline Sousa et al., 2016 & Credit cards & $\begin{array}{l}\text { Payments past due } 90 \text { days or more over } \\
\text { a } 12 \text { month loan performance window }\end{array}$ & Expert \\
\hline
\end{tabular}

Complied by the authors based on the specified sources.

While, as shown by Table 1, authors often rely on expert evaluations, legal acts or recommendations by the Basel Committee on Bank Supervision in the development of credit risk assessment models, such approach does not ensure a link with the actual borrowers' behaviour and can have a negative impact on the discriminatory power of the model. There are two steps in the formulation of the bad debtor definition by quantitative methods: first - setting the optimal loan performance window, second - the formulation of the bad debt definition.

The substance of the loan performance window setting lies in the aim of setting such a period which would be sufficient for the 'maturing' of loans. The loan performance window is characterised by a rather high rate of growth in losses, therefore, if one sets a too short period that does not reflect the effects of independent variables on the phenomenon being projected, the probability that potential losses will not be estimated in full increases, resulting in the classification of part of bad debts as good ones. Debtor characteristics that were assessed at loan making have a tendency for changing in the long term. Therefore, setting of a loan performance window that is too long or too short may have a negative impact on the qualitative characteristics of the model (Thomas, 2000).

Cohort analysis is most often used for the setting of the optimal loan performance window (Choy, Laik, 2009; Anderson, 2007; Siddiqi, 2006). The analysis consists of a number of steps. First, loans made in various months are joined together into homogenous groups - cohorts. Secondly, the average arrears are calculated for each cohort. Thirdly, the results are depicted graphically and analysed. The application of this method results in various lengths of the arrears being analysed (Choy, Laik, 2009; Siddiqi, 2006). In substance, this graphic method aims at 


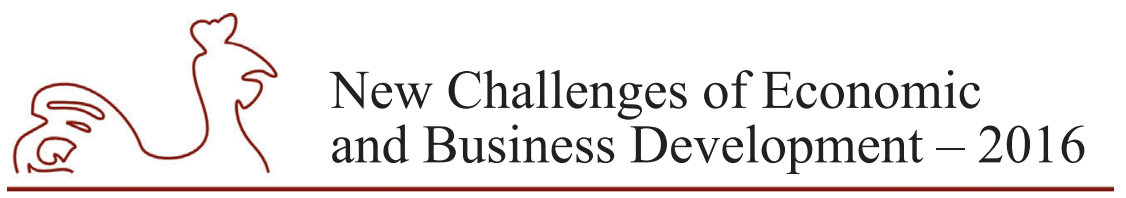

May 12-14, 2016, Riga, University of Latvia

setting such a loan performance window during which the average number of days of delay is increasing rapidly. The sample of the model is formed of mature loans which are characterised by the lowest probability of migrating to the bad loans group.

Markov migration matrices and their modifications are often used for the formulation of a quantitative definition of a bad loan (Choy, Laik, 2009; Anderson, 2007; Siddiqi, 2006). These methods are employed on an assumption that the loan's migration between the states of delay takes place according to the Markov chain process. This assumption means that the migration of loans between states is homogenous in terms of time. In other words, the application of the Markov chain method does not take account of the loan maturity, assuming that the probability of migration is the same throughout the loan performance window. If Markov chain has available states $\{1,2, \ldots \mathrm{k}\}$, probability of a loan being in the state $\boldsymbol{j}$ for one observation after being in the state $\boldsymbol{i}$ in previous observation is defined by $\boldsymbol{P}_{\boldsymbol{i} \boldsymbol{j}}$. The hypothetic representation of the matrix (Hadad et al., 2008) is as follows:

$$
P=\left(\begin{array}{ccccc}
p_{1} & p_{12} & p_{13} & \ldots & p_{1 k} \\
p_{2} & \ldots & \ldots & \ldots & p_{2 k} \\
\vdots & & & & \vdots \\
p_{j-1,1} & p_{j-1,2} & p_{j-1,3} & \ldots & p_{j-1, k} \\
0 & 0 & 0 & 0 & 1
\end{array}\right)
$$

Where $P$ is the migration matrix. Each matrix variable denotes the probability that the object will migrate from $i$ state on the left to $j$ state during a set period. The sum of all the lines of the matrix is 1 .

\section{Research results and discussion}

\section{Setting of the Bad Loan Definition and the Loan Performance Window in the Lithuanian Credit Union Sector}

A survey of credit unions has been conducted in order to determine the bad loan definition used by various credit unions. The survey method was selected having regard to the fact that the bad loan definition can be designated as confidential information by a credit union and that the content of the question may require clarifications. The credit union survey was conducted in the period from 3 June 2015 until 15 September $2015^{2}$. At the time of the survey, there were 74 credit unions and the Lithuanian Central Credit Union (LCCU) operating in Lithuania (LB, 2015).

The results of the survey at each credit union may depend on a multitude of factors and possible combinations thereof, e. g. the amount of the credit union's assets, potential territorial coverage, membership of associations / independence of associations and/or the LCCU, amount of equity, values of risk-limiting ratios, loan portfolio structure, sales channels used, organisational structure etc. Having regard to these characteristics of the survey population, one may conclude that it is not homogenous with respect to the tasks of the survey. Therefore, seeking to ensure that the survey results reflect the real characteristics of the credit unions' population, an objective to survey the whole population as far as possible has been set. It has been possible to survey

Dates of the first and the last surveys. 


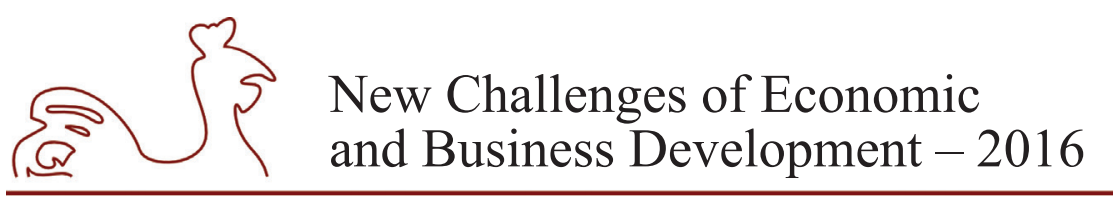

May 12-14, 2016, Riga, University of Latvia

56 credit unions including 28 by the method of person-to-person interview and the remaining ones by the telephone interview method.

Results of a sample survey are always characterised by a higher or lower uncertainty, which decreases along with the increase in the sample size (with the accuracy of the conclusions increased at the same time). The accuracy of conclusions can be evaluated using a formula for the calculation of the minimal sample size $n_{\min }$ (Martišius, 1997; Schutt, 2011):

$$
n_{\min }=\frac{z_{\alpha}^{2} N p(1-p)}{(\Delta p)^{2}(N-1)+z_{\alpha}^{2} p(1-p)} .
$$

where:

$N$ is the population size (The survey includes the 74 credit unions operating in Lithuania plus the Lithuanian Central Credit Union);

$p$ is the attribute probability (Usually unknown. As we have no other information about the value of $p$, we may adopt that $p=0.5$ );

$z_{\mathrm{a}}$ is the normal distribution ratio (In this survey it has been adopted that all results will be obtained with the $95 \%$ probability, therefore, the normal distribution ratio $z_{\mathrm{a}}=1.96$ );

$n_{\min }$ is the minimal sample size (56 credit unions were surveyed in this case);

$\Delta p$ is the attribute part error which can be determined from formula (3).

$$
\Delta p=\sqrt{\frac{z_{\alpha}^{2} p(1-p)\left(N-n_{\min }\right)}{n_{\text {min }}(N-1)}}
$$

Thus, upon collection of data from 56 credit unions, results have been obtained with the $95 \%$ probability and an error of $6.5 \%$.

Apart from the data received during the survey, additional attributes have been assigned to the credit unions: size of the market in which the credit union operates, size of assets, and size of the loan portfolio. The attributes have been grouped into three types: large, medium and small. For the purposes of accuracy in the classification of the objects of study according to the selected attributes, it has been decided to abandon expert distribution and to apply the statistical clusterisation method instead.

The substance of cluster analysis lies in the grouping of objects into clusters of similar objects. The k-average method is one of the most popular methods of cluster analysis, which is suitable when the number of clusters is predetermined (Paulauskienè, 2013). Using this method, objects are grouped into clusters in such a way so as to minimise differences between the objects within a cluster and to maximise differences between the clusters.

First, the 56 credit unions surveyed have been assigned a set of attributes $x_{1}, x_{2}, x_{3} \ldots x_{p}$, according to which the credit unions are grouped into three clusters. Secondly, three objects have been randomly selected as a reference and assigned sequential numbers that are cluster numbers at the same type. Thirdly, point $X_{i}$, with the co-ordinates $x_{i 1}, x_{i 2}, x_{i 3} \ldots x_{i p}$, has been separated out from the remaining 53 objects and, using the Euclidian metrics, the reference (centre) to which the point is closest has been determined. The analysed object is joined with the reference that corresponds to $\min d_{i l}(l=1, \ldots, k)$. Fourthly, the reference has been replaced with a new one that was recalculated. The procedure has been repeated for all the objects, resulting in the assignment of all the credit unions to one of the clusters (Mileris, Glinskienè, 2007). 


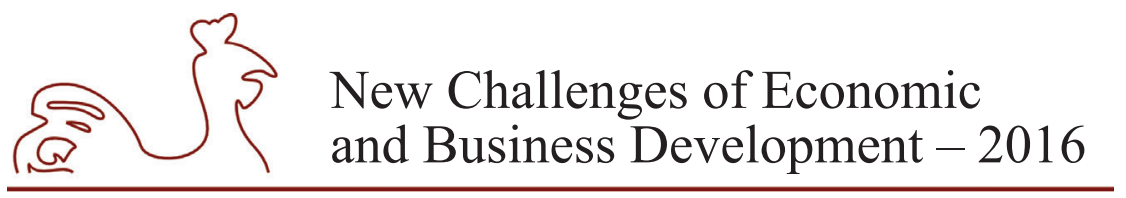

May 12-14, 2016, Riga, University of Latvia

It is known that credit unions operate territorially - they provide services to their members who work, study or live in the municipality in which the credit union is registered, or in the municipalities bordering the municipality of registration (Republic of Lithuania Law on Credit Unions, Official Gazette, 1995, 26-578, Article 12 (1)). Population (number of residents) has been assessed in order to determine the size of the market in which credit unions operate (LRSD, 2015, 2011). A settlement in which the credit union concerned was registered and settlements in which remote branches of the credit union concerned were located have been considered ${ }^{3}$. The potential size of the market for each credit union has been determined from the formula:

where:

$$
K U R D_{n}=P K U B+\sum_{i=1}^{k} P K U N K_{i}
$$

$K U R D_{n}$ is the registered population of the area of operation of credit union $n$;

$P K U B$ is the population of the settlement in which the credit union is registered;

$P K U N K_{i}$ is the population of the settlement in which the credit union's remote branch is located.

Using the k-average clusterisation method, the credit unions have been assigned the attributes of the market size, the asset size and the loan portfolio size. In order to determine the interrelationships of the attributes assigned to the credit unions, the circular diagram method has been employed, which enables a graphic representation of the structure of the relevant attributes' distribution (Figure 1). This method was offered, together with the special open source software (Circos), by Krzywinski, Schein, Birol et al. (2009) and is widely used in the gene engineering and bioinformatics (Darzentas, 2010; Schnable, Ware, Fulton et al. 2009) ${ }^{4}$. While the circular diagram method is most popular in the research in the natural sciences, it can also be applied in other research fields where depiction of interrelationships in the form of a circular diagram is sought.

A. Market size - Asset size

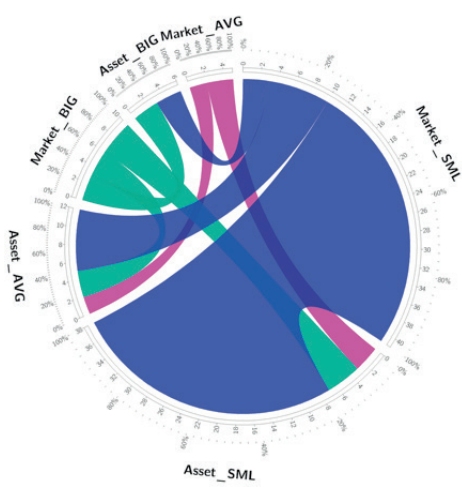

B. Market size - Portfolio size

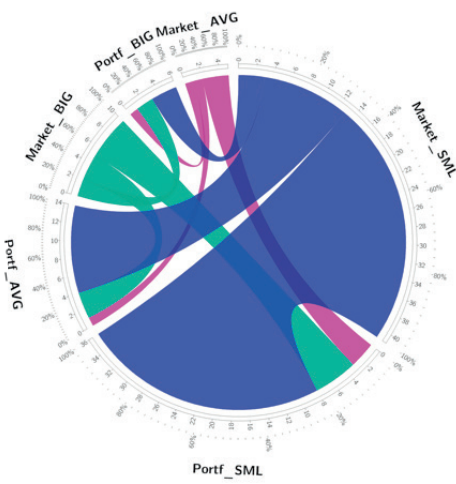

C. Portfolio size - Asset size

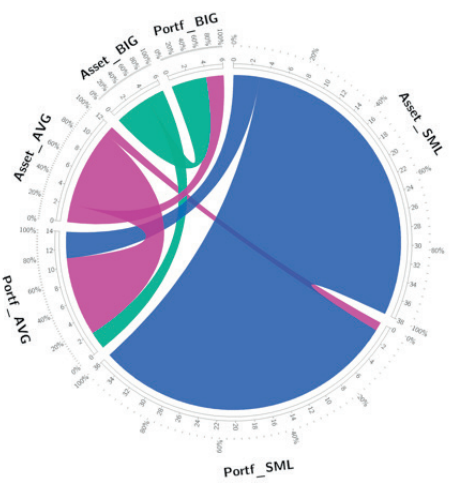

Source: authors construction based on Krzywinski et al. (2009).

Fig. 1. Structural distribution of the credit unions analysed, according to assigned attributes

\footnotetext{
3 Some credit unions still have remote branches in the areas in which they are not entitled to provide services. Such branches were excluded from the research.

${ }^{4}$ A detailed list of scientific publications in which circular diagrams are used as the graphic representation method is posted on the authors (Krzywinski et at. 2009) website http://circos.ca/images/published/.
} 


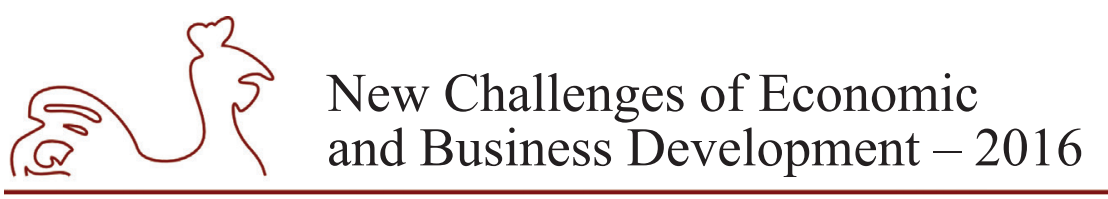

May 12-14, 2016, Riga, University of Latvia

Figure 1 consists of three diagrams. Each diagram shows the structure of the credit unions analysed according two attributes: Diagram A - according to the size of the market in which the credit union operates and the size of the credit union's assets; Diagram B - according to the size of the market in which the credit union operates and the size of the loan portfolio; and Diagram C - according to the size of the credit union's assets and the size of the loan portfolio. The diagrams have structural components that correspond to the assigned attributes and their values (large, medium and small). In case of such pair analysis of the attributes, the circular diagram's links connect the values of a category attribute, which corresponds to various structural components of the diagram, with the values of another attribute, thus showing the distribution of the attributes ' values in the sample being analysed. The width of the links shows proportions, with the visual depiction of the share of the objects (corresponding to a value of an attribute) that corresponds to the value of another attribute, i. e. of the attributes' distribution in a sample. To facilitate the interpretation of the diagrams, values of the attributes being analyses are depicted in different colours, and measurement scales are provided at the diagrams. The first scale, located closer to the centre of the diagram, shows the number of the credit unions in each part of the structural diagram. The second scale, which is at a longer distance from the centre, shows the percentage proportions of each part of the structural diagram. There is an indication at the diagram of which attribute value each structural part of the diagram corresponds to.

As shown by Figure 1, the majority of the credit unions operate in small markets and are small (according to the size of assets and loan portfolios); such credit unions account for $50 \%$ of the respondents. Credit unions operating in small markets account for $73 \%$, credit unions with small assets - for $68 \%$, and credit unions with a small loan portfolio - for $64 \%$ of the respondents. Diagram A shows a clear link between the credit unions' market size and the asset size: $55 \%$ of the credit unions operating in small markets have assets of small size, 13\% - of medium size, and 5\% - of large size. Diagrams A and B are almost identical, which shows a strong interdependence between the asset size and the portfolio size, which is logical - usually, the loan portfolio accounts for a proportionate part of the assets. There are exceptions, however - Diagram $\mathrm{C}$ shows that one credit union the assets of which are classified as assets of medium size manages a small loan portfolio; two credit unions with large loan portfolios are of medium size; three medium-size (according to assets) credit unions manage small portfolios and two such credit unions manage large portfolios. These exceptions show differences in the asset structure and operating strategies of the credit unions - some credit unions tend to keep the larger part of assets in the form of loans, whereas others chose other forms (such as debt securities).

Two conclusions can be drawn from the results of the clusterisation of the respondents by attributes. Firstly, credit unions are not homogenous, with marked differences seen - they operate in markets of different size, have different asset structures, pursue different asset management strategies and are very different in size (in terms of loan portfolios and total assets). Secondly, the majority of credit unions in Lithuania are small by their asset size and loan portfolio size. While the majority of the credit unions operate in small markets, and credit unions in Lithuania operate according to the territorial principle, it is obvious that this is not the main factor hindering the credit unions' development: a considerable part of the credit unions operating in medium- and large-size markets are small as well (in terms of both assets and loan portfolios, 


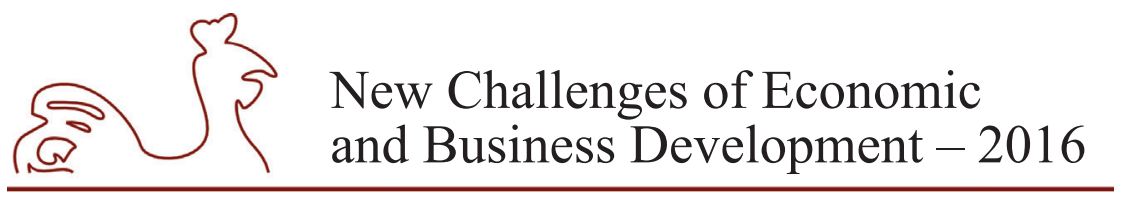

May 12-14, 2016, Riga, University of Latvia

see Figure 1). Such situation in the Lithuanian credit union sector leads to a conclusion that credit unions encounter difficulties in the process of transition from the socially-oriented model to the commercial model ${ }^{5}$.

The respondents were asked to indicate criteria for the definition of a bad loan in their credit union. The number of past due days was specified as the main indicator of a bad loan. Creditors were offered to select one of the five periods that are tolerable to the maximum extent - from one month to one year (in days). It should be noted that, in contrast to the recommendations in the literature (Anderson, 2007; Siddiqi, 2006), the surveyed creditors have not identified different tolerable arrears criteria for different loan segments ${ }^{6}$, however, some creditors would agree to longer periods of arrears in cases where the loan is fully secured by a mortgage of liquid immovable property; such cases, however, were not included in the survey. The results are presented below (Figure 2):

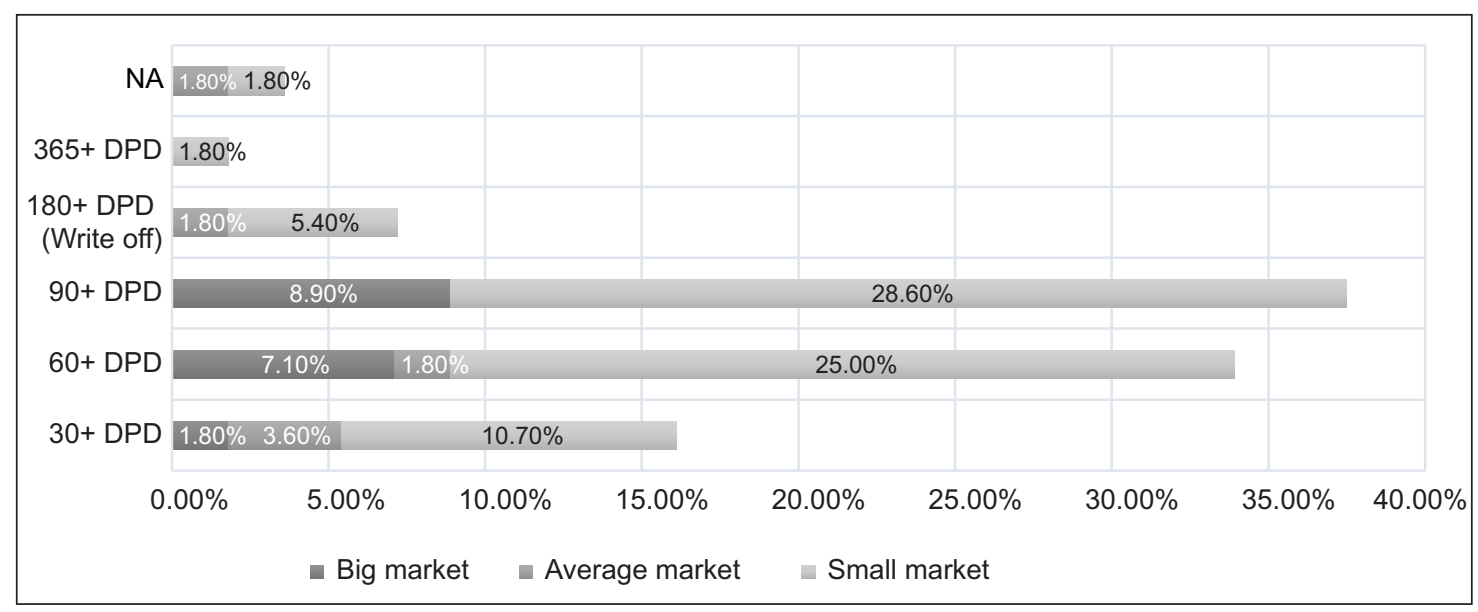

NA - not answered; DPD - days past due.

Compiled by authors.

Fig. 2. Maximum tolerable arrears of loan payments in the credit union sector of Lithuania

Figure 2 shows that the majority of the respondents (38\%) consider 90 days past due to be an indication of a bad loan. A smaller share of respondents $(34 \%)$ tolerate a delay up to 60 days and $17 \%$ up to 30 days. Just $7 \%$ of the respondents have applied the criterion for nonperforming loans stated in Lithuanian legislation, i. e. 180 days past due (LB, 2009). The figure below (Figure 3 ) shows the distribution of credit unions operating in markets of different size according to the maximum tolerable arrears of loan payments.

\footnotetext{
5 For more information about the aspects of credit unions' transition from the socially-oriented model to the commercial model, please refer to the authors' publication "Ankstyvoji kredito unijų istorija ir veiklos modelio raida" (Early History of Credit Unions and the Development of the Operating Model) Špicas, Vijūnas (2016).

6 This can be partially explained by the fact that the respondents surveyed do not apply statistical credit risk assessment methods.
} 
May 12-14, 2016, Riga, University of Latvia

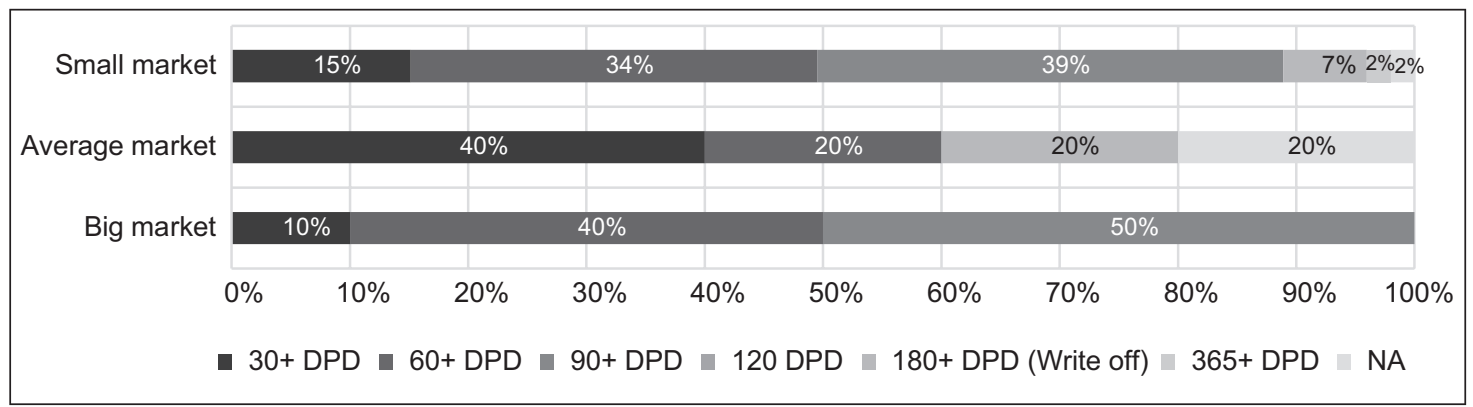

$N A$ - not answered; DPD - days past due.

Compiled by authors.

Fig. 3. Maximum tolerable arrears of loan payments in the credit unions operating in markets of different size

According to Anderson (2007), the bad loan definition is an attribute of risk tolerance. Figure 3 shows the inhomogeneity of credit unions in terms of credit risk tolerance. Those credit unions which operate in markets of small and average size tend to tolerate longer periods of delay than the credit unions operating in large cities. The figure also shows that some credit unions indicate that they would tolerate arrears over $180 \mathrm{DPD}$. The argumentation behind this statement was that credit unions operating in small markets (often in small settlements or communities) perform a social function as well, by reducing financial seclusion of its members. It should be noted that the ability of credit unions to perform the social functions by reducing financial seclusion is treated in the literature with caution (Jones, 2008; Richardson and Lennon, 2001). According to Jones (2008), some credit unions choose members with low income as a target segment due to unrealistic business assumptions and lack of management skills rather than for social self-help reasons.

As shown by the survey, credit unions' attitudes toward the setting of a bad loan definition are quite contradictory. In order to secure good quality of the credit risk assessment model, qualitative methods are used further in the study.

\section{Statistical setting of the bad debt definition and the loan performance window}

The data on the Lithuanian Central Credit Union's loans to legal entities for the period from 1 January 2010 until 12 September 2015 have been used for study; this covers a monthly repayment history of 1,955 loans. Firstly, upon formation of cohorts of loans made in various months, the indicators of loans that were in default at least once are depicted, with the division into 30,60, 90, 120 and 180 DPDs (Figure 5). A four-year period has been taken into order to present a wider picture of the loan maturity cycles. 
New Challenges of Economic and Business Development - 2016

May 12-14, 2016, Riga, University of Latvia

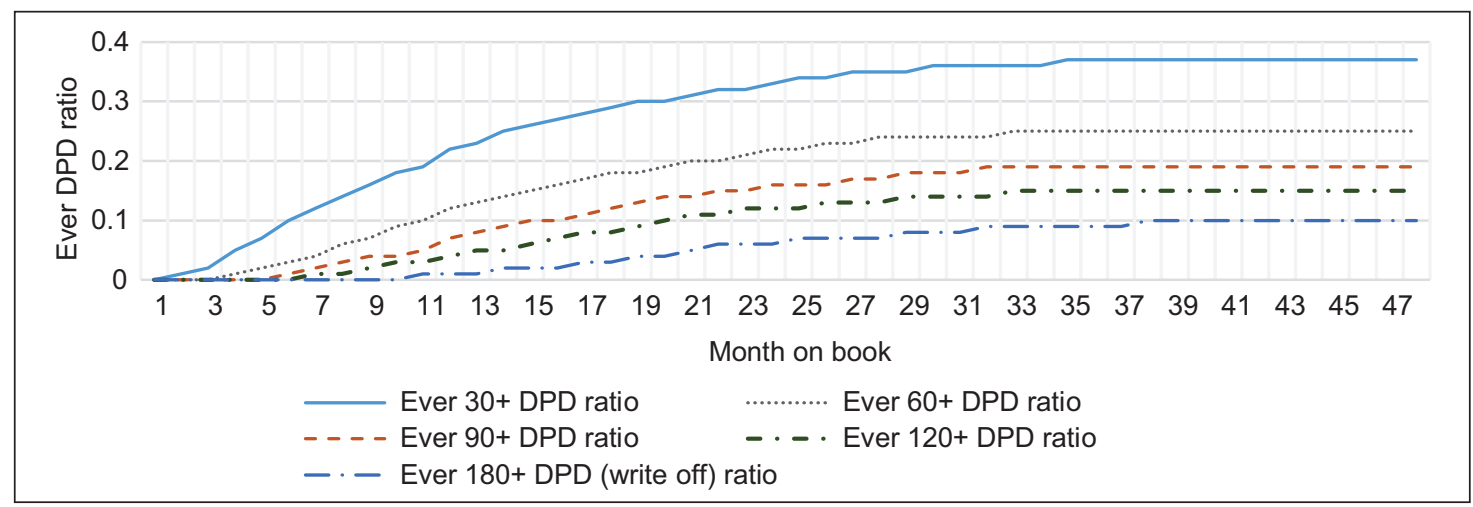

DPD - days past due.

Compiled by the authors.

Fig. 4. Average arrears in payments in various loan maturity period in the credit union sector of Lithuania

Figure 4 shows the loan maturity cycles. Based on this graphical information, the loan performance window is determined by the expert method; in this case it is expedient to set a 24 month window (Figure 5). Different DPDs are selected by the cohort method in the literature (Choy, Laik, 2009; Anderson, 2007; Siddiqi, 2006). In this study, the authors have selected, upon depiction of five different DPDs, a 30 DPD as a reference, however, as shown by Figure 5, the result would be only slight different if other DPDs are selected ${ }^{7}$.

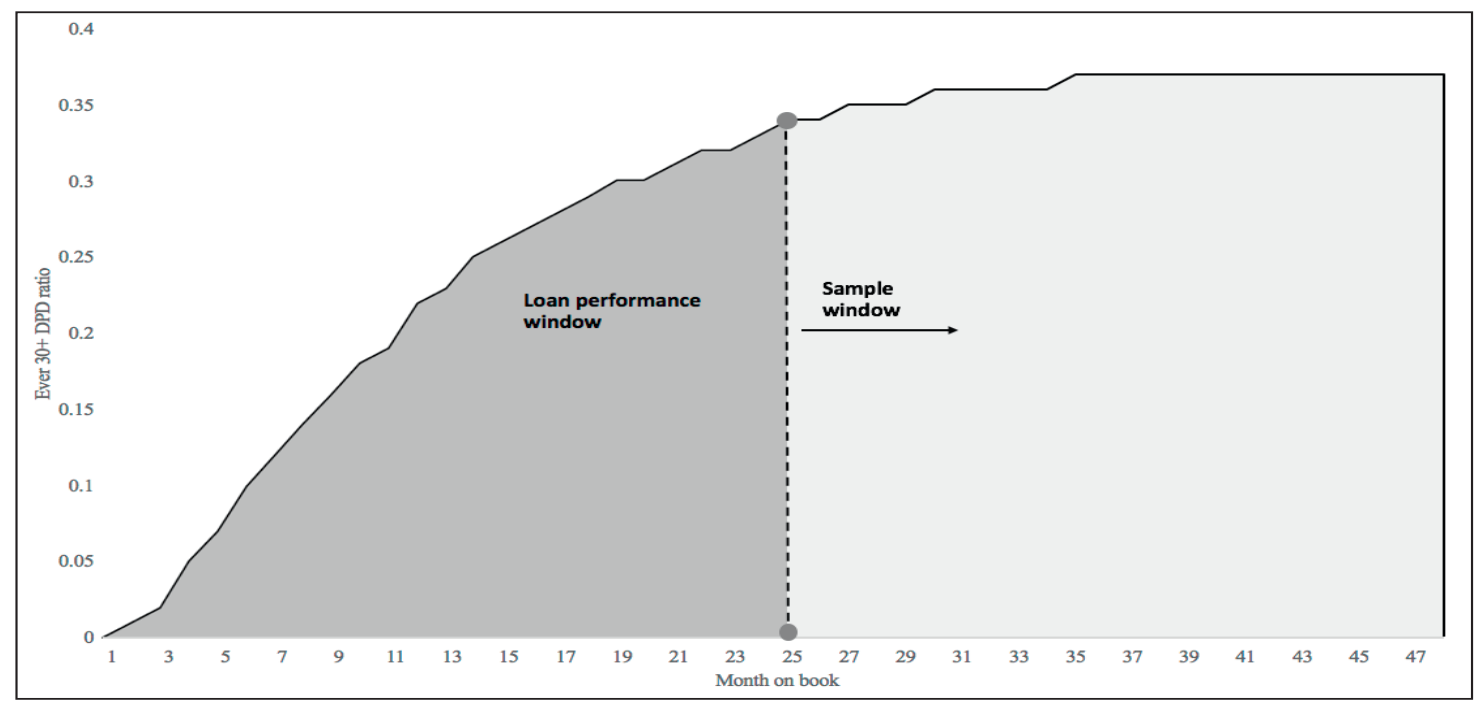

DPD - days past due.

Compiled by the authors.

Fig. 5. Setting of the optimal loan performance window and the sample window based on a 30 DPD

Normally, with the cohort method, 30, 60 or 90 DPDs are selected (Choy, Laik, 2009; Siddiqi, 2006). In Figure 5, 120 and 180 DPDs are shown for information purposes only. 


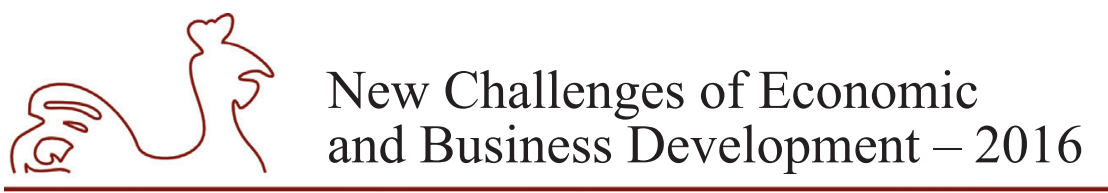

May 12-14, 2016, Riga, University of Latvia

Upon setting of the optimal loan performance window, the annual migration period has been selected for further study; only loans with the period not shorter than 24 months have been included, in this case - 1,383 loans. In the study, the largest arrears of each loan in Year 1 and Year 2 have been considered. The migration probability matrix has been drawn up (Table 2):

Table 2

Migration probability matrix

\begin{tabular}{|l|r|r|r|r|r|r|}
\hline & Current & 30+ DPD & 60+ DPD & 90+ DPD & 120+ DPD & Write off \\
\hline Current & $\mathbf{6 6 \%}$ & $16 \%$ & $6 \%$ & $4 \%$ & $4 \%$ & $4 \%$ \\
\hline $\mathbf{3 0}+$ DPD & $19 \%$ & $\mathbf{2 2} \%$ & $14 \%$ & $15 \%$ & $12 \%$ & $18 \%$ \\
\hline $\mathbf{6 0}+$ DPD & $9 \%$ & $13 \%$ & $\mathbf{1 0 \%}$ & $10 \%$ & $30 \%$ & $28 \%$ \\
\hline $\mathbf{9 0}+$ DPD & $5 \%$ & $7 \%$ & $10 \%$ & $\mathbf{1 5 \%}$ & $34 \%$ & $29 \%$ \\
\hline $\mathbf{1 2 0}+$ DPD & $5 \%$ & $7 \%$ & $2 \%$ & $14 \%$ & $\mathbf{2 5 \%}$ & $48 \%$ \\
\hline Write off & & & & & & $100 \%$ \\
\hline
\end{tabular}

Compiled by the authors.

The formulation of the Markov migration matrix shows that the loans that have reached a 60 DPD or more during Year 1 have a $10 \%$ probability of remaining in the same state and a $68 \%$ probability to migrate into worse states including a $28 \%$ probability that the loan will become a non-performing loan. The loans with 30 DPD or more in Year 1 are characterised by an as much as $59 \%$ higher probability of migrating to a worse state including an $18 \%$ probability of becoming a loss-making loan. In the opinion of the authors, for the purposes of this study, both 30 DPD and 60 DPD can be used as a bad loan definition in the development of the model. A comparison of the study results with the results of recent research (see Table 1) shows that a 30 DPD is rarely selected as the main indication of a bad loan, and normally such short period of arrears is not considered significant (Finlay, 2012). Upon comparison of these results with the results of the credit unions' survey, one sees marked differences in the bad loan definitions determined by the quantitative method and the expert method: only $17 \%$ of the respondents have indicated 30 DPD as the maximum tolerable arrears, and $47 \%$ of the respondents have indicated 90 DPD and more as the main indication of a bad loan. In order to ensure that the model meets the business needs of the credit unions to the largest extent possible, the authors propose that a 25 month loan performance window and a 60 day DPD is used as the main indication of a bad loan.

\section{Conclusions}

In the literature analysing issues of credit risk assessment, bad loans and their loan performance windows are most often determined by expert methods or in accordance with the provisions of legal acts. Such approach can have a negative impact on the discriminatory power of the credit risk assessment model which, in turn, can lead to considerable losses for creditors, Ever delinquency curves are mainly used for quantitative setting of the optimal loan performance window as they enable a graphical determination of the period of rapid growth in new delinquencies, which is to be considered an optimal loan performance window. Markov migration matrices, showing the probability of the loan's migration to a worse state, are usually applied in the quantitative setting of a bad loan definition. 


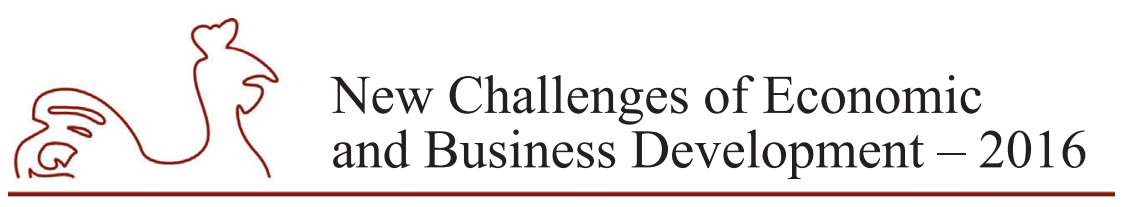

May 12-14, 2016, Riga, University of Latvia

A survey of Lithuania's credit unions has shown that the majority of the respondents $(38 \%)$ consider 90 days past due to be an indication of a bad loan. A smaller share of respondents (34\%) tolerate a delay up to 60 days and $17 \%$ up to 30 days. Just $7 \%$ of the respondents have applied the criterion for non-performing loans stated in Lithuanian legislation, i. e. 180 days past due. The survey has also shown that credit unions operating in small- and medium-size markets tend to tolerate longer periods of arrears compared with credit unions established in larger cities. Some credit unions have indicated that they would tolerate longer than 180-day arrears.

It has been found, during a quantitative study in which delinquency curves were applied, that in the loan sample analysed the most rapid growth of arrears was recorded in the first 25 months. A probability matrix compiled by the authors has shown that those loans which reach a 60 DPD or more in the first year have a $10 \%$ probability of remaining in the same state and a $68 \%$ probability of migrating to a worse state including a $28 \%$ probability of turning into a loss. Loans the repayment of which was in arrears 30 or more days in the first year are characterised by a probability as high as $59 \%$ of migrating to worse groups including an $18 \%$ probability of becoming a loss.

The bad loan definition set by the quantitative method differs considerably from the definitions provided by the credit union during the survey. Just $17 \%$ of the respondents have indicated the 30 DPD as the maximum tolerable period, and $47 \%$ of the respondents have stated that 90 DPD or more is the main indication of a bad loan. As shown by the study, such risk tolerance level may lead to considerable losses, therefore, in further studies the authors will apply, for the purposes of the statistical credit risk assessment model, a 25-month loan performance window and a 60 -day past due as the bad loan definition in statistical sampling.

\section{Bibliography}

Anderson, R., 2007. The Credit Scoring Toolkit: Theory and Practice for Retail Credit Risk Management and Decision Automation. Oxford University Press, New York.

Bank of Lithuania, 2015. Credit unions and Central credit Union in Lithuania: 2015, II quarter, activity Review. Activity of participants of financial market.

Basel Committee on Banking Supervision, 2005. International Convergence of Capital Measurement and Capital Standards. Bank for International Settlements.

Basel Committee on Banking Supervision, 2006. International Convergence of Capital Measurement and Capital Standards. Bank for International Settlements.

Beck, R., Jakubik, P., Piloiu, A., 2013. Non-Performing Loans. What Matters in Addition to the Economic Cycle. ECB Working Paper Series, No. 1515 [Online] Available at http://www.ecb.europa.eu/pub/ pdf/scpwps/ecbwp1515.pdf [Accessed 15 March 2016].

Bendendo, M., Bruno, B., 2012. Credit risk transfer in U. S. commercial banks: What changed during the 2007-2009 crisis? Journal of Banking \& Finance, Vol. 36(12), pp. 3260-3273.

Bloem, A., Freeman, R., 2005. The Treatment of Nonperforming Loans. Issue paper Prepared for the July 2005 Meeting of the Advisory Expert Group on National Accounts. International Monetary Fund.

Bosman, M., 2012. The Potential of Cohort Analysis for Vintage Analysis. An Exploration. University of Twente. [Online] Available at http://essay.utwente.nl/61383/1/MSc_M_Bosman.pdf [Accessed 15 March 2016].

Cardoso, D., Carvalho, D., Alves, D., Souza, D., Carneiro, H., Pedreira, C., Lima, P., Franca, F., 2016. Financial credit analysis via a clustering weightless neural classifier. Neurocomputing, 183, pp. 70-78.

Chambers, C., Ryder, N., 2008. The funding of credit unions - where has all the money gone? Journal of Social Welfare and Family Law, 30 (3), pp. 243-252. 


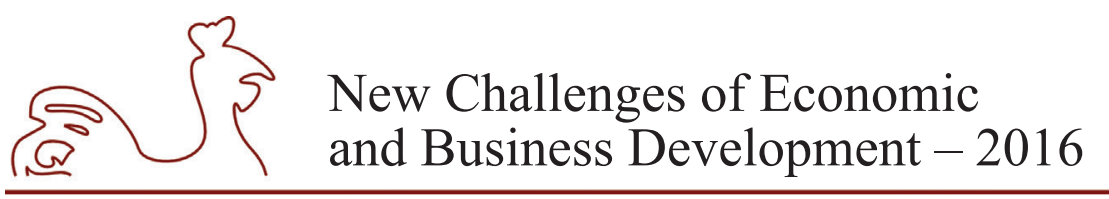

May 12-14, 2016, Riga, University of Latvia

Choy, M., Laik, M., 2010. A Markov Chain approach to determine the optimal performance period and bad definition for credit scorecard. Research Journal of Social Science \& Management. 1(6), pp. 227-234.

Darzentas, N., 2010. Circoletto: visualizing sequence similarity with Circos. Bioinformatics, 26(20), pp. 2620-2621.

Dzidzevičiūtè, L., 2010. Statistinių vertinimo balais modelių kūrimo ir taikymo ypatumai. Pinigu studijos 1, pp. 35-54.

Fernandes, G., Artes, R., 2016. Spatial dependence in credit risk and its improvement in credit scoring. European Journal of Operational Research, 249 (2), pp. 517-524.

Finlay, S., 2012. Credit scoring, response modeling, and insurance rating: a practical guide to forecasting consumer behavior. Palgrave Macmillan.

Glennon, D., Kiefer, N., Larson, C., Choi, H., 2008. Development and validation of credit scoring models. CAE Working Paper, 7(12).

Guinnane, T., 1994. A Failed Institutional Transplant: Raiffeisen's Credit Cooperatives in Ireland, 18941914. Explorations in Economic History, 31 (1), pp. 38-61.

Hadad, M., Santoso, W., Santoso, B., Besar, D., Rulina, D., 2008. Rating migration matrices: empirical evidence in Indonesia. An overview of challenges related to measuring financial innovations, 26.

Jiménez, G., Ongena, S., Peydró, J., Saurina, J., 2014. Hazardous Times for Monetary Policy: What Do Twenty-Three Million Bank Loans Say About the Effects of Monetary Policy on Credit RiskTaking? Econometrica, 82(2), pp. 463-505.

Jones, P., 2008. From tackling poverty to achieving financial inclusion - The changing role of British credit unions in low income communities. The Journal of Socio-Economics, 37(6), pp. 2141-2154.

Kelly, R., O'Malley, T., 2016. The good, the bad and the impaired: A credit risk model of the Irish mortgage market. Journal of Financial Stability 22, pp. 1-9.

Khandani, A., Kim, A., Lo, A., 2010. Consumer credit-risk models via machine-learning algorithms. Journal of Banking and finance, 34(11), pp. 2767-2787.

Khemraj, T., Pasha, S., 2009. The determinants of non-performing loans: An econometric case study of Guyana. Caribbean Centre for Banking and Finance Bi-annual Conference on Banking and Finance, St. Augustine, Trinidad. [Online] Available at: https://mpra.ub.uni-muenchen.de/53128/1/MPRA paper_53128.pdf [Accessed 15 March 2016].

Koutanaei, F., Sajedi, H., Khanbabaei, M., 2015. A hybrid data mining model of feature selection algorithms and ensemble learning classifiers for credit scoring. Journal of Retailing and Consumer Services, Vol. 27, pp. 11-23.

Krzywinski, M., Schein, J., Birol, I., Connors, J., Gascoyne, R., Horsman, D., Marra, M. A., 2009. Circos: an information aesthetic for comparative genomics. Genome research, 19(9), pp. 1639-1645.

Law on Credit Unions of Republic of Lithuania, (No I-796, 21 February 1995).

Leow, M., Crook, J., 2014. Intensity models and transition probabilities for credit card loan delinquencies. European Journal of Operational Research, 236 (2), pp. 685-694.

Leow, M., Crook, J., 2016. A new Mixture model for the estimation of credit card Exposure at Default. European Journal of Operational Research, 249(2), pp. 487-497.

Lietuvos banko valdybos nutarimas dèl kredito unijų veiklos riziką ribojančių normatyvų apskaičiavimo. Valstybès žinios. 2009, Nr. 42-1651.

MacPherson, I., 2007. One Path to Cooperative Studies. A Selection of Papers and Presentations. New Rochdale Press, University of Victoria. [Online] Available at: https:/www.uvic.ca/research/centres/ cccbe/assets/docs/publications/RochdalePress/OnePath_to_CooperativeStudies.pdf [Accessed 15 March 2016].

Manab, N., Theng, N., Md-Rus, R., 2015. The Determinants of Credit Risk in Malaysia. Procedia-Social and Behavioral Sciences, Vol. 172, pp. 301-308.

Markov models. Expert Systems With Applications, 53, pp. 87-105. 


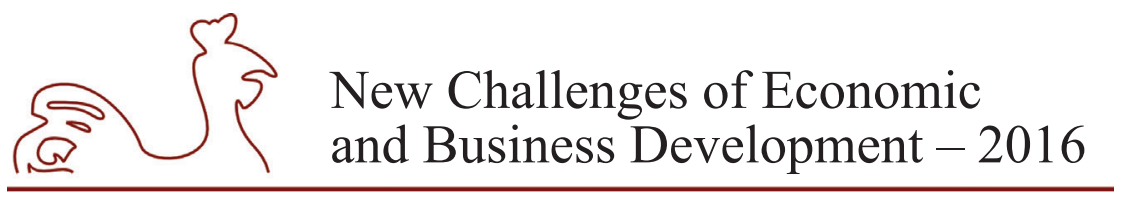

May 12-14, 2016, Riga, University of Latvia

Martišius S., 1997. Statistinių išvadų teorijos pradmenys. Vilnius: VU leidykla.

Mileris, R., Glinskienè, R., 2007. Rinkos segmentavimas klasterinès analizės k-vidurkių metodu. Economics \& Management, pp. 432-439.

Nguyen, H., 2014. Default Predictors in Credit Scoring-Evidence from France's Retail Banking Institution. University of Paris West-Nanterre la Défense, EconomiX.

Paulauskienè, K., 2013. Duomenu tyrybos sistemu galimybiu tyrimas juvairiu apimčiu duomenims analizuoti. Doctoral report. Vilnius university, Department of Mathematics and Informatics.

Petropoulos, A., Chartzis, S., Xanthopuolos, S., 2016. A novel corporate credit rating system based on Student's-t hidden.

Power, C., O’Connor, R., McCarthy, O., Ward, M., 2014. Merging into the mainstream? An empirically based discussion of the potential erosion of competitive advantage in restricted Irish credit union movement. Journal of Co-operative Organization and Management, 2 (2), pp. 55-64.

Rajan, U., Seru, A., Vig, V., 2010. The failure of models that predict failure: distance, incentives and defaults. Journal of Financial Economics 115(2), pp. 237-260.

Regulation (EU) No. 575/2013 of the European Parliament and of the Council, 2013. On prudential requirements for the credit institutions and investment forms and amending Regulation. (EU) No $648 / 2012$.

Richardson, D., Lennon, B., 2001. Teaching Old Dogs New Tricks; the Commercialization of Credit Unions. Development Alternatives, Bethesda, USA.

Schnable, P.Ware, D., Fulton R., Stein J. Wei F. Pasternak S., Minx, P., 2009. The B73 maize genome: complexity, diversity, and dynamics. science, 326(5956), pp. 1112-1115.

Schutt, R., 2011. Investigating the social world: The process and practice of research. Pine Forge Press.

Siddiqi, N., 2006. Credit Risk Scorecards. Developing and Implementing Intelligent Credit Scoring. John Willey \& Sons.

Sousa, M., Gama, J., Brandão, E., 2016. A new dynamic modeling framework for credit risk assessment. Expert Systems with Application, 45, pp. 341-351.

Statistics Lithuania, 2011. Universal Lithuanian population census. [Online] Available at: https://osp.stat. gov.1t/2011-m.-surasymas [Accessed 15 March 2016].

Statistics Lithuania, 2015. Population in early 2015. Lithuania 1991-now. [Online] Available at: https:// osp.stat.gov.lt/temines-lenteles 19 [Accessed 15 March 2016].

Thomas, L., 2000. A survey of credit and behavioural scoring: forecasting financial risk of lending to consumers. International Journal of Forecasting, 16(2), pp. 149-172.

Thomas, L., 2009. Consumer Credit Models: Pricing, Profit, and Portfolios. Oxford University Press.

Valvonis, V., 2006. Šiuolaikinis kredito rizikos vertinimas banke: Paskolos ir skolininko rizika. Pinigu studijos, 1, pp. 80-104.

Сорокин, А. 2014. Построение скоринговых карт с использованием модели логистической регрессии. Интернет-журнал Науковедение 2(21). 
May 12-14, 2016, Riga, University of Latvia

\title{
SOCIAL POLICIES OF THE STATE IN THE CONTEXT OF GLOBALIZATION
}

\author{
Natalia Spiridonova, Saint-Petersburg State University, Russia ${ }^{1}$
}

\begin{abstract}
A sharp change in the financial and demographic situation in many countries of the world leads to a change in the functions and scope of government involvement in the economy. The crisis of the model of the welfare state and social insurance systems in developed countries makes the search for a new socioeconomic model of society that meets the challenges of globalization.

The aim of this work is the analysis of changes in the social policy of the states under the influence of the challenges of globalization. Research object of this article is the socio-political activity of the state and other agents of social policy in the context of globalization. The tasks of the article are: a comparative analysis of models of social policies in developed countries (especially the EU); to assess their effectiveness in the context of globalization; analyze the relationship of the social policies of the state and economic growth; examine the nature of social change in the Russian model of state in modern conditions. This study uses a combination of methods of modern economic theory applied to the study of social and economic relations and the problems of global development. The main methods of this study are functional, comparative analyzes. The study shows that the main objective of social policy in the context of globalization is to create favorable social conditions of society. The social programs implemented by the state must ensure not only social justice, but also the market one.
\end{abstract}

Key words: social policies, welfare state, globalization

JEL code: I30

\section{Introduction}

A sharp change in the financial and demographic situation in many countries of the world leads to a change in the functions and scope of government involvement in the economy. The crisis of the model of the welfare state and social insurance systems in developed countries makes the search for a new socio-economic model of society that meets the challenges of globalization. The aim of this work is the analysis of changes in the social policy of the states under the influence of the challenges of globalization. Research object of this article is the socio-political activity of the state and other agents of social policy in the context of globalization. The tasks of the article are: a comparative analysis of models of social policies in developed countries (especially the EU); to assess their effectiveness in the context of globalization; analyze the relationship of the social policies of the state and economic growth; examine the nature of social change in the Russian model of state in modern conditions. This study uses a combination of methods of modern economic theory applied to the study of social and economic relations and the problems of global development. The main methods of this study are functional, comparative

Corresponding author - e-mail address: sp_nv@mail.ru 


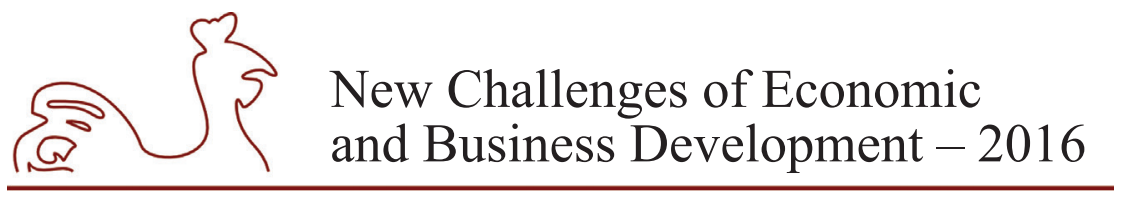

May 12-14, 2016, Riga, University of Latvia

analyzes. The study shows that the main objective of social policy in the context of globalization is to create favorable social conditions of society. The social programs implemented by the state must ensure not only social justice, but also the market one.

The most controversial topics are the following: the definition of social policy (Titmuss, 1974) (Dean, 2010), the impact of social policy on economic growth, the definition of globalization and the impact of globalization on the world economy (Held et al., 1999), the mechanism of the relationship of social policy and globalization on the example of the Western developed countries (Scharpf (2000) Pierson, Paul (1998) (Deacon, 2007). Rodrik, Dani (1998) Habermas). The research results are important for policy-makers and society, supporting social and ethical values in the context of globalization. The study shows the impact of globalization on social policy of nation States; the main approaches to the definition of social policy; the author's classification of basic types of social policy in accordance with two main models of market economies of relatively similar importance: the neo-liberal and socially-oriented (Table 1); inversely proportional dependence of economic growth on social spending demonstrated (Fig. 1); the conclusions about the peculiarities of the model of social policy in Russia. The research results are important for policy-makers and society, supporting social and ethical values in the context of globalization. It is important to focus the direction of future research on the analysis and evaluation of the adequacy of social policy the challenges of globalization.

\section{Interconnection of globalization and social policy}

Fundamental changes in the global economy, transforming the social component of the life of the modern world community, taking place in the past few decades due to globalization processes.

In general terms, globalization is defined as the intensification of economic, political, social and cultural ties between the different countries. International Monetary Fund experts define the globalization of the world economy as the growing economic interdependence of countries around the world as a result of the increasing volume and variety of cross-border movements of goods, services, and international capital flows, as well as through more rapid and widespread diffusion of technology.

The process of globalization has led to the development of international standards and requirements for working conditions, environmental protection, the development of a variety of international standards - social responsibility, social protection and sustainable development, which has a significant impact on the national socio-economic processes.

The impact of globalization on social policy is also evident through the expansion of the activities of international economic and political organizations (IMF, World Bank, WTO, WHO, ILO, etc.), and the nomination of a number of international legislative initiatives, in particular - 'International Covenant on Economic, Social and Cultural Rights' (1966), 'Universal Declaration of Human Rights' (1948), European Social Charter (1961, 1996), that define the social, economic and cultural rights based on the principles of liberty, equality, fraternity and prosperity of all people.

The effects of globalization are ambiguous and contradictory to international community. On the one hand, globalization leads to increased efficiency of the economy, dissemination of new technologies, improvement of living standards, increase revenues. On the other hand, it has 


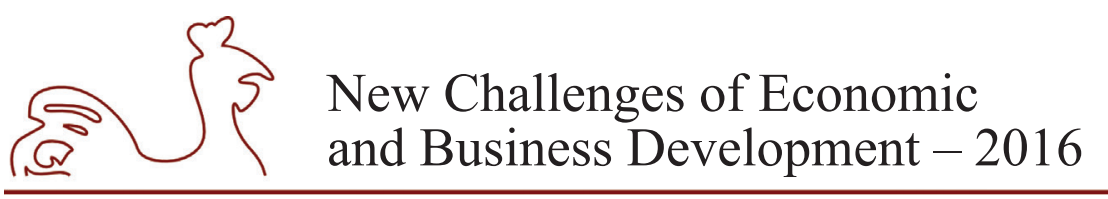

May 12-14, 2016, Riga, University of Latvia

an asymmetric impact on the relations between the countries and the results of their activities. The growing gap between rich and poor countries pushes the second ones on the periphery of the world economy.

The world economy is becoming socio-economically and geographically polarized due to the effect of globalization. This is a potential source of risks, social problems and conflicts. The results of acute global social risks may be: deformation of the demographic and social structure of the society; a sharp reduction in the birth rate and life expectancy; crisis of health systems and social protection; increase consumption of alcohol and drugs; reduction of the spiritual, moral and creative potential of the population, the risk of social destabilization. Reducing the severity of these risks and their minimization, both at the national and at the international level are becoming increasingly relevant.

International economic organizations transferred the scope of solving social problems from the national to the supranational and regional (EU, ASEAN, MERCOSUR, etc.) levels. Thus, the impact of globalization, in any case, mediated by international, national and regional institutions, mechanisms, interests, ideology, etc. (Rodrik, 1996)

Dani Rodrik writes: "The social welfare state has been the flip side of the open economy"; "Social insurance dampens liberalization blow for those who are most severely affected, it helps to maintain the legitimacy of these reforms, and it averts backlashes against the distributional and social consequences of integration into the world economy" (Rodrik, 1996).

Globalization weakens the traditional national system of state regulation of the economy and radically changes the framework of the national organization of society. If globalization is the tendency of unification and standardization, leading to the disappearance of civilizational differences between the countries, the process of regionalization is not confined to the sphere of economy, seize the political, social, cultural and psychological area. Regionalization is the opposite of globalization trend. It forms an independent territorial and socio-cultural commonality influenced by common historical, spatial and geographic and ethnic and cultural conditions, the growing solidarity processes and communications. It leads to the elimination of disparities, ensures the preservation of the integrity of national and cultural identity and the identity of countries.

\section{Comparative analysis of models of social policy}

A common and holistic approach to the definition of social policy is not completely formed yet. The three most typical approach can be identified by analyzing the different points of view: regulatory, institutional and activity approach. Proponents of the first approach think that 'social policy' is an art connection of human interests, a policy that reflects the relationship between classes and social groups, the tool that transforms selfishness into altruism (Titmuss, 1974). In the 'instrumental approach' social policy is seen as a set of measures, methods and mechanisms aimed at solving specific social problems, problems of specific social groups. Social policy in the third approach is considered as one of the areas of activity of the state, which has a direct impact on the welfare of the citizens through the provision of services and income for them. In terms of a sectoral approach, it includes policies in the areas of health, education, culture, housing, demographic, family, youth policy, whereas in terms of functionality - social protection, state regulation of the labor market and employment, and incomes policy (Социальная политика государства и бизнеса, p. 178). 


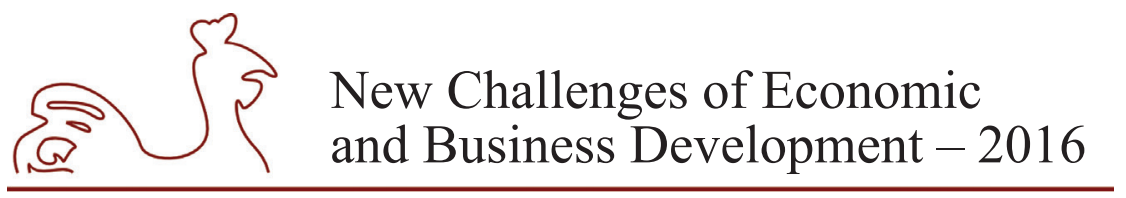

May 12-14, 2016, Riga, University of Latvia

With the deepening of globalization the importance of public institutions as a guarantee of social gains increased too. The level of economic development, the structure of government and civil society, historical and cultural traditions of the country together define national characteristics models of social policy.

The diversity of social policy models requires their classification on the basis of any common characteristics and parameters. A classic example of the classification of social welfare models, does not lose its relevance, is the classification proposed by the Danish sociologist EspingAndersen. Theare are three models of social policy of the welfare state: Liberal (USA, Canada and Australia), Corporatist-Statist (Austria, France, Germany and Italy), Social Democratic (Scandinavian countries) (Esping-Andersen, 1990).

The choice of specific parameters as a basis for classification determines the features of the model. In terms of geographical parameters we distinguish North (Norway), continental (European), Swedish (Nordic) model; in terms of the different principles of social assistance residual and institutional welfare.

Residual model means that you can refer to the relevant public services, social protection services for social assistance in exceptional cases. As a rule, the social problems that people face are solved thanks to the participation of the family, relatives and neighbors. Assistance is temporary and minimal, and it is provided after verifying many circumstances, as well as the inability to solve the problem yourself. United Kingdom is an example of the residual model, focused on social insurance, subsidized in part by the State, combined with a private charity. The institutional model is to provide social assistance to the needy in a systematic manner, proactively, in accordance with the laws, rules and regulations. Such a universal system of social assistance provides solidarity-integrating nature of the institutional system of the state. Within the institutional model of the Central European states is decisions related to the labor market, employment regulation, social partnership are seen as the most important.

Different levels of state involvement in the regulation of the social area allows us to identify different models - liberal, corporate and paternalistic. To identify the model of social policy following parameters are analyzed as a rule: the degree of government involvement in solving social problems, objectives and mechanism of social insurance and social security of the population, the share of social expenditures in GDP, etc. (see Table 1). 


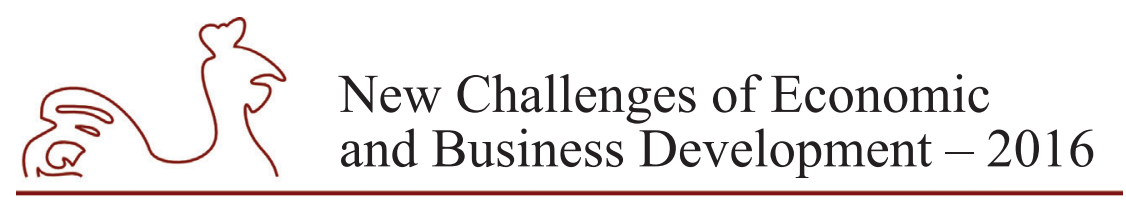

May 12-14, 2016, Riga, University of Latvia

Table 1

Comparative characteristics of the two models of social policy (SP)

\begin{tabular}{|l|c|c|}
\hline \multicolumn{1}{|c|}{ criterion } & Liberal model & Corporate model \\
\hline Role of the state & limited & significant \\
\hline The objectives of SP & $\begin{array}{c}\text { Providing a minimum acceptable } \\
\text { standard of living for the most } \\
\text { vulnerable segments of the } \\
\text { population }\end{array}$ & $\begin{array}{c}\text { Achieving social justice, social } \\
\text { stability, improving the welfare of } \\
\text { all members of society }\end{array}$ \\
\hline The character of SP & passive, defensive in nature & $\begin{array}{c}\text { active, aimed at preventing social } \\
\text { problems }\end{array}$ \\
\hline Key actors of SP & citizens and business & government, business and citizens \\
\hline $\begin{array}{l}\text { Implementation } \\
\text { mechanism }\end{array}$ & $\begin{array}{c}\text { Voluntary social insurance of } \\
\text { citizens, implementation of targeted } \\
\text { social programs }\end{array}$ & $\begin{array}{c}\text { mandatory state social insurance, } \\
\text { the system of social benefits, income } \\
\text { redistribution }\end{array}$ \\
\hline $\begin{array}{l}\text { Social Expenditure, } \% \\
\text { of GDP }\end{array}$ & 20-24 & 26-33 \\
\hline Type of social policy & the residual principle & institutional \\
\hline Country example & United States, United Kingdom & Germany, France, Denmark, Sweden \\
\hline
\end{tabular}

Source: compiled by the author.

Currently, despite the lack of a single European model of social policy the general trend of social policy in the EU is the convergence of different approaches. In the 1950s and 1960s, the continental European model prevailed, whereas in the 1970s, North model became dominant due to the entry of Great Britain, Denmark and Ireland in the EU. In the 1980s, when the Southern European countries joined the EU, the 'Mediterranean version' has become more meaningful. In the 1990s, due to the fact that the EU and the European Economic Area have moved to the north "weight" of the northern model increased. As a result of EU enlargement to the east hybrid model where the socialist past coexists with liberal future has also become one of the models in the EU. Despite the growing institutional differentiation of European countries, there is a common understanding that social justice and social cohesion can benefit the economic development. And vice versa - economic development should go to the benefit of social leveling. Examples of countries with different levels of Social Expendetures and the level of economic growth are shown in Figure 1. 


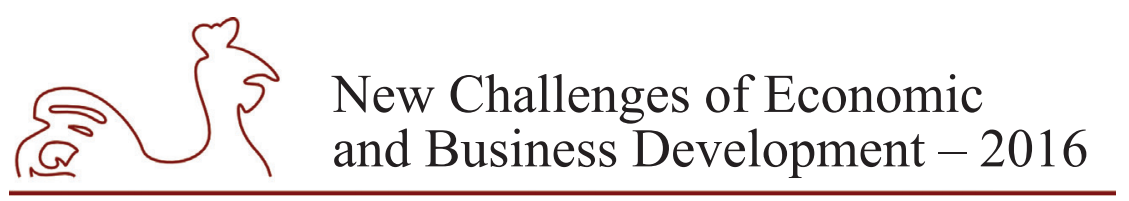

May 12-14, 2016, Riga, University of Latvia

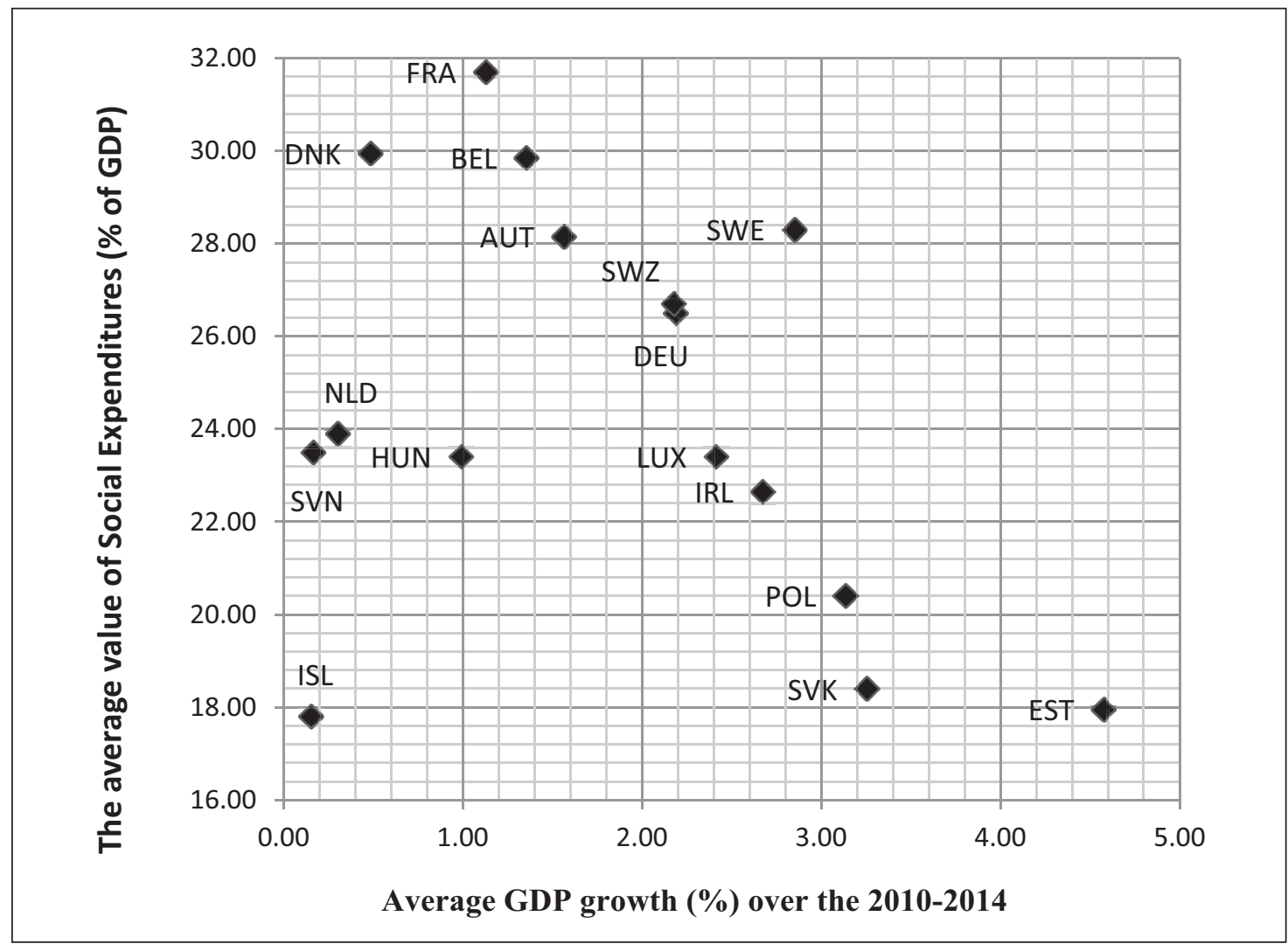

Source: author's construction based on the OECD and the World Bank data.

Fig. 1. The average value of Social Expenditures (\% of GDP) and the average GDP growth (\%) over the 2010-2014 for some countries OECD

As for Russia, its modern social policy has not a set of attributes specific to any of the models of social policies discussed above. There are objective reasons for the underdevelopment of market institutions in Russia, both historical and natural (Karpova, Spiridonova, 2015). The model of social policy in Russia can be described as emerging conditionally-institutional model with elements of paternalism. In 2014, social expenditure amounted to $21 \%$ of GDP, which corresponds to the average in the countries OECD. The share of social spending increased from 25.1\% in 2007 to 34.1\% in 2014 (the section of the State Budget, "Social Policy"). Even during the financial crisis 2008-2010 years the Russian state social spending have not undergone fundamental adjustments that allowed the state to fulfill its social obligations. The social responsibility of the state and increase the social responsibility of business, plus a public understanding of priority development of social sphere, together allow us to say that the model of joint (mutual) social responsibility in Russia could settle down. 


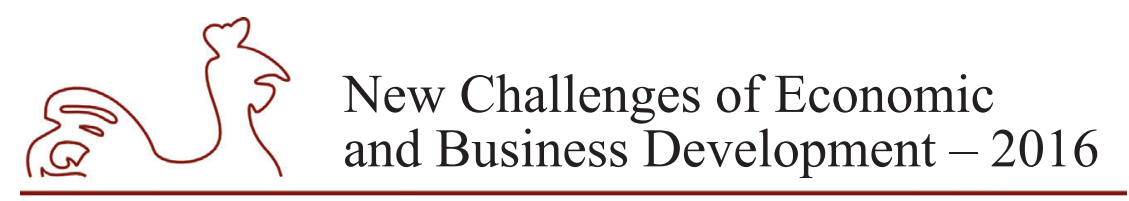

May 12-14, 2016, Riga, University of Latvia

\section{Conclusions, proposals, recommendations}

1. The process of globalization has led to (i) the development of international standards and the general requirements for working conditions, (ii) environmental protection, (iii) the development of international social responsibility standards, social protection and sustainable development, having a significant impact on national socio-economic processes. The impact of globalization on social policy is also evident through the expansion of international economic and political organizations (IMF, world Bank, WTO, who, ILO, etc), the introduction of a number of international humanitarian legislative initiatives. The impact of globalization on the world community is ambiguous and contradictory. On the one hand, it leads to increased efficiency of the economy, dissemination of new technologies, improvement of living standards, the increase incomes and living standards. On the other hand, it is of great socio-economic and geographical (territorial) polarization, which is a potential source of risks, social problems and conflicts.

2. Globalization weakens the traditional national system of state regulation of the economy and radically changes the framework of the national organization of society. International economic organizations transferred the solution of social issues from the national to the supranational and regional levels. If globalization is the tendency of unification and standardization, leading to the disappearance of civilizational differences between the countries, the process of regionalization is not confined to the sphere of economy, seize the political, social, cultural and psychological area. Regionalization is the opposite of globalization trend.

3. Analysis of existing points of view on the content of social policy allows us to identify the three most typical approach: normative, institutional and activity. Different degrees of state involvement in the regulation of the social sphere allows us to distinguish liberal, corporate and paternalistic model. The main parameters for the selection of data of social policy models in the market economy (paternalistic characteristic of the administrativecommand economy), are generally considered the state level of intervention in the solution of social problems, objectives and mechanism of social insurance and social security of the population, the share of social spending in GDP

4. Currently the general trend of social policy in the EU is the convergence of the different approaches although there is no single European model of social policy. Despite the increasing institutional differentiation of European countries, there is a General understanding that social justice and social cohesion can benefit economic development. Conversely, economic development should go to the benefit of social balance.

5. As for Russia, its modern social policy has not a set of attributes specific to any of the models of social policies discussed above. The model of social policy in Russia can be described as emerging conditionally-institutional model with elements of paternalism. 


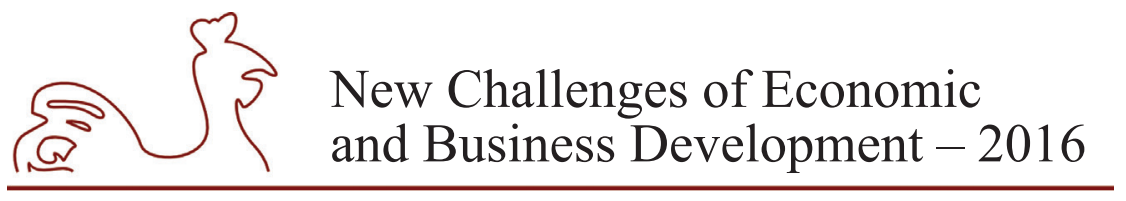

May 12-14, 2016, Riga, University of Latvia

\section{Bibliography}

Alber, Jens and Guy Standing (2000) 'Social dumping, catch-up or convergence? Europe in a comparative global context', Journal of European Social Policy, 10(2): 99-119.

Deacon, B. (2007). Global Social Policy and Governance. London: Sage Publications.

Dean, H. (2010) Understanding Human Need: Social Issues, Policy and Practice. Bristol: The policy Press.

Esping-Andersen, Gøsta (1990). The three worlds of welfare capitalism. Princeton, New Jersey: Princeton University Press. http://isites.harvard.edu/fs/docs/icb.topic 1134169. files/Readings $\% 20 \mathrm{on} \% 20$ Social\%20Democracy/Esping\%20Anderson\%20-\%20THe\%20Three\%20Worlds\%20of\%20 Welfare\%20Capitalism.pdf

Garrett, Geoffrey (1998) Partisan Politics in the Global Economy. Cambridge University Press.

Gough, Ian (2000) Welfare Regimes in East Asia. SPDC paper no.4, University of Bath: http://www.bath. ac.uk/Faculties/HumSocSci/IFIPA/GSP/

Hall, Peter, 2014, "Varieties of Capitalism and the Euro-crisis", West European Politics, 37/6, pp. 12231243

Held, David, Anthony McGrew, David Goldblatt and Jonathan Perraton (eds) (1999) Global Transformations. Polity Press.

Karpova G. Spiridonova N Features of social capital in Russia. Journal of Turiba University "Acta Prosperitatis", № 6, 2015

Pierson, Paul (1994) Dismantling the Welfare State? Reagan, Thatcher and the Politics of Retrenchment. Cambridge University Press.

Pierson, Paul (1998) 'Irresistible forces, immovable objects: post-industrial welfare states confront permanent austerity', Journal of European Public Policy 5(4): 539-560.

Rodrik, Dani (1996), Why Do More Open Economies Have Bigger Governments?, NBER Working Paper no.5537 National Bureau of Economic Research: Cambridge MA1996.

Scharpf, Fritz (2000) 'The viability of advanced welfare states in the international economy: vulnerabilities and options', Journal of European Public Policy 7(2): 190-228.

Spiridonova, N. "Problems of Development of National Socio-economic Systems in Conditions of Globalization." University of Latvia. In International Scientific Conference "New Challenges of Economic and Business Development - 2013", May 2013. Web. 28 Sept. 2015. <http://www.evf. lu.lv/fileadmin/user_upload/lu_portal/projekti/evf/konferences/konference_2013/ report/4Session/ Spiridonova.pdf $>$.

Tanzi, Vito (1998) 'Corruption around the world', IMF Staff Papers 45(4).

Titmuss, R.M. (1974). What is social policy? In Abel-Smith,B. and Titmuss, K. (Eds.) Social Policy (pp. 23-33.) London: George Allen and Unwin.

Ортиз, И. Социальная политика. 2007 С. 25 // http://esa.un.org/techcoop/russian/PN_SocialPolicyNoteRU.pdf

Социальная политика государства и бизнеса. Учебник для бакалавриата и магистратуры / Под. ред. Канаевой О. А./ М.: Юрайт, 2016. 
May 12-14, 2016, Riga, University of Latvia

\title{
MODERN TRENDS IN TAX PLANNING AND MINIMIZATION
}

\author{
Ilze Sproge, Transport and Telecommunication Institute, Latvia ${ }^{1}$ \\ Aina Joppe, University of Latvia, Latvia
}

\begin{abstract}
Nowadays, financial globalization, business is international in nature, it is possible to make a business in the whole world, businessman's must pay close attention to the co-operation of national tax legislation and cooperation characteristics.

Globalizing World business is attractive to low-tax countries, tax havens. With the cooperation of those countries, tax planning, reduce costs, probably makes it possible to save a money on less invoices. For example, the Office in the Centre of London, a subsidiary is in Cyprus, the main production centre in Singapore, a major center of finance in the Netherlands, holding company in Luxembourg.

In practice, most common in those cases where the business is transferred to the neighboring country, where are lower taxes.

Consequently, if the company has succeeded in developing an effective tax planning schemes, in accordance with the co-operation of national tax jurisdiction, it is possible to increase the after-tax income, profits. With earned money they have opportunity to deposit investments to ensure the company's own development, increasing competitiveness and, in general of the national income.

Scientific urgency of paper is determined by tax planning opportunities for foreign economic cooperation. The aim of the research: on the basis of theoretical and empirical analysis to find out advantages and disadvantages of transferring revenues to another country, and as a result optimizing tax payments.

\section{The tasks of the research:}

1. to investigate, sum up and critically analyse the opinions in the scientific literature about the meaning and pros and cons of the shifting of taxes;

2. to analyse critically the experience of the shifting of taxes in Latvia and other countries;

3. to define theoretical guidelines and to make practical recommendations how to use the shifting of taxes in the income an tax planing.

Research methods used: qualitative research methods: scientific literature review (Latvian and foreign literature and scientific publications) based on the analysis of legal norms, legal doctrine, specialized literature and case studies; logically - constructive; quantitative methods: mathematical and statistical methods: such as dynamic row analysis, the graphical method. For quantitative data the sources used are macroeconomic indicators from public databases and statistical series.

The research shows that the shifting of taxes does not create more money together, but less income for the State budget, but more for business, solution is only Global tax harmonization
\end{abstract}

Key words: tax havens, tax competition, global competition

JEL code: H25, H26, F38

Corresponding author - e-mail address: ilze.sprogge@gmail.com 


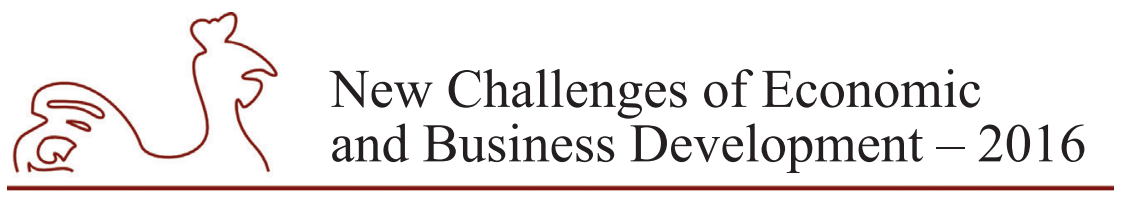

May 12-14, 2016, Riga, University of Latvia

\section{Introduction}

In Europe, the share of corporate income taxe in total revenues of the OECD countries has been rising up since 1975 (Chu, 2014). Reduction of the tax base and profit diversion are the tax strategies which utilise the deficiencies of the international taxation system in order to artificially transfer profit from the countries where it was obtained to low tax and tax-free countries and territories (Nodoklu terminologija, 2015).

The aim of the research: on the basis of theoretical and empirical analysis to find out advantages and disadvantages of transferring revenues to another country, and as a result optimizing tax payments.

\section{The tasks of the research:}

1. to investigate, sum up and critically analyse the opinions in the scientific literature about the meaning and pros and cons of the shifting of taxes;

2. to analyse critically the experience of the shifting of taxes in Latvia and other countries;

3. to define theoretical guidelines and to make practical recommendations how to use the shifting of taxes in the income an tax planing.

Research methods used: qualitative research methods: scientific literature review (Latvian and foreign literature and scientific publications) based on the analysis of legal norms, legal doctrine, specialized literature and case studies; logically - constructive; quantitative methods: mathematical and statistical methods: such as dynamic row analysis, the graphical method. For quantitative data the sources used are macroeconomic indicators from public databases and statistical series.

Due to the limited space, only the most important results of the research are outlined in the paper.

\section{Research results and discussion}

Many economists discuss whether the tax haven is the synonym of the term an "off-shore zone". There are several definitions found in the economics texts. The countries where taxes are low or where there are no taxes are considered tax havens. By registering their company in such countries international companies are able to avoid payment of taxes in their own country. Tax havens usually guarantee information confidentiality to their "clients".

Definitions in the economics texts may differ. The translation of the term "Off-shore" is "away from the shore". One of such definitions would be as follows: An off-shore company is a company registered with a foreign jurisdiction performing all its operations outside its country of registration (Kas ir OFSORS?). This can mostly mean a company registered in one country and actually operating in another country, or an off-shore company is an overseas company owned by an entrepreneur and managed by him from his own country. In most cases these countries are island countries, i.e. the former colonies of Great Britain, and the registration procedures in these countries are very similar.

In essence, the term "off-shore" does not mean anything else besides the fact that transactions are performed outside the domicile country from the legal point of view. As unbelievable as it might seem, even the performance of transactions by using a Lithuanian or an Estonia company, if the transactions are performed by a Latvian resident, should be viewed as off-shore operations from the point of view of international law (Vai "ofsors" ir ...). 


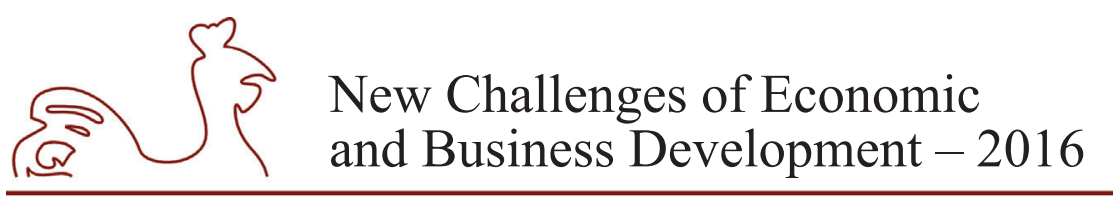

May 12-14, 2016, Riga, University of Latvia

The term "off-shore" should by no means be used as the synonym of non-payment of taxes because off-shore transactions can also be performed in countries with high tax rates, e.g. Great Britain, the USA, Germany etc. Latvia should also be deemed a country of off-shores from the international point of view, moreover, quite an attractive one due to the liberal banking legislation.

The Organisation for Economic Co-operation and Development (OECD) identifies three key factors in considering whether a jurisdiction is a tax haven (Tax Haven Criteria ...):

- zero or only nominal taxes, or are perceived to offer themselves, as a place to be used by non-residents to escape high taxes in their country of residence;

- protection of personal financial information;

- lack of transparency.

Roger Brunet's definition of tax havens highlights a number of features, such as:

- reduced taxation;

- protection of information;

- encouraging the development of the banking sector;

- modern media holding;

- the absence of currency control;

- the promotional advertising;

- favourable tax treaties (Botis, 2014)

Tax havens create distortions on both the macroeconomic and microeconomic level.

As it was stated above, on the macroeconomic level they can threaten the stability of financial systems. Moreover, by not paying taxes or avoiding taxes imposed upon tangible and/ or financial investment, the revenues of countries are reduced and they should be inevitably recovered by taxing the income gained from labour. Therefore, tax havens distort the correct balance between taxing of the capital and the labour.

On the microeconomic level, this causes a distortion between big and small companies, as well as micro companies. Companies representing the three above types have an increasingly less possibilities of using the offer by tax oasis, in particular, avoiding taxes or aggressive planning of taxes.

The major and the most widespread driving forces behind the operation of these havens are money laundering, non-payment of taxes, means for corruption or diversion of means for own companies. These territories act against the debt of the countries facing difficulties and implement broad scale campaigns aimed at protecting the free circulation of capital, these campaigns are joined by mass media, political parties and representatives of authorities.

As Botis highlights: "All tax haven countries provide some protection to bank or commercial information. In the case of a legal inquiry from a foreign government, most countries will not protect this information when the investigation is made under treaties. Otherwise, tax havens refuse to disclose the offered banking secrecy, although, it is a violation of the laws of another country" (Botis, 2014).

All over Russia the banks of Latvia are considered better than the banks of other offshores. The conditions that attract persons and encourage them to perform financial transactions in a particular country can be of both a legal and a financial nature.

When, speaking about transactions taking place in off-shore zones, the jurisdiction is with a different tax regime for residents and non-residents and reliefs are granted to foreign 


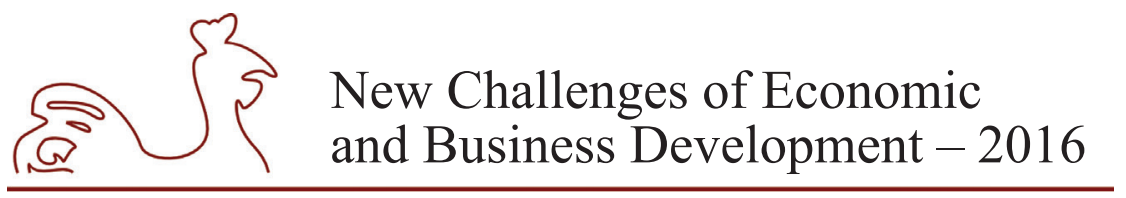

May 12-14, 2016, Riga, University of Latvia

investors in particular economy areas, tax havens are characterised by non-cooperation with tax administrations of the country of origin and non-existence of treaties regarding double taxation. Such treaties usually contain a clause on the exchange of information about gained income. If the tax rate is $0 \%$, such an agreement or a treaty is useless.

The authors refer to the Republic of Cyprus as an example. In this jurisdiction the tax rate for resident companies amounts to $42.5 \%$ and the tax rate for off-shore companies is 10 times lower and amounts to $4.25 \%$. Therefore, Cyprus can be viewed as an off-shore zone. It should be noted that the Republic of Cyprus has concluded double taxation agreements with 30 countries and, based on these agreements, the Republic of Cyprus cannot be listed as a tax haven.

Tax havens are characterised by non-transparency of tax regulation, a non-compliant legislation base, simplified registration procedures and company management, fictious company owners and managers. In essence, there is tax competition. Therefore, it cannot be assured that a tax haven is the same as an off-shore zone.

Jones, C., Temour, Y. (2016) describes tax havens in a matrix where the core goal is increasing advantage at the firm-specific, home country-specific and the host country-specific levels (Figure 1).

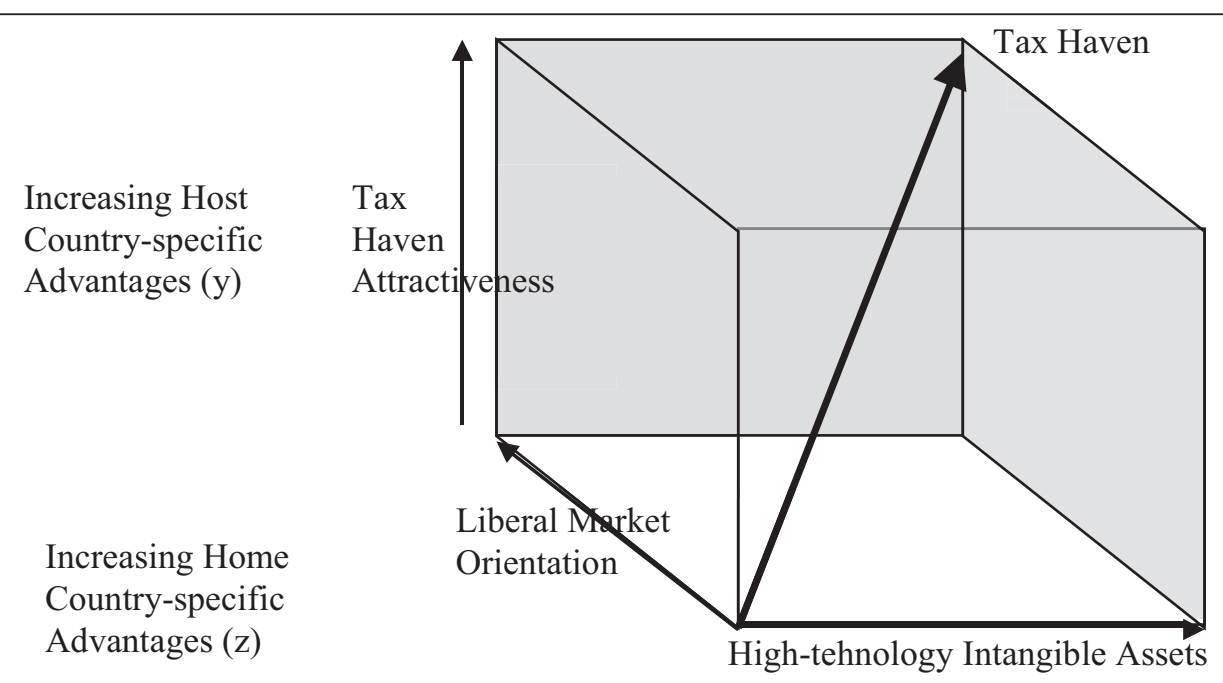

Increasing Firm-specific Advantages (x)

Source: Jones, C., Temour, Y. (2016).

Fig. 1. Tax havens matrix

\section{Off-shore companies in off-shore zones and their types}

The question regarding off-shore companies registered in off-shores is a subject for discussion. Therefore, first the authors would like to clarify what an off-shore is.

There are various approaches as to the division of off-shore companies. There are countries (off-shores) where the legal regulation allows non-payment of taxes or payment of taxes based on a lower rate. Most of these are developing countries. They charge a fixed fee for the registration 


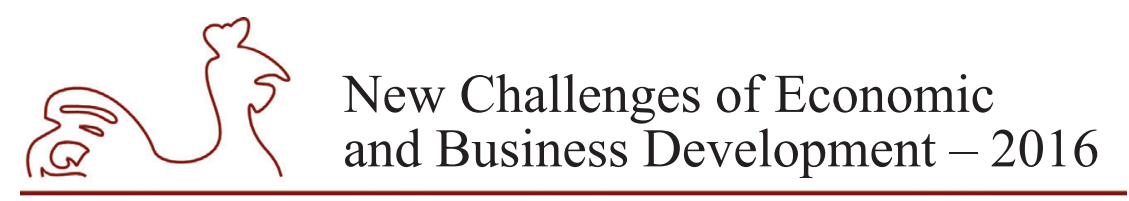

May 12-14, 2016, Riga, University of Latvia

of off-shore companies, thus gaining additional revenue to their budget. The definition "an offshore company" or "off-shore business" does not possess a strict legal, tax or business meaning. The basic definition "an off-shore company" can be expressed as follows: a separate legal entity which is registered, located or managed in a foreign country (Arzonu uznemumu dibinasana ...).

It is important to establish the purpose of use of companies. The authors have concluded that there can be various purposes: tax optimisation, protection of assets, management of an investment, patents and royalties, registration of real estate. In most cases companies need to receive a tax certificate in the country of founding of the company. In this case Cyprus as well as other countries which provide tax registration of the company is most advantageous.

In economics texts there are several types of off-shore companies. Off-shore companies which could be interesting from the point of view of optimisation of taxes and structuring of international business can be divided in three groups (Arzonu uznemumu dibinasana...):

The companies registered in the "classic" off-shores could be included in the first group characterised by the fact that they do not have operations in the country of registration, companies are released from payment of taxes or pay taxes at a $0 \%$ rate; they do not need accounting and audit; there is a fixed annual fee (charge). Globally there are more than half a hundred offshore jurisdictions. Most famous of them are as follows: British Virgin Islands, Panama, Belize, Seychelles, Nevis, Bahamas, Dominican, Mauritius and others.

The second group could include low tax jurisdictions. These countries are not tax-free zones, they have higher international authority than off-shore companies and, by fulfilling certain conditions, tax payments can be very low. Companies that are registered in low tax jurisdictions need to submit accounting reports and to perform annual audit. This group includes Cyprus, Bulgaria, Hong Kong and Singapore.

The third group includes the companies registered in the countries which are not offshores. These are countries with the simple (or even highest) tax collection system; companies have to maintain accounting in the country of registration; companies can be used in agency schemes, formation of holding structures as well as used in non-taxation agreements, and, by complying with certain conditions, they can be lower taxes. These jurisdictions are: in European countries (in particular, Great Britain, Denmark, Switzerland, Estonia), the USA, New Zealand and many others. For example, the income tax rate in Great Britain ranges from 21 to $28 \%$ depending on the profit amount. In New Zealand, the rate is $33 \%$ of the profit obtained from a source in New Zealand.

As regards taxes, it can be concluded that the conditions of assessment of taxes depend on a particular jurisdiction. Classic off-shore jurisdictions provide for release from taxes or set a $0 \%$ rate. The other countries provide for the corporate profit tax: in Cyprus (10\%), Great Britain (from 21 to $28 \%$ ), New Zealand (33\%).

"Classic" off-shore countries rarely enter into double taxation conventions or agreements which can be used for optimizing income from non-residents' structures. Thus, in order to implement double taxation agreements, jurisdictions which are not off-shore and low taxes are used. From the practical point of view it is easy to use Cyprus where the procedure for receiving the "tax residence certificate" is simplest.

The authors have concluded that there is confidentiality. In most off-shore jurisdictions (British Virgin Islands, Belize, Panama and others) the register of enterprises has information 


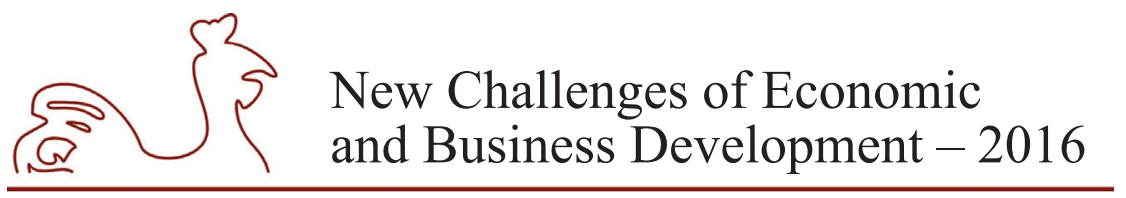

May 12-14, 2016, Riga, University of Latvia

about the company director. However, in low tax and not off-shore jurisdictions (Cyprus, Hong Kong, European countries) registers contain information about directors and shareholders.

At present there are more than 60 countries in the world where companies can be registered with tax reliefs. Most popular of them are as follows: British Virgin Islands, Bahamas, Belize, Seychelles, Panama, Cyprus, Hong Kong and others.

There is also another viewpoint and another classification of low- tax countries. By using the previously conducted studies, the authors summarised the tax policies in low tax countries in Table 1.

Table 1

Tax policy in low tax countries

\begin{tabular}{|c|c|c|}
\hline No & Countries & Taxation \\
\hline 1 & $\begin{array}{l}\text { British Virgin Islands } \\
\text { This territory is still an autonomous colony } \\
\text { of Great Britain }\end{array}$ & $0 \%$ tax rate applicable to business companies. \\
\hline 2 & $\begin{array}{l}\text { Hong Kong is a special administrative } \\
\text { region of the People's Republic of China. } \\
\text { It is no longer a colony of Great Britain as } \\
\text { from } 1997 .\end{array}$ & $\begin{array}{l}0 \% \text { tax rate is applied to income generated from abroad. } \\
\text { The profit obtained outside the territory of Hong Kong } \\
\text { is taxed at the rate of } 16.5 \% \text {. }\end{array}$ \\
\hline 3 & $\begin{array}{l}\text { The Republic of Panama is located between } \\
\text { North America and South America. }\end{array}$ & $\begin{array}{l}\text { If a company does not generate income from other } \\
\text { sources in the territory of Panama a } 0 \% \text { tax rate is } \\
\text { applied. In compliance with Panama legislation, } \\
\text { a company that does not generate income from other } \\
\text { sources in Panama is not viewed as a taxpayer. }\end{array}$ \\
\hline 4 & $\begin{array}{l}\text { Belize has a common border with Mexico, } \\
\text { in the south - with Guatemala. It achieved } \\
\text { independence from Great Britain in 1981. }\end{array}$ & $\begin{array}{l}\text { A } 0 \% \text { tax rate is applied to international business } \\
\text { companies. }\end{array}$ \\
\hline 5 & $\begin{array}{l}\text { New Zealand is located in the South part } \\
\text { of the Pacific Ocean, East from Australia. } \\
\text { New Zealand is a part of the Common- } \\
\text { wealth of Great Britain. }\end{array}$ & $\begin{array}{l}\text { The corporate income tax of the companies whose } \\
\text { shareholders are foreigners equals } 33 \% \text {. }\end{array}$ \\
\hline 6 & $\begin{array}{l}\text { The Republic of Cyprus is an island in } \\
\text { the East of the Mediterranean Sea. This is } \\
\text { a sovereign country with the presidential } \\
\text { democracy }\end{array}$ & $\begin{array}{l}\text { In companies registered in Cyprus and administered } \\
\text { and managed from abroad only the income generated } \\
\text { in Cyprus is taxed. An off-shore company in Cyprus is } \\
\text { released from taxes of foreign dividends, interest and } \\
\text { income from any permanent foreign representation } \\
\text { office, and there are also tax reliefs and compensation } \\
\text { of losses incurred abroad. Companies are not entitled } \\
\text { to tax reliefs provided for by Double Taxation Treaties, } \\
\text { however, the information exchanged provisions of } \\
\text { such treaties are not applicable to them. }\end{array}$ \\
\hline
\end{tabular}




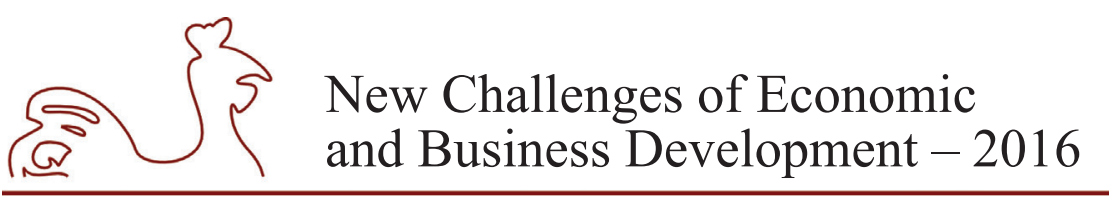

May 12-14, 2016, Riga, University of Latvia

\begin{tabular}{|c|c|c|}
\hline 7 & $\begin{array}{l}\text { Marshall Islands are located in the North } \\
\text { of the Pacific Ocean, approximately in } \\
\text { the middle between Hawaii Islands and } \\
\text { Australia. This is an independent sovereign } \\
\text { country in the region of Asia and the Pacific } \\
\text { Ocean and a rapidly growing financial } \\
\text { centre of off-shores. }\end{array}$ & $\begin{array}{l}\text { Non-residents' companies of Marshall Islands, } \\
\text { including all the joint stock companies, partnerships, } \\
\text { limited partnerships and limited liability companies, in } \\
\text { Marshall Islands are relieved of any taxes. No taxes are } \\
\text { imposed on any income, profit, dividends, royalties, } \\
\text { compensations or any other types of income. }\end{array}$ \\
\hline 8 & $\begin{array}{l}\text { Saint Louis is located in the East of } \\
\text { the Caribbean Sea. In } 1979 \text { it gained } \\
\text { independence as one of the member states } \\
\text { of the Commonwealth of Great Britain. It } \\
\text { has a clean reputation with strict licensing } \\
\text { laws and regulations }\end{array}$ & $\begin{array}{l}\text { Saint Louis IBC can select a release from taxes or } \\
\text { taxation of its income at the rate of } 1 \% \text {. International } \\
\text { business companies do not have to pay the state fee, } \\
\text { withheld tax and capital gain tax. }\end{array}$ \\
\hline 9 & $\begin{array}{l}\text { Commonwealth of Dominican is } \\
\text { the former colony of Great Britain } \\
\text { where currently there is independent } \\
\text { constitutional democracy, located in } \\
\text { the East of the Caribbean Sea }\end{array}$ & $\begin{array}{l}\text { The law provides that the minimum period when taxes } \\
\text { are not applied to off-shore companies is } 20 \text { (twenty) } \\
\text { years as from the date of its registration. }\end{array}$ \\
\hline 10 & $\begin{array}{l}\text { Gibraltar is a city and a port on the Gibraltar } \\
\text { cliff located on the Pyrenees Island, in } \\
\text { the South of Spain, just across the North } \\
\text { coast of Africa. }\end{array}$ & $\begin{array}{l}\text { Income of non-residents' companies is taxed when it is } \\
\text { not derived in the territory of Gibraltar or transferred to } \\
\text { there. In order to qualify for the status of a non-resident, } \\
\text { the company has to administered and managed outside } \\
\text { the territory of Gibraltar. Non-residents' companies are } \\
\text { not taxed by applying local taxes, except the corporate } \\
\text { income tax imposed to income transferred to Gibraltar. } \\
\text { Companies managed by non-residents are allowed } \\
\text { trading in the territory of Gibraltar and with Gibraltar } \\
\text { companies, however, in this case the corporate income } \\
\text { tax is } 35 \% \text {. }\end{array}$ \\
\hline 11 & $\begin{array}{l}\text { Seychelles are located in the Indian Ocean } \\
\text { between the East Coast of Africa and India. }\end{array}$ & $\begin{array}{l}\text { In compliance with the law, IBC's of Seychelles do } \\
\text { not have to pat taxes or duties for income or profit. } \\
\text { They are relieved from the state fee for the transfer of } \\
\text { property and any currency exchange control. }\end{array}$ \\
\hline 12 & $\begin{array}{l}\text { United Kingdom: Great Britain or also } \\
\text { the United Kingdom of England, Scotland, } \\
\text { Wales and Northern Ireland is located on } \\
\text { islands in West Europe, North from France }\end{array}$ & $\begin{array}{l}\text { All the income is split between partners and only then } \\
\text { income is taxed by imposing the income tax provided } \\
\text { for in the country where the relevant partner is residing } \\
\text { or registered. In Great Britain partnerships are no } \\
\text { viewed as companies, therefore the corporate income } \\
\text { tax is not applicable to them. }\end{array}$ \\
\hline 13 & $\begin{array}{l}\text { Saint Kiss and Nevis are located in } \\
\text { Leeward Islands, in the North part of } \\
\text { the Caribbean Sea East }\end{array}$ & $\begin{array}{l}\text { Non-residents' companies are relieved of all types of } \\
\text { taxes. }\end{array}$ \\
\hline
\end{tabular}


May 12-14, 2016, Riga, University of Latvia

\begin{tabular}{|l|l|l|}
\hline 14 & $\begin{array}{l}\text { Bulgaria is located in the South East } \\
\text { Europe, in Balkan region. }\end{array}$ & $\begin{array}{l}\text { In compliance with the Corporate Income Tax Act all } \\
\text { companies and partnerships (including not registered } \\
\text { partnerships) have to pay the corporate income tax } \\
\text { the rate of which is 15\%. It is planned that as from } \\
2006 \text { the corporate income tax will equal 12\%. } \\
\text { Internationally derived income of Bulgarian residents' } \\
\text { companies is taxed. Income generated in Bulgaria by } \\
\text { other companies is taxed. Non-profit organisations } \\
\text { (including state owned companies) have to pay the tax } \\
\text { for their business activity. Although branch offices } \\
\text { are not legal entities, branch offices of non-residents' } \\
\text { companies have a separate Balance Sheet and a Profit/ } \\
\text { Loss Statement. Income of a branch office of non- } \\
\text { residents' companies are taxed by applying the standard } \\
\text { corporate income tax rate of 15\%. }\end{array}$ \\
\hline 15 & $\begin{array}{l}\text { Latvia is strategically located in the East } \\
\text { Europe by the Baltic sea, having several } \\
\text { ice-free ports, good infrastructure and } \\
\text { a land border with Russia, Belarus, Estonia } \\
\text { and Lithuania (Low Tax ...). }\end{array}$ & $\begin{array}{l}\text { All companies registered in Latvia are liable to } \\
\text { corporate income tax at rate 15\%. Dividends paid to } \\
\text { individuals are subject to withholding tax only 10\%, } \\
\text { even reduced rate can be provided by DTA. }\end{array}$ \\
\hline 16 & $\begin{array}{l}\text { Canadian Company Formations } \\
\text { and }\end{array}$ & $\begin{array}{l}\text { No tax on the company's income derived outside } \\
\text { Canada. }\end{array}$ \\
\hline
\end{tabular}

Source: author's created based on Inland Tax Department ..., Inland Revenue Department ..., Inland Revenue New ..., Low Tax Company... .

Hong Kong, which is not an off-shore jurisdiction, still provides for the full tax relief for companies operating outside Hong Kong. This ranks Hong Kong among the most attractive jurisdictions for registration of companies.

Estonia is a Member State of the European Union. In Estonia, a 0\% tax rate is applicable to the company profit, and only the profit distributed among the company owners (for example, in the form of dividends) is taxable. The correct use of Estonian companies allows using them for the purpose of tax optimisation.

The government of Gibraltar plans to refuse the status of a tax oasis, the system where offshore companies are released from payment of taxes (Gibraltars atteiksies no ...). This decision was adopted in response to the international pressure imposed onto all tax oasis in order to achieve equal terms for both local and off-shore firms.

At the same time the corporate profit tax in Gibraltar is reduced to zero for all the companies. The financial sector accounts for approximately $25 \%$ of the economy of Gibraltar and, therefore, plays a vitally important role for the survival and welfare of Gibraltar. The corporate sector will continue paying money which is now collected by the government as corporate taxes and duties from the companies released from payment of taxes. This revenue amounts to approximately GBP 17 million per year. In order to compensate the revenue that is going to be lost due to the reduction of the corporate profit tax to zero, the "corporate wage list tax" will be introduced similarly to how this is done in Bermudan Islands. This tax will be assessed based on the number of employees. The wage tax and the business property borrowing tax will also be introduced and will jointly make up the amount equal to $15 \%$ of the company profit. In addition, all the companies 


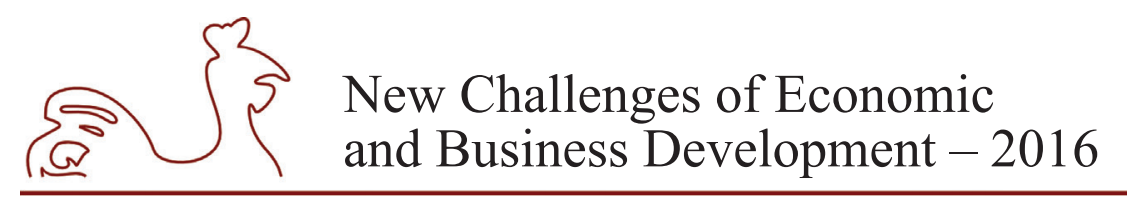

May 12-14, 2016, Riga, University of Latvia

will have to pay the annual registration fee amounting to GBP 300 or a half of this amount if the company does not have any income. Providers of financial services and utilities will have to pay the tax amounting to $8 \%$ of the profit. Due to the above measures many off-shore financial services providers will be forced to pay taxes for the first time. The government of Gibraltar wishes to introduce the reforms in the near future (Gibraltars atteiksies no ...).

There is an interesting question regarding the blacklisted countries. The "Black List" is the list comprising the countries upon which various restrictions have been imposed, for example, regarding taxes or currencies. Classic off-shore jurisdictions (Panama, British Virgin Islands, Seychelles, Belize and others) are included in most "black lists". However, there are also exceptions, for example, Panama is not included in the Ukrainian "black list" and Seychelles are not included in the list of off-shores of the Russian Federation (Arzonu uznemumu dibinasana).

Hong Kong and Cyprus are included in the "black lists" much more rarely and are not viewed as off-shore companies. Of course, jurisdictions which are not off-shores will not be found in any list (Great Britain, New Zealand, Denmark, Estonia etc.)

During the study it was established that in the cases when the prestige of a jurisdiction is an important aspect, the countries which are not referred to as off-shore jurisdictions are selected, for example, Hong Kong, Cyprus, Great Britain, New Zealand, Estonia etc.

Based on the conducted study it can be concluded that the services of off-shores are sufficiently broad and their utilisation is efficient only when they are used in compliance with the company needs and interests. Experts admit that in cases when a company wishes to reduce its tax burden it is worth focusing on off-shore structures, however, when it is more important for a company to protect its assets, it is better to implement active protection thereof by using funds or trusts instead of tax minimisation. In situations when a company operates in the area of information technologies, the use of the free e-commerce zone will seem more attractive to it.

Off-shores offer the establishment of investment funds by means of which it is possible to attract funds to the investment projects of a company and the efficiency of use of off-shores depends on the specifics of the company operations instead of its location.

\section{Tax transparency}

Taking the global experience as the basis, tax transparency is required - the initiative by the European Commission providing for the introduction of automated information exchange between Member States regarding cross-border tax resolutions as from 2015.

Transactions conducted in off-shore companies are confidential in most cases. Therefore, there is no complete statistics about how much of tax money is not transferred to the central budget. For example, according to the assessment made by the non-governmental organisation Tax Justice Network in 2009 developed countries lose approximately EUR 124 billion deposited with the banks of tax havens every year. The Treasury of Great Britain alone loses EUR 4.2 billion per year, moreover, as ironical as it might seem, money is lost in the territories administratively related to Great Britain, in particular, in Jersey Island, Guernsey and Mena Island. The tax haven favoured by Americans is a modest five floor building in Georgetown, the capital of Cayman Islands. In the office building Ugland House more than 18,000 companies are registered despite the fact that 241 people work there. B. Obama has said: "This is either the biggest building in the world or the biggest fraud scheme in the world". 


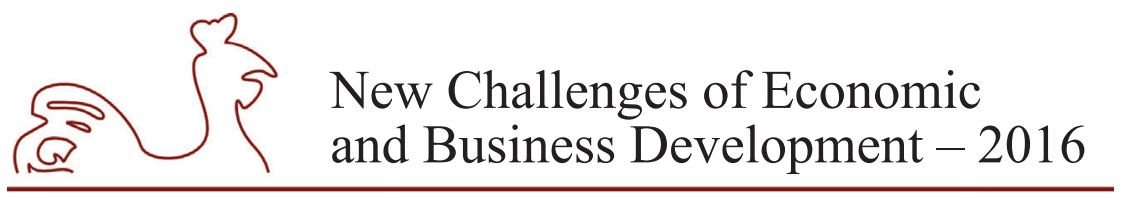

May 12-14, 2016, Riga, University of Latvia

The assumption that the money deposited in off-shores in a majority of cases means unpaid taxes is also confirmed by experts. A tax lawyer admitted to the newspaper "The Times": "Every time when you lift a stone in a tax haven, you find proof that people have been evading taxes."

Besides Cayman Islands, Guernsey and Jersey, Switzerland and Lichtenstein, the list of offshores includes also, for example, Hong Kong, Andorra, Monaco, Bermuda Islands, Antiqua and three countries of the European Union (EU) - Austria, Luxemburg and Belgium. All the three have achieved non-application of the EU regulations providing for information exchange among Member States for preventing tax evasion by citizens in one country by depositing funds in another country towards them (Ofsori raugas uz ...).

The EU experts, first, consider that it is necessary to strengthen the international agreements regarding multilateral treaties in order to obtain information about transactions taking place in a country, second, they recommend to improve the national legislation in order to minimise tax evasion, third, to strengthen the inter-country cooperation in the field of taxes.

\section{Conclusions, proposals, recommendations}

The authors conclude that tax competition in small countries contribute to the attraction of foreign investors. Based on the above the authors draw the following conclusions:

1. In the minimization of tax a distinction should be made between the income of natural persons and legal persons income. Because natural persons are also seeking to minimize tax payments. Natural persons are changing not only residence, but also nationality. Therefore necessary to introduce a time limit for not changing different residence country each year.

2. Due to the large number of tax obligations imposed on taxpayers, they are trying to find ways to avoid or reduce tax liabilities.

3. In the minimization of taxes typically addresses only to income taxes, but recent trends show that is also a value added tax planning by carrying out cross-border transactions and regression.

4. The existing inter-country tax competition has an increasing impact upon the tax policy of individual countries

5. Global tax harmonization could be the only solution regarding tax havens and off-shores.

6. The European policy makers and policy makers all over the world are looking for legal possibilities of terminating tax oasis and the possibilities of avoiding taxes, however, at the same time owners of big companies look for advantages of such oasis and tax transfer possibilities.

\section{Bibliography}

Arzonu uznemumu dibinasana. [Online] Available at: http://www.bspgroup.biz/content/lv/192/\%C4\%80 rzonu-uz $\%$ C5\%86\%C4\%93mumu-dibin\%C4\%81\%C5\%A1ana.html [Access: 16.12.2015].

Blanco, L. Rogers, C. (2012). Competition between Tax Havens: Does Proximity Matter? International Trade Journal. Sep/Oct 2012, Vol. 26, Issue 4, pp. 291-308. 18 p.

Botis, S. (2014). Features and Advantages of Using Tax Havens. Bulletin of the Transilvania University of Brasov. Series V: Economic Sciences. 2014, Vol. 7, Issue 2, pp. 181-188.

Chu, H. (2014). Tax Enforcement Policy and the Provision of Public Goods with the Presence of Tax Havens. Scottish Journal of Political Economy. July 2014, Vol. 61, Issue 3, pp. 304-321. 


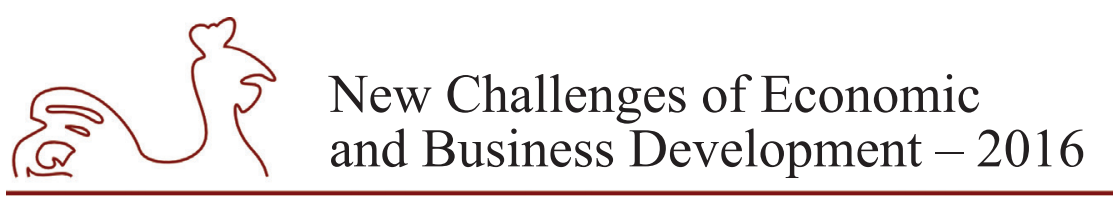

May 12-14, 2016, Riga, University of Latvia

Gibraltars atteiksies no nodokļu oazes statusa. [Online] Available at: http://financenet.tvnet.lv/ zinas/131225-gibraltars_atteiksies_no_nodoklu_oazes_statusa [Access: 21.12.2015].

Inland Revenue Department of Hong Kong Government. [Online] Available at: http://www.ird.gov.hk/ [Access: 16.12.2015].

Inland Revenue New Zealand Government. [Online] Available at: http://www.ird.govt.nz/ [Access: 16.12.2015].

Inland Tax Department of Great Britain. [Online] Available at: http://www.hmrc.gov.uk/ [Access: 16.12.2015].

Jaafar, A., Thornton, J. (2015). Tax Havens and Effective Tax Rates: An Analysis of Private versus Public European Firms. International Journal of Accounting. December 2015 50(4): pp. 435-457.

Jones, C., Temour, Y. (2016). The Determinants of Tax Haven FDI. Journal of World Business. Volume 51, Issue 2, February 2016, pp. 237-250.

Kas ir OFSORS? [Online] Available at: http://www.sfi.lv/ [Access: 20.12.2015].

Low Tax Company. [Online] Available at: http://www.lowtaxcompany.com/lv/ofsoru-valstis/latvia [Access: 20.12.2015].

Nodoklu terminologija. (2015). [Online] Available at: http://www.europarl.europa.eu/news/lv/newsroom/20150529STO61068/Nodoklu-terminologija [Access: 20.12.2015].

Ofsori raugas uz krastu. [Online] Available at: http://www.diena.lv/arhivs/ofsori-raugas-uzkrastu-13826192 [Access: 21.12.2015].

Palan, R. Chavagneux, C. Murphy, R. (2010). Tax Havens: How Globalization Really Works. Cornell Paperbacks. Ithaca, N.Y.: Cornell University Press. 270 p.

Richardson, G. Taylor, G. (2015). Income Shifting Incentives and Tax Haven Utilization: Evidence from Multinational U.S. Firms. International Journal of Accounting. December 2015 50(4): pp. 458-485.

Tax Haven Criteria. [Online] Available at: https://web.archive.org/web/20120512074208/http:/www.oecd. org/document/63/0,3343,en_2649_37427_30575447_1_1_1_37427,00.html [Access: 15.12.2015].

Vai "ofsors" ir sinonims nodoklu nemaksasanai? [Online] Available at: http://financenet.tvnet.lv/ viedokli/143977-vai_ofsors_ir_sinonims_nodoklu_nemaksasanai [Access: 20.12.2015]. 


\title{
POSITIONING STRATEGY DESIGN (RADIO SWH)
}

\author{
Laila Stabulniece, University of Latvia, Latvia ${ }^{1}$ \\ Ilgvars Rukers, University of Latvia, Latvia
}

\begin{abstract}
The need to design a positioning strategy and the topicality of the strategy issue arise from the tough competition experienced in the Latvian radio market. In this market a strong brand must be considered an effective long-term tool in the process of becoming the market leader which is indeed the aim of the JSC Radio $S W H$ group for its radio stations.

The aim of the research is to assess the current position of the radio station Radio SWH in the market compared to its direct competitors, and to formulate recommendations for the development of the positioning-strategy for the branding of Radio SWH. The research is based on theoretical aspects of positioning strategy design, and studies the current status of the company and its brand development with reference to basic positioning models.

Research methodology: the Authors have analyzed the reference material and available research on the topic in the light of the aims stated above; they have analyzed quantitative data relating to the radio audience using SuperNova data-processing software; they have interviewed radio-sector and mediaagency specialists; and they have summarized expert opinions.

In the theoretical analysis of the brand and its positioning strategies the Authors have compared the concepts designed by marketing and brand management specialists and have examined their practical applicability in designing the brand positioning strategy of the radio station. Based on the study of the radio station listening habits among the inhabitants of Latvia the Authors have analysed the overlaps between the target audiences of various radio stations. As a result, the Authors have identified the main direct competitor of the company to be the StarFM radio station, and recommendations have been formulated for the positioning strategy of Radio $S W H$ regarding this competitor.
\end{abstract}

Key words: Positioning, positioning strategy, brand, radio market

JEL code: M31

\section{Introduction}

The need to design a positioning strategy and the topicality of the strategy issue arise from the tough competition experienced in the Latvian radio market. The loyalty of radio listeners is unstable; there are ample opportunities for choosing the preferred radio station. As it is suggested by the Latvian radio market analysis conducted within this research, the participants of this market are mostly profit and short-term oriented and only some radio stations develop their operations based on a properly designed brand positioning strategy. A strong brand in the Latvian radio market must be considered an efficient long-term strategy tool on the way to the market leader position JSC Radio SWH aspires for in the future. The problem question of the research is how to isolate the audiences of mutually directly competing radio stations by developing a radio

1 Corresponding author - e-mail address: laila.stabulniece@lu.lv 


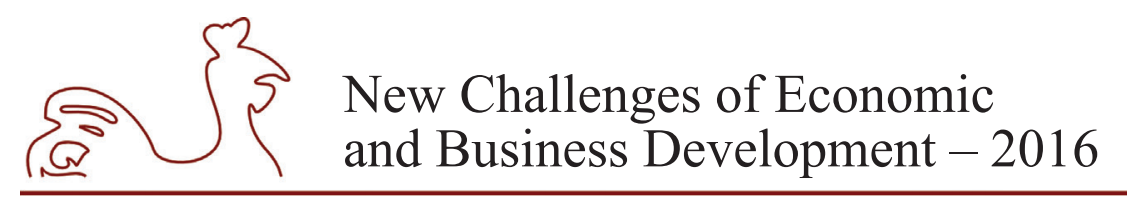

May 12-14, 2016, Riga, University of Latvia

station brand that would correspond to the psychographic profile of the consumers and would promote emotional attachment and long-term loyalty.

The aim of the research is to assess the current position of the radio station Radio $S W H$ in the market compared to its direct competitors, and to formulate recommendations for the development of the positioning-strategy for the branding of Radio SWH. The research is based on theoretical aspects of positioning strategy design, and studies the current status of the company and its brand development with reference to basic positioning models.

In line with the established aim the Authors have structured the results of the research in 4 parts: the description of the theoretical aspects of the brand positioning strategy, assessment of the development trends of the Latvian radio market, identification of Radio SWH competitors and guidelines of the Radio SWH brand positioning strategy.

Research methodology: the Authors have analyzed the reference material and available research on the topic in the light of the aims stated above; they have analyzed quantitative data relating to the radio audience using SuperNova data-processing software; they have interviewed radio-sector and media-agency specialists and summarized expert opinions. The sources of information used in the research are as follows: marketing and brand management literature, regular radio market research data by TNS research agency, materials from information agencies and periodicals as well as unpublished materials.

Based on the research on the radio listening habits of the population of Latvia the article analyses the overlaps of the audiences of various radio stations and describes the demographic and psychographic profile of the consumers (listeners) of the main competing radio stations. The analysis indicates a significant overlapping of the radio listening audiences which confirms the need for strategic planning of the radio station brand development and strengthening its position in the market. The practical significance of the work lies in the Radio SWH positioning strategy guidelines the Authors have designed as a result of the research and coordinated with the mission, vision and core values of Radio SWH. The dynamics of the radio market as well as changes expected in the competition in the future underline the relevance of the radio station brand positioning that would be clearly perceivable and understandable to the consumers (listeners).

\section{Theoretical aspects of brand positioning}

The essence of brand and positioning strategies is rather diversely interpreted in marketing literature in terms of opinions and concepts. In the discussion of the issues of brand positioning such marketing and brand management specialists as Aaker, Kotler, Van Gelder, Trout and others emphasize the diversity of the choices available to modern customers. As one of the most significant aspects for the provision for a long-term attachment of the consumers to the company offering the Authors have pointed out the connection between the brand and the value orientation and life style of the target market consumers. From the company perspective, a brand should be approached as an investment in the long-term growth of the business.

Brand strategist Van Gelder argues that a brand is determined and defined by three basic elements: brand positioning, brand identity and brand personality. Brand positioning determines the parameters by which the specific brand differs and is better than that of the competitors (Van Gelder S., 2003). Trout and Ries point out that the essence of brand positioning is expressed 


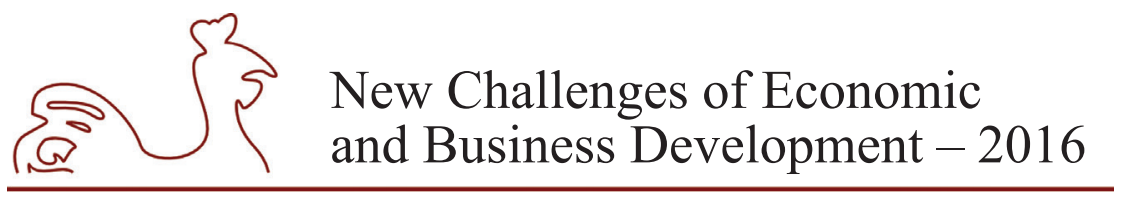

May 12-14, 2016, Riga, University of Latvia

by a certain association in consumer minds. The task of brand positioning is not to deal with products and their functional features, but rather define the difference that would be clearly perceivable and understandable for the consumers when compared to the competitors (Trout J., 2008). Kapferer has a similar opinion - the role of positioning is to underline the different features of a brand that both distinguish it from the competitor brands as well as make it attractive to a certain consumer group (Kapferer J., 2008).

The luxury and life style strategist, Professor Mihailovich of EDHEC Business School (France) widens the brand interpretation concept by including the consumer's emotional experience and relationship loyalty. A business must define and design brand positioning in four levels of consumer perception (Fig. 1).

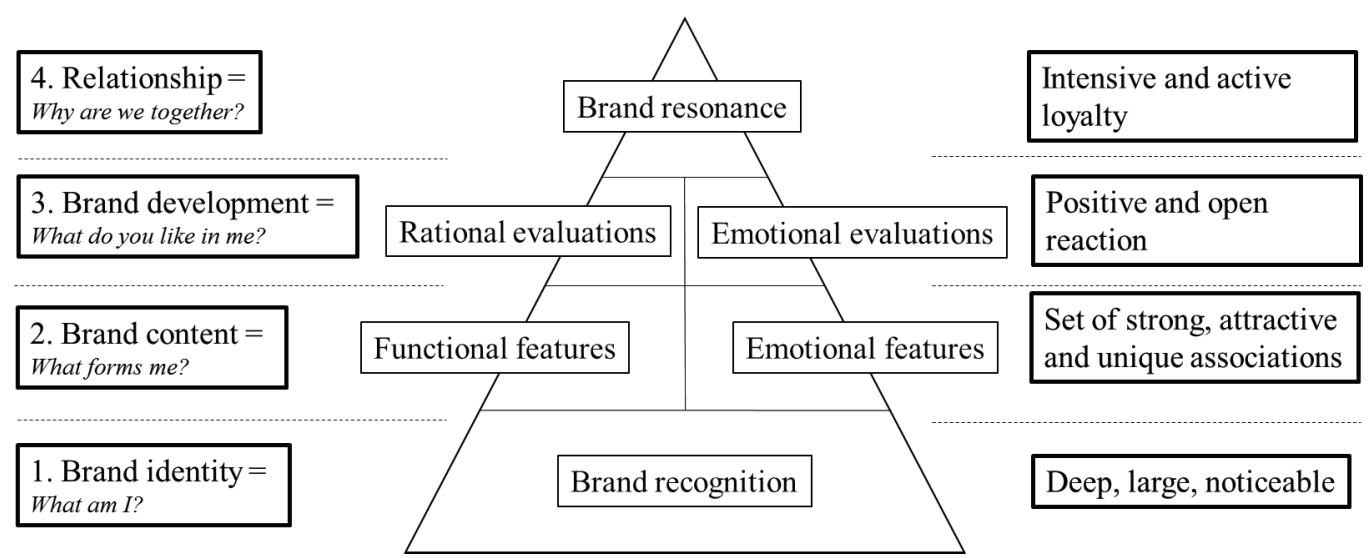

Source: Mihailovich P., 2012.

Fig. 1. Four levels in the relationship between the consumer and brand

According to this concept the aim of a positioning strategy is to reach the highest level of relationship with the consumers in the target market and create long-term relations to achieve active loyalty on the part of the consumers. Each next level of relationship can be achieved only by completing the previous one. Thus, in order to evaluate the content of the brand, they must first know the brand and recognize it. If the consumer has got acquainted with the brand, he is able to assess the brand deeper - both by understanding its functional features as well as perceiving it emotionally. At the moment when the consumer becomes aware of the brand content, he develops a conscious or unconscious opinion about the correspondence of the brand to his personality. At this level of the relationship the consumer both rationally and emotionally evaluates the familiar and communicated features of the brand and decides if he can form longterm and sustainable relations with the brand. If the evaluation is positive the consumer accepts the relationship offered by the brand and becomes its loyal follower (Mihailovich P., 2012).

Van Gelder holds a similar opinion: the positioning of the brand is a strategic document that must provide precise answers for the formulation of the product and service features; it must highlight and define functional and emotional advantages, values and confirmations on how the consumer's daily routine will improve as a result of choosing the brand. The set of the abovementioned features and parameters must be counter-positioned to the competitors; moreover, it must be done along with highlighting and communicating the advantages (Van Gelder S., 2003). 


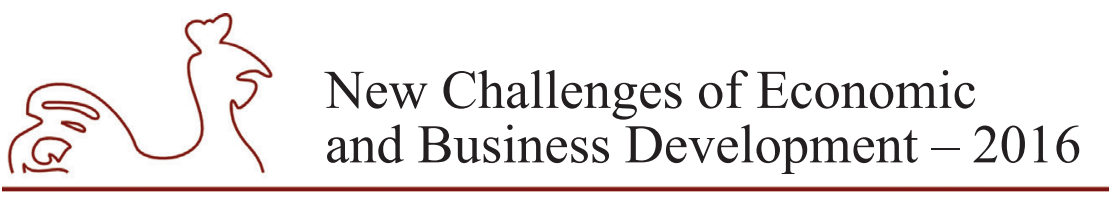

May 12-14, 2016, Riga, University of Latvia

When designing a brand positioning strategy, the Authors of the research recommend using and adapting the TABS Matrix ( $\mathrm{T}$ - territory, $\mathrm{A}$ - association, $\mathrm{B}$ - basic skills, $\mathrm{S}$ - product satisfaction level or unique selling propositions that provide the consumer with satisfaction) model designed by the marketing and communications agency Publicis Worldwide (international agency network). In this model (Fig. 2) the positioning of the brand essentially is the balance between the micro and macro perception levels of the brand. The micro environment is a set of the functional features of a product defined by the brand builders and unique selling propositions. The micro environment, however, is formed by the functional and emotional evaluation of the brand by consumers (the emotionally associative level). In order to give a concise answer to the key questions of each of the quadrants of the matrix it is necessary to conduct an in-depth assessment of the consumer, market and competitors to be able to define the advantages of the product and the desirable and attractive associations with the company brand. The TABS matrix model defines the brand position by linking the offering of the brand creator (on the left side of the matrix) with its "imprint" in the consumer perception (on the right side of the matrix).

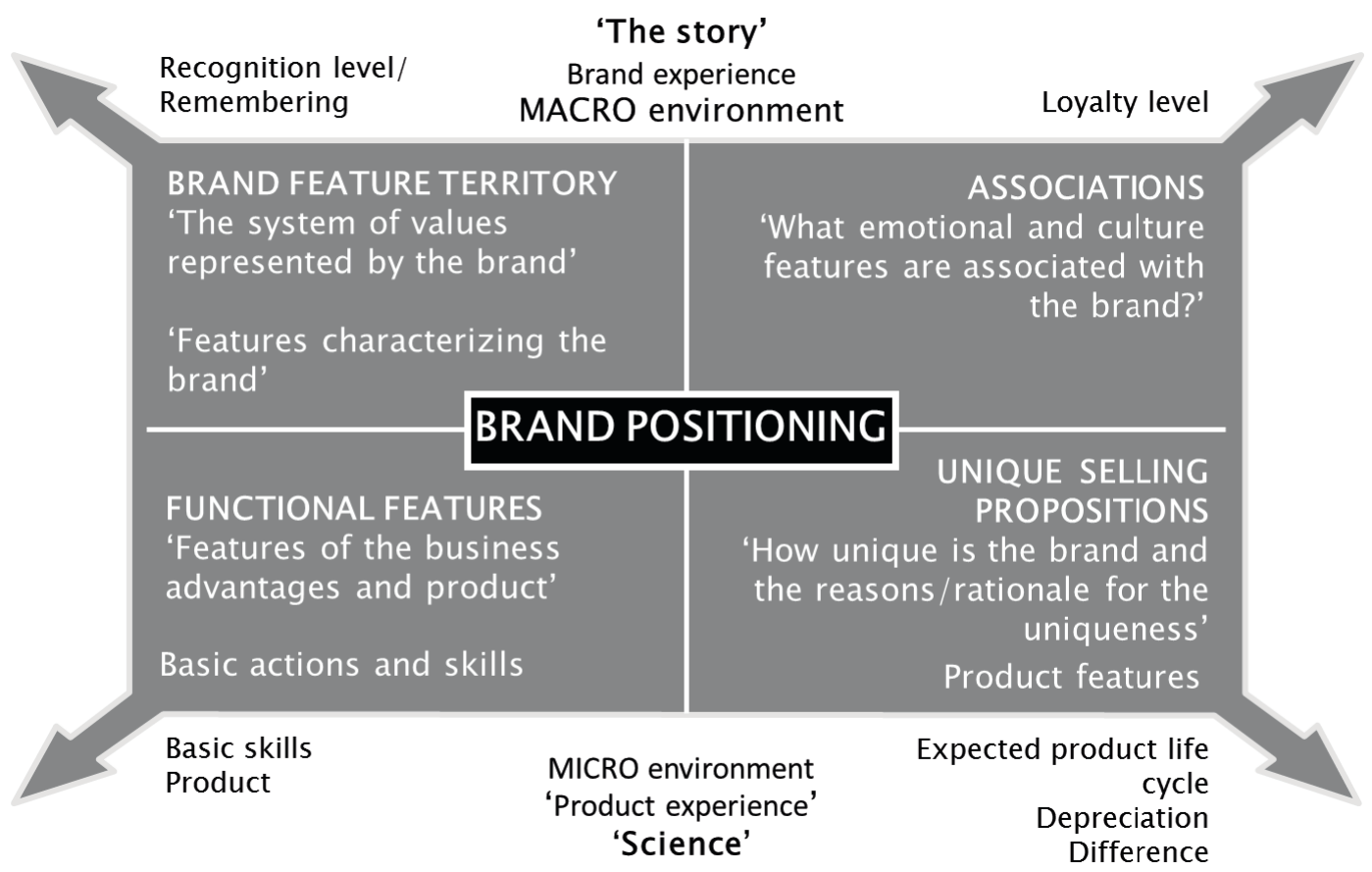

Source: Publicis Worldwide, 2008.

Fig. 2. TABS Matrix model for a brand positioning strategy

To sum up the analysis of the theoretical aspects of brand positioning, the Authors of the research would like to conclude that, when developing a brand positioning strategy in a saturated market environment, one of the main problems faced by companies is to ensure that consumers notice and understand the values represented by the brand and emotionally associate themselves with these values. 


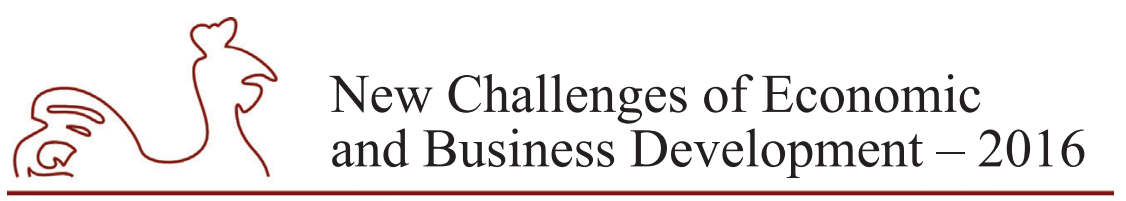

May 12-14, 2016, Riga, University of Latvia

\section{Radio market development trends in Latvia}

The most characteristic feature of the radio industry in Latvia is the high intensity competition. As suggested by the information from the National Council of Electronic Mass Media of Latvia and Lursoft data, there were six major players in the market in year 2015:

1. Latvian Radio (the group comprises six basic radio stations - LR1, LR2, etc., where LR5 is better known as Pieci.lv and LR6 as Radio NABA);

2. Media group Super FM (the group comprises three basic radio stations: European Hit Radio, Russian Hit Radio and Super FM);

3. Radio $\mathbf{S W H}$ (four basic radio stations: Radio $S W H$, Radio $S W H+$, Radio $S W H$ Rock and Radio SWH Gold, as well as local stations - Radio SWH Latgale, Radio SWH Kurzeme and Internet radio station - SPIN FM);

4. Radio Skonto (the group has one basic station with the local stations of Radio Skonto Kurzeme and Radio Skonto Vidzeme which provide locally important information and commercials, but not a local content).

5. Star $\boldsymbol{F M}$ (there is one basic station in the group);

6. Media group MIX Media Group (four basic stations: RADIO MIX FM, RADIO 99.5, also known as Europa Plus, Baltkom radio, RADIO 88.6 FM, also known as Jumor FM).

The revenues from commercials in these radio stations account for $80 \%$ of the total revenues of all radio stations, which means, the market is highly concentrated. The operation of other radio stations is mostly subsidized from other funds and income obtained from other businesses of their owners (National Electronic Mass Media Council, 2015).

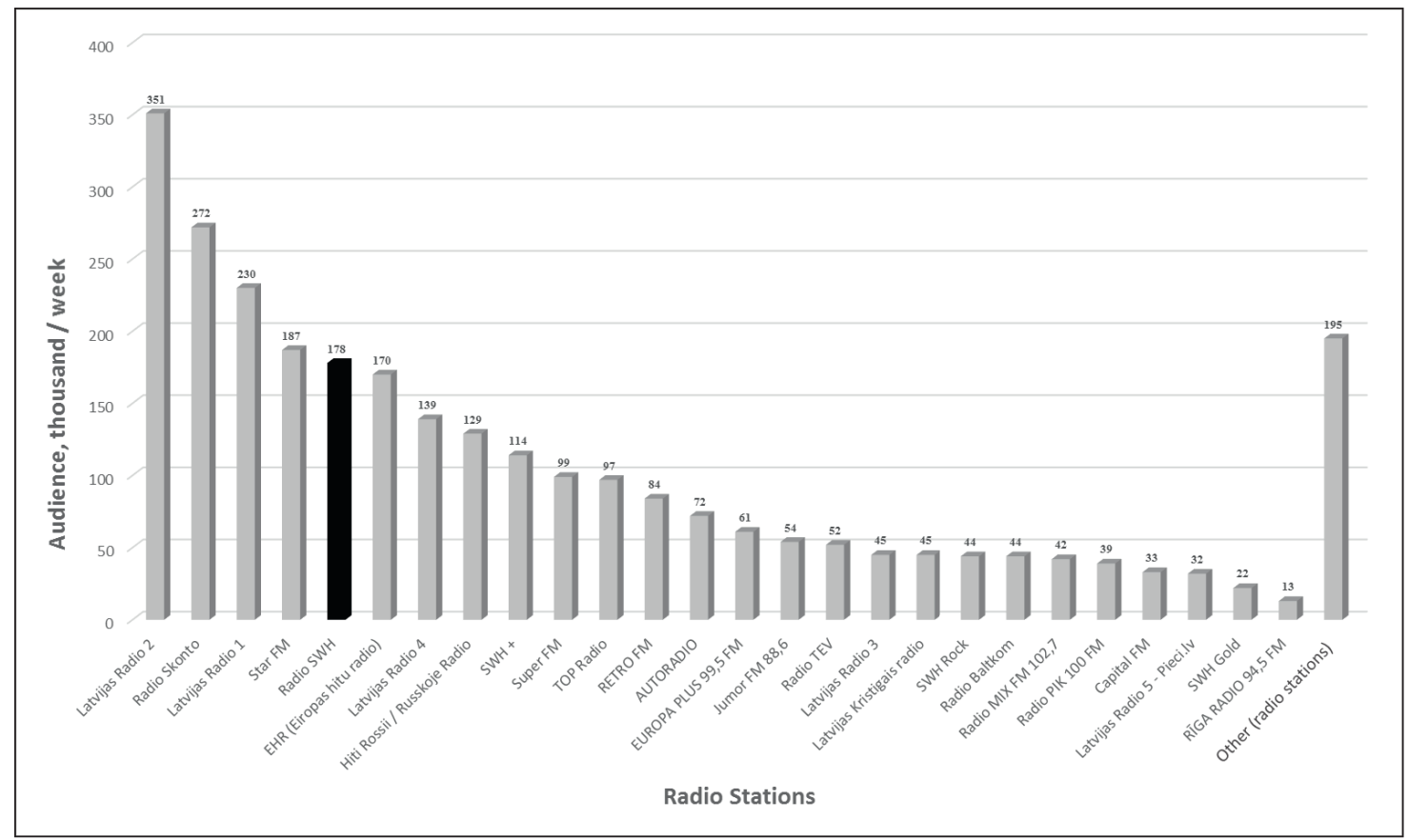

Source: designed by the Authors based on the data from regular radio market research by marketing agency TNS.

Fig. 3. Listening habits to radio stations acc.to TNS winter 2015 ratings, number of listeners, K/week 


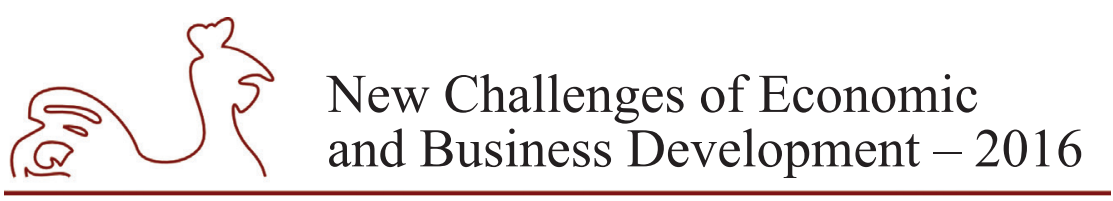

May 12-14, 2016, Riga, University of Latvia

Fig. 3 lists the radio stations in the radio market of Latvia by the intensity of listening to them, according to the data compiled by TNS research agency (TNS Latvia, 2015). The grouping of radio stations in Fig. 3 by the six leading group stations outlines the total market share of Radio SWH group by its listener volume as well as its closest competitors (Fig. 4). As Radio SWH is one of the big players in the market, in designing the positioning strategy namely the big competitors have to be considered as the small stations cannot create an adequate competition in the market. One of the problems to be studied is to identify the direct competitors of the Radio SWH brand striving for the same or occupying a closely existing space in consumer minds.

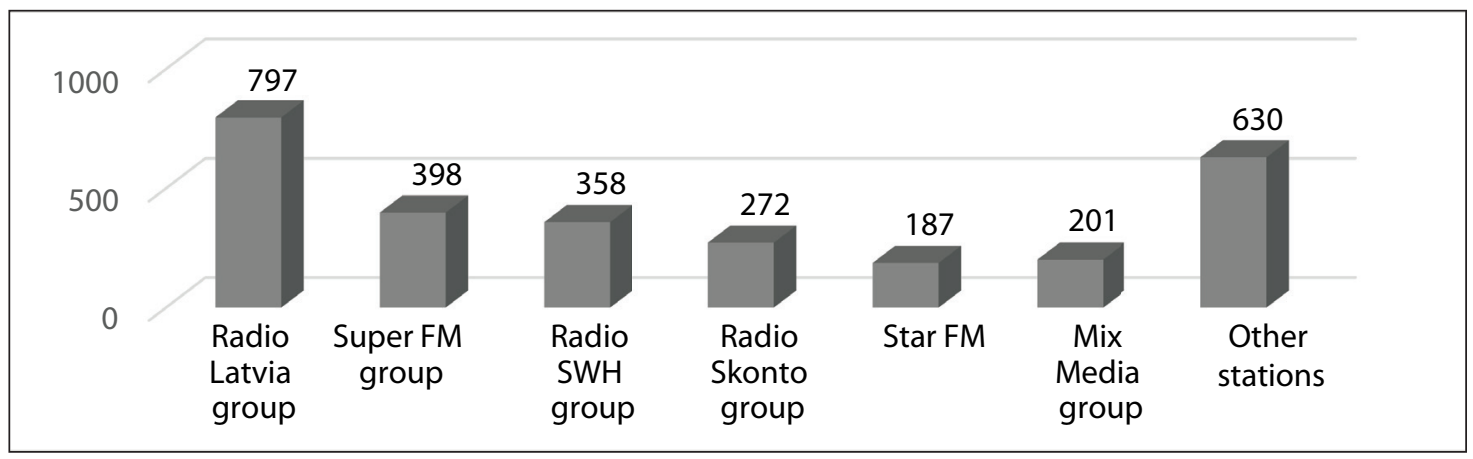

Source: designed by the Authors based on the data from the regular radio market research by marketing agency TNS.

Fig. 4. Listening habits to radio stations acc.to TNS winter 2015 ratings, TOP6 radio station groups of Latvia, by number of listeners, K/week

As radio industry experts indicate in their assessments, the high competition among the radio stations struggling for the listener leads to mutual price fights which, in their turn, lead to the trend towards lower prices for radio commercials and continuous low price pressure on the market participants. According to experts, and the Authors agree to the opinion, the low prices are achieved by competing with low costs in certain activity positions, the most significant of them being the radio content. The cost positions of radio products are basically composed by the following:

1) administrative costs;

2) broadcasting and related costs;

3) copyright payments;

4) marketing and self-advertisement costs;

5) costs of author programme design and fees of radio personalities.

We can conclude that the first three cost positions are binding to everyone pursuing business in radio industry. Consequently, a significant reduction, compared to the competitors, can be acquired by decreasing or completely eliminating marketing, self-advertising and author programme design and radio personality costs. Under the lowest price strategy conditions the market participants massively opt for "producing" a possibly cheaper product or acquiring a ready-made radio product and rebroadcast rights which in terms of costs is a considerably cheaper "raw material". In such a situation the strategic development and correct positioning of the brand become particularly important. The brand that is positioned precisely and in accordance with the market segment will provide for a strong emotional attachment of the loyal listener 


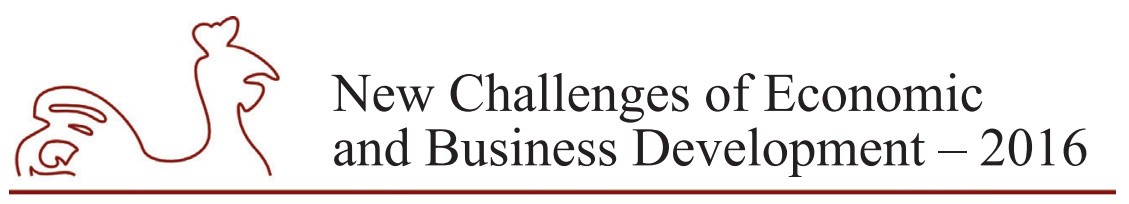

May 12-14, 2016, Riga, University of Latvia

which, together with an elaborated and skilfully differentiated radio product, will not only provide good ratings for the radio station, but also motivate potential advertisers to invest more in the product and radio content, and pay more for the advertising opportunities on the radio.

Unremitting price dumping must be considered a short-term gain both for the advertisers in the radio market of the country as well as consumers. The drop in marketing and selfadvertising costs means leaving both the radio brand development and positioning strategy alone in the public space or not to engage in that at all. The radio that chooses not to invest in planned communication chooses not to invest in the potential listeners. However, by choosing to do without experienced radio personalities, producers and employees working on the unique content design, in the long term the radio risks losing its role - to serve as an objective carrier of information and catalyst of mutual communication. According to experts, the advertisers making pressure on the radio stations for ever lower prices should actually be viewed as a threat to the radio industry as a whole since they threaten the growth and development of the industry - if there are no people who think about improving the radio content and surprising and entertaining the listener in a unique way, that is, if the creative competition disappears, the radio as a medium declines because listeners lose the motivation to listen to the radio regularly.

Regarding the general development trends of the radio market of Latvia and future forecasts, the Authors have arrived to the conclusion that already in the nearest time radio will be radically affected by significant factors that have to be considered when designing the positioning strategy:

- According to forecasts, Radio Latvia might leave the advertising market (LETA, 20.03.2015). As a result, the competition among commercial radio stations in the market will increase and beneficiaries from that will be the radio stations with the best developed brand, clear strategy, more attractive radio content and bigger proportion of the listening audience.

- An increasingly bigger role in the range of the radio products and content integration will belong to digital products, this especially concerns attracting the youth audience. To attract the youth audience, the behavioural characteristics of the generation must be taken into account. These young people were born and have grown up in the information age; they can quickly find and select the information they need. Unique content has become more important than ever. Moreover, the preference is given to visual information - pictures, videos etc. Young people are willing to participate in the creative process. Communication must be able to provide this required feedback - the dialogue with the potential listener. The radio brand, which will have envisaged the change of the paradigm in their development plans and duly prepared for it, will acquire an ever increasing business advantage over the competitors.

- Norway will be the first country in the world which in 2017 will pass over to solely digital broadcasting. According to the calculations of the Norwegian Ministry of Culture, the maintenance of the digital radio infrastructure costs up to eight times less than the analogue one (Diena.lv, 20.04.2015). This means that the format will lose any limits. Already now in a smartphone, by using app TuneIn, it is possible to listen to any radio station in the world on-line and at a very high quality. Radio industry is facing the age of radio brands. The key role of the brand is to provide for emotional difference in consumer minds which is particularly important under almost unlimited choice. The role of the values and emotional promises expressed by brands will experience continuous 


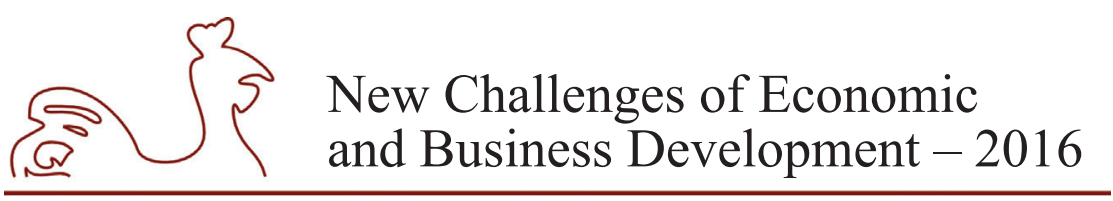

May 12-14, 2016, Riga, University of Latvia

growth as well as will the content offered by the particular radio - its music format, author programmes and radio personalities.

To sum up, radio industry is facing radical changes which will be survived by the companies with a clearly set positioning strategy, in particular those which will have not only designed it, but will also be implementing the strategy. The analysis of the radio market participants and their specific character in Latvia in terms of the positioning strategy leads to the following conclusions:

1) The potential provided by brand development and design of a targeted positioning strategy is underestimated in the industry, although there is economic substantiation to prove it, i.e., the rise in the number of listeners. Listener loyalty and stability in the long term would also mean the growth in the income part of the radio station, which means that investments in brand development, designing of the positioning strategy and implementation are well-founded;

2) The radio market of Latvia is operating under tense competition where a strong brand and clearly defined positioning could serve as an effective long-term strategy tool on the way to the market leader position.

\section{Identification of Radio $S W H$ competitors}

Radio $S W H$ is the first private radio station in Latvia with a self-designed programme. It was founded in 1993, thus creating a new - private media sector in the country. The founder of JSC Radio SWH is Zigmars Liepiņš, the current board chairman of Latvian National Opera House. Over these more than twenty years the key for the success of Radio SWH has been:

1) its live format;

2) radio personalities;

3) highly selective, up-to-date, topical and modern format of music;

4) well-weighed entertainment content in authentic author programmes;

5) objective news, not limited to general information; Radio $S W H$ is one of few radios that offers topical news from various towns and regions as well as news by topic, for example, sports, medicine, culture, auto, construction and other;

6) exciting competitions with a never-ending and considerable range of prizes;

7) strong team that has grown together with the radio station;

8) Radio SWH has introduced various innovations in the radio on-air broadcast and has been pioneers for a range of new radio products.

A critical situation developed in the radio station in year 2010 when a part of the Radio SWH administrative team and several advertising sales specialists together with the leading radio personalities left Radio SWH to found their own radio station-Radio 101. Radio SWH experienced a drop in their ratings which was reflected in their financial performance (in 2011, 2012 and 2013 the radio station was in red). The crisis was overcome with the help of parent company "Communicorp Group Ltd." investment and streamlining measures. The reorganization led by JSC Radio SWH management provided for the overcoming of the internal crisis, stabilizing their operations and being able to develop the radio content. In 2014 JSC Radio SWH succeeded in ending the year in black. On 24 September, 2015 the structure of the shareholders changed the major stake was obtained by Estonian company "Cinamon Holding" as well as the up-to-then 


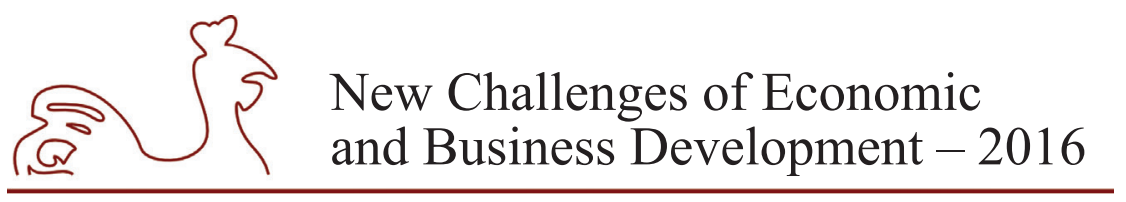

May 12-14, 2016, Riga, University of Latvia

radio board chairman Šipkēvics and finance director Rubenis. Both the changes in the owner structure as well as the evaluation of the latest development trends have underlined the need for designing a positioning strategy for the Radio $S W H$ brand.

In order to design the strategy, first, it is necessary to understand the demographic and social parameters of the consumers as only after understanding the target group the evaluation of its system of values and developing of long-term relations will be possible. In the radio industry the listener is considered to be the consumer as instead of the product the listener receives the radio content, but the radio obtains the listener's attention in return for the listening and over the time the listener accepts to listen to the advertiser's information, which, in its turn, accounts for the biggest part of the radio station income.

The Authors of the research believe that the comparative listener analysis of the competing radio stations gives an idea about the size of the consumer potential. Based on the data from the regular radio market research by marketing agency TNS and SuperNova software for data duplicating, the Authors have analysed the cross-sections of Radio SWH and competitor radio station ratings and overlapping of listener audiences. Thus it is possible to assess how many of the listeners of one specific radio station now and then also listen to the other radio station and vice versa. The bigger the overlapping segment, the bigger is the role of the radio station brand and positioning strategy. The listeners in the overlapping audience sector can be considered questionable both for one radio station and the other. On the other hand, they could be considered a realistic potential for increasing the listener volume as they can be made loyal brand followers already in a short term and no substantial time and resource investments will be needed for acquainting them with the product. The results of analysing the duplicating of the quantitative indicators of radio listener audience are summarized in Fig. 5.

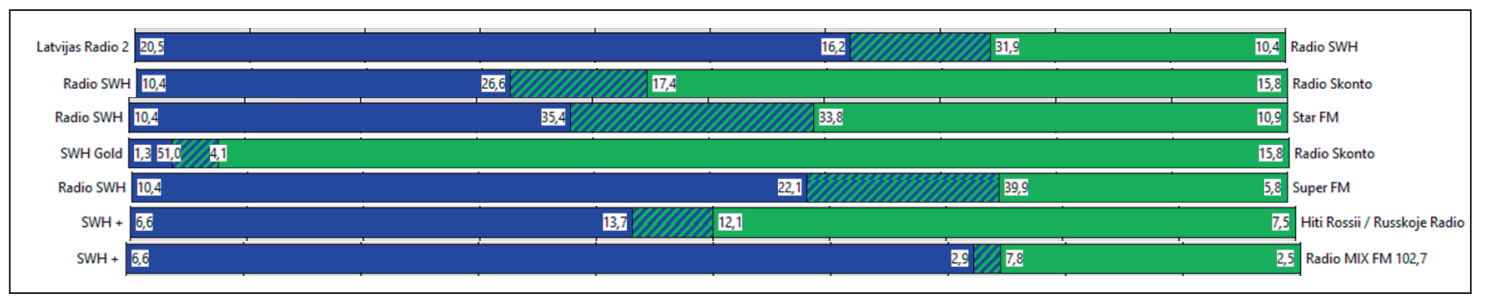

Source: designed by the Authors based on the data from the regular radio market research by marketing agency TNS.

Fig. 5. Direct competitors of JSC Radio $S W H$ group stations (overlapping of radio listener audiences, \%)

From Fig. 5 it can be concluded that the biggest competitor of the Radio SWH brand is Star FM as $35.4 \%$ of all Radio SWH listeners now and then listen to Star FM and vice versa $33.8 \%$ of the Star FM listeners now and then try Radio SWH. This means that more than a third of the listeners of each station migrate and cannot make their final choice in favour of one or the other station. This means that when developing the Radio SWH brand, Star FM must be seen as an pronounced direct competitor as well as a possible potential for increasing the audience on the account of winning/regaining it from the competitor.

When analysing the social and demographic profile of the audiences of both direct competitors, the Authors have found similarities between the most significant parameters 


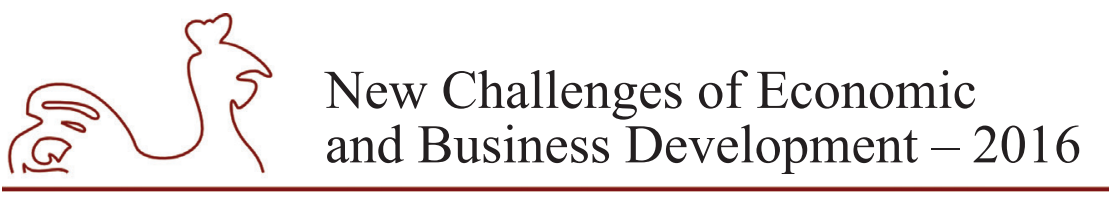

May 12-14, 2016, Riga, University of Latvia

characterizing the audience. The Radio $S W H$ listeners are almost evenly dispersed over the age groups between 25-74 years, with marked majority in the age group of 35-54 years (45\%) (Fig. 6). A similar feature can be observed in the age of the radio Star FM audience with the $40 \%$ proportion of the listeners representing age group 35-54 years and 29\% of listeners being in age group 25-34 years. None of the two radio stations is particularly popular among young listeners, however, it can be seen that the Star FM audience is younger.

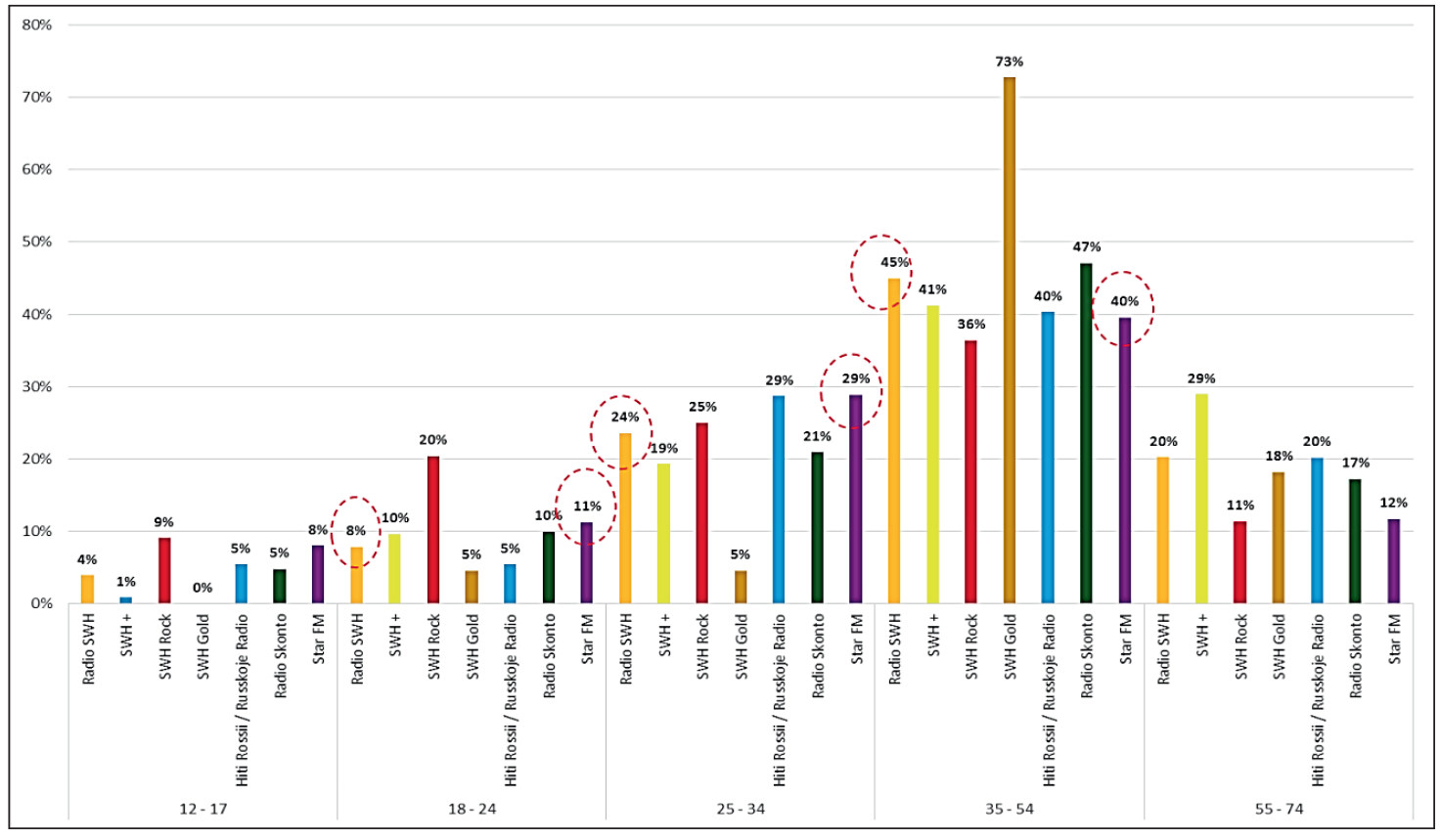

Source: designed by the Authors based on the data from the regular radio market research by marketing agency TNS.

Fig. 6. Listener age structure of JSC Radio $S W H$ group and its direct competitors, \%

The Authors of the research would like to point out that up to now the biggest radio stations of Latvia have not particularly concentrated on attracting the youth audience, design of new radio products has not taken place, the involvement of digital products and social networking sites in the daily work and content of the radio stations has been minimal. Targeted development towards the youth audience is implemented in the programmes and content of Radio Latvia 5 or Pieci.lv. Although in year 2015 the radio station had only 32 thousand listeners (reach per week) and there is virtually no growth, it must be considered that namely this radio station is the founder of the new radio paradigm in Latvia and has the potential of overtaking its competitors in the youth audience group and age group of 25-34 years. This, the so-called "Golden audience", is the most valuable from the advertiser perspective as it is sufficiently well-off, progressive, active and open for various offerings. When designing the positioning strategy of a radio station, one of the basic postulates in the brand development must be a compulsory attraction of new audience. It must be approached not only as an investment into the future and existence of the radio station as a whole, but also as a current advantage in relation to the direct competitors whose audience is aging. 


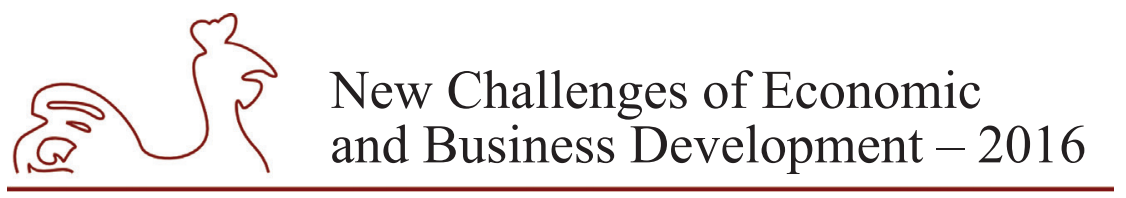

May 12-14, 2016, Riga, University of Latvia

Similarly, when analysing the listener education level, it must be pointed out that the listeners of Radio SWH possess one of the highest levels of education ( $40 \%$ have higher education). This can serve as a significant argument for advertisers when claiming a higher price for reaching one listener. The listener with a higher education has a higher income and such a listener means a potentially bigger turnover for the advertiser, particularly, what regards a higher quality offering. However, it is important to note that a better-off and more educated audience is more demanding toward the quality of the content as well as the brand overall. The education and occupation profile of the listeners of the Radio SWH competitor Star FM is rather similar.

Consequently, the comparative analysis of the parameters of the radio listener audience (age, education, income, occupation) allows the Authors of the research to design an integrated social and demographic matrix of the listeners of the mutually competing radio stations and identify the fields of activity of the direct competitors in the context of the indicated parameters. The matrix in Fig. 7 shows the summary of the social and demographic analysis performed within the research and the differing features of the $S W H$ direct competitors' audiences. Namely the identification of the features of the direct competitors' audiences is a significant pre-condition for designing an adequate brand positioning strategy.

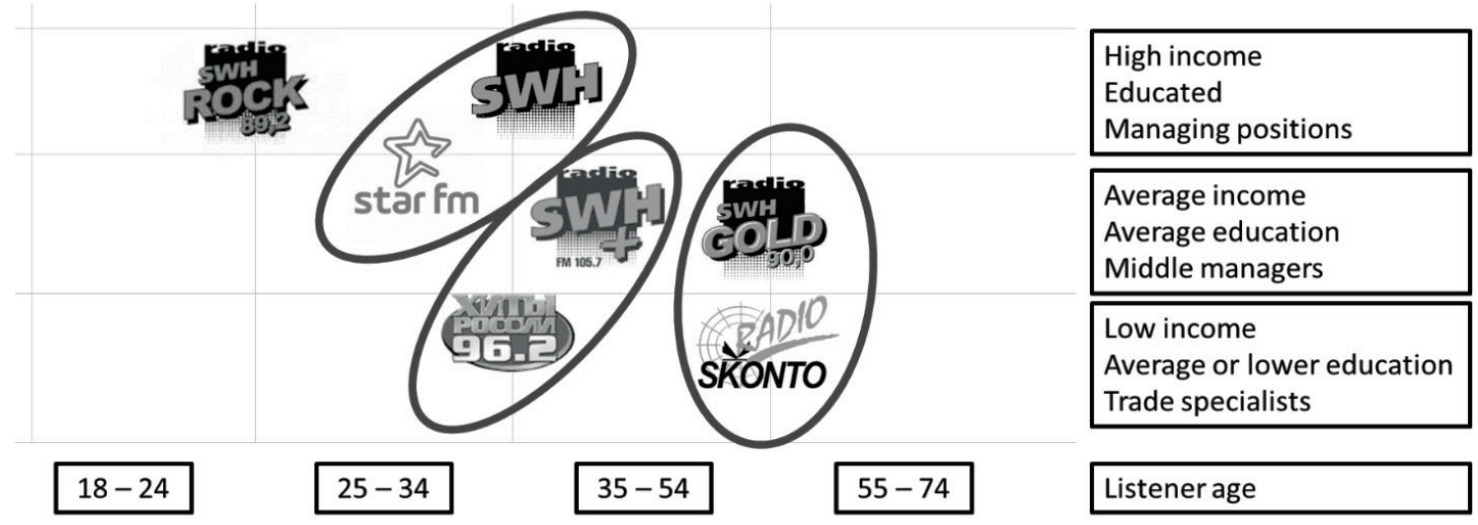

Source: designed by the Authors.

Fig. 7. Social and demographic matrix of the listeners of JSC Radio SWH group station and their direct competitors

By locating the brands of the radio stations in the corresponding positions of the matrix by the listener profile parameters we acquire a clear idea about the borders of the territories where competitor interests collide. We can see that Radio SWH competes with Star FM, but Radio Skonto (which was for a long time considered by the management of Radio SWH its direct competitor) lies in a different zone, the closest to which are the listeners of Radio SWH Gold. However, Radio SWH+ competes with Hiti Rossii not only because there are similar listener profiles, but also because it is the Russian-speaking audience. The best position by the listener profile and content format belongs to Radio $S W H$ Rock, as it occupies a niche position with a clearly differentiated product and qualitative, but not very big audience. 


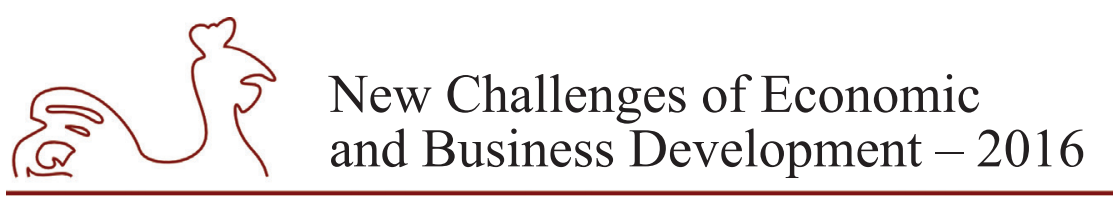

May 12-14, 2016, Riga, University of Latvia

To sum up the results of the comparative analysis of the Radio SWH and competing radio station listeners and to evaluate the Radio $S W H$ brand development prospects, the Authors of the research have concluded the following:

1) The listener audience of Radio $S W H$ is unstable as in terms of percentage a big part of them are unstable in their listening habits. Consequently, the listener loyalty is to be considered relatively low. Obviously, a big part of the listeners do not have emotional attachment to the brand. This means that the Radio SWH brand positioning strategy must be based on values that would provide for subsequent and persistent communication with the listener audience.

2) When designing the brand position strategy for Radio $S W H$, the position against the direct competitor, radio Star FM, must be taken by looking for the differences in the psychographic parameters in the audience segment that is socially and demographically consolidated.

\section{Radio $S W H$ brand positioning guidelines}

As a result of summarizing the opinions of the radio industry and media agency experts about the content, programme and communication features of the competing radio stations Star FM and Radio $S W H$ as well as the profile of the psychographic parameters of the radio listener audiences, the Authors of the research have evaluated the current market position of Radio SWH and designed the positioning strategy guidelines. The guidelines are based on the positioning in relation to their direct competitor (counter-positioning strategy).

The analysis shows that the Star FM listeners are considerably more conservative in their beliefs which can be seen from their willingness to listen to the radio with a more limited playlist. The programme conductors (deejays) of Star FM have limited opportunities to show themselves and improvise on the topics of the conversations, it is only allowed to provide a brief commentary at the end of the previous song and beginning of the next one or the so-called outro-intro (the only exception to this is the morning programme). In the communication, Star FM more performs the informant's role and is more predictable in general - both in terms of the content and music repertoire as well as communication. Star FM always strictly follow the radio management guidelines designed by MTG group and the product offered by the radio station can be assessed as very well considered and selected to meet the needs of the audience, however, it is rather synthetic (as opposed to natural) in its core. The Star FM identity is difficult to perceive (in an express survey the Authors interviewed 20 people; none of them was able to mention any specific features characterizing the Star FM identity).

Conceptually, in designing the positioning strategy emotional and rational advantages and differences must be searched within the existing listener segment that would clearly outline the offering of Radio SWH. This means that the following values must be counter-set to the previously characterized competitor Star FM features:

1) Radio $S W H$ listener is considered to be progressive and having the routine that surpasses the traditional one. This is the listener who expects more than the casual;

2) Consequently, in contrast to the conservative content, Radio SWH aim to be surprising and unpredictable on daily basis;

3) Within the self-advertising of the radio station it is important to create the communication that continues to surprise with creativity and performance; 


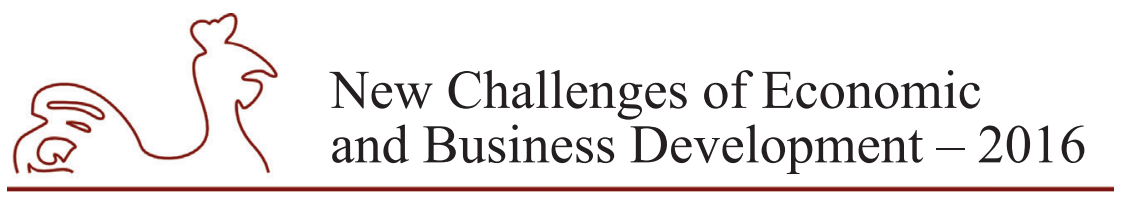

May 12-14, 2016, Riga, University of Latvia

4) Radio $S W H$ has historically been the radio that is more daring. For example, the experts consider the programme BéBe Brokastis with Fredis and Ufo to be the benchmark of Latvian radio morning programmes surpassed by no one in popularity and profitability. This phenomenon was based on outstanding radio personalities who, like all radio personalities in Radio $S W H$, had created a bright and colourful image of the radio. By the time and due to the changes the image has been lost. This means that in creating the positioning strategy Radio SWH must be able to return to its "positive naughty boy" status compared to Star FM's "obedient child" image;

5) In order to be always a step ahead, new things (both in terms of content and technologies) must serve as a daily challenge of the radio station. This will provide for the necessary changes as well as pleasant surprises to the listeners;

6) Radio $\mathrm{SWH}$ must be a natural radio with live radio personalities not restrained in their work by management-imposed limitations (even if there are such). The radio must follow the principle "a superb idea came to mind for the co-operation with the listeners the idea must be immediately implemented" as it suits the "positive naughty boy";

7) Radio $S W H$ has been wearing orange colour identity since its very beginnings and there is no other radio station claiming the orange colour field. This allows capitalizing on the visual element of this identity as owned by the Radio SWH group and using it for increasing the communication effect.

The counter-positioning parameters of Radio $S W H$ when addressing the psychographic parameters of the listener audience are shown in Fig. 8.

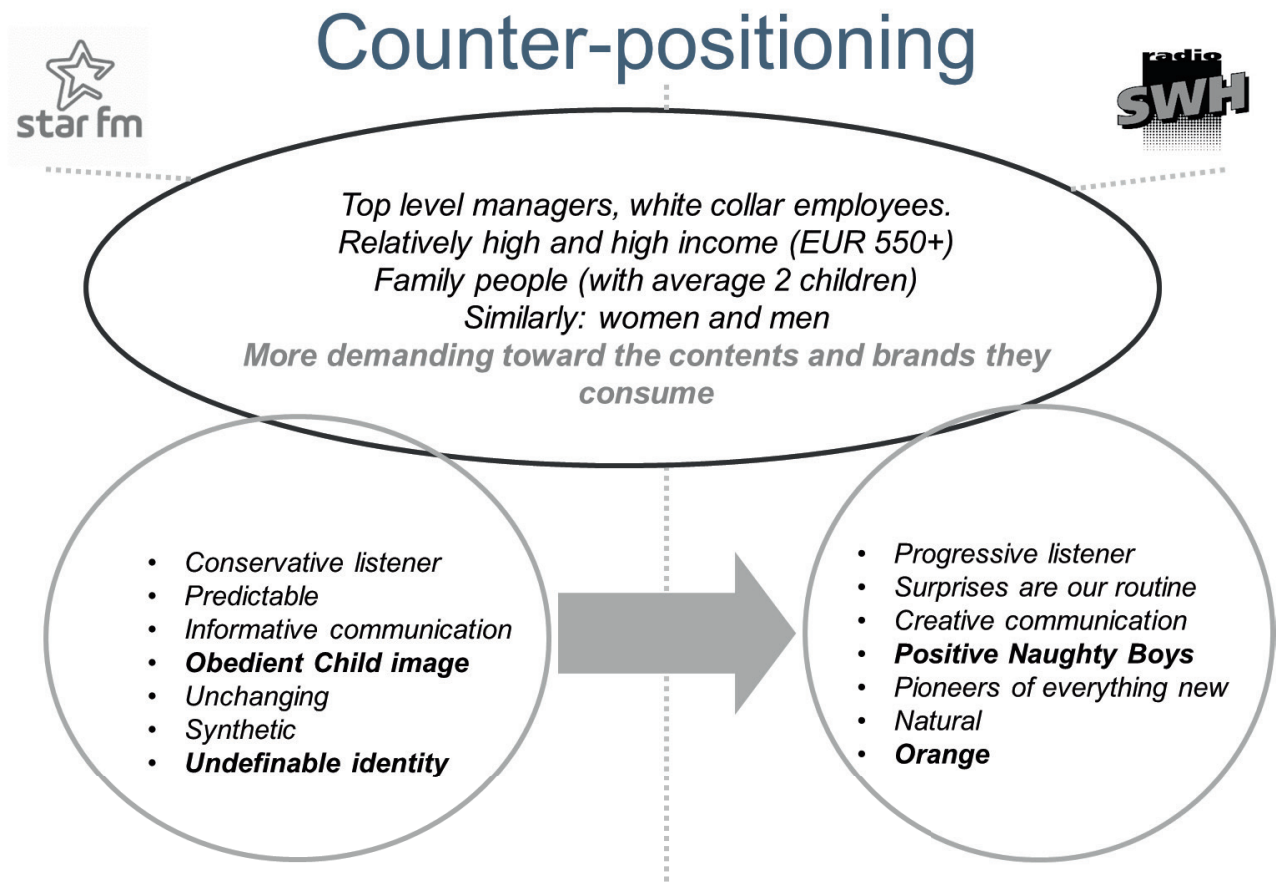

Source: designed by the Authors.

Fig. 8. Psychographic differences of Radio SWH and Star FM listeners in counter-position 


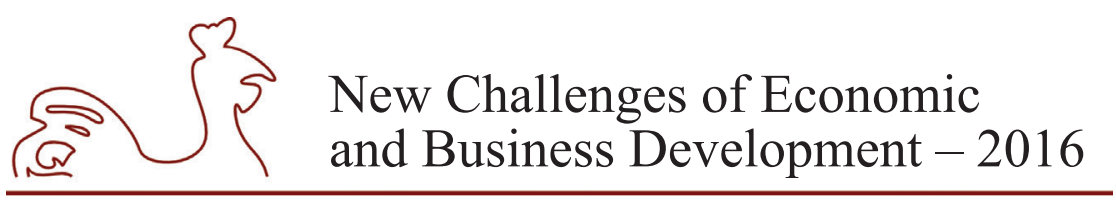

May 12-14, 2016, Riga, University of Latvia

The value orientation of Radio $S W H$ is expressed in the wording of its mission and vision. The Radio SWH mission: With the best radio personalities, outstanding radio team and rubrics systematically to dare more than the casual, sets standards to the direct and side radio products in Latvia. The development vision stipulates that JSC Radio SWH is a steadily growing leader in the radio market of Latvia, whose success is based on the sustainable quality of content, vitality, personality growth and listener loyalty.

The following values of the Radio SWH brand have been defined in line with its mission and vision:

- Personalities;

- Uniqueness of content and activities;

- Trendsetting;

- Daring;

- Stability;

- Surprises;

- Vitality;

- Naturalness.

In line with the brand concept, people must be provided with the emotional experience of the defined values. It is not enough that the radio station only tells its audience and speaks about the brand values; it must develop closer and more intimate relations with its listeners because it is impossible to transfer the brand experience remotely. The brand values must gain their expression during the radio programmes, in events and social networking sites.

In compliance with the desirable positioning it is necessary to design guidelines for the practical implementation of the positioning strategy and its fulfilment in the operation of the radio station. The Authors recommend including the following entries in the guidelines:

1) Radio $S W H$ must additionally stimulate public growth of radio personalities.

2) The radio must develop/recover its previous handwriting because at the moment the recognition has no associative coverage in people's minds; communication and action must leave the borders of the "obedient child" radio. The latter statement more suits Star FM; consequently this is one of the counter-positioning edges. The Right (i.e. boring) against the Wrong (i.e. exciting).

3) In the future the radio will dare to do things that competitors will not. Positive hooliganism based on creativity and outstanding performance.

4) Live personality radio - both in the literate and figurative sense. Vitality means being natural. Radio $S W H$ is not a synthetic product, but rather a natural radio. This is one of the competitive edges in relation to Star FM.

5) Personalities add vitality to a radio. Radio $S W H$ must be reliable, however not forecastable. A stable, but unpredictable radio. Surprises stand for the Radio SWH stability.

6) The personalities award live content to the radio. Thus the radio becomes a personality as well. Only a vital radio with confidence can dare more.

7) In each segment of the audience there are opinion leaders the Radio SWH addresses first.

8) Radio $S W H$ must be a radio trendsetter. To be a step ahead - that is the routine of Radio SWH.

9) A particularly allocated content proportion for the radio products attractive to the youth, which includes participation in the largest music festivals like Positivus and 


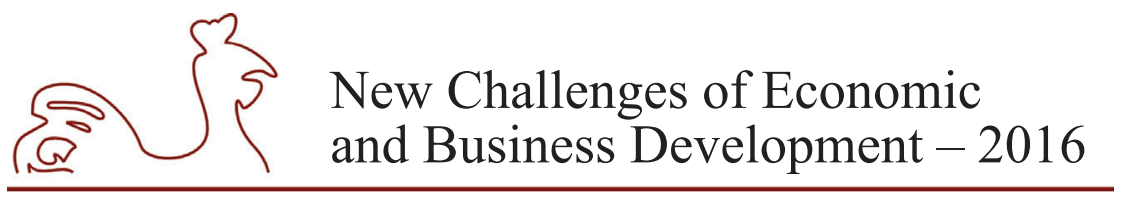

May 12-14, 2016, Riga, University of Latvia

Summersound as the official radio and revitalization of the new music group programme Priekšnams (Lobby).

10) Radio $S W H$ must become the pioneer of digital solutions, thus strengthening the innovator position in the market. A user-friendly digital platform must be developed with unique content which is available both as an Internet and mobile application and would be accessible to both registered and unregistered users. The content of the digital platform must be dynamic, topical, freely accessible on various devices, with the functions that are important and necessary for a modern person - news, random topicalities, music listening and streaming, information search, games. Moreover, the platform must offer unique content that would differentiate the digital platform of Radio SWH and make it competitive with other similar offerings both in the Latvian and global market.

11) Every instance of communication and activity must be unique and unrepeatable in its form and content in order to outline the different imprint in each level of communication. When developing creative solutions they must be evaluated in terms of "Could others also be capable of that? Has this idea been already pronounced anywhere?" This will mark the "Step ahead" position in relation to Star FM and other competitors.

The positioning strategy of the Radio SWH brand is visualized in Fig. 9, where the Authors have used and adapted the previously described brand positioning concept - TABS matrix. The Radio $S W H$ brand is defined with a slogan "Radio that surpasses the frame", by indicating in the matrix the qualities of the brand, its associations, functional features of the product as well as its unique selling propositions.

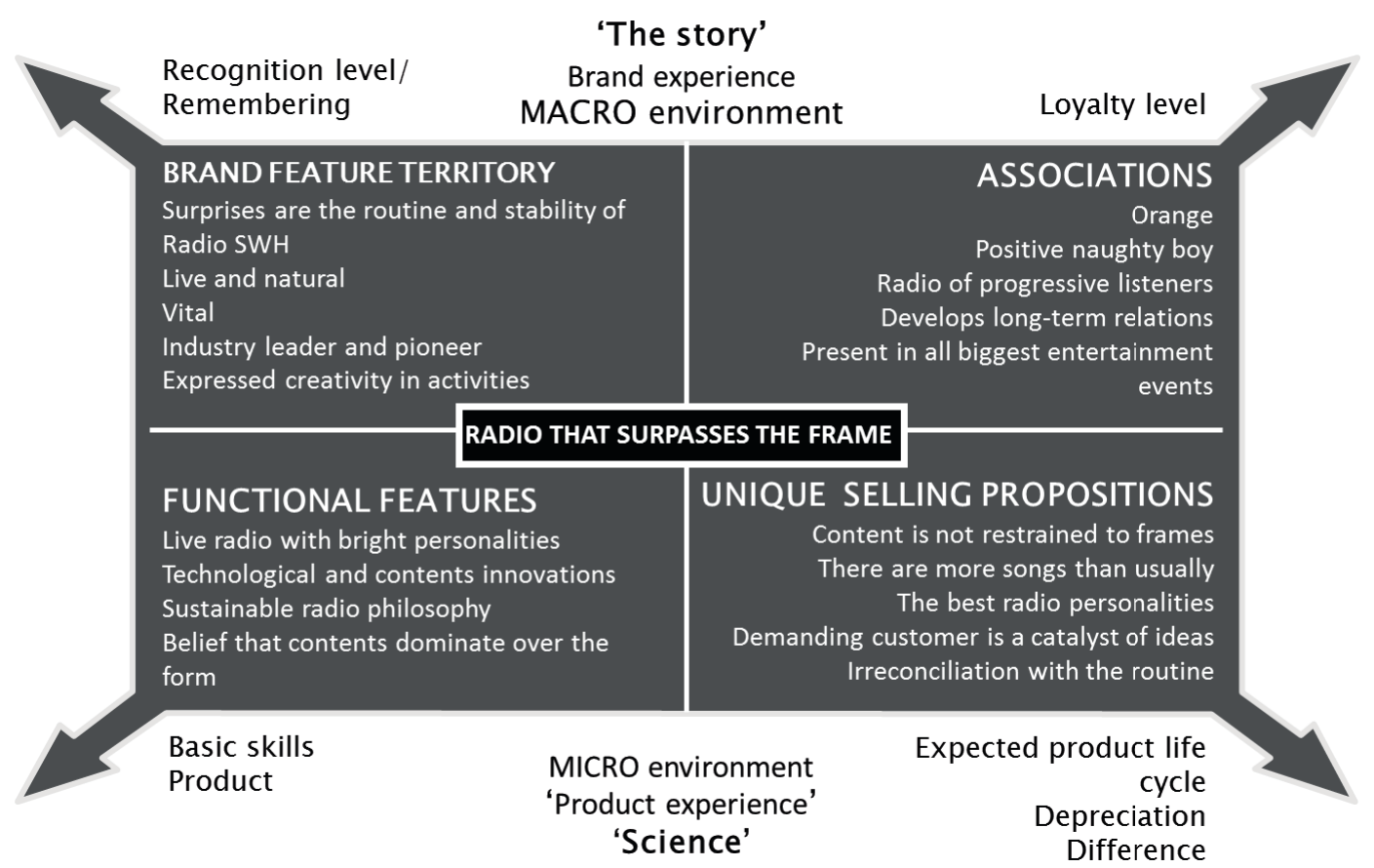

Source: designed by the Authors based on the TABS matrix by Publicis Worldwide.

Fig. 9. Brand positioning strategy matrix of Radio $\mathbf{S W H}$ 


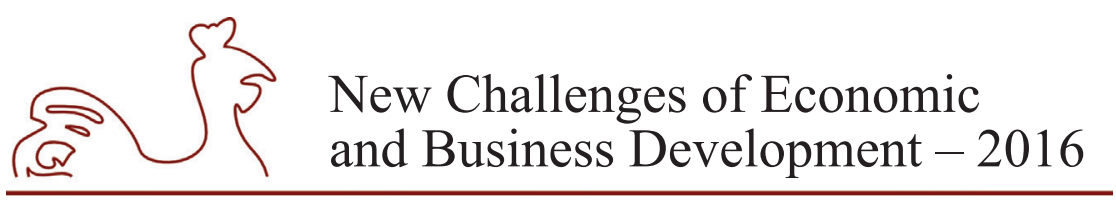

May 12-14, 2016, Riga, University of Latvia

To sum up, in the conclusion the Authors would like to emphasize that the radio industry is facing change and experiencing the transformation of the digital paradigm by leaving the frame of the traditional format. According to experts, Radio $S W H$ is the first radio which is clearly aware of that and is prepared to demonstrate this awareness. The radio can be seen online, followed in the mobile device, it can provide for a telebridge and it can be followed by the people on the other side of the globe. This is the reason why the radio format frame is no longer important. This is the time when the most important role is played by the content and radio personalities, life style and emotional contribution that can be provided by the radio. Radio must be able to meet the content challenge based on a consolidated positioning strategy, clear understanding about the development aims and the desirable position in consumer minds.

\section{Conclusions, proposals, recommendations}

1. The radio market of Latvia is operating under tense competition where a strong brand and clearly defined positioning could serve as an effective long-term strategy tool in the process of achieving the market leader position.

The potential provided by brand development and design of a targeted positioning strategy is underestimated in the industry and only individual radio stations invest in the development of their brand.

2. In order to design the strategy, first, it is necessary to understand the demographic and social parameters of the consumers as only after understanding the target group the evaluation of its system of values and developing of long-term relations by offering an emotionally attractive brand will be possible. The analysis of the overlapping listening audiences allows to identify the direct competitor of Radio $S W H$, which is radio station Star FM, as well as to conclude that the listener audience of Radio $S W H$ is unstable as a big percentage of them are indecisive in their listening habits. The loyalty of Radio SWH listeners is to be considered rather low with no emotional attachment to the brand.

3. When designing the brand positioning strategy for Radio $S W H$, the position against its direct competitor, radio Star FM, must be taken by looking for the differences in the psychographic parameters in the audience segment that is socially and demographically consolidated. The values of the Radio SWH brand to be present everywhere - in on-air programmes, events and social networking sites are the following: Personalities; Uniqueness of the content and activities; Trendsetting; Daring; Stability and surprises; Vitality; Naturalness.

4. The Authors of the research have visualized the brand positioning strategy of Radio SWH by adapting a brand positioning concept - TABS matrix produced by agency Publicis Worldwide. Radio SWH brand has been defined by slogan "Radio that surpasses the frame", by indicating in the matrix the qualities of the brand, its associations, functional features of the product as well as its unique selling propositions.

5. The Authors of the research recommend implementing the positioning strategy guidelines designed in accordance with the desirable positioning of Radio $S W H$ - this will strengthen the competitiveness of Radio SWH in the radio market of Latvia as well as will provide for enlarging the listener audience. It must be stressed that it would be useful to conduct an in-depth study of the listening audience to assess if the offered positioning strategy meets the wishes of the consumers. 


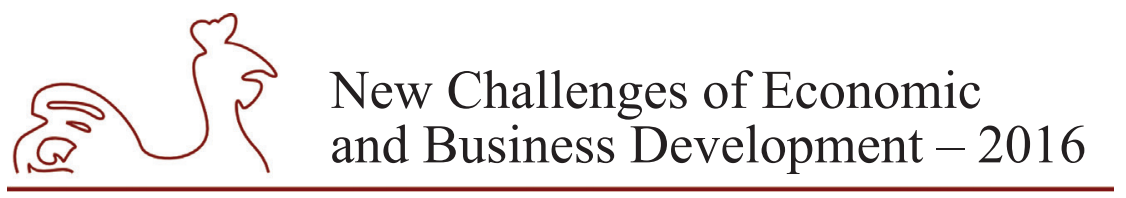

May 12-14, 2016, Riga, University of Latvia

\section{Bibliography}

Aaker, D., 2011. Building Strong Brands. New York: Free Press.

Diena.lv, 20.04.2015. Norvēgija kā pirmā valsts pasaulē gatavojas piln̄̄bā atteikties no FM radio. [Online] Available at: http://www.diena.lv/pasaule/norvegija-ka-pirma-valsts-pasaule-gatavojaspilniba-atteikties-no-fm-radio-14095238 [Acessed 12.03.2015].

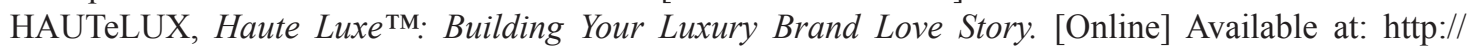
luxurysociety.com/articles/2009/11/haute-luxetm-building-your-luxury-brand-love-story [Acessed 12.03.2015].

Kapferer, J. N., 2008. The New Strategic Brand Management: Creating and Sustaining Brand Equity. London: Kogan Page, Limited,

Keller, K. L., 2013. Strategic Brand Management: Building, Measuring and Managing Brand Equity. New Delhi: Pearson Education,

LETA, 20.03.2015. Belte: Lai sabiedriskie mediji pamestu reklāmas tirgu, nepieciešams divreiz palielināt to finansējumu. [Online] Available at: http://www.diena.lv/latvija/viedokli/belte-lai-sabiedriskiemediji-pamestu-reklamas-tirgu-nepieciesams-divreiz-palielinat-to-finansejumu-14091846 [Acessed 12.03.2015].

Mihailovich P., 2012. Building Powerful Brands. [Unpublished materials] Riga: SSE Riga Executive education.

National Electronic Mass Media Council (NEPLP), 2015. Radio apraide Latvijā - ekonomiskā analīze. Gala ziņojums. [Online] Available at: http://www.neplpadome.lv/lv/assets/documents/Petijumi/ Radio_apraide_Latvija_2015_Jaunaka_versija.pdf [Acessed 12.03.2015].

Publicis Worldwide: The TABS Matrix. 2008. [Unpublished materials] Riga: Balta Komunikācijas.

TNS Latvia, 2015. The National Media Survey: Radio. Winter 2015. [Unpublished materials].

Trout, J., 2008. Differentiate or Die: Survival in our Era of Killer Competition. Hoboken, New Jersey: John Wiley \& Sons, Inc.

Van Gelder S., 2003. Global Brand Strategy: Unlocking Brand Potential Across Countries, Cultures \& Markets. Kogan Page Publishers. 
May 12-14, 2016, Riga, University of Latvia

\title{
PROFILE OF CURRENT AND POTENTIAL EMPLOYEES OF PUBLIC ADMINISTRATION IN LATVIA AND LITHUANIA: EMPIRICAL STUDY
}

\author{
Olga Starineca, University of Latvia, Latvia ${ }^{1}$
}

\begin{abstract}
Organisations have many challenges connected to Human Resource Management (HRM). Some of them are directly linked to the lack of knowledge on peculiarities of current and potential employees. According to the author's previous studies, education on and work for Public Administration (PA) in Latvia and Lithuania has certain differences for a number of reasons including legislative circumstances and biased status of Public Administration employee in each of the countries. It is important to explore the profile of each country's current and potential PA employees.

The major aspect of PA HRM that is a focus within the research presented is recruitment and retention. The aim of the research is to identify the main values and requirements of Public Administration study programs' students in Latvia and Lithuania. The data are collected from a survey that was conducted in tertiary education institutions that provide PA or other relevant graduate and/or postgraduate study program in the countries.

The core difference between the experiences of Latvia and Lithuania lays in study programs supply. Tertiary education institutions of Lithuania provide graduate PA study programs as well as postgraduate ones, while there are only Master's programs available in Latvia.

Respondents from both countries highlight as an important factor organisation's employer brand and its social responsibility considering an employer. The most important areas that PA organisations need to pay attention is in for attracting and retaining employees are working environment and advancement/learning opportunities thus developing job advertisements. Organisations should particularly focus on a part with a list of offers for employee.
\end{abstract}

Key words: Human Resource Management, Public Administration

JEL code: J24, J45, O15

\section{Introduction}

Human Resource Management (HRM) challenges that are directly linked to the lack of knowledge on one of the major organisations' stakeholder group is that employees now become more popular among scientists (Bebenroth R. \& Kanai T., 2010; Brockbank, W., 2012; Guest D. E., Paauwe J., \& Wright P., 2013; Ronald R. S., 2007; Society for Human ..., 2012; Ulrich D. et al., 2012). Public Administration (PA) as an employer has peculiar HRM challenges in some countries because of the certain influence of some organisations' external environment factors. However, the same issues could be true for both public and private organisations. Demographic situation, legislation, and external stakeholders' (such as education institutions and government)

1 Corresponding author - e-mail address: olga.starineca@lu.lv 


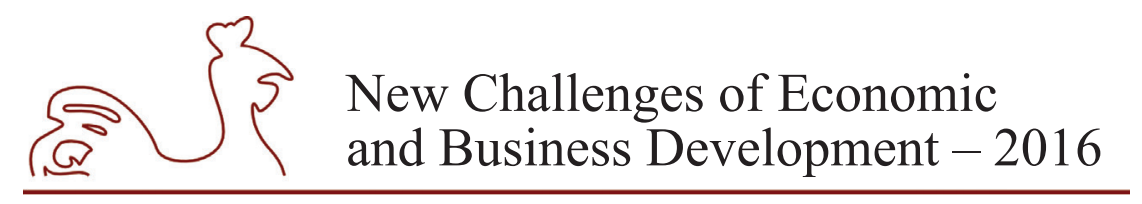

May 12-14, 2016, Riga, University of Latvia

participation in the labour market development certainly impact the strategy of HRM activities implementation (Freeman R.E., 1984; Donaldson T. \& Preston L. E., 1995; Clarkson, M. B. E., 1995; Mitchell R. K. et al., 1997; Freeman R. E. et al., 2007; Jackson, S. E. et al., 2009). The activities mainly are Human Resources (HR) recruitment and selection, Employer Branding (EB), employees' evaluation, etc.

The author focuses on the PA organisations in Latvia and Lithuania as employers within the research. According to the author's previous studies (Voronchuk I. \& Starineca O., 2014; Voronchuk I. \& Starineca O., 2015) education on and work for PA in Latvia and Lithuania has certain differences for a number of reasons including legislative circumstances and biased status of Public Administration employee in the society of each of the countries (Starineca O. \& Voronchuk I., 2015; Starineca O., 2015). It is important to explore the profile of each country's current and potential PA employees, what is easy to implement within the organisation working on the PA employees' evaluation implementing performance reviews and appraisal (Armstrong M., 2009) or assessing the applicants for the vacant positions during some selection activities. However, planning HR pre-actively or proactively (Ackoff R., 1981) it is necessary to consider the peculiarities of future potential employees. Most probably they are students of PA or relevant study programs by the local educational institutions.

To make decisions developing EB, planning HR recruitment and relationships with the certain groups of stakeholders (current and potential employees; educational institutions), it is important to identify and analyse the organisations' stakeholders' needs, values and peculiarities. The present study shows one of the possible ways that some aspects of importance are identification for some HRM activities in organisation.

The author of the present paper focuses on HR recruitment and retention within the research. The main areas of examination are organisations socially responsible (SR) principals, EB elements and main field of assessment calculating sustainability index (SI) in Latvia. These areas were selected based on the research (Starineca O. \& Voronchuk I., 2014; Voronchuk I. \& Starineca O., 2014, 2014a; Voronchuk I. \& Starineca O., 2014) that emphasise their importance in recruiting and retaining employees, especially generation Y representatives. The aim of the research is to identify the main values and requirements of Public Administration study programs' students in Latvia and Lithuania. The data are collected towards a survey that was conducted in tertiary education institutions that provide PA or other relevant graduate and/or postgraduate study program in Latvia and Lithuania. The main tasks performed within this paper are study of population definition, survey of development description and survey results analysis.

The gained and analysed data had a benefit for practitioners, who are dealing with their organisation's Employer Brand development including recruitment and retention activities improvement. This research also supports the theoretical approach to examination of generation Y representatives as employees and job seekers.

The study's limitations are connected to data collection difficulties. The data collected from the small part of the study sample is small itself. Therefore, the results are not a subject of the impactful conclusions, however, it can be a base for further study on the topic.

The research is explorative by design. This research is a part of more comprehensive research that includes assessment of the same and some other criteria and additionally including data collected from the analogical population respondents from Spain. 


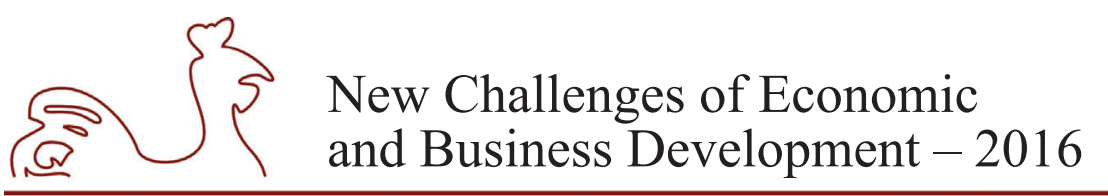

May 12-14, 2016, Riga, University of Latvia

\section{Research results and discussion}

The empirical study's population and sample are described within this section of the paper. In addition, the structure of the questionnaire developed for the survey and the survey conduction procedure are described. The last sub-section is devoted to the study results discussion.

\section{Description of the study population and sample}

The population of the study has been defined as students of Public Administration or other relevant study programs provided by tertiary education institutions of Latvia and Lithuania in age from 18 to 24 years in 2015 and 2016.

Table 1

A list of PA or relevant study programs provided by tertiary education institutions of Latvia and Lithuania in the academic year of 2015/2016 and number of the students and respondents from each program

\begin{tabular}{|c|c|c|c|c|c|c|}
\hline No. & $\begin{array}{c}\text { Study } \\
\text { level }\end{array}$ & $\begin{array}{c}\text { Name of the Study } \\
\text { Program }\end{array}$ & Name of the University & Country & $\begin{array}{c}\text { Total } \\
\text { number } \\
\text { of stu- } \\
\text { dents }\end{array}$ & $\begin{array}{c}\text { Number } \\
\text { of res- } \\
\text { pondents }\end{array}$ \\
\hline 1. & Master's & $\begin{array}{l}\text { Public and institutional } \\
\text { management }\end{array}$ & Daugavpils University & Latvia & 26 & 0 \\
\hline 2. & Master's & $\begin{array}{l}\text { Regional policy and } \\
\text { state management }\end{array}$ & Rīga Stradiņš University & Latvia & 12 & 9 \\
\hline 3. & Master's & State Administration & $\begin{array}{l}\text { The University College of } \\
\text { Economics and Culture }\end{array}$ & Latvia & 0 & 0 \\
\hline 4. & Master's & Public Administration & Turiba University & Latvia & - & 0 \\
\hline 5. & Master's & Public Management & University of Latvia & Latvia & 12 & 11 \\
\hline 6. & Bachelor & Public Administration & $\begin{array}{l}\text { Kaunas University of } \\
\text { Technology }\end{array}$ & Lithuania & 150 & 7 \\
\hline 7. & Master's & Public Administration & $\begin{array}{l}\text { Kaunas University of } \\
\text { Technology }\end{array}$ & Lithuania & 40 & 5 \\
\hline 8. & Bachelor & Public Administration & Klaipèda University & Lithuania & 91 & 3 \\
\hline 9. & Master's & Public Administration & Klaipeda University & Lithuania & 15 & 0 \\
\hline 10. & Bachelor & Public Administration & Mykolas Romeris University & Lithuania & 563 & 18 \\
\hline 11. & Master's & Public Administration & Mykolas Romeris University & Lithuania & 246 & 0 \\
\hline 12. & Bachelor & $\begin{array}{l}\text { Public Policy and } \\
\text { Management }\end{array}$ & Mykolas Romeris University & Lithuania & 198 & 0 \\
\hline 13. & Master's & $\begin{array}{l}\text { Public Policy and } \\
\text { Management }\end{array}$ & Mykolas Romeris University & Lithuania & 9 & 0 \\
\hline 14. & Bachelor & Public Administration & Siauliai University & Lithuania & - & 0 \\
\hline 15. & Master's & Public Management & Siauliai University & Lithuania & - & 0 \\
\hline 16. & Master's & $\begin{array}{l}\text { Public Policy and } \\
\text { Administration }\end{array}$ & Vilnius University & Lithuania & - & 0 \\
\hline 17. & Bachelor & Public Administration & Vytautas Magnus University & Lithuania & - & 0 \\
\hline 18. & Master's & $\begin{array}{l}\text { State Institution } \\
\text { administration }\end{array}$ & Vytautas Magnus University & Lithuania & - & 0 \\
\hline
\end{tabular}

Source: author's created based on the survey of the universities' employees responsible for the programs. 


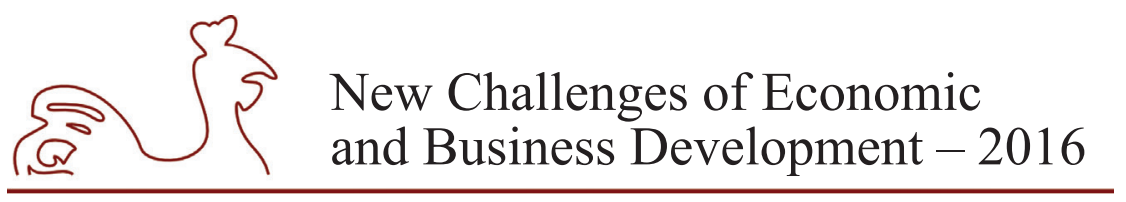

May 12-14, 2016, Riga, University of Latvia

The main focus of the study is on the generation Y representatives (Artner A., 2013; Bawany A., 2014; Camp W., 2014; Bilevičienè T. \& Bilevičiūtė E., 2015). However, the fact that there were just few students from Latvia who could be included in the population by the age criterion, led to the inclusion of the students of the tertiary education institutions of Latvia without age limitation. The type of the sample is convenience: for example, all students that were available during the days of the survey conduction were invited to participate in the survey.

There are five tertiary education institutions those students are from the defined population in Latvia (Table 1). Some of them did not have any students in the academic year of 2015/2016. Turiba University offered only online studies, therefore the students of the Turiba University were not considered for the analysis. Only students from Rīga Stradinš University and the University of Latvia participated in the in-class survey (i.e. the sample of the study in Latvia is equal to 24 students). Twenty questionnaires were collected as the result of the survey conduction in Latvia (Table 1).

There are seven postgraduate PA or relevant study programs provided by six universities of Lithuania and six undergraduate PA or relevant study programs provided by the same six universities of Lithuania the students of which were included into the population (Table 1). Part of the education institutions in Lithuania offered to conduct the survey refused to cooperate or ignored the proposal. Therefore, only students from Mykolas Romeris University bachelor PA study program participated in the in-class survey, and the students from Kaunas University of Technology and Klaipeda University responded filling in the online questionnaire. The sample size in Lithuania is 844 students as only the author focused only on some bachelor programs' students and master's program's students from Kaunas University of Technology. The sample is convenience. 23 questionnaires were collected as the result of the survey conduction in Lithuania (Table 1).

The core difference between experience of Latvia and Lithuania lays in study program's supply. Tertiary education institutions of Lithuania provide graduate PA study programs as well as postgraduate ones, while there are only Master's programs available in Latvia. Characterizing the respondents, it is possible to crystallize that the majority of PA students in Latvia are PA employees older than 24 years old. Students of PA study programs from Lithuania are mainly young unemployed people up to 24 years old, a part of whom wish to work for a private organisation, and employed in public sector postgraduate students. However, there is no significant difference between their values and requirements to the employer in cases of both countries as well as between different age groups.

\section{Description of the survey}

The survey was conducted both in-class (in Latvia and Mykolas Romeris University) and online (all other cases, Table 1). Two types of the questionnaires were developed for online and printed versions. The questionnaire that was provided for the students from the sample in Latvia were translated into the Latvian language, while the students from the sample from Lithuania were provided by the questionnaire in English, and this was a cause for the low respondent rate. Some questions were adapted to the case of each country. The questionnaire developed consists of various sections. The current study is based on the replies on a part of the questionnaire questions. 


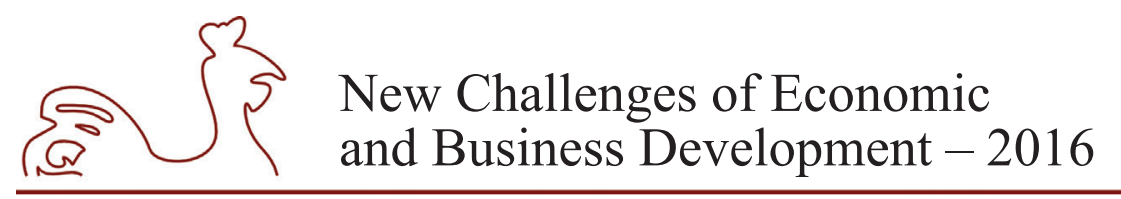

May 12-14, 2016, Riga, University of Latvia

The questionnaire block of questions relevant for the present study is devoted to the respondents' habits on searching for a job. This section helps to collect data that characterises students from the set population as job seekers, inquiring some there as job seekers peculiarities. One of the first questions is about the aspects that are important for the job seekers with higher education choosing an employer from the three main aspects that have been already studied by the author i.e. EB, SR, and SI (Starineca O. \& Voronchuk I., 2014; Voronchuk I. \& Starineca O., 2014, 2014a; Voronchuk I. \& Starineca O., 2014). All these three issues are interconnected.

The SR principles that were offered for the evaluation are (ISO, 2010):

- Accountability

- Ethical behaviour

- Respect for human rights

- Respect for international norms of behaviour

- Respect for stakeholder interests

- Respect for the rule of law

- Transparency.

The EB elements that were offered for the evaluation are (Voronchuk I. \& Starineca O., 2015):

- What the organization (public or private sector employer) is

- What organisation offers for employees

- Organizational processes (vision, mission, goals)

- What kind of employees employed

- What is expected from employees

- Internal communication

- Rewards and recognition

- Learning and development

- Service support

- Measurement system

- Current culture and ethics in the organization

- Job opportunities

- Job learning opportunities

- Key functions and specific characteristics

- Introduction program for new employees

- Advancement opportunities

- Career programs

- Benefits and compensation system

- Working environment

- Recruitment and induction

- Team management

- Performance appraisal

- Past achievements

- Social activities, sponsorship etc.

- Products and services ratings. 


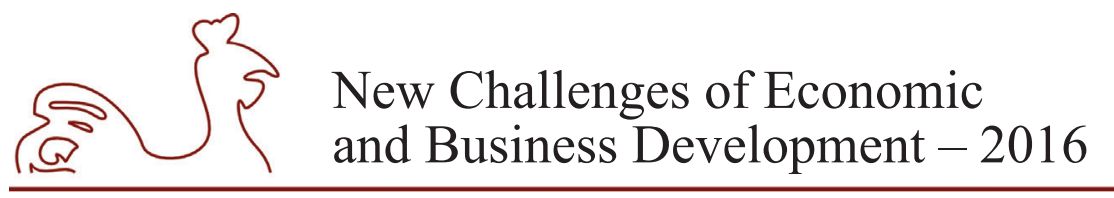

May 12-14, 2016, Riga, University of Latvia

The areas of assessment calculating the SI in Latvia are (Institute for Corporate ..., 2015):

- Environment

- Market relations

- Society [local community]

- Strategy [strategic planning]

- Work environment.

The respondents were also asked to evaluate the importance of organisation's [a future or current employer's] good [positive] employer brand, social responsibility and inclusion in different kind of recognized ratings (as SI rating) considering about an employer.

The respondent needs to assess each aspect using a 10-point scale, where 1 is not absolutely important and 10 is important very much for consideration of a new employer. The survey was conducted from September 2015 to February 2016. The results of the survey are discussed within the next sub-section.

\section{Survey results}

The data analysis was implemented towards IBM SPSS. The first set of aspects that were proposed for the respondents' evaluation by the importance level considering a new employer consists of seven core principles of socially responsible behaviour of a future employer (Fig. 1). 32 out of 33 questionnaires by the respondents of Lithuania were valid for the analysis.

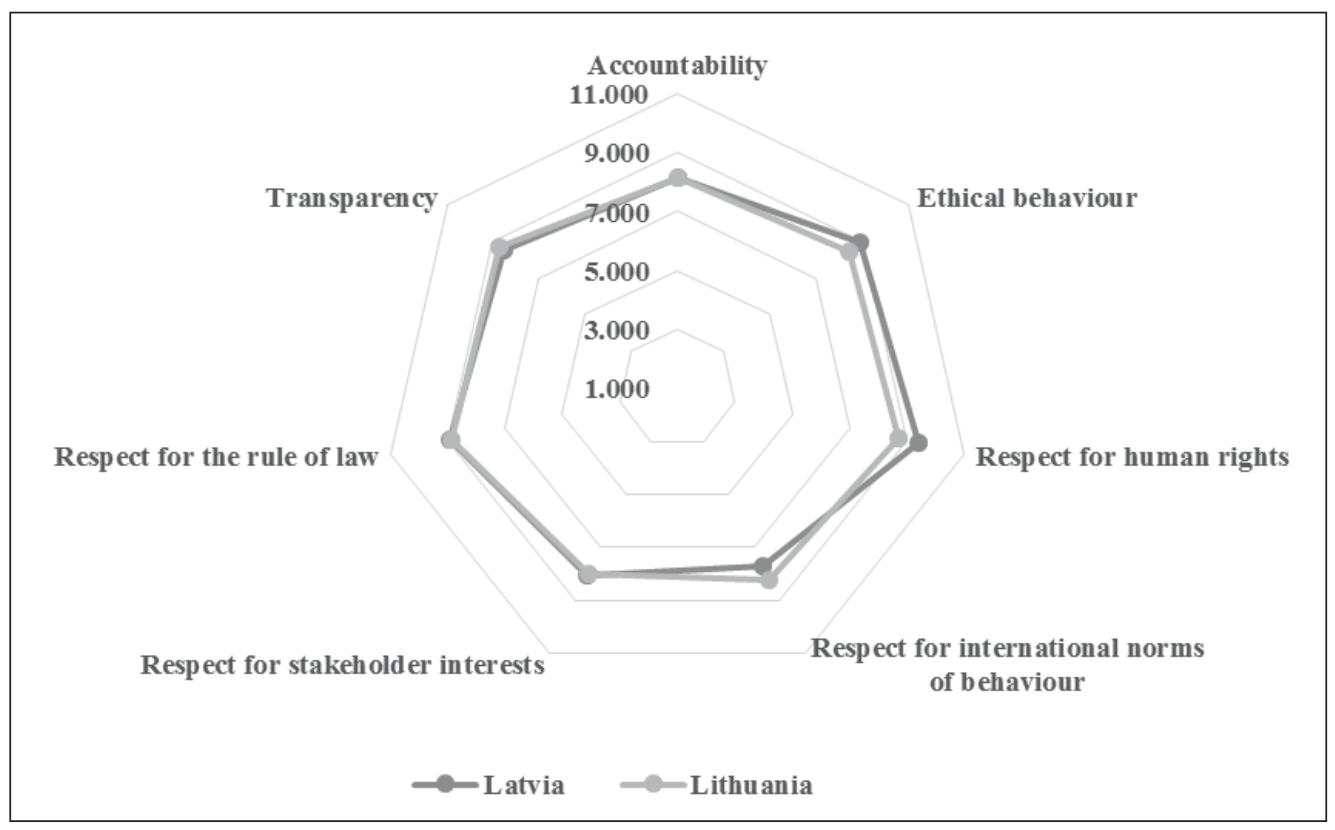

Source: author's construction based on the survey results.

Fig. 1. Respondents' importance evaluation of seven core principles of socially responsible behaviour of a future employer, mean values by countries 


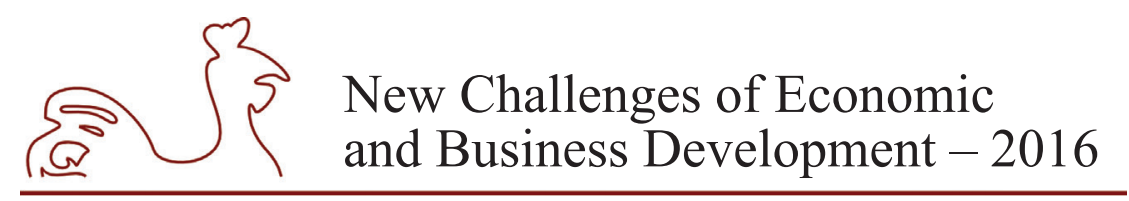

May 12-14, 2016, Riga, University of Latvia

The results show that all respondents from the sample evaluate all factors quite highly giving more than 7.700 points on average. The most important factors for the respondents are Respect for human rights, Respect for the rule of law and Transparency. The respondents from both countries on average gave 8.500 and more points defining the importance level. Respect for international norms of behaviour is the least important SR principle considering a new employee for the respondents from Latvia (7.700 points on average) and Respect for stakeholder interests is the least important principle for the respondents from Lithuania (7.970).

Respect for human rights, Respect for the rule of law and Transparency are the SR principles that are probably are also the most understandable for the respondents, and are well known as sometimes these could be discussions and political speculations around these concepts.

The next block of factors offered for the evaluation consists of assessed areas calculating SI in Latvia (Fig. 2). 32 out of 33 questionnaires by the respondents of Lithuania were valid for the analysis in these case as well.

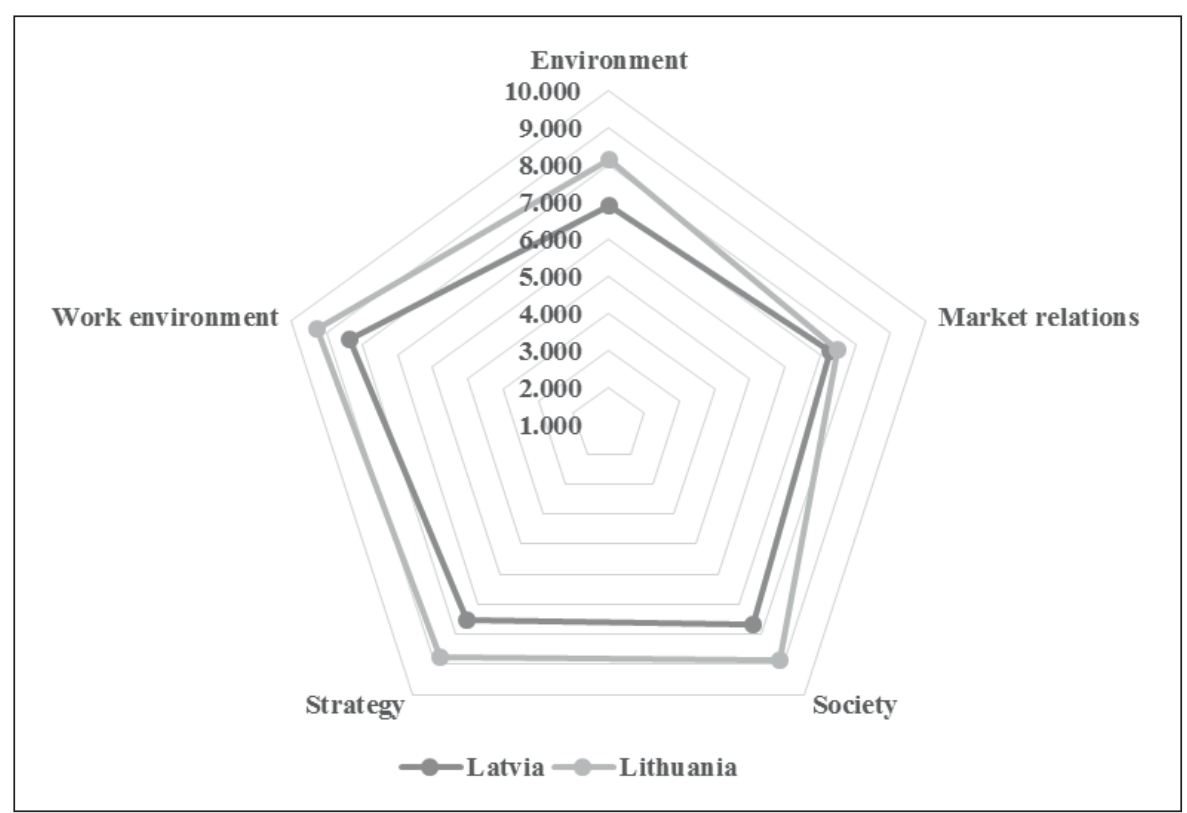

Source: author's construction based on the survey results.

Fig. 2. Respondents' importance evaluation of a future employer's activity in the areas assessed calculating SI in Latvia, mean values by countries

In general, the respondents from Latvia evaluated on average these factors as lower than the respondents from Lithuania (Fig. 2). The least important factors for the respondents from Latvia are Environment (6.900) and Market relations (7.300) - employer's relations with customers and other stakeholders on the business market.

Market relations (7.469) is also the least important factor for the respondents from Lithuania. Work environment is the major factor for both countries respondents (Fig. 2). The employers of the respondents should work more on their work environment development activities manifestation in the external environment, because this kind of information could be crucial for 


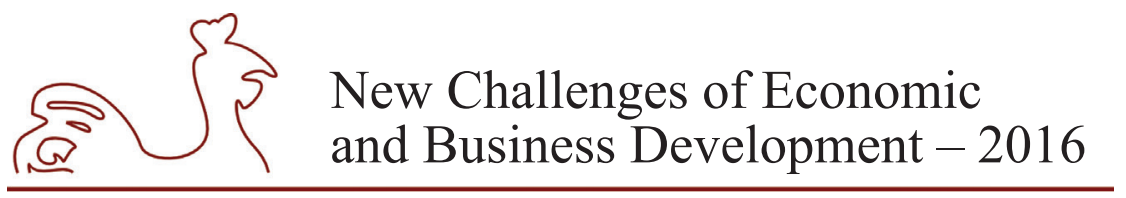

May 12-14, 2016, Riga, University of Latvia

the potential employees' attraction. In general, the employers need to work on creating a work environment that is comfortable and healthy for their current employees to ensure their retention and to make them speak as ambassadors as word of mouth is a powerful tool developing the EB.

The respondents were also asked to evaluate the elements of employer branding as the factors that can influence their decision considering a new employer (Fig. 3). In this case, only 16 out of 33 questionnaires by the respondents of Lithuania were valid for the analysis. The type of organisation (5.200 points on average) is the least relevant for the respondents of Latvia, while the least important EB element in considering a new employee for the respondents from Lithuania is the employer's past achievements (7.750). The top EB elements for both countries are about the same. For the respondents from Lithuania, it is Job learning opportunities (9.000). For the respondents from Latvia, these are the organisation's (employer's) offers for employees (9.100) and Advancement opportunities (9.100). The respondents are focused on the opportunities that are offered by the employer when searching for a job and considering applying for a vacant position. It is also a typical outcome also from other pilot surveys conducted by the author (Starineca O., 2015; Starineca O., 2016).

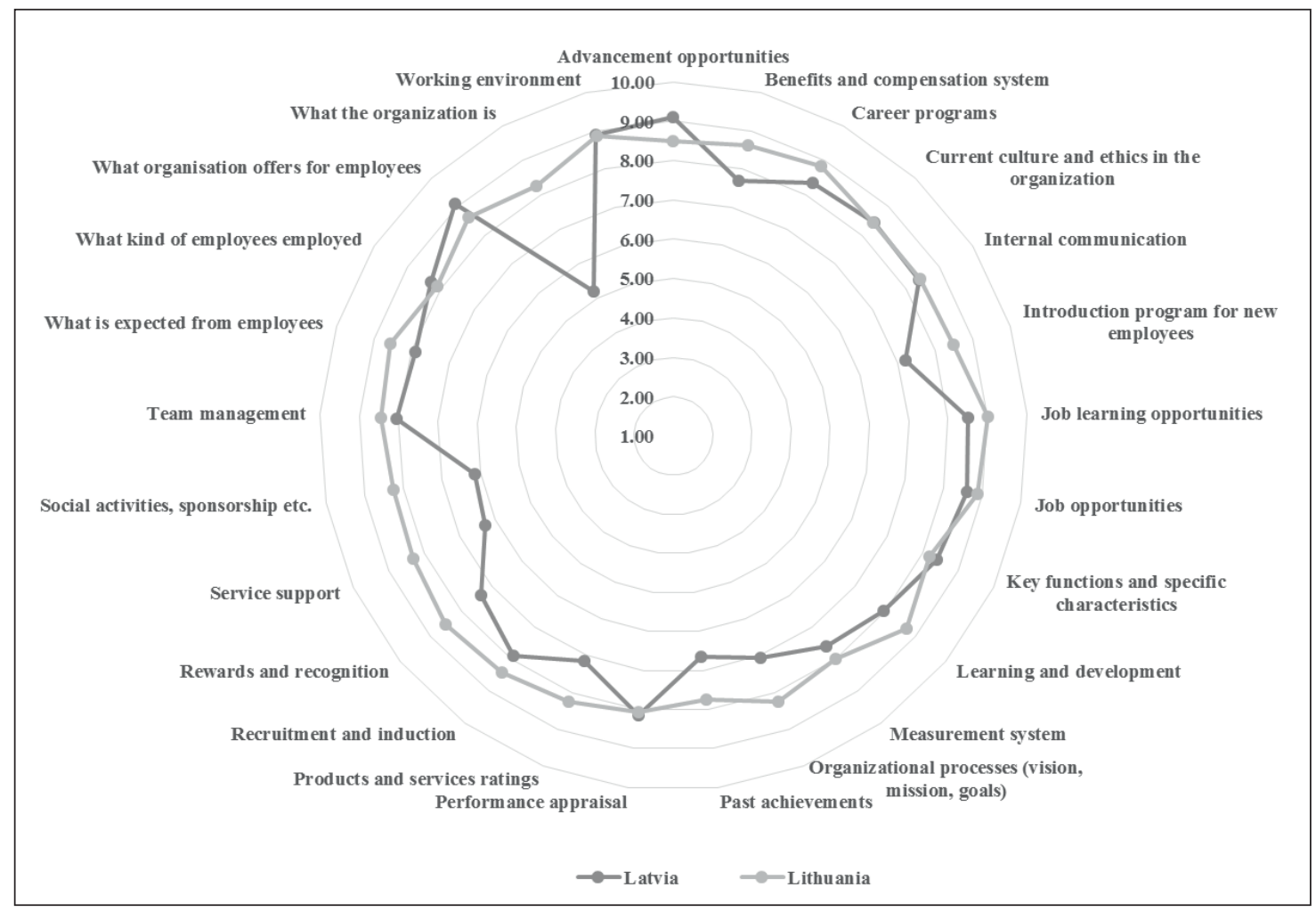

Source: author's construction based on the survey results.

Fig. 3. Respondents' importance evaluation of a future employer's EB elements, mean values by countries 


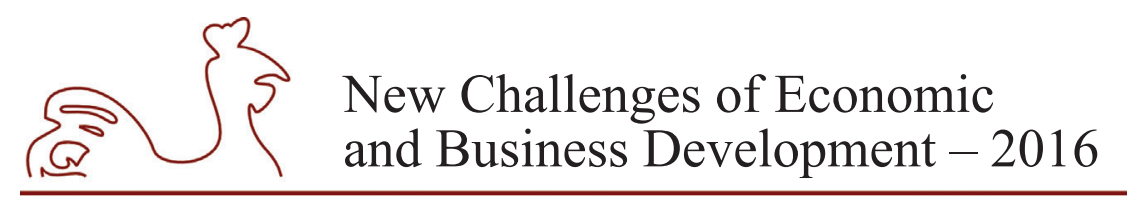

May 12-14, 2016, Riga, University of Latvia

The last question observed within this research focused on the identification of the future employer's status of importance (Fig. 4). Respondents from Latvia on average highlighted organisations' positive employer brand (7.300) as the most important factor from the proposed considering about a new employer, however social responsibility (7.150) also got quite a high score on average from the respondents of Latvia. Respondents from Lithuania would mostly pay attention to the organisation's social responsibility (8.188) and then on its positive employer brand (8.000) and inclusion onto the recognized ratings (8.000) into considering about working for the organisation. However, the average importance level just slightly differs in case of Lithuania.

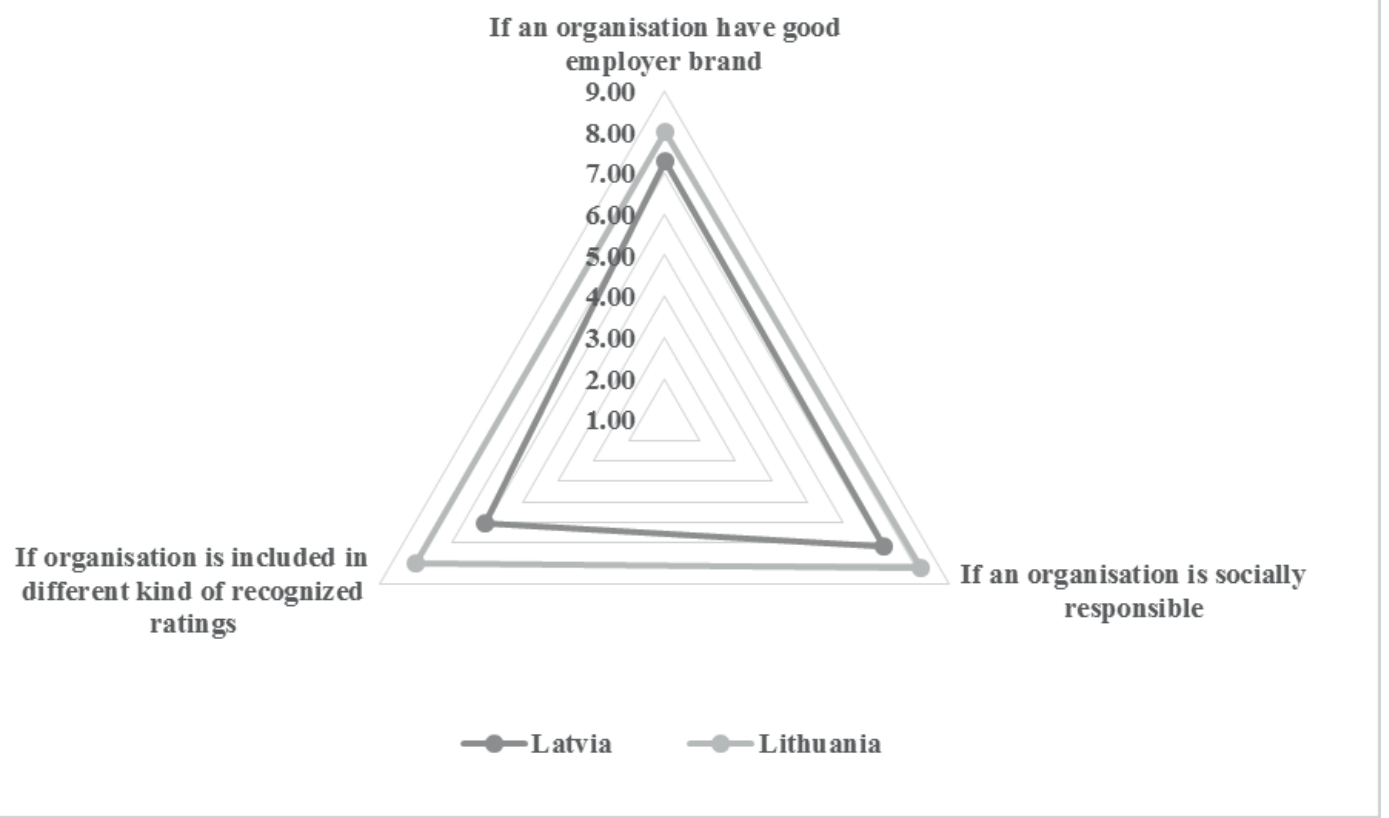

Source: author's construction based on the survey results.

Fig. 4. Respondents' importance evaluation of a future employer's status, mean values by countries

As the respondents from Latvia are older on average than the respondents from Lithuania, the respondents from Latvia are probably more critical in evaluating the factors; and evaluated most factors lower on average than the respondents from Lithuania did.

\section{Conclusions, proposals, recommendations}

The author of the present paper summarized the main conclusions based on the study results. The conclusions could only be drawn considering the certain group of respondents.

1. The core difference between the experience of Latvia and Lithuania lays in study program's supply. Tertiary education institutions in Lithuania provide graduate PA study programs as well as postgraduate ones, while there are only Master's programs available in Latvia. 


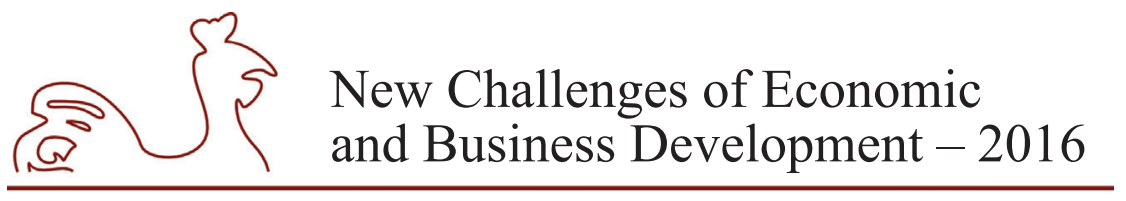

May 12-14, 2016, Riga, University of Latvia

2. The age of the respondents from Latvia is a factor that probably influenced the responses given. Respondents from Latvia are more critical in evaluating the factors and they evaluated quite all factors lower on average than the respondents from Lithuania.

The author of the present paper also has a few proposals for the respondents' potential employers i.e. PA organisations of Latvia and Lithuania.

1. Respondents from both countries highlight as an important factor the organization's employer brand and its social responsibility when considering an employer. Therefore, these two aspects are crucial to emphasize and work on for PA organisations; otherwise, in case of Lithuania, a part of the students with the corresponding education could be employed by organisations that are more modern and publicly active as employers.

2. The most important areas that PA organisations need to pay attention to with attracting and retaining employees are its working environment and advancement/learning opportunities, thus in developing job advertisements, organisations should particularly focus on a section with a list of offers for employees.

3. In addition, the potential employers of the respondents should develop a comfortable working environment, so that their current employees could speak for the employer, creating a positive image in the external environment.

The author has few recommendations for the further studies.

1. As the issues of PA organisations' HRM are topical, the study should be continued to gather more data for the more accurate analysis.

2. The further studies may also include other questions that address more detailed HRM issues, namely attractive job advertisement development, job analysis fulfilment, other HR retention issues etc.

3. The main hypothesis that could be tested in further studies could be "The factors that might influence PA organisations' current employee retention and potential employees' attraction that are linked to the professional growth and career development".

\section{Bibliography}

Ackoff, R., 1981. Creating The Corporate Future: Plan Or Be Planned. New York: John Wiley.

Armstrong, M., 2009. Armstrong's Handbook of Human Resource Management Practice. $11^{\text {th }}$ ed. London/ Philadelphia: Kogan Page Ltd.

Artner, A., 2013. Is Youth Unemployment Really the Major Worry? Debatte. Journal of Contemporary Central and Eastern Europe. 21(2-3), pp. 183-205.

Bawany, A., 2014. Generation Y. Leadership Excellence, 31(8), pp. 6-7.

Bebenroth, R. \& Kanai, T., 2010. Challenges Of Human Resource Management In Japan. Abingdon and New York: Routledge.

Bilevičienè, T. \& Bilevičiūtè, E., 2015. Influence of employment on strategy of sustainable development implementation. Journal of Security and Sustainability Issues, 4(3), pp. 520-535.

Brockbank, W., Ulrich, D., Younger, J. \& Ulrich, M., 2012. The Future Is Now: HR Competencies For High Performance. The RBL Group, pp. 1-6.

Camp, W., 2014. Strategies for working with Generation Y employees. Canadian Manager. 39(1), pp. 24.

Clarkson, M. B. E., 1995. A Stakeholder Framework For Analyzing And Evaluating Corporate Social Performance. Academy of Management Review, 20 (1), pp. 92-117. 


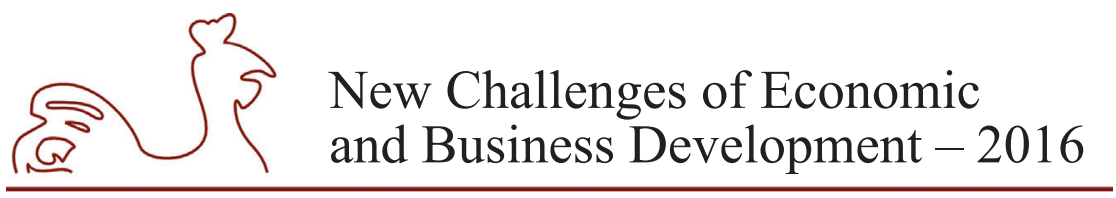

May 12-14, 2016, Riga, University of Latvia

Donaldson, T. \& Preston, L. E., 1995. The stakeholder Theory Of The Corporation: Concepts, Evidence, and Implications. Academy of Management Review, 20 (1), pp. 65-91.

Freeman, R. E., 1984. Strategic management: A stakeholder Approach. Boston: Pitman.

Freeman, R. E., Harrison, J. S. \& Wicks, A. C., 2007. Managing for Stakeholders: Survival, Reputation And Success. New Haven: Yale University Press.

Guest, D. E., Paauwe, J., \& Wright, P., 2013. HRM And Performance: Achievements And Challenges. Chichester: John Wiley \& Sons, Inc.

Institute for Corporate Sustainability and Responsibility, 2015. Atbildīgs bizness 2015. [Online] Available at: http://www.slideshare.net/Ilgtspeja/atbildgs-bizness-2015 [Accessed 2 March 2014].

ISO, 2010. ISO 26000:2010(en). Guidance on social responsibility. [Online] Available at: https://www. iso.org/obp/ui/\#iso:std:iso:26000:ed-1:v1:en [Accessed 2 March 2014].

Jackson, S. E., Schuler, R. S. \& Werner, S., 2009. Managing Human Resources. $11^{\text {th }}$ ed. New York: SouthWestern, Cengage Learning.

Mitchell, R. K., Age, B. R. \& Wood, D. J., 1997. Toward A Theory Of Stakeholder Identification And Salience: Defining The Principle Of Who And What Really Counts. Academy of Management Review, 22 (4), pp. 853-886.

Ronald R. S., 2007. Human Resource Management: Contemporary Issues, Challenges, and Opportunities. USA: IAP.

Society for Human Resource Management, 2012. SHRM Research Spotlight: Future HR Challenges and Talent Management Tactics. [Online] Available at: http://www.shrm.org/Research/SurveyFindings/ Articles/Documents/SHRM-Challenge-HR-2022-Spotlight.pdf [Accessed 29 February 2016].

Starineca, O. \& Voronchuk, I., 2014. Employer Branding Training Development For Public Organisations. Regional Formation and Development Studies, 3 (14), pp. 207-219.

Starineca, O. \& Voronchuk, I., 2015. Peculiarities Of Young Specialists On Labour Market: Case of Latvia. Entrepreneurship and Sustainability Issues, 2(4), pp. 198208.

Starineca, O., 2015. Values And Habits Of Young Job Seekers: Case Of Mykolas Romeris University's Students And Recent Graduates. International Scientific Conference for Young Researchers. Social Transformations in Contemporary Society 2015 (STICS 2015), Abstract book, pp. 50-52.

Starineca, O., 2016. Characteristics of Current and Potential Employees of Public Administration in Latvia: Empirical Study. The $74^{\text {th }}$ conference of the University of Latvia. [Online] Available at: http://www. lu.lv/konference/programma/?user_phpfileexecutor_pi $1 \% 5$ Bdownload_abstract_id\%5D=2249 [Accessed 2 March 2016].

Ulrich, D. Younger, J., Brockbank, W. \& Ulrich, M., 2012. HR from the Outside In: Six Competencies for the Future of Human Resources. Boston: McGraw-Hill Professional.

Voronchuk, I. \& Starineca, O., 2014. Human Resource Recruitment And Selection Approaches In Public Sector: Case Of Latvia. International Scientific Conference "New Challenges of Economic and Business Development - 2014", Conference Proceedings, pp. 417-430.

Voronchuk, I. \& Starineca, O., 2014. Social Responsibility Initiative Implementation In Public Sector In Latvia. Socialiniai tyrimai / Social Research, 3 (36), pp. 67-77.

Voronchuk, I. \& Starineca, O., 2015. Training Outsourcing For Public Administration Employees: Case Of Latvia. Proceedings of the $23^{\text {nd }}$ NISPAcee Annual Conference, NISPAcee PRESS.

Voronchuk, I., \& Starineca, O., 2014a. Knowledge Management And Possibilities Of Professional Development In Public Sector. European Integration Studies, 2014 (8), pp. 168-179. 


\title{
USE OF CASH FLOW STATEMENT IN EVALUATION OF COMPANY'S FINANCIAL SITUATION USING DATA FROM OPERATING AND LIQUIDATED COMPANIES IN THE REPUBLIC OF LATVIA
}

\author{
Dzeina Steinberga, University of Latvia, Latvia ${ }^{1}$ \\ Inta Millere, University of Latvia, Latvia
}

\begin{abstract}
In order to ensure stable business, there is a need to regularly assess the company's financial situation. This can be done by carrying out financial analysis. Often, more attention is paid to the financial analysis of the balance sheet and the income statement results, and the data of these statements is used mostly to analyze the company's financial situation. The authors draw attention to the fact that the ratios which are based on the profit and loss statement may not always indicate the true picture of the company's solvency and financial stability because of the accrual basis, on which the profit and loss statement is based. Financial information that isn't timely assessed can lead to situation when companies may face financial difficulties, which in the authors' opinion can be prevented by paying more attention to the cash flow analysis.

Main goal of the study: to use the data from the financial statements of liquidated and stable and growing companies in the Republic of Latvia to identify and analyze the cash flow statement figures and ratios, and, as a result, make proposals for the application of the cash flow statement in order to assess the financial situation of companies.

To achieve this goal scientific research methods in economics were used - economic analysis and synthesis method - studying the theoretical aspects and corporate reports, statistical methods - data processing and analysis, as well as the logical constructive method of interpreting the results of the study, setting conclusions and recommendations.

In the research, financial statements of 15 liquidated companies in Republic of Latvia and 15 stable and growing companies in Republic of Latvia, were used and as a result financial indicators were defined which can be used in cash flow analysis and evaluation of financial situation and also there were defined ratios on which first of all attention should be paid in solvency estimation cases.
\end{abstract}

Key words: cash flow statement, cash flow ratios, financial analysis, insolvency prediction JEL code: M41, M49

\section{Introduction}

Through regular financial analysis which is based on accurate and comparable information, it is possible to make the right decisions to improve the company's business. In order to indicate the effectiveness of the cash flow statement and demonstrate that the cash flow statement data need to be used to evaluate the company's future development and solvency, the authors chose to investigate this particular report and the information that it provides.

1 Corresponding author - e-mail address: dzeina.steinberga@gmail.com 


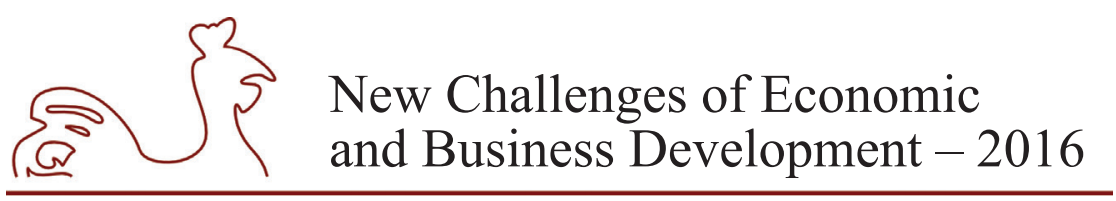

May 12-14, 2016, Riga, University of Latvia

The research findings of the topic justify the insufficiently explored opportunities of the cash flow statement in the financial situation assessment, because this issue is very little reflected in the economic literature; for example in the Republic of Latvia, only K. Subatnieks' work in 2008 (Subatnieks K., 2008) is widely studied, and in practical business activity analysis of the balance sheet and income statement information is mainly used, whereas by using the cash flow statement analysis as well, companies can better forecast the solvency level, which could lead to the prevention or reduction of possible bankruptcy and liquidation as a result of insolvency. The large amount of company insolvency cases in recent years in the Republic of Latvia is based on data about the proposed number of bankruptcy cases of legal entities, which indicates that in 2015 the number of proposed legal person insolvency cases was 802, in 2014 - 959, in $2013-$ 820 , in $2012-881$, but in 2011 - 823 insolvency cases. (Lursoft insolvency register, 2015)

In order to achieve the goal of the study (to use the data from the financial statements of liquidated and stable and growing companies in the Republic of Latvia in order to identify and analyze the cash flow statement figures and ratios, and as a result, make proposals for the application of the cash flow statement in order to assess the financial situation of companies), the authors put forward the main tasks:

- to analyze cash flow statement characterizing factors;

- to calculate and analyze absolute figures and cash flow statement characterizing ratios of fifteen liquidated and fifteen stable companies;

- to develop proposals for the cash flow figures and ratios, that can be used in the company's financial situation assessment.

The research object is 15 liquidated and 15 operating companies in the Republic of Latvia that at first were grouped according to the following criteria:

- in the Republic of Latvia liquidated companies whose reason for liquidation was insolvency proceedings ending with the completion of bankruptcy proceedings, and for the implementation of which, the annual report according to the Article 54 of the "Annual Account Law" have prepared a cash flow statement for at least five financial years before the launching of extra-judicial protection proceedings, judicial protection or insolvency proceedings;

- in the Republic of Latvia working, stable companies whose shares are quoted on the Baltic securities market and which according to the Article 54 of the "Annual Account Law" have prepared a cash flow statement for the last five financial years.

The companies were selected for analysis from 24 operating companies, the assets of which are quoted in the Baltic securities market in October 2015, but the liquidated companies were selected from the 82 companies that were liquidated during the period from January 2014 to October 2015.

Since data contained values, which are comparable and are not completely different, authors used mean values for reflecting absolute values and ratios results. 


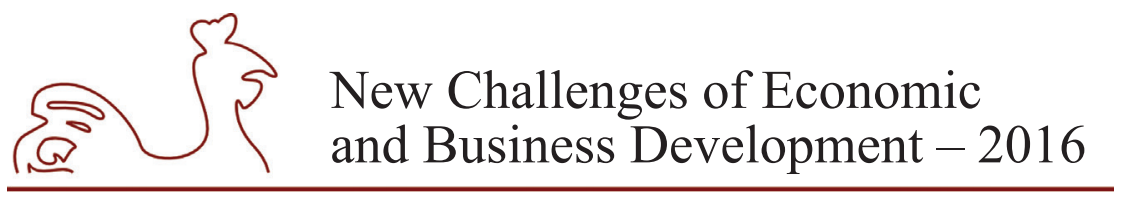

May 12-14, 2016, Riga, University of Latvia

\section{Research results and discussion}

\section{Justification of ratios selected for cash flow statements analysis}

The first scientist to include cash flow indicators in the financial ratio group, was V. Bīvers, who published it in his study in 1966. He was the first scientist who studied changes in share prices of bankrupt companies and concluded that the cash flow indicator is the most appropriate of previously used ratios, because it indicates the possibility of bankruptcy with high accuracy. (Šneidere R., 2009)

By studying works of Subatnieka K., 2008, Robinson G., Henry B., 2009, Needles B. E., Powers M., Crosson S. V., 2005, Fawzi N. S., Kamaluddin A., 2015, Kirkham R., 2012, Dyckman T. R., Dukes R. E., 1992, the authors concluded that the most used cash flow analysis ratios in literature are the ones based on cash flow from operations, although, the authors claim that in order to make more accurate comparisons and conclusions, it is essential to include ratios based on cash flow from financing and investing activities. The authors have specified six cash flow from operations ratios, which, in their opinion, most accurately reflect company solvency problems and informs about the financial stability of a company and which are the most used ratios in other author's works. In the following study the authors will use, calculate and analyse five, in the authors' opinion, most relevant investment and financing cash flow statement analysis ratios. The authors have compiled the most relevant cash flow statement analysis coefficients in Table 1, separately specified operating, investing activities and financing activities ratios used in the analysis.

Table 1

Ratios used for cash flow statement analysis used in the study

\begin{tabular}{|c|c|c|c|}
\hline No. & $\begin{array}{c}\text { Cash flow from operations } \\
\text { ratios }\end{array}$ & $\begin{array}{c}\text { Cash flow from investing activities } \\
\text { ratios }\end{array}$ & $\begin{array}{c}\text { Cash flow from financing activities } \\
\text { ratios }\end{array}$ \\
\hline 1. & $\frac{\text { Cash flow from operations }}{\text { Current liabilities }}$ & $\begin{array}{l}\text { Cash flow from } \\
\text { investing activities } \\
\text { Total liabilities }\end{array}$ & $\begin{array}{l}\text { Cash flow from } \\
\text { financing activities } \\
\text { Total liabilities }\end{array}$ \\
\hline 2. & $\frac{\text { Cash flow from operations }}{\text { Net turnover }}$ & $\begin{array}{l}\text { Cash flow from } \\
\text { investing activities } \\
\text { Total assets }\end{array}$ & $\begin{array}{l}\text { Cash flow from } \\
\text { financing activities } \\
\text { Net turnover }\end{array}$ \\
\hline 3. & $\frac{\text { Cash flow from operations }}{\text { Total liabilities }}$ & $\begin{array}{c}\text { Cash flow from } \\
\text { investing activities } \\
\text { Net turnover }\end{array}$ & \\
\hline 4. & $\begin{array}{c}\text { (Cash flow from operations }+ \\
\text { interest paid }+ \text { taxes paid }\end{array}$ & & \\
\hline 5. & $\frac{\text { Cash flow from operations }}{\text { Total assets }}$ & & \\
\hline 6. & $\frac{\text { Cash flow from operations }}{\text { Net income }}$ & & \\
\hline
\end{tabular}

Source: author's calculations based on Subatnieks K., 2008; Robinson G., Henry B., 2009; Needles B. E., Powers M., Crosson S. V., 2005; Kirkham R., 2012; Fawzi N. S., Kamaluddin A., 2015; Dyckman T. R., Dukes R. E., 1992. 


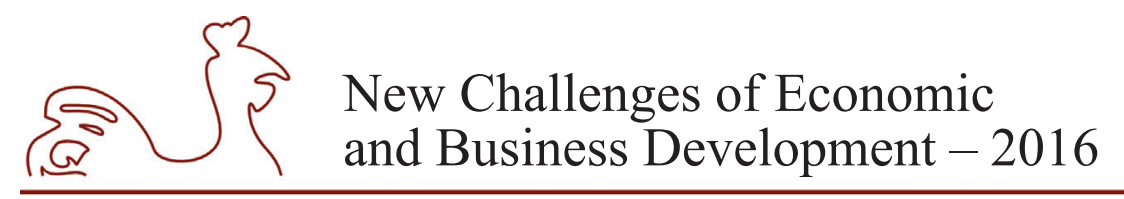

May 12-14, 2016, Riga, University of Latvia

Ratios, which are calculated using operating cash flow, show whether and how much profit a company has gained from its main operations. Ratios based on cash flow from investing activities indicate future prospects of a company using the increase or decrease of company assets. Ratios based on cash flow from financing activities indicate a company's funds and its focus. The justification for using coefficients from Table 1 and the relevance and importance of each ratio used in the study is described further down.

Cash flow from operations to current liabilities ratio estimates whether operating cash flow is able to cover ongoing costs (Dyckman T. R., Dukes R. E., 1992). Outstanding liabilities are the main cause of initiating insolvency proceedings, which is why the authors believe that this coefficient is crucial when assessing financial stability.

Cash flow from operations to net turnover. This ratio indicates the ability of company to convert its income into money which is a useful indicator of a company's financial situation and future prospects of liability settling. "[..] conclusions, which can be drawn from cash flow to turnover ratio analysis can be compared with the results of commercial profitability research, however the conclusions from cash flow to turnover ratio are more advantageous, because the indicator included in the numerator of the coefficient rules out most accountancy assumptions, which determine the profit margin values used for calculating profitability". (Subatnieks K., 2008)

Cash flow from operations to total liabilities ratio, also known as the company liability settling ratio, provides a notion of possible financial risks and financial stability. (Robinson G., Henry B., 2009) The ratio, where a positive value means a company is able to settle its liabilities, provides information about financial stability for financial statement users and is crucial when assessing a company's solvency.

Next is Cash flow from operations, interest paid, taxes paid to interest paid ratio. The authors agree with K. Subatnieks' claim that the ratio shows whether a company will be able to make interest payments for the entire loan amount. It is possible only if the interest coverage ratio is at least 1 . A company that has an interest coverage ratio below 1, risks immediately becoming insolvent. (Subatnieks K., 2008) The authors claim that this ratio is crucial when conducting financial analysis, because it can indicate a company's ability to settle interest liabilities with its operating cash flow. In addition, by taking into account that the cash flow statement provides information of the company's actual cash flow, this ratio, comparing with the interest coverage ratio, which is calculated by using profit or loss estimate data, indicates whether operating assets are sufficient for interest coverage.

Cash flow from operations to total assets ratio. In their work "International financial statement analysis" Robinson T. R., Greuning H., Henry E., Broihahn M. have named this ratio asset return ratio, which shows the portion of money generated from all resources. (Robinson G., Henry B., 2009) Similar is the opinion of Needles B. E., Powers M., Crosson S. V., which is shared in the paper "Financial \& Managerial accounting" by pointing out that operating cash flow to assets ratio indicates asset ability to generate operating cash flow. (Needles B. E., Powers M., Crosson S. V., 2005) In the authors' opinion, similarly to the traditionally used asset profitability ratio, cash flow from operations to assets ratio also indicates a company's competitiveness, because it indicates the profitability of assets used in cash flow generation. Furthermore, in the authors' opinion, by showing that profit or loss estimate is affected by accounting policy and estimates, cash flow statement data, which are created from actual cash and its equivalent flow, more accurately indicate asset profitability in cash flow generation. 


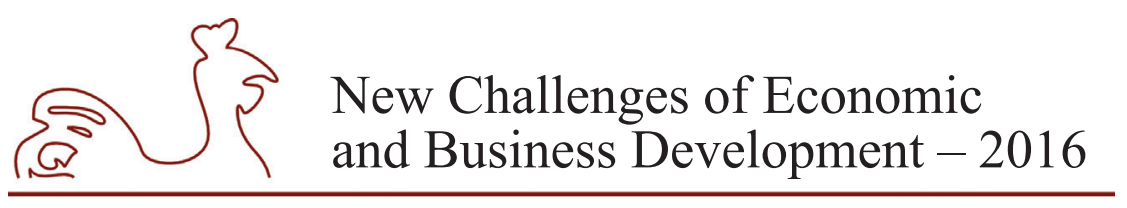

May 12-14, 2016, Riga, University of Latvia

The authors of "Monitoring Distressed Companies through Cash Flow Analysis" claim that cash flow from operations to net income ratio is one of the main profitability indicators and it includes coefficients which measures a company's achievements by using operating cash flow. (Fawzi N. S., Kamaluddin A., 2015)

Cash flow from investing activities to total liability ratio indicates company's ability to cover its total debt with cash. This ratio has a significant negative relationship with financial distress. (Fawzi N. S., Kamaluddin A., 2015) The authors conclude that this ratio provides a notion of a company's future liability settlement possibilities. If the ratio value is negative for a period of several years, then that means that the company's management board is investing additional resources into increasing the company's assets thus causing asset growth.

Cash flow from investing activities to assets ratio. This ratio is also known as asset increase rate, because it indicates the current portion of company assets which are reinvested in longterm investments over a certain period of time. (Subatnieks K., 2008) A negative cash flow from investing activity value indicates that the company invests additional assets in the development of the company. After interpreting the negative ratio value, authors point out that a negative cash flow from investing activities to assets ratio indicates an increase of material or immaterial assets of a company. Positive ratio value indicates a decrease of material or immaterial assets of a company.

Cash flow from investing activities to net turnover ratio has two different results and interpretations. A negative ratio value points to a company expanding and increasing its profits in the future. Positive value means that a company is declining and is selling its capital assets and other long-term investments. (Subatnieks K., 2008) The authors believe that a negative ratio value is necessary for long-term growth, therefore, when evaluating the financial state of a company, the management board of the company has to take into account the ratio of the current growth tendencies when making decisions regarding further development prospects.

Cash flow from financing activities to total liabilities ratio measures the cash generated from financing activities to meet its obligation in the long run. (Fawzi N. S., Kamaluddin A., 2015) This ratio value is essential for financial analysis, because it shows the quality of the cash flow from financing activities.

Cash flow from financing activities to net turnover ratio assesses the direction and amount of the external funding, as well as in order to compare it with other company figures, cash flow from financing activities has to be divided with one of the company indicators, usually, net turnover. (Subatnieks K., 2008) Since company solvency is related to the amount of liabilities and their settlement, cash flow from financing activities to net turnover ratio is useful for determining the financial stability and solvency of a company.

Cash flow statement analysis ratios, which were selected by the authors, will be used for cash flow statement analysis of fifteen liquidated and fifteen operating companies.

\section{Cash flow statement analysis of 15 liquidated and 15 operating companies of the Republic of Latvia}

15 liquidated companies for the analysis were selected using the following criteria: publicly available information regarding the companies, initiated insolvency proceedings, which ended with the closure of the company, publicly available annual statements, which contain cash flow statement for at least five years before initiation of extra-judicial, judicial or insolvency 


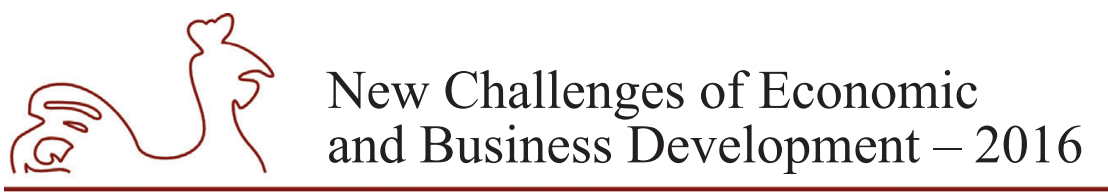

May 12-14, 2016, Riga, University of Latvia

proceedings. Of 82 selected companies, the authors randomly selected 15 companies, which have prepared their reports after the extra-judicial, legal or insolvency proceedings, in order to ensure the truth of the reported financial information in the year when extra-judicial, judicial or insolvency proceedings were initiated. They were 20 companies from 82 companies. 15 companies for the analysis were randomly selected from these 20 companies. Liquidated companies can be seen in Table 2. Since it was impossible, while fulfilling the criteria, for the authors to find 15 companies in one field, the authors selected companies, which operate in different fields.

Liquidated companies were juxtaposed against fifteen stable, growing Latvian companies (see Table 2), which have some of the highest turnover rates in Latvia, their operations are not expected to be terminated due to insolvency and their shares are placed high on the Baltic states securities market. The authors' main goal was to compare the liquidated companies with stable companies. In order to ascertain about the company's stability status there was chosen quoted companies data to fully confirm the validity of the criteria which authors have used. 15 stable companies were randomly selected from 24 companies. Active companies, similarly to closed companies, represent different fields in order to compare them with closed companies.

Table 2

List of liquidated and operating companies selected for analysis

\begin{tabular}{|c|c|c|}
\hline No. & Liquidated companies & Operating companies \\
\hline 1. & “AVT Grupa” LTD & "Olainfarm" JSC \\
\hline 2. & "Būvenergo" LTD & “Daugavpils Lokomotīvju remonta rūpnīca" JSC \\
\hline 3. & “Logistor” LTD & "Grobiņa” JSC \\
\hline 4. & “Kārums V” LTD & "Latvijas Tilti" JSC \\
\hline 5. & "Laticrete Baltic LTD" LTD & “Talsu mežrūpniecība” JSC \\
\hline 6. & "Lauktehnika" LTD & “Tosmares kug̊ubūvētava" JSC \\
\hline 7. & "Lauri Motors" LTD & “Latvijas Gāze” JSC \\
\hline 8. & "Lielauto" LTD & "Latvijas Balzams" JSC \\
\hline 9. & "Melnsils" LTD & "Rīgas autoelektroaparātu rūpnīca" JSC \\
\hline 10. & "Metro Auto" LTD & "Grindeks" JSC \\
\hline 11. & "Riepumeistars" LTD & "Valmieras stikla şķiedra" JSC \\
\hline 12. & "Roņu ieleja" LTD & “VEF Radiotehnika RRR” JSC \\
\hline 13. & “Viesulıi”" LTD & "Kurzemes atslēga 1" JSC \\
\hline 14. & “Topaz TP” LTD & “Ditton pievadksēžu rūpnīca" JSC \\
\hline 15. & “Zuvs” LTD & "Brīvais Vilnis" JSC \\
\hline
\end{tabular}

* authors created table.

In order to compare the cash flow absolute figures of active and closed companies, in Figures 1 and 2 the authors present the average estimates of operating, investing and financing activities cash flow for operating and liquidated companies. Years are numbered from 0 to 5, where for closed companies 0 is the year when extra-judicial, judicial or insolvency proceedings were initiated, while numbers 1 to 5 are years before initiation of the proceedings. For active companies, 0 is the year, when the most recent finance statement is available, while 1 to 5 are 


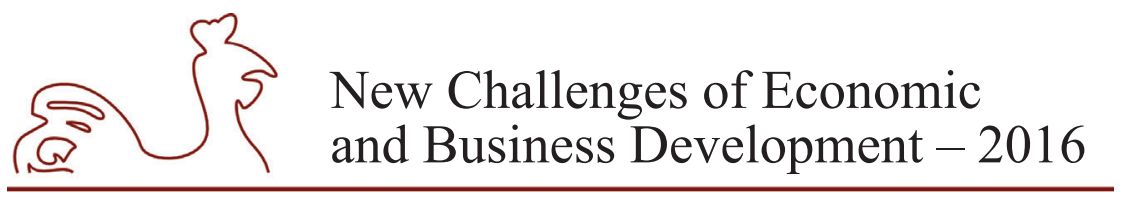

May 12-14, 2016, Riga, University of Latvia

years before the last statement period. Since data contained values, which are comparable and are not completely different, authors used mean values for reflecting absolute values shown in the Figures.

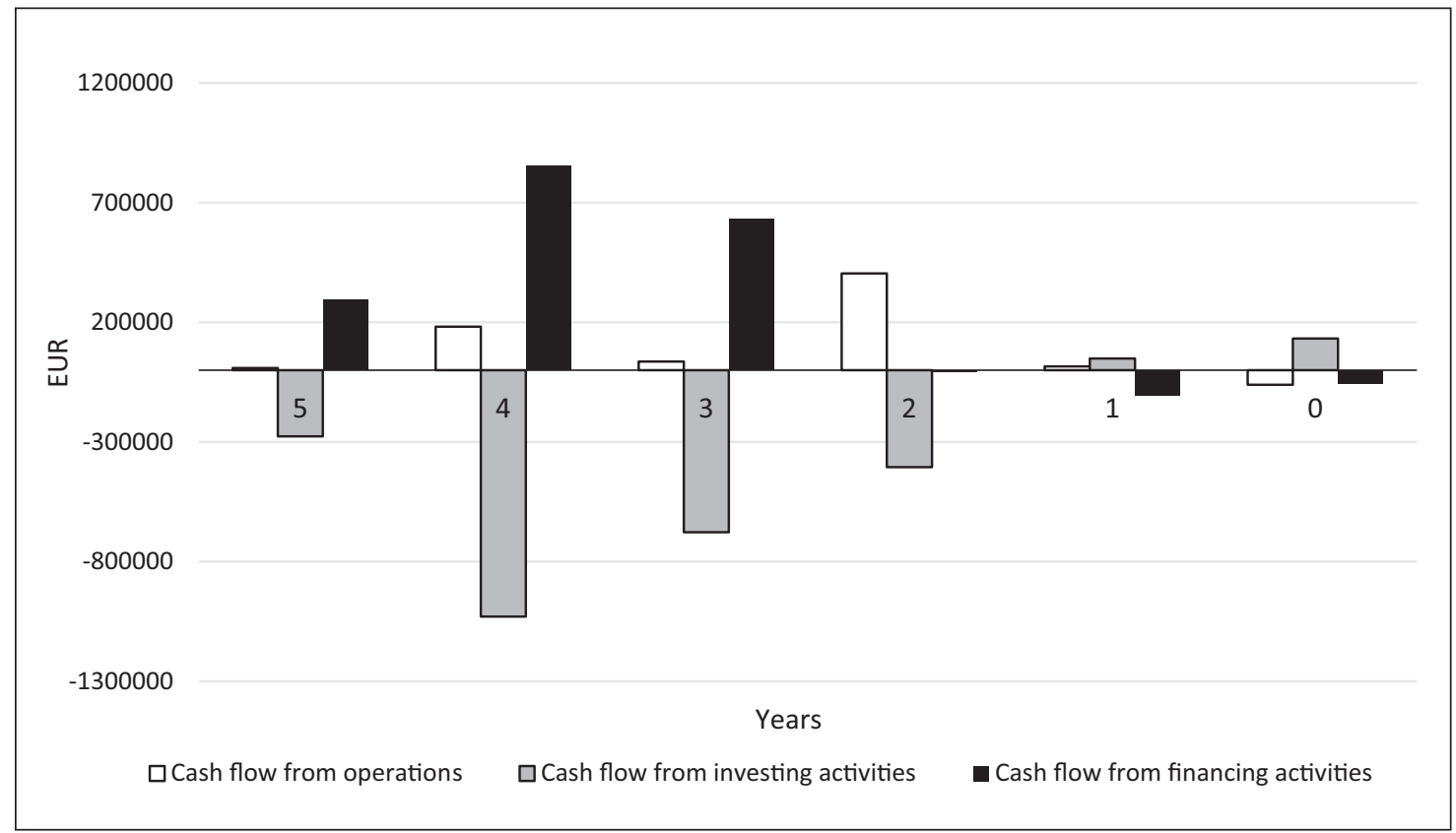

Source: author's construction based on author's calculations.

Fig. 1. The arithmetic mean of the absolute figures of the cash flow of the author's analysed liquidated companies (euros)

As shown in Figure 1, cash flow from operations, investing and financing activities mean values suggest that all closed companies have the tendency to gradually approach zero. In the second year before initiation of extra-judicial, judicial or insolvency proceedings there is a significant increase of operating cash flow compared to the previous year. However, in the following years after the increase, there is rapid and constant decrease of operating cash flow.

A negative value of cash flow from investing activities for closed companies decreases starting with the fourth year before initiation of extrajudicial, judicial or insolvency proceedings, which suggests that companies invest decreased amounts of assets in their development from fourth year of operation and try to exist with those assets, which are already at the company's disposal, and the positive value of cash flow from investing activities suggests that companies most likely sell their assets in the last two analysed periods.

The cash flow from financing activities indicator gradually decreases from the third year before initiation of insolvency proceedings, which suggests that companies attempt to settle their liabilities and do not receive loans at the same amounts as before. In the second year before initiation of insolvency proceedings there is a small decrease in cash flow from financing activities, which proves that companies tried to avoid initiation of extra-judicial, judicial or insolvency procedures with loan assets, but as evidenced by the last analysed period, where cash flow from financing activities decreases again, this solution was not successful. 


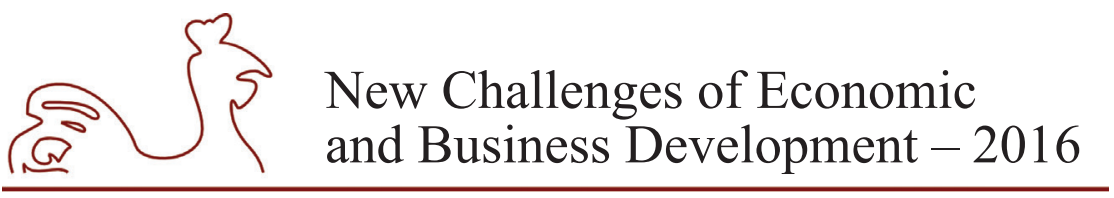

May 12-14, 2016, Riga, University of Latvia

Figure 2 presents the average absolute values of operating, investment activity and financing activity cash flow, which are represented with mean value.

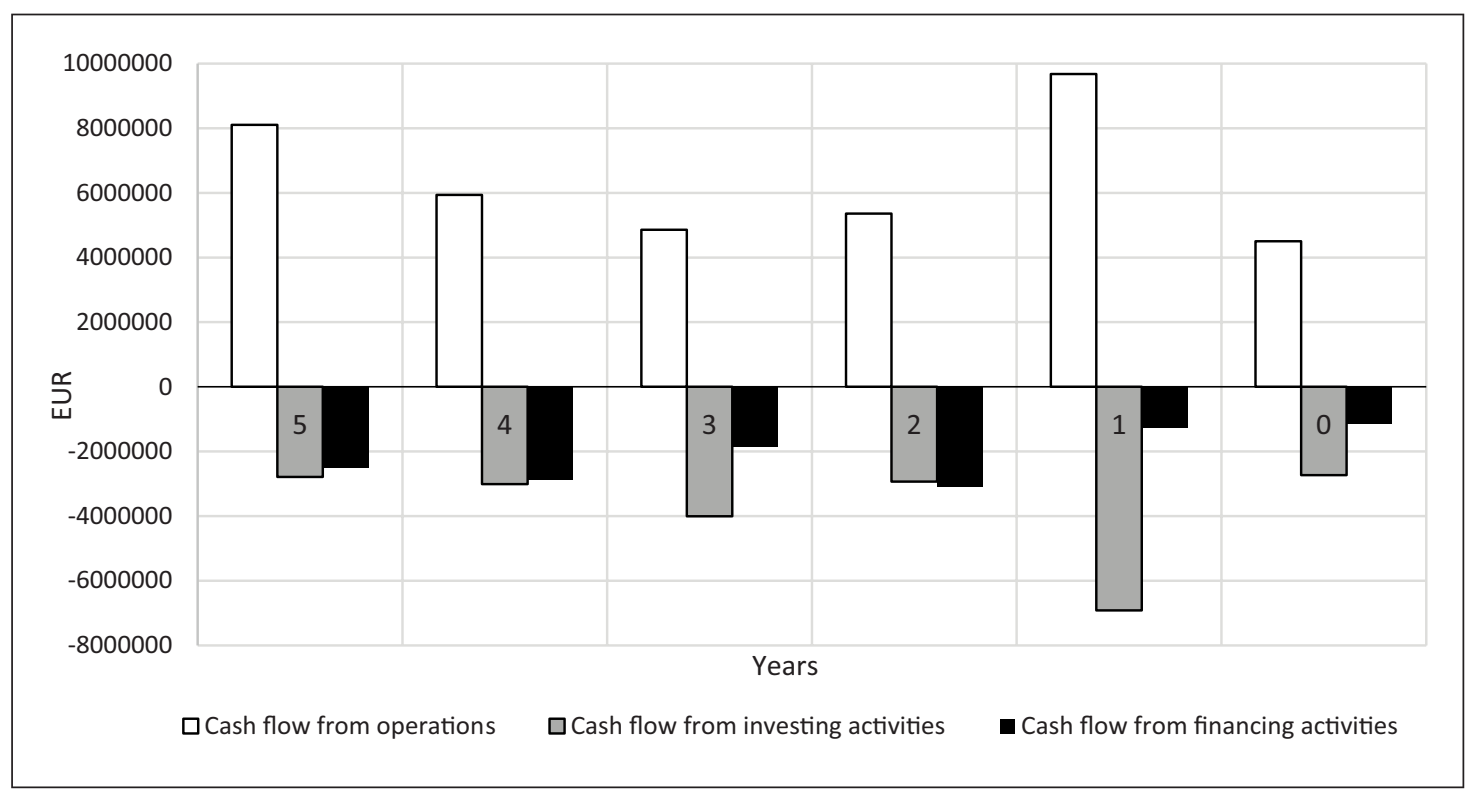

Source: author's construction based on author's calculations.

Fig. 2. The arithmetic mean of the absolute figures of the cash flow of the author's analysed operating companies (euros)

The operating cash flows of the analysed active enterprises of this paper fluctuate, however, show a positive operating cash flow value during all analysed time periods, which points to the financial stability of the active enterprises. As opposed to liquidated enterprises, where the cash flow value due to investment activities was negative during four of six analysed time periods, the cash flow value due to investment activities for active enterprises was negative during all analysed time periods.

The cash flow from financing activities shows a significant difference, when comparing operating and liquidated enterprises, because every year the mean cash flow from financing activities for active enterprises is negative, which indicates that financing activity costs are greater than income. Since financing activity costs include repayment of loans and dividend payout, it is possible that dividend payout makes up for a large part of the total financing activity costs, however, to make accurate conclusions, this would need to be researched more in-depth.

Based on the previously conducted study, analysis and assessment of the mean net cash flow of liquidated and operating enterprises, the authors recommend, when predicting the solvency of an enterprise, to take all cash flows and the following tendencies into account:

- if the operating cash flow level decreases every year, a detailed analysis of the enterprises operating costs and income should be carried out, and, in order for the enterprise to remain solvent, develop a plan for increasing the operating cash flow; 


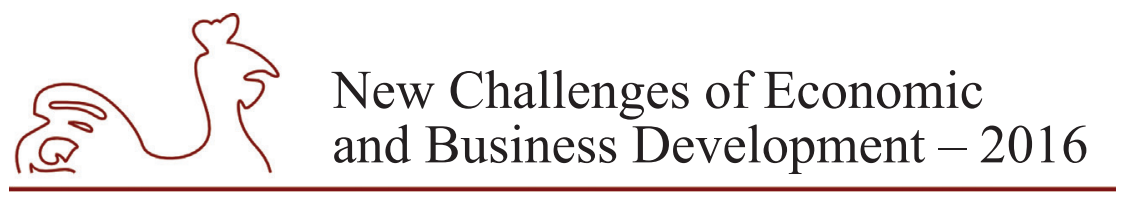

May 12-14, 2016, Riga, University of Latvia

- special attention should also be paid to the cash flow level from investing activities if it has a tendency to approach zero, and carry out a detailed analysis of the enterprises operations, assessing its activity and future prospects;

- if the ratio value of the cash flow from financing activities is consistently high over the course of several time periods, without decreasing, it may indicate an unstable financial state.

During the study the authors calculated the ratios of the summary analysis of the cash flow of 15 selected liquidated and 15 operating enterprises seen in Table 2, and have shown the arithmetic mean of the calculated ratios and their differences over a six year period in Table 3 .

Table 3

The arithmetic mean of the calculated ratios of the summary analysis of the cash flow and their differences by years between liquidated and operating companies used in this study

\begin{tabular}{|c|c|c|c|c|c|}
\hline No. & Ratios & Years & $\begin{array}{l}\text { Liquidated } \\
\text { companies }\end{array}$ & $\begin{array}{l}\text { Operating } \\
\text { companies }\end{array}$ & $\begin{array}{c}\text { Difference } \\
{[5-4]}\end{array}$ \\
\hline 1 & 2 & 3 & 4 & 5 & 6 \\
\hline \multirow{6}{*}{1} & \multirow{6}{*}{$\begin{array}{c}\text { (Cash flow from operations }+ \\
\text { interest paid }+ \text { taxes paid) } / \\
\text { Interest paid }\end{array}$} & 5 & 1.62 & 19.94 & 18.32 \\
\hline & & 4 & 6.51 & 15.94 & 9.43 \\
\hline & & 3 & 1.54 & 17.18 & 15.65 \\
\hline & & 2 & 3.85 & 21.99 & 18.14 \\
\hline & & 1 & 1.20 & 41.82 & 40.62 \\
\hline & & 0 & 0.86 & 21.34 & 20.48 \\
\hline \multirow{6}{*}{2} & \multirow{6}{*}{$\begin{array}{c}\text { Cash flow from operations / } \\
\text { Net income }\end{array}$} & 5 & 0.63 & 2.83 & 2.20 \\
\hline & & 4 & 14.87 & 1.42 & -13.46 \\
\hline & & 3 & 0.51 & 1.14 & 0.62 \\
\hline & & 2 & 12.29 & 1.20 & -11.09 \\
\hline & & 1 & -0.09 & 2.29 & 2.39 \\
\hline & & 0 & - & 1.54 & - \\
\hline \multirow{6}{*}{3} & \multirow{6}{*}{$\begin{array}{c}\text { Cash flow from operations / } \\
\text { Current liabilities }\end{array}$} & 5 & 0.019 & 0.53 & 0.52 \\
\hline & & 4 & 0.21 & 0.52 & 0.31 \\
\hline & & 3 & 0.04 & 0.33 & 0.30 \\
\hline & & 2 & 0.39 & 0.30 & -0.09 \\
\hline & & 1 & 0.02 & 0.45 & 0.44 \\
\hline & & 0 & -0.03 & 0.32 & 0.35 \\
\hline \multirow{6}{*}{4} & \multirow{6}{*}{$\begin{array}{c}\text { Cash flow from operations / } \\
\text { Total liabilities }\end{array}$} & 5 & 0.01 & 0.32 & 0.31 \\
\hline & & 4 & 0.09 & 0.28 & 0.19 \\
\hline & & 3 & 0.01 & 0.21 & 0.19 \\
\hline & & 2 & 0.14 & 0.20 & 0.06 \\
\hline & & 1 & 0.01 & 0.30 & 0.29 \\
\hline & & 0 & -0.02 & 0.17 & 0.19 \\
\hline \multirow{6}{*}{5} & \multirow{6}{*}{$\begin{array}{c}\text { Cash flow from operations / } \\
\text { Net turnover }\end{array}$} & 5 & 0.01 & 0.16 & 0.15 \\
\hline & & 4 & 0.07 & 0.10 & 0.03 \\
\hline & & 3 & 0.01 & 0.08 & 0.07 \\
\hline & & 2 & 0.10 & 0.08 & -0.02 \\
\hline & & 1 & 0.01 & 0.14 & 0.14 \\
\hline & & 0 & -0.05 & 0.07 & 0.12 \\
\hline
\end{tabular}




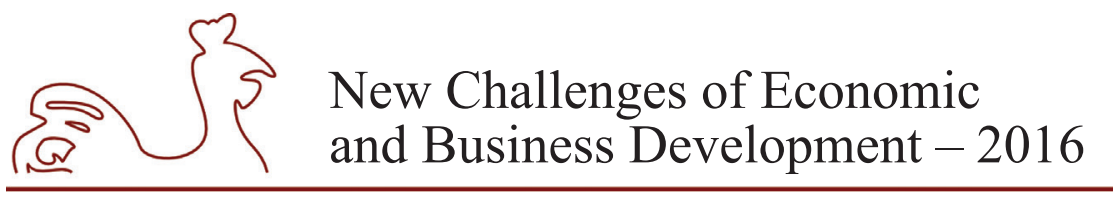

May 12-14, 2016, Riga, University of Latvia

Table 3 cont.

\begin{tabular}{|c|c|c|c|c|c|}
\hline 1 & 2 & 3 & 4 & 5 & 6 \\
\hline \multirow{6}{*}{6} & \multirow{6}{*}{$\begin{array}{c}\text { Cash flow from operations / } \\
\text { Total assets }\end{array}$} & 5 & 0.01 & 0.11 & 0.10 \\
\hline & & 4 & 0.08 & 0.08 & 0.00 \\
\hline & & 3 & 0.01 & 0.06 & 0.05 \\
\hline & & 2 & 0.12 & 0.06 & -0.06 \\
\hline & & 1 & 0.01 & 0.10 & 0.10 \\
\hline & & 0 & -0.03 & 0.05 & 0.08 \\
\hline \multirow{6}{*}{7} & \multirow{6}{*}{$\begin{array}{l}\text { Cash flow from investing } \\
\text { activities / Net turnover }\end{array}$} & 5 & -0.16 & -0.05 & -0.11 \\
\hline & & 4 & -0.41 & -0.05 & -0.36 \\
\hline & & 3 & -0.18 & -0.07 & -0.11 \\
\hline & & 2 & -0.10 & -0.04 & -0.06 \\
\hline & & 1 & 0.02 & -0.10 & -0.12 \\
\hline & & 0 & 0.10 & -0.04 & -0.14 \\
\hline \multirow{6}{*}{8} & \multirow{6}{*}{$\begin{array}{l}\text { Cash flow from investing } \\
\text { activities / Total liabilities }\end{array}$} & 5 & -0.34 & -0.11 & -0.23 \\
\hline & & 4 & -0.51 & -0.14 & -0.37 \\
\hline & & 3 & -0.25 & -0.17 & $\begin{array}{l}-0.07 \\
\end{array}$ \\
\hline & & 2 & -0.14 & -0.11 & -0.03 \\
\hline & & 1 & 0.02 & -0.21 & -0.23 \\
\hline & & 0 & 0.05 & -0.10 & -0.15 \\
\hline \multirow{6}{*}{9} & \multirow{6}{*}{$\begin{array}{l}\text { Cash flow from investing } \\
\text { activities / Total assets }\end{array}$} & 5 & -0.30 & -0.04 & -0.26 \\
\hline & & 4 & -0.47 & -0.04 & -0.43 \\
\hline & & 3 & -0.23 & -0.05 & -0.17 \\
\hline & & 2 & -0.12 & -0.03 & -0.09 \\
\hline & & 1 & 0.02 & -0.07 & $\begin{array}{l}-0.09 \\
\end{array}$ \\
\hline & & 0 & 0.06 & -0.03 & -0.09 \\
\hline \multirow{6}{*}{10} & \multirow{6}{*}{$\begin{array}{l}\text { Cash flow from financing } \\
\text { activities / Total liabilites }\end{array}$} & 5 & 0.37 & -0.11 & 0.48 \\
\hline & & 4 & 0.42 & -0.14 & 0.57 \\
\hline & & 3 & 0.23 & -0.17 & 0.40 \\
\hline & & 2 & -0.002 & -0.11 & 0.11 \\
\hline & & 1 & -0.04 & -0.21 & -0.18 \\
\hline & & 0 & -0.02 & -0.10 & -0.08 \\
\hline \multirow{6}{*}{11} & \multirow{6}{*}{$\begin{array}{l}\text { Cash flow from financing } \\
\text { activities / Net turnover }\end{array}$} & 5 & 0.17 & -0.05 & 0.22 \\
\hline & & 4 & 0.34 & -0.05 & 0.39 \\
\hline & & 3 & 0.17 & -0.03 & 0.20 \\
\hline & & 2 & -0.002 & -0.04 & 0.04 \\
\hline & & 1 & -0.04 & -0.02 & $\begin{array}{l}-0.02 \\
\end{array}$ \\
\hline & & 0 & -0.04 & -0.02 & -0.02 \\
\hline
\end{tabular}

Source: author's calculations based on data of liquidated and operating companies.

As seen in Table 3 the biggest differences between the mean of closed and active companies in all analysed time periods is with the ratio cash flow from operations, interest paid and taxes paid to interest paid. The ratio cash flow from operations to net profit was better for operating enterprises only during three of six analysed time periods, but liquidated enterprises showed a better value during two of six analysed time periods. The remaining operating cash flow ratios 


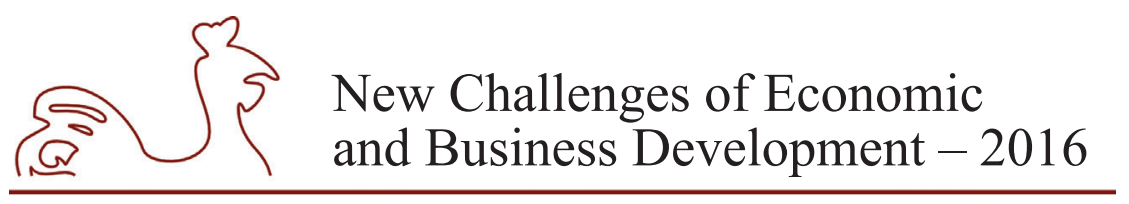

May 12-14, 2016, Riga, University of Latvia

do not indicate significant differences, although, only three of four ratios in one of the analysed time periods showed a better value for closed enterprises - the second year before initiation of extrajudicial, judicial or insolvency proceedings for these ratios: cash flow from operations to current liabilities, cash flow from operations to net turnover and cash flow from operations to total assets. However, the authors believe that, overall, the ratios: cash flow from operations to current liabilities, cash flow from operations to total liabilities, cash flow from operations to net turnover and cash flow from operations to total assets do not show significant differences between active and closed enterprises.

The cash flow ratio from investing activities and cash flow from financing activities for operating and liquidated enterprises indicate the same tendency as the absolute figures when analysing net cash flows - the cash flow ratios from financing activities decrease beginning from the third year before initiation of extrajudicial, judicial or insolvency proceedings they gradually decrease, but the cash flow ratios from investing activities become positive one year before initiation of extrajudicial, judicial or starting of insolvency proceedings.

A conclusion can be made based on the results of this study that, by analysing the data of 15 liquidated and 15 operating enterprises, applying the criteria mentioned earlier, the ratio cash flow from operations, interest paid and tax paid to interest paid shows a significant difference between active and liquidated enterprises, therefore this ratio should be used primarily by financial analysts for assessing the financial state, and special attention should be paid to changes in the net cash flow by taking the aforementioned tendencies into account.

To evaluate the previously stated conclusions and suggestions, the authors compared their research data with the 2007 study by L. Jooste on a similar subject. They analysed L. Jooste's "An evaluation of the usefulness of cash flow ratios to predict financial distress", which was conducted by the Nelson Mandela Metropolitan University in 2007. L. Jooste's study selected 10 closed and 17 active enterprises.

8 cash flow ratios, based on operating cash flow, were selected in L. Jooste's study. The funding ratio values were illustrated using the arithmetic mean, but the absolute figures were not studied, as well as cash flow ratios from investing and financing activities.

L. Jooste concluded that, when compared to active enterprises, the mean figures for closed enterprises are more unstable. The study discovered that the higher the ratio value, the smaller the chance of financial problems, and a positive ratio value indicates a positive cash flow. (Jooste L. 2007)

L. Jooste in his study points out, that financial problems can be observed starting from the third year before closure. The author's calculations indicate that every ratio has a different period when financial problems can be observed. The authors also point out, that the ratios of four closed enterprises pointed to a connection - the ratio values start to decrease starting from the third year before initiation of extra-judicial, judicial or insolvency proceedings, however, the authors do not agree that this limit can be applied to all ratios. Both the authors' and L. Jooste's study indicate the fact that, the higher the ratio values of the operating cash flow is, the smaller the chance for financial problems, which a majority of the ratios in the authors' study clearly indicate. Unlike L. Jooste's study, the authors' study does not suggest that in the fourth year the majority of cash flow ratios of closed enterprises are higher than those of active enterprises, because the authors' study does not confirm such conclusions. 


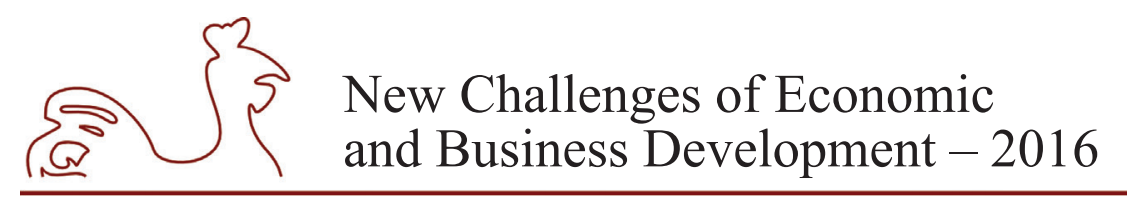

May 12-14, 2016, Riga, University of Latvia

As of 2016 the "Annual Account Law" expires and in its place comes the "Annual Account and Consolidated annual Account Law" adopted by the Supreme Council of the Republic of Latvia on 22 October 2015, which states that enterprises, which conform to the criteria of medium-sized and large corporations, will have to prepare a cash flow statement. A mediumsized corporation is one that is not a small corporation, and the balance on the date of statement does not exceed at least two of three value limits in this section:

- total balance 4000000 EUR - 20000000 EUR;

- net turnover 8000000 EUR - 40000000 EUR;

- the average number of employees in the statement year 50-250.

A large corporation is one whose balance on the date of statement does not exceed at least two of three value limit criteria:

- total balance - 20000000 EUR;

- net turnover - 40000000 EUR;

- the average number of employees in the statement year - 250. (Annual Account and Consolidated Annual Account Law, 2016)

According to the requirements of the former "Annual Account Law", corporations had to prepare a cash flow statement as an inseparable part of the annual statement if the balance on the date of statement exceeded two of the following criteria

- yearly total balance exceeds 400000 EUR,

- yearly net turnover exceeds 800000 EUR,

- the average number of workers in the statement year exceeds 25 (Annual Account Law, 2015)

In the authors' opinion, the new demands of the "Annual Account and Consolidated Annual Account Law" will notably impact the amount of enterprises in the Republic of Latvia, which will have to prepare a cash flow statement, because the criteria limits compared to the "Annual Account Law" have been significantly raised.

\section{Conclusions, proposals, recommendations}

In accordance with the goals of this paper, the authors have studied the figures and ratios used in the analysis of cash flow statements, analysed the data of 15 liquidated and 15 operating enterprises of the Republic of Latvia, and, by comparing the calculated ratios, have come to these conclusions:

1. The operating, investing activity and financing activity net cash flow and their arithmetic mean figures of closed enterprises indicate the approach of the insolvency problem, because the operating cash flow decreases starting from the second year before initiation of extrajudicial, judicial or insolvency proceeding, cash flow from investing activities tends to approach zero starting from the third year before initiation of extrajudicial, judicial or insolvency proceedings, but a year before this process becomes positive, whereas the cash flow from financing activities figures have a tendency to decrease starting from the third year before initiation of extrajudicial, judicial or insolvency proceeding.

2. Of the 11 ratios used in the analysis, the operating cash flow, interest payment and the tax payment to interest payment ratio are best for showing the difference between active and closed enterprises, therefore the use of this ratio for predicting insolvency for enterprises with debts with interest rates is of primary necessity. 


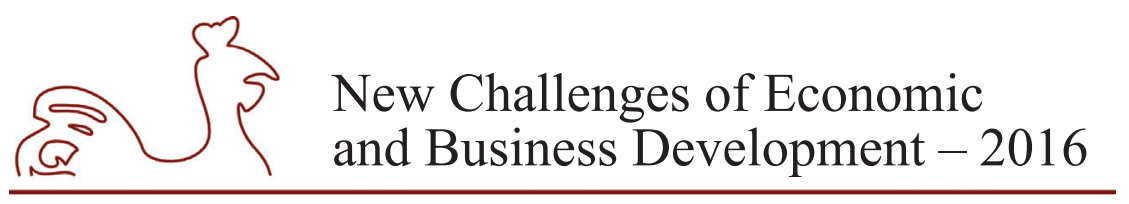

May 12-14, 2016, Riga, University of Latvia

3. The operating cash flow to net profit ratio indicates significant differences, but, as these differences are both positive and negative, there would be no point in using this cash flow ratio for predicting insolvency.

4. The ratios: cash flow from operations to current liabilities, cash flow from opearations to total liabilities, cash flow from operations to net turnover and cash flow from opearations to total assets do not indicate significant differences between liquidated and operating enterprises.

5. The ratio values of financing activities decrease starting from the third year before initiation of extra-judicial, judicial or insolvency proceedings, but investing cash flow becomes less negative starting from the third year before initiation of extra-judicial, judicial or insolvency proceedings, but becomes positive one year before the initiation of this process.

6. The authors, after comparing the results of the analysis with a similar study, conducted by L. Jooste of the Nelson Mandela Metropolitan University in 2007, but which did not include ratio calculations of the net flow and investing and financing activities used in the analysis, agree with L. Jooste, that the higher the operating cash flow ratio value, the lower the chance of financial problems, however, the results of the study did not confirm L. Jooste's statement, that financial problems can be observed starting from the third year before closure, because the ones conducted by the authors did not confirm such a statement. Ratio values calculated using the arithmetic mean figures in L. Jooste's study and the calculated ratio values in the author's paper indicate a difference in time periods, when financial problems can be observed. L. Jooste's ratio calculations cash flow from opearations to operationg income, cash flow from opearations to total assets, cash flow from opearations to interest paid, cash flow from opearations to ordinary dividends payout ratio, using the arithmetic mean show that financial problems can be observed starting from the third year before closure, whereas the author's ratio calculations do not indicate a specific time period, when ratio value worsening can be observed.

By assessing the results of the study the authors believe that it has both theoretical and practical value. When predicting enterprise insolvency using the cash flow statement, special attention should be paid to changes in the cash flow of operating, investing and financing activities by taking the aforementioned tendencies into account, as well as calculate and analyse the following ratios: operating cash flow, interest paid and tax paid to interest paid ratio, operating cash flow to net income ratio, and cash flow from operations to current liabilities ratio, because these showed the greatest differences between operating and liquidated enterprises. The authors also believe that studies on cash flow statements and associated ratio usage for predicting enterprise insolvency should be continued, analysing a larger amount of liquidated and operating enterprise data, as well as analysing them in specific industries.

\section{Bibliography}

Dyckman T. R., Dukes R. E., Davis C. J., Intermediate Accounting. Boston, Irwin INC., 1992, 1418, $1421 \mathrm{p}$.

Fawzi N. S., Kamaluddin A., Sanusi M. D.,“ Monitoring Distressed Companies through Cash Flow Analysis”. [Online] Available at: http://datubazes.lanet.lv:3541/eds/command/detail?sid=46267ad89b42-4159-a4be-a030e91c3256\%40sessionmgr4002\&vid=44\&hid=4203) [Accessed 11 November 2015]. 


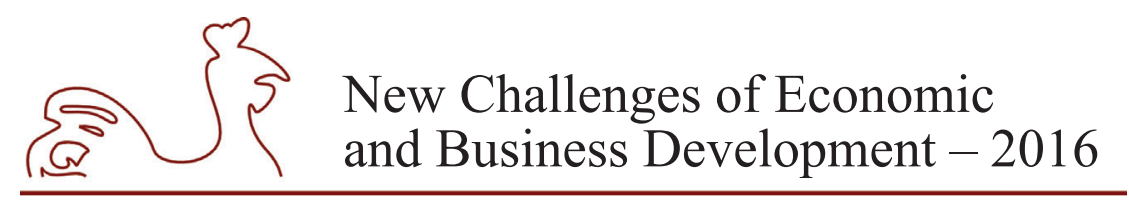

May 12-14, 2016, Riga, University of Latvia

Jooste L., An evalutation of the usefulness of cash flow ratios to predict finansical ditress. [Online] Available at: http://ro.uow.edu.au/cgi/viewcontent.cgi?article=4260\&context=commpapers [Accessed 5 December 2015].

Kirkham R. "Liquidity Analysis Using Cash Flow Ratios and Traditional Ratios: The Telecommunications Sector in Australia". [Online] Available at: http://datubazes.lanet.lv:3541/eds/pdfviewer/pdfviewer? sid=46267ad8-9b42-4159-a4be a030e91c3256\%40sessionmgr4002\&vid=41\&hid=4203) [Accessed 11 November 2015].

Lursoft insolvency register. [Online] Available at: https://www.lursoft.lv/exec?act=MNR_LSTAT\&stat $\mathrm{id}=550$ [Accessed 12 November 2015].

Needles B. E., Powers M., Crosson S. V., Financial \& Managerial accounting. Boston, New York, Houghton Mifflin Company, 2005, 1182 p.

Robinson T. R., Greuning H., Henry E., Broihahn M., International financial statement analysis. Hooboken, John Willey \& Sons 2009, 252-253 p.

Šneidere R., "Finanšu analīzes metodes uzņēmuma maksātnespējas prognozēšanai”, Rīga, Lietišķās informācijas dienests, 2009, 106 p.

Subatnieks K., Komercsabiedrības naudas plūsma. Riga, Drukātava, 2008, 64-81 p.

Supreme Council, 2015 Annual Account and Consolidated Annual Account Law. 12.11.2015. [Online] Available at: http://likumi.lv/ta/id/277779-gada-parskatu-un-konsolideto-gada-parskatu-likums [Accessed 5 February 2016].

Supreme Council, 1992 (as amended). Annual Accounts Law. 14.10.1992. [Online] Available at: http:// likumi.lv/doc.php?id=66461 [Accessed 3 February 2016]. 


\title{
MANAGEMENT OF THE LEARNIT INTERNATIONAL RESEARCH PROJECT IMPLEMENTATION: MAIN CHALLENGES AND FOCUS AREAS
}

\author{
Yulia Stukalina, Transport and Telecommunication Institute, Latvia ${ }^{1}$
}

\begin{abstract}
In the context of creating the European Research Area, many European universities are now engaged in different research activities including international research projects, which can make a valuable contribution to the development of an academic organization. Partnership of three higher education institutions from three countries was organized to implement LEARNIT research project: WSEI (University of Economics and Innovation, Poland), KVK (Klaipeda State College, Lithuania), and TSI (Transport and Telecommunication Institute, Latvia). The key project outcomes are supposed to be the properly equipped Learning Lab and software for mobile devices intended for enhancing the effectiveness of the learning process by stimulating students' concentration. LEARNIT is a complex multidimensional research project that involves people of different professions and positions: researchers, managers, teachers, IT specialists and students. Therefore, the management of LEARNIT is a complicated process that requires strong integration of various resources, as well as different pedagogical and managerial procedures. The aim of the paper is to address the main challenges faced by the LEARNIT management in the project implementation process, and to describe key focus areas of this project. The analysis provided in this paper is based on the academic literature review on the major educational and project management issues; it is also based on the author's experience as the project leader from Transport and Telecommunication Institute. The analysis performed in this paper allows the author to conclude that the implementation of a crossdisciplinary research project demands using the holistic approach to the management of heterogeneous organizational resources. The success of a cross-disciplinary research project is directly related to the accomplishment of a synergistic effect; the expected synergistic effect arises from strong cooperation between main functional domains of a university, so the project should be aligned with the appropriate management functions carried out in the agenda of functional area-specific strategies implementation. The author hopes that whatever lessons this analysis provides would be helpful to managers responsible for implementing a complex research project in a modern university.
\end{abstract}

Key words: educational management, research project, holistic approach

JEL code: M150 IT

\section{Introduction}

Nowadays, a wide range of various factors make education managers think and plan more strategically (Stukalina, 2015). Internationalization and globalization make contemporary higher education institutions to search for human capital, financial resources to boost international competitiveness (Mohrman et al., 2008). Management of a modern university faces serious challenges; from an institutional perspective, universities are forced to become more efficient

1 Corresponding author - e-mail address: Stukalina.J@tsi.lv 


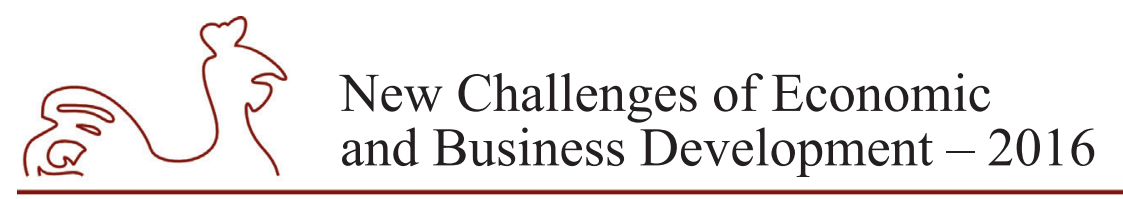

May 12-14, 2016, Riga, University of Latvia

in the realization of their missions - teaching, research and innovation and local economic development (The State of Higher Education 2014: Executive Summary). From a strategic management perspective, management of a contemporary higher education institution has to find the most resourceful means to balance their university's position in terms of internal strengths and weaknesses against external opportunities and threats (Stukalina, 2015).

The European research landscape is now changing fast due to the new environmental and societal challenges that Europe faces today: climate change, use of energy and population ageing; together with competition for better ideas and the funding, it stimulates intensive cooperation across borders, and institutions (Potočnik, 2009). In the context of developing a competitive strategy, international research projects can make a valuable contribution to supporting research and academic excellence of a university and attracting external funds for international education and research, this way providing the university's competitiveness in the global educational market. So, international research projects can be regarded as significant instruments for generating new ideas in the context of creating the European Research Area. They have to contribute fully to the implementation of the European Research Area and to the Lisbon Agenda, which was launched in 2000 for implementing the Lisbon Strategy (COM(2000) 6 final).

As projects become more crucial to organizational strategy and competitive advantage, being a means of formulating strategic moves for accomplishing strategic goals (Davies et al., 2011), new ambitious research projects are undertaken by European universities. Partnership of three higher education institutions from three countries was organized to implement LEARNIT research project: WSEI (University of Economics and Innovation, Poland), KVK (Klaipeda State College, Lithuania), and TSI (Transport and Telecommunication Institute, Latvia). The key project outcomes are supposed to be the properly equipped Learning Lab and software for mobile devices intended for enhancing the effectiveness of the learning process by stimulating students' concentration. LEARNIT is a complex multidimensional research project that involves people of different professions and positions: researchers, managers, teachers, IT specialists and students. Therefore, the management of LEARNIT is a complicated process that requires strong integration of various resources, as well as different pedagogical and managerial procedures.

The aim of the paper is to address the main challenges faced by the LEARNIT management in the project implementation process, and to describe key focus areas of this project. The analysis provided in this paper is based on the analysis provided in this paper is based on the EU documents on higher education, academic literature review on the major strategic management, educational management and project management issues; it is also based on the author's experience as the project leader from Transport and Telecommunication Institute. The analysis performed in this paper allows the author to conclude that the implementation of a cross-disciplinary research project demands using the holistic approach to the management of organizational resources, which presupposes identifying central functional areas involved in the project realization. The author hopes that whatever lessons this analysis provides would be helpful to managers responsible for implementing a complex research project in a modern university. 


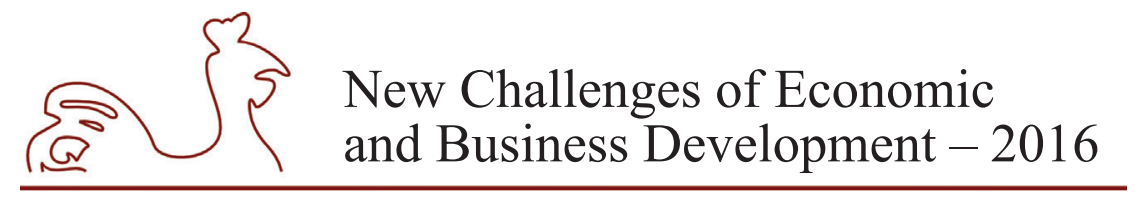

May 12-14, 2016, Riga, University of Latvia

\section{Research results and discussion}

\section{Research projects in the context of achieving competitive advantage of a modern university}

The challenges faced by managers who work in the area of higher education comprise providing their universities with sufficient and sustainable resources, enhancing the university's research and academic excellence, increasing their international attractiveness, supporting collaboration with other academic institutions and enterprises, offering new opportunities to students in the agenda of the global labour market customization and lifelong learning, etc. (COM(2003) 58 final; $\operatorname{COM(2007)~} 61$ final; The European Higher Education Area in 2012: Bologna Process Implementation Report, 2012; Report to the European Commission on Improving the Quality of Teaching and Learning in Europe's Higher Education Institutions, 2013; The State of Higher Education 2013: Executive Summary, 2013).

Management of a modern university being linked to creating institutional policies intended for enhancing its potential for change and a persistent concern for quality (Tabatoni, 2002). Educational management is focused on the purpose and aims of education; these aims are closely related to sustaining and increasing competitiveness of an educational organization (Bush, 2011). They include social, cultural, moral, academic aims (Fiddler, 2002). Numerous strategies can be developed to provide an organization with a competitive advantage (Hill \& Jones, 2013). Thus, in the context of the internalization of higher education and research, education managers may employ different strategies for stimulating international mobility of students and academic staff by means of grants, promoting academic exchange programmes and partnerships between academic institutions, competing for talent, exporting educational services, etc. (VincentLancrin, 2009). The above strategies are all directed towards accomplishing academic and research excellence, which presupposes that central institutional strategies connect teaching and research in the frame of providing organizational competitiveness. According to Jenkins \& Healy (2005), these strategies can be categorized as the strategies aimed at the following:

1) creating institutional awareness and institutional mission (for example, organising events, research studies and publications to increase institutional awareness, creating institutional conceptions and strategies to influence teaching-research relations);

2) creating pedagogical tools to maintain the teaching-research links (for example, establishing and reviewing teaching policies together with employing strategic and operational planning and institutional audit to strengthen to strengthen the teachingresearch connections);

3) generating research policies and strategies to support the teaching-research links (for example, creating and review research policies and implementing strategies directed at increasing the teaching-research connections);

4) developing university structures and attracting staff to support the teaching-research links (for example, developing new personnel training policies, providing effective synergies among organizational entities and structures for teaching and research, and linking these with the associated university strategies).

Thus, each of the above-mentioned strategies represents a different means of generating a competitive advantage. Developing a competitive strategy (strategies) university management 


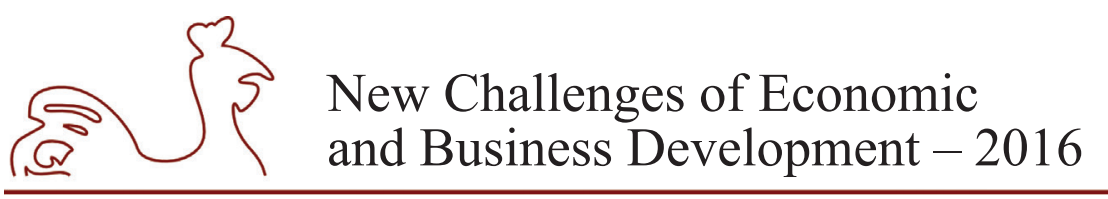

May 12-14, 2016, Riga, University of Latvia

has to take into account the fact that that different strategies have different consequences in different contexts, the choice of a strategy (strategies) depending on various factors: situation in the international labour market and in the international higher education market, social and university context, financial models, leadership and management models, specialization (technical/humanitarian), etc. (Stukalina, 2015).

Having regard to the above, it may be assumed that research and its links with teaching academic disciplines plays a crucial role in the development of a higher education institution. It is useful to highlight in this regard that research projects make a valuable contribution to accomplishing the strategic university's goals, the research project management being an integral part of the university's overall strategy.

The term "project management" implies that it is the planning, organizing, directing, and controlling of organizational resources for a comparatively short-term objective established to achieve specific goals and objectives (Kerzner, 2003). Project management presupposes using particular knowledge, skills, tools and methods for implementing project activities to meet certain project requirements (Prabhakar, 2008). The purpose of project management is supposed to be achieving the set objectives regardless of the emerging risks, project management being concerned commonly with the management of change (Harrison \& Lock, 2004). For effectively implementing a project managers require an appropriate strategy, which can be defined as a "direction in a project that contributes to success of the project in its environment"; it is linked with competitive advantage of the organization in the external environment (Artto et al., 2008).

Aligning projects with the strategic goals of the organization is key for project success (Larson \& Grey, 2011). The corporate strategy will provide the margins for a concrete project, and its goals and results should be related to an organization's vision, so project management demands comprehensive planning for creating suitable conditions for successful project execution (Longman \& Mullis, 2004). Thus, project management involves many challenges, which are related to both the complex internal environment of modern organizations and the highly competitive global environment. The main challenges encountered by the LEARNIT project management will be considered below.

\section{Main challenges faced by the LEARNIT project management}

Project managers experience some special challenges that are not usually faced by other managers (Minavand et al., 2013). The traditional project management addresses such issues as labour, time, and money (Othman et al., 2010); other common challenges embrace managing distributed and matrix managed teams, issue tracking, resource management, prioritization (Sullivan, 2012), selecting people with different specialties and backgrounds, managing crossfunctional teams, keeping the staff motivated (Minavand et al., 2013).

Though, due to the unique nature of each project, which depends on the industry, size, location, nature, complexity, and environment (Prabhakar, 2008), every project management team must addresses some unique issues. Current project management issues of the ICT-based project management include challenges related to the adaption to the new dynamic environments (Othman et al., 2010). Project managers who deal with complex projects within organizational systems that are themselves complex face specific challenges (Heaslip, 2015); this can be fully applied to the management of a cross-disciplinary ICT-based research project in a modern university. 


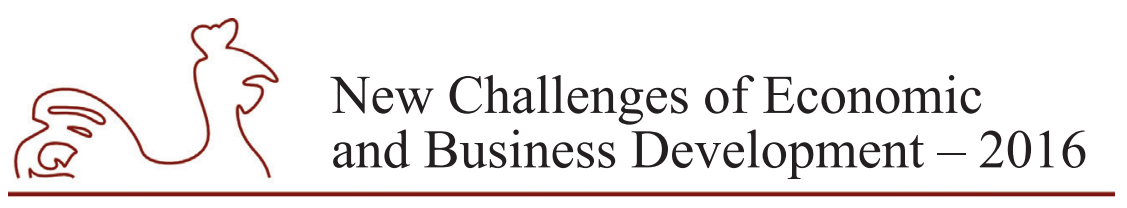

May 12-14, 2016, Riga, University of Latvia

The main challenges encountered by the LEARNIT project management team can be summarized as follows:

- The LEARNIT management occurs at different levels across the university environment.

- LEARNIT is a multidimensional research project engaging people within different areas of expertise.

- The LEARNIT implementation requires tight integration of organizational resources: HR, administrative, technological and educational.

- LEARNIT is a sophisticated ICT-based project.

- Students are actively involved in the LEARNIT implementation, and the expected results are much dependent on the students' contribution to the project.

As seen from the above, the LEARNIT management comprises various perspectives. The categories of complexity encountered by the LEARNIT project team include those mentioned by Heaslip (2015): a) the complexity based on human behaviour, as the project involve different stakeholders; b) the complexity based on system behaviour, which results from the need for projects to interrelate dynamically with "systems" within their environment - functional departments, committees, other projects, etc.

To deal with these categories of complexity, LEARNIT project managers have to synergize the resources distributed in different domains of the complicated organizational environment for supporting basic project activities; these resources embrace tangible, semi-tangible, nontangible resources (Stukalina, 2008; Stukalina, 2010) associated with certain functional areas of a contemporary university, where various functional strategies are implemented. A functional strategy is defined as an action plan for running a functional activity within a business (Thompson \& Strickland, 2003). Functional strategies are usually associated with decisions made by each department in a certain business: marketing, production, finance, human resources; the decisions being mainly related to the effective use of the available resources (Altuntaş et al., 2014). However, we interpret the notion "functional area" more broadly than just a functional department of an organization. Modern universities are complicated multi-level structures. Strategies developed by the university management are aimed at the realization of the university's central activities associated with teaching, research and community service (McBurnie \& Ziguras, 2009).

Therefore, the resources necessary for supporting the learning process are embedded in different functional areas of the university, where functional area-specific strategies are realized (Stukalina, 2014): a) university facilities (a blend of tangible, non-tangible and semi-tangible resources); b) education (a blend of tangible, non-tangible and semi-tangible resources); c) research (a combination of tangible, non-tangible and semi-tangible resources); d) staff (nontangible resources).

The above is also true regarding a cross-disciplinary project implemented in a university. All closely intertwined project areas correspond to the four entangled functional areas of a higher education institution. The embodied intellectual capital can be regarded as the link that connects various functional areas, the educational organization being a community of people united by common goals (Stukalina, 2010).

An integrated leadership, management, and support environment is vital for the management of projects (Implementing organizational project management: A practice guide, 2014). Therefore, the success of a complex research project is directly related to the accomplishment of a synergistic effect. There exist many definitions of the term "synergy", though all of them include 


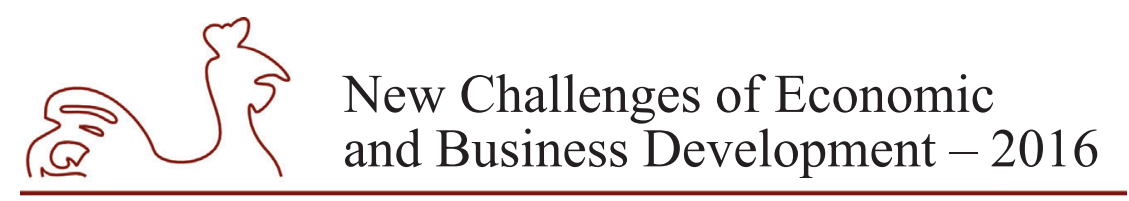

May 12-14, 2016, Riga, University of Latvia

a notion of positive outcomes that are derivatives of the interrelations among all components of a system (Chadwick, 2010). The expected synergistic effect arises from tight cooperation between basic functional domains, the project being aligned with the appropriate management functions performed in the agenda of functional area-specific strategies implementation.

Each function relies on specific techniques to be employed for achieving the project's strategic goals. The university facilities management function can support sustainable project performance through implementing cost-effective university infrastructure based on ICT, including an efficient communication system for the shared knowledge transfer. The staff management function can contribute to sustainable project performance by attracting skilled academicians, researchers, technicians. Besides, the staff management also involves the people engaged in managing projects, for which project management is an essential job requirement: accountants, administrators, scientists, contractors, etc. (Larson \& Grey, 2011). The research management function can donate to sustainable project performance by increasing research opportunities through strengthening support from the university administration, using advanced ICT-based equipment and developing new knowledge and technologies. In turn, the educational activities management function can contribute to sustainable project performance by using advanced educational strategies based on the constructivist approach to learning for targeted student groups (project participants), tailoring the instructional tools to the project requirements. It is especially important in the context of supporting academic excellence of the university, since such a learner-cantered instructional approach as constructivism offers students a good opportunity to build their professional skills through practical experience and real-life activities (Tarnopolsky, 2012), which is vital for their professional development. Table 1 describes the main issues encountered by the LEARNIT project management team and the associated managerial tasks. 


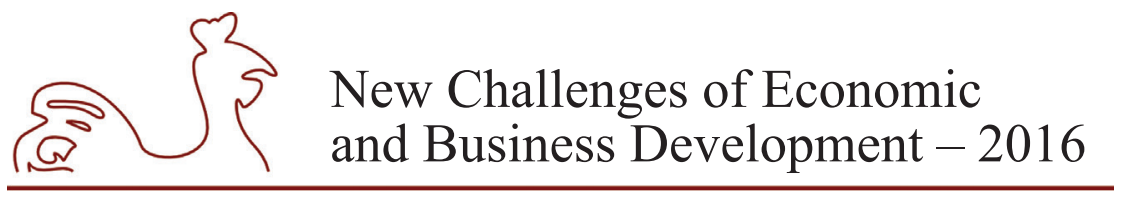

May 12-14, 2016, Riga, University of Latvia

Table 1

Main challenges faced by the LEARNIT project management and the related tasks

\begin{tabular}{|c|l|l|l|}
\hline No. & \multicolumn{1}{|c|}{ Function } & \multicolumn{1}{|c|}{$\begin{array}{c}\text { Main challenges for the } \\
\text { LEARNIT management }\end{array}$} & \multicolumn{1}{c|}{ Related tasks } \\
\hline 1. & $\begin{array}{l}\text { Management of } \\
\text { the academic and } \\
\text { attending staff }\end{array}$ & $\begin{array}{l}\text { Engagement of people of different } \\
\text { professions and positions across } \\
\text { the university environment }\end{array}$ & $\begin{array}{l}\text { - Preparing a detailed job description } \\
\text { for each project participant } \\
\text { - Generating, collecting and sharing } \\
\text { collaborative knowledge through } \\
\text { planned and unplanned knowledge } \\
\text { transfer schemes }\end{array}$ \\
\hline 2. & $\begin{array}{l}\text { Management of } \\
\text { the educational } \\
\text { activities }\end{array}$ & $\begin{array}{l}\text { Involvement of students, which } \\
\text { makes the project results to a } \\
\text { large extent dependent on their } \\
\text { contribution to the project }\end{array}$ & $\begin{array}{l}\text { Providing ICT-based learning resources } \\
\text { necessary for supporting educational } \\
\text { activities in the frame of the project and } \\
\text { tailoring the instructional tools to the } \\
\text { project requirements }\end{array}$ \\
\hline 3. & $\begin{array}{l}\text { Facilities } \\
\text { management }\end{array}$ & $\begin{array}{l}\text { Provision of strong integration } \\
\text { of the organizational resources: } \\
\text { tangible, semi-tangible, non- } \\
\text { tangible as the LEARNIT } \\
\text { management occurs at different } \\
\text { levels across the university } \\
\text { environment }\end{array}$ & $\begin{array}{l}\text { relevant cost-effective infrastructure } \\
\text { for achieving sustainable project } \\
\text { performance } \\
\text { Establishing efficient ICT-based } \\
\text { communication channels for } \\
\text { supporting the project implementation }\end{array}$ \\
\hline 4. & $\begin{array}{l}\text { Management } \\
\text { of the research } \\
\text { activities }\end{array}$ & $\begin{array}{l}\text { LEARNIT focus on ICT-based } \\
\text { research }\end{array}$ & $\begin{array}{l}\text { Increasing research opportunities by } \\
\text { applying advanced technologies created } \\
\text { in the project implementation process }\end{array}$ \\
\hline
\end{tabular}

Source: author's construction based on the author's experience as the project leader from Transport and Telecommunication Institute.

To provide sustainable project performance and ensure that the project participants perform their work in the right context, it is necessary to identify the potential critical success factors contributing to the project's success. They will be discussed in the next section.

\section{Potential critical success factors for the LEARNIT project performance}

Project managers have to be aware of the potential effects of the critical success factors (CSFs) on accomplishing the project's goals in terms of resources, time, financial plan, etc. In the process of the project management, many decisions need to be taken, the decisions at the earlier stage of the project having a bigger impact on the project management practice; the critical success factors are rather useful in decision-making support (Alias et al., 2014). Critical success factors are those inputs to the management system that result either directly or indirectly in the success of a particular project (Cooke-Davies, 2002). CSFs epitomise key performance areas, which are important for the whole organization to accomplish its mission (Parker Gates, 2010). Consequently, critical success factors that may contribute to the success of a particular research project in the university represent its main functional areas involved in the project realization. Table 2 describes basic potential critical success factors for the LEARNIT project performance with regard to the four functional areas engaged in the project implementation in Transport and Telecommunication Institute (TSI): staff, facilities, education and research. 


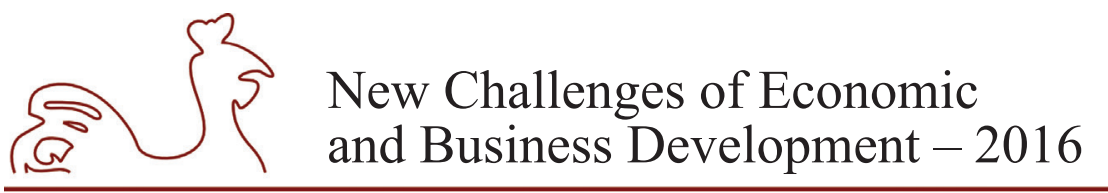

May 12-14, 2016, Riga, University of Latvia

Table 2

Critical success factors for the LEARNIT project performance

\begin{tabular}{|c|c|c|}
\hline No. & Critical success factor & TSI organizational resources and capabilities \\
\hline 1. & $\begin{array}{l}\text { Staff: attracting and keeping } \\
\text { first-class academic, research and } \\
\text { attending staff and maintaining } \\
\text { regular recognition of the staff's } \\
\text { contribution to the project }\end{array}$ & $\begin{array}{l}\text { - Teachers with relevant high-level expertise in the area } \\
\text { of higher education, including those with Doctoral } \\
\text { Degree }-60 \% \\
\text { - High level of the academic staff motivation } \\
\text { - Skilled technical staff, which is due to the strong } \\
\text { technical component of TSI }\end{array}$ \\
\hline 2. & $\begin{array}{l}\text { Education: using advanced } \\
\text { educational strategies based on the } \\
\text { constructivist approach to tailoring } \\
\text { the instructional tools to the project } \\
\text { requirements }\end{array}$ & $\begin{array}{l}\text { - Permanent accreditation in Latvia as a higher } \\
\text { education institution } \\
\text { - All educational directions received accreditation for } \\
\text { the maximum period } \\
\text { - A wide variety of study programs (transport and } \\
\text { logistics, computer sciences, electronics and } \\
\text { telecommunication, economics and management, } \\
\text { aviation transport), which allows the integration of } \\
\text { some elements of multidisciplinary education }\end{array}$ \\
\hline 3. & $\begin{array}{l}\text { Facilities: maintaining a safe and } \\
\text { constructive project environment } \\
\text { conducive to education and research }\end{array}$ & $\begin{array}{l}\text { - TSI infrastructure, being dynamic in nature due } \\
\text { to constant attempt to keep pace with the recent } \\
\text { developments, acts as a facilitator for the effective } \\
\text { delivery of the curriculum } \\
\text { - Well-equipped lecture-rooms and lecture-halls for } \\
\text { dynamic and focused discussions } \\
\text { - Well-equipped modern laboratories for supporting } \\
\text { education and research: Laboratory of Applied } \\
\text { Software, Telecommunications, Electronics and } \\
\text { Robotics centre, Multimedia Laboratory, Cisco } \\
\text { Networking Academy, TSI IT Academy } \\
\text { - Efficient ICT-based communication scheme }\end{array}$ \\
\hline 4. & $\begin{array}{l}\text { Research: maximizing the use } \\
\text { of all research opportunities and } \\
\text { supporting students entry into } \\
\text { research career paths the project }\end{array}$ & $\begin{array}{l}\text { - TSI is a national leader in research and education in } \\
\text { - the fields of transportation modelling, intelligent } \\
\text { transportation systems, systems analysis of complex } \\
\text { transportation systems and transportation analytics } \\
\text { (Latvia: Research Assessment Exercise, 2013) } \\
\text { - Big experience in conducting different types } \\
\text { of research, including those under the Seventh } \\
\text { Framework Programme for Research and } \\
\text { Technological Development (2007-2013) } \\
\text { - EU funding and co-funding of TSI research projects }\end{array}$ \\
\hline
\end{tabular}

Source: author's construction based on the author's experience as the project leader from Transport and Telecommunication Institute.

Thus, sustainable project performance is predominantly determined by the contribution of the integrated resources embedded in its functional areas. In this context, project managers may employ a five-step, resource-based approach to their strategy analysis proposed by 


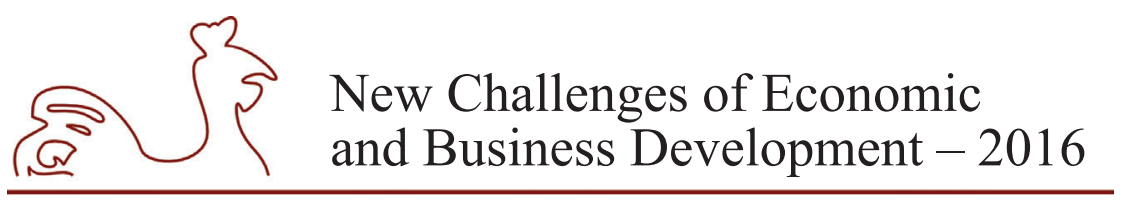

May 12-14, 2016, Riga, University of Latvia

Grant (1991): 1) identifying and categorizing the project's resources with due account for strengths and weaknesses; 2) merging the organization's strengths into specific capabilities and competencies (know-how) for supporting the project's implementation; 3) assessing the potential of these capabilities and competencies in view of their potential for providing sustainable project performance; 4) choosing the strategy that best uses the organization's capabilities and competencies with due regard for external opportunities; 5) recognizing and eliminating resources gaps. The resource-based approach can supply managers with clear rules to create and leverage a variety of resources, ensuring that organizational resources, capabilities and competencies are properly used as competitive tools (Gagnon, 1999).

Thus, the project resources being heterogeneous in nature, the resource-based approach to developing the project's strategy is supposed to be best capable of meeting the challenges of a cross-disciplinary research project implemented in a contemporary university.

\section{Conclusions, proposals, recommendations}

The analysis performed in this paper allows the author to draw a few conclusions. The following points detail some recommendations for project managers responsible for the implementation of multidimensional research projects in a university.

1. Project management involves many issues associated with both the complex internal environment of a modern academia and the highly competitive global environment.

2. From a holistic point of view, management of a multidimensional research project in a higher education institution comprises various perspectives. Contemporary universities are complicated multi-level structures: the resources necessary for supporting a crossdisciplinary research project are embedded in different functional areas of the higher education institution, where functional area-specific strategies are realized.

3. The success of a complex research project is directly related to the accomplishment of a synergistic effect; the expected synergistic effect arises from strong cooperation between main functional domains of a university - staff, facilities, education and research, so the project should be aligned with the appropriate management functions carried out in the agenda of functional area-specific strategies implementation.

4. Each function relies on specific managerial and educational techniques to be used for accomplishing the project's strategic goals.

5. For ensuring sustainable project performance, it is essential to identify the main potential critical success factors that may contribute to the research project's success; potential critical success factors represent key functional areas of the university engaged in the project implementation.

6. In this context of providing sustainable project performance, project managers utilize the resource-based approach to their strategy analysis; the integrated tangible, semi-tangible and no-tangible resources externalized in different functional areas are given the major role in assisting project managers to deal with various challenges, and to achieve higher project performance. 


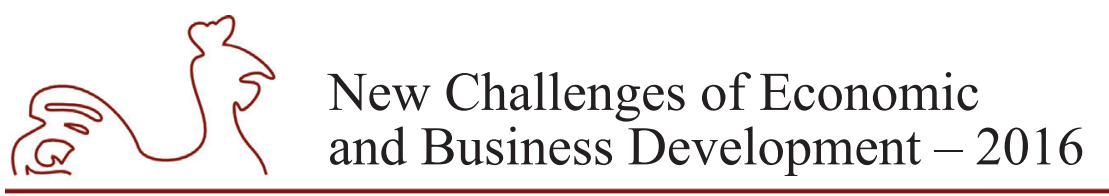

May 12-14, 2016, Riga, University of Latvia

\section{Bibliography}

Artto K., Kujala, J., Dietrich, P. \& Martinsuo, M., 2008. What is Project Strategy?, International Journal of Project Management, Vol. 26, pp. 4-12.

Altuntaş, G., Semerciöz, F., Mert, A. \& Pehlivan, Ç., 2014. Industry Forces, Competitive and Functional Strategies and Organizational Performance: Evidence from Restaurants in Istanbul,Turkey, Procedia - Social and Behavioral Sciences, Vol.150, pp. 300-309.

Alias, Z., Zawawi, E. M. A., Yusof, K. \& Aris, N. M., 2014. Determining Critical Success Factors of Project Management Practice: A Conceptual Framework, Procedia - Social and Behavioral Sciences, Vol. 153, pp. 61-69.

Bush, T., 2011. Theories of Educational Leadership and Management ( $4^{\text {th }}$ ed.). London: SAGE.

Chadwick, C., 2010. Theoretic Insights on the Nature of Performance Synergies in Human Resource Systems: Toward Greater Precision, Human Resource Management Review, Vol. 20, pp. 85-101.

COM (2000) 6 final, 2000. Towards a European research area Brussels, Communication from the Commission to the Council, the European Parliament, the Economic and Social Committee and the Committee of the Regions Brussels, 18.1.2000. [Online] Available at: http://eur-lex.europa.eu/ LexUriServ/LexUriServ.do?uri=COM:2000:0006:FIN:EN:PDF [Accessed 10 November 2015].

COM (2003) 58 final, 2003. The Role of the Universities in the Europe of Knowledge. [Online] Available at: http://europa.eu/legislation_summaries/education_training_youth/lifelong_learning/c11067_ en.htm [Accessed 27 September 2015].

COM(2007) 61 final, 2007. A Coherent Framework of Indicators and Benchmarks for Monitoring Progress towards the Lisbon Objectives in Education and Training", Communication from the Commission of 21 February 2007. [Online] Available at: http://europa.eu/scadplus/leg/en/cha/ c11099.htm [Accessed 11 October 2015].

Cooke-Davies, T., 2002. The "Real" Success Factors on Projects, International Journal of Project Management, Vol. 20, pp. 185-190.

Davies, A., Brady, T., Prencipe, A. \& Hobday, M., 2011. Innovation in Complex Products and Systems: Implications for Project-Based Organizing, Advances in Strategic Management, Vol. 28, Cattani et al. (Eds.), pp. 3-26.

Fiddler, B., 2002. Strategic Management for School Development: Leading Your School's Improvement Strategy. London: SAGE Publications.

Grant, R. M., 1991. Contemporary Strategy Analysis: Concepts, Techniquesand Applications. Cambridge: Black-well Publishers.

Gagnon, S., 1999. Resource-Based Competition and the New Operations Strategy, International Journal of Operations and Producation Management, 19(2), pp. 125-138.

Jenkins, A. \& Healy, M., 2005. Institutional Strategies to Link Teaching and Research, The Higher Education Academy - October 2005. [Online] Available at: https:/www.heacademy.ac.uk/sites/ default/files/resources/id585_institutional_strategies_to_link_teaching_and_research_2.pdf [Accessed 30 January 2016].

Harrison, F. \& Lock, D., 2004. Advanced Project Management: A Structured Approach, (4 ${ }^{\text {th }}$ edition). UK: Gower.

Heaslip, R. J., 2015. Managing Organizational Complexity: How to Optimize the Governance of Programs and Projects to Improve Decision Making, White Paper. Project Management Institute, Inc. [Online] Available at: https://www.pmi.org/ /media/PDF/learning/project-complexity/Managing-orgcomplexity.ashx [Accessed 30 January 2016].

Hill, Ch.W. \& Jones, G. R., 2013. Strategic Management Theory (10th ed.). USA: South-Western, Cengage Learning. 


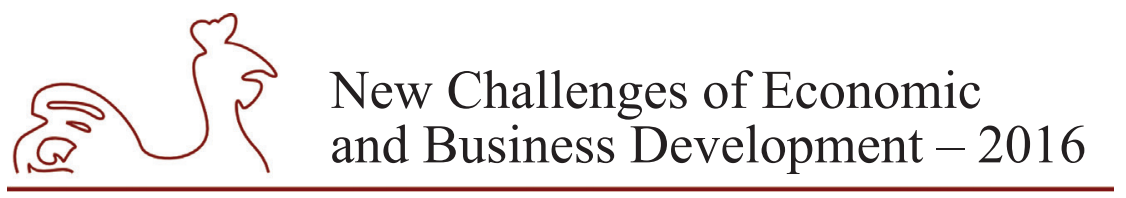

May 12-14, 2016, Riga, University of Latvia

Implementing Organizational Project Management: A Practice Guide, 2014. USA: Project Management Institute, Inc. [Online] Available at: http://www.pmi.org/ /media/PDF/Knowledge\%20Center/ ImplementingOrgPM.ashx [Accessed 10 February 2016].

Kerzner, H., 2003. Project Management: A Systems Approach to Planning, Scheduling and Controlling. New York: John Wiley and Sons.

Larson, E. W. \& Grey, C. F., 2011. Project Management: The Managerial Process (5th edition). NY: MgGraw-Hill/Irwin.

Latvia: Research Assessment Exercise, 2013. Panel Report: Engineering and Computer Science. Technopolis group, November 2013. [Online] Available at: http://www.izm.gov.lv/images/zinatne/ ZISI/zisi_05.pdf [Accessed 17 February 2016].

Longman, A. \& Mullins, J., 2004. Project Management: Key Tool for Implementing Strategy, Journal of Business Strategy, 25(5), pp. 54-60.

McBurnie, G. \& Ziguras, Ch., 2009. Trends and Future Scenarios in Programme and Institution Mobility across Borders, Higher Education to 2030, Vol. 2: Globalisation, pp. 89-108. [Online] Available at: http://www.mfdps.si/Files/Knjiznica/higher\%20educational\%202030\%20OECD.pdf [Accessed 14 October 2015].

Minavand, H., Farahmandian, S. \& Minaei, V., 2013. HR Challenges of Project Managers, IOSR Journal of Business and Management, 11(5), pp. 40-45.

Mohrman, K. Ma, W. \& Baker, D., 2008. The Research University in Transition: The Emerging Global Model, Higher Education Policy, Vol. 21, pp. 5-27.

Othman, M., Zain, A. M. \& Hamdan, A. R., 2010. A Review on Project Management and Issues Surrounding Dynamic Development Environment of ICT project: Formation of Research Area, International Journal of Digital Content Technology and its Applications, 4(1), pp. 96-105.

Parker Gates, L., 2010. Strategic Planning with Critical Success Factors and Future Scenarios: An Integrated Strategic Planning Framework, Technical Report. Carnegie Mellon University. [Online] Available at: http://www.sei.cmu.edu/reports/10tr037.pdf [Accessed 30 January 2016].

Potočnik, J., 2009. Foreword to Diversified Funding Streams for University-Based Research: Impact of external project- based research funding on financial management in Universities, Expert Group Report chaired by S. Herlitschka. Luxembourg: office for official Publications of the European Communities. [Online] Available at: http://ec.europa.eu/invest-in-research/pdf/download_en/ external_funding_final_report.pdf [Accessed 23 January 2016].

Prabhakar, G. P., 2008. Projects and Their Management: A Literature Review, International Journal of Business and Management, 3(8), pp. 3-9.

Report to the European Commission on Improving the Quality of Teaching and Learning in Europe's Higher Education Institutions, 2013. [Online] Available at: http://ec.europa.eu/education/library/ reports/modernisation_en.pdf [Accessed 11 January 2016].

Stukalina, Y., 2008. How to Prepare Students for Productive and Satisfying Careers in the KnowledgeBased Economy: Creating More Efficient Educational Environment, Technological and Economic Development of Economy: Baltic Journal on Sustainability, 14(2), pp. 197-207.

Stukalina, Y., 2010. Using Quality Management Procedures in Education: Managing the Learner-Centered Educational Environment, Technological and Economic Development of Economy: Baltic Journal on Sustainability, 16(1), pp. 75.-93.

Stukalina, Y., 2014. Strategic Management of Higher Education Institutions, Management of Organizations: Systematic Research, No. 70, pp. 80-90.

Stukalina, Y., 2015. Management in Higher Education: Thinking and Planning More Strategically, Journal of Business Management, Issue 10, pp. 70-79. 


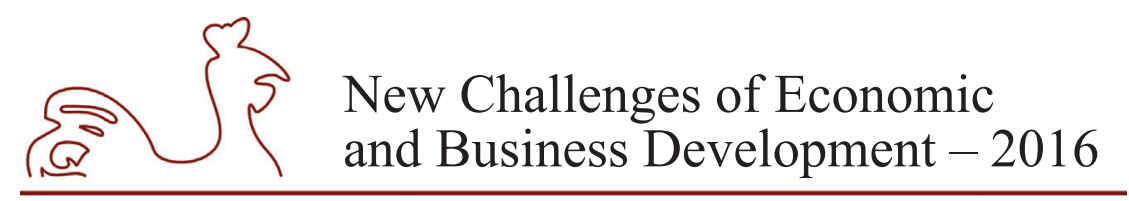

May 12-14, 2016, Riga, University of Latvia

Sullivan, D., 2012. Collaborative and Agile Project Management. The Essential Series. Realtime Publishers. [Online] Available at: https://www.clarizen.com/documents/datasheets/clarizen-theessential-series-top-5-it-project-management-challenges-and-how-to-face-them-datasheet.pdf [Accessed 22 December 2015].

Tabatoni, P., 2002. An Explanatory Glossary, Thema 2, European University Association, pp. 23-28. [Online] Available at: http://www.eua.be/eua/jsp/en/upload/strategic_manag_uni_institutional_ devlpt.1069322397877.pdf [Accessed 12 September 2015].

Tarnopolsky, O., 2012. Constructivist Blended Learning Approach to Teaching English for Specific Purposes. DE GRUYTER OPEN. [Online] Available at: http://www.degruyter.com/view/ product/205438 [Accessed 20 December 2015].

The European Higher Education Area in 2012: Bologna Process Implementation Report, 2012. [Online] Available at: http://www.ehea.info/Uploads/(1)/Bologna\%20Process\%20Implementation\%20 Report.pdf [Accessed 12 December 2015].

The State of Higher Education 2013: Executive Summary. Introduction, 2013. OECD. [Online] Available at: http://www.oecd.org/edu/imhe/StateofHigherEducation2013-ExecutiveSummary.pdf [Accessed 25 September 2015].

The State of Higher Education 2014: Executive Summary. Introduction, 2014. OECD. [Online] Available at: http://www.oecd.org/edu/imhe/SOHE2014-Executive\%20Summary.pdf[Accessed 20 November 2015].

Thompson, A. A. \& Strickland, A. J., 2003. Strategic Management: Concepts and Cases. USA: McGrawHill/Irwin.

Vincent-Lancrin, S., 2009. Cross-border Higher Education: Trends and Perspectives, Higher Education to 2030, Vol. 2: Globalisation, pp. 63-88, [Online] Available at: http://www.mfdps.si/Files/Knjiznica/ higher\%20educational\%202030\%20OECD.pdf [Accessed 14 November 2015]. 


\title{
THE INDICATOR SYSTEMS AND THE SUITABILITY OF THEIR APPLICATION IN CONTROLLING DEPARTMENT ACTIVITY
}

\author{
Daiva Tamuleviciene, Vilnius University, Lithuania ${ }^{1}$
}

\begin{abstract}
Various financial and non-financial indicators are of considerable significance in controlling system because they help to provide objective information on economical and financial situation of the company. However, because of the lack of information, the usage of single indicators is not always efficient. In order to avoid misinterpretation of the indicators and by taking into account the principle of controlling complexity, various indicator systems are formed. They allow not only to quantify the current situation and perform retrospective, operational and perspective diagnostics of financial position, but also to reveal the causes of the origin of the problems.

However, not every indicator system is equally able to highlight the weak points and identify the problems. It is also noteworthy that not every indicator system is characterized by the same level of compatibility of indicators, interconnections and strategic orientation. By considering this, it is possible to identify a problematical field of controlling system, which is the choice of appropriate indicators and their systems in order to provide relevant and structured information that is suitable to make management decisions. The aim of the research is to examine and classify the main financial and non-financial indicator systems and to evaluate the suitability of their application in the controlling department activity A review of the main indicator systems, such as DuPont, EVA, BSC, ZVEI, RL, EFQM and others and the peculiarities of these indicator systems are revealed in the article. The result of the study is a dissection of the indicator systems to eight separate fields according to three dimensions: indicators compatibility level, indicators interconnection level and strategic orientation level. Considering the fact that controlling as an instrument of company management - is oriented towards achieving operational and strategic objectives, strategic orientation level is considered the most important when choosing an indicators system. After performing the main indicator systems analysis, it was determined that the most significant, providing the most relevant amount of information in the controlling system is the BSC system assigned to the eighth field. Its features are: extensive orientation towards strategy, high indicators compatibility and strong relation among indicators. The research methods: comparative and systematic analysis of scientific literature, synthesis, induction, deduction. Generalized information provided applying graphical method.
\end{abstract}

Key words: controlling, the indicator systems, classification of indicator systems

JEL code: M49

\section{Introduction}

Instability of financial-economic environment, high level of competition, complicated technological processes, necessity to solve problems in short time, and other factors influence the decisions of companies' managers when considering the opportunity of introduction innovative management control systems. One of such systems - widely applied in foreign

Corresponding author - e-mail address: daiva.tamuleviciene@ef.vu.lt 


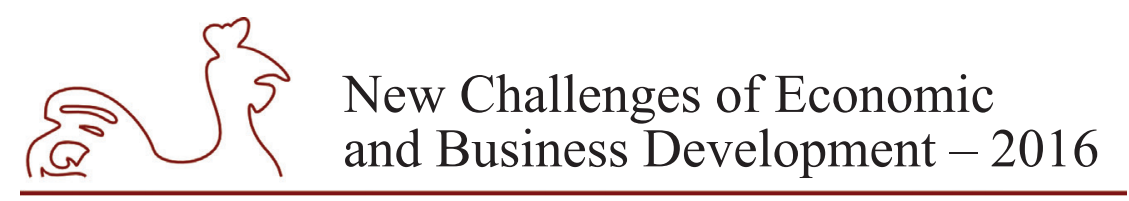

May 12-14, 2016, Riga, University of Latvia

practice, however less familiar in Lithuania - is controlling. Controlling is the management control process of defining, planning and then pursuing goals. It is a process whose full potential can only be realized if controllers and managers are collaborating closely (Internationaler Controller Verein, n.d.). Controlling can also be described as a system of company's goals achievement management (Ананькина, et al., 2002). Since every company distinguishes management goals into strategic (long-term) and operational (short-term), thus controlling has to be examined as a system comprised of two main indistinguishable parts: strategic and operational controlling. The controlling system combines various different subsystems and their elements which allows to provide structured and detailed information about company's past, present and future activity and to offer a complex way of solving company's problems, the final result of which is the increase of organisation's value.

By taking into account the fact that efficient company's management - after implementing the controlling system - mostly depends on the information database quality and thorough data processing, a majority of authors examining controlling issues such as Deyhle (2001); Hahn \& Hungenberg (2005); Horváth (2006); Mann \& Mayer (2000); Reichmann (2011); RoehlAnderson \& Bragg (2004); Weber \& Schäffer (2014); Ананькина, et al. (2002); Карминский, et al. (2006) and many others admit that one of the key elements providing company's management specialists with analytical information is the financial and non-financial data analysis which plays an important role in the system of controlling while the information it provides is of considerable significance when making strategic and operational decisions.

Appliance of economic and financial analysis, as one of the most objective methods of proper evaluation of financial condition and the results of its activity, is primarily connected to computation, analysis and evaluation of various indicators, formation of their sets, as well as the usage of the indicator systems allowing not qualitative evaluation of the situation but also revelation of the origin of problems. However, the choice of appropriate indicators and their systems to provide relevant and structured information for making management decisions and execute other functions of controlling is a problematic field for a controlling department. Furthermore, not every indicator system is equally able to highlight the weak points and identify the problems. It is also noteworthy that not every indicator system is characterized by the same level of compatibility of indicators, interconnections and strategic orientation.

The aim of the research is to examine and classify the main financial and non-financial indicator systems and to evaluate the suitability of their application in the controlling department activity. To this end, the place of indicators and indicator systems in the controlling was analysed, the main criteria of selecting indicator systems were established, classification of the indicator systems applied in a controlling department activity was analysed and the "cube" of indicator systems classification was formed. On its basis the most appropriate indicator systems can be evaluated taking into account three important qualitative characteristics which are indicators compatibility, interconnections and the level of orientation towards strategy. 


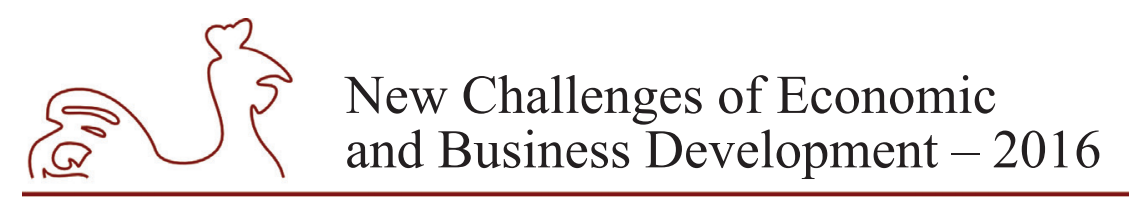

May 12-14, 2016, Riga, University of Latvia

\section{Financial and non-financial indicators and their systems as an important element of strategic and operational controlling system}

Controlling is a management concept widespread among European enterprises and is oriented towards increasing the level of business goals achievement. Controlling could be described as the synthesis of management accounting, planning, control, analysis and other functions necessary to make management decisions and efficiently manage an enterprise in order to achieve projected objectives. This is a system oriented towards long-term effective functioning of enterprise. According to Ананькина, et al. (2002), Карминский, et al. (2006) understanding controlling as a concept of modern management, which emerged at the intersection of economic analysis, planning, administrative accounting and management, transfers the organization management to a new level.

The controlling system comprises different, however interconnected, subsystems and their elements whose interaction helps to make optimal decisions. And even though because of existing various controlling trends and different attitudes there is no strict established provision of what ought to set up a controlling system; however, it must be noted that this system is usually implemented in an organization in two aspects: through strategic controlling and through operational controlling (Horváth, 2006; Mann \& Mayer, 2000; Карминский, et al., 2006). The reason for this is the fact that every company distinguishes its management goals into strategic (long-term) and operational (short-term). Companies apply different instruments, means, and methods to achieve these goals and select different financial and non-financial indicators and criteria to evaluate the results. Thus, the controlling system is primarily distinguished into two subsystems: strategic controlling and operational controlling. Operational controlling is a management activity that comprises the fixing of objectives, budgeting and controlling in the middle-term and single year time span. Typical objectives would be liquidity, profits and business strength. Strategic controlling is a management activity that comprises the planning, testing, implementation and monitoring of strategies. The time span is unlimited and is just as long as the period covered by the strategy. Typical objectives here would be existing and future potentials for success, market shares as well as (free) cash flow (International Group of Controlling, 2010). The subsystems of strategic and operational controlling function proceed in coherence with the object, process, toolbox and the implementation of functions of controlling subsystems (see Fig. 1). 


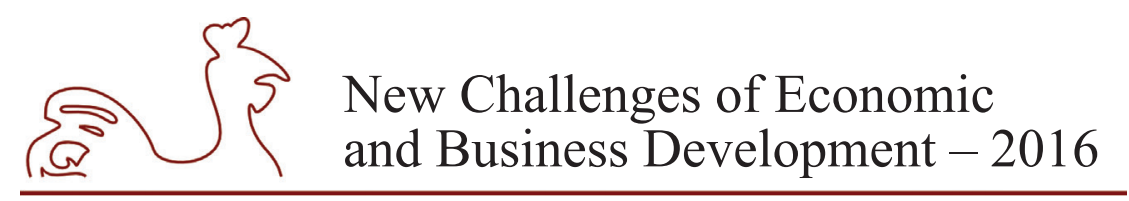

May 12-14, 2016, Riga, University of Latvia

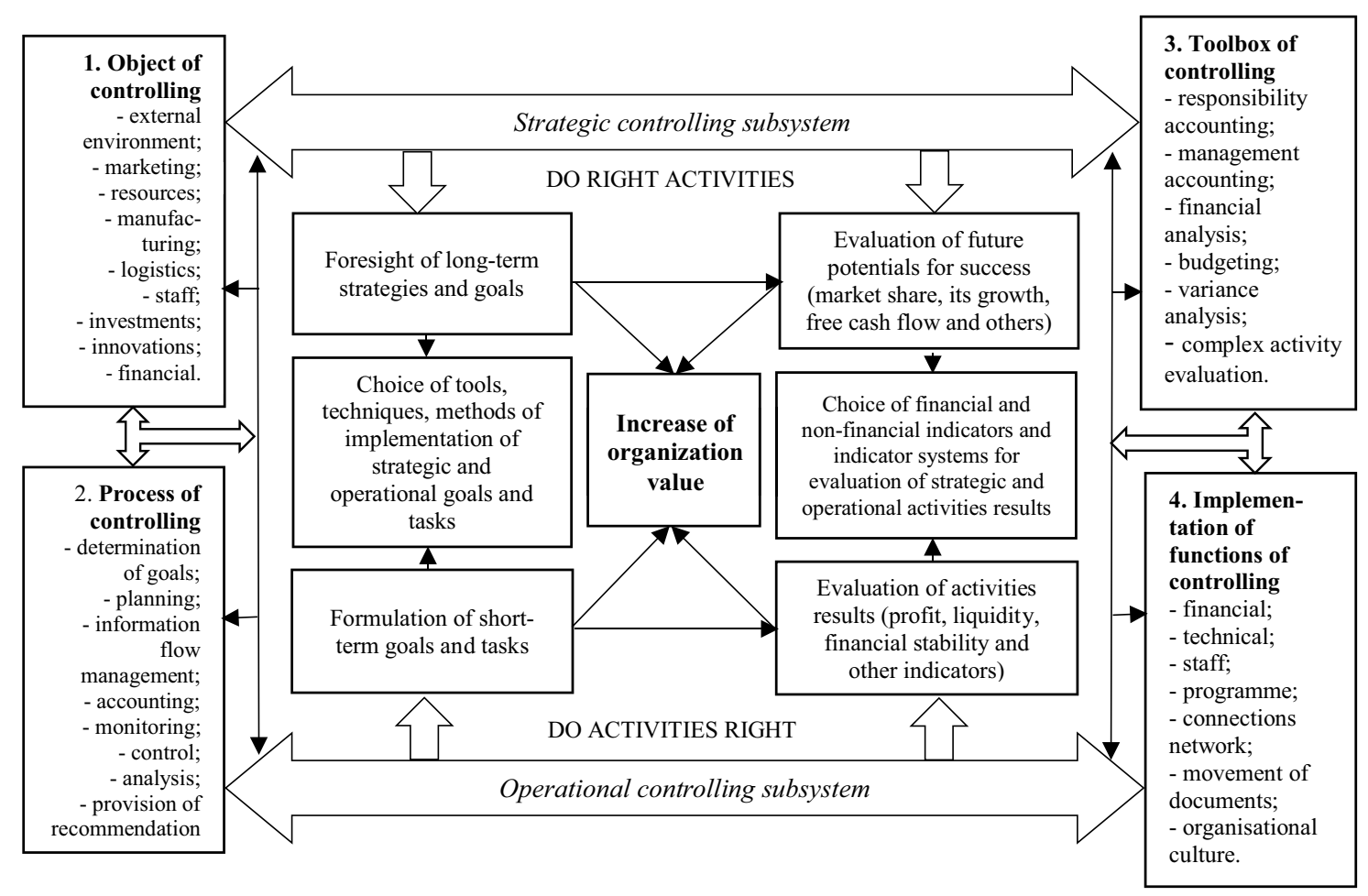

Source: author's construction.

Fig. 1. System of controlling

As we can see in the Figure 1, the controlling system combines various different subsystems and their elements which allows to provide structured and detailed information about company's past, present and future activity and to offer a complex way of solving company's problems, the final result of which is the increase of organization value. Definite functioning of each element of the system contributes to the growth of this result. Selection of financial and non-financial indicators and indicator systems to evaluate strategic and operational activity results plays an important role in the controlling system. Properly selected indicators and their systems help to evaluate both operational and strategic achievement of results in an organization, the attainment of goals and - at the same time - to contribute to the increase of company's value. That is why it is important to analyse and identify those indicators and indicators systems that would evaluate company's activity most clearly both in operational and in strategic aspects.

\section{The criteria of choosing and forming indicator systems}

Controlling system is really efficient and effective when the system spans all parts of the value chain and information is suitable for decision making (Gimžauskienè, 2008). Controlling system should be based on various measures and their interpretation. Controlling measures the deviation of actual performance from the standard performance, discovers the causes of such deviations and helps in taking corrective actions. Dobroszek \& Szychta (2015) notes that there are many different tools and methods used in controlling to measure performance. They 


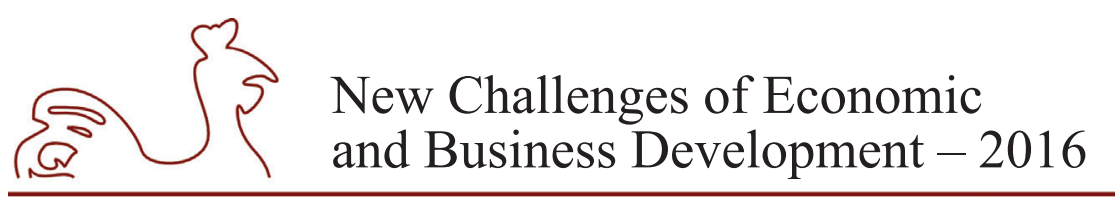

May 12-14, 2016, Riga, University of Latvia

include cost accounting systems, single indicators, indicator systems, variance analysis and others. However, the usage of various financial and non-financial indicators and their systems is the main instrument of a controller when measuring and evaluating company's activity. That some authors suggest a controlling concept oriented towards indicators also proves the fact that indicators play an important role in the controlling system. Among them Reichmann (2011) is noteworthy. Although business indicators have been used for a very long time, a generally accepted definition does not exist. There are several opinions as to what a business indicator is exactly. Staehle (1969) defines business indicators as ratios and absolute indicators that refer to numerical ascertainable business facts in a concentrated mode. According to Lachnit (1979), the indicators are quantitative data used to provide simplified view of complex reality. Köppen (2008) maintains that business indicator is a statistic on business that allows analysis of business performance and predictions of future performance. According to Gladen (2003), business indicators are quantitative information that are pre-processed for specific requirements of the analysis and controlling of the company.

Historically, companies concentrated on financial indicators. Financial indicators are particularly important when seeking to provide general information on company's financial status. This information - not taking into account its high level of aggregation - can provide initial outlook of the company as a whole or as separate segments. According to Brewer \& Speh (2000), Ittner \& Larcker (2003), nowadays it is widely recognized that non-financial and even non-numerical indicators can give valuable information as well. Though, such indicators are more difficult to measure and compare. Krauth, et al. (2005) emphasize, that selecting the right indicators for measuring is rather complicated. A full set of indicators could result in a huge amount of data, which would require a lot of efforts and high costs both in acquiring and in analysing. Another difficulty is that it is not uncommon that the selected indicators turn out to be conflicting, improving one may worsen another. Thus the usage of single indicators not connected by any relations is often inefficient. Other authors also emphasize this. According to Muller (1990, cited in Köppen, 2008, p. 10) single business indicators might be of relevance for executing a planning or controlling function. However, most business cases can be adequately managed if several indicators are employed. Keiner (2003) agrees with this provision. He states that single indicators cannot measure all of the guiding planning objectives. They can only cover a part of the actual spatial development. Many other authors, among which are Deyhle (2001), Hauser (2007), Weber \& Schäffer (2014), Карминский, et al. (2006), and others also note that single indicators are seldom applied in a controlling system due to their limited informative capability; therefore, indicator systems allowing not qualitative evaluation of the situation but also revelation of the origin of issues as well as execution of structural-logical analysis of factors with a significant influence are usually analysed. Köppen (2008) emphasizes that indicator systems have been traditionally used in order to understand, evaluate and rate the current or future state of a business.

However, not every group of indicators can be called an indicator system. Dictionary for controllers (International Group of Controlling, 2010) defines an indicator system as mathematically or logically connected combinations of ratios (absolute or relative figures with special significance). Ratios are derived from planned values or actual data and serve as a standard by which to present cause and effect of operations in a causal. According to Sandt (2004), indicator system can be defined when two or more indicators are related to each other 


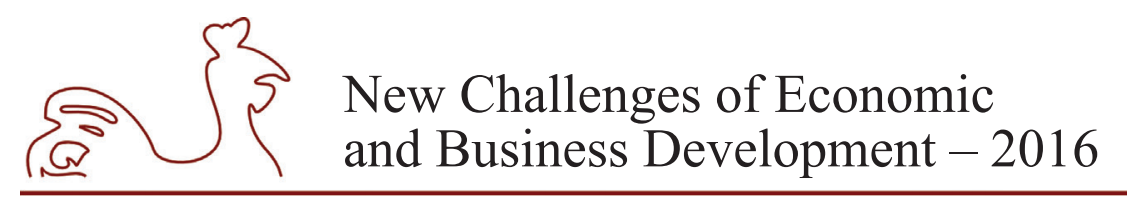

May 12-14, 2016, Riga, University of Latvia

and supplementing or explaining one another. Considering the given definitions, one can state that the most important aspect allowing to identify a set of indicators as an indicator system is the existence of interdependence and interconnections relations among the indicators.

When choosing already existing indicator systems for a particular company in order to analyse and evaluate its business and financial activity, the employees of a controlling department must firstly make sure whether the system is able to identify weak points and reveal their formation causes. If the system cannot guarantee that, it might be modified taking into account the needs of a particular company. As Frank, et al. (2008) note, the design of effective indicator systems is not trivial task. It requires a profound understanding of the relevant business context. Numerous relations and dependencies within an indicator system exist, which need to be analysed thoroughly. Furthermore, it is recommended to take into account how an indicator affects managerial decision making. When forming a modified system and selecting its indicators, it is important to choose those which would be appropriate to evaluate not only the company's activity of previous periods but also to perform operational (current) analysis. It also important that based on prepared financial plans it would be possible to analyse the company's financial status in future, i. e. to perform forward-looking diagnostics of weak points in order to avoid solvency, liquidity and other issues. The system itself should form a hierarchical structure in which relations among different indicators could be seen. The set of financial and non-financial indicators formed this way would be adapted to measure and evaluate activity of a particular company. This is even more important since the indicator systems often have a strong influence on the enterprise.

\section{Classification of indicator systems}

When forming the set of indicators to perform retrospective, operational and perspective diagnostics of organization's financial status, it is suggested to choose among already established and examined in practice indicator systems which usually are classified into two groups: logicaldeductive and empirical-inductive indicator systems (see Fig. 2). The basis of all these systems is computation, analysis and evaluation of absolute financial indicators and financial ratios. This classification is most widely spread in the controlling system.

However, this type of classification has a drawback because it comprises only those indicator systems which combine only financial indicators. However, bearing in mind that non-financial indicators are nowadays as important as financial ones, it is essential to include the indicator systems formed both of financial and non-financial indicators to the classification. 


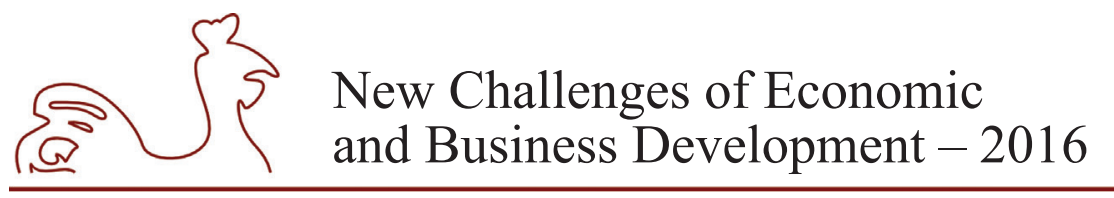

May 12-14, 2016, Riga, University of Latvia

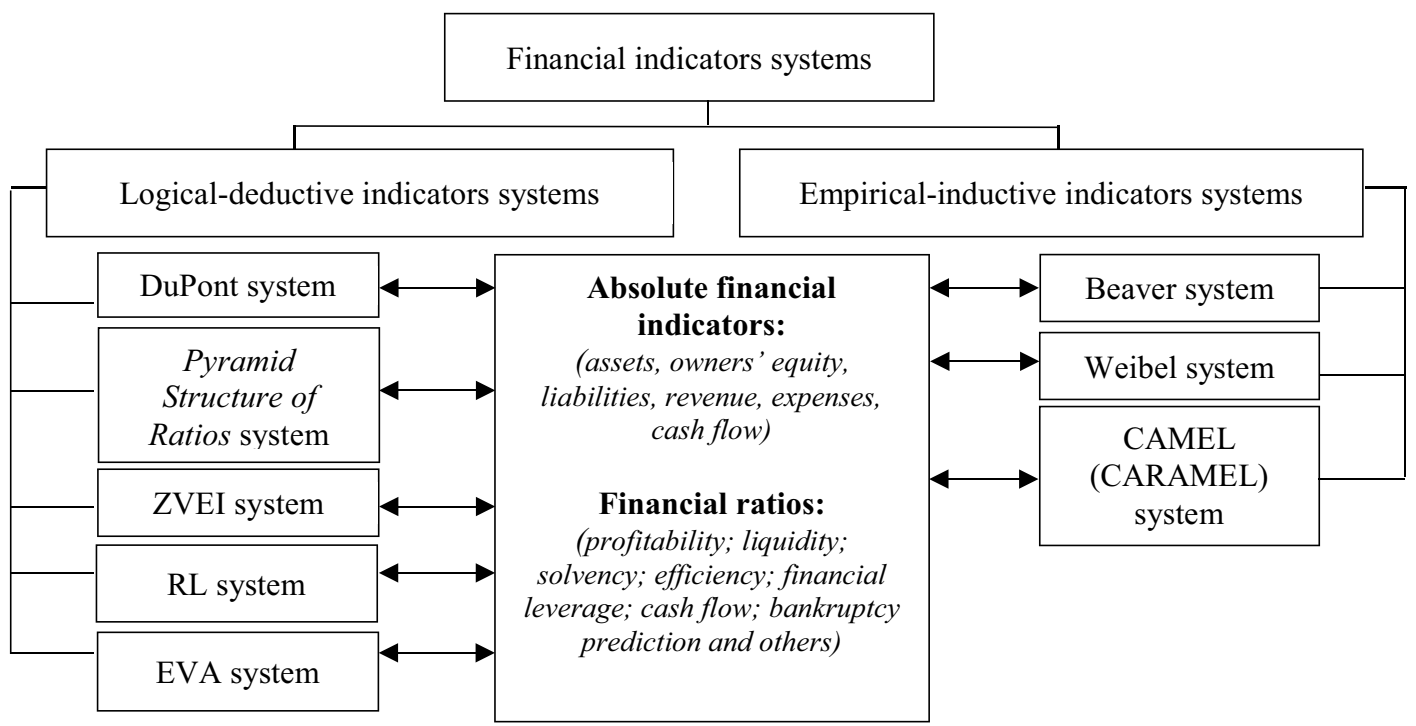

Source: author's construction based on Ingham \& Harrington (1980); Reichmann (2011); Timmerbeil (1999); Карминский, et al. (2002).

Fig. 2. Classification of financial indicator systems

Weber \& Sandt (2001, cited in Weber \& Schäffer, 2014, p. 158) provide a different model of indicator system classification in which the previously mentioned drawback is eliminated. The authors classify indicator systems taking into account two dimensions: the level of indicators interconnections and the level of indicators compatibility. According to the authors, indicator systems may differ depending on the indicators interconnection. It might be mathematical dependence when analysis is begun from the highest level indicator by dividing it into lower level indicators which is seen in DuPont pyramid example. Or the system may be based on cause-and-effect links like in the Balanced Scorecard system. As far as indicators compatibility is concerned, Weber \& Sandt (2001, cited in Weber \& Schäffer, 2014, p. 159) stress that systems differ according to the number of financial and non-financial indicators, the depth and span of the indicators choice when forming a system. Considering these factors, the authors provide 4 fields matrix in which indicator systems are classified into 4 groups taking into account indicators compatibility and interconnections strength. (see Fig. 3). 


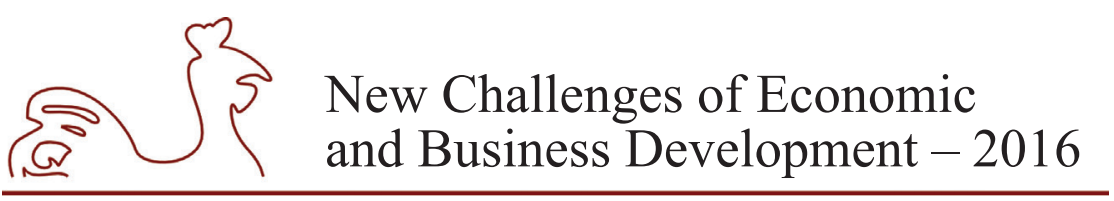

May 12-14, 2016, Riga, University of Latvia

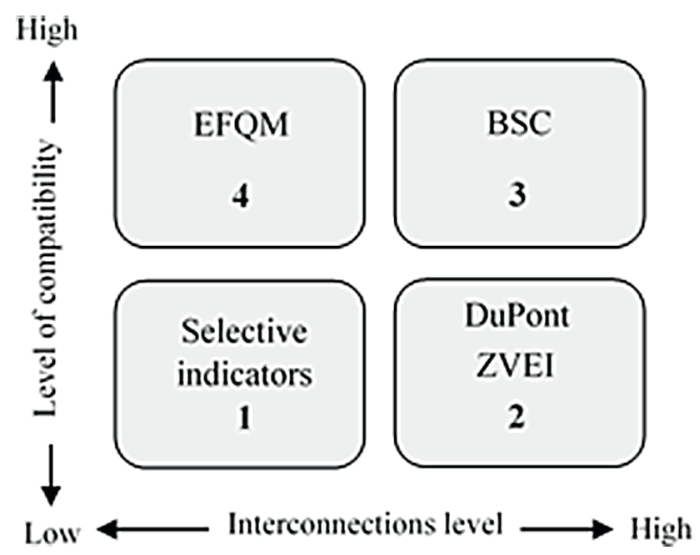

Source: Weber \& Sandt (2001, cited in Weber \& Schäffer, 2014, p. 158).

Fig. 3. Classification of indicator systems

The first matrix field defines indicator system which is strictly oriented towards the weak points of company's business processes. It is expressed by connections among selected indicators. However, according to Weber \& Schäffer (2014) it often becomes "the graveyard of indicators" because, as the time flies, a company uses more and more various indicators. New trends or new concepts allow to apply newer and newer indicators whereas the old ones are also kept. It results in a high number of unused, uncoordinated and hardly internally connected indicators.

The authors (Weber \& Sandt, 2001, cited in Weber \& Schäffer, 2014, p. 159) appoint financial-economic indicator systems, such as DuPont or ZVEI, to the second field. They are based on strict mathematical dependence which means that indicators interconnections are very strong. However, these systems do not show a high level of indicator compatibility because only financial indicators are used to evaluate a company's activity. The Balanced Scorecard system prevents these drawbacks because it comprises both financial and non-financial indicators. Furthermore, the indicators are closely connected among each other by cause-and-effect links. These qualities allowed the authors to assign the BSC system to the extreme third matrix field. The authors assigned EFQM system (European Foundation for Quality Management) to the last - the fourth - field. Such way of assignment is reasoned because the level of indicator compatibility of this system is high. Yet, the system indicators are not characterized by a strict interconnection.

However, such classification evaluates not all characteristics of the indicator systems applied in the controlling department activity. Considering the fact that the controlling system is oriented towards tasks implementation and achievement of strategic goals, it is appropriate to distinguish a third dimension which is orientation towards strategy. More than one author (Kaplan \& Norton, 2000; Smith, 2005; Reichmann, 2011, and others) distinguishes a lack of strategic 


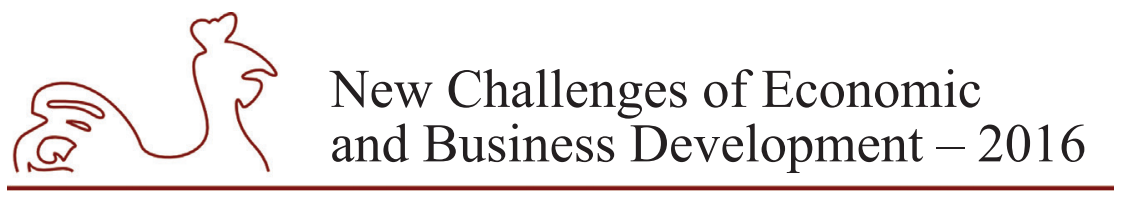

May 12-14, 2016, Riga, University of Latvia

approach in the company's management process. Schmeisser, et al. (2011) provide these exiting strategic management problems: a long-lasting planning process and slow implementation of strategies; vision and mission cannot be implemented; a lack of link between strategy and set targets; a lack of connection between strategy and resource allocation; a lack of strategic feedback; dominance of classical financial indicators and control variances; insufficient external reporting. Thus, considering the aspect that strategic goals achievement is a key management task, it is appropriate to choose those indicator systems in the controlling department activity, whose orientation towards strategy level is high.

\section{The cube of indicators systems and the characteristics of its elements}

Considering the factor that in order to measure and evaluate a company's activity it is important to apply indicator systems rather than single indicators and evaluate the requirements applicable to the indicator systems (the indicators should be balanced; the indicators should be connected by interdependence; the indicator system should be oriented not only towards evaluation of the operational activity but also the strategical one), in the Figure number 4 a cube of indicators classification according to these dimensions is given. After evaluating all characteristics of indicator systems, they will be assigned to one of eight fields of the cube.

It is appropriate to assign the first field to the selective indicator system like in the type of classification suggested by Weber \& Sandt (2001, cited in Weber \& Schäffer, 2014, p.158) (see Fig. 3). To the second field are assigned those systems whose strength of indicator interconnections is high, however, the level of orientation towards strategy and indicators compatibility is relatively low. The DuPont pyramid and Pyramid Structure of Ratios could be assigned to this group. The well known DuPont pyramid is a financial indicator system. The top indicator of this system is ROI, which can be computed as a result of capital turnover and sales profitability. The indicator capital turnover is a quotient of sales and capital, which is divided in current assets and capital assets. Similarly, the ratio sales profitability is divided to earnings and sales. These indicators are decomposed into other indicators. Thus, this system has a strict hierarchical structure.

The Pyramid Structure of Ratios was developed by Ingham \& Harrington in 1958 (Ingham \& Harrington, 1980). This system divides the indicators into primary, supporting and descriptive indicators. The system is very similar to the DuPont system but uses only relative indicators. It was developed assuming that the indicators would build the basis for permanent international comparison (Köppen, 2008). Pyramid Structure of Ratios is primarily used to evaluate company's internal activity. Even though, this system is also based on the DuPont pyramid principle and the starting indicator is profitability of owner's equity, but the lower system indicators are related to distinguishing between variable and fixed costs, manufacture, sales, calculation of administrative expenses to sales revenue ratio, stocks, accounts receivables, cash flow and reflection of other indicators as well as evaluation of their impact on higher level indicators. 


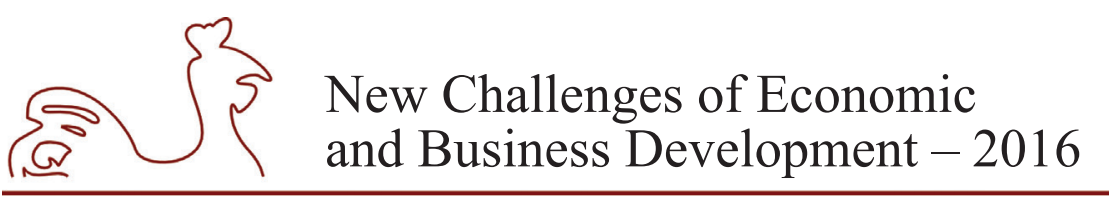

May 12-14, 2016, Riga, University of Latvia

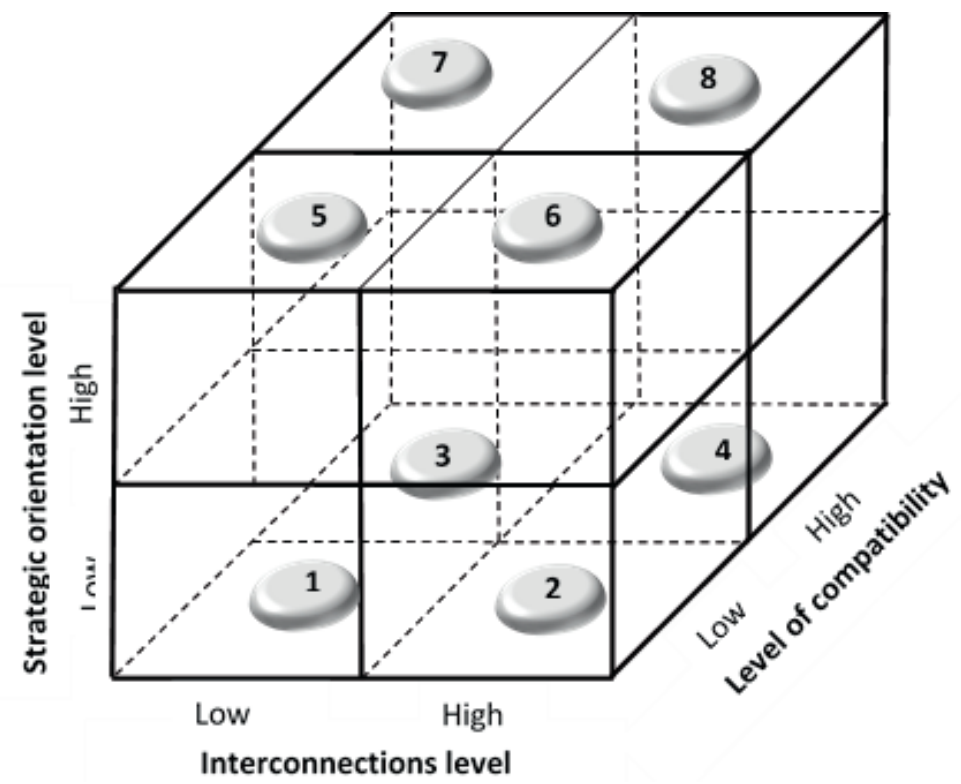

Source: author's construction.

Fig. 4. The cube of indicators systems

RL ratio system, established by Reichmann and Lachnit in 1976 is assigned to the third field. The RL system was designed for analysis purposes, and, moreover, as an aid to management, in order to provide decision-making information within the framework of the planning and control process. The most important ratios in this management system are those relating to profit or loss, and liquidity (Reichmann, 2011). The system takes profit and liquidity into consideration at the same extents: the profitability part with the ordinary result as core parameter and the liquidity part with liquid assets as core parameter. The key performance indicator are split up under logical aspects: the ordinary result is divided into Return on Equity and Return on Total Assets, Return on Investment, Capital Turnover Ratio as well as Return on Sales. The liquid assets are divided into Cash Flow and Working Capital. These indicators are then further broken down. Ratios as well as absolute numbers from external and internal accountancy are used for this purpose (Schmeisser, et al., 2011). It is also noteworthy that RL system is divided into a common and a special part. The common part refers to the whole corporation, whereas the special part is divided into a product specific and a division specific business management. In the common part, business indicators are used as management information that is independent from the type of business. The system aims to control profit and finance at the same time. The special part is used to supplement the controlling system with specific company needs and concrete implementation of the RL system (Köppen, 2008). Precisely this quality allows to characterize RL system as a system of high indicators compatibility level because it combines the indicators which are common to all companies with specific ones that are important only to analyse and evaluate a particular company's activity.

It is appropriate to assign financial indicator systems, also identified as empirical-inductive indicator systems, to the fourth field. Beaver and Weibel indicator systems as well as CAMEL financial indicator system applied in banking sector and its modification CARAMEL applied 


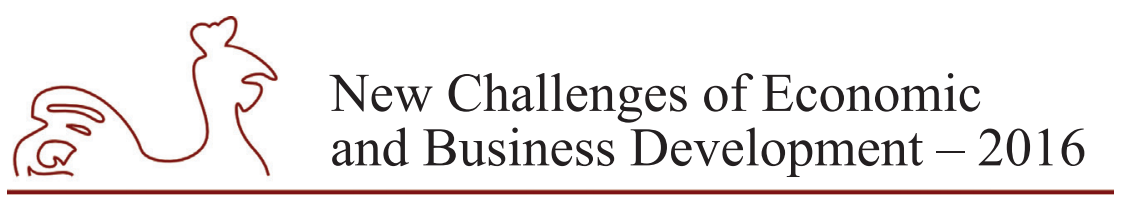

May 12-14, 2016, Riga, University of Latvia

in insurance sector are assigned to this group. All these indicator systems show high indicators compatibility level because they are comprised with the aid of mathematical-statistic methods by selecting the most appropriate key indicators for certain groups of companies. Beaver system was established after evaluating 79 successfully and 79 unsuccessfully operating companies. As a result of the research, six indicators that highlight problems most efficiently were selected. 1) cash flow/total debt; 2) net income/total assets; 3) total debt/total assets; 4) working capital/ total assets; 5) current ratio; 6) no credit interval (Beaver, 1966). Weibel system is based on the research of 72 Swiss companies' results. Also, six most informative indicators were selected, a part of them is exactly like in the Beaver system just in a different order. Cash flow/total debt is the most important and significant in both of these systems. CAMEL system is used in banks activity evaluation. Each letter of the abbreviation stands for an analysed field: (C) capital adequacy; (A) assets; (M) management Capability; (E) earnings; (L) liquidity; (S) sensitivity. CARAMEL system is used to evaluate insurance companies' activity by adding two more additional fields: retrocession and actuarial provisions. It is noteworthy that in this system besides financial indicators are also used non-financial indicators to evaluate company's activity.

To summarize, it can be noted that all systems discussed above have one mutual quality: their level of orientation towards strategy is not high. After considering the factor that the controlling system comprises both operational and strategic controlling subsystems, achievement of strategic goals becomes an important aspect of controlling department's activity. Thus the company's activity measurement indicators must be formed and the results evaluated by taking into account not only weekly, monthly or quarter results, but also strategic indicators of 5-10 years. Systems oriented towards strategy and their appliance in the controlling system helps to ensure achievement of both operational and strategic goals.

\section{Indicator systems oriented towards strategy}

The second "floor" of indicator systems cube (see Fig.4) is designed for indicator systems whose level of orientation towards strategy is significantly higher. Tableau de Bord system might be assigned to the fifth field. The Tableu de Bord was introduced in France in the 1930s and was described as being similar to a "dashboard" (i.e. the literal translation of Tableau de bord) used by "pilots" (i.e. managers) to guide organizations to their destinations. (Bessire \& Baker 2005). In other words, it gives individual managers a concentrated set of information in the form of indicators that they need for (operational) control of their areas of responsibility. Moreover, by creating a consistent system of tableaux de bord, the concept enables the entire company to achieve its overall targets and implement its enterprise strategy successfully (Damn, 2005). That the system is oriented towards strategy is indicated also by other authors. However, restrictions are not applied to indicators selection in the Tableu de Bord system and it determines a factor that indicators interconnection and their compatibility is often not high.

It is appropriate to assign the systems that show high level of orientation towards strategy and high indicator interdependence level to the sixth field. Those are ZVEI and EVA systems. EVA indicator system is well known and widely applied to evaluate activity of companies in many countries. Whereas ZVEI system is less known and applied more rarely. It was determined by the factor that the system was established in Germany and was mostly used particularly in companies of German-speaking countries. Because of limited application of controlling 


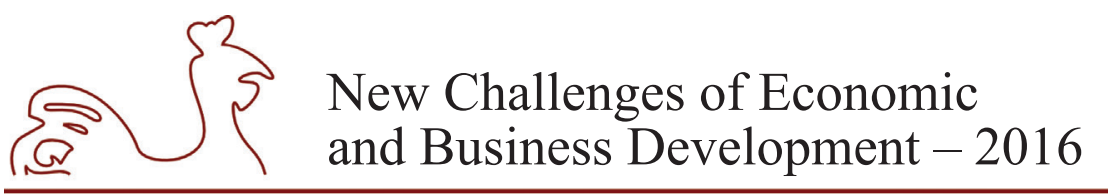

May 12-14, 2016, Riga, University of Latvia

out of the German-speaking countries, the spread of ZVEI indicator system was also limited. The ZVEI system of performance measurement was developed by the Central Association of Electrical Industry (Zentralverband der Elektrotechnischen Industrie-ZVEI) in Germany (Zentralverband Elektrotechnik..., 1989). This system became well known in this country and has spread among many companies. The mixed calculation and classification system - which is also called multifunctional ratio system - is designed as a ratio pyramid. Figure 5 illustrates the schematic construction. Ultimate aim of the ZVEI system is to investigate the company's efficiency through growth and structure analysis. Sales activities, results, capital commitment, value creation and employment are considered in the growth analysis. In the structural analysis, as the main part of the ZVEI system the earning power and the risk of the company is analysed by the means of the key performance indicator Return on Equity (Schmeisser, et al., 2011). The first structural analysis part is growth analysis, which allows to presume that the system is oriented towards strategy. The second part is structural analysis, which provides a view of strict indicators interdependence.

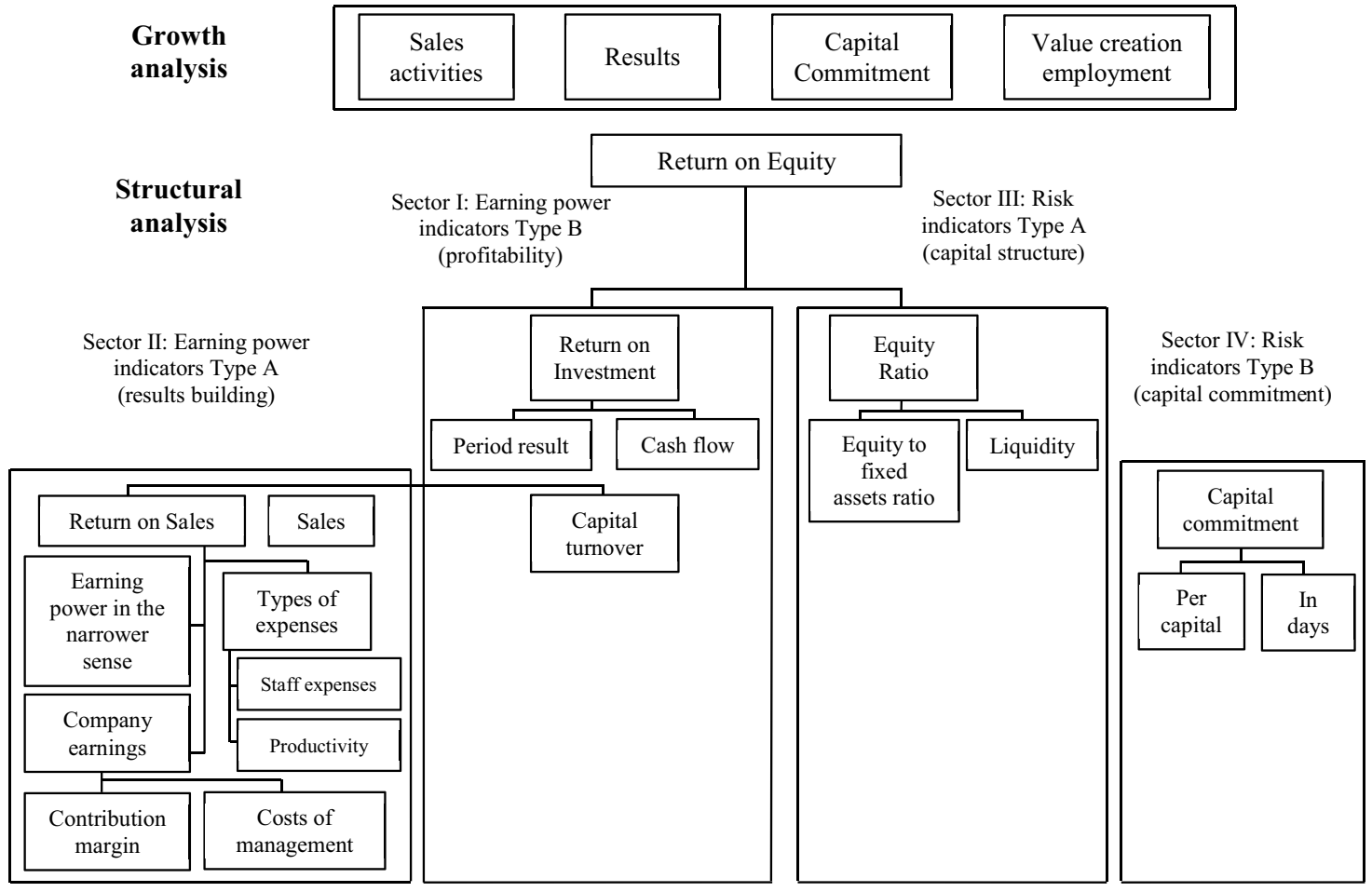

Source: Schmeisser, et al., 2011

Fig. 5. ZVEI system

The EVA indicator system can be assigned to the sixth field of the cube only because the indicators of this system are closely connected by strict mathematical dependence. Also, the system is oriented towards the increase of organisational value which shows high level of orientation towards strategy. Yet, as Weber \& Sandt (2001, cited in Weber \& Schäffer, 2014, 


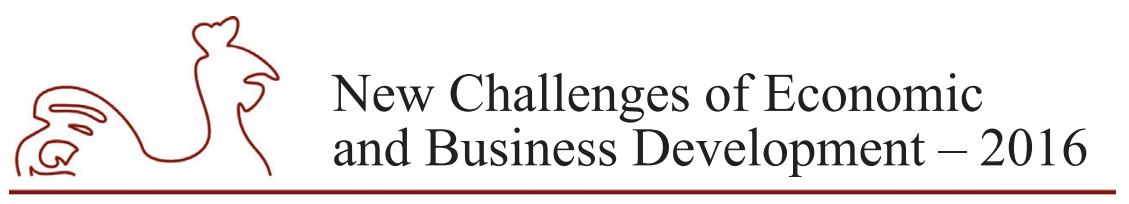

May 12-14, 2016, Riga, University of Latvia

p. 158) noticed, ZVEI and EVA systems use only financial indicators which shows that these indicator systems have characteristics of low indicator compatibility level and cannot be assigned neither to the seventh nor to the eight fields of the cube.

Previously mentioned EFQM system can be assigned to the seventh field because, as it was mentioned before, indicators compatibility level of this system is high. Even though the system is mostly based on non-financial indicators, indicators compatibility level is clear in another aspect: all indicators are selected and coordinated using certain proportions to emphasize the company's success factors. Orientation towards strategy level of the system is also considered high because the system includes an important activity evaluation criterion which is Policy \& Strategy. As EFQM declares: "Excellent Organisations implement their mission and vision by developing a stakeholder focused strategy that takes account of the supply markets trends in which it operates. Organisations explore supply market intelligence when defining and reviewing their strategy" (EFQM, 2006, p. 13). This provision of the system developers as well as a certain part of indicators provided in the system and designed to evaluate strategic activity confirm the presumption that the level of orientation towards strategy of a system is high.

The last element of the cube is attributed to the already widely spread and recognized Balanced Scorecard system. Almost all analysed authors admit that it is the most balanced system, its indicator interconnection is strong and the level of orientation towards strategy is high. This indicator system is special because usual traditional financial indicators were supplemented by three perspectives which are Customer, Internal Business, Learning \& Growth and their respective indicators. Each perspective is characterized by strictly defined amount of indicators, which are connected among each other by cause-and-effect links. However, the most important feature of this indicator system is an ability to form a set of indicators which fits company's requirements the best and ensures the link between operational tasks and strategic goals. Kaplan and Norton - the developers of this system - also emphasize it: "The Balanced Scorecard translates an organization's mission and strategy into a set of performance measures that provides the framework for a strategic measurement and management system." (Kaplan \& Norton, 1999, p. 2)

To summarize, it is important to note that the controlling system is oriented towards achievement of both operational and strategic goals; therefore, the choice of respective indicators and indicator systems becomes an important function of a controlling department. After analysing the main indicator systems and their most important characteristics, it can be concluded that the most suitable system of the strategic and operational controlling is the Balanced Scorecard indicator system because it is oriented towards three main dimensions which describe high quality of an indicator system. However, to ensure the functions of the controlling system, other indicator systems can be applied whose level of compatibility or the level of indicators interdependence is not necessarily high, yet they are strongly oriented towards strategy.

\section{Conclusions}

1. Analysis of the controlling system structure has revealed that it is comprised of two main subsystems: strategic and operational controlling. These subsystems are connected by various elements among which the choice of financial and non-financial indicators and indicator systems for evaluation of strategic and operational activities results is noteworthy. 


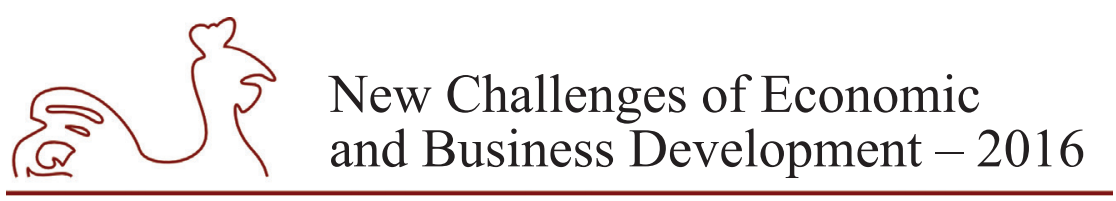

May 12-14, 2016, Riga, University of Latvia

Considering the fact that this element of controlling is directly related to the increase of organisational value, the choice of appropriate indicators and indicator systems, which would ensure not only completion of operational tasks but also measurement and evaluation of strategic goals implementation results, becomes an important controller's function.

2. Even though the usage of various financial and non-financial indicators and their systems is the main instrument of a controller when measuring and evaluating company's activity, the theoretical study has revealed that single indicators are not recommended in a controlling department activity because of their limited informativeness. Instead, it is better to choose already developed indicator systems or develop specific indicator systems of your own which would fit the company's requirements the best. However, when choosing already existing systems or forming new ones, it is important to note that not every group of indicators can be called an indicator system. Firstly, it must exhibit compatibility among indicators and their interdependence.

3. After performing the analysis of already developed and widely applied indicator systems, it was determined that most often is suggested that a controller applies financial indicator systems which are classified into two groups: logical-deductive and empirical-inductive. And even though historically companies concentrated on financial indicators, it is not efficient to apply only financial indicator systems because they do not evaluate all aspects of a company's activity. Bearing in mind that non-financial indicators are nowadays as important as financial ones, a classification system comprising both financial and nonfinancial indicator systems was framed and suggested. Although it was developed based on an already existing four field matrix principle, it is suggested that next to the twodimension matrix including indicators compatibility and indicators interconnection, two important indicator characteristics, the third one is introduced which is orientation towards strategy. Considering the fact that controlling system constitutes strategic and operational controlling subsystems, introduction of the third dimension would create a possibility to choose suitable indicator systems more objectively which would measure the results of both operational and strategic activity.

4. After analysing the characteristics of the main indicator systems, it was determined that in order to ensure an efficient functioning of a controlling department it is appropriate to apply the indicator systems with high level of orientation towards strategy. Those indicator systems are assigned to the 5-8 cube fields in the three-dimension classification system. According to the analysis of these cube elements, it can be seen that the most suitable system is the Balanced Scorecard indicator system because it is oriented towards three main dimensions which describe high quality of an indicator system. However, to ensure the functions of the controlling system, other indicator systems can be applied whose level of compatibility or the level of indicators interdependence is not necessarily high, yet they are strongly oriented towards strategy. Those are Tableu de Bord, ZVEI, EVA and EFQM systems. These indicator systems are suitable for applying controlling in department activity because they ensure efficient operational and strategic controlling system elements functioning and at the same time contributes to increase of organization value. Application of indicator systems assigned to the 1-4 cube fields in the controlling department activity is appropriate only when they are used in accordance with other indicator systems whose level of orientation towards strategy is high. Individual application of the bottom floor 


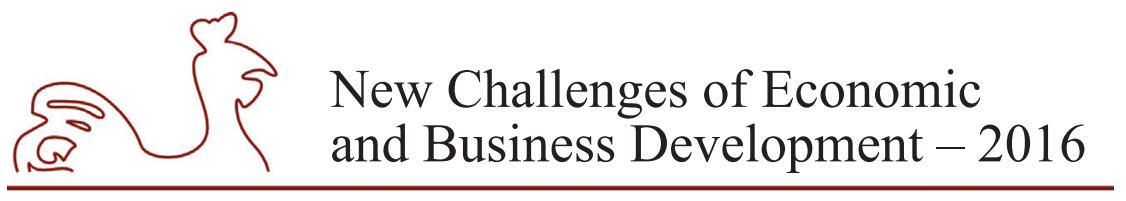

May 12-14, 2016, Riga, University of Latvia

of cube indicator systems is not recommended because organizational activity results measured and evaluated based on them will reflect only operational controlling level of tasks implementation, yet strategic problems will not be solved.

\section{Bibliography}

Beaver, W. H., 1966. Financial Ratios as Predictors of Failure, Empirical Research in Accounting Selected Studies. Supplement to Journal of Accounting Research, 4, p. 71-111. [Online] Available at: http:// www.jstor.org/stable/2490171?seq=1\#page_scan_tab_contents [Accessed 14 March 2016].

Bessire, D. \& Baker, R., 2005. The French Tableau de bord and the American Balanced Scorecard: a critical analysis. Critical Perspectives on Accounting, 16, p. 645-664.

Brewer, P. C. \& Speh, T. W., 2000. Using the balanced scorecard to measure supply chain performance. Journal of Business Logistics, 21(1), p. 75-93.

Daum, J. H., 2005. French Tableau de Bord: Better than the Balanced Scorecard? Der Controlling Berater, 2, p. 459-502. [Online] Available at: http://www.iioe.eu/fileadmin/files/publications/Tableau_de Bord_J_Daum_en.pdf [Accessed 14 March 2016].

Dobroszek, J. \& Szychta, A., 2015. Indicators as an Instrument of Measurement in Management Accounting in Logistics Enterprises in Poland. Management and Business Administration. Central Europe, 23 (4), p. 11-33. [Online] Available at: http://mbace.eu/abstracted.php?level=5\&ICID=1186711 [Accessed 14 March 2016].

EFQM, 2006. The EFQM Framework for Managing External Resources. Driving performance and growth through excellence in managing external resources. [pdf] EFQM. Available at: http://www. eipm.org/research/EFQM\%20EIPM\%20Framework\%20for\%20Exc\%20Ext\%20Resources.pdf. [Accessed 14 March 2016].

Frank, U., Heise, D., Kattenstroth, H. \& Schauer, H., 2008. Designing and Utilising Business Indicator System within Enterprise Models - Outline of a Method. MobIS 2008 -Modellierung zwischen SOA und Compliance Management. Saarbrūcken, Germany, 27-28 November 2008.

Gimžauskienė, E., 2010. When are controlling systems effective and efficient? The perspective of economic conditions changes. Controller Magazine Spezial, September. 8-9 p.

Gladen, W., 2003. Kennzahlen- und Berichtssysteme. Grundlagen zum Performance Measurement. Wiesbaden: Gabler.

Hauser, M., 2007. Profit Centres. Center - Controlling. Strategic business unit: profit, service, cost centers, value centers. Offenburg: Verlag für ControllingWissen.

Ingham, H. \& Harrington, T., 1980. Interfirm Comparison. London: Trafalgar Square Publishing.

Internationaler Controller Verein, n.d. 10 Core-Elements of Sustainable Controlling. [Online] Available at: https://www.icv-controlling.com/en/association/10-core-elements-of-sustainable-controlling.html [Accessed 14 March 2016].

International Group of Controlling, 2010. Dictionary for Controllers. English/German German/English. Stuttgart: Schäffer-Poeschel.

Ittner, C. D., \& Larcker, D. F., 2003. Coming Up Short on Nonfinancial Performance Measurement. Harvard Business Review, 81(11), p. 88-96.

Kaplan, R. \& Norton, D., 1996. The Balanced Scorecard: Translating Strategy into Actions. Harvard Business Review Press.

Kaplan, R. \& Norton, D., 2000. The Strategy-Focused Organization: How Balanced Scorecard Companies Thrive in the New Business Environment. Harvard Business Review Press.

Keiner, M., 2003. Indicator based controlling of cantonal guiding planning in Switzerland: A model for more efficient sustainable planning instruments at the regional level. Spatium. 9, p. 8-13. 


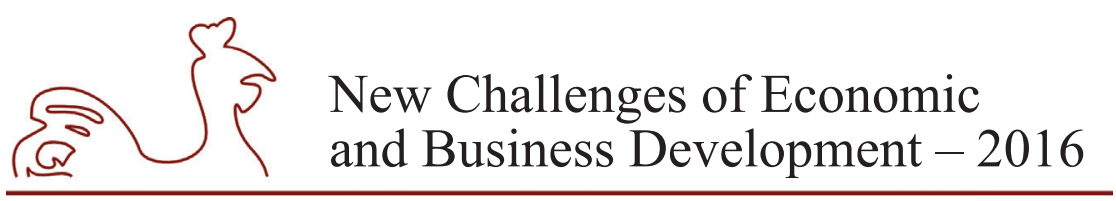

May 12-14, 2016, Riga, University of Latvia

Köppen, V., 2008. Improving the Quality of Indicator Systems by MoSi-Methodology and Evaluation. Dissertation. Freien Universität Berlin. [Online] Available at: http://www.diss.fu-berlin.de/diss/ receive/FUDISS_thesis_000000005285[Accessed 14 March 2016].

Krauth, E., Hans, M., Popova, V. \& Schut, M., 2005. Performance Measurement and Control In Logistics Service Providing. Artificial Intelligence and Decision Support Systems, p. 239-247. [Online] Available at: https://www.academia.edu/293852/Performance_Measurement_and_Control_In_ Logistics Service Providing [Accessed 14 March 2016].

Lachnit, L., 1979. Systemorientiertie Jahresabschlussanalyse. Wiesbaden: Betriebswirtschaftlicher Verlag Gabler.

Mann, R. \& Mayer, E., 2000. Controlling for Beginners. Freiburg: GmbH \& Co. KG.

Reichmann, T., 2011. Controlling: concepts of management control, controllership and ratios. Berlin: Springer.

Roehl-Anderson, J., Bragg, S., 2004. Controllership: the work of the managerial accountant. New Jersey: John Willey \& Sons, Inc., Hoboken.

Sandt, J., 2004. Management mit Kennzahlen und Kennzahlensystemen: Bestandsaufnahme, Determinanten und Erfolgsauswirkungen (Schriften des Center for Controlling \& Management (CCM)). Wiesbaden: Deutscher Universitätsverlag.

Schmeisser, W.; Clausen, L.; Popp, R.; Ennemann, C \& Drewicke, O., 2011. Controlling and Berlin Balanced Scorecard Approach. München: Oldenbourg Verlag.

Smith M., 2005. Performance Measurment \& Management. A Strategic Approach to Management Accounting. London: SAGE Publications.

Staehle, W. H., 1969. Kennzahlen und Kennzahlensysteme als Mittel der Organisation und Führung von Unternehmen Wiesbaden: Betriebswirtschaftlicher Verlag Gabler.

Timmerbeil, F., 1999. Konzeptionierung, Implementierung und produktiver Einsatz eines Produktivitätskennzahlensystems in einem Cost-Center: Am Beispiel der Siemens AG. Diplomarbeit. Hochschule Wismar.

Zentralverband Elektrotechnik- und Elektronikindustrie, 1989. ZVEI-Kennzahlensystem: ein Instrument zur Unternehmenssteuerung. Frankfurt am Main: ZVEI, Betriebswirtschaftlicher Ausschuss.

Ананькина, Е. А., Данилочкин, С. В., Данилочкина, Н. Г., Дерипаска, О.В. \& др., 2002. Контроллинг как инструмент управления предприятием. Под ред. Данилочкиной, Н. Г. Москва: ЮНИТИ.

Вебер, Ю. \& Шеффер, У., 2014. Введение в контроллинг. Пер. с нем. / Перевод Фалько, С. Г. Москва: НП “Объединение контроллеров”.

Дайле, А., 2001. Практика контроллинга. Пер. с нем. / Перевод Лукашевича, М. Л. \& Тихоненковой, Е. Н. Москва: Финансы и статистика.

Карминский, А. М., Оленев, Н. И., Примак, А. Г. \& Фалько, С. Г., 2002. Контроллинг в бизнесе. Москва: Финансы и статистика.

Карминский, А. М., Фалько, С. Г., Жевага, А. А., Иванова, Н. Ю., 2006. Контроллинг. Москва: Финансы и статистика.

Хан, Д. \& Хунгенберг, Х., 2005. Планирование и контроль. Стоимостно - ориентированные концепции контроллинга. Пер. с нем. / Перевод Лукашевича, М. Л., Тихоненковой, Е. Н. Москва: Финансы и статистика.

Хорват, П., 2006. Концепция контроллинга. Управленческий учёт. Система отчетности. Бюджетирование. Пер. с нем. / Перевод Толкача, В., Данишевич, С. \& Гавриша, М. Москва: Альпина Бизнес Букс. 


\title{
PREPARING BUSINESS STUDENTS FOR THE ENTERPRISE 2.0 - A CASE STUDY FROM GERMANY
}

\author{
Wissam Tawileh, Technische Universität Dresden, Germany ${ }^{1}$
}

\begin{abstract}
This paper presents an empirical case study of integrating German business students in a formal international masters' course to develop their professional, interpersonal, communication, English language and intercultural skills by working in interdisciplinary teams with peers in Jordan. Fifteen reflection reports were analysed to identify the benefits, problems, impact, and enhancement potentials of this course as described by the students. The results show high students' satisfaction with the flexibility of the learning environment, high interest in the virtual collaboration with students abroad, and positive expected impact on their future academic and professional life. In addition to missing immediate reaction and body language as in face-to-face collaboration, students proposed less stressed time plan and more structured tasks and were less satisfied with the contribution of their international peers. This empirical study provides implications for higher educational institutions to provide their students with international experience and valuable professional skills during their regular study programs using enjoyable easy-touse technologies.
\end{abstract}

Key words: Virtual Collaborative Learning, Internationalisation at Home, Enterprise 2.0, Web 2.0, Intercultural Communication

JEL code: A23, D83, I21

\section{Introduction}

As Information and Communication Technologies continue to influence enterprise business processes, university students increasingly need adequate preparation for knowledge intensive professional work environments. This preparation is particularly important for business students who will have to adapt after their graduation to the needs of different industries and fulfil challenging requirements to achieve managerial and decision-making positions in their advanced career. However, essential skills for high performance at the modern workplace are usually not within the scope of regular formal university study programs. Computer Mediated Communication (CMC), intercultural communication, interdisciplinary collaboration, negotiation, problem solving, and decision making are examples of important skills required for successful career for business graduates (Crossman and Clarke, 2009; Ledwith and Seymour, 2001; Meisel and Marx, 1999). Another important aspect of preparing business students for the globalized labour market is providing them with an international experience. Working with peers from other countries and cultures increase their understanding of international economic and cultural perspectives, stimulate cognition, learning, and cultural sensitivity, and increase their adaptability and employability (Clarke, 2005; Crossman and Clarke, 2009; Koskinen and Tossavainen, 2003).

Corresponding author - e-mail address: wissam.tawileh@tu-dresden.de 


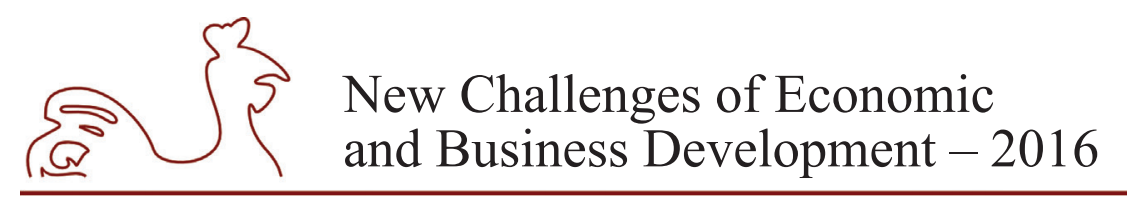

May 12-14, 2016, Riga, University of Latvia

Virtual Collaborative Learning is an innovative approach to allow students to collaborate with peers abroad through Web 2.0 interactive applications as described in the following section.

\section{Virtual Collaborative Learning (VCL)}

Virtual Collaborative Learning follows a project-based constructivist learning paradigm to integrate the benefits of Computer-Supported Collaborative Learning (CSCL) in the Virtual Classroom as an effective group learning environment (Hiltz, 1988). These benefits include: skills improvement, positive impact on atmosphere, positive attitude towards learning, acceptance to deal with more difficult problems, effective group dynamics, and enhanced students' performance (Lehtinen et al., 1999). The Chair of Information Management at the Technische Universität Dresden in Germany develops and implements since 2001 Virtual Collaborative Learning arrangements in formal higher education to improve students' professional competence, team competence, media competence, and intercultural awareness (Schoop, Bukvova and Gilge, 2006). Through cooperation with international partner universities, students have the chance to collaborate with peers and instructors form other countries and gain international academic experience during their regular study program without travelling abroad. This innovative approach to provide business students with an international project-based learning experience was applied recently in a formal university course that connected masters' students from Germany with peers from Jordan. The course is described in the following section and its evaluation from German students' perspective will be discussed further in this paper.

\section{The Case Study}

The module "Collaboration in the Virtual Classroom" is a regular elective masters' module at the Faculty of Business and Economics of the Technische Universität Dresden and is offered as a Virtual Collaborative Learning arrangement, where students from Germany collaborate with students from international partner universities in small groups on an authentic case study to solve a given ill-structured problem. In their self-regulated research and knowledge building activities, students intensively practice: virtual team work, critical thinking, problem solving, collaborative decision making, professional negotiation and presentation skills, cross-cultural communication, and English language for academic work. In the summer term 2015, 18 students ( 8 Female and 10 Male) from the Technische Universität Dresden in Germany and eight students (4 Female and 4 Male) from Princess Sumaya University for Technology in Jordan participated in this course.

The students were divided into five interdisciplinary groups of 5-6 members and registered in the prepared closed learning Social Network that offered the central communication and collaboration platform for all teams. The project-based learning scenario required the students to virtually collaborate in the teams and solve a given problem addressing critical incidents of intercultural communication in business virtual collaboration. The anticipated learning objectives included enhancing: students' media competence through using Web 2.0 applications, self-competence through effective contribution to the group's solution, professional competence through negotiating and presenting a common solution, and intercultural awareness through working out intercultural critical incidents with peers abroad. The intensive virtual collaboration phase was started by a kick-off videoconference, lasted for four calendar weeks (20.04.201518.05.2015), and was finished by a final videoconference. Each group developed and recorded 


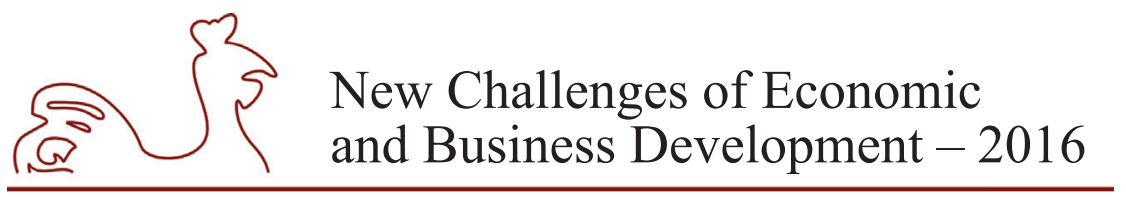

May 12-14, 2016, Riga, University of Latvia

an executive presentation of its solution. One instructor led the course supported by two qualified e-tutors from Germany, who followed-up with the groups for organisational, collaboration and group dynamics questions.

After the virtual collaboration phase, students in Germany were asked to reflect on their experience in the course in a written assignment based on a given structure that addresses their: motivation, overall experience, learning, teamwork, cross-cultural communication, interdisciplinary collaboration, and multi-national collaboration in the virtual classroom. Fifteen delivered documents were then qualitatively analysed (reports from three exchange students were exempted for a homogeneous sample) to identify the benefits, problems, impact, and enhancement potential from German students' perspective. The results of this qualitative evaluation are presented and discussed in the following section.

\section{Research results and discussion}

The content analysis of fifteen German students' reflection reports resulted in a set of subjective evaluation aspects of the attended Virtual Collaborative Learning course, that can be categorised in: Students' Motivation and Expectations, Perceived Benefits and Advantages, Perceived Problems and Disadvantages, and Students' Satisfaction. The following sections present these aspects supported by anchor examples from the analysed documents. Students' names were replaced with codes to protect their privacy $(\mathrm{F}=$ Female, $\mathrm{M}=$ Male).

\section{Students' Motivation and Expectations}

In the first section of the reflection report, German students described their motivation to register for the Virtual Collaborative Learning course, which is offered as an elective masters' module. Six main reasons to attend the course were mentioned by the students as shown in Table 1 in descending order of the absolute appearance frequency in all documents.

Table 1

Students' Motivation and Expectations from the Virtual Collaborative Learning Course

\begin{tabular}{|c|c|c|c|c|c|c|c|}
\hline \multirow{2}{*}{ Code } & \multirow{2}{*}{ Category Name } & \multicolumn{3}{|c|}{ Absolute Frequencies } & \multicolumn{3}{|c|}{ Number of Documents } \\
\cline { 3 - 8 } & & Total & F & M & Total & F & M \\
\hline M1 & Intercultural Collaboration & 17 & 7 & 10 & 12 & 5 & 7 \\
\hline M2 & New Experience & 15 & 9 & 6 & 8 & 5 & 3 \\
\hline M3 & International Collaboration & 10 & 3 & 7 & 9 & 3 & 6 \\
\hline M4 & Virtual Collaboration & 10 & 7 & 3 & 6 & 3 & 3 \\
\hline M5 & Interdisciplinary Collaboration & 8 & 4 & 4 & 7 & 3 & 4 \\
\hline M6 & Improve English Language Skills & 4 & 2 & 2 & 3 & 2 & 1 \\
\hline
\end{tabular}

- Intercultural Collaboration: The main reason for the German students to attend this course was the interest in the intercultural collaboration announced in the course description.

"My expectations for the course had been very high from the beginning on. I was very happy to get the chance to work in an online course with students from another country, with a different, very interesting culture." [M62] 


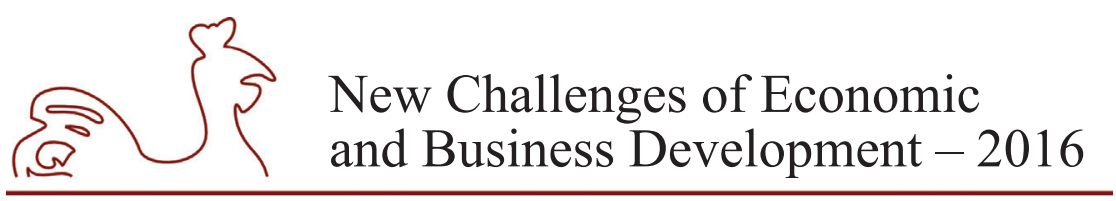

May 12-14, 2016, Riga, University of Latvia

While six students mentioned no effect of the cooperation with a Jordanian university, in particular, on their motivation to attend the course, the interest in intercultural collaboration with Arab students was still noticeable.

"One of my inner motivations was to have direct contact with people from Jordan. I always wanted to get to know people from this culture." [F42]

- New Experience: Another important motivation for the German students to attend the course was their interest in going through a new experience that seemed interesting and challenging to them.

"I was sure that I wanted to do this. The new experiences and the interesting challenge overweighed the effort that comes with it." [F52]

The expected practical orientation was also considered to be a motivational new experience to attend the Virtual Collaborative Learning course.

"the course promised to me to be oriented more practically rather than the other theoretical courses I attend at the university." [M63]

- International Collaboration: Working with students from outside Germany was an appealing chance for German students to participate in the course and gain an interesting international experience.

"Considering the university background it is a very refreshing and interesting concept to let the students experience the international collaboration, rather than only reading about it in a study others did. This way the learned information and experienced interaction will probably stay much longer in memory than in any regular lecture at a university." [M21]

Although German participants were students in an advanced stage of their masters' studies, the Virtual Collaboration Course was the first opportunity for some of them to get in touch with international students at all.

"For me it was the first time to get the opportunity to work with foreign students in a study course. My motivation to work in such an international setting was very high." [M62]

- Virtual Collaboration: Six students reported their interest in getting to know virtual collaboration as a new learning setting and identify its potentials and drawbacks in a practical experience.

"I decided to get a detailed look by attending such a virtual class on my own to experience the different learning atmosphere in a virtual collaboration with students. I wanted to identify the advantages and benefits but also the disadvantaged and challenges of the CVC [Collaboration in the Virtual Classroom]." [F42]

"I decided to register for this course because it was more interesting for me to get to know a new teaching and collaboration method than have an exact planned semester." [M61] 


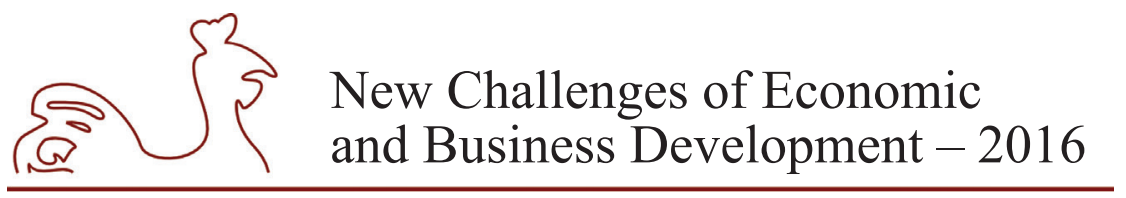

May 12-14, 2016, Riga, University of Latvia

- Interdisciplinary Collaboration: The announced interdisciplinary nature of the course was also an attractive aspect for the participated German students.

"The work with other university disciplines motivated me as well." [F41]

"I think that the outcomes and ideas that can be created in such an environment, are highly valuable. Students form different disciplines can bring their own expertise in the group dynamics" [F61]

- Improve English Language Skills: Three students saw in the course a chance to improve their English language skills both through the learning activities and the interaction with international students who cannot speak German.

"I read that the course will be carried out in English. My first motivation to attend this course was that I would be able to improve my English skills." [F12]

The fact that it was one of the few courses offered in English at its time at the faculty, this course was the first learning experience for some students in English language.

"I liked that the course was in English, since I don't have any other courses in English even though it is the language most scientific papers are written in and it is obligatory when working in an international environment [...] I wanted to [...] improve my English and work in an international environment." [M11]

\section{Perceived Benefits and Advantages}

In the reflection reports, German students evaluated their experience in this Virtual Collaborative Learning course from multiple perspectives. To explore to which extent the course fulfilled their expectations, the benefits and advantages perceived by the students during their participation were identified in the analysed documents. Ten perceived benefits and advantages of the learning setting and activities are presented in Table 2 in descending order of the absolute appearance frequency in all documents.

Table 2

Perceived Benefits and Advantages of the Virtual Collaborative Learning Course

\begin{tabular}{|c|c|c|c|c|c|c|c|}
\hline \multirow{2}{*}{ Code } & \multirow{2}{*}{ Category Name } & \multicolumn{3}{|c|}{ Absolute Frequencies } & \multicolumn{3}{l|}{ Number Documents } \\
\cline { 3 - 9 } & & Total & $\mathbf{F}$ & $\mathbf{M}$ & Total & $\mathbf{F}$ & $\mathbf{M}$ \\
\hline B1 & Useful/Easy-to-Use Technical Tools & 73 & 28 & 45 & 13 & 5 & 8 \\
\hline B2 & Cultural Awareness Increase & 60 & 32 & 28 & 14 & 7 & 7 \\
\hline B3 & Mutual Peer Support & 53 & 29 & 24 & 14 & 6 & 8 \\
\hline B4 & Interdisciplinary Teams & 52 & 19 & 33 & 14 & 7 & 7 \\
\hline B5 & Collaboration with Students/Universities Abroad & 51 & 16 & 35 & 15 & 7 & 8 \\
\hline B6 & Flexibility of Online Learning & 49 & 22 & 27 & 14 & 6 & 8 \\
\hline B7 & English Language Improvement & 27 & 11 & 16 & 15 & 7 & 8 \\
\hline B8 & Documented Collaboration and Efforts & 14 & 6 & 8 & 7 & 3 & 4 \\
\hline B9 & Intensive Communication & 13 & 1 & 12 & 6 & 1 & 5 \\
\hline B10 & High Enjoyment & 12 & 7 & 5 & 7 & 3 & 4 \\
\hline
\end{tabular}




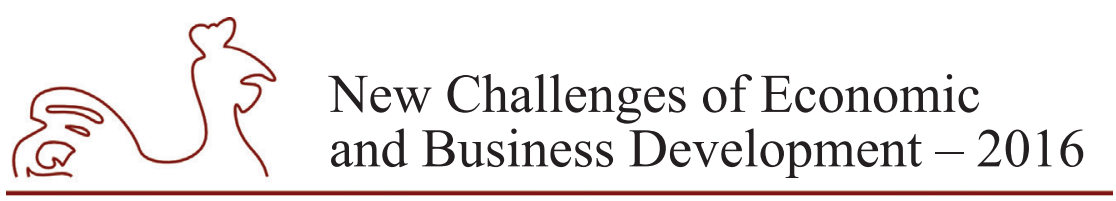

May 12-14, 2016, Riga, University of Latvia

- Useful/Easy-to-Use Technical Tools: The central communication and collaboration platform for the course was built using an open source social network engine (elgg.org) that was new to most participants. It provided them, however, with useful, easy-to-use collaborative tools for effective virtual teamwork, that they would use in professional life.

"The 'elgg' platform was very effective and helpful to communicate with the students. Every group was able to schedule meetings, chat sessions as well as videoconferences. It gave every participant of the class an insight of real life business collaborations at international companies." [F42]

The virtual learning group activities granted the students a practical hands-on experience in the professional use of Social Media applications and a better understanding of their role in effective online collaboration.

"A completely new thing to me was also the communication that took place just online. But thanks to the tools that were provided on the CVC [Collaboration in the Virtual Classroom] platform like discussion tools, bookmarks, blogs, and so on it was easy to collaborate with the other members." [F52]

"I've recognized that social media are not only private fun and entertainment; they are also able to support serious online team working processes in an effective way." [M62]

- Cultural Awareness Increase: The other main benefit German students perceived to have gained from the course was the significant increase in their cultural awareness. Collaborating with students from another culture still located in their home country during their study program without travelling abroad was a "rare" chance for them.

"I think it is really rare to have a real cross-cultural communication in a classical work group scenario at [the] university [...] A big benefit of the virtual communication is of course that you actually are facing people still totally imbedded in their culture in contrast to people who moved here five years ago and have adapted to the culture they are now facing." [F51]

This Collaboration with Jordanian students allowed them to get introduced to a "totally" new culture for them and to better know their own culture through identifying cultural differences in a practical situation. The "first-hand knowledge" they collected in this course helped them to clarify their prejudice and win a better cultural understanding.

"I learned something about my culture, other cultures and as a result learn something about myself. The course made me more aware of my surroundings and showed me how to act in an international context or at least provided me with the necessary skills and views to improve my behaviour in such an environment." [M11]

"I also had some prejudice and stereotypes, which in my opinion is not always something negative. I think they are mostly related to missing personal experience with certain cultures. As an example before the start I thought that we mostly work with male fellow students and if we work with female fellows they would wear a hijab or a burqa. So one of my prejudice and stereotypes had been wrong because there had been nearly the same 


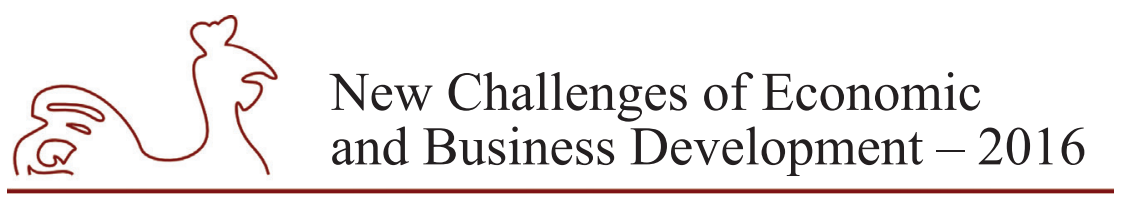

May 12-14, 2016, Riga, University of Latvia

number of male and female students, the other was right because every female student was wearing a hijab on their profile picture." [M62]

- Mutual Peer Support: German students reported a positive effect of the collaborative character of the course that led to intensive mutual peer support in knowledge building, technical and lingual difficulties.

"The main advantage of the VCL [Virtual Collaborative Learning] for me is the mutual support and the knowledge exchange through the other team members because of the collaboration." [F41]

"One member of the group was not fluent in the language. Therefore, I tried my best to help this student by correcting his/her essays and the student asked me when he/she had problems in understanding the context and the assignment of tasks." [F42]

"The team itself was very good organized and helpful all the time. We also liked each other and supplemented our work well. There was no egoistic behaviour or rude behaviour against each other." [M22]

- Interdisciplinary Teams: The expectation of working in interdisciplinary teams that motivated German students to select this course was found fulfilled and useful by most participants.

"Also a big advantage is that you have specialists from every discipline that are required, so that one person alone doesn't have to get the whole knowledge to solve the project. A group of six members from six different disciplines like in our group also means that everybody has different ideas and approaches to solve a task, which can also be helpful. Interdisciplinary work will surely broaden one's horizon.” [F52]

"It is really important to have experts with an interdisciplinary background. We trained this by choosing different virtual departments and also our studying majors are different. This will lead to several benefits. Interdisciplinary knowledge promotes creativity and some important topics of research fall in the interstices among the traditional disciplines." [M61]

- Collaboration with Students/Universities Abroad: Also the collaboration with foreigner students from a university abroad was a motivating factor that was found by all participants to be effective and useful in the virtual classroom.

"I also realized for the first time that not only students see the benefits of virtual collaboration but also the university and its teaching staff which is very promising in regard to the development of new teaching and learning methods." [F51]

"Through working in a multi-national environment students can have a real international experience. That way they can meet someone from a different country and get to know them much better than they would have by only talking to them briefly. If I compare my experiences in this course with my experiences studying abroad I can say that this is really the case." [M11] 


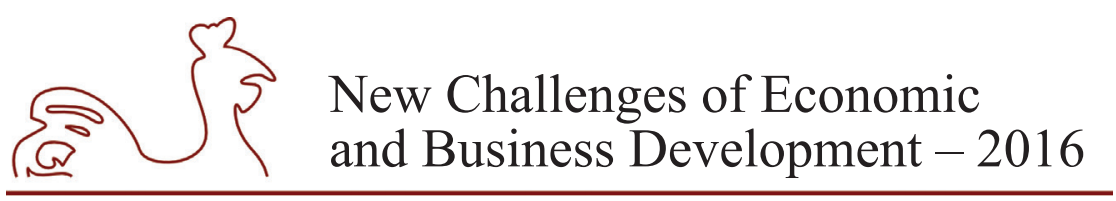

May 12-14, 2016, Riga, University of Latvia

- Flexibility of Online Learning: German students were aware of the flexibility of online learning and benefited from it in this virtual collaboration course. They were able to work at their own pace at their preferred time and location.

"The biggest advantages of virtual collaboration are notably the time factor and the location-independence. Team members don't have to meet at a certain time at a certain place, that would cost most of them time to get there and get home again. With virtual collaboration the work can be done from home, a meeting can take place anytime." [F61]

"One advantage of a virtual collaboration is that there is enough time to read the content again before clicking the send button. So everything can be well reconsidered before submitting. That offers the possibility to control yourself especially in conflict situations." [M61]

"I had the possibility to work from home in the evening, which is my favourite time to work concentrated on projects. This independence made it easier for me to integrate the necessary learning and writing activities in my daily life." [M62]

- English Language Improvement: While only some students were motivated by language improvement to attend this course, all German participants reported a noticeable improvement in their English language skills after the virtual collaboration project.

"Also the language increases at cross-cultural collaboration. During the time of the course my English became better and better. Today I think I learned a lot of new English vocabulary and phrases." [F41]

"I was a little bit afraid that my English skills are not good enough to communicate properly with my team members and fellow students. During the course I gained a lot of confidence especially in my written English, because my team members understood all my posts." [M62]

- Documented Collaboration and Efforts: As final assessment paly an important role for all students, the continuous documentation in the virtual collaboration environment increased participants' confidence in a fair assessment of their individual efforts. The recorded group discussions and activities also ease knowledge exchange and saving.

"Another advantage was that with such a virtual support the working process and their inputs and outputs were documented automatically. Each member has access to the content and the chance to backtrack the working process. So no member is excluded from the working process and the outcome. Thereby the platform has a high transparency for each user." [F12]

"The huge benefit in regard to the virtual classroom and the CVC platform is the documentation and the ability of the tutors to monitor and review the participation of the members." [M21]

- Intensive Communication: The absence of face-to-face meetings in the virtual collaboration environment requires the students to stay in intensive communication to strengthen their team membership. This was a benefit in this course. 


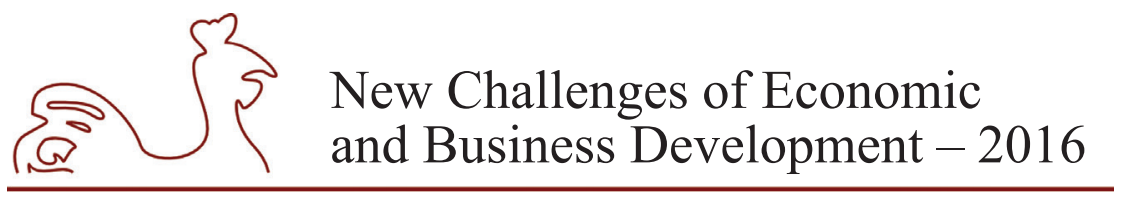

May 12-14, 2016, Riga, University of Latvia

"Another positive aspect is that you can stay in contact permanently for example in regularly daily basis even there is a great distance between the group members. This strengthens working habits and gives some feeling of being familiar with each other than it would have [been] when there were just a hand of meetings a month." [M22]

"it allows a more intense communication and supports also the very important informal exchange between all participants, which in my opinion leads to a more intense mutual understanding among the collaborating cultures." [M62]

- High Enjoyment: Students' intrinsic motivation increases in an enjoyable learning setting. Seven German participants explicitly reported a high enjoyment they experienced in this Virtual Collaborative Learning course.

"I enjoyed working in the CVC [Collaboration in the Virtual Classroom] course very much and would choose the course again if I had the chance to because it was an interesting and fun way to learn and collaborate." [F51]

“All in all, I had a lot of fun in the project." [F52]

\section{Perceived Problems and Disadvantages}

In addition to the benefits and advantages, the students were asked to reflect on problems and disadvantages they faced during their participation in the Virtual Collaborative Learning course. The eight difficulties identified in the analysed documents are presented in Table 3 in descending order of the absolute appearance frequency in all documents.

Table 3

Perceived Problems and Disadvantages of the Virtual Collaborative Learning Course

\begin{tabular}{|c|c|c|c|c|c|c|c|}
\hline \multirow{2}{*}{ Code } & \multirow{2}{*}{ Description } & \multicolumn{3}{|c|}{ Absolute Frequencies } & \multicolumn{3}{|c|}{ Number of Documents } \\
\cline { 3 - 8 } & & Total & F & M & Total & F & M \\
\hline P1 & Limitations of Virtual Teamwork & 51 & 30 & 21 & 15 & 7 & 8 \\
\hline P2 & Permanent Participation / High Workload & 46 & 20 & 26 & 15 & 7 & 8 \\
\hline P3 & Varied Technical Skills / Technical Problems & 43 & 19 & 24 & 15 & 7 & 8 \\
\hline P4 & Coordination / Time Management & 35 & 19 & 16 & 13 & 6 & 7 \\
\hline P5 & Initial Confusion / Anxiety & 33 & 20 & 13 & 12 & 6 & 6 \\
\hline P6 & Unequal Effort / Varied Participation & 30 & 16 & 14 & 11 & 5 & 6 \\
\hline P7 & Limitation to Own Role / Discipline & 16 & 10 & 6 & 9 & 6 & 3 \\
\hline P8 & Varied Language Skills & 11 & 4 & 7 & 7 & 2 & 5 \\
\hline
\end{tabular}

- Limitations of Virtual Teamwork: Disadvantages of Computer Mediated Communication (CMC) seemed to affect the teamwork in this course. Relying mainly on textual asynchronous communication led to some misunderstandings in the groups and the absence of direct communication complicated solving some conflict situations.

"One disadvantage represents the virtual barrier. If problems occur with one member of the group e.g. the student doesn't fulfil his tasks and is not reachable it is almost impossible to solve this problem in a virtual environment. The student cannot be called 


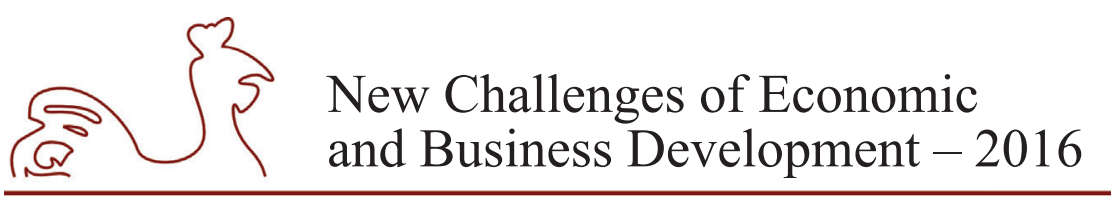

May 12-14, 2016, Riga, University of Latvia

or a direct contact at the university with him/her is not possible as well. I did realize this issue during my participation in the VCL [Virtual Collaborative Learning] class." [F42]

"Possible obstacles are misunderstandings and language problems. In a virtual learning group you can't use gestures and facial expressions, which are important for human communication. In the virtual classroom you have mainly the written word and how everyone translates and understands it for himself." [M41]

- Permanent Participation / High Workload: While intensive communication was seen as an advantage to compensate limitations of virtual communication, the need for continuous collaboration during the short project's duration using Social Software caused a feeling of permanent availability and high workload by all German participants.

"The effort that I invested in the CVC course was more than in regular courses. I was reachable for every team member at any time to help with problems or the task." [F42]

"Due to the short time that we had to complete the project, you even had to work on the tasks on the weekend. It was very stressful, because besides this project everybody had also other things to do for university or the part-time job." [F52]

- Varied Technical Skills / Technical Problems: Enhancing students' media competence by using collaborative Social Software was a learning objective of this course. However, limited technical experience and connectivity problems (mainly on the Jordanian side) seemed to affect the teamwork negatively.

"I am not an expert in technique or virtual work e.g. computers. That's why the work with such virtual platform was the most difficult part for me at the course." [F41]

"A typical main disadvantage is the strong dependence on the used technique. In nearly every online live meeting we spent over 20 minutes before we had been able to start, because of microphone or other technical problems. Due to this problem we resigned using cameras in meetings. I think this leads to another problem: misunderstanding." [M62]

- Coordination / Time Management: In addition to the differences in working days and time zones between Jordan and Germany, the exams scheduled at short notice at the partner university in Amman noticeably complicated the coordination of virtual group meetings and led to time management problems in the course.

"In a group of six members, it is nearly impossible to find a schedule where everybody has enough time for a meeting. So our meetings took place in the late evening, around $9 \mathrm{pm}$ Dresden time and ended around $11 \mathrm{pm}$ Dresden time. That sure is not a time when everybody is highly concentrated" [F52]

"The tasks where not that difficult, but the coordination of the group work was harder than imagined. Due to our different timetables and our studies and work, we had limited time $10 \mathrm{pm}$ in the evening until 2am." [F61]

- Initial Confusion / Anxiety: As Virtual Collaborative Learning was a new experience for most participants, an initial confusion was clear in multiple reflection reports. The collaboration 


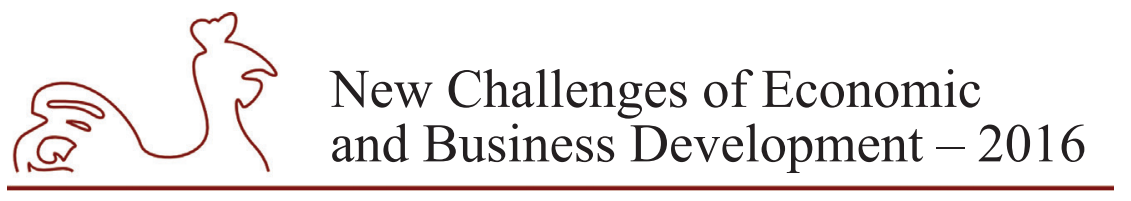

May 12-14, 2016, Riga, University of Latvia

with foreigner students in English language was another aspect that led to anxiety at the beginning of the course.

"When we had the first lecture and I saw the computer and beamer and everything, I started to felt a little nervous because I didn't know what would happen next. As I heard that we would work with students from Jordan, the nervousness increased." [F52]

"I had objections towards the work with people from other countries. First, my English is not the best and I was a little bit nervous communicating in a language, which is not my mother tongue." [M51]

"At the beginning we had some problems organizing the tasks. It was not clear how to efficiently use the CVC [Collaboration in the Virtual Classroom] platform." [M21]

- Unequal Effort / Varied Participation: Due to the fact that most Jordanian masters' students have a full-time job besides their studies, German participants developed a feeling of unequal participation from their peers and had to invest more efforts in the project to keep the teamwork going and fulfil the tasks on time.

"Because of the huge workload of the Jordan students the German students needed to do more sometimes which caused some tensions." [F11]

"The next disadvantage is that not everybody puts in the same effort, so some members had to do the work from the others. Deadlines when documents should have been uploaded were not adhered so that some members had an extra workload." [F52]

"The virtual collaboration in my group could have been more effective if all team members had contributed at an equal level. Some team members were rarely online which made teamwork obviously harder." [M51]

- Limitation to Own Role / Discipline: Although interdisciplinary collaboration was identified both as a motivation and a benefit for the students, close minded appreciation of own discipline and concentration only on own perspective confronted the students with limited exchange and complicated group solution development.

"One representative of the discipline may be thinks that his or her discipline is the most important for the project and should have more relevance for the solution." [F11]

"A problem we encountered during the CVC [Collaboration in the Virtual Classroom] course is that some team members aren't able to think out of the box. They stick to their discipline and role and don't try to empathize with the other team member. With such a tunnel view it is not possible to notice mistakes which aren't connected to the own role and pointing on it to help the other group member solving the problem they didn't notice." [M41]

- Varied Language Skills: Although all participants in this course were masters' students, who usually have to be able to read and write scientific papers in English language, a deficit in conversation skills was noticed. The groups tried to compensate this through mutual peer support, but the intensive collaboration in a short period made it difficult. 


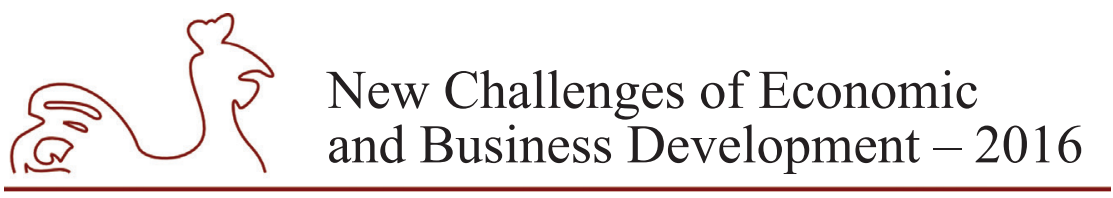

May 12-14, 2016, Riga, University of Latvia

"Another obstacle in this CVC [Collaboration in the Virtual Classroom] course was the language. Some members had problems to share their consolidated knowledge due to English issues. This is a problem that we tried to fix but due to the limited time period it was not really easy." [F42]

"The biggest obstacle for me was the language. It is different to work in a group of people that speak the same language as you do, German, than working with people who don't understand your language and you have to communicate in English." [F61]

"In our group there were a few language problems as the language skill basis was not the same." [M51]

\section{Students' Satisfaction}

In their written reflection reports, all German students participated in this international Virtual Collaborative Learning course showed a very high satisfaction with this new experience from different perspectives.

- Individual and Group Results: Despite the difficulties they faced during the group work, students where satisfied with the achieved results both as individuals and as groups.

"I am very proud about my improvement, which I can now use for future tasks and problems." [F41]

"Achieving surprisingly good results with a team that I never worked with in person is an outcome that has changed my view on teamwork." [M21]

- Fast Orientation and Effectiveness: As the reported initial confusion and anxiety decreased during the project, participants managed to collaborate effectively in satisfactory group dynamics.

"Once everyone got comfortable with the platform and the format of the course the organization and coordination of group tasks became much easier." [M11]

"At the beginning, the most challenging part of the project was to manage the different cultures and the differences in time. But after the first two weeks the problems disappeared as everyone got used to the new routine." [M51]

- Preparation for Future Study and Career: The students noticed a considerable improvement in their skills and competences after the course and considered it a valuable preparation for their future study and career.

"I could tell a difference concerning the English skills after finishing the project. This is another thing that is highly important for the future career of the students." [F52]

"With a lot of courses I had during my duration of study I don't think that they will help me in my future work life. Here however I have no doubt about it." [M11]

"I see the biggest influence to my professional work in the future. The experience broadened my mind and prepared myself to work in international companies or on international projects." [M61] 


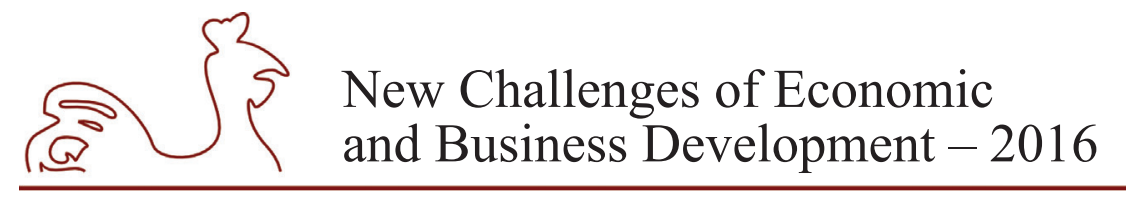

May 12-14, 2016, Riga, University of Latvia

- Recommended Experience: After practicing international virtual collaboration, the participants recommended the course to their fellows as an enjoyable affective experience that would considerably benefit them.

"All in all, the whole concept and execution of this VCL course was extremely well done. I learned a lot about virtual collaboration and because of this course I could experience it. This course was one of the best I've ever participated in and I will remember it a lot longer than most other regular courses." [M21]

"I would definitely recommend the course to other students. It's not like the standard lectures that you usually have und you can learn a lot of things that are useful for your future study and professional work." [F52]

\section{Conclusions}

This paper presented the qualitative evaluation of fifteen reflection reports written by German masters' students participated in an international Virtual Collaborative Learning course with peers from Jordan. The results show a considerable potential of this innovative approach to provide business students with an international experience during their regular study program at their home country. By practicing intercultural virtual collaboration and identifying its advantages and disadvantages, students enhanced their self-competence, professional competence, media competence, and English languages skills. After the course they felt better prepared for future studies and career in the globalised knowledge economy. To maximise the benefits and reduce the obstacles of similar courses, the students recommended extending the duration of the virtual collaboration phase, offering a pre-course training on the technical platform, providing more structured tasks and solution guidance, and securing a constant commitment from the foreigner peers. They recommended the course to all fellow students and requested more similar courses to be offered at the university as highlighted by one participant:

"Learning in a virtual classroom in this VCL [Virtual Collaborative Learning] course showed me, that there is not a single reason to me, why this concept should not be applied to every course in every university." [M21]

Particularly universities in developing countries can benefit from this approach to provide their student with a cost-effective enjoyable international experience using affordable collaborative Social Software (Tawileh, Bukvova and Schoop, 2013). The evaluation of this course from Jordanian students' perspective is reported in a separate study.

\section{Bibliography}

Clarke, K., 2005. Critical, multicultural education for remembering and reconciliation: A discussion of an interdisciplinary social science course for international students in Finland. Compare: A Journal of Comparative Education, 35(4), pp. 479-494.

Crossman, J. E. and Clarke, M., 2009. International experience and graduate employability: stakeholder perceptions on the connection. Higher Education, 59(5), pp. 599-613.

Hiltz, S. R., 1988. Collaborative learning in a virtual classroom: highlights of findings. In: CSCW '88. New York, NY, USA: ACM, pp. 282-290. 


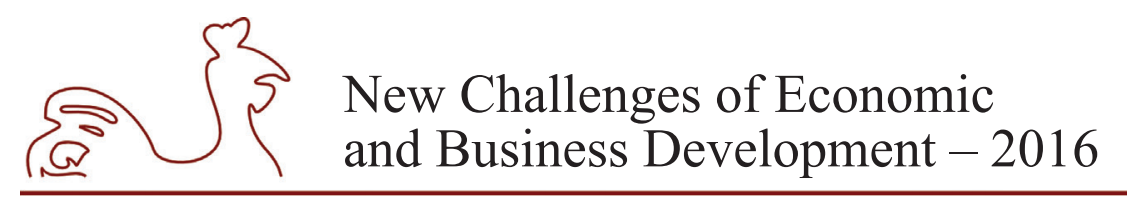

May 12-14, 2016, Riga, University of Latvia

Koskinen, L. and Tossavainen, K., 2003. Relationships with undergraduate nursing exchange students a tutor perspective. Journal of Advanced Nursing, 41(5), pp. 499-508.

Ledwith, S. and Seymour, D., 2001. Home and away: preparing students for multicultural management. The International Journal of Human Resource Management, 12(8), pp. 1292-1312.

Lehtinen, E., Hakkarainen, K., Lipponen, L., Rahikainen, M. and Muukkonen, H., 1999. Computer supported collaborative learning: A review. The JHGI Giesbers reports on education, 10.

Meisel, S. and Marx, B., 1999. Screen to Screen Versus Face to Face: Experiencing the Differences in Management Education. Journal of Management Education, 23(6), pp. 719-731.

Schoop, E., Bukvova, H. and Gilge, S., 2006. Blended Learning - the didactical framework for integrative qualification processes. Proceedings of Conference on Integrative Qualification in eGovernment, pp. 142-156.

Tawileh, W., Bukvova, H. and Schoop, E., 2013. Virtual Collaborative Learning: Opportunities and Challenges of Web 2.0-based e-Learning Arrangements for Developing Countries. In: N. A. Azab, ed., Cases on Web 2.0 in Developing Countries: Studies on Implementation, Application, and Use. 


\title{
THE HISTORY OF FINANCIAL ANALYSIS, ITS FOUNDERS AND THEIR SCHOOLS
}

\author{
Maria Tissen, University of Latvia, Latvia ${ }^{1}$ \\ Ruta Shneidere, University of Latvia, Latvia
}

\begin{abstract}
Financial analysis plays an important role in the life of every enterprise that works for the future and is ready for any kind of development, depending on opportunities and demand. The financial analysis indicators of an enterprise are to find already in the end of $19^{\text {th }}$ century. This was facilitated by widespread of double entry accounting throughout the world, as well as the emergence of accountability forms, that are similar to the modern counterparts.

The aim of the paper - to examine the emergence and formation of financial analysis as a science, starting from the end of the $19^{\text {th }}$ century.

The authors of the paper first of all will analyze the emergence of financial analysis, based on the different papers of the best financial analysis researchers from all over the world. The authors will briefly review different points of view on the origins of the financial analysis, according to academics. In the paper are analyzed first financial analysis schools from the second part of $19^{\text {th }}$ century and from the beginning of the $20^{\text {th }}$ century, where the major scientific figures of that time are marked. Next to the first financial analysis schools, the authors also examine the new financial analysis schools and their main achievements. In the paper the authors are using qualitative method, logically constructive method and empirical research method.

Every author is defining the definition of financial analysis on its own way, depending on the extent of their needs. The authors of the paper analyzed five main financial analysis schools: Empirical Pragmatists School, Ratio Statisticians School, Multivariate Modellers School, Balance studies, Commercial calculation. Based on the background of the above mentioned schools, the authors analyze the modern stage - the beginning of $20^{\text {th }}-21^{\text {st }}$ century, where the authors of the paper take six major financial analysis schools as a basis, they are: Distress Predictors School, Capital Marketers School, Pragmatic Empiricism, Deductive Approach, Inductive Approach, Confirmatory Approach.
\end{abstract}

Key words: financial analysis, major schools, founders

JEL code: A11, B26, G23

\section{Introduction}

Nowadays in the financial world any significant manipulations at an enterprise must have important confirmation and must be due to specific data. Thus the financial analysis indicators of the enterprise that are reflecting the real financial situation of the enterprise on the market play a meaningful role in life of every enterprise.

In the world of technology and innovation more and more new modifications and interpretations of financial analysis indicators of scientists from different schools are to find.

1 Corresponding author - e-mail address: maria@katiss.lv 


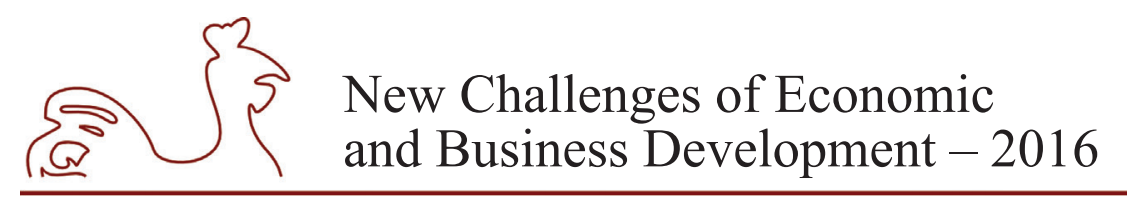

May 12-14, 2016, Riga, University of Latvia

Unfortunately there are very few studies about the origin and development of financial analysis. The history of financial analysis can help analyse the train of thoughts of discoverers and can help the followers, because the knowledge of the present is inconceivable without the knowledge of the past. Neglect of history to some extant will be always disrespectful to its result - future; as well known financier L. V. Khodsky claimed (Khodsky L. V., 1894).

The scientific problems of the paper: Why the definition of "financial analysis" term differs among world class academics? Which time period covered by financial statement of the enterprise should be taken as a basis for the main actual financial analysis ratios of the enterprise to the date?

The aim of the paper is to examine the emergence and formation of financial analysis as a science, starting from the end of the $19^{\text {th }}$ century.

In order to reach the aim five tasks are to be solved: The authors at first consider the determination of the financial analysis and the definition of financial analysis from the view of different scientists. This study analyzes the origins of financial analysis. The authors examine the appearance of the systematic approach to the financial analysis starting from the Renaissance period (the second part of $19^{\text {th }}$ century).

In this research are analyzed the first financial analysis schools of the second part of $19^{\text {th }}$ century and of the beginning of the $20^{\text {th }}$ century, which marked their major scientific figures.

Next to first financial analysis schools the authors study the new financial analysis schools and their main achievements.

Research methods: the authors are using the qualitative, logically constructive and empirical research methods.

The main results of the research - after the analysis on the definition of financial analysis from the perspective of the opinion of different school academics, as the most appropriate interpretation of the term the authors of the paper suggest and share the view of the definition by V. V. Kovalev (Kovalev V. V., 2010). The study on the opinions of different authors who are researching the development of the financial analysis, led the authors of the paper to be of J. O. Horrigans and J. V. Sokolovs opinion (Horrigan J. O., 1968 \& Sokolovs J. V., 2008).

These authors date the emergence of a systematic approach to financial analysis back to the second part of $19^{\text {th }}$ century - the last stage of Americas movement towards industry, transition from business management by enterpreneurs-capitalsists towards to professional management.

In this paper the authors analyse five main financial analysis schools in the second part of $19^{\text {th }}$ and to first part of $20^{\text {th }}$ century, namely: Distress Predictors School, Capital Marketers School, Pragmatically Empiricism School, Deductive Approach School, Inductive Approach School, and Confirmatory Approach School.

In this paper the authors will try to study three main components of the financial management in the current market conditions, by sharing the opinion of V. V. Kovalev, where he names financial analysis, internal analysis of the enterprise, feasibility analysis (Kovalev V. V., 2006).

In the results the authors are reflecting and analyzing nine first financial analysis ratios. To date the financial analysis of the enterprise is based on these financial analysis ratios.

\section{The Term Definition of Financial Analysis}

Before considering the development of the financial analysis in the historical context, it has to be found out, what is actually meant under the term of financial analysis nowadays. The definitions, given by different authors, are slightly different from each other, and the content 


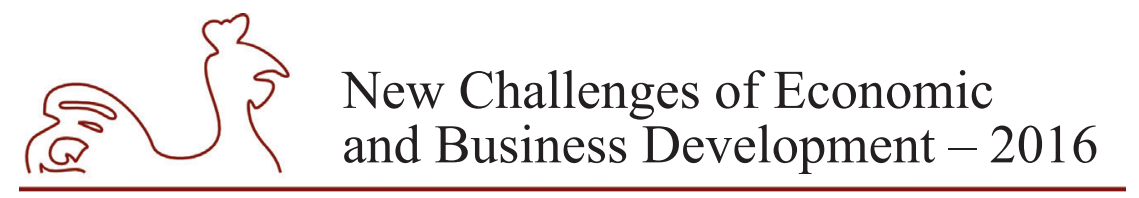

May 12-14, 2016, Riga, University of Latvia

and of the financial analysis methods varies: depending on: a) initial value, b) the aim of the analysis and c) the users of the analysis results (Table 1).

Table 1

The definition of financial analysis used by different researchers

\begin{tabular}{|c|c|}
\hline Researcher & The definition of financial analysis used by the researcher \\
\hline Dybal, S. V. & $\begin{array}{l}\text { "Financial analysis is a method of assessing retrospective (past) and perspective (fu- } \\
\text { ture) financial condition of business entity, based on the basis of study on depend- } \\
\text { ence and dynamics of financial analysis information" (Dybal S. V., 2009). S. V. Dybal } \\
\text { divides financial analysis into internal (conducted on the enterprise for short term, } \\
\text { efficient and long term management of different kind of enterprise activities) and } \\
\text { external (carried out on the basis of publicly available statistical and financial re- } \\
\text { porting by external stakeholder - banks, investors, business partners, auditors etc). }\end{array}$ \\
\hline $\begin{array}{l}\text { Brown, S. J. \& } \\
\text { Kritzman, M. P. }\end{array}$ & $\begin{array}{l}\text { Financial analysis - is "an analysis on the use of quantitative (computational) methods } \\
\text { in connection to the decision making process on investment" (BrownS. J. \& Kritz- } \\
\text { man M. P., 1989), i.e. the emphasis is made on one group of analysis results users - } \\
\text { investors. }\end{array}$ \\
\hline $\begin{array}{l}\text { Brigham, E.\& } \\
\text { Ehrhardt, M. }\end{array}$ & $\begin{array}{l}\text { "The analysis of financial statements includes: 1) a comparison of the effectiveness } \\
\text { of an enterprise with that of other enterprise working in the same field, and 2) an } \\
\text { assessment of enterprises' financial situation tendency over time. These researches } \\
\text { help managers to identify weaknesses and then take action that increase the efficien- } \\
\text { cy of the enterprise" (Brigham E. \& Ehrhardt M., 2001). }\end{array}$ \\
\hline Richard J. & $\begin{array}{l}\text { "The financial economic analysis of an enterprise includes a big amount of different } \\
\text { kinds of their business result evaluation. Primarily it depends on the goal: determination } \\
\text { of yield of the company in order to compare it with those of other companies or evalu- } \\
\text { ation of the company in terms of its market price" (Richard J., 1997). This researcher } \\
\text { points out that it is necessary to distinguish accounting approach (based on the ac- } \\
\text { counting data) and market approach (based on the determination of fair market value } \\
\text { of the company) to the conduct of analysis. At the same time, according to J. Richard, } \\
\text { the old western tradition bring financial analysis to the study of companies profitability } \\
\text { and solvency notice is the subject of criticism of Western experts, as it does not include } \\
\text { non-financial factors associated to the efficiency, inventory levels and others. }\end{array}$ \\
\hline Giroux G. & $\begin{array}{l}\text { "Financial analysis is using financial and other information for preparation of recom- } \\
\text { mendations and decisions. This process can be used for securities investments, deci- } \\
\text { sions on loans, decisions on acquisitions etc." (Giroux G., 2003). }\end{array}$ \\
\hline Kovalev V. V. & $\begin{array}{l}\text { "Financial analysis, understood as an analysis of financial management system, is } \\
\text { based on publicly available financial information and is part of analytical procedures } \\
\text { for assessing the enterprise in terms of valuation and efficiency" (Kovalev V. V., } \\
\text { 2006). This author examines in detail the location of financial analysis in the eco- } \\
\text { nomic analysis system, especially in the use of analysis of various profile specialists. }\end{array}$ \\
\hline $\begin{array}{l}\text { Sheremet A. D.\& } \\
\text { Negashev E. V. }\end{array}$ & $\begin{array}{l}\text { "Financial analysis - analysis of financial indicators that are reflecting business financial } \\
\text { results and financial situation of the organisation" (Sheremet A. D. \& Negashev E. V., } \\
\text { 2012). These authors similarly to S. V. Dybal divide the analysis into external and } \\
\text { internal, they show its place in the frames of enterprises economic activities analysis. }\end{array}$ \\
\hline $\begin{array}{l}\text { Stone D. \& } \\
\text { Hitching K.; } \\
\text { Tyukavkin N. M. }\end{array}$ & $\begin{array}{l}\text { These researchers do not provide the definition of financial analysis as such; they are } \\
\text { merely citing its aims, methods, users of analysis results and information database. } \\
\text { (Stone D. \& Hitching K., 1993; Tyukavkin N. M., 2008). }\end{array}$ \\
\hline
\end{tabular}

Source: research of the authors. 


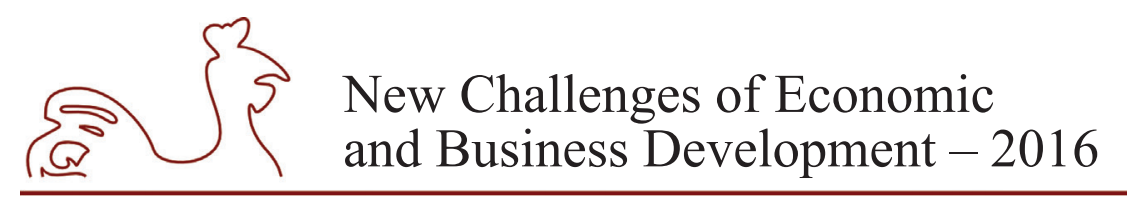

May 12-14, 2016, Riga, University of Latvia

This authors of this paper most share the opinion of financial analysis definition with V. V. Kovalev - Financial analysis, understood as an analysis of financial management system, is based on publicly available financial information and is part of analytical procedures for assessing the enterprise in terms of valuation and efficiency (Kovalev V. V., 2006). This author examines in detail the location of financial analysis in the economic analysis system, especially in the use of analysis of various profile specialists.

We now consider the history of the formation of financial analysis and its main schools. It should be noted that to date there have been published a relatively small number of papers devoted to the historical aspect of financial analysis. The authors dealing with the subject are I. Brown (1955), J. Horrigan (1968, 1994), Roy A. Foulke (1961), V. Kovalev (2006), T. Salmi (1994), R. Gracheva (2013), R. Olegario (2006), Y. Sokolov (2008) certain moments of the financial analysis history are considered in the papers devoted to the history of accounting.

In addition, from all the above-mentioned authors only J. Horrigan leads a clear periodization of the history of financial analysis, understanding financial analysis exceptionally as the analysis of financial statement. J. Horrigan writes about six periods 1) origins, 2) 1900-1919, 3) 19201929, 4) 1930-1939, 5) 1940-1945, 6) 1946 to the present. (Horrigan J., 1994).

\section{Renaissance - second part of $19^{\text {th }}$ Century}

This period of the history of financial analysis is associated with the emergence of systematic approach to the analysis on accounting data of an enterprise. It was facilitated by the widespread double entry in the accounting all around the world, as well because of the emergence of the forms of accounting statements that are close to the modern counterparts. Researchers disagree on the exact time when such systematic approach to the analysis has first emerged. 


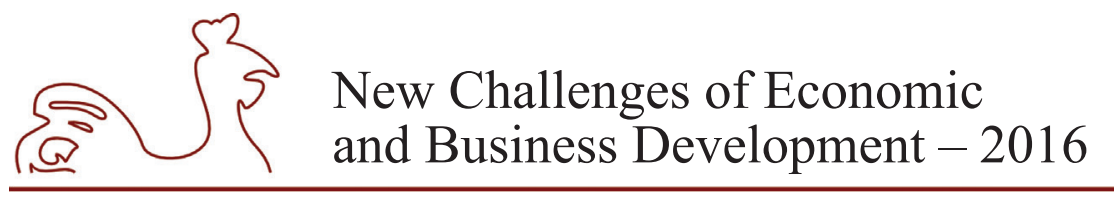

May 12-14, 2016, Riga, University of Latvia

Table 2

Opinions of different researchers on the emergence of systematic approach to the financial analysis

\begin{tabular}{|c|c|}
\hline Researcher & $\begin{array}{l}\text { The opinion of the researcher on the emergence of systematic approach to } \\
\text { the financial analysis }\end{array}$ \\
\hline Horrigan J. & $\begin{array}{l}\text { The ratios for the use of financial statements were first used in the second part of } 19^{\text {th }} \\
\text { century, on the last stage of America's movement towards industrial development. } \\
\text { The appearance of financial statement analysis J. Horiggan connects with the business } \\
\text { management transition from capitalist entrepreneurs to professional managements } \\
\text { and the strengthening role of financial institutes in the economy over the above- } \\
\text { mentioned stages. (Horrigan J., 1968) }\end{array}$ \\
\hline Sokolov Y. & $\begin{array}{l}\text { As the first financial analysis theorist should be considered J. Cannon (Bing G., } \\
\text { 2008). In the end of } 19^{\text {th }} \text { century he suggested the first liquidity ratio and } 9 \text { other } \\
\text { financial analysis ratios. }\end{array}$ \\
\hline Olegario R. & $\begin{array}{l}\text { The current liquidity ratio (the ratio of current assets to current liabilities) became } \\
\text { prevalent by the end of } 1890 \text {-ies. The banks frequently used the ratio as the only } \\
\text { proper mean for determining the reliability of the borrower. The banks started to } \\
\text { advertise "he rule of } 50 \text { percent" (current assets of borrower should not exceed } 50 \% \\
\text { of its current assets). National Association of Credit Management (NACM) issued } \\
\text { relevant directives in 1902, but in } 1905 \text { James Cannon, the president of the Association } \\
\text { proposed a totality of financial analysis ratios in his message for Bankers Association } \\
\text { of New Jersey (Olegario R., 2006). }\end{array}$ \\
\hline Kovalev V. V. & $\begin{array}{l}\text { The founder of systematic approach to analysis (internal financial analysis of an } \\
\text { enterprise) should be considered Jeacque Savari (1622-1690). He created the concept } \\
\text { of syntactical and analytical accounting. Thus the development of the analysis } \\
\text { elements usage could be observed in other countries as well, such as, Italy. Angelo } \\
\text { di Pietro (1550-1590) compared the budgetary appropriations to the actual costs. } \\
\text { Bastiano Venturi (1655) was engaged in the construction and analysis of dynamic } \\
\text { series of economic activities of the enterprise. Later Giuseppe Cerboni (1827-1917) } \\
\text { deepened the ideas of J. Savari by creating the doctrine of the synthetic addition and } \\
\text { analytical expansion of accounting charts (Kovalev V. V., 2006). }\end{array}$ \\
\hline
\end{tabular}

Source: research of the author.

The authors of the paper share the view of J. Horrigan and Y. Sokolov on this subject, despite that J. Savari and Italian authors of the selected time period, contributed to the evolution of financially analytical procedures. The moment when the emergence of financial ratios (that are still the main tool of financial analysis to this date) in the United States in second part of $19^{\text {th }}$ century should be counted as the moment of the emergence of systematic approach to the analysis based on accounting statement of the enterprise.

\section{Second Half of $19^{\text {th }}$ Century - the Beginning of $20^{\text {th }}$ Century}

This phase can be characterized by the emergence of first financial analysis school; here will be presented their description (Table 3). Note that according to the authors of the paper, balance study, also known as "commercial calculation" (or "commercial arithmetic") can also be attributed to the first financial analysis schools. 


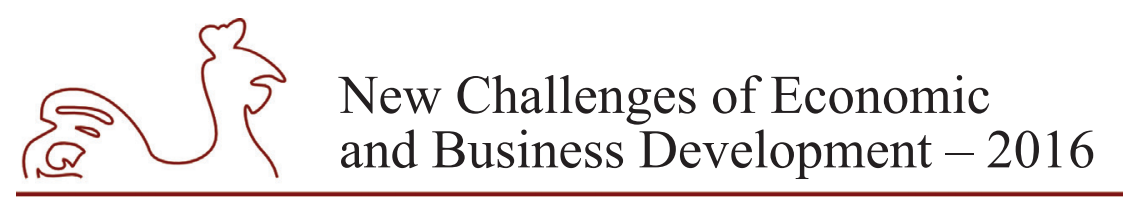

May 12-14, 2016, Riga, University of Latvia

Table 3

First financial analysis schools (second half of $19^{\text {th }}-$ the beginning of $20^{\text {th }}$ century)

\begin{tabular}{|c|c|}
\hline $\begin{array}{l}\text { Name of } \\
\text { the school }\end{array}$ & Representatives of the school and questions developed by the school \\
\hline $\begin{array}{l}\text { Empirical } \\
\text { Pragmatists } \\
\text { School }\end{array}$ & $\begin{array}{l}\text { The representatives of this school include professional analysts who by analyzing } \\
\text { company's creditworthiness developed totality of relative ratios for conduction of } \\
\text { this type of analysis. That means, the purpose of these analysts was to develop a set } \\
\text { of ratios so that these ratios could answer to the question whether the enterprise is } \\
\text { able to pay off its short-term liabilities. Since they accepted this aspect of analysis as } \\
\text { the most important, the ratios that they used were characterizing the enterprises own } \\
\text { working capital, turnover means, and current liabilities. } \\
\text { Major representative of this school is R. Foulke, who in the early fifties of } 20^{\text {th }} \text { century } \\
\text { made developments for the world's largest information enterprise "The Dun and } \\
\text { Breadstreet". According to the opinion of Paul Barnes, the main contribution of this } \\
\text { school to the theory of financial statement analysis is the fact that the members of this } \\
\text { school for the first time made an attempt to show the diversity of financial ratios that } \\
\text { could be calculated based on financial statements. The given ratios might be further } \\
\text { used for management decision-making in the field of finance. }\end{array}$ \\
\hline $\begin{array}{l}\text { "Ratio } \\
\text { Statisticians } \\
\text { School" }\end{array}$ & $\begin{array}{l}\text { Alexander Wall is considered as the founder of the school. In } 1919 \text { he published } \\
\text { a paper on the development of criteria for creditworthiness (Wall, 1919). The main idea } \\
\text { of these schools representatives is the position that the calculation of the analytical } \\
\text { coefficients based on financial statements makes sense only then, when there are } \\
\text { some threshold meanings (criteria) that these coefficients can be compared. It was } \\
\text { proposed to obtain such thresholds by means of statistical processing of the coefficient } \\
\text { distribution into groups of similar enterprises (similar in sectors, sub-sectors and } \\
\text { groups). The selection of individual strata for which it could be possible to develop } \\
\text { separate standards was one of the main tasks of these schools representatives. } \\
\text { Since the sixties, within this school a study on the stability and collinear coefficients } \\
\text { is conducted. Studies have shown that many coefficients are multicollinear in time } \\
\text { and space sections, this is why the classification of all coefficients into groups was } \\
\text { an actual problem. Within each group there is a correlation, however the coefficients } \\
\text { from different groups owns relative independence. }\end{array}$ \\
\hline $\begin{array}{l}\text { "Multivariate } \\
\text { Modellers } \\
\text { School" }\end{array}$ & $\begin{array}{l}\text { The main provision of the representatives of this school is the construction of } \\
\text { conceptual foundations of financial statement analysis. Such a foundation, according } \\
\text { to the founders, is based on the strong connection of private financial coefficients (that } \\
\text { are characterizing financial condition and effectiveness of the company's activities, } \\
\text { such as turnover of funds, gross income etc.) and generalized coefficients of financial } \\
\text { and economic activities (for example, profitability of advanced capital). } \\
\text { The founders of this school to be considered are James Bliss, Arthur H. Winakor and } \\
\text { others who worked in 1920-ies (Smith \& Winakor, 1935; Stevenson, 1925; Bliss, } 1924 \text {. } \\
\text { Creating a pyramid (a system) of ratios was the main objective of the representatives } \\
\text { of this school. Development of computer simulation of interrelated models of } \\
\text { the stock market and analytical coefficients was to determine the development of this } \\
\text { direction. }\end{array}$ \\
\hline
\end{tabular}




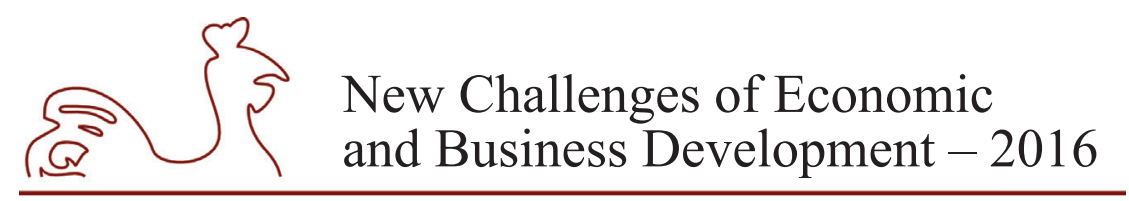

May 12-14, 2016, Riga, University of Latvia

\begin{tabular}{|c|c|}
\hline & Representatives of the school and questions developed by the school \\
\hline Study of balance & $\begin{array}{l}\text { The study of balance emerged as a new branch of accounting in the end of } 19^{\text {th }} \text { and } \\
\text { the beginning of } 20^{\text {th }} \text { century. Mainly the representatives of German accounting } \\
\text { statements developed it. The study of balance has developed in three main areas: } \\
\text { 1) The economical analysis of balance. The representatives of this area are I. Sher, } \\
\text { P. Gerstner, F. Leutner, for example, Gerstner propose to use analytical characteristics } \\
\text { of balance: the ratio of short term and long term liabilities, the determination of } \\
\text { the upper limit of borrowed funds in the amount of } 50 \% \text { of the advanced capital, } \\
\text { mutual relationship of liquidity and financial condition, and others (Gerstner). } \\
\text { 2) The legal analysis of the balance. To the representatives of this trend could be } \\
\text { count R. Beigel, E. Remer, K. Porzig and others. In this area the theory and } \\
\text { practice of financial audit has been developed. In the recent years the financial } \\
\text { audit transformed into audit. } \\
\text { 3) Promotion of knowledge on balance between users. Among the representatives of } \\
\text { this area can be named Brosious, Hubert, Schenwandt and others. } \\
\text { Economic science of Russia was closely correlating with Germans; this is why } \\
\text { the study of balance as a system of some analytical calculations in respect of an } \\
\text { enterprise has found its recognition in Russia. The greatest development of study } \\
\text { of balance in Russia took place in the first part of } 20^{\text {th }} \text { century, but first Russian } \\
\text { accountant, who assessed its role and connection to accounting statement, Kovalev } \\
\text { names A. Roschakhovsky (1910). In the 1920-ies the theory of the study of balance } \\
\text { were completely framed in the papers of Russian scientists A. Rudanovsky (1928), } \\
\text { N. Blatonov (1940), I. Nikolayev (1926) and others. }\end{array}$ \\
\hline $\begin{array}{l}\text { "Commercial } \\
\text { calculations" } \\
\text { (or "commercial } \\
\text { arithmetic" }\end{array}$ & $\begin{array}{l}\text { In addition to the analytical procedures the accountants have to make some financial } \\
\text { calculations. The last calculations emerged with the advent of capitalism and began } \\
\text { to form a separate branch of knowledge in the } 19^{\text {th }} \text { century. At that time they were } \\
\text { named "commercial calculations" or "commercial arithmetic" and included interest } \\
\text { calculations (simple and compound interest), bill calculation of discount and discount } \\
\text { equipment, bill-exchange calculations, calculations of interest-bearing securities and } \\
\text { shares, calculations of financial transactions (short-term and long-term deposits and } \\
\text { loans). The rapid development of a number of countries in the late } 19^{\text {th }} \text { century is } \\
\text { sufficiently associated with the development of commercial systems knowledge. } \\
\text { In pre-revolutionary Russia the development of the theory and practice of commercial } \\
\text { (financial) calculations was associated primarily with the work of the outstanding } \\
\text { Russian mathematician, financial manager and accountant N. Lunsky(1912) (the late } \\
\text { 19th century - first quarter of } 20^{\text {th }} \text { century), see e.g. N.S. Lunsky is considered as } \\
\text { one of the founders of financial management in Russia. Besides N. S. Lunsky to } \\
\text { the Russian scientists who were fruitfully working during those years in this field } \\
\text { can be counted R. Weizmann (1927), A. Gulyaev (1909), A. Lomovissky (1908.), } \\
\text { B. Malashevsky (1890) and others. } \\
\text { Further on the commercial (financial) calculations did not receive any serious } \\
\text { development in Russia/USSR due to the countries orientation on command and } \\
\text { control, planning methods of economy management. In the countries with a focus on } \\
\text { market economy, on the other hand, commercial arithmetic gradually became a part } \\
\text { of the science and practice, and became an independent direction, that nowadays is } \\
\text { known as "financial management" }\end{array}$ \\
\hline
\end{tabular}

Source: research of the authors. 


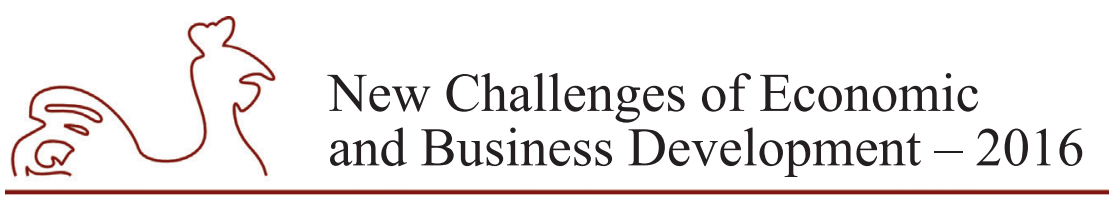

May 12-14, 2016, Riga, University of Latvia

After the analysis on the first financial analysis schools (second part of $19^{\text {th }}$ - first part of $20^{\text {th }}$ century) it can be concluded that in this period of time there was a huge development in all fields of economy and industry. This led to the chain reaction in the development that affected all related activities of the field, including financial analysis.

\section{The Early $20^{\text {th }}$ and $21^{\text {st }}$ Century: Modern Phase}

This phase of financial analysis evolution is connected to the emergence of new financial analysis school, as well as with the development of the old financial analysis schools. According to J. Horrigan (1968), everything that has been initiated in this area continues to develop at the moment, it means, the history of the development question reflects modern practice of financial statement analysis. Let's briefly describe the new schools that have arisen at this stage (Table 4).

Table 4

Modern schools of financial analysis (the early $20^{\text {th }}-$ the early $21^{\text {st }}$ century)

\begin{tabular}{|c|c|}
\hline $\begin{array}{l}\text { Name of } \\
\text { the school }\end{array}$ & Representatives of the school and questions developed by the school \\
\hline $\begin{array}{l}\text { "Distres } \\
\text { Predictors } \\
\text { School" }\end{array}$ & $\begin{array}{l}\text { Unlike the Empirical Pragmatists school, the Distres Predictors School is not focusing } \\
\text { on the analysis of the company's ability to pay its short-term obligation, but on its } \\
\text { financial stability, foresight analysis preferred retrospective analysis. According to } \\
\text { the representatives of this school the accounting statements is valuable only in that } \\
\text { case if it is able to predict the possible bankruptcy of the enterprise. } \\
\text { Winakor (1935) and R. Smith (1930) are the founders of the school; they were } \\
\text { working in the 1930-ies. The techniques and methods of bankruptcy got their most } \\
\text { complete form in the studies made by Edward Altman (1968). }\end{array}$ \\
\hline $\begin{array}{l}\text { "Capital } \\
\text { Marketers } \\
\text { School" }\end{array}$ & $\begin{array}{l}\text { This direction is one of the newest on the time of occurrence and evolves with 1960- } \\
\text { ies. Among the most famous names of the Capital Marketers School, George Foster } \\
\text { (1986) hast to be named. According to Foster financial accounting is valuable insofar } \\
\text { it can be used for the projections of effectiveness and investment risks in securities. } \\
\text { This school differs from others on its excessive theorizing, is developed mainly by } \\
\text { the scientists and is still not recognized by practitioners. }\end{array}$ \\
\hline $\begin{array}{l}\text { "Pragmatical } \\
\text { Empiricism" } \\
\text { (the term was } \\
\text { created by } \\
\text { J. Horrigan } \\
\text { in } 1968, \\
\text { the approach was } \\
\text { singeled out by } \\
\text { T. Salmi) }\end{array}$ & $\begin{array}{l}\text { This approach is based on practical experience and opinions of different authors of } \\
\text { books on finances and accounting, being subjective in its own nature. In a very broad } \\
\text { sense all the authors can be split into } 3 \text { groups of financial ratios: profitability ratio, } \\
\text { the long-term solvency (capital structure) and short-term solvency (liquidity). No } \\
\text { other general point of view of different authors exists. } \\
\text { These authors include Weston and Brigham) (1972), Lev (1974), Tamari } \\
\text { (1978), Morley (1984), White, Sondhi and Fried (1994) and some others. Public } \\
\text { authorities may also give their recommendations or advices in the framework of } \\
\text { this approach. }\end{array}$ \\
\hline
\end{tabular}




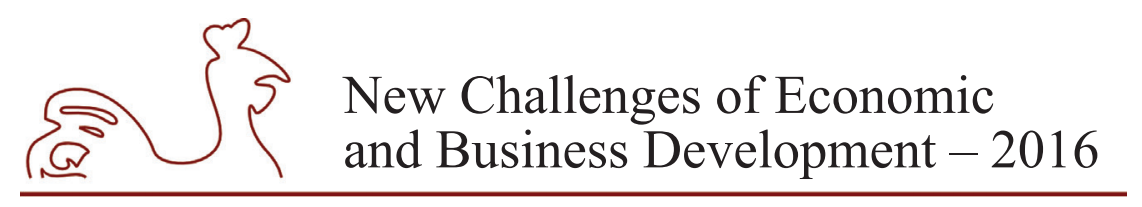

May 12-14, 2016, Riga, University of Latvia

\begin{tabular}{|c|c|}
\hline $\begin{array}{c}\text { Name of } \\
\text { the school }\end{array}$ & Representatives of the school and questions developed by the school \\
\hline $\begin{array}{l}\text { "Deductive } \\
\text { Approach" }\end{array}$ & $\begin{array}{l}\text { "Deductive Approach". The classic of "deductive approach" goes back to } 1919 \text { to } \\
\text { the du Pont triangle system. More recent authors use this approach with a significant } \\
\text { complication. } \\
\text { Courtis (1978) proposed a model that combines } 79 \text { interconnected ratios. Laitinen } \\
\text { (1983) created a model of financial relationship in the enterprise with attached financial } \\
\text { ratios; empirical data based on } 43 \text { publicly traded Finnish firms supports the structure } \\
\text { of the model. Bayldon, Woods, and Zafiris (1984) evaluate a pyramid scheme of } \\
\text { financial ratios. In a case study the pyramid scheme does not function as expected. } \\
\text { The deductive approach to establish relevant financial ratio categories has more or } \\
\text { less stalled, and this approach has become intermixed with "confirmatory approach". }\end{array}$ \\
\hline $\begin{array}{l}\text { "Inductive } \\
\text { Approach" }\end{array}$ & $\begin{array}{l}\text { "Inductive Approaches" characteristic is the emphasis on data and statistical methods. } \\
\text { The empirical rather than the theoretical foundations are playing less important role. } \\
\text { Pinches, Mingo and Caruthers (1973) apply factor analysis to classify } 51 \text { log- } \\
\text { transformed financial ratios of } 221 \text { firms for four cores sections six years apart. } \\
\text { Seven factors that they identify (return on investment, financial leverage, short-term } \\
\text { liquidity and others) explain } 78-92 \% \text { of the total variance of the } 51 \text { chosen financial } \\
\text { ratios with reasonably stable ratios over time. } \\
\text { Johnson (1978) runs the factor analysis for a single year 1972, but for two industries } \\
\text { based on a sample of } 306 \text { primary manufacturing and } 61 \text { retail firms. Congruency } \\
\text { coefficients of financial ratios indicate a good stability of the nine factors for the two } \\
\text { industries. } \\
\text { According to Chen and Shimerda (1981) they pick out } 41 \text { financial ratios, which are } \\
\text { found useful in the earlier studies. They identify } 7 \text { main factors and } 10 \text { financial ratios } \\
\text { that are representative of their seven factors. } \\
\text { Cowen and Hoffer (1982) study the inter-temporal stability of financial ratio } \\
\text { classification in a single, homogeneous industry. Their sample consists of } 72 \text { oil- } \\
\text { crude industry firms for 1967-75. Four or five selected factors for each year for } \\
\text { the } 13 \text { financial ratios have little stability. Many other researchers also find instability } \\
\text { of factors for financial ratios group for different selections. } \\
\text { To the other researchers who use factor analysis for financial ratios based on } \\
\text { the extensive statistical data, can be count Aho (1980), Gombola and Ketz (1983), } \\
\text { Salmi, Virtanen and Yli-Olli) (1990). Yli-Olli and Virtanen (1986, 1989, 1990) } \\
\text { introduce the usage of transformation analysis to study the stability of the financial } \\
\text { ratio patterns. Factorization of financial ratios has also been a part in several } \\
\text { multivariate studies analyzing the economic features of the firms. }\end{array}$ \\
\hline $\begin{array}{l}\text { "Confirmatory } \\
\text { Approach" }\end{array}$ & $\begin{array}{l}\text { An emergence of this idea can be explained by initial optimism the inductive studies } \\
\text { have been unable to agree on a consistent classification of financial ratio factors, } \\
\text { at least beyond the basic factors. Consequently the supporters of confirmatory } \\
\text { approach propose an a priori classification as a hypothesis and then try to confirm } \\
\text { the classification with empirical evidence. } \\
\text { The authors who are studying this field are Laurent (1979), Pohlman and Hollinger } \\
\text { (1981), Luoma and Ruuhela (1991), Kanto and Martikainen (1991). The results of } \\
\text { the use of the given approach are presented as reasonably successful. }\end{array}$ \\
\hline
\end{tabular}

Source: research of the authors. 


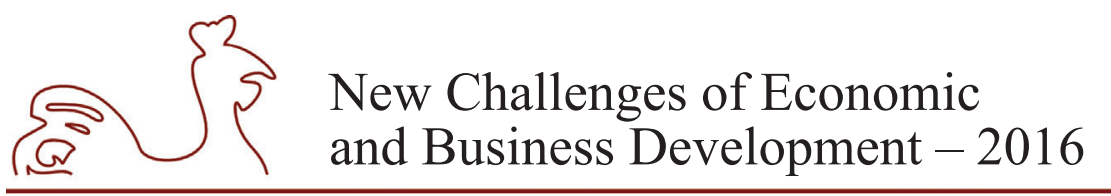

May 12-14, 2016, Riga, University of Latvia

It should be noted that the term "financial analysis" and "analysis of financial statements" are not synonyms, and the analysis of financial statements is usually a major part of the financial analysis. However, natural limitations of statements capabilities to provide data for analysis in recent years have led to the fact that the nearest perspectives for the development of analysis of financial statements are mainly related to two directions: the development of new analytical ratios and the expansion of the analysis information base (Kovalev V. V., 2006).

According to V. V. Kovalev the analysis of financial activity as it was understood before, in today's market conditions splits into 3 parts (Table 5).

Table 5

The components of the analysis of financial activity in the current market conditions

\begin{tabular}{|l|l|}
\hline Name of the component & \multicolumn{1}{|c|}{ The components of the analysis of financial activity } \\
\hline Financial analysis & $\begin{array}{l}\text { The analysis in the frames of financial management, the results of this } \\
\text { analysis are publicly available }\end{array}$ \\
\hline In-house analysis & $\begin{array}{l}\text { Analysis of the common system of management accounting and financial } \\
\text { management, the results of this type of analysis are not available to all, even } \\
\text { within the enterprise }\end{array}$ \\
\hline $\begin{array}{l}\text { Technical economic } \\
\text { analysis }\end{array}$ & $\begin{array}{l}\text { The analysis of the enterprise management; the results of this analysis can be } \\
\text { expressed in different terms, rather than efficiency. In the first line they are } \\
\text { interesting for line managers and are not external users-oriented }\end{array}$ \\
\hline
\end{tabular}

Source: V. V. Kovalev, 2006.

\section{The Main Financial Analysis Ratios, their Emergence and History}

Let us consider the very first financial analysis ratios that we partly mentioned previously in this paper. According to the authors of this study, to such ratios are mainly related ratios proposed by James Cannon in the late $19^{\text {th }}$ and early $20^{\text {th }}$ century (that is why there is no wonder why some researchers believe that Cannon might be the first theorist of financial analysis (Sokolov, 1991; Olegario, 2006) with some exceptions. A description of these ratios (ratio calculation, the purpose of the ratio, the author) is given in the Table 6. 


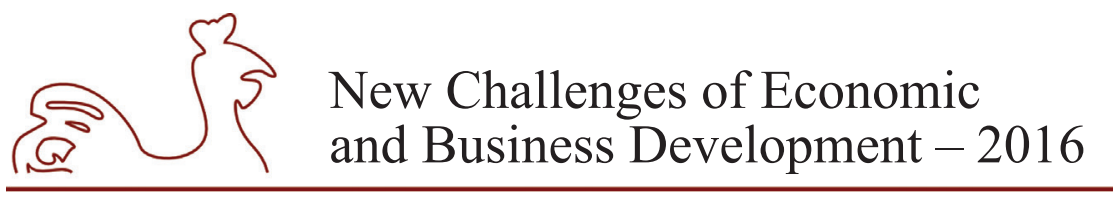

May 12-14, 2016, Riga, University of Latvia

Table 6

The first financial analysis ratios

\begin{tabular}{|c|c|c|c|c|}
\hline No. & $\begin{array}{c}\text { The name of } \\
\text { the ratio }\end{array}$ & $\begin{array}{c}\text { The calculation of } \\
\text { the ratio }\end{array}$ & The purpose of the ratio & The author of the ratio \\
\hline 1 & - & $\frac{\text { Expenses }}{\text { SalesValue }} * 100$ & $\begin{array}{l}\text { The analysis of the share } \\
\text { of expenses in the revenue } \\
\text { of the enterprise }\end{array}$ & $\begin{array}{l}\text { The author is unknown, is } \\
\text { used approximately since } \\
\text { the mid- } 19^{\text {th }} \text { century }\end{array}$ \\
\hline 2 & Current ratio & $\frac{\text { CurrentAssets }}{\text { CurrentLiabilities }}$ & $\begin{array}{l}\text { Determination of } \\
\text { borrowers solvency }\end{array}$ & $\begin{array}{l}\text { The author is unknown; } \\
\text { the ratio became } \\
\text { predominant in the end of } \\
1890 \text {-ies. }\end{array}$ \\
\hline 3 & - & $\frac{\text { QuickAssets }}{\text { Obligations }}$ & $\begin{array}{l}\text { Determination of } \\
\text { borrowers solvency }\end{array}$ & $\begin{array}{l}\text { Proposed by James Cannon } \\
\text { in } 1895 . \text { Under "quick } \\
\text { assets" Cannon meant } \\
\text { more liquid part of current } \\
\text { assets (funds, receivables, } \\
\text { securities, commodities) } \\
\end{array}$ \\
\hline 4 & $\begin{array}{l}\text { Quick assets of } \\
\text { total assets }\end{array}$ & $\frac{\text { QuickAssets }}{\text { TotalAssets }}$ & $\begin{array}{l}\text { Determination of } \\
\text { borrowers solvency }\end{array}$ & $\begin{array}{l}\text { Proposed by James Cannon } \\
\text { in } 1905 .\end{array}$ \\
\hline 5 & $\begin{array}{l}\text { Gross sales per } \\
1 \$ \text { quick assets }\end{array}$ & $\frac{\text { GrossSalesValue }}{\text { QuickAssets }}$ & $\begin{array}{l}\text { The assessment of } \\
\text { management activity and } \\
\text { of the mobility of working } \\
\text { capital }\end{array}$ & $\begin{array}{l}\text { Proposed by James Cannon } \\
\text { in } 1905\end{array}$ \\
\hline 6 & $\begin{array}{l}\text { Gross sales per } \\
1 \$ \text { total assets }\end{array}$ & $\frac{\text { GrossSalesValue }}{\text { TotalAssets }}$ & $\begin{array}{l}\text { The assessment of } \\
\text { management activity and } \\
\text { of the mobility of assets }\end{array}$ & $\begin{array}{l}\text { Proposed by James Cannon } \\
\text { in } 1905\end{array}$ \\
\hline 7 & $\begin{array}{l}\text { Gross business } \\
\text { per one dollar } \\
\text { of working } \\
\text { capital }\end{array}$ & $\frac{\text { GrossBusinessValue }}{\text { WorkingCapital }}$ & $\begin{array}{l}\text { The assessment of } \\
\text { management activity and } \\
\text { of the mobility of working } \\
\text { capital }\end{array}$ & $\begin{array}{l}\text { Proposed by James Cannon } \\
\text { in } 1905\end{array}$ \\
\hline 8 & $\begin{array}{l}\text { Gross business } \\
\text { per one dollar } \\
\text { of total capital }\end{array}$ & $\frac{\text { GrossBusiness Value }}{\text { TotalCapital }}$ & $\begin{array}{l}\text { The assessment of } \\
\text { management activity and } \\
\text { of the mobility of invested } \\
\text { capital }\end{array}$ & $\begin{array}{l}\text { Proposed by James Cannon } \\
\text { in } 1905\end{array}$ \\
\hline 9 & - & $\frac{\text { BorrowedFunds }}{\text { AdvancedCapital }}$ & $\begin{array}{l}\text { The assessment of } \\
\text { the financial sustainability } \\
\text { of the enterprise }\end{array}$ & $\begin{array}{l}\text { Proposed by James Cannon } \\
\text { in } 1905\end{array}$ \\
\hline
\end{tabular}

Source: Olegario R., 2006, Foulk R., 1961, Cannon J., 1905, Gerstner P., 1926.

As it can be seen in Table 6 first financial analysis ratios were suggested by a) unknown authors in $19^{\text {th }}$ century, b) James Cannon in the late $19^{\text {th }}$ and early $20^{\text {th }}$ century and c) Paul Gerstner in the late $19^{\text {th }}$ - early $20^{\text {th }}$ century. These ratios were focused on the analysis of the expenditure share in the revenue of the enterprise, assessment of the current assets liquidity of the enterprise to determine the borrower's creditworthiness, assessment of management activity and of mobility of enterprise's assets, assessment of financial sustainability of the enterprise. 


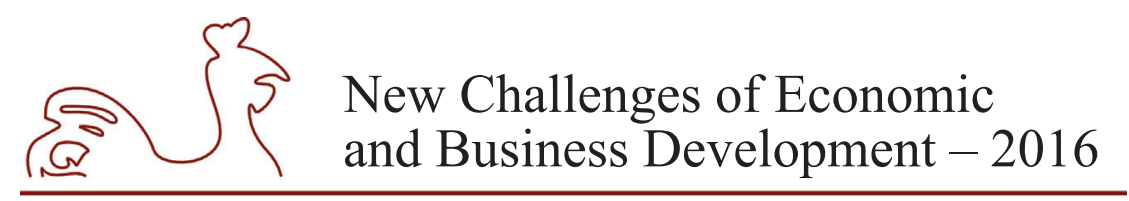

May 12-14, 2016, Riga, University of Latvia

\section{Conclusions}

In this paper the authors accomplished all the tasks specified at the beginning of the research. After studying and analysing the views of different scientists, who are researching financial analysis, its history and development, it can be concluded:

1. To date there is no single definition of the financial analysis; every user is using the procedure and its individual elements for different purposes. The connection and the methods of financial analysis may vary depending on methods and aims of the analysis, analysis results users. For the further research the authors share the view of V. V. Kovalev and adhere to the definition of the financial analysis proposed by him. Financial analysis, understood as an analysis of financial management system, is based on publicly available financial information and is part of analytical procedures for assessing the enterprise in terms of valuation and efficiency

2. The financial analysis' researchers partially disagree on the emergence of systematic approach of the financial analysis. The authors of the paper, after studying the views of different researchers, share the view of J. Horrigan and J. V. Sokolov. They assert, that the financial analysis ratios for the analysis of financial statements were first popular in the second part of $19^{\text {th }}$ century, when the US were on the last stage of the movement towards industrial activity. J. J. Horrigan links the emergence of the financial statement analysis to the transition of business management from capitalist entrepreneurs to professional managers.

3. James Cannon should be considered as the first theorist of the financial analysis. He proposed one of the first groups of financial analysis coefficients for users, based on the financial statements of the enterprise.

4. First financial analysis schools (second part of the $1919^{\text {th }}-$ first part of the $20^{\text {th }}$ century). The analysis of the directions and achievements of five financial analysis schools showed that these schools were popular in their field and were actively working, tried to solve the current issues in the economy. It should be noted that financial analysis schools were developing parallel to the evolution of accounting statements and statistical methods.

5. Modern schools of financial analysis (the early $20^{\text {th }}$ - the early $21^{\text {st }}$ century) can be divided into six approaches, based on the evolution of the schools from previous period. New schools developed those ideas that were laid in the schools of previous period and improve them with elements that are demanded today.

6. One of the first financial analysis ratios were used to detect the share of the expenditure in the revenue of the enterprise, to assess the liquidity of the current assets, to determine the creditworthiness of the borrowers, to evaluate the management activity and mobility of enterprise's assets, assessment of the financial sustainability of the enterprise. All these ratios are relevant today, but are applied in practice in the edited format.

In the further research the authors of the paper will propose their developed matrix of modified financial analysis ratios, where the financial analysis ratios will be classified depending on the user group and the field of enterprise's activity. According to the author, such matrix may help the users to be mobile in their calculations; as well it may help enterprises to reduce the costs for the financial analysis. 


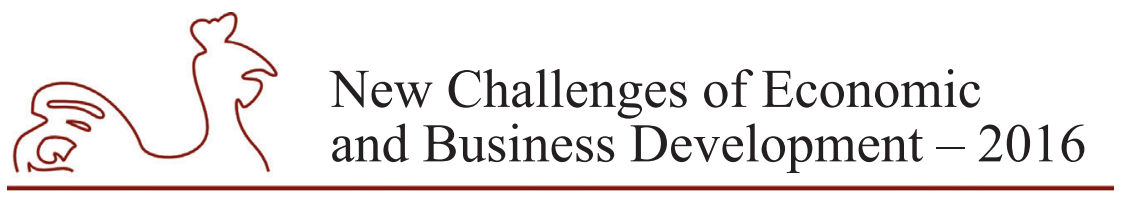

May 12-14, 2016, Riga, University of Latvia

\section{Bibliography}

Aho T., 1980. Empirical Classification of Financial Ratios. Management Science in Finland. Proceeding, ed C. Carlsson.

Altman Edward I., 1968. Financial Ratios, Determinant Analysis and the Prediction of Corporate Bankruptcy. The Journal of Finance, XXIII, Nr. 4, September, pp. 589-609.

Baruch L., 1974. Financial Statement Analysis: a New Approach Prentice-Hall, pp. 262.

Bayldon R., Woods A., Zafiris N., 1984. A Note on the Pyramid technique of Financial Ratio Analysis of Firm Performance. Journal of Business Finance and Accounting. Vol. 11-1, pp. 99-106.

Bing G., 2008. Due diligence: planning, questions, issues. Praeger Publishers, pp. 224.

Brigham Eugene F., Ehrhardt Michael C., 2001. Financial Management: Theory and Practice, $10^{\text {th }}$ Edition. Harcourt College Pub., pp. 1136.

Brown Stephen J., Kritzman Mark P., 1989. Quantitative Methods for Financial Analysis, pp. 230.

Brown I., 1955. The Historical Development of the Use of Ratios in Financial Statement Analysis to 1933. Catholic University of America Press, Washington, D.C.

Bliss. James H., 1924. Management Through Accounts, New York: Ronald, pp. 851.

Cannon J. G., 1895. Losses by Bad Debts. Banker's magazine. Vol 51, pp. 199-201.

Chen K. H., Shimerda, T. A., 1981. An Empirical Analysis of Useful Financial Ratios. Financial Management. Vol. 10, Spring, pp. 51-60.

Chen K. H., Shimerda, T. A., 1981. An Empirical Analysis of Useful Financial Ratios. Financial Management. Vol. 10, Spring, pp. 51-60.

Cowen S. S., Hoffer J. A., 1982. Usefulness of Financial Ratios in a Single Industry. Journal of Business Research. Vol. 10, Issue 1, March., pp. 103-118.

Foster G. 1986. Financial Statement analysis, $2^{\text {nd }}$ Edition, Prentice Hall, pp.704.

Foulke Roy A., 1961. Practical Financial Statement Analysis. $5^{\text {th }}$ ed., Mc Graw-Hill Book Company, New York.

Giroux G., 2003. Financial analysis. A user approach. John Wiley \& Sons, Inc., pp. 298.

Horrigan James O. 1968. A Short History of Financial Ratio Analysis. The Accounting Review, Vol. 43, No. 2, pp. 284-294.

Horrigan James O. 1994. Schools of Thought in the Historical Development of Financial Statement Analysis. Proceedings of the Pacioli Quincentennial Symposia. - Seattle University, Seattle, Washington, USA.

John K. C. 1978. Modelling a Financial Ratios Categoric Framework. Journal of Business Finance \& Accounting. Vol. 5/Dec., Issue 4, pp. 371-386.

Kanto A. J., Martikainen T. 1990 A Confirmatory Test of a Priori Classification Pattern of Financial Ratios: Empirical evidence with U.S. data. Finnish Journal of Business Economics. Vol. 1, pp. 22-38.

Luoma M., Ruuhela R. 1990. Consistency and Comovement of Financial Ratios: a Firm-Specific Approach. Finnish Journal of Business Economics. Vol. 1, pp. 39-49.

Olegario R. 2006. A Culture of Credit: Embedding Trust and Transparency in American Business. Harvard University Press, pp. 288.

Salmi T., Martikainen T. 1994. A Review of the Theoretical and Empirical Basis of Financial Ratio Analysis. The Finnish Journal of Business Economics, 4/94, pp. 426-448.

Salmi T., Virtanen I., Yli-Olli P. 1990. On the Classification on Financial Ratios. A Factor and Transformation Analysis of Accrual cash flow, and market-based ratios. Acta Wasaensia. Nr. 25.

Smith Raymond F., Winakor Arthur H. 1935. Changes in the Financial Structure of Unsuccessful Industrial Corporations. Bureau of Business Research, Bulletin, Nr. 51. Urbana, Illinois.

Stevenson S. B. (1925) Financial Statement Analysis. Haskins \& Sells Bulletin, Vol. 8, Nr. 11. (1925 November), pp. 82-88.

Stone D., Hitching K. 1998. Accounting and financial analysis. Moscow. SIRII, pp. 272). 


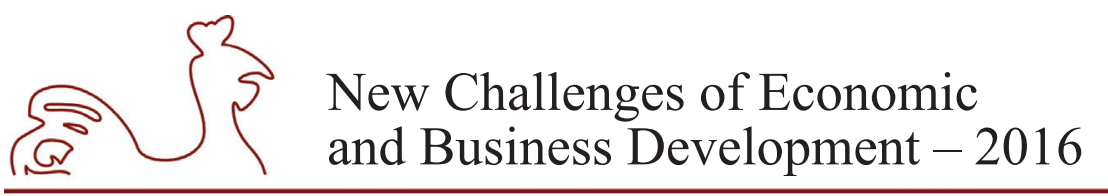

May 12-14, 2016, Riga, University of Latvia

Laurent C. R. 1979. Improving the Efficiency and Effectiveness of Financial Ratio Analysis. Journal of Business Finance and Accounting. Vol. 6, Issue 3, pp. 401-413.

Michael J. G., Ketz E. 1983. A Note on Cash Flow and classification Patterns of Financial Ratios. Accounting Review. Vol. 58, Nr. 1, January, 105-114.

Morley M. F. 1984. Ratio Analysis. Published for the Institute of Chartered Accountants of Scotland by Gree \&Co, pp. 53.

Olegario R. 2006. A Culture of Credit: Embedding Trust and Transparency in American Business. Harvard University Press, pp. 288.

Poholman R. A., Hollinger R. D. 1981. Information Redundancy in Sets of Financial Ratios. Journal of Business Finance and Accounting. Vol 8, Issue 4. December, pp. 511-528.

Pinches G. E., Kent A., Mingo J., Caruthers K. 1973. The Stability of Financial Patterns in Industrial Organizations. The Journal of Finance. Vol. 28, May, Issue 2. pp. 389-396.

Tamari M. 1978. Financial Ratios: Analysis and Prediction. London P. Elek, pp.182.

Wall A. 1919. The Banker's Credit Manual ( $2^{\text {nd }}$ ed.). Indianopolis: The Bobbs Merrill Company Publishers, pp. 272.

Weston J. F., Eugene F. B. 1972. Managerial Finance, Holt, Rinehart and Winston, pp. 768.

White G. I., Ashwinpaul C. S., Dov F. 1994. The Analysis and Use of Financial Statements. Wiley, pp. 1198

Блатон Н. А. 1940. Баланс промышленного предприятия и его анализа (251 с.). Л.: Ленпартиздат.

Вейцман Н. Р. 1927. Курс балансоведения (236 с.). М.: Центросоюз, тип. Центросоюза.

Герстнер П. 1926. Анализ баланса. Пер. с нем. Ревякина под ред. Филимонова Н. Г. М.: Экономическая жизнь. 286 с.

Гуляев А. И. 1909. Системы и формы счетоводства 185 с.

Грачева Р. Е. Анализ - ровесник балансоведения [электронный ресурс], Режим доступа: Сентябрь 13.2013 из http://buhlabaz.ru/bukhgalterskij-uchet/istoriya-bukhgalterskoj-mysli/analiz--rovesnikbalansovedeniya.html

Дыбаль С. В. 2009. Финансовый анализ в концепции контроллинга. Монография. - Спб.: Бизнеспресса. $344 \mathrm{c}$.

Ковалев В. В. 2010. Очерки по истории финансовой науки Москва: Проспект. 542 с.

Ломовисский А. Ф. 1908. Коммерческая арифметика Москва, 178 с.

Лунский Н. С. 1912. Лекции по высшим финансовым вычислениям (155 с.). Часть 1. М.: Т-во Печатня С. П. Яковлева, 155 с.

Малешевский Б. Ф.1890Теория и практика пенсионных касс. Том II. Часть 2.

Николаев И. Р. 1926. Проблема реальности баланса. Л.: Экономическое образование. 187 с.

Ришар Ж. 1997. Аудит и анализ хозяйственной деятельности предприятия. пер. с франц. под ред. Белых Л. П. М.: Аудит, ЮНИТИ, 375 с.

Рудановский А.П. 1928. Теория балансового учета. Оценка, как цель балансового учета. Система исчисления - М., 156 с.

Соколов Я. В. 1985. История развития бухгалтерского учета. М. : Финансы и статистика, 367 с.

Соколов Я. В. 2008. Этапы развития бухгалтерского учета. Бухгалтерский учет. Nr. 1, 56-59 с.

Ходский Л. В. 1894. Основы государственного хозяйства. Пособие по финансовой науке. СПб. 518 с.

Шеремет А. Д., Негашев Е. В. 2012. Методика финансового анализа деятельности коммерческих организаций М.: ИНФРА-М., 208 с. 


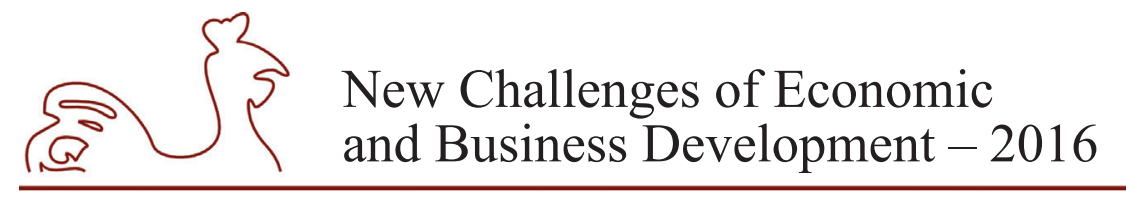

May 12-14, 2016, Riga, University of Latvia

\title{
REVEALING THE STAGE OF DEVELOPMENT OF LATVIAN BOND MARKET
}

\author{
Natalja Tocelovska, University of Latvia, Latvia ${ }^{1}$
}

\begin{abstract}
Latvian corporate bond market has undergone the major development in the period of 2000-2016. Currently the market honours the leading position in the Baltics. With the global focus on the corporate bond market where the European Commission is developing Capital Market Union thus lowering the cost of funding and making the financial system more resilient; Latvian corporate bond market appears moving to the right direction (European Commission, 2016). The latter should be proved by the reasonable analysis. This paper aims to identify the comparative level of the development of Latvian corporate bond market in the global perspective. Numerous researchers have analysed the development of a bond market of a country. The existing academic studies on the topic can be divided into 2 groups: descriptive factor analyses and comparative factor analyses. Comparative factor analyses identify the main dimension of the influencing factors and suggest the metrics to evaluate the bond market development. This paper uses the comparative framework developed by The World Bank (2004). The paper reveals that while there is a progress in the areas of stability of Latvian bond market and efficiency (the significant improvement in the bid-ask spreads is revealed despite still comparatively lower issued amounts outstanding), the problematic areas remain size and access: the amount of domestic issues and amount of domestic corporate issues make Latvia lagging. The paper argues that the opaque methodology and insufficient number of ratios in efficiency and stability groups bring the need for further development of the model.
\end{abstract}

Key words: Bond market, indicators, development

JEL code: G23, G24

\section{Introduction}

Latvian corporate bond market has 43 corporate bonds outstanding in Nasdaq Riga thus being the most developed in the Baltic area (Nasdaq, 2016). Still the relatively high comparative development indicator is based on the low base in Estonia and Lithuania with one public corporate bond in Nasdaq Tallinn and no public bond in Nasdaq Vilnius (Nasdaq, 2016). While the region comparison has little explanatory value to identify the level of the development of Latvian corporate bond market, other relative measurements and instruments should be introduced. Analysis of the academic literature reveals that while various academics have studied the development of bond market, the majority tend to concentrate on the sovereign segment while several explore the corporate bond segment. No previous study on the development of Latvian bond or corporate bond market is identified. The study of Tocelovska (2016) divides the existing academic studies on the level of development of the corporate bond market into two groups: a) descriptive factor analysis: Fabella and Madhur (2003), Burger and Warnock (2005),

${ }^{1}$ Corresponding author - e-mail address natalja.tocelovska@sseriga.edu 


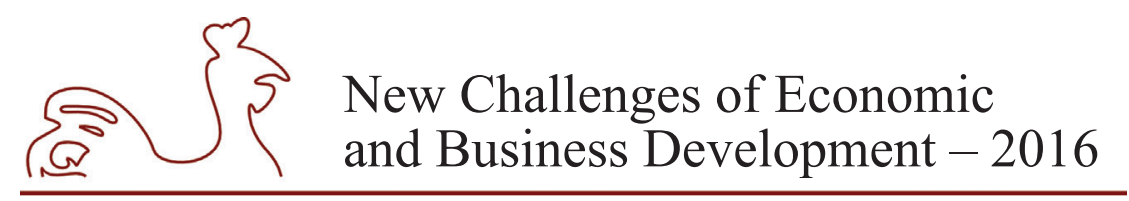

May 12-14, 2016, Riga, University of Latvia

Braun and Briones (2006), Stewart (2009), and Dittmar and Yuon (2008); b) comparative factor analysis: the research by the World Bank (2004) introducing Bond market development indicators, Wyman (2015). The observed descriptive factor analysis studies concentrate on main factors, which influence the development of the corporate bond market of a particular country or group of countries. Depending on the region, period and the methodology, the researches provide different and sometimes contradicting results.

The comparative factor analysis studies introduce a framework for assessment of the bond development in a country by deriving groups of ratios, which influence the development of the corporate bond market in various ways and can be measured. The research by the World Bank (2004) introduces Bond market development indicators or FSDI and divides the relevant ratios into four groups thus measuring the development of the bond market in size, access, efficiency and stability. The study measures the bond market development in sovereign (both domestic and international) and corporate (domestic) segments thus revealing the comparative level of development. This article analysis the comparative development of Latvian bond market (including its corporate segment) by applying FSDI model.

The aim of this article is to reveal the comparative level of development of Latvian corporate bond market by applying the framework by World Bank (2004). While observing the leading position of Latvian corporate bond market in the Baltic region, the author hypothesises that the development of Latvian bond market is comparatively high while the triggering factors are the size of the country and the size of the potential issuers. The author applies correlative and descriptive quantitative research methods.

\section{Bond market development indicators}

Financial sector development indicator model introduced by The World Bank (2004) provides the rare attempt for a comparative measure of the level of the development of the bond market. While the interrelation between the sovereign and corporate segment have been proved by previous researchers: Dittmar and Yuan (2008) prove that sovereign bond segment acts as the benchmark for the corporate bond market and promotes it; the development of Latvian bond market should be analysed. The study of The World Bank (2004) groups the ratios into four categories: size, access, efficiency and stability. The study compares the ratio results between the selected sample of countries by applying four-year period.

The comparative factor analyses undermines the comparison of one country to the selected sample. While the study of The World Bank (2004) provides the framework for comparison, the selection of the countries does not contain Baltic countries. Since the aim of this paper is to identify the comparative level of the development of Latvian corporate bond market in the global perspective, global benchmark countries are applied as the first comparative peers. The difference in the scale of the countries compared is eliminated by the relative basis of the ratios calculated. This article selects Latvia, Germany, Sweden and USA as the country sample and compares it for the period of 2008-2014. All of the selected benchmark countries are included in the study of World Bank (2004), where Sweden is named by the FDSI study as the country with similar fundamentals to Eurozone countries while being outside of Eurozone. Additionally, the choice of the countries is justified by their benchmark roles in the bond market: US Treasury bonds and German bunds are used for benchmarking by the corporate bond market participants. 


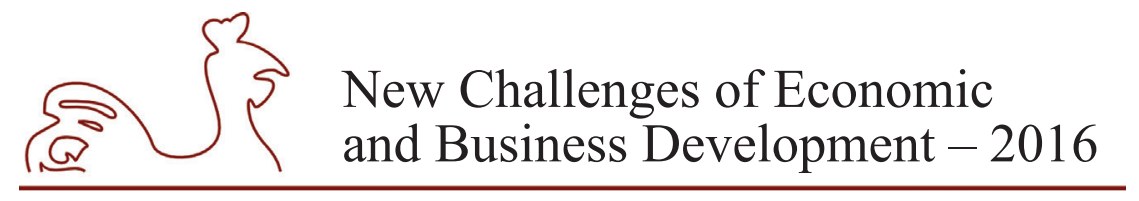

May 12-14, 2016, Riga, University of Latvia

Moreover various academics name USA bond market as the most developed bond market: study of The World Bank (2004); Braun and Briones (2006). The study of The World Bank (2004) groups bonds according to the issuer: public or private (private contains both bonds issued by non-financial and financial institutions); domestic or international.

While the data for bond yields is determined by Bloomberg, the statistics on bond market is retrieved from The World Bank and the Bank for International Settlement database and expanded by the data on Latvia from Nasdaq Riga and Latvian Central Depositary. The ratios of new corporate bonds issues to GDP and the actual amount of new corporate bond issues are not analysed by FSDI on per country basis because of the lack of data available.

\section{Size}

Three ratios are applied in FSDI to measure the size of the bonds market: ratio of public (government) sector bonds to GDP, ratio of private (corporate) sector bonds to GDP and the ratio of international bonds to GDP (The World Bank, 2004). While GDP statistics is provided by The World Bank statistic database, data on the size of the sovereign, corporate and international bond market is imported from the Bank for International Settlement database. For the calculation purposes USA dollar is used as the base currency for all the markets.

Public sector bond markets: analysis of the bond market indicators in FSDI performed by the World Bank in 2004 stated that the size of the public sector varies across regions and income groups, with North America leading and Europe following (The World Bank, 2004). High income OECD countries were found to have substantially larger bond markets. The results of the analysis of the bond market indicators in FSDI performed in this article reveal that even though the relative weight of the public debt increased, the general pattern is the same: USA leading while Germany and Sweden following (Figure 1). The relative weight of the public debt of North America was found by the bond market indicators in FSDI performed by the World Bank in 2004 to be $55 \%$ of the GDP of the country in the period 2000-2003, while the analysis of the bond market indicators in FSDI performed in this article reveals the increase to $89 \%$ of the GDP in 2014 (The World Bank, 2004). Similar trends can be observed in Europe where the combined indicator for Europe and Central Asia was fluctuating at $40 \%$ according to the bond market indicators in FSDI performed by The World Bank (2004), while the data for 2008-2014 indicates the growth from $44 \%$ to $52 \%$ for Germany and from $25 \%$ to $32 \%$ for Sweden. In the observed global environment of increasing need for public borrowing, the ratio of public debt to GDP in Latvia is following the upwards dynamics by increasing from $11 \%$ in 2008 to $26 \%$ in 2014. 


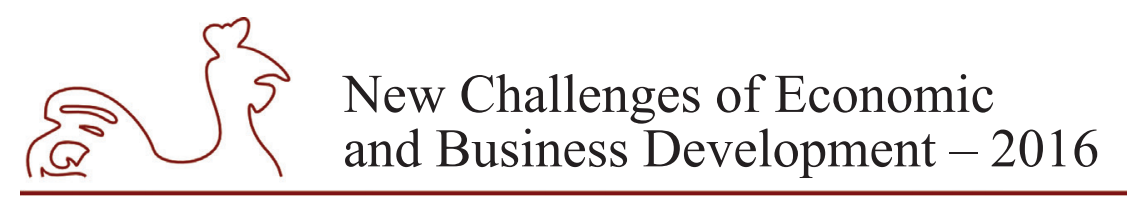

May 12-14, 2016, Riga, University of Latvia

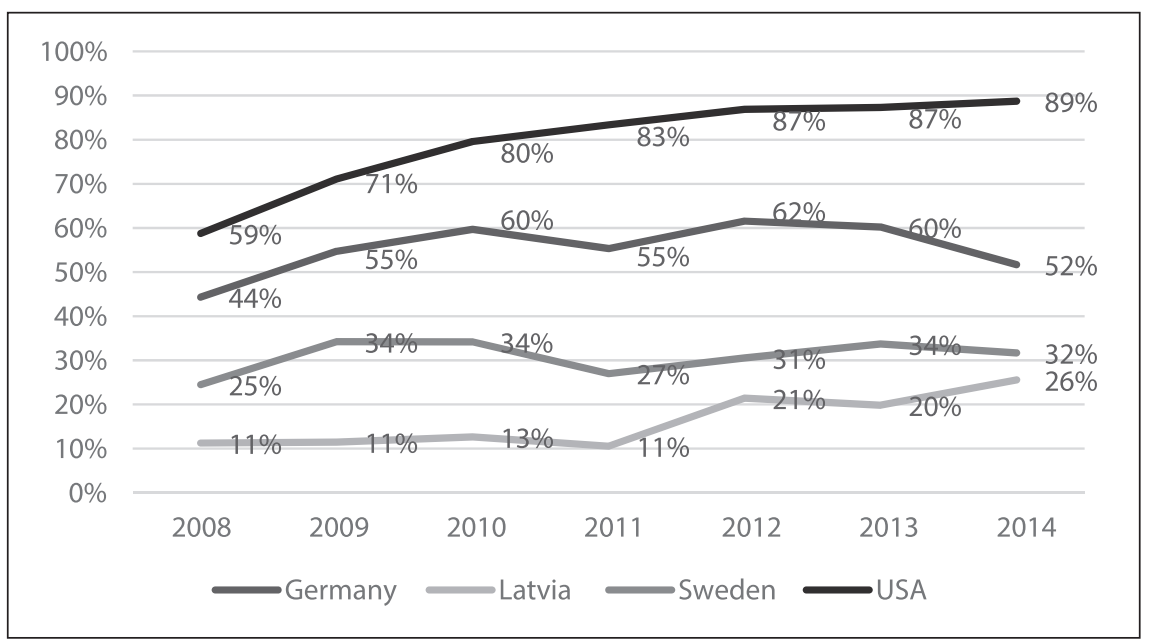

Source: author's construction based on The World Bank and Bank for International Settlement data.

Fig. 1. Ratio of public sector debt to GDP, \%

Private sector bond markets: indicator of private sector bonds over GDP contains both domestic and international public bonds (issued by both financial and non-financial institutions) in the period 2008-2014. The relative amount of private borrowing in the USA, Germany and Sweden is exceeding the amount of GDP, while holding at 3\% in Latvia (Figure 2). Analysis of the bond market indicators in FSDI performed by the World Bank (2004) observes the private sector bond to GDP ratio from the income perspective of the country, where High Income OECD countries have the highest and low Income countries the lowest ratio value. These findings are confirmed by the current data analysis. The difference arises when the relative weight of private sector is calculated. The FSDI performed by the World Bank in 2004 indicated a $40 \%$ ratio of High income OECD countries and 4\% Low Income, while the current analysis of years 20082014 finds 104-116\% and 3\% respectively (The World Bank, 2004).

International sector bond markets: according to the analysis of the bond market indicators in FSDI, international bonds reflect the ability of the country to raise capital globally, where the developing countries experience difficulties utilizing international markets (The World Bank, 2004). The analysis performed in this article for the period 2008-2014 proves that Sweden and Germany are active issuers in the international market, while the ability of USA to borrow internationally is comparatively low (Figure 3). 


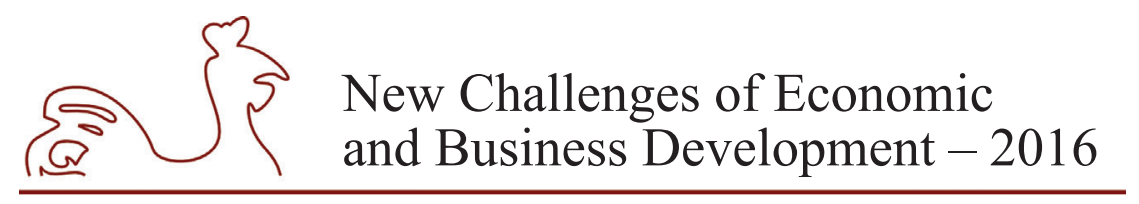

May 12-14, 2016, Riga, University of Latvia

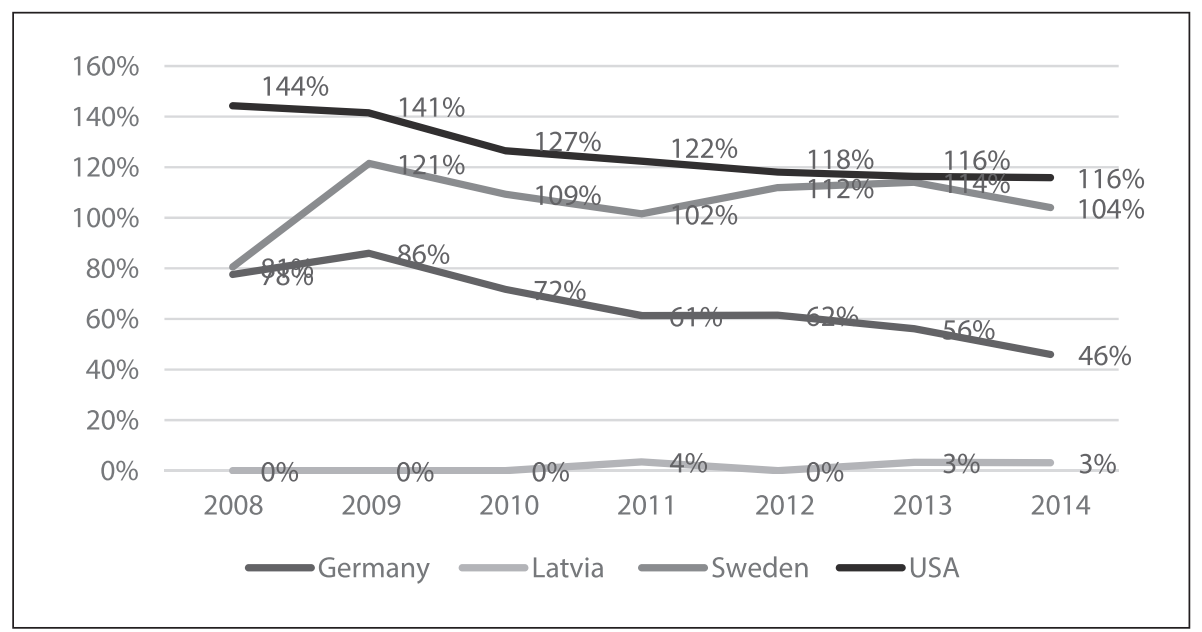

Source: author's construction based on The World Bank and Bank for International Settlement data.

Fig. 2. Ratio of private sector debt to GDP, \%

The latter forms the criticisms to this ratio as an indicator of the ability to raise funds globally - USA market has low international borrowing rate because of its focus on the domestic market, while staying attractive for the international bond market. The international focus of Latvian debt is gradually growing and overcoming USA.

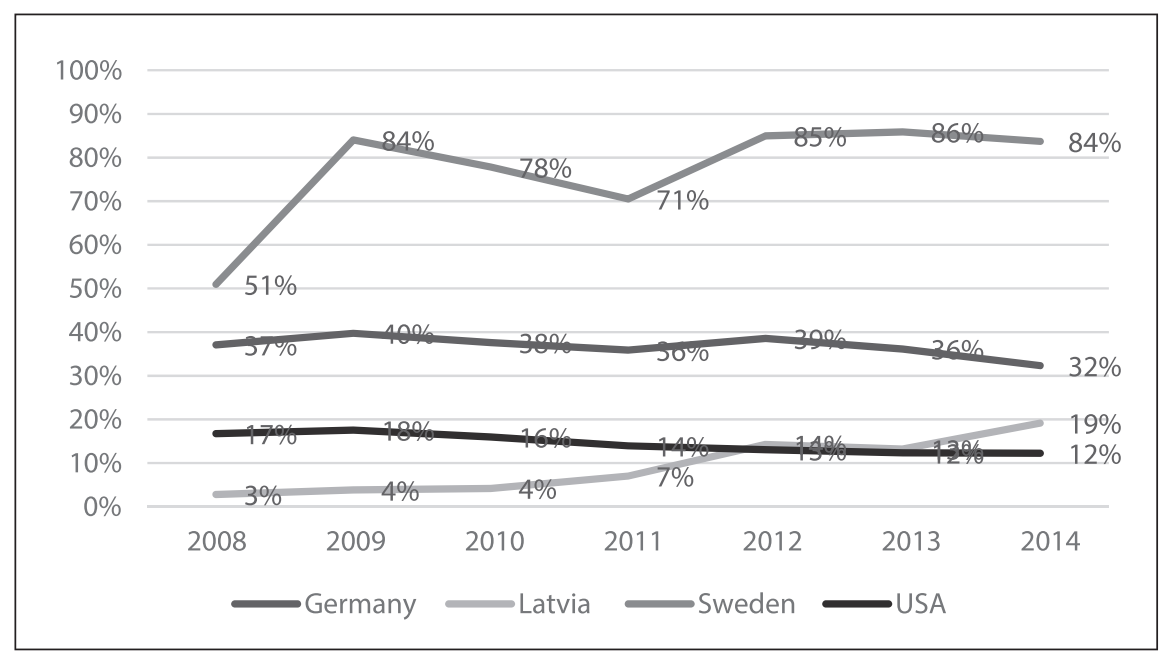

Source: author's construction based on The World Bank and Bank for International Settlement data.

Fig. 3. Ratio of international debt to GDP, \%

\section{Access}

According to FSDI, bond market is efficient when the cost of capital is low (The World Bank, 2004). The necessity to measure the cost of capital determines the first indicator of the government bond yields for 3 months and 10 year bonds, where the ease of accessing the market 


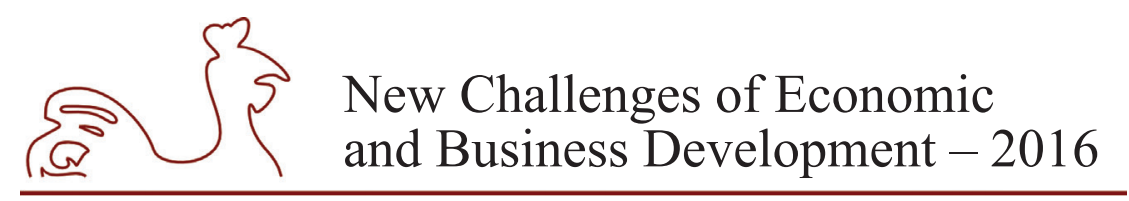

May 12-14, 2016, Riga, University of Latvia

is measured by ratio of domestic bonds to total bonds outstanding and ratio of private bonds to total domestic bonds outstanding. Since four countries analysed in this article have different currencies (EUR, USD and SEK), and USA have only USD issued government bonds, the cash flows of US Treasury bonds with 3 month and 10 year maturities were swapped to EUR cash flows using Bloomberg system and then analysed. Germany, Latvia and Sweden have EUR currency debts.

Government bond yields ( 3 months and 10 years): the analysis of 3 month and 10 year public bonds of the USA, Germany, Sweden and Latvia indicate that while the short term bonds yield negative interest rates, 10 year bonds tend to deliver similar level of return, except of Latvia. The key explanation to the distinction is the difference in the credit risk of the countries, which is reflected by the credit ratings. The USA, Germany, Sweden possess the highest investment grade ratings (S\&P: AAA, AAA and AAA respectively) while Latvia has A- or 6 notches lower (Bloomberg, 2016).

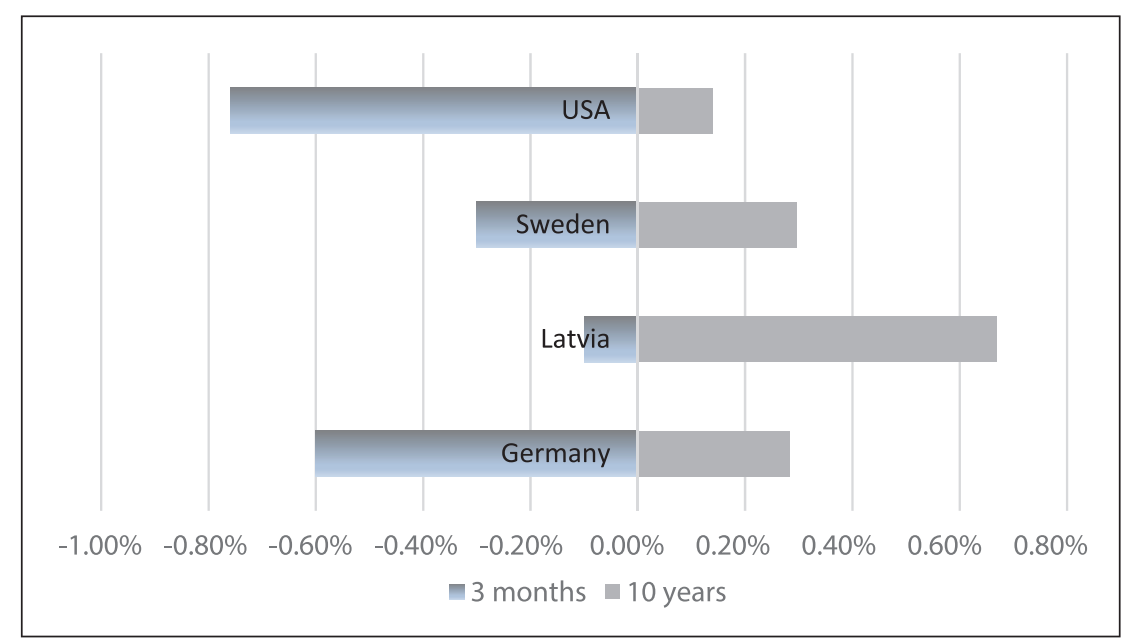

Source: author's construction based on Bloomberg data.

Fig. 4. Cost of capital of sovereign debt, $\%$

Ratio of domestic bonds to total bonds outstanding: according to FSDI, measurement of domestic bonds to total bonds outstanding indicates the capacity of local market to provide capital (The World Bank, 2004). Besides to indicating the local willingness to invest in the local debt, domestic issues theoretically reduce the currency mismatch as domestic borrowing is preferably done in the local currency. 


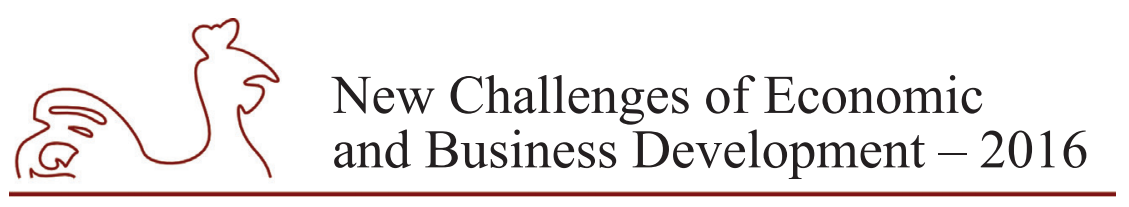

May 12-14, 2016, Riga, University of Latvia

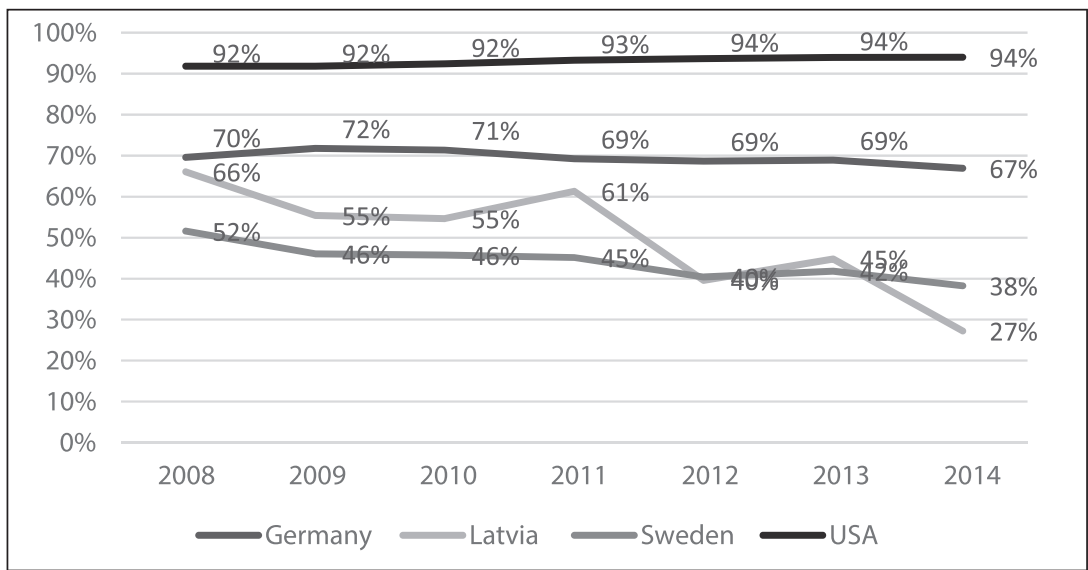

Source: author's construction based on The World Bank and Bank for International Settlement data.

Fig. 5. Ratio of domestic total debt to total debt, \%

Data analysis of the domestic bonds as the proportion of total debt securities of the country in the period 2008-2014 reveals that, while USA and Germany have greater focus on the domestic market, Sweden and Latvia account only $1 / 3$ of their borrowing in the domestic market (Figure 5). Latvia is decreasing its local borrowing capacity. The latter is explained by the unchanged domestic borrowing in the conditions of growing total borrowing and growing international borrowing.

Ratio of domestic private sector bonds to total domestic bonds: according to the World Bank (2004), the measurement of domestic private bonds to total domestic bonds outstanding shows the convenience of private sector to obtain the capital domestically, which indicates the degree of accessibility and affects financing decisions. Although USA had the leading position in the study of The World Bank (2004), FSDI analysis performed in this article reveals that Sweden has the dominating domestic bond market, thus pointing to the willingness of Swedish companies to borrow locally in Swedish kroner. Both Germany and Latvia have $25 \%$ weight of domestic borrowing (Figure 6).

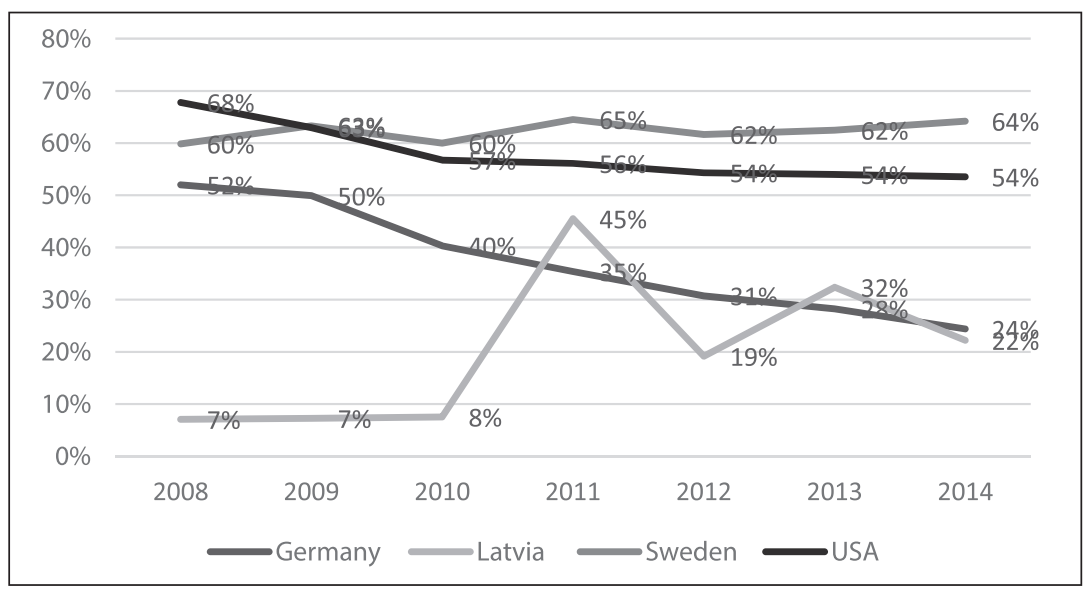

Source: author's construction based on The World Bank and Bank for International Settlement data.

Fig. 6. Ratio of domestic private debt to total domestic debt, $\%$ 


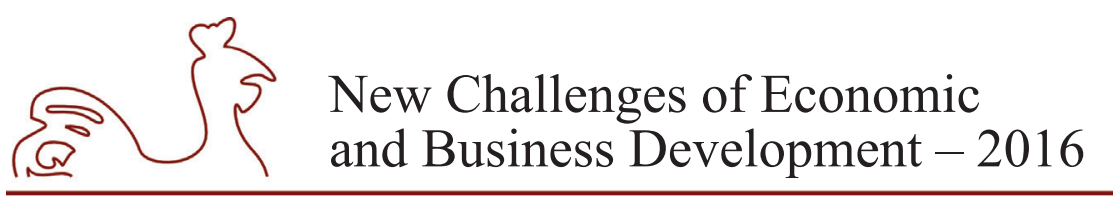

May 12-14, 2016, Riga, University of Latvia

\section{Efficiency}

FSDI groups four ratios as the indicators of the efficiency of the debt market: quoted bid-ask spreads (10-yr government bond yield), turnover of private sector bond on securities exchange, turnover of public sector bond on securities exchange, Settlement Efficiency Index (The World Bank, 2004). The research by the World Bank (2004) challenges the indicators of turnover of private sector bond on securities exchange, turnover of public sector bond on securities exchange because of the over-the-counter base of the transactions with the fixed income securities thus stating that both indicators lack many trades. The Settlement Efficiency Index is neither described nor applied by FSDI. The only indicator used by FSDI as the measure of efficiency is the quoted bid-ask spreads (10-yr government bond yield).

Quoted bid-ask spread of 10 year government bond yields: The analysis of the bid-ask spread of 10-year government debt securities of Germany, Latvia, Sweden and USD for the data on 14/01/2016 confirms the results of the study of The World Bank (2004): Germany and USA have less than $0.007 \%$ bid ask-spread, while Sweden has $0.02 \%$ (Figure 7 ). The study of The World Bank relates the higher bid-ask spread of Sweden to the absence of euro currency while pointing that the country has similar fundamentals to the other Eurozone countries (The World Bank, 2004).

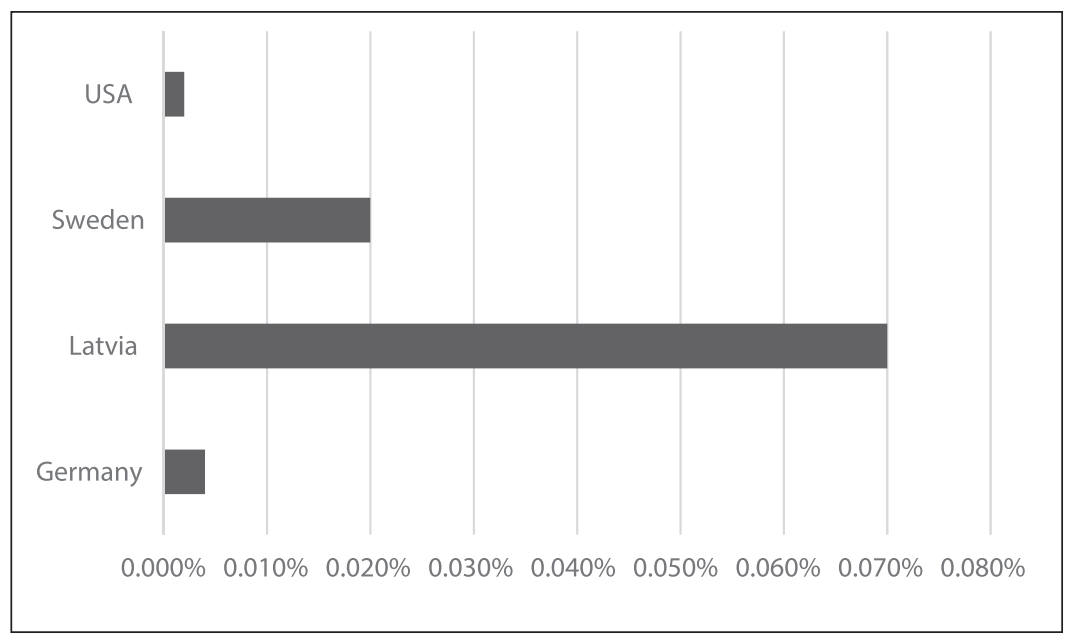

Source: author's construction based on Bloomberg data.

Fig. 7. Bid-ask spread of 10-year government bond yield, \%

The bid-ask spread for Latvian government bonds of 10 year maturity reaches $0.07 \%$, which is substantially higher than the countries analysed in this article. Still the comparison of the bid-ask spread of Latvian government bonds in 2016 and in 2011 indicates an important progress - the bid-ask spread in 2011 reached $0.3 \%$ or $400 \%$ higher than the current value. The existing comparative higher bid-ask spread for Latvian government bonds can be justified by the amounts outstanding of the government bonds and thus lower liquidity of the bonds: Germany EUR 10 billion (ISIN DE0001102390, maturity 15/02/2026), Latvia EUR 0.5 billion (ISIN XS1295778275, maturity 23/09/2025), Sweden SEK 44.7 billion (ISIN SE0007125927, maturity 12/11/2026), USA USD 44.9 billion (ISIN US912828P469, maturity 15/02/2026) (Bloomberg, 2016). 


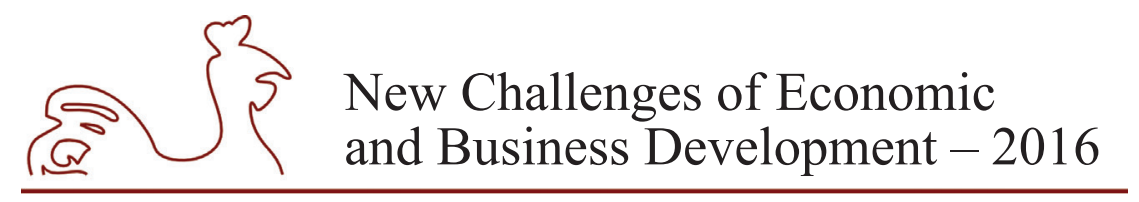

May 12-14, 2016, Riga, University of Latvia

\section{Stability}

Stability is the forth criteria for evaluation of the bond market development by FSID (The World Bank, 2004). The World Bank (2004) stresses that the lack of stability in the bond market can result in the higher cost of borrowing besides to discouraging investors from entering the market. FSDI divides stability indicators into the following areas: volatility, skewness, maturity and correlation, which therefore result in 6 sub-indicators: volatility of sovereign bond index, skewness of sovereign bond index, ratio of short-term to total bonds (domestic), ratio of shortterm bond to total bonds (international), correlation with German bond returns, correlation with US bond returns. Even though this research is using sovereign bond index for measuring volatility and skewness, the author of this article uses 10 year sovereign bond to measure those two indicators as the public bond market of Latvia lacks the index. As suggested by the FSDI framework, stability indicator analysis is performed for public bond segment only.

Volatility of sovereign bond index: FDSI measures volatility by the value of standard deviation thus indicating how widely the values are dispersed from the mean yield of the 10 year sovereign benchmark security. In order to measure the standard deviation of the every country, closing daily ask yields to maturity of 10 -year government debt securities of Germany, Latvia, Sweden and USD are analysed.

10 year sovereign benchmark bond of every country were exported from Bloomberg (Germany ISIN DE0001102390, maturity 15/08/2025, Latvia ISIN XS1295778275, maturity 23/09/2025, Sweden ISIN SE0005676608, maturity 12/05/2026, USA ISIN US912828XB14, maturity 15/05/2025) (Bloomberg, 2016). Standard deviation is calculated for 2015-15/03/2016 (the data for 2015 is analysed since the security is issued) applying the formula below (Doane D. P and Seward L. E., 2011).

$$
\sqrt{\frac{\sum(x-\bar{x})^{2}}{(n-1)}}
$$

The results of the volatility test made reveal that all four countries have the same level of volatility (Table 1).

Table 1

Volatility of 10 year sovereign benchmark bonds

\begin{tabular}{|c|c|c|c|c|}
\hline & Germany & Latvia & Sweden & USA \\
\hline Standard deviation & 0.195 & 0.193 & 0.196 & 0.184 \\
\hline
\end{tabular}

Source: author's calculations based on Bloomberg data.

Skewness of sovereign bond index: the research of The Wold Bank views the skewness indicator as the gauge of the probability of large negative losses associated with the public debt of the country. Statistically skewness shows the degree of asymmetry of a distribution around its mean, where the positive value indicates a distribution with an asymmetric tail extending toward more positive values, while negative - a distribution with an asymmetric tail extending toward more negative values (Press W. H, et al., 1992). 10 year sovereign benchmark bond of every country were exported from Bloomberg (Germany ISIN DE0001102390, maturity 15/08/2025, Latvia ISIN XS1295778275, maturity 23/09/2025, Sweden ISIN SE0005676608, maturity 12/05/2026, USA ISIN US912828XB14, maturity 15/05/2025) (Bloomberg, 2016). Skewness 


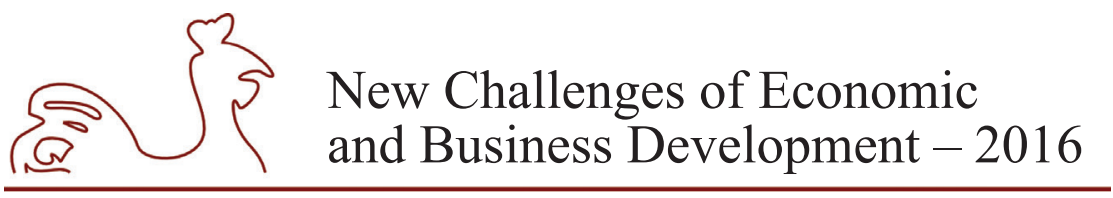

May 12-14, 2016, Riga, University of Latvia

is calculated for 2015-15/03/2016 (the data for 2015 is analysed since the security is issued) applying the formula below (Press W. H, et al., 1992).

$$
\frac{n}{(n-1)(n-2)} \sum\left(\frac{x_{j}-\bar{x}}{s}\right)^{3}
$$

The results of the skewness test of this article (Table 2) contradict to the findings of the World Bank where FSDI research states returns in developed markets in general exhibit less negative skewness.

Table 2

Skewness of 10 year sovereign benchmark bonds

\begin{tabular}{|c|c|c|c|c|}
\hline & Germany & Latvia & Sweden & USA \\
\hline Skewness & -0.86 & -0.50 & -0.19 & -0.81 \\
\hline
\end{tabular}

Source: author's calculations based on Bloomberg data.

Ratio of short-term to total bonds: according to The World Bank, the dominating position that short-term bonds hold within either domestic of international bond segment reflects the relative instability and risk as theoretically the borrower comes to the bond market with the longterm financing needs (The World Bank, 2004). If the dominating maturity is short, this acts as a signal to the market participants about inability to attract longer financing and thus indicating to the relative instability. The proportion of government bonds with the maturity in less than 3 years forms $30-40 \%$ of Latvian and German debt and over $50 \%$ of the debt of Sweden and the USA (Table 3 ). The borrowing needs of each country provides and impact on the indicator.

Table 3

Calculation of ratio of short-term to total bonds

\begin{tabular}{|c|c|c|c|c|}
\hline & Germany & Latvia & Sweden & USA \\
\hline Ratio & $39 \%$ & $34 \%$ & $52 \%$ & $51 \%$ \\
\hline
\end{tabular}

Source: author's calculations based on Bloomberg data.

Composite indicators: the methodology of FSDI framework states that in order to obtain the indicators of every component of the framework: size, access, efficiency and stability, sub indicators for each of the segments are calculated, standardizes by subtracting the median of the distribution and scaled by the standard deviation of the distribution. The standardized scores are then averaged to create the composite indicator for every segment (The World Bank, 2004). In statistics, methodology of data standardization includes the mean not median. Riffenburgh (2012) standardizes the scores by subtracting the mean from every observation and then dividing the result by the standard deviation. Rarely authors use median - according to Nolan (1994) standardization by the removal of the level and the spread from data allows to compare distribution more easily. Removing the level means subtracting the median from the values, which makes features of the distribution such as spread become more apparent. Additionally the spread is also removed. As the methodology of FSDI assumes using median, in order to get sub indicators of size, access, efficiency and stability, standardization of the data is done by formula:

Standardized score of the ratio $=($ ratio-median $) /$ standard deviation. 


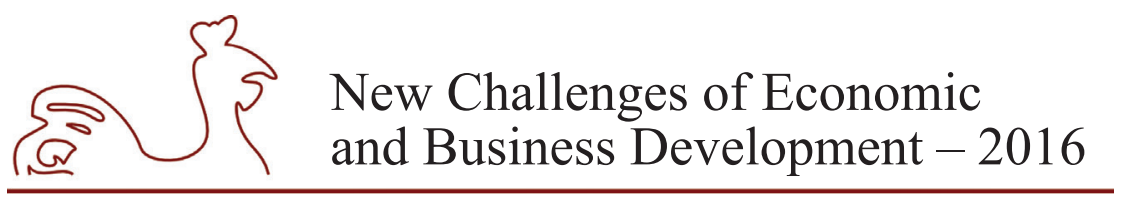

May 12-14, 2016, Riga, University of Latvia

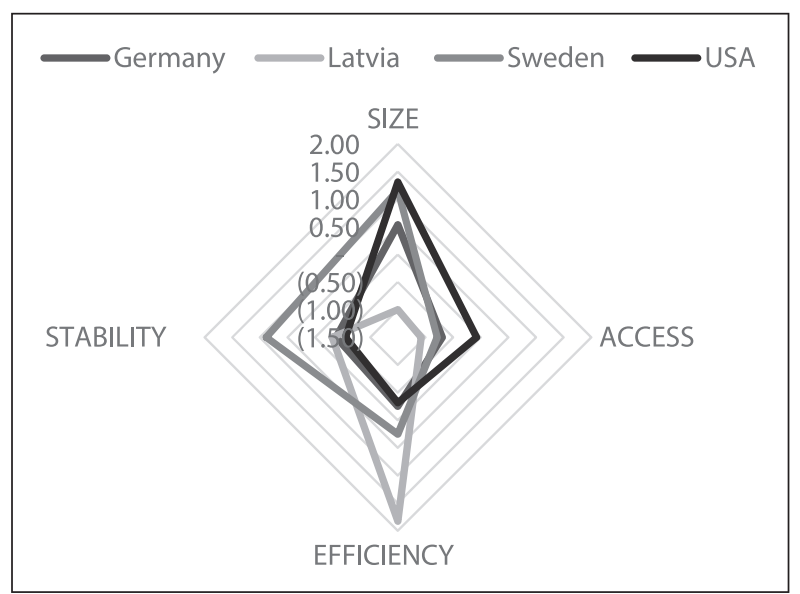

Source: author's construction based on The World Bank, Bloomberg and Bank for International Settlement data.

Fig. 8. Composite bond market indicators

Both Germany and USA provide the framework for the indictors and remain close to each other in the results, while Sweden and Latvia provide more extreme indicators (Figure 8). The obvious dominance by USA and Germany is explained by the FSDI previous research larger bond markets are more efficient and provide easier access to lower cost domestic capital. Latvia has comparatively low level of bonds outstanding from all the three size group indicators observed: private sector relative to GDP, public sector relative to GDP, international bonds relative to GDP. While the size indicator ratios are naturally limited for the substantial development by the scale factor of the country, the current focus of the Ministry of Finance on financing the debt via sovereign debt should be continued joined by the domestic corporate debt. To overcome the scale factor Pan-Baltic issues should be introduced. The demand side should be stimulated for qualitative demand for the pension money management by the reasonable changes in the legislation. Other recommended actions are the support of the sovereign benchmark curve and Primary Dealership program. Domestic sovereign issuance both sovereign and corporate should also support the access area - currently Latvia remains far behind USA, Sweden and Germany, where the weaker indicators are in the comparative weight of the domestic market and domestic corporate issuer weight in all domestic issues outstanding. While holding the weaker position in the previous areas observed, Latvia excels the most in the stability area sharing nearby position with Germany and USA markets. In the number of sub-indicators Latvia has showed very positive dynamics towards stability: relatively decreasing short-term debt, similar to peers volatility indicator. The dynamics of stability area of Latvian corporate bond market displays the progress of the country towards stability thus reaching the level of Germany and USA in this segment. The efficiency area indicators are treated as not sufficiently explored by the author of the article since only one ratio is present as well as the difference in absolute numbers between Latvia and the peers is subtle. In order to get more objective results on the efficiency indicator it is suggested to introduce more indicators to the group. The results of the analysis reveal that while being relatively developed to the peers in stability area, Latvia lags in size and access areas. 
May 12-14, 2016, Riga, University of Latvia

\section{Conclusions, proposals, recommendations}

1) FSDI model developed by The World Bank (2004) measures the comparative development of a bond market in the country. The model groups ratios into four groups: size, access, efficiency and stability. The model is a rare attempt to deliver a structured quantitative assessment of a bond market, thus providing an opportunity to compare several bond markets not only on the qualitative but also on the quantitative basis.

2) This article selects Latvia, Germany, Sweden and USA as the country sample and compares it for the period of 2008-2014. Neither the whole bond market nor its corporate segment has been measured for the level of development before. This study compares the bond market development in Latvia to the countries observed by The World Bank: Germany, Sweden and USA

3) Size indicators for USA, Germany and Sweden are similar. Those results follow the previous findings of FSDI where USA, Germany and Sweden are among the leaders according to the size indicator. The bond market of Latvia from the aspect of size is relatively small. Braun and Briones (2006), indicate that a well-developed bond market is characterized by a large size relative to GDP in all segments, a stable composition between private and public borrowers. According to the comparative factor analysis, Latvia has comparatively low level of bonds outstanding from all the three perspectives explored: private sector relative to GDP, public sector relative to GDP, international bonds relative to GDP. From the perspective of size, the bond market in Latvia is relatively less developed.

4) In access segment USA is the leader, Germany and Sweden share the second position. The study of The World Bank (2004) revealed that access to domestic capital and private capital in Sweden was better than the one in Germany. Latvia remains far behind USA, Sweden and Germany, where the weaker indicators are in the comparative weight of the domestic market and domestic corporate issuer weight in all domestic issues outstanding.

5) Efficiency segment includes the quoted bid-ask spread for 10 year public bond. The relatively wider spread for the sovereign debt security of Latvia excels, while in absolute numbers the difference between the bid-ask spread of Latvian debt security and other peers is only $0.06-0.04 \%$. The bid-ask spread of sovereign 10 year bond of Germany and USA are close to $0 \%$. The bid-ask spread of sovereign 10 year bond of Latvia has narrowed substantially from $0.3 \%$ in 2008 to $0.07 \%$ as observed in this article. In order to get more objective results on the efficiency indicator the author of this article suggests introducing more indicators to the efficiency group.

6) Stability indicator plots Latvia close to Germany and USA markets. In the number of subindicators Latvia has showed very positive dynamics towards stability - its short-term debt dominance has decreased to $34 \%$ or the lowest among the peers, the volatility indicator is the same as for the peers. The author proves that dynamics of Latvia the considerable reflect a progress of Latvia towards stability thus reaching the level of Germany and USA in this segment.

7) The important drawbacks of FSDI are lack of transparency in the methodology. There is the need for the assumptions to be introduced, which can result in a subjective interpretation of FSDI.

8) As the result of this study the author recommends to continue government focus on the sovereign bond market such as Primary Dealer activity, sovereign benchmark presence 


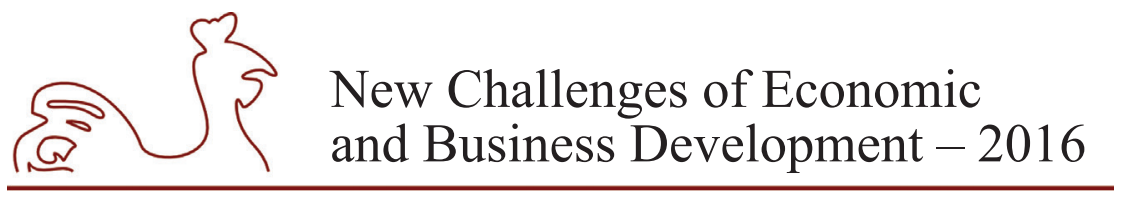

May 12-14, 2016, Riga, University of Latvia

(especially in the domestic bond market) thus supporting size and access areas of the bond market development.

9) As the result of this study the author recommends to explore the potential of increasing the size of the domestic corporate issues both from the supply perspective: Pan-Baltic issues, issues for settlement in European depositories; and demand side: stimulation of the qualitative local pension capital investment (reasonable part) into local corporate bonds.

10) For the further research the author proposes to expand the group of peer comparison by the relevant to Latvia peer countries.

11) For the further research the author proposes to increase the number of ratios measuring the segment of efficiency and stability.

\section{Bibliography}

Bank for International Settlement. Retrieved: http:// http://stats.bis.org/statx/srs/table/c1?p=20114\&c=. Access: 25.02.2016.

Bloomberg. Retrieved: https://bba.bloomberg.net/?utm_source=bloomberg-menu. Access: 10.02.2016, 15.02.2016, 20.02.2016, 10.03.2016, 14.03.2015.

Braun M., Briones I. (2006). The Development of Bond Markets Around the World. Manuscript. Universidad Adolfo Ibanez.

Burger J. D., Warnock F. E. (2005). Foreign Participation in Local-Currency Bond Markets. Darden Business School Working Paper No. 5-7.

Dittmar R. F., Yuan K. (2008). Do Sovereign Bonds Benefit Corporate Bonds in Emerging Markets? The Review of Financial Studies, Vol. 21, Issue 5, pp. 1983-2014.

Doane D. P., Seward L. E. (2011). Applied statistics in business and economics. $4^{\text {th }}$ edition.

European Commission. Retrieved: http://ec.europa.eu/finance/capital-markets-union/index_en.htm. Access: 10.02.2015.

Fabella R., Madhur S. (2003). Bond Market Development in East Asia: Issues and Challenges. ERD Working Paper, Vol. 35, ISSN 1655-5252.

Latvian Central Depository. Retrieved: www.nasdaqbaltic.com/en/csds/latvian-csd/. Access: 10.02.2015, 14.02.2016.

Nasdaq Riga. Retrieved: http://www.nasdaqbaltic.com/market/?pg=bonds\&lang=en. Access: 26.02.2015, 13.03.2016.

Nolan B. (1994). Data analysis. Polity Publisher. p.117.

Press W. H, Teukolsky S. A., Vetterling W. T., Flannery B. P. (1992). Numerical Recipes in C: The Art of Scientific Computing. Cambridge University Press. p. 612.

Riffenburgh R. H. (2012). Statistics in medicine Academic Press. p. 22.

Stewart A. (2009). The Development of Bond Markets in Barbados, Jamaica and Trinidad \& Tobago. Working paper. The Sir Arthur Lewis Institute of Social \& Economic Studies.

The World Bank. (2004). Financial Sector Development Indicators. Bond market development Capital Markets indicators. Working paper. Financial Sector Operations and Policy.

The World Bank Retrieved: http://data.worldbank.org/indicator/NY.GDP.MKTP.CD/countries?display= default. Access: 15.02.2016, 20.02.2016, 10.03.2016, 14.01.2015.

Tocelovska N. (2016). Framework for Analysis of Latvian Corporate Bond Market Development. Proceedings of the 2016 International Conference "Economic Science for Rural Development". Latvia University of Agriculture.

Wyman O. (2015). Accelerating Emerging Development Corporate Development Corporate Bond Markets. Working paper. World Economic Forum. 
May 12-14, 2016, Riga, University of Latvia

\title{
MULTI-CHANNEL DISTRIBUTION APPROACHES IN BUSINESS: SPECIFICS AND APPLICATIONS
}

\author{
Evgeniya Tonkova, University of Economics, Varna, Bulgaria ${ }^{1}$
}

\begin{abstract}
The dynamics in designing and applying new technologies in business has a significant influence on the distribution channels of companies. The multi-channel distribution structures are always enriched by adding new channels. Investments in new channels are predetermined above all by the dynamic changes in consumer behavior in respect to the process of decision making for purchasing and stronger competition. As a reaction to changes companies try to find the suitable configuration of channels which should comply with the conditions of the environment, consumers' expectations and the priorities for long- and shortterm development of business.

The aim of this study is to present the different approaches in designing multi-channel distribution, the advantages of using them and implementation issues when putting them into practice. Reviewed are the approaches of complementarity between channels, competition and integration between channels, with a focus on their characteristic features that distinguish one from another and make them recognizable. The research is based on an online survey among companies registered in Bulgaria. This survey places an emphasis on companies, the distribution channels they use; the channels they add; and the multichannel approach they apply. Companies' intentions to abandon some of the channels used in the past are of particular interest as well.

The results of the research show that adding new distribution channels to the already functioning ones appears as one of the solutions to overcoming the negative effects of long-lasting recessions on businesses, often accompanied by a decline in sales and the outflow of customers.

In the last three years the e-channel has been the most preferable channel for adding to the previously existing structures of distribution by the companies covered by the survey. The most often applied multichannel approach in companies' business is based on the complementarity between channels, followed by integration between channels and competition between them.

The interest of customers and companies in multi-channel distribution will continue to grow. The example of successful channel configurations will be transferred to different spheres of economy and social life thus contributing to better customer service and efficient distribution of products and services.
\end{abstract}

Key words: multi-channel distribution, multi-channel approaches, channel applications

JEL code: M31

\section{Introduction}

The increased interest in applying multi-channel distribution in the last decade and the variety of distribution practices of its implementation has attracted the attention to the approaches of its design. Since there are plenty of definitions of "approach" here we are going to stick to the definition of Cambridge Advanced Learner's Dictionary \& Thesaurus

${ }^{1}$ Corresponding author - e-mail address: evge@mbox.digsys.bg 


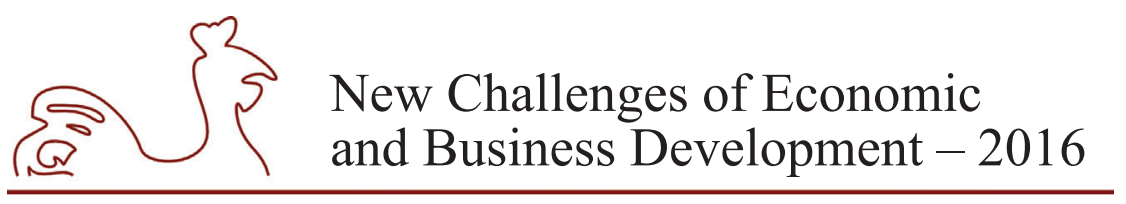

May 12-14, 2016, Riga, University of Latvia

of Cambridge University Press, where approach is defined as "a way of considering or doing something" (Cambridge Advanced..., 2016). The significance and relevance of the research is based on several specific characteristics:

- The research is concentrated thoroughly on the approaches of implementing multichannel distribution;

- The focus of the research goes beyond the traditional scope of former researches in the field of multi-channel distribution;

- The research is carried out among enterprises in Bulgaria which makes it possible to outline the specifics in using approaches of multi-channel distribution in the country.

This study focuses on distribution practices in modern conditions. It involves channel configurations used in enterprises, the implementation of distribution channels and their impact on company's performance, the approaches of multi-channel distribution and the future intentions of companies to make changes in their distribution channels.

The purpose of this study is to present the different approaches in designing multi-channel distribution, the advantages of using them and the implementation issues when putting them into practice. Reviewed are the approaches of complementarity between channels, competition and integration between channels, with an emphasis on their characteristic features that distinguish one from another and make them recognizable. The research is based on an online survey among active companies, registered in Bulgaria. The basic questions in the survey are:

1. What channel or a configuration of channels is used by companies at the time of the study?

2. What channel or a configuration of channels have companies added in the last three years?

3. What is the impact of adding the channel(s) on sales revenues, efficiency of sales revenues, other revenues, profit and attraction of new consumers?

4. What is the approach of multi-channel distribution used by companies?

5. Do companies intend to add new channels this and/or next year and what channel is most likely to be added?

6. Do companies intend to close a channel/channels this and/or next year?

In the main body of the paper and in designing its parameters an explanation is made that by multi-channel distribution we mean a structure comprising two and more channels which provides the distribution of products/services on the target markets of the companies.

The specific characteristics of multi-channel distribution are covered by a number of studies. The interest in them is based on the fact that in practice companies use more than one distribution system (Assael, H., 1985). A position is stated that hybrid channel models are characterized by particular tangible results such as: reducing selling costs, improving the selling profitability and reshaping a company's competitive position (Friedman, L. \& Furey, T., 1999). Some studies stand out that there two main types of multiple channels strategies: simply making multiple channels available and a multi-channel strategy that provides unique cross-channel benefits (Multi-Channel Marketing..., 2000). An opinion is shared that multi-channel distribution systems give a number of advantages to companies and through adding new channels, it contributes to: sales increase, improvement of the market coverage, taking the opportunity for modeling goods and services in the various customer segments (Armstrong, G. \& Kotler P., 2009). Some authors consider that hybrid marketing channels show that the use of only one channel is not sufficient. Multi- 


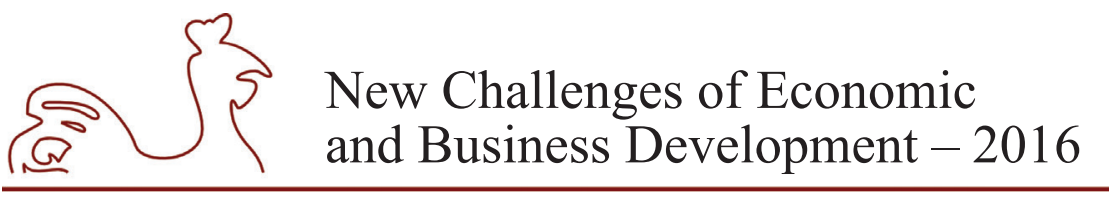

May 12-14, 2016, Riga, University of Latvia

channel architecture optimises channel coverage, adjustability and control, while at the same time minimizing cost and conflict (Segetlija, Z., Mesaric, J. \& Dujak, D., 2011).

\section{Approach of complementarity between channels within multi-channel distribution}

In cases of purposefully designing the multi-channel distribution by companies, the approach to be used is defined as early as the predesigned stage. In business practice three basic approaches of implementing multi-channel distribution are recognized. In this part of the paper the approach which ensures complementarity between the channels of distribution is presented.

Table 1

Features of the approach of complementarity to the existing distribution channels

\begin{tabular}{|l|l|}
\hline $\begin{array}{c}\text { Type of } \\
\text { complementarity }\end{array}$ & \multicolumn{1}{c|}{ Features } \\
\hline $\begin{array}{l}\text { Segment } \\
\text { complementarity }\end{array}$ & $\begin{array}{l}\text { A new channel is developed which is added to the existing ones in the distribution } \\
\text { system; yet, it is designed to sell products in a segment outside those served by } \\
\text { the other channels. Firms may need different channels to reach different segments } \\
\text { (McCarthy, E. \& Perreault, W., 1993). The segments can be separated according } \\
\text { to geographical, economic, and psychographic features or a combination of all. } \\
\text { Companies also establish different channels to sell to different-sized customers } \\
\text { (Pelton, L., Strutton, D. \& Lumpkin, J., 2002). }\end{array}$ \\
\hline $\begin{array}{l}\text { Product/range } \\
\text { complementarity }\end{array}$ & $\begin{array}{l}\text { A new channel is developed which is added to the existing ones in the distribution } \\
\text { system; yet, it is designed to sell products outside those offered by the other channels. }\end{array}$ \\
\hline $\begin{array}{l}\text { Functional } \\
\text { complementarity }\end{array}$ & $\begin{array}{l}\text { A new channel is developed which is added to the existing ones in the distribution } \\
\text { system; yet, it is designed to have different functions from those of the other channels. }\end{array}$ \\
\hline
\end{tabular}

Source: Developed by the author on the ground of studying particular practices of multi-channel distribution and literature review.

A variant of the approach of complementarity is segment complementarity in which each channel serves a particular segment. In this case we differentiate the segment specialization of the channels. Of course, here we exclude the element of competition, as well as the element of integration, since completely different segments are concerned. This approach is more specific and is often used in multi-channel structures which have sales in different geographic segments without overlapping of territories.

A partially limited distribution for the general public is also observed. It is implemented by means of special channels with regulated access (e.g., reaching a particular number of orders, monthly or annual subscription and/or other conditions for access). The cluster identity of the consumer defines his/her access to a particular channel. Product or productrange complementarity within the approach of complementarity to multi-channel distribution is implemented under conditions where the existing channels are not able to sell equally all products or the whole product range and this requires the design of a new channel which will provide the sales of particular products, they could be new or, in limited cases, the existing ones. There are two variants in practice:

- Products are sold in separate (different) channels;

- For selling the product range the same channels are used, yet, there is a significant difference in the structure of sales of the separate product-range positions. 


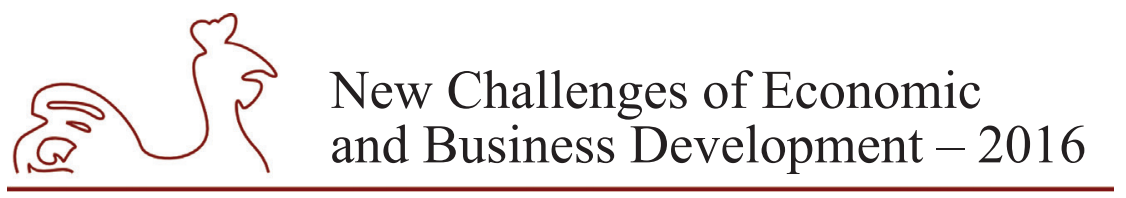

May 12-14, 2016, Riga, University of Latvia

Both variants of the approach are known in practice. One could recognize the second variant when seeing the different structure of sales in the channels by products (Fig. 1)

\begin{tabular}{|l|c|c|c|}
\hline \multicolumn{1}{|c|}{ Product/Channel } & Product 1 & Product 2 & Product 3 \\
\hline Channel 1 & $10 \%$ & $90 \%$ & - \\
\hline Channel 2 & $80 \%$ & $9 \%$ & $11 \%$ \\
\hline Channel 3 & $2 \%$ & $8 \%$ & $90 \%$ \\
\hline
\end{tabular}

Legend: Channel 1, Channel 2 and Channel 3 are active channels of a company. Product 1, Product 2 and Product 3 of a company are distributed through these channels.

Note: The sum total of the relative shares of sales of separate products for each channel equals $100 \%$ (by rows).

Fig. 1. Matrix of distribution channels and relative share of sales of the products they offer

We need to point out that not always these shares result from the company marketing activity. There are cases when legal regulation imposes limitations in selling a particular product in a particular channel in the form of a quota or another designation. Such limitations are observed in direct sales of raw materials and food of animal origin from the animal breeders within EC, countries in Eastern Europe (Direct Marketing of Small Scale Farming Products in the CEE Region and Related Legislative Problems, 2013) and Bulgaria.

Adding channels directed to functional complementarity is a practice which can be explained with considerable limitations in the functions of the existing channels, which hinders the processes of ordering and/or purchasing. It is very likely to overcome these problems through developing new channels. Investing in functionally complementing channels is a modern practice which is explained by the following conditions:

- Enlarging the scope of using new technologies which contribute to the development of new channels, even hybrid ones;

- Development of technologies which use Big Data;

- Significant difference in expenses by separate functions by channels;

- Significant difference in capacity by separate functions by channels;

- Significant difference in the quality of service for channels and others.

All these changes influence favourably the addition of new channels in already functioning distribution systems which are assigned specific functions. Drivers for developing the channels can be development and accessibility of technologies, consumers, changes in legal regulation, competitors' channels and others. Besides the approaches presenting complementarity based on a single feature, multi complementarities are used in practice (combination of complementarity based on segments and products). Often in business there is also channel complementarity based on segments and functions which concerns channel capacity in relation to a separate function and segment sensitivity to the level of service. There is also a variant of complementarity by more than two/three features. The study of the distribution practices in the country and the interviews with managers made it possible to outline the basic advantages of the approach of complementarity (Table 2).

However, the presented method of functional complementarity does not provide an opportunity for equal purchase in each channel. It rather creates conditions for channel specialization (by segment, product and/or function). For example, a channel specialized in receiving and processing orders, a channel for informing consumers, a channel for delivering an ordered product and so on. 
May 12-14, 2016, Riga, University of Latvia

Table 2

Advantages of using the approach of complementarity

\begin{tabular}{|l|l|}
\hline \multicolumn{1}{|c|}{ Advantages } & \multicolumn{1}{c|}{ Features } \\
\hline $\begin{array}{l}\text { Conditions } \\
\text { for increasing } \\
\text { revenues }\end{array}$ & $\begin{array}{l}\text { Adding new channels under conditions of complementarity contributes to } \\
\text { increasing sales revenues. It is also possible to generate other revenues, beyond } \\
\text { those planned in sales (such as revenues from advertising, commissions, } \\
\text { franchising and others). }\end{array}$ \\
\hline $\begin{array}{l}\text { Opportunities for } \\
\text { cutting costs }\end{array}$ & $\begin{array}{l}\text { The advantage strongly manifests itself in those cases where consumers use } \\
\text { channels which service them at relatively lower costs. }\end{array}$ \\
\hline $\begin{array}{l}\text { Conditions for } \\
\text { quality customer } \\
\text { service }\end{array}$ & $\begin{array}{l}\text { Designing distribution channels by segments generates added value through } \\
\text { relevant encompassing, recognition and service in compliance with customer } \\
\text { expectations. The companies which use this approach do not explain to their } \\
\text { customers: What and why is it impossible?"; Actually, they do their best so that } \\
\text { such questions do not arise. }\end{array}$ \\
\hline $\begin{array}{l}\text { Modification of } \\
\text { market offer }\end{array}$ & $\begin{array}{l}\text { Adding new channels under conditions of complementarity creates prerequisites } \\
\text { for a variety of marketing tools, even transition to automatized marketing with } \\
\text { segments which accept and maintain it. }\end{array}$ \\
\hline Specialization & $\begin{array}{l}\text { Channel specialization based on segment, product range or function is } \\
\text { a prerequisite for reaching efficient distribution. Experience, contacts, CRM } \\
\text { techniques and process optimization are characteristic of this type of channel } \\
\text { structures. }\end{array}$ \\
\hline
\end{tabular}

Source: Developed by the author on the ground of studying particular practices of multi-channel distribution.

\section{Approach of competition between channels in multi-channel distribution}

The approach of competition can be viewed from two aspects (Table 3). The first, when factual conditions of competition are due to the functioning of multi-channel distribution; yet, without the competition between the separate channels being a tool for achieving goals. Or, in practice, in this case there might be a side effect of designing the multi-channel distribution. The second aspect of competition is observed in the distribution systems of companies which intentionally design the channels in the multi-channel distribution structure as competitive. In this case competition is designed as a tool and manifests itself as a result.

Table 3

Peculiarities of the approach of competition as part of multi-channel distribution

\begin{tabular}{|l|l|}
\hline \multicolumn{1}{|c|}{$\begin{array}{c}\text { Approach of } \\
\text { competition }\end{array}$} & \multicolumn{1}{c|}{ Features } \\
\hline $\begin{array}{l}\text { Competition due } \\
\text { to intention in } \\
\text { the design process }\end{array}$ & $\begin{array}{l}\text { A new channel is developed which is added to the existing ones. Intentionally it } \\
\text { is prepared to compete with the existing channels. The new channel is directed to } \\
\text { the existing segments, sells the same product range, and has similar functions. }\end{array}$ \\
\hline Real competition & $\begin{array}{l}\text { A new channel is developed which is added to the existing ones in the distribution } \\
\text { system. Even though the channel is designed intentionally as complementary, } \\
\text { the analysis of the results shows that there is real competition. This discrepancy is } \\
\text { a prerequisite for conflicts which could have negative impact on the distribution } \\
\text { system. }\end{array}$ \\
\hline
\end{tabular}

Source: Developed by the author on the ground of studying particular practices of multi-channel distribution. 


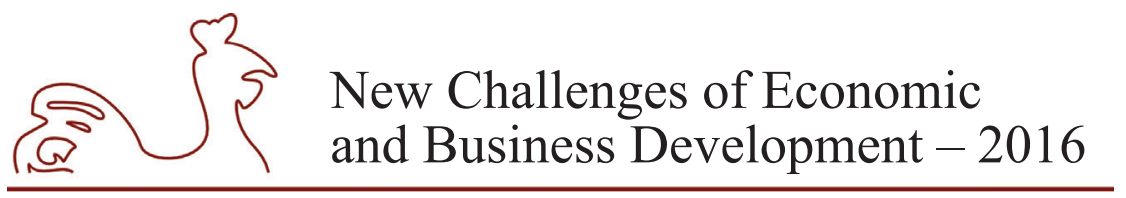

May 12-14, 2016, Riga, University of Latvia

Initially, the approach of channel competition as part of multi-channel distribution looks strange. Yet, the analysis of more than 40 practices of applying the approach gives us the ground to outline the following advantages (Table 4).

Table 4

\section{Advantages of using the approach of competition}

\begin{tabular}{|l|l|}
\hline \multicolumn{1}{|c|}{ Forms } & \multicolumn{1}{c|}{ Advantages of the approach } \\
\hline $\begin{array}{l}\text { Distribution is carried out by } \\
\text { independently registered companies }\end{array}$ & $\begin{array}{l}\text { Competition between separate channels is directed to } \\
\text { maximizing individual revenues in channels/companies. }\end{array}$ \\
\hline $\begin{array}{l}\text { Distribution is carried out within } \\
\text { the company and the different channels are } \\
\text { separated as strategic business units }\end{array}$ & $\begin{array}{l}\text { Competition is directed to maximizing sales revenues and } \\
\text { other revenues by maximizing the individual revenues } \\
\text { in separate channels. It is of internal type with strongly } \\
\text { expressed competitive nature between separate channels. }\end{array}$ \\
\hline $\begin{array}{l}\text { Company distribution is carried out } \\
\text { through a configuration of channels } \\
\text { which service consumers from the same } \\
\text { segments, with similar structure of sales by } \\
\text { products and functions }\end{array}$ & $\begin{array}{l}\text { Competition is directed to encouraging innovation in } \\
\text { the separate channels and searching for flexible solutions } \\
\text { to increase the market share of the separate channels upon } \\
\text { selling company products. }\end{array}$ \\
\hline
\end{tabular}

Source: Developed by the author on the ground of studying particular practices of multi-channel distribution.

Table 5

Problems concerning the approach of competition within multi-channel distribution

\begin{tabular}{|l|l|}
\hline \multicolumn{1}{|c|}{ Problems } & \multicolumn{1}{c|}{ Specifics } \\
\hline $\begin{array}{l}\text { Confrontation between separate } \\
\text { channels }\end{array}$ & $\begin{array}{l}\text { Marketing discrimination against separate channels with respect to } \\
\text { price, promotion, product quality and so on. }\end{array}$ \\
\hline $\begin{array}{l}\text { Use of unfair commercial } \\
\text { practices (Guidance on } \\
\text { the Implementation/Application } \\
\text { of Directive 2005/29/EC...) }\end{array}$ & $\begin{array}{l}\text { Competition between separate channels could make companies, } \\
\text { which administer a particular channel, use forbidden commercial } \\
\text { practices for attracting consumers (misleading and/or aggressive). }\end{array}$ \\
\hline $\begin{array}{l}\text { Channel cannibalism based on } \\
\text { market coverage }\end{array}$ & $\begin{array}{l}\text { It is observed in cases where the new channel takes a considerable } \\
\text { part of the sales of existing channels and makes them face } \\
\text { challenges in remaining on the market. Coverage of a market by } \\
\text { multiple channels may involve channel "shift" - customers moving } \\
\text { from one channel to another (Friedman, L. \& Furey, T., 1999). }\end{array}$ \\
\hline $\begin{array}{l}\text { Lack of links between separate } \\
\text { channels as expected by } \\
\text { customers }\end{array}$ & $\begin{array}{l}\text { Customers expect that channels function as an integrated } \\
\text { system and expect from them some degree of substitutability or } \\
\text { compatibility, which, however, is not maintained by this type of } \\
\text { structures. }\end{array}$ \\
\hline $\begin{array}{l}\text { Growth in sales at the expense } \\
\text { of "stealing" customers. Use of } \\
\text { information from other channels } \\
\text { which is gathered illegally }\end{array}$ & $\begin{array}{l}\text { Use of unethical tools for gathering information about clients of } \\
\text { other channels and getting in touch with them so as to attract them } \\
\text { as clients. } \\
\text { Use of information for financial benefits contrary to marketing } \\
\text { ethics. }\end{array}$ \\
\hline $\begin{array}{l}\text { Marketing aggression to } \\
\text { consumers }\end{array}$ & $\begin{array}{l}\text { Aggressive sales approach aiming at higher average value } \\
\text { of purchase, longer period of contracts and more barriers for } \\
\text { customers to terminate a contract. }\end{array}$ \\
\hline
\end{tabular}

Source: Developed by the author on the ground of studying particular practices of multi-channel distribution. 


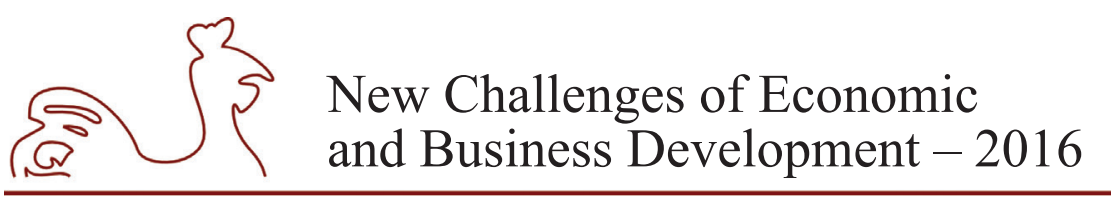

May 12-14, 2016, Riga, University of Latvia

Irrespective of the form of implementing the approach, its application has several strategic expectations:

- To maximize the revenues from each channel, thus maximizing the revenues in the system as a whole;

- The managers of each channel will try to apply various marketing tools for stimulating sales and achieve competitive advantages in comparison with the other channels;

- Stimulating the investment in the field of distribution;

- Stimulating customer loyalty;

- Redirecting customers for purchasing and/or consumption from one distribution channel to another;

- Providing a better competitive environment characterized by a variety of offers by channels (different prices, service and others);

- Providing customers with adequate information.

Implementing the approach of competition in multi-channel distribution can lead to problems in the way the distribution system functions.

\section{Approach of integration between channels in multi-channel distribution}

The third approach of integration has become very popular in the last decade. In literature various categories are used such as "integrated channels", "integrated distribution", "crosschannel integration", "cross-channel cooperation" and others. The approach is directed to maximizing company's total revenues through mutual work of all channels for the benefit of consumers. Investments in new technologies in the last couple of years are made exactly to provide an opportunity for integrating the functions of separate channels and maintain options for coordination, synchronization, tracking, reminder, etc., so that they can guarantee quality customer service. The advantages of this approach are indisputable, which makes it attractive for application by companies with high level of innovative marketing.

In a report of Accenture the following characteristics of Cross channel integration are outlined: optimizing the work of each channel in cooperation with the rest; overall management of the brand in all channels of distribution; focus oriented to a dialogue with the customer; creating process and technological opportunities to meet customer needs; focus on customer experience and managing the transitions between separate channels; a model or organization oriented to the customer rather than to a channel or product.

IBM experts direct their research interest to cross-channel optimization (Cross-channel optimization..., 2005), which allows the use of the opportunities of one of the channels to change favourably the structure of costs of another channel? Solutions and activities are directed to increasing efficiency and decreasing the costs of the distribution system as a whole. As early as 1990 Moriarty and Moran stated the issue of mutual work of channels in hybrid systems of distribution and organizing them (Morarty, R. \& Moran, U., 1990). The results of the literature review and the author's position concerning the advantages in applying the approach of integration are summarized in Table 6. 


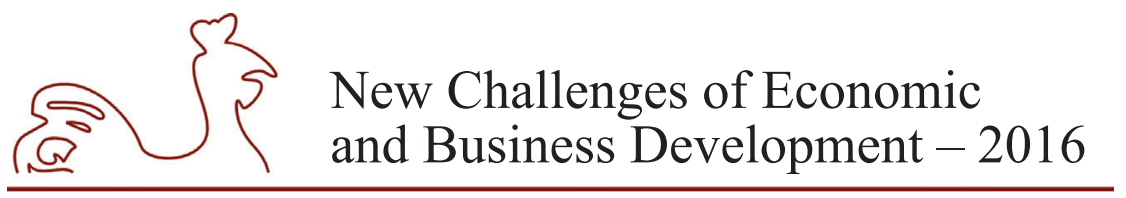

May 12-14, 2016, Riga, University of Latvia

Table 6

Advantages in applying the approach of integration within multi-channel distribution

\begin{tabular}{|c|c|}
\hline Advantages & Peculiarities \\
\hline $\begin{array}{l}\text { Achieving balance between customer } \\
\text { behavior in purchasing and company } \\
\text { economics of sales (Morarty, R.,1990) }\end{array}$ & $\begin{array}{l}\text { Integration of functions within multi-channel distribution } \\
\text { is viewed as a prerequisite for achieving correspondence } \\
\text { between customer expectations and the actual formats for } \\
\text { sales and servicing customers. }\end{array}$ \\
\hline $\begin{array}{l}\text { Increasing profits through reaching } \\
\text { more customers and increasing } \\
\text { the number of products for sale } \\
\text { (Vanheems, R.\& Kelly, S., 2009). } \\
\text { Improving selling profitability } \\
\text { (Friedman, L. \& Furey, T., 1999) }\end{array}$ & $\begin{array}{l}\text { This position corresponds to the theory of economies of scale, } \\
\text { according to which the increase of the volume of activity leads } \\
\text { to a decrease of the values of the produced and sold units. } \\
\text { The primary outcome of channel integration is improved } \\
\text { selling profitability (Friedman, L. \& Furey, T., 1999). }\end{array}$ \\
\hline $\begin{array}{l}\text { Finding the product at a lower price } \\
\text { (Napolitano, M., 2013) }\end{array}$ & $\begin{array}{l}\text { Integrated multi-channel distribution presupposes different } \\
\text { prices in the separate channels, which means that price- } \\
\text { sensitive consumers can find the product at a lower price. In } \\
\text { order to treat this feature as an advantage the company needs } \\
\text { to have a price advantage or another essential competitive } \\
\text { advantage since access to Internet from whichever point } \\
\text { enables a consumer to find the lowest price in other equal } \\
\text { conditions of the offer. }\end{array}$ \\
\hline $\begin{array}{l}\text { More targeted and dynamic } \\
\text { information } \\
\text { (Multi-Channel Marketing..., 2000) }\end{array}$ & $\begin{array}{l}\text { There are several sources of advantages based on information: } \\
\text { Exchange of information between separate channels vertically } \\
\text { and horizontally; dynamic information: targeted information } \\
\text { based on highly-technological marketing and big data. }\end{array}$ \\
\hline $\begin{array}{l}\text { Achieving channel synergy } \\
\text { (Rosenbloom, R., 2013) }\end{array}$ & $\begin{array}{l}\text { The accumulated result of functioning of the integrated system } \\
\text { should exceed the mechanic sum of the individual results of } \\
\text { separate channels. }\end{array}$ \\
\hline $\begin{array}{l}\text { Distribution of functions between } \\
\text { separate channels which contributes to } \\
\text { decreasing total distribution costs and/ } \\
\text { or total purchasing costs }\end{array}$ & $\begin{array}{l}\text { Distribution of functions is based on the logics of demand } \\
\text { and purchase on behalf of consumers. However, it is not } \\
\text { always that companies comply with this logic; instead, they } \\
\text { use mechanisms and tools for stimulating such distribution of } \\
\text { functions in an integrated multi-channel system which leads to } \\
\text { higher efficiency. }\end{array}$ \\
\hline
\end{tabular}

Source: Developed by the author on the ground of literature review and studying particular practices in multi-channel distribution and literature review.

\section{Results from the study on the approaches of multi-channel distribution in active enterprises in Bulgaria}

In order to reveal what are the approaches of multi-channel distribution applied by the companies a study of two stages was carried out. The first stage aims to ensure the consistency of the questions and measurement scales with the actual distribution situation in the enterprises registered in Bulgaria. During the first sub-stage an informal approach to a qualitative study 


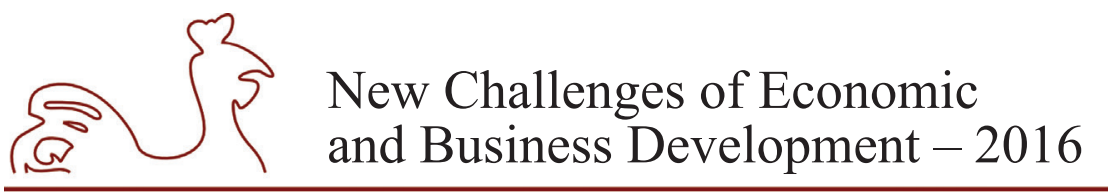

May 12-14, 2016, Riga, University of Latvia

is used which is done through conversations with people directly involved in the distribution management of the enterprises. During the second sub-stage a formal approach to marketing research is used, based on a qualitative method for gathering data. With regards to this, 6 in-depth interviews are organized with people that occupy leading positions in companies and that are responsible for the distribution: among which 3 are in small enterprises, 2 in mediumsized and 1 in a large company. The second stage of the survey includes the application of the sampling approach as a part of the questioning method. To study the problems of multichannel distribution in 2016 an online survey was carried out in 387 enterprises in Bulgaria, which included questions concerning the channel structure used by companies, the addition of new channels in the last three years, the approaches of multi-channel distribution, the results of adding new channels, intention to add new channels and intention to close existing ones.

The results of the study show that multi-channel distribution prevails as a distribution system in enterprises. The share of companies which use single channels is $49 \%$, company's own retail network being the single channel used most often. It is followed by personal sales, e-channel, retail outlets of intermediaries, call channel and mobile channel. The relative share of companies using two channels is $25.6 \%$, the most common combination being a channel of company's own retail outlets and e-channel. The relative share of companies using three channels is $8.4 \%$, the most common combination being a channel through commercial outlets of intermediaries, e-channel and personal sales.

Table 7

Relative share of companies using one, two and three channels in their distribution

\begin{tabular}{|l|l|l|l|}
\hline $\begin{array}{c}\text { Relative share of companies } \\
\text { using one channel (49.0\%) }\end{array}$ & \multicolumn{2}{|c|}{$\begin{array}{c}\text { Relative share of companies using two } \\
\text { channels (25.6\%) }\end{array}$} & $\begin{array}{c}\text { Relative share of companies } \\
\text { using three channels (8.4\%) }\end{array}$ \\
\hline$(1) 9 \%$ & $(1$ and 4) $1 \%$ & $(2$ and 9$) 1.6 \%$ & $(1,5$ and 8$) 1 \%$ \\
\hline$(5) 12.9 \%$ & $(1$ and 5) $4.9 \%$ & $(2$ and 3$) 3.1 \%$ & $(1,9$ and 5) $0.5 \%$ \\
\hline$(6) 1 \%$ & $(1$ and 9$) 0.5 \%$ & $(1$ and 3) $2.6 \%$ & $(2,1$ and 5) $1 \%$ \\
\hline$(2) 17.3 \%$ & $(1$ and 2) $6.2 \%$ & $(3$ and 4) $1 \%$ & $(2,6$ and 5) $1.3 \%$ \\
\hline$(9) 1.3 \%$ & $(2$ and 5) $1.6 \%$ & $(3$ and 5) $4.7 \%$ & $(2,9$ and 5) $0.5 \%$ \\
\hline$(3) 7.5 \%$ & & & $(3,1$ and 5) $1.8 \%$ \\
\hline & & & $(3,1$ and 8$) 1.3 \%$ \\
\hline & & & $(3,5$ and 8$) 1 \%$ \\
\hline
\end{tabular}

Legend: E-channel - 1; Company's own retail network of outlets - 2; Retail outlets through intermediaries - 3; Catalogue channel - 4; Personal sales - 5; Mobile channel (mobile application) - 6; Chat channel - 7; Event channel (sales at the time of events) - 8; Call channel/Call centre - 9; TV - channel - $\mathbf{1 0 .}$

Source: author's calculations based on primary data.

The summarized results by the "used channels" indicator show that $9 \%$ of the companies use four channels and the most common combination in this group is company's own retail network, commercial outlets through intermediaries, electronic channel and event channel $(2.1 \%)$. The share of companies using five channel of distribution is $4 \%$ and only $2 \%$ use six and more channels in their business at the time of the survey. 


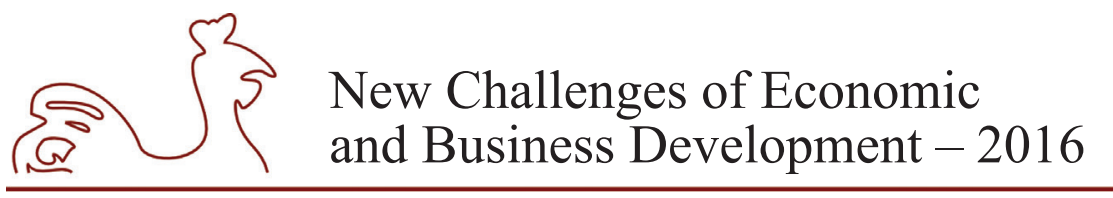

May 12-14, 2016, Riga, University of Latvia

Table 8

Relative share of companies using four, five, six and more channels in their distribution

\begin{tabular}{|l|l|l|}
\hline $\begin{array}{c}\text { Relative share of companies } \\
\text { using four channels } \mathbf{( 9 . 0 \% )}\end{array}$ & $\begin{array}{c}\text { Relative share of companies } \\
\text { using five channels } \mathbf{( 4 . 0 \% )}\end{array}$ & $\begin{array}{c}\text { Relative share of companies using } \\
\text { six and more channels } \mathbf{( 2 . 0} \%)\end{array}$ \\
\hline$(1,6,5$ and 8$) 1 \%$ & $(1,6,9,5$ and 8$) 1 \%$ & $(2,1,6,9,10,5$ and 8$) 1 \%$ \\
\hline$(2,1,6$ and 5$) 0.5 \%$ & $(2,3,1,4$ and 8$) 0.5 \%$ & $(2,3,1,4,5$ and 8$) 0.5 \%$ \\
\hline$(2,1,9$ and 5$) 0.5 \%$ & $(2,3,1,4$ and 9$) 1 \%$ & $(2,3,1,6,4,9,7,5$ and 8$) 0.5 \%$ \\
\hline$(2,1,7$ and 5$) 0.5 \%$ & $(2,3,1,6$ and 8$) 0.5 \%$ & \\
\hline$(2,9,7$ and 5$) 1 \%$ & $(3,1,6,5$ and 8$) 1 \%$ & \\
\hline$(2,3,1$ and 4$) 1.8 \%$ & & \\
\hline$(2,3,1$ and 8$) 2.1 \%$ & & \\
\hline$(2,3,1$ and 5$) 1.6 \%$ & & \\
\hline
\end{tabular}

Legend: E-channel - 1; Company's own retail network of outlets - 2; Retail outlets through intermediaries - 3; Catalogue channel - 4; Personal sales - 5; Mobile channel (mobile application) - 6; Chat channel - 7; Event channel (sales at the time of events) - 8; Call channel/Call centre - 9; TV - channel - $\mathbf{1 0}$.

Source: author's calculations based on primary data.

It is also interesting what part of the possible combinations of the 11 types of channels, included in the study, is actually used by Bulgarian companies. With a total number of 2047 different combinations (excluding the case when the number of distribution channels used by a company equals to 0 ), the companies participating in the study use 40 types of channels, or in fact these are about $2 \%$ of all the possible combinations.

The results of the study show that companies which added new channels in the last three years have predominantly added one channel only (72.6\%). Among those who have added a new channel/new channels the largest share is of the companies which have added an e-channel $(31.3 \%)$, followed by opening a company's own retailing network $(13.6 \%)$ and retailing outlets through intermediaries $(12.1 \%)$.

The study of the activity of adding new channels in the last three years shows that the approach of channel complementarity is most often used by companies and it is characteristic for $44.1 \%$ of the companies which added new channels. Second ranks the approach of integration $-36.3 \%$, the approach of competition accounts for $21.4 \%$ of the surveyed companies. Irrespective of the used approach of multi-channel distribution the companies which added channels in the last three years report the following positive impacts:

- Positive impact on revenues for $75.5 \%$ of the companies which added a new channel/ channels;

- Positive impact on the efficiency of sales revenues for $64.1 \%$ of the companies;

- Generating other revenues (besides sales revenues) for $44.1 \%$;

- Positive impact on profits for $67.8 \%$;

- Positive impact on attracting new consumers for $89.3 \%$ of the companies.

The intention of companies to open new channels this and /or next year was also studied. About one third of them (34.2\%) intend to open new distribution channels; the most possible channel for adding being a company's own retail network $(23 \%)$, commercial outlets through intermediaries $(22.1 \%)$, personal sales $(17 \%)$ and e-channel $(16.4 \%)$. The intention to close a channel was stated by $8.8 \%$ of the companies. 


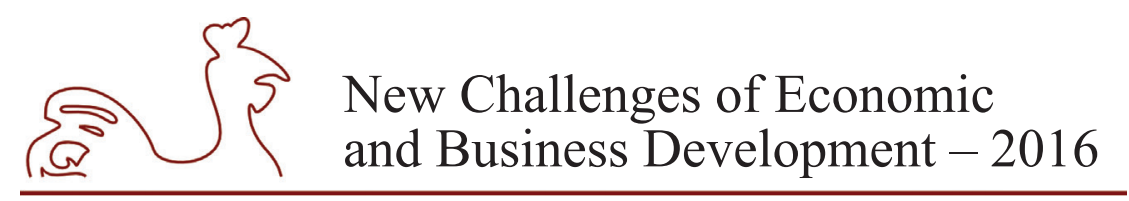

May 12-14, 2016, Riga, University of Latvia

\section{Conclusions}

The literature review, the study of the distribution practices in business and the study of the problems of multi-channel distribution are at the basis of the following summary:

1. The main recognizable approaches of multi-channel distribution are the approach of complementarity, the approach of integration and the approach of competition.

2. Approaches can be defined as early as the stage of designing the multi-channel distribution systems which means that they are considered beforehand. They can also be the result of the functioning of the multi-channel system without the approach being preliminary determined. Or there can be transformation in the preliminary determined approach.

3. The approaches of multi-channel distribution will become even more popular having in mind companies' great interest in adding new distribution channels in the last three years and in the future.

The results of the study carried out among Bulgarian companies show that a little more than half of them use multi-channel distribution. This proves the significance of researchers' interest in using approaches for implementing it. We can draw the following conclusions from the study:

1. The single-channel model (used by $49 \%$ of the companies) and the model of multi-channel distribution (used by $51 \%$ of the companies) in business are almost at equal status.

2. About one third of the companies intend to open a new channel this year and/or next year. It is most probable to develop the following channels: company's own retail network, commercial outlets through intermediaries, personal sales and e-channel. This result is of immense interest because it shows an essential change (even though an intention only) compared to the channels opened in the last three years, where the e-channel had a leadership position. Thus we can point out that even companies which initially developed e-channel (and/or other unconventional channels) now intend to add traditional distribution channels such as those with their own retail outlets and channels through outlets of intermediaries.

3. The positive impact of adding new channels on revenues, efficiency and profits for the predominant part of companies and the opportunity to also generate other revenues will influence positively the investment activity in distribution assets in the coming years.

4. $8.8 \%$ of the companies have the intention to close channels, which means that the balance between opening new channels $(34.2 \%)$ and closing the existing ones favours the increase of the share of multi-channel distribution.

The interest of customers and companies in multi-channel distribution will continue to grow. The example of successful channel configurations will be transferred to different spheres of economy and social life, contributing to better customer service and efficient distribution of products and services. The approach of integrating distribution channels in the conditions of multi-channel distribution will continue to develop and hybrid innovations in the sphere of Internet technologies, information and logistics will be the stimulus for the integration processes. 


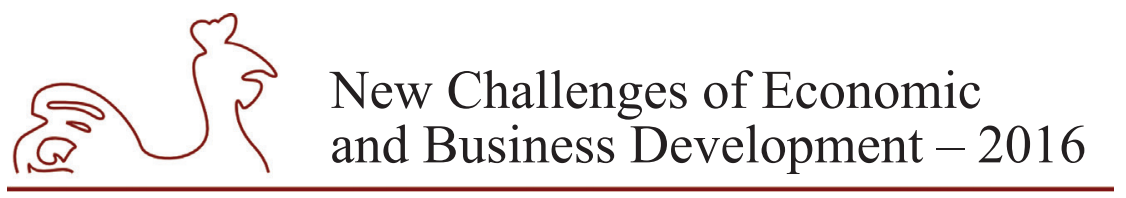

May 12-14, 2016, Riga, University of Latvia

\section{Bibliography}

Armstrong, G. \& Kotler, Ph., 2013(translated in Bulgarian). Vavedenie v marketinga. Klasika i Stil, Sofia, s.408.

Assael, H., 1985. Marketing Management. Strategy and Action. KPC, p. 488.

Accenture, 2010. Cross Channel Integration: The next step for High Performing retailers. A study of the latest trends in the Netherlands, p. 4. [Online] Available at: http://twinklemagazine.nl/ achtergronden/2010/06/onderzoek-crosschannel-shopping-in-nederland/Accenture-Cross-ChannelIntegration-Retail-Trends-in-The-Netherlands.pdf [Accessed 5 January 2016].

Cambridge Advanced Learner's Dictionary \& Thesaurus на Cambridge University Press, 2016. [Online] Available at: http://dictionary.cambridge.org/dictionary/english/approach [Accessed 5 January 2016].

CEEweb, 2013. Direct Marketing of Small Scale Farming Products in the CEE Region and Related Legislative Problems. [Online] Available at: http://www.ceeweb.org/wp-content/uploads/2012/11/ DM-small-scale-farming-legislative-problems.pdf [Accessed 15 January 2016].

CHASE PAYMENTECH, How to keep up with the multichannel consumer. p. 4.

EC, 2009. Guidance on the Implementation/Application of Directive 2005/29/EC on Unfair Commercial Practices. [Online] Available at: http://ec.europa.eu/justice/consumer-marketing/files/ucp guidance_en.pdf [Accessed 15 January 2016].

Friedman, L. \& Furey, T., 1999. The Channel Advantage. BH, pp. 173-183.

IBM, 2005. Cross-channel Optimization. A Strategic Roadmap for Multichannel Retailers. IBM Institute for Business value, p. 4. [Online] Available at: https://www-03.ibm.com/industries/ca/en/retail/ retail_docs/cross_opt.pdf [Accessed 15 January 2016].

McKinsey Marketing Practice, 2000. Multi-Channel Marketing. Making "Brick and Click" Stick. pp. 2-4.

McCarthy, E. \& Perreault, W., 1993. Basic Marketing. A Global Managerial Approach. IRWIN, p. 332.

Morarty, R. \& Moran, U., 1990. Managing Hybrid Marketing Systems. Harvard Business Review, November-December, pp. 153-154.

Napolitano, M., 2013. Omni-channel distribution: Moving at the speed of "now". Logistics Management, p. 43.

Pelton, L., Strutton, D. \& Lumkin, J. 2002. Marketing Channels A Relationship Management Approach. McGraw-Hill IRWIN, second ed., p. 81.

Rosenbloom, R., 2013. Marketing Channels A management View, Cengage Learning, p. 8.

Segetlija, Z., Mesaric, J. and D. Dujak, 2011. Importance of Distribution Channels - Marketing Channels For National Economy, p. 791, [Online] Available at: https://bib.irb.hr/datoteka/529824.Segetlija Dujak_Mesaric.pdf [Accessed 25 January 2016].

Vanheems, R. \& Kelly, S., 2009. Understanding Customer Purchase Switching Behavior When Retailers Use Multiple Channels. International Journal of Integrated Marketing Communications, p. 45. 
May 12-14, 2016, Riga, University of Latvia

\title{
MULTI-CHANNEL DISTRIBUTION DRIVERS AND ARGUMENTS FOR ADDING NEW CHANNELS
}

\author{
Evgeniya Tonkova, University of Economics, Varna, Bulgaria ${ }^{1}$
}

\begin{abstract}
The growing interest in multi-channel distribution and the development of new channel configurations in the last decade is an indisputable fact. The main drivers for the growth in using multi-channel structures and the business arguments for adding new distribution channels are issues of significant interest in this research.

The aim of this study is to make a review of the contemporary drivers of multi-channel distribution and identify the main companies' arguments for adding new marketing channels. The research is based on an online survey among companies registered in Bulgaria. The survey places emphasis on the companies' distribution decisions and argumentation for adding new channels in the last three years.

The paper presents four major drivers for multichannel distribution growth: technological development, legal regulation, logistics industry progress and increasing number of customers using multiple channels to buy products. The paper views the technological developments driving forward the use of various types of channels (conventional, e-channels, vending channels, catalog channels, call channels, direct personal sales and so on). In the last decade the increasing legal regulation of distribution from a distance is also an indisputable factor for the growth in applying multi-channel distribution. A significant driver for the growth in using multi-channel distribution is the development of the logistics industry. The growing number of companies and the enhanced wide range of services they offer support channels from a distance to serve their consumers effectively. The growing number of individuals defined as "cross channel shoppers" who demonstrate active consumer behavior in purchasing by using many channels also stimulates companies to invest in adding new channels for ensuring the balance under the circumstances of supplying and demanding the specific products and services and providing effective "Place" to "Space" channel management.

The results of the research show that adding new distribution channels to the already functioning ones is mainly aimed at attracting new customers, covering new markets/market segments, increasing market share and revenues. The decisions to add new channels are taken primarily under the influence of owners of companies and the example of the best multi-channel practices in the industry.

In conclusion, the technological development will stimulate changes in the quantitative and qualitative parameters of channels, hence their functions and capacity. Applying new technologies in a distribution and logistics will remain an important prerequisite for integrating separate channels in a uniform system which provides effective distribution through balancing the relations benefits/costs/risks for companies and consumers.
\end{abstract}

Key words: multi-channel distribution, channel decisions, drivers of multi-channel distribution

JEL code: M31

1 Corresponding author - e-mail address evge@mbox.digsys.bg 


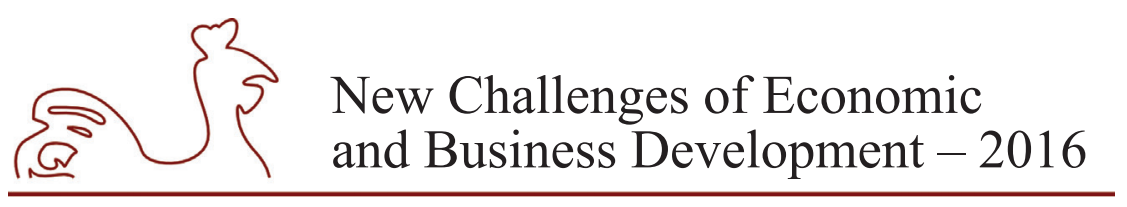

May 12-14, 2016, Riga, University of Latvia

\section{Introduction}

The growing interest in multi-channel distribution and the development of new channel configurations in the last decade is an indisputable fact. The main drivers for the growth in using multi-channel structures and the business arguments for adding new distribution channels are issues of significant interest in this research. The main idea of this survey is to encompass the specific decisions of companies concerning the expansion of their distribution scope through adding new channels. The survey is of special significance to business since it comprises the modern distribution practices and the arguments for change. It is of particular interest to consumers of products and services because the practices of adding new channels have a favourable impact on consumers' choice through providing various alternatives for the place of purchase.

The aim of this study is to make a review of the contemporary drivers of multi-channel distribution and identify the main arguments of companies for adding new marketing channels. The research is based on an online survey among a sample of active companies registered in Bulgaria.

The survey puts emphasis on the companies' distribution decisions and argumentation for adding new channels in the last three years. The main problematic issues in the research are:

- What are the basic arguments for adding a new channel/new channels of distribution?

- What channel/channels are added by companies to the existing distribution ones?

- Who makes the decisions within the managerial framework of distribution channels?

What is new in this study is classifying the arguments for adding a new channel/channels into three groups (marketing, financial and managerial), including them in the questionnaire in the form of a question about the basic argument and drawing conclusions about the priority of the separate groups of arguments after processing the data. Another new element in the survey is that the addition of new distribution channels is not studied separately according to types but it also concerns the various combinations through which companies expand their distribution scope and achieve synergy.

The results presented in the paper are part of a more thorough study of the problems of multichannel distribution which includes issues concerning the specifics of the distribution decisions, the conditions in which they are made, the distribution channels they use, the satisfaction of using them, investment in innovation, adding new channels and arguments for this, the effect of adding new channels, the approaches of multi-channel distribution, the intention for adding and closing channels and the impact on distribution decisions.

\section{Drivers of multi-channel distribution}

The more intensive company activity of investing in new distribution channels in the last couple of years has attracted researchers' interest in the conditions and changes of the environment which influence the development of distribution models.

The development of new technologies, including those which are used for distribution purposes, is ranked first as a driver. The development of Internet and Internet-based technologies contributes to updating company distribution structures and the irreversible transition from conventional to e-distribution (Table 1). 


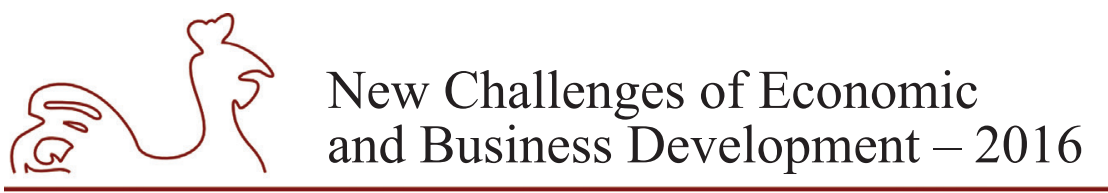

May 12-14, 2016, Riga, University of Latvia

The improvement of auction models in an e-environment also creates conditions for generating interest in adding new channels. The development of auction platforms for servicing business spheres is a prerequisite for applying flexible and dynamic marketing of specific products for which traditional channels have exhausted their potential. The importance of hybrid technologies for distribution in combination with the production process is increasing. These technologies boost the development of vending channels. Companies' interest in vending machines for production and distribution of food under conditions of self-made product is increasing (consumers take part in the product design on their own).

Table 1

Internet technologies as a driver of multi-channel distribution

\begin{tabular}{|c|c|}
\hline $\begin{array}{l}\text { Technological } \\
\text { innovations }\end{array}$ & Their role in developing multi-channel distribution \\
\hline $\begin{array}{l}\text { Internet } \\
\text { technologies }\end{array}$ & $\begin{array}{l}\text { The development of Internet technologies provides new opportunities and value } \\
\text { for consumers and entrepreneurs (Empowering Consumers..., 2007): access to } \\
\text { a vastly expanded choice of products and services, competing offers that can be } \\
\text { quickly and meaningfully compared, increased purchasing power, far greater } \\
\text { convenience; it opens up the opportunity for every European to become an } \\
\text { entrepreneur by significantly lowering the barriers to entry to a global market } \\
\text { and promotes the resale of products, enabling them to be reused or repurposed, } \\
\text { thereby facilitating sustainable consumption. }\end{array}$ \\
\hline $\begin{array}{l}\text { Payment } \\
\text { technologies }\end{array}$ & $\begin{array}{l}\text { Special attention is paid to two groups of characteristics - the first is payment } \\
\text { attributes and includes: an instrument to initiate it, a mechanism to accept it, } \\
\text { a process to undertake it, a currency that is accepted and a clear amount and } \\
\text { valuation. The second group is trust attributes and includes: recognized mark } \\
\text { of authority, known identities undertaken for a good reason, prior experience, } \\
\text { third party attestation and proper authorisation ( } 21^{\text {st }} \text { Century Regulation Putting } \\
\text { Innovation at the Heart of Payments Regulation). }\end{array}$ \\
\hline $\begin{array}{l}\text { Security } \\
\text { technologies }\end{array}$ & $\begin{array}{l}\text { Security technologies are developed in all functional trends: identify, protect, } \\
\text { detect, respond, and recover (Framework for Improving Critical Infrastructure..., } \\
\text { 2014) and affect cyber security, real and potential threats. }\end{array}$ \\
\hline $\begin{array}{l}\text { Technologies } \\
\text { for tracking } \\
\text { consumers }\end{array}$ & $\begin{array}{l}\text { Google Display Ad, for example, use "cookies" in advertised sites in order to } \\
\text { monitor what consumers do online, thus targeting and selling more successfully } \\
\text { their advertising formats. Although such practices are opposed, the problem of } \\
\text { tracking consumers and its boundaries has not been completely solved yet. }\end{array}$ \\
\hline $\begin{array}{l}\text { Social } \\
\text { technologies }\end{array}$ & $\begin{array}{l}\text { Increased role of social technologies (Skaržauskienè, A., Tamošiūnaite, R. \& } \\
\text { Žalèniene, I., 2013) for communication and their large application in business } \\
\text { and public sphere. }\end{array}$ \\
\hline $\begin{array}{l}\text { Mediation } \\
\text { technologies }\end{array}$ & $\begin{array}{l}\text { The development of Global Distribution Systems, distribution platforms, assisted } \\
\text { purchasing and others. }\end{array}$ \\
\hline
\end{tabular}

Source: author's research and literature review.

Another essential driver of multi-channel distribution is improving legal regulations for distance distribution. In this respect some work is done both at EU (distance contracts, rules on hidden charges, an EU wide 14 days cooling off period for distance and off premises contracts and deadline for delivery) and member states level. In the Republic of Bulgaria the improvement 


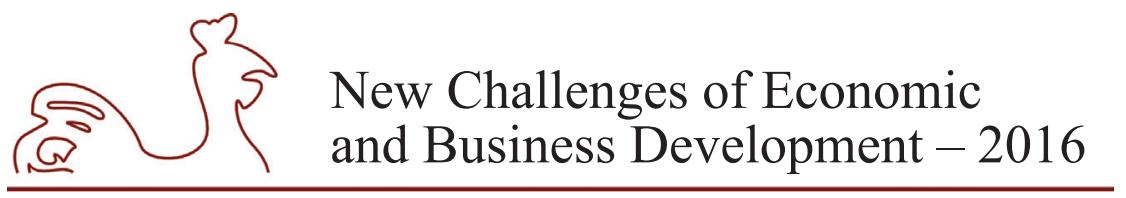

May 12-14, 2016, Riga, University of Latvia

of legislation in the last decade has boosted the expansion of multi-channel distribution by enlarging the scope of channel and product regulation.

A powerful driver for developing multi-channel distribution is also the favourable changes in the logistics sector. Qualitative and quantitative changes in logistic infrastructure, processes and operations influence positively the expansion of multi-channel distribution.

Table 2

Changes in the logistics sector on a global scale, which have a positive impact on multi-channel distribution

\begin{tabular}{|l|l|}
\hline \multicolumn{1}{|c|}{ Changes } & \multicolumn{1}{c|}{ Impact } \\
\hline $\begin{array}{l}\text { Development of } \\
\text { information technologies } \\
\text { which support logistics }\end{array}$ & $\begin{array}{l}\text { The vast use of technologies for automatic identification of loads, } \\
\text { tracking them, technologies for vertical and horizontal exchange of } \\
\text { information and technologies for exchange of real-time information help } \\
\text { to improve the quality of the services provided by logistic companies } \\
\text { and lead to the growth in the demand. }\end{array}$ \\
\hline Fragmentation of orders & $\begin{array}{l}\text { The development of logistics of small supplies contributes to developing } \\
\text { distance channels. }\end{array}$ \\
\hline $\begin{array}{l}\text { Development of forms of } \\
\text { integration }\end{array}$ & $\begin{array}{l}\text { One could observe various forms of integration of logistic companies } \\
\text { with online shops, sites for assisted purchasing, sites for business } \\
\text { announcements and others, which help to effectively encompassing } \\
\text { various geographic segments. }\end{array}$ \\
\hline $\begin{array}{l}\text { Investment in various } \\
\text { logistic infrastructure }\end{array}$ & $\begin{array}{l}\text { Increased share of investment in various logistic infrastructure which is } \\
\text { a prerequisite for offering complex logistics. }\end{array}$ \\
\hline
\end{tabular}

Source: author's research.

There is active development of software products which ensure the integration of logistic functions under conditions of multi-channel distribution. Companies invest funds in applications which provide alternative contact points of servicing consumers, including redirecting them to a suitable channel, outlet, contact point, etc.

The growing number of individuals who use plenty of channels in the process of making a purchasing decision also has a positive impact on distributing multi-channel structures. In literature and practice they are known as "multi-channel shoppers". There are lots of surveys in the field of marketing with a focus on the profile and characteristics of consumers who use many channels. The results of the studies on the "multi-channel shoppers" concerning the development of multi-channel distribution are presented in Table 3. The studies of Oracle in 2009/2010 among US consumers show the following distribution of consumers with respect to the channels used in purchasing (Cross-Channel Commerce: A Consumer Research Study, 2011):

- $22 \%$ of the consumers use 1 channel;

- $48 \%$ use 2 channels;

- $24 \%$ use 3 channels;

- $2 \%$ use 4 channels;

- $4 \%$ of consumers use more than 4 channels.

These data, although not so relevant at the moment, indisputably show preferences in favour of the development of multi-channel distribution. The consumers who buy through many channels stimulate not only the development of multi-channel distribution but also other changes like: 


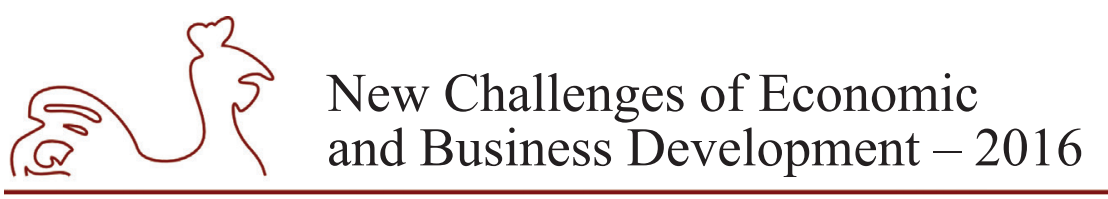

May 12-14, 2016, Riga, University of Latvia

- Increasing competition globally;

- Transformation from competition for "place" to competition for "space";

- Increase of inner channel competition;

- Looking for opportunities for cutting costs for physical distribution;

- Improving the security of multi-channel purchasing.

Table 3

Individuals who use plenty of channels in the process of purchasing decision making as a driver for the development of multi-channel distribution

\begin{tabular}{|c|c|}
\hline Studies & Basic results \\
\hline $\begin{array}{l}\text { A study of PwC (Understanding how US } \\
\text { online shoppers are reshaping the retail } \\
\text { experience, 2012) } \\
\text { PwC made } 7005 \text { online interviews with } \\
\text { consumers on three continents, covering } \\
\text { territories of } 8 \text { countries: USA, China, } \\
\text { Hong Kong, Germany, France, UK, } \\
\text { Switzerland and Holland. }\end{array}$ & $\begin{array}{l}\text { - } 20 \% \text { of consumers made their first purchase online in } \\
\text { the last } 12 \text { months attracted by a great variety through } \\
\text { online presence; } \\
\text { - More online buyers follow their favourite brands in } \\
\text { social media, but only } 3 \% \text { use them for purchasing; } \\
\text { - Looking up products online is defined as a critical } \\
\text { element of multi-channel distribution; } \\
\text { - Consumers are leaders in multi-channel purchasing. }\end{array}$ \\
\hline $\begin{array}{l}\text { A study of Verdegroup (Understanding the } \\
\text { Multi-Channel Shopper, 2011). } \\
\text { The study encompasses 1221 buyers from } \\
\text { USA and aims at studying the dynamics } \\
\text { in purchasing and the drivers for multi- } \\
\text { channel buyers: consumers who use two } \\
\text { and more channels all the time or most } \\
\text { of the time of the purchase, including the } \\
\text { activities in the stages before and after the } \\
\text { purchasing. }\end{array}$ & $\begin{array}{l}\text { - 2/3 of all buyers use regularly more than one channel } \\
\text { when making a purchase; } \\
\text { - The bigger the age of individuals, the smaller the } \\
\text { variety of channels used in the purchasing process; } \\
\text { - Traditional channels still rank first in choosing a } \\
\text { product for purchase; } \\
\text { - The number of used channels correlates with brand } \\
\text { loyalty; } \\
\text { - Multi-channel purchasing goes together with smaller } \\
\text { possibility for channel shifting; } \\
\text { - Multi-channel buyers spend more money for } \\
\text { purchasing; } \\
\text { - Multi-channel buyers are more conscious in making a } \\
\text { choice for purchasing. }\end{array}$ \\
\hline $\begin{array}{l}\text { A study of ATKearney } \\
\text { (Engaging Multichannel Consumers, 2012) } \\
\text { The study encompasses more than } 4000 \\
\text { individuals in USA and is focused on the } \\
\text { sector of retailing and financial institutions. }\end{array}$ & $\begin{array}{l}\text { - The predominant part of consumers use several } \\
\text { channels in purchasing which is valid for all sectors; } \\
\text { - Consumers use several channels for purchasing at the } \\
\text { same time. } \\
\text { As limitations in using the channels consumers point out: } \\
\text { - Difficulties in comparing products and prices; } \\
\text { - Impossibility to test products; } \\
\text { - Difficulties in finding information on product } \\
\text { characteristics; } \\
\text { - Problems in making payment; } \\
\text { - Problems in returning products. } \\
\text { In top three of individual problems there are registered: } \\
\text { "staff has no necessary knowledge", "I have no chance } \\
\text { to speak to someone when I want" and "the product is } \\
\text { unavailable". }\end{array}$ \\
\hline
\end{tabular}

Source: review of available researches. 


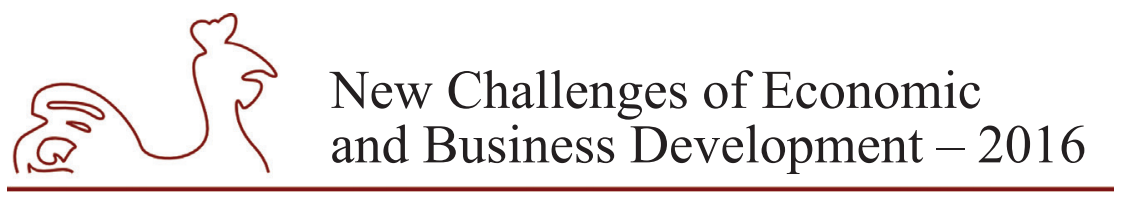

May 12-14, 2016, Riga, University of Latvia

\section{Arguments in favour of multi-channel distribution}

Arguments in favour of multi-channel distribution increased in the last decade. The reasons are mainly related to the promotion of successful multi-channel distribution practices in different spheres and the intensive investment in channel innovation. There are three groups of arguments for classifying those in favour of multi-channel distribution through the use of the classical approach of business functionality: marketing, financial and managerial (Tables 4, 5 and 6).

Table 4

Marketing arguments for multi-channel distribution

\begin{tabular}{|c|c|}
\hline Marketing arguments & Features \\
\hline $\begin{array}{l}\text { Encompassing new } \\
\text { markets/market segments }\end{array}$ & $\begin{array}{l}\text { The favourable changes affecting the opportunity for free movement } \\
\text { of individuals, goods and capitals increase the companies' interest } \\
\text { in developing new market segments. Authors share the opinion that } \\
\text { companies open new channels in order to sell to consumers of different } \\
\text { dimension (Pelton, L., Struton, D. \& Lumkin, J., 2002). }\end{array}$ \\
\hline $\begin{array}{l}\text { Reaching customers and } \\
\text { improving market coverage }\end{array}$ & $\begin{array}{l}\text { The argument is based on the assumption that adding a new channel } \\
\text { will contribute to reaching more potential consumers and increasing } \\
\text { the number of real consumers. Authors' viewpoint is that multi-channel } \\
\text { marketing allows a company to reach consumers in different ways } \\
\text { and improve the reach and improve market coverage (Sharma, A. \& } \\
\text { Mehrotra, A., 2007). }\end{array}$ \\
\hline $\begin{array}{l}\text { Increasing company market } \\
\text { share and reaching market } \\
\text { leadership }\end{array}$ & $\begin{array}{l}\text { The argument is based on the assumption that adding a new channel will } \\
\text { contribute to increasing sales, thus increasing company market share. } \\
\text { An opinion is shared that market leaders will be those who make } \\
\text { considerable investment in new distribution-and-managerial } \\
\text { opportunities (Hollander, D. \& Coleman, M., 2000). }\end{array}$ \\
\hline $\begin{array}{l}\text { Reaching favourable } \\
\text { relation benefits/costs/ } \\
\text { risks for the company and } \\
\text { consumers }\end{array}$ & $\begin{array}{l}\text { By investing in new channels, companies pursue different goals. These } \\
\text { can refer separately to revenues, costs, risks, benefits; yet, companies } \\
\text { can pursue also the goal of reaching a more fabourable relation benefits/ } \\
\text { costs/risks for the company and consumers. Some authors think that } \\
\text { using many channels enables the provision of low-cost (Zhang, J., } \\
\text { Irvin, J., Stenburgh, T, Farris, P., Kushawaha, T. \& Weitz, B., 2009) } \\
\text { access to new channels. An idea is stated that using many channels for } \\
\text { distribution helps to lower risk (Gamarra, L. \& Growitsch, Ch., 2007). }\end{array}$ \\
\hline $\begin{array}{l}\text { A tool for reaching } \\
\text { sustainable competitive } \\
\text { advantages (Rosenbloom, } \\
\text { B., 2013) }\end{array}$ & $\begin{array}{l}\text { According to some authors channels differ with respect to their } \\
\text { opportunities for consumer service and the application of multi-channel } \\
\text { distribution of complementary channels helps to improve it (Agatz, N., } \\
\text { Fleischmann, M. \& Nunen, J., 2008). }\end{array}$ \\
\hline $\begin{array}{l}\text { Suitable communication } \\
\text { with consumers and } \\
\text { improving their experience }\end{array}$ & $\begin{array}{l}\text { This argument is based on the assumption that adding a new channel } \\
\text { will contribute to improving communication and providing better } \\
\text { information environment that welcomes purchasing and other activities } \\
\text { which concern companies' product and product-range development. } \\
\text { Some authors focus on improving consumers' experience (Maclan, } \\
\text { S. and Wilson, H.) by linking it to costs, preferences and consumer } \\
\text { behavior before purchasing. }\end{array}$ \\
\hline
\end{tabular}

Source: author's research and literature review. 


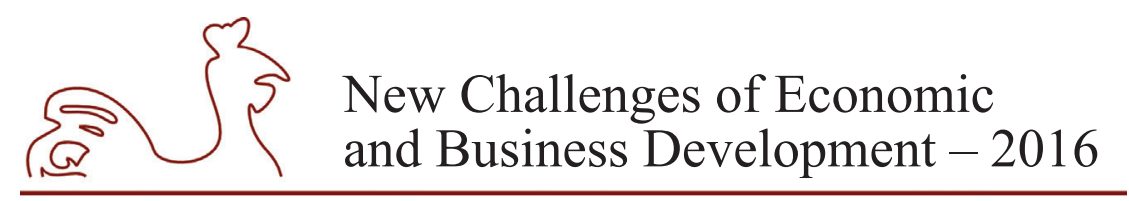

May 12-14, 2016, Riga, University of Latvia

Often marketing arguments are leading in adding new channels to the existing distribution structures. This is expected since distribution is an element of the marketing mix and has direct and transfer impact on company results and market performance.

Table 5

Financial arguments for multi-channel distribution

\begin{tabular}{|l|l|}
\hline \multicolumn{1}{|c|}{ Financial arguments } & \multicolumn{1}{c|}{ Features } \\
\hline Increasing sales revenues & $\begin{array}{l}\text { The argument is based on the assumption that adding a new channel will } \\
\text { contribute to increasing sales revenues. A number of authors support the } \\
\text { idea that adding new channel equals more sales (Friedman, L. \& Furey, T. } \\
\text { 1999). }\end{array}$ \\
\hline Generating extra revenues & $\begin{array}{l}\text { Some authors speak of a "model of revenues" which includes: revenues } \\
\text { from advertising, sponsorship, unions, membership/subscription, from } \\
\text { profiles, deals, market research and information, resending and other } \\
\text { revenues (Kotler, Ph., Jain, D. \& Maesincee, S., 2003). }\end{array}$ \\
\hline $\begin{array}{l}\text { Reaching higher } \\
\text { profitability }\end{array}$ & $\begin{array}{l}\text { The difference in the value of net income, generated in the various } \\
\text { distribution channels, makes companies use distribution channels which } \\
\text { provide higher profitability. }\end{array}$ \\
\hline $\begin{array}{l}\text { Reaching higher } \\
\text { efficiency }\end{array}$ & $\begin{array}{l}\text { The difference in revenues and expenses in channels affects also the } \\
\text { indicators of revenue efficiency and cost efficiency. It is only natural } \\
\text { for companies to strive for reaching higher efficiency through investing } \\
\text { in new channels. Authors who have studied the impact of innovations } \\
\text { in distribution channels on the performance of small and medium } \\
\text { enterprises, share about a significant positive correlation between } \\
\text { innovation and efficiency of distribution (Kuswantoro, F., Rosli, M., } \\
\text { Abdul, R. \& Ghorbani, H., 2012). }\end{array}$ \\
\hline $\begin{array}{l}\text { Making economies of } \\
\text { scale in production and } \\
\text { distribution }\end{array}$ & $\begin{array}{l}\text { In order to make economies of scale in production and distribution } \\
\text { companies try to enlarge the scope of supply through: } \\
\text { - Encompassing new segments; } \\
\text { • Product-range development; } \\
\text { - Increasing the average value of a purchase; } \\
\text { - Increasing the average number of purchased items and others. }\end{array}$ \\
\hline
\end{tabular}

Source: author's research and literature review.

The financial arguments have a significant role in the arguments for shifting to multichannel distribution and this doesn't occur at this stage only. They underpin the distribution of functions and profitability between separate channels, objects and subjects. Financial arguments are the proof for the appropriateness of marketing arguments because adding a channel does not mean mechanical addition of revenues and profits. It is exactly the banking sector that can be an example for the perfect financial argumentation of adding new profitable channels and investment in distribution. 


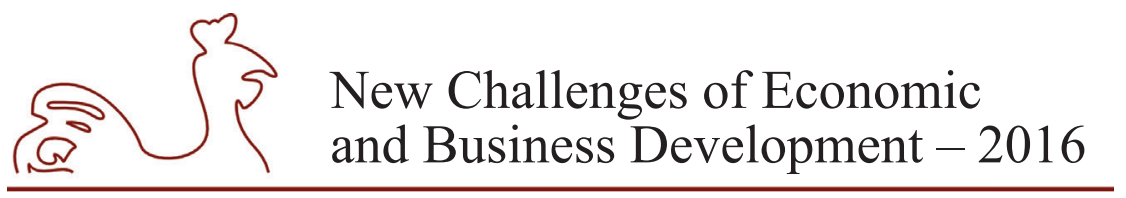

May 12-14, 2016, Riga, University of Latvia

Table 6

Managerial arguments for multi-channel distribution

\begin{tabular}{|l|l|}
\hline \multicolumn{1}{|c|}{ Managerial arguments } & \multicolumn{1}{c|}{ Features } \\
\hline $\begin{array}{l}\text { Diversifying risk with respect to } \\
\text { product distribution }\end{array}$ & $\begin{array}{l}\text { The argument is based on the assumption that in conditions of } \\
\text { multi-channel distribution the risk with respect to the market } \\
\text { distribution of production will be respectively lower. }\end{array}$ \\
\hline $\begin{array}{l}\text { Managing sales with respect to } \\
\text { channels }\end{array}$ & $\begin{array}{l}\text { Applying the concept of "lifecycles" to channels of distribution } \\
\text { sets the issue of investing in new channels. An important aspect } \\
\text { of managing sales concerns the opportunity to redirect consumers } \\
\text { within the distribution system which can help to increase } \\
\text { profitability of sales as a whole. }\end{array}$ \\
\hline $\begin{array}{l}\text { Updating channel structure of } \\
\text { companies }\end{array}$ & $\begin{array}{l}\text { In every business sphere one can identify "typical distribution } \\
\text { channels", "new channels for distribution" and so on. Changes } \\
\text { in the environment make companies update their distribution } \\
\text { channels periodically. }\end{array}$ \\
\hline $\begin{array}{l}\text { Providing a correspondence } \\
\text { between distribution and } \\
\text { production capacity }\end{array}$ & $\begin{array}{l}\text { The discordance between the production and distribution capacity } \\
\text { exposes companies to risks: } \\
\text { - A risk concerning market distribution; } \\
\text { - Financial risk. }\end{array}$ \\
\hline
\end{tabular}

Source: author's research.

Managerial arguments are also included in the logical argumentation of companies to shift to multi-channel distribution. Changes in the environment, the lasting economic crisis and unstable consumption made business subjects face three alternatives: survival, development or closing their business.

\section{Methodological framework and results from the launch/implementation of new channels}

In order to precisely justify the arguments for adding new channels the survey is carried out in two stages. The first stage aims to ensure the consistency of the questions and measurement scales with the actual distribution situation in the enterprises registered in Bulgaria. The first stage is divided into two sub-stages. During the first sub-stage an informal approach to a qualitative study is used which is done through conversations with people directly involved in the distribution management of the enterprises. During the second sub-stage a formal approach to marketing research is used, based on a qualitative method for gathering data. With regards to this, 6 in-depth interviews are organized with people that occupy leading positions in companies and that are responsible for the distribution: among which 3 are in small enterprises, 2 in medium-sized and 1 in a large company. The business scope of all the enterprises is different. Unstructured interviews are conducted - without any preliminary scenarios. The qualitative study provided:

1. First-hand information which is directly or indirectly related to the distribution of the enterprise.

2. Results which will allow the definition of basic questions and will help the structuring of the measurement scales. 


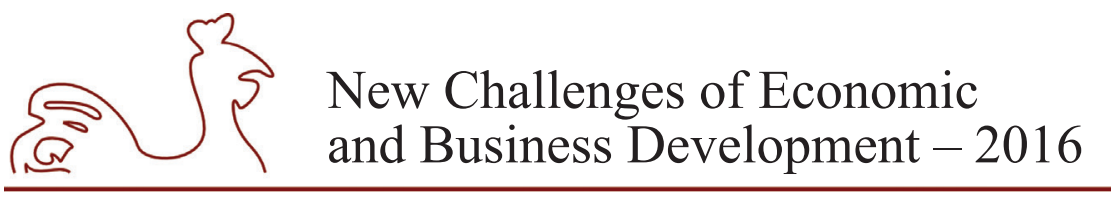

May 12-14, 2016, Riga, University of Latvia

The second stage of the survey includes the application of the sampling approach as a part of the questioning method. The argumentation for applying the approach of questioning managers responsible for distribution in the companies is based on: the active subjects at the moment of the survey are too many to be scoped as a general population; companies have high sensitivity to information affecting their distribution which predetermines the high share of the individuals who will reject to be involved in the survey (the conclusion is made as a result of the informal survey and the interviews made in the previous sub-stage); traditional distribution practices are revealed, practices that are typical for the separate business areas.

The second stage of the survey was carried out between 01.02.2016 and 25.02.2016. The requirements for determining the period of the study through the questionnaire design are met. The individuals have not been put to extra influence during the survey and they have carried out their typical functions in an unchanged environment.

As a result the sample taken for the survey is of non-random selection based on the method of unrestricted self-selected surveys and it involves 387 respondents. Two facts make it possible to work with the results of the survey and draw conclusions about the issues within the scope. Firstly, this number of respondents exceeds the calculated number based on general set and risk of error (0.05) if we assume that a model of probability sampling and selection is used. Secondly, the characteristics of the enterprises within the sample do not differ much from those of the general population.

The online study of issues of multi-channel distribution show that $52.7 \%$ of them have added new distribution channel/channels to the already existing ones. Among the most stated arguments (Table 7) for adding the channel are: attracting new consumers (35.8\%), encompassing new markets/market segments $(24 \%)$ and increasing company market share $(14.2 \%)$. What makes an impression is that the first three positions of arguments used by companies most often for adding new channel/channels are actually the marketing ones. The lowest relative share is that of the arguments "suitable communication with consumers" and "providing conditions for high-technology marketing".

Table 7

Basic arguments of enterprises for adding a new channel/channel in the last three years

\begin{tabular}{|l|c|}
\hline \multicolumn{1}{|c|}{ Arguments } & Valid Percent \\
\hline Attracting consumers & 35.8 \\
\hline Encompassing new markets/market segments & 24.0 \\
\hline Increasing company market share & 14.2 \\
\hline Increasing sales revenues & 10.8 \\
\hline Balancing supply and demand & 4.9 \\
\hline Reaching higher profitability & 3.9 \\
\hline Generating more revenues & 2.5 \\
\hline Suitable communication with consumers & 2.0 \\
\hline Providing conditions for high-technology marketing & 2.0 \\
\hline
\end{tabular}

Source: author's calculations based on primary data. 


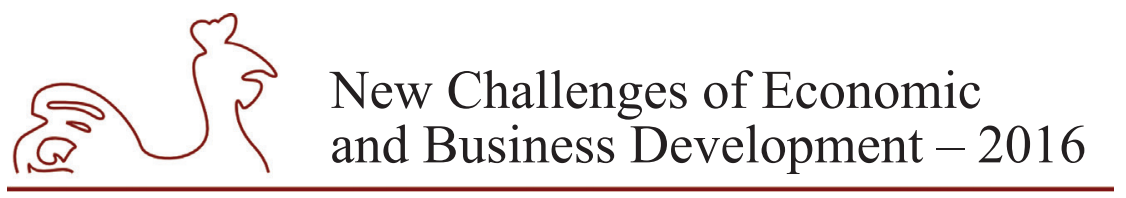

May 12-14, 2016, Riga, University of Latvia

What channel/what combination of channels was added by enterprises in the last three years is of particular interest to researchers. The results of the study show that companies which have added new channel/channels in the last three years have predominantly added one channel only (Table 8). Among those who have added a new channel/new channels the largest share is of the companies which have added an electronic channel (31.2\%), followed by opening a company's own retailing network (13.6\%) and retailing outlets through intermediaries $(12.1 \%)$.

Table 8

Distribution channel added in the last three years by companies which enlarged the number of used channels

\begin{tabular}{|l|r|l|r|}
\hline Channel added in the last three years & Percent & Channel added in the last three years & Percent \\
\hline E-channel & 31.3 & Call channel/Call centre & 1.0 \\
\hline Personal sales & 10.1 & Vending channel & 0.5 \\
\hline Event channel & 4.0 & Retail outlets through intermediaries & 12.1 \\
\hline Company's own retail network of outlets & 13.6 & & \\
\hline
\end{tabular}

Source: author's calculations based on primary data.

The predominant part of companies which have developed new channels in the last three years $(72.6 \%)$ have added one channel to the existing ones, $18.6 \%$ have developed two channels, $6.5 \%$ - three, $1 \%$ - four and $1 \%$ have added the impressive number of 7 distribution channels (Table 9).

Table 9

Distribution channels (more than one) added in the last three years by companies which enlarged the number of used channels

\begin{tabular}{|l|r|l|r|}
\hline Channels added in the last three years & Percent & Channels added in the last three years & Percent \\
\hline$(1)$ and (4) & 2.0 & $(1),(6)$ and (7) & 2.0 \\
\hline$(1)$ and (5) & 2.5 & $(2),(1)$ and (9) & 1.0 \\
\hline$(1)$ and (6) & 2.0 & $(2),(3)$ and (1) & 1.0 \\
\hline$(5)$ and (8) & 1.0 & $(3),(1)$ and (8) & 2.5 \\
\hline$(2)$ and (1) & 1.0 & $(3),(1),(6)$ and (8) & 1.0 \\
\hline$(2)$ and (5) & 3.0 & $(2),(3),(1),(6),(7),(5)$ and (8) & 1.0 \\
\hline$(2)$ and (9) & 1.0 & & \\
\hline$(3)$ and (1) & 5.1 & & \\
\hline$(3)$ and (5) & 1.0 & & \\
\hline
\end{tabular}

Legend for table 9: E-channel - 1; Company's own retail network of outlets - 2; Retail outlets through intermediaries - 3; Catalogue channel - 4; Personal sales - 5; Mobile channel (mobile application) - 6; Chat channel - 7; Event channel (sales at the time of events) - 8; Call channel/Call centre - 9; TV-channel-10.

Source: author's calculations based on primary data.

Impressive is the high relative share of "viewpoint of the owner" (49.6\%) about the impact on companies' distribution decisions and the exceptionally low share of "experts' opinion within the framework of consultancy services" $(1.1 \%)$. Remarkable is that companies comply 


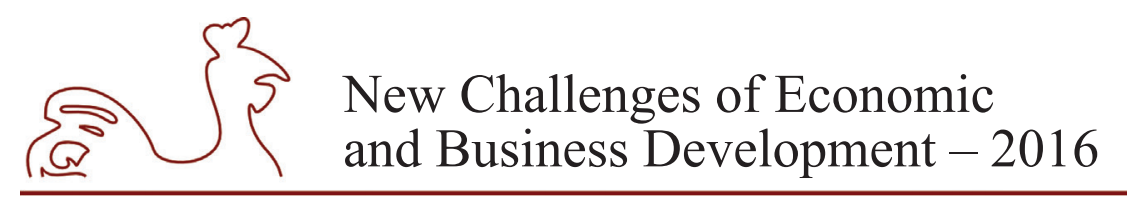

May 12-14, 2016, Riga, University of Latvia

their distribution with "the example of the best in the branch" (19.5\%), "marketing manager's competences" (17.1\%) and "manager's viewpoint" (12.8\%) which could have a favourable impact on the investments in new channels and searching for new sources of competitive advantages.

\section{Conclusions}

Within this paper the review of literature related to multi-channel distribution and the emphasis on the four key drivers for its development give us the ground to make the following conclusions:

- Internet technologies will keep on being crucial for distribution. They will have an impact on designing new distribution channels and modifying the existing ones.

- Updating legislation under conditions of multi-channel distribution will continue to develop in favour of business, consumers and society as a whole.

- Logistic technologies will give impetus to a change in favour of the use of the multichannel distribution model by companies;

- Cross-channel shoppers will keep their position as key consumers who bear the potential of favourable business change.

The study carried out among enterprises and the analysis of relevant variables allow us to summarize as follows:

1. The prevailing part of companies was oriented to the development of new channels in the last three years.

2. The greatest interest is registered with respect to developing and adding a new channel to the existing distribution ones. Most companies add one channel at a time over a threeyear period. One observes less interest in adding more than one channel in the form of various channel configurations.

3. The leading arguments for adding a new channel/channels are the marketing ones and they reflect companies' marketing goals for attracting new consumers, developing new markets/market segments and increasing their market share.

4. The distribution decisions experience the exceptionally strong influence of owners in a large part of companies which questions the professionalism in developing the channels and company performance in the future.

In conclusion, the development in the sphere of technologies, the improvement of legislative regulation and logistic environment of business and the higher consumer interest in multi-channel distribution will continue to have an impact in favour of the expansion and enhancement of multi-channel distribution. Companies and institutions outside business will continue to cooperate in order to overcome the registered problems (in the field of security, freedom of consumers and their rights) and to lower the risk for the participants in multi-channel transactions. 


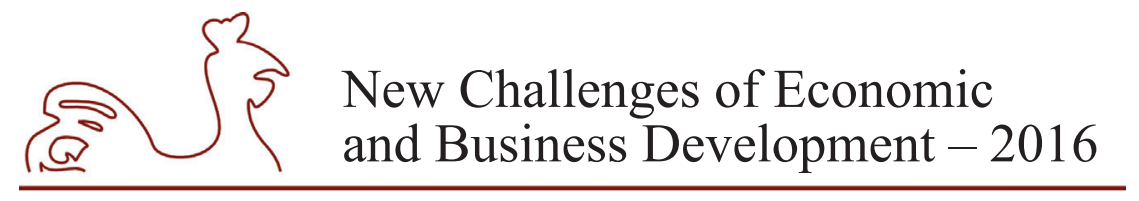

May 12-14, 2016, Riga, University of Latvia

\section{Bibliography}

Agatz, N., Fleischmann, M. \& Nunen, J., 2008. E-fulfillment and Multi-channel Distribution - A Review. European Journal of Operational Research, Volume 187 (2), pp. 339-356.

ATKearney, 2012. Engaging Multichannel Consumers. [Online] Available at: https://www.atkearney. com/documents/4773014/4786367/Engaging+Multichannel+Consumers.pdf/d3c31b47-42274b3e-a0c6-0a170f65fcda [Accessed 20 January 2016].

Ebay, 2007. Empowering Consumers by Promoting Access to the 21st Century Market. [Online] Available at: http://ec.europa.eu/competition/sectors/media/ebay_call_for_action.pdf_[Accessed 25 January 2016].

Friedman, L. \& Furey, T. 1999. The Channel Advantage. BH, pp. 9-11.

Gamarra, L. \& Growitsch, Ch., 2007. Single- versus Multi-Channel Distribution Strategies in the German Life Insurance Market, Institute of Economics in its series Thuenen-Series of Applied Economic Theory, (81), p. 7. [Online] Available at: http://www3.imperial.ac.uk/pls/portallive/docs/1/48187709. PDF [Accessed 01 February 2016].

Hollander, D. \& Coleman, M., 2000. Enabling Multichannel Distribution, Technology insight, p. 185.

Kotler, Ph., Jain, D. \& Maesincee, S., 2003. Marketing Moves. A New Approach to Profit, Growth and Renewal. Klasikastil, Bulgarian Ed., p. 159-163.

Kuswantoro, F., Rosli, M., Abdul, R. \& Ghorbani, H., 2012. Impact of Distribution Channel Innovation on the Performance of Small and Medium Enterprises. International Business and Management, Vol. 5 (1), p. 56.

Maclan, S. \& Wilson, H., Developing Multi-Channel Strategy, Cranfield University School of Management, pp. 4-5.

National Institute of Standards and Technology, 2014. Framework for Improving Critical Infrastructure Cybersecurity, [Online] Available at: http://www.nist.gov/cyberframework/upload/cybersecurityframework-021214-final.pdf [Accessed 25 January 2016].

Oracle, 2011. Cross-Channel Commerce: A Consumer Research Study. An Oracle White Paper. [Online] Available at: http://www.oracle.com/us/products/applications/commerce/atg/cross-channel-commercesurvey-333315.pdf [Accessed 20 January 2016].

PayPal, $21^{\text {st }}$ Century Regulation Putting Innovation at the Heart of Payments Regulation. [Online] Available at: https://www.paypalobjects.com/webstatic/en_US/mktg/public-policy/PayPal-PaymentRegulations-Booklet-US.pdf [Accessed 25 January 2016].

Pelton, L., Struton, D. \& Lumkin, J., 2002. Marketing Channels a Relationship Management Approach. McGraw-Hill IRWIN, p. 81.

PricewaterhouseCoopers LLP, 2012. Understanding How US Online Shoppers are Reshaping the Retail Experience. 2012. [Online] Available at: https://www.pwc.com/us/en/retail-consumer/publications/ assets/pwc-us-multichannel-shopping-survey.pdf [Accessed 20 January 2016].

Rosenbloom, B., 2013. Marketing Channels: A Management View, Eighth Edition, South-Western, Cengage Learning, pp. 9-10.

Sharma, A. \& Mehrotra, A., 2007. Choosing an Optimal Channel Mix in Multichannel Environments. Industrial Marketing Management. Vol. 36 (1), pp. 21-28.

Skaržauskienè, A., Tamošiūnaite, R. \& Žalènienè, I., 2013. Defining Social Technologies: Evaluation of Social Collaboration Tools and Technologies. The Electronic Journal Information Systems Evaluation, Volume 16 (3), pp. 232-241.

Verdegroup, 2012. Understanding the Multi-Channel Shopper. [Online] Available at: http://www. verdegroup.com/wp-content/uploads/2012/10/The-Multi-Channel-Shopper-Market-Study.pdf [Accessed 5 February 2016].

Zhang, J., Irvin, J., Stenburgh, T, Farris, P., Kushawaha, T. \& Weitz, B., 2009. Crafting Integrated Multichannel Retailing Strategies. [Online] Available at: http://www.hbs.edu/faculty/Publication\%20 Files/09-125.pdf [Accessed 1 February 2016]. 


\title{
GLOBAL EDUCATION FOR FUTURE BUSINESS LEADERSHIP. WHAT DO THE TEACHERS SAY?
}

\author{
Visvaldis Valtenbergs, Advanced Institute of Social and Political Research, Latvia ${ }^{1}$ \\ Inguna Irbite, Center of Development of Education, Latvia \\ Inese Ebele, Vidzeme University of Applied Sciences, Latvia
}

\begin{abstract}
In todays world of growing economic, political and cultural interconnectedness education in schools can affect the transformation of the economy and business. Achieving transformation through education and learning can be complex and painstakingly slow process, therefore it is important to look at causal factors which shape the competencies of the $21^{\text {st }}$ century generation.

In this paper we took a closer look at emerging subfield of education - global education. Global education is not a new teaching subject, but an interdisciplinary field which emerged in education, especially in social sciences during the end of the $20^{\text {th }}$ century. The main themes of global education are: globalization, economic and political interconnections, culture diversity, environment and sustainability, social justice and civic education. We show how these themes have become more relevant with the reference to business leadership qualities.

The study examines internal and external factors that contribute to teacher's motivation in teaching about global issues.

Study design is based on integral theory formulated by Ken Wilber and Sean Esbjörn-Hargens, which examines four complementing dimensions - teacher's personal and social values as well as the role of institutional framework in their motivation to implement global education. Study sample consists of 135 secondary school teachers who have participated in global education training project. Based on findings from teachers' survey and a focus group discussion we concluded that the motivation of teachers is positively affected by their personal values, beliefs and attitudes. The social values currently are less supportive for the implementation of global education but they do not seem to have a significant impact on professional activity of the teachers. Legislative and institutional framework plays a neutral role. Current teaching standards and programs for education curricula are compatible with the global development topics and their inclusion in school curricula. The study recommends to support teachers in the implementation of the teaching methods related to global education and to upscale several successful initiatives in schools.
\end{abstract}

Key words: global education, teachers, leadership, development

JEL code: A20

\section{Introduction}

Changing context of the modern world also affects the content of education and the learning process. With intensive contact between cultures and identities, a number of educational directions have been formulated. These directions offer to go beyond traditional disciplinary

1 Corresponding author - e-mail address: visvaldis.valtenbergs@va.lv 


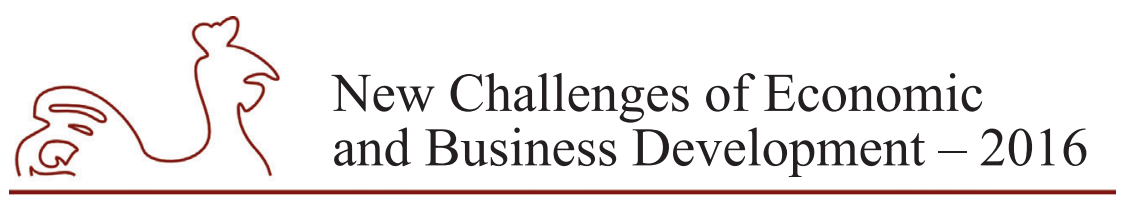

May 12-14, 2016, Riga, University of Latvia

boundaries and strengthen competencies that are appropriate to the $21^{\text {st }}$ century - critical, systemic and creative thinking skills, social skills, respect for diversity, as well as personal motivation to engage common collective problem solving (UNESCO, 2014). One of these areas is the global education. Global education is not a new subject, but a cross-cutting dimension in the curriculum mainly in social sciences. It's themes are globalization, political and economic interaction, cultural diversity, the environment and sustainability, human rights, social justice, civic participation. Global education has been the subject of education research but relatively little attention has been paid to the main party involved - the teachers. Therefore, the objective of the study is to find out how teacher's personal and social values contribute to the global education and what is the role played by institutional factors. Studying teacher's attitudes is relevant because they are directly involved with shaping of the next generation of organizational leaders. Developing organizational leaders to become conscious leaders of change is a primary strategic level for planetary transformation to higher quality of life, more positive economic and social outcomes. (Anderson, 2013)

Study design was adopted from Ken Wilber and Sean Esbjörn-Hargen's integrated fourquadrant model that covers personal values, beliefs, behavior, and collective societal norms, attitudes, institutional / regulatory context (Esbjörn-Hargens, 2009). The study is based on the master's thesis of Inguna Irbite who conducted the survey of teachers, two focus group discussions, analysis of the regulatory framework (Irbīte, 2014). The study covers 135 teachers from 21 Latvian general educational institutions of all Latvian regions. Surveyed teachers taught different subjects and worked with students of all ages - from primary to secondary school level. The research results are structured in accordance with the integrated approach quadrant model to provide answers to questions about how teacher's motivation contributes to their personal values, collective public opinion, as well as educational normative and institutional framework. The study shows that the implementation of global education is not only a matter of institutional support but a matter of teachers' inner motivation and the collective value of the environment in which they work as education professionals.

\section{The Concept and Evolution of Global Education}

Global education concept is relatively new. It first became used since the 90 ies of the $20^{\text {th }}$ century when the processes of globalization and changes in the national internal development also affected educational philosophy and curriculum. Both the concept of global education and the related concept of "Development Education" (which is sometimes used interchangeably) has several meanings. One of the most widely adopted meanings is contained within the Maastricht Global Education Declaration where global education is seen as education that opens people's eyes and minds to the realities of the global world and awakens in them the desire for greater justice in the world, equality and human rights for all (Maastricht Global Education Declaration, 2002). European NGO global education network CONCORD offers an explanation - development / global education is an active learning process that allows to develop an understanding of international developments, to explore the causes of global problems and the impact of their personal involvement and informed decision-making. Global education is based on the principles of solidarity, equality, inclusion and co-operation (Concord, 2009). In countries with longer history of global education, several related education concepts are used. For example, in the UK 


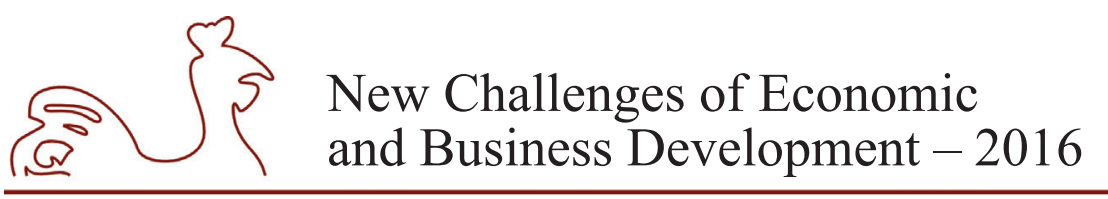

May 12-14, 2016, Riga, University of Latvia

popular terms is Global Learning and the Education for the Global Citizenship. The latter is defined as a field of education that helps young people to develop core competencies for active involvement in world affairs and to build a fairer and more sustainable world. It is also stressed that the Education for Global Citizenship is best implemented to revitalize the whole school subjects. In Estonia the concept emphasizes the role of the Global Education in expanding personal growth - global education is an active learning process that makes it possible to move from the basic level of understanding of the global causal understanding of personal involvement and informed action (Helin, 2009). Global / development education concept has always been closely associated with such educational areas as education for sustainable development, environmental education, human rights education, intercultural education, civic education. Different national environments or specific areas of the authors interpretations of the terms have been used interchangeably, as mutually overlapping or alternative concepts.

One can notice three main trends in global / development education objectives:

- Global education as a field of education to raise awareness of development issues.

- Global education area is about achieving the changes in behavior and promoting active involvement of the target groups in the learning process.

- Global education helps to strengthen the skills and competences necessary for life in the complex and dynamic world. Consequently, it helps to attain a wider view, leading to the fulfilling life and social change.

In its 2014-2017 curriculum UNESCO identified global citizenship as one of its priorities, because "it plays a crucial role in providing learners with competencies that are essential to life in a dynamic and interdependent world of the $21^{\text {st }}$ Century" (UNESCO, 2014). UNESCO updates a holistic approach to global development issues related to teaching, including the competence as knowledge of global issues and universal values, such as justice, equality, dignity; understanding of the multi-level identities and collective identity potential in excess of the individual cultural, religious, ethnic or other differences, such as the feeling of belonging to a common humanity and respect for diversity; the ability to think critically, creatively and systemically, by adopting different perspectives; social skills such as empathy, the ability to resolve conflicts, communication skills, the ability to network and cooperate with different origin and cultural people; ability to act jointly and to find global solutions to global problems (UNESCO, 2014). In current generation of global education major educational themes are: globalization, global, national and individual interactions, economic, social and environmental sustainability, human rights and social justice, cultural diversity, values and beliefs, conflict and security, etc. The paradigm promoted by global education presents the interconnected world with profound impact on people's worldviews and behaviors. There is no doubt that organizations are becoming the fields for change both in terms of their business models and management. Senge (1996) has described the leadership in such organization as a "process of creating a domain in which human beings continually deepen their understanding of reality and become more capable of participating in the unfolding of the world... allowing life to unfold through me."

\section{Implementation of Global Education}

There are different approaches to implementing the global education in Europe. In the public sector the main actor is usually Ministry of Foreign Affairs or it's agencies. Consequently, 


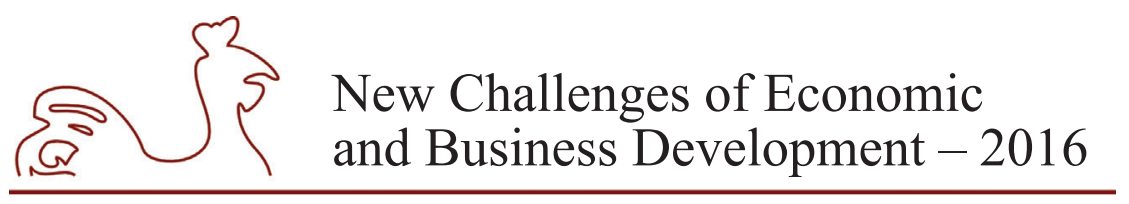

May 12-14, 2016, Riga, University of Latvia

the global education can also be one of the sub-policies (directions) of development cooperation policy. Less frequently global education is related to the domains of the Ministry of Environment and the Ministry of Education. Although the aim of formal education is crucial to ensure the population access to the widest range of population the Ministry of Education is actually not considered to be the most influential actor of implementation in many countries (Krause, 2010). Developments in recent years show that greater attention is paid to the place of global education in school's curricula and school practice and in the preparation of further education of teachers. However, only in some countries global education appears in national policy documents. The most outstanding positive examples in Europe are Germany, Finland, Sweden. In Finland global education is included not only in teachers' training but also in professional development programs of school administrators and support staff. Since 2007, the National Centre for teachers' professional development has included the global theme of teacher training programs. After 2008, implemented curriculum reform programs included in the global education themes (GENE, 2010). In 2009 CONCORD - an international NGO platform for relief and development published a study where it was concluded in most European countries, for which data are available, global education issues are represented in geography (74\%), history (44\%), the teaching environment (44\%), as well as cross-curricular themes (66\%). Most frequently discussed issues in the learning process are human rights, climate change, global poverty, cultural diversity, global trade, globalization, conflict, anti-racism and fair trade (Concord, 2009).

Important role is also played by the NGO sector. Currently in Europe, most powerful development / global education NGO networks is the Global Education Network (Global Education Network Europe - GENE), the European Development Education Exchange Project (Development Education Exchange in Europe Project - DEEEP), the Development Education Association (Development Education Association - DEA), etc. some of the NGO networks dealing primarily with global education, for others it is the only one of its direction to development cooperation projects and humanitarian organization, and other activities. In many countries NGO platforms brings together most of the relevant national organizations in this field. A striking example of how a small community of activists can become a broad and influential network of organizations, is a British non-profit confederation Oxfam. In 1942 it was established as charitable movement of Quaker religious organization. At present, Oxfam unites 17 organizations working in 94 countries around the world. Development education is just one of its many working areas. However, Oxfam's impact should be seen mores than the exception than the rule. The relationship between state and non-governmental sector in the implementation of global education differs from country to country. In countries with earlier global education traditions, the Ministry of Foreign Affairs is usually a permanent source of funding for the NGO sector. This funding usually comes from Official Development Assistance (ODA) budget. A different picture exists in most new EU member states, where development cooperation has not been among the top political priorities and therefore the global education has not become an important policy matter or an issue of financial urgency. As a result, the implementation of global education activities has largely an episodic nature, and it depends on the ability to attract external funding on project basis.

In Eastern and Central European countries, including Latvia, global education activities are implemented "from the bottom" - through various non-governmental activities, school initiatives and activities of individual enthusiasts. General public awareness, understanding 


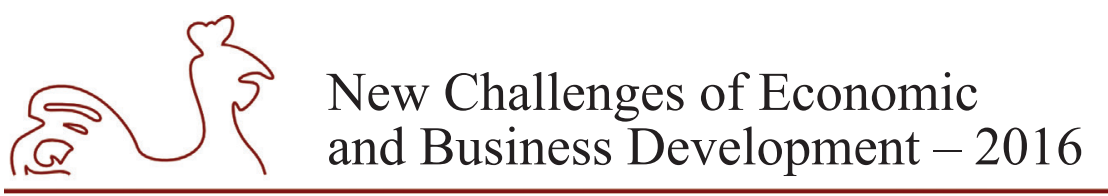

May 12-14, 2016, Riga, University of Latvia

and level of support for development cooperation and global education in Latvian is not high. The European Commission's Eurobarometer survey on citizens' views on international development cooperation and assistance in the development of the year 2014 show that $77 \%$ of Latvian respondents believe that it is important to help people in developing countries. Although it seems like a lot, it is the third lowest rate among countries surveyed (Special Eurobarometer 421, 2014). Latvian respondents also believe that the fight against poverty in developing countries should not be one of the main priorities of the EU (52\%). Latvian respondents are among those who would not be willing to pay more for products from developing countries (Latvian-27\%, the EU average of $49 \%$ ) or to be personally involved in providing assistance to developing countries (Latvian-10\%, the EU average of 35\%). The relatively low level of support for the Latvian population can be explained by the lack of colonial history, lack of missionary volunteering and inexperience, as well as the transition period to a market economy in which more people increasingly turned to solving their own personal economic problems. Perhaps for these reasons, development issues still do not occupy an important place in the national political agenda. In addition, the Official Development Assistance to decreased in Latvia. In 2012 and 2013 it was $0.08 \%$ of GDP, while in 2014 only $0.07 \%$. This is several times lower than the EU average $(0.39 \%)$ and does not exceed the new EU member states average $(0.1 \%)$ (European Council on EU Development Aid Targets, 2015).

In Latvian school environment, global education concept is relatively little known. However, thematically close to it there such education fields as Democracy and Human Rights Education and Environmental Education. In the period after the restoration of independence of Latvian schools became partners in international networks and programs - international Eco school program of UNESCO sustainable network of schools and human rights education program of the World Wildlife Fund for children's environmental school initiatives, Soros Foundation which initiated democracy education programs like Open School, Changes in Education, etc. These projects allowed the schools to push new learning models, modern curriculum and interactive learning methodologies. Support for Environmental Education provided mostly by the companies were given and still give an opportunity to strengthen company and school reputation for corporate social responsibility. Examples include - paper mill Ligatne waste paper collection of contests, Latvian State Forests initiative program Mother Nature, ZAAO, Latvian Plywood, Cemex, Green Belt and many others.

Inclusion of environmental and other sustainability related aspects - saving resources, saving costs help increasing the visibility of the school and ensure it's positive reputation in wider community. The most active NGOs in the field of global education is the Education Development Centre (EDC), GLEN Latvia, the Association of Education for Sustainable Development, Humana People to People in Latvia, Green freedom etc. Like in most countries also in Latvia Global Education in schools is not a separate subject, but a cross-cutting theme of several subjects. The analysis of teaching standards and programs reveal that most global issues are represented in the content of social sciences, history, geography, biology, politics and law (IAC, 2013). The topics related to global dimension are not only implemented via the classroom, but also through different extra-curricular activities - projects, students' selfgovernment initiatives, activities for parents and the general public, teacher lessons, camps, debate clubs, students' scientific research activities etc. 


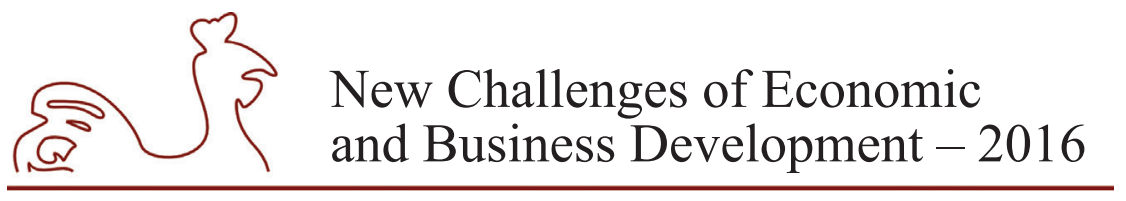

May 12-14, 2016, Riga, University of Latvia

\section{Integral Methodology for Analyzing Global Education Process}

So far, the studies on global education have seen teachers mainly as information providers without examining their value orientations and inner motivations. In order to obtain a more comprehensive picture integrated approach based on the integral theory, whose founder is an American philosopher Ken Wilber, was chosen. Integrated approach recommends that any process analysis carried out from four perspectives, or quadrants, which represent four basic dimensions - the interior and exterior of the individual and collective. These are designated as the Upper Left (interior-individual), Upper Right (exterior-individual), Lower Left (interiorcollective), and Lower Right (exterior-collective). The quadrants correspond with "I," "We," "It" and "Its" perspectives. I perspective includes human internal development - knowledge, values, beliefs, attitudes, interests and feelings. IT perspective analyzes the external observation and empirical action and behavior, for example, shopping habits, leisure activities, civic activities, conduct the profession. WE perspective marks the groups norms, beliefs and values, as well as the relations between them. ITS perspective examines a larger scale of the context variables, such as political, economic and social systems (Esbjörn-Hargens, 2009). Integrated approach in education has been adapted in pedagogy research, such as curriculum development and assessment, and specific curriculum areas such as environmental and sustainability education (Akiyama, 2014). Four-quadrant model is not only descriptive. It also promotes self-reflection by offering a way to teacher must better understand their role in the classroom. Integral teacher must be prepared to self-knowledge and personal growth (Feldman, 2011). From integral point of view, a definition of business is: "an open social system composed of individuals and their relationships, with shared values and purpose who promote experiences that support the development of society" (Cardoso, Ferrer, 2013).

\section{Findings}

\section{I perspective}

To explore teachers' individual value perspective, the study applied two of the most widely used frameworks of value research - the model of Salome Schwartz's theory of value (Schwartz, 2012) and Ronald Inglehart's material/post material values (Inglehart, 2008). Schwartz's model has identified 57 values, which are arranged in ten blocs. These are universalism, benevolence, tradition, conformism, security, power, success, hedonism, stimulation, self-determination. Schwartz's value model questions were included in teachers' questionnaires, but in the study the values of transcendence blocks were analyzed. Transcendence block measures universalism (understanding, appreciation, tolerance, openness to all human well-being and environmental protection, wisdom, social justice, equality, peace and beauty in the world, unity with nature, environmental protection) and benevolence (human well-being improvement, helpfulness, honesty, forgiveness, loyalty, responsibility) (Schwartz, 2003).

In the implementation of global education teachers are mostly motivated by their personal values, interests, beliefs about the significance of global issues and to some extent also about their sense of self confidence. The most inhibiting factors are the lack of knowledge, compounded by difficulty to navigate the wide range of information, knowledge of foreign languages and information technology literacy gap. Teachers are more interested in global education topics 


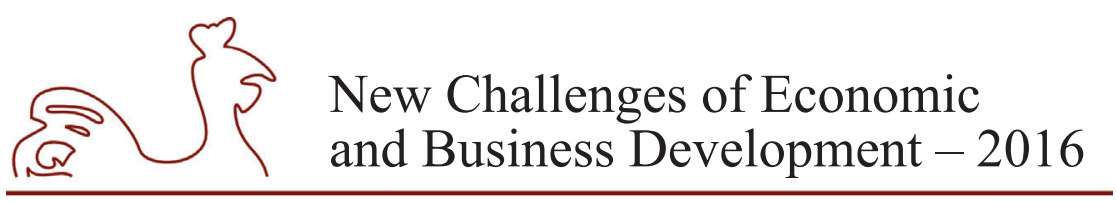

May 12-14, 2016, Riga, University of Latvia

that primarily affect their daily lives, but have less interest in broader international issues and geographically remote regions. The study found that teachers' value hierarchy (by Schwartz model) is dominated by transcendence values (universalism, benevolence), which positively affect teachers' internal motivations to address also global development themes. However, the teachers, just as general Latvian population mostly prefer material values. Personal economic and social insecurity partially hinders teachers' openness to global themes. Teachers experience more belonging to local territories (region, city), Latvia (93.1\%) and Europe (62.5\%) but significantly less to the rest of the world (42\%). For these reasons the themes connecting local specific issues to the global level agenda, such as migration, the environmental issues are generally more supported by the teachers. Teachers are generally positive in their attitude towards the inclusion of global issues in the curriculum, but their personal motivation in teaching is hindered by the lack of personal confidence in personal competence about the themes. A small proportion of respondents also point to the lack of knowledge of foreign language skills that would enable working better with resources accessible via the information and communication technology.

Table 1

Schwartz's Value Orientations Among Teachers

\begin{tabular}{lcc}
\hline & Similar to me (\%) & Not similar to me (\%) \\
\hline Self-transcendence & $\mathbf{9 3 . 4}$ & $\mathbf{6 . 6}$ \\
Universalism & 93.1 & 6.9 \\
Benevolence & 93.9 & 6.2 \\
Conservation & $\mathbf{7 6 . 6}$ & $\mathbf{2 3 . 4}$ \\
Conformity & 60.4 & 39.6 \\
Tradition & 74.1 & 26.0 \\
Security & 93.4 & 4.7 \\
Self-enhancement & $\mathbf{6 0 . 6}$ & $\mathbf{3 9 . 4}$ \\
Achievement & 69.2 & 30.9 \\
Hedonism & 65.7 & 34.4 \\
Openness to Change & $\mathbf{7 8 . 8}$ & $\mathbf{2 1 . 2}$ \\
Stimulation & 63.7 & 36.4 \\
Self-direction & 93.9 & 6.1 \\
\hline
\end{tabular}

Based on: Irbīte, I (2014) Globālās izglîtības īstenošanu sekmējoši faktori: skolotāja perspektīva. Mağistra darbs. Vidzemes Augstskola.

\section{IT perspective}

Results of teacher behavior study show that teachers use wide range of teaching methods. Also, teachers' daily behavior and lifestyle habits is compatible with global education values. Most respondents had purchased local products $(84.7 \%)$, or purchased an article with Fair Trade logo (79.8\%). Significantly less had cut down on their water consumption $11.4 \%$ or participated in charity campaign for people outside the country (14.5\%). This might be explained by the lack of such similar campaigns in the local society. Among the most taught topics are globalization and global-local interactions $-58.2 \%$, migration $-58.2 \%$, contemporary wars and conflicts $-50 \%$, environment and sustainable development $68 \%$. Significantly less is taught 


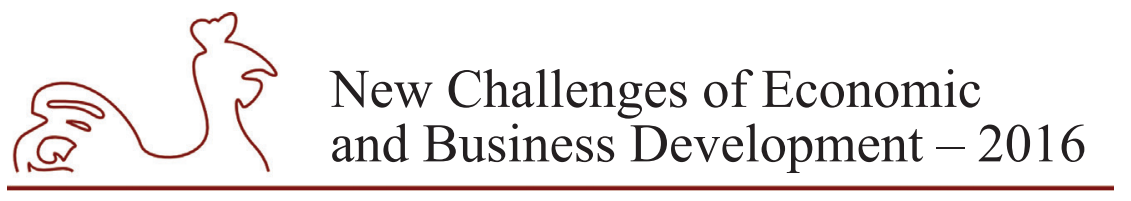

May 12-14, 2016, Riga, University of Latvia

about relationships between the developed countries and developing countries $(23.7 \%)$, and international organizations $(34.4 \%)$.

\section{WE perspective}

Broader social attitudes towards the global education are split. National sociological polls show public support for universal values, but it is difficult to tell, if these values are actually practiced in people's lives. Lack of public support (attributed to WE domain) sometimes make teachers feel misunderstood and undervalued. Most teachers admit that among the motivating factors are their own interest and values $77.9 \%$, and the interest of their pupils (68.8\%). Less teachers report that their own personal level of knowledge and competence is motivating them $(30.3 \%)$ and only $9.8 \%$ refer to the demand of society and parents. It seems that teacher's job is relatively autonomous as they have a chance to close the door behind her class and conduct classes with their children about things that they consider to be of value.

\section{ITS perspective}

Existing educational standards for teaching subjects and curricula are compatible with the goals and content of global education. However, the orientation of students in preparing for exams, and so-called mandatory requirements reduces the time that teachers are willing to spend in order to teach about the global issues. Latvian NGOs offer wide range of study materials about the global education. However, teachers' awareness about the available materials is not always sufficient. Valuable learning resources are also individual enthusiasts and educators who are involved in non-governmental sector implemented global education projects.

\section{Conclusions}

1. Global education is important to shaping of tomorrows leaders therefore it was important to investigate the role of the teachers who are involved in global education.

2. Topics addressed by global education allow to better understand challenges of the globalized economy - global labor market changes, challenges of migration and integration policies local and global increase in inequality and other challenges.

3. The study shows that teachers involved in the study have the will, ability and tools to talk about these topics, in order to prepare students to the challenges that await them in private and professional life.

4. In times when school systems are often blamed for the fact that the training content remains unchanged for years and that teachers teach the children of today with yesterday's methods to life the world of tomorrow, this research shows that there is no shortage of that flexibility to respond to changes include the world's major global issues into the learning subject content.

5. The study design confirms that further progress can be ensured by balancing the potential of individual (I, IT perspectives) and collective growth (WE perspective). Results of the study encourages educators to be inspired by positive examples, to realize more missed opportunities and find a positive motivation for the global dimension of the integration of learning content. 


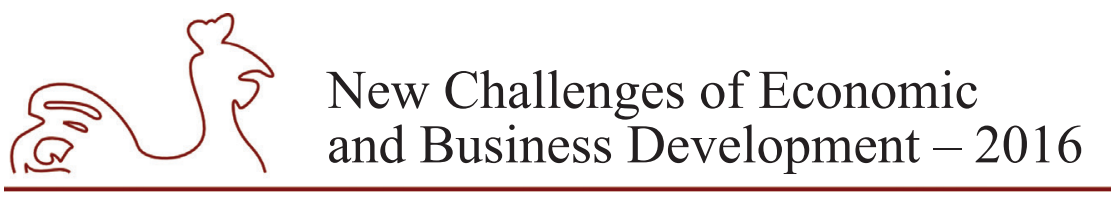

May 12-14, 2016, Riga, University of Latvia

\section{Bibliography}

Akiyama, T. et al. 2010. Integral Approach to Environmental Leadership Education: An Exploration in the Heihe River Basin, Northwestern China, the University of Tokyo. Proceedings of the $8^{\text {th }}$ International Symposium on Southeast Asian Water Environment. Available: http://repository.dl.itc.utokyo.ac.jp/dspace/bitstream/2261/54845/1/Akiyama_et_al_2010.pdf

Anderson, D. 2013. An Integrated System for Organizational Transformation. Journal of Integral Theory and Practice.

Cardoso, M., Ferrer, R. 2013. The Integral Management Meta-Model. A Management Model for SecondTier Organizations. Journal of Integral Theory and Practice.

Concord. 2009. Development Education and the School Curriculum in the European Union. A report on the status and impact of development education in the formal education sector and school curriculum in member states of the European Union.

Esbjörn-Hargens, S. (2009) An Overview of Integral Theory. An All-Inclusive Framework for $21^{\text {st }}$ Century. Integral institute. Resource paper. Available: https://www.integrallife.com/integral-post/overviewintegral-theory

Feldman, L. D. 2011. An Example of Integral Pedagogy. http://nextstepintegral.org/wp-content/ uploads/2011/04/an-example-of-integral-pedagogy-Lynne-Feldman.pdf

GENE. 2010. Global Education in Poland. National Report. The European Global Education Peer Review Process. pp. 19-20, 33. Available: https://www.polskapomoc.gov.pl/National,report,on,global,educ ation, in,Poland, $974 . \mathrm{html}$

Helin, J. 2009. Development Education in School Curricula in Europe: Global Challenge for Estonian Schools. Citizenship, Social and Economics Education. June 2009. p. 128.

IAC. 2013. Globālā dimensija izglītības normatīvajos dokumentos. Zinojums par attīstības/globālās izglītības aspektu izpēti sociālo zinātnu mācību priekšmetos. Rīga.

Inglehart, R. (2008) Changing Values among Western Publics from 1970 to 2006. West European Politics, Vol. 31. Nos.1-2, January-March. Available: http://www.doublemakemoney.com/wvs/articles/ folder_published/publication_559/files/values_1970-2006.pdf

Irbīte, I . 2014. Globālās izglītības īstenošanu sekmējoši faktori: skolotāja perspekt̄̄va. Magistra darbs. Vidzemes Augstskola.

Krause, J. 2010. The European Development Education Monitoring Report. Development Education Watch. Brussels: DEEEP.

Maastricht Global Education Declaration. 2002. https://www.coe.int/t/dg4/nscentre/Resources/ Publications/GE_Maastricht_Nov2002.pdf

Special Eurobarometer. 2014. The European Year for Development-Citizens' views on development, cooperation and aid, 421. Available: http://ec.europa.eu/public_opinion/archives/ebs/ebs_421_ en.pdf

UNESCO. 2014. Global Citizenship Education: Preparing learners for the challenges of the $21^{\text {st }}$ century. Retrieved: 04.03.2015.

Senge, P. M. 1990. The Fifth Discipline: The Art and Practice of the Learning Organization. New York: Doubleday/Currency

Senge, P. M., Jaworski, J. 1996. Synchronicity: Inner path to leadership. San Francisko, CA: BerretKoehler

Senge, P. M. 2009. The fifth order in action: strategies and tools of establishing a learning organization. Translated by Khdemi Gerashi, M., Soltani, M. \& Rastgar, A. Tehran: Asia.

Sharman, C. 2005. Leadership and learning organization. UMI Pro Quest: digital dissertation state university of New York Empire State College. 


\title{
THE MOTIVATION AND BARRIERS FOR IMPLEMENTING THE EUROPEAN FOUNDATION FOR QUALITY MANAGEMENT BUSINESS EXCELLENCE MODEL IN LATVIAN ENTERPRISES
}

\author{
Andzela Veselova, University of Latvia, Latvia ${ }^{1}$
}

\begin{abstract}
Excellent organizations can achieve and sustain outstanding levels of performance that exceed meeting the expectations of their stakeholders. The EFQM Excellence Model allows people to understand the relation between what their organization does and the results it achieves. This paper presents the results of an empirical study conducted in enterprises which are immersed in the implementation process of the European Foundation for Quality Management (EFQM) excellence model. The aim is to find out what kind of factors impacts both positively and negatively the EFQM Business Excellence Model implementation. To achieve the objective, were raised the following tasks: 1) to describe the EFQM model, 2) on the basis of theorical knowledge, to develop a questionnaire on the factors and their impacts on the EFQM Business Excellence Model use of enterprises, 3) based on the survey results, to draw conclusions and make proposals to reduce the barriers to the model implementation in Latvian enterprises. The research is based on the following hypothesis: The Latvian executives' choice to use EFQM Business Excellence model to measure the business performance is influenced by many supporting and delaying factors.

The methodology consists of a descriptive analysis in order to determine the importance of motivation and barriers. In the research were also used focus groups and interviews with experts. In the focus groups participated 20 representants of various areas of business. Ten experts were from the Quality area: the Prezident of Lavtia's quality association, evaluators of EFQM model etc.

The survey results show that the most important motivations that drive Latvian firms to implement the EFQM are internal motivations, and that the most important barriers are related to the lack of physical and financial resources and the lack of time. The structure of barriers is made up of more groups: resource barriers, organizational barriers, behavioral and cultural barriers. In the research was noticeable the coincidence of both expert and focus group results, pointing out the fundamental importance of the support of top management to EFQM use in the organization - this factor was evaluated with 4,9 points out of 5. Referring to possible delaying factors, the opinions did differ. Consequently, the lack of support of top management was recognized as the most meaningful delaying factor.
\end{abstract}

Key words: excellence, barriers, motivation, Excellence model

JEL code: L15

\section{Introduction}

Previously quality management focused only on quality inspection. Quality inspection deals with counting, grading and sorting to ensure that customers do not receive defective products. Then quality inspections included quality assurance and finally total quality management (TQM). Quality control applies various statistical techniques such as control charts and sampling plans to monitor processes. Quality assurance emphasizes process control to conform to customer

1 Corresponding author - e-mail address andzela.veselova@lu.lv 


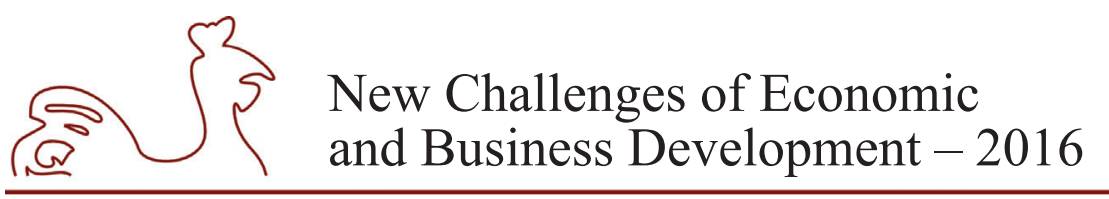

May 12-14, 2016, Riga, University of Latvia

requirements. The traditional quality management approach was reactive and result-oriented, whereas the modern approach to quality management is broader and now also emphasizes quality at source or process control, at every stage, to prevent any errors that could cause defects. The latter is a proactive process-oriented approach [2].

The place of excellence category can be seen following through evolution of the quality concept: inspection; quality control (emphasis firstly in prevention, and secondly on product and processes); quality assurance (emphasis firstly in the customer and secondly in continuous improvement); total quality; excellence (emphasis on ethics aspects and social commitment). Another describe a so-called evolution of excellence based on a series of phases started form the pre-excellence and leading to today's excellence 5.0, which is describe as an "innovative integrated development which is fundamentally viewed as a combination of strategic management and change". [3]

In the global competitive marketplace, the demands of customers have modified the rules of competition and forced organizations to focus on quality. Companies direct their efforts towards creating a competitive advantage that allows them to provide products and services that meet or exceed customer needs. This implies that to survive, organizations must device new management systems based on the principles of Total Quality Management (TQM).[13] The quality awards, specifically the Malcolm Baldrige National Quality Award (MBNQA) and the European Foundation for Quality Management (EFQM), have been used as a guide to implement the TQM philosophy in both the business and institutional areas (Bou-Llusar, Escrig-Tena, RocaPuig, \& Beltra'n- Martı'n, 2009; Stading \& Vokurka, 2003). Factual research has demonstrated that EFQM and MBNQA contain the largest part of the TQM dimensions, suggesting that these models constitute an appropriate framework to guide the systematic implementation of TQM (Bou-Llusar et al., 2009; Van der Wiele, Dale, \& Williams, 2000; Westlund, 2001). [1]

The EFQM model presents a non-prescriptive framework that analyzes the relationships between what an organization does and the results that it is able to attain, assuming that there are different approaches to attaining excellence (Ghobadian, Woo 1996).[9] (this The EFQM, founded in 1988, launched and designed the EFQM Model in 1991. The EFQM model introduces basic principles for effective TQM implementation in any type of organization and is currently being used by over 800 organizations in Europe. The Model can see on Figure 1.

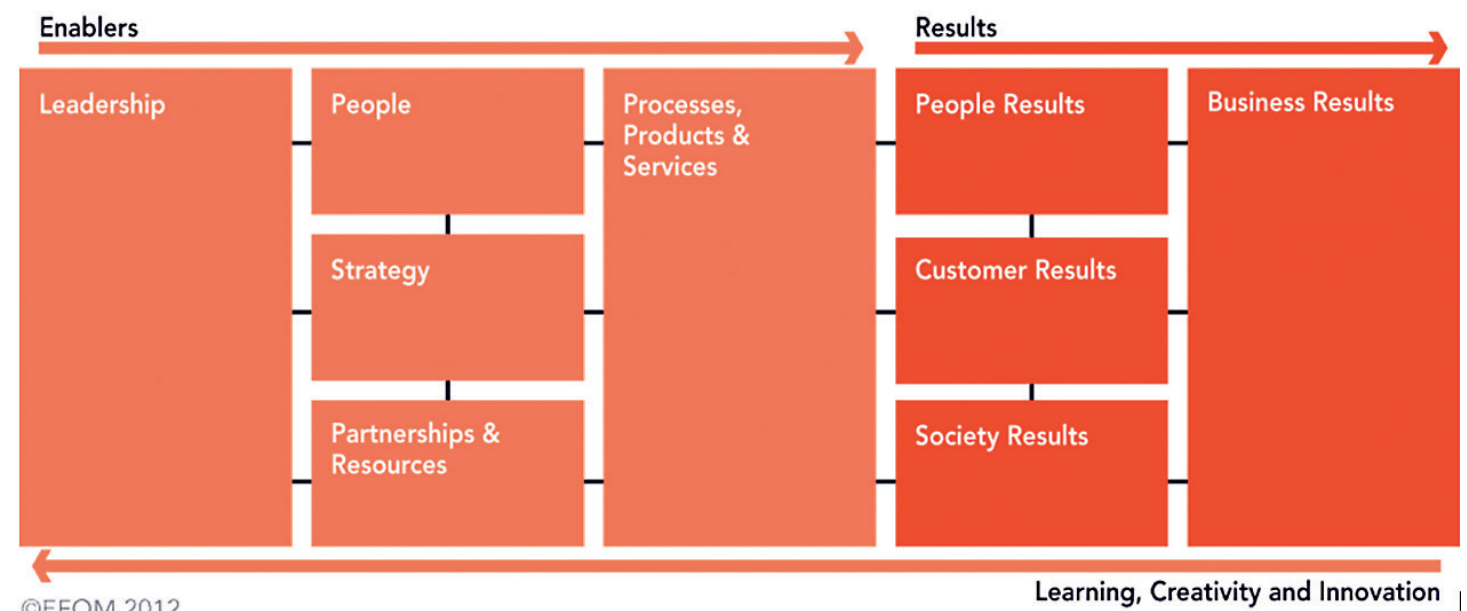

(C)EFQM 2012

Learning, Creativity and Innovation

Fig. 1. Model criteria [10] 


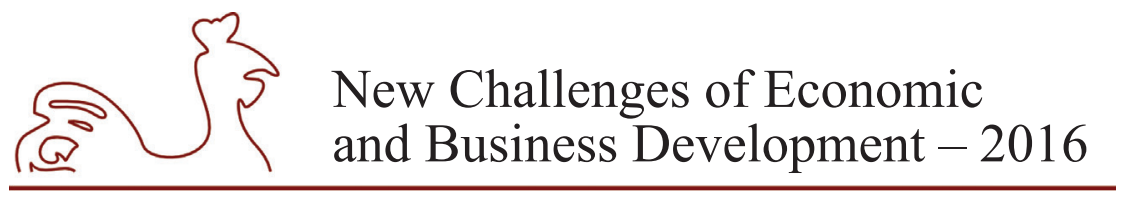

May 12-14, 2016, Riga, University of Latvia

The arrows emphasize the dynamic nature of the Model, showing learning, creativity and innovation helping to improve the Enablers that in turn lead to improved Results. The beauty of the Model is that it can be applied to any organization, regardless of size, sector or maturity. It is non-prescriptive and takes into account a number of different concepts. It provides a common language that enables members to effectively share their knowledge and experience, both inside and outside their own organization. It ensures that all the management practices used by an organization form a coherent system, which is continually improved, and delivers the intended strategy for the organization. [11]

The EFQM excellence model is grouped into 2 parts and based on 9 criteria, 5 enabler criteria (Leadership; Strategy, People; Partnerships and Resources; and Products, Processes, and Services), and 4 results criteria (People Results, Customer Results, Society Results, and Business Results). The enablers represent the results concentrate on achievements relating to organizational stakeholders (EFQM, 2013) and the way the organization operates. [14] There is a dynamic relationship between the results and the enablers, as excellence in the enablers will be visible in the results. The EFQM approach is applied in 3 ways: 1) the criteria of the model are used for the European Quality Award (EQA); 2) the model is used as a frame of reference for the quality management of organizations. In most of the cases, the decision to use the EFQM is a corporate-level decision in order to improve internal organization and productivity and as a base to improve its own quality management system; 3) the model is used as a self-assessment tool. [7]

To achieve sustained success, an organization needs strong leadership and clear strategic direction. They need to develop and improve their people, partnerships and processes to deliver value-adding products and services to their customers. In the EFQM Excellence Model, these are called the Enablers. If the right Enablers are effectively implemented, an organization will achieve the Results they, and their stakeholders, expect.

A Model based on a measuring system and these 9 criteria allows the organization to discern clearly its strengths and areas in which improvements can be made, and culminates in planned improvement actions. In that case a team of experienced consultants or quality managers collects the information and writes a report which is admitted and scored by EFQM assessors. The assessors use the RADAR Scoring Matrix to allocate points to each of the sub-criterion elements in the model. This matrix is based on the results-approach-deployment-assessment-review (RADAR) logic, which is a variant of the Plan, Do, Check, Act (PDCA) improvement cycle. The assessors use a rating scale from 0 to 1000 points. The jury of the EQA chooses among all prize-winners the best for the EFQM Award in different categories (EFQM, 2013). If the rating is about 620 points, the organization is a prize-winner, and if the assessors come to a rating higher than 550 points after the site visit, the applicant is a finalist. [8]

\section{Research results and discussion}

\subsection{Theoretical aspects on the motivation and barriers of implementing the EFQM excellence model}

The results obtained concerning internal and external reasons that lead companies to implement TQM through the EFQM excellence model. 


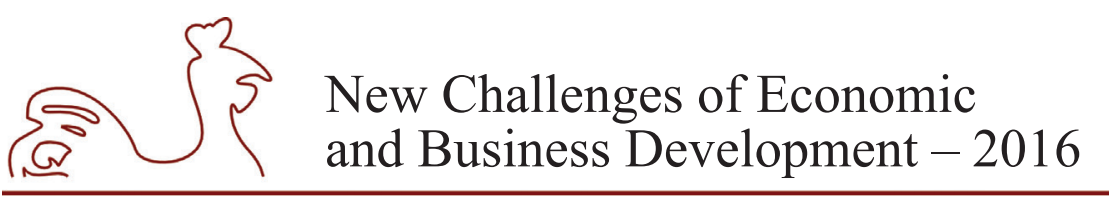

May 12-14, 2016, Riga, University of Latvia

In order to identify the reasons for an organization deciding to carry out the process of certification, we have conducted a systematic review of the literature following the same procedure as in the case of the motivations of implementing the EFQM excellence model. Theorical discussion within this study has been inspired by the more scholars. Table 1 shows the results obtained concerning concrete reasons both internally and externally that have been identified in the literature.

Table 1

External and internal reasons for EFQM implementation. [6, 5-7 p.]

\begin{tabular}{|c|c|c|}
\hline & References & Reasons \\
\hline $\begin{array}{l}\text { External } \\
\text { reasons }\end{array}$ & $\begin{array}{l}\text { Taylor (1995), Tsiotras and Gotzamani (1996), } \\
\text { Huarng et al. (1999), Escanciano et al. (2001), } \\
\text { Gustafson et al. (2001), Mathews et al. (2001), } \\
\text { Poksinska et al. (2002), Corbett et al. (2003), } \\
\text { Heras et al. (2006), Prajogo (2009), Beattie and } \\
\text { Sohal (1999), Lee and Palmer (1999), Withers } \\
\text { and Ebrahimpour (1996), Fuentes et al. (2000), } \\
\text { Torre et al. (2001), Sun and Cheng (2002), } \\
\text { Magd and Curry (2003), Heras-Saizarbitoria } \\
\text { et al. (2011), Carlsson and Carlsson (1996), } \\
\text { Lipovatz et al. (1999), Anderson et al. (1999), } \\
\text { Buttle (1997), Withers and Ebrahimpour } \\
\text { (2001) }\end{array}$ & $\begin{array}{l}\text { Improve company image } \\
\text { Increase market share } \\
\text { Improve competitive position } \\
\text { Customer demand } \\
\text { Meet national and international } \\
\text { market demand } \\
\text { Operate in global markets } \\
\text { Show effectiveness of } \\
\text { management practices } \\
\text { Anticipate future customer } \\
\text { demand } \\
\text { Anticipate market trends } \\
\text { Commercialization advantages } \\
\text { Required for competing in sector } \\
\text { Supplier pressure } \\
\text { Competitors pressure } \\
\text { Government pressure }\end{array}$ \\
\hline $\begin{array}{l}\text { Internal } \\
\text { reasons }\end{array}$ & $\begin{array}{l}\text { Fuentes et al. (2000), Mathews et al. (2001), } \\
\text { Withers and Ebrahimpour (2001), Sun and } \\
\text { Cheng (2002), Taylor (1995), Idris et al. (1996), } \\
\text { Tsiotras and Gotzamani (1996), Skrabec et al. } \\
\text { (1997), Escanciano et al. (2001), Magd and } \\
\text { Curry (2003), Prajogo (2009), Gotzamani and } \\
\text { Tsiotras (2002), Heras et al. (2006), Heras- } \\
\text { Saizarbitoria et al. (2011), Withers and } \\
\text { Ebrahimpour (1996), Huarng et al. (1999), Lee } \\
\text { and Palmer (1999), Withers and Ebrahimpour } \\
\text { (2000), Carlsson and Carlsson (1996), Beattie } \\
\text { and Sohal (1999), Corbett et al. (2003) }\end{array}$ & $\begin{array}{l}\text { Corporate-level decision } \\
\text { Improve internal organization } \\
\text { and productivity } \\
\text { Optimize necessary resources } \\
\text { Motivate staff } \\
\text { Improve product/service quality } \\
\text { Base to improve its } \\
\text { own quality management system } \\
\text { Costs reduction } \\
\text { Company survival }\end{array}$ \\
\hline
\end{tabular}

The table contains an overview from academic publications about some important internal and external reasons. These reasons are important to EFQM implementation.

It is a growing interest from companies performing the TQM by implementing excellence models, such as Malcolm Baldrige or EFQM (Stading \& Vokurka, 2003); however, studies focused on the barriers for implementing EFQM excellence model are still quite scarce (HerasSaizarbitoria, Casadesu's, \& Marimonc, 2011). This may be due to the fact that, as has been argued in specialist literature (Haversjo, 2000), a global register of companies implementing EFQM does not exist. [12] 


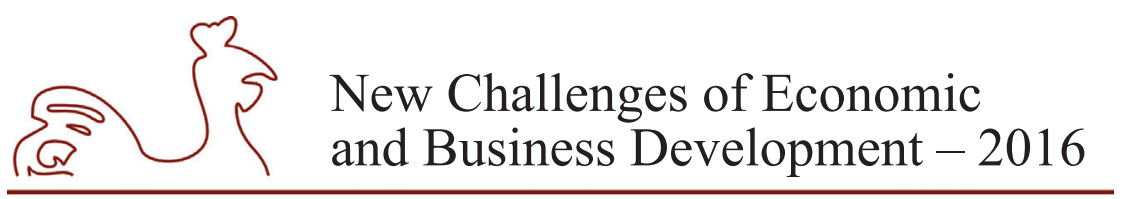

May 12-14, 2016, Riga, University of Latvia

To begin with, all works which have focused on the study of barriers for an organization deciding to carry out the implementation process of EFQM will be presented. Table 2 shows the results obtained concerning concrete barriers that have been identified in the literature.

Table 2

Barriers to implementing the EFQM. $[2 ; 5,5-7$ p. $]$

\begin{tabular}{|c|c|c|c|c|c|c|c|}
\hline Barriers & 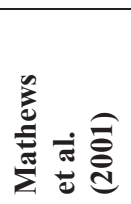 & 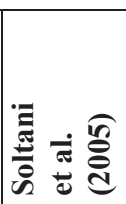 & 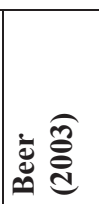 & 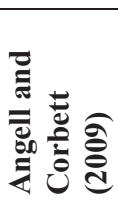 & 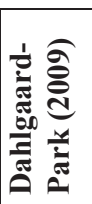 & 恶 & 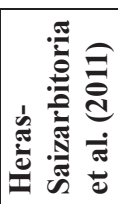 \\
\hline Resistance to change & $\mathrm{X}$ & $\mathrm{x}$ & & & & & \\
\hline $\begin{array}{l}\text { Lack of top } \\
\text { management } \\
\text { motivation and } \\
\text { participation }\end{array}$ & $\mathrm{X}$ & $\mathrm{x}$ & $\mathrm{x}$ & $\mathrm{x}$ & $\mathrm{x}$ & $\mathrm{x}$ & $\mathrm{x}$ \\
\hline $\begin{array}{l}\text { Lack of top } \\
\text { management } \\
\text { training }\end{array}$ & $\mathrm{X}$ & $\mathrm{x}$ & & & $\mathrm{x}$ & & \\
\hline $\begin{array}{l}\text { Lack of employees' } \\
\text { motivation and } \\
\text { participation }\end{array}$ & $\mathrm{X}$ & $\mathrm{x}$ & $\mathrm{x}$ & $\mathrm{X}$ & $\mathrm{x}$ & $\mathrm{x}$ & $\mathrm{x}$ \\
\hline $\begin{array}{l}\text { Lack of employee } \\
\text { training }\end{array}$ & $\mathrm{X}$ & $\mathrm{x}$ & & & $\mathrm{x}$ & & \\
\hline $\begin{array}{l}\text { Lack of } \\
\text { physical and } \\
\text { financial resources }\end{array}$ & $\mathrm{X}$ & $\mathrm{x}$ & & $\mathrm{X}$ & & $\mathrm{x}$ & $\mathrm{x}$ \\
\hline $\begin{array}{l}\text { Ineffective } \\
\text { Management } \\
\text { team }\end{array}$ & & & $\mathrm{x}$ & & & & \\
\hline Lack of time & $\mathrm{X}$ & & & & $\mathrm{x}$ & $\mathrm{x}$ & $\mathrm{x}$ \\
\hline $\begin{array}{l}\text { Lack of } \\
\text { commitment/ } \\
\text { implication }\end{array}$ & $\mathrm{X}$ & $\mathrm{x}$ & $\mathrm{x}$ & $\mathrm{X}$ & $\mathrm{x}$ & $\mathrm{x}$ & $\mathrm{x}$ \\
\hline $\begin{array}{l}\text { Lack of } \\
\text { leadership }\end{array}$ & $\mathrm{X}$ & $\mathrm{x}$ & & & & $\mathrm{x}$ & \\
\hline $\begin{array}{l}\text { Departmental } \\
\text { barriers }\end{array}$ & $\mathrm{X}$ & & & & & & \\
\hline $\begin{array}{l}\text { Lack of } \\
\text { communication }\end{array}$ & & $\mathrm{x}$ & $\mathrm{x}$ & $\mathrm{X}$ & & & \\
\hline Work overload & & $\mathrm{x}$ & & $\mathrm{X}$ & & & \\
\hline $\begin{array}{l}\text { Lack of } \\
\text { customer } \\
\text { orientation }\end{array}$ & & $\mathrm{x}$ & & & & & \\
\hline $\begin{array}{l}\text { Lack of clear } \\
\text { measurement } \\
\text { systems }\end{array}$ & & $\mathrm{x}$ & $\mathrm{x}$ & & & & \\
\hline $\begin{array}{l}\text { Complexity of } \\
\text { model }\end{array}$ & & $\mathrm{x}$ & $\mathrm{x}$ & $\mathrm{X}$ & & & $\mathrm{x}$ \\
\hline
\end{tabular}




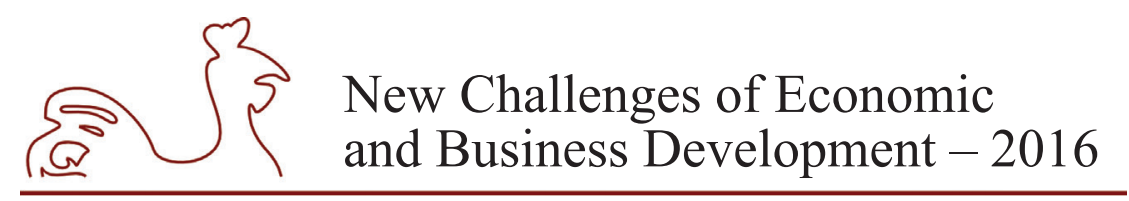

May 12-14, 2016, Riga, University of Latvia

One aspect that is identified commonly by the studies under consideration is the fact that the implementation success of a quality management program must begin with the commitment and involvement of top management in the objectives, strategies, and priorities of the firm. [3] In addition, the tendency of many firms to focus principally on tangible aspects and targets, leaving in second place other factors such as the participation and training of human resources, can in turn lead to resistance to the changes needed for the implementation of TQM. The fact that many companies are 'pushed' into quality management by their competitors can be derived from a lack of commitment and real understanding on the part of upper management or company directors concerning all of the implications of a quality management program.

Some problems encountered by firms during the process of implementation are the lack of organizational resources, not only physical and financial ones. [5, 3-4 p.] With regard to internal obstacles, studies have found that a management team incapable of carrying out coordination and communication tasks amongst the different areas of the value chain of the firm is a barrier which employees perceive as an extremely important one in the implementation process. [4] Another point which stands out is the lack of vertical communication (top-down and bottomup) derived from fear or the norms of silence, which in turn reduces the learning about quality in the organization and impedes honest feedback concerning how the implementation is being carried out and what are the main points that need improving. To the same extent, the lack of leadership and departmental barriers are aspects which also hinder the implementation of quality management. Moreover, firms are sometimes forced to abandon the process due to the complexity of the model, and problems to understand its language and to assimilate the criteria and principles on which it is based.

\subsection{Practical aspects on the motivation and barriers of implementing the EFQM excellence model in Latvian enterprises.}

Based on the theoretical part in the article, were explored the EFQM model influencing motivating and barriers. The author created a table with Disadvantage and Contributing factors. 


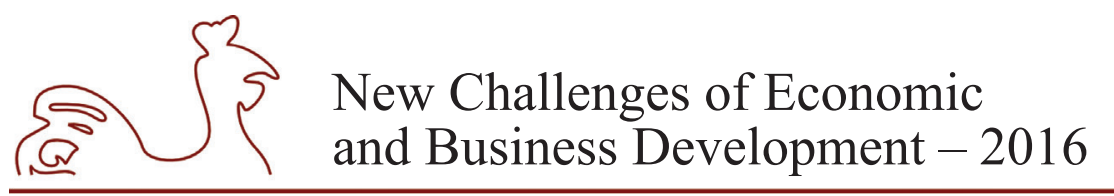

May 12-14, 2016, Riga, University of Latvia

Table 3

Contributing and Disadvantages factors [author]

\begin{tabular}{|c|l|l|}
\hline Nr. & \multicolumn{1}{|c|}{ Contributing factors } & \multicolumn{1}{|c|}{ Disadvantages factors } \\
\hline 1. & Availability of financial resources & $\begin{array}{l}\text { Lack of funding for man excellence-driven } \\
\text { Approach }\end{array}$ \\
\hline 2. & Staff Support & Lack of employees' knowledge and skills \\
\hline 3. & Employees Initiative & Lack of employees' support \\
\hline 4. & Management Support & Resistance from employees \\
\hline 5. & Management Initiative & Lack of management support \\
\hline 6. & Availability of information resources & Lack of management knowledge about model \\
\hline 7. & Chance to receive the prize & $\begin{array}{l}\text { Lack of the company's internal knowledge on the } \\
\text { model application }\end{array}$ \\
\hline 8. & $\begin{array}{l}\text { Company's strengths and weaknesses } \\
\text { awareness through self-assessment }\end{array}$ & $\begin{array}{l}\text { Costs of purchase of the Excellence Model self- } \\
\text { assessment tool }\end{array}$ \\
\hline 9. & $\begin{array}{l}\text { Desire to improve the company's operating } \\
\text { results }\end{array}$ & Possible bureaucracy \\
\hline 10. & $\begin{array}{l}\text { Competitor activity screening as an input to } \\
\text { continuous business improvement }\end{array}$ & Lack of time \\
\hline 11. & Partners proposal & Lack of training \\
\hline 12. & Investor initiative & $\begin{array}{l}\text { Unawareness of business performance } \\
\text { improvement self-assessment methods } \\
\text { unawareness (unnecessary spending of money) }\end{array}$ \\
\hline 13. & $\begin{array}{l}\text { Special events (seminars, conf.) dedicated } \\
\text { to quality issues }\end{array}$ & Lack of Management motivation \\
\hline 14. & Support from Quality associations & Lack of competition \\
\hline 15. & $\begin{array}{l}\text { Companies examples of positive } \\
\text { experiences }\end{array}$ & $\begin{array}{l}\text { Consumer indifference / lack of interest on the } \\
\text { company's success }\end{array}$ \\
\hline 16. & Electronic self-assessment tools & Partners' disinterest \\
\hline 17. & Increasing competitiveness & Investors' disinterest \\
\hline 18. & The company's image improvement & Lack of positive examples \\
\hline 19. & Other factor & Lack of information from Quality society \\
\hline 20. & - & Other factors \\
\hline & & \\
\hline 1 & &
\end{tabular}

The table summarizes the most important factors that may affect the implementation of the EFQM Excellence Model.

The author created a questionnaire, to which answered experts and the focus group. As the experts were professionals of Latvian Quality Association, Latvian Technical University Professor, and EFQM specialists. The expert questionnaire was held in June 2015. The focus group was composed by different business representatives. Was also conducted focus groups and expert opinions comparison. 


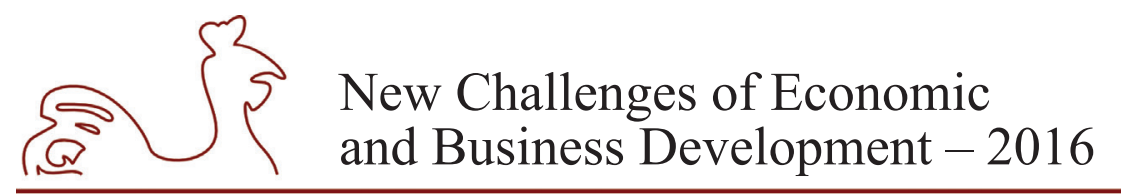

May 12-14, 2016, Riga, University of Latvia

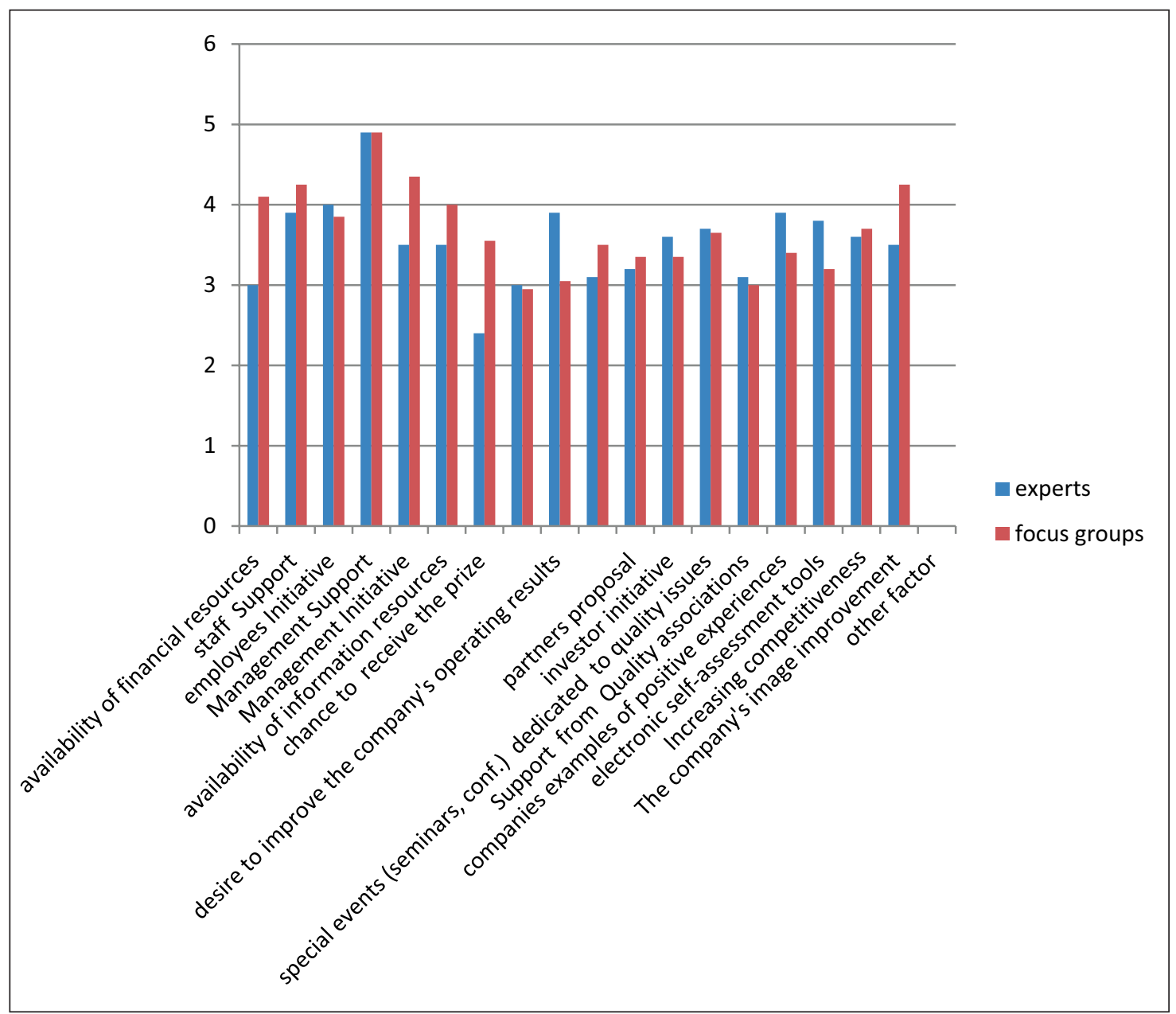

Fig. 2. Contributing factors [author]

Can be seen in the figure that management support was considered by experts and focus groups as a major contributing factor (4.9 points out of 5). Differences of one score were observed on several questions. For example, the availability of financial resources was rated as a key factor by the focus group with 4.1 points (out of 5), while the experts rated this factors with 3 points out of 5. The Possibility of receiving prizes was pointed out as a significant factor with a 3.55 rate, by the focus group, but with 2.4 points from 5 by the experts. Other significant differences were observed in such factors, such as the company's image improvement, pointed out as an important factor by the focus group, in comparison to the experts. Another example is the desire to improve the company's performance, which experts rated with 3.09, but to which the focus group did not grant excessive importance - only 3.05 points. The results of Disadvantages factors can be seen in the Figure 3. 


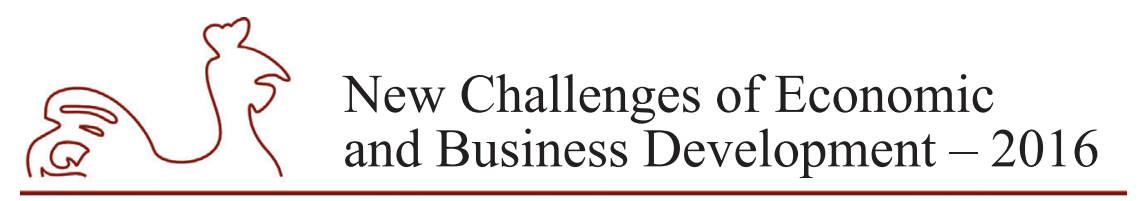

May 12-14, 2016, Riga, University of Latvia

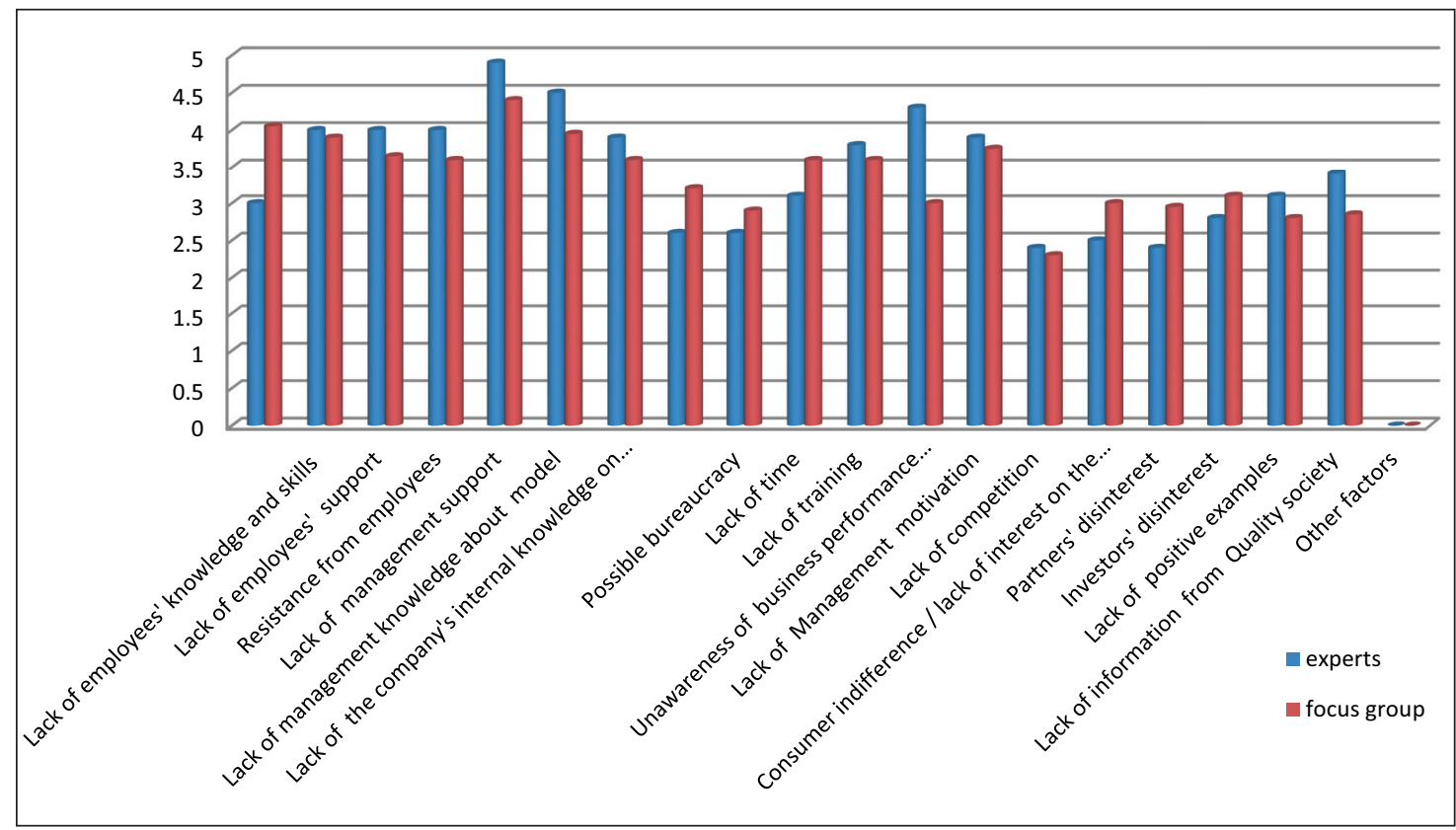

Fig. 3. Disadvantages factors [author]

Speaking of disadvantages, experts with 3 points from 5 on average noted the lack of funding for excellence-driven Approach initiatives, but the focus group evaluated -this factor with 4.05 points, giving more importance to the impact of this factor. As a significant inhibiting factor experts recognized the unawareness of self-assesment methods for the company's performance improvement. This factor was estimated at 4.3 points, but the focus group rated only with 3 points, which shows differences of opinion. As a key hindering factor, the experts indicated the quality of information from Quality Society - 3.4 points out of 5, but focus group rated this factor with 2.8 points from 5 , which shows a low degree perceived impact of this factor.

\section{Conclusions, proposals, recommendations}

- The author's research confirms the hypothesis, suggesting that the EFQM Business Excellence Model application in various companies Latvian is affected by various factors.

- In the coincidence between the experts' and the focus group point of view stranded out one of the main factors with positive effects on the use of the Model: the top management support. This was evaluated with 4.9 points out of 5 .

- There was no coincidence of points of view referring to the negative factors: the evaluation of the factors did differ considerably among both groups.

- The main barriers identified from experts side were -the lack of management support, the lack of knowledge management as a model of self-evaluation for the business' performance improvement, indefiniteness of methods for performance improvement (resulting in unnecessary spending of money), lack of information from quality 


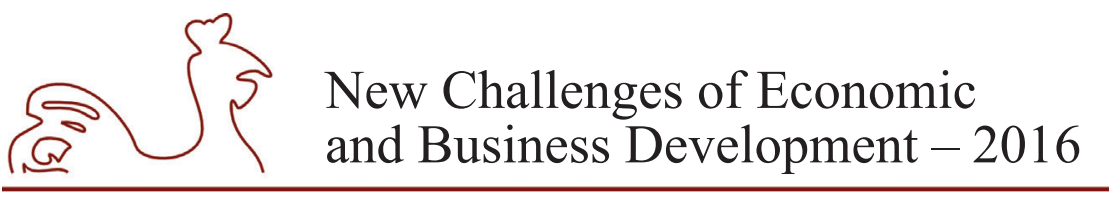

May 12-14, 2016, Riga, University of Latvia

associations. From focus group side, were point out the lack of funding for excellence implementation initiatives, lack of management support, consumer indifference about the company's progress, investor disinterest.

\section{Proposals:}

- The Society for Quality EFQM working group, when promoting the use of the EFQM model, should organize seminars for business leaders on the EFQM model focusing on practical use;

- The Society for Quality EFQM working group should promote the EFQM model application possibilities for self-evaluation, so that companies are able to assess their own strengths and weakness areas;

- The company's management, when opting to use the EFQM model, should explain to employees the benefits, in order to motivate the participation in the process;

- The company's management should engage in a self-assessment process, so as to give example to workers, aiming to gain their support to the initiative.

\section{Bibliography}

1. Akyuz, G. A. (2014). Quality excellence in complex supply networks: EFQM excellence model reconsidered. Total Quality Management \& Business Excellence. DOI: 10.1080/14783363. 2014.929253.

2. Gomez-Gomez, J., Martınez-Costa, M., \& Martı'nez Lorente, A. R. (2011). A critical evaluation of the EFQM model. International Journal of Quality \& Reliability Management, 28(5), 484-502.

3. International Journal of Quality \& Reliability Management, 19(2), 151-169.

4. Mathews, B. P., Ueno, A., Periera, Z. L., Silva, G., Kekal, T., \& Repka, M. (2001). Quality training:

5. Raquel Gómez-López, María Concepción López-Fernández \& Ana María Serrano-Bedia (2015): Implementation barriers of the EFQM excellence model within the Spanish private firms, Total Quality Management \& Business Excellence, DOI: 10.1080/14783363.2015.1106314.

6. Raquel Gómez-López, Ana María Serrano-Bedia \& María Concepción López-Fernández (2015): Motivations for implementing TQM through the EFQM model in Spain: an empirical investigation, Total Quality Management \& Business Excellence, DOI: 10.1080/14783363.2015.1068688.

7. Santos, M. L., Alvarez, I., \& Gonzalez, L. (2007). TQM and firms performance: An EFQM excellence model research based survey. Journal of Business Science and Applied Management, 2(2), 21-42.

8. Sharma, B. (2006). Quality management dimensions, contextual factors and performance: An empirical investigation. Total Quality Management and Business Excellence, 17(9), 1231-1244.

9. Suárez Eva . Roldán José L \& Calvo-Mora Arturo A structural analysis of the EFQM model: an assessment of the mediating role of process management Journal of Business Economics and Management, 2014, 15(5): 862-885, 865.

10. EFQM model criteria. http://www.efqm.org/efqm-model/model-criteria.

11. A Framework for Excellence http://www.businessballs.com/dtiresources/TQM_excellence_model. pdf

12. Dilip Bhatt .EFQMExcellence Model and Knowledge Management Implications. http://www. eknowledgecenter.com/articles/1010/1010.htm

13. Business Excellence tools. http://www.businessexcellencetools.com/business-excellence/

14. European Foundation for Quality Management (EFQM). http://base-uk.org/knowledge/europeanfoundation-quality-management-efqm 


\title{
THE DIGITAL ECONOMY \& SOCIETY INDEX AND NETWORK READINESS INDEX: PERFORMANCE OF LATVIA ON EUROPEAN UNION ARENA
}

\author{
Renate Vidruska, University of Latvia, Latvia ${ }^{1}$
}

\begin{abstract}
Technologies are playing very important role in nowadays business and people lives. Some global and European level indices were created to be able to capture digitization and ITC related processes. One of such indicator is The Digital Economy and Society Index (DESI, European Union level) that was created in context with digital agenda for Europe in 2020. The other is Network Readiness Index (NRI, global level). Also other indicators exist showing country's performance compared with other countries. In this paper the authors compares these indicators between Latvia and other EU countries. No previous research exist that analysis both indicators for European Union.

If we take some of the latest indicators in Latvia and compare with previous years, many have improved. This is good. Unfortunately, it turns out that it is not enough. It is revealed that overall Latvia show low performance in mentioned indicators compared with average level of European Union, as well as the other Baltic States. Accordingly in DESI 2015 Latvia has rank 18 (among 28 EU countries), while Lithuanian rank is 11, but Estonian is 7. If we take The Global Information Technology Report 2015, then Latvian rank is 33 (among 143 countries), while Lithuania is $31^{\text {th }}$ and Estonia is 22 .

Latvia is the lowest in the EU in Integration of Digital Technology dimension; very low indicators are related to selling on-line and cross-border online sales. Other indicators reveal that internet usage by businesses is very low, for example, companies don't fully use internet marketing.

There are at least two main cons for country showing low performance. First, these indicators highlight issues that should be improved and identify where more should be done to improve digitization impact on country's performance.

Second, the author analyzes indicators that are usually compared within different countries and widely published Thus providing policymakers and business with insights into current market conditions. For country place marketing it is essential to have better results in such indicators as DESI or NRI. This low performance can result in spoiled prestige, while high performance can improve country's reputation. We all know good examples of country level marketing. For instance, Finland for years is known as country with an excellent education system, because of showing high performance within some indicators that were widely compared with other countries.
\end{abstract}

Key words: DESI, NRI, digitization, ITC, country marketing

JEL code: F63, M31

\section{Introduction}

The information and communication technologies (ICTs) have potential to transform economies, create employment, improve rural area development etc. While there exist a lot

1 Corresponding author - e-mail address renate.vidruska@gmail.com 


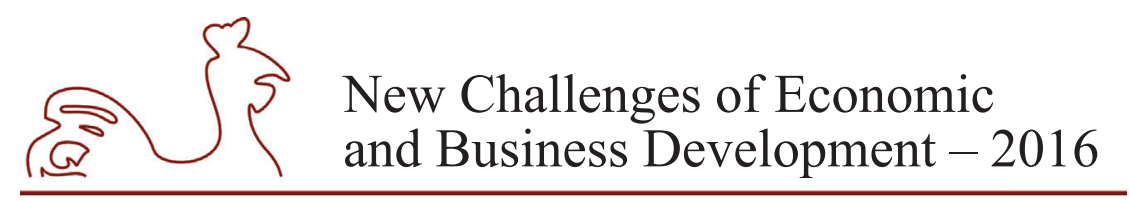

May 12-14, 2016, Riga, University of Latvia

of different indicators related to ICTs but given space limitations this paper is focusing on two benchmarking indices (for more detailed discussion on ICT indicators from different aspects see Taylor, R. D., Zhang B., 2007; Binsdfeld J., Whalley J., Pugalis L., 2015). The Network Readiness Index was created to benchmark the ICT readiness and the usage of countries' economies worldwide. It has become well known and cited indicator. Some researchers have analysed NRI both from theoretical point of you (for instance, Wei-Wen W., Lawrence W. L., 2012 or Alper D., Çiğdem A., Başak D., 2015) and statistical analysis for specific country (for instance, Binsdfeld J., Whalley J., Pugalis L., 2015), but no research exists with focus on NRI and DESI for European Union countries. The Digital Economy and Society Index is relatively new, but already widely mentioned and discussed as one of indicators that shows digitisation level of European Union countries. NRI is usually compared only among all world countries, thus it would be useful to create some comparison on EU level as it shows different tendencies.

Latvia is a country with good ICTs potential. In recent years leading ICT companies have often emphasized developed and modern infrastructure. However, today it becomes clear that Latvia doesn't use its potential enough. On the European Union arena Latvia's ranks in both indices are quite low. In aggregated indices as well as on many more detailed indicators Latvia is performing worst than the European Union on average. First, this could be important signal that digitisation processes in Latvia are not growing as fast as necessary compared with EU. Second, from country's place marketing perspective it is important to have higher ranks. Thus it is important to understand main strengths and weaknesses of country based on given indices' values.

During the discussion also some methodological issues are addressed.

The research is based on secondary statistical data (provided by The World Economic Forum's and the European Commission) and its analysis. Data for EU countries is analyzed. To the best of the authors' knowledge no study that looks deeper into NRI and DESI indicators for Latvia and EU28 countries has been performed before. Comparing NRI among EU28 countries gives additional and different conclusions to those that arise when comparing among all countries covered within NRI.

\section{Research results and discussion}

The Network Readiness Index (NRI) is published and maintained by The World Economic Forum (WEF) as a part of Global Information Technology Report (GITR). It is composite index that consists of multiple dimensions (see Table 1 for more details). NRI allows identifying the areas of priority to more fully leverage ICTs for development and measures the preparedness of nations of the networked world. NRI 2015 edition covers economies of 143 countries worldwide including all European Union (EU) countries. Most of the data that follows include data only about EU as this is the main focus of this paper.

The Digital Economy and Society Index (DESI) is maintained by the European Commission. DESI is a composite index and summarizes indicators on Europe's digital performance and tracks the evolution of EU member states in digital competitiveness. DESI is available only for EU countries thus making difficult to compare it with non-EU regions. The latest DESI was calculated in 2016 (most of the data available in DESI 2016 contains data for year 2015 or previous years). First time DESI was calculated in 2014, however, it should be noted that 


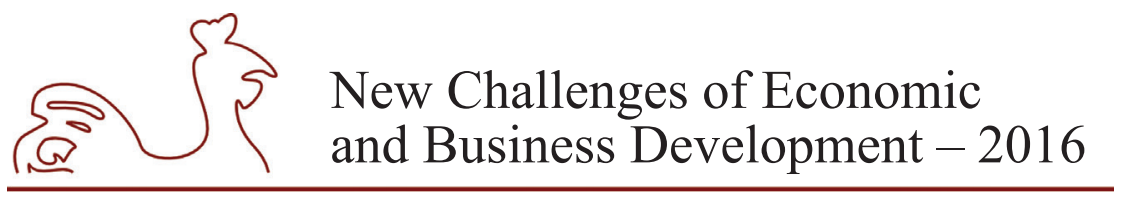

May 12-14, 2016, Riga, University of Latvia

many of index's indicators were calculated also before and are available online (European Commission, 2015a).

Both indices are tending to measure readiness for digitization; however, methodologies and indicators uses are quite different. Author believes that some of NRI index indicators could be biased as are measured based on expert evaluations (local experts in each country). Taking into account that there are so many countries to be evaluated, expert evaluations could be different. ICT sector is very dynamic and fast developing, thus methodology should be adjusted often to include latest trends for measuring ICTs usage and readiness.

Table 1

Main information about the Network Readiness index and the Digital Economy and Society index

\begin{tabular}{|l|l|l|}
\hline Index name & The Network Readiness Index & The Digital Economy and Society Index \\
\hline Abbreviation & NRI & DESI \\
\hline Main dimensions & $\begin{array}{l}\text { environment, readiness, usage, } \\
\text { impact - all 25\% }\end{array}$ & $\begin{array}{l}\text { Connectivity (25\%), human capital (25\%), } \\
\text { use of internet (15\%), integration of } \\
\text { digital technology (20\%), digital public } \\
\text { services (15\%) }\end{array}$ \\
\hline Total indicator count & 53 & 30 \\
\hline Countries included & $\begin{array}{l}\text { all over the world, 143 } \\
\text { (NRI 2015) }\end{array}$ & $\begin{array}{l}\text { EU28 countries (DESI 2016) and } \\
\text { candidates }\end{array}$ \\
\hline Maintained by & the World Economic Forum & the European Commission \\
\hline Possible range of index & $1-7$ & $0-0.7$ \\
\hline Period available & $2003-2015$ & $2013-2015$ \\
\hline
\end{tabular}

Source: author's constructions based on The Global Information Technology Report 2014-2015 and European Commission, $2016 \mathrm{a}, \mathrm{b}$.

By author opinion NRI doesn't cover all trends right now. NRI has longer history and researchers already have questioned different aspects of NRI methodology. The methodological aspects of NRI are out of scope of this paper as despite critiques and limitations still NRI is one of the benchmarking indices. Both indices include internet usage, speed etc. as one of important factors. This is true was internet can affect development in different ways - allows to overcome information barriers and improve inclusion, can make processes more effective and also generate innovations.

Another difference currently is that DESI contains latest data compared with NRI latest edition.

\section{The importance of internationally recognizable indices}

Some researchers (for instance, Eglitis J., 2009) have stressed that indices could play important role from country's marketing perspective, especially those that are maintained and published by internationally recognized authorities. These indices are more often cited and discussed nevertheless the methodology that is behind those indices. International indices do 


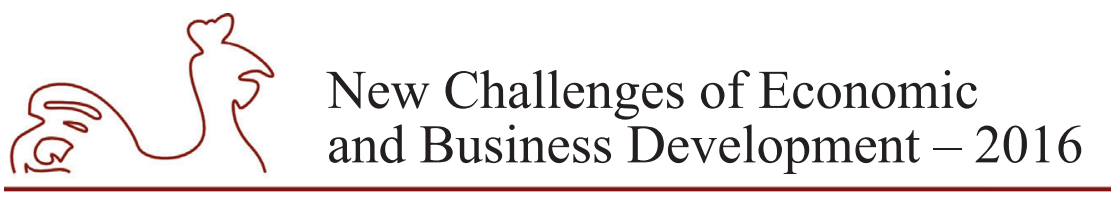

May 12-14, 2016, Riga, University of Latvia

not only show how country performs compared with other nations, indices that are comparable among different countries also bring additional information:

- for government and policy makers allowing to identify potential problems, weaknesses and strengths; some indices can provide background for legislation and development agendas;

- for companies and citizens providing them with information on how country is performing compared with other countries;

- for investors - high performance can result in additional interest from investors that could transform into new opportunities for economic development and growth.

For instance, Finland is one of the countries that is an example of good country's marketing regarding to education system. Finland's education system is often cited in media as amazing success story (Hancock, 2011). Nevertheless, Asian countries like Korea, Japan start to outperform Finland and drawback appear in Finland education system, Finland is still often cited as one of the countries with the best education system in the world.

Estonia is another success story. Active business and public sector cooperation lead to successful ITC sector development and international recognition. Estonia managed to use Skype success story. "Skype remains the most prominent example of the innovative approach that typifies Estonian ICT" (Ericsson, 2012). Estonia has already gained an international reputation for technical expertise coupled with innovations and continues to maintain its positions. In the next sections it would be also shown that Estonia outperforms other Baltic State countries and performs very well in international indices. Some countries even set goals to achieve certain position in international ranking (see Binsfeld N., Whalley J., Pugalis L., 2015).

\section{Latvia's overall results on NRI and DESI indices}

The latest available edition of index (DESI 2016 \& NRI 2015) provided in Table 2 and Figure $1 \& 2$ shows that the Nordic countries are the leaders. There is no much difference regarding the position of countries if compared both indices (the largest difference is seen for Denmark - it is $1^{\text {st }}$ in DESI 2016, but NRI shows only $7^{\text {th }}$ rank).

Table 2

NRI 2015 and DESI 2016 values and ranks for the Baltic States, 2014-2015

\begin{tabular}{|c|c|c|c|c|c|c|c|c|}
\hline & & \multicolumn{2}{|c|}{ Latvia } & \multicolumn{2}{|c|}{ Lithuania } & \multicolumn{2}{|c|}{ Estonia } & \multirow{2}{*}{$\begin{array}{l}\text { Top } 5 \text { World } \\
\text { (non-EU } \\
\text { countries } \\
\text { underlined) }\end{array}$} \\
\hline & & World & EU28 & World & EU28 & World & EU28 & \\
\hline \multirow{3}{*}{$\begin{array}{c}\text { Network } \\
\text { Readiness } \\
\text { Index } 2015 \\
(2014)\end{array}$} & & & & & & & & \multirow{3}{*}{$\begin{array}{l}\text { Singapore, } \\
\text { Finland, Sweden, } \\
\text { Netherlands, } \\
\text { Norway }\end{array}$} \\
\hline & Kanks & $33(39)$ & $10(19)$ & $31(31)$ & $15(14)$ & $22(21)$ & $9(8)$ & \\
\hline & Values & \multicolumn{2}{|c|}{$4.75(4.58)$} & \multicolumn{2}{|c|}{$4.86(4.78)$} & \multicolumn{2}{|c|}{$5.35(5.27)$} & \\
\hline \multirow{2}{*}{$\begin{array}{c}\text { Digital } \\
\text { Economy and } \\
\text { Society Index } \\
2015(2014)\end{array}$} & Ranks & - & 19 (19) & - & $13(11)$ & - & $7(8)$ & \multirow{2}{*}{$\begin{array}{c}\text { Denmark, } \\
\text { Netherlands, } \\
\text { Sweden, Finland, } \\
\text { Belgium }\end{array}$} \\
\hline & Values & \multicolumn{2}{|c|}{$0.49(0.46)$} & \multicolumn{2}{|c|}{$0.55(0.54)$} & \multicolumn{2}{|c|}{$0.59(0.57)$} & \\
\hline
\end{tabular}

Source: author's calculations based on The Global Information Technology Report 2015 and 2014; European Commission, 2016a. 


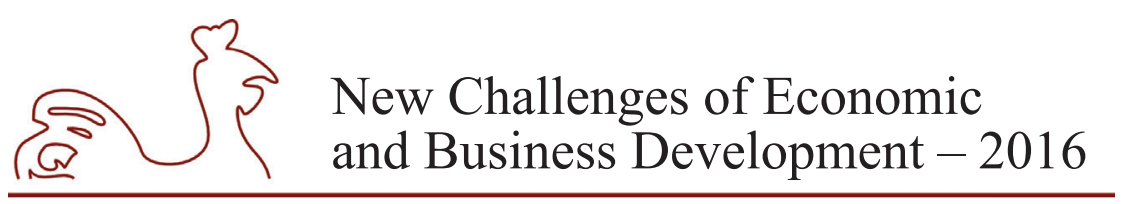

May 12-14, 2016, Riga, University of Latvia

For both aggregated indices Latvia shows low performance having aggregated values less than EU28 countries on the average. Most of post-soviet countries are having low-performance. Nevertheless, comparing the Baltic State countries, Lithuania slightly outperforms Latvia, while Estonia has much higher results and tries to catch the Nordic leaders. Latvia has improved overall values (DESI from 0.46 to 0.49 ; NRI from 4.58 to 4.75 ); nevertheless, Latvia has not improved its DESI rank that suggests that other EU countries are leveraging ITCs faster; however, NRI ranks have improved from 19 to 16.

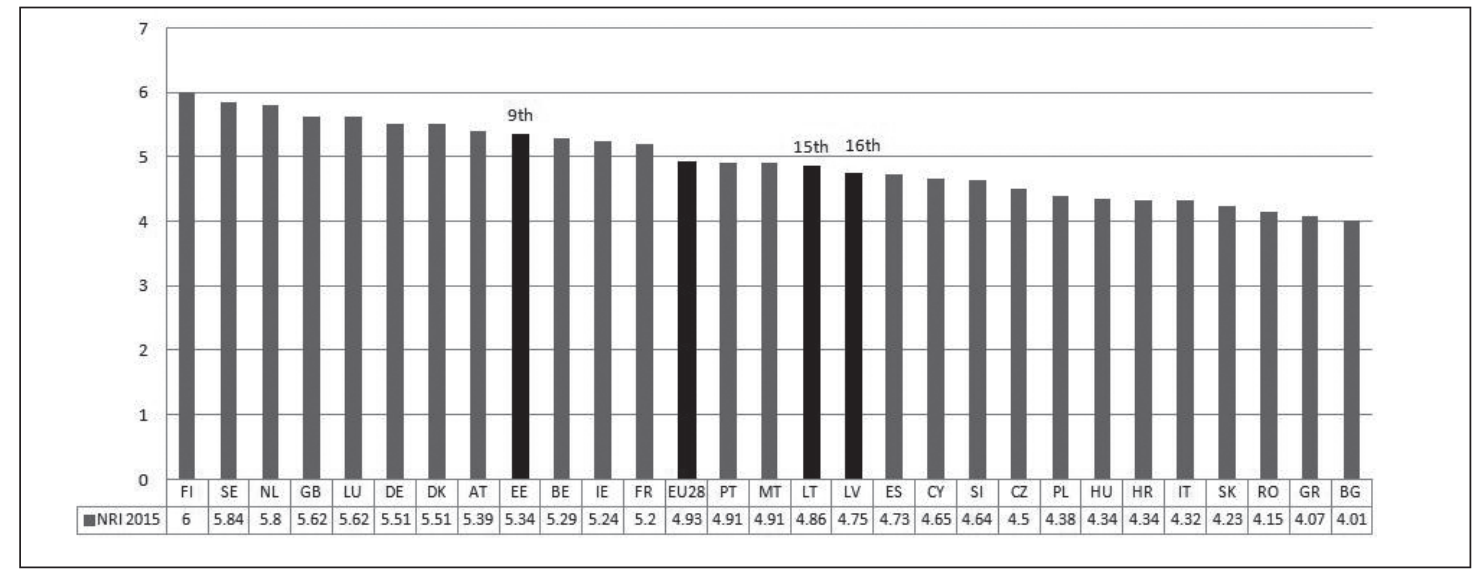

Source: author's constructions based on The Global Technology Report 2015.

Fig. 2. NRI 2015 aggregated values, EU28 countries, 2015

Difference between best and worst scores is higher for DESI and values are spread more compared with NRI where differences among countries are smaller. If compared with previous available editions (DESI 2015 \& NRI 2014), the gap between the best and the worst country has decreased that is more likely a good trend.

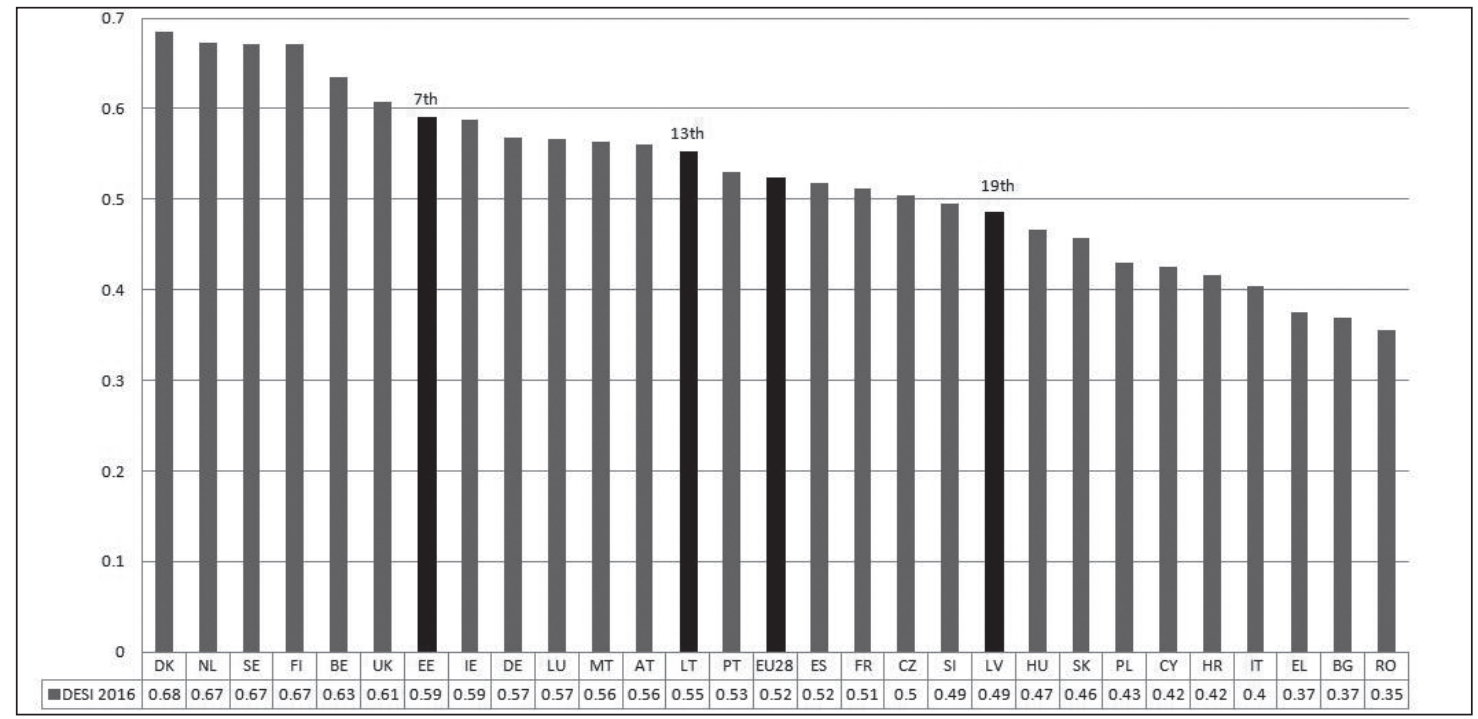

Source: author's constructions based on European Commission, 2016a.

Fig. 1. DESI 2016 aggregated values, EU28 countries, 2015 


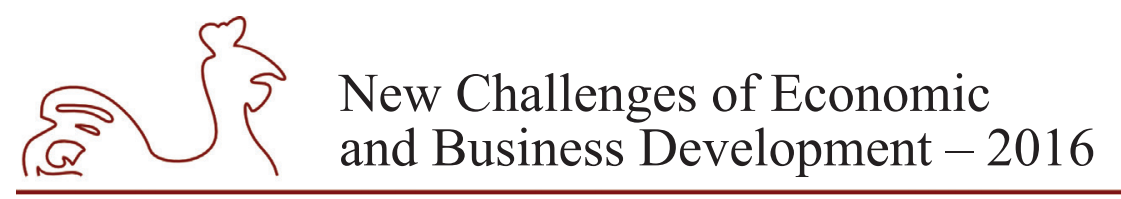

May 12-14, 2016, Riga, University of Latvia

The latest available Digital Score Board (European Commission, 2016c) suggests dividing countries into clusters based on two indicators - overall performance and growth comparing the two latest years available, thus introducing 4 clusters. The author created two scatter plots using standardized values for DESI and NRI (see Figure 3 and Figure 4).

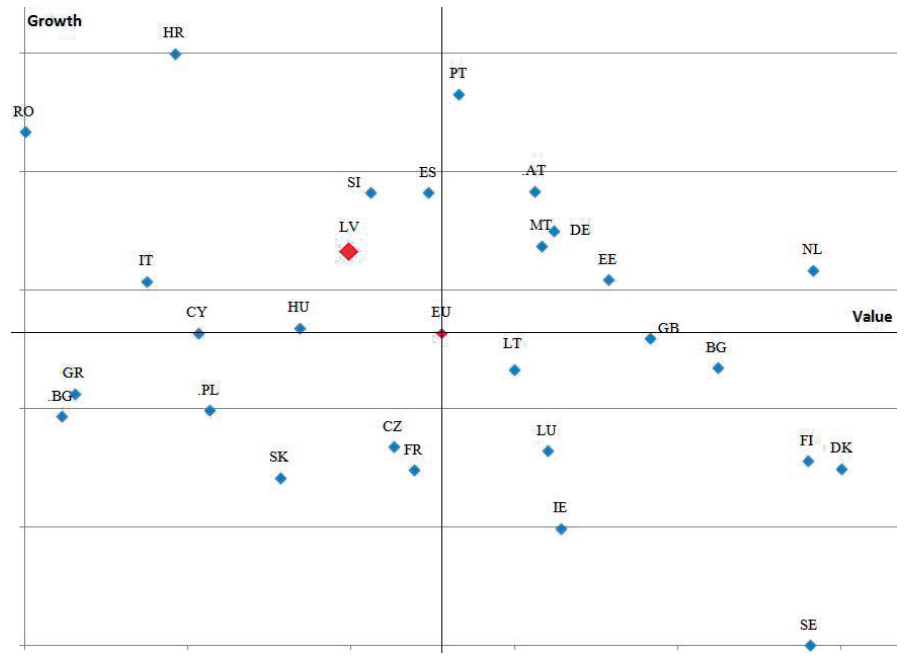

Source: author's constructions based on The Global Technology Report 2014-2015.

Fig. 3. DESI countries' clusters based on aggregated score and growth, EU28, 2014-2015

For both indices Latvia falls into cluster of countries who score below the EU average but whose score grew faster than that of the EU as a whole in comparison to the DESI 2015. Latvia is one of the countries that growth faster than EU on average. If ranking countries by NRI progress from 2012 to 2015 Latvia would be in TOP 10 most improved countries (all the world) and number 1 in EU (see Fig. 4 a).
a) Growth $=2015$ year value -2012 year value
b) Growth $=2015$ year value -2014 year value
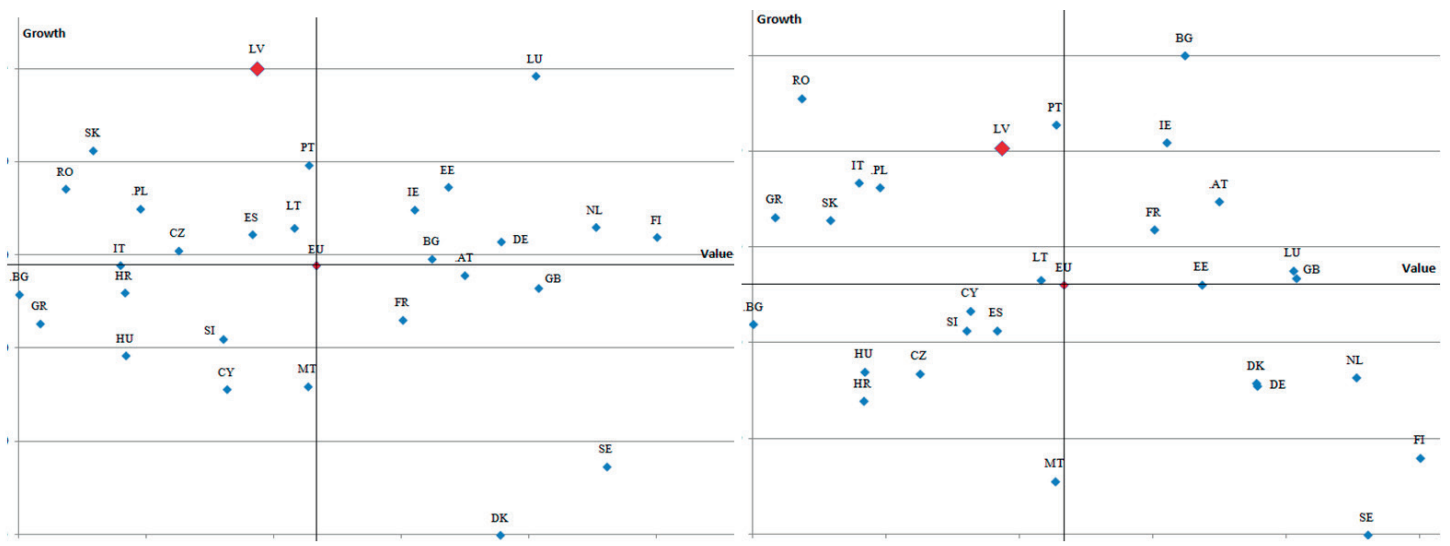

Source: author's constructions based on European Commission 2016a.

Fig. 4. NRI countries' clusters based on aggregated score and growth, EU28, 2012-2015 


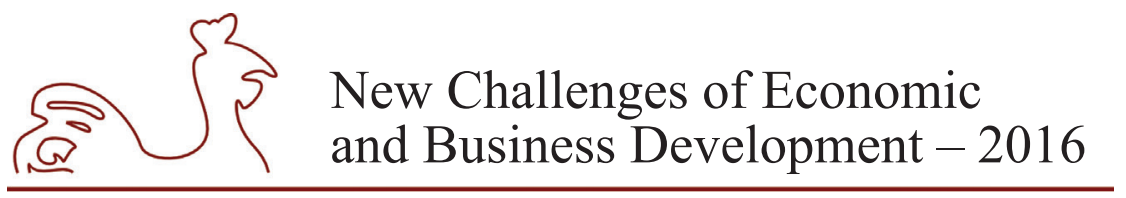

May 12-14, 2016, Riga, University of Latvia

Compared DESI and NRI clusters there are some differences in countries positions / clusters, but many commonalities. In both figures Latvia falls into the same cluster - low performance, but with steady (high) growth. Comparing 2012 and 2015 years Latvia have even highest growth compared with all countries.

\section{Detailed analysis on NRI and DESI indicators}

Aggregated indices show overall trends, however, it is very important to look at the composition of each index. Moreover DESI methodological notes (European Commission, 2016d) suggests that country's positions are quite sensitive to main dimensions weights (changing weights country positions can change a lot). Table 3 and 4 summarizes countries' performance for NRI and DESI components. Each index has different breakdown by components. The author also calculates average EU values.

Table 3

NRI sub-components, Latvia compared with EU28 countries, 2014-2015

\begin{tabular}{|c|c|c|c|c|c|c|}
\hline Dimension & $\begin{array}{c}\text { Rank of } \\
\text { LV / EU28 }\end{array}$ & $\begin{array}{c}\text { LV value, } \\
2014\end{array}$ & $\begin{array}{c}\text { LV value, } \\
2015\end{array}$ & $\begin{array}{c}\text { EU28, } \\
2014\end{array}$ & $\begin{array}{l}\text { EU28, } \\
2015\end{array}$ & Best score \\
\hline A. Environment subindex & 16 & 4.44 & 4.51 & 4.64 & 4.66 & $5.57(F I)$ \\
\hline Political and regulatory env. & 18 & 4.02 & 4.06 & 4.47 & 4.48 & $5.88(\mathrm{LU})$ \\
\hline Business and innovation env. & 11 & 4.86 & 4.97 & 4.80 & 4.84 & $5.42(\mathrm{NL})$ \\
\hline B. Readiness subindex & 22 & 5.60 & 5.40 & 5.63 & 5.66 & $6.71(F I)$ \\
\hline Infrastructure & 23 & 5.03 & $4.81 \downarrow$ & 5.67 & 5.65 & $6.999(\mathrm{SE})$ \\
\hline Affordability & 13 & 6.21 & $\underline{5.78 \downarrow}$ & 5.52 & 5.61 & $6.68(\mathrm{AT})$ \\
\hline Skills & 17 & 5.56 & 5.61 & 5.69 & 5.71 & $6.53(\mathrm{FI})$ \\
\hline C. Usage subindex & 17 & 4.35 & 4.60 & 4.79 & 4.83 & $5.91(S E)$ \\
\hline Individual usage & 14 & 5.25 & 5.55 & 5.43 & 5.62 & $6.83(\mathrm{DK})$ \\
\hline Business usage & 18 & 3.81 & 3.98 & 4.42 & 4.47 & $5.90(\mathrm{SE})$ \\
\hline Government usage & 17 & 3.97 & 4.28 & 4.51 & 4.39 & $5.47(\mathrm{ES})$ \\
\hline D. Impact subindex & 16 & 3.94 & 4.48 & 4.38 & 4.59 & $5.92(N L)$ \\
\hline Economic impacts & 18 & 3.71 & 3.89 & 4.24 & 4.33 & $6.08(\mathrm{FI})$ \\
\hline Social impacts & 14 & 4.17 & $\underline{5.08}$ & 4.53 & 4.86 & $6.07(\mathrm{NL})$ \\
\hline
\end{tabular}

Source: author's constructions based on The Global Technology Report 2014-2015.

* underlined values indicate that value is above average EU level. 


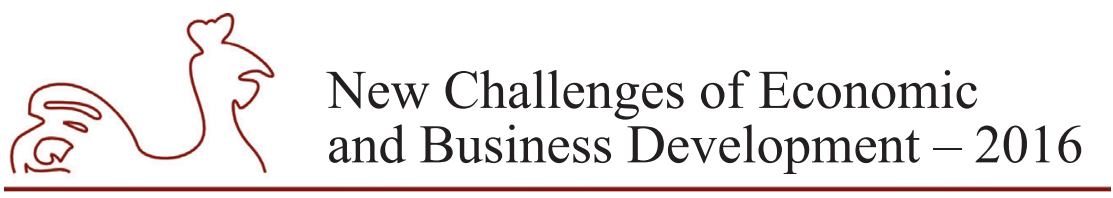

May 12-14, 2016, Riga, University of Latvia

Table 4

DESI 2016 sub-components, Latvia compared with EU28 countries, 2014-2015

\begin{tabular}{|l|c|c|c|c|c|c|}
\hline \multicolumn{1}{|c|}{ Dimension } & LV rank & $\begin{array}{c}\text { LV value } \\
\mathbf{2 0 1 4}\end{array}$ & $\begin{array}{c}\text { LV value } \\
\mathbf{2 0 1 5}\end{array}$ & $\begin{array}{c}\text { EU28 value } \\
\mathbf{2 0 1 4}\end{array}$ & $\begin{array}{c}\text { EU28 } \\
\text { value 2015 }\end{array}$ & Best score \\
\hline Connectivity & 10 & 0.64 & $\underline{0.65}$ & 0.57 & 0.59 & $0.81(\mathrm{DK})$ \\
\hline Human Capital & 23 & 0.45 & 0.46 & 0.58 & 0.59 & $0.87(\mathrm{FI})$ \\
\hline Use of Internet & 9 & 0.51 & $\underline{0.54}$ & 0.43 & 0.45 & $0.67(\mathrm{NO})$ \\
\hline $\begin{array}{l}\text { Integration of Digital } \\
\text { Technology }\end{array}$ & 27 & 0.19 & 0.22 & 0.33 & 0.36 & $0.56(\mathrm{IE})$ \\
\hline Digital Public Services & 14 & 0.49 & $\underline{0.57}$ & 0.54 & 0.55 & $0.87(\mathrm{DK})$ \\
\hline
\end{tabular}

Source: author's constructions based on European Commission data, 2016a.

* underlined values indicate that value is above average EU level.

Table 3 shows that in general Latvia performs worse than EU28 average in most of the indicators summarised above. Among 10 sub-dimensions seen in Table 3, only three have values above EU28 average. Most of values have increased compared with previous year excluding two dimensions (Infrastructure and Affordability). Table 4 shows a bit better results as only two (Human Capital and Integration of Digital Technology) of five values are less than EU28.

DESI 2016 reveals that the most worrisome indicators are "Human Capital" and "Integration of Digital Technology". By NRI 2015 the worst indicators are "Political and regulatory environment", "Infrastructure", "Skills", "Business usage", "Government usage", "Economic impacts".

Integration of Digital Technology (DESI) is covered in DESI and it measures "the digitisation of business and their exploitation of the online sales channel" (European Commission, 2016b). While in this dimension Latvia shows some progress almost in all indicators (not listed here), Latvia is the second worst country in EU28. Other countries are improving their performance much better and their businesses are more opened to ICTs. Only $8.3 \%$ of Latvian SMEs are selling online. The number of SMEs selling online cross-border $(3.9 \%)$ has even reduced. According to growth accounting theories (European Commission, 2016d) is one of the most important drives of growth There is no disputes that E-commerce is an opportunity and it is not used by Latvian SMEs enough, however, we can also see that "Integration of Digital Technology" component value is on average the lowest value in EU (only 0.33), even the best score owner (Denmark) has only 0.56 points here. Lithuania ( $8^{\text {th }}$ rank, value 0.44 ) outperforms Latvia and Estonia (22 th rank, value 0.28 ) here a lot. This is the dimension whose value should increase in the near future.

The most similar indicator within NRI is "Business-to-business internet use" and "Business-to-consumer internet use" (under Business usage component). Latvia has $18^{\text {th }}$ and $8^{\text {th }}$ ranks here; later is much better results compared with DESI. However, the author argues if this indicator is plausible. Based on NRI methodology (World Economic Forum, 2015) this indicator is calculated based on experts' evaluations answering on question ("In your country, to what extent do businesses use the Internet for selling their goods and services to consumers? [ $1=$ not at all; 7 = to a great extent] | 2013-2014 weighted average"). This could lead to bias as experts from different countries are given evaluations only for their country. Moreover, using European Commission data it can be showed that there is significant differences if compared online selling 


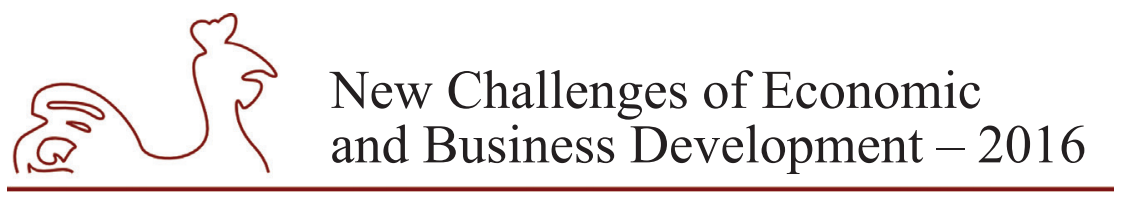

May 12-14, 2016, Riga, University of Latvia

between SMEs and large enterprises. NRI doesn't cover these differences; while DESI does (data are available for SMEs).

DESI Digital Technology integration is very connected to internet, while NRI contains other aspects of Technology usage within "Business usage" dimension (see Table 5).

Table 5

NRI Business usage components, Latvia compared with EU28, 2015

\begin{tabular}{|l|c|c|c|c|}
\hline \multicolumn{1}{|c|}{ Indicator } & LV rank & $\begin{array}{c}\text { LV value } \\
\mathbf{2 0 1 5}\end{array}$ & $\begin{array}{c}\text { EU28 } \\
\text { value } \\
\mathbf{2 0 1 5}\end{array}$ & $\begin{array}{c}\text { Best } \\
\text { score }\end{array}$ \\
\hline Firm-level technology absorption & 17 & 5.0 & 5.18 & 5.98 \\
\hline Capacity for innovation 1-7 (best) & 23 & 3.6 & 4.37 & 5.60 \\
\hline PCT patent applications applications/million pop. & 18 & 13.4 & 80.91 & 312.82 \\
\hline ICT use for business-to-business transactions 1-7 & 20 & 5.3 & 5.50 & 6.40 \\
\hline Extent of staff training 1-7 & 12 & 4.4 & 4.43 & 5.40 \\
\hline Internet use for business-to-consumer transactions 1-7 & 8 & 5.6 & 5.58 & 5.28 \\
\hline
\end{tabular}

Source: author's constructions based on World Economy Forum, 2015.

Human Capital (DESI) is another worrisome dimension for Latvia where country is positioned towards the worst end. It reveals that Latvia has very low share of ICT specialists and STEM graduates; the number is even decreasing. By indicator "Basic digital skills" Latvia takes only $20^{\text {th }}$ place having value below EU average (49\% vs. 55\%). This means that users do not possess at least a basic level of digital skills "which measures whether citizens have at least basic skills in at least one of four Digital Competence domains: information, communication content-creation, problem-solving. Human Capital (with Connectivity) is two dimensions that are the most relevant and have higher weights. "Internet users" is part of Human Capital in DESI and the values are satisfactory $-75 \%$ of individuals in Latvia are using internet (14 ${ }^{\text {th }}$ rank). This indicator improves overall dimension score. The similar value is found in NRI.

The important methodological notice here is that DESI 2014 and DESI 2015 do not capture "Basic digital skills" at all; nevertheless, this doesn't significantly affect the scores or rankings (European Commission, 2016d).

NRI doesn't cover Human Capital in the same sense; however, Skills are related to Human Capital and are measured mainly by basic education system rather than any ICT specific skills. Latvia has score below average EU28 raking only $17^{\text {th }}$ due to low evaluations for overall quality of education (local experts evaluated very low giving only 3.76 points out of 7 possible; Finland has highest rank having value 5.86) and relatively low secondary education enrolment that was measured in $2012\left(97.71 \%\right.$ having $17^{\text {th }}$ rank, while Spain where secondary education is compulsory has the highest rank with value 131\%). Math and science education for Latvia was evaluated higher $-13^{\text {th }}$ rank ( 4.88 for Latvia and best score 6.26 for Finland). The author questions if secondary education enrolment is the indicator for ICTs usage. Education of quality indicators are based on local experts' evaluations and, as already mentioned previously, that could be very biased. It would be better to use other indicators to evaluate overall education system, for instance, taking into account results of kids or education index that is calculated within Human 


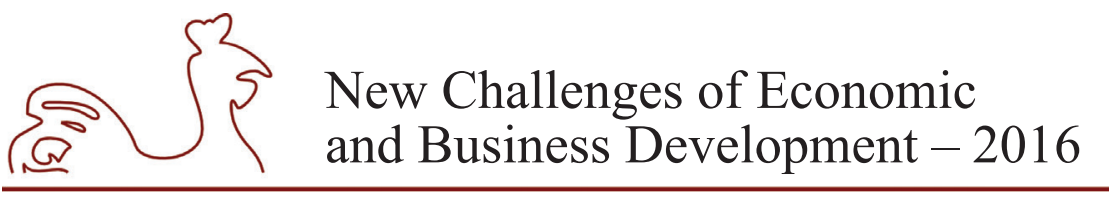

May 12-14, 2016, Riga, University of Latvia

Development Report (UNDP, 2015). Quality of educations in Latvia was evaluated by local experts very low giving only 3.76 points out of 7 possible (Finland has highest value having value of 5.86),

Connectivity (DESI) dimension values for Latvia are acceptable, but could be better taking into account that connectivity is one of the drives of all other dimensions. Today simple presence of internet connection is no longer sufficient, thus this dimension is measured by internet quality (speed), price (affordability) and usage indicators.

From one point of view, Latvia lacks behind EU level in fixed broadband coverage $\left(24^{\text {th }}\right.$ rank with value 93\% coverage) and fixed broadband take-up (FBB) reaching 65\% of all households. Price for the cheapest standalone fixed broadband for Latvia is on average level. From another point of view, availability of Next Generation Access and subscriptions to fast BB are very high. NGA coverage reach $91 \%$ ranking $8^{\text {th }}$ while EU28 average level is only $71 \%$ that is relatively low result. Fast Broad Band subscriptions have increased slightly to 56\% from 54\% compared with EU28 average level $30 \%$ (this result in rank falling from $4^{\text {th }}$ to $8^{\text {th }}$ ). However fall in rank shows that other countries take opportunities to improve connectivity more than Latvia does. For instance, Lithuania overtook Latvia and become the leader in NGA development.

Latvia is number 2 in Spectrum that is measured by \% of target for spectrum to be harmonised at EU level.

Some reports suggests (Van DIJK Management Consultants, 2015) correlation between Fixed broadband price and take-up, however, the author have not found strong correlation here $\left(\mathrm{R}^{2}=0.32\right.$ on DESI 2014-2016 data, see Figure 5).

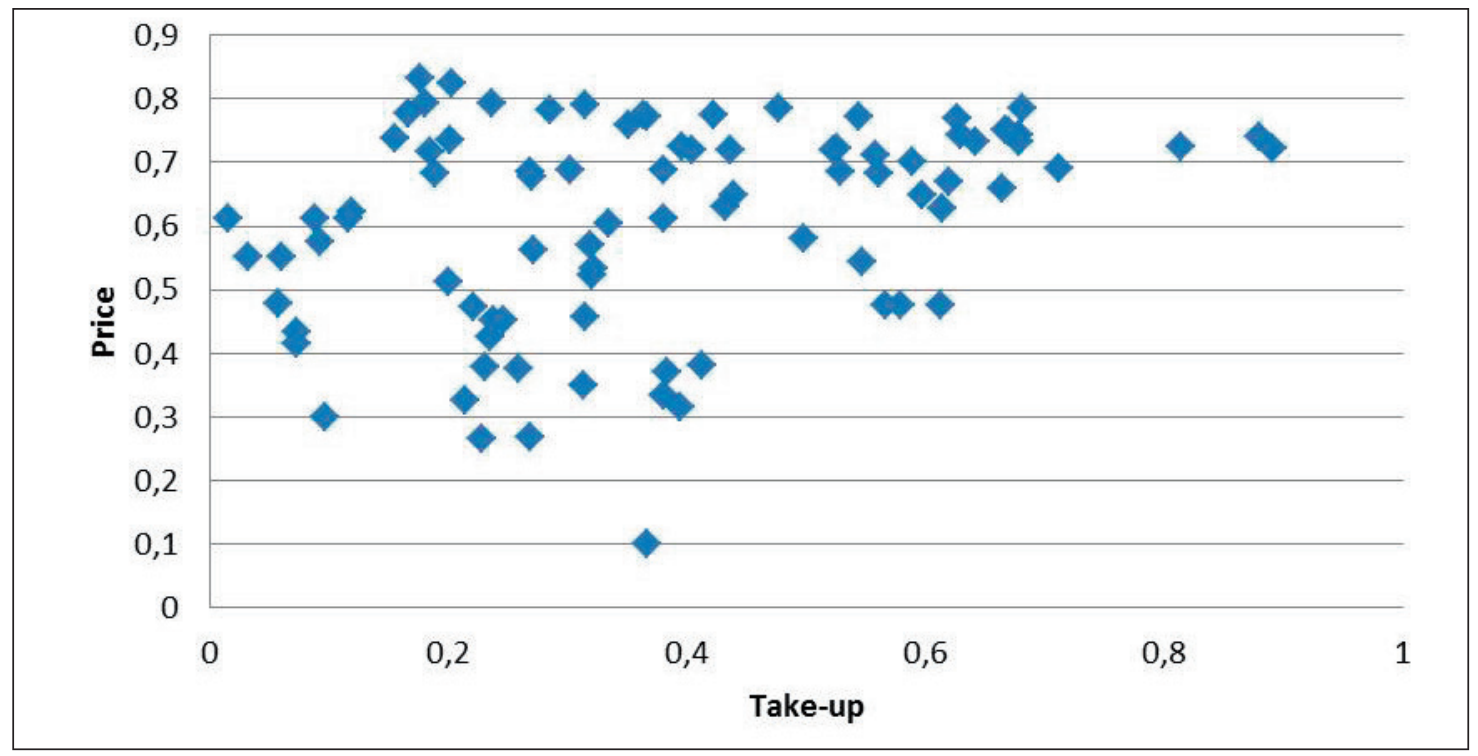

Source: author's constructions based on European Commission data, 2016a.

Fig. 5. Fixed broadband price and take-up scatter plot, normalized data (1 - best), EU28 countries, 2014-2016 


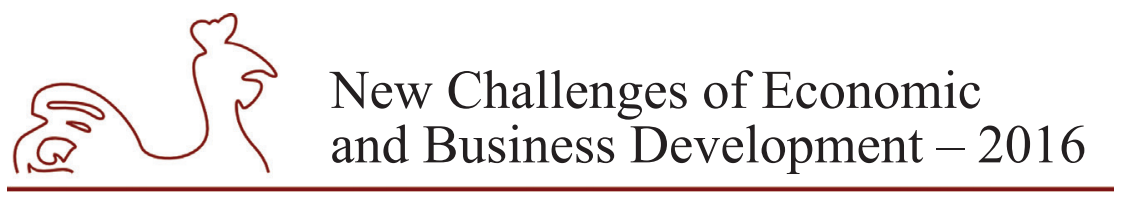

May 12-14, 2016, Riga, University of Latvia

For instance, in Estonia fixed bb prices are relatively high $\left(20^{\text {th }}\right.$ rank $)$, but still take-up is quite high $\left(7^{\text {th }}\right.$ rank). Lithuania is number 1 for Fixed BB Price indicator, however, take-up is small (only $60 \%$ giving $24^{\text {th }}$ position). Thus price level is not the only or main reason for low fixed broadband take-up.

NRI also covers very similar aspects in their Infrastructure (only $23^{\text {th }}$ rank) and Affordability $\left(13^{\text {th }}\right.$ rank) dimension, as well as partly in Individual usage dimension. Infrastructure and affordability are measured by multiple indicators. To understand the source of low results, detailed indicators should be examined (see Table 6).

Table 6

NRI sub-components Affordability, Infrastructure, Individual usage* breakdown, EU28, 2014-2015

\begin{tabular}{|l|c|c|c|c|}
\hline & Rank & Value & EU28 value & Best \\
\hline Affordability (1-7 best) & 13 & $\underline{5.78}$ & 5.61 & 6.69 (AT) \\
\hline Mobile cellular tariffs PPP (\$/minute) & 11 & 0.23 & 0.30 & 0.06 (DK) \\
\hline $\begin{array}{l}\text { Fixed broadband Internet tariffs } \\
\text { (PPP \$/month) }\end{array}$ & 15 & 28.99 & 28.57 & 14.38 (UK) \\
\hline $\begin{array}{l}\text { Internet and telephony sectors } \\
\text { competition index (0-2) }\end{array}$ & 24 & 1.77 & 1.89 & 2 (17 countr.) \\
\hline $\begin{array}{l}\text { Infrastructure and digital content } \\
\text { (1-7 best) }\end{array}$ & 23 & 4.81 & 5.65 & 6.999 (SE) \\
\hline Electricity production (kWh/capita) & 26 & 2958.67 & 6224.16 & 17378.24 (SE) \\
\hline Mobile network coverage (\% pop.) & 27 & 98.8 & 99.55 & $100(6$ countr.) \\
\hline $\begin{array}{l}\text { International Internet bandwidth } \\
\text { (kb/s/user) }\end{array}$ & 23 & 68.07 & 398.11 & $6445.76(\mathrm{LU})$ \\
\hline Secure Internet servers (million pop.) & 18 & 272.18 & 767.28 & 2382.14 (NL) \\
\hline Individual usage & - & - & - & - \\
\hline $\begin{array}{l}\text { Mobile-cellular telephone } \\
\text { subscriptions (100 pop.) }\end{array}$ & 1 & 228.4 & 131.00 & 228.4 (LV) \\
\hline $\begin{array}{l}\text { Fixed-broadband Internet } \\
\text { subscriptions (100 pop.) }\end{array}$ & 19 & 23.5 & 26.78 & 40.16 (DK) \\
\hline $\begin{array}{l}\text { Mobile-broadband subscriptions } \\
\text { (100 pop.) }\end{array}$ & 18 & 71.6 & 71.60 & 94.63 (NL) \\
\hline $\begin{array}{l}\text { Households with a personal } \\
\text { computer (\%) }\end{array}$ & 62.34 & 61.04 & 123.47 (FI) \\
\hline Households with Internet access (\%) & 71.7 & 77.41 & 95.17 (NL) \\
\hline
\end{tabular}

Source: author's constructions based on World Economic Forum, 2014-2015.

* not all Individual usage indicators are included in the table, only those related to connectivity and infrastructure.

As we see, Latvia has low performance in Mobile network coverage. Latvia have to improve the coverage to cover all population, however, the value already is relatively high $(98.8 \%$ coverage) - only $1.2 \%$ of population have no mobile coverage. Thus, even if indicator shows relatively low performance ( $27^{\text {th }}$ rank) difference with first rank is not high. The same could be 


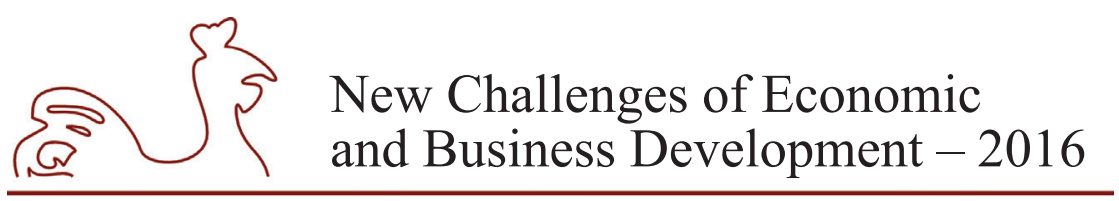

May 12-14, 2016, Riga, University of Latvia

said for "Internet and telephony competition" where Latvia is $24^{\text {th }}$ having value of 1.77 , while 17 countries have value 2. From methodological point of view this indicator is not applicable, as too small variance is seen here (even if we look to all countries that NRI covers - 62 of 143 countries have maximum value 2). So, as a result it is seen that Affordability for Latvia is acceptable.

No doubt that Latvia should think about electricity production as it is almost the last country in electricity production in EU. However, it is also questionable if electricity production really fits Infrastructure and digital content dimension from ICT perspective. NGA where Latvia has good performance is not covered at all. Two indicators here show low performance - international internet bandwidth and secure internet servers.

Unfortunately for some reason households with a personal computer are only $71.7 \%$ (and thus households with internet access also is the same level).

On other two other DESI dimensions Latvia's results are quite good; however, both dimensions have smaller weights. The reasons behind this is that basically Connectivity (Infrastructure) and probably also Human Capital are drives for the two following dimensions and strengthen (or weakens) them.

In Internet usage (DESI) Latvia shows good performance, however, this indicator is less important compared with others (the weight of this subindex is only 15\%). Author believes that most crucial indicators in this component are banking usage ( $81 \%$ of internet users, $6^{\text {th }}$ rank). It could be noted, that from marketing perspective $-48 \%$ of users are shopping online and $73 \%$ of them are using social networks; these numbers are increasing. This should be sufficient reason for companies to go online. Latvia has high ranks on new reading online $\left(87 \% ; 5^{\text {th }}\right.$ rank) compared with average EU level $-68 \%$. Overall internet usage and social network is also mentioned in NRI with the same performance.

Digital Public Services (DESI) or eGovernment shows positive tendencies. Latvia was able to increase government services online significantly by increasing eGovernment value from 0.49 to 0.57 . Citizens are more often using eGovernment services. The growth was higher than for most EU countries. Similar trends are seen in NRI Government usage - Online Service Index. Latvia has improved its ranking from $19^{\text {th }}$ to $10^{\text {th. }}$

NRI contains e-participation index under Social impact dimension to assess "the quality, relevance and usefulness of government website sin providing online information and participatory tools and services to their citizens" and raking $10^{\text {th }}$.

The important consideration is that previous DESI versions contained also eHealth indicator, however, it was removed from DESI 2016 because it was impossible to collect all data (European Commission, 2016d). The author believes that this indicator should and would be included in the future. Taking previously available results for eHealth show that Latvia is performing very bad having all eHealth sub-indicator below EU average level. If eHealth results were taken from Digital Agenda Scoreboard Unfortunately eHealth indicator for Latvia is very low and could importantly decrease value of Digital Public Services if included.

NRI contains also a list of other indicators that are not covered in DESI. Table 7 covers indicators that are related to political and regulatory environment, as well as government ITC promotions. 


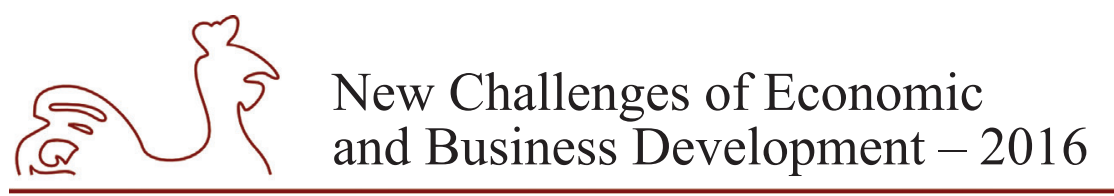

May 12-14, 2016, Riga, University of Latvia

Table 7

NRI indicators related to government and regulatory environment not covered above, Latvia and EU28, 2015

\begin{tabular}{|c|c|c|c|c|}
\hline & Rank & Value & EU28 value & Best \\
\hline Political and regulatory environment & - & - & - & - \\
\hline Effectiveness of law-making bodies, 1-7 (best) & 20 & 3.44 & 4.01 & $5.64(\mathrm{FI})$ \\
\hline Laws relating to ICTs $1-7$ (best) & 18 & 4.36 & 4.67 & $5.94(\mathrm{EE})$ \\
\hline Judicial independence, 1-7 (best) & 17 & 4.01 & 4.60 & $6.57(\mathrm{FI})$ \\
\hline $\begin{array}{l}\text { Efficiency of legal system in challenging regs, } \\
1-7 \text { (best) }\end{array}$ & 18 & 3.04 & 3.59 & $5.57(\mathrm{FI})$ \\
\hline Effectiveness of law-making bodies, 1-7 (best) & 19 & 3.44 & 4.01 & $5.64(\mathrm{FI})$ \\
\hline Intellectual property protection, 1-7 (best) & 17 & 4.00 & 4.59 & $6.19(\mathrm{FI})$ \\
\hline Software piracy rate $\%$ software installed & 24 & 53 & 39.25 & $20(\mathrm{LU})$ \\
\hline No. procedures to enforce a contract & 7 & 27 & 32.36 & 21 (IE) \\
\hline No. days to enforce a contract & 12 & $\underline{469}$ & 576.04 & 300 (LT) \\
\hline Individual usage & - & - & - & - \\
\hline $\begin{array}{l}\text { Mobile-cellular telephone subscriptions } \\
\text { (100 pop.) }\end{array}$ & 1 & $\underline{228.4}$ & 131.00 & $228.4(\mathrm{LV})$ \\
\hline $\begin{array}{l}\text { Fixed-broadband Internet subscriptions } \\
\text { (100 pop.) }\end{array}$ & 19 & 23.5 & 26.78 & $40.16(\mathrm{DK})$ \\
\hline Mobile-broadband subscriptions (100 pop.) & 12 & $\underline{62.34}$ & 61.04 & $123.47(\mathrm{FI})$ \\
\hline Households with a personal computer (\%) & 20 & 71.7 & 77.41 & $95.17(\mathrm{NL})$ \\
\hline Households with Internet access (\%) & 18 & 71.6 & 71.60 & $94.63(\mathrm{NL})$ \\
\hline Government usage (not covered previously) & - & - & - & - \\
\hline $\begin{array}{l}\text { Importance of ICTs to government vision of the } \\
\text { future } 1-7\end{array}$ & 19 & 3.51 & 4.04 & $5.50(\mathrm{LU})$ \\
\hline Government success in ICT promotion 1-7 & 17 & 4.12 & 4.32 & $5.85(\mathrm{LU})$ \\
\hline Business and innovation environment & - & - & - & - \\
\hline $\begin{array}{l}\text { Gov. procurement of advanced technology } \\
\text { products }(1-7)\end{array}$ & 18 & 3.22 & 3.47 & $4.62(\mathrm{LU})$ \\
\hline $\begin{array}{l}\text { No of procedures required to start a } \\
\text { business procedures }\end{array}$ & $7-14$ & 4 & 5.14 & $2(\mathrm{SI})$ \\
\hline Time required to start a business days & 16 & 12.5 & 11.57 & $2.5(\mathrm{PT})$ \\
\hline
\end{tabular}

Source: author's constructions based on World Economic Forum, 2014-2015.

* underlined values indicate that value is above average EU level.

It could be seen that absolute majority of all indicators are below average EU28 level. Political and regulatory environment should be improved, the same as government attitude regarding ITCs - government should be more involved in ICT technology development and progress. No considerable strengths can be seen here. 
May 12-14, 2016, Riga, University of Latvia

\section{Conclusions, limitations, future research}

1) There is no internationally accepted methodology for measuring digitization of countries and society. NRI and DESI are indices that show how countries are leveraging and using ICTs. Both indices are using different measurements; some measurements are comparable. Author believes that some indicators included in NRI index calculations are based on such experts' evaluations that could create bias. NRI currently seems to have more methodological issues compared with DESI.

2) Aggregated NRI and DESI scores as well as dimension scores suggests that Latvia is low performing country that falls behind the average level of other European Union countries. Lithuania outperforms Latvia slightly, while Estonia has much higher results (ranks and values) in aggregate indices and many components. Most of DESI and NRI dimensions are performing worse than EU average level. Lithuania is slightly outperforming Latvia, while Estonia is almost unreachable.

3) From country's place marketing perspective it is very important to increase country's results in internationally recognizable indicators such as NRI or DESI; these indicators not only show possible weaknesses for researchers or police makers, but can be a good opportunity to attract investors. Estonia is a good example how high performance with good country marketing can create ICT opportunities.

4) DESI 2016 reveals that the most worrisome indicators seemed to be "Human Capital" and "Integration of Digital Technology" - usage of internet and social media, as well as digital skills are very low and should be improved. E-commerce and companies' online presence could be an opportunity that is not used by Latvian SMEs.

5) By NRI 2015 the worst indicators are "Political and regulatory environment", "Infrastructure", "Skills", "Business usage", "Government usage", "Economic impacts".

6) In Latvia infrastructure (connectivity) is on average level, however, one of the main strength of Latvia is quite high Next Generation Access level. Latvia has to use this opportunity and continue development of it, while other countries have not outstripped it as, for example, Lithuania did this year become the leader in NGA. The overall number of internet users would increase subscriptions, as well as lower prices. Affordability is acceptable. From infrastructure dimension International internet bandwidth and secure internet servers count should be increased. Connectivity is one of the driving factors for other components.

7) More consistent regulatory environment in information and communications technologies. Government should be more active in developing, procuring and pushing ITC usage.

8) Latvia performs very well in such dimensions as Internet usage and Digital Public Services. Internet usage have increased, more users are online, involved in banking, shopping and social media. Author believes that Internet usage is not crucial dimension. Latvia has shown important progress in Digital Public Services and was able to increase government services online.

9) While in general Latvia is low performing country and doesn't show good overall results if only aggregated results are published. Latvia is one of those countries whose growth of indices was higher than EU countries on average. 


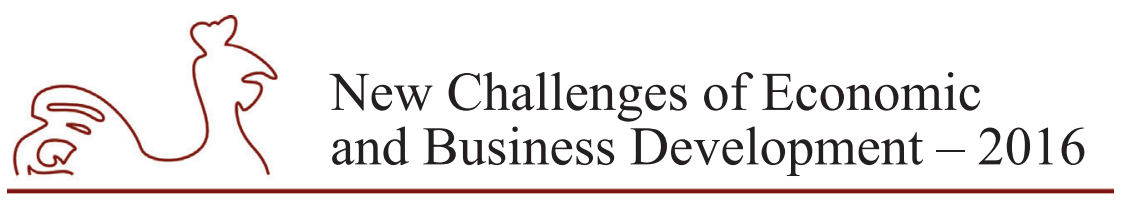

May 12-14, 2016, Riga, University of Latvia

10) Working with international indices, the methodology of index construction should be clarified. Sometimes expert evaluations are used, that could lead to important biases if many different experts (from different cultures) are evaluation their own country.

11) In the future more detailed analysis is needed. NRI and DESI are only two of composite indicators that are analyzed within this paper. There are other indicators that could show ITCs usage within country. If one wants to dig deeper into one of the dimensions, then additional indicators are available, for instance, Eurostat provides such data. Also NRI and DESI could be analyzed together with some other of well-known indices like GCI and HDI.

12) To be able to give more practical conclusions and suggestions, expert interviews or surveys are needed. This would help to understand why Latvia falls behind in many indicators (for instance, why business does not see internet as opportunity to increase their markets) and exactly what should be done to improve the results.

13) From theoretical point of view, author suggests to conduct a research related to technology acceptance in Latvia compared with other EU or Baltic States countries.

14) The NRI's and DESI's main focus is on ICTs usage and leverage of ICTs; this doesn't cover another part of ICTs - ICTs sector as a whole with such important questions as what part of GDP is created by ICTs sector, what is ICTs share in export etc.

\section{Bibliography}

Alper D., Çiğdem A., Başak D., 2015, Analyzing Information Technology Status and Networked Readiness Index in Context of Diffusion of Innovations Theory, Social and Behavioral Sciences, Vol. 195, pp. 1553-1562.

Binsdfeld J., Whalley J., Pugalis L., 2015. Lessons from Luxembourg's Networked Readiness Index (NRI). European Institute for Knowledge and Value-Management. [online] Available at: http:/www.eikv. org/downloads/2015_NRI\%20Lessons\%20Luxembourg.pdf [Accessed 28 January 2016]

Eglītis J., 2009. Reitingi un indeksi - valsts mārketings vai attīstības faktors. / Ratings and Indexes - State Marketing or the Factor of Development, Scientific Papers of University of Latvia, Economics. Business Administration, Vol. 743 Riga: University of Latvia Press.

Ericsson, 2012. Life in E-stonia: How a Small Nation Became an ICT Poowerhouse, Ericsson Business Review, Vol. 18, Issue 2. [online] Available at http://www.ericsson.com/res/thecompany/docs/ publications/business-review/2012/issue2/life_in_e-stonia.pdf [Accessed 1 March 2016].

Van DIJK Management Consultants, 2015. Mobile Broadband Prices. [online] Available at: http:// ec.europa.eu/newsroom/dae/document.cfm?doc_id=14653 [Accessed 2 March 2016].

European Commission, 2016a. Digital Agenda key indicators. [online] Available at: http://digital-agendadata.eu/datasets/digital_agenda_scoreboard_key_indicators [Accessed 9 March 2016].

European Commission, 2016b. Digital Scoreboard Progress by Country, [online] Available at: https:// ec.europa.eu/digital-single-market/en/progress-country [Accessed 8 March 2016].

European Commission, 2016c, Digital Economy and Society Index 2016, Country Profile, Latvia. [online] Available at: http://ec.europa.eu/newsroom/dae/document.cfm?action=display\&doc_id=14131 [Accessed 1 March 2016].

European Commission, 2016d, DESI 2016 Methodological note. [online] Available at: http://ec.europa. eu/information_society/newsroom/cf/dae/document.cfm?action=display\&doc_id=8846 [Accessed 1 March 2016].

Hancock, L. N., 2011. Why are Finland's schools successful? The country's achievements in education have other nations, especially the United States, doing their homework. Smithsonian Magazine. 


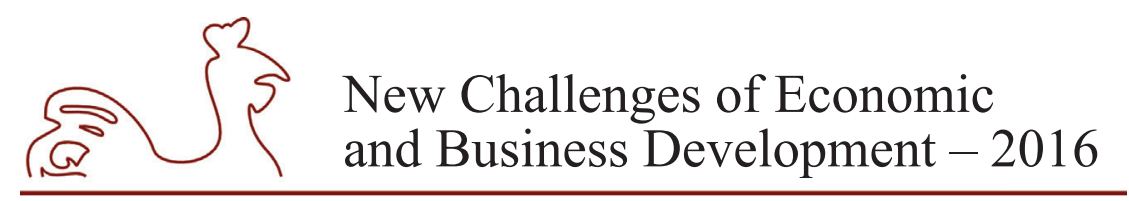

May 12-14, 2016, Riga, University of Latvia

Taylor, R. D., Zhang, B., 2007. Measuring the Impcat of ICT: theories of information and development. In Telecommunications Policy Research Conference, September, 26-28, Washington DC, pp. 1-39.

United Nations Development Programme, 2015. Education Index. [online] Available at: http://hdr.undp. org/en/content/education-index [Accessed 27 February 2016].

Wei-Wen W., Lawrence W. L., 2012. Exploring the critical pillars and causal relations within the NRI: An innovative approach. European Journal of Operational Research, Vol. 218, pp. 230-238.

World Economic Forum, 2014. The Global Information Technology Report 2015. [online] Available at: http://www3.weforum.org/docs/WEF_GlobalInformationTechnology_Report_2014.pdf [Accessed 9 March 2016].

World Economic Forum, 2015. The Global Information Technology Report 2015. [online] Available at: http://www3.weforum.org/docs/WEF_Global_IT_Report_2015.pdf [Accessed 9 March 2016]. 
May 12-14, 2016, Riga, University of Latvia

\title{
WHAT CAUSES THE GENDER WAGE GAP IN LATVIA?
}

\author{
Karlis Vilerts, University of Latvia, Latvia ${ }^{1}$ \\ Olegs Krasnopjorovs, Bank of Latvia, Latvia
}

\begin{abstract}
Gender wage gap raises concerns of possible discrimination in the labour market, therefore it is highly discussed topic not only in Latvia, but also in the European Union. We use anonymised micro data from Labour Force Survey to measure the gender wage gap in Latvia and identify the factors behind it. Our results imply that gender wage gap decreased during the economic crisis and increased afterwards thus exhibiting procyclical behaviour. In 2007 men on average earned around 25\% more than women. In 2009 the difference shrank to $10 \%$ and then rose again to $14 \%$ in 2014 . Oaxaca-Ransom decomposition results reveal that on average around one fourth of the observed gender wage gap is explained by differences in characteristics while the rest remains unexplained. The most important factor in explaining the gender wage gap is the segregation by sectors, which is partly offset with higher education levels for women (albeit segregation by fields of education is significantly in favour of men). Gender segregation by occupational groups worked in favour of men before the economic crisis but afterwards this factor ceased to be important. Our results imply that with equal characteristics as well as distributions by sectors, occupational groups and fields of education, men would earn approximately $10 \%$ more than women. Furthermore, we show that the observed gender wage gap is statistically significant in all deciles of wage distribution. Moreover, gender wage gap seems to be increasing with wage.
\end{abstract}

Key words: gender wage gap, gender inequality, gender discrimination, Oaxaca-Ransom decomposition, quantile regression

JEL code: J31, J71

\section{Introduction}

Difference between average wage of men and women (gender wage gap) is highly discussed topic not only in Latvia, but also in the European Union. In 2013 the average wage for women in European Union (EU) was 16\% lower than the average wage for men (EC, 2013); meanwhile in Latvia, according to Central Statistical Bureau (CSB), the difference was 17\%. European Commission (EC, 2013) points out that gender differences in average wage result in significantly lower lifetime earnings for women which in turn raise the poverty risk, particularly once the pension age is reached. Therefore EC highlights the importance of abolition of any form of gender discrimination.

There are however various reasons why wages can differ between various population groups. One obvious reason is the differences in characteristics like average education level or job experience. Other reasons include segregation in different occupations or sectors that can imply different productivity profiles. One of course can argue whether segregation is a form of

${ }^{1}$ Corresponding author - e-mail address: Karlis.Vilerts@bank.lv 


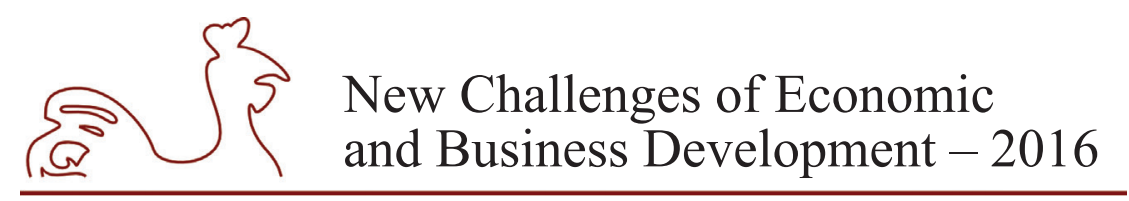

May 12-14, 2016, Riga, University of Latvia

discrimination (restricted access) or simply a choice made by individual. The discrimination comes in various forms for example traditional roles in family, limited access to some particular positions or just lower pay for equal amount of work (EC, 2013).

Analysis of the gender wage gaps has been a popular topic in international literature for decades, however in case of Latvia only few papers have addressed the issue. Furthermore, ones that did-looked at the gender wage gap before or during the crisis (see Hazans, 2007 or Gaveika \& Skrūzkalne, 2012). We used anonymised micro data from Labour Force Survey (LFS) and chose the research period to be 2007-2014 which allowed us to measure how the gender wage gap changed during the period of economic crisis and afterwards.

Understanding the factors that cause the gender wage gap is the first step towards introduction of policies and strategies that ensure equal opportunities in the labour market. Therefore the aim of this research is to identify the factors that cause gender wage gap in Latvia. In order to do that we employed Oaxaca-Ransom decomposition method and showed how much of the gender wage gap is explained by the differences in observed characteristics and how much remains unexplained.

Decomposition models usually deal with the differences in average wage; however there are models that look at differences along the distribution of wage by employing quantile regression (see methodology in Chernozhukov, Fernandez-Val \& Melly, 2009; Fortin, Lemieux \& Firpo, 2011 or Melly, 2005). Quantile decomposition methodology provides further insights on how does the wage gap vary amongst high-earners and low-earners. We used quantile decompositions in order to see whether gender wage gap in Latvia changes along the wage distribution.

Paper is structured as follows. First chapter reviews the data and methodology used in the empirical analysis. Second chapter presents the main findings and the final chapter concludes.

\section{Research results and discussion}

\section{Data and methodology}

We used anonymised micro data from LFS (obtained from the CSB) to measure the gender wage gap in Latvia and identify the factors behind it. LFS is a large household sample survey and is representative for the general population living in private households. It focuses on economic activity of working age population, but also includes information on family status, education and earnings from the employment at the main job. Therefore, it is well suited for wage gap decomposition analysis. Importantly, according to special agreement with CSB, we obtained earnings as a precise number, rather than interval as commonly reported.

Research period (2007 to 2014) allows us to measure how gender wage gap has changed during the period of economic crisis and afterwards. In 2007, LFS sample was increased more than twice (to 24128 households per annum), which is essential in order to obtain enough observations for every sector and occupation. In 2013 and 2014 the sample was widened even more (to 26676 and 29588 households respectively).

Survey sample was narrowed to working age population (18-64). Since LFS contains wage data for employees only, self-employed and company owners were excluded. Moreover, observations with missing wage (or unrealistically low wage), occupation, sector, education level and hours usually worked per week were excluded. The resulting sample consists of 16792-20113 individuals per year, of which 9064-12016 are wage earners. 


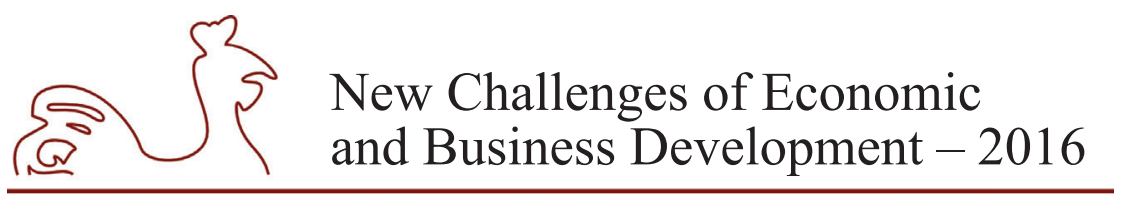

May 12-14, 2016, Riga, University of Latvia

We use log of net hourly wage as a dependent variable. Since net hourly wage is not directly observable in the data set, it was calculated from net monthly wage, taking into account hours usually worked per week. We also checked the robustness of our results by using the monthly wage as a dependent variable and limiting the sample to the employees that worked at least 30 hours per week. To avoid possible heteroskedasticity, we used robust standard errors to estimate the statistical significance of all coefficients.

In literature wage gaps are usually analysed using Oaxaca-Blinder approach that stems from fundamental papers of Oaxaca (1973) and Blinder (1973). Oaxaca-Blinder model employs a decomposition technique that splits the observed wage gap into two components: one attributable to differences in observed characteristics (endowment effect) and other, so called unexplained part.

When wages of men $\left(Y_{M}\right)$ and women $\left(Y_{F}\right)$ are expressed as a function of factors that determine them $\left(X_{M j} \& X_{F j}\right)$, gender wage gap can be written as:

$$
\ln \left(\overline{Y_{M}}\right)-\ln \left(\overline{Y_{F}}\right)=\overline{X_{M j}} \beta_{M j}-\overline{X_{F j}} \beta_{F j}
$$

where $\left(\beta_{m j} \& \beta_{f j}\right)$ are the respective regression coefficients. Splitting the equation 1 into two parts yields:

$$
\ln \left(\overline{Y_{M}}\right)-\ln \left(\overline{Y_{F}}\right)=\overline{X_{F j}}\left(\beta_{M j}-\beta_{F j}\right)+\beta_{M j}\left(\overline{X_{M J}}-\overline{X_{F J}}\right)
$$

where $\beta_{M j}\left(\overline{X_{M J}}-\overline{X_{F J}}\right)$ is part of the observed gender wage gap that is explained by differences in characteristics (endowment effect) and $\overline{X_{F j}}\left(\beta_{M j}-\beta_{F j}\right)$ is the unexplained part, which basically shows the wage gap that would be present if men and women shared the same observable characteristics.

Assumption regarding the choice of reference wage equation alters not only the estimates, but also the interpretation of results. If one chooses to use female wage equation as the reference all unexplained wage gap is interpreted as favouritism towards men. In turn choosing the male equation as a reference changes the interpretation of unexplained part to discrimination against women. In order to avoid extreme assumptions Oaxaca \& Ransom (1994) advises to use population wage equation (with respective regression coefficients $\beta_{p j}$ ), as a reference, therefore splitting the gender wage gap into three parts:

$$
\ln \left(\overline{Y_{M}}\right)-\ln \left(\overline{Y_{F}}\right)=\overline{X_{F J}}\left(\beta_{p j}-\beta_{F j}\right)+\overline{X_{M J}}\left(\beta_{M j}-\beta_{p j}\right)+\beta_{p j}\left(\overline{X_{M J}}-\overline{X_{F J}}\right)
$$

where differences in wages $\left(\ln \left(\overline{Y_{M}}\right)-\ln \left(\overline{Y_{F}}\right)\right)$ is divided into differences in observed characteristics, $\beta_{p j}\left(\overline{X_{M J}}-\overline{X_{F J}}\right)$, and the unexplained part which consists of discrimination against women, $\overline{X_{f j}}\left(\beta_{p j}-\beta_{f j}\right)$, and the favouritism towards men, $\overline{X_{M j}}\left(\beta_{M j}-\beta_{p j}\right)$. In this paper we employ OaxacaRansom methodology and report the unexplained part as an aggregation of discrimination and favouritism. Unexplained part however reflects also the differences in unobserved factors that are significant determinants of wage (for example motivation). One might argue that due to the generous maternity leave benefits in Latvia some young women might be less motivated to invest in on-the-job-training than males. As motivation is not observed, differences in wage caused by different motivation levels are reflected in unexplained part. 


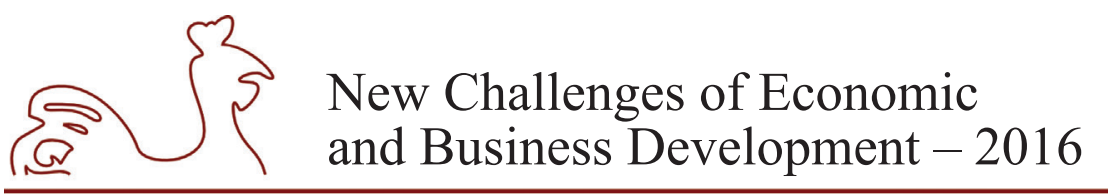

May 12-14, 2016, Riga, University of Latvia

Results of decomposition analysis depend on the choice of variables included in wage equation (see for example Heckman, Lyons \& Todd, 2000), therefore it is important to specify the wage equation as precisely as possible while not losing the economic interpretability. In addition to human capital variables included in wage equations like years of schooling and job experience, authors tend to include sector and occupation variables as well. This is done to capture the gender segregation by sectors and occupations which might result in different productivity profiles. Apart from human capital variables, sector (NACE classification) and occupational groups (ISCO 2-digit classification) we also included field of education, job tenure, current education activity both formal and informal (we indicate informal studies as on-the-job training), years passed since the highest ISCED education level was obtained, origin (ethnicity and citizenship), region (NUTS-3 breakdown), company size as well as dummy variables if person works in a public sector and if person has a supervisory role.

Years that individual spent in schooling is not directly observable. It was calculated from the highest level of education (ISCED) obtained. Data set included 18 ISCED levels in 2014 (and 13 levels in earlier years) starting from no school attendance at all to doctoral degree. Transformation of the education level variable to the years of schooling variable and vice versa is often used in the literature (e.g., Fersterer and Winter-Ebmer, 2003; Strauss and Maisonneuve, 2010). As data set contained information only on highest completed education level, years of schooling for those with unfinished degrees were underestimated. Therefore we increased years of schooling by one if a person was in studies at the time of interview. For a robustness check we use wage-differential model, distinguishing three education levels: basic (ISCED 0-2), secondary (ISCED 3-4) and higher (ISCED 5-6) education. Individuals with secondary education and undefined education field are used as a control group.

Job experience variable was not directly observed in our database. It was calculated as the difference between individuals' age and years of schooling. As shown in previous studies the results of wage equation for Latvia are robust to alternative experience definitions (see Vilerts, Krasnopjorovs \& Brēksis, 2015). To account for possible non-linear effects, we included also squared term of job experience as it is usually done in Mincer-type equations. Job tenure variable is directly observed in our data set. In order to account for a fact that newly hired employees are often underpaid (see Fadejeva and Krasnopjorovs, 2015), we included a dummy variable whether a person has changed employer during the last year.

Furthermore we also use quantile decompositions of the wage gap. This method allows the gender wage gap and its' components to be different along the distribution of wage. We follow Chernozhukov et al. (2009) and Melly (2005) and decompose the gender wage gap in to three parts:

$$
\begin{aligned}
\hat{q}\left(\widehat{\beta_{M}}, X_{M}\right)-\hat{q}\left(\widehat{\beta_{F}}, X_{F}\right)= & {\left[\hat{q}\left(\widehat{\beta_{M}}, X_{M}\right)-\hat{q}\left(\widehat{\beta_{m M r F}}, X_{M}\right)\right] } \\
& +\left[\hat{q}\left(\widehat{\beta_{m M r F}}, X_{M}\right)-\hat{q}\left(\widehat{\beta_{F}}, X_{M}\right)\right] \\
& +\left[\hat{q}\left(\widehat{\beta_{F}}, X_{M}\right)-\hat{q}\left(\widehat{\beta_{F}}, X_{F}\right)\right]
\end{aligned}
$$




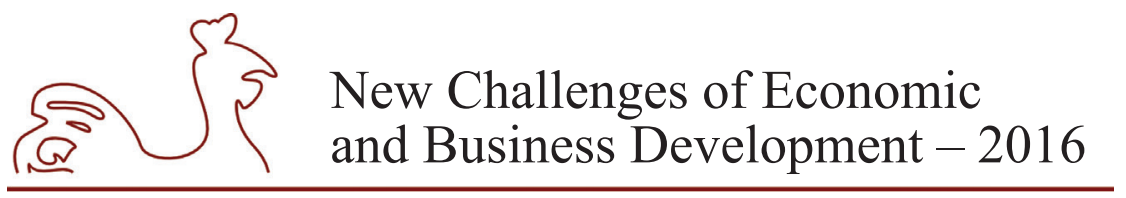

May 12-14, 2016, Riga, University of Latvia

where first part on the right-hand side is the differences in residuals, second part is the differences in median coefficients and the third part is the endowment effect. ${ }^{2}$ Term $\hat{q}\left(\widehat{\beta_{m M r F}}, X_{M}\right)$ represents the distribution that would have prevailed if the coefficients were the same for both genders, but the residuals were distributed as in the female distribution. Term $\hat{q}\left(\widehat{\beta_{F}}, X_{M}\right)$ is the counterfactual wage distribution of men if they had women's wage equation. Quantile decomposition is useful to understand how the wage gap varies amongst high-earners and low-earners. For example one might argue that the wage gap is the widest at the higher end of the wage distribution, reflecting differences in access to jobs with relatively high wages i.e. glass ceilings (Chiang \& Ohtake, 2014) or the opposite - at the lower-end (Christofides, Polycarpou \& Vrachimis, 2013).

\section{Empirical findings}

Our findings show that the gender wage gap in Latvia has been statistically significant in each year from 2007 to 2014 . Observed gender wage gap decreased during the economic crisis and then increased slightly afterwards, exhibiting weakly procyclical behaviour. In 2007 men earned approximately $25 \%$ more than women. In 2009 the difference shrank to $10 \%$ and then rose again to $14 \%$ in 2014 .

Oaxaca-Ransom decomposition results reveal that on average around one fourth of the observed wage gap is explained by differences in characteristics while remainder remains unexplained. Our results imply that with equal characteristics as well as distribution by sectors, occupations and fields of education, men would earn approximately $10 \%$ more than women (see Figure 1).

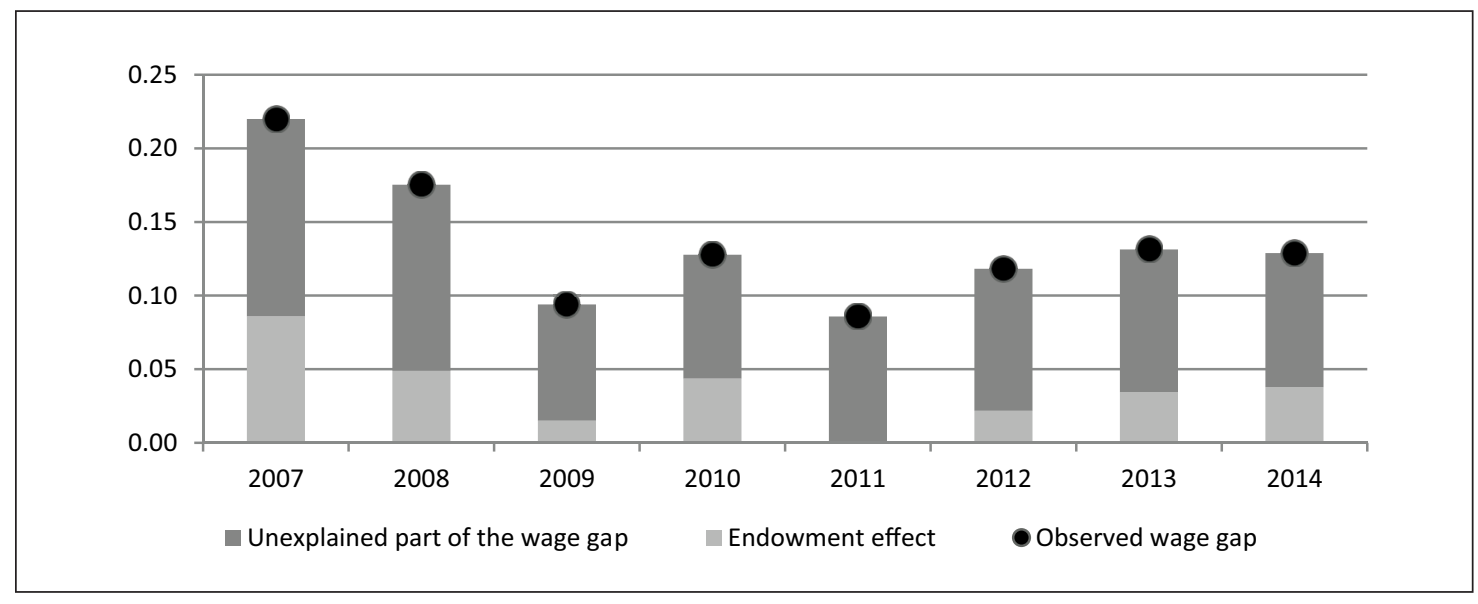

*Difference in \% can be calculated as exp(difference in log points)-1.

Source: authors' calculations based on LFS micro data.

Fig. 1. Decomposition of the gender wage gap in log points* (2007-2014)

Our results are broadly in line with Christofides et al. (2013), Hazans (2007) and Gaveika \& Skrūzkalne (2012) who found that the largest part of the gender wage gap in Latvia remains

2 First two components are presented as unexplained part of the wage gap. 


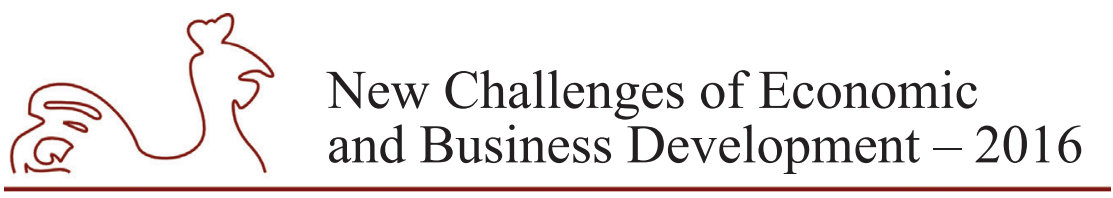

May 12-14, 2016, Riga, University of Latvia

unexplained even when controlling for occupation. Though a large share of the unexplained gender wage gap could relate to the differences in unobserved variables, we cannot exclude that some part of it is caused by discrimination.

In addition Gaveika \& Skrūzkalne (2012) noted that gender wage gap declined during the economic crisis, however as their dataset concluded with year 2009 procyclicality was not observed. However caution must be taken when comparing the results with different papers as decomposition methodologies and the choice of explanatory variables may yield different results.

More attention to the decomposition of the gender wage gap has been paid in the neighbouring Estonia, possibly because Estonia has one of the highest gender wage gaps in Europe (approximately 30\%-40\%; see, Anspal, 2015; Christofides et al., 2013). Though the observed gender wage gap in Estonia significantly exceeds the one present in Latvia, according to Christofides et al. (2013) unexplained part of the gender wage gaps do not differ significantly. Anspal (2015) points out that Estonia has significant gender segregation by sectors and occupations with significantly higher share of women being employed in occupations with low wages. Therefore compared with other European countries the endowment effect in Estonia explains a rather large part of observed gender wage gap.

Breakdown of the endowment effect in Latvia reveals that differences in the observed characteristics exhibit partially offsetting effects (see Figure 2).

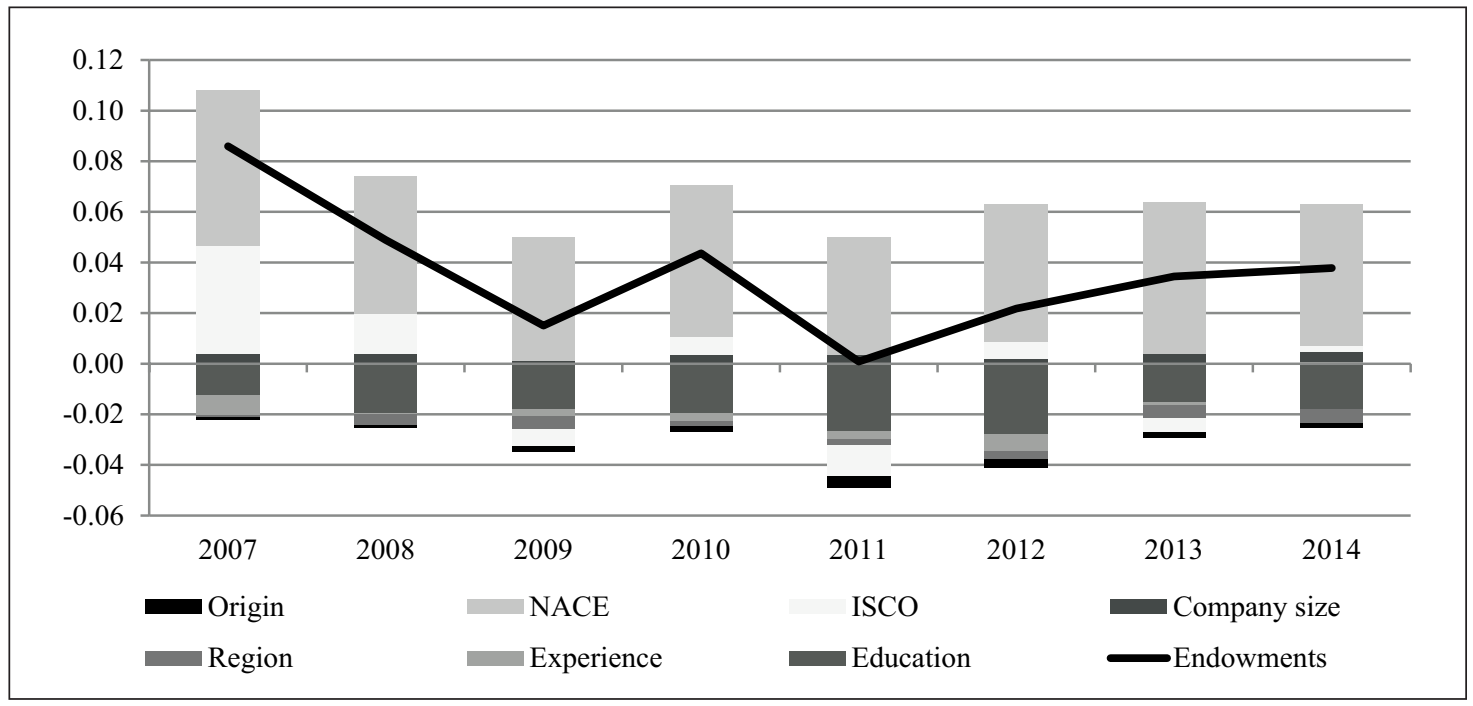

*Difference in \% can be calculated as exp(difference in log points)-1

Source: authors' calculations based on LFS micro data.

Fig. 2. Breakdown of the endowment effect (gender wage gap; log-points*; 2007-2014)

Education variables are the main factors in favour of women while segregation in better paying sectors is the main factor in favour of men. In 2007, men also benefited from occupational segregation while this factor loosed its role over time. Women are more likely than men to work in small companies where wages tend to be lower than average. This plays a significant, but 


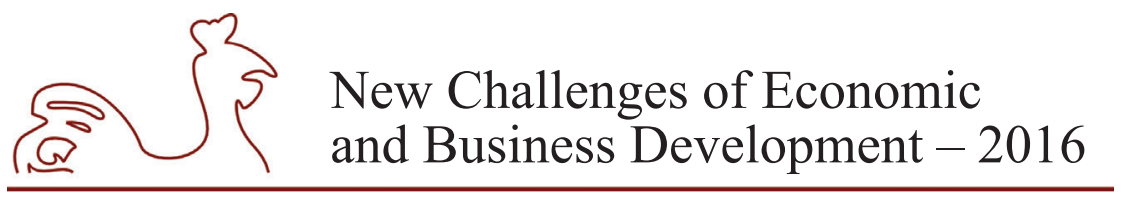

May 12-14, 2016, Riga, University of Latvia

small role in explaining the gender wage gap. Similarly gender segregation by region has a minor effect. Both genders are similar in terms of origin and job experience.

Segregation by sectors explains a part of the gender wage gap with main effect coming from low wages in female dominant sectors like education, health and social work activities as well as in accommodation and food services; and above average wages in male dominant sectors like transportation and storage, IT and construction (See Table 1). Before and during the economic crisis statistically significant effect in explaining the gender wage gap came from low wages in trade, the most popular sector amongst employed women.

Table 1

Sectors which significantly contributed to gender wage gap in 2014

\begin{tabular}{|c|r|r|}
\hline Gender & Above average wage & Below average wage \\
\hline Male* & $\begin{array}{r}\text { Information and Communication (J) } \\
\text { Construction (F) }\end{array}$ \\
& Industry (B-E) \\
& Fransportation and storage (H) & $\begin{array}{r}\text { Education (P) } \\
\text { Female** }\end{array}$ \\
& Financial Intermediation (K) & $\begin{array}{r}\text { Health and social work (Q) } \\
\text { Accommodation and food Services (I) } \\
\end{array}$ \\
Other services (RSTU)
\end{tabular}

Source: created by authors, based on LFS micro data.

Bold: impact of segregation in occupation on the observed ethnic wage gap is statistically significant with at least 95\% confidence level in majority of years from 2007 to 2014.

* Share of males employed in particular sector out of all employed males larger than share of females employed in particular sector out of all employed females. **The opposite.

The only sectors that showed an offsetting effect in explaining the gender wage gap were financial intermediation (sector with highest wages and relatively high share of women) and industry sector (male dominant and below average wages).

Before the crisis gender segregation by occupational groups partially explained why men have higher wages than women which is in line with Hazans (2007) who found that occupational segregation explains about $13 \%$ of the observed wage gap. We find that the aggregate impact of segregation by occupational groups decreased over time; however some particular occupational groups consistently contributed in explaining it (see Table 2). 


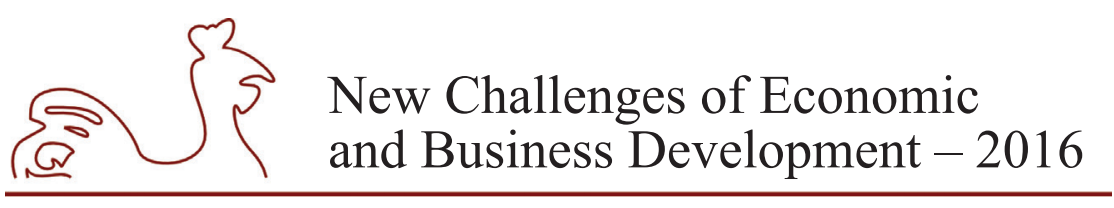

May 12-14, 2016, Riga, University of Latvia

Table 2

Occupational groups which significantly contributed to gender wage gap in 2014

\begin{tabular}{|c|l|l|}
\hline Gender & \multicolumn{1}{|c|}{ Above average wage } & \multicolumn{1}{c|}{ Below average wage } \\
\hline Male* & $\begin{array}{l}\text { Science and engineering professionals } \\
\text { (21) } \\
\text { Science and engineering associate } \\
\text { professionals (31) }\end{array}$ & $\begin{array}{l}\text { Skilled agricultural, forestry and fishery } \\
\text { workers (6), } \\
\text { Building and related trades workers (71) } \\
\text { Elementary occupations (9) }\end{array}$ \\
\hline \multirow{3}{*}{ Female** } & $\begin{array}{l}\text { Health professionals (22) } \\
\text { Teaching professionals (23) } \\
\text { Business and administration } \\
\text { professionals (24) }\end{array}$ & $\begin{array}{l}\text { Clerical support workers (4) } \\
\text { Personal service workers (51) } \\
\text { Sales workers (52) } \\
\text { Personal care and protective services } \\
\text { workers (53-54) }\end{array}$ \\
\hline
\end{tabular}

Source: created by authors, based on LFS micro data.

Bold: impact of segregation in occupation on the observed ethnic wage gap is statistically significant with at least $95 \%$ confidence level in majority of years from 2007 to 2014.

* Share of males employed in particular sector out of all employed males larger than share of females employed in particular sector out of all employed females. **The opposite.

For instance, gender wage gap may be partly explained with high wages among science and engineering professionals (and associate professionals), which are male-dominant occupational groups; and a lion's share of women among occupational groups like clerical support, personal service, sales and personal care workers who earn relatively low wages. This impact however, was broadly offset with male segregation into low wage occupations such as agricultural workers, building workers and elementary occupations as well as by high female share among professionals in health, education and business administration.

In Latvia women spend on average a year more in education than men do, therefore the observed wage gap is smaller than it would be if both genders had the same level of schooling. Education and specially higher education has gained a lot of popularity in Latvia, particularly amongst women. According to Central Statistics Bureau of Latvia (CSB) in 2002 approximately $24 \%$ of economically active women had attained tertiary education. By 2015 the figure had increased to approximately $44 \%$. In turn the increase in share of men with tertiary education was smaller (from $16 \%$ to $23 \%$ ). These results have a significant implication when addressing the issue of equality in the labour market. Policies that aim to reduce wage gap by increasing female education attainment could close the observed wage gap, however it wouldn't solve the underlying causes of it.

Our results imply that on average women have obtained their education in fields with relatively low returns, particularly in manufacturing and processing, or education. Therefore the impact of gender segregation by field of education partly offsets the impact of the differences in educational attainment (see figure 3). 


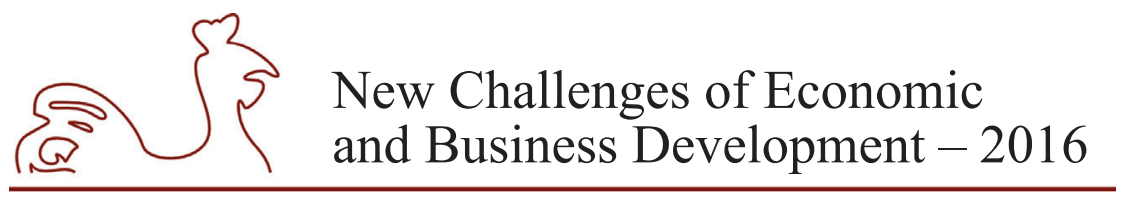

May 12-14, 2016, Riga, University of Latvia

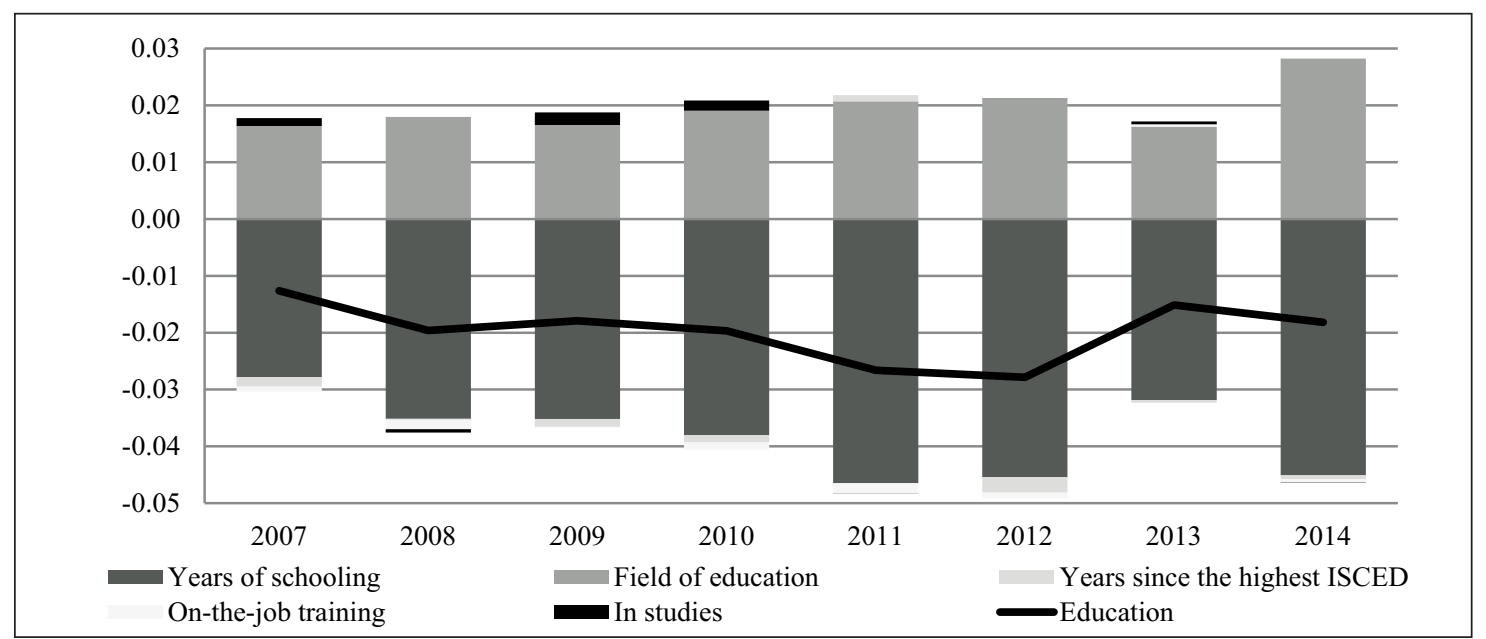

*Difference in \% can be calculated as exp (difference in log points)-1

Source: authors' calculations based on LFS micro data

Fig. 3. Breakdown of education effects (gender wage gap; log-points*; 2007-2014)

As a robustness check instead of years of schooling we used binary variables that indicate highest obtained education level. The results are robust to the choice of the variable that reflects the education attainment. The results are also robust when monthly wage is used as the dependent variable and the sample is limited to those employees who worked at least 30 hours per week. In turn the monthly wage gap is significantly larger than hourly wage gap when this sample restriction is not used, reflecting the differences in hours worked per week.

We further look at the gender wage gap at different points of wage distribution by following methodology proposed by Melly (2005) and Christofides et al. (2013). Our results show that observed gender wage gap is statistically significant in all deciles of wage distribution (see figure 4 for 2014).

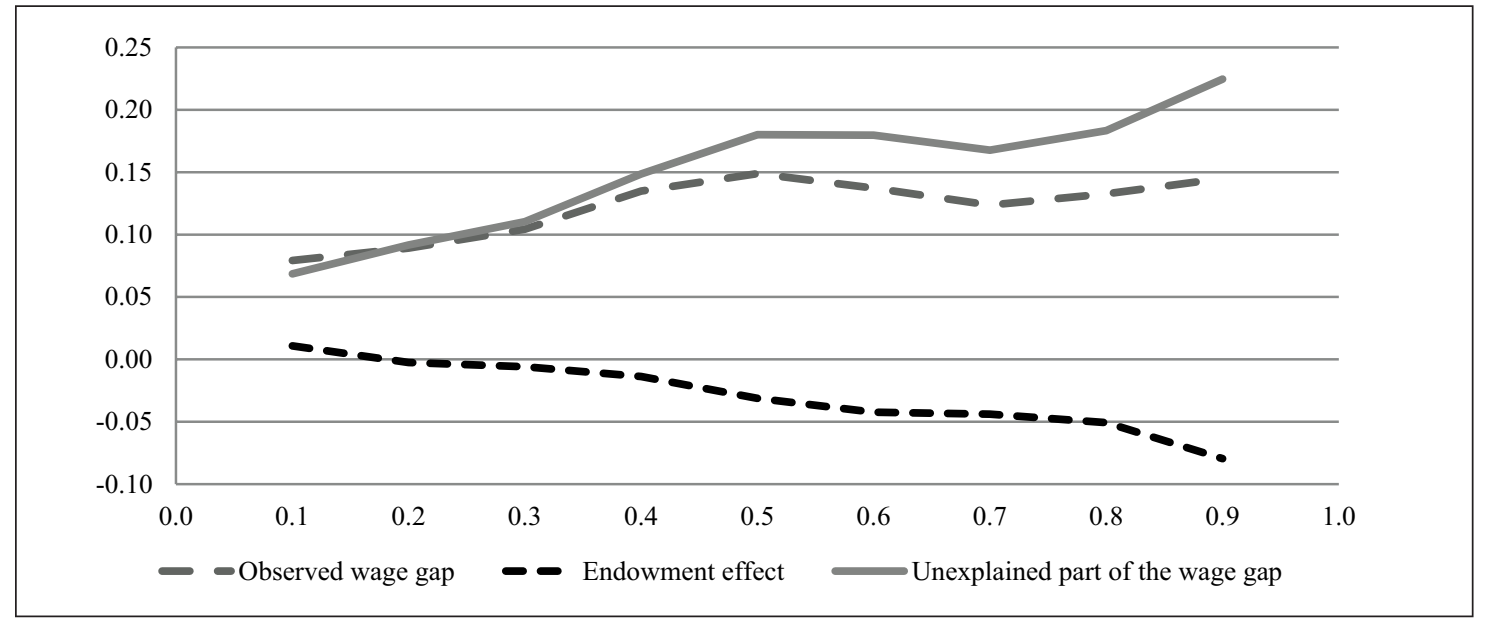

*Difference in \% can be calculated as exp(difference in log points)-1

Source: authors' construction based on LFS micro data

Fig. 4. Decomposition of the gender wage gap by deciles in 2014 (log points*) 


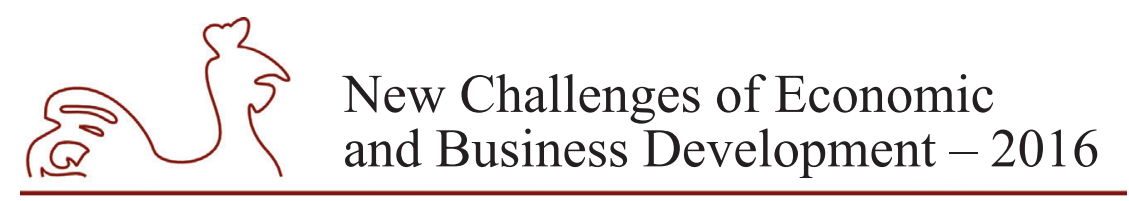

May 12-14, 2016, Riga, University of Latvia

The observed wage gap seems to be increasing with wage, showing signs of possible glass ceiling effect. However this statement lacks statistical confirmation as the difference between wage gaps in $5^{\text {th }}$ and $9^{\text {th }}$ deciles are not statistically significant in any year. In turn the increase of the observed wage gap from 1st to 3rd decile is significant in all years from 2007 to 2014 . This could be partially caused by relatively high share of minimum wage earners in Latvia. As minimum wage is fixed by law, small gender wage gap at lowest deciles is expected.

Shape of the observed wage gap as well as the endowment effect and unexplained wage gap is fairly similar in all years of analysis. Though the observed wage gap in 2007 and 2008 seem to be increasing with wage as in all other years, it becomes slightly lower in highest deciles. These results are in line with Christofides et al. (2013) who found similar observed wage gap pattern for Latvia in 2006. Starting from 2009 the observed wage gap increased with wage and did not decrease in highest deciles. This finding is in line with Gaveika \& Skrūzkalne (2012) who found similar pattern in 2009.

Gender differences in endowments don't have a significant effect at lowest deciles, but they became significant at highest, therefore rendering the unexplained wage gap substantially larger than the observed wage gap. These results imply that if men in highest deciles shared the same characteristics as women in highest deciles, the wage gap would be even larger than the one actually observed.

\section{Conclusions, proposals, recommendations}

1. The gender wage gap in Latvia has been statistically significant in each year from 2007 to 2014. Observed gender wage gap exhibited weakly procyclical behaviour by decreasing in the economic crisis and then increasing slightly afterwards.

2. Oaxaca-Ransom decomposition results reveal that on average around one fourth of the observed wage gap is explained by differences in characteristics while the rest remains unexplained. Though a large share of the unexplained gender wage gap relates to the differences in unobserved variables, we cannot exclude that some part of it is caused by discrimination.

3. Education variables are the main factors in favour of women while segregation in better paying sectors is the main factor in favour of men. Women are more likely than men to work in small companies where wages tend to be lower than average. This plays a significant, but small role in explaining the gender wage gap. Similarly gender segregation by region has a minor effect. Both genders are similar in terms of origin and job experience. Occupational segregation loosed its role in explaining the gender wage gap over time.

4. In Latvia women spend on average a year more in education than men do, therefore the observed wage gap is smaller than it would be if both genders had the same level of education. However the impact of gender segregation by field of education partly offsets the impact of the differences in education attainment as on average women have obtained their education in fields with relatively low returns (like manufacturing and processing, or education).

5. Gender differences in endowments don't have a significant effect at lowest deciles, but they become significant at highest, therefore rendering the unexplained wage gap substantially larger than the observed wage gap. These results imply that if men in highest deciles shared 


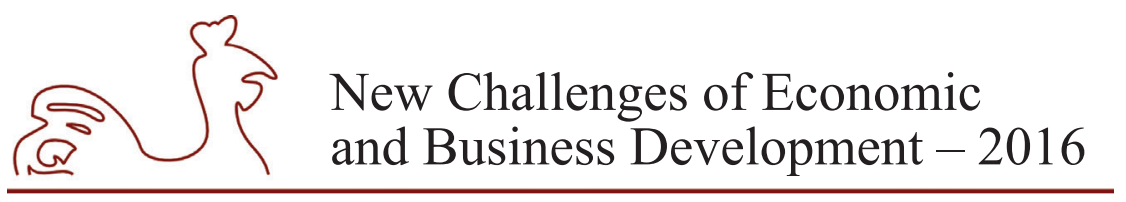

May 12-14, 2016, Riga, University of Latvia

the same characteristics as women in highest deciles, the wage gap would be even larger than the one actually observed. The existence of possible glass ceiling effect, however, lacks statistical confirmation.

6. The results are robust to the choice of wage and education variables. However monthly wage gap is significantly larger than hourly wage gap when the sample is not limited to those employees who worked at least 30 hours per week, reflecting the differences in hours worked per week.

\section{Bibliography}

Anspal, S., 2015. Gender Wage Gap in Estonia: a Non-parametric Decomposition. Baltic Journal of Economics, 15(1), pp. 1-16.

Blinder, A., 1973. Wage Discrimination: Reduced Form and Structural Estimates. The Journal of Human Resources, 8(4), pp. 436-455.

Chernozhukov, V., Fernandez-Val, I. \& Melly, B., 2009. Inference on Counterfactual Distributions. [Online] Available at: http://dx.doi.org/10.2139/ssrn.1235529 [Accessed 21 January 2016].

Chiang, H. \& Ohtake, F., 2014. Performance-pay and the Gender Wage Gap in Japan. Journal of the Japanese and International Economies, 34, pp. 71-88.

Christofides, L. N., Polycarpou, A. \& Vrachimis, K., 2013. Gender Wage Gaps, 'Sticky Floors' and 'Glass Ceilings' in Europe. Labour Economics, 21, pp. 86-102.

European Commission, 2013. Tackling the Gender Pay Gap in the European Union. Publications Office of the European Union. Available from: http://ec.europa.eu/justice/gender-equality/files/gender pay_gap/130422_gpg_brochure_en.pdf [Accessed 20 January 2016].

Fadejeva, L. \& Krasnopjorovs, O., 2015. Labour Market Adjustment During 2008-2013 in Latvia: Firm Level Evidence. [Online] Available at: https://www.macroeconomics.lv/sites/default/files/wp_22015 en.pdf [Accessed 11 January 2016].

Fersterer, J. \& Winter-Ebmer, R., 2003. Are Austrian Returns toEducation Falling Over Time? Labour Economics, 10(1), pp. 73-89.

Fortin, N., Lemieux, T. \& Firpo, S., 2011. Decomposition Methods in Economics, Handbook of Labor Economics, 4 th Edition. North Holland: Elsevier.

Gaveika M. \& Skrūzkalne, K., 2012. Gender Wage Gap in Latvia. Available from: http://www.sseriga.edu/ download.php?file=files/researchPapers/gaveika_skruzkalne_rp.pdf [Accessed 11 January 2016].

Hazans, M., 2007. Coping with Growth and Emigration: Latvian Labor Market Before and After EU Accession. [Online] Available at: http://dx.doi.org/10.2139/ssrn.971198 [Accessed 24 January 2016].

Heckman, J. J., Lyons, T. M. \& Todd, P. E., 2000. Understanding Black-White Wage Differentials: 19601990. The American Economic review, 90(2), pp. 344-349.

Melly, B., 2005. Decomposition of Differences in Distribution Using Quantile Regression. Labour Economics, 12(4), pp. 577-590.

Oaxaca, R. L., 1973. Male-Female Wage Differentials in Urban Labor Markets. International Economic Review, 14(3), pp. 693-709.

Oaxaca, R. L. \& Ransom R. R., 1994. On Discrimination and the Decomposition of Wage Differentials. Journal of Econometrics, 61(1), pp. 5-21.

Strauss, H. \& De La Maisonneuve, C., 2010. The Wage Premium on Tertiary Education: New Estimates for 21 OECD Countries. OECD Journal: Economic Studies, 2009(1), pp. 1-29.

Vilerts, K., Krasnopjorovs, O. \& Brēksis, E., 2015. Does Education Affect Wages During and After Economic Crisis? Evidence From Latvia (2006-2012). [Online] Available at: https://www.macroeconomics.lv/ sites/default/files/wp_3-2015_en_f.pdf [Accessed 12 January 2016]. 


\title{
New Challenges of Economic
} and Business Development - 2016

May 12-14, 2016, Riga, University of Latvia

\section{EVALUATION OF CURRENT LOCATION AND PROSPECTS OF THE EUROPEAN AND RUSSIAN UNIVERSITIES AMONG THE WORLD'S LEADING UNIVERSITIES WITH THE USE OF NEURAL NETWORK METHODS CLUSTERING OF DATA}

\author{
Mikhail Zaboev, Saint Petersburg State University, Russia ${ }^{1}$ \\ Mikhail Meleshkin, Saint Petersburg State University, Russia \\ Vladimir Khalin, Saint Petersburg State University, Russia
}

\begin{abstract}
The paper presents the results of research on evaluating the positions of the European and Russian universities in the world university ranking, which is based on the use of the neural network methods of clustering. The method of clustering based on the self-organizing Kohonen maps allows to get university ranking with a minimum level of subjectivity.

The results of clustering allow to identify five groups of universities with similar characteristics and thus with similar goals and opportunities for development.

When the clusters were determined it is possible to define for each cluster the threshold values of indicators, which certain university should reach for entering into the cluster. For example, to get into the leading cluster according to created rules for Moscow state University it is required to increase indicators Papers int co-author / Papers and Acad staff int / Acad staff at only 0.01 points.

It is also fruitfully to analyze tendencies of development for each individual cluster.

Below is presented a possible interpretation of the most significant results obtained from the evaluation of trends of universities development:

- Dynamic of development of all universities included in the study sample over the period 2004-2012 indicates a steady increase in the number of publications according to Web of Science;

- There is a common trend of reducing the ratio of academic staff to the number of students that, according to the author, due to the increase in the number of students studying in leading universities.
\end{abstract}

Key words: international rankings, clustering, Artificial Neural networks, Self-organizing Kohonen maps, decision trees

JEL code: C80

\section{Acknowledgements}

The research is partially supported by the Russian Foundation for Basic Research (RFBR), grant 16-06-00221.

\section{Introduction}

Globalization of the processes of knowledge creation and transfer in the field of education makes competition between universities stronger. Universities should constantly improve their

1 Corresponding author - e-mail address: m.zaboev@spbu.ru 


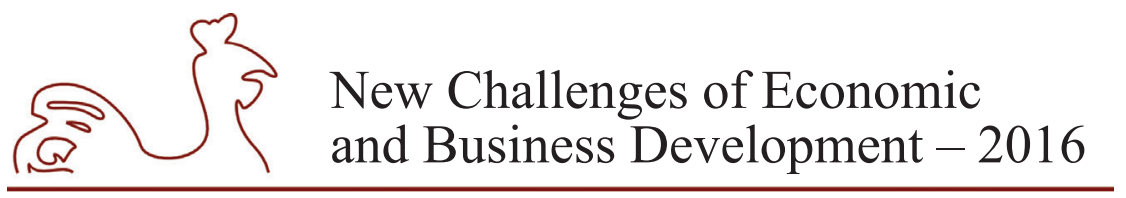

May 12-14, 2016, Riga, University of Latvia

efficiency to be competitive in the market of educational services and hold positions among other leading universities.

Currently, in many countries for evaluation the quality of activities of the leading universities are widely used various world rankings. At the same time, high places of universities in these rankings are often considered as a matter of national pride and serve as a kind of indicator of the success of the national higher education system and, on the contrary, the low places of universities in these ratings have a negative impact on the prestige of the country and assessment of the competitiveness level of the national universities (Khalin, 2011).

Meanwhile, despite the obvious advantages of the use of the world rankings for performance evaluation of leading universities, they have significant drawbacks. For example:

- High positions of universities in one competent world ranking do not guarantee them high positions in other rankings. For example, in 2015 the first hundred of $\mathrm{ARWU}^{2}$ rankings contains one Russian university and no universities from China, and at the same time in the top-100 of THE WUR ${ }^{3}$ there are twenty Chinese universities and no one universities from Russia;

- Changes in the positions of certain university in one world ranking could significantly (up to the opposite) different from the dynamics in other ratings. For example, from 2014 to 2015 St. Petersburg State University's place in the QS ${ }^{4}$ ranking has changed from 233 to 265, but in ARWU ranking position has improved;

- The number of universities, which are presented in top-100 of the best universities in the both rankings: THE WUR and QS in 2015, is equal only to 54, although their total number is 150 universities;

- Methodologies of world rankings are improved and changed frequently, that leads to significant changes in the positions of a number of universities in these rankings (Zaboev et al., 2015).

The purpose of current research is to describe the overall scheme of the method for assessing the global competitiveness of leading universities, based on the use of data mining techniques, in particular, on the use of artificial neural networks and self-organizing Kohonen maps. The main advantage of this approach is to obtain quantitative estimates of the global competitiveness of the leading universities, as well as carrying out their multi-criteria ranking based on objective, quantitative indicators of their activities.

\section{Research results and discussion}

\section{The main steps of the method, information base, statement of the problem}

The main objectives of the developed method are the following:

- Detection of clusters (groups) of universities on the basis of targets indicators of their activities presented in the database InCites ${ }^{\mathrm{TM}}$;

\footnotetext{
2 ARWU - Academic Ranking of World Universities by the Center for World-Class Universities at Shanghai Jiao Tong University.

3 THE WUR - Times Higher Education World University Rankings.

${ }^{4}$ QS - Quacquarelli Symonds World University Rankings.
} 


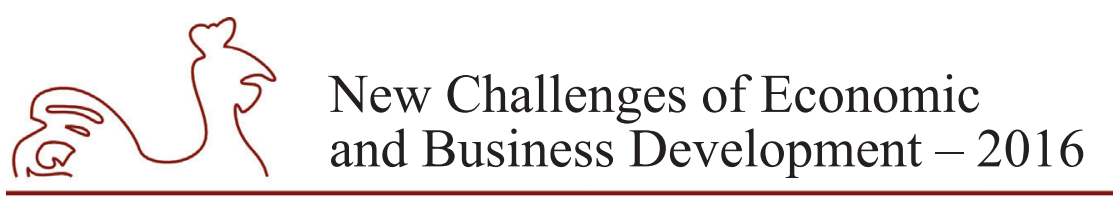

May 12-14, 2016, Riga, University of Latvia

- Evaluation of the current location of Russian and European universities among the world's leading universities;

- Identification of the targets indicators of universities activities, which is necessary to reach for Russian and European universities to enter the leading clusters.

On the first step of developed method it is necessary to select a list of world rankings, in the context of which it is supposed to assess the global competitiveness of leading universities, and to clarify the information database about the activities of the universities that is used in these ratings. It is reasonable to consider three world rankings: ARWU, THE WUR, QS and as information base of research were selected InCites ${ }^{\text {TM }}$ database, Web of Science and Scopus.

On the second step of the method implementation is carried out the analysis of the information base, which aim is to select the quantitative indicators and factors that characterize the global competitiveness of universities for the further use them instead of subjective expert's estimates. On this step is occurred the justification and implementation of a multi-level procedure of selection the key factors and indicators of performance of the leading universities in the context of enhancing their global competitiveness.

Thereby, as a result of analyzing the methodologies of the world rankings ARWU, THE WUR, QS and database InCites ${ }^{\mathrm{TM}}$, which contains about 100 different criteria characterizing the activities of the universities, the following eight key indicators of global competitiveness of leading universities were selected:

1. Acad staff / Stdnt - academic staff/ number of students;

2. Acad staff int / Acad staff - the share of foreign teachers in the total number of academic staff;

3. Doctoral degree / Acad staff - the number of science degrees awarded during the year / Academic staff;

4. Normalized citation impact-country adj-the number of citations per one publication, taking into account adjustments for the country;

5. Papers - total number of publications according to the database of science citation Web of Science during one year;

6. Int Papers co-author / Papers - the share of publications in international collaboration;

7. Res income / Acad staff - the volume of revenues from University R\&D (in USD) per unit of academic staff;

8. Stdnt int / Stdnt - the share of foreign students (Zaboev \& Meleshkin, 2015).

Seven of these indicators are used for calculating THE WUR rating

In the present article are used indicators from the database InCites ${ }^{\mathrm{TM}}$, which form the basis for developing of the Times Higher Education international rating. Access to this data is performed through the web site interface http://incites.thomsonreuters.com/.

The third step is to fulfill the procedure of clustering, multi-criteria evaluation and ranking in the context of global competitiveness on the base of the selected key factors and indicators of the leading universities. So, based on the selected eight key indicators, using technique of artificial neural networks and self-organizing Kohonen maps, conducted the procedure of clustering of universities, evaluation and multi-criteria ranking. In particular, five clusters were obtained by clustering on these key indicators. 


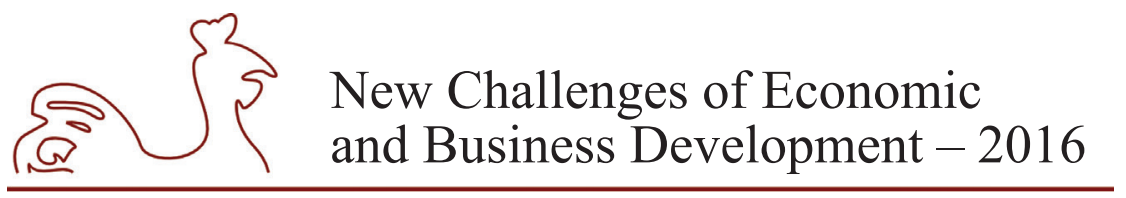

May 12-14, 2016, Riga, University of Latvia

\section{The model of clustering the universities based on Kohonen maps}

From the entire data set presented by InCites $^{\mathrm{TM}}$ database we take into account information on the activities of 692 universities for which data are available for all 8 selected indicators for $2012^{5}$ and the value of the Total number of publications in the database Web of Science for 2012 (indicator Papers for 2012) exceeds 100. The introduction of a threshold of the publication activity of university employees takes its roots from the requirements of authors of the international rankings to the minimum number of publications.

As a tool for building the models is used Russian analytical platform Deductor. Clustering of universities is fulfilled using the construction of self-organizing Kohonen maps, which are based on the artificial neural networks models. The parameters of the model are determined by a heuristic approach taking into account the recommendations on the selection of optimal neural network architecture and the need of high quality visualization and interpretation of results (Botvin \& Zaboev, 2011).

Kohonen map is based on the neural network, which consists of $12 \times 16$ hexagonal cells; the nodes of network are represented by artificial neurons. To provide easy analysis and interpretation of results was selected number of clusters equal to five.

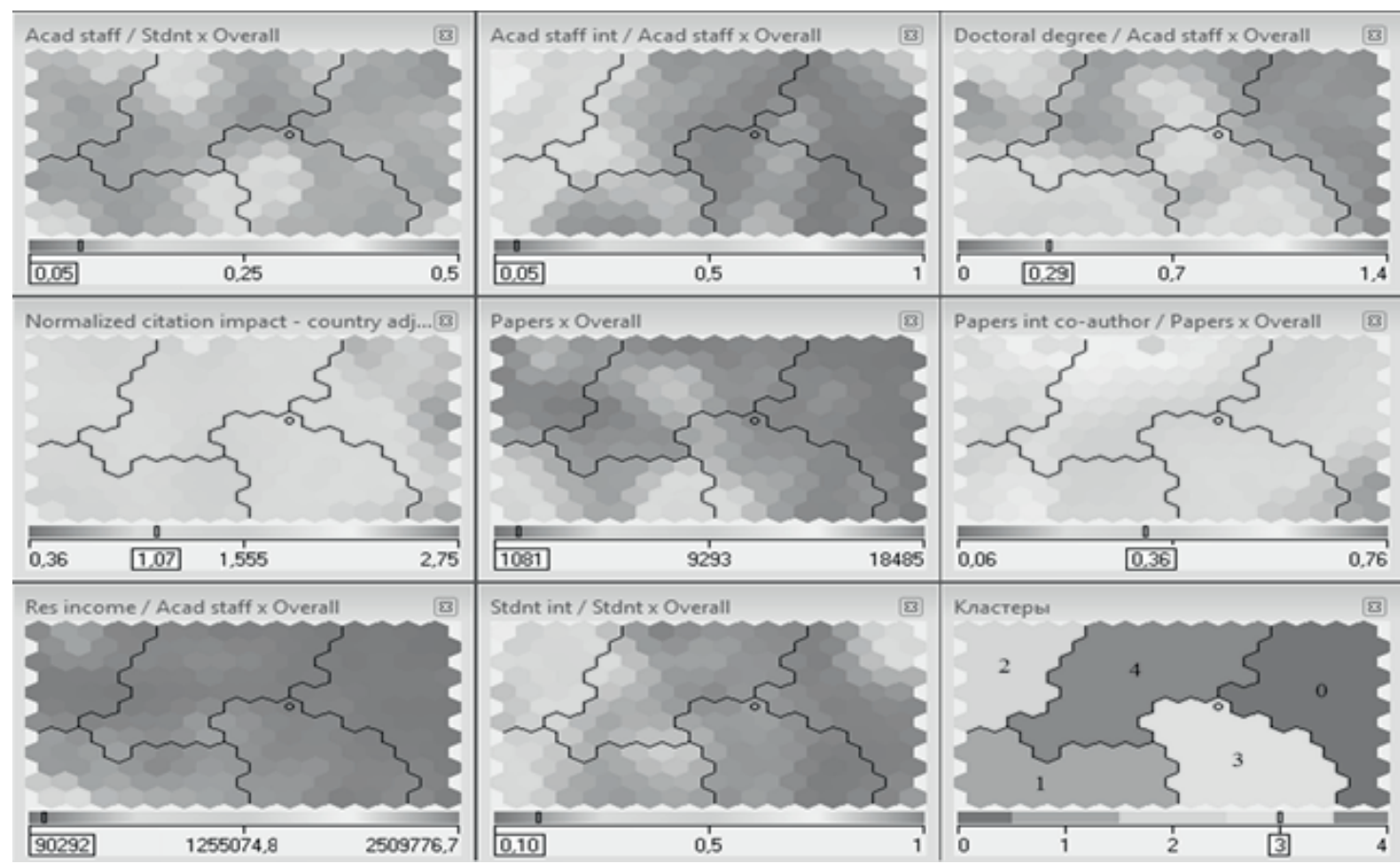

Source: author's construction based on self-organizing Kohonen maps, which use retrospective data from InCites ${ }^{\mathrm{TM}}$ database for 2012.

Fig. 1. The result of clustering of universities based on 2012 data

5 Data for 2012 were used to form university rankings of 2014/15 year. 


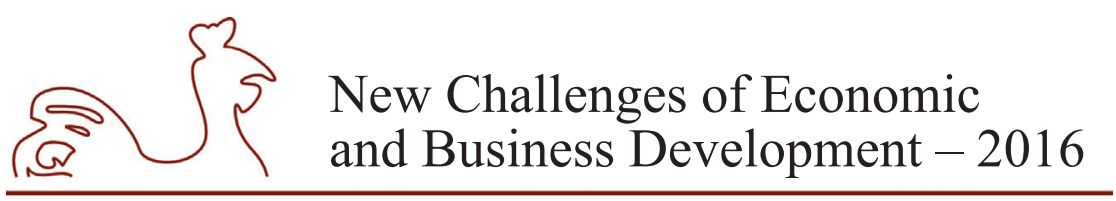

May 12-14, 2016, Riga, University of Latvia

Fig. 1 shows the results of clustering for 2012 data. For each cluster can be given a generalized description.

- $1^{\text {st }}$ cluster consists of the leading universities. First cluster includes 107 universities, which are characterized by a high rate of publication activity that confirmed by the color gamut of corresponding map (Papers), where the cells corresponding to the 1st cluster are painted in more light tones referring the high values of indicator Papers. Also the universities from the 1st cluster show the high values of the indicator Res income / Acad staff and values higher than average for the remaining 6 selected indicators.

- $2^{\text {nd }}$ cluster is characterized by the high level of international activity (lighter tones on the maps, which respond to the indicators Stdnt int / Stdnt Acad staff and Acad staff int / Acad staff) with "medium" values of other variables. This cluster includes 83 universities;

- $3^{\text {rd }}$ and $4^{\text {th }}$ clusters consist of the universities which occupy the "middle" position. These two clusters includes totally 323 universities;

- In the $0^{\text {th }}$ cluster enter universities that have positions "below average" -179 universities.

The more detail analysis of the $1^{\text {st }}$ cluster shows that it contains only one university from the Eastern Europe - The University of Bucharest (it is necessary to highlight that none of selected rankings contains The University of Bucharest in the top-100 for 2015/2016) and the total number of European universities in the $1^{\text {st }}$ cluster is equal to 36 . The set of the universities which take part in clustering process includes, for example, 28 German universities: 9 of them belong to the $1^{\text {st }}$ leading cluster and others 19 to the $3^{\text {rd }}$ and $4^{\text {th }}$ clusters. The list of German universities from the $1^{\text {st }}$ cluster is below: Darmstadt University of technologies, Eberhard Karls university of Tubingen, Free university of Berlin, Karlsruhe institute of technologies, Technological university of Dresden, University of Gottingen, University of Kiel, University of Munich, University of Ulm.

Under the conditions of the model presented in the current research two leading Russian universities: Moscow state University and St. Petersburg state University were included in the $4^{\text {th }}$ cluster according to the results of clustering based on the data of 2012.

Concerning universities from the Baltic region countries: Estonian, Latvian, Lithuanian, we can find Riga Technical University and Tallinn University of Technology in the $0^{\text {th }}$ cluster and The University of Tartu and Vilnius University - in the $4^{\text {th }}$ cluster.

\section{Analysis of the dynamic of universities development in different clusters}

On the base of cluster analysis it is possible to identify five groups of universities with similar characteristics and thus with similar goals and opportunities for development. Thus it is fruitfully to analyze tendencies of development for each individual cluster. On the Fig. 2 in the form of a diagram presents the coefficients, which are equal to the ratio of average values of indicators in 2018, formed on the basis of linear models, which use retrospective data in the period 2004-2012, to the actual values in 2012 for each cluster. We use a six-year forecasting horizon because of this time period usually considered when medium-term plans of organization development are created. 


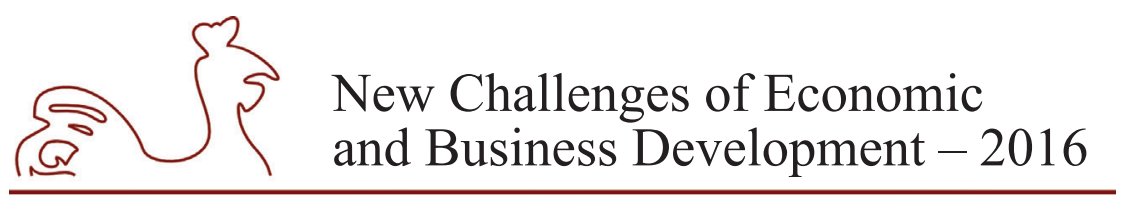

May 12-14, 2016, Riga, University of Latvia

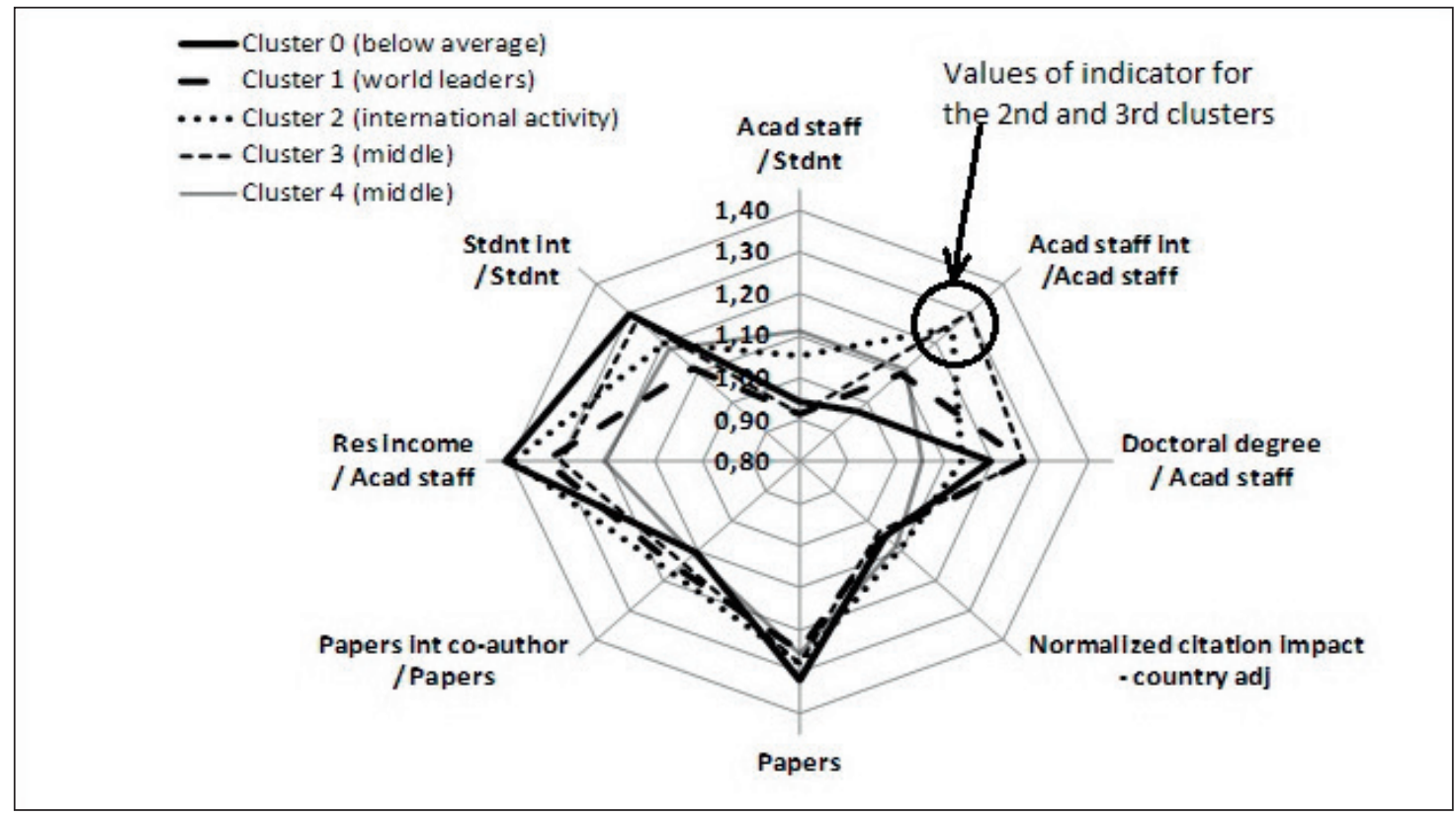

Source: author's construction based on linear models, which use retrospective data from InCites ${ }^{\mathrm{TM}}$ database for the period 2004-2012.

Fig. 2. Factors reflecting trends in the performance indicators of universities in clusters

Below is presented a possible interpretation of the most significant results obtained from the evaluation of trends of universities development:

- There is a significant increase in the share of foreign teachers, not only among universities of the $2^{\text {nd }}$ cluster, focused on international activity, but also among the universities of the $3^{\text {rd }}$ cluster, which occupy middle position. This conclusion can be drawn by analyzing the coefficients of change in the indicator Acad staff int / Acad staff, typical for the representatives of the $2^{\text {nd }}$ and $3^{\text {rd }}$ clusters, which correspond to dotted and dashed lines on Fig. 2. These coefficients are equal to values significantly greater than one (see the highlighted area on Fig. 2). The described trend may indicates that many universities of the $3^{\text {rd }}$ cluster as a priority goal in their strategic development chose the internationalisation of educational services, which may allow them to enter the group of leading universities;

- Dynamics of development of all universities included in the study sample over the period 2004-2012 indicates a steady increase in the number of publications according to Web of Science. The growth in the number of publications of Moscow state University and St. Petersburg state University significantly below average: this indicator for SPBU for 8 years, almost not changed, and Moscow state University has an average annual growth of less than 3\%; thus, in order at least to keep up with the leading universities, need to "run" even faster;

- There is a common trend of reducing the ratio of academic staff to the number of students that, according to the author, due to the increase in the number of students studying in leading universities. 


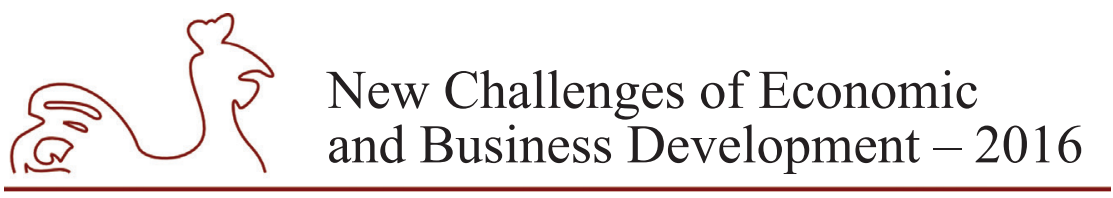

May 12-14, 2016, Riga, University of Latvia

\section{The model of clustering the universities based on Kohonen maps}

When the clusters were determined it is possible to define for each cluster the threshold values of indicators, which certain university should reach to get into the target cluster. As a result we have opportunities to predict on the base of the scenario modeling the positions of the universities in clusters and as a consequence potential university place in the prestigious world rankings.

Criteria for universities to enter in the $1^{\text {st }}$ leading cluster presented on self-organizing map, shown on Fig. 1, can be formed as a result of building a "Decision Trees" on the basis of a widely used algorithm C4.5 for constructing the classification tree, designed by John Ross Quinlan (Meleshkin \& Zaboev, 2014).

To formalize the criteria of classifying the universities to a particular cluster was constructed a decision tree containing 35 nodes, on the basis of which is formed 18 rules and 7 of them define the conditions of entering in the $1^{\text {st }}$ cluster and are listed below:

1. it is necessary very high value of indicator Doctoral degree / Acad staff:

- Doctoral degree / Acad staff >0.65;

2. it is necessary the simultaneous fulfillment of the following conditions:

- Doctoral degree / Acad staff >0.21;

- Normalized citation impact - country adj $>1.42$;

3. it is necessary the simultaneous fulfillment of the following conditions:

- Acad staff int / Acad staff $>0.22$

- Doctoral degree / Acad staff $>0.21$;

4. it is necessary the simultaneous fulfillment of the following conditions:

- Papers int co-author / Papers (share of publications in international collaboration) $>0.39$;

- Normalized citation impact - country adj > 0.89;

- Acad staff int / Acad staff >0.19;

5. it is necessary the simultaneous fulfillment of the following conditions:

- Papers int co-author / Papers (share of publications in international collaboration) $>0.39$;

- Doctoral degree / Acad staff >0.5;

6. it is necessary the simultaneous fulfillment of the following conditions:

- Acad staff int / Acad staff $>0.45$

- Doctoral degree / Acad staff $>0.37$;

7. it is necessary the simultaneous fulfillment of the following conditions:

- Acad staff int / Acad staff $>0.45$;

- Papers $>5363$.

The closest threshold values for Moscow State University to enter in the $1^{\text {st }}$ cluster with leading universities are combinations presented in the $3^{\text {rd }}$ and $4^{\text {th }}$ rules. For example, according to the $4^{\text {th }}$ rule for MSU it is required to increase indicators Papers int co-author / Papers and Acad staff int / Acad staff at only 0.01 points (see values in Table 1) and it must be emphasized that these targets also mentioned in the Development Programme of MSU till 2020. (Development Programme of MSU) The $3^{\text {rd }}$ rule defines the necessity of improving only one indicator Acad staff int / Acad staff at 0.04 points. 


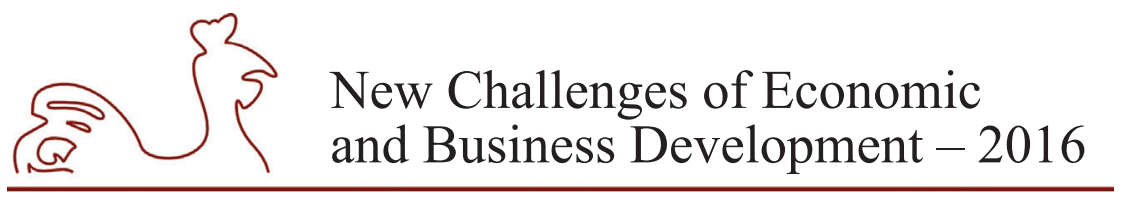

May 12-14, 2016, Riga, University of Latvia

Table 1

Values of indicators that characterize the global competitiveness of universities

\begin{tabular}{|c|l|c|c|c|c|}
\hline № & \multicolumn{1}{|c|}{$\begin{array}{c}\text { The name of indicator in } \\
\text { InCites }\end{array}$} & $\begin{array}{c}\text { Values for } \\
\text { Moscow State } \\
\text { University }\end{array}$ & $\begin{array}{c}\text { Values for St. } \\
\text { Petersburg } \\
\text { State University }\end{array}$ & $\begin{array}{c}\text { Values for } \\
\text { Riga Technical } \\
\text { University }\end{array}$ & $\begin{array}{c}\text { Values for the } \\
\text { University of } \\
\text { Tartu }\end{array}$ \\
\hline 1 & Acad staff / Stdnt & 0.13 & 0.17 & 0.05 & 0.05 \\
\hline 2 & Acad staff int / Acad staff & 0.18 & 0.02 & 0.00 & 0.05 \\
\hline 3 & Doctoral degree / Acad staff & 0.26 & 0.08 & 0.12 & 0.13 \\
\hline 4 & $\begin{array}{l}\text { Normalized citation impact - } \\
\text { country adj }\end{array}$ & 0.96 & 0.87 & 0.41 & 1.08 \\
\hline 5 & Papers & 3625 & 1016 & 112 & 855 \\
\hline 6 & Papers int co-author / Papers & 0.38 & 0.44 & 0.35 & 0.56 \\
\hline 7 & Res income / Acad staff & 124917 & 34867 & 45632 & 123630 \\
\hline 8 & Stdnt int / Stdnt & 0.2 & 0.09 & 0.04 & 0.03 \\
\hline
\end{tabular}

Source: author's calculations based on data from InCites ${ }^{\mathrm{TM}}$ database for 2012.

The values of SPSU activity indicators for 2012, which are listed in the Table 1, do not allow to enter in the $1^{\text {st }}$ cluster. In this case closest threshold values to enter in the $1^{\text {st }}$ cluster with leading universities is combination presented in the $2^{\text {nd }}$ rule, but it is necessary to double or even more the indicators Doctoral degree / Acad staff and Normalized citation impact-country adj. The same condition is properly for The University of Tartu, but the difference between the actual and targets values is less, than for SPSU. For Riga Technical University with its values of indicators for 2012 it is very hard to pretend to enter in the $1^{\text {st }}$ cluster, the more realistic scenario is to get into the $4^{\text {th }}$ cluster: according to one of created rules it is necessary to improve, first of all, the indicator Normalized citation impact - country adj and try reach the value 0.89 .

\section{Conclusions, proposals, recommendations}

In the research was presented an approach to evaluation of current location of the Russian and European Universities inside the international educational system and to defining the threshold values to get into the leading groups of the universities on the base of self-organizing Kohonen maps.

The main advantages of suggested approach are:

1. The high level of objectivity of the results due to use of quantitative indicators and factors that characterize the global competitiveness of universities instead of subjective expert's estimates;

2. The use of soft computing, which consists in the construction and training of a neural network of specific form - self-organazing Kohonen map, provides wide opportunities for automation the procedure of data analysis;

3. The simplicity and ease of interpretation of results for analytics. 


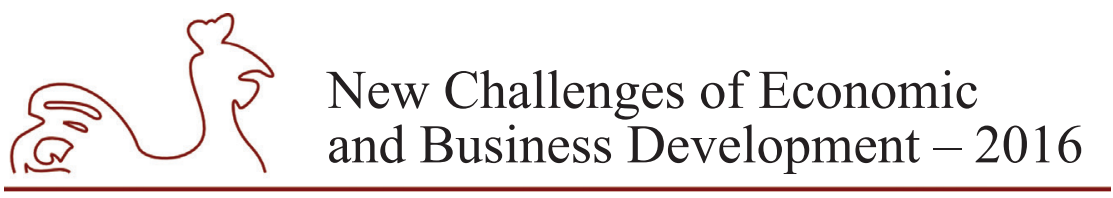

May 12-14, 2016, Riga, University of Latvia

Application of the described method allows to:

1. Get multicriteria evaluation and ranking of the leading universities in the context of global competitiveness relative to selected world rankings;

Example: Moscow state University, St. Petersburg state University, The University of Tartu and Vilnius University according to the results of clustering based on the data of 2012 were included in the $4^{\text {th }}$ cluster, which consist of the universities which occupy the "middle" position.

At the same time Riga Technical University and Tallinn University of Technology are included in the 0 -th cluster with universities which have positions "below average".

2. Select a cluster of universities - world leaders, which with a high probability will have high level of global international competitiveness;

3. Define the threshold values for key factors and indicators of certain universities, which significantly hinder the development of their global competitiveness;

Example: for Moscow State University to enter in the $1^{\text {st }}$ cluster with leading universities it is required to increase indicators Papers int co-author / Papers and Acad staff int / Acad staff at only 0.01 points.

4. Estimate for the leading Russian and European universities sufficiency or insufficiency of the values of indicators for entry into the cluster universities world leaders.

\section{Bibliography}

Botvin, G. \& Zaboev, M., 2011. Clustering country performance using artificial neural networks. RISK: resources, information, procurement, competition, No. 4, pp. 552-556.

Database of research, evaluation and assessment of institutional performance Incites. [Online] Available at: http://incites. isiknowledge.com [Accessed 12 March 2016].

Development Programme of MSU [Online] Available at: http://www.msu.ru/news/official/2014/ 115520140626.pdf [Accessed 12 March 2016].

Development Programme of SPSU. [Online] Available at: http://spbu.ru/images/programm.doc [Accessed 12 March 2016].

Zaboev, M. \& Meleshkin, M., 2015. Evaluation of the prospects Russian universities to be among the first hundred of the world's leading universities with the use of neural network methods clustering of data. Journal of Applied Informatics, Vol. 10, No. 3 (57), pp. 52-61.

Zaboev, M. \& Meleshkin M. \& Halin V., 2015. Data mining methods in assessing the competitiveness of the leading universities // Information technologies, energy and economy, XII International Scientific Conference for students and post graduates, MEI department in Smolensk, pp. 132-137.

Khalin, V., 2011. Financing of higher education in Russia: Status and Prospects. Vestnik of St. Petersburg. State University. Ser. 5: The Economy, Vol. 1, pp. 47-53.

Meleshkin, M. \& Zaboev, M., 2014. The application of self-organizing Kohonen maps for evaluation of the competitive position of the leading Russian universities among the world's academic centers. Management Consulting, 10 (70), pp. 102-114.

Shin, J. \& Toutkoushian, R. \& Teichler, U., 2011. University Rankings: Theoretical Basis, Methodology and Impacts on Global Higher Education. Springer, pp. 73-75. 


\title{
NINE MONTHS OF QUANTITATIVE EASING IN THE EUROZONE: EMPIRICAL EVIDENCE FROM BAYESIAN VAR
}

\author{
Andrejs Zlobins, University of Latvia, Latvia ${ }^{1}$
}

\begin{abstract}
The European Central Bank announced the Asset Purchase Programme (APP) on January 22, 2015 in order to prevent the Eurozone economy from entering a deflationary spiral and to achieve its main goal - maintain price stability. The purchases of public and private securities started in March 2015 and are intended to be carried out until March 2017 or until inflation path is consistent with inflation target. The programme amounts to $€ 60$ billion of monthly purchases. The aim of this paper is to evaluate macroeconomic effects of the APP on the Eurozone's output and inflation in the first nine months of implementation. It is necessary to understand whether quantitative easing can be used to stimulate output and inflation when stable conditions prevail in financial markets.

In order to assess the macroeconomic effects of the APP, the author estimates a Bayesian vector autoregression (VAR) with Minnesota - Litterman prior. The model is then used to conduct counterfactual analysis. The counterfactual scenario is based on empirical evidence from Altavilla et al. (2015) which suggests that, on average, the APP lowered the euro area long - term bond yields by about 40 basis points at 10 - year maturity. The author implements this impact on long - term interest rates by constructing a counterfactual path for the long - term interest rate spread. The results from the Bayesian VAR model suggest that the APP has had a positive impact both on output and inflation after the first nine months of implementation. The analysis also indicates that quantitative easing is an effective policy option to boost output and price level in times of low financial stress as the results do not significantly differ from studies which evaluate the effects of quantitative easing in other countries during the financial crisis.
\end{abstract}

Key words: Asset Purchase Programme, quantitative easing, Eurozone, Eurosystem, Bayesian VAR JEL code: C54, E47, E58

\section{Introduction}

Following the Great Recession, central banks in advanced economies implemented unconventional monetary policy measures such as quantitative easing. The aim of these measures was to safeguard financial stability and ultimately stimulate output and increase inflation sufficiently to meet the inflation target (Stone, Fujita, Ishi (2011) and Bridges, Thomas (2012)). Conventional monetary policy instruments were no longer effective because advanced economies became constrained by the Zero Lower Bound.

${ }^{1}$ Corresponding author - e-mail address andrejs.zlobins@inbox.lv 


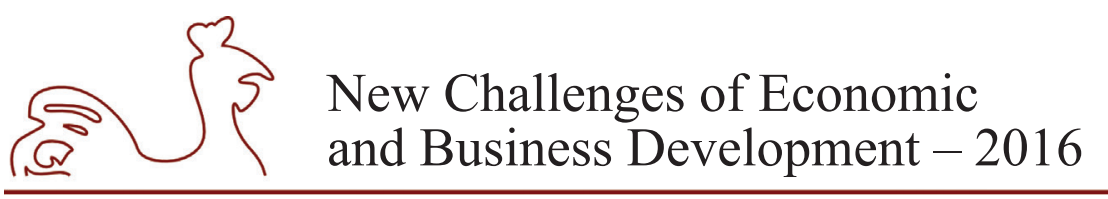

May 12-14, 2016, Riga, University of Latvia

In order to prevent the Eurozone economy from entering a deflationary spiral and to achieve its main goal - maintain price stability, the European Central Bank (ECB) announced the Asset Purchase Programme (APP) on January 22, 2015. The purchases of public and private securities started in March 2015 and are intended to be carried out until March 2017 or until inflation path is consistent with inflation target. The programme amounts to $€ 60$ billion of monthly purchases.

The aim of this paper is to evaluate macroeconomic effects of the APP on the Eurozone's output and inflation in the first nine months of implementation. The evidence currently available focuses on the APP impact on financial markets (see Altavilla, Carboni, Motto (2015)). Contrary to the US and the UK quantitative easing policies which were carried out in times of financial crisis, the APP is implemented in times of low financial stress (Altavilla et al. (2015)). As they point out, the existing literature show that asset purchases exert larger effects on the asset prices when financial stress is high. Thus, the literature which focuses on macroeconomic effects of the US and the UK quantitative easing policies only provide evidence for effectiveness of such policies in times of financial crisis. But it is also crucial to understand whether quantitative easing can be used to stimulate output and inflation when stable conditions prevail in financial markets.

In order to assess the macroeconomic effects of the APP, the author estimates a Bayesian vector autoregression (VAR) with Minnesota - Litterman prior. Bayesian VAR is appropriate model for analysis of quantitative easing shock because it captures complex relationships in a large macroeconomic dataset while imposing minimum amount of theoretical structure. The model is then used to conduct counterfactual analysis. The counterfactual scenario is based on empirical evidence from Altavilla et al. (2015) which suggests that, on average, the APP lowered the euro area long - term bond yields by about 40 basis points at 10 - year maturity. The author implements this impact on long - term interest rates by constructing a counterfactual path for the long - term interest rate spread, assuming that it would be 40 basis points higher from March 2015 to December 2015 without the APP. This approach allows to estimate the effects of the APP on the output and price level through the portfolio balance channel. As Kapetanios, Mumtaz, Stevens and Theodoridis (2012) notes, this is the key transmission channel of quantitative easing, at least in times of financial crisis. This paper extends the literature on macroeconomic effects of the quantitative easing by assessing the effects of asset purchases passed through the portfolio balance channel on the real economy in times of low financial stress.

The counterfactual results from the Bayesian VAR model suggest that the APP has had a positive impact both on output and inflation after the first nine months of implementation. However, the results should be treated with caution because the asset purchases will continue at least until March 2017 and it remains to be seen whether the inflation is on path to meet the ECB target rate.

The paper is organised as follows. Section 1 reviews the literature related to unconventional monetary policy measures in the Eurozone, the UK and other advanced countries. Section 2 describes the Bayesian VAR model, data and the counterfactual assumptions used in analysis of the APP macroeconomic effects. Section 3 presents the empirical evidence from the model and section 4 concludes. 


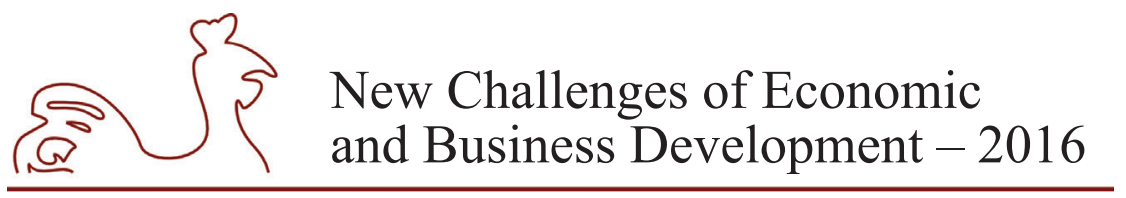

May 12-14, 2016, Riga, University of Latvia

\section{Empirical literature on macroeconomic effects of unconventional monetary policy measures}

One of the first studies which estimate macroeconomic effects of the non-standard monetary policy instruments adopted by the ECB on the onset of the Great Recession, is by Lenza, Pill and Reichlin (2010). Using a large Bayesian VAR estimated over period before implementation of non - standard monetary instruments from January 1991 to December 2007, they conduct a counterfactual exercise to analyse the impact of contraction in money market spreads caused by the ECB actions. They find that the "enhanced credit support" measures lowered short - term interest rates and thus had a positive impact on credit conditions. The authors also provide evidence that these measures had a positive effect both on output and inflation albeit with a delay of several months.

Baumeister and Benati (2010) using a Bayesian structural VAR with time - varying parameters show impulse response functions of euro area real GDP growth and GDP deflator inflation to a negative long - term bond spread shock. Such shock can be awaited following implementation of quantitative easing policy and the impulse response functions of output and inflation display a powerful positive effect after a compression in long - term bond spread.

Turning to literature covering the effects of the Asset Purchase Programme, Altavilla et al. (2015) evaluate impact of the APP on asset prices by using event study approach. They estimate that the APP announcements lowered the euro area long - term bond yields by 30-50 basis points at 10 - year maturity. The authors point out that, despite low financial stress in the euro area markets at the time of announcement, the APP has been effective. It is a promising sign that the programme will also have sizeable macroeconomic effects.

Part of the literature, which studies the macroeconomic effects of quantitative easing in countries which used such policy following the Great Recession, have used findings on the effect on long - term bond yields from event studies to simulate quantitative easing shock in time series models. For example, Kapetanios et al. (2012) employ Bayesian VAR, Time - varying parameter structural VAR and Markov - switching structural VAR to perform counterfactual simulations using evidence from Joyce, Lasaosa, Stevens and Tong (2011) event study that Quantitative Easing in the United Kingdom lowered long - term bond yields by 100 basis points. The average estimate of Kapetanios et al. (2012) from three models is that Quantitative Easing boosted output by approximately $1.5 \%$ and inflation by 1.25 percentage points.

Similar strategy is also employed by previously mentioned paper of Baumeister and Benati (2010) to evaluate effectiveness of asset purchases in the US and the UK. To exercise counterfactual simulations, for the UK they use evidence from Meier (2009) that Quantitative Easing lowered long - term interest rates by at least 35-60 basis points. For simulations they take the average estimate of 50 basis points to construct a counterfactual path for long - term bond spread. While for the US authors use evidence from Gagnon, Raskin, Remache and Sack (2010) where they exploit both event study approach and regression model. Both methodologies give similar estimate of the Large - Scale Asset Purchase Programme impact on the US 10 - year bond yield. Baumeister and Benati (2010) prefer to use average estimate from the regression model which indicate that 10 - year government bond yield spread would be 60 basis points higher without asset purchases. Their counterfactual simulations of real GDP growth and inflation for 


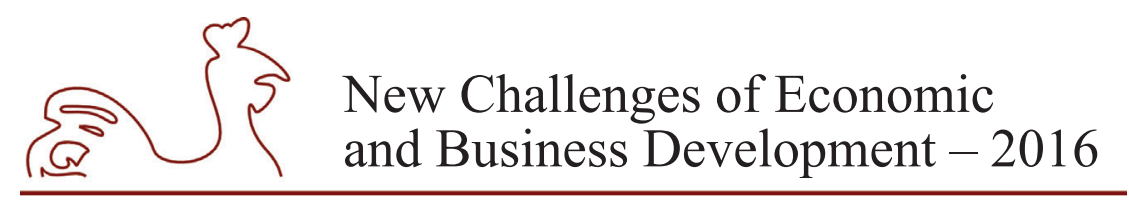

May 12-14, 2016, Riga, University of Latvia

both the UK and the US reveal that a compression in long - term bond spread has a large positive effect although only on impact after which the effect quickly dissipates.

A potential caveat of studies which model the impact of quantitative easing through a reduction in long - term bond spread is that they only capture the effects on the economy through the portfolio balance channel. This has prompted that part of the quantitative easing literature concerned with macroeconomic effects, model the shock from either monetary base or central bank balance sheet variable. As Schenkelberg and Watzka (2011) point out, this "agnostic" approach is more reliable because these variables are directly affected by asset purchases.

Schenkelberg and Watzka (2011) provide evidence for the Japanese experience of quantitative easing as Bank of Japan was the first major central bank to implement such unconventional measures. To analyse the effects of quantitative easing, they impose sign restrictions on the impulse response functions. Quantitative easing shock is identified by imposing restrictions on a monetary base component (current account balances held at the Bank of Japan) not to decrease, additionally, they specify stock prices and exchange rate not to decrease. Interestingly, they choose to refrain from imposing restrictions on long - term interest rates because economic theory suggests that asset purchases can cause a rise in long - term bond yields as inflation expectations increase. This is contrary to other studies which model the quantitative easing shock as a reduction in long - term bond spread. The impulse response functions from structural VAR model of Schenkelberg and Watzka (2011) confirm such a view although they find that asset purchases did not affect inflation. However, they provide evidence that quantitative easing in Japan was successful in stimulating output. On the other hand, Gambacorta, Hofmann and Peersman (2012) argue that it is not clear whether Japanese experience with quantitative easing can be generalized. In their paper, they study the macroeconomic effects of central bank balance sheet shock by estimating a panel structural VAR for eight advanced economies: Canada, Eurozone, Japan, Norway, Sweden, Switzerland, the UK and the US. To identify unconventional monetary policy shock, they impose similar sign restrictions as Schenkelberg and Watzka (2011) on central bank assets to increase and stock market volatility index VIX not to increase. Gambacorta et al. (2012) are particularly concerned about structural change in parameters following the financial crisis of 2007, so they estimate their model over sample period from January 2008 to June 2011. In this period advanced economies were in a liquidity trap and with short - term interest rates at their lower bounds, unconventional monetary policy measures became the main policy instruments to stabilize macroeconomic conditions. The panel results of their study indicate that central bank balance sheet shock has a significant positive impact on economic activity and inflation. Individual country results also bring evidence to their argument about that Japanese experience with unconventional monetary policy measures cannot be generalized to other advanced countries. The author would add that, as Anderson, Botman and Hunt (2014) argue, it seems that deflation in Japan is more demographic rather than monetary phenomenon.

However, the choice of central bank balance sheet as the policy variable to estimate the macroeconomic effects of the APP could potentially lead to biased results as the number of observations under this policy is limited. Thus, similar approach to Baumeister and Benati (2010) and Kapetanios et al. (2012) is used to assess the macroeconomic effects of the APP. Next section describes the econometric approach used to estimate the impact of the APP on output and inflation. 


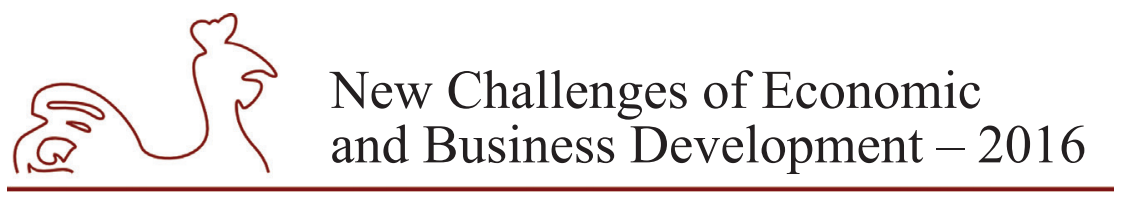

May 12-14, 2016, Riga, University of Latvia

\section{Econometric framework}

As the previous section demonstrates, most studies utilize some sort of VAR model to evaluate macroeconomic impact of quantitative easing. In this study, the author employs a large Bayesian VAR in spirit of Lenza et al. (2010) and Kapetanios et al. (2012) to assess the effects on economic activity and price level from quantitative easing shock in the euro area. When Bayesian methods are used to estimate a VAR model, the parameters are treated as random variables and a priori information is used to limit the parameter space. Bayesian shrinkage is appropriate tool to overcome the over - parametrization problem which would occur if a large VAR with many variables would be estimated by traditional methods. Banbura, Giannone, and Reichlin (2010) show that if the data has a collinearity, which is true for the macroeconomic datasets, then relevant sample information is not lost when over - parametrization is resolved by means of Bayesian inference.

The author estimates the following $\operatorname{VAR}(\mathrm{p})$ model:

$$
y_{t}=a_{0}+\sum_{j=1}^{p} A_{j} y_{t-j}+\epsilon_{t},
$$

where $\mathrm{a}_{0}$ is a vector of constants, $\mathrm{y}_{\mathrm{t}}$ for $\mathrm{t}=1, \ldots, \mathrm{T}$ is an $\mathrm{m} \times 1$ vector of $\mathrm{m}$ variables and $\epsilon_{\mathrm{t}}$ is an $\mathrm{m} \times 1$ vector of Gaussian white noise. The model can be compactly rewritten as:

$$
Y=X A+E,
$$

or

$$
y=\left(I_{m} \otimes X\right) \theta+e,
$$

where $\mathrm{Y}$ and $\mathrm{E}$ are $\mathrm{T} \times \mathrm{m}$ matrices and $\mathrm{X}$ is $\left(\mathrm{x}_{1}, \ldots, \mathrm{x}_{\mathrm{t}}\right)$ is a $\mathrm{T} \times(\mathrm{mp}+1)$ matrix for $\mathrm{x}_{\mathrm{t}}=\left(1, \mathrm{y}_{\mathrm{t}-1}, \ldots\right.$ $\left.\mathrm{y}_{\mathrm{t}-\mathrm{q}}\right), \mathrm{I}_{\mathrm{m}}$ is the identity of dimension $\mathrm{m}, \theta=\mathrm{vec}(\mathrm{A})$ and $\mathrm{e} \sim \mathrm{N}\left(0, \Sigma_{\epsilon} \otimes \mathrm{I}_{\mathrm{T}}\right)$.

Specifying the prior probability distribution on the parameters is a fundamental step in Bayesian VAR modelling in order to overcome the over - parametrization problem. In this paper, the author follows standard prior specification scheme developed by Litterman (1986). As Doan, Litterman and Sims (1984) argue, most macroeconomic time series are characterised by simple random walk processes, which implies that the prior mean of the first own lag is one while other coefficients shrink towards zero. Thus, the Minnesota - Litterman prior assumes that the prior of $\theta \sim N\left(\theta_{0}, V_{0}\right)$, where $\theta_{0}=\mu_{1} i_{m p}$ is the coefficient mean and $V_{0}$ is a non - zero prior covariance. In order to embed the belief that macroeconomic variables are characterized by high persistence, hyper - parameter $\mu_{1}$ is set to 0 . Additionally, this prior implies the view that own lags give more information about the variation of a given equation than lags of other variables and that the most recent lags contain more information than do more distant lags. The rest of prior covariance $V_{0}$ is diagonal matrix $v_{i j}^{l}$. Assuming that coefficient matrices $\mathrm{A}_{1}, \ldots, \mathrm{A}_{j}$ are normally distributed, the 


\section{New Challenges of Economic and Business Development - 2016}

May 12-14, 2016, Riga, University of Latvia

prior distribution of the coefficients related to lag $1=1, \ldots, p$ of variable $\mathrm{j}$ in the equation for variable $\mathrm{i}$ is given by:

$$
E_{i j}^{l}=\left\{\begin{array}{ll}
1, & \text { if } i=j \\
0, & \text { if } i \neq j,
\end{array} \quad v_{i j}^{l}= \begin{cases}\left(\frac{\lambda_{1}}{l^{\lambda_{3}}}\right)^{2}, & \text { if } i=j \\
\left(\frac{\lambda_{1} \lambda_{2} \sigma_{i}}{l^{\lambda_{3}} \sigma_{j}}\right)^{2}, & \text { if } i \neq j\end{cases}\right.
$$

where $\lambda_{1}$ is a hyper - parameter which controls the overall tightness. For example, if tight prior with $\lambda_{1}=0$ is used, then prior information dominates the sample and the data has no impact on the estimates. On the other hand, if loose prior with $\lambda_{1}=\infty$ is implemented, the data dominate the sample and the estimates converge to the OLS estimates. To make the prior operational and give significant weight on the data in the estimates, the author follows the approach used in Lenza et al. (2010) and Kapetanios et al. (2012). As Lenza et al. (2010) point out, this approach is based on evidence that short - term interest rates, which are set following Taylor - type rules, are well described by linear functions of present and future inflation and economic activity. The author finds the value for the tightness parameter empirically, ensuring that the in - sample fit of the 3 - month Euribor equation is equivalent to fit achieved by a smaller VAR estimated by OLS. The author includes first ten variables from the Table 1 in the small VAR. $\lambda_{2}$ is a hyper parameter which controls the relative cross - variable tightness. Since it is assumed that lags of other variables are less informative, then $\lambda_{2} \leq 1$. If $\lambda_{2}=0$ then model is collapsed into a vector of univariate models. The author sets $\lambda_{2}=0.5$ which is the original value used in Litterman (1986). ${ }^{2}$ Hyper - parameter $\lambda_{3}$ controls the relative tightness of the variance of lags other than the first one. The author sets this parameter equal to 2 as in Koop and Korobilis (2010). ${ }^{3}$ To complete the specification of the prior, it is assumed that the covariance matrix of the residuals is known, fixed and diagonal: $\Sigma_{\epsilon}=\operatorname{diag}\left(\sigma_{1}^{2}, \ldots, \sigma_{n}^{2}\right)$ and that the prior on constant $a_{0}$ is diffuse. Considering such specification of the prior, the posterior for $\theta$ has the following form: $\theta \sim N(\bar{\theta}, \bar{V})$, where

$$
\bar{\theta}=\bar{V}\left[V_{0}^{-1} \theta_{0}+\left(\Sigma_{\epsilon}^{-1} \otimes X\right)^{\prime} y\right] \text { and } \bar{V}=\left[V_{0}^{-1}+\left(\Sigma_{\epsilon}^{-1} \otimes X^{\prime} X\right)\right]^{-1} .
$$

The choice of the Minnesota - Litterman prior to restrict the parameter space is motivated by the evidence that it leads to good forecasting performance from VAR models with large data sets (Banbura et al. (2010)). In addition, Minnesota - Litterman prior is conjugate i.e. both prior and posterior come from the same distributional family which allows for analytical estimation of the model instead of simulation - based estimation of the posterior.

\subsection{Data}

The macroeconomic dataset is comprised of 27 monthly variables covering the euro area real economic activity, price dynamics, monetary aggregates, yield curve and financial sector. Main macroeconomic variables of the US are included to capture global economic conditions. The list of variables is provided in Table 1 .

2 Results remain robust after setting $\lambda_{2}=0.99$ to ensure that almost no cross - variable shrinkage takes place.

3 Results remain robust after setting $\lambda_{3}^{2}=1$ to assume a linear decay as in Kadiyala and Karlsson (1997). 


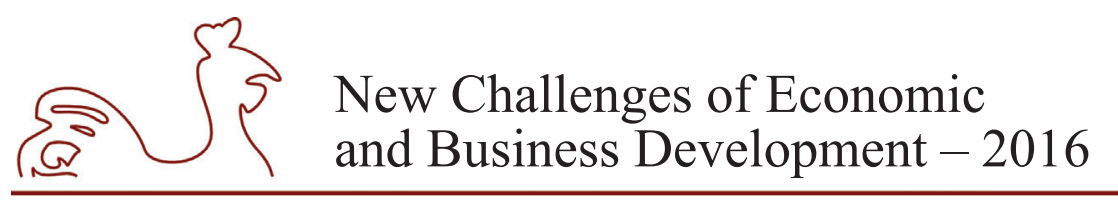

May 12-14, 2016, Riga, University of Latvia

As can be observed from Table 1, then variables enter the model in form of log - levels with exception of those variables which are expressed as rates. As Sims, Stock and Watson (1990) demonstrate, such specification allows to capture cointegrating relationships between the variables as well as gives consistent parameter estimates even when unit roots are present. As for the sample period, the author estimates the model with data covering the period from January 1999 to December 2015 i.e. since the creation of the euro area. While it is possible that the APP alters the parameters of the model, currently available evidence from Giannone et al. (2014) speak in favour of parameter stability in the euro area. They employ a very similar Bayesian VAR model for the euro area as this paper and show that model parameters were not significantly affected by the Great Recession, a much greater shock than the APP, and unconventional monetary policy instruments implemented by the ECB at the time. However, the author places an empirical investigation of this matter in his future research agenda. The lag order is set to $13 .{ }^{4}$ Industrial production and 3 - month Euribor are used as proxy for the output and short - term interest rates respectively.

4 The results qualitatively do not differ with other lag specifications. 


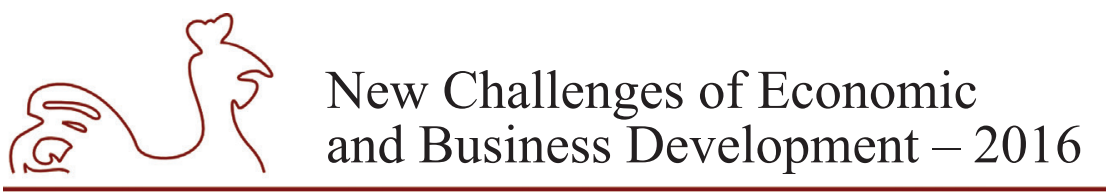

May 12-14, 2016, Riga, University of Latvia

Table 1

Dataset description and transformations

\begin{tabular}{|c|c|c|c|}
\hline Variable & Description & Transformation & Data source \\
\hline Industrial Production & $\begin{array}{l}\text { Volume index of production for Mining and } \\
\text { quarrying; manufacturing; electricity, gas, steam and } \\
\text { air conditioning supply. } 2010=100 .\end{array}$ & Log-levels & Eurostat \\
\hline HICP & All - items HICP. $2005=100$. & $\begin{array}{l}\text { Log- levels, base } \\
\text { year changed to } \\
2010 .\end{array}$ & Eurostat \\
\hline Unemployment & Monthly average unemployment rate, $\%$. & Levels & Eurostat \\
\hline Producer Prices Index & $\begin{array}{l}\text { Total output price index for Mining and quarrying; } \\
\text { manufacturing; electricity, gas, steam and air } \\
\text { conditioning supply. } 2010=100 \text {. }\end{array}$ & Log-levels & Eurostat \\
\hline $\begin{array}{l}\text { US Industrial } \\
\text { Production }\end{array}$ & $\begin{array}{l}\text { Volume index of production for manufacturing, } \\
\text { mining, and electric, and gas utilities. } 2012=100 .\end{array}$ & $\begin{array}{l}\text { Log - levels, base } \\
\text { year changed to } \\
2010 . \\
\end{array}$ & $\begin{array}{l}\text { Federal } \\
\text { Reserve }\end{array}$ \\
\hline US CPI & All - items CPI. $1982-1984=100$. & $\begin{array}{l}\text { Log - levels, base } \\
\text { year changed to } \\
2010 . \\
\end{array}$ & $\begin{array}{l}\text { Federal } \\
\text { Reserve }\end{array}$ \\
\hline US Federal Funds Rate & Effective Federal Funds Rate. & Levels & $\begin{array}{l}\text { Federal } \\
\text { Reserve }\end{array}$ \\
\hline Euribor 3 months & Money market interest rate. & Levels & Eurostat \\
\hline Euribor 12 months & Money market interest rate. & Levels & Eurostat \\
\hline Consumer Confidence & Consumer confidence indicator & Levels & Eurostat \\
\hline Commodity prices & Non - Fuel Price Index, $2005=100$. & $\begin{array}{l}\text { Log - levels, base } \\
\text { year changed to } \\
2010 . \\
\end{array}$ & IMF \\
\hline Oil price & Europe Brent Spot Price FOB (Dollars per Barrel) & Log-levels & EIA \\
\hline US/Euro exchange rate & Monthly average value of the euro against US dollar. & Log-levels & Eurostat \\
\hline Stock prices & Dow Jones Euro Stoxx 50 Price Index & Log-levels & ECB \\
\hline 2 - year bond rate & Par yield curve & Levels & Eurostat \\
\hline $3-$ year bond rate & Par yield curve & Levels & Eurostat \\
\hline 5 - year bond rate & Par yield curve & Levels & Eurostat \\
\hline 7 -year bond rate & Par yield curve & Levels & Eurostat \\
\hline $10-$ year bond rate & Par yield curve & Levels & Eurostat \\
\hline M1 & Outstanding amounts at the end of the period (stocks) & Log-levels & ECB \\
\hline M2 & Outstanding amounts at the end of the period (stocks) & Log-levels & ECB \\
\hline M3 & Outstanding amounts at the end of the period (stocks) & Log-levels & ECB \\
\hline $\begin{array}{l}\text { Loans to non- } \\
\text { financial corporations }\end{array}$ & $\begin{array}{l}\text { Outstanding amounts at the end of the period } \\
\text { (stocks), total maturity }\end{array}$ & Log-levels & ECB \\
\hline Credit for consumption & $\begin{array}{l}\text { Outstanding amounts at the end of the period } \\
\text { (stocks), total maturity }\end{array}$ & Log-levels & ECB \\
\hline $\begin{array}{l}\text { Loans for house } \\
\text { purchases }\end{array}$ & $\begin{array}{l}\text { Outstanding amounts at the end of the period } \\
\text { (stocks), total maturity }\end{array}$ & Log-levels & ECB \\
\hline Other loans & $\begin{array}{l}\text { Outstanding amounts at the end of the period } \\
\text { (stocks), total maturity }\end{array}$ & Log- levels & ECB \\
\hline $\begin{array}{l}\text { Long - term interest } \\
\text { rate spread }\end{array}$ & $\begin{array}{l}\text { Spread between } 10 \text { - year bond rate and } 3 \text { - month } \\
\text { Euribor }\end{array}$ & Levels & $\begin{array}{l}\text { Author's } \\
\text { calculations }\end{array}$ \\
\hline
\end{tabular}




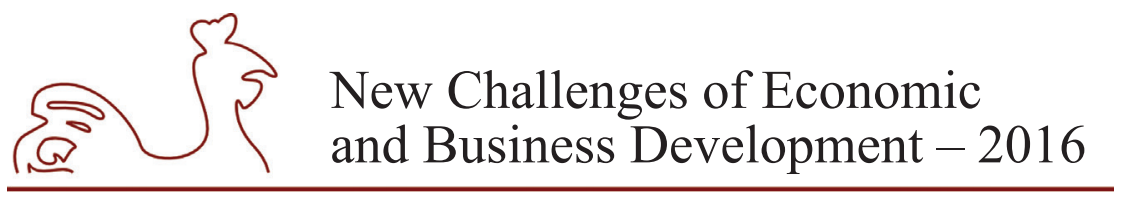

May 12-14, 2016, Riga, University of Latvia

\subsection{Counterfactual assumptions}

In this paper, the author uses similar approach to assess the macroeconomic effects of the APP as Baumeister and Benati (2010) and Kapetanios et al. (2012). The counterfactual scenario is based on empirical evidence from Altavilla et al. (2015) which suggests that the APP lowered the euro area long - term bond yields by 30-50 basis points at 10 - year maturity. The author takes the average estimate of 40 basis points to construct a counterfactual path for the long term interest rate spread. Figure 1 depicts the actual euro area long - term interest rate spread and the counterfactual path for the period from March to December 2015.

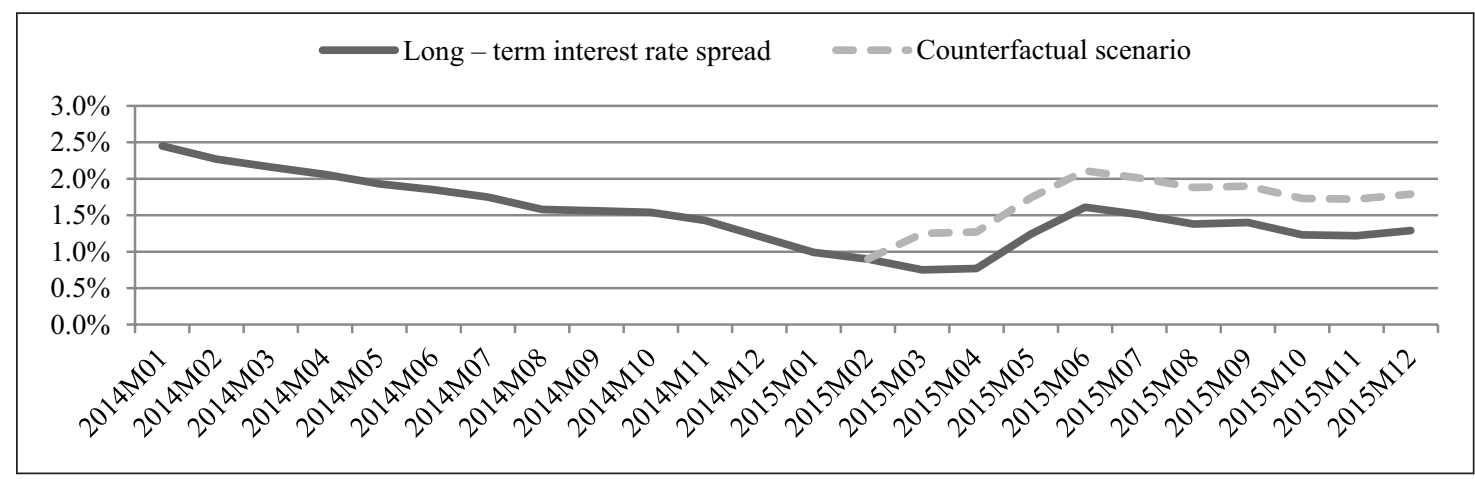

Source: Author's calculations.

Fig. 1. Euro area long - term interest rate spread

This approach estimates the macroeconomic effects of the APP resulting from the compression in long - term interest rate spread. Thus, only the effects on the real economy through the portfolio balance channel are captured.

The counterfactual analysis is based on the estimated Bayesian VAR model. Given the values of variables included in the model up to time $t$ and conditional value of the long - term interest rate spread at time $t$, the one - step - ahead forecasts $\mathrm{z}_{T+1}$ are obtained. To obtain forecasts at $\mathbf{z}_{T+2}$, forecasted values of endogenous variables obtained at previous period and counterfactual value of the long - term interest rate spread at time $t+1$ is used, and so on. Thus, the forecasted values depend on the previous period forecasts and the counterfactual path for the long - term interest rate spread.

For the policy scenario, the author uses actual level of long - term interest rate spread from March to December 2015 to produce forecasts for the Eurozone output and price level. This is necessary in order to exclude other factors which influence output and price level and are not explained by the model. This approach allows to identify the impact of the APP from other shocks. This can also be written as: $\Psi_{T+h}(x)=\left\{x_{T+1}, \ldots, x_{T+h}\right\}$, where $\mathrm{x}$ is long - term interest rate spread.

Under the no policy scenario, the author takes the counterfactual path for long - term interest rate spread as shown in Figure 1, where it is assumed that without the APP, the spread would have been 40 basis points higher from March to December 2015. This can be rewritten as:

$\Psi_{T+h}\left(x^{0}\right)=\left\{x_{T+1}^{0}, \ldots, x_{T+h}^{0}\right\}$. 


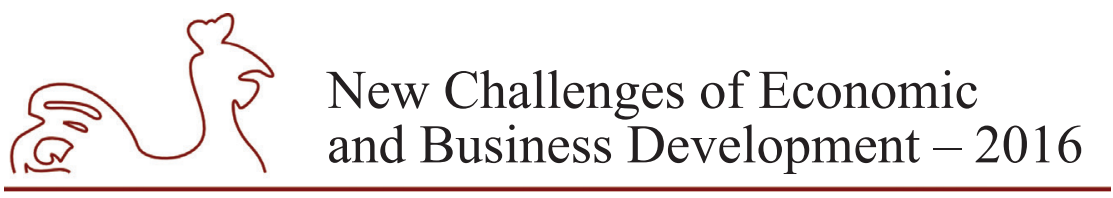

May 12-14, 2016, Riga, University of Latvia

To quantify the macroeconomic effects of the APP, the author compares the conditional forecasts for the output and price level between the scenarios mentioned above. The effect of the programme is estimated as the difference between those scenarios:

$d_{t+h}=E\left(z_{t+h} \mid \Omega_{T}, \Psi_{T+h}(x)\right)-E\left(z_{t+h} \mid \Omega_{T}, \Psi_{T+h}\left(x^{0}\right)\right)$, where $\Omega_{T}=\left\{y_{t}\right.$ for $\left.t=T, T-1, T-2, \ldots\right\}$ is macroeconomic data available at time $t, z_{t}$ is one of the variables from matrix $y_{t}$ with exception of $x_{t}$.

\section{Empirical evidence}

In this section of the paper, the author presents the counterfactual results from Bayesian VAR model to quantify the effects of the Asset Purchase Programme on the euro area output and price level.

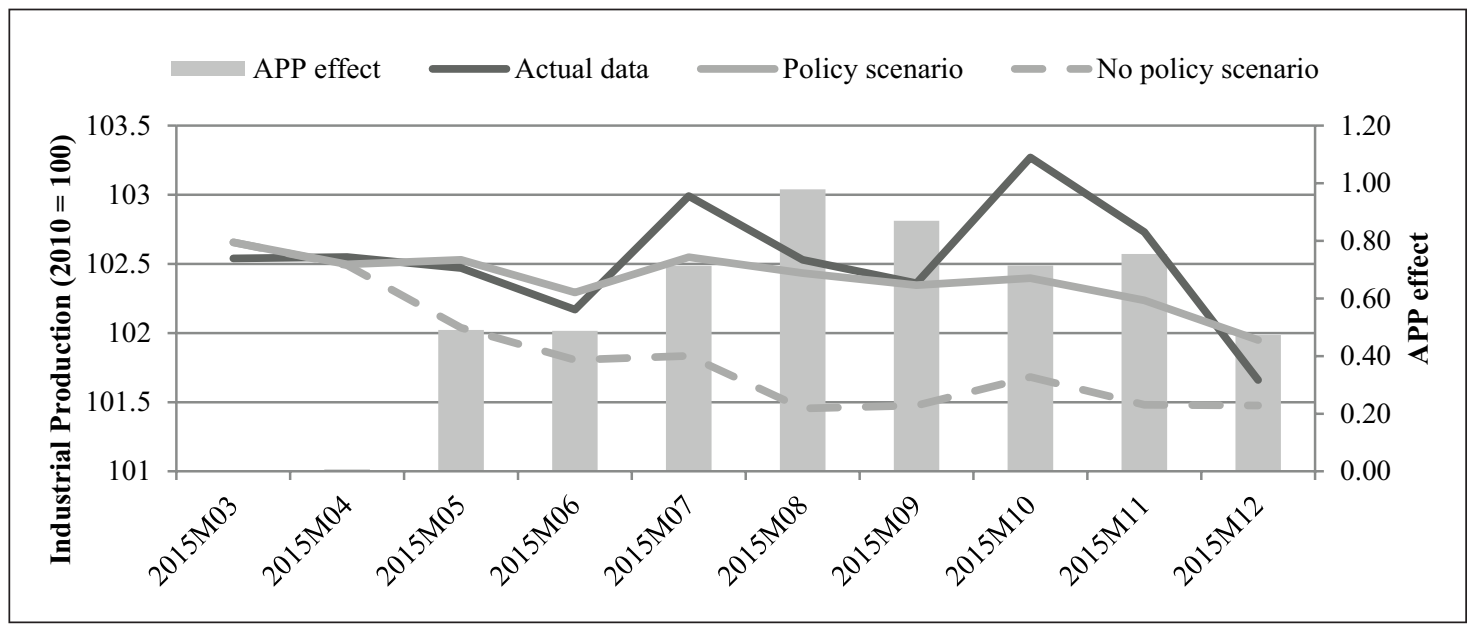

Source: Eurostat and author's calculations.

Fig. 2. Effect of the APP on the euro area output

Figure 2 illustrates the estimated effect of the Asset Purchase Programme on output using the counterfactual scenario for the long - term interest rate spread over the forecast horizon. The results show that the APP has had a significant positive impact on the Eurozone's output in the first nine months of implementation. The maximum effect occurs in August 2015 when the APP boosted output by 98 basis points. On average, the APP increased output by 55 basis points in the first nine months of execution, which is a sizeable effect considering the stable conditions in the euro area financial markets. In addition, the results are in line with Gambacorta et al. (2012) individual country results for the euro area, where they show that the maximum impulse response of output after a quantitative easing shock occurs approximately after 6 months. Evidence from Kapetanios et al. (2012) also suggests that quantitative easing had its peak impact on output after 6-9 months in the UK when it increased the level of GDP by $1.5 \%$.

The main reason for launching the APP was to counter the fall in price level and maintain price stability in the Eurozone. Thus, the main object of interest for the monetary policy makers in the euro area is the effect of the programme on price level. The results are presented in 


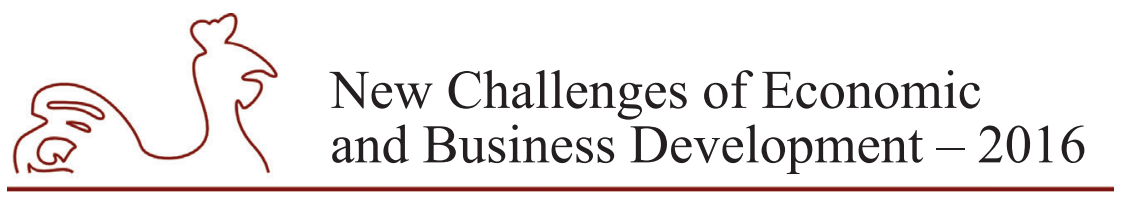

May 12-14, 2016, Riga, University of Latvia

Figure 3. The counterfactual results from the Bayesian VAR demonstrate that the APP has been effective in increasing the euro area price level after first nine months of execution. The peak impact on price level occurs in November 2015 when the APP increased price level by 58 basis points. On average, the programme raised price level by 31 basis points. While the effects on price level are undoubtedly smaller than on output, they are still significant. Furthermore, the literature reviewed in Section 1 also suggests that quantitative easing has a less pronounced effect on price level than on output. For example, Kapetanios et al. (2012) demonstrate that the level of GDP in the UK displays more powerful effect than the CPI inflation and that peak effect on inflation of about 1.25 percentage points occurred after a year -3 to 6 months later than on output. Both panel and individual country results of Gambacorta et al. (2012) also show that output is more affected by quantitative easing shock than price level.

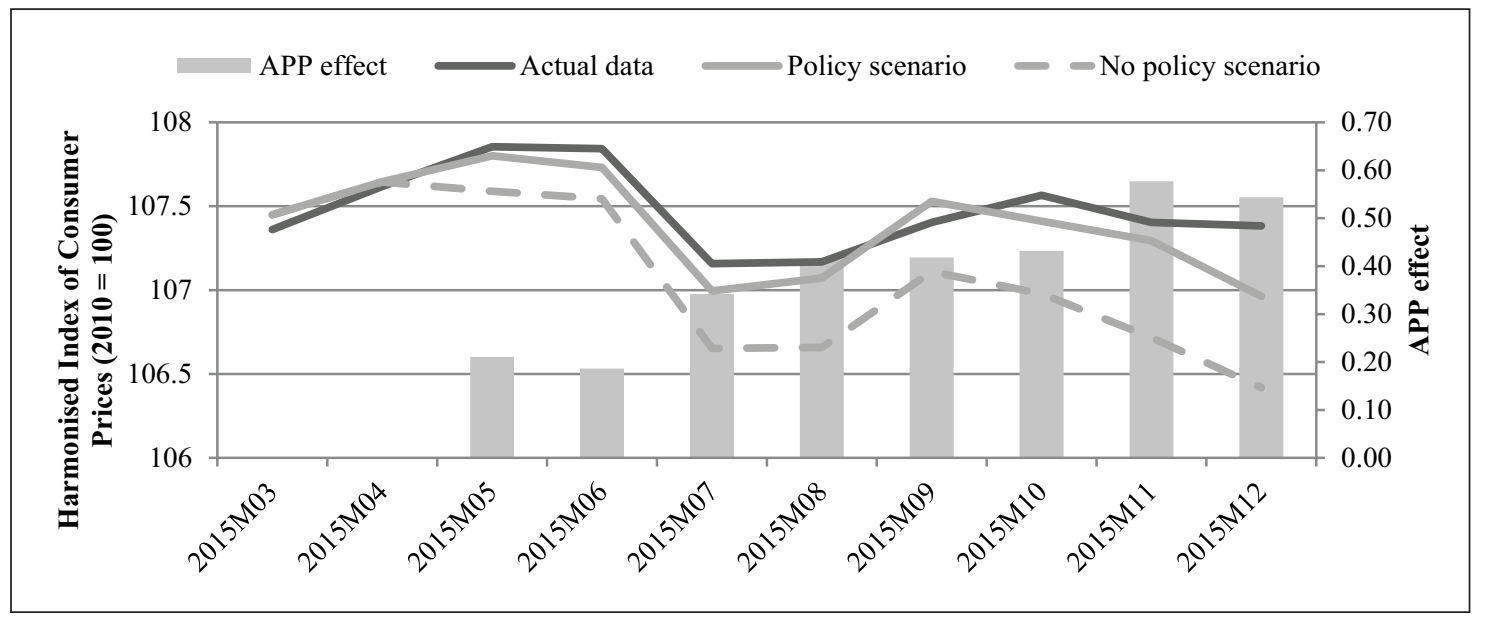

Source: Author's calculations.

Fig. 3. Effect of the APP on the euro area price level

ECB President Mario Draghi in his December 4, 2015 speech argues that the Eurozone's inflation in 2015 would be negative without the Asset Purchase Programme. To bring evidence to this argument, the author has calculated the inflation rate in no policy scenario by taking actual data for HICP and subtracting the estimated APP effect on price level. The results are illustrated in Figure 4. The results show that without the APP it is indeed likely that the euro area would be in deflation for much of 2015 and the annual rate of inflation in 2015 would be $-0.2 \%$. 
May 12-14, 2016, Riga, University of Latvia

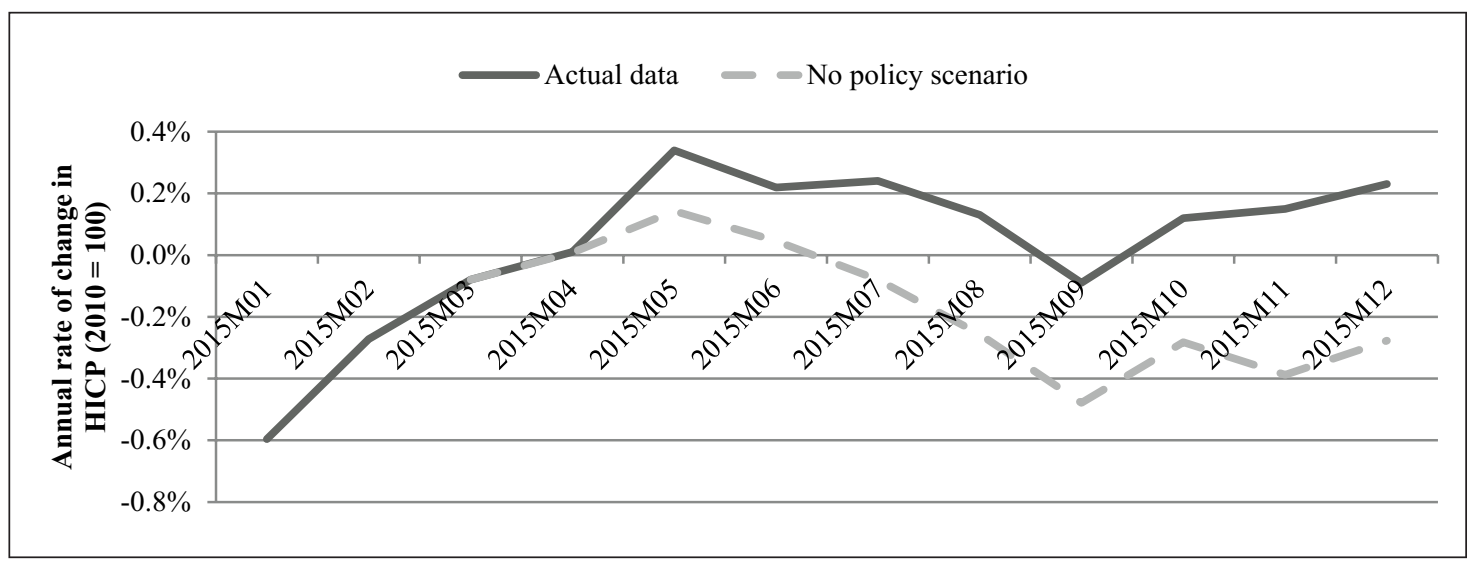

Source: Author's calculations.

Fig. 4. Effect of the APP on the euro area inflation

The counterfactual simulations from the Bayesian VAR performed in this paper demonstrate that the Asset Purchase Programme has been an effective measure to boost output and counter deflation in the euro area from March 2015 to December 2015. The analysis also indicates that quantitative easing is an effective policy option to boost output and price level in times of low financial stress as the results do not significantly differ from studies which evaluate the effects of quantitative easing during the financial crisis. The results confirm that also in times of low financial distress, portfolio balance channel is effective transmission channel of asset purchases made by the central bank.

However, the author shall point out the caveats which need to be kept in mind. First, the counterfactual forecasts from VAR models become less certain as forecast horizon lengthens. Second, the APP will continue at least until March 2017 and it remains to be seen whether the inflation is on path to meet the ECB target rate. In spite of these caveats, this paper presents a credible analysis for evaluating the impact of the APP on the real economy.

\section{Conclusions}

This paper evaluates macroeconomic effects of the APP on the Eurozone's output and inflation in the first nine months of implementation. The author estimates a Bayesian VAR with Minnesota - Litterman prior over the period from January 1999 to December 2015. The model is then used to conduct counterfactual analysis. The counterfactual scenario is based on empirical evidence from Altavilla et al. (2015) which suggests that, on average, the APP lowered the euro area long - term bond yields by about 40 basis points at 10 - year maturity. The author implements this impact on long - term interest rates by constructing a counterfactual path for the long - term interest rate spread.

The main conclusions of this paper are:

1. The counterfactual simulations from the Bayesian VAR demonstrate that the Asset Purchase Programme has been an effective measure to boost output and counter deflation in the euro area from March 2015 to December 2015. 


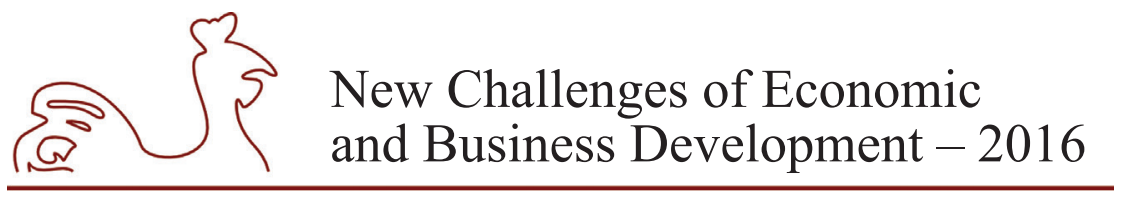

May 12-14, 2016, Riga, University of Latvia

2. The analysis indicates that quantitative easing is an effective policy option to boost output and price level in times of low financial stress as the results do not significantly differ from studies which evaluate the effects of quantitative easing in other countries during the financial crisis.

3. The results confirm that also in times of low financial distress, portfolio balance channel is effective transmission channel of asset purchases made by the central bank.

Future research agenda includes further assessment of the APP impact on the euro area output and price level as well as on other macroeconomic variables. Futhermore, the author plans to use a VAR model with time - varying parameters to investigate for the possible structural change.

\section{Bibliography}

Altavilla, C., Carboni, G., Motto, R., 2015. Asset Purchase Programmes and Financial Markets: Lessons from the Euro Area. [pdf] ECB Working Paper No. 1864. Available at: https://www.ecb.europa.eu/ pub/pdf/scpwps/ecbwp1864.en.pdf

Anderson, D., Botman, D. P. J., Hunt, B., 2014. Is Japan's Population Aging Deflationary? [pdf] IMF Working Paper No. 14/139. Available at: https://www.imf.org/external/pubs/ft/wp/2014/wp14139.pdf

Banbura, M., Giannone, D., Reichlin, L., 2010. Large Bayesian Vector Auto Regressions. Journal of Applied Econometrics, 25(1), pp. 71-92.

Baumeister, C., Benati, L., 2010. Unconventional Monetary Policy and the Great Recession - Estimating the Impact of a Compression in the Yield Spread at the Zero Lower Bound. [pdf] ECB Working Paper No. 1258. Available at: https://www.ecb.europa.eu/pub/pdf/scpwps/ecbwp1258.pdf.

Bridges, J., Thomas, R., 2012. The Impact of QE on the UK Economy - Some Supportive Monetarist Arithmetic. [pdf] Bank of England Working Paper No. 442. Available at: http://www.bankofengland. co.uk/research/Documents/workingpapers/2012/wp442.pdf

Doan, T., Litterman, R., Sims, C. A., (1984): Forecasting and Conditional Projection Using Realistic Prior Distributions. Econometric Reviews, 3, pp. 1-100.

Draghi, M., 2015. Global and Domestic Inflation. [speech] 4 December 2015. Available at: https://www. ecb.europa.eu/press/key/date/2015/html/sp151204.en.html

Gagnon, J., Raskin, M., Remache, J., Sack, B., 2011. The Financial Market Effects of the Federal Reserve's Large - Scale Asset Purchases. International Journal of Central Banking, 7(1), pp. 3-43.

Gambacorta, L., Hofmann, B., Peersman, G., 2014. The Effectiveness of Unconventional Monetary Policy at the Zero Lower Bound: A Cross-Country Analysis. Journal of Money, Credit and Banking, 46, pp. 615-642.

Giannone, D., Lenza, M., Reichlin, L., 2014. Money, credit, monetary policy and the business cycle in the euro area: what has changed since the crisis? [pdf]. Available at: http://www.lucreziareichlin.eu/ AjaxRequestHandler.ashx?Function=GetSecuredDOC\&DOCUrl=App_Data/lucreziareichlin_eu/ Work-in-Progress_en-GB/_Documents_2013-14/Money,\%20credit, $\% 20$ monetary $\% 20$ policy $\overline{\%} 20$ and $\% 20$ the $\% 20$ business $\% 20$ cycle $\% 20$ in $\% 20$ the $\% 20$ euro $\% 20$ area $\% 20-\% 20$ what $\% 20$ has $\% 20$ changed $\% 20$ since $\% 20$ the $\% 20$ crisis.pdf

Joyce, M., Lasaosa, A., Stevens, I., Tong, M., 2011. The Financial Market Impact of Quantitative Easing. International Journal of Central Banking, 7(3), pp. 113-161.

Kadiyala, K. R., Karlsson, S., 1997. Numerical Methods for Estimation and Inference in Bayesian VAR models. Journal of Applied Econometrics, 12(2), pp. 99-132.

Kapetanios, G., Mumtaz, H., Stevens, I. and Theodoridis, K., 2012. Assessing the Economy - wide Effects of Quantitative Easing. The Economic Journal, 122, pp. F316-F347. 


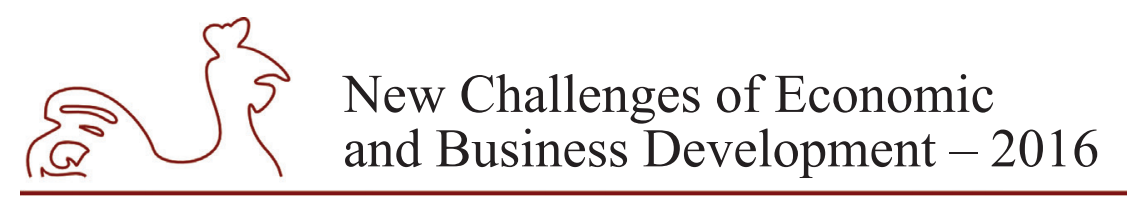

May 12-14, 2016, Riga, University of Latvia

Koop, G., Korobilis, D., 2010. Bayesian Multivariate Time Series Methods for Empirical Macroeconomics. Foundations and Trends in Econometrics, 3(4), pp 267-358 .

Lenza, M., Pill, H., Reichlin, L., 2010. Monetary Policy in Exceptional Times. Economic Policy, 25(62), pp. 295-339.

Litterman, R., 1986. Forecasting with Bayesian Vector Autoregressions - Five Years of Experience. Journal of Business and Economic Statistics, 4, pp. 25-38.

Meier, A., 2009. Panacea, Curse, or Nonevent? Unconventional Monetary Policy in the United Kingdom. [pdf] IMF Working Paper No. 09/163. Available at: https://www.imf.org/external/pubs/ft/wp/2009/ wp09163.pdf

Schenkelberg, H., Watzka, S., 2011. Real Effects of Quantitative Easing at the Zero Lower Bound: Structural VAR - based Evidence from Japan. [pdf] Cesifo Working Paper, 3486. Available at: https://www.cesifogroup.de/portal/pls/portal/docs/1/1206161.PDF

Sims, C.A, Stock, J., Watson, M., 1990. Inference in Linear Time Series Models with Some Unit Roots. Econometrica, 58, pp. 113-144.

Stone, M., Fujita, K., Ishi, K., 2011. Should Unconventional Balance Sheet Policies be Added to the Central Bank Toolkit? A Review of the Experience So Far. [pdf] IMF Working Paper No. 11/145. Available at: https://www.imf.org/external/pubs/ft/wp/2011/wp11145.pdf 


\title{
PREDICTIVE ANALYTICS AND CLOUD COMPUTING TECHNOLOGIES FOR THE BUSINESS DATA ANALYSIS
}

\author{
Rita Zuka, University of Latvia, Latvia ${ }^{1}$ \\ Juris Krasts, University of Latvia, Latvia \\ Uldis Rozevskis, University of Latvia, Latvia
}

\begin{abstract}
Predictive analytics integrates the multitude of methods of analysis, both the historical facts and current data for the compilation of predictions about possible future events. Predictive analytics is used in the variety of areas, such as trade, insurance, medicine, finance, banking, etc. But it is quite a complex set of methods and technologies. In order to use it in practice, firstly, a correct approach to the choice of algorithms and analysis techniques is required, and, secondly, the ability to use the data correctly is required.

This paper is aimed at analysing the approaches to the use of predictive analytics techniques as well as analysing of how predictive analytics is easy to use by an end user. Rate the simplicity and the possibility of using two IBM SPSS Modeler and Microsoft ML Azure software's tools to create a predictive model and its application by end-users.

The use of cloud technologies and combined models simplifies the process of modelling and the application of ready-models.

The research on the use of the predictive analytics cloud computing technology is performed by means of software documentation study and by practical application of predictive modelling techniques and the applications for business data analysis.
\end{abstract}

Key words: Analytics, Data Mining, Predictive Modelling

JEL code: M15, M53

\section{Introduction}

Gartner states that the analytics becomes more strategically important tool for enterprises. In order to more quickly analyse the data that determines the requirements of growing competition, the enterprises attempt to democratize analytics through the use of self-service tools. The main difference between modern and traditional BI-platform lies in the work at the modelling stage, which was previously performed by IT staff and currently by an analyst, as well in the amount of expertise needed for preparation of data for analytics (Gartner group, 2015). According to Gartner, during the past several years, the user demand for BI platform has shifted toward "easy-to-use tools that support a full range of analytic workflow capabilities". Gartner predicts, that "by 2018, most business users and analysts in organizations will have access to self-service tools to prepare data for analysis as part of the shift to deploying modern BI platforms" (Gartner group, $2016 \mathrm{a}$ ). And the fastest growing segment of business analytics market is predictive analytics. According

${ }^{1}$ Corresponding author-e-mail address: rita.zuka@lu.lv 


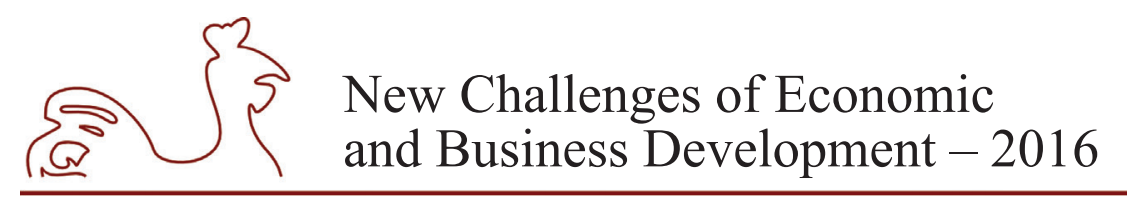

May 12-14, 2016, Riga, University of Latvia

to the study by Gartner, "by 2020, predictive and prescriptive analytics will attract $40 \%$ of enterprises' net new investment in business intelligence and analytics" (Gartner group, 2016 b). As the business has to process huge amounts of data and to implement the results of the analysis to the business processes "on the fly", the use of cloud platforms for business intelligence helps to speed up the process of gaining access to data and the results of data analysis.

The purpose of the study is to analyse the process of creating the predictive model and to find out the extent to which the process of creating the predictive model would be simple, convenient and accessible for nontechnical users. This paper describes the process of creating predictive models of customer's creditworthiness by using two predictive analytics software: IBM SPSS Modeler and Microsoft Azure Machine Learning.

\section{Formulating the problem}

The model must be created to predict customer's solvency assessment based on available information on the customers to make a decision to grant a loan. The model is based on historical data that is on the analysis of previous loan experience. The database contains information on the credit history of customers of one of the loan companies. The sample contains 12053 customers' records. Each customer is characterized by 13 parameters (attribute). They are Gender, Age, Marital status, Number of dependents, Education Level, Institution, Average salary, Market value, Quick sales value, Loan amount, Salary credited to the bank, Due date, Delay count. The data stored in Excel file.

\section{Predictive model creation}

The process of creating the predictive model consists of the following steps: Data access; Data preparation; Creation of training and test sets; Selection of a modelling algorithm; Training the model; The model testing; Evaluating the model; Deploying the model.

The process of creating the model is considered based on the model creation examples in two environments: IBM SPSS Modeler and Microsoft Azure Machine Learning. IBM SPSS Modeler is a predictive analytics platform that offers the set of data mining tools for predictive models developing. For model creating there was used IBM SPSS Modeler 17.0. Microsoft Azure Machine Learning is a cloud service to perform predictive analytics tasks. The service provides the special development tool for predictive models, which is Azure ML Studio. The Azure ML Studio has web-interface and provides the means to retrieve data, data preparation, data analysis, model building and evaluation ().

To data access IBM SPSS Modeler are offered sources nodes that provide data import stored in a number of formats and sources such as ODBC-compliant relational databases, Excel file, XML file, and other different flat files. "Excel node" was used for access data within this task (Figure 6).

As an input data source in Azure ML Studio there can be used a relational database from Azure SQL Database, non-relational NoSQL sources, OData-services, as well as various texts formats. To connect to the source data in the development environment Azure ML Studio, the modules from the groups "My Dataset" or "Data Input and Output" are used. In this study, the module "My Dataset" is used for connecting to the source of customers' data converted in csv format file (Figure 8). 


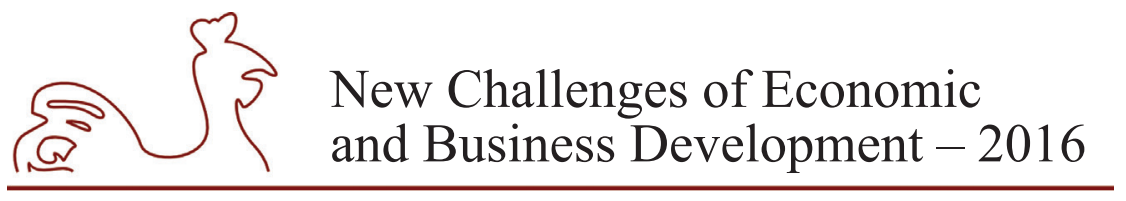

May 12-14, 2016, Riga, University of Latvia

Data preparation tasks include checking the completeness of the data set, as the accuracy of the model depends on the sample quality. One of the conditions for constructing of the model is an equal number of observations for each variable. It is desirable to exclude observations with missing variables from the analysis.

And one of the main problems in the process of creating the model is the skill to properly select the variables (input attribute values) and, if necessary, even create new variables. Selection of the independent variables is mainly based on the consecutive searching method of features. The objective is to find the best subset of predictors (independent variables) with which the constructed model shows the best result.

The choice of a dependent variable is defined by the purpose of creating of the predicting model. The dependent variable can be selected from existing variables list or it can be created. In the considered model, the dependent variable accepts a categorical scale of measurement with two categories: "the reliable borrower" and "the unreliable borrower". The customers which have not repaid the credits within the prescribed terms (i.e., the customers with bad credit history) have been brought to the group "unreliable borrower". The customers not having outstanding loans (i.e. the customers with good credit history) were attributed to the group of "reliable borrower". The presence of credit history the customer of untimely payments is defined by an independent variable "Delay count". The dependent variable "Reliable borrower" is assigned a value "true" and the customer is appropriated to the group of "reliable borrowers" if value of independent variable "Delay count" is equal to 0 . The dependent variable "Reliable borrower" is assigned a value "false" if value of independent variable "Delay count" exceeds 0. And the customer is appropriated to "unreliable borrowers" group.

In IBM SPSS Modeler the dependent variable "Reliable borrower" is created using the "Derive" node. The value of the dependent variable will be predicted to new customers that is not available credit history. Data on the customers can be gathered and stored in different storage data types such as a string and number, integer, real number, date and time, image. The storage data type defines the measurement scales of independent variables.

IBM SPSS Modeler supports the following measurement levels: Default, Continuous, Categorical, Flag, Nominal, Ordinal, Typeless.

- Default measurement is used for data whose storage type and values are unknown yet.

- Continuous measurement is used for numeric values which data type are integer, real number, or date/time.

- Categorical measurement is used for string values with unknown number of values.

- Flag measurement is used for data with two distinct values.

- Nominal measurement is used for data with two or more distinct values.

- Ordinal measurement is used for data with multiple distinct values which can be ordered on importance degree.

- Typeless measurement is used for data that do not fit into any one of the supported measurements (IBM Knowledge Center 2016).

The variables both with quantitative, and string types of data have been used for creation of model. The variables list and data measurement level was defined in IBM SPSS Modeler using a "Type node" as shown in the Figure 1. 


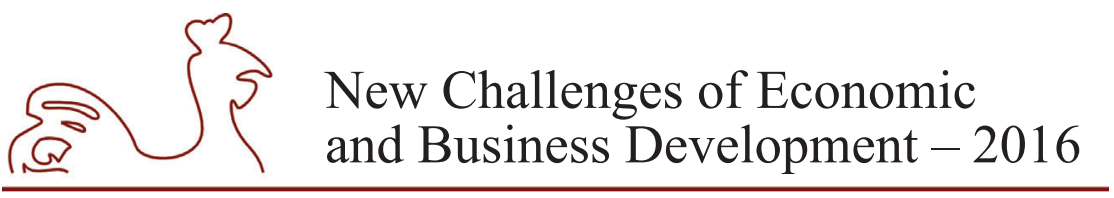

May 12-14, 2016, Riga, University of Latvia

\begin{tabular}{|c|c|c|}
\hline Field & Measurement - & Values \\
\hline 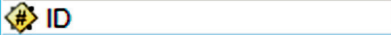 & $\&$ Continuous & {$[1.0,12096.0]$} \\
\hline A Gender & 8 Flag & male/female \\
\hline स Age & $\&$ Continuous & {$[24.0,58.0]$} \\
\hline A Marital_status & 8 Nominal & married,single \\
\hline \#) Number_of_dependents & 8 Nominal & $0.0,1 \cdot 0,2 \cdot 0,3 \cdot 0,4.0$ \\
\hline A] Education_Level & 대 Ordinal & higher,"lower seconda... \\
\hline A Institution & 8 Flag & "private enterprise"I"go... \\
\hline \#. Average_salary & $\&$ Continuous & {$[77.0,3518.0]$} \\
\hline (A) Market_value & $\&$ Continuous & {$[1400.0,43200.0]$} \\
\hline «. Quick_sales_value & $\&$ Continuous & {$[1400.0,36400.0]$} \\
\hline \#. Loan_amount & $\&$ Continuous & {$[1000.0,35000.0]$} \\
\hline A Salary_credited_to_the_bank & 8 Flag & "wages are not credite... \\
\hline \#. Due_date & $\&$ Continuous & {$[1.0,20.0]$} \\
\hline Delay_count & 8 Nominal & $0.0,2 \cdot 0,4 \cdot 0,5.0,6 \cdot 0,7.0, \ldots$ \\
\hline A Reliable borrower & \& Flag & True/False \\
\hline
\end{tabular}

Fig. 1. Measurement definition for each variable in the "Type" node IBM SPSS Modeler

The Azure Machine Learning service for data preparation and variables selection provides different modules which are united in a module group "Data Transformation". The "Project Columns" module from this group was used for the selection of variables for data analysis. Preclean records from missing values are carried out in the module "Clean Missing Data". Also, the numerous tools for statistical data analysis are offered in "Statistical Functions" section, that help to understand data structure, allow assessing the strength of the correlation between the variables. For this purpose, IBM SPSS Modeler supports "Data Audit" node and "Statistics" node. For quantitative variables there is calculated such basic descriptive statistics as min, max, mean, median, standard deviation, count, standard error of mean, the share of missing values that can give an idea of the integrity and consistency of data. The calculation results are represented by histograms and tables (Figure 2). Statistical analysis showed that these data were non-normal and skewed.

\section{The training and test sets}

The model is based on a sample containing historical data, which is (in this case) about the credit history of customers. The sample is split into two samples: the training set and a test set. Both sets contain observations for which the value of the dependent variable is already known. The model is trained on the training sample only. Observations of the test set are not used in training the model. They are used to verify the adequacy and to evaluate accuracy of the prediction model. The training and tests set are generated by the method of random selection. The sizes of samples depend on the size of original sample, and the ratio of the sets may vary.

The "Partition" node is used to split the data into separate samples in IBM SPSS Modeler. The "Partition" node supports the ability to specify the ratio of the sample sizes. In this paper, the original sample was split into two samples: the training set containing $60 \%$ of observations and a test set containing $40 \%$, respectively. 


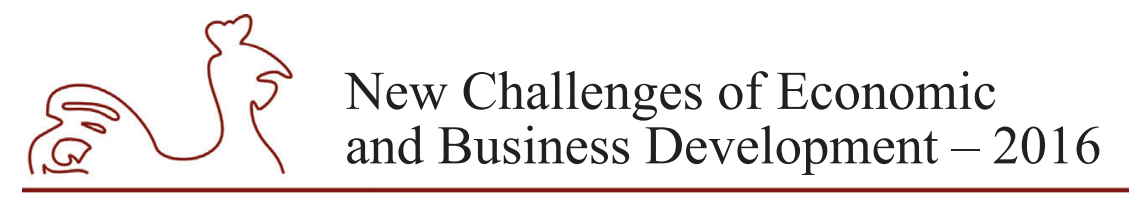

May 12-14, 2016, Riga, University of Latvia

\begin{tabular}{|c|c|c|c|c|c|c|c|c|c|}
\hline Field = & Sample Graph & Measurement & Min & Max & Mean & Std. Dev & Skewness & Unique & Valid \\
\hline$\Delta$ Gender & & 8 Flag & - & - & - & - & - & 2 & 12053 \\
\hline Age & & Continuous & 24.000 & 58.000 & 37.933 & 8.352 & 0.395 & - & 12053 \\
\hline$\Delta$ Marital_status & & $\&$ Nominal & - & - & - & - & - & 2 & 12053 \\
\hline 邻 Number_of_dependents & & $\&$ Nominal & 0.000 & 4.000 & - & - & - & 5 & 12053 \\
\hline 圆 Education_Level & & dill Ordinal & - & - & - & - & - & 4 & 12053 \\
\hline Institution & & 8 Flag & - & - & - & - & - & 2 & 12053 \\
\hline 〈A Average_salary & & $\Rightarrow$ Continuous & 77.000 & 3518.000 & 546.003 & 357.642 & 3.881 & - & 12053 \\
\hline 〈A Market_value & & 8 Continuous & 1400.000 & 43200.000 & 14089.223 & 9248.425 & 0.986 & - & 12053 \\
\hline
\end{tabular}

Fig. 2. Descriptive statistical analysis in the "Data Audit" node IBM SPSS Modeler

Azure Machine Learning offers a special module "Split Data" that provides sample splitting into two samples: training dataset and test dataset. In the module there must be specified the data splitting algorithm and ratio of sample sizes.

\section{Modelling Algorithm selection and training}

The core of creation the model is the modelling algorithm selection and trains it to find the pattern between a set of input parameters (predictors) and the expected result. Training should takes place using large volumes of data. And it assumes that all samples (subsets) of the data have the same relationship between attributes. Thus, the trained algorithm can then be applied to new data sets.

The predictive model, which gives correct forecasts for the training sample, will then be applied to the test sample. Similar precision results obtained on the training and the test samples are indicative of the fact that the model will work well on the similar data. Should the deviation of results between the training and the test sample be considerable, the model is re-created. Prior to re-creating the model, it is necessary to analyze the data on the presence of outlier observations and remove such cases from the training sample.

IBM SPSS Modeler modeling methods are taken from machine learning, artificial intelligence, and statistics. IBM SPSS Modeler offers three categories of modeling methods: Classification, Association and Segmentation methods. Each category combines various nodes of modeling algorithms. The program offers both separate nodes that contain only one specific modelling algorithm and the nodes comprising multiple different modelling algorithms. They are called as automated modeling nodes. Automatic modeling nodes allow to train each multiple models at the same time by using different modeling methods and to compare the results. In fact, the program selects a number of possible models with different parameters. Moreover, the program will automatically analyze the input data and the possibility of their application to a specific model, and also define the input parameters for each of the models. The advantage 


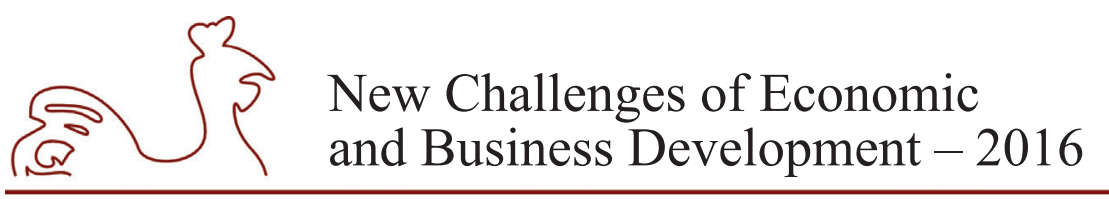

May 12-14, 2016, Riga, University of Latvia

of using this node is that not only experienced analysts can build up an adequate model, as the node itself explores every possible combination of options. Of course, the accuracy of such a model "with the default settings" can give less accurate results than the model with specified parameters for each modelling algorithm (IBM SPSS Modeler 17 Modeling Nodes, 21.p.).

In this study, the automated modeling node "Auto Classifier" was used to create the models too. "Auto Classifier" node offers 14 modelling algorithms with possibility to choose the suitable model type for a given task (Figure 3).

\begin{tabular}{|c|c|c|}
\hline Use? & Model type & Model parameters \\
\hline$\nabla$ & C委 C5 & Default \\
\hline$\nabla$ & $\mathcal{L}$ Logistic regression & Default \\
\hline$\nabla$ & Decision List & Default \\
\hline$\nabla$ & ob Bayesian Network & Default \\
\hline$\nabla$ & Discriminant & Default \\
\hline$\nabla$ & KNN Algorithm & Default \\
\hline$\nabla$ & L LSVM & Default \\
\hline$\nabla$ & $P_{\text {P Random Trees }}$ & Default \\
\hline$\nabla$ & $\therefore$ SVM & Default \\
\hline$\nabla$ & 和乐 Tree-As & Default \\
\hline$\nabla$ & \&f Neural Net & Default \\
\hline$\nabla$ & 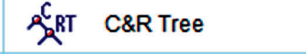 & Default \\
\hline$\nabla$ & 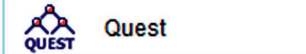 & Default \\
\hline$\nabla$ & 乐尔 CHAID & Default \\
\hline
\end{tabular}

Fig. 3. Model type in the "Auto Classifier" node IBM SPSS Modeler

In Azure Machine Learning, the same machine learning algorithms are supported as in IBM SPSS Modeler, and they are: regression, classification, clustering. Azure Machine Learning offers single modules for each algorithm. Appropriate modules of algorithms provide the possibility to configure key parameters of the selected algorithm (Microsoft Azure documentation, 2016). In the study, two models were created: model by using the decision forest algorithm and model by using the neural network algorithm. For training the selected algorithms is used "Train Model" module (Figure 8).

\section{Evaluating models}

IBM SPSS Modeler "Auto Classifier" node provides opportunity to specify the parameters for each type of models, and to define the criteria for evaluating models, and to specify number of the created models to use. Modeler provides the opportunity to evaluate the obtained models on the training set and the test set. And then models can be compared and ranked using by following metrics "Overall accuracy", "Area under the ROC curve", "Profit (Cumulative)", 


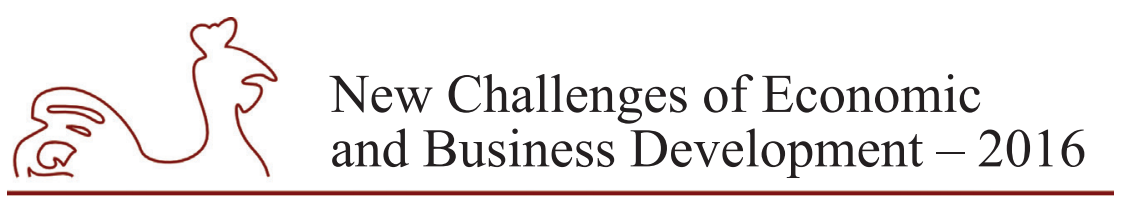

May 12-14, 2016, Riga, University of Latvia

"Lift (Cumulative)", "Number of input fields used" (IBM SPSS Modeler 17 Modeling Nodes). In this study, 12 modeling algorithms (machine learning models) were analyzed (Figure 3).

The best overall accuracy was shown by the models created by using the following algorithms: the C5.0, the Neural Net and the Classification and Regression (C \& R) (Figure 4). And the best overall accuracy result was provided by $\mathrm{C} 5.0$ algorithm based model. At the same time the Neural Net algorithm based model shown the best result in the other metric of "Area under the ROC curve".

For comparing the models there can be used Gains chart, which shows the ratio of the overall number of customers in a category "Reliable borrower" by targeting a ratio of the total number of customers (Figure 5).

\begin{tabular}{|c|c|c|c|c|c|c|c|c|c|}
\hline Use? & Graph & Model & $\begin{array}{l}\text { Build Time } \\
\text { (mins) }\end{array}$ & $\begin{array}{l}\text { Max } \\
\text { Profit }\end{array}$ & $\begin{array}{l}\text { Max Profit } \\
\text { Occurs in }\end{array}$ & Lift\}Top $30 \ldots$ & \begin{tabular}{|l} 
Overall \\
Accuracy (\%)
\end{tabular} & $\begin{array}{l}\text { No. Fields } \\
\text { Used }\end{array}$ & $\begin{array}{l}\text { Area Under } \\
\text { Curve }\end{array}$ \\
\hline$\nabla$ & & & $<1$ & 18079,0 & 50 & 1,973 & 98,773 & 9 & 0,993 \\
\hline$\nabla$ & & & $<1$ & 18055,0 & 50 & 1,972 & 98,705 & 13 & 0,995 \\
\hline$\nabla$ & & & $<1$ & 16532,482 & 50 & 1,951 & 94,560 & 13 & 0,981 \\
\hline
\end{tabular}

Fig. 4. Compare models in "Auto Classifier" node

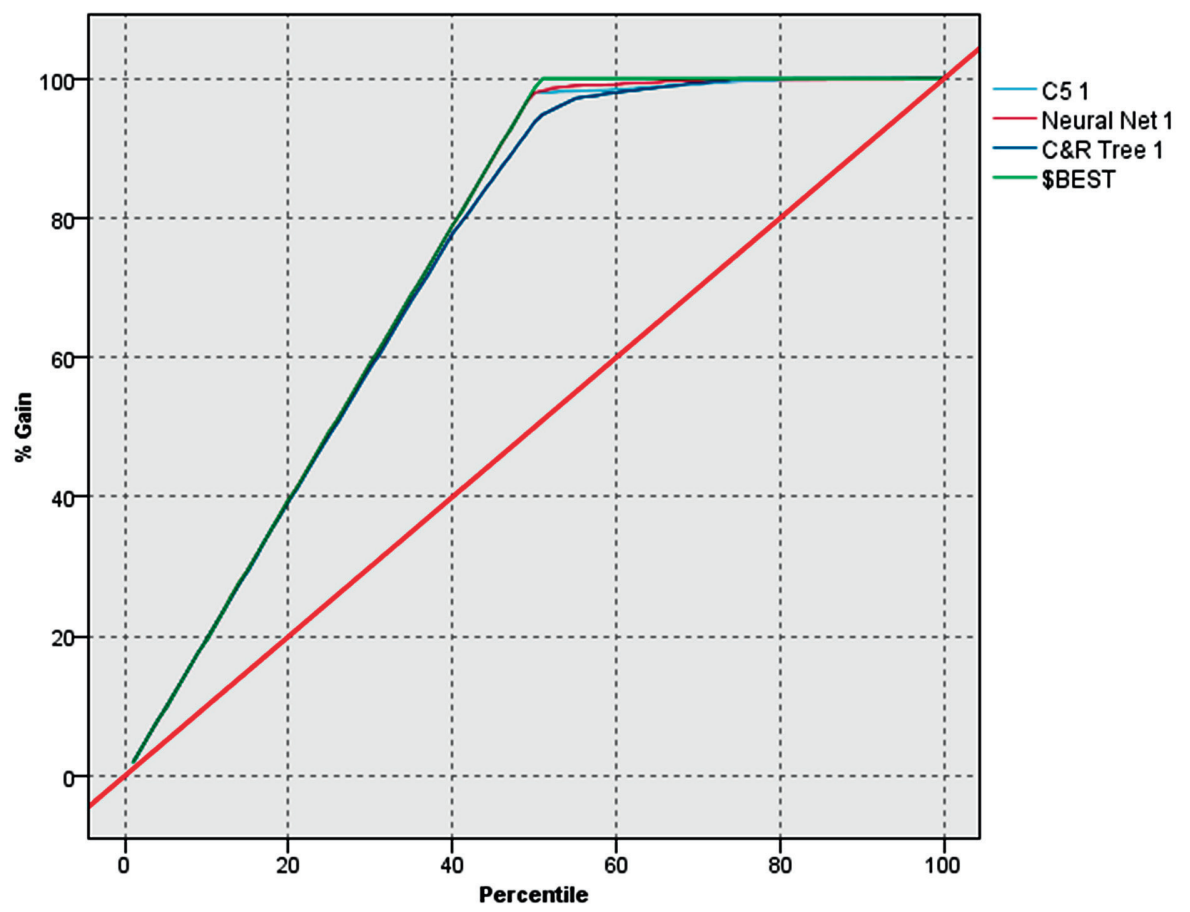

Fig. 5. Evaluating models by Gains chart 


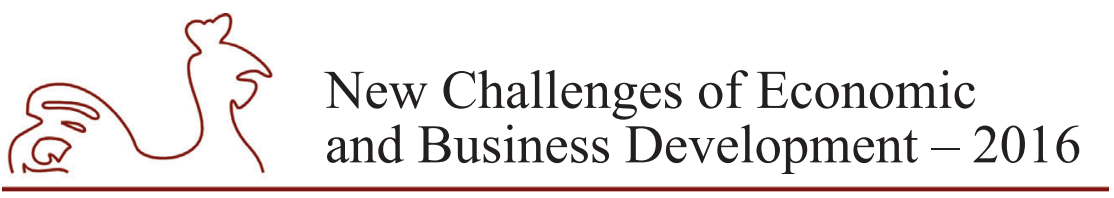

May 12-14, 2016, Riga, University of Latvia

By using "Auto Classifier" node, it is possible to use not one separate model for the forecast, but an ensemble model from several models which have shown the best accuracy results. At combining the predictions from several models, it is possible to avoid the restrictions imposed on a separate model and to receive the higher overall accuracy (IBM Knowledge Center 2016).

In this study, a combined model gives better prediction accuracy using a combination of three models: the C5.0, the Neural Net and the Classification and Regression (C\&R). Combined model with the best two models testing results (the C5.0, the Neural Net models) and 4 models have shown a worse prediction accuracy. The test results of the separated models showed that single models have less accurate prediction as compared with the combined model of the 3 models. The test results are shown in Table1.

Table 1

The models testing results in IBM SPSS Modeler

\begin{tabular}{|l|c|c|c|c|c|}
\hline \multicolumn{1}{|c|}{ Models } & \multicolumn{2}{c|}{ Correct cases } & \multicolumn{2}{c|}{ Wrong cases } & AUC \\
\hline $\begin{array}{l}\text { The ensemble model of 3 models: the C5.0, } \\
\text { the Neural Net and the Classification and } \\
\text { Regression (C \& R) models }\end{array}$ & 11907 & $98.79 \%$ & 146 & $1.21 \%$ & 0.997 \\
\hline $\begin{array}{l}\text { The ensemble model of 2 models: the C5.0, } \\
\text { the Neural Net }\end{array}$ & 11893 & $98.67 \%$ & 160 & $1.33 \%$ & 0.996 \\
\hline $\begin{array}{l}\text { The ensemble model of 4 models: The } \\
\text { C5.0, the Neural Net the Classification and } \\
\text { Regression (C \& R), the Chaid models }\end{array}$ & 11895 & $98.69 \%$ & 158 & $1.31 \%$ & 0.996 \\
\hline Single C5 model & 11906 & $98.78 \%$ & 147 & $1.22 \%$ & 0.992 \\
\hline Single Neural Net model & 11888 & $98.63 \%$ & 165 & $1.37 \%$ & 0.995 \\
\hline
\end{tabular}

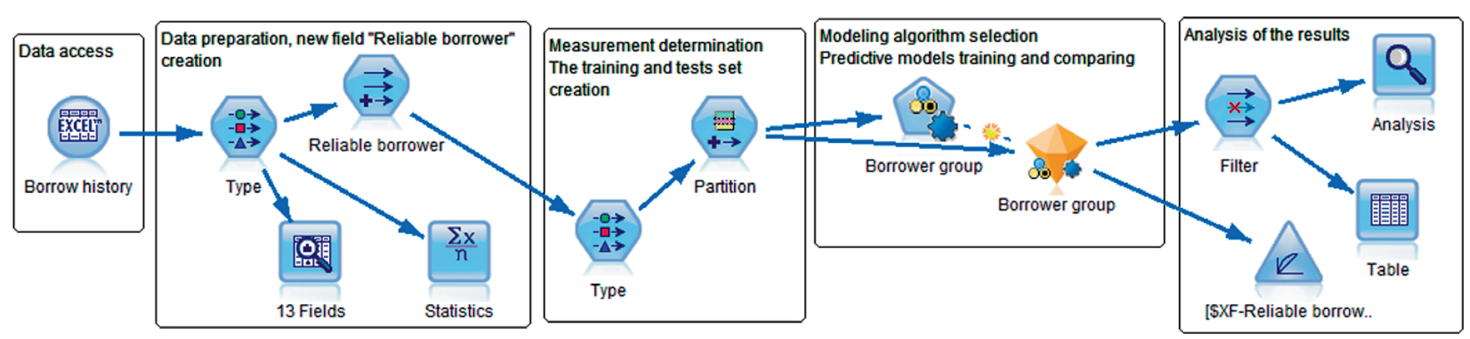

Fig. 6. The predictive model creation process in IBM SPSS Modeler

Thus, the created predictive model can be used in the analysis of new customers for which the outcome is unknown yet. Results may be displayed or stored in a database table, a spreadsheet or a text file.

Azure Machine Learning service offers the "Score Model" module for testing the trained model by generating predictions (Figure 8). The predicted value format depends on the model and input data. For classification model, the module outputs a predicted value for the class, as well as the probability of the predicted value (Microsoft Azure documentation, 2016). 


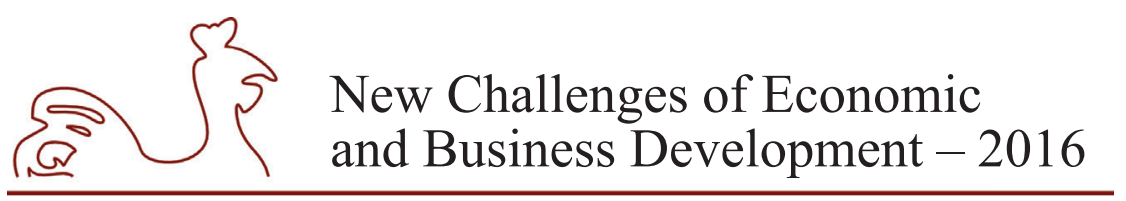

May 12-14, 2016, Riga, University of Latvia

ML Azure Learning provides the possibility to compare the test results of the two models only. This can be done at the node "Evaluate Model" (Figure 8). As a result, the overall accuracy of predictive ability for each model is calculated and compiled confusion matrix. Confusion matrix contains correctly detected cases (True - True and False - False), and incorrectly detected cases (True - False and False - True) using trained models on a test sample (test dataset) (Figure 7). The test results showed that the model based on "the decision forest" algorithm has the best predictive accuracy.

Metrics

\begin{tabular}{ll}
\hline Overall accuracy & 0.987832 \\
Average accuracy & 0.987832 \\
Micro-averaged precision & 0.987832 \\
Macro-averaged precision & 0.988184 \\
Micro-averaged recall & 0.987832 \\
Macro-averaged recall & 0.98767 \\
& \\
\hline
\end{tabular}

Predicted Class

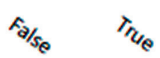

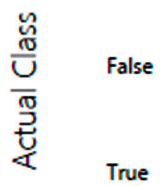

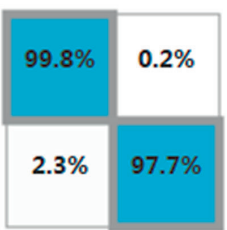

Metrics

\begin{tabular}{ll}
\hline Overall accuracy & 0.986726 \\
Average accuracy & 0.986726 \\
Micro-averaged precision & 0.986726 \\
Macro-averaged precision & 0.987225 \\
Micro-averaged recall & 0.986726 \\
Macro-averaged recall & 0.986525 \\
& \\
\hline Confusion Matrix & \\
\hline
\end{tabular}

Predicted Class
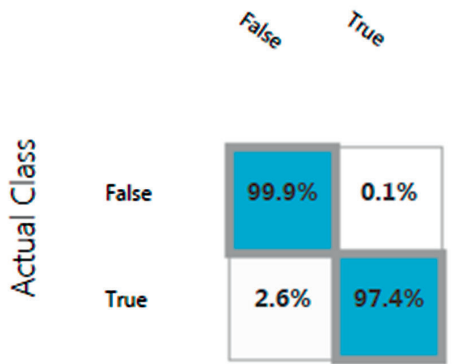

Fig. 7. Accuracy value and confusion matrix for model based on "the decision forest" algorithm (first column) and model based on "the neural network" algorithm (second column) by results testing 


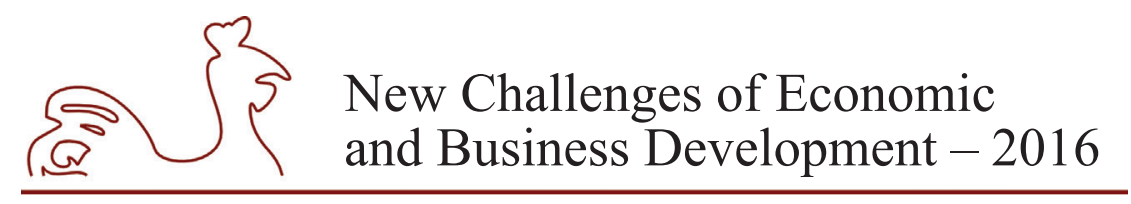

May 12-14, 2016, Riga, University of Latvia

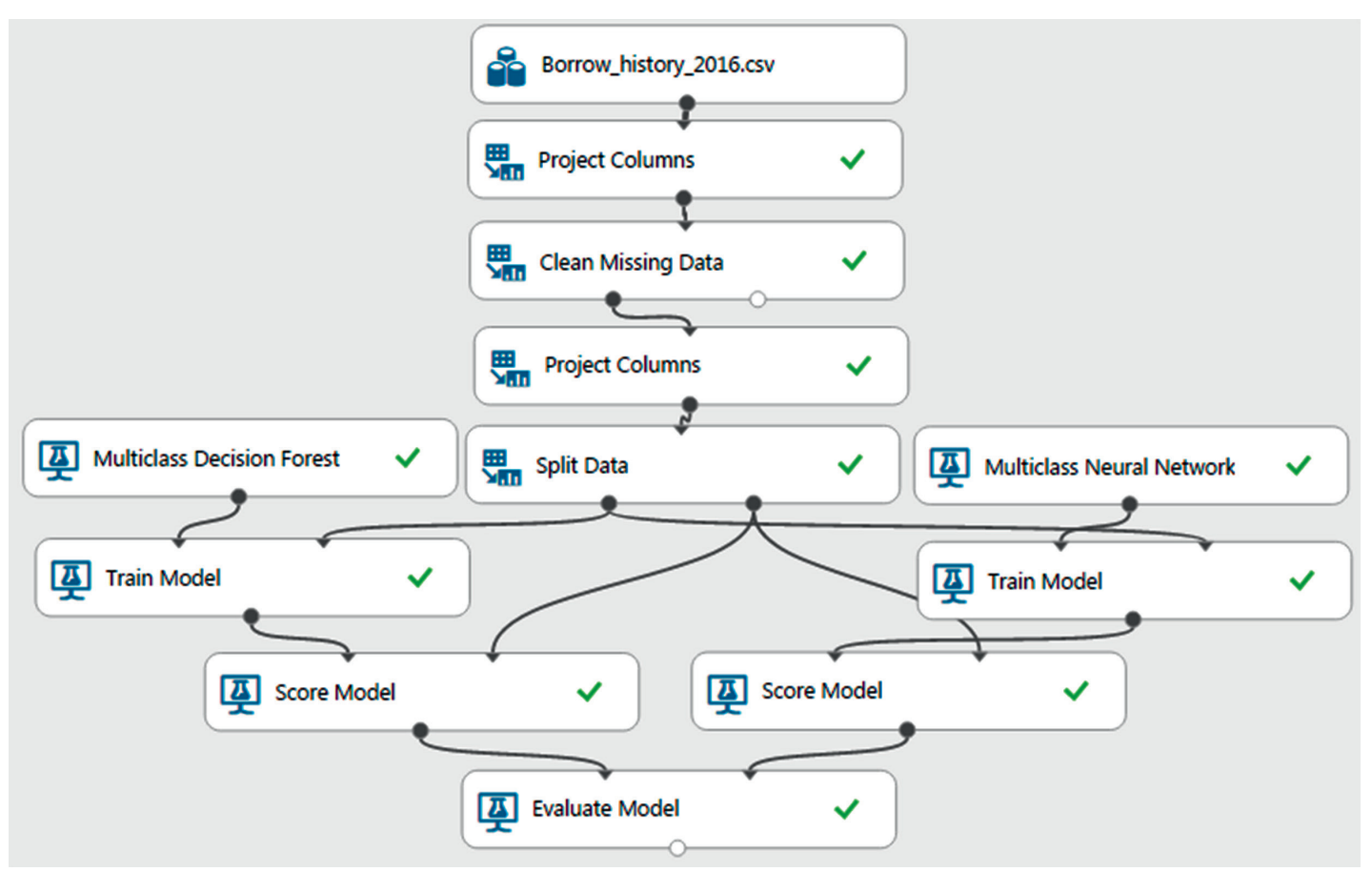

Fig. 8. The predictive model creation process in Azure Machine Learning

Models built in Azure ML Studio, can be deployed as web service for the use in different applications: web applications, mobile applications, custom desktop applications and Excel applications. The Excel file with the implemented services connection is created automatically. Open application programming interface (API) allows updating the model Azure ML directly from the application. This is important for the model automatic re-training in the case of emerging new data, and it can improve the model quality.

\section{Conclusions}

The paper considers the process of creating predictive models in the IBM SPSS Modeler and in the Azure Machine Learning Studio platforms in order to predict the possibility of the customers' loan repayment.

Predictive analytics is a complex set of methods and technologies, wherein there are combined the data management tools, statistics and mathematical methods as well as artificial intelligence methods. Both platforms offer tools with intuitive visual interface to create a model at all stages of the process of creating models. Nevertheless, for creating a predictive model it is necessary to understand and observe the stages of model building.

One of the preconditions for successful application of predictive modelling technology is knowledge of data mining techniques. Although along with the separate algorithms for creating a model, IBM SPSS Modeler offers a combined node to create ensemble model. The use of the combined node simplifies only the decision on how to choose the best prediction algorithm for a specific task. And in certain cases, the combined model has better predictive ability. But for specifying the parameters of algorithm, being aware of the principles of algorithms operation 


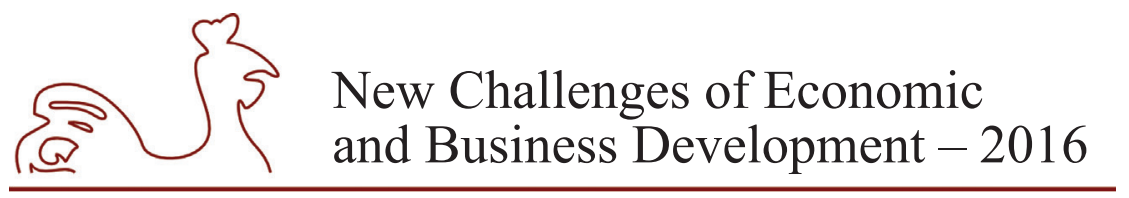

May 12-14, 2016, Riga, University of Latvia

is required. So Microsoft ML Azure technology requires the user to be more experienced in machine learning methods.

Using the cloud computing technology simplifies the process of gaining access to the model development tools and application of created models. In addition, a trained prediction model requires retraining after the new data have been accumulated. Azure Machine Learning service provides simplified access to the created model and it simplifies the use of models in applications and retraining it due to implementation thereof as APIs and a web service. Cloud computing could reduce costs associated with the development and maintenance of models.

\section{Bibliography}

Gartner group, 2015, Technology Insight for Modern Business Intelligence and Analytics Platforms, [Online] Available at: https://www.gartner.com/doc/reprints?id=1-2ODLE0V\&ct=150930\&st=sb [Accessed 8 February 2016].

Gartner group, 2016 a, Magic Quadrant for Business Intelligence and Analytics Platforms, [Online] Available at: https://www.gartner.com/doc/reprints?id=1-2XXET8P\&ct=160204 [Accessed 17 February 2016].

Gartner group, 2016 b, Magic Quadrant for Advanced Analytics Platforms [Online] Available at: https:// www.gartner.com/doc/reprints?id=1-2YEIILW\&ct=160210\&st=sb, [Accessed 17 February 2016].

IBMSPSS Modeler 17 Modeling Nodes, [Online]Available at: ftp://public.dhe.ibm.com/software/analytics/ spss/documentation/modeler/17.0/en/ModelerModelingNodes.pdf[Accessed 8 February 2016].

IBM Knowledge Center 2016, SPSS Modeler 17.0.0. [Online] Available at:https://www-01.ibm.com/ support/knowledgecenter/SS3RA7_17.0.0/clementine/typenode_kindsoftypes.dita[Accessed 17 February 2016].

Microsoft Azure documentation,2016, Machine Learning Modules, [Online] Available at:https://msdn. microsoft.com/library/azure/e8b401fb-230a-4b21-bd11-d1fda0d57c1f, [Accessed 26 February 2016]. 


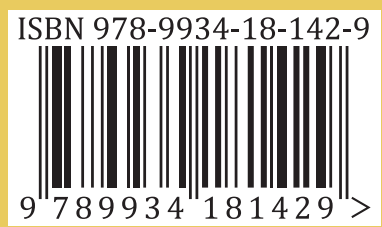

Organised by

Faculty of Economics and Management, University of Latvia

in cooperation with

Latvian European Community Studies Association

Institut CEDIMES - Lettonie

Econometrists Association of Latvia

Latvian Information and Communications Technology Association

Association of Statisticians of Latvia

Baltic Sea Region University Network (BSRUN)

Creativity Week radi!

Conference is supported by

Latvijas Mobilais Telefons SIA
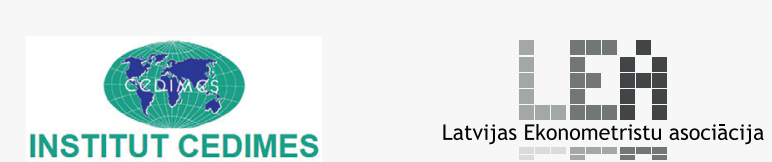

radi!

Radošās darbības nedēḷa 2016

\section{LIKTA}
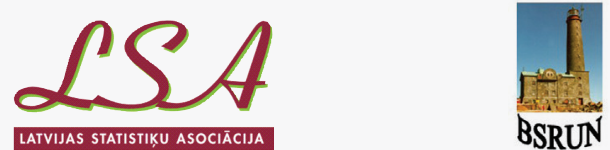